\title{
Applying Socioeconomic Optimisation on Blue-Green Climate Adaptation Projects in an Urban Catchment
}

\author{
Davidsen, Steffen; Kruse, Thomas; Stausgaard Munk, Trine; Arnbjerg-Nielsen, Karsten
}

Published in:

Proceedings of the 11th International Conference on Urban Drainage Modelling

Publication date:

2018

Document Version

Publisher's PDF, also known as Version of record

Link back to DTU Orbit

Citation (APA):

Davidsen, S., Kruse, T., Stausgaard Munk, T., \& Arnbjerg-Nielsen, K. (2018). Applying Socioeconomic Optimisation on Blue-Green Climate Adaptation Projects in an Urban Catchment. In G. Mannina (Ed.), Proceedings of the 11th International Conference on Urban Drainage Modelling (pp. 1146-1151).

\section{General rights}

Copyright and moral rights for the publications made accessible in the public portal are retained by the authors and/or other copyright owners and it is a condition of accessing publications that users recognise and abide by the legal requirements associated with these rights.

- Users may download and print one copy of any publication from the public portal for the purpose of private study or research.

- You may not further distribute the material or use it for any profit-making activity or commercial gain

- You may freely distribute the URL identifying the publication in the public portal 
UDM
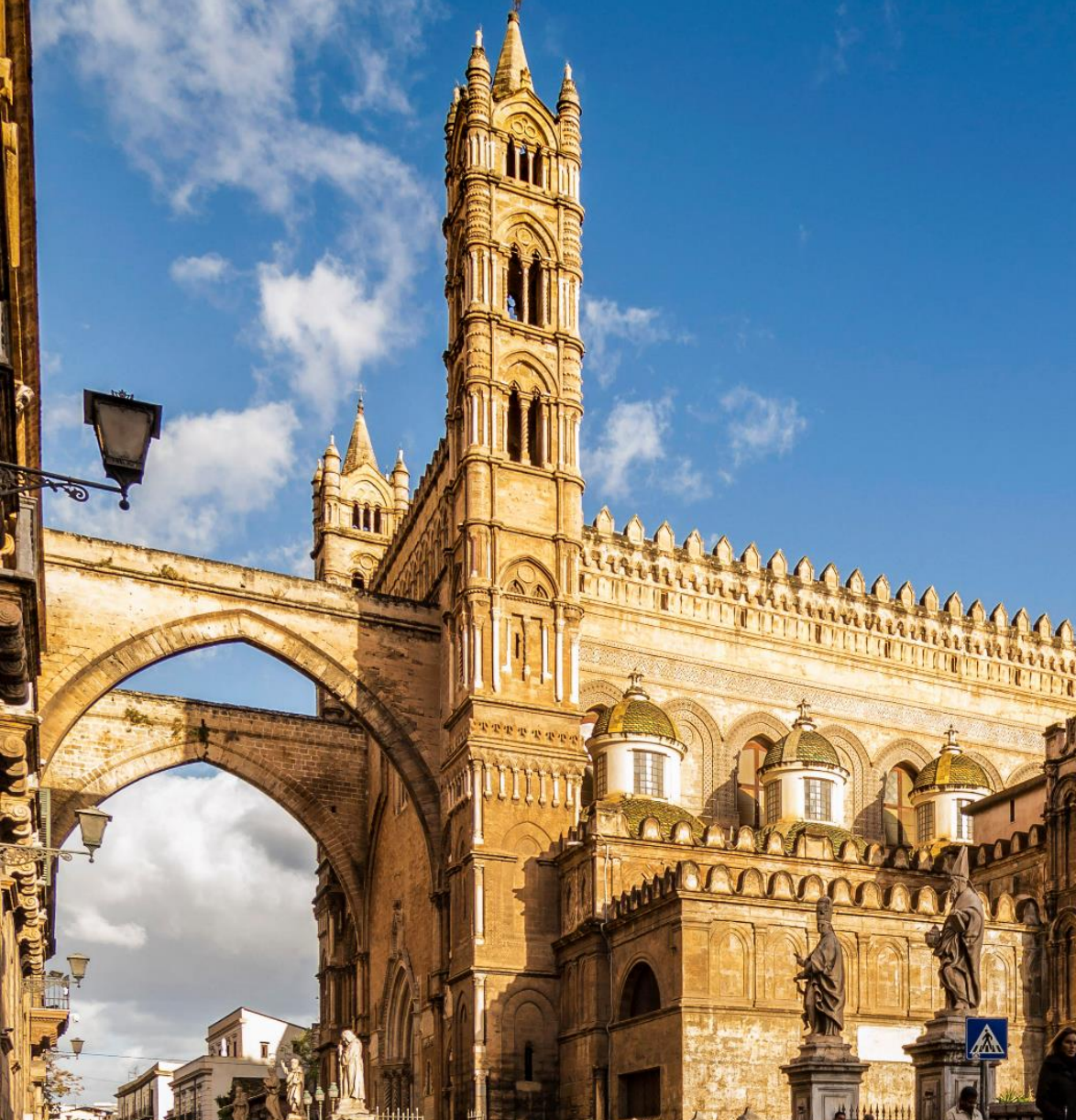

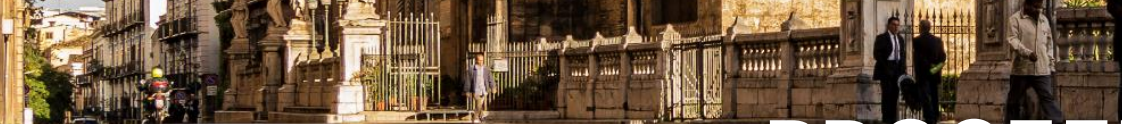

\section{PROGEEDINGS}

1 th international Conference on Urban Drainage Modelling (UDM)

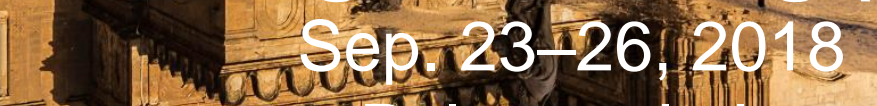

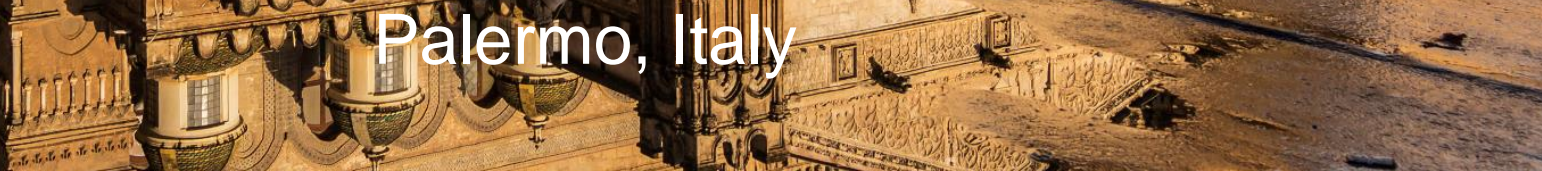

8

पाiा

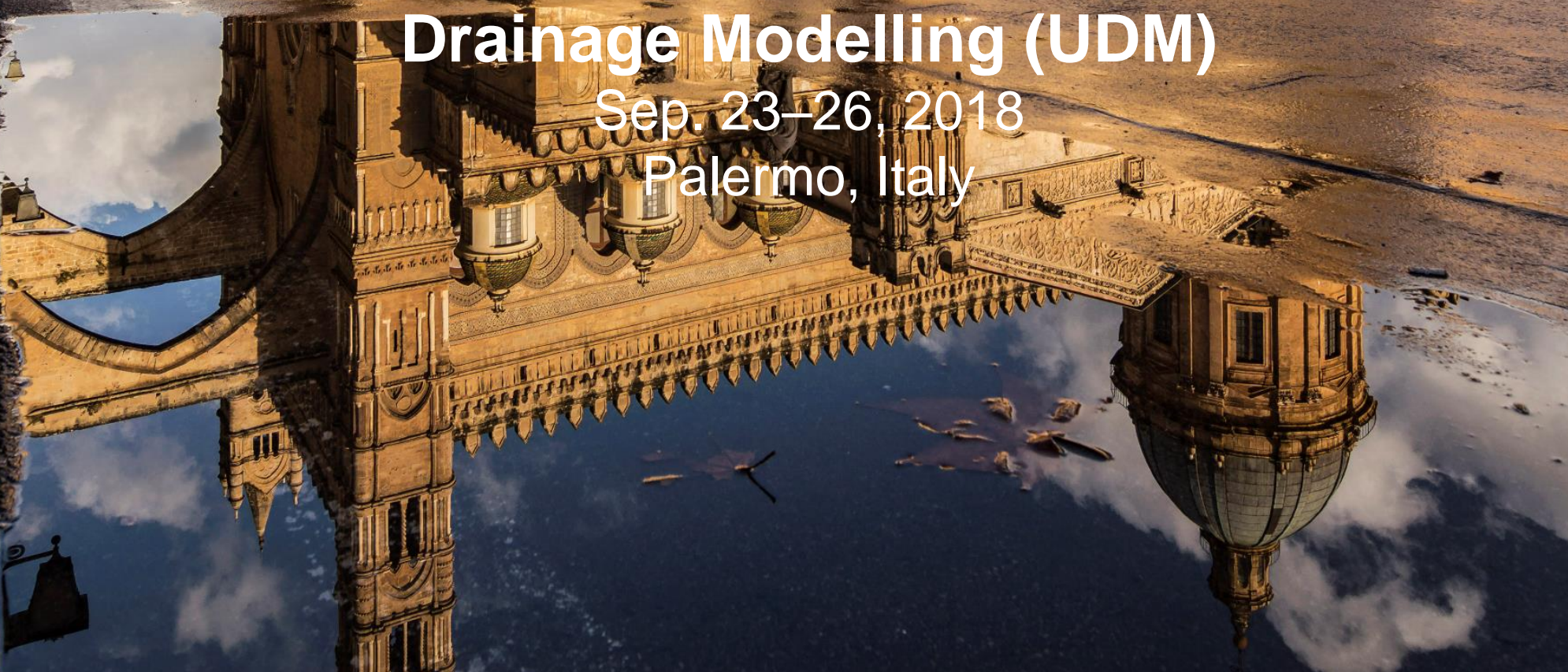





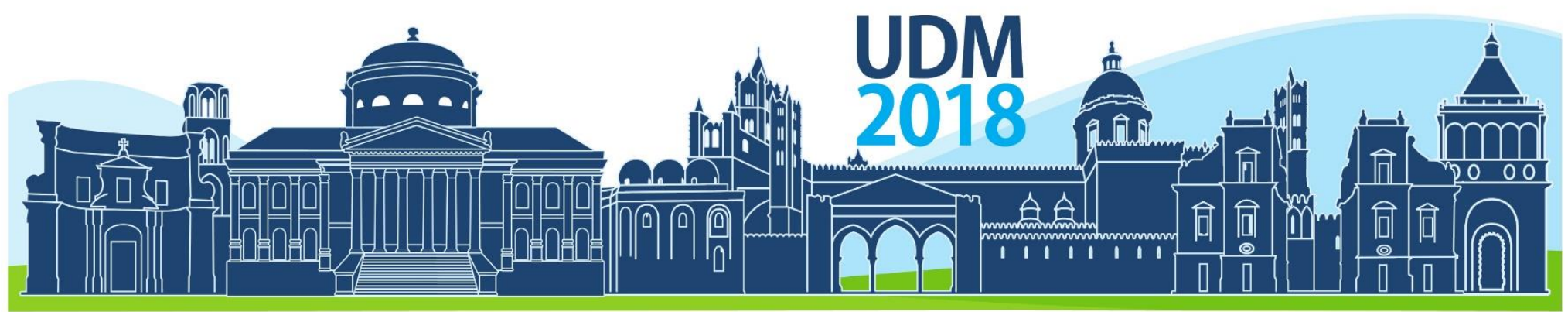

$11^{\text {th }}$ International Conference on Urban Drainage Modelling 23-26 Sep | Palermo - Italy

\section{PROCEEDINGS}

11th International Conference on Urban Drainage Modelling (UDM) Sep. 23-26, 2018 Palermo, Italy

Edited by Giorgio Mannina
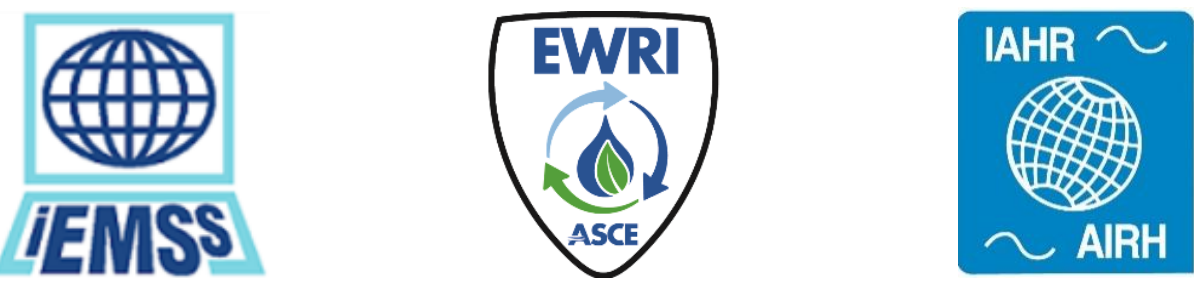


\section{Proceedings of 11th International Conference on Urban Drainage}

Modelling

Sep. 23-26, 2018, Palermo, ITALY.

How to cite the full proceedings: Mannina, G., 2018. Proceedings of 11th International Conference on Urban

Drainage Modelling

Sep. 23-26, 2018, Palermo, ITALY.

How to cite an individual paper:

Author, A., Author, B., Author, C..., 2018. This is the title of your paper. In: Mannina, G., 2018. Proceedings of 11th International Conference on Urban

Drainage Modelling Sep. 23-26, 2018, Palermo, ITALY.

Peer Review:

Each paper has been peer reviewed by at least three independent reviewers with possible outcomes of reject, revise, and accept. 


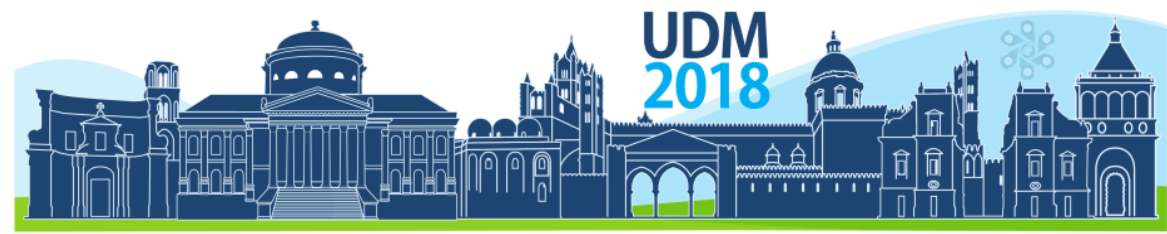

$11^{\text {th }}$ International Conference on Urban Drainage Modelling

23-26 Sep | Palermo - Italy

\section{Table of contents}

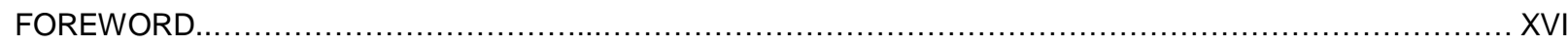

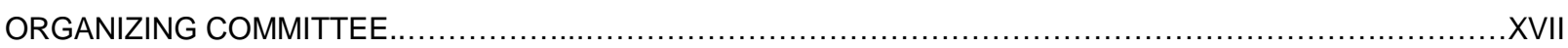

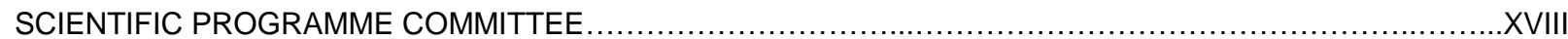

\section{Part A - Drainage and impact mitigation}

Keynote - From Rainwater Harvesting to Rainwater Management Systems

prof. D. Butler

Modelling to support the planning of sustainable urban water systems

A. Deletic, K. Zhang, B. Jamali, A. Charette-Castonguay, M. Kuller, V. Prodanovic, P.M. Bach.

A physically based model for mesoscale SuDS - an alternative to large-scale simulations

S. Haghighatafshar, M. Yamanee-Nolin, M. Larson.

Model-Based Sewer Network Control - Practical Experiences

C. Brepols, H. Dahmen, M. Lange, A. Sohr, R. Kiesewski, R. Rohlfing

Use of shrimp-shell for adsorption of metals present surface runoff

A. Schuck Rech, J. C. Rech, J. Caprario, F. A. Tasca 4, M. Á. Lobo Recio, A. Rodrigues Finotti

Nitrogen in infiltrated water from pervious pavements under different rainfall regimes and pollution build-up levels C. Hernández-Crespo, M. Fernández-Gonzalvo, M. Martín, I. Andrés-Doménech.

Where does infiltrated stormwater go? Interactions with vegetation and sub-surface anthropogenic features

J. Bonneau, T.D Fletcher, J. F Costello, P.J. Poelsma, R. B James, M. J Burns

Shifts of Resilience and Recovery of Aquatic Metabolism in Stormwater Green Infrastructure

T. Adyel, C. Oldham, M. Hipsey.

The Rainfall Interception Performance of Urban Tree Canopy in Beijing, China

X.Liu, Q. Chang.

Flood Risk Management in an Urban Area Applying LID Techniques

H. Ghafghazi, B. Dionisi, A. Zarlenga......

Enhancing the Retention Performance of a Small Urban Catchment by Green Roofs

A. Palla, I. Gnecco, P. La Barbera.

Model Testing and Laboratory Validation of Real-Time Control Strategy for Stormwater Biofilters

P. Shen, A. Deletic, D. McCarthy.

Understanding the impacts of stormwater control measures at the streetscape scale

M. J. Burns, T. D. Fletcher, P.J. Poelsma, R. B. James, J. Kunapo, T.J. Craig.

A Method to Identify Key Sub-catchments for LID Placement based on Monte Carlo Sampling

H. Guo, S. Zeng, X. Dong....

Assessing stakeholder receptivity to flood mitigation adaptation pathways

A. Wright, D. Rika Marthanty, C. Brodnik, C. Urich....

Green infrastructure and storage unit combinations for mitigating peak flows in drainage systems 


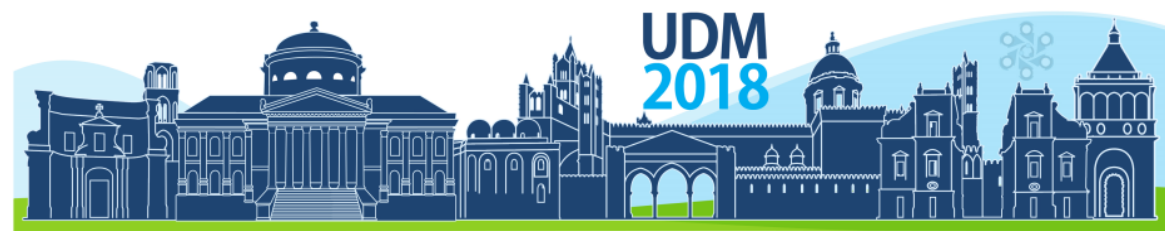

$11^{\text {th }}$ International Conference on Urban Drainage Modelling

23-26 Sep | Palermo - Italy

Y. Yang, T. F. May Chui.

Effects of LID-based Urban Designs on Water Balance

A. Khadka, T. Kokkonen, E. Lähde, T. Niemi, N. Sillanpää, H. Koivusalo

Internal fluctuations in green roof substrate moisture content during a storm event

Z. Peng, V. Stovin.

Developing a Stochastic Sewer Input Model to Support Sewer Design Under Water Conservation Measures

O. Bailey, J.A.M.H. Hofman, T.C. Arnot, Z. Kapelan, M. Blokker, J. Vreeburg.

Impact of biochar on treatment performance of roadside sand filters - field monitoring and geochemical modelling E. Assmuth, N. Sillanpää, L. Wendling, H. Koivusalo.

Measurement and planning-level modelling of retention of trace metals $(\mathrm{Cu}, \mathrm{Pb}, \mathrm{Zn})$ in soils of three urban drainage grass swales

S. Gavrić, T. Larm, H. Österlund, J. Marsalek, A. Wahlsten, M. Viklander.

Adaptation of SuDS Modelling Complexity to End-Use Application

Mohamad H. EL Hattab, A. Mijic.

Modelling Stormwater Pollutant Reduction with LID Scenarios in SWMM

C. Tuomela, D. Jato-Espino, N. Sillanpää, H. Koivusalo.

Water Recycling Long Term Plan for Managing Growth Risk

K. Rhodes, V. Greaves.

Resilience and its relation to system structure of combined sewer systems: virtual case study based on stochastic generation

D. Zhang, X. Dong, S. Zeng....

Developing a new modelling tool to allocate Low Impact Development practices in a cost optimized method N. R. Helmi, B. Verbeiren, M. El Hattab, A. Mijic, W. Bauwens.

Modelling of Green Permeable Car Park Water Retention

L. Varnède, D. Ramier, P. Georgel, Gromaire M.-C

Modelling study on the impacts of BMPs at Riacho Fundo (Brasília, Brazil)

V.T. Mineiro Camuzi, M. E. Leite Costa, A.Tavares Schleicher, J.da Costa, S. Koide.....

Advanced modelling of surface drainage systems drainage systems in reducing pluvial flood risk in urban areas

D. Rappazzo, G. T. Aronica.

Use of retention basin for flood mitigation and urban requalification in Mesquita, Brazil

O. Moura Rezende, M. Martins de Sousa, A. C. Pitzer Jacob, L. Batista de França Ribeiro, A. Krishnamurti Beleño de Oliveira, C. Matos Arrais, M. Gomes Miguez.

Quantifying Long-term Benefits of Multi-Purpose Rainwater Management Systems

P. Melville-Shreeve, D. Butler.

Swinging self-cleaning screen bars the Tube Hobas CSO Chamber, their physical properties and design

J. Prochazka, J. Pollert, O. Svanda.

A prioritization tool for SUDS planning in large cities by coupling an Urban Drainage Model with Mixed Integer Linear Programming

M. Narine Torres, Z. Zhu, J. P. Rodríguez.

Modelling bioretention systems

A. Finotti, M. C. Gromaire 


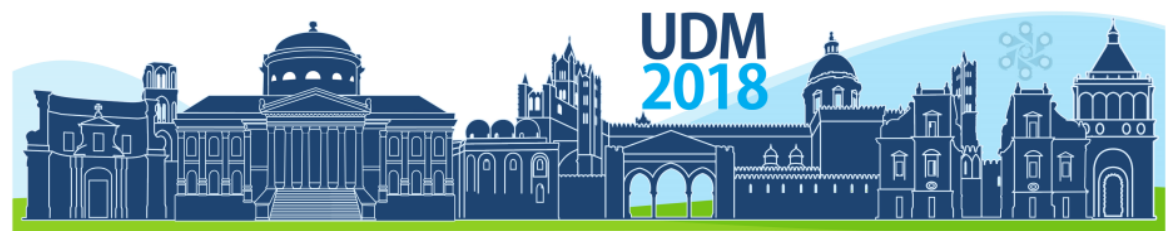

$11^{\text {th }}$ International Conference on Urban Drainage Modelling

23-26 Sep | Palermo - Italy

Overall Rate Kinetics Model of Chlorine Demand in Urban Drainage

J. Dickensoni, J. Sansalone.

Surface Runoff in Urban Area - Case Study

M. Zeleňáková, Z. Vranayová, A. Repel, D. Kaposztasová

Modelling different types of stormwater treatment facilities considering irreducible concentrations

T. Larm, A. Wahlsten.

Performance analysis of low impact development (LID) practices for the management of surface runoff: Applying the sponge city concept to a campus area

W. Yang, K. Brüggemann, K. D. Seguya, A. Sadeghikhah, J. Zhang, P. Krebs

Metals potential removal efficiency of permeable pavement

M. Turco, G. Brunetti, M. Porti, G. Grossi, M. Maiolo, P. Piro

Comparison of cost benefits of new installation and retrofitted rainwater harvesting systems for commercial buildings

N. H. Md Lani, A. Syafiuddin, Z. Yusop.....

Study on the Evaluation Methods for Drainage System of Ancient Buildings

J. Li, S. Zhang, S. Wu

Rainwater reuse in urban areas: a mathematical model and a long-term modelling approach

G. Freni, G. Mannina, M. Torregrossa, G. Viviani....

Long term efficiency analysis of infiltration trenches subjected to clogging

G. Freni, G. Mannina.

\section{Part B - Frontiers in urban drainage}

Keynote - Controlling Urban Drainage Systems

prof. G. Olsson.

Development of a smart system for the operation of a complex sanitation system

A. Lastra, J. Suárez, J. Puertas, J. Anta, X. Falcó, M. Ortega, A. Pinilla

Study on Realization of Storm Water Sewerage with Water Level Monitoring by the Use of Inundation Simulation

T. Kiyosu, K. Kariya, I. Ideta, H. Matsuoka

Holistic Water Cycle Management in Priority Growth Area in Sydney's West by Managing the Water Cycle Strategies of Individual Precincts

M. Pinto

Interaction between City Subsurface Infrastructure and Groundwater

C. Radu Gogu, M. Amine Boukhemacha, D. Gaitanaru, I. Moraru....

Assessment of Separation Efficiency of Reconstructed Combined Sewer Overflow in Debr (Czech Republic)

K. Soukupova, J. Nabelkova, J. Pollert, Petr Chmatal.

Frontiers in urban drainage - An analysis of a Preliminary Water Quality Recovery Program Plan in a developing country

F. A. Tasca, C. E. Januário Silva, M. V. de Abreu Lima, A. Rodrigues Finotti.

Modelling for Integrated Stormwater Management of the Renfrew Neighbourhood: A Pilot Study

S. Struck, M. Leisenring, L. Nguyen, D. Seeliger, B. van Duin, P. Lopez Hernandez, J. Cantone. 


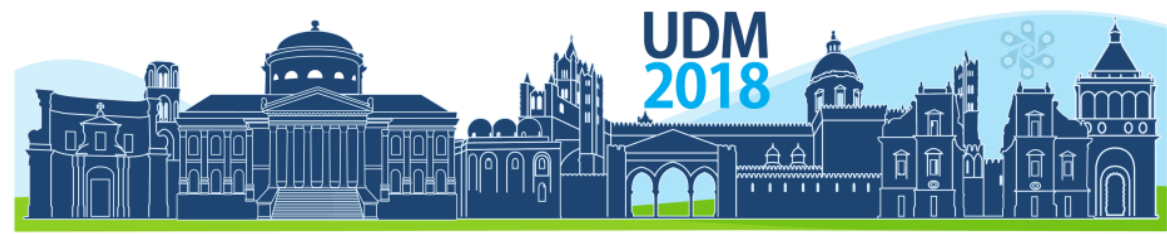

$11^{\text {th }}$ International Conference on Urban Drainage Modelling

23-26 Sep | Palermo - Italy

Urban Tunnel Systems for Conveyance and Storage of Storm- and Wastewater: Features, Classification, and Modelling

R. Palmitessa, M. Borup, P. S. Mikkelsen.

Continuous SWMM modelling of LID infrastructure in the Upper Qing Catchment, Beijing

M. Randall, M. Bergen Jensen......

Development of Screening Methods for Secondary Settling Tanks Monitoring and Optimization

O. Švanda, J. Pollert, I. Johanidesová.

FAVEUR - A Simple Model for Design Extensive Green Roofs

D. Ramier, E. Berthier, B. de Gouvello.

LID quantity and quality efficiencies in a subtropical urban catchment

C. A. Ferreira do Lago, M.a Batalini de Macedo, M. Hofheinz Giacomoni, E. M. Mendiondo......

Assessing uncertainty of a biofilter micropollutant transport model MPiRe

A. Randelovic, K. Zhang, D. McCarthy, A. Deletic.

Study for the proper management of rainwater withing the Mexican Water Technology Institute

R. Santos-Tellez, O. Llaguno Guilberto, M. Rodriguez Varela, M. Figueroa Mendiola.

Understanding Pollutant Transport in Urban Floodwater for Health Impact Assessment using a Physical Scale Model

J. Shucksmith, M. Rubinato, R. Martins, G. Kesserwani, J. Leandro, S. Djordjevic

Frontiers in Urban Drainage - How will Ubiquitous Sensing Change Urban Drainage Management?

J. Rieckermann, F. Blumensaat, J.P. Leitão, C. Ort, A. Scheidegger, P. A. Vanrolleghem, K. Villez.

Policy Analysis for Better Protection of Receiving Waters during Wet Weather

L. Manny, M. Fischer, J. Rieckerman.

Exploring the Use of Low Impact Development Strategies in a Low-Income Settlement in São Carlos, Brazil

M. F. Nóbrega dos Santos, A. F. Vasconcelos, A. Paceli Barbassa.

Controlling Stormwater Runoff from Impermeable Areas by Using Smart Inlets

N. Kändler, I. Annus, A. Vassiljev, R. Puust, K. Kaur...

Multi-criteria Evaluation of Sustainable Urban Drainage Systems

M. Radinja, J. Comas, LI. Corominas, N. Atanasova.

Exploring Uncertainty in Uncalibrated Bioretention Models

E. Fassman-Beck, F. Saleh.

Promoting Successful Urban Watershed Restoration through Enhanced Bioretention Cell Modelling

W. Lisenbee, J. Hathaway, R. Winston.

Wastewater modification processes in a stabilization reservoir: a new mathematical model

G. Mannina, G. Viviani, S. C. Chapra.

\section{Part C - Receiving water quality}

Keynote - Advances in river water quality modelling \& management: where we come from, where we are, and where we're going?

prof. S. C. Chapra.

Analysis of the Po River Environmental Compatibility

D. Panepinto, M. Zanetti, E. Lorenzi, M. Deceglia. 


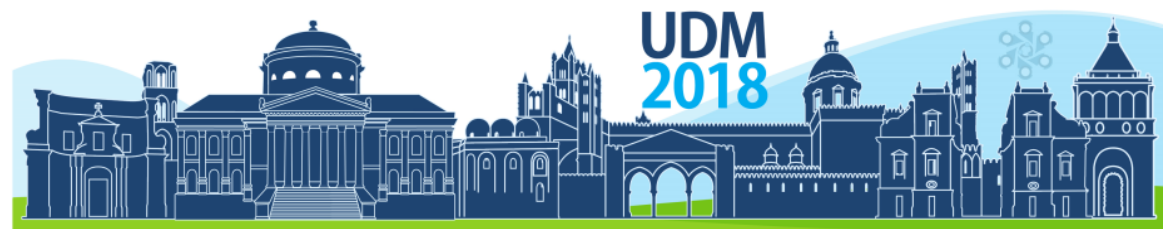

$11^{\text {th }}$ International Conference on Urban Drainage Modelling

23-26 Sep | Palermo - Italy

Parametric inference in large water quality river systems

A. Moreno-Rodenas, J. Langeveld, F. Clemens.

Interfacing stakeholder involvement into a surface water-quality modelling system for water management and policy development

K. E. Lindenschmidt, E. Akomeah, H. Baulch, L. Boyer, J. M. Davies, E. Hassanzadeh, L. Morales Marin, G. Strickert, M. Wauchope...

Transport of Traffic-Related Microplastic Particles in Receiving Water

M. Bondelind, A. Nguyen, E. Sokolova, K. Björklund.

Hybrid Filtration System for Treatment of Stormwater Runoff

J.H. Lee, S.H. Yang, D.H. Song.

Flow Features of an Unstable Tangential Vortex Intake

S.N. Chan, Q.S. Qiao, J.H.W. Lee.....

An integrated approach for assessing the impact of urban stormwater discharge on the fecal contamination in a recreational lake near Paris

Y. Hong, C. Li, B. J. Lemaire, F. Soulignac, J. R. Scarati Martins, A. Roguet, F. Lucas, B. Vinçon-Leite.

Digitalization meets reality - Concept and Experiences from long-term wireless data collection with $50+$ sewer monitors

F. Blumensaat, A. Scheidegger, C. Ebi, S. Dicht, F. Schaltegger, A. Rüst, U. Schmitt, M. Maurer 360

Flood risk mitigation in a Mediterranean Urban Area: the case study of Rossano Scalo (CS - Calabria, Italy)

P. Piro, M. Maiolo, V. Cataldo Talarico, S. Falco, G. Nigro, M.Pezzagno, F. C. Pavesi, F. Berteni, G. Grossi.

Flume test facility for the study of sediment transport in sewer pipes with raw wastewater

M. Regueiro-Picallo, J. Anta, J. Suárez, E. Sañudo, J. Puertas, A. Jácome.

Use of a 2D shallow waters model to assess the physical model topography obtained with a low cost photogrammetric technique.

J. Naves, J. Anta, J. Puertas, M. Regueiro-Picallo, J. Suárez, E. Sañudo.

Urban Flood Risk Modelling using Geospatial Tools for Bhubaneswar City, India

S. Bhattacharjee, P. Kumar, P. Thakur, K. Gupta.

Calibrating urban flood models with qualitative probabilistic flooding information extracted from CCTV footage

M. Moy de Vitry, S. Kramer, K. Villez, J. D. Wegner, J. Leitão.

Should we account for unexpected sources in improving the prediction of urban stormwater quality?

B. Shi, A. Lintern, P. Bach, K. Zhang, R. Coleman, L. Metzeling, D. McCarthy, A. Deletic.

Dissolved phosphorus treatment in stormwater biofilters enhanced with media amendments

A. Aiello, C. Berretta, M. Tillotson.

Measuring and modelling the nutrients residual load from the combined sewer of the eastern shore of Lake Iseo

L. Barone, M. Pilotti, M. Murgioni, G. Valerio, S.C. Chapra, M. Balistrocchi, L. Milanesi. 392

Multiregression analysis of the kinetic constants in ephemeral rivers: the case study of the Oreto river

A. Candela, G. Mannina, G. Viviani.

\section{Part D - Rainfall in urban areas}

A Generator-Disaggregation Approach for Evaluating Climate Change Impact on Urban Drainage W. Lu, X. Qin. 


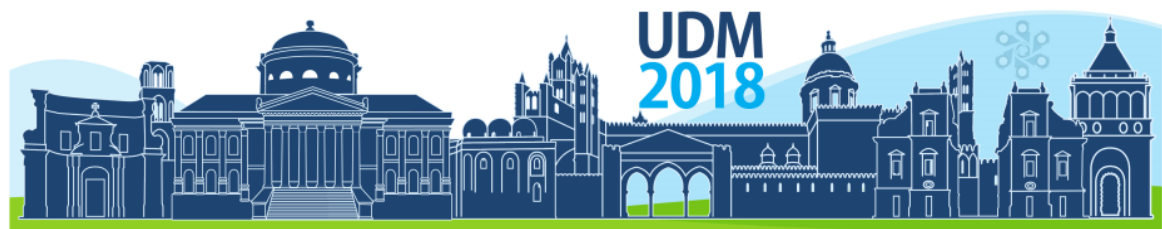

$11^{\text {th }}$ International Conference on Urban Drainage Modelling

23-26 Sep | Palermo - Italy

The influence of household rainwater harvesting system design on water supply and stormwater management efficiency

S. Ahilan, P. Melville-Shreeve, Z. Kapelan, D. Butler.

Anomalous Extreme Rainfall Variability Over Europe — Interaction Between Climate Variability and Climate Change H. Tabari, P. Willems.

Temporal Pattern Analysis of Rainstorm Events for Supporting Rainfall Design in a Tropical City

C. Jun, X. Qin, W. Lu...

Modelling of Green and Grey Roofs in Cold Climates using EPA's Storm Water Management Model

V. Hamouz, T. Merete Muthanna.

Coordinated Precipitation Evaluation of Damage-Producing Events: First Steps

T. Einfalt, S. Hinsken, M. Scheibel....

Influence of flood water contribution from multiple sources in extreme event statistics of urban flooding

S. Thorndahl, D. Murla-Tuyls, R. V. Nielsen, M. Schleiss, J. Olsson.....

Investigation of Impacts of Spatial Variability and Motion of Rainfall in Urban Drainage Modelling

C. B. Andersen, S. Thorndahl...

Performance of High-Resolution Numerical Weather Predictions with a Rapid Updating Cycle for Urban Runoff Forecasting

J. W. Pedersen, L. Vezzaro, H. Vedel, H. Madsen, P. S. Mikkelsen.

Urban Stormwater Monitoring and Modelling at the Riacho Fundo Sub-basin Brasilia - DF

T. Mitsuko Tsuji, M. E. Leite Costa, S. Koide.

Rain Gauge vs. Radar Measurements - Modelling an Extreme Rain Event with High Spatial Variability

T. Vonach, T. Einfalt, W. Rauch, M. Kleidorfer.

System-Wide Real Time Control Strategies for Overflow Volume Reduction - Extrapolating Annual Performance Indicators

L. Vezzaro.......

Influence of dynamic properties of rainfall on urban drainage infrastructure

M. Mrowiec, E. Ociepa, R. Malmur.

Modeling Infiltration Wells in SWMM and Comparing Its Performance with a Real-Scale Well

A. F. Vasconcelos1 T. S. Ferreira, M. F. Nóbrega dos Santos, A. P. Barbassa.

Modelling of storm precipitation

V. Ilinich, A. Belolubtcev, A. Cavalli, I. Veliev, M. Lapushkin.

Real-time CSO spill control using existing in-sewer storage.

N. Simões, L. Girão, L. Maluf, W. Shepherd, S. Ostojin, A. Sá Marques, S. Mounce, P. Skipworth, S. Tait, J. P. Leitão........

Type II (and Atlas 14) Storm Distribution Assumptions Yield Massive Over-estimates of Rainfall Intensity J. S. Tyner, D. C. Yoder......

Efficient calibration and validation of physical stormwater quality modelling by meta-model based approach J. Y. Hong, Q. Liao, C. Bonhomme, G. Chebbo...

Automatic Calibration Approach for Multiple Rain Events in SWMM using Latin Hypercube Sampling

B. Wagner, J. D. Reyes-Silva, C. Förster, J. Benisch, B. Helm, P. Krebs 


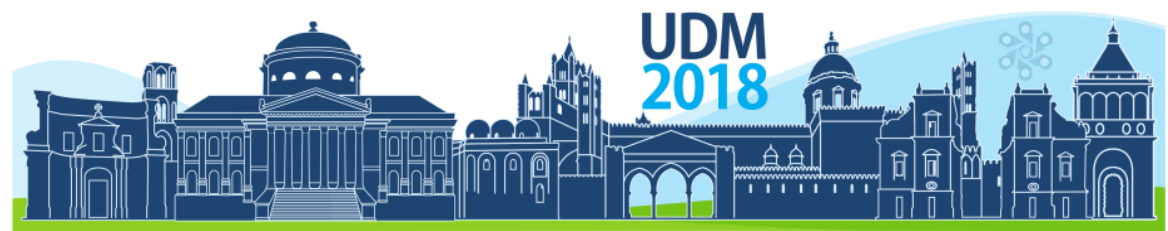

$11^{\text {th }}$ International Conference on Urban Drainage Modelling

23-26 Sep | Palermo - Italy

Commercial Microwave Links in Urban Drainage Modelling: On Deriving Precipitation Estimates for Various Link Lengths

J. Pastorek, M. Fencl, J. Rieckermann, V. Bareš. 488

Flash floods in urban areas: case studies in Reggio Calabria (Italy)

M. De Franco, M. Minniti, R. Versaci, G. Foti, C. Canale, P. Puntorieri.....

\section{Part E - Urban hydrologic and hydraulic processes}

Automatic Discretization and Parameterization of watersheds using a digital elevation model K. Finney, R. James, N. Perera, T. Xiao.

A Determination of pluvial flood hazards for critical infrastructures and buildings taking in account impacts of grid resolution in grid-based flood models

M. Jeskulke, A. Liebscher, H. Hoppe, T. G. Schmitt.

Seasonal variations in green roof hydrology

S. De-Ville, V. Stovin.

Analysing the cause of urban pluvial flooding in a hillside settlement

L. Simperler, F. Kretschmer, T. Ertl.

Implementation of GIS and Hydrologic/Hydraulic Modelling for Integrated Floodplain/Stormwater Management.

P. A. DeBarry P.E. P.H. GISP D.WRE, G. W. Longenecker P.E., R. Burrows P.E. CSI.

Uncertainty Quantification of Flood Damage Estimation for Urban Drainage Risk Management

M. Morita, Y. K.Tung.

Hydrological Modelling of a Road-side Vegetated Filter Strip: Validation of a Coupled 2D Subsurface Flow and 1D Overland Flow Model

T. Kanso, M. C. Gromaire, D. Ramier, G. Chebbo.

CA-ffe - a Cellular Automata Fast Flood Evaluation Model

B. Jamali, L. Cunningham, P. M. Bach, A. Deletic.

Importance of Subdivision Resolution of Surrogate Models for Emulating Catchment Response and Surcharge

C. Thrysøe, M. Borup, K. Arnbjerg-Nielsen.

Hydrologic performance simulation of green infrastructures: why data-driven modelling can be useful?

Y. Yang, T. F. M. Chui.

The Use of an Autocorrelation Function to Determine Urban Hydrological Catchment Characteristics

A. Bailey, A. Schellart, S. Tait.....

Assessing cost-effectiveness of different system structural characteristics in enhancing resilience of urban drainage systems

Z. Xu, Y. Zhao, X. Dong, P. Du

Multilayer Modelling as a Supporting Tool for Flood Diagnosis and Drainage System Design

M. Gomes Miguez, F. Dias Radesca, A. Pires Veról, M. Martins de Sousa, L. Feu Grancer Silva Oliveira.

A data analysis and modelling approach to understand the role of urbanization features on the hydrological regime.

G. Petrucci, K. De Bondt, P. Claeys.... .559

Sensitivity of water balance components to green roof parameters

J. Leimgruber, G. Krebs, D. Muschalla. 


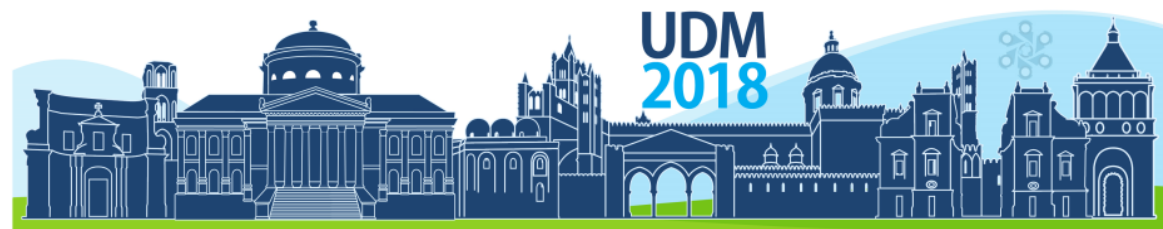

$11^{\text {th }}$ International Conference on Urban Drainage Modelling

23-26 Sep | Palermo - Italy

Transport capability of intake vortices at horizontal intake structures

N. Voßwinkel, J. Steinhardt, A. Schlenkhoff, R. Mohn.

Uncertainty analysis of pollutant-hydrograph model in assessing inflow and infiltration of sanitary sewer system

M. Wang, M. Zhang, Y. Liu...

Integration of green areas into a suburban flood model

B. Richter, C. Stapel, J. Tränckner....

Modelling Road Transport Congestion Due to Flooding

K. Pyatkova, A. S. Chen, D. Butler, S. Djordjević.

How important is the Physical interpretation and the role of the model user in urban flooding simulation?

M. Martins de Sousa, A. Krishnamurti Beleño de Oliveira, B. M. Gomes da Silva, M. Gomes Miguez.

Integrated urban flash flood risk assessment

S. Leitner, R. Maier, A. Sauer, C. Jöbstl, R. Ortlepp, R. Hornich, D. Muschalla.

Numerical and CFD-based modelling of concentrated domestic slurry in turbulent flow through circular pipes

D. Mehta, A. K. T. Radhakrishnan, J. van Lier, F. Clemens

A Framework to Assess Urban Floods Resilience

O. M. Rezende, A. B. Ribeiro da Cruz de Franco, A. Krishnamurti Beleño de Oliveira, A. C. Pitzer Jacob, M. Gomes Miguez.

Challenge of Transport: Exploring the Limit of Gravity Sewers to Transport Concentrated Domestic Slurries

A. Thota Radhakrishnan, J. Langeveld, J. van Lier, F. Clemens.

Impact of urbanization (trends) on hydrological behaviour of Belo Horizonte watersheds (Brazil)

M. Seidl, L. Palmier, G. Petrucci, N. Nascimento.

Urban Flood Management Based on Ensemble Precipitation Forecasts

T. Einfalt, S. Hellmers, A. Jasper-Tönnies.

Hydrology of Green Walls: Factor Assessment and Water Balance Modelling

V. Prodanovic, A. Wang, A. Deletic.

Modelling runoff in watershed without calibration using PCSWMM

D. Junqueira Carvalho, M. E. Leite Costa, J. da Costa, S. Koide...

Modelling Urban Drainage in Taquari - Federal District in Brazil

T.J. Brandão, M. E. Leite Costa, C. de Maria Albuquerque.

Evaluation of urban flooding hazard through the application of Bayesian Modelling Ensemble

G. Freni, V. Notaro.

\section{Part F - Tools, techniques and analysis in urban drainage modelling including Real-Time Control}

Keynote - Uncertainty in environmental water quality modelling: where do we stand?

Prof. A. Jakeman, B. Croke, B. Fu.

Integrated 1D/2D Urban Inundation Modelling with Refined Grid and OpenMP Parallelization

S. Lee.

Multiple regression analysis as a comprehensive tool to model flood hazard in sewersheds

D. Jato-Espino, N. Sillanpää, I. Andrés-Doménech, J. Rodriguez-Hernandez. 


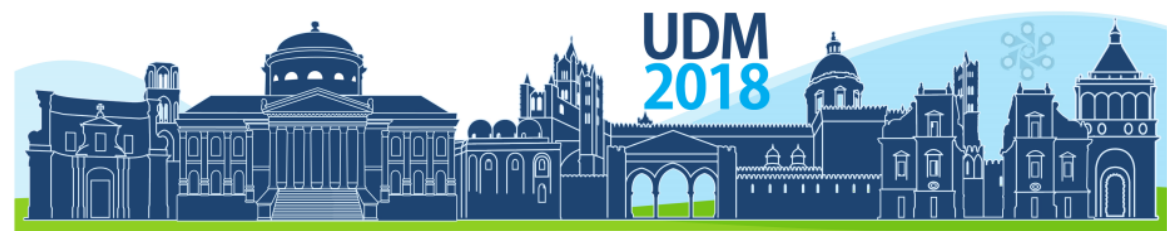

$11^{\text {th }}$ International Conference on Urban Drainage Modelling

23-26 Sep | Palermo - Italy

Generation of stormwater drainage networks using spatial data

A.Döring, I. Neuweiler.

A new Saint-Venant solver for SWMM

B. R. Hodges, F. Liu, A. C. Rowney.

Benefits of Real Time Control for Catchment Scale Stormwater Harvesting in Cape Town, South Africa

J. Okedi, N. P. Armitage.

SWMM Model Data Management and Development Using FME Software

L. Sänkiaho, T. Lampola.

Emulation of a Detailed Urban Drainage Simulator to Be Applied For Short-Term Predictions

M. Mahmoodian, J. A. Torres-Matallana, U. Leopold, G. Schutz, F. Clemens

Automated Approach for Rainfall-Runoff Model Generation

T. J. Niemi, G. Krebs, T. Kokkonen.

Comparison of Volume-based and Pollution-based Model-Predictive Controllers for Combined Sewer Network Regulation

B. Joseph-Duran, T. Maruejouls, D. K. Ly, J. Meseguer, G. Cembrano

Revisiting conceptual stormwater quality models by alternative linear and non-linear formulations: an event-based approach

S. Sandoval, J.L. Bertrand-Krajewski

Real-time water level prediction based on artificial neural networks

S. Berkhahn, I. Neuweiler, L. Fuchs.

Selection of calibration events for modelling green urban drainage

I. Broekhuizen, G. Leonhardt, J. Marsalek, M. Viklander.

Potential of Using Mass-Volume Curve Prediction for Water Quality-based Real Time Control

D. K. Ly, T. Maruéjouls, G. Binet, J. L. Bertrand-Krajewski.

Conceptual Framework for Integrating Real-Time Control and Source Control Solutions for CSO Frequency Control. M. Ė. Jean, S. Duchesne, G. Pelletier, M. Pleau.

Using the Ensemble Kalman Filter to update a fast surrogate model for flow forecasting.

N. Lund, M. Mazzoleni, H. Madsen, O. Mark, P. S. Mikkelsen, D. Solomatine, M. Borup......

Active Control of Combined Sewer Systems Based on Flow and Water Quality

T.T. Tanyimboh.

Long wave oscillations in a canal explained by a dynamic (PC)SWMM model

N. Peyron, W. James.

Can a surface overflow model predict particulate matter separation of unit operations?

S. S. Pathapati, J. Sansalone.

Experimental design to support water quality modelling of sewer systems

J. M. Ledergerber, T. Maruéjouls, P. A. Vanrolleghem......

Robust model for estimating pump characteristics and sewer flows from pumping station data

M. Fencl, M. Grum, M. Borup, P. S. Mikkelsen.

A graph-theory based algorithm to generate decentralized urban drainage layouts.

A. E. Bakhshipour, M. Bakhshizadeh, U. Dittmer, W. Nowak, A. Haghighi... 


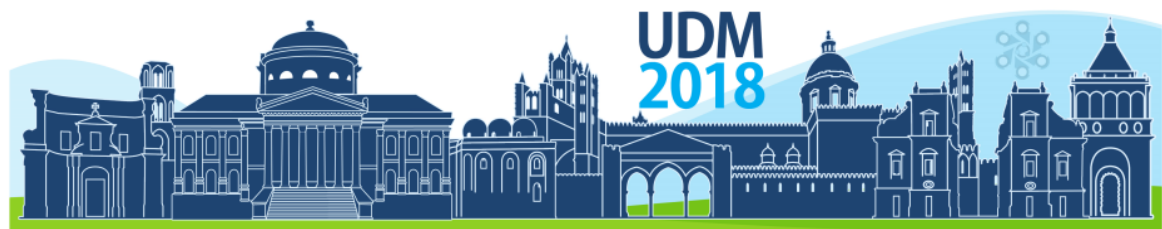

$11^{\text {th }}$ International Conference on Urban Drainage Modelling

23-26 Sep | Palermo - Italy

Supporting the needs and necessity for urban green stormwater infrastructure - a novel planning-support system

M. Kuller, P. M Bach, S. Roberts, D. Browne, A. Deletic..

Electro-Magnetic Velocity meters: Assessment of the (Missing) Technical Parameters

D. Ivetic, D. Prodanovic, L. Stojadinovic.

Urban Flooding and Adaptation to Climate Change in Sukhumvit Area, Bangkok, Thailand

S. Wongsa, V. Vichiensan, N. Piamsa-nga, S. Nakamura..

Hydrological Modelling and Detention Ponds Evaluation at Paranoa Lake - Brazil

F. Pereira de Souza, M. E. Leite Costa, S. Koide.

Using Precipitation and Combined Sewer Overflow Data for Predicting Hygienic Contaminations in Bathing Waters - A Data Analysis

A. Bachmann-Machnik, U. Dittmer, A. Schönfeld. .759

FloodCitiSense: Early Warning Service For Urban Pluvial Floods For And By Citizens and City Authorities

B. Verbeiren, S. Dagnachew Seyoum, I. Lubbad, T. Xin, M.C. ten Veldhuis, C. Onof, L. P. Wang, S. Ochoa-Rodriguez,

C. Veeckman, M. Boonen, L. See, D. Nalpas, B. O'Brien, A. Johnston, P. Willems.

Mitigation of Urban Surface Runoff through LID solutions: Case study in Mediterranean Area

F. Principato, A. P. Ferrante, F. Frega, M. Bartolo, P. Piro.

GESTOR: a new tool for the proactive management of sewer systems

O. Gutierrez, LI. Corominas, S.Busquets, L. Bosch, J. Garcia-Garcia, P. J. Martinez, O. Macias, I. Tormos, J. G.

Berlanga, N. Pi, A. P. Figueres, O. Soria..

Urban Flood Area Delimitation using Reverse Water Local Flow Paths

S. Rosim, J. R. de Freitas Oliveira, M. De Martino, A. Quarati, A. Copertino Jardim.

Numerical Unsaturated Flow Model of Railway Drainage Systems

L. Pinedo Ortiz de Mendivil, C. Berretta, A. Sleigh.

Characterization of the Dynamics of Microbiological and Chemical Contaminants in an Urban Catchment in South of France: From Field Data Collection to Modelling

M. Rio, M. G. Tournoud, C. Salles, C. Bancon-Montigny, P. Monfort, C. Rodier, M. Toubiana, P. Marchand........785

Water Quality-Quantity Model for Avcılar Campus of Istanbul University Incorporating LID Implementation

S. Gülbaz, A. Yıldırım, C. M. Kazezyılmaz-Alhan.

Combined Sewer Flow Prediction Using Hybrid Wavelet Artificial Neural Network Model

Z. Ayazpour, A. E. Bakhshipour, U. Dittmer. .794

\section{Part G - Modelling interactions and integrated systems}

Keynote - Frontiers in integrated modelling

Prof. W. Rauch.

From unknown to uncertain: A statistical model on gully pot silting

M. Rietveld, J. Langeveld, N. Mobron, F. Clemens.

Forecasting pollution transport in drainage water

R. Sämann, I. Neuweiler, T. Graf.....

Impact evaluation of Wet-weather Events on Influent Flow and Loadings of a Water Resource Recovery Facility

S. Borzooei, R. Teegavarapu, S. Abolfathi, Y. Amerlinck, I. Nopens, M. Zanetti. 


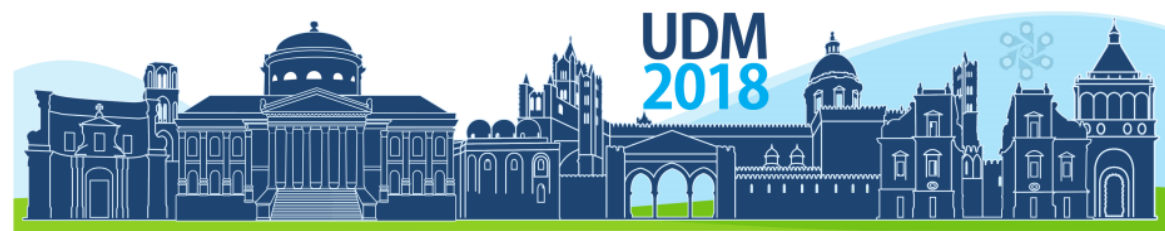

$11^{\text {th }}$ International Conference on Urban Drainage Modelling

23-26 Sep | Palermo - Italy

Modelling strategies to enable the uptake of decentralised water treatment technologies

A. C. Castonguay, M. S. Iftekhar, C. Urich, A. Deletic.

Wastewater System Ventilation - a Friend or Adversary?

S. Adkins, S. Djordjević, D. A. Savić.

Influence of drainage network and compensatory techniques on urban flooding susceptibility

J. Caprario, A. S. Rech, F. A. Tasca, A. Rodrigues Finotti.

An integrated model to develop and optimize wet weather strategies for river water quality in Odense (DK)

J. Hénonin, L. Benedetti, A. Brink-Kjær, E. J. Gill, P. Rasch, P. Hallager, P. H. Nielsen.

Sensitivity Analysis of an Integrated Urban Flood Model

R. Nielsen, S. Thorndahl.

Quantifying Benefits of Permeable Pavement on Surface Runoff, an Agent-Based-Model with NetLogo

O. Cortier, M. Boutouil, O. Maquaire.

Estimating flows in urban creeks - two case studies in Finland

L. Harilainen, P. Hyöty, T. Okkonen, A. Lunden-Morris.

Coupling Urban Water and Energy Budgets with TEB-Hydro: Case Study on the French Catchment Pin Sec

X. Stavropulos-Laffaille, K. Chancibault, A. Hervé, A. Lemonsu, V. Masson.

Calculation of the hydraulic capacity of grate inlets with supercritical surface flow and unsurcharged drainage flow conditions

S. Kemper, A. Schlenkhoff.

An Alternative Model Calibration Strategy for Watersheds Lacking Proper Data Records: Case Study of Riohacha, Colombia

A. K. Beleño de Oliveira, O. M. Rezende, M. M. de Sousa, M. Gomes Miguez 862

Model based assessment of sanitation systems for the integrated management of industrial discharges

L. M. García, J. A. Pelegino, L. Sancho, A. Ciriza, M. Gutiérrez, T. Fernández-Arévalo.

Effect of Aged Pipe Roughness's on Urban Flooding: Results from Sensitivity Tests with SWMM Model

M. Gourcerol, A. Moreno-Rodenas, M. Lepot, F.H.L.R Clemens.

Implementing sustainable sanitation in an integrated Model - A straightforward approach for long-term simulation

C. Campusano Garcia, I. Kaufmann Alves......

Cellular Automata Approach for 2D pollution transport modelling in urban groundwater

M. Milašinović, A. Ranđelović, N. Jaćimović, D. Prodanović.

Numerical soil model for analysing sewer pipe-soil interactions

I. C. Scheperboer, A. S. J. Suiker, E. Bosco, F. H. L. R. Clemens.

QUICS: how to deal with misconceptions in integrated model applications?

F. Tscheikner-Gratl, V. Bellos, A. Schellart, J. Langeveld, F. Clemens, G. B. M. Heuvelink, L. Benedetti, M. A.Rico-

Ramirez, R. F. Carvalho, L. Breuer, J. Shucksmith, S. Tait.

Longer pipes or smaller treatment plants? Impacts of connecting neighbouring sewer systems considering construction, detrimental emissions and its control strategies

LI. Corominas, S. Morera, O. Gutierrez...... 899

Sewer-groundwater Interaction in Urban Coastal Areas

T. Liu, M. Beheshti, X. Su, V. Prigiobbe. 


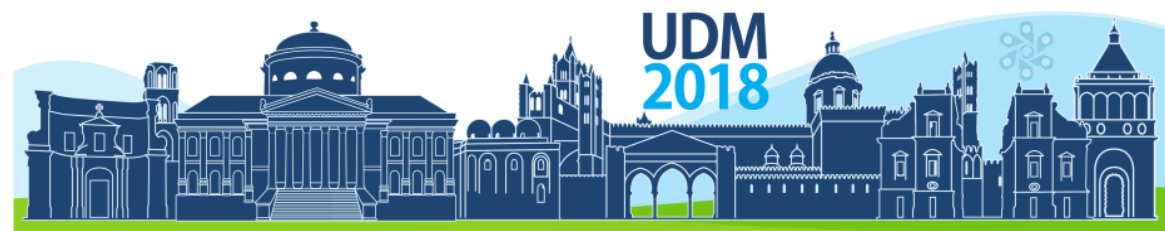

$11^{\text {th }}$ International Conference on Urban Drainage Modelling

23-26 Sep | Palermo - Italy

Validation of an unsteady flow numerical model for sediment transport induced by flushing operation in combined sewers

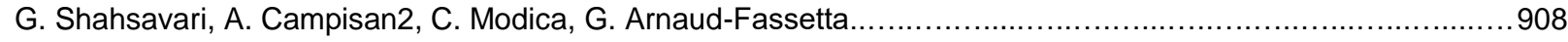

Smart Rain Barrels: Advanced LID management through measurement and control

M. Oberascher, J. Zischg, S. A. Palermo, C. Kinzel, W. Rauch, R. Sitzenfrei.

Numerical Modeling of Biogenic Sulphide Corrosion in Concrete Sewer Pipes

F.A.M. Rooyackers, E. Bosco, A.S.J. Suiker, F.H.L.R. Clemens.

Virtual modelling of city defence from spring flood with help of water reservoir

V. Ilinich, A. Perminov, F. Khairullina.

Visual Risk Communication of Urban Flooding in 3D Environments based on Terrestrial Laser Scanning

R. De Santis, F. Macchione, P. Costabile, C. Costanzo.

Water Quality Characterization of Irrigation and Storm Runoff for a Nursery

M. N. Yazdi, D. J. Sample, D. Scott, J. S. Owen.

Sewer flow prediction at a large urban scale: influence of radar rainfall spatial resolution

S. S. Cipolla, G. P. Di Ventura, M. Maglionico, P. P. Alberoni, A. Castellarin......

Integrated hydraulic and hydrological modeling of a constructed wetland for storm water management

P. Mancipe, A. Torres.

Uncertainty Propagation In Integrated Urban Water Quality Modelling

G. Mannina.

\section{Part H - Transport and sewer processes including Micropollutants and pathogens}

Percolation of Water from Surface Runoff - Case Studies

M. Zeleňáková, P. Hluštík, G. Markovič, G. Hudáková, L. Tometz.

Mathematical Modelling of In-sewer Processes as a Tool for Sewer System Design

G. Mannina, P. S. Calabrò, G. Viviani.

Detection of exfiltration in sewer systems with tracers

B. Stegeman, J. Langeveld, T. Bogaard, F. Clemens

Improving the hydraulic integrity to separate the sewer system in hilly regions using a new manhole design

A. Abbas, I. Carnacina, F. Ruddock, R. Alkhaddar, G. Rothwell, R. Andoh

Dynamic Modelling and Comparison of H2S Mitigation Strategies

B. Tomicic, M.J. Kjølby, M. H. Andersen.

Testing new stormwater pollution build-up algorithms informed by genetic programming approach

K. Zhang, P. Bach,, D. McCarthy, A. Deletic....

Estimation of Faecal Indicator Bacteria in Stormwater by Multiple Regression Modelling and Microbial Partitioning to Solids

H. Galfi, H. Österlund, J. Marsalek, M. Viklander.

Illicit Connections and Antibiotic Resistant Bacteria in Urban Surface Water: What is Their Relation?

R. Schilperoort, H. Blaak, H. Schmitt, A. Hof, J. Meijerink, B. Palsma, J. Langeveld.

Evaluation of hydrogen sulphide formation in a mega-sized tunnel sewer system: experimental and modelling Investigations

Z. Liang, J. Sun, F. Jiang. .988 


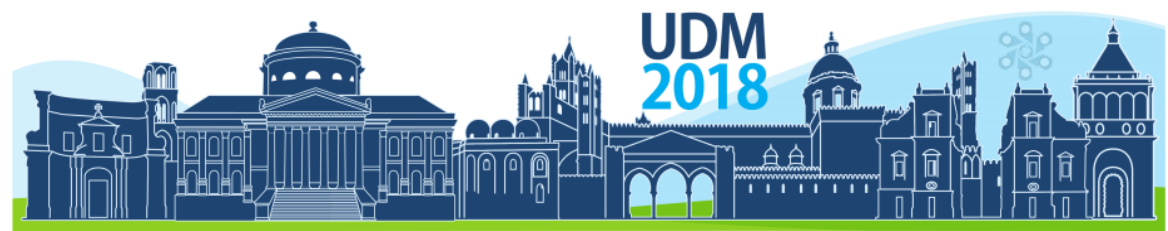

$11^{\text {th }}$ International Conference on Urban Drainage Modelling

23-26 Sep | Palermo - Italy

A Dynamic Pharmaceuticals Loads Source Generator

T. Pouzol, Y. Lévi, J. L. Bertrand-Krajewski.....

Developing and Validating a Model to Assess Sewer Sediment Issues from Changing Wastewater Inflows and Concentration

M. K. Murali, M. R. Hipsey, A. Ghadouani, Z. Yuan. .997

Using Mass-Volume-Curves to Assess the Empirical Pollutant Modelling Concept

D. Leutnant, D. Muschalla, M. Uhl.

Conceptualizing the sewage collection system for integrated sewer-WWTP modelling and optimization

L. Guo, S. Tik, J. M. Ledergerber, D. Santoro, E. Elbeshbishy, P. A. Vanrolleghem.....

Modelling of heavy metals and PAHs concentration in urban stormwater runoff

A. Sadeghikhah, J. Zhang, P. Krebs.

Multiphase CFD-Simulation of Transport Phenomena in Sewer Systems

K. Teuber, T. Broecker, S. D. Jaydev, G. M. Goitom, M. Sielaff, D. Despot, D. Stephan, M. Barjenbruch, R. Hinkelmann

The efficiency of storm water sedimentation tanks for fine particles in urban run-off

M. Wietbüscher, N. Voßwinkel, R. Mohn.

Relevance Of Different CSO Outlets For Bathing Water Quality In A River System

M. Riechel, W. Seis, A. Matzinger, E. Pawlowsky-Reusing, P. Rouault.

Pollutant loading of different particle size fractions compared to the pollutant loads of urban stormwater runoff events

B. Philipp, D. Ulrich.

Spatiotemporal modelling of sediment-related blockages in the sewer system of Bogotá (Colombia)

E. Soriano Pulido, C. Valencia Arboleda, J. P. Rodríguez Sánchez.

Modeling storm water pipe leakage: transient vs. steady-state groundwater flow

A. Peche, T. Graf, J. Kidmose, H. B. Christiansen, L. Fuchs, I. Neuweiler.

Just Suspended Speed For Solid Particle Transport In Torus Reactor

A. Alouache, A. Selatnia, F. Halet, L. Abdelouhab, S. Houssem Eddine, B. Nadjemi.

Stormwater Runoff Treatment Filtration System and Backwashing System

J.H. Lee, M.J. Lee, S.H. Yang.

Microalgae Cultivation using Various Sources of Organic Substrate for High Lipid Content

H. Kamyab, S. Chelliapan, C. T. Lee, S. Rezania, A. Talaiekhozani, T. Khademi, A. Kumar.

Partitioning of metals in urban drainage from paved source area catchments

I. Gnecco, A. Palla, J. Sansalone.

\section{Part I - Water management, society and climate change}

Keynote - Advances in modelling particle transport in urban storm- and wastewater systems

Prof. P.A. Vanrolleghem, S. Tik, P. Lessard.

Redesign of water quality network for the urban rivers in Salitre in Bogotá, Colombia, using an artificial neural network

C. Peña-Guzmán, P. Balaguera, N. Hernandez, R. Sierra..

Uncertainties in estimating the economic benefits from blue and green stormwater infrastructure

R. Ashley, B. Gersonius, B. Horton, C. Digman, P. Shaffer.... 


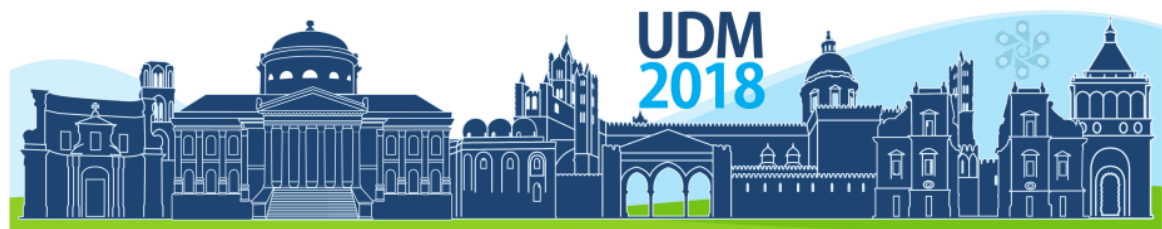

$11^{\text {th }}$ International Conference on Urban Drainage Modelling

23-26 Sep | Palermo - Italy

Evaluating city scale surface water management using a rapid assessment framework in Melbourne, Australia J. L. Webber, M. J. Burns, G. Fu, D. Butler, T. D. Fletcher.

Optimizing SVM model as predicting model for sewer pipes in the two main cities in Colombia

N. Hernández, N. Caradot, H. Sonnenberg, P. Rouault, A. Torres.

Climate Change Impact on Water Supply Demands: Case Study of the City of Skopje

K. Donevska, A. Panov.

Impacts of in-sewer defects on human health risks compared with impacts of climate change

H. Korving, M. van Bijnen

Combined sewer overflow management: proof-of-concept of a screening level model for regional scale appraisal of measures

A. Pistocchi, C. Dorati

Early stage planning tools for stormwater quantity and quality management in Denmark and China

D. M. Reinholdt Jensen, S. M. Lerer, L. Vezzaro, H. J. D. Sørup, K. Arnbjerg-Nielsen, X. Li, P. S. Mikkelsen.....1097

Selection of the Best Water Supply Scenario for Urban Demand based on the Risk Analysis in Decision-Making Model R. J. Sabbaghian, A. P. Nejadhashemi.

How to make our models relevant for decision-makers by using stakeholder analysis?

J. Skrydstrup, H. M. Madsen, R. Löwe, H. Thorén, K. Arnbjerg- Nielsen.

Impacts of urban development on urban water management at varying spatial and temporal scales

R. Löwe, M. Mair, A. N. Pedersen, W. Rauch, M. Kleidorfer, K. Arnbjerg-Nielsen.

Rainwater harvesting system efficiency and economic assessment for different residential building typologies.

S. Corvaro.

Model based estimation of a natural water balance as reference for planning in urban areas

M. Henrichs, A. Steinbrich, H. Leistert, I. Scherer, T. Schuetz, M. Uhl, M. Weiler....

Preliminary analysis about the effects on the SPI values computed from different best-fit probability models in two Italian regions

C. Mineo, B. Moccia, F. Lombardo, F. Russo, F. Napolitano

Energy Assessment of Seawater Toilet Flushing in Qatar

H. R. Mackey, S. Hafiz, S.G. Al Ghamdi.

Modelling climate changes impacts in a subtropical urban drainage

C. A. Ferreira do Lago, M. Batalini de Macedo, E. M. Mendiondo.....

Heavy metals in wash-off from facade and road surface

Z. Wang, P. Hua, A. Sadeghikhah, J. Zhang, P. Krebs.

An assessment of per capita water consumption in Sirte, Libya

I. Alharsha, F. Memon, R. Farmani.

Applying Socioeconomic Optimisation on Blue-Green Climate Adaptation Projects in an Urban Catchment S. Davidsen, T. Kruse, T. Stausgaard Munk, K. Arnbjerg-Nielsen

Virtual Reality in Water Sensitive Urban Design - new data and insight or just playful participation?

P. M. Bach, H. J. Bragge, M. Saberi.

Conceptual Modeling of Micropollutant Fate in Sewer Systems - A GIS-Based Approach to Define Model Structure. R. Delli Compagni, F. Polesel, K. J.F. von Borries, Z. Zhang, A. Turolla, M. Antonelli, L. Vezzaro. 


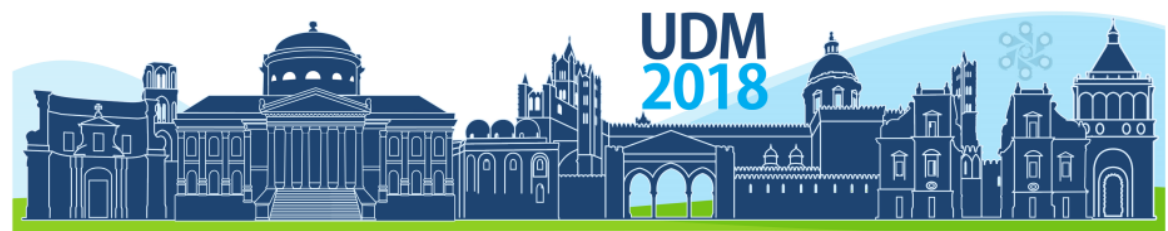

$11^{\text {th }}$ International Conference on Urban Drainage Modelling

23-26 Sep | Palermo - Italy

Valuable outcomes in urban hydrology deriving from CFD modelling approach

K. G. Lipeme

Modelling overland flow from local inflows in "almost no-time" using Self-Organizing Maps

J. P. Leitão, M. Zaghloul, V. Moosavi....

Parameter Sensitivity of a Microscale Hydrodynamic Model

S. A. Palermo, J. Zischg, R. Sitzenfrei, W. Rauch, P. Piro.

Modelling of Food Waste Disposer particle transport through a sewer network

A. Legge, A. Nichols, H. Jensen, R. Ashley, S. Tait.

Data-driven Method to Modeling Flows Across Combined Sewer Systems

Y. Hu, B. Kerkez

Leveraging Open Source Software and Parallel Computing for Model Predictive Control Simulation of Urban Drainage Systems using EPA-SWMM5 and Python

J. M. Sadler, J. L. Goodall, M. Behl, M. M. Morsy

Remobilization of Sediments in Gully Pots During High Intensity Precipitation Events

T. M. Muthanna, M. Viklander

Distributed Sewer System RTC in Öhringen - On the Way to the Internet of Things

M. Schütze, N. Suchold, H. Geiger 


\title{
Foreword
}

In recent decades, urban drainage systems are receiving increased attention as interests in sustainable water resources grow. Modelling of urban drainage system is of paramount importance for enhancing human life. Specifically, modelling of urban drainage system focuses on the main and advanced topics (e.g., water quality and quantity, urban flooding and modelling, urban flood forecasting and risk analysis, socio-economic interactions and modelling tools, etc... ) by paying the attention on the interrelationships among the entire water cycle, environment and society.

The book contains contributions presented during the 11th International conference on Urban drainage modelling (UDM) was held in September 23-26, 2018 in Palermo, ITALY. This was the eleventh in the series of UDM events and is a joint activity of: the International Working Group on Data and Models of the Joint IAHR / IWA Committee on Urban Drainage, the Environmental and Water Resources Engineering | ASCE, the International Environmental Modelling and Software Society (iEMSs). The UDM Conference was hosted and received also the support of the University of Palermo.

The UDM final aim was to create a forum for promoting the discussion amongst scientists, professionals and academia in different areas of the broader themes.

The conference was organized in nine parallel sessions and for each of them a keynote by a referral researcher was presented. Specifically, the keynotes were held by the following professors, whose contributions were highly inspiring: Jean-Luc Bertrand-Krajewski, David Butler, Steven Chapra, Ana Deletic, Anthony Jakeman, William James, Gustaf Olsson, Wolfgang Rauch and Peter Vanrolleghem.

The wealth of information exchanged during UDM was of great benefit to all involved in challenging environmental issues.

The book is organized in nine parts: Part A - Drainage and impact mitigation (BMP, LID, CSO quality and quantity, etc), Part B - Frontiers in urban drainage, Part C - Receiving water quality, Part D - Rainfall in urban areas, Part E - Urban hydrologic and hydraulic processes, Part F - Tools, techniques and analysis in urban drainage modelling including Real-Time Control, Part G - Modelling interactions and integrated systems, Part H Transport and sewer processes including Micropollutants and pathogens and Part I Water management, society and climate change.

Each contribution of the conference has been peer-reviewed by at least two members of the scientific committee. Their efforts have contributed to the high quality of the final book contributions and, therefore, their reviewing activity is acknowledged and appreciated.

I do hope that the reader will find the book a source of inspiration for both research and professional life.

\author{
Giorgio Mannina \\ Professor of Sanitary and environmental engineering \\ University of Palermo, Palermo (Italy) \\ Fulbright Research Fellow at Columbia University (New York, USA) \\ Chair of the 11th IWA/IAHR International Conference on Urban drainage modelling
}




\section{Organizing Committee}

Giorgio Mannina, Conference Chair, University of Palermo - Italy Angela Candela, University of Palermo - Italy Giovanni B. Ferreri, University of Palermo - Italy Goffredo La Loggia, University of Palermo - Italy Enrico Napoli, University of Palermo - Italy Michele Torregrossa, University of Palermo - Italy Gaspare Viviani, University of Palermo - Italy 


\section{Scientific Programme Committee}

Giorgio Mannina, Italy - Conference Chair

Dan Ames, USA

Karsten Arnbjerg-Nielsen, Denmark

Giuseppe Aronica, Italy

Richard Ashley, UK

Simon Beecham, Australia

Vincenzo Belgiorno, Italy

Lorenzo Benedetti, Croatia

Jean-Luc Bertrand-Krajewski, France

David Butler, UK

Alberto Campisano, Italy

Pierluigi Claps, Italy

Francois Clemens, The Netherlands

Ana Deletić, Australia

Slobodan Djordjevic, UK

Thomas Einfalt, Germany

Raymond A. Ferrara, USA

Tim Fletcher, Australia

Lothar Fuchs, Germany

Haifeng Jia, China

Ivana Kabelkova, Czech Republic

Manfred Kleidorfer, Austria

Jeroen Langeveld, The Netherlands

Yanchen Liu, China

Jacek Makinia, Poland

Cedo Maksimovic, UK

Jiri Marsalek, Canada

David McCarthy, Australia

Peter Steen Mikkelsen, Denmark

Dirk Mushalla, Austria

Fumiyuki Nakajima, Japan

Patrizia Piro, Italy

Francesco Pirozzi, Italy

Wolfgang Rauch, Austria

Jorg Rieckermann, Switzerland

Gilles Rivard, Canada

Juan Pablo Rodriguez Sanchez, Colombia

Ignasi Rodriguez-Roda, Spain

Takashi Sakakibara, Japan

John Sansalone, USA

Keshab Sharma, Australia

Manfred Schuetze, Germany

Robert Sitzenfrei, Austria

Virginia Stovin, UK

Geoff Syme, Australia

Simon Tait, UK

Soren Thorndahl, Denmark

Peter A. Vanrolleghem, Canada

Gaspare Viviani, Italy

Jes Vollertsen, Denmark

Patrick Willems, Belgium

Mariachiara Zanetti, Italy 


\section{Part A - Drainage and impact mitigation}




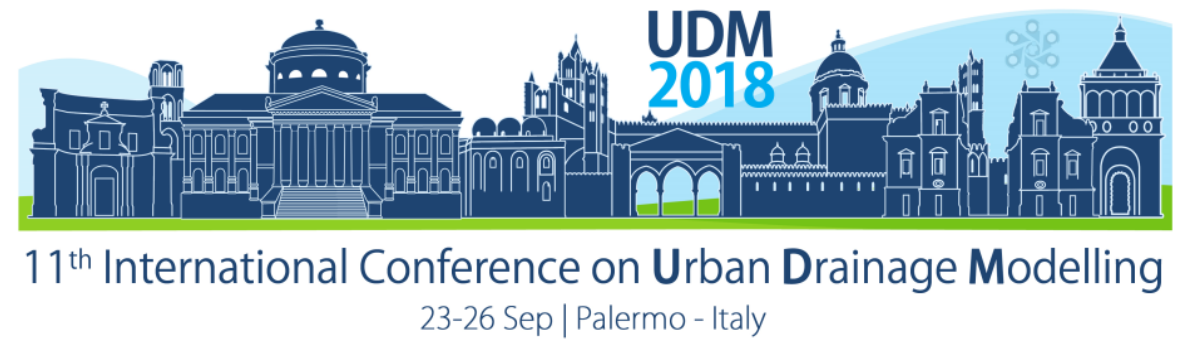

\title{
From Rainwater Harvesting to Rainwater Management Systems
}

\author{
David Butler \\ University of Exeter, Centre for Water Systems, Exeter, UK
}

\begin{abstract}
This keynote extended abstract investigates the recent shift in the drivers, objectives and application of rainwater harvesting. A review of historical rainwater harvesting technologies was undertaken and the context set for rainwater to be valued as an alternative water resource in specific circumstances. Recent research and exemplars were reviewed which suggest that the widespread use of the term rainwater harvesting, no longer captures the nuanced applications of rainwater capture and control technologies. A conceptual model was presented which sees rainwater management systems used as a term to cover installations and associated technologies and practices where rainwater harvesting features are also used to manage stormwater discharges. Global exemplars were identified where active / smart rainwater management systems have been successfully deployed to achieve wide ranging benefits. To evidence the broader benefits of rainwater management systems, a supply-demand analysis was used to investigate three different rainwater management types for a household in Palermo, Sicily. The abstract concludes with reflections on the future of rainwater management systems and the opportunities they could pose to increase urban resilience to threats such as water shortages, extreme hot weather, stormwater flooding, sewerage overflows, and a changing climate.
\end{abstract}

Keywords: Alternative water systems; rainwater harvesting; rainwater management systems; stormwater management; SuDS; water efficiency.

\section{INTRODUCTION}

In recent decades, rainwater harvesting $(\mathrm{RWH})$ deployment has seen a resurgence in urban settings (Burns et al., 2014; DeBusk et al., 2013; Herrmann and Schmida, 1999). The capture, storage and use of rainwater as a non-potable water supply is supported by policy and design standards throughout many developed nations (e.g. BSI, 2013; Standards Australia, 2008). Furthermore, RWH systems are deployed in developing nations as a simple, low cost solution to providing local water supplies (Naddeo et al. 2013). The technology ranges from very simple solutions $(<\$ 50)$ to complex multi-objective systems $(>\$ 100,000)$ which can include real-time control features, treatment to potable standards and SCADA-style monitoring systems (Campisano et al., 2017; Melville-Shreeve et al. 2016). With a growing set of technologies now described under the heading $\mathrm{RWH}$, this keynote extended abstract seeks to investigate the emerging transition from rainwater harvesting to rainwater management systems. Following a review of RWH solutions deployed in previous millennia, contemporary RWH systems are described through reference to published works and design manuals. A conceptual model and alternative terminology is proposed. The performance of a rainwater management system (RMS) is investigated at a case study location. The future application of and opportunities for RMS are discussed, particularly in terms of threat mitigation and multiple benefits. 


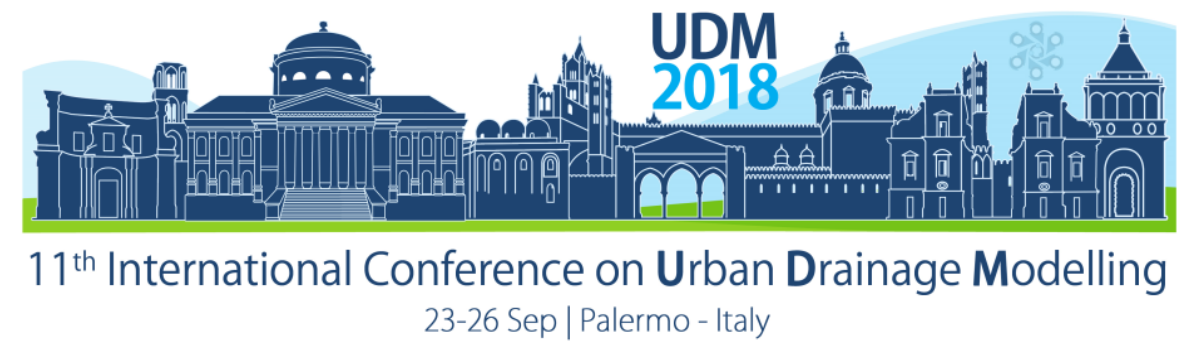

\section{RAINWATER HARVESTING}

RWH has been a staple of water provision throughout many parts of the world for millennia (Crasta, 1982; Radharkrishna, 2003). The technology involves the interception, capture, storage and use of rainwater falling on roofed areas (Herrmann and Schmida, 1999). In parts of the globe with low levels of economic development, the practice of harvesting rainwater still represents a key water resource (Islam et al., 2010, Ishaku et al., 2012,). Early examples of $\mathrm{RWH}$, include cisterns lined with waterproof lime identified as far back as Neolithic times (5500BC) in Palestine (Mays et al. 2013). Water storage structures in India were constructed to collect water from manmade rain catchments where some existing water infrastructure dates back over 1000 years. In the Middle East, stone inscriptions offer insights to ancient empires and their need for water storage infrastructure. AbdelKhaleq \& Ahmed (2007) describe the Moabite Stone which documents water storage efforts in Jordan as far back as 850BC. In each case, these ancient structures illustrate the viability of rainwater as a water resource in a preindustrial age. Furthermore, they exemplify the benefits of high quality construction and the need for long term design horizons. The existence of these structures and their ongoing use illustrate that simple RWH systems are not a novel idea. Their longevity demonstrates the need to evaluate RWH systems over long time frames as both financial and environmental benefits may not be realised when short term financial goals are prioritised.

Contemporary RWH saw a further resurgence in developing nations as the deployment of outhouses and sanitary systems required decentralised water resources. Patents illustrate $\mathrm{RWH}$ technologies were being used to deliver rainwater to toilets in Victorian Britain (Adams, 1928). However, without relatively low cost and reliable tanks and pumps, deployment was constrained to local efforts, as there was a lack of strategic policy driving its uptake. By the 1980 s, Germany is one example of a country which embraced the opportunities presented by decentralised RWH systems and efforts to drive it's uptake through policy have continued for decades (Soler et al. 2018). These policies have led to significant uptake of RWH with Partzsch (2009) reporting 80,000 installations per annum at a value of $340 \mathrm{~m}$ Euros. Meanwhile similar policy has successfully driven RWH deployment in urban settings as a reaction to periods of drought in parts of the USA and Australia. For example, following the incentives instigated after the Millennium Drought, Melbourne is reported to have RWH at $30 \%$ of households (Low et al. 2015). Globally, the growth of RWH policy incentives are likely to continue on a planet where population growth, population density and a changing climate present a positively reinforcing need for local rainwater capture and reuse (Haque et al., 2016). The whole life financial viability of RWH has been shown to be precarious, particularly at single household level (Roebuck et al., 2011). However, LCA studies have shown significant wider benefits from the wide deployment of such systems (Wang \& Zimmerman, 2014). Current research focuses on low cost, low energy systems and the particular challenge of retrofittable solutions (MelvilleShreeve et al. 2016).

\section{RAINWATER MANAGEMENT SYSTEMS}

In recent years, there has been a shift in focus (particularly in the academic community) from single objective RWH for water retention (with the purpose of water use), to RWH for water retention and detention (with the additional purpose of stormwater management). Evidence from recent papers (Campisano et al., 2017, Melville-Shreeve et al., 2016) suggests that the term rainwater harvesting $(\mathrm{RWH})$ does not necessarily suitably describe this new function and the complex settings and niches associated with the global deployment of the technology. Even when supported by other terms (e.g. dual-purpose RWH) the reader remains uncertain 


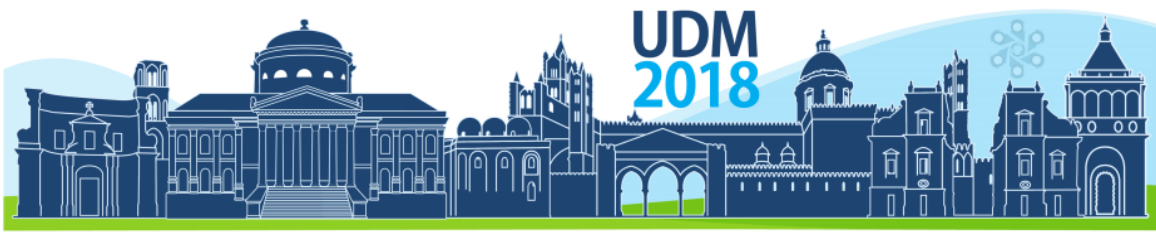

$11^{\text {th }}$ International Conference on Urban Drainage Modelling

23-26 Sep | Palermo - Italy

as to which dual-purposes the RWH has been designed, and furthermore, they have no understanding as to which purpose (if any) was the key design driver. It is therefore suggested that such systems could sit within a niche termed "rainwater management systems" (RMS) as illustrated in Figure 1. In this figure, the term SuDS (sustainable drainage systems) is used as a shorthand for non-pipe based stormwater management options as described in detail by Fletcher et al. (2015). The key distinguishing features of RMS are that they are decentralised and manage rainfall at source for multiple purposes.

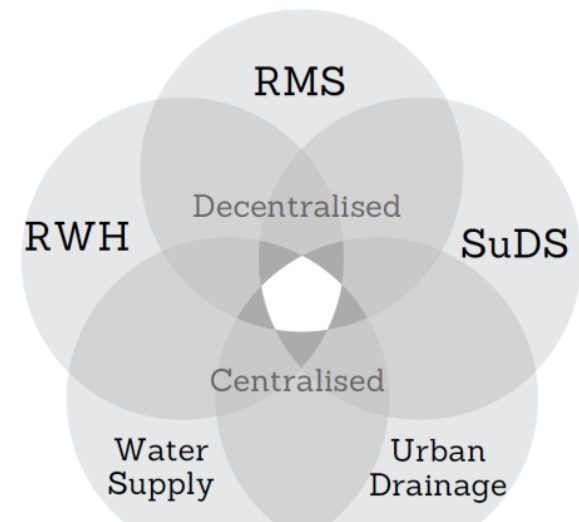

Figure 1. Conceptual model indicating role of Rainwater Management Systems (RMS)

RMS can be categorised into three broad categories:

1. Water supply plus indirect stormwater management - systems with oversized single tanks to maximise the detention of stormwater in addition to water for supply (potable or non-potable, depending on context)

2. Water supply plus direct, passive stormwater management - two tank (or tank compartment) systems designed to operate passively.

3. Water supply plus direct, active stormwater management - two tank (or tank compartment) systems designed to be operated actively, either locally or remotely.

To illustrate the potential for RMS, a hypothetical house located in Palermo, Sicily has been evaluated in terms of rainwater use and stormwater discharges for the year 2008 (European Climate Assessment \& Dataset, 2018). A large storage tank (3000 L) is specified for a house with $100 \mathrm{~m}^{2}$ roof area (0.9 runoff coefficient), 3 inhabitants each using $50 \mathrm{l} /$ day non-potable water. The system is represented using a daily supply-demand balance model of rainfall, water demand and overflow discharges based on "yield after spillage" (Fewkes and Butler, 2000).

Figure 2 shows the daily rainfall and roof runoff for one year without an RMS fitted. Figure 3 illustrates the performance of a Type 1 system showing volumetric tank level on each day and the reduced rainfall-runoff discharges over the year (47\% rainwater demand met, $88 \%$ reduction in runoff volume). However, the system is less effective at reducing peak runoff (13\% reduction of maximum daily discharge). Figure 4 illustrates the performance of a type 2 RMS with the same overall volume, but divided into two equal zones. Here, runoff volume reduction is now $96 \%$ and the maximum daily reduction is $61 \%$. 
Proceedings of the 11th Int. Conference on Urban Drainage Modelling, 23-26 Sep. 2018, Palermo (ITALY). Ed. prof. Giorgio Mannina

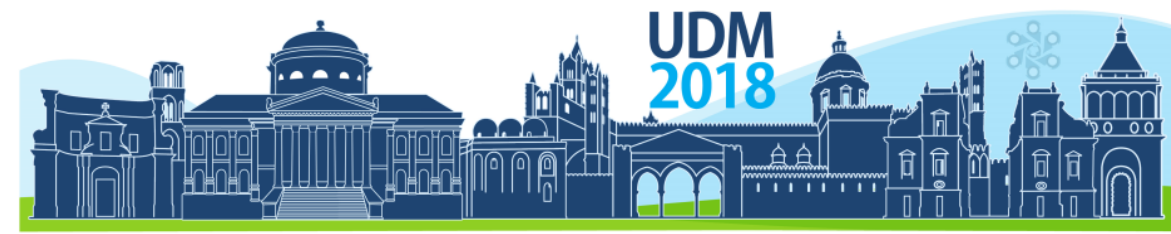

$11^{\text {th }}$ International Conference on Urban Drainage Modelling

23-26 Sep | Palermo - Italy

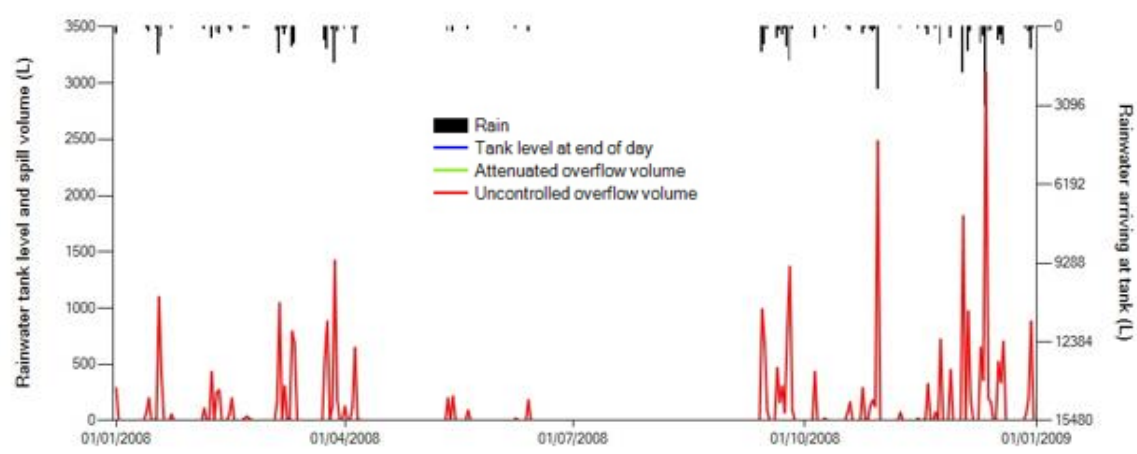

Figure 2. No Rainwater System (No rainwater demand met, $100 \%$ discharge to sewer)

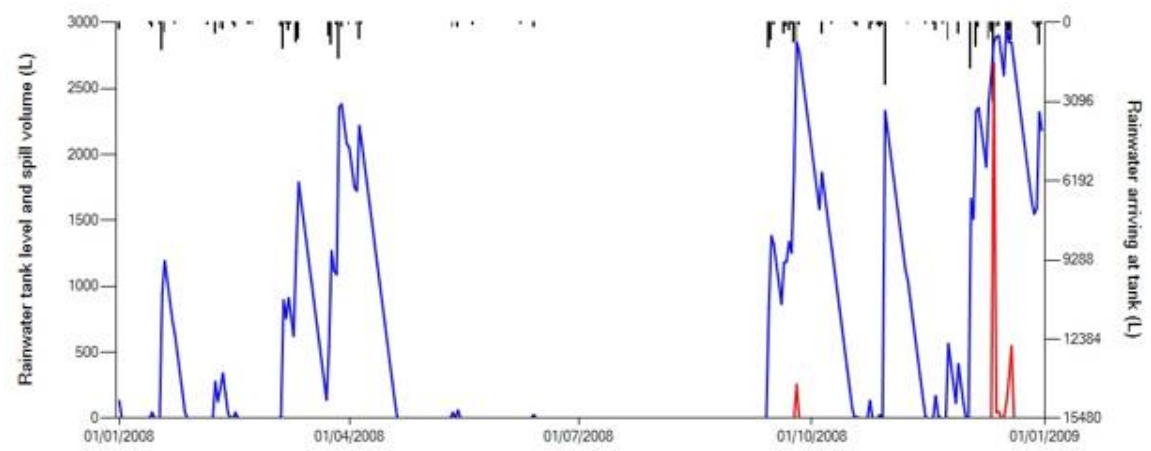

Figure 3. Water supply plus indirect stormwater management (Type 1 system)

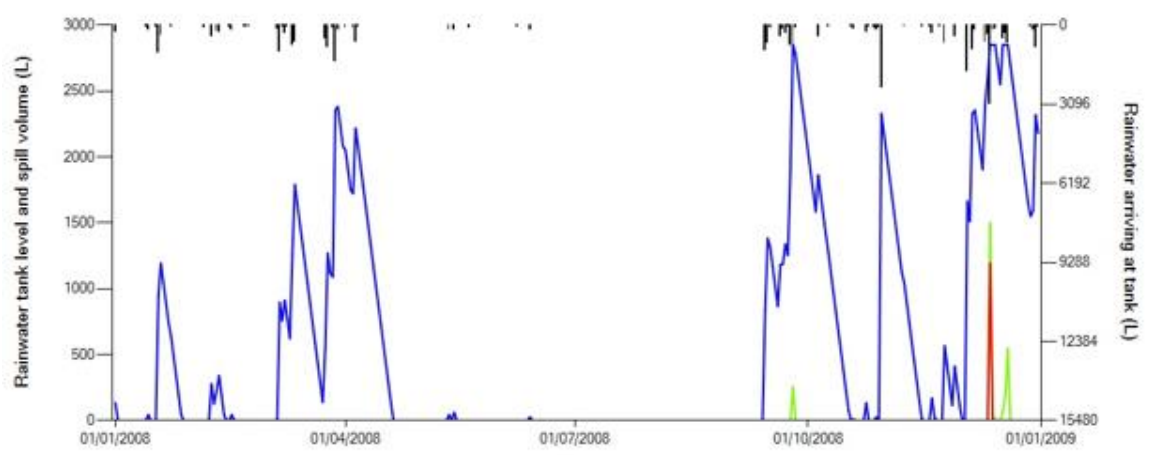

Figure 4. Water supply plus direct, passive stormwater management (Type 2 system)

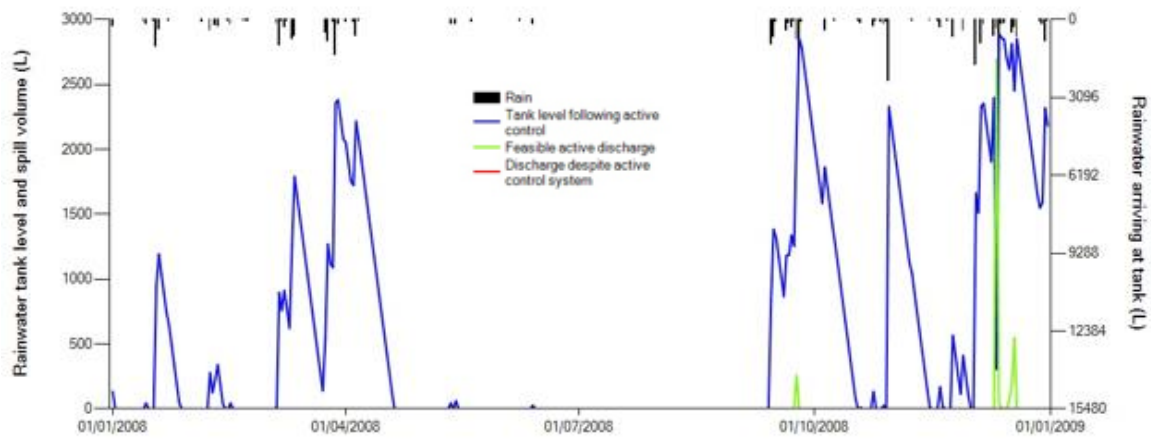

Figure 5. Water supply plus direct, active stormwater management (Type 3 system) 


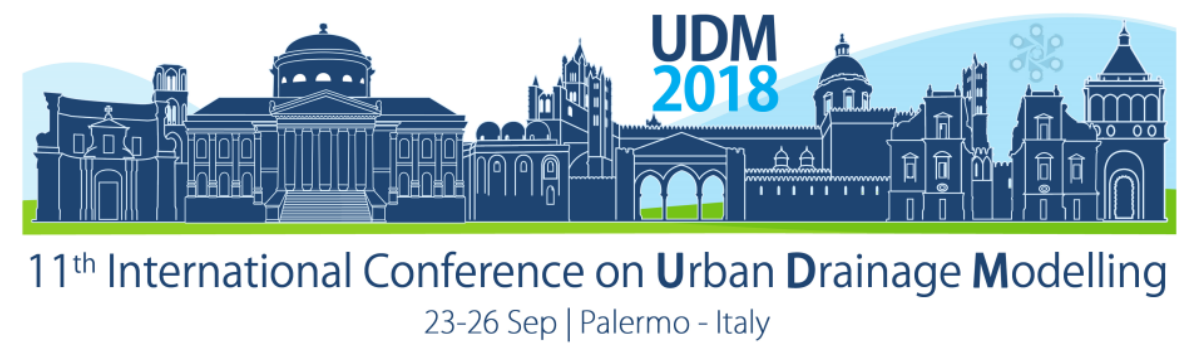

Figure 5 shows the same system with active control discharging rainwater prior to a storm events arrival (when feasible), based on a weather forecast. This design is found to satisfy the same water demand as the simple RWH system and also achieves a $100 \%$ volumetric and peak flow reduction for the largest storm identified in the 2008 rainfall data set.

In contrast to traditional RWH, RMS can meet multiple water management objectives. Systems can be designed to meet primary benefits such as reducing water demand and peak stormwater discharges. Designs can also be readily adjusted for the effects of climate change. In addition, active or smart control of these systems will enable practitioners to incorporate and value additional benefits. For example, RMS can increase resilience to supply disruption (e.g. during regional burst events following cold weather), discharge flows on hot days to irrigate green space and combat urban heat island effects, or release environmental flows to local watercourses at times of low-flow. Globally, exemplar's have been identified which enable water levels in RMS to be monitored and controlled using active management protocols such as rainfall forecasts or targeted tank levels (Han \& Mun, 2011, Reidy, 2011). The future deployment and value of such systems warrants further research effort to enable quantification and understanding of the broad whole life costs and benefits to be achieved.

\section{CONCLUSIONS}

Through investigation of the literature, best practice and investigation of a case study scenario, the following conclusions can be drawn. 1) A historical review has provided evidence that RWH has evolved as a technology of choice over previous millennia in regions throughout the world without plentiful surface water resources. 2) The benefits of current versions of these systems can be evaluated in financial and environmental terms using whole life cost (WLC) and life cycle analysis (LCA) approaches. 3) The full benefits associated with RWH installations are generally not evaluated in best practice guidance or existing WLC assessments. 4) Evidence from the literature illustrates that RWH is increasingly being deployed as part of a stormwater management hierarchy, and the value of a system's capability to temporarily detain rainwater can potentially exceed its value to retain flow for water supply augmentation. 5) Where RWH is designed to also achieve stormwater management, it is argued that they should be termed "rainwater management systems". 6) Recent exemplars illustrating the successful deployment of RMS with real-time control features were identified across the world. 7) Evidence from supply-demand flow balance modelling of a typical household installation located in Palermo, Scilly illustrated that an RMS could both supply $47 \%$ of non-potable demand and, with increasing sophistication of design and operation, reduce annual and daily peak runoff by $100 \%$ (in 2008). 8) Further work is warranted to evaluate the global potential for these technologies, as to date, few academic studies have been completed to evaluate the holistic value that such RMS systems could present. 9) Future research is needed to evaluate the potential for RMS to achieve multiple benefits including for water supply augmentation, stormwater control, combined sewer overflow reduction, urban flood mitigation, climate change adaptation, water system resilience enhancement and reduction in urban heat island effects.

\section{ACKNOWLEDGEMENTS}

This work is supported by two EPSRC projects: TWENTY65 (EP/N010124/1) and Urban Flood Resilience in an Uncertain Future (EP/P004318/1). Thanks to Dr Peter Melville-Shreeve and Dr Ahilan Sangaralingam for their significant contribution to this work, including use of the Rainwet model. 


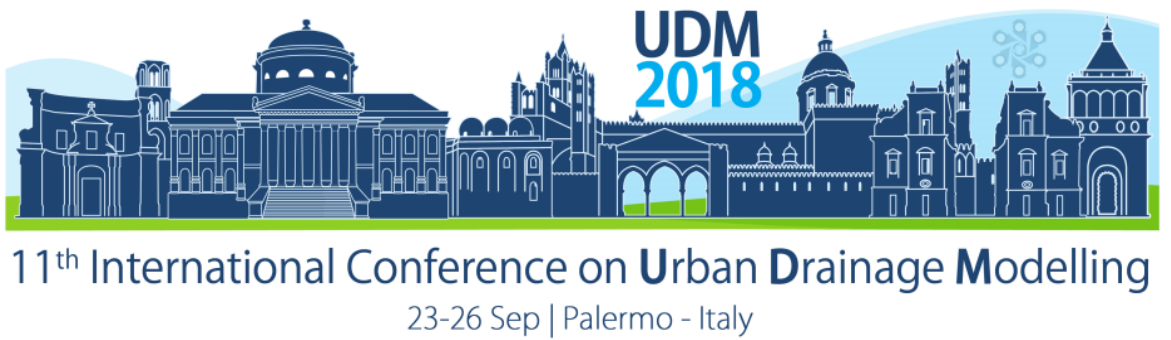

\section{References}

Adams, J.M. (1928). Patent 293-224.

AbdelKhaleq, R.A \& Alhaj Ahmed, I. (2007). Rainwater harvesting in ancient civilizations in Jordan. Water Science Technology: Water Supply, 7 (1) 85-93.

BSI (2013). BS8595:2013 Code of practice for the selection of water reuse systems. British Standards Institute, London.

Burns, M. J., Fletcher, T. D., Duncan, H. P., Hatt, B. E., Ladson, A. R. \& Walsh, C. J. (2014). The performance of rainwater tanks for stormwater retention and water supply at the household scale: an empirical study. Hydrological Processes,. 29, 152-160.

Campisano, A., Butler, D., Ward, S., Burns, M. J., Friedler, E., DeBusk, K., Fisher-Jeffes, L. N., Ghisi, E., Rahman, A., Furumai, H. \& Han, M. (2017). Urban rainwater harvesting systems: Research, implementation and future perspectives. Water Research, 115, 195-209.

Crasta, F., Fasso, C., Patta, F. \& Putzu, G. (1982). Carthaginian - roman cisterns in Sardinia. Proc. Of international conference on rainwater cistern systems, University of Hawaii, Honolulu, 37-45.

DeBusk, K. M., Hunt, W. F. \& Wright, J. D. (2013). Characterizing rainwater harvesting performance and demonstrating stormwater management benefits in the humid southeast USA. JAWRA Journal of the American Water Resources Association, 49(6), 1398-1411.

European Climate Assessment \& Dataset (https://www.ecad.eu/). Accessed 24 February 2018.

Fewkes, A. \& Butler, D. (2000). Simulating the performance of rainwater collection and reuse systems using behavioural models. Building Services Engineering Research \& Technology, 21(2), 99-106.

Fletcher, T. D., Shuster, W., Hunt, W. F., Ashley, R., Butler, D., Arthur, S., Trowsdale, S., Barraud, S., SemadeniDavies, A., Bertrand-Krajewski, J.-L., Mikkelsen, P. S., Rivard, G., Uhl, M., Dagenais, D. \& Viklander, M. (2015). SuDS, LID, BMPS, WSUD and more - the evolution and application of terminology surrounding urban drainage. Urban Water Journal, 12(7), 525-542.

Han, M. Y. \& Mun J. S. (2011). Operational data of the Star City rainwater harvesting system and its role as a climate change adaptation and a social influence. Water Science and Technology, 63, 2796-2801.

Haque, M. M., Rahman, A., Samali, B. (2016). Evaluation of climate change impacts on rainwater harvesting. Journal of Cleaner Production, 137, 60-69.

Herrmann, T. \& Schmida, U. (1999). Rainwater utilisation in Germany: efficiency, dimensioning, hydraulic and environmental aspects. Urban Water, 1(4), 307-316.

Ishaku, H. T., Majid, M. R. \& Johar, F. (2012). Rainwater harvesting: an alternative to safe water supply in Nigerian rural communities. Water Resources Management, 26(2), 295-305.

Islam, M. M., Chou, F. N. F., Kabir, M. R. \& Liaw, C. H. (2010). Rainwater: a potential alternative source for scarce safe drinking and arsenic contaminated water in Bangladesh. Water Resources Management, 24, 3987-4008.

Low, K. G., Grant, S. B., Hamilton, A. J., Gan, K., Saphores, J-D., Arora, M. \& Feldman, D,L. (2015). Fighting drought with innovation: Melbourne's response to the Millennium Drought in Southeast Australia. Wiley Interdisciplinary Reviews: Water, 2(4), 315-328.

Mays, L., Antoniou, G. \& Angelikas, A. (2013). History of Water Cisterns: Legacies and Lessons. Water, 5(4), 19161940.

Melville-Shreeve, P., Ward, S. \& Butler, D. (2016). Rainwater harvesting typologies for UK houses: a multi criteria analysis of system configurations. Water, 8(4), 129.

Naddeo, V., Scannapieco, D. \& Belgiorno, V. (2013). Enhanced drinking water supply through harvested rainwater treatment. Journal of Hydrology, 498, 287-291.

Partzsch, I. (2009). Smart regulation for water innovation - the case of decentralized rainwater technology. Journal of Cleaner Production, 17(11), 985-991.

Radharkrishna, B. P. (2003). Rainwater harvesting, a time honoured practice: need for revival. Current Science, 85 , 1259-1261.

Reidy, P. (2011). Real-time Monitoring and Active Control of Green Infrastructure: Growing Green Infrastructure in New York. Central New York Green Infrastructure Symposium, Sheraton Syracuse University Conference Center November 17.

Roebuck, R.M., Oltean-Dumbrava, C. \& Tait, S. (2011). Whole life cost performance of domestic rainwater harvesting systems in the United Kingdom. Water \& Environment Journal, 25(3), 355-365.

Soler, N.G., Moss, T., Papasozomenou, O. (2018). Rain and the city: Pathways to mainstreaming rainwater harvesting in Berlin. Geoforum 89. 96-106.

Standards Australia \& Australian Rainwater Industry Development Association \& Standards Association of Australia (2008). Rainwater tank design and installation handbook, 2nd ed, Standards Australia, Sydney, N.S.W. Accessed: 19/2/2018. http://trove.nla.gov.au/work/21050379?selectedversion=NBD43800085

Wang, R. \& Zimmerman, J. (2014). Economic and environmental assessment of urban rainwater harvesting systems in various us cities. Environmental Science \& Technology, 49 (3), 1768-1778. 


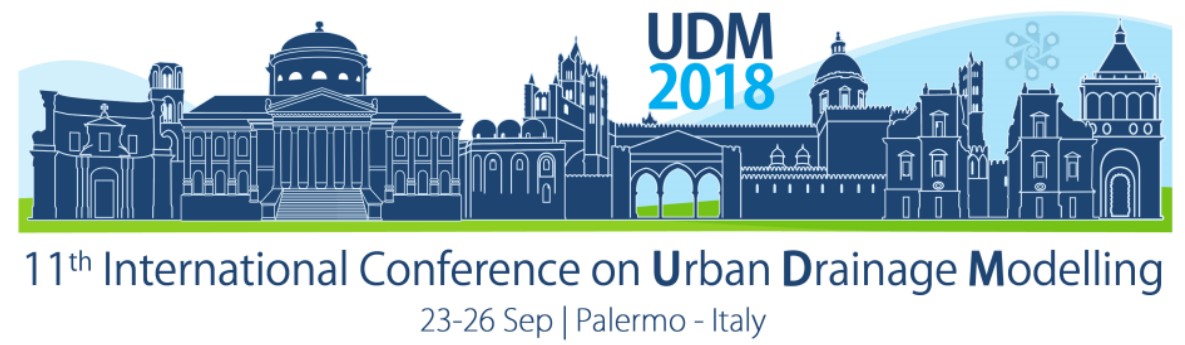

\title{
Modelling to support the planning of sustainable urban water systems
}

\author{
Ana Deletic ${ }^{1}$, Kefeng Zhang ${ }^{1}$, Behzad Jamali ${ }^{2}$, Adam Charette-Castonguay ${ }^{2}$, Martijn Kuller ${ }^{2}$, \\ Veljko Prodanovic ${ }^{1}$ and Peter M. Bach ${ }^{2,3,4}$

\footnotetext{
${ }^{1}$ School of Civil and Environmental Engineering, University of New South Wales (UNSW) NSW 2052 Australia

${ }^{2}$ Monash Infrastructure, Department of Civil Engineering, Monash University, Clayton, 3800 VIC, Australia

${ }^{3}$ Swiss Federal Institute of Aquatic Science \& Technology (Eawag), Dübendorf 8600, Switzerland ${ }^{4}$ Institute of Environmental Engineering, ETH Zürich, 8093 Zürich, Switzerland
}

\begin{abstract}
Water Sensitive Urban Design (WSUD) is commonly employed to restore urban water systems back to pre-developed conditions and can provide multiple benefits. However, WSUD planning is a challenging task that involves multidisciplinary effort to deal with highly complex and uncertain futures. Hence, an integrated approach is required to address this task with a high level of scientific rigour. This paper introduces an integrated modelling tool - UrbanBEATS (Urban Biophysical Environments And Technologies Simulator) which supports the planning and development of sustainable urban water strategies. Initially developed to plan WSUD stormwater infrastructure for management of runoff, pollution and stormwater harvesting, UrbanBEATS' ecosystem is currently being extended and includes, among others, three new modules, which are introduced in this paper: (1) uptake, needs and suitability assessment module for simulating the behaviour of the main actors in urban stormwater management to assess uptake, suitability and needs for WSUD technologies; (2) mapping of water pollution emissions, linking detailed information of the urban form and land use with stormwater pollution algorithms (allowing identification of pollution hotspots within the catchment to guide pollution management strategies); and (3) a novel cellular automata fast flood evaluation model known as CA-ffé for the rapid prediction of inundation extent, depths and flood risks in urban areas (including assessment of the WSUD benefits for reducing flood damages).
\end{abstract}

Keywords: planning-support system; stormwater; Water Sensitive Urban Design; ecosystem services; pollution emission; flood management

\section{INTRODUCTION}

Water Sensitive Urban Design (WSUD), also known as Low Impact Development (LID), Nature Based Solutions (NBS) or Sponge City (SC), is commonly employed to restore urban water systems back to pre-developed conditions (Fletcher et al., 2015). They are sustainable urban water systems that have multiple benefits, e.g. stormwater pollution management (Davis et al., 2009, Li et al., 2012, Zhang et al., 2014), frequent flood mitigation (Schubert et al., 2017), waterway health protection (Fletcher et al., 2007), microclimate improvement and enhancing the amenity of urban landscapes (Polyakov et al., 2015).

To achieve these benefits, planning and development of WSUD solutions within urban environments is necessary. However, it is a challenging task as the future is highly complex and uncertain (Bernini and Franchini, 2013), with multiple aspects to be considered, including urban and water infrastructure planning, design and performance evaluation in all different aspects (e.g. environmental, microclimate, social and economic benefits). This requires an interdisciplinary approach integrating not just engineering, but also ecology, social sciences, economics, environmental sciences, urban climatology, etc. An exploratory, integrated modelling tool can address and support this interdisciplinary planning problem. 


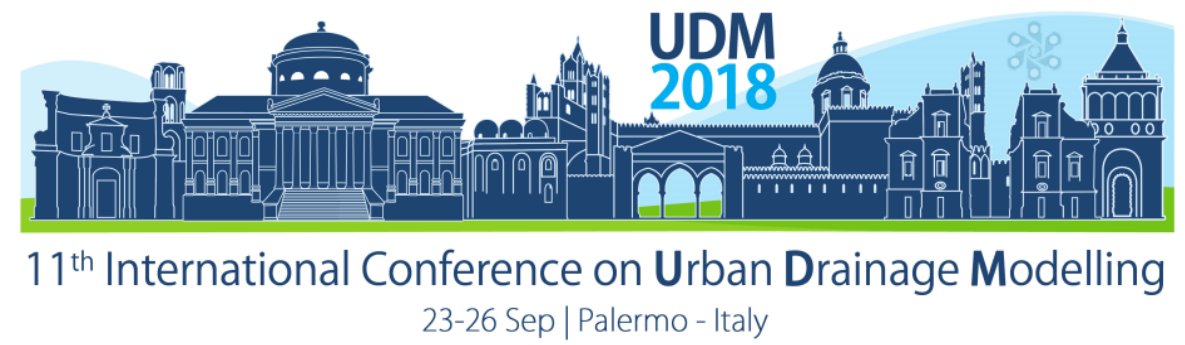

This paper introduces the UrbanBEATS model (Urban Biophysical Environments And Technologies Simulator) which was developed to support the planning and development of sustainable urban water strategies by integrating water infrastructure, urban planning and design (Bach, 2014, Bach, 2017). UrbanBEATS was originally developed to plan WSUD infrastructure for management of runoff pollution and stormwater harvesting and is currently expanding its modelling ecosystem to incorporate latest developments in integrated urban water management (Sitzenfrei et al., 2017, Bach et al., 2018). This paper will introduce three new modules focussed on WSUD that are currently under development in UrbanBEATS: (1) uptake, needs and suitability assessment module, (2) pollution emission mapping module and (3) flood management module. We present results from a number of case studies that have been used in their development.

\section{MATERIALS AND METHODS}

\subsection{The UrbanBEATS model}

UrbanBEATS' development began in 2010 under the European Union FP7 Project PREPARED enabling change. Its initial purpose was to investigate the placement of WSUD stormwater infrastructure in urban catchments (Bach, 2014). Since then, UrbanBEATS has expanded in size, scope and complexity to encompass a greater variety of planning challenges (e.g. urban development, future climate) and water infrastructure (e.g. centralised and decentralised systems in water supply, sanitation and drainage). Despite its complexity, UrbanBEATS nevertheless maintains its core philosophy of being pragmatic, holistic and easyto-use such that it can support a collaborative planning process.

UrbanBEATS is a spatial model used for rapidly exploring water infrastructure and management options in urban environments at a variety of spatial scales (e.g. lot, street, neighbourhood) and for a variety of objectives (e.g. alternative water supply, resource recovery, stormwater pollution, urban flooding). The key features of UrbanBEATS are presented in the model structure in Figure 1. Several key model application examples include:

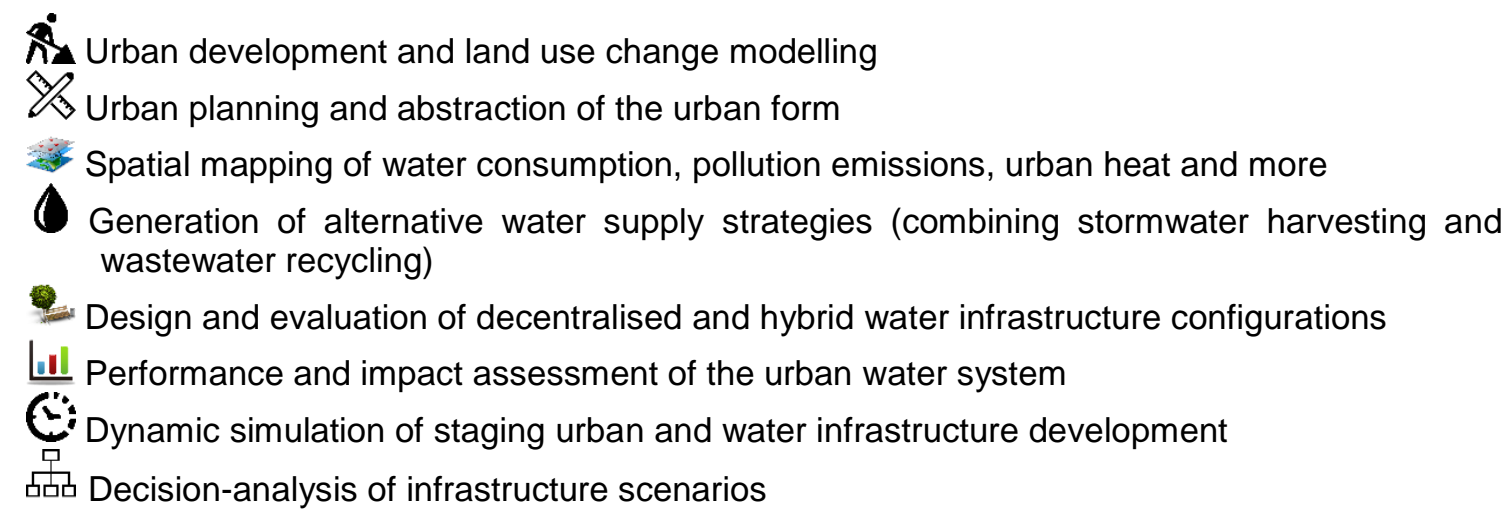

UrbanBEATS cycles through 4 simple steps (marked as (1) to (4) in Figure 1) with the option to enhance simulations with urban development and water infrastructure planning (!). Input data of a city's land use, population and topography are transformed into maps of conceptualised city with implemented WSUD infrastructure. Core algorithms developed for abstraction of the urban form (steps (1) to (2) are presented in Bach et al. (2013a) and Bach et al. (2018). The development of the algorithms that underpin placement (step (3)) and evaluation (step (4)) of 


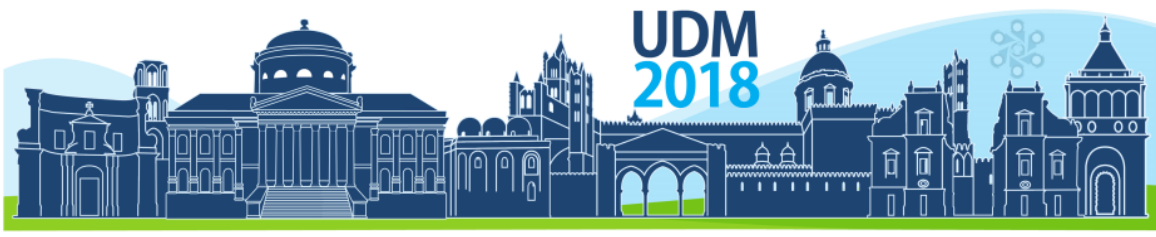

$11^{\text {th }}$ International Conference on Urban Drainage Modelling

23-26 Sep | Palermo - Italy

WSUD are presented in Bach et al. (2013b) and Bach et al. (under review). There are many ways of generating and evaluating different future scenarios. However, probably the most powerful mode is to use the model for dynamic simulations of possible future scenarios of city and water infrastructure development; Bach et al. (2015) and Rauch et al. (2017) show a preliminary study on how UrbanBEATS was used for such simulations.

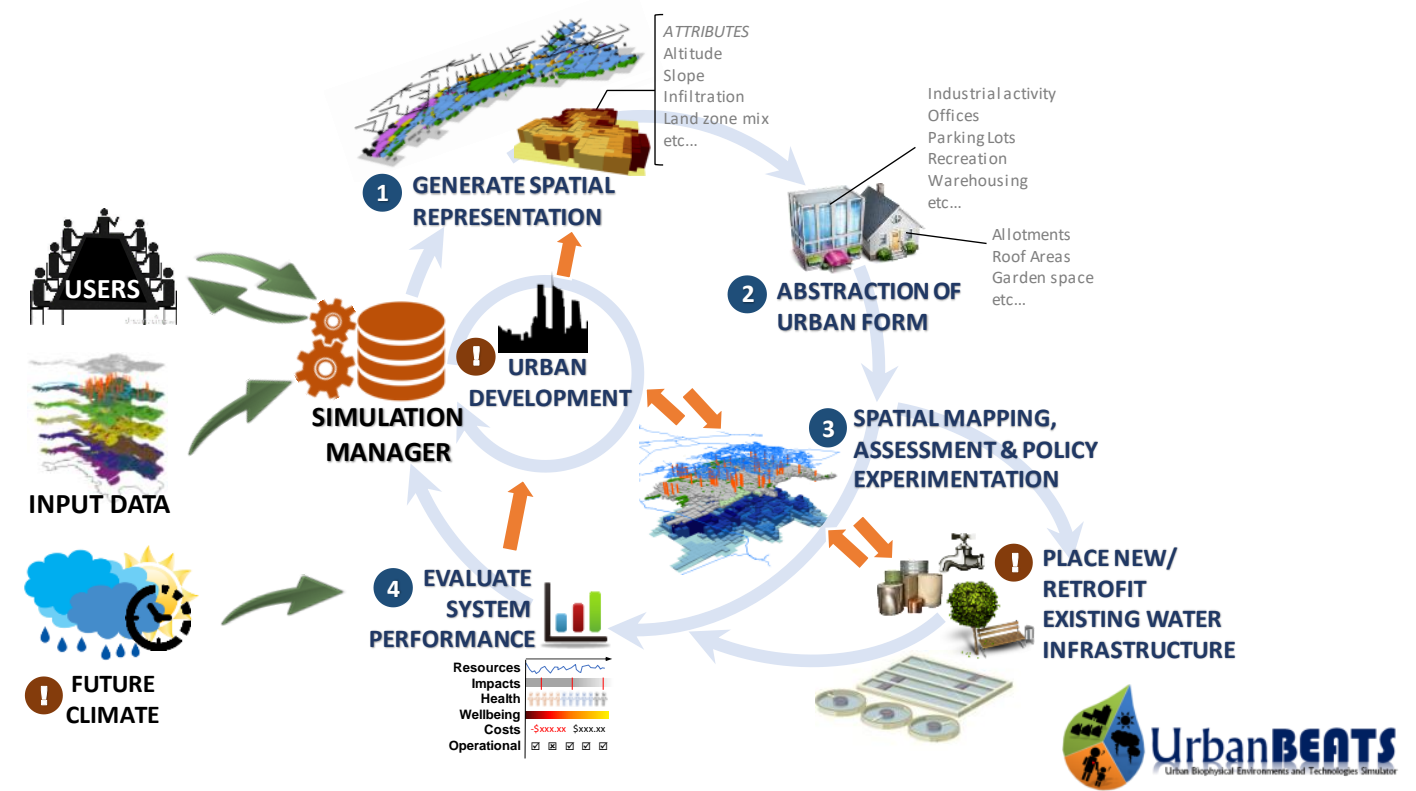

Figure 1. Structure of the UrbanBEATS Planning-Support Model

The growing list of modules is continuously being expanded to encompass newly available research. Here, we cover three substantial modules (currently under development) that will enhance UrbanBEATS as an integrated platform for comprehensive assessment of multiple WSUD benefits.

\subsection{Uptake, needs and suitability assessment}

An extensive review of 2,000 current WSUD asset locations throughout metropolitan Melbourne reveals the ad-hoc and opportunistic planning processes underlying WSUD planning (Kuller et al., 2018a). The results of this study call for more strategic approaches, which take a more comprehensive consideration of the opportunities and needs of the urban context in which WSUD is to be implemented. Spatially explicit planning support tools are wellsuited to support urban planners in their effort to improve strategic planning of WSUD. The urgent need of spatial tools that are easy to learn, commonly used throughout industry and holistic yet simple is confirmed by a recent study among WSUD planning practitioners across relevant organisations (local government, water authority, state government and private sector) in Melbourne (Kuller et al., in press).

This module uses GIS-based Multi-Criteria Decision Analysis techniques to create spatially explicit estimates of suitability for WSUD implementation. A comprehensive suitability framework developed by Kuller et al. (2017) lies at the heart of this analysis. This framework defines suitability from two sides: opportunities for WSUD (biophysical, socio-economic and planning \& governance related criteria) and needs for WSUD (related to ecosystem services of provision, regulation, cultural and habitat associated with WSUD). By assigning weights to 


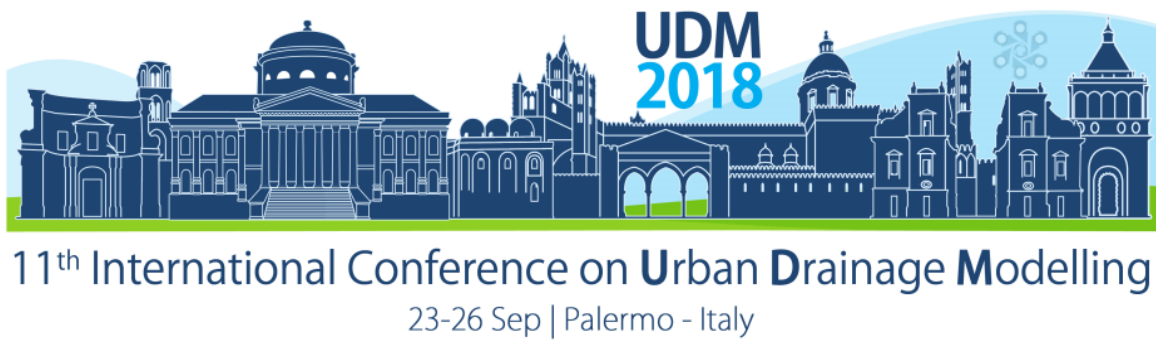

each relevant criterion in the analysis, users have the option to have their insights represented in the tool's output.

Besides identifying suitable locations for WSUDs, this decision-making module aims to explore the behaviour and interactions of the main actors in urban stormwater management, i.e., local councils, water utilities, the community and developers. The behaviour of agents is simulated to replicate the uptake of public WSUD assets (e.g., raingardens, constructed wetlands) (Castonguay et al., 2018a), the adoption of private blue-green infrastructure (e.g., rainwater tanks or green roofs) and the adoption of policy options and economic instruments to influence the installation of technologies (e.g., rebates on rainwater tanks) (Castonguay et al., 2018b). Aside from socio-technical factors, the decisions of different stakeholders are based on economics factors (e.g., water tariffs, costs of technologies and willingness to pay to avoid water restrictions) and responsive to external pressures such as population growth, climate change and land use change. The validation of the model is then performed by comparing attributes of simulated and observed technologies, and uncertainty analysis is carried out through Monte Carlo sampling to determine the robustness of model results.

\subsection{Pollution emission module}

Rapid development of cities inevitably impacts stormwater pollution within urban area. Unfortunately, reliable and accurate stormwater pollution models do not exist (Dotto et al., 2012, Kanso et al., 2003), primarily due to poor understanding of processes that govern stormwater pollution generation and pollutant spatial variability. The links between stormwater pollution levels and land use are being investigated by collecting existing data sets, together with measurement of new emission data sets to develop a pollution emissions inventory with respect to scale, urban planning rules and human activities; a new semi-stochastic pollution generation algorithms is also under development for better simulation of stormwater quality within urban catchments. The algorithms are based on a stochastic pollution generation model presented in (Daly et al., 2014). However they will also include assessment of sources that previously have not been directly considered in pollution generation modelling (illegal industrial discharges, sewer cross-connections, emergency sewer overflows, etc). For this purpose, a comprehensive database on pollution emissions is under construction. The results outline the conceptual framework used in this development.

\subsection{Flood management module}

Whilst WSUD systems contribute to flood mitigation by reducing stormwater peaks and volumes (Schubert et al., 2017), we can only speculate on their true benefits for flood control as no assessment tools are available to predict their impact on long-term flood damage costs. The commonly used practice for estimation of urban flooding and the impact of WSUD on risk mitigation is the event-based method based on design storms. Continuous simulation on the other hand considers the above-mentioned dynamics and can provide a long-term assessment on cumulative benefits of WSUD for flood mitigation. Time series of flood damage costs estimated by continuous simulation can be directly used for damage costs frequency analysis and life-cycle cost assessment of WSUD. Continuous simulation is, however, limited by the high computational burden especially when two dimensional (2D) hydrodynamic flood models are used to simulate surface inundations. To overcome this issue, we are developing a twostep approach, where a newly developed Cellular Automata Fast Flood Evaluation model ( $C A-$ ffé) for mapping inundation is integrated within a semi-continuous simulation framework to assess benefits of WSUD in reducing cumulative damages of flooding. 


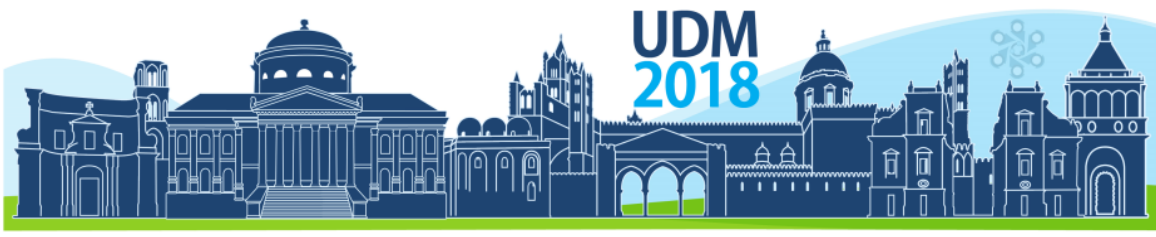

$11^{\text {th }}$ International Conference on Urban Drainage Modelling

23-26 Sep | Palermo - Italy

$C A$-ffé has been developed for the rapid prediction of inundation extent and depths in urban areas (Jamali et al., 2018). This reduced complexity model uses simple transition rules based on surface topography and the water balance equation. It can be used as a stand-alone package or coupled to a 1D drainage network models such as SWMM. We demonstrate the applicability of rapid flood inundation models for flood inundation and damage cost predictions (Jamali et al., under review). CA-ffé was coupled to a 1D drainage network model and applied in our semi-continuous simulation framework to investigate the long-term benefits of rainwater tanks on pluvial flood damage cost reduction. In this integrated framework we coupled a continuous rain tank balance simulation model to a stochastic demand generator for predicting water levels in each tank. Flood simulation was undertaken solely for wet periods by identifying separate storm events within the rainfall time series. At the start of each storm event, water levels in rain tanks were used as a boundary condition in hydraulic models.

\section{RESULTS AND DISCUSSION}

\subsection{Uptake, needs and suitability: Rainwater in households, wetlands in open spaces}

Validity and capability for the simulation of suitability were extensively explained and tested by comparing its outputs to existing, human WSUD planning decision-making outcomes for the municipality of Darebin in Melbourne (Kuller et al., 2018b). It was successful in reproducing suitability calculations and spatial outputs that compared well against selected priority WSUD sites (Kuller et al., in preparation). Another case study location was the Upper-to-Middle Dandenong Creek catchment in Melbourne (Figure 2a). The tool can simulate suitability for a diverse set of technology types including rain gardens, green roofs, swales, ponds \& lakes and wetlands. Figure $2 \mathrm{a}$ shows the results of opportunities for wetlands. The distribution of suitability is represented spatially and in a histogram. The tool's interactive map allows the user to click anywhere on the map and get a summary of the local suitability value, combined with the underlying causes for that suitability, including the most impactful factors at that location and the suitability value for each individual criterion at that location. This provides users with greater insight into the urban environment's 'enabling' and 'disabling' aspects.

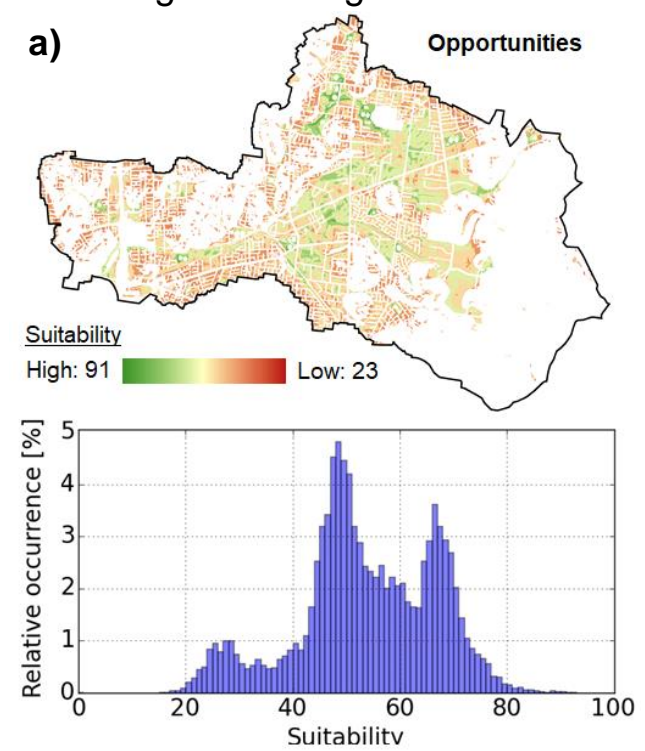

b)

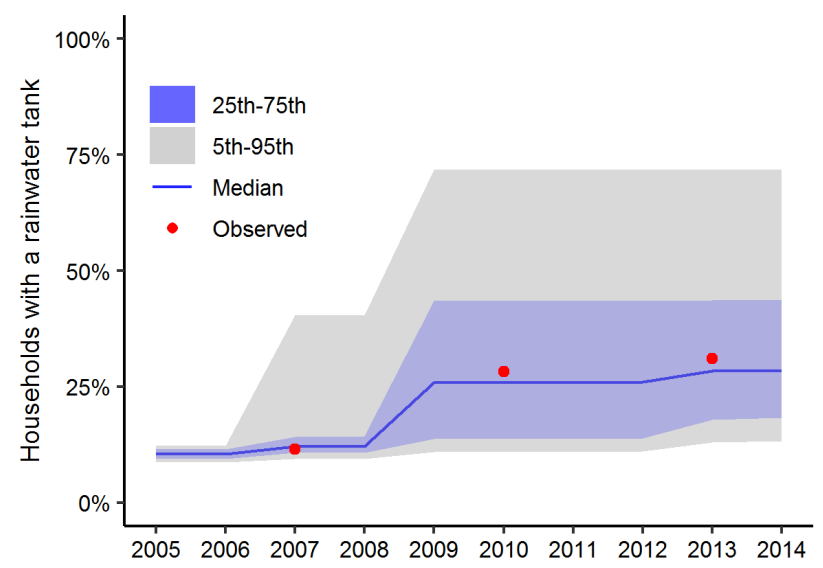

Figure 2. a) Suitability results for the opportunities of constructed wetlands in the Upper to Middle Dandenong Creek Catchment and b) Rainwater tank uptake in Scotchman's Creek catchment after 5000 simulations (source: Castonguay et al., 2018b). 


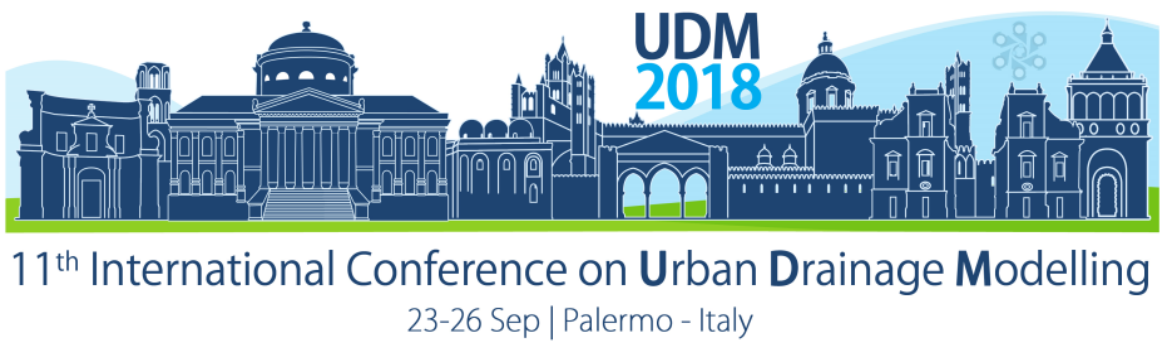

The model was also able to replicate the uptake of rainwater tanks in the Scotchman's Creek catchment using household agents (Figure 2) for the 2005-2014 simulation period. Grey and blue-shaded areas represent the uncertainty range after 5000 simulations (5th-95th and 25th75th percentiles, respectively). The median simulated uptake (solid blue line) shows a good fit compared to the observed uptake of rainwater tanks (red dots). These types of fast, interactive, spatial modelling approaches enable iterative and collaborative strategic planning and generate informed justification and business cases which were emphasised by practitioners to be critical for WSUD planning going forward (Kuller et al., in press).

\subsection{Pollution emission module: mapping the pollution emissions of catchments}

Figure 3 presents an initial concept of the database that is under preparation to support the development of the emission module in UrbanBEATS. The database with four different categories spanning from physical layers (land use, population, elevation, etc), Water quality and quantity, water infrastructure and emission inventory will be stored online (PostgreSQL); it can allow new input of data from different uses (developers, local governments, etc). The data base can then be used by various modules of UrbanBEATS (e.g. new pollution emission module) and existing urban planning modules.

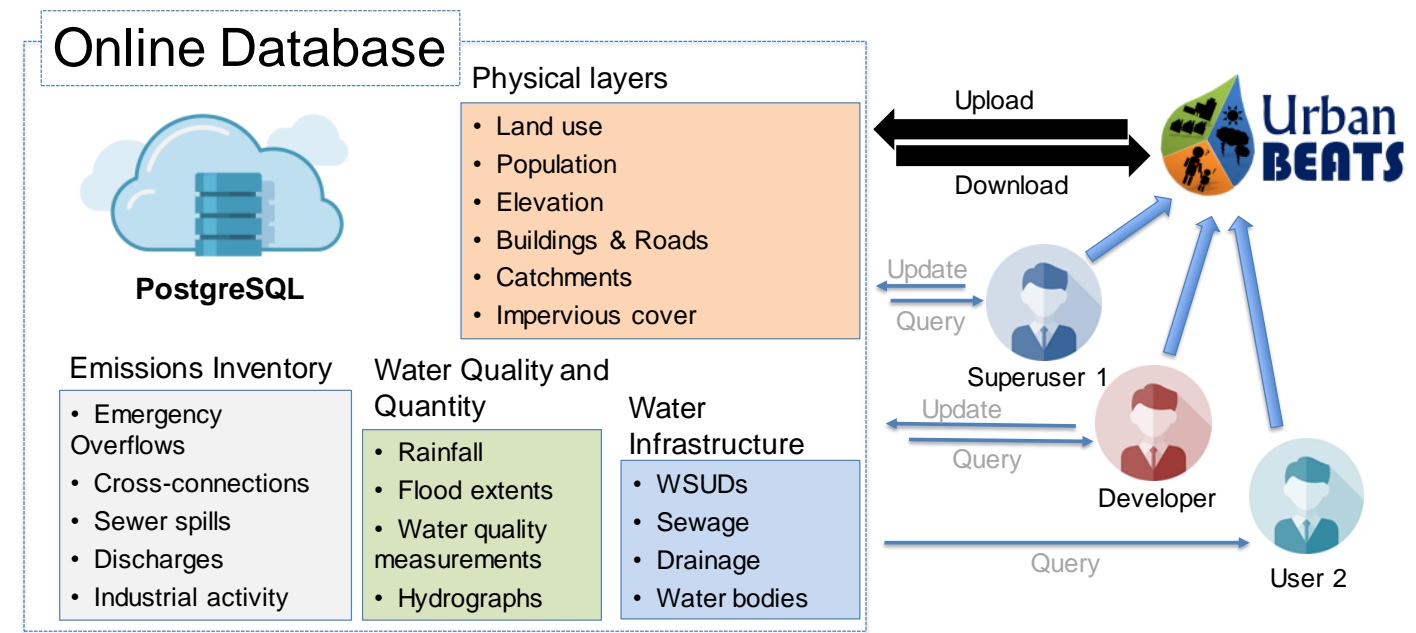

Figure 3. Preliminary concept of the database that can support the pollution emission module in UrbanBEATS

The emissions inventory supports the pollution emissions module, which is able to map and identify pollution hotspots within the catchment and can subsequently guide pollution management strategies (clean-up policies, driving land use change, etc.). This provides a better understanding of pollution levels in not only residential, but also industrial and commercial zones, informing pollutant relationships within urban development models.

\subsection{Flood management module: comparison of CA-ffé and hydrodynamic modelling}

CA-ffé was successfully tested in a number of case studies by comparing its results with two detailed hydrodynamic models: HEC-RAS and TUFLOW (two examples were provided in Figure 4). CA-ffé performed well in predicting the maximum inundation depth and extent especially in depression areas (where the flood depth is higher), however, the model under or over-estimated flood depth in flow path areas where the flood behaviour is driven by flow momentum and velocity.

Simulating flood damage costs for 90-years of historical rainfall record in a small suburban catchment in Melbourne showed that the extensive use of rainwater tanks can reduce the 


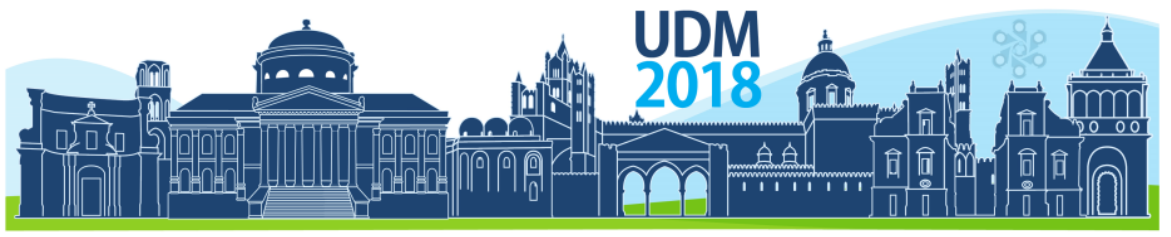

$11^{\text {th }}$ International Conference on Urban Drainage Modelling

23-26 Sep | Palermo - Italy

expected annual flood damage cost by $14 \%$ to $32 \%$. Variations in their benefits were due the way tanks had been used; maximum benefits were gained if tanks were always empty (e.g. if so called 'leaky tanks' were installed) while minimum benefits were achieved if tanks were used for supplying only outdoor or indoor demand. Rainfall temporal patterns also had a significant impact on the performance of rain tanks as the available storage could be filled by pre-burst rainfall within the rain event especially if the rain event is long (e.g. 1 day). It was found that rain tanks could provide significant reduction in cumulative flood damage costs.
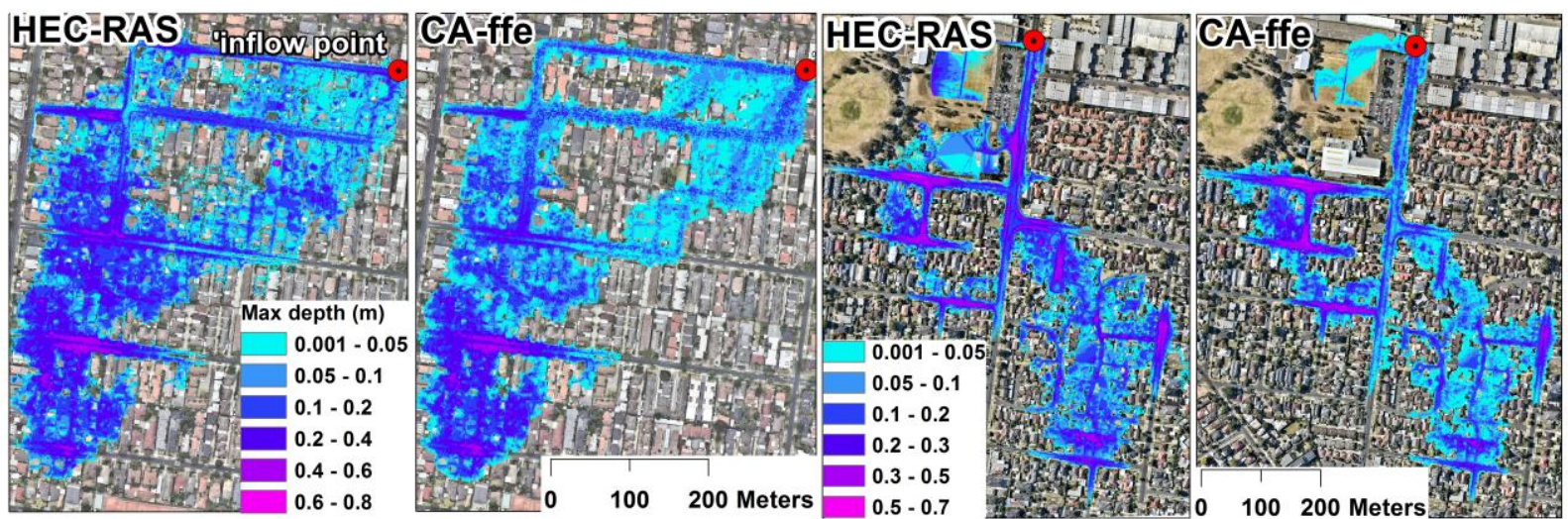

Figure 4. Flood inundation predicted by 2D HEC-RAS and CA-ffé in two small case studies in Melbourne. Flooding originated from a point source (red point - total volume of $8,000 \mathrm{~m}^{3}$ ), adapted from Jamali et al., 2018

\section{CONCLUSIONS}

Planning and development of sustainable urban water systems is important in a rapidly changing urban environment and climate. UrbanBEATS, enables a diversity of urban water stakeholders to undertake collaborative planning to determine sustainable urban water futures. The new uptake, needs and suitability module provides UrbanBEATS with the capacity to simulate the 'softer' underlying social dynamics surrounding WSUD planning over time for a variety of economic and policy contexts. Once developed, the pollution emissions module will assist in more accurate stormwater pollution generation modelling and more reliable assessment of impacts of mitigation strategies. WSUD benefits for flood protection can now be assessed using the novel rapid flood simulation model CA-ffé in semi-continuous simulations of rainfall/runoff in urban areas, providing results that are comparable in terms of flood inundation to hydrodynamic models, but at a fraction of the time cost.

\section{ACKNOWLEDGMENTS}

The ongoing development of UrbanBEATS is supported by the Australian Research Council (ARC) Linkage Project LP160100241 titled "Advancing water pollution emissions modelling in cities of the future" and ARC Discovery Early Career Researcher Award (DECRA) project DE170100042 titled "Virtual Reality for Planning of Green Urban Water Infrastructure".

\section{REFERENCES}

Bach, P. M. (2014) UrbanBEATS: a virtual urban water system tool for exploring strategic planning scenarios. Monash University. Faculty of Engineering. Department of Civil Engineering.

Bach, P. M. (2017) UrbanBEATS. An exploratory model for strategic planning of urban water infrastructure: http://urbanbeatsmodel.com (Accessed: 28 Nov 2017).

Bach, P. M., Deletic, A., Urich, C. and McCarthy, D. T. (2018) 'Modelling characteristics of the urban form to support water systems planning', Environmental Modelling \& Software, 104, pp. 249-269.

Bach, P. M., Deletic, A., Urich, C., Sitzenfrei, R., Kleidorfer, M., Rauch, W. and McCarthy, D. T. (2013a) 'Modelling Interactions Between Lot-Scale Decentralised Water Infrastructure and Urban Form - a Case Study on Infiltration Systems', Water Resources Management, 27, pp. 4845-4863. 


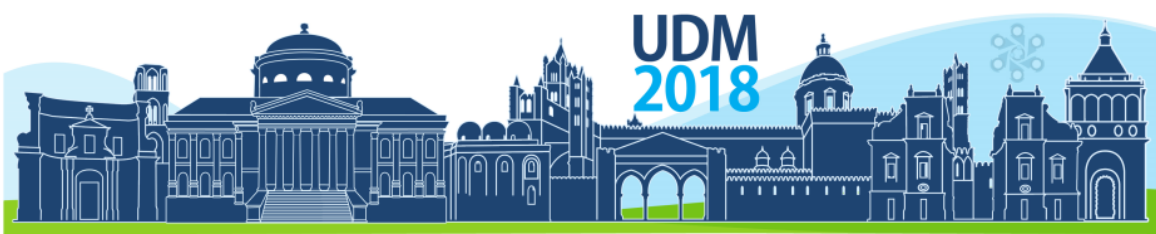

$11^{\text {th }}$ International Conference on Urban Drainage Modelling

23-26 Sep | Palermo - Italy

Bach, P. M., McCarthy, D. T. and Deletic, A. (2015) 'Can we model the implementation of Water Sensitive Urban Design in evolving cities?', Water Science \& Technology, 71(1), pp. 149-156.

Bach, P. M., McCarthy, D. T. and Deletic, A. (under review) 'An integrated model to support the planning of sustainable urban water technologies'.

Bach, P. M., McCarthy, D. T., Urich, C., Sitzenfrei, R., Kleidorfer, M., Rauch, W. and Deletic, A. (2013b) 'A planning algorithm for quantifying decentralised water management opportunities in urban environments', Water Science \& Technology, 68(8), pp. 1857-1865.

Bernini, A. and Franchini, M. (2013) 'A Rapid Model for Delimiting Flooded Areas', Water Resources Management, 27(10), pp. 3825-3846.

Castonguay, A. C., Iftekhar, M. S., Urich, C., Bach, P. M. and Deletic, A. (2018a) 'Integrated modelling of stormwater treatment systems uptake', Water research, 142, pp. 301-312.

Castonguay, A. C., Urich, C., Iftekhar, M. S. and Deletic, A. (2018b) 'Modelling urban water management transitions: a case of rainwater harvesting', Environmental Modelling \& Software, 105, pp. 270-285.

Daly, E., Bach, P. M. and Deletic, A. (2014) 'Stormwater pollutant runoff: A stochastic approach', Advances in Water Resources, 74, pp. 148-155.

Davis, A. P., Hunt, W. F., Traver, R. G. and Clar, M. (2009) 'Bioretention technology: Overview of current practice and future needs', Journal of Environmental Engineering, 135(3), pp. 109-117.

Dotto, C. B. S., Mannina, G., Kleidorfer, M., Vezzaro, L., Henrichs, M., McCarthy, D. T., Freni, G., Rauch, W. and Deletic, A. (2012) 'Comparison of different uncertainty techniques in urban stormwater quantity and quality modelling', Water Research, 46(8), pp. 2545-2558.

Fletcher, T., Mitchell, V., Deletic, A., Ladson, T. and Seven, A. (2007) 'Is stormwater harvesting beneficial to urban waterway environmental flows?', Water Science \& Technology, 55(4), pp. 265-272.

Fletcher, T. D., Shuster, W., Hunt, W. F., Ashley, R., Butler, D., Arthur, S., Trowsdale, S., Barraud, S., Semadeni-Davies, A., Bertrand-Krajewski, J.-L., Mikkelsen, P. S., Rivard, G., Uhl, M., Dagenais, D. and Viklander, M. (2015) 'SUDS, LID, BMPs, WSUD and more - The evolution and application of terminology surrounding urban drainage', Urban Water Journal, 12(7), pp. 525-542.

Jamali, B., Cunningham, L., Bach, P. M. and Deletic, A. 'Caffe - a Cellular Automata Fast Flood Evaluation Model', 11th International Conference on Urban Drainage Modelling, Palermo - Italy, 23 - 26 September.

Jamali, B., Löwe, R., Bach, P. M., Urich, C., Arnbjerg-Nielsen, K. and Deletic, A. (under review) 'A Rapid Urban Flood Inundation and Damage Assessment Model', submitted to Journal of Hydrology.

Kanso, A., Gromaire, M., Gaume, E., Tassin, B. and Chebbo, G. (2003) 'Bayesian approach for the calibration of models: application to an urban stormwater pollution model', Water Science \& Technology, 47(4), pp. 77-84.

Kuller, M., Bach, P. M., Ramirez-Lovering, D. and Deletic, A. (2017) 'Framing water sensitive urban design as part of the urban form: a critical review of tools for best planning practice', Environmental Modelling \& Software, 96, pp. 265-282.

Kuller, M., Bach, P. M., Ramirez-Lovering, D. and Deletic, A. (2018a) 'What drives the location choice for water sensitive infrastructure in Melbourne, Australia?', Landscape and Urban Planning, 175, pp. 92-101.

Kuller, M., Bach, P. M., Roberts, S., Browne, D. and Deletic, A. 'Supporting the needs and necessity for urban green stormwater infrastructure - a novel planning-support system', 11th International Conference on Urban Drainage Modelling, Palermo, Italy.

Kuller, M., Bach, P. M., Roberts, S., Browne, D. and Deletic, A. (in preparation) 'A holistic spatial multi-criteria decision analysis tool for urban green stormwater infrastructure placement'.

Kuller, M., Farrelly, M., Deletic, A. and Bach, P. (in press) 'Building effective planning support systems for green urban water infrastructure - practitioners' perceptions ', Environmental Science and Policy.

Li, Y. L., Deletic, A., Alcazar, L., Bratieres, K., Fletcher, T. D. and McCarthy, D. T. (2012) 'Removal of Clostridium perfringens, Escherichia coli and F-RNA coliphages by stormwater biofilters', Ecological engineering, 49, pp. 137-145.

Polyakov, M., Iftekhar, S., Zhang, F. and Fogarty, J. 'The amenity value of water sensitive urban infrastructure: A case study on rain gardens. ', 59th Annual Conference of the Australian Agricultural and Resource Economics Society, Rotorua, N.Z.

Rauch, W., Urich, C., Bach, P. M., Rogers, B. C., de Haan, F. J., Brown, R. R., Mair, M., McCarthy, D. T., Kleidorfer, M., Sitzenfrei, R. and Deletic, A. (2017) 'Modelling transitions in urban water systems', Water Research, 126, pp. 501-514.

Schubert, J. E., Burns, M. J., Fletcher, T. D. and Sanders, B. F. (2017) 'A framework for the case-specific assessment of Green Infrastructure in mitigating urban flood hazards', Advances in Water Resources, 108(Supplement C), pp. 55-68.

Sitzenfrei, R., Zischg, J., Sitzmann, M. and Bach, P. M. (2017) 'Impact of Hybrid Water Supply on the Centralised Water System', Water, 9(11), pp. 855.

Zhang, K., Randelovic, A., Page, D., McCarthy, D. T. and Deletic, A. (2014) 'The validation of stormwater biofilters for micropollutant removal using in situ challenge tests', Ecological Engineering, 67, pp. 1-10. 


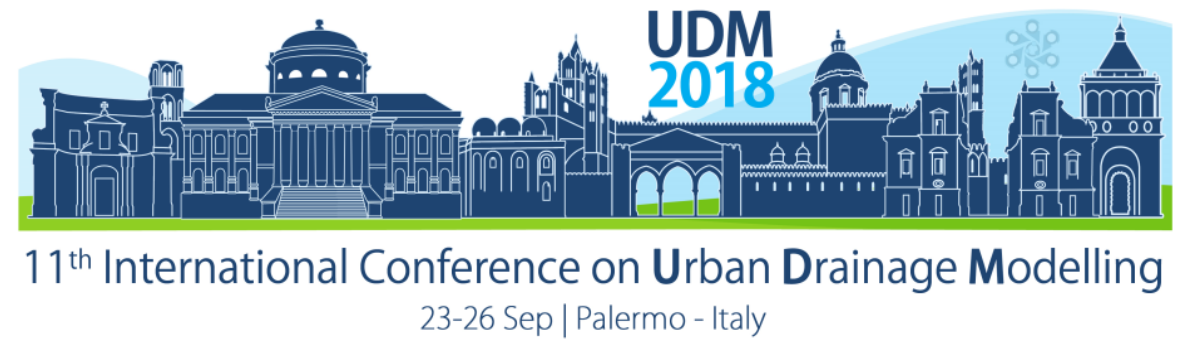

\title{
A physically based model for mesoscale SuDS - an alternative to large-scale simulations
}

\author{
Salar Haghighatafshar ${ }^{1}$, Mikael Yamanee-Nolin², Magnus Larson ${ }^{3}$ \\ ${ }^{1}$ Water and Environmental Engineering, Department of Chemical Engineering, Lund University, P.O. Box 124, \\ SE-221 00 Lund, Sweden \\ 2 Department of Chemical Engineering, Lund University, P.O. Box 124, SE-221 00 Lund, Sweden \\ ${ }^{3}$ Department of Water Resources Engineering, Lund University, P.O. Box 118, SE-221 00 Lund, Sweden
}

\begin{abstract}
This study presents a deterministic, lumped model to simulate mesoscale SuDS based on a conceptualization of the SCMs making up the system and their influence on the runoff process. The conceptualization mainly relies on parameters that are easily quantifiable based on the physical characteristics of the SCMs. Introducing a nonlinear reservoir model at the downstream end of the SuDS results in a fast model that can realistically describe the runoff process at low computational cost. Modelled hydrographs for the study area in Malmö, Sweden, matched data with regard to the overall shape of the hydrograph as well as the peak flow and lag time. These output parameters are critical factors to be considered in the design of large systems consisting of mesoscale SuDS. The algebraic foundation of the developed model makes it suitable for large-scale applications (e.g., macroscale), where the simulation time is a decisive factor. In this respect, city-wide optimization studies for the most efficient implementation location of SuDS are substantially accelerated due to fast and easy model setup. Moreover, the simplicity of the model facilitates more effective communication between all the actors engaged in the urban planning process, including political decision makers, urban planners and, urban water engineers.
\end{abstract}

Keywords: SuDS; SCM; modelling; hydraulics; rainfall-runoff

\section{INTRODUCTION}

Sustainable drainage systems (SuDS) are considered as a viable alternative for urban drainage in a changed climate (Haghighatafshar et al., 2018; Zhou, 2014). SuDS as a concept has been around since the 1970s, but has gained substantial attention in the research community due to full-scale implementations during the recent decades. Thus, the hydraulic behavior of SuDS is of great significance and different modelling approaches have been suggested for describing individual stormwater control measures (SCMs) as constituents of SuDS (Roldin et al., 2013; Locatelli et al., 2014; García-Serrana et al., 2017). However, examples of models covering both the mesoscale (neighborhood-scale) and macroscale (cityscale) processes are relatively rare. Two major factors are the main reasons for the lack of appropriate modelling approaches at these scales: (1) scarce large-scale implementations of SuDS in cities and (2) complexity of the existing modelling methodologies leading to extensive parameter estimation and calibration/validation procedures as well as computationally costly models (Locatelli et al., 2014). Therefore, studies regarding upscaling of SuDS to a city-wide level are presently not feasible using the available distributed hydrodynamic models (e.g., MIKE 21 and MIKE FLOOD).

Haghighatafshar et al. (2017) introduced a conceptual model for SuDS, developed using observed discharge patterns from a full-scale implementation of unique mesoscale SuDS in 


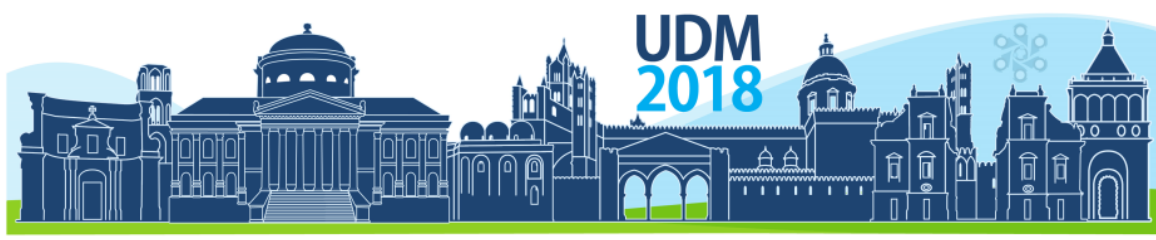

$11^{\text {th }}$ International Conference on Urban Drainage Modelling

23-26 Sep | Palermo - Italy

downtown Malmö, Sweden. The model schematized mesoscale SuDS as a 1-dimensional series of interconnected retention basins (SCMs) of different sizes and types (Figure 1a). It was shown that the order and placement of the constituent SCMs determine the overall performance of the SuDS. The aim of the present study is to mathematically develop and enhance this conceptual model to simulate the discharge volumes and the entire discharge hydrograph from mesoscale SuDS with the objective to predict the peak flow and lag time, which are important parameters in the design of individual SCMs as well as meso- and macroscale SuDS. The algebraic foundation of the developed model makes it suitable for large-scale applications (e.g., macroscale), where the simulation time is a decisive factor.

\section{METHODOLOGY}

\subsection{Schematization of mesoscale SuDS}

Mesoscale SuDS consist of multiple interconnected SCMs, as shown in Figure 1, through which proportions of the rainfall are intercepted in upstream SCMs (i.e., $R_{e}^{i}$ ), and the rest of the runoff flows to the immediate downstream SCM (i.e., $V_{\text {out }}^{i}$ ). Consequently, a discharge from the entire system is initiated when the retention capacity of the most downstream SCM is exceeded. Thus, the model operates by employing a volume transfer approach, where the storage volumes and the volume transfers are derived from the properties of the SCMs and the general characteristics of the catchment. The governing equations are given by equations (1) and (2). In order to develop the volume-based equations (1) and (2) to describe flow from the SuDS, the rainfall data should be introduced as an equidistant accumulated rain depth time series. In this study, the constant time-step is selected to be 5 minutes (i.e., $\Delta t=5 \mathrm{~min}$ ). Thus, for any given time $(t)$, equation (2) can be transformed to equation (3). No flow distribution is considered for the discharge from the components; the outflow from a component is obtained as an average flow for the entire time step.

$$
\begin{aligned}
& R_{e}^{i}=\frac{\left(S_{f b}^{i}+S_{\text {inf }}^{i}\right) \times A_{S C M}^{i}}{D C I A^{i}} \\
& V_{\text {out }}^{i}=\frac{\left(R-R_{e}^{i}\right) \times D C I A^{i}}{1000}+\sum_{j=1}^{n} V_{\text {out }}^{i-j} \\
& q^{i, t}=\frac{V_{\text {out }}^{i, t}-V_{\text {out }}^{i, t-1}}{\Delta t}=\frac{\left(R^{a c c, t}-R_{e}^{i}\right) \times D C I A^{i}}{\Delta t \times 1000}+\frac{V_{\text {out }}^{i, t-1}}{\Delta t}-q^{i, t-1}, \text { for } i=1 \ldots n
\end{aligned}
$$

in which $R_{e}^{i}$ is the effective retention capacity of the SCM i (mm), $S_{f b}^{i}$ is the storage depth in the freeboard of the SCM $(\mathrm{mm}), S_{i n f}^{i}$ is the storage depth in the infiltration layer, $A_{S C M}^{i}$ is the area occupied by the SCM $\left(\mathrm{m}^{2}\right), D C I A^{i}$ is the directly connected impervious area to the SCM $\left(\mathrm{m}^{2}\right)$, $V_{\text {out }}^{i}$ is the discharged volume from the $\operatorname{SCM}\left(\mathrm{m}^{3}\right), R$ is the rainfall depth $(\mathrm{mm})$, and $V_{\text {out }}^{i-1}$ is the sum of the inflow to the SCM from the adjacent upstream $\operatorname{SCM}(\mathrm{s})\left(\mathrm{m}^{3}\right)$. In equation (3), $q^{i, t}$ is the discharge from component $i$ at time $t$ and $R^{a c c, t}$ is the accumulated rainfall $(\mathrm{mm})$ at time $t$. This equation is used to describe the discharge from components $\mathrm{i}=1 \ldots \mathrm{n}$.

Notice that if $V_{\text {out }}^{i}<0$, it should be set equal to zero. 


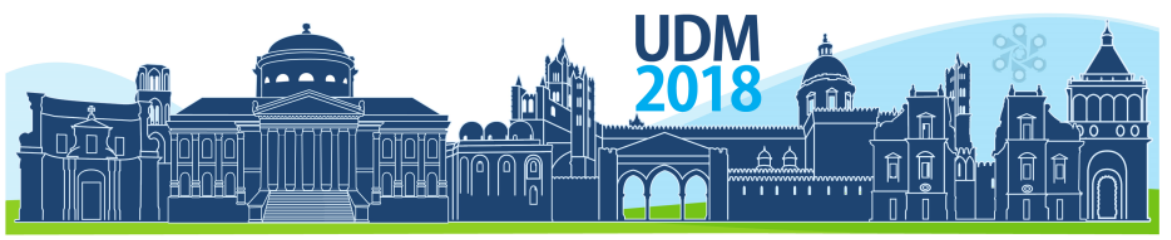

$11^{\text {th }}$ International Conference on Urban Drainage Modelling

23-26 Sep | Palermo - Italy

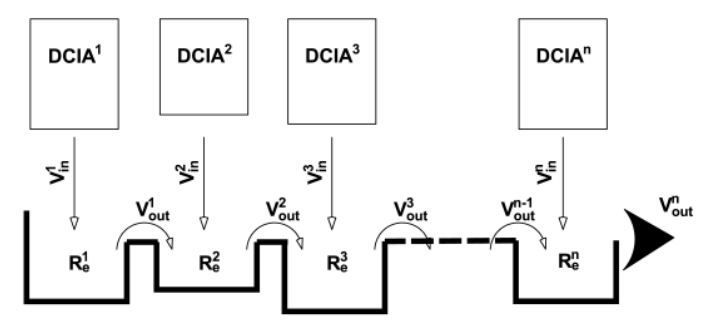

(a)

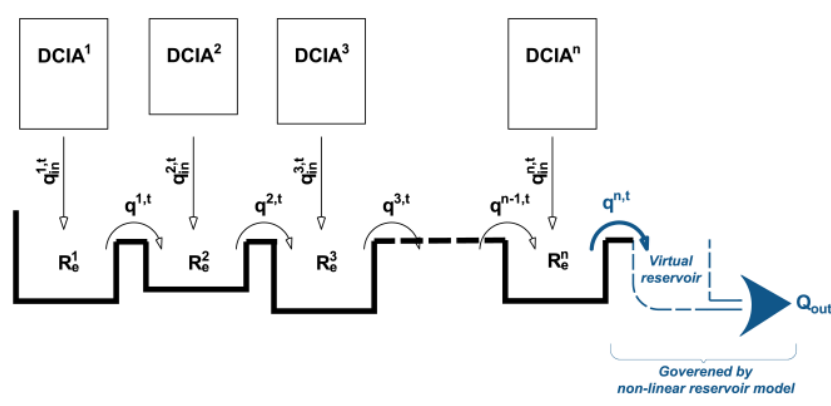

(b)

Figure 1. (a) Schematization of mesoscale SuDS based on the conceptual model introduced by Haghighatafshar et al. (2017). (b) Enhanced version of the volume-transfer model resulting in discharge (flow) simulation.

The characteristics of the discharge at the most downstream point in the SuDS (n) is especially important when simulating the influence of the entire urban drainage network on the runoff process. In the schematization used in this paper, the discharge from component $(n)$ is assumed to be the inflow to a virtual component $\left(Q_{\text {in }}\right)$, for which the discharge $\left(Q_{\text {out }}\right)$ is simulated using a non-linear reservoir model. Figure $1 \mathrm{~b}$ shows how the final discharge is treated in the applied scheme, leading to the following equation:

$$
\frac{d S}{d t}=Q_{\text {in }}-Q_{\text {out }} \stackrel{Q_{\text {out }}=k S^{m}}{=} \frac{d S}{d t}=Q_{\text {in }}-\boldsymbol{k} \boldsymbol{S}^{\boldsymbol{m}}
$$

where $S\left(\mathrm{~m}^{3}\right)$ is the dynamic storage volume in the virtual reservoir, $k\left(\mathrm{~min}^{-1}\right)$ and $m$ (no units) are the reservoir coefficients.

\subsection{Rainfall-runoff measurements}

The Augustenborg area in the center of Malmö, Sweden, contains unique examples of mesoscale SuDS. The area consists of two separate SuDS (denoted as the Northern and Southern SuDS), in total encompassing a drainage area of about 16 ha. Both rainfall and runoff measurements from the Northern and Southern SuDS have been carried out during 2 years. The nine largest rainfall events during the study period, which led to discharge from the SuDS, were selected for the calibration and validation of the model.

\section{RESULTS AND DISCUSSION}

Four rainfall events with different volumes and durations were selected for the model calibration process. The Nash-Sutcliffe Efficiency Index (NSE-Index) was employed to objectively estimate the optimum $k$ and $m$ parameters in equation (4) through maximization of the NSE-Index. The results of the calibration showed that $m$-values for both the Northern and Southern SuDS were always close to 1 . Thus, the hydrographs were best simulated by a linear reservoir model. The parameter $k$ was calibrated to $0.017 \mathrm{~min}^{-1}$ and $0.014 \mathrm{~min}^{-1}$ for the Northern and Southern SuDS, respectively. Figure 2 shows examples of modelled versus observed hydrographs for the SuDS in Augustenborg yielding values of the NSE-Index of 0.92 and 0.83 for the Northern and the Southern SuDS, respectively. The model is able to satisfactorily predict the discharge rates from both the Northern and Southern SuDS for all events using similar parameter values, which indicate reliability and robustness. Such a fast and easily applicable model, which generates the entire hydrograph from mesoscale SuDS in 


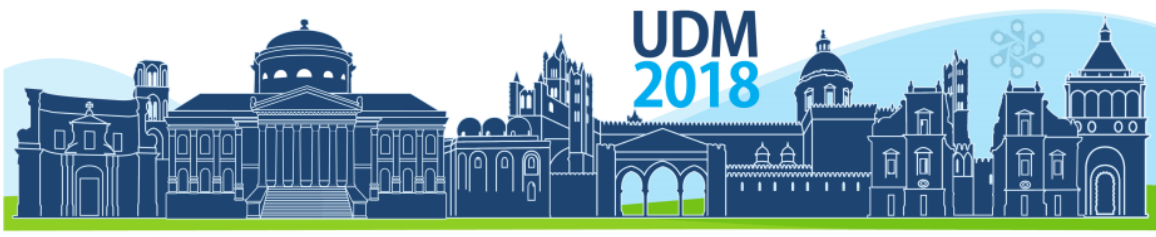

$11^{\text {th }}$ International Conference on Urban Drainage Modelling

23-26 Sep | Palermo - Italy

a matter of seconds, is essential for demanding simulations (e.g., city-wide modeling, application of long-term rainfall time series, Monte-Carlo techniques), but will also play an important role in facilitating the communication between urban water engineers and urban planners who are tasked with the design and implementation of SuDS through a mutual perspective and collaboration.
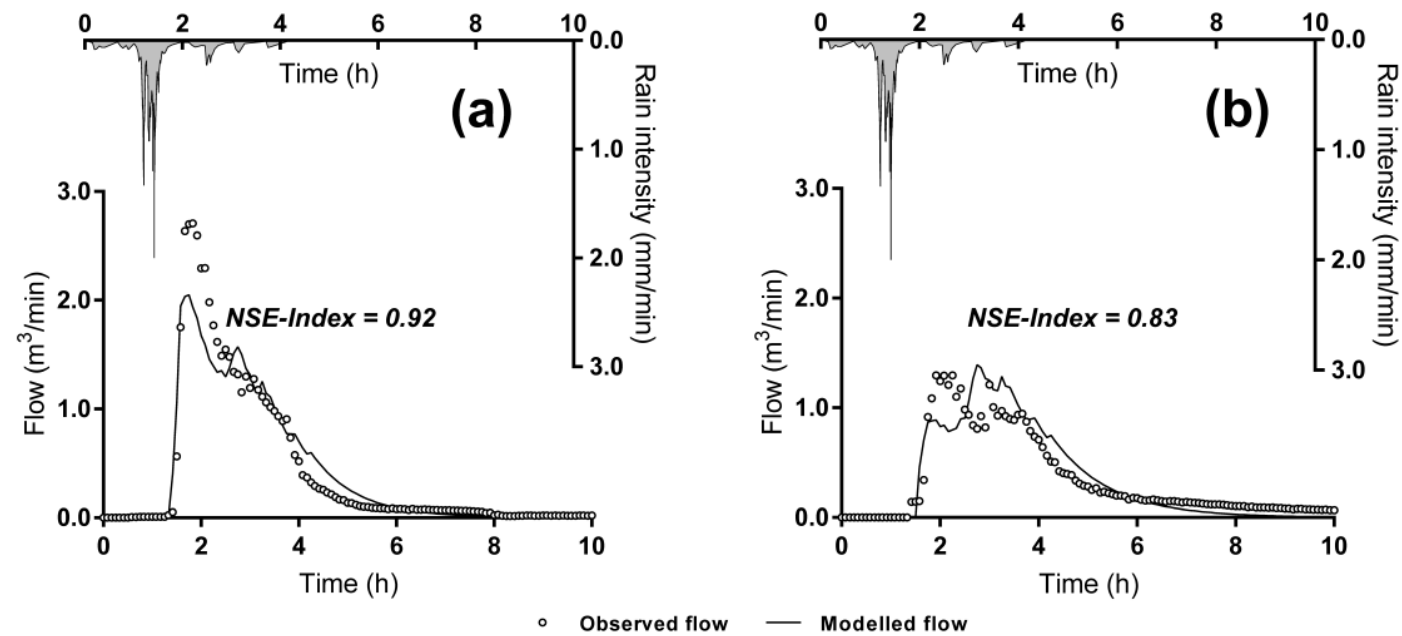

Figure 2. Observed versus modelled discharges from the Northern (a) and Southern SuDS (b) in Augustenborg.

Figures 3 and 4 illustrate the performance of the model with regard to peak flow and lag time for all rainfall-runoff events recorded in this study for the Northern and Southern SuDS, respectively. The model produces comparable results for the Northern SuDS (see Figures $3 a$ and $4 a$ ), whereas the simulations for the Southern SuDS (Figures $3 b$ and $4 b$ ) show less good agreement with the observed data. This can partly be explained by the more complex discharge conditions that prevail in the Southern SuDS (Haghighatafshar et al., 2017). Overall,

(a)

Northern SuDS

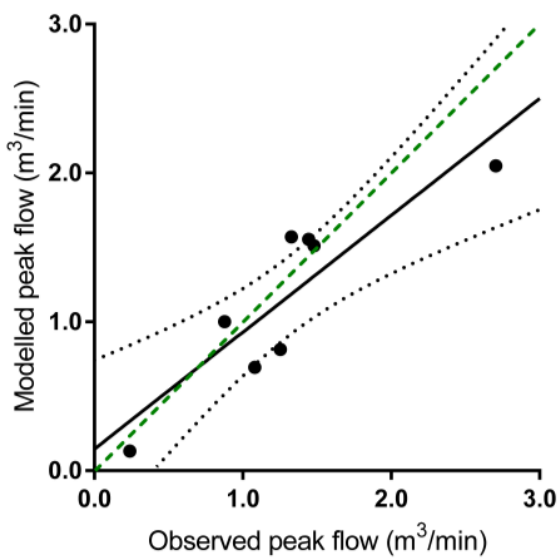

(b)

Southern SuDS

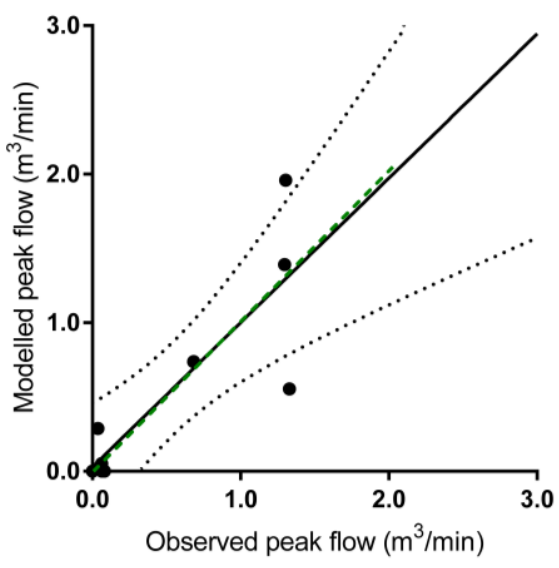

-.- 1:1 indicator - Linear regression $95 \%$ confidence bands

Figure 3. Model performance with regard to peak flow for Northern (a) and Southern SuDS (b) in Augustenborg. 


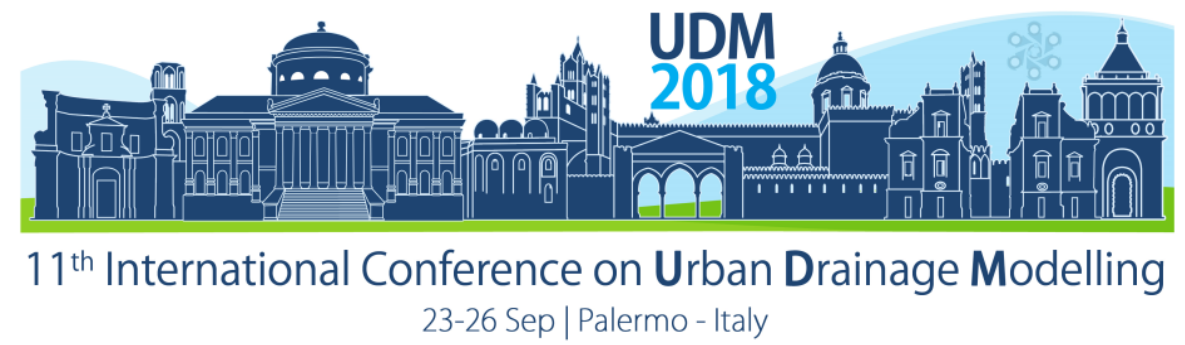

the model is found to produce acceptable results considering the simplifications made to achieve fast and easy simulations at low computational costs.

(a)

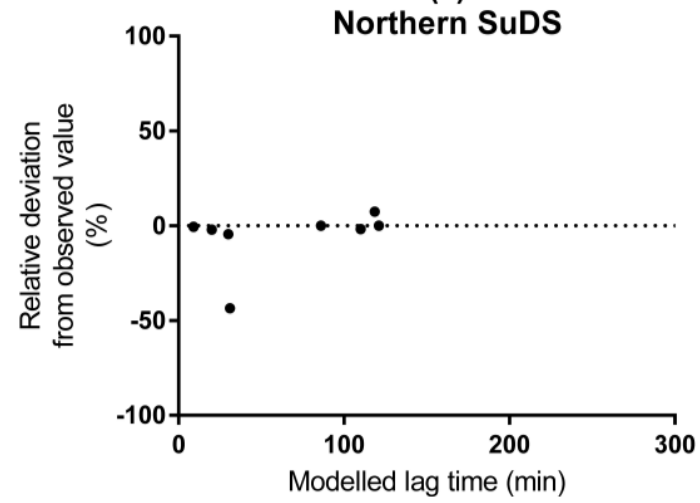

(b)

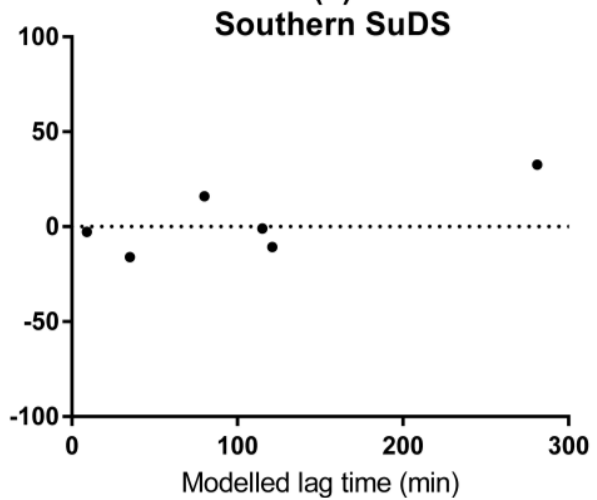

Figure 4. Relative deviation of modelled lag times from observed values, normalized against the total duration of the rainfall.

\section{CONCLUDING REMARKS}

The model developed in this study fulfills the overall objective, which was to predict the discharge pattern (hydrograph) from mesoscale SuDS at low computational costs and with acceptable accuracy. The complete hydrograph from a mesoscale SuDS for a 10-hour rainfall event is generated in a couple of seconds. This model property facilitates large-scale/city-wide optimization studies that are essential for long-term, sustainable performance of urban drainage networks. Presently, the model uses the nonlinear reservoir equation only to characterize the last compartment in the SuDS. A more detailed and representative approach would be to apply the nonlinear reservoir model to the discharges from all the upstream SCMs as well, i.e., $q^{1, t}, q^{2, t}, \ldots, q^{n-1, t}$. However, for validation this would require more extensive data collection at many discharge points from the SCMs. Furthermore, it means that the $k$ and $m$ constants have to be quantified for each compartment (SCM), which will make the model a more complicated tool to use. On the other hand, depending on the type of SCM, analytical or empirical expression may be developed for $k$ and $m$.

\section{References}

García-Serrana, M., Gulliver, J. S., and Nieber, J. L. (2017) Non-uniform overland flow-infiltration model for roadside swales. Journal of Hydrology, 552, 586-599.

Haghighatafshar, S., la Cour Jansen, J., Aspegren, H., and Jönsson, K. (2017) "Introduction of a novel conceptual model for sustainable drainage systems based on observed rainfall-runoff patterns - a case study" in In Proceedings of the 14th International Conference on Urban Drainage, Prague, Czech Republic, 10-15 September 2017. Prague, Czech Republic, 991-998.

Haghighatafshar, S., Nordlöf, B., Roldin, M., Gustafsson, L.-G., la Cour Jansen, J., and Jönsson, K. (2018) Efficiency of blue-green stormwater retrofits for flood mitigation - Conclusions drawn from a case study in Malmö, Sweden. Journal of Environmental Management, 207.

Locatelli, L., Mark, O., Mikkelsen, P. S., Arnbjerg-Nielsen, K., Bergen Jensen, M., and Binning, P. J. (2014) Modelling of green roof hydrological performance for urban drainage applications. Journal of Hydrology, 519, 3237-3248.

Roldin, M., Locatelli, L., Mark, O., Mikkelsen, P. S., and Binning, P. J. (2013) A simplified model of soakaway infiltration interaction with a shallow groundwater table. Journal of Hydrology, 497.

Zhou, Q. (2014) A Review of Sustainable Urban Drainage Systems Considering the Climate Change and Urbanization Impacts. Water, 6(4). 


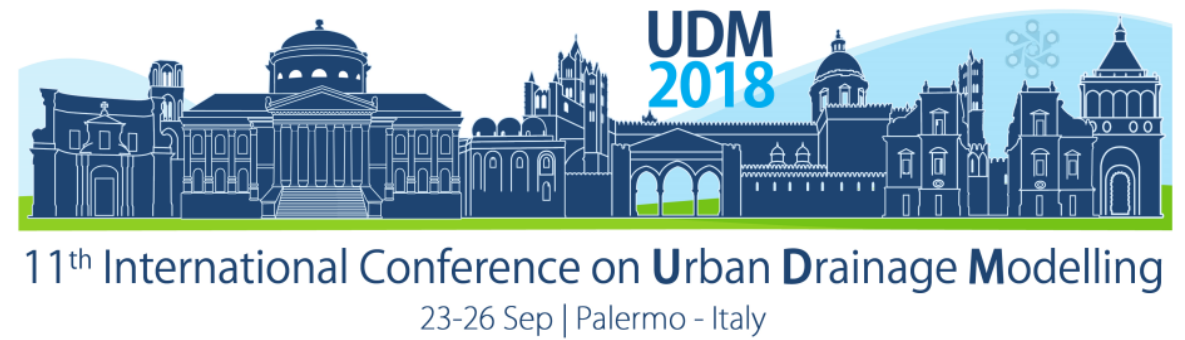

\title{
Model-Based Sewer Network Control - Practical Experiences
}

\author{
Christoph Brepols ${ }^{1}$, Heinrich Dahmen ${ }^{1}$, Maja Lange ${ }^{2}$, Annelie Sohr ${ }^{3}$, Reinhold Kiesewski ${ }^{1}$ and Richard \\ Rohlfing ${ }^{4}$ \\ ${ }^{1}$ Erftverband, Bergheim/Erft, Germany \\ 2 FiW, Aachen, Germany \\ ${ }^{3}$ Siemens AG, München, Germany \\ ${ }^{4}$ PFI Planungsgemeinschaft GmbH, Hannover, Germany
}

\begin{abstract}
A model-based flow control system was installed at an existing sewer network. On-line radar data and radar forecasting are used to model the inflow to the sewer system. Based upon these data the model evaluates optimised flow control set-points at twelve storm-water-retention-basins in the sewer network. Flow rates of adjacent pumps and throttles are thus controlled by a central unit. The use of radar-data in discharge control systems is new and provides proper and reliable results. The overall system is now operative since more than two years. During this time, high operational stability could be achieved. The modular design also allows the addition of further elements of sewer network control. Practical experiences with the flow control system from early design to implementation in the field and ongoing operations are presented. The operation of the system significantly reduces storm-water overflows to rivers and water bodies an more storm-water is treated at the central wastewater treatment plant and retention soil filter.
\end{abstract}

Keywords: sewer network control; radar data; modelling; case-study

\section{INTRODUCTION}

Combined sewer networks fulfil various functions: (a) collection of rainwater from paved surfaces, (b) collection of sewage from households, business- and industrial-sites, (c) transportation of sewage over long distances as well as (d) storage and treatment of rainwater and (e) eventual discharge of excess rainwater into surface waters. Sewers, stormwater retention tanks, overflows, retention soil filters, throttles and pumping stations are elements which are designed and operated to achieve proper network services and reduce environmental effects of storm-water overflow and storm-water discharge into rivers and water-bodies. Storm-water overflows that regularly exceed the natural hydraulic capacity of a river can be seen as a main impediment in achieving a good ecological according to the EU Water framework (BWK, 2008).

Sewer network control systems can be a way to improve network operations by channelling, holding back and adjusting flows in the sewer network. Generally different goals can be attained by implementing a sewer network control system: (a) reduced quantity and improved quality of storm-water discharges to surface waters, (b) improved sewer operations or (c) reduced cost for new storm-water retention volume (DWA, 2005). Regardless of these benefits and the state of scientific research, there have been relatively few practical examples for permanent implementation in existing sewer networks in Germany over the last 30 years. 


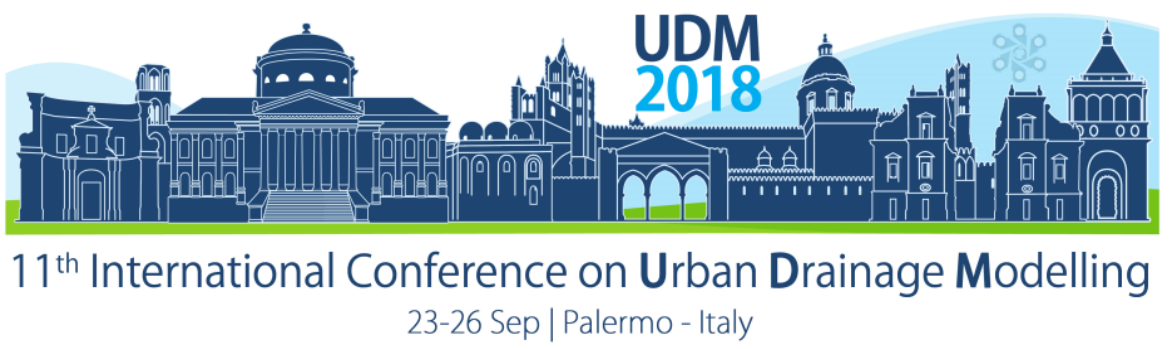

\section{MATERIALS AND METHODS}

\subsection{Project Area}

The catchment area of the wastewater treatment plant (WWTP) of Bergheim-Kenten consists mainly of mixed-sewer-systems and it comprises an overall area of $24.5 \mathrm{~km}^{2}$. Geographically the region belongs to the lowlands of the so-called Kölner Bucht, situated west of the Rhineriver close to Cologne, Germany. The catchment has several villages and small cities with almost 100,000 inhabitants and has a mostly flat topography. The longest point-to-point hydraulic flow time in the sewer-systems is at 10 hours. Today 34 storm-water tanks, four sewer outlets and one retention-soil-filter are operated in the network with an overall retention volume of $65,000 \mathrm{~m}^{3}$. The WWTP is designed for a maximum inflow during stormweather of $54,000 \mathrm{~m}^{3} / \mathrm{d}$.

\subsection{Model-Setup}

The flow control system was originally tested for 10 central retention tanks with an overall volume of $40,000 \mathrm{~m}^{3}$. The flow control system in the catchment area of the Kenten WWTP was designed and implemented in two project phases between 2012 and 2016 and is currently being continued and expanded. In the first project phase, potential benefits of flow and discharge control were evaluated based on a simulation model (MKUNLV, 2012).

Inflow to the sewer network is forecasted by online radar data. Radar data from various sources are compiled and the spatial and temporal distribution of the rainfall in the catchment area is generated for 15-minute blocks using the HEC-HMS model (HEC-MHS, 2017). Flow variations inside the sewer network are then modelled and forecasted in 15 minute intervals at 13 decisive points (figure 1). These data are then fed into the control system. The control algorithm uses non-linear optimization and is implemented in the network management assistance system SIWA SEWER provided by Siemens AG. The control system evaluates optimised operational set-points for pumping stations and throttles in the sewer network.

\subsection{Field Installations}

In the second, practical phase, all technical means were installed (measuring technology, connections to the existing tele control system, data management and data storage) to test the control system at large scale in the field. An initial one-year trial was used for data acquisition and evaluation in uncontrolled network operations and simultaneous offline simulation of the control operation. Adjustments to the system could be made in the network and models alike. Additionally a failure strategy for the control system was implemented. Finally live-operations started in 2016 (MKUNLV, 2016).

\section{RESULTS AND DISCUSSION}

\subsection{Operational Reliability}

Since January 2016, the control system has been running in continuous operation with only minor disruptions. In 2017 the modularity of the system allowed a relatively easy expansion: Control of two additional storm-water-tanks was implemented, such that the system today comprises a total of 12 controlled basins with more than $47,000 \mathrm{~m}^{3}$ of overall retention volume. The operational availability of the overall system was at $95 \%$. The use of online radar data for rainfall also showed a high availability with failure rates almost close to zero. 


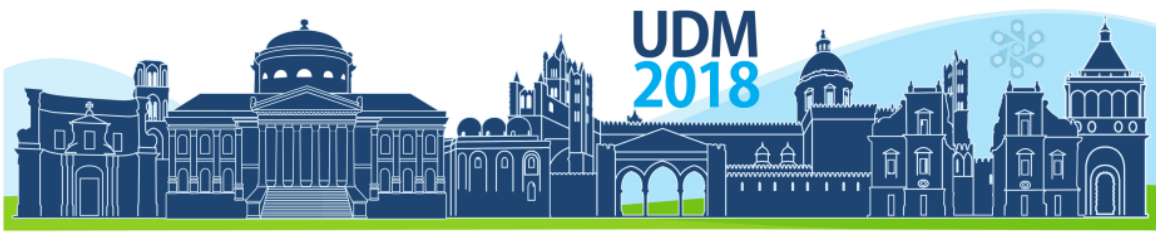

$11^{\text {th }}$ International Conference on Urban Drainage Modelling

23-26 Sep | Palermo - Italy

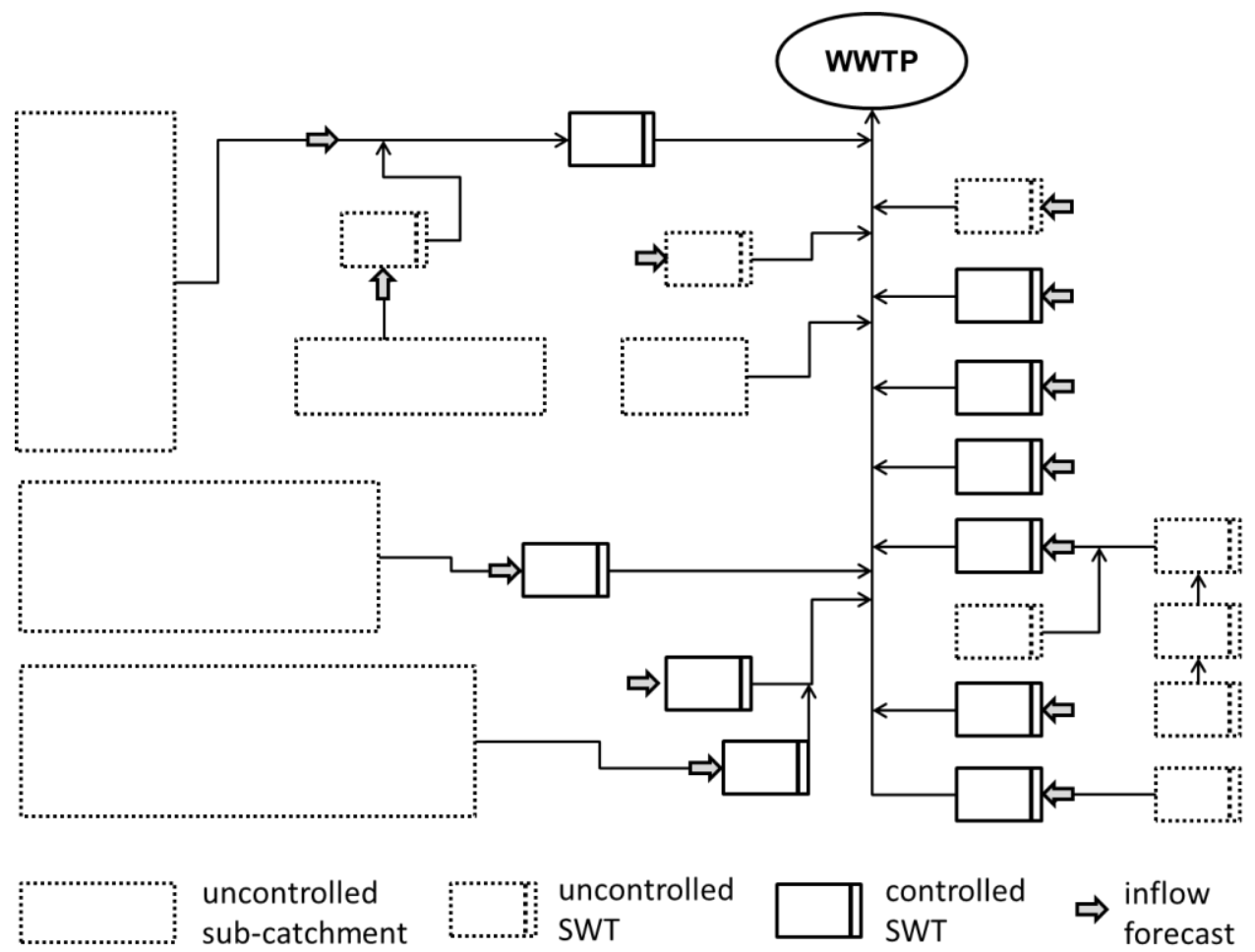

Figure 1. Schematic layout of the sewer network with controlled and uncontrolled storm-water tanks (SWT).

\subsection{Improved Strom-water Treatment}

By the end of 2016 it could be seen that the total amount of rainwater which was finally treated at the WWTP increased from a long term average of roughly 2.4 million $\mathrm{m}^{3}$ to almost 2.9 million $\mathrm{m}^{3}$ and thus reducing the direct discharge into the rivers by $450.000 \mathrm{~m}^{3}$. For selected single rainfall events the discharged volume could be reduced by up to $85 \%$ (see figure 2). Additionally retention times storm-water stored in the tanks could also be reduced.

\section{CONCLUSIONS}

The case-study of the catchment area of the Kenten WWTP illustrates that flow control is a suitable instrument to improve surface water protection also at an industrial scale. It could be shown, that the system works reliably and effective in an existing low-laid, wide-spread sewer network. It still has to be evaluated if the system can be equally beneficial for sewer networks with different topographies in other geographical surroundings. Besides reduced storm-water discharges, the flow control could also help to reduce the amount of required storage volume in order to comply with governmental regulations like the EU Water Framework Directive. 


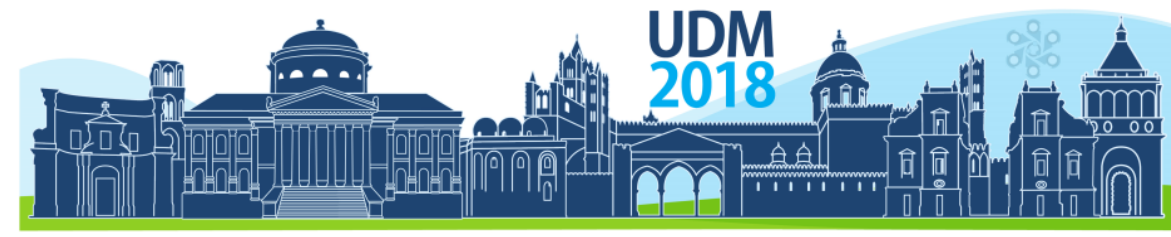

$11^{\text {th }}$ International Conference on Urban Drainage Modelling

23-26 Sep | Palermo - Italy

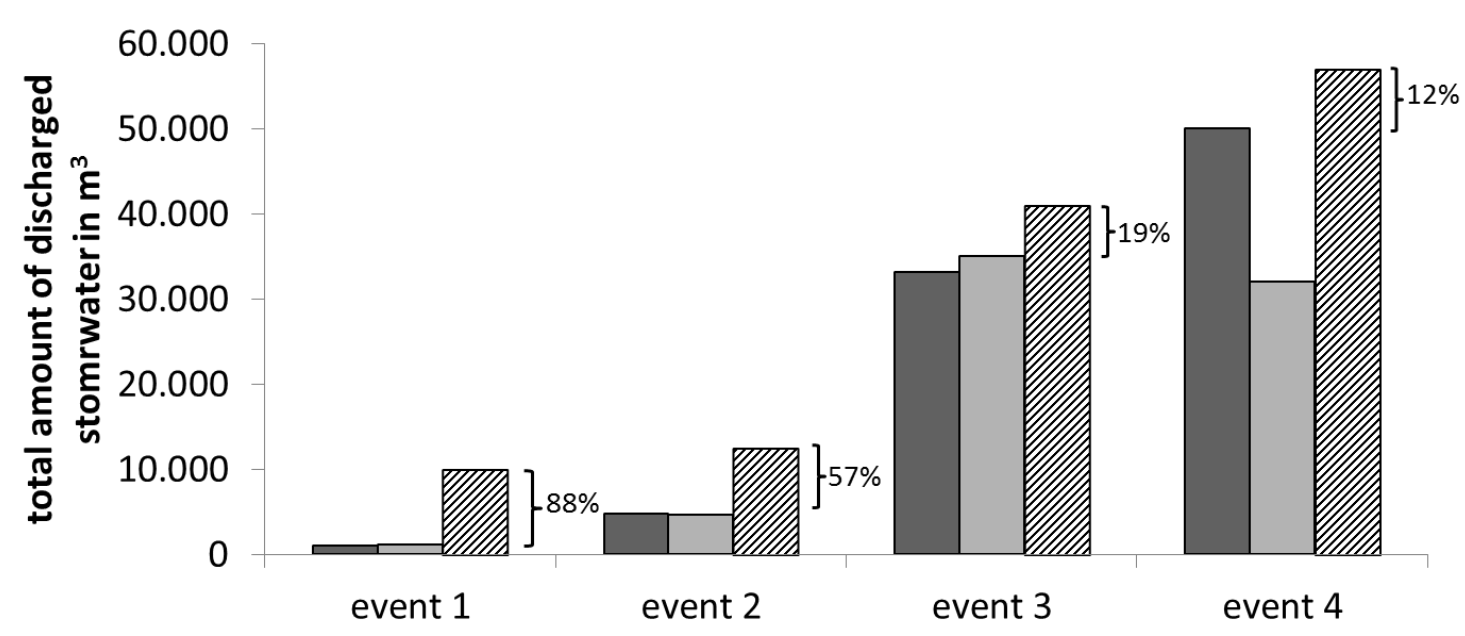

measured $\square$ modelled - controlled $\square$ modelled - uncontrolled

Figure 2. Rainwater discharge from the sewer network for four selected storm-water-events, measured and modelled discharge volumes with and without sewer-network-control.

\section{ACKNOWLDGEMENTS}

As part of a research project funded by the Ministry of the Environment, Agriculture, Nature Conservation and Consumer Protection of North-rhine Westphalia, Germany (MKULNV), sewer control was implemented and operated successfully for over two years in a cooperation between Erftverband, the Research Institute for Water and Waste Management at the RWTH Aachen e.V. (FiW), PFI Planungsgemeinschaft GbR, Hannover and Siemens AG.

\section{References}

BWK (2008): Detaillierte Nachweisführung immissionsorientierter Anforderungen an Misch- und Niederschlagswassereinleitungen gemäß BWK-Merkblatt 3, November 2008. Sindelfingen: BWK, 2008.

DWA (2005): DWA-Merkblatt M 180 - Handlungsrahmen zur Planung der Abflusssteuerung in Kanalnetzen - mit Programmpaket PASST, Deutsche Vereinigung für Wasserwirtschaft, Abwasser und Abfall, Dezember 2005, Hennef.

MKULNV (2012): Großtechnische Erprobung eines standardisierten Optimierungs-und Simulationswerkzeugs zur Online-Kanalnetzsteuerung am Beispiel des Einzugsgebiets der Kläranlage Kenten im Erftverbandsgebiet, Abschlussbericht der Phase I, gefördert vom Ministerium für Klimaschutz, Umwelt, Landwirtschaft, Natur- und Verbraucherschutz des Landes Nordrhein-Westfalen (MKULNV), Juni 2012, download: https://www.lanuv.nrw.de/uploads/tx_mmkresearchprojects/Abschlussbericht_Grosstechnische_Erprobung.p df.

HEC-HMS (2017): Hydrologic Modeling System. Freiverfügbares Simulationsmodell des Hydrologic Engineering Center, abrufbar unter http://www.hec.usace.army.mil/, Oktober 2017.

SIWA-SEWER (2018): Zentrale Steuerung von Wasserkapazitäten mit dem SIWA Sewer Management System, Siemens AG, München, 2018, download: https://w3.siemens.com/mcms/waterindustry/de/Documents/E20001-A130-T122_DB_SIWA\%20Sewer_DE.pdf

MKULNV (2016): Großtechnische Erprobung eines standardisierten Optimierungs-und Simulationswerkzeugs zur Online-Kanalnetzsteuerung am Beispiel des Einzugsgebiets der Kläranlage Kenten im Erftverbandsgebiet, Abschlussbericht der Phase II, gefördert vom Ministerium für Klimaschutz, Umwelt, Landwirtschaft, Naturund Verbraucherschutz des Landes Nordrhein-Westfalen (MKULNV), Dezember 2016, unpublished. 


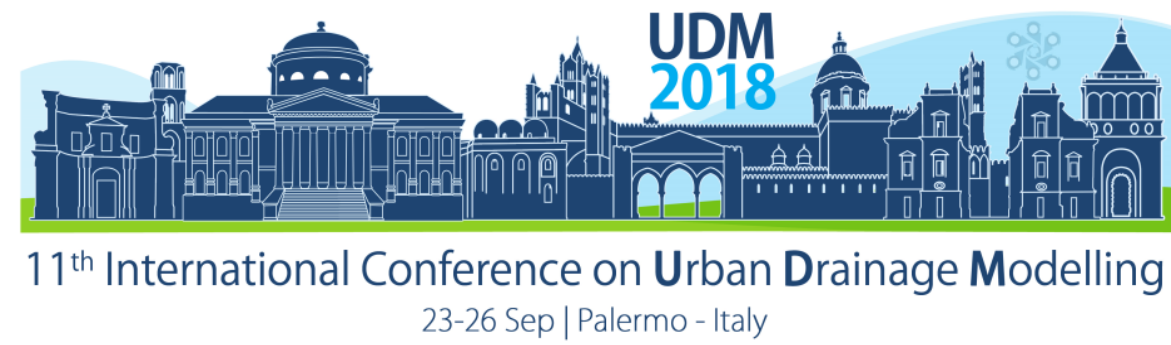

\title{
Use of shrimp-shell for adsorption of metals present surface runoff
}

\author{
Aline Schuck Rech ${ }^{1}$, Julio Cesar Rech ${ }^{2}$, Jakcemara Caprario ${ }^{3}$, Fabiane Andressa Tasca ${ }^{4}$, María \\ Ángeles Lobo Recio ${ }^{5}$ and Alexandra Rodrigues Finotti ${ }^{6}$ \\ 1, 3, 4, 5, 6 Federal University of Santa Catarina, Department of Sanitary and Environmental Engineering, \\ Florianópolis, Santa Catarina, Brazil. E-mails: aline.schuck@unc.br; jakcemara@hotmail.com; \\ fabitasca@gmail.com; maria.lobo@ufsc.br; alexandra.finotti@ufsc.br \\ 2 University of Contestado, Department of Civil Engineering, Concórdia, Santa Catarina, Brazil. E-mail: \\ juliocesar@unc.br
}

\begin{abstract}
This research analyzes the use of in nature shrimp shells for biosorption of metallic ions in surface runoff. Tests were carried out with different amounts of shrimp shells $(5 \mathrm{~g}$ and $10 \mathrm{~g})$ for $200 \mathrm{~mL}$ of runoff, with shaking of $100 \mathrm{rpm}$ for $24 \mathrm{~h}$. The results evidenced the high presence of metal ions in the shrimp shells and that it directly influenced the results of the tests with the different amounts of biosorbent. The shrimp shells in nature had high concentrations of metal ions $(\mathrm{Pb}, \mathrm{Ni}$ and $\mathrm{Cu}$ ), which have high toxicity to the environment, however there had been specific metal ions ( $\mathrm{Fe}, \mathrm{Mn}, \mathrm{Zn}$ and $\mathrm{Cr}$ ) removing. According to the results, a pretreatment is required for biosorbents prior to full scale use.
\end{abstract}

Keywords: shrimp-shell; heavy metals; surface runoff.

\section{INTRODUCTION}

The surface runoff from waterproofed areas contains organic and inorganic compounds, which influence on the quality of surface water and groundwater. Inorganic pollutants include metals, such as $\mathrm{Fe}, \mathrm{Al}, \mathrm{Zn}, \mathrm{Cu}, \mathrm{Cd}, \mathrm{Ni}$ and $\mathrm{Pb}$. These metals are derived from economic activities carried out in the drainage area, mainly involving derivatives of agricultural products and residues from vehicle traffic (TORRES, 2010).

In this scenario, this research studied the biosorption using in nature (headless) shrimp shells for the removal of metallic ions present in surface runoff. According to NúñezGómez et al. (2017), biosorption is the process of removing compounds, metal ions or other materials using an inactive (non-living) sorbent of biological origin, by means of pulling forces between the removed material and the biosorbent. This process involves physical-chemical mechanisms, physical adsorption, ion exchange, complexation, coprecipitation and precipitation. The use of the natural shrimp shell was studied for effluents with acid $\mathrm{pH}$ and high concentrations of metals and metalloids (Gamage and Shahidi, 2007; Núñez-Gómez et al., 2016, Núñez-Gómez et al., 2017), presenting satisfactory results.

However, the use of inorganic shrimp as a biosorbent for the removal of metallic ions in superficial flows is incipient in the world. Laboratory tests with adsorbent and locally abundant materials may direct their use in compensatory drainage structures for remediation of pollutants. It should be emphasized the abundance of this material in the Coast of Santa Catarina - Brazil and the high index of infiltration structures. According to Caprario (2017), only the Campeche District, in Florianópolis, the capital of this state, has more than a thousand infiltration structures. In this way, the use of biosorbents in compensatory drainage structures becomes an investigative and promising field. 


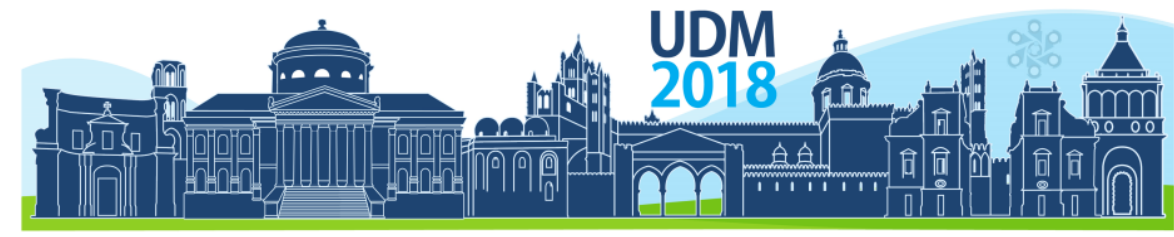

$11^{\text {th }}$ International Conference on Urban Drainage Modelling

23-26 Sep | Palermo - Italy

\section{MATERIALS AND METHODS}

The infiltration swale is located in the Campeche District, in the Florianópolis city, situated in Santa Catarina State, South region of Brazil (Figure 1). To prepare this article were used bibliographic and laboratory information. Initially, articles dealing with heavy metal removal with the use of biosorbents were reviewed, aiming at the use of fresh shrimp shells (without head and organic matter). Subsequently, laboratory tests were carried out with this biosorbent and surface runoff samples from an area of intense traffic of vehicles and that had concentrations of metallic ions.

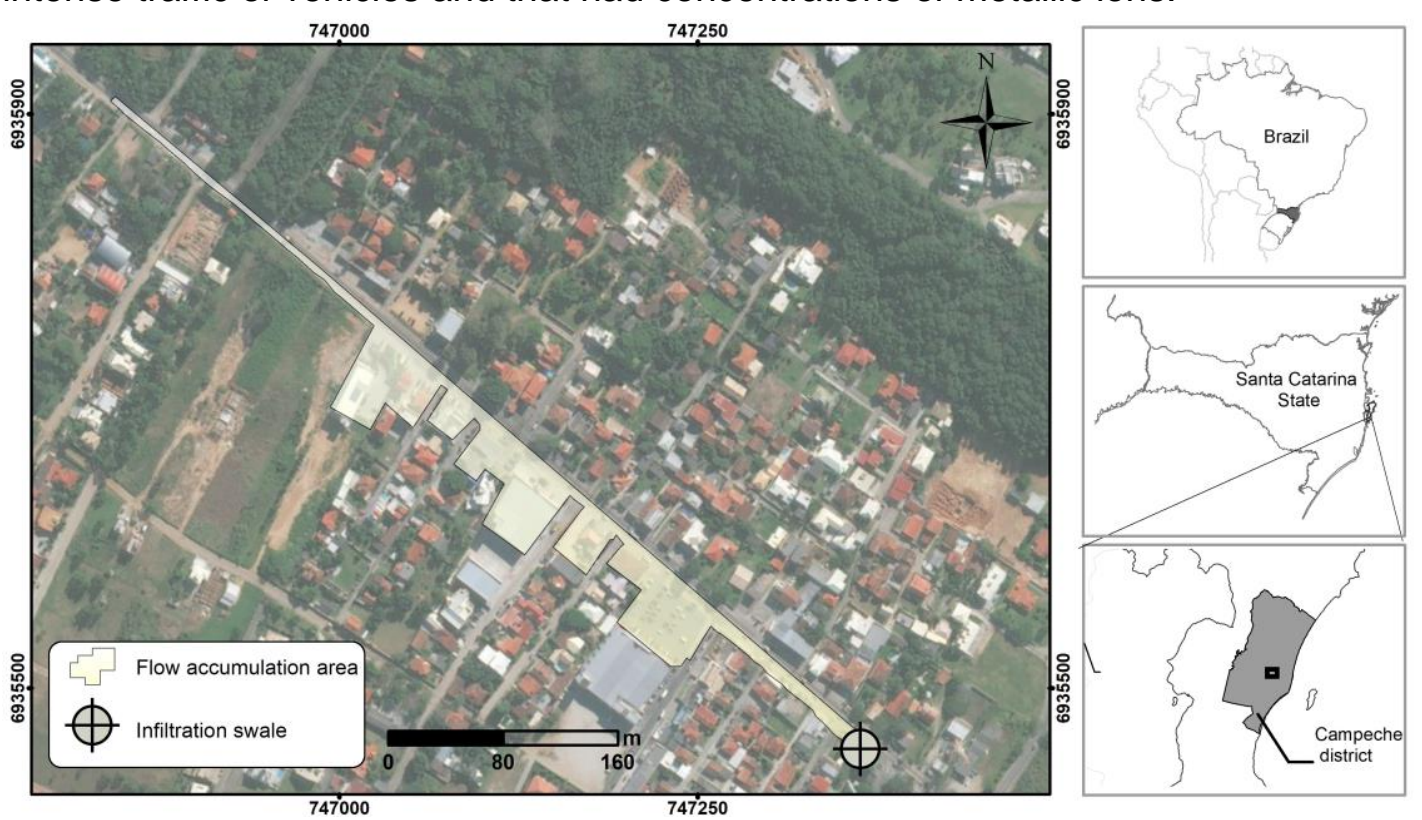

Figure 1. Infiltration swale location.

\subsection{Shrimp-shell}

The procedure used for the fresh shrimp shells preparation was based on the methodology described by Gomez-Nunez et al. (2017). The authors suggest that the shrimp shells (without the head) should be carefully washed for the removal of organic matter. Afterwards the shrimp shells were dried in the oven for a period of $72 \mathrm{~h}$ at $100^{\circ} \mathrm{C}$ and then stored at a temperature of $50^{\circ} \mathrm{C}$ until the tests were carried out. The shells were grounded in order to maintain homogeneity in size. The shrimp shells in nature were obtained in an animal food processing industry located in Laguna city, in the Santa Catarina state- Brazil.

\subsection{Surface runoff}

The effluent tested in this article was collected in an infiltration swale that came from the District of Campeche located in the city of Florianópolis, in Santa Catarina - Brazil. The area is characterized by intense road flow, mixed constructive uses (residential, commercial and industrial), absence of sewage collection networks, and numerous infiltration structures. The collection of surface runoff occurred inside the compensatory drainage structure. The sample was preserved and sent to the laboratory. The infiltration swale is over 15 years old and is managed by the city government. In addition, the surface runoff collected in the swale has high concentrations of $\mathrm{Cd}, \mathrm{Cu}$, 


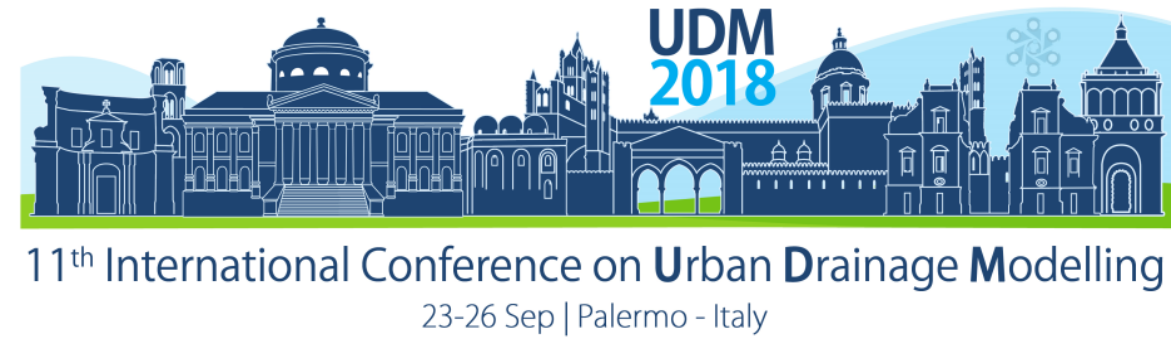

$\mathrm{Pb}$ and $\mathrm{Cr}$ (PACHECO, 2015), increasing the risk of contamination of soil, surface water and groundwater.

\subsection{Laboratory Tests}

Five tests were carried out to verify the adsorption of the following heavy metals: $\mathrm{Cr}$, $\mathrm{Pb}, \mathrm{Ni}, \mathrm{Cu}, \mathrm{Zn}, \mathrm{Fe}$ and $\mathrm{Mn}$ (Table 1). The definition of the metal analysis is based on the research of Pacheco (2015) for the characteristics of Campeche District. In sequence, the second test called "white test", has verified the concentration of metals present in the shrimp shell. In this test the proportions of $5 \mathrm{~g}$ of shrimp shell in $200 \mathrm{~mL}$ of distilled water were used. The sample remained in a glass vessel for 24 hours under a low-speed stirring table (0-100 rpm).

The third test used $5 \mathrm{~g}$ of shrimp shell with $200 \mathrm{~mL}$ of runoff collected in the infiltration swale. In the fourth test, the concentration of metals in $10 \mathrm{~g}$ of shrimp shell in distilled water was analyzed. In the fifth test, we analyzed the removal of metals with $10 \mathrm{~g}$ of shrimp shells for the volume of $200 \mathrm{~mL}$. Triplicates were performed for all analyzes.

Table 1. Analyzes performed in the laboratory using in-shell shrimp shells.

\begin{tabular}{|c|c|c|c|c|c|}
\hline Test & Quantity (g) & Solution & $\begin{array}{c}\text { Contact } \\
\text { time }\end{array}$ & $\begin{array}{l}\text { Agitation } \\
\text { (rpm) }\end{array}$ & Metals \\
\hline $1^{\mathrm{a}}$ Test & - & $\begin{array}{l}200 \mathrm{~mL} \text { of } \\
\text { runoff }\end{array}$ & - & 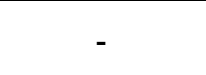 & \multirow{5}{*}{$\begin{array}{c}\mathrm{Cr}, \mathrm{Pb}, \mathrm{Ni}, \mathrm{Cu}, \\
\mathrm{Zn}, \mathrm{Fe} \text { e } \mathrm{Mn} .\end{array}$} \\
\hline $\begin{array}{l}2^{\mathrm{a}} \text { Test - } \\
\text { White }\end{array}$ & $\begin{array}{l}5 \mathrm{~g} \text { of shrimp } \\
\text { shell }\end{array}$ & $\begin{array}{l}200 \mathrm{~mL} \text { of } \\
\text { distilled water }\end{array}$ & $24 \mathrm{~h}$ & \multirow{4}{*}{ (0-100 rpm) } & \\
\hline $\begin{array}{l}2^{a} \text { Test - } \\
\text { Shrimp-shell }\end{array}$ & $\begin{array}{l}5 \mathrm{~g} \text { of shrimp } \\
\text { shell }\end{array}$ & $\begin{array}{l}200 \mathrm{~mL} \text { of } \\
\text { runoff }\end{array}$ & $24 \mathrm{~h}$ & & \\
\hline $\begin{array}{l}3^{\mathrm{a}} \text { Test - } \\
\text { White }\end{array}$ & $\begin{array}{l}10 \mathrm{~g} \text { of } \\
\text { shrimp shell }\end{array}$ & $\begin{array}{l}200 \mathrm{~mL} \text { of } \\
\text { distilled water }\end{array}$ & $24 \mathrm{~h}$ & & \\
\hline $\begin{array}{l}3^{\mathrm{a}} \text { Test - } \\
\text { Shrimp-shell }\end{array}$ & $\begin{array}{l}10 \mathrm{~g} \text { of } \\
\text { shrimp shell }\end{array}$ & $\begin{array}{l}200 \mathrm{~mL} \text { of } \\
\text { runoff }\end{array}$ & $24 \mathrm{~h}$ & & \\
\hline
\end{tabular}

The calibration of the $\mathrm{pH}$ occurred before and after each test, through a potentiometer with electrode. A shaker table of the brand Cientec (CT-145) with stirring speed of 0$100 \%$ or $100 \mathrm{rpm}$ was used. The concentration of the metals of each sample was measured by the SM 3111B atomic absorption / flame method.

\section{RESULTS AND DISCUSSION}

\subsection{Adsorption with shrimp-shell}

The results of the laboratory tests are described in Table 2. The results of the tests with in shell shrimp and distilled water (white tests) indicated high concentrations of $\mathrm{Pb}, \mathrm{Ni}$ and $\mathrm{Cu}$. These concentrations directly influenced the following tests with surface water and solvents. These chemical elements indicated the contamination in the aqueous medium. The best biosorption results were for the tests with $5 \mathrm{~g}$ for $\mathrm{Fe}(62,8 \%)$ and for $\mathrm{Cr}(55.6 \%)$. The tests with $10 \mathrm{~g}$ of fresh shrimp shells showed satisfactory results for $\mathrm{Fe}$ $(63 \%)$ and $\mathrm{Cr}(62.2 \%)$. For the other analyzed metals the removal was considered low.

Table 2. Results of laboratory tests using in-shell shrimp shells.

\begin{tabular}{|c|c|c|c|c|c|c|c|}
\hline Analyzes & $\begin{array}{c}1^{a} \\
\text { Test }\end{array}$ & $\begin{array}{l}2^{\text {a }} \text { Test - } \\
\text { White }\end{array}$ & $\begin{array}{c}2^{\mathrm{a}} \text { Test - } \\
\text { Shrimp-shell }\end{array}$ & $\begin{array}{c}\% \\
\text { removal }\end{array}$ & $\begin{array}{l}\text { 3a Test } \\
\text { - White }\end{array}$ & $\begin{array}{c}3^{\text {a }} \text { Test - } \\
\text { Shrimp-shell }\end{array}$ & $\begin{array}{c}\% \\
\text { removal }\end{array}$ \\
\hline $\mathrm{pH}$ inicial & 6,03 & - & 6,03 & - & - & 6,03 & - \\
\hline $\mathrm{pH}$ final & - & - & 7,41 & - & - & 7,45 & - \\
\hline
\end{tabular}




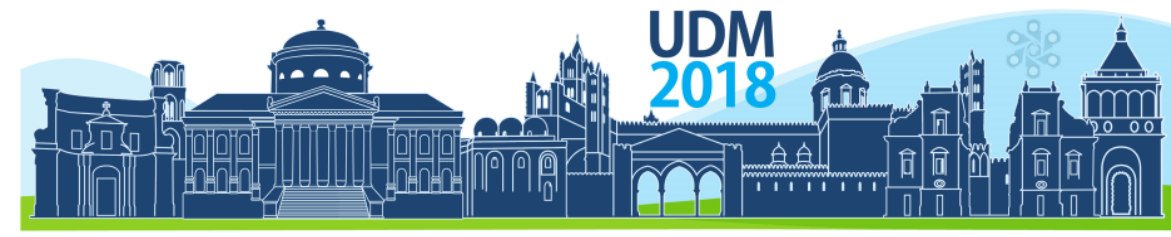

$11^{\text {th }}$ International Conference on Urban Drainage Modelling 23-26 Sep | Palermo - Italy

\begin{tabular}{|c|c|c|c|c|c|c|c|}
\hline Analyzes & $\begin{array}{c}1^{\mathrm{a}} \\
\text { Test }\end{array}$ & $\begin{array}{l}\text { 2a Test - }^{\text {a Te }} \\
\text { White }\end{array}$ & $\begin{array}{c}2^{\mathrm{a}} \text { Test - } \\
\text { Shrimp-shell }\end{array}$ & $\begin{array}{c}\% \\
\text { removal }\end{array}$ & $\begin{array}{l}\text { 3 Test } \\
\text { - White }\end{array}$ & $\begin{array}{c}3^{\text {a }} \text { Test - } \\
\text { Shrimp-shell }\end{array}$ & $\begin{array}{c}\% \\
\text { removal }\end{array}$ \\
\hline $\mathrm{Cr}(\mathrm{mg} / \mathrm{L})$ & 0,033 & 0,003 & 0,016 & 55,6 & 0,004 & 0,014 & 62,2 \\
\hline $\mathrm{Pb}(\mathrm{mg} / \mathrm{L})$ & 0,014 & 0,020 & 0,081 & $-138,2$ & 0,126 & 0,130 & 7,1 \\
\hline $\mathrm{Ni}(\mathrm{mg} / \mathrm{L})$ & 0,015 & 0,050 & 0,103 & $-58,5$ & 0,093 & 0,125 & $-15,7$ \\
\hline $\mathrm{Cu}(\mathrm{mg} / \mathrm{L})$ & 0,034 & 0,136 & 0,167 & 1,8 & 0,234 & 0,274 & $-2,2$ \\
\hline $\mathrm{Zn}(\mathrm{mg} / \mathrm{L})$ & 0,130 & 0,190 & 0,248 & 22,5 & 0,359 & 0,432 & 11,7 \\
\hline $\mathrm{Fe}(\mathrm{mg} / \mathrm{L})$ & 5,390 & 0,421 & 2,161 & 62,8 & 0,789 & 2,262 & 63,4 \\
\hline $\mathrm{Mn}(\mathrm{mg} / \mathrm{L})$ & 0,089 & 0,158 & 0,162 & 34,4 & 0,199 & 0,245 & 14,9 \\
\hline
\end{tabular}

The $\mathrm{pH}$ of the runoff increased from 6.03 to 7.45 . The fresh shrimp shells contain calcium and chitin present, leaving the sample alkaline. The results found are not satisfactory, the shrimp shell has high concentrations of metallic ions, $\mathrm{Pb}, \mathrm{Ni}$ and $\mathrm{Cu}$. These chemicals have high toxicity. Specific metal ions $\mathrm{Fe}, \mathrm{Mn}, \mathrm{Zn}$ and $\mathrm{Cr}$ were removed. The concentrations of metals in the shrimp shell became a warning to the use of alternative materials without pretreatment as metal biosorbents. Annually numerous researches are carried out using biosorbents found locally in abundance, trying to use them in the removal of pollutants, but without adequate techniques and processes these biosorbents can transfer pollutants to the environment.

\subsection{Alternative materials for removal of pollutants}

In the world, numerous researches test biosorbents for the removal of pollutants. The research of Núñez-Gómez et al. (017) used commercial chitin for the removal of metallic ions ( $\mathrm{Ni}, \mathrm{Pb}, \mathrm{Zn}, \mathrm{Fe}, \mathrm{Al}, \mathrm{Cr}, \mathrm{Mn}, \mathrm{Mg}$ ) presented in mine waters and obtained satisfactory results for the removal of $\mathrm{Fe}, \mathrm{Ni}, \mathrm{Al}, \mathrm{Cu}, \mathrm{Mn}$. The researchers used 9.36 g.L -1 of shrimp shells at a stirring speed of $188 \mathrm{rpm}$. Commercial chitin is a biopolymer resulting from the processing of shrimp, crab and lobster waste. After the processing, the material presents low content of metal and calcium carbonate, allowing the neutralization of the $\mathrm{pH}$.

The researchers Gamage and Shahidi (2007) used chitosan derived from crab for the removal of metallic ions present in industrial wastewater. The results were satisfactory for $\mathrm{Hg}, \mathrm{Fe}, \mathrm{Ni}, \mathrm{Pb}, \mathrm{Cu}$ and $\mathrm{Zn}$. Chitosan is derived from the deacetylation process of chitin, being constituted mainly by exoskeletons of crustaceans. It should be emphasized the importance of performing laboratory analyzes and of pretreatment of biosensors before the application in real scale.

\section{CONCLUSION}

This research investigated the use of fresh shrimp shell as biosorbent of metallic ions in runoff. Initial tests indicated high concentrations of metal ions in the shrimp shell, which increased the final concentrations of them in the runoff. It can be concluded that the fresh shrimp shells cannot be used in the removal of metal ions without a pretreatment. Therefore, future tests with commercial chitin for the same effluent should be carried out in order to compare and verify the removal of metallic ions.

\section{References}

CAPRARIO, J. Desenvolvimento de um instrumento para o mapeamento de áreas suscetíveis a alagamentos e inundações urbanas. Dissertação de Mestrado no Programa de Pós Graduação em Engenharia Ambiental - PPGEA - Universidade Federal de Santa Catariana - UFSC, 2017. 
Proceedings of the 11th Int. Conference on Urban Drainage Modelling, 23-26 Sep. 2018, Palermo (ITALY). Ed. prof. Giorgio Mannina

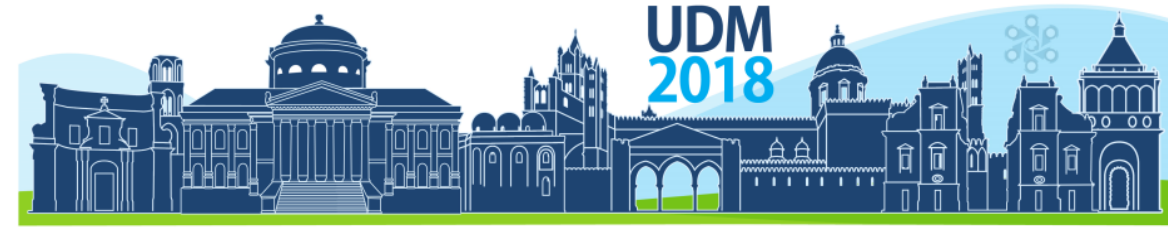

$11^{\text {th }}$ International Conference on Urban Drainage Modelling

23-26 Sep | Palermo - Italy

CAPRARIO, J.; RECH, A. S.; FINOTTI, A. R. Vulnerability assessment and contamination potencial of uncofined aquifer from compensatory infiltration techniques. In: 14th IWA Leading Edge Conference on Water and Wastewater Technologies, 2017, Florianópolis - SC.

Gamage, A.; Shahidi, F. (2007) Use of chitosan for the removal of metal ion contaminants and proteins from water. ScienceDirect-Food Chemistry 104, 989-996.

Núñez-Gómez, D.; Alves, A. A. A.; Lapolli, F. R.; Lobo-Recio, M. (2017) Aplication of trhe statistical experimental design to optimize mine-impacted water (MIW) remediation using shrimo-shell. ScienceDirect- Cemosphere 167, 322-329.

Núñez-Gómez, D.; Hessemer, M. E. N.; Lapolli, F. R.; Lobo-Recio, M. (2016) Potentional of shrimp-shell residue in natura for the remediation of mine impacted water (MIW). Polímeros vol.26, $7 \mathrm{p}$.

Pacheco, E (2015). Avaliação Quali-Quantitativa do desempenho de uma vala de infiltração de águas pluviais impantadas em Florianópolis. Dissertação de Mestrado - Programa de Pós Graduação em Engenharia Ambiental da Universidade Federal de Santa Catarina - UFSC, 200p. 


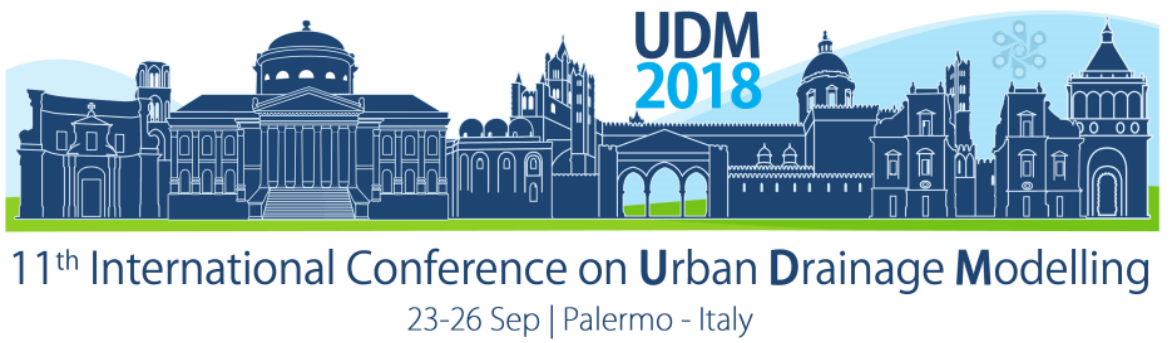

\title{
Nitrogen in infiltrated water from pervious pavements under different rainfall regimes and pollution build-up levels
}

\author{
Carmen Hernández-Crespo ${ }^{\mathbf{1 a}}$, Miriam Fernández-Gonzalvo ${ }^{\mathbf{1 b}}$, Miguel Martín ${ }^{\mathbf{1 c}}$, Ignacio Andrés-Doménech ${ }^{\mathbf{1 d}}$, \\ 1 Universitat Politècnica de València (UPV), Instituto de Ingeniería del Agua y Medio Ambiente, Valencia, Spain \\ (1acarhercr@upv.es; ${ }^{1 b}$ mifergon@upv.es; ${ }^{1 c}$ mmartin@hma.upv.es; 1digando@hma.upv.es)
}

\begin{abstract}
Sustainable urban drainage systems (SUDS) are a nature based solution for best management of rainwater in urban areas. Pervious pavements are one of the SUDS typologies. This study evaluates the water quality filtered by a type of pervious pavement and the influence of the rainfall regime (Atlantic and Mediterranean) and the pollution buildup degree. Total nitrogen (TN) infiltrate concentrations have increased over the study due to the increasing of sediment build-up levels on the pavement surface, with maximum concentrations between 2.7 and $5.0 \mathrm{mg} \mathrm{N} / \mathrm{l}$ depending on the rainfall regime and the pavement configuration; temperature also influences significantly the leachability of nitrogen. In fact, linear regression models for TN as dependent variable and accumulated mass and temperature have been obtained with a high goodness-of-fit. TN leached over the study represents between $22 \%$ and $31 \%$ of the total nitrogen present in the sediments accumulated on the pavement surface so the total load is much lower than what would have occurred in an impervious pavement under the same build-up conditions.
\end{abstract}

Keywords: permeable pavement; rainfall regimes; water quality; infiltrate; nitrogen

\section{INTRODUCTION}

Best management of rainwater is one of the current challenges for urban planners. Sustainable urban drainage systems (SUDS) represent nature based solutions (NBS) that contribute to returning certain naturalness to the water cycle in urban environments. Its implementation already has some decades of experience and its hydraulic efficiency is more than proven, especially in humid climates. In semi-arid climates there are fewer examples of application, although their number is growing thanks to the dissemination of the results obtained in pilot experiences, which are an excellent demonstration tool to make decisionmakers aware of the multiple environmental and economic benefits that these systems provide (Perales-Momparler et al. 2017). The effects of SUDS on water quality represent a less studied aspect and concern to the authorities responsible for maintaining the receiving water bodies in good status. Pervious pavements are one of the SUDS typologies that promote the water infiltration process, which is currently very limited in most cities. This communication is framed in an experimental study performed to evaluate the water quality filtered by a type of permeable pavement, the data obtained in which will be used to develop a model of pollutants transport in pervious pavements. The influence of the rainfall regime and the pollution build-up level on hydraulic efficiency and water quality filtered has been tested. Specifically, the results obtained for nitrogen are shown because of its importance in the contamination of groundwater.

\section{MATERIALS AND METHODS}

The experimental equipment consists of a battery of four infiltrometers designed to evaluate the hydraulic capacity of a permeable surface and the quality of the infiltrated water, under 


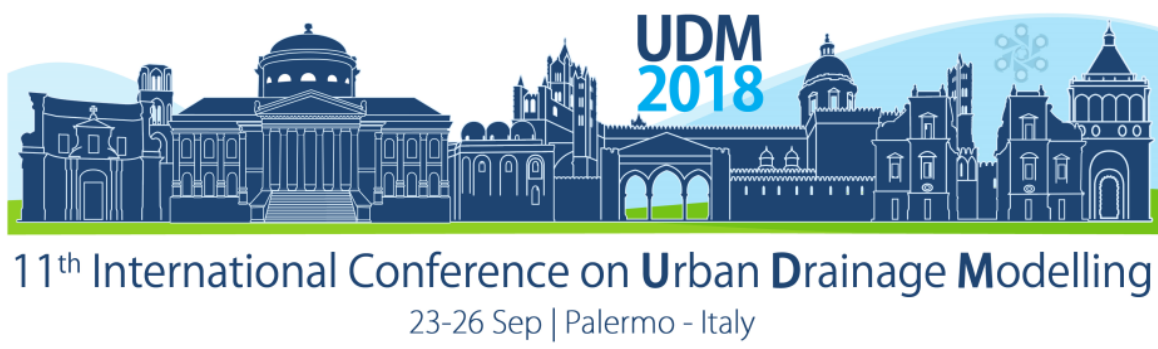

different climatic conditions and configuration of the different pavement layers (see Figure 1). The climatic conditions tested correspond to two of the rainfall regimes of Spain, the Atlantic and the Mediterranean. The simulated rainfall reproduces the average rainfall regime of Valencia (Mediterranean) and Santander (Atlantic): events with a volume of $16 \mathrm{~mm}$ and 30 minutes duration, with a weekly frequency for the Atlantic climate and biweekly in the Mediterranean climate (Andrés-Doménech et al., 2010). To simulate the rainfall, deionized water has been used (Electrical Conductivity: $21 \mu \mathrm{S} / \mathrm{cm}, \mathrm{pH}: 6.9$ ), dosed through a rain simulator composed of a water storage tank, a pump (Multi-1300 SICCE) and a grid of drip irrigation pipes consisting of 7 rows with 13 drippers/row evenly distributed. The rain simulator is placed $50 \mathrm{~cm}$ above the pavement surface. Likewise, two configurations of the pavement layers have been tested in order to analyse the influence of the sub-base layer: configuration $\mathrm{C} 1$ (from bottom to top: geotextile layer $+25 \mathrm{~cm}$ of sub-base layer of washed limestone aggregate with a particle size of $4-40 \mathrm{~mm}+1$ geotextile layer $+5 \mathrm{~cm}$ of base layer of fine washed limestone gravel with a particle size of 2-4 $\mathrm{mm}+$ precast porous concrete blocks); configuration C2 (from bottom to top: geotextile layer $+5 \mathrm{~cm}$ of base layer of fine washed limestone gravel with a particle size of 2-4 mm + precast porous concrete blocks).

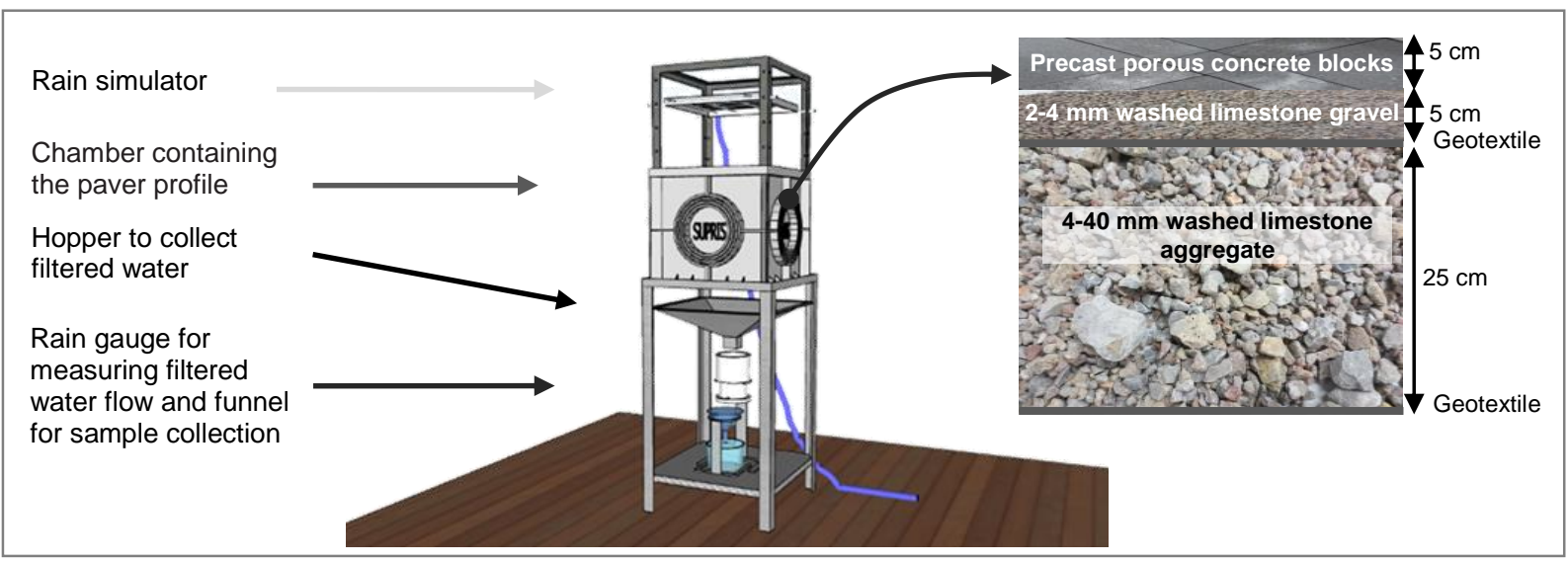

Figure 1. Scheme of the experimental setup.

The influence of progressive clogging is being studied by dry sprinkling of sediments on the pavement surface. The applied material has been collected in different urban road infrastructures at the university, by mechanical sweeper. The applied deposition rate (5 $\mathrm{g} / \mathrm{m}^{2} / \mathrm{d}$ ) has been selected according to the information provided by the cleaning services (mass collected, surface swept and cleaning frequency) and contrasted with scientific references (Vaze and Chiew, 2002), and it is the same for all the tests.

The flow of infiltrated water, once measured by the rain gauges, is collected in containers and kept in refrigeration until analysis. Water quality variables analysed in this paper are the following: Total Nitrogen (TN) (Spectroquant ${ }^{\circledR}$ test: ISO 11905-1 + Photometry), Ammonium (Spectroquant $^{\circledR}$ test: ISO 7150/1), Nitrites (Spectroquant ${ }^{\circledR}$ test: EPA354.1), Nitrates (Spectroquant $^{\circledR}$ test).

\section{RESULTS AND DISCUSSION}

\subsection{Sediment physico-chemical characteristics}

The material used is characterized by a humidity of $2 \%$, a content of volatile matter of $8.2 \%$ in dry weight, a total nitrogen content of $1351 \mathrm{mg} / \mathrm{kg}$ and a granulometric composition with a high proportion of sands (gravel: $13.2 \%$, sands: $85.0 \%$, silt and clays: $1.8 \%$ in dry weight). 


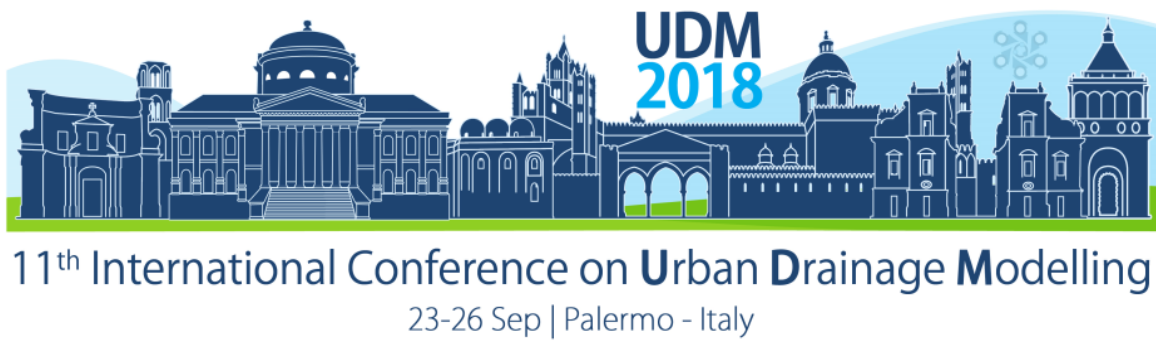

\subsection{Quantity of infiltrated water}

The volume drained by permeable pavements is significantly higher in the Atlantic rainfall regime $(p<0.05)$, which seems reasonable due to its higher humidity and frequency of rainfall. On average, the volume drained is $68 \%$ of the volume of rain applied $\left(16 \mathrm{l} / \mathrm{m}^{2}\right.$ per event) under the Atlantic conditions and $55 \%$ under the Mediterranean conditions. With the information available so far, the pavement configuration ( $\mathrm{C} 1$ or $\mathrm{C} 2$ ) does not affect significantly the drained volume ( $p>0.05)$. It is worth mentioning that water drainage occurs freely, that is, the infiltrated water is not slowed by a layer of soil that, being saturated or not, would undoubtedly slow down the percolation rate. In a real installation, the effect of an underlying soil layer would surely make the benefit of the additional gravel layer more evident.

From the beginning of the tests to the present (12 months), a decrease of the drained volume has not been observed. Therefore the degree of sediments built up reached so far (1900 $\mathrm{g} / \mathrm{m}^{2}$ accumulated in 1 year) has not yet caused a significant decrease in the volumetric capacity of the system, that is, there is no loss of storage capacity due to occupation of voids by sediments.

\subsection{Quality of infiltrated water}

Electrical conductivity and $\mathrm{pH}$ of the filtered water have decreased exponentially throughout the study period, from values around $2700 \mu \mathrm{S} / \mathrm{cm}$ to values around $300 \mu \mathrm{S} / \mathrm{cm}$ and the $\mathrm{pH}$ from 12 to 9 . This decrease is considered to be associated with the washing of the material and in the Atlantic rainfall regime it has been significantly higher than in the Mediterranean climate $(\mathrm{p}<0.05)$ because the former has been subjected to a greater rainfall washing. The strong $\mathrm{pH}$ increase that water experiences, from 6.9 (rainwater) to values higher than 9 (infiltrated water), is related to the washing of the precast porous concrete blocks. They have a high proportion of cement, which gives it a high basicity. This increase in $\mathrm{pH}$ in water filtered by porous concrete pavements has been observed by several authors (Drake et al. 2014; Brown and Borst, 2015).

Regarding total nitrogen (Figure 2), the average values during the period are 1.50 and 2.57 $\mathrm{mg} \mathrm{N} / \mathrm{l}$ for the Atlantic and Mediterranean climates respectively, being significantly higher for Mediterranean climate $(p<0.05)$. The lower rainfall volume applied explains this fact. The pavement layer configuration does not have a significant influence on the TN present in the filtered water. The dissolved inorganic nitrogen (DIN) represents $57 \%$ and $52 \%$ for the Atlantic and Mediterranean climates respectively, with nitrate being the major component of DIN, although the concentrations are well below the limit established in the legislation to catalog groundwater bodies vulnerable to nitrate contamination (50 $\mathrm{mg} \mathrm{NO}_{3} / \mathrm{l}$ or $11.3 \mathrm{mg} \mathrm{N} / \mathrm{l}$ ). There is a temporal trend to increase over the studied period, related to the growing build-up of sediments on the pavement surface. TN and its organic fraction present a positive correlation with temperature, which can be explained by a greater by a greater leachability capacity during warmer months. In fact, multiple linear regression models have been obtained for TN concentrations as dependent variable and accumulated mass of sediments and temperature as independent variables with a high goodness-of-fit (see Figure 2).

A fraction of $31 \%$ of the total nitrogen added with the sediment was leached in pavements under the Atlantic climate whereas the $22 \%$ was leached under the Mediterranean climate. Therefore, although the concentration is higher in the latter, the impact in terms of total mass leached is lower. In both cases the nitrogen discharged into the receiving waterbody is much 


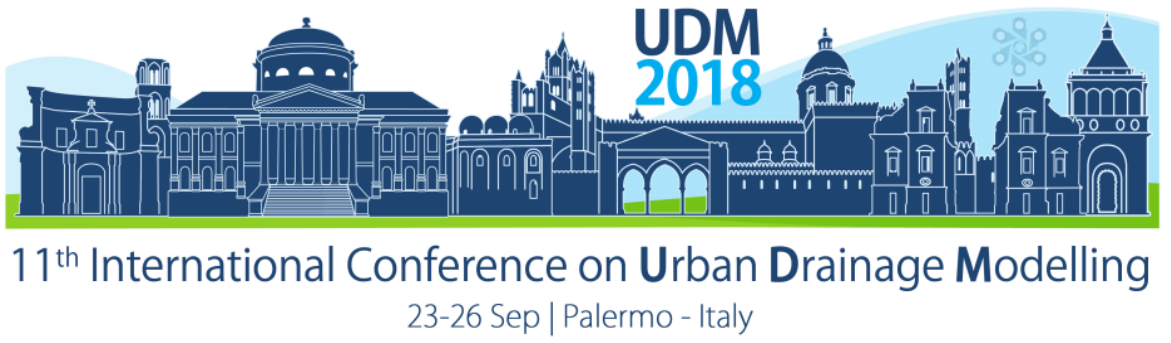

lower than what would have occurred from an impervious pavement under the same build-up conditions, without compromising the quality of groundwater.

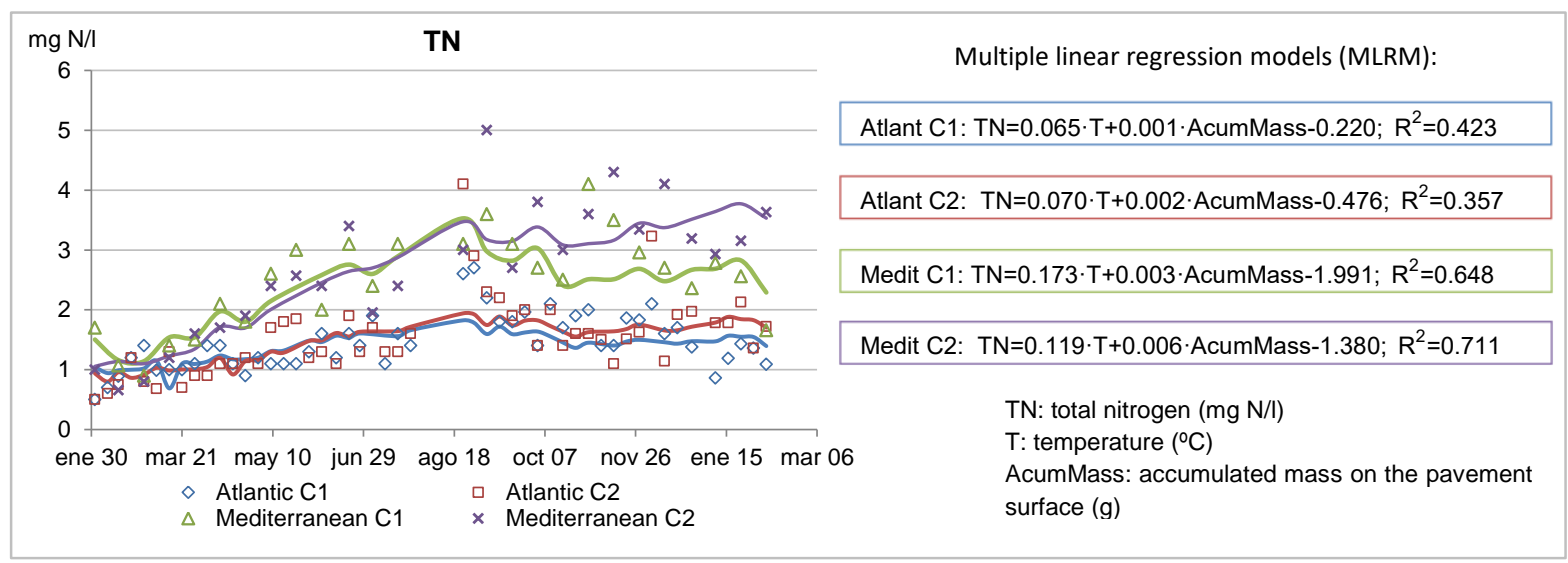

Figure 2. Results of total nitrogen concentrations measured in infiltrated water over the study period for the four pavement configurations (Atlantic Configuration 1, Atlantic Configuration 2, Mediterranean Configuration 1 and Mediterranean Configuration 2) and corresponding linear regression models (dots are experimental data and continuous lines are the MLRM).

\section{CONCLUSIONS}

Water infiltrated by the precast porous concrete blocks tested in this study presents high values of electrical conductivity and $\mathrm{pH}$ which decrease significantly after several rainfall events. Total nitrogen infiltrate concentrations have increased over the study due to the increasing of sediment build-up levels on the pavement surface and temperature also influences significantly the leachability of nitrogen. Total nitrogen leached over the study represents between $22 \%$ and $31 \%$ of the total nitrogen present in the sediments accumulated on the pavement surface, so the total load is much lower than what would have occurred from an impervious pavement under the same build-up conditions, without compromising the quality of groundwater.

\section{Acknowledgements}

This research is developed in the frame of projects SUPRIS-SUReS (Ref. BIA2015-65240-C2-1-R MINECO/FEDER, UE) and SUPRIS-SUPel (Ref. BIA2015-65240-C2-2-R MINECO/FEDER, UE) supported by the Ministry of Economy and Competitiveness and the European Regional Development Fund (ERDF).

\section{References}

Andrés-Doménech, I., Montanari, A., Marco, J.B. (2010). Stochastic rainfall analysis for storm tank performance evaluation. Hydrology and Earth System Sciences 14, 1221-1232.

Drake, J., Bradford, A., Van Seters, T. (2014) Stormwater quality spring-summer fall effluent from three partialinfiltration permeable pavement systems and conventional asphalt pavement. Journal of Environmental Management 139, 69-79.

Brown, R.A. and Borst, M. (2015) Nutrient infiltrate concentrations from three permeable pavement types. Journal of Environmental Management 164, 74-85.

Vaze, J. and Chiew, F.H.S. 2002. Experimental study of pollutant accumulation on an urban road surface. Urban Water 4, 379-389.

Perales-Momparler, S., Andrés-Doménech, I., Hernández-Crespo, C., Vallés-Morán, F., Martín, M., EscuderBueno, I., Andreu, J. (2017). The role of monitoring sustainable drainage systems for promoting transition towards regenerative urban built environments : a case study in the Valencian region, Spain. Journal of Cleaner Production 163, S113-S124. 


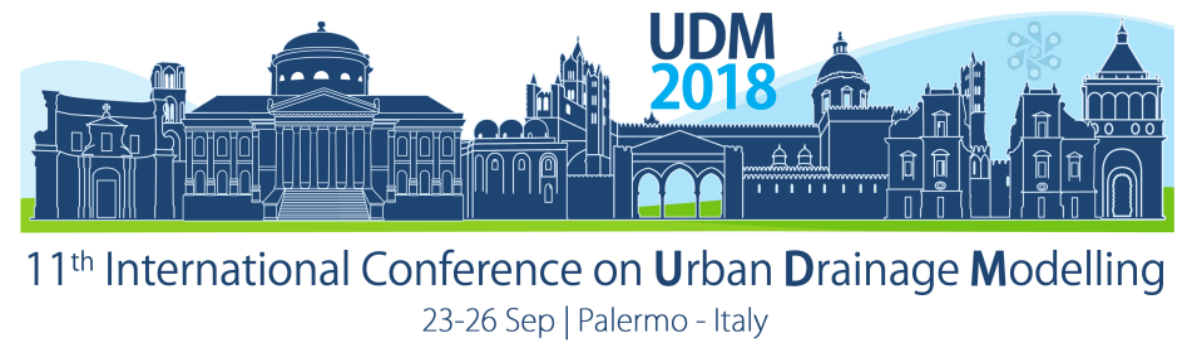

\title{
Where does infiltrated stormwater go? Interactions with vegetation and sub-surface anthropogenic features
}

\author{
Jeremie Bonneau ${ }^{\mathrm{a}, 1}$, Tim D Fletcher ${ }^{\mathrm{a}, 3}$, Justin F Costelloe ${ }^{\mathrm{b}, 4}$, Peter J Poelsma ${ }^{\mathrm{a}, 5}$, Robert B James \\ a,6, Matthew J Burns ${ }^{a, 2}$ \\ ( ${ }^{a}$ School of Ecosystem and Forest Sciences, University of Melbourne, 500 Yarra Boulevard, Burnley, Victoria 3121 \\ Australia, b Department of Infrastructure Engineering, The University of Melbourne, Parkville, Victoria,3010, \\ Australia) \\ ${ }^{1}$ Corresponding author: Jeremie Bonneau, jeremie.bonneau@gmail.com, School of Ecosystem and Forest \\ Sciences, University of Melbourne, 500 Yarra Boulevard, Burnley, Victoria 3121 Australia, +61497347694
}

\begin{abstract}
The practice of stormwater infiltration is widely used to reduce the amount of urban stormwater runoff delivered to drainage systems and receiving waters. In theory, the practice recharges groundwater, leading to increased urban stream baseflows. However, little is known about the fate of infiltrated stormwater. We tracked the fate of infiltrated stormwater from an infiltration basin using a network of piezometers for three years. We found that groundwater levels downslope of the basin were increased while water levels in an array of reference piezometers lateral to the basin showed no change. In summer, most of the infiltrated stormwater was evapo-transpired by the vegetation downslope of the basin, and thus did not reach the receiving stream. The reverse was true in the colder months, where some infiltrated stormwater did reach the stream as plant water use declined. Particularly during these Summer-Autumn months, anthropogenic disturbances interacted with the plume of infiltrated stormwater: infiltrated stormwater seeped into nearby sewer infrastructure. The study provides evidence that the fate of infiltrated stormwater largely depends on surrounding land use and that urban groundwater pathways are susceptible to disturbance by anthropogenic features. Infiltrated stormwater may not always reach receiving streams as baseflow as often assumed, which has implications for the design and placement of infiltration structures. This experimental data can be used to refine conceptual models of urban catchments and stormwater models.
\end{abstract}

Keywords: Infiltration, stormwater, baseflow

\section{INTRODUCTION}

In response to urbanization and consequent changes in hydrology (reduced infiltration and evapotranspiration), alternative stormwater management strategies have become popular, with the aim of restoring the pre-development water balance through; 1) restoring evapotranspiration through vegetated systems or mimicking it by stormwater harvesting and, 2) promoting infiltration of stormwater (Fletcher et al., 2014). In particular, large investments are made in stormwater infiltration systems to recharge groundwater and promote low flows in urban streams, especially in dry Australian climates. However, little is known about the fate of infiltrated stormwater (Hamel et al., 2011). Understanding the fluxes and pathways of infiltrated stormwater is therefore an important pre-requisite to understanding the efficiency of stormwater infiltration as a strategy to recharge groundwater and increase stream baseflow. Field based evidence of stormwater infiltration resulting in increased baseflow is emerging (Loperfido et al., 2014; Bhaskar et al., 2016), but the route taken by infiltrated stormwater between the infiltration systems and the stream is not known. The impact of stormwater infiltration on groundwater and stream hydrology is therefore hard to predict and relies on 


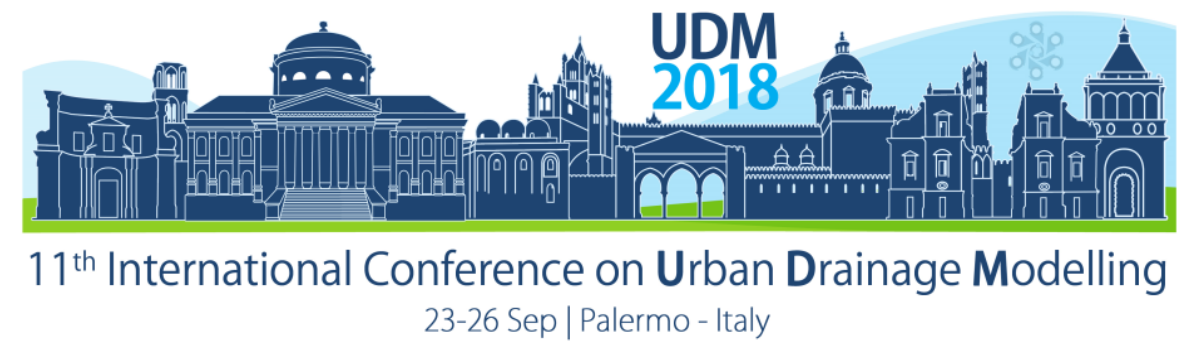

assumptions rather than field observations (Hamel and Fletcher, 2014). To track the fate of infiltrated stormwater, an infiltration basin and its surroundings were equipped with piezometers instrumented with water level probes. The research questions of the study were:

- How much water infiltrates from the basin to the ground?

- How much of this water contributes to the baseflow of the urban stream?

The hypothesis was that infiltrated stormwater recharges local groundwater and contributes to baseflow of a nearby stream (located just $75 \mathrm{~m}$ downstream of the basin) through natural subsurface pathways. Results show that the fate of infiltrated stormwater was controlled by water use of the vegetation downslope and that the hypothesised recharge of groundwater by the infiltration basin was affected by sub-surface infrastructure before it reached the stream.

\section{MATERIALS AND METHODS}

The studied infiltration basin, Wicks Reserve Infiltration Basin, is located $75 \mathrm{~m}$ upslope of Dobsons Creek, in a peri-urban catchment in the eastern suburbs of Melbourne, Australia. Built in 2011, the basin is $1,800 \mathrm{~m}^{2}$ in surface area The infiltration basin receives stormwater from 5 ha of impervious areas (house roofs, driveways and roads), equivalent of $15 \%$ of the 33-ha total catchment aream drained by a conventional, separated stormwater drainage network. Mean annual rainfall of the catchment is $730 \mathrm{~mm}$, reasonably evenly distributed over the year, with a winter-spring bias, and mean annual potential evapotranspiration (PET) is $1050 \mathrm{~mm}$ (BoM, 2016).

We built a network of 16 piezometers to monitor groundwater levels in the basin, ranging 1.5$4 \mathrm{~m}$ in depth. We calculated the volume of infiltrated stormwater using water level variations within the basin (building rating curves). Groundwater levels in and around the infiltration basin were recorded from 2015 to 2018 to track the pathway of infiltrated stormwater. A water balance taking into account the fluxes of water contributing to recharge or depletion of the plume of infiltrated stormwater was calculated, as: Baseflow $=$ Inf + Recharge $-E T$, where Baseflow is the contribution of the basin to stream baseflow, Inf is the volume of infiltrated stormwater, Recharge is the volume of rainfall recharging groundwater, ET the water use of downslope vegetation consumption. This allowed us to assess the volume of infiltrated stormwater from the basin contributed to stream baseflow

\section{RESULTS AND DISCUSSION}

\subsection{Water level variations}

The water level within the infiltration basin showed both seasonal behaviour and responses to individual rain events. Bores located upslope and laterally away from the basin were dry during the entire monitoring period. In contrast, water was consistently observed in the three bores located just downslope of the basin. In these bores, groundwater levels varied both seasonally and with rainfall events, which coincided with variations of the water level in the basin, inferring that infiltrated stormwater had raised groundwater levels downslope of the infiltration basin (Figure 1). 


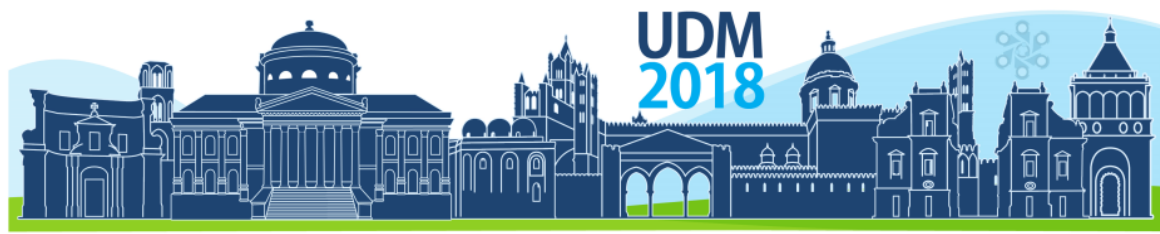

$11^{\text {th }}$ International Conference on Urban Drainage Modelling

23-26 Sep | Palermo - Italy

However, the groundwater monitoring bores in two bores located downslope of the sewer pipe gave zero values during summer months (from January-February to May-June).The water table was also deeper than $0.8 \mathrm{~m}$ below the stream bed near the stream indicating no discharge of infiltrated stormwater to the stream. Conversely, in winter, a seasonal increase of the water table resulted in groundwater being intersected in the bores downslope of the sewer trench.

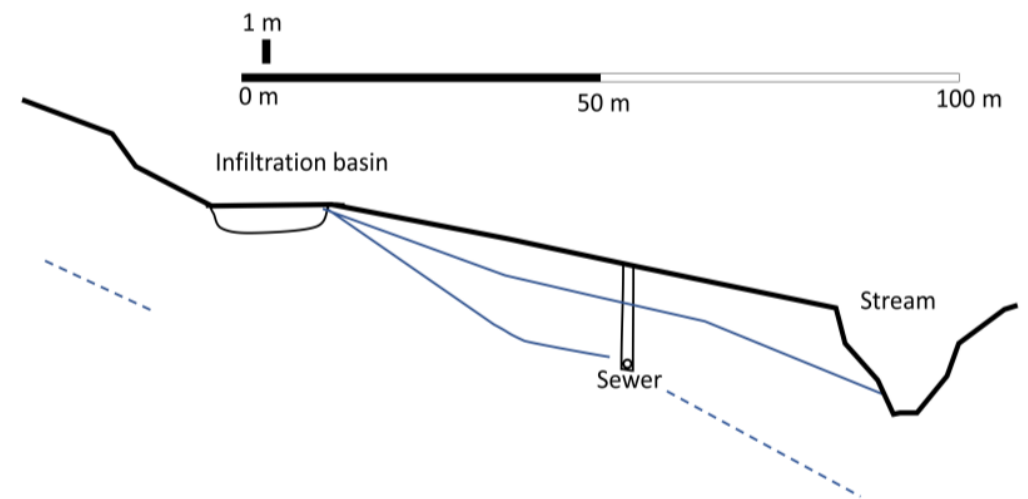

Figure 1: Seasonal groundwater levels (high in winter, low in summer) observed downslope of the infiltration basin. Dotted lines for dry bores.

\subsection{Fate of infiltrated stormwater}

An average of $400 \mathrm{~m}^{3}$ month $^{-1}$ infiltrated from the infiltration basin to the ground, with some small seasonal variations. For months with rainfall higher than ET (typically from June to August), the contribution of rainfall recharge to the area influenced by the plume of infiltrated stormwater, ranged 65-125 $\mathrm{m}^{3} \mathrm{month}^{-1}$. This water (infiltrated stormwater + rainfall recharge) was observed in bores downslope of the sewer trench. For the rest of the year, the vegetation accessed phreatic water (i.e. the plume of infiltrated stormwater) to satisfy the fraction of their water demand rainfall could not supply. This volume ranged $40-400 \mathrm{~m}^{3} \mathrm{month}^{-1}$, sometimes nearing the volume of infiltrated stormwater (Figure 2). During these months the plume of infiltrated stormwater is not observed past the sewer trench, as it was mostly consumed by vegetation downslope. Water was also observed to seep into sewer infrastructure located parallel to the creek, locally lowering the water table and preventing water to get to the stream 


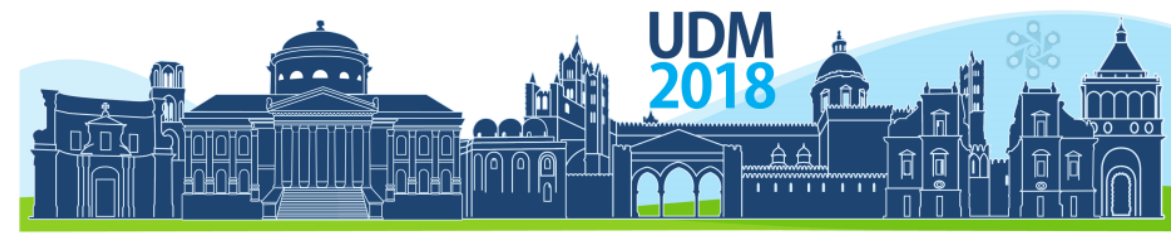

$11^{\text {th }}$ International Conference on Urban Drainage Modelling

23-26 Sep | Palermo - Italy

\section{CONCLUSIONS}

This work has theortical and practical implications:

- Infiltration of stormwater does not always translate as stream baseflow

- Urban groundwater pathways are impacted by land use and deserve consideration to understand low flows in urban streams

- The fate of infiltrated stormwater need to be considered during design phase of infiltration systems.

- Constant high groundwater levels means that construction downslope of such an infiltration basin would require specific engeering

- Infiltrated stormwater seeping into wastewater plants increase costs of treatment.

This work has modelling implications as it highlights the need to take into account infiltrated stormwater to comprehensively predict the impact of infiltration-based stormwater management on urban flow regimes. Until recently, most stormwater models did not even include a baseflow routine, reflecting on the traditional impervious-only focus of stormwater generation (Elliott, 2007). This works points to the need to take into account sub-surface processes in urban catchment to model the fate of infiltrated stormwater, as many modelers today assumed that either all infiltrated stormwater contributes to baseflow or that none infiltrated stormwater contributes to baseflow.

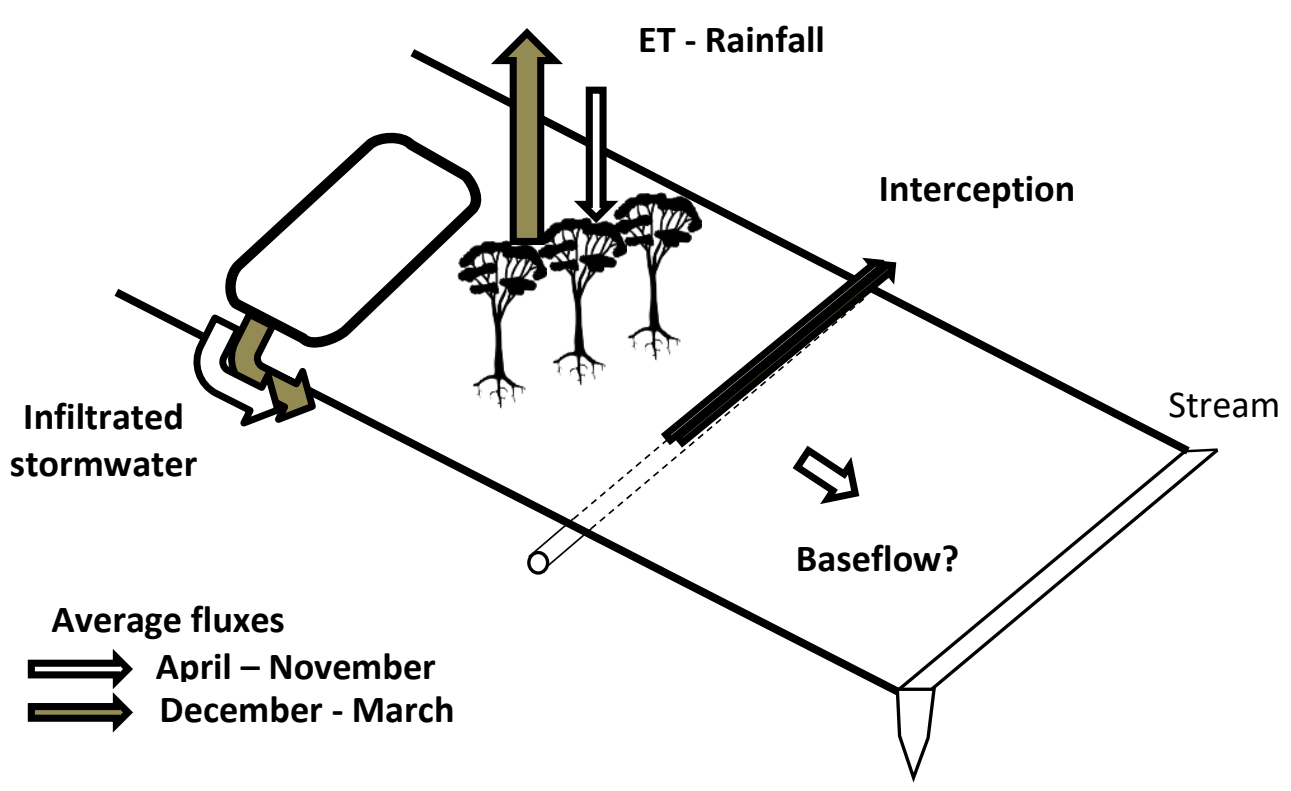

Figure 2: conceptual figure of the fate of infiltrated stormwater 


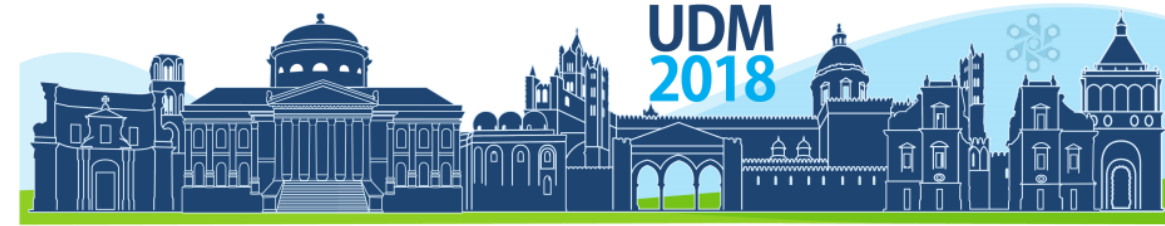

$11^{\text {th }}$ International Conference on Urban Drainage Modelling

23-26 Sep | Palermo - Italy

\section{References}

Bhaskar AS, Hogan DM, Archfield SA. 2016. Urban base flow with Low Impact Development. Hydrological Processes. DOI: 10.1002/hyp.10808.

BoM. 2016. Rainfall in Victoria. Bureau of Meteorology.

Elliott, A. H., \& Trowsdale, S. A. (2007). A review of models for low impact urban stormwater drainage. Environmental modelling \& software, 22(3), 394-405.

Fletcher TD, Shuster W, Hunt WF, Ashley R, Butler D, Arthur S, Trowsdale S, Barraud S, Semadeni-Davies A, Bertrand-Krajewski J-L, Mikkelsen PS, Rivard G, Uhl M, Dagenais D, Viklander M. 2014. SUDS, LID, BMPs, WSUD and more - The evolution and application of terminology surrounding urban drainage. Urban Water Journal: 1-18. DOI: 10.1080/1573062x.2014.916314.

Hamel P, Fletcher TD. 2014. Modelling the impact of stormwater source control infiltration techniques on catchment baseflow. Hydrological Processes, 28: 5817-5831. DOI: 10.1002/hyp.10069.

Hamel P, Fletcher TD, Walsh CJ, Plessis E. 2011. Quantifying the restoration of evapotranspiration and groundwater recharge by vegetated infiltration systems.

Loperfido JV, Noe GB, Jarnagin ST, Hogan DM. 2014. Effects of distributed and centralized stormwater best management practices and land cover on urban stream hydrology at the catchment scale. Journal of Hydrology, 519: 2584-2595. DOI: 10.1016/j.jhydrol.2014.07.007. 


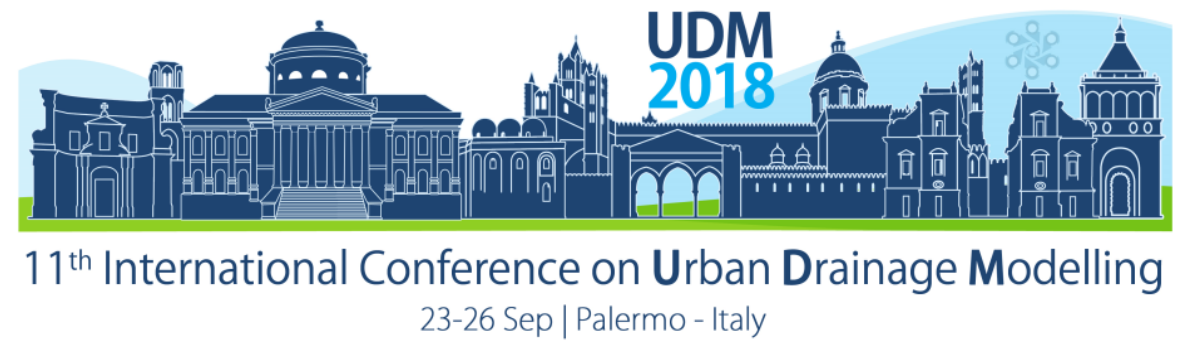

\title{
Shifts of Resilience and Recovery of Aquatic Metabolism in Stormwater Green Infrastructure
}

\author{
Tanveer Adyel ${ }^{1}$, Carolyn Oldham ${ }^{2,3}$ and Matthew Hipsey ${ }^{3,4}$ \\ ${ }^{1}$ Department of Civil Engineering, Monash University, Melbourne, Australia \\ ${ }^{2}$ School of Civil, Environmental and Mining Engineering, The University of Western Australia, Perth, Australia \\ ${ }^{3}$ Cooperative Research Centre for Water Sensitive Cities, Melbourne, Australia \\ ${ }^{4}$ School of Agriculture and Environment, The University of Western Australia, Perth, Australia
}

\begin{abstract}
This research showed the effectiveness of aquatic metabolism as a proxy indicator of urban stormwater green infrastructure (SGI) performance, and how resilience and recovery of metabolism shift during storm events. Sensor-based dissolved oxygen (DO) data from an SGI in Western Australia during fourteen storm events over two years period were used to develop metabolism metric. The SGI showed positive and negative metabolism depending on stormwater flow, DO level and time of the events. Water level, water volume, hydraulic retention time, inflow rate, antecedent dry days, etc. were some major factors to determine the recovery and resilience of metabolism during the storm perturbation. The system showed metabolism resistivity during small events or event that took place during the frequent rainfall time that made SGI lotic. The SGI recovered metabolism quickly during the less frequent rainfall event, particularly during the summer when SGI became lentic. The strong correlation between positive metabolism and nutrient attenuation indicating metabolism's applicability to assess SGI performance in absence of routine water sampling.
\end{abstract}

Keywords: Dissolved oxygen; Green Infrastructure; Stormwater; Water sensitive urban design

\section{INTRODUCTION}

A paradigm shift in stormwater management is taking place through the adoption of Stormwater Green Infrastructure (SGI) according to Water Sensitive Urban Design principles (Fletcher et al. 2015). In most Australian cities, it is now common practice to retain and treat stormwater within the catchment to prevent degradation of downstream waterways using a range of SGls, including constructed wetlands (CWs), biofilters, rain gardens and green roofs (Adyel et al. 2016; Fletcher et al. 2013). CWs are less susceptible than other SGls to sudden stormwater pulses and can apply at large-scale (Adyel et al. 2016). The implementation and monitoring of CWs come at significant cost to both government and private developers. Water regulatory authorities are putting efforts and resources to ensure urban sustainability through SGI. However, these SGls can experience with diverse hydrological and biogeochemical variability and hence can provide unpredicted treatment performance. For instance, CWs in Western Australia (WA) experience with diverse hydrological features with low to near zero flow during the dry summer, and episodic storm pulses and groundwater input during the wet winter making CW performance estimation challenging. It is important to find if SGI meets its performance as the design under hydrological regime shift. An affordable index is necessary to determine whether an SGI is achieving its pollutant reduction targets as routine sampling is cost-intensive. This research developed low cost dissolved oxygen (DO) based aquatic "metabolism" as a proxy indicator of CW function. The study also investigated how resistant the $\mathrm{CW}$ is during storm pulses and how long it takes by the $\mathrm{CW}$ to return to its pre-storm pulse 


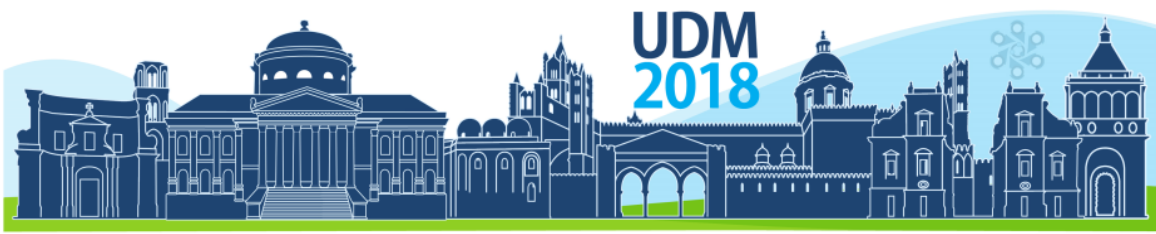

$11^{\text {th }}$ International Conference on Urban Drainage Modelling

23-26 Sep | Palermo - Italy

conditions. The metabolism regime shifts in term of recovery or resilience are important to optimize SGI function under a wide range of biogeochemical and hydrological variability. Significantly, the research and metabolism concept allowed the prediction of SGI performance under variable climate using cost-effective metric by achieving nutrient removal targets.

\section{MATERIALS AND METHODS}

\subsection{Field site, data collection}

The Anvil Way Compensation Basin (AWCB), an approximately 0.9 ha CW in WA was selected as a study site (Figure 1). The CW was built in 2004 and restored in 2010 as a "living stream". High resolution DO data was monitored at 10-min intervals from June 2014 to July 2015 using low cost DO sensor (PME, USA). The DO sensor was placed at top $20 \mathrm{~cm}$ of the water column in the meandering channel, and the area was subject to influence by periodic solar exposure and water flow variation. Within this time-frame, total fourteen storm events were selected and analyzed for the metabolism estimation and metabolism regime shifts.

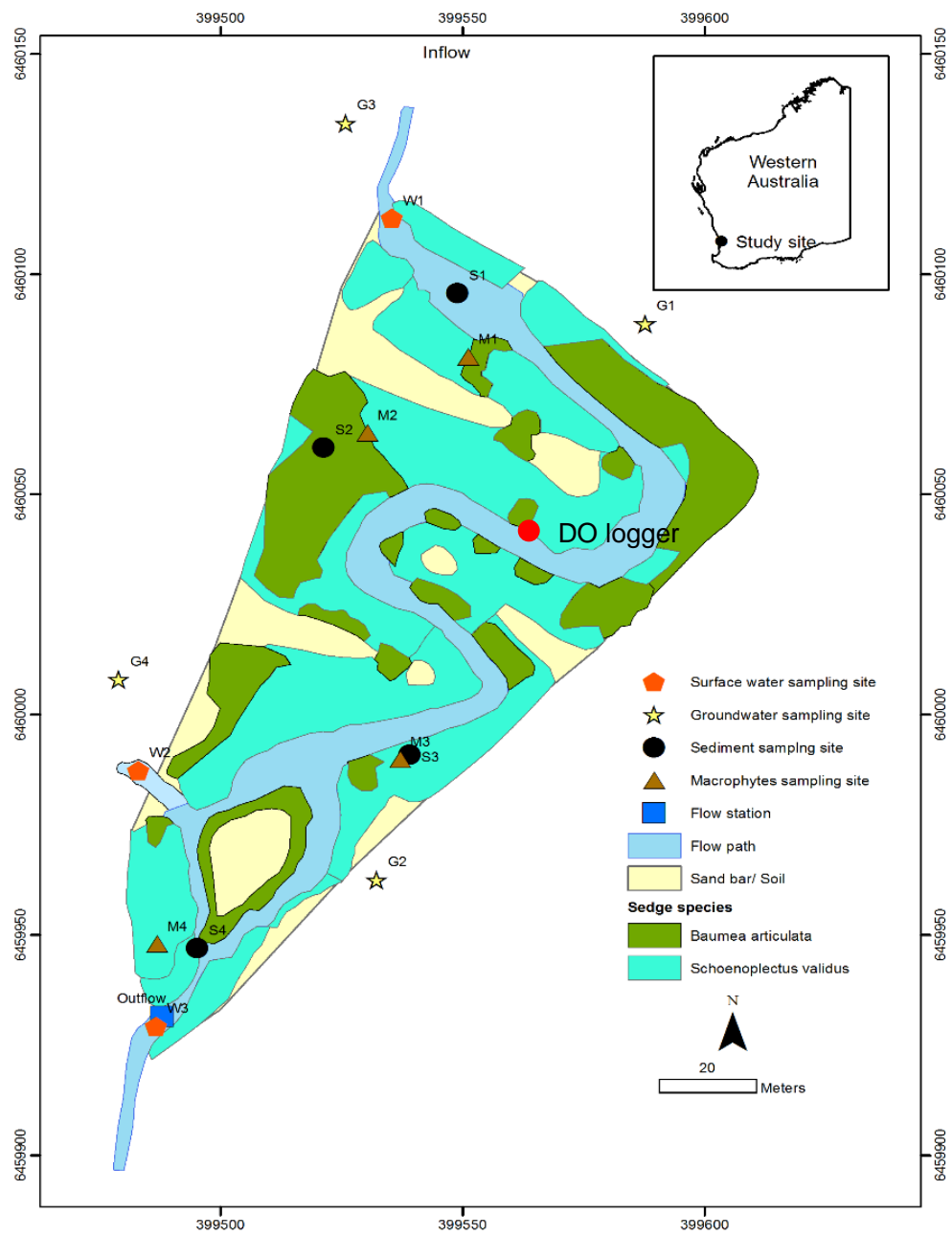

Figure 1. Sampling points in the AWCB. Surface water, groundwater, sediment and macrophytes sampling points are represented as $\mathrm{W}, \mathrm{G}, \mathrm{S}$ and $\mathrm{M}$, respectively. 


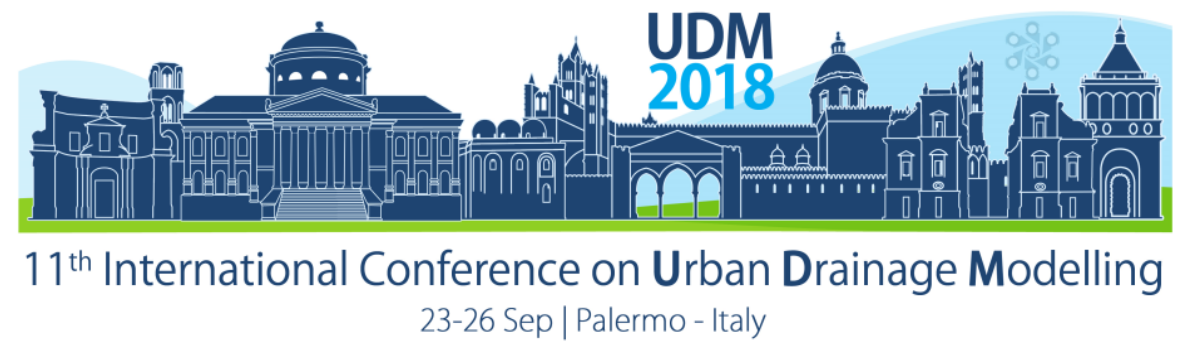

\subsection{Metabolism estimation}

Metabolism of SGI as $\Delta \mathrm{DO}(\%)$ during storm pulses was defined as the daily fluctuation of the maximum and minimum DO saturation (Adyel et al. 2016). Metabolism during storm event was analysed over four consecutive days before and after the storm perturbation. Average metabolism over four consecutive days before the storm perturbation, $\overline{\Delta \mathrm{DO}}_{\text {pre }}$ (\%), was estimated as (Adyel et al. 2017b):

$\overline{\Delta D O}_{\text {pre }}=\frac{\sum_{i=1}^{n}\left(D O_{\max _{i}}-D O_{\min _{i}}\right)}{n}$

where $D O_{\text {max }_{i}}$ is the average maximum DO saturation per day during the afternoon before the storm perturbation over four consecutive days (\%), $D O_{\min _{i}}$ is the average minimum DO saturation per day during the morning before the storm perturbation over four consecutive days $(\%)$ and $\mathrm{n}$ is number of studied days i.e., 4 days.

Similarly, average metabolism over four consecutive days after the storm perturbation, $\overline{\Delta \mathrm{DO}}_{\text {post }}(\%)$, was estimated as (Adyel et al. 2017b):

$\overline{\Delta D}_{\text {post }}=\frac{\sum_{i=1}^{n}\left(D O_{\max _{i}}-D O_{\min _{i}}\right)}{n}$

where $D O_{\text {max }_{i}}$ is the average of maximum DO saturation per day during the afternoon after the storm perturbation over four consecutive days (\%), $D O_{\text {min }_{i}}$ is the average of minimum DO saturation per day during the morning after the storm perturbation over four consecutive days $(\%)$ and $n$ is number of studied days i.e., 4 days.

The overall average change in metabolism due to a storm perturbation, $\Delta(\overline{\Delta \mathrm{DO}})(\%)$, was estimated as (Adyel et al. 2017b):

$\Delta(\overline{\Delta D O})=\overline{\Delta D O}_{\text {post }}-\overline{\Delta D O}_{\text {pre }}$

where $\overline{\Delta D O}_{\text {post }}$ is average metabolism over four consecutive days after the storm perturbation (\%) and $\overline{\Delta D O}_{\text {pre }}$ is average metabolism over four consecutive days before the storm perturbation (\%).

Based on metabolism of the pre-storm condition, we then calculated how resistant the SGI was to storm events in different hydro-meteorological conditions, and once metabolism shifted after events, how quickly the SGI recovered the metabolism. We also collected water samples at $2 \mathrm{hrs}$ intervals for up to $96 \mathrm{hrs}$ during three storm events event 1 (E1): 11-19 March 2015, event 2 (E2): 6-12 April 2015, and event 3 (E3): 15-18 May 2015. These water samples were subject to analysis of nitrogen $(\mathrm{N})$ and phosphorus $(\mathrm{P})$ based nutrient, particularly filtered ammonia $\left(\mathrm{NH}_{3}\right)$, filtered total oxidised nitrogen (NOx), total nitrogen (TN), filtered reactive phosphorus (FRP), total phosphorus (TP), etc.

\section{RESULTS AND DISCUSSION}

The SGI showed a distinct diurnal DO signal, with night-time anoxia and day-time peaks, particularly during the dry summer when water flow is relatively very low and even near zero. We observed the maximum DO levels between 12:00 to $15: 00 \mathrm{hr}$ on a diurnal scale during the pre-event, however, the scenario disrupted during the post-events. Low diurnal DO level probably due to available sludgy sediment, senescent macrophytes, and inputs of anoxic groundwater during the dry summer (Adyel et al. 2017a). For instance, the CW experienced with $\mathrm{DO}<2 \mathrm{mg} / \mathrm{L}$ concentrations or $5 \%$ saturation during the day-time during dry periods i.e., 


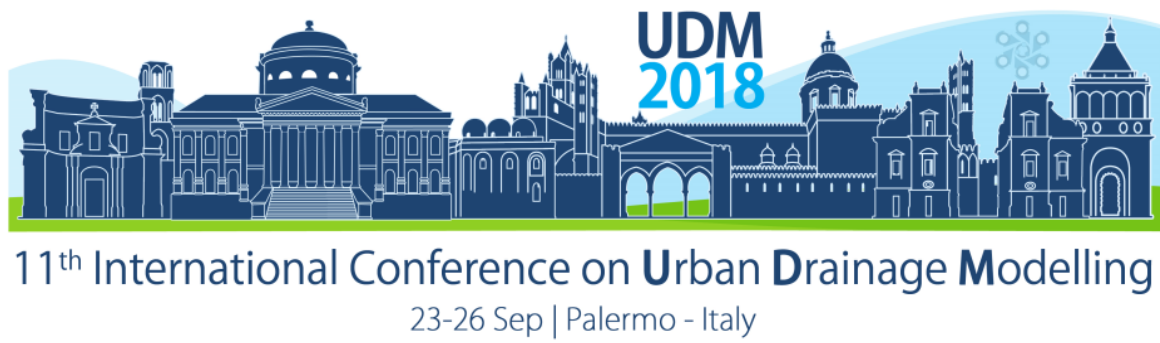

November to May. However, DO level increased above $6 \mathrm{mg} / \mathrm{L}$ during the wet season i.e., June to October. Frequent rainfall during the wet period increased DO concentrations due to aeration, and flushing of anoxic water and other oxygen-consuming substances (Tuttle et al. 2008; Reeder 2011).

We estimated metabolism over four consecutive days during the pre-and post-event to indicate the function of the SGI at the diverse flow conditions (Figure 2). We found overall positive metabolism when the post-event metabolism was higher than the pre-event metabolism. Similarly, overall negative metabolism took place when the pre-event metabolism was higher than the post-event metabolism. Metabolism after storm-perturbation augmented in some storm events, while also reduced in other events (Figure 2). The pre-event metabolism in the SGI showed correlation with different parameters (Figure 3), particularly solar exposure $\left(R^{2}=0.67\right)$, water temperature $\left(R^{2}=0.47\right)$ and antecedent dry days $(A D D)\left(R^{2}=0.55\right)$ (Adyel et al. 2017b). Interestingly, these correlations shifted at after-event because of the modification of $\mathrm{CW}$ volume, hydraulic retention time, water level, saturation of riparian zone and inflow rate.

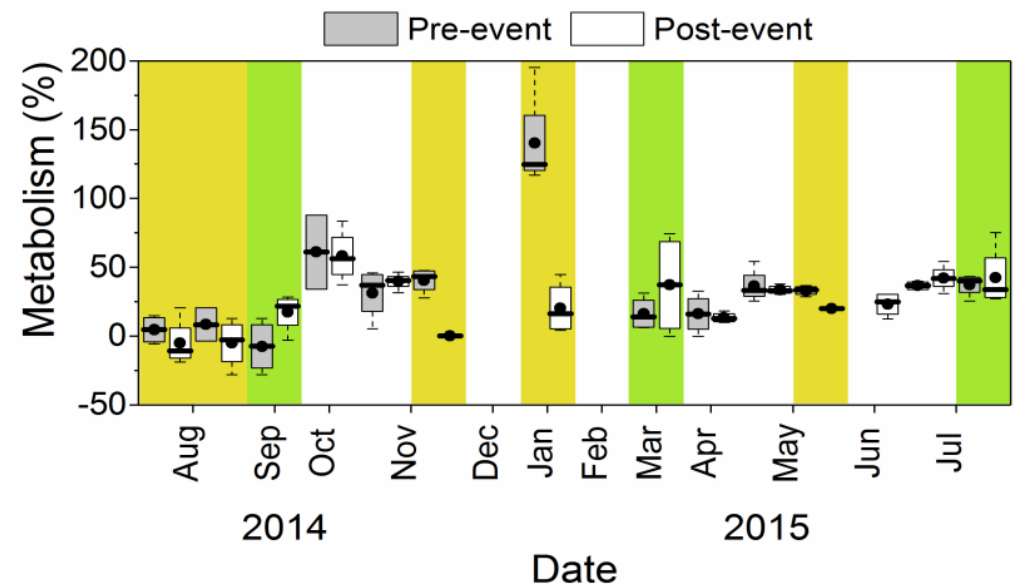

Figure 2. Temporal variability of aquatic metabolism within the studied SGI over four consecutive days of pre and post-storm events. Error bars of the box plots indicate standard error. Solid circles and lines in individual boxes indicate mean and median values, respectively. Green and yellow panels indicate that significantly positive and negative metabolism, respectively, took place during the pre-event conditions compared to the post-event conditions (Adyel et al. 2017b).

We investigated how long the SGI took to return its pre-storm state during fourteen events to assess the metabolism resistant and recovery (Figure 2). We found that the studied SGI was resistant to the storm-perturbation during seven events. The system showed resistivity during small events or event that took place during the frequent rainfall time. However, the SGI recovered its metabolism quickly during the less frequent rainfall event, particularly during the summer when CW becomes lentic. Moreover, large flow pulses can cause full-bed mobilization and convert the SGI from lentic to lotic stage that disrupts stream metabolism by destroying periphyton habitats with long recovery times (Adyel et al. 2017b). These factors might contribute to low metabolism and make the CW more resistant to overall DO fluctuations during different storm events. Moreover, due to macrophyte senescence within the system and organic-rich incoming nutrients, oxygen-consuming process can be intensified throughout the year leading to intense daily DO fluctuations (Adyel et al. 2017b). Interestingly, the resistivity or recovery of metabolism also depends on the scale of overall system disturbance due to the 


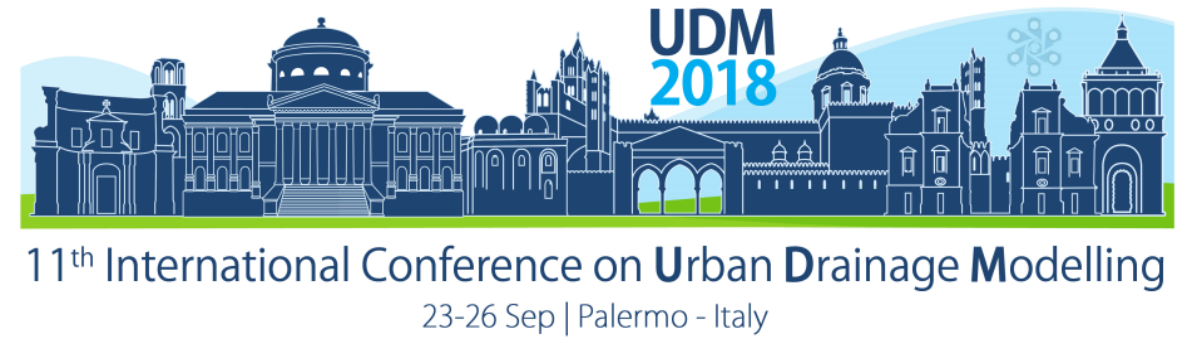

event. O'Connor et al. (2012) found two types of recovery time: $<5$ and $>15$ days when the disturbance is about $30 \%$ and $70 \%$, respectively. Usually, large flow pulses can damage the periphyton habitats and hence cause full-bed mobilization and ultimately delay the metabolism recovery time. Estimation of metabolism resistance and recoverys and their drivers in SGI need to be further investigated under diverse hydrological and biogeochemical variabilities.

Nutrient concentrations at the outlet of the CW showed a diurnal trend responding to DO concentrations and available sunlight (Adyel et al. 2017b). Therefore, periodic autotrophic and heterotrophic conditions were suitable for $\mathrm{NH}_{3}$ and Nox attenuation in the CW. Interestingly, the overall system was net autotrophic in time when diurnal DO concentrations increased from morning to afternoon, indicating that average daily photosynthesis exceeded respiration. We also took attempt to correlate SGI metabolism during storm perturbation with nutrient attenuation. Interestingly, positive metabolism was correlated with the attenuation of nutrients i.e., $\mathrm{NH}_{3}\left(R^{2}=0.84\right)$, NOx $\left(R^{2}=0.9\right)$, $\mathrm{FRP}\left(R^{2}=0.98\right)$, and TP $\left(R^{2}=0.75\right)$ (Adyel et al. 2017b).

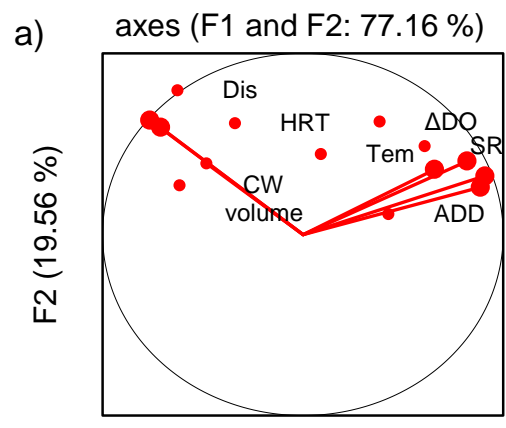

F1 $(57.60 \%)$

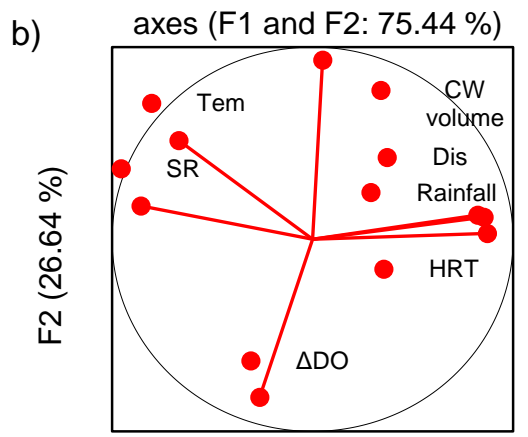

$\mathrm{F} 1(48.80 \%)$

Figure 3. Principal component analysis of different parameters (average across four consecutive days) during the (a) pre-event and (b) post-event conditions in the studied SGI. SR: Solar radiation exposure (Adyel et al. 2017b).

\section{References}

Adyel T.M., Oldham C.E. \& Hipsey M.R. (2016). Stormwater nutrient attenuation in a constructed wetland with alternating surface and subsurface flow pathways: Event to annual dynamics. Water Research, 107, 66-82.

Adyel T.M., Hipsey M.R. \& Oldham C.E. (2017a). Temporal dynamics of stormwater nutrient attenuation by an urban constructed wetland experiencing summer low flows and macrophytes senescence. Ecological Engineering, 102, 641-661.

Adyel T.M., Oldham C.E. \& Hipsey M.R. (2017b). Storm event-scale nutrient attenuation in constructed wetlands experienceing a mediterranean climate: A comparision of a surface flow and hybrid surface-subsurface flow system. Science of the Total Environment, 598, 1001-1014.

Fletcher T.D., Andrieu H. \& Hamel P. (2013). Understanding, management and modelling of urban hydrology and its consequences for receiving waters: A state of the art. Advances in Water Resources, 51, 261-279.

Fletcher, T.D. et al., (2015). SUDS, LID, BMPs, WSUD and more - The evolution and application of terminology surrounding urban drainage. Urban Water Journal, 12(7), 525-542.

O'Connor B.L., Harvey J.W. \& McPhillips L.E. (2012). Thresholds of flow-induced bed disturbances and their effects on stream metabolism in an agricultural river. Water Resources Research, 48. W08504.

Reeder B.C. (2011). Assessing constructed wetland functional success using diel changes in dissolved oxygen, $\mathrm{pH}$, and temperature in submerged, emergent, and open-water habitats in the Beaver Creek Wetlands Complex, Kentucky (USA). Ecological Engineering, 37, 1772-1778.

Tuttle C.L., Zhang L. \& Mitsch W.J. (2008). Aquatic metabolism as an indicator of the ecological effects of hydrologic pulsing in flow-through wetlands. Ecological Indicators, 8, 795-806. 


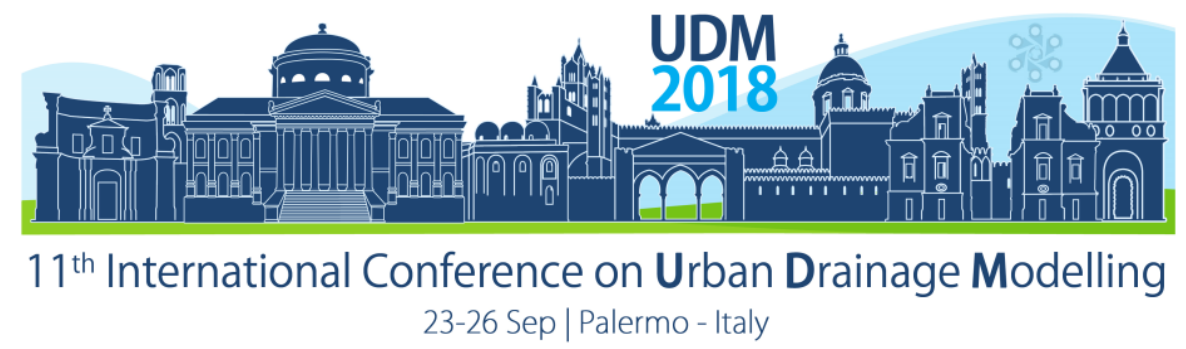

\title{
The Rainfall Interception Performance of Urban Tree Canopy in Beijing, China
}

\author{
Xiaowen Liu, ${ }^{1,2}$, Qing Chang ${ }^{2}$ \\ ${ }^{1}$ School of Architecture, Tianjin University, Tianjin, China \\ ${ }^{2}$ College of Horticulture, China Agriculture University, Beijing, China
}

\begin{abstract}
Green spaces play an important role in low impact development and runoff mitigation, but rain loss intercepted by tree canopies affiliated to green spaces are always overlooked. In this research, common garden trees in urban area were selected to explore the rainfall interception performance and the relationship between tree feathers and rainfall characteristics by monitoring variabilities including precipitation, interception, tree features, etc. for 24 rainfall events. The results show that ranging from less than $40.8 \mathrm{~mm}$ rainfall, interception increases and hasn't saturated among most species, while rainfall rate declines. Interception of conifers declines when rainfall intensity increases but it not obvious in the deciduous. Interceptions show a positive correlation with crown density which means lusher trees may intercept more rain, but the interception effect would be damaged by garden pruning. Some species of deciduous trees such as lilytree, purple-leaf plum and maple have a better interception performance than conifers. Smaller branch angles may facilitate intercepting. Good performed species and appropriate managements are suggested to apply to LID to mitigate runoff.
\end{abstract}

Keywords: urban tree canopy; rainfall interception; LID

\section{INTRODUCTION}

Green spaces in low impact development (LID) become new strategies in mitigating stormwater runoff, such as rain garden, bioswale and permeable pavement. Most researches and practices focus on the technology to facilitate runoff infiltration, but often overlook the losses caused by rainfall intercepting of tree canopy which can redistribute rainfall decrease the rainfall coming to the ground, and surface runoff (Adam Berland et al., 2017). Interception effects of trees in forest are not inadequate to apply in urban trees for different biology systems, and the same species may perform dissimilarly between China and Europe because the climates especially the precipitation characteristics are different. Rainfall characteristic is the most major effecting factor of interception than other meteorological factors (Zhang Q, et al., 2011). But whether it causes a same effect among species is not well known. Conifers intercept more than the deciduous in same rainfall condition (Qingfu Xiao et al. 2016), but exceptions exist. Knowing and anticipating interception effects of different trees are good for selecting candidate trees for LID practices and decreasing runoff, further, for parameter setting of tree-interception models and stormwater management models. For the above, ten tree species common seen in urban area were selected in Beijing City in order to identify good performed species in intercepting to provide references to LID planning and modelling.

\section{MATERIALS AND METHODS}

\subsection{Site and tree material}




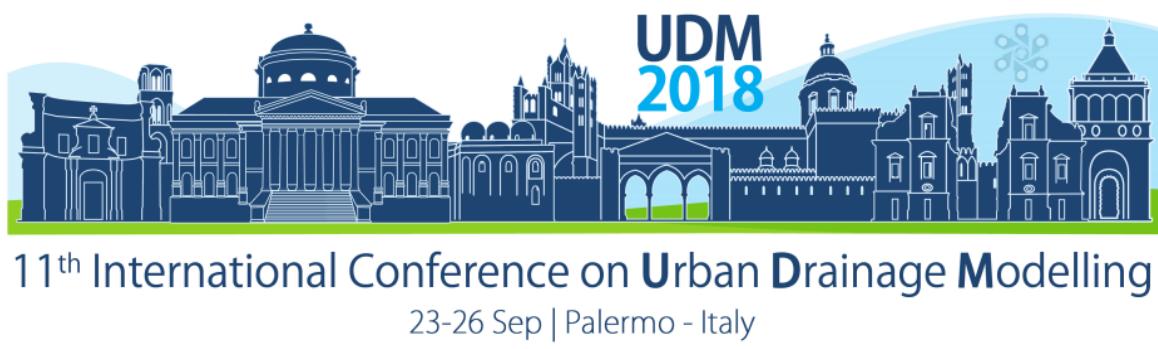

The study site is located in the campus of China Agriculture University, a kind of urban zone of Beijing City. For the typical north temperate semi-humid continental monsoon climate, the annual average rainfall is $528 \mathrm{~mm}$, and $80 \%$ of the precipitation events including heavy rainstorms that runoff more likely occur in Beijing are taken place during June and August. The observation proceeded between June and September in 2014, and were excluded in other months for little rainfall or snow.

Ten tree species common seen in the study site were selected. They were Chinese red pine (Pinus tabuliformis Carr.), cedar (Cedrus deodara (Roxb.) G. Don), white-bark pine (Pinus bungeana Zucc. ex Endl), lilytree (Magnolia denudata Desr), Chinese scholar tree (Sophora japonica L), longzhao pagoda tree (Sophora japonica var. pendula Loud), maple (Acer truncatum Bunge), purple-leaf plum (Prunus cerasifera Ehrh. cv. Atropurpuren), paper mulberry (Broussonetia papyrifera (L.) L'Herit. ex Vent), and amur honeysuckle (Lonicera maackii (Rupr.) Maxim).

\subsection{Methods}

Precipitation $(P)$ was measured with two rain gauges in open amenity grassland. Throughfall (Th) was measured with 4 or 6 rain gauges located below each canopy symmetrically and vertically, and three heathy trees for each species. The average value of the measured values of $P$ and Th were taken into the calculation. The volume of interception and interception rate are calculated as E1and E2.

$$
\begin{array}{ll}
I=P-T h & (\mathrm{E} 1) \\
I r=I / P & (\mathrm{E} 2)
\end{array}
$$

Where $I$ is interception, $P$ is gross precipitation for each rain event, Th is throughfall and $I r$ is interception rate.

Crown density $(C D)$ performs better in indexing throughfall than other biomass like leaf-area index and complexity of vertical crown (Livesley etc., 2014, Inkiläinen etc., 2013). So a gradient of crown density $(C D)$ by $0.55-0.69,0.70-0.79,0.80-0.89$, and $0.90-0.99$ of a cedar community canopies were selected to research the relationship between $I$ and $C D$, the $T h$ were measured with 5 rain gauges on each $C D$ gradient.

The stem flow was neglected in this method for it always counts less than 5\% (Guevara, etc., 2007; Livesley, etc., 2014).

\section{RESULTS AND DISCUSSION}

\subsection{Rainfall characteristic and interception}

Between June and September in 2014, 24 rainfall events were monitored with a $301.4 \mathrm{~mm}$ accumulated rainfall. 4 heavy rain $(25-50 \mathrm{~mm})$ events occurred and counted $17 \%$ of the total rainfall. The maximum and minimum rainfall record was $40.8 \mathrm{~mm}$ and $0.8 \mathrm{~mm}$.

Regression analysis shows that mostly the relationship between I and $P$ fit exponential functions, Ir and $P$ fit logarithmic or exponential function mostly except amur honeysuckle (Figure 1). Ir has a negative correlation with $P$, and declines more quickly when $P$ is less than $20 \mathrm{~mm}$. I $r$ tends to be stable when $P$ increasing, it indicates that there is a limit for tree canopy on rainfall interception or water retention. 


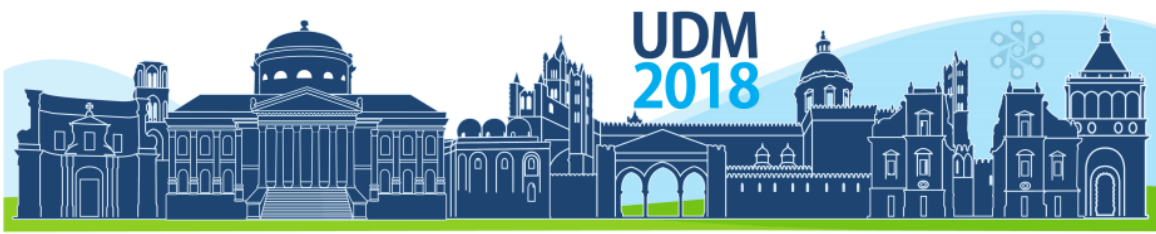

$11^{\text {th }}$ International Conference on Urban Drainage Modelling 23-26 Sep | Palermo - Italy
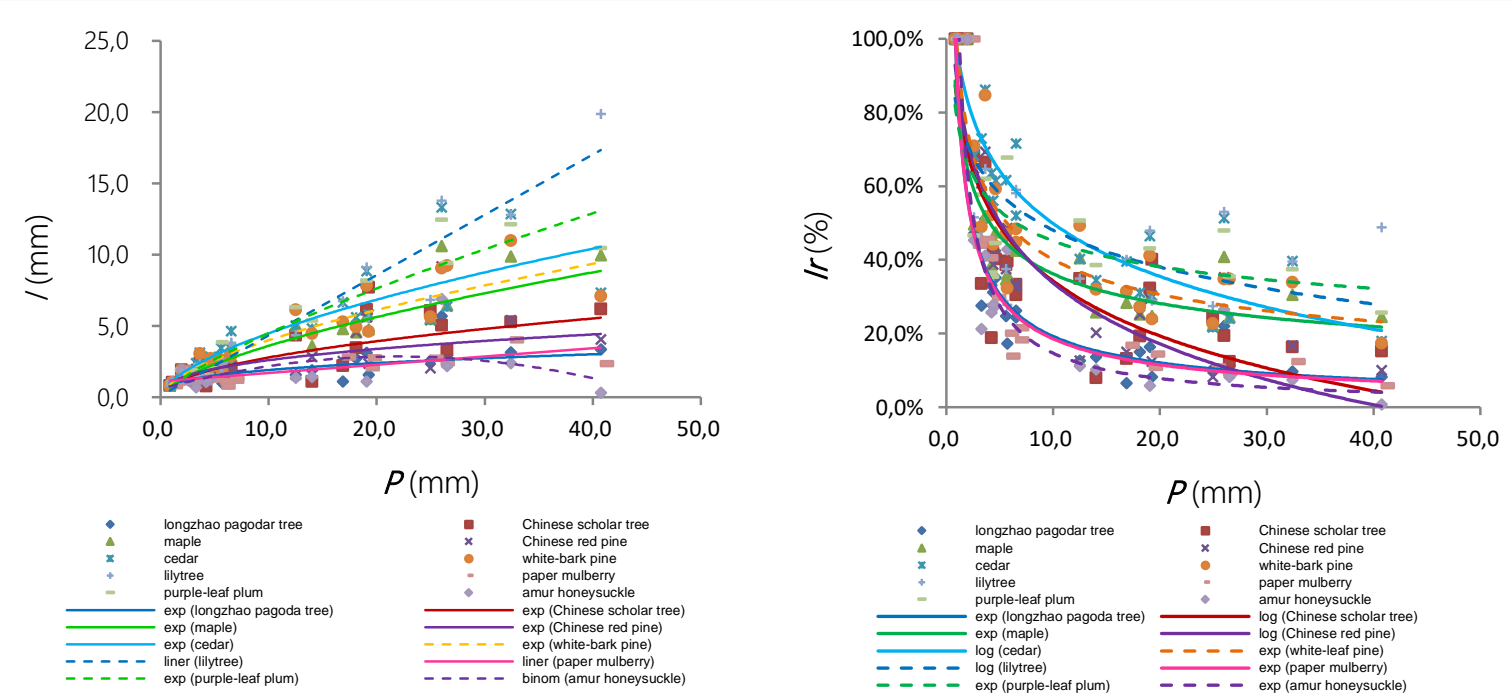

Figure 1. Regression curve of $I-P$ (left) and $I r-P$ (right) of ten tree species. $I$ increases with $P$ and hasn't saturated within $40.8 \mathrm{~mm}$ rainfall. Ir declines rapidly within $20 \mathrm{~mm}$ and tends stabilized when rainfall extends the value.
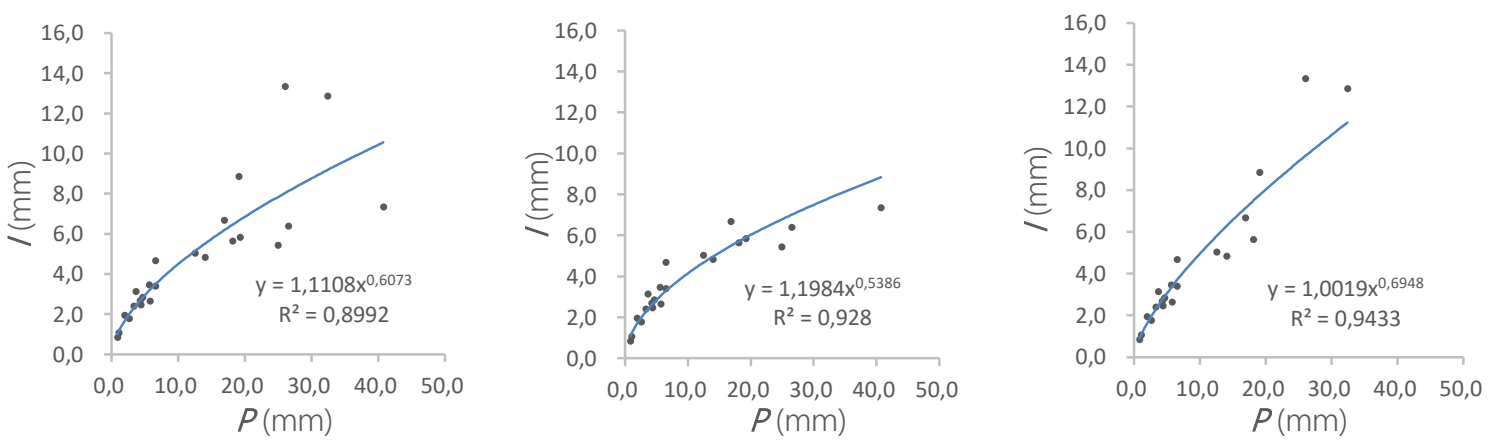

Figure 2. This is the $I-P$ curve of cedar. The $I$ values are dispersive (left) when $P$ extends about $20 \mathrm{~mm}$. The regression curve fits better if $I$ is parted into High (middle) and Low (right) rainfall intensity by $6.6 \mathrm{~mm} / \mathrm{h}$.

The I curve increases more gradual at higher rainfall intensity (above $6.6 \mathrm{~mm} / \mathrm{h}$ ) compared to low intensity when rainfall extends $16 \mathrm{~mm}$ on conifers (Figure 2), while the deciduous don't show such an effect markedly. It indicates that greater rainfall intensity may reduce canopy interception especially in some conifer species.

\subsection{Interception and crown density}

The Th of 20 different $C D$ sites from 0.55 to 0.99 below cedar community crown was measured in 2 rain events (rainfall were $19.1 \mathrm{~mm}$ and $32.4 \mathrm{~mm}$ ). The average $/ \mathrm{r}$ of each $C D$ grade is $11.1 \%, 14.8 \%, 27.6 \%$ and $46.6 \%$. Both $I$ and $I r$ grow when $C D$ is increasing (Figure $3)$, means that a more density crown intercepts more rain.

For Chinese red pine, the average $I r$ is $22.2 \%$ in this research, but $35.8 \%$ in Vulture Peak and $34.0 \%$ in West Mountain in Beijing (Chen, et al., 2013, Wang et al., 2012) at a similar gross rainfall. The possible reason is the $C D$ in forests is 0.9 , higher than that in urban green space of 0.7 which is a result of pruning-a garden management. This management decreases about $30 \%$ interception of Chinese red pine. These indicate that tree canopy with 


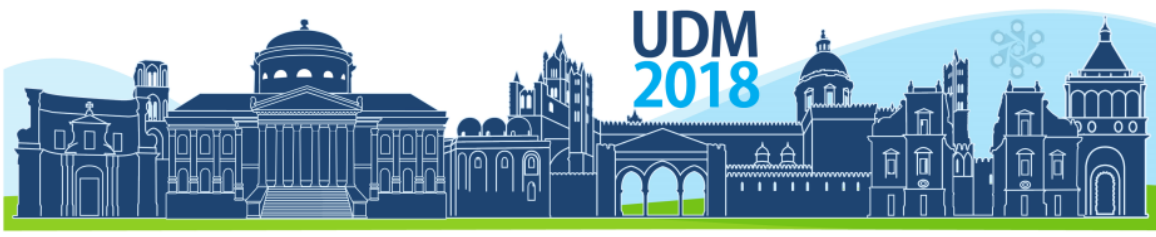

$11^{\text {th }}$ International Conference on Urban Drainage Modelling

23-26 Sep | Palermo - Italy

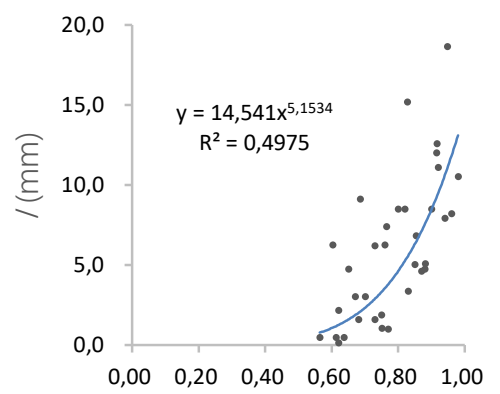

$C D$

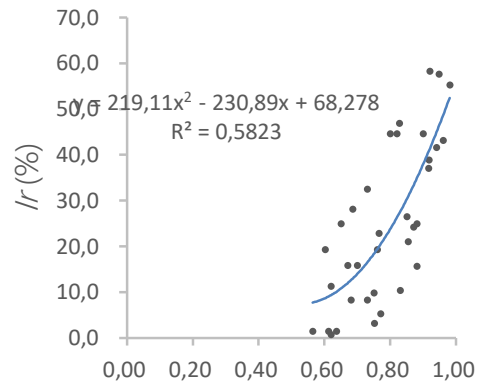

$C D$

Figure 3. The left $I-C D$ curve of cedar shows that $I$ and $C D$ have a positive correlation. So do $I r$ and $C D$ in the right side.

a greater crown density would intercept more rainfall, while a great crown density is always a result of great biomass. Pruning with a purpose of beautifying the city will damage the ecology function of urban vegetation.

\subsection{Interception and species}

Trees show big interception dissimilarity in species. The interceptions of 10 tree species in 11 rain events were compared (Table 1 ). We find the conifers, compared to the deciduous, intercept more water in small rains but intercept with little difference in heavy rains. In fact, in the highest rain event $(40.8 \mathrm{~mm})$, the Ir of lilytree, purple-leaf plum, and maple are $48.8 \%$, $25.7 \%$ and $24.5 \%$, they are higher than cedar (18.0\%), white-bark pine (17.4\%) and Chinese red pine (15.2\%). Generally supposed that conifers intercept more than deciduous (Crockford etc., 1990; Llorens etc., 2007), but it is on the contrary in this paper. So the interception performance has a great relation with tree species. Good interception performed trees species whatever conifers or deciduous should be considered and selected into LID management in order to mitigating surface runoff in heavy rain.

Table 1. Interception capacity of different tree species in small, middle and heavy rains. (AP is the accumulative volume precipitation of small, middle or heavy rain.)

\begin{tabular}{lcccccc}
\hline \multirow{2}{*}{ Tree species } & \multicolumn{2}{c}{ Small rain $(0-10 \mathrm{~mm})$} & \multicolumn{2}{c}{ Middle rain $(10-25 \mathrm{~mm})$} & \multicolumn{2}{c}{ Heavy rain $(25-50 \mathrm{~mm})$} \\
\cline { 2 - 7 } & $\mathrm{AP}(\mathrm{mm})$ & $\operatorname{Ir}(\%)$ & $\mathrm{AP}(\mathrm{mm})$ & $\operatorname{Ir}(\%)$ & $\mathrm{AP}(\mathrm{mm})$ & $\operatorname{Ir}(\%)$ \\
\hline Conifers & 22.7 & 62.6 & 19.1 & 39.0 & 99.1 & 26.7 \\
Deciduous trees & 22.7 & 50.0 & 19.1 & 30.1 & 99.1 & 25.2 \\
Shrubs & 22.7 & 44.5 & 19.1 & 5.8 & 99.1 & 9.8 \\
\hline
\end{tabular}

Branch angles also influence interception. Partial correlation analysis shows that $I$ and $I r$ have significant positive correlation with the first class branch angles, and have negative correlation with third class angles. Such as Chinese scholar tree and its varietas-longzhao pagoda tree that looks like an umbrella, the first class branch angles and average I $r$ of the former are $19.0^{\circ}$ and $25.0 \%$, and $84.5^{\circ}$ and $17.6 \%$ for the varietas. Smaller first class branch angles may facilitate water storage in branch gaps or produce stem flow.

The hirsute leaves may be a significant reason of low average $\operatorname{Ir}(15.0 \%)$ of paper mulberry for the hirsute repelling water. Amur honeysuckle also performs poor in intercepting for its cambered and sparse shape impedes water storage. Such shaped trees like longzhao 


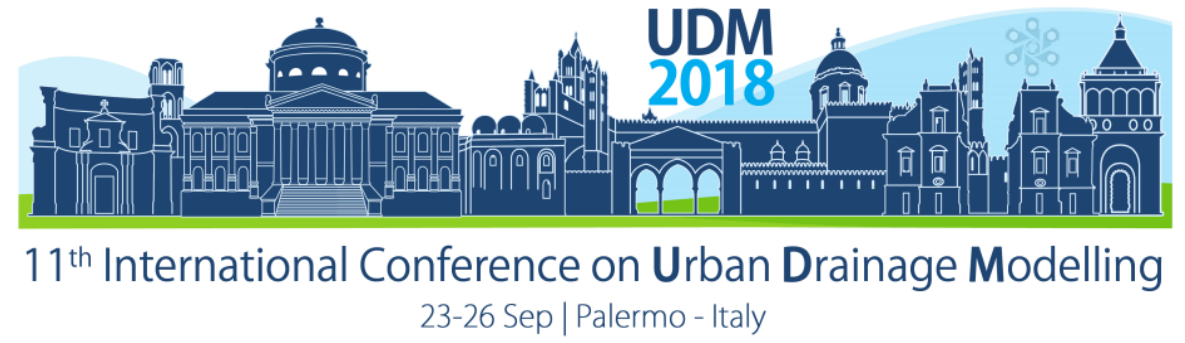

pagoda tree and amur honeysuckle, and hirsute leave-plant are not suggested to apply in mitigating rainfall.

\section{CONCLUSIONS}

In this research, we find that conifers' interception performs better in small rain events, and has a similar interception effect with deciduous in heavy rains. The conifers' interception declines more obviously than the deciduous with rainfall intensity increasing when rainfall extends $16 \mathrm{~mm}$.Interception performance depends on trees species largely and conifers don't always perform best. High canopy density is conductive to intercept water. Branch angles may effect interception performance and need more research on the mechanism.

Good interception performed tree species, and lush canopies are suggested to LID practices and surface runoff mitigation. Some urban tree managements such as garden pruning should also be limited to keep trees' ecological functions instead of beauty effect only. More good interception tree species should be recognised and modelling of tree interception should be more elaborate in the future.

\section{References}

Berland A, Shiflett S. A., Shuster W. D., Garmestani A. S., Goddard H. C., Herrmann D. L., and Hopton M. E. (2017) The role of trees in urban stormwater managemet. Landscape Urban Plan. 162(2017), 167-177.

Chen L., Zhang Y., Yu X., Shi Y., and Huang Z. (2013) Interception characteristic and modeling of typical forest vegetation in mountainous area in Beijing. J Basic Sci Eng. 21(3), 423-431. (in Chinese)

Crockford R. H., Richardson D. P. (1990) Partitioning of rainfall in a eucalypt forestand pine plantation in southeastern Australia: II stemflow and factors affecting stemflow in a dry sclerophyll eucalypt forest and a Pinus radiata plantation. Hydrol Process, 4, 145-155.

Guevara A. E., Gonza'lez E. S., Ve'liz C. C., Ventura E. R., Ramos M. S. (2007) Rainfall interception and distribution patterns of gross precipitation around an isolated Ficus benjamina tree in an urban area. $J$ Hydrol. 333(2-4), 532-541.

Inkiläinen E. N. M, McHale M R, Blank G B, James A. L., and Nikinmaa E. (2013) The role of the residential urban forest in regulating throughfall: A case study in Raleigh, North Carolina, USA. Landscape Urban Plan, 119(2013), 91-103.

Livesley S J, Baudinette B, and Glover D. (2014) Rainfall interception and stem flow by eucalypt street trees The impacts of canopy density and bark type. Urban Fore Urban Gree, 13(1), 192-197.

Llorens P., Domingo F. (2007) Rainfall partitioning by vegetation under Mediterranean conditions. A review of studies in Europe. J Hydrol. 335(1-2), 532-541.

Wang H., Yu X., and Zhao Y. (2012). Ecological use of water of four dominant forests in mountainous area of Beijing City. Soil Water Conserv. 32(4), 62-64, 70. (in Chinese)

Xiao, Q, McPherson, E.G. (2016) Surface water storage capacity of twenty tree species in Davis, California. $J$ Environ Qual.45, 188-198.

Zhang Q, Zhang H., Cheng J., Zhang J., Sun L., and Ma X. (2011) Brief analysis on canopy interception effect and influencing factors of five forest types in Simian Mountain of Chongqing. J Northwest $A F$ Uni. 39(11), 173-179. (in Chinese) 


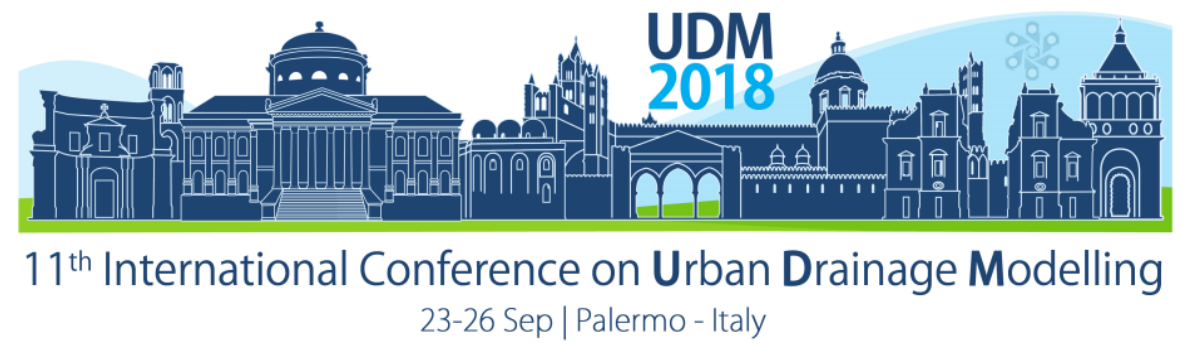

\title{
Flood Risk Management in an Urban Area Applying LID Techniques
}

\author{
Hamed Ghafghazi ${ }^{1}$, Beatrice Dionisi ${ }^{1}$, Antonio Zarlenga \\ 1 Department of Engineering, Roma Tre University, Rome, Italy \\ Via Vito Volterra, 62, Rome, Italy
}

\begin{abstract}
We analyze the benefits of a practical application of Low Impact Development (LID) structures in an urbanized area in terms of reduced flooding volumes and peak flow. LID techniques are fairly economic and easy to implement solutions for the hydraulic restoration and improvement of the efficiency of existing urban drainage networks. The case study is the New Rome Fair, a recent urban development where flooding problems have been observed in the last few years. The study illustrates the potential of LID structures together with a dual system, and their impact on flooding occurrences, for two different Return Periods, highlighting the need for attentive and feasible applications of such structures in a heavily urbanized environment, harmoniously with the related architectural aspects.
\end{abstract}

Keywords: Low Impact Development; Flood Risk Mitigation; Environmental Sustainability; Urban Hydrology; Green Architecture.

\section{INTRODUCTION}

The increasing anthropization and impermeabilization of the land due to the urban expansion causes an increased stress of the existing sewer system, resulting in more frequent flooding events(Yanga et al., 2011). Several Low Impact Development (LID) tools, and green infrastructure in particular, were introduced in the last two decades for mitigating flooding risk, and a large body of literature has been published in the recent years (see, e.g., Fletcher et al., 2015). Such techniques are based on a new paradigm for water management, which combines both hydraulic and environmental aspects, together with landscape livability (Ellisa et al., 2004). LID may also decrease environmental pollution and increase resilience to future climate change (Pyke et al., 2011).

In this work, we analyze the hydraulic performance of different green infrastructures for the flooding risk mitigation in a specific area of Rome. Moreover, the study focuses on the hydraulic performance of LID structures, namely flooding risk, which takes into account also aesthetic and architectural aspects, together with the actual and feasible implementation of such structures (see, e.g., Haifeng et al., 2011).

The New Rome Fair is a strategic area of the city that has been subjected to flooding after heavy rain events in the last decade. In this study, we design the hydraulic restoration of the area by using LID systems, green infrastructures, particularly which allow the flooding control by increasing the water infiltration and by introducing water detention, retention, and storage (Ashley et al., 2011). Moreover, the LIDs implementations have been selected appropriately for the specific area in order to achieve optimal integration with the surrounding environment. Figure 1 shows the overview of area (a), the scheme of the existing sewerage (b) and two details of the architectural project with the green infrastructures (c, d). The overall efficiency of the system is quantified in terms of global parameters such as the flooding volume and peak 


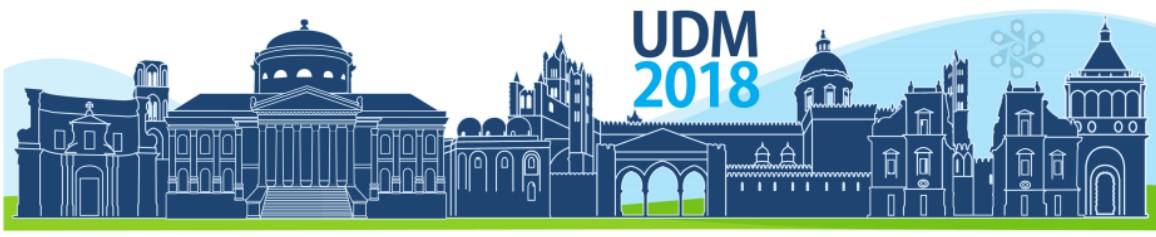

$11^{\text {th }}$ International Conference on Urban Drainage Modelling

23-26 Sep | Palermo - Italy

flow reductions. Numerical simulations of water flow were performed for two Return Periods (RP), 50 years and 10 years, respectively, employing the software EPA SWMM 5.1 (Rossman, 2010).

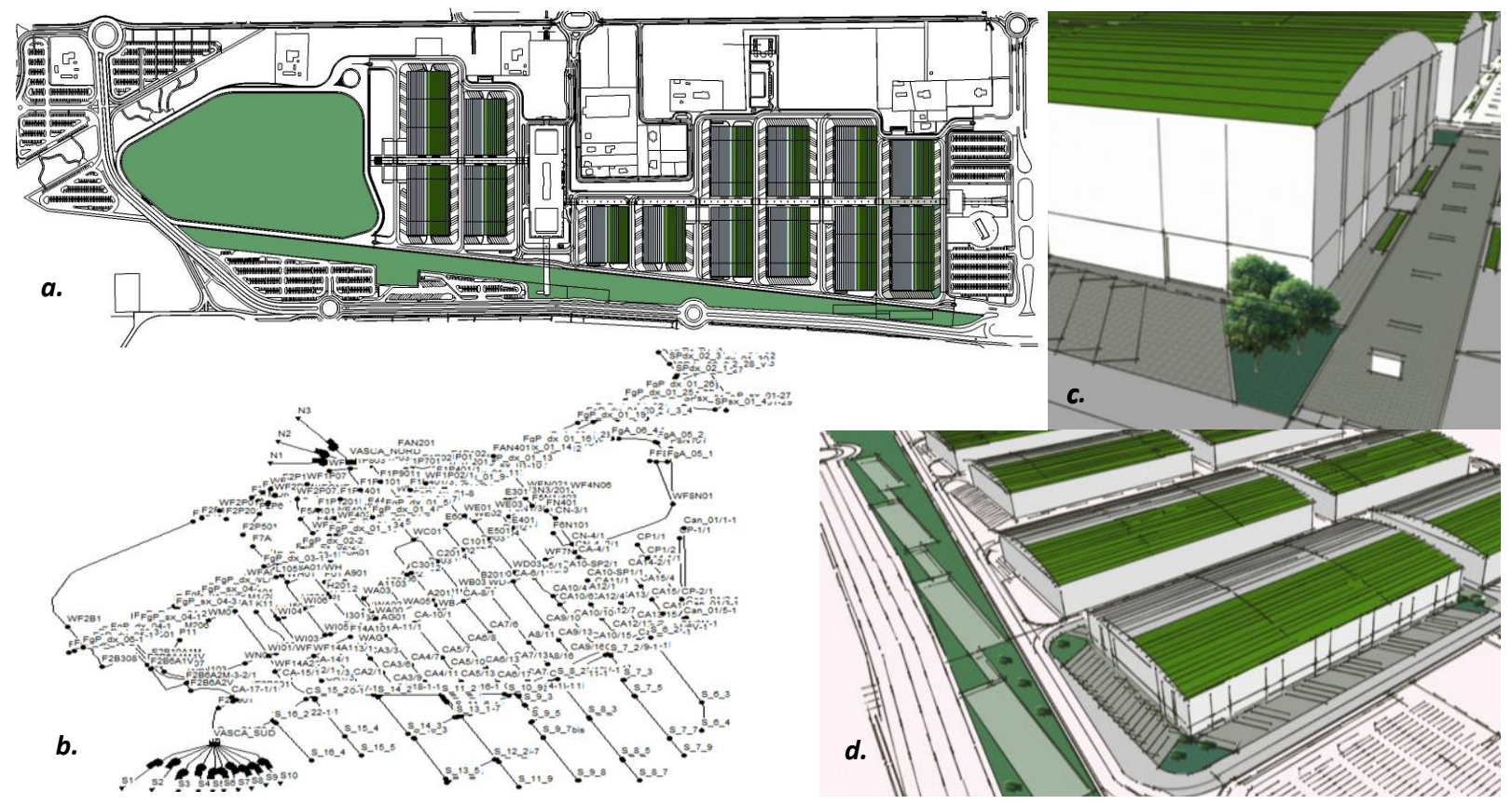

Figure 1. Sketches of integration of LID techniques in the study area: (a) overview of the pavilions zone, (b) the schematic sewer system implemented in SWMM, (c, d) details of the arrangements of prefabricated green roofs, permeable pavements, rain gardens, vegetated swales, retention basins and tree well strips.

The main contributions of this work are (i) the analysis of the LIDs efficiency across increasing return periods; (ii) the study of additional techniques for the management of the flooding risk in urban context, and particularly a combination of green and grey infrastructures (dual system) that allows a greater flexibility for flood protection under variable return periods. This study also suggests that the LID design cannot be driven only by hydrological and hydraulic aspect; in fact, it needs also the deep analysis of landscape design, architecture, urbanistic and ecological aspects in order to achieve a more general optimum.

\section{MATERIALS AND METHODS}

The exhibition part of New Rome Fair, which covers 37 ha, includes 13 pavilions, is drained by a sewer system delivering stormwater to the Tiber River. Significantly, in the current situation, named "scenario 0", the surface runoff is totally conveyed to the existing sewer system. Correspondingly, four nodes identifying the main catchments of interest are adopted as control sections for estimating the efficiency of the applied LIDs.

Accordingly, rain barrels, vegetated swales, retention basins, green roofs (Palla et al., 2010), rain gardens and tree well filters were introduced in the urban texture, with increasing levels of complexity. Furthermore, three scenarios were investigated in order to identify the more efficient and effective alternatives for the 10 and 50 years RP as described below:

A. LIDs connected to the existing sewer system;

$B$. Dual System: scenario A supplemented by a system of surface canals for the overflow conveyance to a retention basin when the sewer flow exceeds the pipe capacity; 


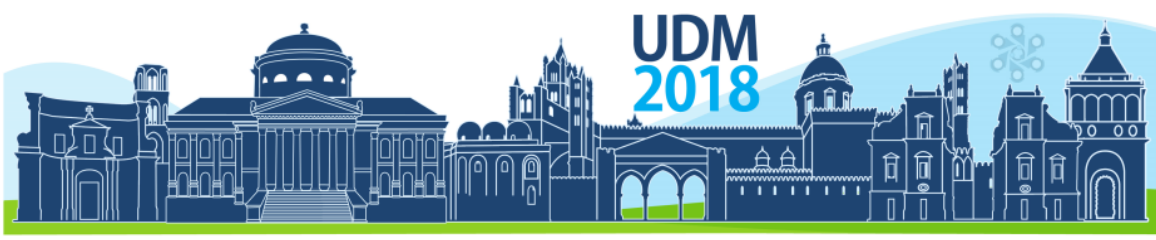

$11^{\text {th }}$ International Conference on Urban Drainage Modelling

23-26 Sep | Palermo - Italy

C. LIDs linked to a dedicated drainage network (grey infrastructures), separated from the existing one (without surface canals).

Furthermore, in the scenarios B and C, the LID tools are connected to a series of retention basin, created in the lowest ground level zones, which is located in the southern area of each pavilion.

The stormwater flow is generated by a Chicago synthetic hyetograph. The detailed drainage network is simulated in the transient regime with the software EPA SWMM 5.1; LIDs were simulated by the dedicated suite of tools (Rossman, 2010).

Because of the scarcity of data, the calibration of the hydrological and hydraulic parameters (scenario 0) has been performed by adopting parameters from past studies in the neighboring similar areas. In addition, an a-posteriori verification has been carried out by matching the simulated and observed flooding nodes and water depths during 2 events (July and December 2015); literature parameters have been used for the LIDs.

\section{RESULTS AND DISCUSSION}

Figure 2 represents the flooding volume as a function of time; different scenarios are depicted in different colors. Figure 3 shows the values of the peak flow for each outlet node for all scenarios; four groups for RP 50 years and two groups for RP 10 years.

We start the analysis from the higher Return Period (50 years). As a result, the scenario $A$ (Figure 2, blue line) leads to a significant reduction of the peaks flow, about 13\%, with respect to the existing conditions (scenario 0); each control node has a different peak discharge reduction, ranging from $5 \%$ up to $21 \%$. As we have seen, those values somewhat reflect the percentage of catchment area interested by LID applications. The flooding volume is also significantly reduced by $32.7 \%$ than pertaining to scenario 0 .

According to our analysis, the best solution for this RP is represented by scenario $B$ (red line in Figure 2), with the lowest flooding volume. Moreover, the peak flow value is decreased considerably in each outlet node in comparison to scenario 0 (Figure 3).

Scenario $C$ is an intermediate solution between scenario $A$ and $B$. The flooding volume is reduced about the $80 \%$ respect to the existing situation; the peak values of the flow are also significantly reduced. Despite this, the presence of the LIDs together with a dedicated sewer system does not completely solve the problem of the area for such RP, resulting in some flooded areas surrounding the pavilions.
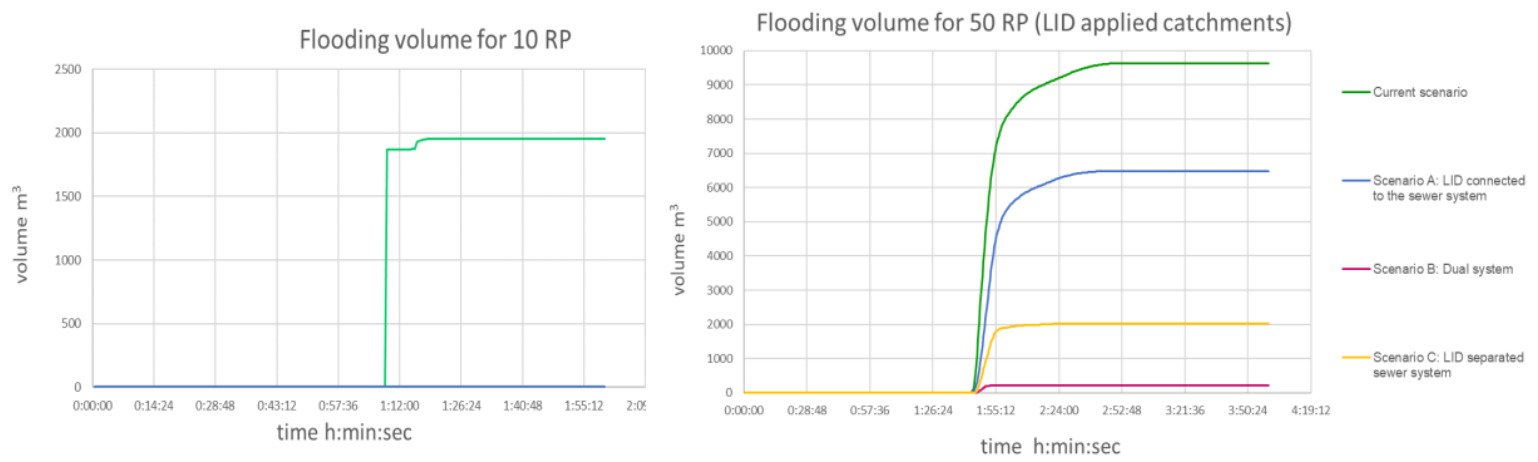

Figure 2. Comparison of flooding volume in the different scenarios and for the two Return Periods considered. 


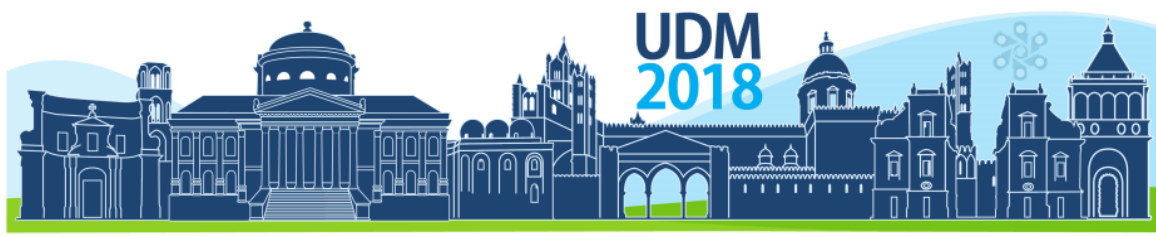

$11^{\text {th }}$ International Conference on Urban Drainage Modelling

23-26 Sep | Palermo - Italy

In the final analysis, LID structures allow the complete hydraulic restoration of the area for the 10 years RP, which is a typical value adopted for the sewer system design. In addition, the reduction of flow peaks is about $15 \%$.

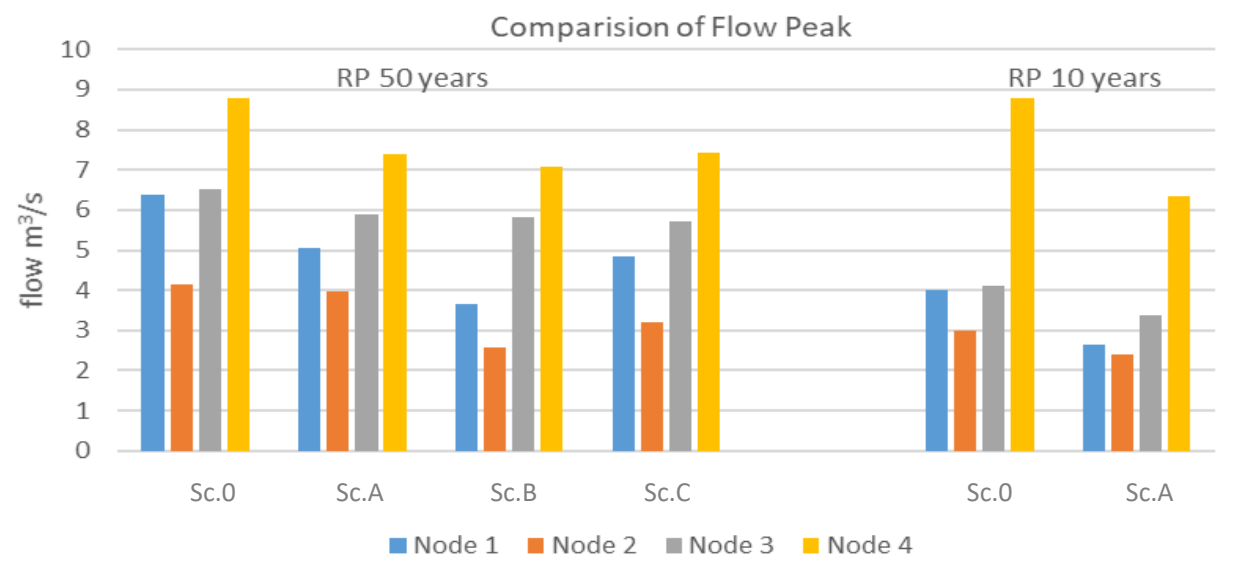

Figure 3. Comparison of peak flows for 50 years and 10 years Return Periods

\section{CONCLUSIONS}

We have investigated the effect of Low Impact Development solutions for the flooding risk mitigation in a recently urbanized area in Rome. Different LID strategies have been applied to simulate a few alternative solutions to counteract the impact of the urbanization and limit as much as possible the flooding risk (Palla et al., 2016). Therefore, the LIDs have been introduced considering the existing sewer system, the available space as well as architectural considerations. A few scenarios have been considered, and their effects have been simulated through the numerical model SWMM.

The main conclusions of the work can be listed as follows:

- LID application is an efficient solution to contain storm flow for small/intermediate Return Periods, for which they may solve the flooding problem and allow a noteworthy reduction of the surface runoff and flow in the sewage system;

- For high Return Periods, LIDs are less effective and should be supported by a structural measure, in this case, an additional system of surface canals (dual system) for the overflow conveyance to a repository different from the sewage network;

- Besides the reduction of flood risk, the careful adoption of suitable LIDs provides a unique opportunity to create extra multi-functional spaces and increase the economic and aesthetic value of the urban environment.

The present study confirms that there is no universal approach to apply LID techniques in urban areas, and they should be carefully introduced and adapted to the specific urban texture under consideration Hence, a multidisciplinary approach is typically required to effectively integrate LID technologies in urban and environmental contexts. 


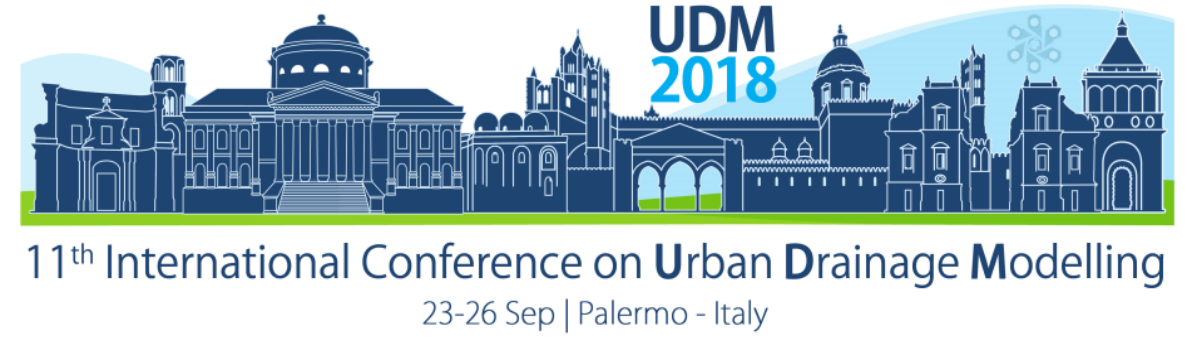

\section{References}

Ashley, R.M, Nowell, R., Gersonius, B., Walker, L. (2011) Surface Water Management and Urban Green Infrastructure in the UK: A review of benefits and challenges. Review of Current Knowledge. Foundation for Water Research, Conference Paper, Marlow, UK, FR/R0014.

Ellisa, J.B., Deutschb, J.C., Mouchelb, J.M., Scholesa, L., Revitta, M.D (2004) Multicriteria decision approaches to support sustainable drainage options for the treatment of highway and urban runoff. Science of The Total Environment, 334-335, 251-260, doi: 10.1016/j.scitotenv.2004.04.066.

Fletcher, T.D., Shuster, W., Hunt, F., Ashley, R., Butler, D., Arthur, S., Trowsdale, S., Barraud, S., Semadeni-Davies A., Bertrand-Krajewski, J.L., Mikkelsen, P. S., Rivard, G., Uhl, M., Dagenais, D., Viklander, M. (2015) SUDS, LID, BMPs, WSUD and more - The evolution and application of terminology surrounding urban drainage. Urban Water Journal, 2, 525-542, doi: 10.1080/1573062X.2014.916314.

Haifeng, J., Yuwen, L., Shaw, L., Yurong, C. (2011) Planning of LID-BMPs for urban runoff control: The case of Beijing Olympic Village. Separation and Purification Technology, 84, 112-119, doi: 10.1016/j.seppur.2011.04.026.

Palla, A., Colli, M., Candela, A., Aronica, G.T., Lanza, L.G. (2016) Pluvial flooding in urban areas: the role of surface drainage efficiency. Journal of Flood Risck Management, 11, S663-S676, doi: 10.1111/jfr3.12246.

Palla A., Gnecco. I., Lanza. L. G. (2010) Hydrologic Restoration in the Urban Environment Using Green Roofs. Water journal, 2, 140-154, doi: 10.3390/w2020140.

Pyke, C., P. Warren, M., Johnson, T., LaGro, Jr J., Scharfenberg, J., Groth, Ph., Freed, R., Schroeer, W., Main, E. (2011) Assessment of low impact development for managing stormwater with changing precipitation due to climate change. Landscape and Urban Planning, 103, 166-173, doi: 10.1016/j.landurbplan.2011.07.006.

Rossman, L.A. (2010) Modeling Low Impact Development Alternatives with SWMM. Journal of Water Management Modeling R236-11, doi: 10.14796/JWMM.R236-11.

Yanga, G., Bowlinga, L. C., Cherkauerb, K. A., Pijanowskic, B. C. (2011) The impact of urban development on hydrologic regime from catchment to basin scales. Landscape and Urban Planning, 103, 237-247, doi: 10.1016/j.landurbplan.2011.08.003. 


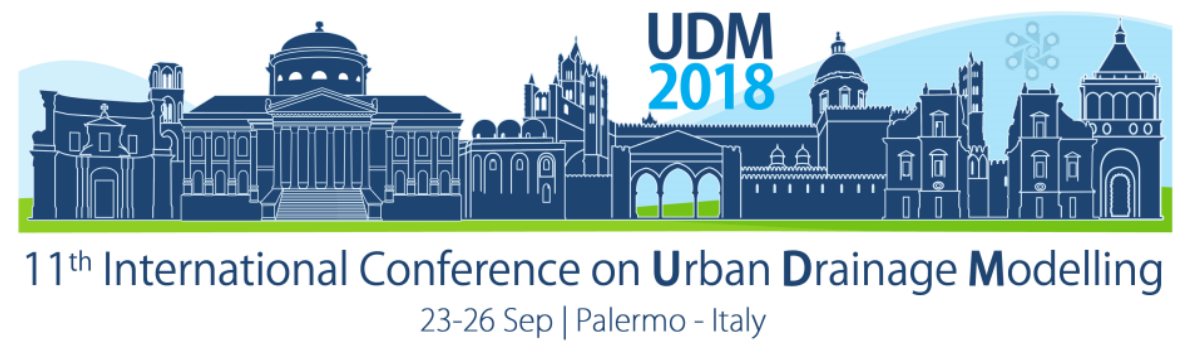

\title{
Enhancing the Retention Performance of a Small Urban Catchment by Green Roofs
}

\author{
Anna Palla ${ }^{1}$, Ilaria Gnecco ${ }^{1}$ and Paolo La Barbera ${ }^{1}$ \\ ${ }^{1}$ Department of Civil, Chemical and Environmental Engineering, University of Genova, Genoa, Italy
}

\begin{abstract}
In existing urban areas the drainage systems can be retrofitted in order to address flooding and water quality problems. In this study, the installation of green roofs is assumed as hypothetic retrofitting scenario according to a sustainable storm water mitigation strategy for a selected urban catchment. The modelling is undertaken using EPA SWMM; the simulations are performed over a continuous simulation of 26 -years of rainfall records. The modelling results point out that the retrofitting scenario contributes to the storm water runoff mitigation mainly in terms of volume and peak reduction.
\end{abstract}

Keywords: evapotranspiration; green roof; hydrologic modelling;

\section{INTRODUCTION}

In urban areas existing drainage systems can be retrofitted in order to address flooding and water quality problems. To this aim, Low Impact Development (LID) principles and applications have been designed to mimic the pre-development hydrologic conditions thus promoting storage, infiltration and evapotranspiration (ET) processes.

Although the LIDs hydrologic performance is widely recognized (see e.g. Palla et al., 2015), the effectiveness of LIDs implementation at the urban catchment scale is still debated mainly referring to the long-term benefits. Recently, several studies (e.g. Burszta-Adamiak and Mrowiec 2013; Poë et al.2015; Cipolla et al. 2016) have been focused on the impact of ET on the retention performance of green roofs since ET is a keystone in long-term simulations. Both experimental and modelling results confirm that the characteristics of green infrastructure (in term of field capacity) determine the retention capacity while ET process is the hydrological process responsible for the restoring of water holding capacity of green infrastructures.

In this framework, the main objective of this paper is to investigate the role of green roofs in storm water runoff mitigation at the urban catchment scale by analysing the long-term simulation results.

\section{METHODOLOGY}

\subsection{Test site description}

The urban catchment of Colle Ometti (Genoa , IT) is selected as a test site for the hydrologic modelling of a LID retrofitting scenario. This 5.5 ha catchment was urbanised in the eighties with 500 houses built on a previously undeveloped hill slope. Actually the management of storm water is addressed according to the traditional approach: no LID source control solutions (such as green infrastructures, permeable pavements etc.) are installed in the catchment. The land use data reveals that $60 \%$ of Colle Ometti catchment is covered with impervious surfaces. 


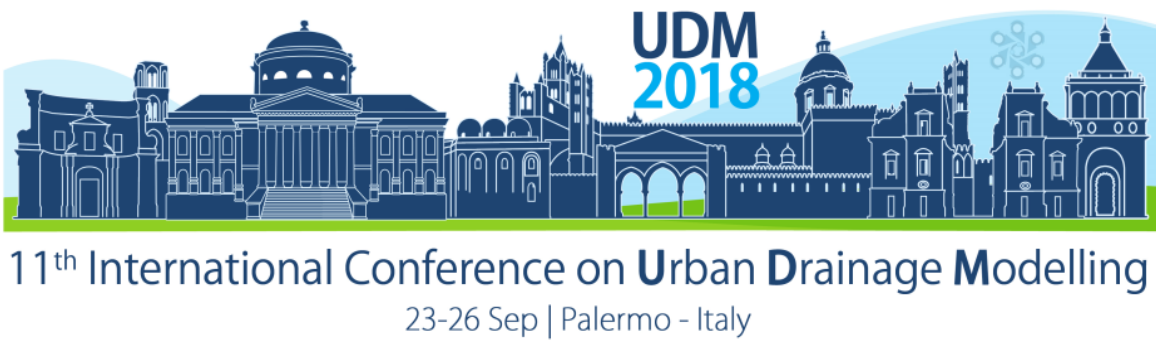

The installation of green roofs (for all rooftops of the catchment) is here assumed as hypothetic retrofitting scenario according to a sustainable storm water mitigation strategy. Referring to the Effective Impervious Area (EIA) that is defined as the impervious area directly connected to the storm drainage system (Shuster et al., 2005), in the present study the EIA reduction corresponding to the green roof retrofitting scenario is equal to the $31 \%$ of the catchment area. By considering long-term performance, the maintenance operation strategies adopted to maintain the LID systems permeability should be taken into account; however the selection of green roofs as retrofitting scenario reveals suitable for assessing long terms performance since green roofs are less sensitive to clogging phenomena compared with other green infrastructures (Brown and Borst, 2015).

\subsection{EPA SWMM model}

The modelling scenarios (relating to the "do nothing" and LID retrofitting) concern continuous simulation performed over 26-years at 1-minute time interval. The simulations are undertaken using EPA SWMM model (v. 5.1.011) and the green roofs are implemented using the corresponding LID control modules. The detail descriptions of the model schematization and calibration procedure are available elsewhere (Palla and Gnecco, 2015).

In order to simulate the evapotranspiration process the climatology editor of SWMM is set up; in particular the potential ET (PET) is calculated using the Hargraves equation based on daily air temperature and solar radiation at the study site. SWMM allows calculating the actual ET as a constant portion of PET in order to account a crop-specific factor; however the actual ET is significantly affected by the substrate moisture content when its value decreases below the field capacity (Stovin et al. 2013). In order to suitable account for the reduced levels of actual ET due to the substrate moisture conditions, a simplified procedure proposed by Peng and Stovin (2017) has been adopted in the present study. In particular a k-factor representing the ratio between the actual ET and PET, evaluated on monthly basis has been calibrated with respect to a green roof module and subsequently adopted in the retrofitting scenario (see Figure 1)

In order to assess the role of LID systems in storm water runoff mitigation the peak and volume reduction rates are calculated for each rainfall event and statistically examined. For this purpose, 1434 rainfall event are selected using a threshold filter able to extract events with total depth and antecedent dry weather period respectively exceeding $2 \mathrm{~mm}$ and 6 hours.

\section{SIMULATION RESULTS}

Results of the continuous simulation (26-year long) provide a fully characterization of the hydrologic-hydraulic behaviour of the investigated catchment including the selected LID system at 1 -minute time resolution.

Based on the simulation results, it emerges that the values of peak and volume reduction rates, evaluated for the 1434 rainfall events, are respectively equal to 0.3 on average, while the maximum values are 0.96 for peak and 0.86 for volume.

Aiming at pointing out the influence of precipitation regime, the 1434 rainfall events are classified based on the following characteristics on event basis: the rainfall depth, the maximum rainfall intensity over 15 minutes and the antecedent dry weather period (ADWP). Fig. 2 shows the non-parametric distribution of the volume (hatched box) and peak (grey box) reduction rates for each class of the investigated rainfall event characteristics. Looking at data reported in Fig. 2, it clearly emerges that the ADWP longer than 5 days (120 h) reveal 


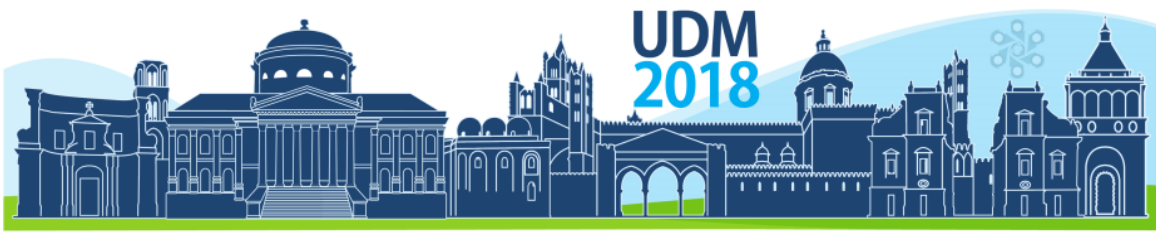

$11^{\text {th }}$ International Conference on Urban Drainage Modelling

23-26 Sep | Palermo - Italy

the highest performance both in terms of peak and volume reduction rate respectively equal to 0.49 and 0.46 , on average. During the dry period between two subsequently rainfall event, the ET plays a crucial role in affecting the initial moisture contrition (at the beginning of next rainfall event) according to the literature (e.g. Palla and Gnecco 2015). On the other hand, the total rainfall depth significantly affects the hydrologic performance: the median values of the both reduction indexes range between 0.38 and 0.61 for rainfall depth lower than $16 \mathrm{~mm}$ while rapidly decrease when the rainfall depth exceeds $32 \mathrm{~mm}$. As for rainfall intensity, the hydrologic performance is more consistent across the different classes, the exception occurs for the highest intensity ( $>34 \mathrm{~mm} / \mathrm{h}$ ) where the median values of the peak and volume reduction rate are respectively equal to 0.32 and 0.16 .

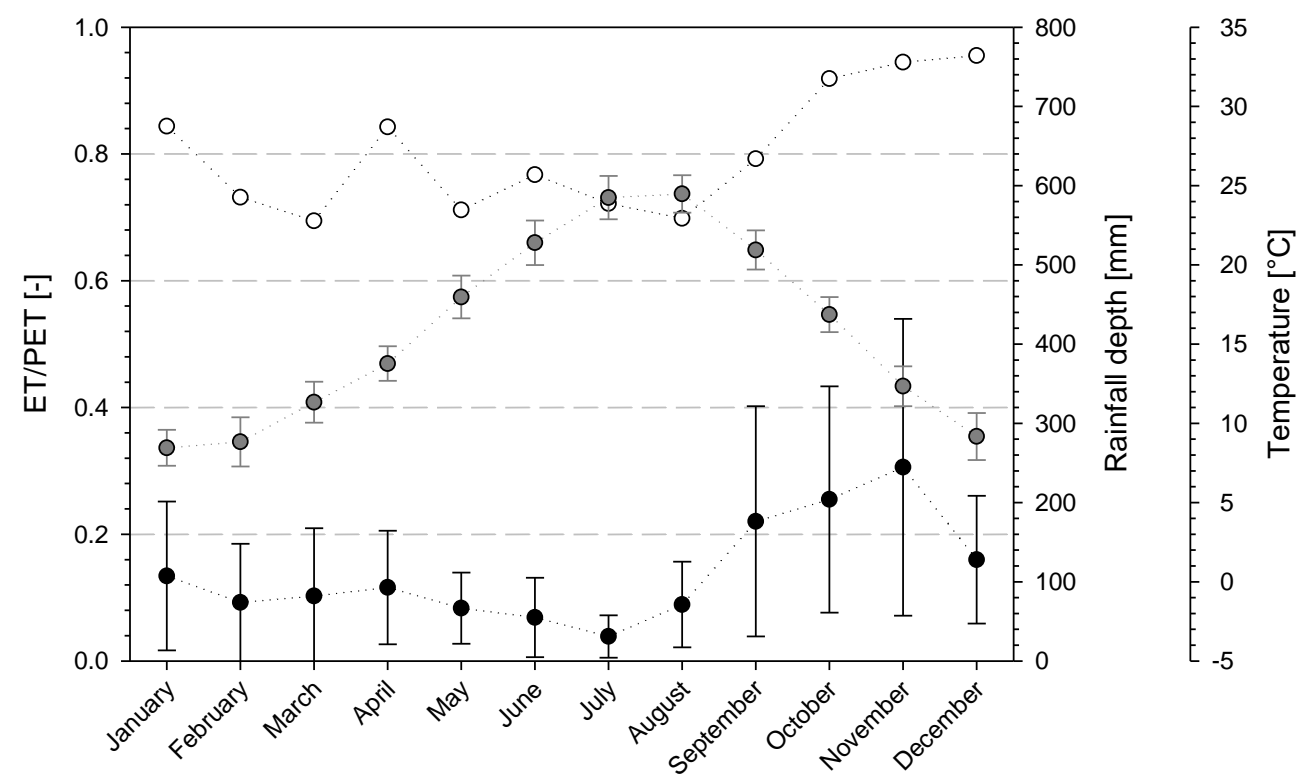

Figure 1. Monthly ET rate (proportion of PET) and climatic characteristics on monthly basis (rainfall depth and temperature) for the time series climate records (1990-2015) of Villa Cambiaso (Genoa, IT). The mean and the corresponding standard deviation values are reported for the climatic characteristics, the white dots refer to the ET rate, the grey dots to the temperature and the black ones to the rainfall depth data.

\section{CONCLUSIONS}

The hydrologic performance of the retrofitted urban drainage system equipped with green roof and permeable pavements has been assessed based on modelling results of the 26year continuous simulation.

Findings of the present study point out that the LID retrofitting can significantly contribute to improve the storm water runoff management in densely urbanised catchment. As expected, the hydrologic performance of the urban catchment with retrofitted green roofs even limited when compared to the performance of the single installation, significantly increase when the ADWP is longer than 5 days. Furthermore retrofitted green roofs still impact on the hydrologic response even for rainfall events with total depth greater than $32 \mathrm{~mm}$.

Although the impact of green roofs on runoff quality is still an open debate (Gnecco et al., 2013), the retention capacity of green roofs contributes to limit the runoff volume discharge into the receiving water body thus the pollutant mass delivery associated to storm water 


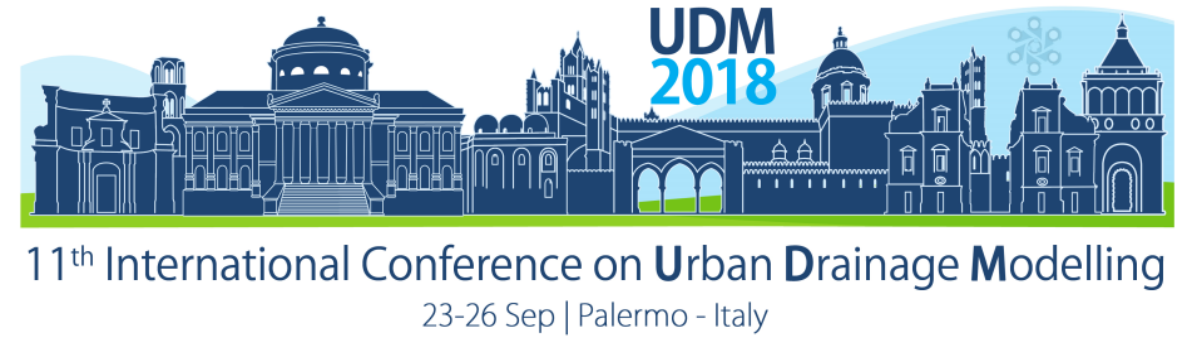

runoff. In light of such considerations, it is reasonable to assume that the widespread of LID systems at the urban catchment scale positively impact on the quali-quantity aspects of urban water management.

\section{References}

Brown, R.A. and Borst, M. (2015) Evaluation of surface and subsurface processes in permeable pavement infiltration trenches. J. Hydrol. Eng. 20(2), 04014041.

Burszta-Adamiak, E. A. and Mrowiec, M.(2013) Modelling of green roofs' hydrologic performance using EPA's SWMM. Wat. Sci. Tech. 68(1), 36-42.

Cipolla S.S., Maglionico, M. and Stojkov, I. (2016) A long-term hydrological modelling of an extensive green roof by means of SWMM, J. Ecol. Eng. 95, 876-887.

Gnecco, I., Palla, A., Lanza L.G. and La Barbera P. (2013) The Role of Green Roofs as a Source/sink of Pollutants in Storm Water Outflows. Wat. Res. Manag., 27(14) , 4715-4730.

Palla A. and Gnecco I. (2015) Hydrologic modeling of Low Impact Development systems at the urban catchment scale. J. Hydrol. 528, 361-368.

Palla, A., Gnecco, I., Carbone, M., Garofalo, G., Lanza, L.G. and Piro, P. (2015) Influence of stratigraphy and slope on the drainage capacity of permeable pavements: laboratory results. Urban Wat. J. 2(5), 394-403.

Peng, Z. and Stovin, V. (2017) Independent Validation of the SWMM Green Roof Module, J. Hydrol. Eng. 22(9), 04017037.

Poë, S., Stovin, V. and Berretta, C. (2015) Parameters influencing the regeneration of a green roof's retention capacity via evapotranspiration. J. Hydrol. 523, 356-367.

Shuster, W.D., Bonta, J., Thurston, H., Warnemuende, E. and Smith, D.R. (2005) Impacts of impervious surface on watershed hydrology: a review. Urban Wat. J. 2(4), 263-275.

Stovin, V., Poë, S., and Berretta, C. (2013) A modelling study of long term green roof retention performance, J. Env. Manag. 131, 206-215. 
Proceedings of the 11th Int. Conference on Urban Drainage Modelling, 23-26 Sep. 2018, Palermo (ITALY). Ed. prof. Giorgio Mannina

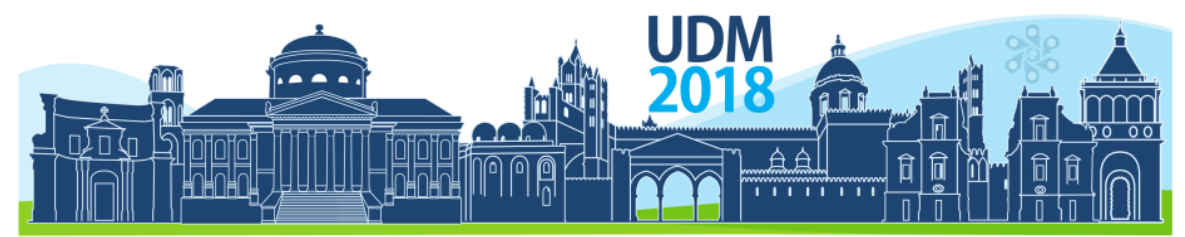

$11^{\text {th }}$ International Conference on Urban Drainage Modelling 23-26 Sep | Palermo - Italy

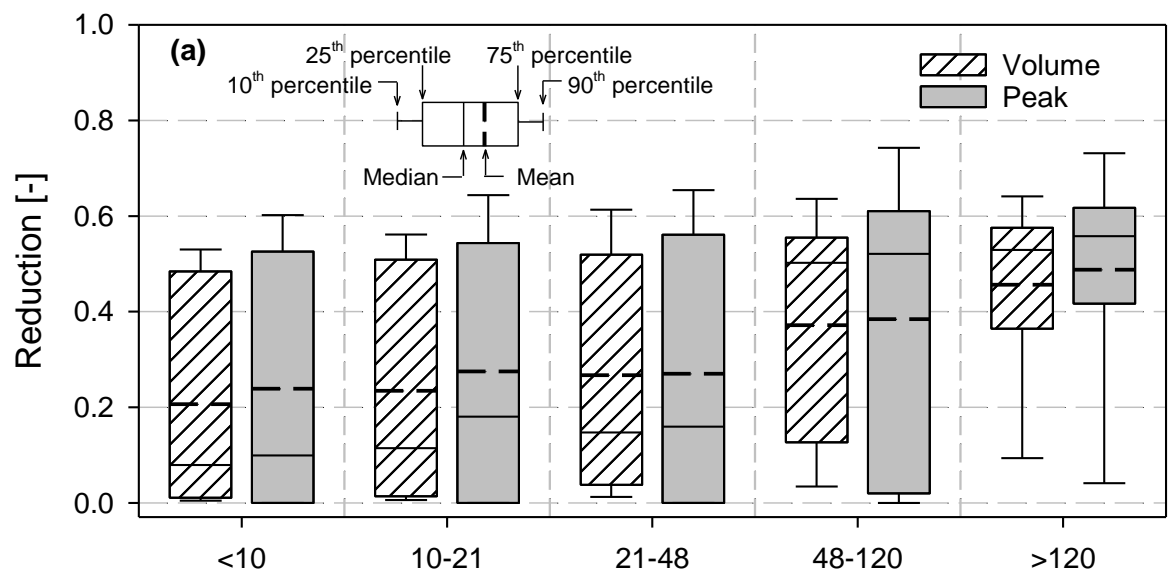

Antecedent Dry Weather Period [h]
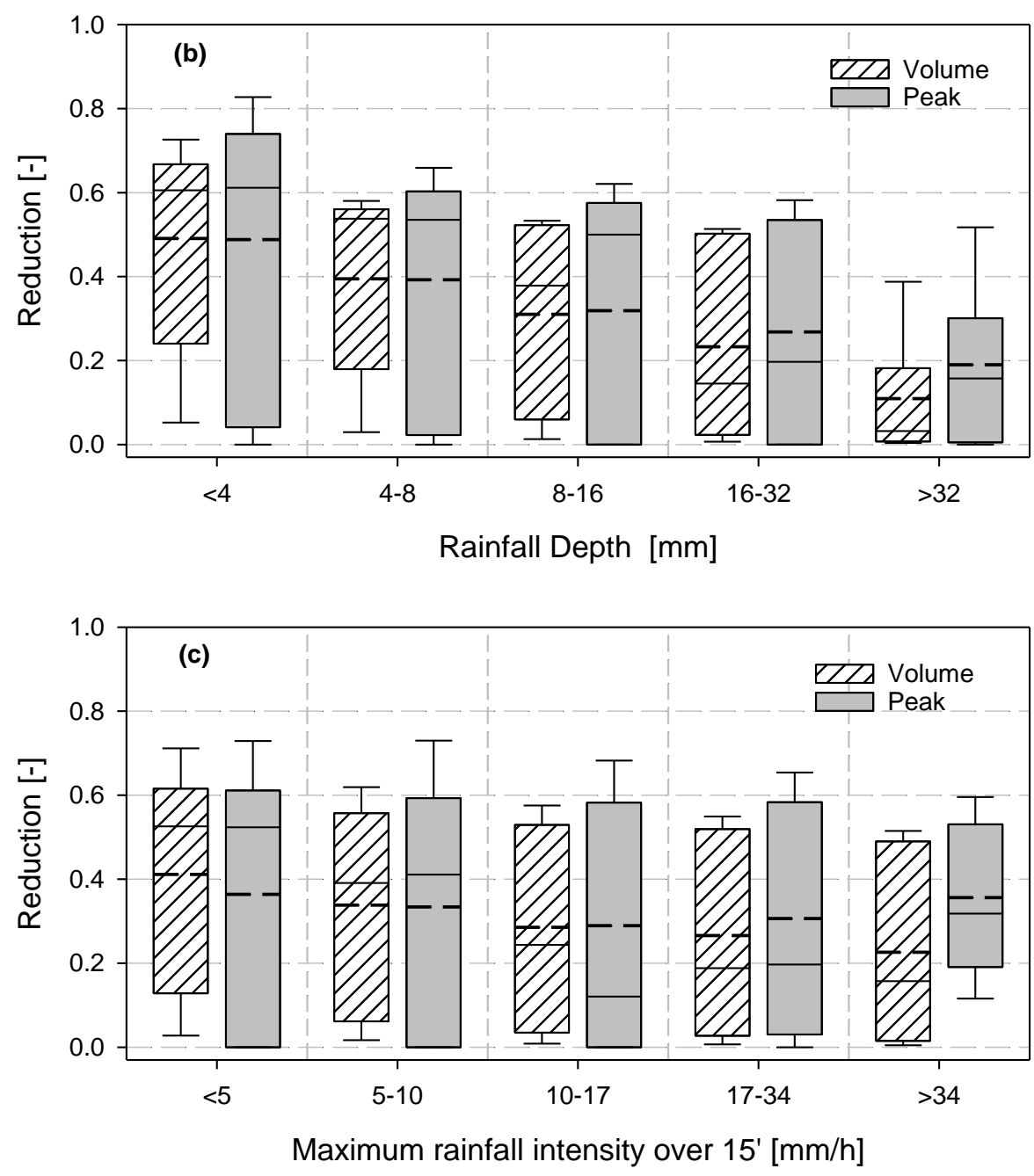

Figure 2. Non-parametric distribution of the volume (hatched box) and peak (grey box) reduction rates for each class of the rainfall characteristics. 


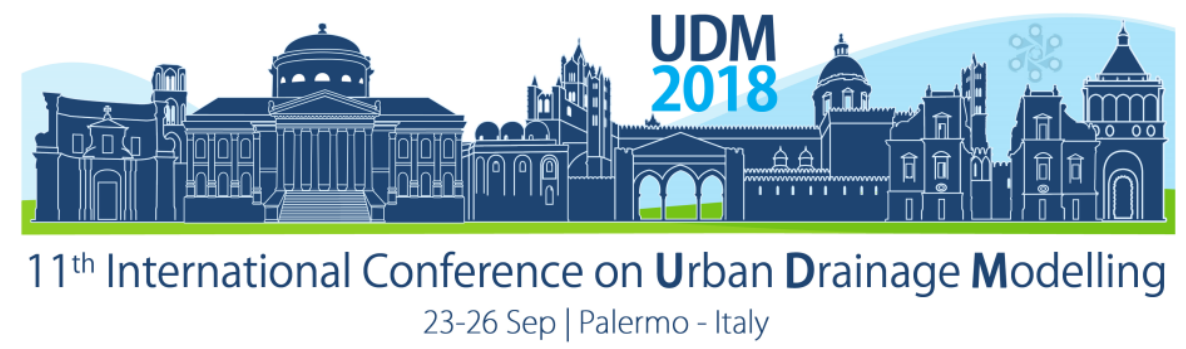

\title{
Model Testing and Laboratory Validation of Real-Time Control Strategy for Stormwater Biofilters \\ Pengfei Shen ${ }^{1}$, Ana Deletic ${ }^{1,2}$ and David McCarthy ${ }^{1}$ \\ ${ }^{1}$ Environmental and Public Health Microbiology Laboratory (EPHM Lab), Department of Civil Engineering, Monash University, Melbourne, VIC 3800, Australia \\ ${ }^{2}$ School of Civil and Environmental Engineering, University of New South Wales, Sydney, NSW 2052, Australia
}

\begin{abstract}
A real-time control (RTC) strategy was developed for stormwater biofilters aiming to harvest and reuse stormwater without any further treatment. The general rule of this RTC is: only utilising the submerged zone water with sufficient retention time. The strategy was tested with a previously developed and calibrated model, and validated with new laboratory experiments. Our study showed that the biofilters operated with RTC strategies reduced $E$. coli concentrations by more than 1.74 orders of magnitude ( $98 \%$ removal rate), while those operated without RTC strategies could only reduce them by 0.56 orders of magnitude $(72 \%$ removal rate). The treated water from biofilters with RTC always met the requirement of secondary contact for recreational use. Considering the high uncertainties in the measurement of $E$. coli, the model was still able to satisfactorily reflect the laboratory data (Nash-Sutcliffe Efficiency $E=0.37$ ) and the best-fit parameter values reflected those reported in past literature. However, lower performance was found when predicting the results from biofilters with RTC compared to those without RTC, likely because the preferential flow paths that observed in laboratory data were not captured by the model.
\end{abstract}

Keywords: Real-time control; Stormwater; Biofilters; Modelling; Validation

\section{INTRODUCTION}

To remove microbial pollutants in stormwater runoff, biofilters have been widely applied for stormwater harvesting and reuse. Stormwater biofilters are soil-plant based systems with the enhancement of infiltration and evapotranspiration. The major processes for microbial removal in biofilters include adsorption, desorption and die-off (Stevik et al., 2004). The removal of microbes can be optimised by either careful design or careful operation. While much effort has been placed in optimising the design of biofilters for better microbial sequestration (Chandrasena et al., 2014b), very little has been done to control the operational conditions experienced by biofilters, even though they are recognised as governing microbial removal (Chandrasena et al., 2014a).

To help develop RTC strategies to better control biofilter operational conditions, for the purpose of harvesting and reusing the water treated by biofilters, Shen et al. (2018) developed a biofilter microbe model, while Shen et al. (2017) used this model to optimise various RTC scenarios. Unfortunately, the RTC strategies proposed by Shen et al. (2017) has not yet been validated with real lab or field datasets, undermining whether the RTC strategies are in fact able to produce better quality water as compared to non-RTC systems, and whether the model can adequately represent the conditions imposed on the biofilter by the RTC strategy. Therefore, the aim of this paper is to evaluate the performance of biofilters with and without RTC through laboratory experiments and modelling. The main objectives of this study are to demonstrate the benefits of implementing RTC, and to validate the model performance in RTC prediction. 


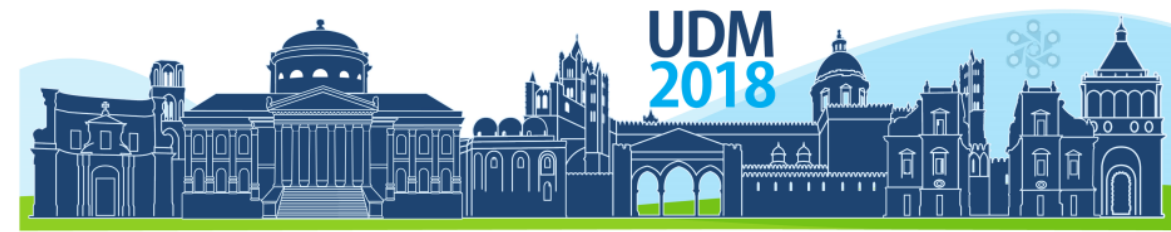

$11^{\text {th }}$ International Conference on Urban Drainage Modelling

23-26 Sep | Palermo - Italy

\section{MATERIALS AND METHODS}

\subsection{Real-time control strategy for stormwater harvesting and reuse}

A typical biofilter consists of three parts: (1) the ponding zone (PZ) - a temporary pond on the top, (2) the unsaturated zone (USZ), and (3) the submerged zone (SZ) that created by a raised outflow pipe (Figure 1). For microbial removal, die-off process governs the survival of microbes that trapped in filter media and in the water retained in SZ during dry days.

Figure 1. A typical stormwater biofilter with submerged zone.

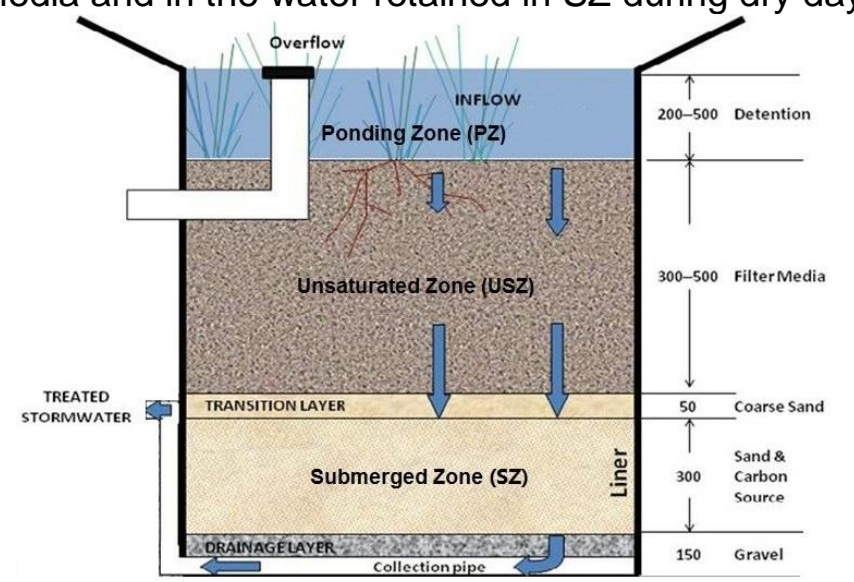

(1) If $T_{s z}<T_{\min }$ : keep inlet valve closed

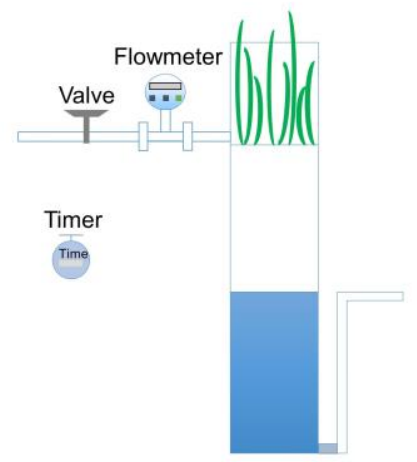

(2) If $T_{s z} \geq T_{\min }$ : open inlet valve; record $V_{\text {in }}$

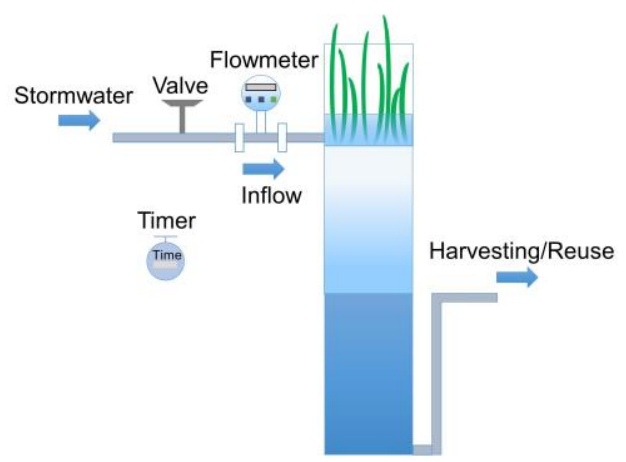

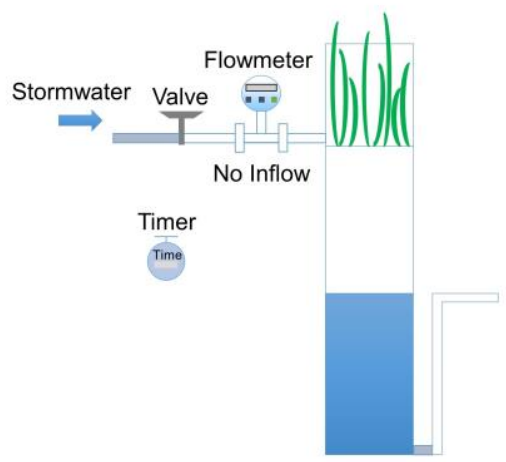

(3) If $V_{\text {in }}=V_{s z}$ : close inlet valve; $T_{s z}$ reset to 0

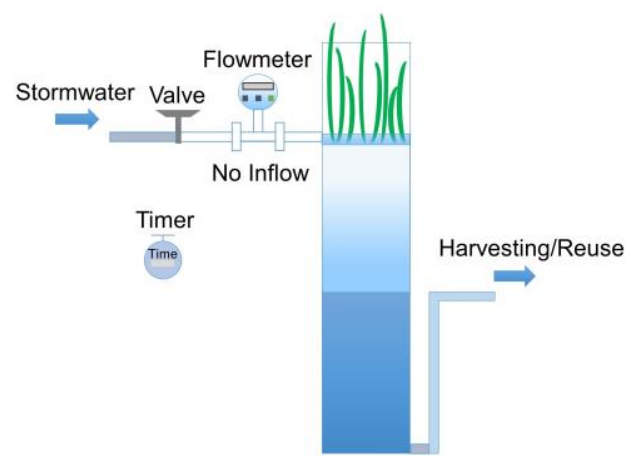

Figure 2. Schematic of the processes for RTC implementation 


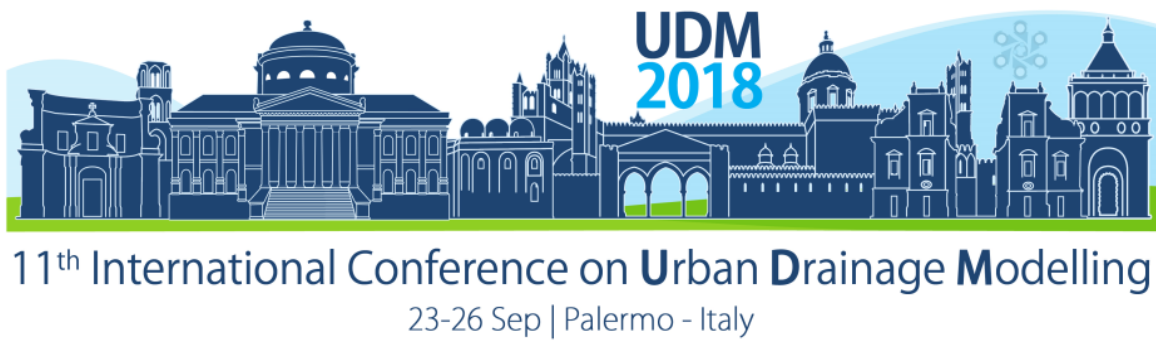

The real-time control (RTC) strategy developed by Shen et al. (2017) was simplified and adopted. The general rule is, only utilising the submerged zone (SZ) water with sufficient retention time to experience die-off. To implement this strategy, , typical facilities include a timer to record the retention time of SZ water, a flowmeter to detect the inflow volume during each event, and a valve in the inflow pipe to control the amount of stormwater that enters into biofilters (Figure 2).

The main processes of RTC implementation are (Figure 2): (1) set a minimum retention time of SZ water $\left(T_{\min }\right)$; when new stormwater runoff comes, record the current retention time of $\mathrm{SZ}$ water ( $T_{s z}$ ) ; if $T_{s z}<T_{\min }$, bypass the stormwater and do not allow any inflow; (2) if $T_{s z} \geq T_{\min }$, let water in and start to record the inflow volume $\left(V_{i n}\right)$; (3) when $V_{\text {in }}$ reaches to SZ volume $V_{s z}$, bypass the remaining stormwater runoff - in this way, only the "old" SZ water that has a longer retention time than $T_{\min }$ is pushed out through the outflow pipe, and the SZ is filled by the newly entered stormwater.

\subsection{Laboratory experiments setup}

To validate the RTC strategy, ten biofilter columns with the same design were set up in a greenhouse at Monash University, Australia. The columns were divided into two groups, RTC biofilters (i.e. controlled with RTC) and non-RTC biofilters (i.e. operated as normal biofilters without control), with five replicates each. Each column was planted with Carex appressa, and the filter media was washed sand. The diameter of each column is $240 \mathrm{~mm}$; the depths of USZ and SZ were $400 \mathrm{~mm}$ and $440 \mathrm{~mm}$ respectively. The SZ volume is $10 \mathrm{~L}$.

Eleven sampling events were conducted to compare the performance of RTC biofilters with non-RTC biofilters. These events all simulated the historical events with various rainfall sizes and antecedent dry periods, including: four big events that represented 1 in 3 month average recurrence interval $(A R I)$ rainfall events $(17.68 \mathrm{~mm})$; four median events that stood for 1 in 1 month ARI events $(8.84 \mathrm{~mm})$; and three small events in which the inflow volumes were equal to $S Z$ volume $(4.42 \mathrm{~mm})$. The length of dry days ranged from 1 day to 21 days. Especially, for RTC biofilters, the minimum retention time $T_{\min }$ was set as two days. During the experiments, RTC strategy was manually implemented on RTC biofilters: in each sampling event, dosing was stopped when the inflow volume $\left(V_{i n}\right)$ reached the $S Z$ volume $\left(V_{s z}\right)$; when the next sampling event came within 2 days, no water was dosed into RTC biofilters. Escherichia coli (E. coli) was selected as an indicator to represent microbial behaviour in all biofilters. The inflow of each event was spiked with $E$. coli, with a concentration that ranged from 134 to 3.11 $\times 10^{5} \mathrm{MPN} / 100 \mathrm{~mL}$. Composite inflow and outflow samples were collected in all events. E. coli concentrations were analysed for all samples using the Colilert method ${ }^{\mathrm{TM}}$ (IDEXXLaboratories, 2007).

\subsection{Model testing methods}

The model developed by Shen et al. (2018) was employed to test the RTC strategy. Onedimensional advection-dispersion equations were used to simulate microbial transport and fate. The model includes four parameters: adsorption rate $\left(k_{\text {att }}\right)$, desorption rate $\left(k_{\text {det }}\right)$, the standard die-off rate $\left(\mu_{0}\right)$ and the temperature coefficient for die-off $(\theta)$. The parameters have been calibrated with previous experiments conducted on the same columns that described in Section 2.2; the calibrated parameter sets were utilised in this study for model prediction. 


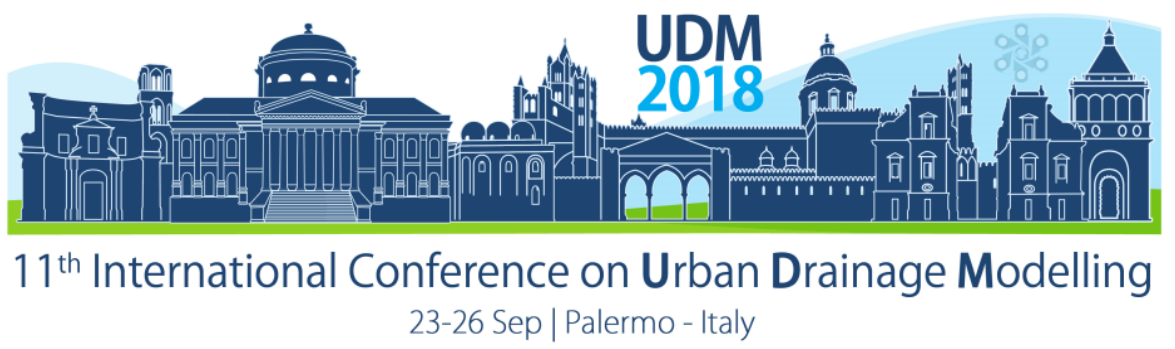

The model inputs simulated the dosing regime and inflow concentrations in the laboratory. The modelled outflow concentrations were compared with the observation from the laboratory study; the Nash-Sutcliffe Efficiency, $E$, was used to evaluate the model performance. Uncertainty analysis was conducted by generating $90 \%$ probability bands of prediction $\left(5^{\text {th }}-\right.$ $95^{\text {th }}$ percentile) and comparing it with observed data points.

\section{RESULTS AND DISCUSSION}

\subsection{Laboratory experimental results}

After implementing RTC, the microbial removal efficiency was dramatically improved with a more stable performance (much lower standard deviation) (Errore. L'origine riferimento non è stata trovata.). In addition, the treated water from RTC biofilters could meet the requirement of secondary contact for recreational water use in Victoria, Australia (median concentration $\leq 1000$ E. coli/100 mL) (VGG, 2003); while for non-RTC biofilters, this requirement was not fulfilled, demonstrating the benefits of RTC for stormwater reuse. On the other hand, for RTC biofilters, only $40 \%$ total volume of inflow was treated and the rest was bypassed, while nonRTC biofilters treated all the inflow.

Table 1. Comparion of microbial removal performances between RTC biofilters and non-RTC biofilters.

\begin{tabular}{lcc}
\hline & RTC biofilters & non-RTC biofilters \\
\cline { 2 - 3 } Mean log removal of concentration (standard deviation) & $1.74(0.49)$ & $0.56(1.12)$ \\
Mean removal rate of concentration & $98 \%$ & $72 \%$ \\
Median outflow concentration (MPN/100 mL) & 740 & 6867 \\
Meet the secondary contact requirement? & Yes & No \\
\hline
\end{tabular}

\subsection{Model testing results}

A satisfying $E$ value (0.37) was achieved, indicating model prediction fitted laboratory observation, especially when comparing with the results from other similar studies (e.g. McCarthy et al. (2011) reported a $E$ value of 0.25 to 0.41 in the modelling of microbial concentration in stormwater). The parameter values in the best-fit parameter set $\left(k_{\text {att: }}: 0.89 \mathrm{~h}^{-1}\right.$; $k_{\text {det: }} 0.0476 \mathrm{~h}^{-1} ; \theta: 1.011 ; \mu_{0}: 0.59$ day $^{-1}$ ) all fell into the ranges that reported in literature (Shen et al., 2018). The predicted mean log reduction for RTC and non-RTC biofilters were 2.26 and 0.92 respectively, which were higher than the observation. The reason is, in the laboratory experiments, preferential flow occurred due to soil cracking during dry days and/or macropores caused by plant roots. Therefore, SZ water was contaminated by newly entered water in the collected samples. However, this difficult-to-model, and often random phenomenon was not captured in the model. As such, the model overestimated the removal efficiency of both types of biofilters.

According to the uncertainty analysis (Figure 3), for the prediction with the best-fit parameter set, $25.8 \%$ of the prediction was within the $90 \%$ uncertainty bands. The prediction uncertainty is higher for RTC biofilters than non-RTC biofilters: $12.5 \%$ observed data points from RTC biofilters and $30.4 \%$ from non-RTC biofilters were within the uncertainty band. It is mainly due to the impact of preferential flow as stated above: since preferential flow influences $S Z$ water, and all samples collected in RTC biofilters were "old" SZ water, higher error was more likely to occur in the prediction for RTC biofilters. Especially, a noticeable difference was found between the prediction and observation for RTC biofilters in Event 6 (the $6^{\text {th }}$ Event), as in this event, a long antecedent dry periods (8 days, which reduces SZ water volumes) and a high inflow 


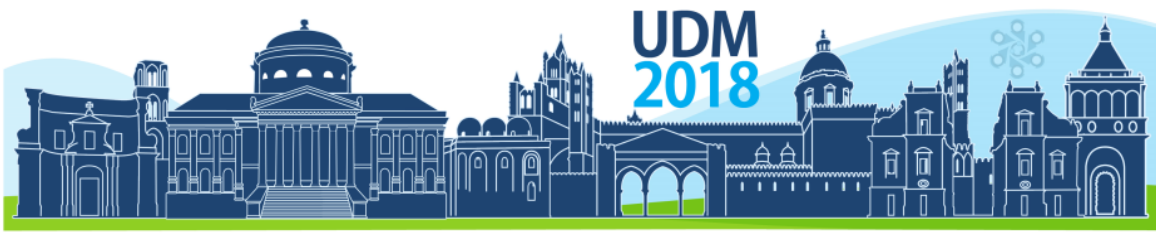

$11^{\text {th }}$ International Conference on Urban Drainage Modelling

23-26 Sep | Palermo - Italy

concentration (E. coli: $2.28 \times 10^{5} \mathrm{MPN} / 100 \mathrm{~mL}$ ) resulted in high preferential flow with strong impact to the concentrations of collected SZ water.

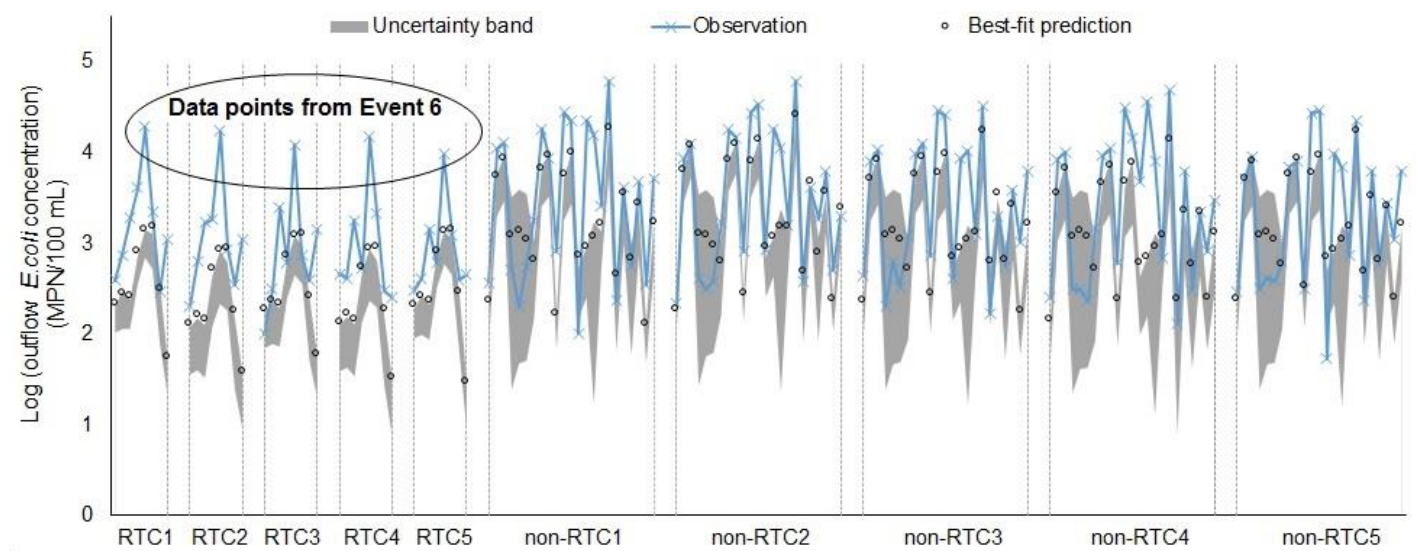

Figure 3. Model prediction of event-averaged outflow concentrations including best-fit prediction, $90^{\text {th }}$ percentile uncertainty bands and observed concentrations. The labels in x-axis stand for the data from different columns, e.g. "RTC1" means the the first column of RTC biofilters, "non-RTC5" means the fifth column of non-RTC biofilters.

\section{CONCLUSIONS}

The developed RTC strategy to only harvest/reuse the submerged zone (SZ) water with sufficient retention time is effective, as demonstrated through our laboratory experiments. Log reductions of microbial concentration in the outflow has been remarkably improved after implementing this RTC strategy, and the treated stormwater from RTC biofilters could meet the requirement of secondary contact for recreational water use. The observed results from laboratory studies were represented in modelling, and the model's performance is comparable to other microbial models. However, prediction uncertainty is higher for RTC biofilters compared to non-RTC biofilters, which is mainly due to the preferential flow that occurred in the experiments that was not captured by the model.

\section{References}

Chandrasena G. I., Deletic A., McCarthy D. T. Survival of Escherichia coli in stormwater biofilters. Environmental Science and Pollution Research 2014a; 21: 391-401.

Chandrasena G. I., Pham T., Payne E. G., Deletic A., McCarthy D. T. E. coli removal in laboratory scale stormwater biofilters: Influence of vegetation and submerged zone. Journal of Hydrology 2014b; 519: 814-822.

IDEXX-Laboratories. Colilert® Test Kit, edited, IDEXX-Laboratories, Maine, USA, 2007.

McCarthy D. T., Deletic A., Mitchell V. G., Diaper C. Development and testing of a model for Micro-Organism Prediction in Urban Stormwater (MOPUS). Journal of Hydrology 2011; 409: 236-247.

Shen P., Deletic A., Urich C., Chandrasena G. I., McCarthy D. T. Stormwater Biofilter Treatment Model for Faecal Microorganisms. Science of the Total Environment 2018.

Shen P., Deletic A., Urich C., McCarthy D. Real time control of biofilters for stormwater harvesting. 14th IWA/IAHR International Conference on Urban Drainage, Prague, Czech Republic, 2017.

Stevik T. K., Aa K., Ausland G., Hanssen J. F. Retention and removal of pathogenic bacteria in wastewater percolating through porous media: a review. Water Research 2004; 38: 1355-1367.

VGG. Victoria Government Gazette S107 - Variation to State Environment Protection Policies, (Waters of Victoria). Craftsman Press Pty. Ltd., Victoria, Australia, 2003. 


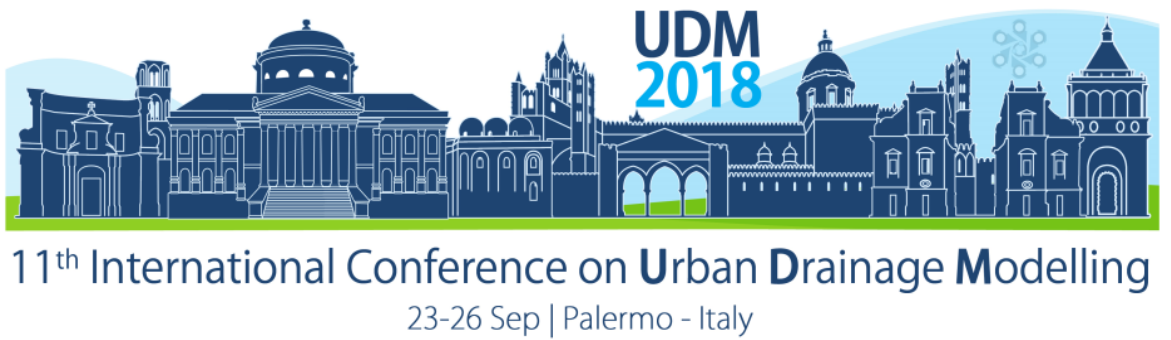

\title{
Understanding the impacts of stormwater control measures at the streetscape scale
}

\author{
Matthew J Burns ${ }^{1}$, Tim D Fletcher ${ }^{1}$, Peter J Poelsma ${ }^{1}$, Robert B James ${ }^{1}$, Joshphar Kunapo', and Timothy \\ J Craig ${ }^{1}$ \\ ${ }^{1}$ The University of Melbourne, School of Ecosystem and Forest Sciences, 500 Yarra Boulevard, RICHMOND VIC \\ 3121, Australia
}

\begin{abstract}
Stormwater control measures (SCMs) are increasingly being used to manage urban stormwater runoff. Many monitoring and modelling studies have shown that SCMs can perform well at small scales. However, few studies have quantified the impacts of SCMs at larger scales. Here we monitored the piped-discharge of two adjacent streetscapes-one with distributed SCMs (impact) and the other without SCMs (control). We also modelled the individual SCMs in the impact streetscape to understand if site scale performance should propagate to larger scales. Monitoring surprisingly showed that total discharge was slightly higher in the impact streetscape than in the control. This was despite the modelling results which indicated that a downstream impact of SCMs could be possible. We think our results are due to the complex nature of how rainfall becomes discharge in urban catchments. One hypothesis is that pervious discharge is being generated in the impact streetscape even for small rainfall events. Our results suggest that SCMs be implemented in ways which target as much urban stormwater runoff as possible.
\end{abstract}

Keywords: Hydrology, rainwater tank, urban,

\section{INTRODUCTION}

Stormwater control measures (SCMs) are increasingly being used to manage urban stormwater runoff (Fletcher et al., 2015). Use of SCMs is central in alternative approaches towards stormwater management which focus on restoring natural flow regimes (Walsh et al., 2016). They can also play a role in flood management (Webber et al., 2018) and reducing the frequency of combined sewer overflows (Dechesne, Barraud, \& Bardin, 2004). A range of SCMs exist and include technologies like: rainwater tanks, vegetated infiltration systems (e.g. rain-gardens), green roofs, pervious pavement, etc.

Many monitoring and modelling studies have shown that SCMs can perform well at small scales. For example, Hamel et al. (2012) found that an allotment scale infiltration-based system rarely overflowed, with most inflow retained and exfiltrated into surrounding soils. In terms of modelling studies, Campisano and Modica (2014) predicted that rainwater tanks could retain most inflows from rainfall events in Sicily, Italy. Despite these encouraging signs, there is little evidence on the performance of SCMs at larger scales-e.g. streetscape and catchment. This is particularly true in relation to monitoring studies (Li, Fletcher, Duncan, \& Burns, 2017).

Our aim for this paper was to understand the hydrologic impact of SCMs (implemented at source) at the streetscape scale (several ha). We monitored the piped-discharge of two adjacent streetscapes which were similar in land-use but different in the degree of SCM implementation. 


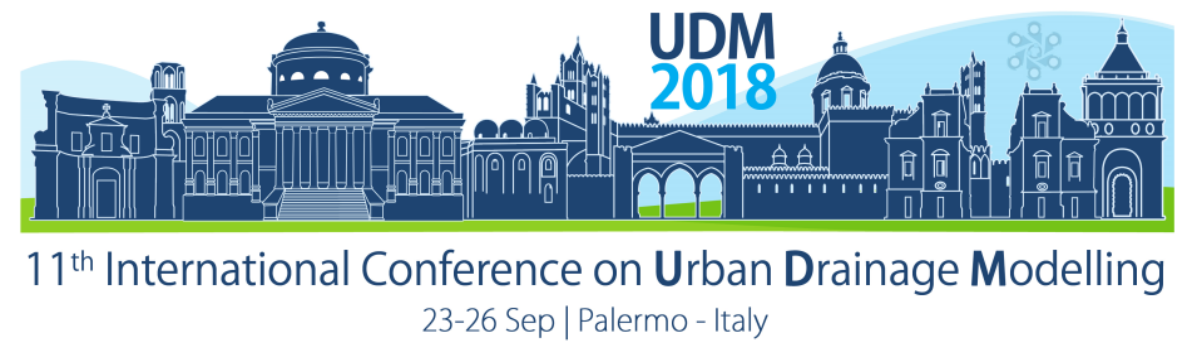

\section{MATERIALS AND METHODS}

Our study streetscapes are located in the eastern suburbs of Melbourne, Australia. The impact streetscape features 11 SCMs in the catchment-9 rainwater tanks and 2 vegetated infiltration systems (hereafter rain-gardens). All the SCMs were implemented at source, with the rainwater tanks draining residential roofs and the rain-gardens draining road areas. The total drainage area of the impact streetscape is 2.6 ha whereas the control is smaller at 2.2 ha. There is less impervious area in the impact streetscape than in the control $\left(6,600 \mathrm{~m}^{2} \mathrm{vs} .8,100\right.$ $\mathrm{m}^{2}$ ). Most impervious area in the streetscapes is drained using conventional stormwater drainage systems, which are separate to sewer pipes. And the streetscapes are very close to each other (within $\sim 250 \mathrm{~m}$ ).

For three years, we monitored the piped-outlets of the streetscapes using acoustic Doppler flow-meters. The probes were calibrated at low-flows using a bucket and stop watch. To calibrate higher flows, we directed water from nearby fire hydrants to the underground pipes. Pipes from the hydrants were instrumented with magnetic flow meters. We concurrently monitored rainfall in the study area using tipping bucket rain gauges.

Using the rainfall and piped-discharge data, we selected $>100$ rainfall events for subsequent analysis. We then calculated a range of event-based flow metrics-total discharge, peak discharge, and time-to-peak-and compared them between the two streetscapes. One of our hypotheses was that total discharge will be lower in the streetscape featuring SCMs.

In addition to the empirical work, we modelled the individual SCMs in the impact streetscape to understand if site scale performance should propagate to larger scales. This was carried out using the commonly used stormwater model MUSIC (a conceptual rainfall-runoff model). SCM behaviour was simulated for the same three monitoring years. We extracted inflows and outflows from the software in order to quantify the retention afforded by the SCMs.

\section{RESULTS AND DISCUSSION}

\subsection{Empirical analysis}

From our event-based analysis, we surprisingly found that total discharge (averaged across the rainfall events) was slightly higher in the impact streetscape than in the control-around $43 \mathrm{~m}^{3} /$ event versus $38 \mathrm{~m}^{3} /$ event. What makes this result even more surprising is that there is less impervious area in the impact streetscape than in the control. Median values of total discharge were almost the same between streetscapes-around $20 \mathrm{~m}^{3} /$ event (Figure 1). 


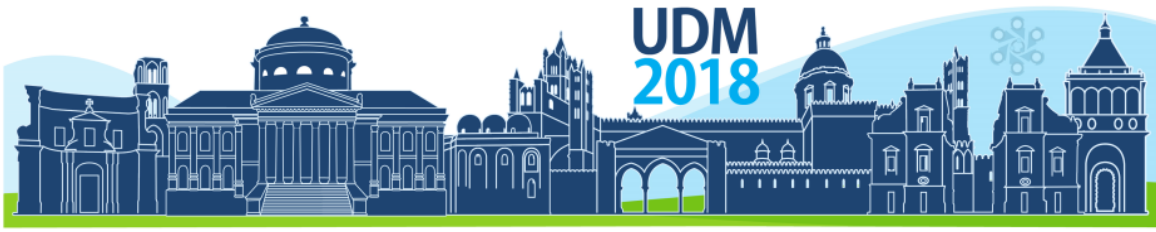

$11^{\text {th }}$ International Conference on Urban Drainage Modelling

23-26 Sep | Palermo - Italy

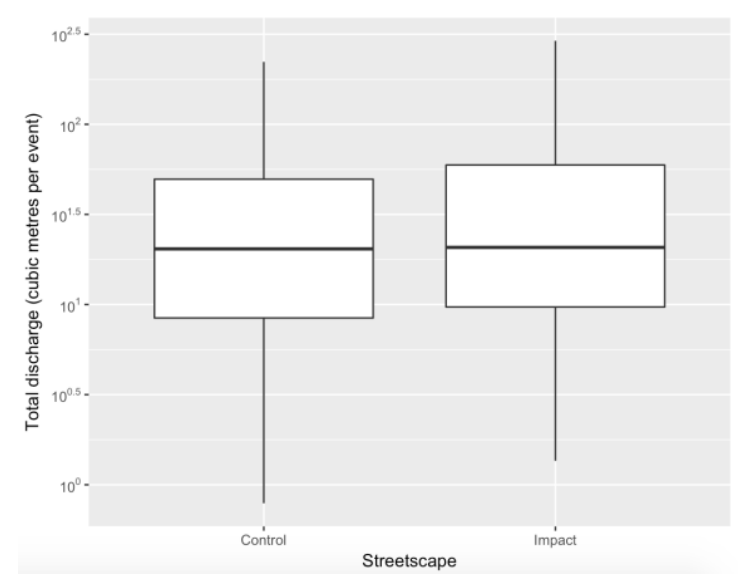

Figure 1. Box and whisker plot of total discharge for the study streetscapes based on the selected rainfall events.

We found that peak discharge was higher in the control streetscape than in the impactmedian values of $\sim 12 \mathrm{l} / \mathrm{s}$ versus $\sim 5 \mathrm{l} / \mathrm{s}$. Also, the discharge in both streetscapes reached maximum value in a similar time-median time-to-peak of 90 minutes.

\subsection{Modelling of the SCMs}

The modelling work suggested that the SCMs in the impact streetscape could retain most inflows (e.g. Figure 2). This finding suggests that the retention afforded by SCMs in the impact streetscape should propagate to impacts downstream (which were actually not detected). It is possible that the modelled performance of the SCMs was not representative of actual behaviour. For example, actual water demand for some of the rainwater tanks could have been lower than modelled inputs. A consequence of this would be lower retention capacity of tanks in the field vs. the modelled ones.

\section{Rainwater tank in the impact streetscape}

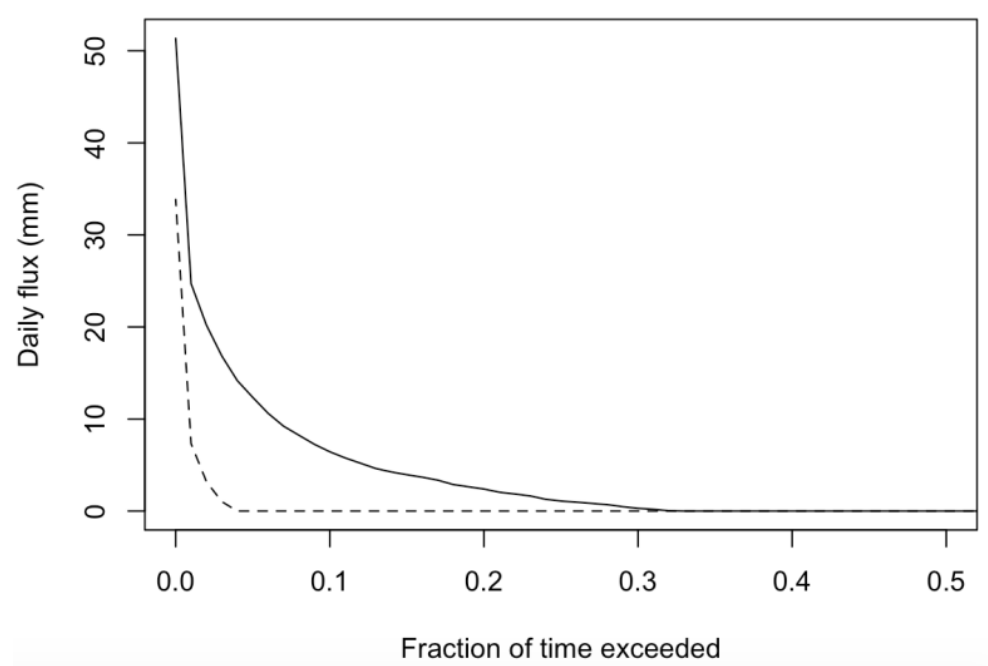

Figure 2. Flow duration curve for inflows (solid line) and outflows (dashed line) for a representative rainwater tank in the impact streetscape. 


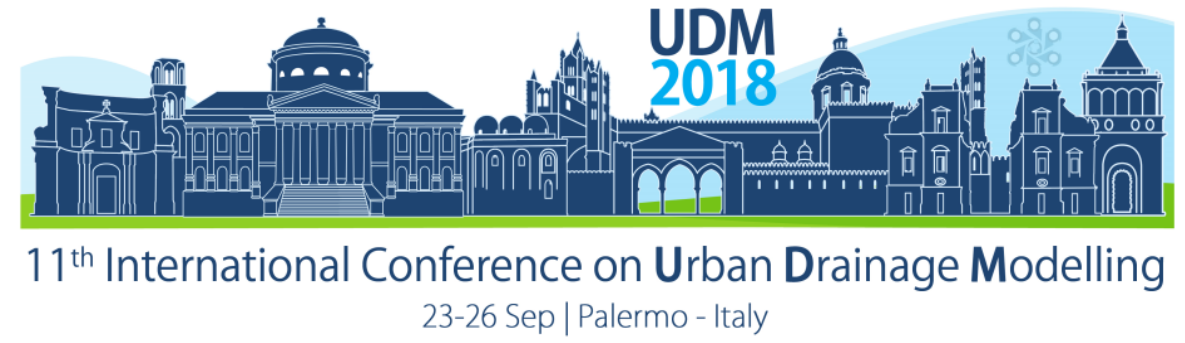

\subsection{Discussion}

We could not detect a clear impact of SCMs at the streetscape scale. This was despite some modelling work which indicated that a downstream impact of the SCMs could be possible. Our findings could be related to the complex nature of how rainfall becomes piped-discharge in urban catchments. It could be that pervious discharge is being generated in the impact streetscape even for small rainfall events. Another explanation could relate to losses and gains within stormwater pipes.

In terms of management implications, our work suggests that SCMs be implemented in ways which target as much urban stormwater runoff as possible. While high levels of SCM implementation might seem ambitious, it will almost certainly be easier for new urban developments.

\section{CONCLUSIONS}

We studied the hydrology of two adjacent streetscapes-one with distributed SCMs (impact) and the other without SCMs (control). Surprisingly, total discharge across a range of rainfall events was slightly higher in the impact streetscape compared to the control. The work highlights the potentially complex pathways rainfall can take in urban catchments. Future work in this area should investigate the sources of piped-discharge, along with flow pathways (both surface and sub-surface).

\section{References}

Campisano, A., \& Modica, C. (2014). Selecting time scale resolution to evaluate water saving and retention potential of rainwater harvesting tanks. Procedia Engineering, 70, 218-227. doi:10.1016/j.proeng.2014.02.025

Dechesne, M., Barraud, S., \& Bardin, J.-P. (2004). Indicators for hydraulic and pollution retention assessment of stormwater infiltration basins. Journal of Environmental Management, 71(4), 371-380. doi:https://doi.org/10.1016/i.jenvman.2004.04.005

Fletcher, T. D., Shuster, W., Hunt, W. F., Ashley, R., Butler, D., Arthur, S., . . Viklander, M. (2015). SUDS, LID, BMPs, WSUD and more - The evolution and application of terminology surrounding urban drainage. Urban Water Journal, 12(7), 525-542. doi:10.1080/1573062X.2014.916314

Hamel, P., Fletcher, T. D., Daly, E., \& Beringer, J. (2012). Water retention by raingardens: implications for localscale soil moisture and water fluxes. Paper presented at the 7th International Conference on Water Sensitive Urban Design, Melbourne, Australia. Available online: http://search.informit.com.au/documentSummary; $\mathrm{dn}=827442596402236$;res=IELENG.

Li, C., Fletcher, T. D., Duncan, H. P., \& Burns, M. J. (2017). Can stormwater control measures restore altered urban flow regimes at the catchment scale? Journal of Hydrology, 549, 631-653. doi:https://doi.org/10.1016/i.jhydrol.2017.03.037

Walsh, C. J., Booth, D. B., Burns, M. J., Fletcher, T. D., Hale, R. L., Hoang, L. N., . . Wallace, A. (2016). Principles for urban stormwater management to protect stream ecosystems. Freshwater Science, 35(1), 398-411. doi:10.1086/685284

Webber, J. L., Gibson, M. J., Chen, A. S., Savic, D., Fu, G., \& Butler, D. (2018). Rapid assessment of surface-water flood-management options in urban catchments. Urban Water Journal, 15(3), 210-217. doi:10.1080/1573062X.2018.1424212 


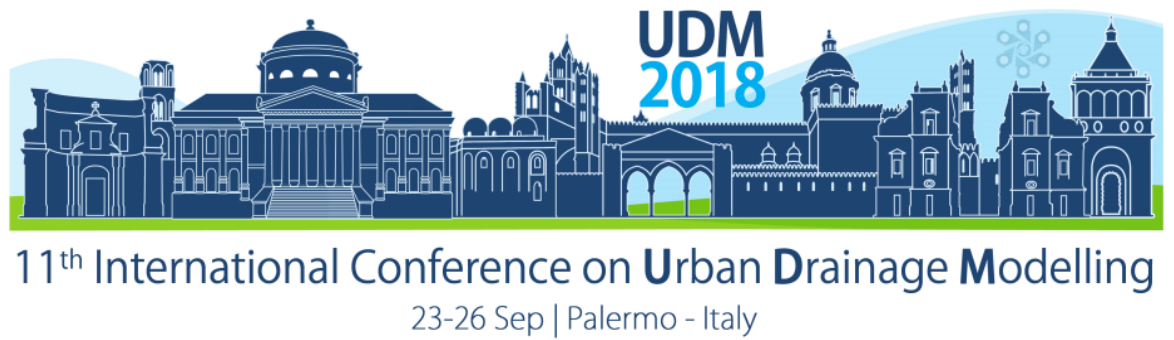

\title{
A Method to Identify Key Sub-catchments for LID Placement based on Monte Carlo Sampling
}

\author{
Hao Guo', Siyu Zeng ${ }^{1}$ and Xin Dong ${ }^{1}$ \\ ${ }^{1}$ School of Environment, Tsinghua University, Beijing, China, 100084
}

\begin{abstract}
Low impact development (LID) can treat excess urban runoff and improve the performance of urban drainage system. LID located in different sub-catchments has quite different effect. However, using optimization algorithm to find the key sub-catchments will cost much computing resources and time. This research proposed a method to rapidly identify key sub-catchments for LID placement by a new index called Rank Score. A case study area in Kunming, China is adopted to test the validity of the method. The application of Rank Score is found to be effective and key sub-catchments are recognized to generate optimized solutions. It is discovered that compared to the average of Monte Carlo samples, optimized performance indices are $41.7 \%, 26.8 \%$ and $42.4 \%$ less in terms of the amount of flooding, CSO and shock to WWTP respectively. The numeric features and spatial characteristics of Rank Score distribution are discussed as well.
\end{abstract}

Keywords: Low impact development; Urban drainage system; Monte Carlo sampling

\section{INTRODUCTION}

Low impact development (LID) measures have been widely studied and used to solve the problems in urban drainage systems (UDSs), such as urban flooding, combined sewer overflow (CSO) and shock to waste water treatment plant (WWTP) (Dong et al., 2017). LID and urban drainage network function together to treat excess urban runoff, indicating the existence of synergy effects between them. In cities, where urban drainage networks exist already, implementation of LID measures in different sub-catchments can lead to distinct performance of UDSs. In order to acquire better performance of UDSs with limited budgets for LID construction, it is important and useful to recognize key sub-catchments which will form the basis of better LID solutions.

A direct way to realize the above-mentioned goal is to apply optimization algorithm to model simulations to search for the target sub-catchments (Damodaram and Zechman, 2012). However, optimization algorithm, such as the commonly used genetic algorithm, takes much computing resources and time, and faces the risk of failing to get the optimal solutions, especially for large-scale and complex UDSs. For example, the case area in this research has 162 sub-catchments, indicating that the population size of genetic algorithm needs to be at least 150-200. By test, it costs about 500-1000 generations to reach the algorithm convergence, therefore 75,000-200,000 simulations are required in all. 1 simulation costs 10 20 minutes by non-parallel computation, and the whole algorithm will cost 130-694 days by a computar with 4 core CPU.

To shorten the computing time to a reasonable level, this research proposed a rapid method to identify key sub-catchments for LID placement based on Monte Carlo sampling. A new index, Rank Socre, is defined to reflect the superiority of a certain sub-catchment in terms of 


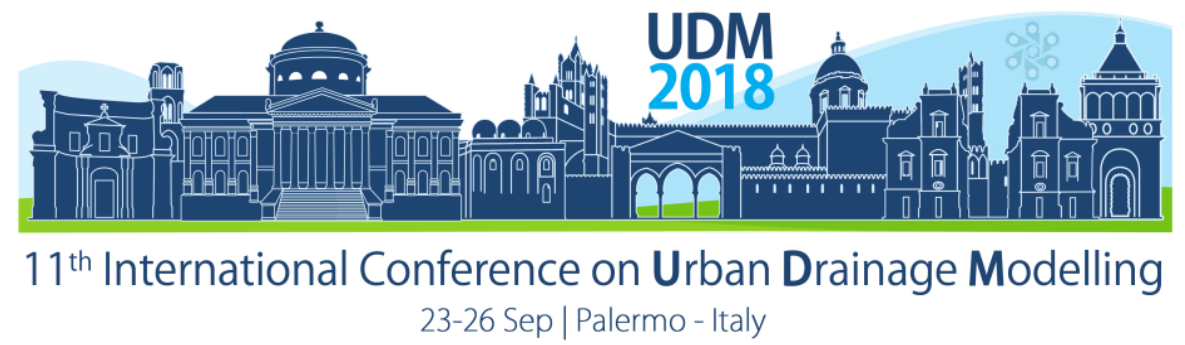

certain performance indices. With the new index, only 1000 simulations are needed to find better LID solutions, costing about $1 \%$ computing time compared to genetic algorithm.

\section{MATERIALS AND METHODS}

\subsection{Definition of Rank Score}

Assume that there are $m$ sub-catchments in the target area and the percentage of each subcatchment available for LID placement is [I_limit, $u \_$limit] (I limit, $u$ limit $\in[0,1]$ \& I_limit < $u_{-}$limit). Determine the total area for LID construction $S_{T}$ and select $k$ performance indices of UDSs. Then operate Monte Carlo sampling for $n$ times subject to the following constraint:

$S_{i}-$ Area of sub-catchment $i$

$$
\sum_{i=1}^{m} S_{i} \cdot p_{i}=S_{T}
$$

$p_{i}$ Percentage of LID area in sub-catchment $i$ to $S_{i}\left(p_{i} \in[\right.$ [llimit, u_limit $\left.]\right)$.

Run simulations based on the $n$ samples and get $k$ performance indices for each sample. For a certain performance index $l_{j}$, sort the samples based on the value of $l_{j}$. Divide the $n$ sorted samples into 5 categories: Category 1 , which includes samples with values of $l_{j}$ taking up the top 0-20\% positions; Category 2, 20\%-40\%; Category 3, 40\%-60\%; Category 4, 60\%-80\%; Category $5,80 \%-100 \%$. Then the new index, Rank Score, is defined as below:

$$
\text { Rank Score }{ }_{i, j}=\sum_{s=1: 5} \frac{\left(\sum_{t \in \text { Category } s} p_{t}\right) \cdot s}{\sum_{t=1: n} p_{t}}
$$

Rank Score , $_{i, j}$ Rank Score of sub-catchment $i$ in terms of performance index $l_{j}$ (Rank Score $\in[1,5])$;

$\mathrm{s}$ - Order of categories.

If LID in a certain sub-catchment $i$ can lead to better system performance, then $p_{i}$ tends to appear more frequently in the top categories when the sampling times $n$ is large enough. Then sub-catchment $i$ is supposed to get a lower Rank Score value in terms of performance index $l_{j}$. Therefore, a lower Rank Score value indicates that LID in this sub-catchment has a high probability to result in better performance in terms of $l_{j}$.

\subsection{Introduction of case study area}

The case study area is a newly developing urban area in the north of Kunming, a city in the southwest of China. It occupies an area of $10.4 \mathrm{~km}^{2}$ with $2.7 \times 10^{5}$ inhabitants in 2015 . The drainage network here is designed as separated sewer system, but actually a hybrid of separated and combined sewer system. The area is generalized using the Storm Water Management Model (SWMM) developed by United States Environmental Protection Agency. There are 162 sub-catchments, 2836 junction nodes, 9 outfalls and 7 storage tanks in all.

\subsection{Parameters of sampling and simulations}

Considering local land use conditions, __limit and $u$ _limit are selected as 0.3 and 0.9 respectively. Three kinds of LID measures are applied, i.e. green roof, permeable pavement and bio-retention, with area proportion of 4:4:2. To explore the influence of total LID area on 


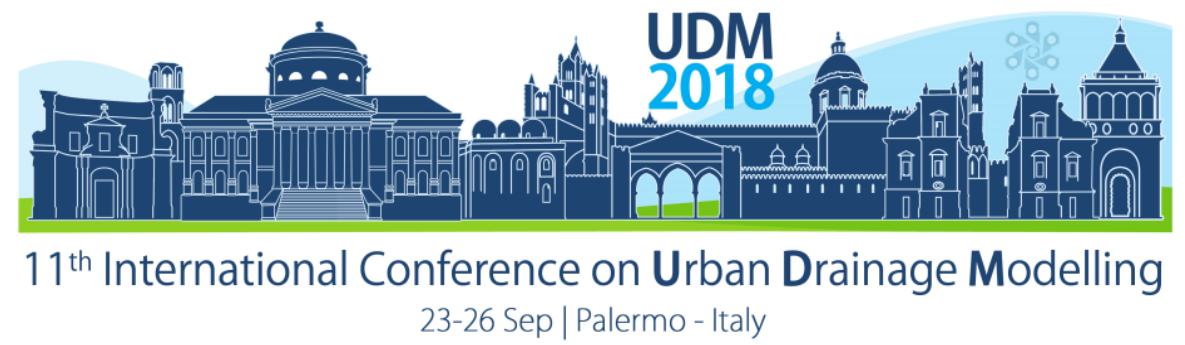

Rank Score distribution, two $S_{T}$ values are determined: $10 \%$ and $20 \%$ of the whole study area. By pre-test, sampling times $n$ is set to be 1000 for each value of $S_{T}$. Three performance indices are selected: total amount of urban flooding, total amount of CSO and total shock amount to WWTP. The rainfall used to carry out the simulations is selected as 0.5 year return period, $1 \mathrm{~h}$ duration.

\section{RESULTS AND DISCUSSION}

\subsection{Distribution of Rank Score values}

As displayed in Figure1, the average Rank Score values of 162 sub-catchments are very close to 3 for all performance indices. Above $90 \%$ of the values are between $3 \pm 0.5$ when $S_{T}$ accounts for $10 \%$ of the whole area. This range is narrowed down to $3 \pm 0.3$ when $S_{T}$ occupies $20 \%$ of the whole area. Still, there are a few extreme values which are lower than 2 and the lowest one is 1.38 .

While the average Rank Score values are nearly the same for distinct $S_{T}$, things are quite different for the standard deviations. The deviation values are $0.25,0.26$ and 0.26 for flooding, CSO and shock to WWTP respectively with $S_{T}$ set at $10 \%$ of the whole area, then drop to $0.15,0.16,0.17$ when $S_{T}$ rises to $20 \%$ of the whole area. The Rank Score values are more centralized when $S_{T}$ increases. A possible explanation is that the effectiveness of LID in a single sub-catchment is relatively reduced when the total LID area grows substantially.

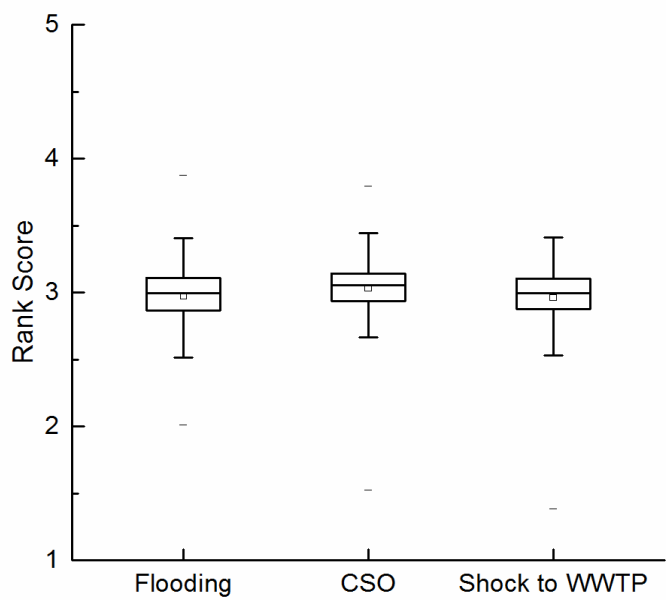

(a)

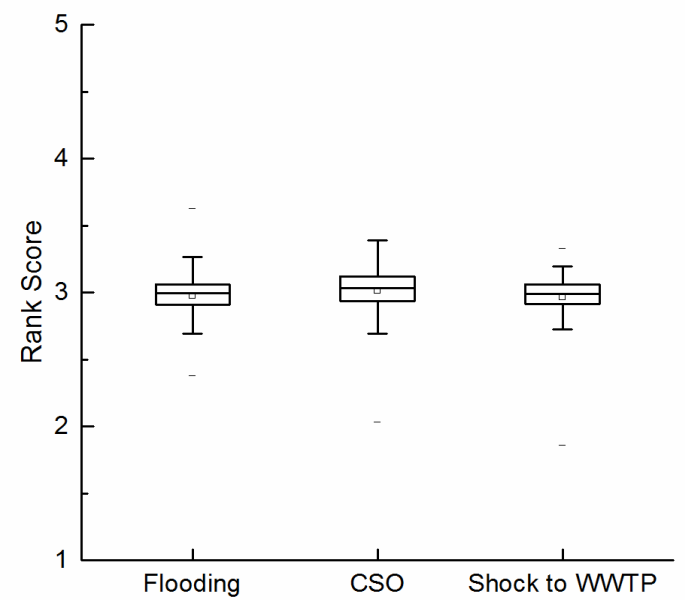

(b)

Figure 1. Distribution of Rank Score values of 162 sub-catchments in terms of flooding, CSO and shock to WWTP. (a) $S_{T}$ equals $10 \%$ of the whole area; (b) $S_{T}$ equals $20 \%$ of the whole area.

Figure 2 displays the spatial distribution of Rank Score values. Deep blue and blue areas represent the relative key sub-catchments while yellow and orange areas mean the subcatchments of relative poor performance. The key sub-catchments for flooding reduction are mostly in the upstream area, far from CSO discharge outfalls and the WWTP. Contrarily, the key sub-catchments for CSO control are just the unfavourable sub-catchments for flooding 


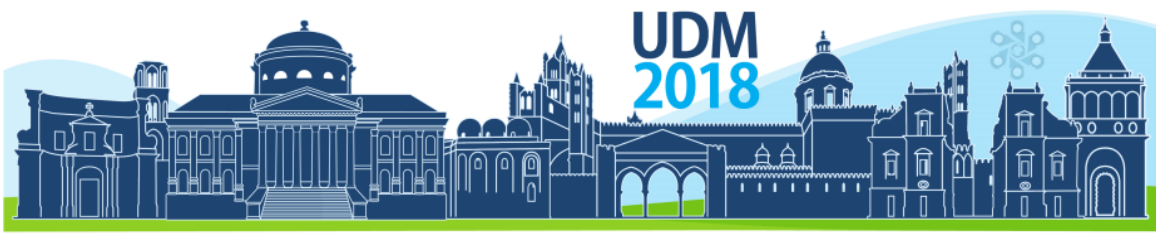

$11^{\text {th }}$ International Conference on Urban Drainage Modelling

23-26 Sep | Palermo - Italy

reduction, and the sub-catchments of poor performance for CSO control are the key subcatchments for flooding reduction. It indicates the conflicting relationship between flooding and CSO reduction with LID facilities. Finally, the key sub-catchments for shock to WWTP are located quite near to the WWTP. It can be discovered that LID located in different areas can lead to quite different system performance characteristics.

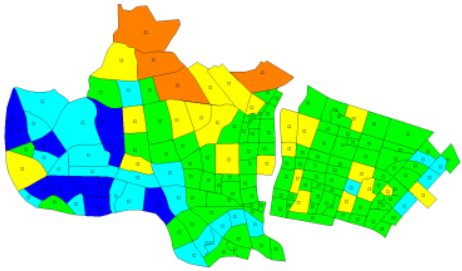

(a) $10 \%$ LID - Flooding

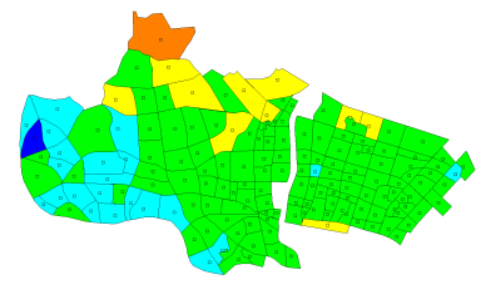

(d) $20 \%$ LID - Flooding

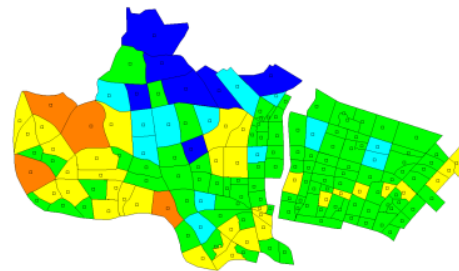

(b) $10 \%$ LID - CSO

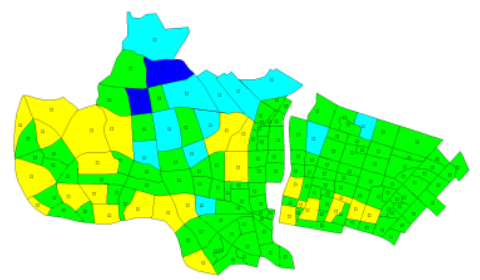

(e) $20 \%$ LID - CSO

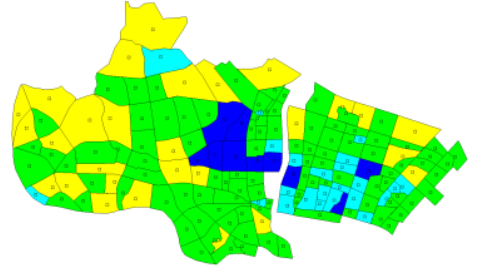

(C) $10 \%$ LID - Shock to WWTP

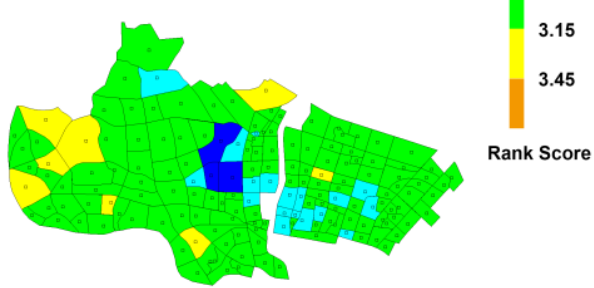

(f) $20 \%$ LID - Shock to WWTP

Figure 2. Spatial distribution of Rank Score values of 162 sub-catchments in terms of flooding, CSO and shock to WWTP. (a)-(c) $S_{T}$ equals $10 \%$ of the whole area; (d)-(f) $S_{T}$ equals $20 \%$ of the whole area.

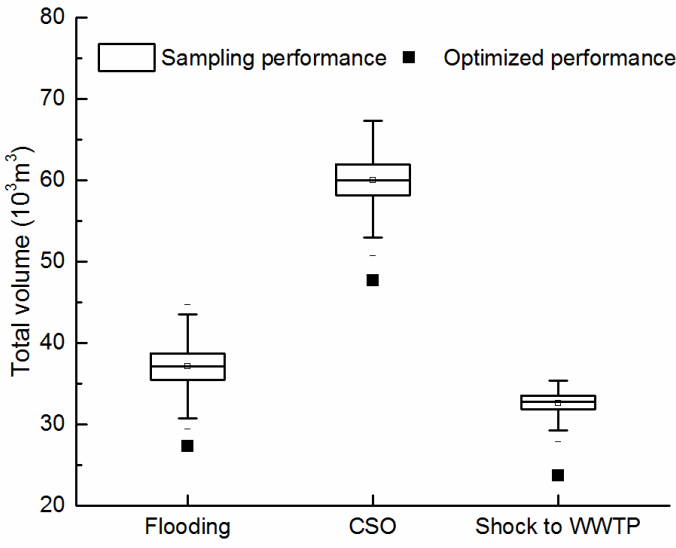

(a)

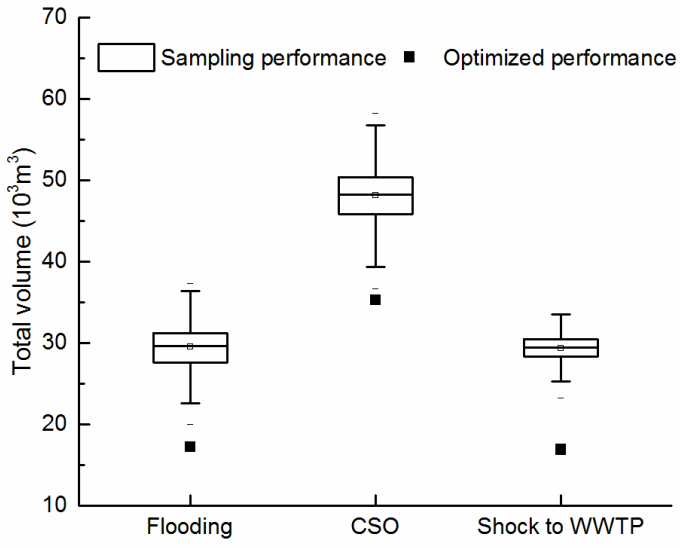

(b)

Figure 3. Comparison of indices values of sampling performance and optimized performance. (a) $S_{T}$ equals $10 \%$ of the whole area; (b) $S_{T}$ equals $20 \%$ of the whole area.

\subsection{Verification of identified key sub-catchments}

In order to test the validity of the identified key sub-catchments, extra simulations are carried out with LID only located in the key sub-catchments. The minimum value in the extra simulations is picked out as the optimized performance index. Figure 3 compares the performance of the optimized one and the 1000 samples for the three indices. The optimized value is significantly lower than the sampling values. For example, compared to the average 


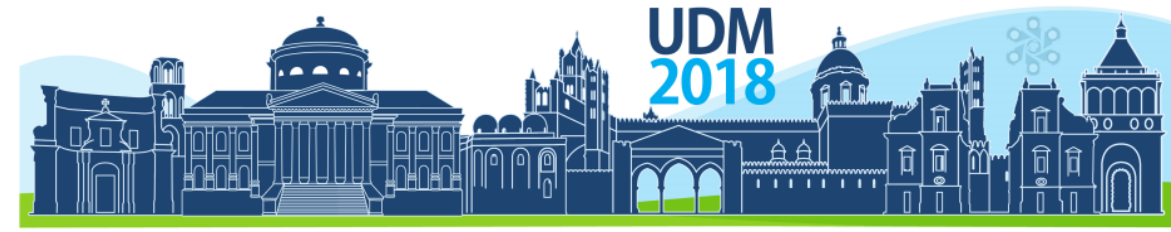

$11^{\text {th }}$ International Conference on Urban Drainage Modelling

23-26 Sep | Palermo - Italy

value of sampling performances, optimized performances are $41.7 \%, 26.8 \%$ and $42.4 \%$ less in terms of the amount of flooding, CSO and shock to WWTP respectively, when $S_{T}$ occupies $20 \%$ of the whole area.

\section{CONCLUSIONS}

This research proposed a method to rapidly identify key sub-catchments for LID placement by a new index called Rank Score. By applying the method to the case study area, the validity is tested and the characteristics of Rank Score are discussed as well. It is possible to recognize key sub-catchments in terms of certain performance indices with reasonable computing resources and time, and then make decisions of LID placement by preference of concerned problems, such flooding, CSO and WWTP. More features of Rank Score will be studied in the later work.

\section{References}

Damodaram, C., \& Zechman, E. M. (2012). Simulation-optimization approach to design low impact development for managing peak flow alterations in urbanizing watersheds. Journal of Water Resources Planning and Management, 139(3), 290-298.

Dong, X., Guo, H., \& Zeng, S. (2017). Enhancing future resilience in urban drainage system: Green versus grey infrastructure. Water research, 124, 280-289. 


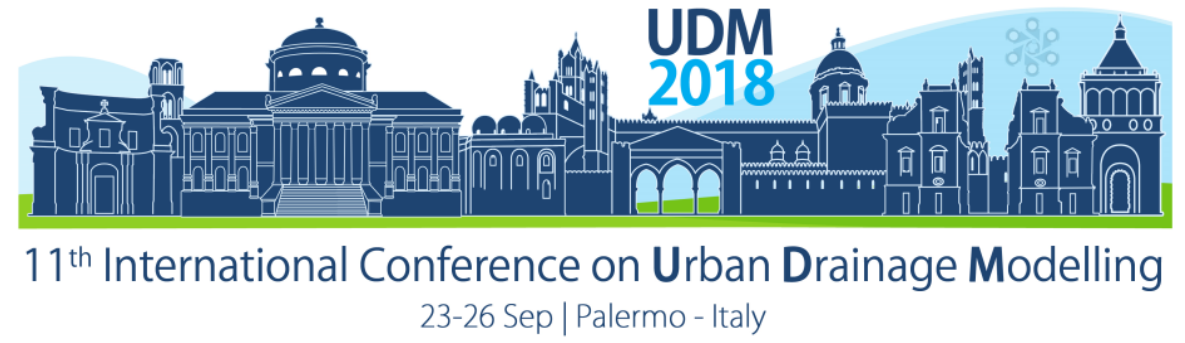

\title{
Assessing stakeholder receptivity to flood mitigation adaptation pathways.
}

\author{
Ashley Wright ${ }^{1}$, Dwinanti Rika Marthanty², Christoph Brodnik ${ }^{3}$, and Christian Urich ${ }^{1}$ \\ ${ }^{1}$ Monash University, Department of Civil Engineering, Clayton, Australia \\ 2 Universitas Indonesia, Department of Civil Engineering, Depok, Indonesia \\ ${ }^{3}$ Monash University, School of Social Science, Clayton, Australia
}

\begin{abstract}
The combination of rapid urbanisation and anthropogenically induced climate change contributes towards urban cities facing increasing levels of flood risk. It is hypothesized that the visual presentation of various adaptation pathways given uncertain future scenarios will aid in identifying potential barriers towards the implementation of the proposed adaptation pathways. This research models the 1D/2D flood dynamics in an urban catchment that is subject to uncertain future scenarios of varying rainfall events, sea level rise, and urbanisation due to population growth. Adaptation pathways which include land use controls, rainwater harvesting, and drainage maintenance are evaluated for their ability to mitigate floods under uncertain future scenarios. A visual presentation of various adaptation pathways given uncertain scenarios is presented to stakeholders to aid in the assessment of stakeholder receptivity towards proposed adaptation pathways. Stakeholder receptivity will be assessed using surveys with which the results will be used to develop an understanding of the requirements for adaptation pathways to be implemented.
\end{abstract}

Keywords: Urban flooding; adaptation pathways; receptivity

\section{INTRODUCTION}

Floods impede the ability of developing countries and countries with climate reliant industries to grow socioeconomically. Climate change, and urbanisation place increasing stresses on flood resisting communities, rendering flood resistance measures unsustainable (Liao, 2012).

For centuries civilizations have primarily dealt with floods by resisting measures such as dams and dikes (Kundzewicz, 2002). When a community relies primariliy on structural flood protection measures, the impacts of floods as well as the ability to respond effectively to a flood event are often forgotten (Bosschaart et al., 2016). Further, the failure of a resisting systems is often catastrophic (Liao, 2012). Resilient communities rely on a balanced combination of structural and non-structural flood mitigation measures. A resilient system that is subject to shocks will respond by adapting to a new acceptable state.

Non-structural measures that contribute towards a communities flood resilience include; policy, laws, regulations, zoning, economic instruments, private mitigation measures, evacuation planning, flood forecast and warning systems, flood databases, flood risk assessments, maintenance of drainage infrastructure, and flood education programs (Kundzewicz, 2002). 


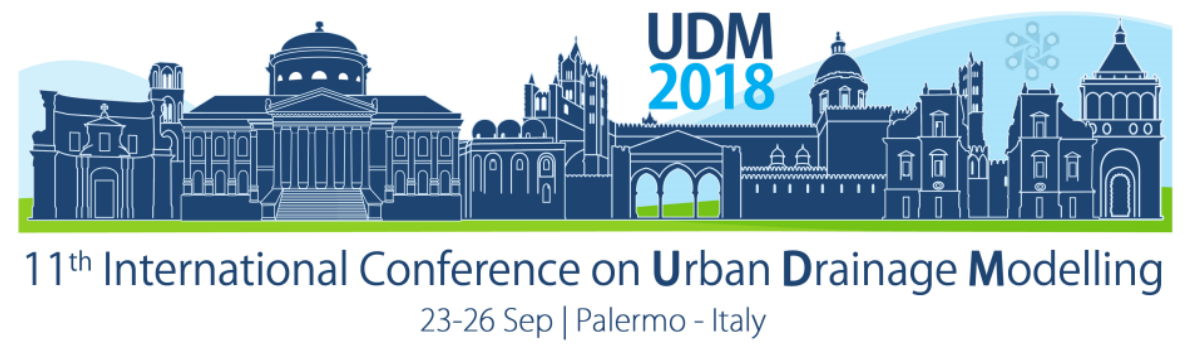

The understanding of a communities flood risk is an essential step towards resilience. Flood risk is defined as a function of; hazard, exposure, and vulnerability (Allen et al., 2011). For resilient flood mitigation measures to be implemented it is necessary that flood risks for alternative adaptation pathways given uncertain future scenarios be conveyed to stakeholders. Model visualisations are a powerful tool that can be used to enhance communication and learning (Voinov et al., 2016).

Educational attempts focused on flood risk have targeted flood risk awareness and flood risk perception. A review of the literature (Wachinger et al., 2013) has demonstrated that an increased risk awareness or risk perception does not necessarily correlate with increased protective actions. For flood risk mitigation measures to be adopted it is essential that the receptivity (Jeffrey \& Seaton, 2004) of stakeholders be assessed. (Farrelly \& Brown, 2014) used the receptivity model to assess and contrast a communities expected receptivity towards resilient alternative water supply options for uncertain climates with the actual receptivity of the community. Thus allowing the identification of potential barrier towards the adoption of resilient water supply policy. There are no current studies in the urban drainage modelling literature that use visually based flood assessments of flood adaptation pathways to aid in the assessment of receptivity in stakeholders. This study will aid in the identification of potential barriers towards the adoption of flood resilient policies.

\section{MATERIALS AND METHODS}

To assess the uncertain future scenarios and adaptation pathways a flood model for the Elster creek catchment of Victoria Australia is developed. Scenarios and adaptation pathways are simulated using the Two dimensional Unsteady FLOW (TUFLOW) Heavily Parallelised Compute (HPC) module. To provide a baseline initial receptivity is assessed. Model visualisations are used to educate stakeholders on the effectiveness of flood mitigation adaptation pathways given uncertain future scenarios. Receptivity is retested to determine remaining barriers towards implementation of flood resilient adaptation pathways.

\subsection{Description of study sites}

Elster creek. The Elster creek catchment is an urbanized catchment of $39 \mathrm{~km}^{2}$. The Elster creek catchment is built primarily on swamp land and is subject to pluvial and tidal flooding events. The provision of $1 \mathrm{~m}$ resolution lidar data, detailed topography and drainage network make the Elster creek catchment an ideal catchment to explore and visualise adaptation pathways under the influence of uncertain climate and population scenarios.

Cibinong. Cibinong, the capital of Bogor Regency, Indonesia is currently undergoing rapid urbanisation and similar to the Elster creek catchment is predominantly built upon swamp land. There is currently insufficient high resolution data to model the impact various adaptation pathways have on floods given uncertain climate and population scenarios. It is hypothesized that visualizations of adaptation pathways from the Elster creek catchment will either improve receptivity towards adaptation pathways or aid in the identification of potential barriers towards the implementation of adaptation pathways. 


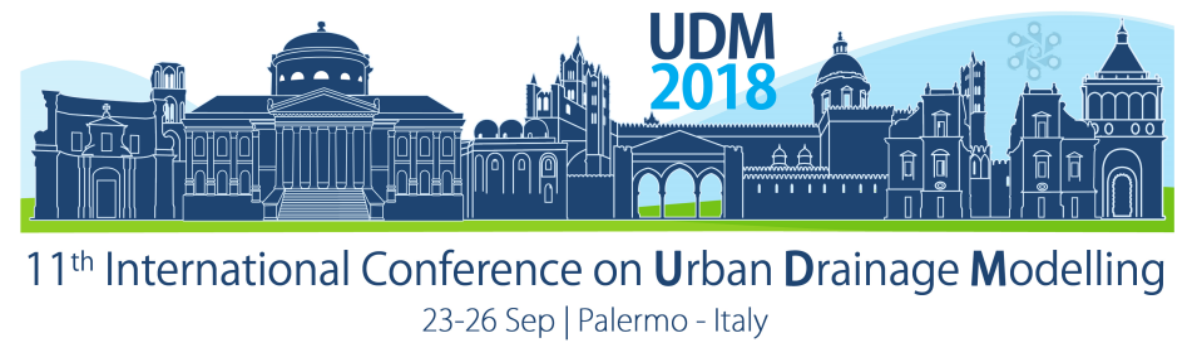

\subsection{TUFLOW}

The TUFLOW HPC module is used to model the coupling of the 1D creek network with the 1D pipe network and 2D surface drainage network for numerous adaptation pathways under the influence of uncertain scenarios. The model is forced by rainfall on grid and has a downstream tidal boundary condition. To maintain speed and efficiency when assessing the adaptation pathways under uncertain scenarios a $5 \mathrm{~m}$ cell resolution is used.

\subsection{Scenarios}

If sustainable and resilient flood mitigation strategies are to be proposed, it is essential that flood models consider the uncertainty associated with future scenarios. The current flood model is used as a benchmark for scenarios based on projections for 2030, and 2045.

Climate induced rainfall changes. Given the trajectory of projected Representative Concentration Pathways (RCPs) there is considerable uncertainty in the Intensity Frequency and Duration (IFD) of future rainfall events. Using RCP 2.6 and 8.5, rainfall intensities for events with Average Exceedance Probability (AEP) of 0.181 and 0.049 are used.

Climate induced sea level rise. A number of urban catchments are connected to the sea and are susceptible to increased flooding as a result of rising sea levels. Consequently, high, and low sea level rise scenarios are used as the downstream boundary condition.

Population growth. Urban development is highly dependent on population growth and economic development. To adequately assess flood mitigation strategies it is necessary to consider a range of population growth scenarios.

\subsection{Adaptation pathways}

To determine appropriate solutions that are resilient under the uncertain future scenarios adaptation pathways that include the use of rainwater tanks as flood storage measures, land zoning in undeveloped regions, and maintenance of drainage infrastructure will be assessed.

Rainwater harvesting. Rainwater tanks provide multiple benefits. Their use as a distributed smart flood storage network is currently underexplored in the urban drainage modelling literature. Adaptation pathways in which two different uptakes of $3 \mathrm{~kL}$ rain tanks are modelled.

Land zoning. The prevention of development in currently undeveloped flood prone areas and restriction of further development in currently developed areas will be contrasted with the unrestricted development in flood prone areas.

Maintenance of drainage infrastructure. Without the provision of adequate maintenance schedules, solid wastes impede drainage networks and increase flood risk (Bankoff, 2003). Models of unblocked and partially blocked drainage networks will be used to assess the extent a partially blocked drainage network can exacerbate flood risk in an urban environment.

\subsection{Receptivity model}

The receptivity model described by (Jeffrey \& Seaton, 2004) comprised of four components that is be used to identify the capacity of different stakeholders to absorb, accept and utilize innovation options. The four components are: 


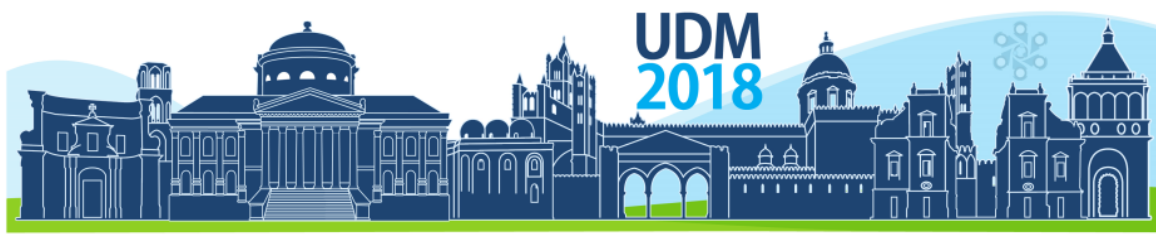

$11^{\text {th }}$ International Conference on Urban Drainage Modelling

23-26 Sep | Palermo - Italy

- Awareness - Prior knowledge of an issue or problem.

- Association - Recognition of the potential value of a proposed solution.

- Acquisition - Ability to acquire technologies or exploit new knowledge.

- Application - Ability and motivation to obtain long term benefit from proposed solutions.

Receptivity of the stakeholders to the proposed adaptation pathways will be assessed in Cibinong through surveys before and after the presentation of study results.

\subsection{Workshops}

Workshops are currently planned to be conducted in Cibinong. To assess receptivity the workshops will consist of an introductory receptivity survey, visual presentation of adaptation pathways for uncertain scenarios and then conclude with a survey that assess receptivity.

\section{RESULTS AND DISCUSSION}

No results are currently available. The modelling of adaptation pathways for uncertain scenarios will provide visual results that demonstrate the combined utility of drainage maintenance programs, land use controls and rain water harvesting. Surveys of receptivity will highlight potential barriers towards the effective implementation of adaptation pathways.

\section{CONCLUSIONS}

Visualisations of flood impacts are provided for varying rainfall, sea level, and urbanisation scenarios. Land use controls, rainwater harvesting, and drainage maintenance adaptation pathways are assessed. Visual presentations of these adaptation pathways are presented to stakeholders in Cibinong to aid in the assessment of stakeholder receptivity towards these adaptation pathways. This methodology will contribute towards the identification of potential barriers that the implementation of adaptation pathways faces.

\section{References}

Allen, S. K., Barros, V., Burton, I., Lendrum, D. L., Cardona, O. D., Cutter, S. L., et al. (2011). Managing the Risks of Extreme Events and Disasters to Advance Climate Change Adaptation, 30.

Bankoff, G. (2003). Constructing Vulnerability: The Historical, Natural and Social Generation of Flooding in Metropolitan Manila. Disasters, 27(3), 224-238.

Bosschaart, A., van der Schee, J., \& Kuiper, W. (2016). Designing a flood-risk education program in the Netherlands. J. Environ. Educ., 47(4), 271-286.

Farrelly, M. A., \& Brown, R. R. (2014). Making the implicit, explicit: time for renegotiating the urban water supply hydrosocial contract? Urban Water J., 11(5), 392-404.

Jeffrey, P., \& Seaton, R. A. F. (2004). A Conceptual Model of "Receptivity" Applied to the Design and Deployment of Water Policy Mechanisms. Environ. Sci., 1(3), 277-300.

Kundzewicz, Z. W. (2002). Non-structural Flood Protection and Sustainability. Water Int., 27(1), 3-13.

Liao, K.-H. (2012). A Theory on Urban Resilience to Floods--A Basis for Alternative Planning Practices. Ecol. Soc., 17(4), art48.

Voinov, A., Kolagani, N., McCall, M. K., Glynn, P. D., Kragt, M. E., Ostermann, F. O., et al. (2016). Modelling with stakeholders - Next generation. Environ. Model. Softw., 77, 196-220.

Wachinger, G., Renn, O., Begg, C., \& Kuhlicke, C. (2013). The Risk Perception Paradox-Implications for Governance and Communication of Natural Hazards. Risk Anal., 33(6), 1049-1065. 
Proceedings of the 11th Int. Conference on Urban Drainage Modelling, 23-26 Sep. 2018, Palermo (ITALY). Ed. prof. Giorgio Mannina

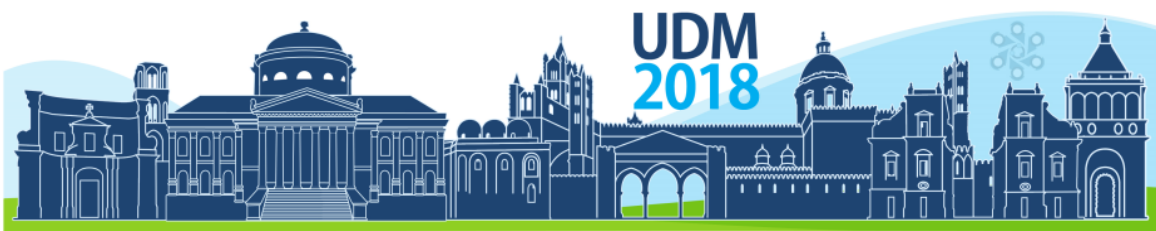

$11^{\text {th }}$ International Conference on Urban Drainage Modelling 23-26 Sep | Palermo - Italy 


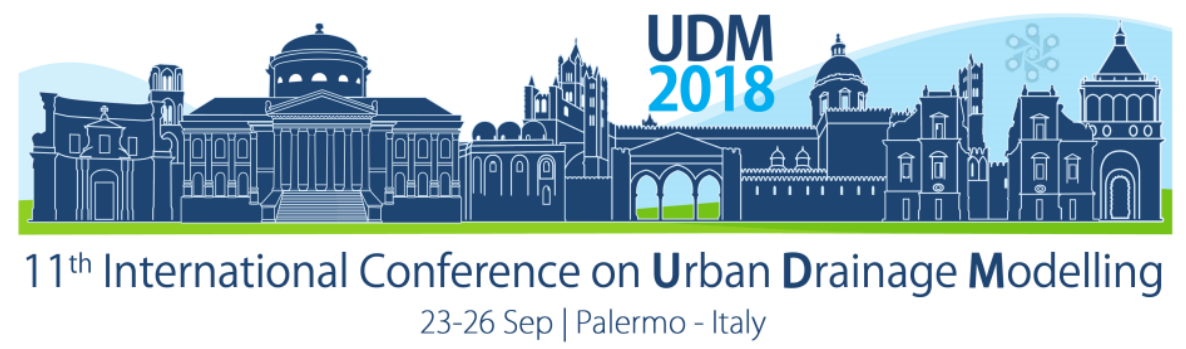

\title{
Green infrastructure and storage unit combinations for mitigating peak flows in drainage systems
}

\author{
Yang Yang ${ }^{1}$ and Ting Fong May Chui ${ }^{1}$ \\ ${ }^{1}$ The University of Hong Kong, Department of Civil Engineering, Hong Kong SAR, China \\ (Room 6-18A, Haking Wong Building, The University of Hong Kong, Pokfulam Road, \\ Hong Kong; Corresponding to Chui: maychui@hku.hk)
}

\begin{abstract}
Existing urban drainage systems may need to be constantly upgraded due to urban development and climate change. Storage units, such as on-line storage tanks, have been frequently adopted to provide temporary storage volumes for enhancing the capability of the existing drainage systems. Their design and layout optimizations have been intensively studied. Green infrastructure, a decentralized semi-natural landscape solution, among other viable options, has received increasing attention. Although the commonly used green infrastructures, such as green roofs and bioretention cells, are shown to be effective in mitigating peak flows and runoff volumes, they may not be able to handle extremely large storms alone. It is, therefore, necessary to derive the optimal combinations of the storage units and green infrastructures. This study presents an optimization problem as a case study, in which the design standard of an urban drainage system is increased from a 5-year design storm to a 10-year design storm, and the objective is to use green roofs and storage units to reduce the peak flows at the outlet while minimizing the total cost and eliminating the flood at each subcatchment. The size of the green roofs, and the volume and the dimension of outflow orifice of the storage units are optimization variables. The drainage system is modelled using SWMM, and the optimization problem is solved using the NSGA-II multiobjective optimization algorithm. The result suggests that green infrastructures can be effective for reducing the required volume of the storage units.
\end{abstract}

Keywords: Green infrastructure; storage unit; optimization

\section{INTRODUCTION}

Urban drainage systems may need to be constantly upgraded to handle the increased discharge rates and runoff volumes resulted from urbanization and climate change. Storage unit is one of the commonly-used measures for retrofitting and upgrading the existing drainage systems. Storage units are commonly adopted to reduce flood volume (Butler and Davies, 2011) or to regulate flow to minimize the impact to the downstream. Storage units vary in physical configurations and operation rules. On-line storage units are constructed in series within the drainage network, and the outflow is controlled by flow regulators, such as orifices or overflow weirs. This type of storage unit can often be constructed in the local subcatchments, while maintaining the function of the existing drainage network. They are thus often implemented to upgrade the existing drainage system for flood prevention. The optimal layout and sizing of these practices in a drainage network have been investigated in Cunha et al. (2016). 


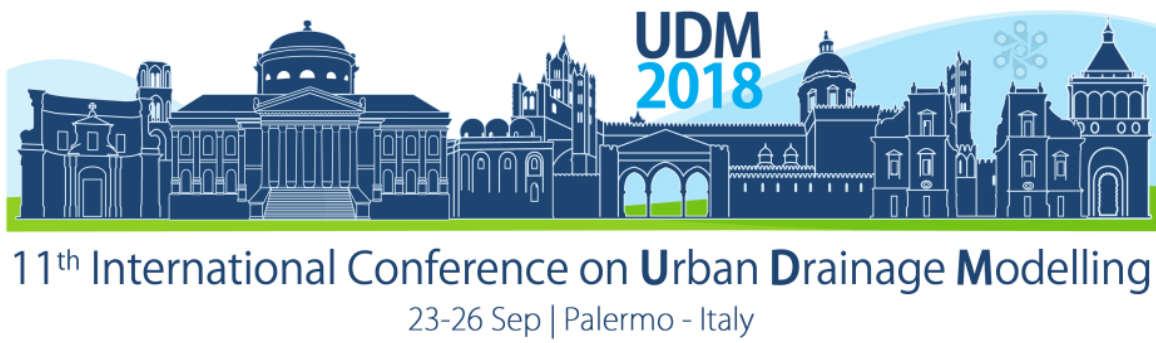

Green infrastructures (GI) are decentralized landscape solutions for managing stormwater runoff. They have received increasing attention in urban stormwater management in recent years (Fletcher et al., 2015). Gl can be useful in stormwater runoff quality and quantity management. However, GI have seldom been designed to handle extremely large rainfalls, since their effectiveness in peak flow reduction generally decreases as the rain intensity increases. This suggests, other drainage measures are indispensable for safety consideration when $\mathrm{Gl}$ are adopted. It is, therefore, meaningful to consider using the combination of GI and other facilities, such as storage units, for flood risk mitigation. However, the design of the integrated system of GI and storage have not been thoroughly studied.

This study aims to investigate whether the presence of $\mathrm{Gl}$ can reduce the required design level of the storage tanks (such as storage volume). In addition, we also attempt to identify the optimal combinations of $\mathrm{Gl}$ and storage units for peak flow mitigations.

\section{MATERIALS AND METHODS}

\subsection{SWMM and NSGA-II}

This study uses Storm Water Management Model (SWMM) as its computational engine. SWMM is software developed by the United States Environmental Protection Agency for simulating the hydrological/hydraulic processes in the urban drainage system (Huber et al., 2005). It can model the major components of the conventional drainage system (including conduits and storage units) as well as various types of Gl (such as green roof, porous pavement, and bioretention cell).

The optimization problem in this study is solved by the NSGA-II algorithm. NSGA-II is one type of Evolutionary Algorithm for solving multi-objective optimization problems (Deb et al., 2002). NSGA-II proposes a new way for ranking candidate solutions and for selecting the elite members for reproduction. The SWMM model and NSGA-II are coupled by extending the toolbox in R programming language developed in Yang and Chui (2018).

\subsection{Study site}

A hypothetical urban catchment modified from Gironás et al. (2010) is shown in Figure 1. It consists of 7 subcatchments, with the areas ranging from $8,000 \mathrm{~m}^{2}$ to $24,000 \mathrm{~m}^{2}$, and the imperviousness ranging from $35 \%$ to $95 \%$. The current drainage network is designed using a 5 -year design storm (25 mm rainfall in 2 hours). A drainage network upgrading plan is proposed, that 3 storage units (SU1 through SU3 in Figure 1) are planned to be installed at the local nodes to enable the drainage network to handle 10-year design storms $(50 \mathrm{~mm}$ rainfall in 2 hours) without flooding. The depths of these storage units are fixed ( $2 \mathrm{~m}$ to $2.5 \mathrm{~m})$ and the outflow in each unit is regulated by a single circular orifice at the bottom; the areas of storage units and the dimensions of the orifices are design variables (i.e., 6 variables). Green roofs are also planned in catchment S1, S3, S5, and S7; the design variables are the sizes of the green roofs (i.e., 4 variables). The optimization problem is defined as, determining the 10 variables (i.e., $6+4$ ) that minimize both the peak flow rate at the main outlet and total cost of constructing storage tanks and green roofs, assuming $1 \mathrm{~m}^{3}$ of storage tank equals to $30 \mathrm{~m}^{2}$ green roof; the constraints are no flooding at any subcatchment and the maximum implementation areas of these practices in different catchments. 


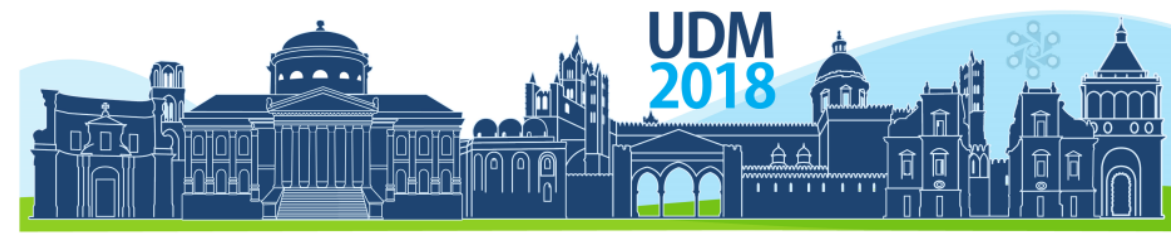

$11^{\text {th }}$ International Conference on Urban Drainage Modelling

23-26 Sep | Palermo - Italy

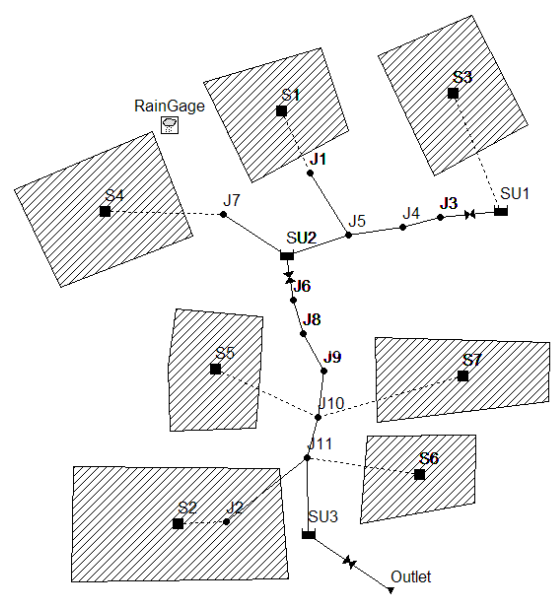

Figure 1. Layout of the drainage network and the subcatchment (S1 through S7) in SWMM; the potential location of the storage units is also shown (SU1 through SU3).

\section{RESULTS AND DISCUSSION}

\subsection{Optimization results}

In NSGA-II, the population size was set to be 48 and the individuals evolved through 60 generations. The results of every 10 generation were tracked for screening the optimization progress. As shown in Figure 2, in the final generation (i.e., generation 60), the peak flow at the outlet decreases with the increase in the total cost. This correlation is non-linear and it shows the trade-off between cost and benefit, which can be valuable for decision making. The progress of the optimization is also shown in Figure 2.

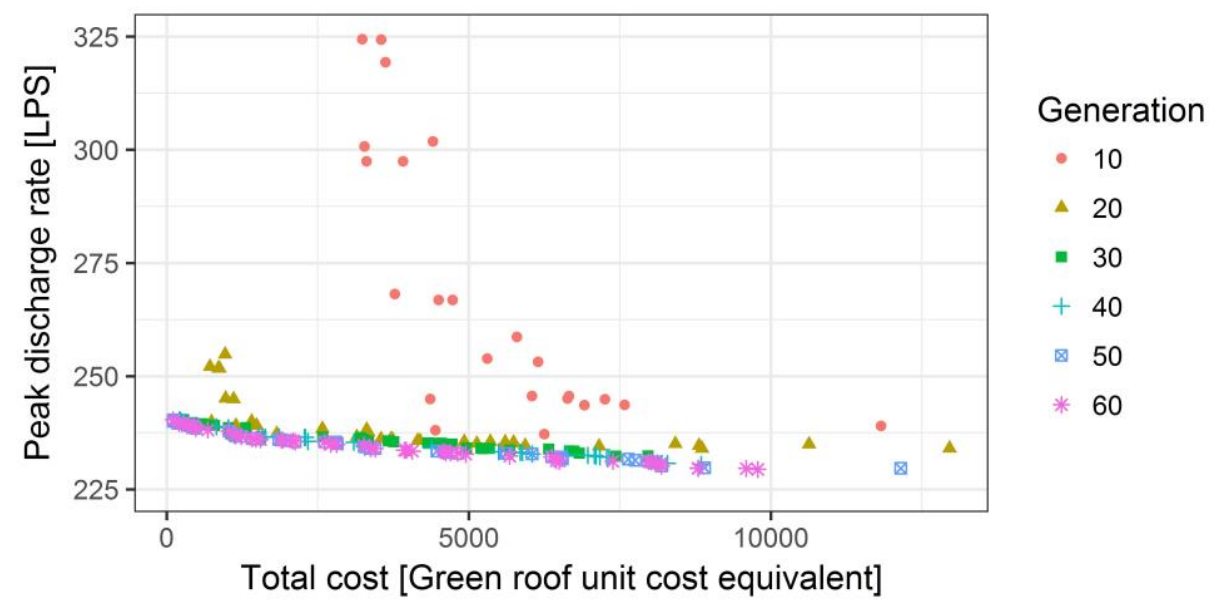

Figure 2. Candidate solutions in different generations; infeasible solutions (where flooding occurs) are not shown.

\subsection{Importance of green infrastructure in integrated designs}

The solutions of the last generation are examined. The solutions on the Pareto front is shown in Figure 3, with the size of the dots representing the percentage of investment made to the GI. This result indicates that green roof can be valuable for peak flow mitigation when designed together with on-line storage units. We also notice that the results vary significantly in different solutions. To estimate the uncertainty of the optimization solutions, multiple optimization runs are suggested. 

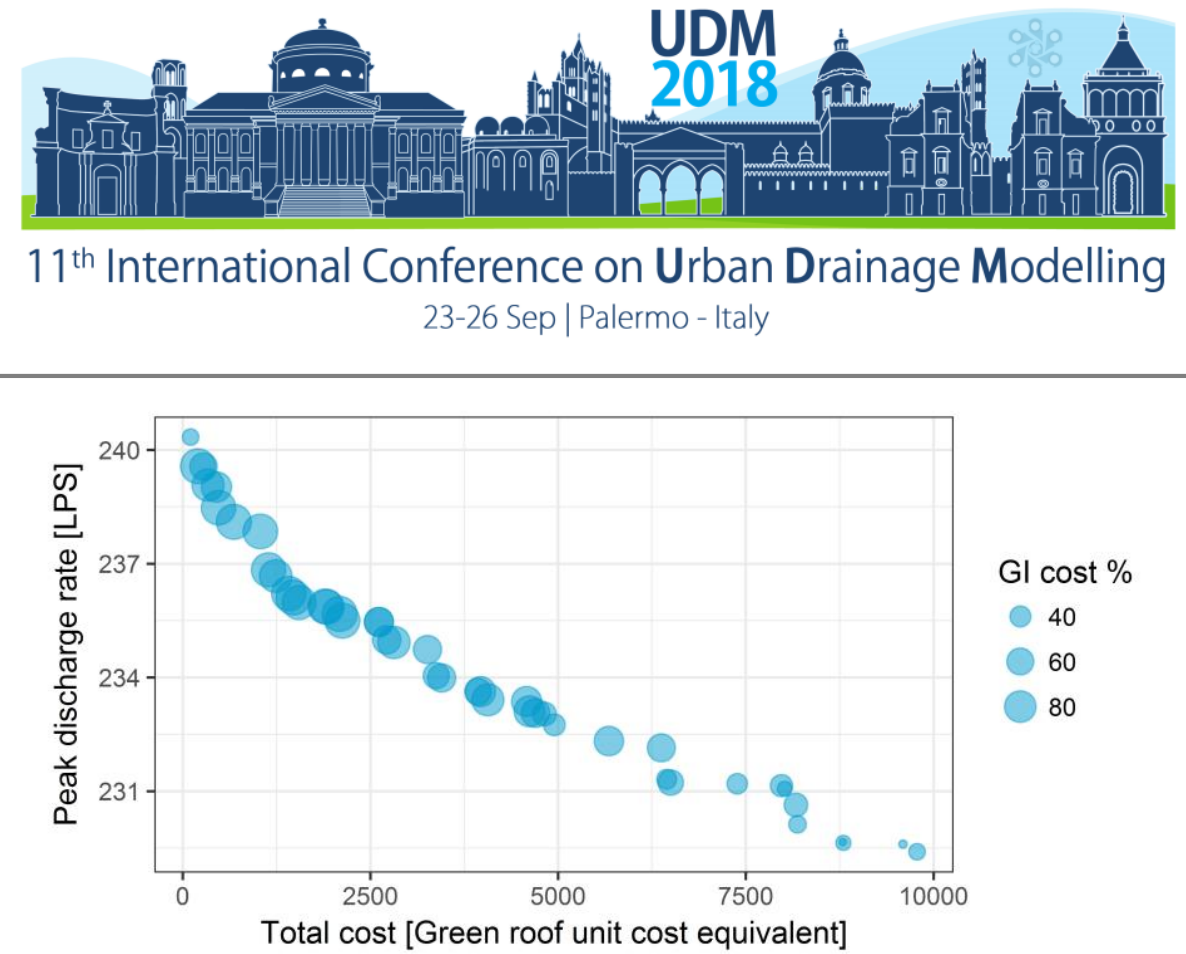

Figure 3. Last generation candidate solutions on the Pareto front. The size of the dots represents the percentage of investment made to the green infrastructure

\section{CONCLUSIONS}

This study shows that green infrastructure can help to reduce the design level of the on-line storage units by using a modelling approach. In an optimization context, where the combination of green roofs and storage units is being designed, green roof appears to be important constituent of the optimal solutions. We recommend future researches to investigate the effectiveness of the combined design of other types of GI and storage units, or to identify the optimal green infrastructure type in different locations in the drainage networks.

\section{Acknowledgments}

This study was supported by a grant from the Research Grants Council of the Hong Kong Special Administrative Region, China (Project No. HKU17255516).

\section{References}

Cunha, M.C., Zeferino, J.A., Simões, N.E. and Saldarriaga, J.G., 2016. Optimal location and sizing of storage units in a drainage system. Environmental Modelling \& Software, 83: 155-166.

Butler, D., Davies, J.W., 2011. Urban Drainage, third ed. CRC Press, London.

Deb, K., Pratap, A., Agarwal, S. and Meyarivan, T., 2002. A fast and elitist multiobjective genetic algorithm: NSGA-II. IEEE transactions on evolutionary computation, 6(2): 182-197.

Fletcher, T.D., Shuster, W., Hunt, W.F., Ashley, R., Butler, D., Arthur, S., Trowsdale, S., Barraud, S., Semadeni-Davies, A. and Bertrand-Krajewski, J.-L., 2015. SUDS, LID, BMPs, WSUD and moreThe evolution and application of terminology surrounding urban drainage. Urban Water Journal, 12(7): 525-542.

Gironás, J., Roesner, L.A., Rossman, L.A. and Davis, J., 2010. A new applications manual for the Storm Water Management Model (SWMM). Environmental Modelling \& Software, 25(6): 813-814.

Huber, W.C., Rossman, L.A. and Dickinson, R.E., 2005. EPA storm water management model, SWMM5. Watershed Modeling, CRC Press, Boca Raton, FL: 339-361.

Yang, Y. and Chui, T.F.M., 2018. Optimizing surface and contributing areas of bioretention cells for stormwater runoff quality and quantity management. Journal of Environmental Management, 206: 1090-1103. 


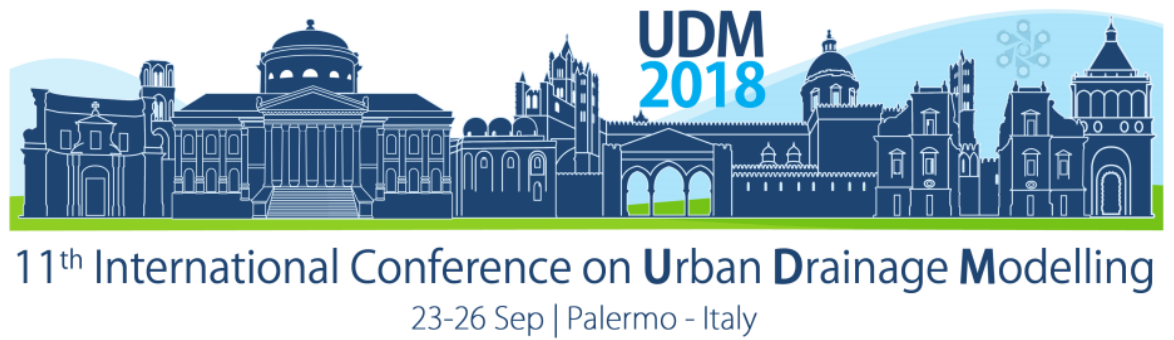

\title{
Effects of LID-based Urban Designs on Water Balance
}

\author{
Ambika Khadka1, Teemu Kokkonen ${ }^{1}$, Elisa Lähde ${ }^{2}$, Tero Niemi' ${ }^{1}$, Nora Sillanpää1 and Harri \\ Koivusalo ${ }^{1}$ \\ ${ }^{1}$ Aalto University, School of Engineering, Department of Built Environment, Espoo, Finland \\ ${ }^{2}$ Aalto University, School of Arts, Design and Architecture, Department of Arts and Design, Espoo, Finland
}

\begin{abstract}
Low impact development (LID) has received significant attention in supplementing urban drainage designs. This study demonstrates the effects of LID-based urban designs on water balance components for an urban catchment. Two LID-based urban designs $(A, B)$ are simulated for short term (E1) and long term (E2) periods and the effects of the various designs on different water balance components are assessed. The goal of the study is to demonstrate the performance of the designs to realize the sponge city concept. For the intensive short event, scenario A with $15 \%$ LID is not effective whereas scenario B with $49 \%$ LID is highly effective. For the longer period, both scenarios are highly effective in replicating sponge city concept. In addition, the $A$ scenario possesses a potential for producing sponge city concept for rain events for return periods lower than 100 years.
\end{abstract}

Keywords: Low impact development (LID); SWMM; Water balance components

\section{INTRODUCTION}

Low Impact Development (LID) has been considered to augment drainage based urban designs by translating urban storm water runoff into adaptable resources (Burns et al., 2012; Fletcher et al. 2013). LID as an urban drainage design tool focuses on controlling urban storm water with the objective to replicate natural hydrological functioning (Fletcher et al., 2014). LID aims to enhance on-site storage, infiltration, and evaporation, hence delaying and reducing discharge to the receiving water bodies. LID has been introduced as a concept for constructing "sponge cities" in China. Sponge city proposes to retrofit urban areas into a flexible system, which stores and infiltrates storm water runoff close to the impervious surfaces generating runoff during storm events (Jia et al., 2017). Hydrological effects of LID based urban designs have recently been studied at relatively larger catchments $\left(1-20 \mathrm{~km}^{2}\right)$ using design storms and long term data to demonstrate the sponge city concept (Qin et al., 2013; Jia et al., 2015; Xu et al., 2017). However, the effectiveness of the concept at smaller development areas is sparsely studied. The goal of this study is to demonstrate the efficiency of the concept to control water balance in a 14.5 ha catchment in the city of Turku, Finland. In this study, the effectiveness of two LID-based designs in realizing a sponge city in Turku catchment is assessed for an intense rain event and a long term period.

Storm Water Management Model (SWMM) (Rossman et al. 2016) is a common tool to simulate runoff, infiltration, evaporation and flow routing through a system of heterogeneous subcatchments, closed pipes, open channels, and a variety of different LID structures in urban areas. Using SWMM, this study demonstrates the effects of two LID-based urban designs on water balance components simulated using on-site rainfall data for a very intense storm event E1 (71 mm in 4 hours) with a return period of 1/100 years, and for a longer 7 month period E2 with $392 \mathrm{~mm}$ of rainfall. The performance of the two LID designs in realizing a sponge city is studied in terms of the relative shares of various water balance components (discharge, flooding, evaporation and infiltration as losses, and storage). 


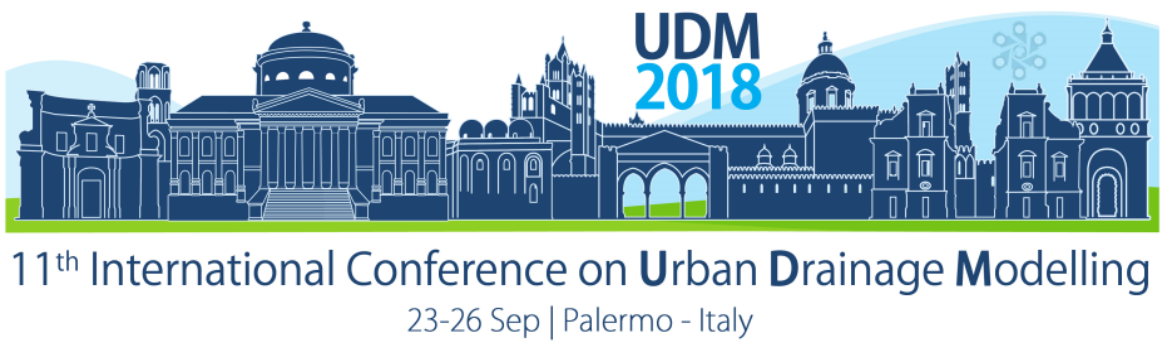

\section{MATERIALS AND METHODS}

\subsection{Study area}

The study focuses on a 14.8 ha urban catchment located at Kirstinpuisto in the city of Turku with the outfall located at $60^{\circ} 26^{\prime} 51.05^{\prime \prime} \mathrm{N}$ and $24^{\circ} 14^{\prime} 08.83^{\prime \prime} \mathrm{E}$ (Figure 1a). It is an industrial area with a high proportion of empty lots, gravel, as well as vegetated surfaces. The dominant underlying soil in this lowland area is mostly clay. In near future, the study area will undergo development aiming to create a multi-functional landscape. Most of the area will be newly built, with a $35 \mathrm{~m}$ wide park in the center creating a vibrant location for storm water management and other urban functions such as recreation and public spaces.

\subsection{Urban designs}

Two LID-based urban designs have been proposed for the Kirstinpuisto area. Their aim is to supplement the conventional drainage network in order to reduce flooding and discharge, and realize a sponge city. Scenario $A$ of LID-based urban design represents a realistic combination of infiltration and storage based LID tools (15\%) for storm water regulations and other urban functions. Scenario $B$ of LID-based urban design is an ambitious combination of infiltration and storage based LID (49\%) where storm water regulation precedes over other urban functions (Table 1). The LID structures of both $A$ and $B$ include green roofs for initial inception of rain, vegetative swales and a channel for supplemented conveyance of stormwater, as well as bioretention cells and permeable pavements for storage and infiltration of stormwater into the underlying soil (Figure 1b, 1c). However, the area covered by LIDs varies across the scenarios (Table 1). As the underlying soil is dominantly clay, it is likely that infiltration into the underlying soil is limited and therefore storage based LIDs were selected for the design scenarios.

Table 1. Proportion of LIDs in the catchment for current and urban design scenarios

\begin{tabular}{lrrrrrrr}
\hline & $\begin{array}{r}\text { Pervious } \\
\text { surface }\end{array}$ & $\begin{array}{r}\text { Impervious } \\
\text { surface }\end{array}$ & $\begin{array}{r}\text { Vegetative } \\
\text { swale }\end{array}$ & $\begin{array}{r}\text { Bioretention } \\
\text { cells }\end{array}$ & $\begin{array}{r}\text { Green } \\
\text { roofs }\end{array}$ & $\begin{array}{r}\text { Permeable } \\
\text { pavements }\end{array}$ & $\begin{array}{r}\text { Total } \\
\text { LID }\end{array}$ \\
\hline Current & 42.8 & 57.2 & & & & & \\
Scenario $A$ & 25.2 & 59.8 & 2.4 & 0.4 & 3.2 & 9.0 & 15 \\
Scenario $B$ & 29.0 & 22.0 & 5.0 & 0.5 & 22.3 & 21.2 & 49 \\
\hline
\end{tabular}

\subsection{Simulations}

SWMM was firstly parameterized to describe the hydrological response of a 14.5 ha catchment in its current undeveloped state (Figure 1a). The catchment was divided into small homogeneous subcatchments sharing the same land surface types. The subcatchment characteristics were then determined based on topographic and stormwater network dataset, and reference values from literature (Krebs et al., 2014; Sillanpää \& Koivusalo, 2018) The SWMM model for the current state was calibrated against three rainfall-runoff events measured between October 2017 and January 2018. The model showed consistent and good performance in reproducing the observed runoff with the Nash-Sutcliffe efficiency (Nash and Sutcliffe, 1970) exceeding 0.80 for $2 / 3$ events. As the model was incapable of producing the observed dry spell baseflows, calibration was only conducted for events with significant rainfall. The calibrated parameter values representing different surface types and literature values were then used to construct the parameterizations for the above mentioned LID-based design scenarios. (Figure 1b, 1c). The storage at a given time step $\left(S_{t}\right)$ is computed from simulated water balance components using Eq. 1.

$S_{t}=S_{t-1}+R_{t}-F_{t}-D_{t}-I_{t}-E_{t}$ 


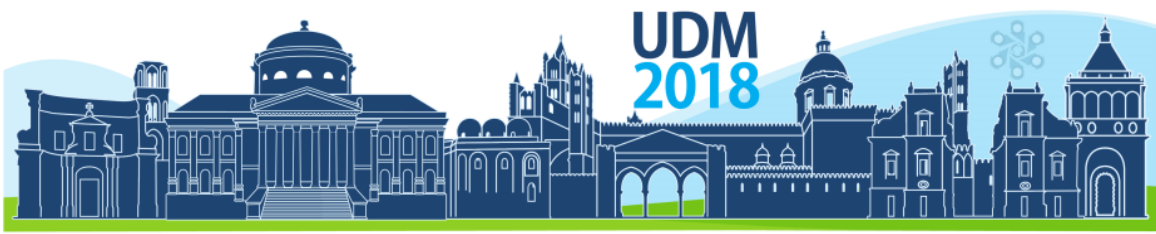

$11^{\text {th }}$ International Conference on Urban Drainage Modelling

23-26 Sep | Palermo - Italy

Where $S_{t-1}$ is storage in the previous time step $t-1, R_{t}$ is the rainfall, $F_{t}$ is the stormwater lost from drainage network defined as flooding, $D_{t}$ is the discharge from the outfalls, $I_{t}$ is the stormwater infiltrating into the underlying soil and $E_{t}$ is the stormwater lost as evapotranspiration at time step t.

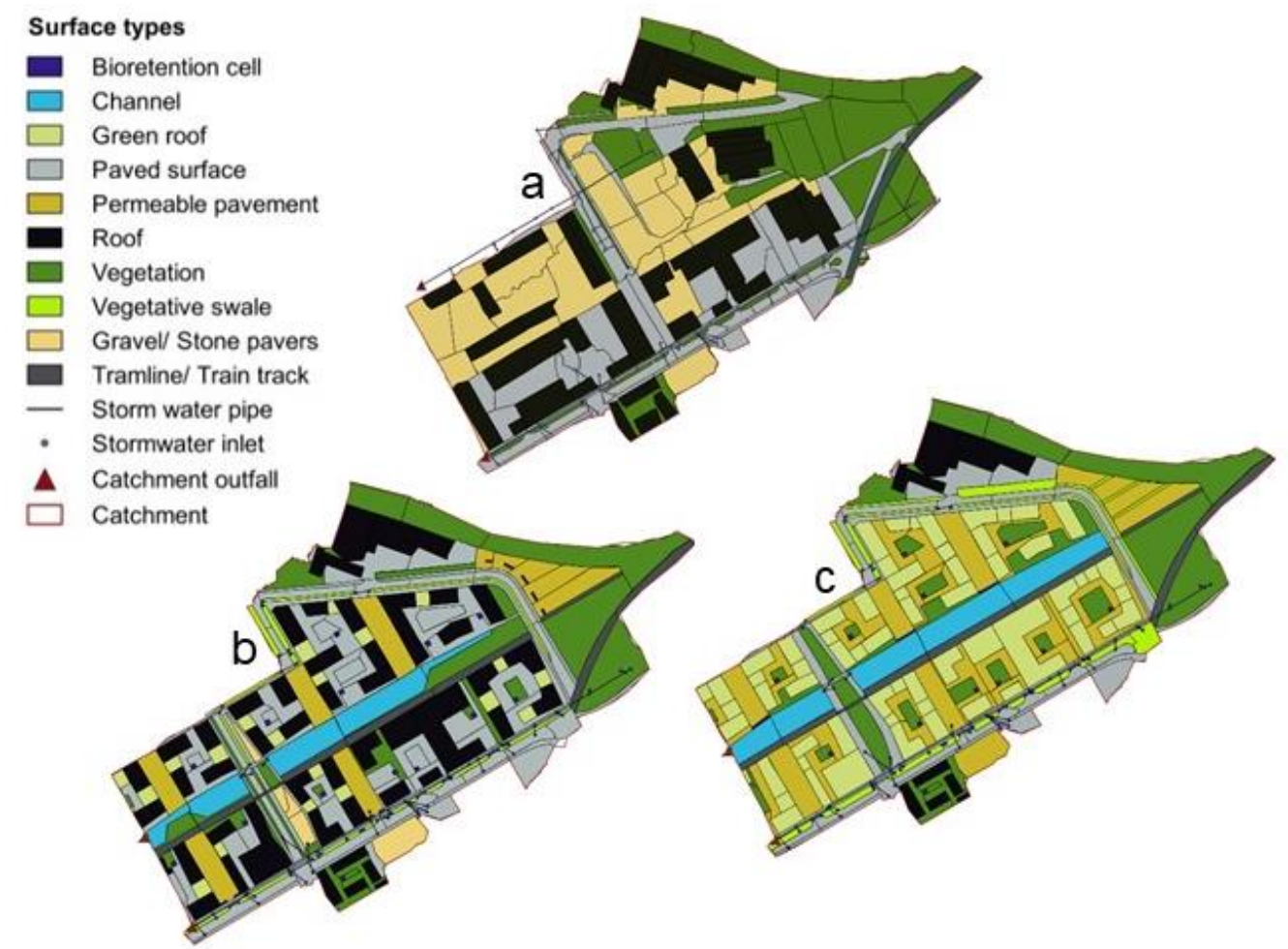

Figure 1. Surface description of study area. a) Current, b) Scenario A, and c) Scenario $B$

\section{RESULTS AND DISCUSSION}

Scenario $B$ with the maximum sponge city resemblance is highly effective in alleviating flooding and reducing discharge in the short term intense event E1 (Table 2). The share of flooding in water balance is reduced from $44 \%$ (Current) to $6 \%$ for $A$ and $0 \%$ for $B$, which is complemented by the discharge changing from $34 \%$ to $55 \%$ for $A$ and $14 \%$ for $B$. The shares of discharge suggest that scenario $B$ is highly effective in alleviating flooding and reducing discharge. Although the share of discharge for scenario $A$ is high, it still suggests the potential of the scenario in conveying storm water away from source during intense event to avoid flooding. The high discharge in $A$ is mostly storm water flow in the open channel (see Figure 1b), which functions as a slow conveyance system.

Table 2. Shares of water balance components for $E 1$

\begin{tabular}{lccccc}
\hline & Precipitation & Infiltration \& Evap loss & Flooding & Discharge & Storage \\
\cline { 2 - 6 } & $(\mathrm{mm})$ & $(\mathrm{mm})$ & $(\mathrm{mm})$ & $(\mathrm{mm})$ & $(\mathrm{mm})$ \\
\hline Current & 70.56 & 14.49 & 31.05 & 23.13 & 1.10 \\
Scenario A & 70.56 & 11.76 & 4.04 & 38.77 & 15.63 \\
Scenario B & 70.56 & 12.23 & 0.00 & 9.96 & 47.82 \\
\hline
\end{tabular}




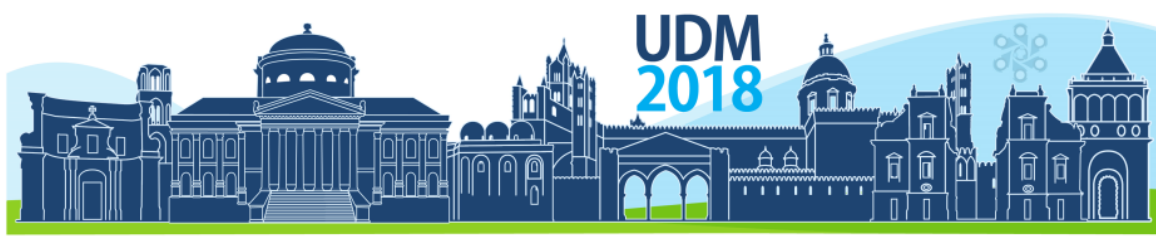

$11^{\text {th }}$ International Conference on Urban Drainage Modelling

23-26 Sep | Palermo - Italy

The decrease in flooding and discharge results in increased water storage for scenarios $A$ and $B$. The share of storage space in water balance is increased from $1 \%$ for current to $22 \%$ for scenario $A$ and to $68 \%$ for $B$, indicating that scenario $A$ with moderate storage ability may have potential for sponge city concept for moderate rain events, even though it may not achieve it for intense events like $\mathrm{E} 1$. On the other hand, the high storage water volume for scenario $B$ suggest that it can perform effectively as a sponge city even in an intense event such as E1.

Only small changes in infiltration and evaporation are observed between current situation $(21 \%), A(17 \%)$, and $B(17 \%)$. The smaller loss of infiltration and evaporation for the scenarios $A$ and $B$ than in the current situation can be attributed to precedence of storage over infiltration for systems with storage based LIDs although the imperviousness in the scenarios increases from the current state. However, the impervious areas in the scenarios are replaced with LIDs.

The reduction in discharge and increase in storage is also seen from the long term water balance components for E2 (Figure 2). In this long term simulation, the $8 \mathrm{~mm}$ of flooding for the current situation is diminished for scenarios $A$, and $B$. Additionally, the cumulative discharge is reduced from $150 \mathrm{~mm}$ for the current situation to $118 \mathrm{~mm}$ for $A$ and to $18 \mathrm{~mm}$ for $B$. The reduction in discharge is complemented by increase in the storage, which increases from 0 in current situation to 15 and $56 \mathrm{~mm}$ for $A$ and $B$. The infiltration and evaporation loss are increased by $10 \%$ and $26 \%$ for scenarios $A$ and $B$ as compared to the current, which is mostly due to changes in evaporation of stored water in LID system. It is evident that both scenarios are highly effective at reducing flooding and discharge, due to increased storage capacity, infiltration and evaporation. As the storage has a major role in decrease of flooding and discharge for the LID scenarios, the recovery of the LID storage space between rain events poses an important control on the functioning of the LID setups and requires further assessment.

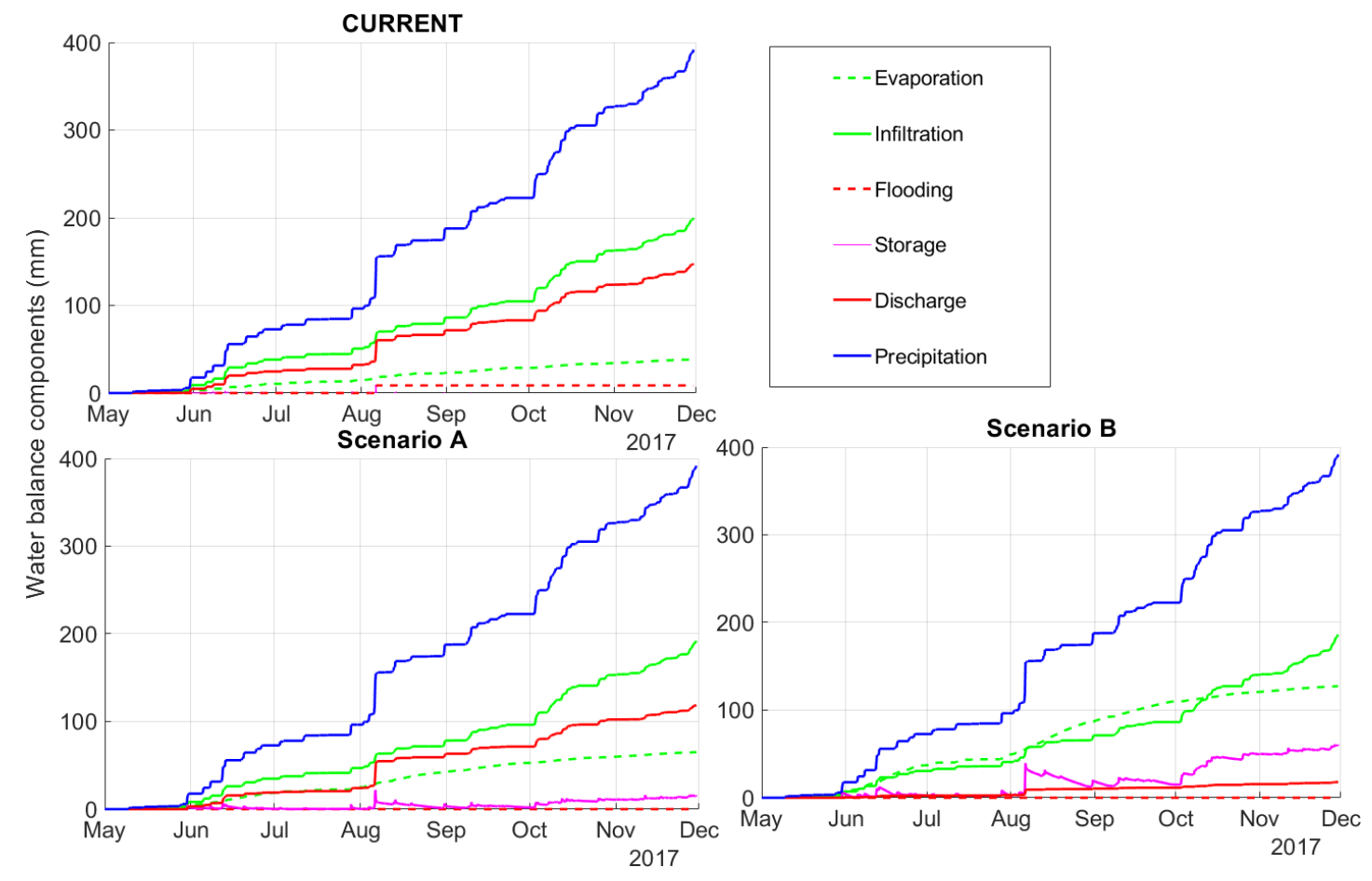

Figure 2. Cumulative water balance for the current state and the two design scenarios in E2. 


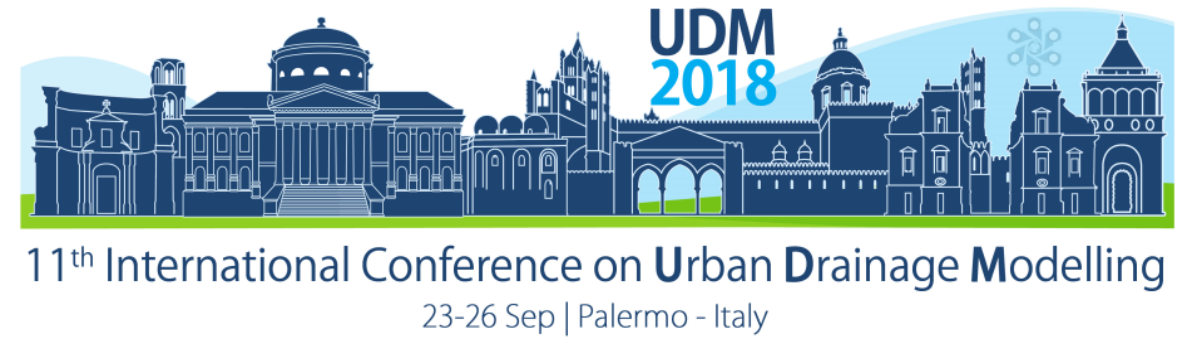

\section{CONCLUSIONS}

This study demonstrated the effectiveness of two LID-based urban designs in realizing the sponge city concept for two rainfall events. The effectiveness is quantified by assessing the relative shares of various water balance components. For the intense short-term event $E 1$, scenario $B$ reproduced a sponge city by effectively reducing flooding and discharge, and storing a large share of rain. Scenario $A$ was less effective at reducing flooding. However, even if $A$ cannot function as a sponge for intense events such as $\mathrm{E} 1$, it shows potential for less intense events with shorter return periods. This is supported by the results for the long term simulation (E2), where both scenarios were very effective at reducing flooding and discharge.

\section{ACKNOWLEDGEMENTS}

Authors are grateful for the funding from the Ministry of Agriculture and Forestry, Finland, and the Schlumberger Foundation. The study is conducted as a part of the larger UrbanStormwaterRiskProject project coordinated by the ELY Centre for Southwest Finland.

\section{References}

Burns, M. J., Fletcher, T. D., Walsh, C. J., Ladson, A. R., \& Hatt, B. E. (2012). Landscape and Urban Planning Hydrologic shortcomings of conventional urban stormwater management and opportunities for reform. Landscape and Urban Plan. 105(3), 230-240.

Fletcher, T. D., Andrieu, H., \& Hamel, P. (2013). Understanding, management and modelling of urban hydrology and its consequences for receiving waters: A state of the art. Adv. Water Resour. 51, 261-279.

Jia, H., Ma, H., Sun, Z., Yu, S., Ding, Y., \& Liang, Y. (2014). A closed urban scenic river system using stormwater treated with LID-BMP technology in a revitalized historical district in China. Ecol. Eng. 71, 448-457.

Krebs, G., Kokkonen, T., Valtanen, M., Setälä, H., \& Koivusalo, H. (2014). Spatial resolution considerations for urban hydrological modelling. J. Hydrol. 512, 482-497.

Nash, J.E., Sutcliffe, J.V., 1970. River flow forecasting through conceptual models part I - A discussion of principles. J. Hydrol. 10, 282-290.

Rossman, L.A. (2016). A Storm Water Management Model User's Manual. EPA/600/R-05/040, U.S. Environmental Protection Agency, Cincinnati, OH, USA.

Sillanpää, N., \& Koivusalo, H. (2018). "Modelling tools for enhanced stormwater management", in Kling et al. (2018), Storm filter project guideline (in press).

Qin, H. peng, Li, Z. xi, \& Fu, G. (2013). The effects of low impact development on urban flooding under different rainfall characteristics. J. Environ. Manage. 129, 577-585.

Xu, T., Jia, H., Wang, Z., Mao, X., \& Xu, C. (2017). SWMM-based methodology for block-scale LID-BMPs planning based on site-scale multi-objective optimization: a case study in Tianjin. Front. Environ. Sci. Eng. 11(4). 


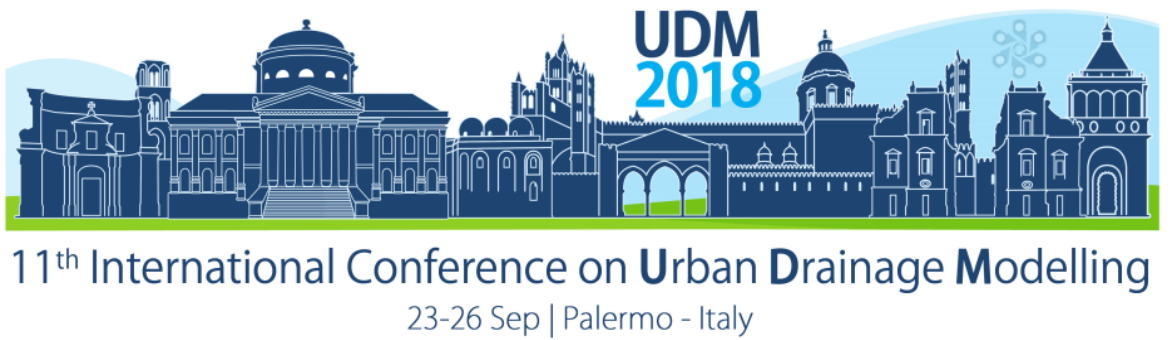

\title{
Internal fluctuations in green roof substrate moisture content during a storm event
}

\author{
Zhangjie Peng ${ }^{1}$ and Virginia Stovin ${ }^{1}$ \\ ${ }^{1}$ The University of Sheffield, Civil and Structural Engineering, Sheffield, UK \\ (zpeng3@sheffield.ac.uk; v.stovin@sheffield.ac.uk)
}

\begin{abstract}
Understanding how the moisture content in a green roof substrate varies during a storm event is essential for accurately modelling runoff detention. During a storm event, rainfall in excess of field capacity is held in temporary storage. Two alternative detention models, based on reservoir routing and Richard's equation, were validated against the measured green roof runoff and temporary moisture storage data. In most cases, moisture responses at different depths occur simultaneously during storms, although the recorded data indicate a vertical gradient in the absolute values of local field capacity. Both reservoir routing and Richard's equation can accurately estimate the runoff profile from a green roof system. Moisture content responses can be regenerated satisfactorily by both models in terms of timing and shape. Further studies are required on substrate physical properties to improve the accuracy of detention modelling using Richard's equation.
\end{abstract}

Keywords: Green roof; Substrate; Detention modelling; Moisture content

\section{INTRODUCTION}

Green roofs can potentially contribute to urban stormwater management through two hydrological processes, the retention of rainfall and the detention of runoff. In terms of retention, it is widely understood that moisture lost via evapotranspiration prior to a storm event provides retention capacity within the substrate. It has also been demonstrated that in shallow green roof systems, losses due to evapotranspiration reduce when there is restricted moisture available. Berretta et al. (2014) used data from moisture content probes located within four green roof test beds located in Sheffield (UK) to clearly demonstrate these moisture content responses during dry weather periods. In this paper we use the same moisture content data to explore changes in substrate moisture content during storm events, focusing on how the data from the moisture content probes can help us to understand and model the detention (or delay) in runoff.

\section{MATERIALS AND METHODS}

\subsection{Monitored Data}

A complete description of test beds configurations can be found in Berretta et al. (2014), DeVille et al. (2018) and Stovin et al. (2015). Test beds (TB) 1 to 3 are sedum vegetated green roofs with heather and lavender substrate (HLS), sedum carpet substrate (SCS) and light expanded clay substrate (LECA) respectively, and TB7 is an unvegetated bed with SCS substrate. In each test bed, three moisture probes were installed at $20 \mathrm{~mm}, 40 \mathrm{~mm}$ and $60 \mathrm{~mm}$ below test bed surface. On-site climate, rainfall, and runoff data were also collected. 444 identified rainfall events were used to determine the maximum moisture content. Two rainfall events from TB1 were used for further analysis and preliminary model validation. 


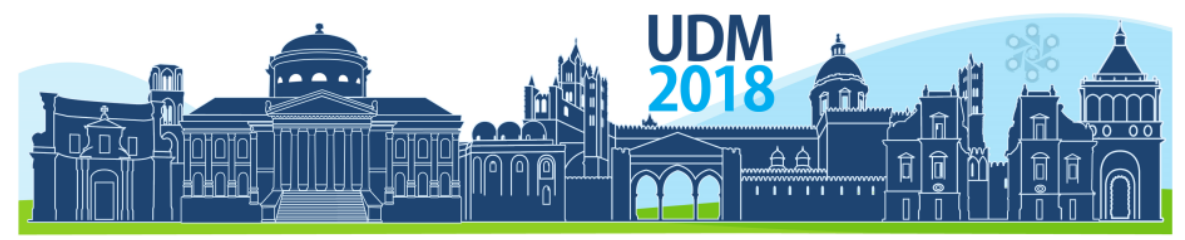

$11^{\text {th }}$ International Conference on Urban Drainage Modelling

23-26 Sep | Palermo - Italy

\subsection{Detention Modelling}

Two approaches are commonly taken to modelling the detention effect: a lumped (black box) approach based on reservoir routing (equations 1 and 2) or a physically-based finite element approach based on unsaturated flow hydraulics and the Richard's equation (e.g. as implemented in the widely-used HYDRUS-1D model) (equations 3, 4 and 5). During a rainfall event the substrate moisture content temporarily rises above field capacity, leading to the generation of runoff. For the lumped reservoir routing model:

$$
\begin{gathered}
\text { Qout }_{t}=\boldsymbol{k h}_{t-1}^{n} \\
\boldsymbol{h}_{t}=\boldsymbol{h}_{t-1}+\operatorname{Qin}_{t} \Delta t-\text { Qout }_{t} \Delta t
\end{gathered}
$$

where $\boldsymbol{Q i n}$ is the inflow due to rainfall, Qout is the runoff from the green roof system, $\boldsymbol{h}$ is the stored water and $\boldsymbol{k}$ and $\boldsymbol{n}$ are routing parameters. A 5-minute time step was used with $k=$ 0.203 and $n=1.818$. For the Richard's equation:

$$
\frac{\partial \theta}{\partial t}=\frac{\partial}{\partial z}\left[K(h)\left(\frac{\partial h}{\partial Z}-1\right)\right]
$$

where $\boldsymbol{\theta}$ is volumetric water content, $\boldsymbol{K}(\boldsymbol{h})$ is hydraulic conductivity at matric head $\boldsymbol{h}$. The water retention characteristic was determined by the Van-Genuchten model (equation 4), and the Maulem equation (equation 5) was used to estimate unsaturated hydraulic conductivity as a function of matric head.

$$
\begin{gathered}
S_{e}=\frac{\theta-\theta_{r}}{\theta_{s}-\theta_{r}}=\left[1+(\alpha h)^{n}\right]^{-m} \\
K\left(S_{e}\right)=K_{s} S_{e}^{0.5}\left[1-\left(1-S_{e}^{1 / m}\right)^{m}\right]^{2}
\end{gathered}
$$

where $\boldsymbol{S}_{\boldsymbol{e}}$ is the relative saturation, $\boldsymbol{\theta}_{\boldsymbol{r}}$ is residual water content, $\boldsymbol{\theta}_{\boldsymbol{s}}$ is saturated water content, $\boldsymbol{\theta}$ is volumetric water content, $\boldsymbol{h}$ is matric suction, $\boldsymbol{\alpha}, \boldsymbol{n}, \boldsymbol{m}$ are empirical parameters, $\alpha$ is the inverse of air-entry value, $n$ is a pore size distribution index and $\boldsymbol{m}=\mathbf{1}-\mathbf{1} / \boldsymbol{n}, K_{S}$ is saturated hydraulic conductivity, $K\left(S_{e}\right)$ is the unsaturated hydraulic conductivity at $S_{e}$, and the tortuosity parameter in this equation is assumed to be 0.5 . The parameter values were based on the pressure plate experiments conducted by Berretta et al. (2014). In this case $\boldsymbol{\theta}_{\boldsymbol{r}}=0.02 \mathrm{v} / \mathrm{v}, \boldsymbol{\theta}_{\boldsymbol{s}}$ $=0.569 \mathrm{v} / \mathrm{v}, \boldsymbol{\alpha}=0.0347 \mathrm{~cm}^{-1}, \boldsymbol{n}=1.329$, and $\boldsymbol{K}_{S}=0.8 \mathrm{~cm} / \mathrm{min}$. As the Richard's equation model only represents the substrate layer, a reservoir routing model was added to represent detention due to the underlying drainage layer $(\boldsymbol{k}=0.138 ; \boldsymbol{n}=2.072)$.

\section{RESULTS AND DISCUSSION}

\subsection{Maximum observed water content}

Figure 1 illustrates the maximum water content of each test bed at three depths during all 444 monitored rainfall events. Substrate and vegetation contribute to the difference in maximum moisture content between test beds. TB1, 2 and 3 have the same vegetation but maximum moisture content shows variation between test beds, which is believed to be caused by differences in substrate physical properties. TB1 and TB7 share the same substrate (TB7 is un-vegetated), but moisture content in TB1 is higher than in TB7, which indicates the influence of vegetation. Runoff will not occur if the maximum moisture content is below field capacity. From monitored moisture content data, for individual TB, the maximum moisture content is 


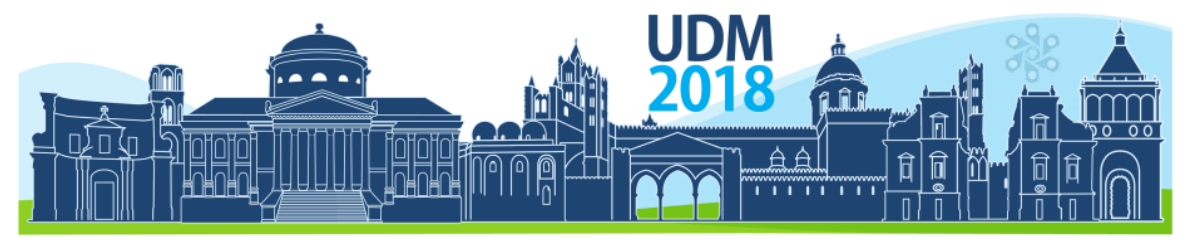

$11^{\text {th }}$ International Conference on Urban Drainage Modelling

23-26 Sep | Palermo - Italy

always in the lowest part of the substrate, which may indicate the presence of a vertical gradient in the substrate's physical characteristics (Berretta et al., 2014).

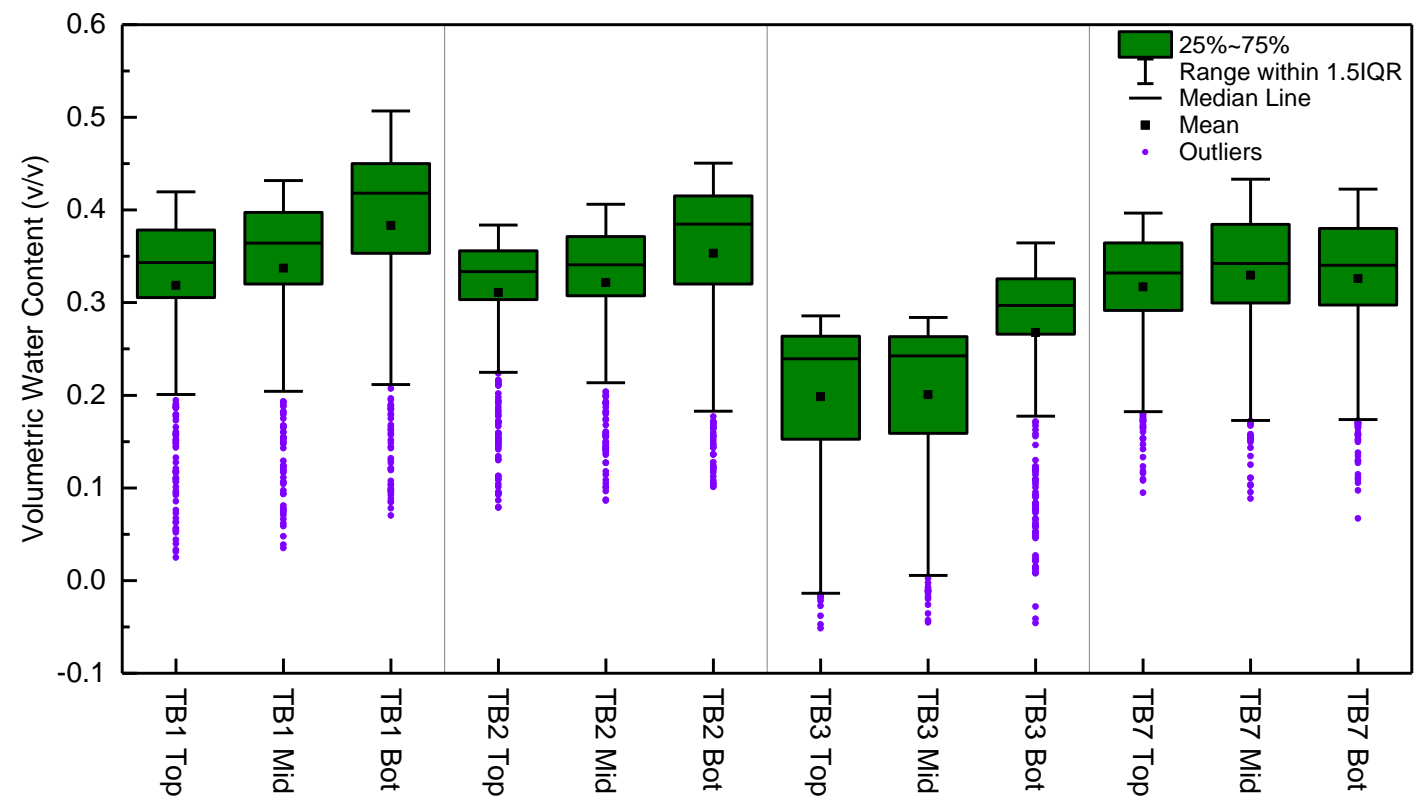

Figure 1. Maximum Volumetric water content for 444 rainfall events

\subsection{Moisture content behaviour during storms}

The top row in Figure 2 presents the rainfall, runoff and moisture content data from two sample events for which the initial moisture content was at or close to apparent field capacity at the onset of rainfall (onset rainfall apparent field capacity was determined using the approach proposed by De-Ville et al., (2018)). Both events had $>8 \mathrm{~mm}$ rainfall and generated at least 7 $\mathrm{mm}$ runoff. Temporary increases in moisture content may be seen to occur in response to rainfall, after which the monitored moisture content returns to a constant value (assumed equal to field capacity). Consistent with Fig. 1, the three moisture content probes indicate slightly different moisture content levels at field capacity. Differences in the absolute values are to be expected in coarse-grained heterogeneous green roof substrates that may have consolidated over time. The substrate moisture content tends to increase simultaneously with rainfall. The temporary storage in the substrate was generally less than $0.02 \mathrm{v} / \mathrm{v}$, equivalent to $1.6 \mathrm{~mm}$ in an $80 \mathrm{~mm}$ deep roof.

\subsection{Model Validation}

The middle row in Figure 2 confirms that both reservoir routing and Richard's equation models can achieve satisfactory results for runoff prediction (secondary Y-axis), although both methods tend to underestimate the peak runoff slightly. This type of model validation has been presented elsewhere; however, further independent validation is provided by the monitored moisture content data. The modelled temporarily stored runoff (Primary Y-Axis, depthaveraged data) is less satisfactory; whilst the timing is modelled well, the reservoir routing model tends to underestimate, and Richard's equation tends to overestimate, the temporary storage in the substrate. As the Richard's equation is solved over a depth profile, validation of the vertical moisture content profile is possible. Figure 2 (bottom row) compares the modelled 


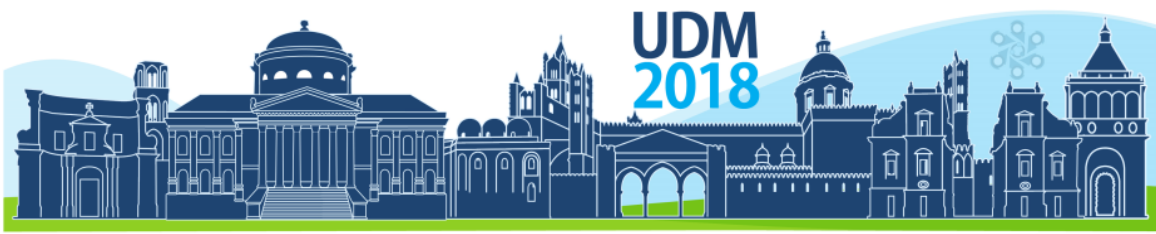

$11^{\text {th }}$ International Conference on Urban Drainage Modelling

23-26 Sep | Palermo - Italy

(Richard's equation) and observed moisture content fluctuations at three depths. These preliminary comparisons reveal stronger vertical gradients in the modelled responses compared with the observed data, which require further investigation.

\section{CONCLUSIONS}

This paper used monitored moisture content data to investigate moisture content changes in green roof substrate during storm events. Even in significant storm events the increase in moisture content associated with temporarily stored (detained) moisture amounts to less than $2 \mathrm{~mm}$. Moisture responses at all three depths occur simultaneously, rather than as a wetting front moving downwards. Both the lumped reservoir routing model and Richard's equation model can provide reasonable predictions of runoff profiles, and overall temporary storage dynamics. However, discrepancies between the measured and modelled (Richard's equation) vertical depth profiles were observed. Further research is required to investigate the green roof substrate's water retention characteristic and unsaturated hydraulic conductivity to develop a better understanding of moisture content response within substrates.
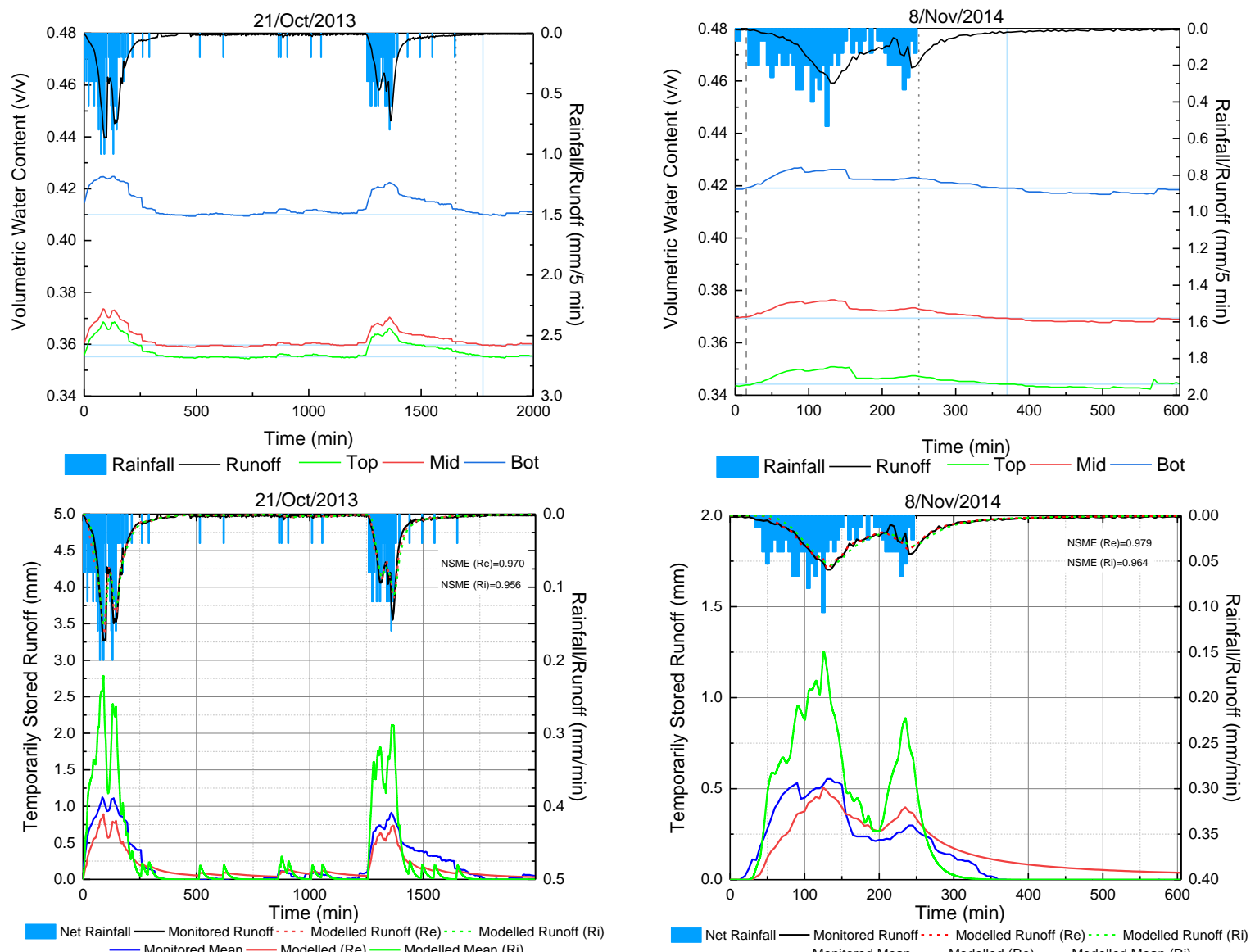

- Monitored Mean — Modelled (Re) — Modelled Mean (Ri) 
Proceedings of the 11th Int. Conference on Urban Drainage Modelling, 23-26 Sep. 2018, Palermo (ITALY). Ed. prof. Giorgio Mannina

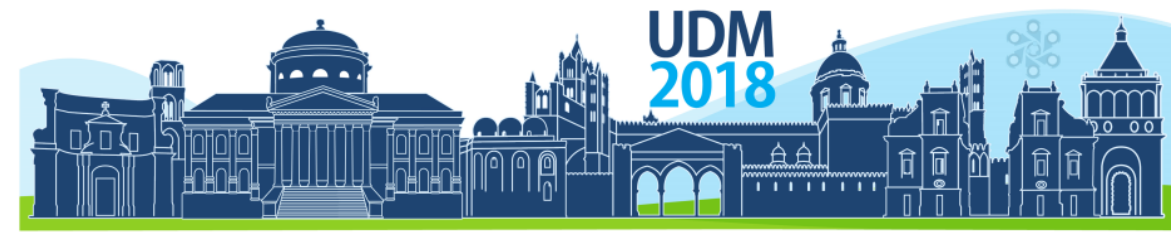

$11^{\text {th }}$ International Conference on Urban Drainage Modelling 23-26 Sep | Palermo - Italy
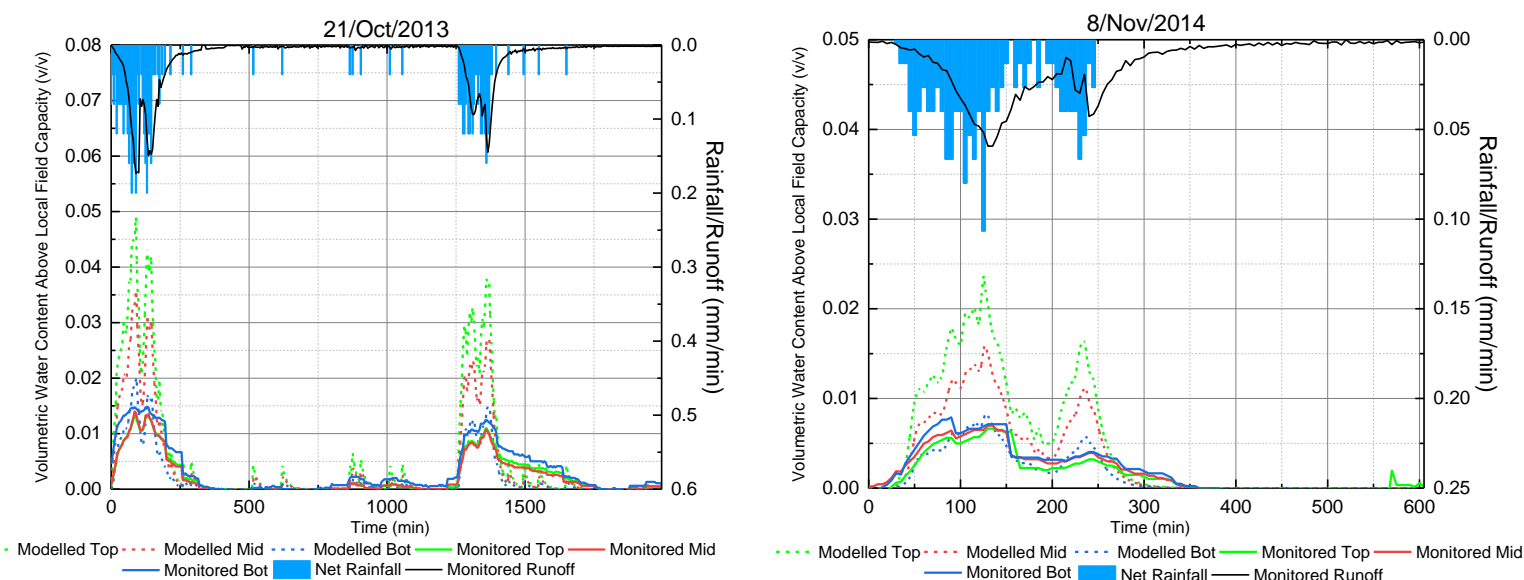

Figure 2. Top row: monitored rainfall, runoff and moisture content profiles for TB1 (vertical dotted line is the time rainfall stops, solid blue vertical line indicates field capacity); Middle row: validation of temporarily stored moisture

(depth averaged); Bottom row: validation of temporarily stored moisture (individual probes, vertical profile).

\section{References}

Berretta, C., Poë, S., Stovin, V., 2014. Moisture content behaviour in extensive green roofs during dry periods: The influence of vegetation and substrate characteristics. J. Hydrol. 511, 374-386.

De-Ville, S., Menon, M., Stovin, V., 2018. Temporal variations in the potential hydrological performance of extensive green roof systems. J. Hydrol. 558, 564-578.

Stovin, V., Poë, S., De-Ville, S., Berretta, C., 2015. The influence of substrate and vegetation configuration on green roof hydrological performance. Ecol. Eng. 85, 159-172. 


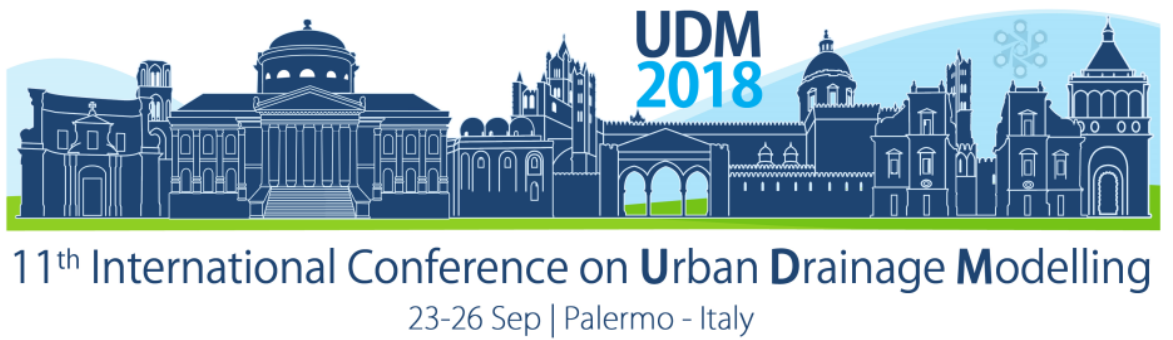

\title{
Developing a Stochastic Sewer Input Model to Support Sewer Design Under Water Conservation Measures
}

\author{
O. Bailey', J.A.M.H. Hofman ${ }^{1}$, T.C. Arnot ${ }^{1}$, Z. Kapelan², M. Blokker ${ }^{4}$, J. Vreeburg ${ }^{2,3}$ \\ ${ }^{1}$ Water Innovation \& Research Centre, and Dept. of Chemical Engineering, University of Bath, Bath, BA27AY, UK \\ ${ }^{2}$ CEMPS, University of Exeter, Harrison Building, N Park Rd, Exeter, EX4 4QF, UK \\ ${ }^{3}$ Evides Water Company, PO Box 4472, 3006 AL Rotterdam, The Netherlands \\ ${ }^{4}$ KWR Watercycle Research Institute, PO Box 1072, 3430 BB Nieuwegein, The Netherlands
}

\begin{abstract}
Population growth and climate change place a strain on water resources. There is growing motivation to reduce household water use. UKWIR (2016) have stated the aim to halve water abstraction by 2050 . This will significantly reduce inflow to the sewer and drive up wastewater concentration. How will our sewers respond to this and could changes in design lead to a more efficient system in the future? This work presents the development and calibration of a stochastic sewer input model that will predict both hydraulic and pollutant loading for various water saving scenarios. For the first time the stochastic water demand model SIMDEUM® will be integrated with InfoWorks ICM (Sewer Edition), software for hydraulic sewer modelling. This enables accurate time dependent predictions of water, BOD and nitrogen loads from household discharges to the sewer under dry weather conditions. Calibration has been carried out using two sets of sewerage data from small residential catchments in the Wessex Water region of the UK. The model gives an accurate prediction of the diurnal patterns of sewage discharge at a household level. This will be used as an input to future sewer simulation models to accurately predict changes to flow velocity and pollutant concentration as a consequence of water conservation.
\end{abstract}

Keywords: Sewer Design; Water Conservation; Stochastic Sewer Modelling

\section{INTRODUCTION}

Rising water scarcity, pressure for sustainability and the need for water efficiency will drive reduction in water consumption and hence flow to sewer. Anglian Water (2017) is aiming for less than $80 \mathrm{~L}_{\text {capita-1 }}^{-1} \mathrm{~d}^{-1}$ water consumption, and UKWIR (2016) wishes to halve abstraction by 2050 . What will be the effect on sewer systems and the way we dispose of wastewater?

A new sewer design capable of transporting more concentrated wastewater could increase efficiency and sustainability of our wastewater networks. Increasing concentration of wastewater could lead to more effective sewage treatment and resource recovery as well as reduced pollution to receiving waters (Verstraete \& Vlaeminck, 2011). It has been suggested that sewer transport efficiency will be affected (Parkinson et al, 2005; Penn et al, 2013). The work presented here outlines the development and calibration of a stochastic wastewater discharge model. This will lead to a stochastic load model for accurate prediction of dynamic pollutant and sedimentation changes, resulting from widespread water conservation. This is part of a wider project aiming to predict effects on velocity and wastewater quality in sewers, to identify necessary design modifications that best support the sewer under heavily reduced water use. The overall aim is to re-think sewerage systems to better serve communities through water conservation, resource recovery and providing a cleaner environment. 


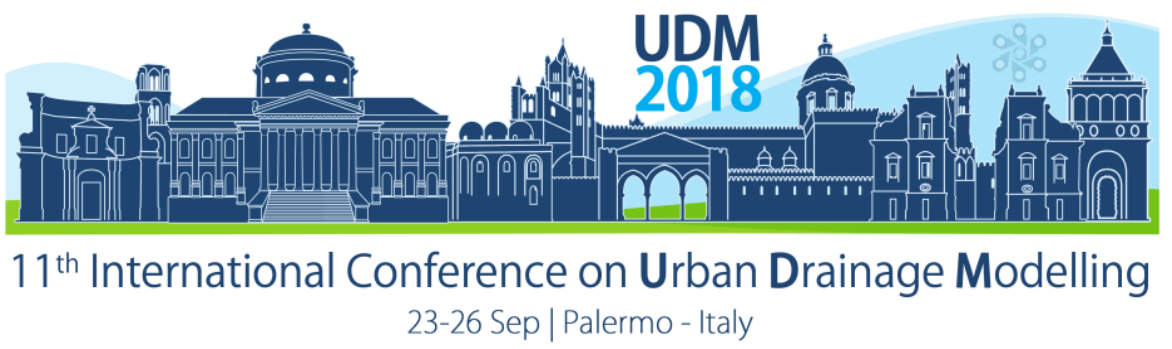

\section{METHODOLOGY}

\subsection{Hydraulic Sewer Modelling}

InfoWorks ICM (Sewer Edition; Innovyze Ltd, Oxfordshire) has been used to simulate two residential, separated sewer networks within the Wessex Water region of the UK. These catchments, serving around 200 households, were divided into smaller sub-catchments for demographic and water use analysis. SIMDEUM® was used to incorporate a stochastic wastewater discharge element into the model, based on occupancy statistics and appliance usage characteristics (Blokker et al, 2010; Blokker, 2011). Editing MATLAB® codes behind SIMDEUM® enabled integration with InfoWorks ICM to produce a stochastic sewer model.

\subsection{Model Calibration}

SIMDEUM® generates stochastic profiles using embedded probability functions based on occupancy, home presence and appliance usage, as described in Blokker et al (2010). This software was developed in the Netherlands and therefore required adaption to a UK context. The discharge patterns were first calibrated using 2011 UK Census data (Office of National Statistics, 2011) to give an accurate occupancy based prediction of water use. Output profiles were compared to observed data from the catchment sourced from water meters. Further calibration was necessary by assuming the appliance types that are present in the households. Profiles for typical households $\left(\sim 140 \mathrm{~L} \mathrm{person}^{-1} \mathrm{~d}^{-1}\right)$ were combined with those of low water usage households ( $\sim 50 \mathrm{~L} \mathrm{person}^{-1} \mathrm{~d}^{-1}$ ) in ratios of 70:30, 50:50 and 30:70 (Average house: Eco house). This produced a representative discharge profile of the observed data. Error analysis between cumulative frequency plots identified a realistic prediction method for sewer inflow.

\section{RESULTS AND DISCUSSION}

\subsection{Understanding the observed data}

Figure 1 indicates how water use varies within one catchment by averaging meter outputs. Some areas were largely metered (sub-catchment 5/6) hence there is confidence that the data offers a representative sample of the full population, other subcatchments are not metered so heavily. The data suggests that widespread metering leads to lower water use, this may link to demographic detail. The figure shows that average water use varies by as much as $100 \mathrm{~L}$ household ${ }^{-1}$ day $^{-1}$, therefore household size variation and demographical changes between sub-catchments are likely to be an important factor when calibrating discharge patterns.

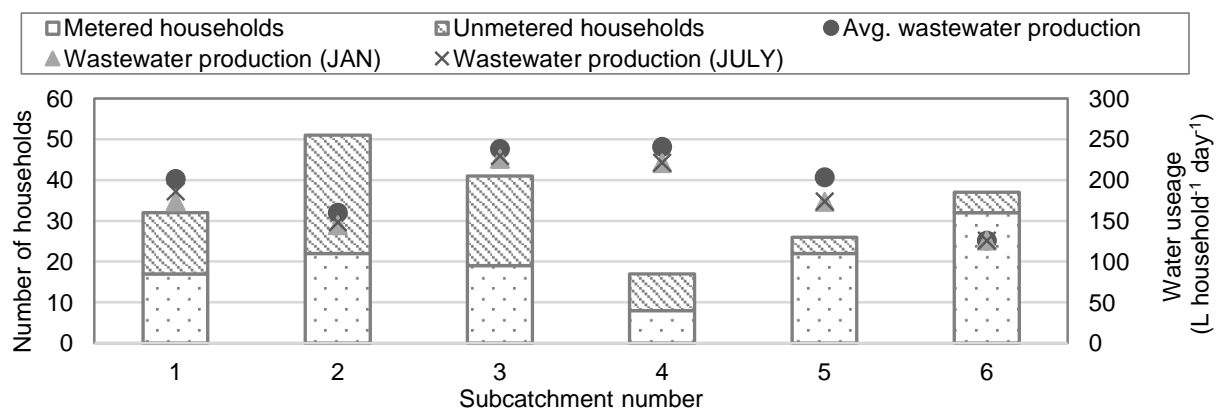

Figure 1. Proportion of metering in catchment sub-sections and wastewater discharge variation throughout the area

\subsection{Calibration of stochastic discharge model to UK situation}

To recognise variability in water use over time, recent meter readings (2017) were compared with historical data, dating back to 2010 . This gave a 95\% confidence interval for the newest 


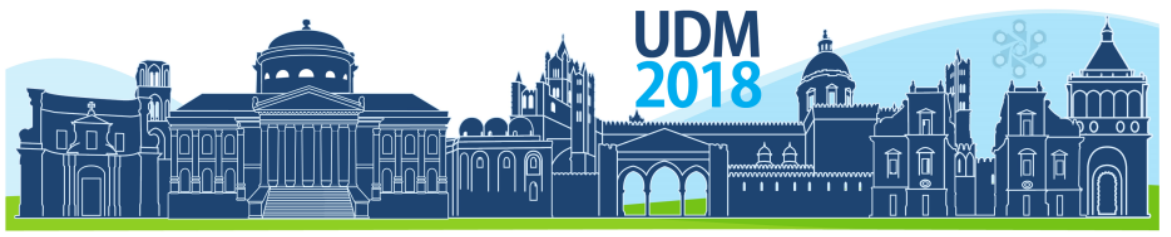

$11^{\text {th }}$ International Conference on Urban Drainage Modelling

23-26 Sep | Palermo - Italy

readings. Average meter readings from both catchments, the present day data range, and $95 \%$ confidence interval from historical data are shown in Figure 2. This shows how different profiles generated by SIMDEUM® compared during the calibration process to ensure accurate stochastic predictions for this region. The cumulative frequency plot indicates the proportion of households that use certain amounts of water. There is no value in calibrating this model to individual meters but rather using the meters to show the trend of water use in this region.

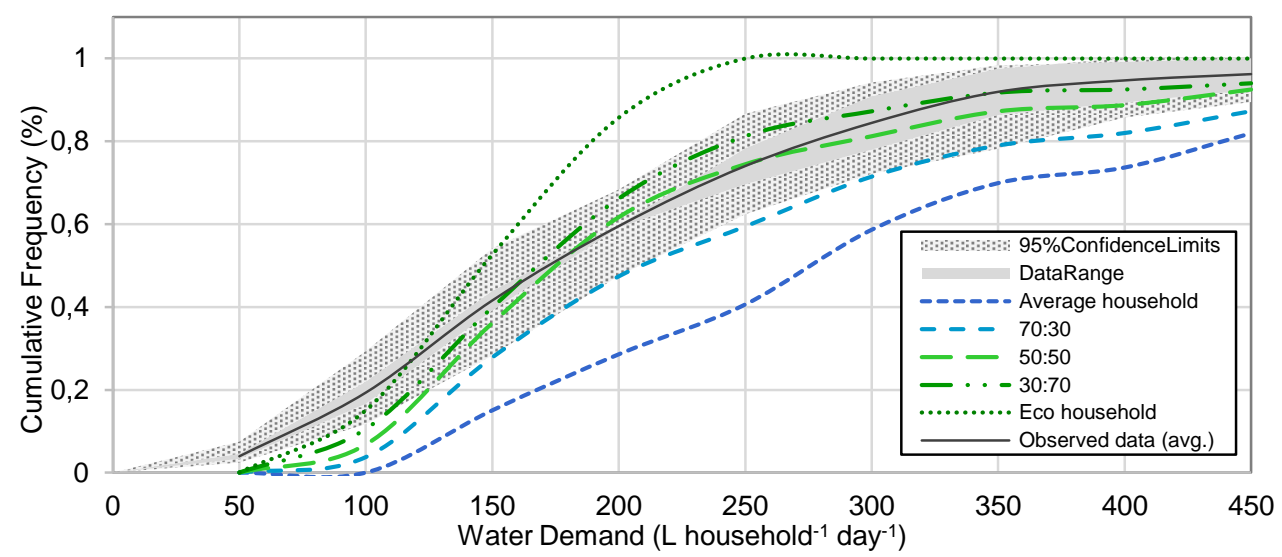

Figure 2. Cumulative frequency of household water demand for patterns generated with SIMDEUM®. This shows the calibration of the software to meet the observed values by using two SIMDEUM® demo patterns. Patterns were overlapped in ratios of 70:30, 50:50 and 30:70 (Average house: Eco house consumption). The observed data range and $95 \%$ confidence interval from historical data are shown as regions around the average demand.

Table 1 shows the most representative pattern generator is the case where $30 \%$ of households use $140 \mathrm{~L}_{\text {person }}{ }^{-1}$ day $^{-1}$ and $70 \%$ of households use $50 \mathrm{~L}^{\text {person }}{ }^{-1}$ day $^{-1}$. Average water consumption in the UK is about $150 \mathrm{~L}_{\text {person }}^{-1}$ day $^{-1}$, so this data suggests that most people in these sub-catchments use much less. However, sewer discharge excludes external water use, so the average will be less than for demand data. In Fig. 2, SIMDEUM® tends to underestimate frequency of lower usage households, this could imply a larger proportion of single person homes than accounted for in the model. Knowledge of occupancy was acquired from the 2011 census which covered a larger area than these catchments, occupancy statistics may have changed in the past 7 years hence improvement to prediction is possible in this area.

Table 1. The sum of squared errors for each generated SIMDEUM® prediction, used to evaluate the accuracy of the stochastic prediction against the observed data

\begin{tabular}{cccccc}
\hline SIMDEUM® Pattern & & \multicolumn{3}{c}{ Average house : Eco house } & \\
\cline { 3 - 4 } Generator & Average house & $70: 30$ & $50: 50$ & $30: 70$ & Eco house \\
\hline$\Sigma\left(\right.$ Error $\left.^{2}\right)$ & 0.496 & 0.155 & 0.035 & $\mathbf{0 . 0 2 5}$ & 0.187 \\
\hline
\end{tabular}

Figure 3 shows the result of feeding the calibrated stochastic profile into InfoWorks ICM for more accurate prediction of sewer flow conditions. A common assumption in sewer modelling is that a continuous diurnal pattern is produced by each household (left of Figure 3 ). The more accurate representation shows short sharp discharge peaks which eventually blend into pseudo-continuous flow downstream (right of Figure 3). Flow velocity fluctuates in a selection of differently sized pipes at various points throughout the network. The morning peak is higher and mid-day trough much lower in the stochastic profile than the continuous one. 


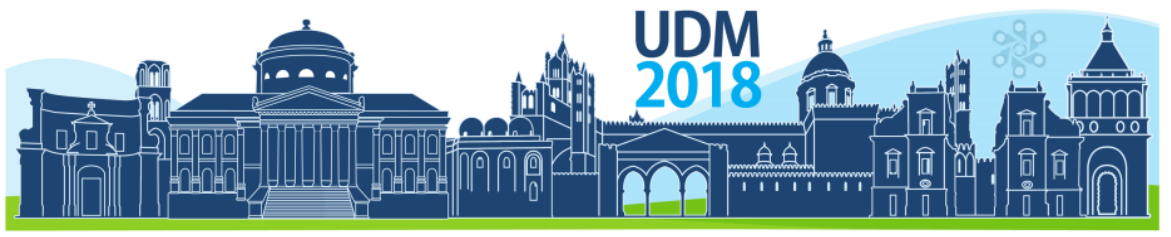

$11^{\text {th }}$ International Conference on Urban Drainage Modelling 23-26 Sep | Palermo - Italy
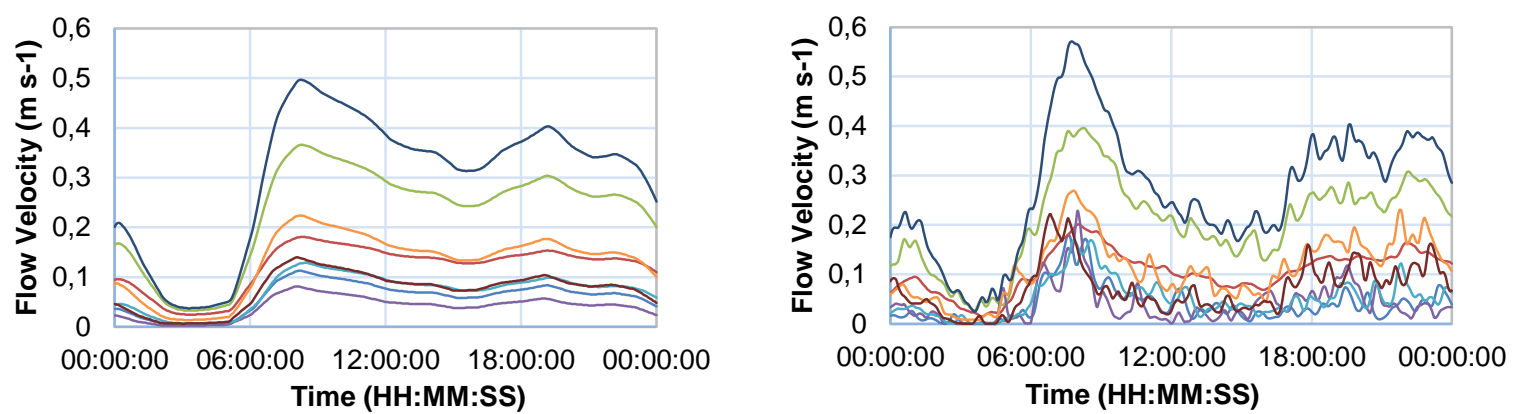

Figure 3. A comparison between continuous and stochastically generated wastewater profiles, plot shows a selection of pipes of various sizes and locations within the network.

Following calibration, it is intended to further utilise the capabilities of SIMDEUM® to generate stochastic pollutant profiles for household discharge under dry weather conditions. Within SIMDEUM® it is known which appliance generates water flow, and thus attribute water quality parameters to each discharge. This allows discharge simulation of various wastewater characteristics (temperature, organics, pharmaceuticals and nutrients) (Pieterse-Quirijns et al, 2012). By integrating this output with InfoWorks ICM, use of built-in water quality models will assess organic/nutrient concentrations and sediment build-up for varied wastewater scenarios.

\section{CONCLUSIONS}

It is important to understand the effect that significant water conservation will have on our sewerage systems and how this could help (re)design better networks to reap the potential benefits. A stochastic household discharge model has been produced and calibrated to achieve this. The model gives accurate prediction of the diurnal patterns of sewage discharge at household level. This will be used as input to future sewer system simulations to accurately predict changes to flow velocity and pollutant concentration due to water conservation.

\section{Acknowledgements}

This study was conducted as part of the WISE Centre for Doctoral Training, funded by the UK Engineering and Physical Sciences Research Council, Grant No. EP/L016214/1.

\section{References}

Anglian Water (2017) Our Innovation Shop Window, 2017. Available online: http://www.anglianwater.co.uk/aboutus/shop-window.aspx [Accessed 7 June 2017.]

Blokker, E. J. M., Vreeburg, J. H. G. \& van Dijk, J. C. (2010) Simulating Residential Water Demand with a Stochastic End-Use Model. Journal of Water Resources Planning and Management, 136(1), 19-26.

Blokker, M. (2011) Stochastic water demand modelling; Hydraulics in water distribution networks. IWA, London.

Office of National Statistics (2011) UK Census Data, 2011. Available online: http://www.ukcensusdata.com [Accessed 1 February 2018.].

Parkinson, J., Schütze, M. \& Butler, D. (2005) Modelling the impacts of domestic water conservation on the sustainability of the urban sewerage system. Journal of the Chartered Institution of Water and Environmental Management, 19(1), 49-56.

Penn, R., Schütze, M. \& Friedler, E. (2013) Modelling the effects of on-site greywater reuse and low flush toilets on municipal sewer systems. Journal of Environmental Management, 114, 72-83.

Pieterse-Quirijns, E. J., Agudelo-Vera, C. M. \& Blokker, E. J. M. (2012) Modelling sustainability in water supply and drainage with SIMDEUM®, CIBW062 Symposium.

UKWIR (2016) Our Research "Big Questions", 2016. Available online: https://www.ukwir.org/172496 [Accessed 23 May 2017.]

Verstraete, W. \& Vlaeminck, S. E. (2011) ZeroWasteWater: short-cycling of wastewater resources for sustainable cities of the future. International Journal of Sustainable Development \& World Ecology, 18(3), 253-264. 


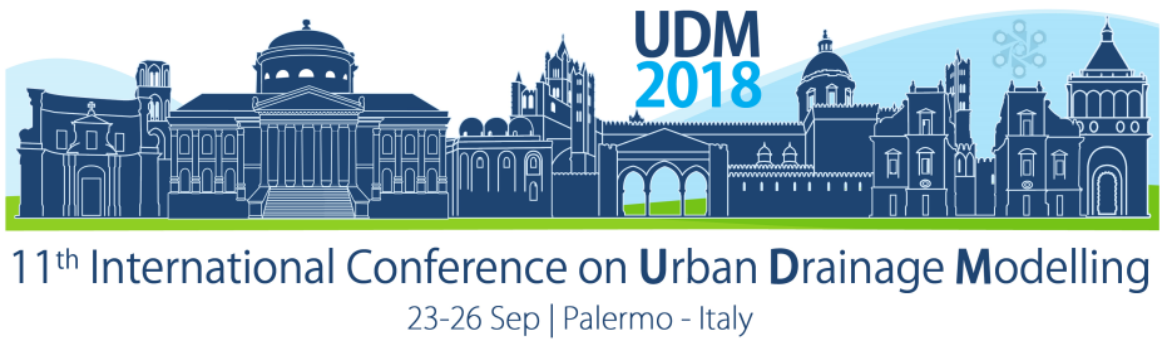

\title{
Impact of biochar on treatment performance of roadside sand filters - field monitoring and geochemical modelling
}

\author{
Eero Assmuth ${ }^{1}$, Nora Sillanpää ${ }^{1}$, Laura Wendling ${ }^{2}$ and Harri Koivusalo ${ }^{1}$ \\ ${ }^{1}$ Aalto University School of Engineering, Department of Built Environment, Espoo, Finland \\ 2 VTT Technical Research Centre Ltd, Espoo, Finland
}

\begin{abstract}
Roadside filters can be used to treat polluted stormwater. In this study, sand and sand-biochar filters were investigated in full-scale field conditions during three rain events. Stormwater influent and effluent of the filters were sampled with high frequency and up to 29 water quality parameters were determined. The obtained field data was analyzed and used as an input for geochemical modelling. The study showed promising results for both filter types with respect to retention of metals, total suspended solids and total phosphorus. Biochar amendment had clear improvement only for nitrogen removal; some release of organic carbon from biochar filter material was observed. Concentrations of most measured parameters varied considerably during and between the studied events. Geochemical modelling showed that precipitation is one possible removal mechanisms for many pollutants along with sorption and physical filtration.
\end{abstract}

Keywords: Stormwater filtration; Biochar amendment; PHREEQC

\section{INTRODUCTION}

Urban runoff contains a wide range of pollutants originating from human activities and thus degrades surface water quality. One of the simplest stormwater treatment structure types is a roadside filter, which is a sand-containing pit next to a road. The sand filter matrix can be mixed with amendments, such as biochar, to improve its performance (Reddy et al., 2014). Due to the novelty of the discipline, there is lack of scientific information about the performance of stormwater filtration systems under realistic field conditions (Genç-Fuhrman et al., 2007). In this study, the main objective was to investigate stormwater filters in real field conditions in Southern Finland and apply the obtained data in modelling to reveal mechanisms occurring in pollutant removal. Similar studies of biochar-amended sand filters are rare and the current study is among the first under field conditions.

\section{MATERIALS AND METHODS}

\subsection{Study site}

A filtration system for road runoff located in the City of Vantaa, Finland $\left(60^{\circ} 18^{\prime} 52^{\prime \prime}\right.$ N, $24^{\circ} 52^{\prime} 52^{\prime \prime}$ E), was investigated during summer 2017. The site includes two different filters: a sand filter and a sand-biochar filter. The filters are located along a road with an average annual daily traffic (AADT) load of 7610 vehicles (2016). Agricultural fields surround the study site area. Catchment areas of the filters, ca. $100 \mathrm{~m}^{2}$ each, consist of road and walkway surfaces. Both filters were constructed in January 2017.

The surface area of both filters is $34 \mathrm{~m}^{2}$ and their respective depth is $1.2 \mathrm{~m}$. The sand used in the filters is $0.2-2 \mathrm{~mm}$ in grain size. The filters were built to be as identical as possible, except for the 300-mm thick birch (Betula) biochar layer at a depth of $200 \mathrm{~mm}$ from the surface in the sand-biochar filter. The different layers are separated from one another with a filter fabric. Both filters are isolated from the surrounding soil with a bentonite clay liner, and underdrains are 


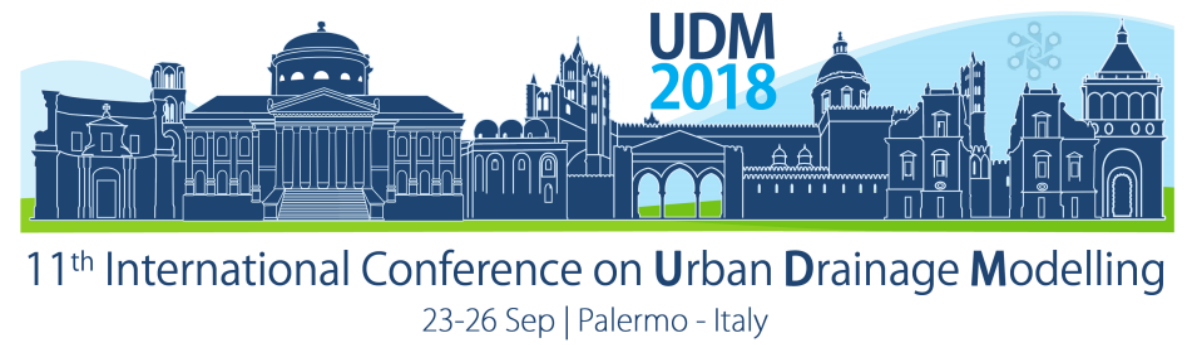

installed at the bottom of each filter. The underdrains discharge into a ditch next to the road, which allowed flow rate monitoring and quality sampling of separate outflows from each filter.

\subsection{Field measurements}

The field monitoring was conducted during three rain events on June 8 (precipitation of 23.8 $\mathrm{mm}$ ), June $20(10.6 \mathrm{~mm})$ and July $11(9.4 \mathrm{~mm}), 2017$. Two on-site rain gauges (IM523 by PessI Instruments) recorded precipitation with 1-minute temporal interval and $0.2 \mathrm{~mm}$ resolution. Outflow from the filters was monitored with automatic flow gauges (Hydrus DN $50 \mathrm{~mm}$ by Diehl). Because automatic flow gauges did not perform accurately during the periods of low flow rates, the flow monitoring was complemented with frequent manual flow measurements during the three rain events.

Water samples were manually collected from the filter outflows throughout the rain events. To assess the impact of the filters, influent (untreated) stormwater from the road area was sampled from a bridge downspout ca. $250 \mathrm{~m}$ away from the filters. The influent flow rate was estimated based on the on-site measured rainfall and catchment areas of the filters. In total, 122 influent and effluent samples were gathered, which were analyzed for 14-29 water quality parameters. The analyzed parameters were TSS, TN, $\mathrm{NH}_{4}, \mathrm{NO}_{2}+\mathrm{NO}_{3}, \mathrm{TP}, \mathrm{PO}_{4}, \mathrm{TOC}, \mathrm{DOC}$, $\mathrm{Cd}, \mathrm{Cu}, \mathrm{Pb}, \mathrm{Ni}, \mathrm{Zn}, \mathrm{Mn}, \mathrm{Si}, \mathrm{Fe}, \mathrm{SO}_{4}, \mathrm{Cl}, \mathrm{Ca}, \mathrm{Mg}, \mathrm{K}, \mathrm{Na}, \mathrm{Al}, \mathrm{pH}$, alkalinity, electrical conductivity, turbidity, UV-absorbance and redox potential.

\subsection{Data analysis}

Event mean concentrations $(E M C)$ of influent and filter effluents were determined as flowweighted average concentrations for each event.

Pollutant removal efficiencies of the filters were assessed using mass efficiencies ( $m_{\text {eff }}$ ), which consider water losses within the filters and were determined by:

$$
m_{\text {eff }}=\frac{L_{\text {in }}-L_{\text {out }}}{L_{\text {in }}} 100 \%
$$

where $L_{\text {in }}$ is the pollutant load of the influent and $L_{\text {out }}$ is the pollutant load of the effluent (Law et al., 2008).

\subsection{Geochemical modelling}

Geochemical modelling of mineral saturation indices (SI) using PHREEQC (Appelo \& Postma, 2007) was conducted to assess the mechanisms of pollutant removal within the filters. Results of filter effluent water quality analyses were used as an input to the geochemical modelling. $S I$ is defined as:

$$
S I=\log \left(\frac{I A P}{K_{S}}\right)
$$

where IAP is the ion activity product and $K_{s}$ is the solubility product (Appelo \& Postma, 2007). The values of $K_{s}$ were derived from databases phreeqc.dat and wateq4f.dat, and 89 mineral phases were included in the modelling. The $S I$ describes whether a mineral phase is theoretically oversaturated, undersaturated or in equilibrium with respect to the solution (in this case the water in the filter) (Appelo \& Postma, 2007). Oversaturation of a mineral indicates its potential precipitation and thus long-term removal within the filter. 


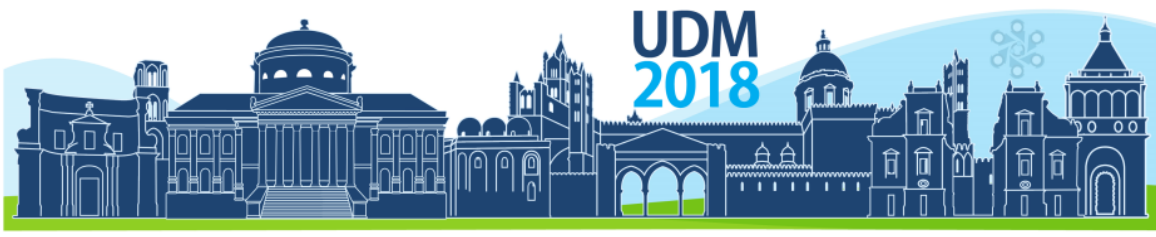

$11^{\text {th }}$ International Conference on Urban Drainage Modelling

23-26 Sep | Palermo - Italy

\section{RESULTS AND DISCUSSION}

\subsection{Pollutant concentrations}

The pollutant concentrations and the outflow rates from the filters expressed clear temporal variability both during (Figure 1a) and between the examined rain events. More than 1000-fold variability in the concentrations underlined the importance of sample timing and need for continuous sampling throughout rain events for accurate estimation of pollutant attenuation. Concentrations of TSS and TOC, for example, increased during high flows, whereas TN concentrations decreased.

Overall, the EMCs of road runoff and the filter effluents varied highly between the studied events. $\mathrm{Cu}, \mathrm{Pb}$ and $\mathrm{Zn}$ EMCs of the untreated road runoff exceeded the lower limits by Stockholm Vatten (2001; Figure 1b), indicating need for treatment. TSS and TP EMCs also exceeded the higher limit (Stockholm Vatten, 2001) in some of the events (data not shown).
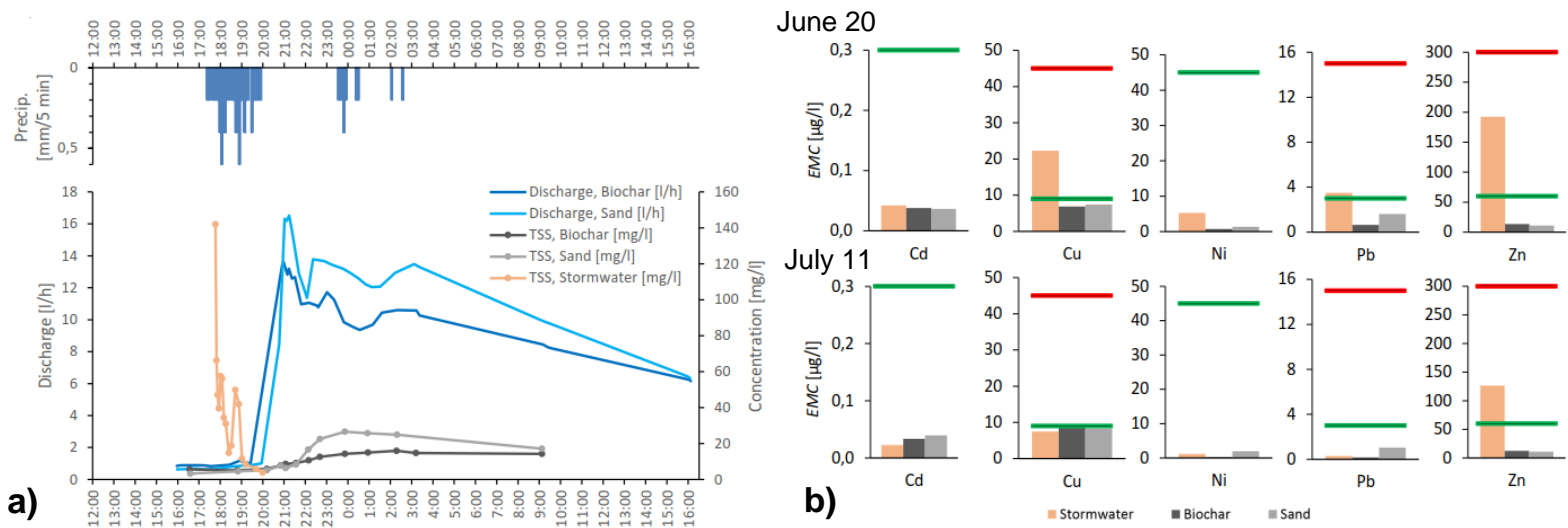

Figure 1. a) An example of precipitation, discharge flow rates and total suspended solids concentrations (TSS) during the rain event on July 11, 2017. b) Metal EMCs of rain events on June 20 and July 11, 2017. Green lines indicate the lower thresholds and red lines the higher thresholds by Stockholm Vatten (2001).

\subsection{Filter efficiencies}

Based on the mass efficiencies (Table 1), the addition of biochar to the sand filter had the greatest impact on nitrogen removal, namely $\mathrm{NO}_{3}$. The observed $m_{\text {eff }}$ value for $\mathrm{NO}_{3}$ was greater than values for vegetated filters without biochar reported by Valtanen et al. (2017). Conversely, the sand-biochar filter exhibited lesser TOC removal than the sand filter, and even increased TOC compared to untreated stormwater in the June 8 rain event. Both filters had good ability to retain TP but they were observed to increase $\mathrm{PO}_{4}$ amounts. This suggest that particulate phosphorus was efficiently removed but some of it was solubilized into form of $\mathrm{PO}_{4}$ within the filters and leached out, or the filter media itself released $\mathrm{PO}_{4}$. Interestingly, Valtanen et al. (2017) reported more than $90 \% m_{\text {eff }}$ values for $\mathrm{PO}_{4}$. Differences in other pollutant removal $m_{\text {eff }}$ between filter types were typically minor but varied between the events.

In general, pollutant removal efficiencies were high when the influent EMCs were high, and vice versa. This suggests that removal efficiency alone is not a reliable measure of filter performance as noted also by Law et al. (2008). However, comparison based on mass efficiencies was assumed to be more reliable than comparison based only on EMCs because the sand-biochar filter retained a relatively greater quantity of runoff due to its higher water holding capacity and, hence, delayed and reduced the outflows. 


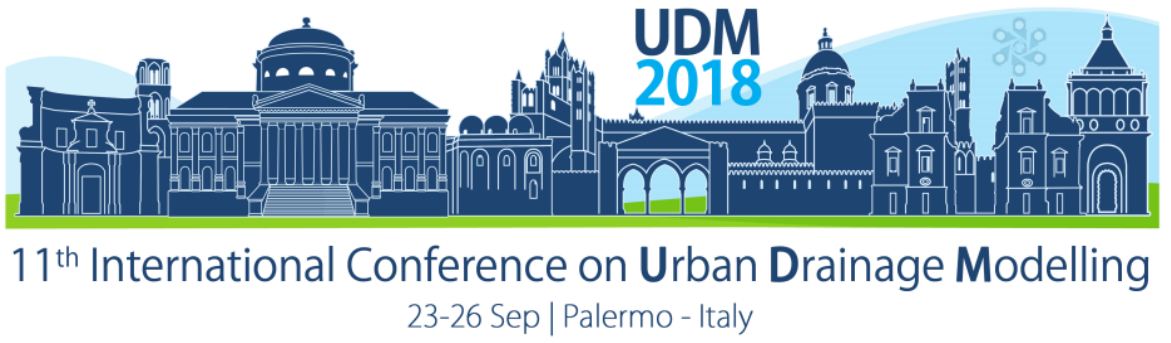

Table 1. Mass efficiencies (\%) of the sand-biochar filter (B) and sand filter (S). Negative value indicates increase in the pollutant load. Bolded value indicates that EMC of the influent stormwater exceeded the lower limit by Stockholm Vatten (2001). $\mathrm{NO}_{2,3}$ refers to $\mathrm{NO}_{2}$ and $\mathrm{NO}_{3}$.

\begin{tabular}{|c|c|c|c|c|c|c|c|c|c|c|c|c|c|}
\hline & & TSS & TOC & TN & $\mathrm{NH}_{4}$ & $\mathrm{NO}_{2,3}$ & TP & $\mathrm{PO}_{4}$ & $\mathrm{Cd}$ & $\mathrm{Cu}$ & $\mathrm{Ni}$ & $\mathrm{Pb}$ & $\mathrm{Zn}$ \\
\hline June & $B$ & 37 & -71 & 58 & - & 83 & 78 & 19 & - & - & - & - & - \\
\hline 8 & $S$ & 44 & 46 & -46 & - & -230 & 63 & -732 & - & - & - & - & - \\
\hline June & $B$ & 99 & 28 & 88 & - & 97 & 95 & -29 & 83 & 94 & 97 & 97 & 99 \\
\hline 20 & $S$ & 97 & 66 & -28 & - & -171 & 91 & -267 & 73 & 90 & 92 & 85 & 98 \\
\hline July & $B$ & 88 & 26 & 83 & 100 & 85 & 54 & -335 & 58 & 67 & 95 & 83 & 97 \\
\hline 11 & $S$ & 81 & 70 & 57 & 100 & 11 & 42 & -539 & 48 & 67 & 48 & -9 & 97 \\
\hline
\end{tabular}

\subsection{Pollutant removal mechanisms}

Based on the modelled Sls, the removal of $\mathrm{Cu}$ (Table 1) was likely due to precipitation reactions, suggesting long-term removal. Also Genç-Fuhrman et al. (2007) reported $\mathrm{Cu}$ precipitation, but precipitation as a possible removal mechanism is often ignored in stormwater studies. Zn, P, Al and Fe may have precipitated within the studied filters, but their removal was likely due to a combination of mechanisms (sorption, physical sieving and precipitation). Physical sieving was likely an important removal mechanism for most of the pollutants as previous studies have shown metals in stormwater to be strongly associated with particulates. This is supported by the minor differences in Sls and removal efficiencies between the filters.

\section{CONCLUSIONS}

Both sand and sand-biochar filters had mainly positive impact on stormwater quality but neither one of the filters clearly excelled with respect to stormwater treatment performance. Both filters yielded high removals for metals, TSS and TP. The greatest benefit of biochar addition to the sand filter matrix was greater nitrate removal compared with the plain sand filter. Therefore, the biochar amendment seems to be a promising option for locations with high nitrogen loads. Otherwise, sand alone provided similar treatment performance as the sand-biochar filter.

Geochemical modelling showed that precipitation is a possible mechanism for pollutant removal, but that the dominant pollutant removal mechanisms are likely physical sieving and sorption processes. Where physical sieving is the main pollutant removal mechanism, biochar amendment yields little additional pollutant removal benefit. The study highlighted rapid changes in pollutant concentrations both in untreated and treated stormwater during rain events. Hence, high intensity monitoring data is a prerequisite for understanding the mechanisms affecting pollutant retention in treatment systems and, therefore, for the development of effective filter materials and designs.

\section{References}

Appelo, C.A.J. and Postma, D. (2007) Geochemistry, groundwater and pollution. 2nd edition. A.A. Balkema publishers. Leiden, the Netherlands. ISBN 0415364280.

Genç-Fuhrman, H., Mikkelsen, P.S. and Ledin, A. (2007) Simultaneous removal of As, Cd, Cr, Cu, Ni and Zn from stormwater: Experimental comparison of 11 different sorbents. Water research, 41(3), 591-602.

Law, N., Fraley-McNeal, L., Cappiella, K. and Pitt, R. (2008) Monitoring to Demonstrate Environmental Results: Guidance to Develop Local Stormwater Monitoring Studies Using Six Example Study Designs. Center for Watershed Protection, Ellicott City, MD.

Reddy, K.R., Xie, T. and Dastgheibi, S. (2014) Evaluation of biochar as a potential filter media for the removal of mixed contaminants from urban storm water runoff. Journal of Environmental Engineering, 140(12), 04014043.

Stockholm Vatten AB. (2001) Klassificering av dagvatten och recipienter samt riktlinjer för reningskrav- del 2 , Dagvattenklassificering. Available in Swedish: http:/www.stockholmvattenochavfall.se/globalassets/pdf1/rapporter/dagvatten/dagvattenklassificeringdel2.pdf

Valtanen, M., Sillanpää, N. and Setälä, H. (2017) A large-scale lysimeter study of stormwater biofiltration under cold climatic conditions. Ecological Engineering, 100, 89-98. 


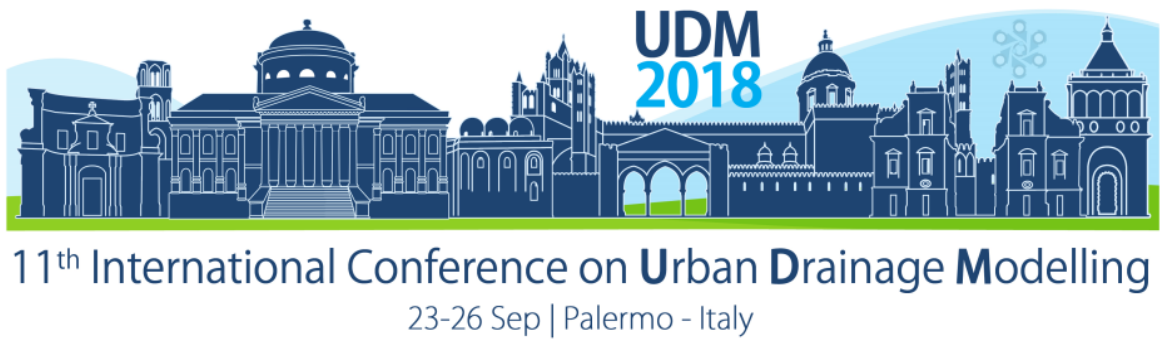

\title{
Measurement and planning-level modelling of retention of trace metals $(\mathrm{Cu}, \mathrm{Pb}, \mathrm{Zn})$ in soils of three urban drainage grass swales
}

\author{
Snežana Gavrić ${ }^{1}$, Thomas Larm ${ }^{2}$, Heléne Österlund ${ }^{1}$, Jiri Marsalek ${ }^{1}$ Anna Wahlsten ${ }^{2}$ and Maria \\ Viklander ${ }^{1}$ \\ ${ }^{1}$ Urban Water Engineering, Department of Civil, Environmental and Natural Resources Engineering, Luleå \\ University of Technology, Luleå, Sweden \\ ${ }^{2}$ StormTac AB, Stockholm, Sweden
}

\begin{abstract}
Grass swales are important elements of urban green infrastructure that convey, attenuate and improve the quality of urban runoff mostly through stormwater infiltration into and retention of conveyed pollutants by swale soils. Such processes were addressed in this study, investigating the enrichment of swale soils by ubiquitous urban trace metals, $\mathrm{Cu}, \mathrm{Pb}$ and $\mathrm{Zn}$. Three swales were selected for study in the City of Lulea (Northern Sweden) and their soils were sampled by coring. Sample cores covered soil depths up to $30 \mathrm{~cm}$, but only the results from the top $5 \mathrm{~cm}$ layer characterized by 9-15 samples in each swale are discussed here. After estimating metal mass in this layer in individual swales, such burdens were compared to those modelled by the proprietary StormTac Web model, which estimates annual loads of specific constituents for given land uses and is supported by an extensive database referenced to Swedish environmental conditions. The annual loads modelled for individual swales were multiplied by the swale age to obtain long-term inputs of the trace metals. A good agreement between the measured and modelled loads in soils was obtained and characterized by the ratio $L_{\text {mod }} / L_{\text {meas }}$, with an average value of 0.96 and standard deviation of 0.55 . Such results suggest the feasibility of assessing the long-term performance of grass swales by modelling trace metal $(\mathrm{Cu}, \mathrm{Pb}, \mathrm{Zn})$ inputs into swales, estimating the metal loads retained in soils by sampling and analyses, and taking the difference $\left(L_{\text {in }}-L_{\text {ret }}\right)$ as the exported load.
\end{abstract}

Keywords: grass swales; trace metals transport; swale soils; planning-level modelling of trace metal transport

\section{INTRODUCTION}

In urban drainage systems, grassed swales contribute to mitigation of the impacts of urbanization by attenuating runoff quantity and enhancing its quality. Short-term water quality performance of swales has been investigated in previous research by comparing the quality of runoff entering and exiting swales by sampling actual runoff generated by rainfall (Stagge et al., 2012), or runoff simulated by irrigation (Deletic and Fletcher, 2006). General difficulties in measuring low flows and pollutant concentrations, and analytical costs limit the number of analysed parameters and the collection of high-quality long-term data that could be used in stormwater quality modelling. However, the long-term performance of grass swales remains to be of interest to urban stormwater managers. Large-scale processes, including catchment rainfall, the pollutant build-up and wash-off, and street sweeping and snow removal, generate runoff draining into the swales and influence its quality, which can be characterized in various ways (e.g., by pollutant concentrations, forms, and bioavailability). Generally, the previous research recognised that grass swales enhance runoff quality through infiltration into swale soils (i.e., preventing pollutant transport) and settling. Trace metals, e.g., $\mathrm{Cu}, \mathrm{Pb}$, and $\mathrm{Zn}$, 


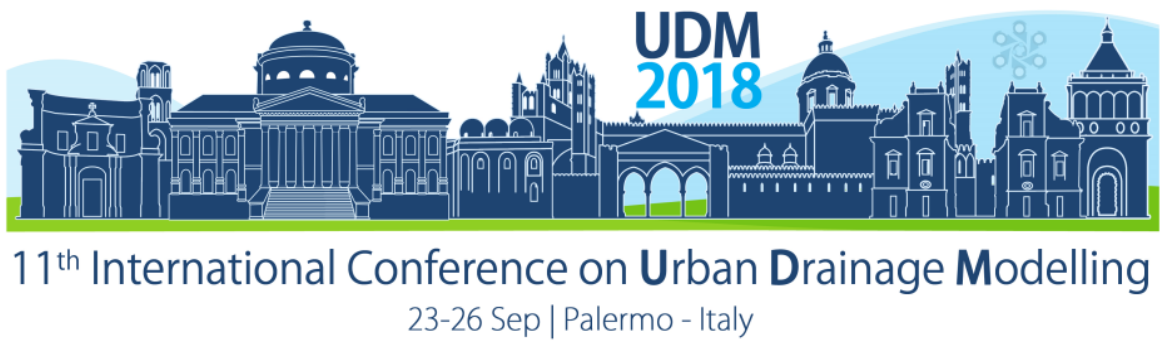

accumulate in top layers of grass areas $(10-30 \mathrm{~cm})$, with the highest concentrations found in the topsoil layer near the runoff inflow (Tedoldi et al., 2016).

The objective of the study presented herein is to examine the feasibility of estimating the total input loads of $\mathrm{Cu}, \mathrm{Pb}$ and $\mathrm{Zn}$ into the tested swales by runoff modelling with the StormTac Web model, and the mass of the same metals retained in swale soils by both modelling and soil sampling and chemical analyses. The mass balance can be used to estimate the loads exported from swales $\left(L_{i n}-L_{\text {ret }}\right)$ and the overall long-term swale performance in stormwater quality control.

\section{MATERIALS AND METHODS}

\subsection{The study sites}

Three swale catchments were selected for study in the City of Luleå (Northern Sweden). The first swale (L1) is located in a small commercial catchment and receives lateral runoff from a parking lot $\left(408 \mathrm{~m}^{2}\right)$, small roof $\left(5 \mathrm{~m}^{2}\right)$, and a one-lane road $\left(241 \mathrm{~m}^{2}\right)$ with the average daily traffic (ADT) 2,750. The second swale catchment (L2), located close to the downtown, drains a two-lane road $\left(728 \mathrm{~m}^{2}\right)$ with the highest ADT in Luleå $(11,650)$ and is subject to road salt applications during winter road maintenance. The third swale (L3) is located in a small residential catchment and receives lateral runoff from a parking lot $\left(287 \mathrm{~m}^{2}\right)$, a roof $\left(812 \mathrm{~m}^{2}\right)$, a grassed area $\left(726 \mathrm{~m}^{2}\right)$, and a two-lane road $\left(520 \mathrm{~m}^{2}\right)$ with ADT 2,500.

\subsection{Soil samples}

Soil sampling was performed in October 2017 with a 5-cm diameter stainless steel corer, 30 $\mathrm{cm}$ long. At each site, $20 \mathrm{~m}$ long swale sections that received direct runoff from only roads and parking lots were selected and sampled along three cross-sections, $10 \mathrm{~m}$ apart. In total, seven samples were collected along each cross-section at distances 40,80 , and $120 \mathrm{~cm}$ from the edge of the contributing drainage area, at the deepest point of the cross-section. Each core sample was divided into $5 \mathrm{~cm}$ slices, using a stainless steel knife, placed in a plastic bag and refrigerated until analysed (up to 7 days). During the sampling campaign, location data ( $x-y-$ $z$ coordinates) were collected at numerous points along the swale using a real-time kinematicGPS device with the precision of $1.5 \mathrm{~cm}$ (for $x$ and $y$ ) and $2 \mathrm{~cm}$ for $z$.

\subsection{Laboratory analysis}

Ninety-six samples, representing the top three soil layers and the deepest one, were preprocessed in the university laboratory according to the standard ISO 11464, and analysed for conductivity, $\mathrm{pH}$, and particle size distribution (PSD). Analyses of chloride, total metals ( $\mathrm{Cu}$, $\mathrm{Pb}$ and $\mathrm{Zn}$ ), and loss on ignition ( $\mathrm{LOI}$ ) were done by an accredited commercial laboratory.

\subsection{Modelling methods}

Using land-use input data (the area and database pollutant concentrations), estimates of average annual pollutant loads entering the swales, and the loads retained in the swales, were produced by the StormTac Web model (Larm, 2000).

\section{RESULTS AND DISCUSSION}

In order to compare model results [kg/year] with the soil chemistry data [mg/kg] total pollutant mass retained in the swale soils since the construction was calculated as the simulated annual load retained in the swale multiplied by the swale age. According to the Lulea municipality, swale L2 is 57 years old, and swales L1 and L3 are 38 years old; these ages were used for 


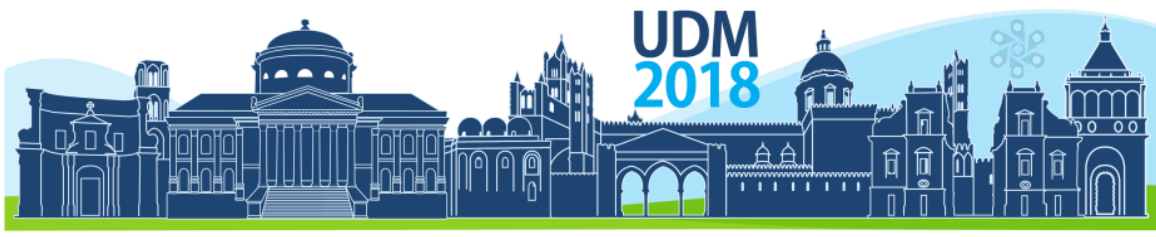

$11^{\text {th }}$ International Conference on Urban Drainage Modelling

23-26 Sep | Palermo - Italy

calculating the total pollutant mass. The mean pollutant concentration [mg/kg] (Table 1) in a layer was multiplied by the mass of soil $(<2 \mathrm{~mm})[\mathrm{kg}]$ for that layer, which was estimated from the soil specific gravity $\left[\mathrm{kg} / \mathrm{m}^{3}\right]$ and the layer volume $\left[\mathrm{m}^{3}\right]$. The mean total metal concentrations in various soil layers at each site (L1-L3) are shown in Table 1. The coefficient of variation (CV $[\%]$ ) and the number of samples in the layer (n) are shown in the brackets.

Table 1. Mean concentrations of $\mathrm{Cu}, \mathrm{Pb}$ and $\mathrm{Zn}$ in four soil layers of three swales (in brackets, the coefficient of variation [\%] and the number of samples)

\begin{tabular}{|c|c|c|c|c|c|}
\hline \multicolumn{2}{|c|}{$\begin{array}{l}\text { Soil layer depth } \\
{[\mathrm{cm}]}\end{array}$} & $0-5$ & $5-10$ & 10-15 & $25-30$ \\
\hline \multirow{3}{*}{$\begin{array}{c}\mathrm{Zn} \\
{[\mathrm{mg} / \mathrm{kg}]}\end{array}$} & L1 & $81(18 ; 15)$ & $53(34 ; 9)$ & $47(36 ; 9)$ & $17(18 ; 4)$ \\
\hline & L2 & $83(26 ; 15)$ & $104(12 ; 9)$ & $94(23 ; 9)$ & $61(19 ; 2)$ \\
\hline & L3 & $49(28 ; 9)$ & $30(6 ; 3)$ & $25(21 ; 3)$ & $17(26 ; 3)$ \\
\hline \multirow{3}{*}{$\begin{array}{c}\mathrm{Cu} \\
{[\mathrm{mg} / \mathrm{kg}]}\end{array}$} & L1 & $25(23 ; 15)$ & $17(26 ; 9)$ & $14(33 ; 9)$ & $6(20 ; 4)$ \\
\hline & L2 & $31(37 ; 15)$ & $45(17 ; 9)$ & $32(23 ; 9)$ & $19(13 ; 2)$ \\
\hline & L3 & $20(33 ; 9)$ & $11(15 ; 3)$ & $10(33 ; 3)$ & $7(10 ; 3)$ \\
\hline \multirow{3}{*}{$\begin{array}{c}\mathrm{Pb} \\
{[\mathrm{mg} / \mathrm{kg}]}\end{array}$} & L1 & $8(16 ; 15)$ & $8(26 ; 9)$ & $8(18 ; 9)$ & $3(264)$ \\
\hline & L2 & $42(70 ; 15)$ & $50(96 ; 9)$ & $156(108 ; 9)$ & $80(20 ; 2)$ \\
\hline & L3 & $9(28 ; 9)$ & $9(17 ; 3)$ & $9(42 ; 3)$ & $4(30 ; 3)$ \\
\hline
\end{tabular}
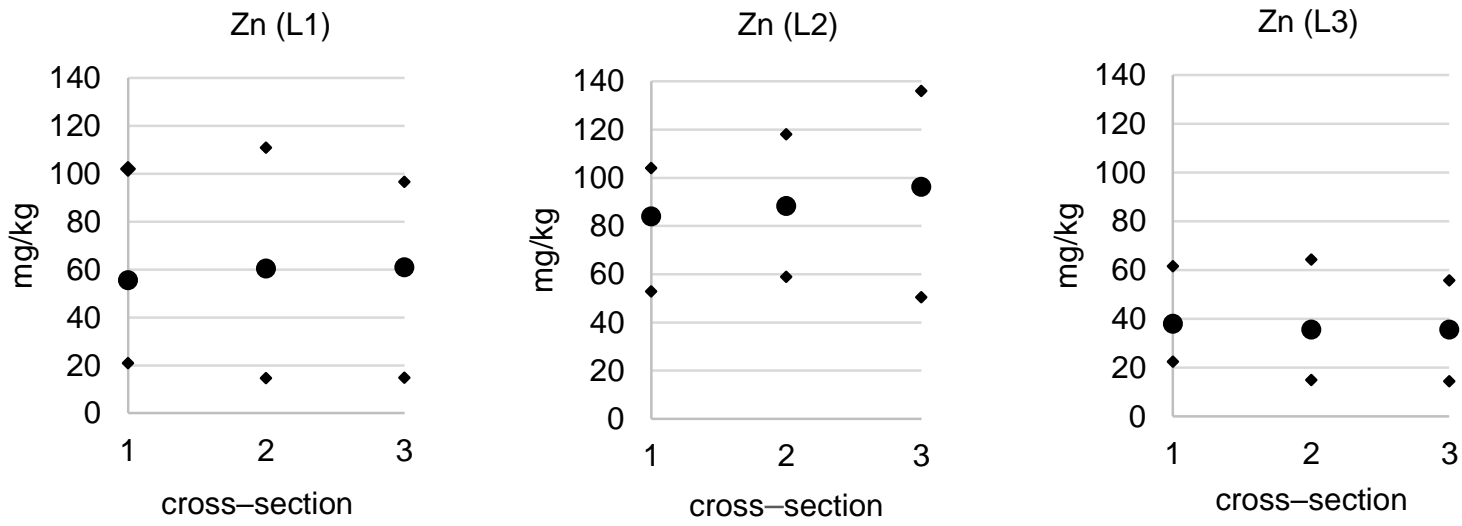

Figure 1: Maximum, mean, and minimum values of total $\mathrm{Zn}$ concentrations at each cross-section for three swales

As an example, Figure 1 shows the basic statistics of $\mathrm{Zn}$ concentrations at three crosssections sampled, where cross-section 1 is the upstream section, and sections 2 and 3 are 10 and $20 \mathrm{~m}$ downstream, respectively. The data in Figure 1 show distinctly higher $\mathrm{Zn}$ concentrations in soil samples from swale L2, which is exposed to runoff from the site with the highest ADT intensity. This agrees with the previous research that showed that increasing ADT and stop-and-go traffic contributed to increased metal concentrations $(\mathrm{Cu}, \mathrm{Cd}, \mathrm{Cr}, \mathrm{Pb}, \mathrm{Zn})$ in swale soils (Horstmeyer et al., 2016).

StormTac Web simulations of annual input and retained loads are shown in Table 2, together with two estimates of the total retained pollutant mass since the swale construction: modelled and calculated from soil samples. 


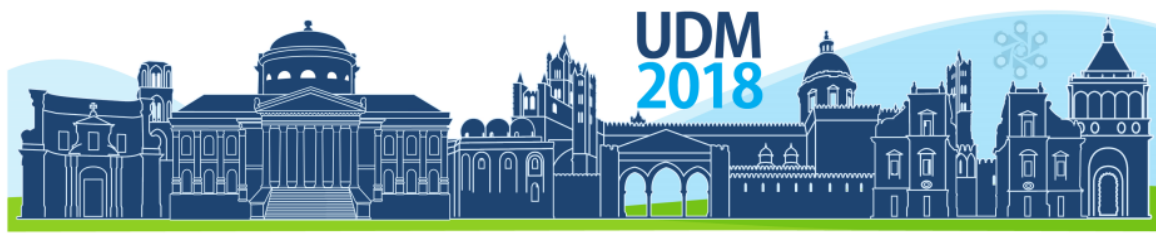

$11^{\text {th }}$ International Conference on Urban Drainage Modelling

23-26 Sep | Palermo - Italy

Table 2. Comparison of retained metal load in top $5 \mathrm{~cm}$ obtained from the model and from soil samples

\begin{tabular}{|c|c|c|c|c|}
\hline & & $\mathrm{Pb}$ & $\mathrm{Cu}$ & $\mathrm{Zn}$ \\
\hline \multirow{5}{*}{ L1 } & Input load [kg/year/ha] & 0.099 & 0.17 & 0.55 \\
\hline & Input load [kg/year] & 0.0065 & 0.011 & 0.036 \\
\hline & Retained load [kg/year] & 0.0049 & 0.0077 & 0.028 \\
\hline & Retained $\left({ }^{*} 38 \text { years }\right)_{\text {model }}[\mathrm{kg}]$ & 0.2 & 0.3 & 1.1 \\
\hline & Retained $(0-5 \mathrm{~cm})_{\text {samples }}[\mathrm{kg}]$ & 0.1 & 0.3 & 0.9 \\
\hline \multirow{5}{*}{ L2 } & Input load [kg/year/ha] & 0.065 & 0.20 & 0.91 \\
\hline & Input load [kg/year] & 0.0047 & 0.015 & 0.066 \\
\hline & Retained [kg/year] & 0.0035 & 0.01 & 0.06 \\
\hline & Retained $\left({ }^{*} 57 \text { years }\right)_{\text {model }}[\mathrm{kg}]$ & 0.2 & 0.7 & 3.2 \\
\hline & Retained $(0-5 \mathrm{~cm})_{\text {samples }}[\mathrm{kg}]$ & 2.4 & 1.8 & 4.8 \\
\hline \multirow{5}{*}{ L3 } & Input load [kg/year/ha] & 0.029 & 0.069 & 0.21 \\
\hline & Input load [kg/year] & 0.0068 & 0.016 & 0.050 \\
\hline & Retained [kg/year] & 0.0046 & 0.0098 & 0.037 \\
\hline & Retained $\left({ }^{*} 38 \text { years }\right)_{\text {model }}[\mathrm{kg}]$ & 0.2 & 0.4 & 1.4 \\
\hline & Retained $(0-5 \mathrm{~cm})_{\text {samples }}[\mathrm{kg}]$ & 0.2 & 0.4 & 1.1 \\
\hline
\end{tabular}

StormTac Web simulations of annual loads were done for the current catchment layout and the most recent ADT data. The total pollutant load entering the swale is partly incorporated into the soil matrix, mostly in the top $30 \mathrm{~cm}$ layer, and partly passes through the swale unabated. The retained annual pollutant load, as modelled by StormTac Web, represents retention by all soil layers. By comparison, the retained pollutant mass calculated from soil samples accounts just for the first $5 \mathrm{~cm}$; thus, the mass reported in Table 2 would increase if deeper layers were considered as well. The model uses standard pollutant concentrations from the database to calculate average annual loads. Each pollutant concentration has been categorized into three levels of uncertainty, based on the number and coefficient of variation (CV) of input data (i.e., $C V<0.5,0.5-1.25$, and $>1.25$, indicates high, intermediate, and low certainties, respectively). Based on these criteria, concentrations of $\mathrm{Cu}, \mathrm{Pb}$, and $\mathrm{Zn}$ are of average certainty for parking lots and grass areas, and of low certainty for the roofs. In addition, the calculated reduction efficiency of swales is of high certainty. For the roads, different criteria are used, based on the regression coefficient (R2-value), and according to the criteria the concentrations are of high certainty (R2-value $>0.75$ ). Mean uncertainties of the analytical methods used to determine $\mathrm{Cu}, \mathrm{Pb}$ and $\mathrm{Zn}$ concentrations in soil samples were in the range $19-21 \%$. Furthermore, in the procedure applied here, it was assumed that the mean pollutant layer concentration (obtained for the 20-m swale section) was representative for the entire swale. This can lead to a load overestimation, if the pollutant concentration in the swale increases in the downstream direction. Moreover, higher $\mathrm{Pb}$ concentrations in stormwater in the past, due to the leaded gasoline, could explain higher $\mathrm{Pb}$ mass calculated from soil samples. Even though considerable uncertainties are associated with the estimation of longterm pollutant loads, further substantiation of the modelling results is provided by the earlier research performed at swale L2. In cold climate, snow-handling practices include urban snow storage in roadside swales and applications of anti-skid materials in winter. In swale snow deposits, pollutants accumulate during the winter, and after the snowmelt, a part of these 


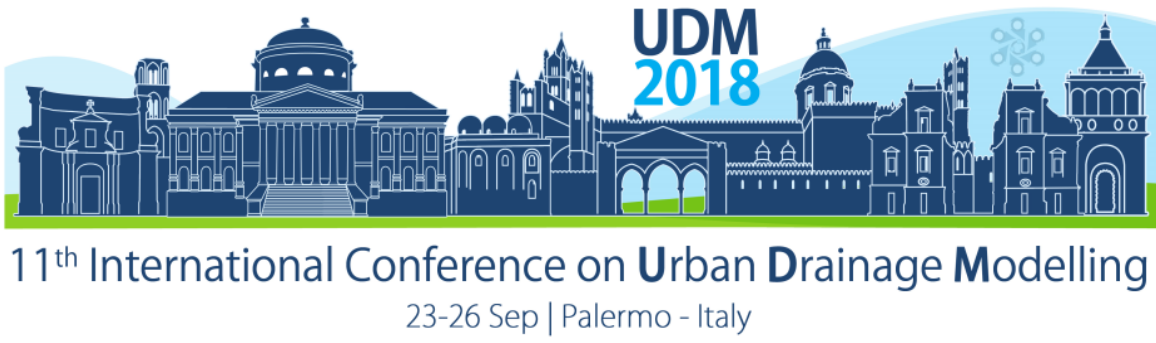

accumulations penetrates swale soils and contribute to their pollution, which is not specifically considered in the StormTac Web model. Such residual mass loads per one square metre of snow (period Jan.-Apr.) for $\mathrm{Cu}, \mathrm{Pb}$, and $\mathrm{Zn}$ were 58, 51, and $144\left[\mathrm{mg} / \mathrm{m}^{2}\right]$, respectively (Viklander, 1999). Moreover, the anti-skid materials are ground by vehicle tires, and small particles with attached metals are washed off from the roads and dispersed by street sweepers, eventually ending up in the roadside swales and contributing to their pollution. The mass of street sediment accumulated during the winter season that stayed on the L2 road after the snowmelt was $372 \mathrm{~g} / \mathrm{m}$ (mass per metre of street length), whereas the metal content in the smallest analysed fraction $(75 \mu \mathrm{m})$ of $\mathrm{Cu}, \mathrm{Pb}$ and $\mathrm{Zn}$ was 143,75 , and $250 \mu \mathrm{g} / \mathrm{g}$, respectively (Viklander, 1998).

\section{CONCLUSIONS}

A hypothesis that the long-term swale performance in retaining ubiquitous particulate-bound traffic pollutants, such as $\mathrm{Cu}, \mathrm{Pb}$ and $\mathrm{Zn}$, can be estimated from swale soil samples was tested, by comparing the mass of pollutants accumulated in the swale since its construction, using the soil chemistry data, and the mass produced by a source-based runoff quality StormTac Web model. Although, considerable uncertainties are associated with estimates of total retained pollutant masses, the suggested method offers opportunities to facilitate planning- level modelling of such accumulations and provides the chemical status of swale soils.

\section{References}

Deletic, A., and Fletcher T. D. (2006) Performance of Grass Filters Used for Stormwater Treatment - A Field and Modelling Study. J Hydrol 317(3-4), 261-75.

Horstmeyer, N., Huber M., Drewes J. E., and Helmreich B. (2016) Evaluation of Site-Specific Factors Influencing Heavy Metal Contents in the Topsoil of Vegetated Infiltration Swales. Sci. Total Environ. 560-561, 19-28.

ISO 11464, (2006) Soil quality - Pretreatment of Samples for Physico-Chemical Analysis. International Organization for Standardization, Geneva

Larm, T. (2000) Watershed-Based Design of Stormwater Treatment Facilities: Model Development and Applications. Dept of Civil and Environ Eng., Royal Institute of Technol, Stockholm, Sweden.

Stagge, J. H., Davis A. P., Jamil E., and Kim H. (2012) Performance of Grass Swales for Improving Water Quality from Highway Runoff. Water Research 46(20): 6731-42.

Tedoldi, D., Chebbo G., Pierlot D., Kovacs Y., and Gromaire M.-C. (2016) Impact of Runoff Infiltration on Contaminant Accumulation and Transport in the soil/filter Media of Sustainable Urban Drainage Systems: A Literature Review. Sci. Total Environ. 569-570, 904-926

Viklander, M. (1998) Particle Size Distribution and Metal Content in Street Sediments. Journal of Environmental Engineering 124(August), 761-66

Viklander, M. (1999) Substances in Urban Snow. A Comparison of the Contamination of Snow in Different Parts of the City of Luleå, Sweden. Water, Air, and Soil Pollut. 114(3), 377-394. 


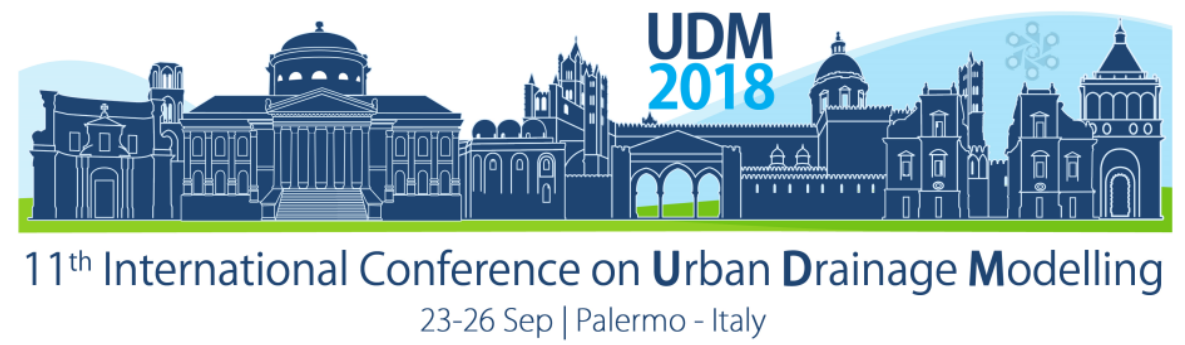

\title{
Adaptation of SuDS Modelling Complexity to End-Use Application
}

\author{
Mohamad H. EL Hattab', and Ana Mijic ${ }^{1}$ \\ ${ }^{1}$ Imperial College London, Department of Civil and Environmental Engineering, London, UK \\ (South Kensington Campus, London SW7 2AZ)
}

\begin{abstract}
Sustainable urban Drainage Systems (SuDS) have gained popularity over the last two decades as an effective and optimal solution to continuous population growth and urban creep. SuDS do not only provide resilience towards pluvial flooding but they also provide multiple benefits ranging from amenity improvement to ecological and social well-being amelioration. To understand these complex interactions SuDS modelling is the tool to inform decision makers. Major developments in SuDS modelling techniques have been observed in the last decade, from simple lumped or conceptual models to very complex models. Several software packages have been developed to aid planning and implementation of SuDS. These often require extensive amount of data and calibration to reach acceptable level of accuracy. However, in many cases simple models may fulfill the aims of a particular stakeholder. Thus, it is very important to understand stakeholders' priorities and aims and optimize the selection of modelling techniques according to the end-use application.
\end{abstract}

Keywords: SuDS; Modelling; Stakeholder

\section{INTRODUCTION}

Traditional management of urban water systems considers all components independent of each other in a fragmented manner (e.g. Rauch et al., 2005). With new drivers for development such as rapid urban growth and needs for infrastructure rehabilitation and climate change adaptation, and stimulated by improvements in computational efficiency, integrated urban water modelling is currently expanding in new directions. Integrated 1D-2D modelling of the interactions between urban drainage systems and urban landscapes (i.e. streets, parks, etc.) during large pluvial flooding incidents has become possible in the recent decade (e.g. Bamford et al., 2008; Chen et al., 2010; Domingo et al., 2010), and modelling of more than the strictly technical and biophysical domain of the water system (e.g. social and economic domains) is increasingly attracting interest in recent years (e.g. Ward et al., 2012).

Integrated Urban Drainage Models (IUDM) have been one of the most well-known and recognised forms of integrated models, These typically comprise studying upgrade options for a local WWTP, assessing ways of reducing CSO emissions or showing the combined impact of different parts of the drainage stream on receiving waters (Bach P.M. et al., 2014). They recognise both combined and separate drainage systems. Recent studies have taken this experience further in developing real-time control (RTC) strategies.

Hydrological models are often classified based on their spatial and temporal resolution. Models vary in their temporal resolution, with daily models increasingly being replaced by models running at small time steps (e.g. 1 or $5 \mathrm{~min}$ ), which are necessary to represent the fast response typical of urban catchments. In addition to their temporal resolution, urban hydrologic models can be groupped into five categories: (1) lumped; (2) semi-distributed using subcatchments; (3) Hydrologic Response Unit (HRU) based, where an HRU represents a 


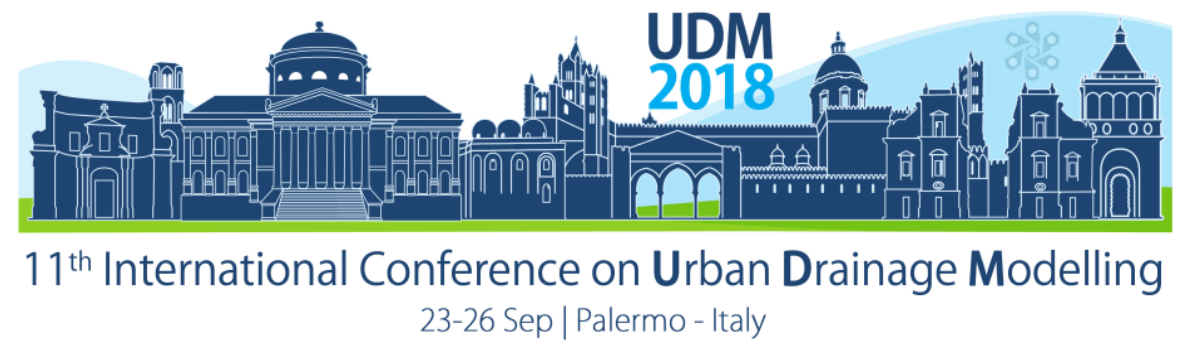

combination of the same soil and land use type; (4) grid-based spatially distributed; (5) Urban Hydrological Element (UHE) based.

Since IUDM has experienced significant advances in the previous years, there is a tendency nowadays to use complex models even when simple lumped models would serve the purpose. In this paper we highlight the importance of understanding any problem at hands and the desired output in order to select the level of complexity required in the modelling exercise.

\section{MATERIALS AND METHODS}

\subsection{Classification of end-use application}

Given the array of stakeholders involved in SuDS planning, and implementation, the decision about what level of complexity should be adopted in SuDS modelling can be classified based on the target stakeholders. These can be grouped as shown in Table 1; for instance, the modelling output required to explain the benefits of SuDS to residents or local councils is not the same as for designers or water utilities. The latter needs more in-depth representation of SuDS features in order to plan, design, assess, and realise SuDS projects.

Table 1. Classification of stakeholders involved in SuDS and the desired level of modelling complexity

\begin{tabular}{|c|c|c|}
\hline Stakeholder & Usage of modelling output & $\begin{array}{l}\text { Level of complexity } \\
\text { required }\end{array}$ \\
\hline Water Utilities & $\begin{array}{c}\text { Planning, performance } \\
\text { assessment, }\end{array}$ & Complex \\
\hline Local Councils & Master planning & Moderate \\
\hline Policy makers & Set-up new legislations & Moderate \\
\hline Designers & $\begin{array}{c}\text { Detailed SuDS design, feasibilty } \\
\text { studies etc. }\end{array}$ & Very Complex \\
\hline Researchers & $\begin{array}{l}\text { Develop new techniques for } \\
\text { techno-economical assessmnet }\end{array}$ & Very Complex \\
\hline Residents & Knowledge of SuDS benefits & Light \\
\hline $\begin{array}{l}\text { Environmental } \\
\text { regulators }\end{array}$ & $\begin{array}{l}\text { Determine impacts on nearby } \\
\text { environment/ecology }\end{array}$ & Complex \\
\hline
\end{tabular}

\subsection{Case Study}

Counters Creek is one of the lost rivers of London and is situated on the boundary of the London Borough of Hammersmith and Fulham (LBHF) and the Royal Borough of Kensington and Chelsea (RBKC). This former river and its catchment is now part of the sewerage system, draining surface water from buildings and roads, as well as foul water from toilets, bathrooms and kitchens. There are over 1,700 properties across parts of LBHF \& RBKC reported at risk of sewer flooding (TWUL 2013), so one of the upraised solutions to deal with that is to retrofit SuDS in these hotspots. Three streets in London, each with a nearby control street, were chosen to implement SuDS retrofitting technologies. SuDS featured in this case study included rain gardens, permeable pavement, and porous asphalt. The outlet of each of the SuDS technologies is equipped with a V-notch weir to continuously monitor the outflow rate. Rainfall is monitored through a network of six rain gauges distributed around the catchment. 


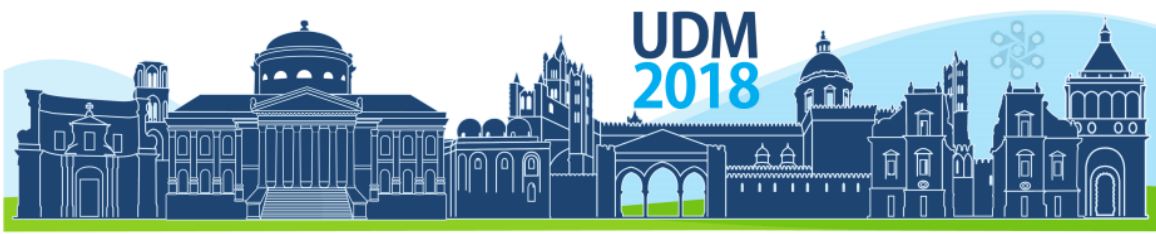

$11^{\text {th }}$ International Conference on Urban Drainage Modelling

23-26 Sep | Palermo - Italy

Multiple stakeholders are involved in this pilot project including the water company, the local councils, the residents, the designers, and a research institute among others. Hence, results produced about the performance of different SuDS differ in terms of technical level depending on the stakeholder addressed.

\section{RESULTS AND DISCUSSION}

Based on a survey circulated to all stakeholders involved within the project, they were asked to answer different questions related to SuDS. The questions focused on four main clusters namely: Economical, Technical, Socio Environmental, and other Benefits. The priorities of each stakeholder were calculated using the Analytic Network Process (ANP) method. The results are shown in Figure 1.

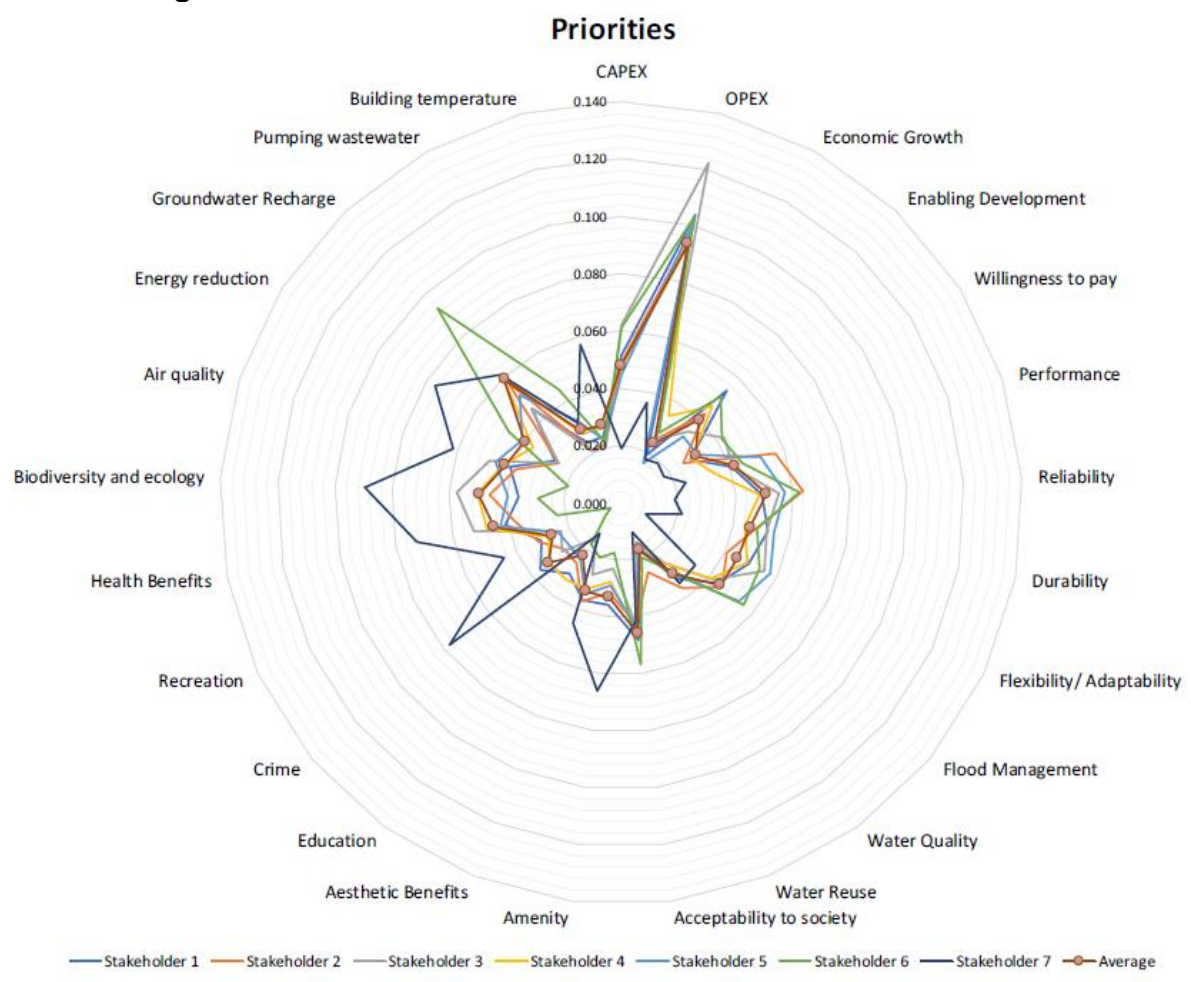

Figure 1. Priorities of each stakeholder and the average of them using ANP

It is clear from Figure 1 that different stakeholders have different interests in SuDS; therefore, it is necessary to understand their interests before starting any modelling exercise. Reliability in the modelling results may be tolerated by some stakeholders, for instance having an $80 \%$ accurate results from a lumped model could be enough for a local council or resident to draw conclusions about SuDS performance. On the other hand, a reliability of less than $90 \%$ may not be accepted by designers or researchers whose work is used to write guidelines or to construct SuDS where over design would result in unnecessary extra cost and under design may pose a risk of failure.

Initial results from the present study suggest that lumped models could produce not less than $80 \%$ confidence in results, whereas semi-distributed models may increase the confidence level to $90 \%$ and fully-distributed models could have a confidence level not less than $95 \%$. Further 


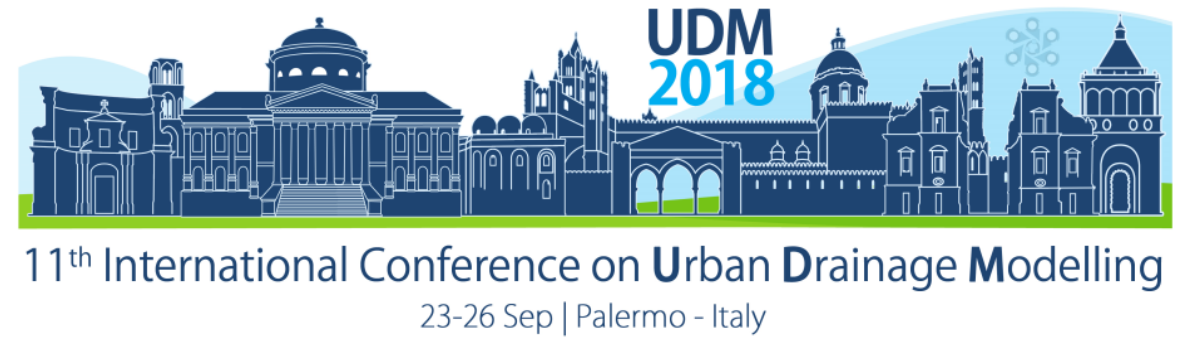

elaboration on different modelling techniques are currently being investigated and validated in the current case study, more robust results will be provided in the revised version of this abstract in due course.

\section{CONCLUSIONS}

SuDS projects often involve multiple stakeholders due to the wide benefits they provide. Stakeholders expanding over different disciplines have different priorities thus the level of hydraulic/hydrologic modelling required to achieve their goals is not the same. Master planners and policy makers need less complex models than designers and utility providers. Acknowledging the end use of any modelling results helps optimising time and efforts of highly trained personnel.

There is a trend nowadays to use highly sophisticated modelling packages in any type of projects, this is not really necessary if less complex techniques would serve the purpose. The confidence level of different modelling approaches and to what level it fulfils the stakeholders goals is rather less established, further investigation towards establishing these thresholds is needed.

\section{ACKNOWLEDGEMENTS}

The authors would like to thank the EPSRC CDT in Sustainable Civil Engineering at Imperial College London and Thames Water Utilities Limited for funding the outlined research via EPSRC Grant Reference (EP/L016826/1).

\section{References}

Rauch, W., Seggelke, K., Brown, R., Krebs, P. (2005) Integrated approaches in urban storm drainage: where do we stand? Environ. Manag. 35 (4), 396-409.

Bamford, T.B., Balmforth, D.J., Lai, R.H.H., Martin, N. (2008) Understanding the complexities of urban flooding through integrated modelling. In: 11th International Conference on Urban Drainage. Edinburgh, Scotland, UK.

Chen, A.S., Djordjevic, S., Leandro, J., Savic, D.A. (2010) An analysis of the combined consequences of pluvial and fluvial flooding. Water Sci. Technol. 62 (7),1491-1498.

Domingo, N.D.S., Refsgaard, A., Mark, O., Paludan, B. (2010) Flood analysis in mixed urban areas reflecting interactions with the complete water cycle through coupled hydrological-hydraulic modelling. Water Sci. Technol. 62 (6), 1386-1392.

Ward, S., Farmani, R., Atkinson, S., Butler, D., Hargreaves, A., Cheng, V., Denman, S., Echenique, M. (2012) Towards an integrated modelling framework for sustainable urban development. In: 9th International Conference on Urban Drainage Modelling (9UDM). Belgrade, Serbia.

Bach, P.M., Rauch, W., Mikkelsen, P.S., Mccarthy, D.T. and Deletic, A. (2014) A critical review of integrated urban water modelling-Urban drainage and beyond. Environmental modelling \& software, 54, 88-107.

TWUL (2013). "Why we need the Counters Creek storm relief sewer." Retrieved from https://www.thameswater.co.uk/sitecore/content/counterscreek/counterscreek/theproblem/why-we-need-thestorm-relief-sewer, [accessed March 2018] 


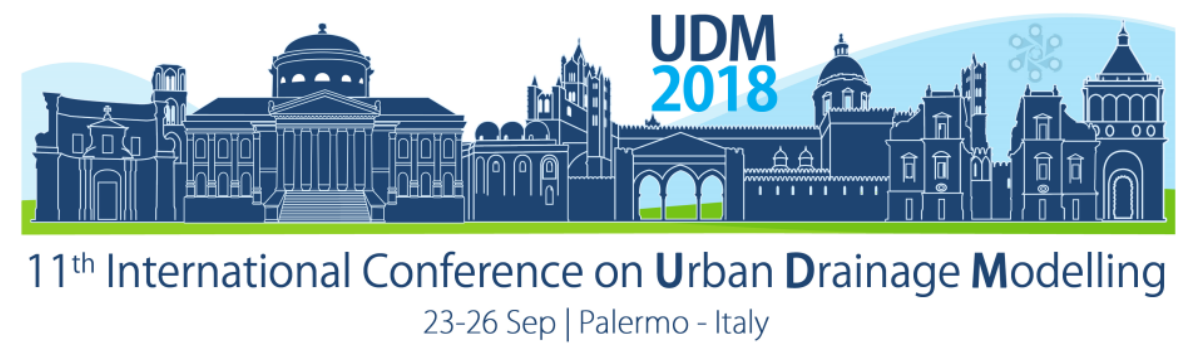

\title{
Modelling Stormwater Pollutant Reduction with LID Scenarios in SWMM
}

\author{
Camilla Tuomela ${ }^{1}$, Daniel Jato-Espino ${ }^{2}$, Nora Sillanpää ${ }^{1}$ and Harri Koivusalo ${ }^{1}$ \\ ${ }^{1}$ Department of Built Environment, Aalto University School of Engineering, P.O. Box 15200, 00076 Aalto, Finland \\ ${ }^{2}$ GITECO Research Group, Universidad de Cantabria, Av. de los Castros 44, 39005 Santander, Spain
}

\begin{abstract}
Simple and automatic optimization approaches were used to create Low Impact Development (LID) scenarios for a residential catchment in Espoo, Finland. Ten LID scenarios were simulated with the Storm Water Management Model (SWMM) to evaluate their impact on urban runoff and pollutant load on a catchment scale. Permeable pavements and bioretention cells were located at the asphalted areas in the catchment. A large variability was observed in the simulated load reduction depending on the LID type, location and pollutant. Scenarios with permeable pavements reduced pollutants effectively, but require knowledge about the pollutant sources and pathways. Scenarios with bioretention cells benefitted the most from location optimization due to their smaller spatial footprint and storage capacity compared with permeable pavements.
\end{abstract}

Keywords: LID location; Optimization; Stormwater quality

\section{INTRODUCTION}

Urban runoff has an impact on surface water quality and therefore plays an important role in creating sustainable living environments. Low Impact Development (LID) offers a solution to urban runoff problems with decentralized systems aiming at capturing and treating runoff and pollutant loads near their source (Elliott \& Trowsdale, 2007). LID systems are small-scale treatment units that can reduce the negative impacts of urbanization on water cycle and pollutant loads by first providing storage and then by retaining or detaining runoff (Burns et al., 2012). Little attention has been given towards the transport of stormwater pollutants within a catchment. An earlier study (Tuomela, 2017; Tuomela et al., 2017) showed that in a residential area stormwater pollutants were generated from various different sources and the importance of these sources depended on the type of pollutant. To reach cost-efficient management of stormwater quality and maximize the potential of LID systems, the placement of LID units within the catchment should be carefully evaluated. To find optimal locations for LID units in a catchment, modelling can be utilized. Models are an essential tool for the prediction, analysis and management of urban water pollution, when on-site urban runoff quality data is often absent or imperfect (Zhu et al., 2012).

For the placement of LID units in a catchment, simple guidelines by authorities can be followed, such as recommendations for focusing on runoff from parking or street areas. In these simple approaches, an analysis of pollutant sources and pathways within a catchment are not included in the planning process. On the other hand, the LID location optimization based on geographic information (Jato-Espino et al., 2016) can be utilized to combine local conditions with various targets related to pollutant sources. The objective of this study was to compare simple and optimized approaches in the location prioritization of decentralized LID units and to evaluate their impact on the catchment-scale runoff generation and pollutant load. 


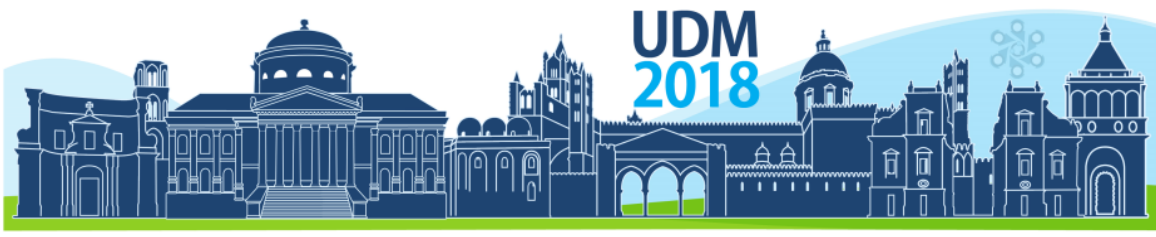

$11^{\text {th }}$ International Conference on Urban Drainage Modelling

23-26 Sep | Palermo - Italy

\section{MATERIALS AND METHODS}

The stormwater quantity and quality was simulated with SWMM 5.1 (Rossman, 2015) at the Vallikallio catchment in Espoo, Finland. Vallikallio is an 11.4 ha high-density residential area with a separate storm sewer system (Figure 1). The soil consists of mainly sandy till, and was modelled as silty clay loam. A detailed catchment delineation was made based on land cover types: roads, walkways, parking areas, vegetated areas, roofs, sand/gravel, stone/tile pavers and open rock as illustrated in Figure 1. The pollutant washoff was simulated with SWMM using literature based, land cover specific event mean concentrations (EMCs) for total suspended solids (TSS), total phosphorus (TP), total nitrogen (TN), lead (Pb), copper (Cu) and zinc $(\mathrm{Zn})$. The water quality model was validated against on-site water quality measurements (Tuomela, 2017; Tuomela et al. 2017). Monitored rainfall from three summers (June to August 2003, 2005 and 2006) were used in the simulations.

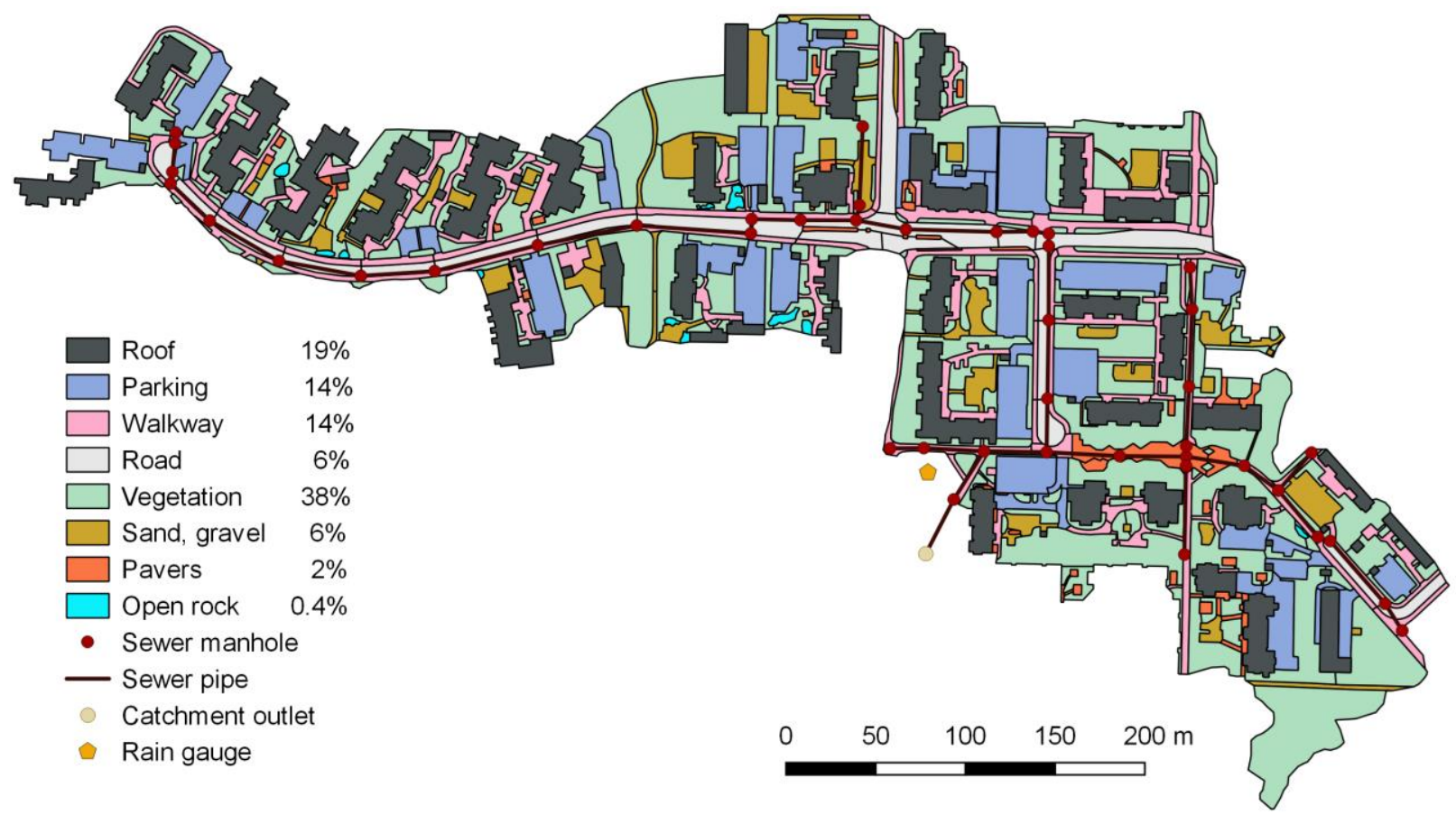

Figure 1. The model of Vallikallio with land cover based subcatchments and their percentage of the total catchment area.

Based on an earlier water quality modelling study (Tuomela, 2017), six LID scenarios were formed with the simple approach assuming that pollutants were mainly contributed from one specific land cover type: parking areas, walkways or vehicular roads. Permeable pavements (PP) and bioretention cells (BR) were chosen as the most likely alternatives for retrofitting an existing urban area. For the optimized approach, four LID scenarios were created based on the criteria by Shoemaker et al. (2009) and the recommendations of the Riverside County (2011) and City of San Francisco (2010) for suitable locations for BR and PP in the catchment. The LIDs were located at the most critical areas in terms of pollutant washoff in the subcatchments, as long as the recommended siting restrictions concerning drainage area, soil infiltration, slope, water table depth and setbacks were met. Two of the optimized scenarios included both PP and BR at the most critical areas, in the first mainly BR on roads and PP on parking areas and in the second mainly BR on parking areas and PP on roads. In this study, 


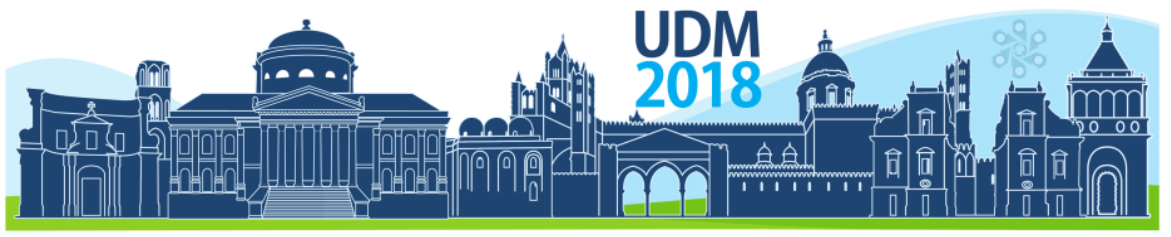

$11^{\text {th }}$ International Conference on Urban Drainage Modelling

23-26 Sep | Palermo - Italy

the optimization was made based on the intermediate summer 2003 and the TSS>TP>TN prioritization order. It is noteworthy that a different prioritization would change the results.

Runoff quantity and pollutant loads were simulated using on-site rainfall data for three summers representing a wide range of weather conditions: a dry summer (2006 with $52 \mathrm{~mm}$ rainfall from June to August), an average summer (2003, $180 \mathrm{~mm}$ ), and a wet summer (2005, $348 \mathrm{~mm}$ ). Runoff and pollutant load reductions for each scenario was determined based on comparisons with simulated washoff from a catchment with and without LID units. In SWMM, the LID simulation is based on reduced runoff volume and thus reduced pollutant mass loads, while the pollutant removal within the LID system is not considered (Rossman, 2015). Thus, literature based pollutant removal rates for LID materials (Table 1) were used to estimate the additional pollutant reduction by the processes occurring in the LID system.

Table 1. Literature based pollutant removal rates for pervious pavements and bioretention systems.

\begin{tabular}{llllllll}
\hline Pollutant & TSS & TP & TN & Pb & Cu & Zn & References \\
Removal rate $(\%)$ & $95^{(\mathrm{a}}$ & $9^{(\mathrm{b}}$ & ${85^{(\mathrm{a}}}^{(\mathrm{b}}$ & $9^{(\mathrm{b}}$ & $8^{(\mathrm{b}}$ & $91^{(\mathrm{b}}$ & a) Field \& Sullivan (2003), b) VTT (2017) \\
\hline
\end{tabular}

\section{RESULTS AND DISCUSSION}

Table 2 presents a range of reduction rates for each scenario depending on the varying weather conditions during different summers. The weather conditions had the smallest impact on the LID scenarios utilizing PPs due to their large storage capacity. The clearest influence of weather conditions was seen with BR as low ranges of pollutant reduction based on reduced runoff, which is explained by the exceedances of the storage capacity during very rainy periods. However, the inclusion of pollutant removal rates in Table 1 evened out the differences between the simulated summers especially for the BR scenarios (Table 2).

Table 2. Simulated LID scenarios, the proportion of LID units of the catchment area, the range of runoff and pollutant load reductions on catchment scale for the three summers 2003, 2005 and 2006.

\begin{tabular}{|c|c|c|c|c|c|c|c|c|c|c|c|c|c|c|c|}
\hline \multirow[t]{2}{*}{$\begin{array}{l}\text { LID } \\
\text { type }\end{array}$} & \multirow[t]{2}{*}{ Location } & \multirow{2}{*}{$\begin{array}{c}\begin{array}{c}\text { Area } \\
\text { covered }\end{array} \\
(\%)\end{array}$} & \multirow{2}{*}{$\begin{array}{c}\begin{array}{c}\text { Runoff } \\
\text { reduction }\end{array} \\
(\%)\end{array}$} & \multicolumn{6}{|c|}{$\begin{array}{l}\text { Pollutant reduction (\%) based on } \\
\text { reduced runoff }\end{array}$} & \multicolumn{6}{|c|}{$\begin{array}{l}\text { Pollutant reduction (\%) based on } \\
\text { reduced runoff and pollutant removal } \\
\text { within the LID unit }\end{array}$} \\
\hline & & & & TSS & TP & TN & $\mathrm{Pb}$ & $\mathrm{Cu}$ & $\mathrm{Zn}$ & TSS & TP & TN & $\mathrm{Pb}$ & $\mathrm{Cu}$ & $\mathrm{Zn}$ \\
\hline PP & Parking & 14 & $29-32$ & $47-49$ & $26-28$ & $41-43$ & $25-28$ & $23-24$ & $48-52$ & $47-49$ & $27-28$ & $42-43$ & $25-28$ & 23-24 & $48-53$ \\
\hline PP & Walkway & 14 & $30-35$ & $27-32$ & $64-68$ & $39-46$ & $39-47$ & $43-49$ & $20-26$ & $60-63$ & $78-80$ & $61-63$ & $52-60$ & $53-59$ & $54-59$ \\
\hline PP & Road & 6.4 & $21-22$ & 39 & $36-41$ & $25-28$ & $41-44$ & $47-51$ & $15-17$ & $73-75$ & $51-55$ & $46-52$ & $56-64$ & $58-69$ & $53-54$ \\
\hline BR & Parking & 0.7 & $24-29$ & $16-45$ & $8-26$ & $12-41$ & 7-24 & $6-21$ & $17-46$ & $40-47$ & $20-27$ & $28-42$ & $20-24$ & $16-21$ & $42-47$ \\
\hline BR & Walkway & 0.7 & $16-28$ & $7-26$ & $19-60$ & $10-36$ & $11-37$ & $12-39$ & $6-18$ & $43-58$ & $35-74$ & $32-58$ & 28-51 & $25-49$ & $43-53$ \\
\hline BR & Road & 0.3 & $15-23$ & $8-36$ & $7-36$ & $5-25$ & 8-39 & $10-46$ & $3-14$ & $45-72$ & $24-51$ & $27-49$ & $26-60$ & 23-63 & $41-52$ \\
\hline PP & Optimized & 10 & 25 & $42-44$ & $34-39$ & $30-34$ & $36-39$ & $39-44$ & $28-29$ & $48-50$ & $38-42$ & $34-38$ & $40-44$ & $42-48$ & 33-34 \\
\hline BR & Optimized & 0.6 & $26-32$ & $15-54$ & $9-40$ & $10-42$ & $9-42$ & $10-44$ & $13-39$ & $53-59$ & $36-45$ & $32-46$ & $40-51$ & $40-55$ & $38-42$ \\
\hline $\mathrm{PP}+\mathrm{BR}^{(1}$ & Optimized & 5.7 & $24-29$ & $22-48$ & $14-41$ & $16-38$ & $14-42$ & $14-46$ & $20-32$ & $48-53$ & $36-45$ & $31-41$ & $38-49$ & $39-54$ & $34-35$ \\
\hline $\mathrm{PP}+\mathrm{BR}^{(2}$ & Optimized & 5.1 & $29-31$ & $36-48$ & $32-44$ & $25-44$ & $30-43$ & $37-55$ & $23-40$ & $42-48$ & $40-44$ & $34-45$ & $37-44$ & $51-56$ & $37-40$ \\
\hline
\end{tabular}

The runoff and pollutant load reduction was highest for the scenarios including PPs (Table 2), which is explained by the larger areal extent and, therefore, larger storage capacity of the LID system. The differences between the pollutants were impacted by the land cover specific EMCs and the areal coverage and runoff generation potential of each land cover type. When the simple approach in placing LIDs was followed, the pollutant load reduced unevenly depending on the pollutant. For example, PPs on parking areas reduced $\mathrm{Zn}$ and TSS by $50 \%$, whereas only $23 \%$ reduction in Cu load was observed. The optimized PP scenario reduced all 


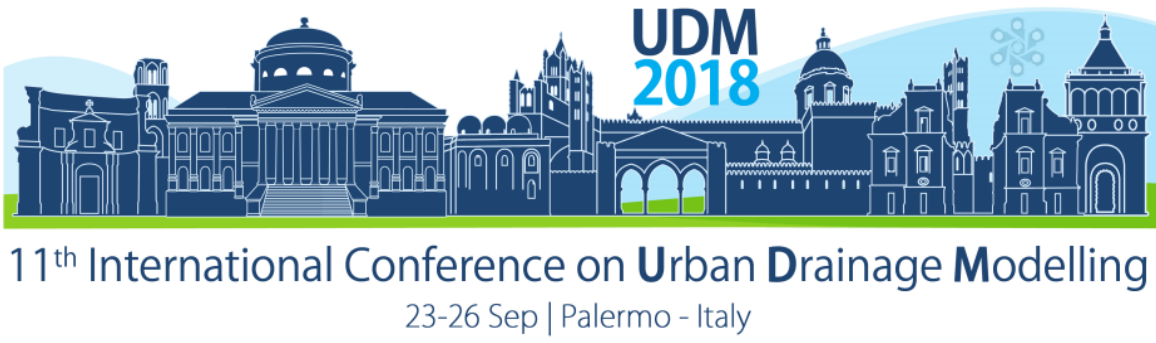

pollutants more evenly, by $33-50 \%$. The PP scenarios with the simple approach can reduce runoff and pollutants effectively, when the sources and transport pathways of different pollutants are understood. The scenarios with BR benefitted the most from optimization. Challenges with BR scenarios are their smaller areal footprint and storage capacity compared with PP, yet on the other hand, the small areal coverage is an advantage when retrofitting existing urban areas.

\section{CONCLUSIONS}

The reduction of runoff and stormwater pollutant loads were impacted by the location of the LID units within the catchment. Although the pollutant removal rate of a single LID unit was high, considerable reductions in the catchment scale pollutant load might not be achieved. Based on the simulated runoff reduction, the pollutant load reduction of scenarios with permeable pavements were largest. Different pollutants originated from different land cover types so the simple approaches treating runoff from a single land cover type reduced pollutants unevenly. Designs relaying on bioretention benefitted the most from the location optimization due to their smaller storage capacity and areal coverage. If the management target is to maximize the runoff and pollutant reduction, the permeable pavement scenarios on roads and walkways appear most effective. Given an additional target to minimize the areal coverage of LID units, the optimized scenarios with both permeable pavements and bioretention can be seen as cost-efficient solutions. Although the results achieved are site-dependent, they demonstrate the importance of LID location for reducing stormwater pollution. The proposed approach of LID location optimization is applicable to other residential catchments and different climatic conditions.

\section{References}

Burns, M.J., Fletcher, T.D., Walsh, C.J., Ladson, A.R. and Hatt, B.E. (2012) Hydrologic shortcomings of conventional urban stormwater management and opportunities for reform. Landscape and Urban Planning. 105, 230-240.

City of San Francisco. (2010) San Francisco Stormwater Design Guidelines. Appendix A: BMP Factsheets. San Francisco, California. U.S. City of San Francisco, Public Utilities Commission, Port of San Francisco.

Elliott, A.H. and Trowsdale, S.A. (2007) A review of models for low impact urban stormwater drainage. Environmental Modelling \& Software. 22, 394-405.

Field, R. and Sullivan, D. (2003) Wet-weather flow in the urban watershed: Technology and management. CRC Press LLC, Boca Raton, Florida, USA. ISBN: 1-56676-916-7. 384 p.

Jato-Espino, D., Sillanpää, N., Charlesworth, S.M. and Andrés-Doménech, I. (2016) Coupling GIS with Stormwater Modelling for the Location Prioritization and Hydrological Simulation of Permeable Pavements in Urban Catchments. Water. 8, 451.

Riverside County. (2011) Design Handbook for Low Impact Development Best Management Practices. Riverside, CA. U.S. Riverside County Flood Control and Water Conservation District.

Rossman, L.A. (2015) Storm Water Management Model User's Manual Version 5.1. Cincinnati, Ohio. U.S. Environmental Protection Agency.

Shoemaker, L., Riverson, J. Alvi, K., Zhen, J.X., Paul, S. and Rafi, T. (2009) SUSTAIN - A Framework for Placement of Best Management Practices in Urban Watersheds to Protect Water Quality. Cincinnati, Ohio. U.S. Environmental Protection Agency.

Tuomela, C. (2017) Modelling Source Area Contributions of Stormwater Pollutants for Stormwater Quality Management. M. Sc. thesis, Department of Built Environment, Aalto University School of Engineering, Finland.

Tuomela, C., Sillanpää, N. and Koivusalo, H. (2017) Modelling source area contributions of stormwater pollutants with Storm Water Management Model (SWMM). Proc. 14th IWA/IAHR Conference on Urban Drainage, Prague, Czech Republic.

VTT. (2017) Column test results: pollutant removal capacity. StormFilter-project, work package 2: Geomaterials for stormwater filtration. Unpublished material.

Zhu, H., Xu, Y., Yan, B. and Guan, J. (2012) Snowmelt runoff: a new focus of urban nonpoint source pollution. International Journal of Environmental Research and Public Health. 9, 4333-4345. 


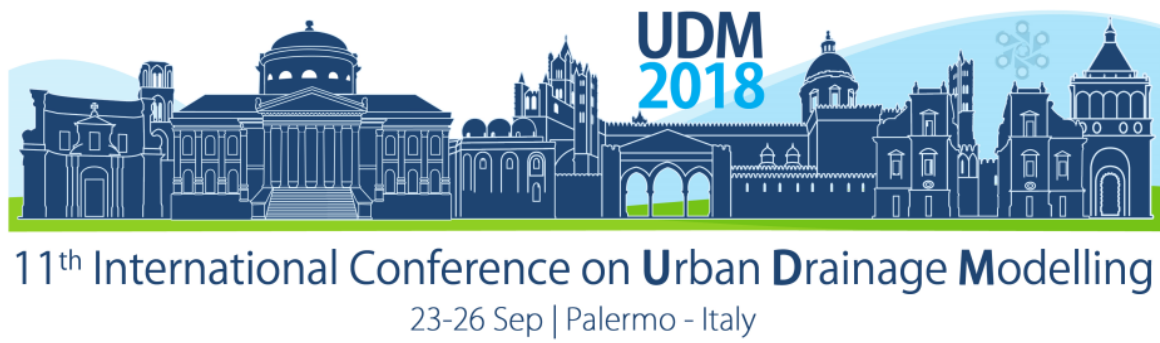

\title{
Water Recycling Long Term Plan for Managing Growth Risk
}

\author{
Kerry Rhodes ${ }^{1}$, Vanessa Greaves ${ }^{2}$ \\ ${ }^{1}$ Anglian Water Services Limited, Supply Demand Strategy Team, Peterborough, England. \\ ${ }^{2}$ Anglian Water Services Limited, Infrastructure Modelling Team, Peterborough, England.
}

\begin{abstract}
The Anglian Water region is the fastest growing region in the UK. We recognise the value in understanding our capacity to support growth, to create sustainable environments to live and work. Our water recycling system must provide reliable, affordable and sustainable levels of service for customers, while fully protecting the environment. We have developed our first 'Water Recycling Long Term Plan' (WRLTP) to provide transparency at how we plan to manage the supply of water recycling services to meet the demands of our growing customer base, urban creep and climate change. We have taken a risk based approach to developing our strategies. Our WRLTP promotes sustainable solutions for maintaining reliable and affordable levels of service, and facilitates working in partnership to mitigate flood risk.
\end{abstract}

\begin{abstract}
The timing of investments involves trade-offs of cost and risk between current and future customers and we have a responsibility to ensure services are provided for both. We must reconcile the need to keep bills affordable with the need to plan for future challenges. The timing and scale of growth is inherently uncertain, so our long term strategies are adaptive to change and respond to the key indicators we monitor. 'Live' modelling will ensure delivery of least regret solutions that consider our confidence in the need to invest, and include opportunities to reduce risk in the long term. We are proud of our WRLTP, which leads the industry as an innovative means of providing more certainty and effectiveness in securing environmental protection whilst accommodating growth.
\end{abstract}

Keywords: long term plan; risk based approach; live; least regret

\section{INTRODUCTION}

Our vision is for a fully integrated water and water recycling system which provides reliable, affordable and sustainable levels of service for customers and business, while fully protecting the environment. We want this system to be resilient to the effects of growth, climate change and severe drought; to minimise our water and carbon footprints; to enhance biodiversity and to increase the resilience of natural systems in our region, upon which we depend.

The investment needed over the next 25-years to balance the supply and demand for water recycling services is described in our first Water Recycling Long Term Plan (WRLTP). The plan considers risk from growth, climate change, severe drought, and customer behaviours. It promotes sustainable solutions for maintaining reliable and affordable levels of service. We want this system to be resilient to the effects of growth, climate change and severe drought; to minimise our water and carbon footprints; to enhance biodiversity and to increase the resilience of natural systems in our region, upon which we depend.

The timing of necessary investments involves trade-offs of cost and risk between current and future customers and we have a responsibility to ensure services are provided for both. We must reconcile the need to keep current bills affordable with the need to plan for future challenges. The timing and scale of these needs are inherently uncertain, so we have 


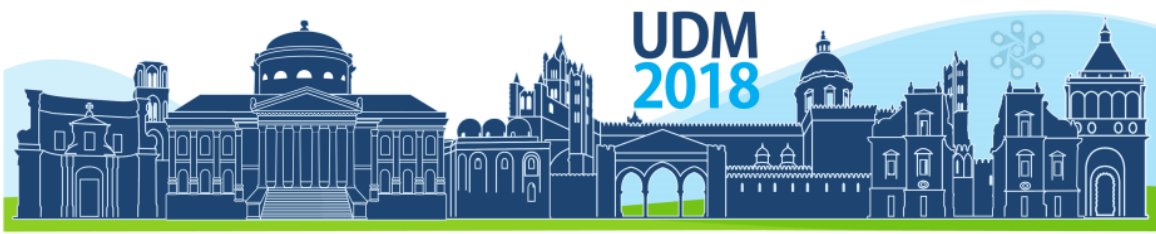

$11^{\text {th }}$ International Conference on Urban Drainage Modelling

23-26 Sep | Palermo - Italy

developed Long Term strategies that are adaptive to change and respond to the key indicators we monitor. This Long Term view enables us to identify solutions of least regret that are phased according to our confidence of the need for investment, and include opportunities to reduce risk to service to our customers in the long term.

We know growth is one of the biggest challenges for us - and one of the areas where we can do most to support our customers and our regions. That's why we've taken up the ambition to enable economic and housing growth. The flood risk heat map (right) demonstrates the impact of growth on our region, under a 'do nothing' scenario.

The timing of investments involves trade-offs of cost and risk between current and future customers and we have a responsibility to ensure services are provided for both. We must reconcile the need to keep bills affordable with the need to plan for future challenges. The timing and scale of growth is inherently uncertain, so our long term strategies are adaptive to change and respond to the key indicators we monitor. 'Live' modelling, of these key indicators and long term strategies, will ensure delivery of least regret solutions that consider our confidence in the need to invest, and include opportunities to reduce risk in the long term.
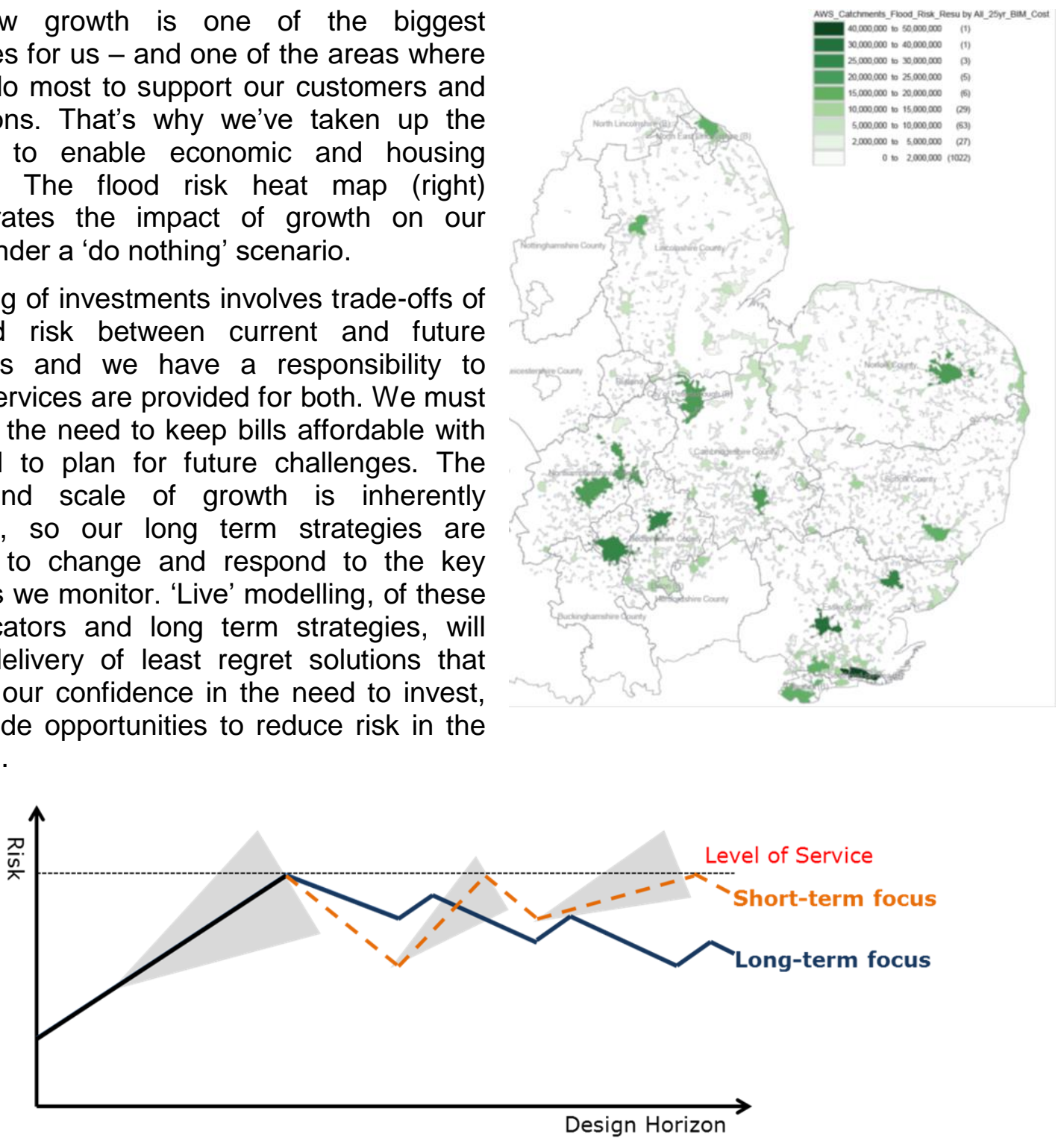

\section{MATERIALS AND METHODS}

\subsection{Approach overview}

The development of the WRLTP starts with our company Outcomes and Water Recycling Policies, and is further supported through the guiding principles of the Drainage Strategy Framework (DSF), as shown below. The DSF was commissioned by Ofwat and the Environment Agency to provide good practice guidance, (Drainage Strategy Framework, May 2013). 


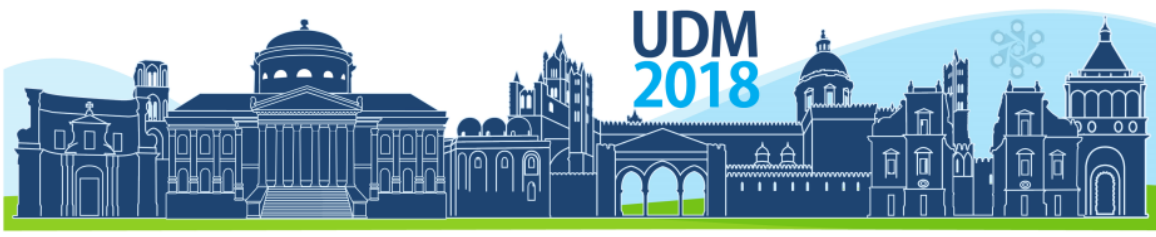

$11^{\text {th }}$ International Conference on Urban Drainage Modelling

23-26 Sep | Palermo - Italy

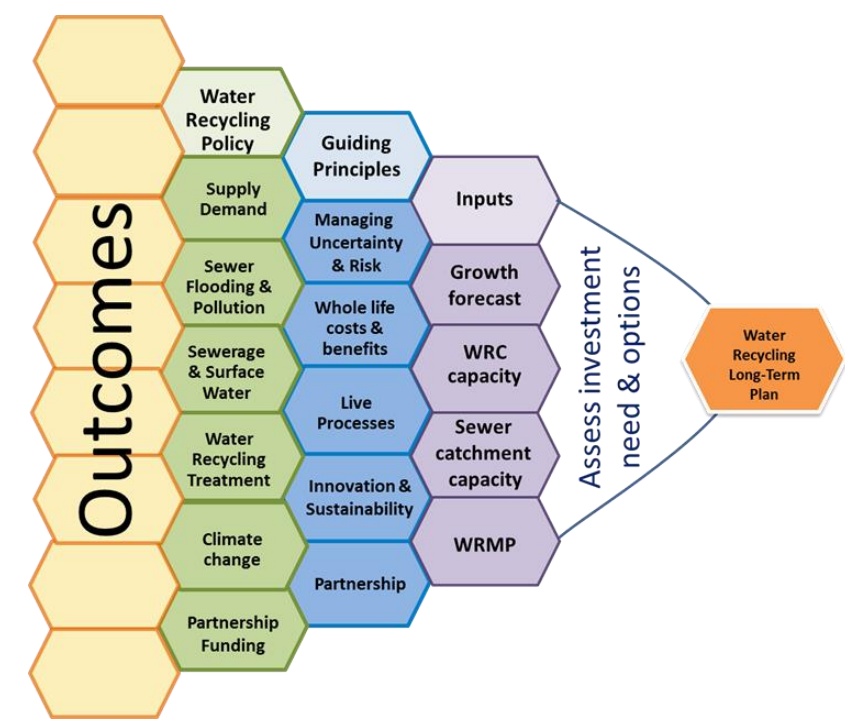

\subsection{Growth forecast}

Our Growth Forecast Model produces a modular, unified Water and Water Recycling growth forecast to support investment planning and capital delivery decisions. It utilises spatial data systems (GIS) to facilitate data management, apportionment, reporting and visualisation in a spatially flexible manner for various geographies. Due to the large number of discrete sewer catchments we serve, changes to growth site locations have significant impact to the solutions we consider.

The demand forecasts at catchment level have been assessed in terms of confidence across a number of AMP periods; being categorized as Bronze, Silver or Gold, based on the LAUA Local Plan status. This enables selection of an appropriate design horizon for the solutions to manage growth and identifies where we need to monitor future growth closely to gather more intelligence;

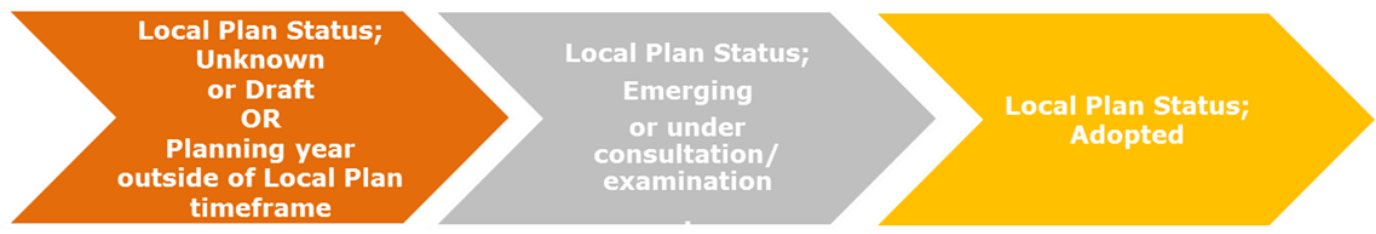

\subsection{Sewer catchment capacity assessment}

We have used a three stage risk assessment process to assess sewer catchment capacity deficit. All of our 1000+ catchments are taken through the Bronze capacity deficit risk assessment which uses an Infonet tool to assess upsizing requirements at the nearest connection point. The results are considered alongside predictive detriment analysis to identify those at highest risk to promote to the next stage. The Silver assessment uses the Infonet tool with a more confident spatial growth forecast, promoting those at high risk to Gold. The Gold assessment provides us with greater confidence in the capacity deficit, and provides valuable data to assist in the next stage of preparing solution options. Gold hydraulic modelling considered a strategic approach to catchment growth and promotes surface water management solutions wherever possible. Gold outputs also include the first year of detriment caused by growth only, to facilitate programming, and the identification of 'trigger' points in the catchment where we will monitor flow. This information will feed into 


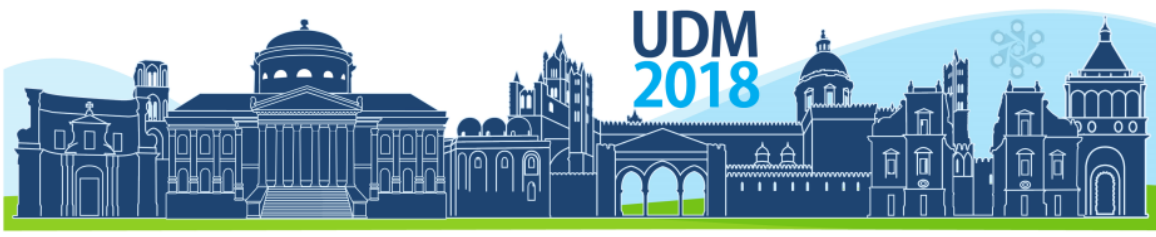

$11^{\text {th }}$ International Conference on Urban Drainage Modelling

23-26 Sep | Palermo - Italy

'live' modelling to enable us to review the risk, and reprioritise investment where required, as an adaptive strategy to manage growth uncertainty;

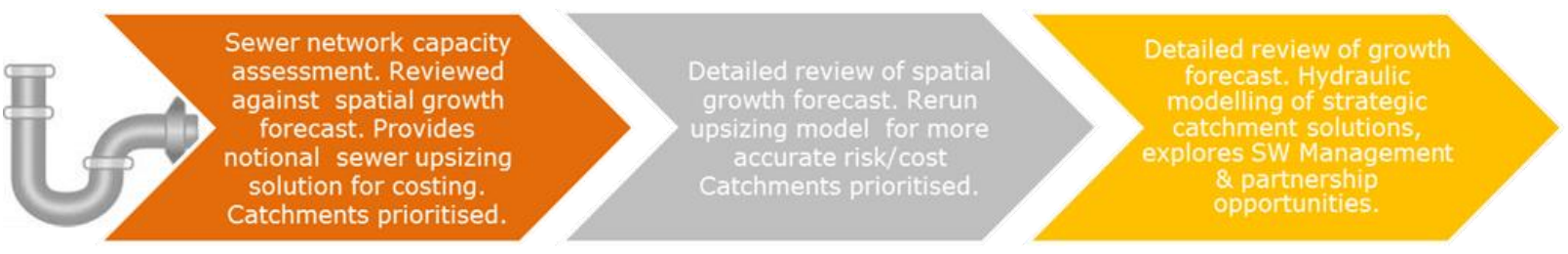

\section{RESULTS AND DISCUSSION}

\subsection{Investment strategies}

We have defined investment strategies according to confidence in the growth forecast and capacity deficit assessment. This three tiered approach is aligned with the Waste Water Supply Demand Framework (UKWIR, 2014).

\begin{tabular}{|ll|}
\hline $\begin{array}{l}\text { UKWIR } \\
\text { Investment Category }\end{array}$ & $\begin{array}{l}\text { UKWIR } \\
\text { Infrastructure Investment Definition }\end{array}$ \\
\hline Defined scheme & $\begin{array}{l}\text { High certainty that investment is required \& it is possible to identify the } \\
\text { appropriate solution at the time of business plan preparation. }\end{array}$ \\
\hline Defined contingent & $\begin{array}{l}\text { Preferable to wait for the outcome of a key uncertainty before deciding which of } \\
\text { the identified (and costed) investment options should be undertaken. }\end{array}$ \\
\hline Emerging & $\begin{array}{l}\text { Not possible to pre-define or allocate investment to specific assets or low } \\
\text { confidence in risk assessment. }\end{array}$ \\
\hline
\end{tabular}

A combination of surface water management and catchment upsizing solutions are proposed for Defined schemes. Our delivery timeline considers the first year of modelled detriment and lead times. However, we will adapt delivery as we use 'live' models to monitor key indicators.

\subsection{Customer engagement}

We are currently consulting with our key customers and stakeholders to seek feedback on our approach and the level of detail in our WRLTP. We are also liaising with flood risk partners to under opportunities to work together on sustainable solutions. This feedback will be considered prior to publication in summer 2018.

\section{CONCLUSIONS}

This innovative approach to the development of our WRLTP provides transparency of our processes to manage risk to our service to customers from growth, urban creep and climate change. Our adaptive strategies consider the confidence of the growth forecast and capacity assessment. Monitoring of key 'trigger' points in the sewer network, and gathering intelligence from our relationships with local authorities and developers, will enable least regret solutions to be delivered, that are phased according to the investment need, and consider our customers affordability.

\section{References}

Environment Agency and Ofwat, (2013) Drainage Strategy Framework.

UKWIR, (2014) Wastewater Supply-Demand Framework. 


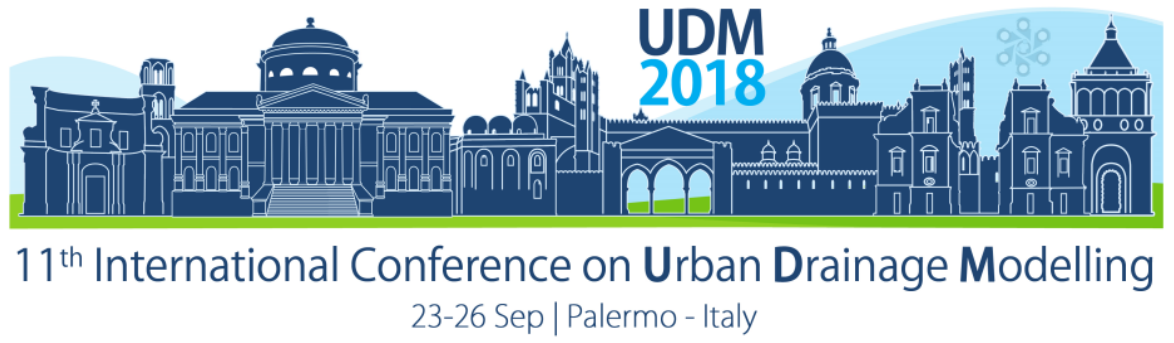

\title{
Resilience and its relation to system structure of combined sewer systems: virtual case study based on stochastic generation
}

\author{
Dazhen Zhang ${ }^{1}$, Xin Dong ${ }^{1}$ and Siyu Zeng ${ }^{1}$ \\ ${ }^{1}$ School of Environment, Tsinghua University, Beijing, China
}

\begin{abstract}
Resilience is a system's ability to minimize failure consequences when faced with exceptional conditions. This paper studies the relation between resilience and system structure of combined sewer systems. Stochastic generation model is used to obtain systems with various structures and their performance is tested in Storm Water Management Model (SWMM). Results show that resilience is mostly affected by the total count of combined sewer overflow (CSO) outfalls. The count of wastewater treatment plants (WWTP) also influences resilience but not remarkably. The cost-effectiveness of each system structure is also discussed. This study provides insight into the structural characteristics of combined sewer systems and can provide guidance for their planning and design.
\end{abstract}

Keywords: combined sewer system; resilience; system structure; stochastic generation; combined sewer overflow.

\section{INTRODUCTION}

Critical infrastructures such as urban water systems, power grid, communication network and transportation, provide essential services for people's daily life. Failure of such systems would lead to unacceptable damage. Infrastructure's resilience is defined as the system's ability to minimize failure magnitude and duration under disruptive events (U. S. National Infrastructure Advisory Council, 2010).

Urban drainage systems (UDS) typically fail under acute rainfall. Strategies to enhance resilience of UDS proposed by literature include mitigating external pressure (e.g. low impact development (Dong et al., 2017)), adding buffer capacity within the system (e.g. storage tanks (Mugume et al., 2015)) or overlapping functions (e.g. parallel pipes). In the meantime, our study shows that despite the many extra measurements, structure of the system itself plays an important role in affecting resilience.

This paper deals with combined sewer systems, where excess rainfall runoff is discharged directly into receiving water, known as combined sewer overflow (CSO). The structure of such systems is usually determined by the count and locations of WWTP(s) and CSO outfalls, and pipeline layout, etc. A stochastic generation model is built to obtain a large number of virtual systems with various structures. The resilience index is estimated by real-time simulation. The relation between resilience and system structure is discussed using statistical analysis.

\section{MATERIALS AND METHODS}

\subsection{Definition of system's resilience index}

Combined sewer systems operate under multiple boundary conditions. It is considered as "fail" if either urban flooding (social impact), combined sewer overflow (CSO) (environmental 


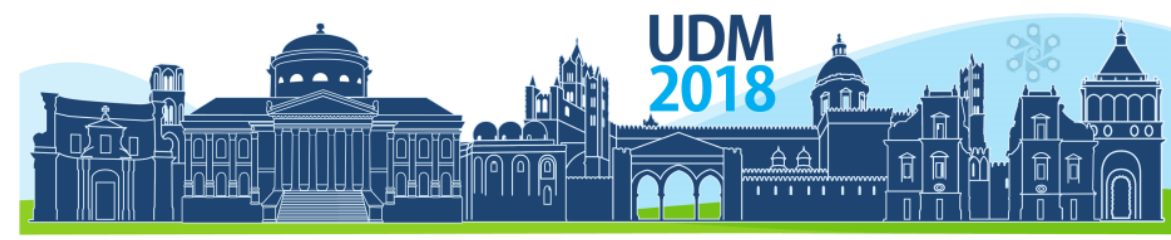

$11^{\text {th }}$ International Conference on Urban Drainage Modelling

23-26 Sep | Palermo - Italy

impact) or shock loading to wastewater treatment plant (WWTP) (technical impact) happens. This study adopts the resilience index defined in Dong et al., 2017:

$$
R e s=\sum_{T} \frac{1}{T} \frac{1}{1+k_{s} \frac{S e v_{s}}{Q_{t w}}+k_{e} \frac{S e v_{e}}{Q_{t w}}+k_{t} \frac{S e v_{t}}{Q_{t w}}}
$$

where $T$ is the return period of test rainfall, $k$ is a coefficient indicating the relative importance of each impact and Sev (severity) is calculated as failure magnitude times duration (see Dong et al., 2017 for detail). $Q_{t w}$ is the total dry weather flow to make the formula dimensionless.

\subsection{Stochastic generation model of combined sewer systems}

The stochastic generation model assumes that pipelines are built under each road of the city. Each subcatchment is assigned a certain road towards which rainfall runoff and wastewater would discharge. It can be used to generate sewer systems for either a real or an ideal city.

Basic procedure of the model (Fig. 1): (1) Locations of WWTPs and CSO outfalls are randomly chosen among the given potential locations. (2) Pipelines upstream to the CSO outfalls are designed by a random-spanning-tree process, while sewage mains connecting CSO outfalls and WWTPs are chosen as the shortest paths. (3) The remaining procedures (sizing of pipes, etc.) are based on China's national guideline, which targets at a design rainfall with predetermined return period.

Storm Water Management Model (SWMM) is used to evaluate system's performance under a single rainfall event. Acute rainfalls with much larger return periods than the design rainfall is used to test the virtual systems.

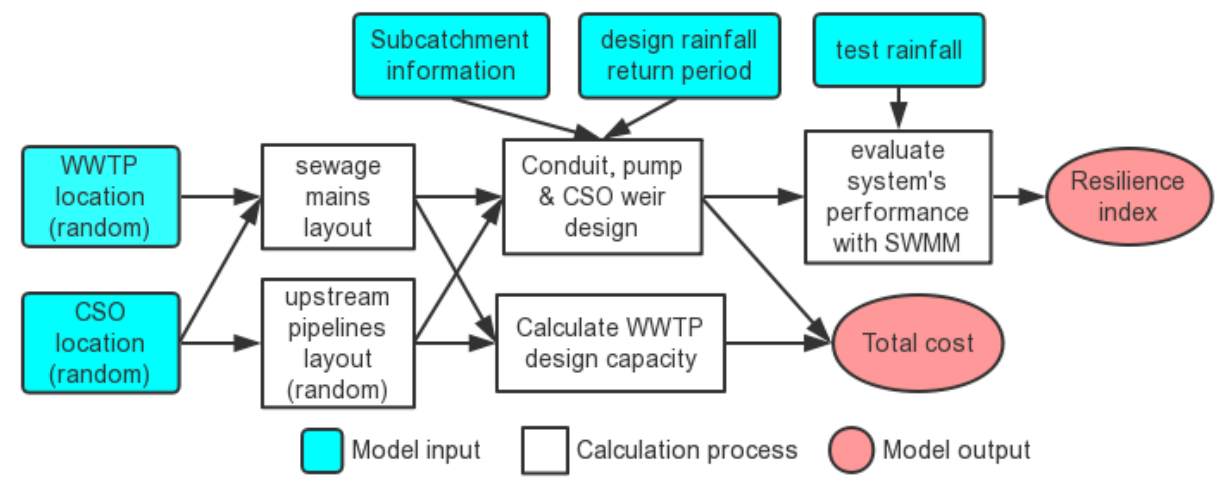

Figure 1. Procedure of the stochastic generation model.

\section{RESULTS AND DISCUSSION}

\subsection{Case study overview}

The case is based on a real-world urban area in southwest China, with an area of $42 \mathrm{~km}^{2}$. Altogether 100,000 virtual systems with different number and location of WWTP(s) and CSO outfalls + different layout of upstream pipelines were generated and evaluated.

\subsection{Relation between resilience and the count of WWTPs and CSO outfalls}

Fixing the total count of CSO outfalls and WWTPs, the average and standard deviation of systems' resilience are plotted in Fig. 2. On most occasions, systems with 4 WWTPs 


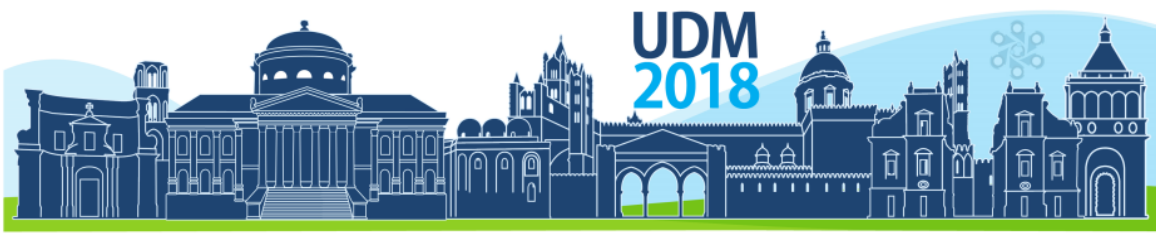

$11^{\text {th }}$ International Conference on Urban Drainage Modelling

23-26 Sep | Palermo - Italy

outperform others on average, while those with 1 WWTP perform worst (Fig. 2a). This shows that 1 WWTP is too few for the area, while too many may also hinder system's performance.

Systems with more CSO outfalls exhibit larger resilience on average (Fig. 2a). However, when CSO outfalls are fewer, the standard deviation of resilience is high (Fig. 2b), showing that resilience is more affected by other factors (i.e. the actual location of CSO outfalls, location of WWTPs and layout of pipelines). It also indicates that although the average is low, it is possible for an individual system to have high resilience if the other factors are designed properly.
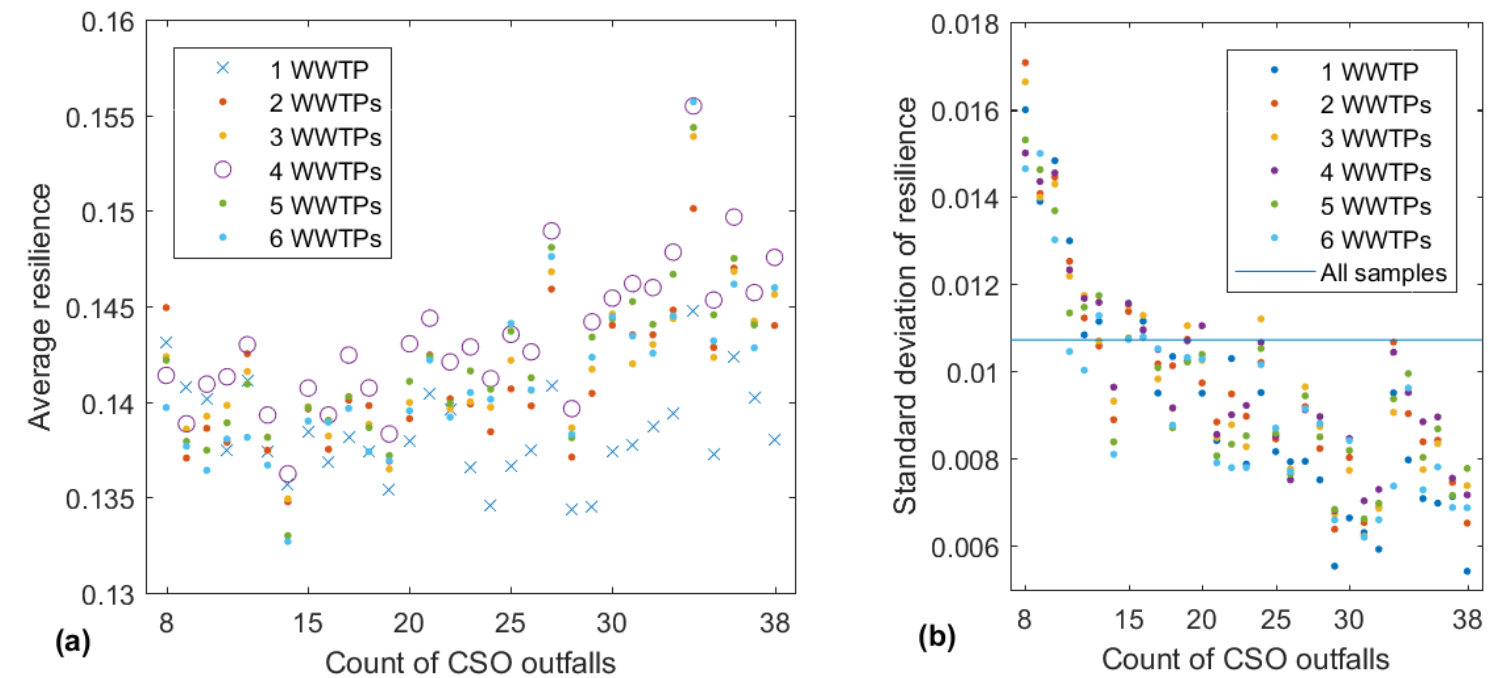

Figure 2. (a) Average and (b) standard deviation of system's resilience, fixing WWTP and CSO outfall counts.

\subsection{Characteristics of the cost-effective resilient systems}

Taking system's construction and maintenance cost into consideration, we use a multiobjective sorting method (Deb et al., 2002) to obtain systems with both high resilience and low cost. 1,008 ( 1\%) samples were selected as the "frontier" for further analysis (Fig. 3).
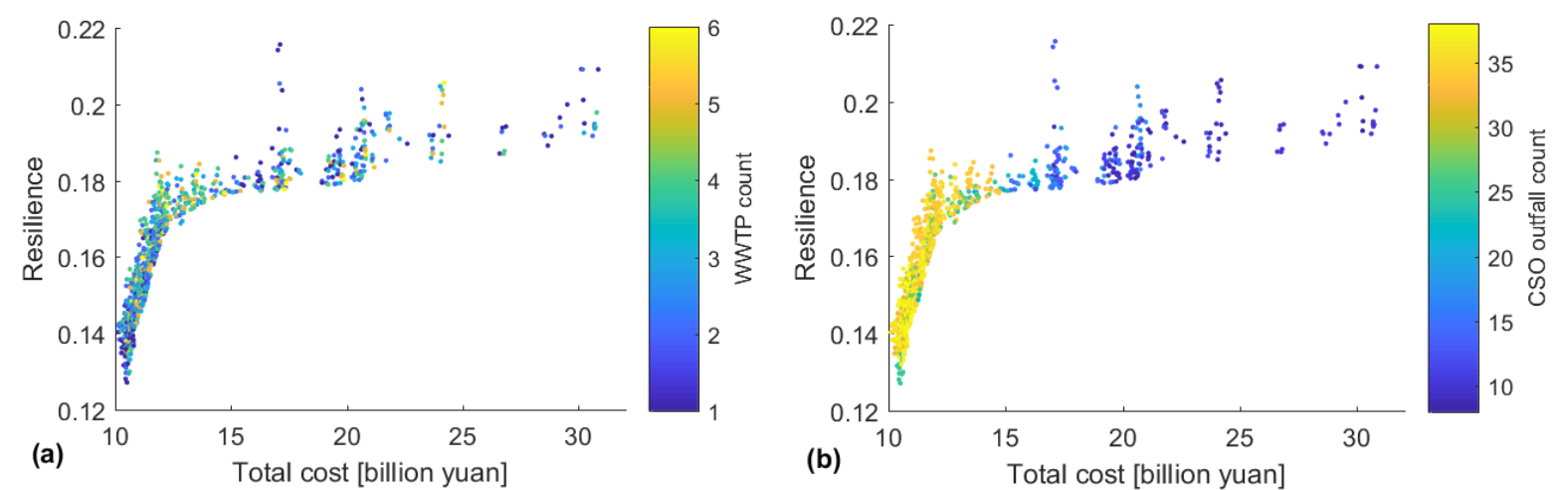

Figure 3. Resilience, total cost and (a) WWTP count, (b) CSO outfall count of the 1,008 selected systems.

A turning point on the frontier can be spotted. Compared to WWTP count (Fig. 3a), CSO outfall count is found to be a determining factor for system's cost and resilience (Fig. 3b). It is costeffective to increase resilience from 0.13 to 0.18 , with more than 25 CSO outfalls in the system.

Resilience cannot be further increased (to $>0.18$ ) unless the system changes to a more centralized structure (fewer CSO outfalls). Statistical analysis found that system with many 


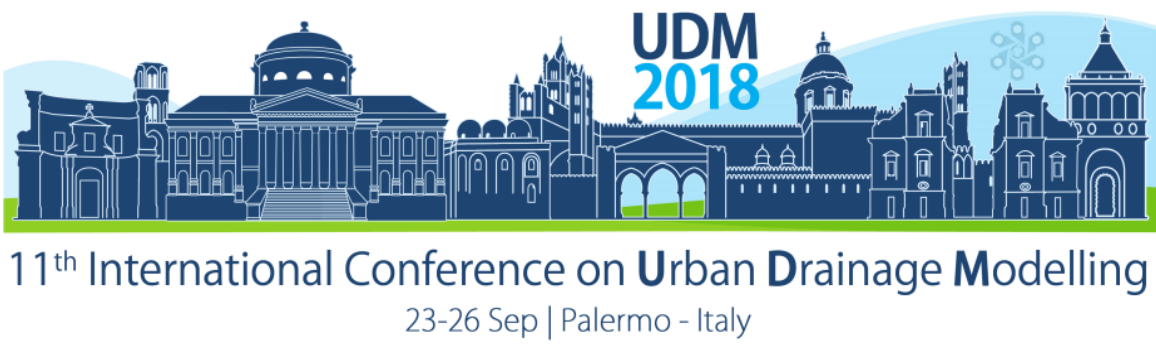

outfalls inevitably have a larger amount of CSO (Fig. 4) and are thus unable to achieve the highest resilience. On the other hand, it's also worth noticing that systems with fewer outfalls must be supplemented with proper design of the "other factors" (as mentioned above), otherwise it may come out as a dominated solution with both low resilience and a huge cost.

\subsection{Enhancing system resilience cost-effectively by reducing CSO}

Although "fewer CSO outfalls" is a feasible solution to increase resilience, it would result in a dramatic cost increase. Enlarging the intercept ratio (ratio between the runoff volume treated in WWTP and dry weather flow) is evaluated as an alternative. Allowing intercept ratio to change, the strategy to enlarge intercept ratio appears before the "fewer CSO outfalls" option on the new frontier (Fig. 5). This indicates that a strategy specifically tackling CSO may be more cost-effective than changing the whole system to a more centralized structure.

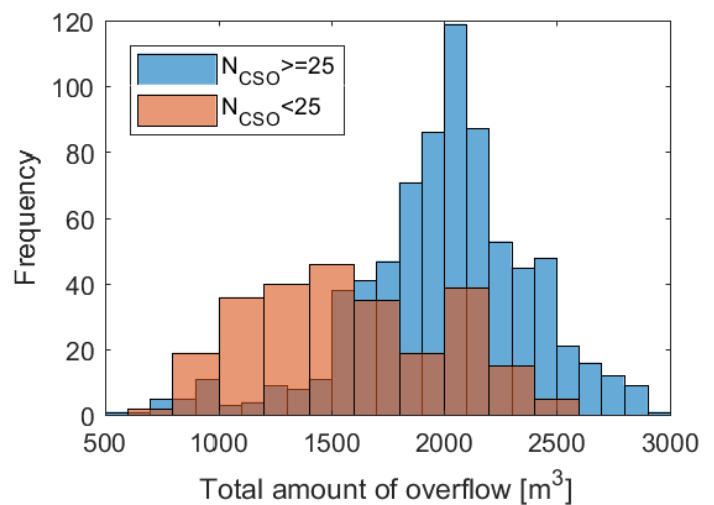

Figure 4. Distribution of overflow amount in systems with $>=25$ or $<25$ CSO outfalls.

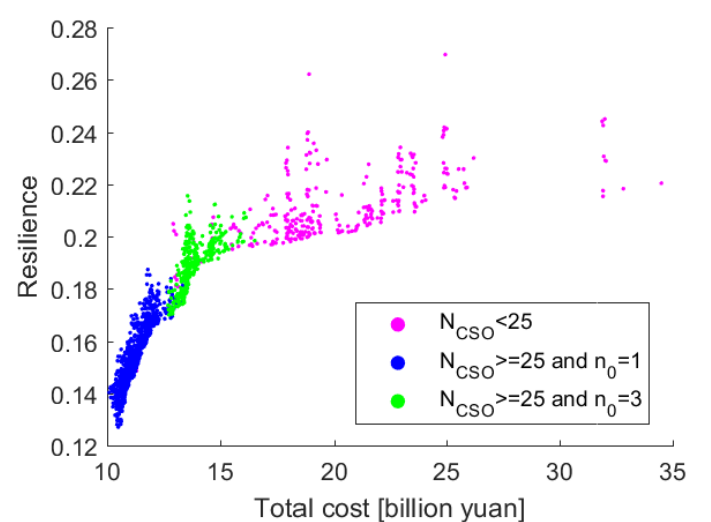

Figure 5. The new frontier when interception ratio $\left(\mathrm{n}_{0}\right)$ is allowed to vary between 1 and 3 .

\section{CONCLUSIONS}

The relation between resilience and system structure of combined sewer systems is studied. The stochastic generation model has proven to be suitable for this purpose and some nontrivial results are obtained. The count of CSO outfalls is found to be most influential to both system's resilience and cost. More CSO outfalls significantly reduces the cost, but it is costeffective only when the demand for resilience is low. When a high resilience is demanded, CSO has to be controlled to a low level. To achieve this, decreasing the count of CSO outfalls is feasible, but very cost-ineffective, while enlarging the intercept ratio is shown to be a more cost-effective strategy.

\section{Acknowledgement}

This work was supported by the National Key Research and Development Program of China (2016YFC0401401).

\section{References}

Deb, K., Pratap, A., Agarwal, S. and Meyarivan, T. (2002) A fast and elitist multiobjective genetic algorithm: NSGAII. IEEE Transactions on Evolutionary Computation 6(2), 182-97.

Dong, X., Guo, H. and Zeng S. (2017) Enhancing future resilience in urban drainage system: Green versus grey infrastructure. Water Research 124, 280-9.

Mugume, S. N., Diao, K., Astaraie-Imani, M., Fu, G., Farmani R. and Butler D. (2015) Enhancing resilience in urban water systems for future cities. Water Science \& Technology: Water Supply 15(6), 1343-52.

National Infrastructure Advisory Council (2010) A Framework for Establishing Critical Infrastructure Resilience Goals. https://www.dhs.gov/publication/niac-framework-establishing-resilience-goals-final-report (last visited on 10 JUN 2018). 


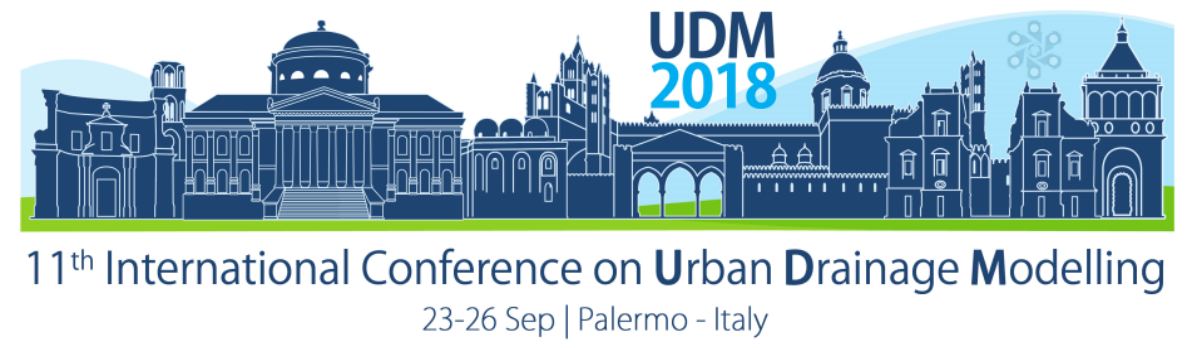

\title{
Developing a new modelling tool to allocate Low Impact Development practices in a cost optimized method
}

\author{
Nahad Rezazadeh Helmi ${ }^{1}$, Boud Verbeiren², Mohamad El Hattab ${ }^{3}$, Ana Mijic ${ }^{4}$ and Willy \\ Bauwens $^{5}$ \\ ${ }^{1}$ Vrije Universiteit Brussel, Department of Hydrology and Hydraulic Engineering, Brussels, Belgium \\ ${ }^{2}$ Vrije Universiteit Brussel, Department of Hydrology and Hydraulic Engineering, Brussels, Belgium \\ ${ }^{3}$ Imperial College London, Department of Civil and Environmental Engineering, London, UK \\ ${ }^{4}$ Imperial College London, Department of Civil and Environmental Engineering, London, UK \\ ${ }^{5}$ Vrije Universiteit Brussel, Department of Hydrology and Hydraulic Engineering, Brussels, Belgium
}

\begin{abstract}
Nowadays there is a need to overcome the effects caused by rapid urbanisation with more innovative methods. Recently, source control approaches, known as Low Impact Development (LID), are being used by urban planners to cope with water related problems and any other environmental issues due to their cost-effectiveness and reliability. To meet the needs of decision makers, the effects of these practices should be analysed at catchment scale. To do this, allocation of LID techniques in most suitable locations is essential. In this research a new modelling tool called LID locator is added to the WetSpa-Urban software package for more accurate placement of these techniques. The maximum area that can be covered by different types of LIDs are defined by finding the potential areas prone to generate runoff in combination with suitability maps calculated based on size limitation and implementation restriction for each LID measures. Then, the new cost-optimization tool is added through new procedure. This study is testified in the Watermaelbeek catchment situated in Brussels capital region.
\end{abstract}

Keywords: Urbanisation; Source control; Low Impact Development; Locator tool, Cost-optimization

\section{INTRODUCTION}

In recent years urbanization growth rapidly causes sealing of land surface to facilitate living for habitant. According to the UN population division (2014), more than $97 \%$ of the Belgian population live in urban areas. This alters the hydrology in cities by reducing infiltration and evapotranspiration, which leads to an increase in volume and velocity of surface runoff and may cause shorter response time of the catchment (Kaushal and Belt, 2012; Martin-Mikle et al., 2015; Rose and Peters, 2001; White and Greer, 2006).

To overcome the problems associated with sealing the natural landuse as a cause of urbanization, there are two major methods: the end-of-pipe solution and the source control Green Infrastructure (Gl) approach known as LID (Booth et al., 2002; County, 1999; Dorn and Ranjithan, 2003; Ellis et al., 2004; Martin et al., 2007; Martin-Mikle et al., 2015; Scholz, 2006; Villarreal et al., 2004). In the last decade, LID practices have been more implemented in urban areas compared to the other conventional approaches due to their cost-effectiveness and good performance to mitigate water related problems in terms of both quantity and quality and additional environmental issues (Dietz, 2007; Kuo and Sullivan, 2001; Kurtz, 2009; Montalto et al., 2007; Pyke et al., 2011; Roehr et al., 2008; Urbonas and Stahre, 1993; Van Roon, 2005). The reason for using $\mathrm{Gl}$ is to mitigate the effects of urbanization on the hydrological cycle by increasing the infiltration rate, storage volume and also coarsening the surface (Elliott and 


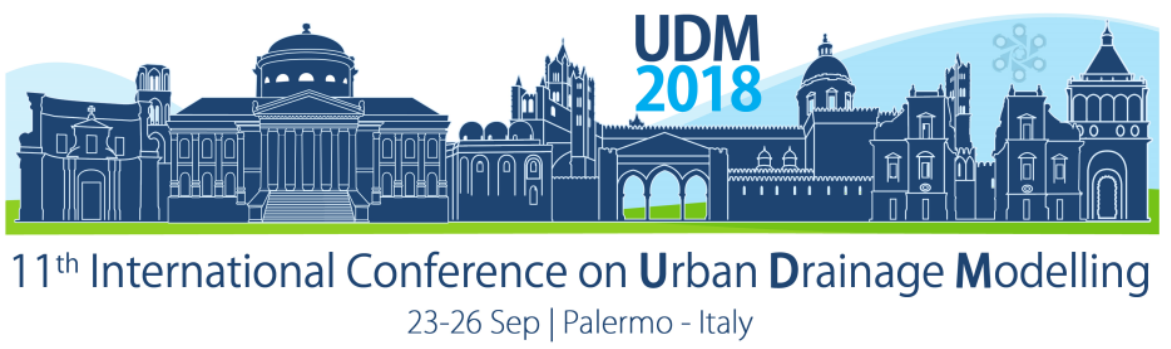

Trowsdale, 2007; Lai et al., 2007; Wong et al., 2002). This may lead to slower runoff, more infiltration to the soil, less flooding and more evapotranspiration in urban catchments (Coffman, 2000; Doug et al., 2005; EPA, 2000; Lawson, 2010; Weinstein et al., 2006, 2009).

Over the past years, most researches have been focused on investigating the effect of experimental LID techniques, implemented at small scale (Bengtsson, 2005; Farahbakhsh et al., 2008; Gregoire and Clausen, 2011; Stovin et al., 2012; Wossink and Hunt, 2003) but only few studies examine the impact of them on a watershed scale to reach amore sustainable city (Carter and Jackson, 2007; Levallius, 2005; Palla et al., 2008; Versini et al., 2015). Implementing and modelling LID on a watershed scale is different compared to the building scale. The difference is mainly due to the importance of placing each LID practices in the most suitable locations. As remotely sensed data can collect sufficient information about the terrain with the details and accuracy needed for heterogeneous urban catchments, they will be of great help in the process of finding suitable locations for different types of LIDs. To meet the main aim of urban planners, the most crucial is to identify the best locations for LID techniques with highest potential to reduce flooding in the region.

Many modelling tools are used by different researchers to answer the above questions which try to detect the best implementation of LIDs in a suited way. A research is done to categorize different softwares used in this scope (Lerer et al., 2015). The devision has been done based on the ability of each software packages to answer the following questions: (1) How much?, (2) where? and (3) which?. The first term trying to investigate the ability of the modelling tools to cover the effect of implimentation of LID on water quantity, quality, economic impacts and any other non-flow impacts. The second and third questions also trying to categorize simulation tools based on their ability to find out the best location of LIDs and their degree of coverage in the study area, respectively. It is important to note that most of them are able to answer only one or two of the mentioned questions and only some of them are capable to cover all aspects. As an example, the EPA Storm Water Management Model (SWMM) (Rossman, 2010) can only analyse the effect of LID practices on water quantity. In addition to that, one problem associated with some of the more complete software packages is the availablity of them in order to use freely.

Although the physical processes in urban and natural catchments are the same, as a cause of the high complexity in urban areas due to the human induced changes in slope, soil type and landuse classes, the use of spatially distributed simulation models is recommended (Versini et al., 2014). In this study, the newly developed rainfall-runoff model called WetSpa-Urban is used and a new module is added to the model for the allocation of LIDs with an accurate method.

\section{MATERIALS AND METHODS}

\subsection{Case Study}

This research tests the newly developed module on the most urbanized part of upper Woluwe catchment (Watermaelbeek sub-catchment) which is located in the North West of the upper Woluwe. The elevation ranges from $54 \mathrm{~m}$ to $121 \mathrm{~m}$ above the sea level. Moreover, loamy soil is the most dominant soil type in this region (Chormanski et al., 2008). 


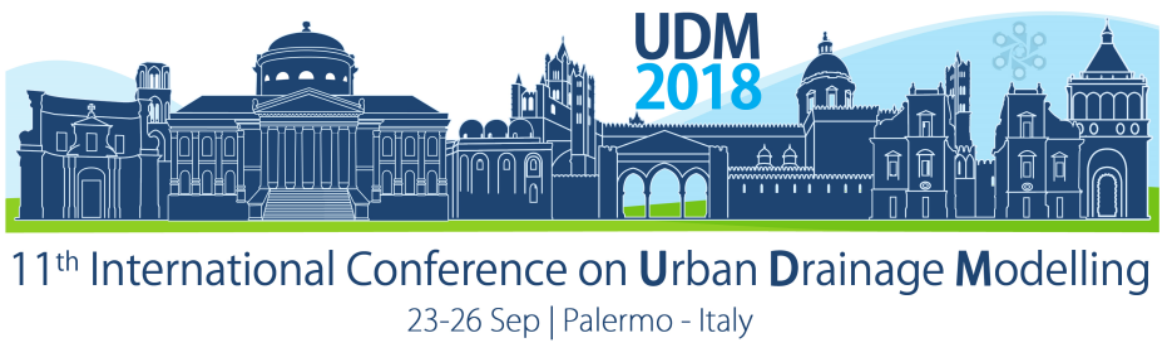

\subsection{Software package}

To develop a locator tool for applications of LIDs there is a need for rainfall-runoff simulation software which calculates over-ground processes based on remotely sensed data. The reason why WetSpa-Urban is selected as a source tool for the development of the LID locator tool is, firstly, because of the possibility of using input maps with highest precision for the placement of LIDs in the most suitable locations. The second reason is due to the possibility of the model to be further developed as the model is openly available and written modularly within Python. The WetSpa-Urban software is generated based on the integration of two different tools named WetSpa (Liu and De Smedt, 2004) and SWMM (Rossman, 2010). This tool is very useful in urban areas as the over-ground processes are simulated by distributed geographic information system (GIS) and Remote Sensing (RS) based maps and underground processes are calculated by the hydraulic simulation tool.

A new module for the allocation of different types of LID is added to WetSpa-Urban. The general concept of the LID locator tool added to the model is presented in the following chart.

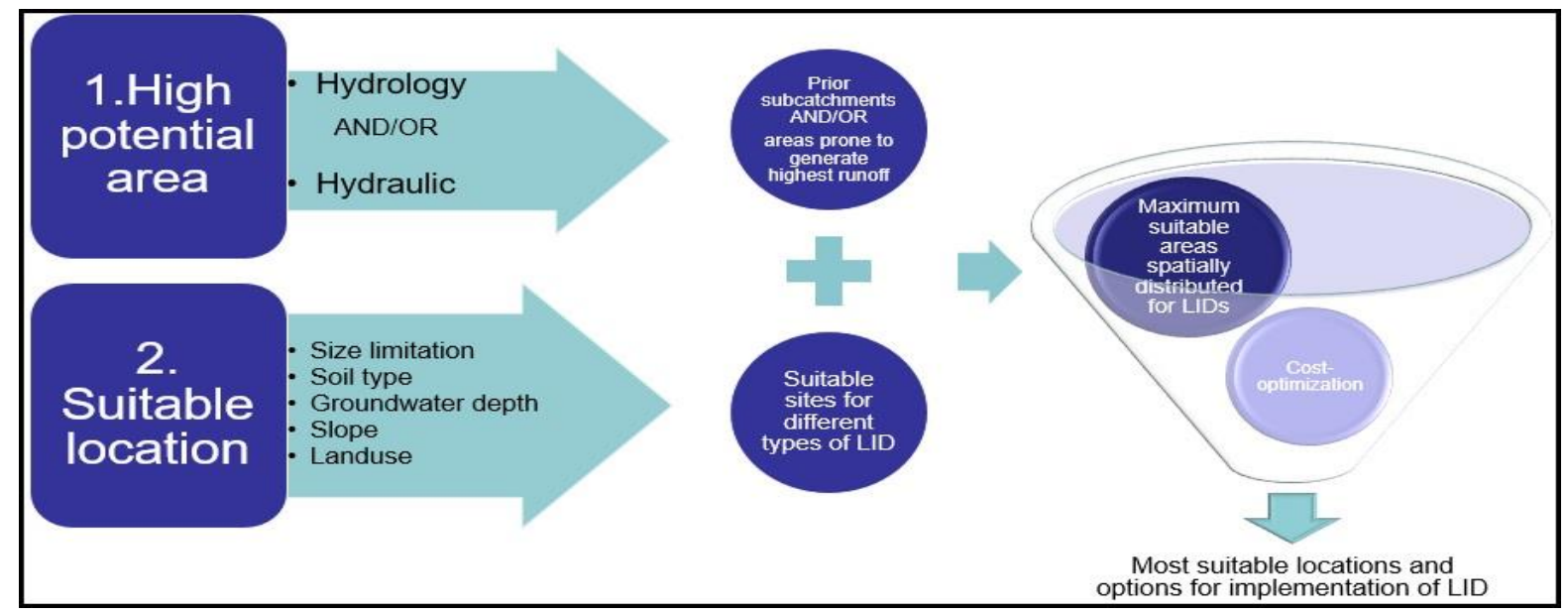

Figure 1. General concept beside WetSpa-Urban LID locator tool.

The LID locator tool is a GIS-based decision support tool that assists the user to select not only areas where LIDs could be implemented within a large catchment, but also to answer what is the best spatial combination to achieve the best possible performance in a very costeffective way. To do this it goes through a stepwise approach. As can be seen from Figure 1, this tool contains 3 different steps: Finding high potential areas to implement source control approaches, finding suitable locations for different types of LIDs and finally a cost optimization tool to find the most cost beneficial selection.

In the first step, the high potential areas for the implementation of LIDs are defined based on a hydrological and hydraulic calculation. The outcome of the hydrological calculation is a map showing areas prone to generate runoff based on a runoff coefficient calculation (Liu and De Smedt, 2004) and a topographic index, $\lambda$, (Quinn et al., 1991). Moreover, the hydraulic section will comb any sub-catchments in the region that cause high pressure in the sewer network by analysing maximum over full flow in links. By overlaying these search algorithms, the high potential area for implementation of LIDs is defined.

In the second step, the most suitable locations for four types of LIDs in a high potential area are detected by running eight different search algorithms. Up to now, raingarden, riparian zone, 


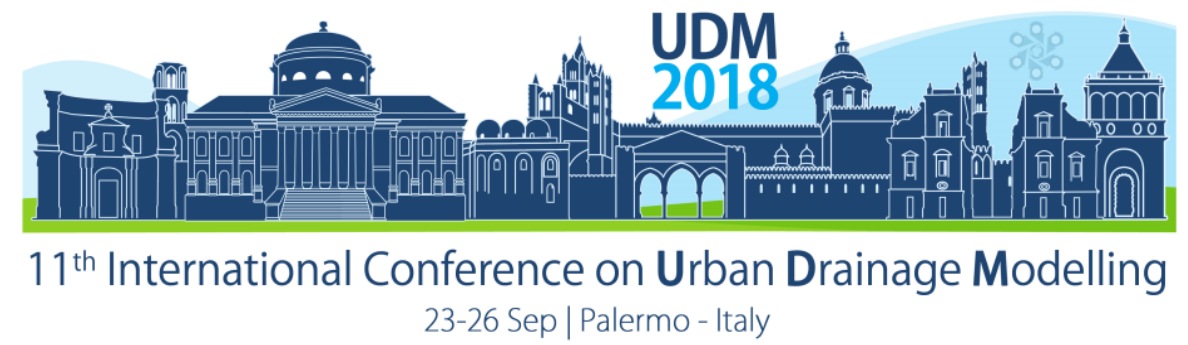

permeable pavement and green roof are the main four types of LIDs executed in the tool. After prioritizing them on the basis of user preferences, a new landuse map with the highest possible coverage in the most suitable locations for four applications of LIDs is be given.

In the last step, a Multi Criteria Evaluation (MCE) (Carver, 1991) approach is used where various measures need to be analysed to reach a specific objective. In this case, reducing urban surface flow with the lowest cost is the main objective. A unique procedure is added to the optimization tool by taking four options with different aim into consideration before calculating the size and location of each LID. In the first option, the main idea is to reduce flooding outlets only through the implementation of LIDs in the responsible source subcatchments. Source sub-catchments are the sub-catchments that provide more water to the sewer network compared the volume available the specific manholes. The second option wants to check how flooding is reduced by introducing LID techniques in the closest responsible sub-catchments whether they are sources or not. LID type, size and location for the third option is calculated by the help of a programming technique called Breadth-first search (BFS) (Zuse, 1972). Compared to the first option, source sub-catchment for each flooding outlet is not restricted to only one sub-catchment. The algorithm is written in a way to find as many source sub-catchments as possible which can be responsible for flooding in different manholes. Then the LID practices are placed into the responsible source sub-catchments for each manhole by filling first the closest one and then the others based of their distance from the flooded manhole. Last but not least, aggregation of the selected areas for LIDs as an outcome of the first three options are considered as fourth option by precedence of third solution over second and first.

\section{RESULTS AND DISCUSSION}

At the moment, the tool is generated with easy to use GUI that makes the software userfriendly. In addition, the tool will be able to produce user-friendly maps indicating the best and most cost-efficient locations and combinations for LIDs in the Watermaelbeek catchment. This will help urban planners and decision makers to implement sustainable water management in this area. The resulting maps and tables for the Watermaelbeek case study will be generated in coming months.

\section{References}

Bengtsson, L.: Peak flows from thin sedum-moss roof, Hydrol. Res., 36(3), 269-280, 2005.

Booth, D. B., Hartley, D. and Jackson, R.: FOREST COVER, IMPERVIOUS-SURFACE AREA, AND THE MITIGATION OF STORMWATER IMPACTS1, JAWRA J. Am. Water Resour. Assoc., 38(3), 835-845, 2002.

Carter, T. and Jackson, C. R.: Vegetated roofs for stormwater management at multiple spatial scales, Landsc. Urban Plan., 80(1), 84-94, 2007.

Carver, S. J.: Integrating multi-criteria evaluation with geographical information systems, Int. J. Geogr. Inf. Syst., 5(3), 321-339, 1991.

Chormanski, J., Van de Voorde, T., De Roeck, T., Batelaan, O. and Canters, F.: Improving distributed runoff prediction in urbanized catchments with remote sensing based estimates of impervious surface cover, Sensors, 8(2), 910-932, 2008.

Coffman, L.: Low-impact development design strategies, an integrated design approach, Prince George's Cty. Md. Dep. Environ. Resour. Programs Plan. Div., 2000.

County, P. G.: Low-Impact Development Hydrologic Analysis, Prep. Prince George's Cty. Md. Dep. Environ. Resour. Programs Plan. Div., 1999.

Dietz, M. E.: Low impact development practices: A review of current research and recommendations for future directions, Water. Air. Soil Pollut., 186(1-4), 351-363, 2007. 


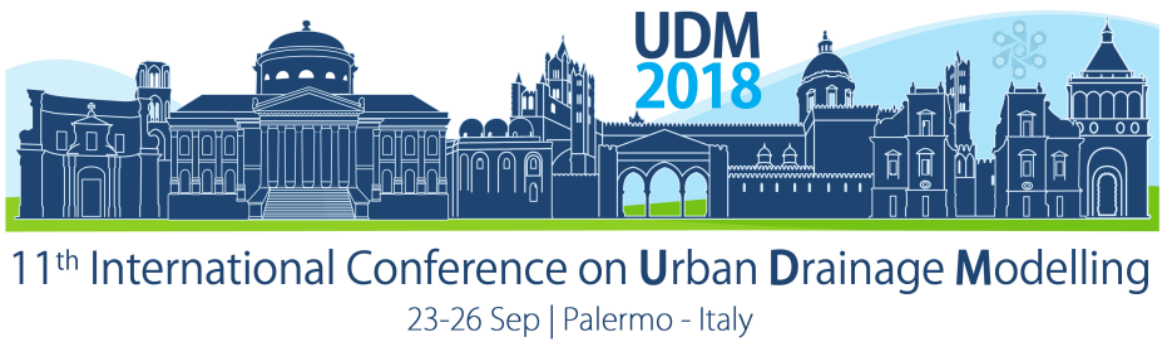

Dorn, J. L. and Ranjithan, S. R.: Evolutionary multiobjective optimization in watershed water quality management, in International Conference on Evolutionary Multi-Criterion Optimization, pp. 692-706, Springer., 2003.

Doug, B., Hitesh, D., James, L. and Paul, M.: Report on the environmental benefits and costs of green roof technology for the city of Toronto, 2005.

Elliott, A. H. and Trowsdale, S. A.: A review of models for low impact urban stormwater drainage, Environ. Model. Softw., 22(3), 394-405, 2007.

Ellis, J. B., Deutsch, J.-C., Mouchel, J.-M., Scholes, L. and Revitt, M. D.: Multicriteria decision approaches to support sustainable drainage options for the treatment of highway and urban runoff, Sci. Total Environ., 334, 251-260, 2004.

EPA, U.: Low Impact Development (LID); A Literature Review, Wash. DC US Environ. Prot. Agency Off. Water Low Impact Dev. Cent., 2000.

Farahbakhsh, K., Despins, C. and Leidl, C.: Evaluating the feasibility and developing design requirements and tools for large-scale rainwater harvesting in Ontario, Canada Mortgage and Housing Corporation., 2008.

Gregoire, B. G. and Clausen, J. C.: Effect of a modular extensive green roof on stormwater runoff and water quality, Ecol. Eng., 37(6), 963-969, 2011.

Kaushal, S. S. and Belt, K. T.: The urban watershed continuum: evolving spatial and temporal dimensions, Urban Ecosyst., 15(2), 409-435, 2012.

Kuo, F. E. and Sullivan, W. C.: Environment and crime in the inner city does vegetation reduce crime?, Environ. Behav., 33(3), 343-367, 2001.

Kurtz, T.: Flow monitoring of three ecoroofs in Portland, Oregon, in Low Impact Development for Urban Ecosystem and Habitat Protection, pp. 1-10., 2009.

Lai, F., Dai, T., Zhen, J., Riverson, J., Alvi, K. and Shoemaker, L.: SUSTAIN-AN EPA BMP process and placement tool for urban watersheds, Proc. Water Environ. Fed., 2007(5), 946-968, 2007.

Lawson, S. O.: A Planning Framework for Low Impact Development (LID) in Stormwater Management-An Ontario Perspective, 2010, 2010.

Lerer, S. M., Arnbjerg-Nielsen, K. and Mikkelsen, P. S.: A mapping of tools for informing water sensitive urban design planning decisions—questions, aspects and context sensitivity, Water, 7(3), 993-1012, 2015.

Levallius, J.: Green roofs on municipal buildings in Lund: modeling potential environmental benefits, Lunds Univ. Naturgeografiska Inst.-Semin., 2005.

Liu, Y. B. and De Smedt, F.: WetSpa extension, a GIS-based hydrologic model for flood prediction and watershed management, Vrije Univ. Brussel Belg., 1-108, 2004.

Martin, C., Ruperd, Y. and Legret, M.: Urban stormwater drainage management: The development of a multicriteria decision aid approach for best management practices, Eur. J. Oper. Res., 181(1), 338-349, 2007.

Martin-Mikle, C. J., de Beurs, K. M., Julian, J. P. and Mayer, P. M.: Identifying priority sites for low impact development (LID) in a mixed-use watershed, Landsc. Urban Plan., 140, 29-41, 2015.

Montalto, F., Behr, C., Alfredo, K., Wolf, M., Arye, M. and Walsh, M.: Rapid assessment of the cost-effectiveness of low impact development for CSO control, Landsc. Urban Plan., 82(3), 117-131, 2007.

Palla, A., Berretta, C., Lanza, L. G. and La Barbera, P.: Modelling storm water control operated by green roofs at the urban catchment scale, in 11th International Conference on Urban Drainage, Edinburgh, Scotland, UK., 2008. Pyke, C., Warren, M. P., Johnson, T., LaGro, J., Scharfenberg, J., Groth, P., Freed, R., Schroeer, W. and Main, E.: Assessment of low impact development for managing stormwater with changing precipitation due to climate change, Landsc. Urban Plan., 103(2), 166-173, 2011.

Quinn, P., Beven, K., Chevallier, P. and Planchon, O.: The prediction of hillslope flow paths for distributed hydrological modelling using digital terrain models, Hydrol. Process., 5(1), 59-79, 1991.

Roehr, D., Laurenz, J. and Kong, Y.: Green envelopes: Contribution of green roofs, green facades and green streets to reducing stormwater runoff, co emissions and energy demand in cities, in International Low Impact Development Conference., 2008.

Rose, S. and Peters, N. E.: Effects of urbanization on streamflow in the Atlanta area (Georgia, USA): a comparative hydrological approach, Hydrol. Process., 15(8), 1441-1457, 2001.

Rossman, L. A.: Storm water management model user's manual, version 5.0, National Risk Management Research Laboratory, Office of Research and Development, US Environmental Protection Agency Cincinnati., 2010. 


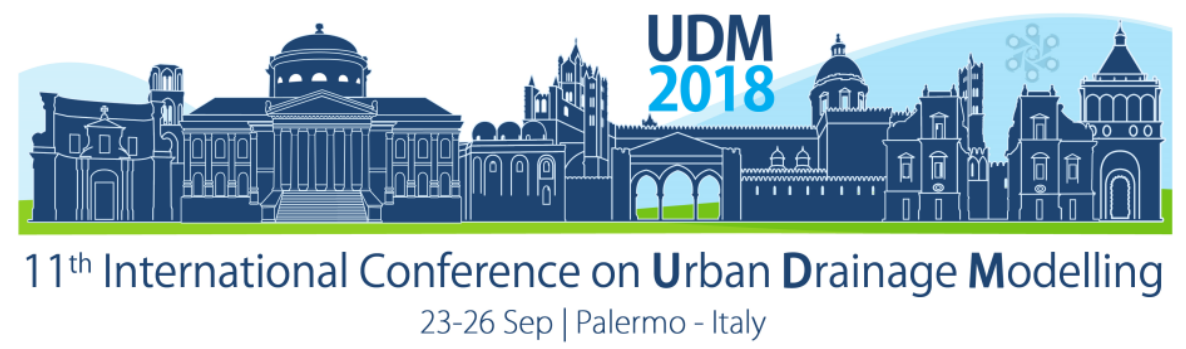

Scholz, M.: Wetland systems to control urban runoff, Elsevier., 2006.

Stovin, V., Vesuviano, G. and Kasmin, H.: The hydrological performance of a green roof test bed under UK climatic conditions, J. Hydrol., 414, 148-161, 2012.

Urbonas, B. and Stahre, P.: Stormwater: best management practices and detention for water quality, drainage, and CSO management., 1993.

Van Roon, M.: Emerging approaches to urban ecosystem management: the potential of low impact urban design and development principles, J. Environ. Assess. Policy Manag., 7(01), 125-148, 2005.

Versini, P.-A., Gires, A., Abbes, J.-B., Giangola-Murzyn, A., Tchiguirinskaia, I. and Schertzer, D.: Simulation of Green Roof Impact at Basin Scale by Using a Distributed Rainfall-Runoff Model, in 13th International Conference on Urban Drainage (ICUD), pp. 1-9., 2014.

Versini, P.-A., Ramier, D., Berthier, E. and De Gouvello, B.: Assessment of the hydrological impacts of green roof: From building scale to basin scale, J. Hydrol., 524, 562-575, 2015.

Villarreal, E. L., Semadeni-Davies, A. and Bengtsson, L.: Inner city stormwater control using a combination of best management practices, Ecol. Eng., 22(4), 279-298, 2004.

Weinstein, N., Glass, C., Heaney, J. P., Huber, W. C., Jones, P., Kloss, C., Quigley, M., Stephens, K. and Strecker, E.: Decentralized stormwater controls for urban retrofit and combined sewer overflow reduction, Water Environment Research Foundation Alexandria, VA, United States., 2006.

Weinstein, N., Cotting, J., Nees, D., Downing, S., Lee, J., Tauber, B., English, A., Kloss, C., Glass, C. and Huber, W. C.: Decentralized Stormwater Controls for Urban Retrofit and Combined Sewer Overflow Reduction: Phase 2, Water Environment Research Foundation., 2009.

White, M. D. and Greer, K. A.: The effects of watershed urbanization on the stream hydrology and riparian vegetation of Los Penasquitos Creek, California, Landsc. Urban Plan., 74(2), 125-138, 2006.

Wong, T. H., Fletcher, T. D., Duncan, H. P., Coleman, J. R. and Jenkins, G. A.: A Model for Urban Stormwater Improvement: Conceptualization, in Global Solutions for Urban Drainage, pp. 1-14., 2002.

Wossink, A. and Hunt, W. F.: An evaluation of cost and benefits of structural stormwater best management practices in North Carolina, NC Cooperative Extension Service., 2003.

Zuse, K.: Der Plankalkül, Gesellschaft für Mathematik und Datenverarbeitung., 1972. 


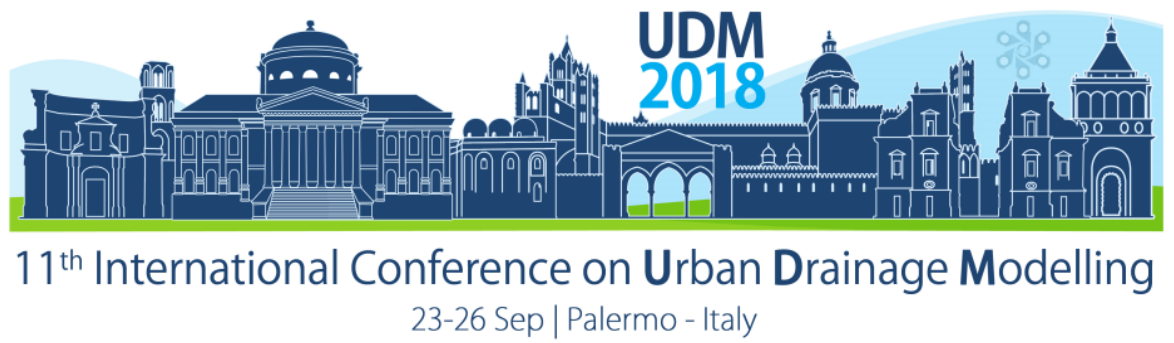

\title{
Modelling of Green Permeable Car Park Water Retention
}

\author{
Varnède Lucie ${ }^{123}$, Ramier David ${ }^{2}$, Georgel Pierre ${ }^{1}$ and Gromaire Marie-Christine ${ }^{3}$ \\ ${ }^{1}$ ECOVEGETAL, Broué, France \\ ${ }^{2}$ Cerema, Direction territoriale d'île de France, Trappes, France \\ ${ }^{3}$ Ecole Nationale des Ponts et Chaussées, LEESU, Champs-sur-Marne, France
}

\begin{abstract}
Permeable car parks, as part of SuDS (Sustainable Drainage Systems), are developed for better management practice of urban stormwater. Even if lots of researches studied permeable pavements, none specifically studied green permeable pavement impact on urban water quantity and quality, or modelled its behaviour. In this study three types of experimental parking places ( 1 with gravels and 2 with vegetation) are monitored. The data obtained from a simulated rain event and a natural rain event, served to test and adapt a reservoir model, initially developed for green roofs. First calibration tests showed that permeable car parks (vegetalized or not) behaviour can be simulated with the reservoir model with a calculated water mass balance around $+/-15 \%$ for different conditions. However, the model needs to be improved to have better water mass balance results, and to be better adapted to green permeable car park.
\end{abstract}

Keywords: Green permeable car park; Modelling; Water management

\section{INTRODUCTION}

Permeable parking lots is one of the most common use of permeable pavements. Permeable pavements are part of SuDS (Sustainable Drainage System). They are used to collect, store, treat and reuse urban stormwater. As part of SuDS, a permeable car park allows stormwater to infiltrate into the permeable structure, to be stored and gradually released into stormwater networks or infiltrated into the subsoil. Some studies tried to model permeable pavement (Illgen, 2008; Korkealaakso et al., 2014). However, no studies tried to model green permeable pavement even if models are developed for other permeable pavements. Vegetation can be included as a parameter in some models as in SWMM (Storm Water Management Model) but is considered negligible, since fractions are low (maximum of 0.2) (Korkealaakso et al., 2014).

Thus, the objective of the study is to develop a model as a support for designing and managing green permeable car parks. For that objective, rain and outflows are being measured since 2012 for three green permeable car parks systems (1 mineral and 2 vegetalized) developed by ECOVEGETAL, a French company specialised in green roofs, permeable car parks and equestrian floors. A natural rain event and a simulated rain event were used to analyse the three systems responses for different water storage initial conditions and rain intensities. Since green permeable car parks and green roofs' substrates are comparable (both with important interception capacity), data obtained from permeable car park are used to adapt a reservoir model named FAVEUR (Functional model for Assessment of VEgetative green roof impacts on URban runoff), initially developed for green roofs (Ramier et al., 2018).

Firstly, the three experimental places, the monitoring, and rain simulations will be described, as well as the FAVEUR-Model. Secondly, the model calibration and adaptation to permeable car park will be shown and discussed. 


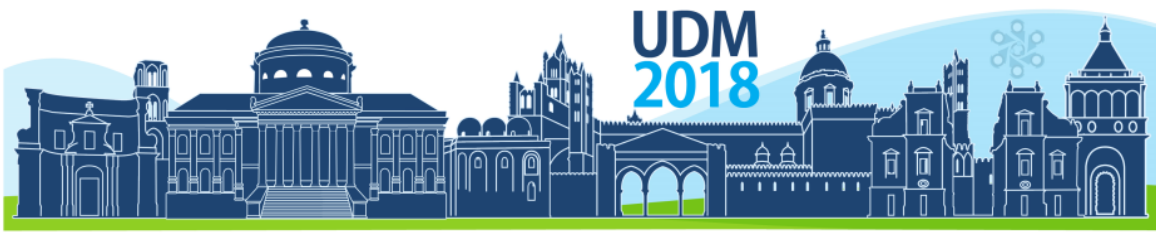

$11^{\text {th }}$ International Conference on Urban Drainage Modelling

23-26 Sep | Palermo - Italy

\section{MATERIALS AND METHODS}

\subsection{Experimental places description and monitoring}

Three types of lysimetric parking places, representative of the three permeable car park systems developed by ECOVEGETAL (Figure 1a) were monitored. Those places possess an impermeable bottom (Figure 1b), preventing water to infiltrate into the subsoil and thus limiting the number of unknown parameters such as infiltration.

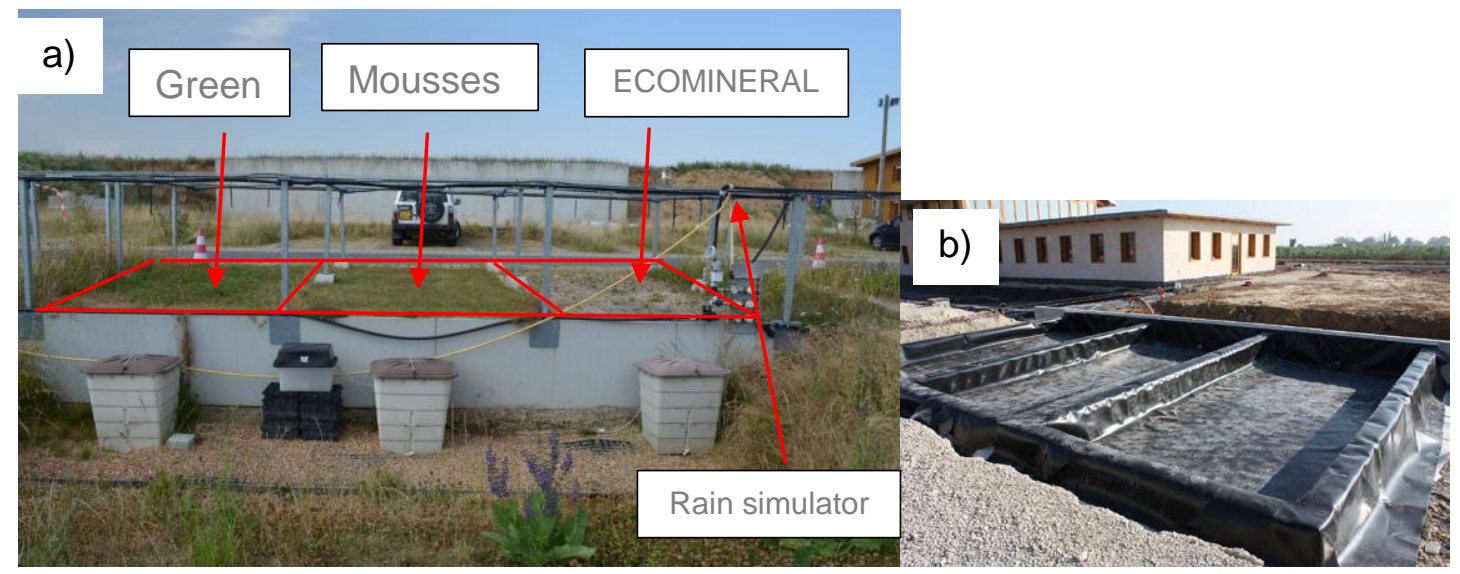

Figure 1. a) The 3 experimental places and rain simulator, b) the impermeable layer setup

These places of $13.26 \mathrm{~m}^{2}$ each, are located in Broué (Eure-et-Loir, France). The Ecomineral ${ }^{\circledR}$ place consists of plastic grids filled with gravels $(<10 \mathrm{~mm})$. For Ecovegetal ${ }^{\circledR}$ Mousses, the plastic grid is filled with a mineral substrate $(3 / 15 \mathrm{~mm})$ and planted with mosses (sedums, thymes, white clovers, fescues). It lies on a Mosses' substrate ( $3 / 15 \mathrm{~mm}$ of crashed ceramics, compost, pozzolan). For Ecovegetal ${ }^{\circledR}$ Green, the plastic grid is filled with an organic substrate $(0 / 3 \mathrm{~mm})$ planted with grass. This layer lies on two kinds of substrates: FERTILIT ${ }^{\circledR}(0 / 15 \mathrm{~mm}$ of crushed ceramics, compost, natural organic fertilizers) as bedding $(4 \mathrm{~cm})$, and a mixture between stones $(30 / 60 \mathrm{~mm})$ and HYDROFERTIL ${ }^{\circledR}(0 / 25 \mathrm{~mm}$ of crushed ceramics, compost, peat, natural organic fertilizers) as a fertile base $(20 \mathrm{~cm})$. Draining aggregates $(40 / 80 \mathrm{~mm})$ of Ecomineral $\AA$ and Ecovegetal $\AA$ Mousses are $35 \mathrm{~cm}$ thick and $15 \mathrm{~cm}$ thick for Ecovegetal ${ }^{\circledR}$ Green. Each place is drained by a $100 \mathrm{~mm}$ diameter drain where runoff discharges are measured at the outlet with tipping buckets of $130 \mathrm{ml}$.

Data used for the model calibration were obtained with a simulated rain event, conducted to analyse each systems responses to different initial substrate water content conditions and rain intensities, and a natural rain event, to have a maximum initial water content (such an event was not simulated). The simulator, installed above the three places (Figure 1a), consists of 27 nozzles with a $120 \mathrm{l} / \mathrm{h}$ maximum intensity spread evenly along 6 spraying ramps and 12 nozzles with a maximum intensity of $200 \mathrm{l} / \mathrm{h}$. Simulations lasted $6 \mathrm{~h}$. Rain intensity was slowly increased from $18 \mathrm{~mm} / \mathrm{h}$ to a peak of $66 \mathrm{~mm} / \mathrm{h}$ after $3 \mathrm{~h}$, by controlling the number of opened ramps. Then, intensity decreased back to $18 \mathrm{~mm} / \mathrm{h}$. The simulated rainfall was $43 \mathrm{~mm}$ (Broué's decennial rain), while it was of $14 \mathrm{~mm}$ for the natural rainfall. For the natural event, the places were near maximum water content before rainfall since this event succeeded another one. For the simulated event the places were not at maximum water content before the simulation but were still humid. 


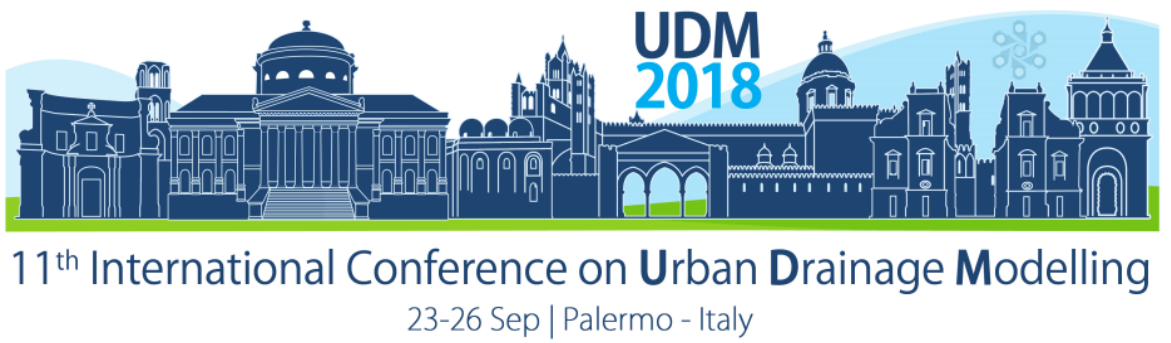

\subsection{Modelling assumptions and calibration}

The base model used to be adapted for modelling green car park is the FAVEUR model, a reservoir model developed for green roofs (for more details see : Ramier et al., 2018). This model uses a limited number of parameters. In this study, evapotranspiration is neglected, since we worked at a single rain event scale. Green parking place structure is represented by a reservoir having a maximum storage capacity Cint. This reservoir is only filled by rain (noted $P$ ), since no surface runoff was observed from around the places. For each time step, t, water storage level inside the reservoir, Sint, is updated. Various initial water content can be simulated by setting initial water storage Sint at a given value. Runoff discharge occurs when Sint exceeds the maximum capacity of the reservoir Cint (fixed parameter). So, the runoff quantities, $\mathrm{R}$, is computed, at each time-step, as follows:

$$
R^{t}=\left\{\begin{array}{l}
S_{i n t}^{t-1}+P^{t}-C_{i n t} \quad \text { if }\left(S_{i n t}^{t-1}+P^{t}-C_{i n t}\right)>0 \\
0 \quad \text { else }
\end{array}\right.
$$

Where $\mathrm{t}$ is the calculation time-step ant $\mathrm{t}-1$, the previous time-step.

Advantage of this simple model is that only two parameters need to be fixed, the maximum water storage capacity Cint, and the initial water content equivalent to the water stored in the reservoir at $\mathrm{t}=0, \mathrm{~S}_{\mathrm{int}}{ }^{0}$. Two hypotheses were tested for Cint. The first one consisted to take the total field capacity of the structure as the maximum interception storing capacity. The value was obtained by summing field capacity estimated for all substrates and gravels used for the permeable parking developed by ECOVEGETAL. Total field capacity for Ecomineral®, Ecovegetal ${ }^{\circledR}$ Mousses and Ecovegetal ${ }^{\circledR}$ Green are 67, 79 and $108 \mathrm{~mm}$ respectively. The second hypothesis consisted to only take the field capacity of the plastic grid layer and the bedding layer as the maximum interception storing capacity. Assumption is made that there is no storage in the draining aggregates. Thus Cint for ECOMINERAL $\circledast$, Ecovegetal® Mousses and Ecovegetal ${ }^{\circledR}$ Green were 10, 22, and $84 \mathrm{~mm}$ respectively. Quality of the model is estimated with water mass balance criterion which should approach 0 .

\section{RESULTS AND DISCUSSION}

Table 1. shows the best water mass balances calculated for the two hypotheses and for the two events for each parking place. First results show equivalent and acceptable water mass balance (around +/- $15 \%$ ), no matter the type of system, the hypothesis or the kind of event. Even if, the two hypotheses seem to give equivalent results, the first one (Cint = maximum field capacity) seems to be more suitable since Cint can be more emptied since it has a higher value. Indeed, the different tests done to obtain the best water mass balance graphically showed better results with the first hypothesis than with the second for which Cint is quickly emptied, limiting calibration possibilities (especially for ECOMINERAL $\circledast$ ) and ECOVEGETAL Mousses).

Table 1 also shows different recovery capacities of the interception reservoir for the three systems, with a $4 \mathrm{~mm}$ difference between Cint and $\operatorname{Sint}^{0}$ for Ecovegetal ${ }^{\circledR}$ Green while those parameters are equal for the two other systems, for the natural event at maximum water content capacity. However, for the simulated event which is drier than the natural event, the difference between Cint and $\operatorname{Sint}^{0}$ is greater for Ecomineral ${ }^{\circledR}$ and Ecovegetal $\AA$ Mousses (17 and $19 \mathrm{~mm}$ respectively) compared to Ecovegetal® Green (14mm). Thus, Ecovegetal® Green recovers more quickly an interception capacity than the two other systems, but it is also slower 


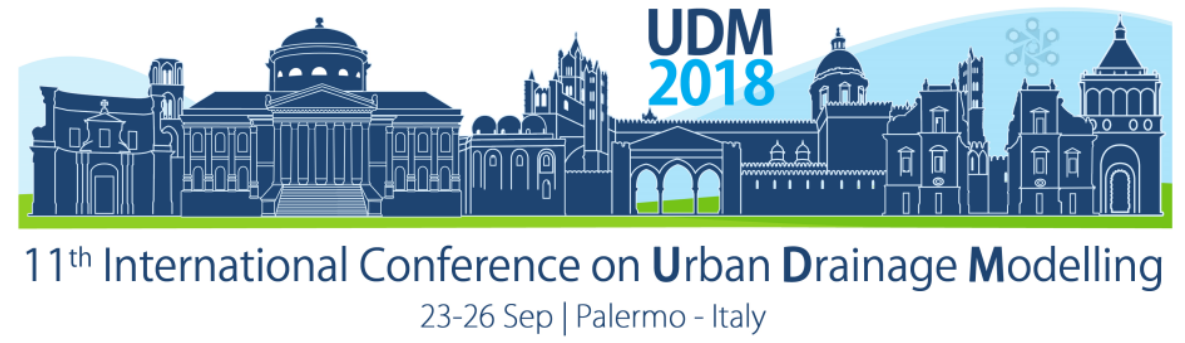

to dry. This difference is certainly due to the important interception capacity (total field capacity of $108 \mathrm{~mm}$ for Ecovegetal® Green) which leads to recover an interception capacity quicker than the other systems but tends to stay humid longer.

Table 1. Water Mass Balance comparison between the two hypotheses, and between a simulated and a natural event

\begin{tabular}{|c|c|c|c|c|c|c|}
\hline & \multicolumn{4}{|c|}{ Ecomineral® } & \multicolumn{2}{|c|}{ Ecovegeta } \\
\hline $\begin{array}{l}\text { Cint } \\
(\mathrm{mm})\end{array}$ & \multicolumn{2}{|c|}{$\begin{array}{c}\text { Hyp. } 1 \\
67\end{array}$} & \multicolumn{2}{|c|}{$\begin{array}{c}\text { Hyp. } 2 \\
10\end{array}$} & \multicolumn{2}{|c|}{$\begin{array}{l}\text { Hyp. } 1 \\
79\end{array}$} \\
\hline $\begin{array}{l}\operatorname{Sint}^{0} \\
(\mathrm{~mm})\end{array}$ & $\begin{array}{l}\text { Simulated } \\
\text { Event } \\
50\end{array}$ & $\begin{array}{c}\text { Natural } \\
\text { Event } \\
67\end{array}$ & $\begin{array}{l}\text { Simulated } \\
\text { Event } \\
0\end{array}$ & $\begin{array}{c}\text { Natural } \\
\text { Event } \\
10\end{array}$ & $\begin{array}{c}\text { Simulated } \\
\text { Event } \\
60\end{array}$ & $\begin{array}{c}\text { Natural } \\
\text { Event } \\
79\end{array}$ \\
\hline \multirow[t]{5}{*}{$\begin{array}{l}\text { Water mass } \\
\text { balance (\%) }\end{array}$} & - 18.1 & -17.0 & 7.4 & -18.0 & -15.4 & -16.3 \\
\hline & & & \multicolumn{4}{|c|}{ Ecovegetalß Green } \\
\hline & & $\begin{array}{l}\text { Cint } \\
(\mathrm{mm})\end{array}$ & \multicolumn{2}{|c|}{$\begin{array}{c}\text { Hyp1. } \\
108\end{array}$} & \multicolumn{2}{|c|}{$\begin{array}{c}\text { Hyp. } 2 \\
84\end{array}$} \\
\hline & & $\begin{array}{l}\operatorname{Sint}^{0} \\
(\mathrm{~mm})\end{array}$ & $\begin{array}{l}\text { Simulated } \\
\text { Event } \\
95\end{array}$ & $\begin{array}{c}\text { Natural } \\
\text { Event } \\
104\end{array}$ & $\begin{array}{l}\text { Simulated } \\
\text { Event } \\
70\end{array}$ & $\begin{array}{c}\text { Natural } \\
\text { Event } \\
80\end{array}$ \\
\hline & & $\begin{array}{l}\text { ater mass } \\
\text { lance (\%) }\end{array}$ & 7.5 & 18.4 & 3.7 & 17.8 \\
\hline
\end{tabular}

Although results presented in this study can be an acceptable, the FAVEUR-Model needs to be modified to best suit the permeable car park behaviour and improve water mass balance. Evapotranspiration processes should be included to allow long term simulation. Moreover, hypothesis on system of drainage drain and the physical properties of subgrade, must be made to better represent real systems.

\section{CONCLUSIONS}

Even if several studies developed models for different types of permeable pavements, green permeable pavements were neglected. The objective of the study being the development of a model for green permeable car park, we tried to adapt a reservoir model, FAVEUR, developed for green roofs since their substrates are similar to green permeable car parks. The calibration of the model with parameters of permeable car parks showed acceptable results but the model needs to be modified to be better adapted to green permeable car parks. Once the calibration will show good results, the model will be validated by comparing continuous observed data to simulated outflows. The final objective is to be able to model a complete permeable car park with different types of permeable pavements.

\section{References}

Illgen, M., 2008. Infiltration and surface runoff processes on pavements: physical phenomena and modelling, in: Proc. 11th Int. Conf. on Urban Drainage, 31 Aug-5 Sept 2008, Edinburgh, Scotland, UK.

Korkealaakso, J., Kuosa, H., Niemeläinen, E., Tikanmäki, M., (2014) Review of Pervious Pavement Dimensioning, Hydrological Models and Their Parameter Needs. State-of-the-Art.

Ramier, D., Berthier, E., De Gouvello, B., 2018. FAVEUR - A Simple Model for Design Extensive Green Roofs. Submitted to UDM 2018. 


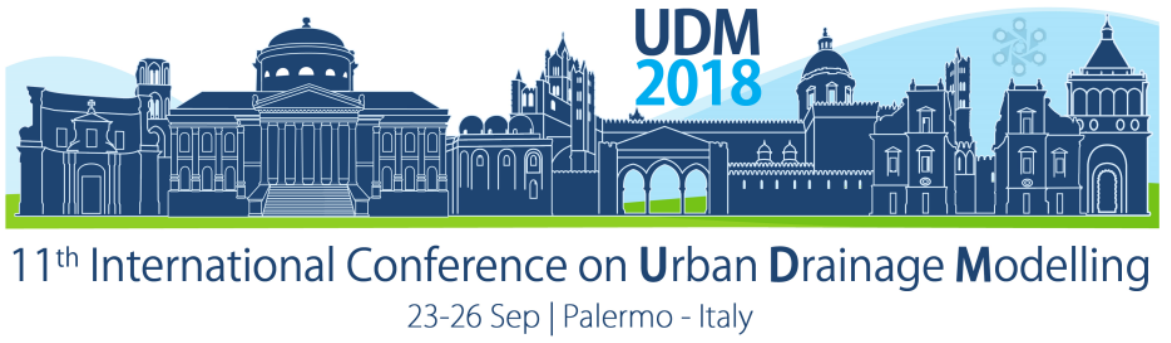

\title{
Modelling study on the impacts of BMPs at Riacho Fundo (Brasília, Brazil) \\ Vítor Tomaz Mineiro Camuzi ${ }^{1}$, Maria Elisa Leite Costa ${ }^{1}$, Arthur Tavares Schleicher ${ }^{1}$, Jeferson da Costa ${ }^{2}$ and Sérgio Koide ${ }^{1}$. \\ ${ }^{11}$ University of Brasília, Program of Environmental Technology and Water Resources, Brasília, Brazil \\ ${ }^{2}$ Federal District Water, Energy and Sanitation Regulatory Agency (ADASA), Brasilia, Brazil (vcamuzi@gmail.com; mariaelisa@unb.br, arthur.schleicher@yahoo.com.br, jeferson.costa@adasa.df.gov.br, skoide@unb.br)
}

\begin{abstract}
High urbanization affects significantly on cities, intensifying runoff and impairing old urban drainage systems, which may cause floods. Solutions analyzed in this study include management of rainwaters in cities by means of mitigation measures. Riacho Fundo drainage network simulation was carried out using PCSWMM software to evaluate the system behaviour. The simulations evidenced the observed high flows and other problems such as system overloading. BMPs were tested in the model to indicate do the stakeholders which measures can lead to better improvements.
\end{abstract}

Keywords: Urban drainage, Simulation, PCSWMM.

\section{INTRODUCTION}

In the second half of $20^{\text {th }}$ century, high urbanization rate changed the Brazilian reality, when the country, mainly rural in the 1950s, changed dramatically and by the first decade of the $21^{\text {st }}$ century, which $84 \%$ of its population was already living in cities (IBGE, 2010). Because of this high urbanization rate, most of the time unplanned, enhanced impermeable areas, reducing the interception and water infiltration in the soil, increasing runoff, and causing floods (Baptista et al. 2005). Most of the urban drainage systems in Brazil have been implemented under the sanitary concept that it is important to drain rainwater (Grecco, at al, 2012) as fast as possible in order to avoid urban areas flooding and its consequences to human population (diseases, economic damages, casualties, and others). By this concept, pipes and galleries were constructed to convey stormwaters to outside the cities (Baptista et al, 2005). Such systems, however, transfer the stormwater management problems to downstream usually aggravating environmental problems.

There are, thus, mitigation measures, by which the management of water in the urban environment is integrated. It is applied, then, the harvesting principle, which is performed as a means to promote the storage and infiltration of rain water, providing a downstream controlled drainage. Brito (2006) says that mitigation techniques have many advantages when compared to the conventional solution, not only quantitatively, because of the reduction in downstream draining, but also qualitatively, since it contributes to improve the receiving waters. Some controlling measures were simulated, they are presented and described in Table 1 for the purpose of analyzing the reduction in surface drainage.

Table 1. Mitigation measures simulated

\begin{tabular}{|l|l|}
\hline Trenches & $\begin{array}{l}\text { Linear systems that keep runoff inside the soil, providing a temporary storage and } \\
\text { infiltration (Brito, 2006). }\end{array}$ \\
\hline Permeable & $\begin{array}{l}\text { Structures projected mainly to temporarily storage the surface flow, making } \\
\text { possible the slow infiltration into the subsoil (Shaffique e Kim, 2015). }\end{array}$ \\
\hline $\begin{array}{l}\text { Green } \\
\text { roofs }\end{array}$ & $\begin{array}{l}\text { Controlling measures for the temporary storage of water flows and that are } \\
\text { developed with water flow regulation systems associated with a determined } \\
\text { maximum flow (Brito, 2006) }\end{array}$ \\
\hline
\end{tabular}




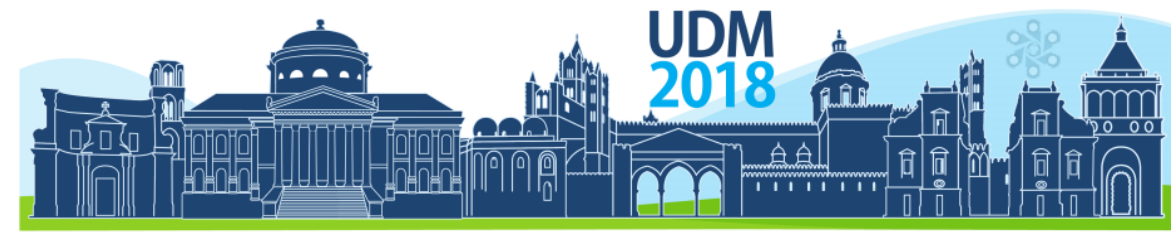

$11^{\text {th }}$ International Conference on Urban Drainage Modelling

23-26 Sep | Palermo - Italy

\begin{tabular}{|l|l|}
\hline $\begin{array}{l}\text { Rain } \\
\text { gardens }\end{array}$ & $\begin{array}{l}\text { Filtration systems that use biological activity to treat surface flow waters, besides } \\
\text { contributing to mitigate flood peaks. }\end{array}$ \\
\hline $\begin{array}{l}\text { Detention } \\
\text { basins }\end{array}$ & $\begin{array}{l}\text { Structures of temporary rainwater storage, used to subside floods, reduce surface } \\
\text { flow volumes and reduce diffuse pollution provoked by rainwater. (Baptista, et al, } \\
2005) .\end{array}$ \\
\hline
\end{tabular}

\section{MATERIALS AND METHODS}

Simulation of the mitigation measures was performed by PCSWMM - CHIWater software and the SWMM (Stormwater Model Management) by USEPA (United States Environment Protection Agency). PCSWMM software features a friendly interface to handle input data obtained by Geographic Information System (Costa, 2013). Simulation of the surface runoff was performed considering the behavior of sub-basin as non-linear reservoirs, represented by Manning's and Continuity equations. The nonlinear differential equation can be solved by the iterative Newton-Raphson method and the runoff propagation through the drainage system is calculated by the complete Saint Venant equation (Collodel, 2009). A network of nodes (junction, flow dividers, storage units or emissaries) and conduits (connected to nodes or to another with pipelines and channels, pumps or outputs) models the drainage system. Finally, a group of data objects including curves, time series, time patterns and controlling rules were used to characterize inflows and the operating behavior of the many physical objects in SWMM (Rossman, 2016).

The area studied is a 191.3 ha polygon in the Administrative Region of Riacho Fundo, located in Distrito Federal. This area was chosen because it has a well-defined drainage system, with only one outfall, in which the receptor body is Riacho Fundo River, an affluent of Paranoá Lake, a new source used to supply water in Distrito Federal. The hydrographic basin is well known by the researchers from the Environmental and Civil Engineering of the University of Brasília, so all the support and information could be easier found and studied.

To simulate the drainage system, some characteristics must be considered. For the infiltration, the Curve Number method from the National Resources Conservation Soil were used. The Soil is characterized as a thick red latosol with clay-rich, iron-rich texture, which is classified in the hydrologic group A according to Tucci (2003). The city is characterized as an urbanized city, which was classified in four classes, and its $\mathrm{CN}$ values are seen in Table 2.

Tabel 2. CN values by category of land use.

\begin{tabular}{|c|c|c|}
\hline Class & Hydrological group & CN \\
\hline Asphalt & A & 98 \\
\hline Exposed soil & A & 68 \\
\hline Vegetation and gardens & A & 45 \\
\hline Urban Zone & A & 92 \\
\hline
\end{tabular}

The rainfall curve used was the IDF rainfall (Intensity, Duration, Frequency) for Brasilia, defined in the Distrito Federal Urban Drainage Master Plan (PDDU-DF) with a 10-year return period, a 24-hour period discretized in 5 minutes. The IDF rainfall is exposed the formula:

$$
i=\frac{1574,7 \times T_{r}^{0,207}}{(t c+11)^{0,884}}
$$




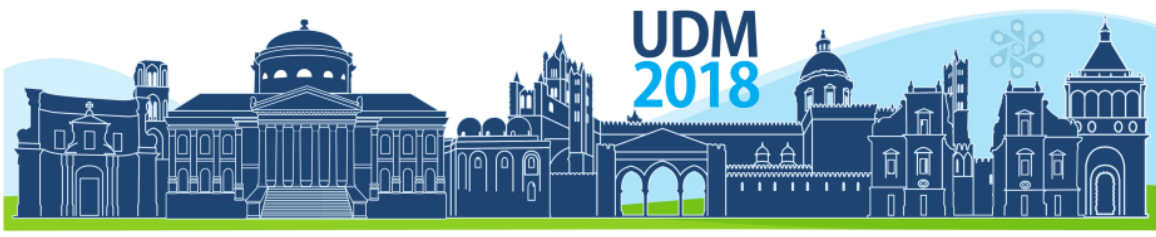

$11^{\text {th }}$ International Conference on Urban Drainage Modelling

23-26 Sep | Palermo - Italy

$\mathrm{i}=\mathrm{IDF}$ in $\mathrm{mm} / \mathrm{h}$;

$\operatorname{Tr}=$ Return time in years;

tc $=$ rain duration in minutes .

\section{RESULTS AND DISCUSSION}

The studied region was analyzed by creating two scenarios exemplified in Figure 1:

- Scenario 1: Includes the current status of usage and occupation of soil in Riacho Fundo, simulating as well the urban drainage system in the Administrative Region. The purpose is to evaluate the current capacity.

- Scenario 2: Includes the current status of the system with the implementation of 11 detention basins, infiltration trenches, green gardens, permeable pavement and rain gardens, distributed through the system in locations that the implementation of such measures may be possible.

After simulating the system with the current setting of soil usage and occupation (Scenario 1), it was obtained a peak flow in the outfall of $18.42 \mathrm{~m}^{3} / \mathrm{s}$, in a region that according to ADASA's Resolution No. 09/2011 should be $24.4 \mathrm{l} / \mathrm{s}$.ha $(4,66 \mathrm{~m} 3 / \mathrm{s})$ maximum. It was observed by the simulation that there is a flooding condition in the system, that is, the overflow of rainwater through manholes. $80.5 \%$ of the manholes are currently in such situation, which results in a water volume of $37930 \mathrm{~m}^{3}$ that overflows and floods the city. Manhole called J195 located in the south of the drainage system is the node that has the highest overflow rate, equivalent to 10.2 from all the flood in the city. The maximum speed in the conduits allowed by the Distrito Federal supervising agencies is $6.0 \mathrm{~m} / \mathrm{s}$, however in four conduits of the system the speed exceeds this limits. Due to these major problems, it was necessary the establishment of efficient controlling measures to handle the surface run-off throughout the system.

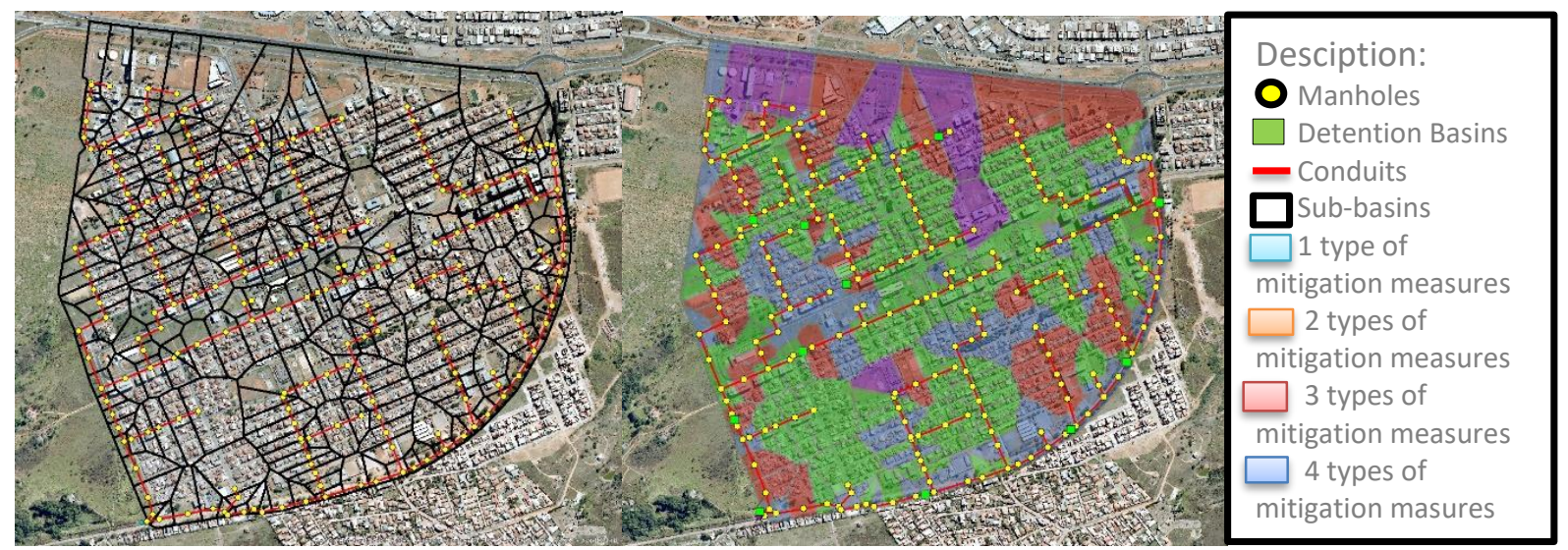

Figure 1. Scenarios 1 and 2, respectively.

Scenario 2 was developed to solve overflow problems upon a high-level water flow release in the receiving water body, identified in Scenario 1. This scenario was developed, nevertheless, without evaluating the costs to implement the project. Thus, it was used mitigation measures in all the sub-basins, taking into consideration the available area and the occupation type to define which and where measures would be implemented. It is important to emphasize that the scenario 2 were designed without considering any financial analyses, the only purpose of 


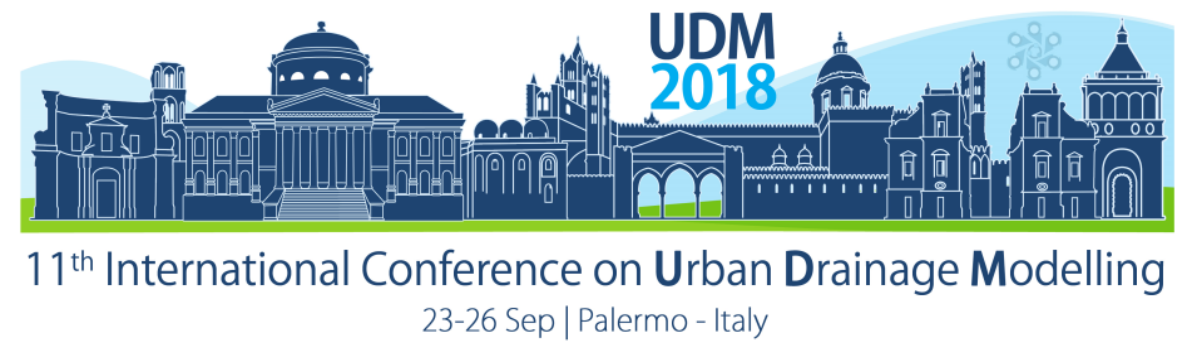

the job were try to solve the flooding problem. Figure 2 presents a graphic comparing the two scenarios developed, considering the peak flow released in outfall. Runoff in Scenario 2 represents $13.91 \%$ from all run-off in Scenario 1 and maintains the limits established by ADASA's Resolution No. 09/2011 regarding release. Another parameter that is worth mentioning concerns the water speed in the conduits. In the second scenario, speed in all the conduits were within the maximum limit allowed, and the highest speed found was $4.71 \mathrm{~m} / \mathrm{s}$.

Regarding the floods, scenario 2 was able to totally solve all the flooding points, even though there are still $18 \%$ of the conduits and $3 \%$ of the manholes operating in overflow, which means that for a rainfall higher than the one simulated there might be flooding problems.

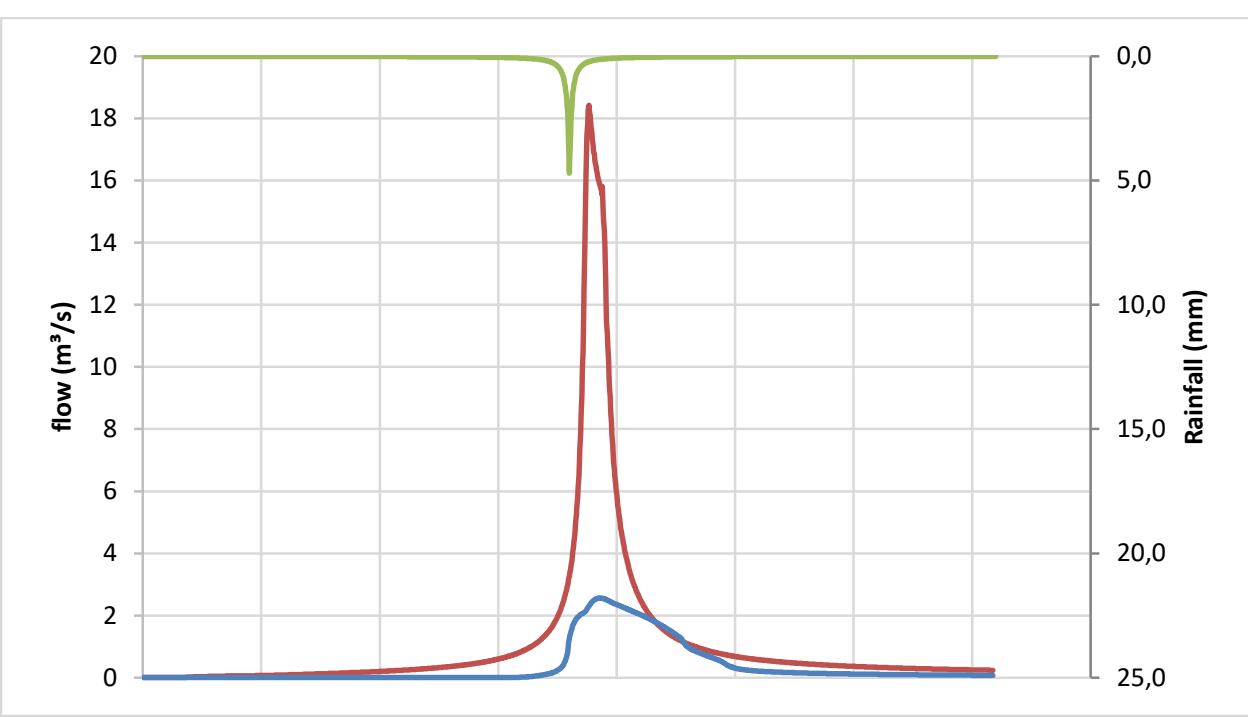

Figure 2. Flow peak generated between scenarios 1 (red) and 2 (blue). There's also, the rainfall peak (green).

\section{CONCLUSIONS}

After simulations, it was possible to identify many problems in the current drainage system that impact on the city population. Such problems will only be solved after many structural interventions throughout the polygonal area. Scenario 2 considers the intervention in the city seeking to transform it in a green city with the flow control in the urban lots and in a macro scale. Nonetheless, this scenario does not consider the modification of the material and the specifications of the conduits and galleries, which could be also an alternative measure along with the presented ideas. It is thus clear that the urban drainage issue in the region should be reconsidered and the use of alternative measures that aim to maintain rainwater in the urban environment is the right path to reduce the impacts provoked on the city.

\section{References}

Baptista, Márcio Benedito; Nascimento, Nilo de Oliveira, Barraud, Sylvie. Técnicas Compensatórias em Drenagem Urbana. Brazilian Water Resource Association (ABRH), 2005, 266p. Porto Alegre, Brazil.

Brito, D. S. (2006). Metodologia para seleção de alternativas de sistemas de drenagem. Master's thesis on Environmental Technology and Water Resources, from the Civil and Environmental Engineering Department, University of Brasilia, Brasilia, Distrito Federal. 
Proceedings of the 11th Int. Conference on Urban Drainage Modelling, 23-26 Sep. 2018, Palermo (ITALY). Ed. prof. Giorgio Mannina

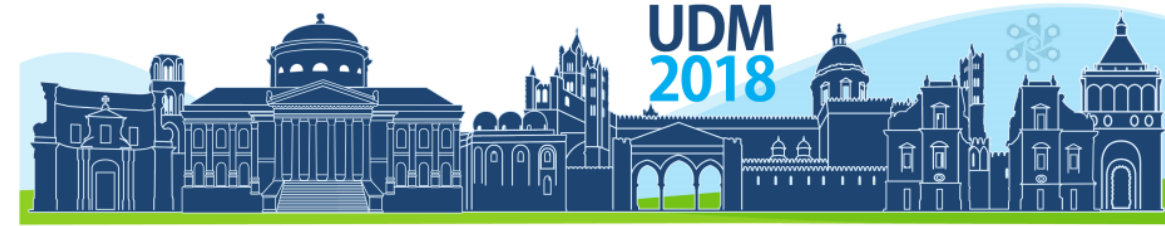

$11^{\text {th }}$ International Conference on Urban Drainage Modelling

23-26 Sep | Palermo - Italy

Collodel, M. G., 2009, Aplicação do modelo hidrológico SWMM na avaliação de diferentes níveis de detalhamento da bacia hidrográfica submetida ao processo de transformação chuva-vazão. Master's thesis in Civil Engineering - Engineering School, University of Sao Paulo, Sao Carlos, 2009.

Grecco, L. B.; Mandelli, M. S.; Reis, J. A. T.; Mendonça, A. S. F. Influência da Seleção de Variáveis Hidrológicas no Projeto de Sistemas Urbanos de Macrodrenagem -Case Studies for the Municipality of Vitoria, Espirito Santo State. Brazilian Journal of Water Resources (RBRH). Vol. 17 No.4 - Oct/Dec. 2012, 197-206.

The Brazilian Institute of Geography and Statistics (IBGE). 2010 Population Census, Rio de Janeiro: Ministry of Planning, Budget and Management, November 4, 2011.

Rossman, L. A., 2016, Storm water management model Reference manual Version 5.1. Cincinnati: U. S. Enviromental Protection Agency, 2016. 233 p.

Shafique, M., Kim, R., Low Impact Development Practices: A review of current research and recommendations for future directions. Ecological Chemistry and Engineering S. The Journal of Society o Ecological Chemistry and Engineering, Vol. 22, Issue 4, p. 343-363, Dez de 2015.

Tucci, C. E. M., 1993. Hidrologia ciência e aplicação. Porto Alegre: University's Publisher: ABRH.

Tucci, C. E. M., 2003. Inundações Urbanas na América do Sul - Porto Alegre: Associação Brasileira de Recursos Hídricos, 2003. 


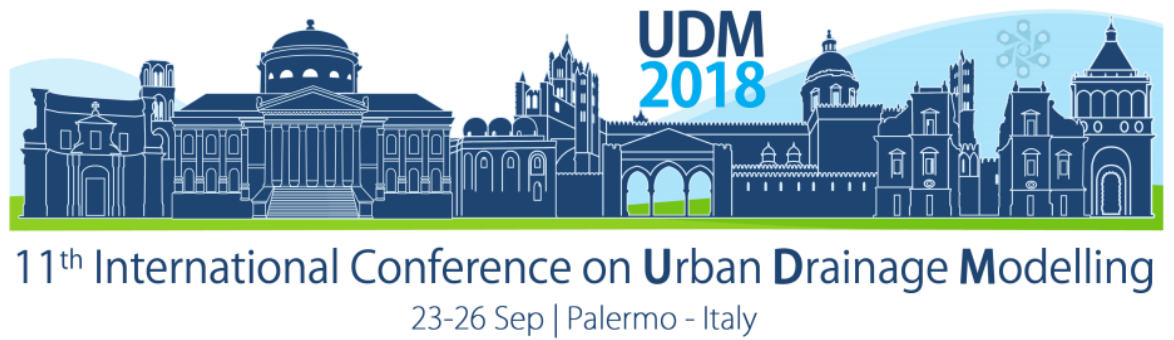

\title{
Advanced modelling of surface drainage systems drainage systems in reducing pluvial flood risk in urban areas. Dario Rappazzo', and Giuseppe Tito Aronica²
}

\author{
${ }^{1}$ University of Messina, Dipartimento di Ingegneria, Messina, Italy \\ 2 University of Messina, Dipartimento di Ingegneria, Messina, Italy
}

\begin{abstract}
Among all disasters, flooding is the most dangerous and ordinary natural hazard. In last years the increment of the impermeable surfaces led to an increase in volume runoff, peak discharge and a decrease of the time of concentration. Permeable pavement is a SuDS strategy, that encourage infiltration of storm water into the various layers of the soil. This strategy can considerably decrease volumes of storm water and discharge rates and improves the quality of water. These pavements cannot traffic loads, and are used as car parks, pedestrian paths and bike paths. Storm water passes through the pavement and infiltrates into the underlying soil. Many mathematical equations as Richards' equation, Horton's equation, Philip's equation, try to define the process of infiltration. To simulate infiltration into a permeable pavements of three layers, a onedimensional code is been made, based on the Green \& Ampt model. To assess this code, it was tested on experiments data taken from literature. In a second phase the code was implemented in a two-dimensional hydrodynamic model (FLURB), to verify the effectiveness of permeable pavements in urban areas.
\end{abstract}

Keywords: Infiltration; Runoff surface; permeable pavement

\section{INTRODUCTION}

Among all disasters, flooding is the most dangerous and ordinary natural hazard. As matter of fact, flooding is very frequent and it kills thousands of people every year all over the world. In recent years urban floods have become more frequent worldwide. The increase of urbanisation is a consequence of growth in population as well as in the percentage of population living in city centres. The densification of population and the consequential construction of buildings have produced an increase of paved surfaces and roofs, and therefore an increase of impermeable areas. This intensive urbanisation, in addition to the impact of climate change, has increased significantly the frequency of urban floods. In fact, an increment of impermeable surfaces, along with the removal of the vegetation, has determined an increase in volume runoff, peak discharge and a decrease of the time of concentration and evapotranspiration. Furthermore, in many cities, new buildings have covered flood prone areas and natural drainage channels, making urban drainage inadequate. Therefore, in last years, new techniques have been developed to manage the flood risk in urban areas, as Sustainable Urban Drainage Systems (SuDS). Suds are a set of measures to mitigate flood risk in urban areas facilitating infiltration into soil, instead of forcing surface water into pipes. In this work, it was implemented a infiltration code (Rappazzo and Aronica, 2017) in the two-dimensional hydrodynamic model FLURB (Aronica 1998,Aronica and Lanza 2005, Palla et al 2013), to verify the effectiveness of permeable pavements in urban areas.

It was used a bi-dimensional hydrodynamic model (FLURB) to simulate runoff discharges, infiltration and outflow hydrographs. A synthetic case was made with the commercial 


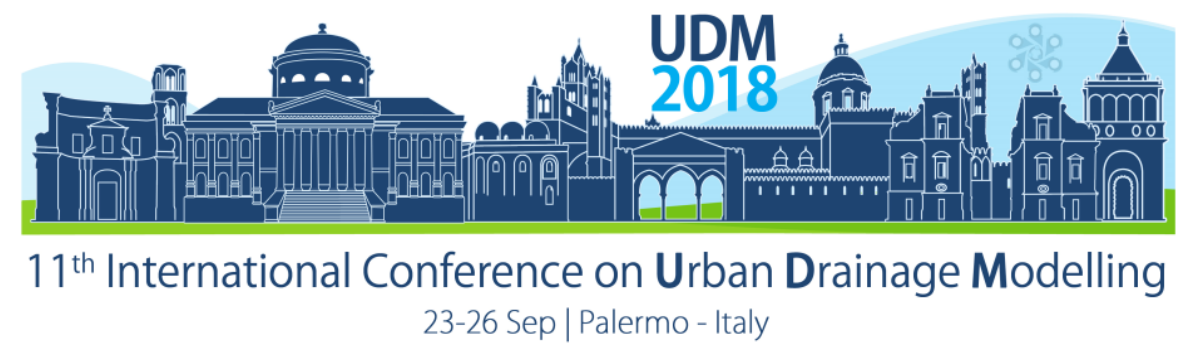

software Argus One(C). It consists in two impermeable roads that converge in a permeable parking lot. A range of simulated rainfalls and flows, which varied in intensity, was applied to the model. Initially, in FLURB, simulations were made using the runoff coefficient (RC), and subsequently simulations with multilayer infiltration code, implemented in FLURB, were carried out. In reducing peak flows and runoff depth, has been verified the influence of the percentage of pervious area. Therefore, simulations were carried out with four different percentages of permeable parking area.

\section{MATERIALS AND METHODS}

\subsection{Bi-dimensional simulations}

A synthetic case was made with Argus one (c). It consists in two impermeable roads which converge in a pervious parking lot. the layout is composed of two impermeable roads of equal dimensions $(6 \mathrm{~m} \times 50 \mathrm{~m})$, and a permeable parking lot $(30 \mathrm{~m} \times 30 \mathrm{~m})$. In a second series of simulations, only $50 \%$ of the parking area was considered permeable.

For simulations was used a rainfall with a duration of 3 hours, with a return time $T r=50$ years. The height of rainfall was calculated taking data from the meteorological observatory of Messina. Hence for the simulations it was used a rectangular hyetograph and a hyetograph with a shape similar to Chicago hyetograph, using a duration of 3 hours and a height of rainfall of $113.7 \mathrm{~mm}$. Rectangular hyetograph has a constant rainfall intensity of $37,9 \mathrm{~mm} / \mathrm{h}$, and the other hyetograph has an average intensity of $37,9 \mathrm{~mm} / \mathrm{h}$ and a maximum intensity of $190.8 \mathrm{~mm} / \mathrm{h}$.

A range of simulated rainfalls and flows, which varied in intensity, was applied to the model. Initially, in FLURB, simulations were made using different values of the runoff coefficient (RC $=0.7,0.5,0.3$ ), and subsequently simulations with multilayer infiltration code, implemented in FLURB, were carried out.

The parking lot was considered as a system of total infiltration, where the rainfall passes through the sub-structure into the soils beneath.

In the model was considered three layer of permeable pavement. The first layer includes porous asphalt and the used a value of vertical permeability is based on the work of Ranieri (Ranieri et al. 2017). The second layer includes sub-base layer, and the third layer includes soil subgrade.

It was considered permeable parking in two different situations: after one month of use (high permeability) with a subgrade of loam; and a permeable parking after some years of use, when the infiltration rates declined significantly due to clogging (e.g. Yong et al, 2012, Sansalone et al., 2012), with a subgrade of clay, and therefore with a lower permeability (low permeability).

At last, to verify the influence of pervious parking area in reducing water depth, simulations with four different percentages of pervious area were made (100\%, $75 \%, 50 \%$ and $25 \%)$. In tables 19 and 20 and in figures 123 and 124 there is a summary comparison of water depth percentage reduction for the various pervious parking areas.

\section{RESULTS AND DISCUSSION}

\subsection{Water depth and outflow rate}

Model simulation results show how the water depth and outflow decrease when the permeability of parking lot decreases. Furthermore, when the permeable parking area is reduced a smaller reduction of water depth and outflow is clearly noted. 


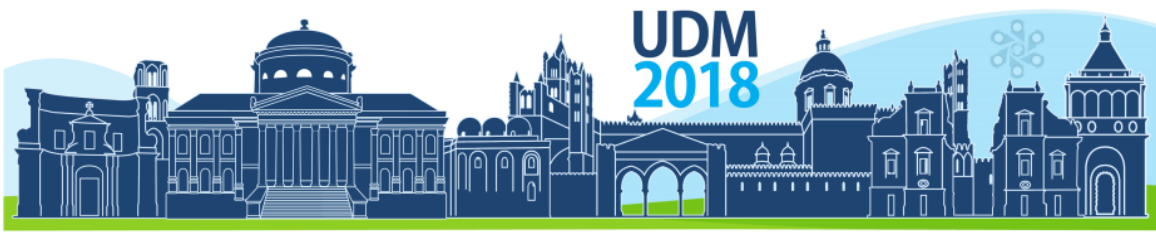

$11^{\text {th }}$ International Conference on Urban Drainage Modelling

23-26 Sep | Palermo - Italy

Histograms in figure 1 are summarized bi-dimensional simulations made with infiltration code when the hyetograph is similar to Chicago rainfall (Scenario B). The figure shows how with the percentage decrease of pervious parking area, there is a sensible water depth peak reduction.

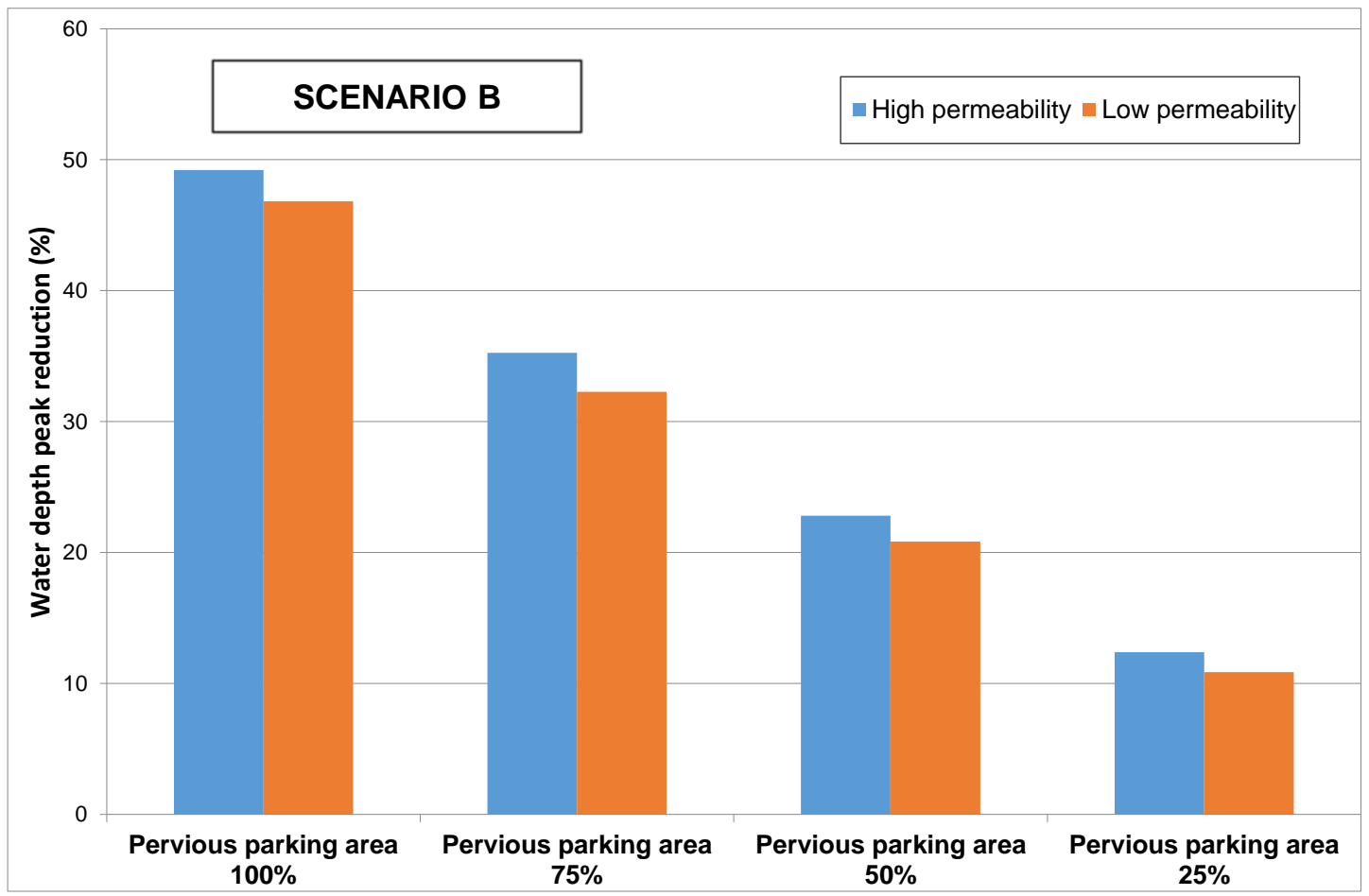

Figure 1. Percentage of water depth peak reduction compared to impervious area when parking area has different percentage of permeability (Scenario B).

\section{CONCLUSIONS}

Initially bi-dimensional simulations with FLURB were carried out using different values of the runoff coefficient $R C$. The simulations series were made for eight different scenarios, which are designed, combining different hydrographs and hyetographs. . Model simulation results show how the water depth and outflows decrease as the runoff coefficient $R C$ decreases. The results show how parking lot has a good hydrologic performance for a rainfall with a return period $\mathrm{Tr}=50$ years, and when hyetograph is similar to a Chicago rainfall (Scenario B). Furthermore, the results show how the percentage reductions of water depth and peak flow rate are almost equal. This means that hydrologic performance of permeable parking is not affected by the value of the peak of triangular inflow rate. Bi-dimensional simulations with infiltration code were made for two different scenarios (rectangular hyetograph and hyetograph similar to Chicago Rainfall). The results show as permeable parking performance is greater in Scenario B when the hyetograph is similar to a Chicago rainfall. Furthermore, results show how the parking lot has a good performance also when the permeability is lower. This is due to the fact that although low permeability is referred to a permeable parking after some years of use, with a lower infiltration rate (due to clogging), and with a subgrade of clay, the permeability of parking is however greater than a traditional pavement, and hence it is able to infiltrate a large amount of water. In a future work it will be important to verify the real effectiveness of parking lot in a city, and also verify how parking area influence 


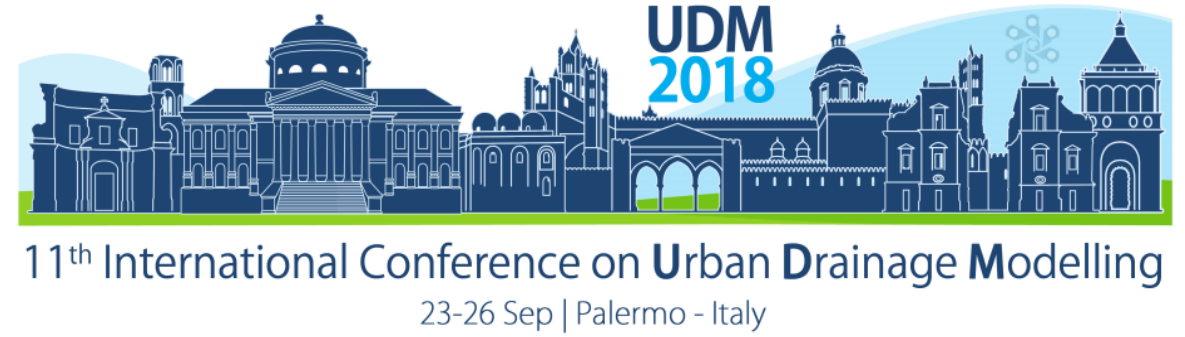

the runoff surface in different points of city, and how many parking lots are necessary to reduce significantly hydraulic risk. Therefore it will be possible understand how a parking lot can influence spatially surface runoff in a city.

\section{References}

Aronica, G., Hankin, B., and Beven, K.,(1998a). Uncertainty and equifinality in calibrating distributed roughness coefficients in a flood propagation model with limited data. Advances in Water Resources, 22(4), 349-365.

Aronica,G.T., Tucciarelli, T., and Nassello,C.,(1998b). 2D multi-level model for flood Wave propagation in floodaffected-areas. Journal of Water Resources Planning and Management, 124(4), 210-217.

Aronica,G.T., Lanza,L.G.,(2005). Drainage efficiency in the urban environment, Hydrological processes, 19(5), 1105-1119.

Palla,A., Aronica,G.T., Gnecco,I. and Lanza,L.G.,(2013). Surface drainage system efficiency and its impact on pluvial flooding: a physically-based stochastic approach. International Conference on Flood Resilience: Experience in Asia and Europe 5-7 September 2013,Exeter, United Kingdom.

Ranieri,V., Kowalski, K.J., Berloco, N., Colonna, P, and Perrone,P.,(2017). Influence of wax additives on the properties of porous asphalts, Construction and building materials, 145 (2017) 261-271.

Rappazzo,D. and Aronica,G.,(2017). Including permeable pavements in a 2D model for flood propagation in urban reas. Icud 2017

Sansalone, J., Kuang, X., Ying, G., Ranieri, G.,(2012). Filtration and clogging of permeable pavement loaded by urban drainage, Water Res. 46 (20), 6763-6774.

Yong,C.F., McCarthy,D.T., Deletic, A.,(2012). Predicting physical clogging of porous and permeable pavements, Journal of Hydrology 481, 48-55. 


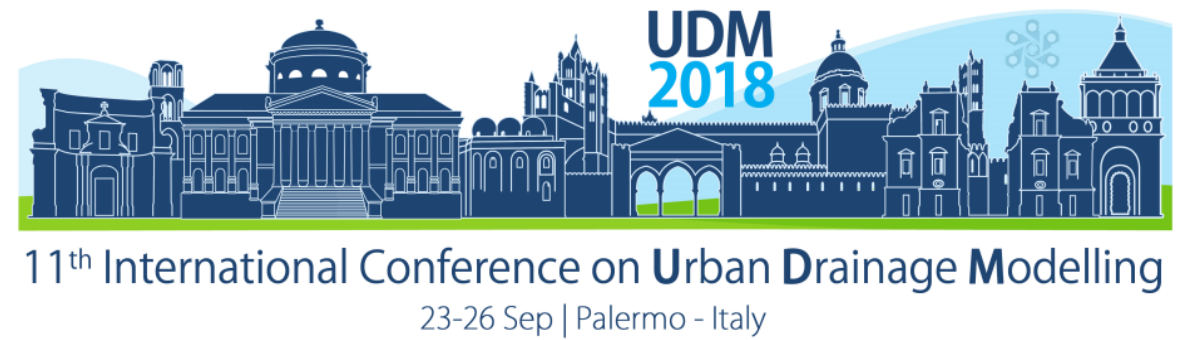

\title{
Use of retention basin for flood mitigation and urban requalification in Mesquita, Brazil
}

\author{
Osvaldo Moura Rezende ${ }^{1,2}$, Matheus Martins de Sousa ${ }^{1,2}$, Ana Caroline Pitzer Jacob1, Luiza Batista de \\ França Ribeiro ${ }^{1}$, Antonio Krishnamurti Beleño de Oliveira² ${ }^{2}$, Cícero Matos Arrais ${ }^{1}$, and Marcelo Gomes \\ Miguez $^{2}$ \\ ${ }^{1}$ AquaFluxus Water Resources and Environmental Consulting, Rio de Janeiro, Brazil \\ Universidade Federal do Rio de Janeiro, Programa de Engenharia Civil, Rio de Janeiro, Brazil
}

\begin{abstract}
Unplanned urbanization is one of the main factors responsible for worsening floodrelated problems in cities, increasing the frequency and flooding depths and degrading the environment. Considering this, the use of engineering techniques that reduce runoff and promote the urban requalification are efficient for the management of rainwaters. This paper presents a case study of flood control project using a storm water retention pond, designed to allow multiple use of an urban space. The operation of the system is evaluated by a Cell Model, developed in the Computational Hydraulic Laboratory of of the Federal University of Rio de Janeiro (LHC-COPPE/UFRJ), known as MODCEL. The results showed the best configuration of the layout of "Celso Peçanha" Retention Basin, considering the area restrictions imposed by the City of Mesquita - Brazil, optimized to damp rainfall flows resulting from rainfall with return periods up to 50 years. The solution proposed is concerned about social urban space use, revitalising degraded areas and giving it different possibilities of use.
\end{abstract}

Keywords: compensatory techniques; multifunctional landscapes; urban drainage

\section{INTRODUCTION}

In face of the unplanned urbanization, which is a very common process in Brazil, the occurrence of high-intensity hydrological events shows the fragility of traditional drainage systems (ANDOH \& IWUGO, 2002 and MELVILLE-SHREEVE Et al., 2018).This kind of system is usually composed by techniques that accelerate flows, such as river canalisation works (TUCCI \& BERTONI, 2003 AND TUCCI \& MENDES, 2006). These techniques end up transferring the problem downstream, without controlling the related consequences. Neglecting source control, this approach implies in continuous interventions following the flood events.

This article seeks to exemplify, in a practical way, the benefits of sustainable drainage with a focus on urban requalification. In this way a retention basin is designed to temporary store and to dampen the discharges of a minor drainage system of an urban catchment (TRAVIS \& MAYS, 2008). The hydrodynamic analysis of the operation of this retention pond was carried out for an enterprise in the municipality of Mesquita, Brazil. The study area, called the watershed of Governador Celso Peçanha Avenue, drains to Sarapuí River and suffer constant flooding in the summer seasons.

\section{MATERIALS AND METHODS}

The design of the local minor drainage considers the implementation of a retention basin to dampen the rainwaters before discharging to the Sarapuí River. In this way, a rainwater 


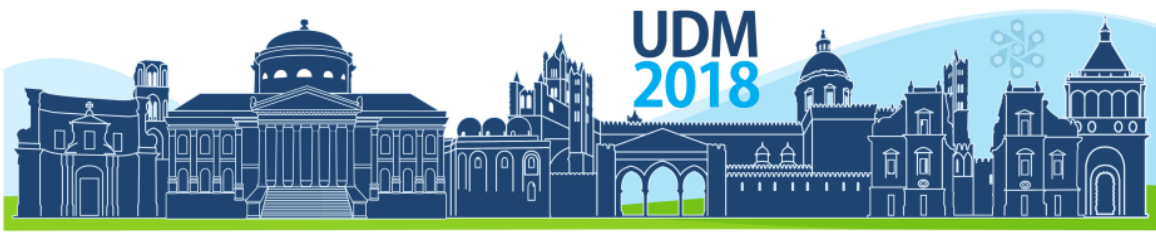

$11^{\text {th }}$ International Conference on Urban Drainage Modelling

23-26 Sep | Palermo - Italy

retention structure was designed to be also associated to leisure uses in its internal area, ensuring social uses of urban space, through the environmental and urban valorisation of the entire neighbourhood. The final layout is shown in the Figure 1.

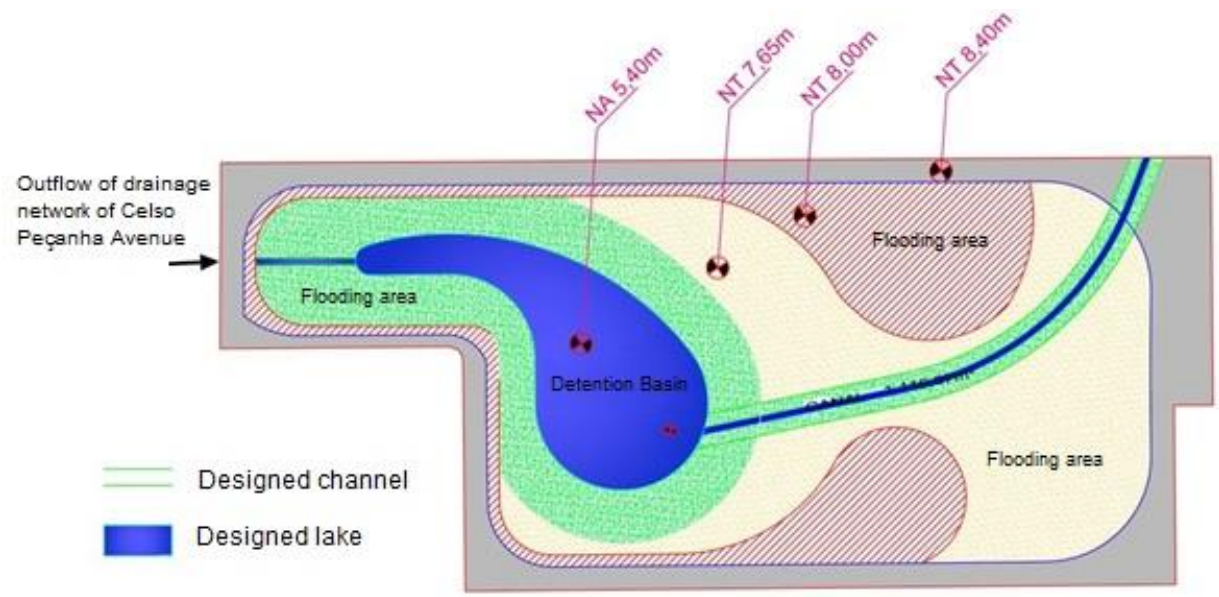

Figure 1 - Celso Peçanha Retention Basin Project.

This study used a hydrodynamic model to simulate the drainage system - MODCEL (MIGUEZ, 2001 and MIGUEZ et al., 2017) - and the HIDROFLU system (MAGALHÃES et al., 2005), which offers a useful hydrologic model for small urban catchments.

\subsection{Hydrological Studies}

The hydrological studies were performed in order to build design rainfalls for different return periods. Previous hydrologic studies conducted for this region were used as references. These studies were part of the "Water Resources Master Plan of the Iguaçu/ Sarapuí River Basin" developed by the Laboratory of Hydrology and Environmental Studies at UFRJ (LABHID, 1996). The different design rainfall events were calculated using the following premises:

- The rainfall duration equals 76,38 minutes, referring to the calculated time of concentration for the studied watershed;

- Different values of runoff coefficient were established to each cell, according to the analysis of satellite images for land use evaluation.

Table 1 presents values of design rainfall calculated for different Return Periods (RP) and peak flow hydrograph that resulted from each rainfall event, used in the simulation of the proposed retention basin operation.

Table 1. Values of design rainfall calculated for different Return Periods (RP).

\begin{tabular}{lcccc} 
Return Period (years) & RP5 & RP10 & RP20 & RP50 \\
\hline Total Height Rainfall (mm) & 62.5 & 70.7 & 77.6 & 89.2 \\
Peak Flow (m $\mathbf{m} / \mathbf{s})$ & 1.71 & 2.03 & 2.32 & 2.81 \\
\hline
\end{tabular}

\subsection{Hydraulic Studies}

The representation of the retention basin was made by dividing its internal area into 12 flow cells, with one more cell in the external area to represent the storm drain that connect to Sarapuí River. From this division, a topological scheme was built for data entry in the 


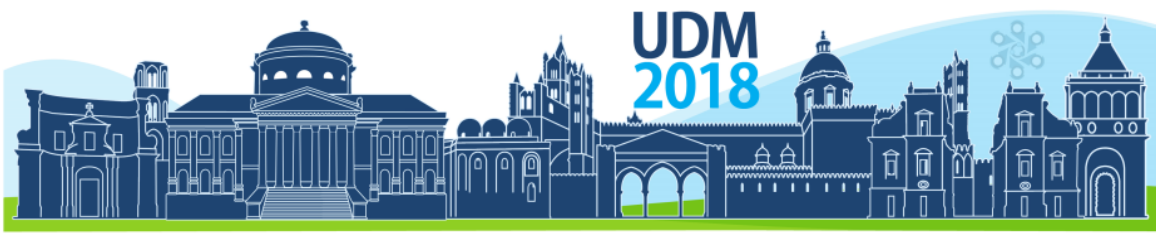

$11^{\text {th }}$ International Conference on Urban Drainage Modelling

23-26 Sep | Palermo - Italy

mathematical model MODCEL. The cell division and the associated topological scheme can be seen in Figure 2.

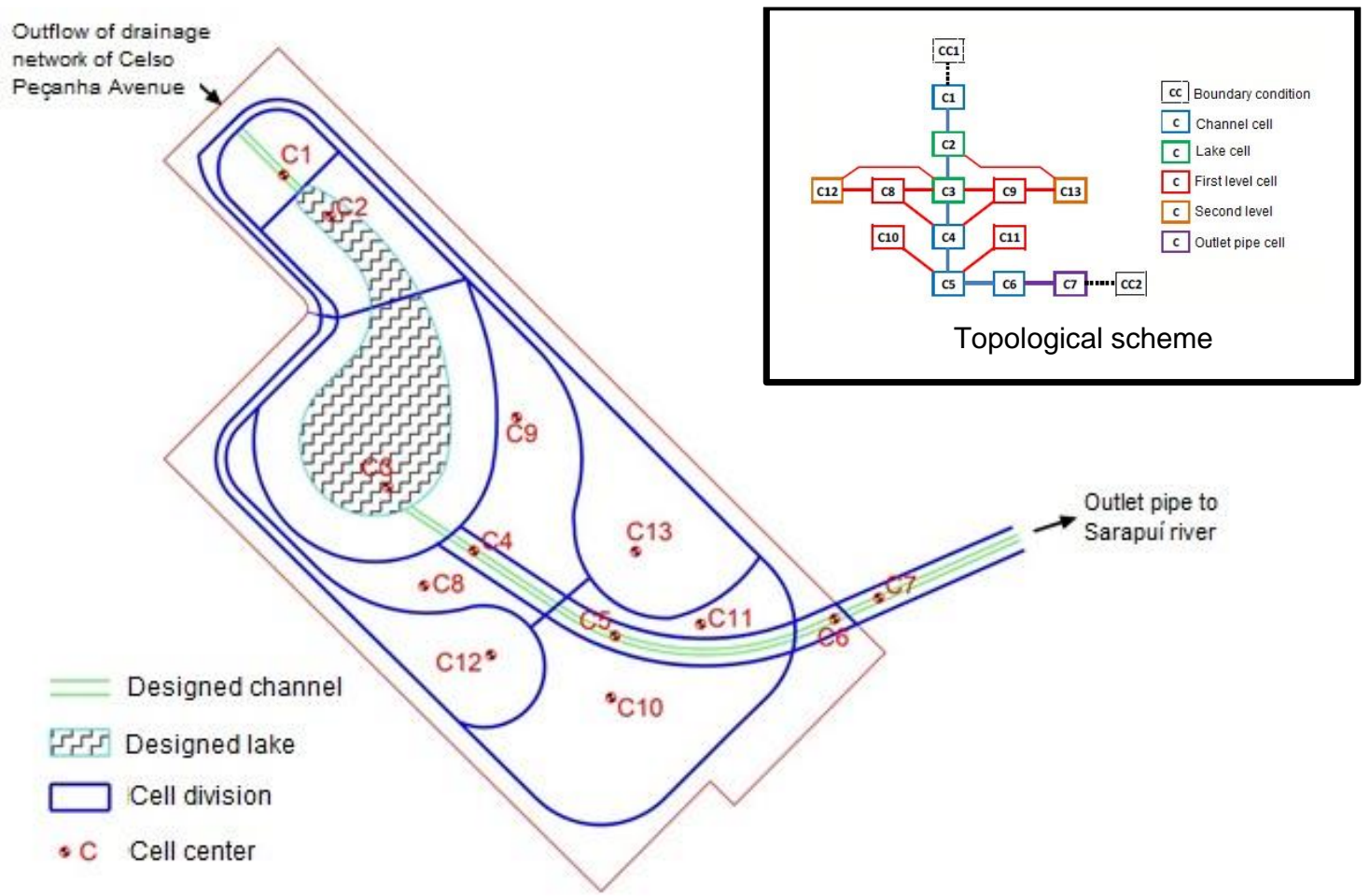

Figure 2 - Cell division and the topological scheme.

The boundary conditions defined for the model represent: (1) the flood hydrograph entering the square, representing the outfall of the drainage network coming from the Governador Celso Peçanha Avenue; and (2) the water level of Sarapuí River, in the outfall of the storm drain designed downstream the retention basin.

\section{RESULTS AND DISCUSSION}

The results of the simulations allowed the analysis of the filling of the retention basin and water levels for each scenario considering the different rainfall events, as well as the outflows of the basin. In this way, it was possible to evaluate the damping efficiency of the proposed structure. The results of the hydrodynamic evaluation are presented in the form of inflow and outflow hydrographs for the retention basin and water levels. The inflow hydrographs refer to the minor drainage network contribution coming from Celso Peçanha Avenue and the outflows refer to the exit of the retention basin into Sarapuí River. .

The graph of Figure 3-A shows the damping efficiencies for each design rainfall. It is observed that the retention basin provides a significant damping effect, reaching an efficiency of $84 \%$ for the design rainfall event of RP 50 years. The water surface elevation in the inner area of the basin, presented in the graph of Figure 3-B, shows the retention basin filling pattern, for each design rainfall. Table 2 presents the damping efficiencies. 


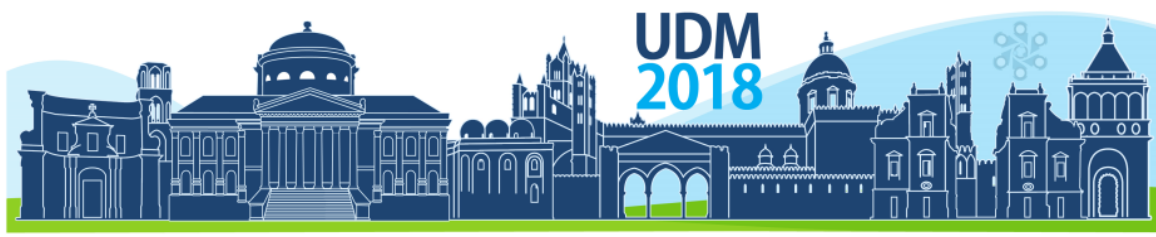

$11^{\text {th }}$ International Conference on Urban Drainage Modelling

23-26 Sep | Palermo - Italy

Table 2. Damping efficiencies for each design rainfall

\begin{tabular}{lllll} 
Return Period (years) & RP5 & RP10 & RP20 & RP50 \\
\hline Efficiency & $76 \%$ & $79 \%$ & $81 \%$ & $84 \%$ \\
\hline
\end{tabular}

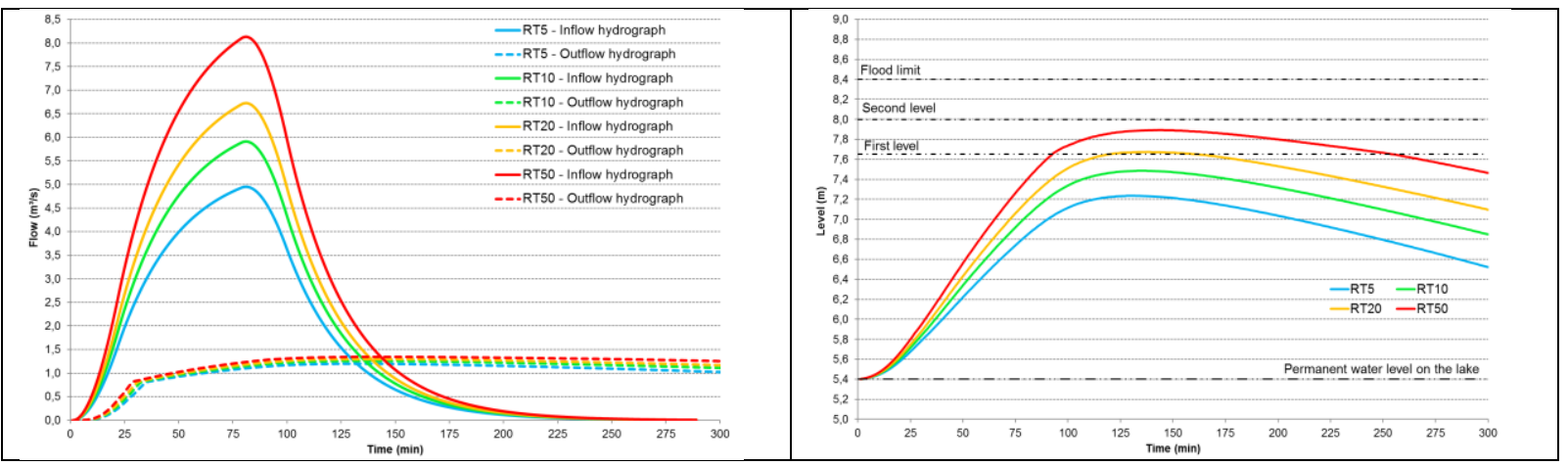

Figure 3 - Inflow and outflow hydrographs for all(\$ihulated rainfalls $(A)$ and water surface elevation in the(B) retention basin for the simulated rainfalls $(B)$.

\section{CONCLUSIONS}

The use of a retention basin proved to be efficient to reduce the runoff volume generated in a densely urbanized watershed, reducing the drained flows to the receiving body. Drainage solutions integrated with urban revitalization programs can be an important option for flood control, due to the possibility of drawing distributed actions in the urbanized watershed and optimization of public resources, since they are directed to multipurpose activities, using the concept of multifunctional landscapes. This type of solution also adds urban, social and environmental value to the region of interest and takes advantage of the potential of integrating engineering projects with urban design, considering the social function of urban spaces.

\section{References}

Andoh, R. Y., \& Iwugo, K. O. (2002). Sustainable urban drainage systems: a UK perspective. In Global Solutions for Urban Drainage (pp. 1-16).

LABHID. (1996). Plano diretor de recursos hídricos da Bacia dos Rios Iguaçu-Sarapuí. Rio de Janeiro: Fundação Superintendência Estadual de Rios e Lagoas.

Magalhães, L. P. C., Magalhães, P. C., Mascarenhas, F. C. B., Miguez, M. G., Colonese, B. L., \& Bastos, E. T. (2005). Sistema HIDRO-FLU para apoio a Projetos de Drenagem. XVI Simpósio Brasileiro de Recursos Hídricos. ABRH, João Pessoa.

Melville-Shreeve, P., Cotterill, S., Grant, L., Arahuetes, A., Stovin, V., Farmani, R., \& Butler, D. (2018). State of SuDS delivery in the United Kingdom. Water and Environment Journal, 32(1), 9-16.

Miguez, M. G. (2001) Modelo Matemático de Células de Escoamento para Bacias Urbanas. [thesis] COPPE/UFRJ, Rio de Janeiro.

Miguez, M., Peres Battemarco, B., Martins De Sousa, M., Moura Rezende, O., Pires Veról, A., \& Gusmaroli, G. (2017). Urban Flood Simulation Using MODCEL-An Alternative Quasi-2D Conceptual Model. Water, 9(6), 445.

Travis, Q. B., \& Mays, L. W. (2008). Optimizing retention basin networks. Journal of Water Resources Planning and Management, 134(5), 432-439.

Tucci, C. E., \& Bertoni, J. C. (2003). Inundações urbanas na América do Sul. Ed. dos Autores.

Tucci, C. E., \& Mendes, C. A. (2006). Avaliação ambiental integrada de bacia hidrográfica. Ministério do Meio Ambiente. 


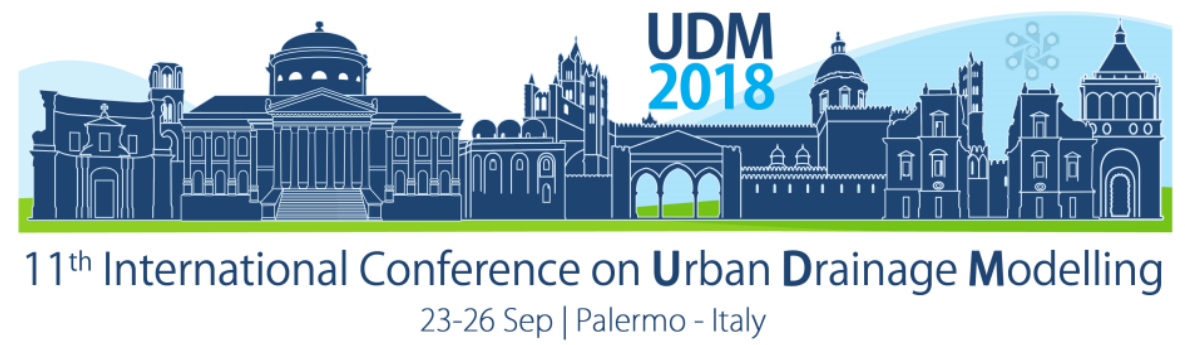

\title{
Quantifying Long-term Benefits of Multi-Purpose Rainwater Management Systems
}

\author{
Peter Melville-Shreeve ${ }^{1}$, and David Butler ${ }^{1}$ \\ 1 University of Exeter, Centre for Water Systems, Exeter, UK
}

\begin{abstract}
This paper investigates the performance in terms of yield, peak stormwater discharges and annual stormwater reductions for a set of four rainwater management scenarios tested against a hypothetical household in England. The work builds on recent progress in modelling of rainwater management systems (RMS) using a mass balance approach. The novelty lies in the ability to investigate both; local water provision; and the reduction in stormwater discharges associated with the RMS strategies. Recent research studies and case study exemplars demonstrate a shift away from single objective rainwater harvesting systems. Projects are now being delivered using dual-purpose RMS to control discharges as well as augment water supply. The study illustrates for the first time, how a long time series rainfall record ( 85 years) can be used to drive mass balance simulations and enable key metrics to be calculated. The results illustrate how well-designed RMS can reduce stormwater discharges whilst also meeting design needs for water resource augmentation. The length of rainfall dataset analysed enables long performance evaluation including during low probability events that exceed the UK's current stormwater drainage design standards (e.g. 1 in 30 year rainfall event). The study also investigates the potential for climate change to affect performance. It concludes that an actively controlled RMS with a 3000 l tank can potentially reduce the largest rainfall event in the 85 year dataset by $72 \%$, up from just $6 \%$ for a traditional RWH configuration with the same tank storage capacity.
\end{abstract}

Keywords: Rainwater Harvesting; Rainwater Management Systems; SuDS; Water Efficiency

\section{INTRODUCTION}

Rainwater harvesting (RWH) installations increased in the UK and elsewhere as environmentally focussed policies have taken hold in recent decades (Burns et al., 2014, DeBusk et al., 2013 Herrmann and Schmida, 1999). The capture, storage and use of rainwater as a non-potable water supply is now promoted by policy statements in the UK, where both national guidance and the London Plan support the technology as the priority drainage method for new development sites. Despite this, property developers continue to undervalue the potential benefits of well-designed RWH and frequently rule the solution out based on a perception that capital costs are unnecessarily increased when RWH is included. There remains a lack of understanding that RWH systems can also be designed as a rainwater management system (RMS), i.e. one which has multiple purposes that reach beyond the desire to secure a local water resource. RMS can be designed to capture rainwater whilst also meeting a stormwater control objective (e.g. reduce rainwater discharge during 1 in 10 year storm by $90 \%$ ). This paper investigates these approaches and demonstrates the water savings and stormwater control reductions using a long time series analysis.

\section{METHODOLOGY}

High-level RWH studies can be executed using mean monthly rainfall totals to drive mass balance simulations. More recently, high resolution investigations have focussed on RWH performance as an alternative water resource using a daily time-step (Roebuck et al. 2012). In 


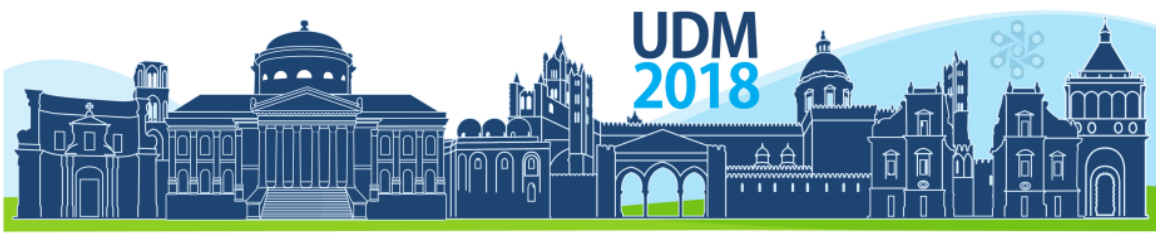

$11^{\text {th }}$ International Conference on Urban Drainage Modelling

23-26 Sep | Palermo - Italy

the last decade, time series analysis approaches have been defined which can investigate the stormwater management benefits of RMS alongside the traditional RWH benefits (MelvilleShreeve et al., 2016). Another trend has been to increase the resolution of the rainfall data, with recent works now being completed at a 15 minute time-step (Campisano \& Modica, 2014). However, work has yet to be undertaken that looks at long term rainfall datasets to illustrate how RMS respond to long time series rainfall data. This study uses a mass balance analysis approach developed by the University of Exeter's Centre for Water Systems into a commercial tool named RainWET - The RainWater Harvesting Evaluation Tool (Melville-Shreeve, 2017). The YAS algorithm (Fewkes and Butler, 2000) is used to drive simulations at a daily time-step via a user interface. Rainfall data is input and the software provides metrics on the water efficiency, total stormwater discharge reduction and peak stormwater discharge reduction achieved by the proposed RMS scenario. Through iterative design, the user is able to test strategies in order to meet a design objective. In this instance, the software is used to demonstrate the long-term benefits of 3 RMS strategies against a "do nothing" strategy for a typical house in Central England.

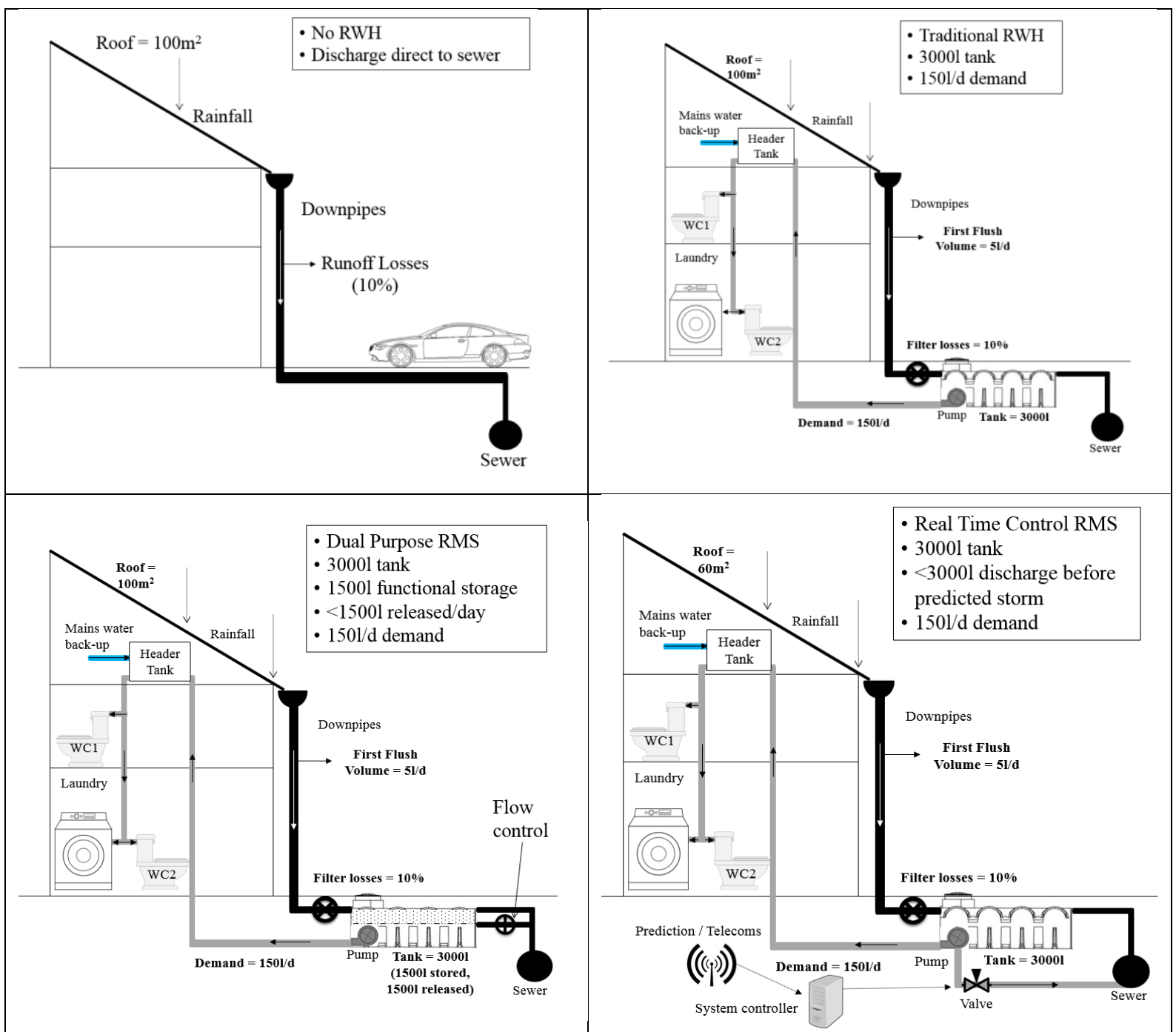

Figure 1. Four Household Rainwater Management Scenarios Modelled (Adapted from Melville-Shreeve, 2017) 


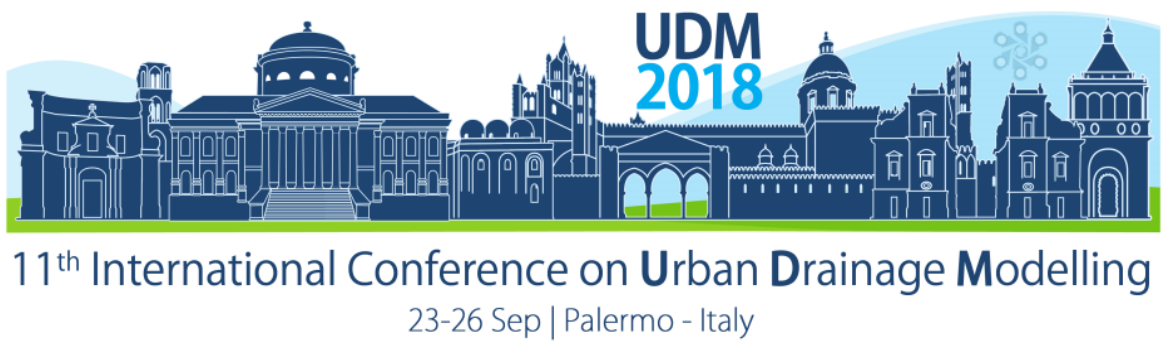

The property was assumed to have; a roof area of $100 \mathrm{~m}^{2}(\mathrm{~A}) ; 3$ occupants with a 150l/day rainwater demand; filter losses fixed at $10 \%$ of incoming flows; and a first flush volume of 5 litres per day. An 85 year rainfall data was used to drive the simulations for a range from 19312015. The configurations tested are illustrated in Figure 1.

S1) No RMS: The house has no RMS. The rainfall is assumed to discharge as an overflow to the receiving sewer with a fixed runoff coefficient of 0.9 . (i.e.10\% losses are assumed).

S2) Traditional RMS: A traditional rainwater configuration with a below ground tank that feeds a loft-based header tank via a submersible pump. It has no stormwater control features. The system has a 3,000l tank with 3,000l functional storage.

S3) Dual Purpose RMS with Passive Control Outlet: A novel RMS configuration with a below ground tank that feeds a loft-based header tank via a submersible pump. It has a passive discharge control to release rainwater when the tank level exceeds $50 \%$. The system has a 3,000 l tank with 1,500 l functional storage. The remaining upper region of the tank comprises a 1,500 l source control volume which captures and releases large storm events at a controlled rate on the same day as the storm.

S4) Real Time Control RMS: A novel RWH configuration with a below ground tank that feeds a loft-based header tank via a submersible pump. It has a real time active discharge control to predictively release stormwater the day prior to a storm. The system has a 3,000I tank with 3,000 l functional storage. The real time control system enables rainwater to be released from the entire tank at the previous time-step to accommodate projected rainfall arriving during the current time-step. The controller is assumed to have a daily rainfall forecast for the next timestep which is $100 \%$ accurate.

\section{Results}

Evidence from the four scenarios is summarised in Table 1. The data shows that the location has an average of 264 raindays giving $649 \mathrm{~mm} /$ annum (range $425-876 \mathrm{~mm} / \mathrm{annum}$ ). A traditional RWH system (S2) installed at a UK house over an 85 year period, could provide $86 \%$ of non-potable water demand and limit discharges by $99 \%$. However, only S4 (which includes an RTC element) was able to notably reduce the largest daily storm event which occurred in the 85 year data set (72\% reduction). To further illustrate the potential impacts of climate change impacts, the daily rainfall data was factored by 0.6 and 1.4 to represent $a+/-$ $40 \%$ fluctuation in daily rainfall totals. Well, designed RMS should arguably cope with a range of future climate change scenarios, and hence these two scenarios offer an indication of the opportunity for RMS to be designed as a low regret option regardless of future shifts in rainfall patterns. 


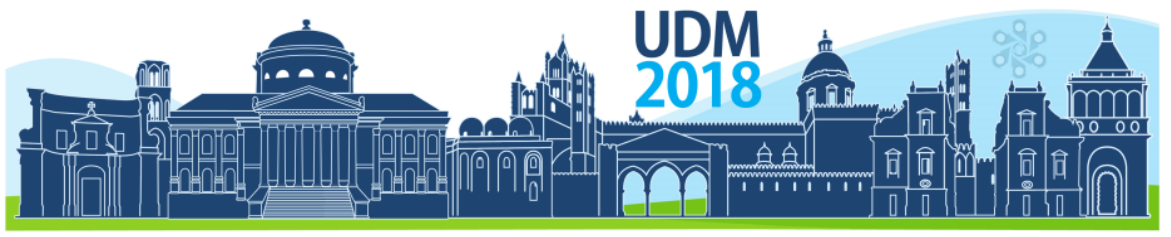

$11^{\text {th }}$ International Conference on Urban Drainage Modelling

23-26 Sep | Palermo - Italy

Table 1. Output Metrics for Four RMS Scenarios

\begin{tabular}{|l|c|c|c|c|c|c|c|c|c|}
\hline \multicolumn{1}{|c|}{ Scenario } & \multicolumn{3}{|c|}{$\begin{array}{c}\text { Mean water Demand } \\
\text { Met }\left(\mathrm{m}^{3} / \text { annum) }\right.\end{array}$} & \multicolumn{3}{c|}{$\begin{array}{c}\text { Mean stormwater } \\
\text { discharge prevented or } \\
\text { controlled }\left(\mathrm{m}^{3} / \text { annum }\right)\end{array}$} & \multicolumn{2}{c|}{$\begin{array}{c}\text { Reduced discharge for } \\
\text { largest storm in data set } \\
\left(\mathrm{m}^{3} / \text { day }\right)\end{array}$} \\
\hline Rainfall Factor & 0.6 & 1.0 & 1.4 & 0.6 & 1.0 & 1.4 & 0.6 & 1.0 & 1.4 \\
\hline S1 - No RWH & - & - & - & - & - & - & - & - & - \\
\hline $\begin{array}{l}\text { S2 - } \\
\text { Traditional } \\
\text { RWH }\end{array}$ & $\begin{array}{c}34 \\
(61 \%)\end{array}$ & $\begin{array}{c}47 \\
(86 \%)\end{array}$ & $\begin{array}{c}51 \\
(94 \%)\end{array}$ & $\begin{array}{c}35 \\
(99 \%)\end{array}$ & $\begin{array}{c}48 \\
(82 \%)\end{array}$ & $\begin{array}{c}51 \\
(63 \%)\end{array}$ & $\begin{array}{c}1.58 \\
(58 \%)\end{array}$ & $\begin{array}{c}0.25 \\
(6 \%)\end{array}$ & $\begin{array}{c}0.20 \\
(3 \%)\end{array}$ \\
\hline $\begin{array}{l}\text { S3 - Dual } \\
\text { Purpose RMS }\end{array}$ & $\begin{array}{c}32 \\
(59 \%\end{array}$ & $\begin{array}{c}43 \\
(78 \%)\end{array}$ & $\begin{array}{c}47 \\
(85 \%)\end{array}$ & $\begin{array}{c}35 \\
(100 \%)\end{array}$ & $\begin{array}{c}58 \\
(99 \%)\end{array}$ & $\begin{array}{c}80 \\
(97 \%)\end{array}$ & $\begin{array}{c}2.38 \\
(88 \%)\end{array}$ & $\begin{array}{c}1.77 \\
(39 \%)\end{array}$ & $\begin{array}{c}1.73 \\
(27 \%)\end{array}$ \\
\hline S4 - RTC RMS & $\begin{array}{c}34 \\
(61 \%)\end{array}$ & $\begin{array}{c}47 \\
(86 \%)\end{array}$ & $\begin{array}{c}51 \\
(94 \%)\end{array}$ & $\begin{array}{c}35 \\
(100 \%)\end{array}$ & $\begin{array}{c}59 \\
(100 \%)\end{array}$ & $\begin{array}{c}82 \\
(99 \%)\end{array}$ & $\begin{array}{c}2.70 \\
(100 \%)\end{array}$ & $\begin{array}{c}3.00 \\
(72 \%)\end{array}$ & $\begin{array}{c}3.00 \\
(51 \%)\end{array}$ \\
\hline
\end{tabular}

\section{Conclusions}

The study presented illustrates the ability for RMS to provide water demand and stormwater control benefits based on a long, 85 year time series analysis. The following conclusions can be drawn from the simulations: 1) The traditional RWH system reduced average stormwater discharges by $82 \%$ over 85 years whilst providing a yield of $47 \mathrm{~m}^{3} /$ annum. 2) RMS with a real time control element was able to limit the largest storm in the simulation by $72 \%$ whilst also reaching a $47 \mathrm{~m}^{3} /$ annum yield. 3 ) Increased or decreased daily rainfall totals cause greater fluctuation in peak stormwater discharges than rainwater yield. 4) Further work is now needed to investigate these effects at 15 minute time-steps and upscaled to invstigate impacts on a catchment scale.

\section{ACKNOWLEDGEMENTS}

This work is funded by the EPSRC under TWENTY65 (EP/N010124/1)

\section{References}

Campisano, A., Butler, D., Ward, S., Burns, M. J., Friedler, E., DeBusk, K., Fisher-Jeffes, L. N., Ghisi, E., Rahman, A., Furumai, H. \& Han, M. 2017. Urban rainwater harvesting systems: Research, implementation and future perspectives. Water Research, 115, 195-209.

DeBusk, K. M., Hunt, W. F. \& Wright, J. D. 2013. Characterizing rainwater harvesting performance and demonstrating stormwater management benefits in the humid southeast USA. JAWRA Journal of the American Water Resources Association, 49, 1398-1411.

Campisano, A., Modica, C. 2014. Selecting time scale resolution to evaluate water saving and retention potential of rainwater harvesting tanks. Procedia Engineering, 70, 218-227.

Fewkes, A., Butler, D. 2000. Simulating the performance of rainwater collection and reuse systems using behavioural models. Building Services Engineering Research and Technology. Volume: 21 issue: 2, page(s): 99-106

Herrmann, T. \& Schmida, U. 1999. Rainwater utilisation in Germany: efficiency, dimensioning, hydraulic and environmental aspects. Urban Water, 1, 307-316.

Melville-Shreeve, P. Rainwater Harvesting for Drought Mitigation and Flood Management. Engineering Doctorate Thesis, University of Exeter, Exeter.

Melville-Shreeve, P., Ward, S. \& Butler, D. 2016. Rainwater harvesting typologies for UK houses: a multi criteria analysis of system configurations. Water, $8,129$.

Roebuck, R. M., Oltean-Dumbrava, C. \& Tait, S. 2012. Can simplified design methods for domestic rainwater harvesting systems produce realistic water-saving and financial predictions? Water and Environment Journal, $26,352-360$. 


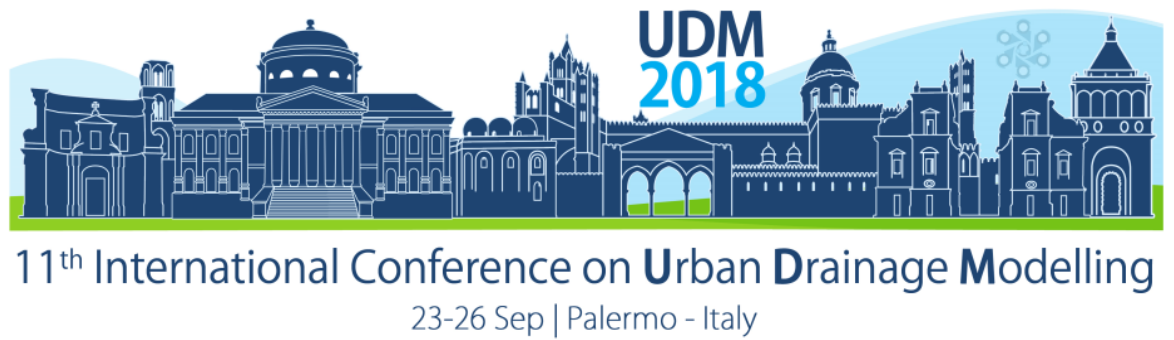

\title{
Swinging self-cleaning screen bars the Tube Hobas CSO Chamber, their physical properties and design
}

\author{
Jiri Prochazka', Jaroslav Pollert ${ }^{1}$ and Ondrej Svanda ${ }^{1}$ \\ ${ }^{1}$ Czech Technical University in Prague, Department of Sanitary and Ecological Engineering, Prague 6, Czech \\ Republic
}

\begin{abstract}
This paper deals with the design of the suitable shape of the swinging rods in the Tube overflow chamber (CSO HOBAS CHAMBER), in order to support the selfcleaning effect of the screen bars. The self-cleaning effect is caused by the free ends of the rods, which are swinging in the $45^{\circ}$ range and freely vibrating in the stream. By oscillation, the settled dirt is released into the lower part of the CSO, from where it is subsequently discharged to the WWTP. The main objective of the research was to find suitable shapes of swinging rods so that the self-cleaning effect of the screen bars could be supported at different rod lengths. The measurement was carried out on a physical model made in $1: 1$ scale and was captured on a high-speed camera. The design criteria for swinging screens on CSO HOBAS CHAMBER of different sizes was established after analysis of created slow footage. It is a commercial product manufactured by HOBAS. Information about the standards of this technology can be found on the HOBAS webside.
\end{abstract}

Keywords: overflow chamber; rain separator; uniform sewerage; physical model, pressure losses; environment

\section{INTRODUCTION}

The main drawback of overflow chambers (CSO) is generally direct connection of sewer nets with recipients. Even though the water gets heavily diluted, it still contains large amount of pollution. It is necessary to clean this pollution. Self-cleaning screen bars and overflow should serve to this purpose. These parts of the CSO are due to the pre-treatment of the rough dirt, point of origin of local losses and friction losses, which are increased with the amount of impurities deposited on rags. For example, clogging the overflow slot. Losses are an important aspect in hydrotechnical calculation of CSO, so we implement local loss coefficients and coefficients of friction losses. Local losses are especially substantial at CSO, as pressure flow occurs during the overflow at the supply pipeline. By filling the relief chamber there may be a decrease in waste water runoff, an increase of its water level and the subsequent unnecessary flooding of the objects on the sewer network and off it. Advantage of self-cleaning screen bars is that the relief chamber and its follow-up flooding.

\section{RESEARCH OF MECHANICAL PROPERTIES OF SWING SELF- CLEANING SCREEN-BARS}

The research was built on the problematics of mechanical properties of the swinging intelligent self-cleaning screen bars for the CSO HOBAS Chamber. Screen bars are being developed in a water management laboratory in a hydraulic trough in a scale of $1: 1$. Most advantageous for the construction of the rods seem to be composite materials, as they are lightweight and durable. Mechanical properties, such as bending strength, are important (an important property when crushing impurities, which increase the pressure losses on the 


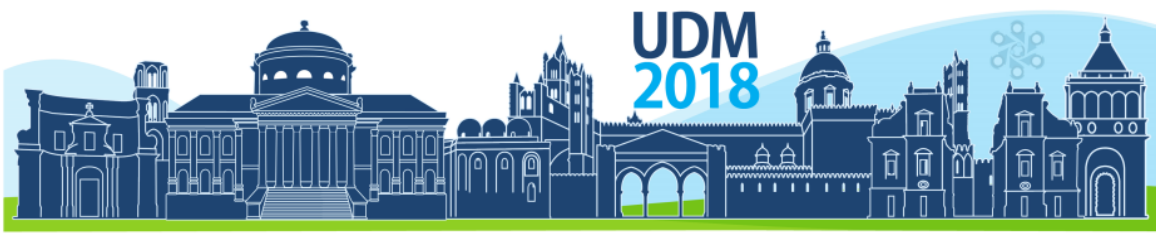

$11^{\text {th }}$ International Conference on Urban Drainage Modelling

23-26 Sep | Palermo - Italy

screen bars and increase the forces acting on the floor), roughness of the surface (a smooth surface prevents the deposit of dirt on the screen bars and their clogging) and oscillation of the free ends of the rods in the stream (the oscillation function of the rods, vibration releases already settled dirt). A suitable diameter of individual rods, their lengths and spacing between individual rods is also examined on the physical model in pursuit of a higher efficiency of separating impurities and their removal of throttling lines to WWTP.
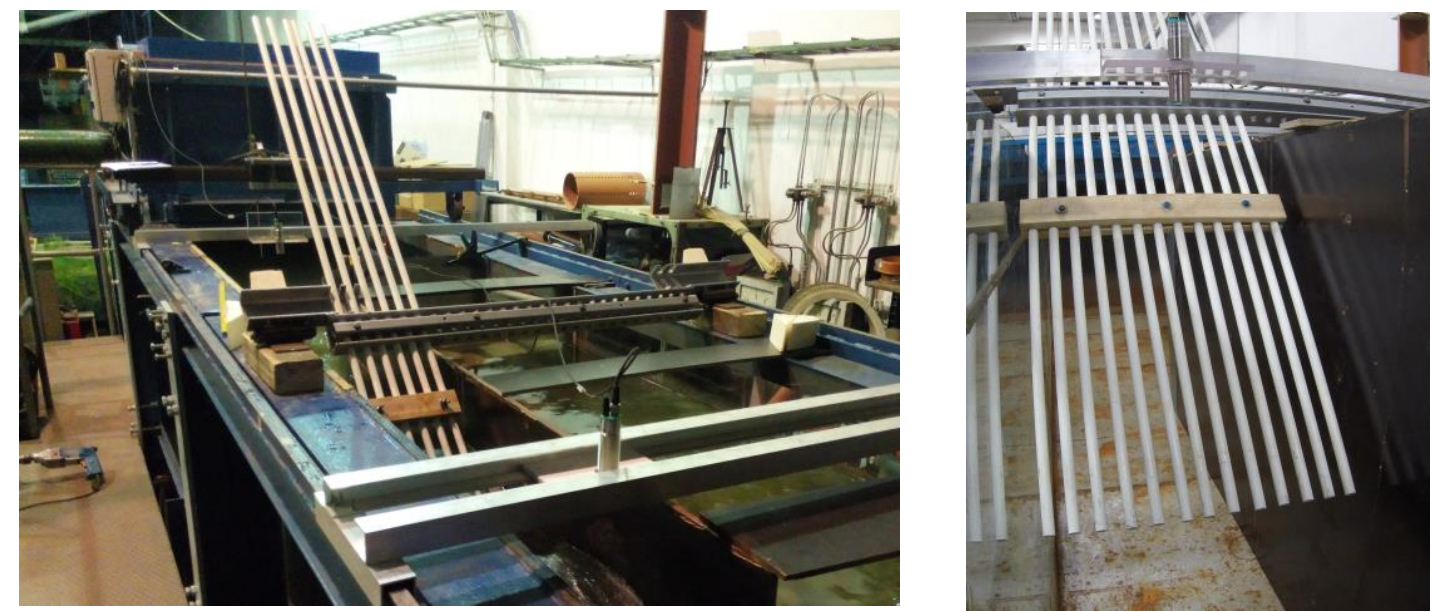

Figure 1 and 2. Physical model of swing intelligent self-cleaning screen bars in scale 1:1

A total of 135 states were measured at a flow rate ranging from 79 I / s to $200 \mathrm{I} / \mathrm{s}$ and a flow velocity from $v=0.7 \mathrm{~m} / \mathrm{s}$ to $0.9 \mathrm{~m} / \mathrm{s}$. The angle of inclination of self-cleaning rods was gradually changed at $15^{\circ}$ from vertical to $45^{\circ}$. With each change in flow or pitch, the changes in the position of the level before and after the screen bars were measured. All 45 states were captured on a high-speed camera, where the footage was slowed down and subsequently the number of vibrations of individual rods per second and the swing distance in $\mathrm{mm}$ were determined.

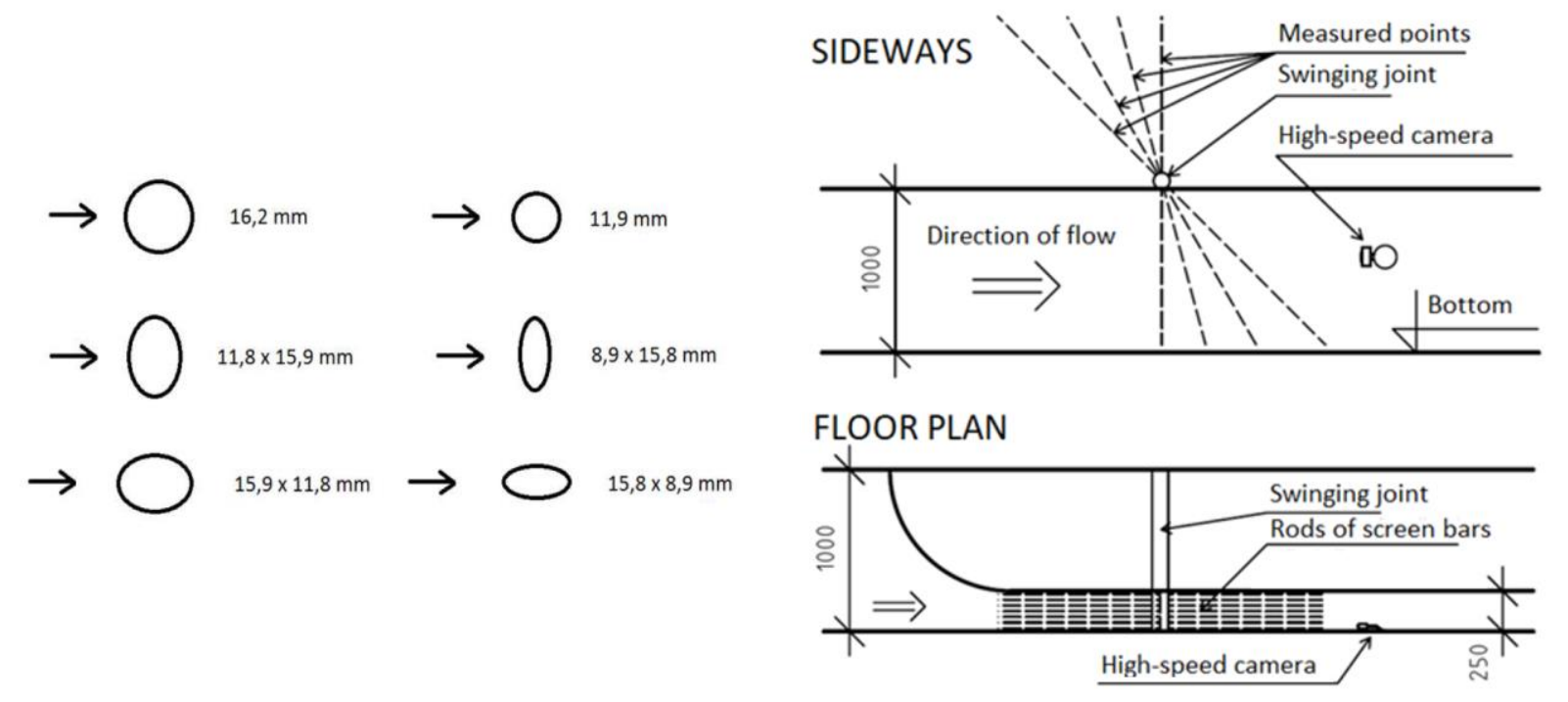

Figure 3. Diameters of tested rod in mm Figure 4. Diagram of the location of the members in the hydraulic trough 


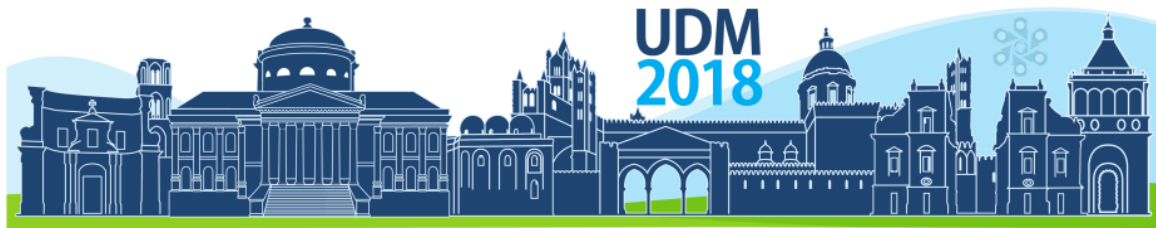

$11^{\text {th }}$ International Conference on Urban Drainage Modelling 23-26 Sep | Palermo - Italy
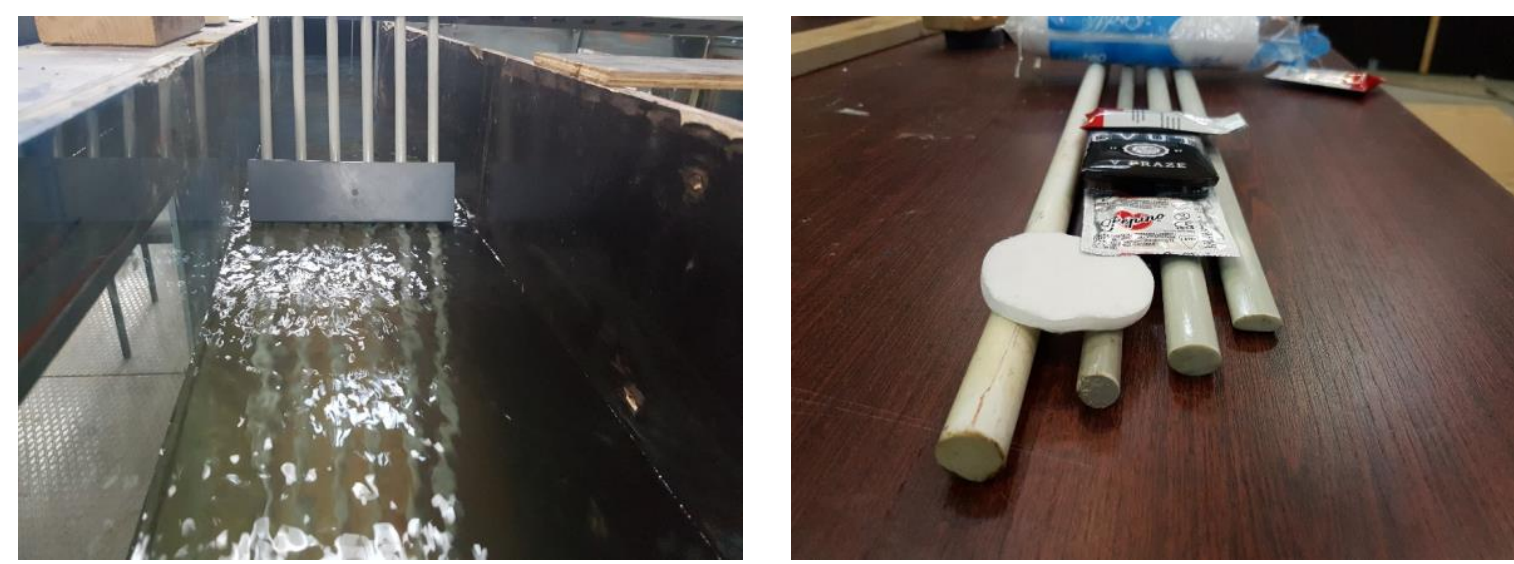

Figure 5. and 6. Screen bars with floating dirt
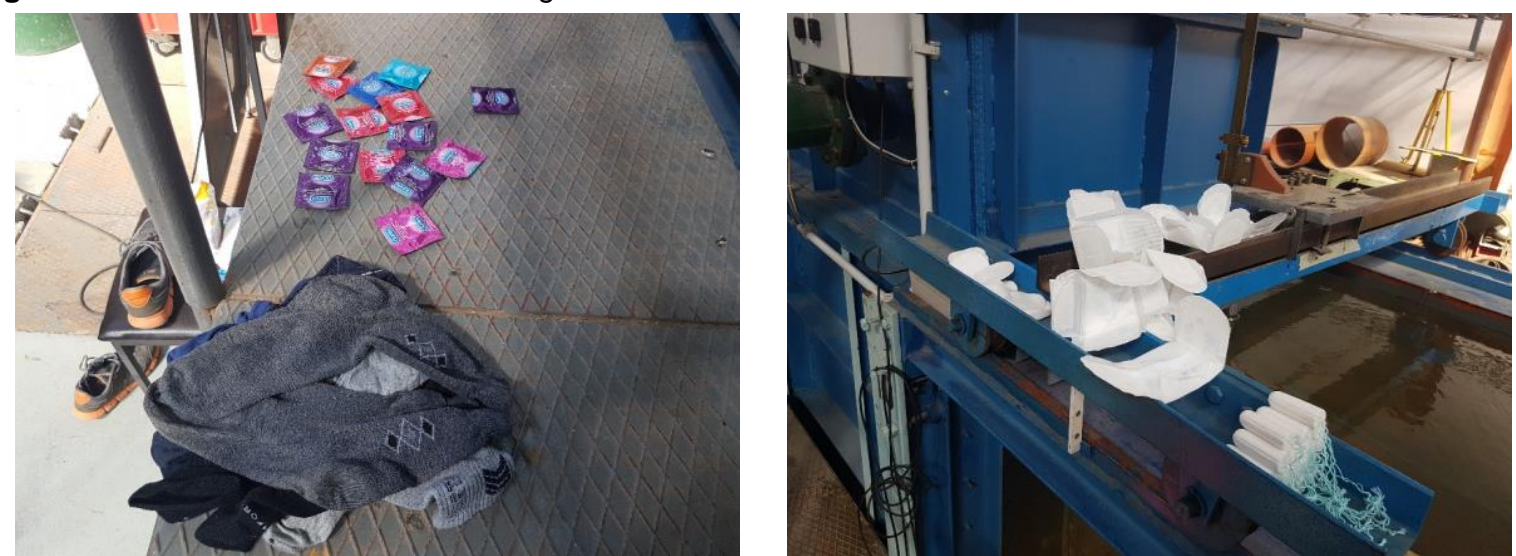

Figure 7. and 8. Impurities used during the testing of screen bars

\section{RESULTS AND DISCUSSION}

The individual rods are $36 \mathrm{~mm}$ in axial spacing. The shape of the rods is round and elliptical in different dimensions, see Figure 3 . The length of the rods ranges from $50 \mathrm{~cm}$ to $140 \mathrm{~cm}$. The rod oscillation was captured on a high-speed camera and then slowed to $1: 8$. Slow footage was analysed and processed into following graphs:
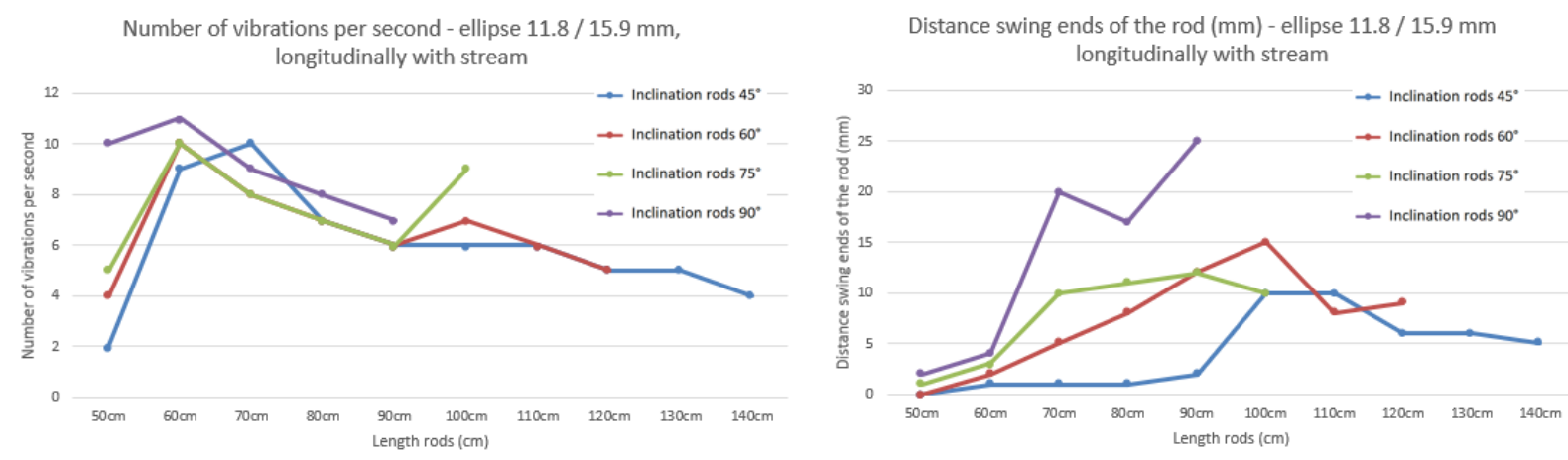


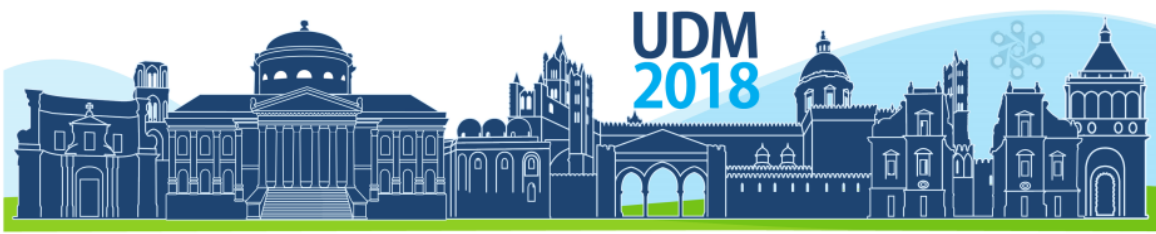

$11^{\text {th }}$ International Conference on Urban Drainage Modelling 23-26 Sep | Palermo - Italy
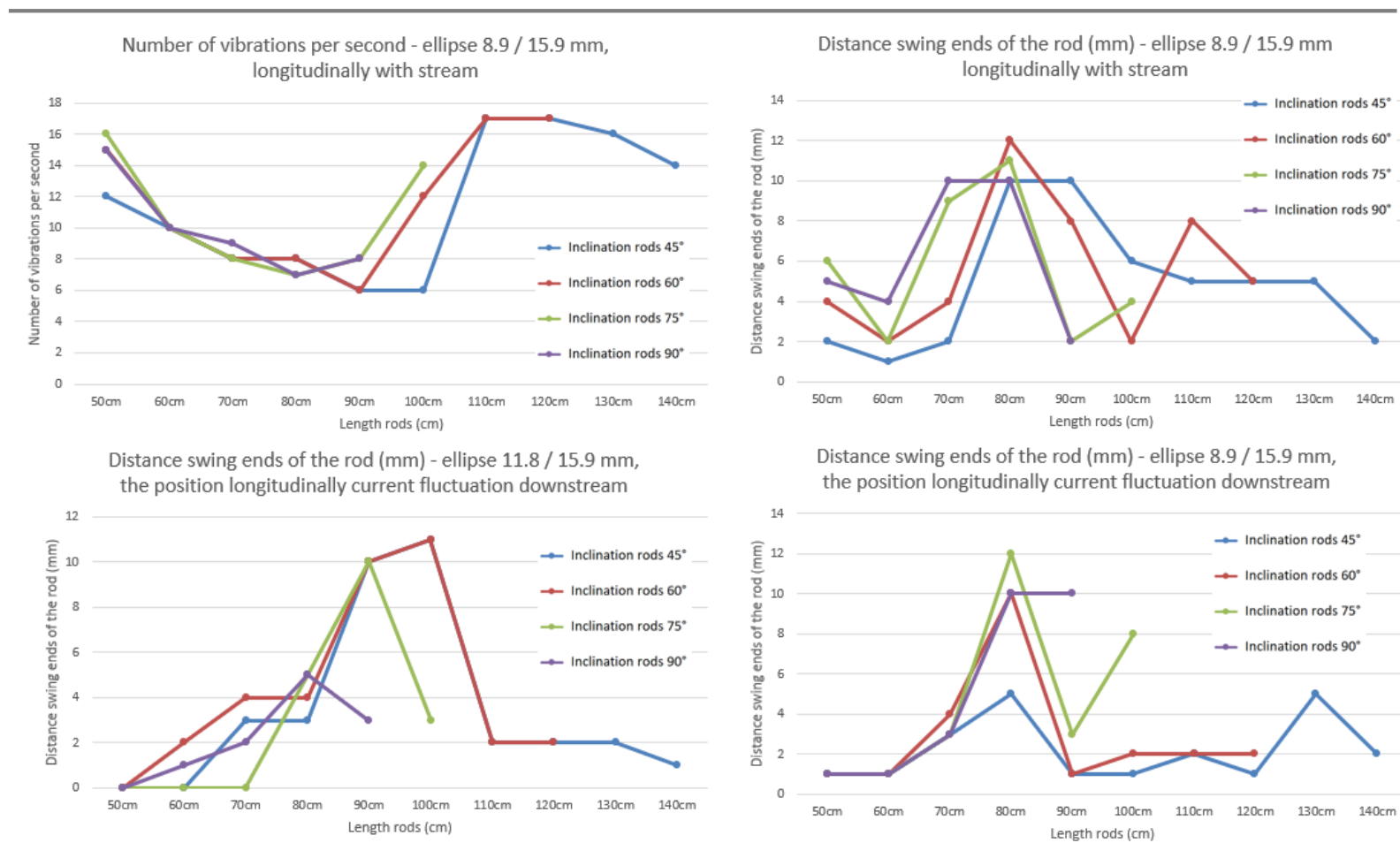

Figure 9. to 14. Oscillations and fluctuations of the free ends of self-cleaning screen bars

\section{CONCLUSIONS}

During the research of the mechanical properties of self-cleaning screen bars it was found that elliptical rods placed perpendicular to the flow reach swing in both directions so much that they are unusable due to the mutual collision of the individual rods. Circular rods have a very similar number of vibrations in both diameters (11.9 and $16.2 \mathrm{~mm}$ ). However, in terms of swinging, $11.9 \mathrm{~mm}$ rods are more suitable because they do not collide during any measurement states. While there were free collisions in $16.2 \mathrm{~mm}$ rods ends at rod lengths over $80 \mathrm{~cm}$. Elliptical screen bars located along their longitudinal axis in the direction of flow appear as the most appropriate. With rod lengths up to $1 \mathrm{~m}$, higher vibrations reach the $11.8 / 15.9 \mathrm{~mm}$ profile bars and above $1 \mathrm{~m}$ have higher vibrations $8.9 / 15.9 \mathrm{~mm}$ profile bars. Swinging of the rods placed longitudinally with the flow has no collisions between the free ends of the rods.

In general, the oscillation speed of the free end of the rod increases with the rod length higher oscillation speed helps the self-cleaning effect of screen bars. For designing swinging screen bars with self-cleaning function, we would recommend elliptical rods placed with its longitudinal axis in the direction of flow. For a rod length up to $1 \mathrm{~m}$, we would choose a profile of $11.8 / 15.9 \mathrm{~mm}$ and for lengths of bars over $1 \mathrm{~m}$ profile of $8.9 / 15 / 9 \mathrm{~mm}$.

\section{ACKNOWLEDGEMENT}

This work was supported by TACR, project no. TE02000077, Smart Regions

\section{References}

Pollert, J. (2008) Tube combined sewer overflow as economical-ecological solution. Vodní hospodářství. 2, 33-36. ISSN 1211-0760 


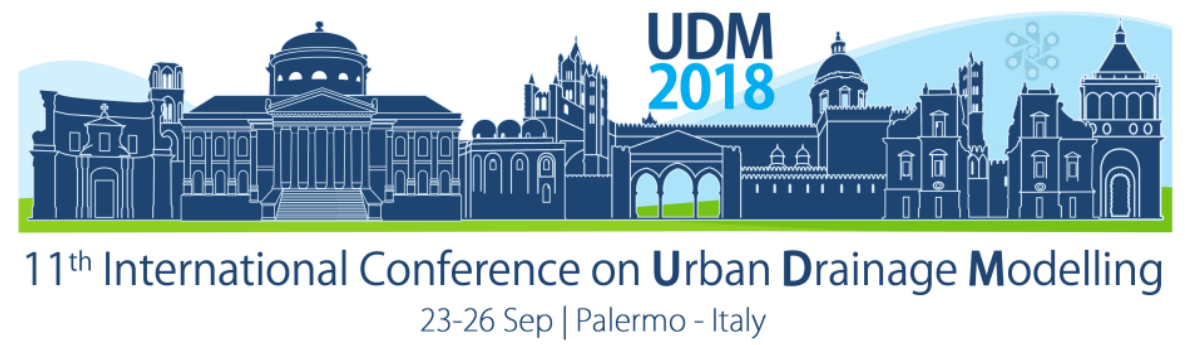

\title{
A prioritization tool for SUDS planning in large cities by coupling an Urban Drainage Model with Mixed Integer Linear Programming
}

\author{
María Narine Torres ${ }^{1,2}$, Zhenduo $\mathrm{Zhu}^{2}$ and Juan Pablo Rodríguez ${ }^{1}$ \\ ${ }^{1}$ Universidad de los Andes, Centro de Investigaciones en Ingeniería Ambiental (CIIA), Bogotá, Colombia \\ 2University at Buffalo, Department of Civil, Structural and Environmental Engineering, Buffalo, New York, USA.
}

(mn.torres132@uniandes.edu.co; zhenduoz@buffalo.edu; pabl-rod@uniandes.edu.co)

\begin{abstract}
Decision making regarding Sustainable Urban Drainage Systems (SUDS) sitting is an analytical complex process, as it involves the evaluation of a high number of environmental, physical and technical considerations. Additionally, as the resources are always limited (e.g budget and land availability), the prioritization of sub-catchments for SUDS placement would help decision makers to determine where is most beneficial to locate these infrastructures. This study proposes a methodology that couples an urban drainage model and Mixed Integer Linear Programming (MILP) to determine where is more beneficial to locate SUDS to reduce both runoff volumes and combined sewer overflows (CSOS). To achieve this goal, the City Drain model is used to model the runoff generation and the flows among sub-catchments. Three indexes are proposed to quantify the reduction on both CSO and runoff volumes, and a lexicographic multi-objective model is used to find the prioritized sub-catchments within a city. The methodology was applied to sub-catchments of Bogotá (Colombia), comprising an area of $38 \mathrm{~km}^{2}$. Preliminary results showed that the prioritized sub-catchments were highly dependent on land availability and the optimal solution did not necessarily involve the selection of the sub-catchments that yield most runoff. This study demonstrates the importance and usefulness of the prioritization tool for SUDS planning, which can be used by other large cities like Bogotá.
\end{abstract}

Keywords: Sustainable Urban Drainage Systems; Spatial Allocation; Mixed Integer Linear Programming

\section{INTRODUCTION}

Sustainable Urban Drainage Systems (SUDS) are engineered-as-natural multifunctional systems whose performance depend on their spatial location (Zhang et al., 2018). The strategic planning for SUDS sitting involves the type selection, design and sizing on individual practices at different spatial scales. Given the multi-objective nature of SUDS, the objectives of such planning strategies can vary such as reduction of runoff volumes, reduction of a target pollutant and social benefits (Yang and Best, 2015). During the last decades, researches have applied optimization techniques to deal with the spatial allocation problem in small to mediumsize drainage areas. However, few studies have been conducted at a city-wide or larger scale. Previous works have used Geographical Information Systems (GIS) to preliminarily determine feasible locations of SUDS at large scales (cities and nation-wide scales) (Wickham et al., 2010), but no optimization technique has been applied to find the optimal configuration at such a scale. This work aims to identify the prioritized sub-catchments and SUDS areas that minimize both runoff and combined sewer overflows (CSOs) volumes using a Mixed Integer Linear Program (MILP). This prioritization is important for decision makers to focus efforts and budget in the detailed design of spatial configuration of SUDS within prioritized subcatchments.

\section{MATERIALS AND METHODS}




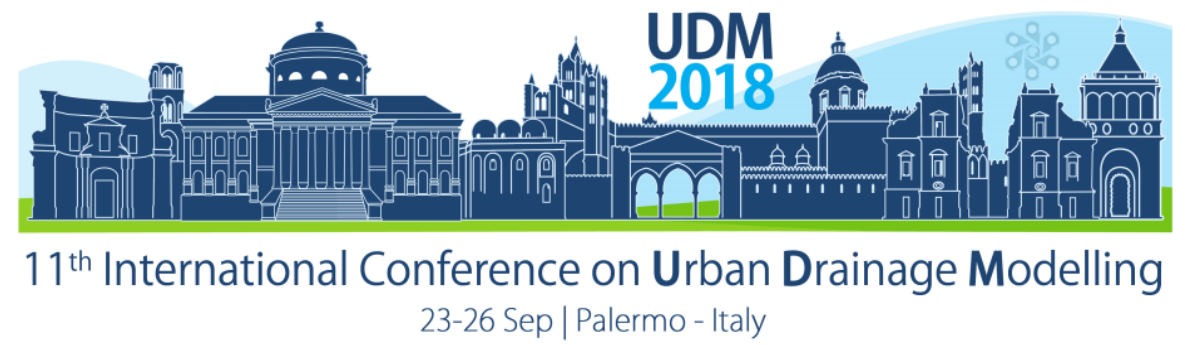

The methodology herein proposed starts with the processing of spatial data in GIS to obtain the parameters required by the MILP. Results from the optimization model are loaded into GIS platform for visualization.

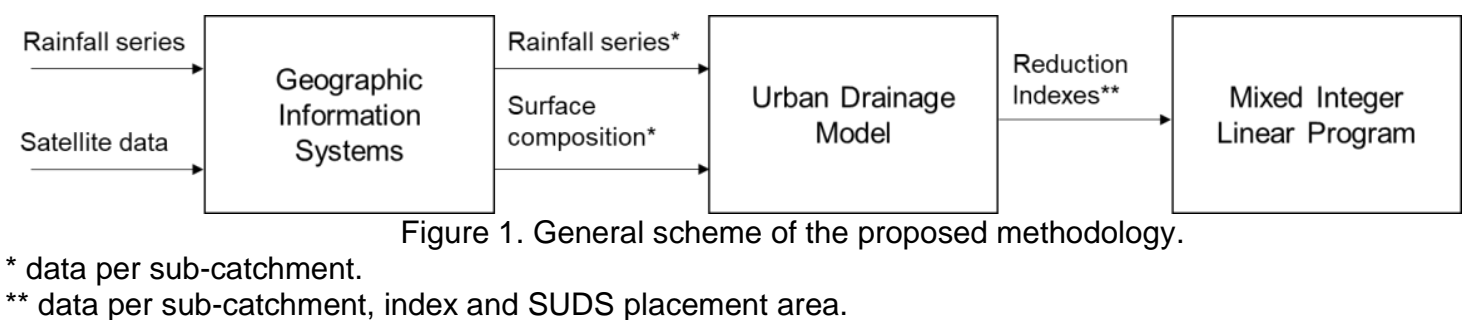

\subsection{The GIS pre-processing}

A satellite image is used for identifying pervious and impervious surface and assigning runoff coefficient values, initial and permanent rainfall losses. Additionally, from the surface classification analysis the available area for SUDS installation is approximated as a percentage of the green area (e.g. gardens, parks, green corridors) per sub-catchment. The precipitation information is georeferenced, and a kriging interpolation is carried out to obtain rainfall series inputs for the gauged and ungauged sub-catchments.

\subsection{The urban drainage model (UDM)}

The methodology proposes the use of City Drain II, an opensource toolbox developed in the Matlab/Simulink® environment. City Drain II implements a simple conceptual model that offers short simulation by means of solving discrete formulations of Muskingum method to model flow transportation (Achleitner et al., 2007). City Drain II implements both the catchment loss model and the catchment flow model to convert rainfall to runoff flows.

Rainfall series processed in step 1 (see Figure 1) are used as an input to City Drain II to calculate runoff water and CSOs series. SUDS implementation is modelled as a percentage of area that is changed from impervious to pervious surface, which means modifying two parameters in the UDM: runoff coefficient and depressions storage coefficient. The effect of SUDS is measured as the difference in runoff volume, peak flow and CSOs volume, compared to the baseline condition (without SUDS implementation). Using Equation 1, a set of reduction indexes, $\left(R I_{i}\right)$, are calculated to asses the effect of SUDS implementation, where $i \in \mathcal{J}$ corresponds to: Runoff Reduction Index (RRI), CSOs Reduction Index (CSORI) and Peak Runoff Volume Reduction Index (PRRI). In equation 1, $f(t)$ is the time series observed without SUDS implementation and $f^{\prime}(t)$ is the time series observed when an area of SUDS is implemented.

$$
R I_{i}=\frac{\int f(t) d t-\int f^{\prime}(t) d t}{\int f(t) d t}
$$

(Equation 1)

\subsection{The optimization model}

The mathematical model proposes a piecewise linear approximation of the index $\boldsymbol{i} \in \boldsymbol{J}$ functions using a set of lines $\boldsymbol{r} \in \mathcal{R}$ for sub-catchments $\boldsymbol{u} \in \mathcal{U}$. The model is built upon the assumption that there is a linear behaviour between two SUDS installation areas in terms of reduction indexes. $\boldsymbol{\kappa}_{\boldsymbol{u}}$ and $\boldsymbol{\phi}_{\boldsymbol{u r}}$ are the upper and lower limits of the abscissa (SUDS installation area) of the line-segment $\boldsymbol{r} \in \mathcal{R}$ of the sub-catchment $\boldsymbol{u} \in \boldsymbol{U}$, while $\boldsymbol{\mu}_{u r}^{i}$ and $\boldsymbol{\theta}_{u r}^{i}$ are the slope and intercept segment $\boldsymbol{r} \in \mathcal{R}$ of the sub-catchment $\boldsymbol{u} \in \mathcal{U}$ and index $\boldsymbol{i} \in \mathcal{J}$. Variable 


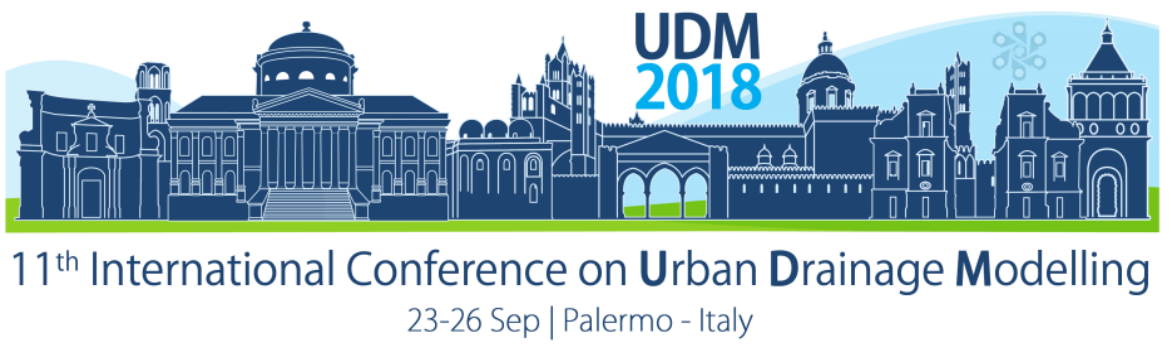

$\boldsymbol{y}_{\boldsymbol{u}}$ indicates 1 if the area to be installed in sub-catchment $\boldsymbol{u} \in \boldsymbol{U}$ is within the range of the segment $\boldsymbol{r} \in \mathcal{R}$ and $\boldsymbol{x}_{\boldsymbol{u}}$ is the variable representing the value of the SUDS area. $\boldsymbol{q}_{\boldsymbol{u}}^{\boldsymbol{i}}$ is defined as the total index (sum of all installed SUDS contributions) for the sub-catchment $\boldsymbol{u} \in \boldsymbol{u}$ and and index $\boldsymbol{i} \in \mathcal{J} . \boldsymbol{q}_{\boldsymbol{u}}^{\boldsymbol{i}}$ is calculated as expressed in equation 2 .

$$
q_{u}^{i}=\sum_{r \in \mathcal{R}} \theta_{u r}^{i} y_{u r}+\sum_{r \in \mathcal{R}} \mu_{u r}^{i} x_{u r}
$$

The lexicographic multi-objective or $\varepsilon$-constraint method (Cococcione et al., 2018) consists on solving three sequential MIP models, each corresponding to the maximization of one of the indexes. The first step model seeks to maximize sum of RRI index, the second one the CSORI and the third the PRRI index, as illustrated in Figure 1. Each subsequent step involves the addition of one constraint that limits the detriment of the previous step's objective value.

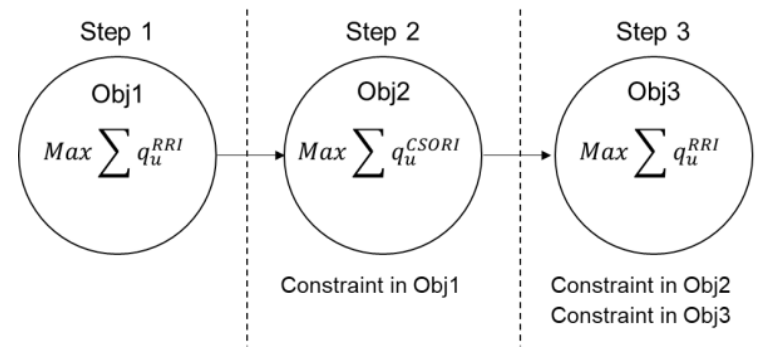

\section{RESULTS AND DISCUSSION}

The methodology was applied to a subset of sub-catchments of Bogotá city. In total 48 subcatchments (comprising $38 \mathrm{~km}^{2}$ ) located in the northwest of the city were considered for SUDS implementation. By means of a 1-meter resolution 3-band satellite image, green areas were identified within each sub-catchment. Results showed that for more than $70 \%$ of the subcatchments, the green area correspond to less than $30 \%$ of the surface area. As a proxy, a percentage of the green area was used to define the area availability for SUDS sitting (which corresponds to the maximum area that can be installed in each sub-catchment). 5 SUDS installation areas per sub-catchment were modelled per sub-catchment using an average year precipitation daily series and the runoff and CSOs series were extracted from City Drain II. Results were obtained for 4 different available-for-SUDS-installation areas and are summarized in Table 1. Higher indexes values are obtained for larger installation areas (indicating higher reductions of runoff and CSO) and a higher number of catchments were selected from the original set of 48 catchments. The spatial distribution of selected catchments is illustrated in Figure 2, which shows the distribution of the optimal solution. By comparing with the simple ranking in term of highest reduction indexes, the results showed that the optimal solution does not necessarily involve the selection of the of "best" isolated sub-catchments. The model also determined the SUDS area to be installed in each sub-catchment, results showed that SUDS areas varied from $100 \mathrm{~m}^{2}$ to $2400 \mathrm{~m}^{2}$.

Table 1. Obtained Reduction Indexes values and number of sub-catchments for SUDS placement.

\begin{tabular}{ccccc}
\hline $\begin{array}{c}\text { Available area for } \\
\text { SUDS installation } \\
\text { (ha) }\end{array}$ & RRI & CSORI & PRRI & No. of sub-catchments \\
\hline 1 & 0.6 & 1.1 & 0.4 & 12
\end{tabular}




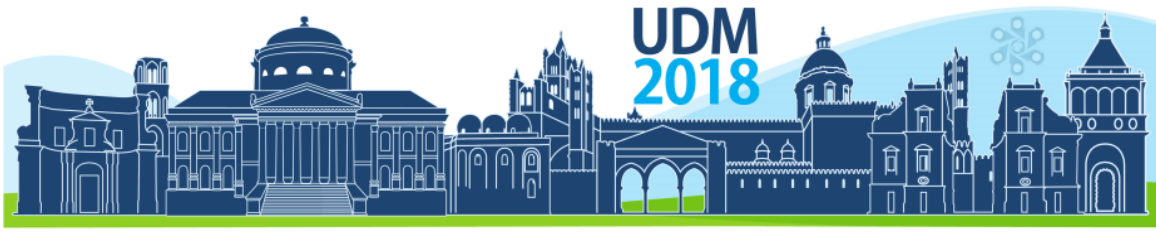

$11^{\text {th }}$ International Conference on Urban Drainage Modelling

23-26 Sep | Palermo - Italy

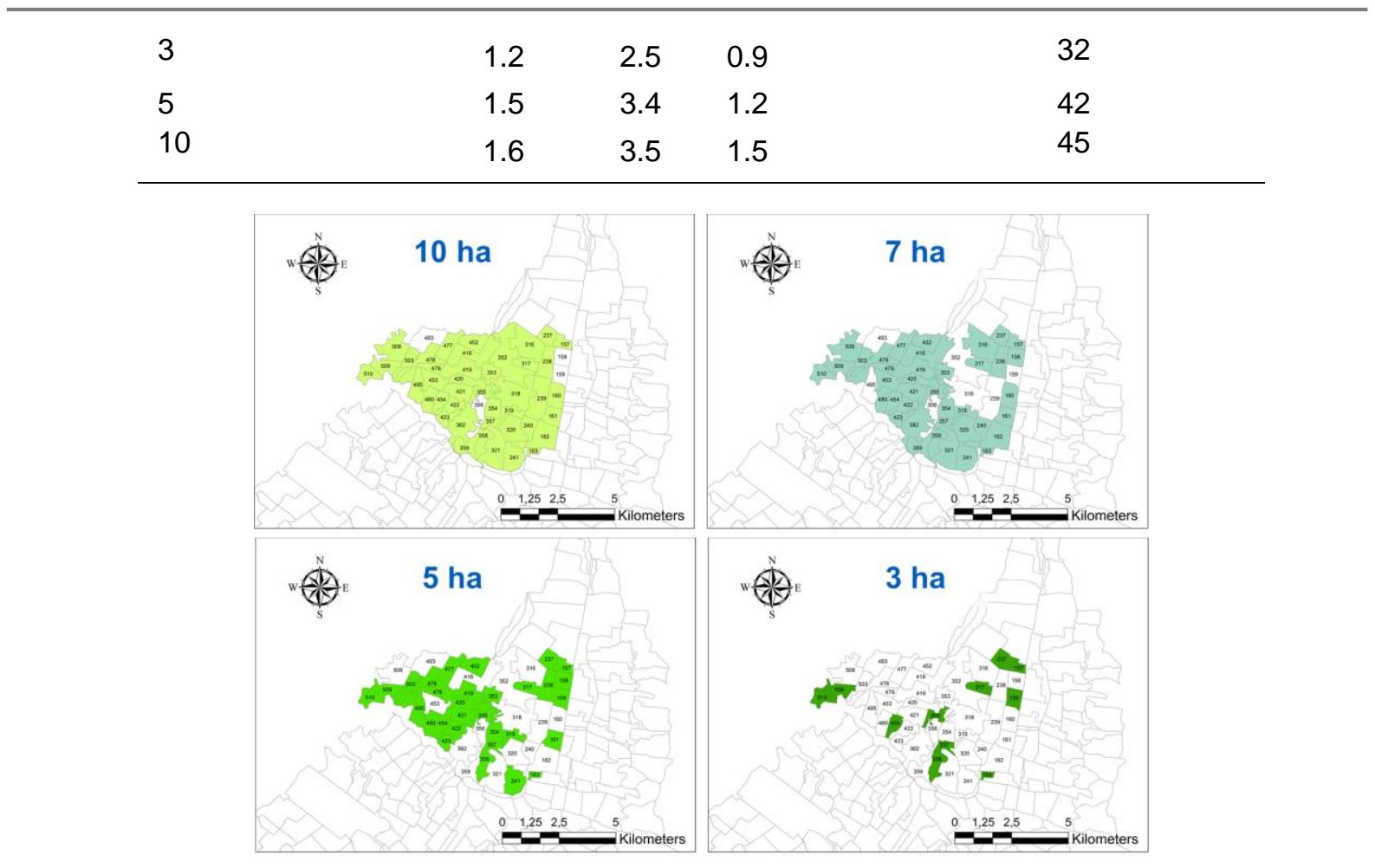

Figure 2. Selected sub-catchments and area for SUDS implementation

\section{CONCLUSIONS}

The proposed methodology was successfully tested in a subset of sub-catchments of Bogotá city. The model was able to determine the spatial distribution that optimizes the reduction of runoff and CSOs volumes. Two questions were answered using the methodology: in which sub-catchments and what area per sub-catchment should be designated for SUDS installation. This information is valuable for decision makers to understand where efforts and resources should be focused to develop further analysis: e.g. which SUDS typology and where exactly within the sub-catchment the SUDS are to be installed. Current work is focused in applying the model in the whole city area and applying a stochastic MIP to consider several precipitation scenarios with corresponding probabilities of occurrence.

\section{References}

Achleitner, S., Moderl, M., Rauch, W., 2007. CITY DRAIN ( ) An open source approach for simulation of integrated urban drainage systems. Environ. Model. Softw. 22 (8), 1184-1195.

Cococcioni, M., Pappalardo, M., \& Sergeyev, Y. D. (2018). Lexicographic multi-objective linear programming using grossone methodology: Theory and algorithm. Appl. Math. Comput., 318, 298-311.

Wickham, J.D., Ritters, K.H.,Wade, T.G., Vogt, P., 2010. A national assessment of green in- frastructure and change for the conterminous United States using morphological image processing. Landsc. Urban Plan. 94, 186-195

Yang, G., Best, E.P.H., 2015. Spatial optimization of watershed management practices for nitrogen load reduction using a modeling-optimization framework. J. Environ. Manag. 161, 252-260

Zhang, K., \& Chui, T. F. M. (2018). A comprehensive review of spatial allocation of LID-BMP-Gl practices: Strategies and optimization tools. Sci. Total Environ., 621, 915-929. 


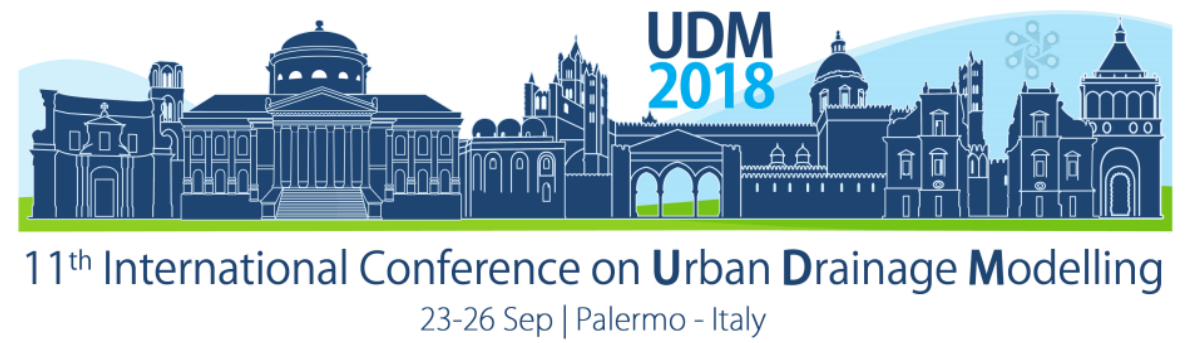

\title{
Modelling bioretention systems
}

\author{
Alexandra Finotti ${ }^{1}$ and Marie Christine Gromaire ${ }^{2}$ \\ ${ }^{1}$ Federal University of Santa Catarina, Department of Environmental Engineering, Florianópolis, Brazil \\ 2 Paristech, Laboratoire Eaux Environement et Systems Urbain, Paris, France
}

\begin{abstract}
Bioretention systems are of great importance LID structures for acting in runoff control and pollutant removal. Modelling bioretention systems are defying because many process and functions are involved. There are many efforts in modelling such systems. In this paper, we reviewed literature in order to stablish what are the functions and process involved in the systems modeling and the most important gaps. Bioretention performance in controlling flood and in pollutant removal are of great variability. Process considered in models and their mathematical representation are very diverse. Clogging, evapotranspiration, chemical removal were the most defying process to be modelled.
\end{abstract}

Keywords: Bioretention; LID; Modelling

\section{INTRODUCTION}

Bioretention are complex systems (Liu et al. 2014) and their design are still very empirical. Since it is more than a volume control, dimensioning must consider also the function of pollutant retention (Davis et al., 2012). Modelling of bioretention systems (BRS) is a tool that can aide in the conceptualization of a standardized procedure for designing. For Ahiablame et al. (2012) simulation modeling can also provide valuable insight to extrapolate information to different spatial and temporal scales.

Modeling BRSs is still an uncompleted task. Many models have been used, adapted or specifically developed but there are some aspects that still have to be improved. Liu et al. (2014), Roi-Poirier et al. (2010), Elliott e Trownsdale (2007), Ahiablame et al. (2012), Brown et al. (2012), Liu et al. (2014). As bioretention systems gather importance and their application grows, the effort made in better modelling this systems is very important and should be improved. We decided to contribute with this task by reviewing the effort of simulation of bioretention systems in order to: 1) present the state of the art of bioretention modelling, 2) identify key elements that are not well represented in modelling bioretention and 3) encourage bioretention modelling development.

\section{MATERIALS AND METHODS}

To undergo the review we followed the systematic review approach. The results of the work were organized in a way to facilitate the perception of weak points in simulation of bioretention systems. We found 108 works dealing with BRS modelling. In this paper we focus on the performance of boretention systems and in identifying process that presents more difficulties in modelling. Water and mass balance published were reviewed as a tentative to address the relative importance of each process in bioretention systems to evaluate how existing models accounts for them. We only considered the models that were effectively used to simulate BRS and not the potential models that could be used for this propose.

\section{RESULTS AND DISCUSSION}




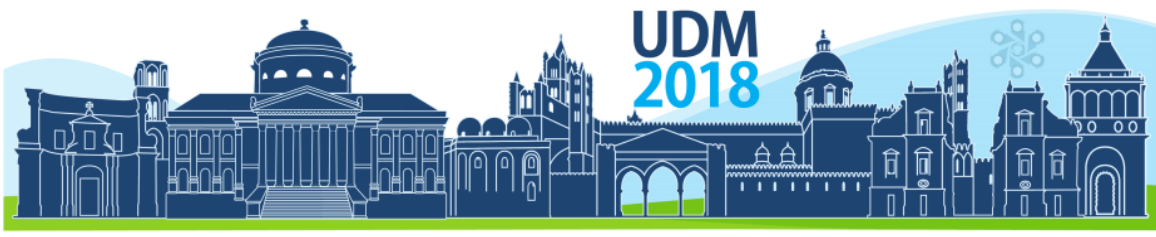

$11^{\text {th }}$ International Conference on Urban Drainage Modelling

23-26 Sep | Palermo - Italy

We can say that biofilters are one of the most complex BMPs. It can be composed by the processes of superficial flow, storage, infiltration, evapotranspiration, flow in underdrains, interaction with planted vegetation, sedimentation, filtration, adsorption, biological processes and heat transfer. The most important functions we found to bioretention systems are synthesized in: runoff volume control, peakflow reduction and retardation, improvement of water quality or runoff pollution control and as a paysagistic element in urban areas. In Figure 01 the BRSs functions are correlated with the process that takes place in the systems.

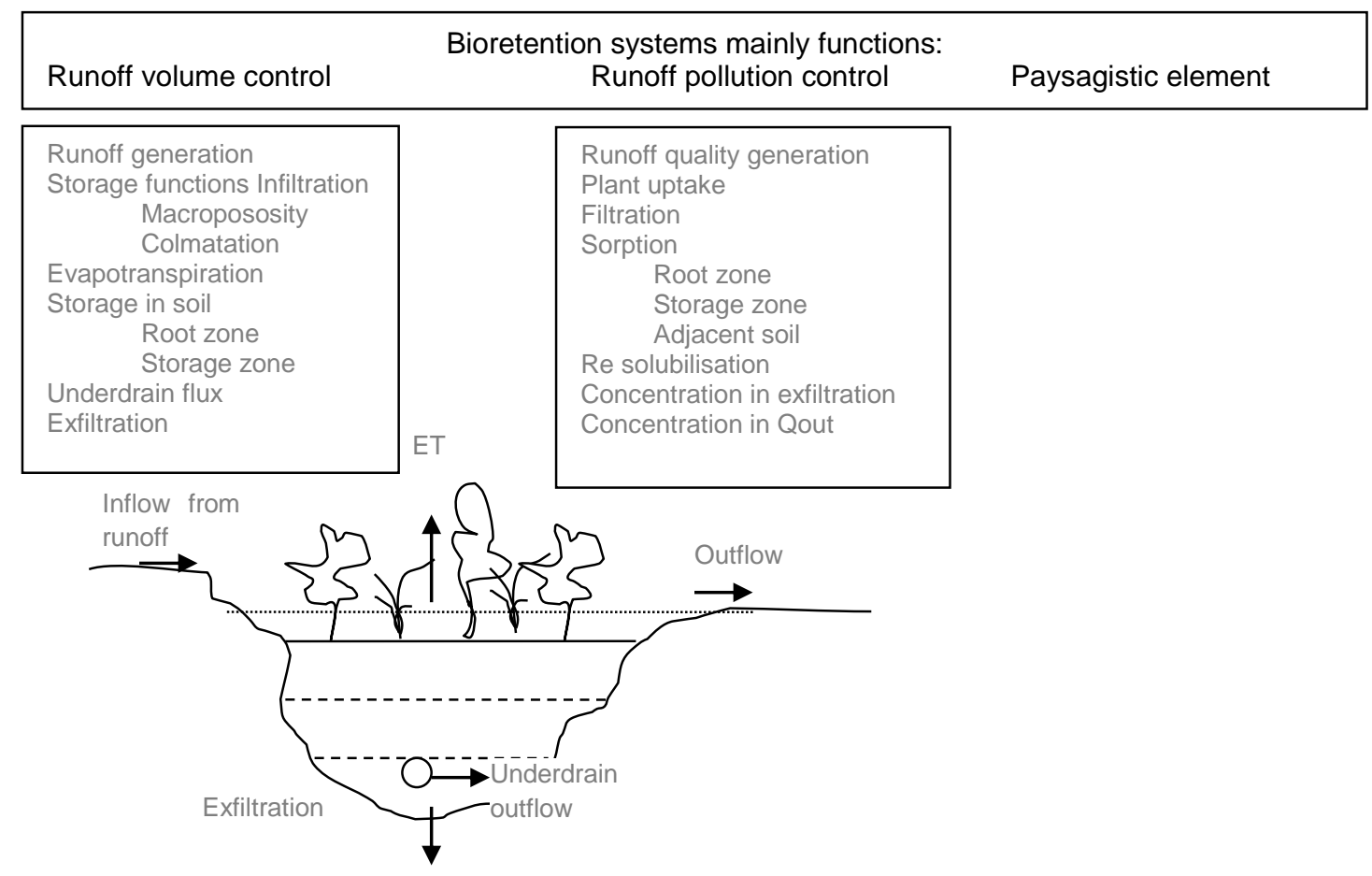

Figure 1. Functions of a bioretention system and processes involved.

Since the first BRS work published in 2001 (Davis et al., 2001) many research groups presented and discussesed the processes undergone in the BRSs and the efforts to represent or simulate them. We synthesize in this section the processes cited in the literature and bring data generated along this years of BRSs studies. The objective is to identify the relative importance of each process, evaluate the variation interval authors found in their research and verify the adherence of modeling efforts in covering the processes identified in BRSs functionality.

The processes most likely discussed are related to BRSs water balance: infiltration (exfiltration), evapotranspiration. Factors that can interfere in these balances were identified: temperature, presence of macropores, clogging and plant interaction. Hydrological performance of BRSs are verified by runoff volume and peak reduction. Values revised to these parameters (table 01 ) showed a variation from 0 to $100 \%$ in runoff volume control and from 0 to $99 \%$ to peak reduction. The range of variation is directed lied to soil and climatic characteristics that influences the processes of infiltration, exfiltration, evapotranspiration. 


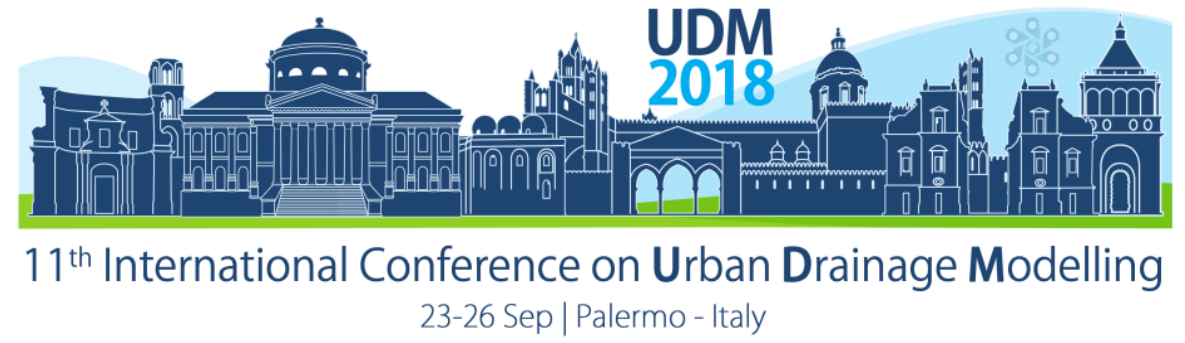

In terms of water quality variation in BRSs the review summarize data from the studies of: and allowed to establish removals shown in Table2. As for the hydrologic performance the same pattern of great variation is observed in pollutant removal in bioretention systems.

Table 1. Revised hydrologic performance of BRSs.

\begin{tabular}{lc}
\hline Reference & Runoff volume reduction \\
\hline Dietz and Clausen (2006) & $99 \%$ \\
Hunt et al. (2006) & $78 \%$ \\
Brown and Hunt (2008) & 50 to $98 \%$. \\
Davis (2008) & 52 to $65 \%$. \\
Li et al. (2009) & 0 to $60 \%$. \\
Chapman and Horner (2010) & 48 to $74 \%$ \\
DeBusk and Wynn (2011) & $97 \%$ \\
Brown and Hunt (2011) & 89 to $100 \%$ \\
Brown and Hunt (2012) & 63 to $89 \%$ \\
Olszewski and Davis (2013) & $79 \%$ \\
\hline & Peak reduction \\
\hline Brown and Hunt (2012), Davis (2008), DeBusk and Wynn (2011), Hunt & 0 to $99 \%$ \\
et al. (2008), Li et al. (2009) and Olszewski and Davis (2013) & \\
\hline
\end{tabular}

Table 2. Revised Review of Contaminant removal in BRSs

\begin{tabular}{lc}
\hline Contaminant & Remotion range (mass load reduction) \\
\hline total suspended solids & -170 to $99 \%$ \\
total nitrogen & 3 to $99 \%$ \\
Total phosphorus & -240 to $100 \%$ \\
Coliforms & 71 to $100 \%$ \\
Zinc & 60 to $99 \%$ \\
Cuprum & $43^{*}$ to $99 \%$ \\
Plumbum & 31 to $100 \%$ \\
\hline Data from: Ahiablame et al. (2012), Brown et al. (2009), Brown and Hunt (2008, 2011, 2012), Chapman and \\
Horner (2010), Chen (2013), Davis (2007), Davis et al. (2001, 2003, 2006), DeBusk and Wynn (2011), Dietz and \\
Clausen (2005, 2006), Glass and Bissouma (2005), Hathaway et al. (2011), Hsieh and Davis (2005), Hong et al. \\
(2006), Hunt et al. (2006, 2008), Li and Davis (2008, 2009), Liu et al. (2014), Passeport and Hunt (2009), Roseen \\
et al. (2006), Rusciano and Obropta (2007), Sharkey (2006), Sun and Davis (2007), Zhang et al. (2010, 2011). \\
\hline
\end{tabular}

BRSs were modeled in 26 works since 2004 until 2013. Two trends were identified. Use of global or watershed models adapted to model BRSs and the development of specific models to represent BRS. Watershed model were used in 12 works which used HEC-HMS, SWMM, MUSIC, HIDROCAD and SewerGem. The other 14 works are composed of programs developed exclusively to BRSs or adapted to simulate it: DRAINMOD, RECHARGE, RECARGA, R2D, Quinn and Dussaillant (2013a,b), Li and Davis (2008), Wild and Davis (2009), He and Davis (2011), Daly et al. (2012), Zhang and Guo (2014), Roy Poirier (2010) and Paus et al. (2013).

\section{CONCLUSIONS}

BRS modelling showed varying performances. The presence of vegetation and soil removal pollutants are the most important process that difficulties modelling. Clogging and evapotranspiration consideration are other unresolved questions. Furthermore, the great variability in runoff control and pollutant removal showed by the BRSs, difficulties models 


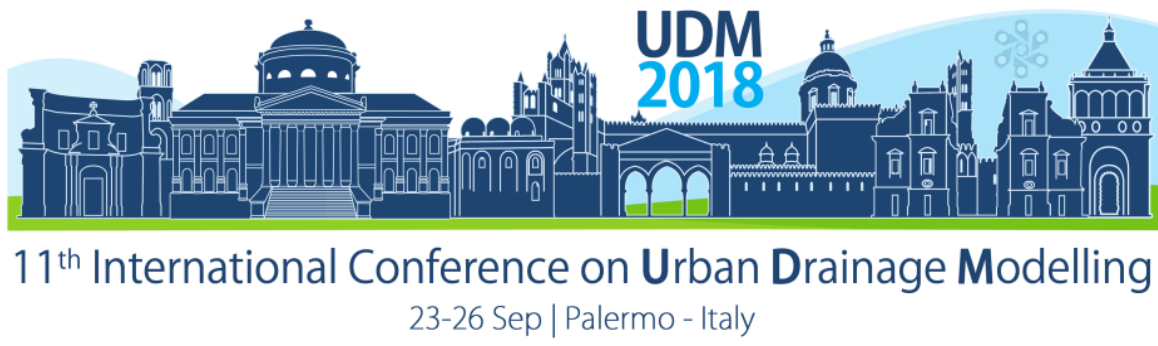

performance in representing all situations. Some models were very site specific. We can conclude that BRS modelling still have much to evolve.

\section{References}

Ahiablame, L. M., Engel, B. a., \& Chaubey, I. (2012). Effectiveness of Low Impact Development Practices: Literature Review and Suggestions for Future Research. Water, Air, \& Soil Pollution, 223(7), 4253-4273..

Brown, R.; Hunt, W. Bioretention Performance in the Upper Coastal Plain of North Carolina. In Low Impact Development for Urban Ecosystem and Habitat Protection; ASCE, USA, 2008; pp. 1-10.

Brown, R.; Hunt, W. Underdrain configuration to enhance bioretention exfiltration to reduce pollutant loads. $J$. Environ. Eng. 2011, 137, 1082-1091.

Brown, R.A., Hunt, W.F., Davis, A.P., Traver, R.G., and Olszewski, J.M. 2009. Bioretention performance in the midatlantic. In Proc. of the World Env.I and Water Resources Congress 2009, ASCE, Reston, Va. pp. 904-913.

Brown, R.A.; Hunt, W.F. Improving bioretention performance with restorative maintenance. W S \& T. $2012,65,361$.

Chapman, C., \& Horner, R. R. (2010) Performance assessment of a street-drainage bioretention system. Water Envt Res., 82(109), 109-119.

Chen, X.L.; Peltier, E.; Sturm, B.S.M.; Young, C.B. Nitrogen removal and nitrifying and denitrifying bacteria quantification in a stormwater bioretention system. Water Res. 2013, 47, 1691-1700.

Davis, A. P., Asce, F., Traver, R. G., Asce, M., Hunt, W. F., Lee, R., Olszewski, J. M. (2012). Hydrologic Performance of Bioretention Storm-Water Control Measures. J of Hydrol Eng., 17(May), 604-614.

Davis, A. P., Shokouhian, M., Sharma, H., \& Minami, C. (2006). Water quality improvement through bioretention media: nitrogen and phosphorus removal. Water Envi Res, 78, 284-293.

Davis,A. Shokouhian, M.; Sharma, C. Minami, Laboratory Study of Biological Retention for Urban Stormwater Management, Water Environment Research. 2001, 73 (1), 5-14.

DeBusk, K.M., \&Wynn, K.M. (2011). Storm-water bioretention for runoff quality and quantity mitigation. Journal of Environmental Engineering, 137, 800-808.

Dietz, M. E., \& Clausen, J. C. (2005). A field evaluation of rain garden flow and pollutant treatment. Water, Air and Soil Pollution, 167(1-4), 123-138.

Dietz, M. E., \& Clausen, J. C. (2006). Saturation to improve pollutant retention in a rain garden. ES\&T 40(4), 1335.

Elliott, a, \& Trowsdale, S. (2007). A review of models for LID urban drainage. Envi Model \& Soft, 22(3), 394-405.

Glass, C., \& Bissouma, S. (2005). Evaluation of a parking lot bioretention cell for removal of stormwater pollutants. Ecosystems and Sustainable Development V (81, pp. 699-708). Southampton: WIT Press.

Hathaway, J.; Hunt, W.; Graves, A.; Wright, J. Field evaluation of Bioretention indicator bacteria sequestration in Wilmington, North Carolina. J. Environ. Eng. 2011, 137, 1103-1113.

Hong, E., Seagren, E. A., \& Davis, A. P. (2006). Sustainable oil and grease removal from synthetic storm water runoff using bench-scale bioretention studies. Water Environment Research, 78(2), 141-155.

Hsieh, C., \& Davis, A. P. (2005). Evaluation and optimization of bioretention media for treatment of urban storm water runoff. Journal of Environmental Engineering, 131(11), 1521-1531.

Hunt, W. F., Jarrett, A. R., Smith, J. T., \& Sharkey, L. J. (2006). Evaluating bioretention hydrology and nutrient removal at three field sites in North Carolina. Journal of Irrigation and Drainage Engineering, 132(6), 600-608.

Hunt, W. F., Smith, J. T., Jadlocki, S. J., Hathaway, J. M., \& Eubanks, P. R. (2008). Pollutant removal and peak flow mitigation by a bioretention cell in urban Charlotte, NC. J of Env Eng, 5(134), 403-408.

Li, H., Sharkey, L. J., Asce, M., Hunt, W. F., Davis, A. P., \& Asce, F. (2009). Mitigation of Impervious Surface Hydrology Using Bioretention in North Carolina and Maryland. Jl of Hydrol Eng, 14(April), 407-415.

$\mathrm{Li}, \mathrm{H}$.; Davis, A.P. Wat quality impr reductions of pollutant in bioretention. J. Environ. Eng. 2009, 135, 567-576.

Liu, J., Sample, D., Bell, C., \& Guan, Y. (2014). Review and Research Needs of Bioretention Used for the Treatment of Urban Stormwater. Water, 6(4), 1069-1099.

Olszewski, J.; Davis, A. Comparing the hydrologic performance of a bioretention cell with predevelopment values. J. Irrig. Drain. Eng. 2013, 139, 124-130.

Passeport, E.; Hunt, W.; Line, D.; Smith, R.; Brown, R. Field study of the ability of two grassed Bioretention cells to reduce storm-water runoff pollution. J. Irrig. Drain. Eng. 2009, 135, 505-510.]

Roseen, R. M., Ballestero, T. P., Houle, J. J., Avelleneda, P., Wildey, R., \& Briggs, J. (2006). Stormwater LID, conventional structural, and manufactured strategies for parking lot runoff. J Transp Res Bo, 1984, 135-147.

Rusciano, G. M., \& Obropta, C. C. (2007). Bioretention column study: fecal coliform and total suspended solids reductions. Transactions of the ASABE, 50(4), 1261-1269.

Sharkey, L.J. 2006. The performance of bioretention areas in North Carolina: A study of water quality, water quantity, and soil media. North Carolina State University, Raleigh, NC.

Sun, N., \& Hall, M. (2013). Coupling human preferences with biophysical processes: modeling the effect of citizen attitudes on potential urban stormwater runoff. Urban Ecosystems.

Zhang, L., Seagren, E.., Davis, A., \& Karns, J. (2010). The capture and destruction of E coli from simulated urban runoff using conventional bioretention media and iron oxide-coated sand. Wat Env Res, 82, 701-714. 


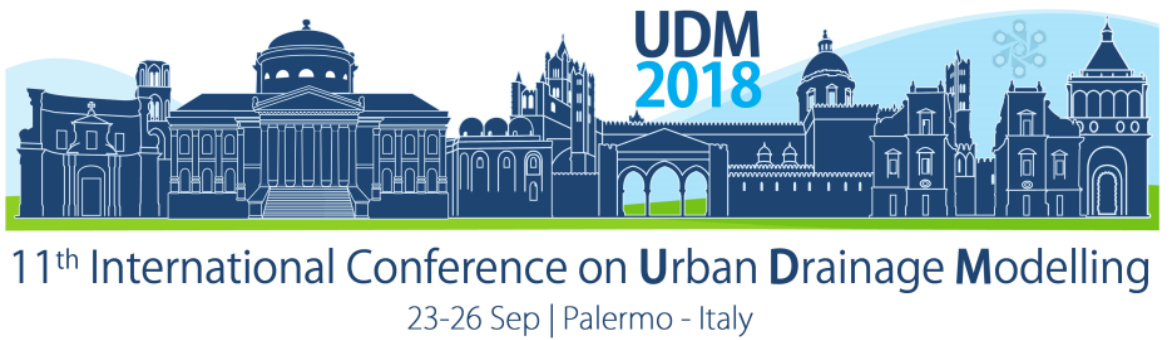

\title{
Overall Rate Kinetics Model of Chlorine Demand in Urban Drainage
}

\author{
Joshua Dickensoni ${ }^{1}$, John Sansalone ${ }^{2}$ \\ ${ }^{1}$ University of Florida, Engr. School of Sustainable Infrastructure \& Environment, Gainesville, FL, 32611, USA \\ 2 University of Florida, Engr. School of Sustainable Infrastructure \& Environment, Gainesville, FL, 32611, USA
}

\begin{abstract}
Hydrologic cycle modification by the urban environs significantly alters the urban drainage response and the transport of particulate matter (PM), chemicals, and biological constituents. Urban water sustainability requires mitigation of runoff impacts while providing a potential resource to traditional water supply sources. Chlorination of wastewater, combined sewer overflows (CSOs) and reuse waters is the most common disinfection practice to ensure public health. Chlorine demand models have been developed for source waters and wastewaters. The current study adds to this knowledge base through modeling of hypochlorite demand kinetics for both PM and dissolved phases in urban source area drainage utilizing dissolved chemical oxygen demand (CODd). Second order rate models of hypochlorite demand are developed for both phases, with the PM phase subdivided into three fractions on a granulometric basis. These PM (suspended, settleable, sediment) fractions exert a significant hypochlorite demand as compared to the dissolved fraction of urban drainage. Ultimate hypochlorite demand $\left(\mathrm{as}_{2}\right)$ translates to $36 \%$ of the $\mathrm{COD}_{\mathrm{d}}$ of which $39 \%$ of the demand is exerted in less than five minutes. Hypochlorite demand is 350 $\mathrm{mg} / \mathrm{g}$ for suspended, $320 \mathrm{mg} / \mathrm{g}$ for settleable, and $650 \mathrm{mg} / \mathrm{g}$ for sediment PM.
\end{abstract}

Keywords: Chemical Oxygen Demand, Disinfection, Urban Particulate Matter

\section{INTRODUCTION}

Urban drainage generated by rainfall-runoff is a significant source of hetero-disperse PM, chemicals and microbial loadings to combined sewer flows or directly to receiving waters. Effective treatment and reuse options are needed given urban water demands and regulations. Untreated microbial loading in urban runoff can impair receiving waters and pose a potential public health risk in reuse applications. Chlorine is the most commonly utilized disinfectant worldwide (Hrudey and Hrudey, 2004) and is utilized in many wastewater treatment plants for high level disinfection of reclaimed water for urban irrigation. Efficacy of chlorine disinfection is dependent on the available residual (Taras, 1950).

Urban runoff differs from wastewater and can represent a significant but variable volumetric fraction of CSOs. Kim and Sansalone (2010) compared PM from untreated runoff from 8 events to wastewater treatment plant (WWTP) influent sampled six times daily for six consecutive days. The study demonstrated that WWTP primary influent PM was relatively fine (median diameter: $\mathrm{d}_{50 \mathrm{~m}}=26 \mu \mathrm{m}$ ), mono-disperse (80th to 20th percentile dispersivity index: $d_{80 m} / d_{20 m}=3.1$ ), with a specific gravity of 1.5 , and a volatile fraction of suspended PM of $76 \%$ (a surrogate indicator of organic content) and transport is relatively steady with regular diurnal fluctuations in flow. In comparison, the runoff gradation was relatively coarse $\left(d_{50 \mathrm{~m}}=136 \mu \mathrm{m}\right)$, hetero-disperse $\left(\mathrm{d}_{80 \mathrm{~m}} / \mathrm{d}_{20 \mathrm{~m}}=50.5\right)$, with a specific gravity of 2.3 , a volatile fraction of suspended PM of $27 \%$ and was transported spatio-temporally by episodic events. It is hypothesized that these runoff differences will provide distinct chlorine demand kinetics as compared to first order decay models commonly utilized for wastewater (Haas and Karra 1984). It is hypothesized 


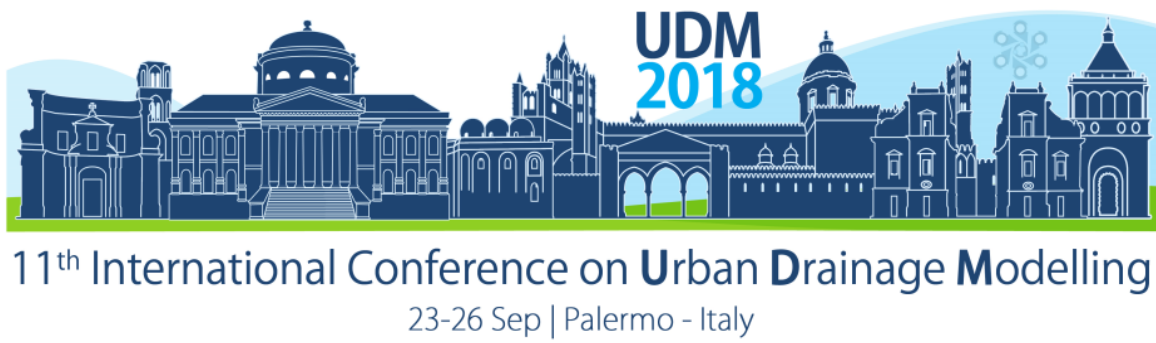

that the temporally varying loads with multiple potential limiting factors and constituents require a second order model, similar to (Clark and Savaganesan, 2002), but with the inclusion of PM demand, and correlation of the model parameters to runoff chemistry parameters. Furthermore, as runoff can be the dominant volumetric factor in combined sewerage flows, by a factor of 100 in a Philadelphia study (EPA, 1973), chlorine demand kinetics in runoff have direct application to CSOs. Quantifying chlorine demand of PM fractions allows decisionmaking with respect to PM separation and advanced computational modeling of unit operations and processes. Therefore the objective of this study is to model chlorine demand kinetics for urban runoff and compare the kinetics for dissolved and PM fractions. Results of this study are applicable to treatment and reuse schemes in urban settings where primary unit operations are utilized in a decentralized treatment train. Results elucidate the primary phases and PM fractions in urban runoff for chlorine demand.

\section{MATERIALS AND METHODS}

The catchment for this study was an urban source area located in Florida, USA. Land use is a $13,000 \mathrm{~m}^{2}$ carpark catchment which was delineated, instrumented and monitored for this study. The "runoff matrix" refers to the filtered and autoclaved dissolved fraction. PM was fractionated by wet sieving and filtration; into sediment PM $(4750-75 \mu \mathrm{m})$, settleable PM (75 $-25 \mu \mathrm{m})$, suspended PM $(25-0.45 \mu \mathrm{m})$, and dissolved fractions $(<0.45 \mu \mathrm{m})$.

Continuously stirred batch reactors (CSBR) were utilized for chlorine demand kinetics and the framework consisted of two replicate analysis of three sodium hypochlorite doses (15, 30, and $45 \mathrm{mg} / \mathrm{L} \pm 2 \mathrm{mg} / \mathrm{L}$ ) for each runoff fraction for a total of 24 reactors. Control CSBRs were also utilized to determine the effects of autoclaving the runoff matrix and losses to the atmosphere by volatilization or UV breakdown of $\mathrm{HOCl} / \mathrm{OCl}$.

The second order potential driving model of this study assumes that chlorine demand $(f)$ kinetics is the result of two parallel reactions (derivation in full paper). To aid in the physical significance of the model a hypothetical ultimate chlorine demand term $\left(\mathrm{CB}_{0}\right)$ is introduced and reacts on a one to one stoichiometric basis with free chlorine. In addition, $\mathrm{CB}_{0}$ is assumed to be a fractional component of $\mathrm{COD}_{d}$. $\mathrm{COD}_{d}$ is reasonable given the ease of measurement and the basis is an oxidation reaction. Reaction kinetics were modeled as a second order potential driving model and solution of the differential equation yielded:

$$
\frac{t}{q_{t}}=\frac{t}{q_{e}}+\frac{1}{k_{P M} q_{e}^{2}}
$$

In (1), $q_{t}[\mathrm{mg} / \mathrm{g}]$ is the ratio free chlorine mass transferred to the PM mass fraction in the reactor at time, $t$ [min]; and $q_{e}[\mathrm{mg} / \mathrm{g}]$ is the ratio of the free chlorine mass transferred to PM mass fraction at equilibrium. Initial $\mathrm{K}_{\mathrm{PM}}\left[\mathrm{g}^{1} \mathrm{mg}^{-1} \mathrm{~min}^{-1}\right]$ and $\mathrm{q}_{\mathrm{e}}$ were determined by plotting $\mathrm{t} / \mathrm{q}_{\mathrm{t}}$ versus t. Parameter values favor data endpoints due to linearization and were refined by minimizing the normalized root mean square error (NRMSE) utilized to evaluate model performance.

\section{RESULTS AND DISCUSSION}

Table 1 presents a comparison of the modeled demand of the dissolved and particulate fractions on an event mean basis for the monitored storms. The sediment PM fraction accounts for greater than $56.1 \%$ of all potential hypochlorite demand for each event and up to $92.7 \%$ of the potential hypochlorite demand for the 27 September 2010 event. In addition, the 


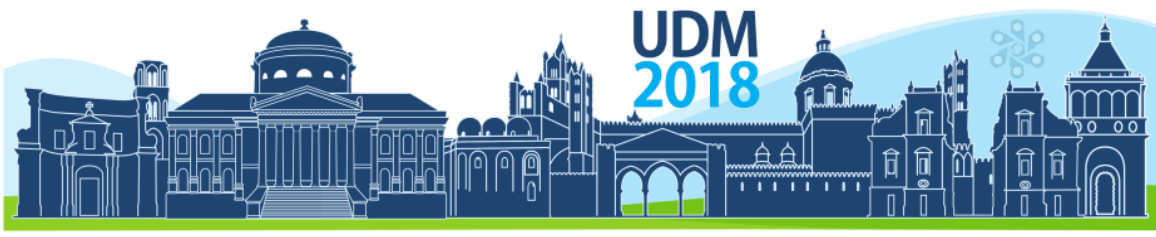

$11^{\text {th }}$ International Conference on Urban Drainage Modelling

23-26 Sep | Palermo - Italy

demand from all PM fractions for the monitored events represent over $77 \%$ of the potential chlorine demand illustrating the potential benefits of treatment by sedimentation or filtration prior to chlorination from a chlorine demand perspective. In addition, effective PM demand reduction can be accomplished through the use of membrane treatment. The dissolved phase demand, represented by $f C O D_{d}$, exerts a range of hypochlorite demand from $7.6 \mathrm{mg} / \mathrm{L}$ to 88.7 $\mathrm{mg} / \mathrm{L}$. Chlorine demand can be linked to disinfectant by product formation, thus, providing motivation for demand removal (PM separation) prior to treatment with hypochlorite.

Table 1. Hypochlorite event-based ultimate demand of urban stormwater fractions for the monitored storms. Calculations utilize $f=0.36$, suspended qe $=350 \mathrm{mg} / \mathrm{g}$, settleable $q e=320 \mathrm{mg} / \mathrm{g}$, and sediment qe $=650 \mathrm{mg} / \mathrm{g}$. Results indicate that the constituents of the sediment PM fraction exert the largest portion of $\mathrm{HOCl}$ demand on an event mean basis.

\begin{tabular}{|c|c|c|c|c|c|c|c|c|c|c|c|c|}
\hline \multirow[b]{2}{*}{$\begin{array}{l}\text { Event } \\
\text { (2010) }\end{array}$} & \multicolumn{2}{|c|}{$\begin{array}{c}\text { COD } \\
(\mathrm{mg} / \mathrm{L})\end{array}$} & \multicolumn{3}{|c|}{$\begin{array}{c}\mathrm{PM} \\
(\mathrm{mg} / \mathrm{L})\end{array}$} & \multicolumn{3}{|c|}{$\begin{array}{c}\text { PM HOCl Demand } \\
(\mathrm{mg} / \mathrm{L})\end{array}$} & \multicolumn{4}{|c|}{$\begin{array}{l}\mathrm{HOCl} \text { Demand } \\
(\%)\end{array}$} \\
\hline & $C O D_{d}$ & $f \mathrm{COD}_{\mathrm{d}}$ & 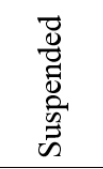 & 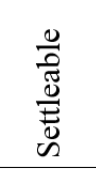 & 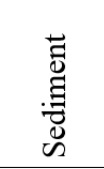 & 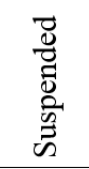 & 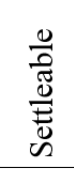 & 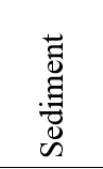 & $\begin{array}{l}\overrightarrow{0} \\
\stackrel{D}{0} \\
0 \\
.0 \\
.0 \\
.0\end{array}$ & 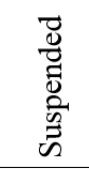 & 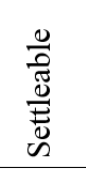 & 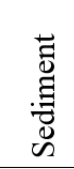 \\
\hline 7-Aug & 19.5 & 7.0 & 13.1 & 32.2 & 222.5 & 4.6 & 10.3 & 144.6 & 4.2 & 2.8 & 6.2 & 86.8 \\
\hline 21-Aug & 80.5 & 29.0 & 2.2 & 36.8 & 301.1 & 0.8 & 11.8 & 195.7 & 12.2 & 0.3 & 5.0 & 82.5 \\
\hline 27-Sep & 35.7 & 12.9 & 44.5 & 50.0 & 874.1 & 15.6 & 16.0 & 568.2 & 2.1 & 2.5 & 2.6 & 92.7 \\
\hline 4-Nov & 166.5 & 59.9 & 93.6 & 51.5 & 486.6 & 32.8 & 16.5 & 316.3 & 14.1 & 7.7 & 3.9 & 74.3 \\
\hline $16-\mathrm{Nov}$ & 227.5 & 81.9 & 123.2 & 137.8 & 332.2 & 43.1 & 44.1 & 215.9 & 21.3 & 11.2 & 11.5 & 56.1 \\
\hline
\end{tabular}

The left plot of Figure 1 is the physical representation of the parameters of the parallel 2 nd order demand model. $\mathrm{Cl}_{0}$ is the initial concentration of free chlorine; $\mathrm{CB}_{0}$ is the ultimate free chlorine demand of the reactor (note $a / b=1$ ) which is estimated by a fractional component, $f$, of the reactor initial dissolved COD; $X$ is the ratio of the ultimate chlorine demand that reacts quickly with the second order rate constant $\mathrm{k}_{1} ;(1-\mathrm{X})$ is the ratio of the ultimate chlorine demand that reacts slowly with the second order rate constant $\mathrm{k}_{2}$; and $\mathrm{C}^{*}$ represents the remaining free chlorine concentration at equilibrium. Note that as a parallel model, the effects of the slower reaction, $\mathrm{k}_{2}$, are also exerted during the initial portion, but as the time-scale of this reaction is several orders of magnitude slower than the quick initial reaction, the initial interval is well illustrated by the parameters $\mathrm{k}_{1}$ and $\mathrm{X}$.

The right plot of Figure 1 represents the maximum particle free chlorine demand as $\mathrm{mg} \mathrm{Cl}_{2}$ per $\mathrm{g}$ PM. For under-chlorinated reactors, the modeled chlorine demand at equilibrium, $\mathrm{q}_{\mathrm{e}}$, is limited by the maximum chlorine available in the reactor, $q_{e}$ max. For the over-chlorinated reactors, $q_{e}$ for the suspended $P M$ reaches an asymptotic maximum of $350 \mathrm{mg} / \mathrm{g}, \mathrm{q}_{\mathrm{e}}$ for the settleable PM reaches an asymptotic maximum of $320 \mathrm{mg} / \mathrm{g}$, and $\mathrm{q}_{\mathrm{e}}$ for the sediment PM reaches an asymptotic maximum of $650 \mathrm{mg} / \mathrm{g}$. Reactors chlorinated near the plateau point exhibit a transitional region where $q_{e}$ increases up to the asymptotic maximum. 


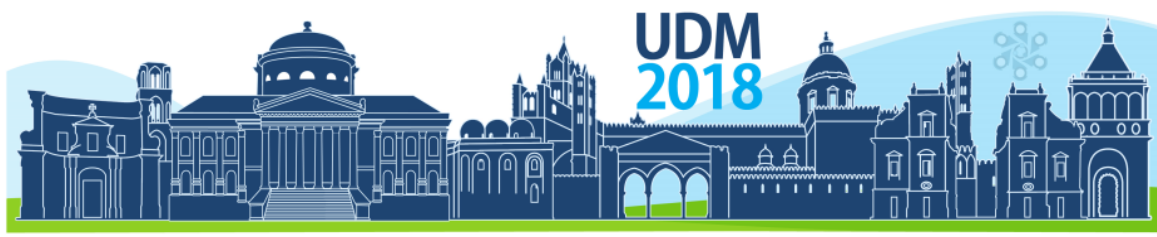

$11^{\text {th }}$ International Conference on Urban Drainage Modelling

23-26 Sep | Palermo - Italy
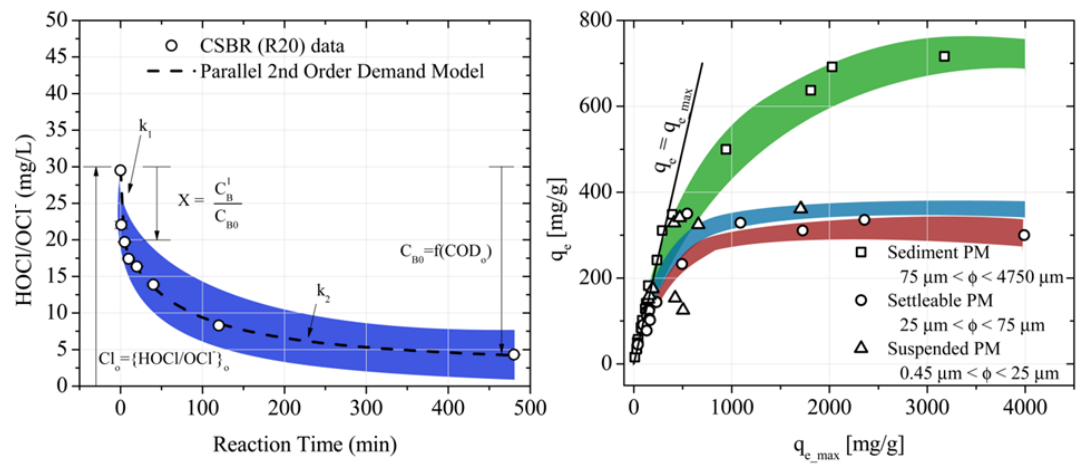

Figure 1. The left plot conceptually illustrates the parallel second order chlorine demand model and the right plot represents the maximum PM free chlorine demand

\section{CONCLUSIONS}

The modeling developed in this study provide a methodology for estimating the kinetic chlorine demand of urban rainfall-runoff PM fractions and the dissolved phase. Results indicate a significant chlorine demand by each PM fraction, although the predominance of the demand is from the sediment PM fraction of higher organic content as compared to suspended or settleable PM fractions. This study models the chlorine demand kinetics of PM fractions and the dissolved phase of runoff by combining rainfall-runoff event monitoring utilizing CODd, the gravimetric-based PSD of PM fractions, and a batch reactor framework for the generation of hypochlorite demand parameters. The models are based on the primary water chemistry parameter CODd, which enables the model to be utilized in conjunction with CODd transport models based on hydrologic parameters, such as $\mathrm{PDH}$, peak flow rate, and rainfall intensity. Results enable evaluation of hypochlorite disinfection as a unit process for the conditioning of urban runoff for potential reuse. Implementation of these results allows balancing of primary and secondary unit operation requirements for source area runoff reuse with hypochlorite demand of each PM fraction and the dissolved runoff phase.

\section{References}

Clark, R. M. and Savaganesan, M. Predicting Chlorine Residuals in Drinking Water: Second Order Model. J. Water Resour. Plann. Manage. 2002, Vol. 128(2), 152-161.

Haas, C. N. and Karra, S. B. Kinetics of wastewater chlorine demand exertion. J. Water Pollut. Control Fed. 1984, 56(2), 170-173.

Hrudey, S.E., and Hrudey, E.J. (2004), Safe Drinking Water: Lessons from Recent Outbreaks in Affluent Nations, IWA Publishing, London, UK

Kim, J. and Sansalone, J.J. Representation of Particulate Matter COD in Rainfall-Runoff from Paved Urban Watershed. Water, Air and Soil Pollution (2010), 205:113-132.

Taras, M. J. Preliminary Studies on the Chlorine Demand of Specific Chemical Compounds. J. Am. Water Works Assoc. 1950, 42, 462. 


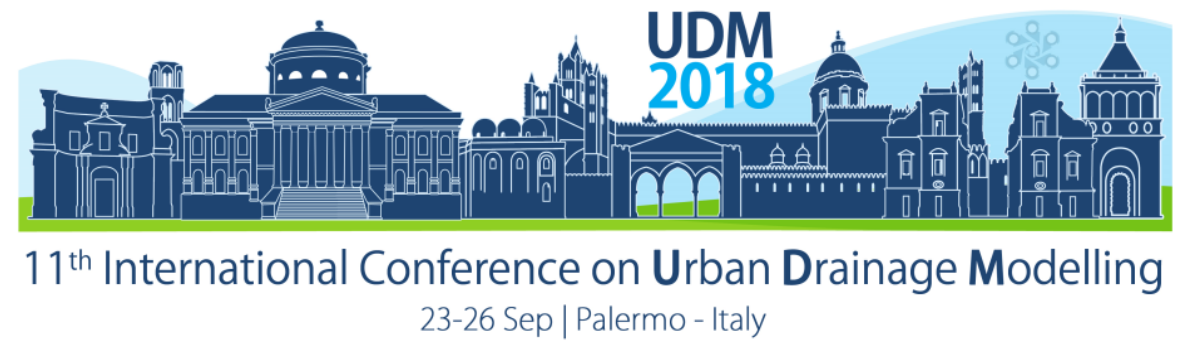

\title{
Surface Runoff in Urban Area - Case Study
}

\author{
Martina Zeleňáková1, Zuzana Vranayová², Adam Repel ${ }^{1}$ and Daniela Kaposztasová2 \\ ${ }^{1}$ Technical University of Košice, Department of Environmental Engineering, Košice, Slovakia \\ ${ }^{2}$ Technical University of Košice, Department of Architectural Engineering, Košice, Slovakia
}

\begin{abstract}
The world's population nowadays is concentrated in urban areas. This change in demography has brought land-use and land-cover changes that have a number of documented effects on stream flow. The most consistent effect is an increase in impervious surfaces within urban catchments, which alters the hydrology and geomorphology of streams. In addition to imperviousness, runoff from urbanized surfaces as well as municipal and industrial discharges results in increasing floods in urbanized areas as it decreasing river bed capacity for flow. Rainwater management should be considered as a sustainable strategy for reconstruction of rural and urban settlements from the aspects of environmental management and social criteria. The paper presents the current state of runoff condition in the study area taking into account the urban development in the last 30 years, mainly newly built hypermarkets. The goal of the study was an evaluation of surface condition, calculation of the runoff coefficient and design of potential measures to stabilize conditions in the drainage basin of Myslavský creek in eastern part of Slovakia.
\end{abstract}

Keywords: land use; runoff coefficient; Myslavský creek

\section{INTRODUCTION}

An accurate estimate of runoff from rain and snowmelt is one of the most important elements of the flood forecast process. It is important for flood control channel construction and for possible flood zone hazard delineation. A high runoff coefficient $(C)$ value may indicate flash flooding areas during storms as water moves fast overland on its way to a river channel or a valley floor. It is measured by determining the soil type, gradient, permeability and land use. Urbanization lowered potential maximum storage, and thus increased runoff coefficient values (Weng, 2001; Bronstert, et al., 2002; Wilby, 2007; Zeleňáková, Rejdovjanová, 2011; Vranayová, et al. 2011). As a consequence of increasing urbanization as well as rainfall totals and intensities over the second half of the 20th century, signs of increased flooding probability in many areas of the basins have been documented. These changes affecting rainfall characteristics are most evidently due to an increase in westerly atmospheric circulation types. Land use changes, particularly urbanization, can have significant local effects in small basins (headwaters) with respect to flooding, especially during heavy local rainstorms (Pfister et al., 2004; Dziopak, Słyś, 2006; Nirupama, Simonovic, 2007). The rainfall-runoff process depends not only on the space-time distribution of the rainfall occurrence, but also on the kind and the state of the basin, which in turn, depend on climatic condition and vegetation states. Therefore, chat is really important is a unified description of the complex behaviour of the dynamical system arising from the coupling of all its components (Sivakumar et al., 2000; Zeleňáková, et al., 2011; Šlezingr, Fialová, 2012; Markovič et. al., 2014). 


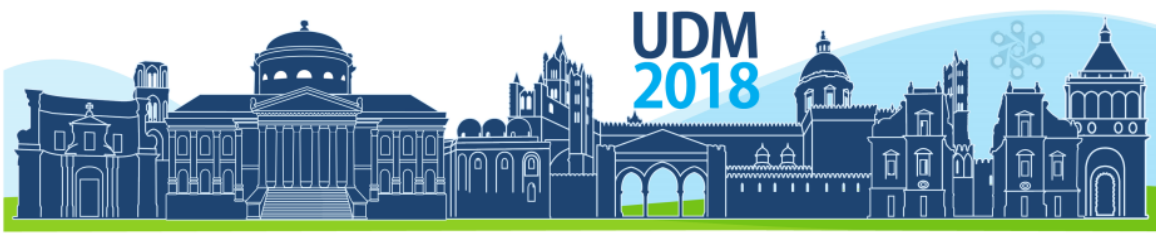

$11^{\text {th }}$ International Conference on Urban Drainage Modelling

23-26 Sep | Palermo - Italy

The goal of the paper is an evaluation of surface condition, calculation of the runoff coefficient and design of potential measures to stabilize conditions in the drainage basin of Myslavský creek on the degree of flood protection in low-lying areas. The paper presents the current state of drainage situation in the study area - part of Kosice City in Slovakia - taking into account the existing outlets of rainwater drainage of the newly built constructions buildings, hypermarkets etc..

\section{MATERIALS AND METHODS}

\subsection{Study area}

Myslavský creek, is the right-hand tributary of the Hornád, which mouths into the southern part of Košice (Figure 1) (Hornád river basin).

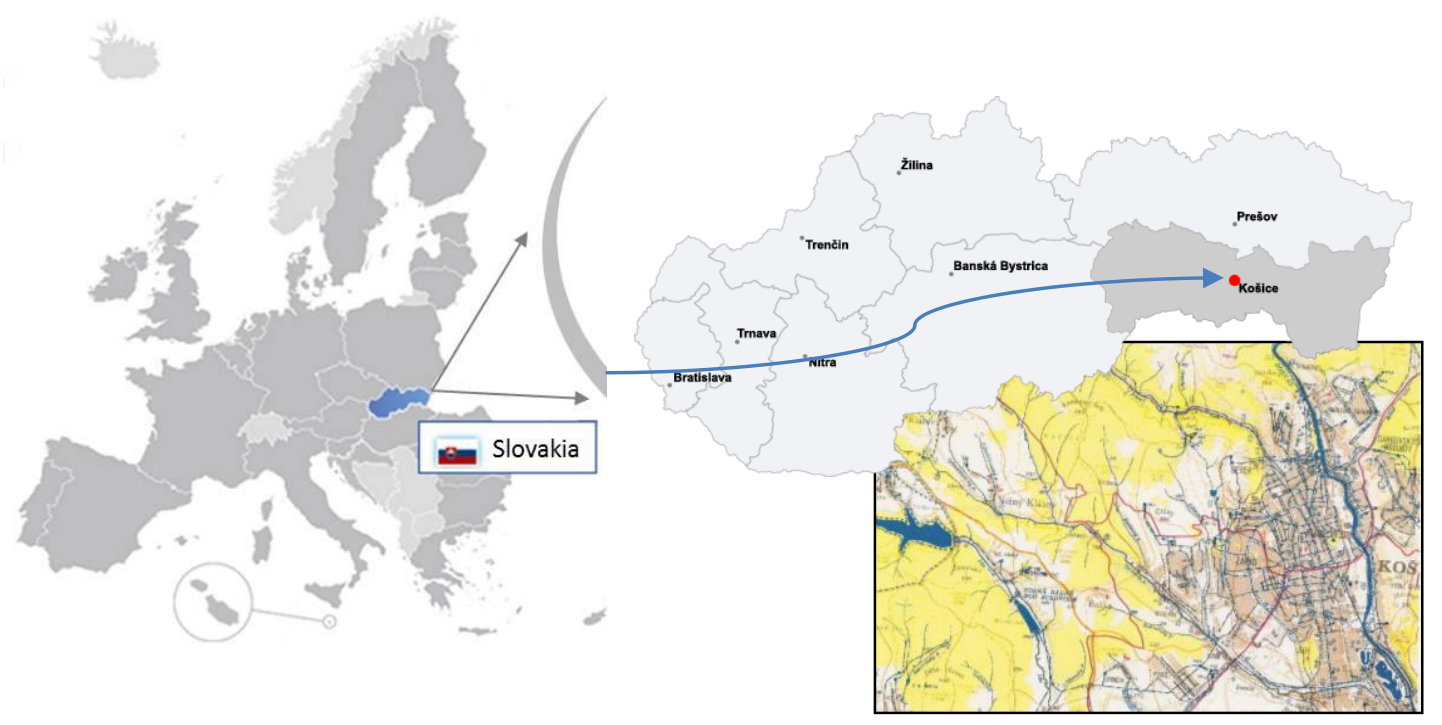

Figure 1. Location of study area.

Myslavský creek was regulated mainly within the boundaries of the city of Košice and Myslava (Dobrotka et al., 1997). A number of unilateral purpose bank reinforcement and many different types of bridges were made by landowners in gardening area. A large part of the basin is located in urbanized area, which may significantly alter hydrological conditions.

\subsection{Runoff calculations}

The Rational method of runoff coefficient (C) calculation is a function of the soil type and drainage of the basin. The larger values correspond to higher runoff and lower infiltration (Urcikán, 1991). The Rational equation is the simplest method to determine peak discharge from drainage basin runoff. Rational equation is as follows (Urcikán, 1991):

$$
Q_{\max }=C \cdot i \cdot A \quad\left(\text { I. } \mathrm{s}^{-1}\right)
$$

Where $Q_{\max }=$ peak discharge $\left(\mathrm{Is}^{-1}\right), C=$ rational method runoff coefficient $(-), i=$ rainfall intensity $\left(\mathrm{I} . \mathrm{S}^{-1} \cdot \mathrm{ha}^{-1}\right)$ in time $t(\mathrm{~min}), A=$ drainage area (ha). 


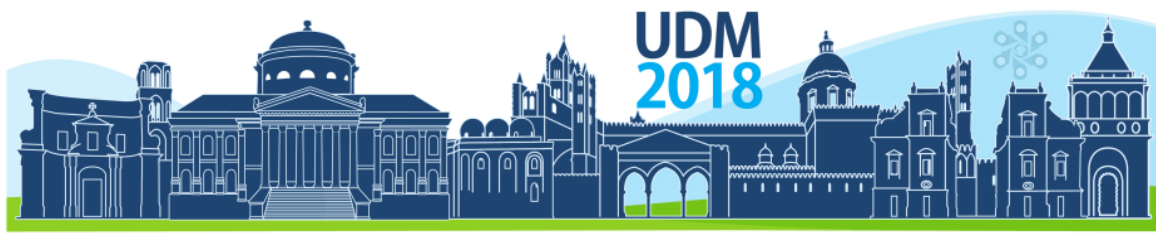

$11^{\text {th }}$ International Conference on Urban Drainage Modelling

23-26 Sep | Palermo - Italy

Runoff coefficient for the whole area was calculated as weighted average

$$
C=\frac{\Sigma\left(C_{i} \cdot A_{i}\right)}{\Sigma A_{i}}
$$

The rainfall intensity $(I)$ is typically found from Intensity/Duration/Frequency curves for rainfall events in the geographical region of interest. The duration is usually equivalent to the time of concentration of the drainage area. The storm frequency is typically stated by local authorities depending on the impact of the development. A 10-yr, 25-yr, 50-yr, or even 100-yr storm frequency may be specified.

\section{RESULTS AND DISCUSSION}

There were prepared two maps for years 1980 and 2010 for the whole catchment of the Myslavský creek (Tóthova, 2011). The maps of the selected area of the catchment, exactly the area of Košice city, where land use changes and human activity are manifested the most are presented at Figures 2.
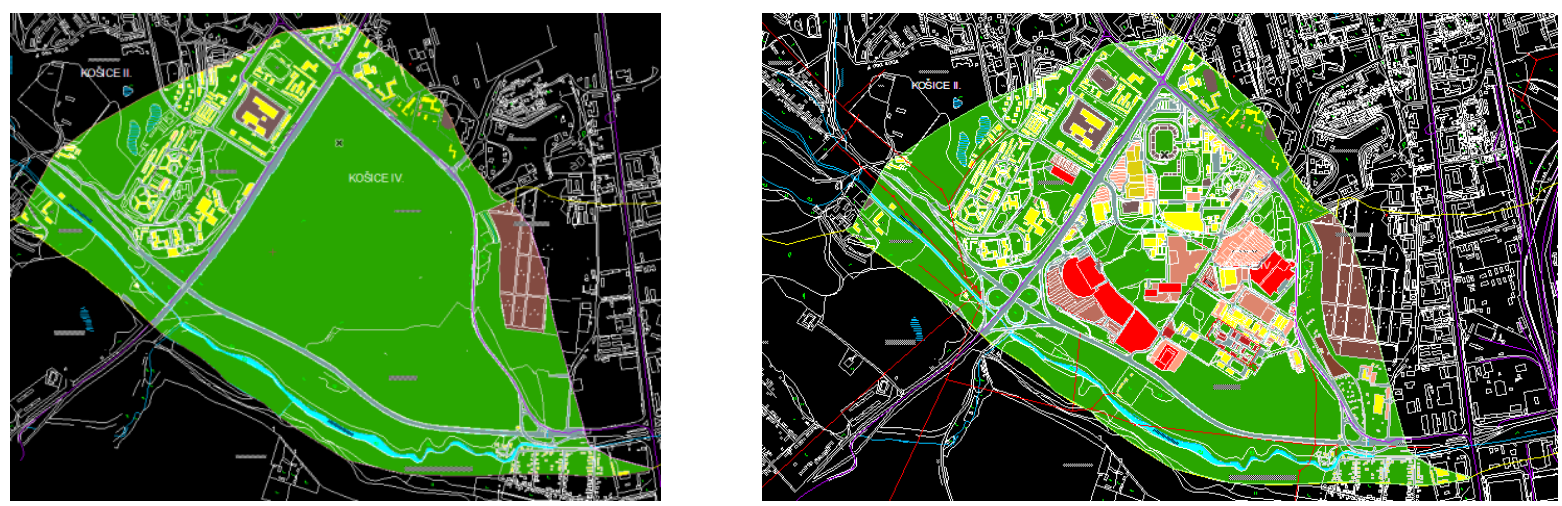

Legend:
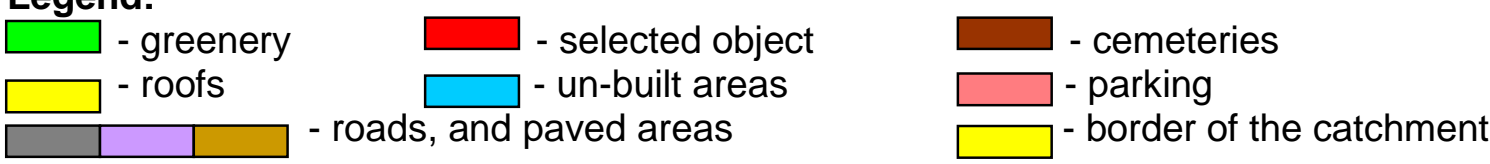

Figure 1. The selected area of Myslavský creek catchment - land use in 1980 and 2010

According to equation (2) were manually calculated runoff coefficients for the two time periods for significantly influenced locality by human activity, with different area of different land use of Myslavský creek catchment. The value of runoff coefficient is changed by 0.10 over the 30-years. Based on the calculated total runoff coefficients $C$, the drainage area of Myslavský creek and for a specific amount of rainfall were calculated maximum runoff for both time periods year 1980 and 2010 according to equation (1). The results are presented in Table 1.

Table 1 Determination of the maximum discharge $Q$

\begin{tabular}{cccccc}
\hline Year & $\begin{array}{c}C \\
(-)\end{array}$ & $\begin{array}{c}i \\
\left(\mathrm{I} . \mathrm{s}^{-1} . \mathrm{ha}^{-1}\right)\end{array}$ & $\begin{array}{c}A \\
(\mathrm{ha})\end{array}$ & $\begin{array}{c}t \\
(\mathrm{~min})\end{array}$ & $\begin{array}{c}Q \\
\left(\mathrm{l.s} \mathrm{s}^{-1}\right)\end{array}$ \\
\hline 2010 & 0.3404 & 139.8 & 431.9609 & 15 & 20556.12 \\
1980 & 0.2412 & 139.8 & 431.9609 & 15 & 14565.62 \\
\hline
\end{tabular}




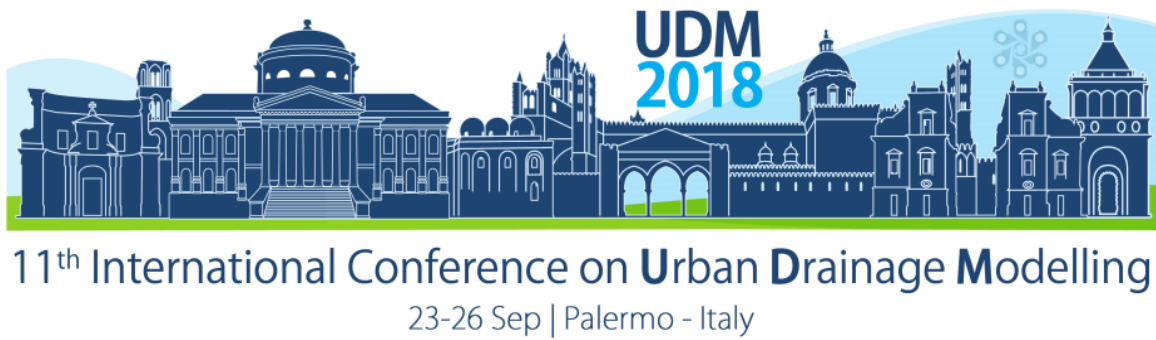

The above values indicate that by the duration of rain at $15 \mathrm{~min}$. the maximum runoff $Q$ for

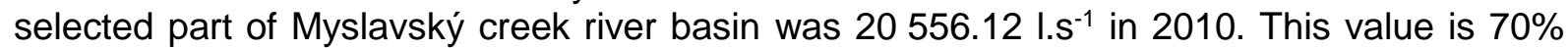
higher compare to the same drainage area in 1980, which was calculated for $14565.621 . \mathrm{s}^{-1}$.

\section{CONCLUSIONS}

The task of this work was to analyze the drainage conditions of river basin Myslavský creek with the aim to prove increasing flood risk in the area of Hornád river basin due to newly constructed built areas. The methodology is not a new but a similar study was not done for the study area and is important mainly for flood protection of the low-lying urban areas.

Drainage conditions of the reference area were compared on the basis of two time periods, for year 1980 and for 2010. Two maps of land use area were processed for the both years. Total runoff coefficients were calculated based on processed maps, which differed, because in 1980 the territory was not so built as currently. In the past, rainwater has infiltrated from the earth's surface directly into the soil, so as not to large flooded area had occurred. Today the situation is different, because in 30 years the enormously increased number of built and paved areas and all rainwater is collected and discharged through rainwater drainage discharges into the watercourse Myslavský creek. Given that the study area is almost all rainwater drained into the Myslavský creek, as well as rainwater from selected objects, increases the discharge in Myslavský creek, and thus its flow capacity for amount of drained rainwater is poor.

\section{Acknowledgement}

This work was supported by project VEGA 1/0202/15 Sustainable and Safe Water Management in Buildings.

\section{References}

Bronstert, A., Niehoff, D., Bürger, G. (2002). Effects of climate and land-use change on storm runoff generation: present knowledge and modelling capabilities. Hydrological Processes. Special Issue: The Future of Distributed Hydrological Modelling. 16(2), 509-529.

Pfister L., Kwadijk J., Musy A., Bronstert, A., Hoffmann, L. (2004). Climate change, land use change and runoff prediction in the Rhine-Meuse basins. River Research and Applications. 20(3), 229-241.

Dziopak, J., Słyś, D. (2006). Physical and mathematical model of gravitation-pump storage reservoir in sewage system, Environment Protection Engineering, 32(2), 127-137.

Markovič, G., Káposztásová, D., Vranayová, Z. (2014). The analysis of the possible use of harvested rainwater in real conditions at the university campus of Kosice, In: Recent Advances in Environmental Science and Geoscience: (ESG'14): March 15-17, 2014, Venice, Italy. p. 82-88.

Nirupama N., Simonovic S.P. (2007). Increase of Flood Risk due to Urbanisation: A Canadian Example. Natural Hazards, 40(1), 25-41.

Sivakumar, B., Berndtsson, R., Olsson, J. Jinno, K., Kawamura, A. (2000). Dynamics of monthly rainfall-runoff process at the Gota basin: A search for chaos. Hydrology and Earth System Sciences, 4(3), 407-417, 2000.

Šlezingr, M., Fialová, J. (2012). An examination of proposals for bank stabilization: the case of the Brno water reservoir (Czech Republic). Moravian Geographical Reports. 2012. Vol. 20, No. 2, p. 47-57.

Vranayová, Z., Karelová, Z., Očipová, D. (2011) Precipitation Monitoring Methodology at the Campus of Technical University of Košice. In: Selected Scientific Papers. Journal of Civil Engineering. 6(2).

Weng, Q. (2001) Modeling Urban Growth Effects on Surface Runoff with the Integration of Remote Sensing and GIS. Environmental Management, 28(6), 737-748.

Wilby, R.L. (2007) Review of Climate Change Impacts on the Built Environment. Built Environment, 33(1), 31-45.

Zeleňáková, M., Rejdovjanová, G. (2011) Facilities for the percolation of precipitation water in the area of the Technical University in Košice. In: SGEM 2011: 11th international: conference proceedings: Volume 1: 20-25 June, 2011, Bulgaria, Albena. Sofia: STEF92 Technology Ltd., 2011 P. 451-457.

Zeleňáková, M., Rejdovjanová, G., Zvijáková, L. (2011)The concept of rainwater managment in Košice City. In: Environmental Engineering: 8th International Conference: proceedings: selected papers: May 19-20, 2011, Vilnius, Lithuania. Vilnius : GTU, 2011 P. 723-726. 


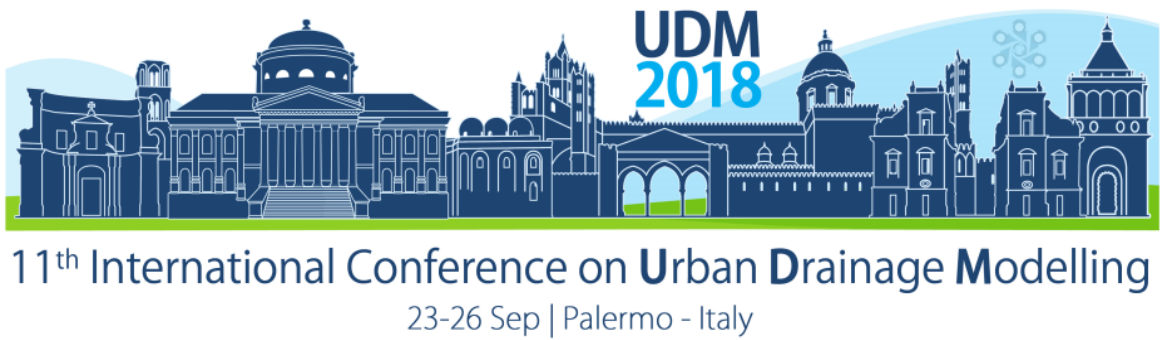

\title{
Modelling different types of stormwater treatment facilities considering irreducible concentrations
}

\author{
Thomas Larm and Anna Wahlsten \\ StormTac corporation, Stockholm, Sweden
}

\begin{abstract}
To design Stormwater Treatment Facilities (STFs) properly, we recommend the use of an urban drainage model that should include the calculation of runoff quality, to be based on a detailed land use specification, include site-specific design parameters, calculated outflow concentrations and loads of specified pollutants of relevance for the receiving water. This study compiles minimum outflow concentrations from stormwater databases of different types of STFs (wet ponds, wetlands, biofilters and underground retention basins with filters). These concentration data are used for the suggested values of specific "irreducible concentrations" ( $\left.C_{\text {irr }}\right)$. Suggested $C_{\text {irr }}$ for phosphorus $(P)$ varies from 20$40 \mu \mathrm{g} / \mathrm{l}$ depending on facility type, for copper (Cu) 1.8-4.0 $\mu \mathrm{g} / \mathrm{l}$, for zinc ( $\mathrm{Zn}$ ) 2.0-15 $\mu \mathrm{g} / \mathrm{l}$ and for total suspended solids (TSS) 2 900-5 $000 \mu \mathrm{g} / \mathrm{l}$. Corresponding data for 70 substances are compiled in the StormTac database and employed in the urban drainage model StormTac Web. Cirr have significant impact regarding the choice of facility type and its calculated dimensions. This design parameter and the calculated outflow concentrations can be used to investigate the need for combined serial facilities or complemented design elements with more planted vegetation or installed filters. Such elements can be required to decrease $C_{\text {irr }}$ and thereby reach project specific limit outflow concentrations and loads. The suggested data will be further evaluated and updated with respect to more data from different facility types and more substances.
\end{abstract}

Keywords: Irreducible concentration; Stormwater; Treatment

\section{INTRODUCTION}

Stormwater management are required to meet specific objectives considering site-specific as well as receiving water conditions, instead of using general percent removal rates (Clark and Pitt, 2012). Effluent (outflow) concentrations and loads need to be calculated. In urban drainage modelling, designers therefore need to apply design methods that includes parameters such as areal or volumetric relations to the reduced watershed area (area x runoff coefficient), inflow concentrations, vegetated area, flow detention and the minimum outflow concentrations (Larm and Hallberg, 2008). These parameters have great impact on the design and resulted outflow quality.

The minimum outflow concentrations or "irreducible concentrations" $\left(C_{\text {irr }}\right)$ refer to a Stormwater Treatment Facility's (STF's) inability to reduce pollutant concentrations below a certain level. Consequently, if the inflow concentrations are close to $\mathrm{C}_{\text {irr }}$ no further reduction is likely. If they are equal to or falls below $C_{\text {irr }}$ there could even be a negative removal (Schueler, 1996). This important design parameter is further studied here for different types of STFs. Cirr is affected by incoming content and internal processes in facilities. Examples are decomposition of plants, leakage from the bottom due to lack of oxygen, the exchange with sediment, stirring sediment because benthic animals, background content of materials in filter materials and vegetation beds (Center of watershed protection, 2007; Schueler and Holland, 2000). 


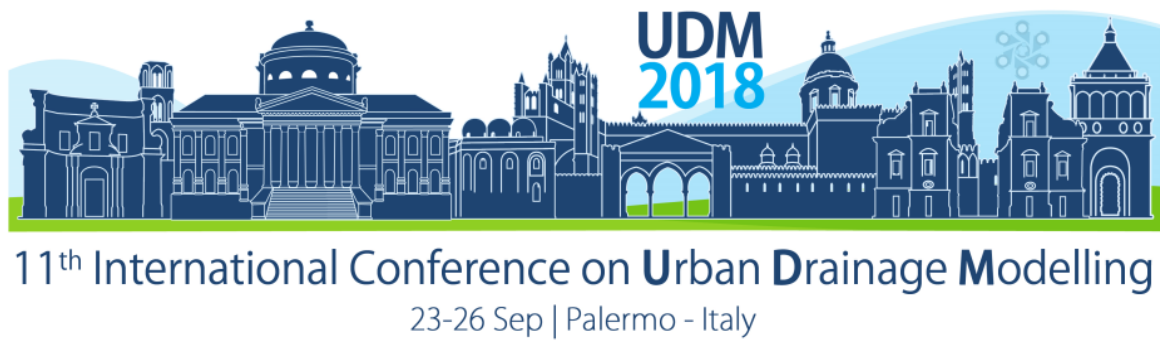

The findings of Randall et al. (1982) and Urbonas and Stahre (1993) suggest a lowest reachable outflow concentration for TSS around $10000-20000 \mu \mathrm{g} / \mathrm{l}$, for facilities relying primary in sedimentation. There is a limit to sedimentation basins efficiency for smaller particles. Since metals are associated with smaller particles, filtration may be required to meet potentially very low discharge limits. Organic media such as filtration media has a background contamination but increased removal and reduced $\mathrm{C}_{\text {irr }}$ can be reached with e.g. adapted materials for certain pollutants, increased contact time etc. (Clark and Pitt, 2012). Normally it

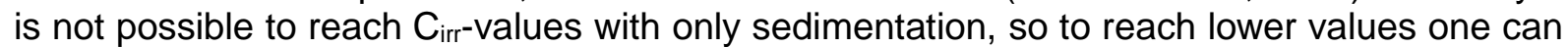
use other or combine facilities in a "treatment train" (Pitt, 2010), plant more vegetation, add a filter or improve the maintenance of the facility etc. A stormwater management model is required to include site-specific parameters to design STFs to meet these objectives, e.g. StormTac Web (Larm, 2000). Irreducible concentrations are here presented for phosphorus $(\mathrm{P})$, copper $(\mathrm{Cu})$, zinc $(\mathrm{Zn})$ and suspended solids (SS). These 4 substances are selected since there are much available data and they are generally of priority in different countries, used in water quality criteria and as basis for designing STFs (Larm and Hallberg, 2008). C irr are suggested to be estimated from outflow data from different types of STFs.

\section{MATERIALS AND METHODS}

\subsection{StormTac Web}

Runoff quality in the stormwater and recipient model StormTac Web (Larm, 2000) is estimated based on land use from e.g. the National Stormwater Quality Database (NSQD) (Clark and Pitt, 2012) and the StormTac Database (Larm, 2018). Estimated reduction efficiencies and outflow concentrations are simulated based on site-specific parameters such as inflow concentrations and $\mathrm{C}_{\text {irr. }}$. The simulations are performed for $>100$ land uses and 70 substances.

\subsection{Irreducible concentration}

Schueler (1996) suggested a preliminary estimate of $C_{\text {irr }}$ of pollutants in general stormwater practice outflows as $150-200 \mu \mathrm{g} / \mathrm{l}(\mathrm{P})$ and $20000-40000 \mu \mathrm{g} / \mathrm{l}$ for TSS. Outflow concentration data from different STFs has been compiled from the International BMP Database 2016 summary statistics (Geosyntec Consultants, Inc. and Wright Water Engineers, Inc., 2017) and

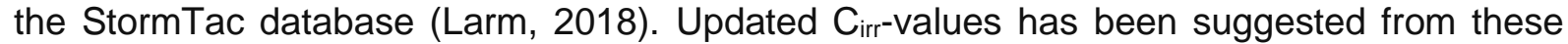
data, compiled in Table 1 . The reduction efficiency $R E(\%)$ of a stormwater treatment facility can be expressed as a function of pollutant inflow and outflow loads or concentrations. Furthermore, RE depends on site-specific parameters. Higher inflow concentration and more vegetation can e.g. result in higher RE, and $\mathrm{C}_{\text {irr }}$ can stop further treatment (Larm and Alm, 2014). To consider $C_{\text {irr }}$ in the design processes we present simply the general functions of $R E$ as a function of inflow concentration $\mathrm{C}_{\text {in }}$ and outflow concentration $\mathrm{C}_{\text {out, }}$ (Eq. 1), from which $\mathrm{C}_{\text {out }}$ is calculated in Eq. (2). The condition of $\mathrm{C}_{\text {irr }}$ in Eq. (3) is used to calculate the maximum achievable RE, RE achievable (Eq. 4) (Minton, 1998):

$$
\begin{aligned}
& R E=100\left(C_{\text {in }}-C_{\text {out }}\right) / C_{\text {in }} \\
& C_{\text {out }}=C_{\text {in }}-C_{\text {in }} R E / 100 \\
& C_{\text {irr }} \leq C_{\text {out }} \\
& R E_{\text {achievable }}=100\left(C_{\text {in }}-C_{\text {irr }}\right) / C_{\text {in }}
\end{aligned}
$$




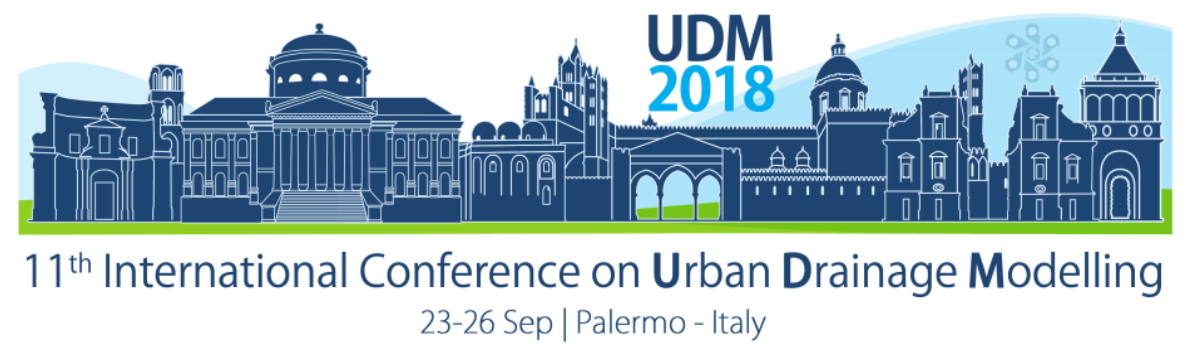

To evaluating data, the "BMP-weighted" and "storm-weighted" approaches can be used (Geosyntec Consultants, Inc. and Wright Water Engineers, Inc., 2017). The BMP-weighted approach represents each BMP with one value representing the central tendency and variability of each individual BMP study. The storm-weighted approach combines all the storm events for the BMPs in each category and analyses the overall storm-based data set. When implementing the concept of $\mathrm{C}_{\text {irr }}$ the hypothesis is that the BMP-weighted should be used, since it considers periods with releases of pollutants from the facility materials or sediments to the

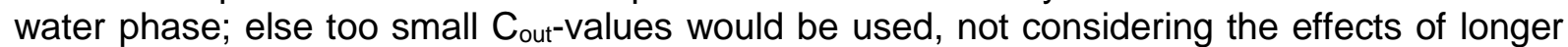
time periods. To further show how $\mathrm{C}_{\text {irr }}$ can have great impacts on the choice of type and size of treatment facilities, StormTac Web was used in an example case study designing stormwater treatment for a 20 ha residential area.

\section{RESULTS AND DISCUSSION}

\subsection{Results}

In Table 1, minimum outflow concentrations from the International BMP Database and the StormTac database are compiled for different facility types. The compiled data from the BMP database are storm-weighted, the approach was selected for the referred report because it provides a much larger data set for analysis (Geosyntec Consultants, Inc. and Wright Water Engineers, Inc., 2017). The BMP data shows that it occasionally, without taking to account the long-time effects, can give very low outlet concentrations. StormTacs database shows BMPweighted data. They represent long-term performance data from each case study whereby they are suggested as irreducible concentrations, $\mathrm{C}_{\text {irr. }}$.

Table 1. Minimum total outflow concentration $(\mu \mathrm{g} / \mathrm{l})$, excluding outliners. Compiled data from StormTac database represents suggested irreducible concentration $\left(\mathrm{C}_{\text {irr }}\right.$ for each facility.

\begin{tabular}{|c|c|c|c|c|c|}
\hline & 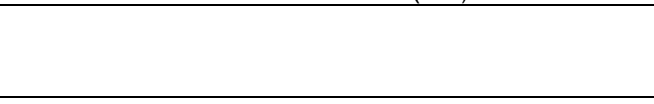 & $\begin{array}{c}\mathbf{P} \\
{[\mu \mathrm{g} / \mathrm{l}]}\end{array}$ & $\begin{array}{c}\mathrm{Cu} \\
{[\mu \mathrm{g} / \mathrm{l}]}\end{array}$ & $\begin{array}{c}\mathbf{Z n} \\
{[\mu \mathrm{g} / \mathrm{l}]}\end{array}$ & $\begin{array}{c}\text { TSS } \\
{[\mu \mathrm{g} / \mathrm{l}]}\end{array}$ \\
\hline \multirow{2}{*}{ Wet pond } & StormTac database, BMP-weighted ( $\mathrm{C}_{\text {irr }}$ ) & 20 & 1.8 & 14 & 2900 \\
\hline & BMP database, Storm-weighted & 5.0 & 0.70 & 2.0 & 300 \\
\hline \multirow{2}{*}{ Wetland } & StormTac database, BMP-weighted ( $\left.\mathrm{C}_{\text {irr }}\right)$ & 30 & 3.0 & 15 & 5000 \\
\hline & BMP database, Storm-weighted & 8.0 & 0.40 & 2.5 & 300 \\
\hline \multirow{2}{*}{ Biofilter } & StormTac database, BMP-weighted ( $\left.\mathrm{C}_{\text {irr }}\right)$ & 40 & 4.0 & 7.0 & 3000 \\
\hline & BMP database, Storm-weighted & 6.0 & 0.80 & 0.70 & 400 \\
\hline $\begin{array}{l}\text { Smaller } \\
\text { underground } \\
\text { retention } \\
\text { filter basin }\end{array}$ & StormTac database, BMP-weighted $\left(\mathrm{C}_{\text {irr }}\right)$ & 30 & 2.0 & 2.0 & 5000 \\
\hline
\end{tabular}




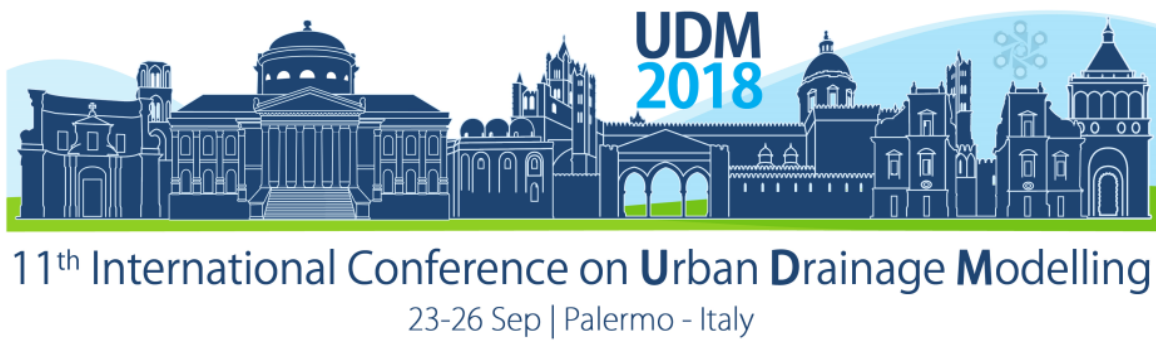

\section{Example case study}

A wet pond was simulated for $Z n$ reduction from a 20 ha residential area with StormTac Web, with an assumed critical outlet concentration $\left(\mathrm{C}_{\text {crit }}\right)$ of $10 \mu \mathrm{g} / \mathrm{l}$. The total $\mathrm{Zn}$ concentration from the residential area to the wet pond was $\mathrm{C}_{\mathrm{in}}=62 \mu \mathrm{g} / \mathrm{l}$. The permanent pool area of the wet pond was $2500 \mathrm{~m}^{2}$ and gave reduction efficiency $(R E)=77 \%$ and $C_{\text {out }}=14 \mu \mathrm{g} / \mathrm{l}$, see the left picture in Figure 1. $C_{\text {irr }}(Z n)$ for a wet pond is $14 \mu \mathrm{g} / \mathrm{l}$ (Table 1), the simulation has stopped further treatment due to e.g. leakage from the sediments and the decomposition of plants. To reduce $\mathrm{C}_{\text {out }}$ further, a larger pond would not give any effect in this case, using the concept of $\mathrm{C}_{\text {irr. }}$.
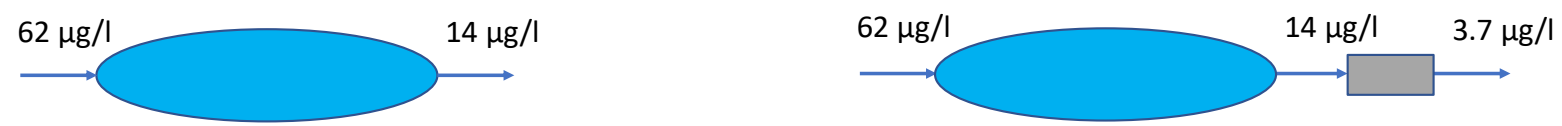

Figure 1. To the left a wet pond treating the stormwater and to the right a wet pond combined with a smaller underground retention filter basin.

To get further reduced $\mathrm{C}_{\text {out }}$ we simulated a smaller underground retention filter basin downstream the wet pond. This type of facility has the potential to reduce $C_{\text {out }}$ to $2.0 \mu \mathrm{g} / \mathrm{l}$ (Table 1 ), if simulated site-specific conditions so permit. An underground retention filter basin with a treatment volume of $25 \mathrm{~m}^{3}$ were simulated in series with the wet pond which resulted in an overall $\mathrm{RE}=94 \%$ and $\mathrm{C}_{\text {out }}=3.7 \mu \mathrm{g} / \mathrm{l}<\mathrm{C}_{\text {crit, }}$, i.e. sufficient treatment, see the right picture in Figure 1. The very high $R E$ of $Z n$ in this example case study can be explained by a large wet pond in a series with an underground retention filter basin. Furthermore, the results assume good maintenance of the sediments and the in- and outlets of the facilities, and that the selected filter can perform high $\mathrm{Zn}$ removal.

\subsection{Discussion}

The data in Table 1 are all compiled in the StormTac database, together with data for many more substances and facility types. The aim is that $C_{\text {irr }}$ shall represent minimum values of sites with a certain facility type, but minimum of mean outflow concentrations during annual periods from each site. $C_{i r r}$ should not be based on short term minimum concentrations since there e.g. could be release processes during events of high flow or decomposition processes from plants, if not harvested. This will be further evaluated after planned studies of complementary data from more facility types and more substances. In StormTac Web, the reduction efficiency is adjusted so that not less than Cirr $_{\text {ir }}$ is obtained at the outlet (Larm and Alm, 2014). However, it is possible to unlock this restriction if it is believed possible to achieve lower levels by adapting the choice of plants or add filters or the like.

\section{CONCLUSIONS}

Stormwater treatment facilities need to be designed based not on general percent removals, but instead based on site-specific conditions for different treatment components, considering irreducible concentrations $\left(\mathrm{C}_{\text {irr }}\right)$. The compiled results indicate that there is no general irreducible barrier and that much lower $C_{\text {irr }}$ than preliminary suggested by Schueler (1996) may be achieved. Irreducible concentration is a relative concept as opposed to using the concept as an absolute delimiter. It is possible to get concentrations as low as desired, but it is often not practical to design facilities to achieve extremely low concentrations since that would require e.g. treatment trains and/or chemical addition (Geosyntec Consultants, Inc. and Wright Water Engineers, Inc. (2009). Earlier research (ASCE, 2000) and the compiled minimum effluent data in Table 1 indicate large variations between different BMP types. There is a $\mathrm{C}_{\text {irr }}$ 


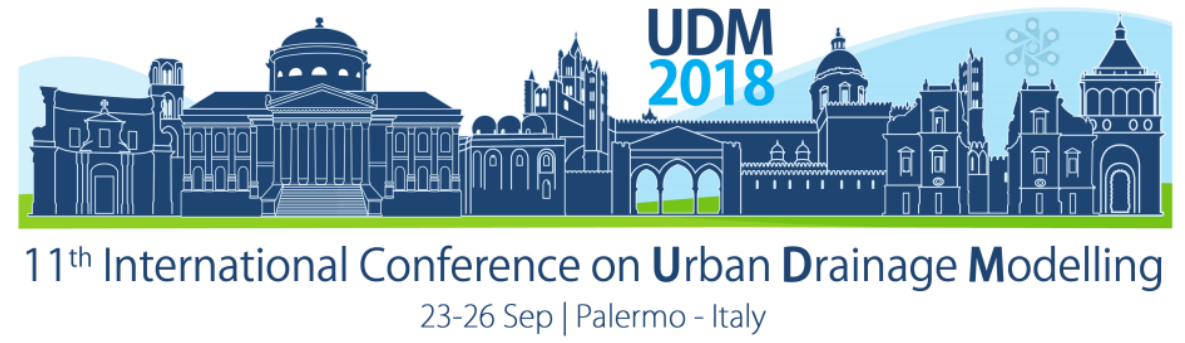

that normally can be achieved for a certain type of facility, which can affect the choice and dimension of the chosen type of facility. In many cases, a treatment train incorporating different processes that target different pollutant characteristics can be needed to achieve strict discharge limits. It can be composed of sedimentation (e.g. in wet ponds) followed by filtration unit processes (e.g. in biofilters) (Pitt, 2010). If it is required to lower the calculated outflow concentration of a certain substance, then it is possible to complement the facility with more plants or to add an outlet filter with materials adapted for better reduction. Based on presented results, $C_{\text {irr }}$ for phosphorus $(\mathrm{P})$ varies from 20-40 $\mu \mathrm{g} / \mathrm{l}$ depending on facility. For copper $(\mathrm{Cu})$ $\mathrm{C}_{\text {irr }}$ varies between 1.8-4.0 $\mu \mathrm{g} / \mathrm{l}$. For zinc $(\mathrm{Zn}), \mathrm{C}_{\text {irr }}$ varies between $2.0-15 \mu \mathrm{g} / \mathrm{l}$ and for total suspended solids (TSS) between 2900-5 $000 \mu \mathrm{g} / \mathrm{l}$ depending on facility. This outflow concentration and load data can be simulated with e.g. StormTac Web or the like, beginning with calculating inflow quality from land use data. Also, other site-specific parameters are to be considered in the design.

Continued studies will focus on compiling updated BMP-weighted effluent concentrations from the BMP database (www.bmpdatabase.org) in Access format, by weighting each event effluent concentration by the event flow, and then calculating minimum concentrations per facility type. These minimum data will be compiled in the StormTac database (www.stormtac.com), used to update the suggested irreducible concentrations in Table 1 for several more BMP types and substances. These are to be further implemented in StormTac Web.

\section{References}

ASCE (2000). Data Evaluation Report, Task 3.4. National Stormwater Best Management Practices Database Project, October 2000.

Center for Watershed Protection (2007). National Pollutant Removal Database. Appendix C: Updated BMP Removal Efficiencies from the National Pollutant Removal Database \& Acceptable BMP Table for Virginia. Center for watershed Protection, Ellicott City, Maryland, USA.

Clark S.E. and Pitt R. (2012) Targeting treatment technologies to address specific stormwater pollutants and numeric discharge limits. Water research 46, 6715-6730.

Geosyntec Consultants, Inc. and Wright Water Engineers, Inc. (2009). Urban stormwater BMP Performance monitoring. October 2009.

Geosyntec Consultants, Inc. and Wright Water Engineers, Inc. (2017). International Stormwater BMP Database 2016 summary statistics, 2017.

Larm T. (2000). Watershed-based design of stormwater treatment facilities: model development and applications. PhD thesis, Royal Institute of Technology, Stockholm, Sweden.

Larm T. (2018). StormTac database, www.stormtac.com.

Larm T. and Alm H. (2014). Revised design criteria for stormwater facilities to meet pollution reduction and flow control requirements, also considering predicted climate effects. Water practice and Technology.

Larm T. and Hallberg M. (2008) Design methods for stormwater treatment - site specific parameters. 11th International Conference on Urban Drainage, ICUD, Edinburgh, Scotland, UK, 2008.

Minton G.R. (1998). Stormwater Treatment Northwest, Vol. 4, August.

Pitt R. (2010). Evaluation of Biofiltration Media for Engineered Natural Treatment Systems. Report from University of Alabama to Geosyntec Consultants, CA. May 10, 2010.

Randall W.C., Ellis K., Grizzard J.T., Knocke W.R. (1982) Urban Runoff Pollutant Removal by Sedimentation, Stormwater Detention Facilities. Proceeding from Conference on Stormwater Facilities, ASCE.

Schueler T.R. (1996). Irreducible pollutant concentrations discharged from stormwater practices. Article 65. Technical note \#75 from watershed protection techniques. 2(2): 369-372.

Schueler T.R. and Holland H.K. (2000). The Practice of Watershed Protection. Article 65 Irreducible Pollutant Concentrations Discharged from Stormwater Practices. In Watershed Protection Techniques. 2(2): 369372. Center for watershed Protection. www.cwp.org.

Urbonas B.R. and Stahre P. (1993). Stormwater Best Management Practices Including Detention. USA. 


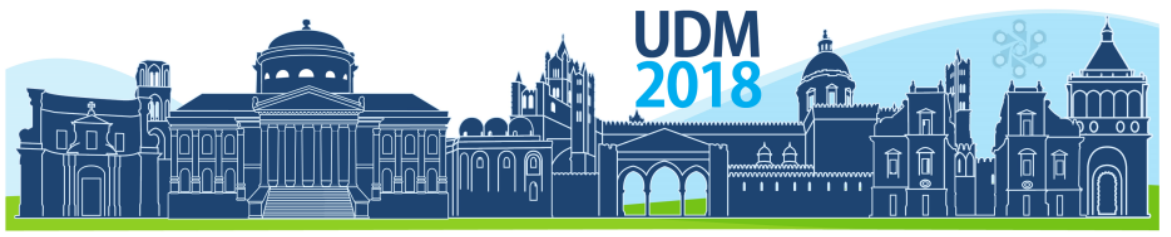

$11^{\text {th }}$ International Conference on Urban Drainage Modelling

23-26 Sep | Palermo - Italy

\title{
Performance analysis of low impact development (LID) practices for the management of surface runoff: Applying the sponge city concept to a campus area
}

\author{
Wenyu Yang1, Kurt Brüggemann ${ }^{3}$, Kiwanuka David Seguya ${ }^{1}$, Afshin Sadeghikhah ${ }^{1}$, Jin Zhang ${ }^{1,2 \text {, }}$ \\ ${ }^{*}$ and Peter Krebs ${ }^{1}$ \\ 1 Institute of Urban Water Management, Technische Universität Dresden, 01062 Dresden, Germany \\ 2 Institute of Groundwater and Earth Sciences, Jinan University, 510632 Guangzhou, China \\ 2 Institute of Management of Material Fluxes and of Resources, UNU-FLORES 01067 Dresden, Germany \\ ${ }^{*}$ Corresponding author's e-mail: Afshin.sadeghikhah@tu-dresden.de
}

\begin{abstract}
The influence of low impact development (LID) practices on surface runoff has been investigated by applying a storm water management model (SWMM) and pertinent cost-effectiveness analysis to a campus area in Dresden, using nine design storms with different return periods and durations. Combined LID practices perform better than single LID practices in runoff reduction, giving reduction ranges of $5.30-34.66 \%$ and $3.48-19.38 \%$ respectively. Regarding cost-effectiveness analysis, rain barrels (RB) show the lowest costeffectiveness ratio for individual LID practices while rain barrels with infiltration trenches or rain barrels with Porous pavements were the most cost-effective combinations.
\end{abstract}

Keywords: low impact development (LID), stormwater management model, cost-effectiveness analysis,

\section{INTRODUCTION}

Approaches like Low Impact Development (LID) or 'sponge cities' technologies have recently received immense attention as alternatives to address the limitations of conventional urban stormwater management systems (Dietz and Clausen, 2005; Uda et al., 2013; Palla and Gnecco 2015; Baek et al., 2015; Vogel et al., 2015) which aim to convey runoff from urban areas as fast as possible. Conversely, LID practices aim to capture and retain stormwater at or near the areas of generation, in so doing diverting it from reaching centralized storm management systems and hence relieving them of overflowing thus minimizing flood risks, pollutant discharges and stream erosion as well as maintaining groundwater levels and stream base flows (Dietz, 2007; Elliott and Trowsdale, 2007; Joksimovic and Alam, 2014). Most studies (Vogel et al., 2015), however, have focused on the performance of LIDs in cutting stormwater peak flows and volumes, yet the cost of the technologies could be limiting their application at large scales. This study was therefore carried out to analyse the performance of LIDs in stormwater management and thus focused on:

(1) the identification of the potential to implement green infrastructure in Technische Universität Dresden Campus;

(2) the determination of the optimal combination of LID practices that improves the performance at lowest cost.

\section{METHODOLOGY}

\subsection{Study area and model construction}




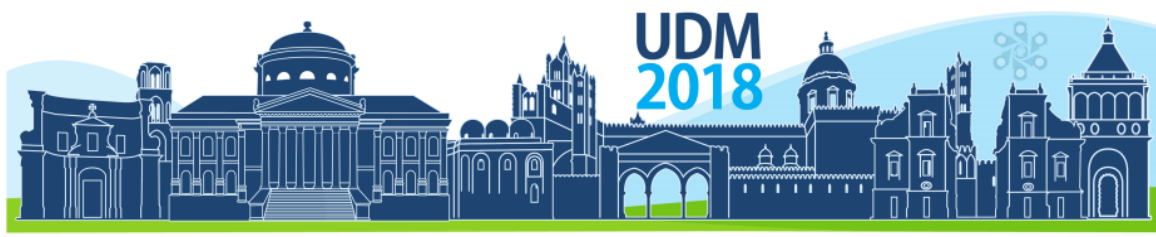

$11^{\text {th }}$ International Conference on Urban Drainage Modelling

23-26 Sep | Palermo - Italy

The study area is a located in the campus of Technische Universität Dresden, Germany, which is an urbanized district with a total area of about 29.92 ha and served by the separate drainage system as seen in Fig. 1.

The software Stormwater Management Model (SWMM) consists of hydrological and hydraulic model. The hydrological model was used to simulate the hydrological events, such as timevarying precipitation, rainfall interception from depression storage and flow routing of surface runoff (Rossman, 2010). The hydraulic model was used to simulate some hydro-mechanic processes, such as external inflow, rainfall-dependent infiltration, flow-routing through pipelines and various possible flow regimes, such as backwater and surcharging, and provides visualization techniques that include hydraulic line profiles, calibration and error analyses (Preissmann, 1961). The drainage system model is shown in Fig. 1.

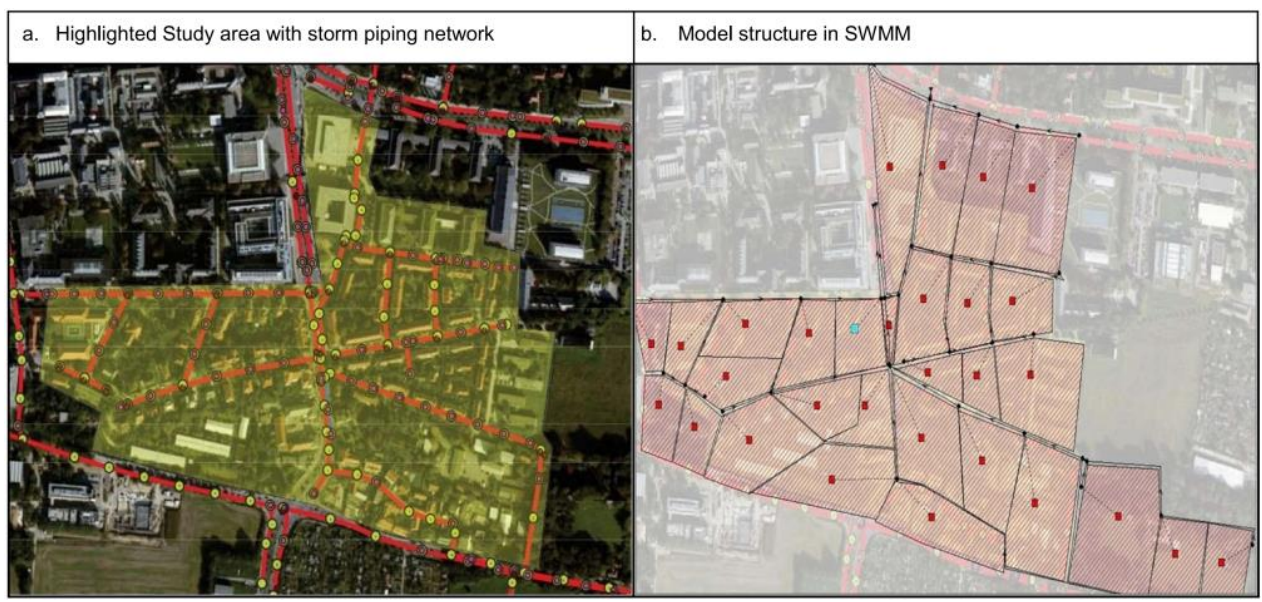

Fig. 1. Study area and model structure

Several storm events from 1995-2015 were used for calibration and validation. Comparing observed and simulated discharge, the correlation coefficient $R$ varies from 0.994 to 0.996 . The validation results are shown in Fig. 2, and calibrated key parameters with the empirical range value (Rossman and Huber, 2016) are shown in Tab. 2.

Fig. 2. Validation results

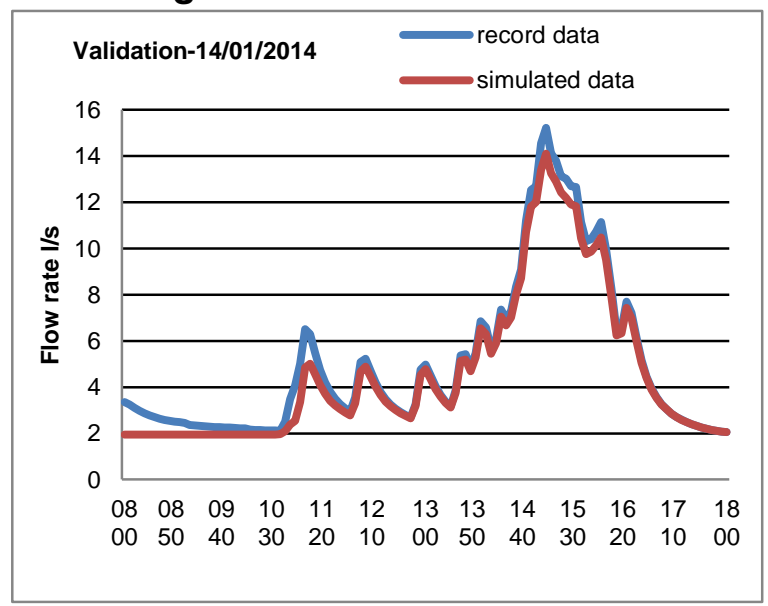

Tab. 2. Calibrated parameters

\begin{tabular}{ccc}
\hline $\begin{array}{c}\text { Key } \\
\text { Parameter }\end{array}$ & Range & $\begin{array}{c}\text { Calibrated } \\
\text { Value }\end{array}$ \\
\hline $\begin{array}{c}\mathrm{N} \text { - } \\
\text { Impervious }\end{array}$ & $\begin{array}{c}0.011- \\
0.015\end{array}$ & 0.012 \\
N-Pervious & $\begin{array}{c}0.15- \\
0.40\end{array}$ & 0.2 \\
Dstore- & $0.05-$ & \\
Impervious \\
[inch] \\
$\begin{array}{c}\text { Dstore- } \\
\text { Pervious } \\
\text { [inch] }\end{array}$ & 0.10 & 0.05 \\
\hline
\end{tabular}




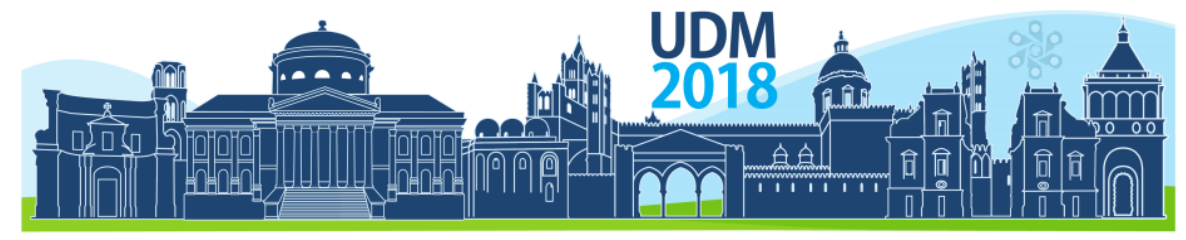

$11^{\text {th }}$ International Conference on Urban Drainage Modelling

23-26 Sep | Palermo - Italy

\subsection{Design rainfall pattern and LID application}

The design rainfall pattern has a direct impact on the occurrence of water logging. The Chicago rainfall pattern with a time-to-peak ratio $r$ of 0.375 can be used for design storm in this model (Keifer and Chu, 1957). The intensity equation was shown below ( $\mathrm{i}$ - storm intensity in $\mathrm{mm} / \mathrm{min}$; $\mathrm{P}$ - design return period in years; $\mathrm{T}$ - rainfall duration in $\mathrm{min}$ ):

$$
\mathrm{i}=\frac{6.041+8.910 \lg \mathrm{P}}{(\mathrm{T}+14,71)^{0.704}}
$$

The runoff flow rate directly influences the operation of the drainage system, and LID measures are regarded as an effective measure to control surface runoff. Nowadays, major LID practices include Green Roof (GR), Rain Barrel (RB), Bio Retention (BR), Vegetative Swale (VS), Infiltration Trench (IT), and Porous Pavement (PP) (Rossman, 2010). The LID technologies have different applicability and engineering expense, and fit for different land-cover types (Shengquan, Che, \& Wei Yan, 2015). To avoid the reconstruction or low efficient performance, four types of LID practices were applied in model based on land-cover types, demonstrated in Tab. 3.

Tab. 3. Land-cover types and associated LID practices

\begin{tabular}{c|c|c|c|c|c|c|c}
\hline $\begin{array}{c}\text { Land-cover } \\
\text { type }\end{array}$ & Area $\left(\mathrm{m}^{2}\right)$ & $\begin{array}{c}\text { Imperviousness } \\
(\%)\end{array}$ & $\begin{array}{c}\text { LID } \\
\text { control }\end{array}$ & $\begin{array}{c}\text { LID } \\
\text { scale }\end{array}$ & Unit & $\begin{array}{c}\text { Life } \\
\text { span } \\
\text { (year) }\end{array}$ & $\begin{array}{c}\text { Estimated } \\
\text { cost rate } \\
\text { (\$/unit-year) }\end{array}$ \\
\hline $\begin{array}{c}\text { Building roof } \\
\text { Sub-road }\end{array}$ & 5263 & 95 & GR & 2600 & $\mathrm{~m}^{2}$ & 40 & 5.01 \\
Parking lots & 1910 & 90 & IT & 4469 & $\mathrm{~m}^{2}$ & 50 & 1.56 \\
Single building & 220872 & 75 & PP & 1910 & $\mathrm{~m}^{2}$ & 30 & 3.71 \\
\hline
\end{tabular}

\section{RESULT}

After the LID practices were applied in model, scenarios with four single units and four LID combinations were simulated under nine design rainfall events, long-term simulation with 20 years' rainfall is also carried out. As the engineering expense of LID practices over the whole life span is considered, the cost-effectiveness analysis (CEA) based on the long-term performance is used for selecting the best LID application. The result of the cost-effectiveness analysis is listed in Tab. 4 and visualized in Fig. 3.

\section{DISCUSSION AND CONCLUSION}

For the long-term performance, Rain Barrel (RB) and Infiltration Trench (IT) have the highest and lowest reduction rate among single units respectively. And the combination of RB+PP can reduce over $95 \%$ of surface runoff in last 20 years.

Regarding the CEA, Rain Barrel (RB) has the lowest cost-effectiveness ratio (C/E) for individual LID practices, while rain barrels with Infiltration Trenches and Rain Barrels with Permeable Pavements (IT+RB and RB+PP) were the most cost-effective combinations.

In conclusion, the performance of LID practices is strongly affected by surrounding environment, for instance, the geographical characteristics of catchments, the construction type and distribution, and the local hydrological events can be the factors which influence the 


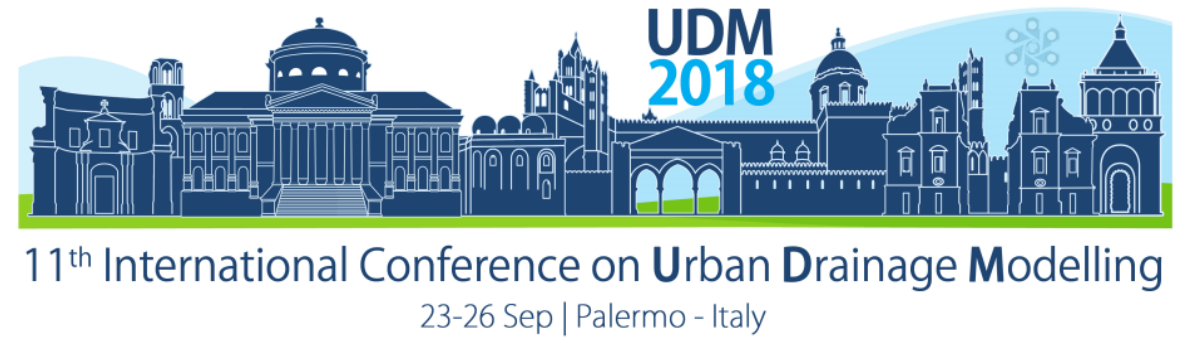

applicability and performance of LID practices. LID combination is an appropriate approach to improve the reduction rates of surface runoff, while the applicability and the structure factors should be considered in this. When implementing LID practices in other cases, these factors should be in consideration. The model has successfully presented how the 'sponge city' concept can be applied to the campus area of Technische Universität Dresden, in a costeffective way.

Tab. 5. Result of Cost-effectiveness analysis

Fig. 4. Cost-effectiveness analysis diagram

\begin{tabular}{c|c|c|c}
\hline $\begin{array}{c}\text { LID } \\
\text { controls }\end{array}$ & $\begin{array}{c}\text { Reductio } \\
n \text { rate [\%] }\end{array}$ & $\begin{array}{c}\text { PVC } \\
\text { [\$/unit-year] }\end{array}$ & $\mathrm{B} / \mathrm{C}$ \\
\hline IT & 36.35 & 1.56 & 0.23 \\
RB & 70.99 & 0.80 & 0.89 \\
PP & 46.64 & 3.71 & 0.13 \\
GR & 57.75 & 5.01 & 0.12 \\
IT+RB & 52.06 & 2.36 & 0.22 \\
IT+PP & 64.59 & 5.27 & 0.12 \\
RB+PP & 95.76 & 4.51 & 0.21 \\
IT+RB+P & 71.45 & 6.07 & 0.12 \\
P &
\end{tabular}

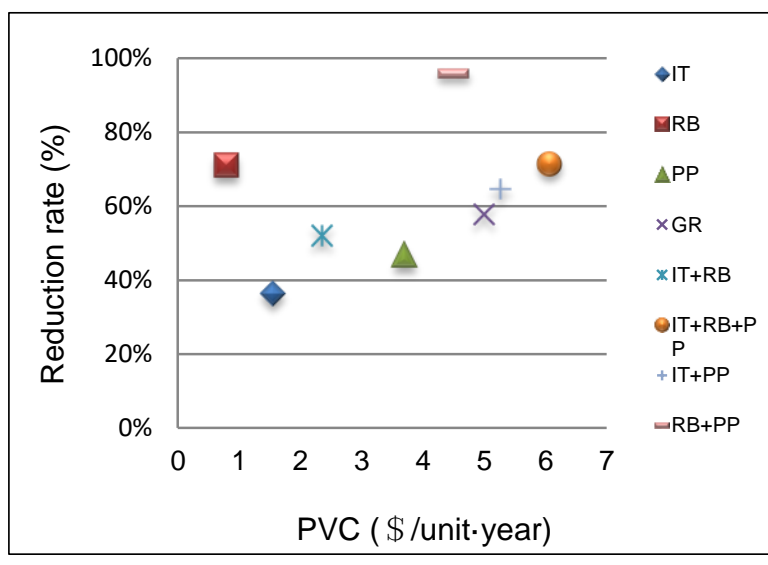

\section{References}

Baek S.-S., Choi D.-H., Jung J.-W., Lee H.-J., Lee H., Yoon K.-S. \& Cho K. H. 2015 Optimizing low impact development (LID) for stormwater runoff treatment in urban area, Korea: Experimental and modelling approach. Water Research,86, 122-131.

Dietz M. 2007 Low impact development practices: A review of current research and recommendations for future directions. Water, Air, \& Soil Pollution, 186, 351-363.

Dietz M.E. \& Clausen J.C. 2005 A field evaluation of rain garden flow and pollutant treatment. Water, Air, \& Soil Pollution, 167, 123-138.

Elliott A.H. \&Trowsdale S.A. 2007 A review of models for low impact urban stormwater drainage. Environmental Modelling \& Software,22, 394-405.

Keifer D.J. \& Chu H. H. 1957 Synthetic storm pattern for drainage design. Journal of the Hydraulics Division, 83(4), $1-25$.

Palla A. \&Gnecco I. 2015 Hydrologic modelling of low impact development systems at the urban catchment scale. Journal of Hydrology,528, 361-368.

Preissmann, A. 1961 Propagation of translatory waves in channels and rivers. In: Proc., 1st Congress of French Association for Computation, Grenoble, France, pp. 433-442.

Rossman L. A. \& Huber W. C. 2016Storm Water Management Model Reference Manual Volume I, Hydrology.https://nepis.epa.gov/Exe/ZyPDF.cgi?Dockey=P100NYRA.txt (accessed 21 June 2017)

Rossman, L. A. 2010 Modelling low impact development alternatives with SWMM. Journal of Water Management Modeling, 167-182.

Uda M., Van Seters T., Graham C. \& Rocha L. 2013 Evaluation of Life Cycle Costs for Low Impact Development Stormwater Management Practices. Sustainable Technologies Evaluation Program, Toronto and Region Conservation Authority, Toronto, Canada.

VogelJ. R., Moore T. L., Coffman R. R., Rodie S. N., Hutchinson S. L., McDonough K. R.\& McMaine J. T.20150 Critical review of technical questions facing low impact development and green infrastructure: A perspective from the Great Plains. Water Environment Research, 87(9), 849-862. 


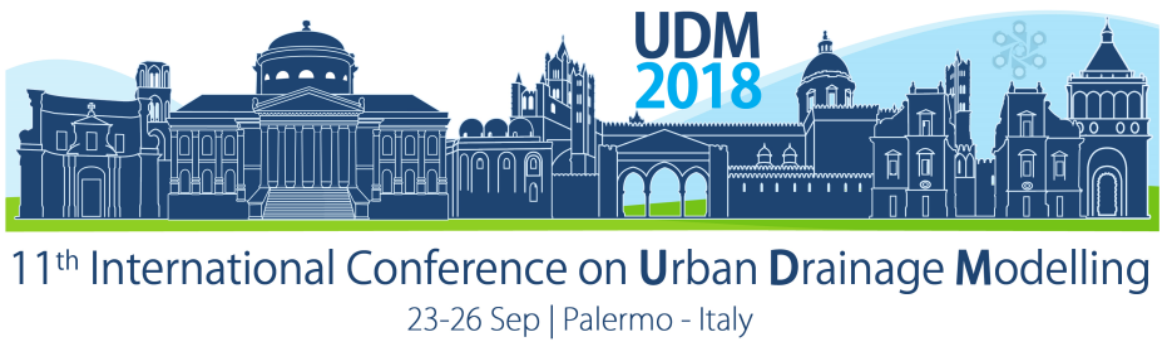

\title{
Metals potential removal efficiency of permeable pavement
}

\author{
Michele Turco ${ }^{1 \star}$, Giuseppe Brunetti ${ }^{2}$, Michele Porti ${ }^{1}$, Giovanna Grossi ${ }^{3}$, Mario Maiolo ${ }^{4}$ \& Patrizia Piro ${ }^{1}$ \\ ${ }^{1}$ University of Calabria, Department of Civil Engineering, Arcavacata di Rende, Italy \\ 2 University of California Davis, Department of Land, Air and Water Resources, Davis, California USA \\ ${ }^{3}$ University of Brescia, Department of Civil Engineering, Architecture, Environment, Mathematics, Brescia, Italy \\ ${ }^{4}$ University of Calabria, Department of Environment and Chemistry Engineering, Arcavacata di Rende, Italy
}

*michele.turco@unical.it

\begin{abstract}
Permeable Pavement (PP) represents a good solution to solve stormwater management problems both in quantitative and qualitative way. In this way, the potential removal efficiency of a permeable pavement in treating metals was assessed by performing a monitoring campaign at a lab-scale system constructed for the purpose. Based on literature experiences, different relatively high-level concentrations of Copper and Zinc were applied during 8 different synthetic rainfall events. Results shown that the removal rates of $\mathrm{Cu}$ and $\mathrm{Zn}$ of the lab-scale pavements range from $85 \%$ to $92 \%$ and from $65 \%$ to $82 \%$, respectively. Results also shown that the Cu removal rates of the lab-scale pavement are higher than $\mathrm{Zn}$ removal rate.
\end{abstract}

Keywords: stormwater treatment; metals; permeable pavement.

\section{INTRODUCTION}

Urbanization, consisting of replacing permeable areas with impermeable materials, prevent precipitation from infiltrating into native soil so leads to water quantity problems such as high peak flows and surface runoff volumes, and loss of groundwater recharge (Brunetti et. In addition, the increased surface runoff contains various pollutants and becomes a potential source of pollution for receiving water bodies (Chai et al., 2012; Davis et al., 2001). Types and concentrations of pollutants mainly depend on the land use. For example, in urban areas there are several mechanisms for depositing pollutants. These include the atmospheric pollutants buildup, direct application of some materials on the surface, fertilizers and pesticides, applications which are unintentional but a normal result of urban activity, such as oil drippings from motor vehicles. Several studies in the literature highlight that one of the main source of pollution of the residential areas is given by the traffic vehicles on the roads and one of the main pollutant site could be the car parks with different pollutants coming from the combustion processes of the motor vehicles or directly from the vehicles materials (Kumar et al., 2016; Sansalone et al., 2008). In this way, urban drainage traditional techniques, designed to collect stormwater in pipe and transport it away from urban areas in the shortest possible time, seem to be inadequate for the purpose. To mitigate the negative effects of urbanization, Low Impact Development systems (LID), an innovative stormwater management approach, have gained popularity. LID systems consist of a series of facilities whose purpose is to reproduce the site's pre-developed hydrological processes using design techniques that infiltrate, filter, store, evaporate, and detain runoff close to its source. These techniques usually do not require large capital investments, but rather a major commitment to maintenance. Among these techniques, 


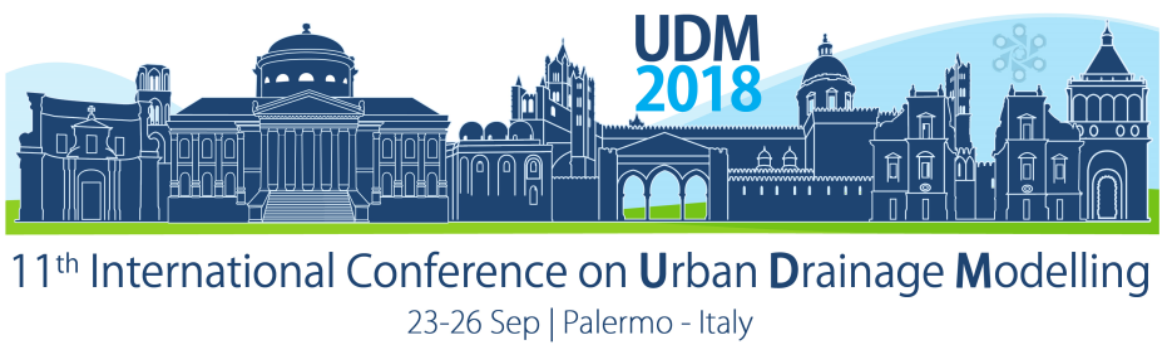

Permeable Pavement (PP) represents a good solution to solve stormwater management problems both in quantitative and qualitative terms (Brattebo and Booth, 2003; Kumar et al., 2016; Carbone et al., 2014). In this way, numerical analysis of these systems, related to quantity performances, have been widely investigated in the literature (Brunetti et al., 2018; Huang et al., 2016). In this work the first experimental results on metals removal efficiency of a lab-scale permeable pavement have been presented.

\section{MATERIALS AND METHODS}

In order to study the behaviour of a permeable pavement, the lab-scale test bed cited in the work of Turco et al. (2017) have been used. It consisted of a Plexiglas container (dimensions of the bottom $59 \times 59 \mathrm{~cm}$, height of $41 \mathrm{~cm}$ ) with a circular outlet in the centre of the bottom (diameter of $10 \mathrm{~cm}$ ) and layers of construction materials (Figure 1) for a total thickness of 41 $\mathrm{cm}$.

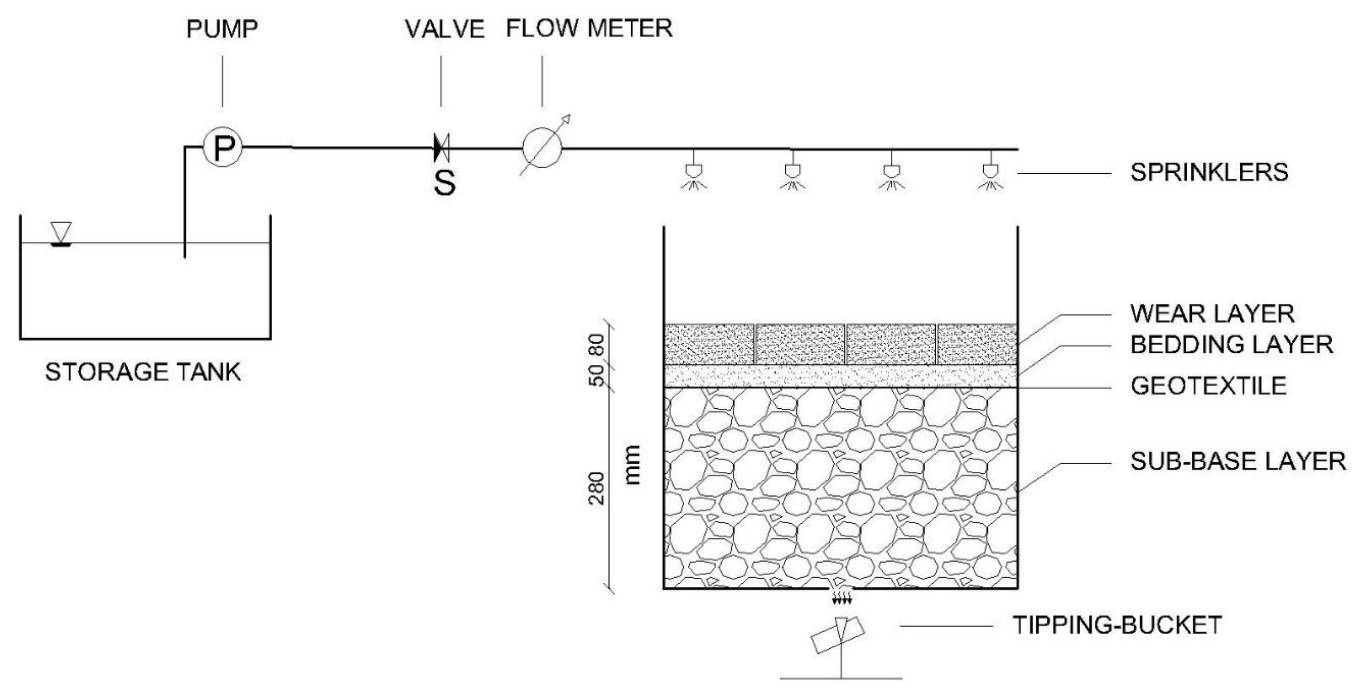

Figure 1. A schematic of the lab-scale permeable pavement system

The layer types and their construction thickness for the lab-scale porous modular pavement were chosen according to the CIRIA report (Kellagher et al., 2015), considering a traffic category of 3 (small car parks subject to cars, light vans and motorcycle access) and a California Bearing Ratio index (CBR) of $5 \%$ or greater. An analysis based on Life Cycle Assessment of pavement materials should be considered (Maiolo et al., 2017). The wear layer consists of porous concrete blocks characterized by high permeability. Sub-base and bedding layers were constructed following the suggestions of the Interlocking Concrete Pavement Institute (ICPI), which recommends some ASTM stone gradations. A fine gravel was considered as bedding layer while for the sub-base layer crushed stones have been used.

Rainfall intensity was regulated by a valve and the actual rainfall intensity was measured by a flow meter. Preferential flows along the test box side walls were prevented by sealing them. In urban areas, rains that deserve special attention are those of short duration such as subhourly. In this way, critical rainfall events occur in a very short time (Carbone et al., 2015). Given that, 8 irrigation events were simulated (Table 1). The Impervious/Pervious ratio reported in Table 1 represents the ratio of impervious run-on area to permeable pavement. It must be emphasized that the rainfall simulator was not able to reproduce variable precipitation patterns. Thus, a constant precipitation has been simulated in the laboratory. The hydraulic 


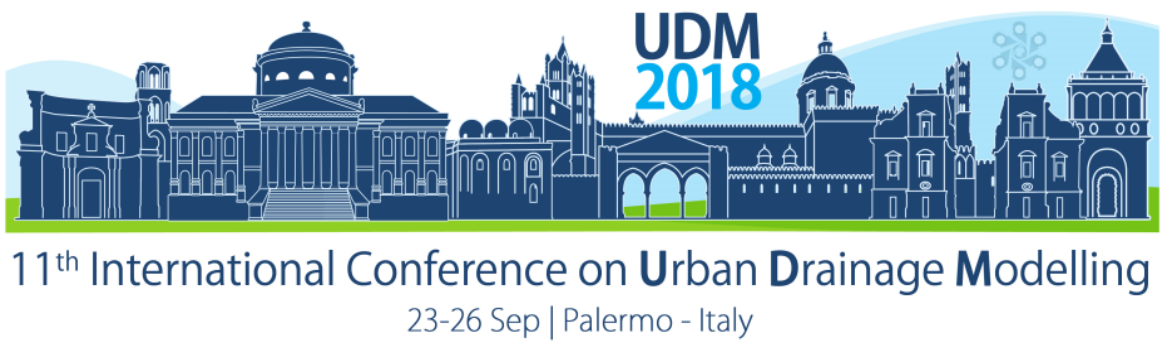

conductivity $K_{s}$ of the construction materials involved in the pavement were performed in the work of Turco et. Al (2017) and reported in Table 2.

Table 1. Characteristic of the rainfall events simulated during the experimental campaign

\begin{tabular}{lcccr}
\hline Rainfall events [-] & Duration [min] & Rainfall Intensity [mm/h] & Volume [l] & Impervious/Pervious \\
\hline Day 1 & 30 & 73.00 & 12.30 & $<5: 1$ \\
Day 2 & 30 & 64.00 & 10.70 & $<5: 1$ \\
Day 3 & 30 & 66.00 & 11.10 & $<5: 1$ \\
Day 4 & 15 & 85.60 & 7.20 & $<5: 1$ \\
Day 5 & 15 & 95.10 & 8.00 & $<5: 1$ \\
Day 6 & 15 & 71.90 & 6.05 & $<5: 1$ \\
Day 7 & 30 & 69.60 & 11.70 & $<5: 1$ \\
Day 8 & 30 & 69.00 & 11.60 & $<5: 1$ \\
\hline
\end{tabular}

Table 2. Hydraulic conductivity of the construction materials

\begin{tabular}{lc}
\hline Layer & $\mathrm{K}_{\mathrm{s}}\left[\mathrm{cm} \mathrm{min}^{-1}\right]$ \\
\hline Porous concrete blocks & 1.56 \\
Fine gravel & 69.27 \\
Crushed Stones & 96.70 \\
\hline
\end{tabular}

Water quality performance of the permeable pavement was assessed by spraying two dissolved metals (Copper and Zinc) on the laboratory pavement surface during 8 synthetic rainfall events. In actual situations, besides the dissolved metal load, there would be also the particulate fraction load generally exceeding the former one (Huber et al., 2016). The pavement response to the dissolved Zinc and Copper loads was analyzed by comparing the inflow (in) and outflow concentrations (out).

The concentrations of the metals ( $\mathrm{Cu}$ and $\mathrm{Zn}$ ) applied to the PP were based on relatively high-level concentrations in stormwater runoff recommended by Reddy et al. (2014). The concentrations and the sources of chemicals used to prepare synthetic stormwater were 5-15 $\mathrm{mg} / \mathrm{L}$ of dissolved $\mathrm{Cu}$ using $\mathrm{Cu}(\mathrm{SO})_{4}$, and 6-15 mg/L of $\mathrm{Zn}$ using $\left.\mathrm{Zn}\left(\mathrm{CH}_{3} \mathrm{COO}\right)_{2} 2 \mathrm{H}_{2} \mathrm{O}\right)$. It was recognized that the concentrations of dissolved $\mathrm{Cu}$ and $\mathrm{Zn}$ used were rather high but deemed acceptable in these experiments considering the preliminary nature of the investigations, limitations of the available laboratory analytical equipment, and a higher likelihood of obtaining measurable concentrations when working at higher levels.

\section{RESULTS AND DISCUSSION}

During the experiments, the outflow from the pavement have been collected. The samples were taken into flasks of $50 \mathrm{ml}$ with a one-minute frequency then placed in a laboratory centrifuge in order to separate any solids particles inside then filtered through the $0.450 \mu \mathrm{m}$ filter paper and finally the concentration of the samples was measured by using the Atomic Absorption Spectrophotometer (AAS). Before each measurement campaign, the AAS has always been calibrated by measuring some standard solutions prepared for this purpose.

Figure 2 describes the removal efficiency of Copper and Zinc of the permeable pavement under several inflow concentrations. As concentration outflow for each pollutant was considered the maximum value in the outflow, while inflow was constant rate. 


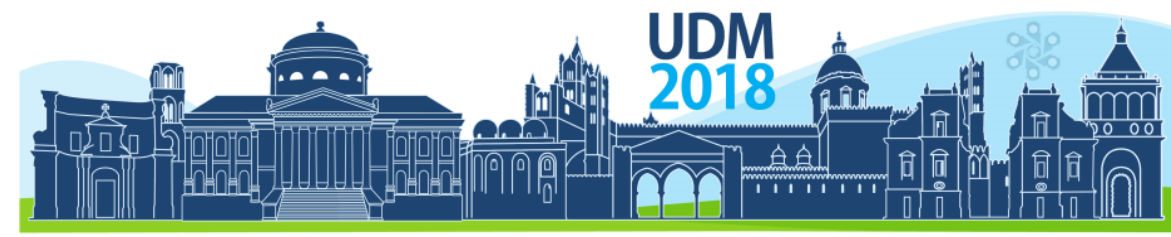

$11^{\text {th }}$ International Conference on Urban Drainage Modelling

23-26 Sep | Palermo - Italy

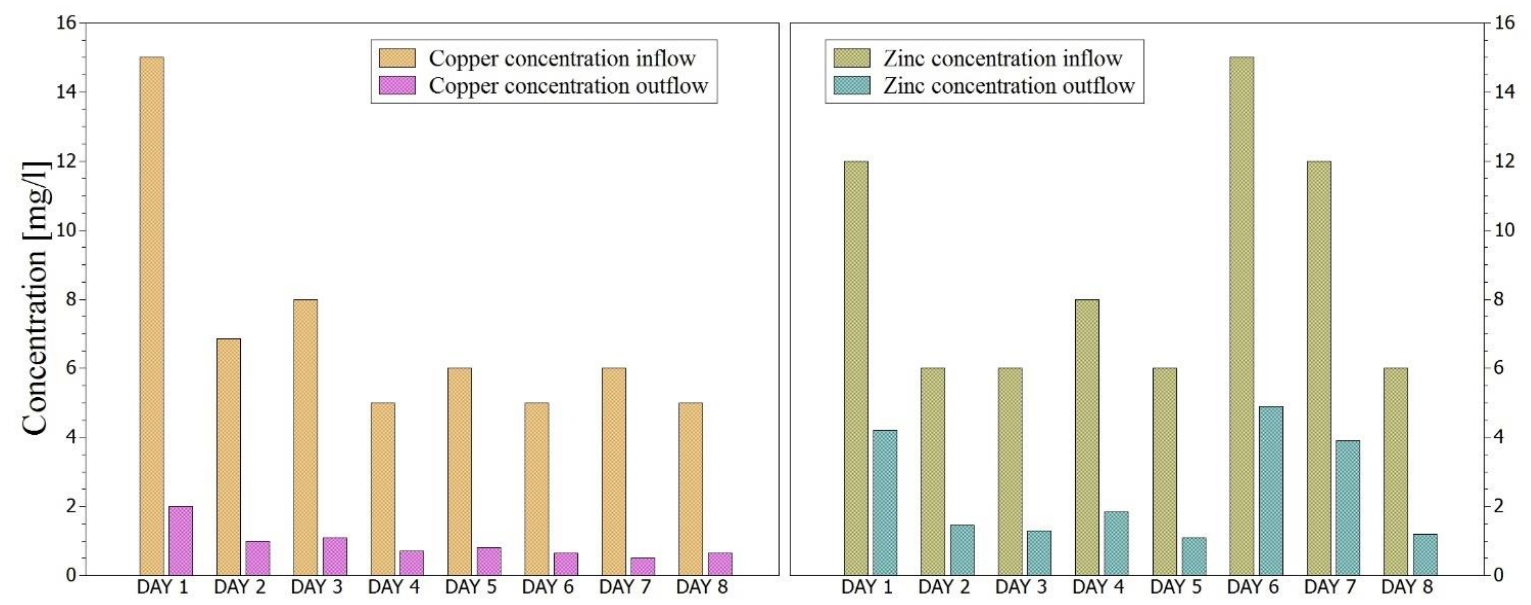

Figure 2. Removal efficiency of the lab-scale system

Results shown that the removal rates of $\mathrm{Cu}$ and $\mathrm{Zn}$ of the lab-scale pavements range from $85 \%$ to $92 \%$ and from $65 \%$ to $82 \%$, respectively (Table 3 ) and also shown that the Cu removal rates of the lab-scale pavement are higher than $\mathrm{Zn}$ removal rate.

Table 3. Metals removal rates from lab-scale system

\begin{tabular}{lcccccc}
\hline Rainfall events [-] & $\mathrm{Cu}_{\text {in }}[\mathrm{mg} / \mathrm{l}]$ & $\mathrm{Cu}_{\text {out }}[\mathrm{mg} / \mathrm{l}]$ & $\mathrm{Zn}$ in $[\mathrm{mg} / \mathrm{l}]$ & $\mathrm{Zn}_{\text {out }}[\mathrm{mg} / \mathrm{l}]$ & $\% \mathrm{Cu}$ & $\% \mathrm{Zn}$ \\
\hline DAY 1 & 15.00 & 2.00 & 12.00 & 4.20 & 86.67 & 65.00 \\
DAY 2 & 6.85 & 1.00 & 6.00 & 1.45 & 85.40 & 75.83 \\
DAY 3 & 8.00 & 1.10 & 6.00 & 1.30 & 86.25 & 78.33 \\
DAY 4 & 5.00 & 0.70 & 8.00 & 1.85 & 86.00 & 76.88 \\
DAY 5 & 6.00 & 0.80 & 6.00 & 1.10 & 86.67 & 81.67 \\
DAY 6 & 5.00 & 0.65 & 15.00 & 4.90 & 87.00 & 67.33 \\
DAY 7 & 6.00 & 0.50 & 12.00 & 3.90 & 91.67 & 67.50 \\
DAY 8 & 5.00 & 0.65 & 6.00 & 1.20 & 87.00 & 80.00 \\
\hline
\end{tabular}

\section{CONCLUSIONS}

This work tried to improve knowledge on the water quality performance of a permeable pavements in order to justify the feasibility of the use of this systems to stormwater management. The work included the application of experimental and laboratory techniques. A lab-scale experimental facility was used as case study to investigate the behavior of the pavement to treat metals. Overall, experiments confirmed the potential of this systems to treat metals.

\section{References}

Brattebo, B.O., Booth, D.B., 2003. Long-term stormwater quantity and quality performance of permeable pavement systems. Water Res. 37, 4369-4376. doi:10.1016/S0043-1354(03)00410-X

Brunetti, G., Šimůnek, J., Turco, M., Piro, P., 2018. On the use of global sensitivity analysis for the numerical analysis of permeable pavements. Urban Water J. 15, 269-275. 


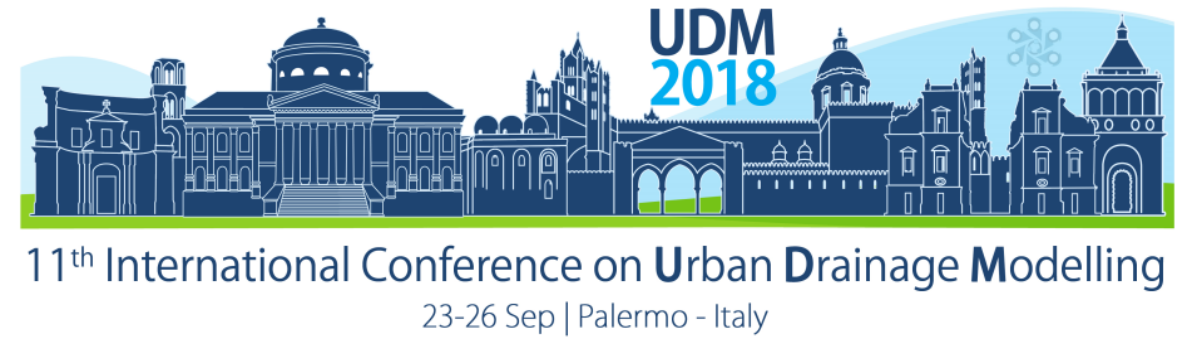

doi:10.1080/1573062X.2018.1439975

Chai, L., Kayhanian, M., Givens, B., Harvey, J.T., Jones, D., 2012. Hydraulic Performance of Fully Permeable Highway Shoulder for Storm Water Runoff Management. J. Environ. Eng. 138, 711722. doi:10.1061/(asce)ee.1943-7870.0000523

Carbone, M., Turco, M., Nigro, G., Piro, P., 2014. Modeling of hydraulic behaviour of green roof in catchment scale, in: 14th SGEM GeoConference on Water Resources. Forest, Marine And Ocean Ecosystems. p. 471-478 pp. doi:10.5593/SGEM2014/B31/S12.061

Carbone, M., Turco, M., Brunetti, G., Piro, P., 2015. A Cumulative Rainfall Function for Subhourly Design Storm in Mediterranean Urban Areas. Adv. Meteorol. 2015, 1-10. doi:10.1155/2015/528564

Davis, A.P., Shokouhian, M., Ni, S., 2001. Loading estimates of lead, copper, cadmium, and zinc in urban runoff from specific sources. Chemosphere 44, 997-1009. doi:10.1016/S00456535(00)00561-0

Huang, J., He, J., Valeo, C., Chu, A., 2016. Temporal evolution modeling of hydraulic and water quality performance of permeable pavements. J. Hydrol. 533, 15-27. doi:10.1016/j.jhydrol.2015.11.042

Huber, M., Welker, A., Helmreich, B., 2016. Critical review of heavy metal pollution of traffic area runoff: Occurrence, influencing factors, and partitioning. Sci. Total Environ. doi:10.1016/j.scitotenv.2015.09.033

Kellagher, R., Martin, P., Jefferies, C., Bray, R., Shaffer, P., Wallingford, H.R., Woods-Ballard, B., Woods Ballard, B., Construction Industry Research and Information Association, Great Britain, Department of Trade and Industry, Environment Agency, 2015. The SUDS manual, Ciria, .... doi:London $\mathrm{C} 697$

Kumar, K., Kozak, J., Hundal, L., Cox, A., Zhang, H., Granato, T., 2016. In-situ infiltration performance of different permeable pavements in a employee used parking lot - A four-year study. J. Environ. Manage. 167, 8-14. doi:10.1016/j.jenvman.2015.11.019

Maiolo, M., Carini, M., Capano, G., Piro, P., 2017. Synthetic sustainability index (SSI) based on life cycle assessment approach of low impact development in the Mediterranean area. Cogent Eng. 4. doi:10.1080/23311916.2017.1410272

Reddy, K.R., Xie, T., Dastgheibi, S., 2014. Removal of heavy metals from urban stormwater runoff using different filter materials. J. Environ. Chem. Eng. 2, 282-292. doi:10.1016/j.jece.2013.12.020

Sansalone, J., Kuang, X., Ranieri, V., 2008. Permeable Pavement as a Hydraulic and Filtration Interface for Urban Drainage. J. Irrig. Drain. Eng. 134, 666-674. doi:10.1061/(ASCE)07339437(2008)134:5(666)

Turco, M., Kodešová, R., Brunetti, G., Nikodem, A., Fér, M., Piro, P., 2017. Unsaturated hydraulic behaviour of a permeable pavement: Laboratory investigation and numerical analysis by using the HYDRUS-2D model. J. Hydrol. 554, 780-791. doi:10.1016/j.jhydrol.2017.10.005 


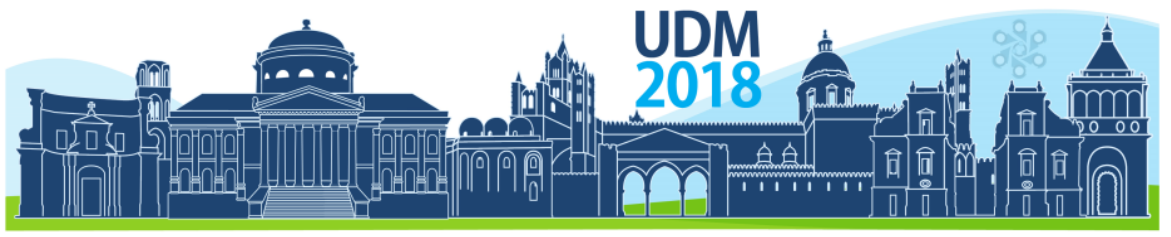

$11^{\text {th }}$ International Conference on Urban Drainage Modelling

23-26 Sep | Palermo - Italy

\title{
Comparison of cost benefits of new installation and retrofitted rainwater harvesting systems for commercial buildings
}

\author{
Nor Hafizi Md Lani ${ }^{1}$, Achmad Syafiuddin ${ }^{1,2}$ and Zulkifli Yusop ${ }^{1,2}$ \\ ${ }^{1}$ Department of Water and Environmental Engineering, Faculty of Civil Engineering, \\ Universiti Teknologi Malaysia, 81310 UTM Johor Bahru, Johor, Malaysia \\ ${ }^{2}$ Centre for Environmental Sustainability and Water Security (IPASA), Research Institute for Sustainable \\ Environment, Faculty of Civil Engineering, Universiti Teknologi Malaysia, 81310 UTM Johor Bahru, Johor, \\ Malaysia \\ authors' addresses: udenfisika@gmail.com (A.S); zulyusop@utm.my (Z.Y)
}

\begin{abstract}
This paper aims to evaluate cost benefits of new installation and retrofitted rainwater harvesting system (RWHS) for commercial building. The selected commercial building is AEON Taman Universiti, Johor, Malaysia. Daily rainfall data were obtained from the Senai International Airport station. The mass balance model was adopted for the simulation approach. Several economic parameters, namely, net present value (NPV), return on investment $(\mathrm{ROI})$, and benefit-cost ratio $(\mathrm{BCR})$ are used for the evaluation. Maximum NPV, BCR, and ROI of the new installation RWHS are 1.9, 1.5, and 5.5 times higher, respectively, than those of the retrofitted RWHS. It is concluded that new installation RWHS provides more economic benefits compared to the retrofitted RWHS.
\end{abstract}

Keywords: Rainwater harvesting; Economic benefits; Rainfall

\section{INTRODUCTION}

Rainwater harvesting system (RWHS) is a promising technique that is widely implemented to provide an alternative water resource for potable and non-potable uses. It is well established that the system has many benefits including economic, environment, and technology. For instance, annual domestic cost savings of up to $\$ 240$ per house can be obtained when the system was installed in residential area in Australia (Tam et al., 2010). In addition, the implementation of RWHS in South Korea was found to have capability to reduce the flood up to $10 \%$ (Kim and Yoo, 2009). RWHS can also be used to delay the development of a new storage infrastructure because of its ability to reduce the dependency on domestic water supply (Coombes et al., 2002). Recently, the performance of urban RWHS was also evaluated for different major cities of Bangladesh (Bashar et al., 2018). Their study found that the payback periods for the proposed system were from 2 to 6 years with up to $40 \%$ reliabilities depending on the considered variables and climatic conditions.

Although RWHS provides many benefits, it also still has challenges due to high installation cost, high maintenance cost, and poor public acceptance. Therefore, an optimum RWHS design is highly beneficial to maximize the benefits by reducing the material construction cost. The minimum installation cost can also be achieved by the material selection. Designing RWHS by the gravity flow can be implemented to reduce the operation and maintenance cost compared to that system with pumping operation. Alternatively, providing subsidies and rebates by government are encouraged to promote RWHS in wider scales. Moreover, training and awareness campaigns can be carried out to encourage the interest of the community. 


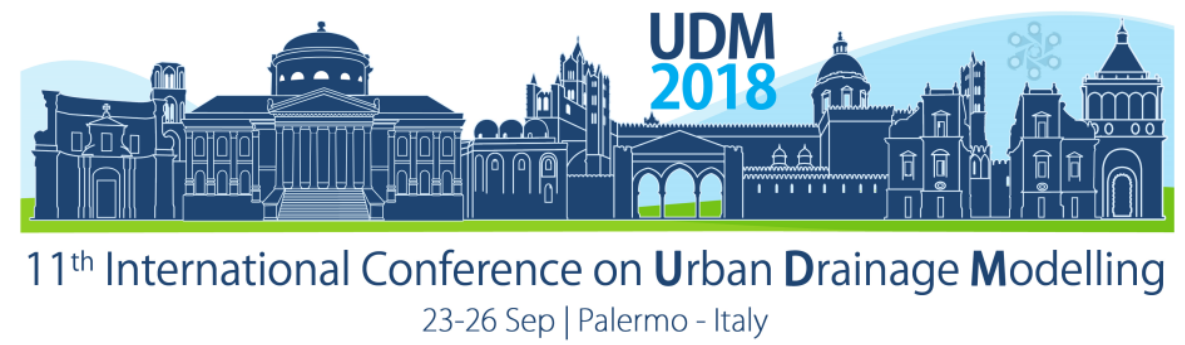

Recently, the implementation of RWHS for commercial buildings is widely reported in the scholarly literatures (Chilton et al., 2000; Foo et al., 2017; Matos et al., 2015). Since commercial buildings provide higher roof area, higher water consumption, and higher water tariff, the benefits of RWHS for commercial buildings are more rewarding compared to small installations for houses. However, there is still debatable to install RWHS in the early during the design and construction phase or after construction of commercial buildings. A recommendation was proposed that the benefits of RWHS are more attractive when it is installed early during the design and construction phase as opposed to the high retrofitting cost (Hafizi Md Lani et al., 2018).

Therefore, this study aims to evaluate cost benefits of new installation and retrofitted RWHS for commercial building. The selected commercial building in this study is AEON Taman Universiti, Johor, Malaysia. In the simulation approach, the mass balance model was adopted (Su et al., 2009).

\section{MATERIALS AND METHODS}

\subsection{Description of the selected commercial building}

The selected building is AEON Taman Universiti (1³2'33.1"N 1033ㄱ'44.1"E). AEON Taman Universiti is a shopping mall in Johor Bahru, Johor, Malaysia.

\subsection{Rainfall characteristics}

Daily rainfall data from 1975 to 2008 are obtained from the Senai International Airport station $\left(1^{\circ} 38^{\prime} 17.2^{\prime \prime} \mathrm{N} 103^{\circ} 40^{\prime} 10.3^{\prime \prime} \mathrm{E}\right)$. Potential rainwater harvested was estimated using the following equation:

$$
P R H=A_{R T} \times R C \times R I
$$

where $P R H$ is the potential rainwater harvesting $\left(\mathrm{m}^{3}\right), A$ is the area of the rooftop $\left(\mathrm{m}^{2}\right), R C$ is the runoff coefficient $(-)$, and $R I$ is the daily rainfall $(\mathrm{m})$.

\subsection{Simulation model}

The mass balance model for the storage capacity was adopted for this simulation (Su et al., 2009). The model can be expressed mathematically as:

$$
R_{t}=\left\{\begin{array}{lll}
D_{t} & \text { if } & W I_{t}+W S_{t-1} \geq D_{t} \\
W I_{t}+W S_{t-1} & \text { if } & W I_{t}+W S_{t-1}<D_{t}
\end{array}\right.
$$

$R_{t}$ is the daily release $\left(\mathrm{m}^{3}\right), D_{t}$ is the daily demand $\left(\mathrm{m}^{3}\right), W I$ is the inflow $\left(\mathrm{m}^{3}\right)$, and $W S_{t-1}$ is the tank storage at the end of the preceding day $\left(\mathrm{m}^{3}\right)$.

\subsection{Economic parameter evaluations}

Net present value (NPV), return on investment (ROI), and benefit-cost ratio $(B C R)$ were estimated (Morales-Pinzón et al., 2014). These parameters can be expressed as:

$$
N P V=\sum_{t=0}^{s} \frac{S_{t} P_{t}-I_{t}-M_{t}}{(1+r)^{t}}
$$




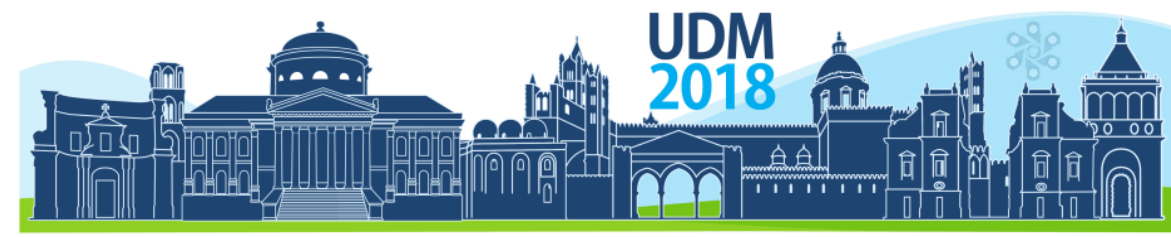

$11^{\text {th }}$ International Conference on Urban Drainage Modelling

23-26 Sep | Palermo - Italy

$$
\begin{gathered}
R O I=\frac{\sum_{t=0}^{s} S_{t} P_{t}-I_{t}-M_{t}}{\sum_{t=0}^{s} I_{t}+M_{t}} \\
B C R=\frac{\sum_{t=0}^{s} \frac{S_{t} P_{t}}{(1+r)^{t}}}{\sum_{t=0}^{s} \frac{I_{t}+M_{t}}{(1+r)^{t}}}
\end{gathered}
$$

where $S_{t}$ is the volume of water saved over a period of time $t\left(\mathrm{~m}^{3}\right), P_{t}$ is the cost of water over a period of time $t\left(\mathrm{RM} / \mathrm{m}^{3}\right), I_{t}$ is the investment required for a period of time $t(\mathrm{RM}), M_{t}$ is the maintenance costs over a period of time $t(\mathrm{RM}), s$ is the system life span (year), $t$ is the system operation period (year), and $r$ is the interest rate (\%).

The operational cost was estimated using the following equation:

$$
O C=\frac{W s}{P F S} P_{E} E_{t}
$$

where $O C$ is the annual operation cost (RM), $W s$ is the water saved $\left(\mathrm{m}^{3}\right), P F S$ is the pump flow speed $\left(\mathrm{m}^{3} / \mathrm{hr}\right), P_{E}$ is the pump energy $(\mathrm{kWH})$, and $E_{t}$ is the electricity tariff $(\mathrm{RM} / \mathrm{kWH})$. In this analysis, PFS and $P_{E}$ used are decided to be $30 \mathrm{~m}^{3} / \mathrm{hr}$ and $2.2 \mathrm{kWH}$.

The initial investment was assumed to be obtained from a loan. Hence, annual year-end payment (annuity) needed to be paid is estimated using the following equation:

$$
A_{y p}=I_{n v}\left[\frac{r(1+r)^{t}}{(1+r)^{t}-1}\right]
$$

where $A_{y p}$ is the annual year-end payment (RM), $I_{n v}$ is the investment (RM), $r$ is the interest rate (\%), and $t$ is the time (year). Moreover, the optimum tank sizes are determined from the maximum BCR and ROI, which basically give the highest benefit. In general, other parameters for this simulation are roof area, daily water consumption, water tariff, length of pipe, cost of pump, runoff coefficient, cost of tank, cost of pipe, maintenance cost, retrofitting cost, electricity tariff, average interest rate, water tariff, replacement of tank, replacement of pump, and life

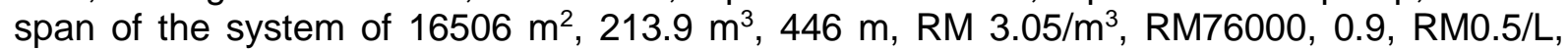
RM24.1/m, RM133/month, RM4000/pipe, $0.43 \mathrm{RM} / \mathrm{kWH}, 4.25 \%$, RM3.05/ $\mathrm{m}^{3}$, after 20 years, after 10 years, and 30 years, respectively.

\section{RESULTS AND DISCUSSION}

Fig. 1 shows comparison of NPV, BCR, and ROI between new installation and retrofitted RWHS for the present commercial building under different tank sizes. NPVs for new installation and retrofitted RWHS range from RM3900 to RM10000 and RM-818 to RM5200, respectively. At the optimum tank size, NPV for new installation RWHS was 1.9 times higher than that value of retrofitted RWHS. Retrofitted RWHS has negative NPVs for tank size ranging from $100 \mathrm{~m}^{3}$ to $118 \mathrm{~m}^{3}$ as shown in Fig. 1(a). Interestingly, new installation RWHS provides positive NPVs for all proposed tank sizes. 


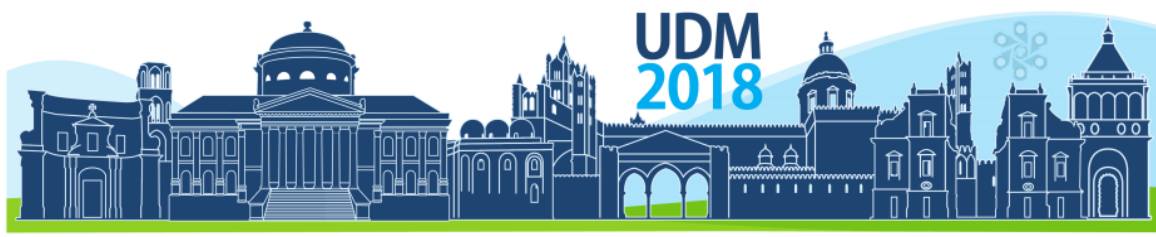

$11^{\text {th }}$ International Conference on Urban Drainage Modelling

23-26 Sep | Palermo - Italy

Comparison of BCR for new installation and retrofitted RWHS is shown in Fig. 1(b). It is found that the values are in the range of 1.24 to 2.11 and 0.91 to 1.34 for new installation and retrofitted RWHS, respectively. These findings revealed that new installation RWHS provided BCR values above 1 for all simulated tank sizes.

In addition, comparison of ROI between new installation and retrofitted RWHS is depicted in Fig. 1(c). It can be observed that -0.02 to 0.55 and -0.25 to 0.10 of $\mathrm{ROI}$ values for new installation and retrofitted RWHS were obtained, respectively. At the optimum tank size, BCR and $\mathrm{ROI}$ for the new installation RWHS are 1.5 and 5.5 times higher than those values of the retrofitted RWHS. In general, findings from this work provide evidences that the new installation RWHS are more attractive compared to the retrofitted RWHS. This is in agreement with the recommendation from the previous work proposing that the installation of RWHS for commercial building has more benefits if the system is installed early during the design and construction phase for opposing high retrofitting cost (Hafizi Md Lani et al., 2018).
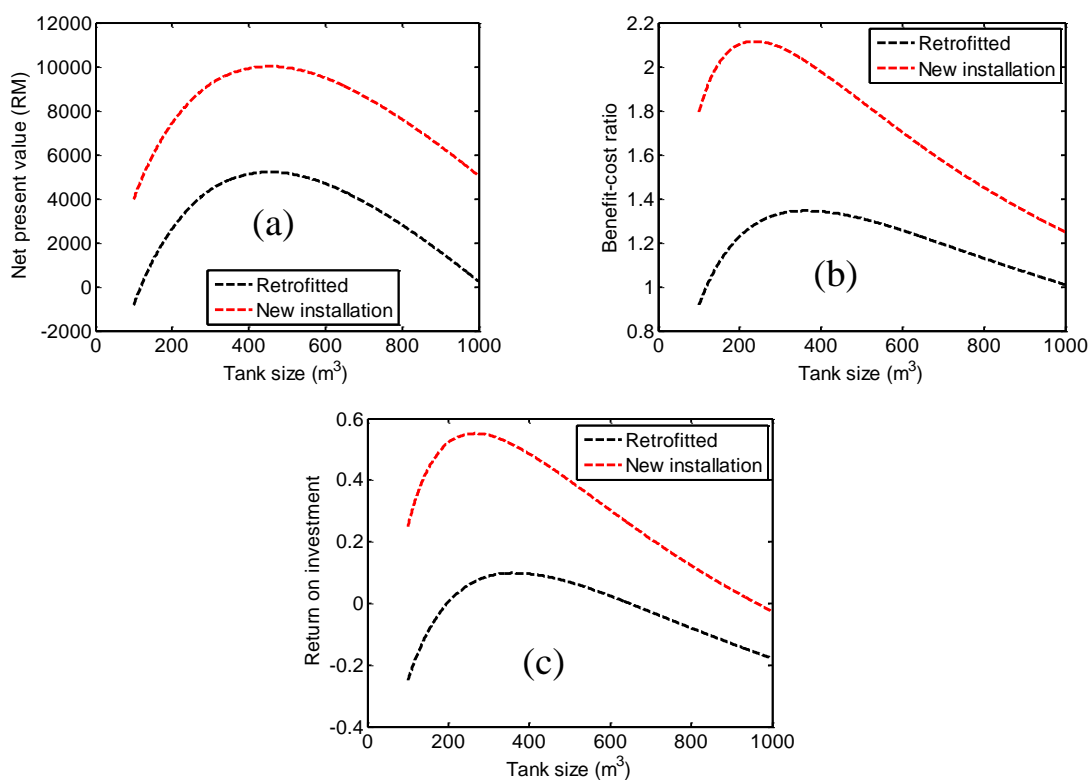

Fig. 1 (a) NPV, (b) BCR, and (c) ROI of new installation and retrofitted RWHS for the present commercial building.

\section{CONCLUSIONS}

The aim of this study was to evaluate cost benefits of new installation and retrofitted RWHS for commercial building. Up to RM10000 and RM5200 of NPV can be obtained for new installation and retrofitted RWHS, respectively. In addition, BCR values above 1 for all simulated tank sizes can be only achieved when the new installation RWHS was selected. Moreover, up to 0.55 and 0.10 of ROI values for new installation and retrofitted RWHS can be obtained, respectively. At the optimum tank size, it was found that NPV, BCR, and ROI of the new installation RWHS are 1.9, 1.5, and 5.5 times higher, respectively, than those values of the retrofitted RWHS. In general, the new installation RWHS provides more economic benefits compared to the retrofitted RWHS. This study recommends that RWHS for commercial building are encouraged to be installed early during the design and construction phase. 


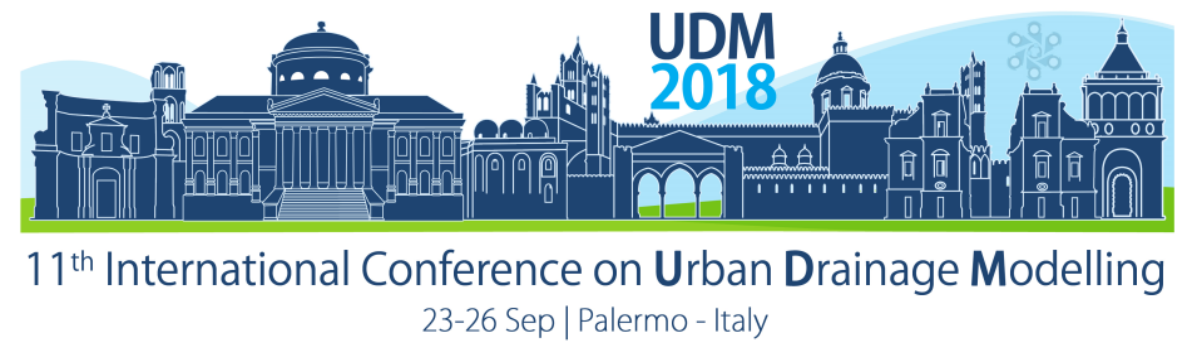

\section{References}

Bashar, M.Z.I., Karim, M.R., Imteaz, M.A. (2018) Reliability and economic analysis of urban rainwater harvesting: A comparative study within six major cities of Bangladesh. Resour. Conserv. Recycl. 133 (6), 146-154.

Chilton, J.C., Maidment, G.G., Marriott, D., Francis, A., Tobias, G. (2000) Case study of a rainwater recovery system in a commercial building with a large roof. Urban Water 1 (4), 345-354.

Coombes, P.J., Kuczera, G., Kalma, J.D., Argue, J.R. (2002) An evaluation of the benefits of source control measures at the regional scale. Urban water 4 (4), 307-320.

Foo, S.W., Mah, D.Y.S., Ayu, B.E. (2017) Modelling rainwater harvesting for commercial buildings. Water Pract. Technol. 12 (3), 698-705.

Hafizi Md Lani, N., Yusop, Z., Syafiuddin, A. (2018) A review of rainwater harvesting in Malaysia: Prospects and challenges. Water 10 (4), 1-21.

Kim, K., Yoo, C. (2009) Hydrological modeling and evaluation of rainwater harvesting facilities: Case study on several rainwater harvesting facilities in korea. J. Hydrol. Eng. 14 (6), 545-561.

Matos, C., Bentes, I., Santos, C., Imteaz, M., Pereira, S. (2015) Economic analysis of a rainwater harvesting system in a commercial building. Water Resour. Manag. 29 (11), 3971-3986.

Morales-Pinzón, T., Lurueña, R., Gabarrell, X., Gasol, C.M., Rieradevall, J. (2014) Financial and environmental modelling of water hardness - Implications for utilising harvested rainwater in washing machines. Sci. Total Environ. 470-471 (Supplement C), 12571271.

Su, M.-D., Lin, C.-H., Chang, L.-F., Kang, J.-L., Lin, M.-C. (2009) A probabilistic approach to rainwater harvesting systems design and evaluation. Resour. Conserv. Recycl. 53 (7), 393-399.

Tam, V.W.Y., Tam, L., Zeng, S.X. (2010) Cost effectiveness and tradeoff on the use of rainwater tank: An empirical study in Australian residential decision-making. Resour. Conserv. Recycl. 54 (3), 178-186. 


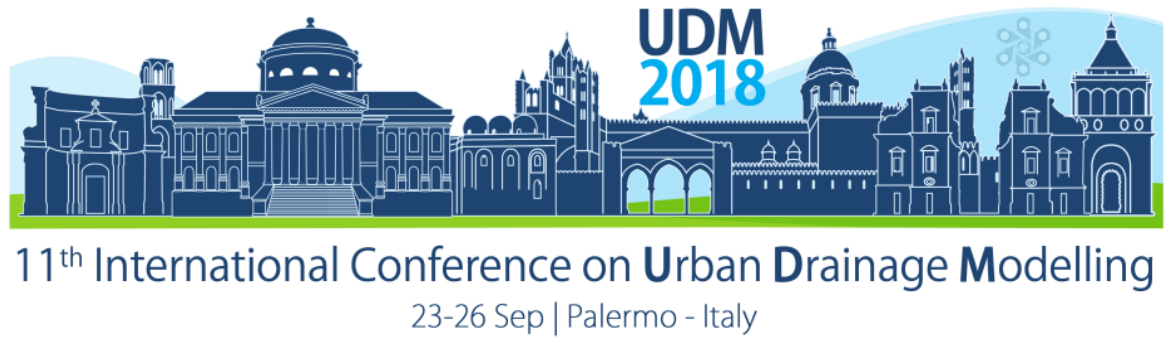

\title{
Study on the Evaluation Methods for Drainage System of Ancient Buildings
}

\author{
Jun $\mathrm{Li}^{1}$, Shaoqin Zhang ${ }^{2}$ and Shan $\mathrm{Wu}^{3}$ \\ 1.2.3 College of Civil Engineering, Beijing University of Technology, Beijing, China \\ (100 Pingleyuan Chaoyang Beijing, 100124, China)
}

\begin{abstract}
Ancient buildings have important historical and cultural value, whose rainwater drainage systems play an important role to control the discharge of rainwater and protect the environment. In order to apply modern techniques and methods to evaluate the healthy degree of ancient buildings' drainage system, as well as establish a scientific and reasonable evaluation system, the comprehensive evaluation methods for the channel drainage system were explored and carried out, with taking a certain ancient building area as a pilot. The data for evaluation was based on survey. First, the structural defects and functional defects of the channels were evaluated. And then, based on SWMM, the operation of this regional drainage system was simulated under the special rainfall conditions. The assessment results have provided a strong support for repairing and reconstructing the drainage ditches in this pilot area. And those evaluation methods for the ancient buildings' drainage system are reasonable and effective enough to reference.
\end{abstract}

Keywords: Ancient buildings; Drainage system; Simulation calculus

\section{INTRODUCTION}

Owing to its great value, protecting ancient buildings has a high requirement. As one of the most critical infrastructure, the drainage systems need to have a healthy structure and efficient drainage capacity to minimize the risk of waterlogging. After several dynasties' change, expansion or repair work, integrity of the drainage system information has been lacked. For instance, part of the paths are unclear now, and coupled with changes in geological conditions and other factors, scientific assessment is necessary.

Combined with modern scientific testing methods and computer technology, a set of scientific assessment methods in ancient drainage system was explored. It is both a scientifictechnological progress and cultural significant work to detect and present the drainage ditches overtly or covertly, vertical and horizontal.

Taking a Case study area, with the obtained preliminary drainage channel information and referring to the relevant technical standards of urban drainage system, the evaluation criteria for structural and functional defects in this study area were put forward. At the same time, by using the hydraulic model and setting different conditions, the operations of the channel system were simulated to assess the drainage capacity. Based on above evaluation and analysis results, a strong basis for the repair and maintenance of the drainage channels in this region can be provided.

\section{RESEARCH EXAMPLE AND METHODS}

\subsection{Regional Overview}

The study area is located in Beijing, about 4.372 ha. Its rainwater drainage system can be 


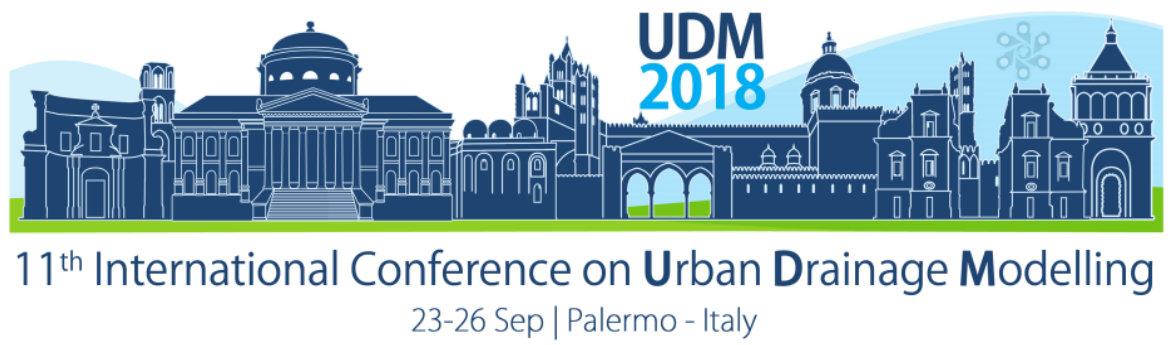

divided into ditches, covered gutters and underground drain. Due to the intertwined-hidden underground ditches, it is still hard to implement a comprehensive survey. Therefore, in the course of this research project, through literature reading and data collection, combined with field reconnaissance to obtain basic situation of the whole drainage system. Finishing the survey, the information of 60 conduits was gathered.

\subsection{Defect evaluation}

According to the data such as drawings, photographs and video clips provided by survey, study and determine the actual state of these channels. Referring to modern technical regulations, it was divided into structural defect and functional defect (CN-CJ 2012). Propose the general classification of defects in the actual state, determine the including respective types, and put forward the scoring criteria. Defect levels and rating methods were defined by scoring points, and the two kinds of defects are evaluated comprehensively, which can provide the basis for repair and maintenance. Defects can be divided into 6 items base on survey, to classify the defect levels and give a reasonable score for each item.

\subsection{Assessment of drainage capacity based on model}

The model based on SWMM of this area was established. Considering return periods and whether a channel is in a good condition, 16 kinds of working conditions were designed for simulation in Table 1. Full flow rate is a common index in drainage capacity evaluation (Yuan 2013). In this study, the regional rainwater drainage system capacity was judged by both of return periods and full flow rate.

As follows, Figure 1 shows the overload percentages (full flow rate) of important/ secondary channels in each return period under ideal conditions; Figure 2 shows the overload percentages of important channels in each return period under ideal/ defective conditions.

\section{RESULTS AND DISCUSSION}

1) In important channels, the proportion of class I accounts for the highest in structural defects, II and III occupy a large proportion; I and III are main in functional defects, then followed by II and IV.

2) In secondary channels, class II is the maximum in the ratio, I and III also occupy a large proportion in structural defects; for functional defects, class I is absolutely of the most proportion, then followed by II and III, with rarely existing IV.

3) From the full flow rate of all channels, there is a large difference among important channels, while nearly half of secondary channels have not been full ever. It suggests that after the rainwater drainage system was divided into important channels and secondary channels, there is a certain degree of mismatch respectively in the two categories when they work.

4) In ideal conditions, the proportions of the important channels are always less than that of secondary channels. For secondary channels, there is a larger overload proportion, but a little change with the increasing return periods. When the return period is small, overloading does not occur in important channels. 
Proceedings of the 11th Int. Conference on Urban Drainage Modelling, 23-26 Sep. 2018, Palermo (ITALY). Ed. prof. Giorgio Mannina

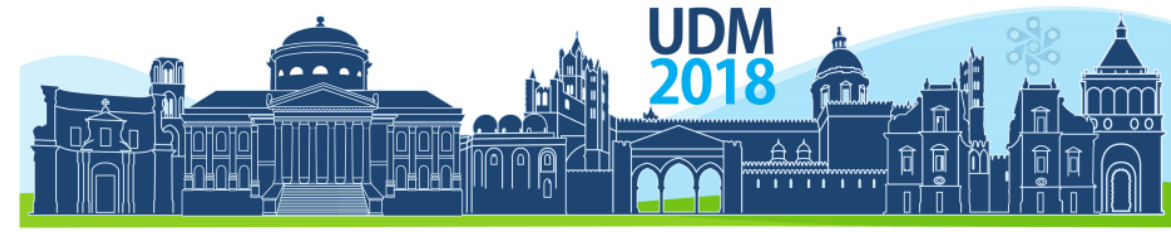

$11^{\text {th }}$ International Conference on Urban Drainage Modelling

23-26 Sep | Palermo - Italy

Table 1. 16 simulation conditions.

\begin{tabular}{cc|cc}
\hline Code & working condition & Code & working condition \\
\hline 1 & $2-s$ & 9 & $2-y$ \\
2 & $5-s$ & 10 & $5-y$ \\
3 & $10-s$ & 11 & $10-y$ \\
4 & $15-s$ & 12 & $15-y$ \\
5 & $20-s$ & 13 & $20-y$ \\
6 & $25-s$ & 14 & $25-y$ \\
7 & $50-s$ & 15 & $50-y$ \\
8 & $100-s$ & 16 & $100-y$ \\
\hline
\end{tabular}

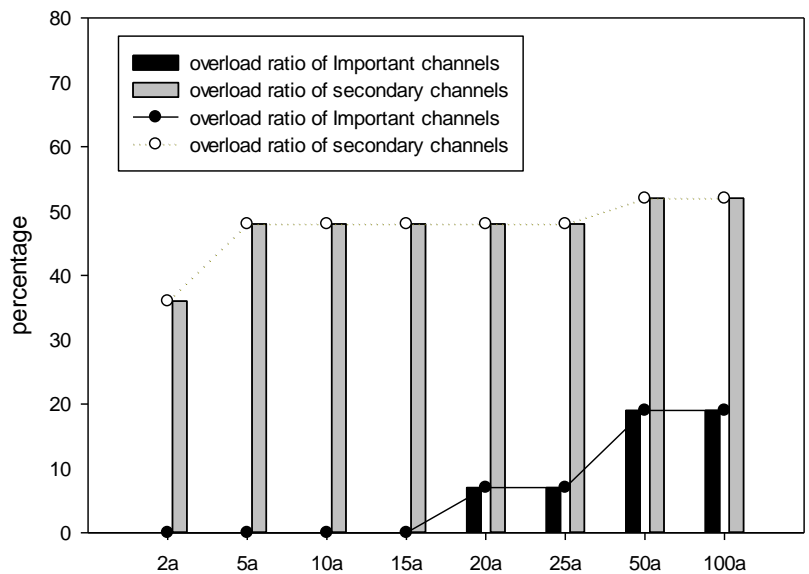

Figure 1. The overload percentages of important/ secondary channels in each return period under ideal conditions.

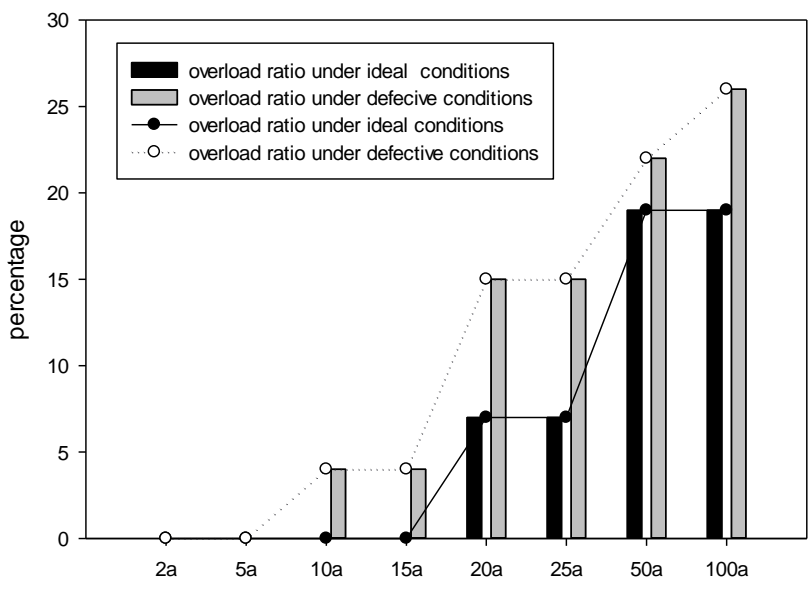

Figure 2. The overload percentages of important channels in each return period under ideal/ defective conditions. 


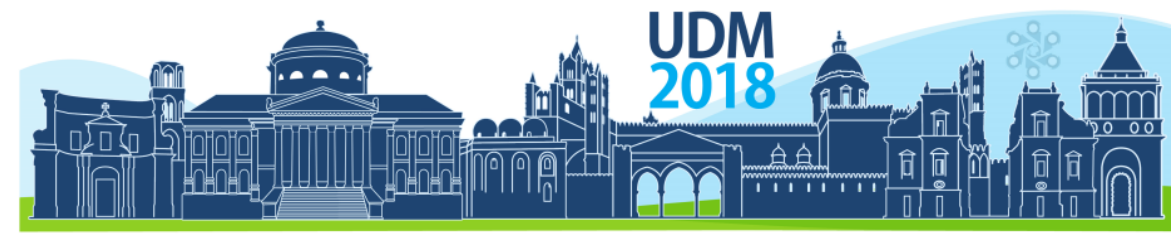

$11^{\text {th }}$ International Conference on Urban Drainage Modelling

23-26 Sep | Palermo - Italy

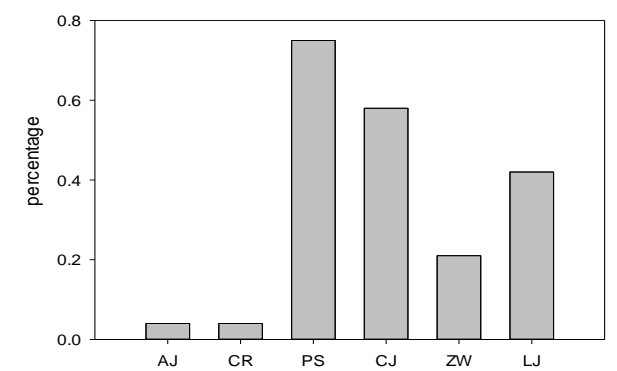

Figure 3. The proportions of various defect types in secondary channels.

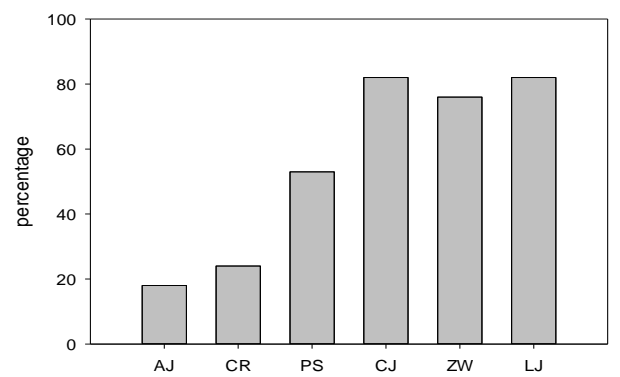

Figure 4. The proportions of various defect types in important channels.

\section{CONCLUSIONS}

By defining the defects, determining the levels of a single defect and channel defect levels, the health degree assessment of the channels was completed. The drainage capacity of this system was analysed under different conditions by SWMM model.

For structural defects, the severe level (III) ratio of the secondary channels is higher than that of important channels. For functional defects, the difference between important and secondary channels is not great. Through modelling analysis, it is found that there is a significant mismatch in the drainage capacity between important channels and secondary channels. Secondary channels' capacity has been insufficient just with smaller rainfall intensity, which would limit the ability of the whole drainage system to drain rainwater, result in extending the discharge time and lead to a waterlogged pitch.

The proposed evaluation method for ancient architecture channel drainage system is reasonable and effective.

\section{References}

Zhou YW and Zhao HB. (2000). "Theory and calculation of drainage pipe network." China Architecture \& Building Press, Beijing.

Wang HP. (2011). "A study of the health assessment of urban drainage system."

Water \& Wastewater Engineering, Beijing, 37(8), 112-116.

CN-CJ. (2012). Technical specification for inspection and evaluation of urban sewer, July, China.

Lewis A.R. (2010). "Storm water management model user's manual." US Environmental Protection Agency.

Yuan H. (2013). "A study of the health assessment of urban drainage system." Southwest Jiaotong University, Chengdu. 


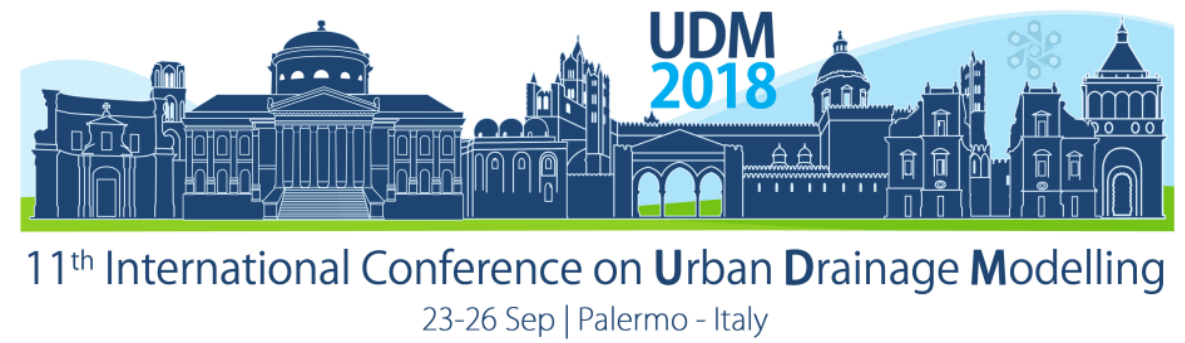

\title{
Rainwater reuse in urban areas: a mathematical model and a long- term modelling approach
}

\author{
Gabriele Freni $^{1}$, Giorgio Mannina ${ }^{2}$, Michele Torregrossa ${ }^{2}$ and Gaspare Viviani ${ }^{2}$ \\ ${ }^{1}$ Facoltà di Ingegneria ed Architettura, Università "Kore" di Enna, Cittadella Universitaria, 94100 Enna (IT), Italy \\ ${ }^{2}$ Dipartimento di Ingegneria Civile, Ambientale, Aerospaziale, dei Materiali, Università di Palermo, Viale delle \\ Scienze, Ed. 8, Palermo (IT), Italy
}

\begin{abstract}
Natural water resources are becoming increasingly limited due to global-scale climate change and water availability issues have become so severe that they must be addressed. Given these issues, reuse of wastewater and rainwater provides a promising way to cope with water shortages. This paper describes an investigation into the efficiency of rainwater usage systems. A conceptual model was built to assess the behaviour of rainwater tanks and their effectiveness in coping with water shortages. The study is based on a long-term simulation (12 years) of different rainwater reuse tank schemes. The associated reductions in residential freshwater demand (water reuse efficiency) and wetweather runoff delivered to the sewer system (sewer discharge efficiency) were surveyed. The results clearly show that rainwater usage systems can significantly reduce drinking water consumption. The specific volumes required for the reuse of rainwater are high; however, for local scale application, the specific volumes necessary are comparable to the reservoir volumes already used to store freshwater resources during potable water shortage.
\end{abstract}

Keywords: Rainwater reuse; water saving measures; mathematical models; long-term efficiency analysis

\section{INTRODUCTION}

Rainwater reclamation has historically been used in Mediterranean countries for domestic applications (e.g. use of stormwater roof runoff for in-house non-potable purposes). Recent regulations in European countries (e.g. the EU Water Framework Directive in 2000 and the German DWA-A 138 in 2005). Environmental concerns about rainwater quality are primarily focused on the accumulation and subsequent wash-out of pollutants (Khare et al., 2004; Hu et al., 2003). Runoff from traffic areas can also vary in pollutant concentration depending on traffic density and vehicle types (Drapper et al. 2000). Other impervious surfaces (e.g., commercial and industrial areas) can degrade rainwater runoff quality to the point that runoff reuse is either not recommended or not economic due to extensive treatment requirements. Previous work has paid particular attention to water quality in the first flush, which is generally the most polluted due to the wash-off of accumulated pollutants (Deletic et al., 1997; Vaes and Berlamont, 2001).

Once the most polluted runoff (the first flush) has been excluded, currently available rainwater treatment technologies can obtain high reduction efficiencies. Simple mechanical technologies, such as filtration, have been shown to reduce heavy metals by $95 \%$ and hydrocarbons by $99 \%$ (Dierkes et al., 2005) while simultaneously removing suspended solids, bacteria, trash and debris. As a result, a large quantity of water can be reclaimed at considerably reduced cost relative to conventional treatment plants, thus making these solutions accessible to both developed and developing countries (Ghisi and Mengotti de 


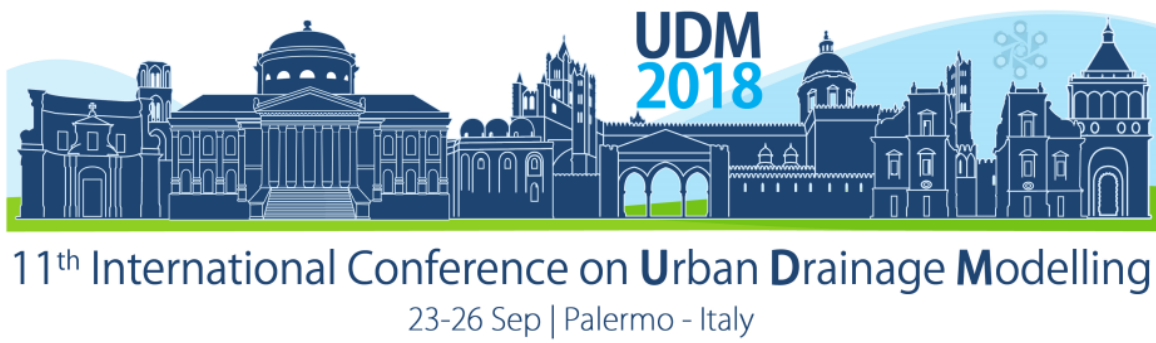

Oliveira, 2007). Including first flush diversion in the treatment process can reduce the amount of biological and mechanical treatment necessary, facilitating small, household-scale application of rainwater reuse. There are many residential uses for non-potable water, so fresh potable water can be saved by implementing affordable treatment systems that provide reused, non-potable rainwater. An inevitable trade-off exists between the volume of fresh water that can be saved and the installation complexity and dimensions of rainwater reuse systems (Dixon et al. 1999). The volume of fresh water than can be saved is commonly assessed during the design of rainwater collection systems, and several models have been described that evaluate this quantity as a function of rainfall amounts, catchment characteristics and users' water demand (Kim and Yoo, 2009; Mitchell et al., 2009; Liu et al., 2010).

The present study will address both issues in an integrated analysis. The main objective is to assess the effects of rainwater reuse on urban drainage systems using a modelling-based approach. The study is focused on local stormwater reuse facilities because they require lower investment costs and treatment costs. A long-term simulation is conducted using 12 years of rain data and a range of storage volumes, roof areas and water consumption rates. The resulting impacts on system efficiency and the frequency and severity of overflow events are discussed.

\section{MATERIALS AND METHODS}

\subsection{The proposed model}

A simplified conceptual model was developed to evaluate the performance of rainwater reuse systems. A schematic of the modelled rainwater system is shown in Figure 1. The system consists of a rainwater tank equipped with an overflow weir and an inflow pipe. This pipe redirects the roof runoff after mechanical treatment designed to remove some of the pollutants washed off by rainfall. As was previously described, pollutants accumulate on catchment surfaces during periods of dry weather. The first stage of a rain event, known as the first flush, is generally the most polluted, so a first flush tank can be added to the system to store and subsequently dispose of this extremely polluted initial runoff. The system is simulated using a linear reservoir modelling approach. After starting from the total rainfall and subtracting hydrologic losses, the effective rainfall runoff (Qrain) is evaluated.

\subsection{The case study}

To test the model and evaluate the effectiveness of rainwater reuse, the model described in the previous section was applied to a specific case study. Rainwater reuse efficiency depends on a combination of factors:

- meteorological conditions, which control rainfall volumes, intensities and frequencies;

- $\quad$ population density, which controls potential rainfall water production by indirectly determining the impervious area per capita; and

- water demand, i.e. the amount of rainwater that is needed. 


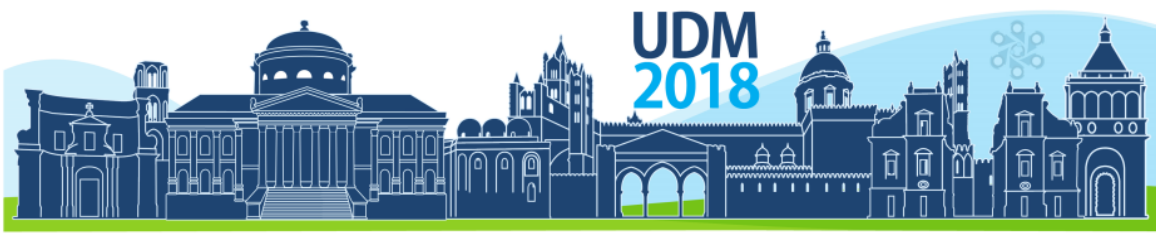

$11^{\text {th }}$ International Conference on Urban Drainage Modelling

23-26 Sep | Palermo - Italy

(a)

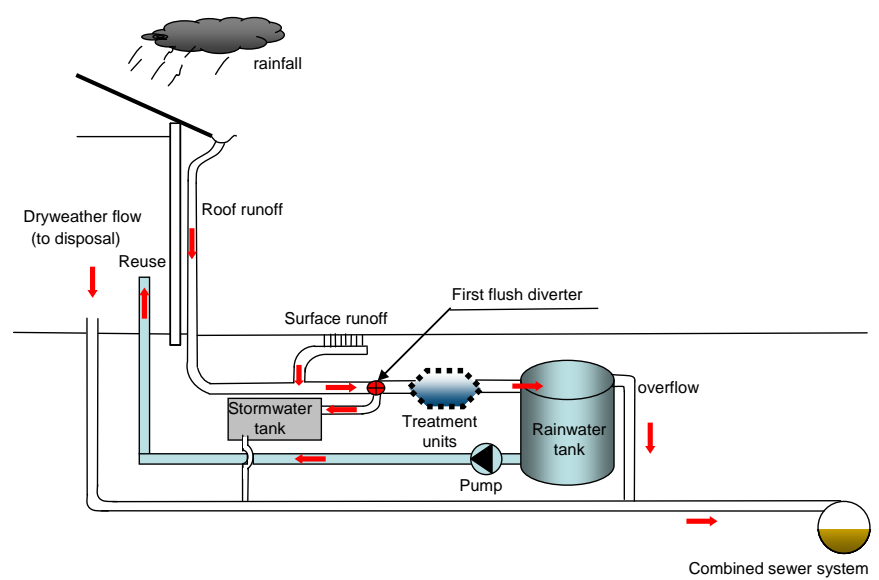

(b)

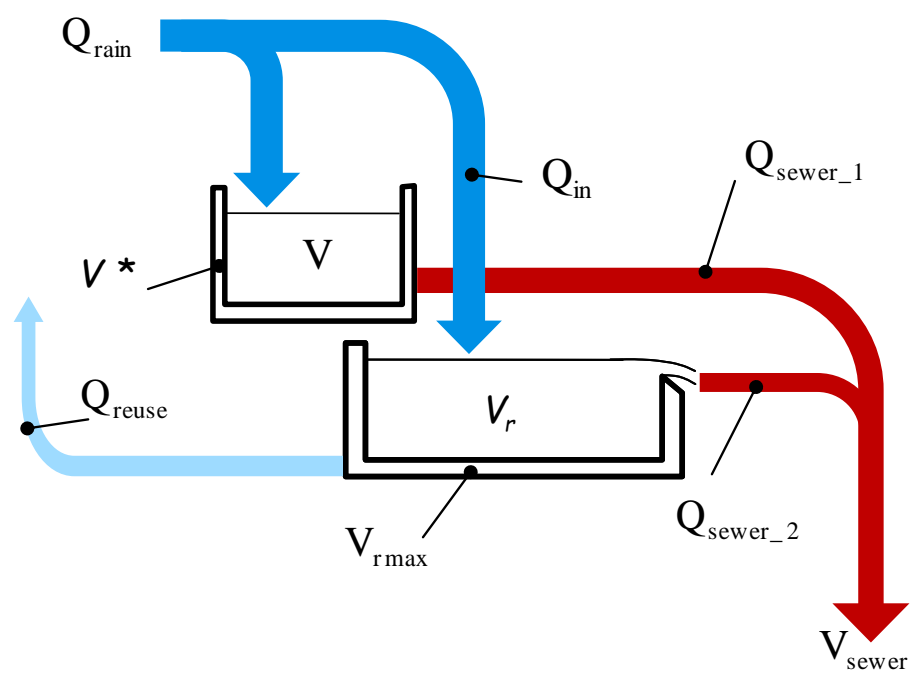

Figure 1. (a) Overview of a rainwater storage system. (b) A schematisation of the rainwater storage system model.

Rainfall data were collected in the Palermo urban area using a Parco d'Orleans rain gauge. The data have been collected continuously using a tipping bucket rain gauge with a volume equivalent to $0.2 \mathrm{~mm}$ and a data logger with the highest possible time resolution of $1 \mathrm{sec}$. For this study, 12 years between 1993 and 2004 were selected. Meteorological conditions at Palermo are typically Mediterranean with a warm, dry summer and a rainy winter season that extends from October to April. Average yearly rainfall is around $600 \mathrm{~mm}$, so the local climate is not arid. Nonetheless, the longest yearly dry period is 64 days on average.

For the other two parameters (population density and water demand), representative values for the area were chosen. The population density in Palermo ranges from less than 100 inhabitants/ha to more than 1400 inhabitants/ha in the city. High population densities were not considered in the study because the ratio of rainwater production to demand is too low for practical application. Water demand depends on the uses that can be accommodated by reclaimed rainfall and it is the main parameter of this study. As previously mentioned, rainwater can be used for applications that do not require potability such as WC cleaning and gardening. 


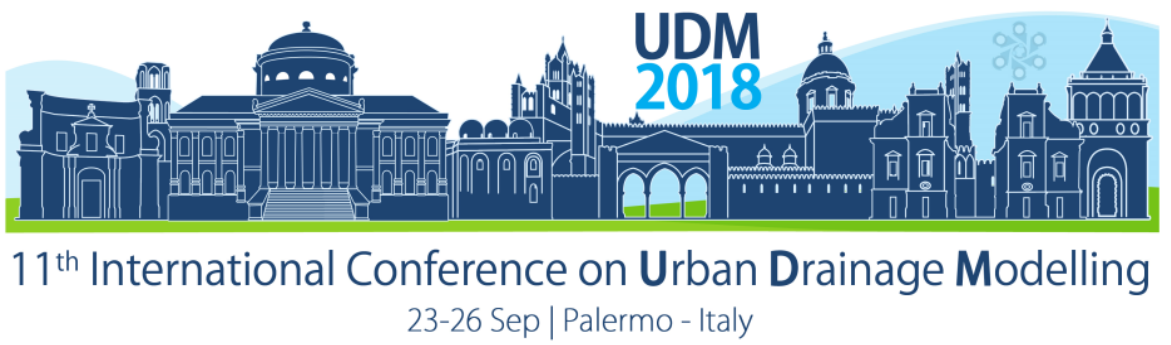

The total local water demand (D) is obtained by multiplying the per capita rainwater demand by the population density. This quantity was the main independent parameter used in this study and will appear in the graphs shown in the next section.

\section{RESULTS}

In this study, different rainwater reuse applications were compared in terms of their required rainwater tank dimensions and their need for a first flush separation tank. Different configurations were compared using two measures of system efficiency:

- The water reuse efficiency $\eta_{\text {reuse, }}$ defined as the ratio of the rainwater demanded by the user to the rainwater provided by the reuse system.

- The sewer discharge efficiency sewer $\eta_{\text {sewer, }}$ defined as the ratio of the volume of rainwater supplied for reuse to the runoff volume.

The water reuse efficiency is useful for evaluating the potential water savings of the reuse system, while the sewer discharge efficiency is useful for assessing the environmental impact of reuse in terms of the reduction of in sewer discharge during wet weather. The efficiency of several model reuse configurations was analysed using long-term simulations initialised from rainfall data (described in the previous section) and assuming constant rainwater demand over the entire period of the analysis. The first configuration was designed to maximise rainwater reuse efficiency by not including a first flush separation device. Figure 2 shows the average efficiencies for this system over the 12-year period of the analysis.

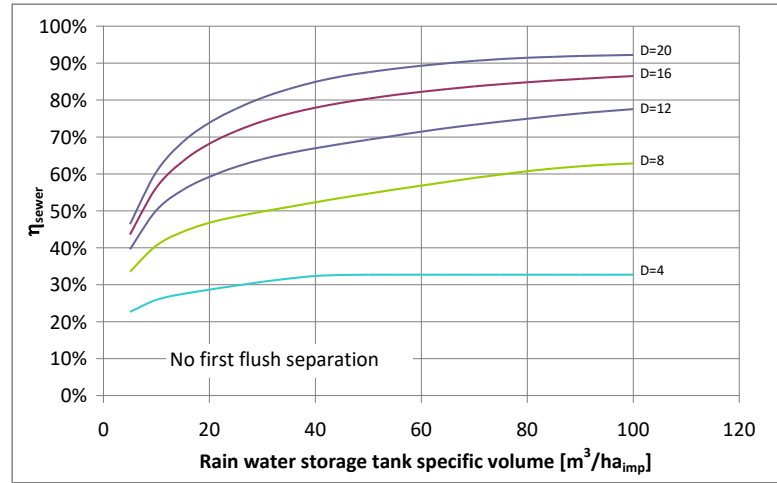

[a]

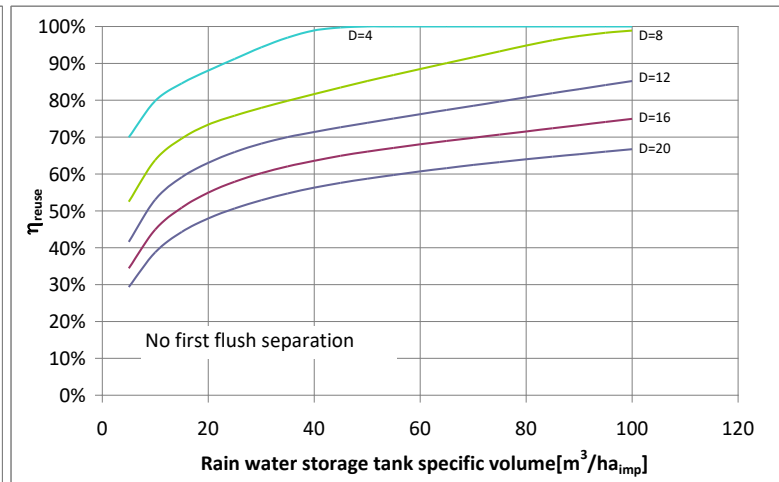

[b]

Figure 2. Rainwater reuse efficiencies for a system without a first flush separation device, plotted for different values of total local rainwater demand $D\left[\mathrm{~m}^{3} /\left(\mathrm{ha}^{*} \mathrm{~d}\right)\right]$. The graphs show [a] sewer efficiency and [b] reuse efficiency.

\section{CONCLUSIONS}

This paper presents an analysis of a model designed to evaluate the potential benefits of reusing rainwater to satisfy residential water needs. The results show beneficial outcomes of rainwater reuse measures, including both reduced residential fresh water demand (high water reuse efficiency) and reduced wet weather runoff to sewers (high sewer discharge efficiency). Rainwater reuse leads to environmental benefits, including both fresh water savings and less 


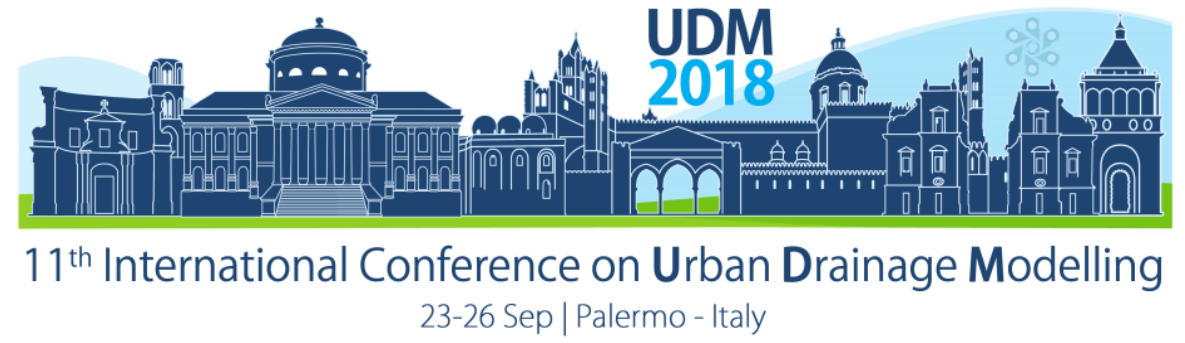

frequent sewer overflows. The conclusions of the study can be summarised with the following points:

- Rainwater reuse efficiency is highly dependent on the ratio of available impervious surfaces to rainwater demand and population density. When this ratio is unbalanced by excessive demand or reduced runoff availability, excessively large rainwater harvesting tanks are needed.

- First flush tanks can reduce the amount of treatment needed before water can be reused. However, in the climate analysed here, the inclusion of first flush tanks reduces the rainwater reuse efficiency and thus may decrease interest in adopting these water saving measures.

- Rainwater reuse measures can provide environmental benefits because they can greatly reduce the frequency and severity of stormwater discharge events during wet weather, thus reducing sewer overflows from the drainage system.

\section{References}

Barton, A. B., and Argue, J. R. (2009). Integrated urban water management for residential areas: a reuse model. Water science and technology, 813-823.

Deletic, A. (1998) The first flush load of urban surface runoff. Water Research, Volume 32(8), 2462-2470.

Deutsche Vereinigung fur Wasserwirtschaft, Abwasser und Abfall - DWA-A (2005). Planning, Construction and Operation of Facilities for the Percolation of Precipitation Water. April, ISBN 978-3-937758-74-9

Dixon, A., Butler, D., and Fewkes, A. (1999). Water saving potential of domestic water reuse systems using greywater and rainwater in combination. Water science and technology, 25-32.

Drapper, D., Tomlinson, R. \& Williams, P. (2000): Pollutant Concentrations in Road Runoff: Southeast Queensland Case Study. Journal of Environmental Engineering April: $313-320$.

Evans, C.A., Coombes, P.J., Dunstan, R.H., Harrison, T. (2009) Extensive bacterial diversity indicates the potential operation of a dynamic micro-ecology within domestic rainwater storage systems. Science of The Total Environment, Volume 407, Issue 19, 5206-5215

Ghisi, E., Mengotti de Oliveira, S. (2007). Potential for potable water savings by combining the use of rainwater and greywater in houses in southern Brazil. Building and Environment vol. 42 (4) pp. 1731-1742

Khare, P., Goel, A., Patel, D., \& Behari, J. (2004). Chemical characterization of rainwater at a developing urban habitat of Northern India. Atmospheric Research, 69, 135-145.

Kim, K., and Yoo, C. (2009). "Hydrological Modeling and Evaluation of Rainwater Harvesting Facilities: Case Study on Several Rainwater Harvesting Facilities in Korea." J Hydrol Eng, 14(6), 545-561.

Liu, S., Butler, D., Memon, F. A., Makropoulos, C., Avery, L., and Jefferson, B. (2010). "Impacts of residence time during storage on potential of water saving for grey water recycling system." Water Res, 44(1), 267-277.

Mitchell, V. G, McCarthy, D. T, Deletic, A, Fletcher, T. D. (2008) Urban stormwater harvesting - sensitivity of a storage behaviour model Environmental Modelling \& Software vol. 23 (6) pp. 782-793

Vaes, G., Berlamont, J. (2001) The effect of rainwater storage on design storms. Urban water Vol 3(4), 303-307. 


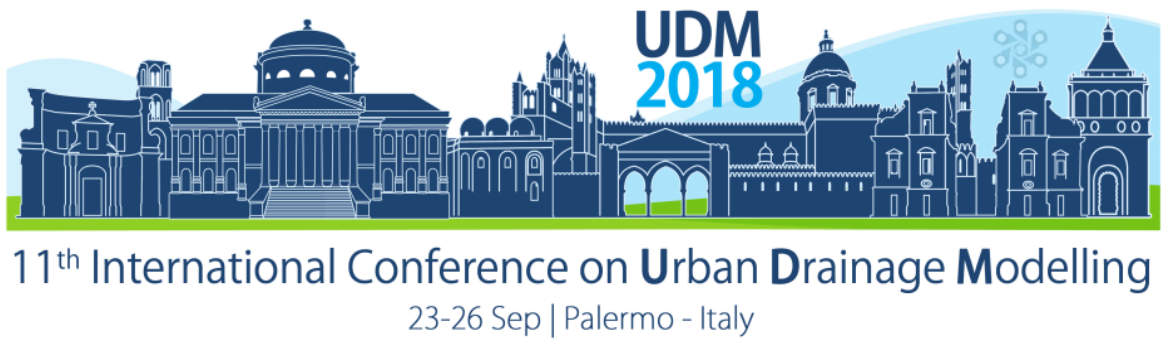

\title{
Long term efficiency analysis of infiltration trenches subjected to clogging
}

\author{
Gabriele Freni ${ }^{1}$, Giorgio Mannina ${ }^{2,3}$ \\ ${ }^{1}$ Facoltà di Ingegneria ed Architettura, Università "Kore" di Enna, Cittadella Universitaria, 94100 Enna (IT), Italy \\ 2 Dipartimento di Ingegneria Civile, Ambientale, Aerospaziale, dei Materiali, Università di Palermo, Viale delle \\ Scienze, Ed. 8, Palermo (IT), Italy \\ ${ }^{3}$ Department of Earth and Environmental Engineering, Columbia University, 500 West 120th Street, New York, \\ NY 10027, USA
}

\begin{abstract}
In recent years, limitations linked to traditional urban drainage schemes have been pointed out and new approaches were developed introducing more natural methods for retaining and/or disposing of stormwater. Such practices include infiltration and storage tanks in order to reduce the peak flow and retain part of the polluting components. The impact of such practices on stormwater quantity and quality is not easily assessable because of the complexity of physical and chemical processes involved. In such cases, integrated urban drainage models may play a relevant role providing tools for long term analysis. In this study, the effect of the clogging phenomenon has been assessed by means of a simplified conceptual modelling approach developed in previous studies has been employed and different soils as well as different design criteria have been considered. On the basis of a long-term simulation of 6 years rain data, the performance as well as the effectiveness of an infiltration trench measure are assessed. The study confirmed the important role played by the clogging phenomenon on such infiltration structures.
\end{abstract}

Keywords: Best Management Practices, water quality, drainage system, infiltration, integrated urban drainage management

\section{INTRODUCTION}

The introduction of EU Water Framework Directive 60/2000 pushed the application of new sustainable technologies for disposing of stormwater like distributed infiltration structures and local storage (Chave, 2001). Such techniques are often considered as more 'natural' measures for managing stormwater in urban areas because they mainly try to revert the impact of urbanisation on the natural water cycle. Small infiltration and storage structures are often used to achieve control of stormwater quality and quantity in small catchment such as a parking lot or residential areas (Guo, 1998; Freni et al., 2004). Guo (1998) considered trench infiltration basins to be used as a means of storm water control and presented analytical expressions based on two-dimensional flow. However, in his study, it seems that the physics of flow is inadequately described. Youngs et al. (1996) investigated the unsteady groundwater paths below an irrigation ditch using a hydraulic sand tank model and Hele-Shaw analogue. Finite difference or finite element methods have not been used extensively for solution of these types of problems, due to the difficulty arising from the dynamic position of the water table and the need to solve the problem iteratively for the entire solution domain; at the opposite, simplified methods based on one-dimensional approximation of the infiltration process are preferred for their simple and inexpensive application (Demetracopoulos and Hadjitheodorou, 1996). Apart their easiness of use, simplified models may be constrained to highly restrictive hypotheses leading to excessive safety factors when used for design or unreliable results when used for 


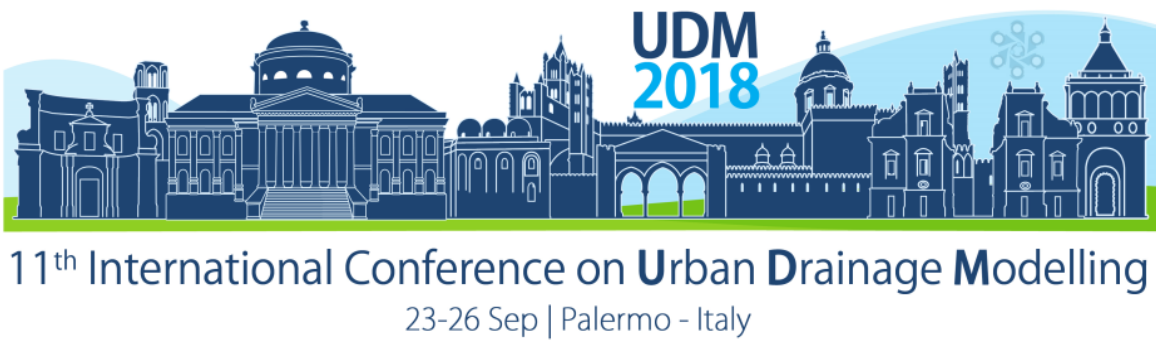

efficiency analysis. The considerations discussed above suggest the improvement of infiltration structure mathematical models following two directions: the improvement of processes interpretation obtaining more detailed models for the single structure and the integration of such models in urban drainage integrated ones, i.e. models analysing the sewer system, the wastewater treatment plant and the receiving water body as a whole (Rauch et al, 2002; Mannina et al., 2018). The latter approach took the development of simplified conceptual models characterised by low computational requirements and able to be replicated several time in the integrated approach in order to simulate a large number of stormwater management facilities spread over the catchment. Two main assumptions are usually adopted in such models: a constant infiltration rate, assuming saturated soil conditions (Schlüter et al., 2007); dynamic infiltration rates assuming that they depend on soil saturation (Barraud et al., 2002; Browne et al., 2008). Another process that affects infiltration over time is clogging. Clogging is due to the presence of sediments in the runoff entering in the infiltration structure; sediments accumulate in the pores of the filler material or along the bottom and the sides of the infiltration structure and therefore reduce its infiltration capacity and its effective storage volume. A number of studies indicate that the performance of infiltration systems will decrease with time due to clogging effects from fine particles that enter the system via the stormwater inflow (see for instance Revitt et al., 2003). Due to the clogging a reduction of the infiltration rate occurs and this leads to more overflows from the trenches to the sewer system and prevents the system from functioning as intended (Bergman et al., 2010). The present study is aimed at studying the effect of soil type on the clogging phenomenon on infiltration structure by means of long term analysis. The study was carried out by long term simulations of different trench specific volumes and different soil types, trying to track both the effective structure volume and its infiltration capacity. The analysis has been performed considering hypothetical trenches located in the experimental catchment of Parco d'Orlèans (Palermo, Italy).

\section{MATERIALS AND METHODS}

\subsection{The proposed model}

In the present study, in order to simulate the dynamic processes of an infiltration trench, a previously developed model was employed (Freni et al., 2009). Specifically, the model is characterised by one input from the urban drainage model (simulating the runoff produced on the catchment) and by two outputs: the overflows to the drainage system simulated by a weir function and the infiltration discharge to the soil simulated by a non-linear function. $A_{\text {eff }}$ is defined in the model as "effective infiltration area", i.e. the horizontal area below the structure bottom where the infiltration paths start to be vertical parallel. In synthesis, $A_{\text {eff }}$ becomes the fundamental model parameter to be calibrated both when the infiltration structure is clean and when clogging takes part. Freni et al. (2009) proposed two correlation relationships to link $A_{\text {eff }}$ to the infiltration structure bottom area $A_{\text {eff, }, 0}$ and to the sediment level $h_{\text {sed. }}$. The clogging processes is simulated by the mass balance for suspended solids at rainfall event scale. The height of sediments $h_{\text {sed }}$ is computed by dividing the intercepted mass by sediment bulk density, infiltration structure void ratio and bottom area. The computation is made assuming that the distribution of sediments in the infiltration structure is uniform and that the solid accumulation on the walls of the structure may be negligible. The model takes into account the particle size of the sediments that can be accumulated and washed off over the catchment (Chebbo et al., 1990; Deletic et al., 1997). In the present study, two particle classes (equally proportioned in mass) are adopted in order to properly simulate different types of sediment transport: the fine ones $\left(d_{50}=50 \mu \mathrm{m}\right.$, bulk density equal to $\left.1600 \mathrm{~kg} / \mathrm{m}^{3}\right)$ are transported as suspended load while the coarse ones $\left(d_{50}=500 \mu \mathrm{m}\right.$, bulk density equal to $\left.2000 \mathrm{~kg} / \mathrm{m}^{3}\right)$ are mainly transported as 


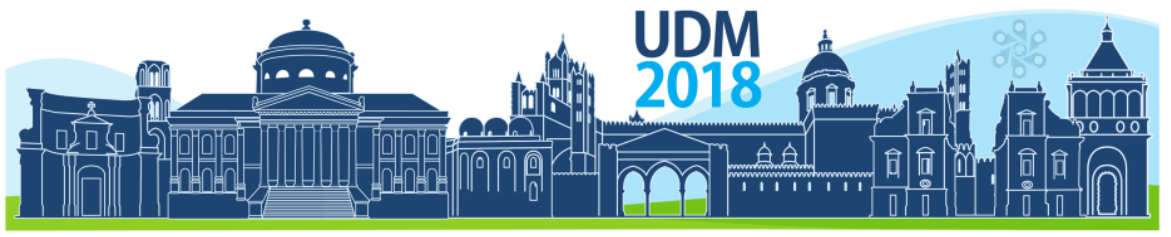

$11^{\text {th }}$ International Conference on Urban Drainage Modelling

23-26 Sep | Palermo - Italy

bed load. More details about the model may be found in Mannina and Viviani (2010). The following infiltration structure characteristics were considered in the present study: trench specific volume equal to $20 \mathrm{~m}^{3}$ per hectare of connected impervious area; filling material void ratio equal to 0.5 , trench cross-sectional area equal to $2 \mathrm{~m} \times 2 \mathrm{~m}$; trench length was computed accordingly to the connected impervious area and to the design specific volume. The effect of infiltration facilities and the impact of clogging was analysed at rainfall event scale by computing two efficiency criteria: the stormwater volume reduction efficiency and the solid mass interception efficiency $\eta_{\text {TSS, }}$, were estimated as in the following:

$\eta_{Q}=\frac{V_{\text {in }}-V_{\text {out }}}{V_{\text {in }}} \quad \eta_{\text {TSS }}=\frac{M_{\text {sed, in }}-M_{\text {sed }, \text { out }}}{M_{\text {sed }, \text { in }}}$

where $V_{\text {in }}$ is the input water volume from the catchment, $V_{\text {out }}$ is the output water volume to the sewer, $M_{\text {sed,in }}$ and $M_{\text {sed,out }}$ represent, respectively, the mass inflow from the catchment and mass outflow by the weir to the sewer (the mass outflow by infiltration is considered null). The continuous simulations were run for four different soil classes, reported in table 1, and two commonly adopted design specific volumes: (20 and $40 \mathrm{~m}^{3} / \mathrm{ha}_{\text {imp }}$ ).

Table 1. Soil characteristics and parameters.

\begin{tabular}{|c|c|c|c|c|c|c|}
\hline & PARAMETER & $\begin{array}{c}\text { Sandy- } \\
\text { Loam }\end{array}$ & $\begin{array}{c}\text { Loamy- } \\
\text { Sand }\end{array}$ & Sand & Gravel & Unit \\
\hline \multirow{3}{*}{ Soil } & $\mathrm{q}_{\mathrm{s}}$ & 0.45 & 0.43 & 0.44 & 0.55 & - \\
characteristics & $\mathrm{q}_{0}$ & 0.05 & 0.04 & 0.02 & 0.01 & - \\
& $\psi$ & 0.11 & 0.10 & 0.09 & 0.08 & $\mathrm{~m}$ \\
& $\mathrm{k}_{\mathrm{s}}$ & 2.18 & 6.12 & 23.41 & 36 & $\mathrm{~cm} / \mathrm{h}$ \\
\hline
\end{tabular}

\subsection{The case study}

In order to evaluate the long term infiltration structure efficiency, an application has been carried out in the experimental catchment Parco d'Orlèans (Palermo - Italy). The Parco d'Orlèans experimental urban catchment is located in the University Campus. Its total drainage surface is 12.8 ha with $68 \%$ of impervious area, and the drainage system is separated and the stormwater system is made of concrete circular and egg-shaped pipes. Rainfall data have been collected since 1994 with a tipping bucket raingauge and data logger at maximum time resolution of 1 second. Discharge data have been collected since the same year with an ultrasonic flow meter installed at the basin outlet. A 6-year long continuous rainfall series was extracted by this database and used for the simulations. Starting from the database outlined above, a long term simulation has been carried out considering different soil types in order to assess their effect on the clogging phenomena. Further, the effect of the infiltration trench dimension has been quantified as well.

\section{RESULTS}

The current analysis was based on long term simulations carried out by means of a calibrated mathematical model. Different soil types were considered in order to obtain the different infiltration trench behaviour that may be expected for the analysed catchment. Different values 


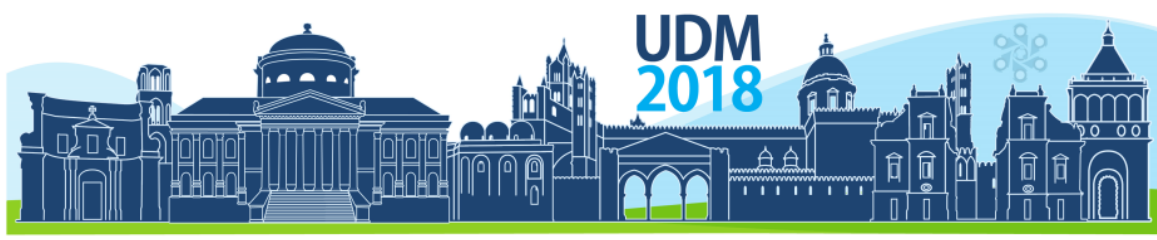

$11^{\text {th }}$ International Conference on Urban Drainage Modelling

23-26 Sep | Palermo - Italy

of specific volume for the hypothetic trench were considered in order to assess the impact of design criteria on the infiltration structure efficiency both in the short term (when the structure is new and clean) and in the long term (after some years of operations and developing clogging). Infiltration structure efficiency dependency on its specific volume and type of soil is showed in Figure 1 and Figure 2 for an example structure having effective volume equal to 20 $\mathrm{m}^{3} / \mathrm{ha}_{\text {imp. }}$ In the figures, storm events are not presented in their chronological order but in descending order according to the obtained efficiency. Each point in the graphs represents the storm events showing efficiencies higher than the one presented by each curve (either in terms of number of events or in terms of cumulated volume or in terms of cumulated TSS mass). In details, figure 1 shows efficiencies regarding the runoff volume versus the number of rainfall events (figure 1a) and the overall rainfall volume for the entire simulated period (figure 1b). Figure 2 shows the same graphs regarding suspended solids interception efficiency.
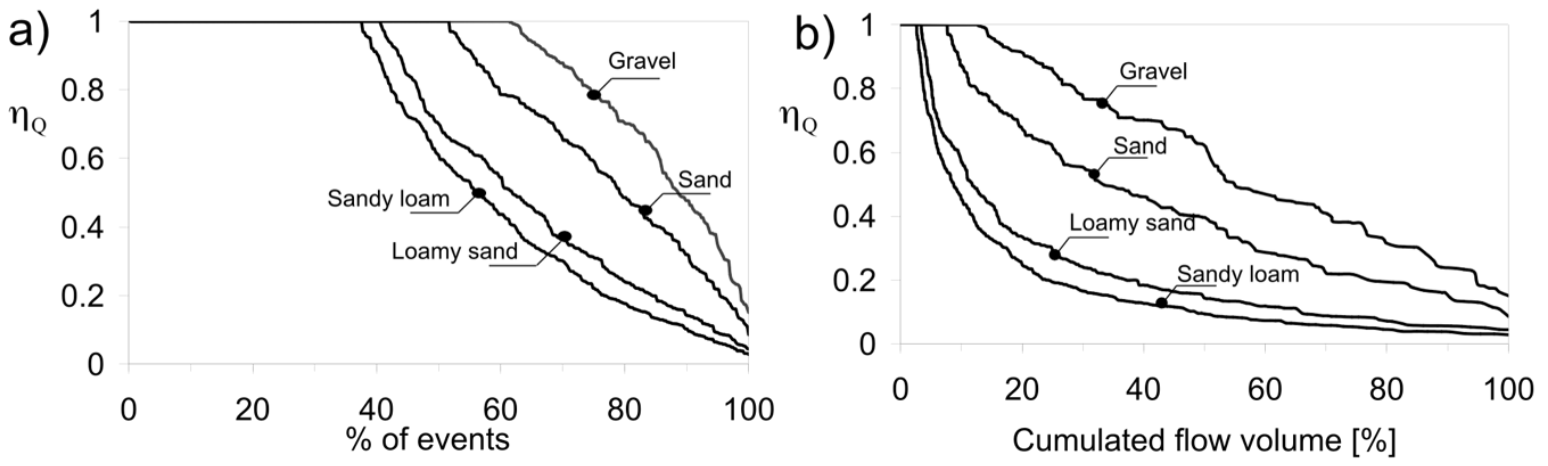

Figure 1. Infiltration structure water efficiency in terms (a) of number of rainfall events and (b) in terms of cumulated flow volume, for a design specific volume of $20 \mathrm{~m}^{3} / \mathrm{ha}$.
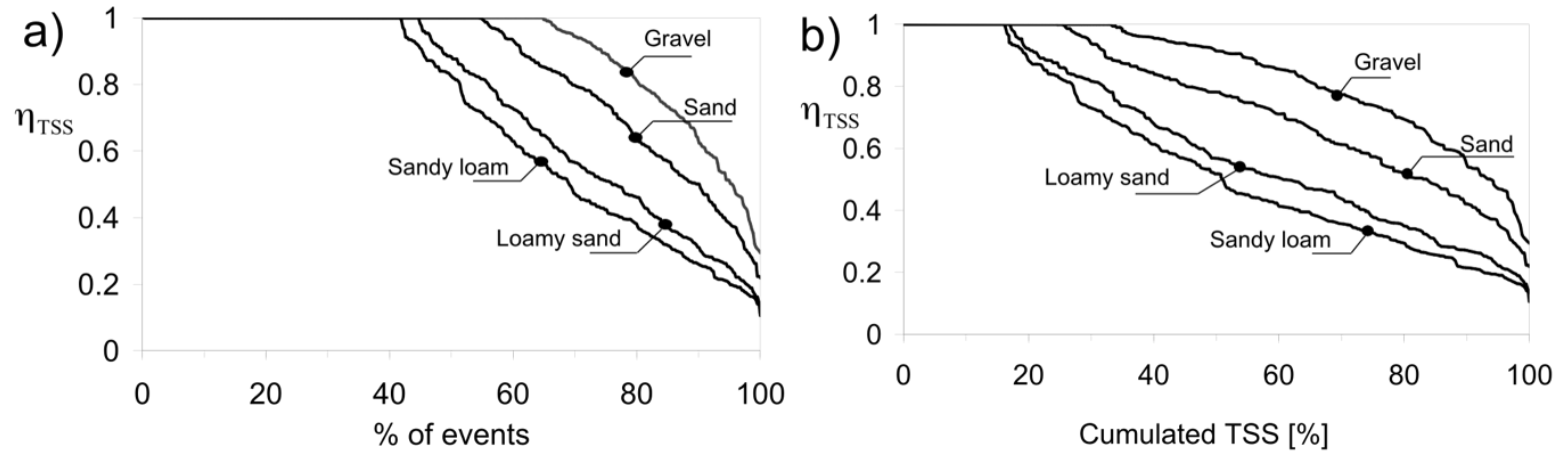

Figure 2. Infiltration structure TSS efficiency in terms (a) of number of rainfall events and (b) in terms of cumulated TSS for a design specific volume of $20 \mathrm{~m}^{3} / \mathrm{ha}$.

The results allow for some interesting considerations:

- figure 1 confirms that, in Mediterranean climate characterised by short and intense rainfall events, infiltration facilities can totally intercept only a small percentage of the total rainfall events (less then $40 \%$ in sandy loam soils) corresponding to an even smaller percentage of rainfall volume (less than $5 \%$ of the total runoff volume); 


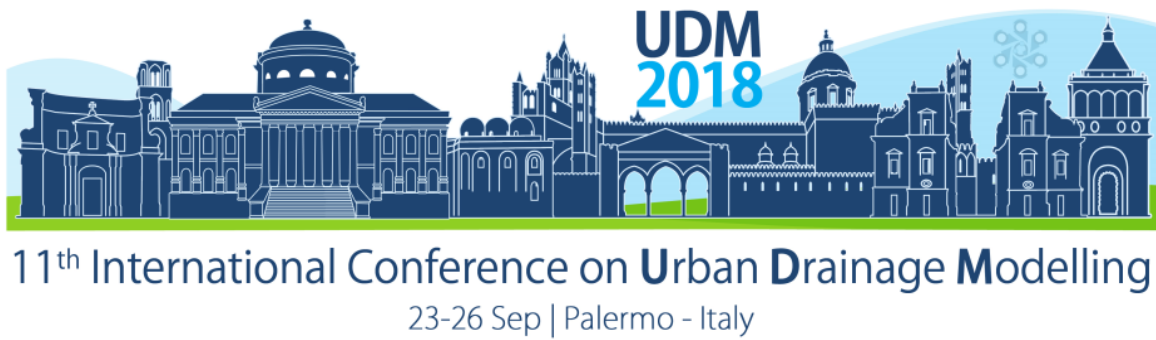

- runoff reduction efficiency decreases rapidly considering longer and more intense events (right side of the graphs in figure 1) highlighting that infiltration measures have marginal efficiency in peak flow control. Average runoff volume reduction in the analyzed period is lower than $20 \%$ for sandy-loam and loamy-sand, lower than $45 \%$ for sand and around $60 \%$ for gravel;

- TSS mass reduction efficiency is much higher showing that this kind of structure is suitable to stormwater quality mitigation. The lower design specific volume considered allows for average event mitigation efficiencies in terms of overall sediment mass between $40 \%$ and $80 \%$ depending on the soil type.

\section{CONCLUSIONS}

A simplified infiltration trench model was applied in order to evaluate the long term efficiency of infiltration trenches in different soil conditions and considering two different design criteria. The results showed that the infiltration devices are more effective for the quality than for the quantity control. Runoff reduction efficiency decreases rapidly considering longer and more intense events highlighting that infiltration measures have marginal efficiency in peak flow control. TSS mass reduction efficiency is much higher showing that this kind of structure is suitable to stormwater quality mitigation. The efficiencies rise when considering higher specific design volumes but the amount of events that are totally intercepted remains low because of the climatic characteristics of the area. The effect of climate is also displayed by the short difference between the two considered infiltration device specific volumes confirming that, in the Mediterranean area, large volume increments are needed for slightly increasing mitigation efficiencies: even in the most favourable soil conditions, the structure having $40 \mathrm{~m} 3 / \mathrm{haimp}$ generated overflows in almost the $20 \%$ of the simulated events meaning by this a spill frequency of 9-10 events per year. Infiltration structures maintain a good performance for a short period after their installation because of the clogging phenomena and the absence of any pre-treatment structure. The performed analysis suggests to generally over-design the structure volume in order to allocate space for the collected sediments and in order to avoid the rapid reduction of structure performance in time. At the same time, the Mediterranean characteristics of adopted rainfall data showed that infiltration device efficiency is lower than the results presented in literature.

\section{References}

Barraud, S., Gibert, J., Winiarski, T., and Bertrand Krajewski, J. L. (2002). "Impact of a storm infiltration drainage system on soil and groundwater-Presentation of the OTHU project." Water Sci. Technol., 45(3), $203-210$.

Browne, D., Deletic A., Mudd G. M., Fletcher T. D. (2008). A new saturated/unsaturated model for stormwater infiltration systems. Hydrological Processes, 22, 4838-4849.

Chave, P. (2001). "The EU Water Framework Directive: an introduction." IWA Publishing, London.

Chebbo, G., Musquere, P., Bachoc, A. (1990). "Solids transferred into sewers." Proc., 5th Int. Conf. on Urban Storm Drainage, 23.-27.7.1990 Osaka (Japan), 325 - 332

Deletic, A., Maksimovic, C., Ivetic, M., (1997). "Modelling of storm wash-off of suspended solids from impervious surfaces." J. Hydr. Res., 35(1), 99-118.

Demetracopoulos, A. C., and Hadjitheodorou, C. (1996). Seepage from surface canals by boundary element method. J. Irrig. Drain. Eng., 122(1), 40-48.

Duchene, M., McBean, E.A. and Thomson N.R. (1994) "Modelling of Infiltration from Trenches for Storm-Water Control" J. Water Resour. PIng. and Mgmt. 120(3), 276-293.

Freni, G., Oliveri, E., Viviani, G. (2004). "Infiltration facilities design: comparison between simplified approaches and detailed physically based modelling" 5 th International Conference on sustainable techniques and strategies in 


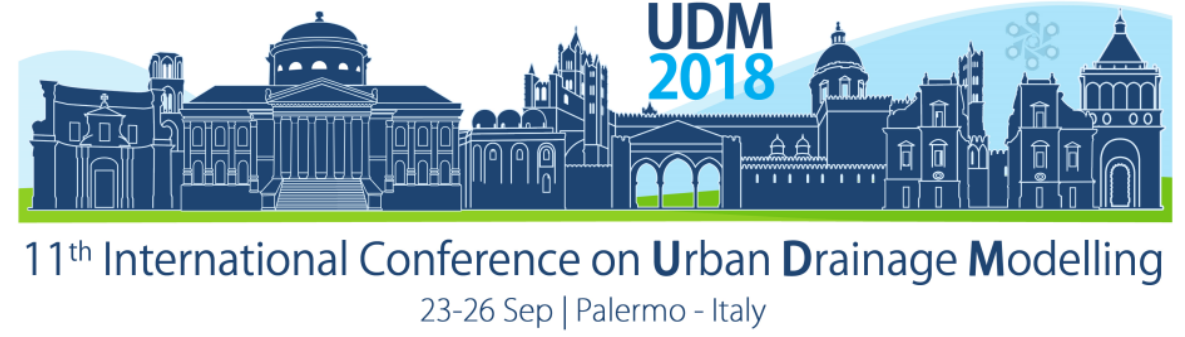

urban water management - NOVATECH. Michel Desbordes et Bernard Chocat, Editors, 6-10 June 2004, Lyon France, Vol II, 1105-1112.

Freni G., Mannina G. Viviani G. (2009). Stormwater infiltration trenches: a conceptual modelling approach. Water Science and Technology, vol. 60 (1) pp. 185-199.

Green, W. H., and Ampt, G. A. (1911). "Studies on soil physics. I. The flow of air and water through soil." J. Agric. Sci., $9,1-24$.

Guo, J. C. Y. (1998). Surface-Subsurface Model for Trench Infiltration Basins.Journal of Water Resources Planning and Management, 124(5), 280-284.

Mannina and Viviani (2010). An urban drainage stormwater quality model: model development and uncertainty quantification. Journal of Hydrology, Vol 381(3-4), 248-265.

Mannina, G., Butler, D., Benedetti, L., Deletic, A., Fowdar, H., Fu, G., Kleidorfer, McCarthy, D., Mikkelsen, P.S., Rauch, Sweetapple C., Vezzaro, L., Yuan, Z., Willems, P. 2018. Greenhouse gas emissions from integrated urban drainage systems: Where do we stand?, Journal of Hydrology, Volume 559, Pages 307-314.

Rauch W., Bertrand-Krajewski J. L., Krebs P., Mark O., Schilling, W., Schutze, M., Vanrolleghem, P. A. (2002). Deterministic modelling of integrated urban drainage system. Wat. Sci. Tech., 45,(3), 81-93.

Revitt, M., Ellis, B. and Scholes, L., (2003). Report 5.1 Review of the use of stormwater BMPs in Europe. Project under EU RTD 5th Framework Programme. WP5 / T5.1 / D5.1. Middlesex University.

Schlüter, W., Jefferies, C. and Zhang, X. X. (2007). Modelling of flow through gravel-filled trenches, Urban Water Journal,4:4,241-251.

Youngs, E. G., Spoor, G., and Goodall, G. R. (1996). Infiltration from surface ponds into soils overlying a very permeable substratum. J. Hydrol., 186, 327-334. 


\section{Part B - Frontiers in urban drainage}




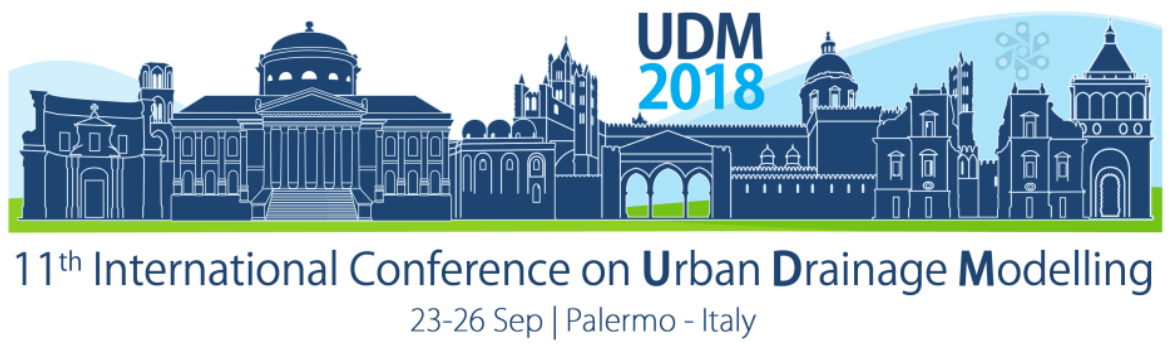

\title{
Controlling Urban Drainage Systems
}

\author{
Gustaf Olsson \\ Lund University, Lund, Sweden, gustaf.olsson@iea.Ith.se
}

\begin{abstract}
The key issue in urban drainage (UD) systems, looking from a control engineering perspective, is operation. Measurements, feedback, control and automation are tools to address the challenges. Measurement technology combined with analysis and parameter estimation are used to obtain relevant information for decision and control. The UD control problem is truly multivariable with many sensors and actuators. A major concern is how to define performance indices that reflect requirements from the natural and urban environment and how to translate this into operational variables. This makes the UD system operation a multi-objective control problem.
\end{abstract}

Keywords: Measurement; monitoring; control; automation

\section{INTRODUCTION}

Looking at urban drainage (UD) systems from a control engineering perspective means that operational rather than design aspects are considered. The key issues are related to measurements, feedback, control and automation capabilities.

The UD system should provide capacity to transport used water from urban users to a treatment plant. In a combined system rainwater is also collected and treated together with municipal and industrial wastewaters. There is a big challenge to control the water transport, in particular in combined sewers where rainwater may overload the system. The purpose of controlling a sewer system is to reduce the effects of disturbances, both on the surrounding environment and on downstream used water treatment. The ultimate task is to find out how far the UD system can be controlled, and then how to act if it is not controllable. For example, a gravity sewer has much less controllability than a sewer supplied with pumps. This was demonstrated in Christchurch, New Zealand after the great earthquake. Several pumps have been installed in the sewer system to make it more controllable (Harmes, 2016).

Feedback control is a powerful concept. It can convert poorly performing components into good systems and it can stabilize unstable systems. Control is the scientific methodology to make a system behave in a desired manner despite disturbances. A controller senses the state of the operation of a system (in this case the UD system), compares it against a desired response, computes corrective actions - sometimes based on a model of the system's response to external inputs - and actuates the system to effect the desired change. This basic feedback loop of sensing, computation and actuation is the central concept in control, Figure 1.

The word "smart" is used nowadays as a characteristic of devices, people and phenomena. It may mean clever, sharp or intelligent. A smart operation will fulfil the requirements of producing an acceptable product or behaviour while keeping energy and resource requirements at a minimum. A smart system will provide service at a required level. Such a system should respond quickly and in an adequate way to disturbances and recover quickly after a major upset. The operation of the system must be sufficiently transparent so that people involved in the operation are well informed to make rational decisions.

It should be recognized how the operation of the various urban water cycle components are related to each other. The term "smart sewer systems" is used quite commonly nowadays. The meaning of "smart" is quite different among the users of the term, but we will here describe some of the basic properties. 


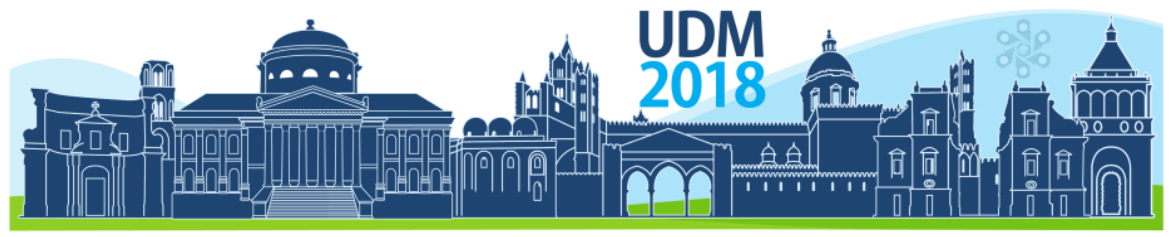

$11^{\text {th }}$ International Conference on Urban Drainage Modelling

23-26 Sep | Palermo - Italy

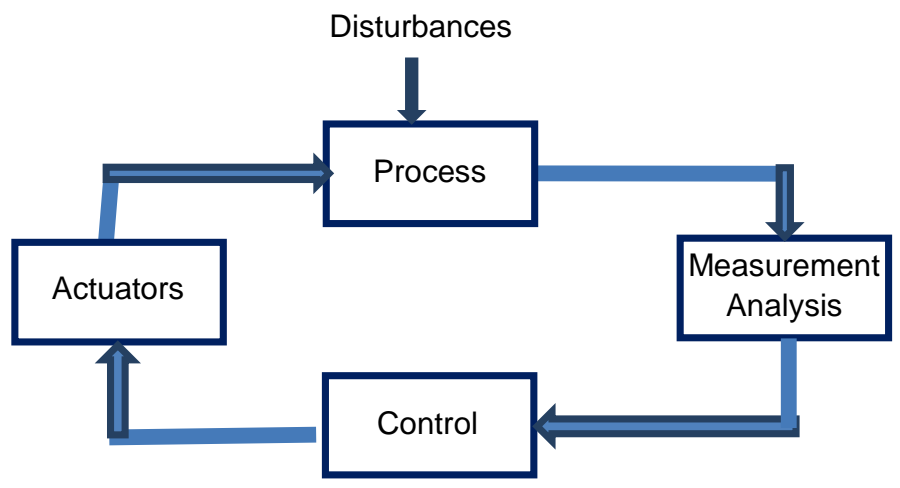

Figure 1. Illustration of the feedback principle.

Three major operational aspects can be distinguished:

- Mass flows: keep track of the flow and solids and dissolved components;

- Resources: use electrical energy, thermal energy, and chemicals efficiently;

- Information flow: use measurement and information technology to achieve operational decisions.

Here we concentrate on the third dimension, the information flow. The basis for the information flow is the simple framework that a control engineer defines as a feedback loop, Figure 1. We have called it the "MAD" approach in Ingildsen and Olsson (2016). The acronym stands for 'measure' (M), 'analytics' (A) and 'decision-making' (D).

To measure is to know: the ' $M$ ' emphasizes that we need adequate data in space and in time. Measurements include not only signals from sensors and instruments, but also results of laboratory analysis, observations and human communications. Data must be analysed, understood and interpreted - the ' $A$ ' - in order to become useful information. This is the basis for some decision - the ' $D$ ' - manual or automatic. A water operation can only be smart if people in all positions get involved, so that they can see their respective role in the whole plant or system operation.

The primary aim of developing our utilities into a higher level of smart, is now developing from a singular focus on cost savings in operations to a broader view of making the whole water infrastructure adapt and interface seamless with the natural water systems we depend on and operate inside in a sustainable and economic fashion.

The control problem can be structured in three levels:

- Keep the system running. Around each component - motor, pump, valve or sensor - in the UD system there has to be information about the current status. It has to be assured that an actuator is running or that an instrument is alive.

- Satisfy requirements. The primary goal of sewer operations is to avoid combined sewer overflows (CSO). However, there are several other goals that should be satisfied, for example to limit the load to the downstream treatment plant so that a maximum treatment quality is achieved. 


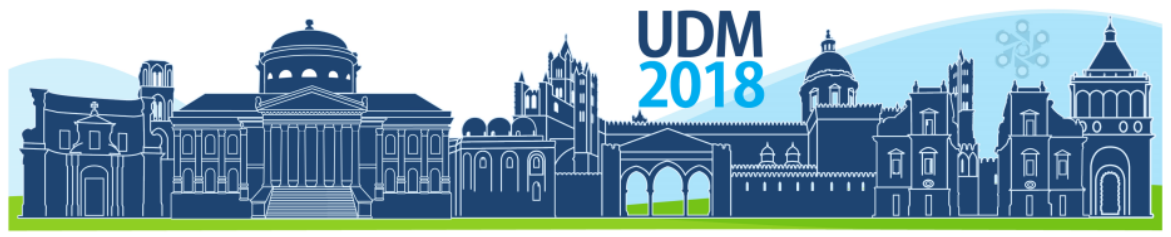

$11^{\text {th }}$ International Conference on Urban Drainage Modelling

23-26 Sep | Palermo - Italy

- Minimize costs and resource requirements. Electrical energy consumption as well as detrimental impact of sewer spills into the urban or natural environment should be minimized.

The feedback (or "MAD") principle can be applied at all three levels, typically in different time scales and often in some hierarchical structure.

It has been recognized for decades that the operation of the UD system should not be isolated from the rest of the urban water cycle. However, not until recently the measurement and computational tools are available to realize system-wide control and operation.

System-wide aspects were discussed already at the first IWA conference (then called IAWPRC, the International Association on Water Pollution Research and Control) on ICA (instrumentation, control and automation) in water and wastewater treatment and transport systems, held in London in 1973 (see Olsson, 2012). At the 1973 ICA conference R. Kukudis discussed the aim of sewer control, to use available but often un-used capacities. This motivated an absolute need for control of flow in the sewers. "We must speak of automation in the entire system - the network of sewers and the plants". Kukudis had applied sewer control in Cleveland in the early 1970s (see Olsson, 2012). During dry periods flow equalization was used. During storm periods the system was designed to primarily capture and treat the first 20 minutes of flow during the storm period, in other words the first flush. Any necessary bypassing after the first period would be of diluted effluent.

All integration requires a compromise. If there were no interactions, then the individual optimisation of each subprocess would be the best strategy. In the combined sewer and used water treatment operation the individual system operations are sometimes in conflict, so the overall goal of minimising the load to the receiving water has to overrule the individual goals. Following the advent of deterministic models three decades ago, the issue was researched by several groups, such as Nielsen et al. (1996), Bauwens et al. (1996), Pfister et al. (1998), Rauch and Harremoës (1996a, 1996b), Schütze et al. (1999), Rauch and Harremoës (1999), Vanrolleghem et al. (2005), and Benedetti et al. (2009). These studies demonstrated the potential of integrated control, which paved the way to practical implementations.

A sustainable drainage system can lessen the sewer capacity problem by storing the rainwater at source. This decreases the flow rate into the sewer (Butler and Parkinson, 1997). Furthermore, the rainwater can be treated before it is entering the sewer system (MelvilleShreeve et al., 2016). It was realized early (Kollatsch, 1993) that by removing the transport of stormwater from urban wastewater would be the most important measure to obtain more efficient drainage systems.

Interesting contributions to real-time control of sewer systems have been presented by Weinreich et al. (1997), Pleau et al. (2001), Schütze et al. (2002), Zacharov et al., (2003), Erbe and Schütze (2005), Pleau et al. (2005), Seggelke et al. (2005), and Vanrolleghem et al. (2005). Integrated control is now being achieved in real life, for example in The Netherlands (Weijers et al., 2012; Benedetti et al., 2013), in Denmark (Grum et al., 2011), and in Germany (Seggelke et al., 2013).

\section{THE OPERATIONAL GOAL OF URBAN DRAINAGE}




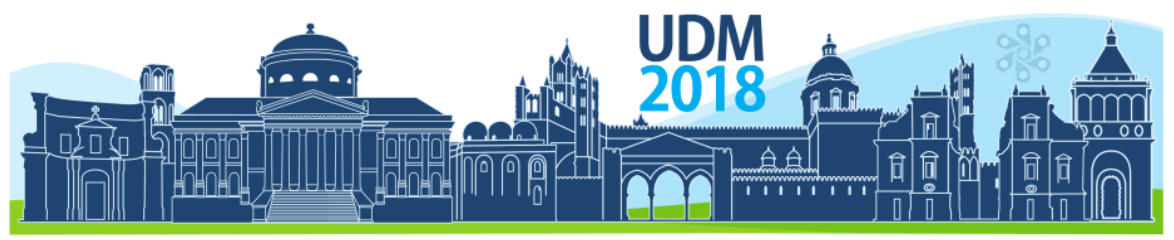

$11^{\text {th }}$ International Conference on Urban Drainage Modelling

23-26 Sep | Palermo - Italy

Control of UD systems has many aspects. The primary consideration is the performance of the system. What is a good performance? There are several aspects to consider, for example:

- Avoid combined sewer overflows (CSO). Protect both the urban and the natural environment;

- Do not overload the downstream treatment plant;

- Minimize electric energy consumption;

- Avoid odours;

- Minimize generation of greenhouse gases;

- Avoid settling in the sewers.

It is apparent that the goals sometimes are contradictory and forces the control to adopt a system-wide perspective. The primary goal is to provide enough capacity in the system. However, this is a design goal. For the operation the goal is to make the best possible use of existing design and capacity.

The performance criteria mentioned above are in fact not the ultimate criteria for good control and performance but are replacing the real criteria characterising the environmental performance, for example represented by the receiving water quality and frequency of flood events. This is described for example by Fu et al. (2008) and Dong et al. (2012).

Integrated control requires both reliable sensors and accurate dynamic models of the included systems. A primary consideration in all control is the time scale. Information is obtained from instruments, sensors and observations. How can the system be manipulated? Pumping is the primary manipulated variable. The result of pump control will propagate quite differently in the sewer network. Flows close to the pump will be influenced quicker, while flow rates further away will be more slowly affected by the pumping operation.

The feedback loop, Figure 1, also symbolises a more complex picture than a single measurement and a single actuator. Measurements in a UD network include all information from the sewer, such as levels, flow rates, rain intensity, and concentrations. Based on the combination of all this information a decision has to be made. This is influencing not one but a whole range of actuators such as pumps and valves. It also comprises decisions about chemical dosages. So, the complex multivariable control decision should influence flow rates as well as biological activities in the drainage system.

A fundamental question is how far existing actuators can compensate for disturbances in the system. Therefore the control authority of the actuators in the system is a key issue. How large disturbances can be compensated for without causing any CSO or overload of the wastewater treatment plant? There are obvious situations, such as too much rain, where the control authority of the sewer operations is not sufficient. Then other actions must be initiated, such as flood warning. In other words, to identify the current state of the system, here called monitoring, is a fundamental condition to make the right decision.

\section{MEASUREMENTS}




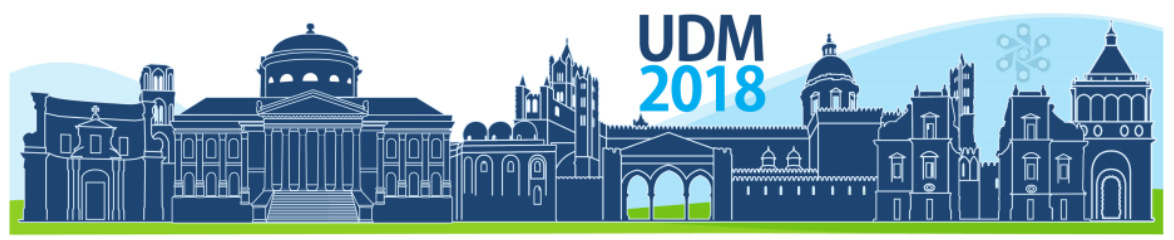

$11^{\text {th }}$ International Conference on Urban Drainage Modelling

23-26 Sep | Palermo - Italy

To measure is to know. It is obvious that sensors should provide adequate data so adequate measurements are the very foundation of "smart" (Ingildsen and Olsson, 2016, Chapter 3). The measured or observed phenomena form the basis for all feedback. In UD systems it is apparent that knowledge of flow rates, levels and rain intensity is necessary for good operation. However, we also see the need to know a multitude of concentrations and quality parameters to operate the system satisfactorily. We ought to know conditions for greenhouse gas formation as well as odour problems. There is also an increasing interest to get information about pathogens to find out about the spread of diseases.

As noted above, an essential task of any process control is to ensure that the plant equipment is working adequately. If any operating failure is noted an automatic alarm should be directed to the operating personnel. Such information includes meters of electric motor speeds, acoustic noise measurements, and indicators that can ensure that pumps and valves are operational. Simple level measurements or weight sensors can confirm that levels are within acceptable limits. Gas analysers observe methane production. The whole idea is to ensure normal operation.

On the next level we need to know more accurately about flow rates, water velocities, levels, and analysis of greenhouse gases.

It is not trivial to measure flow rates in drainage systems. For example, measuring flow rate in CSO structures is often quite inaccurate since the structures are not built primarily to measure flow rate, see below. Measuring low flows in sewers is typically difficult and has large relative errors (Bertrand-Krajewski et al., 2003; Vezzaro et al., 2013). As analysed by Mignot et al. (2012) the location of a flow rate sensor is important, since the accuracy depends on the position of the device.

To minimize odour problems is crucial in UD and wastewater treatment. There are odour monitors that can be positioned in various parts of the network. They can be connected to the operators by either $3 G$ or $4 G$ systems or via Internet to alert the operations team if there are any expected high odours from anywhere in the works. This enables proactive odour management rather than having to respond to customer complaints or rely on casual observations.

\section{ANALYSIS}

Control actions are performed at different levels. At the equipment level there are many feedback loops. For example, a single pump control is based on level or flow rate measurements. The measurements should be analysed to remove high-frequency noise or outliers. The system should recognize if the measured value is reasonable by comparing the measurement with alarm limits for absolute values or rates of change. The analysed value is the basis for local control.

To control the flow rates in a drainage network means a much higher level of complexity. Many (analysed) measurements of levels or flow rates are the basis for control of many pumps or valves. Considering the spatial distribution of the network it also means that flows from different parts of the system will propagate at different time scales, and the influence of a certain pump will reach different parts of the drainage system at different times. All of this requires that a dynamical model of the drainage forms the basis for control decisions. Several 


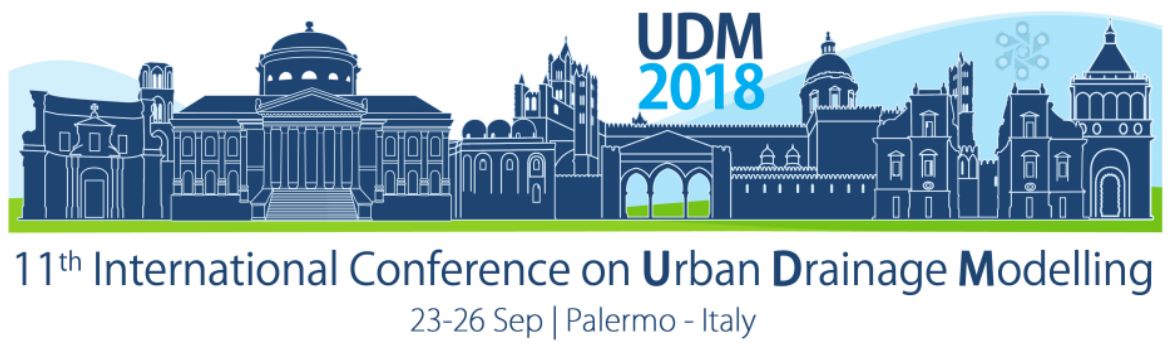

tools are being developed in hydroinformatics to support this kind of integrated decisionmaking (Savić, 2017).

The problem to calculate the volume of CSO is investigated by Ahm et al. (2016). As mentioned above, CSO overflow structures are not primarily designed for measurements but to effectively discharge excess water. By using models and estimation it is possible to quantify the CSO discharge so that adequate mass balance calculations can be accomplished. The authors have derived soft sensors, i.e. estimated flow rates based on level measurements in the system. The data-driven software sensor concept was developed by utilising correlation analysis between physical water level sensors and discharge measurements. The authors achieved good accuracy when the estimates were compared with electromagnetic flow measurements. Another software sensor concept is based on computational fluid dynamics (CFD) simulations of the physical layout of the CSO structures. This software sensor is an independent estimation and does not need any calibration to discharge measurements.

Part of the challenge is to consider observability. A key question is to compute how many flow rate and level measurements are necessary to get a complete picture of the hydraulics of the UD system. The more measurements that are made the better the accuracy of the estimation. However, it must be a balance between cost of measurements and accuracy of the estimated parameter or state of the system.

\section{INFORMATION SYSTEMS}

The geographical distribution of a UD system brings about particular challenges. Sensor information is collected from distant places and actuators must be controlled from remote locations. Two key technologies provide solutions to this:

- Hydroinformatics, and

- Internet of things loT.

Hydroinformatics (also known as Water Informatics or Water Information Engineering) has grown rapidly in recent years and seeks to take full advantage of the proliferation of remotely sensed information from sensors with increasing capabilities in terms of temporal and spatial resolution. Hydroinformatics define and supply the modelling tools that support integrated decision-making to manage aquatic resources and the environment (Savić, 2017).

Wireless communication is part of the development of Internet of Things (IoT) and makes it possible to easier achieve field measurements from distant locations, thus increasing the probability to successfully obtain early warning systems. It is not surprising that information and control infrastructure is the focus of many smart control initiatives. Various predictions for growth in the loT and machine-to-machine markets have been staggering. Considering that 4.9 billion loT devices were in use in 2015, the estimates for 2020 range from 21 to 75 billion (Hosain, 2016).

\section{MONITORING}

Unlike humans, computers are infinitely attentive and can detect abnormal patterns in operating data. Monitoring indicates tracking the operational state of a process or a machine via online instrumentation. By making use of vigilant monitoring of key parameters we can reduce the risks for operational problems and growing errors. A consistent monitoring of the 


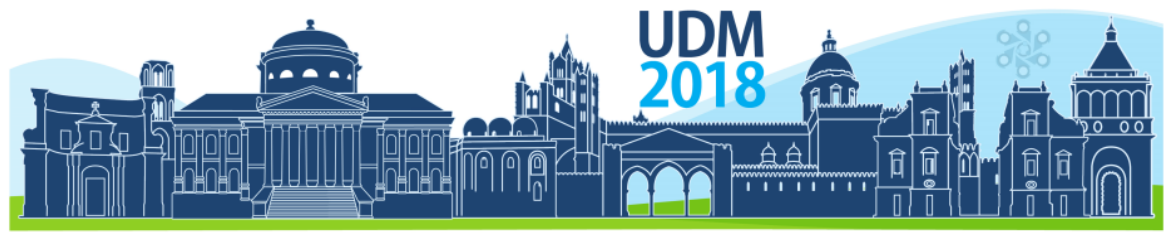

$11^{\text {th }}$ International Conference on Urban Drainage Modelling

23-26 Sep | Palermo - Italy

performance will help to avoid that problems may grow too large, as illustrated in Figure 2. By rapidly detecting deviations from "normal" it is possible to minimize the costs of abnormal behaviour. There are numerous applications of monitoring in wastewater systems. An overview is given in Olsson et al. (2014).

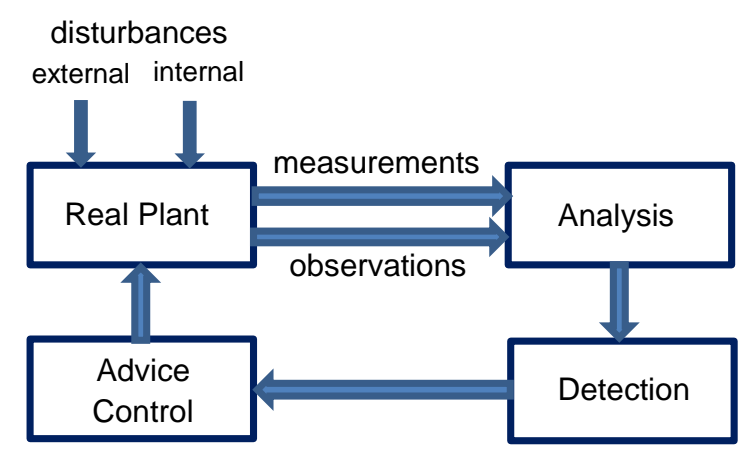

Figure 2. A monitoring system is based on analysis of the measurements and observations. A fault or failure can often be detected automatically. Based on the result some advice can be given and a control action can take place.

Process knowledge is an essential condition for adequate diagnosis. A primary observation may lead to a whole chain of examinations of the problem, similar to procedures in medical diagnosis. For example, a high flow rate in one location may be the primary warning. The reason may be a local rain, a calibration error, a failing pump elsewhere etc. By backchaining and asking questions (automatically or manually), the diagnosis will look for the primary cause for the problem.

There are two classes of early warning system to consider. The primary early warning system is for the operator to become aware of operational problems in the system. This can be extreme flow rates but also information of failing equipment or infiltration. The other early warning system is aiming for the general public. There can be several scenarios: (1) warning for flooding, (2) warning a hospital for an outbreak of a disease

\subsection{Equipment monitoring}

Monitoring equipment behaviour has an impact on both equipment reliability and system performance. Such a system should monitor pumps and motors to predict when they might fail. Failures of major equipment like that can contribute to overflow situations. If it is detected that a pump is not acting the way it should, it is possible to take action to prevent a failure from happening in the first place.

A too common pump problem is clogging caused by rags, pre-moistened wipes and other consumer goods marketed as flushable. This causes sewage backups in the collection system. The flushable market is on the rise, led by marketing efforts to position these products as more convenient and more effective cleaning tools than their dry paper counterparts. Therefore, pump clog problems seem to be increasing. One design solution that has been applied is installing a special impeller that helps to counterbalance hydraulic forces and create a balanced, single flow path that passes problem flushables. Another (maybe complementary) 


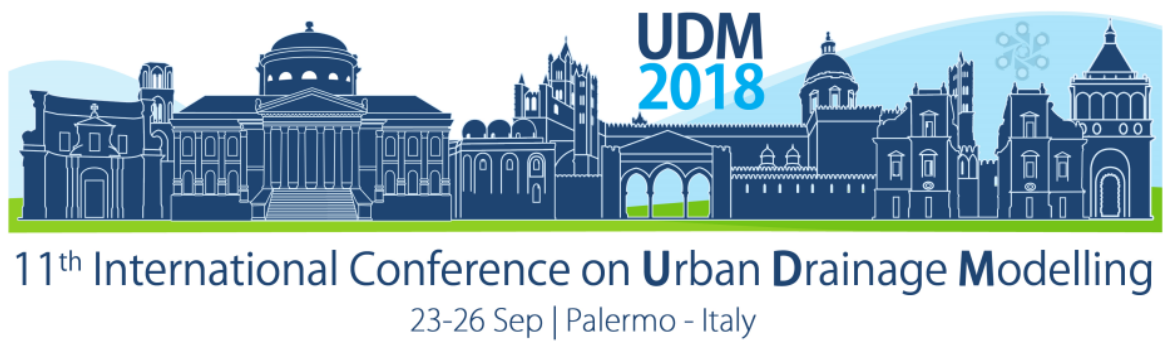

approach, online monitoring, is to compare the flow rate and the motor current. With clogging more power is needed to bring about a certain flow rate.

\subsection{Infiltration and inflow}

Infiltration and inflow $(\mathrm{I} / \mathrm{I})$ of unwanted water in the sewer system is not desirable since this will lead to a higher hydraulic load and may hydraulically overload a wastewater treatment plant (De Bénédittis and Bertrand-Krajewski, 2005; Ellis and Bertrand-Krajewski 2010, Beheshti et al., 2015). Obviously, any decrease of the $1 /$ l will decrease the probability for CSO or an overload of the treatment plant. There are various methods to detect, localize and quantify $\mathrm{I} / \mathrm{I}$ in the sewer systems. Traditional methods to estimate the $\mathrm{I} / \mathrm{I}$ are based on flow rate measurements, analysis of diurnal flow and load variation and balancing water inputs and outputs (Ellis and Bertrand-Krajewski 2010). Flow rate methods are typically used off-line. Other off-line methods include tracer tests.

One qualitative on-line method is using temperature measurements. Fibre-optic Distributed Temperature Sensing (DTS) can measure temperature with high resolution and frequency. This method has been widely used in other industries, for example to detect fractures in oil pipelines (Vosse et al. 2013, Schilperoort et al. 2013). Storm-water inflow can be detected as long as the temperature of this inflow differs from the in-sewer temperatures (Langeveld et al. 2012).

Another on-line method is based on conductivity measurements (Zhang et al., 2018). The authors have used conductivity measurements to estimate rainfall-derived $\mathrm{I} / \mathrm{I}$ when overflow happens at the same time. Usually it is difficult to distinguish between the two phenomena. Variations in the flow and water quality during dry weather conditions were analysed using Fast Fourier Transform and a model was developed for the rainfall-derived $\mathrm{I} / \mathrm{l}$. The method and the model have been successfully tested for light, medium and heavy rains.

\subsection{Flood warning}

If a CSO situation can be predicted sufficiently early, then it is often possible to divert the excess flow to storage facilities so that the water can be processed at a more normal pace once the wet-weather event has subsided.

If a severe flood is detected, then it should be recognized that the control authority of the UD system pumps is not sufficient to eliminate such a disturbance. In other words, some limited action can take place in the UD operation, but other actions must be taken outside the UD system, in the urban environment, to minimize the consequences of the flood. Hydraulic models are used to guide the operation of the system. They often consist of coupled 1D drainage network and 2D surface models to predict inundation depths in the surrounding area.

As emphasized by Savić (2017) the prediction horizon is crucial. The model must provide sufficient lead time for the flood prediction so that necessary actions can be taken. This means that model simplifications of large networks may have to be realised so that the computations can be finished in time. Savić (2017) describes two methods: fast overland flood modelling and data-driven (machine learning) sewer surcharge modelling. The overland flood modelling is realized by a 2D cellular automata model (Ghimire et al., 2013; Guidolin et al., 2016). This approach increases the computational speed about an order of magnitude compared to traditional methods. 


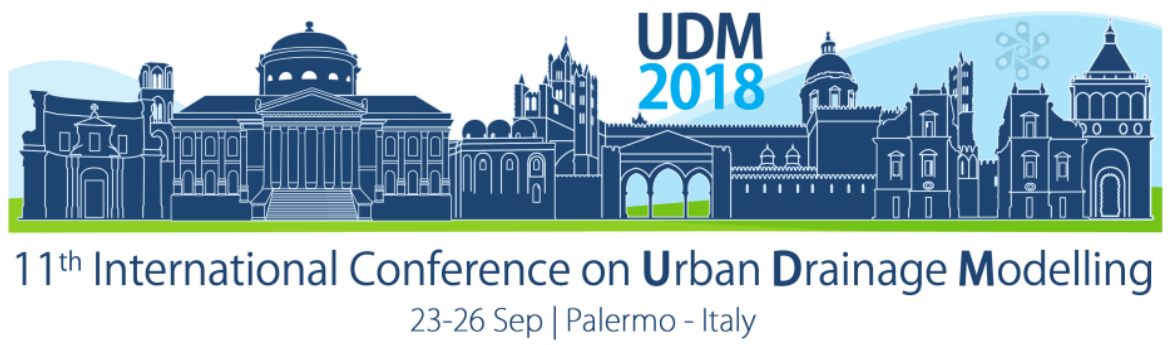

The other approach described by Savić (2017) is using machine learning, where the model is updated using an artificial neural network (ANN) model that is using computational data from several flood calculations using traditional models and combined with rainfall radar forecasts (Duncan et al., 2011, 2013). The model is then compared to real events. A similar approach is described by Rjeily et al. (2017). The flood risk is calculated by estimating the water depth variation within critical manholes. The ANN parameters describe how water depth variation in manholes is related to rainfall intensities.

Climate change is already causing an increase of extreme events, such as large rain storms. Kleidorfer et al. (2018) analyse such an event of heavy rain in Austria. The authors emphasize that the models may be calibrated for more common events like a 10-year rain. However, data for extreme and rare events is seldom available, which makes flood prediction models unreliable, because the relationship between rainfall intensities and flooding is nonlinear.

\subsection{Early warning of blockage events}

An innovative early warning method for spills has been developed by a company Nukon (http://www.nukon.com.au/). Often the first notification of a spill comes from a member of the public, hours and sometimes days after the first spill. The challenge is to find a way to predict the spill before it happens. A model was developed using data from previous spills with the goal to find out if the model could detect a spill earlier than other methods. One indicator is the time between pump runs. This means that a pump will start running when a wet well is filled. The time-to-fill was identified for on-peak, off-peak, weekends and weekdays under normal behaviour. The model then identifies blockages by detecting non-normal time-to-fill behaviour. For example, if the fill time is unexpectedly long during peak times or the pump does not run, it is an indicator of abnormality or possible blockage. The model has been tested successfully and could detect historical blockages more than 12 hours before they were reported by a customer.

\subsection{Odour detection and control}

The formation of odour in the UD system can be limited by design, for example to limit the retention times for sewage in force mains and pump stations. The ventilation of the sewer system affects the release of odour. Chemicals are often dosed to control the production and accumulation of hydrogen sulfide in sewers (Sharma et al., 2012). To address the operational problem of odour control, The University of Queensland has developed highly praised research on odour management and control design to mitigate hydrogen sulfide (Jiang et al., 2015; Liu et al., 2015; Ganigué et al., 2018). The methodology is based on real time prediction of sewage flows and characteristics both at sources and across the network. Based on these predictions chemical dosage control has been demonstrated to greatly reduce the chemical usage.

\subsection{Early warning of public health}

The sewer system contains a lot of information that is related to the health of a community. This insight has led to a multi-disciplinary project Underworlds, centered around several researchers in not only civil and environmental engineering at MIT (Massachusetts Institute of 


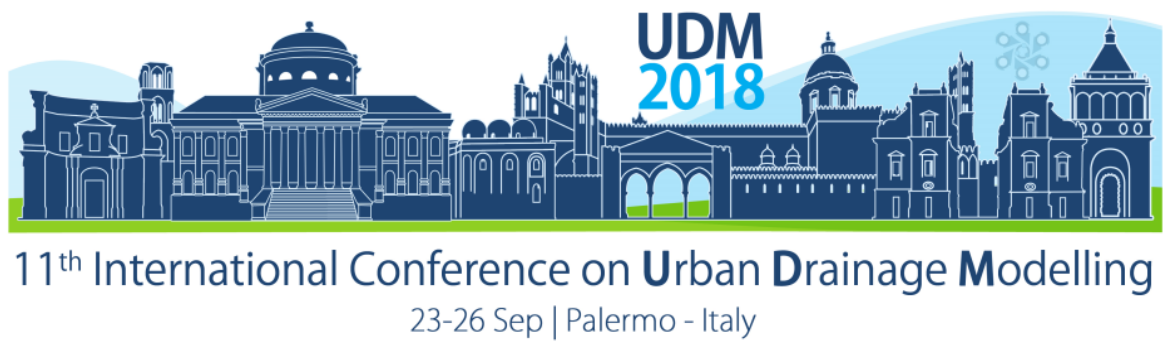

Technology) but also computer scientists, biologists, physicists, planners and social scientists. The overall goal is to find out how the sewer flow can reveal spread of illnesses, drug-use and the general health of the urban population. The Underworld platform is designed to detect and characterize viruses, bacteria, and chemicals in a city's sewage (Barr, 2016).

Naturally sample collection is both a risky and dirty job. For this purpose a robot has been developed. The device will enter the sewer system, take samples from certain areas and is guided remotely using an iPhone app. The samples are brought to the lab and analysed to report bacteria, viruses, and more and the samples are prepared for DNA extraction and sequencing.

By monitoring patterns in bacteria an early warning system can be built to detect illnesses like a new flu strain or even epidemics. The potential is much bigger. By studying the microbiome of the urban population through sewage-water analysis patterns in diets and drug use can be revealed.

Gao et al. (2018) have approached the public health issue of consumption of alcohol and tobacco. They work with wastewater-based epidemiology (WBE) to use biomarkers in a real rising main sewer to estimate the consumptions. The researchers used rhodamine and acesulfame to find out the hydraulic pattern in the sewer and then tried out different biomarkers for alcohol and nicotine. A key issue is still the in-sewer degradation of the biomarkers.

\section{CONTROL}

Control theory and practice today can offer "almost anything" in terms of methods and algorithms that the water operator would need. Automatic control is sometimes called the hidden technology. It appears everywhere around us and we do not even think about it. We only notice it when it does not work. Even if control is applied in completely different areas, there is a common theory that is independent of the applications. There are literally hundreds of textbooks on control. A superior textbook has been published recently by Åström and Murray (2014). The authors are world leaders in the development of control theory and engineering. The complete book is available for free on the web and includes the complete text of the book as well as additional examples, exercises, and frequently asked questions.

In his excellent survey Harremoës (2002) demonstrates that the idea of controlling sewer networks has been on the agenda for a long time. He points out that in 2002 most sewers and wastewater treatment plants were designed and operated on an empirical basis. Discharges from the system to receiving waters were still formulated on an empirical basis instead of the overall environmental impact, as remarked above. He points out that this was not only due to lack of knowledge, but also due to a significant conservatism in the profession.

Harremoës found interesting development pointing at real time control of sewers. Dynamic models were increasingly used for simulation of the hydrology and hydraulics of sewer systems and applied to predict flooding and hydraulic loads on the treatment plant and on receiving waters. Pollution transport in the sewer is highly important when considering pollution discharged from CSOs. Simplified models for real time control were getting in use. However, there was a high uncertainty associated with the simulations and is still a challenge. Harremoës noted that real time control still was not applied widely. The complexity was considered too large and the risk for technical and software failures hindered the acceptance of the methods. It should be noted however, that on-line measurements and on-line estimation of parameters 


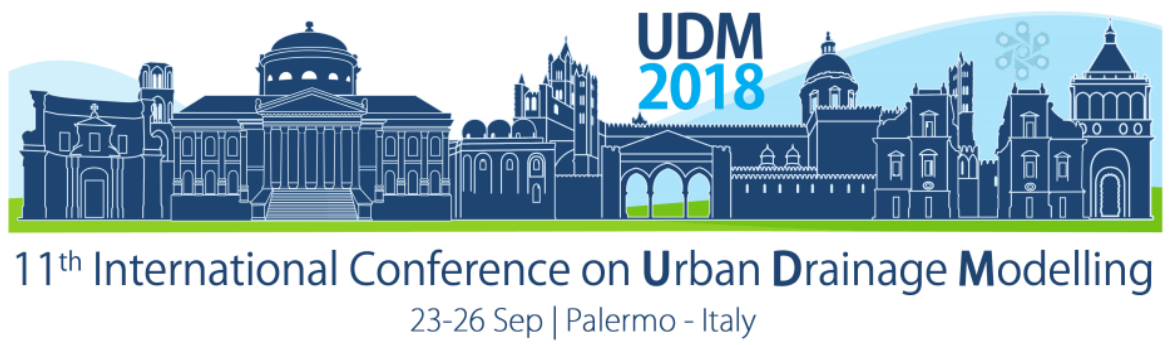

in models adapted for control could be used for short-term prediction and control (Harremoës and Rauch, 1999).

Later on, real time control of sewer systems has been studied extensively and the benefits have been demonstrated by for example Schütze et al. (2004), Beeneken et al. (2013) and García et al. (2015). Various control structures and algorithms have been applied, but it is difficult to compare the benefits of each one of them, since the systems and the operating conditions are not identical. A similar dilemma was expressed already in the 1990s in wastewater treatment control. This led to the development of a benchmark system called the Benchmark Simulation Model (BSM) that has been extremely successful in the wastewater treatment control community to test and compare control strategies for wastewater treatment systems (Gernaey et al., 2014). A benchmark system for UD systems based on a similar philosophy has now been developed by a working group 'Integral Real Time Control' of the German Water Association (DWA). The test bed is called Astlingen (Schütze et al., 2018).

\section{CONCLUSIONS}

As described this field of ICA is heavy in science and technology and it may seem like a daunting task to get a full overview. However, keeping the MAD principle in mind actually simplifies things. One way is a kind of backward analysis thinking: what decision do I need to make effectively and efficiently. Where are the control handles? For this we need measurements and analysis. What measurements are available? Which is the best analysis we can make to obtain to a good decision? Or the other (forward analysis) way: with the knowledge from this sensor at this position, what decisions can be made better and more precisely? Which questions have to be answered by the analysis?

The principle of MAD is applicable in automation and all the way up to high-level strategic decisions. The framework is always the same, whereas the measurements, the analysis and the decisions are different. Hence, it is of crucial importance that a critical amount of people understand this way of thinking in order for utilities to become smarter, more robust, more resilient, more efficient, more effective and not the least: more sustainable.

To maximise the capacity of the UD system it is important to systematically analyse all the aspects of feedback:

- How to translate the general goal of protecting the urban and natural environment into operational goals of the UD system control?

- Is there sufficient control authority of the system? Can the controllability be increased by installing more pump capacity?

- How can models be used for predictive control?

- What kind of early warnings are desirable?

- How can the need for information be met by sensors?

- How to build up an information system that can connect all sensors, control computers, actuators and people?

\section{References}




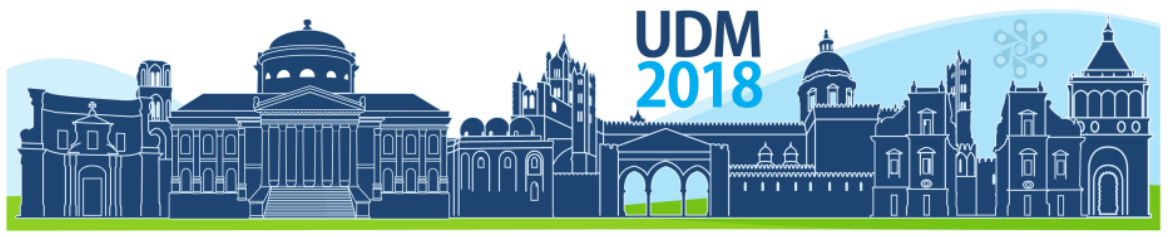

$11^{\text {th }}$ International Conference on Urban Drainage Modelling

23-26 Sep | Palermo - Italy

Ahm M., Thorndahl S., Nielsen J.E. and Rasmussen M.R. (2016). Estimation of combined sewer overflow discharge: a software sensor approach based on local water level measurements. Wat. Sci. Tech. 74(11), 2683-2696.

Åström K.J. and Murray R.M. (2014). Feedback Systems: An Introduction for Scientists and Engineers. The complete book is available for free on the web, called FBSwiki http://www.cds.caltech.edu/ murray/amwiki/index.php/Main_Page (accessed 15 Feb. 2018).

Barr J. (2016). Stopping the Spread of Sickness with Sewage? Slice of MIT. An MIT Alumni Association Publication. https://alum.mit.edu/slice/stopping-spread-sickness-sewage (accessed 24 April 2018).

Bauwens W., Vanrolleghem P.A. and Smeets M. (1996). An evaluation of the efficiency of the combined sewer wastewater treatment system under transient conditions. Wat. Sci. Tech. 33(2), 199-208.

Beeneken T., Erbe V., Messmer A., Reder C., Rohlfing R., Scheer M., Schütze M., Schumacher B., Weilandt M. and Weyand M. (2013). Real time control (RTC) of urban drainage systems - A discussion of the additional efforts compared to conventionally operated systems. Urban Water Journal 10(5), 293-299.

Beheshti M., Sagrov S. and Ugarelli R. (2015). Infiltration/Inflow Assessment and Detection in Urban Sewer System. Vann 01, 24-34, Norway.

Benedetti L., Prat P., Nopens I., Poch M., Turon C., De Baets B. and Comas J. (2009). A new rule generation method to develop a decision support system for integrated management at river basin scale. Wat. Sci. Tech. 60(8), 2035-2040.

Benedetti L., Langeveld J., Comeau A., Corominas L., Daigger G., Martin C., Mikkelsen P.S., Vezzaro L., Weijers S. and Vanrolleghem P.A. (2013). Modelling and monitoring of integrated urban wastewater systems: review on status and perspectives. Wat. Sci. Tech. 68 (6), 1203-1215.

Bertrand-Krajewski J.-L., Bardin J.P., Mourad M. and Beranger Y. (2003). Accounting for sensor calibration, data validation, measurement and sampling uncertainties in monitoring urban drainage systems. Wat. Sci. Tech. 42(2), 95-102.

Butler D. and Parkinson J. (1997). Towards sustainable urban drainage. Wat. Sci. Tech. 35(9), 53-63.

De Bénédittis J. and Bertrand-Krajewski J.-L. (2005). Infiltration in sewer systems: comparison of measurement methods. Wat. Sci. Tech. 52(3), 219-227.

Dong X., Zeng S., Chen J. and Zhao D. (2012). An integrated urban drainage system model for assessing renovation scheme. Wat. Sci. Tech. 65(10), 1781-1788.

Duncan A.P., Chen A.S., Keedwell E.C., Djordjevic S. and Savic D. (2011). Urban flood prediction in real-time from weather radar and rainfall data using artificial neural networks. Weather Radar and Hydrology. In Proceedings of a symposium held in Exeter, UK, April (IAHS Publ. 351, 2012) (pp. 568-573).

Duncan A., Chen A.S., Keedwell E., Djordjevic S. and Savic D. (2013). RAPIDS: early warning system for urban flooding and water quality hazards. In: Machine Learning in Water Systems Symposium: Part of AISB Annual Conference, pp. 1-5.

Ellis J.B., Bertrand-Krajewski J.-L. (2010). Assessing infiltration and exfiltration on the Performance of Urban Sewer systems (APUSS). IWA Publishing. ISBN: $184339149 X$. ISBN 13: 9781843391494.

Erbe V. and Schütze M. (2005). An integrated modelling concept for immission-based management of sewer system, wastewater treatment plant and river. Wat. Sci. Tech. 52 (5), 95-103.

Fu G., Butler D. and Khu S.-T. (2008). Multiple objective optimal control of integrated urban wastewater system. Environmental Modeling and Software 23(2), 225-234.

Gao J., Li J., Jiang G., Yuan Z., Eaglesham G., Covaci A., Mueller J.F. and Thai P.K. (2018). Stability of alcohol and tobacco consumption biomarkers in a real rising main sewer. Wat. Res. 138, 19-26. doi:10.1016/j.watres.2018.03.036

Ganigué R., Jiang G., Liu Y., Sharma K., Wang Y.-C., Gonzalez J., Nguyen T. and Yuan Z. (2018). Improved sulfide mitigation in sewers through on-line control of ferrous salt dosing. Wat. Res. 135, 302-310. doi:10.1016/j.watres.2018.02.022

García L., Barreiro-Gomez J., Escobar E., Téllez D., Quijano N. and Ocampo-Martinez C. (2015). Modeling and real-time control of urban drainage systems: a review. Adv. Wat. Resources 85, 120-132.

Gernaey K., Jeppsson U., Vanrolleghem P.A. and Copp J.B. (2014). Benchmarking of Control Strategies for Wastewater Treatment Plants. Scientific and Technical Report No. 23. IWA Publishing.

Ghimire B., Chen A.S., Guidolin M., Keedwell E.C., Djordjević S. and Savić D.A. (2013). Formulation of a fast 2D urban pluvial flood model using a cellular automata approach. Journal of Hydroinformatics 15(3), 676-686.

Grum M., Thornberg D., Christensen M.L., Shididi S.A. and Thirsing C. (2011). Full-scale real time control demonstration project in Copenhagen's largest urban drainage catchments. In Proceedings of the $12^{\text {th }}$ Int. Conf. on Urban Drainage, Porto Alegre, Portugal.

Guidolin M., Chen A.S., Ghimire B., Keedwell E.C., Djordjević S., and Savić D.A. (2016). A weighted cellular automata 2D inundation model for rapid flood analysis. Environmental Modelling \& Software 84, 378-394. 


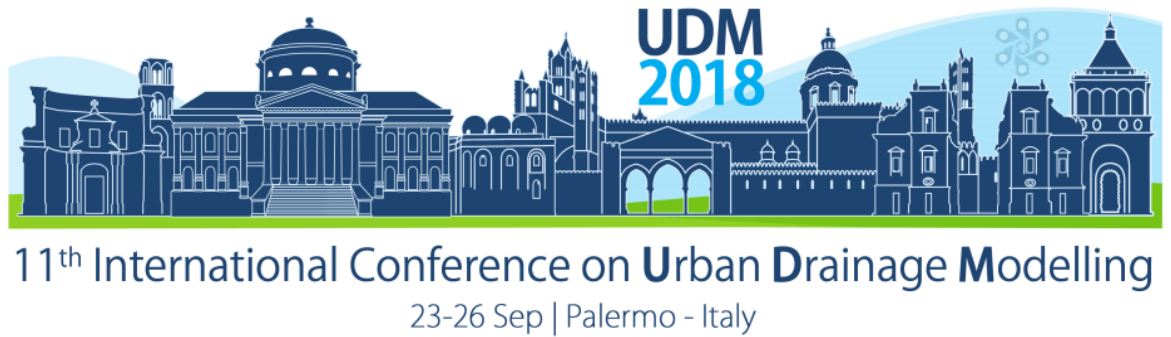

Harmes J. (2016). Smart metering .... for sewers? Water Finance \& Management. https://waterfm.com/smartmetering-sewers/ (accessed 23 April 2018).

Harremoës P. (2002). Integrated urban drainage, status and perspectives. Wat. Sci. Tech. 45(3), 1-10.

Harremoës P. and Rauch W. (1999). Optimal design and real time control of the integrated urban run-off system. Hydrobiologia, 410, 177-184.

Hosain S.Z. (2016). Reality Check: 50B loT devices connected by 2020 - beyond the hype and into reality. RCR Wireless News. http://www.rcrwireless.com/20160628/opinion/reality-check-50b-iot-devices-connected-2020beyond-hype-reality-tag10 (accessed 24 April 2018).

Ingildsen P. and Olsson G. (2016). Smart water utilities. IWA Publications, London.

Jiang G., Sun J., Sharma K. and Yuan Z. (2015). Corrosion and odor management in sewer systems. Current Opinion in Biotechnology 33(10), 1016.

Kleidorfer M., Tscheikner-Gratl F., Vonach T. and Rauch W. (2018). What can we learn from a 500-year event? Experiences from urban drainage in Austria. Wat. Sci. Tech. 77(8), 2146-2154.

Kollatsch D-Th. (1993). Futuristic ideas to create a most efficient drainage system. Proc. $6^{\text {th }}$ International Conf. on Urban Storm Drainage, Niagara Falls, Ontario, Canada, Sep. 12-17, 1993, 1225-1230.

Langeveld J.G., de Haan C., Klootwijk M. and Schilperoort, R.P.S. (2012). Monitoring the performance of a storm water separating manifold with distributed temperature sensing. Wat. Sci. Tech.66(1), 145-150.

Liu Y., Sharma K.R., Fluggen M., O'Halloran K., Murthy S. and Yuan Z. (2015). Online dissolved methane and total dissolved sulfide measurement in sewers. Wat. Res. 68(1), 109-118

Melville-Shreeve P., Ward S., and Butler D. (2016). Rainwater Harvesting Typologies for UK Houses: A Multi Criteria Analysis of System Configurations. Water, 8(4), 129.

Mignot E., Bonakdari H., Knothe P., Lipeme Kouyi G., Bessette A., Rivière N. and Bertrand-Krajewski J.-L. (2012). Experiments and 3D simulations of flow structures in junctions and their influence on location of flowmeters. Wat. Sci. Tech. 66(6), 1325-1332.

Nielsen M.K., Carstensen J. and Harremoës P. (1996). Combined control of sewer and treatment plant during rainstorm. Wat. Sci. Tech. 34(3), 181-187.

Olsson G. (2012). ICA and me - a subjective review. Wat. Res. 46(6), 1585-1624.

Olsson G., Carlsson B., Comas J., Copp J., Gernaey K.V., Ingildsen P., Jeppsson U., Kim C., Rieger L., RodríguezRoda I., Steyer J.-P., Takács I., Vanrolleghem P.A., Vargas Casillas A., Yuan Z. and Âmand L. (2014). Instrumentation, Control and Automation in wastewater- from London 1973 to Narbonne 2013. Wat. Sci. Tech. 69(7), 1373-1385. doi: 10.2166/wst.2014.057.

Pfister A., Stein A., Schlegel S. and Teichgräber B. (1998). An integrated approach for improving the wastewater discharge and treatment systems. Wat. Sci. Tech. 37(1), 341-346.

Pleau M., Pelletier G., Coias H., Lavaliee P. and Bonin R. (2001). Global predictive real-time control of Quebec Urban Community's westerly sewer network. Wat. Sci. Tech. 43 (7), 123-130.

Pleau M., Colas H., Lavallee P., Pelletier G. and Bonin R. (2005). Global optimal real-time control of the Quebec urban drainage system. Environmental Modelling and Software 20(4), 401-413.

Rauch W. and Harremoës P. (1996a). The importance of the treatment plant performance during rain to acute water pollution. Wat. Sci. Tech. 34(3-4), 1-8.

Rauch W. and Harremoës P. (1996b). Minimizing acute river pollution from urban drainage systems by means of integrated real time control. In Proc. $1^{\text {st }}$ Int. Conf. on New/Emerging Concepts for Rivers (RIVERTECH'96), Chicago, USA.

Rauch W. and Harremoës P. (1999). Genetic algorithms in real time control applied to minimize transient pollution from urban wastewater systems. Wat. Res. 33(5), 1265-1277.

Rjeily Y.A., Abbas O., Sadek M., Shahrour I., and Chehade F.H. (2017). Flood forecasting within urban drainage systems using NARX neural network. Wat. Sci. Tech. 76(9), 2401-2412.

Savić D. (2017). A Smart City without Smart Water is Only a Pipe Dream! Keynote paper, Int. Assoc. for HydroEnvironment Engineering and Research (IAHR) World Congress, Kuala Lumpur, Malaysia 2017.

Schilperoort R., Hoppe H., de Haan C., Langeveld J. (2013). Searching for storm water inflows in foul sewers using fibre-optic distributed temperature sensing. Wat. Sci. Tech. 68(8), 1723-1730.

Schütze M., Butler D. and Beck M.B. (1999). Optimisation of control strategies for the urban wastewater systeman integrated approach. Wat. Sci. Tech. 39(9), 209-216.

Schütze M., Butler D., Beck M.B. and Verworn H.R. (2002). Criteria for assessment of the operational potential of the urban wastewater system. Wat. Sci. Tech. 45(3), 141-148.

Schütze M., Campisano A., Colas H., Schilling W. and Vanrolleghem P. (2004). Real time control of urban wastewater systems - where do we stand today? Journal of Hydrology 299, 335-348.

Schütze M., Lange M., Pabst M. and Haas U. (2018). Astlingen - a benchmark for real-control control (RTC). Wat. Sci. Tech., in press. 


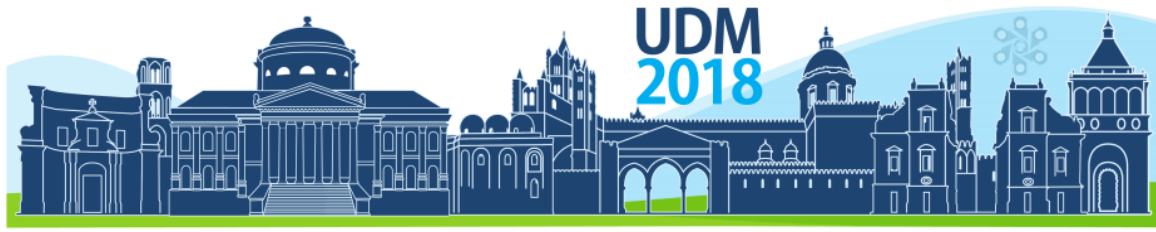

$11^{\text {th }}$ International Conference on Urban Drainage Modelling

23-26 Sep | Palermo - Italy

Seggelke K., Rosenwinkel K.H., Vanrolleghem P.A. and Krebs P. (2005). Integrated operation of sewer system and WWTP by simulation-based control of the WWTP inflow. Wat. Sci. Tech. 52 (5), 195-203.

Seggelke K., Löwe R., Beeneken T. and Fuchs L. (2013). Implementation of an integrated real-time control system of sewer system and waste water treatment plant in the city of Wilhelmshaven. Urban Water Journal, 10(5), 330-341.

Sharma K.R., Corrie (2012) and Yuan Z. (2012). Integrated modelling of sewer system and wastewater treatment plant for investigating the impacts of chemical dosing in sewers. Wat. Sci. Tech. 65(8), 1399-1405.

Vanrolleghem P.A., Benedetti L. and Meirlaen J. (2005). Modelling and real-time control of the integrated urban wastewater system. Environmental Modelling and Software 20 (4), 427-442.

Vezzaro L., Steen Mikkelsen P., Deletic A. and McCarthy D. (2013). Urban drainage models - simplifying uncertainty analysis for practitioners. Wat. Sci. Tech. 68(10), 2136-2143.

Vosse M., Schilperoort R., de Haan C., Nienhuis J., Tirion M., and Langeveld J. (2013). Processing of DTS monitoring results: Automated detection of illicit connections. Wat. Practice and Tech. 8(3), 375-381. doi:10.2166/wpt.2013.037

Weijers S.R., De Jonge J., Van Zanten O., Benedetti L., Langeveld J., Menkveld H.W. and Van Nieuwenhuijzen A.F. (2012). KALLISTO: cost effective and integrated optimization of the urban wastewater system Eindhoven. Wat. Practice and Tech. 7(2), 1-9.

Weinreich G., Schilling W., Birkely A. and Moland T. (1997). Pollution based real time control strategies for combined sewer systems. Wat. Sci. Tech. 36(8-9), 331-336.

Zacharof A.I., Schütze M. and Butler D. (2003). A methodology for assessing the operational potential of the urban wastewater system using integrated modelling. Wat. Sci. Tech.:Water Supply 3 (1-2), 271-277.

Zhang, M., Liu, Y., Cheng, X., Zhu, D.Z., Shi, H. and Yuan, Z. (2018). Quantifying rainfall-derived inflow and infiltration in sanitary sewer systems based on conductivity monitoring. J. of Hydrology, 558, 174-183. doi:10.1016/j.jhydrol.2018.01.002 


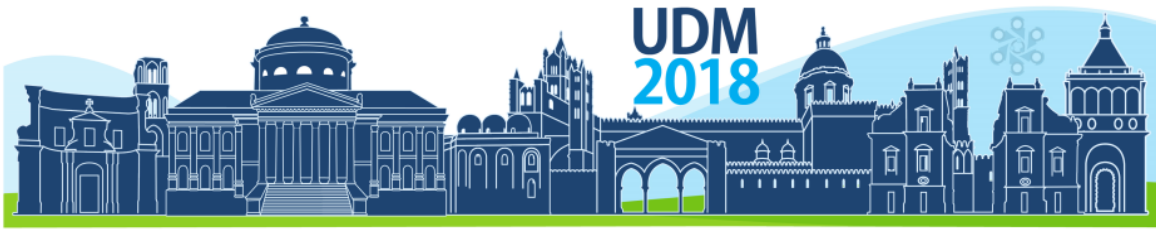

$11^{\text {th }}$ International Conference on Urban Drainage Modelling 23-26 Sep | Palermo - Italy

\title{
Development of a smart system for the operation of a complex sanitation system
}

\author{
Antonio Lastra ${ }^{1}$, Joaquín Suárez ${ }^{2}$, Jerónimo Puertas ${ }^{3}$, José Anta $^{4}$, Xavier Falcó ${ }^{5}$, Mónica \\ Ortega $^{6}$ and Alejandro Pinilla ${ }^{7}$ \\ 1, 6,7 Canal de Isabel II, R+D+i Department, Madrid, Spain \\ 2, 3, 4 Universidade da Coruña, Water and Environmental Engineering Group, A Coruña, Spain \\ ${ }^{5}$ AQUATEC, Water Engineering Department, Barcelona, Spain
}

\begin{abstract}
The urban runoff contains a significant amount of pollutants. Due to CSO limitations and WWTP's biological processes, wastewater discharge must be regulated not only in quantity but also in quality. In this regard, Canal de Isabel II is working on the Manzanares Sanitation System project to characterise pollution in different rainfall scenarios by profiling the collected rainwater pollutants. The results will be used to develop an integrated management protocol for the stormwater tanks during rain events focused on minimising not only the discharged volume, but mainly the environmental impact produced by the discharge into the receiving water bodies. After a storage period, the effluent pollution is noticeably reduced for the mere reason to be stored into the stormwater tank. As a conclusion, the sewer system's dimensioning idea based on characterisation of sewage is gaining straight over first flush or dilution concept. The project, headed by Canal de Isabel II, takes place in the city of Madrid and studies the CSS that belongs to Manzanares river's catchment.
\end{abstract}

Keywords: Urban pollution, stormwater tank, watershed management, integrated system, sewer system

\section{INTRODUCTION}

Canal de Isabel II is the Madrid's water utility company. It manages the drinking water supply, drainage system, wastewater treatment and reuse water. Within the sanitation system, the $\mathrm{I}+\mathrm{D}+\mathrm{i}$ Department is testing the effectiveness and the efficiency of new management approaches and technologies in the field.

The city of Madrid covers an area of $604,43 \mathrm{Km}^{2}$ and its current population is around six million inhabitants. It counts on a combined sewer system (CSS) with around $16.000 \mathrm{~km}$ length, $90 \%$ of whom discharges into Manzanares river and is known as Manzanares System.

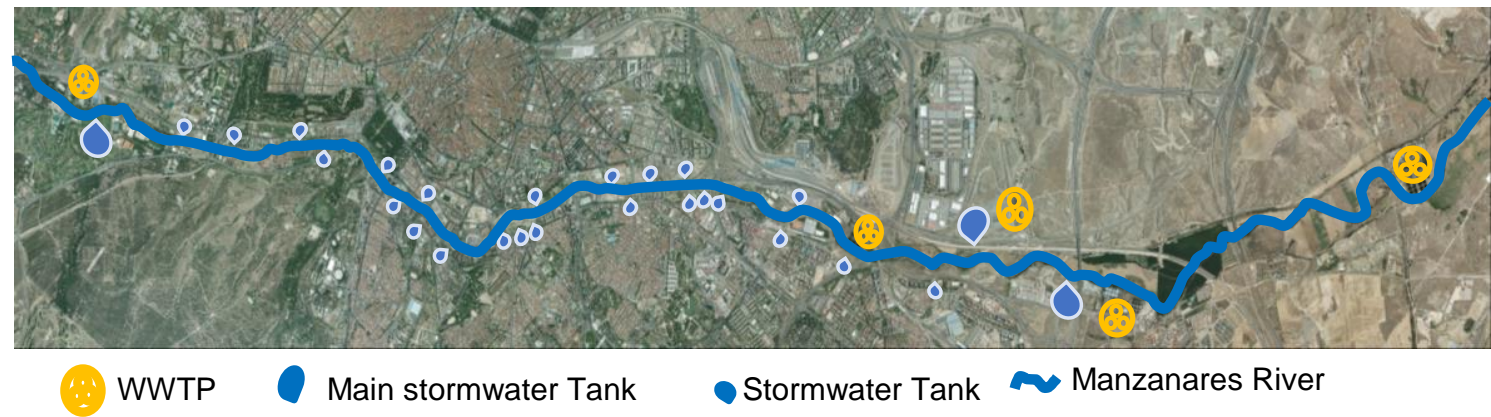

Manzanares sanitation system consists primarily of 32 stormwater tanks, several weirs, some wastewater treatment plants and two big sewer pipes that run along the riversides. The 


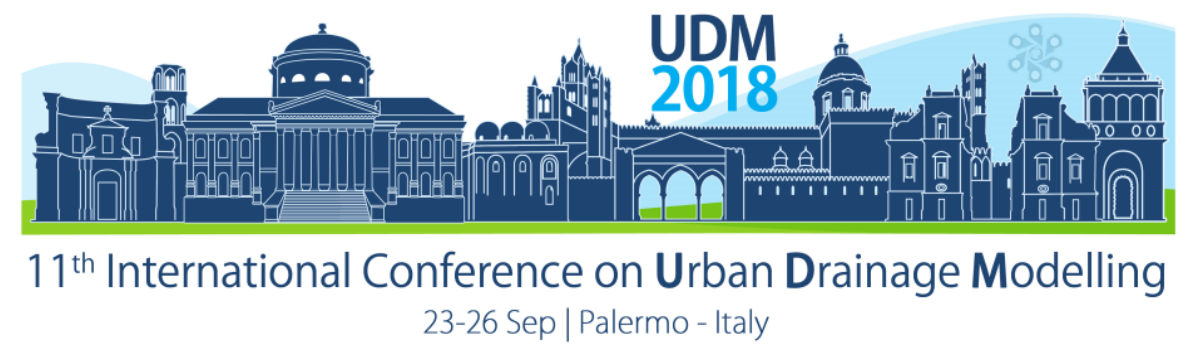

drainage infrastructures were built in different phases over time because of the urban growth, so that the management is currently not carried out in an integrated system operating. Thus, a watershed could work in a different manner than its immediate neighbour but then discharge the sewage into its sewer pipes, which could be full within the worst scenario case. Therefore, it could overflow into weirs or receiving water for non-capacity reasons, but drainage network's watershed management causes.

For the last decade, concerns about environmental health have spotlight the increasing urban pollution that contributes to degrade the ecosystems through the "Programa de Mejora de la Calidad del Río Manzanares: Reducción de la contaminación generada por la Descarga de Sistemas Unitarios (DSU)"1. Among others, this program sets up environmentally-friendly operations in the sewage system with the aim of improving the river ecological status.

The aim of the project is to develop an integrated management protocol that consolidates and coordinates the Manzanares System Management. The project mainly cares of weather conditions, urban runoff, the quality of wastewater flow, pollutants concentration and river ecological status. The protocol will serve as a tool for decision making by the system operator.

\section{DEVELOPMENT OF A SMART SYSTEM}

\subsection{Urban drainage system's main issues}

Urban surface runoff drags pollutants arising from air pollution, road traffic and waste materials into the sewer system. When the system cannot cope with the water flow, it is discharged into the Manzanares river, which contributes to the degradation of its aquatic ecosystem. The remaining sewage leads to the wastewater treatment plant (WWTP), which has quality restrictions because of biological processes, high pollutants concentration contributes to its failure performance. Thus, Canal de Isabel II addresses the study of sewage pollution impact on the urban drainage system.

\subsection{The project}

The study, from the preliminary work to the end of the project, was organised by sub-basins. Every sub-basin contains information about its area and drainage components' performance. The preliminary work's purpose is to define the significant infrastructures and its control sections where the characterisation of sewage is going to happen.

\subsubsection{Preliminary work}

It was collected all the existing information as well as a full review of the Manzanares system operation and its operating strategies during dry and wet weather conditions. Likewise, it was needed independent information about Manzanares river such as water level, biological and physicochemical status and CSO effects. Canal de Isabel II has been collecting historical monitoring data during the last years.

Regarding to this groundwork, it was stablished the following main components:

- Five wastewater treatment plants whose treated daily volume is $1.552 .362 \mathrm{~m}^{3}$.

- Two big sewer pipes running along Manzanares riversides.

- 32 stormwater tanks where volume ranges from 600 to $400.000 \mathrm{~m}^{3}$.

${ }^{1}$ (English Tittle) Manzanares River Quality-Improvement Program: Pollution reduction caused by CSO 


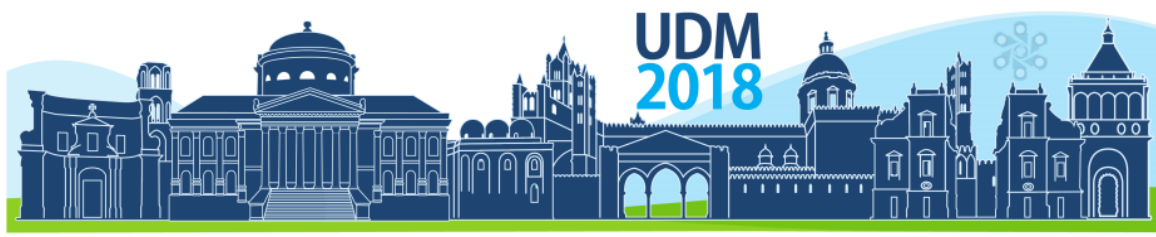

$11^{\text {th }}$ International Conference on Urban Drainage Modelling

23-26 Sep | Palermo - Italy

The control sections were chosen according to the following criteria: in the sewer pipes, the most important sections where in the inlet and outlet's Manzanares system and regarding to stormwater tanks, the control sections where chosen by tank dimension, typology, infrastructure complexity and location within the system.

Table 1 Main stormwater tanks from Manzanares Sanitation System

Figure 1 Arroyofresno stormwater tank

\begin{tabular}{l|r}
\hline \multicolumn{1}{c|}{ Infrastructure } & \multicolumn{1}{c}{ Volume } \\
\hline Arroyofresno stormwater tank & $400.000 \mathrm{~m}^{3}$ \\
\hline Pozuelo stormwater tank & $30.000 \mathrm{~m}^{3}$ \\
\hline Butarque stormwater tank & $400.000 \mathrm{~m}^{3}$ \\
\hline Albroñigal stormwater tank & $200.000 \mathrm{~m}^{3}$ \\
\hline La China stormwater tank & $120.000 \mathrm{~m}^{3}$ \\
\hline Valdemarín stormwater tank & $28.000 \mathrm{~m}^{3}$ \\
\hline
\end{tabular}

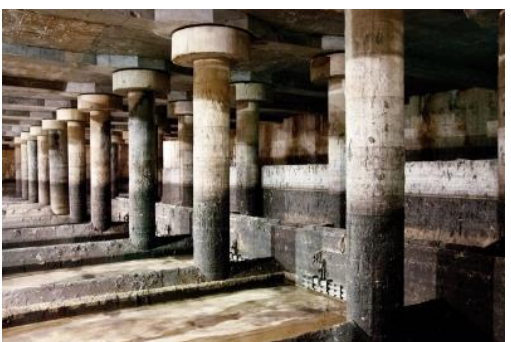

\subsubsection{Characterisation of sewage}

During wet weather conditions, sewage flow is diverted into stormwater tanks which perform with the aim of collecting the highest flow and if in any case it exceeds the tank capacity, it is always possible to use the weirs to discharge into Manzanares river.

A sewage characterisation campaign was meant to study the real pollutants evolution along the sub-basins that shed into Manzanares system. The campaign was designed to range from dry to wet weather conditions in order to obtain hydrograph and pollutograms. Every sub-basin has its own sampling protocol which defines sampling rainfall events, number of samples per rainfall event and parameters to measure. In some cases, it was also necessary to implement additional measuring equipment. On average, four rainfall events on every tank have been characterised.

\section{RESULTS AND DISCUSSION}

Once the urban area of Madrid was characterised, it was found out the following hydraulic information about the sewage flow balance (Figure 2) as well as the pollutograms during dry and wet weather flow in the urban area of Madrid (Figure 3). This characterisation campaign was held in 2016.

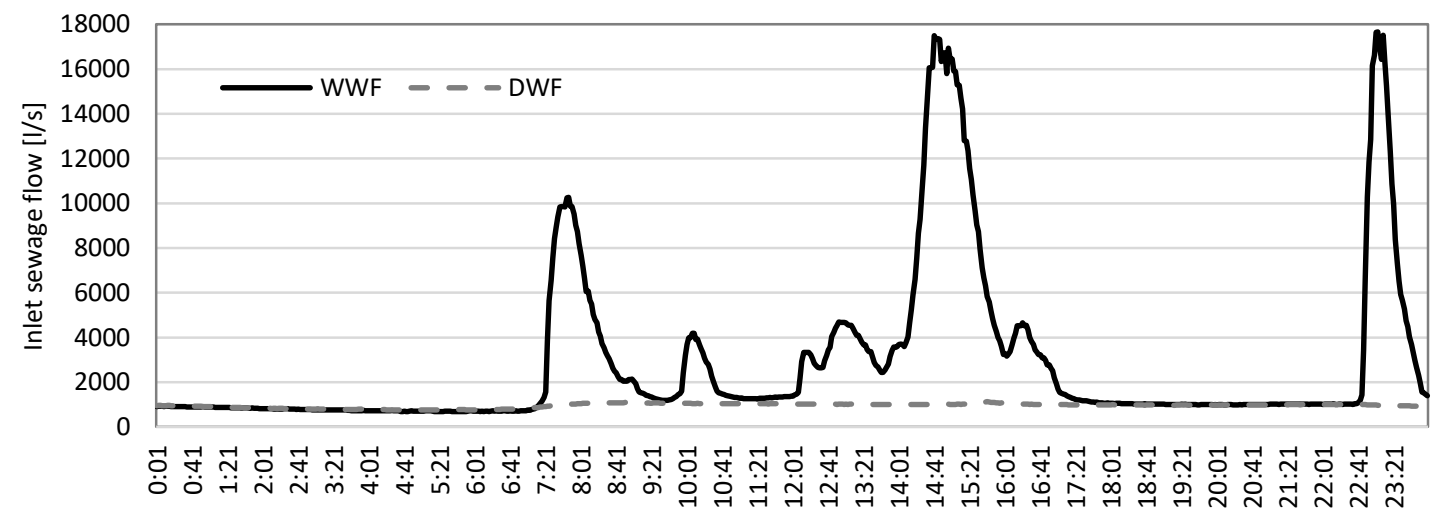

Figure 2 Dry and wet weather flow during working day upstream an offline stormwater tank 
Proceedings of the 11th Int. Conference on Urban Drainage Modelling, 23-26 Sep. 2018, Palermo (ITALY). Ed. prof. Giorgio Mannina

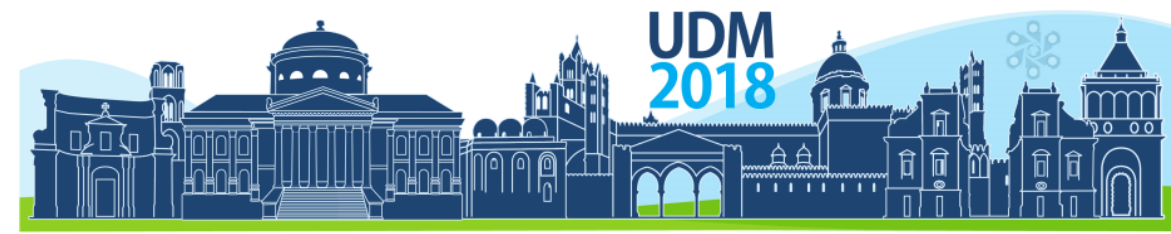

$11^{\text {th }}$ International Conference on Urban Drainage Modelling 23-26 Sep | Palermo - Italy

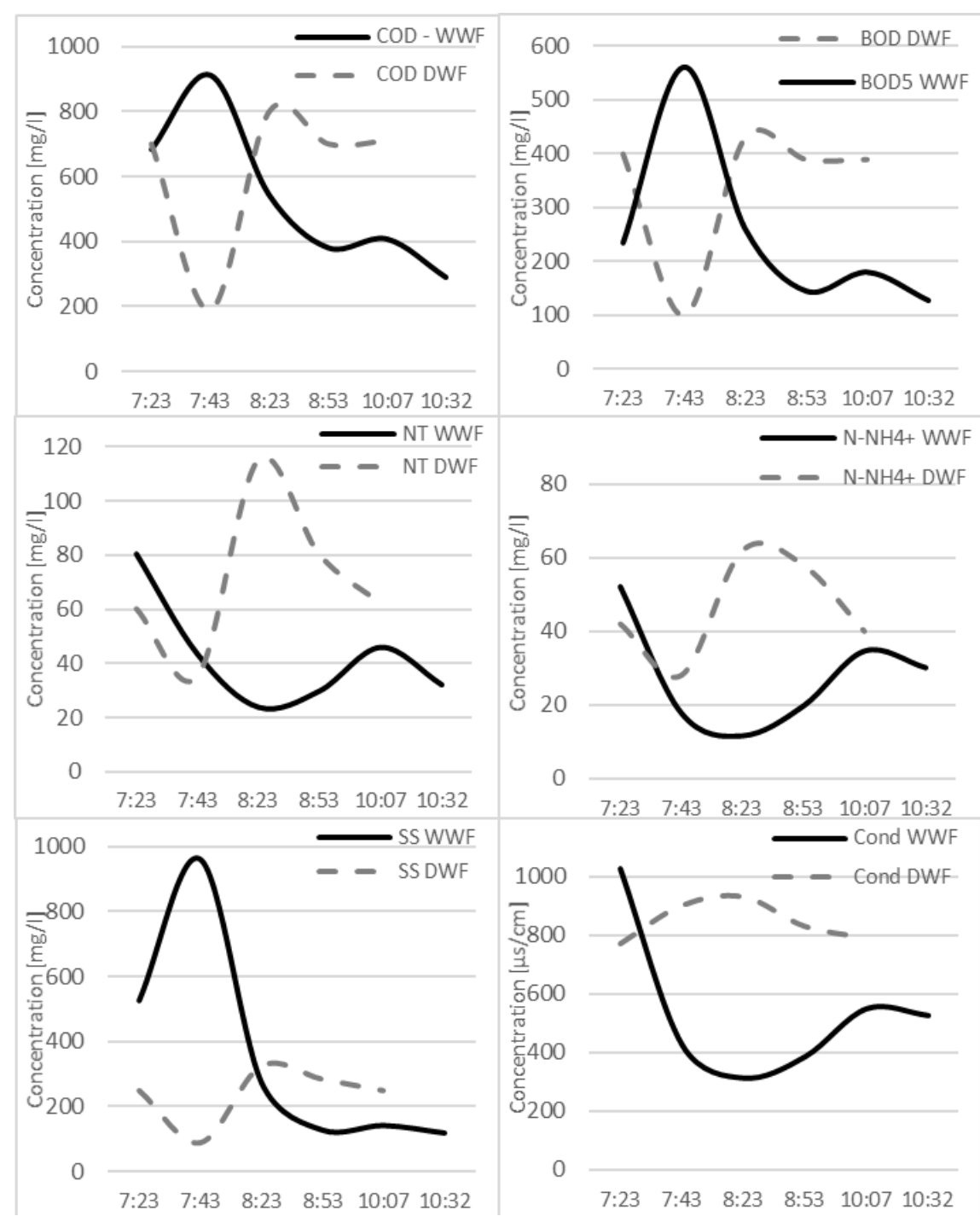

Figure 3 Pollutants evolution at the entrance of a stormwater tank. Comparison between dry and wet weather conditions.

The following figures summarize the pollutants evolution from the tank effluent (Figure 4) and in the stormwater tank (Figure 5). It refers to three stormwater tanks listed in Table 1.

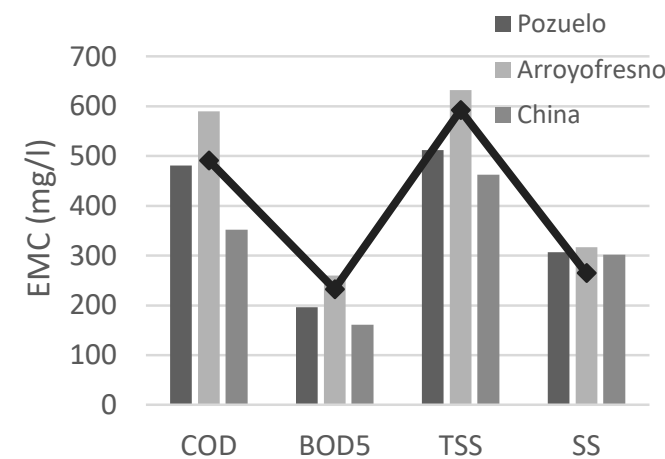

Figure 4 Pollutant event mean concentration (EMC) from the tanks effluent at the beginning of the rainfall event

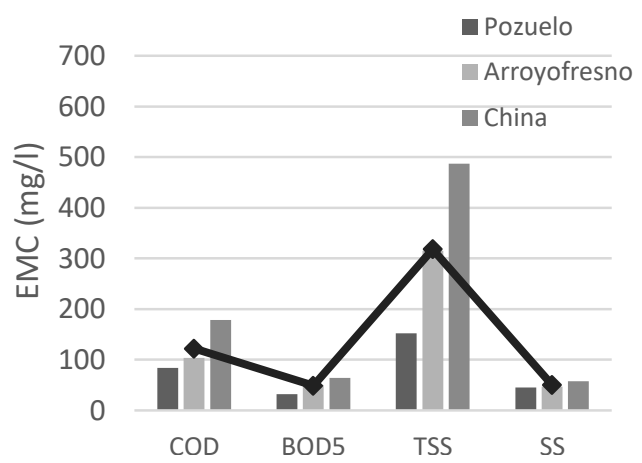

Figure 5 Pollutant event mean concentration (EMC) at the tanks 5 hours after the end of the rainfall 


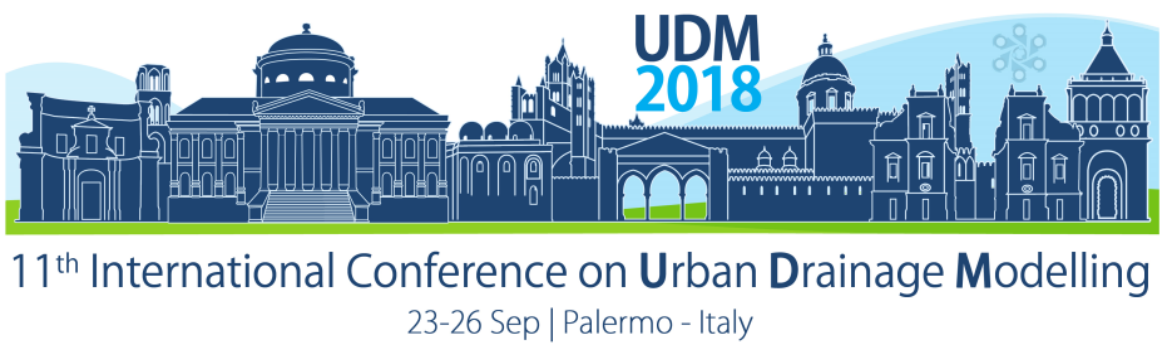

\section{CONCLUSIONS}

Based on the Manzanares System characterization during DWF and WWF (Figure 2 and Figure 3), Canal de Isabel II proved the fact that, in comparison with dry weather conditions, at the beginning of a rainfall event pollutogram peaks reach up higher concentrations.

Furthermore, it was verified that first flush effects can last from two hours (time required for pollutants concentration to reach the mean values during dry weather) to four hours (time required for pollutants concentration to reach the low values during dry weather).

Likewise, it was tested that after a storage period, the effluent pollution is noticeably reduced for the mere reason to be stored into the stormwater tank. Because of settling phenomenon, turbidity and suspended solids decrease as well as macronutrients and oxygen demands.

Outcomes lead to a better system operative for every infrastructure itself but above all the full system management. It seems reasonable to promote the systematical use of stormwater tanks to storage the first flush water. Thus, when a rainfall event begins after a long dry Weather period, it is possible to decide the need to empty the tank to wait a higher pollutant concentration.

On the bases of known results, it is identified the need, not only for more efficient sewer system's operation and maintenance, but above all the urgent need to provide a change of paradigm for infrastructure design criteria. The infrastructure dimensioning criteria based only on dilution concept is at least, questionable. Weirs and stormwater tanks should be designed not only based on quantity criteria but above all in quality criteria.

Although it is true that Manzanares infrastructures were not built in a homogeneous way along the time, all have in common that divert into the big sewer pipes along the river and the stormwater tanks are located offline. Thus, it enables a controlled and variable management of the sewage along the sewer system.

\section{References}

Anta, J. Bermúdez, M. Cea, L. Suárez, J. Ures, P. Puertas, J. (2015) Modelización de los impactos por DSU en el río Miño (Lugo). Ingeniería del agua. Fundación para el Fomento de la Ingeniería del Agua ISSN: 11342196, Valencia.

Canal de Isabel II, S.A. - I+D+i Department (2014) Pliego de prescripciones técnicas que ha de regir en el contrato para la implantación de un sistema avanzado para la operación del Sistema Manzanares, Contrato №: 284/2014.

Comas, P. Falcó, X. García, J. Malgrat, P. Sunyer, D. Villanueva, A. Anta, J. Puertas, J. Suárez, J. (2014) Manual nacional de recomendaciones para el diseño de tanques de tormenta. Ministerio de Agricultura, Alimentación y Medio Ambiente (MAGRAMA). Gobierno de España.

Suárez, J. Puertas, J. (2005) Determination of COD, BOD, and suspended solids loads during CSO events in some combined cathments in Spain. Elsevier Ecological Engineering Vol. 24, 199-217. 


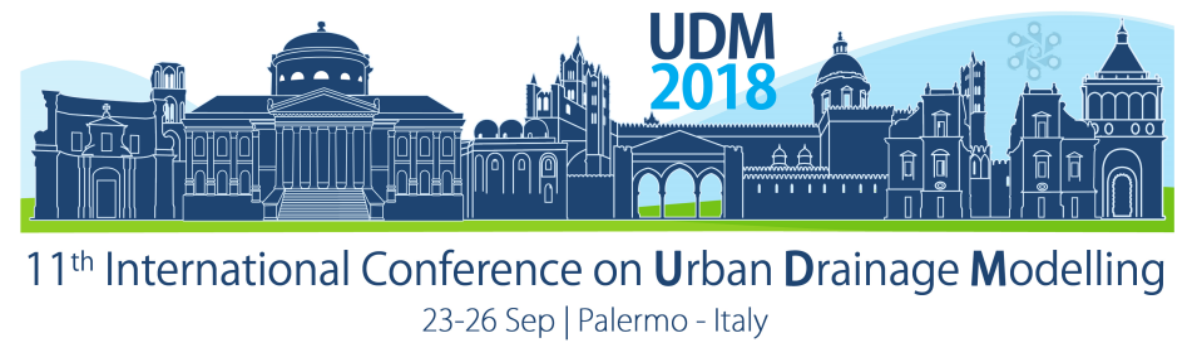

\title{
Study on Realization of Storm Water Sewerage with Water Level Monitoring by the Use of Inundation Simulation
}

\author{
Takuma Kiyosu', Kaoru Kariya ${ }^{1}$, Isao Ideta ${ }^{1}$, and Hidekazu Matsuoka ${ }^{1}$ \\ ${ }^{1}$ Tokyo Branch, Tokyo Engineering Consultants Co., Ltd., Tokyo, Japan \\ 3-7-1 Kasumigaseki Chiyoda-ku, Tokyo 100-0013, Japan
}

\begin{abstract}
In Japan, suspensions of urban functions and accidents affecting people's lives have been occurring recently due to inundations of underground facilities. In order to cope with this situation, local governments in charge of storm water drainage are trying to enhance safety against inundation damages for areas with underground streets etc., which are considered to be vulnerable to inundation, by setting water level in a drainage sewer to give warning for evacuation. This study aims to show an example how to select the suitable sewer, at which water level is to be monitored, closely related to the inundation occurrence at underground facilities in a drainage area, for setting a critical water level for issuing evacuation warning. This is carried out by runoff simulation in an area with several rainfall magnitudes and hyetograph shapes. Moreover, time allowance from the start of overflow from a drainage sewer to the occurrence of underground street inundation is also studied.
\end{abstract}

Keywords: Storm water sewerage with water level monitoring (SSWLM); 2 dimensional inundation simulation; Soft countermeasures against inundation damages

\section{INTRODUCTION}

Recently in Japan, inundation damages have been frequently occurred due to rainfall exceeding a planned one. It is especially worried that catastrophic inundation damages may occur in underground space of heavy use. These damages are caused increasingly by inundation due to the insufficiency of drainage capacity. It is financially difficult to cope with this simply by development of hard facilities, additional drainage sewers and/or storage facilities. Thus, a national government is trying to promote storm water sewerage with water level monitoring (hereinafter referred to as SSWLM) to give evacuation warning for a drainage district having underground streets etc. to reduce inundation damages (MLIT, 2016). When monitored water level is reached to the critical level at which inundation is assumed to occur in underground facilities, warnings with water level data are sent out to administrators of underground facilities in SSWLM. SSWLM with such information aims to help administrators take actions and issue evacuation order to underground facility users timely.

Since SSWLM is an unprecedented attempt in Japan, this study has been carried out with inundation simulation to investigate the appropriate way of identifying a drainage sewer most suitable for monitoring purpose.

\section{MATERIALS AND METHODS}

\subsection{Purpose}

The purpose of this study is to identify a point in drainage sewers at which water levels are to be monitored most suitable to set a water level for issuing an evacuation warning at the time of heavy rain. In this study, the following three viewpoints are considered in establishing a method to identify a point of sewer to be monitored.

- Estimation of inundation situation by the use of 2-dimensional inundation simulation, such as the time when inundation starts and inundated water amount (JIWET, 2017) 


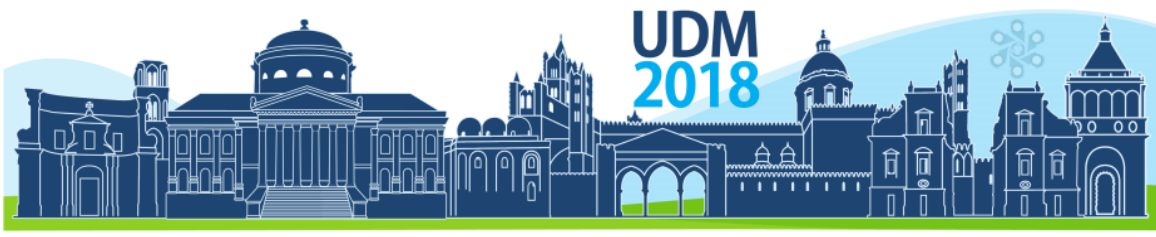

$11^{\text {th }}$ International Conference on Urban Drainage Modelling

23-26 Sep | Palermo - Italy

- Grasp of water levels in a sewer and inundation situation on the ground in time series during the time of inundation in underground streets

- Analysis of relationship between water levels in the drainage sewer and inundation situation in underground streets, i.e. time allowance from the start of overflow at the drainage sewer to the start of inundation in underground streets

\subsection{Study flow}

Study flow of selecting a suitable drainage sewer of an area for monitoring water levels is shown In Figure 1 below.

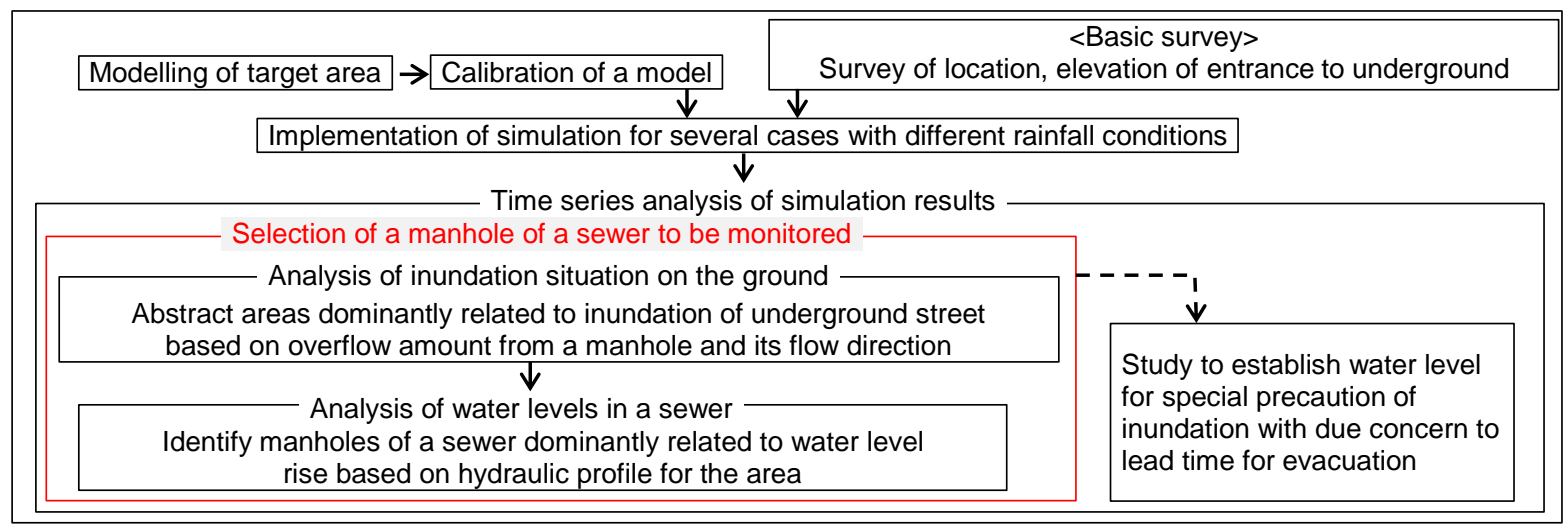

Figure 1. Study flow for establishing warning system for inundation in SSWLM

\subsection{Study area and model outline}

\section{Modelling of target area}

Target area of this study is gravity flow district of approximately 1,100 ha. Sewers and ground surface were modelled for approximately 200 ha with underground streets as inundation simulation area and only sewers for approximately 900 ha hinterland catchment area. It is worried that catastrophic inundation damages may occur in the downstream area of this district, where large scale underground streets are densely developed. In target area, a rainfall storage pipe of about $4,000 \mathrm{~m}^{3}$ is provided for inundation prevention purpose. Outline diagram of the target area is illustrated in Figure 2.

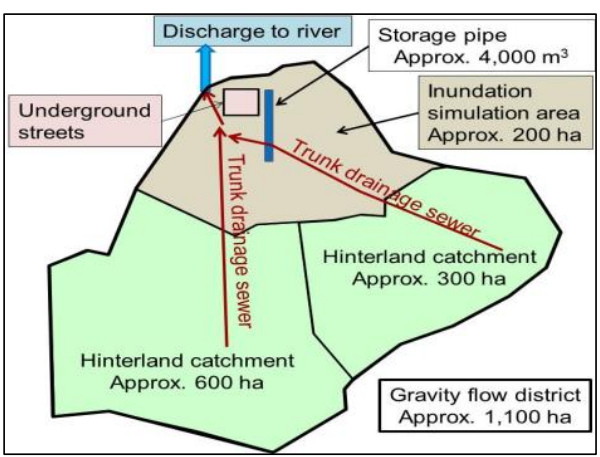

Figure 2. Target area and facilities

\section{Conditions of modelling}

A simulation model of the target area is constructed with the following conditions:

- InfoWorks ICM is used for simulation with a pipeline model combined with a ground surface model.

- Ground surface except building sites is modelled by producing triangulated irregular network (TIN) with 5 to $25 \mathrm{~m}^{2}$ triangles based on 5-meter mesh DEM data. 0.04 is employed as roughness coefficient of ground surface.

- Planned runoff coefficient for simulation is considered to be almost equal to the current one and is set to $80 \%$. 


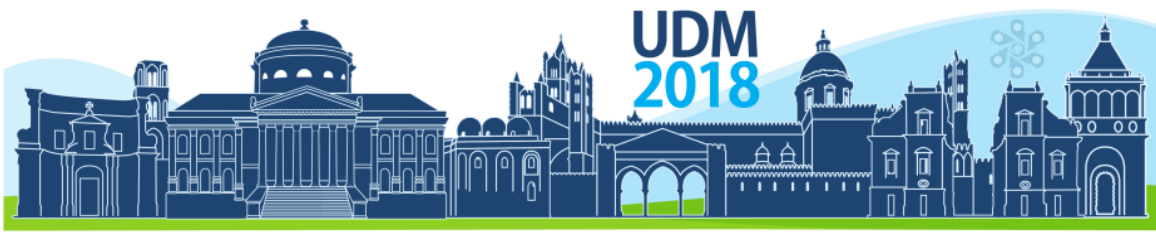

$11^{\text {th }}$ International Conference on Urban Drainage Modelling

23-26 Sep | Palermo - Italy

- A model has been calibrated by comparing water levels in a drainage sewer of simulation results with actual measurements during rainfalls actually observed in the target district.

\subsection{Target rainfalls}

Two rainfalls employed in this study are summarized in Table 1. Rainfall 1 is an actual rainfall which caused severe damages with 65,000 refugees and 70,000 housing damages, a representative long rainfall like one in a typhoon. Rainfall 2 is a centrally peaked rainfall of 100 year return period exceeding a planned rainfall of $50 \mathrm{~mm} / \mathrm{hr}$, a short concentrated rainfall like what is called guerrilla rainfall. Hyetographs of both target rainfalls are illustrated in Figure 3.

Table 1. Target rainfalls

\begin{tabular}{cccc}
\hline Target rainfall & Hyetograph & Hourly peak & Total rainfall \\
\hline Rainfall 1 & Actual & Approx. $114 \mathrm{~mm} / \mathrm{hr}$ & Approx. $580 \mathrm{~mm}$ \\
\hline Rainfall 2 & Centrally peaked & Approx. $100 \mathrm{~mm} / \mathrm{hr}$ & Approx. $153 \mathrm{~mm}$ \\
\hline
\end{tabular}

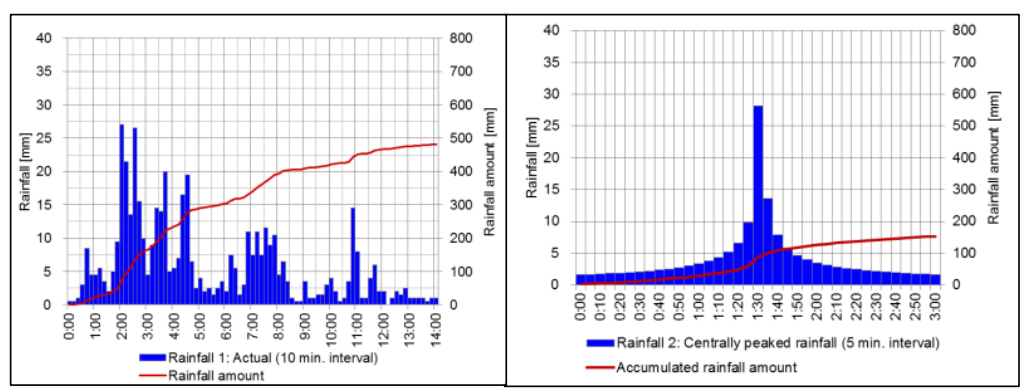

Figure 3. Hyetograph of target rainfalls

\section{RESULTS AND DISCUSSION}

\subsection{Abstract manholes dominantly related to underground street inundation}

\section{Study method}

An area with overflown manholes dominantly related to underground street inundation was identified. Accumulated amount at the start of underground street inundation is computed for each manhole. Then, manholes dominantly related to underground street inundation based on the analysis of flow directions of overflow estimated by simulation was abstracted. Figure 4 shows an example of the flow direction of overflow on the ground with arrows.

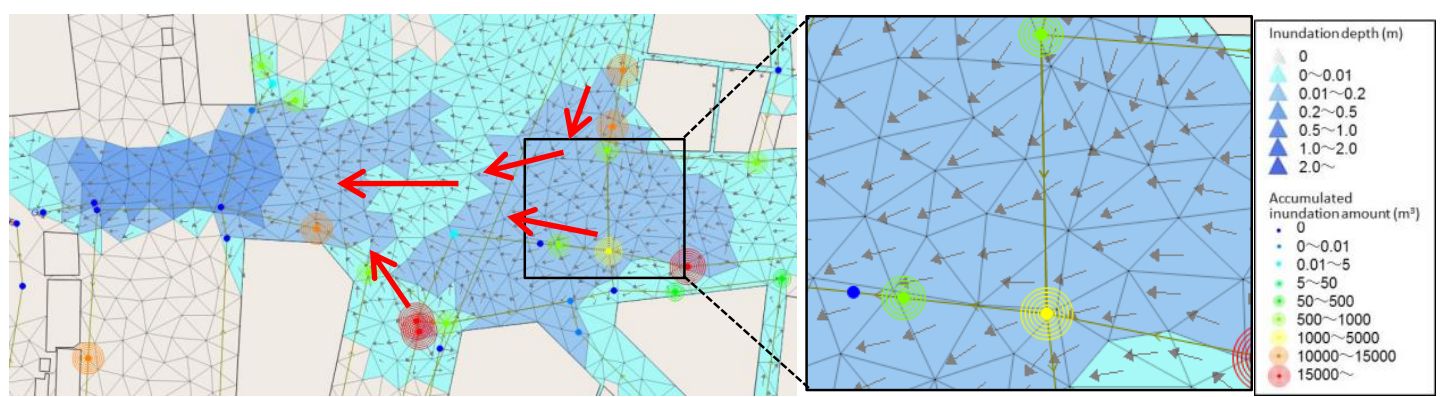

Figure 4. Diagram showing flow directions of overflow on the ground

Study results with actual rainfall (Rainfall 1)

Area $A$ and Area $B$ at upstream of Area $A$ as shown in Figure 5 have been identified as areas with large accumulated overflow. Figure 5 also shows the inundation situation on the ground 


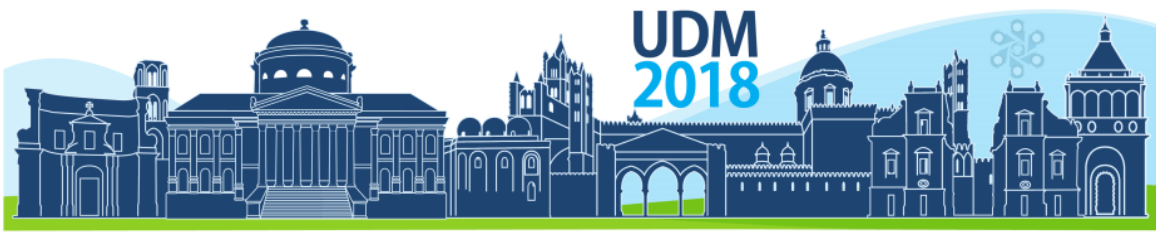

$11^{\text {th }}$ International Conference on Urban Drainage Modelling

23-26 Sep | Palermo - Italy

at the start of underground street inundation. Based on simulation results shown in Figure 6 , inundation occurred in Area $A$ at 2 hours and 3 minutes (2:03) after the start of simulation and then in Area $B$ at 2:04. At the underground street entrance, inundation started at 2:09 and its depth started to increase and finally underground inundation occurred at 2:12. There was only 9 minutes from inundation on the ground in Area $A$ to that in underground street.

Accumulated overflow in Area $A$ until underground street inundation was estimated about $1,760 \mathrm{~m}^{3}$ and that in Area B about $960 \mathrm{~m}^{3}$. With due concern to the location of both areas relative to the entrance, the accumulated overflows estimated above, and the time length from the start of inundation on the ground in each area to that in underground street, it has been concluded that Area $A$ is dominantly related to the inundation of underground street.
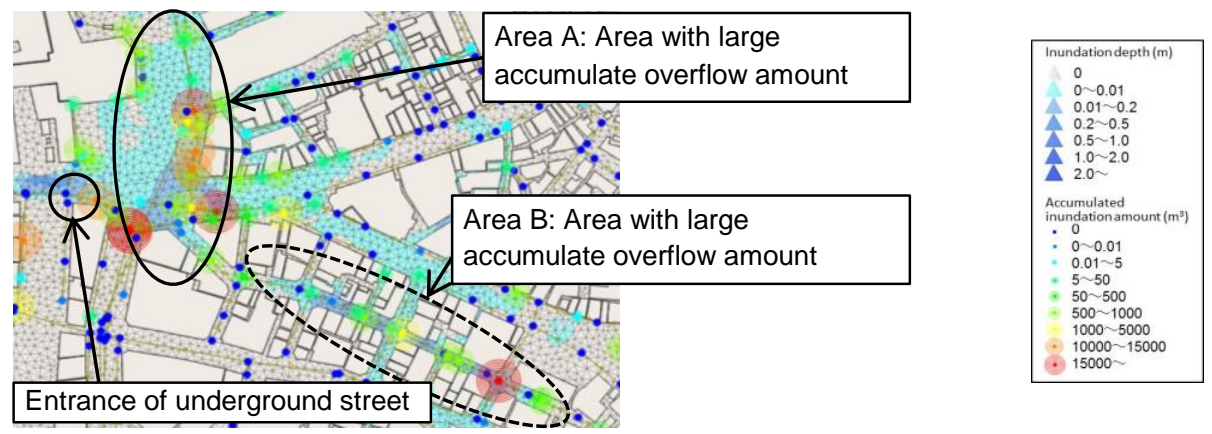

Figure 5. Simulation result with Rainfall 1 (At the start of underground street inundation)
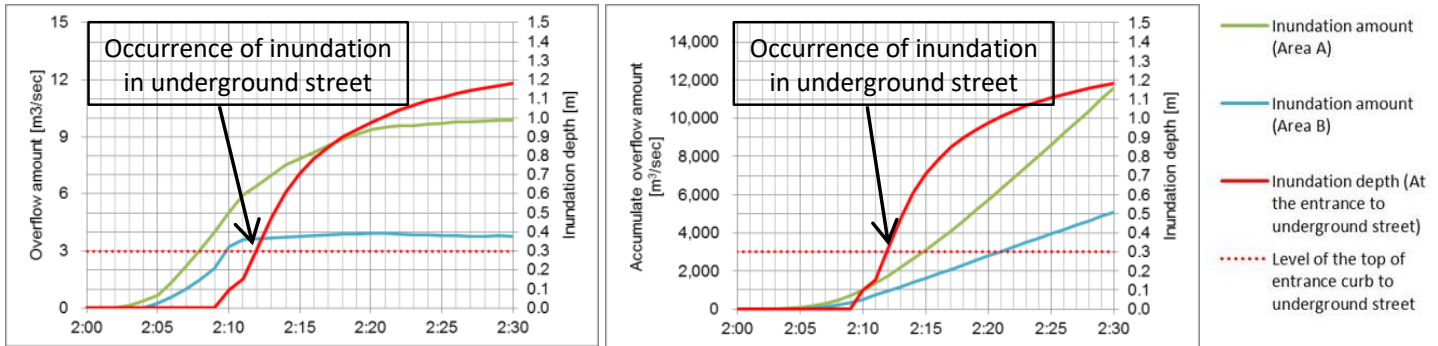

Figure 6. Amount of overflow and accumulated overflow in Areas A and B (Rainfall 1)

Study results with $100 \mathrm{~mm} / \mathrm{hr}$ centrally peaked artificial rainfall (Rainfall 2)

Same Areas A and B have also been identified as areas with relatively large accumulated overflow also with Rainfall 2. Based on simulation results, inundation occurred in Area $B$ at $1: 25$ and then in Area $A$ at 1:35. At the underground street entrance, inundation started at $1: 38$ and its depth started to increase and finally underground inundation occurred at 1:45. There was only 10 minutes from ground inundation in Area $A$ to that in underground street.

Accumulated overflow in Area $A$ until the start of underground street inundation was estimated about $490 \mathrm{~m}^{3}$ and that in Area B 1,710 $\mathrm{m}^{3}$. Considering the location of areas and the time length from the start of ground inundation to that in underground street, it has been concluded that Area $A$ is also dominantly related to the inundation of underground street.

\section{Considerations}

It has been confirmed that overflow from Area $A$ is mostly influential to the occurrence of underground street inundation and the time allowance from the inundation in Area $A$ to that in underground street is merely 10 minutes. But since rapid inundation level increase around the entrance to the underground street did not occur only due to overflow in Area $B$, inundation in Area B was judged to have little to do with underground inundation. 


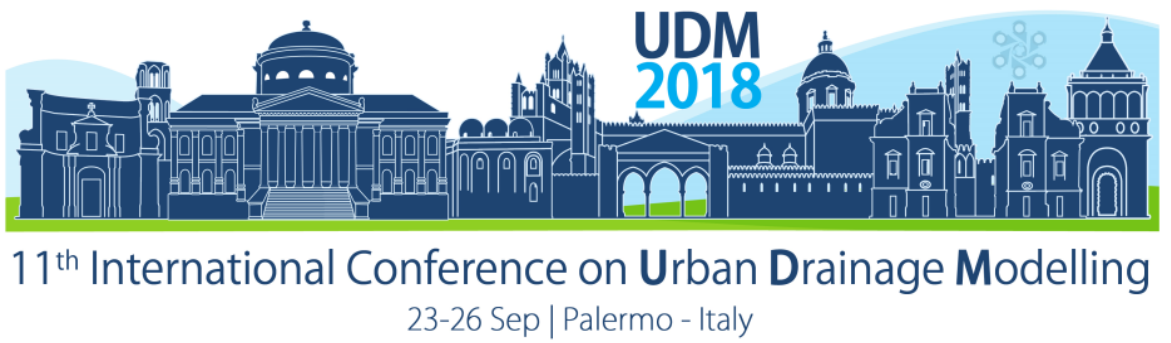

\subsection{Analysis on water levels in a drainage sewer}

As for Area A, reasons for the water level rise in a sewer was analysed to identify a manhole at which water level is to be monitored by comparing water level in a sewer in area $A$ with that in the storage pipe constructed for runoff control in time series. (Refer to Figure 7.)

For actual rainfall, water level rise in a sewer is positively linked to that in the storage pipe and underground street inundation occurs after storage pipe becomes full. Thus, water level measurement either at a manhole in Area $A$ or one at the storage pipe suffices for our purpose. For $100 \mathrm{~mm} / \mathrm{hr}$ rainfall, overflow from manholes in Area A occurs before the storage pipe becomes full. Thus, water level is to be measured at a certain manhole in Area A.
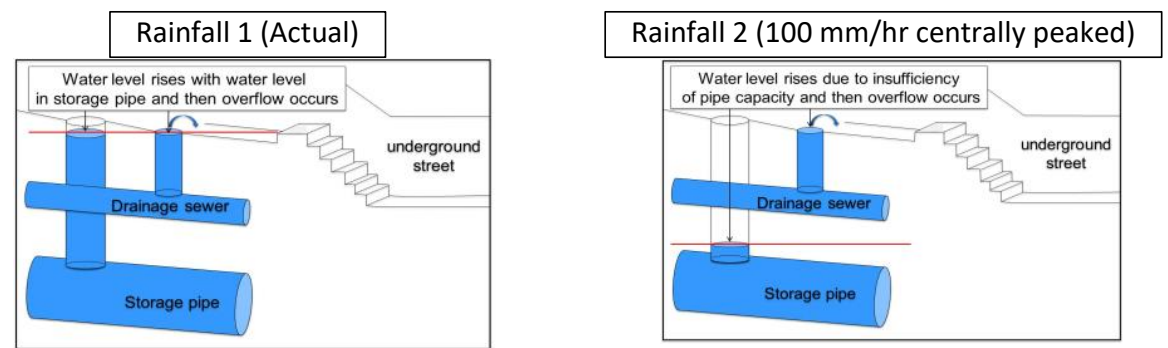

Figure 7. Water levels in sewers at the time of overflow in Area A (Schematic diagram)

\subsection{Considerations}

Overflow from manholes in Area A was dominantly related to underground street inundation as mentioned above. Water levels at both manholes at the storage pipe and at the sewer were found to be related to underground inundation occurrence for Rainfall 1, whereas only water level at the sewer was found to be related to the underground inundation for Rainfall 2 since the inundation occurred before the storage pipe was filled up. Thus, it has been concluded that water level is to be measured at a manhole in Area A for our purpose.

\section{CONCLUSIONS}

Analysis of inundation and water level in sewers was carried out to reduce underground inundation damages with the minimum number of water level meters for the realization of SSWLM. Based on analysis, manholes for the water level measurement have been identified.

It is further needed to determine reference water level(s) to issue warning with due concern to time necessary for evacuation of underground street users. For this purpose, further study is planned to be carried out with more target rainfall events in the near future. It is definitely difficult only by hard measures to reduce inundation damages in underground streets which are caused by rainfalls exceeding a planned one. Therefore it is important to work out soft measures as risk management for underground street administrator by identifying a sewer in an area, water level of which may be indicative of underground street inundation occurrence.

With tremendous amount of data obtained by water level measurement, moreover, further study might be carried out by using Al to establish optimal reference water levels for issuing warnings and to work out inundation damage reduction guideline for underground streets.

\section{References}

Japan Institute of Wastewater Engineering and Technology (JIWET) (2017) Manual on the Use of Runoff Simulation Models. Tokyo, Japan.

Sewerage Division, Water and Disaster Management Bureau, Ministry of Land, Infrastructure, Transport and Tourism (MLIT) (2016) Technical Document for Storm Water Sewerage with Water Level Monitoring (SSWLM) System. Tokyo, Japan. 


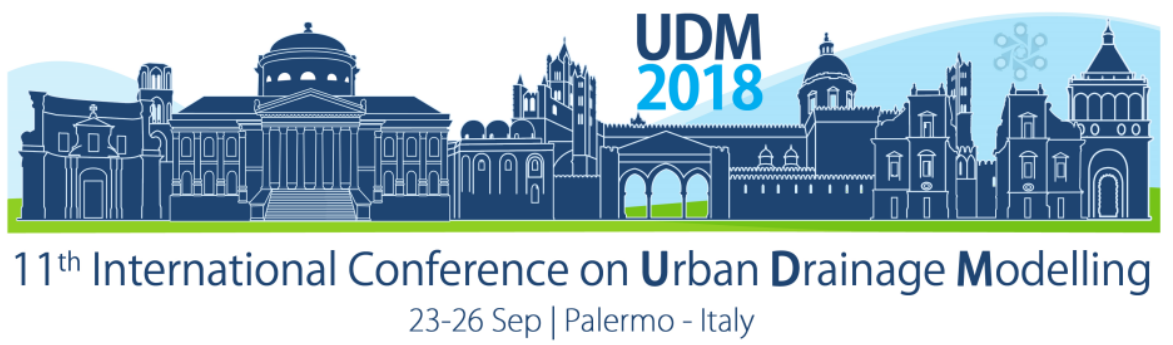

\title{
Holistic Water Cycle Management in Priority Growth Area in Sydney's West by Managing the Water Cycle Strategies of Individual Precincts
}

\begin{abstract}
Maria Pinto ${ }^{1}$
${ }^{1}$ Camden Council, Oran Park, NSW, Australia

Abstract

The most significant development in Sydney is taking place in Priority Growth Areas (PGA) along the South Creek corridor, Sydney's West. The Water Cycle Management (WCM) Strategy is a key component in the development of PGA. WCM strategies for PGA precincts development carried out in isolation were reviewed. Their shortcomings were addressed through a regional 2D TUFLOW hydraulic model. This $2 \mathrm{D}$ regional model was used to control the cumulative impacts of Leppington precinct development. The Urban Site Detention (USD) guidelines were prepared to maintain pre-developed hydrological behaviour. USD guideline for 50\% Annual Exceedance Probability (AEP) was used to mitigate waterways stability impacts reducing erosion and Total Suspended Solids (TSS), while $1 \%$ AEP USD guideline was used to mitigate flooding. The adoption of the USD guidelines enhanced the stability of bed and bank, biotic habitats and ecosystem health of creeks. Water quality requirements were addressed by Water Sensitive Urban Design (WSUD). WSUD and the reuse of stormwater planning were based on MUSIC modelling. Climate change impacts were considered. The precinct planning integrates stormwater management with liveability by reducing flood risks to properties and infrastructure and increases the safety and security of residents. This paper will discuss the application of updated strategies in WCM for Leppington precinct and its achievements in holistic WCM strategy in PGA development.
\end{abstract}

Keywords: cumulative impact, development, Water Cycle Management

\section{INTRODUCTION}

The most significant development in Sydney is taking place in Priority Growth Areas (PGA) along the South Creek corridor in Sydney's West. The Government has identified an area of 27,000 hectares for this development to accommodate 180,000 future residents with all facilities including an airport within next 20 years. PGA development has been staged based on precincts, and the precinct development is presently at different stages from planning to construction.

In the development of PGA, Water Cycle Management (WCM) is a key component. The WCM includes the management of stormwater quality, quantity and its reuse. In WCM of individual precincts, the stormwater quality is managed by Gross Pollutant Traps (GPT) and bio-filtration. Rainwater is harvested in rainwater tanks. The stormwater quantity is managed by regional detention basins for residential developments and lot based On Site Detention for commercial and industrial developments. Water reuse is achieved through stormwater harvesting, effluent reuse and condensing water vapour in cooling towers. In the development of PGA, Water Cycle Management strategies have been independently prepared for individual precincts. The assessment of WCM reports of individual precincts shows that the fundamental criteria of maintaining post-development peak flows at pre-development conditions have been met. However, some other aspects of the Water Cycle have been overlooked. They include (1) cumulative impacts of precincts development on downstream areas (2) increased postdevelopment total flow volumes (3) potential for stream erosion from minor events (4) loss of flood storage by filling existing farm dams and regional storages. (5) Impacts of other major 


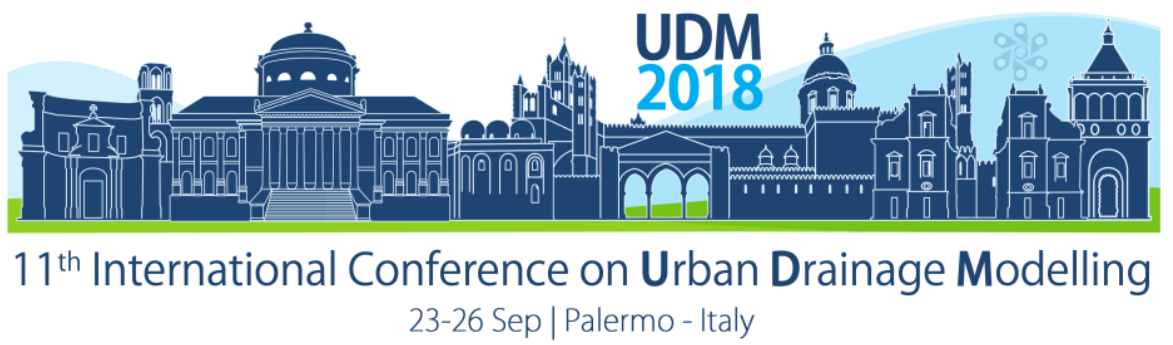

developments, such as transport infrastructure development. Having identified these shortfalls further studies were conducted to assess the above issues in the light of WCM in PGA and to address them. This paper attempts to address these issues by developing a methodology for preparing WCM strategy in individual precincts, and to apply it to future precinct development using Leppington precinct as a test precinct (Fig. 1).

\section{MATERIALS AND METHODS}

As a result of detailed assessment of WCM study reports prepared for four individual precincts $(1-4$, Fig. 1), the following methodology was developed to address the identified shortfalls listed in the introduction (Cardno, 2017).

- A 2D TUFLOW regional hydraulic model was developed to assess the cumulative impacts. Piolet testing was undertaken using the flood models available for four individual precincts to identify appropriate adjustments to roughness and design losses for inclusion of precinct developments. The adjustments to initial loss, continuing loss and roughness parameters replicated the precinct development. The loss of flood storage due to removal of farm dams scattered all over the floodplain was also considered for developed scenario of the regional model.

- Urban Site Detention (USD) guidelines were developed to maintain pre-developed hydrological behaviour. The USD guidelines estimate the detention volumes for $1 \%$ and $50 \%$ Annual Exceedance Probability (AEP).

- A comprehensive suite of planning controls was prepared to ensure WCM strategies are observed through Development Assessment and Construction phases.

- The water quality guidelines were addressed by Water Sensitive Urban Design (WSUD) with innovative approaches. The WSUD and reuse of stormwater were based on MUSIC modelling.

The above methods were first applied to Leppington precinct WCM preparation, with the objective of assessing the developed methodology in addressing the impacts of individual precinct development for a holistic WCM in the PGA. The Leppington precinct has an area of 658 hectares to accommodate 9,000 dwellings. 


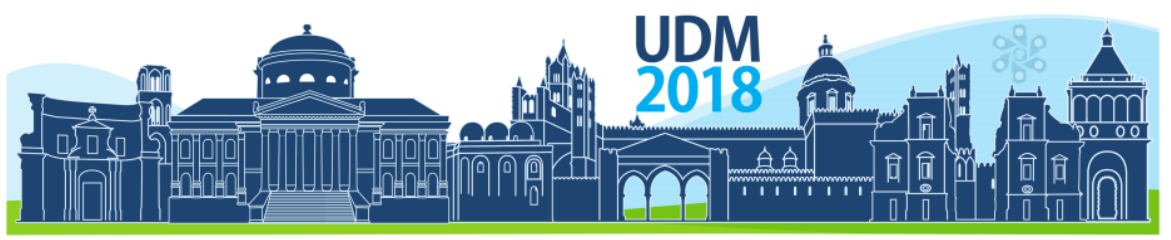

$11^{\text {th }}$ International Conference on Urban Drainage Modelling 23-26 Sep | Palermo - Italy

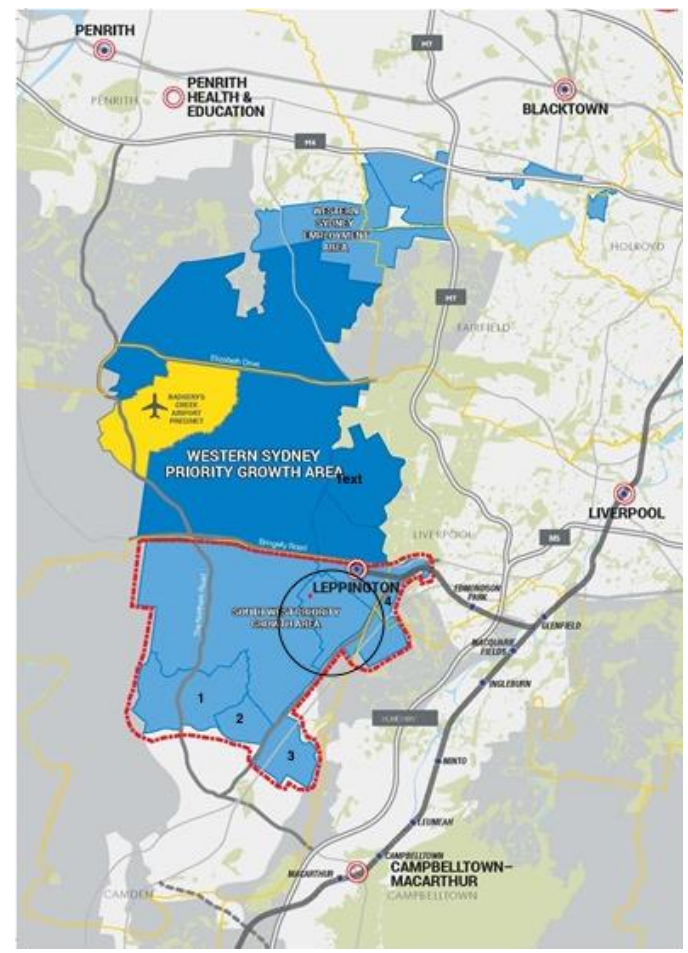

Figure 1. Priority Growth Area with Leppington Precinct, Sydney's West (source: Planning New South Wales)

\section{RESULTS AND DISCUSSION}

\section{Flooding and drainage}

In precinct development, the water quantity management objectives are to attenuate stormwater runoff up to the $1 \%$ AEP event, and maintain safe flood conveyance through the site for events greater than the 1\% AEP. In Leppington precinct, the stormwater quantity was managed by regional detention basins for residential developments, and lot based On-SiteDetention for commercial developments. Water quantity was designed initially by determining the volume of USD for $1 \%$ AEP required for the precinct and then using hydrologic and hydraulic models. The USD Guidelines estimate $320 \mathrm{~m}^{3} / \mathrm{ha}$ and $190 \mathrm{~m}^{3} /$ ha detention volumes for $1 \%$ and $50 \%$ AEP (100-year and 2-year Annual Recurrence Interval) events respectively, in low density residential development. The cumulative impacts were assessed and controlled by comparing the $1 \%$ AEP developed Leppington precinct hydrographs with the $1 \%$ AEP hydrographs of the 2D TUFLOW regional hydraulic model at the precinct downstream boundaries. Figure 2 shows the comparison of Leppington precinct developed scenario 1\% AEP 2-hour hydrograph with regional 2D TUFLOW model hydrograph at the downstream boundary of the precinct. The comparable hydrographs ensure maintaining the pre-developed peak flows, total flow volumes and consideration of loss of flood storage by filling existing farm dams in developed scenario. The USD for 50\% AEP guideline includes multiple benefits of detention and stability of waterways, combining sustainability with water management. Eleven online detention basins for water quantity management and eight off line basins combined with biofilters for water quality and quantity management are required in Leppington precinct (Parsons Brinckerhoff, 2013). The flood related development controls prepared for PGA 


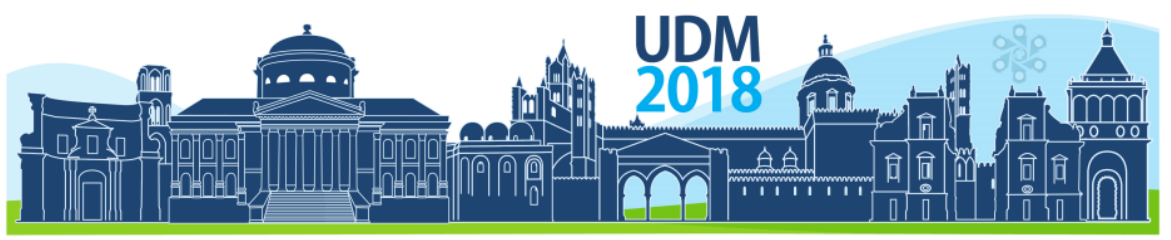

$11^{\text {th }}$ International Conference on Urban Drainage Modelling

23-26 Sep | Palermo - Italy

provide best land use planning that prevents flood damages to public and private property. This also provides planning of evacuation roads, high ground refuge areas and emergency response plans for extreme flood events.

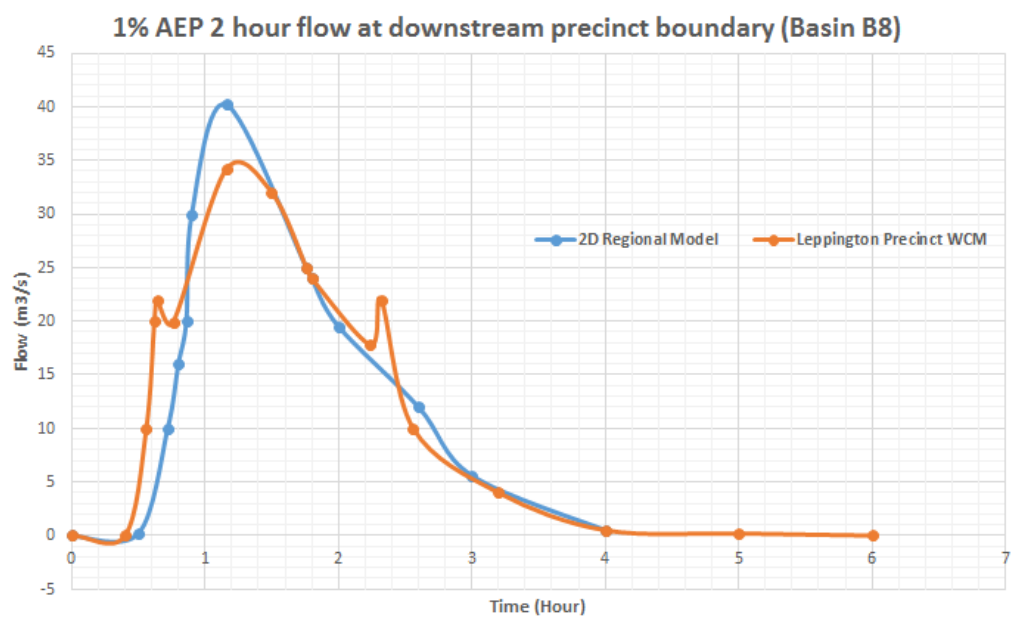

Figure 2. Hydrograph comparison at the downstream boundary

\section{Water quality and stream erosion}

The GPTs are to be provided to collect litter, debris and sediment prior to bio-filtration. The bio-filtration basins located in open space outside of the core riparian zone have been proposed in the WCM strategy to control stormwater quality. The best planning practice targets for GPT designs are to reduce coarse sediment $(>0.5 \mathrm{~mm})$ by $60-80 \%$, medium sediment $(0.1-0.5 \mathrm{~mm}) 50-70 \%$, fine sediment $(<0.1 \mathrm{~mm}) 40-60 \%$ and Gross Pollutants 80 $-100 \%$. Bio-retention are to reduce TSS by $85 \%$, TP by $65 \%$, TN by $45 \%$ and Gross Pollutants by $90 \%$. Fifty-four biofilter footprints including 8 biofilters co-located in detention basins, equivalent to $0.3 \%$ of the developed area need to be provided for water quality management to achieve set water quality targets (Parsons Brinckerhoff, 2013). By co-locating biofilters in detention basins, water quality and quantity controls have been integrated, reducing construction cost and saving land. In some instances, the bio-filters have integrated with playing fields for minimal land take. The compliance with USD guidelines for $50 \%$ AEP ensures the stability of waterways, delaying the early peaks and reducing the attenuation duration of hydrographs, and reducing erosion and TSS in creeks.

\section{Stormwater reuse}

The reuse of stormwater was based on rainwater tank capacity and the green roof area in the precinct development. The best planning practice developed for rainwater tanks in the precinct was 15 lots/ha with a tank capacity of $3 \mathrm{~kL}$, serving $365 \mathrm{~L} / \mathrm{d} /$ lot to serve 3.5 persons/lot for use in toilet flushing, laundry and garden watering. The green roofs strategy in WSUD as a best planning practice was used to reduce impervious surfaces, improve air quality, amenity, ambient air temperature, building insulation, bird habitat and the aesthetic quality of the urban environment. When the reuse strategy of the WCM in precinct development is implemented, it will make a significant contribution to reduce potable water demand. Future potable water demand is reduced in the precinct by implementing stormwater harvesting, effluent reuse and cooling towers. 


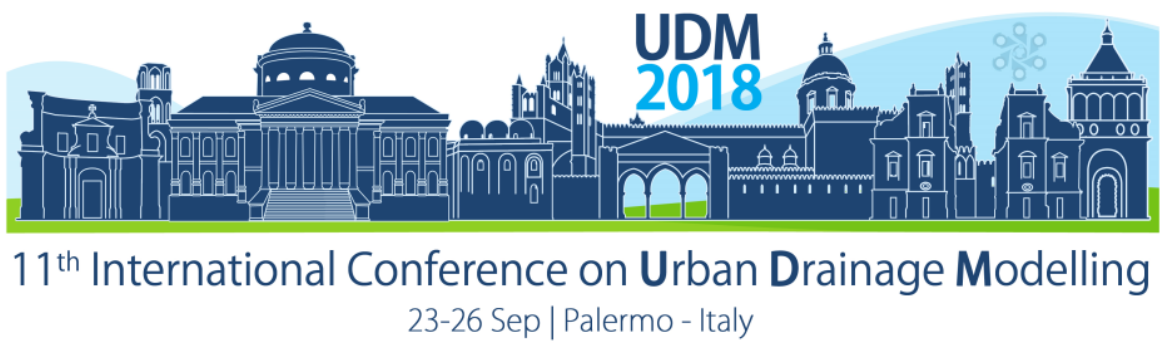

\section{Adaptation to climate change}

Impacts of climate change have been taken in to consideration in the water quantity model through increasing rainfall intensity (from $10 \%$ to $30 \%$ in 1\% AEP design rainfall). The impacts at key crossing locations were found to be less than $110 \mathrm{~mm}$ increase in flood levels. It was considered that the $500 \mathrm{~mm}$ freeboard included in the flood planning level is sufficient to manage climate change impacts (Parsons Brinckerhoff, 2013).

\section{Other outcomes}

Public Health and Safety. The implementation of WSUD would reduce public health risks by reducing the density of faecal coliforms and frequency of algal blooms in creeks. Further, the implementation of developed methodology in precinct planning would provide flood-controlled development that ensures the safety of residents.

Property damage and flood insurance. As a result of flood-free and flood-controlled urban development, damage to private and public property from floods will be reduced and achieved through the planning controls. It will also influence the flood insurance premiums positively. Liveability. Liveability is often assessed in terms of the level of risk, quality of transport, goods and services, environment, recreation and town planning. Leppington precinct integrates stormwater management with liveability by reducing flood risks to properties and infrastructure and increases the safety and security of residents. The PGA development is basically an economic project, where the land-use value is increased significantly. This project demonstrates excellence in economic factors in optimising land use by combining water management with other land uses. The project also improves the social factors of future residents by planning for liveable, resilient and sustainable precincts.

\section{CONCLUSIONS}

The application of developed methodologies; 2D regional flood model for cumulative impact assessment, USD guidelines, and flood related planning controls for WCM strategies in Leppington precinct addresses the shortcomings of previous precinct planning. This demonstrates the achievement of the objectives of holistic WCM in the PGA, while managing the Water Cycle in individual precincts in isolation. It satisfies the adoption of an Integrated Water Cycle Management Strategy for new and existing developments holistically, as required by the Water Management Act 2000 in providing sustainable and integrated management of water resources for the benefit of both present and future generations.

\section{References}

Cardno (NSW/ACT). (2017) Upper South Creek Floodplain Risk Management Study and Plan, Draft Report, February, $65 \mathrm{pp}+$ Apps

Cardno (NSW/ACT). (2017) Upper South Creek - The TUFLOW Model User Guide, Sydney

Parsons Brinckerhoff. (2013) Leppington Precinct South West Growth Centre Water Cycle Management Strategy, Report prepared for Department of Planning and Infrastructure NSW Government, April, 48 pp + Apps 


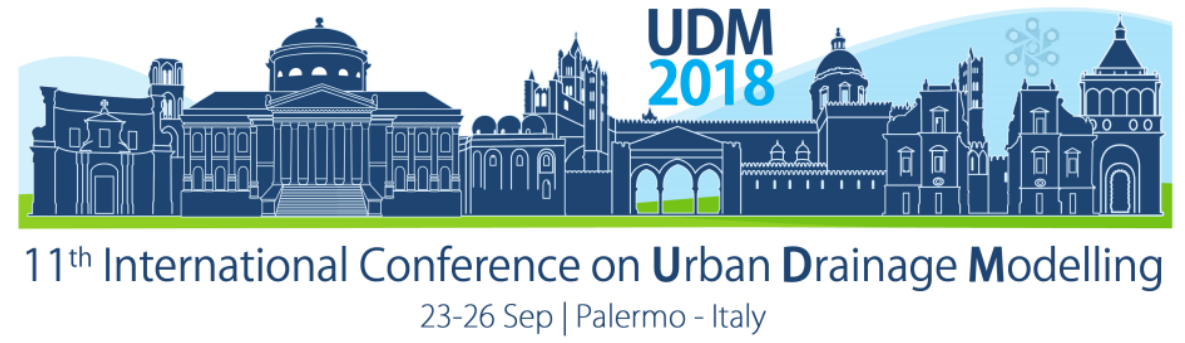

\title{
Interaction between City Subsurface Infrastructure and Groundwater
}

\author{
Constantin Radu Gogu1 ${ }^{1}$, Mohamed Amine Boukhemacha ${ }^{2}$, Dragos Gaitanaru ${ }^{1}$ and Irina Moraru ${ }^{3}$ \\ ${ }^{1}$ Technical University of Civil Engineering Bucharest, Romania \\ ${ }^{2}$ National Polytechnic School, Alger, Algeria \\ ${ }^{3}$ National Institute of Hydrology and Water Management, Bucharest, Romania
}

\begin{abstract}
The interaction between the underground infrastructure and groundwater generates hydrogeological problems in Bucharest city (1.9 million people $/ 228 \mathrm{~km}^{2}$ surface). One is the barrier effect produced by an extensively channelized river, increasing consequently the groundwater hydraulic heads in the surrounding areas. A second one is due to the strong hydraulic interaction between sewerage and the groundwater. As result, the seepage into the sewer network increases the influent flowrate received by the waste water treatment plant. Restoration of the sewer conduits triggers consequently the groundwater hydraulic heads increase. Answers to these problems have been foreseen by developing the Bucharest city hydrogeological model with the support of several institutions, companies, and experts. As a first step the 3D geological model, for the first $50 \mathrm{~m}$ below ground level, has been developed. The spatial intersection between the urban infrastructure elements (subway, parking lots, etc.) and the geological model, provided the geometrical parameters needed to quantify their groundwater flow barrier effect. It also enabled to identify the location of the sewer conduits and their potential hydraulic connection with the aquifer strata. The hydrogeological model englobes the following datasets: hydraulic heads, surface water, groundwater recharge from precipitation and from the water supply system losses, drainage systems and seepage into tunnels. The resulted hydrological water balance identified that about $0.92 \mathrm{~m}^{3} / \mathrm{s}$ wastewater surplus originates from seepage. It has been determined that more than $20 \%(96.7 \mathrm{~km})$ of the sewer network is completely or partially immersed into groundwater. Scenarios to neutralize the groundwater sink impact have been simulated.
\end{abstract}

Keywords: urban hydrogeology; groundwater modelling; subsurface infrastructure; sewer network

\section{INTRODUCTION}

Water resources management in urban areas has to include the interaction between the underground infrastructure and the groundwater. This can be performed only by using modeling. The models can provide truthful results if they are based on accurate data and they properly reproduce the hydraulic and the hydrological processes.

Two main groundwater related problems produced by the interaction between the aquifer system and the underground infrastructure could be found in Bucharest, a city of about 1.9 million inhabitants that covers a surface of about $228 \mathrm{~km}^{2}$. The barrier effect produced by the extensively channelized Dambovita River that cuts Bucharest city, from NW to SE, is one of them (Figure 1a). Consequently, it increases the groundwater hydraulic heads in the surrounding areas. Aging process of the sewer conduits, the second problem, produced a strong hydraulic interaction between the sewer system and the groundwater. If the seepage into the sewer network increases considerably the wastewater flow rates, the possible refurbishment of the conduits could further increase the already high groundwater levels in several city centre districts. 


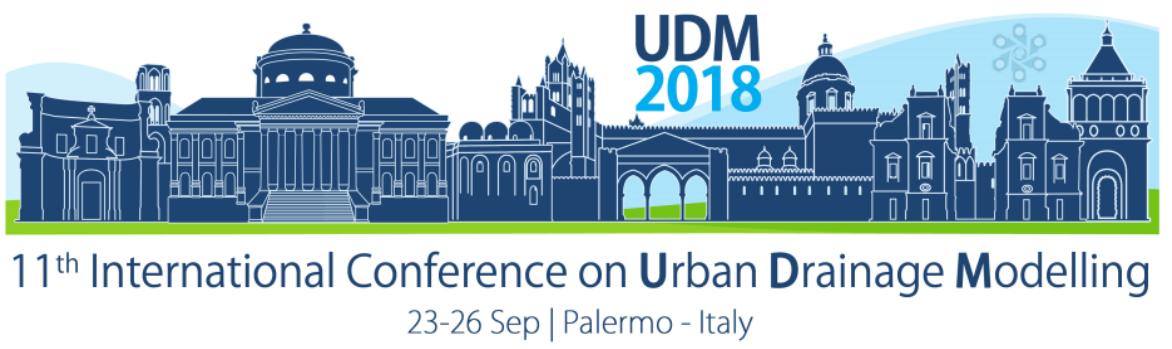

\section{MATERIALS AND METHODS}

\subsection{Urban subsurface analysis steps}

The Bucharest city urban hydrogeological model (CCIAS 2013) has been developed within an interdisciplinary research project. Institutions, companies, and experts brought data and knowledge to perform this work. An accurate 3D geological model (Serpescu et al. 2013) focusing the Quaternary sedimentary deposits of the first $50 \mathrm{~m}$ below ground level has been developed. It was used to delineate and hydraulically characterize the shallow aquifer system composed by the first two shallow aquifer layers, separated by an aquitard. Further, these units have been spatially intersected (Figure 1b) with the subsurface urban infrastructure (3D sewer system, 3D subway network, etc.).

\subsection{Characteristics of the Bucharest city urban groundwater modelling process}

The initial main objective of the groundwater flow model focused the quantitative assessment of the groundwater-sewer system interaction. The model has been developed considering the sewer conduits larger than $400 \mathrm{~mm}$ in diameter. It has been developed on the basis of the above mentioned 3D geology - infrastructure geometrical intersection result.

The first step was to quantify the sewer conduits hydraulic connection with the aquifer strata as well as to assess the groundwater flow barrier effect (Boukhemacha et al. 2015) induced by different civil engineering works (subway, underground parking lots, and others). For the numerical integration of the model, in steady state conditions, has been used the finite difference method within Modflow solver (Harbaugh et al. 2000). Several realizations of the urban groundwater model, focusing on the interaction between urban infrastructure and the groundwater, were carried out for May 2013, December 2014, and October 2015.

The hydrogeological model has been developed by enclosing the following datasets: hydraulic head data, surface water levels, groundwater recharge coming from precipitation as well as from the water supply system distributed losses, drainage systems and seepage into the subway tunnels. The water supply operator estimated that the total losses from the entire water supply network of the Bucharest city are about $2.42 \mathrm{~m} 3 / \mathrm{s}$. These losses are coming from the following distinct subsystems: (a) Industrial water system $\left(0.02 \mathrm{~m}^{3} / \mathrm{s}\right)$; (b) Aqueducts $(0.098$ $\left.\mathrm{m}^{3} / \mathrm{s}\right)$; (c) Low pressure pipes $\left(1.93 \mathrm{~m}^{3} / \mathrm{s}\right.$ ); and (d) High pressure pipes $\left(0.38 \mathrm{~m}^{3} / \mathrm{s}\right)$. Groundwater recharge from the water supply network has been considered $70 \%$ of the total water losses. This contribution has been introduced as a recharge rate into the hydrogeological model.

The interaction between groundwater and sewer system has been modelled using the leakage factor approach. This approach is based on the assumptions that sewers conduits might have defects showing a uniform distribution along each conduit and the defect area is proportional to the sewer wetted perimeter. In addition, the sewer conduits in the aquitard are subjected to exfiltration only and all other conduits can exhibit infiltration or exfiltration. To use this approach, the location of each sewer pipe into the aquifer system had to be identified. The assumption that each sewer conduit is leaking has been made for the conduits located into the 


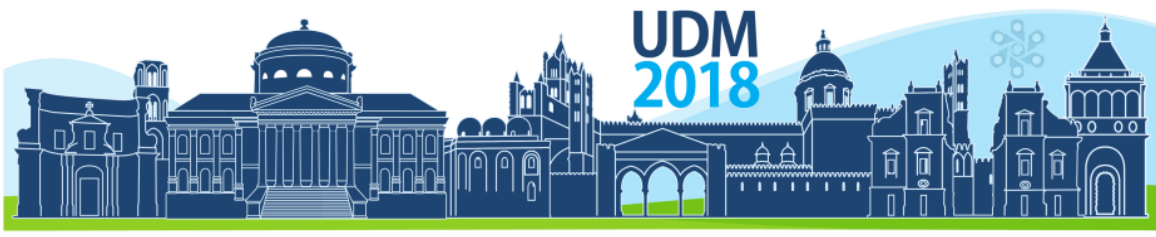

$11^{\text {th }}$ International Conference on Urban Drainage Modelling

23-26 Sep | Palermo - Italy

aquitard units. Leakage or groundwater seepage into the conduits could occur for those crossing the aquifer units.

The hydraulic function of the sewer conduit (leak or groundwater seepage) is dependent on the position within the aquifer system (Figure 1b). The exchange with groundwater was modelled by dividing the sewer system conduits into two categories: sewer conduits located entirely into the aquitard and sewer conduits located partially or totally into the upper aquifer. Hydraulic modelling details are given by Boukhemacha et al. (2015).

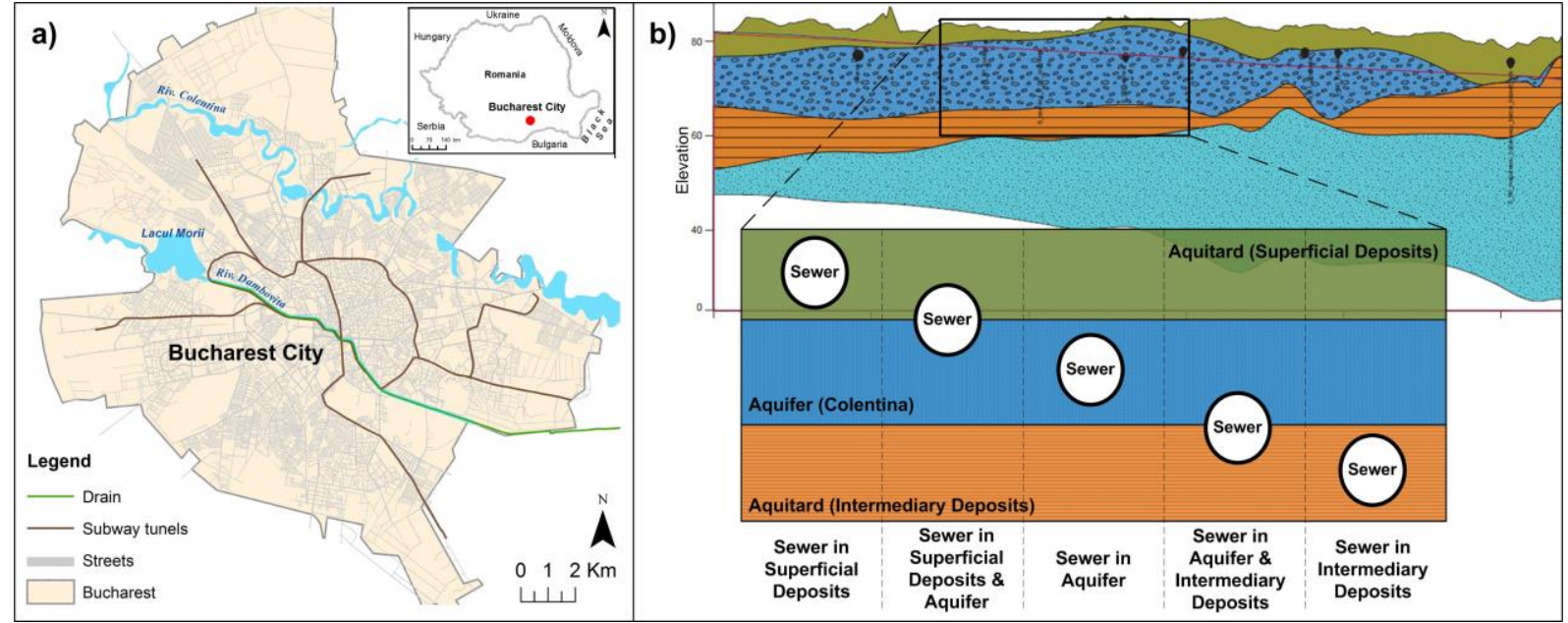

Figure 1. a) Bucharest city main infrastructure elements; b) Location of sewer conduits within the geological matrix

The groundwater recharge from precipitation has been estimated using the SCS-Soil Conservation Service- model (US Department of Agriculture, 1954) adapted for urban conditions. The recharge of the upper aquifer unit coming from rainfall was quantified using the mean multi annual precipitation rate of $600 \mathrm{~mm} /$ year.

Several subway tunnels and stations cross the study zone (Figure 1a). These elements have the barrier and drainage effects in relationship to groundwater. The drainage effect is due to groundwater seepage into tunnels. The subway operator reports annually a value of $0.08 \mathrm{~m}^{3} / \mathrm{s}$ as the mean total seepage flow rate. This effect has been taken into consideration into the hydrogeological model as a specified flow rate distributed along the subway network. The barrier effect consists of total or partial obstruction of the groundwater flow, causing a local oscillation of the hydraulic head as well as a variation of the natural flow direction.

\section{RESULTS AND DISCUSSION}

For the entire city sewer system, the hydrogeological model predicts a total infiltration flow rate of about $1.326 \mathrm{~m}^{3} / \mathrm{s}$ from groundwater. The infiltrating sewer conduits are completely or partially located into the shallow aquifer unit, therefore they are partially or entirely immersed. The model also predicts a total leakage of about $0.41 \mathrm{~m}^{3} / \mathrm{s}$ for the entire city sewer network. This flow rate represents about $3.4 \%$ of the dry weather flow. The difference between the groundwater seepage and sewer network leakage, for the entire network, gives the total inflow rate of about $0.92 \mathrm{~m}^{3} / \mathrm{s}$ as a result of the exchange between groundwater and the sewer 


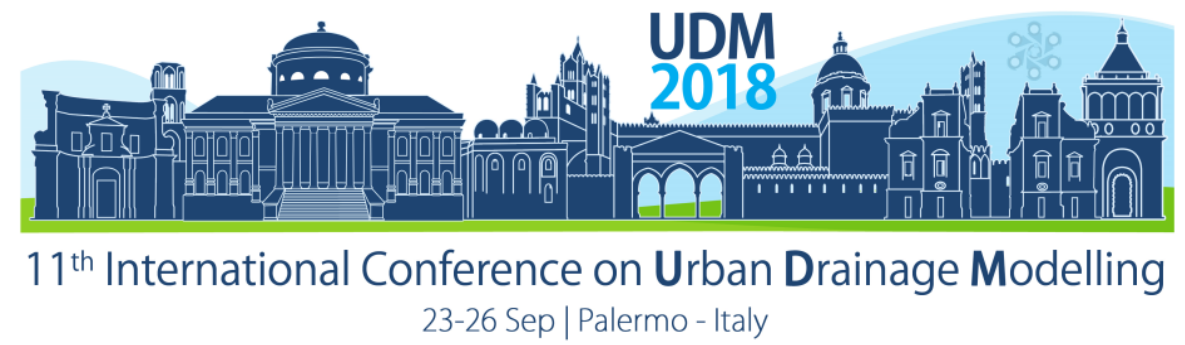

conduits. This additional flowrate is received by the Bucharest city wastewater treatment plant, able to treat a maximum of $9 \mathrm{~m}^{3} / \mathrm{s}$.

The results allowed also the identification of the sewer conduits showing a possible hydraulic interaction with groundwater. The sewer segments showing leakage conditions can be classified function of their position into the geological matrix (Figure 1b). The sewer segments presenting leakage conditions are located totally or partially into the shallow aquifer unit and they could be partially immersed or located above the water table. There are also sewer segments located into the aquitard units but the leakage rates are assumed to be insignificant. The sewer segments presenting groundwater infiltration conditions intersect the upper aquifer unit. These are totally or partially immersed into groundwater and the groundwater level is higher than the water level into the sewer. These segments are predominantly located along the Dambovița River.

The analysis of the sewer conduits location associated to the groundwater levels indicates that, if considering the total length of the sewer system (estimated to be about $474.3 \mathrm{~km}$ ), about $16.9 \mathrm{~km}$ of sewer conduits are completely immersed into groundwater and about $79.8 \mathrm{~km}$ of the conduits are partially immersed. Thus, more than $20 \%$ of the sewer system is entirely or partially immersed into groundwater.

\section{CONCLUSIONS}

The urban hydrogeological model represents a powerful tool for urban groundwater management in Bucharest City. It allows simulations to assess the impact on the urban groundwater of the sewer system rehabilitation, the consequences of future underground works development (tunnels, building basements and deep foundations etc), the effects of natural based solutions (green infrastructure) projects, and many others.

This project has been possible due to an institutional collaboration framework between the researchers, the city water operator, and other various institutions. This scientific partnership increased the model quality triggering additional studies related to hydrogeological and geotechnical topics, underground infrastructure development, groundwater protection and environmental impact.

\section{References}

Boukhemacha, M.A., Gogu, R.C., Serpescu, I., Gaitanaru, D., Bica, I., (2015) A hydrogeological conceptual approach to study urban groundwater flow in Bucharest city, Romania. Hydrogeology Journal vol.23/issue 3, pp 437-450, DOI: 10.1007/s10040-014-1220-3

Groundwater Engineering Research Centre, Technical University of Civil Engineering Bucharest - CCIAS (2013) Hydrogeological flow model for the Moesic aquifer system (Bucharest Area). Research project: Sedimentary Media Modelling Platform for Groundwater Management In Urban Areas (SIMPA). - Scientific Report, No 10, Unpublished results, Bucharest

Harbaugh AW, Banta ER, Hill MC et al (2000) MODFLOW-2000, the U.S. Geol Survey modular ground-water model - User guide to modularization concepts and the Ground-Water Flow Process. U.S. Geological Survey OpenFile Report 00-92

Serpescu I, Radu E, Gogu CR et al. (2013) 3D Geological model of Bucharest city Quaternary deposits. 13th SGEM GeoConference on Sci and Tech in Geology, Exploration and Min 2:1-8., DOI: 10.5593/sgem2013/BA1.V2/S02.001

US Department of Agriculture (1954), National Engineering Handbook. Washington DC 


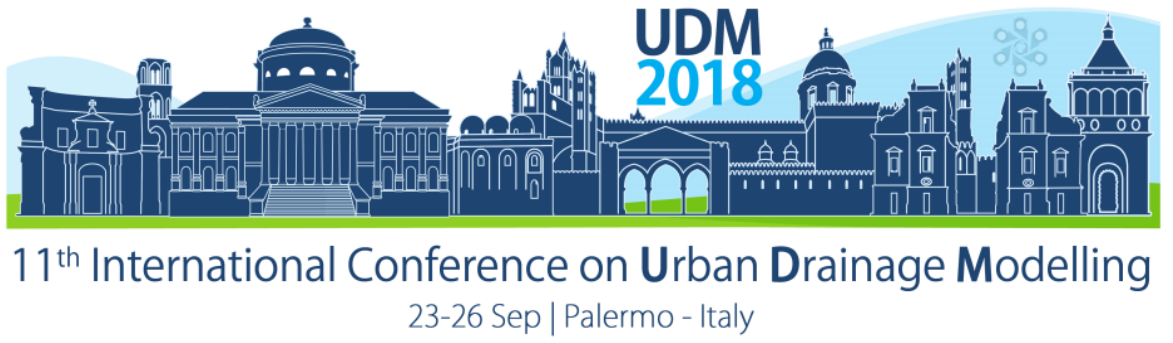

\title{
Assessment of Separation Efficiency of Reconstructed Combined Sewer Overflow in Debr (Czech Republic)
}

\author{
Kristyna Soukupova ${ }^{1}$, Jana Nabelkova ${ }^{1}$, Jaroslav Pollert ${ }^{1}$ and Petr Chmatal $^{1}$ \\ ${ }^{1}$ Czech Technical University in Prague, Department of Sanitary and Ecological Engineering, Prague 6, Czech \\ Republic
}

\begin{abstract}
This paper is aimed to assess the function of renovated combined sewer overflow (CSO) in Debr nad Jizerou. The former lateral CSO, which did not meet the requirements, was replaced with a modified type of tube CSO in 2012. The main goal of this study was to determine separation efficiency of the new CSO and to compare it to the previous situation. Monitoring itself included online observation of hydrological indicators in the sewer system, then continuous sampling during precipitation events and its assessment, moreover the chemical quality water judgment in recipient body in both immediate and long-term view. Comparing of current and older results, it is clear that the new CSO works better than the former CSO. The newly installed CSO decreases the pollution into the receiving body about $30-50 \%$ on average. Separation efficiency is improved and also values of the basic chemicals indicators in the recipient are better. Measuring on CSO showed the relevant correspondence of actual separation efficiency of suspended solids with the mathematical model.
\end{abstract}

Keywords: combined sewer overflow, online monitoring, separation efficiency, chemical status, mathematical modelling

\section{INTRODUCTION}

In the Czech Republic, the most widespread type of sewer system is the combined system. This type brings many economic and technological advantages, but it also carries the disadvantages, especially in water management. Combined sewer overflows (CSO) are fundamental objects of a combined sewer system and its main deficiency. Even during lowintensity precipitations, CSOs have a significant effect on water quality and even though the recipients receive highly diluted water, it still contains a large amount of pollution which has acute toxicity effect to the aquatic environment (Casadio et al., 2010). Together with the overflowing water, the recipient gets undissolved substances to which dangerous pollutants, such as heavy metals, are adsorbed (Nguyen at al., 2017).

With increasing awareness of the negative impacts of CSO on the environment are increasing demands for designing new structures to reduce CSOs. Although, until recently, particular emphasis was placed on water dilution ratio, today it is taken into account the ability of the CSO to mechanically purify the water that gets into the recipient. For this reason, new CSOs are being developed, which reduce the negative consequences of the overflow into the recipient. The developed type of CSO The representative of CSO with mechanical pretreatment is the Tube CSO (Pollert, 2008). 


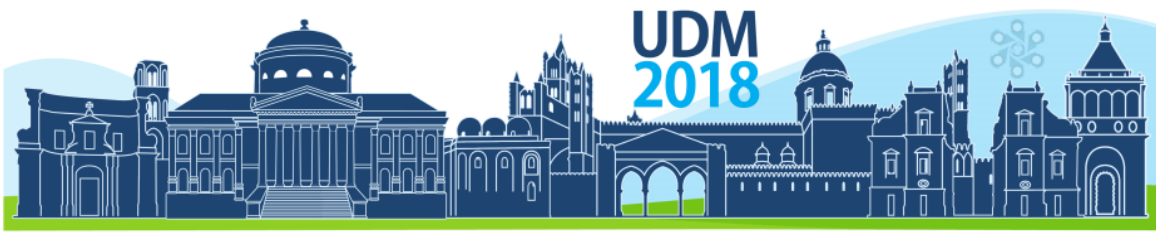

$11^{\text {th }}$ International Conference on Urban Drainage Modelling

23-26 Sep | Palermo - Italy

\section{DESCRIPTION OF STUDIED AREA}

Monitored area is located in village Debr nad Jizerou (approx. $70 \mathrm{~km}$ northeast from Prague, Czech Republic). Until 2012 there was a dysfunctional CSO, which was replaced by new CSO in November 2012. Original CSO was atypical with double-faced lateral overflow (Fig. 1 left). Original conditions were measured in two campaigns between years 2010 and 2012. Based on the evaluation of these campaign's results and mathematical modelling it was decided to replace the chamber with a modified type of HOBAS CSO (Fig. 1 right). Monitoring after reconstruction ran through summer 2013. Overflow from original as well as from new CSO runs down into ameliorating ditch in the inundation area of the Jizera River, which is approximately $200 \mathrm{~m}$ long and flows to the Jizera River.

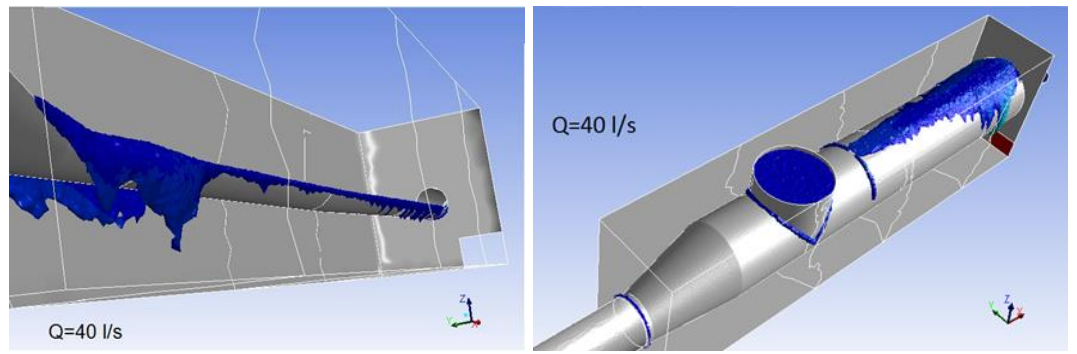

Figure 1. Comparison of overflows at original (left) and reconstructed (right) sewer overflows by mathematical modelling

\section{MATERIALS AND METHODS}

The Tube combined sewer overflow consists of two tubes stored on the top of each other (Fig. 2). Tubes are connected by a longitudinal slit. In dry weather conditions, wastewater simply flows through the chamber to wastewater treatment plant. There is a slowdown of undissolved substances in the main chamber and their discharge to the bottom of the drain. The positive effect on the separation of undissolved substances has a lateral flow that promotes their sedimentation. Pre-treatment of wastewater is ensured also by scum board and screen bars which can be optionally placed to the chamber. During heavy rainfall, the water level rises up, wastewater flows through the overflow slit to the upper tube and water which is low in solid content is delivered to a recipient.

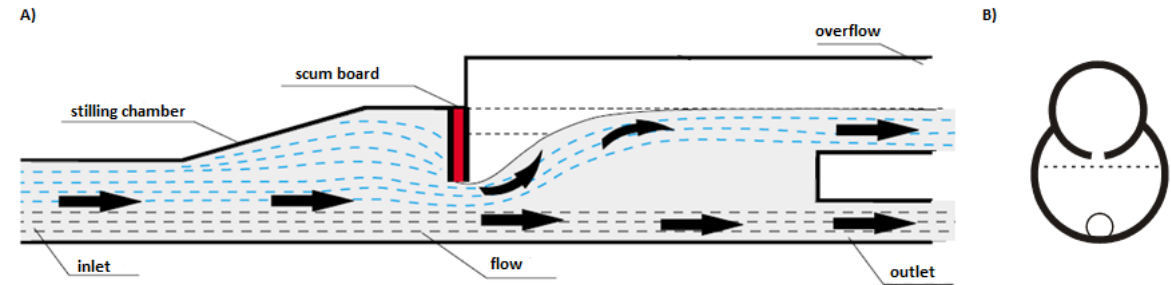

Figure 2. Longitudinal cut (A) and the cross-section (B) of the Tube combined sewer overflow

The separation efficiency of sewer overflows has been assessed both quantitatively and qualitatively. The quantitative assessment is based on the measurement of the inflow and overflow discharge and calculation of the outflow from their difference. Qualitative assessment compares the difference between concentrations of suspended solids at inflow and overflow (1). If the separation efficiency reaches $100 \%$, it means that clean water overflows. If the 


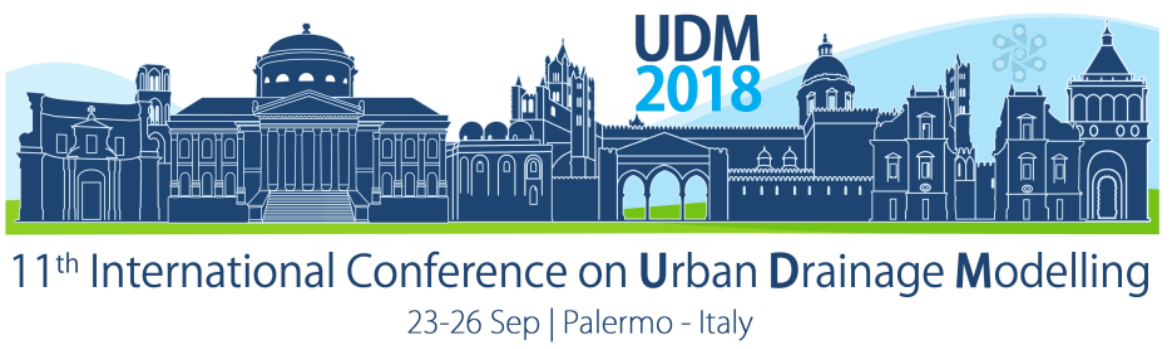

overflowing water is as dirty as the inflowing water the efficiency is $0 \%$. Negative values of separation efficiency can be achieved if the overflowing water is dirtier than the water at the inlet. Also, long-term impact on receiving water body through chemical analyses of water and sediment samples was monitored during campaigns.

$$
\eta=\frac{C_{\text {inflow }}-C_{\text {overflow }}}{C_{\text {inflow }}}
$$

For monitoring of suspended solids concentrations (TSS) at inflow was used online monitoring technique (opacity submersible digital probe) installed in the shaft. Continuously were recorded values of surface speed and TSS. Concentrations at overflow were monitored with autosampler (sampling up to 24 subsequent samples). Samples from overflow were taken to laboratory for chemical and bacteriological analysis.

Measured data from inflow and outflow were used for mathematical modelling. The base and used mathematical model of flow was model $k-\varepsilon$, which complies with all required criteria on speed, stability and calculation exactness. For free surface modelling there was used multiphase modelling (VOF model with HRIC discretization). Waste water pollution was simulated with particle trajectory. First, the contamination in the inflowing water is determined, the particles are divided into various densities and diameters in certain percentage cover. Particles are released into the object and their behaviour is monitored. The efficiency of the chamber on the separation of insoluble matter is obtained from the ratio of number of particles at inflow, overflow or outflow.

For monitoring of waste water quality during urgent events as well as for evaluation of longterm conditions were used indicators listed in Table 1. Samples for determination of the quality of water overflowing out of the chambers during urgent precipitations events were taken from autosampler installed at the outflow. Samples for recipient impact assessment were taken from 2 profiles in amelioration ditch, where the chamber's outflow leads to and from the Jizera River (above and under amelioration ditch). Analysed concentrations in water were compared with Environmental Quality Standards (EQS) given by Czech Governmental Order No. 401/2015. For the evaluation of sediment, US EPA criterion, toxicological benchmark: TEC (Threshold effect concentration) and PEC (Probable effect concentration) were applied, because Czech legislation lacks suitable criteria for sediments.

Table 1. Parameters and methods used for chemical and microbiological assessment

\begin{tabular}{|c|c|c|c|}
\hline \multicolumn{2}{|c|}{ Samples } & \multirow{2}{*}{ Parameters } & \multirow{2}{*}{ Methods of determination } \\
\hline water & sediment & & \\
\hline$\checkmark$ & $x$ & $\mathrm{pH}$, conductivity & potentiometric measuring \\
\hline$\checkmark$ & $x$ & $\mathrm{COD}, \mathrm{Cl}^{-}, \mathrm{NH}_{4}{ }^{+}-\mathrm{N}, \mathrm{N}-\mathrm{NO}_{3}, \mathrm{PO}_{4}{ }^{3-}-\mathrm{P}$ & cuvette test HACH LANGE \\
\hline$\checkmark$ & $x$ & coliform bacteria, E. Coli & Colilert method \\
\hline$\checkmark$ & $x$ & suspended solids & gravimetric method \\
\hline$\checkmark$ & $\checkmark$ & $\mathrm{Cd}, \mathrm{Cr}, \mathrm{Cu}, \mathrm{Ni}, \mathrm{Pb}, \mathrm{Zn}$ & atomic absorption spectrometry \\
\hline$x$ & $\checkmark$ & organic matter & loss of ignition \\
\hline
\end{tabular}

\section{RESULTS AND DISCUSSION}

Comparison of TSS concentrations at overflow and inflow before and after reconstruction is presented in Fig. 3. According to graphs the improvement of the situation after the installation 


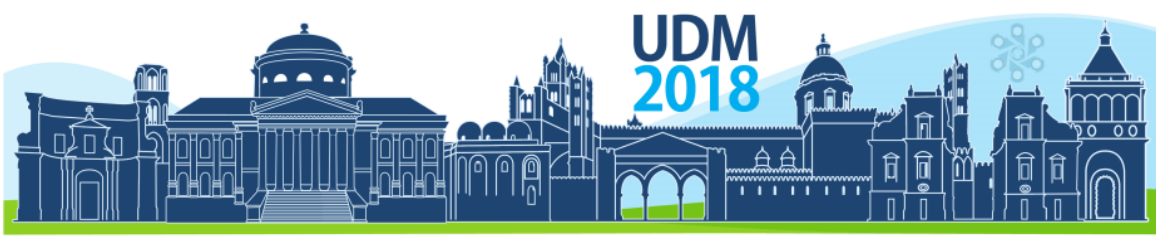

$11^{\text {th }}$ International Conference on Urban Drainage Modelling

23-26 Sep | Palermo - Italy

of new CSO is obvious. While the level of TSS at the overflow in 2010 reaches almost the same values as concentrations at the inflow, TSS concentrations at the overflow after the reconstruction are significantly lower than at the inflow. At the beginning of overflow during rain event in 2010 concentrations at the overflow were even higher than at the inflow. New CSO decreases concentrations of TSS at overflow more than twice against values at the inflow.
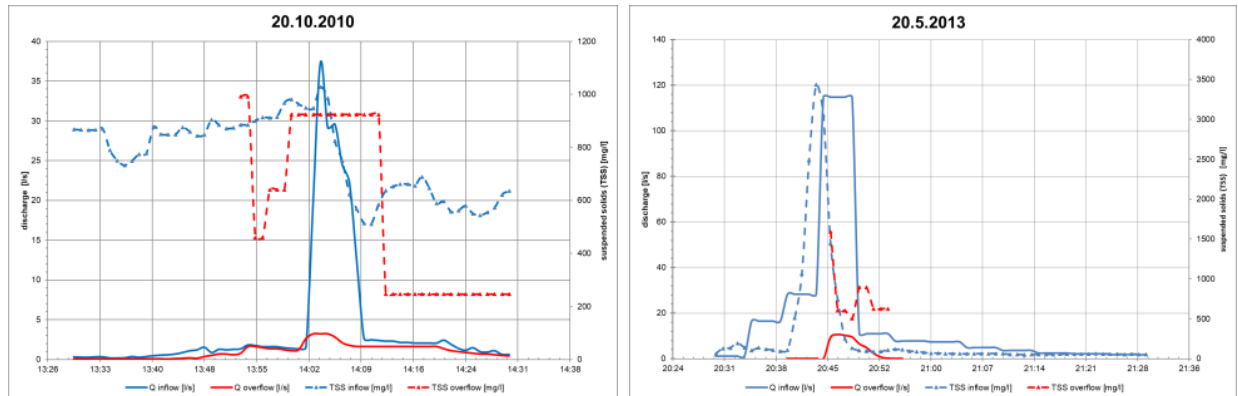

Figure 3. Course of discharges and suspended solids concentration during selected overflows in Debr before reconstruction (left) and after sewer overflow reconstruction (right)

Before reconstruction separation efficiency of TSS was zero, even negative hypothetically (higher TSS at overflow than at inflow). Negative separation efficiency was caused by the rinsing of settled material in the original CSO at the beginning of the rainfall event. After reconstruction is the efficiency of new CSO much better (Fig. 4). Separation efficiency after reconstruction is $65 \%$ on average. The results proved relatively good conformity of data measurement with mathematical modelling. For comparison Daligault, et al. (1999) have reported the mean removal efficiency for suspended solids for lamella separators $54 \%$. Pollert and Stransky (2003) who worked at the experimental catchment in Hostivar (Prague) found that the separation efficiency is directly proportional to the grain size. Their computations for CSO with side weir have shown separation efficiency below $20 \%$, for the material where $75 \%$ of particles with $\mathrm{d}<0.1 \mathrm{~mm}$, in cases where was the material with $75 \%$ particles with $\mathrm{d}>0.1 \mathrm{~mm}$ efficiency exceeded $50 \%$.

As was mentioned above, monitored CSO leads to amelioration ditch in inundation area of the Jizera River. Outflow from CSO is the only source of water in the ditch (except precipitation). Chemical indicators that exceeded environmental quality standards (EQS) before the reconstruction are still high but there have been significant improvements. There are permanently exceeded EQS for ammonium ions, phosphates, COD, TSS and coliforms bacteria. Graphs in Fig. 4 show improvement for COD concentrations after reconstruction. Due to the length of the ameliorating ditch, CSO has negligible influence on the recipient (the Jizera River).
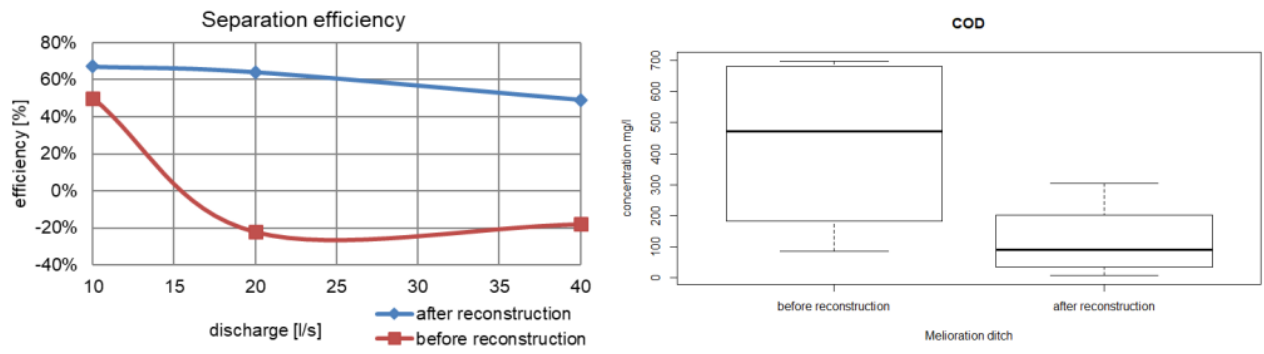

Figure 4. Situation in Debr nad Jizerou before and after reconstruction- separation efficiency (left), COD concentrations in amelioration ditch (right) 


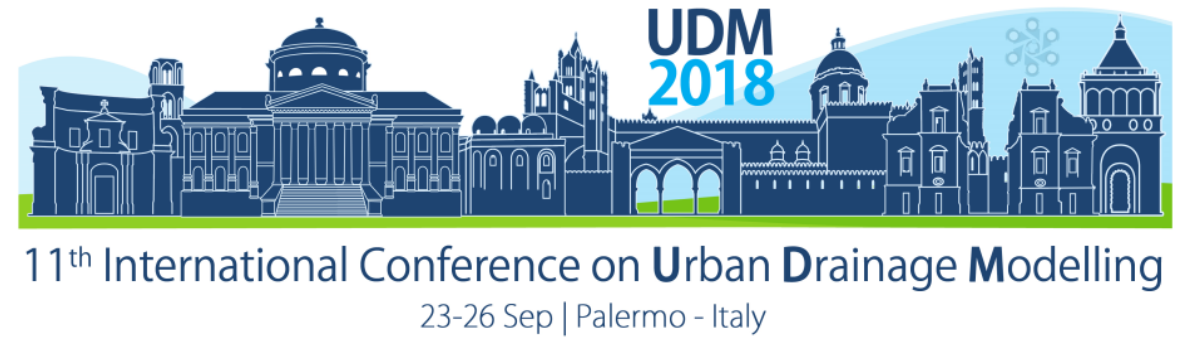

Obtained data confirmed previous results (Nabelkova and Kominkova, 2006) and findings of other published studies (Qu and Kelderman, 2001, Stead-Dexter and Ward, 2004) about metals behaviour in aquatic environment, i.e. heavy metals prefer binding into solid phase. Concentrations in water are in low levels and do not create long term risk for the aquatic environment. Comparing heavy metals concentrations in sediment of the amelioration ditch and from the Jizera River with US EPA criteria it can be said that in Debr location there are not ecotoxicological problems with metals. In all sampling sites measured values were almost always below these limits, only in rare cases $\mathrm{Cu}$ and $\mathrm{Pb}$ concentrations in sediment were higher than TEC criterion (28 mg/kg for $\mathrm{Cu}, 34.2 \mathrm{mg} / \mathrm{kg}$ for $\mathrm{Pb}$ ). All measured values were always under PEC criterion.

\section{CONCLUSIONS}

The main aim of this study was to evaluate the function of the reconstructed CSO in Debr (CZ), assess of its impact on the recipient and compare the state after reconstruction with the condition found out before the reconstruction. Measuring performed in Debr reconfirmed suitability of combination of online field research monitoring with mathematical modelling. After reconstruction the monitored CSO decreases the value of pollution overflowing into the receiving body at about $30-50 \%$. The impact of CSO on water quality in the Jizera River is trivial considering the length of the amelioration ditch.

\section{ACKNOWLEDGEMENT}

This works was supported by TACR, project no. TE02000077, Smart Regions.

\section{References}

Casadio, A., Maglionico, M., Bolognesi, A., \& Artina, S. (2010). Toxicity and pollutant impact analysis in an urban river due to combined sewer overflows loads. Water Science and Technology, 61(1), 207-215.

Daligault, A., Meaudre, D., Arnault, D., Duc, V., Bardin, N., Aires, N., Biau, D., Schmid, J., Clement, P., Viau, J. Y. (1999). Stormwater and lamella settlers: efficiency and reality, Water Science and Technology, 39 (2), 93-101

Nabelkova, J. and Kominkova, D. (2006). Distribution of heavy metals in freshwater ecosystem of a small stream impacted by urban drainage. Water Sci and Tech. 54 (6-7), 339-346

Nguyen, T. N., Strady, E., Nhu-Trang, T. T., David, F., \& Marchand, C. (2017). Trace metals partitioning between particulate and dissolved phases along a tropical mangrove estuary (Can Gio, Vietnam). Chemosphere. 196, 311-322

Pollert, J. and Stransky, D. (2003). Combination of computational techniques-evaluation of CSO efficiency for suspended solids separation. Water Science and Technology, 47(4), 157-166

Pollert, J. (2008) Tube combined sewer overflow as economical-ecological solution. Vodní hospodářství. 2, 33-36. ISSN 1211-0760

Qu, W. and Kelderman, P. (2001) Heavy metal contents in the Delft canal sediments and suspended solids of the River Rhine: multivariate analysis for source tracing. Chemosphere 45, 919-925

Stead-Dexter, K. and Ward, N.I. (2004) Mobility of heavy metals within freshwater sediments affected by motorway stormwater. Sci. of the Tot. Env. 334-335, 271-277 


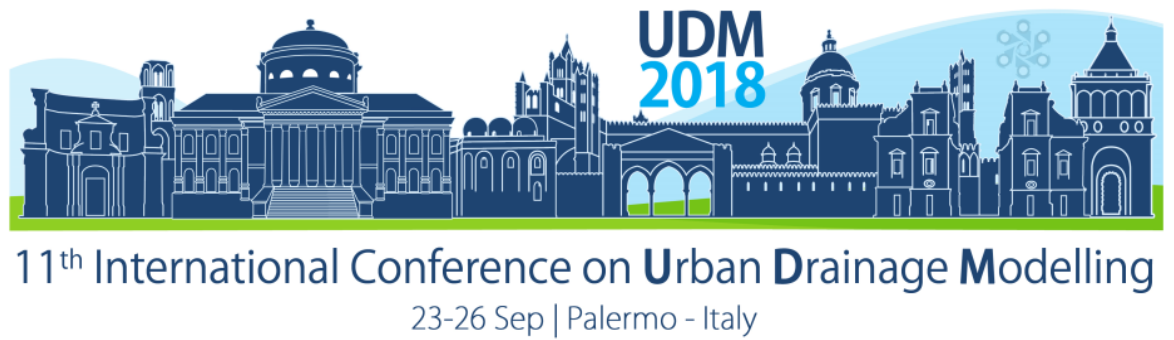

\title{
Frontiers in urban drainage - An analysis of a Preliminary Water Quality Recovery Program Plan in a developing country
}

\author{
Fabiane Andressa Tasca ${ }^{1}$, Camila Ely Januário Silva ${ }^{1}$, Maria Vitart de Abreu Lima ${ }^{1}$ and \\ Alexandra Rodrigues Finotti ${ }^{1}$ \\ ${ }^{1}$ Federal University of Santa Catarina, Department of Environmental Engineering, Florianópolis, Brazil
}

\begin{abstract}
Rapid growth and high population density concentrated in small areas became inadequate urban water resources, especially in the developing countries. The pollution of rivers and degradation of ecosystems are the result. Rivers restoration appears as a solution to improve this panorama. In this way, this paper analysed one of these projects. It was developed by a Brazilian university in response to a Public Civil Action. The actions described in the program are still insufficient and they can be summarized as monitoring of the current situation. These streams are degraded due to sewage and wastewater pollution from external and internal sources of the university, which has been proven by studies on water quality. Despite of this, the program actions contemplate only interventions within the territory of the university. From a holistic view it is believed that these actions are insufficient to recover the water quality of the rivers.
\end{abstract}

Keywords: Stormwater management; River restoration; Water Quality.

\section{INTRODUCTION}

The nature and gravity of the urban water problems in the developing countries need immediate attention. Rapid growth and high population density concentrated in small areas became inadequate urban water resources (STEPHENSON, 2001). Most of the rivers in urban areas are the end of effluents discharged along the watershed. We have the pollution of rivers and degradation of ecosystems as result. Therefore, river restoration is an increasingly popular management strategy for improving the physical and ecological conditions of degraded urban streams (Bernhardt and Palmer 2007).

In this paper, a Preliminary Water Quality Recovery Program Plan (PWQRPP) that is being delineated within the scope of a federal university located in a developing country (Brazil) was analysed. The reflections generated in this paper can help managers on decision making regarding water resources management in educational institutions.

\section{MATERIALS AND METHODS}

Methodology was divided into two stages. In the first one, a Preliminary Water Quality Recovery Program Plan (PWQRPP) was chosen and its actions were detailed. Besides that, a water quality diagnosis was performed through previous data. In step 2, a land use map was developed for the watershed and it was compared to the water quality, allowing analysis of anthropogenic pressure on water resources. Finally, a cross between all stages was made and an overall analysis of the proposals of PWQRPP was carried out (Results).

\subsection{Preliminary Water Quality Recovery Program Plan}




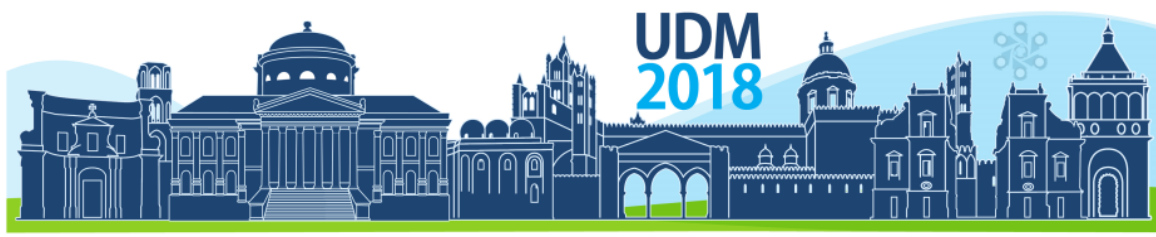

$11^{\text {th }}$ International Conference on Urban Drainage Modelling

23-26 Sep | Palermo - Italy

A river restoration program is being developed by Federal University of Santa Catarina (UFSC). UFSC is located in the Florianópolis city, situated in Santa Catarina State, South region of Brazil (Figure 1). UFSC region is characterized by intense urbanization in its surroundings, which exerts a strong pressure on the existing water resources. The analysed program has part of Water Quality Recovery Program Plan for the rivers and streams within the university campus, and it is an obligation motivated by Public Civil Action. These streams are degraded due to sewage and wastewater pollution from both external and internal sources. Figure 1 shows the UFSC boundaries as well as the rivers that cross its territory. In addition, it is possible to observe the connections of the rivers and the existence of conservation units in the region. It is noteworthy that the rivers that cross the university flow into the Itacorubi mangrove, an ecosystem with characteristics that classify it as highly sensitive. These rivers and streams that cross the UFSC have a great potential to form an ecological corridor between the conservation units and they can establish a connection between these fragmented ecosystems.

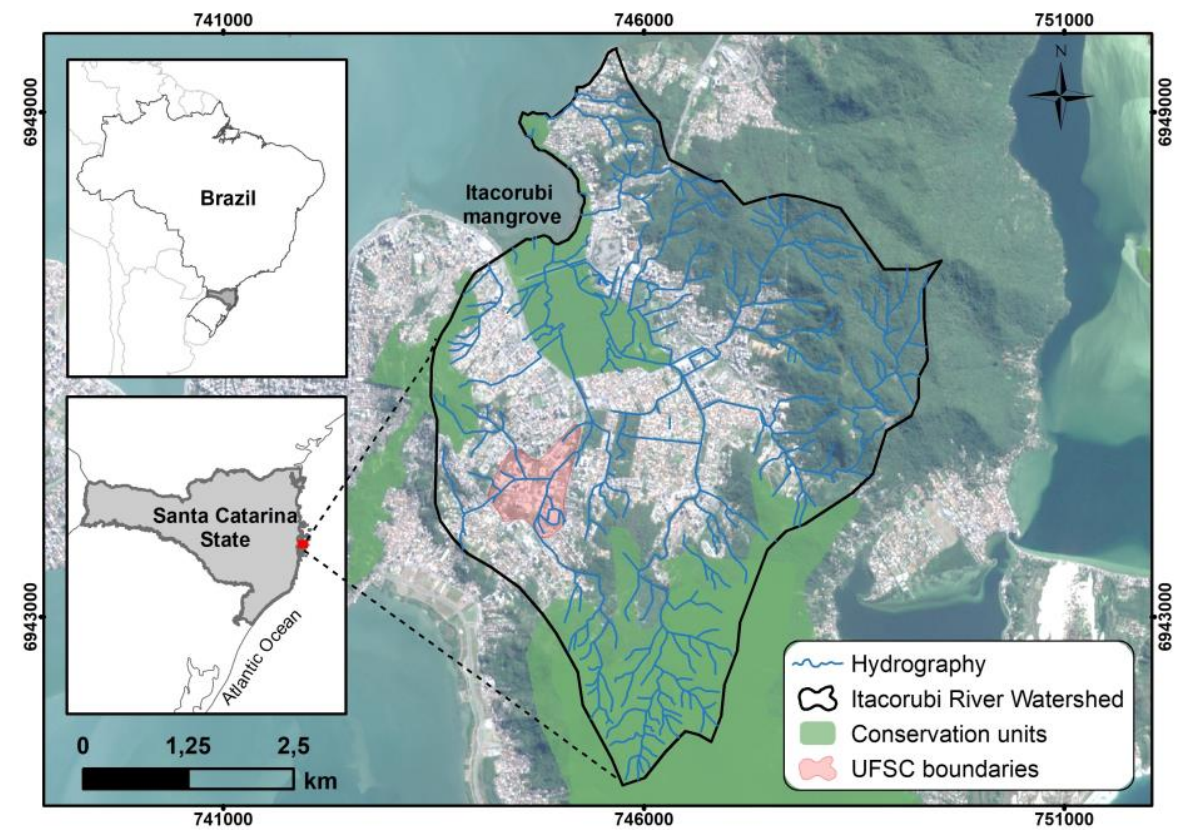

Figure 1. Location of study area and its insertion in the context of the watershed.

PWQRPP began in March 2015 and it should have been completed in 2017, but due to delays it is still active. Managers responsible for it do not know when it will be finalized. Thus, this study identified "what has been done so far" and analysed aspects that may contribute to the final project. PWQRPP actions are described in Table1, in which five general actions were identified. Until now, this project is restricted to the identification and monitoring of these actions. Therefore, it was called a preliminary project in this study. The most urgent activitiessuch as the implementation of pollution recovery and control projects- were not started.

It is noteworthy that the main internal source of streams pollution is car washing in campus parking, which discharge a large amount of detergent and other chemicals into the rivers. This activity is authorized by the university, but there is no pollution control. Already the main external source of pollution refers to clandestine sewage from communities around the university. Despite of this, the program has been implementing only within the university and 


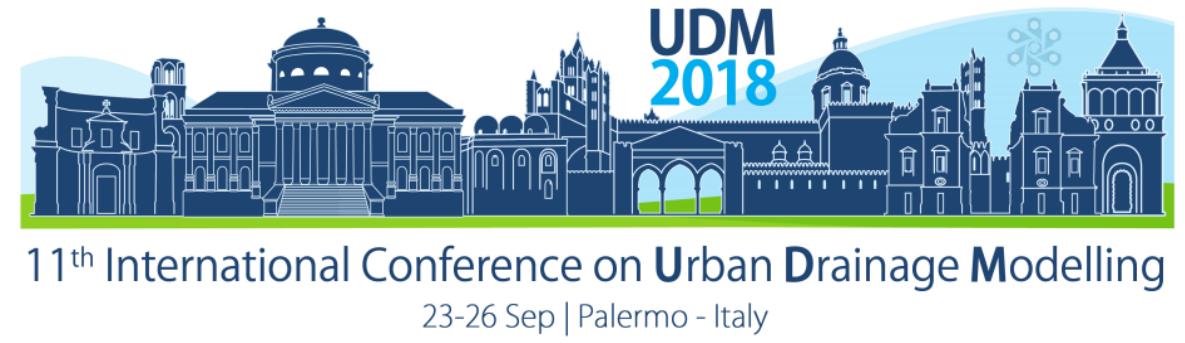

whose pollution has been caused by its activities. This leads us to discuss the frontiers in the urban drainage management and to what extent this type of intervention can be effective.

Table 1. Actions in the Preliminary Water Quality Recovery Program Plan

\begin{tabular}{|c|c|}
\hline Description & Progress \\
\hline Mapping of all effluent discharged on stream-water & $\begin{array}{l}39 \text { identified discharges and identification } \\
\text { of origin of } 13 \text { of these sources. }\end{array}$ \\
\hline Quality and quantity monitoring of river and streams & Annual reports and disposition in digital \\
\hline $\begin{array}{l}\text { Investigation report of the potential sources of } \\
\text { contamination. Notice to the responsible authorities } \\
\text { when the contamination source is external to the } \\
\text { university }\end{array}$ & $\begin{array}{l}\text { Analysis of the Water Quality Index. } \\
\text { Identification of } 6 \text { contaminated effluents } \\
\text { and } 20 \text { points listed as suspected of } \\
\text { contamination }\end{array}$ \\
\hline Implementation of stream restoration projects & $\begin{array}{l}\text { Not Completed and not described in the } \\
\text { WQRPP }\end{array}$ \\
\hline Pollution control & $\begin{array}{l}\text { Not Completed and not described in the } \\
\text { WQRPP }\end{array}$ \\
\hline
\end{tabular}

Source: Data extracted from UFSC (2016)

Two studies about Water quality index (WQI) were found for the study area: Matias (2008) and UFSC (2016). A WQI helps in understanding the general water quality status of a water source. We calculated the mean WQI of monitoring one-year for each study, considering parameters such as $\mathrm{pH}$, dissolved oxygen (DO), temperature, turbidity, total solids, biochemical oxygen demand, thermotolerant coliforms, total phosphates and nitrates (Table 2). There are four coincident points between both studies, which ranged from bad to very bad in both periods.

Table 2. Water quality index and rating

\begin{tabular}{ccccc}
\hline Point & \multicolumn{2}{c}{$2006-2007$} & \multicolumn{2}{c}{$2015-2016$} \\
\hline 1 & 29.0 & Bad & 22.17 & Very bad \\
2 & 31.1 & Bad & 18.25 & Very bad \\
3 & 22.6 & Very bad & 35.42 & Bad \\
4 & - & - & 36.33 & Bad \\
5 & 23.3 & Very bad & 32.00 & Bad \\
6 & - & - & 26.50 & Bad \\
7 & - & - & 16.25 & Very bad \\
\hline
\end{tabular}

Source: Data extracted from Matias (2008) and UFSC (2016).

\subsection{Step 2}




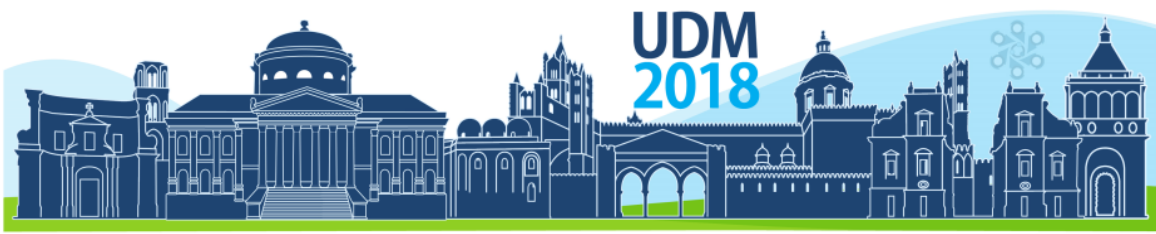

$11^{\text {th }}$ International Conference on Urban Drainage Modelling

23-26 Sep | Palermo - Italy

In this step, a land use of the UFSC watershed was performed in order to analyse the pressure exerted by the urbanization (impervious surface) in the water resources. It was used Sentinel 2A images (Red/Green/Blue composite imagery and image resolution of 10 meters), from July 2017. ArcMap 10.4.1 was used to processes this image and collect the information of interest. Supervised classification of images was used to automatically compute the impermeable areas, through the pixel classification algorithm (Maximum Likelihood). It was designed a classifier from 30 training samples to guide this process, and two classes of land use were chosen: permeable (vegetation/forest) and impermeable (surfaces and public roads).

\section{RESULTS AND DISCUSSION}

Figure 2 presents the results of the latest analysis of the WQI (UFSC, 2016) and land use for the study area. Point 4 (Pantanal river), point 5 (located at the junctions between Cesar Seara and Eletrosul rivers) and point 6 (Carvoeira river) have a bad water quality. Point 3 (Meio river) has a bad quality too, and it follows its own course through the campus where it merges with its tributaries (quoted points added from the point 7-Serrinha river), which gets a lower quality (point 2). So, Meio river flows with a very bad water quality until the outflow point of UFSC watershed (Point 1), which goes into the Itacorubi mangrove. The bad water quality occurs even before entering the campus as result of clandestine sewage connections to the stormwater system. There is a pressure exerted by urbanization on water resources and green areas/ conservation unit as shows in Figure 2.

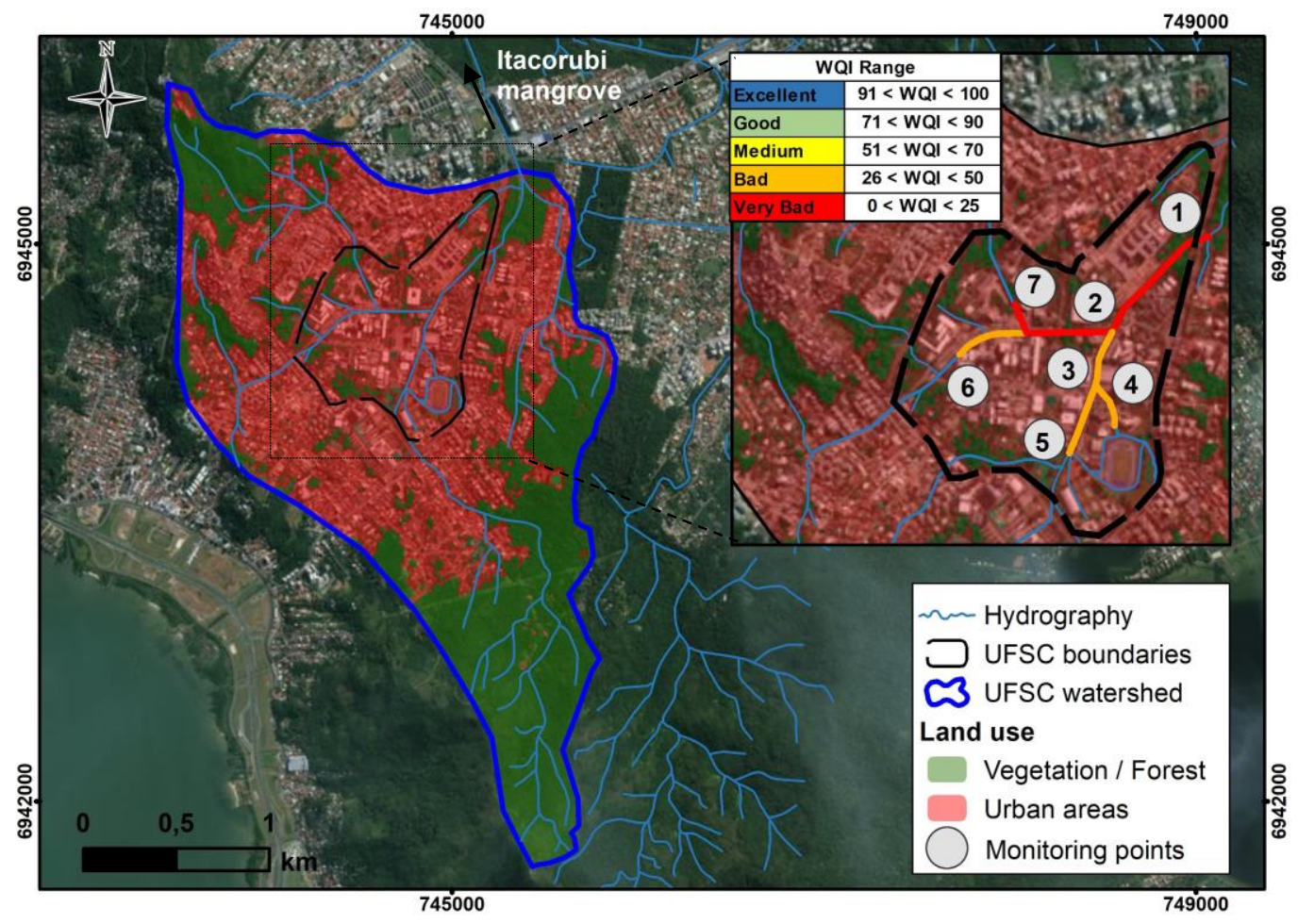

Figure 2. Land use map and WQI in the rivers that cross the university. 


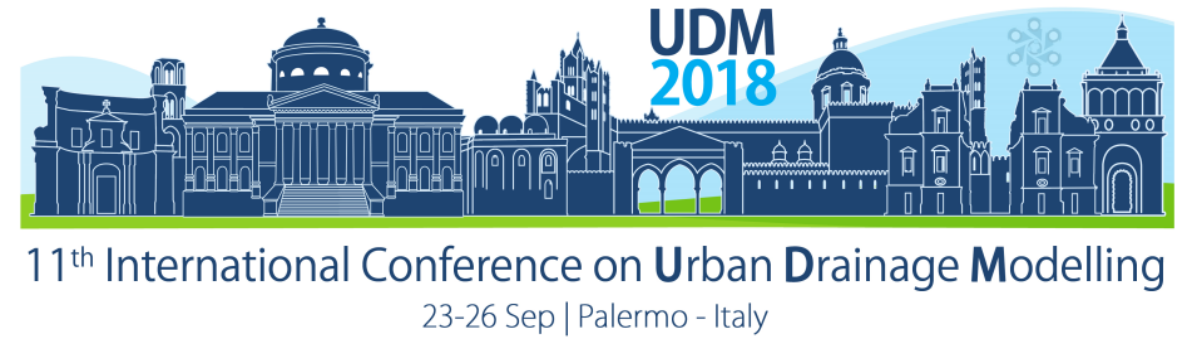

Water Quality Recovery Program Plan is intended only for the rivers and streams within the university campus. However, the river ecosystem can not be reduced to territorial limits, since significant pollution comes from external sources of the university. It is imperative to efficiently manage urban stormwater in order to reduce these urbanization impacts. From a holistic view it is believed that these actions (ie, stop the pollution caused within university) are insufficient to recover the water quality of the rivers. This recognition can be useful and lead to some changes of the framework of the Water Quality Recovery Program Plan. The program plan is preliminary, but it is expected to raise awareness among educational managers about the scope planning and frontiers of urban rivers.

\section{CONCLUSIONS}

It is believed that actions contained in the Water Quality Recovery Program Plan are insufficient because they must consider, at least, the watershed. An integration of all efforts to reach the project objectives and greater political will to address this problem are needed. It is hoped that the reflections contained in this paper can assist managers in making decisions regarding the scope of the project.

\section{References}

Bernhardt, E. S. and Palmer, M. A. (2007) Restoring streams in an urbanizing world. Freshwater Biology 52(4), 738-751.

Matias, W.G. (2008) Monitoramento da Qualidade da Água da Bacia Hidrográfica do Campus da UFSC (Water Quality Monitoring in the UFSC watershed). University Extension Project. Federal Univ. of Santa Catarina, Florianópolis, Brazil.

Stephenson, T. (2001) Problems of developing countries. In Frontiers in Urban Water Management-Deadlock or Hope (pp. 264-312).

UFSC (2016) Recuperação da Qualidade das Águas dos Córregos do Campus Reitor João David Ferreira Lima (Water Quality Recovery Program Plan into Reitor João David Ferreira Lima Campus). Institutional report. Federal Univ. of Santa Catarina, Florianópolis, Brazil. 


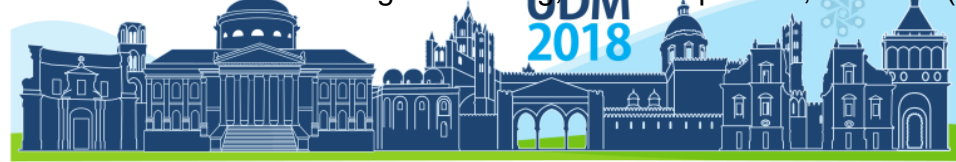

$11^{\text {th }}$ International Conference on Urban Drainage Modelling

23-26 Sep | Palermo - Italy

\title{
Modelling for Integrated Stormwater Management of the Renfrew Neighbourhood: A Pilot Study
}

\author{
Scott Struck1, Marc Leisenring ${ }^{1}$, Lucas Nguyen', David Seeliger² Bert van Duin ${ }^{\text {, }}$, and Pablo Lopez \\ Hernandez ${ }^{3}$, and Joshua Cantone ${ }^{4}$ \\ ${ }^{1}$ Geosyntec Consultants, Portland, OR, USA \\ ${ }^{2}$ MPE, Calgary, Canada \\ ${ }^{3}$ City of Calgary, Water Resources Department, Calgary, Canada \\ ${ }^{4}$ Optimatics, Chicago IL, USA
}

\begin{abstract}
The Renfrew Neighbourhood within the City of Calgary is about $1.3 \mathrm{~km}^{2}$ and is undergoing infill redevelopment with effective lot imperviousness increasing three-fold, straining the existing storm sewer system. Combined with existing localized flooding, the City of Calgary is challenged with providing adequate flood storage and improving downstream water quality. These challenges are not unique to the Renfrew Neighbourhood, but permit the project and location to be used as a pilot study to compare the cost effectiveness of different retrofit options using a novel benefit optimization approach. Four potential retrofit options were identified for integrated stormwater management: pipe replacement (size) inlet flow controls, distributed management (LID/SUDS/WSUDS), regional or community storage, and a combination of controls. Hydrologic and hydraulic analyses conducted using EPA SWMM was coupled with an extension software package (Optimizer ${ }^{\mathrm{TM}}$ ) to determine the placement and sizing of improvements for each scenario that most cost-effectively managed runoff for future redevelopment conditions. Optimization can often result in significant cost savings over more traditional infrastructure planning approaches. By using optimization software, planning can minimise costs and maximize flood control and water quality benefits. Runoff conditions from small storm events through a 50-yr, 4hr design event for the 2076 redevelopment conditions were considered in scenario optimization. Results from the analyses demonstrate the value of using an optimization approach for long-term integrated stormwater planning which can serve as a template for future capital improvements.
\end{abstract}

Keywords: Optimization; Integrated Stormwater Management, LID/SUD/WSUD; SWMM; Optimizer ${ }^{\mathrm{TM}}$

\section{INTRODUCTION}

The community of Renfrew is in the northeast quadrant of Calgary. The community is an established, largely single-family residential Neighbourhood, with some multi-family and institutional parcels. The minor, storm sewer system and most of the major overland drainage system in the study area drain east towards Nose Creek, with the minor system discharging at Outfall NC9 (Nose Creek Watershed Management Plan, 2007). The Renfrew Neighbourhood was selected because of the pace of redevelopment, existing flooding and basement backup issues, a distinct and defined catchment leading to a single outfall, and the existing level of service that was representative of many other areas within the City of Calgary. The Renfrew Pilot Study assessed the value of alternative stormwater infrastructure upgrade strategies to mitigate increased stormwater runoff as the Neighbourhood redevelops.

A cost benefit analysis using two components, an optimization model and a post-processing triple bottom line (TBL) assessment, was used to assess infrastructure upgrade alternatives needed to provide a minimum level of service under redevelopment conditions. The scenarios conceived for optimization reflected City preferred management strategies including: pipe replacement (typically upsize); inlet control devices (ICDs); distributed stormwater management systems such as Green Stormwater Infrastructure (GSI) and similar approaches such as Sustainable Urban Drainage Systems (SUDs), and Water Sensitive Urban Design Systems (WSUDS); as well as regional or community storage. A combination of these controls was also evaluated. The modelling component used the U.S. Environmental Protection Agency's Stormwater Management Model (EPA SWMM; US EPA, 


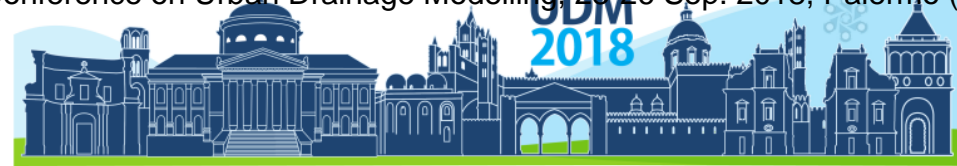

$11^{\text {th }}$ International Conference on Urban Drainage Modelling

23-26 Sep | Palermo - Italy

2017), an open source hydrologic and hydraulic modelling software package, combined with an extension software package, Optimizer ${ }^{\mathrm{TM}}$ (Optimatics, 2017), applying multi-objective meta-heuristic optimization genetic algorithms to evaluate numerous asset features against multiple objectives, including hydraulic and water quality performance. These two modelling tools were used to evaluate the preferred, least-cost stormwater infrastructure upgrade types, locations, and sizes for each scenario. The optimization software evaluates potential capital improvement outcomes and costs based on user-defined input. This abstract and presentation will focus on the process and results of the optimization modelling using EPA SWMM and the optimization software.

\section{METHODS}

Optimizer ${ }^{\mathrm{TM}}$ uses cloud-based storage and processing to analyze costs and benefits of alternative capital improvement projects for stormwater and sewer collection systems. For this project, Optimizer ${ }^{\mathrm{TM}}$ was configured to operate on the EPA SWMM v5.1.012 platform.

The optimization for the software was formulated with two primary objectives, minimising cost and maximizing hydraulic level of service. The software allows the user to identify several alternative decision variables such as conveyance upgrades, storage, and green infrastructure to compare with multiple objectives. Each option has a cost and a corresponding hydraulic performance which is measured based on criteria such as volume of flooding (e.g., depth at node) and water quality estimates. The software uses a proprietary multi-objective meta-heuristic optimization algorithm that was developed and tested for industrial scale wastewater and stormwater networks. The software allows the development of a Pareto curve which is applied to identify optimal plans for the desired objectives. For this application, the software was set up to evaluate five types of asset improvements including pipe conduit size, flow restriction with inlet control devices, implementation of onlot cisterns, inclusion of storage and volume loss using right of way bioretention facilities, and storage and volume reduction via community storage facilities. These asset improvements and associated cost curves were compared to achieving multiple targets.

Scenario development was a critical step in alternative analysis modelling. For each scenario, infrastructure upgrades were applied to the Renfrew Neighbourhood using the coupled SWMM model and Optimizer ${ }^{\mathrm{TM}}$ software (Figure 1). Scenario infrastructure upgrade selection was based on implementation costs and deviations from flood control and water quality design criteria (Bylaw of the City of Calgary to Regulate Storm Sewers and Storm Drainage, 2005). Flood control criteria non-attainment were evaluated with assigned penalties for: hydraulic grade line exceedances (e.g., freeboard below ground surface and top of pipe), depth of street ponding, and system overflow into adjacent watersheds. Water quality design criteria non-attainment were evaluated with cost penalties (with costs, in most cases, specific to the City of Calgary) for exceeding specific City of Calgary goals for annual volume discharged and annual total suspended solids (TSS) load.

The four scenarios evaluated are defined below with the varying optimization decisions as shown in Table 1.

Scenario 1 - Storm Sewer Upgrades: This scenario considers size upgrades to storm sewer pipe and/or installation of ICDs. Optimizer ${ }^{\mathrm{TM}}$ was used to determine the optimal size of pipe replacement to manage the runoff from a 50-yr, 24-hr event under the predicted 2076 redevelopment conditions to achieve targeted flow rate, timing, and flooding limitations. 


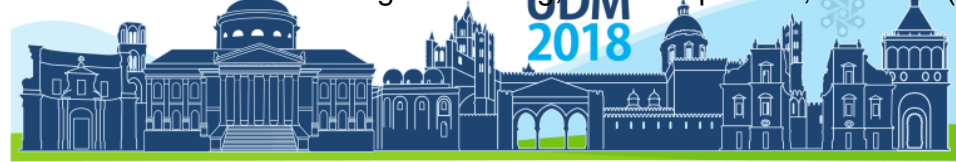

$11^{\text {th }}$ International Conference on Urban Drainage Modelling

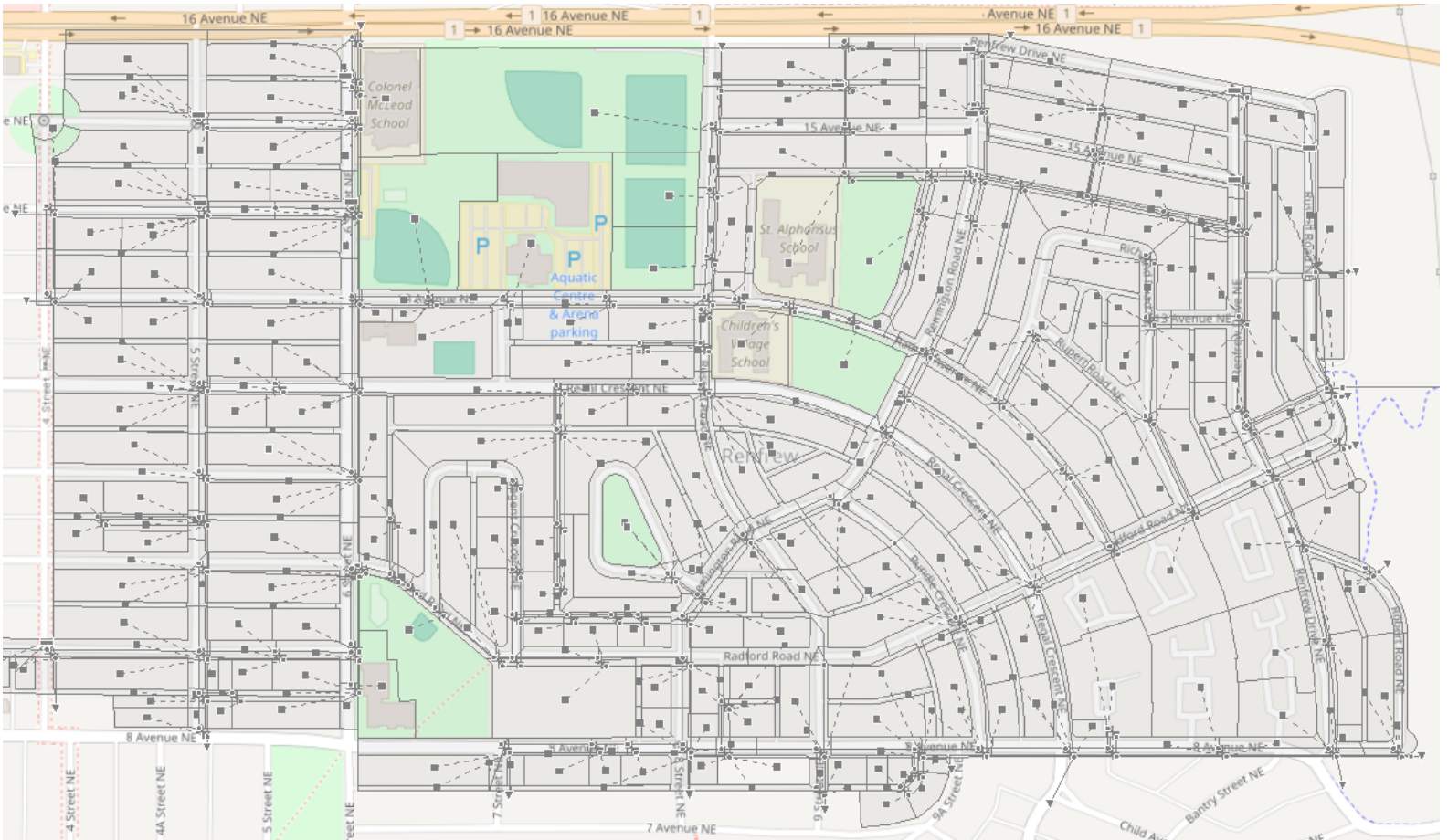

Figure 1. Overview of parcels and model layout for the Renfrew Neighbourhood.

Scenario 2 - Community Storage and Storm Sewer Upgrades: This scenario used the variables included in Scenario 1 (i.e., pipe upsizing, ICDs) and added community detention storage facilities. Four storage locations were pre-determined within the Renfrew Neighbourhood where storage (surface and/or underground) and re-use (greenspace or playing field irrigation) was feasible.

Scenario 3 - Distributed Storage: Scenario 3 was a baseline for implementation of green stormwater infrastructure without pipe upgrades (but included ICDs). Scenario 3 was developed using four potential facility types: on-lot cisterns and right-of-way (ROW) bioretention or tree trenches. Level of implementation and sizing for each facility type was based on implementation cost and flood prevention targets/penalties. Cisterns were only applied to redevelopment lots and bioretention and tree trench facilities were only applied within the public ROW, when needed.

Scenario 4-Combinations of Scenarios 1,2,3 and Community Storage: This scenario is a combination of Scenarios 1, 2, and 3 along with community storage. As in Scenarios 2 and 3 , sizing of facilities was determined through the optimization process.

Table 1. Optimization Variables used in Scenario Development.

\begin{tabular}{lcccc}
\hline Optimization Decision Variable & Scenario 1 & Scenario 2 & Scenario 3 & Scenario 4 \\
\hline Pipe Upsize & $\mathrm{X}$ & $\mathrm{X}$ & & $\mathrm{X}$ \\
Inlet Control Devices & $\mathrm{X}$ & $\mathrm{X}$ & $\mathrm{X}$ & $\mathrm{X}$ \\
Community Storage & & $\mathrm{X}$ & & $\mathrm{X}$ \\
ROW Bioretention & & & $\mathrm{X}$ & $\mathrm{X}$ \\
On-lot Cisterns & & & $\mathrm{X}$ & $\mathrm{X}$ \\
\hline
\end{tabular}

Each decision variable was linked to a cost table or function that represents the unit cost of infrastructure improvements or penalty costs if targets are not met (Figure 2). The total cost of all decisions is referred to as "implementation costs." Penalty costs are a monetized 


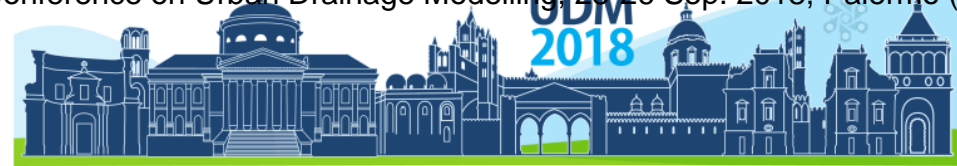

$11^{\text {th }}$ International Conference on Urban Drainage Modelling

23-26 Sep | Palermo - Italy

function of the exceedance of a target, such as the volume of flooding, which were based upon insurance information derived from multiple City of Calgary flood events. Model runs compared selected design criteria implementation costs combined with penalty costs with the existing conditions of the base model. A decision may cause penalties to decrease (less flooding) or increase (more flooding). Thus, if the costs of improvements plus the cost of the penalties were less than the costs of the penalties in the base model, the new model had better performance (referred to as model "fitness"). Each variation of model variables either increased or decreased the model fitness. Optimizer ${ }^{\mathrm{TM}}$ was used to automate this iterative evaluation process by initiating multiple model runs at a time, selecting the most "fit" model, and then reintroducing the most "fit" model with the next iteration of changes. This iterative optimization process continued with a new batch of simulations until the fitness of the best model from batch to batch no longer improves, resulting in a "near-optimal" scenario that was the most "fit." The result of this process was a model scenario that minimised implementation costs while also minimising penalty costs.
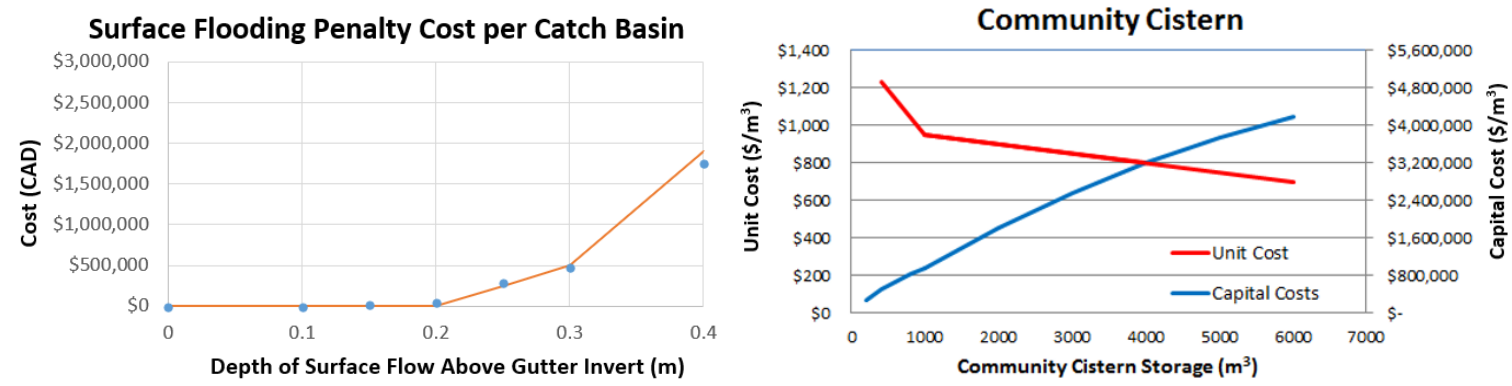

Figure 2. Examples of unit cost, capital cost, or penalty cost functions used in optimization (costs in CAD).

\section{RESULTS AND DISCUSSION}

All four scenario evaluations have been completed. In all, 106 pipe conduit segments, 133 inlet control devices, 221 on-lot cisterns, 119 right of way bioretention facilities, and four regional storage facilities were considered for the optimization. For Scenario 1, two approaches were evaluated for pipe upgrades, one as independent pipe segments and the other as grouped segments. Grouped pipe segment sizing ensured that downstream pipes for a connected line were the same diameter, similar diameter (not more than two standard pipe sizes in difference), or greater for all selected pipe upsizing opposed to being completely independent. The grouped pipe approach showed similar results to the independent pipe model run and are a preferred implementation approach for the City (Table 2). Figure 3 shows a figure of the grouped model output where pipes were proposed for replacement, and penalties occur for the near-optimal scenario for Renfrew. Results for all modelling analyses will be included in the paper and presentation.

Table 2. Model results for Scenario 1 to achieve 2076 redevelopment conditions meeting targeted flow rate, timing, and flooding limitations (costs in CAD).

\begin{tabular}{lcccc} 
Costs/Penalty Costs & Input Model & $\begin{array}{c}\text { Max Pipe / } \\
\text { Max ICD }\end{array}$ & $\begin{array}{c}\text { Optimized Plan } \\
\text { (Grouped Sizing) }\end{array}$ & $\begin{array}{c}\text { Optimized Plan } \\
\text { (Independent Sizing) }\end{array}$ \\
\hline Pipe costs $(\$)$ & $\$ 0$ & $\$ 70,239,584$ & $\$ 30,376,471$ & $\$ 32,859,123$ \\
Surface Flooding penalties $(\$)$ & $\$ 44,558,520$ & $\$ 0$ & $\$ 353,880$ & $\$ 1,114,066$ \\
System Overflow penalties $(\$)$ & $\$ 34,981,084$ & $\$ 792$ & $\$ 370,036$ & $\$ 457,628$ \\
Junction Freeboard penalties $(\$)$ & $\$ 58,607,370$ & $\$ 0$ & $\$ 3,260,758$ & $\$ 4,594,748$ \\
Fitness $(\$)$ & $\$ 138,146,975$ & $\$ 70,240,376$ & $\$ 34,361,145$ & $\$ 39,025,565$ \\
\hline
\end{tabular}




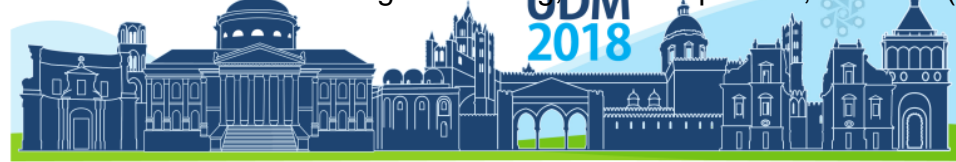

$11^{\text {th }}$ International Conference on Urban Drainage Modelling

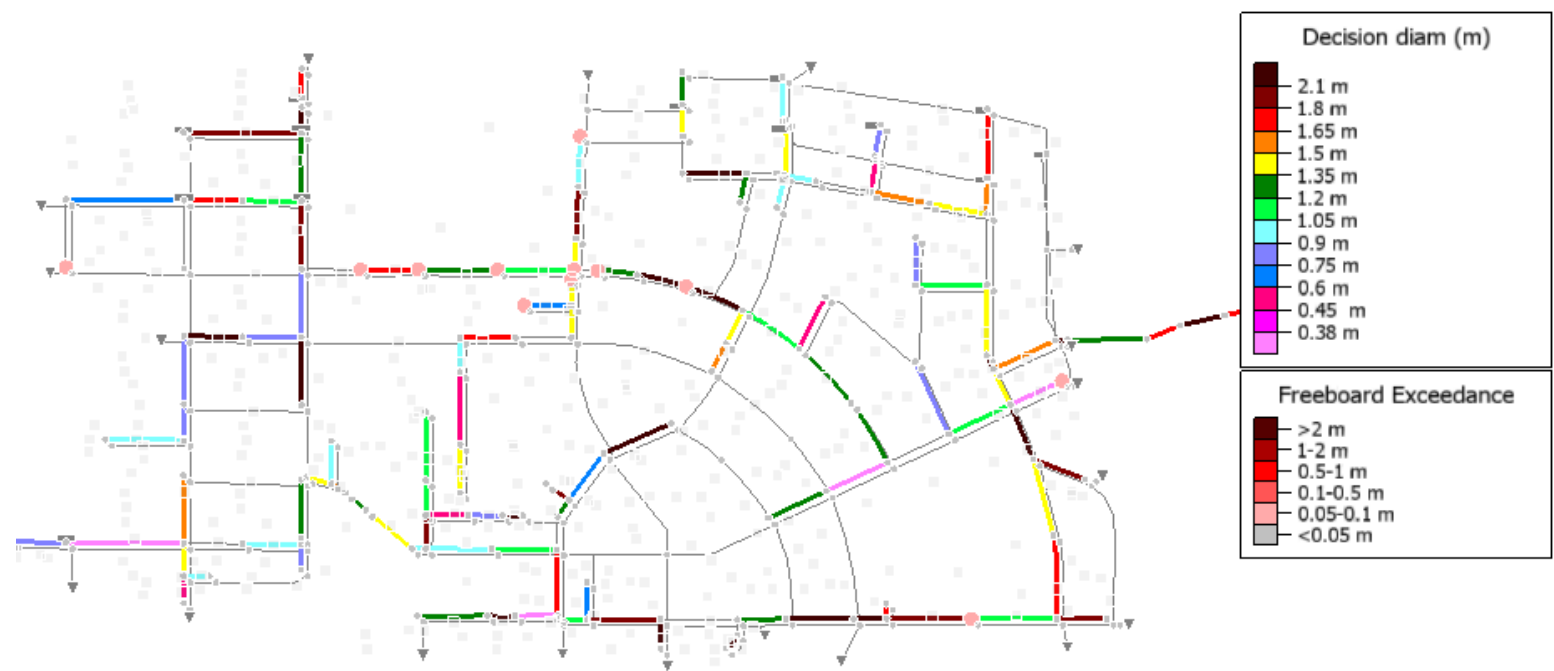

Figure 3. Map of the "optimal" model results of recommended gray infrastructure pipe size changes and areas of freeboard exceedances that are anticipated to have localized flooding (receive penalties) in Scenario 1.

\section{CONCLUSIONS}

With operation on a complete hydrologic/hydraulic network, the use of a coupled SWMM with a multi-objective meta-heuristic optimization algorithm software package was a useful tool for efficiently (cost-effectively) defining and evaluating combinations of gray and green stormwater infrastructure-based upgrades and solutions. Applying a tool such as this allows for the development of flexible targets and optimization objectives that can meet integrated stormwater management goals related to flow, flood control, and water quality. The ability to define optimization objectives and criteria within a truly networked system, the transparency of the workflow, and ability to customize variables sets this approach apart from less flexible, less transparent optimization platforms, and labour intensive iterative approaches.

\section{REFERENCES}

City of Calgary, 2005. Bylaw of the City of Calgary to Regulate Storm Sewers and Storm Drainage. Bylaw Number 37M2005.

City of Calgary, 2011. Stormwater Management and Design Manual. http://www.calgary.ca/PDA/pd/Documents/urban development/bulletins/2011-stormwater-managementand-Design.pdf. Accessed 24/02/2018.

City of Calgary, 2006. Total Load Management Plan. http://www.calgary.ca/UEP/Water/Pages/Water-andwastewater-systems/Storm-drainage-system/History.aspx. Accessed 05/10/2017.

Nose Creek Watershed Management Plan, 2007. The Nose Creek Watershed Partnership. (https://calgary.ca/UEP/Water/Documents/Water-Documents/nose creek water mgmt plan.pdf, Accessed 28/06/2018.

Optimatics. (2017) Optimizer ${ }^{\mathrm{TM}}$. Adelaide, Australia.

United States Environmental Protection Agency (US EPA). (2017) Storm Water Management Model (SWMM) Version 5.1.012. Washington D.C. Available at: https://www.epa.gov/water-research/storm-watermanagement-model-swmm 


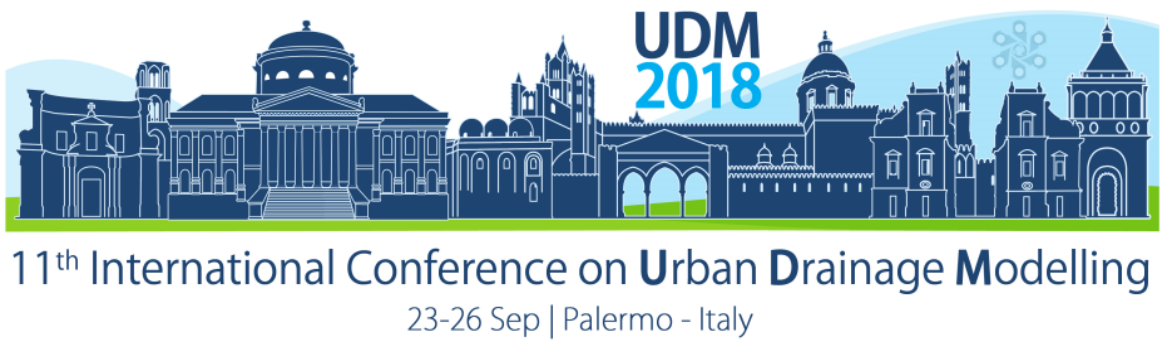

\title{
Urban Tunnel Systems for Conveyance and Storage of Storm- and Wastewater: Features, Classification, and Modelling
}

\author{
Rocco Palmitessa ${ }^{1}$, Morten Borup ${ }^{1}$ and Peter Steen Mikkelsen ${ }^{1}$ \\ ${ }^{1}$ Technical University of Denmark, Department of Environmental Engineering, Kgs. Lyngby, Denmark
}

\begin{abstract}
Tunnels have been integrated in many urban drainage systems to assist in preventing combined sewer overflows and flooding. Despite a wide range of designs, these structures share a common defining feature: conveying and storing large quantities of water. Urban tunnel systems can then be classified based on the type of water conveyed (wastewater, stormwater, or combined). The analysis of a representative sample of case studies shows how tunnels have been adapted to different economic, demographic, and climatic contexts. Across different designs, the management of existing urban tunnels can be optimized with intelligent monitoring and control strategies. These require models capable of providing real-time system-wide state estimates and reliable forecasts.
\end{abstract}

Keywords: deep tunnel; drainage; CSO; real time control; data assimilation.

\section{INTRODUCTION}

Tunnels have been integrated in many urban drainage systems as an effective solution to combined sewer overflow (CSO) and flooding. The substantial growth of the urban population, the greater proportion of hard surfacing, and the higher frequency of intense rain events have drastically increased flows in the drainage network. When the design capacity is exceeded, excess water overflows to the natural recipients or backs up into the drainage system, causing street flooding. Responses to this problem typically include a combination of green (reducing or delaying runoff at source) and grey (diverting and temporarily storing excess water) solutions. The choice between green or grey strategies is the outcome of complex political, environmental, technical, economic and social factors (Dolowitz et al., 2018). Tunnels fall into the second category, as they are used to store water during peak flows and convey it to treatment or discharge. Although originally designed specifically for control of pollution and flooding from combined sewers (Koelzer et al., 1969), urban tunnels have also been adopted to convey and store source separated stormwater or wastewater. The variety of uses and designs results in a plethora of expressions referring to similar systems (e.g. deep storage tunnel for combined stormwater and sewage vs. CSO tunnel).

Real time control (RTC) has the potential of turning drainage systems from passive transportation infrastructure into "smart" storage devices, thus reducing the need for investment in new infrastructure (Eggimann et al., 2017). Control decisions can be based not only on the monitored state of the system but also on forecasts, technique known as model predictive control (MPC). Urban tunnels are particularly suitable for testing and implementing MPC, due to the high degree of controllability and the potential economic benefits (e.g. reduction of pumps' energy consumption). However, there is a need for fast and accurate models, and methods for assimilating on-line observations (Lund et al., 2018).

As a starting point for future research on real time management of urban tunnel systems, this work analyses a representative sample of case studies with the aim of i) defining common features of tunnel systems, ii) suggesting a classification, and iii) identifying opportunities for enhancements in modelling and control. 


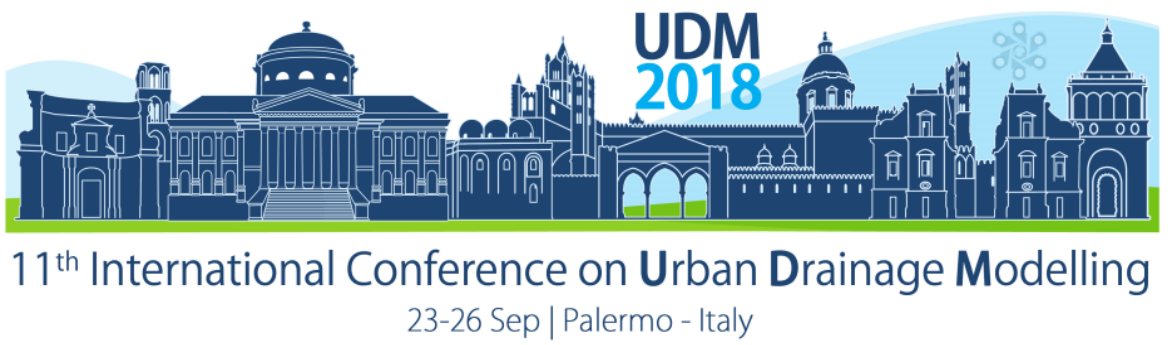

\section{MATERIALS AND METHODS}

Terminology. The word tunnel refers to "an artificial underground passage", and is associated with a category of construction techniques rather than a specific use. The construction method depends on the ground material and conditions, and can be highly automated using tunnel boring machines, with a consequent reduction in costs. A major advantage of bored tunnels is the minimal disruption generated at the surface level during construction, which is particularly convenient in existing urban areas. Specifically, water tunnels are used as underground channels to transport large quantities of water, either for supply or disposal. When considering also their auxiliary infrastructure, urban tunnels for water disposal can be regarded as a sub-system of the larger urban drainage system. Hereafter the word tunnel refers to a tunnel system for drainage of water in urban areas.

Case studies. The selected case studies (Table 1) are meant to represent the variety of catchments in which tunnels have been built or planned around the world. Many factors are expected to influence choices in the planning and design of a tunnel. First of all, tunnels need to be cost-effective, meaning that the high initial investment has a short enough return period. This requires a robust economy and/or a large number of users served, conditions often satisfied in metropolitan areas. Moreover, the extent of the supplementary storage capacity provided by the tunnels should be defined with regards to the actual and estimated inflows in the drainage network, in terms of magnitude, frequency and spatial distribution. For simplicity, three key parameters are respectively used for the economic, demographic, and climatic characterization of the tunnel catchment: per capita gross domestic product (GDP) for year 2012 (OECD, 2012), density of population for year 2014 (OECD, 2012), and average annual precipitation (retrieved from the national meteorological institutes). To compare tunnels of different typology three key design parameters are used: cumulative length of the tunnels belonging to the same system, maximum internal diameter, and maximum depth.

Table 1. Overview of case studies, including urban area served by the tunnel, name of the project, year of start of operations (a planned start is mark with *), and key benefit (as stated by the water utility companies).

\begin{tabular}{llll}
\hline Location & Project name & $\begin{array}{l}\text { Start of } \\
\text { operations }\end{array}$ & Key benefit \\
\hline Abu Dhabi, UAE & $\begin{array}{l}\text { Strategic Tunnel Enhancement } \\
\text { Programme }^{1}\end{array}$ & 2017 & Greywater reuse \\
Chicago, IL, USA & Tunnel and Reservoir Plan $^{2}$ & 1985 & Pollution prevention \\
Copenhagen, DK & Østerbro Stormwater Tunne ${ }^{\beta}$ & 2017 & Couldburst relief \\
London, UK & Thames Tideway Tunne $^{4}$ & $2023^{*}$ & CSO reduction \\
Mexico City, MX & Tunnel Emisor Oriente & $2018^{*}$ & Flood prevention \\
Singapore, SG & $\begin{array}{l}\text { Deep Tunnel Sewerage System } \\
\text { Kuala Lumpur, MY }\end{array}$ & 2008 & Land use optimisation \\
Kurmwater Management And & 2007 & Multi-functional \\
\hline
\end{tabular}

https://www.adssc.ae/en-us/Steps/Pages/Snappy.aspx (accessed 12/03/2018)

2 https://www.mwrd.org/irj/portal/anonymous/tarp (accessed 12/03/2018)

3 https://www.hofor.dk/pressemeddelse/regnvandstunnel-skal-skybrudssikre-ydreoesterbro/?hilite=\%27Regnvandstunnelen\%27 (accessed 12/03/2018)

https://www.tideway.london/ (accessed 12/03/2018)

http://201.116.60.81/sustentabilidadhidricadeIValledeMexico/TunelEmisorOriente.aspx (accessed 12/03/2018)

6 https://www.pub.gov.sg/dtss (accessed 12/03/2018)

http://smarttunnel.com.my/smart/what-is-smart/ (accessed 12/03/2018) 


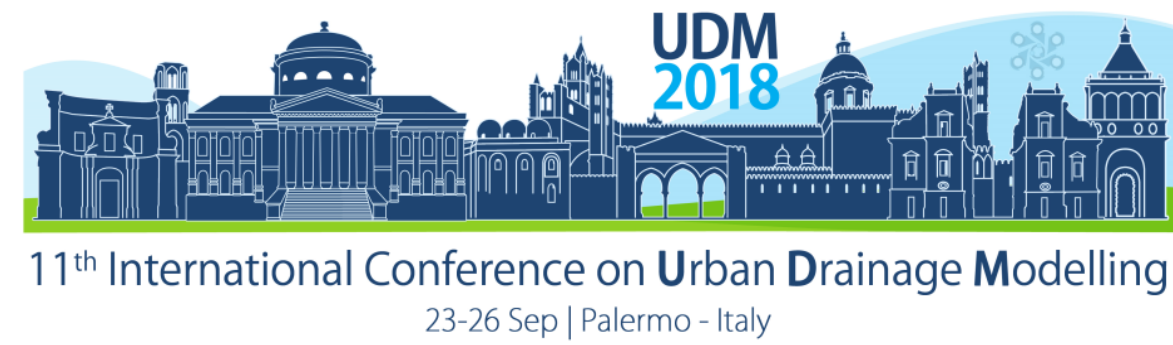

\section{RESULTS AND DISCUSSION}

Features. The wide range in the design parameters of the selected case studies (Table 2) reflects the flexibility of tunnels in adapting to different contexts and purposes. The tunnel system in Chicago is a pioneering project conceived in the late 60s to intercept and store combined sewer overflows in a long network of tunnels and reservoirs, protecting the water quality in Lake Michigan, which is used for water supply. London's tunnels will serve a similar purpose and are being built under the Thames River, to optimise combined sewer overflow interception. In spite of a less wealthy economy, Mexican authorities opted for a deep tunnel system to prevent flooding in the densely populated valley of the Mexico City area, which currently hosts around 20 million inhabitants. The tunnels in Abu Dhabi and Singapore are both part of a separate sewer system, and are designed for the centralised drainage of sewage, although built in areas with significantly different amounts of precipitation (arid vs. tropical). The relatively small stormwater tunnel in Copenhagen is an example of how these structures can also respond to local needs, instead of serving the whole urban catchment. Finally, the tunnel in Kuala Lumpur is used both for vehicular traffic and stormwater diversion, with the dual purpose of traffic congestion relief and flood prevention. In all cases, tunnels are designed to intercept water by gravity and convey it to final treatment and/or discharge, while the large internal diameter allows for temporary storage. The connection to the existing drainage network upstream and the downstream recipient requires the construction of some auxiliary infrastructure, which typically includes i) a series of link sewers and/or interception chambers, ii) dropshafts, usually divided in two parts to allow air to exit as water enters the system at high velocity, iii) pumping stations, located at the termination of the tunnels, in addition to iv) inspection shafts and v) a network of sensors, for monitoring and maintenance purposes.

Classification. The analysis of the case studies doesn't provide evidence that the design criteria are predominantly influenced by any of the catchment parameters investigated. It is, rather, a combination of these (and other) factors that determines the specific design requirements of a tunnel. Therefore, we suggest a classification of tunnels based on the type of water that needs to be conveyed: wastewater, stormwater, or a mixture of the two (combined). Wastewater tunnels enable a centralised control of the drainage network, and allow to decommission intermediate pumping stations, freeing up valuable land. Stormwater tunnels protect urban areas from the risk of flooding, draining away stormwater during intense rain events. Finally, combined tunnels prevent pollution of the receiving water bodies, intercepting and storing combined sewer overflows (CSOs).

Modelling. Many numerical models exist that are capable of simulating the hydraulic behaviour of the drainage networks, and additional models have been developed to specifically represent tunnel hydraulics (Morales et al., 2017). These can range from a steady-state conveyance model to an unsteady, mixed-flow (air mixed with water) model, to 3-dimensional computation flow dynamics (CFD) models of selected structures. Models can support control strategies aimed at reducing the high operational costs and preventing adverse phenomena, e.g. excessive sedimentation, unwanted chemical and biological reactions, and problems related to rapid filling. When used for control purposes, however, the models need to be kept in touch with reality based on observations from the system and furthermore the models need to provide quantitative uncertainty estimates. This might be accomplished using e.g. ensemble based data assimilation methods, but this is research for the near future. 


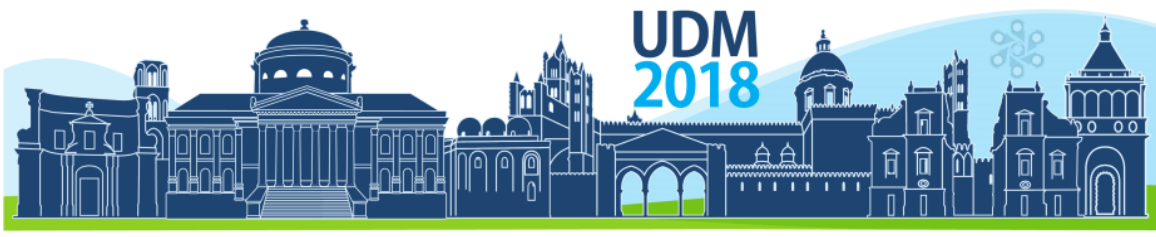

$11^{\text {th }}$ International Conference on Urban Drainage Modelling

23-26 Sep | Palermo - Italy

Table 2. Comparison of selected case studies based on catchment parameters (per capita gross domestic margin (GDP), density of population, and average annual precipitation), and design parameters (cumulative length, maximum internal diameter, and maximum depth).

\begin{tabular}{|c|c|c|c|c|c|c|c|}
\hline \multicolumn{2}{|c|}{ TUNNEL } & \multicolumn{3}{|c|}{ CATCHMENT } & \multicolumn{3}{|c|}{ DESIGN } \\
\hline Location & Typology & $\begin{array}{c}\text { Per cap. } \\
\text { GDP } \\
\text { (USD) }\end{array}$ & $\begin{array}{c}\text { Population } \\
\text { density } \\
\left(1 / \mathrm{km}^{2}\right)\end{array}$ & $\begin{array}{c}\text { Annual } \\
\text { precip. } \\
\text { (mm) }\end{array}$ & $\begin{array}{l}\text { Length } \\
(\mathrm{km})\end{array}$ & $\begin{array}{c}\text { Max } \\
\text { diameter } \\
(\mathrm{m})\end{array}$ & $\begin{array}{c}\text { Max } \\
\text { depth } \\
\text { (m) }\end{array}$ \\
\hline Abu Dhabi & wastewater & 95,000 & 1,200 & 57.1 & 41 & 7 & 85 \\
\hline Chicago & combined & 58,288 & 510 & 937 & 176 & 10 & 110 \\
\hline Copenhagen & stormwater & 49,019 & 496 & 523 & 0.6 & 2.5 & 13 \\
\hline London & combined & 54,382 & 1792 & 602 & 25 & 7.2 & 70 \\
\hline Mexico City & combined & 20,960 & 4000 & 846 & 62 & 7.5 & 200 \\
\hline Singapore & wastewater & 52,962 & 7807 & 2343 & 78 & 6 & 50 \\
\hline $\begin{array}{l}\text { Kuala } \\
\text { Lumpur }\end{array}$ & $\begin{array}{c}\text { stormwater } \\
\text { (+traffic) }\end{array}$ & 19,258 & 6890 & 2628 & 9.8 & 11.8 & 16 \\
\hline
\end{tabular}

\section{CONCLUSIONS}

Urban tunnel systems have the potential of solving various problems in urban water management, and their benefits can be maximized by implementing intelligent control strategies. The scientific and technical literature refers to urban tunnel systems with a wide range of terms, and this reflects the variety of contexts in which they are built, and the consequent design criteria. However, their defining feature is the ability to convey and store large quantities of water in urban areas, with minimal disruption at the surface level and attractive cost-benefit ratios. "Urban tunnel systems" encompasses the whole category, with a suggested classification based on the type of water conveyed (wastewater, stormwater, or combined).

Excavating large tunnels to expand the storage capacity of the drainage network is not enough to future-proof urban drainage systems, if this supplementary volume is not adequately monitored and controlled. Data assimilation techniques pave the way for optimizing the management and control of both existing and newly built tunnels, being capable of providing real-time system-wide estimates of state variables and reliable forecasts. However, for a successful implementation, these tools need to be adjusted to the specific needs of urban tunnel systems, and be transferable across a range of different typologies and designs.

\section{References}

Dolowitz, D. P., Bell, S., \& Keeley, M. (2018). Retrofitting urban drainage infrastructure: green or grey? Urban Water Journal, 15(1), 83-91.

Eggimann, S., Mutzner, L., Wani, O., Schneider, M. Y., Spuhler, D., Moy De Vitry, M., ... Maurer, M. (2017). The Potential of Knowing More: A Review of Data-Driven Urban Water Management. Environmental Science and Technology, 51(5), 2538-2553.

Koelzer, V. A., Bauer, W. J., \& Dalton, F. E. (1969). The Chicago area deep tunnel project-a use of the underground storage resource. J. Water Pollution Control Federation, 41(4), 515-534.

Lund, N. S. V., Falk, A. K. V., Borup, M., Madsen, H., \& Steen Mikkelsen, P. (2018). Model predictive control of urban drainage systems: A review and perspective towards smart real-time water management. Critical Reviews in Environmental Science and Technology, 48(3), 279-339.

Morales, V. M., Mier, J. M., \& Garcia, M. H. (2017). Innovative modeling framework for combined sewer overflows prediction. Urban Water Journal, 14(1), 97-111. https://doi.org/10.1080/1573062X.2015.1057183

OECD. (2012). Redefining urban areas in OECD countries. New Way to Measure Metropolitan Areas. 


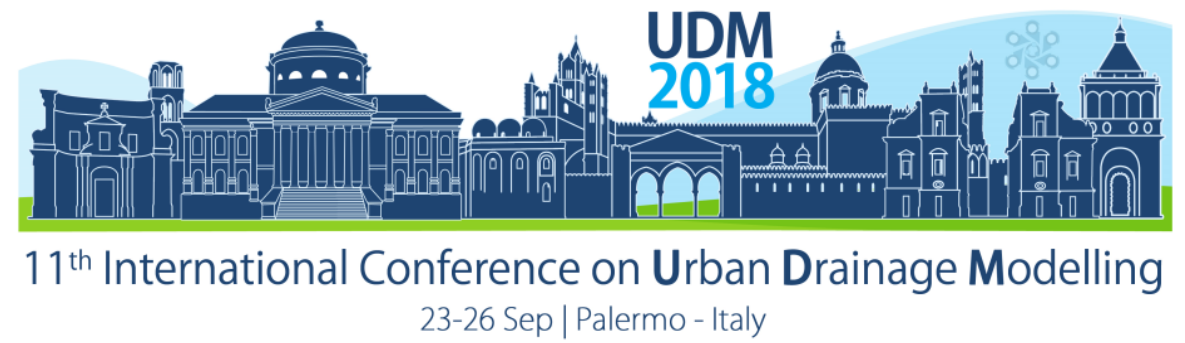

\title{
Continuous SWMM modelling of LID infrastructure in the Upper Qing Catchment, Beijing
}

\author{
Mark Randall' ${ }^{1}$ Marina Bergen Jensen ${ }^{1}$ \\ ${ }^{1}$ University of Copenhagen, Department of Geosciences and Natural Resources Management, \\ Frederiksberg, Denmark
}

\begin{abstract}
China has begun a rapid move towards Sponge City implementation, which will include widespread installation of various Low Impact Development (LID) infrastructure. Ambitious goals have been set for all Sponge Cities, including a target capture rate of 80 $85 \%$ of annual precipitation in Beijing. However there has so far been limited investigation into whether these capture goals are obtainable at the catchment scale. This paper demonstrates the use of long term continuous hydrologic modelling to evaluate the potential of meeting rainfall capture goals over a long time period for a case study area in Beijing. A synthetic high resolution rainfall time series was generated based on historic daily observations and the Beijing design storm distribution then used as input to run the model continuously for three decades. Feasible LID model scenarios based on widespread implementation of rain gardens, permeable pavement and green roofs were compared in terms of potential annual runoff capture volumes. Results of the continuous modelling demonstrated that LID implementation could allow for the capture of more than $80 \%$ of annual rainfall on average, indicating that the Sponge City goals could be met within the case study area over the long term.
\end{abstract}

Keywords: Sponge City; China; Low Impact Development; SWMM; continuous modelling;

\section{INTRODUCTION}

In China urban populations are continuing to increase, as is impervious urban landcover (Du et al., 2012). In response to increasing stormwater management challenges associated with urbanization, the term "Sponge City" has been widely used in China since 2014 to describe a new paradigm in urban drainage design which aims to make cities act like a sponge that can absorb water during wet periods and release it during water scarce periods (MoHURD, 2014). A central component of the Sponge City approach involves the widespread implementation of LID practices to promote infiltration, evapotranspiration, and storage. A primary goal for China's Sponge City construction is to capture between 60 and $90 \%$ of rainwater onsite depending on the geographic location of the city, however there has so far been limited research on whether this goal is achievable on large scales and over long time periods.

Studies have investigated the extent to which LID practices can be implemented on individual lots or small catchments and the resulting hydrologic impacts (Gao et al., 2015; Jia et al., 2012). However there are currently few detailed quantitative assessments of the hydrological impacts of LID implementation that go beyond this relatively small spatial scale (Ahiablame and Shakya, 2016). Evaluation of LID impacts at a larger scale of decision-making will be necessary to generalize and provide guidance for stormwater management and LID practices (Lee et al., 2012). Li et al. (2017) suggested that currently the research foundation for Sponge City construction on larger scales remains weak. 


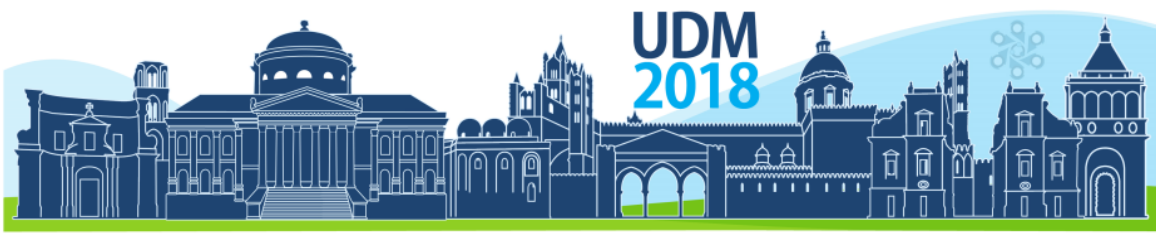

$11^{\text {th }}$ International Conference on Urban Drainage Modelling

23-26 Sep | Palermo - Italy

In additional to the evaluation of hydrologic impacts of LID at larger spatial scales there is a need to consider extended temporal scales (H. Li et al., 2017). With continuous modelling of LID scenarios a more complete picture of the hydrologic changes caused by LID implementation can be obtained than with the common design event approach (Khin et al., 2016). The primary objective of this study is to determine whether the Sponge City rainfall capture targets can be met over the long term for a study catchment in Beijing using continuous modelling.

\section{MATERIALS AND METHODS}

\subsection{Study Area}

The $170 \mathrm{~km}^{2}$ Qing watershed in Beijing rests almost completely within the Beijing City boundary in the districts of Haidan and Chaoyang. The most highly urbanized upper portion of the Qing catchment chosen as a study area is equal to approximately 77 percent of the whole catchment area and 19 percent of the entire Beijing City Area. Since the year 2000, there has been a drastic decrease in agricultural areas and increase in impervious areas within the Qing catchment (Zhang et al., 2018).

\subsection{Hydrologic Model}

The open source software SWMM (Stormwater Management Model) was used to evaluate the hydrologic changes in the study area. A high resolution remote sensing based model of the Upper Qing catchment developed and calibrated as previously described in Randall et al. (forthcoming 2018) was used to simulate the developed scenarios. The model contain 86,000 'microcatchments' to represent urban landcover in detail as well as a coarse representation of the open channel and subsurface drainage systems (Figure 1).

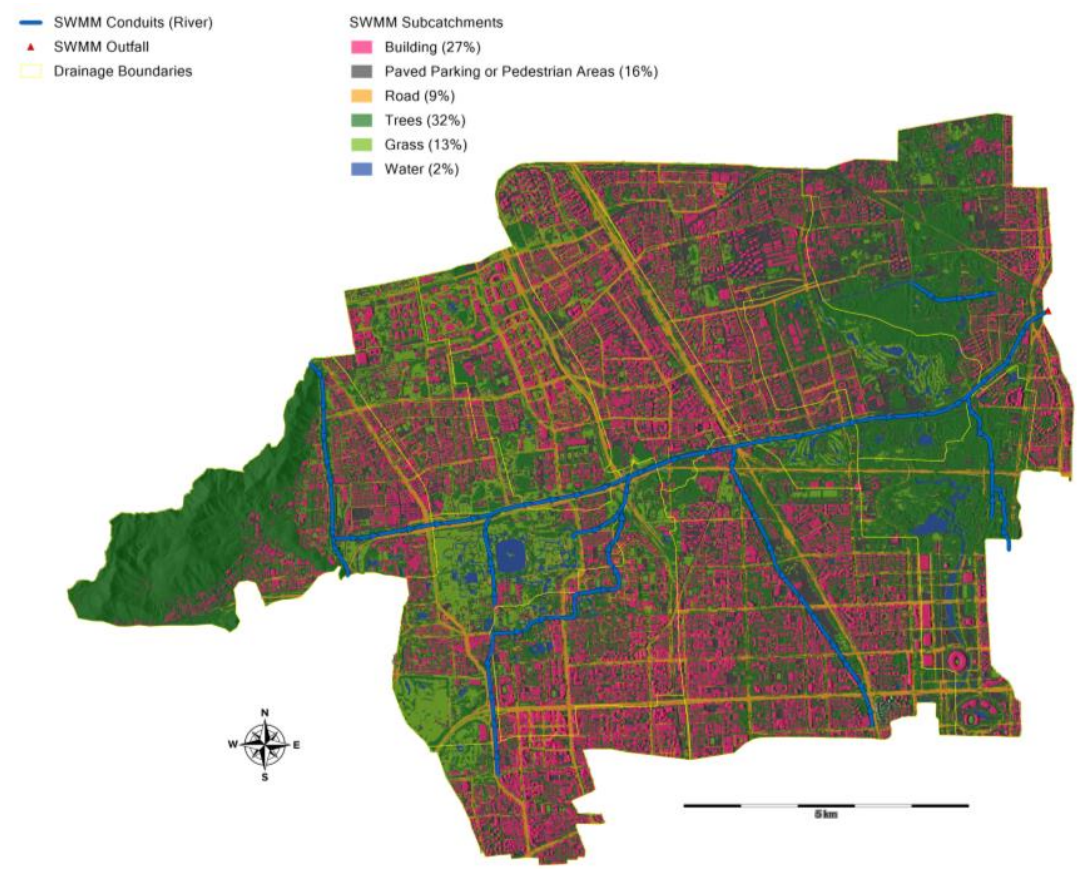

Figure 1. Upper Qing Catchment SWMM model 


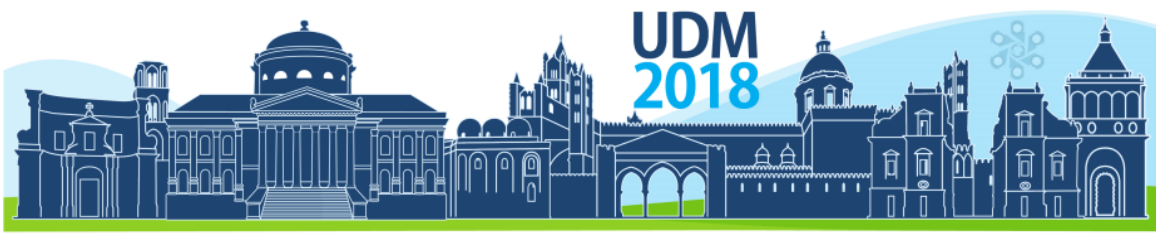

$11^{\text {th }}$ International Conference on Urban Drainage Modelling

23-26 Sep | Palermo - Italy

\subsection{Sponge City Scenarios}

In this study three scenarios were modelled - a 'No LID' scenario which assumed that no LID infrastructure is implemented, a 'High LID' scenario and a 'Low LID'. The estimates of LID conversion rate for the High LID scenario in this study were based on the Sponge City Guidelines (MoHURD, 2014) and are as follows: $60 \%$ roofs converted to green roofs, $70 \%$ of paved areas converted to permeable pavement and $20 \%$ of green areas converted to raingardens. The Low LID scenario assumes that land can be converted at a rate half that of the High LID scenario rate.

\subsection{Continuous Simulation}

Several sophisticated methods for disaggregation of coarse resolution rainfall have been developed, however such methods work best with an accompanying high resolution data set to characterize local rainfall distribution patterns. In the current study where such data was not available, a simplified approach was taken to simulate realistic intensities where the 5 minute resolution Beijing design storm distribution pattern was applied to each of the daily rainfall values. The resulting 32 year duration, 5 minute interval rainfall time series used as input to the model preserves daily rainfall totals while also having a distribution and peak rainfall intensity that is realistic for the Beijing region.

\section{RESULTS AND DISCUSSION}

Figure 2 shows the annual rainfall and the percentage of rainfall that could have been captured (and eventually infiltrated or evapotranspired) each year from 1985 to 2016 for each infrastructure scenario. The mean annual rainfall during the simulation period was $559 \mathrm{~mm}$ and SWMM model results indicated that both the Low and High Scenarios exceeded the $80 \%$ capture target while the baseline scenario did not.

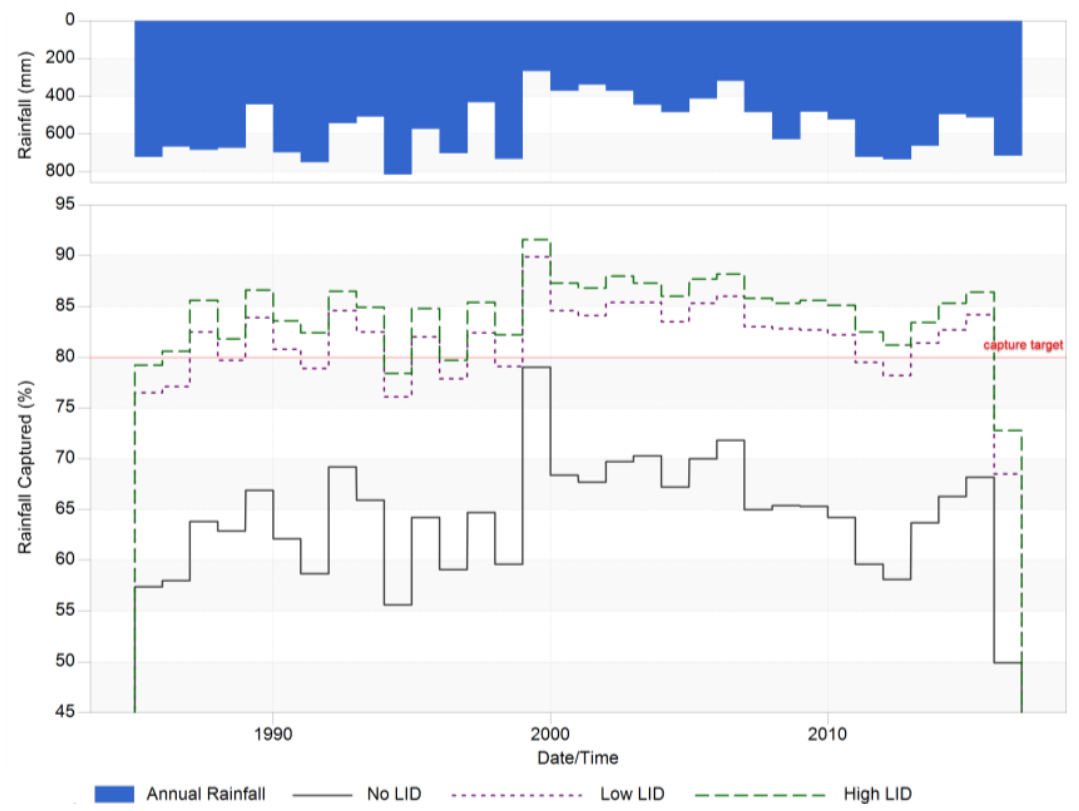

Figure 2. Annual rainfall capture from 1985 to 2016 for three modelled stormwater infrastructure scenarios 


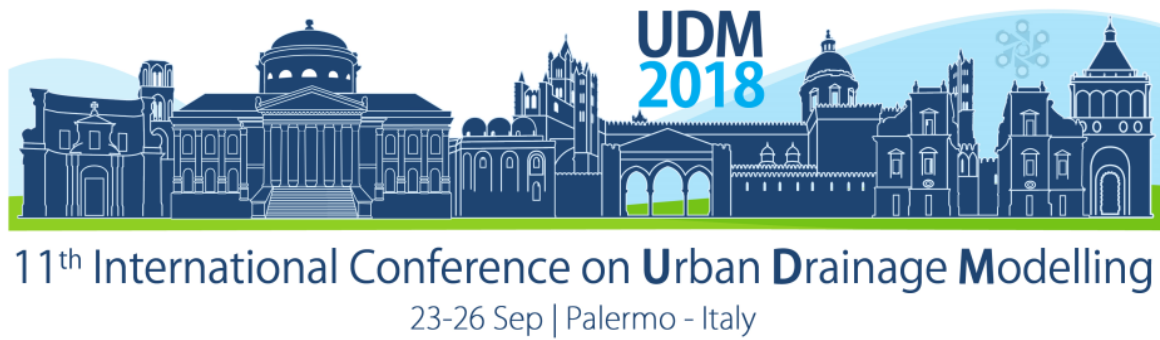

Somewhat unexpected was the result that a doubling of LID infrastructure coverage in the Low LID scenario increased the average annual capture rate by less than $3 \%$. The fact that the High LID scenario provides only marginally more capture than the Low LID scenario indicates that there is a point at which additional LID implementation provides only minimal benefit in terms of annual rainfall capture.

As noted by Li et al. (2017), there remains a high level of uncertainty associated with modelling of LID impacts at the catchment scale, and often model results do not agree with observations. However it is relevant to perform these studies while continuing to monitor existing installations and improve representation of LID devices in models. With the use of high resolution landcover information rather than the broad landuse types (e.g. industrial, residential) typically used in studies of Chinese urban catchments, the current study attempts to reduce the uncertainty related to the potential extent of LID implementation. However there remains a high degree of uncertainty related to many subcatchment parameters, particularly infiltration rates. Despite the uncertainty, the current study provides a realistic estimate of the range of annual precipitation capture rates that can be expected and indicates that meeting the current Sponge City guidelines is possible in this particular catchment. Future work building on this study may involve the inclusion of cost optimization and choice of LID type, incorporation of field monitoring results as well as consideration of potential climate changes.

\section{CONCLUSIONS}

Ambitious targets have been set for rainfall capture in China's Sponge cities and so far limited research has been done to verify whether these goals are obtainable at the catchment scale. Results of this study indicate that the target of $80-85 \%$ capture of annual precipitation in Beijing could be met in the study catchment during the majority of years with a moderate degree of LID infrastructure implementation as represented in the 'Low-LID' scenario (e.g. 30\% roofs converted to green roofs, $35 \%$ of paved areas converted to permeable pavement and 10 percent of green areas converted to raingardens). The developed model has the potential to provide a useful decision making basis for stormwater planners, designers and managers with an interest in Sponge City development.

\section{References}

Ahiablame, L., Shakya, R. (2016) Modeling flood reduction effects of low impact development at a watershed scale. Journal of Environmental Management 171, 81-91.

Du, J., Qian, L., Rui, H., Zuo, T., Zheng, D., Xu, Y., Xu, C.-Y., (2012) Assessing the effects of urbanization on annual runoff and flood events using an integrated hydrological modeling system for Qinhuai River basin, China. Journal of Hydrology 464-465, 127-139.

Gao, J., Wang, R., Huang, J., Liu, M. (2015) Application of BMP to urban runoff control using SUSTAIN model: Case study in an industrial area. Ecological Modelling 318, 177-183.

Jia, H., Lu, Y., Yu, S.L., Chen, Y., 2012. Planning of LID-BMPs for urban runoff control: The case of Beijing Olympic Village. Separation and Purification Technology 84, 112-119.

Khin, M.M.L., Shaker, A., Joksimovic, D., Yan, W.Y. (2016) The use of WorldView-2 satellite imagery to model urban drainage system with low impact development (LID) Techniques. Geocarto International 31, 92-108.

Lee, J.G., Selvakumar, A., Alvi, K., Riverson, J., Zhen, J.X., Shoemaker, L., Lai, F. (2012) A watershed-scale design optimization model for stormwater best management practices. Environmental Modelling \& Software 37, 6-18.

Li, C., Fletcher, T.D., Duncan, H.P., Burns, M.J. (2017). Can stormwater control measures restore altered urban flow regimes at the catchment scale? Journal of Hydrology 549, 631-653. https://doi.org/10.1016/j.jhydrol.2017.03.037 
Proceedings of the 11th Int. Conference on Urban Drainage Modelling, 23-26 Sep. 2018, Palermo (ITALY). Ed. prof. Giorgio Mannina

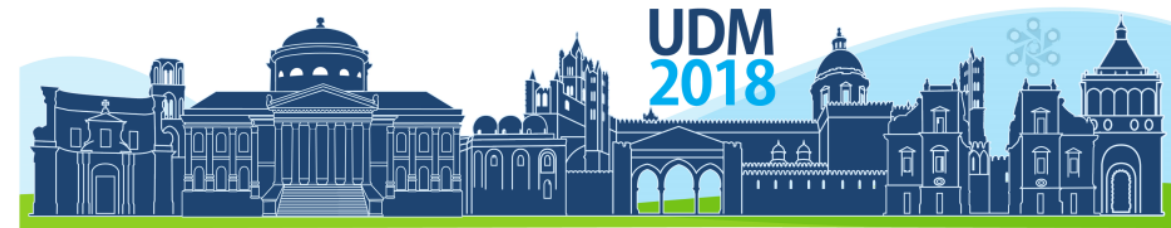

$11^{\text {th }}$ International Conference on Urban Drainage Modelling

23-26 Sep | Palermo - Italy

Li, H., Ding, L., Ren, M., Li, C., Wang, H. (2017) Sponge City Construction in China: A Survey of the Challenges and Opportunities. Water 9, 594

MoHURD (2014) Technical Guide for sponge cities-construction of low impact development.

Zhang, Yongyong, Xia, J., Yu, J., Randall, M., Zhang, Yichi, Zhao, T., Pan, X., Zhai, X., Shao, Q. (2018) Simulation and assessment of urbanization impacts on runoff metrics: insights from landuse changes. Journal of Hydrology. 


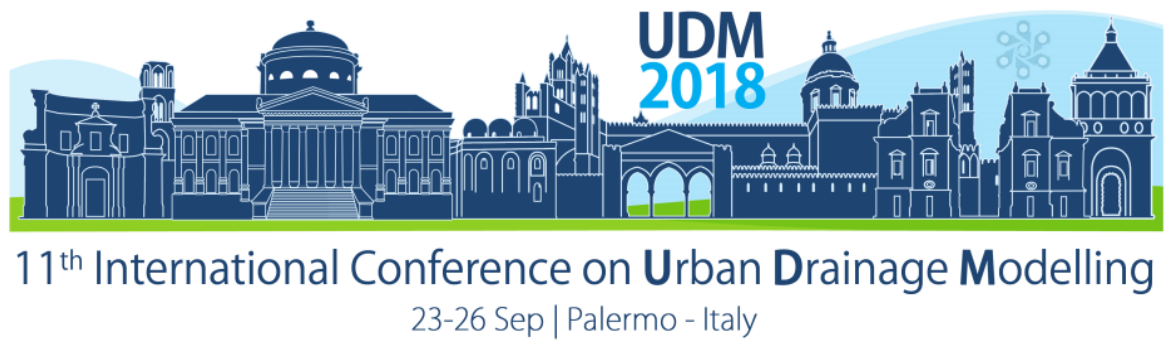

\title{
Development of Screening Methods for Secondary Settling Tanks Monitoring and Optimization
}

\author{
Ondřej Švanda ${ }^{1}$, Jaroslav Pollert ${ }^{2}$ Iva Johanidesová ${ }^{3}$ \\ ${ }^{1}$ CTU in Prague, dep. of Sanitary and Ecological Engineering, Prague, CZE \\ ${ }^{2}$ CTU in Prague, dep. of Sanitary and Ecological Engineering, Prague, CZE \\ ${ }^{3}$ CTU in Prague, dep. of Sanitary and Ecological Engineering, Prague, CZE
}

\begin{abstract}
Lately, the environmental awareness that leads to legislation changes has been pushing the waste water treatment plant (WWTP) operators to increase the secondary settling tanks' (SST) efficiency in order to meet the new requirements. The SST efficiency is commonly understood as the ability to separate suspended solids from the effluent water. The internal SST dynamics depends strongly on both physical and biochemical properties of the activated sludge and thus the sludge properties are specific for every tank. Also, the geometry of the influent and effluent objects determine the sludge behaviour and are therefore often a subject to research and modification through the use of numerical models. The aim of this paper is to describe an innovative screening method that enables for better capturing of the current state SST sludge behaviour and with the cooperation of the numerical model provides a tool for SST geometry optimization. The benefit of this method compared to traditionally used models lays in utilizing both the experimental measuring data and numerical model data together to provide for a good calibrated model that can be used for efficient SST optimization.
\end{abstract}

Keywords: Secondary Settling Tank; Screening Method; Numerical Model

\section{INTRODUCTION}

The secondary settling tanks (SSTs) are one of the last facilities within the waste water treatment plant (WWTP) and play a key role in the amount of contamination that is discharged into the water body. Therefore, a proper function of the SST in a way of separating suspended solids is required. The sludge behaviour is determined by the biological, chemical and physical properties. The biological and chemical properties are given by the upstream WWTP configuration and thus are not significantly influenced by the SST design. Hence, the most efficient way to increase the SST efficiency is the optimization of influent (stirring well) and effluent objects (Kinnear et al., Clercq de et al., Griborio, 2004). The optimization should ensure a laminar regime in the entire sedimentation zone and also a uniform sludge inflow. It is very costly to create a physical model of the SST and perform the optimization, thus it has become a common practice that different numerical models are deployed for the SST optimization. The downside of the numerical models is that they need to be calibrated for every SST as the properties of the activated sludge are dependent on the upstream WWTP configuration, loads, biochemical processes and are therefore SST specific. Since there are many factors influencing the general sludge mixture behaviour, it is very difficult and inefficient to develop a generic numerical model that would be applicable to any SST without calibration. That leads 


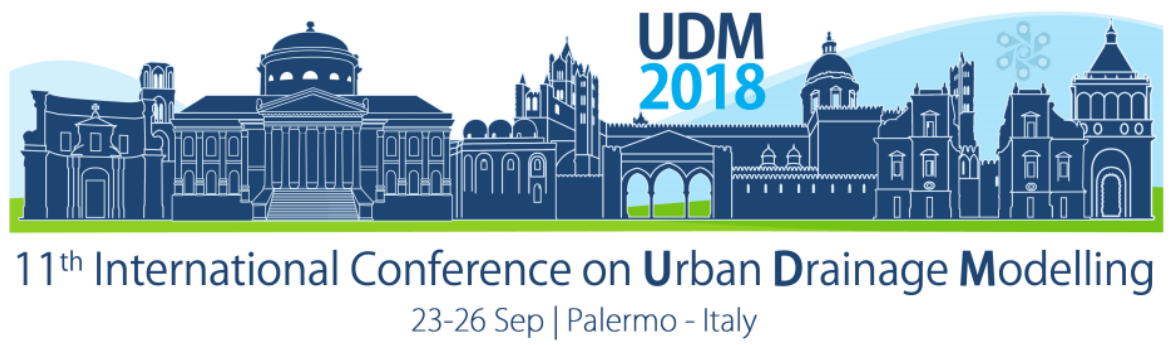

to the necessity of conducting a measuring campaign to provide the specific sludge properties relevant to the specific SST such as sludge settling abilities and rheological properties and those data are then used to calibrate the model. Nevertheless, some properties such as Particle Residence Time (PRT) cannot be easily obtained through the experimental measuring. This paper describes a method that combines experimental data collection and numerical model outputs to coherently develop a numerical tool that is used for improved SST efficiency optimization.

\section{SST SCREENING METHODS}

The main tasks of the SST is to separate the suspended solids from the activated waste water sludge and to allow for its recirculation back to the activation process. The separation process occurs via gravity as the suspended solid are of a higher density than water. It is then important to design the SSTs in a way that the PRT is long enough to allows for the flocs sedimentation.

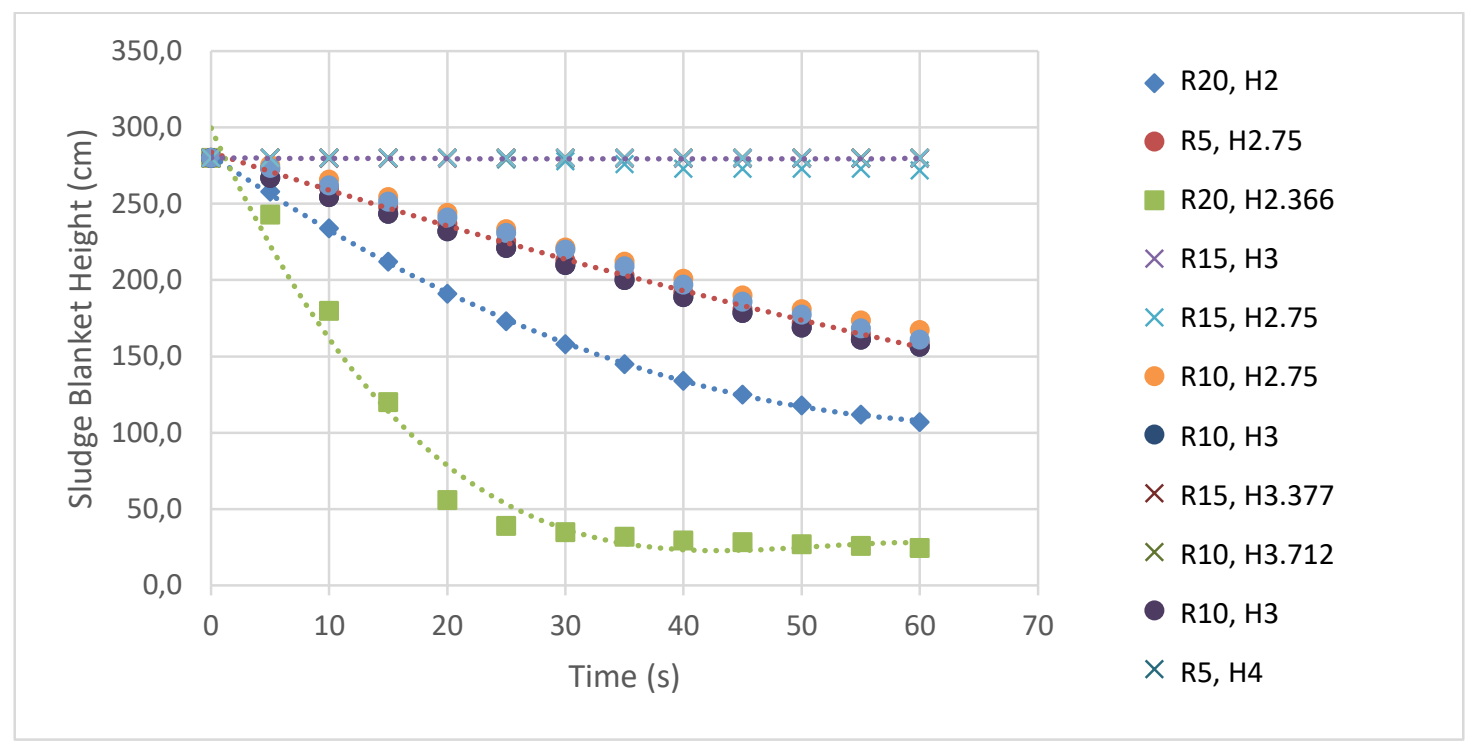

Figure 1. Settling curves for samples taken at different locations within the SST. "R" corresponds to the radius from the centre of SST and "H" is the height from the surface level.

As it is shown in Figure 2, the PRT has a strong influence on the settleability of the sludge together with the strain rate. Getting the PRT within the entire SST via experimental measuring campaign would be excessively expensive and time consuming due to large amounts of samples that would need to be taken. That leads to the idea of using the CFD numerical model to obtain PRT and then modify the Sludge Behaviour Model accordingly as it shown in the Figure 2. 


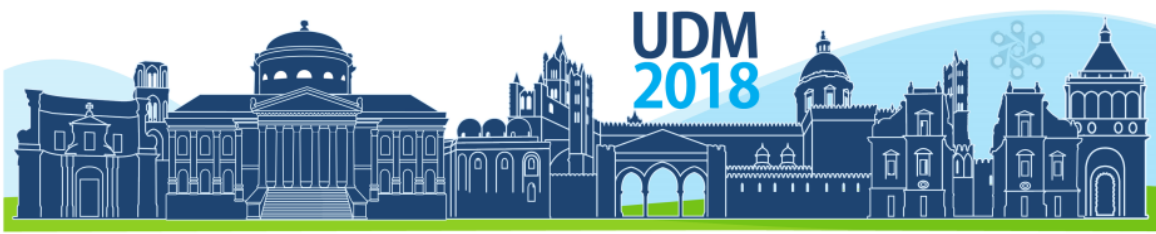

$11^{\text {th }}$ International Conference on Urban Drainage Modelling

23-26 Sep | Palermo - Italy
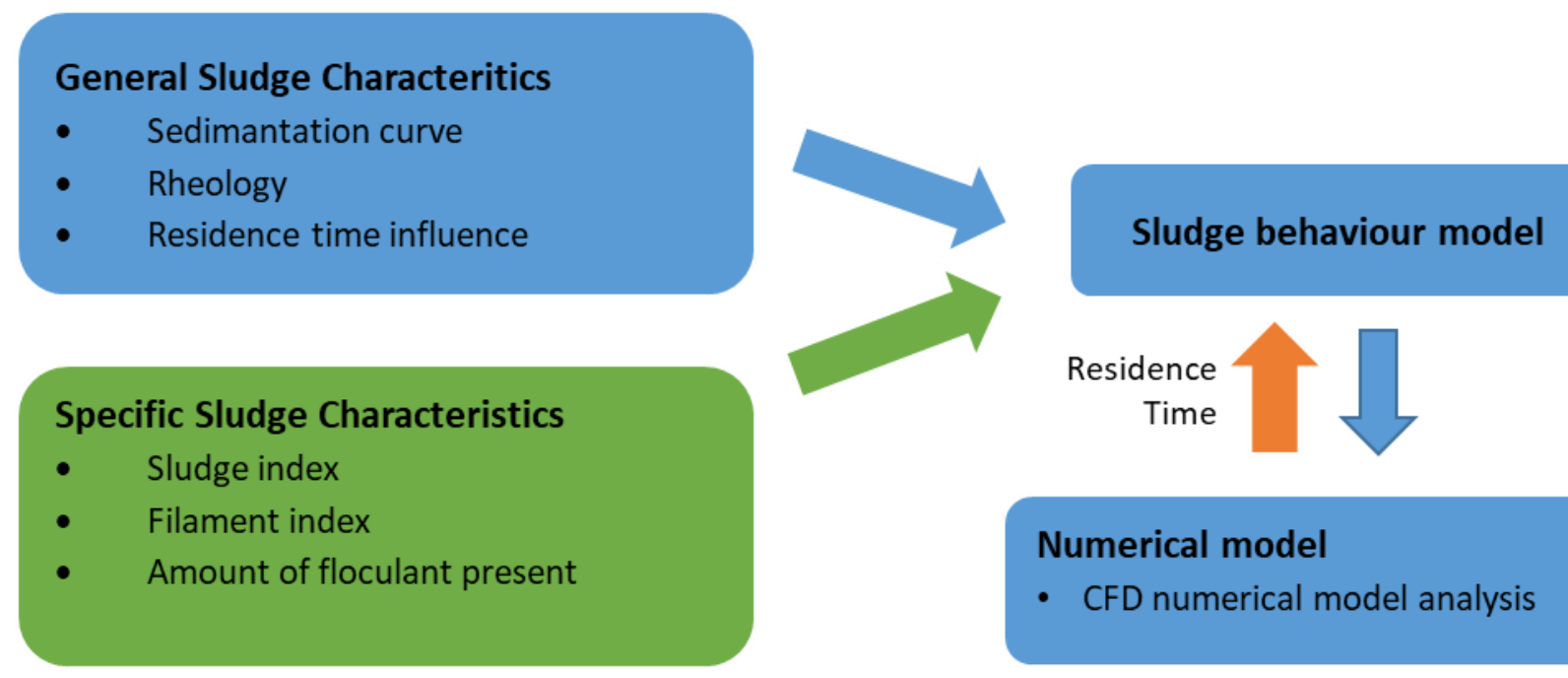

Numerical model

- CFD numerical model analysis

Figure 2. Schematics of the model development relations.

The flocculation process occurs within the discrete and flocculent particle settling regime (IWA Water Science \& Technology 2008) and it is a function of both time (PRT) and strain rate. To obtain the experimental data relevant to the settling behaviour, it is a common practice to perform a cylinder sedimentation test which outputs sludge settling curves resulting in zone sedimentation velocity (Wanner, 1994) that is consequently used as a input for the numerical model. Contrarily, the nature of the settling test does not provide any information about the particle residence time within SST and strain rate, thus it is not possible to describe the flocculation process based solely on a standard measuring campaign.

\subsection{Experimental measuring methods}

The campaign was conducted on the main WWTP in Prague from April to September 2017. The sedimentation tanks with a height of $2.8 \mathrm{~m}$ with a radius of $0.15 \mathrm{~m}$ we used for the sedimentation tests. Zone sedimentation velocity, rheological properties, density, temperature and sludge volume index (SVI) were measured on-site. The samples were taken from 29 different places within the SST in order to obtain the sludge properties development through the SST.

A new method was used to monitor the suspended solids concentration within the SST. Using the Multitracker from Cerlic it was possible to create a 2D map of solids concentration. This method is very beneficial for numerical model calibration as it provides an overall state of the suspended solids concentration in the SST upon which the numerical model can be calibrated (Figure 3).

Combining the standard experimental values with the multitracker data creates a complex image of the sludge hydraulic whereabouts in the SST which is then used to setup the numerical model. 


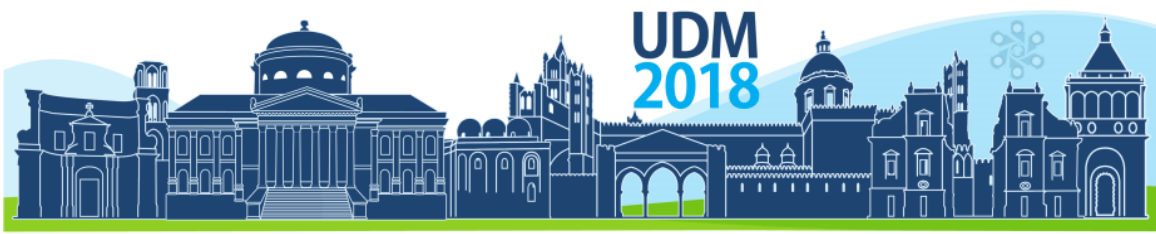

$11^{\text {th }}$ International Conference on Urban Drainage Modelling 23-26 Sep | Palermo - Italy

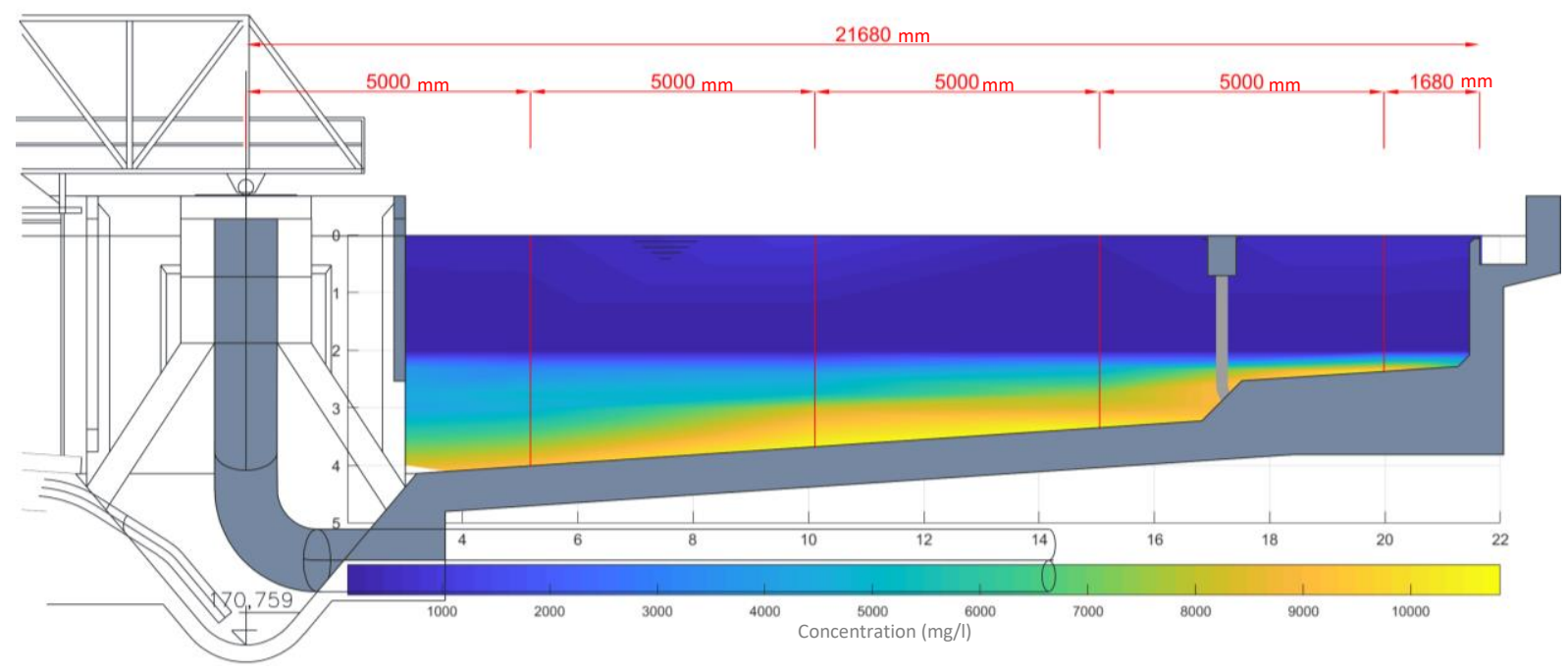

Figure 3. Real suspended solids concentration based on the multitracker probe data.

\section{CONCLUSIONS}

This paper presents an innovative SST screening method that enables for better understanding of the sludge flow dynamics within the SST. The combination of standard settling tests, rheology measuring and multitracker suspended solids visualization provides a complex set of information that can be consequently used for the setup of the numerical model. The innovative approach is then to use the numerical model to compute PRT in the entire SST which provides a way to improve the Sludge Behaviour Model. That gives us the ability to include the time dependant sludge properties such as the flocculation into the model without extensive measuring campaign. Ultimately, the numerical model is used for SST influent and effluent geometry optimization to improve the SST efficiency.

\section{ACKNOWLEDGEMENT}

The published results were achieved under the grant TAČR TE02000077 Smart Regions Buildings and Settlements Information Modelling, Technology and Infrastructure for sustainable Development.

\section{References}

De Clercq, B. (2003). Computational fluid dynamics of settling tanks: development of experiments and rheological, settling, and scraper submodels. Ph.D. Thesis, BIOMATH, Ghent University, Belgium.

Ekama, G.A., Barnard, J.L., Günthert, F.W., Krebs, P., McConcordale, J.A., Parker, D.S., Wahlberg, E.J. (1997).

Secondary Settling Tank: Theory, Modelling, Design and Operation. Scientific and Technical Report No. 6.

IAWQ, London, UK. 105-116.

Environment Protection Agency (EPA). Evaluation of energy conservation measures. 2010.

Griborio, A. (2004). Secondary Clarifier Modeling:A Multi-Process Approach. Ph.D. Thesis, University of New Orleans, New Orleans, Louisiana, USA.

Karpinska, Anna and Bridgeman, John. CFD-aided modelling of activated sludge systems - A critical review. Water research. Volume 88, 2016. 


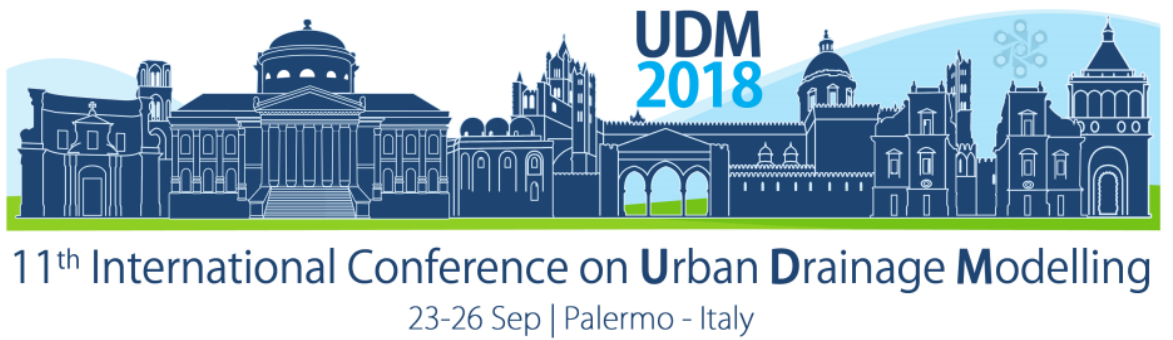

\title{
FAVEUR - A Simple Model for Design Extensive Green Roofs
}

\author{
Ramier David ${ }^{1}$, Berthier Emmanuel ${ }^{1}$ and de Gouvello Bernard ${ }^{2,3}$ \\ ${ }^{1}$ Cerema, Direction Territoriale Île-de-France, Trappes \\ ${ }^{2}$ Centre Scientifique et Technique du Bâtiment (CSTB), Nantes, France \\ ${ }^{3}$ Université Paris Est, LEESU (MA102), École des Ponts ParisTech, UPEC, AgroParisTech, Marne la Vallée,
} France

\begin{abstract}
With their development, green roofs appear to be now a useful tool for urban water management and are considered as part of BMP's. However, there is still a need for a tool able to help the sizing and design of green roof in order to comply with local water management rules. For this purpose, a simple functional model was developed. This model, named FAVEUR, needs only rain and potential evapotranspiration and mainly two parameters, related to the vegetation and substrate to estimate runoff outflow from different types of green roofs. According to good results obtained in comparison with observed data, an online-tool is now available to estimate runoff coefficient and water retention for different extensive green roof substrate thickness and vegetation covers.
\end{abstract}

Keywords: Green roofs; Conceptual model; Urban runoff

\section{INTRODUCTION}

Extensive green roofs (GR) are becoming increasingly used and seem suitable for sustainable rainwater management. Nevertheless, a useful and simple model of green roof must allow improvement for planning green roof development and estimation of their effect on rainwater management. Numerous studies are now devoted to the representation of hydrological behavior of green roof but they still have some limits. Some works were realized only for single rain event or very short-time duration (Hilten et al., 2008) and others studies used physicallybased models (Hilten et al., 2008, Palla et al., 2009). When conceptual models are used for different types of GR, they are often compared with observations obtained for small scale GR test beds (Stovin et al., 2013, Soulis et al., 2017). In this study, a functional model named FAVEUR is presented. This model was developed from more than one-year-hydrological observations of $6 \mathrm{GR}$. Firstly, experimental setup that made it possible to obtain these observations is presented. Then, the main equations of FAVEUR is described. Finally, comparisons between FAVEUR simulations and observations are presented.

\section{MATERIALS AND METHODS}

\subsection{Experimental setup}

The experimental roofs are situated in Trappes, a small city of Paris suburb, $30 \mathrm{~km}$ SouthWest from central Paris. An existing $300 \mathrm{~m}^{2}$ flat roof was transformed into 6 green roofs ( 35 $\left.\mathrm{m}^{2}, 7 \times 5 \mathrm{~m}\right)$. In order to test effects of the green roof composition on the quantity of runoff, six different GR are tested with differences according to the type of vegetation: mix of sedum or 


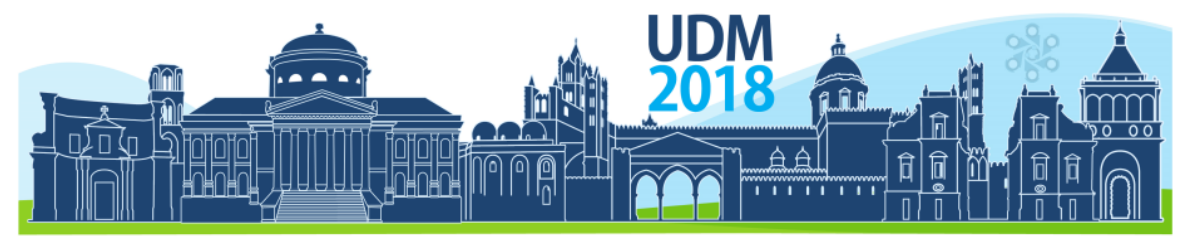

$11^{\text {th }}$ International Conference on Urban Drainage Modelling

23-26 Sep | Palermo - Italy

mix of grasses, perennial plants and sedums or without vegetation; the type of substrate: more or less organic; the substrate depth: 3 or $15 \mathrm{~cm}$; the drainage layer: expanded polystyrene or lava stones (see also legend of Figure 2 and for more details, Gromaire et al. 2013).

Rainfall is measured with a tipping buckets pluviometer located on the roof, with a resolution of $0.1 \mathrm{~mm}$. Runoff flow from each GR is measured in continuous at the outlet of the downspouts with tipping buckets with a resolution of $0.01 \mathrm{~mm}$. Runoff stand here as the percolated water through substrate and drainage layer (runoff surface was never observed). Rainfall and runoff are continuously monitored since June $15^{\text {th }}, 2011$.

\subsection{FAVEUR-Model presentation}

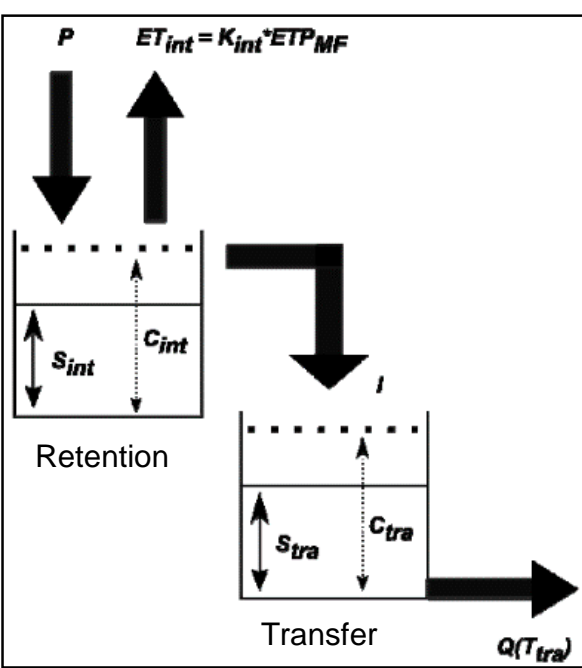

Figure 1. Scheme of FAVEUR (see text for futher details)

The choice was made to develop the model only with data easily available like rain and potential evapotranspiration. The main characteristics driving GR water transfers should also be easy to assess and if possible be based on data provided by substrate manufacturer (like the maximum water capacity, FLL, 2008). Following these main principles, FAVEUR (Functional model for Assessment of VEgetative green roof impacts on URban runoff) is a two-reservoirs model that represent two main functions of green roofs: retention and transfer (Figure 1). First reservoir is dedicated to the retention function of the $\mathrm{GR}$, that is to say, the water intercepted by the vegetation and retained by the substrate, allowing reduction of rain water runoff. The second reservoir represents the transfer function of the GR that simulates the water flow inside the substrate and the drainage layer. Main equations governing FAVEUR are described hereafter. Each term of the model are computed at each time step, t. All variables are expressed as $\mathrm{mm}$ of water.

Actual evapotranspiration (ET $\mathbf{T}_{\text {int }}$ ) of the model is assessed from potential evapotranspiration provided by French national meteorological service (Météo-France ; $\mathbf{E T P}_{\mathbf{M F}}$ ) and a factor ( $\mathbf{K}_{\text {int }}$ ) depending on the season and the type of vegetation. Moreover, evapotranspiration is possible only if water storage in retention reservoir, $\mathbf{S}_{\text {int }}$, allows it:

$E T_{\text {int }}{ }^{t}= \begin{cases}S_{\text {int }}{ }^{t-1} & \text { if } S_{\text {int }}{ }^{t-1}<K_{\text {int }} \times E T P_{M F}{ }^{t} \\ K_{\text {int }} \times E T P_{M F}{ }^{t} & \text { else }\end{cases}$

Water stock in retention reservoir, $\mathbf{S}_{\text {int, }}$ is filling by the rain $(\mathbf{P})$ and emptying by water excess, I and evapotranspiration. Water excess occurs when $S_{\text {int }}$ reaches the water storage capacity, $\mathrm{C}_{\text {int. }}$. Then excess water is transferred to the transfer reservoir:

$I^{t}=\left\{\begin{array}{l}S_{i n t}{ }^{t-1}+P^{t}-E T_{\text {int }}{ }^{t}-C_{\text {int }} \\ 0 \text { else }\end{array}\right.$

Then, water stock in the retention reservoir is updated :

$S_{\text {int }}{ }^{t}=S_{\text {int }}{ }^{t-1}+P^{t}-E T_{\text {int }}{ }^{t}-I^{t}$

Runoff outflow is compute from water stock in transfer reservoir $\mathbf{S}_{\text {tra, }} \mathbf{I}$ and the maximum water storage capacity of the transfer reservoir $\mathbf{C}_{\text {tra: }}$ : 


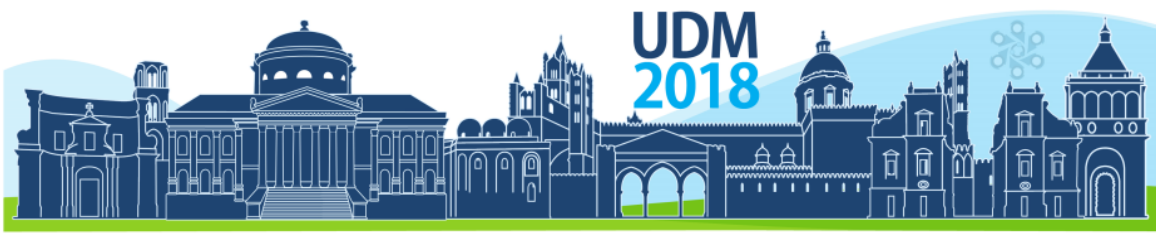

$11^{\text {th }}$ International Conference on Urban Drainage Modelling

23-26 Sep | Palermo - Italy

$$
Q^{t}=\left\{\begin{array}{l}
S_{t r a}^{t-1}+I^{t} \quad \text { if } \quad\left(S_{t r a}^{t-1}+I^{t}\right)<\frac{d t}{T_{t r a}} *\left(\frac{S_{t r a}^{t-1}+I^{t}}{C_{t r a}}\right) *\left(S_{t r a}^{t-1}+I^{t}\right) \\
\frac{d t}{T_{t r a}} *\left(\frac{S_{t r a}{ }^{t-1}+I^{t}}{C_{t r a}}\right) *\left(S_{t r a}^{t-1}+I^{t}\right) \text { else }
\end{array}\right.
$$

where $\mathbf{d t}$ is the duration of the time step, $\mathbf{T}_{\text {tra }}$ is a temporal parameter related to the geometry of GR. Finally, water storage in the transfer reservoir is updated:

$S_{\text {tra }}{ }^{t}=S_{\text {tra }}{ }^{t-1}-I^{t}-Q^{t}$

Only four parameters, $\mathbf{C}_{\text {int }}, \mathbf{K}_{\text {int }}, \mathbf{C}_{\text {tra, }}, \mathbf{T}_{\text {tra }}$ have to be known. After a sensitivity study and a calibration (Ramier et al., 2013), simulation was made for a continuous period of 13 months at a 3-min time step. Quality of the model is assessed by comparison of observed and simulated runoff discharge at a 30-min time step. Nash criterion and cumulative annual runoff differences are also calculated.

\section{RESULTS AND DISCUSSION}

Figure 2 shows comparison between simulated and observed runoff outflow at a 30-min time step. This comparison proves that FAVEUR is fully able to reproduce outflow of different green roofs having different structures. Nash criteria are quite good and vary between 0.78 for GR SE15Y (see legend of figure 2 for explanation of GR notation) to 0.89 for SE3Y and NE3Y. Results for annual runoff are more variables: cumulative annual runoff is overpredicted $(+12 \%)$ for SE3Z et NE3Y and underpredicted (-13\%) for SE15Y et GI15Y.

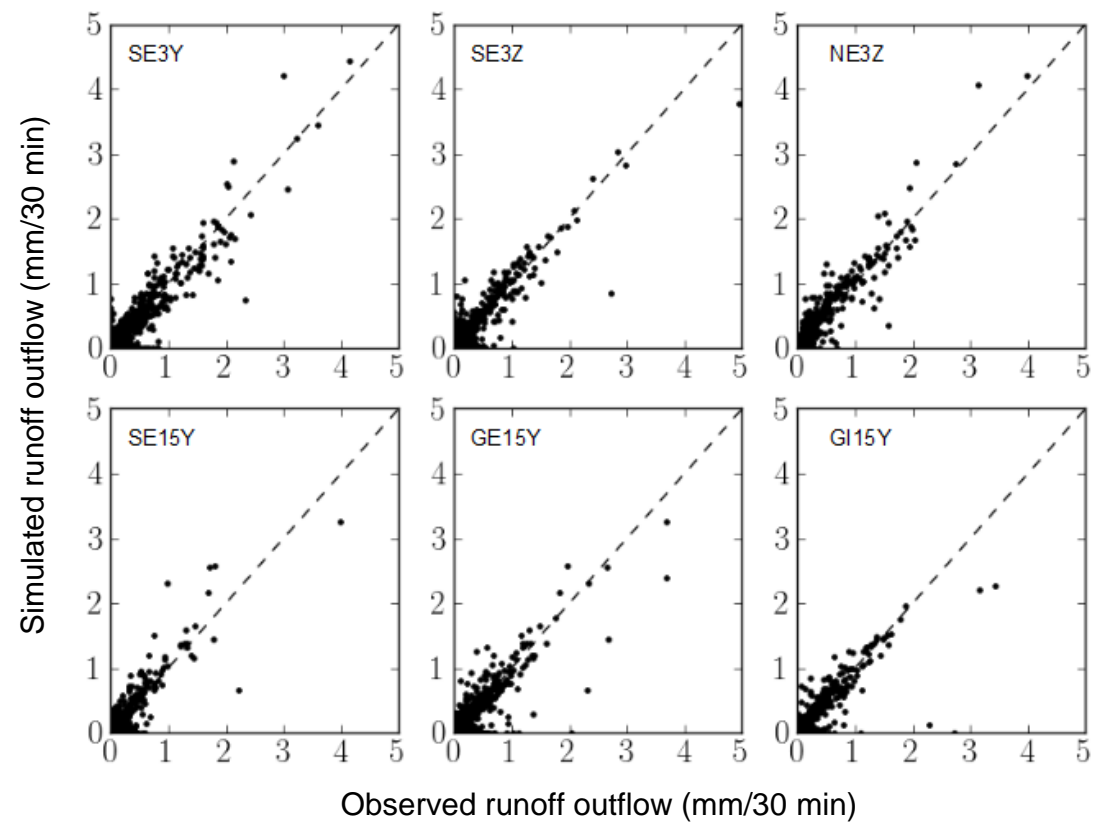

Figure 2. Scattergram between sımulated and observed runott outtlow at a 3U-mın tıme step (each GR are named according to: the type of vegetation: $\mathbf{S}$ for mix of sedum; $\mathbf{G}$ for mix of grasses, perennial plants and sedums, $\mathbf{N}$ for no vegetation - the type of substrate: $\mathbf{E}$ for the less organic; I for the more organic - the substrate depth: $\mathbf{3}$ or $\mathbf{1 5} \mathrm{cm}$ - the drainage layer: $\mathbf{Y}$ for expanded polystyrene; $\mathbf{Z}$ for lava stones). 


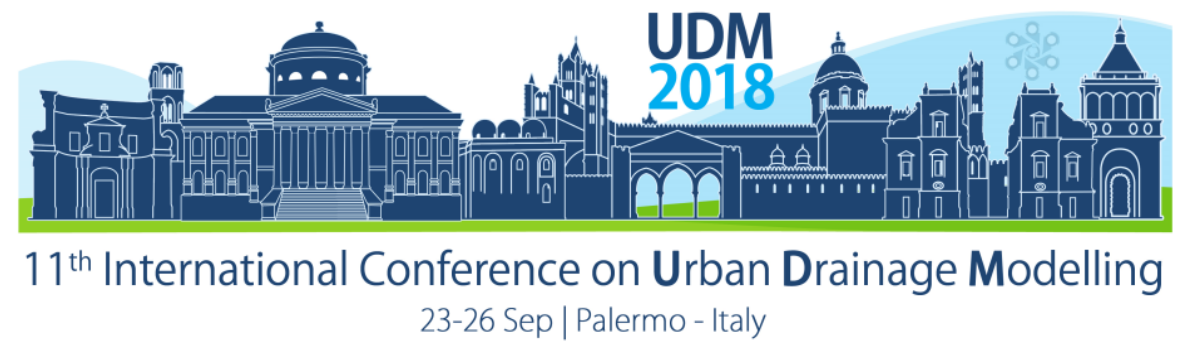

Figures 3 et 4 present hydrographs at a 3-min time step, for observed and simulated runoff for SE3Y and SE15Y. These GR have only different substrate depths $(3$ and $15 \mathrm{~cm})$ but the results of the simulations are contrasted. Nash criteria vary from 0.89 to 0.78 and cumulative annual runoff are underpredicted from $-1 \%$ to $-11 \%$, for SE3Y and SE15Y, respectively).

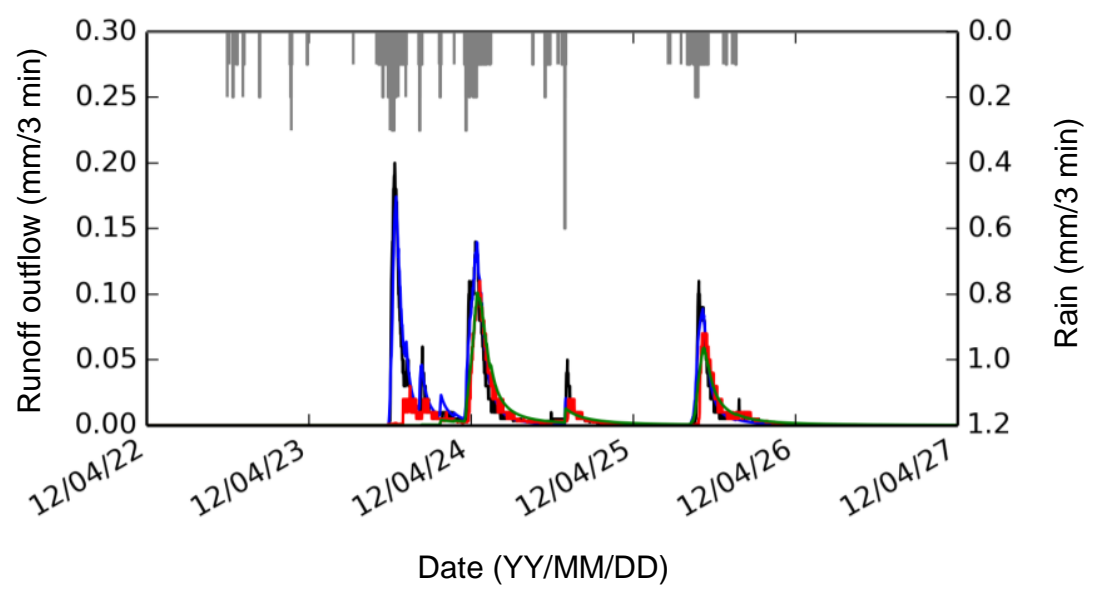

Figure 3. Rainfall and runoff observed and simulated for SE3Y and SE15Y during a rainfall event (3-min data between 22 April 2012 and 27 April 2012). In black, SE3Y observed runoff, in blue, SE3Y simulated runoff, in red, SE15Y observed runoff and in green, SE15Y simulated runoff. Bars at the top represent the rain.

Event on Figure 3 lasted about 3 days and produced $26 \mathrm{~mm}$ of rain. Hydrograph comparison shows a good agreement between simulated and observed runoff for both GR as suggested by the high Nash criteria. However, it should be noticed that peaks of runoff are slightly underestimated with the model. This observation is confirmed by Figure 4. During this smaller rain event (duration of 32 hours and 36 min with $7.8 \mathrm{~mm}$ of rain), even if dynamics of runoff is reproduced, simulated runoffs are largely below observed runoff.

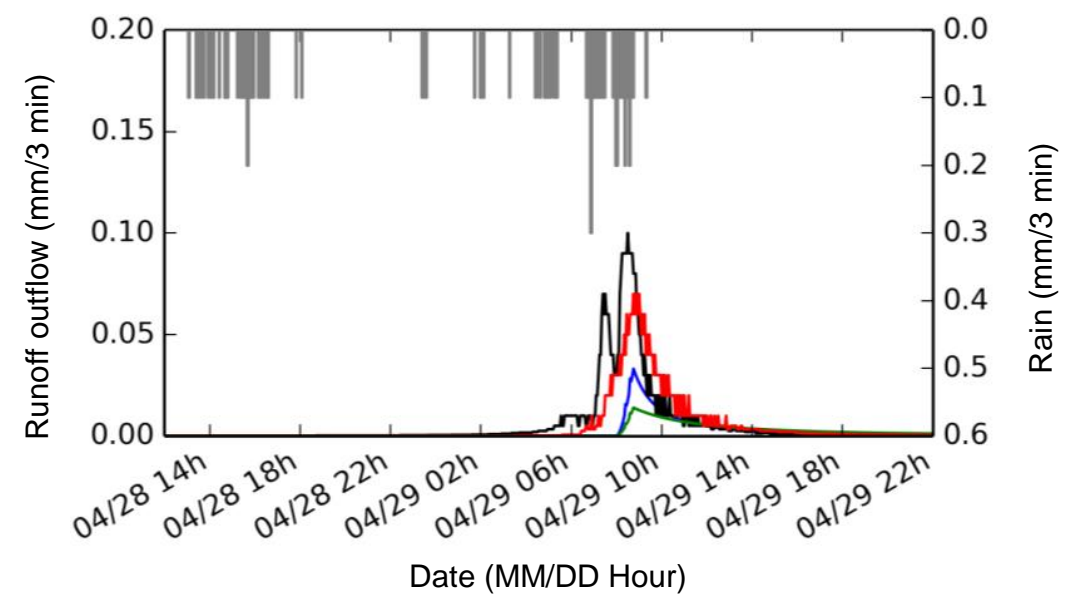

Figure 4. Rainfall and runoff observed and simulated for SE3Y and SE15Y during a rainfall event (3-min data between 28 April 2012 12:00 and 27 April 2012 22:00). In black, SE3Y observed runoff, in blue, SE3Y simulated runoff, in red, SE15Y observed runoff and in green, SE15Y simulated runoff. Bars at the top represent the rain.

The sensitivity study has shown that results were mainly affected by changes in $\mathbf{C}_{\text {int }}$ and $\mathbf{K}_{\text {int }}$ values. Thus, these two parameters need to be well know. $\mathbf{K}_{\text {int }}$ represents vegetation and seasonal effect on evapotranspiration. Our evapotranspiration scheme is very simple and differs from classical model where evapotranspiration is linked to substrate water content. Our 


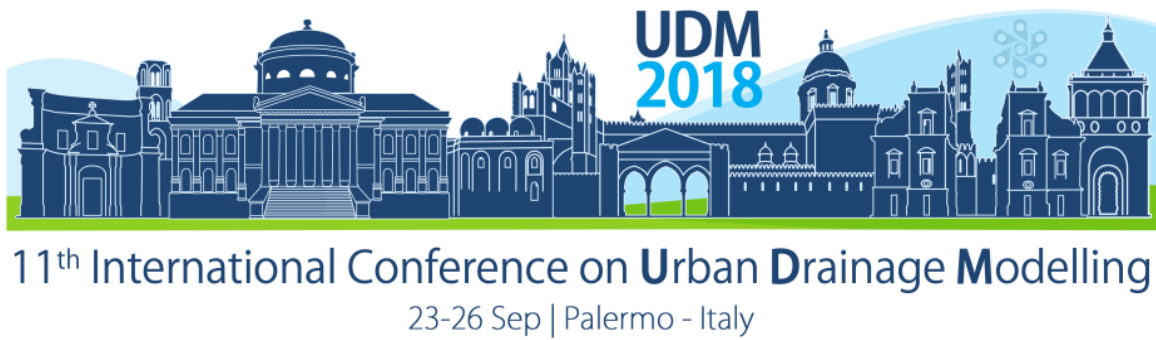

comparisons of the two different schemes did not show significant improvement. So, we decided to keep our simple scheme as it needs less parameters. Estimation of the values of $\mathbf{K}_{\text {int }}$ could be based on our value in the case of GR with identical vegetation. Nevertheless more data on a wide range of different GR could help to create a useful database of $\mathbf{K}_{\text {int. }}$. It is also important to highlight that these results were obtained with retention water storage capacity values, $\mathbf{C}_{\text {int }}$, very close, for shallow depth substrate, to the maximum water capacity (MWC) provided by substrate manufacturer (below $5 \mathrm{~cm}$ ). For higher substrate depth, value of $\mathbf{C}_{\text {int }}$ are low in comparison to these MWC and values presented by Ramier et al. (2017). Some recent studies suggested that best estimation of substrate maximum storage could be the difference between MWC and permanent wilting point (Szota et al., 2017). According to our data, MWC seems to be a good approximation and it is very simple to obtain as manufacturer gives this value whereas permanent wilting point is not so easy to obtain. However, further simulations and a deep uncertainties analysis with different types of GR structure and longer periods would allow to confirm and extend these results.

\section{CONCLUSIONS}

A simple model, named FAVEUR was developed to reproduced with good results runoff outflow from six different green roofs. This model need simple data since only rain and potential evapotranspiration are required as entry parameters. Only four parameters are necessary to describe green roof composition in this model but only two, related to vegetation and substrate water storage capacity, have an impact on runoff. The ability of FAVEUR to works with well know characteristics of green roof like maximum water content, allowed to use it to develop a Web-based online-tools for design green roof with water retention objectives (http://faveur.cerema.fr, in French).

\section{References}

Allen, R.G., Peireira, L.S., Raes, D., Smith, M. (1998) Crop evapotranspiration: guidelines for computing crop water requirements. FAO Irrigation and drainage paper. Food and Agriculture Organization of the United Nations, Rome.

FLL (2008) Guidelines for the planning, construction and maintenance of green roofing. Forschungsgesellschaft Landschaftsentwicklung Landschaftsbau, Bonn, Germany.

Gromaire, M.-C., Ramier, D., Seidl, M., Berthier, E., Saad, M., De Gouvello, B. (2013) Incidence of extensive green roof structures on the quantity and the quality of runoff waters - first results from an experimental test bench in Paris area, in: Novatech. Presented at the NOVATECH, Lyon, France, 23-27 June.

Hilten, R.N., Lawrence, T.M., Tollner, E.W. (2008). Modeling stormwater runoff from green roofs with HYDRUS-

1D. J. Hydrol. 358, 288-293

Palla, A., Gnecco, I., Lanza, L.G. (2009). Unsaturated 2D modelling of subsurface water flow in the coarse-grained porous matrix of a green roof. J. Hydrol. 379, 193-204

Ramier, D., Berthier, E., GALLIS, D., Dussuchale, A., Pinta, P., Versini, P.-A., De Gouvello, B., 2013. Analyse du fonctionnement hydrologique de toitures végétalisées: observations et modélisation, in: Quelles Innovations Pour La Gestion Durable Des Eaux Pluviales En Milieu Urbain. Nantes, France.

Ramier, D., Foughali, M., Berthier, E. (2017) Maximum water content in vegetated green roofs substrate. Effect of substrate thickness. Presented at the SUITMA 9, Moscow, Russia, 22-26 May.

Soulis, K.X., Valiantzas, J.D., Ntoulas, N., Kargas, G., Nektarios, P.A. (2017). Simulation of green roof runoff under different substrate depths and vegetation covers by coupling a simple conceptual and a physically based hydrological model. Journal of Environmental Management 200, 434-445.

Stovin, V., Poë, S., Berretta, C. (2013). A modelling study of long term green roof retention performance. Journal of Environmental Management 131, 206-215.

Szota, C., Fletcher, T., Desbois, C., Rayner, J., Williams, N., Farrell, C. (2017). Laboratory Tests of Substrate Physical Properties May Not Represent the Retention Capacity of Green Roof Substrates In Situ. Water. 9, 920. 


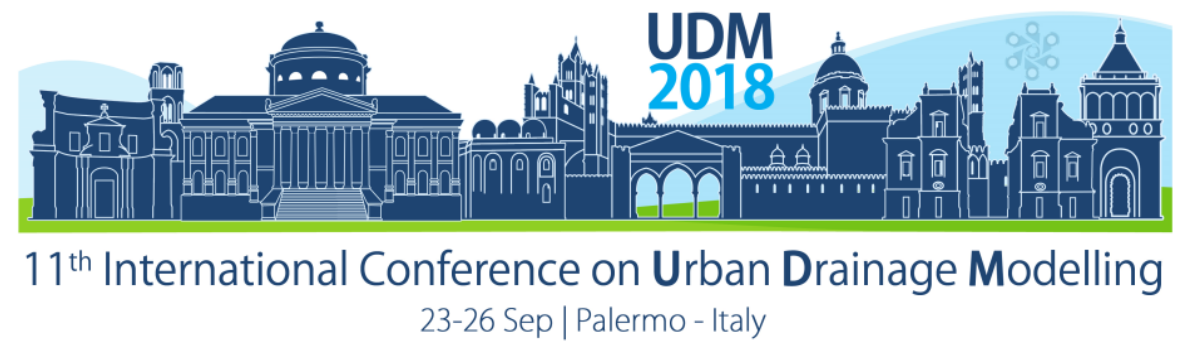

\title{
LID quantity and quality efficiencies in a subtropical urban catchment
}

\author{
César Ambrogi Ferreira do Lago', Marina Batalini de Macedo' Marcio Hofheinz Giacomoni ${ }^{1}$ Eduardo Mario \\ Mendiondo ${ }^{1}$ \\ ${ }^{1}$ University of Sao Paulo, Sao Carlos School of Engineering, Sao Carlos, Brazil \\ Av. Trab. São-Carlense, 400, Parque Arnold Schimidt, São Carlos, SP, 13566-590. \\ ${ }^{2}$ University of Texas at San Antonio, Department of Civil and Environmental Engineering \\ UTSA Circle, San Antonio, TX 78249, EUA
}

\begin{abstract}
Urbanization increases water insecurity, increasing flood risks and degrading the quality of water bodies. Low impact developments (LID), such as bioretention, are being used to mitigate these impacts. However, the performance of LIDs in tropical zones need to be better evaluated, since hydrological responses in these areas differs from those in temperate regions. This study modelled a bioretention quantity and quality efficiencies in a subtropical catchment in Sao Carlos, Brazil. The bioretention inflow was simulated using PCSWMM software with four years of rainfall data, and the runoff quality was predicted through buildup/washoff model. A water balance was used to simulate its outflow, to better represent stormwater ponding at its surface, which has a triangular weir. It is estimated that, in four years, the bioretention has absorbed $51 \%$ of the total runoff. The pollutants removal efficiency vary according to the washoff characteristics upstream to the bioretention. Results show that pollutants with higher w1 coefficient presented better removal, iron (Fe) that has the higher w1 value, for example, had $72 \%$ retained, while nitrite $\left(\mathrm{NO}_{2}\right)$ had only $56 \%$. The w2 parameter was also evaluated; pollutants with its value closer to 1 are more dependent on quantity efficiency. Both predictions of quantity and quality efficiencies were satisfactory in the analysed period, which indicates that the bioretention cell contributes for improving water security in the city of Sao Carlos.
\end{abstract}

Keywords: Low impact developments; performance modelling; subtropical urban drainage

\section{INTRODUCTION}

Alteration in is hydrological cycle is one of the main consequences of urbanization. It raises soil imperviousness, and consequentially increasing runoff volume (Lucas \& Sample 2015, Guan, Sillanpää, \& Koivusalo, 2015), risks of floods (Sun, Tong \& Yang 2016, Sun et al. 2017) and the amount of pollutants washed off (Flecther, Andrieu \& Hamel, 2013). Therefore it compromises water security in urban centres, either in quantitative or qualitative aspect. To mitigate and prevent these impacts, Low impact Developments (LID), such as bioretention cells, are being used to treat stormwater not only quantitatively, but also improving its quality for a more sustainable urban drainage system (Macedo, 2017).

Temperate climates have different hydrological response when compared to tropical climates. In tropical zones, due to higher intensity rainfalls, runoff are generated faster (Piro \& Carbone, 2014), and pollutants are washed more easily. However, there are few studies evaluating LIDs efficiencies with this type of rainfall regime.

This study simulated a bioretention outlet through a specific model, which has a weir at its surface. Then, the bioretention performance could be analysed. The pollutants removal efficiencies were also evaluated according to their washing characteristics.

\section{MATERIALS AND METHODS}

The studied bioretention has a $60 \mathrm{~m}^{2}$ area, located at the University of São Paulo, São Carlos- Brazil. The city has a Cfa climate classification, according to Köppen e Geiger. The 


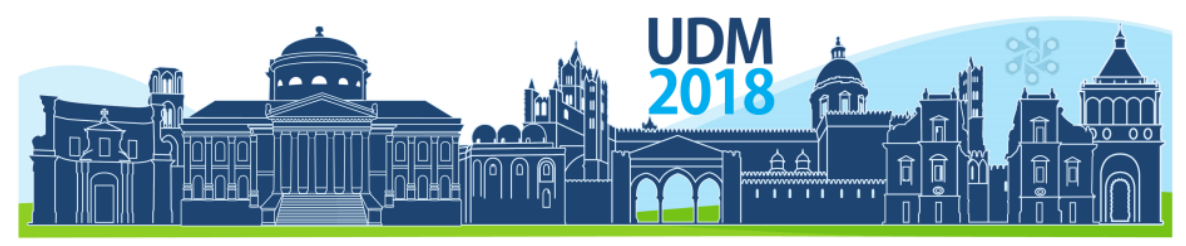

$11^{\text {th }}$ International Conference on Urban Drainage Modelling

23-26 Sep | Palermo - Italy

rainfall annual average is $1422 \mathrm{~mm}$ with great amplitude between driest and wettest months, with averages of $15.5 \mathrm{~mm}$ (Jul) and $269 \mathrm{~mm}$ (Jan) respectively (Miranda et al., 2012).

It receives runoff from a 2.3 hectares urban catchment, composed by $22 \%$ of imperviousness. Eleven monitored events were used to calibrate and validate the inlet and outlet volume and pollutants mass in the bioretention. However, only seven were used to calibrate and validate the outlet, because some of them were monitored prior to some maintenances, which had improved the surface hydraulic conductivity (Macedo, 2017).

The inlet runoff quantity was simulated in PCSWMM software using rainfall data from 2013 to 2017 . The runoff quality was estimated using exponential buildup/washoff equations. Six pollutants were simulated, which includes total organic carbon (TOC), phosphate $\left(\mathrm{PO}_{4}\right)$, nitrate $\left(\mathrm{NO}_{3}\right)$, nitrite $\left(\mathrm{NO}_{2}\right)$ iron $(\mathrm{Fe})$, and zinc $(\mathrm{Zn})$.

The bioretention outlet was determined through water balance at its surface since its storage had never surpassed $65 \%$ of its capacity and have no influence on its performance. The outlet can be basically describe by eq.1, that is function of the ponding, which could be determined through a water balance (eq.2).

$$
\begin{gathered}
\text { Qout }=0 \text { if } H \leq h \\
\text { Qout }=1.427(H-h)^{2.5} \text { if } H>h \\
\text { Qout }=1.427 h b^{2.5}+\text { A. } \varnothing a .(H-h b) \text { if } H>h b \\
\Delta H=\frac{(\text { Qin }- \text { Qout })}{A . \emptyset a}+P-f-E
\end{gathered}
$$

for a ponding depth $H$, a height $h$ of the weir e and a $h b$ berm height. $\Delta \mathrm{H}$ is the variation of the level at the surface of the bioretention, Qin is the inflow, Qout surface exit flow, $A$ is the surface area of the bioretention, $\varnothing \mathrm{a}$ is the fraction of the unoccupied surface area, $P$ is the precipitation, $f$ is the infiltration, $\mathrm{E}$ is the evapotraspiration. Penman-Monteith was used to calculate the evapotranspiration and Green-Ampt, the infiltration.

\section{RESULTS AND DISCUSSION \\ 3.1 Outlet calibration and validation}

Table 1 compares the simulated and observed bioretention outflows. Values of NSE and R2 were satisfactory, except in event 7 with 0.32 and 0.56 respectively, it might be explained by no prominent peack. However, predicted and observed efficieny and peak reduction are close in this event. Simulated and observed quantity efficiencies are close in both calibration and validation, the largest difference in efficiency is observed for event 11, despite high values of NSE and R2. The simulated peak reduction also represents well the observed. Ev 5 is the event with the largest difference between observed and simulated percentages, by underestimating the peak reduction in approximately $17 \%$, even this event presenting one of the best approximations among quantity efficiencies.

Table 1: Outflow calibration.

\begin{tabular}{cccccccc}
\hline & & & & \multicolumn{2}{c}{ Efficiency } & \multicolumn{2}{c}{ Peak reduction } \\
& & NSE & $\mathbf{R}^{\mathbf{2}}$ & Predicted & Observed & Predicted & Observed \\
\hline \multirow{3}{*}{ Calibration } & Ev 4 & 0.76 & 0.69 & $64.4 \%$ & $76.6 \%$ & $32.6 \%$ & $35.0 \%$ \\
& Ev 5 & 0.84 & 0.97 & $95.3 \%$ & $93.6 \%$ & $76.8 \%$ & $59.1 \%$ \\
& Ev 6 & 0.88 & 0.91 & $77.2 \%$ & $64.6 \%$ & $29.4 \%$ & $15.6 \%$ \\
\hline \multirow{3}{*}{ Validation } & Ev 7 & 0.32 & 0.56 & $81.7 \%$ & $85.3 \%$ & $71.7 \%$ & $73.6 \%$ \\
& Ev 8 & - & - & $98.4 \%$ & $100.0 \%$ & $96.5 \%$ & $100.0 \%$ \\
& Ev 10 & 0.9 & 0.91 & $95.4 \%$ & $94.4 \%$ & $77.5 \%$ & $73.1 \%$ \\
& Ev 11 & 0.94 & 0.97 & $47.6 \%$ & $34.2 \%$ & $12.2 \%$ & $0.3 \%$ \\
\hline
\end{tabular}




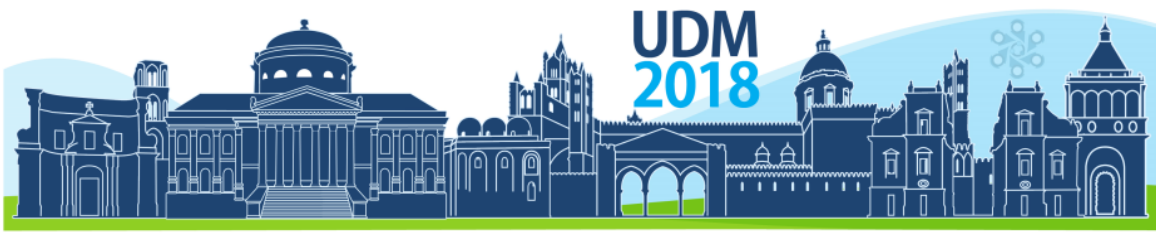

$11^{\text {th }}$ International Conference on Urban Drainage Modelling

23-26 Sep | Palermo - Italy

\subsection{Bioretention performance analysis}

The bioretention performance is shown in table 2. It is estimated that $1091 \mathrm{~mm}$ of runoff has entered the bioretention and $539 \mathrm{~mm}$ left, representing a retention of $552 \mathrm{~mm}$ or $50.6 \%$.

Table 2: Bioretention performance.

\begin{tabular}{|c|c|c|c|c|c|c|c|}
\hline & Runoff (mm) & $\mathrm{Fe}(\mathrm{g} / \mathrm{ha})$ & NO3(g/ha) & NO2(g/ha) & PO4 (g/ha) & TOC (g/ha) & Zn (g/ha) \\
\hline Inlet & 1091.7 & 9270.7 & 3650.6 & 84.2 & 294.5 & 30747.6 & 455.5 \\
\hline Outlet & 539.0 & 2528.1 & 993.7 & 36.8 & 119.2 & 13362.9 & 191.3 \\
\hline Period Efficiency & $50.6 \%$ & $72.7 \%$ & $72.8 \%$ & $56.3 \%$ & $59.5 \%$ & $56.5 \%$ & $58.0 \%$ \\
\hline Events average efficiency ${ }^{*}$ & $76.6 \%( \pm 26.4 \%)$ & $78.0 \%( \pm 25.0 \%)$ & $76.9 \%( \pm 25.4 \%)$ & $76.7 \%( \pm 26.1 \%)$ & $77.8 \%( \pm 25.5 \%)$ & $76.9 \%( \pm 26.0 \%)$ & $77.5 \%( \pm 25.7 \%)$ \\
\hline
\end{tabular}

All pollutants have removal efficiency greater than the quantity efficiency. Fe has the highest removal efficiency $(72.7 \%)$ and the lowest $\mathrm{NO} 2$, with $56.3 \%$. If the efficiency is analyzed through the average all the events, the qualitative efficiencies of the pollutants are closer. This suggests that the pollutants present greater efficiencies for larger events, since events with higher rainfall volumes are less frequent and weigh less in the average.

The washoff parameter w1 and w2 directly influence a pollutant removal efficiency, as verified in figure 1 . The closer to 1 is the value of w2 the more linear the relationship between qualitative and quantitative efficiency. That is because if a pollutant has $w 1=1$, the concentration pollutograph will have the exact same behavior as the hydrograph, if disregarding buildup exhaust. Coefficient w2 over 1 results in greater concentrations for higher discharges, while values w2 below 1 generates opposite results.

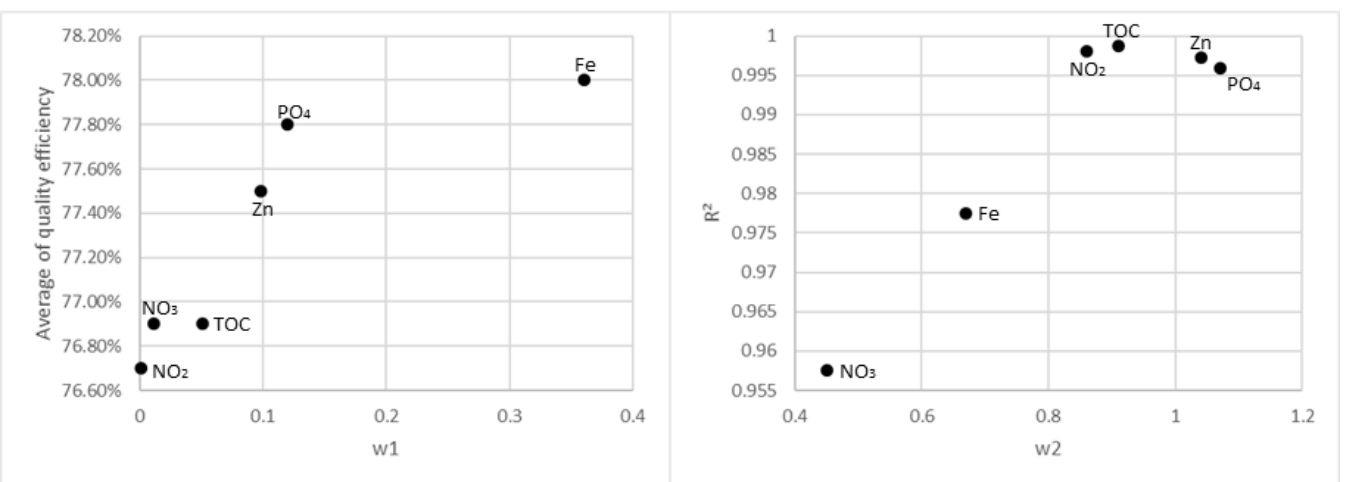

Figure 1: w1 and w2 influence

It can be observed that higher w1 results in better average efficiency. To illustrate this pattern, the event with higher difference between Fe removal and quantity efficiency was separated and is shown in figure 2. This event started with low buildup available, due to previous events. The initial buildup is depleted by small discharge at the beginning of the event, as shown by the drop in concentration over the event. When Fe concentration is high, the inflow is sufficiently low for a total absorption into the bioretention, thus retaining a larger portion of the pollutant. When the inflow increases, the bioretention is not able to retain most of it, reducing the quantity efficiency. It occurs when the Fe concentration is already low, minimizing the output of the pollutant mass. 


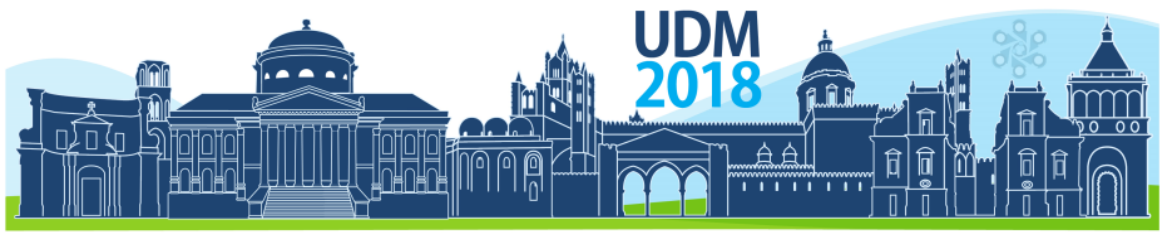

$11^{\text {th }}$ International Conference on Urban Drainage Modelling 23-26 Sep | Palermo - Italy
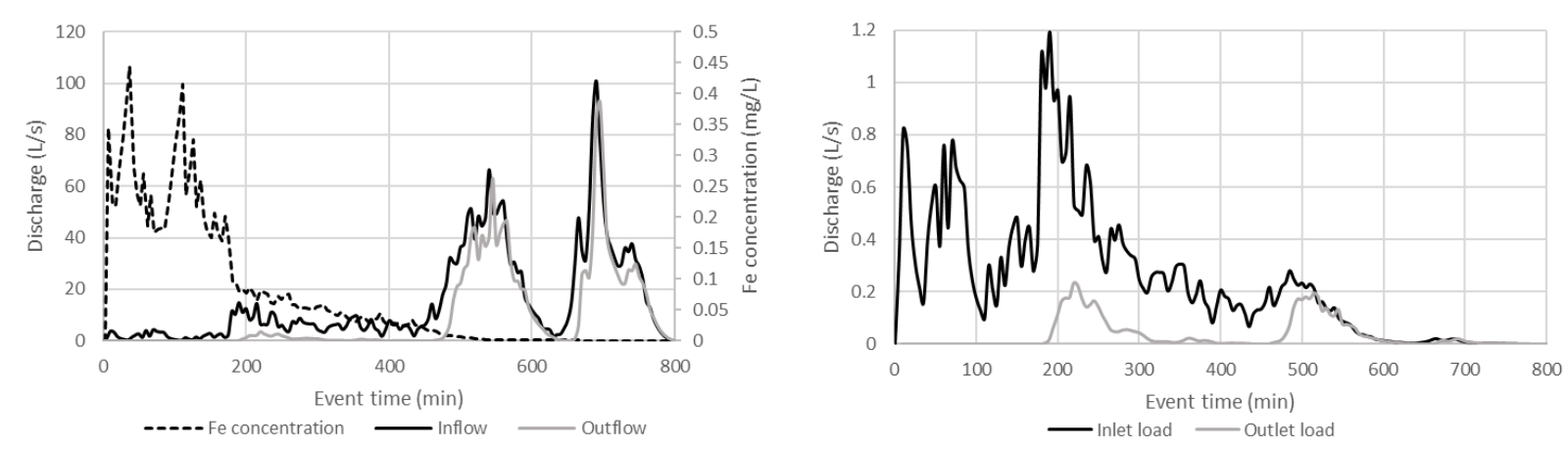

Figure 2. Events with the highest difference on quantity and Fe removal efficiencies.

\section{CONSLUSIONS}

The water balance on the bioretention surface properly represented its outlet with satisfying results in both calibration and validation, therefore enabling trustworthy simulations.

This study than evaluated the pollutants removal efficiencies according to their washoff characteristics. In general, quality efficiencies tend to be higher than quantity efficiencies. However, each pollutant removal depend on its washoff characteristics. Pollutants with higher w1 have higher removal potential, and those with w2 closer to 1 are more linear dependent on quantity efficiency. Understanding the removal pattern based on washoff characteristics can be useful for urban planning to target a specific pollutant.

The results show that the bioretention can be used to alleviate the urbanization impacts, in both quantitative and qualitative aspects. Retaining runoff volume reduces floods risks, while pollutants removal helps to ameliorate urban water bodies quality.

The quality modelling, in the bioretention, was performed considering the same pollutants concentration washing in and out, since the outlet weir is located at the same level of the bioretention surface. Therefore, further investigations are required to better elucidate the physical and biological processes occurring at its surface, which might have an impact on the outlet runoff quality.

\section{References}

Guan, M., Sillanpää, N., \& Koivusalo, H., 2015. Modelling and assessment of hydrological changes in a developing urban catchment. Hydrological Processes, 29(13), 2880-2894.

Fletcher, T. D., Andrieu, H., \& Hamel, P., 2013. Understanding, management and modelling of urban hydrology and its consequences for receiving waters: A state of the art. Advances in Water Resources, 51, 261-279.

Macedo, M. B., Rosa, A., do Lago, C. A. F., Mendiondo, E. M., \& de Souza, V. C. B. (2017). Learning from the operation, pathology and maintenance of a bioretention system to optimize urban drainage practices. Journal of Environmental Management, 204, 454-466.

Miranda, M. J., Pinto, H. S., Zullo Júnior, J., Fagundes, R. M., Fonsechi, D. B., Calve, L., \& Pellegrino, G. Q. (2012). Clima dos municípios paulistas. CEPAGRI Meteorologia UNICAMP. Available at: http://www. cpa. unicamp. br/outras-informacoes/clima-dos-municipios. Acessed 07/20/2017(Portuguese).

Sun, S., Barraud, S., Branger, F., Braud, I., \& Castebrunet, H. (2017). Urban hydrologic trend analysis based on rainfall and runoff data analysis and conceptual model calibration. Hydrological Processes, 31(6), 1349-1359.

Sun, Y., Tong, S., \& Yang, Y. J. (2016). Modeling the cost-effectiveness of stormwater best management practices in an urban watershed in Las Vegas Valley. Applied Geography, 76, 49-61.

Piro, P., \& Carbone, M. (2014). A modelling approach to assessing variations of total suspended solids (TSS) mass fluxes during storm events. Hydrological Processes, 28(4), 2419-2426. 


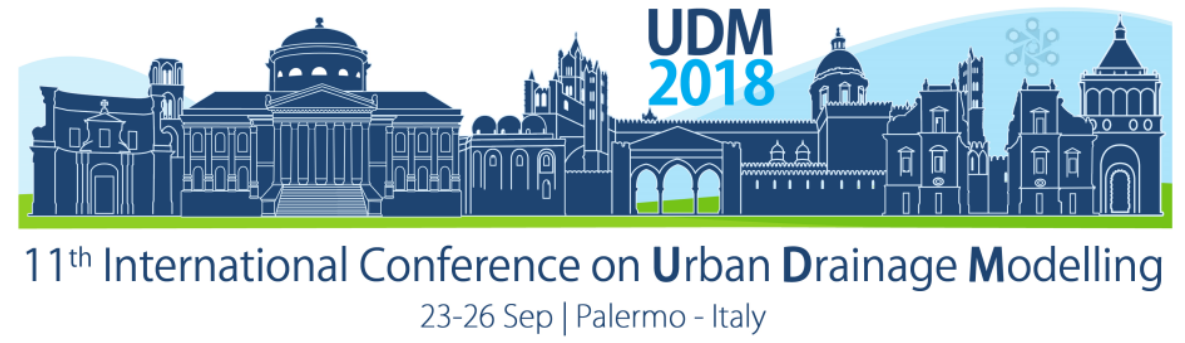

\title{
Assessing uncertainty of a biofilter micropollutant transport model MPiRe
}

\author{
Anja Randelovic ${ }^{1}$, Kefeng Zhang ${ }^{2}$, David McCarthy ${ }^{3}$ and Ana Deletic ${ }^{2}$ \\ ${ }^{1}$ University of Belgrade, Faculty of Civil Engineering - Institute for Hydraulic and Environmental Engineering, \\ Belgrade, Serbia (arandjelovic@grf.bg.ac.rs) \\ ${ }^{2}$ Water Research Centre, Department of Civil and Environmental Engineering, University of New South Wales, \\ Sydney, Australia \\ ${ }^{3}$ Environmental and Public Health Laboratory (EPHM Lab), Department of Civil Engineering, Monash University, \\ Melbourne, Australia
}

\begin{abstract}
MPiRe (Micro-Pollutants In RaingardEns) model was developed to predict both flows and removal of micropollutants by stormwater biofilters. It is a conceptual 1D model that includes sorption/desorption, biodegradation and volatilization processes. This paper presents an uncertainty evaluation of MPiRe using the GLUE methodology with atrazine as a representative pollutant. The uncertainty analysis shows that the soil-water partitioning coefficient (normalized to organic carbon content) is the most sensitive model parameter, while there is some correlation between sorption parameters and high uncertainty in the degradation rate estimation. It is hypothesized that the correlation between sorption parameters can be diminished by choosing two different combinations of calibration parameters (e.g. variations of their mutual products), and this hypothesis will be further tested. The practical implication of this analysis is that particular care should be given to measurements of initial outflow concentrations of events (to decrease the uncertainty in the degradation rate estimation). Additionally, if it is necessary to prioritize between monitoring procedures, the most attention should be given to sorption kinetics.
\end{abstract}

Keywords: stormwater biofilters, MPiRe, micropollutant transport, atrazine, uncertainty analysis

\section{INTRODUCTION}

Stormwater biofilters are soil-based filtration systems that contain a rich plant community which enhances their physical, chemical and biological treatment processes. They are capable of removing sediments, nutrients, heavy metals and micropollutants to some extent (Bratieres et al., 2008, Zhang et al., 2014). But, for biofilters to be used as effective stormwater management measures, it is important to model their performance, since only through continuous simulations of their hydraulic and treatment efficiencies can their longterm impact on reduction of stormwater pollution levels and loads be predicted.

MPiRe model has been developed (Randelovic et al., 2016) that predicts both flows and removal of pollutants by biofilters (validated for several micropollutants: atrazine, simazine, prometryn, glyphosate, and chloroform). However, uncertainties in this model have not yet been evaluated.

The paper presents assessment of calibration uncertainties (calibrated model parameters, calibration data selection) and a sensitivity analysis using the GLUE methodology. The future research will be dedicated to the model structure uncertainty (selection of equations, numerical solver etc.). 


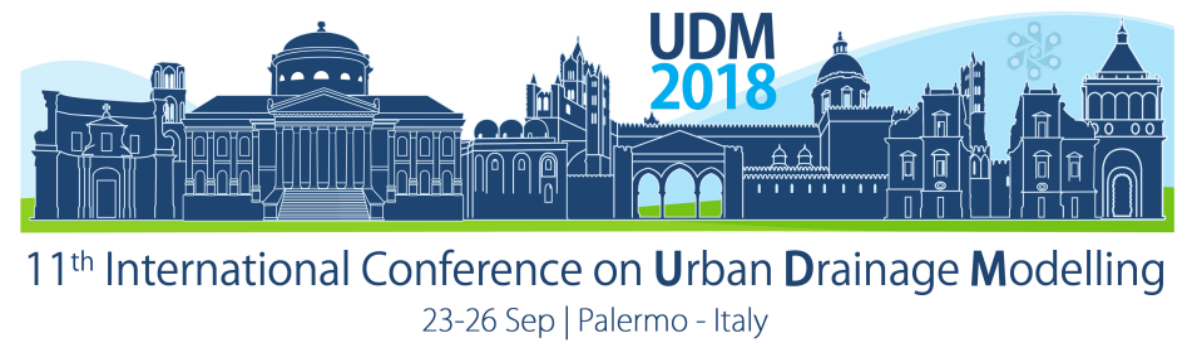

\section{MATERIALS AND METHODS}

Model structure. Water flow model is a linear reservoir model with three zones: ponding, filter media and submerged zone, with a total of three parameters. Pollutant transport model follows the water model zones, and includes sorption/desorption, biodegradation and volatilization processes based on advective-dispersive transport, and has a total of five parameters. For further information on the model, and its setup, please refer to Randelovic et al. (2016).

Experimental data. The MPiRe model was used to model transport and fate of atrazine at the Monash Car Park biofilter (field data). This is a sandy soil biofiltration unit $(850 \mathrm{mg} / \mathrm{kg}$ TN, $255 \mathrm{mg} / \mathrm{kg}$ TP, SOM 2.2\%, pH 7.5), with a submerged zone, and Melaleuca ericifolia. This data comes from a series of "Challenge tests" (see Zhang et al., 2014).

Calibration uncertainty - availability of data. To assess the influence of used calibration dataset on model uncertainty, available dataset of measured results was divided into several smaller datasets. All those datasets were used for separate model calibration.

Sensitivity analysis. Creation of probability density (PDs) histograms of model parameters was done using Generalized Likelihood Uncertainty Estimation method (GLUE, by Beven and Binley, 1992), similar to other urban drainage water modelling studies (e.g. Dotto et al, 2012, Mannina and Viviani, 2010, Vezzaro et al, 2012).

Prior parameter PDs were assumed to be uniform. The ranges for parameters of the hydraulic module were: hydraulic conductivity, $K_{f} 10-250 \mathrm{~mm} / \mathrm{h}$, porosity, $n \quad 0.15-0.55$ and starting filter pore saturation $s 0.0-1.0$. The range for each parameter of the pollutant module was estimated using manual calibration and is shown in Table 1 with respective likelihood function thresholds.

Table 1. Parameter range for uniform prior PDs with the $E$ - threshold for Atrazine

\begin{tabular}{lll}
\hline Parameter & Explanation of parameter & Atrazine \\
\hline logK ${ }_{\text {oc }}$ & $\begin{array}{l}\text { Soil water partitioning coefficient normalized to organic carbon } \\
{\left[\mathrm{L}^{-3} \mathrm{M} \text { soil }\right] \text { - logarithmic value }}\end{array}$ & $-1.6-3.6$ \\
& $\begin{array}{l}\text { Sorption parameter: fraction of exchange sites assumed to be in } \\
\text { equilibrium instantaneously }\end{array}$ & $0-1$ \\
& Sorption parameter: kinetic sorption rate $\left[\mathrm{T}^{-1}\right]$ & $1 \mathrm{e}-07-1 \mathrm{e}-05$ \\
$\alpha_{\mathrm{k}}\left[\mathrm{s}^{-1}\right]$ & Biodegradation half-life $[\mathrm{T}]$ & $5-300$ \\
$\mathrm{~T}_{1 / 2}[$ day $]$ & Nash-Sutcliffe coefficient & 0.4 \\
E-threshold & & \\
\hline
\end{tabular}

\section{RESULTS AND DISCUSSION}

Table 2 shows pollutant module parameter values estimated for each of the test days and for the complete continuous test series for atrazine at Monash Carpark biofilter. The most sensitive parameter is found to be the soil-water partitioning coefficient normalized to organic carbon content, $\mathrm{K}_{\mathrm{oc}}$, which differs over 2 orders of magnitude (in logarithmic scale) between different calibration periods. 


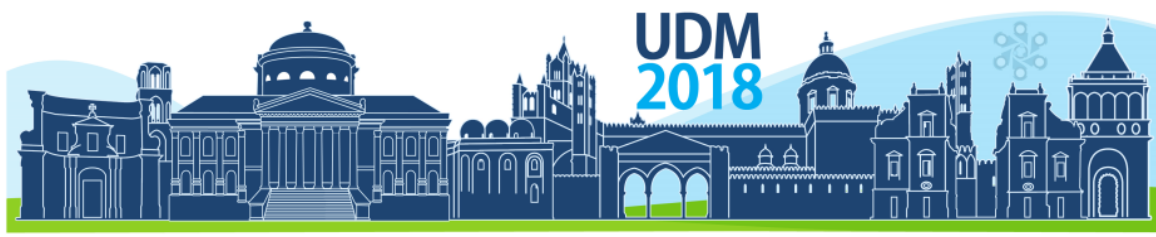

$11^{\text {th }}$ International Conference on Urban Drainage Modelling

23-26 Sep | Palermo - Italy

Table 2. Model parameter and Nash-Sutcliffe values for different calibration periods for atrazine at Monash Carpark biofilter

\begin{tabular}{lllll}
\hline & Test event 1 & Test event 2 & Test event 3 & Continuous series* \\
\hline $\log \mathrm{K}_{\mathrm{oc}}[\log \mathrm{L} / \mathrm{kg}]$ & 5.44 & 2.72 & 3.04 & 2.83 \\
$\mathrm{fe}[-]$ & 0.431 & 0.113 & 0.029 & 0.095 \\
$\alpha_{\mathrm{K}}\left[\mathrm{s}^{-1}\right]$ & $2.46 \mathrm{e}-05$ & $1.35 \mathrm{e}-06$ & $7.85 \mathrm{e}-05$ & $5.66 \mathrm{e}-05$ \\
Nash-Sutcliffe $(\mathrm{E})$ & 0.721 & 0.899 & 0.857 & 0.776 \\
\hline
\end{tabular}

* Continuous series are joined single events

Figure 1 shows the parameter sensitivity for atrazine at Monash Carpark biofilter using GLUE with the likelihood function cut-off $E>0.4$. The posterior parameter PDs show that the soil-water partitioning coefficient, $K_{o c}$, and fraction of instantaneous sorption sites, $f_{e}$, have clear peaks, indicating that their optimal values are easily identified. Posterior PDs for kinetic sorption rate, $\alpha_{k}$, and degradation half-life, $T_{1 / 2}$, do not have clear peaks (they may be considered multi-modal, or almost uniform); therefore, their calibrated values have a high uncertainty.

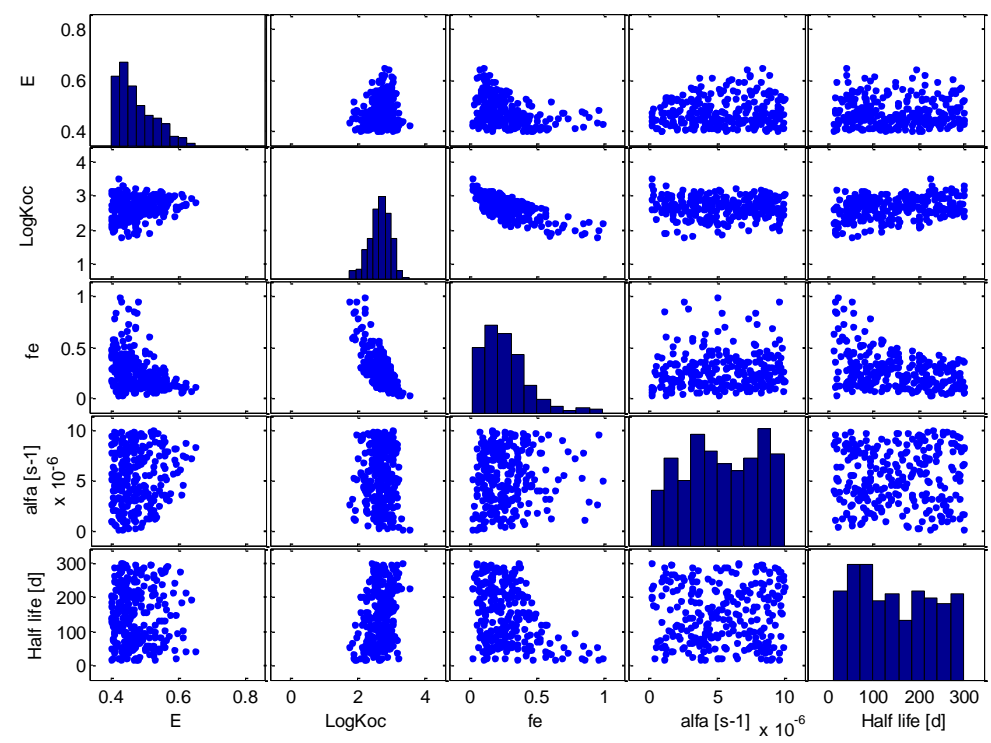

Figure 1. Matrix plot of cross-correlation scatter plots (off-diagonal), efficiency density (upper left corner) and posterior parameter probability density functions (diagonal) for atrazine concentrations at Monash Carpark biofilter using GLUE and likelihood E > 0.4

Table 3, that includes parameter cross-correlation coefficients for atrazine at Monash Carpark biofilter, using GLUE with a cut-off $\mathrm{E}>0.4$, shows that parameters $\log K_{o c}$ and $f_{e}$ are substantially correlated, with $\mathrm{R}=-0.711$. This means that the two compensate for each other: combination of high $\log K_{o c}$ and low $f_{e}$ produces similar sorption results to low $\log K_{o c}$ and high $f_{e}$. This is expected, as the sorption model includes their mutual product. However, although they are correlated, it is not difficult to find their optimal values. The correlation and high peaks indicate that calibration would probably be better performed (with less uncertainty) for two unrelated parameters formed from the combination of $K_{o c}$ and $f_{e}$ such as (1) their product and (2) another relation derived from kinetic sorption model (Doherty, 2013). 


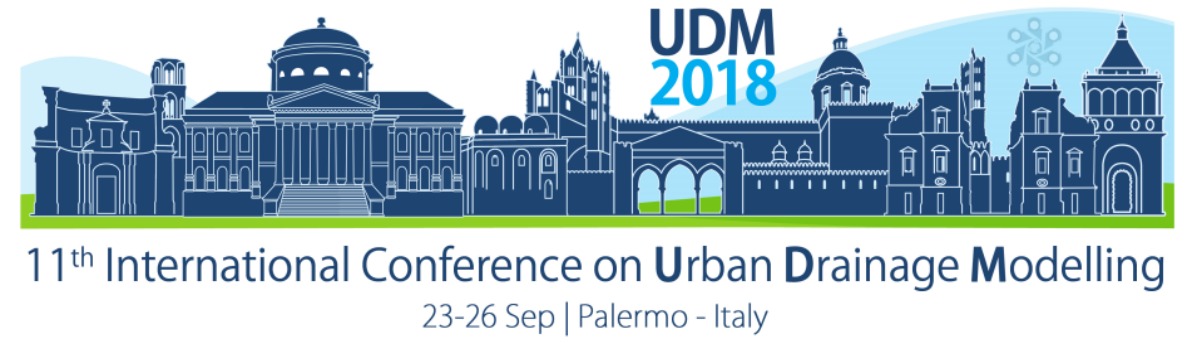

Table 3. Matrix of parameter cross-correlation coefficients for atrazine at Cell 2, using GLUE, E > 0.4

\begin{tabular}{cccccc} 
Atrazine & $\mathrm{E}$ & LogKoc & $\mathrm{fe}$ & $\alpha_{k}$ & $\mathrm{~T}_{1 / 2}$ \\
\hline $\mathrm{E}$ & 1 & 0.176 & -0.377 & 0.099 & -0.032 \\
LogKoc & & 1 & $-\mathbf{0 . 7 1 1}$ & -0.044 & 0.277 \\
$\mathrm{fe}$ & & & 1 & 0.084 & -0.357 \\
$\alpha_{k}$ & & & & 1 & 0.031 \\
$\mathrm{~T}_{1 / 2}$ & & & & & 1 \\
\hline
\end{tabular}

\section{CONCLUSIONS}

The MPiRe model was checked with micropollutant data at Monash Car Park biofilter. The model was successfully calibrated, and then model uncertainty analysed. The following is concluded:

- $\quad$ Different calibration datasets produce different optimal model parameters, with soilwater partitioning coefficient (normalized to organic carbon content) being the most sensitive to this procedure.

- The longest dataset gives the most average values of parameters, and the lowest value of likelihood function.

- Uncertainty analysis performed with GLUE confirmed that the soil-water partitioning coefficient (normalized to organic carbon content) is the most sensitive model parameter, but also found correlation between sorption parameters, and high uncertainty in the degradation rate estimation. It is suggested that these procedure needs to be redone with longer continuous series of measured outflow pollutant concentrations (with more events).

Additionally, the predictive uncertainty is assessed by making $95 \%$ confidence intervals for model predictions, and it suggests that the model is sound. (This will be shown at the conference).

\section{ACKNOWLEDGEMENTS}

This study was funded by CRC for Water Sensitive Cities and TR37010 project of the Serbian Ministry of Science - Urban Drainage Systems as Key Infrastructures in Cities and Towns.

\section{References}

Beven, K.J., Binley, A.M., (1992) The future of distributed models - Model calibration and uncertainty prediction. Hydrological Process 6, 279-298

Bratieres, K., Fletcher, T.D., Deletic, A. and Zinger, Y. (2008) Nutrient and sediment removal by stormwater biofilters: A large-scale design optimisation study. Water Research 42(14), 3930-3940.

Dotto C.B.S., Kleidorfer M., Deletic A., Rauch W., McCarthy D.T. (2014) Impacts of measured data uncertainty on urban stormwater models. Journal of Hydrology 508, 28-42

Mannina G., Viviani G. (2010). An Urban Drainage Stormwater Quality Model: Model Development and Uncertainty Quantification. Journal of Hydrology, vol. 381 (3-4), pp. 248-265.

Randelovic A., Zhang K., Jacimovic N., McCarthy D., \& Deletic A. 2016 Stormwater treatment model (MPiRe) for selected micro-pollutants. Water Research, 89, 180-191

Vezzaro L., Eriksson E., Ledin A., Mikkelsen P.S. (2012) Quantification of uncertainty in modelled partitioning and removal of heavy metals (Cu, Zn) in a stormwater retention pond and a biofilter. Water Research, vol. 46(20), pp. 6891-6903

Zhang K., Randelovic A., Page D., McCarthy D. \& Deletic A. 2014 The validation of stormwater biofilters for micropollutant removal using in-situ challenge tests. Ecological Engineering, 67(1), 1-10 


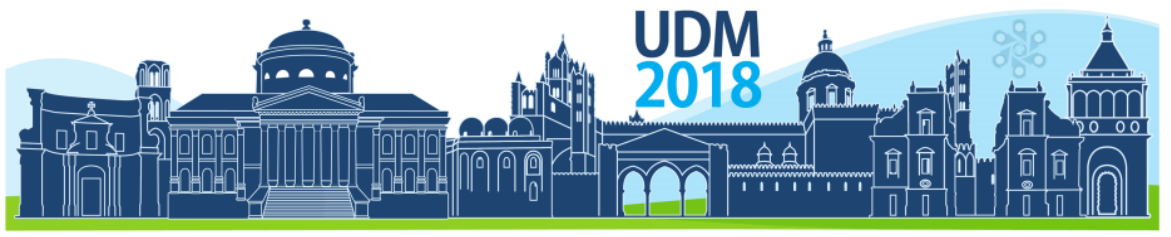

$11^{\text {th }}$ International Conference on Urban Drainage Modelling 23-26 Sep | Palermo - Italy

\title{
Study for the proper management of rainwater withing the Mexican Water Technology Institute
}

\author{
Rodrigo Santos-Tellez ${ }^{1}$, Oscar Llaguno Guilberto², Manuel Rodriguez Varela ${ }^{3}$ and Manuel Figueroa \\ Mendiola ${ }^{4}$ \\ 1,2,3,4 Mexican Institute of Water Technology, Urban Hydraulics Department, Jiutepec, Morelos, México
}

\begin{abstract}
The Mexican Water Technology Institute (IMTA) is located at the meeting point of two streams that tend to saturate and overflow during the rainy season. Several flooding incidents have taken place throughout past decades resulting in complications for the IMTA and surrounding zones. This article presents the results of the analysis of basins-ofcontribution drainage, the behavior of the streams and the flood zones for different return periods. A proposal to modify the pluvial-drainage network was developed with the results of the analysis in order to mitigate flood impacts. The efficiency of the proposed infrastructure was evaluated under the same conditions of the original scenario. All of this was carried out with the aid of a digital elevation model (DEM), of the basins of contribution, a hydrological study performed with the help of software developed at the IMTA. Several drainage coefficients were taken into account for the distinct uses of land in the zone, primarily urban, and mathematical simulation models were created in two dimensions that included current pluvial infrastructure, the digital elevation model, and the sub-basins with their particular characteristics.
\end{abstract}

Keywords: digital elevation model; hydraulic model's; flood risks

\section{INTRODUCTION}

Every year during the rainy season, the IMTA facilities are affected by a great volume of water running off onto its grounds, this happens when it rains for several consecutive days, causing the ground in the basin to saturate. When it rains heavily, there is water runoff which surpasses the capacity of the pluvial drainage network of the institute. Some of the heaviest floods on record took place on the 12th of June 2001 with flow of $86 \mathrm{~mm}$, on the 13th of October, 1997 with $39 \mathrm{~mm}$, and on the 21st of August, 1992, with only $33 \mathrm{~mm}$. These inundations impede the pedestrian and vehicular circulation at the Institute as can be seen in Figure 1, resulting in economic losses and loss of time.
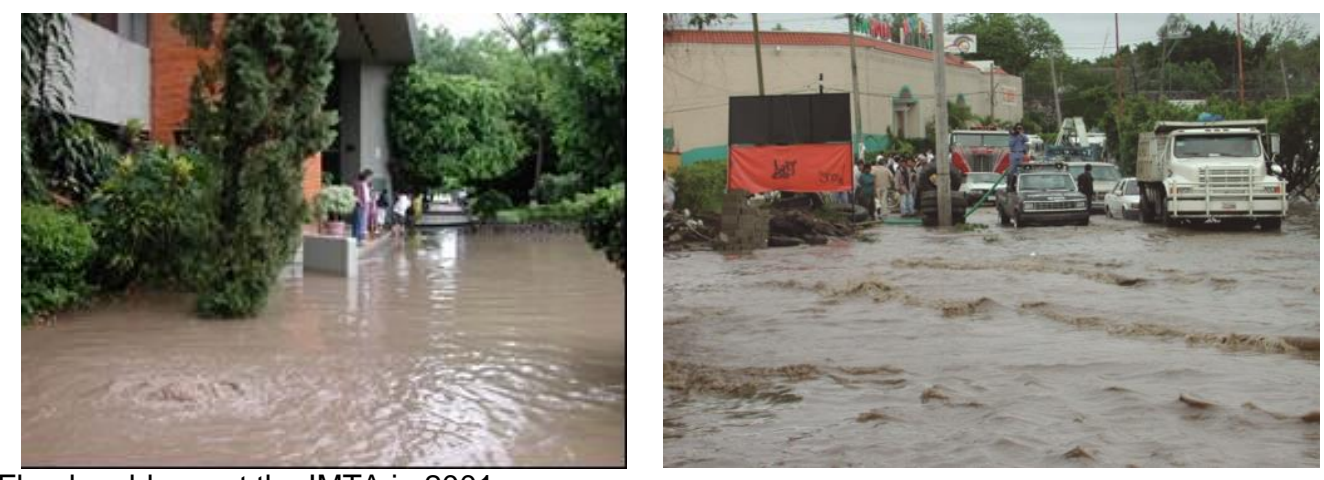

Figure 1. Flood problems at the IMTA in 2001

\subsection{Application Site}

The IMTA is found within the urban zone of the city of Cuernavaca, Morelos. Its subbasin is located in the northern part of the institute (Figure 2) and has an area that is relatively small, around the order of $0.67 \mathrm{~km}^{2}$. 


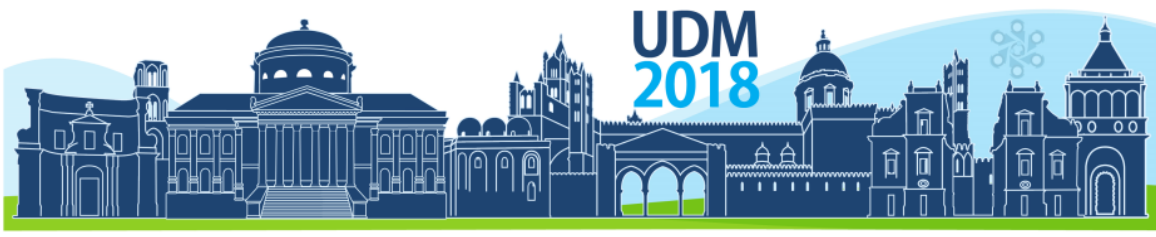

$11^{\text {th }}$ International Conference on Urban Drainage Modelling 23-26 Sep | Palermo - Italy

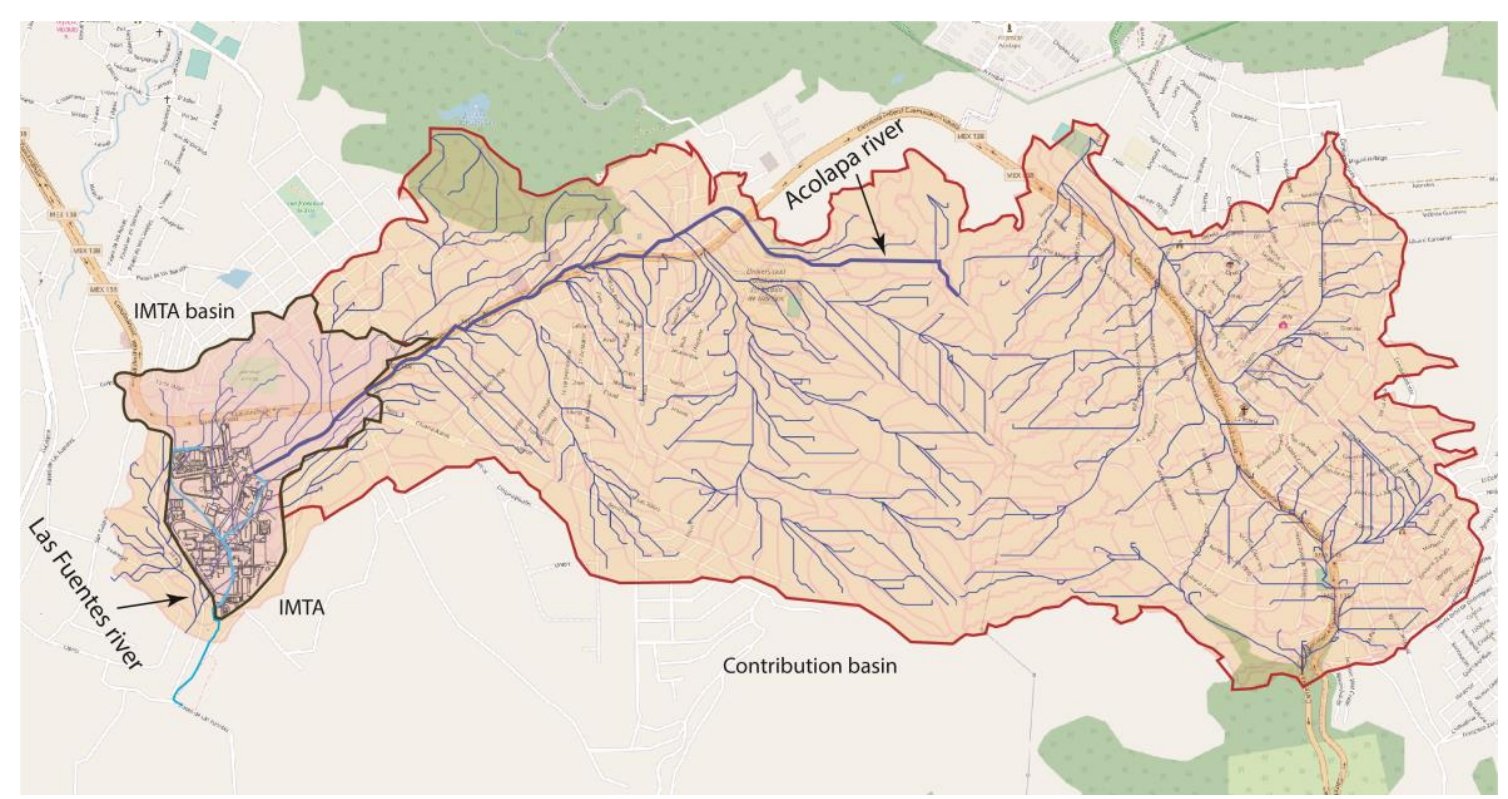

Figure 2. Basins of contribution to IMTA

Nevertheless, the Acolapa river easily flows over due to its low capacity, causing almost all runoff to go into the basin that corresponds to the IMTA and afterwards, towards the drainage channels of the institute. This increases the contribution area of the basin to $6,848 \mathrm{~km}^{2}$.

\subsection{Study objective}

The objective of the study lies in determining the flows for different return periods generated by contributing basins and redesigning the pluvial drainage network of the institute since its current capacity is not enough to transport the flows caused by the rains.

\section{MATERIALS AND METHODS}

\subsection{Hydrological study}

The calculation of rains for different return periods was done using a distribution of frequency analysis with nine functions that were processed and evaluated in the program AFA v.1.1, developed by the IMTA. When deciding on the type of rainfall to use, the precipitation that took place in 2001 was chosen, which had a duration of 14.5 hours and a precipitation of 111.16 $\mathrm{mm}$.

\subsection{Creation of a digital elevation model}

A digital elevation model (DEM) was created with a topographical rendering which then served to make a triangulated irregular network (TIN), observe in figure 3.

\subsection{Land use}

To properly model basin runoff, a database was created logging the different types of land uses for the zone. Each land use type was assigned a corresponding runoff factor: for streets it was 0.95 , sidewalks were 0.85 , the planimetry or constructed zones 0.95 , level-ground areas 0.85 , the jogging trail 0.17 , the green areas as well as the perimeter fence were 0.70 , the natural canal was 0.35 , the concrete canal was 0.95 and finally the green areas were 0.25 . 


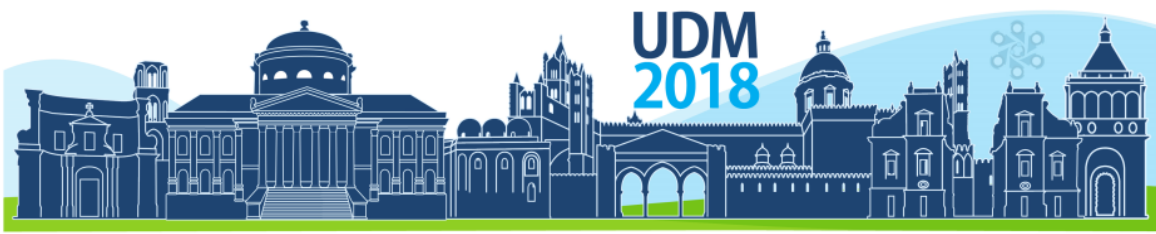

$11^{\text {th }}$ International Conference on Urban Drainage Modelling 23-26 Sep | Palermo - Italy

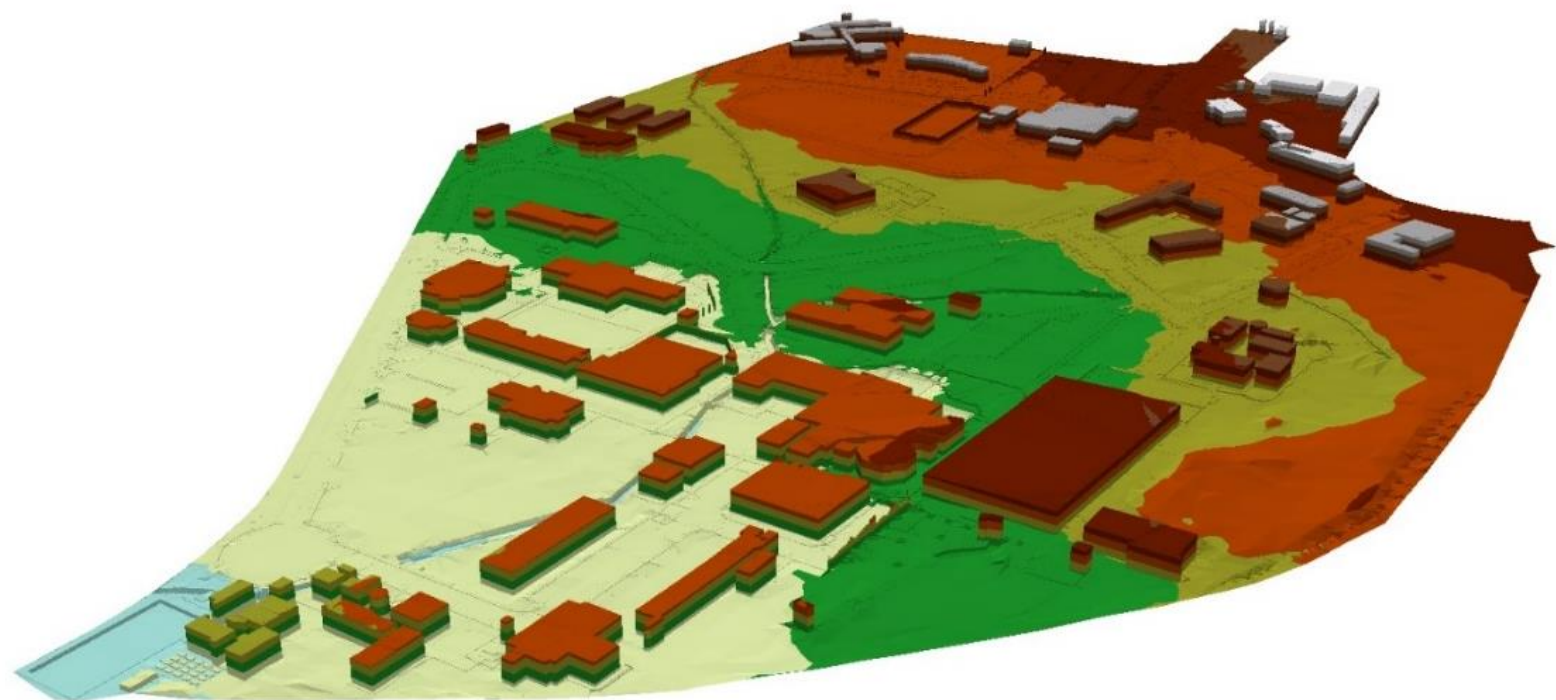

Figure 3. Digital elevation model of IMTA

\subsection{Rainfall drainage within the institute}

Additionally, rainfall drainage data for the IMTA infrastructure was included with the purpose of evaluating current capacity to drain rainfall. There are pipes with diameters that range from $0.15 \mathrm{~m}$ up to $0.76 \mathrm{~m}$, overall, the current network covers $3.07 \mathrm{~km}$.

\subsection{Hydraulic model}

A hydraulic model was created that included the plotted lines and sections of canal pipes, the piping of the pluvial infrastructure, the digital elevation model and the micro-watersheds with their particular characterizations. The mesh proposed for the modeling is rectangular with a varying size that makes up the $5 \times 5 \mathrm{~m}$ zone of the institute, the first main contribution zone is $10 \times 10 \mathrm{~m}$ and the secondary contribution zone is $20 \times 20 \mathrm{~m}$. Six hydraulic simulations were done for different return periods $(2,5,10,35,50$ and 100 years), this storm design along with the 505 contributing micro-watersheds, the pluvial infrastructure, the retention deposits and the projected collectors were brought together in a hydraulic simulation model in which maximum flows were calculated.

The cost of surveying in Mexico is very costly, the budgetary confines of the project obligated a specific plotting practice to know the elevations, flat areas were allotted more space and less space was used in more pronounced ones. The $5 \times 5$ resolution in the DEM explicitly represents the topographical possibilities of the terrain, given that sidewalks, streets and buildings were surveyed independently for the TIN.

A Geographic Information System (QGIS) was used to process data, which created a rendering of the morphometric characteristics of the basin and then geopositioned the urban infrastructure of the institute. For the modeling, the PCSWMM $2 \mathrm{~d}$ program was used, which creates a $1 d-2 d$ interaction so as to generate the rainfall-runoff process in the basins and in the pluvial system in order to identify piping capacities and overflow.

\section{RESULTS AND DISCUSSION}

\subsection{Hydraulic model results}

The hydraulic model's results are arrived at using the computational scenarios proposed for different return periods, each linked to a storm design. Figure 4 presents the maximum flows 


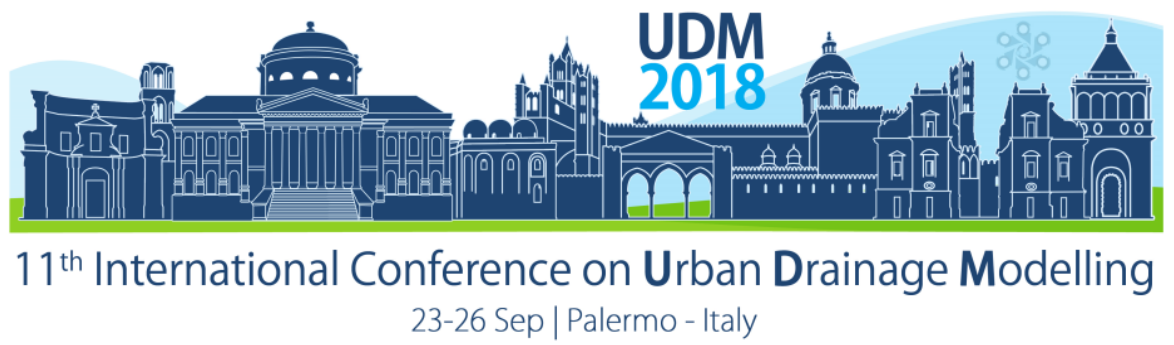

that resulted from the simulation, and makes evident that the most affected zone is in the southern part of the institute.

\subsection{Proposed solution}

The hydraulic model was used in the effort to tackle the inundation and puddling problems using diverse proposals like works. The optimal solution requires installing five infiltration and retention systems along with collectors that would permit rainfall to be drained in less time. Figure 4 presents a side-by-side comparison of the current conditions with the proposed solution for a return period of 25 years.

\subsection{Solución óptima}

The optimal solution was identified via the employment of available knowledge of the areas and the maximum flows that are presented, afterwards, the proper dimensioning of retention ponds was worked out and finally a pluvial system was established that will improve the transport of water to avoid flooding. The IMTA, being an institute that receives students of different hydrological degrees throughout the year, allows them to get to know the retention and detention infrastructure as a means to avoid flooding.

The Institute has a channel system the permits the evacuation of water coming from the higher elevations and from the basin, this system is very useful for return periods of less than ten years, for anything beyond that though, there are losses in the form of intangible and tangible costs. The problem is complex because the annual average precipitation in Morelos is $900 \mathrm{~mm}$, which indicates that storms here are of a short duration. The use of low-impact works was considered but they would only help with return periods under 10 years.

\section{CONCLUSIONS}

The development of an optimal solution for reducing flood risks is an interdisciplinary task. The new pluvial system that the IMTA requires was developed using more adequate mathematical tools but more importantly, was richly supplied with data from rainfall measurements and drainage flows in the field under strict collection standards. The precision of the mathematical model permitted the significant prediction of flood areas caused by rainfall with a return period of 20 years, these results were presented in June 2017. This flood allowed model results to be calibrated and corroborated, thus assuring that the projected infrastructure meet its objective. Moreover, an economic evaluation was carried out for the project considering distinct, existing technologies like prefabricated retention systems, and diverse materials for collectors among them reinforced concrete, polyethylene, galvanized piping and PVC. 
Proceedings of the 11th Int. Conference on Urban Drainage Modelling, 23-26 Sep. 2018, Palermo (ITALY). Ed. prof. Giorgio Mannina

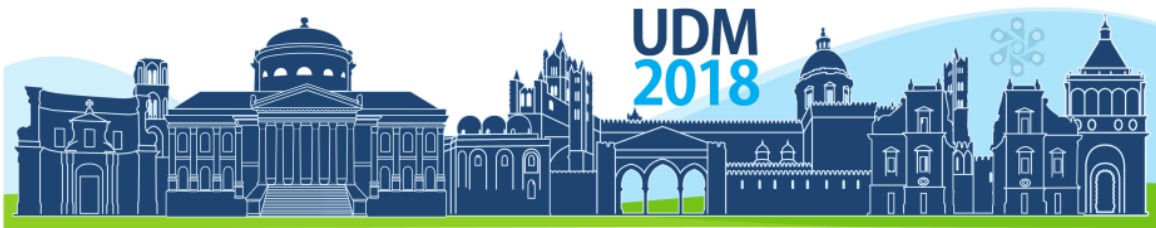

$11^{\text {th }}$ International Conference on Urban Drainage Modelling 23-26 Sep | Palermo - Italy
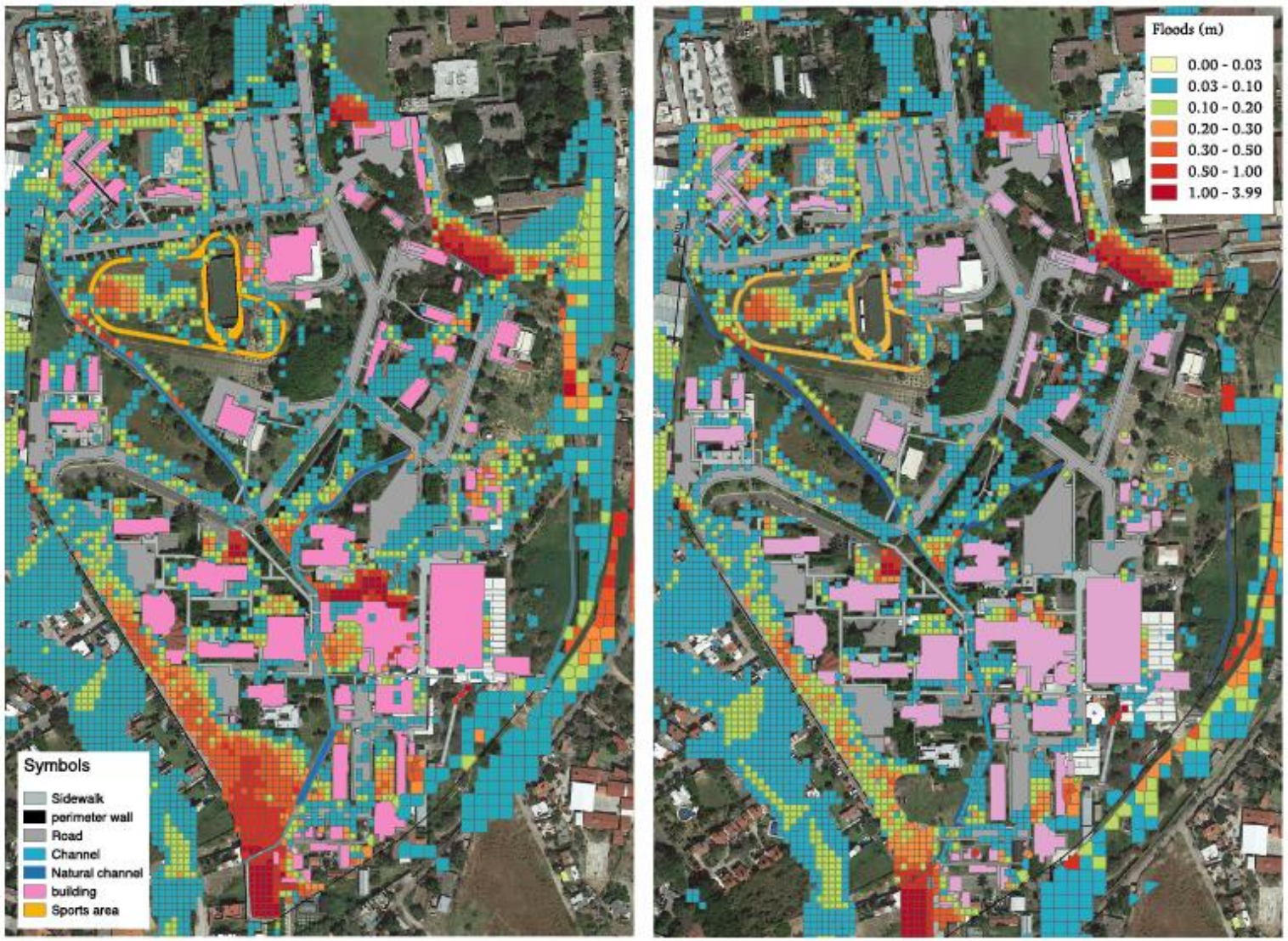

Figure 4. Comparison of maximum flows for the current situation and the proposed solution for a return period of 25 years

\section{References}

Lafragua y Aguilar (2002) Hydrological analysis of the IMTA basins of contribution, hydraulic-technology coordination. September 2002 (original title in Spanish).

AFA V.1.1 Frequency analysis. Mexican Water Technology Institute.

MAPAS (2015). Urban Pluvial Drainage. Potable Water Sewer Drainage Manual. National Water Commission. Mexico City, Mexico (original title in Spanish).

INEGI (2017). Topographical maps 1:50,000 collected by http://www.inegi.gob.mx/

Peucker T., 1978, the Triangulated Irregular Network, Department of Geography Simon Fraser University Burnaby, B.C., Canada, V5A 1 S6.

Rodríguez V., J. M., Maldonado S., J., Albornoz G., P. M., \& Alcocer Y., V. H. (2012). Pluvial water management Program for the city of Chetumal, Quintana Roo. Jiutepec, Morelos, internal key HC1235.3: IMTA (original title in Spanish). 


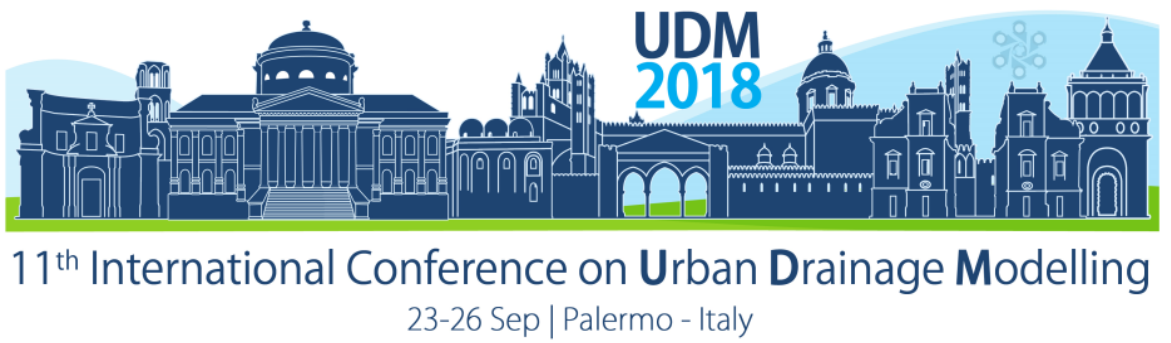

\title{
Understanding Pollutant Transport in Urban Floodwater for Health Impact Assessment using a Physical Scale Model
}

\author{
James Shucksmith1, Matteo Rubinato', Ricardo Martins', Georges Kesserwani' ${ }^{1}$, Jorge Leandro², \\ Slobodan Djordjevic ${ }^{3}$. \\ 1 The University of Sheffield, Dept. of Civil and Structural Engineering, Sheffield, United Kingdom \\ ${ }^{2}$ Technical University of Munich, Department of Civil, Geo and Environmental Engineering, Munich, Germany \\ ${ }^{3}$ University of Exeter, Centre for Water Systems, Exeter, United Kingdom
}

\begin{abstract}
Urban flood models are commonly used to evaluate risk to buildings and infrastructure. However it also recognised that urban floods have a significant public health impact. Approaches have been developed utilizing the Advection Diffusion Equation (ADE) to determine the concentration of surcharging sewer water in overland flood flows and estimate health risk. Such modelling approaches are dependent on the evaluation of local velocity fields and turbulent diffusion coefficients. This paper presents new datasets from a physical scale model of an above/below ground system in which depth averaged solute transport is quantified over a range of sewer surcharge flow conditions. Datasets from the facility can be used to calibrate models and evaluate the potential of ADE based approaches to simulate contaminant transport in urban flood waters. Initial results demonstrate the temporal and spatial variability of concentration fields around surcharge events, caused by the hydraulic complexity of the flow field.
\end{abstract}

Keywords: Urban Flood Modelling; Pollutant Transport; Health Risk Assessment

\section{INTRODUCTION}

Hydraulic models are commonly used to analyse and mitigate the risks of flooding in urban areas. Detailed dual drainage models simulate flow within both the drainage network (using a 1D pipe network approach) and on the surface (2D overland flow approach). Dual drainage hydraulic models are commonly used to assess the potential damage to property and infrastructure (Martins et al., 2018), and utilise this information to inform decision makers in terms of cost effective asset investment strategies or flood mitigation options. There is an increasing awareness that the risks associated with urban flooding extend to impacts on public health from exposure to contaminated flood water. Surcharge from combined or foul sewer systems during flood events leads to the presence of faecal contamination within flood water and contamination of urban surfaces that can persist for extended periods after floodwater has receded (ten Veldhuis et al., 2010). Understanding the risks posed by contaminated floodwaters is a challenging task as health impacts are affected by numerous variables including the composition of bacteria, concentration, exposure time and vulnerability (Fewtrell et al., 2010). Nevertheless recent attempts have been made to include health risk assessment within urban flood models based on a prediction of wastewater concentration within surface flood waters (Mark et al., 2018). To determine wastewater concentrations and how they vary spatially and temporally relative to sewer surcharge events, current modelling approaches are based on the solution of the Advection Diffusion Equation (ADE). The ADE was originally developed by Taylor (1953) for turbulent pipe flow, although it is now commonly applied within a range of water quality applications in including surface waters and urban drainage networks. Accurate implementation of the $2 \mathrm{D}$ ADE requires understanding of both the local $2 \mathrm{D}$ velocity 


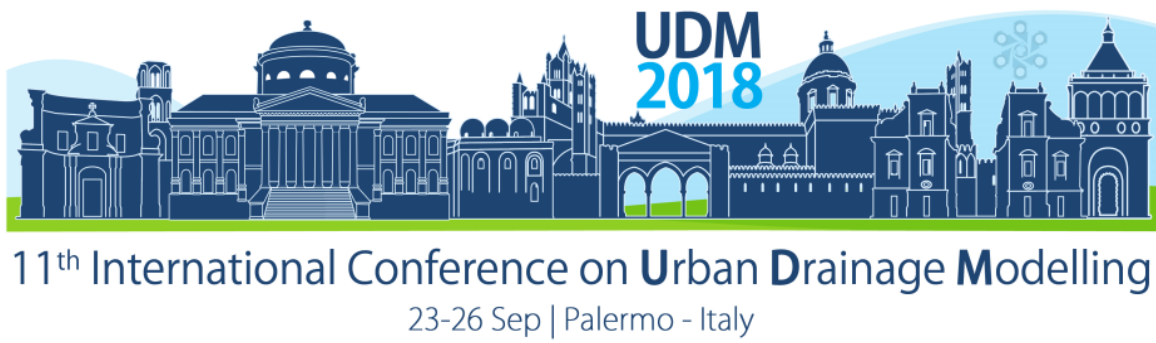

fields as well as the turbulent diffusion coefficients. Within urban flood models velocity fields can be obtained from the 2D hydraulic scheme. However there is a current lack of data concerning appropriate diffusion coefficients in the context of urban flood waters. Within other applications diffusion coefficients are known to be variable, being dependant on both the local turbulence as well as differential advection processes arising from the depth averaged treatment of the flow.

This paper presents new solute transport data from a physical scale model of an above/below ground urban flood system. A Planar Concentration Analysis (PCA) system has been developed such that depth averaged concentration of soluble tracer (Rhodamine WT) can be measured. A series of experiments have been carried out in which tracer has been introduced to the pipe network during manhole surcharge events. The resulting concentrations within the surface flow are quantified and spatial and temporal variations around the surcharging manhole are presented. It is expected that the resulting concentration fields can be used to calibrate and validate new 2D ADE models of concentration in urban flood flows, and thus provide improved confidence for health impact modelling.

\section{MATERIALS AND METHODS}

The project has utilised a scale model urban drainage facility at the University of Sheffield. The system comprises of a $75 \mathrm{~mm}$ pipe featuring an in-line circular manhole of $240 \mathrm{~mm}$ diameter, and $0.478 \mathrm{~m}$ height. The top (crest) of the manhole is aligned with the base of an 'urban surface' of dimensions $8 \mathrm{~m} \times 4 \mathrm{~m}$, set at a slope of 1/1000. Flow onto the surface is regulated by a full length weir at the upstream end of the facility. Downstream flow in controlled by an adjustable tailgate. Flows into both the pipe and surface system are controlled by automated valves such that both steady state and time variable flow events can be simulated. The facility has the capacity to simulate both drainage (i.e. net flow from surface to pipe via the manhole), and surcharge (i.e. net flow from pipe to surface via the manhole) conditions. Flow into and out of both the piped and surface systems are monitored using magnetic flow meters. Flow depths and pressures are logged in real time using a number of pressure transducers placed both in the pipe and on the surface. A full description of the experimental facility can be found in Rubinato et al $(2017,2018)$. The project has developed a new instrumentation system to measure 2D velocity fields and depth averaged solute concentrations in the surface flow using an array of overhead cameras, lighting and a soluble tracer. Soluble tracer is injected within the pipe network $3.80 \mathrm{~m}$ upstream of the flowmeter. Either continuous or time varying 'pulses' can be injected. Within the pipe network soluble concentrations are quantified using Cyclopes Fluoromters (Turner Designs) at discrete positions in the pipe. Tests conducted in sewer surcharge conditions result in solute being exchanged to the surface flow.

GoPro Hero 4 Black Edition cameras (set to record frames of size 1440x1920 pixels) were fitted at a height of $1.48 \mathrm{~m}$ directly above facility in line with the manhole inlet to acquire video frames for the application of the Planar Concentration Analysis (PCA) to determine depth averaged (2D) concentration maps within the surface flow. Camera lens distortion effects were removed from the images by dewarping the frames based on the use of a calibration chequerboard image. An external timer was used to synchronise the images from all the cameras and 'stich' the images together. Since the Rhodamine WT dye absorbs green (500$575 \mathrm{~nm}$ ) light arrays of $550 \mathrm{~nm}$ LEDs were installed above the facility. The facility was covered in reflective material to minimise outside (variable) illumination. This resulted in near-uniform green illumination to the measurement area. To perform a PCA calibration the flume surface was hydraulically sealed and known concentrations were distributed on the surface. Ten different concentrations were recorded in order to characterize the intensity response to the 


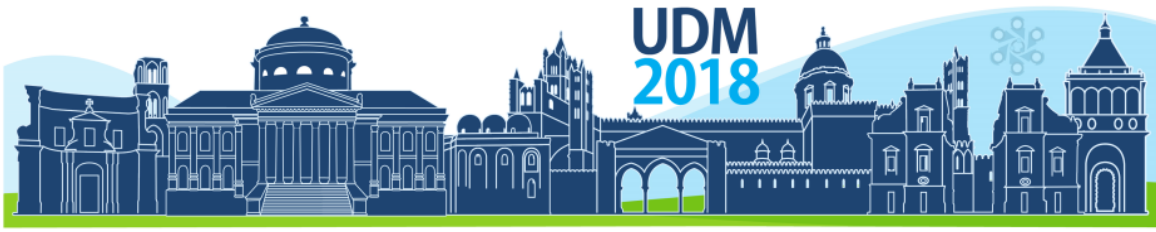

$11^{\text {th }}$ International Conference on Urban Drainage Modelling

23-26 Sep | Palermo - Italy

dye concentration at each $10 \times 10$ cell area $\left(10 \mathrm{~mm}^{2}\right)$. This was conducted for nine water depths (between 9 and $54 \mathrm{~mm}$ ). It was found that the recorded light intensity was best related to the concentration by a third order polynomial. Coefficients representing the best fit polynomial regression were calculated for each measurement area within the image frame. This would theoretically allow any recorded green intensity to be converted to a depth-averaged concentration value at each measurement point. Further details of the PCA measurement techniques can be found in Arques et al (2018).

\section{RESULTS AND DISCUSSION}

A range of tests have been conducted in which both continuous and time varying pulses of tracer were injected into pipe network, with both steady and unsteady sewer surcharge events. Example results in this paper present instantaneous images and resulting depth averaged concentration fields around a steady sewer surcharge event into a steady overland flow after a 10 second pulse of Rhodamine WT is injected into the pipe network. Conditions are reported at five 10s time steps after the dye is first identified within the surcharging flow. The surface flow has a constant upstream unit width discharge of $0.7 \mathrm{l} / \mathrm{sm}$, measured upstream flow depth of $24 \mathrm{~mm}$ and Froude number of 0.22 . The flow surcharges from the manhole as a constant rate of $5.1 \mathrm{l} / \mathrm{s}$ through a grate with a total open area of $0.0145 \mathrm{~m}^{2}$. Figure 1 presents the images from the cameras and the resulting depths averaged concentration maps at five timesteps after injection over a measurement area of 3.6 by $2 \mathrm{~m}$.
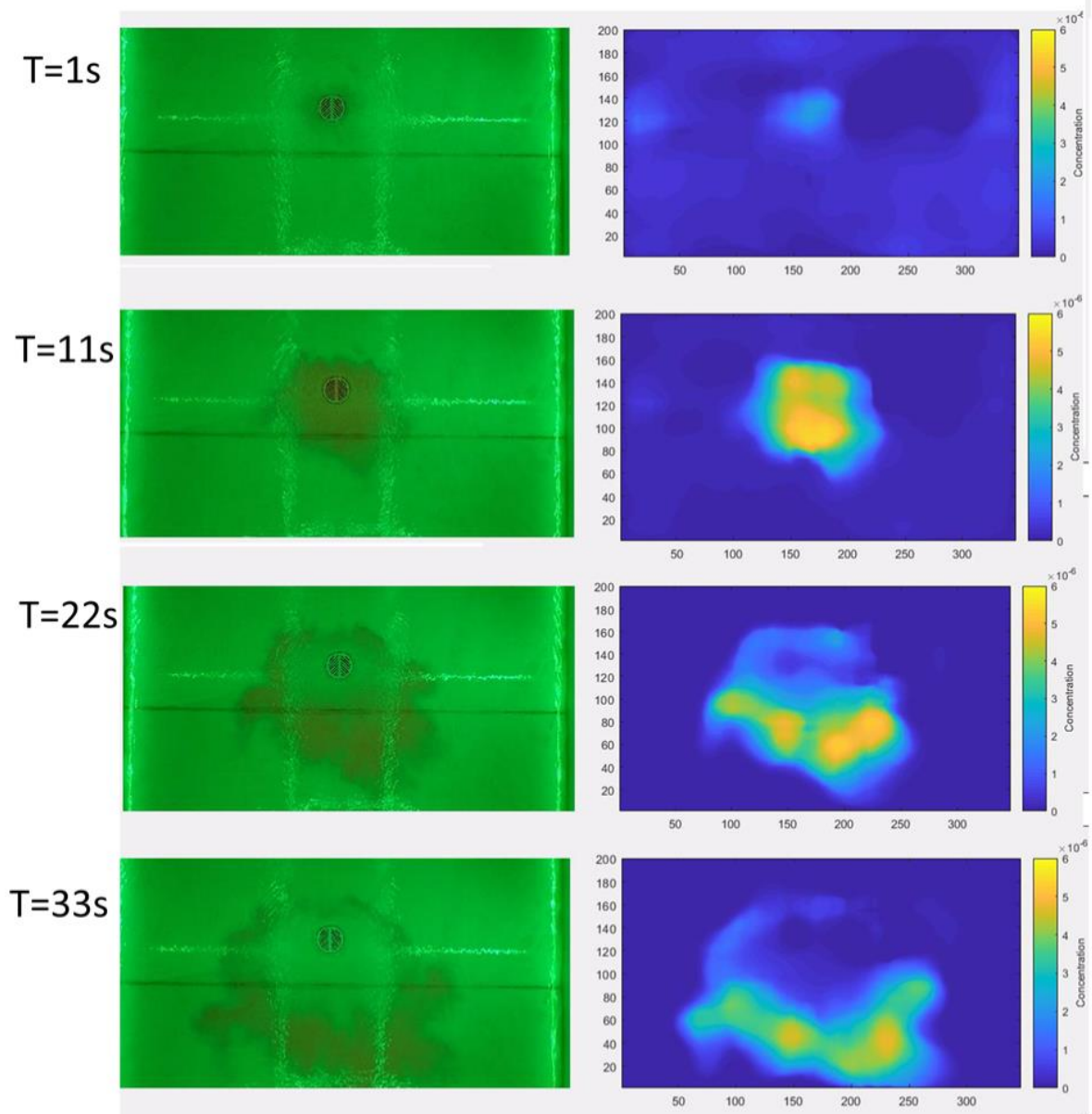


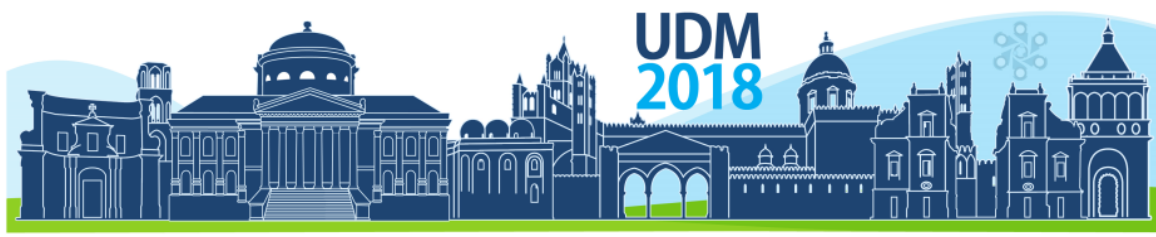

$11^{\text {th }}$ International Conference on Urban Drainage Modelling 23-26 Sep | Palermo - Italy
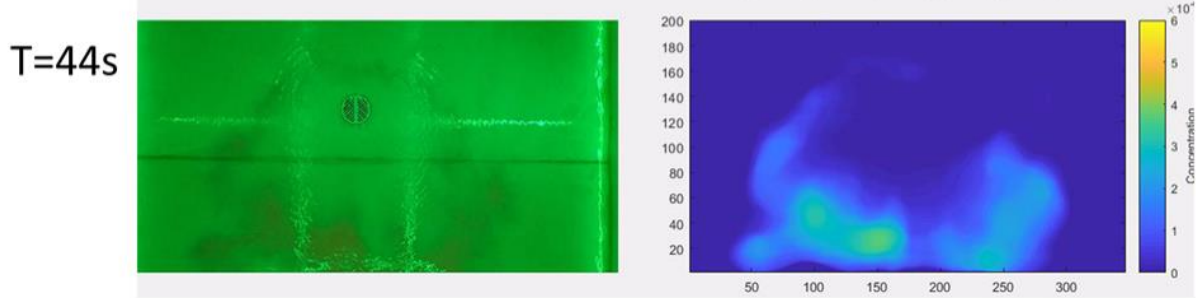

Figure 1. Images (left) and depth averaged tracer concentrations (right) around manhole grate at five time steps (T) following injection of tracer into the pipe network during surcharging conditions. Dimensions are in $\mathrm{cm}$ and units of concentration are $\mathrm{l} / \mathrm{l}$.

\section{CONCLUSIONS}

Initial results demonstrate the high spatial and temporal variability of solute concentrations around a surcharging manhole within shallow urban flood conditions. The results presented in this example are relatively simple, with steady state hydraulics and uniformly distributed upstream overland flow. Significant additional variations are likely to be introduced in more complex conditions, such as those featuring sub-super critical transitions around the manhole (Martins et al., 2017), time varying surcharge events or more complex overland flow profiles. Successful modelling of pollutant exchange to surface flow would also benefit from improved understanding of complex manhole hydraulics in surcharge conditions Beg et al., (2018), as well as the impacts of surface flow features on mixing processes. Future work will calibrate and test 2D ADE pollutant transport model against further lab data gathered over a range of more complex flow conditions.

\section{Funding}

The research was supported by the UK EPSRC [EP/K040405/1].

\section{References}

Arques, S., R., Rubinato, M., Nichols, A., Shucksmith, J. Cost effective measuring technique to to simultaneously quantify 2D velocity fields and depth-averaged solute concentrations in shallow water flows. Submitted to Flow Measurement and Instrumentation

Beg, N.A., Carvalho, R.F., Tait, S., Brevis, W., Rubinato, M., Schellart, A., Leandro, J. (2018) A comparative study of manhole hydraulics using stereoscopic PIV and different RANS models. Water Science and Technology. In Press, wst2018089; DOI: 10.2166/wst.2018.089

Fewtrell, L. , Kay, D. , Watkins, J. , Davies, C. and Francis, C. (2011), The microbiology of urban UK floodwaters and a quantitative microbial risk assessment of flooding and gastrointestinal illness. Journal of Flood Risk Management, 4: 77-87. doi:10.1111/j.1753-318X.2011.01092.x

Mark, O. , Jørgensen, C. , Hammond, M. , Khan, D. , Tjener, R. , Erichsen, A. and Helwigh, B. (2018), A new model of health risk from urban flooding. J. Flood Risk Manage, 11: S28-S42. doi:10.1111/ffr3.12182

Martins R., Kesserwani, G., Rubinato, M., Lee, S., Leandro, J., Djordjević, S., Shucksmith, J. (2017) Validation of 2D shock capturing flood models around a surcharging manhole, Urban Water Journal, 14:9, 892-899, DOI: 10.1080/1573062X.2017.1279193

Martins, R. , Leandro, J. and Djordjević, S. (2018), Influence of sewer network models on urban flood damage assessment based on coupled 1D/2D models. J Flood Risk Management, 11: S717-S728. doi:10.1111/jfr3.12244

Rubinato, M., Martins, R., Kesserwani, G., Leandro, J., Djordjević, S., Shucksmith, J. (2017) Experimental calibration and validation of sewer/surface flow exchange equations in steady and unsteady flow conditions, Journal of Hydrology, 552, 421-432, https://doi.org/10.1016/j.jhydrol.2017.06.024.

Rubinato, M., Martins, R., Shucksmith, J.D. (2018) Quantification of energy losses at a surcharging manhole, Urban Water Journal. DOI: 10.1080/1573062X.2018.1424217

Taylor, G., (1954) The dispersion of matter in turbulent flow through a pipe, Proc. R. Soc. Lond. A $1954223446-$ 468; DOI: 10.1098/rspa.1954.0130.

ten Veldhuis, J.A.E., Clemens, F.H.L.R. Sterk, G. Berends, B.R. (2010) Microbial risks associated with exposure to pathogens in contaminated urban flood water, Water Research, 44(9), 29102918,https://doi.org/10.1016/j.watres.2010.02.009. 


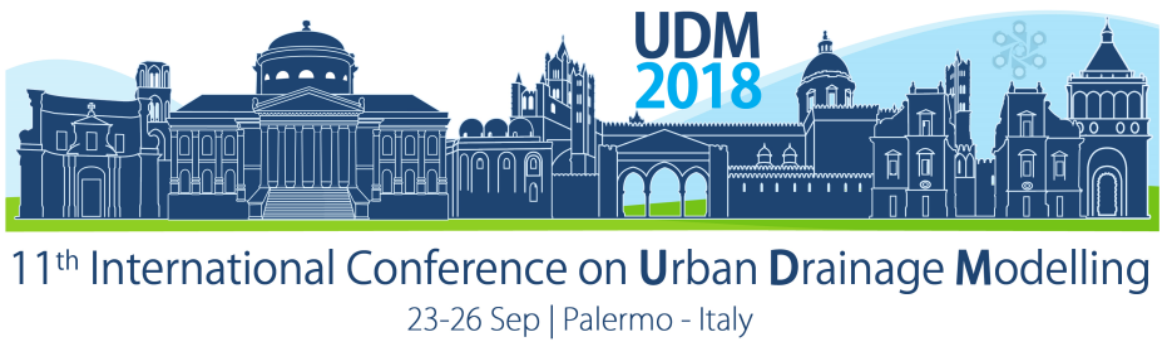

\title{
Frontiers in Urban Drainage - How will Ubiquitous Sensing Change Urban Drainage Management?
}

\author{
Jörg Rieckermann', Frank Blumensaat' ${ }^{1,2}$, João P. Leitão', Christoph Ort' ${ }^{1}$, Andreas Scheidegger ${ }^{1}$, Peter A \\ Vanrolleghem ${ }^{1,3}$, Kris Villez ${ }^{1}$ \\ ${ }^{1}$ Eawag, Urban Water Management, Dübendorf, Switzerland \\ ${ }^{2} \mathrm{ETH}$ Zurich, Institute of Environmental Engineering, Chairs of Urban Water Management, Zürich, Switzerland \\ ${ }^{3}$ Département de génie civil et de génie des eaux, modelEAU, Université Laval, Québec, Canada
}

\begin{abstract}
In the "internet of things"-future, several billion connected sensors will create many opportunities and threats for urban drainage which are currently not well understood. To identify the most relevant trends, we performed a horizon scan regarding how ubiquitous sensing will shape the future of urban drainage and wastewater management. Our survey of the international got a good response from both the academic and professional communities and shows, that emerging topics for urban water will often involve experts from aquatic ecology as well as IT and computer science. Novel topics either require i) cross-disciplinary training, such as importing new developments from the IT sector, or ii) extended research, such as open questions in aquatic ecology. These results are a call for interdisciplinary research beyond the own discipline. They also demonstrate that the urban drainage community is not yet prepared for the "internet of things" future and a lot remains to be done to harvest the upcoming opportunities.
\end{abstract}

Keywords: Ubiquitous sensing, internet of things, community survey, forecasting, Horizon Scan

\section{FROM GRAB SAMPLING TO UBIQUITOUS SENSING - WHAT TO DO WITH 50 BILLION SENSORS BY 2020?}

Traditionally, Urban Water Management suffered from too little data on key variables or boundary conditions, such as current and future serviced population, variability of rainfall or pollutant dynamics. This was mostly, because online process monitoring was either not available, or not observing the true variability or loads into a system. In recent decades, online sensors of water quantity and quality variables have been developed, which offer a much more detailed understanding of relevant processes, such as source and fate of pollutants and provide efficient solutions, such as integrated real-time control (Campisano et al. 2013), and consider pollution from both urban and agricultural areas (Wittmer et al. 2011). Nowadays, communication services, such as GSM, LoRaWAN, and NBIOT, in combination with autonomous energy supplies make it economically viable to collect data from several tens to hundreds of sensors, even in remote or underground locations (Blumensaat et al. 2017).

Unfortunately, the urban water community has not yet fully grasped the value and implications of such information. Data quality control is almost non-existent, gross errors, such as sensor failures, are not detected automatically and, most critically, lacking metadata often renders experimental or routine data useless after a few months or years. Also, many distributed sensors could create security issues and, last but not least, there is not yet an "open science" culture where experimental data are systematically shared with the community. In other words, it is difficult to "learn" from data on urban water systems, because they do not exist, cannot be accessed, or are erroneous. 


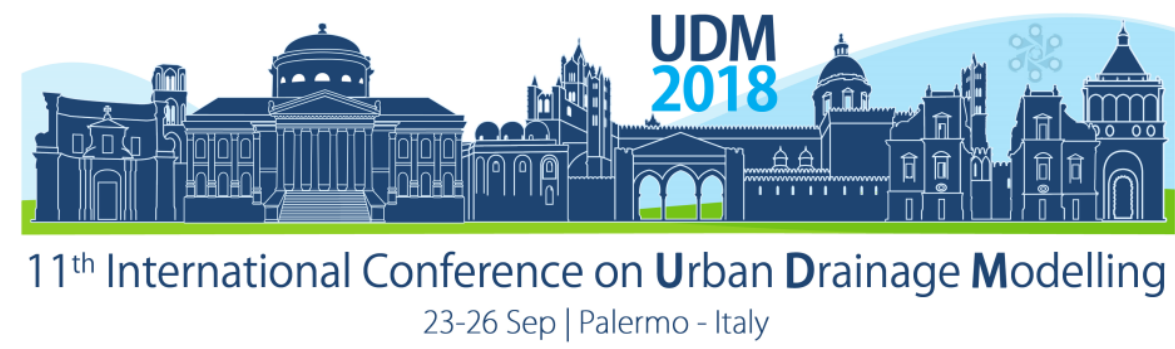

In the future, these challenges will be even greater due to the "internet of things" communication technologies, which lead to "ubiquitous sensing" capabilities with predicted 50 billion sensors by 2020 ("Internet of Things" 2018). At the same time, such an explosion of sensors will create many opportunities which are currently not well understood (Eggimann et al. 2017). Fragmented examples i) use proxies to infer important system variables, ii) harvest social media, iii) involve citizen scientists and, interestingly, iv) provide feedback to society, which could raise awareness and create a sense of empowerment and 'ownership' among local communities for their water systems.

To better understand these challenges and opportunities, we performed a horizon scan of emerging issues regarding the future of urban drainage and wastewater management.

\section{2. 'HORIZON SCANNING' TO IMPROVE SOCIETAL PREPAREDNESS FOR FUTURE OPPORTUNITIES AND THREATS}

"Horizon scanning is a systematic process that aims to identify potential threats and opportunities relative to a given set of objectives or phenomena to improve societal preparedness." (Sutherland et al. 2016). Horizon scanning is a common procedure in other scientific fields to identify issues which have just (not yet) emerged in mainstream investigation or debate, but may be important for the urban wastewater community. This is, because it is very realistic that they will occur, e.g. blockchain technology, or because they will have a strong impact on urban water management, e.g. a Bubonic Plague-type pandemic.

Methodologically, we modelled our horizon scan after those of Sutherland et al. (2017, 2016), which is performed annually since 10 years. In a series of first meetings, our core group of seven participants defined the objective: "What are emerging topics related to data that are not yet widely known to the water professionals and could have substantial effects on the monitoring and/or management of urban storm- and wastewater systems." Then, we proceeded as follows: i) initial collection of topics $(n=38)$, ii) curating topics into a final selection ( $n=36$ ), iii) consulting the global community via an online survey (see below), also collecting additional topics from the participants, iv) performing an intermediary workshop with a interdisciplinary expert panel and $v$ ) data analysis.

The online survey was designed to consult the global community about: i) familiarity with a topic and ii) importance of a topic, i.e. impact on urban wastewater management. Additionally, for each topic, we formulated one possible future scenario, describing how a topic will have manifested in the year 2030 (Vision2030). Familiarity and importance of a topic as well as how desirable and realistic a scenario is had to be indicated with a slider on scale from 0-100. Furthermore, we encouraged the respondents to suggest alternative scenarios and additional topics we may have missed. The survey was sent via email on 22 August 2017 (reminder 8 September 2017) to more than 2000 people in different communities and mailing lists. Respondents were asked to provide answers for all topics if possible, but were also able to skip any theme.

Regarding data analysis, we defined emerging topic as "more important than familiar". To identify the top ten emerging topics, we calculated the percentage of answers per topic where importance was higher than familiarity. We also identified the top ten emerging topics regarding importance and most feared Vision2030. 


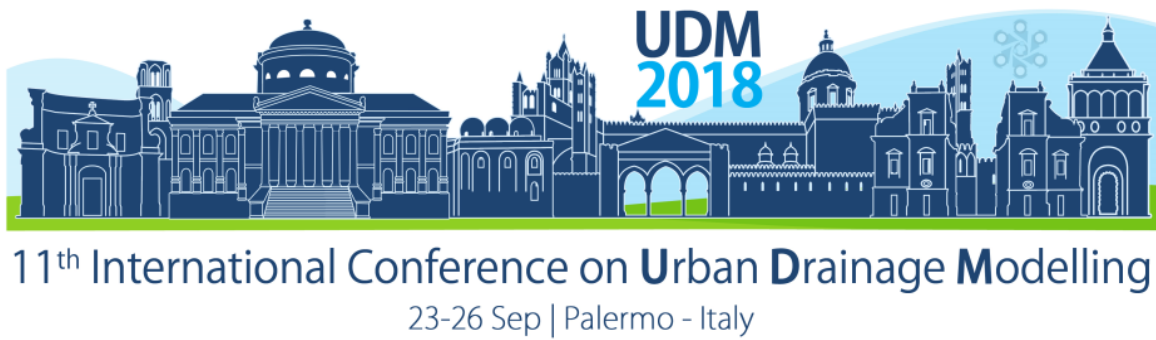

\section{THE TOPICS}

The top three topics regarding novelty were i) Linking Aquatic Ecology to Emissions, ii) Reinforcement learning and iii) Ontologies (Figure 1). The topics considered most important by the community were i) Integrated Management of sewers, WWTP and surface waters, ii) Data Validation and iii) Regulations. The mostly feared visions were those formulated for i) Global Changes, ii) Augmented Reality and iii) Serious Games (Table 1). A detailed description of the formulated visions and survey is available on the OSF project homepage ${ }^{1}$.

\section{CONCLUSIONS}

In the "internet of things" future, ubiquitous sensing will create many opportunities for urban drainage to overcome the data scarcity it has been struggling with for ages. On the other hand, new challenges arise with this transition. To better prepare for this future, we performed a Horizon Scan regarding emerging topics related to data that are not yet widely known to the water professionals and could have substantial effects on the monitoring and/or management of urban storm- and wastewater systems. Interestingly, our results suggest that a rather classical problem, i.e. the link between emissions and aquatic ecology, is still considered to be "novel" in the sense that the academic and professional communities consider it important, but are not familiar with it. This clearly shows a high demand for further research in this field. In addition, urban drainage should prepare for both push and pull drivers of urban water data collection. In our view, the revolutionary aspect of the modern digitization is that, first, data are now less costly and ubiquitously available, i.e. information on important boundary conditions such as population, or weather, etc., will be pushed through the internet. Second, and more relevant, other entities will be more interested in our data and "pull" urban water management data into external applications. Our positive feedback from the community suggests that Horizon Scanning is a useful exercise. Therefore, the urban drainage community, and especially our associations (e.g. IWA, IAHR) and working groups (e.g. IWGDM, SPN) should discuss who could take over such a foresight/stewardship activity on a routine basis.

\section{References}

Blumensaat, F., C. Ebi, S. Dicht, J Rieckermann, and M. Maurer. 2017. "Langzeitüberwachung Der Raum-Zeit-Dynamik in Entwässerungssystemen Mittels Niedrigenergiefunk - Ein Feldexperiment Im Großmaßstab.” Korrespondenz Abwasser 64 (07).

Eggimann, Sven, Lena Mutzner, Omar Wani, Mariane Yvonne Schneider, Dorothee Spuhler, Matthew Moy de Vitry, Philipp Beutler, and Max Maurer. 2017. "The Potential of Knowing More: A Review of Data-Driven Urban Water Management." Environmental Science \& Technology 51 (5): 2538-53. https://doi.org/10.1021/acs.est.6b04267.

"Internet of Things." 2018. Wikipedia. https://en.wikipedia.org/w/index.php?title=Internet_of_things\&oldid=835513023.

Sutherland, William J., Phoebe Barnard, Steven Broad, Mick Clout, Ben Connor, Isabelle M. Côté, Lynn V. Dicks, et al. 2017. "A 2017 Horizon Scan of Emerging Issues for Global Conservation and Biological Diversity." Trends in Ecology \& Evolution 32 (1): 31-40. https://doi.org/10.1016/j.tree.2016.11.005.

Sutherland, William J., Steven Broad, Jacqueline Caine, Mick Clout, Lynn V. Dicks, Helen Doran, Abigail C. Entwistle, et al. 2016. "A Horizon Scan of Global Conservation Issues for 2016." Trends in Ecology \& Evolution 31 (1): 44-53. https://doi.org/10.1016/j.tree.2015.11.007. Campisano, A., J. Cabot Ple, D. Muschalla, M. Pleau, and P. A. Vanrolleghem. 2013. "Potential and Limitations of Modern Equipment for Real Time Control of Urban Wastewater Systems." Urban Water Journal 10 (5): 300-311.

Lee, Dae Sung, and Peter A. Vanrolleghem. 2003. "Monitoring of a Sequencing Batch Reactor Using Adaptive Multiblock Principal Component Analysis." Biotechnology and Bioengineering 82 (4): 489-97

${ }^{1}$ https://osf.io/v76ju/ 
Proceedings of the 11th Int. Conference on Urban Drainage Modelling, 23-26 Sep. 2018, Palermo (ITALY). Ed. prof. Giorgio Mannina

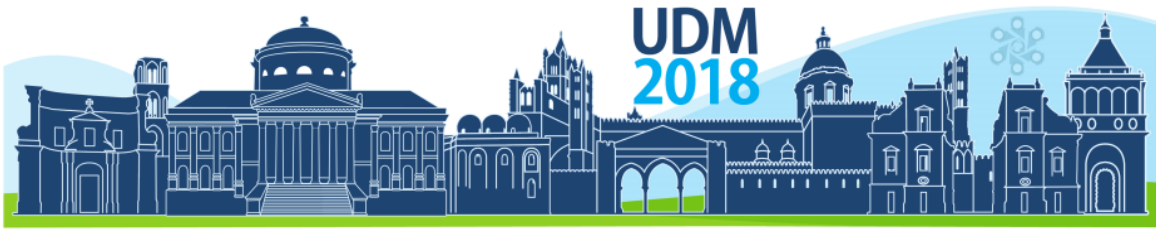

$11^{\text {th }}$ International Conference on Urban Drainage Modelling

23-26 Sep | Palermo - Italy

Table 1. The final ranking of topics according to novelty, importance for urban wastewater management and most feared manifestation. It can be seen that there are only few topics which are both unfamiliar and important. Interestingly, topics which relate to computer and information science, e.g. "Cybersecurity" rank comparably high across all areas.

\begin{tabular}{|c|c|c|c|}
\hline Rank & Most novel topics & Most important topics & Most feared visions 2030 \\
\hline 1 & 2.9 Linking Aquatic Ecology to Emissions & 4.3 Integrated Management & 6.5 Global Changes \\
\hline 2 & 2.7 Reinforcement learning & 2.1 Data Validation & 3.2 Augmented Reality \\
\hline 3 & 3.1 Ontologies & 6.1 Regulations & 3.3 Serious Games \\
\hline 4 & 3.5 Cybersecurity & 5.3 Resource Recovery & 3.6 Complexity - Blind Trust \\
\hline 5 & 1.5 Micropollutant and Pathogen Monitoring & 4.1 Decentralization & 3.5 Cybersecurity \\
\hline 6 & 1.6 Environmental DNA & 2.5 Real-Time Models & 6.2 Index-Based Insurances \\
\hline 7 & 3.6 Complexity - Blind Trust & 3.5 Cybersecurity & 1.8 Explicit Crowd-Sourcing \\
\hline 8 & 6.5 Global Changes & $\begin{array}{l}\text { 2.2 Metadata Collection and } \\
\text { Organization }\end{array}$ & 2.8 Software Sensing \\
\hline 9 & 5.1 Secondary Health Benefits & $\begin{array}{l}2.9 \text { Linking Aquatic Ecology to } \\
\text { Emissions }\end{array}$ & $\begin{array}{l}\text { 4.4 Data Collected at Personal } \\
\text { Resolution }\end{array}$ \\
\hline 10 & 1.1 Onsite High-Res. Mass Spectr. & 5.1 Secondary Health Benefits & 3.4 Smart Meters and Privacy \\
\hline
\end{tabular}

\begin{tabular}{|c|c|c|}
\hline \multirow[t]{8}{*}{ New Data Sources } & 1.1 Onsite High-Resolution Mass Spectrometry (144) & 10 \\
\hline & 1.2 Autonomous Sensor Platforms and Remote Sensing (136) & \\
\hline & 1.3 Sensing at High Spatial Resolution (145) & \\
\hline & 1.4 Low-Tech Sensors (138) & \\
\hline & 1.5 Micropollutant and Pathogen Monitoring (133) & \\
\hline & 1.6 Environmental DNA (107) & \\
\hline & 1.7 Implicit Crowd-Sourcing (129) & \\
\hline & 1.8 Explicit Crowd-Sourcing (130) & \\
\hline \multirow{9}{*}{$\begin{array}{l}\text { Data Management } \\
\text { \& Modelling }\end{array}$} & 2.1 Data Validation (127) & \\
\hline & 2.2 Metadata Collection and Organization (119) & \\
\hline & 2.3 Optimal Experimental Design (113) & \\
\hline & 2.4 Heterogeneous Data Quality (111) & \\
\hline & 2.5 Real-Time Models (113) & \\
\hline & 2.6 Data-Driven Models (105) & \\
\hline & 2.7 Goal-Oriented Learning (99) & \\
\hline & 2.8 Software Sensing (94) & \\
\hline & 2.9 Linking Aquatic Ecology to Emissions (100) & \\
\hline \multirow{6}{*}{$\begin{array}{l}\text { Interaction Data } \\
\text { \& Stakeholders }\end{array}$} & 3.1 Ontologies (66) & \\
\hline & 3.2 Augmented Reality (73) & \\
\hline & 3.3 Serious Games (72) & \\
\hline & 3.4 Smart Meters and Privacy (78) & \\
\hline & 3.5 Cybersecurity $(74)$ & \\
\hline & 3.6 Complexity ... Blind Trust (76) & \\
\hline \multirow{4}{*}{$\begin{array}{l}\text { New Water } \\
\text { Technologies }\end{array}$} & 4.1 Decentralization (102) & \\
\hline & 4.2 Technology Diversification (94) & \\
\hline & 4.3 Integrated Management (100) & \\
\hline & 4.4 Data Collected at Personal Resolution (85) & \\
\hline \multirow[t]{3}{*}{ New Services } & 5.1 Secondary Health Benefits (85) & \\
\hline & 5.2 Public Health Information (74) & \\
\hline & 5.3 Resource Recovery (91) & \\
\hline \multirow{6}{*}{$\begin{array}{l}\text { Societal Values \& } \\
\text { Implementation }\end{array}$} & 6.1 Regulations (79) & \\
\hline & 6.2 Index-Based Insurances (58) & \\
\hline & 6.3 Water Tariffs (74) & \\
\hline & 6.4 Transparent Compliance Assessment (55) & \\
\hline & 6.5 Global Changes (63) & 8 \\
\hline & 25 & 75 \\
\hline
\end{tabular}

Figure 1. Ranking of Topics according "novelty". The number in brackets indicates the number of respondents per topic, the number at the end of the bar the rank. Participants consider a proper model "Linking Aquatic Ecology to Emissions" (2.9) most unfamiliar, yet important for the field. Surprisingly, other contemporary topics, such as providing unprecedented "Public Health Information" (5.2) from wastewater analysis or transparent compliance assessment via blockchain technology (6.4) were already familiar or considered less important. 


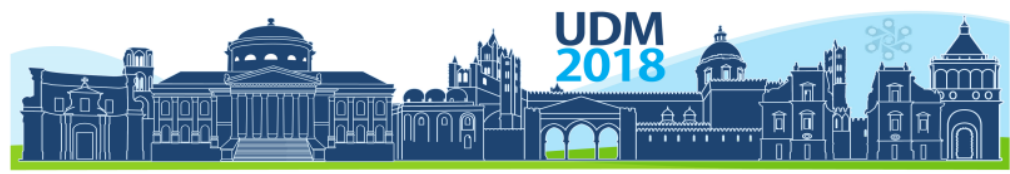

$11^{\text {th }}$ International Conference on Urban Drainage Modelling

23-26 Sep | Palermo - Italy

\title{
Policy Analysis for Better Protection of Receiving Waters during Wet Weather
}

\author{
Manny Liliane ${ }^{1}$, Fischer Manuel ${ }^{2}$ and Rieckermann Jörg ${ }^{1}$ \\ ${ }^{1}$ Eawag, Urban Water Management, $\mathrm{CH}-8600$ Dübendorf \\ ${ }^{2}$ Eawag, Environmental Social Sciences, $\mathrm{CH}-8600$ Dübendorf
}

\begin{abstract}
Although CSOs are expensive infrastructures, which are important to reduce pollution from urban areas during wet weather, they are often not operated effectively. Despite of technical difficulties, major problems in CSO monitoring and performance assessment are caused by non-technical bottlenecks. Through a policy analysis we identified organisational and political problems as the biggest obstacles to the effective operation of CSOs. In addition, we investigated effective measures or incentives to overcome organisational and political obstacles. Our results suggest that a surprisingly high $84 \%$ of the CSOs operated by Swiss wastewater associations are monitored. In most cases the information is used to improve operation, but not for better planning or for regulatory performance assessment. The most desirable instrument seem to be legislative performance targets, which is preferred by both wastewater associations and cantonal stakeholders. From a political point of view, the cantonal authorities also consider a transfer of competences from the municipalities to the wastewater associations to be effective, i.e. wastewater associations should operate CSOs instead of municipalities. In contrast, Swiss associations prefer financial incentives, such as a one-off subsidy for the installation of CSO monitoring equipment. Before implementing certain instruments, and in particular regulatory instruments, we highly recommend to assess their impact on overall policy processes and individual stakeholders. In the long term, only the implementation of a carefully balanced, uniform strategy can overcome organizational and political barriers and thus can lead to effective success in water protection.
\end{abstract}

Keywords: Receiving water protection during wet weather, monitoring, digitization, policy analysis

\section{IMPROVEMENTS IN RECEIVING WATER PROTECTION NEED MORE THAN JUST TECHNICAL SOLUTIONS}

Wastewater treatment plants (WWTP) are built in such a way that they treat all wastewater during dry weather. In contrast, during wet weather, rainfall runoff by far exceeds the hydraulic capacity of the WWTP and most of it is discharged untreated into rivers and lakes. To better protect receiving waters, combined sewer overflow tanks (CSOs) temporarily store runoff from small and medium-sized rain events. Although CSOs are rather expensive infrastructures, they are often not operated in an optimal way (Dittmer et al. 2015; Hoppe et al. 2016). The non-optimal operation concerns several elements. Firstly, operational data on the storage and overflow behaviour of the systems are often missing. Secondly, where measurement data are available, there is often a lack of understanding of how the data should be handled. For example, they are incorrectly logged, only stored in aggregated form, e.g. daily mean values, or only evaluated for operational aspects, e.g. triggering alarms in the event of malfunctions. Thirdly, for an effective implementation of water protection requirements, not only the operator should know about alarms, but data should also i) be reported periodically to regulators and ii) be processed and archived for future planning purpose. Finally, organisational processes with respect to data sharing and beyond are often not clearly regulated. The most common example is that WWTPs and CSOs are operated by different entities, which do not coordinate their efforts and thus do not operate the entire wastewater system in an optimal way (Rieckermann, Gruber, and Hoppe 2017). 


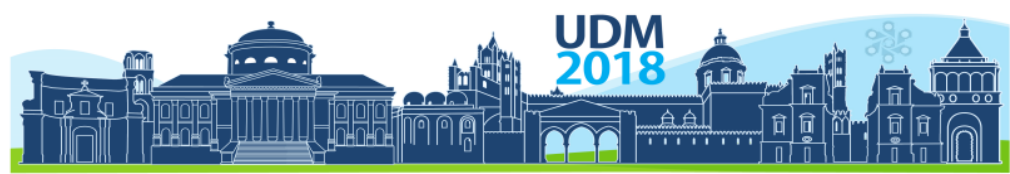

$11^{\text {th }}$ International Conference on Urban Drainage Modelling

23-26 Sep | Palermo - Italy

\begin{abstract}
While all four problems have more or less technical components and can therefore possibly be addressed with technical solutions, they all also have an organisational and political dimension. First, several hurdles on the organizational, legal and personal level can explain why measurement data at the level of WWTPs are missing. Second, different instruments could improve the understanding of the different stakeholders regarding the handling of CSO monitoring data, so that they can benefit from the full value of the data. Third, how exactly organisational processes related to measurement, data treatment and data sharing can be improved remains unclear. In this paper, we identify i) the biggest obstacles to the effective operation of CSOs and ii) investigate effective measures or incentives to overcome organisational and political obstacles.
\end{abstract}

\title{
2. POLICY ANALYSES SHOULD SHOW WHERE THE BIGGEST ORGANISATIONAL AND POLITICAL OBSTACLES ARE
}

We have applied methodological approaches from the field of public policy analysis, such as surveys, descriptive and concluding statistical methods, and related theories on policy instruments, actors' motivations, and policy processes (Fischer and Maggetti 2017; Fischer and Sciarini 2015). Specifically, we carried out a carefully designed survey and conducted expert interviews to elicit i) the current state of monitoring CSOs in Switzerland, ii) the handling of measurement data and iii) the opinion of cantonal authorities, which regulate receiving water protection during wet weather.

To assess the current state of monitoring CSOs, we first identified all actors in urban drainage practice and categorised them with regard to their functions and competencies. From this we derived wastewater associations as an important group of operators of CSOs in Switzerland and in addition the cantonal authorities as important regulators. In a second step, we designed an online survey for the wastewater associations, in close cooperation with the Swiss Water Association (VSA), where variables assessing technical, politicalorganizational and individual factors were collected. In a third step, complementary face-toface interviews were carried out with 23 (out of 26) cantonal authorities. For this purpose, a separate questionnaire was designed based on the online survey. In this way, the same variables can be examined from different stakeholder perspectives.

\section{ALTHOUGH BOTH ACTORS WOULD LIKE TO SET SPECIFIC TARGETS, REGULATORY AUTHORITIES ARE CRITICAL OF PERFORMANCE INDICATORS}

With 118 evaluable responses from 162 known wastewater associations in Switzerland, the online survey achieved a very good response rate of $73 \%$. As space is restricted, only selected results can be presented in this abstract.

The current state of monitoring CSOs in Switzerland: 98 of 118 wastewater associations in Switzerland operate at least one CSO. In total, the online survey covers 879 CSOs in Switzerland, which means that a surprising $84 \%$ of these CSOs are monitored. Furthermore, it is shown that approx. $30 \%$ of the wastewater associations do not store operational data with their original high temporal resolution, e.g. minutes, but in aggregated form as hourly or daily average values, which practically destroys the information and no longer corresponds to the state of the art. In addition, $47 \%$ do not, or only irregularly, evaluate this data, and $61 \%$ do not transfer them to engineering consultants or report performance to a regulator. Regarding the motivation to install measurement technology, we found that $76 \%$ use data primarily for operational purposes (Fig. 1, green bars), less to improve planning (yellow) and least for performance assessment (red). 


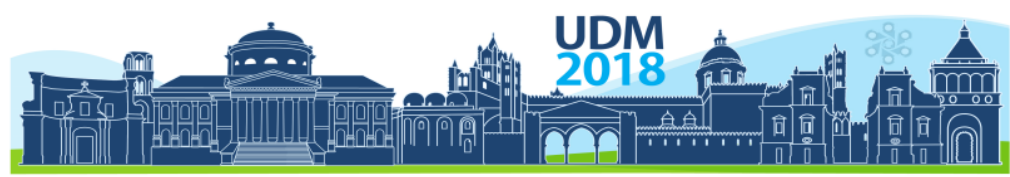

$11^{\text {th }}$ International Conference on Urban Drainage Modelling

23-26 Sep | Palermo - Italy

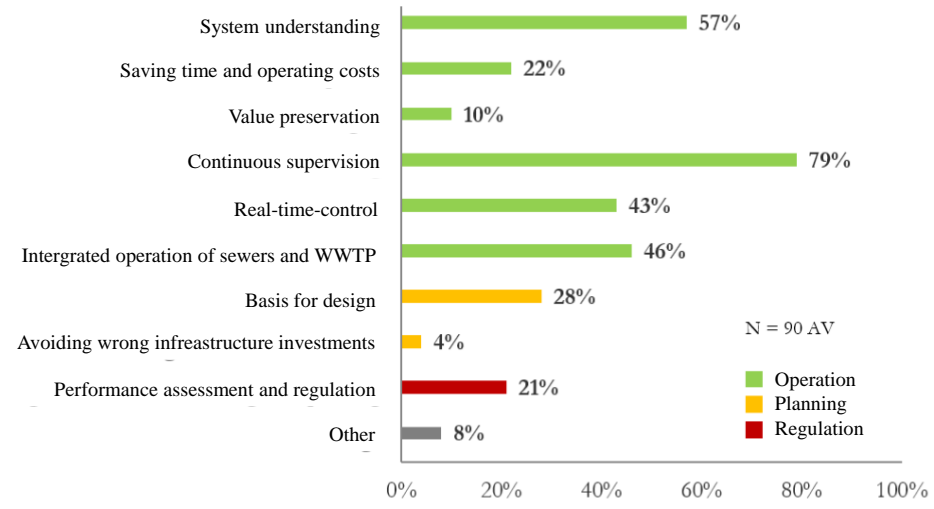

Figure 1. Motivation of wastewater associations $(\mathrm{N}=90)$ in Switzerland to use measurement technology in mixed water treatment plants. In order to better exploit the value of the measurement data, they should not only be used for operational optimisation (green), but also as planning bases (yellow) or for success control (red).

Effective measures or incentives to overcome organisational and political obstacles: A desirable instrument which should aid the use of data in better receiving water protection during wet weather (Table 1) seems to be legislative targets (rank 1). Interestingly, these are preferred by both wastewater associations $(\mathrm{AV})$ and cantonal stakeholders $(\mathrm{K})$. In contrast, the private sector, which could provide specifically-tailored products and services, does not seem to play a large role (rank 9 ) in Switzerland. From a political point of view, the cantonal authorities also consider a transfer of competences from municipalities to wastewater associations to be effective (rank 2). Specifically, regulators believe that the use of monitoring data only improves if wastewater associations take over the operation of CSOs from the municipal owners. In contrast, associations prefer financial incentives, such as a one-off subsidy for the installation of CSO monitoring equipment. Cantonal authorities

Table 1. Instrument ranking for wastewater associations (AV) and cantonal agencies $(\mathrm{K})$, incl. specific addressee for the implementation of the respective instrument. While targets are rated very positively by both actors, it is surprising that performance indicators are not highly rated by regulators.

\begin{tabular}{|c|c|c|c|c|}
\hline Suggested instrument & $\begin{array}{c}\text { Rank } \\
\text { (AV) }\end{array}$ & $\begin{array}{l}\text { Rank } \\
(\mathrm{K})\end{array}$ & $\begin{array}{l}\text { Who } \\
\text { (AV) }\end{array}$ & $\begin{array}{l}\text { Who } \\
\text { (K) }\end{array}$ \\
\hline Guideline & 2 & 4 & $\mathrm{~B} / \mathrm{K}$ & B \\
\hline Regulatory requirements (monitoring data) & 1 & 1 & $\mathrm{~B} / \mathrm{K}$ & $\mathrm{B}$ \\
\hline Performance indicators & 5 & 9 & VSA & $\mathrm{B}$ \\
\hline Subsidies (Montoring technology) & 3 & 6 & B & $\mathrm{K}$ \\
\hline Subsidies (Data analysis) & 5 & 7 & $\mathrm{~B}$ & $\mathrm{~K}$ \\
\hline Better products & 9 & 9 & & \\
\hline Tailored services & 7 & 5 & & \\
\hline (Further) education & 8 & 3 & & \\
\hline Events & 7 & 6 & VSA & \\
\hline Increased regulatory activities & 6 & 8 & & \\
\hline Transfer of competences & 4 & 2 & & \\
\hline Own suggestions & 10 & & & \\
\hline
\end{tabular}

AV: Wastewater associations, K: Cantonal autorities, B: Federal authorities, VSA: Swiss wastewater associtation 


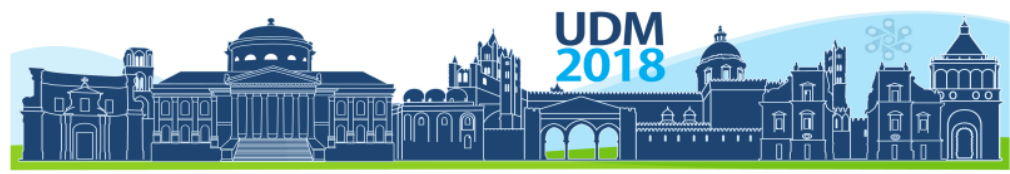

$11^{\text {th }}$ International Conference on Urban Drainage Modelling

23-26 Sep | Palermo - Italy

consider further education and training as very relevant, which is less the case for the associations. It is astonishing that wastewater associations take a rather positive view of performance indicators for a performance review of the CSOs (rank 5), while these take the last place in the cantonal ranking.

Our regression analyses show that the older a wastewater association is, the more likely it is that measurement data from all CSOs will be collected in a SCADA system and archived in a database. This also applies to larger wastewater associations with many municipalities and the presence of a managing director. The more recently a system-wide general drainage plan has been developed and the more recently it was updated, the more likely CSO data will be evaluated on a regular basis, e.g. several times per year or even monthly. This is also the case with an increasing integrated view of the entire wastewater system, i.e. jointly operating sewers and WWTP.

\section{CONCLUSIONS}

Our research suggests that both wastewater associations and cantonal authorities in Switzerland prefer regulatory instruments to promote the use of monitoring data to better protect receiving waters from urban wet-weather impacts. The first priority for both is the introduction of targets, e.g. number of CSO spills per year, which must be met by the operators. If targets are set, this requires firstly that operators collect measurement data, secondly that these are forwarded to the regulator and thirdly that they are used in performance assessment. Consequently, operators and cantonal authorities are equally involved in the introduction of targets. It is surprising, to say the least, that the associations themselves are in favor of intervention from cantonal or federal government. It is therefore assumed that the wastewater associations lack a trend-setting guideline. A transfer of competences from the municipalities to the wastewater associations is also generally preferred.

A major organizational obstacle lies in the division of the operation of wastewater treatment plants, CSOs and sewerage systems among three different operators which are municipalities, wastewater associations and private individuals. This split of competencies also prevents the integrated operation of sewers and WWTPs (and receiving waters). In our view, before designing certain instruments, and regulatory instruments in particular, we highly recommend to assess their impact on overall policy processes and individual stakeholders.

In the long term, success in water protection can only be achieved if a carefully balanced, uniform and common strategy is developed and implemented. Specifically, there is not much sense in reporting the functioning of the CSOs to regulatory authorities if it is not precisely defined how they are used to monitor success and what happens if performance is unsatisfactory.

\section{References}

Dittmer, U., P. Alber, C. Seller, and W. Lieb. 2015. "Kenngrössen Für Die Bewertung Des Betriebes von Regenüberlaufbecken." In .

Fischer, Manuel, and Martino Maggetti. 2017. "Qualitative Comparative Analysis and the Study of Policy Processes." Journal of Comparative Policy Analysis: Research and Practice 19 (4):345-61. https://doi.org/10.1080/13876988.2016.1149281.

Fischer, Manuel, and Pascal Sciarini. 2015. "Drivers of Collaboration in Political Decision Making: A Cross-Sector Perspective." The Journal of Politics 78 (1):63-74. https://doi.org/10.1086/683061.

Hoppe, H., K. Fricke, S. Kutsch, C. Massing, and G. Gruber. 2016. "Von Daten Zu Werten - Messungen in Entwässerungssystemen." Aqua \& Gas 96 (10):26-31.

Rieckermann, J., G. Gruber, and H. Hoppe. 2017. Zukunftsfähige Systeme Zur Regenwasserbehandlung Brauchen Datenbasierte Betriebs-, Planungs- Und Vollzugskonzepte. 


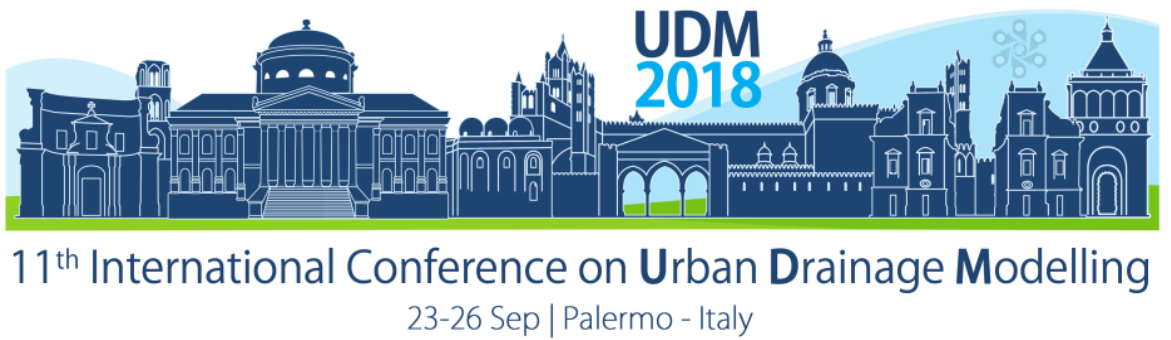

\title{
Exploring the Use of Low Impact Development Strategies in a Low-Income Settlement in São Carlos, Brazil
}

\author{
Maria Fernanda Nóbrega dos Santos ${ }^{1}$, Anaí Floriano Vasconcelos ${ }^{1}$ and Ademir Paceli Barbassa ${ }^{1}$ \\ ${ }^{1}$ Federal University of São Carlos (UFSCar), Department of Civil Engineering, São Carlos, Brazil
}

\begin{abstract}
The challenges of applying integrated stormwater management strategies in developing countries such as Brazil are particularly complex due to economic, environmental, and wider social issues in these localities. Factors like housing deficits, real estate speculation, urban land costs, massive demand for affordable housing, and the attempt to associate economic development with environmental preservation have led researchers in the drainage field to seek different models of urbanization. In this context, the present work aims to explore the possibilities of using low impact development (LID) strategies in a low-income settlement in the city of São Carlos, Brazil for the runoff management (two-year return period). To evaluate the feasibility and hydrological performance of the proposals, three scenarios were simulated in Storm Water Management Model (SWMM): Scen.CONV, a conventional urbanization and storm sewer drainage system; Scen.WELL, a conventional urbanization associated with the use of an infiltration well to disconnect the lots; and Scen.LID, which uses vegetative swales and infiltration trenches associated with urbanistic changes such as land use/imperviousness coefficients and roads typologies. Comparing Scen.CONV with Scen.WELL, the results indicated a potential 18\% reduction in the linear length of buried conduits and a $40 \%$ reduction in the number of curb inlets. In the Scen.LID, the use of combined LID strategies allowed for the source control of all of the surface runoff, excluding the need for conventional drainage systems. The results also indicated a decrease of $60 \%$ in the peak flows of Scen.CONV in comparison with Scen.WELL and of $100 \%$ in relation to Scen.LID.
\end{abstract}

Keywords: Low Impact Development; Low-Income Settlement; Scenarios Modelling

\section{INTRODUCTION}

Stormwater management systems, which formerly had control over water quantity as their main purpose, now comprise many other objectives as important as the initial one. Zhou (2014) discussed how population growth and climate changes have added challenges to the field, indicating that nowadays, water quality control, visual amenity of the projects, multiple uses of these areas, and protecting the natural environment are frequent themes in urban stormwater management projects.

In the search for methodologies that can both achieve the sustainability goals and propose practical project guidelines for integrated stormwater management in urban areas, several initiatives have emerged worldwide; although they use different terminology, they still feature a great consonance in their objectives (Fletcher et al., 2015).

In a summarized form, the hydrological importance of these approaches is the possibility of reducing the negative impacts on the water cycle as a result of urbanization. By runoff source control (decreasing its speed and volume) using certain storage and infiltration techniques, time of concentration and pre-occupation flows of the basins are maintained, effects that Urbonas and Stahre (1993) earlier described. 


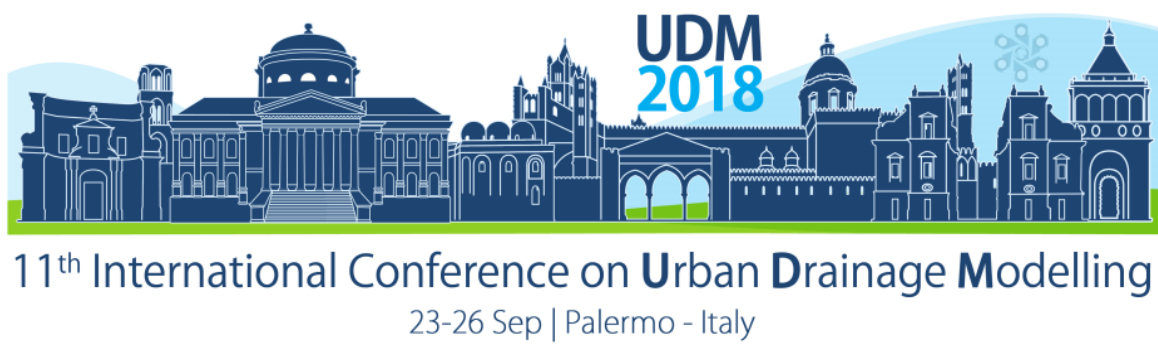

One of integrated stormwater management approaches is low impact development (LID), a widespread term in North America and New Zealand. LID emerged as a multidisciplinary proposal, gathering urban planning, landscape ecology, environmental sciences and hydrology, as defined in Prince George's County LID Manual (PGCo, 1999).

According to LID approach, hydrological objectives must be incorporated into urban planning as early as possible, following these key concepts: using hydrology as the integrating framework; thinking micromanagement; controlling stormwater at the source; using simplistic, nonstructural methods and creating a multifunctional landscape (PGCo, 1999, p. 22).

However, applying LID principles become especially complex in low-income settlement projects that are being built in developing countries. The social inequality present in these countries, real estate speculation, and the high value of urban land, has reduced the size of the lots, making LID strategies difficult to implement; as they usually require a considerable amount of permeable area and some investment by the owners (Eckart et al., 2017).

To better understand the challenges of introducing LID strategies into a low-income settlement, it can mentioned the discrepancy between the concepts of high density and minimum lot sizes found in the Brazilian reality versus those presented in the LID manuals, an important source of LID technical guidance (e.g. WSU, 2012; MDE, 2009; PGCo, 1999).

WSU (2012) classifies urban areas with more than 6 dwelling units per acre (DUA) as high density (lot area of $674 \mathrm{~m}^{2}$ ), and recommends to minimize individual lot sizes to 278-372 $\mathrm{m}^{2}$. Jacob and Lopez (2009), when studying the relationship between urban density in the USA and runoff quality parameters, proposes to increase the standard suburban density of 3-5 DUA (lots with areas ranging from 1348 to $809 \mathrm{~m}^{2}$ ) to 8 DUA (lot area of $505 \mathrm{~m}^{2}$ ), in order to achieve a significant reduction in per capita pollutant loads.

Fletcher et al. (2015), also indicates that one of the frontiers in the sustainable drainage field, is actually laying on the discussion about how these approaches will evolve face to the current trends of densification, since urban sprawl was prevalent at the time LID emerged.

In this context, the objective of this work is to explore the possibilities and the effects of applying LID strategies for stormwater management in a low-income settlement in Brazil, with the additional challenges presented by high density land use pattern (18 DUA), small lots (average lot area of $172.5 \mathrm{~m}^{2}$ ) and social-economic constraints. Further, this research validates the feasibility of these projects using hydraulic-hydrological scenarios modelling.

Discussing ways of adapting LID principles into these localities reality is also an important issue, given the perspective that in Brazil alone, there is currently a deficit of more than six million housing units, including those that are considered to be inadequate and irregular settlements, like the favelas (FJP, 2017).

\section{MATERIALS AND METHODS}

\subsection{Site and study object}

The city of São Carlos is situated in the center of São Paulo state. The region's soil is mainly characterized by its high permeability to water, confirmed by the conduction of double ring infiltrometer testing in the project area (the results indicated an infiltration rate of $226 \mathrm{~mm} / \mathrm{h}$ ). Regarding its climate, São Carlos is described as Aw, Group A, according to the Köppen classification. The average annual precipitation is $1558.3 \mathrm{~mm}$ (INMET, 2010). 


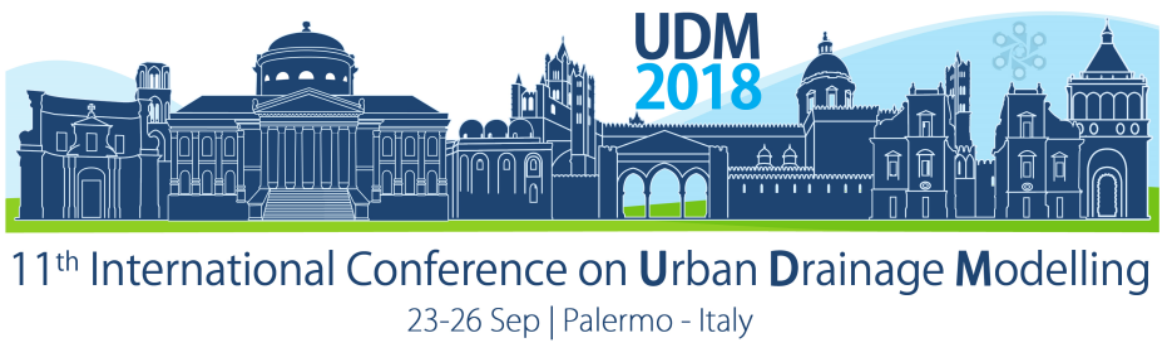

The settlement "Américo Alves Margarido" was chosen for the study since it is representative of low-income housing not only in São Carlos, but also in medium-sized municipalities in Brazil. The settlement was built in 1999; it has a total area of $209730 \mathrm{~m}^{2}$ divided into 698 lots with an average area of $172.5 \mathrm{~m}^{2}$ (lot dimensions: $7.5 \times 23.0 \mathrm{~m}$ ).

The following conditions were assumed in order to design the drainage systems: runoff management with a two-year return period, a project rain that was 12 minutes in duration (equal to basin's time of concentration), and a rainfall intensity of $85.34 \mathrm{~mm} / \mathrm{h}$ based on São Carlos intensity-duration-frequency (IDF) curve (Barbassa, 1991). The conventional drainage network was pre-dimensioned by the rational method and according to the guidelines of the São Paulo State Environmental Agency (CETESB, 1980); the techniques' storage volumes were determined using the rain-envelope method (Urbonas and Stahre, 1993).

\subsection{Modelled scenarios}

The scenarios were simulated in SWMM, version 5.1, using Horton's infiltration method and kinematic wave flow routing method. In what follows, a description of modelled scenarios.

Scen.CONV. This scenario was modelled by simulating the real characteristics of the settlement. The configuration of the lots, roads, and the conventional drainage system were reproduced (curbs, gutters, inlets, and storm sewer pipes). The imperviousness coefficients were as follows: $100 \%$ for roads, $80 \%$ for lots, and $20 \%$ for other urban areas.

Scen.WELL. This was modelled to represent one of the techniques that have been mostly used in this type of settlement: the infiltration wells (in part because they require small areas for their implantation, and also because the municipalities have recently been encouraging them under urban regulations). The current urbanization patterns were maintained.

Scen.LID. This was based on LID combined structural and non-structural strategies. In this scenario, some modifications were made in the lots' occupation patterns to allow the use of vegetative swales as well as in the roads' configuration to enable the use of swale trenches. This was done in order to achieve the objective of $100 \%$ of runoff source control.

\section{RESULTS AND DISCUSSION}

One of the solutions to make possible applying LID principles, even with the settlement constraints, was to change the streets configuration. These modifications allowed not only the implantation of infiltration and detention techniques, but also provided a more livable urban area, pedestrian oriented design and socially focused community.

Figure 1 contains an actual image of one of the settlement streets and a perspective of how the same street would look with the suggested changes, according to the Scen.LID project.

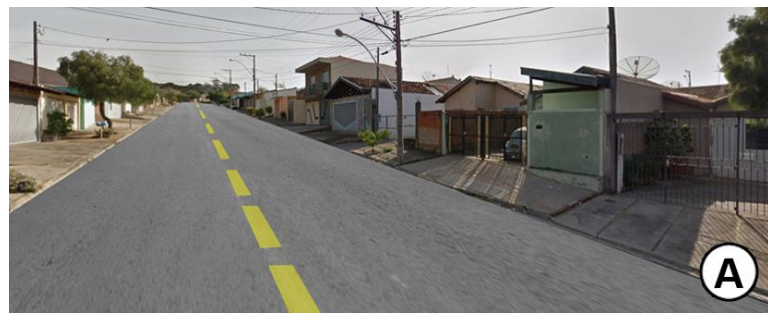

Figure 1. A) Image of one of the settlement streets.

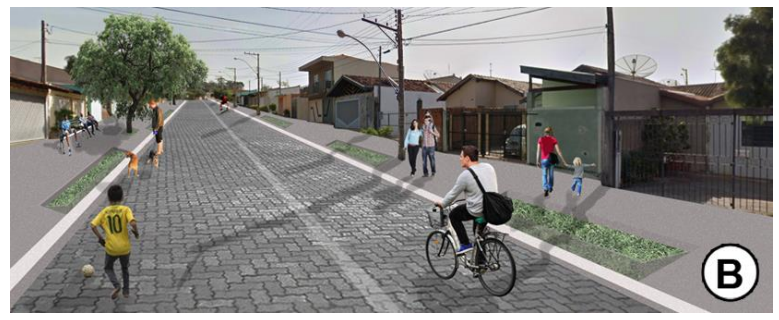

B) Photomontage of the same street in the Scen.LID. 


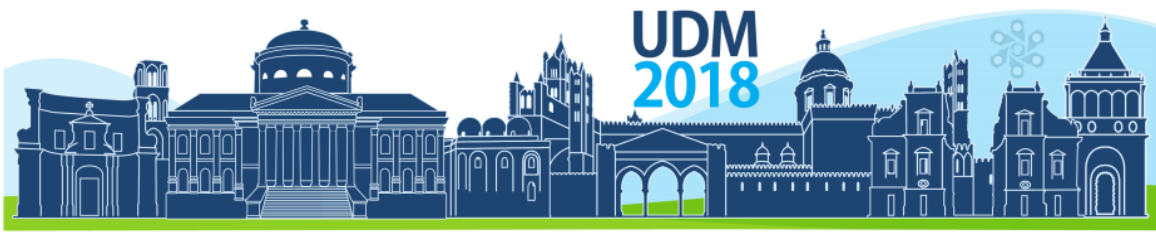

$11^{\text {th }}$ International Conference on Urban Drainage Modelling

23-26 Sep | Palermo - Italy

When comparing the Scen.CONV with Scen.WELL, the use of the infiltration wells to disconnect the lots led to a reduction of both diameter and extension of the buried conduits (18\% decrease in storm pipes' total linear length) and in the number of curb inlets $(40 \%$ decrease). These reductions were even greater in Scen.LID: the use of LID combined strategies eliminated the need for conventional drainage systems, as presented in Table 1.

Table 1. Scenarios' drainage systems summary.

\begin{tabular}{|c|c|c|c|c|c|c|c|c|c|c|c|c|}
\hline \multirow{3}{*}{ Scenarios } & \multicolumn{6}{|c|}{ Conventional Drainage System } & \multicolumn{6}{|c|}{ Low Impact Development Strategies } \\
\hline & \multicolumn{5}{|c|}{ Storm pipes' total linear length } & \multirow{2}{*}{$\begin{array}{l}\text { Curb } \\
\text { inlets } \\
\text { (unit) }\end{array}$} & \multicolumn{3}{|c|}{ Street controls } & \multicolumn{3}{|c|}{ Lot controls } \\
\hline & $\begin{array}{c}\varnothing 0.4 \\
(\mathrm{~m})\end{array}$ & $\begin{array}{c}\varnothing 0.6 \\
(\mathrm{~m})\end{array}$ & $\begin{array}{c}\varnothing 0.8 \\
(\mathrm{~m})\end{array}$ & $\begin{array}{c}\varnothing 1.0 \\
(\mathrm{~m})\end{array}$ & $\begin{array}{c}\varnothing 1.2 \\
(\mathrm{~m})\end{array}$ & & Type & $\begin{array}{c}\mathrm{Vol}^{*} \\
\left(\mathrm{~m}^{3} / \mathrm{m}^{2}\right)\end{array}$ & $\begin{array}{l}\text { Items } \\
\text { (unit) }\end{array}$ & Type & $\begin{array}{c}\text { Vol }^{*} \\
\left(\mathrm{~m}^{3} / \mathrm{m}^{2}\right)\end{array}$ & $\begin{array}{l}\text { Items } \\
\text { (units) }\end{array}$ \\
\hline Scen.CONV & 409 & 406 & 179 & 118 & 139 & 60 & & - & - & & - & - \\
\hline Scen.WELL & 365 & 514 & 139 & - & - & 36 & - & - & - & Well & 0.024 & 794 \\
\hline Scen.LID & & - & - & - & - & - & $\mathrm{Sw}-\mathrm{Tr}$ & 0.021 & 406 & Swale & 0.016 & 698 \\
\hline
\end{tabular}

${ }^{*}$ Specific volume: for each technique, the necessary volume to control the imperviousness area runoff in $\mathrm{m}^{3} / \mathrm{m}^{2}$

Figure 2 illustrates the settlement master plan with the conventional drainage system (storm sewer pipes) as well as the lots and roads configurations in the three different scenarios.
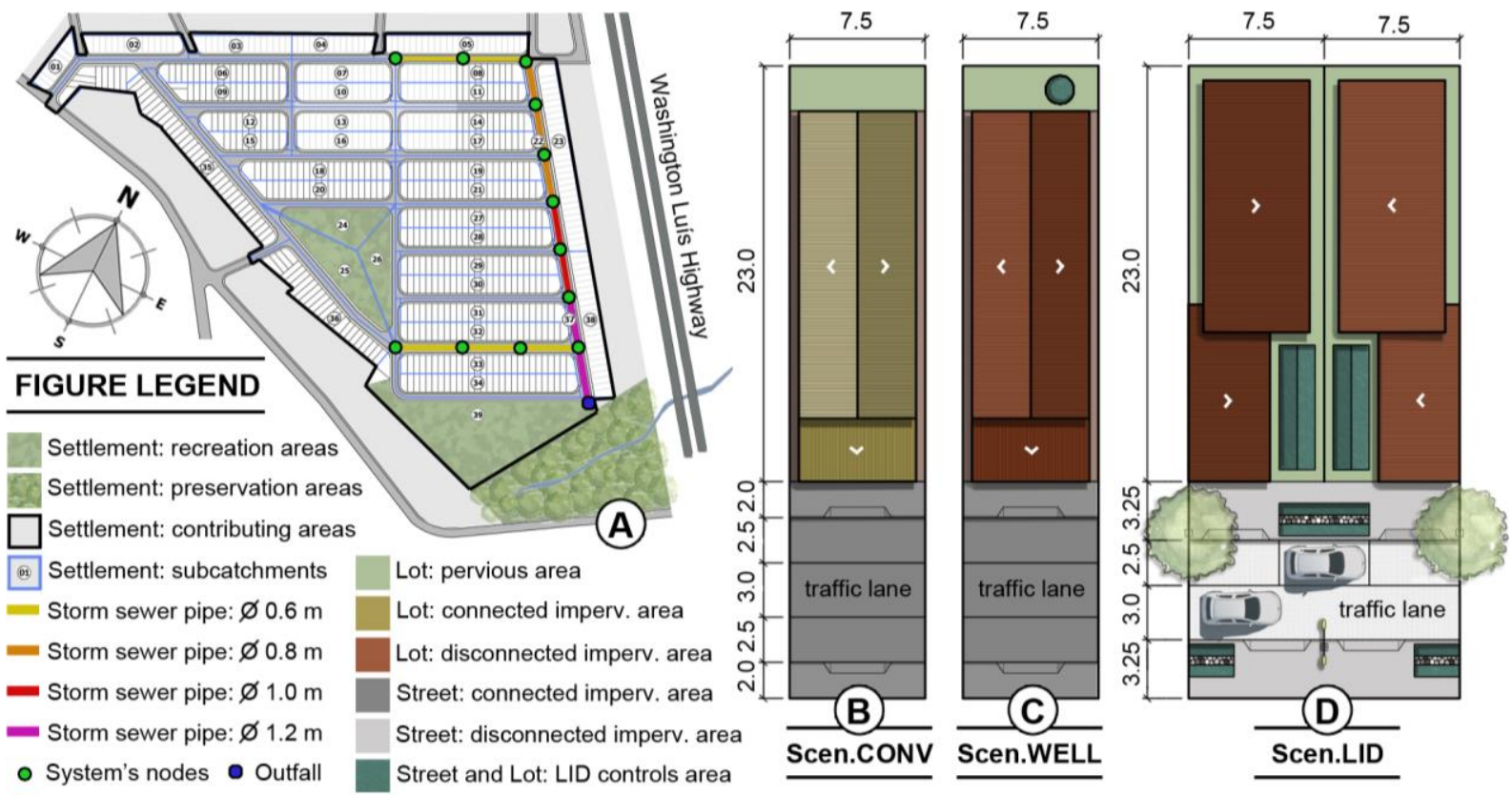

Figure 2. A) Settlement master plan and drainage system. B) Lot and road configuration for Scen.CONV.

C) Lot and road configuration for Scen.WELL. D) Lot and road configuration for Scen.LID.

Adapted from Google Maps (2018).

Adapted from Google Maps (2018).

The data analysis revealed a peak flow decrease in the outfall node of the conventional drainage system from $3.3 \mathrm{~m}^{3} / \mathrm{s}$ in Scen.CONV to $1.3 \mathrm{~m}^{3} / \mathrm{s}$ in Scen.WELL; it reached zero in Scen.LID. The total volume outflow in Scen.CONV was $2458 \mathrm{~m}^{3}$ and $913 \mathrm{~m}^{3}$ in Scen.WELL. 


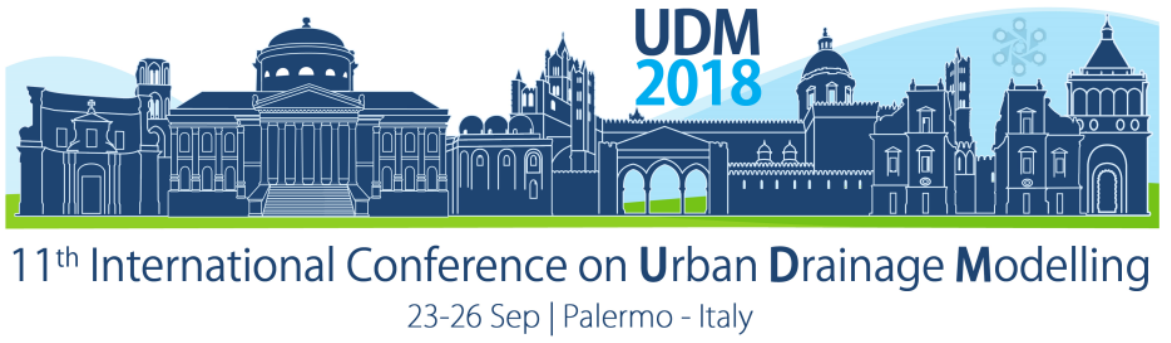

\section{CONCLUSIONS}

Even though the small dimensions of this low-income settlement imposed constraints, characteristics like the local soil's high permeability and the adoption of urban changes in the ScenLID allowed for successful source control of all of the area runoff for the return period.

By transforming the settlement's inner streets into one-way local roads, reducing the number of parking lanes by half, and increasing the sidewalk width, areas that previously were exclusively meant for vehicles now can be used to implement infiltration techniques. Besides, these areas can be used to build gardens, tree planting, street furniture, and also, to provide more security and walkability for pedestrians, turning the street into a multifunctional space.

The hydraulic-hydrological modelling results confirmed the proposal feasibility for the project conditions, evidencing the potential that LID approach could have in these settlements. Further studies are now assessing the social and economic benefits of the project.

\section{Acknowledgements}

The authors would like to thank the National Council for the Improvement of Higher Education (CAPES) for the scholarship grant and financial support for research.

\section{References}

Barbassa, A.P. (1991) Simulação do efeito da urbanização sobre a drenagem pluvial na cidade de São Carlos, SP. PhD thesis, Dept. Hydraulic and Sanitation, Univ. of São Paulo, São Carlos, Brazil.

CETESB. (1980) Companhia Ambiental do Estado de São Paulo, Departamento de Águas e Energia Elétrica. Drenagem urbana: Manual de Projeto. São Paulo: DAEE/CETESB.

Eckart, K.; McPhee, Z. and Bolisetti, T. (2017) Performance and implementation of low impact development - A review. Science of The Total Environment, 607-608(12/2017), 413-432.

FJP. (2017) Fundação João Pinheiro, Diretoria de Estatística e Informações. Relatório do Déficit Habitacional no Brasil, elaborado com base nos dados do IBGE/PNAD 2015. Belo Horizonte: DIREI/FJP.

Fletcher, T.D.; Shuster, W.; Hunt, W.F.; Ashley, R.; Butler, D.; Arthur, S.; Trowsdale, S.; Barraud, S.; SemadeniDavies, A.; Bertrand-Krajewski, J.; Mikkelsen, P.S.; Rivard, G.; Uhl, M.; Dagenais, D. and Viklander, M. (2014) SUDS, LID, BMPs, WSUD and more - The evolution and application of terminology surrounding urban drainage. Urban Water Journal 12(7), 525-542.

INMET. (2010) Instituto Nacional de Meteorologia. Normais Climatológicas Brasil: 1981-2010. Brasília: INMET.

Jacob, J.S. and Lopez, R. (2009) Is denser greener? An evaluation of higher density development as an urban stormwater-quality best management practice. Journal of the American Water Resources Association 45(3), $687-701$.

MDE. (2009) Department of the Environment - Water Management Administration. Maryland Stormwater Design Manual: Volumes I and II. Maryland.

PGCo. (1999) Prince George's County. Department of Environmental Resources. Low-Impact Development Design Strategies: an integrated design approach. Maryland.

Urbonas, B. and Stahre, P. (1993) Stormwater detention for drainage, water quality and CSO management. New Jersey: Practice-Hall.

WSU. (2012). Washington State University. Low impact development technical guidance manual for Puget Sound. Puget Sound Partnership. Washington.

Zhou, Q. (2014) A review of sustainable urban drainage systems considering the climate change and urbanization impacts. Water. MDPI. Basel 6(4), 976-992. 


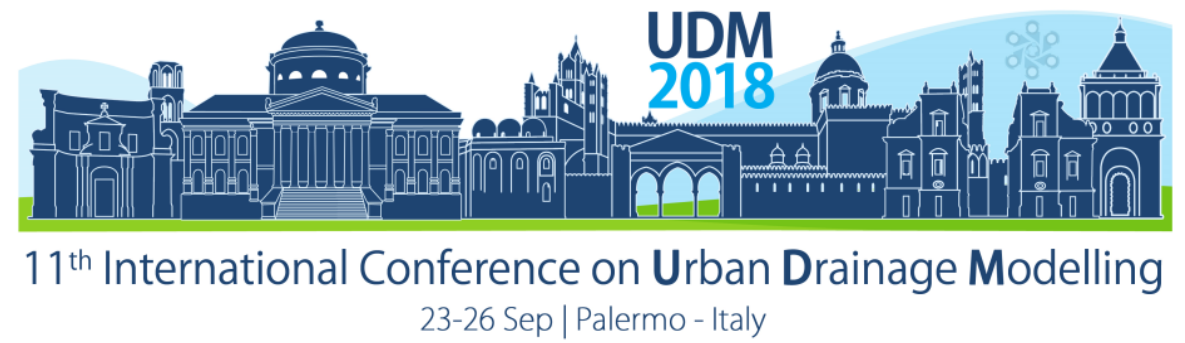

\title{
Controlling Stormwater Runoff from Impermeable Areas by Using Smart Inlets
}

\author{
Nils Kändler ${ }^{1}$, Ivar Annus ${ }^{1}$, Anatoli Vassiljev ${ }^{1}$, Raido Puust ${ }^{1}$ and Katrin Kaur ${ }^{1}$ \\ ${ }^{1}$ Tallinn University of Technology, Department of Civil Engineering and Architecture, Tallinn, Estonia
}

\begin{abstract}
Climate change and rapid urbanization are driving the need for improved urban stormwater runoff strategies. Urban stormwater drainage systems are severely affected by the changing climate bringing along inter alia more intense rainfall events. The pipeline system, usually having limited capacity, is unable to cope with these excessive flows and becomes surcharged. This may trigger overland flow from the drainage manholes and activate combined sewer overflows. Both events have negative consequences and therefore should be avoided. There are available effective solutions, like low impact development techniques for the catchments under development. However, options for retrofitting the existing drainage facilities are much more limited. Enlarging the pipelines, which has been a traditional response for rising demands is often financially unrealistic due to the large scope of the work. Therefore, recent advances in „smart“ water system technologies are considered as an opportunity to meet the future challenges. In this study the concept for controlling stormwater outflow from impervious catchment areas, i.e. parking lots is developed. The target is to find a solution that is affordable and can be implemented with minor disturbances in the area. For that, a novel approach of controlling water flow by regulating the inflow to the manholes is analysed. The adjustable gullies are real time controlled by coupling rulebased algorithms with distributed model predictive control. The concept is successfully tested in a 12 ha impervious catchment area in Tallinn.
\end{abstract}

Keywords: urban drainage system; real time control; stormwater inlet control; controlled floods

\section{INTRODUCTION}

Stormwater systems in urban areas are facing greater stress due to fast spatial development and more intense rainfall events caused by changing climate (Langeveld et al., 2013). Increase in the area of impervious surfaces accelerate the runoff response of the urban drainage system (UDS) therefore rising the peak flow and the risk of the system surcharge. According to the trend analysis of extreme precipitations in Europe, the frequency of these events will rise in the future (Madsen et al., 2014). This means that UDS have to operate outside their design limits more often. The volume of water exceeding system capacity will be released through the street manholes and will consequently cause overland flow. The activation of combined sewer overflows (CSO) leading untreated wastewater into the nature is the other way of system response. Both events have negative consequences to the urban environment (Sörensen et al., 2016).

Cities and towns have traditionally responded to the increasing demand by adjusting the capacity of the grey infrastructure, i.e. pipelines. Taking into account the rapid urbanization and trend analysis for the future rainfall events, the task of rebuilding the existing UDS seems financially unrealistic (de Bruijn et al., 2017). Therefore, there are several methods under investigation, like low impact development (LID), to create more feasible options for urban runoff reduction (Houdeshel et al., 2011; Joksimovic and Alam, 2014). LID is usually an option 


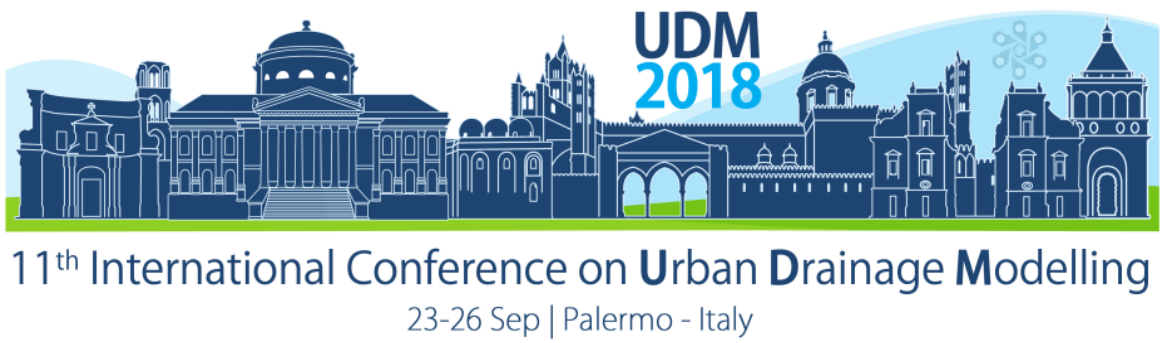

for new urban catchments under development, while real time control (RTC) is utilized to improve the operation of the existing UDS (Beeneken et al., 2013).

Although there are quite many handbooks and guidelines available for planning LID for new catchment areas, methods for retrofitting existing systems having substantial imperviousness and dense urban environment still need to be improved (Campisano et al., 2013). Parking lots situated around shopping centres are good example of this type of areas. The surface of these areas is usually covered with watertight layer and the site has limited space to place more natural retention systems like LID. As these areas contribute highly on urban runoff, it is evident that water utilities responsible for UDS operation are trying to compel landowners for runoff reduction. Because of limited options available this endeavour is prone to failure (Bach et al., 2014). This study attempts to fill this gap to develop affordable and effective control strategy that could be applied for reducing runoff from existing impermeable areas, i.e. parking lots.

\section{MATERIALS AND METHODS}

Parking lots with large impermeable areas usually have drainage systems that consist of stormwater inlets, i.e. gullies, manholes and pipelines. Surface layer of the lot has a slight slope towards the inlets. Each inlet usually has catchment area up to $1000 \mathrm{~m}^{2}$. The area is surrounded by raised pedestrian walkways with street curbs by avoiding side flow and creating a safe route for people. The system is designed to capture and direct the rainfall to the downstream as fast as possible.

As discussed in many articles, this design target is in contradiction to modern urban drainage management principles (Eckart et al., 2017). It has been found that keeping water upstream of the system for a limited period by triggering controlled minor flood will reduce the peak flow significantly. To follow this approach, a strategy was developed in this research to use the existing surface for accumulation of excessive flow. This task was achieved by applying recent advances in "smart" control techniques, i.e. sensors, actuators and algorithms.

Existing inlets have to be replaced with smart manhole covers. Each cover is equipped with a communication unit, water depth sensor and mechanism to adjust the inlet of the gully. As those actuators have low energy consumption, solar panels can be used to feed the system. This means that there is no need to rebuild existing manholes and demolish the pavement to install the cables. Outlet of the system has to be equipped with water level sensor and one additional sensor is needed to detect the rainfall. The system has a novel two level control algorithm - centralised rule based control (RBC) for activating the system and distributed model predictive control (DMPC) for grid adjustments. Both RBC and DMPC are seen as effective ways to drive real time control of UDS (García et al., 2015). The concept of the system is presented in Figure 1. 


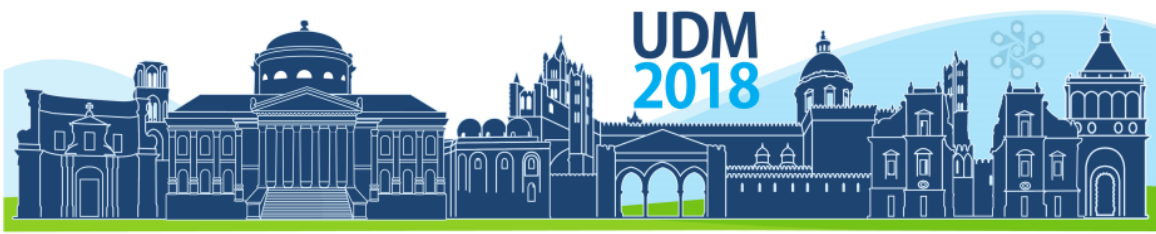

$11^{\text {th }}$ International Conference on Urban Drainage Modelling

23-26 Sep | Palermo - Italy

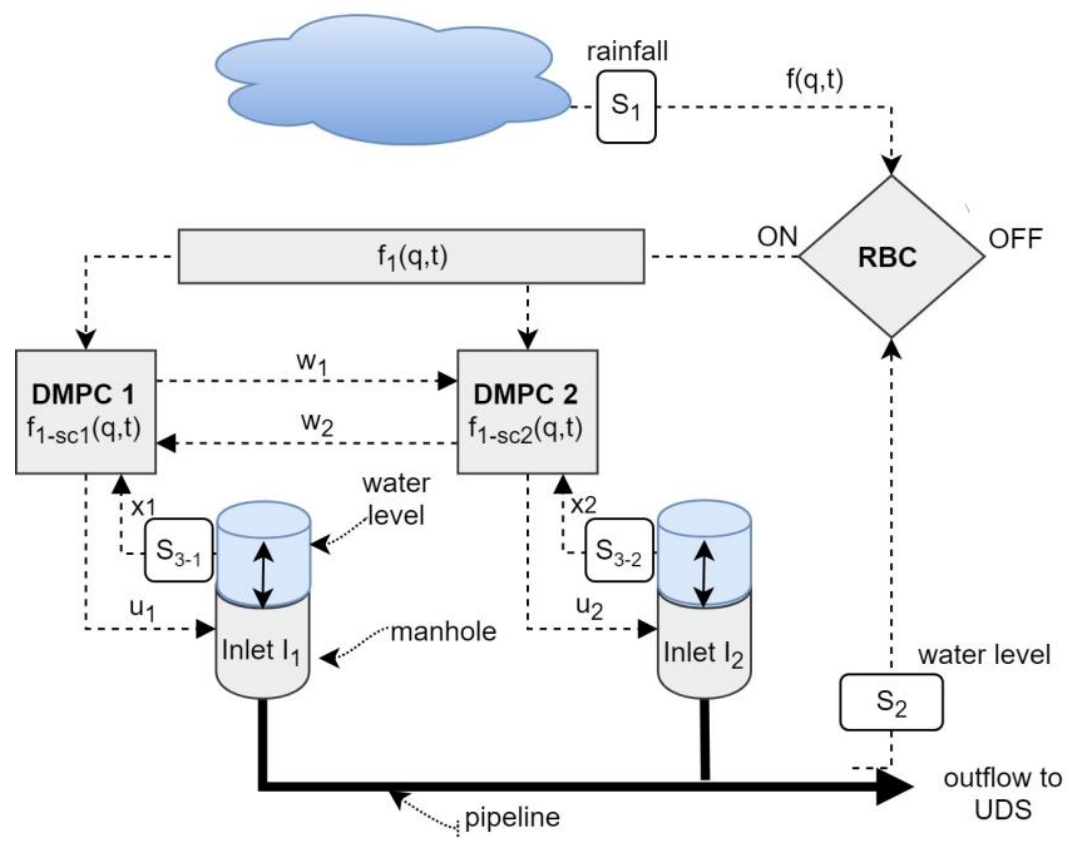

Figure 1. Concept of the real time control (RTC) strategy of the stormwater runoff from a parking lot.

To set up the system the user has to determine the acceptable maximum flood height in every inlet and the desired outflow from the system. The flow and height relationship at the outflow will be found by hydraulic modelling. Modelling is also used to test the concept for specific site to reduce the risks related to later adjustments.

The RTC is switched to the active status on the basis of the measurements from the rain and the water level sensors, $S_{1}$ and $S_{2}$ respectively. Measured rainfall hydrograph $f(q, t)$ is modified to $f_{1}(q, t)$ in order to meet the constraints at the outflow. The hydrograph is sent to the DMPC units as a cost function and scaled according to the catchment properties. Inlet $I_{n}$ is adjusted on the basis of DMPC output variable $u_{n}$ and $x_{n}$ is providing feedback about the inlet status. For that water depth above the manhole cover is measured by $S_{3}$. In addition, DMPC controllers exchange periodically information $\mathrm{w}_{\mathrm{n}}$ about their statuses in order to ensure similar water depth at each inlet. This procedure is repeated in frequent time steps and terminated if the rainfall is over and the outflow is below the target level.

In case of RTC system failure, i.e. the inlets are improperly closed or blocked, the MPA unit recognizes mismatch between system hydrograph $f_{1}(q, t)$ and actual measurements from $S_{2}$. In this case all inlets will be opened and warning message sent to the owner, i.e. water company about the risk of flood in downstream system. Malfunctioning inlets will be listed in order to facilitate the repair.

It has been found by (Malik et al., 2018) that new low-power long-range communication technologies like narrowband internet of things (NB-IOT) are reliable for linking the control units in underground urban drainage systems. These technologies have sufficiently low energy consumption, wide signal coverage and information rate to suit also for the described RTC system. 


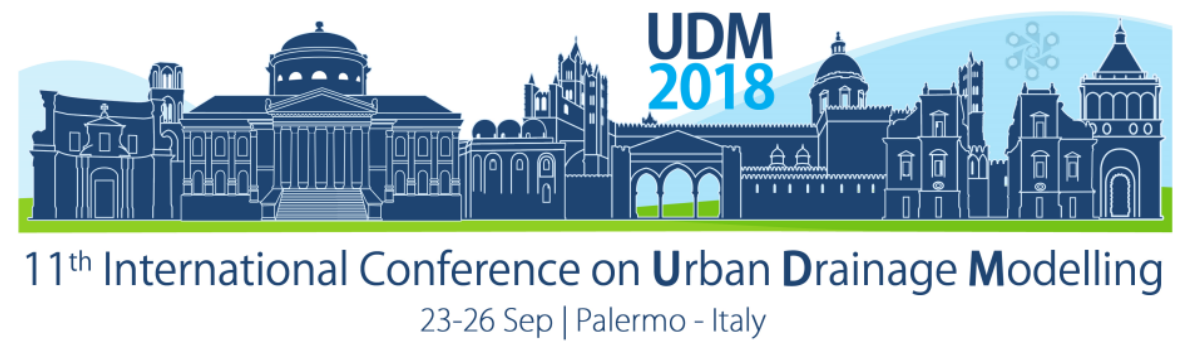

\section{RESULTS AND DISCUSSION}

The concept was tested in a typical parking lot in the city of Tallinn with an area of 12 ha. The site has a concert hall, a hockey arena and several shopping centres. The rate of imperviousness of the parking area is merely $100 \%$, therefore it is not possible to place any LID solutions for runoff reduction. EPA SWMM 5.1 software was used to test the control strategy and evaluate the results. The model was calibrated on the basis of the measured precipitation data (Koppel et al., 2014). Control strategy was applied for 57 inlets and the system was tested with extreme rainfall measured in Tallinn, exceeding highly the design target of the system. The outflow was restricted to $500 \mathrm{l} / \mathrm{s}$, which is the initial target according to the design. Maximum allowed depth of controlled flood water level was $10 \mathrm{~cm}$. It can be seen from Figure 2 that applying RTC enabled to reduce the peak ca $50 \%$ and thus managed to keep the flow in design limits.

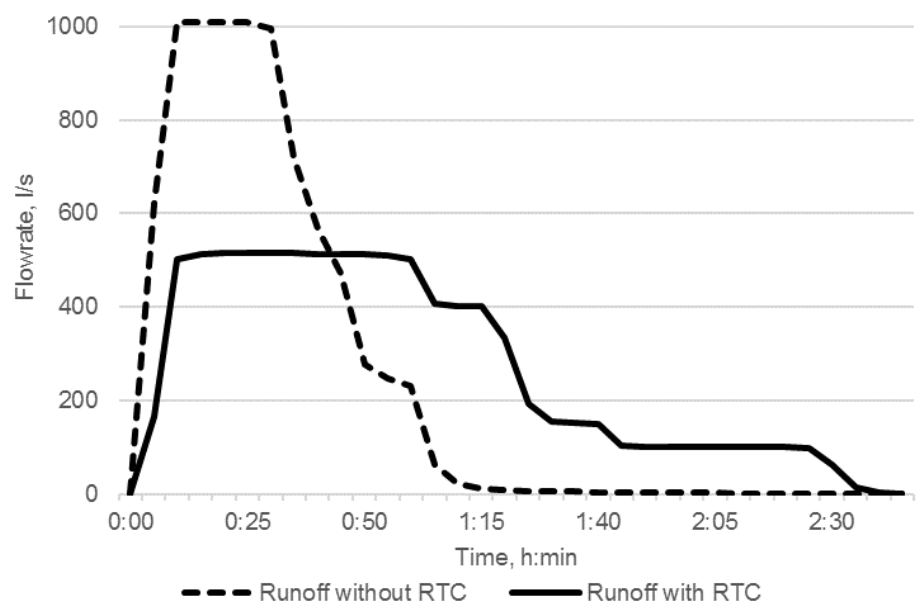

Figure 2. Results of the controlling stormwater runoff from impermeable areas by using smart inlets and RTC.

Costs of implementing the strategy were also analysed. It was found that investment costs (IC) of RTC were merely 2.5 times lower than of construction of stormwater detention tanks traditional method to tackle the catchment impact. The IC were respectively 0.67 MEUR and 1.6 MEUR. Taking into account the net present value (NPV) of the investment with penalty costs including disturbance of business activities in the area, maintenance (i.e. effort to clean the detention tanks from sediments) and replacement of RTC components, traditional method overtops the RTC even 4.2 times.

\section{CONCLUSIONS}

Real time control strategy was developed for the catchment areas with substantial impermeable surfaces in dense urban environment. The strategy utilizes the storage capacity of the sealed surface itself and thus needs no extra storage. The methodology was applied for test area in Tallinn. The results showed high effect of RTC on the outflow. It is also financially the most feasible solution to apply with minimum disturbance of the area.

Further research and development activities are still needed to create an adjustable manhole gully that is necessary for implementation of the solution in real life. In addition, mind-set of citizens needs a shift from fighting against water to living with it. 


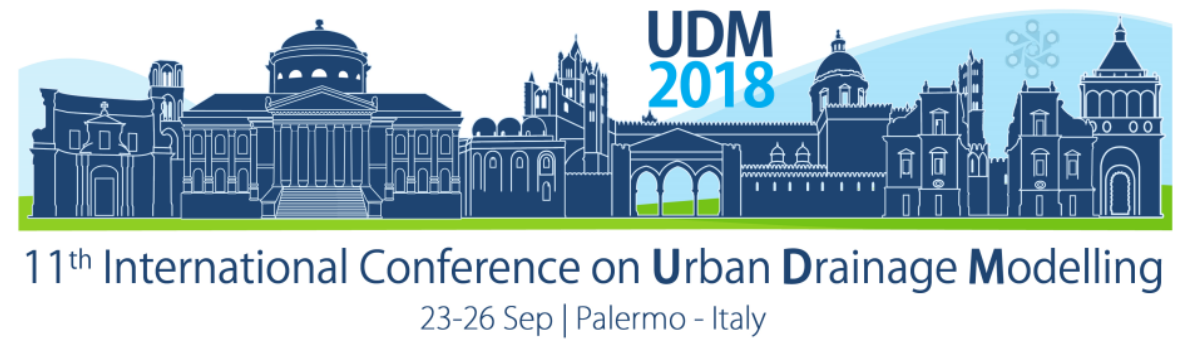

\section{References}

Bach, P.M., Rauch, W., Mikkelsen, P.S., McCarthy, D.T. and Deletic, A. (2014) A Critical Review of Integrated Urban Water Modelling - Urban Drainage and beyond. Environ. Modell. Softw. 54, 88-107.

Beeneken, T., Erbe, V., Messmer, A., Reder, C., Rohlfing, R., Scheer, R.M., Schuetze, M., Schumacher, B., Weilandt, M. and Weyand, M. (2013) Real Time Control (RTC) of Urban Drainage Systems - A Discussion of the Additional Efforts Compared to Conventionally Operated Systems. Urban Water J. 10(5), 293-99.

Bruijn, K., Buurman, J., Mens, M., Dahm, R. and Klijn, F. (2017) Resilience in Practice: Five Principles to Enable Societies to Cope with Extreme Weather Events. Environ. Sci. and Policy 70, 21-30.

Campisano, A., Cabot Ple, J., Muschalla, D., Pleau, M. and Vanrolleghem, P.A. (2013) Potential and Limitations of Modern Equipment for Real Time Control of Urban Wastewater Systems. Urban Water J. 10(5), 300-311.

Eckart, K., McPhee, Z. and Bolisetti', T. (2017) Performance and Implementation of Low Impact Development - A Review. Sci. Total Environ. 607-608, 413-32.

García, L., Barreiro-Gomez, J., Escobar, E., Téllez, D., Quijano, N. and Ocampo-Martinez, C. (2015) Modeling and Real-Time Control of Urban Drainage Systems: A Review. Adv. Water Resour. 85, 120-32.

Houdeshel, C, Pomeroy, C., Hair, L. and Moeller, J. (2011) Cost-Estimating Tools for Low-Impact Development Best Management Practices: Challenges, Limitations, and Implications. J. Irrig. Drain. E. 3(4), 183-89.

Joksimovic, D., and Alam, Z. (2014) Cost Efficiency of Low Impact Development (LID) Stormwater Management Practices. Procedia Engineer. 89, 734-41.

Koppel, T., Vassijev, A., Puust, R., Laanearu, J. (2014) Modelling of stormwater discharge and quality in urban area. J. Ecol. Sci. Envir. E. 1(3), 80-90.

Langeveld, J. G., Schilperoort, R.P.S. and Weijers, S.R. (2013) Climate Change and Urban Wastewater Infrastructure: There Is More to Explore. J. Hydrol. 476, 112-19.

Madsen, H., Lawrence, D., Lang, M., Martinkova, M. and Kjeldsen, T.R. (2014) Review of Trend Analysis and Climate Change Projections of Extreme Precipitation and Floods in Europe. J. Hydrol. 519, 3634-50.

Malik, H., Kändler, N., Alam, M.M., Annus, I., Moullec, Y.L., Kuusik, A. (2018) Evaluation of Low Power Wide Area Network Technologies for Smart Urban Drainage Systems, IEEE International Environmental Engineering Conference, Milan, 12th-14th March 2018, in-press

Sörensen, J., Persson, A., Sternudd, C., Aspegren, H., Nilsson, J., Nordström, J., Jönsson, K. (2016) Re-Thinking Urban Flood Management-Time for a Regime Shift. Water (Switzerland) 8(8). 


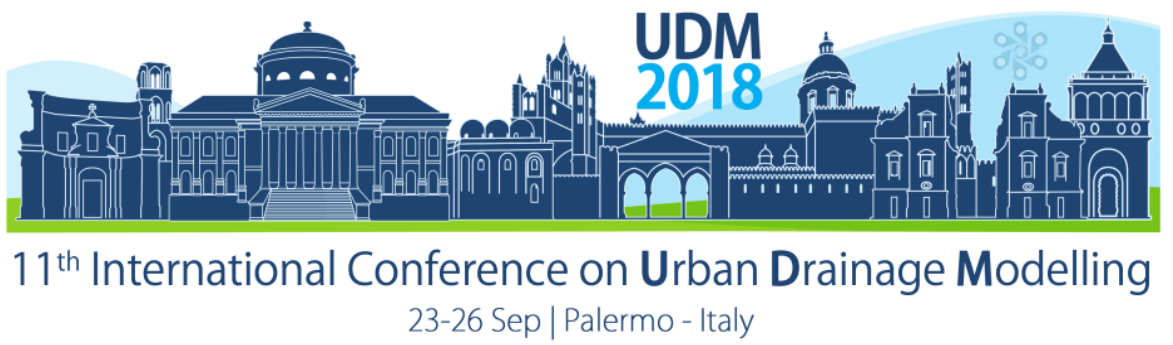

\title{
Multi-criteria Evaluation of Sustainable Urban Drainage Systems
}

\author{
Matej Radinja ${ }^{1}$, Joaquim Comas ${ }^{2}$, Lluis Corominas ${ }^{3}$, Nataša Atanasova ${ }^{1}$ \\ ${ }^{1}$ Faculty of Civil and Geodetic Engineering, University of Ljubljana, 1000 Ljubljana, Slovenia \\ ${ }^{2}$ LEQUiA, Institute of the Environment, University of Girona, E-17071 Girona, Spain \\ ${ }^{3}$ Catalan Institute for Water Research, E-17071 Girona, Spain
}

\begin{abstract}
This paper evaluates the use of Sustainable Urban Drainage Systems (SUDS) measures with hydrological-hydraulic modelling and multi-criteria analysis on a case study of Girona, Spain. To assess their effectiveness for rainwater runoff reduction and consequently the reduction of combined sewer overflow (CSO) the software Giswater was employed for development of the urban catchment model. This software couples spatial data from QGIS with EPA Storm water management model (SWMM). In accordance with the conditions in the urban catchment, five scenarios were developed consisting of following SUDS measures: infiltration basins, infiltration trenches, green roofs and their combinations. These scenarios were evaluated with multi-criteria analysis based on CSO reduction, CAPEX, OPEX, amenity, biodiversity, and feasibility regarding ownership. According to the results, the scenario that included only infiltration basins was most favourable (average grade: $4.1 / 5$ ), followed by the scenario which combined infiltration basins and tranches (average grade: $3.5 / 5$ ).
\end{abstract}

Keywords: sustainable urban drainage systems; combined sewer overflow; Giswater; QGIS; SWMM

\section{INTRODUCTION}

Due to their multiple benefits, SUDS are being increasingly recognised as a worthy substitute or complementary solution to conventional mixed sewer systems, which are becoming difficult to maintain due to growing urbanisation and related environmental problems caused by combined sewer overflows (CSOs). However, they are still not used as a solution for drainage problems on a systemic level. Some hydrological-hydraulic models include modules that incorporate SUDS, including their influence on water quality, yet their additional benefits, derived from their multifunctionality, are not included (Zellner, 2016). As a consequence, this benefits can be overlooked and only partially considered by stakeholders in the decision making process (Chow, 2014).

The goal of this research is to evaluate the implementation of SUDS by their basic function (urban drainage) as well as by other criteria (CAPEX, OPEX, amenity, biodiversity, feasibility regarding ownership) using a modelling and scenario simulation approach on a case study of the city of Girona (Spain). The urban subcatchment covers $2.7 \mathrm{~km}^{2}$ and is drained by $51 \mathrm{~km}$ of mixed sewer system pipes, conveying collected waters towards WWTP through the observed 


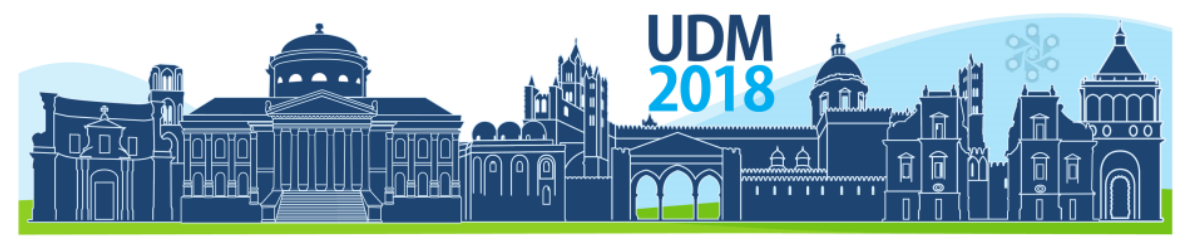

$11^{\text {th }}$ International Conference on Urban Drainage Modelling

23-26 Sep | Palermo - Italy

CSO. The main goal of the SUDS implementation for this case study is mitigating the CSO impact on the river Onyar, flowing through the city.

\section{MATERIALS AND METHODS}

\subsection{Design and simulation}

The methodology for SUDS design and scenario simulation is presented in Figure 1. It includes collection of data (existing and measured), developing, calibrating and validating a hydrologyhydraulic model using Giswater (Giswater Association, 2015), the SUDS elements design and implementation in the model, developing and simulating SUDS scenarios and their multicriteria analysis.

Figure 1. Methodology.

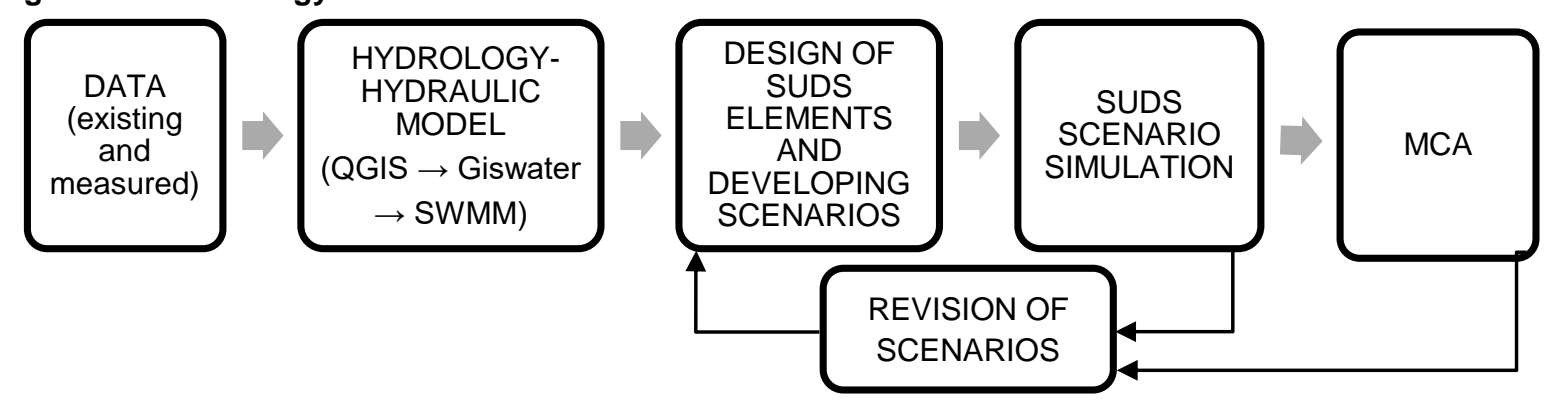

Data set comprises precipitation data, sewer network data, land use coverage map and soil map. In addition, infiltration and flow rate measurements in the CSO channel were performed. The hydrology-hydraulic model was implemented in the open source software Giswater (Giswater Association, 2015), which couples spatial data in QGIS (QGIS Development Team, 2018) with EPA SWMM (Rossman, 2015). The modelling procedure comprised selection of initial parameter values, parameters calibration on measured water volume at the CSO and validation on one rain event as presented in Table 1.

Table 1. Characteristics of events used for model calibration and validation.

\begin{tabular}{cccccc}
\hline Procedure & \multicolumn{3}{c}{ Rain event } & \multicolumn{2}{c}{ Measured overflow at CSO } \\
\hline Calibration & Date & $\begin{array}{c}\text { Total precipitation } \\
(\mathrm{mm})\end{array}$ & $\begin{array}{c}\text { Duration } \\
(\mathrm{hh:mm})\end{array}$ & $\begin{array}{c}\text { Volume }\left(\mathrm{m}^{3}\right) \\
\left(\mathrm{m}^{3} / \mathrm{s}\right)\end{array}$ \\
Calibration & 23.4 .2016 & 10.8 & $03: 10$ & 1,820 & 1.05 \\
Validation & 9.5 .2016 & 12.4 & $11: 40$ & 1,998 & 0.81 \\
\hline
\end{tabular}

\subsection{Scenarios and SUDS design}

Five scenarios including design of various SUDS measures were developed and simulated with the model. Scenario 1 (SC1) includes implementation of infiltration basins; scenario 2 (SC2) includes implementation of infiltration trenches; scenario 3 (SC3) includes 


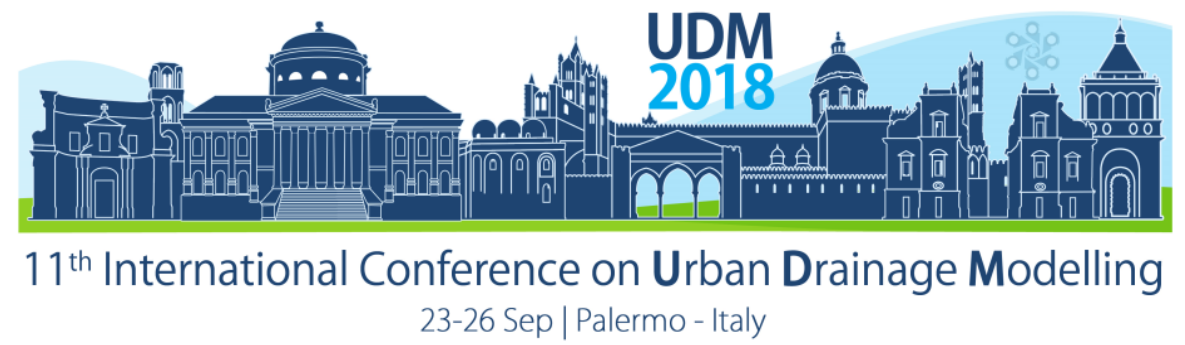

implementation of green roofs; scenario 4 (SC4) is a combination of SC1 and SC2; scenario 5 (SC5) is a combination of SC1, SC2 and SC3.

Using the hydrology-hydraulic model each scenario was simulated for rain events with durations: $15 \mathrm{~min}, 1 \mathrm{~h}, 6 \mathrm{~h}$ and return periods of 2, 5, 10 years for each duration.

Design procedures of infiltration basins and infiltration trenches by (CIRIA, 2015) and (DWA, 2005) were crosschecked on one test location, resulting in similar results. Later on, the procedure by CIRIA (2015) was used for calculating the maximum depth for infiltration basins (Eq. 1) and trenches (Eq. 2).

Where:

$$
\begin{aligned}
& h_{\max }=\frac{D(R i-q)}{n}[m] \\
& h_{\max }=a\left[e^{(-b D)}-1\right][m] ; a=\frac{A b}{P}-i \frac{A d}{P q} ; b=\frac{P q}{n A b}
\end{aligned}
$$

D - storm duration [h];

$R=A_{d} / A_{b}$ - drainage ration, $A_{d}$ - area to be drained $\left[m^{2}\right], A_{b}$ - infiltration surface area $\left[\mathrm{m}^{2}\right]$;

$\mathrm{i}$ - rainfall intensity $[\mathrm{m} / \mathrm{h}]$;

$\mathrm{q}$ - infiltration coefficient $[\mathrm{m} / \mathrm{h}]$;

$\mathrm{n}$ - porosity of granular fill material;

$\mathrm{P}$ - perimeter of the soakaway base $[\mathrm{m}]$.

Green roofs were introduced into the model by accounting for $5 \mathrm{~mm}$ of storage depth, same as for pervious areas in urban and residential district land use types. Thus, the total impervious area in these districts was decreased by $20 \%$ and converted into pervious area. This resulted in approximately $50 \%$ of all roofs becoming green roofs.

\subsection{Multi-criteria analysis}

CAPEX and OPEX per unit of SUDS measure were adopted from (Royal HaskoningDHV, 2012), comprising SUDS prices in the UK. To consider price differences between countries (the UK and Spain), price level indices for civil engineering work by Eurostat-OECD for 2015 were applied. These costs only include direct investment costs, whereas costs like project documentation, buying land, retrofitting parts of existing combined sewer system into separated sewer system, etc. are not included.

Scenarios were graded for every criterion with grades from 1 to 5 , where 5 is the best one. Grades were adopted from (Collett, 2013) and The SuDS Manual (CIRIA, 2015). Average grade has been calculated as arithmetic mean of all grades.

Table 2. Criteria for grading scenarios.

\begin{tabular}{ll}
\hline CRITERIA & Description \\
\hline $\begin{array}{l}\text { CSO reduction: per 1,000 implemented units / per 10,000 } € \text { invested } \\
\text { OPEX }{ }^{* *}\end{array}$ & grade $=\frac{\text { reduction }}{\text { reduction_max }} \cdot 5$ \\
Feasibility with respect to real estate ownership & grade OPEX $=\frac{\text { OPEX_min }}{\text { OPEX }} \cdot 5$ \\
& $\begin{array}{l}\text { 1: private ownership; 3: mixed } \\
\text { ownership; 5: public ownership. }\end{array}$
\end{tabular}




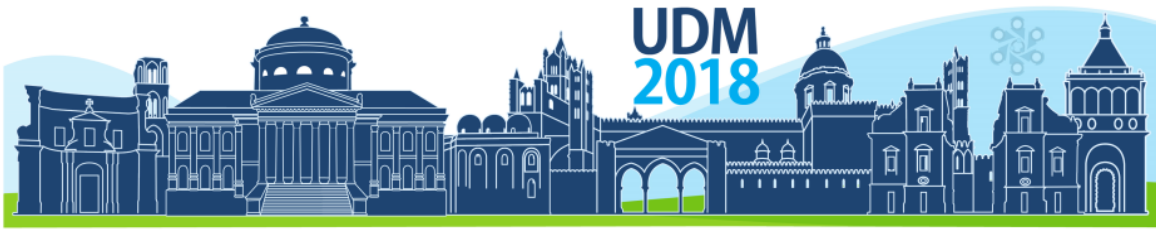

$11^{\text {th }}$ International Conference on Urban Drainage Modelling

23-26 Sep | Palermo - Italy

Influence on amenity (multi-functional use of space, climate resilience, improved air quality, reduced noise levels, aesthetically pleasing and natural environment)

1: low; 3: moderate; 5: high.

Influence on biodiversity (level of the ecological value of the system) 1: low; 3: moderate; 5: high. *reduction of scenario under evaluation, divided by maximal overflow reduction (\%) of all scenarios

${ }^{* *}$ minimal OPEX $(€)$ of all scenarios, divided by OPEX $(€)$ of scenario under evaluation

\section{RESULTS}

After calibration, the model achieved a good fit between measured and simulated CSO data. Validation of the model is presented in Figure 2.

Figure 2. Measured and simulated overflow at the CSO object in Girona, Spain, 21. 4. 2016.

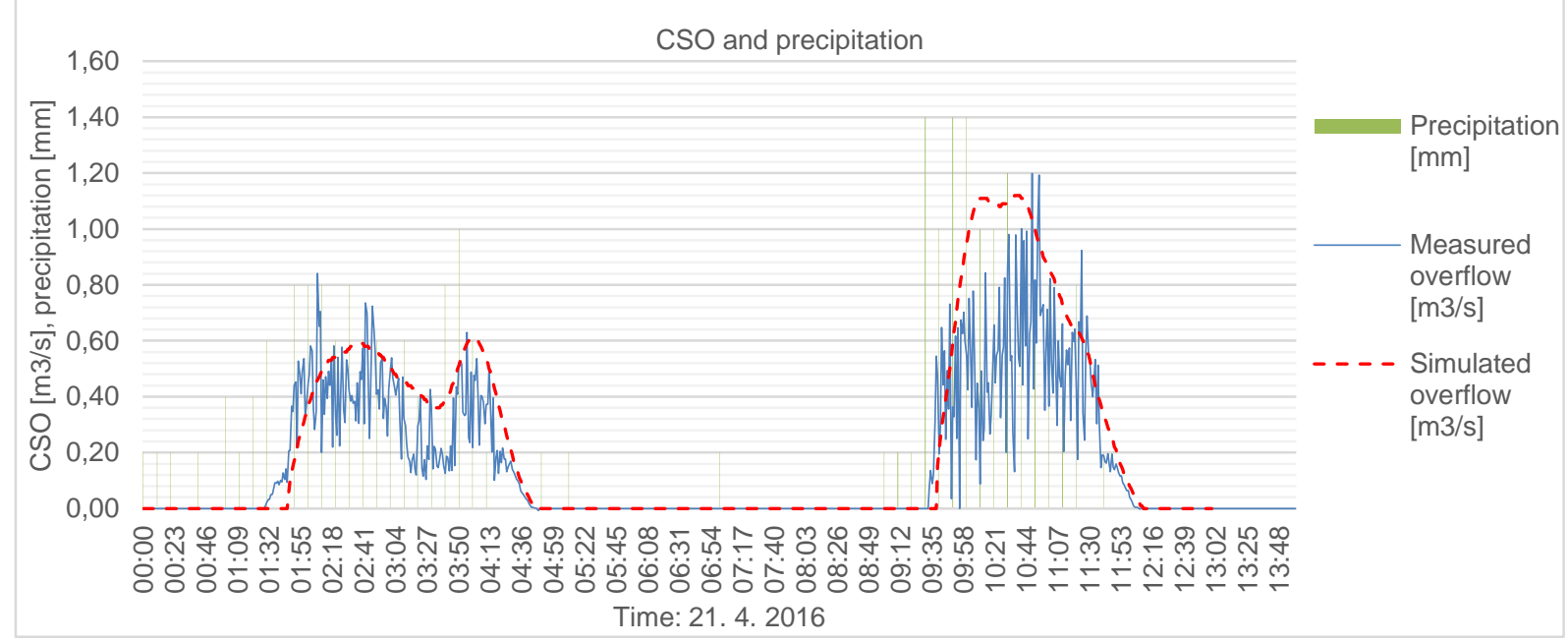

Five scenarios were implemented and simulated with the model to estimate their contribution to CSO reduction, for the rain events listed in Section 2. Average reduction for each scenario was taken into account for multi-criteria analysis.

Table 3. Scenario characteristics (surface, area, CAPEX, OPEX) and performance (overflow reduction).

\begin{tabular}{lccccccccc}
\hline & $\begin{array}{c}\text { Surface } \\
\text { Area }\left(\mathrm{m}^{2}\right)\end{array}$ & $\begin{array}{c}\text { Number } \\
\text { of Units }\end{array}$ & $\begin{array}{c}\text { Unit } \\
\end{array}$ & $\begin{array}{c}\text { Adjusted } \\
\text { CAPEX } \\
\text { per unit } \\
(€)\end{array}$ & $\begin{array}{c}\text { Adjusted } \\
\text { OPEX } \\
\text { per unit } \\
(€)\end{array}$ & $\begin{array}{c}\text { CAPEX } \\
(€)\end{array}$ & $\begin{array}{c}\text { OPEX } \\
(€)\end{array}$ & $\begin{array}{c}\text { Average } \\
\text { overflow } \\
\text { reduction } \\
(\%)\end{array}$ \\
\hline SC1: Infiltration basins & 36,550 & 83,500 & {$\left[\mathrm{~m}^{3}\right]$} & 13 & 0.26 & 566,313 & 11,326 & 49 \\
SC2: Infiltration trenches & 5,930 & 16,055 & {$\left[\mathrm{~m}^{3}\right]$} & 52 & 0.85 & 501,540 & 8,150 & 11 \\
SC3: Green roofs & 115,380 & 115,380 & {$\left[\mathrm{~m}^{2}\right]$} & 36 & 0.13 & $4,124,835$ & 14,999 & 10 \\
SC4: SC1+SC2 & 42,480 & 99,555 & {$\left[\mathrm{~m}^{3}\right]$} & & & $1,067,853$ & 19,476 & 61 \\
SC5: SC1+SC2+SC3 & 157,860 & 214,935 & $\begin{array}{c}{\left[\mathrm{m}^{3}\right.} \\
\mathrm{and}^{3} \\
\left.\mathrm{~m}^{2}\right]\end{array}$ & & & $5,192,688$ & 34,476 & 69 \\
& & & & & & & &
\end{tabular}




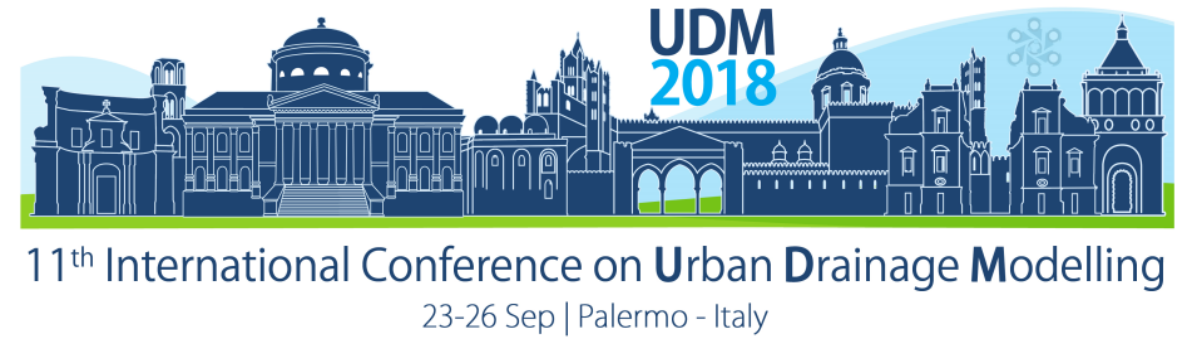

Based on the grading system presented in Table 1, scenarios were evaluated according to their performance (Table 4). Infiltration basins (SC1) have the highest average grade (4.1) among single SUDS measure scenarios, followed by scenario SC4 (grade 3.5) which combines infiltration basins and trenches. Green roofs and infiltration trenches received an average grade of 2.8. All criteria in this analysis were considered equally important.

Table 4. Multi-criteria analysis.

\begin{tabular}{|c|c|c|c|c|c|c|c|}
\hline & 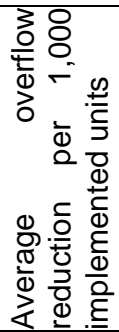 & 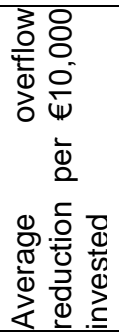 & 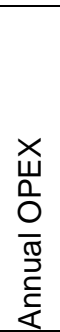 & 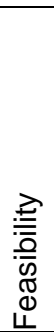 & $\begin{array}{l}\frac{\lambda}{\frac{\pi}{d}} \\
\frac{\varepsilon}{\alpha}\end{array}$ & $\begin{array}{l}\frac{\lambda}{\bar{D}} \\
\frac{D}{0} \\
\frac{2}{0} \\
\frac{0}{0}\end{array}$ & 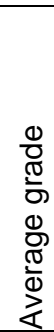 \\
\hline SC1: Infiltration basins & 4.9 & 5.0 & 2.5 & 5 & 4 & 4 & 4,1 \\
\hline SC2: Infiltration trenches & 4.9 & 1.2 & 0.8 & 5 & 2 & 3 & 2,8 \\
\hline SC3: Green roofs (extensive) & 0.4 & 0.1 & 5.0 & 2 & 5 & 4 & 2,8 \\
\hline SC4: SC1+SC2 & 5.0 & 3.3 & 1.8 & 5 & 3 & 3 & 3,5 \\
\hline SC5: SC1+SC2+SC3 & 1.8 & 0.8 & 3.2 & 4 & 4 & 3 & 2,8 \\
\hline
\end{tabular}

\section{CONCLUSIONS}

Hydrologic-hydraulic model and multi-criteria analysis were applied to evaluate SUDS scenarios to highlight their comparative pros or cons. The criteria included: urban drainage performance, CAPEX and OPEX, feasibility with respect to ownership, amenity and biodiversity. These criteria were considered as equally important within the analysis. For a more comprehensive approach they should be weighted according to relevant stakeholders' requirements and given conditions. The methodology was applied to urban subcatchment in the city of Girona (Spain) and demonstrated efficiency and transparency in presenting multiple benefits of SUDS.

\section{References}

Chow, J. F., Savić, D., Fortune, D., Kapelan, Z. and Mebrate, N. (2014) Using a systematic multi-criteria decision support framework to evaluate sustainable drainage designs. Procedia Engineering 70, (343-352).

CIRIA (2015) The SuDS Manual. London. Construction Industry Research and Information Association. Department of Environment Food and Rural Affairs: 888.

Collett, B. (2013) Low Impact Development. University of Tennessee. Knoxville. Landscape Architecture Program: 204.

DWA Deutsche Vereinigung für Wasserwirtschaft, Abwasser und Abfall e.V., (2005) DWA-A 138E: Planning construction and operation of facilities for the percolation of precipitation water.

Giswater Association (2015) Giswater documentation. Retrieved from http://www.old.giswater.org/en/documentation.

QGIS Development Team, (2018) QGIS User Guide: Release 2.18.

Rossman, L. A. (2015) Storm Water Management Model User's Manual. (EPA/600/R-14/413b), 1-353.

Royal HaskoningDHV, (2012) Cost and Benefits of Sustainable Drainage Systems. Peterborough. Royal HaskoningDHV: 24.

Zellner, M., Massey, D., Minor, E. Gonzalez-Meler, M. (2016) Exploring the effects of green infrastructure placement on neighborhood-level flooding via spatially explicit simulations. Computers, Environment and Urban Systems 59(2016), 116-128. 


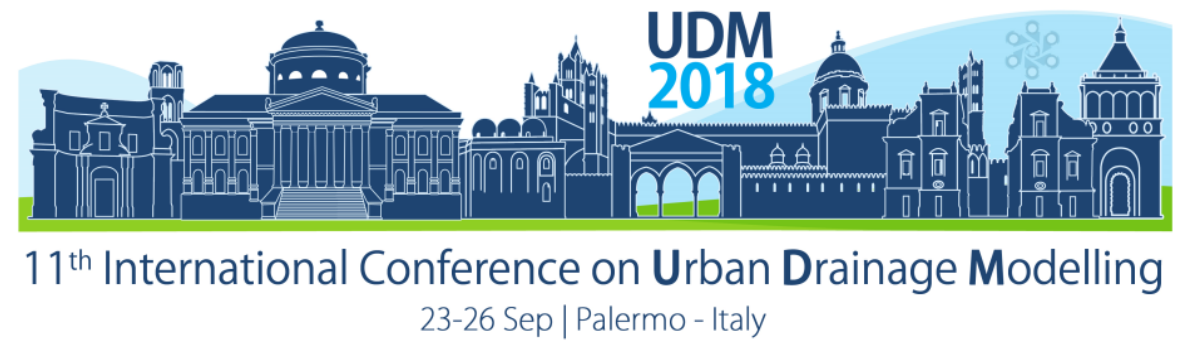

\title{
Exploring Uncertainty in Uncalibrated Bioretention Models
}

\author{
Elizabeth Fassman-Beck ${ }^{1}$, Firas Saleh ${ }^{1}$ \\ ${ }^{1}$ Stevens Institute of Technology, Department of Civil, Environmental, and Ocean Engineering, Hoboken, USA \\ (efassman@stevens.edu, fsaleh@stevens.edu)
}

\begin{abstract}
Using SWMM 5.0.016, a case study of a street right-of-way bioretention system (ROWB) configured as a storage node is compared against SWMM's "LID Controls". Through a series of 1 -yr continuous simulations, the uncalibrated models indicate that a storage node representation of a media-filled system substantially underestimates stormwater retention and detention compared to the LID Control. This is because the latter explicitly accounts for dynamic flow through porous media. Lined/underdrained ROWB may provide significant stormwater mitigation because the majority of storms are small, thus fully captured by the media without the need for exfiltration. As the storage node approach is typical of the current (USA) industry for green infrastructure or low impact development modeling, outcomes raise concern around over-design (and misspent resources). Sensitivity analysis of the LID Control parameterization indicates that the relative difference between the engineered media's porosity and field capacity have the most significant influence on performance. This may be an artefact of the calculation procedure rather than actual physical phenomenon. Future work should prioritize calibration with observed data sets from multiple sites (i.e. multiple media), and actual measurement of field capacity and porosity for multiple examples of bioretention.
\end{abstract}

Keywords: stormwater; bioretention; hydrologic modelling; green infrastructure; SUDS; LID

\section{INTRODUCTION}

Increasingly, solutions to manage stormwater in the USA rely on green infrastructure (GI) or low impact development (LID) technologies, such as bioretention (rain gardens), green roofs, permeable pavement, etc. Many of these reasonably new technologies controls runoff by routing flow through porous media. Of the existing commercial and open source watershed planning models currently available, only the US Environmental Protection Agency's (US EPA) Stormwater Management Model (SWMM) specifically contains routines to explicitly model the processes thought to govern the hydrology and hydraulics of media-filled GI systems.

The majority of stormwater control measure (SCM) design and planning occurs with uncalibrated models. With the massive nationwide investment in GI (e.g., over US\$1B in New York City and Philadelphia, and over \$2B in Omaha, etc.), the importance of modelling accuracy and/or understanding uncertainty is evident. Through sensitivity analysis, this investigation explores sources of uncertainty introduced by uncalibrated models for a $\mathrm{Gl}$ SCM. A SWMM case study of a street right-of-way bioretention system (ROWB) configured as a storage node is compared against configuration using SWMM's GI-specific routine. The effects of flow process representation and input variable parameterization on stormwater retention and detention performance metrics are considered. 


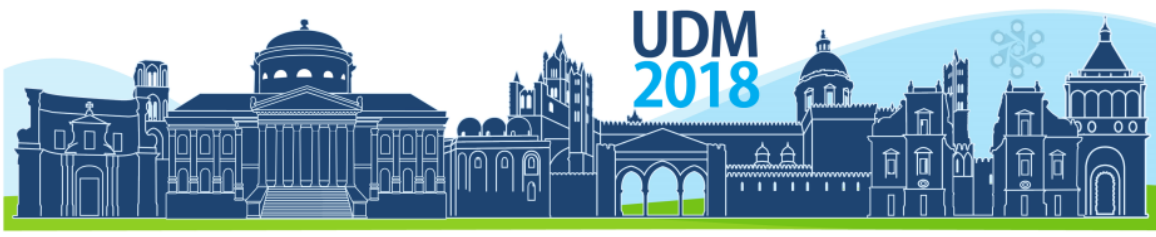

$11^{\text {th }}$ International Conference on Urban Drainage Modelling

23-26 Sep | Palermo - Italy

\section{MATERIALS AND METHODS}

An existing ROWB in Brooklyn, NYC is the basis of the sensitivity analysis. The ROWB's drainage area is approximately 0.1 -ha of an urban street (assumed $98 \%$ impervious), and is served by a combined sewer (Figure 1). The ROWB is straight-sided, $6 \mathrm{~m} \times 1.5 \mathrm{~m}(\mathrm{~L} \times \mathrm{W})$. It is filled with $0.6 \mathrm{~m}$ of engineered media described as loamy sand, above $0.6 \mathrm{~m}$ of gravel storage. (NYCDEP, 2014).
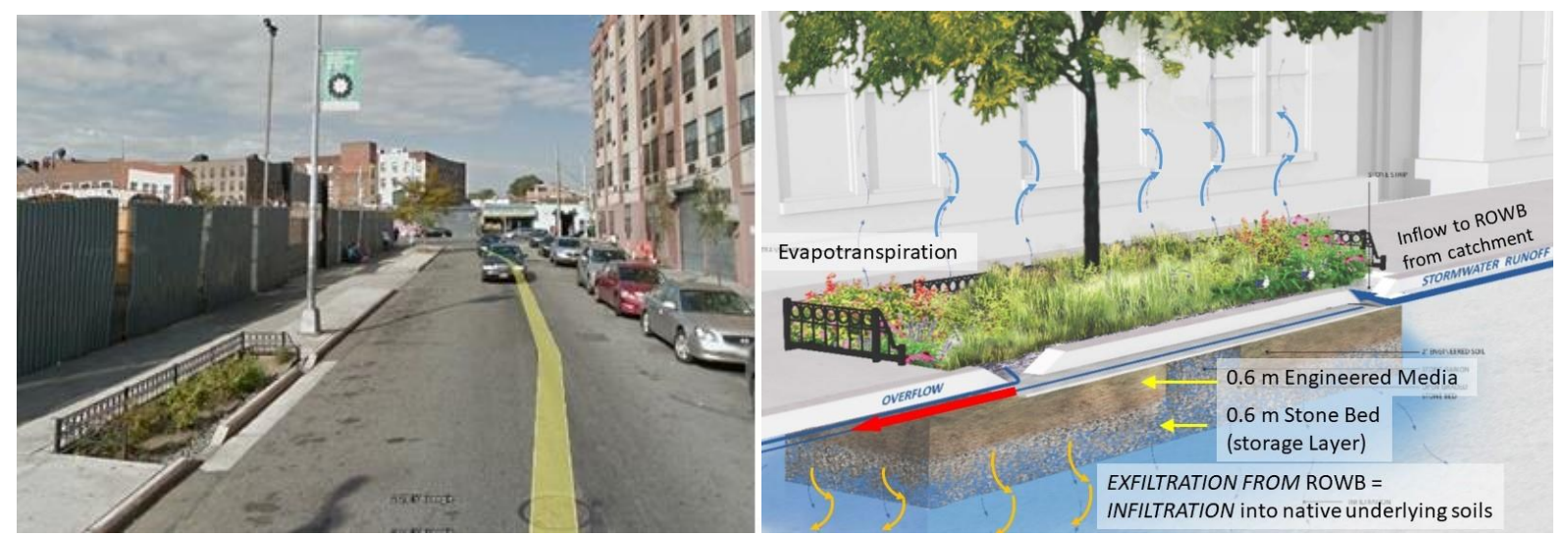

Figure 1 (L)The modelled ROWB on Junius St., Brooklyn, NY (Source: Google Earth); (R) ROWB Representation (adapted from NYCDEP 2014)

The study site was modelled using multiple continuous simulations in SWMM version 5.0.016. Each continuous simulation was executed at a 60 second time step using 2008's hourly rainfall data from John F. Kennedy International Airport. The total annual accumulated precipitation was $\sim 1.2 \mathrm{~m}$. Runoff from the catchment to the ROWB was modelled using the full dynamic wave flow routing option based on the Saint-Venant equations.

For consistency with the USA industry's current common approach, the ROWB was modelled using a storage node with a static maximum capture capacity equal to $25 \mathrm{~mm}$ of runoff from the managed drainage area, in accordance with design documentation (Arcadis 2016). Runoff in excess of 1" bypasses the system. The storage node empties through vertical exfiltration at $4.5 \mathrm{~cm} / \mathrm{hr}$, and evaporation (assumptions regarding evaporation or evapotranspiration have not been investigated herein). For comparison, the storage node configuration was also simulated with an assumed lower exfiltration rate of $1.3 \mathrm{~cm} / \mathrm{hr}$.

SWMM uses the term "LID [Low Impact Development] Control", rather than GI SCM. Two ROWB configurations were modelled to quantify its effects on retention and detention: unlined/exfiltrating (Figure 1R) and lined/underdrained ROWBs. A lined ROWB has an impermeable layer on the bottom and sides, preventing exfiltration to the underlying soils. Excess flow discharges via an underdrain installed in the storage layer, connected to a downstream drainage network element. SWMM implements a modified form of Green-Ampt infiltration to model flow through the engineered fill media of the ROWB (Rossman and Huber 2016). Ranges of media parameter values were defined from the literature on GreenAmpt infiltration for various soil classes and a few actual bioretention systems (Aravena and Dussaillant 2009; Brown et al. 2013; Dussaillant et al. 2005; Fassman-Beck et al. 2105; Liu and Fassman-Beck 2016; Rawls, Brakensiek, and Miller 1983; Torbati 2010). In all cases, in 


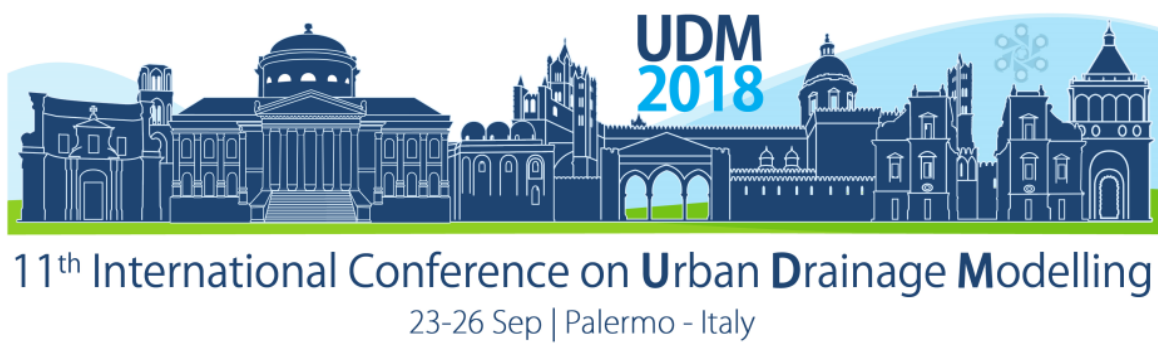

SWMM, the porosity must exceed the field capacity to avoid a numerical error. For surface and storage layers, parameter defaults were adopted as per the user's manual (Rossman and Huber 2016).

An automated sensitivity analysis framework was implemented for parameter combinations built by sampling values for each parameter from uniform distributions. Limited parameterization of the surface layer and storage layers were also investigated. The sensitivity analysis framework is controlled by a set of automated Python and R scripts that generate LID Control parameters, pre- and post-process inputs/outputs, and coordinate the exchange of files between the generated random parameters of the ROWB and the SWMM input files.

\section{RESULTS AND DISCUSSION}

The effect of model parameterization was evaluated in terms of the annual volumetric runoff coefficient and the number of events exceeding a threshold value for catchment discharge, as representative metrics for evaluating stormwater retention and detention, respectively. Table 1 demonstrates that the storage node representation of an ROWB substantially underestimates runoff retention compared to the LID Control. Even a lined/underdrained ROWB provides significant annual retention because the engineered media can fully capture and evapotranspire the majority of runoff from small storms. Analysis of 69 years' of precipitation data for JFK Airport indicates that $80 \%$ of daily rainfall totals are less than $20 \mathrm{~mm}$.

While the storage node detention metric falls within the range of prediction for the infiltrating ROWB, a lined ROWB nonetheless substantially reduces the number of observed peak flows compared to the baseline case for existing conditions. The implications are that lined systems can contribute substantially to urban stormwater mitigation, for example providing peak flow reduction and delay which are important to combined sewer overflow mitigation.

Table 1. Comparative Performance - Simple Metrics

\begin{tabular}{lcc}
\hline Scenario & \# Peak Flows > $\mathbf{0 . 8 5}$ L/s & Annual Runoff Coefficient \\
\hline Baseline (existing conditions) & 63 & 0.96 \\
Storage Node (exfiltration @4.5 cm/hr) & 27 & 0.61 \\
Storage Node (exfiltration @1.3 cm/hr) & 36 & 0.72 \\
SWMM LID Control: Infiltrating ROWB (9000 & $17-28^{1}$ & $0.19-0.55^{2}$ \\
simulations) & & \\
SWMM LID Control: Lined/Underdrained & $18-40^{3}$ & $0.45-0.85$ \\
ROWB (8000 simulations) & & \\
\hline
\end{tabular}

1. Monte Carlo simulation: all parameters perturbed over allowable ranges; 2. Single parameter perturbation + Monte Carlo simulation; 3. Perturbing drain coefficient only

Single-parameter sensitivity analysis for an unlined ROWB using the LID Control showed that the annual runoff coefficient is only sensitive to engineered media parameters of field 


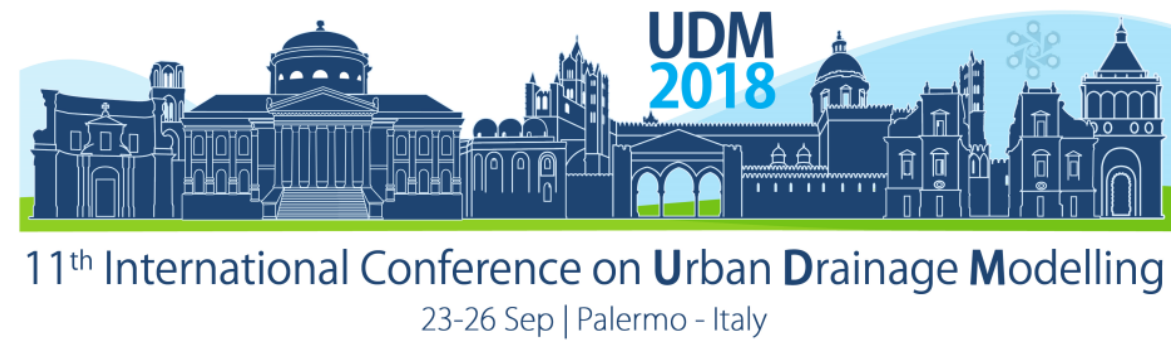

capacity and porosity. More importantly, the relative difference between these parameters is a performance-limiting feature introduced by the LID Control's calculation procedure.

At each time step, the model calculates a water balance between the surface ponding zone, engineered media, and underlying storage layer of an ROWB (Rossman and Huber 2016). The amount of water entering the media layer from the ponding layer at any time step is limited by the media layer's available storage. Available storage is the difference between the actual moisture content at any time and the porosity, and the rate at which water drains out of the media and into the underlying storage layer. This latter step is not usually limiting, because the storage layer in an ROWB is usually large rock that drains freely. When field capacity is low compared to porosity, there is significant pore space for water to seep into the media layer. For a media whose field capacity value is close to the porosity, infiltration from the surface is substantially limited at any time after the media's moisture content equals field capacity. In this case, even if drainage is significant, the available temporary storage is always low, preventing infiltration from the surface and thereby causing an increase in system bypass. In practice, preferential flow paths occur, and the media is not necessarily saturated (as per Green-Ampt model assumptions) (Liu and Fassman-Beck 2018). Assumptions that drainage does not occur until the field capacity is satisfied, and that temporary storage is limited by the relationship between field capacity and porosity are seen as limitations to the LID Control calculations that create error and uncertainty (Liu and Fassman-Beck 2017).

\section{CONCLUSIONS}

Representation of a ROWB as a storage node in SWMM does not reflect the dynamic operation of a media-filled GI SCM that fills and drains concurrently, thus likely underrepresenting runoff mitigation. As the storage node approach is typical of the current (USA) industry for green infrastructure or low impact development modeling, outcomes raise concern around over-design (and misspent resources). Although a better representation physically of the actual flow process in an ROWB, sensitivity analysis of SWMM's LID Control routine demonstrates that the relative difference between the media's field capacity and porosity has a significant influence on annual runoff prediction. This is likely a numerical artefact of the calculation, rather than an actual limiting phenomenon in practice.

These results are for comparison of how model configuration influences results, and highlights the uncertainty inherent in any uncalibrated model. Accuracy cannot be assessed because there is no comparison to observed performance. Calibration to multiple observed data sets emerges as an essential priority. Likewise, availability of actual measurements of field capacity and porosity for bioretention systems is severely lacking.

\section{References}

Arcadis of New York: Green Infrastructure Performance Metrics Report prepared for the City of New York Department of Environmental Protection, 2016. http://www.nyc.gov/html/dep/html/stormwater/nyc_green_infrastructure_plan.shtml accessed 02/28/2017.

Aravena JE, Dussaillant A. (2009). Storm-water infiltration and focused recharge modeling with finite-volume twodimensional Richards equation: Application to an experimental rain garden. Journal of Hydraulic Engineering, 135(12), 1073-1080.

Brown, R. A., Skaggs, R. W., and Hunt, W. F. (2013). Calibration and validation of DRAINMOD to model bioretention hydrology. Journal of Hydrology, 486, 430-442. 


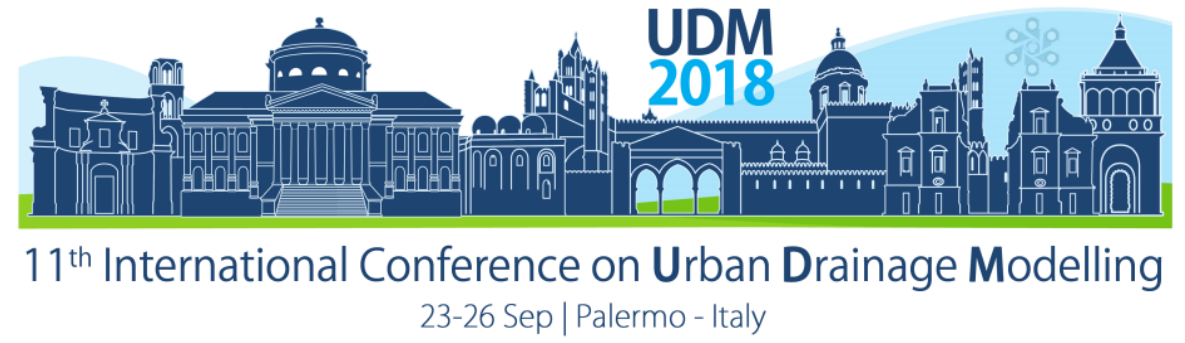

Dussaillant AR, Potter KW, Wu CH. (2005). Infiltration of stormwater in bioretention cells: Numerical model and field experiment. Ingenieria Hidraulica Mexico, 20(2), 5-17.

Fassman-Beck, E., Wang, S., Simcock, R., Liu, R. Assessing the Effects Assessing the Effects of Bioretention's Engineered Media Composition and Compaction on Hydraulic Conductivity and Water Holding Capacity. Journal of Sustainable Water in the Built Environment 1(4): 04015003-1, 2015.

Tim D. Fletcher, William Shuster, William F. Hunt, et al. (2014) SUDS, LID, BMPs, WSUD and more - The evolution and application of terminology surrounding urban drainage, Urban Water Journal, 12(7): 525542, DOI: 10.1080/1573062X.2014.916314

Liu, R., and Fassman-Beck, E. (2016a). Hydrologic response of engineered media in living roofs and bioretention to large rainfalls: experiments and modeling, Hydrological Processes, 31: 556-572.

Liu, R., and Fassman-Beck, E. (2016b). Effect of Composition on Basic Properties of Engineered Media for Living Roofs and Bioretention, Journal of Hydrologic Engineering, 21(6):06016002.

Liu, R., and Fassman-Beck, E. (2017). Hydrologic Experiments and modeling of two laboratory bioretention systems under differenct boundary conditions, Frontiers of Environmental Science and Engineering, 11(4):10.

Liu, R., Fassman-Beck, E. (2018). Pore structure and unsaturated hydraulic conductivity of engineered media for living roofs and bioretention based on water retention data. Journal of Hydrologic Engineering 23(3).

New York City Department of Environmental Protection (NYC DEP) (2014). Report for Post-Construction Monitoring Green Infrastructure Neighborhood Demonstration Areas, http://www.nyc.gov/html/dep/pdf/cso long term control plan/post-construction-monitoring-report-gineighborhood-demonstration-areas.pdf, 2014. Accessed online 06/12/2017.

Rossman, L. and Huber, W. (2016). Stormwater Management Model Reference Manual Volume III - Water Quality. EPA/600/R-16/093.

Torbati, S. S. (2010). Pollutant removal evaluation and hydrologic characterization by continuous simulation for a concrete lined bioretention cell. Master's thesis, Univ. of Auckland, Auckland, New Zealand. 


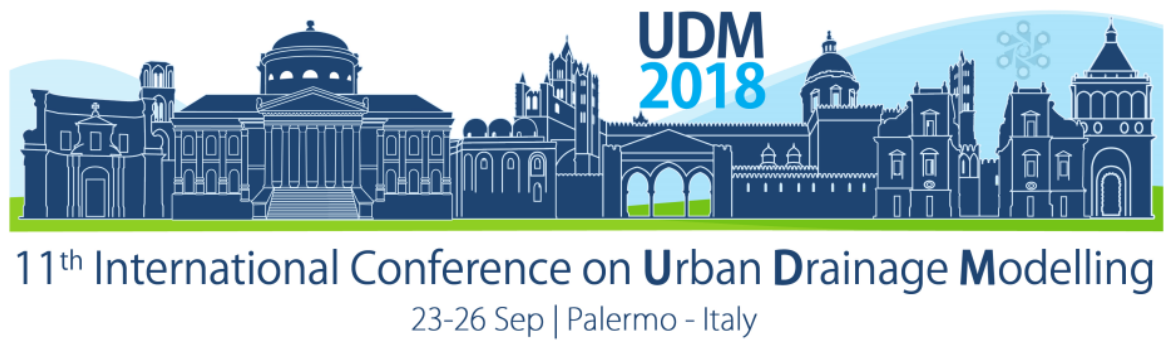

\title{
Promoting Successful Urban Watershed Restoration through Enhanced Bioretention Cell Modelling
}

\author{
Whitney Lisenbee ${ }^{1}$, Jon Hathaway ${ }^{1}$ and Ryan Winston ${ }^{2}$ \\ ${ }^{1}$ University of Tennessee, Civil and Environmental Engineering Department, Knoxville, TN, USA \\ ${ }^{2}$ Ohio State University, Department of Food, Agricultural, and Biological Engineering, Columbus, OH, USA
}

\begin{abstract}
Urban runoff and stormwater is one of the top ten leading causes of water quality impairment in lakes, estuaries and streams in the United States (USEPA 2009). Over the last decade, bioretention systems have become a leading stormwater control measure (SCM) that contributes to the restoration of urban streams and watersheds. Bioretention cells increase infiltration of stormwater thereby reducing urban runoff volumes and peak flows which alter the hydrology of local waterways. Although these systems have proven to perform well in many site-scale field studies, less is known about how well these systems work when implemented en masse. Modelling of bioretention allows designers to scale local impacts to the larger watershed. However, current hydrologic models with bioretention capabilities consist of lumped parameters and simplifications that do not fully account for fundamental hydrologic processes. DRAINMOD is an agricultural drainage model that has shown promise when applied to bioretention systems. However, because DRAINMOD was designed for agricultural purposes, it cannot currently accommodate the rapid response time of an urban runoff hydrograph, instead aggregating data to a daily timeframe. For this study, DRAINMOD has been recoded to allow high temporal resolution inputs and outputs, more closely matching the travel times of urban systems. DRAINMOD simulations were conducted both with and without the time scale modifications (original vs. bioretention-specific model) to determine if improvements in sitescale modelling were realized. Future work will compare these results to those of simplistic, lumped-parameter bioretention modelling.
\end{abstract}

Keywords: Bioretention; DRAINMOD; Infiltration

\section{INTRODUCTION}

Modelling of bioretention allows designers to better optimize the function of bioretention cells, provide guidance for design standards, and scale local impacts to the larger watershed. This provides an understanding of potential benefits of implementation prior to investing large amounts of time and money into a given project or watershed restoration effort. Improved modelling at the site-scale must be achieved before watershed effects can be considered.

Existing models applied to bioretention use simplifications that do not fully account for the fundamental hydrologic processes. Many early bioretention models lacked long-term, continuous simulation which ignored the effect of antecedent moisture conditions in the soil, an important consideration that affects the infiltration capabilities of the system (Davis et al., 2011; Heasom et al., 2006). Further, many models use infiltration processes that assume saturation although bioretention systems are variably saturated and unsaturated (Brown et al., 2013). Another limitation of current bioretention models is that many are never calibrated with underdrains despite this being a common design feature. 


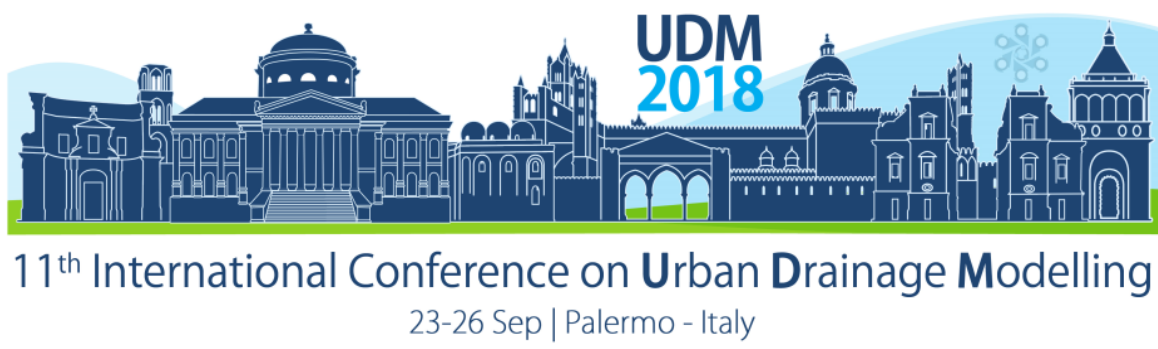

DRAINMOD is an agricultural drainage model that has shown promise when applied to bioretention systems (Brown et al., 2013, Hathaway et a., 2014, Winston et al., 2016). It has the capability of using the soil-water characteristic curve (SWCC) to obtain detailed water balances over a continuous time-period (both advances over other models for bioretention). Use of the SWCC to account for soil moisture improves upon models that assume field capacity. For instance, Brown et al. (2013) showed that calculating the total volume drained using the SWCC compared to assuming a moisture content of saturation minus field capacity created very large percent differences $(-6017$ to -14$)$ especially at high water table depths. Therefore, the SWCC is a better parameter to use in determining infiltration through bioretention systems where the water level is often near the surface. Because DRAINMOD was designed for agricultural purposes, it currently cannot accommodate the rapid response time of an urban runoff hydrograph, instead aggregating data to a daily timeframe. For this study, DRAINMOD has been recoded to create a bioretention-specific model (DRAINMODUrban) that will allow high temporal resolution inputs and outputs, more closely matching the travel times of urban systems.

The objective of this research was to evaluate if DRAINMOD-Urban can produce accurate output hydrographs compared to measured data for multiple bioretention cells in Ohio. Then, DRAINMOD and DRAINMOD-Urban simulations were compared to determine if improvements in site-scale modelling were realized. These site-scale improvements can later be confidently expanded to a watershed scale model to explore bioretention benefits to the overall system.

\section{MATERIALS AND METHODS}

\subsection{Site Descriptions}

Three bioretention sites in Ohio, USA, from a study by Winston et al. (2016) were chosen to calibrate the new DRAINMOD-Urban model. In this abstract, the focal point will be the bioretention cell at Ursuline College. The Ursuline College (UC) cell had an area of $182 \mathrm{~m}^{2}$ and was connected to a $3600 \mathrm{~m}^{2}$ drainage area that was primarily parking lot for a total of $77 \%$ imperviousness. The cell was filled with typical bioretention media $(87 \%$ sand, $4 \%$ silt, $9 \%$ clay). Cleveland, $\mathrm{OH}, \mathrm{USA}$, has a humid, continental climate (Köppen Dfa).

\subsection{DRAINMOD modifications}

DRAINMOD was re-coded to better represent the rapid response time of an urban runoff hydrograph. The original DRAINMOD accepted hourly precipitation inputs as the smallest timescale available. It also provided a "Contributing Area Runoff" function but did not allow for input of measured runoff entering the bioretention system from the drainage area. DRAINMODUrban was created to allow 1-minute precipitation inputs and also 1-minute inflow from the drainage area. The outputs (Infiltration, Drainage (Outflow), Runoff (Overflow), ET, and Seepage) are also at 1-minute intervals. This can be used to examine the hydrograph of each water balance component, which was not possible previously in the model.

\subsection{Original DRAINMOD Calibration Procedure}

The Winston et al. (2016) study, found that 34 out of 50 storm events (68\%) produced no drainage or overflow at UC. Thus, the remaining drainage and overflow events were used to calibrate and validate the drainage (outflow) and runoff (overflow) from the system. The original DRAINMOD was parameterized based on the configuration and characteristics of the UC cell. 


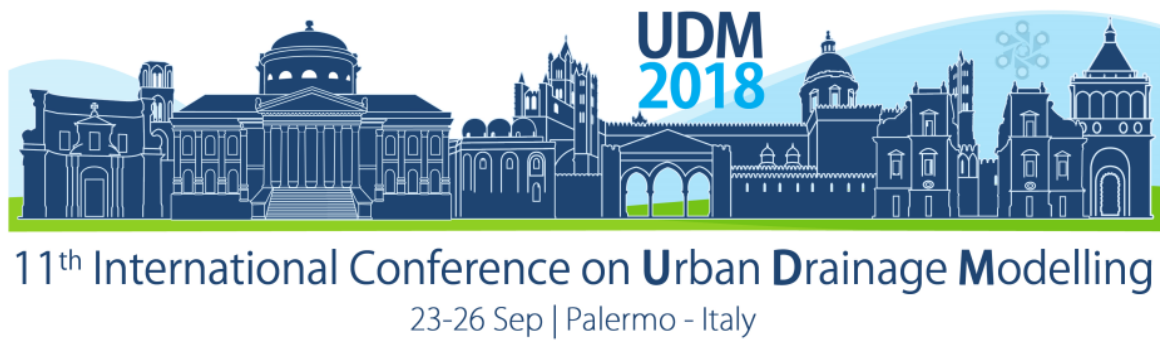

The model parameters that could not be measured, such as the piezometric head of the contributing aquifer and thickness of the restricting layer, were used as calibration parameters. These parameters were changed to maximize the goodness-of-fit tests, namely the NashSutcliffe Efficiency (NSE) parameter.

\subsection{DRAINMOD-Urban Calibration Procedure}

The design configuration and soil parameters used for the calibrated original DRAINMOD simulation of the UC cell was kept the same for the initial DRAINMOD-Urban simulation (these may change in future efforts). The precipitation was now entered on a 1-minute interval. The inflow at UC consisted of sheet flow that was unable to be measured through a flume, so the estimated runoff hydrograph from the drainage area was developed using the Storm Water Management Model (SWMM). This 1-minute interval inflow was also input into DRAINMODUrban.

To test the difference in performance of the original and re-coded models, DRAINMOD-Urban was populated with initial inputs and calibration parameters that were the same (other than precipitation and inflow as described above) as those of Winston et al. (2016). This initial simulation for the UC cell produced 1-minute drainage (outflow) and runoff (overflow) for the same storm events as those of Winston et al. (2016). Next, Nash-Sutcliffe Efficiency (NSE) will be calculated for each individual event to describe the fit of each hydrograph and parameters such as the piezometric head and the drainage coefficient will be adjusted in DRAINMODUrban to optimize the NSE.

\section{RESULTS AND DISCUSSION}

\subsection{Original DRAINMOD Results}

The calibrated DRAINMOD model produced high NSE values, 0.94 for drainage and 0.97 for overflow for the UC bioretention cell (Winston et al., 2016). The values during the validation period were 0.98 for drainage and 0.73 for overflow. The overflow NSE is likely lower during validation due to a small number of overflow events during that period. This suggests excellent performance of the model when data are aggregated and comparisons of modeled versus measured data are based on total event volumes of overflow and drainage.

\subsection{DRAINMOD-Urban Results}

To test the model's ability to predict hydrology at a finer scale (1-minute), output from DRAINMOD-Urban was compared to the observed data. As described above, the model was initially populated with the same calibration parameters as that of Winston et al. (2016). The DRAINMOD-Urban output showed poor fit with the hydrographs of both drainage and overflow for many events (Figures 1a and 1b). Some events showed lack of correlation with the timing and duration of the event while others showed discrepancies in volume and peak flow rates for both drainage and overflow. This suggests that further calibration of the model is needed (and will be completed by September 2018) as there are fine scale processes not being well represented by the model. 


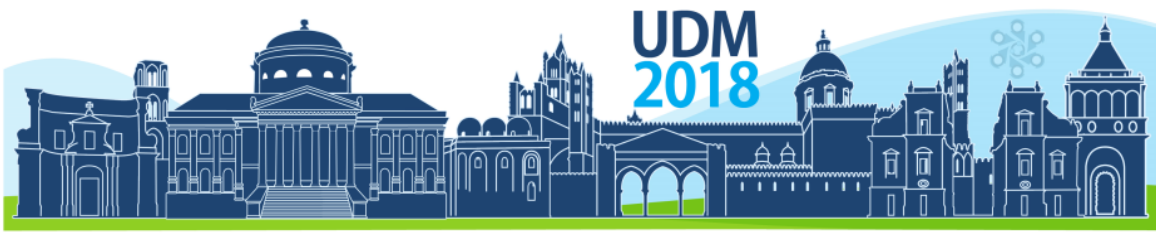

$11^{\text {th }}$ International Conference on Urban Drainage Modelling 23-26 Sep | Palermo - Italy
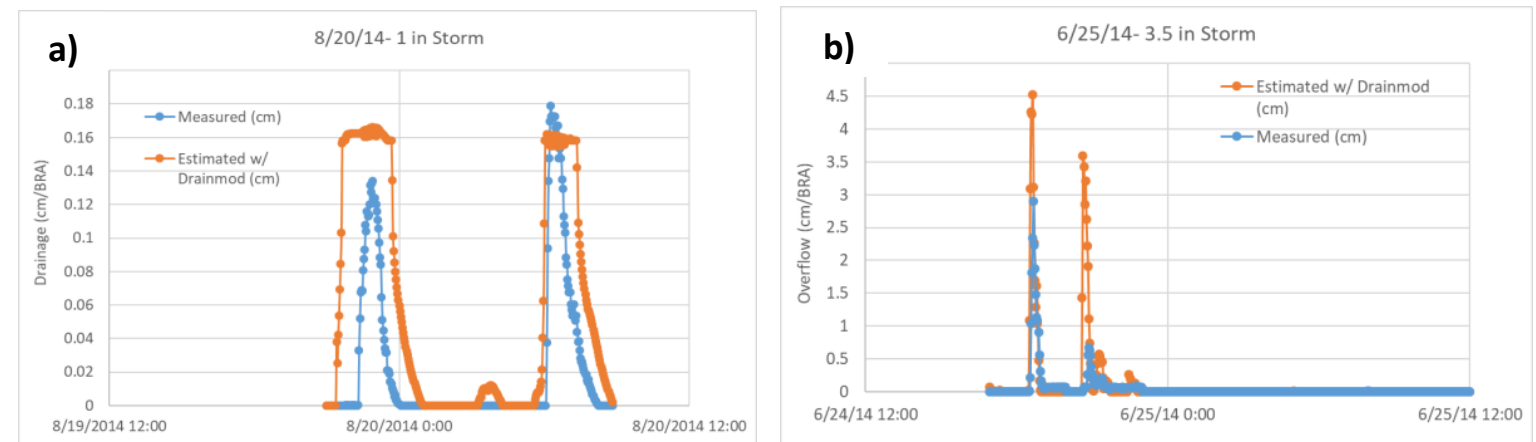

Figure 1. a) Example of a drainage hydrograph that has overestimated event duration and flow volume b) Example of an overflow hydrograph that shows good correspondence with duration and time to peak but overestimated the flow volume and peak flow rate.

\section{CONCLUSIONS}

This study shows the strong influence of scale in model performance. When a very accurate bioretention model was disaggregated to a finer time scale, performance suffered. When data are aggregated, these issues are not critical, but become important when accurate outflow hydrographs are desired to understand how bioretention functions when combined at the watershed scale, that is, when there is a need to understand how individual site scale hydrographs are combined at the system level. DRAINMOD-Urban will be fully calibrated by the time of this conference. As the model is fully calibrated, attention will be placed on what parameters affect the timing versus the volume of the drainage and overflow, a critical consideration. It is expected that the NSE for the hydrographs from DRAINMOD-Urban will be lower than the DRAINMOD results due to the higher level of detail, but could still perform better than other common bioretention models. Ultimately, we hope to show that DRAINMOD-Urban is well suited to modelling the flashy nature of urban bioretention while considering the influence of antecedent soil moisture and internal drainage.

\section{References}

Brown, R. A., Skaggs, R. W., \& Hunt, W. F. (2013). Calibration and validation of DRAINMOD to model bioretention hydrology. Journal of Hydrology, 486, 430-442. doi:10.1016/j.jhydrol.2013.02.017

Davis, A. P., Traver, R. G., Hunt, W. F., Lee, R., Brown, R. A., \& Olszewski, J. M. (2011). Hydrologic performance of bioretention storm-water control measures. Journal of Hydrologic Engineering, 17(5), 604-614.

Hathaway, J. M., Brown, R. A., Fu, J. S., \& Hunt, W. F. (2014). Bioretention function under climate change scenarios in North Carolina, USA. Journal of hydrology, 519, 503-511.

Heasom, W., Traver, R. G., \& Welker, A. (2006). Hydrologic modeling of a bioinfiltration best management practice. JAWRA Journal of the American Water Resources Association, 42(5), 1329-1347.

Pennino, M. J., McDonald, R. I., \& Jaffe, P. R. (2016). Watershed-scale impacts of stormwater green infrastructure on hydrology, nutrient fluxes, and combined sewer overflows in the mid-Atlantic region. Sci Total Environ, 565, 1044-1053. doi:10.1016/j.scitotenv.2016.05.101

Environmental Protection Agency. (2009). National Water Quality Inventory: Report to Congress, 2004 Reporting Cycle (EPA Publication No. 841-R-08-001). Washington, DC: U.S. Environmental Protection Agency.

Wang, H. W., Mao, Y. F., Gao, Y., Fan, J. H., Zhang, S. F., \& Ma, L. M. (2013). Analysis of Bioretention Cell Design Elements Based on Fourier Amplitude Sensitivity Test (FAST). Advanced Materials Research, 779-780, 13691375. doi:10.4028/www.scientific.net/AMR.779-780.1369

Winston, R. J., J. D. Dorsey, and W. F. Hunt (2016). "Quantifying volume reduction and peak flow mitigation for three bioretention cells in clay soils in northeast Ohio". Science of the Total Environment, 553, 83-95. 


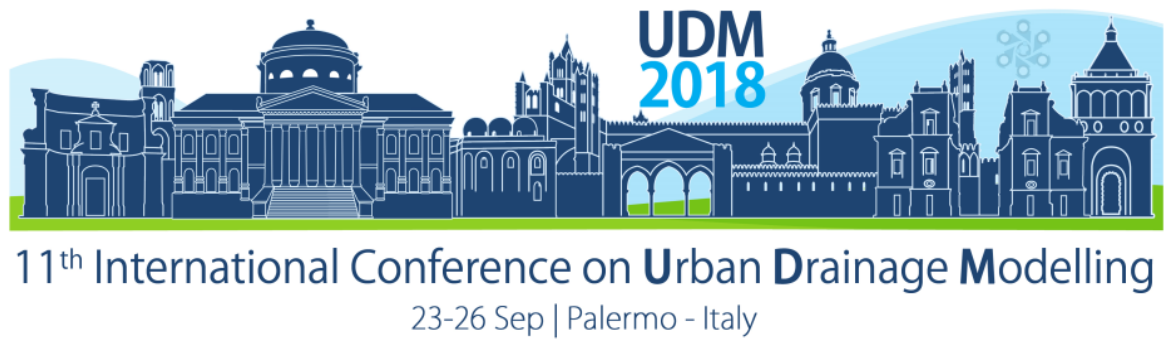

\title{
Wastewater modification processes in a stabilization reservoir: a new mathematical model
}

\author{
Giorgio Mannina $^{1,2}$, Gaspare Viviani ${ }^{2}$ and Steven C. Chapra ${ }^{3}$ \\ ${ }^{1}$ Dipartimento di Ingegneria Civile, Ambientale, Aerospaziale, dei Materiali, Università di Palermo, Viale delle \\ Scienze, Ed. 8, Palermo (IT), Italy \\ 2 Department of Earth and Environmental Engineering, Columbia University, 500 West 120th Street, New York, \\ NY 10027, USA \\ ${ }^{3}$ Civil \& Environmental Engineering Department, Tufts University, Medford, MA 02155, USA
}

\begin{abstract}
The paper presents a mathematical model for the simulation of the ecology of a wastewater stabilization reservoir (WSR). WSRs are hypertrophic aquatic systems devoted to water storage in warm countries where shortage conditions are often encountered. Several factors that affect the stabilization reservoir's effluent quality were taken into account: hydraulics and hydrology, solar radiation, reaeration, algae, zooplankton, organic matter, pathogens, and sediment-water interactions. The model quantifies the specific influence of each factor on effluent quality, and evaluating the correlation between the different factors. State variables included in the model were: algae, dissolved oxygen, organic matter, zooplankton and indicator bacteria. The model was applied to an Italian stabilization reservoir located in the south part of Sardinia: Simbirizzi lake. The model generated satisfactory results and can be employed as a useful tool for environmental water quality management of stabilization reservoirs.
\end{abstract}

Keywords: Water resources management, mathematical modelling, stabilization reservoir, wastewater treatment

\section{INTRODUCTION}

In recent decades, many areas experienced modifications to local rainfall characteristics, including the annual number of rainfall events, their average volume, and the frequency of intense rainfall events. Many authors have suggested an increasing trend in high intensity rainfall (De Michele et al., 1998; Pagliara et al., 1998; Brath et al., 1999; Kamaguchi et al., 1999). All these results have been ascribed to climate change which leads to a progressive increase of global temperatures and may progressively reduce water supply and increase water demand. In view of these conditions, alternative water resource management approaches can be of great benefit for coping with shortage conditions. More specifically, wastewater reuse for agricultural irrigation can be a good solution. Indeed, it is becoming a common and rapidly increasing practice in arid and semi-arid regions around the world, where treated wastewater serves as extra supplementary water source for the rural sector. New projects for reclamation and reuse of wastewater are frequently reported in countries across the globe. These consist of a variety of options including wastewater reuse systems, wastewater storage and treatment reservoirs, and stabilization reservoirs. These units allow for regulation between treated wastewater inflow, which occurs throughout the year, and withdrawal of irrigation effluent, which occurs during the dry summer months (Juanico and Shelef, 1994). Although these units were first used to accumulate treated effluent for irrigation purposes, thanks to their stabilization potentials, they are also used to treat raw wastewater (Mara and Pearson, 1992; Juanico and Shelef, 1994). Such reservoirs are similar to wastewater stabilization ponds. However, as these reservoirs are much deeper with much 


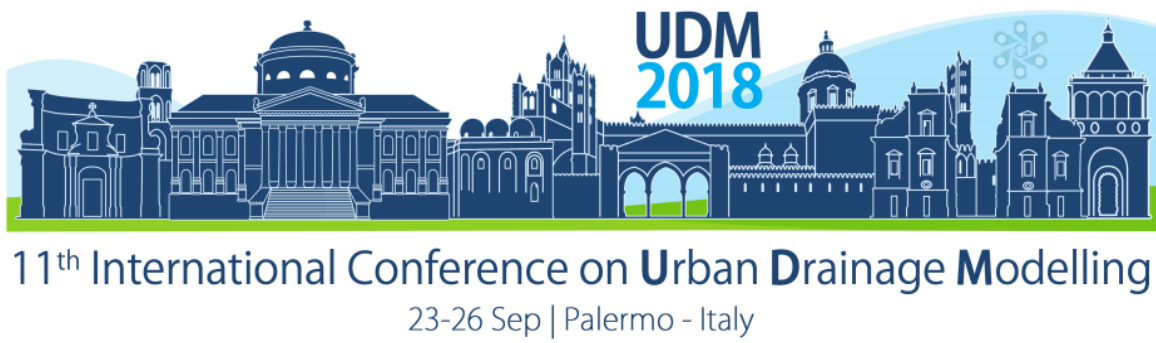

larger volumes, they are like small lakes. Therefore, limnological phenomena become more important in their dynamics (Friedler et al., 2003). Anaerobic stabilization ponds offer a costeffective way to treat wastewater with high organic content, since they are mechanically simple, easy to operate by non-professionals and require less land than facultative and aerobic ponds (Arbeli et al., 2006). However, this simplicity belies the high complexity of their physical, chemical and microbial processes. As a consequence, the microbial process within lagoon systems is less understood than in biological reactors, while the effluent quality is less predictable (Grady et al.,1999). Mathematical models can provide a powerful tool to gain deeper insight into their ecology. In particular, comprehensive mathematical models, which simulate the main reservoir's primary physical, chemical, and biological processes that govern their water quality, can allow for more economical and sustainable reservoir management. The paper presents a semi-empirical mechanistic model derived by modification of previous models (Friedler et al., 2003; Mannina et al., 2008). The model takes into account various processes that influence effluent quality such as: hydraulics and hydrology, solar radiation, atmospheric reaeration, algae, zooplankton, organic matter, pathogen bacteria, and sediment/ water interactions. The model was calibrated to an Italian reservoir located in the south part of Sardinia. The model showed satisfactory results demonstrating the model's potential value as a tool for reservoir management.

\section{MATERIALS AND METHODS}

\subsection{The mathematical model}

The model is an ecological simulation model that describes the physico-chemical and biological water quality changes. It is a semi-empirical mechanistic model that takes into account the settling of particulate components and key chemical/biological processes. The model algorithms, which are partially derived from literature (Friedler et al., 2003; Mannina et al., 2008; Thébault and Salencon, 1993), consists of two connected sub-models: a thermal sub-model and a biological model. The former is superimposed as a forcing function and simulates the temperature of the hypolimnion and epilimnion by means of the following model equation:

$T=T_{m}-a_{t} \cdot \cos \left[2 \pi \times \frac{i+s f s+b_{t}}{365}\right]$

where $T$ is the temperature, $T_{m}$ is the average annual temperature, $i$ is the time in days, sfs is the lag-time between the first day of the year and the beginning of the simulation period, $b_{t}$ is a coefficient and $a_{t}$ is a coefficient which represents the waive amplitude.

By means of the derived temperatures of the hypolimnion and epilimnion, the model takes into account the possible formation of seasonal thermal stratification. Specifically, the water mass is divided into two spatially homogenous layers representing seasonal thermal stratification on the basis of the temperature profiles. In case of stratification, the surface layer or the epilimnion, is separated from the less turbulent bottom layer, the hypolimnion. Each layer is characterized by its volume, temperature, its depth and its solar radiation. Therefore, in the the water body is seasonally thermally stratified.

The biological sub-model simulates the reservoir's main biological processes. The model takes into account five model state variables for the water-column simulation (phytoplankton, 


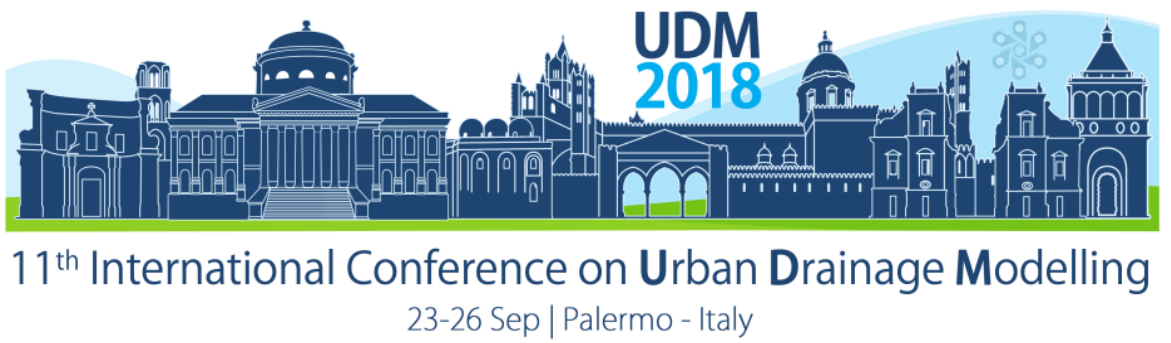

dissolved oxygen, organic matter, zooplankton and indicator bacteria) and two model state variables for the sediments (organic matter and indicator bacteria). Model equations were set up taking into account the local conditions as in the case of evaporation where the Indelicato formula was applied (Indelicato et al., 1989). The biological sub-model was mainly based on the following hypothesis (Friedler et al., 2003; Mannina et al., 2008):

- the waterbody is divided in two zones: upper zone and sediment zone;

- the sediment zone is divided into $5 \mathrm{~cm}$ sediment layer height zones;

- the dynamic of each component is described by the mass conservation principle;

- molecular diffusion is negligible except for dissolved oxygen (DO).

The operational regime, physical structure of the reservoir, quality of the incoming effluent, precipitation, solar radiation, and thermal regime were treated as model forcing functions.

\subsection{The case study}

Simbirizzi lake is a water reservoir located about $8 \mathrm{~km}$ east of Cagliari (Sardinia, Italy). It has a maximum surface area of $3.2 \mathrm{~km}$, and is the last link of the Flumendosa-Campidano system. Stretching from the Gennargentu (a mountainous system situated in the central part of Sardinia) to the island's southern coast, the above-mentioned system consists of several lakes, rivers, and man-made canals supplying drinking water to approximately one third of Sardinia's population.

The reservoir has a maximum storage capacity of $28.8 \mathrm{Mm}^{3}$ and it represents the last tank of the main transportation line of the water resources of the Flumendosa's system. Simbirizzi's lake has been designed, during the winter period, as a regulation reservoir for the treated wastewater flow from the Is Arenas treatment plant, and to guarantee a mixing with the waters from Flumendosa's lake and Fluminimannu's catchment. Simbirizzi'lake is characterized by a persistent eutrophic state with a tendency to hypereutrophy. In order to limit the phosphorus inflow to Simbirizzi's lake from the wastewater treatment plant, the latter has been upgraded to include phosphorus removal. From 2002 to 2003, an extensive field data gathering campaign has been carried out for collecting both quantity and quality data for the lake. Specifically, monitored parameters were sampled and analyzed according to standard procedures recommended by APHA (1999), and included: chemical-physical parameters: BOD5, COD, total suspended solids, chlorophyll a, total phosphorus, $\mathrm{NH}_{4}-\mathrm{N}, \mathrm{NO}_{2}-\mathrm{N}, \mathrm{NO}_{3}-\mathrm{N}$, $\mathrm{Ca}^{++}, \mathrm{Mg}^{++}, \mathrm{K}^{+}, \mathrm{Na}^{+}$, chlorides, sulphates, fluorides, boron; microbiological parameters: total coliforms, faecal coliforms (FC), faecal streptococci, E. coli, Salmonella and Helminth eggs (Ascaris lumbricoides, Taenia). Temperature, specific conductance, $\mathrm{pH}$ and dissolved oxygen were measured on site, using portable equipment.

\section{RESULTS AND DISCUSSION}

The model was applied for a continuous period of two years from 2002 through 2003.. The calibrated parameters have been limited to the most sensitive ones as well as field data availability with the different values of the parameters with respect to the mean values given only for the calibrated parameters. The model parameters were evaluated on a combination of measured data, literature data and model calibration using a uniform random search and by minimizing an object function calculated as the root square of the error variance.

In Figure 1 the results in terms of temperature and water budget are reported. As can be observed (Figure1a), the reservoir exhibited thermal stratification during the highest and lowest temperatures. Such a fact influenced the biological processes and therefore the overall 


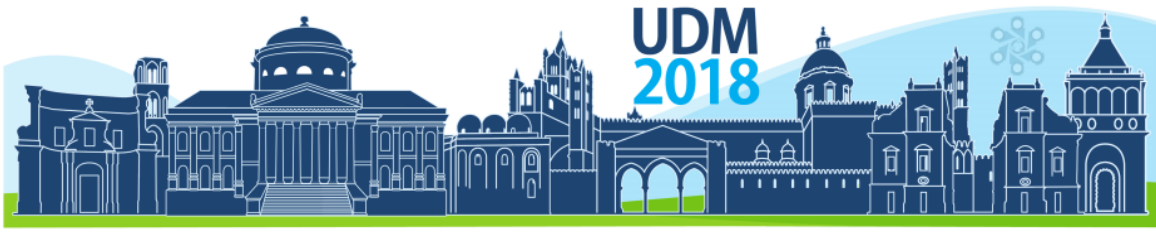

$11^{\text {th }}$ International Conference on Urban Drainage Modelling

23-26 Sep | Palermo - Italy

receiving water quality. The reservoir was characterized by continuous periods of non-zero inflows and outflows. Specifically, during a first period (namely until March 2003) the water budget was positive thus accumulating water. Conversely, after March 2003 the cumulative volume was negative thus indicating an emptying of water.
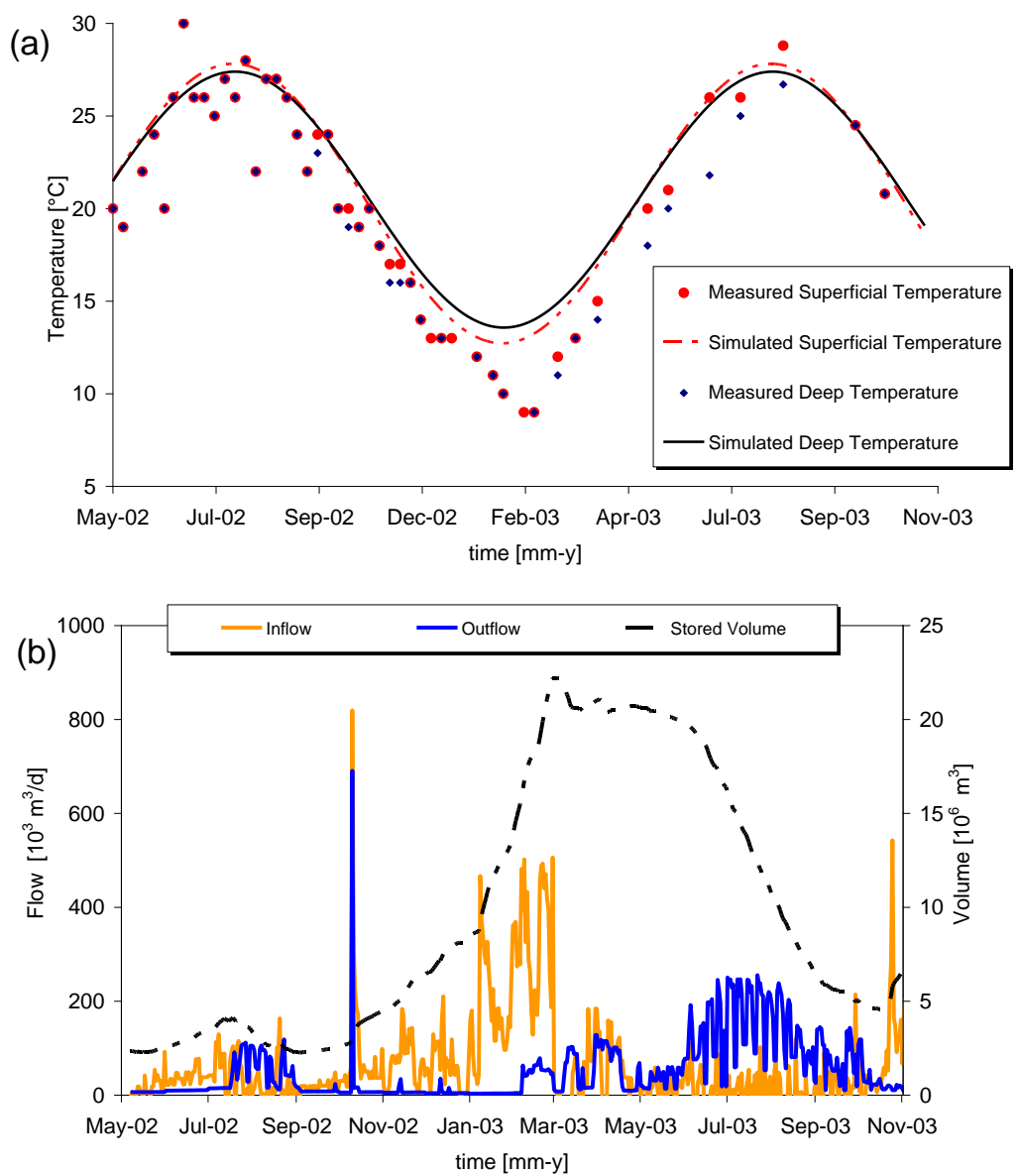

Figure 1. Temperature profiles (a); water budget balance (b).

It is important to stress that biological models do not allow the exact superimposition of simulated and measured data as for the case of physical process models (Thébault and Salencon, 1993). Indeed, measurements provide an instantaneous image of an ecosystem which is subjected to major space-time fluctuations, whereas the model simulates only the evolution of the mean variables. Bearing in mind such considerations, discrepancies between measured and simulated data have to be expected. 


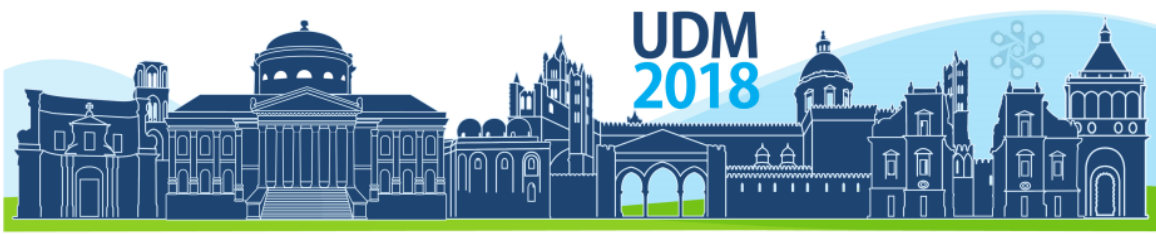

$11^{\text {th }}$ International Conference on Urban Drainage Modelling

23-26 Sep | Palermo - Italy
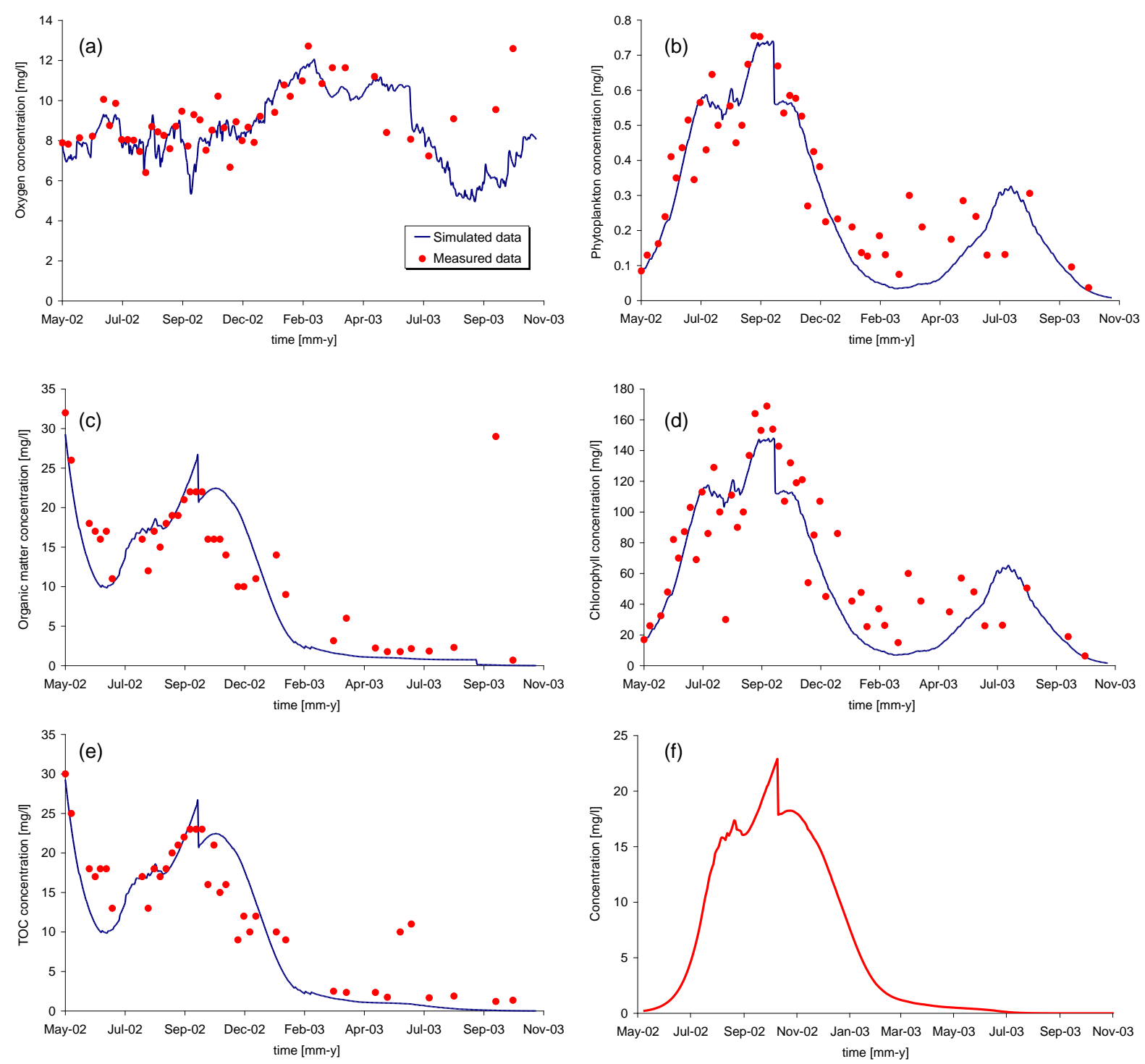

Figure 2. Model results in terms of: oxygen concentration (a); phytoplankton(b); organic matter (c); chlorophyll (d); TOC (e) and zooplankton (f).

Figure 2 shows model results for the five model outputs; namely: organic matter, oxygen concentration, phytoplankton, chlorophyll and total organic carbon (TOC). At first glance, there is a globally good agreement between measured and modelled data. The model is able to satisfactory simulate the system reproducing the main physical/chemical and biological processes.

The results indicate that the reservoir was affected by two periods of algal bloom: a first period where the algal bloom was much more intensive, August-September 2002 and another smaller bloom during the period July 2003. The higher intensity of the first period was caused by the simultaneously occurrences of several phenomena: inflow of wastewater in the reservoir, thermal stratification, and solar radiation intensity. All these phenomena caused an increase of the photosynthesis rate leading to the high algal bloom (Figure2b-d). 


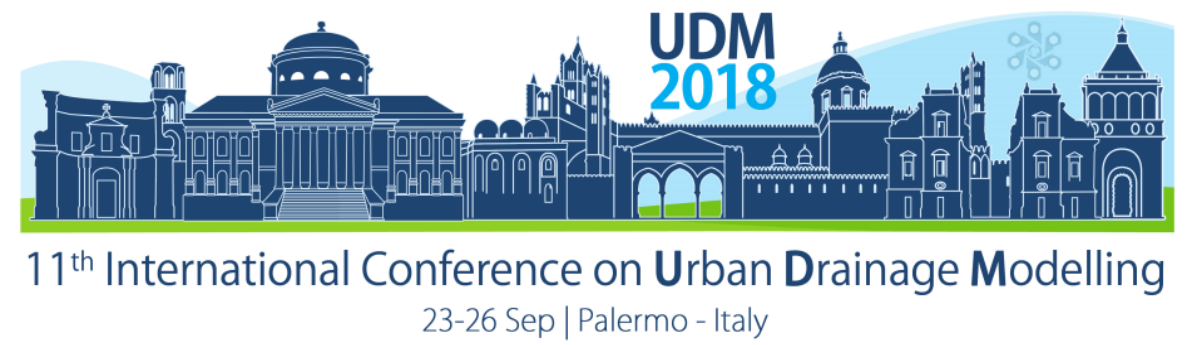

The gradual reduction during the winter periods could be due to the activity of the bacteria that reducing the organic matter, reduce the oxygen concentration leading to a worse environment for the algal.

Based on Figure 2, the following observations can be drawn:

- During the initial simulated periods, the inflow of wastewater and the lower water column heights in the reservoir caused the establishment of a high organic matter concentration.

- During the winter and spring periods, when the reservoir was completely mixed, the organic matter was uniform in the reservoir.

- During the thermally stratified period, the reservoir consisted of two different water masses: an upper and a lower one. The first one was characterized by high oxygen concentrations. Conversely, the lowest one was characterized by a higher sediment oxygendemand (SOD) thus resulting in anaerobic and anoxic conditions. Because the thermocline isolated the hypolimnion, during the period June-August, the oxygen concentration is reduced. On the other hand, as soon as the reservoir was completely mixed, a oversaturation of oxygen took place.

- During the last period of the reservoir simulation, the outflow volumes were higher than the inflow volume and the reservoir started to be emptied (Figure 1b). Such a fact led to a reduction of the reservoir's depth and allowed complete mixing. This latter condition coupled with the limited inflow caused a reduction of the organic matter and phytoplankton bacteria. As a matter of the fact, the oxygen concentration of the latter simulated period showed a decreasing trend reaching the minimum values of the overall simulated period.

\section{CONCLUSIONS}

A mathematical model for the simulation of the behaviour of a stabilization reservoir was presented. The model was applied to a reservoir that stores wastewater located in the South part of Sardinia (Italy). The reservoir was fed by a continuous inflow and was characterized by two periods: a first period during which the cumulative volume was positive thus indicating an accumulation of water and a second period characterized by a decreasing trend of the cumulative volume. The model showed good agreement with the measured data thus indicating its efficacy. The model can be applied for a stabilization reservoir performance assessment enabling a comparison between different management strategies. Specifically, the model can be employed for predicting water quality. Therefore, the model allows the assessment different management scenarios in order to optimize the economic management costs maintaining healthy reservoir ecological status.

\section{References}

APHA American Public Health Association (1999). Standard Methods for the Examination of Water and Wastewater, 19th edn. Washington D. C.

Barbagallo, S., Cirelli, G.L. and Indelicato, S. (2001). Wastewater reuse in Italy. Water Science and Technology, 43(10), 43-50.

Barbagallo, S., Cirelli, G., Consoli, S., and Somma, F. (2003). Wastewater quality improvement through storage: a case study in Sicily. Water Science and Technology, 47(7), 169-176.

Colomer F.L. and Rico D.P. (1993) Mechanistic model for facultative stabilization ponds. Research notes (7-8), 679685.

Dor, I., Raber., M. (1990). Deep wastewater reservoirs in Israel: Empirical data for monitoring and control. Water Research, 24, $1077-1084$. 


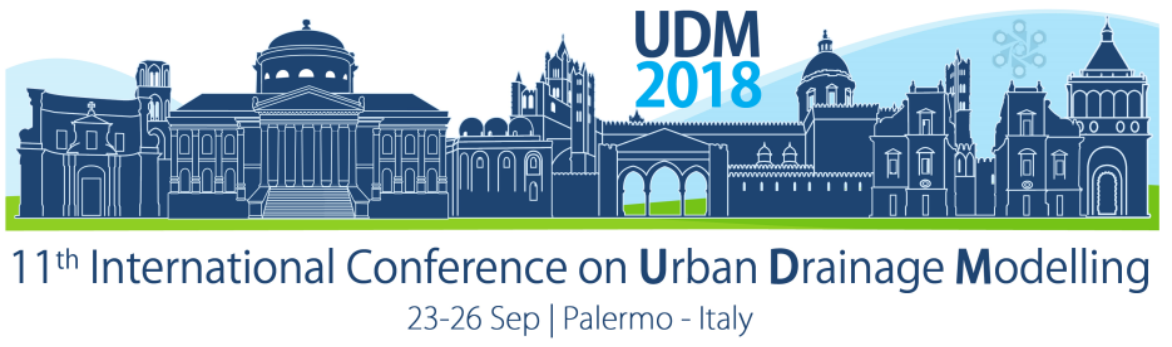

Ferrara R. and Harleman, D.R.F. (1980) Dynamic nutrient cycle model for wastewater stabilization ponds. ASCE EE, 106(2), 37-54

Friedler, E., Juanico, M. and Shelef, G. (2003) Simulation model of wastewater stabilization reservoirs. Ecological Engineering, 20, 121-145.

Fritz, J.J., Middleton A.C., Meredith D.D. (1979) Dynamic process modelling of wastewater stabilization pond. Journal of WPCF, 51(11) 2724-2743

Hull, V., Mocenni, C., Falcucci, M., Marchettini, N. (2000) A trophodynamic model for the lagoon of Fogliano (Italy) with ecological dependent modifying parameters. Ecological Modelling 134(2-3), $153-167$

Indelicato S., Tamburino, V., Barbagallo, S., Mazzola, G. (1989). Risorse idriche nei grandi serbatoi artificiali siciliani C.S.E.I.- Catania.

Indelicato, S., Bargaballo, S., Cirelli, G.L., Zimbone, S.M. (1996) Reuse of municipal wastewater for irrigation in Italy. Proc. Of the 7th International conference on water and irrigation. Tel Aviv, Israel 13-16 May.

Indelicato, S., Barbagallo, S., Cirelli, G.L. (1997). Agricultural use of municipal wastewaters: irrigation methods and health hazards. Int. conf. on water and irrigation "Water management, salinity and pollution control towards sustainable irrigation in the Mediterranean region" Valenzano (Bari), 22 - 26 September.

Juanico M. and Dor I. (1999), Reservoirs for Wastewater Storage and Reuse: Ecology, Performance, and Engineering Design, Springer-Verlag Telos

Juanico, M., Friendler, E. (1994). Hydraulic age distribution in perfectly mixed non steady state reactor. Journal of Engineering, $120(6), 1427-1445$.

Juanico, M., Shelef, G., (1994). Design, operation and performance of stabilization reservoir for wastewater irrigation in Israel. Water Research, 28, 175 - 186.

Liran, A., Juanico, M., Shelef, G. (1994). Coliform removal in a stabilization reservoir for wastewater irrigation in Israel. Water Research, 28, 1205 - 1314.

Mancini, G., Barone, C., Roccaro, P., Vagliasindi, F.G.A. (2007) The beneficial effects of storage on the quality of wastewater for irrigation: a case study in Sicily. Water Science and Technology, 55(1-2), 417-424.

Mannina G., Mancini G., Torregrossa M., Viviani G. (2008) Wastewater modification processes assessment in a stabilization reservoir. Water Science and Technology, Vol 57(7),1037-1045.

Salençon, M., Thébault, J. M. (1996) Simulation model of a mesotrophic reservoir (Lac de Pareloup, France): melodia, an ecosystem reservoir management model. Ecological Modelling 84(1-3), 163-187

Zhang, J., Jørgensen, S. E.; Mahler, H. (2004) Examination of structurally dynamic eutrophication model. Ecological Modelling 173(4), 313-333 


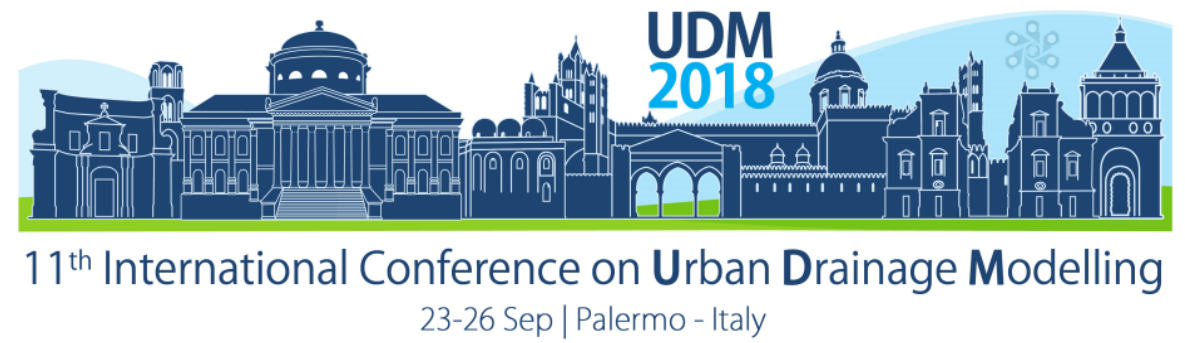

\title{
Advances in river water quality modelling \& management: where we come from, where we are, and where we're going?
}

\author{
Steven C. Chapra ${ }^{1}$ \\ ${ }^{1}$ Tufts University, Civil \& Environmental Engineering Dept., Medford, MA USA
}

\begin{abstract}
The historical roots of environmental engineering and water-quality management are traced to mid-19th century London when engineers and public health workers worked to control and manage the major water-quality problems derived from urbanization. This is followed by a brief review of the field's subsequent century-plus evolution. The talk then turns to the current state of the art and a delineation of key research issues and frontiers. These include the modelling of "black water", scum formation, the nepheloid layer, floatables (plastics \& weeds), macrophytes, zooplankton, and uncertainty analysis of large model frameworks. Beyond specific research needs, global warming and mega-urbanization mean that, in the future, water-quality management must be expanded beyond the traditional reduction of pollutant inputs with novel approaches essential to maintain acceptable water quality in a sustainable fashion. Several case studies are used to illustrate possible approaches including dissolved oxygen bubblers, pure oxygen injection, lake hypolimnetic electron acceptor injection, boom deployment to capture floatables, flushing flows for oxygen and pathogen control, and deep lake siphons. Many of these schemes will be facilitated by coupling improved observational technology such as drones, robots, and sensors with water quantity and quality models. Real time, model-based distributed control could allow the development of "smart waters" where in situ interventions could be implemented in a sustainable fashion.
\end{abstract}

Keywords: eutrophication; oxygen; pathogens; sustainability, control

\section{INTRODUCTION}

\subsection{The Past}

As summarized by Chapra (2011), the historical roots of water-quality management can be traced to mid-19th century London where engineers and public health workers joined together to control water-quality problems caused primarily by the huge influx of people from the UK's rural areas to London. These problems, which including waterborne epidemics and the heavily polluted Thames Estuary, resulted in the birth of modern sanitary (AKA environmental) engineering. These engineers subsequently developed large-scale urban waste collection systems, water and wastewater treatment plants, and water-quality models.

Over the ensuing century, scientific advances and political will motivated environmental engineers to develop a host of water-quality management and modelling technologies. Initial management efforts concentrated on the reduction of first point and then non-point pollution via waste treatment and best management practices. Over the same period, the evolution of water-quality modelling has resulted in a variety of modelling constructs that encompass both conventional and toxic pollutants. In addressing specific water-quality problems (e.g., dissolved oxygen depletion, eutrophication, toxic contamination, acid rain, etc.), the models incorporated a comprehensive array of physical, chemical, and biological processes to simulate the transport and fate of a broad variety of pollutants. The outcome was that, by 20th century's end, the quality of most North American and European waterbodies was elevated to environmentally healthy and economically sustainable levels. 


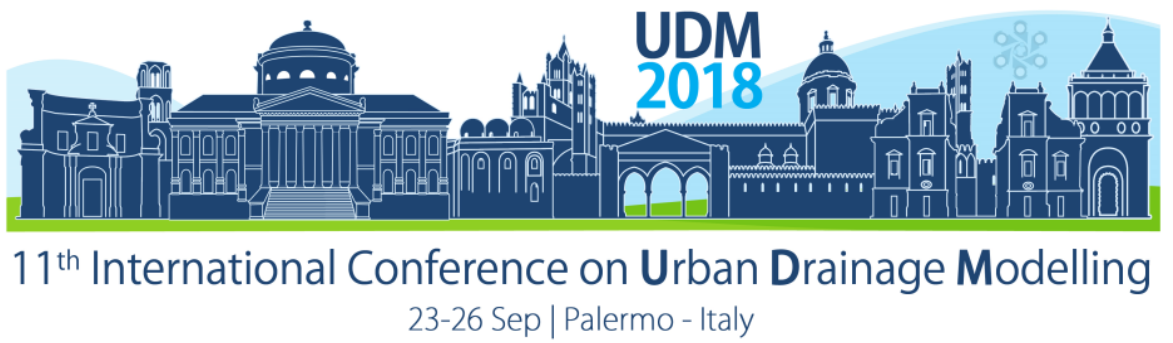

\subsection{The Present}

Today, the 19th century scenario is being repeated on much larger scales as rural populations pour into megacities across the planet, particularly in underdeveloped and developing regions. In contrast to the 19th and early 20th centuries, climate impacts on temperature and hydrology are making aqueous environments more sensitive to pollution impacts. This tandem of mega-urbanization and climate change means that exclusive reliance on reduction of external pollutant inputs will be inadequate to totally confront the new challenges. This position paper makes the case that model-based interventions such as in situ treatment and real-time model-based control could figure prominently in future efforts to alleviate pollutant impacts in a sustainable, cost-effective fashion.

\section{THE INEVITABLE FUTURE}

The future assumed here is predicated on three inevitabilities:

1. Regardless of existing and future short-term control efforts, severe climate change is inevitable. Just as it has taken a century for significant climate impacts to emerge, there is no reason to expect that a reversal will be achieved on significantly shorter time scales.

2. Mega-urbanization will persist unabated as world population continues growing over the coming century (Gerland et al. 2014).

3. No revolutionary economical treatment technology will emerge as a deus ex machina to save the day.

\subsection{Global Warming}

Climate change will have myriad effects on water quality. I will limit the present discussion to two potentially devastating impacts directly connected with one aspect of climate change: global warming. These are (a) the reduction of dissolved oxygen saturation, and (b) the increase of harmful algal blooms (or "HABs").

Dissolved Oxygen Saturation. Most aquatic animals require a minimum dissolved oxygen below which their health will be imperilled (hypoxia). Further, if oxygen levels drop to zero (anoxia), chemical reactions can cause nutrients, toxic metals, and noxious gases to be released into the water from bottom sediments which greatly expands and exacerbates the original oxygen problem.

A critical factor in maintaining adequate oxygen levels is the dissolved oxygen saturation concentration. Dictated by water temperature, salinity, and atmospheric pressure, the saturation concentration is what would occur in a pristine water in equilibrium with atmospheric oxygen. Hence, the saturation minus the hypoxic concentration represents a waterbody's "slack". i.e., its capacity to assimilate oxygen demanding pollutants without destroying aquatic life.

As in Fig. 1, freshwater at sea level drops from about $14.6 \mathrm{mg} / \mathrm{L}$ at freezing to $6.4 \mathrm{mg} / \mathrm{L}$ at $40^{\circ} \mathrm{C}$. For marine waters, the presence of salt decreases these values across all temperatures by an additional $20 \%$. The impact of reduced atmospheric pressure is even more pronounced. Thus, for the world's highest navigable lake (Lake Titicaca, Bolivia at 3.81 $\mathrm{km}$ ) the freshwater values are reduced by almost $40 \%$ to 9.1 to $4.0 \mathrm{mg} / \mathrm{L}$ at $0^{\circ} \mathrm{C}$ and $40^{\circ} \mathrm{C}$, respectively. The take-home message is that (a) rising temperatures will significantly reduce the planet's natural waters capacity to assimilate oxygen demanding pollutants and maintain 


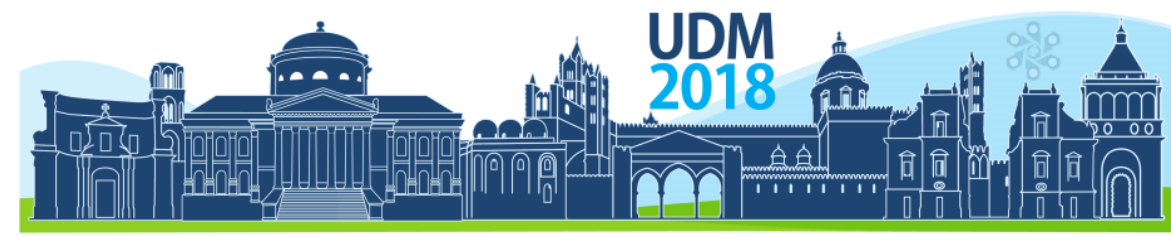

$11^{\text {th }}$ International Conference on Urban Drainage Modelling

23-26 Sep | Palermo - Italy

aerobic conditions for fish and other oxygen-requiring organisms, and (b) that this impact will be exacerbated for estuarine and high elevation systems.

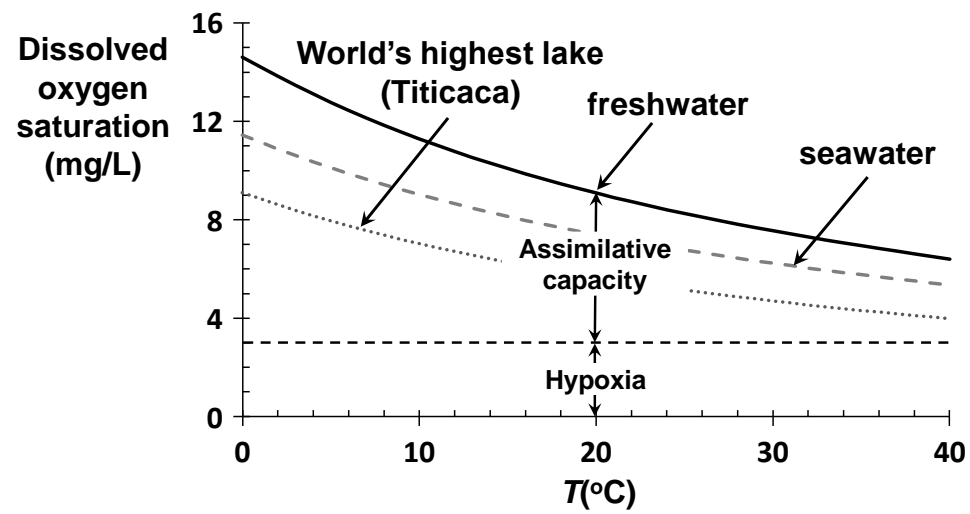

Figure 1. Dissolved oxygen saturation versus temperature for sea level freshwater (solid), seawater (dashed), and Lake Titicaca, Bolivia (dotted). A waterbody's "assimilative capacity" is represented by the difference between the pristine state (saturation) and hypoxia (3 mg/L as in U.S. EPA 1986), the level that can no longer support living aquatic organisms.

Harmful Algal Blooms. In freshwater, harmful algal blooms (or HABs) invariably consist of excessive growth of cyanobacteria, commonly known as "blue-green algae." These algae can produce toxins, form unsightly scums, create taste and odour problems, and are largely inedible by higher organisms like fish. It is well known that whereas most phytoplankton cannot live above some maximum temperature, these toxic algae flourish at elevated temperatures and so global warming should foster their dominance in natural waters. As depicted in Fig. 2, other more beneficial phytoplankton such as diatoms and green algae, cannot grow at very high temperatures whereas the harmful cyanobacteria thrive. Thus, as discussed elsewhere (Chapra et al. 2017), rising water temperatures along with increased nutrient loads will lead to more freshwater harmful algal blooms.

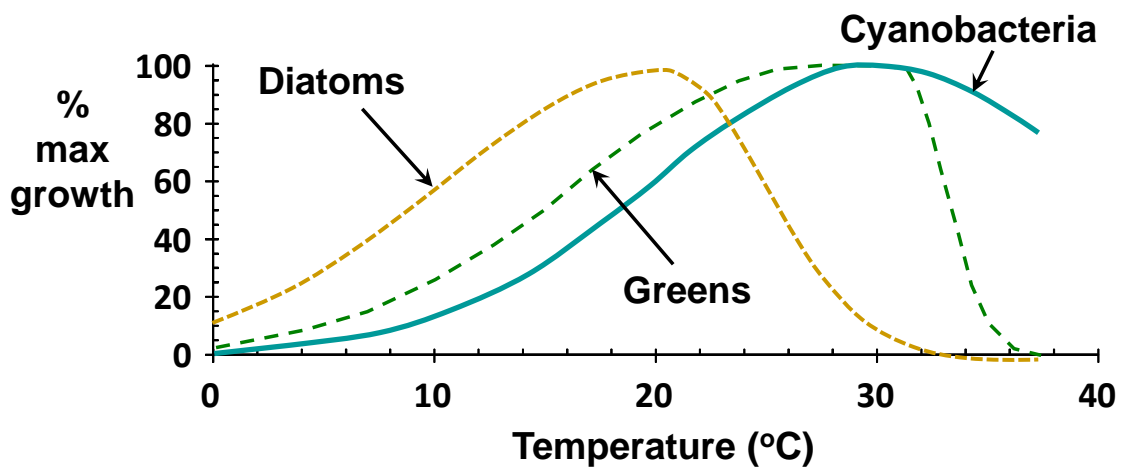

Figure 2. The effect of temperature on the maximum growth rate of common freshwater phytoplankton as a function of temperature as reported by Paerl and Otten (2013). Note how the "good" algae (diatoms and greens) cannot grow at higher temperature whereas the harmful cyanobacteria persist

\subsection{Mega-Urbanization}

The foregoing water-quality impacts, as well as myriad other effects of climate change, will be intensified by the growth of megacities; that is, urban areas with populations over 10 


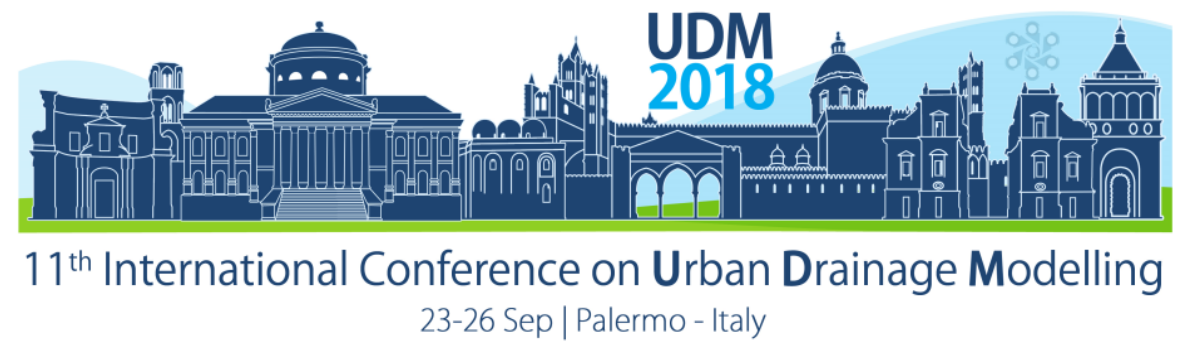

million. By the end of the 21st century, it is predicted (Hoornweg and Pope, 2016) that 15 to 23 per cent of world population (1.6 billion to 2.3 billion) will live in the 101 largest cities. Further, impoverished populations have shifted from the 19th century's inner-city slums to the sprawling favelas on the fringes of many $21^{\text {st }}$ century megacities. Such decentralization makes waste collection and treatment much more difficult and costly to implement than was the case for the dense inner-city slums of the $19^{\text {th }}$ and $20^{\text {th }}$ centuries.

Although traditional wastewater management will undoubtedly remain an important option, the inevitability of climate change and mega-urbanization suggests that large-scale wastewater management and infrastructure (sewers, centralized waste treatment, etc.) alone will be inadequate to confront the new challenges. The fact that large-scale wastewater treatment requires wealth, political stability, and effective tax collection means that alternative approaches will be a necessity particularly in the poorer underdeveloped parts of the planet. Thus, as suggested in the following section, engineers and scientists will have to expand their repertoire of management actions to meet these challenges.

\section{THE "POSSIBLE” FUTURE}

In this section, several remedies are outlined that could prove useful where desirable water quality cannot be achieved via pollutant input reduction. The following cases in no way exhaust the feasible options, but are intended to provide a few examples of effective alternatives or supplements to waste reduction. Note that some of these have been proposed but have not been implemented. Nevertheless, they illustrate possible alternatives to conventional waste reduction.

\subsection{Gas \& Chemical Injection}

Stationary oxygen injection. Oxygen can be pumped into water to prevent anoxia on an asneeded basis. For example, salmon migration through the chronically anoxic Stockton Ship Channel in California only occurs for short periods during certain times of year. Aerators could be deployed along the side of the channel closest to the migration path to provide salmon with safe passage during these spawning period.

Mobile oxygen injection. During the warmer months, short duration, severe rainstorms can cause combined sewers (i.e., carrying both rainwater and sewage) to overflow into the Thames estuary in the heart of London. Several barges called "bubblers" are deployed when oxygen probes in the river indicate dropping concentrations. Such vessels are now being utilized in other parts of the world such as Shanghai, China.

\section{Addition of Electron Acceptors Other Than Oxygen.}

After the bottom waters go anoxic, organic carbon is broken down by a series of electron acceptors, the first of which is nitrate. The process, called denitrification, converts the nitrate to harmless nitrogen gas. In addition, this prevents certain contaminants from being released from the bottom sediments as well as suppressing the release of the potent greenhouse gas, methane or for systems with high sulphate, the noxious gas hydrogen sulphide. Such a scheme developed by the Upstate Freshwater Institute, presently injects nitrate from derived from Syracuse, New York's wastewater stream into Onondaga Lake for this purpose. 


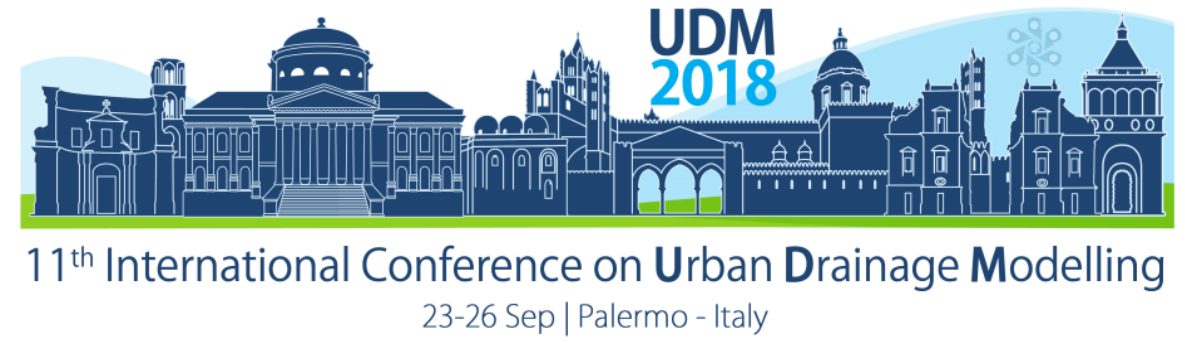

\subsection{Chemical Additions}

Phoslock is the commercial name for a bentonite clay which allows it to bind with phosphates and thereby remove them from the water column. Eutrophication (excessive plant growth due to elevated levels of nutrients) of many lakes around the world has been reduced dramatically by Phoslock application.

\subsection{Flow manipulation}

Following the 2010 earthquake, a catastrophic cholera epidemic swept down Haiti's largest river (the Artobonite) killing nearly 8,000 people who used the river water. If a reservoir located at the river's headwaters had released water immediately after the first reported cases, the cholera organisms would have been rapidly flushed to the Caribbean and the epidemic greatly reduced.

\section{AUTOMATED REAL-TIME DISTRIBUTED CONTROL}

Although it has not been widely utilized, the foregoing cases point toward an even more powerful approach to pollution reduction: automated real-time distributed control. Developed in fields such as chemical engineering, the approach applies control theory in combination with advanced sensor technology, and predictive mathematical models to optimize control of distributed systems. Such approaches have been developed to maximize the delivery of water and minimize wasted water for large complex irrigation systems. It is easy to envisage how such technology could be applied to economically manage the water quality of natural waters such as rivers with multiple pollutant sources in real time.

\section{CONCLUSIONS}

In the face of climate change and mega-urbanization, environmental engineers and managers will have to develop new control schemes beyond waste reduction and centralized waste treatment. Many of these schemes will be facilitated by coupling improved observational technology such as drones, robots, and sensors with water quantity and quality models. Real time, model-based distributed control could allow the development of "smart waters" where in situ interventions could be implemented in a timely and sustainable fashion.

\section{References}

Chapra, S.C. (2011) Rubbish, stink, and death: The historical evolution, present state, and future direction of water-quality management and modeling. Environ. Eng. Res. 16(3): 113-119.

Chapra, S.C., Boehlert, B., Fant, C., Henderson, J., Mills, D., Mas, D.M.L., Rennels, L., Jantarasami, L., Martinich, J., Strzepek, K.M., Bierman, V.J.,Jr., Paerl, H.W. (2017) Climate change impacts on harmful algal blooms in U.S. freshwater. Environ. Sci. \& Technol. 51(16): 8933-8943.

Gerland, P., Raftery, A.E., Ševčíková, H., Li, N., D. Gu, T. Spoorenberg, L. Alkema, B. K. Fosdick, J. Chunn, N. Lalic, G. Bay, T. Buettner, G. K. Heilig, J. Wilmoth, (2014) World population stabilization unlikely this century. Science. 346, 234-237. 10.1126/science.1257469pmid:25301627 doi:10.1126/science.1257469.

Hoornweg, D. and Pope, K. (2016) Population predictions for the world's largest cities in the 21 st century. Environment \& Urbanization, 29(1), 195-216. DOI: $10.1177 / 0956247816663557$.

Paerl, H.W. and Otten, T.G. (2013) Harmful cyanobacterial blooms: causes, consequences, and controls. Microb. Ecol. 65, 995-1010.

U.S. EPA (1986). Quality criteria for water. United States Environmental Protection Agency Office of Water Regulations and Standards. EPA 440/5-86-001. May I, 1986. 


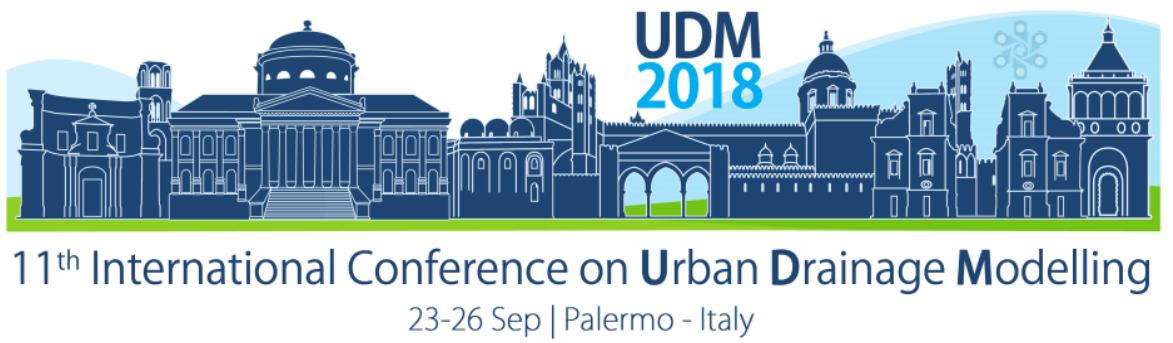

\title{
Analysis of the Po River Environmental Compatibility
}

\author{
Deborah Panepinto', Mariachiara Zanetti ${ }^{1}$, Eugenio Lorenzi ${ }^{2}$, Margherita Deceglia² \\ ${ }^{1}$ Politecnico di Torino, DIATI, Torino, Italia \\ 2 SMAT (Società Metropolitana Acque Torino SpA), Torino, Italia \\ (deborah.panepinto@polito.it,mariachiara.zanetti@polito.it, eugenio.lorenzi@smatorino.it, \\ margherita.deceglia@smatorino.it)
}

\begin{abstract}
The aim of this paper is to examine water quality of the Po River in a small stretch in Piedmont region (northern Italy). In this stretch a large pollution load, derived from Turin's metropolitan area (about 2 million population equivalent) is mainly treated in the wastewater treatment plant (WWTP) located in Castiglione Torinese, and discharged in the Po River. The study quantified and modelled (using the tool of the mass balance) this load (in particular for the two parameters Total Nitrogen and Total Phosphorous) in order to understand the sources, destinations and effects of the emitted pollutants.

The objective was to define the environmental impact produced by the Castiglione Torinese Wastewater Treatment Plant on the water quality of the river, based on various hydrological conditions and the possible interventions on the point and diffuse loads.

The obtained results show that the environmental status of the Po River is only minimally influenced by the Castiglione Torinese WWTP discharge and so an intervention on the diffuse load is necessary.
\end{abstract}

Keywords: water quality; flow rate; wastewater treatment plant; pollution load

\section{INTRODUCTION}

The condition of the water in the stretch of the Po River that runs through the city of Torino, already critical, is subjected to pollution loads from several sources. In this work a modeling approach was chosen in order to analyze the Po River water quality in the stretch between Castiglione Torinese and Chivasso-localities situated in Piedmont (northern Italy). This selected river stretch is affected by three principal types of loads that affect the water quality in the Torino area and in the stations downstream. Two of these loads are of diffused origin (one from agricultural sources and the other from meteoric waters) while the third is of point origin: the effluent from the SMAT wastewater treatment plant (the biggest plant in Italy).

In this work a model has been built of the average load, by using the mass balance method (Boskidis et al., 2012; Xia et al. 2009), and the influence of the SMAT wastewater treatment plant on the Po River water quality over a period of 4 years, 2007 to 2011 was analyzed. Subsequently, on the basis of a sampling campaign, the SMAT wastewater treatment plant discharge influence has been defined. A comparison was performed between the actual (sampling) and historical data, in order to determine whether the pollution loads are changing.

\section{MATERIALS AND METHODS}

The study considered the stretch of the Po River between Castiglione Torinese and Chivasso) approximately $20 \mathrm{~km}$ length. In this stretch, the river runs past the SMAT wastewater treatment plant and also through a territory primarily used for agriculture. The SMAT wastewater 


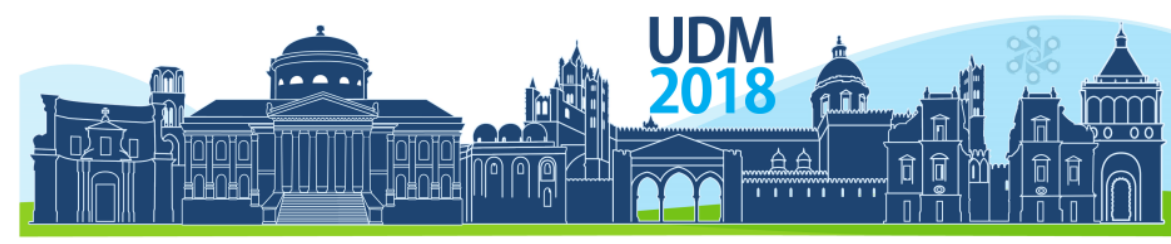

$11^{\text {th }}$ International Conference on Urban Drainage Modelling

23-26 Sep | Palermo - Italy

treatment plant is the largest Italian wastewater treatment plants, treating the metropolitan wastewater of the entire Torino area (with more than 2 million inhabitants).

The aim of this work was to determine the influence of the SMAT wastewater treatment plant discharge on the quality of the river water.

In this work three kinds of analyses were performed:

- The first analysis consisted, after reconstructing the hydrological and qualitative framework with historical data (2007 - 2011), in the following simulation: definition of the load increase in the stretch between Castiglione Torinese and Chivasso, and the separation of this load increase into two parts, one attributable to the SMAT discharge and the other to the diffusive source;

- The second analysis consisted in a simulation parallel to the previous one but based on a sampling campaign to reconstruct the hydrological and qualitative framework;

- The third analysis consisted of a comparison between the simulation performed with historical and actual data (obtained from the sampling campaign).

\section{RESULTS AND DISCUSSION}

\subsection{Analysis of the historical data}

The aim of the analysis was the definition of the influence of the SMAT wastewater treatment plant compared to that of the other main source (a diffused source, due primarily to the agricultural discharge), on the increased pollution between the two stations Castiglione Torinese and Chivasso. For the analysis it has been used the following equation:

Load increase CHIVASSO-CASTIGLIONE $=$ Load CHIVASSO - Load CASTIGLIONE

Influence of SMAT $=(\text { Load SMAT / Load increase CHIVASSO-CASTIGLIONE })^{*} 100$

(2)

Diffuse load $=$ Load increase CHIVASSO-CASTIGLIONE - Load SMAT

The analysis was performed for the two parameters total nitrogen and total phosphorous.

The following figures show the load increase and its split in the two sources, the point load source (attributable to the SMAT wastewater treatment plant) and the diffuse source.
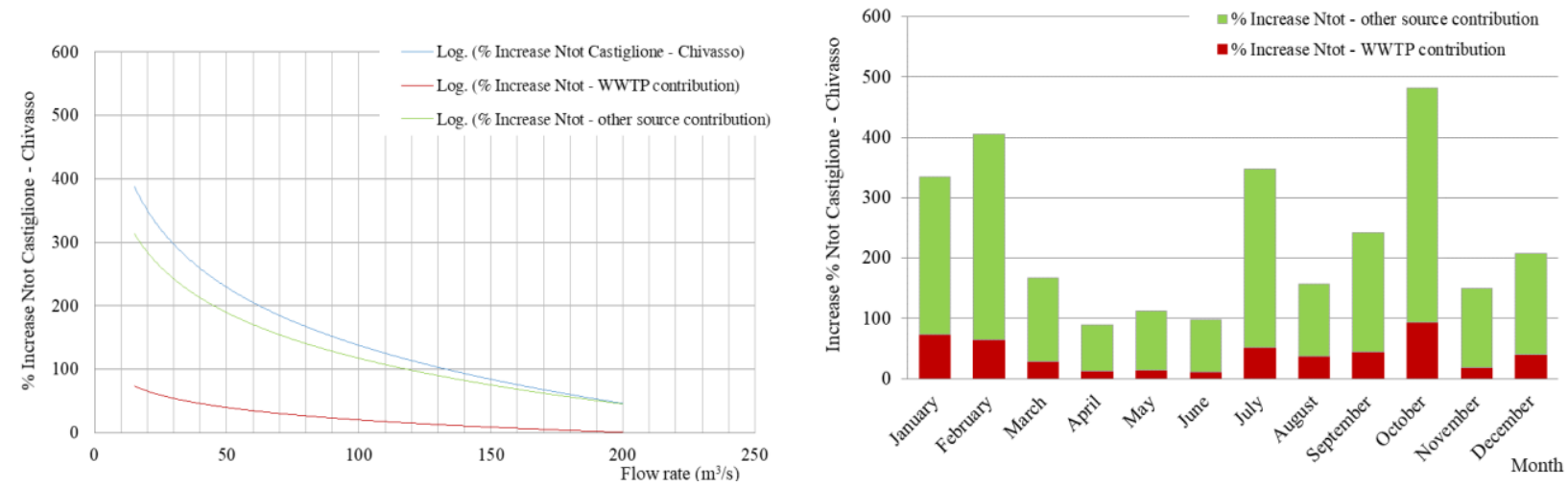

Figure 1 Total nitrogen load increase, split between point and diffuse sources (historical period 2007 - 2011) 


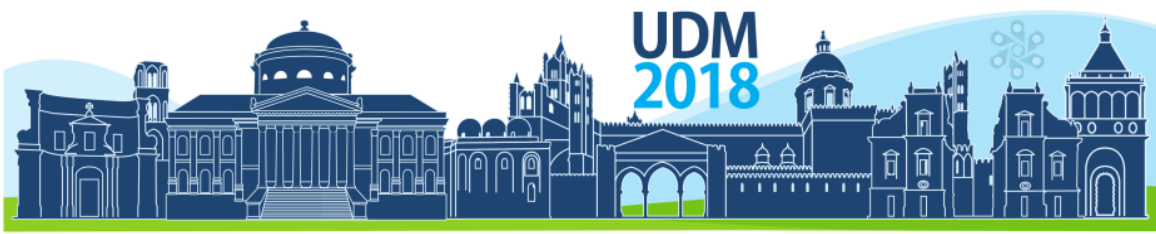

$11^{\text {th }}$ International Conference on Urban Drainage Modelling 23-26 Sep | Palermo - Italy
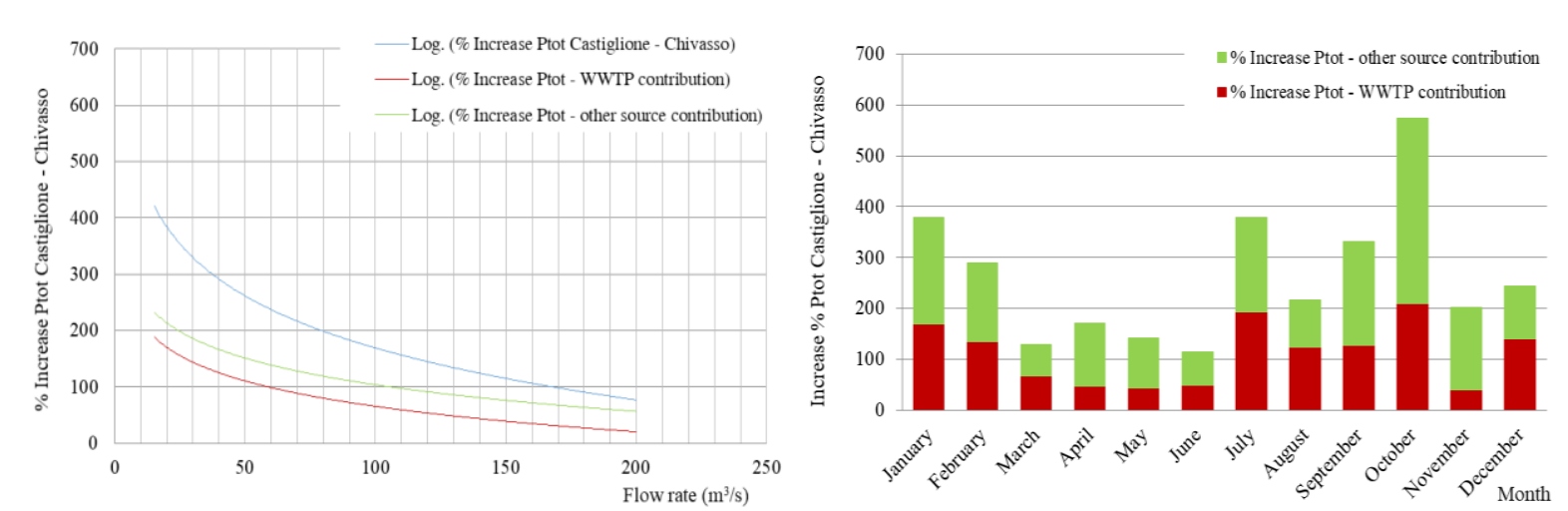

Figure 2 Total phosphorous load increase, split between point and diffuse sources (historical period 2007 - 2011)

By analyzing Figure 1 and 2 it is possible to observe that the trend of the parameters Total Nitrogen and Total Phosphorous decreases in connection of the Flow rate increasing. The contribution of the SMAT wastewater treatment plant to the increase pollutant load between the stations Castiglione and Chivasso was lower than the contribution of the diffuse source.

\subsection{Analysis of the sampling data}

On the basis of the sampling campaign it has been defined the influence of both the SMAT wastewater treatment plant and the diffuse source (due primarily to agricultural discharge) on the increased pollution between the two stations Castiglione Torinese and Chivasso. Analyses were conducted separately for the two parameters Total Nitrogen, and Total Phosphorous.
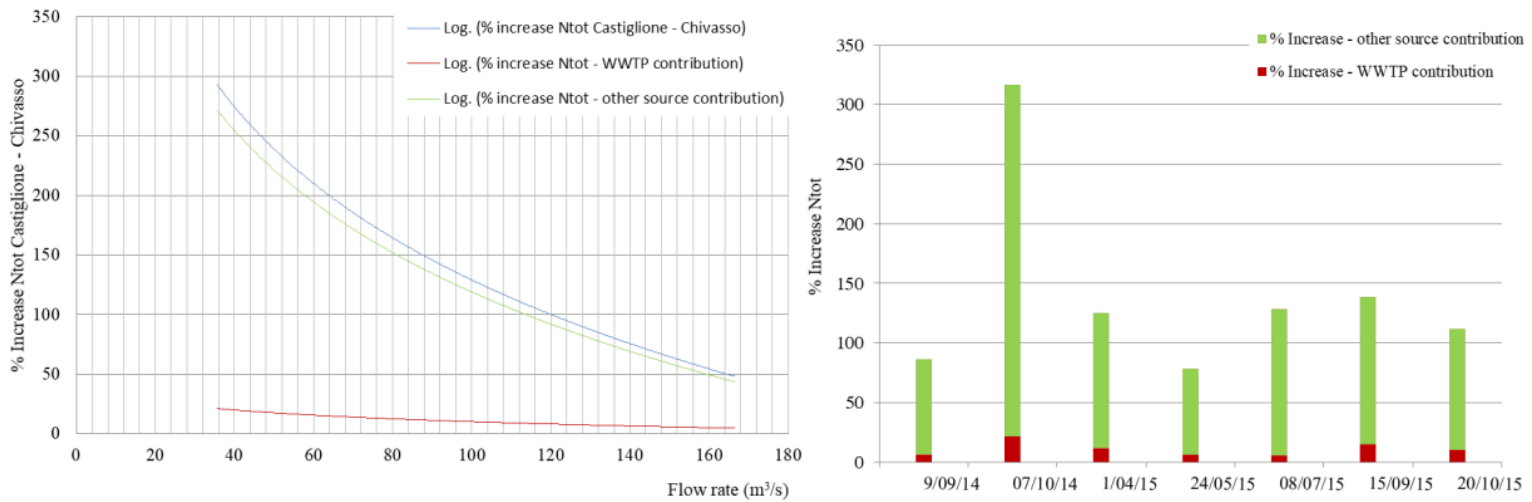

Figure 3 Total nitrogen load increase, split between point and diffusive sources (years 2014 - 2015) 


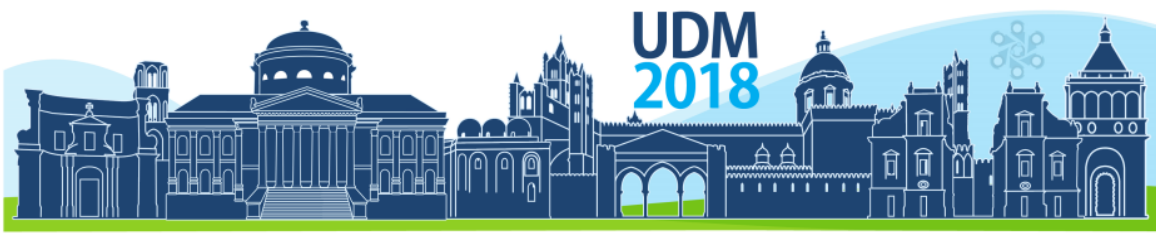

$11^{\text {th }}$ International Conference on Urban Drainage Modelling

23-26 Sep | Palermo - Italy
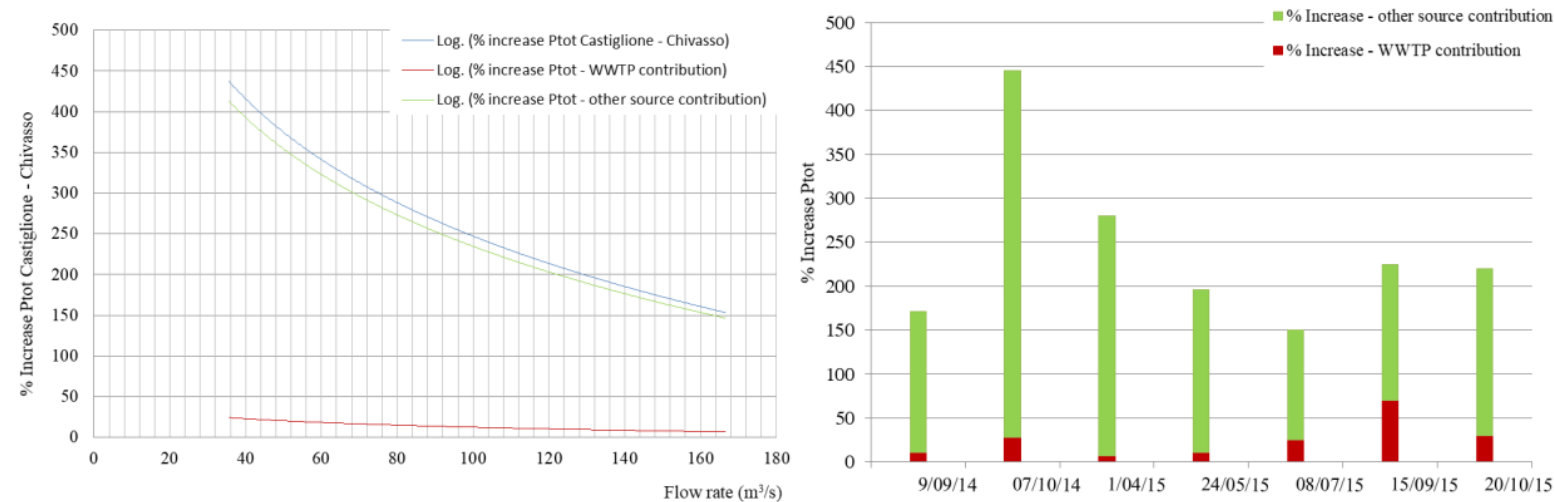

Figure 4 Phosphorous load increase, split between point and diffusive sources (years 2014 - 2015)

Figures 3 and 4 show for the pollutant parameters Total Nitrogen and Total Phosphorous the trend of the pollution increase between Castiglione Torinese and Chivasso stations as a function of the flow rate measured in Castiglione station and how this load increase is split between the two sources.

By analyzing these Figures it is possible to note that:

- the amount of load increase in the considered stretch decreases as a function of increasing flow rate;

- the contribution of the SMAT wastewater treatment plant was very low in comparison with the contribution of the diffuse source.

\section{CONCLUSIONS}

The results of this interpretation of historical water quality data for the Po River and analysis of the current conditions indicate some general trends, as follows:

- The influence of the discharge of the Turin WWTP on the quality of the Po River can be considered low in comparison with that from the diffused loads coming from agricultural activities or from surface leaching waters (considering the entire Castiglione T.se - Chivasso stretch);

- By comparing the historical and current data, it is possible to observe a significant decrease in the impact of the WWTP on the river quality, because of increased removal efficiency of the plant.

\section{References}

Boskidis I., Gikas G.D., Sylaios G.K., Tsihrintzis V.A. (2012) Hydrologic and Water Quality Modeling of Lower Nestos River Basin, Water Resour. Manag., 26, 3023-3051;

Xia X., Yang Z., Wu Y. (2009), Incorporating Eco-environmental Water Requirements in Integrated Evaluation of water Quality and Quantity_A Study for the Yellow River, Water Resour. Manag., 23, 1067 - 1079. 


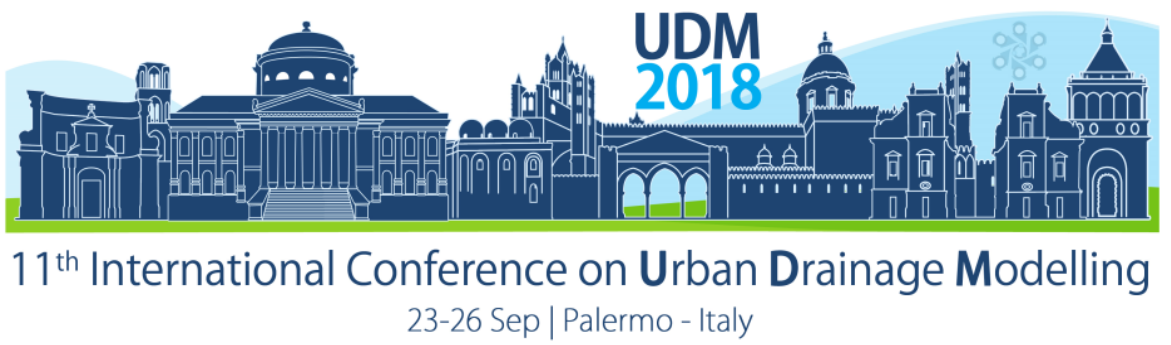

\title{
Parametric inference in large water quality river systems
}

\author{
Antonio Moreno-Rodenas ${ }^{1}$, Jeroen Langeveld ${ }^{1}$ and Francois Clemens ${ }^{1,2}$ \\ ${ }^{1}$ Delft University of Technology, Sanitary Engineering, Water Management, Delft, The Netherlands \\ 2 Deltares, Delft, The Netherlands
}

\begin{abstract}
Environmental models often contain parameters, which are not measurable, yet conceptual descriptions of some physical process. The value of such parameters is often derived by measuring internal state model variables in the system and indirectly tuning/calibrating the value of the parameters so some degree of match is achieved. Bayesian inference is a widely used tool in which the modeller can transfer some prior beliefs about the parameter space, which is updated when additional knowledge on the system is acquired (e.g. more measurements are available). However, the amount of simulations required to perform a formal inference becomes prohibitive when using computationally expensive models. In this work the inference of the hydraulic and dissolved oxygen processes is presented for a large scale integrated catchment model. Two emulator structures were used to accelerate the sampling of the river flow and dissolved oxygen dynamics. Posterior parameter probability distributions were computed using one year of measured data in the river.
\end{abstract}

Keywords: Integrated Catchment Modelling, Emulation and Water Quality

\section{INTRODUCTION}

The description of processes in environmental modelling is seldom purely physically based. This is due to an incomplete understanding of the real underlying dynamics, to the lack of field measurements or due to a need of simplification. This leads to the use of non-physical parameters, which cannot be directly measured or that lump several processes. The value of such parameters is calibrated such that the model and reality have a quantifiable degree of resemblance. The transferability of parameters from one system to others is mostly limited, yet the modeller often has some prior knowledge acquired by simulating similar cases, which could be used in the calibration process. This process is often approached from a Bayesian perspective, in which the modeller encodes its knowledge as a joint probability distribution of the parameters, which are updated in view of new data.

Integrated urban water modelling focuses on the joint simulation of processes affecting water dynamics through the urban-river system. These models jointly evaluate wastewater treatment processes, urban drainage and river dynamics. This often generates a rapid escalation of complexity. The representation of all subsystems involved produces highly parameterized conceptualizations, which requires a large amount of data in the identificationcalibration process. Additionally, the dynamics of interest often occur at very different timespace scales, for instance, urban CSO discharges have a characteristic time of minuteshours whereas river dissolved oxygen dynamics is at hourly-monthly scale. This sometimes leads to the inference been performed on long time-series and often in several measured state-variables. Although, when possible, calibration is done sequentially by decomposing the model in upstream to downstream independent regions, it is common to have an inference set-up, which depends in a computationally expensive model to be evaluated at long time-series samples. 


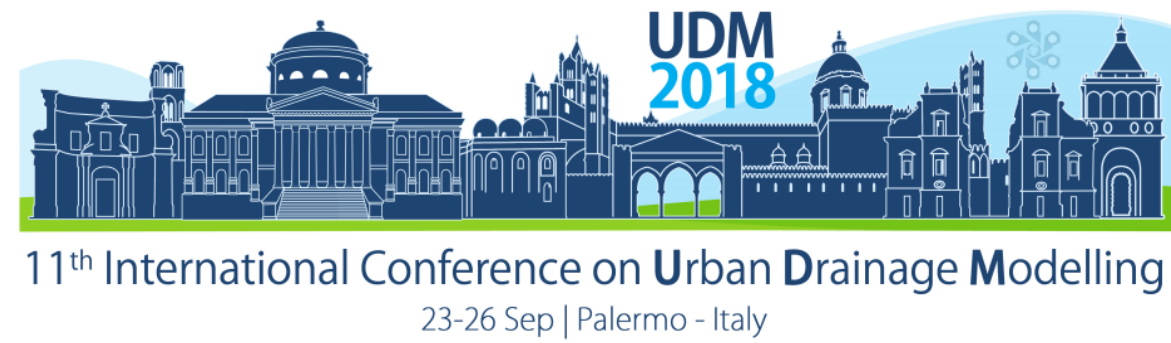

Inference schemes often require a large number of model evaluations $(\sim 10,000$ s) to reach convergence. This renders the inference in the original model impractical. This problem has been approached from two main directions: a) reducing the number of required samples by creating optimal sampling schemes (Laloy and Vrugt 2012), b) accelerating model sampling through model emulation (Carbajal et al. 2017).

Data-driven model emulation focuses on reproducing the link between a set of given inputs/parameters to one or more outputs of interest. This is achieved by creating known samples at a series of given inputs-outputs and creating an interpolator, which approximates the model output at new given inputs. This process becomes a challenge when the dimensionality of the problem grows. In this work we present a case in which a flow and dissolved oxygen modelled time-series ( 1 year) is emulated to 4 and 8 parameters respectively in a large-scale integrated catchment system. This emulator is then used to infer the posterior probability distribution of the model parameters by using a measured dataset.

\section{MATERIALS AND METHODS}

\subsection{Integrated Catchment modelling}

The river Dommel is located in the south of The Netherlands. This river system presents severe oxygen depletion processes under heavy rainfall conditions. This is mainly originated by Combined Sewer Overflow (CSO) discharges in the river result of the overloading of the urban drainage system. The river receives the discharge of several municipalities through $\sim 200$ CSOs. A full-scale integrated catchment model has been used in the system in order to assess the origin of pollution and direct measures for its reduction. The model is developed in WEST (DHI) and includes urban drainage, wastewater treatment and river processes with the objective of simulating dissolved oxygen processes in the receiving water body. Further information on the case study can be found in (Langeveld et al. 2013, Moreno-Rodenas et al. 2017). One year of measured data are available in the system (Jan - Dec 2012).

\subsection{Emulator}

A polynomial chaos expansion was used to link the vector of hydraulic and water quality parameters to the targeted outputs of the model (Bellos et al. 2017, Xiu and Karniadakis 2002). A model response database was built assuming uniformly distributed parameters under a Latin hypercube sampling scheme. This was created by drawing 1000 samples of flow and 2000 of dissolved oxygen dynamics to combinations of the model parameters. From those simulations 200 were used to validate the emulator performance and the rest were used during the training process. Lagrange polynomials were used of order 4 and 5 .

\subsection{Inference}

The prior knowledge was encoded as uniform distributions. An independently and identical Gaussian distribution was initially proposed as a likelihood description. However, a first inference attempt rendered a non-stationary variance in the residual structure. Thus the model error was updated using a linearly related variance with the variable's value:

$$
\sigma^{2}\left(Q_{t}\right)=\left(s t d 1+s t d 2 \cdot Q_{t}\right)^{2}
$$

this generated two extra error model hyper-parameters std1 and std2 which are also to be inferred from the available data, $Q_{t}$ attended to the value at time $t$ of the simulated variable. Thus the log likelihood took the form: 


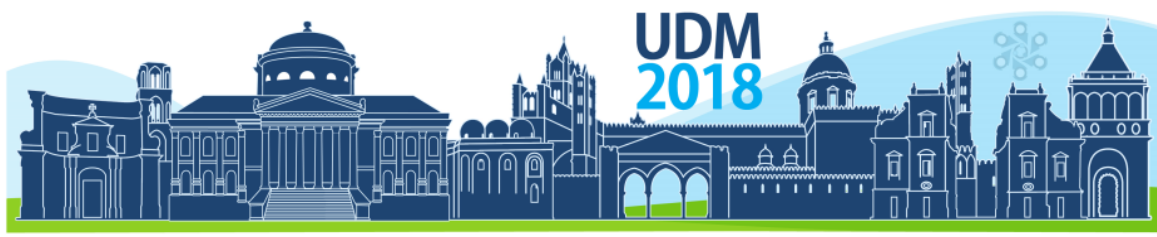

$11^{\text {th }}$ International Conference on Urban Drainage Modelling

23-26 Sep | Palermo - Italy

$$
L(Y \mid \theta)=-\frac{1}{2} \log (\operatorname{det}(\Sigma))-\frac{1}{2}(Y-M(\theta))^{T} \cdot \boldsymbol{\Sigma}^{-1} \cdot(Y-M(\theta))
$$

where $\boldsymbol{\Sigma}=\mathbf{I} \cdot \bar{\sigma}^{2}(Q)$ with $\mathbf{I} \in \mathbb{R}^{m x m}$ the identity matrix and $\bar{\sigma}^{2} \in \mathbb{R}^{m x 1}$ the vector of variances (from eq(1)). $M(\theta) \in \mathbb{R}^{m x 1}$ is the model's output and $Y \in \mathbb{R}^{m x 1}$ the observations. A MCMC algorithm was used to sample from the posterior distribution of the parameters. 50,000 samples were drawn in each case. The process adopted for the inference was the following: 1) Create a database of model parameter-outputs. 2) Propose an emulator structure through a polynomial expansion. 3) Validate the emulator performance by using a testing dataset. 4) Propose a model/measurement error structure. 5) Use measured data in the system to infer the posterior parameter distribution. 6) Validate the assumptions made in the error model.

\section{RESULTS AND DISCUSSION}

Figure 1 shows the Nash-Sutcliffe efficiency performance indicator between emulator structures and the simulator output for one-year of flow and DO dynamics at 200 parameter combinations from the validation dataset. The values for both series are consistently close to 1 , which indicates a good agreement with the simulator behaviour, thus allowing substituting the model by its emulator during the inference process.

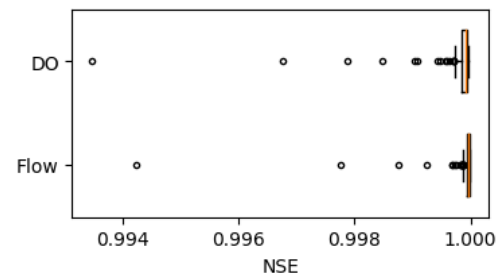

Figure 1. Box plot of NSE performance emulator vs simulator for the flow and DO dynamics

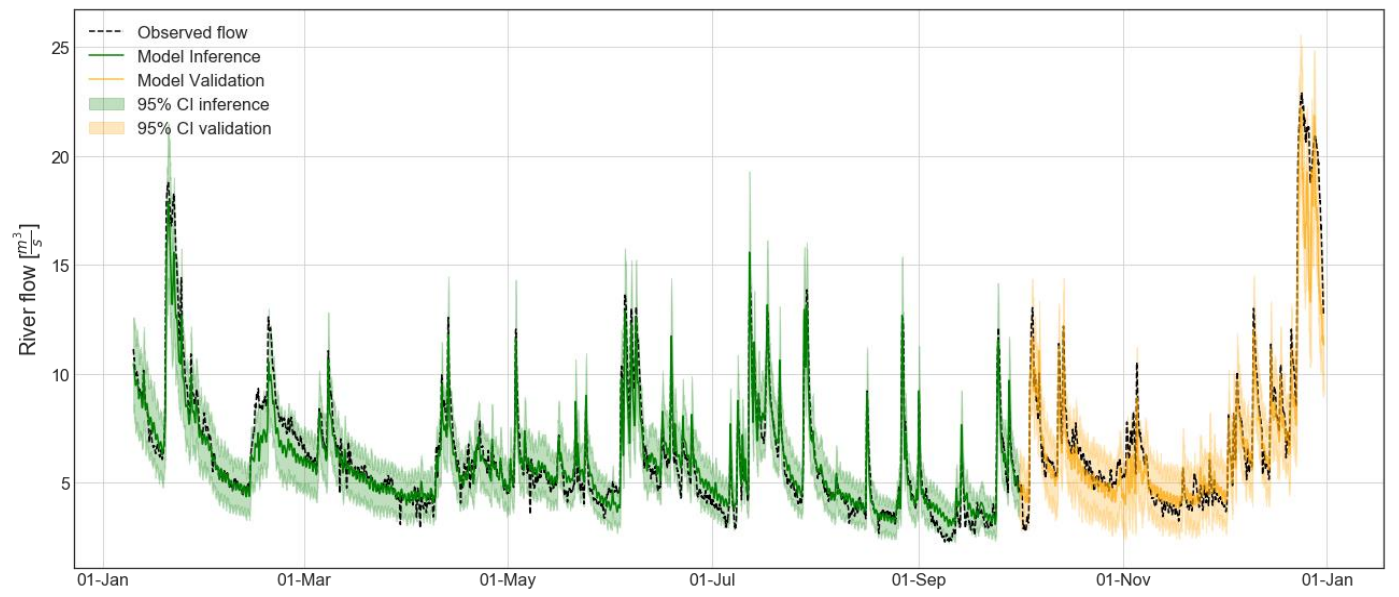

Figure 2. Measurements vs inferred model mean and $95 \%$ confidence interval for the inferred and validation river flow time-series.

Figure 2 and Figure 3 present the model expected value and its $95 \%$ confidence interval for the inferred dynamics of flow and DO respectively. 9 months were used in the inference process and 3 months where used for validation purposes. The residual structure presented a certain autocorrelation, which would require updating the error model. However, the generalization of the likelihood to accommodate time-dependency becomes highly 


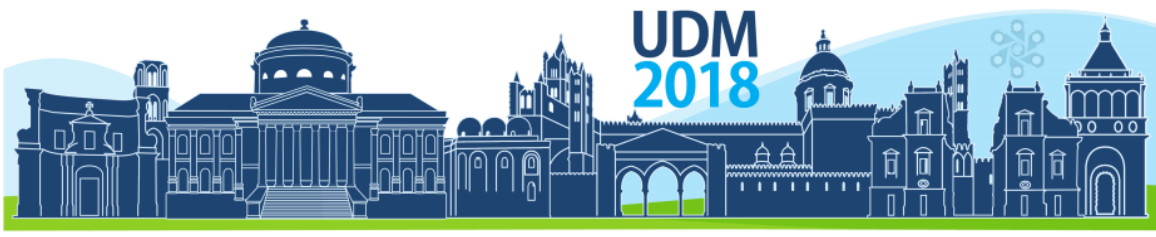

$11^{\text {th }}$ International Conference on Urban Drainage Modelling

23-26 Sep | Palermo - Italy

computationally expensive in this case (since the number of measured points is very large 8000). The inference at the DO dynamics generated a large model error variance. This can be due to the fact that the model could not capture some oxygen depletion events (meaning that some process might be missing in the model conceptualization) or that the error description was insufficient. Which will be further explored.

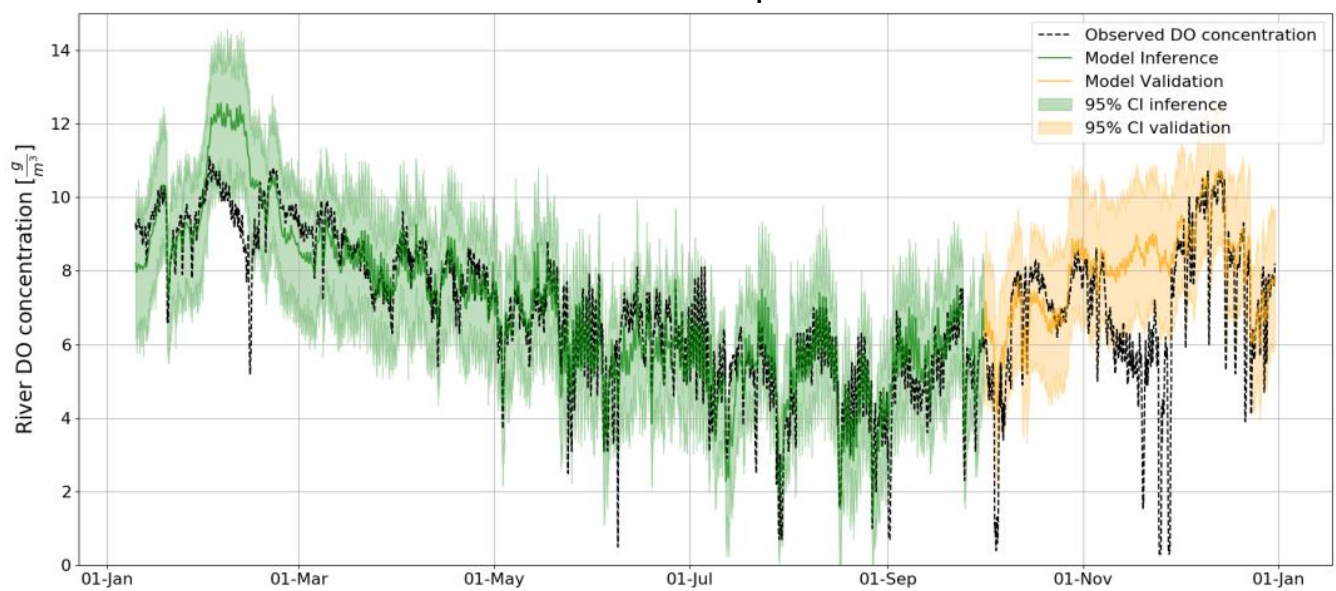

Figure 3. Measurements vs inferred model mean and 95\% confidence interval for the inferred and validation river DO time-series.

\section{CONCLUSIONS}

Performing parameter inference becomes prohibitive when using computationally expensive models. This hampers severely the use of Bayesian inference in large scale Integrated Catchment Modelling (ICM). In this work an example is presented in which an ICM is used to simulate flow and dissolved oxygen depletion processes during one year. The use of an emulator made the inference of the model parameters feasible. Also, this can be easily extended to generate fast uncertainty quantification schemes in large integrated catchment simulators.

\section{References}

Bellos, V., Kourtis, I., Moreno-Rodenas, A. and Tsihrintzis, V. (2017) Quantifying Roughness Coefficient Uncertainty in Urban Flooding Simulations through a Simplified Methodology. Water 9(12), 944.

Carbajal, J.P., Leitão, J.P., Albert, C. and Rieckermann, J. (2017) Appraisal of data-driven and mechanistic emulators of nonlinear simulators: The case of hydrodynamic urban drainage models. Environmental Modelling \& Software 92, 17-27.

Laloy, E. and Vrugt, J.A. (2012) High-dimensional posterior exploration of hydrologic models using multipletry DREAM(ZS)and high-performance computing. Water Resources Research 48(1).

Langeveld, J.G., Benedetti, L., de Klein, J.J.M., Nopens, I., Amerlinck, Y., van Nieuwenhuijzen, A., Flameling, T., van Zanten, O. and Weijers, S. (2013) Impact-based integrated real-time control for improvement of the Dommel River water quality. Urban Water Journal 10(5), 312-329.

Moreno-Rodenas, A., Cecinati, F., Langeveld, J. and Clemens, F. (2017) Impact of Spatiotemporal Characteristics of Rainfall Inputs on Integrated Catchment Dissolved Oxygen Simulations. Water 9(12), 926.

Xiu, D. and Karniadakis, G.E. (2002) The Wiener--Askey polynomial chaos for stochastic differential equations. SIAM journal on scientific computing 24(2), 619-644. 


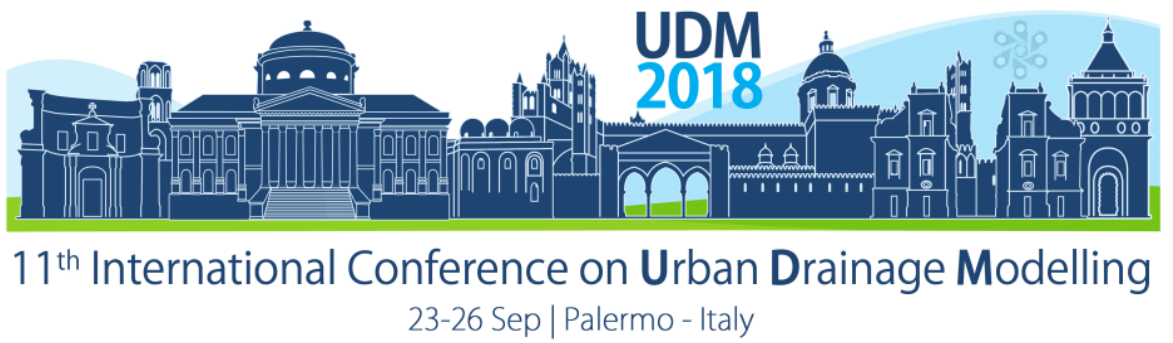

\title{
Interfacing stakeholder involvement into a surface water-quality modelling system for water management and policy development
}

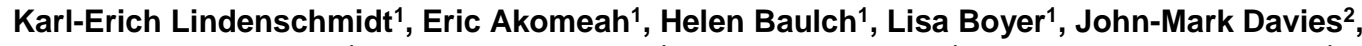 \\ Elmira Hassanzadeh ${ }^{1}$, Luis Morales Marin ${ }^{1}$, Graham Strickert ${ }^{1}$ and Michelle Wauchope ${ }^{1}$ \\ ${ }^{1}$ Global Institute for Water Security, University of Saskatchewan, Saskatoon, Canada \\ ${ }^{2}$ Water Security Agency, Saskatoon, Canada
}

\begin{abstract}
Water quality has been under unprecedented pressure over the past few decades due, in part, to increasing nutrient pollution from cities, industrial zones and agricultural areas entering river systems. The dynamics of these impacts on water quality are complex and stem from decisions and activities of different groups of stakeholders, who can have different business plans, values and attitudes towards water quality. This means that, improving the quality of water requires incorporating stakeholders' viewpoints and decisions into water quality management processes. This study proposes a modelling framework to engage stakeholders in selecting practices and policies that can improve riverine and lacustrine water quality.
\end{abstract}

Keywords: Qu'Appelle River; stakeholder-modelling interface; surface water-quality modelling

\section{INTRODUCTION}

A modelling system of the Qu'Appelle River, Saskatchewan was developed and implemented to provide an interface between local stakeholders and nutrient-reduction scenarios. The modelling system consists of (i) an instream water quality model, (ii) a nutrient export model that quantifies the sources and loadings from the river's basin into the receiving waters, (iii) a field sampling campaign to determine the impact of nutrients on bio-productivity and nutrient retention and mobilisation characteristics to complement the modelling exercise and (iv) a systems dynamic model that refines the nutrient loading into the Qu'Appelle River system and provides the interface with stakeholders (see Figure 1). The strong socio-hydrology component accompanying the modelling system provides stakeholder input into the modelling process by using beneficial management practice implementation to reduce loading to the Qu'Appelle River watershed. Stakeholder preferences were incorporated using the system dynamics model to assess capacities required to implement future policies to reduce human-derived nutrient sources from entering the river's ecosystem.

\section{METHODS, RESULTS AND DISCUSSION}

\subsection{WASP in-stream model}

The phytoplankton and nutrient cycles of the Qu'Appelle River have been modelled using the Water quality Analysis Simulation Program (WASP). Parallel model setups were completed for the upper Qu'Appelle (Qu'Appelle Dam to Buffalo Pound Lake) and the middle Qu'Appelle reach (Lumsden to Katepwa Lake) (see Figure 2). Since sediment oxygen demand (SOD) measurements, which account for more than half the oxygen demand in the water column, were sparse it was necessary to estimate SOD by calibrating a lower complexity model. To allow for a proper estimate of riverine and lake SOD, other processes were constrained in the model (Akomeah and Lindenschmidt, 2017). The complexity of the model was then increased 


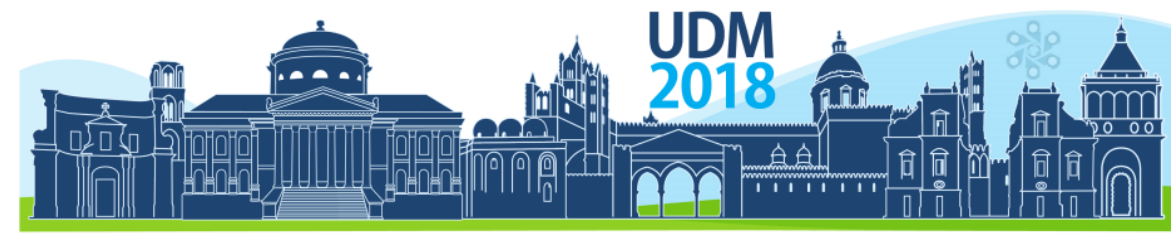

$11^{\text {th }}$ International Conference on Urban Drainage Modelling

23-26 Sep | Palermo - Italy

to characterize eutrophication in the river (Akomeah et al., submitted). This model included instream water quality processes such as dissolved oxygen balance, phytoplankton growth/death and nutrient cycles. Model validation showed good agreement with observed data. The model depicts the spatio-temporal behaviour of in-stream water quality. A parallel modelling exercise (Hosseini et al., submitted) also characterize nutrient dynamics in the upper Qu'Appelle River to simulate management scenarios.

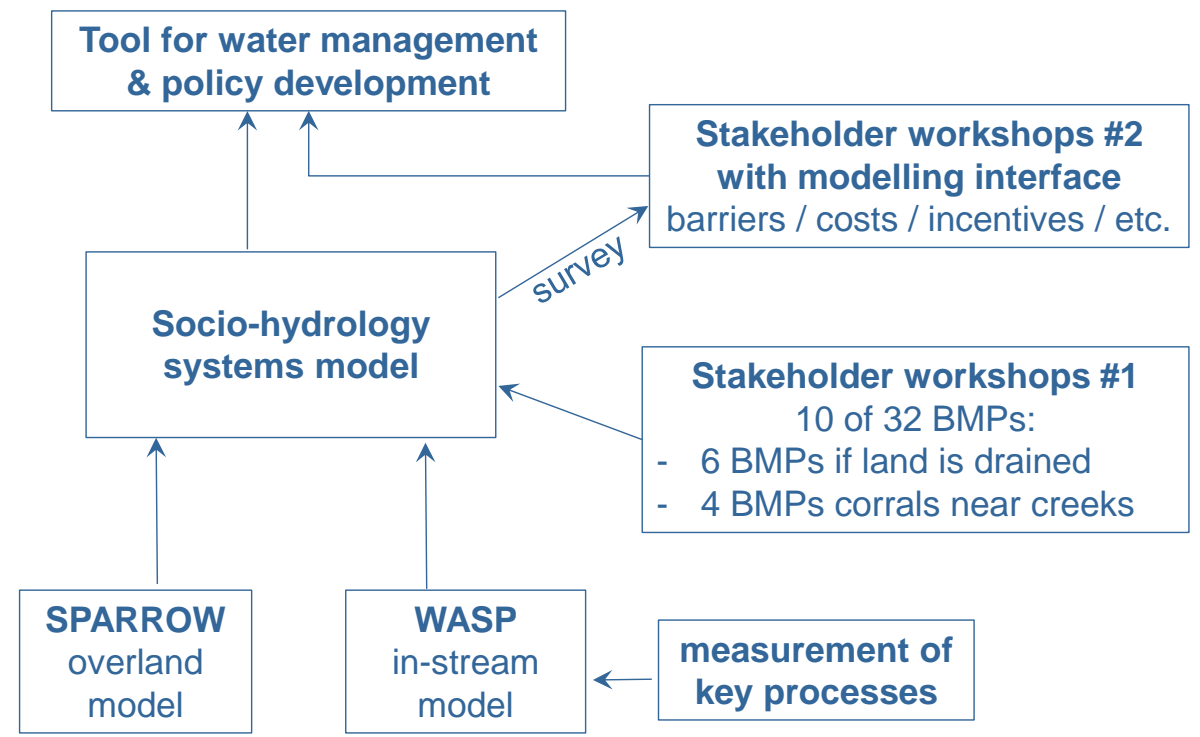

Figure 1. Structure of Qu'Appelle River basin project with interfaces between stakeholders and modelling

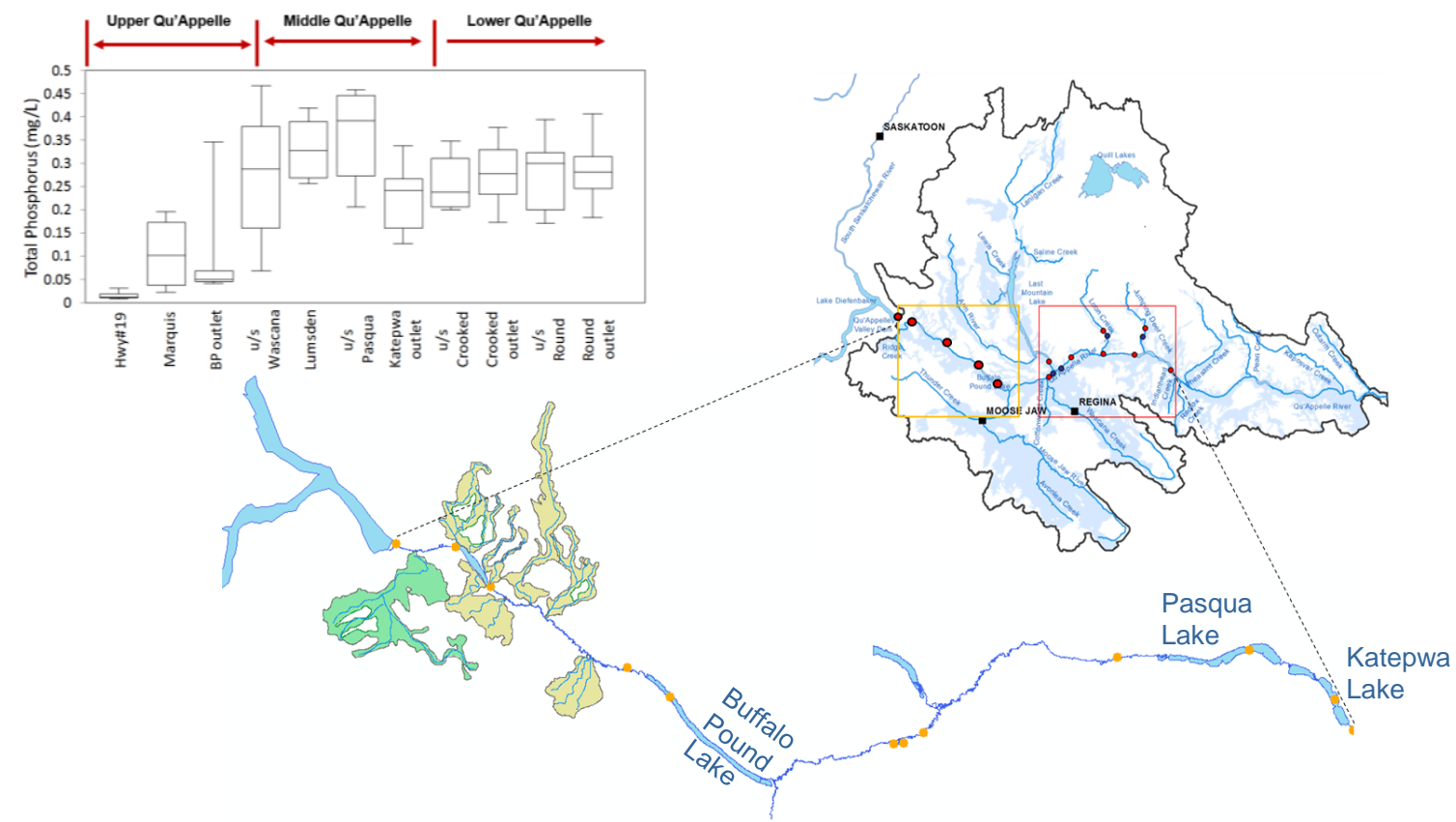

Figure 2. Map of the Qu'Appelle River watershed showing the Qu'Appelle River and major tributaries to the Qu'Appelle River, major urban centres, gauging stations, and water quality monitoring stations. 


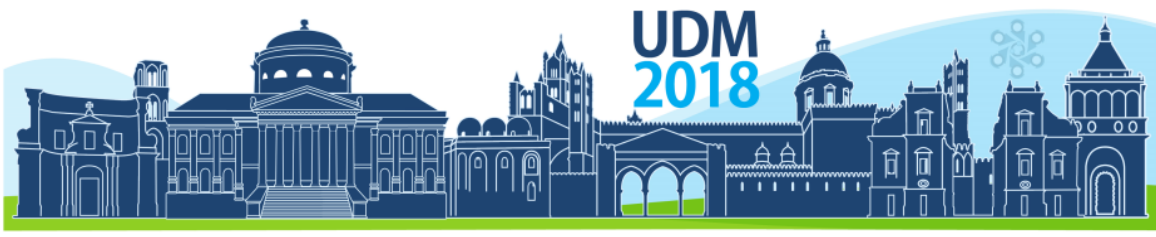

$11^{\text {th }}$ International Conference on Urban Drainage Modelling

23-26 Sep | Palermo - Italy

\subsection{SPARROW overland model}

A large-scale steady-state nutrient export model for the Qu'Appelle River basin was set up using the SPAtially-Referenced Regressions On Watershed attributes (SPARROW) model to estimate annual averages of total nitrogen (TN) and total phosphorus (TP) loadings (see Figure 3) and concentrations across the basin. The model estimates nutrient loads in a river network composed of around 15,000 reaches and basin sub-catchments. The model integrates landscape variables and water quality observations to estimate nutrient export at a large-scale. It uses multiple explanatory variables such as fertilizer and manure application, population and land uses. It also uses land-to-water delivery variables such as precipitation, temperature, land-surface slope and soil permeability. SPARROW is designed to inform on the main nutrient sources and sinks in the catchment and is used to estimate total loads at the outlets of the main sub-catchments. In the modelling system of this study SPARROW was used to drive the system dynamic model (Section 2.4) to simulate local stakeholder implementation of beneficial management practices for assessing possible changes in nutrient exports.

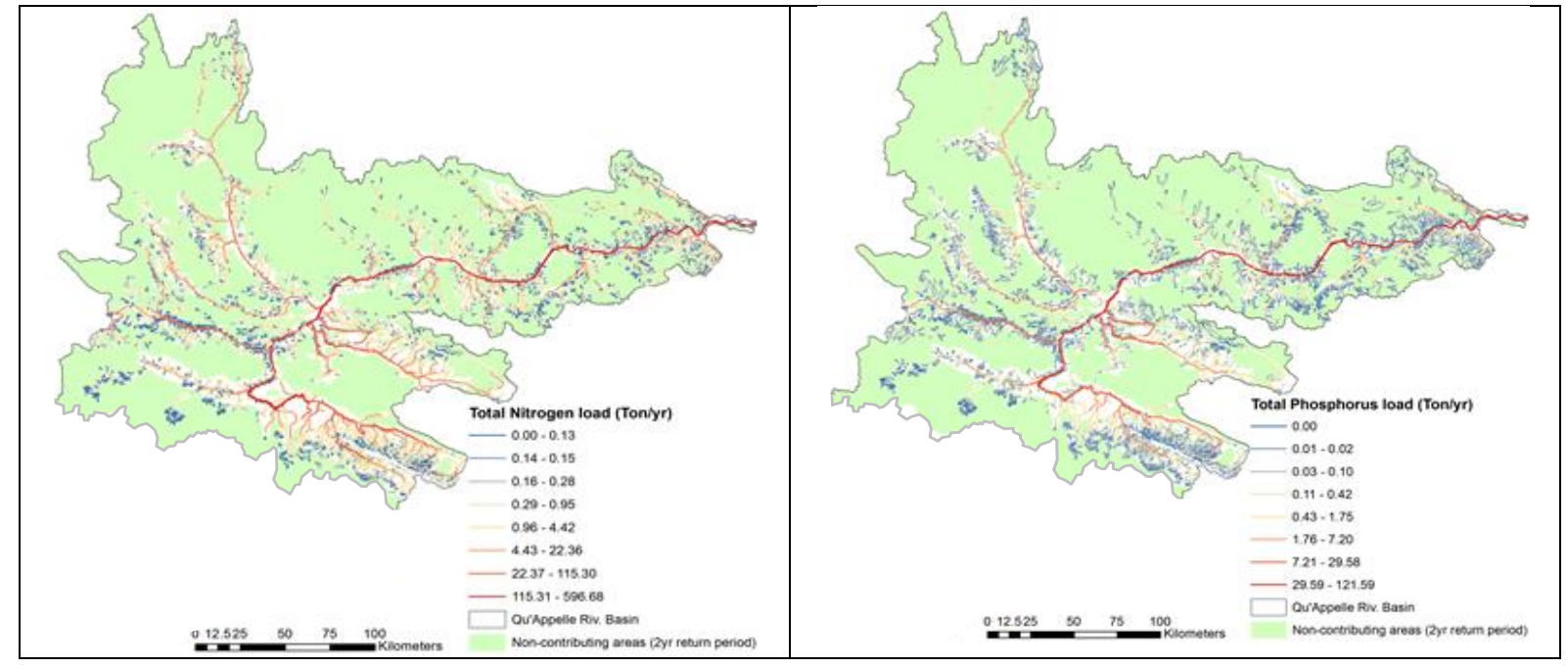

Figure 3. Annual averages of total nitrogen load (left map) and total phosphorus load (right map).

\subsection{Measurement of key processes}

Field work along the river and lake segments of the Qu'Appelle River complemented the modelling work. Rates of nitrogen fixation were measured within Buffalo Pound, Pasqua and Katepwa lakes. Phytoplankton biomass was often dominated by cyanobacteria. Nitrogenfixing cyanobacteria consisted predominantly of Anabaena sp. and Aphanizomenon sp. with extreme concentrations in shoreline surface scum formations found at Buffalo Pound Lake. Given normal physiological rates of fixation, these data suggest that atmospheric nitrogen may be a strong local nutrient source in nearshore environments where biomass tends to accumulate. Additional measurements of internal phosphorus loading were made in Pasqua Lake with preliminary rates again indicative of relatively high rates of internal loading and substantive phosphorus fluxes, even under oxic conditions. There is a large iron-bound 


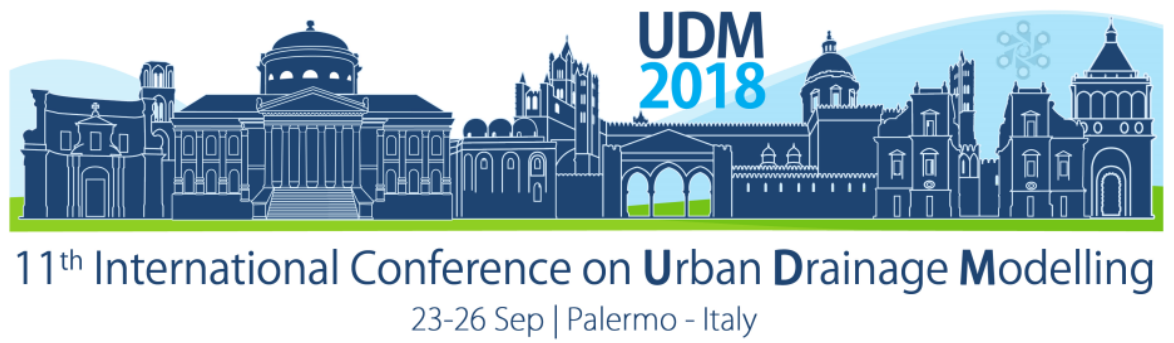

fraction in the sediments of all lakes, with smaller aluminium bound and loosely bound fractions. Recalcitrant organics are a large fraction of the phosphorus in all studied lakes.

\subsection{Stakeholder engagement and water quality policies}

A number of beneficial management practices (BMPs) that can potentially reduce water pollution were summarized based on the provincial government's recommendation and reports for the region of interest. Stakeholders were then asked to rank these BMPs from the most to the least effective based on their perspectives. Accordingly, the q-methodology was used to analyse the stakeholders' ranked BMPs and identify their distinct viewpoints regarding the same problem. A System Dynamics (SD) approach was then implemented to develop a simple, transparent, and user-friendly water quality model to simulate nutrient loads before and after implementation of effective BMPs identified by stakeholders. The SD model was then used in real-time engagement with stakeholders in model simulations to demonstrate the potential effects of BMPs on water quality. Through surveys, stakeholders were asked to indicate their preferred policies to implement BMPs. Finally, the provincial government's water agency was provided with stakeholder-preferred BMPs and policies to take actions. The results of the qmethodology show that, despite different viewpoints, all stakeholders agreed on the need to change existing conditions to improve water quality. The policy analysis shows that stakeholders are willing to implement these BMPs but their main concern, as expected, is the cost of implementation. This framework can assist in better understanding the stakeholders' viewpoints to propose effective BMPs and policies that are in line with stakeholder values and preferences.

\section{CONCLUSIONS}

Ultimately, in partnership with the provincial Saskatchewan Water Security Agency, the goal of the work is to contribute to improving nutrient management in the Qu'Appelle River watershed. This includes incorporating climate change effects and land use changes. An important outcome of the research is the development of predictive capacity to assess how changes in management, such as inter-basin water transfer, wastewater treatment plant upgrades, and implementation of beneficial management practises are anticipated to affect downstream changes in water quality. An interface between the modelling work and stakeholder involvement is considered to be an important step in this process.

\section{References}

Akomeah, E. and Lindenschmidt, K.-E. (2017) Seasonal Variation in Sediment Oxygen Demand in a Northern Chained River-Lake System. Water 9(4), 254.

Hosseini, N., Akomeah, E., Davies J.M, Baulch H. and Lindenschmidt, K. E (submitted) Water quality modeling of a prairie river-lake system.

Akomeah, E., Davies J.M. and Lindenschmidt, K. E (submitted) Water quality modelling of phytoplankton and nutrient cycles of a complex cold-region river-lake system 


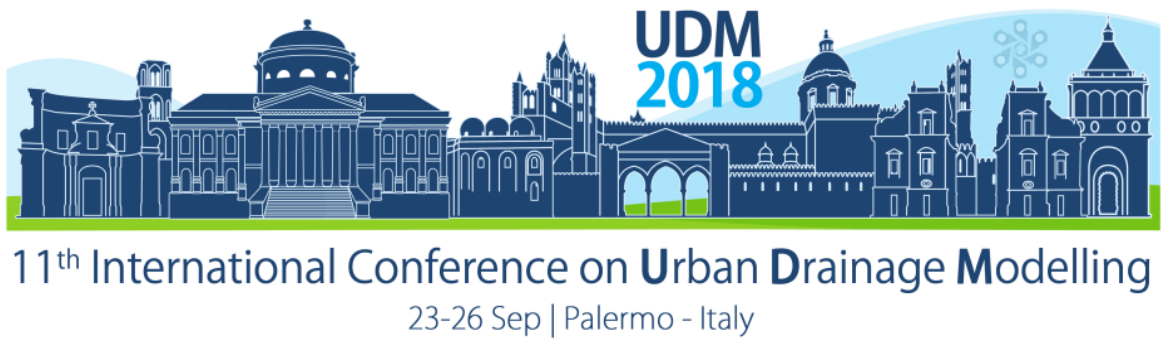

\title{
Transport of Traffic-Related Microplastic Particles in Receiving Water
}

\author{
Mia Bondelind ${ }^{1}$, Ailinh Nguyen ${ }^{1}$, Ekaterina Sokolova ${ }^{1}$ and Karin Björklund ${ }^{1}$ \\ ${ }^{1}$ Chalmers University of Technology, Department of Architecture and Civil Engineering, 41296 Gothenburg, \\ Sweden
}

\begin{abstract}
A majority of microplastic particles (MPs) in marine waters are transported with rivers from land-based sources. Traffic is estimated to be one of the largest sources of MPs, hence stormwater and subsequently urban waterways are expected to be important transportation routes of MPs to marine waters. However, there is currently little knowledge of MP fate from land sources to marine waters. The aim of this study is to investigate the transport of traffic-related microplastic particles in a receiving freshwater body using hydrodynamic modelling. A $16 \mathrm{~km}$ stretch of the Göta River, Sweden's largest river, was set up using MIKE 3 FM software. The model builds on data on water flows in the river and its tributaries, water levels and salinity stratification in the Kattegat strait, and meteorological conditions. Concentrations of MPs in stormwater and MP characteristics data, including prevalent particle sizes and density of commonly occurring polymers, were found in the literature. The simulations show that peak concentrations of MPs have a short duration; however, elevated concentrations of MPs may be present for hours after rainfall. If the MPs do not settle, as is the case for low density MPs including tyre rubber, a high load of MPs from the city of Gothenburg will reach the marine environment. Biofouling and MPs adhering to mineral particles, as has been shown in marine waters, may considerably change the characteristics of MPs and should be considered in future studies.
\end{abstract}

Keywords: Hydrodynamic modelling; Microplastic fate; Traffic-related emissions

\section{INTRODUCTION}

Plastic in the oceans is considered one of our most serious global environmental problems as plastic pollution and microplastics are present in all bodies of waters on the planet. Microplastics (MPs) are small plastic fragments (usually defined as $<5 \mathrm{~mm}$ ), and most of them are formed unintentionally when plastic objects are worn or degraded and plastic particles are released. Microplastics are small enough to be ingested by marine biota and transferred through the food chain (Barboza \& Gimenez 2015). As a result, MPs have been detected in organisms at all levels of the marine food chain.

It is estimated that $70-80 \%$ of marine MPs originates from land-based sources, transported mainly via rivers (Horton et al. 2017). Estimations by Siegfried et al. (2017) show that roadrelated MPs, transported with stormwater, account for the highest proportion $-42 \%-$ of the total MP load into European rivers, whereas polymer-based textiles, transported with wastewater, account for $29 \%$ of the MP load. In contrast to domestic wastewater, only $8 \%$ of the stormwater volume in Sweden is currently treated, either in wastewater treatment plants (4 $\%$ ) or in local treatment facilities (4\%) (Magnusson et al. 2016). This implies that the majority of MPs from urban areas in Sweden is directly discharged into receiving waterways.

Microplastics from road surfaces will either sink and accumulate in sediments or be transported through the stormwater system to receiving waters. Turbulence in sewers and sediment traps (e.g. ponds and settling tanks) can cause re-suspension of high-density MPs and redistribution 


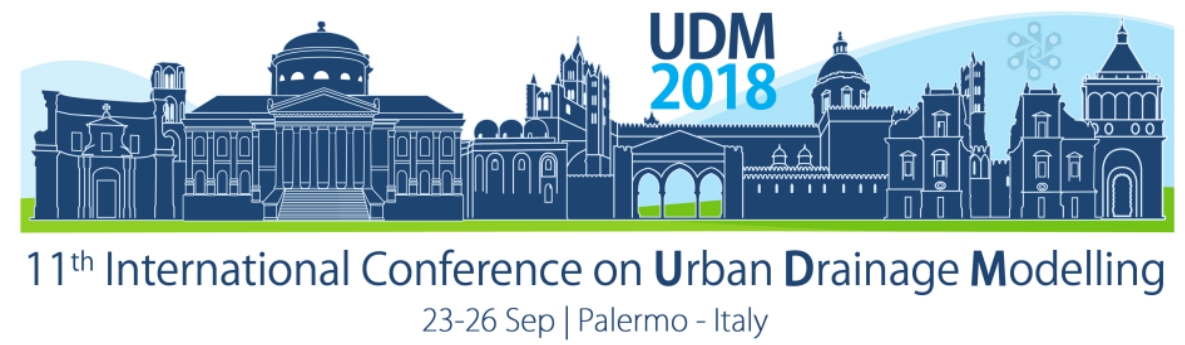

throughout the water column, leading to further transport of high density MPs into receiving waters (Anderson et al. 2016; Magnusson et al. 2016). In recent years, advances have been made in the area of transport modelling of particles in water sources and stormwater ponds. Vermeiren et al. (2016) have designed conceptual models for MP transport in estuaries in order to define the MP distribution in the water column; it was suggested that physical and chemical processes affecting the MP fate and transport, e.g. the effect of wind or high UV exposure, should be investigated further. Besseling et al. (2017) demonstrated in an estuary model, which accounted for advective transport, aggregation, sedimentation-resuspension, degradation, presence of biofilm and sediment burial of MPs, that particle size had a major effect on the fate and accumulation of MPs. More general sediment removal mechanisms in stormwater ponds have been modelled where residence time, vegetation, wind, turbulence, stratification, inflow and outflow are factors of importance (Gu et al. 2017).

Although traffic-related stormwater is expected to be a major transportation route of MPs into receiving freshwater bodies and subsequent transport to marine waters, there is currently little knowledge of MP fate from land sources to marine waters. The aim of this study is to investigate the transport of traffic-related microplastic particles in a receiving freshwater body using hydrodynamic modelling. The Göta River in south-west Sweden was chosen as case study, as it is the largest river in Sweden, both in terms of catchment area $\left(50000 \mathrm{~km}^{2}\right)$ and discharge (average $570 \mathrm{~m}^{3} / \mathrm{s}$ ). Also, the Göta River passes through Gothenburg, the second largest city of Sweden; hence the river is expected to be a major discharge point of MPs into Swedish marine waters.

\section{MATERIALS AND METHODS}

\subsection{Model set-up}

A $16 \mathrm{~km}$ stretch of the Göta River was set up using MIKE 3 FM (MIKE Powered by DHI) software. The modelling domain is $3 \mathrm{D}$ and is described using a flexible computational mesh: resolution 20-30 $\mathrm{m}$ in the horizontal and $1 \mathrm{~m}$ in the vertical direction. The model builds on data on water flows in the river and its tributaries, water levels and salinity stratification in the Kattegat strait, and meteorological conditions. The hydrodynamic model was validated in a previous study (Tyréns AB 2016).

\subsection{Simulation scenarios}

One period (5-13 July) was simulated for the year 2015. Precipitation during this period occurred as one rain event $(27 \mathrm{~mm})$. In the model, 22 points of discharge from separate stormwater sewers were included. Concentrations of MPs in stormwater from urban areas, particle size distribution, and density of common polymers found in stormwater were identified through the literature (Corcoran 2015; Jannö 2016; Auta et al. 2017).

The simulated scenarios are:

- Case 1 (results shown in abstract): One stormwater discharge point with assumed high impact from traffic-related MP emissions. Concentration in stormwater is 105 microplastic particles/100 mL (Jannö 2016). Particle size is assumed $30 \mu \mathrm{m}-400 \mu \mathrm{m}$. No settling. 


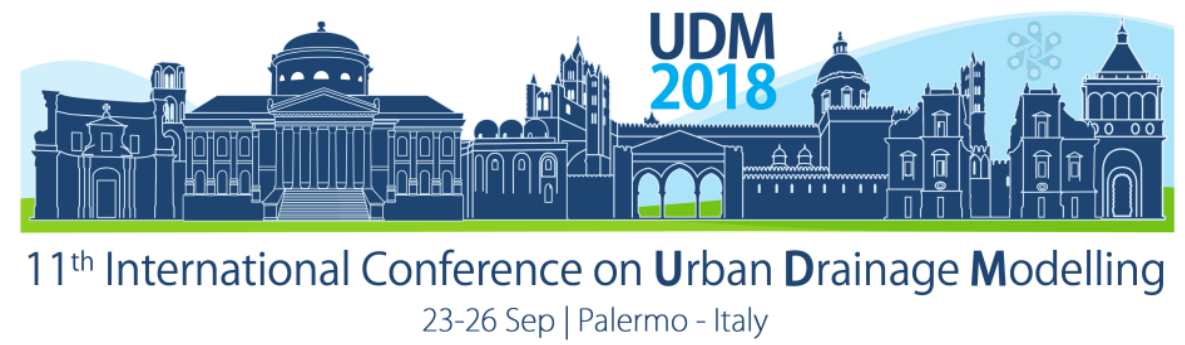

- Case 2: One stormwater discharge point with assumed high impact from traffic-related MP emissions. Concentration $105 \mathrm{MPs} / 100 \mathrm{~mL}$. Particle size $30 \mu \mathrm{m}-400 \mu \mathrm{m}$, with settling.

- Case 3: Twenty-two stormwater discharge points. Concentration of microplastic particles from each discharge point depends on the traffic load in the subcatchment area. Particle size $30 \mu \mathrm{m}-400 \mu \mathrm{m}$, with settling. This scenario illustrates the total MP load from stormwater to the Göta River.

\section{RESULTS AND DISCUSSION}

Simulations indicate that peak concentrations of MPs released into the river exhibit a short duration, as shown in Figure 1. However, increased concentrations of the MPs may be present for hours after rainfall, even in the main stream of the river where water velocities vary between 900 and $1600 \mathrm{~m} / \mathrm{h}$.

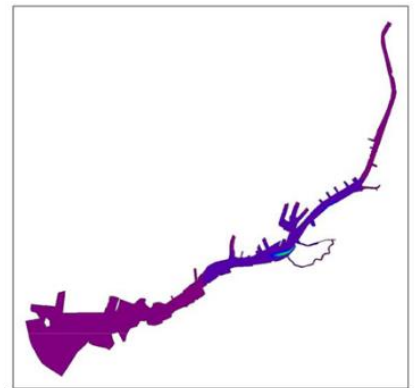

(a) $06 \mathrm{Jul}$ at 05.10

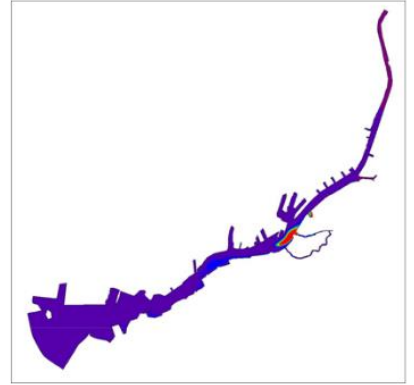

(d) 08 Jul at 19.40

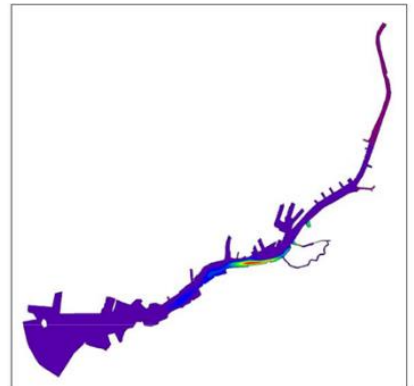

(b) $08 \mathrm{Jul}$ at 07.10

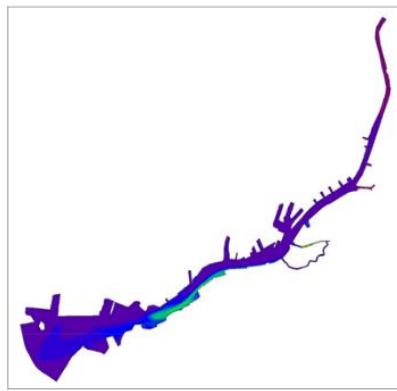

(e) 09 Jul at 04.00

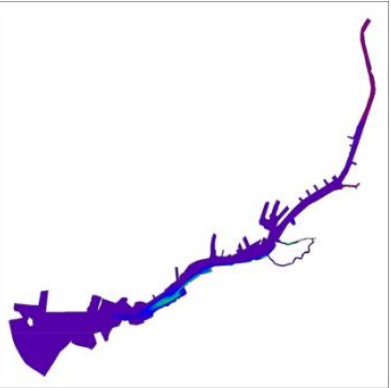

(c) $08 \mathrm{Jul}$ at 11.20

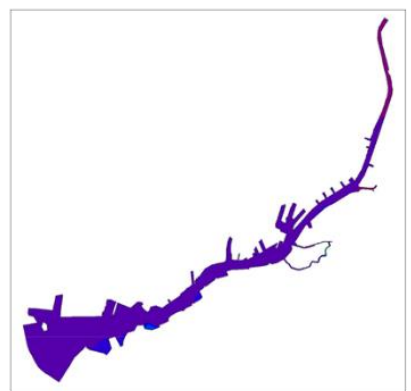

(f) 09 Jul at 12.20

\section{$0.0-0.013 \mathrm{MP} / 100 \mathrm{ml}$}

\section{(1)}

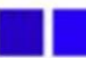

above $0.2 \mathrm{MP} / 100 \mathrm{~m}$

Figure 1. The simulated concentration of microplastic particles in the Göta River. Purple and red colours represent the concentrations $0.00-0.2 \mathrm{MPs} / 100 \mathrm{~mL}$, respectively.

If the MPs do not settle, as is the case for low density MPs including tyre rubber particles, a high load of MPs from the city of Gothenburg will reach the marine environment (Figure 1). However, research show that MPs may adhere to mineral particles, which exhibit higher density than many polymers (Corcoran 2015). Also, MPs are object to biofouling by bacteria, algae and other organisms which causes increased particle density. Further simulations should take these morphological changes into account as they may affect the transport and final fate of MPs in receiving waters. 


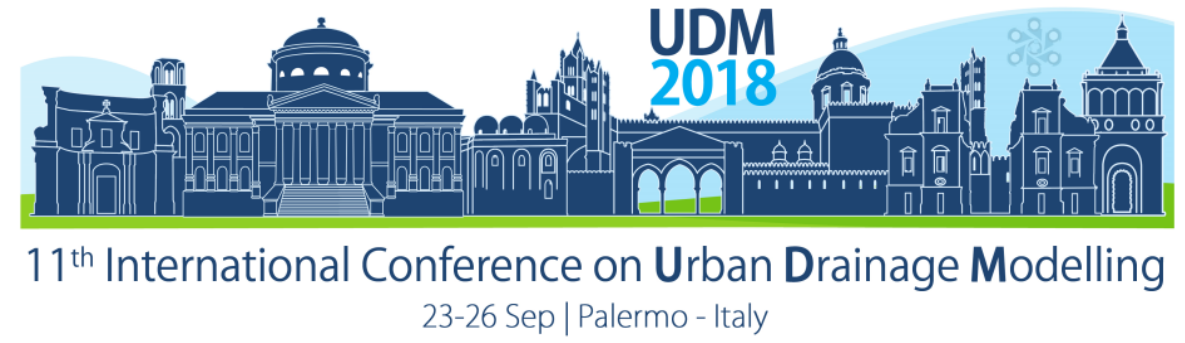

If the goal is to reduce the abundance of MPs in the marine environment, the city of Gothenburg needs to address MPs before they reach the stormwater sewer system. Mitigating pollution from highways with high traffic counts, e.g. through street cleaning, has the potential to considerably reduce MP loads in marine waters, as traffic is one of the largest land-based sources to MPs.

\section{CONCLUSIONS}

- Peak concentrations of MPs have a short duration; however, increased concentrations of the MPs may be present for hours after rainfall.

- If the MP does not settle, as is the case for low density MPs including tyre rubber, a high load of MP from the city of Gothenburg will reach the marine environment.

\section{References}

Anderson J. C., Park B. J. and Palace V. P. (2016). Microplastics in aquatic environments: Implications for Canadian ecosystems. Environmental Pollution 218, 269-80.

Auta H. S., Emenike C. U. and Fauziah S. H. (2017). Distribution and importance of microplastics in the marine environment: A review of the sources, fate, effects, and potential solutions. Environment International 102, 165-76.

Barboza L. G. A. and Gimenez B. C. G. (2015). Microplastics in the marine environment: Current trends and future perspectives. Marine Pollution Bulletin 97(1-2), 5-12.

Besseling E., Quik J. T. K., Sun M. and Koelmans A. A. (2017). Fate of nano- and microplastic in freshwater systems: A modeling study. Environmental Pollution 220, 540-8.

Corcoran P. L. (2015). Benthic plastic debris in marine and fresh water environments. Environmental Science: Processes \& Impacts 17(8), 1363-9.

Gu L., Dai B., Zhu D. Z., Hua Z., Liu X., van Duin B. and Mahmood K. (2017). Sediment modelling and design optimization for stormwater ponds. Canadian Water Resources Journal 42(1), 70-87.

Horton A. A., Svendsen C., Williams R. J., Spurgeon D. J. and Lahive E. (2017). Large microplastic particles in sediments of tributaries of the River Thames, UK - Abundance, sources and methods for effective quantification. Marine Pollution Bulletin 114(1), 218-26.

Jannö A. (2016). Förekomst av mikroplast i dagvatten från väg och trafik i Göteborg - Provtagning och analysering. Bachelor thesis, Department of Biological and Environmental Sciences, Göteborg University, Göteborg, Sweden.

Magnusson K., Eliasson K., Fråne A., Haikonen K., Hultén J., Olshammar M., Stadmark J. and Voisin A. (2016). Swedish sources and pathways for microplastics to the marine environment: A review of existing data, Report number C 183, IVL Swedish Environmental Research Institute, Stockholm, Sweden.

Siegfried M., Koelmans A. A., Besseling E. and Kroeze C. (2017). Export of microplastics from land to sea. A modelling approach. Water Research 127, 249-57.

Tyréns AB (2016). Badvattenkvalitet Göta älv - modelleringsstudie (Bathing water quality in the Göta River modelling study), Göteborg, Sweden.

Vermeiren P., Muñoz C. C. and Ikejima K. (2016). Sources and sinks of plastic debris in estuaries: A conceptual model integrating biological, physical and chemical distribution mechanisms. Marine Pollution Bulletin 113(1-2), 7-16. 


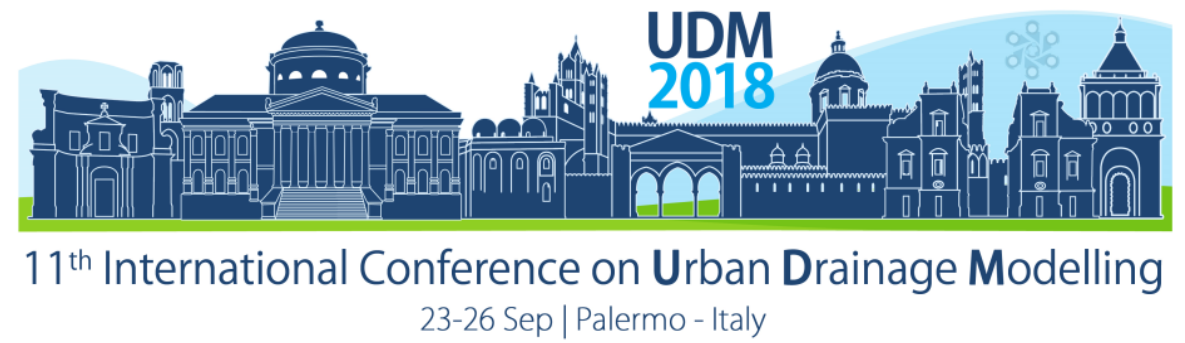

\title{
Hybrid Filtration System for Treatment of Stormwater Runoff
}

\author{
J.H. Lee ${ }^{1}$, S.H. Yang ${ }^{2}$, D.H. Song ${ }^{3}$ \\ ${ }^{123}$ Division of Civil, Environmental \& Urban-Transportation Engineering, Korea National University of \\ Transportation, 50 University Road, Chungju, Chungbuk, 27469, Korea
}

\begin{abstract}
Hydrocyclone is widely used in industry, for its simple design, high capacity, low maintenance and low operational cost. The objective of this study is to develop ballasted hydrocyclone flocculation and filtration systems (BHFF) system. The BHFF system is consisted of hydrocyclone ballasted coagulation with polyaluminium chloride silicate (PACS) and upflow filter to treat micro particles in urban storm runoff. Roadside sediment particles $(<100 \mu \mathrm{m})$ was mixed with tap water to make various turbid suspensions to determine the optimum PACS dosage. The experiment of Jar test was applied with rapid mixing at 200rpm for $1 \mathrm{~min}$, slow mixing at $50 \mathrm{rpm}$ for $3 \mathrm{~min}$, and settling period for $5 \mathrm{~min}$. The results of Jar test showed that PACS optimum dosage was $7.0 \mathrm{mg} / \mathrm{L}$, which these conditions left residual turbidity to less than 2.0NTU. The synthesized turbidity was made with roadside sediment particles to evaluate performance of BHFF system. There are two modes (without PACS use and with PACS use) of operation for BHFF system. In case of without coagulant use, the range of SS, turbidity removal efficiency were $42.9-95.8 \%$ (mean $80.8 \%$ ), 20.2-88.2\% (mean $61.7 \%$ ), respectively. And, the recovery rate of filter was $72.8-85.9 \%$ (mean $80.9 \%$ ) the rate of remained solid loading in filter media was 16.6$27.2 \%$ (mean 19.1\%) after backwashing. The results of Jar test showed that PACS optimum dosage was $7.0 \mathrm{mg} / \mathrm{L}$, which these conditions left residual turbidity to less than 2.0NTU. In case of BHFF run with coagulant use, the range of SS, turbidity removal efficiency were 62.2-100.0 (mean 88.8\%), 64.5-99.8\% (mean 88.7\%), respectively. Based on SS loading mass balance analysis, the recovery rate of filter was $87.5-90.1 \%$ (mean $89.2 \%$ ). It was found that removal efficiency was enhanced with PACS dosage. In case of coagulant use, the particle size of effluent is bigger than influent particle size. The BHFF system, which came out to solve the problems of low efficiency of removing micro particles of upflow filtration type stormwater treatment devices, therefore HBFF is considered as an alternative system.
\end{abstract}

Keywords: stormwater; hydrocyclone; upflow filtration; backwashing

\section{INTRODUCTION}

Among the BMPS, the upflow direct filtration system is quite outstanding for SSO and CSO treatment (Bernardo, 2006). Many pollutants in urban stormwater are present in the particulate phase, attached to particles transported in suspension, with diameters ranging from a few $\mu \mathrm{m}$ to $1 \mathrm{~mm}$, and a median diameter $\mathrm{d}_{50}=30-40 \mu \mathrm{m}$ (Torres et al., 2008). Solid particles smaller than $30 \mu \mathrm{m}$ in diameter are not easily separated by conventional types of upflow filtation system. To overcome this problem, upflow filter combined with hydrocyclone flocculator has been applied to treatment of the micro particles in urban storm runoff. Hydrocyclones are widely used as separators or classifiers in chemical, environmental, and mineral processing industries to separate solid particles from a solid liquid suspension based on the size of particles (Hwang et al., 2008). We have conducted a laboratory scale studies on treatable potential of micro particles using ballasted hydrocyclone flocculation and filtration systems (BHFF) which used $4 \sim 5 \mathrm{~mm}$ rectangular shape floating fiber media made of polypropylene and polyethylene materials. This study has been carried out to evaluate the applicability of the BHFF and determine the optimum operational parameter such as coagulation dosage concentration, with or without coagulants, surface loading rate and backwashing conditions. In order to determine the efficiency for various operation conditions, a series of experiments were performed with different particle material and solid concentrations. 


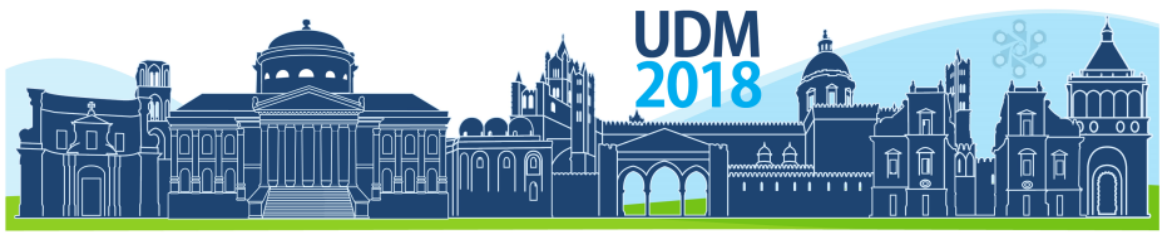

$11^{\text {th }}$ International Conference on Urban Drainage Modelling

23-26 Sep | Palermo - Italy

\section{MATERIALS AND METHODS}

\subsection{Desciption of the ballasted hydrocyclone flocculation and filtration systems}

The laboratory scale ballasted hydrocyclone flocculation and filtration systems (BHFF) flow loop used for experiments is shown in schematically in Figure 1. It consisted of two hydrocyclones for coagulation and flocculation, filter column, backwash blower and pump, air flow meter, pressure gauge, valve fitting, centrifugal pump, switch controller, chemical or particle injection pump, electromagnetic flow meter, effluent and underflow storage tank. Influent pumped from the storm water storage tank with coagulant to hydrocyclone and underflow returned to the influent pipe to improve flocculation ballasting.

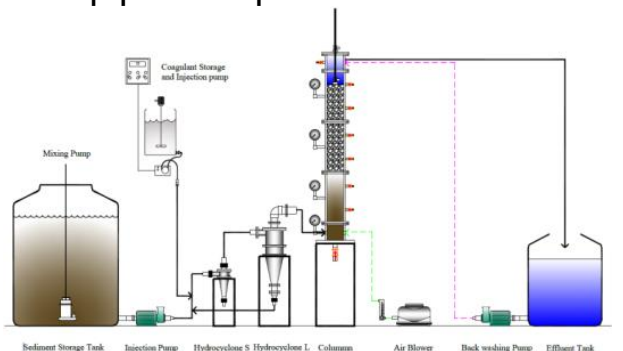

Figure 1. Schematic diagram and installation of the laboratory scale BHFF.

\subsection{Process operation and measurement method}

Simulated stormwater was used in the laboratory scale investigations because of the shortage of real stormwater. Simulated stormwater was synthesized with various materials including road side sediment $(S G=2.0)$ to simulate suspended solids $(S S)$ in stormwater. The particle sizes of sediment were less than $100 \mu \mathrm{m}$. After drying, these materials were fractionated according to particle size using sieve and dilution with water to make simulated stormwater runoff with various SS concentrations. Graded materials were vigorously mixed with water and stored at storage tank and mixed continuously using a mixer in order to obtain homogeneity. The influent and effluent samples were taken simultaneously and the SS was measured by weighing the retained GF/C filter mass after 2 hrs drying at $105^{\circ} \mathrm{C}$. A laser diffraction particle size analyzer (Shimadzu model SALD-2101) was used to determine the particle size and distribution. The measured particle size was ranged from 0.03 to $1000 \mu \mathrm{m}$ and distributed into 50 intervals. Accumulated size percentage of solid, a number of particles, mean diameter based on volume, and $90 \%$ particle size $\left(\mathrm{d}_{90}\right)$ were directly measured by this analyzer.To determine the removal efficiency for various influent SS concentrations and turbidity (NTU), a series of tests were performed. The range of linear velocity for filtration was from 18.9 to $25.5 \mathrm{~m} / \mathrm{hr}$ (mean $21.5 \mathrm{~m} / \mathrm{hr}$ ). The influent SS concentrations were varied ranging from 135 to $768 \mathrm{mg} / \mathrm{L}$ (mean $338.6 \mathrm{mg} / \mathrm{L}$ ). And the influent turbidities were varied ranging from 74.7 to 364.0 NTU (mean 147.2 NTU). During the experimental runs, the removal efficiency (\%) was calculated by equation (1).

$$
\text { Removal Efficiency }(\%)=\frac{S_{I}-S_{o}}{S_{I}} \times 100 \%
$$

where, $S_{1}$ and $S_{\circ}$ are $S S(m g / L)$ and turbidity(NTU) of influent and effluent.

\section{RESULTS AND DISCUSSION}

\subsection{BHFF operation without coagulant}

The BHFF run without coagulant dosing had an average duration of $1.6 \mathrm{hr}$. Through more than 5 experiments were carried out with various conditions such as different $S S$ concentration. Results calculated in terms of SS and turbidity removal efficiency are shown in Table 1 and Figure 2 and 3 . As shown Table 1, results showed that the range of SS, turbidity removal efficiency were 42.9-95.8\% (mean 80.8\%), 20.2-88.2\% (mean 61.7\%), respectively. Solid loading, $\mathrm{L}\left(\mathrm{kg} / \mathrm{m}^{2}\right)$ was calculated by equation (2). 


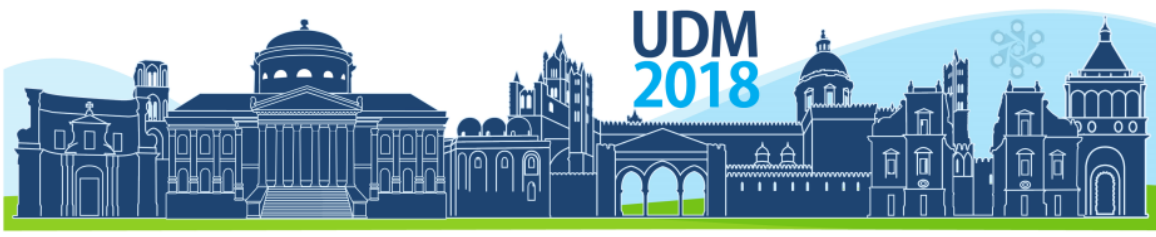

$11^{\text {th }}$ International Conference on Urban Drainage Modelling

23-26 Sep | Palermo - Italy

$$
\mathrm{L}=\frac{Q \cdot C \cdot T}{A}\left(\mathrm{~kg} / \mathrm{m}^{2}\right)
$$

where, $Q=$ influent $\left(\mathrm{m}^{3} / \mathrm{min}\right), C=$ influent $\mathrm{SS}(\mathrm{mg} / \mathrm{L}), \mathrm{T}=$ duration $(\mathrm{min})$, and $A=$ filter surface area $\left(\mathrm{m}^{2}\right)$. When solid loading increased, SS removal efficiency was rapidly decreased. The calculated average solid load was $11.1 \mathrm{~kg} / \mathrm{m}^{2}$.

\subsubsection{Filter backwashing and solid mass balance}

To backwash a filter, the influent value is closed, and drained whole wastewater. After drain colume as filled with effluent and $1^{\text {st }}$ backwashing by blowing air $3 \mathrm{~min}$, and repeat twice in the same way. The BHFF system was backwashed by blowing air with effluent water through for $3 \mathrm{~min}$ at a rate of $60 \mathrm{~m}^{3} / \mathrm{m}^{2} / \mathrm{hr}(10.0 \mathrm{~L} / \mathrm{min})$, after twice backwashing, whole drained wastewater was collected for mass balanced analysis. 5 series of backwashing experiments were conducted to determine the effectiveness of air blowing. The recovery rate of filter was $72.8-85.9 \%$ (mean $80.9 \%$ ) the rate of remained solid loading in filter media was 16.6$27.2 \%$ (mean $19.1 \%$ ) after backwashing.

A number of samples were analyzed for particle size distribution. The most commonly used metrics when describing particle size distributions are D-Values $\left(D_{10}, D_{60} \& D_{90}\right)$ which are the intercepts for $10 \%, 60 \%$ and $90 \%$ of the cumulative mass. The range of $D_{\text {Mean }}$ for influent and effluent were 21.8-49.8 $\mu$ m(mean $31.8 \mu \mathrm{m}$ ), 4.3-20.0 $\mu$ m(mean $10.4 \mu \mathrm{m}$ ) respectively.

\subsection{BHFF operation with coagulant}

The BHFF run with coagulant dosing had an average duration of $1.4 \mathrm{hr}$. Among the several types of coagulants, polyaluminium chloride silicate (PACS) was selected for stormwater treatment. As the results of Jar test showed that PACS optimum dosage was $7.0 \mathrm{mg} / \mathrm{L}$, which these conditions left residual turbidity to less than 2.0NTU. Through more than 3 experiments were carried out with various conditions such as different SS concentration. Results calculated in terms of SS and turbidity removal efficiency are shown in Figure 1 and 2 . The range of influent flowrate and surface loading rate were $18.1-24.0 \mathrm{~m} / \mathrm{hr}$ (mean $21.5 \mathrm{~m} / \mathrm{hr}$ ), 4.3- $5.8 \mathrm{~m}^{3} /$ day (mean $5.2 \mathrm{~m}^{3} /$ day), respectively. The influent turbidity, SS concentrations were 82.4 - 235.9 NTU (mean 152.4 NTU), 222.0- 456.0 mg/L (mean $329.3 \mathrm{mg} / \mathrm{L}$ ), respectively. The range of PACS dosage concentration was $6.0-8.1 \mathrm{mg} / \mathrm{L}$ (mean $6.9 \mathrm{mg} / \mathrm{L}$ ). As shown Table 3 , results showed that the range of SS, turbidity removal efficiency were $62.2-100.0$ (mean 88.8\%), 64.5-99.8\% (mean 88.7\%), respectively. In this case, turbidity and SS removal rate was $17 \%, 8 \%$ higher than that with no coagulant use. The variation of solid loading and SS, turbidity removal efficiency were shown the solid loading increased, SS removal efficiency was rapidly decreased. The calculated average solid load was $10.2 \mathrm{~kg} / \mathrm{m}^{2}$.

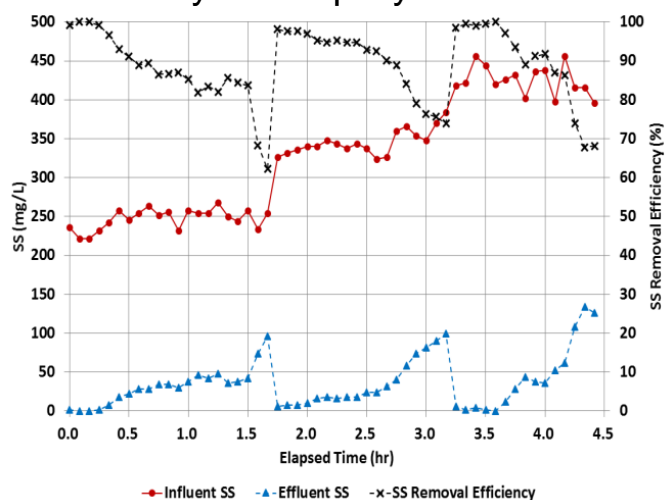

Figure 1. SS removal efficiency with elapsed time (with coagulant).

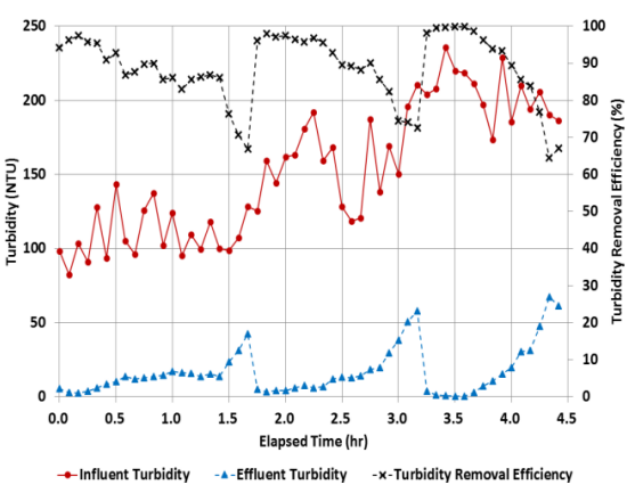

Figure 2. Turbidity removal efficiency with elapsed time (with coagulant). 


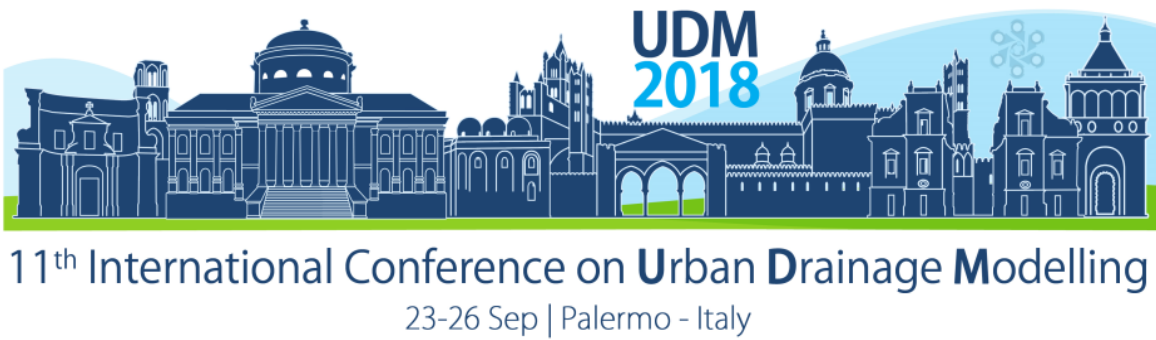

The results of 3 series of the backwashing experiments and SS loading mass balance analysis are summarized in Table 4 and Figure 16. The recovery rate of filter was $87.5-90.1 \%$ (mean $89.2 \%$ ) the rate of remained solid loading in filter media was $9.9-12.5 \%$ (mean $10.8 \%$ ) after backwashing. It was found that removal efficiency was enhanced with PACS dosage. Table 4 summarizes the range and average values for $D_{\text {Mean }}, D_{10}, D_{60}$ and $D_{90}$ for HBFF influent, effluent and drained wastewater samples in case of coagulant use. The range of $D_{\text {Mean }}$ for influent and effluent were $8.4-12.7 \mu$ m(mean $11.2 \mu \mathrm{m}$ ), 19.7-83.3 $\mu$ mean $55.5 \mu \mathrm{m}$ ) respectively. In case of coagulant use, the particle size of effluent is bigger than influent particle size.

\section{CONCLUSIONS}

This study has been carried out to evaluate the applicability of the ballasted hydrocyclone flocculation and filtration systems (BHFF) and determine the optimum operational parameter such as coagulation dosage concentration, with or without coagulants, surface loading rate and backwashing conditions. In case of without coagulant use, the range of SS, turbidity removal efficiency were 42.9-95.8\% (mean 80.8\%), 20.2-88.2\% (mean 61.7\%), respectively. And, the recovery rate of filter was $72.8-85.9 \%$ (mean $80.9 \%$ ) the rate of remained solid loading in filter media was $16.6-27.2 \%$ (mean 19.1\%) after backwashing. The results of Jar test showed that PACS optimum dosage was $7.0 \mathrm{mg} / \mathrm{L}$, which these conditions left residual turbidity to less than 2.0NTU. In case of BHFF run with coagulant use, the range of SS, turbidity removal efficiency were 62.2-100.0 (mean 88.8\%), 64.5-99.8\% (mean 88.7\%), respectively. Based on SS loading mass balance analysis, the recovery rate of filter waS $87.5-90.1 \%$ (mean $89.2 \%$ ). It was found that removal efficiency was enhanced with PACS dosage. In case of coagulant use, the particle size of effluent is bigger than influent particle size. The BHFF system, which came out to solve the problems of low efficiency of removing micro particles of upflow filtration type stormwater treatment devices, therefore BHFF is considered as an alternative system.

\section{ACKNOWLEDGEMENTS}

This was supported by Korea National University of Transportation in 2018.

\section{References}

Balmforth D.J., (1990), The pollution aspects of storm-sewage overflows, Water and Environment Journal, 4(3), 219-226.

Lee J.H., Bang K.W.,(2000), Urban stormwater runoff treatment by the RFS, Journal of Korean society of Environmental Engineers, 22(1), 159-167.

Bedient P.B., et al., (1979), Urban watershed management : Flooding and water quality", Rice Univ., Studies, Houston, Tex., 65(1), p. 204.

Sartor J.D., et al., (1974), Water pollution aspects of street surface contaminants, Journal of WPCF., 46(3), 458467.

Filtration+Seperation.(March/April 2010), Wastewater treatment: Enhanced biological treatment of storm flows. Bernard M. K.(2010), Inventory of stormwater management practice in the city of Oxford, Ohio", Miami Univ.

Torres A., Bertrand-Krajewski J.L., (2008)., Evaluation of uncertainties in settling velocities of particles in urban stormwater runoff", Water Science and Technology, 57(9), 1389-1396.

Hwang K.J, et al., (2008), Mechanism of particle separation in small hydrocyclone, Drying Technology, 26, 10021010.

Shimadzu Corporation, (2008), Particle size analyzer model : SALD-2101. 


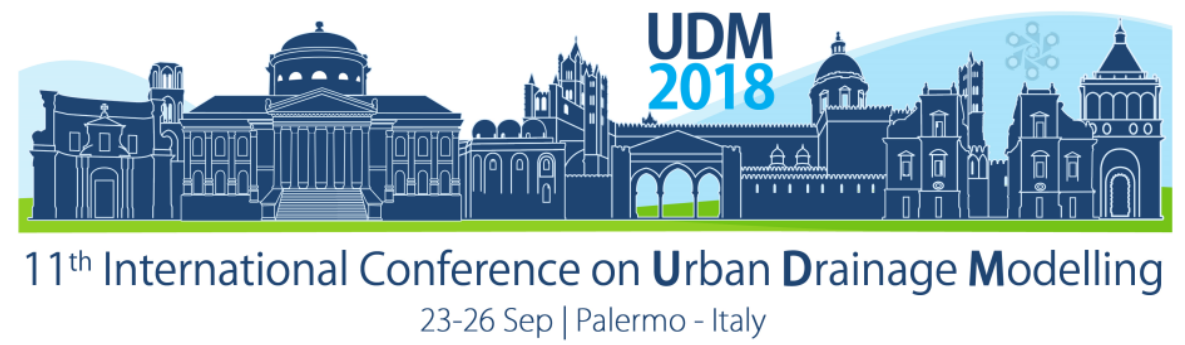

\title{
Flow Features of an Unstable Tangential Vortex Intake
}

\author{
S.N. Chan ${ }^{1,2}$, Q.S. Qiao ${ }^{1}$ and J.H.W. Lee ${ }^{1}$ \\ ${ }^{1}$ Department of Civil and Environmental Engineering, The Hong Kong University of Science and Technology, \\ Hong Kong SAR, China \\ ${ }^{2}$ Institute for Advanced Study, The Hong Kong University of Science and Technology, Hong Kong SAR, China
}

\begin{abstract}
Tangential vortex intakes are compact hydraulic structures commonly used in water supply, drainage and sewerage systems to convey water from high to low elevations efficiently. For certain design of tangential vortex intakes, flow instability can occur in the approach channel and the vortex dropshaft, resulting in undesirable hydraulic jump and shock waves. Due to the complex three-dimensional (3D) flow in the tangential vortex intake, current theoretical models are not sufficiently complete to interpret the flow process reliably. This paper presents an experimental and 3D Computational Fluid Dynamics (CFD) modeling study of an unstable tangential vortex intake flow. The CFD predictions are in good agreement with detailed point velocity and air core size measurements. Despite of the hydraulic jump at the tapering channel, the swirling flow at the vortex drop shaft is similar to that of a stable vortex intake with Rankine vortex behaviour.
\end{abstract}

Keywords: Tangential vortex intake; Swirling flow; Computational fluid dynamics; Volume-of-fluid; Laser Doppler Anemometry; Stormwater management

\section{INTRODUCTION}

Vortex intakes are commonly used in water supply, drainage and sewerage systems. A tangential vortex intake consists of an approach channel with horizontal bottom and rectangular cross section, and a steep tapering channel connected to a dropshaft. The inflow enters tangentially into the dropshaft via the tapering channel, and the flow swirls down the dropshaft. The strong centrifugal effect in the swirling flow results in an air core which allows any entrained air to escape. However, under certain design of the vortex intake, flow instability can occur in the approach channel and the vortex dropshaft, resulting in undesirable hydraulic jump and shock waves (Yu and Lee, 2009). The complex three-dimensional (3D) vortex flow in the intake has hitherto not been clearly understood. Current theoretical models (e.g. Jain, 1984; Yu and Lee, 2009) are not sufficiently complete to interpret the flow process reliably. To better understand the flow processes of an unstable vortex intake design, detailed velocity measurement and 3D computational modelling is required.

Detailed flow field and air core measurement for a stable vortex intake has been attempted, using point Laser Doppler Anemometry (LDA) (Qiao et al. 2013). With the development of computational modeling techniques and advancement in computation power, attempts have been made to tackle the air-water flow in vortex intake problems using 3D Computational Fluid Dynamics (CFD) models with the Volume-of-Fluid (VOF) method. Plant and Crawford (2016) has reported the use of a commercial CFD code on the design of a tangential vortex intake. Chan et al. (2018) also studied the flow field of a stable vortex intake using the VOF method and revealed important flow details. The model is successfully validated against velocity and 


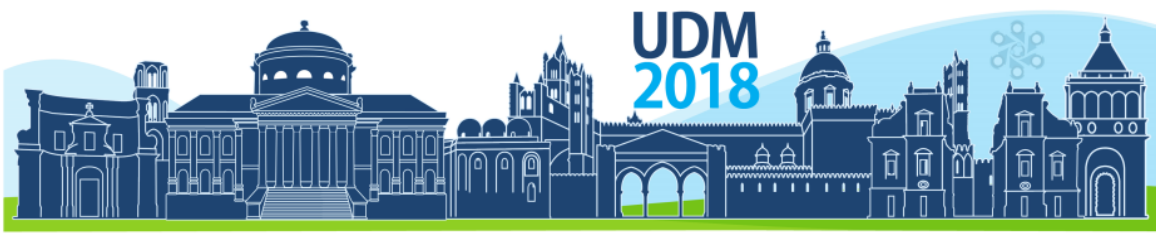

$11^{\text {th }}$ International Conference on Urban Drainage Modelling

23-26 Sep | Palermo - Italy

air core size measurement. This paper presents an experimental study and 3D CFD modeling on an unstable tangential vortex intake.

\section{EXPERIMENTS AND CFD}

\subsection{Physical Model}

The flow characteristics of a tangential vortex intake is mainly determined by the design parameters of junction width $e$, approach channel width $B$, drop shaft diameter $D$, bottom slope of tapering section $\beta$ and tapering angle of width of tapering section $\theta$ (Fig. 1a). The tapering channel has a steep 1:1 slope, in contrast with milder slope in the stable design reported previously (Qiao et al. 2013; Chan et al. 2018). Based on the one-dimensional theory of $\mathrm{Yu}$ and Lee (2009), the free drainage discharge $\left(Q_{f}=18.2 \mathrm{~L} / \mathrm{s}\right)$ is estimated less than the critical discharge of the intake $\left(Q_{c}=20.2 \mathrm{~L} / \mathrm{s}\right)$, suggestive of unstable flow behavior. The air core size is measured by a specially designed eight-leg ruler (Yu and Lee, 2009) for flow rates $Q=1-20$ $\mathrm{L} / \mathrm{s}$. Detailed point velocity measurement is made using two-component LDA at the junction and at different azimuth angles of vortex dropshaft, with a specially designed measurement panel mounted at the external wall of the dropshaft for typical flows (Qiao et al. 2013).

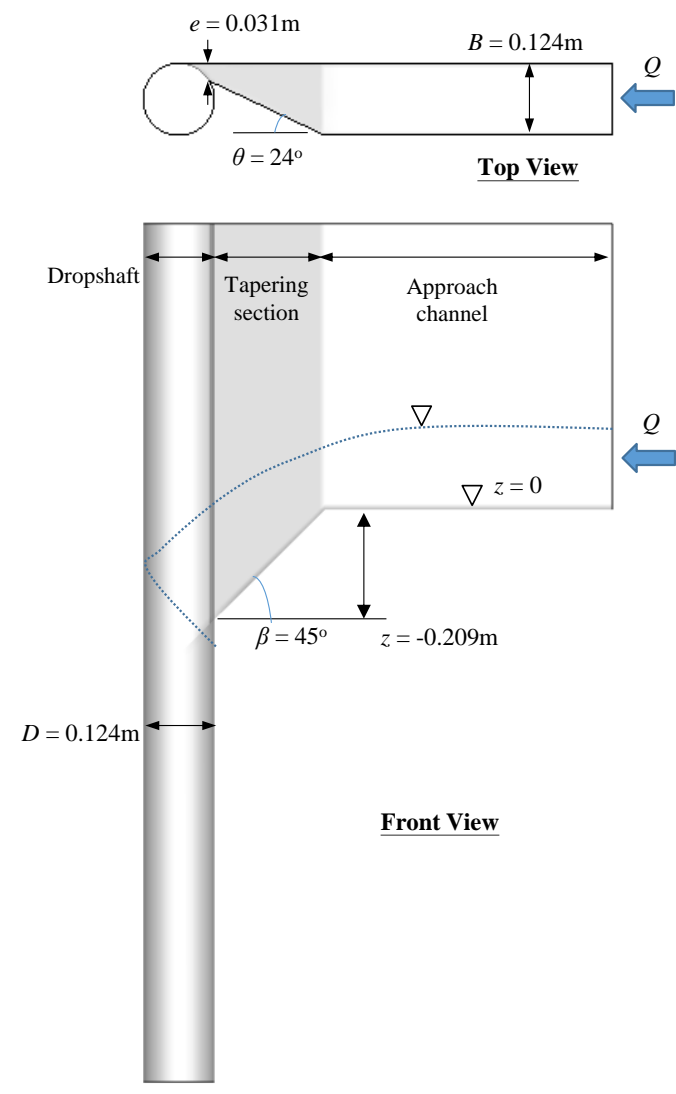

(a)

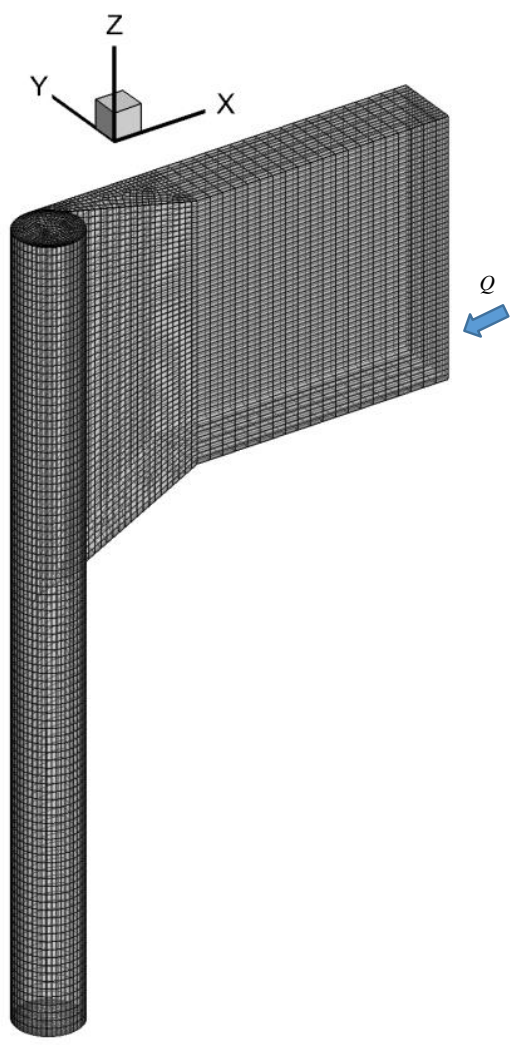

Figure 1. (a) Geometry of the unstable tangential vortex intake and (b) the CFD model mesh.

(b)

\subsection{CFD Model}

The VOF model (Hirt and Nichols, 1981) predicts two immiscible fluids (water and air) by solving a single set of momentum equations and tracking the volume fraction of each of the 


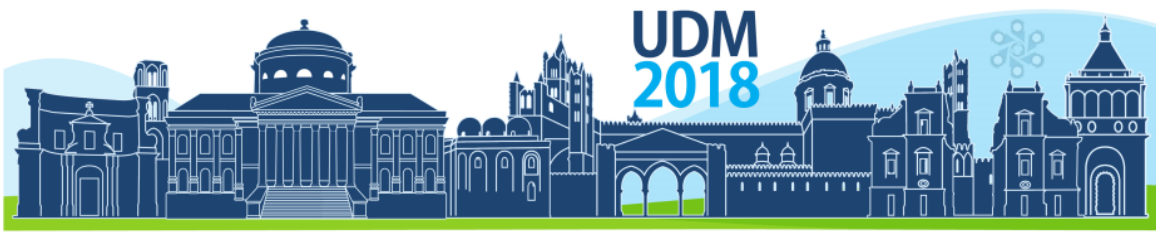

$11^{\text {th }}$ International Conference on Urban Drainage Modelling

23-26 Sep | Palermo - Italy

fluids throughout the computational domain. The tracking of the interface between the phases is accomplished by the solution of a continuity equation for the volume fraction of one of the phases. The resulting velocity field is shared among the two phases through the phaseaveraged density and viscosity. The standard k- $\varepsilon$ model is used for turbulence closure of airwater mixture flow. The governing equations are solved numerically using the "interFoam" solver in OpenFOAM 4.0 for two incompressible, immiscible fluids based on the interface capturing approach (OpenFOAM, 2016).

An unstructured boundary-fitted mesh with 76,320 hexahedral cells is developed according to the experimental design (Fig. 1b). Mesh refinement is made to close to the dropshaft wall to resolve the swirling flow, with minimum grid size of about $1 \mathrm{~mm}$. The computational model has three open boundaries - the inflow, the bottom outflow of the dropshaft and the top atmospheric boundary. The model is initiated from dry bed condition and the flow is developed from the inlet until quasi steady-state. A variable time step of $\sim 0.1-1 \mathrm{~ms}$ is used to maintain computational stability. The computation time for one minute of flow on a single node 12 -core $2.3 \mathrm{GHz}$ high performance computing cluster is about 1 hour.

\section{RESULTS AND DISCUSSION}

\subsection{Approach and Tapering Channel Flow}

The predicted free surface profile at the approach and tapering channel is shown in Fig. 2 for $Q=4$ and $8 \mathrm{~L} / \mathrm{s}$. For $Q=4 \mathrm{~L} / \mathrm{s}$ (Fig. 2a), the flow remains supercritical in the entire tapering channel. For $Q=8 \mathrm{~L} / \mathrm{s}$ (Fig. 2b), the flow transforms from critical flow at upper end of tapering channel to subcritical flow near the junction through an inclined hydraulic jump at the tapering channel. The flow accelerates towards the junction, due to the narrowing and sloping of the tapering channel. Predicted free surface compares well with the measurement. Near the junction, the horizontal velocity $u$ is nearly constant in the vertical direction and about the same for both flow rates (Fig. 3a). The vertical velocity $w$ varies linearly in the vertical direction, increasing from the surface to the bottom (Fig. 3b). The predicted flow velocity compares satisfactorily with point LDA flow measurement, despite the unstable flow due to the hydraulic jump.
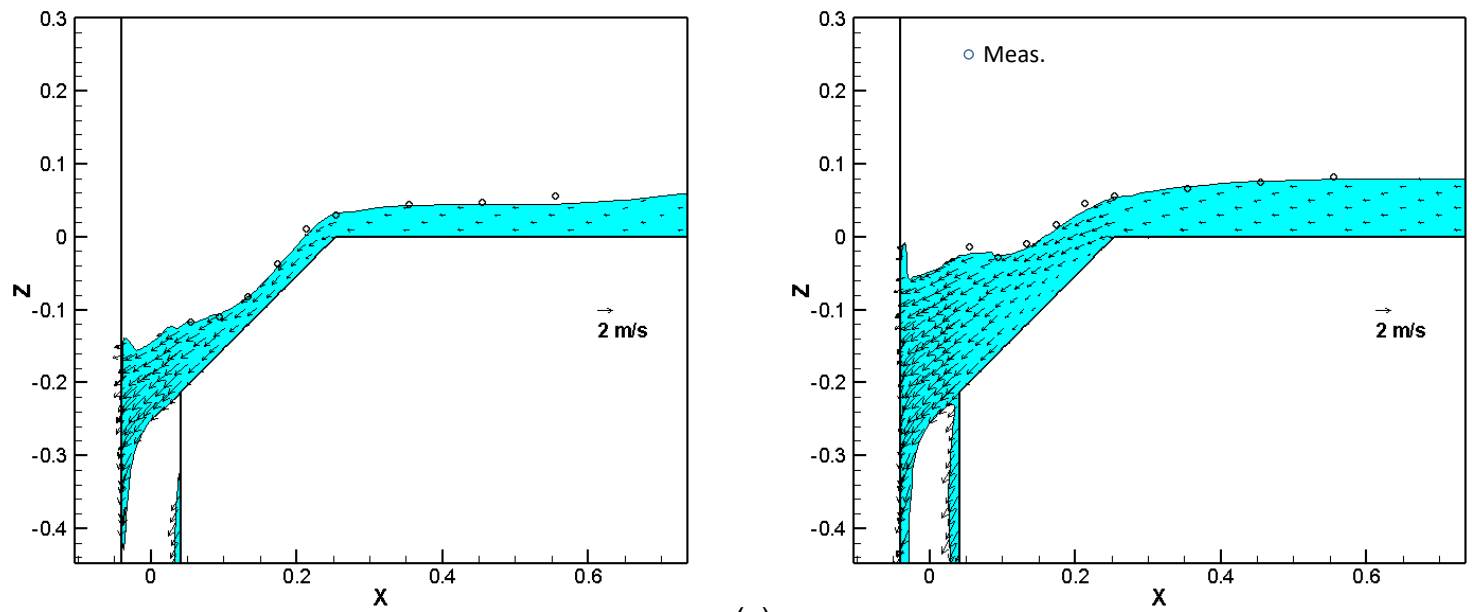

(a)

(b)

Figure 2. Free surface profile and flow field at the approach and tapering channels for (a) $Q=4 \mathrm{~L} / \mathrm{s}$, (b) $Q=8 \mathrm{~L} / \mathrm{s}$. Open circles are measurement along the channel centreline. 


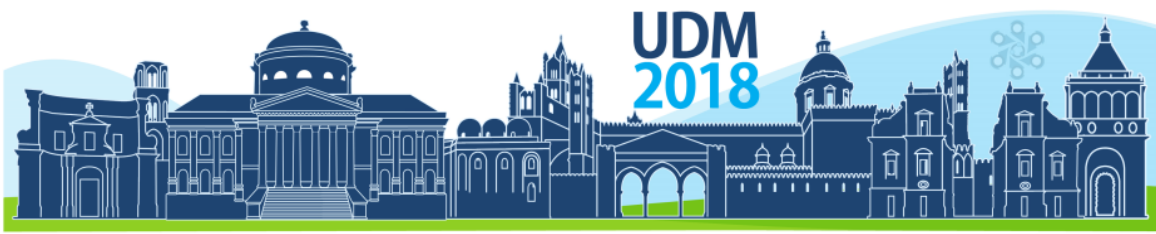

$11^{\text {th }}$ International Conference on Urban Drainage Modelling

23-26 Sep | Palermo - Italy
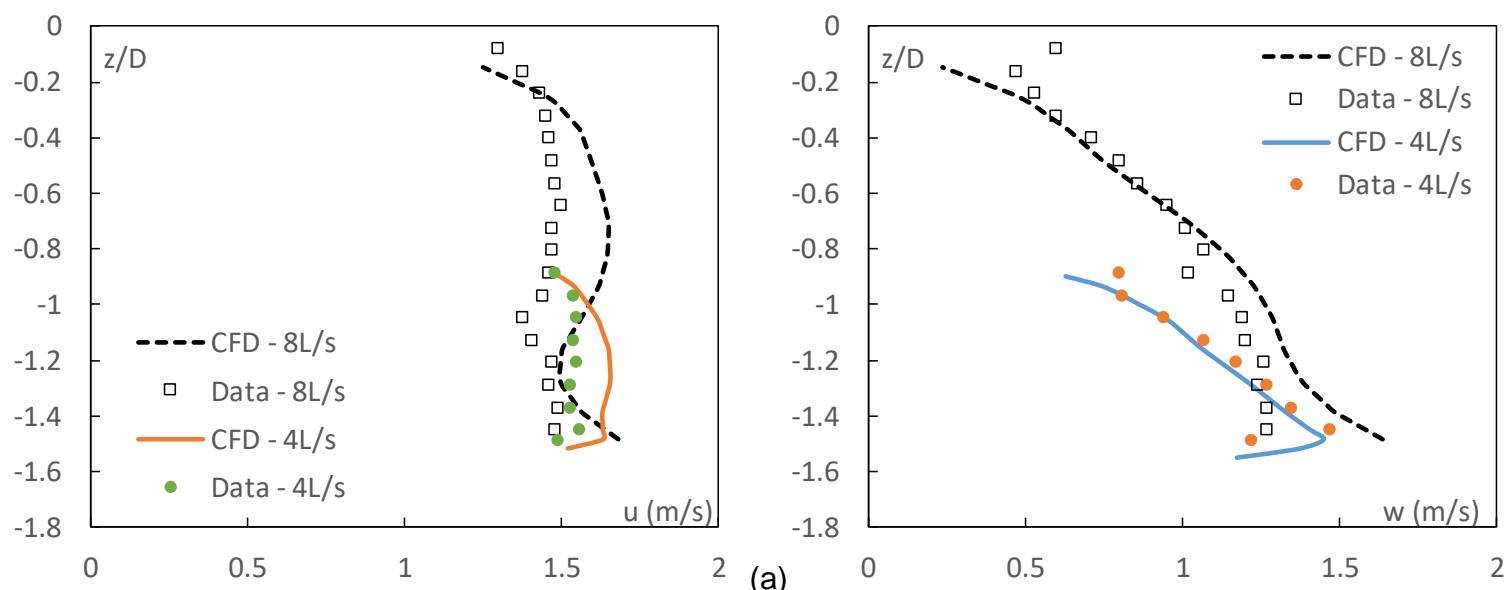

Figure 3. Measured and predicted (a) horizontal velocity and (b) vertical velocity at the junction of $\operatorname{dropshaft}(Q=$ 4 and $8 \mathrm{~L} / \mathrm{s}$ )

\subsection{Air core area}

Figure 4a shows the predicted minimum air core $(z=-0.12 \mathrm{~m})$ and the swirling flow field in the dropshaft for $Q=16 \mathrm{~L} / \mathrm{s}$. The inflow from the tapering channel enters the dropshaft as a slot jet. The air core is significantly asymmetrical about the axis of the drop shaft; the flow thickness is largest near the junction entry and decreases gradually to a minimum at $270^{\circ}$ as it swirls around the circumference. The air core area ratio $\lambda$ (air core size to dropshaft area) first decreases down the dropshaft (Fig. 4b), reaching a minimum at $z=-0.1$ to $-0.2 \mathrm{~m}$ (bottom level of junction), and then increases again. The CFD prediction of air core size compares satisfactorily with laboratory measurement.
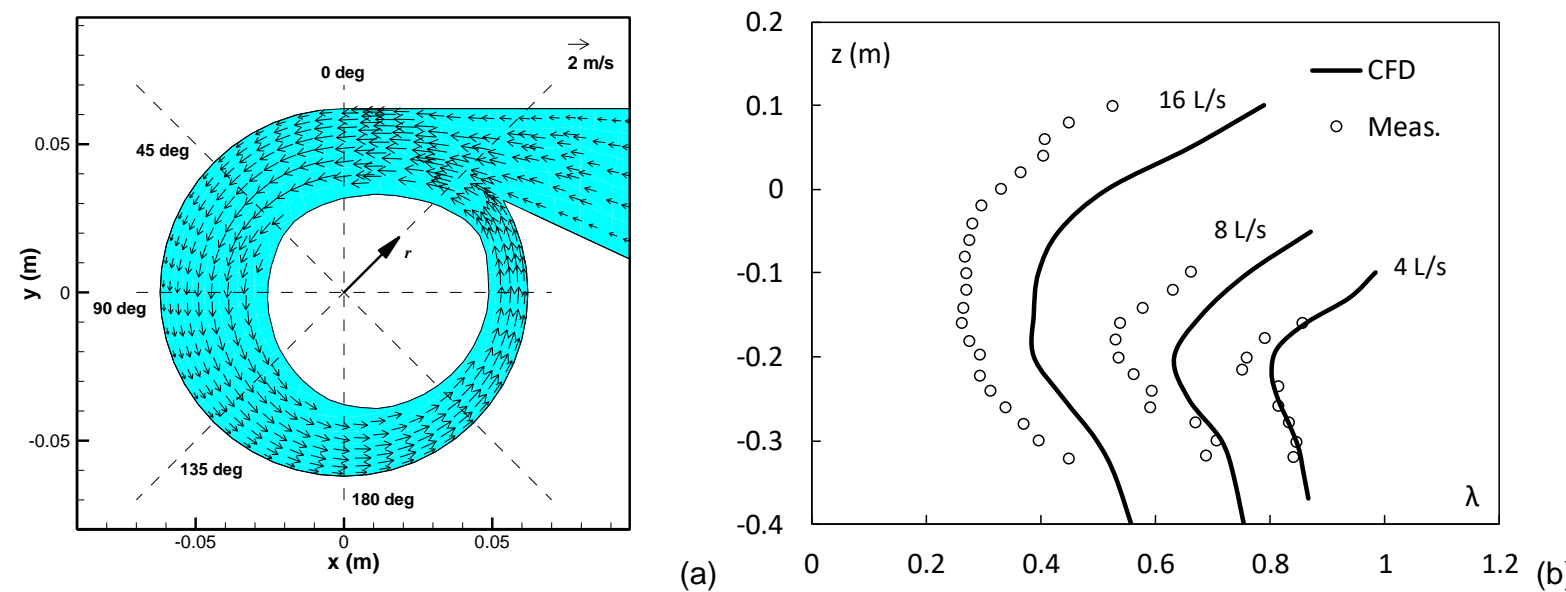

Figure 4. (a) Predicted air core and swirling flow field for $z=-0.12 \mathrm{~m}$ (throat), $Q=16 \mathrm{~L} / \mathrm{s}$. (b) Predicted and measured air core area ratio $\lambda$ for three flow rates. 


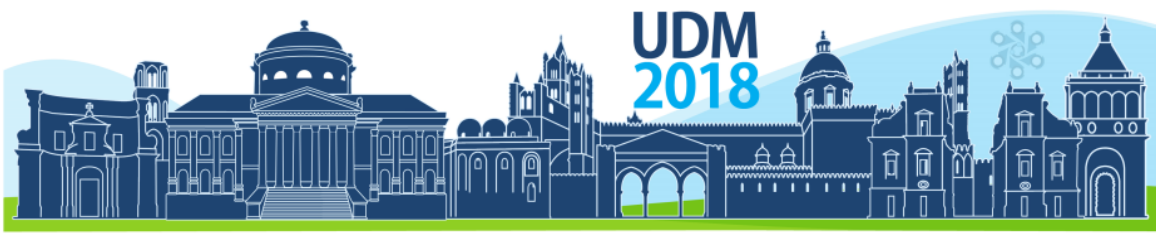

$11^{\text {th }}$ International Conference on Urban Drainage Modelling

23-26 Sep | Palermo - Italy

\subsection{Swirling Flow at Dropshaft}

The predicted and measured tangential and vertical velocities of the swirling flow agree reasonably well at the throat in the dropshaft $(z=0 \mathrm{~m}$ and $-0.12 \mathrm{~m}$, Fig. 5). The tangential velocity $u_{\theta}$ first increases with radius near the air core, suggestive of solid body rotation (forced vortex) behaviour. It increases to a maximum at $r=0.04 \mathrm{~m}$, then reduces again, suggesting free vortex behaviour. The vertical velocity remains constant for the thickness of the flow. Similar swirling flow feature at the dropshaft is also found in a stable vortex intake design (Chan et al. 2018).
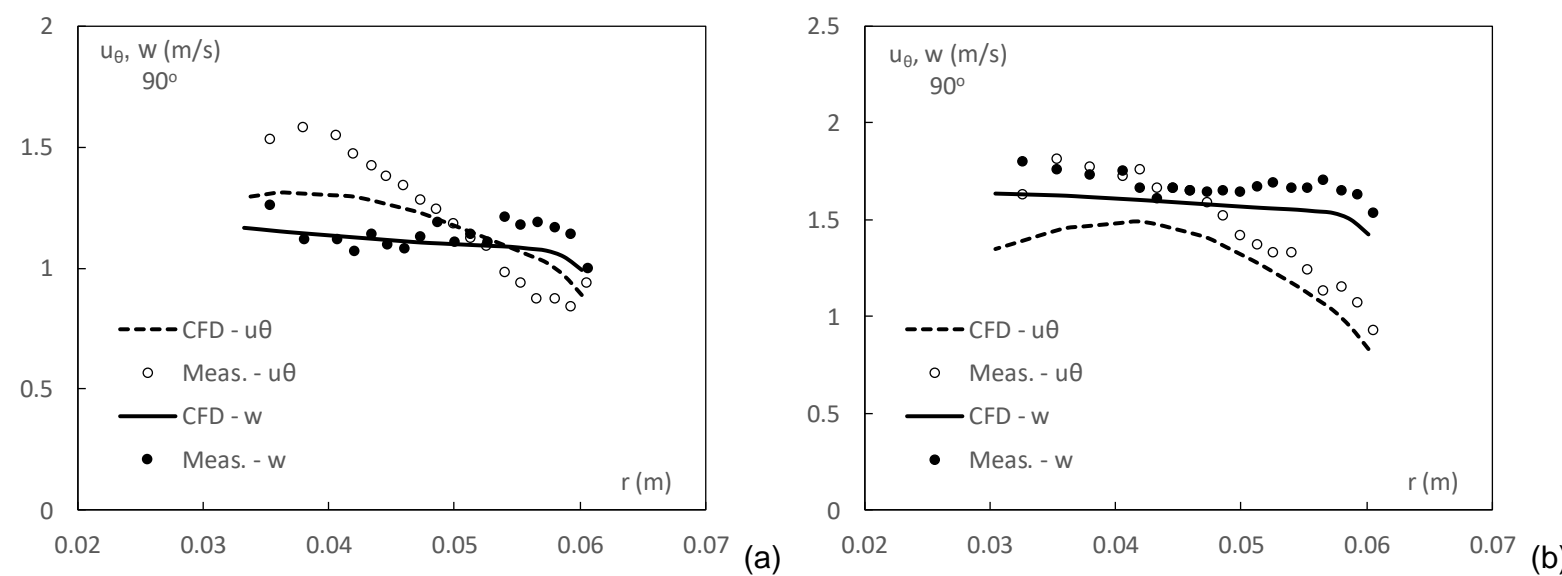

Figure 5. (a) Predicted and measured tangential and vertical velocity at the dropshaft, azimuth angle of $90^{\circ}$, for $Q$ $=16 \mathrm{~L} / \mathrm{s},(\mathrm{a}) \mathrm{z}=0 \mathrm{~m}$, (b) $z=-0.12 \mathrm{~m}$.

\section{CONCLUSIONS}

A numerical study of an unstable tangential vortex intake flow has been conducted using the open source 3D CFD code OpenFOAM and validated with experimental measurement. The CFD model predictions are validated against flow profile, air core and detailed point velocity measurements, offering comprehensive insights of tangential vortex intake flow and providing a basis for the hydraulic design of such vortex intake structures.

\section{References}

Chan, S.N., Qiao, Q.S. and Lee, J.H.W. (2018). On the three-dimensional flow of a stable tangential vortex intake. Journal of Hydro-Environment Research (under review)

Hirt, C. W. and Nichols, B. D. (1981). Volume of fluid (VOF) method for the dynamics of free boundaries. Journal of Computational Physics, 39(1), 201-225.

Jain, S.C. (1984). Tangential vortex-inlet. Journal of Hydraulic Engineering, 110(12), 1693-1699.

OpenFOAM (2016). OpenFOAM - The Open Source CFD Toolbox - User Guide. Version 4.0

Plant, J. and Crawford, D. (2016). Pushing the limits of tangential vortex intakes: is higher capacity and flow measurement possible in a smaller footprint? Proceedings of WEFTEC 2016, New Orleans, Water Environment Federation.

Qiao, Q.S., Lee, J.H.W. and Lam, K.M. (2013). Steady vortex flow in tangential intake. Proceedings of 2013 IAHR World Congress, Chengdu, China.

Yu, D.Y. and Lee, J.H.W. (2009). Hydraulics of tangential vortex intake for urban drainage. Journal of Hydraulic Engineering, 135(3), 164-174. 


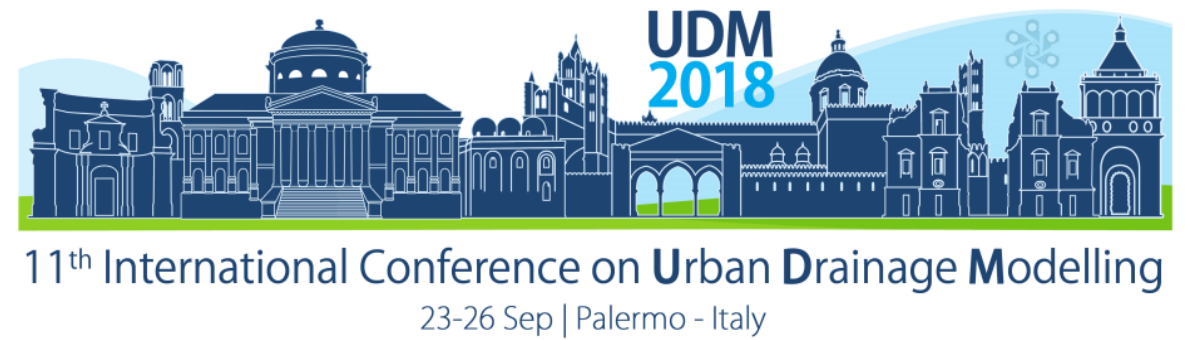

\title{
An integrated approach for assessing the impact of urban stormwater discharge on the fecal contamination in a recreational lake near Paris
}

\author{
Yi Hong ${ }^{1}$, Chenlu Li', Bruno J. Lemaire ${ }^{1}$, Frédéric Soulignac ${ }^{2}$, José R. Scarati Martins ${ }^{3}$, Adélaïde Roguet ${ }^{4}$, \\ Françoise Lucas ${ }^{1}$ and Brigitte Vinçon-Leite ${ }^{1}$ \\ ${ }^{1}$ LEESU, MA 102, École des Ponts ParisTech, AgroParisTech, UPEC, UPE, 77420 Champs-sur- Marne, France \\ 2 ENAC, Ecole Polytechnique Fédérale de Lausanne, CH-1015 Lausanne, Switzerland \\ ${ }^{3}$ School of Engineering, University of Sao Paulo, Sao Paulo, Brazil \\ ${ }^{4}$ School of Freshwater Sciences, University of Wisconsin-Milwaukee, Milwaukee, WI 53204, USA
}

\begin{abstract}
Urban stormwater discharges contribute to the fecal contamination of recreational lakes. It is essential to assess the spatial and temporal distribution of fecal bacterial indicators in the receiving waterbodies, to prevent public health risks. This study develops for the first time in continental waters an integrated monitoring and modelling approach, linking the SWMM and Delft-3D models and including a detailed monitoring of the stormwater discharge and at different points of the lake, for assessing Escherichia coli (E.coli) dynamics in stormwater discharges and the receiving urban lake. This integrated approach is applied to a recreational shallow lake and its adjacent urban catchment, with a single stormwater outlet which discharges into the lake. The SWMM model parameters are calibrated and validated with continuous measurements of the flow rate and mean concentration of E. coli in the stormwater discharge measured during each rainfall event. Using the simulated flow rate and $E$. coli concentration at the sewer outlet, the Delft3DFLOW-WAQ model simulates $E$. coli transport in the urban lake with previously calibrated hydrodynamic parameters and default values of $E$. coli parameters. Comparing simulations with $E$. coli concentrations measured at different points in the lake, this integrated modelling approach yields promising results. Further studies will focus on the development of automatic model coupling and parameter optimisation, as well as on the evaluation of long-term impacts and management scenarios.
\end{abstract}

Keywords: Integrated monitoring and modelling; SWMM model; Delft-3D model; Escherichia coli; Stormwater discharges; Urban lake

\section{INTRODUCTION}

Urban stormwater discharge is one of the major sources for fecal contamination in recreational lakes. Sanitary regulations are usually based on Escherichia coli densities as a fecal bacterial indicator. During rainfall events, the levels of E.coli in surface waters may greatly exceed the existing recreational water guidelines due to combined sewer overflow or or stormwater discharges (Marsalek and Rochfort, 2004). To safely manage aquatic recreational activities and water supply for human consumption, it is essential to assess the impacts of urban stormwater discharge on the spatial and temporal dynamics of $E$. coli in receiving waterbodies.

Integrated monitoring and modelling is an effective approach to assess the hydro-biological dynamics of $E$. coli over different spatial scales, such as urban surfaces, sewer networks and freshwater bodies. Over the past decade, some integrated systems have been developed, 


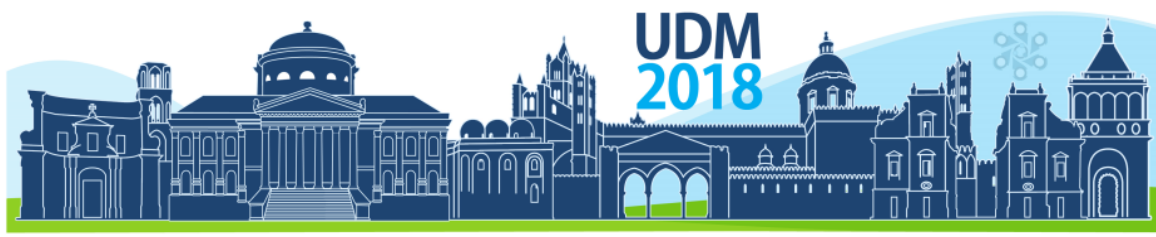

$11^{\text {th }}$ International Conference on Urban Drainage Modelling

23-26 Sep | Palermo - Italy

however, very limited attention has been paid to link urban stormwater quality models with physically-based lake models (Bach et al., 2014). In this study, we coupled two widely used models, the SWMM model (Rossman, 2010) and the Delft-3D model (Deltares, 2016), and combined them with a detailed monitoring, to assess $E$. coli dynamics in an urban catchment and its receiving waterbody.

\section{MATERIALS AND METHODS}

\subsection{Study site}

The study area is located at South-eastern Paris (Créteil, Val-de-Marne, France), consisting of a recreational lake of 42 ha (Lake Creteil) and an urban catchment of 95 ha, with a single stormwater outlet into the lake (Figure 1). Lake Creteil, a sand-pit lake, is mainly supplied by alluvial ground water from the nearby Seine and Marne river. A meteorological station (Vaisala WXT520) is located $2 \mathrm{~m}$ above the lake surface. Three monitoring buoys equipped with sensor chains are set on the lake: at point $S$ close to the stormwater outlet, point $\mathrm{C}$ in the deepest part of the lake (nearly $6.5 \mathrm{~m}$ ) and point $O$ near to the regulated lake outlet.

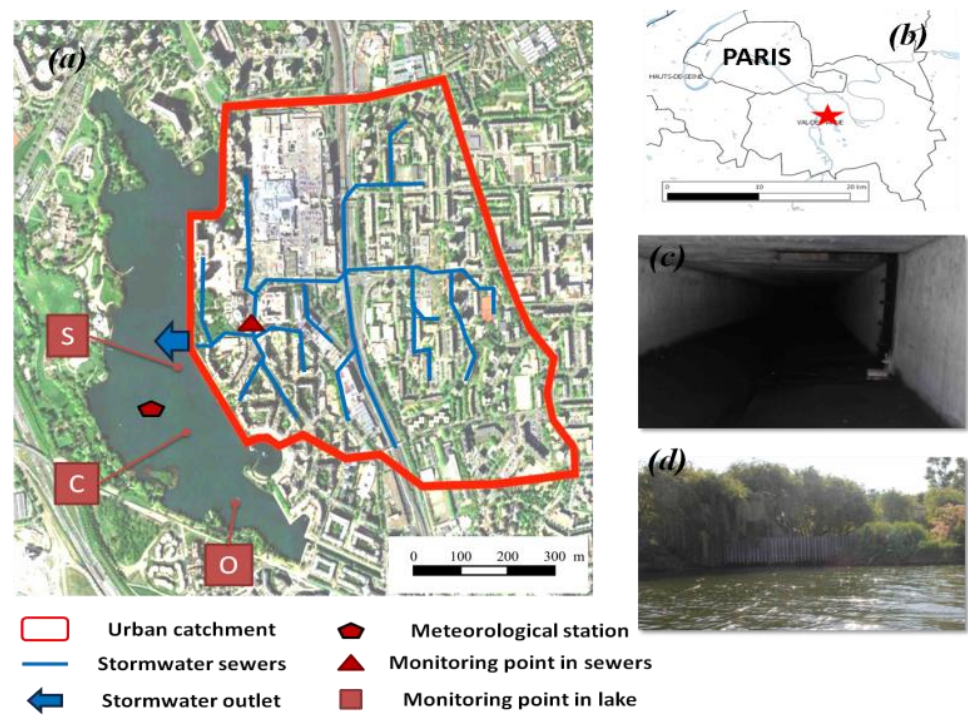

Figure 1. Study area at South-eastern Paris, France. (a) Urban catchment, recreational lake, stormwater sewer network and monitoring points; (b) Site location; (c) Monitoring equipment inside the sewer; (d) Sewer outlet.

\subsection{On-site monitoring and sampling}

The monitoring equipment for stormwater discharge is set up at the downstream end of the main stormwater sewer of the catchment, before it divides into two conduits towards the outlet. In this sewer, a flow valve diverts dry weather flow due to cross-connections into the wastewater network. Water depth (DRUCK PTX630) and water flow rate (CR2M SAB600 ASN) are recorded with a 2 min time interval. During the rainfall events, representative effluent samples are collected using an auto-sampling (HACH Sigma SD900). Immediately after recovering the effluent samples, a sampling campaign was performed on Lake Créteil on station $\mathrm{S}, \mathrm{C}$ and $\mathrm{O}$. The effluent and lake water samples were then inoculated onto MUG/EC microplates following the French ISO standards NF EN ISO 9308-3. E. coli concentrations were estimated by the most probable number method. From October to November 2013, E. coli densities were evaluated for four campaigns (Roguet et al., 2017). 


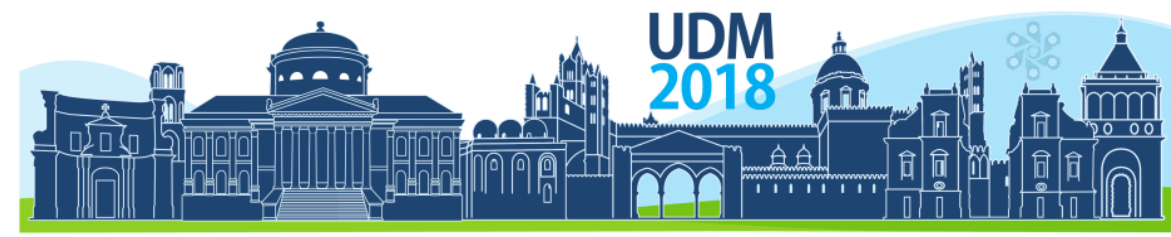

$11^{\text {th }}$ International Conference on Urban Drainage Modelling

23-26 Sep | Palermo - Italy

\subsection{Model description}

SWMM model is used for the modelling of rainfall-runoff, sewer networks, production and transport of $E$. coli in the studied urban catchment. The total catchment is divided into 21 sub-catchments according to land-use. The sub-catchments are treated as nonlinear reservoirs, surface runoff occurs when the depth of water in the "reservoir" exceeds the initial losses, outflows are then given by the Manning's equation. The build-up and washoff processes of $E$. coli are calculated by using exponential equations, where the rate of pollutants production is proportional to a maximum possible build-up and a scaling factor, and the rate of pollutants washoff depends on the water flow and the remaining particles with two controlling coefficients. Water flow in the sewer network is computed by the 1D kinematic wave equations. For the $E$. coli routing within conduits, it is assumed that the latter behave as continuously stirred tank reactors (CSTR).

Using the simulated flow rate and $E$. coli concentration at the sewer outlet, the Delft3DFLOW-WAQ model simulates $E$. coli transport in Lake Creteil. The model solves the unsteady shallow water equations for hydrodynamic simulations. The dynamics of $E$. coli is computed by an advection-diffusion-mortality equation, where the mortality of $E$. coli depends on water temperature, salinity and solar radiation. In the 3D-model, the horizontal surface of the lake is meshed with 981 Cartesian cells of $20 \mathrm{~m} \times 20 \mathrm{~m}$, while the vertical direction of the model is divided into 18 layers of $33 \mathrm{~cm}$ (Soulignac et al., 2017).

\section{RESULTS AND DISCUSSION}

\subsection{Water flow and $E$. coli in stormwater sewers}
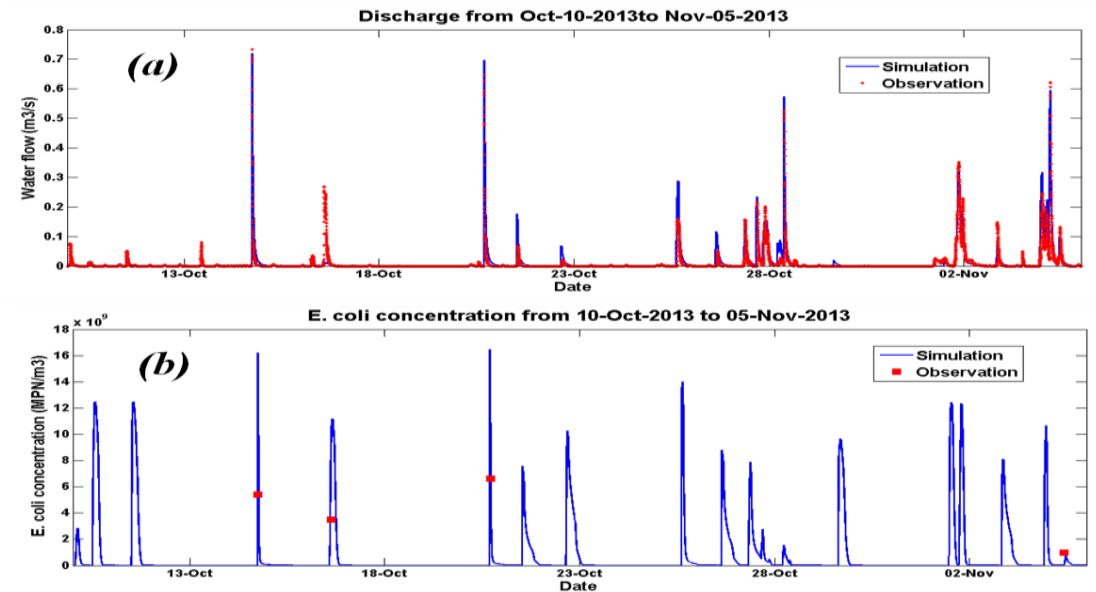

Figure 2. Simulations and observations of (a) flow rate and (b) E. coli concentrations in the stormwater sewer.

Comparing the simulated discharges and E. coli concentrations with the continuous measurements of water flow and the measured EMC of $E$. coli, respectively, the hydraulic/hydrologic and build-up/washoff parameters of SWMM model are calibrated for the rainfall event of Oct. 14th, 2013, and validated for the events of Oct. 20th and Nov. 3rd, 2013. Simulation is then performed with the optimized parameters for the period from Oct. 10th to Nov. 5th, 2013. Simulations and observations at the monitoring point in stormwater 


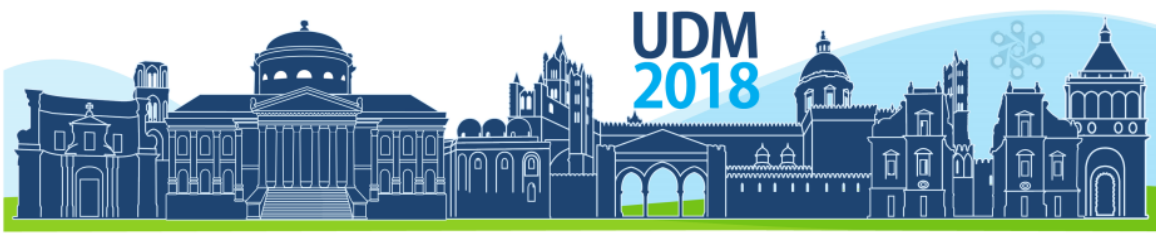

$11^{\text {th }}$ International Conference on Urban Drainage Modelling

23-26 Sep | Palermo - Italy

sewer are presented in Figure 2. As can be seen in the figure, simulated flow rate and E. coli concentration fit well with the measurements.

\subsection{Spatial-temporal dynamics of $E$. coli in Lake Créteil}

Using the hydrodynamic parameters obtained in a previous study (Soulignac et al., 2017) and the default values of $E$. coli parameters of the Delft3D model, depth-averaged simulated and observed concentrations of $E$. coli are compared at the monitoring points (Figure 3 ). Considering the large uncertainties in measurements of $E$. coli, these results indicate that the presented approach can achieve realistic simulations for representing $E$. coli dynamics.

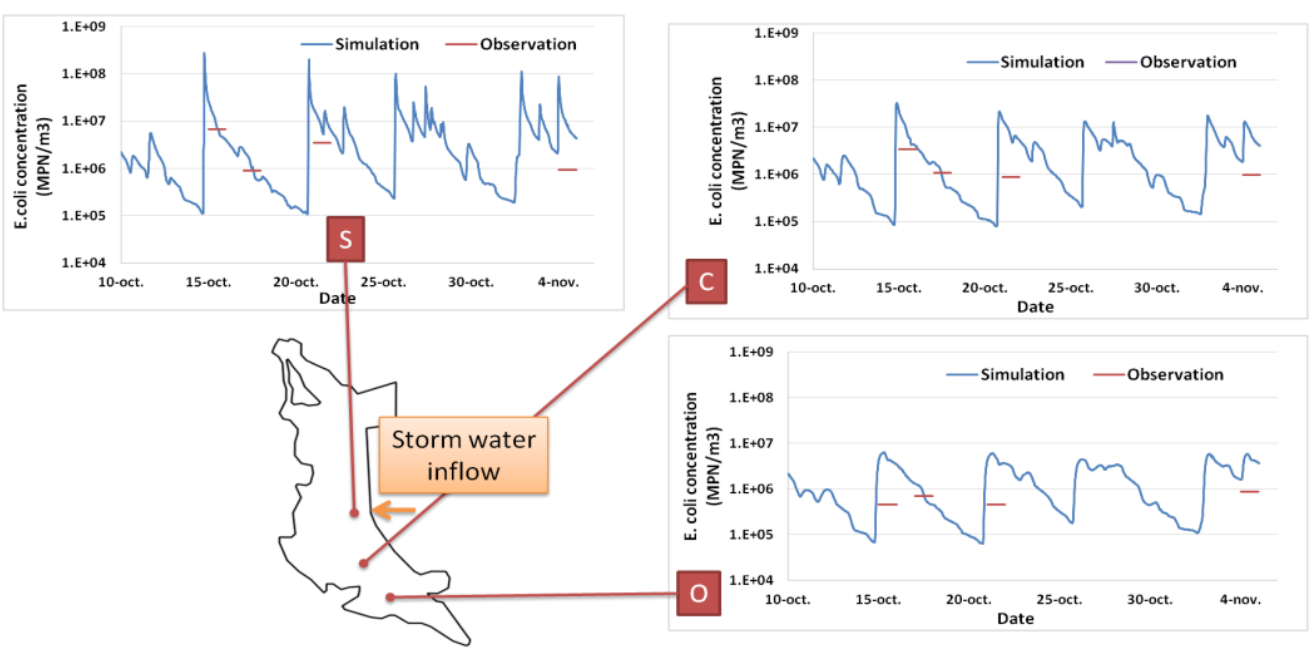

Figure 3. Simulations and observations of Escherichia coli concentrations at the three monitoring points.

\section{CONCLUSIONS AND PERSPECTIVES}

In this study, we coupled for the first time the SWMM model and Delft-3D model to assess the impact of stormwater discharge on the fecal contamination in an urban recreational lake. Comparing with detailed monitoring data, this integrated approach yielded promising results in reproducing the spatial and temporal dynamics of $E$. coli. Further studies will focus on the development of automatic model coupling and parameter calibration, as well as on the assessment of long-term impacts and management scenarios.

\section{References}

Bach, P.M., Rauch, W., Mikkelsen, P.S., McCarthy, D.T., Deletic, A., 2014. A critical review of integrated urban water modelling - Urban drainage and beyond. Environ. Model. Softw. 54, 88-107.

Deltares, 2016. 3D/2D modelling suite for integral water solutions - Delft3D.

Marsalek, J., Rochfort, Q., 2004. Urban Wet-Weather Flows: Sources Of Fecal Contamination Impacting On Recreational Waters And Threatening Dringking-Water Sources. J. Toxicol. Environ. Health A 67, 17651777.

Roguet, A., Therial, C., Catherine, A., Bressy, A., Varrault, G., Bouhdamane, L., Tran, V., Lemaire, B.J., VinconLeite, B., Saad, M., Moulin, L., Lucas, F.S., 2017. Importance of Local and Regional Scales in Shaping Mycobacterial Abundance in Freshwater Lakes. Microb. Ecol.

Rossman, lewis A., 2010. Storm water management model user's manual version 5.0. National risk management research and development U.S. environmental protection agency, Cincinnati, $\mathrm{OH} 45268$.

Soulignac, F., Vinçon-Leite, B., Lemaire, B.J., Scarati Martins, J.R., Bonhomme, C., Dubois, P., Mezemate, Y., Tchiguirinskaia, I., Schertzer, D., Tassin, B., 2017. Performance Assessment of a 3D Hydrodynamic Model Using High Temporal Resolution Measurements in a Shallow Urban Lake. Environ. Model. Assess. 22, 309-322. 


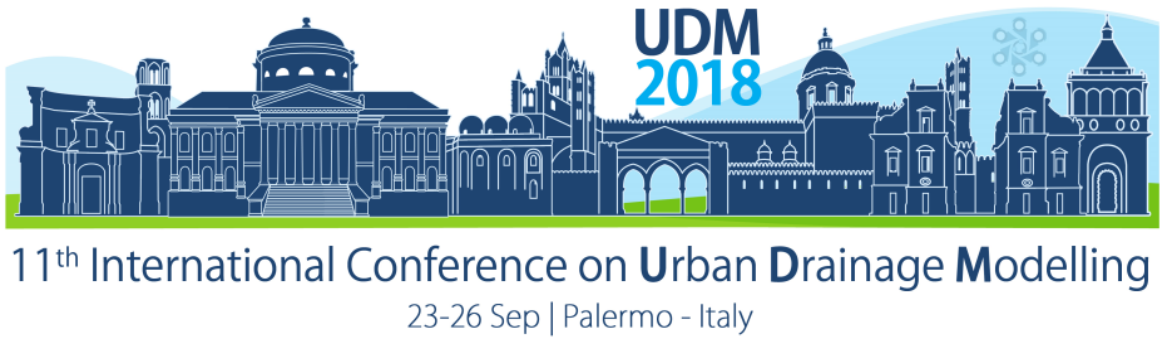

\title{
Digitalization meets reality - Concept and Experiences from long- term wireless data collection with $50+$ sewer monitors
}

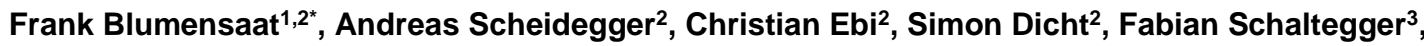 \\ Andreas Rüst ${ }^{3}$, Uwe Schmitt ${ }^{4}$ and Max Maurer ${ }^{1,2}$ \\ ${ }^{1}$ Institute of Environmental Engineering, Chair of Urban Water Systems, ETH Zurich, Switzerland \\ 2 Swiss Federal Institute of Aquatic Science and Technology, Eawag, Switzerland \\ ${ }^{3}$ ZHAW Winterthur, Institute of Embedded Systems, Switzerland \\ ${ }^{4}$ Scientific IT Services, ETH Zurich, Weinbergstrasse 11, 8092 Zurich, Switzerland
}

\begin{abstract}
Blossoming visions foresee an ubiquitous availability of data enabled through emerging sensors, novel transmission technologies and revisited data analysis techniques. It is often expected that this likewise applies to urban water management (Kerkez et al., 2016; Eggimann et al., 2017). Contrary to the envisioned easiness to collect data, an increasing number of studies report about a declining effort to conduct experimental field research in catchment and urban hydrology, implying the risk of scientific advancement to be misdirected (Blume et al., 2017; van Emmerik et al., 2018). In this paper, we present results from a unique sensor network that collects, transmits, and organizes very high resolution status information from an urban drainage catchment. Our findings are based on a two-year operation at full-scale with more than 50 sensor nodes connected to a low-power wireless sensor network (LPWSN). In essence we i) illustrate the scalability of LPWSNs, ii) reveal telemetry limitations of the LoRaWAN standard (LoRa®Alliance 2015), iii) suggest a novel technique (LoRaMesh) to master this constraint, and iv) discuss challenges associated with managing the amount of data collected from diverse sources. We find: 1 . the proposed transmission technique considerably improves telemetry performance of the en tire network without introducing additional gateway stations (total packet loss $2.2 \%$ ). 2 . Dynamic and flexible data management solutions come at a price. 3 . It is not the pure amount of data that is most challenging but the diversity of different signals. 4. Full metadata integration in the data warehouse is laborious but clearly consolidates data interpretation in the long-term run.
\end{abstract}

Keywords: distributed monitoring; low-power wireless sensor networks; spatio-temporal in-sewer dynamics; LoRaWAN; data management

\section{Introduction}

Miniaturization of hardware components, increasing computational capacities and an omnipresent integration of various types of technology in our everyday life promise a data pletho$\mathrm{ra}$ in the near future. It is often expected that this likewise applies to urban water management (Kerkez et al., 2016; Eggimann et al., 2017). Despite such novel techniques that evolved through digital transition, experimental field work in hydrology remains hard. Our contribution aims at discussing this apparent contradiction from a conceptual and a practical point of view. With sharing our experiences from the Urban Water Observatory (UWO) a long-term (two years) distributed data collection campaign, we intend to test the visions of digitalization against reality.

In the following we focus on two central aspects of UWO: i) the performance and improvements of the wireless underground transmission and ii) how the diverse data obtained can be 


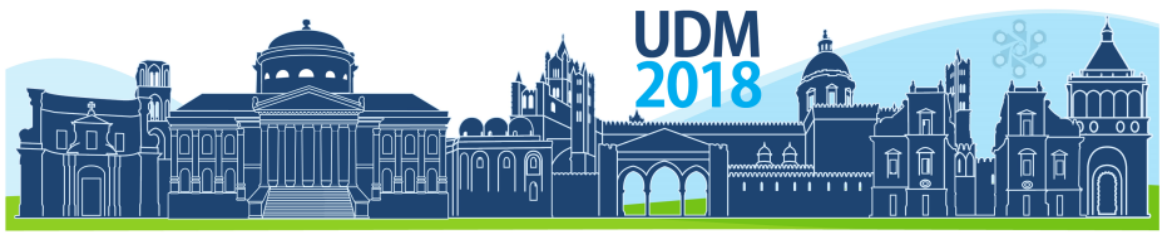

$11^{\text {th }}$ International Conference on Urban Drainage Modelling

23-26 Sep | Palermo - Italy

efficiently structured and managed (see Figure 1). We previously reported on specific technical details of the UWO including sensor technology, network layout and principles of the low-power transmission technique LoRaWAN (see Blumensaat et al., 2017).

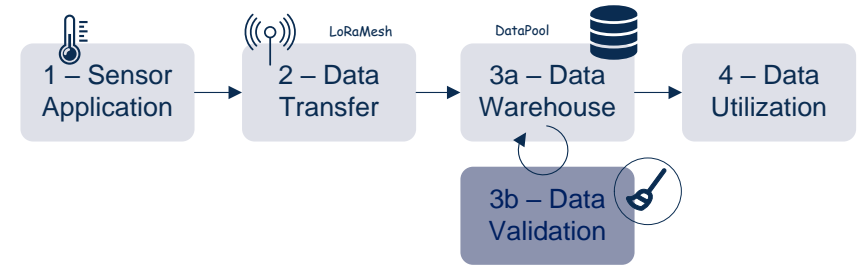

Figure 1: schematic overview data collection process as referred to in this paper.

\section{MATERIAL AND MOTIVATION}

Sensor network evolution: the 60 monitors deployed in the UWO can be partitioned into a) 9 backbone monitors, i.e. conventional rain gages, flow monitors operated on batteries and GSM data loggers, and b) a low-power wireless sensor network (LPWSN) consisting of two LoRaWAN gateways and 51 low-power sensor nodes that monitor in-sewer dynamics, e.g. water levels, temperature, conductivity. With the establishment of the first backbone monitors in Feb. 2016, and the ongoing LPWSN rollout started we steadily increased the number of UWO monitors since May 2016. To date we collect 37'000 data points per day. This corresponds to overall 123 monitoring signals representing the system status in a $5 \mathrm{~min}$ resolution.

Data transmission: A telemetry performance analysis of the LoRaWAN network revealed an average data packet loss of approximately $10 \%$ through imperfect transmission (1 year of data; 23 of 34 radio nodes located underground). While this is an achievement, particularly for underground nodes, there is room for improvement. An in-depth examination shows that the Quality of Service (QoS) linearly decreases with increasing distance to the preferred gateway, and it depends on whether a radio node is positioned above or below ground. For underground nodes, a critical distance to the preferred gateway was found to be at approximately $500 \mathrm{~m}$ (see Fig. 2). Interestingly, varying weather conditions (rainfall) do not significantly influence the transmission.

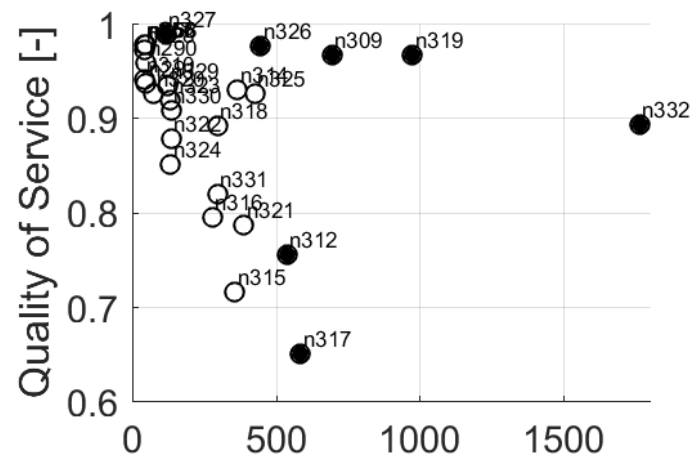

Figure 2: Quality of Service [-] (defined as fraction of packets reaching gateway) vs. distance from gateway [m] for original LoRaWAN transmission (Data: Jan - Dec 2017). Filled circles indicate above-ground radio nodes; empty circles sensor nodes positioned below ground.

Data Management: With an increasing amount and diversity of observations, the data management concept gains importance. Diversity in type of sensors, (undocumented) file formats, units, time zones (daylight saving) increase the efforts needed to unify the data. Furthermore, only by linking the observations with metadata the obtained data are of value. While certain tasks cannot be automated (e.g. writing scripts to convert between different file formats), a good data management system ensures that such efforts are not duplicated by every analysts. Our justified hypothesis is that a systematic and consistent data management requires high efforts in the start-up period, but it pays off in the long-term as it makes data usage much more efficient. 


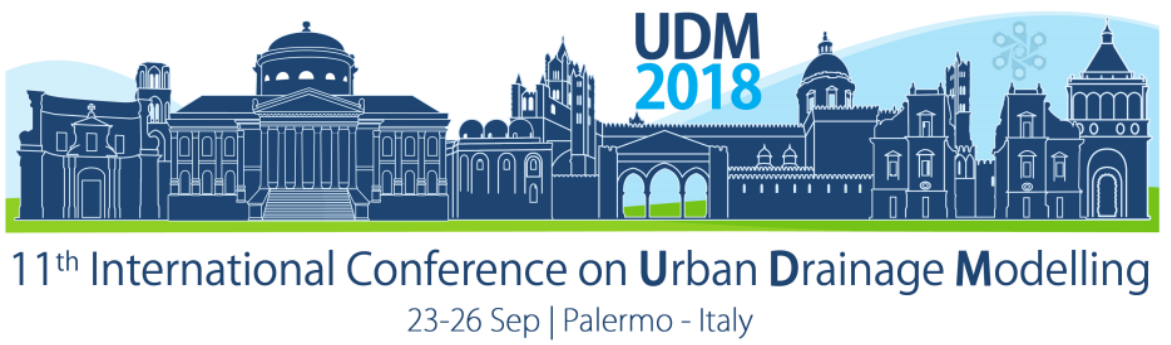

\section{METHODS, RESULTS, DISCUSSION}

Data transmission: To address the LoRaWAN telemetry limitation we developed a new transmission protocol 'LoRaMesh' that allows forming individual sub-networks by introducing intermediate repeater nodes (RN). This way, we modify the original LPWAN architecture from an exclusively star-type (LoRaWAN) towards a tree-type network topology, enabling a multi-hop transmission and thus achieving a more resilient routing. Still, both protocols are based on the same physical layer (LoRa®); the deployed radio node hardware is identical.

Verified through in a repeated field test (operation period: 45 days, 11 test locations) we provide a proof-of-concept for a LoRa-based LPWSN extended by the LoRaMesh protocol. Figure 3 illustrates the enhanced telemetry performance where we achieve a reduced packet loss of, in average $2.2 \%$ compared to the standard LoRaWAN protocol (10\%).

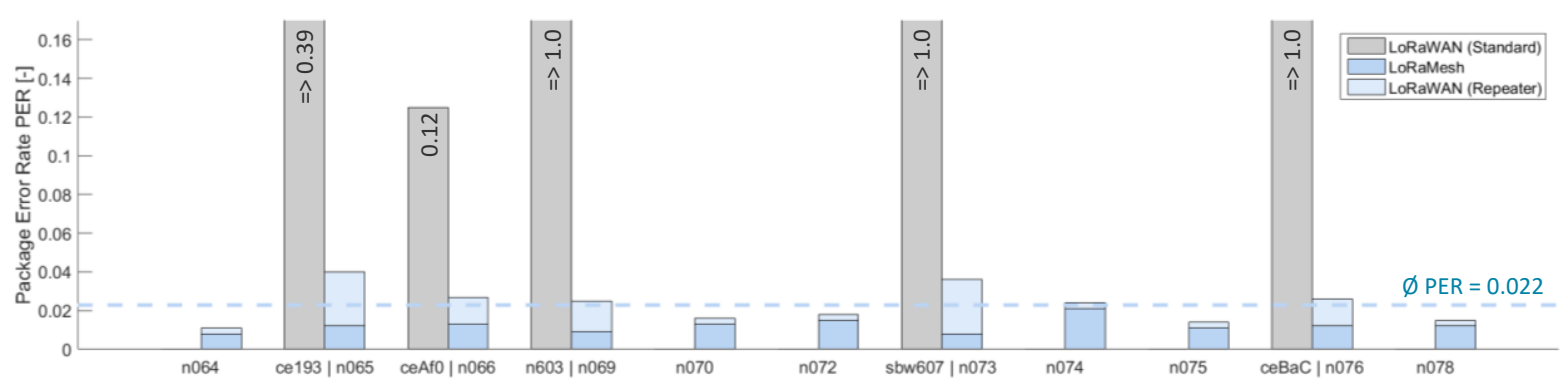

Figure 3: comparison of the total Packet Error Rate (PER = 1 - QoS) for selected underground monitoring locations (node IDs at x-axis) for i) the standard LoRaWAN network (grey bars) and ii) the, with LoRaMesh extended network. An PER of =>1 indicates that there was no radio coverage at all before introducing the extended routing.

Data Warehouse application: Existing data management solutions are generally designed with a very specific work- and dataflow in mind - which is most unlikely to correspond to exactly your needs. So even while the required database concepts are very common and wellestablished, every application needs a careful technical specification, a design concept and an individual configuration. For the UWO we aimed at a solution that i) can handle diverse data of potentially not yet known sources and formats, ii) stores and links data and metadata simultaneously, iii) ensures consistency of the data whenever possible, iv) makes data usage at the front-end easy, and v) does not require in-depth IT skills to add novel data sources. Note, the flexibility of point i) limits the potential for automatization and makes point v) inevitably harder.

Datapool, our implemented data management solution is based on separation of concerns: a field scientist (cf. data provider - Figure 4) adding a new sensor is responsible for i) providing a file with meta data and ii) a conversion script ( $R$, Python, Julia or Matlab) to transform raw files from the sensor into a standardized text format. As soon a new raw file arrives from a sensor the Datapool applies automatically the corresponding script and imports the data into a relational database (here: PostgreSQL). Finally, data users can either directly SQL query the (meta)data, use a handy $R$ package with a basic set of query functions, or use a web interface ${ }^{1}$. To make this rather simple workflow robust, Datapool must essentially perform consistency checks, provide error logs, be designed to guarantee scalability, and manage $\mathrm{read} /$ write-permission of the different users. 


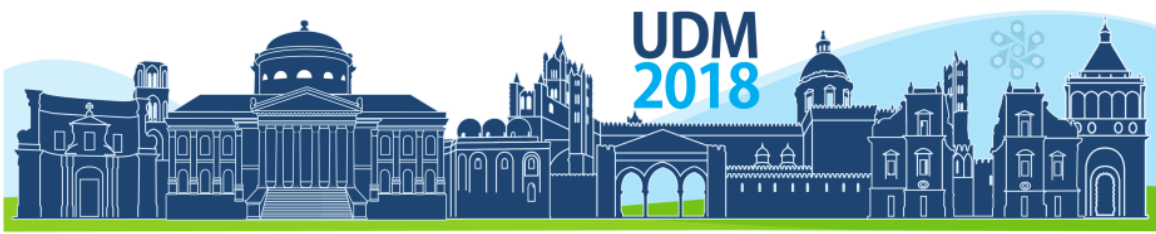

$11^{\text {th }}$ International Conference on Urban Drainage Modelling 23-26 Sep | Palermo - Italy

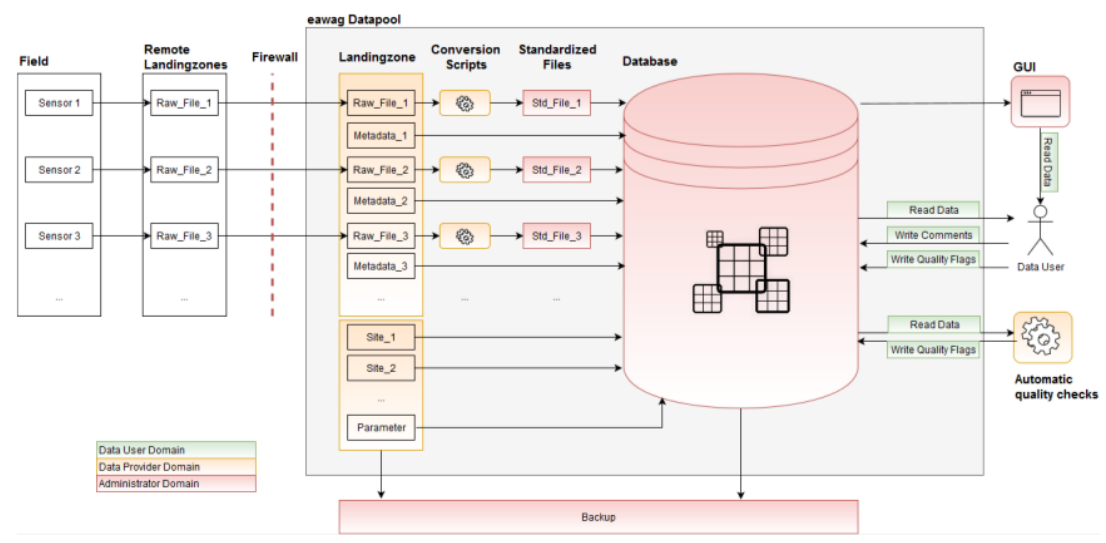

Figure 4: Dataflow of the data warehouse application DataPool.

\section{CONCLUSION}

The recent technical developments make the "data driven urban water management" envisioned by Eggimann et al. (2017) more feasible than ever. Still, many of these novel techniques are in its infancy or need adaptions for the application in sewers, requiring a considerable engineering and scientific efforts before a wide spread adaption becomes possible. By providing concepts and sharing real-world experiences we hope to contribute to a new era of data collection in drainage networks with various useful implications, also for the modelling community.

\section{ACKNOWLEDGEMENTS}

The authors are thankful for support from the municipality Fehraltorf $(\mathrm{CH})$, the LoRaWAN hardware developers from Decentlab (Dübendorf, $\mathrm{CH}$ ), the backend experts from loriot.io (Thalwil, $\mathrm{CH}$ ), and we particularly thank Philipp Bachmann for his tremendous contribution to the final hardware prototyping phase.

\section{REFERENCES}

Blume, T., van Meerveld, I., and Weiler, M. (2017). "The role of experimental work in hydrological sciences - insights from a community survey." Hydrological Sciences Journal, 62(3), 334-337.

Blumensaat, F., Ebi, C., Dicht, S., Rieckermann, J., and Maurer, M. (2017). "Highly Distributed Long-Term Monitoring of in-Sewer Dynamics Using Low-Power Radio Technology." 12th IWA Specialized Conference on Instrumentation, Control and Automation, P. A. Vanrolleghem, ed., IWA, Québec City, Québec, Canada.

Camhy, D., Gamerith, V., Steffelbauer, D., Muschalla, D., and Gruber, G. "Scientific Data Management with Open Source Tools - An Urban Drainage Example." 9th International Conference on Urban Drainage Modelling, Belgrade.

Eggimann, S., Mutzner, L., Wani, O., Schneider, M. Y., Spuhler, D., Moy de Vitry, M., Beutler, P., and Maurer, M. (2017). "The Potential of Knowing More: A Review of Data-Driven Urban Water Management." Environmental Science \& Technology, 51(5), 2538-2553.

Kerkez, B., Gruden, C., Lewis, M., Montestruque, L., Quigley, M., Wong, B., Bedig, A., Kertesz, R., Braun, T., Cadwalader, O., Poresky, A., and Pak, C. (2016). "Smarter Stormwater Systems." Environmental Science \& Technology, 50(14), 7267-7273.

LoRa®Alliance. (2015). "LoRaWAN ${ }^{\top M}$ What is it? - A technical overview of LoRa® and LoRaWAN ${ }^{\top M}$." LoRa® Alliance.

Sonnenberg, H., Rustler, M., Riechel, M., Caradot, N., Rouault, P., and Matzinger, A. (2013). "Best data handling practices in water-related research." Water Practice and Technology, 8(3-4).

Tarboton, D., Horsburgh, J., and R. Maidment, D. (2008). CUAHSI Community Observations Data Model (ODM) Version 1.1 Design Specifications.

van Emmerik, T., Popp, A., Solcerova, A., Müller, H., and Hut, R. (2018). Reporting negative results to stimulate experimental hydrology. 


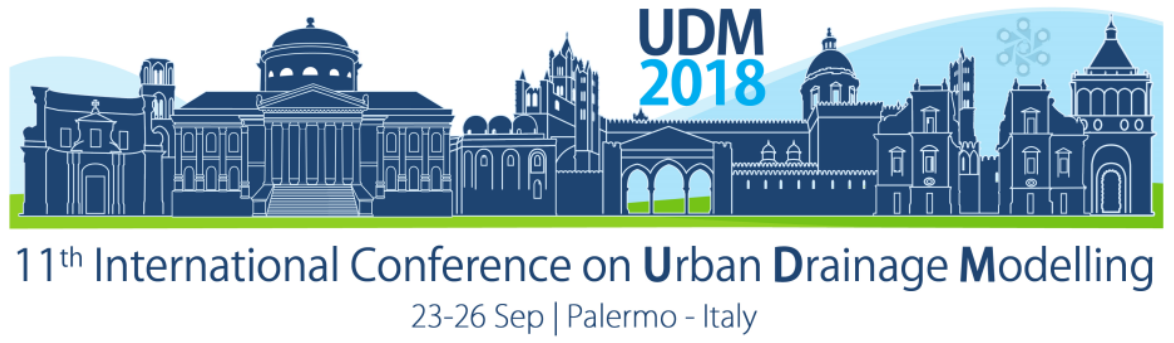

\title{
Flood risk mitigation in a Mediterranean Urban Area: the case study of Rossano Scalo (CS - Calabria, Italy)
}

\author{
Patrizia Piro1, Mario Maiolo², Vito Cataldo Talarico1, Salvatore Falco', Gennaro Nigro1, Michèle Pezzagno³, \\ Filippo Carlo Pavesi ${ }^{3}$, Francesca Berteni ${ }^{3}$ and Giovanna Grossi ${ }^{3}$ \\ ${ }^{1}$ Università della Calabria, Department of Civil Engineering, Rende (CS), Italy \\ 2 Università della Calabra, Department of Environmental and Chemical Engineering, Rende (CS), Italy \\ ${ }^{3}$ Università degli studi di Brescia, DICATAM, Brescia, Italy
}

\begin{abstract}
Urban flooding is recently affecting several towns in the Italian Mediterranean region. The study focuses on the interconnection between the sewer network of the town (Rossano Scalo) and the main water course (the Citrea Creek) flowing through it. An integrated approach considering both town planning and hydraulic aspects lead the search for potential flood risk mitigation solutions. Through the use of GIS and field surveys a highly urbanized sub-basin was selected and analysed.. The hydrologic- hydraulic system was simulated through SWMM software, paying attention to interactions between the minor and the major system. Critical nodes (urban flooding points) were finally considered for planning potential mitigation solutions.
\end{abstract}

Keywords: Flood risk mitigation, GIS, Spatial planning, Stormwater management, Urban hydrology.

\section{INTRODUCTION}

Urban population growth is increasing the fraction of impervious areas with a drastic change in natural hydrologic cycle, characterized by the reduction of infiltration and evapotranspiration and the increase of runoff volumes (Garofalo et al, 2016). Progressing urbanization produces large alterations of the natural environment and, in particular, of the water cycle. Thus, the water cycle in urban areas, commonly referred to as the urban water cycle, requires increasingly sophisticated management reflecting population growth and economic activities, legislative pressures and economic links (Piro and Carbone,

2014). In recent years, climate change and the growing waterproofing land have favoured the occurrence, in urban areas, of critical situations causing surface flooding. Floods are the most dangerous meteorological hazard in the Mediterranean areas due to both the number of people involved and the relatively high frequency by which human activities and goods suffer damage and losses (Maiolo and Pantusa, 2016; Maiolo et al., 2017). Flooding in urban areas can occur due to several factors that vary according to the kind of drainage system used (separate or combined sewers) and its design characteristics. A crucial issue is the limited capacity of drainage systems (sewer flooding). The critical phase, in particular, occurs when this capacity is exceeded, resulting in the backwater effect in some elements of the sewer network (minor system). Outgoing excess flows may fill surface depressions or flow overland through preferential paths (major system). In urban areas the major system typically includes roads, sidewalks, natural depressions and small streams. Through the major systems overland flow 


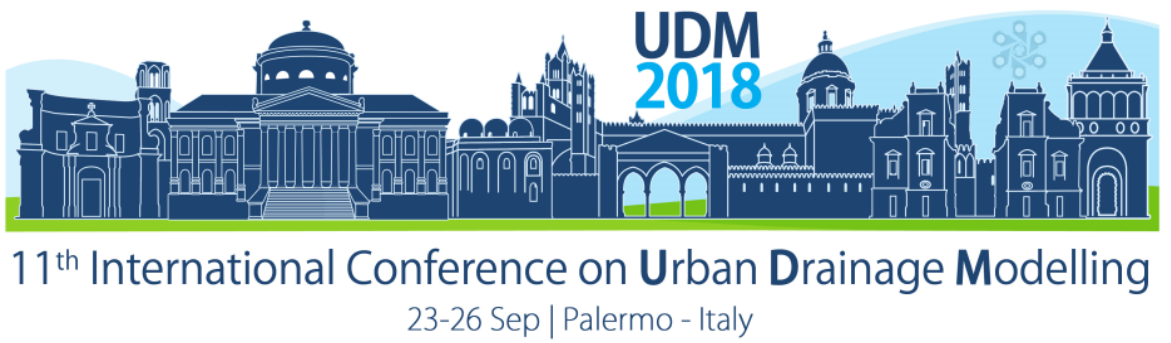

can travel considerable distances, causing flooding in areas quite far from the cross section where the outflow occurs.

Urban drainage modelling requires a detailed representation of the overland flow network of ponds and pathways to reliably represent storage areas, flow paths and water volumes and flows. Although surface pathways over urban areas are mainly bounded by buildings and streets, water often flows elsewhere through gardens and other open spaces. Significant progress has been made in the last decades in wrapping conventional urban drainage models with sophisticated interfaces and gluing routines, to link them with a Geographical Information System (GIS) for the automatic creation of input files.

However, to date, urban drainage simulation models did not accurately represent several important features of surface flow, including overland flow taking place during heavy storms, flow into and from the underground drainage network, flow along streets, surface ponds and flow across the urban catchment along preferential paths different from streets.

This study shows an integrated application of GIS techniques for the definition of the boundaries of urban sub-basins in the municipality of Rossano Scalo (Calabria region - South Italy), in order to support the analysis of the interaction between the natural and the artificial drainage network. Synthetic pluviograms derived from depth-duration frequency curves were built to represent the meteorological forcing of the system and evaluate its response through hydrological and hydraulic modelling of a sample urban area.

\section{MATERIALS AND METHODS}

\subsection{Territorial framework of the urban area in Rossano Scalo (CS)}

Rossano Scalo is a small town located along the Jonian Coast of the Province of Cosenza (CS). Its population increased by $50 \%$ in the second half of the last century and is now reaching the saturation limit, according to the typical urban population growth of the XX century. In fact the population of Rossano Scalo consisted of 20171 inhabitants in 1951, 33694 in 1991, 35835 in 2001 and finally 36347 in 2011 . The construction of the railroad in a decentralised position with respect to the main settlement favoured new territorial dynamic events, inducing soil sealing also in water courses adjacent areas (Figure 1).

The urban pattern of the town shows residual limited green areas, mainly at the boundary of the urban area. This is a critical issue when efficient mitigation measures of drainage network failures have to be sought and integrated in town planning tools, limiting the possibility of adopting innovative multifunctional solutions (Murray, 2017; EEA, 2017). As a matter of fact traditional solutions mainly based on gray infrastructures due to the land-take phenomena and soil sealing in urban area, are nowadays not suitable to cope with dynamic flood risk alone (ISPRA 2015, 2017). A strong integration between spatial planning and water management is absolutely needed in urban areas in order to better reduce risk and provide protection for citizens also in relation to climate change phenomena. This includes new planning perspectives, technical and design tools such as the introduction of Natural Water Retention Measures in order to increase the retention capacity of the urban area and reach a new adaptive capacity of the existing settlements (Sustainable Development Goals 2030, Agenda signed in 2015). 


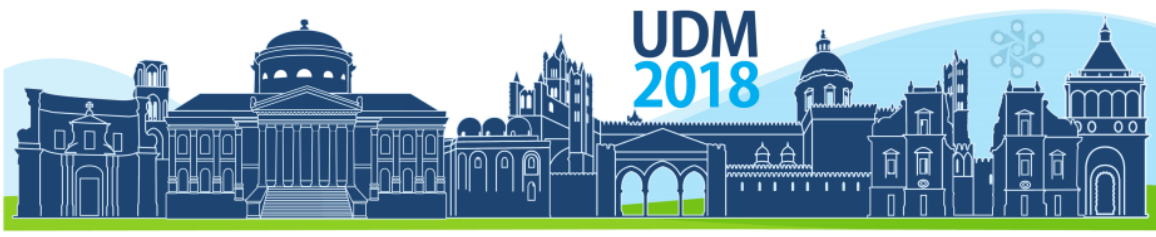

$11^{\text {th }}$ International Conference on Urban Drainage Modelling

23-26 Sep | Palermo - Italy

In order to investigate in detail the hydrological behaviour of the urban area and its surroundings, all sub-basins were extracted in a GIS environment, verified in the field and imported in a CAD environment. Geomorphic parameters and land use for each sub-basin were assessed by comparing thematic maps of Calabria Region to field survey outcomes and digital reliefs. The spatial pattern of both the natural drainage network (essentially the Citrea Creek crossing the main settlement) and the sewer network was carefully analysed in order to check their potentially dangerous interconnections.

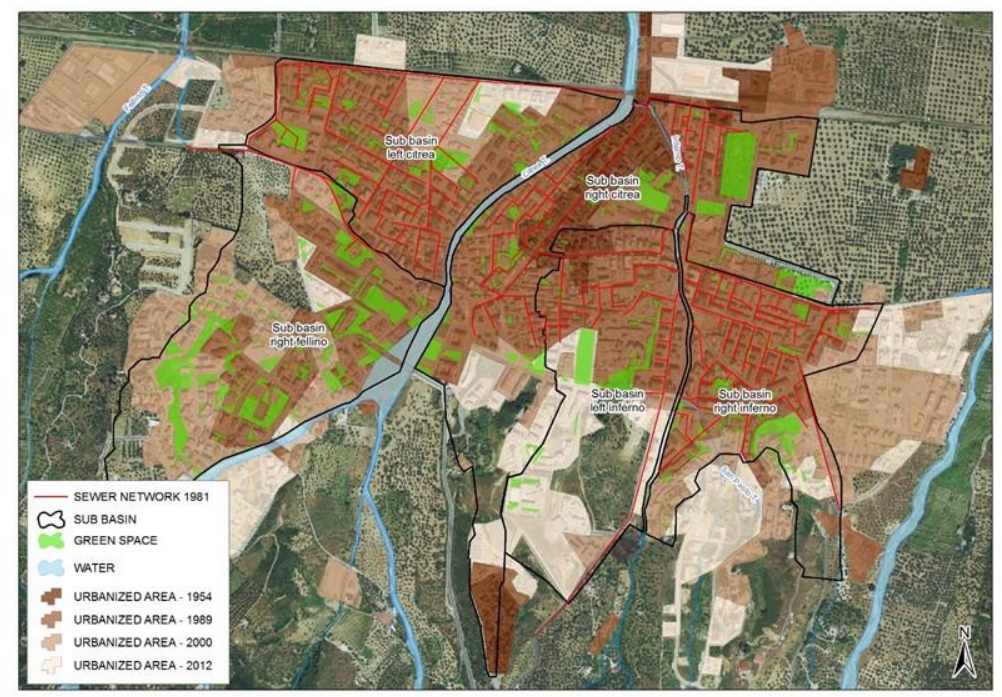

Figure 1. The territorial framework of the Municipality of Rossano Scalo: sewer network, sub-basins and urban area growth (suburb) from mid XX century to nowadays.

\subsection{Rainfall- runoff modelling framework}

A sample urban sub-basin located on the right side of the Citrea Creek basin was selected for the analysis, providing a meaningful example of natural and artificial drainage network connection.

The Storm Water Management Model (SWMM) developed by US EPA was applied to simulate the water flow in the drainage sewer system of the selected sub-catchments (Piro et al., 2010). Synthetic hyetographs were derived from depth-duration frequency curves, the parameters of which were estimated on the basis of long time series of hourly rainfall observations and regionalisation techniques (Carbone et al., 2015). Net rainfall was evaluated through the application of the $\mathrm{CN}$ methodology.

\section{RESULTS AND DISCUSSION}

The integrated modelling framework was used to analyse the behaviour of a sample sub-basin located on the right side of the Citrea Creek (Figure 2). Simulation runs provided flood hydrographs and total flood volumes at the creek cross section where the sewer outflow joins the water course for different return period $(T)$ scenarios: flood volume increases from 1153 $\mathrm{m} 3$ for $\mathrm{T}=10$ years to $1373 \mathrm{~m} 3$ for $\mathrm{T}=50$ years. 


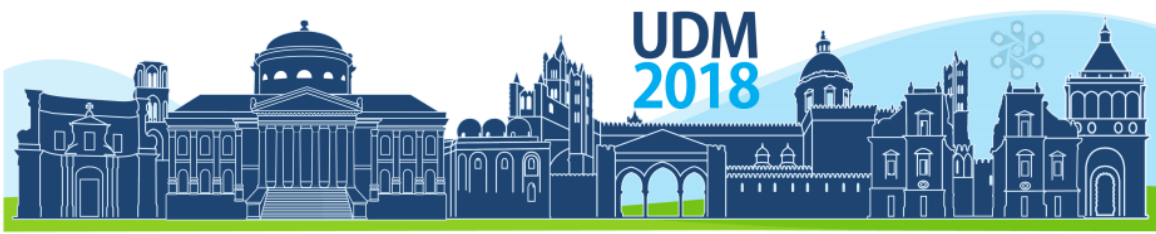

$11^{\text {th }}$ International Conference on Urban Drainage Modelling 23-26 Sep | Palermo - Italy
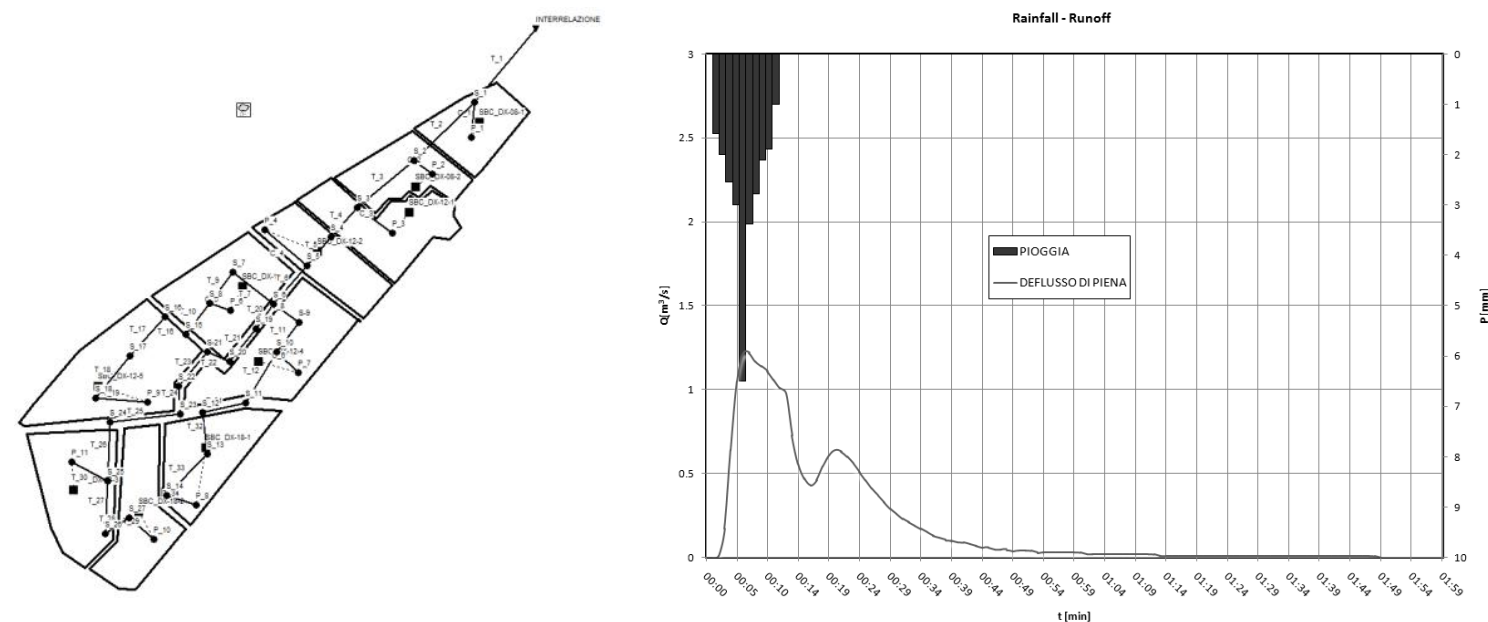

Figure 2. Left: Sample sub-basin boundary and sewer network. Right: synthetic hyetograph and corresponding hydrograph for a return period of 40 years.

\section{CONCLUSIONS}

The proposed integrated methodology for the analysis and modelling of flooding in urban areas shows the fundamental role played by a great number of factors that can affect the evaluation of flood volumes and flows. Primary importance has to be given to the identification of the urban sub-basins to be analyzed in all their parts. GIS analysis needs to be integrated with and compared to results of field survey in order to avoid errors. A strong integration between spatial planning and water management is encouraged in order to better mitigate flood risk in urban areas, not neglecting climate change effects.

\section{Acknowledgments:}

The study was co-funded by Rossano Scalo (CS) Municipality : agreement called "Hydraulic study of storm water in Rossano Municipality (CS) (2015) and partially developed within the framework of the URBAID (Assisted and Integrated Urban Restoration) project, University of Brescia Health\&Wealth call 2015, co-funded by Università della Calabria, Studio Artec Ing . e Arch. S.r.I., McMaster University, Majone\&Partners S.r.I.

\section{References}

Murray A. (2017) Natural Flood Management, Adopting eco system approaches to managing flood risk, Friend of the Earth.

EEA - European Environment Agency (2017) Green Infrastructure and Flood Management, Promoting cost-efficient flood risk reduction via green infrastructure solutions, REPORT n' 14.

ISPRA (2017) Consumo di suolo, dinamiche territoriale e servizi ecosistemici,.

ISPRA (2015) Dissesto idrogeologico in Italia: pericolosità e indicatori del rischio.

Garofalo, G., Palermo S., Principato F., Theodosiou T., and Piro, P. (2016) The influence of hydrologic parameters on the hydraulic efficiency of an extensive green roof in Mediterranean area" Water 2016, 8(2), 44; doi:10.3390/w8020044.

Piro P., Carbone M. (2014) A modelling approach to assessing variations of total suspended solids (TSS) mass fluxes during storm events", Hydrological Processes, 28(4), pp. 2419-2426

Piro P., M. Carbone, G. Garofalo and J.J. Sansalone (2010) Management of CSOs based on observations from the urbanized Liguori catchment of Cosenza, Italy". Water Science \& Technology, 61(1), pp. 135-143. doi: 10.2166/wst.2010.805.

Carbone M., Turco M., Brunetti G., Piro P. (2015) "A Cumulative Rainfall Function for Subhourly Design Storm in Mediterranean Urban Areas", Hindawi Publishing Corporation Advances in Meteorology, Article ID 528564, 10 pages http://dx.doi.org/10.1155/2015/528564.

Maiolo, M., Pantusa, D. (2016) An optimization procedure for the sustainable management of water resources, Water Science and Technology: Water Supply.

Maiolo, M., Carini, M., Capano, G., Piro, P. (2017) "Synthetic sustainability index (SSI) based on life cycle assessment approach of low impact development in the Mediterranean area", Cogent Engineering. 


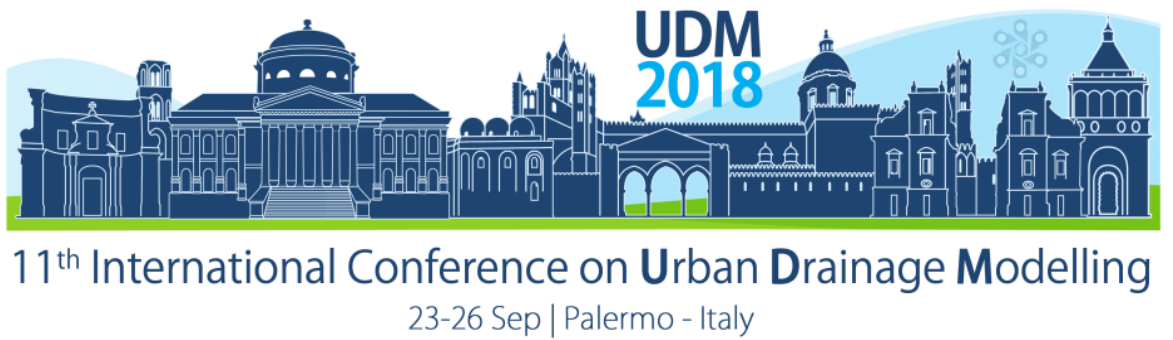

\title{
Flume test facility for the study of sediment transport in sewer pipes with raw wastewater
}

\author{
Manuel Regueiro-Picallo', Jose Anta ${ }^{1}$, Joaquín Suárez ${ }^{1}$, Esteban Sañudo', \\ Jerónimo Puertas ${ }^{1}$ and Alfredo Jácome ${ }^{1}$ \\ 'Univesidade da Coruña, Water and Environmental Engineering Group (GEAMA), A Coruña, Spain \\ (Corresponding author's e-mail: manuel.regueiro1@udc.es)
}

\begin{abstract}
Most of the in-sewer sediment transport formulas are based in past experimental studies at laboratory facilities. The resulting transport models were obtained testing noncohesive or artificial sediments without considering fully in-sewer biological processes. Recent studies suggest that sediment erosion is significantly influenced by these biological processes. Therefore, experimental facilities with real wastewater supply and controlled laboratory conditions are required in order to develop more realistic sediment transport models. In this study, a new supply system of raw wastewater is presented for the GEAMA flume test facility placed at A Coruña Wastewater Treatment Plant (WWTP). In addition, plastic smooth and a corrugated pipes were installed to study the deposition and resuspension of sediments. The raw wastewater provided a higher mean particle size in the inlet sediments and, consequently, a higher accumulation in the pipes.
\end{abstract}

Keywords: Combined sewer; Flume test facility; Sediment transport; Sewer sediments; Wastewater

\section{INTRODUCTION}

Most of the sediment transport models for combined sewer systems has been approached from studies at laboratory scale facilities (Ashley et al., 2004). These models derived mainly from experiments with non-cohesive and surrogate sediments (Rushforth et al., 2003a; Banasiak et al., 2005). The lack of organic particles, fibers and gross solids avoids the occurrence of chemical and microbiological transformation processes, which have a significant influence on the bed deposits resistance (Seco et al., 2018). Therefore, the application of these models shows unrepresentative behaviour of the sediment transport in combined sewer systems.

Sediment transport modelling could be improved by performing experiments with real wastewater in controlled laboratory conditions. However, few laboratory facilities were found with the possibility of operate with raw wastewater (Rushforth et al., 2003b; Lange and Wichern, 2013). In this context, the Water and Environmental Engineering Group (GEAMA) has been developing several studies in a flume test facility fed with urban wastewater located in the WWTP of A Coruña $(600,000$ inhabitants). The objective of those studies were to characterize the sediment transport in different cross-section pipes with real wastewater conditions (Regueiro-Picallo et al., 2017; Regueiro-Picallo et al., 2018). In the present research, a new supply system for the facility is presented in order to provide raw wastewater to the pipes, including fibers and gross solids. Furthermore, an experimental campaign is being performed in a smooth and a corrugated PVC $315 \mathrm{~mm}$ pipes. The main objective of this campaign is to assess the difference between geometries with different roughness regarding the sediment accumulation and transport processes. 


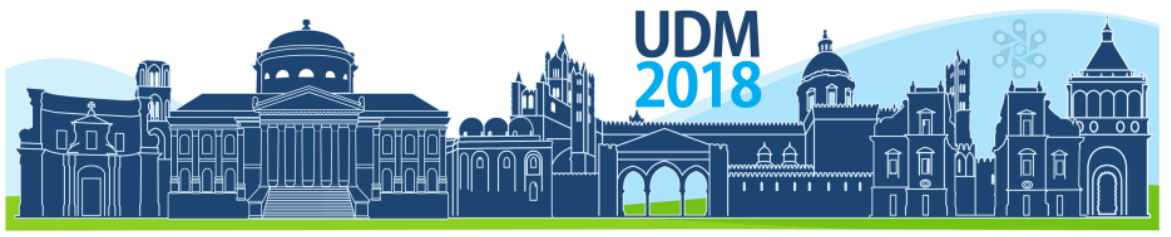

$11^{\text {th }}$ International Conference on Urban Drainage Modelling

23-26 Sep | Palermo - Italy

\section{MATERIALS AND METHODS}

This study was performed at the flume test facility, which is $10 \mathrm{~m}$ long and $0.8 \mathrm{~m}$ wide (Figure 1a). A detailed description of the facility can be referred to Regueiro-Picallo et al. (2017). In the first configuration of the facility, the inlet wastewater was only pumped from the postsieving system with a submergible pump (ABS JS44). Therefore, the presence of gross solids and fibers through the pipes was limited by the sieving aperture of $3 \mathrm{~mm}$. For this study, the wastewater supplying system was modified. A new gravity flow supply system was built from the raw wastewater inlet tank of the WWTP (Figures $1 \mathrm{~b}$ and 1c), allowing a higher flowrate range (Qmax: $50 \mathrm{~L} / \mathrm{s}$ ) in comparison with the pumping system (Qmax: $15 \mathrm{~L} / \mathrm{s}$ ). Despite of this new gravity flow system, the pumping system has been preserved.
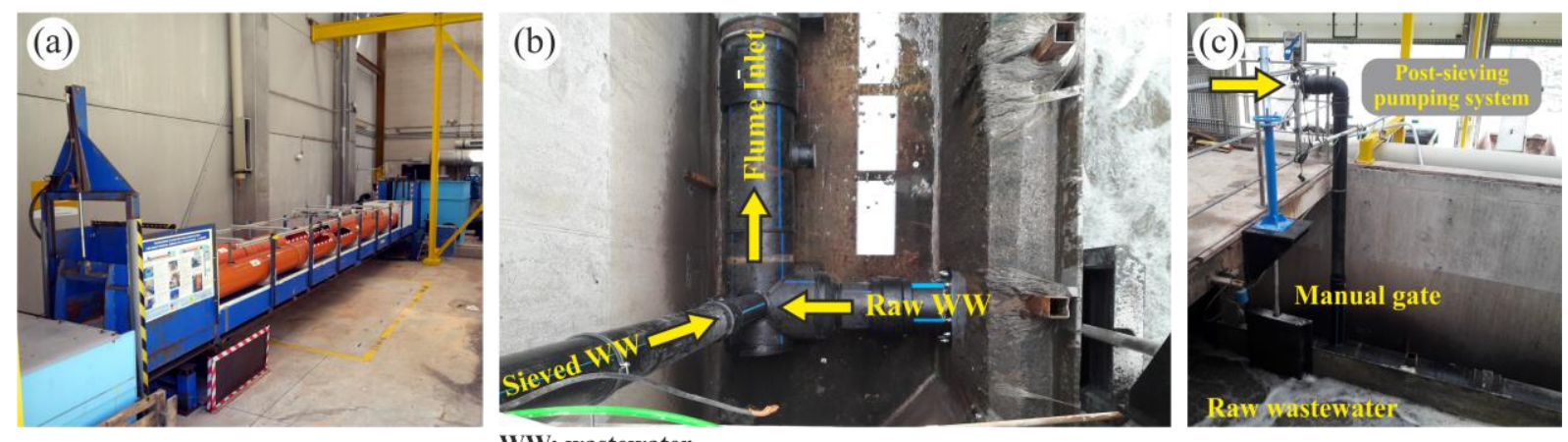

Figure 1. General view of the flume test facility (a) and pictures of the new raw wastewater supply system (b, c).

A smooth and a corrugated $315 \mathrm{~mm}$ PVC pipes were installed in the flume test facility. These geometries are being tested with different slopes [0-1]\% and flowrates [3-15] L/s in order to study the differences regarding the sediment transport. Constant dry weather flowrates were set to force the appearance of bed deposits during a period of 7 to 20 days and, afterwards, higher flowrates were applied to study the resuspension of these deposits, following the procedure of Regueiro-Picallo et al. (2018).

The wastewater inlet conditions were continuously monitored in the flume. The inlet discharge was controlled with an electromagnetic flowmeter. Besides, five holes were opened in each pipe to install ultrasonic sensors and record water levels. The wastewater loads were also monitored with turbidity, conductivity and UV absorption probes (SOLITAX; LANGE 3798-S; UVAS). Additionally, an automatic sampler was installed with a sampling period of 6 hours. Furthermore, two main windows were opened in the pipes to control the bed deposits accumulation in the pipe contours, to take manual samples of the sediments and to measure centerline velocity profiles with an Acoustic Doppler Velocimeter (ADV). The mass of bed deposits was measured with the Structure from Motion (SFM) technique. A detailed description of the application of this technique in the sediment transport analysis can be found in Regueiro-Picallo et al. (2018).

The manual sampling of bed deposits was performed in order to measure the physicochemical properties for different accumulation periods. The parameters analysed were the Total Solids (TS), Volatile Solids (VS), density and the particle size distribution according to the standard methods. The COD and the Oxygen Uptake Rate (OUR) were the organic properties studied (see more details about the procedure in Regueiro-Picallo et al. 2017 and 2018). 


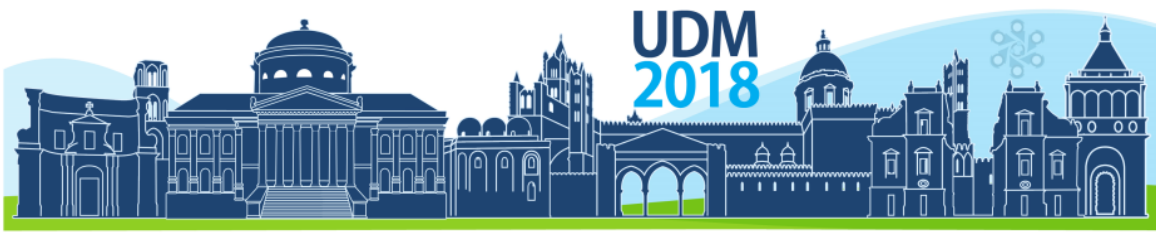

$11^{\text {th }}$ International Conference on Urban Drainage Modelling

23-26 Sep | Palermo - Italy

\section{RESULTS AND DISCUSSION}

The new supplying system for the flume test facility provided a different sediment composition compared with the post-sieving pumping system. In order to state this difference, grab samples were taken at the inlet of both pipes. According to the results presented in Table 1, the mean particle size $\left(d_{50}\right)$ is $50 \%$ higher and the organic content is $18 \%$ lower with the new supplying system. Furthermore, a higher blockage of bed deposits would be produced due to the presence of fibers through the pipelines supplied by the new raw wastewater system. Therefore, a higher accumulation rate and a slightly lower biological activity would be expected in-pipe deposits for this new configuration. Regarding the density and moisture content, the new supplying system provides slightly higher values.

Table 1. Comparison of bed deposits properties for the pumping and raw wastewater systems: wet density $\left(\mathrm{kg} / \mathrm{m}^{3}\right)$, moisture content $(\%)$, mean particle size $\mathrm{d}_{50}(\mu \mathrm{m})$ and organic content VS/TS $(\%)$.

\begin{tabular}{lcccc}
\hline Supplying system & \multicolumn{4}{c}{ Sediment properties } \\
\cline { 2 - 5 } & $\begin{array}{c}\text { Wet density } \\
\left(\mathrm{kg} / \mathrm{m}^{3}\right)\end{array}$ & $\begin{array}{c}\text { Moisture content } \\
(\%)\end{array}$ & $\begin{array}{c}\mathrm{d}_{50} \\
(\mu \mathrm{m})\end{array}$ & $\begin{array}{c}\mathrm{VS} / \mathrm{TS} \\
(\%)\end{array}$ \\
\hline $\begin{array}{l}\text { Pumping system } \\
\text { Raw wastewater }\end{array}$ & 1,362 & 45 & $270^{1)}$ & 20.1 \\
system & 1,416 & 47 & 553 & 16.5 \\
\hline
\end{tabular}

1) Regueiro-Picallo et al. (2017)

Considering the particle size distribution (Figure 2), the post-sieving pumping system provided a uniform distribution with a mean particle size of $270 \mu \mathrm{m}$ and $16^{\text {th }}$ and $84^{\text {th }}$ percentiles of $d_{16}=112 \mu \mathrm{m}$ and $d_{84}=590 \mu \mathrm{m}$. Conversely, the new supply system introduced coarser solids with a mean particle size of $553 \mu \mathrm{m}$ and a wider particle size range of $d_{16}=216$ $\mu \mathrm{m}$ and $\mathrm{d}_{84}=2045 \mu \mathrm{m}$. Besides, the raw wastewater showed a lower volatile fraction of $30 \%$ for the coarser size classes $(>630 \mu \mathrm{m})$, while the percentage of organic matter was $83 \%$ for the pumping system. This difference in the volatile fraction of the largest particles would also support a higher sediment deposition with the raw wastewater supply system.
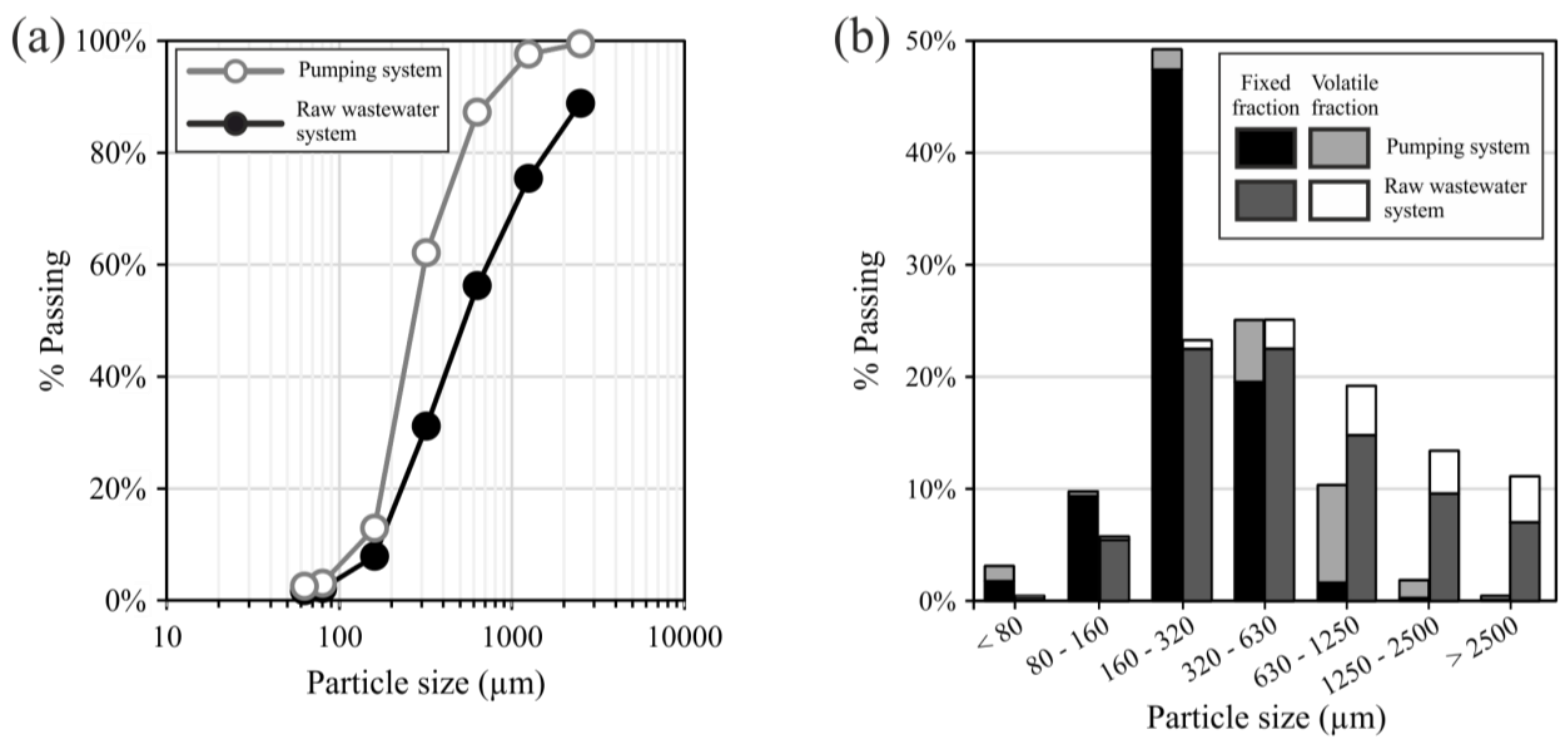

Figure 2. Particle size distribution (a) and fixed and volatile fractions (b) of inlet sediments for the pumping and raw wastewater systems. 


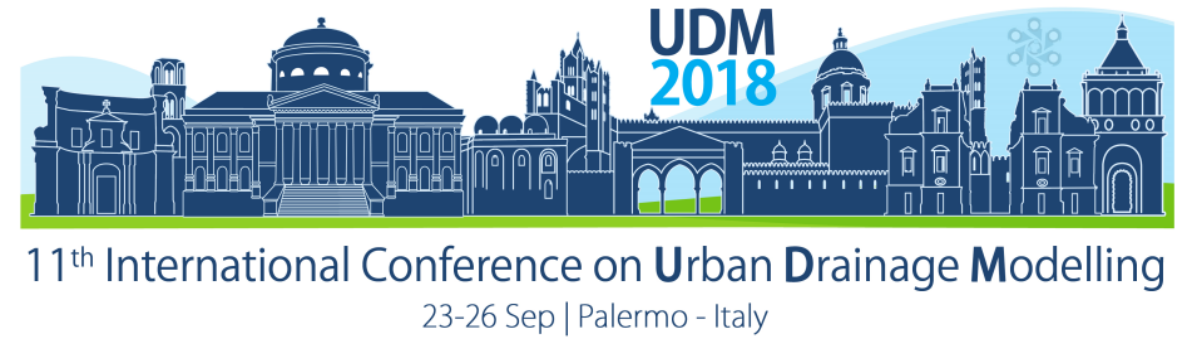

\section{CONCLUSIONS}

A new supplying system was built to feed a flume test facility with urban raw wastewater from the inlet tank of a WWTP. This upgrade at the facility allowed to test pipelines in a close to reality conditions and also to increase the wastewater discharge capacity. Furthermore, a comparative analysis is being performed between two pipes with different roughness installed over the flume, regarding the sediment accumulation and transport capacity. To achieve this objective, the facility was completely monitored to measure the hydraulic parameters and to perform the characterization of the accumulated and eroded sediments.

\section{ACKNOWLEDGEMENTS}

This research was funded by the projects 'SEDUNIT' Ref. CGL2015-69094-R and 'OVALPIPE II' Ref. RTC-2016-4987-5 (MINECO/FEDER, EU). The authors would like to thank Ms. Montse Recarey and the companies EDAR Bens SA, EMALCSA and ABN Pipe Systems S.L.U. for their assistance with the experimental work.

\section{References}

Ashley, R., Bertrand-Krajewski, J. L., Hvitved-Jacobsen, T. and Verbanck, M. (2004) Solids in sewers. Scientific \& Technical Report No. 14. IWA Publishing, London, UK.

Banasiak, R., Verhoeven, R., De Sutter, R., and Tait, S. (2005) The erosion behaviour of biologically active sewer sediment deposits: Observations from a laboratory study. Water Res. 39(20), 5221-5231.

Lange, R. L. and Wichern, M. (2013) Sedimentation dynamics in combined sewer systems. Wat. Sci. Technol. 68(4), 756-762.

Regueiro-Picallo M., Naves, J., Anta, J., Suárez, J. and Puertas, J. (2017) Monitoring accumulation sediment characteristics in full scale sewer physical model with urban wastewater. Wat. Sci Technol. 76(1), 115-123.

Regueiro-Picallo M., Anta, J., Suárez, J., Puertas, J., Jácome, A. and Naves, J. (2018) Characterization of sediments during transport of solids in circular sewer pipes. Wat. Sci Technol. in press, doi: 10.2166/wst.2018.055.

Rushforth, P. J., Tait, S. J. and Saul, A. J. (2003a) Modeling the erosion of mixtures of organic and granular insewer sediments. J. Hydraul. Eng. 129(4), 308-315.

Rushforth, P. J., Tait, S. J. and Saul, A. J. (2003b) Use of a full-scale test facility to examine sewer-sediment mobility. Water Environ. J. 17(1), 40-44.

Seco, I., Schellart, A., Gómez-Valentín, M., and Tait, S. (2018) Prediction of Organic Combined Sewer Sediment Release and Transport. J. Hydraul. Eng. 144(3), 04018003. 


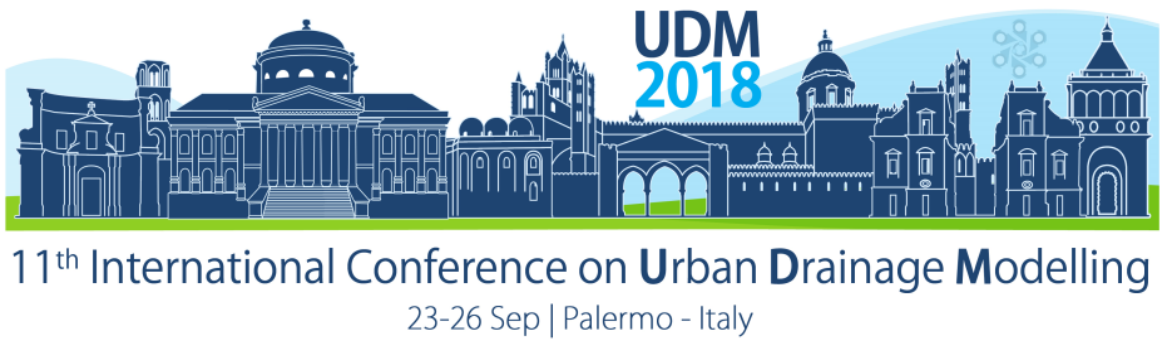

\title{
Use of a 2D shallow waters model to assess the physical model topography obtained with a low cost photogrammetric technique
}

\author{
Juan Naves ${ }^{1}$, Jose Anta ${ }^{1}$, Jerónimo Puertas ${ }^{1}$, Manuel Regueiro-Picalloํㅜ, Joaquín Suárez ${ }^{1}$ and Esteban \\ Sañudo ${ }^{1}$ \\ 1Universidade da Coruña, Water and Environmental Engineering Group (GEAMA), A Coruña, Spain
}

\begin{abstract}
A detailed topography of an urban drainage physical model $\left(36 \mathrm{~m}^{2}\right)$ was obtained with the photogrammetric technique Structure from Motion and compared with a manually measured elevation grid. The results show that using the low cost technique presented in this communication, it is possible to achieve elevation data with a similar accuracy (resulting a RMSE less than $0.006 \mathrm{~m}$ ) and with a quite higher spatial resolution than manual point measurement. In addition, the effect of the different topographies was also analysed in a two-dimensional shallow water model. The use of the high resolution resulted topography reveals the presence of main drainage channels where depths and velocities are increased up to roughly two and three times respectively from the manual topography.
\end{abstract}

Keywords: Structure from Motion; 2D shallow water model; Physical model

\section{INTRODUCTION}

Elevation data is a key factor in the accuracy of the surface flow due to the low depths developed in two-dimensional urban drainage models. This sensitivity to the topography is increased in the case of small basins or laboratory physical models, where a smaller area is considered. Therefore the element sizes of the meshes are in the order of centimetres or millimetres and a more precise and accurate data of elevations and dimensions are needed to obtain suitable results. This implies, among other things, an increase in the time and the resources employed. In this regard, visualization techniques are presented as a possible low cost alternative to traditional methodologies for obtain elevation grid data. In recent years this type of techniques are been using in the field of hydraulic engineering with practical applications. For example, Detert et al. (2016) carried out a topographic survey of a river course by means of the photogrammetric technique Structure from Motion (SFM), which has been used in this work. On a much smaller scale, Regueiro et al. (2017) also used the same technique to quantify the sediment bedload accumulation in a combined sewer pipe.

The main aim of this work is apply this novel SFM technique to obtain, in a short time and with a low cost, an accurate elevation grid of a $36 \mathrm{~m}^{2}$ physical model. Then, the new elevation data is implemented in the two-dimensional shallow water model IBER, and the results were compared with those obtained with a manually measured elevation grid.

\section{MATERIALS AND METHODS}

\subsection{Physical model}

The laboratory installation consists of a full-scale street section built in the Hydraulic Laboratory of the Centre of Technological Innovation in Construction and Civil Engineering 


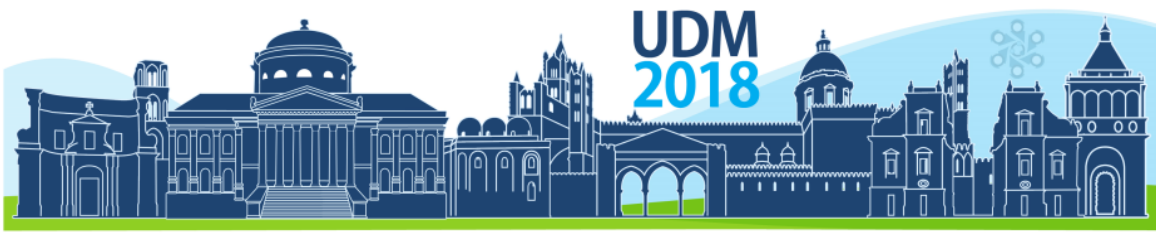

$11^{\text {th }}$ International Conference on Urban Drainage Modelling

23-26 Sep | Palermo - Italy

(CITEEC) at the University of A Coruña. The model is formed by a rainfall simulator placed over a $6 \times 6 \mathrm{~m}^{2}$ concrete street surface, divided into a tiled pavement and a roadway (Figure 1a). The runoff generated by rain drains into a sewer drainage system by means of three gully pots, two of them located along the curb and a third one at the end of a lateral outflow channel. The surface has an approximate transversal slope of $2 \%$ to the $0.15 \mathrm{~m}$ high concrete curb and a $0.5 \%$ longitudinal slope to the outflow channel. A more detailed description of the physical model can be consulted in Naves et al. (2017).

\subsection{Structure from motion technique}

The SFM technique, which is based on stereoscopic principles, allows the reconstruction of a 3D object by means of overlapped images. The main difference from conventional photogrammetric procedures is that the geometry and the position and orientation of the camera is resolved by computations. Free licence software VisualSFM (Wu et al., 2011; Wu, 2013) was used to perform the 3D reconstruction of the physical model surface. To that end, a total number of 50 images were taken from different positions around the street section with a Lumix GH4 camera, using a focal length of $28 \mathrm{~mm}$ and an image resolution of $3264 \times 2448$ pixels. In order to obtain accurate measurements with this methodology, an overlap of the images of around $60 \%$ are required. This allows the software increase the number of points obtained by triangulation. Enough contrast in the surface of the measured object is also needed to distinguish and correlate the common points between the images. In this particular case, the concrete surface is very homogeneous and it was no possible to directly apply this methodology. Instead, an image was projected over the surface of the model with the aim of providing texture and allowing to obtain a dense enough point cloud (Figure 1b).
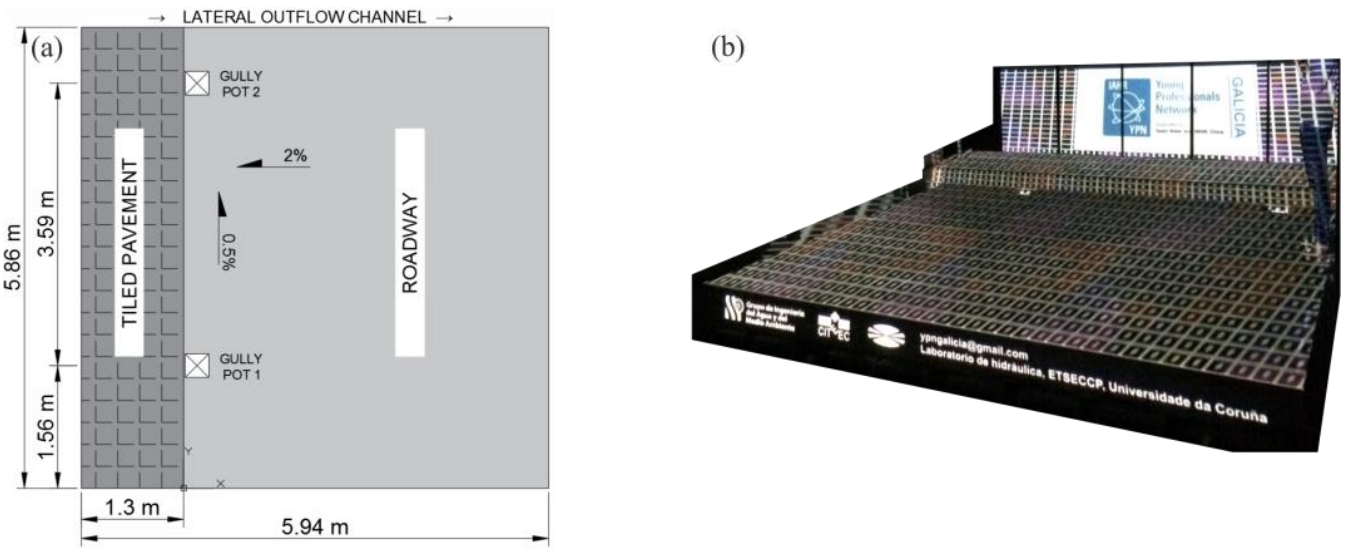

Figure 1. Schematic view from top of the physical model and (a) projected image over the physical model surface (b).

\subsection{Elevation grids}

Manually measured. The coordinates of a $0.5 \mathrm{~m}$ rectangular grid (a total of 144 points of the model surface) are obtained measuring the distance to an horizontal reference laser plane. This elevation grid is used as a reference topography to assess the accuracy of the novel technique presented in this work.

Photogrammetry. Once the point cloud is obtained by means of the SFM technique, it was scaled and referenced using the open source software Meshlab (Cignoni et al., 2008). To 


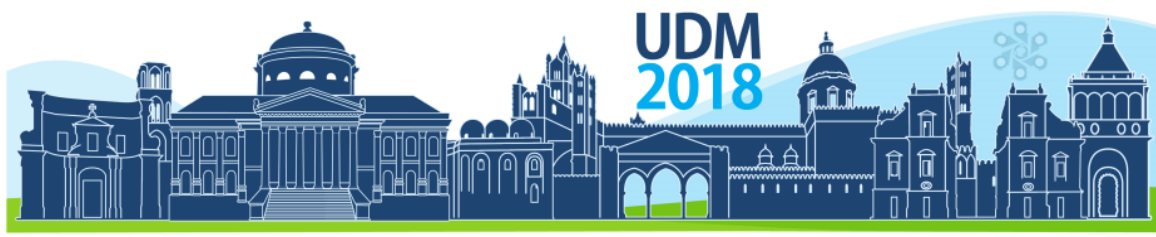

$11^{\text {th }}$ International Conference on Urban Drainage Modelling

23-26 Sep | Palermo - Italy

this end, five points were used to transform the model into a known coordinate system with an error of $0.5 \%$. These points are obtained in the same way as the manually measured elevation grid. Then, after filtering the raw point cloud (about 967,000 elements) with a 50 elements size two-dimensional median, a $0.005 \mathrm{~m}$ grid was obtained.

\subsection{Numeric model}

The software lber (Bladé et al., 2014), a two-dimensional shallow water model, was used to simulate the rainfall-runoff transformation over the physical model surface. A roughness of 0.018 and a rainfall intensity of $50 \mathrm{~mm} / \mathrm{h}$, the medium intensity generated by the rainfall simulator, were kept constant in order to compare velocities and depths using both elevation grids. According to the comparison between both elevation data showed in the following section, a $0.05 \mathrm{~m}$ size and non-structured mesh was selected.

\section{RESULTS AND DISCUSSION}

\subsection{Elevations}

The elevation data resulted from the photogrammetric technique, the manually measured elevation grid and the comparison between them are shown in Figure 2. A RMSE of less than $0.006 \mathrm{~m}$ was resulted between both topographies. This shows how the photogrammetry technique is able to obtain a similar accuracy with a much higher spatial resolution.
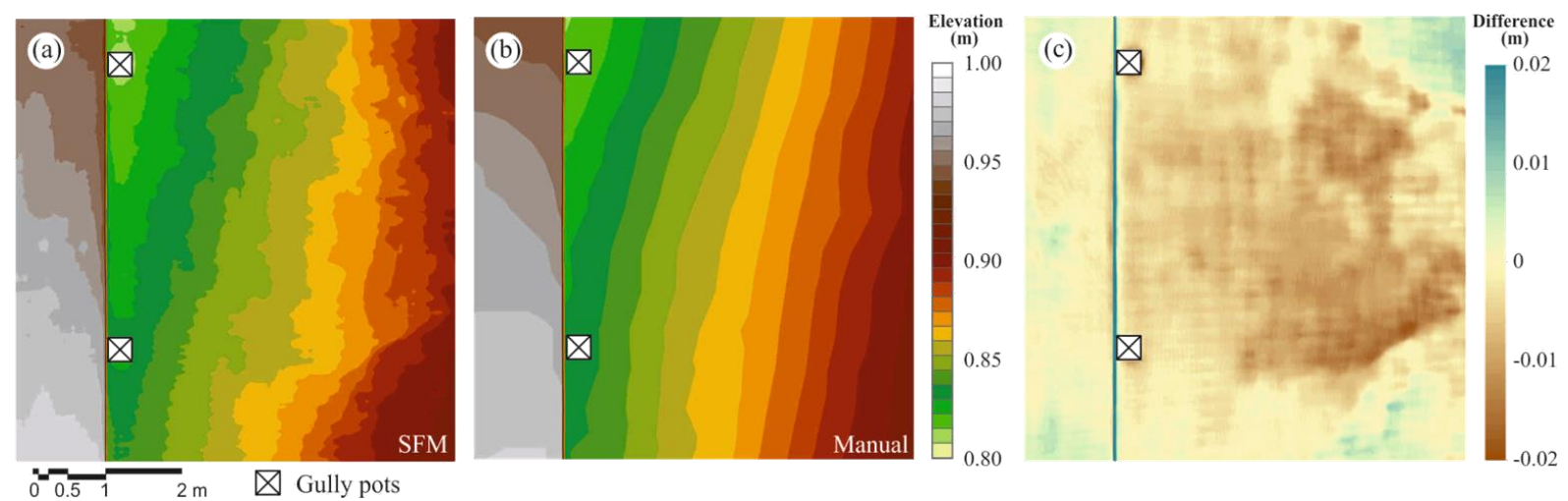

Figure 2. (a) SFM elevation data, (b) manually measured elevation data and (c) differences between both of them.

\subsection{Superficial flow}

Both elevation data were implemented in a two-dimensional shallow water model and were also compared in order to analyse the effect of a more detailed elevation data on surface depths and velocities (Figure 3). Thanks to this higher resolution, the model is able to reproduce and detect main channels that remained hidden with the conventional bathymetric survey, where the depths and velocities are increased up to two and three times respectively.

\section{CONCLUSIONS}

The Structure from Motion photogrammetric technique was presented as an useful resource to obtain a detailed topography of an urban drainage physical model. This methodology 


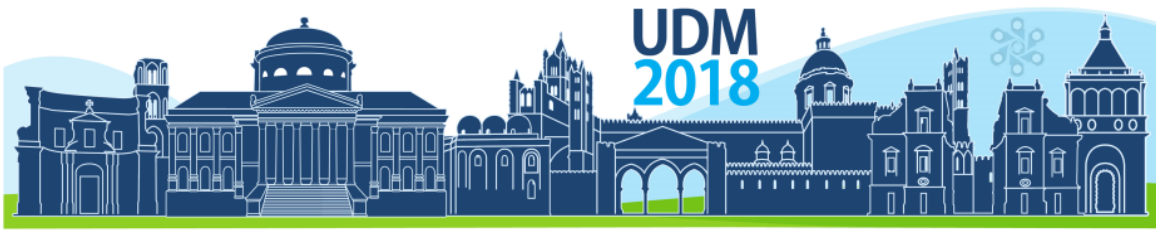

$11^{\text {th }}$ International Conference on Urban Drainage Modelling

23-26 Sep | Palermo - Italy

provide a similar accuracy (RMSE less than $0.006 \mathrm{~m}$ ) and with a quite higher resolution $(0.005 \mathrm{~m})$ than manually measured elevations. The main advantage of this low cost procedure is that allows to measure small details in the physical model surface, as the main channels observed in this particular case, which could be only measured with sophisticated and expensive topographic devices.
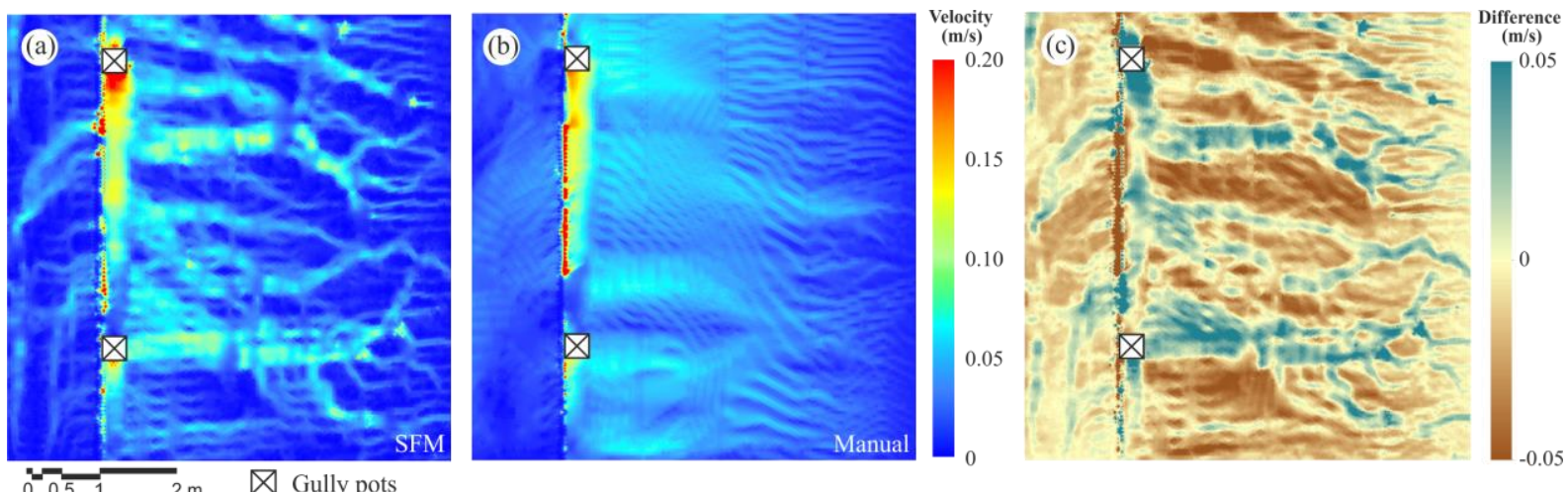

Figure 3. Velocities: SFM elevation data (a), manually measured elevation data (b) and differences between both of them (c).

\section{Acknowledgment}

The first author was in receipt of an FPU grant from the Spanish Government (FPU14/01778). This work was partially funded by the project CGL2015-69094-R (MINECO/FEDER, EU). The authors also would like to thank to Francisco Vallés and Beatiz Nácher (UPV) for their proposal to project an image over the physical model surface in the scope of the course 'Visualization Techniques in Hydraulic Engineering' during the ' $\mathrm{V}$ Jornadas de Ingeniería del Agua' in A Coruña.

\section{References}

Bladé, E.; Cea, L.; Corestein, G.; Escolano, E.; Puertas, J.; Vázquez-Cendón, E.; Dolz and J.; Coll, A. Iber: Herramienta de simulación numérica del flujo en ríos. Iber-River modelling simulation tool. Rev. Int. Métodos Numér. Para Cálc. Diseño Ing. 2014, 30, 1-10. (In Spanish)

Cignoni, P.; Callieri, M.; Corsini, M.; Dellepiane, M.; Ganovelli, F.; Ranzuglia, G. (2008). MeshLab: an OpenSource Mesh Processing Tool. Sixth Eurographics Italian Chapter Conference, page 129-136, 2008

Detert, M., Huber, F. and Weitbrecht, V. (2016). "Unmanned aerial vehicle-based surface PIV experiments at Surb Creek". Proceedings of the River Flow 2016, Julio 12-15, St. Louis, MO, USA, pp. 563-568.

Naves, J., Jikia, Z., Anta, J., Puertas, J., Suárez, J. and Regueiro-Picallo, M. (2017). "Experimental study of pollutant washoff on a full-scale street section physical model". Water Science and Technology; 76(10): 2821-2829.

Regueiro-Picallo, M., Naves, J., Anta, J., Suárez, J., Puertas, J. and Jácome, J. (2017). "Aplicación de la técnica Structure From Motion (SFM) para la determinación de la acumulación de sedimentos en redes de saneamiento". V Jornadas de Ingeniería del Agua, Octubre 25-26, A Coruña, España, pp. 202-203.

Wu, C., Agarwal, S., Curless, B. and Seitz, S.M. (2011). "Multicore bundle adjustment". Proceedings of the Computer Vision and Pattern Recognition (CVPR), Junio 20-25, Colorado Springs, CO, USA, pp. 3057-3064.

Wu, C. (2013). "Towards Linear-time Incremental Structure From Motion". Proceedings of the 2013 International Conference on 3D Vision-3DV 2013, Junio 29 - Julio 1, Seattle, WA, USA, pp. 127-134. 


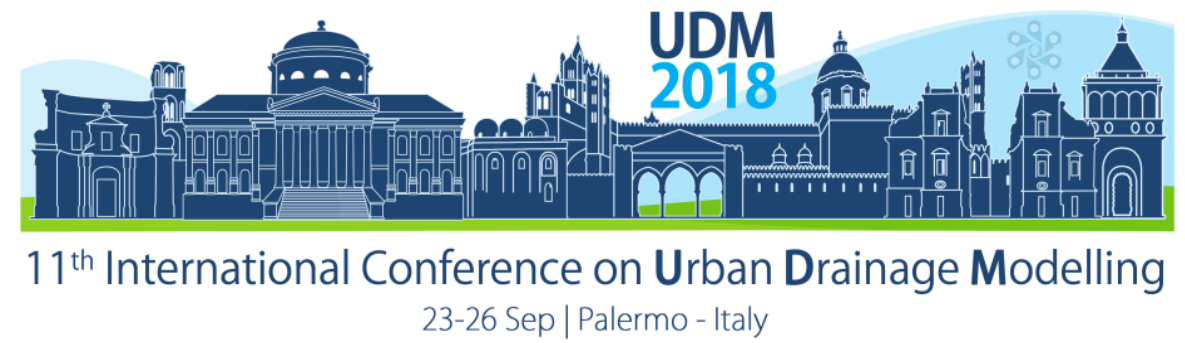

\title{
Urban Flood Risk Modelling using Geospatial Tools for Bhubaneswar City, India
}

\author{
Sutapa Bhattacharjee ${ }^{1}$, Pramod Kumar ${ }^{2}$, Praveen Thakur ${ }^{3}$ and Kshama Gupta ${ }^{2}$ \\ ${ }^{1}$ Indian Institute of Technology, Department of Civil Engineering, Guwahati, India \\ ${ }^{2}$ Indian Institute of Remote Sensing, Urban and Regional Studies Department, Dehradun, India \\ ${ }^{3}$ Indian Institute of Remote Sensing, Water Resources Department, Dehradun, India
}

\begin{abstract}
Urban flooding and water-logging are causing menace in many cities of the world from the perspective of day-to-day functioning, health and hygiene, communication, and the consequent damages they cause to urban environment. The present study is an attempt to understand the risk associated with urban flooding conditions in urban areas with reference to the hydro-dynamic set up of Bhubaneswar city, India and its level of urbanization. Using Storm Water Management Model (SWMM), the peak flow analysis and flooding extent have been assessed while taking into consideration the elevation, slope, land use/ land cover (LULC), and designed storm water drainage (SWD) infrastructure of the city. High resolution data have been utilised to extract slope, elevation and microwatersheds boundary using DEM from airborne LiDAR sensor $(1 \mathrm{~m})$ and imperviousness according to the land use character of the city from Cartosat-2 (PAN) and LISS-4 (MS) fused product. The peak runoff volume simulated by the model is relatively higher i.e. 0.5 $1.0 \mathrm{cms}$ (cubic meter per second) for many micro-watersheds and even rising to more than $1.5 \mathrm{cms}$ for some, indicating the severity of urban flooding in the city. While integrating the simulated flooding pattern with the vulnerability associated with socio-economic conditions of the city dwellers, the flood risk has been assessed. The study suggests that the estimated capacity of designed and existing SWD system needs to be re-evaluated and restructured according to the present and predicted flooding conditions for the city.
\end{abstract}

Keywords: Urban Flooding, SWD, SWMM, Peak Flow, High Resolution Data

\section{INTRODUCTION}

Urban flooding has become a recurring problem in many cities across the globe, especially more acute and critical in the developing countries (Nkwununwo, Whitworth and Baily, 2016). It is a typical flooding or waterlogging condition for a certain duration either caused by intensive downpour for a short duration or incessant rainfall for considerable period of time, overwhelming the capacity of drainage system. It is a lacunae in systematic urban planning and infrastructure development which results in a hazardous situation in the city both during and after the flooding phase; leading to the initiation of many other allied problems such as submergence of dwelling units and city streets, loss of life and property, disruptions in mobility, health and hygiene problems, chaotic city functions, huge wastage of time and money, physical as well as mental harassment of the city dwellers, etc. (Hewitt and Burton, 1971). It is a serious challenge to address this problem especially in the older and core areas of the cities due to higher population density and insufficient drainage capacity, presence of a large number of obstacles of varying shapes and length scales, the storages in the buildings, the complex geometry of the city, etc. (Ojo, Dzhusupova and Curry, 2016) Therefore, it is important to identify the different parts of a city according to their level of vulnerability and frequency of inundation, so that appropriate and smart planning measures can be adopted. Bhubaneswar, an important city of the eastern coast of India (about $40 \mathrm{~km}$ west of northern Bay of Bengal), extending from $20^{\circ} 11^{\prime} 32^{\prime \prime} N$ to $20^{\circ} 24^{\prime} 34^{\prime \prime} \mathrm{N}$ latitude to $85^{\circ} 44^{\prime} 16^{\prime \prime} \mathrm{E}$ to 


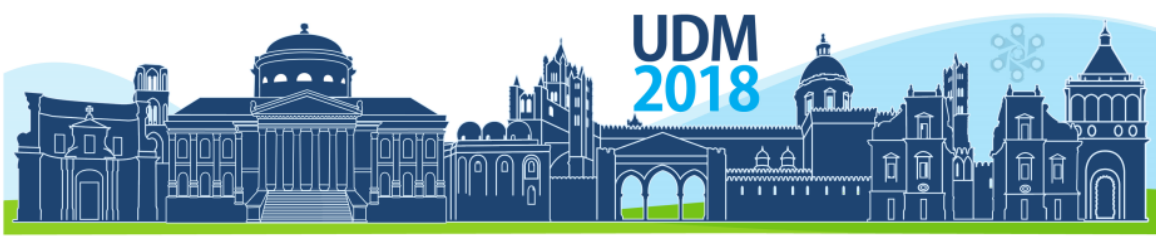

$11^{\text {th }}$ International Conference on Urban Drainage Modelling

23-26 Sep | Palermo - Italy

805'09" E longitude (Fig. 1a) has been considered for the present study. It has been identified as the first city for development under 'Smart City Mission' by the Government of India but has been experiencing recurrent water-logging problem in the recent times.

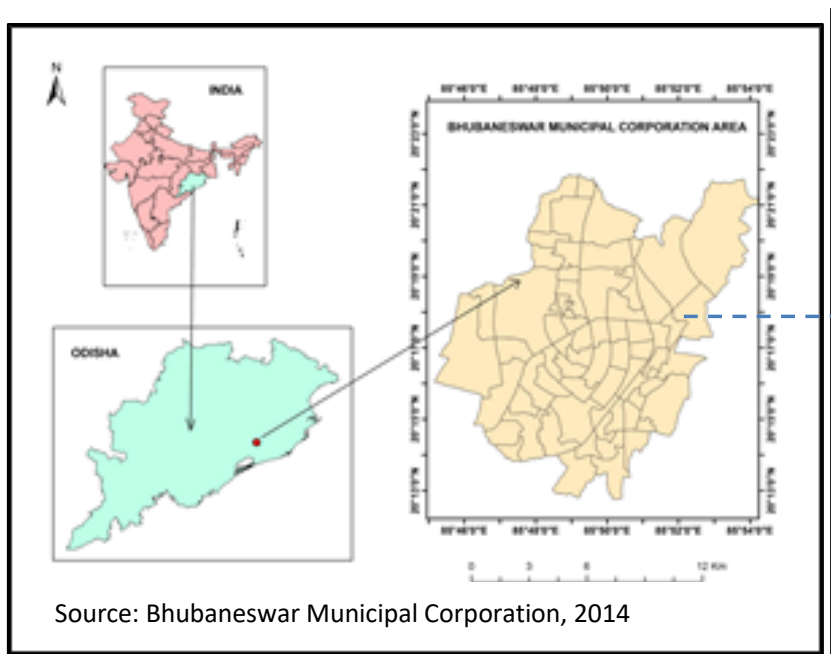

Figure1(a). Study Area,

Bhubaneswar Municipal Corporation (BMC) Area

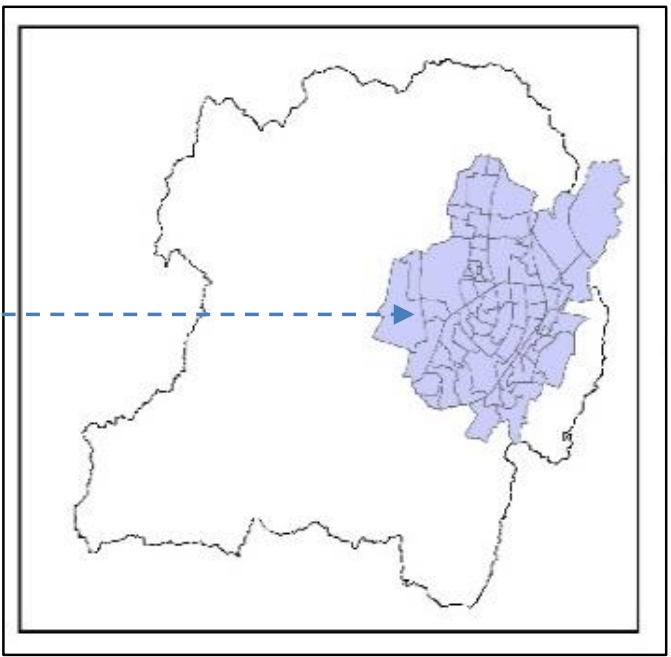

Figure1(b). Watershed containing the Bhubaneswar city

\section{MATERIALS AND METHODS}

\subsection{Data Required}

Cloud-free high-resolution satellite imagery i.e. Cartosat-2 and LISS-4 have been used to estimate the total built-up extent and land use/land cover (LULC) characteristics of the city. CartoDEM $(10 \mathrm{~m})$ is used for watershed boundary demarcation and high-resolution LiDAR DEM has been used for delineating the micro-watershed boundaries and slope calculation. The hourly rainfall data for a period of 30 years for Bhubaneswar station from Indian Meteorological Department (IMD) has been used for peak runoff analysis. A detailed highresolution soil map and historic data of flooding pattern, topography, and land cover, etc. were also incorporated from various sources. The design storm water drainage network developed in accordance with the Smart City infrastructure standards till the tertiary-level drainage channels, including their slope, width, depth and many other calibration parameters, was used in the study. The socio-economic conditions of the city-dwellers and their attitude towards such flood events have also been collected from Census of India and from primary field investigations for assessing the vulnerability of urban settlements towards the flooding problem.

\subsection{Methodology Adopted}

The present study is an integration of urban flood modelling or hazard analysis considering the hydro-meteorological set up of the city and vulnerability analysis on the basis of its level of urbanization and response of the people. The runoff potential for the catchment area surrounding the Bhubaneswar city (Fig. 1b) was estimated using the Natural Resources Conservation Service (NRCS) Curve Number (CN) method for the monsoon month (September, 2014), when the soil gets saturated and loses its capacity to infiltrate at a significant level. The storm water modelling was then performed for the city core which lies in the highest runoff potential zone, consisting of three major catchments of the existing primary drains for the highest rainfall day of the same year. Micro-watersheds according to each 


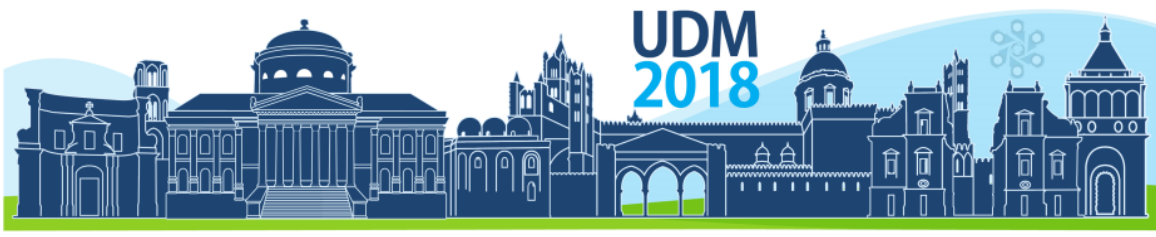

$11^{\text {th }}$ International Conference on Urban Drainage Modelling

23-26 Sep | Palermo - Italy

SWD channels were generated from the high-resolution LiDAR DEM for the detailed analysis using the widely used Environment and Planning Agency-Storm Water Management Model (EPA SWMM Version 5.1). Major input parameters such as geometrical and physical properties of each sub-catchment, nodes and conduits were fed into the model and simulations were performed. Since, the model works sub-watershed wise, each subwatershed acts as a non-linear reservoir and the overland runoff $\left(Q\right.$ in $\left.\mathrm{m}^{3} / \mathrm{s}\right)$ is calculated while considering the excess rainfall using Manning's equation as given below (Rossman, 2010)-

$$
Q=\frac{W}{n}(d-d p)^{5 / 3} S^{1 / 2}
$$

where, $W$ is the characteristic width in $m, n$ is Manning's coefficient of roughness in $s / m^{1 / 3}, d$ is the water depth in $\mathrm{m}$, dp is maximum depression storage in $\mathrm{m}$ and $\mathrm{S}$ is the slope in \%.

The model result is validated using the information collected during field visits and also according to the information obtained from secondary sources. The simulations were again repeated for different rainfall return periods and also according to the predicted growth pattern of the city. The vulnerability zones of the city were identified using the Analytical Hierarchical Process (AHP) considering different criteria ranging from physical infrastructure of the city to the socio-economic condition of the dwellers. Each criterion was assigned a weight according to their susceptibility towards the phenomena and also in comparison to each other (Saaty, 1980). Later, the combined weightage was calculated to decide their contribution in making the area as flood prone. Finally, all the layers were overlaid to prepare the vulnerability map for the city.

\section{RESULTS AND DISCUSSION}

The NRCS curve number method showed that the runoff potential is relatively high in dense urban settlements, i.e. in the city core. Thus, the model was simulated for 24-hour highest rainfall event (25/06/2014) i.e., $122 \mathrm{~mm}$ of rainfall distributed over a period of 17 hours.

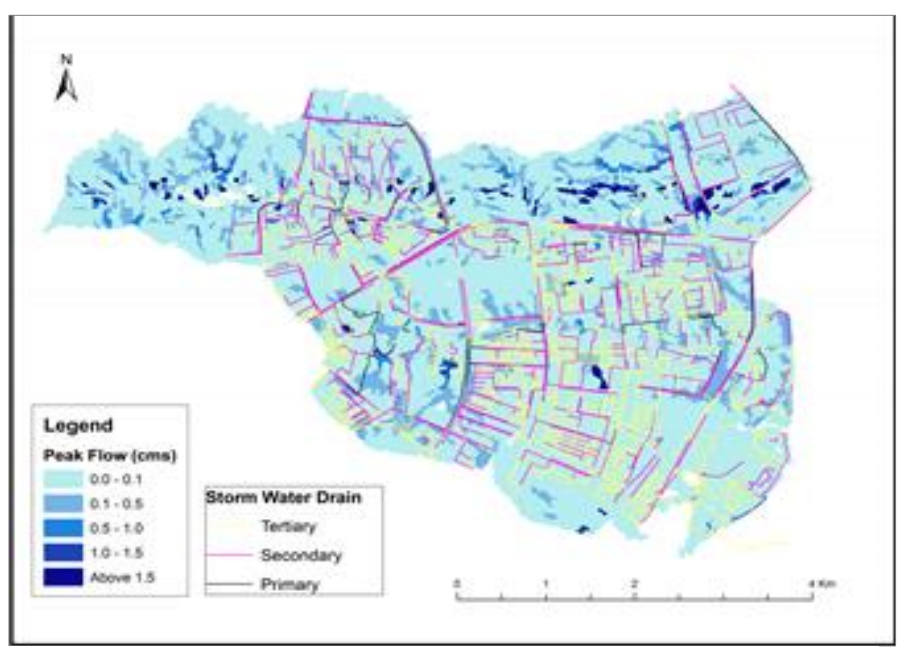

Figure 2. Peak Flow in the Catchments in 24 hours along with the SWD network

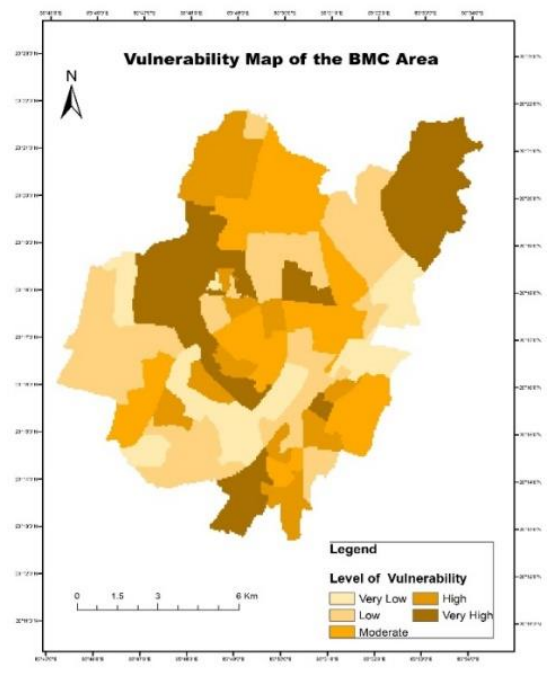

Figure 3. Vulnerability Map

The simulation results showed that the volume of peak flow ranges from 0.1 to $0.5 \mathrm{cms}$ for most of the micro-watersheds. However, the peak flow volume in some of the microwatersheds even rose higher than $1.5 \mathrm{cms}$ (Fig. 2). An individual layer was generated for each contributing factor and then all the layers were superimposed to produce the final 


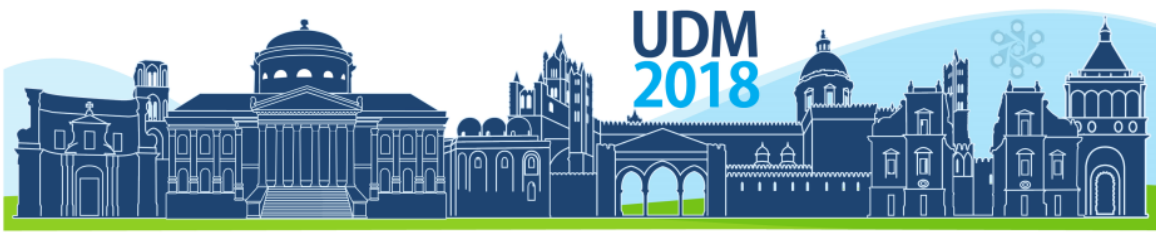

$11^{\text {th }}$ International Conference on Urban Drainage Modelling

23-26 Sep | Palermo - Italy

vulnerability map for the entire city (Fig. 3). Finally, after integrating the flooding and vulnerability maps, the risk factor was computed corresponding to the scale of the hazard and the drainage capacity of the urban settlements. The results matched with the first-hand information acquired from the ground which showed that the majority of the locations identified as flood prone in the city coincided with the simulated results.

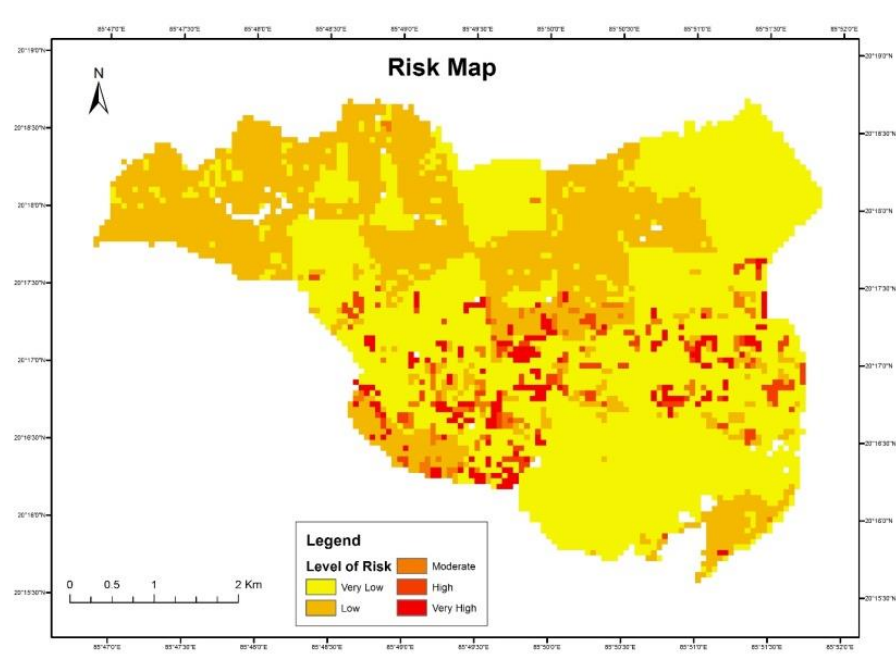

Figure 4. Risk Map

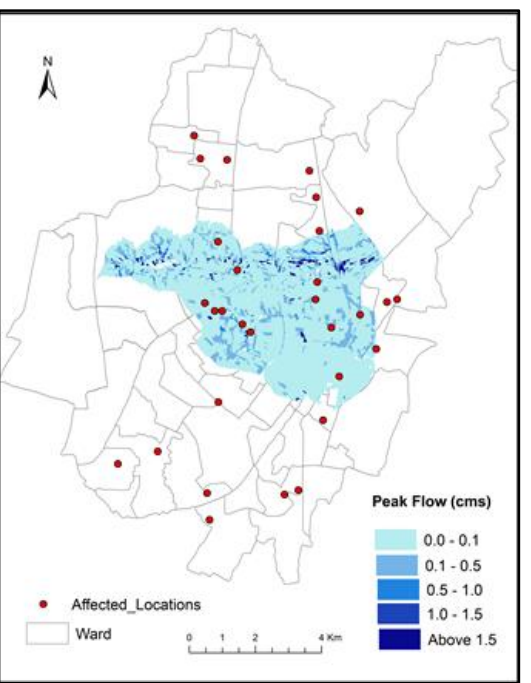

Figure 5. Ground Validation of Model results

\section{CONCLUSIONS}

The design storm water drainage infrastructure of Bhubaneswar city is observed to be insufficient to flush out the storm water accumulated during high rainfall event. The 24-hour rainfall event considered in the present study is relatively moderate and frequently experienced by the Bhubaneswar city which indicates its high vulnerability towards frequency of urban flooding. The areas which are totally devoid of SWD network has higher tendency to get flooded followed by the highly compact residential areas which are only served by the third order drainage lines, mostly narrower and having lesser depth, insufficient to handle the sudden inflow of storm water leading to inundation. However, some parts where the flooding is not that high, but due to high vulnerability conditions, the urban flood risk has increased. The least affected areas are those where both the conditions are comparatively low. Similar trend along with an increase in the flooding extent have been observed for different return periods and the predicted growth pattern of the city.

\section{References}

Hewitt, K. and Burton, I., (1971), "The hazardousness of a place: A regional geology of damaging events," in Department of Geography Research Publication, University of Toronto, Toronto, Canada

Nkwununwo, U.C., Whitworth, M. and Baily, B., (2016), "Review article: A review and critical analysis of the efforts towards urban flood risk management in the Lagos region of Nigeria," Nat. Hazards Earth Syst. Sci., vol. 16, pp. 349 - 369, doi:10.5194/nhess-16-349-2016

Ojo, A., Dzhusupova, Z. and Curry, E., (2016), "Exploring the Nature of the Smart Cities Research Landscape," in J. R. Gil-Garcia et al. (eds.), Smarter as the New Urban Agenda A Comprehensive View of the 21st Century City, Public Administration and Information Technology 11, Springer International Publishing Switzerland, DOI: 10.1007/978-3-319-17620-8_2

Rossman, L.A., (2012), "Storm Water Management Model User's Manual Version 5.0." National Risk Management Research Laboratory, United States Environmental Protection Agency, Cincinnati, Ohio, EPA/600/R-05/040.

Saaty, T.L., (1980), The Analytic Hierarchy Process; McGraw-Hill: New York, NY, USA 


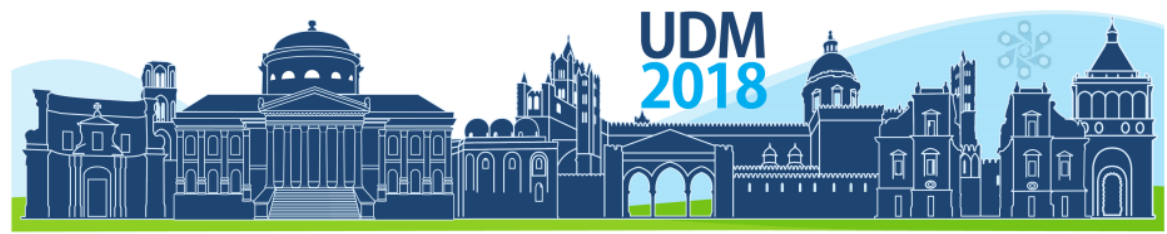

$11^{\text {th }}$ International Conference on Urban Drainage Modelling

23-26 Sep | Palermo - Italy

\title{
Calibrating urban flood models with qualitative probabilistic flooding information extracted from CCTV footage
}

\author{
Matthew Moy de Vitry', ${ }^{1,}$ Simon Kramer², Kris Villez ${ }^{1}$, Jan Dirk Wegner², and João Leitão1 \\ ${ }^{1}$ Eawag, Urban Water Management, Dübendorf, Switzerland \\ 2 ETH Zurich, Photogrammetry and Remote Sensing Group, Zurich, Switzerland
}

(Corresponding author email: matthew.moydevitry@eawag.ch)

It is of common agreement that urban flood modelling should be supported with monitoring data, be it for validating the simulation results or for calibrating the model parameters. Nevertheless, many practitioners develop and apply flood models on the basis of only limited monitoring data. This failure can largely be attributed to the lack of suitable sensing technology for urban floods. CCTV systems are an already existing source of flooding information that in recent years has been starting to be used for flood modelling. However, privacy concerns and the sheer volume of potentially available data call for automated data interpretation and assimilation techniques. In this work, we will demonstrate an automated methodology by which qualitative CCTV-sourced information can be used to calibrate a flood model, thus improving the model's predictive performance. First, a deep learning algorithm based on convolutional neural networks is trained to detect flood water in CCTV images. Second, the qualitative evolution of flood depth is then estimated with an dimensionless index. Third, trend periods of rising and falling water are identified with quantified certainty. Finally, a flood model is calibrated with a novel objective function that takes into account the uncertainty of the trend information. The method will be demonstrated with experimental flash flood data, by which we hope to quantify the value of qualitative flooding information for modelling. If successful, the methods developed could pave the way to a new paradigm in urban flood model calibration.

Keywords: Calibration, Flood modelling, Big data, Deep learning, Trend analysis, CCTV

\section{Introduction}

Around the world, cities are under increasing pressure from population that continues to grow and concentrate in urban areas. At the same time, weather patterns in certain regions are becoming more extreme and the risk of pluvial, fluvial, and coastal flooding is increasing. In these conditions, urban drainage managers must plan and construct infrastructure in order to maintain flood risk within an acceptable range.

Today, the assessment of flood risk and evaluation of risk mitigation measures is often done with numerical flood models. The importance of calibrating these flood models is well recognized. This is highlighted by the amount of research invested into the algorithms, selection of objective functions, input and monitoring data for model calibration. Specifically, 


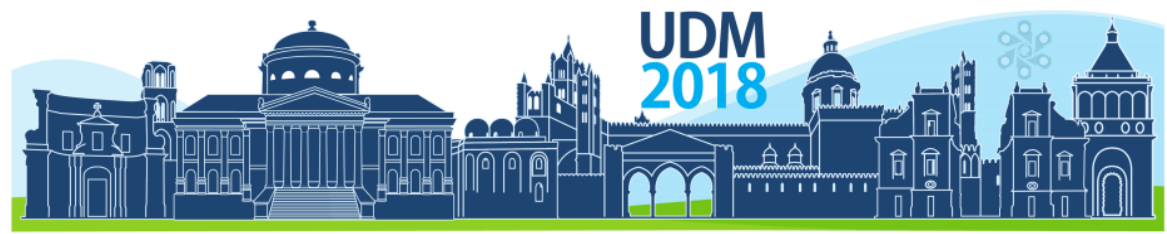

$11^{\text {th }}$ International Conference on Urban Drainage Modelling

23-26 Sep | Palermo - Italy

Tscheikner-Gratl et al. (2016) showed that model calibration allows systematic flood model errors to be reduced. Also among practitioners, model calibration is given increasing importance and included in certain water management guidelines. Nevertheless, model calibration is often neglected (Tscheikner-Gratl et al., 2016), a fact that can be attributed to the cost and complexity of measurement campaigns, and intermittency of flood events. In general, conventional sensors are not suited for measuring surface flooding in urban areas and the need for new methods is well-known (Hunter et al., 2008). In this context, some researchers have started looking beyond conventional sensors and started considering crowd sourcing, social media and surveillance cameras as potential sources of flood monitoring information (Le Boursicaud et al., 2016; Lo et al., 2015; Yu et al., 2016).

On a new front, we have recently proposed extracting qualitative water level information from CCTV footage, using a fully automated approach based on deep learning (Moy de Vitry et al., submitted). It is imperative, however, that the uncertainties and limited information content be considered when assimilating qualitative flooding data. In the current work, we aim to show that despite the challenges, urban flood models can indeed be calibrated with qualitative information derived from CCTV footage when appropriate methods are used. This work builds on previous work in order to complete the method toolbox. First, we introduce a method for extracting trend information from noisy dimensionless time series. The method also provides a certainty level for the estimated trend for each time step. Second, we propose an objective function that enables the calibration of flood models with qualitative and probabilistic monitoring data.

\section{Methods}

\subsection{Flood water detection with convolutional neural networks}

Deep convolutional neural networks (DCNN) are the current go-to methods for advanced computer vision problems. In this work, we use a deep convolutional neural network for the segmentation (i.e. pixel-wise annotation) of images into wet, flooded, and dry classes. In particular, the DCNN architecture used is that of U-Net (Ronneberger et al., 2015). This architecture is composed of an equal number of encoding and decoding layers which allow the extraction and interpretation of complex patterns and visual features in the image. Additionally, U-Net has skip connection that short-circuit the network, allowing high-resolution information to inform the segmentation prediction.

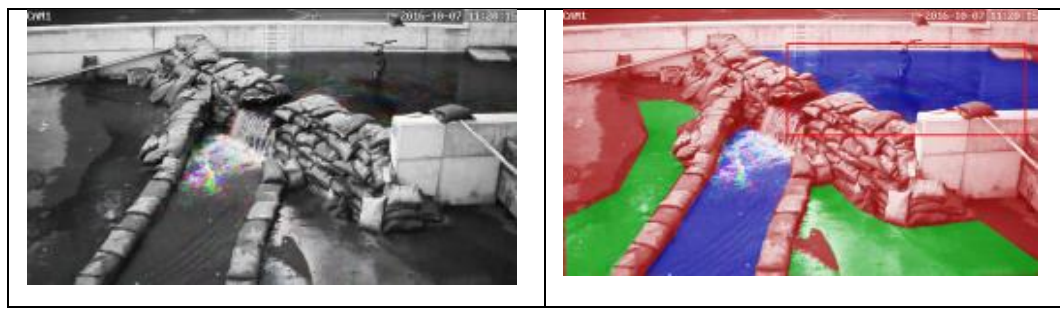

Figure 1: CCTV footage frame of flooding (left), and manually segmented image (right).

To interpret CCTV footage, frames are extracted at regular intervals and segmented with the DCNN. The result is a large number of images with time stamps in which flooded areas, if present, are highlighted. This procedure is documented in (Moy de Vitry et al., submitted). 


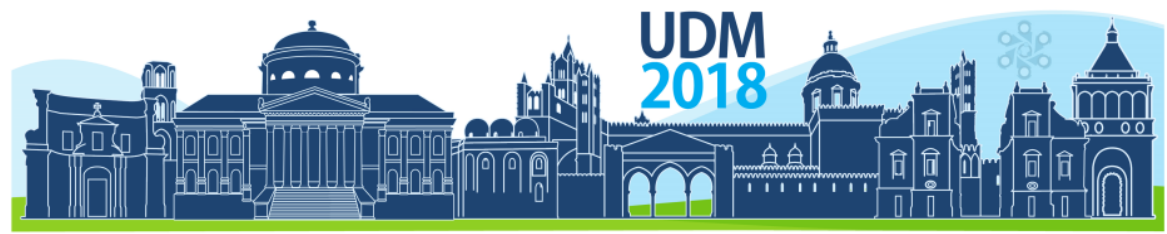

$11^{\text {th }}$ International Conference on Urban Drainage Modelling

23-26 Sep | Palermo - Italy

\subsection{Qualitative estimation of water level evolution}

The next step is estimate the temporal evolution of flooding visible in the video frames over time. This is done with the Static Observer Flooding Index (SOFI), as presented in (Moy de Vitry et al., submitted). This index is designed to reduce sensitivity to segmentation errors thanks to an area-averaging approach. By estimating the SOFI index for each segmented frame, a time series describing the evolution of visible water surfaces can be generated (Figure 2, black line). In (Moy de Vitry et al., submitted), we showed with a series of examples that the SOFI index is positively correlated with the water level.
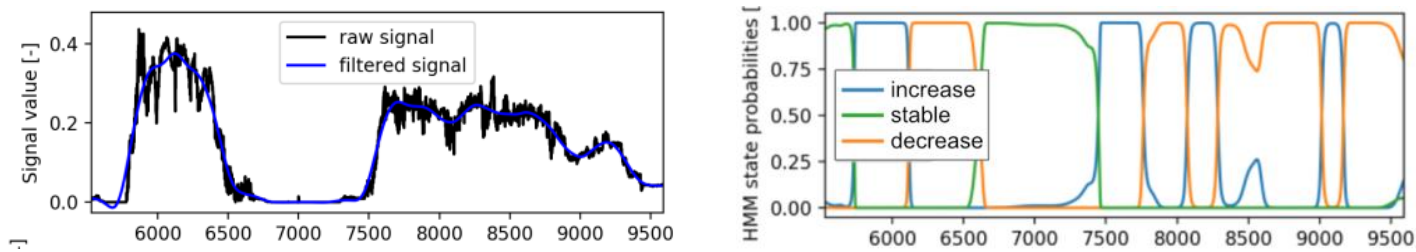

Figure 2: Flood index time series (left) and estimated trends (right)

\subsection{Water level trend extraction from qualitative noisy time series}

Due to the nature of the flooding index computed in the previous step, the only concrete insight about the flooding that can be gathered from the time series is whether the water level is increasing, decreasing, or stable. This information is extracted in a multi-step process inspired from the Qualitative State Estimator (QSE) (Villez, 2015), as follows. First, a first-order regression is performed on a sliding window of the data, providing at each step an estimate of the regression coefficients. The regression coefficients are then used to assign the system an instantaneous state, or "primitive". Finally, a Markov chain is applied estimate system state probabilities with consideration of previous system states and prior knowledge about the system (Figure 2, right). A core advantage of this approach is that it explicitly extracts relevant information from the signal while carrying over uncertainty due to noise.

\subsection{Objective function for qualitative probabilistic monitoring data}

The final component required for model calibration is an objective function that is suited to probabilistic qualitative data. This part of the work is still in progress, but the function could be based on metrics commonly used to evaluate classification performance.

\subsection{Model calibration}

The flood model will be calibrated with a standard parameter optimization routine, implemented in python. To assess the value of trend extraction for calibration, the model will also be calibrated directly with SOFI index data using the Spearman rank correlation coefficient (Spearman, 1904), which evaluates the correlation between two signals.

\section{Experiments}




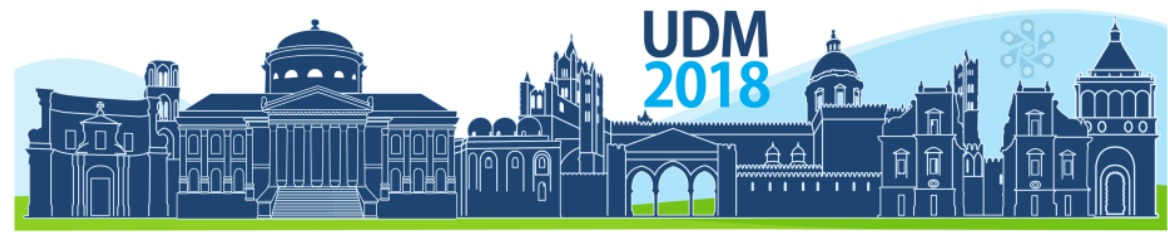

$11^{\text {th }}$ International Conference on Urban Drainage Modelling

23-26 Sep | Palermo - Italy

\subsection{Data and model}

The data supporting this research was collected from real-world experiments at a flood response training facility rented for this purpose and equipped with conventional sensors as well as CCTVs. The facility is documented by (Moy de Vitry et al., 2017). A SWMM model will be used to simulate flooding. Since the experimental flood events are generally restricted to pipes, ponds, and open channels, the flows can be assumed to be one-dimensional.

\section{Conclusions}

As the work is still underway, no general conclusions can be made. The initial trend extraction results, as shown in Figure 2, are promising.

\section{References}

Le Boursicaud, R., Pénard, L., Hauet, A., Thollet, F. and Le Coz, J. (2016) Gauging extreme floods on YouTube: application of LSPIV to home movies for the post-event determination of stream discharges, Hydrol. Process., 30(1), 90-105, doi:10.1002/hyp.10532.

Hunter, N. M., Bates, P. D., Neelz, S., Pender, G., Villanueva, I., Wright, N. G., Liang, D., Falconer, R. A., Lin, B., Waller, S., Crossley, A. J. and Mason, D. C. (2008) Benchmarking 2D hydraulic models for urban flooding, Proc. Inst. Civ. Eng. - Water Manag., 161(1), 13-30, doi:10.1680/wama.2008.161.1.13.

Lo, S. W., Wu, J. H., Lin, F. P. and Hsu, C. H. (2015) Visual sensing for urban flood monitoring, Sensors (Switzerland), 15(8), 20006-20029, doi:10.3390/s150820006.

Moy de Vitry, M., Dicht, S. and Leitão, J. P. (2017) floodX: urban flash flood experiments monitored with conventional and alternative sensors, Earth Syst. Sci. Data, 9(2), 657-666, doi:10.5194/essd-9-657-2017.

Moy de Vitry, M., Wegner, J. D. and Leitao, J. P. (submitted) Robust Flood Level Fluctuation Monitoring in CCTV Footage with a Convolutional Neural Network Classifier, IEEE Sens. J.

Ronneberger, O., Fischer, P. and Brox, T.: U-net (2015) Convolutional networks for biomedical image segmentation, Lect. Notes Comput. Sci. (including Subser. Lect. Notes Artif. Intell. Lect. Notes Bioinformatics), 9351, 234-241.

Spearman, C. (1904) The Proof and Measurement of Association between Two Things, Am. J. Psychol., 15(1), 72, doi:10.2307/1412159.

Tscheikner-Gratl, F., Zeisl, P., Kinzel, C., Leimgruber, J., Ertl, T., Rauch, W. and Kleidorfer, M. (2016) Lost in calibration: why people still don't calibrate their models, and why they still should - a case study from urban drainage modelling, Water Sci. Technol., 395, doi:10.2166/wst.2016.395.

Villez, K.: Qualitative path estimation (2015) A fast and reliable algorithm for qualitative trend analysis, AIChE J., 61(5), 1535-1546, doi:10.1002/aic.14736.

Yu, D., Yin, J. and Liu, M. (2016) Validating city-scale surface water flood modelling using crowd-sourced data, Environ. Res. Lett., 11(12), 124011, doi:10.1088/1748-9326/11/12/124011. 


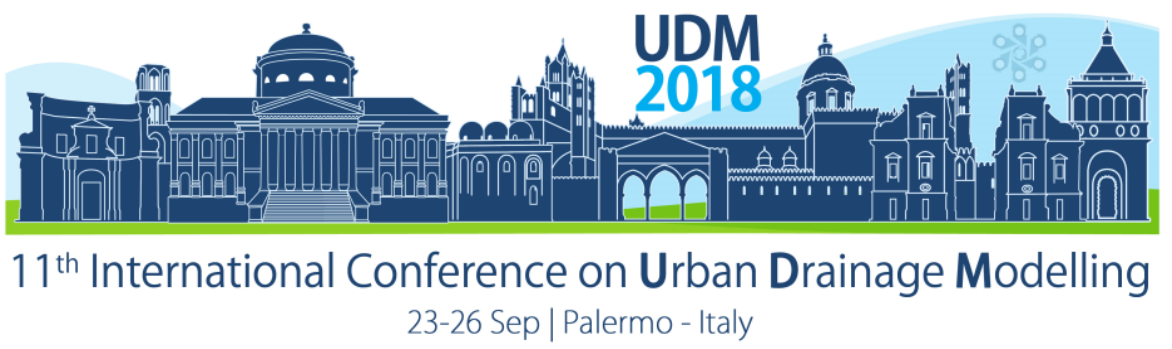

\title{
Should we account for unexpected sources in improving the predic- tion of urban stormwater quality?
}

\author{
Baiqian Shi ${ }^{1,2}$, Anna Lintern ${ }^{1,2}$, Peter Bach ${ }^{2,3}$, Kefeng Zhang ${ }^{4}$, Rhys Coleman ${ }^{5}$, Leon Metzeling ${ }^{6}$, \\ David McCarthy ${ }^{1,2}$ and Ana Deletic ${ }^{4}$ \\ ${ }^{1}$ Environmental and Public Health Microbiology Laboratory, Department of Civil Engineering, Monash University, \\ Wellington Road, Clayton, VIC 3800, Australia \\ ${ }^{2}$ Monash Infrastructure Research Institute, Department of Civil Engineering, Monash University, Wellington Road, \\ Clayton, VIC 3800, Australia \\ ${ }^{3}$ Swiss Federal Institute of Aquatic Science \& Technology (Eawag) / ETH Zürich, Switzerland \\ ${ }^{4}$ Department of Civil and Environmental Engineering, University of New South Wales, Sydney, 2052, Australia \\ ${ }^{5}$ Melbourne Water Corporation, Victoria, 3008, Australia \\ ${ }^{6}$ Environment Protection Authority Victoria, Macleod, Victoria, 3085, Australia
}

\begin{abstract}
The pollution generation of urban catchments varies spatially and temporally. In order to determine dominant parameters for future models of pollution generation processes, we analysed the relationship between Melbourne's in-stream water quality and key catchment characteristics (GIS generated). The catchment characteristics considered include land use and the presence of unexpected sources (cross-connections, sewer blockages and industrial discharge). An in depth historical study was also conducted for Cherry Creek and Anderson Creek: two catchments with high level of TP and heavy metals. It has been found that (a) land use is a poor predictor of heavy metals such as $\mathrm{Cu}$ and $\mathrm{Zn}$; and (b) apart from surface runoff, unexpected sources could be another key contributor to urban water pollution, especially TP. Therefore, in our future work, these factors will be included in a semistochastic urban water quality model.
\end{abstract}

Keywords: urban stormwater; water quality; spatial and temporal variability; land use; unexpected sources

\section{INTRODUCTION}

Stormwater from urbanised catchments contains significant levels of pollutants including sediments, nutrients, and heavy metals. Discharging such polluted water to waterways could cause adverse impact to the downstream ecosystem and human health. In order to effectively assess the health of urban waterways and review policies to better regulate our streams and rivers, regulators rely on urban water quality modelling to replace routine sampling. However, currently available models are unable to provide robust results (Dotto et al., 2010). Especially at the basin scale, models require a large amount of observed data for calibration to find bestfitted parameters, but cannot provide reliable information as the conceptualised algorithms do not replicate the natural process (Bonhomme and Petrucci, 2017). Hence, in order to improve the performance of water quality models to better assist regulators and engineers, we first need a better understanding of pollution generation processes in urban waterways.

Surface runoff has been considered as the major source of pollution in urban catchments. However, how urban water quality response to various land uses is still unclear at catchment scale. Even in basins with separate drainage systems, wastewater could enter the stormwater drainage network via cross-connections, illegal discharges, and sewer emergency overflows (Panasiuk et al., 2015). Current models do not account for unexpected sources as a pollution contributor, which could be another reason for poor model performance. Therefore, the aim of this study is to verify the water quality response of various urban land uses, and to understand the relationship between land uses and unexpected sources. We address this by analysing the influence of land use on spatial variability in the water quality of Melbourne's catchments, and 


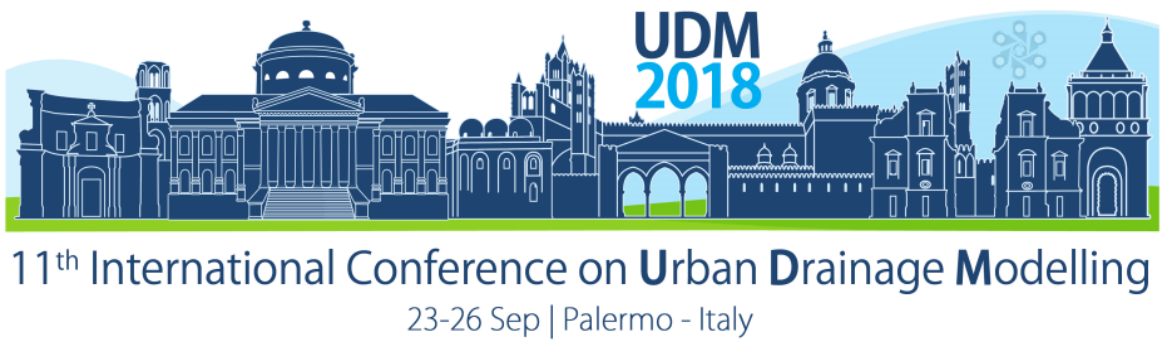

analysing the temporal variability of water quality of catchments having defined unexpected sources.

\section{MATERIALS AND METHODS}

\subsection{Water quality and catchment characteristic data}

The concentration of TSS, TP, $\mathrm{Cu}$ and $\mathrm{Zn}$ of 20 catchments with a single homogenous land use was obtained from Melbourne Water's long-term monitoring campaign. Water quality data are weekly grab samples from 1994 to 2016. These catchments include 2 industrial, 6 low density residential, 6 medium density residential, 2 agricultural, and 4 forested sites. Catchment characteristics including historical land use (from 2006 to 2014), impervious fraction, and population density were collected from the Victorian open data repository, Melbourne Water, and the Australian Bureau of Statistics, respectively in GIS shapefile format. Historical aerial images (2006 and 2017) were collected from Nearmap, an online satellite image provider.

\subsection{Data Analysis}

The non-parametric statistical analyses and descriptive statistics were utilised to minimise the impact of extreme values from the observed dataset. The median concentration of each catchment (over time) was calculated first. To describe the spatial differences between land uses, Spearman rank-order coefficients $(\alpha=0.05)$ were calculated to test the monotonicity of the relationship between median concentrations and catchment characteristics. To understand sitespecific variability for different land uses, box-plots (5\% and $95 \%$ bar conditions) were utilised to compare each site.

Two urban catchments: Cherry Creek $\left(53.52 \%\right.$ of industrial, $19 \mathrm{~km}^{2}, 40.4 \%$ imperviousness and $121 \mathrm{pp} / \mathrm{km}^{2}$ ) and Anderson Creek (66.82\% low density residential, $16.1 \mathrm{~km}^{2}, 16.68 \% \mathrm{im}-$ perviousness and $312 \mathrm{pp} / \mathrm{km}^{2}$ ), demonstrate historically increasing or decreasing trends of pollution concentrations. A Spearman correlation analysis was conducted between water quality indicators (e.g. TP, TSS, heavy metals) and other catchment characteristics (e.g. rainfall intensity, number of septic tanks in use). The level of urban expansion at these two sites over last 10 years was also analysed to understand the tendency of pollution levels.

\section{RESULTS AND DISCUSSION}

\subsection{Results of spatial and temporal analysis}

The Spearman Rank correlation coefficients indicate that $\mathrm{Zn}$ and $\mathrm{Cu}$ are strongly correlated with the proportion of impervious area $(\rho=0.80$ and 0.74$)$, and population density. However, there is no strong correlation between catchment land uses and site median pollutant concentration. The box-plot also shows that $\mathrm{Zn}$ levels increase as catchment imperviousness increases regardless of the type of urban land uses (see Figure 1(a)).

The median TSS concentration between clean land use catchment are similar, but two low density residential sites demonstrate high TSS level compare with other catchments. Nutrient indicators, TP and TN, show no strong correlation with any catchment characteristic. Land use analysis demonstrates that three low density residential catchments could generate much higher levels of TP even compared with median density residential sites, whereas another three low density residential catchments have low TP concentrations that are close to the emission level of forest area (see Figure 1(b)). Cherry Creek, the most industrialised catchment has the highest TP concentration with wide variability. 


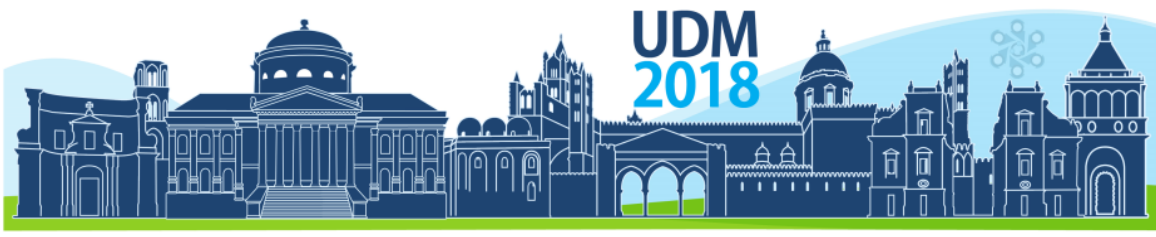

$11^{\text {th }}$ International Conference on Urban Drainage Modelling

23-26 Sep | Palermo - Italy
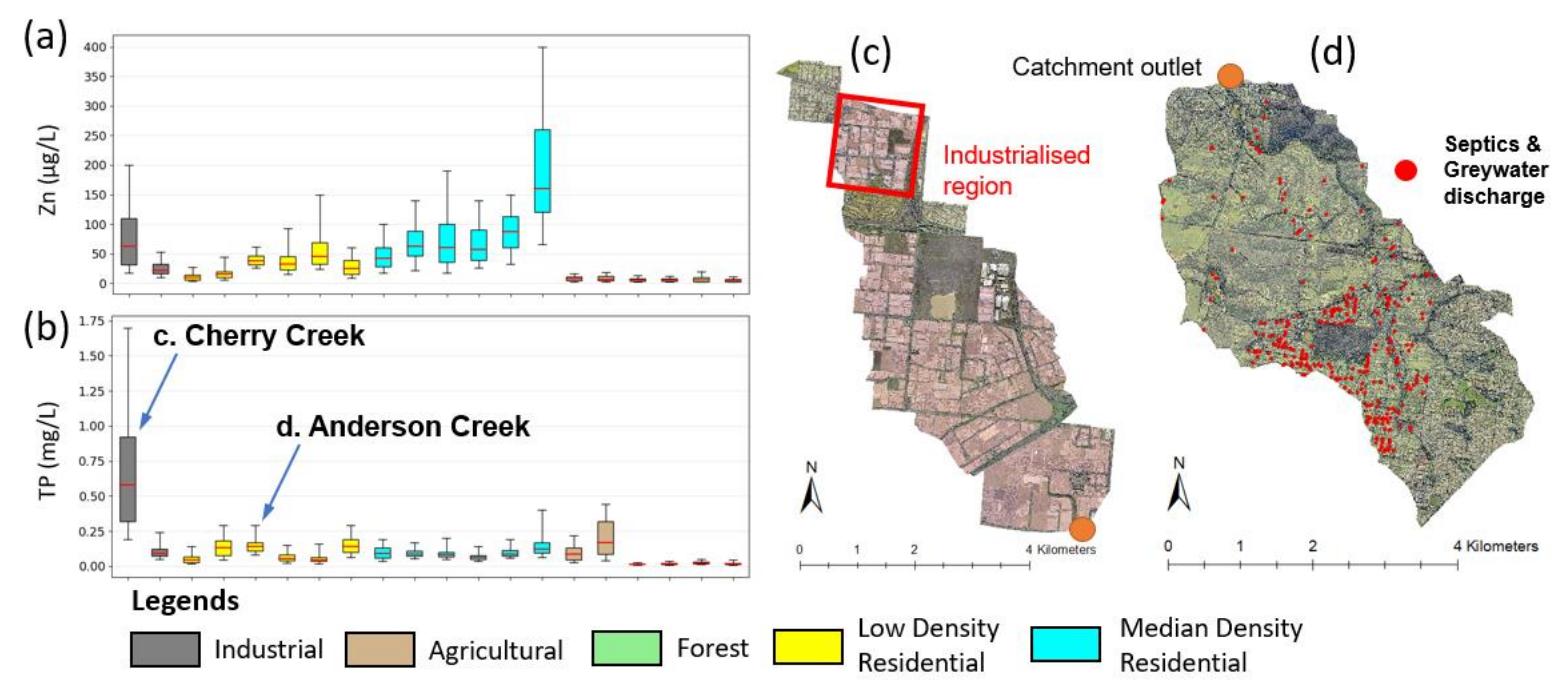

Figure 1. (a) Zn level of Melbourne's clean land use catchments; (b) TP level of Melbourne's clean land use catchments; (c) aerial image of Cherry Creek catchment; (d) aerial image of Anderson Creek catchment

Since 2010, Cherry Creek's TSS and heavy metals concentrations have been increasing significantly with larger variability (see Figure 2(a)). Historical land use and aerial image analysis indicates that intensive industrial expansions started around 2009 (see Figure 1(c)). The temporal correlation analysis results (see Table 1) show that $\mathrm{Cu}$ and $\mathrm{Zn}$ highly correlate with each other and turbidity at Cherry Creek, but such a correlation relationship was not observed for other Melbourne's catchments.

Anderson Creek is an example of Melbourne's un-sewered residential sites. The TP concentrations of Anderson Creek experienced a continually decreasing trend from 1994 to 2016 (see Figure 2(b)). Offsite discharge of untreated greywater and high probability of failed septic systems were identified as two major causes of historically poor water quality (see Figure 1(d)). By connecting properties to the trunk sewer system since 2009, the number of septics significantly decreased and this decrease strongly correlates with a reduction in TP concentrations $(\rho=0.73, p<0.05)$.

Table 1. Temporal correlation analysis between pollution parameters of Cherry Creek

\begin{tabular}{c|cccc}
\hline$\rho$ & Turb & SS & Cu & Zn \\
\hline Turb & 1.00 & & & \\
SS & 0.83 & 1.00 & & \\
Cu & 0.75 & 0.62 & 1.00 & \\
Zn & 0.68 & 0.49 & 0.82 & 1.00 \\
\hline
\end{tabular}

\subsection{Discussion of land uses and unexpected sources}

The level of heavy metals is highly correlated with the degree of urbanisation of a catchment. Impervious fractions could directly reflect origins of $\mathrm{Cu}$ and $\mathrm{Zn}$ such as roof cover materials. In this sense, unexpected sources are not important enough to include in future urban water quality models. On the contrary, the level of TSS and TP of specific catchments could be highly variable compared with that of other catchments belong to same land use group. Such temporal variance could potentially be explained by the appearance of unexpected sources. 


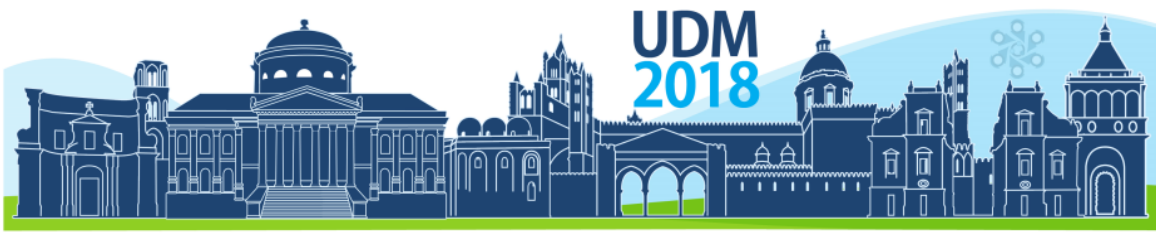

$11^{\text {th }}$ International Conference on Urban Drainage Modelling 23-26 Sep | Palermo - Italy
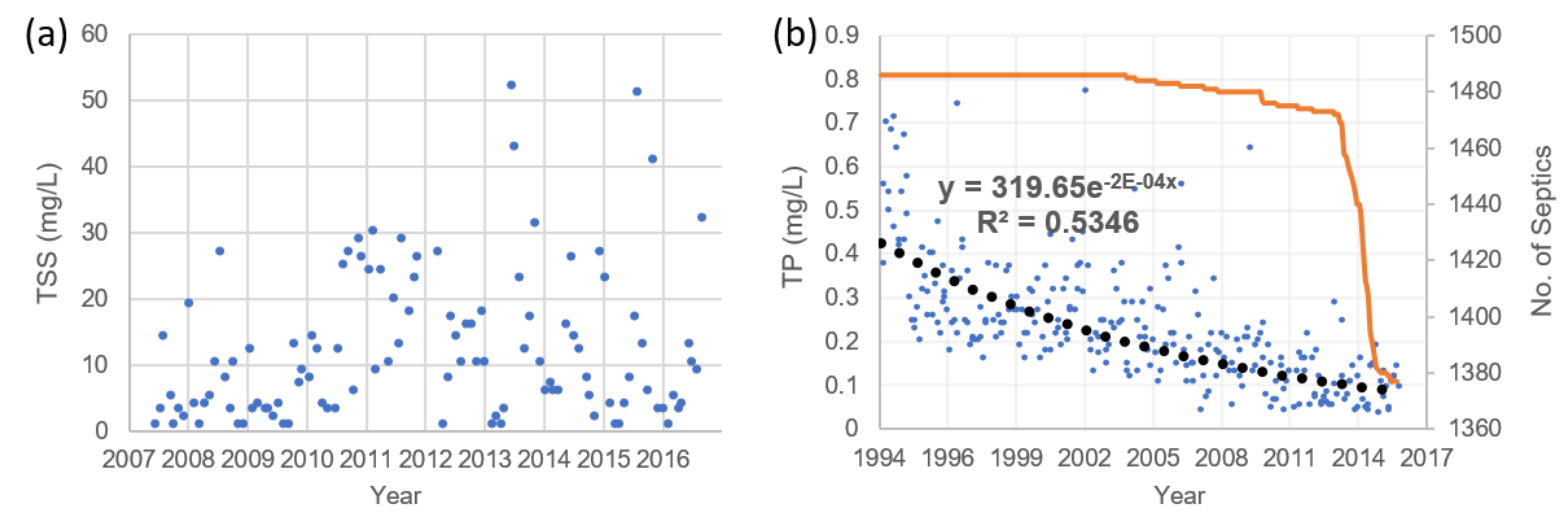

Figure 2. Time series plots of (a) TSS levels for Cherry Creek and (b) TP concentrations for Anderson Creek.

For Cherry Creek, a high correlation between heavy metals and turbidity indicates that sediments (either from construction activities or soil erosion) could be a common source of pollutants. The high level of TP could be caused by unexpected sources like illegal discharges from industrial activities. Cherry Creek is an extreme example of poor urban water quality, but similar cross-connections could happen to $2 \%$ to $30 \%$ of properties in any separate drainage catchment (Ellis and Butler, 2015).

The historical data analysis of Anderson Creek suggests that the offsite discharge of greywater and on-site septic tanks have been the main contributor of pollution, because the water quality improved significantly since these unexpected sources were removed. This indicates that in some catchments, such as the Anderson Creek catchments, unexpected sources need to be considered as a significant source of pollution, and should be included in urban water quality models to better replicate the nature of pollution generation processes.

\section{CONCLUSIONS}

In this study, we aim to identify factors that affect spatial and temporal variability of urban water quality models. To achieve this, we conducted the statistical analysis based on Melbourne's clean catchments to test the water quality response to various land uses and unexpected sources. It can be concluded that: (a) land uses and unexpected sources are not predominant parameters for some pollutants like heavy metals and so do not necessarily need to be included in water quality models; (b) for other pollutants such as TP, unexpected sources are a key factor affecting water quality, and should be included in water quality models.

\section{Acknowledgements:}

This project is funded by the Australian Research Council (ARC), Linkage Project LP160100241, titled "Advancing water pollution emissions modelling in cities of the future".

\section{References}

BONHOMME, C. \& PETRUCCI, G. 2017. Should we trust build-up/wash-off water quality models at the scale of urban catchments? Water Research, 108, 422-431.

DOTTO, C. B., KLEIDORFER, M., DELETIC, A., FLETCHER, T. D., MCCARTHY, D. T. \& RAUCH, W. 2010. Stormwater quality models: performance and sensitivity analysis. Water Science \& Technology, 62, 837-43.

ELLIS, J. B. \& BUTLER, D. 2015. Surface water sewer misconnections in England and Wales: Pollution sources and impacts. Science of The Total Environment, 526, 98-109.

PANASIUK, O., HEDSTROM, A., MARSALEK, J., ASHLEY, R. M. \& VIKLANDER, M. 2015. Contamination of stormwater by wastewater: a review of detection methods. Journal of Environmental Management, 152, 241-50. 


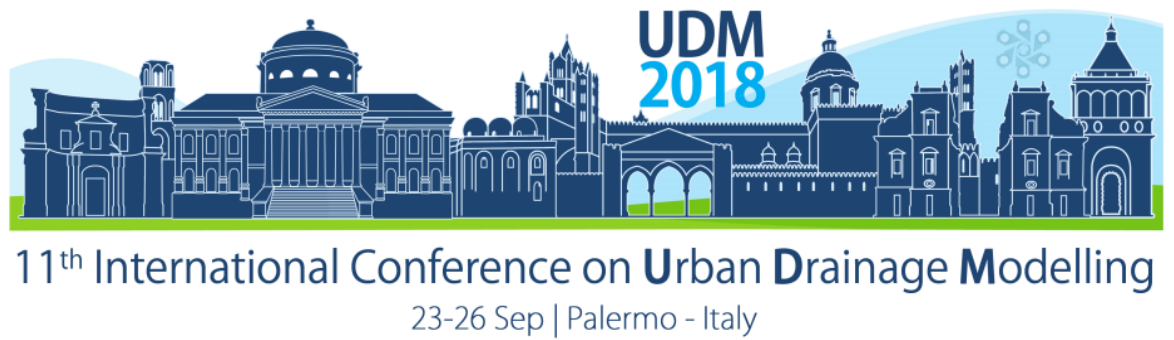

\title{
Dissolved phosphorus treatment in stormwater biofilters enhanced with media amendments
}

\author{
Andrea Aiello, Christian Berretta and Martin Tillotson \\ University of Leeds, Civil engineering, Leeds, United Kingdom
}

\begin{abstract}
Biofiltration systems are one type of vegetated sustainable drainage systems particularly suited for diffuse pollution control and with a relatively compact footprint that make them an ideal choice for retrofit in urban areas. Existing knowledge on dissolved pollutant fate in biofilters, the influence of their design and configuration on hydrological, pollutant removal and long term performance is limited. This paper focuses on investigating the influence of amended media on the removal performance of dissolved pollutants through a laboratory study using batch test and mesocosms under controlled condition. Duplicate control and three amended configurations comprising of Zeolite, Granular Activated Carbon, and a mix of both, were dosed with synthetic stormwater runoff simulating typical pollutants concentration of urban runoff areas. In this paper the results for phosphate removal are reported. Preliminary results suggested that there is significant difference between inlet and outlet phosphate concentration $(P<0.001)$ with the configurations with both the amendments and the zeolite resulting in highest average removal performance. Mean phosphate removal performance for the four configurations were lower than 27\%. Batch test highlighted the occurrence of leaching from topsoil and woodchips used in the biofilters. Higher phosphate removal was observed after longer dry periods between runs.
\end{abstract}

Keywords: Biofilter; Media amendments; Phosphate removal

\section{INTRODUCTION}

Biofiltration systems are a promising retrofit option in urban areas due to the vertical arrangement of treatment stages that leads to a relatively compact footprint. The flexibility with respect to design and pollutant removal mechanisms generates a requirement for characterisation of the different treatment functions and their interactions in order to tailor functionality to specific sites (i.e. runoff pollutants, requirements of recipient water bodies). The design and choice of plants, media composition, and drainage configuration all impact upon hydrological, water quality and long term performance. Dissolved pollutants constitute a major threat for water quality due to their bioavailability and the difficulty in their control (ManiquizRedillas \& Kim, 2016). Phosphate removal could be affected by potential leaching from biofilter media (Liu \& Davis, 2014). Existing knowledge on dissolved pollutant fate in biofilters and the use of media amendments to enhance their removal is not exhaustive (LeFevre et al., 2015). Amendments have the potential to increase the adsorption capacity and thus, to extend the biofilter lifetime. This paper focuses on the influence of media amendments, specifically Zeolite, Granular Activated Carbon (GAC) and Yellow sand on the removal of phosphate.

\section{MATERIALS AND METHODS}

The experimental setup included 8 PVC columns (150mm internal diameter, $1300 \mathrm{~mm}$ height) with sandblasted inner wall to minimise preferential path, and a raised outlet to establish a permanent saturation area (Figure 1).

The tested biofilter's design comply with CIRIA and CRCWSC guidelines (Payne et al., 2015; Woods Ballard et al., 2015). A control column (C) has been tested against three configurations including an amended layer containing Zeolite (Z), Granular Activated Carbon (GAC) and a 


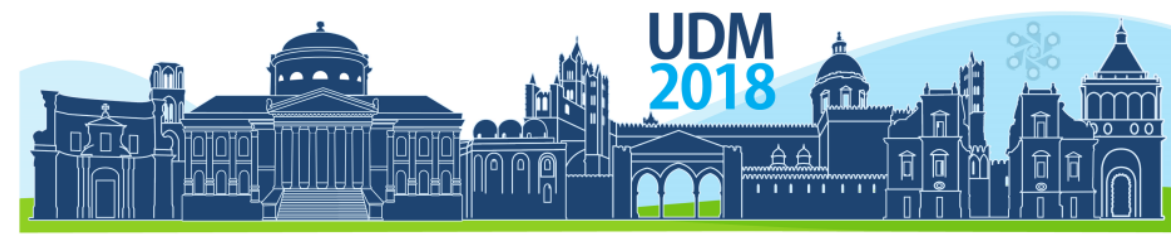

$11^{\text {th }}$ International Conference on Urban Drainage Modelling

23-26 Sep | Palermo - Italy

mixture of the two $(Z+G A C)$. Two duplicate columns for each configuration were tested. All the configurations included a mix of White sand, Vermiculite, Perlite, Top soil, and, for the amended configurations, $Z$ and GAC in the filter media; Woodchip and sand in the saturation zone; gravel in the drainage layer. A detailed description of the biofilter layers characteristics is reported elsewhere (Berretta et al., 2018).

The selected media amendments are commonly used in water treatment, and their high specific surface area, $46 \mathrm{~m}^{2} / \mathrm{g}$ for Zeolite and $1200 \mathrm{~m}^{2} / \mathrm{g}$ for GAC, contribute to enhance the adsorption capacity and the available site for biofilms.

Vegetation was not assessed within this set of tests that aimed at identifying the media configuration to undergo further testing including two plant species.

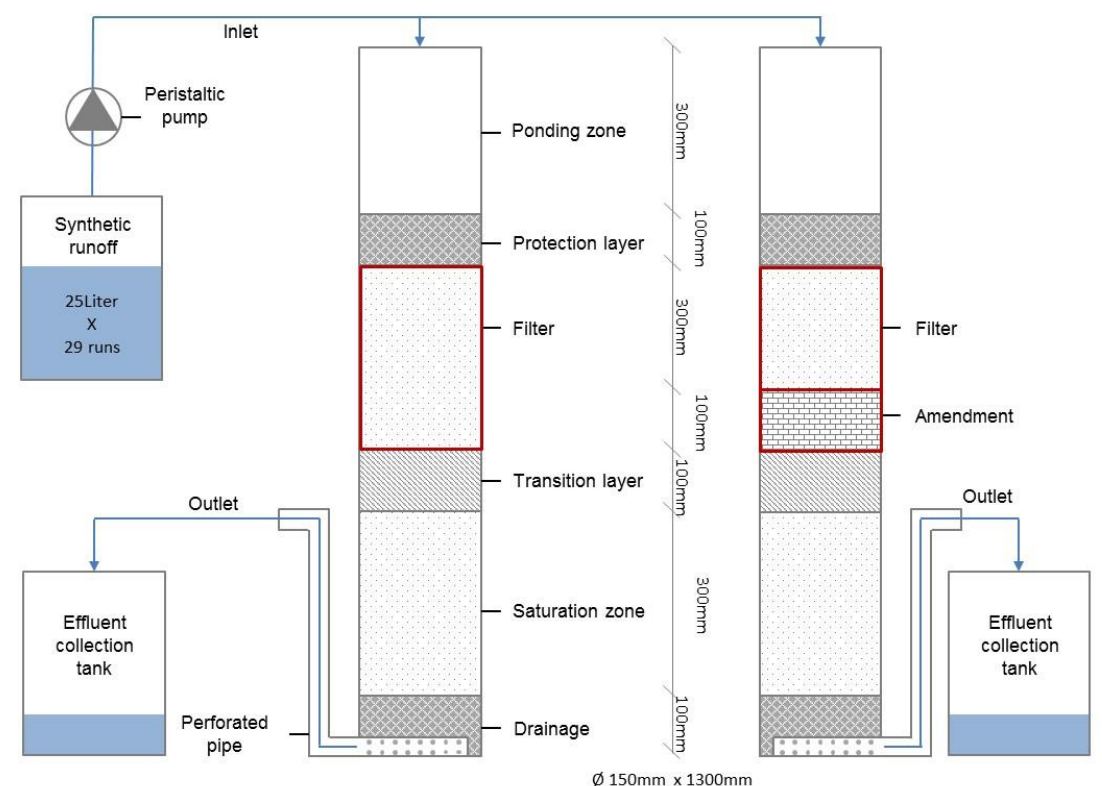

Figure 1. Experimental setup and tested biofilter configuration: control (on the left) and amendment position (on the right)

Mesocosms were dosed with synthetic stormwater runoff with dissolved metal concentration typical of UK roadside runoff (Revitt et al., 2014) (Table 1). The total applied volume was equivalent to the average yearly runoff volume in Leeds (UK) for a biofilter sized $2 \%$ of the catchment area. The filters were dosed with $25 \mathrm{~L}$ of water for each run using a peristaltic pump for a total of 26 runs. Additional runs were performed to assess the influence of dry periods on the removal performance. The dry periods between two runs varied from 0.5 to 494 hours. Samples were taken at the inlet and at the outlet with discrete and composite samples. This data is presented in terms of Removal Performance (RP) (1)

$$
R P=\frac{M_{\text {inflow }}-M_{\text {out flow }}}{M_{\text {inflow }}} \times 100
$$

Where $\mathrm{M}_{\text {inflow }}$ and $\mathrm{M}_{\text {outflow }}$ are the inflow and outflow mass of constituent.

Batch test assessed the adsorption capacity $\left(Q_{e}\right)(2)$ of the media used in the column test. $1 \mathrm{~g}$ of media was shaken in $230 \mathrm{ml}$ of synthetic stormwater at $100 \mathrm{rpm}$ on an orbital shaker table. 


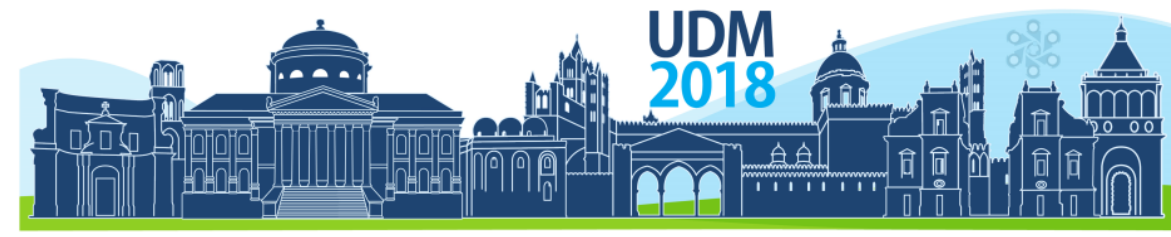

$11^{\text {th }}$ International Conference on Urban Drainage Modelling

23-26 Sep | Palermo - Italy

$$
Q_{e}=\frac{\left(C_{0}-C_{24}\right) V}{W}(2)
$$

Where $Q_{e}$ is the adsorption capacity at equilibrium $\left(\mathrm{mg} \mathrm{g}^{-1}\right), \mathrm{C}_{0}$ initial solution concentration, $\mathrm{C}_{24}$ concentration of solution after 24 hours, $\mathrm{V}$ is the volume of the solution (L), and $\mathrm{W}$ is the dry mass of adsorbent used (g).

Table 1. Synthetic stormwater inflow composition and source

\begin{tabular}{cccc}
\hline Parameter & Mean & SD & Source \\
\hline $\mathrm{Cu}(\mu \mathrm{g} / \mathrm{L})$ & 198 & 35.6 & $\mathrm{CuSO} 4$ \\
$\mathrm{Zn}(\mu \mathrm{g} / \mathrm{L})$ & 460.71 & 33.85 & $\mathrm{ZnCl}$ \\
$\mathrm{Cd}(\mu \mathrm{g} / \mathrm{L})$ & 0.86 & 0.04 & $\mathrm{CdCl}_{2}$ \\
$\mathrm{PO}_{4}{ }^{3-}(\mathrm{mg} / \mathrm{L})$ & 2.98 & 0.11 & Tap water \\
$\mathrm{pH}$ & 7.35 & 0.23 & Tap water \\
Conductivity $(\mu \mathrm{S} / \mathrm{cm})$ & 378.07 & 45.1 & Tap water \\
Temperature $\left({ }^{\circ} \mathrm{C}\right)$ & 22.07 & 2.35 & Tap water \\
\hline
\end{tabular}

\section{RESULTS AND DISCUSSION}

Results for the batch experiment are presented in Table 2. Despite the low $Q_{e}$ of sand if compared to Zeolite and GAC, Yellow sand showed higher adsorption capacity than White sand. It is evident that Woodchip and Top soil are a source of phosphate as shown by negative $Q_{\mathrm{e}}:-0.071$ and $-0.180 \mathrm{mg} / \mathrm{g}$ respectively which is thought to affect the removal performance of phosphate. Column test results showed a more consistent behaviour of per event RP among the tested configurations after the first seven runs (Figure 2). In particular, higher RP were observed in the first runs for $Z$. The mean phosphate RP for $C, Z, G A C$, and Z+GAC configurations were 23.39 ( \pm 17.74$), 26.63$ ( \pm 19.46$), 18.86( \pm 16.02)$, and $24.27( \pm 18.64)$ respectively. The mean phosphate RP excluding the initial period for $C, Z, G A C$, and Z+GAC configuration were $23.49( \pm 19.97), 25.18,( \pm 21.34), 20.80 \quad( \pm 14.70), 26.93( \pm 20.69)$ respectively with $Z+G A C>Z>C>G A C$. Higher phosphate $R P$ values in runs $11,13,28$, and 29 were observed after longer dry periods (DWP) between runs. A moderate correlation was found between DWP and RP using a non-parametric Spearman test (Spearman $r=0.757$ $\mathrm{n}=112 \mathrm{p}<0.005)$. This could be due to the formation of ferric oxyhydroxide in aerobic condition as highlighted also by other studies (Hatt et al., 2007). After longer dry periods, it has also been noted an increased concentration of dissolved iron in the effluent, that could have promoted the removal of phosphate.

Table 2 Adsorptive capacity $Q_{e}(\mathrm{mg} / \mathrm{g})$ for the media used in the column experiment.

\begin{tabular}{cc|cc}
\hline Media & $\begin{array}{c}\text { Adsorptive } \\
\text { capacity } \\
(\mathrm{mg} / \mathrm{g})\end{array}$ & Media & $\begin{array}{c}\text { Adsorptive } \\
\text { capacity } \\
(\mathrm{mg} / \mathrm{g})\end{array}$ \\
\hline Zeolite & 0.044 & Woodchip & -0.071 \\
GAC & 0.055 & Topsoil & -0.18 \\
White sand & 0.012 & Vermiculite & 0.085 \\
Yellow sand & 0.024 & Perlite & 0.029 \\
\hline
\end{tabular}




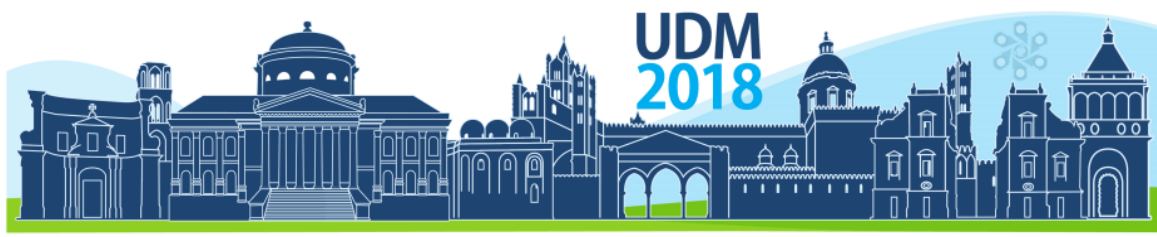

$11^{\text {th }}$ International Conference on Urban Drainage Modelling

23-26 Sep | Palermo - Italy

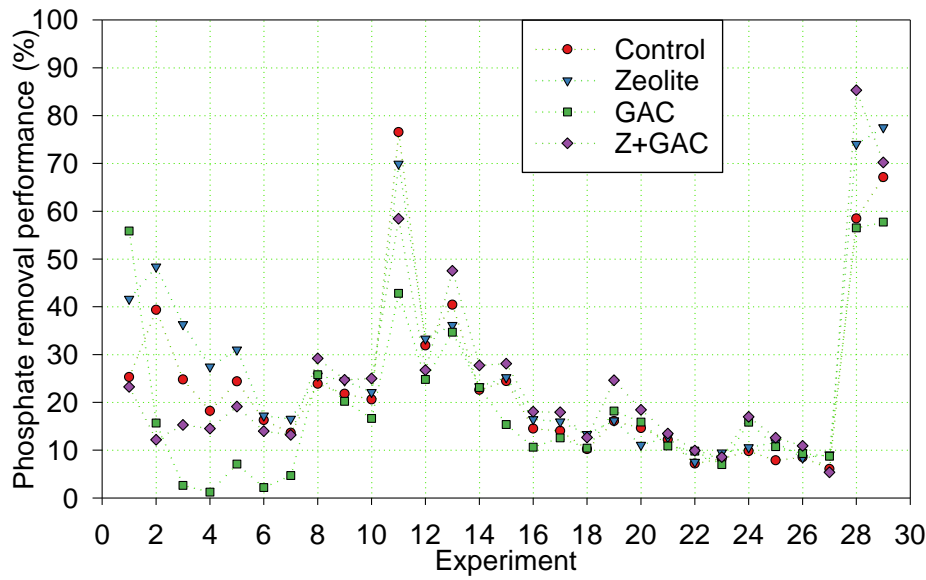

Figure 2 Removal performance for phosphate.

\section{CONSLUSIONS}

The tested biofilter configurations showed low retention of phosphate. Leaching occurred for Top soil and Woodchip. Despite the low $Q_{e}$ of sand, Yellow sand showed higher adsorption capacity than White sand. Preliminary laboratory results suggested that there is significant difference between inlet and outlet phosphate concentration $(P<0.001)$ with the configurations with both the amendments and the zeolite resulting in highest average removal performance. Further tests that include two plant species are in progress and are investigating the influence of media amendments on plant growth, and the hydrological and removal performance in a temperate climate. The results from these laboratory tests will identify the biofilter configuration to undergo a long term field test.

\section{Acknowledgments}

This research project is supported by the White Rose University Consortium through the Collaboration Fund and the Sustainability Service of the University of Leeds through the Sustainability Living Lab initiative. Andrea Aiello is supported by an Engineering and Physical Sciences Research Council DTC studentship.

\section{References}

Berretta, C., Tillotson, M.R., Aiello, A., Boxall, A., Stovin, V. \& Jensen, H.S. (2018) Influence of design and media amendments on the performance of stormwater biofilters. Water Management, 171 (2), pp.87-98.

Hatt B.E., Fletcher T.D. \& Deletic A. (2007) The effects of drying and wetting on pollutant removal by stormwater filters. Proceedings of the 6th International Conference on Sustainable Techniques and Strategies in UrbanWater Management - NOVATECH 2007

LeFevre, G.H., Asce, S.M., Paus, K.H., Natarajan, P., Gulliver, J.S., Asce, F., Novak, P.J. \& Hozalski, R.M. (2015) Review of Dissolved Pollutants in Urban Storm Water and Their Removal and Fate in Bioretention Cells. Journal of Environmental Engineering, 141.

Maniquiz-Redillas, M.C. \& Kim, L.-H. (2016) Evaluation of the capability of low-impact development practices for the removal of heavy metal from urban stormwater runoff. Environmental technology, 37 (19), pp.2265-2272.

Payne, E.G.I., Hatt, B.E., Deletić, A., Dobbie, M.F., McCarthy, D.T. \& Chandrasena, G.I. (2015) Adoption Guidelines for Stormwater Biofiltration Systems, Melbourne, Australia: Cooperative Research Centre for Water Sensitive Cities.

Revitt, D.M., Lundy, L., Coulon, F. \& Fairley, M. (2014) The sources, impact and management of car park runoff pollution: A review. Journal of Environmental Management, 146, pp.552-567.

Woods Ballard, B., Wilson, S., Udale-Clarke, H., Illman, S., Scott, T., Ashley, R. \& Kellagher, R. (2015) The SuDS manual. CIRIA 2015 


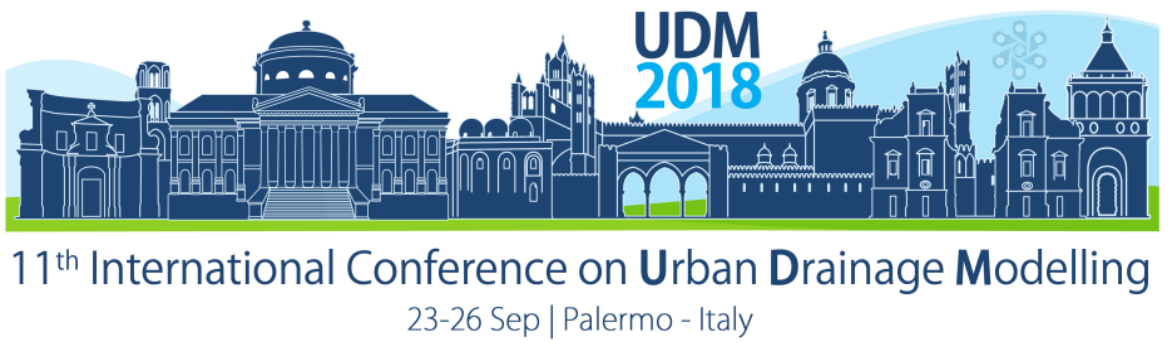

\title{
Measuring and modelling the nutrients residual load from the combined sewer of the eastern shore of Lake Iseo
}

\author{
Laura Barone $^{1,3}$, Marco Pilotti ${ }^{\star}{ }^{\star}$, Manuel Murgioni $^{3}$, Giulia Valerio1 ${ }^{1}$, Steven C. Chapra ${ }^{2}$, Matteo Balistrocchi ${ }^{1}$ \\ and Luca Milanesi ${ }^{1}$ \\ 1 Dipartimento di Ingegneria Civile Ambiente Territorio Architettura e Matematica, Università degli Studi di \\ Brescia, Brescia, Italy \\ ${ }^{2}$ Civil \& Environmental Engineering Department, Tufts University, Medford, MA 02155, USA \\ ${ }^{3}$ Acque Bresciane - Servizio Idrico Integrato, Rovato (BS), Italy \\ *email: marco.pilotti@unibs.it
}

\begin{abstract}
The research is motivated by the need to understand the nutrient pollution dynamics in combined sewer overflows (CSOs) contributing to the eutrophication of Lake Iseo, the fifth largest Italian lake in terms of volume. To this end, the effectiveness of the combined sewer system along the lake's eastern shore is assessed. The sewer's efficiency is quantified with regard to the residual nutrients load from CSOs, which was originally reckoned at no more than $3 \%$ of the overall sewer load. A hydrodynamic model of the sewer system was developed by SWMM and calibrated by a long time series of measurements collected at two selected CSOs. This data allowed to investigate in detail the occurrence of first flush and to estimate the pollutant loads discharged during wet weather periods. The calibrated model then allowed to extrapolate the results of the year-long campaign to a 10year simulation period providing, for the first time, quantitative information on the total residual loads to the lake. Such loads are at least 5 times larger than the design value. This research provides important insight into the potential impact of CSOs on the other deep lakes of the pre-alpine chain (e.g., lakes Como, Maggiore, and Garda in Italy), that are struggling with growing environmental stressors, opening the way to important technical and management considerations regarding remedial actions.
\end{abstract}

Keywords: Water quality monitoring; Combined sewer modelling; Lakes eutrophication

\section{INTRODUCTION}

Lake Iseo is one of Europe's most important sub-alpine lakes (area of $61 \mathrm{~km}^{2}$; maximum depth of $258 \mathrm{~m}$ ) and is a fundamental economic and environmental resource for Italy. During the second half of the 20th century it underwent a transition from oligotrophy to eutrophy and the oxygen content of the bottom waters decreased from $9 \mathrm{mg} / \mathrm{l}$ (in 1967) to zero from mid-1995s till the mid-2000s (Pilotti et al., 2014). There is evidence that complete overturn is becoming less frequent and in the future the lake could likely turn meromictic. Undoubtedly, the high human pressure in the lake's watershed can be blamed for the gradual increase of the trophic level, coupled with the accumulation of nutrients deriving from the limited exchange of deep waters. From this viewpoint, the situation is further hindered by current climatic trends, that may completely prevent the regular overturn of deep water (Valerio et al., 2015).

In this study, we focused on the lake's eastern coastal area. Over the last 15 years, a combined sewer pipe was constructed along the lake shore (Figure 1). This was intended to limit the nutrient load discharged into the lake, improving its water quality. The design was predicated on the assumptions that the pollutant concentrations in the discharge overflows during wet weather periods is low, and that overflows seldom happen with limited volumes. 


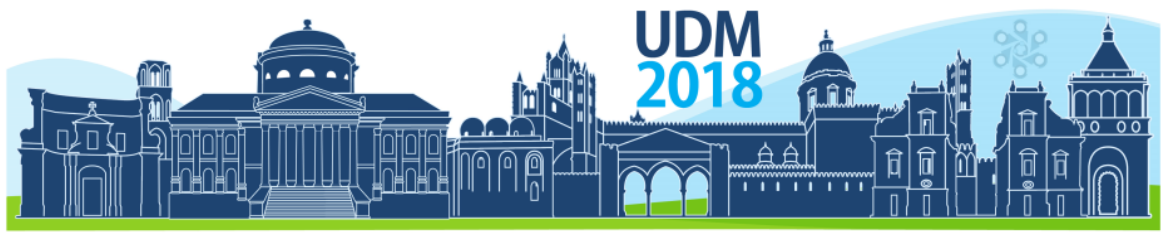

$11^{\text {th }}$ International Conference on Urban Drainage Modelling

23-26 Sep | Palermo - Italy

Unfortunately, the improvement was only partial because during wet periods the mix of stormwaters and wastewaters frequently exceeds the sewer conveyance and treatment plant processing capacities, with a significant excess load discharged directly into the lake through combined sewer weirs. Our study quantified the actual residual load still delivered to the lake, that might trigger lake eutrophication and bacterial pollution. To this end, for the first time in the history of the deep Italian lakes, we implemented a monitoring and modelling effort to better understand the hydraulics of the main sewer and its interaction with the lake. The fundamental steps to better understand the main pipe hydraulics are related to the quantification in time and space of the amount of infiltration from the groundwater and the lake, as well as the frequency and amount of sewage overflows entering the main pipe from the municipal sewers. These results were obtained through an extensive coupled modelling and experimental activity.

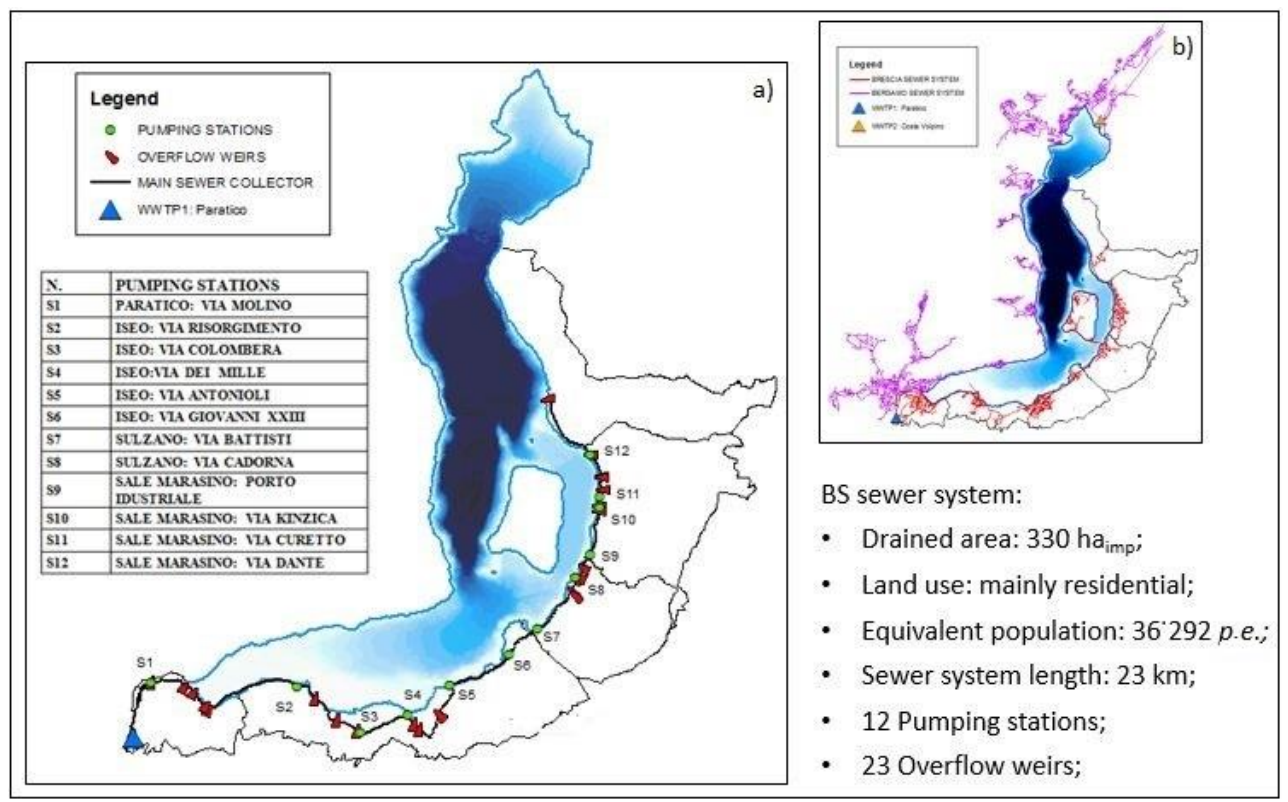

Figure 1. Main sewer pipe draining the eastern shore of Lake Iseo (Brescia) showing pumping stations and overflow weirs (a). Brescia sewer system (red) and Bergamo sewer systems (pink) around Lake Iseo (b).

\section{MATERIALS AND METHODS}

\subsection{The hydraulic-hydrological and water quality model}

After conducting a detailed survey of the geometric data and management practices of the pipes, of the pumping stations and of the combined overflow weirs, the hydrologic-hydraulic behaviour of the main sewer pipe was modelled by using EPA's SWMM (Storm Water Management Model) software. The main sewer network has a length of $23 \mathrm{~km}$ and collects the sewage coming from several secondary (or "municipal") sewers, that drain lateral urbanised watersheds of the overall catchment. Owing to the complexity of the overall system and due to lack of adequate geometrical information, we eventually decided to monitor and model in detail only two municipal sewer systems (Corte Franca and Provaglio d'Iseo), whereas the contributions coming from the other secondary sewers were represented as lumped systems and inserted directly at their junction with the main sewer. The detailed study of these two systems provides valuable information on the behaviour of the other unmonitored subcatchments and demonstrated that SWMM model suitably reproduced rainfall-runoff transformation processes. The urbanized drained areas in the watershed were identified 


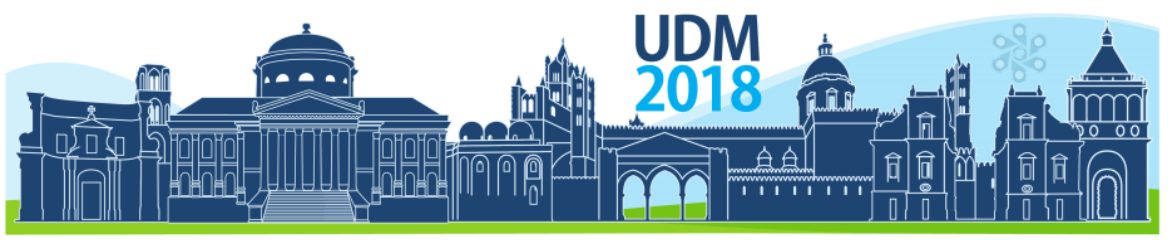

$11^{\text {th }}$ International Conference on Urban Drainage Modelling

23-26 Sep | Palermo - Italy

through a pre-processing of Sentinel 2 satellite images, with a resolution of $10 \mathrm{~m}$. Three rain gauges located within the watershed of Corte Franca and two within Provaglio provided the rainfall series necessary as input for the municipal hydrological model. Both the sewers have a lateral weir upstream of the junction with the main sewer. To verify the results obtained by the model, the complex hydraulic functioning of these weirs was monitored through a detailed measuring campaign and numerically modeled in MATLAB, using a simple 1D approach (e.g. Maranzoni et al., 2017).

The overall hydraulic model of the main pipe was widely calibrated by operating it on the base of Sarnico rainfall series provided by ARPA Lombardia (time step: 10 minutes) and infiltrations for the year 2016 and by comparing the results with measured flow at Paratico (time step 5 minutes), the pipe outlet. The linear correlation between measured average daily flow and model results obtained is equal to 0.90 (Figure 2). The models show that critical events leding to sewer overflows are more frequent than expected and provide the means to calculate the frequency and the volumes of the residual discharged sewage.

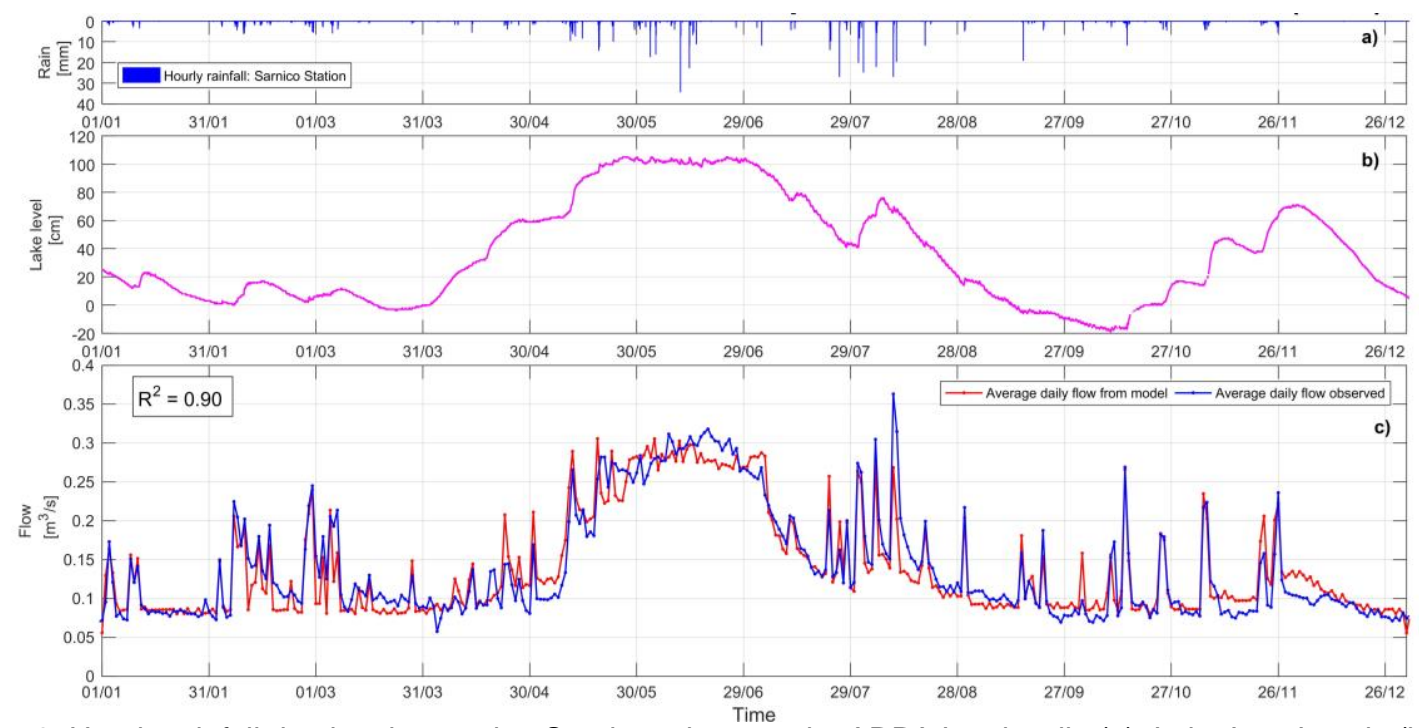

Figure 2. Hourly rainfall depths observed at Sarnico raingauge by ARPA Lombardia (a). Lake Iseo Levels (b). Comparison between measured and modelled average daily flowrates at the pipe outlet for the year 2016 (c).

The model was validated in correspondence of some events of 2017 by comparison between modelled and measured flowrate entering in the terminal part of Brescia main pipe and between discharged flow from terminal CSO of the main pipe at Paratico. The measured data about flow discharged by the latter CSO are available from May 2017. In Figure 3, an example of model validation is shown.

\subsection{Field measurements}

The significant impact on the quality of receiving water bodies related to stormwater uncontrolled discharge is a well know issue in literature since decades (Sartor and Boyd, 1972; EPA, 1993). Hence, a number of studies have been performed to investigate this crucial issue under various perspectives: assessing pollution dynamics in combined sewer systems, in particular the occurrence of the first flush phenomenon (Bertrand-Krajewski et al., 1998; Sansalone and Cristina, 2004, Bach et al., 2010), evaluating the efficiency of stormwater storage tanks (Balistrocchi et al., 2009), reducing the impact on receiving water bodies 


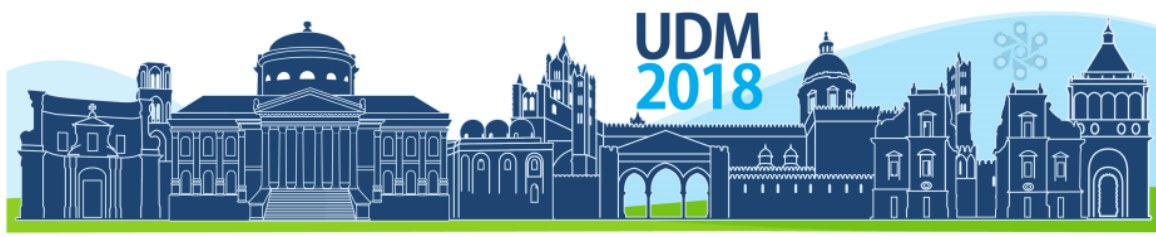

$11^{\text {th }}$ International Conference on Urban Drainage Modelling

23-26 Sep | Palermo - Italy

(Todeschini et al., 2011), and improving sampling techniques for quality monitoring (McCarthy et al., 2018).

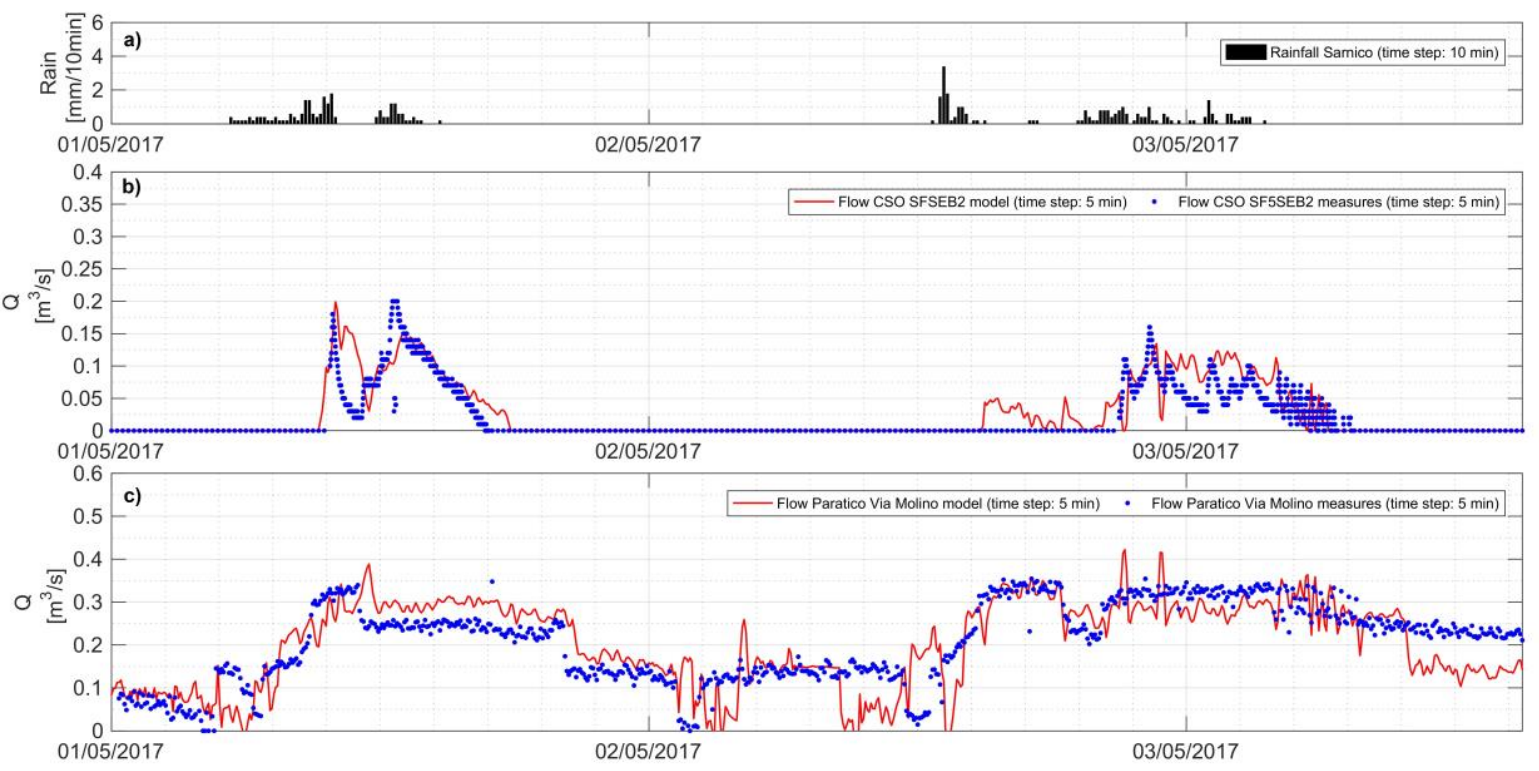

Figure 3. Rainfall depths observed at Sarnico raingauge by ARPA Lombardia (time step 10 minutes) (a). Measured and modelled flow discharged by the terminal weir of main pipe at Paratico, Via Marconi (time step 5 minutes) (b). Comparison between measured and modelled flowrates at the pipe outlet for the period 01/05/201-3/05/2017 (time step: 5 minutes), out of the calibration period (c).

To this purpose, the site of the terminal overflow weir (OW) of the municipal sewer system of Corte Franca was instrumented. At this site, the incoming flow was measured by a Bazin weir. Downstream, a lateral weir, controlled by a flap gate, and a Venturi channel are present. Two ultrasonic level sensors were installed, one upstream of the Bazin weir and another upstream of the Venturi channel. A mathematical model of this site was developed and, using the measured data, successfully calibrated, to obtain flowrates from levels. An automatic sampler was installed and nutrient concentrations in the overflow were measured. Furthermore, a multiparameter probe was installed to obtain a continuous time series of specific conductivity and temperature. Finally, a second automatic sampler with an ultrasonic level sensor for the estimation of the flow discharged into the lake was placed at the lateral weir along the main pipe at Paratico.

\section{RESULTS AND DISCUSSION}

\subsection{Results}

Using available rainfall data, the calibrated model was used to reproduce the behaviour of the sewer during the last 10 years. This allowed us to compute, for the first time, the frequency, volume and residual mass delivered to the lake from the sewer. The results indicate that the residual loads from the CSOs are at least 5 times larger than the design value. The measured data during CSOs at the OW of Corte Franca showed the high concentration of pollutants in the wet weather flow as well as the occurrence, in most events, of maximum concentration during the first part of the stormwater runoff (first flush flow). On the other hand, the analysis 


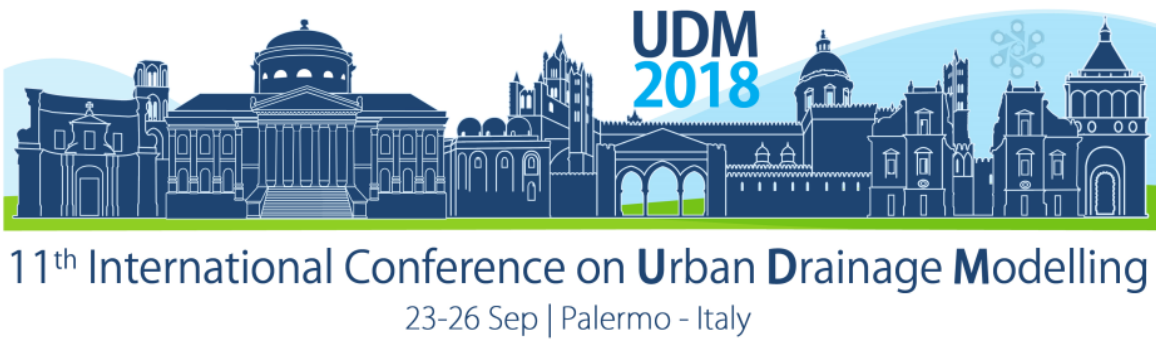

of measured data in the flow discharged directly from the main pipe at the Paratico OW did not indicate first-flush occurrence, with concentrations relatively constant during events.

\subsection{Discussion}

In addition to provide important insights into the hydraulic functioning of the sewer network, the model provides a useful tool for improving the management of the sewer system. For instance, it has been used to quantify economic saving in terms of energetic costs that would be obtained by eliminating infiltration. The quality of the results provided by the mathematical model of Corte Franca and Provaglio weirs shows that, using level sensors at other sites, reliable stagedischarge curves could be obtained. Furthermore, the comparison between measured flow and flow obtained with SWMM at the outlets of the two municipal sewer systems demonstrate the reliability of the implemented model. The analysis of concentrations of nutrients discharged by the weirs of Corte Franca and Paratico underscores that the first flush phenomenon occurs in CSOs of municipal sewers while in the overflow from main pipes the concentration remains constant during the events.

\section{CONCLUSIONS}

The main goal of this study was the modelling of the combined sewer serving the east shore of Lake Iseo, and to compute the mass of pollutants produced in the watershed that still overflows into the lake during wet weather. The quantification of volumes and pollutant masses can lead to the design of systems suitable to reduce the overflow weir impact on the receiving water bodies, i.e. storage tanks or constructed wetlands. We believe that this research provides valuable information about the potential impact of CSOs on the other deep Italian prealpine lakes, that are struggling with growing environmental stressors, opening the way to important technical and administration considerations regarding management and remediation.

\section{References}

Bach, P.M., McCarthy, D.T., Deletic, A. (2010). Redefining the stormwater first flush phenomenon, Water Res., Volume 44, Issue 8, pages 2487-2498.

Balistrocchi, M., Grossi G., Bacchi, B. (2009). An analytical probabilistic model of the quality efficiency of a sewer tank, Water Resour. Res., Volume 45, Issue 12, W12420.

Bertrand-Krajewski, J.L., Chebbo, G., Saget, A., (1998). Distribution of pollutant mass vs volume in stormwater discharges and the first flush phenomenon, Water Res., Volume 32, Issue 8, pages 2341-2356.

Environmental Protection Agency (1993). Urban runoff pollution prevention and control planning, U.S. Environmental Protection Agency, Report EPA/625/R-93/004, Cincinnati, Ohio.

Maranzoni, A., Pilotti, M., Tomirotti M. (2017). Experimental and numerical analysis of side weir flows in a converging channel, J. Hydraulic Eng. ASCE, Volume 143, Issue 7, 04017009.

McCarthy, D.T., Zhang, K., Westerlund, C., Viklander, M., Bertrand-Krajewski, J.-L., Fletcher, T.D., Deletic, A. (2018). Assessment of sampling strategies for estimation of site mean concentrations of stormwater pollutants Water Res., Volume 129, pages 297-304.

Pilotti, M., Simoncelli, S., Valerio, G. (2014), A simple approach to the evaluation of the actual water renewal time of natural stratified lakes, Water Resour. Res., Volume. 50, Issue 4, pages 2830-2849.

Sansalone, J.J., Cristina, C.M. (2004). First flush concepts for suspended and dissolved solids in small impervious watersheds J. Environ. Eng., Volume 130, Issue 11, pages 1301-1314.

Sartor, J.D., Boyd ,G.B. (1972). Water pollution aspects of street surface contaminants, Environmental Protection Agency Report R2-72-081-USEPA, Washington.

Todeschini, S., Papiri, S., Sconfietti, R. (2011). Impact assessment of urban wetweather sewer discharges on the Vernavola River (Northern Italy), Civ. Eng. Environ. Syst., Volume 28, Issue 3, pages 209-229.

Valerio, G., Pilotti, M., Barontini, S., Leoni, B. (2015), Sensitivity of the multiannual thermal dynamics of a deep prealpine lake to climatic change, Hydrological Processes, Volume 29, Issue 5, pages 767-779. 


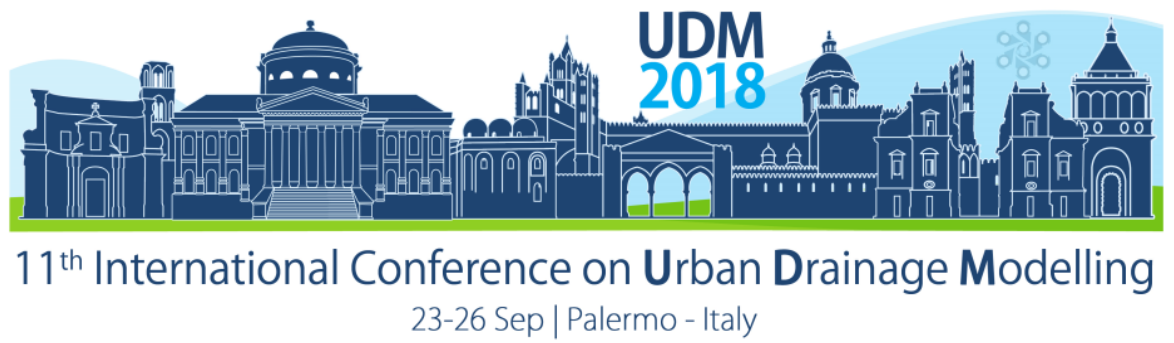

\title{
Multiregression analysis of the kinetic constants in ephemeral rivers: the case study of the Oreto river
}

\author{
Angela Candela, Giorgio Mannina and Gaspare Viviani \\ University of Palermo, DICAM, Palermo, Italy \\ (angela.candela@unipa.it,giorgio.mannina@unipa.it,gaspare.viviani@unipa.it)
}

\begin{abstract}
Profuse efforts have been committed to develop efficient tools to measure the ecological status of the receiving water body quality state. The recurrence to mathematical models as support tools for the receiving water body quality assessment can be an optimal choice. Indeed, mathematical models can allow to build-up the cause effect relationship between polluting sources and receiving water quality. Regarding the river water quality modelling, two different kinds of river can be single out: large and small rivers. In the modelling approach, the main differences between the two types of rivers are reflected in the model kinetic constants. Indeed, the main quality processes which control and govern the quality state play a differ rule. As a results, the application of model approaches as well as kinetic constants derived for large river, can lead to wide biases thus misevaluating the river quality state. The paper presents a study where a multiregression analysis was carried out for assessing relationships to be employed for the evaluation of the kinetics constants for small rivers. To accomplish such a goal, the kinetic constants derived by a previous application of a river water quality model applied to a real case study were used. Such kinetics constants were employed for deriving new multiregression equations for the assessment of the kinetics constants for small rivers.
\end{abstract}

Keywords: Water quality modelling, reareation constants, model calibration

\section{INTRODUCTION}

Environmental quality preservation is one of the main goals of the EU Water Framework Directive in order to achieve a good quality status in surface waters (Even et al., 2007; Ani et al., 2009; Wagenscheinand and Rode, 2008). However, such water quality models require accurate model calibration, in order to specify model parameters, that requires an extensive array of water quality data that are, generally, rare and resource-intensive. Many of the major results from studies of large rivers could not be applicable to small rivers (Mannina and Viviani, 2010a,b,c). Indeed, small rivers, as ephemeral Mediterranean rivers are, have certain unique features, due to the fact that for them, the role played by physical/chemical/biological processes is different, and parameter values for modelling these processes can differ by as much as an order of magnitude from larger riparian systems. Indeed, for instance as pointed out by Kirk (1994) the atmospheric reaeration can be much higher for small rivers due to the fact that they are characterized by shallow water depths (which have higher surface area-to-volume ratios than larger rivers) and, especially during storm events when the discharged flow is generally higher compared to the base flow; in such a case, the major oxygen contribution comes from the reaeration with the atmosphere due to the intense flow turbulence. These facts constitute major complications in the application of water quality models, such as those provided by the US Environmental Protection Agency: QUAL2E (Brown and Barnwell, 1987), QUAL2K (Chapra and Pellettier, 


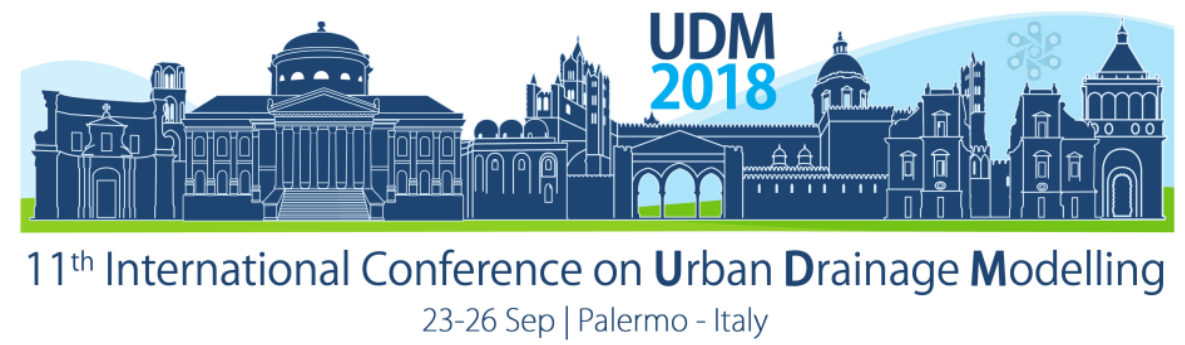

2003), WASP6 (Wool et al., 2006), or the IWA River Quality Model No. 1 (Reichert et al., 2001), which require more information regarding the river system than is often available. To cope with such a problems parsimonious models are advisable which, as every model, need to be calibrated. Despite the potentiality of such empirical equations, attention has to be paid on their usage due to the fact that they were derived almost for large rivers. Indeed, as recently demonstrated by Mannina and Viviani (2010a), kinetic constants for small rivers can be order of magnitude different from those of small river. Bearing in mind such considerations, the paper explore the possibility to adapt previous empirical equations first derived for large rivers to small ones.

\section{MATERIALS AND METHODS}

\subsection{The river water quality model}

The model is based on a modified version of the Streeter-Phelps model. It takes into account the following processes: degradation of dissolved carbonaceous substances; ammonium oxidation; algal uptake and denitrification; dissolved oxygen balance including depletion by degradation processes and supply by physical reaeration and photosynthetic production. It is described, in details in Mannina and Viviani (2010a).

\subsection{Case study}

The analysis was applied to an Italian river: the Oreto river. Its catchment is located near Palermo in the north-western part of Sicily, Italy (Fig. 1) and covers an area of $110 \mathrm{~km}^{2}$. Residential, commercial, agricultural, and industrial settlements cover almost the entire area. The hydrological response of this basin is dominated by long dry seasons followed by wet periods during which even large inputs of rainfall may produce little or no response at the basin outlet. The measurement network consists of six rain gauges managed by the Regional Hydrographic Service, and one level gauge, located $10 \mathrm{~km}$ upstream on the river's mouth. The river receives a number of point-source discharges from small villages and some periurban areas on the outskirts of Palermo, most of them untreated. The river has been divided into 12 cross sections for monitoring. Five point sources have been identified along the river and these contribute significantly to the evaluation of the receiving water body quality state (Fig. 1).

For each cross section, both flow and water quality data were collected, in terms of: water temperature, $\mathrm{O}_{2}, \mathrm{BOD}, \mathrm{COD}, \mathrm{NH}_{4}, \mathrm{NO}_{3}$, SST, total phosphorus, and ortho-phosphate, in order to describe the physical, chemical and microbiological characteristics of the river water. Stream water samples were collected approximately once every three months from Jan 1998 to Dec 1999. Therefore, a total of six measuring campaigns were carried out, building a discrete data set for the assessment of the river's water quality. Concerning the river's morphology, two main stretches have been identified for the Oreto, with average slopes of $4.6 \%$ and $1.1 \%$. and model parameters have been calibrated separately for each stretch. The Oreto's catchment is affected by point sources rather than non point sources, the latter constitute a small amount of the total load, less than $5 \%$ (Candela et al., 2004). For such a reason, in the presented modelling approach, diffuse sources have been neglected. 


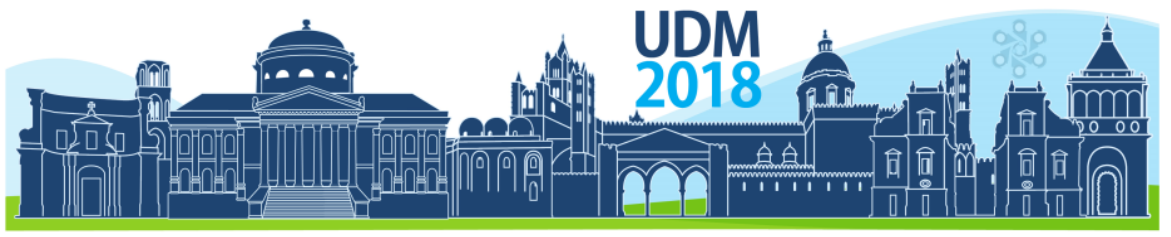

$11^{\text {th }}$ International Conference on Urban Drainage Modelling 23-26 Sep | Palermo - Italy
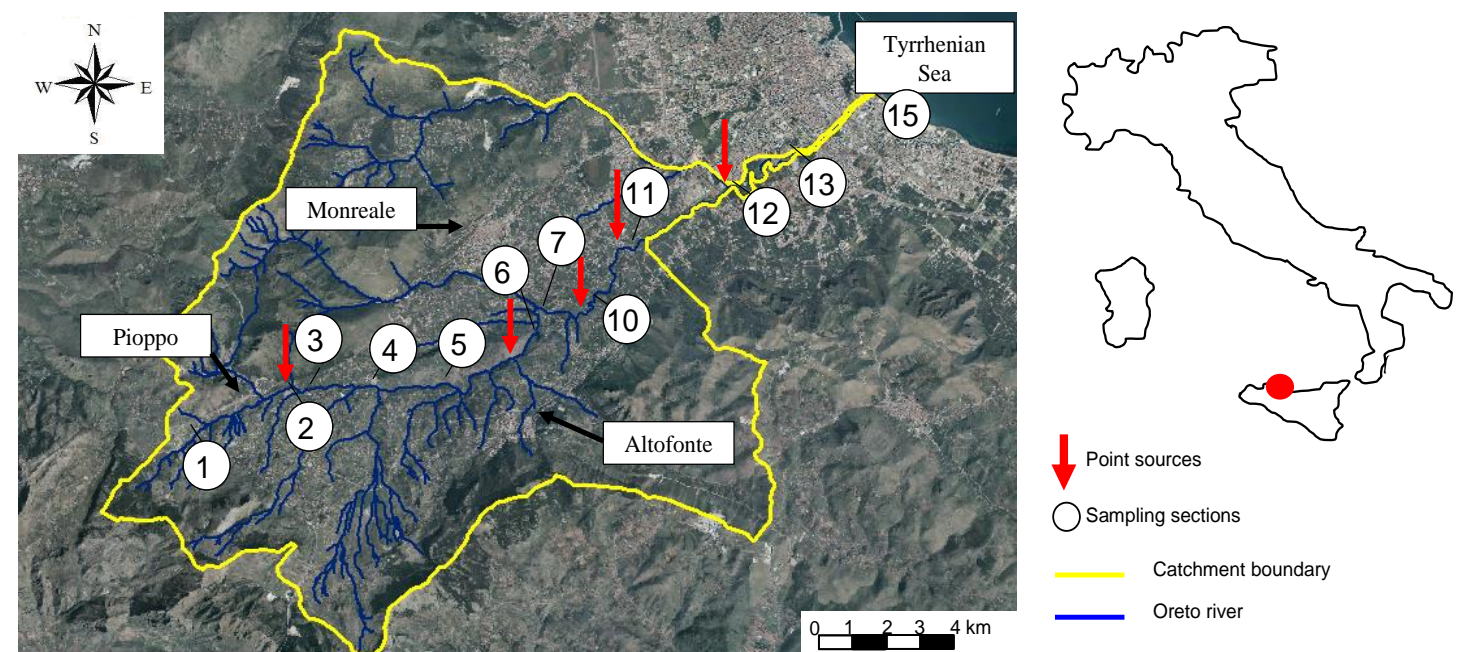

Figure 1. Oreto catchment and sampling sections considered in the monitoring campaign.

\section{RESULTS AND DISCUSSION}

The river water quality model was calibrated to the Oreto river. The results of the calibrated river quality model showed satisfactory agreement with the measured data and results revealed important differences between the kinetic river constants used to model small rivers as compared to those for large rivers (Mannina and Viviani, 2010a; Mannina, 2011). Particularly, in terms of reareaction coefficient, the calibrated values for the Oreto river were of orders of magnitude higher than the literature values (O' Connor and Dobbins, 1956; Owens et al., 1964; Bennett and Rathburn, 1972; Thyessen et al., 1987). These results appeared related to the different roles played by physical-chemical-biological processes in small rivers as compared to larger systems. As a consequence, a multiregression analysis has been carried out in order to point out general relationships for small rivers between kinetic river constants (i.e. reareaction coefficient, $K_{R}$ ) and river characteristics, both morphological and hydraulic. Particularly, it was hypothesised that $K_{R}$ coefficient could be expressed as a function of one or more of the following variables:

$$
K_{R}=f(U, H, S, T)
$$

where $U[\mathrm{~m} / \mathrm{s}], H[\mathrm{~m}], \mathrm{S}[\mathrm{m} / \mathrm{m}]$ and $T\left[{ }^{\circ} \mathrm{C}\right]$ are, respectively, the mean flow velocity, the mean flow dept, the river slope and the water temperature in the generic river cross section.

The data was subject to different regression equations: multiple linear (LIN), multiple exponential (EXP) and sum of exponential (EXPSUM) to establish possible relationship for $K_{R}$ coefficient and the various river characteristics. Two statistical indicators were used to assess the goodness of fit of the resultant formulae and these were the sum of squared errors in the form of Nash and Sutcliffe (1970) Efficiency Criterion (NS), and the Root Mean Square Error (RMSE) as measure of accuracy of prediction. The calibration of all regression equation was carried out considering all monitoring campaign for each river stretch taking into account the different river slope values. A Monte Carlo procedure was used to generate large numbers $\left(10^{4}\right)$ of sets of parameters for all models, each parameter value being drawn from feasible ranges. Simulations were performed for each stretch and for each parameter set for comparison with calibrated reareaction coefficients. Specifically, 10000 Monte Carlo 


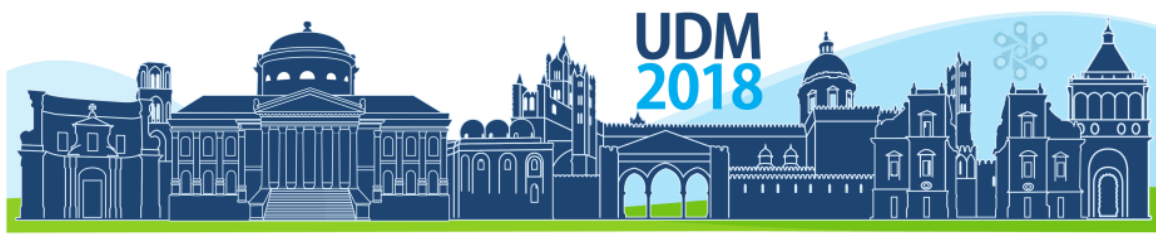

$11^{\text {th }}$ International Conference on Urban Drainage Modelling

23-26 Sep | Palermo - Italy

runs were generated considering a uniform random sets of regression coefficients and using these sets to perform model simulation in terms of NS efficiency and RMSE.

As example figure 2 shows for a particular regression equation (EXPSUM01 for stretch 2) scatter plots for the efficiency based on NS for each parameters sampled. Each dot represents one run of the model with different randomly chosen parameter values within the feasible ranges. These dotty plots are projections of the surface of the likelihood measure within a three dimension parameter space into single parameter axes. In particular, the most parameters are $c_{0}$ and $c_{1}$, meanwhile, $c_{2}$ shows a classical equifinality behaviour; indeed, different combinations of model parameters values are capable of producing outputs with similar performance statistics (Beven and Binley, 1992). A best fit parameter set has been fixed for all parameters distributions; these sets have been chosen corresponding to maximum efficiency values in terms of NS and to minimum values of RMSE.

For each river stretch, parameter set values for maximum efficiency and corresponding NS and RMSE values have been assessed. Particularly, for the first stretch NS value ranging from 0.02 to 0.64 and the RMSE ranging from 300.00 to 155.27 ; for the second stretch the NS values ranging from 0.17 to 0.99 and the RMSE ranging from 237.29 to 2.59. Comparing results, in terms of NS and RMSE values, is difficult to assess the best configuration model. On the whole, the best regression equations are functions of $U$ and $H$ variables.
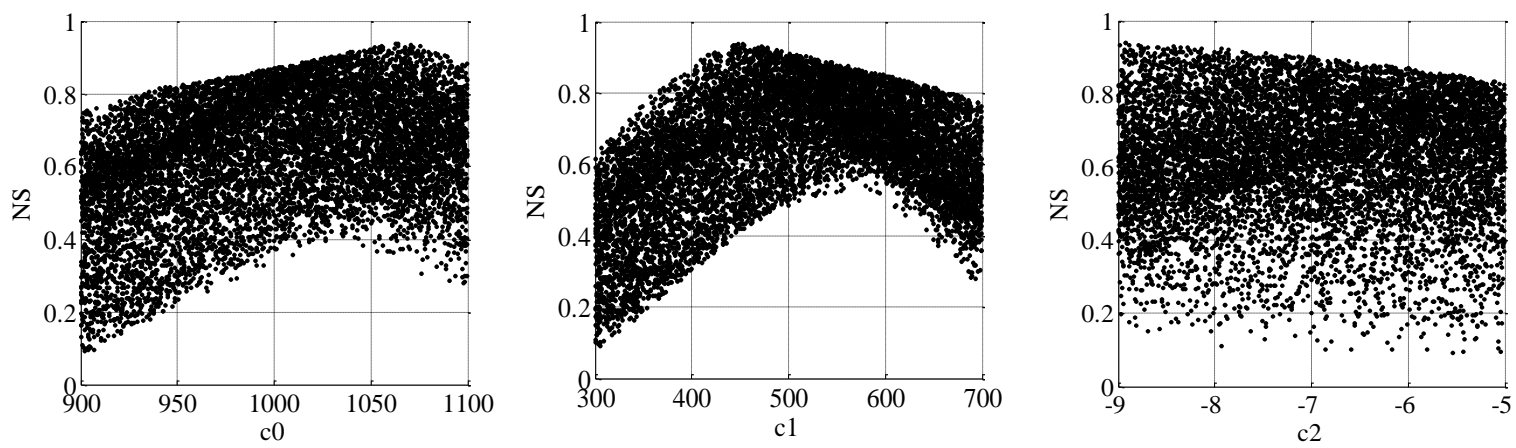

Figure 2. Scatter plots of EXPSUM01 model parameters.

The coefficients of the equations are site specific and are function of the river characteristics, both morphological and hydraulic. With further similar analysis of data from others similar catchments it may be possible to establish standard coefficients for application to made to a range of small catchments and ephemeral river systems

\section{CONCLUSIONS}

Multiregression analysis were carried out in order to point out general relationships for small rivers between kinetic constants and river characteristics, in terms of flow velocity, flow dept, the river slope and the water temperature along a river. The modelling methodology proposed was used in order to select and develop the most appropriate models to simulate kinetic constants in ephemeral rivers. The usefulness of the regression models was assessed by comparing the results of a river water quality model developed in previous studies with calibrated kinetic constants. Reasonable agreement was observed for the majority of the configuration empirical equations. Comparing results, in terms of NS and 


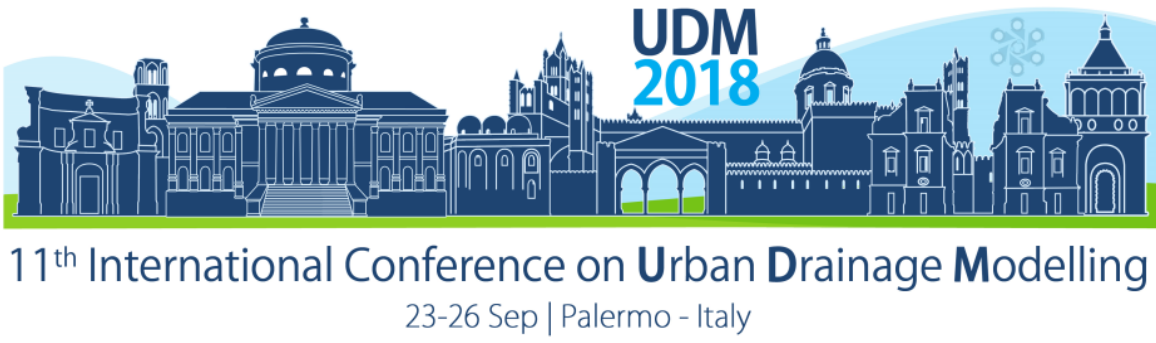

RMSE values, it was difficult to assess the best equations, although $U$ and $H$ variables seemed to be the most significant.

It was concluded, therefore, that within the limitations of the regressional approach adopted, the kinetic river constants may be predicted, with reasonable confidence, using the derived relationships between the flow velocity, the flow depth, the river slope and the water temperature along the river. The derived equations, which at this stage are site specific, may be used to establish significant relationship, more general, between the kinetic river constants and river characteristics.

\section{References}

Ani, E.C., Wallis, S., Kraslawski, A., and Agachi, P.S. (2009) Development, calibration and evaluation of two mathematical models for pollutant transport in a small river. Environ. Model. Soft., 24(10), 1139-1152.

Bennett JP, and Rathburn RE. (1972) Reaeration in open-channel flow. USGS Professional paper. 737:75.

Beven, K.J., and Binley, A.M. (1992), The future of distributed models - model calibration and uncertainty prediction, Hydrol. Proc. 6(3), 279-298.

Brown L.C., and Barnwell, T.O. (1987), The Enhanced Stream Water Quality Models QUAL2E and QUAL2EUNCAS EPA/600/3-87-007, U.S. Environmental Protection Agency, Athens, GA.

Candela, A., Cannarozzo, M., Nicosia, S., Torregrossa, M., and Viviani, G. (2004) Monitoring activity to assess quality condition of a river: the case study of Oreto, Italy. Proceed. Simposio Internazionale di Ingegneria Sanitaria ABES - ANDIS, Taormina, 23 - 26 June.

Chapra S., and Pellettier, G. (2003), QUAL2K: A Modeling Framework for Simulating River and Stream Water Quality. Documentation and Users Manual, Civil and Environmental Engineering Dept., Tufts University, Medford.

Even, S., Mouchel, J.M., Servais, P., Flipo, N., Poulin, M., Blanc, S., Chabanel, M., Paffoni, C., (2007) Modelling the impacts of combined sewer overflows on the river Seine water quality. Sci Total Environ 375, 140-151.

Freni, G., Mannina, G., and Viviani, G. (2008), Uncertainty in urban stormwater quality modelling: The effect of acceptability threshold in the GLUE methodology, Water Res, 42(8-9), 2061-2072.

Freni, G., Mannina, G., and Viviani, G. (2009), Identifiability analysis for receiving water body quality modeling, Environ ModellnSoftw, 24(1), 54-62.

Kirk JTO. (1994) Light and photosynthesis in aquatic environments, 2nd ed.Cambridge University Press, p.509.

Mannina G. (2011) Uncertainty assessment of a water quality model for ephemeral river using GLUE analysis. J. Environ Engin (ASCE), 137(3), 177-186.

Mannina, G. and Viviani, G. (2010a) Water quality modelling for ephemeral rivers: model development and parameter assessment. J Hydrol, 393(3-4), 186-196.

Mannina, G. and Viviani, G. (2010b) An urban drainage stormwater quality model: Model development and uncertainty quantification. J Hydrol, 381(3-4), 248-265.

Mannina, G. and Viviani, G. (2010c) A parsimonious dynamic model for river water quality assessment. Water Sci Techol, 61(3), 607-618.

O'Connor DJ, and Dobbins WE. (1956) Mechanism of reaeration in natural streams. Trans Am Soc Civil Eng 1956;123, $641-667$.

Owens M, Edwards R, and Gibbs J. (1964) Some reaeration studies in streams.Int J Air Water Pollut; 8, 469 486.

Reichert, P., Borchardt, D., Henze, M., Rauch, W., Shanahan, P., Somlyody, L., and Vanrolleghem, PA., (2001), River Water Quality Model 1, IWA, London.

Thyssen N, Erlandsen M, and Jeppesen E, (1987) Reaeration of oxygen in shallow, macrophyte rich streams: IDetermination of the reaeration rate coefficient. Int Revue ges Hydrobiol, 72(4), $405-429$.

Wagenschein, D., and M., Rode, (2008), Modelling the impact of river morphology on nitrogen retention-A case study of the Weisse Elster River (Germany). Ecol. Modell, 211, 224-232.

Wool, T.A. Ambrose, R.B., Martin J.L., and Comer, E.A. (2006), Water Quality Analysis Simulation Program (WASP) Version 6.0 DRAFT: User's Manual, U.S. Environmental Protection Agency, Athens, GA. 


\section{Part D - Rainfall in urban areas}




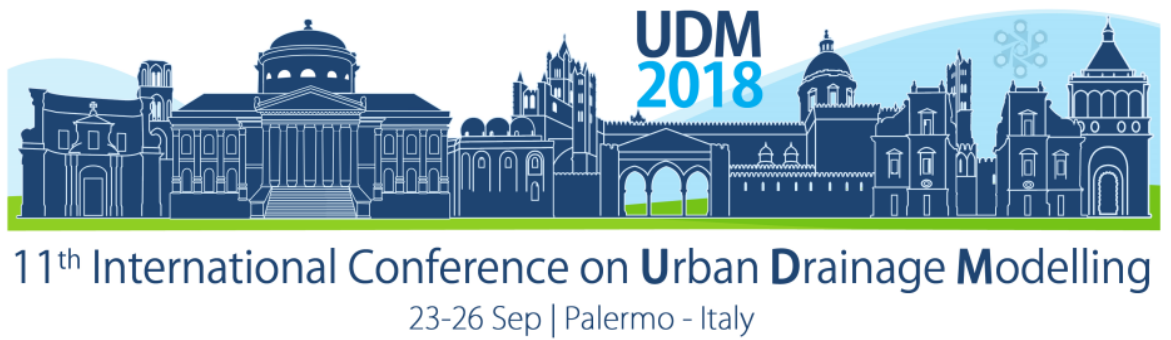

\title{
A Generator-Disaggregation Approach for Evaluating Climate Change Impact on Urban Drainage
}

\author{
Wei Lu, Xiaosheng Qin* \\ School of Civil and Environmental Engineering, Nanyang Technological University, Singapore \\ xsqin@ntu.edu.sg
}

\begin{abstract}
Climate change on a global scale results in more intensive and frequent extreme rainfall events, which would likely increase the vulnerability of the urban drainage systems. Combing techniques of weather generator, Gumbel distribution, rainfall disaggregation and urban drainage modelling, this study examined impact of climate change on urban drainage flow based on the output from a number of global climate models (GCMs) for the timeline of the second half of this century. The proposed methods were employed on a small catchment in the tropical area for demonstration. The results showed that the selection of different GCMs (i.e., future climate conditions) exerted a remarkable effect on prediction of future maximum daily rainfall and the flooding condition of the drainage system. The impact of climate-induced extreme events is of significant concern and deserves more thorough investigation in the future.
\end{abstract}

Keywords: Climate change impact; urban drainage system; LARS-WG

\section{INTRODUCTION}

Urban drainage system is one of the most essential urban infrastructures to accommodate rainfall-induced runoff and mitigate urban flooding that is of serious concern to damages of transportation, industry and human lives (Lu et al., 2017). Previous studies found that changes in climate (e.g., precipitation and temperature) would increase the vulnerability of urban drainage systems and bring along higher flooding risks (Willems, 2013; Neumann et al., 2015; Lu et al., 2016). However, these studies rarely track from weather generator and GCMs to an actual urban drainage system, and the latest emission scenarios defined by Representative Concentration Pathways (RCPs) are insufficiently employed in previous research works within the context of a tropical city. Therefore, this study reported a preliminary work on assessing climate change impact on daily rainfall and urban drainage system using Singapore climatological condition for case demonstration.

\section{METHODOLOGY}

\subsection{Weather generator and future climate scenarios}

Figure 1 shows a flowchart of the overall methodology. First, the observed weather data for the study location are collected at a daily interval. These data will be used as the input to a weather generator for site analysis and model calibration. In this study, LARS-WG is adopted to simulate the future climate scenarios. It is a single-site stochastic weather generator popularly used to synthesize the current and project the future climate conditions (Semenov et al., 1998). The output from this tool offers useful weather time-series that are of analogous statistical properties as those from the observed data (Semenov et al., 2002). Then, future climate scenarios (i.e., GCMs, emission scenarios and simulation periods) are setup and 


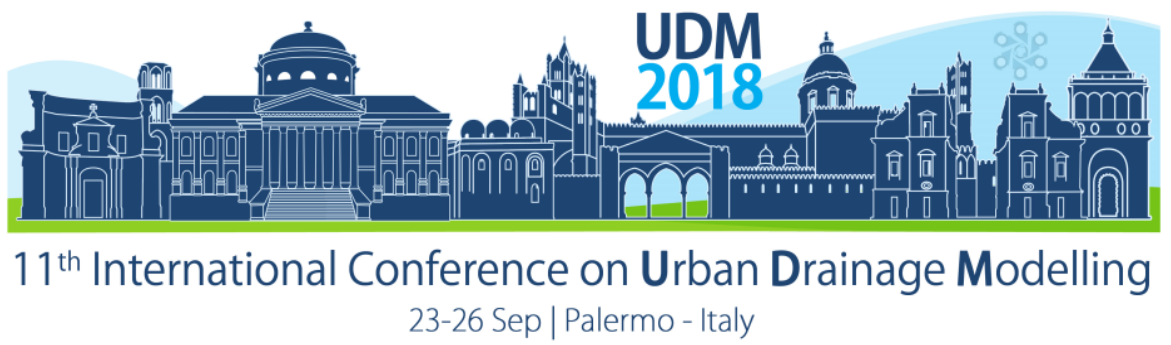

executed by the generator, and the synthesised daily data representing future climatechange scenarios are used for further processing and analysis.

\subsection{Rainfall disaggregation}

The future annual maximum rainfall events are extracted from the generated results of LARS-WG for deriving intensity-duration-frequency (IDF) curves. As LARS-WG only outputs daily climate data, the duration is fixed at 24 hours. Gumbel distribution, as one of the most common extreme value probability density function for analysis of climate extremes and their return levels under a wide range of conditions (Gumbel, 2012; Cheng et al., 2014), is adopted to build the IDF curve and predict the rainfall intensity under certain return periods. For urban drainage modelling, a finer temporal resolution of rainfall is normally desired (Willems, 2013). The US Soil Conservation Service (SCS) rainfall distributions (USDA, 2011; Cronshey, 1986) is then adopted correspondingly. It consists four types of curves in the form of percentage mass curves based on 24-hr rainfall of the desired frequency. A storm with duration of $24-\mathrm{hr}$ is considered acceptable in this work to determine peaks and runoff volumes for relatively large drainage areas.

\subsection{Impact on urban drainage}

Changes in storm intensity associated with climate change may overburden the urban drainage network, which may prompt the decision-makers to increase investment in drainage system upgrading. In this study, the Storm Water Management Model (SWMM) developed by U.S. EPA (Rossman, 2010) was chosen to model the rainfall-runoff process in the study catchment. The disaggregated sub-hourly rainfall events are inputs used for driving the SWMM model. Interested information (e.g., peak flow, time to peak and flood volume of the system) is extracted from the running results, which will be compared with the baseline (i.e., present) scenario.

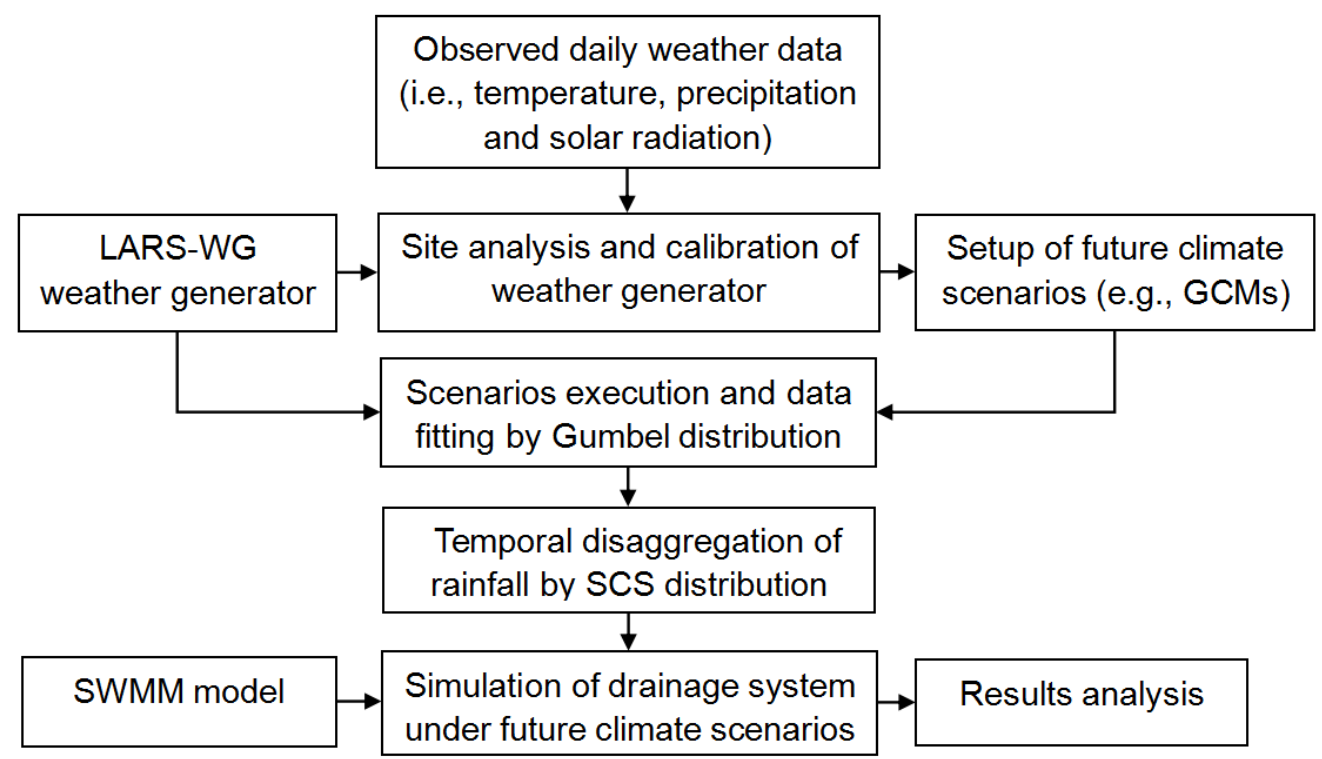

Figure 1. The framework of the proposed study. 


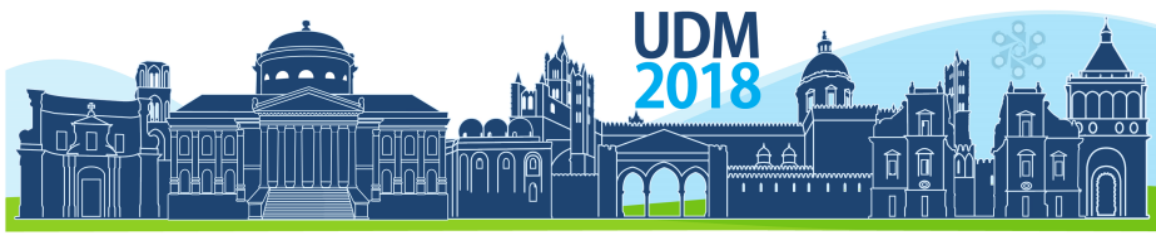

$11^{\text {th }}$ International Conference on Urban Drainage Modelling

23-26 Sep | Palermo - Italy

\section{CASE STUDY}

A hypothetical urban catchment with an area of $25.14 \mathrm{~km}^{2}$, adapted from a typical catchment in Singapore, is selected for demonstrating the methodology. Figure 2 illustrate the layout of the drainage system within this area. The observed weather data (i.e., Max. and Min. temperature, precipitation and solar radiation, all from 1980 to 2010) for the study area are acquired from various sources, e.g. local weather service and Climate Forecast System Reanalysis (NCEP, 2018). LARS-WG has been calibrated based on the observed data accordingly. For future climate scenarios, we adopt five GCMs (as shown in Table 1) with the emission of RCP8.5 and the projection period of 2061-2080. The detailed description of these GCMs can be referred to Semenov and Stratonovitch (2010). The generated annual maximum rainfall series are fitted into Gumbel distribution for deriving future IDF-curves (see Figure 3). According to Code of Practice (PUB, 2011), for a drainage system which serves more than $10 \mathrm{~km}^{2}$, the return periods adopted for the design should be $50-100$ years (here 50 -years is selected). SCS type II distribution is adopted for downscaling the 24-hour rainfall volume to half-hourly time series.

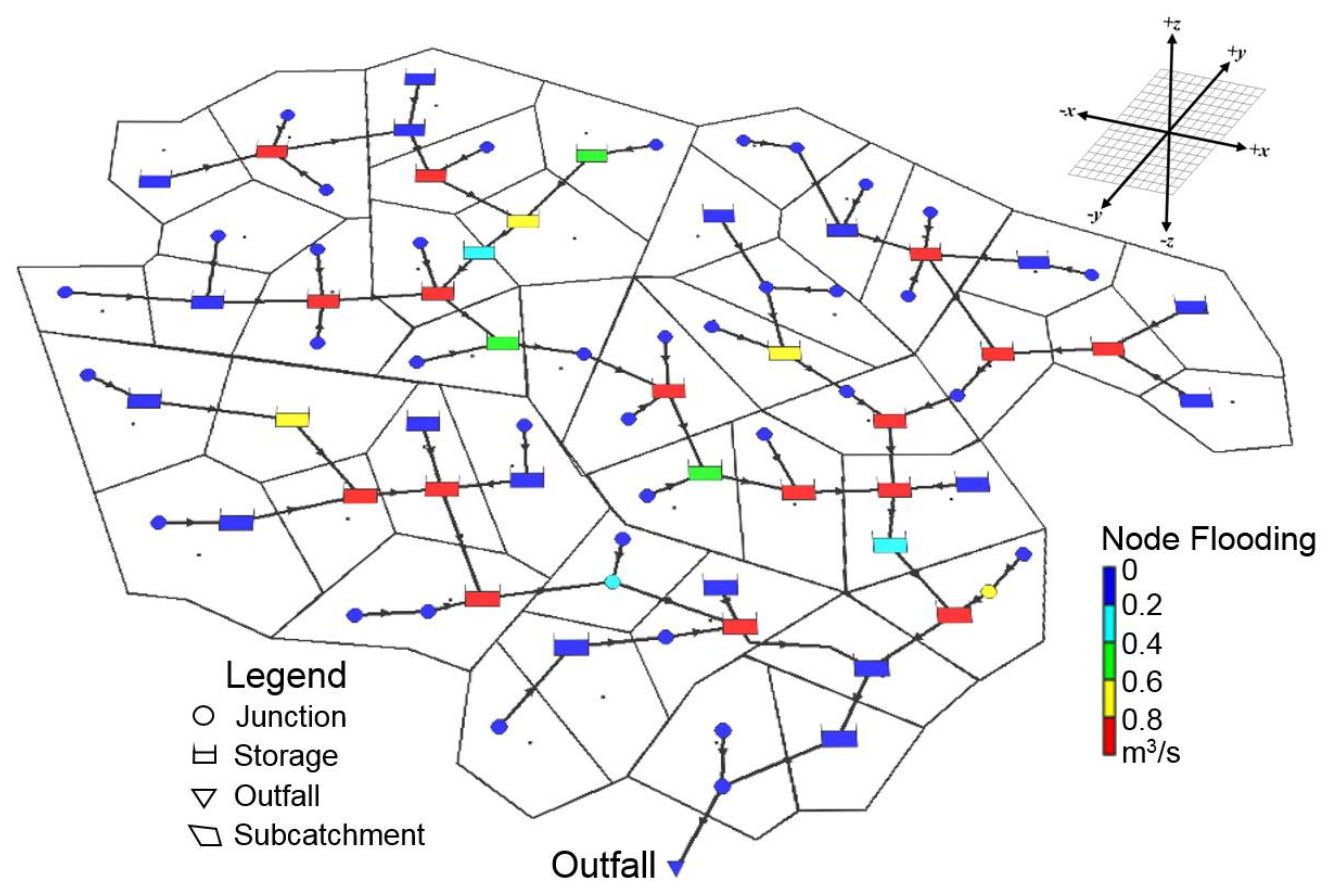

Figure 2. Case study and node flooding at 14:00 under the GCM of CFDL-CM3. 


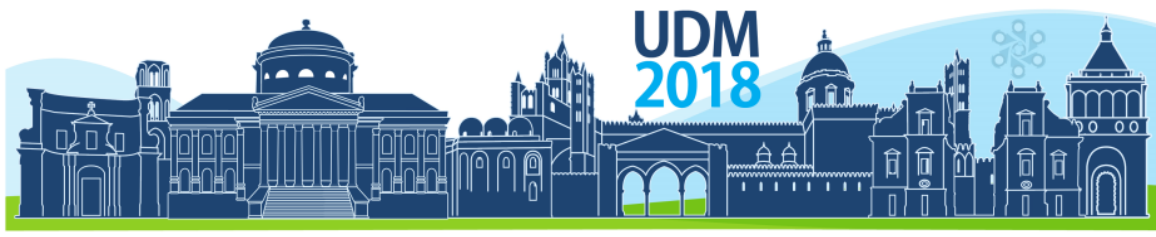

$11^{\text {th }}$ International Conference on Urban Drainage Modelling

23-26 Sep | Palermo - Italy

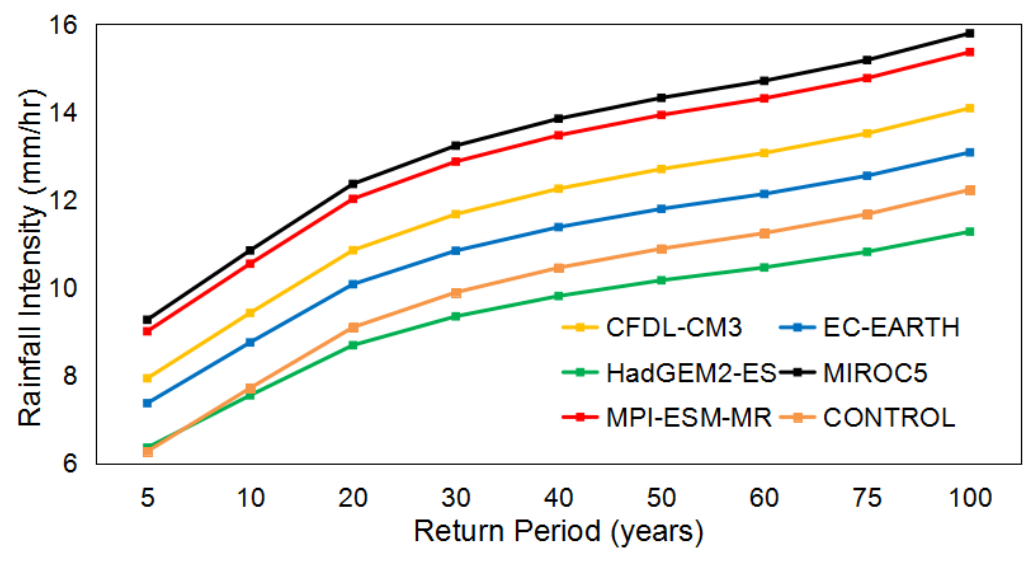

Figure 3. IDF curves from five GCMs and control (baseline) scenario.

Table 1 shows the simulated results of SWMM under the downscaled rainfall events. Indexes for the performance of drainage network are the total runoff volume $T_{r}$ and time to peak $T_{p}$ at the outfall, as well as the total flood volume $T_{f}$ of the system during the events. The total inflow means the total volume of runoff come into the outfall during the entire simulation process. From Table 1, it is clear that under different GCMs, the magnitude of rainfall has limited influence on the outfall loading (i.e. $T_{r}$ and $T_{p}$ ). However, it would affect the flood condition of the whole drainage system. The most severe flood comes from MIROC5 at $1841.3 \mathrm{~m}^{3}$. In contrast, the HadGEM2-ES turns out a flood volume at $846.2 \mathrm{~m}^{3}$, which is even lower than the baseline scenario at $996 \mathrm{~m}^{3}$. As an example, Figure 2 illustrates the flooding on each node at 14:00 (the simulation period is from 0:00 to 24:00) under the GCM of CFDLCM3.

Table 1. Performance of drainage network under baseline and climate change scenarios of 5 GCMs.

\begin{tabular}{lccc}
\hline GCM & $T_{r}\left(10^{3} \mathrm{~m}^{3}\right)$ & $T_{p}(\mathrm{hr}: \mathrm{min})$ & $T_{f}\left(10^{3} \mathrm{~m}^{3}\right)$ \\
\hline CFDL-CM3 & 112.6 & $12: 16$ & 1420.4 \\
EC-EARTH & 110.4 & $12: 16$ & 1200.0 \\
HadGEM2-ES & 106.3 & $12: 18$ & 846.2 \\
MIROC5 & 116.9 & $12: 15$ & 1841.3 \\
MPI-ESM-MR & 115.6 & $12: 16$ & 1738.2 \\
CONTROL & 107.8 & $12: 17$ & 996.0 \\
\hline
\end{tabular}

\section{CONCLUSIONS}

This study proposed an integrated approach for assessing climate change impact on daily rainfall and urban drainage system. Weather generator, rainfall disaggregation and urban drainage modelling are employed for downscaling the output of 5 global climate models (GCMs) to sub-hourly rainfall series and applied it to an urban drainage system. The results showed that the selection of different GCMs has limited influence on the outfall loading of the catchment, but could bring along a remarkable impact on the future extreme storms as well as the flooding condition of the drainage system when compared with the present situation. $A$ more comprehensive understanding on the risk of climate-introduced extreme events is desired to be carried out in further studies, such as comparing the impact of different types of 


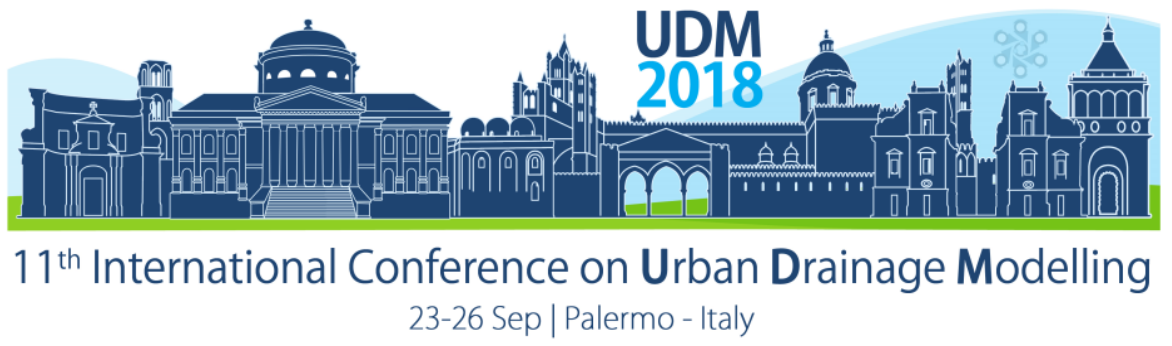

SCS distributions on runoff responses, or coupling the SWMM model with an inundation model for an exhaustive flood risk evaluation.

\section{ACKNOWLEDGEMENTS}

The research work was supported by Singapore's Ministry of Education (MOE) AcRF Tier 1 Project (Ref No. RG170/16; WBS No.: 4011766.030).

\section{References}

Cheng, L., AghaKouchak, A., Gilleland, E. and Katz, R. W. (2014). Non-stationary extreme value analysis in a changing climate. Climatic change, 127(2), 353-369.

Cronshey, R. (1986). Urban hydrology for small watersheds. US Dept. of Agriculture, Soil Conservation Service, Engineering Division.

Gumbel, E. J. (2012). Statistics of extremes. Courier Corporation.

Lu, W., Qin, X.S. and Jun, C., 2017. (In press) A Parsimonious Framework of Evaluating WSUD Features in Urban Flood Mitigation. J. Environ. Inf., 0. Retrieved from http://www.jeionline.org/index.php?journal=mys\&page=article\&op=view\&path\%5B\%5D=201700373

Lu, Y., Qin, X. S. and Xie, Y. J. (2016). An integrated statistical and data-driven framework for supporting flood risk analysis under climate change. J. Hydrol., 533, 28-39.

National Centers for Environmental Prediction (NCEP). (2018). Global Weather Data for SWAT. https://globalweather.tamu.edu (accessed Feb. 10, 2018)

Neumann, J. E., Price, J., Chinowsky, P., Wright, L., Ludwig, L., Streeter, R., ... and Martinich, J. (2015). Climate change risks to US infrastructure: impacts on roads, bridges, coastal development, and urban drainage. Climatic Change, 131(1), 97-109.

Public Utility Board (PUB). (2011). Code of Practice on Surface Water Drainage. (Sixth Edition) https://www.pub.gov.sg/Documents/COP_Final.pdf (accessed Feb. 10, 2018)

Rossman, L.A. (2010). Stormwater Management Model User's Manual, Version 5.0: Water Supply and Water Resources Division. National Risk Management Research Laboratory, U.S. Environmental Protection Agency, Cincinnati.

Semenov, M. A., Brooks, R. J., Barrow, E. M. and Richardson, C. W. (1998). Comparison of the WGEN and LARS-WG stochastic weather generators for diverse climates. Clim. Res., 10(2), 95-107.

Semenov, M. A., Barrow, E. M. and Lars-Wg, A. (2002). A stochastic weather generator for use in climate impact studies. User Man Herts UK.

Semenov, M. A. and Stratonovitch, P. (2010). Use of multi-model ensembles from global climate models for assessment of climate change impacts. Clim. Res., 41(1), 1-14.

United States Department of Agriculture (USDA). (2011). SCS Standard Rainfall Distributions. https://www.nrcs.usda.gov/wps/portal/nrcs/detailfull/national/water/?cid=stelprdb1044959 (accessed Feb. 10, 2018)

Willems, P. (2013). Revision of urban drainage design rules after assessment of climate change impacts on precipitation extremes at Uccle, Belgium. J. Hydrol., 496, 166-177. 


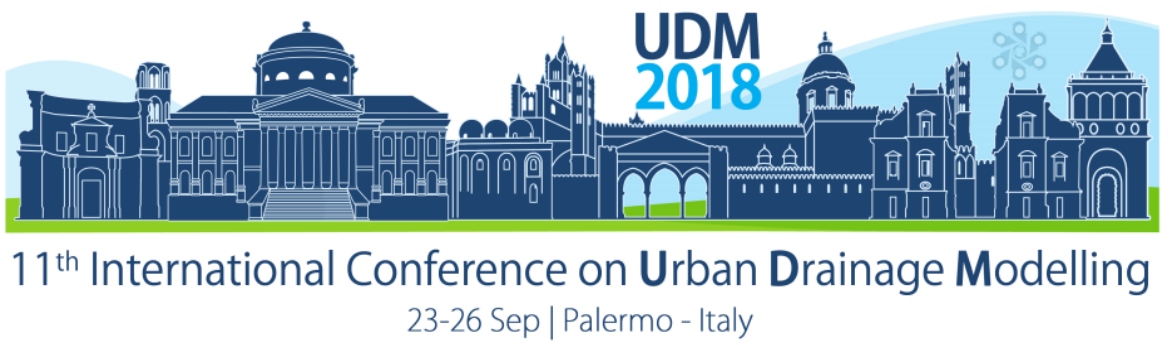

\title{
The influence of household rainwater harvesting system design on water supply and stormwater management efficiency
}

\author{
Sangaralingam Ahilan, Peter Melville-Shreeve, Zoran Kapelan and David Butler \\ University of Exeter, Centre for Water Systems, Exeter, UK
}

\begin{abstract}
Rainwater harvesting is increasingly being recognised as a sustainable option for both urban water and stormwater management. This study explores the potential impact of household rainwater harvesting on water supply augmentation and stormwater management in a typical three-bedroom house in Newcastle-upon Tyne, NE England. The continuous simulation of historical rainfall events at 15-minutes resolution over a 30-year period (19842013) is carried out to evaluate the system's water saving and stormwater control efficiencies. Current and future rainfall projections are also incorporated in the analysis. The British Code of practice (BS 8515) is adopted to design the rainwater harvesting system. Results indicate that a rainwater harvesting system which is primarily designed for water supply augmentation with the size of $2.4 \mathrm{~m}^{3}$ contributes $64 \%$ of non-potable water demand (toilet flushing) and an $86 \%$ reduction of stormwater runoff volume into the sewer system. A larger system $\left(6.5 \mathrm{~m}^{3}\right)$ which is sized for both water supply augmentation and flood management provides $70 \%$ non-potable water supply and $96 \%$ reduction of stormwater runoff volume, indicating that a system which is designed for water supply only may be sufficient to achieve dual benefits. The relationship between storage and system efficiencies are explored for commercially available tanks for historical and future rainfall events. The influence of storage volume on flood peak attenuation is also explored for the historical flood events.
\end{abstract}

Keywords: Rainwater harvesting; Water supply; Stormwater management, Continuous simulation

\section{INTRODUCTION}

Growing urban populations and changes in rainfall patterns lead to ever-increasing pressure on potable water resources and urban flood risk in many countries including the UK. In recent years, Rainwater Harvesting $(\mathrm{RWH})$ is increasingly being recognised as a potential decentralised option for both water supply augmentation and stormwater management. Earlier UK RWH studies typically focused on the potential impact of RWH on water supply augmentation only (Fewkes \& Warm, 2000; Fewkes \& Butler, 2000). Recent studies are beginning to explore their associated stormwater management benefits (Melville-Shreeve et al., 2017). However, it is still unclear is what benefits can be obtained from a simple, single volume tank, what efficiencies are achievable with respect to standard design methods and what is the relationship between water supply augmentation and stormwater management.

This paper presents a preliminary modelling exercise to systematically evaluate both water supply and source control benefits of a household RWH system in a typical three-bed room house in Newcastle-upon-Tyne, NE England. In the paper, the study site is described, together with-it rainfall regime and water demand. Evaluation is carried out using three indices to compare the performance of systems designed using British Standard Code of Practice for RWH design (BSI, 2013) under current and future climatic scenarios. 


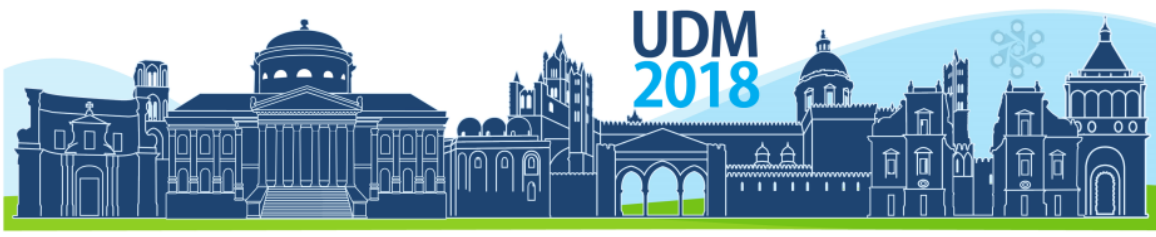

$11^{\text {th }}$ International Conference on Urban Drainage Modelling

23-26 Sep | Palermo - Italy

\section{METHODOLOGY}

\subsection{Study site}

This study focuses on a household rainwater harvesting system in a typical three-bedroom house in Newcastle-upon Tyne, NE England with a roof area of $80 \mathrm{~m}^{2}(\mathrm{~A})$ and an occupancy of 4 (Figure 1). Newcastle is vulnerable to surface flooding as over $90 \%$ of the city centre surface is impermeable. Recent widespread, localised flooding incidents have had a significant impact on society and the economy which indicates the need for more sustainable stormwater management solutions the city. Rainfall data sets over a 30-year period (19842013) at 15 minutes resolution at the Jesmond Dene rainfall gauging station were obtained from the Environment Agency and utilised in the study. UK Climate Projection 2009 (UKCP09) rainfall data sets at the daily interval were also generated and incorporated to evaluate the relative impact of future rainfall patterns (2050 - high emission scenario). The water consumption for toilet flushing is assumed as $50 \mathrm{l} /$ person/day and evenly distributed throughout the day.

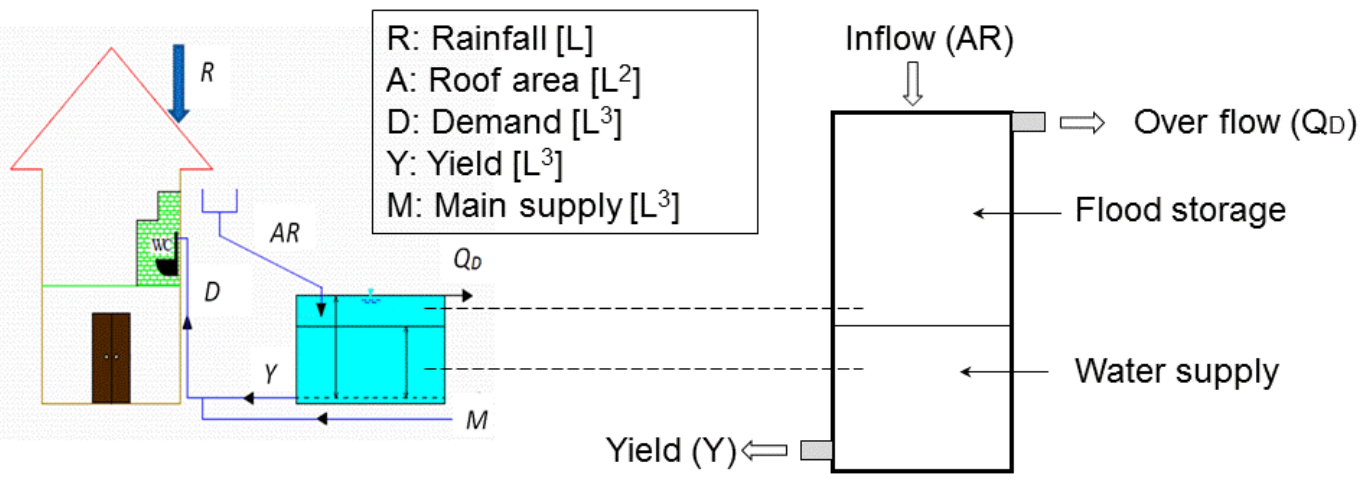

Figure 1. Schematic of the household rainwater harvesting system

\subsection{System's performance evaluation}

The performance of the rainwater harvesting system was modelled using a yield-after -storage (YAS) reservoir operating regime. The YAS operating rule is defined as:

$$
\begin{gathered}
Y_{t}=\min \left[D_{t}, V_{t-1}\right] \\
V_{t}=\min \left[\left(V_{t-1}+Q_{t}-Y_{t}\right),\left(S-Y_{t}\right)\right] \\
Q_{t}=\left(A \times R_{t} \times H_{t}\right)-F_{t}
\end{gathered}
$$

where $Y_{\mathrm{t}}\left[\mathrm{L}^{3} / \mathrm{T}\right]$ - rainwater supply (yield) at time step $t ; D_{\mathrm{t}}\left[\mathrm{L}^{3} / \mathrm{T}\right]$ - water demand at time step $t$, $\mathrm{S}$ - store capacity $\left[\mathrm{L}^{3}\right] ; V_{\mathrm{t}}$ and $V_{\mathrm{t}-1}$ are volume in store $\left[\mathrm{L}^{3}\right]$ at time step $t$ and $t-1$ respectively. The rational method (Eqn. 3) is used to estimate the volume of rainwater runoff $Q_{t}\left[L^{3} / T\right]$ arriving at storage tank. $H_{\mathrm{t}}$ is the hydraulic loss coefficient, which account for losses in the infiltration, evaporation and filtration processes in the system. $R_{\mathrm{t}}$ and $F_{\mathrm{t}}$ are rainfall amount at time step $t$ and the first flush losses. In this simulation, $H_{\mathrm{t}}$ and $F_{\mathrm{t}}$ are assumed as 0.9 and 0 respectively. Three non-dimensional indices are considered to evaluate system performance. The first index measuring water-saving efficiency, $\mathrm{E}_{\mathrm{T}}$, as defined by Dixon et al. (1999), is the ratio between the volume of rainwater supplied and the non-potable water demand (e.g. toilet flushing) during the simulation period is defined as: 


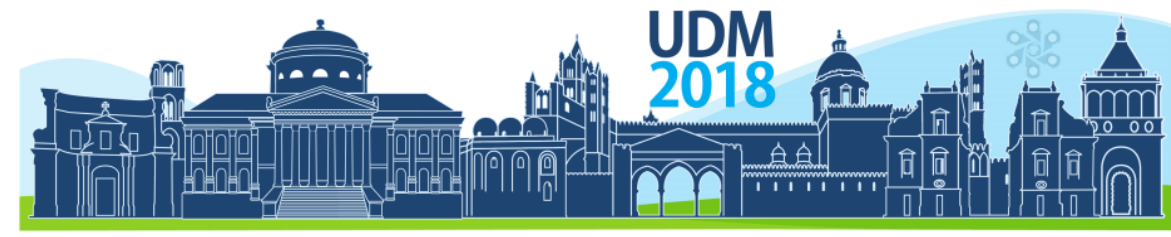

$11^{\text {th }}$ International Conference on Urban Drainage Modelling

23-26 Sep | Palermo - Italy

$$
E_{T}=\frac{\sum_{t=1}^{T} Y_{t}}{\sum_{t=1}^{T} D_{t}}
$$

where, and $T$ is the total number of time steps.

The second index, rainwater overflow ratio, $\mathrm{O}_{\mathrm{T}}$, is defined as the volume of rainwater stored in the system divided by the inflow to the rainwater harvesting system during the specified time interval as modified from Campisano \& Modica (2012):

$$
O_{T}=\frac{\sum_{t=1}^{T} A R_{t}-Q_{D_{t}}}{\sum_{t=1}^{T} A R_{t}}
$$

where $Q_{D}$ t $\left[L^{3}\right]$ represents the rainwater exceeding the system capacity at each time step $t, A$ is the roof area, $R_{t}[L]$ is the rainfall amount at each time step, and $T$ is the entire period under consideration.

The third index RPO represents the reduction in peak discharge because of rainwater storage over the simulation period as modified from Melville-Shreeve et al. (2017):

$$
R P O=\frac{Q_{P}-Q_{R W H}}{Q_{P}}
$$

where RPO, $Q_{P}\left[L^{3} / T\right]$ and $Q_{R W H}\left[L^{3} / T\right]$ represent the 'Reduction in Peak Overflow', peak discharge and peak discharge with rainwater harvesting system over the simulation period respectively.

\section{RESULTS AND DISCUSSION}

\section{Household RWH system performance evaluation}

The modelled water-saving efficiency $\left(\mathrm{E}_{T}\right)$ and the rainwater overflow ratio $\left(\mathrm{O}_{T}\right)$ of $\mathrm{RWH}$ systems over a 30-year (1984 - 2013) period for a range commercially available RWH system sizes $\left(1.5-15 \mathrm{~m}^{3}\right)$ is shown in Figure 2 ( $\mathrm{E}_{\mathrm{T}}\left(1984-2013\right.$ \& $\mathrm{O}_{\mathrm{T}}(1984-2013)$. In addition, 100 equiprobable 30 -year, daily rainfall time series were also used in the simulation to evaluate the potential impact of future rainfall patterns under a high emissions scenario. The mean of these results is shown in Figure 2 ( $E_{T}$ UKCP09 2050 \& OT UKCP09 2050).

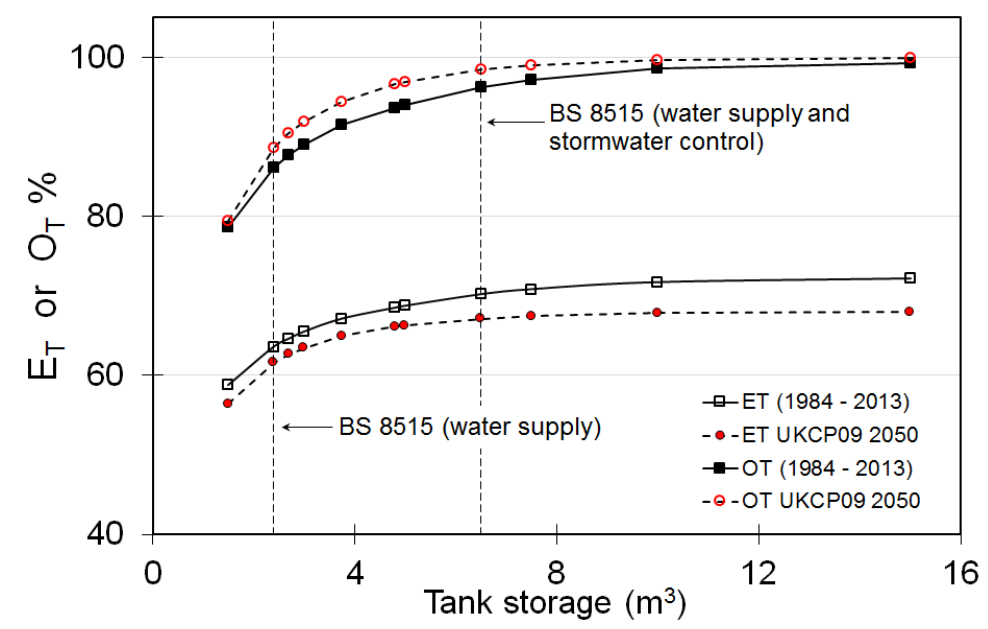

Figure 2. Water-saving and stormwater control efficiencies of the RWH systems

As shown in Figure 2, both $\mathrm{E}_{\mathrm{T}}$ and $\mathrm{O}_{\mathrm{T}}$ increase with tank size to a certain point whilst further increases in storage doesn't improve the efficiencies greater extent since inflow is fixed. The 


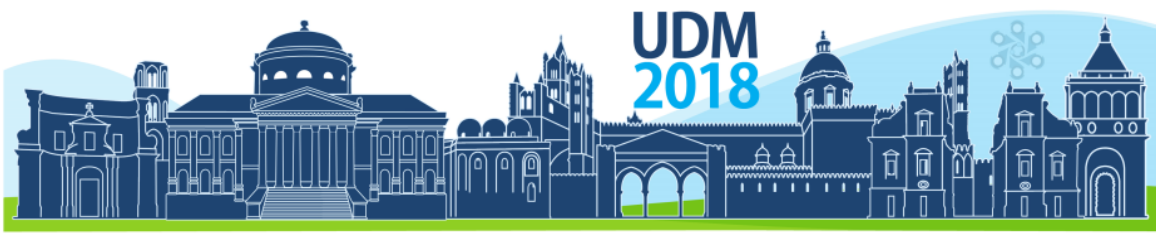

$11^{\text {th }}$ International Conference on Urban Drainage Modelling

23-26 Sep | Palermo - Italy

(BSI, 2013) is adopted to dimension the RWH tank. As shown in Figure 2, the system which is designed for water supply augmentation only has a volume of $2.4 \mathrm{~m}^{3}$ contributes $64 \%$ of the non-potable water demand (WC) and a $86 \%$ reduction in stormwater runoff into the sewer system. A larger system $\left(6.5 \mathrm{~m}^{3}\right)$, which is dimensioned for both water supply augmentation and stormwater management provides $70 \%$ of non-potable water supply and $96 \%$ stormwater control. Changes in future rainfall patterns with more dry spells lower the RWH system's watersaving efficiency (up to 6\%) and increases the stormwater control efficiency (up to 3\%). A $25 \%$ larger size tank $\left(3 \mathrm{~m}^{3}\right)$ is required to meet the same $(64 \%)$ non-potable water demand in 2050. Flood attenuation effect of dual purposes RWH system is shown in Figure 3 over the 30-year simulation period.

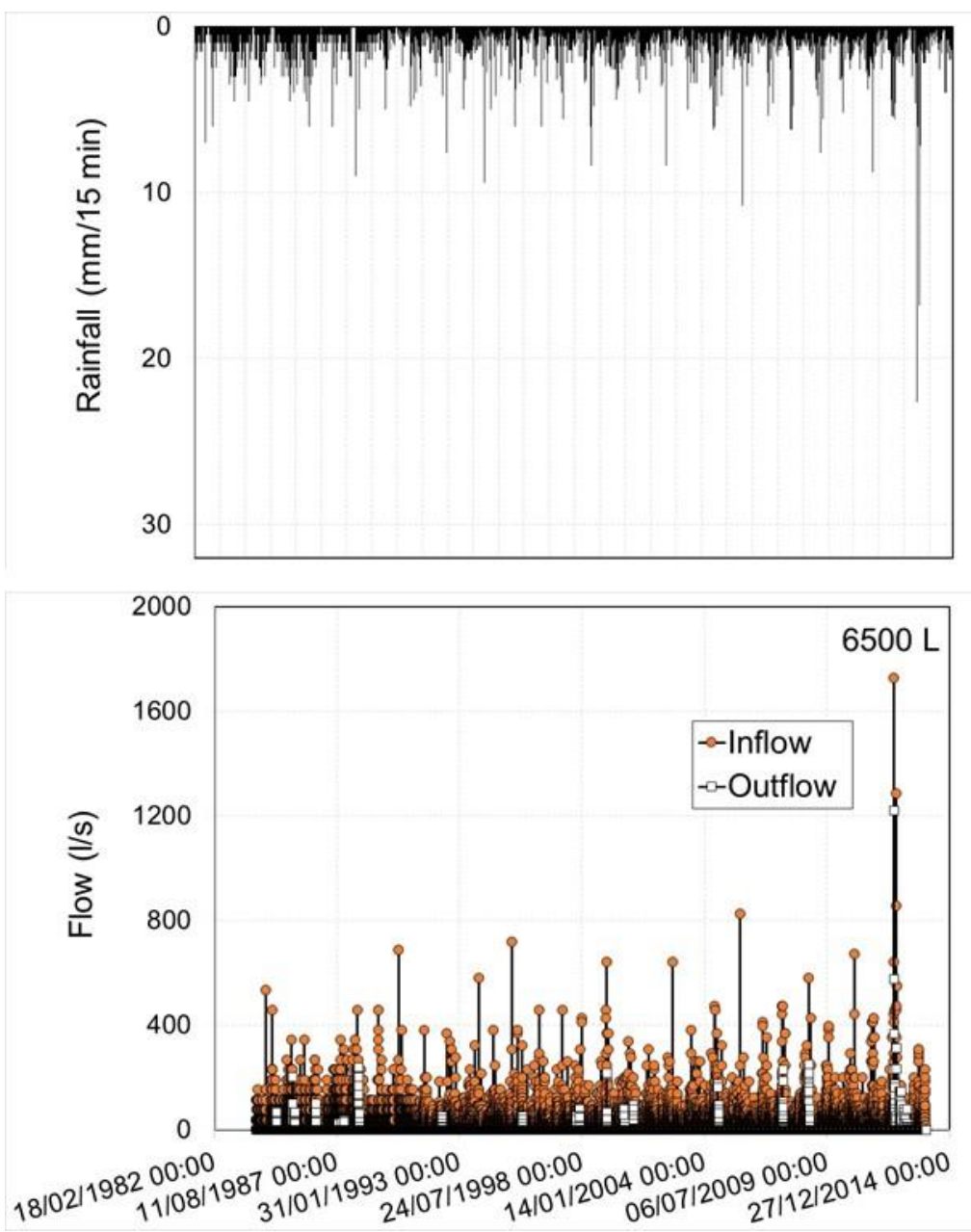

Figure 3. Flood attenuation effect of RWH system

As shown in Figure 3, the RWH system significantly reduces stormwater overflow into the sewer system which consequently reduces combined sewer overflows and volume of wastewater to treat from combined drainage systems. In addition, reduction in stormwater runoff from housing development also enables to mitigate urban flooding to a certain extent. 


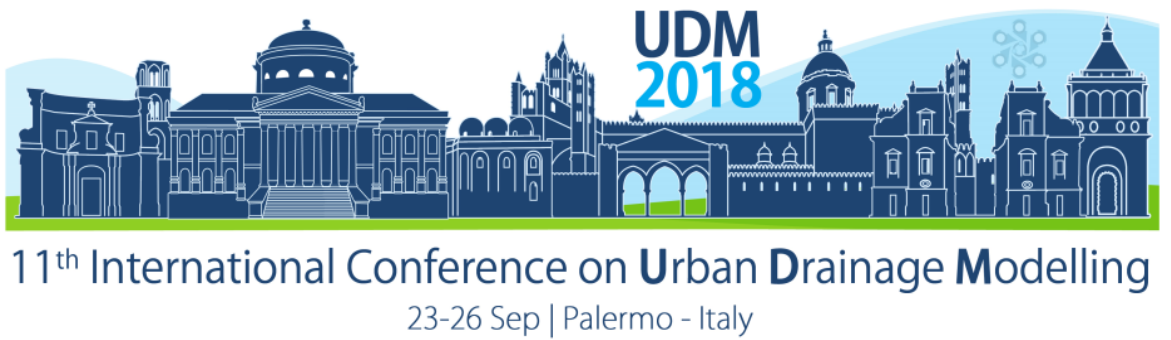

Table 1 summarises the impact of the RWH system on flood peak attenuation for the 20 largest roof runoff events over a 30-year period with $2.4 \mathrm{~m}^{3}$ and $6.5 \mathrm{~m}^{3}$ tank sizes. Estimated Minimum (Min), first quartile $\left(Q_{1}\right)$, Median, third quartile $\left(Q_{3}\right)$ and Maximum RPO of these 20 runoff events are shown in Table 1.

Table 1. RPO for the 20 largest historical events

\begin{tabular}{lrr}
\hline & 2400 I & 6500 I \\
\hline Min & $10 \%$ & $29 \%$ \\
$Q_{1}$ & $46 \%$ & $100 \%$ \\
Median & $77 \%$ & $100 \%$ \\
Q3 & $100 \%$ & $100 \%$ \\
Max & $100 \%$ & $100 \%$ \\
\hline
\end{tabular}

The $2.4 \mathrm{~m}^{3}$ tank exhibits relatively larger variations in RPO than $6.5 \mathrm{~m}^{3}$ tank as expected. As indicted these are substantial reductions in the peak of major storms even for the smaller tank. However, both tanks would have been unable to cope with most extreme historical rainfall event (circa. 100-year event) which occurred on $28^{\text {th }}$ June 2012 when $50 \mathrm{~mm}$ rain fell in around 2 hours of which $22.6 \mathrm{~mm}$ fell in 15 minutes. For Newcastle, this is equivalent to the expected rainfall for the whole month of June. The smaller and larger tank provides $10 \%$ and $29 \%$ RPO for the 2012 event respectively. This is because the volume of the 2012 rainfall event is so high and the both tanks has nearly reached its storage capacity.

\section{CONCLUSIONS}

This study explores potential benefits of RWH system on water supply augmentation and stormwater control in a three-bed rooms house in Newcastle-upon Tyne, NE England. The simulation results indicate that around $2 / 3$ of WC demand could be supplemented by the domestic rainwater system. Simulation results also indicate that future rainfall patterns (2050 - high emission scenario) would require a $25 \%$ increase in the tank storage to meet the current water supply capacity. Furthermore, continuous simulation over the 30-year period (1984-2013) shows that the RWH system could provide over $75 \%$ flood peak attenuation and over $85 \%$ reduction in stormwater runoff volume.

\section{References}

BSI (2013) BS 8515:2009 + A1:2013 Rainwater harvesting systems - Code of practice. BSI, London.

Campisano, A., Modica, C. (2012) Optimal sizing of storage tanks for domestic rainwater harvesting in Sicily. Resources, Conservation and Recycling, 63, 9-16.

Dixon, A., Butler, D. and Fewkes, A. (1999) Computer simulation of domestic water reuse systems: investigating greywater and rainwater in combination. Wat. Sci. Tech. 39(5), 25-32.

Fewkes, A. (2000) Method of modelling the performance of rainwater collection systems in the United Kingdom. Proc. CIBSE A: Building Serv. Eng. Res. Tech. 21(4), 257-265.

Fewkes, A. and Butler, D. (2000) Simulating the performance of rainwater collection and reuse systems using behavior models. Proc. CIBSE A: Building Serv. Eng. Res. Tech. 21(2), 99-106.

Melville-Shreeve, P.J., Ward, S. and Butler, D. (2017) Dual-Purpose Rainwater Harvesting System Design. Sustainable Surface Water Management: A Handbook for SuDS, Edited by Susanne M. Charlesworth \& Colin Booth. 


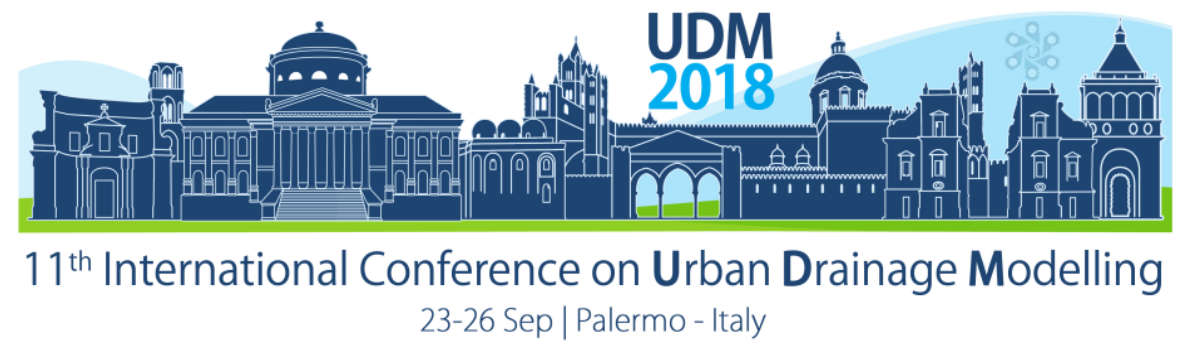

\title{
Anomalous Extreme Rainfall Variability Over Europe - Interaction Between Climate Variability and Climate Change
}

\author{
Hossein Tabari ${ }^{1}$ and Patrick Willems ${ }^{1,2}$ \\ ${ }^{1} \mathrm{KU}$ Leuven, Department of Civil Engineering, Hydraulics Division, Leuven, Belgium \\ (Email: hossein.tabari@kuleuven.be; tabari.ho@gmail.com) \\ ${ }^{2}$ Vrije Universiteit Brussel, Department of Hydrology and Hydraulic Engineering, Brussels, Belgium
}

\begin{abstract}
Climate variability and change are expected to alter the frequency, intensity and duration of extreme rainfall and urban flooding, which in turn will pose challenges to the urban drainage systems and management. This study analyses the decadal variability of daily extreme rainfall at 263 European stations and its connection with North Atlantic Oscillation (NAO), Western Mediterranean Oscillation (WeMO) and Southern Oscillation Index (SOI) over a roughly centennial period (1925-2015). The impact of climate change on the linkage between the anomalies of extreme rainfall and atmospheric circulations is also investigated. The results show a strong imprint of winter NAO and summer WeMO on extreme rainfall variability in Europe, with significant relationships $(\alpha=0.05)$ at $70 \%$ and $45 \%$ of the stations, respectively. About $10-15 \%$ of the significant relationships is because of the underlying trend in the anomaly series due to climate change. Further investigation of climate change impact on the linkage reveals that the significant positive trend $(\alpha=0.05)$ in winter NAO and summer WeMO anomaly series is accompanied by the same trend in extreme rainfall anomaly series at $67 \%$ and $37 \%$ of the stations for winter and summer, respectively. These results provide new insights into the climate variability versus trends and corresponding changes in extreme rainfall.
\end{abstract}

Keywords: Extreme rainfall; Atmospheric circulations; Climate change

\section{INTRODUCTION}

Extreme weather event risks are of a particular concern due to their frequent accordance in recent years (IPCC, 2013; Tabari and Willems, 2016; Papalexiou et al., 2018), posing serious challenges to human livelihood, socioeconomic developments and the environment. Based on the 2017 Global Risks Report by the World Economic Forum, extreme weather events are ranked as the top global risk in terms of their likelihood and impact. Among them, pluvial flooding is of considerable importance because of high population density along with expensive infrastructure and heavy industrialization in urban areas. Europe has been hit by several devastating urban floods in recent years, of which the most destructive ones were those in summer 2002 and 2013 in Central Europe. During these events, the extremely heavy rainfall caused tens of fatalities and damage of billions of euros. Such anomalous behaviour of extreme rainfall over Europe needs to be investigated for a better understanding of climate variability and a skilful forecasting of dangerous extreme events for the future. It would provide the insights required to achieve a resilient, future proof urban drainage system design, planning and management.

This study more specifically aims at analysing the decadal variability of daily extreme rainfall over Europe and examining its possible atmospheric drivers. To this end, the relationships of winter and summer extreme rainfall anomalies with North Atlantic Oscillation (NAO), Western 


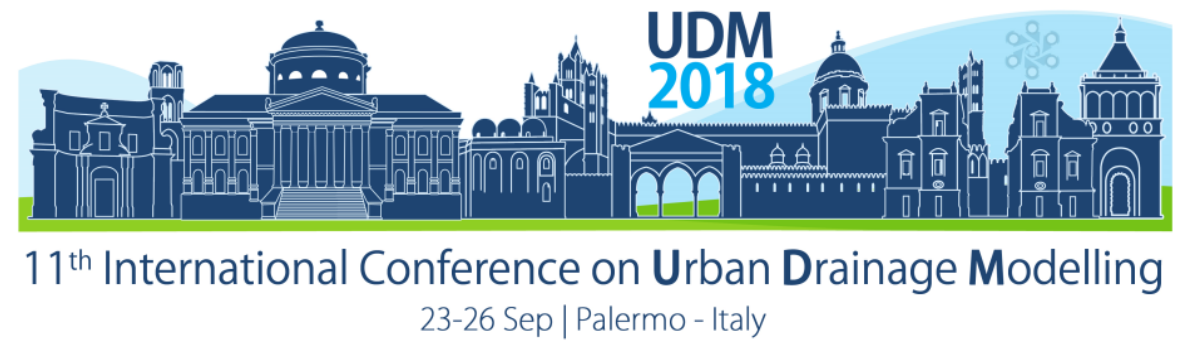

Mediterranean Oscillation (WeMO) and Southern Oscillation Index (SOI) are investigated for 263 European stations over a roughly centennial period (1925-2015). The likely impact of climate change on these relationships is also scrutinized.

\section{MATERIALS AND METHODS}

\subsection{Data}

Daily rainfall data from 263 European stations for the period 1925-2015 are used. The location of the stations is shown in Figures 1 and 2. To detect the possible atmospheric drivers of the extreme rainfall anomalies, they are connected to three climate indices indicating atmospheric circulations over different regions. The NAO, WeMO and SOI are defined based on the sea level pressure (SLP) difference between two specific locations: Azores and Iceland for NAO, Cádiz-San Fernando (Spain) and Padua (Italy) for WeMO and Tahiti and Darwin for SOI. The daily NAO data developed by Cropper et al. (2015) are used, while due to unavailability of daily WeMO and SOI data, we develop them using the 20th Century Reanalysis V2c (Compo et al., 2011).

\subsection{Methods}

The quantile perturbation method (QPM; Ntegeka and Willems, 2008; Willems, 2013) is applied to analyse decadal anomalies in daily extreme rainfall and climate indices in winter and summer seasons. In this method, anomaly is computed by comparing the quantiles in a 10 -year sub-period with those in the full period with the same return period. For all quantiles above a given threshold (95th percentile of all rainfall data in our case), the relative difference between the sub-period based quantile and the corresponding full period based quantile is calculated. To compare the extremes between any possible sub-period and the full period, the time slice in the sub-period is moving with a sliding window of one year from the beginning towards the end of the full series. The higher quantile values in the sub-period compared to the full period denote a positive anomaly $(>1)$, while lower quantile values in the sub-period lead to a negative anomaly $(<1)$.

Once the anomalies are calculated, the relationships between the anomalies of extreme rainfall and climate indices are investigated using correlation analysis. Due to using a sliding window in the QPM method, the resulting anomaly series have significant serial correlations up to several lags. To limit the influence of serial correlations on the correlation coefficients, a similar procedure to the method of Hamed and Rao (1998) for the variance correction in the Mann-Kendall test is used. In our case, the variance of the predictor and predictand is first corrected separately, leading to specific correction factors for the predictor and predictand. Finally, the corrected variances are implemented for the computation of correlation coefficients.

Owing to the widespread increases in humidity throughout the mid-latitudes, a part of the relationship between extreme rainfall and atmospheric circulations may be due to the underlying trend in the context of climate change. To explore the implications of the nonstationary in or climate change impact on the relationships, the anomaly series of extreme rainfall and climate indices are linearly detrended prior to the correlation analysis and the results are compared with the correlation results before detrending. The trend in the anomaly series is also detected using the Mann-Kendall test modified for considering serial correlation 


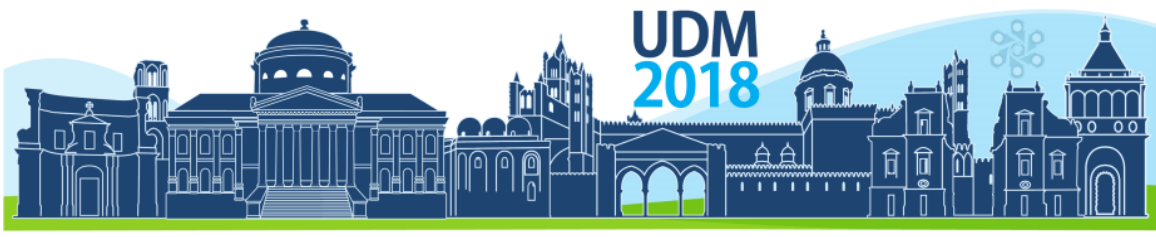

$11^{\text {th }}$ International Conference on Urban Drainage Modelling

23-26 Sep | Palermo - Italy

effects (see Tabari et al. (2015) for the mathematical procedure) to further investigate the influence of climate change on the decadal variations.

\section{RESULTS AND DISCUSSION}

The contemporaneous correlations between daily extreme rainfall anomaly and climate indices show a strong influence of winter NAO and summer WeMO on extreme rainfall variability over Europe (Figure 1). The influence of the atmospheric circulations over the Pacific Ocean (i.e., SOI) is relatively weaker, although effective for winter with significant correlations $(\alpha=0.05)$ at $23 \%$ of the stations (not shown). The most effective atmospheric circulation for winter rainfall extremes is NAO. With a significant positive correlation in the north and west of Europe and a negative correlation for the southern parts, a dipole-type pattern is created for the winter NAO influence (Figure 1). A similar but weaker pattern is observed for the influence of summer WeMO. The explained variance in extreme rainfall by winter NAO and summer WeMO goes up to $14 \%$ and $16 \%$, respectively.

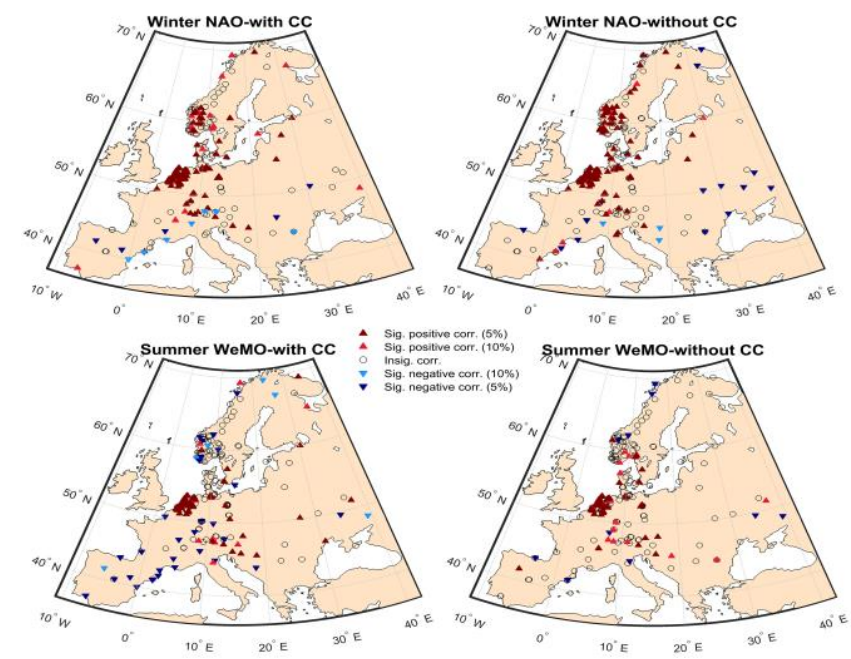

Figure 1. Contemporaneous correlations of daily extreme rainfall anomaly with winter NAO and summer WeMO at 263 European stations for the period 1925-2015.

A research question is arisen here as how much the relationships between extreme rainfall and atmospheric circulations are due to climate change. The comparison of the results before and after detrending indicates that about $15 \%$ and $10 \%$ of the significant relationships respectively with winter $\mathrm{NAO}$ and summer WeMO decrease after removing the underlying trend. Similarly, the magnitude of the correlation coefficients averaged over the stations decreases by $4 \%$ and $28 \%$ for winter NAO and summer WeMO, respectively. From a spatial distribution point of view, the stations located in the south of Europe mostly lose their significant correlations with summer WeMO after detrending. Further analysis of the underlying trends reveals that there is a significant increasing trend in winter NAO and summer WeMO anomaly series at the 0.05 level. The same direction of the trend in the extreme rainfall anomaly time series results in an increased correlation coefficient, leading to overestimated influence of climate indices. The significant increasing trend at the 0.05 level is observed in winter and summer rainfall anomaly series at $67 \%$ and $37 \%$ of the stations, respectively. 


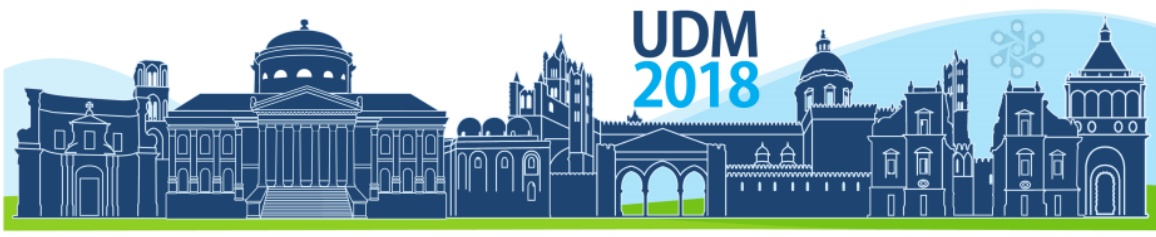

$11^{\text {th }}$ International Conference on Urban Drainage Modelling 23-26 Sep | Palermo - Italy

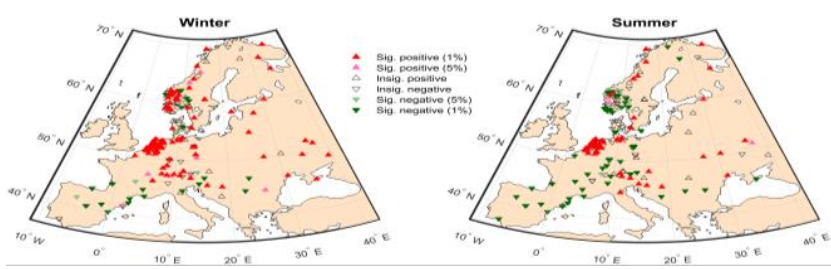

Figure 2. Trends in daily extreme rainfall anomaly for winter and summer at 263 European stations for the period 1925-2015 using the modified Mann-Kendall test.

\section{CONCLUSIONS}

The decadal anomalies of daily extreme rainfall at 263 stations over Europe for the period 1925-2015 and their possible linkage with NAO, WeMO and SOI were analysed. The influence of similar underlying trends due to climate change on the correlation results was also examined. It was found that European extreme rainfall variability is strongly modulated by winter NAO and summer WeMO. A significant relationship $(\alpha=0.05)$ with the aforementioned climate indices was found at $70 \%$ and $45 \%$ of the stations, respectively. The non-stationarity in the anomaly series increased the number of significant relationships by $10-15 \%$. This increase is driven by a significant increasing trend in both climate index and extreme rainfall anomalies. The concurrent increasing trend was observed in winter and summer extreme rainfall anomaly series at $67 \%$ and $37 \%$ of the stations, respectively. The results of this study reveal the importance of both climate variability - over decadal time scales - and climate change in extreme rainfall variability over Europe. Both have to be accounted when designing or planning for new infrastructure. Given the life-time of installed urban drainage systems, they have to be robust and able to cope with the intrinsic decadal natural variations in meteorological pressures next to the longer term gradual trends due to climate change.

\section{References}

Compo, G.P., Whitaker, J.S., Sardeshmukh, P.D., Matsui, N., Allan, R.J., Yin, X., Gleason, B.E., Vose, R.S., Rutledge, G., Bessemoulin, P., Brönnimann, S., Brunet, M., Crouthamel, R.I., Grant, A.N., Groisman, P.Y., Jones, P.D., Kruk, M.C., Kruger, A.C., Marshall, G.J., Maugeri, M., Mok, H.Y., Nordli, Ø., Ross, T.F., Trigo, R.M., Wang, X.L., Woodruff, S.D. and Worley, S.J. (2011) The twentieth century reanalysis project. Q. J.R. Meteorol. Soc. 137,1- 28.

Cropper, T., Hanna, E., Valente, M.A. and Jónsson, T. (2015) A daily Azores-Iceland North Atlantic Oscillation index back to 1850. Geosci. Data J. 2, 12-24.

Hamed, K.H. and Rao, A.R. (1998) A modified Mann-Kendall trend test for autocorrelated data. J. Hydrol. 204, 182-196.

IPCC (2013) Summary for Policymakers. Climate Change. in The Physical Science Basis, Contribution of Working Group I to the Fifth Assessment Report of the Intergovernmental Panel on Climate Change (eds. Stocker, T.F., Qin, D., Plattner, G.K., Tignor, M., Allen, S.K., Boschung, J., Nauels, A., Xia, Y., Bex, V. and Midgley, P.M.).

Ntegeka, V. and Willems, P. (2008) Trends and multidecadal oscillations in rainfall extremes, based on a more than 100-year time series of 10 min rainfall intensities at Uccle, Belgium. Water Resour. Res. 44, W07402, doi:10.1029/2007WR006471.

Papalexiou S., AghaKouchak A., Trenberth, K. and Foufoula-Georgiou, E. (2018) Global, Regional and Megacity Trends in the Highest Temperature of the Year: Diagnostics and Evidence for Accelerating Trends. Earth's Future 6(1), 71-79.

Tabari, H. and Willems, P. (2016) Daily precipitation extremes in Iran: decadal anomalies and possible drivers. J. Am. Water Resour. As. 52(2), 541-559.

Tabari, H., Taye, M. T. and Willems, P. (2015) Statistical assessment of precipitation trends in the upper Blue Nile River basin. Stoch. Environ. Res. Risk. Assess. 29(7), 1751-1761.

Willems, P. (2013) Multidecadal oscillatory behaviour of rainfall extremes in Europe. Climatic Change 120, 931944. 


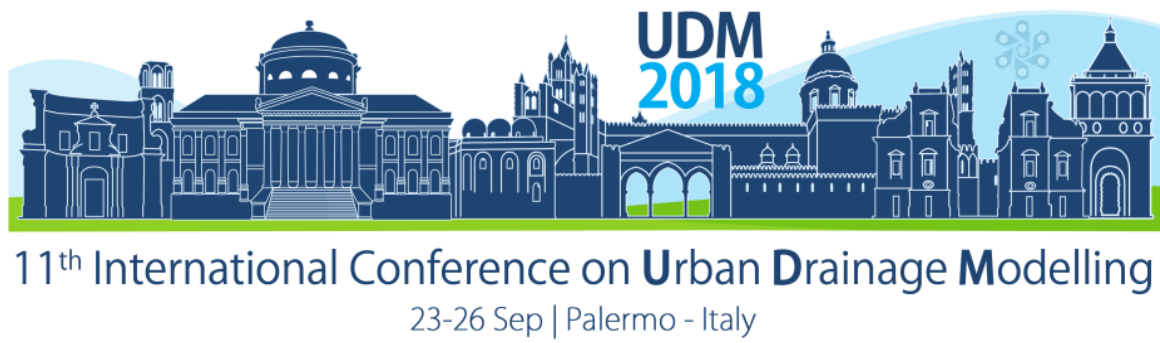

\title{
Temporal Pattern Analysis of Rainstorm Events for Supporting Rainfall Design in a Tropical City
}

\author{
Changhyun Jun ${ }^{1^{*}}$, Xiaosheng Qin ${ }^{2}$ and Wei $\mathrm{Lu}^{2}$ \\ ${ }^{1}$ Xi'an Jiaotong-Liverpool University, Department of Civil Engineering, Suzhou, China, \\ Changhyun.Jun@xjtlu.edu.cn \\ ${ }^{2}$ Nanyang Technological University, School of Civil and Environmental Engineering, Singapore
}

\begin{abstract}
Synthetic rainfall distributions of the design storm have been commonly used for the hydrological design of urban stormwater infrastructures in many regions of the world. However, there are still limited studies in a tropical city dealing with design storm hyetographs for flood estimation even though rainfall intensity/depth-duration-frequency (IDF/DDF) relationships have been derived to estimate rainfall depths for a specific rainfall duration and return period. This study presents a storm-event based rainfall analysis method to determine a representative quartile of the design storm in which, both interevent time definition (IETD) and depth/duration/intensity thresholds are considered. Similar to Huff's method, 5-min rainfall data during three years at two rain gauge stations in Singapore were used to obtain the percentage frequency of the four types of quartile storms depending on the location where the heaviest rainfall occurred in each storm duration. It was found that the proposed approach could give the shape and magnitude of the design storm hyetograph from the location of peak rainfall corresponding to the largest portion of quartile storms. As a result, the second quartile design storm was suggested to be applied for flood estimation in order to better address the temporal characteristic of actual rainstorm events in the study area. It offers an alternative way of describing the temporal distribution of rainfall within a design storm period, which is helpful in improving the design of urban stormwater infrastructures in a tropical region.
\end{abstract}

Keywords: Design storm; Temporal distribution; Peak rainfall; Huff's method; Singapore

\section{INTRODUCTION}

In engineering practice, the design rainfalls have been used to estimate flood quantiles at a catchment scale (Varga et al., 2009), which is especially useful for the hydrologic design of urban stormwater infrastructures such as culverts and drainage systems. The magnitude of precipitation extremes corresponding to various frequencies and durations was firstly determined from the rainfall intensity-duration-frequency (IDF) or depth-duration-frequency (DDF) relationships (Liew, 2012). The different shapes of synthetic hyetographs were then considered along with design storm's temporal patterns (Wenzel, 2013). One particular approach to the development of synthetic hyetographs is the Huff's method (Huff, 1967). It separates rainstorm events into four groups, followed by the location where the maximum intensity occurred during each storm duration. The method of characterizing dimensionless storm mass curves is provided for a given elapsed time, which describes a probabilistic representation of cumulative rainfall depths corresponding to the considered storm duration (Liew, 2012).

For tropical regions, some studies were reported in temporal distribution of rainfall. Koon (1969) analyzed temporal patterns of 377 rainstorm events at five climate stations located in Singapore and suggested the use of an average temporal pattern for flood estimation in 


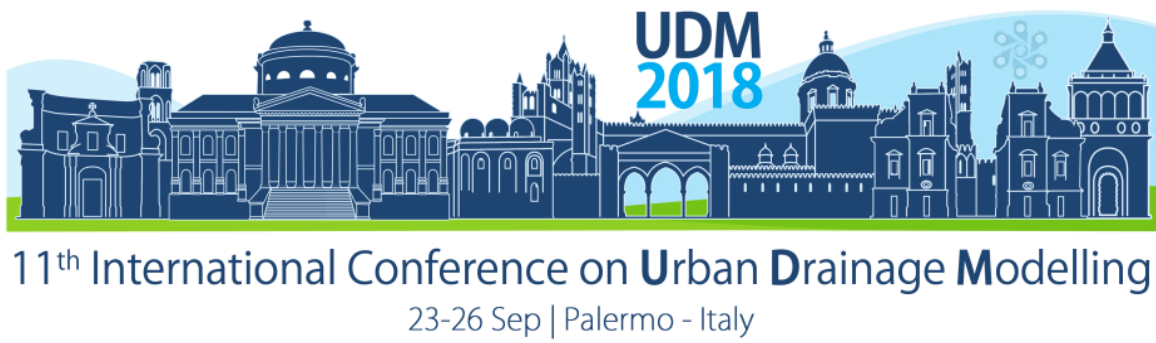

designing drainage networks, obtained from the dimensionless mass curve. Tan and Sia (1997) developed an algorithm for simulating tropical rainfall using a Markov chain. In the past years, the storm-event based approaches were applied to properly reflect rainfall characteristics of actual rainstorm events (Yoo et al., 2016). These approaches tend to separate individual rainstorm events from rainfall time series over the entire record period and help mitigate the limitations of the rainfall quantities corresponding to the pre-selected time intervals. More detailed information about the definition of rainstorm events is given in Jun et al. (2017). Overall, there is a lack of study that focuses on using storm-event based concept to study temporal pattern of rainstorm events in the tropical region like Singapore.

The objective of this study is then to preliminarily tackle such a gap by proposing a stormevent based approach for determining a representative quartile of the design storm for the benefit of supporting rainfall design. Individual rainstorm events are retrieved from choosing proper values for the inter-event time definition (IETD) and depth/duration/intensity thresholds. IETD is defined as the minimum no-rain periods between consecutive rainstorm events (Jun et al., 2017). Followed by the location of the heaviest rainfall during each storm duration, the retrieved events are divided into four groups. The proposed approach is applied to 5-min rainfall data at two rain gauge stations in Singapore. The methodology is presented first, followed by application results and discussion, and conclusions.

\section{METHODOLOGY}

The overall methodological framework of determining the representative quartile of the design storm in a tropical city is summarized in Figure 1. Each rainstorm event needs to be defined for investigating general characteristics of the temporal variation in its rainfall intensity. From the observed rainfall time series (Step 1), we only consider rainfall data with intensity larger than $0.3 \mathrm{~mm}$ per $5 \mathrm{~min}$ and duration longer than $5 \mathrm{~min}$ to retrieve proper rainstorm events (Step 2), which can reduce the error in determining quartiles of each rainstorm events followed by the location where the maximum intensity occurred within a storm duration. The IETD of $20 \mathrm{~min}$ is applied to retrieve individual rainstorm events (Step 3). Among them, a sequence of rainstorm events with total storm depths larger than $3 \mathrm{~mm}$ is determined firstly (Step 4) and then the individual rainstorm events of interest are obtained finally, which have storm durations longer than 30 min (Step 5). Based on the Huff's method, they are divided into four groups depending on the location where the peak rainfall intensity occurred, i.e., during the first, second, third or fourth quarter of the storm duration (Step 6). It is noted that each threshold value needs to be determined from regional characteristics including precipitation extremes.

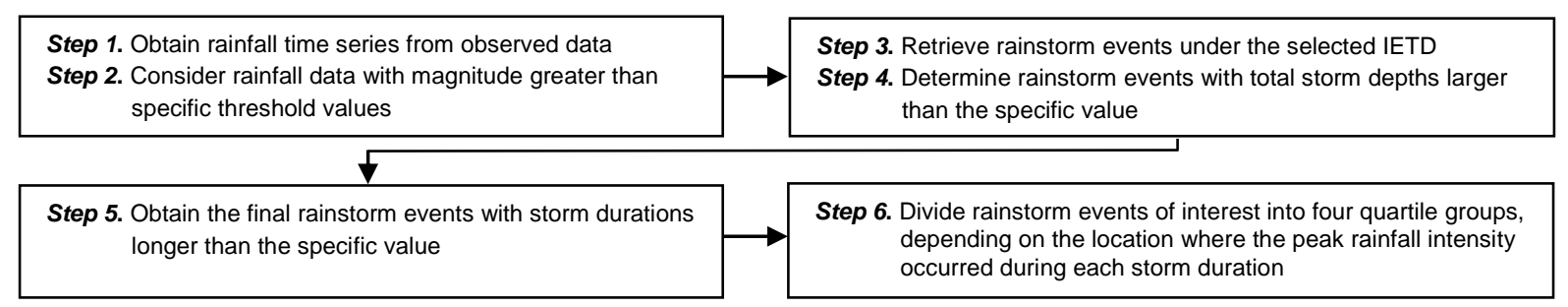

Figure 1. Flow chart of a storm-event based approach for determining the representative quartile of the design storm in a tropical city 


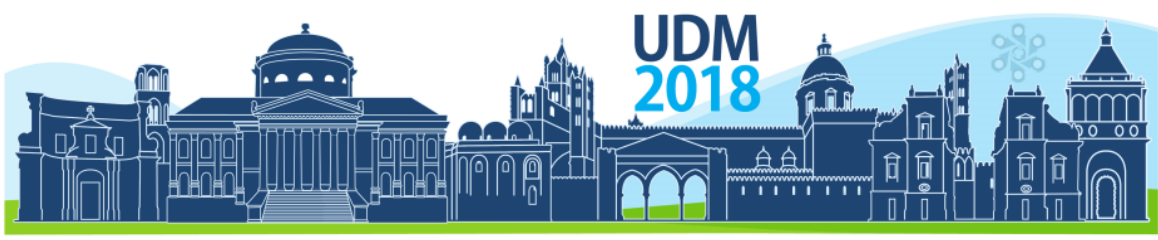

$11^{\text {th }}$ International Conference on Urban Drainage Modelling

23-26 Sep | Palermo - Italy

\section{APPLICATION RESULTS AND DISCUSSION}

\subsection{Data}

Singapore is located in Southeast Asia with average annual rainfall depths around 2,400 mm (PUB, 2011). Even though the rainfall IDF or DDF relationships have been developed to estimate design rainfalls corresponding to a specific rainfall duration and return period, there are still limited studies dealing with design storm hyetographs for flood estimation in Singapore. This study analyzed 5-min rainfall series during three years (July 2010 - June 2013) and retrieved a sequence of rainstorm events from rainfall time series at two rain gauge stations; one is located at the middle part of the island, namely MacRitchie Reservoir (Station \#1) and the other is on the eastern side, namely Changi Airport (Station \#2). The total number of retrieved rainstorm events was 308 and 248, respectively. The locations of the considered rain gauge stations and the statistical characteristics of retrieved rainstorm events are summarized in Figure 2. It is noted that the values of mean and standard deviation are close to each other even though two rain gauge stations are located relatively far apart. Especially, the mean value of storm durations is about one hour, which potentially reflecting the importance of temporal patterns in storms corresponding to relatively short durations for designing urban stormwater infrastructures in the tropical region like Singapore.
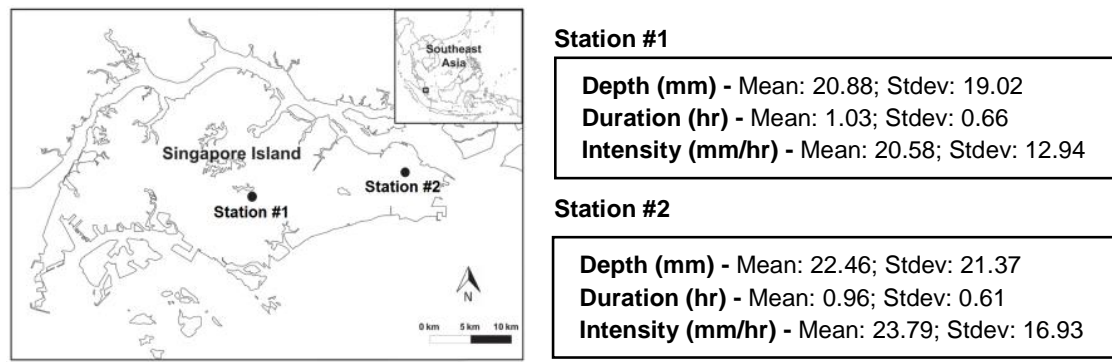

Figure 2. The locations of two rain gauge stations and the statistical characteristics of retrieved rainstorm events

\subsection{Temporal pattern of rainstorm events in Singapore}

The retrieved rainstorm events were divided into four groups, depending on the location where the heaviest rainfall occurred in each storm duration (Figure 3).
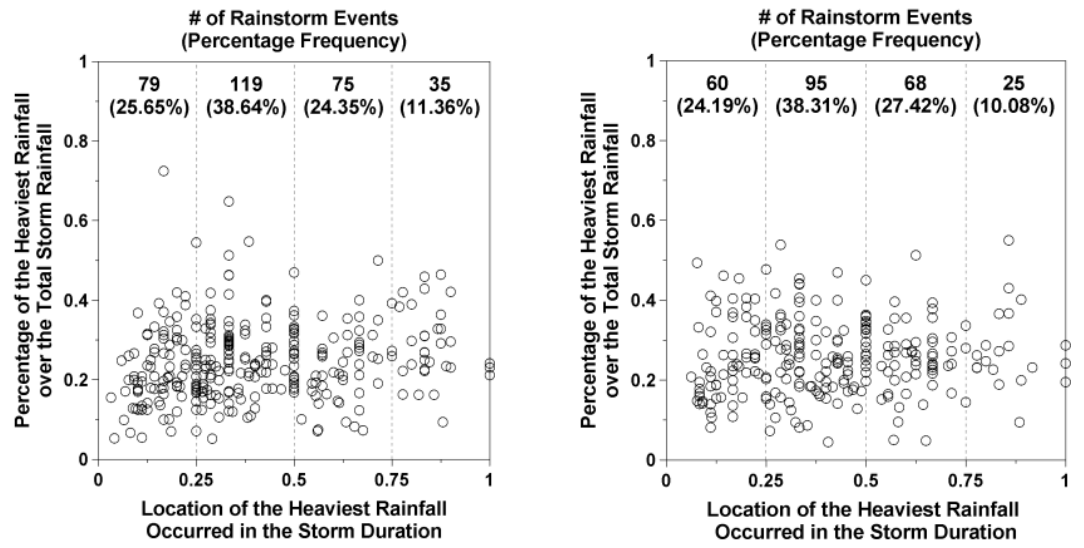

Figure 3. The scatter plot for identifying a representative temporal pattern of rainstorm events in Singapore with the number of rainstorm events corresponding to each quantile storm and their percentage frequencies: (a) Station \#1; (b) Station \#2 


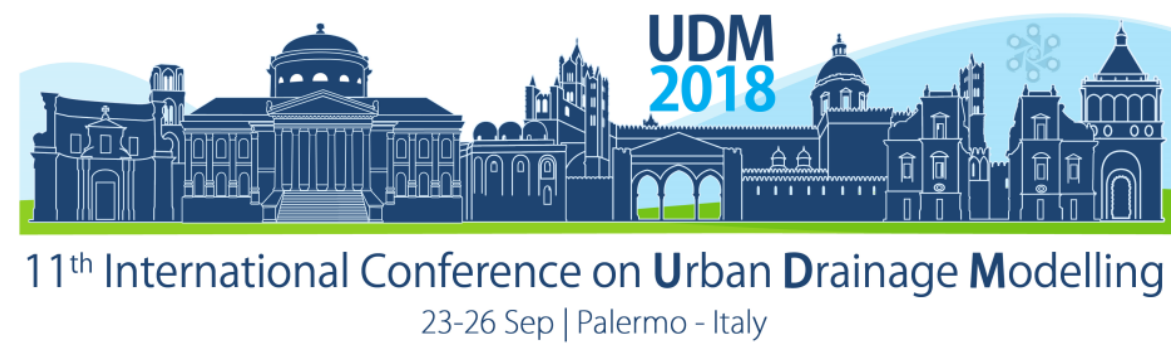

From the percentage frequency of the four types of quartile storms, it is noted that the second quartile storms correspond to the largest portion of rainstorm events, i.e. $38.64 \%$ for Station \#1 and $38.31 \%$ for Station \#2. It implies that the second quartile storms could represent the main temporal characteristics of actual rainstorm events in Singapore. The proposed approach helps figure out the shape of design storm hyetographs followed by the location of the heaviest rainfall in a storm duration even though there are still limitations such as the selection of IETD and depth/duration/intensity thresholds, the absolute number of the considered rain gauge stations, types of quartiles and time interval of observation data. We leave it to further studies.

\section{CONCLUSIONS}

This study proposed a storm-event based approach for determining a representative quartile of the design storm, focusing on the location of the heaviest rainfall in a storm duration. Both inter-event time definition (IETD) and depth/duration/intensity thresholds were considered to retrieve rainstorm events of interest from rainfall time series of observed data. The retrieved rainstorm events were divided into four groups followed by the location where the heaviest rainfall occurred during the first, second, third or fourth quarter of the storm duration. This proposed approach was applied to analyze storm characteristics of 5-min rainfall data during three years at two rain gauge stations in Singapore. The study demonstrated that the percentage frequency of the second quartile storms was the highest among the considered four types of quartile storms, which represent temporal characteristics of actual rainstorm events in Singapore. It depends on the selected values of the IETD and thresholds and thus the proposed approach needs to consider regional characteristics including precipitation extremes. The study results could be applied to develop different shapes of synthetic hyetographs in a tropic city, which is important for flash flood estimation, hydraulic structure design and risk/uncertainty analysis.

\section{Acknowledgments}

This research was supported by Basic Science Research Program through the National Research Foundation of Korea (NRF) funded by the Ministry of Education (2016R1A6A3A03010544).

\section{References}

Jun, C., Qin, X., Gan, T.Y., Tung, Y.-K. and De Michele, C. (2017) Bivariate frequency analysis of rainfall intensity and duration for urban stormwater infrastructure design. Journal of Hydrology. 553, 374-383.

Koon, C.K. (1969) Temporal pattern of design storms for Singapore. Jour. oflnst. of Engineers, Singapore. 16, 340-341.

Liew, S.C. (2012) A novel approach, using regional climate model, to derive present and future intensity-durationfrequency curves. Ph.D. Dissertation, Department of Civil and Environmental Engineering, National University of Singapore, Singapore.

Public Utilities Board (PUB). (2011) Code of practice on surface water drainage, Singapore.

Tan, S.K. and Sia, S.Y. (1997) Synthetic generation of tropical rainfall time series using an event-based method. Journal of Hydrologic Engineering. 2(2), 83-89.

Varga, C., Ball, J.E. and Babister, M. (2009) A hydroinformatic approach to development of design temporal patterns of rainfall. IAHS Publication, 331, 20-29.

Wenzel, H. G. (2013) Rainfall for urban stormwater design in urban stormwater hydrology. American Geophysical Union, Washington, D.C., The United States.

Yoo, C., Park, C. and Jun, C. (2016) Evaluation of the concept of critical rainfall duration by bivariate frequency analysis of annual maximum independent rainfall event series in Seoul, Korea. Journal of Hydrologic Engineering. 21(1), doi:10.1061/(ASCE)HE.1943-5584.0001259. 


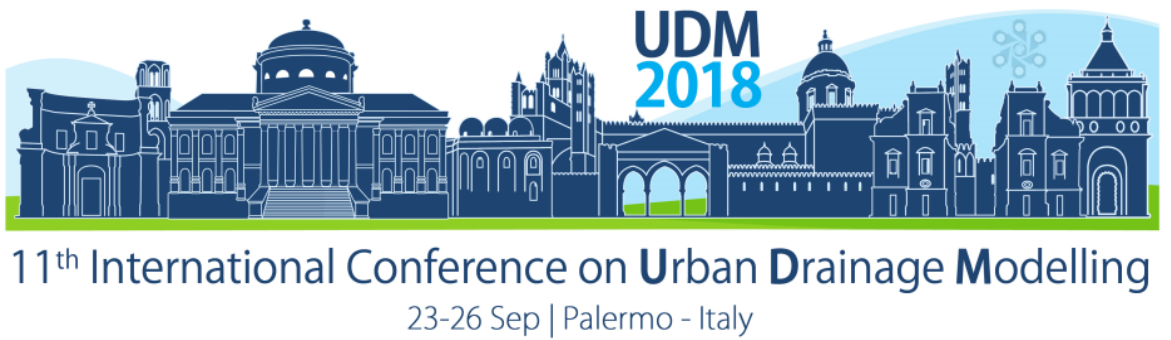

\title{
Modelling of Green and Grey Roofs in Cold Climates using EPA's Storm Water Management Model
}

\author{
Vladimír Hamouz ${ }^{1}$, Tone Merete Muthanna ${ }^{1}$ \\ ${ }^{1}$ Department of Civil and Environmental Engineering, Norwegian University of Science and Technology (NTNU),
}

\begin{abstract}
Rooftops retrofitting, typically extensive green roofs, is a favoured sustainable drainage system technology in densely developed urban areas. They provide multiple benefits in terms of stormwater retention and runoff detention. The latest version of Storm Water Management Model (SWMM) 5.1.012 with Low Impact Development (LID) Controls was used to model hydrological the performance of a green and grey (non-vegetated) roof by defining the physical parameters of individual layers in LID Control editor. In this study, high-resolution 1-minute data from a previously monitored green and grey roof were used to calibrate the SWMM LID Green Roof module. Results from the un-calibrated model were unsatisfactory considering the hydrological response of the green and grey roof. After calibration, the observed and simulated runoff had Nash-Sutcliffe model efficiency (NSME) of 0.88 (green roof) 0.68 (grey roof). This indicates that better fit between observed and modelled runoff could be achieved with calibration, primarily of the grey roof. Ideally the calibrated parameter set of the LID modules should be transferable between watersheds given the same LID structural build up. This should be investigated through further research finding the optimal parameter set, and data validation of proposed parameters across catchments.
\end{abstract}

Keywords: Green/grey roof; Storm Water Management Model (SWMM); Hydrological performance; Long-term simulation.

\section{INTRODUCTION}

The combined effect of urbanization, with increasing imperviousness, and climate change continues to alter hydrological balance in urban developed areas. In this urban landscape rooftops typically remain unused, despite the fact that they cover large part of the impervious surfaces. Rooftop retrofitting, using either vegetated (Stovin, 2010) or non-vegetated (Hamouz et al., 2018) solutions, has shown to provide multiple benefits in terms of hydrology, building physics, biodiversity, and usage as living areas. The rooftop retrofitting as a form offers a method to manage stormwater at the source while providing stormwater retention and runoff detention (Cipolla et al., 2016). However, the current knowledge of the hydrological performance of the different solutions under variable climates and geographical locations must be developed, especially on a larger scale rather than a small pilot test. Applying modelling software in combination with observed data offers a tool to simulate expected hydrological performance under various current and future climate conditions (Peng and Stovin, 2017). Therefore, more generic approach has been adopted in order to model green and grey roof hydrological performance on-site. In this study, the Storm Water Management Model (SWMM) and the LID module for green roofs has been applied. SWMM is physically based model, which allows to simulate stormwater in urban areas as well as snowmelt challenges in cold regions (Moghadas et al., 2016).

The research questions that this study aims to answer are:

1) Performance of the SWMM for long-term continuous simulations of a green roof in coastal wet and cold regions? 


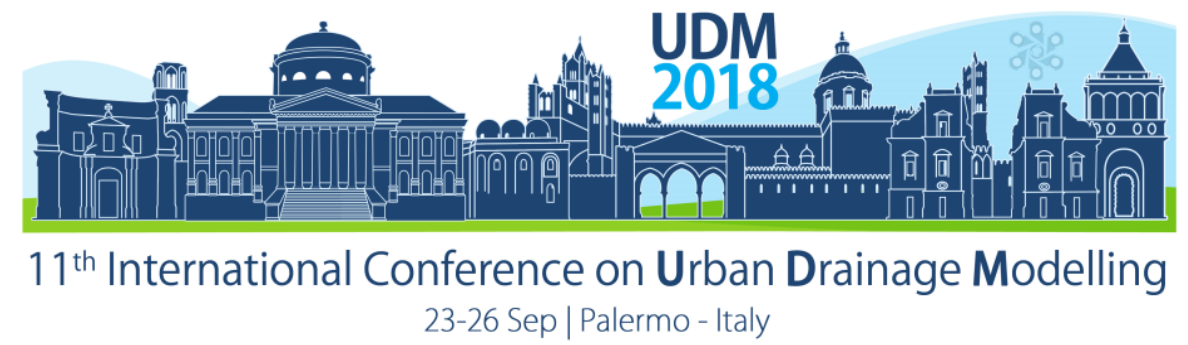

2) Performance of the SWMM for long-term continuous simulations of a grey roof in coastal wet and cold regions?

\section{MATERIALS AND METHODS}

\subsection{Characteristics of green and grey roof}

A full-scale field setup was built in order to study the hydrological performance of three different roof configurations in Trondheim, Norway (Hamouz et al., 2018). A conventional (black) roof served as reference to the green and grey roof. The dimensions of each roof were $8 \times 11 \mathrm{~m}$, with a longitudinal slope of $2 \%$. The structure composition of the grey roof was made up of an underlying protection layer, a $200 \mathrm{~mm}$ thick layer of LECA ${ }^{\circledR}$ lightweight aggregates (LWA), and covered with concrete pavers $(200 \times 200 \times 70 \mathrm{~mm})$. The green roof consisted of an underlying protection layer, a plastic drainage layer (egg box), a retention mat and an extensive Sedum mat.

\subsection{Input data}

The data collection period was April to July of 2017. Precipitation was measured by a heated tipping bucket rain gauge (Lambrecht meteo $\mathrm{GmbH} 1518 \mathrm{H}$, Lambrecht meteo $\mathrm{GmbH}$, Göttingen, Germany) with a resolution of $0.1 \mathrm{~mm}$ at 1 -min intervals. Runoff was measured using a weight-based system with two tanks downstream of the drainage outlets. The collection tanks were automatically emptied based; (1) Automatically emptied every $30 \mathrm{~min}$; (2) When the weight of the water approached the capacity of the tank. All the data were collected and recorded at 1-min intervals with a CR 1000 data logger (Campbell Scientific, Inc.). Evapotranspiration was estimated as water loss from direct measurements of precipitation and runoff, thus rather actual evapotranspiration was applied. At the same time, as confirmed by other studies (Johannessen et al., 2017; Hamouz et al., 2018), evapotranspiration may be neglected in the cold season (November - March). Soil moisture sensors were not available during model calibration process. Therefore, the first rainfall event was used as a preprecipitation event in order to let the model assimilate to the initial condition. The curve number method was used since this infiltration model only requires the curve number and the time it takes a fully saturated soil to completely dry.

\subsection{Model application and parameters estimation}

Storm Water Management Model (SWMM) 5.1.012, including Low Impact Development (LID) Controls module specifically designed for modelling SuDS structures, was used for long-term and short-term simulation of runoff quantity. The green and the grey roofs were modelled as a subcatchment in SWMM, where $88 \%$ of the subcatchment was occupied by the rooftop, and $12 \%$ impervious area, which includes the separation walls and the parapet (a low protective wall along the edge of the roof). The impervious area is covered by a standard asphalt roofing, typically used on conventional roofs. For this layer, the Manning's surface roughness was set to 0.015 and depression storage to 0.01 . Simultaneously, the impervious area was routed to the LID module. The LID module consists of three layers (surface, soil and drainage mat). The surface layer, however, has no effect on runoff detention since there is no ponding on the green roofs. Therefore, parameters included in the soil and drainage layer were chosen for calibration, as they are considered to have significant effect on runoff detention, namely 4 parameters within soil layer: porosity, field capacity, conductivity, conductivity slope, and 2 parameters within drainage mat: void fraction and roughness. The initial green and grey roof parameters were estimated from field measurements, literature (Rosa et al., 2015, Peng and Stovin, 2017) or defaults (Rossman, 2015). Simulating a simply LID system without drainage network steady flow routing was chosen as it is insensitive to the time step employed and is appropriate for preliminary analysis using long-term continuous simulations. 


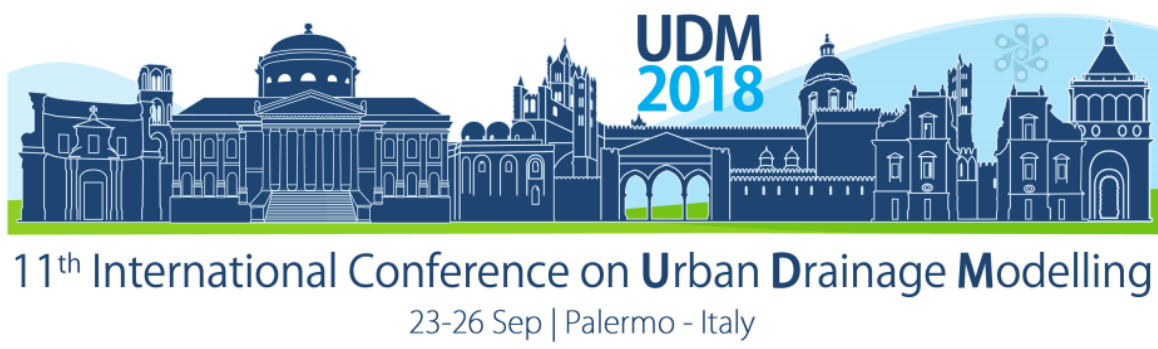

The measured precipitation and outflow was compared how well the model matched this outflow using the Nash-Sutcliffe Model Efficiency (NSME) ranging from - infinite to 1 . The NSME was used as an objective function in order to find the optimal parameter set, and measure goodness of fit. In general, the closer the model efficiency is to 1 , the more accurate the model can predict the performance of green roofs, whilst an NSME greater than 0.5 indicates acceptable model performance (Rosa et al., 2015). The final parameters were achieved by applying the Shuffle Complex Evolution (SCE) algorithm (Duan et al., 2015). The SCE method is based on four concepts that aims to efficient global optimization. The calibration process was based on random sampling from a predefined variable range where each parameter had lower and upper bound delineated. The SCE algorithm uses an initial guess to generate a sequence of improving approximate solutions in order to reach the highest NSME; where the $n$-th approximation was derived from the previous ones. The termination criteria of the calibration process were based on the principle of convergence.

\section{RESULTS AND DISCUSSION}

The selected parameters from before and after calibration of the individual LID layers: surface, soil and drainage mat, is presented (Table 1). One can see NSME achieved from the initially estimated parameters and after the long-time continuous calibration. It was decided to perform the long-time continuous calibration in order to prevent eventual validation issues while comparing events with different characteristics. Substantial improvement was achieved after the calibration of the grey roof parameters. The NSME calculated from observed and simulated runoff from the green roof improved from 0.44 to 0.88 , of the grey roof improved from insufficient -3.93 to 0.68 . During the calibration process, nearly 2000 iterations were carried out within the green roof and nearly 3000 within the grey roof.

Table 1. LID Control editor and its individual parameters with initial and calibrated values.

\begin{tabular}{|c|c|c|c|c|}
\hline \multirow{2}{*}{$\begin{array}{l}\text { Control name } \\
\text { Parameter }\end{array}$} & \multicolumn{2}{|c|}{ Green roof } & \multicolumn{2}{|c|}{ Grey roof } \\
\hline & Initial value & After calibration & Initial value & After calibration \\
\hline \multicolumn{5}{|l|}{ SURFACE } \\
\hline Berm Height (mm) & 500 & - & 500 & - \\
\hline Vegetation Volume Fraction & 0.1 & - & 0 & - \\
\hline Surface Roughness (Manning's $n$ ) & 0.05 & - & 0.015 & - \\
\hline Surface Slope (\%) & 2 & - & 2 & - \\
\hline \multicolumn{5}{|l|}{ SOIL } \\
\hline Thickness (mm) & 40 & - & 200 & \\
\hline Porosity (volume fraction)* & 0.5 & 0.52 & 0.6 & 0.56 \\
\hline Field Capacity (volume fraction) ${ }^{*}$ & 0.3 & 0.25 & 0.02 & 0.03 \\
\hline Wilting Point (volume fraction) & 0.05 & - & 0.01 & - \\
\hline Conductivity $(\mathrm{mm} / \mathrm{hr})^{*}$ & 25 & 90.5 & 1432 & 2488.9 \\
\hline Conductivity Slope* & 15 & 35.2 & 10 & 18.1 \\
\hline Suction Head (mm) & 110 & - & 10 & - \\
\hline \multicolumn{5}{|l|}{ DRAINAGE MAT } \\
\hline Thickness (mm) & 10 & - & 1 & - \\
\hline Void Fraction* & 0.5 & 0.023 & 0.5 & 0.171 \\
\hline Roughness (Manning's n)* & 0.1 & 0.057 & 0.015 & 0.049 \\
\hline NSME & 0.44 & 0.88 & -3.93 & 0.68 \\
\hline
\end{tabular}

* parameters for calibration

Long-term model simulation and comparison of the observed and simulated runoff from the green and the grey roof following calibration is shown in Figure 1. The simulated cumulative runoffs were close to the observed data. In comparison, the proportional difference between the simulated and observed runoff from the grey roof counted $0.34 \%$, and $8.21 \%$ of the runoff from the green roof. The larger discrepancy within the cumulated runoff from the green roof, therefore, is likely influenced by incorrect evapotranspiration rates. The low retention ability within the grey roof may be decisive for the low volume error when water transpiration was 


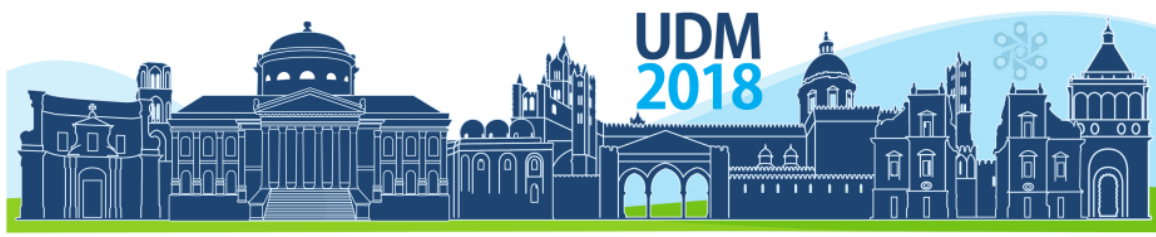

$11^{\text {th }}$ International Conference on Urban Drainage Modelling

23-26 Sep | Palermo - Italy

neglected. The simulated runoff from the green roof underestimated the observed peak flow responses to rainfall with high intensity. On the other hand, opposite effect of overestimation can be seen on the grey roof configuration.

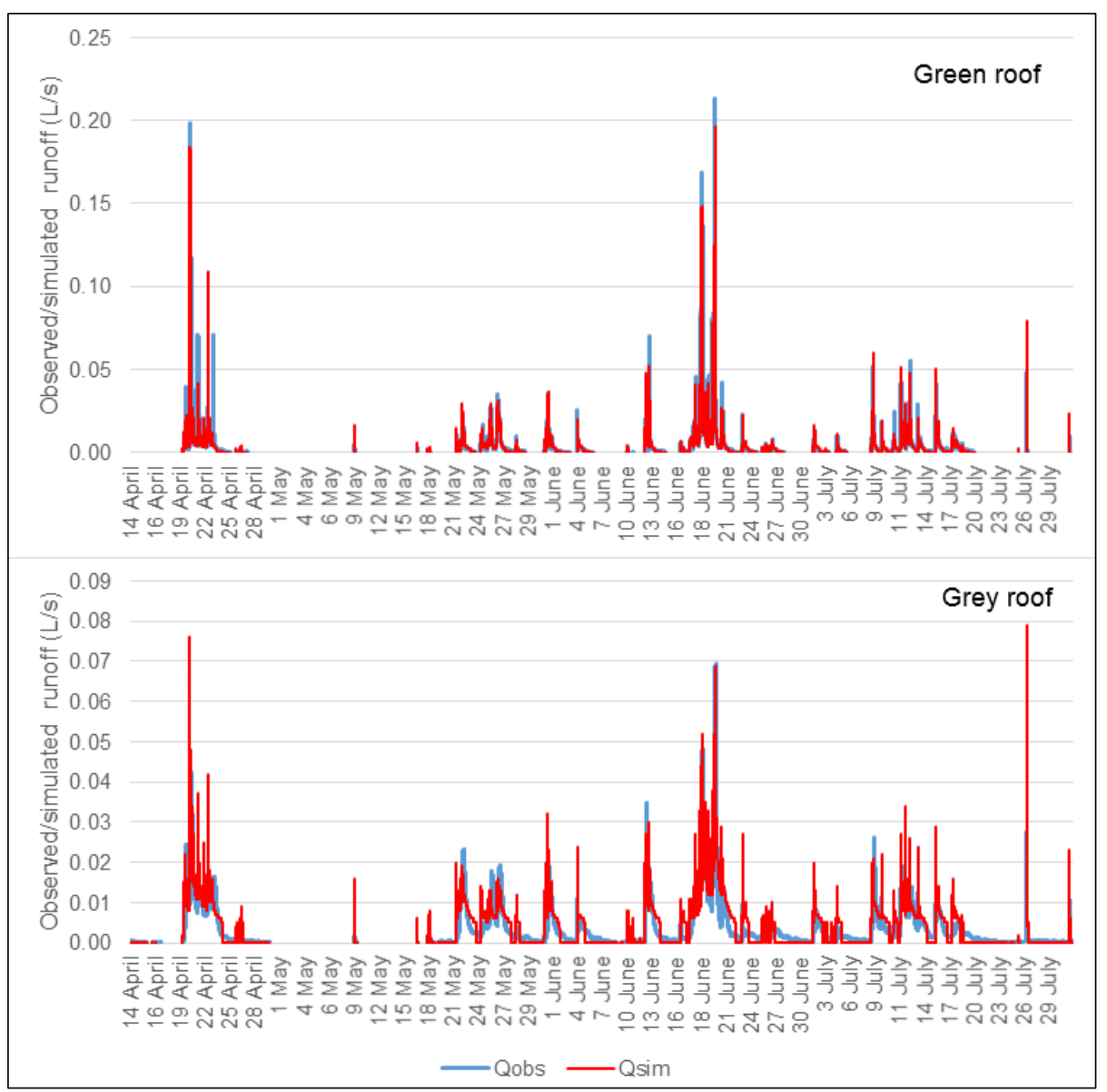

Figure 1. Comparison of observed and simulated runoff from green (up) and grey (below) roof after calibration

One can see difficulties with the simulation and the underestimation of the runoff tails in the grey roof. This may be explained by compensation while overestimation of the runoff peak flows. Thus, the ability of the model to simulate the runoff detention is partly limited. Therefore, the parameters within the drainage mat serving to the estimation of the baseflow should get more attention in term of the slower runoff release. The estimation of the drainage mat thickness, which could represent the flow through the lightweight aggregate was not appropriate.

Comparisons of NSME of the green and grey roof are illustrated in Figure 2. The simulation of the runoff from the green roof after the calibration gives high NSME value, which indicates accurate model results. However, one can clearly see discrepancies showed by mismatch of the observed and simulated runoff from the green roof, which were caused by snowfall and following snowmelt. This occurred during the grey roof runoff simulation as well. The sparse data of the observed and simulated runoff from the grey roof demonstrate needs for further research in order to model the hydrological behaviour more precisely while finding the best parameter set, specifically within modelling detention performance. The reason for that may 


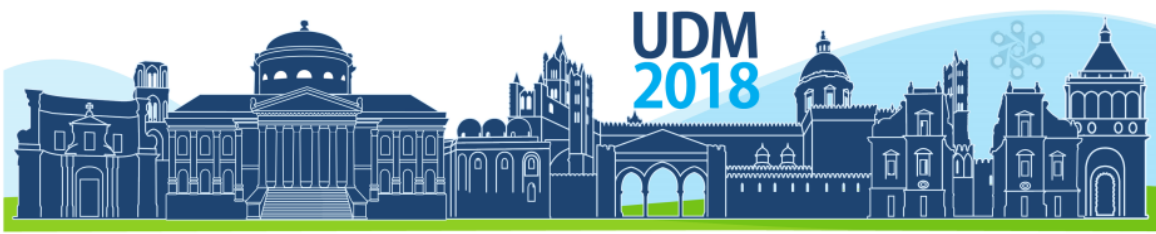

$11^{\text {th }}$ International Conference on Urban Drainage Modelling

23-26 Sep | Palermo - Italy

be due to inability of the model to correctly simulate percolation (water flow through porous media).
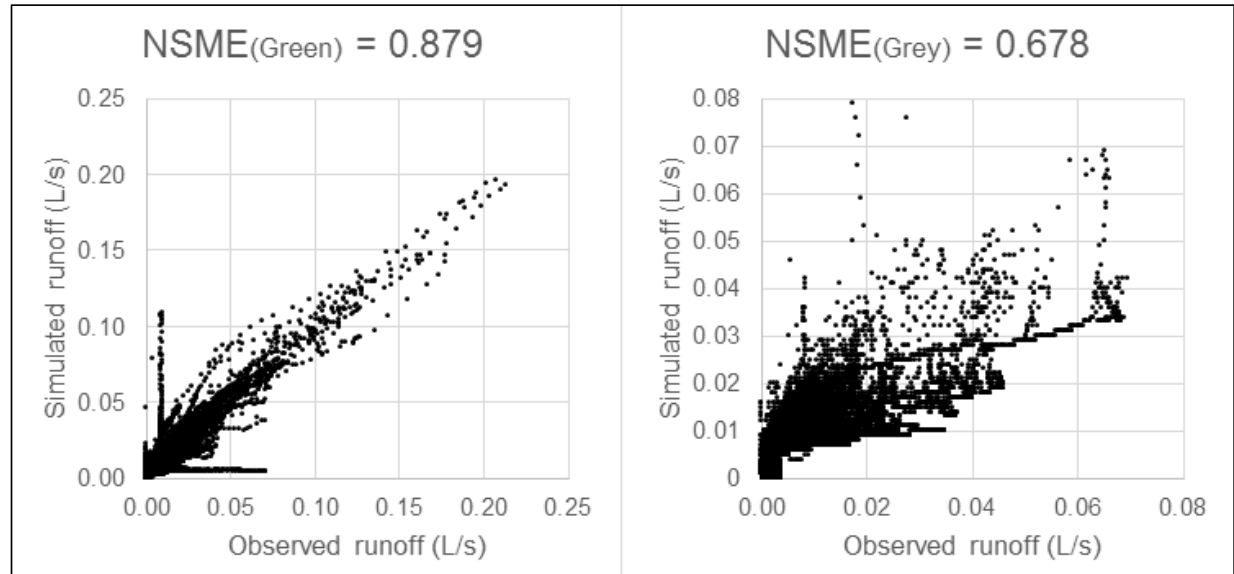

Figure 2. Comparison of NSME of green (left) and grey (right) roof after calibration

In order to obtain higher confidence in calibrated parameters, it might be good to test a different period of the year during the calibration process as well as cross-validation of obtained parameters.

\section{CONCLUSIONS}

In this study, the runoff from a green and grey rooftop retrofitting were simulated using SWMM version 5.1. For each configuration, the best parameter sets were found to give the highest NSME (closest to 1). The calibrated model was able to simulate the runoff with a good fit, 0.88 (green roof) 0.68 (grey roof) values of Nash-Sutcliffe model efficiency (NSME). However, the results indicate that there is a need for more research related to snowmelt and winter season in cold climates. More simulations are being performed in order to find other decisive parameters for retention and detention simulations giving better NSME values as well as study parameter sensitivity with respect to rainfall characteristics and initial conditions and to validate the proposed parameters.

\section{References}

Cipolla, S. S., Maglionico, M., \& Stojkov, I. (2016). A long-term hydrological modelling of an extensive green roof by means of SWMM. Ecological engineering, 95, 876-887.

Duan, Q., Sorooshian, S., \& Gupta, V. (1992). Effective and efficient global optimization for conceptual rainfall-runoff models. Water resources research, 28(4), 1015-1031.

Hamouz, V., Lohne, J., Wood, J. R., \& Muthanna, T. M. (2018). Hydrological Performance of LECA-Based Roofs in Cold Climates. Water, 10(3), 263.

Johannessen, B. G., Hanslin, H. M., \& Muthanna, T. M. (2017). Green roof performance potential in cold and wet regions. Ecological Engineering, 106, 436-447.

Moghadas, S., Gustafsson, A. M., Muthanna, T. M., Marsalek, J., \& Viklander, M. (2016). Review of models and procedures for modelling urban snowmelt. Urban Water Journal, 13(4), 396-411.

Peng, Z., \& Stovin, V. (2017). Independent Validation of the SWMM Green Roof Module. Journal of Hydrologic Engineering, 22(9), 04017037.

Rosa, D. J., Clausen, J. C., \& Dietz, M. E. (2015). Calibration and verification of SWMM for low impact development. JAWRA Journal of the American Water Resources Association, 51(3), 746-757.

Rossman, L. A. (2015). Storm water management model user's manual version 5.1, EPA/600/R-14/413b, U.S. Environmental Protection Agency, Cincinnati.

Stovin, V. (2010). The potential of green roofs to manage urban stormwater. Water and Environment Journal, 24(3), 192-199. 


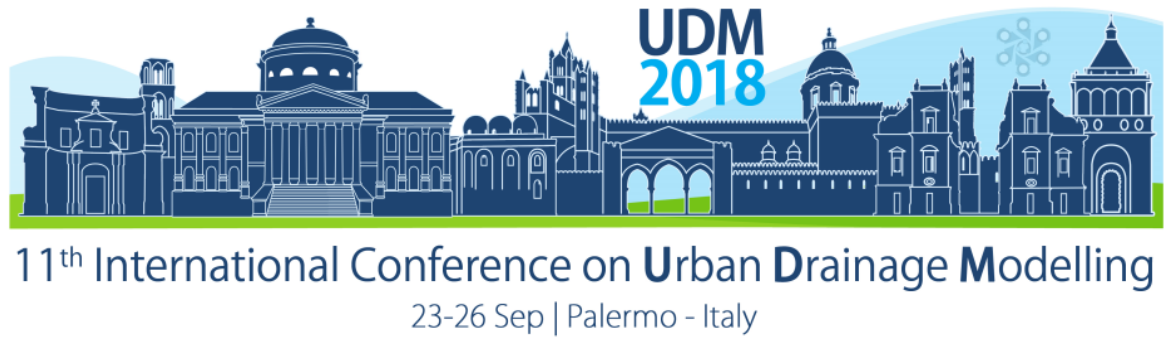

\title{
Coordinated Precipitation Evaluation of Damage-Producing Events: First Steps
}

\author{
Thomas Einfalt ${ }^{1}$, Sascha Hinsken ${ }^{2}$ and Marc Scheibel ${ }^{3}$ \\ ${ }^{1}$ hydro \& meteo GmbH \& Co. KG, Lübeck, Germany \\ ${ }^{2}$ City of Düsseldorf, Düsseldorf, Germany \\ ${ }^{3}$ Wupperverband, Wuppertal, Germany
}

\begin{abstract}
Damage after rainfall events requires detailed analysis of causes and rainfall extremity for the determination of liability: the question who has to pay for what. Recent years have shown that damage has increased, but also the insight that extreme events call for the whole municipal community and not only the single citizen or sewer agency. The determination which rainfall category occurred requires thorough inspection of all available data. This includes weather radar, station data, flow data and damage data. It is important to be able to rely on quality controlled high resolution data for detailed analyses in mainly urban areas. This contribution presents important corner stones on the road towards a more harmonized way of evaluating damage producing precipitation events.
\end{abstract}

Keywords: extreme precipitation events; damage; liability

\section{INTRODUCTION}

There is a growing number of requests for an analysis of damage producing events and its classification as "normal" (within the limitations of design standards and should be therefore handled by existing structures) or "exceptional" (known as force majeure) for liability purposes. Since this classification is crucial for the decision who is liable for occurred damage, a standard procedure is required for transparent decisions processes on compensation, which is also accepted by courts and can be a basis for accords or even verdicts.

Damage sites - regarding convective events - may be very local and therefore, the rainfall data need to have a high spatial resolution $1 \times 1 \mathrm{~km}$ or better). Also, flow paths or the whole hydrological catchment must be considered since a damage site may differ from the location of the highest precipitation observed.

Current practice shows that there is not always enough care given to the sophisticated task to properly analyse an extreme precipitation event. This frequently results in underestimation of the true extent of precipitation due to limited spatial coverage of data, e.g. when station data from a sparse network are used, or such data are taken for adjustment.

Therefore, this paper recalls the results from two events which have been carefully analysed and draws conclusions for good practice procedures. These events are an event in the Wupper area in Germany of 2007, and an event causing tremendous damage in Münster, Germany in 2014. 


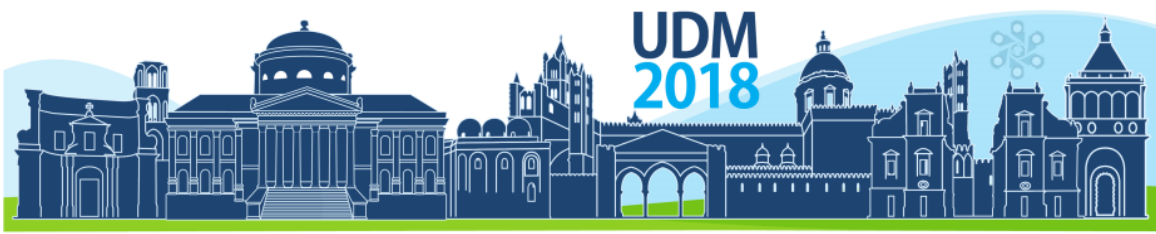

$11^{\text {th }}$ International Conference on Urban Drainage Modelling

23-26 Sep | Palermo - Italy

\section{MATERIALS AND METHODS}

\subsection{Damage events}

The first example is a damage producing event in the Wupper area, dated 6th August 2007 which has been analysed in a previous paper (Einfalt et al., 2012).

The second example from Münster has been analysed by numerous authors since it has been the highest precipitation event ever in this area. More than $290 \mathrm{~mm}$ have fallen within less than 7 hours.

Other available examples from Canada and Germany cannot be presented for legal reasons.

\subsection{Wupper area event analysis}

Radar data. Adjusted and corrected radar data have been prepared according to the procedures in Frerk et al. (2012).

Damage data. Basic data on the damage side were the number of natural forces damage insurance contracts, the cumulated insurance sum, the number of loss events (daily resolution in time and post code district resolution in space, usually several $\mathrm{km}^{2}$ ) and the claims expenditure (sum of the reported losses).

Overlay of damage and radar. The visual check already showed a good match between reported losses and heavy precipitation (Figure 1). The background colours represent the insurance information: white areas are without insurance cover, grey areas are with insurance cover and no reported losses, coloured areas are with insurance cover and reported losses. The foreground colours illustrate the precipitation event sum, restricted to values above $36 \mathrm{~mm}$. This corresponds to the precipitation amount for a duration of 1 hour and a ten year return period.

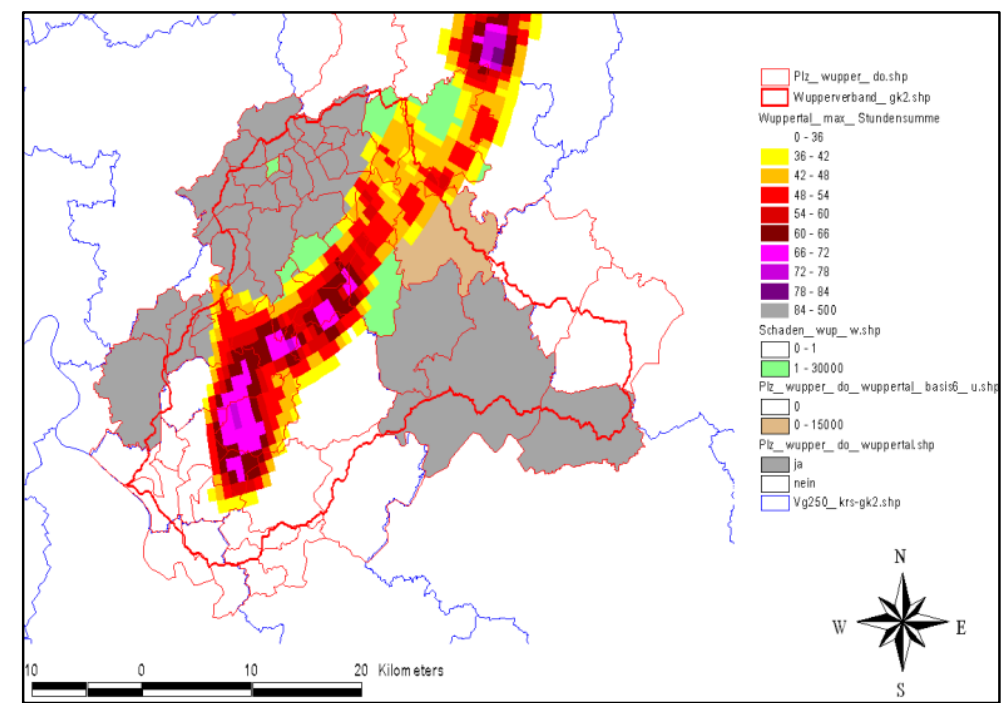

Figure 1. - radar rainfall over damage areas (coloured areas) - Wuppertal event 2007.

Damage function. The statistics between different loss parameters and the different precipitation parameters showed a partly good fit, also in terms of correlation coefficient (Figure 2). 


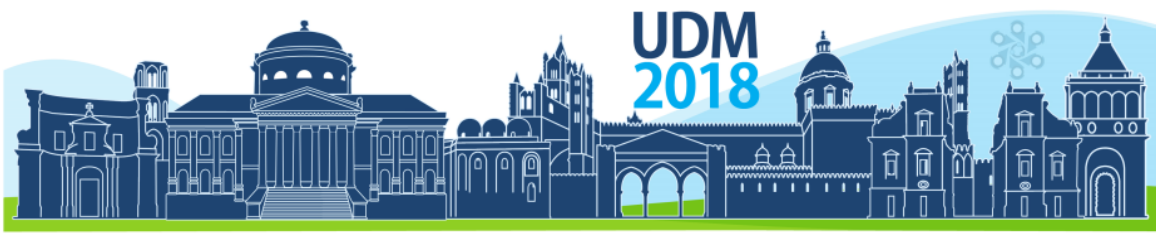

$11^{\text {th }}$ International Conference on Urban Drainage Modelling

23-26 Sep | Palermo - Italy

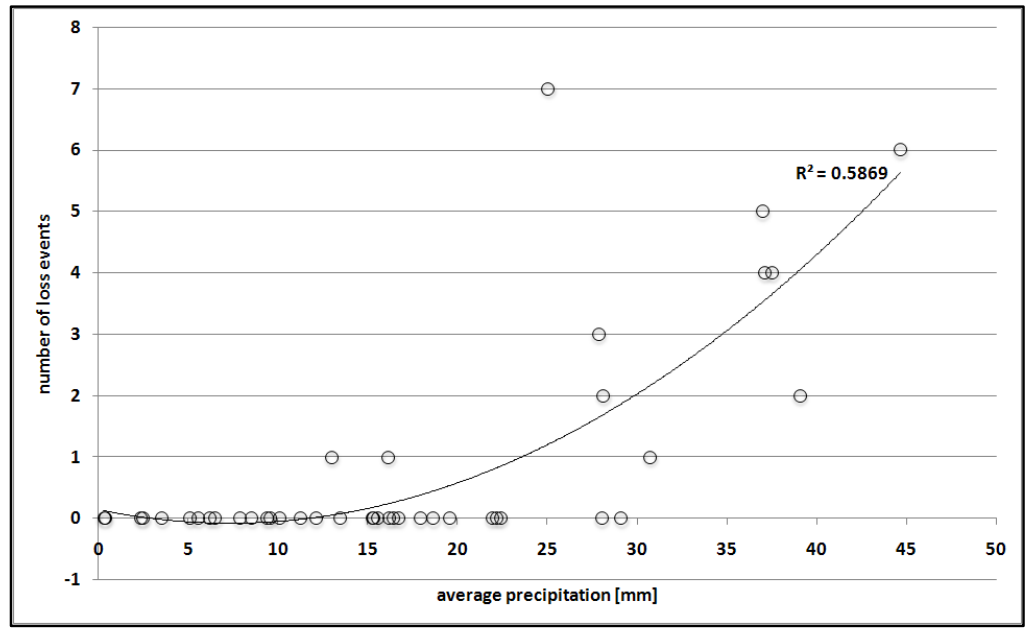

Figure 2 - Rainfall hourly maximum versus number of loss events - Wuppertal event 2007.

Conclusion for station statistics. The case study showed that damages occurred when the amount of precipitation was higher than the design storm as given by e.g. DIN EN 752.

\subsection{Münster event analysis}

Radar characteristics. Radar data have been processed by the German Weather Service (DWD) with their RADOLAN product. It became clear in the event analysis that the sparse rain gauge network REGNIE (Figure 3, left) was not able to detect the extreme event. The network density also plays a role for radar adjustment (Figure 1, centre) where the adjusted radar still considerably underestimates the peak precipitation sum of $292 \mathrm{~mm}$ measured by an external rain gauge of the State Environmental Agency.

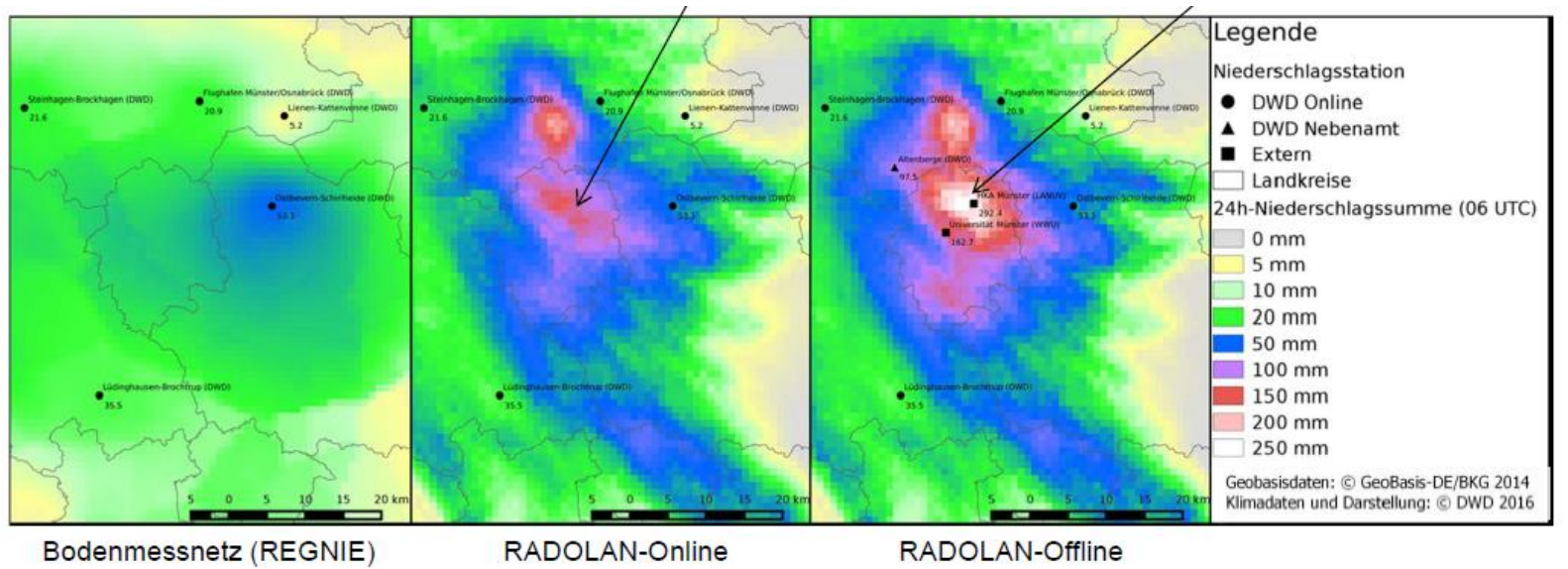

Figure 3 - Rainfall event sum for Münster, seen by REGNIE rain gauges (left), online adjusted radar (centre) and offline analysed radar (right) - from Winterrath (2017).

Damage information. About 30.000 insured loss cases with overall costs of 200 million Euro were reported (GDV, 2015). 


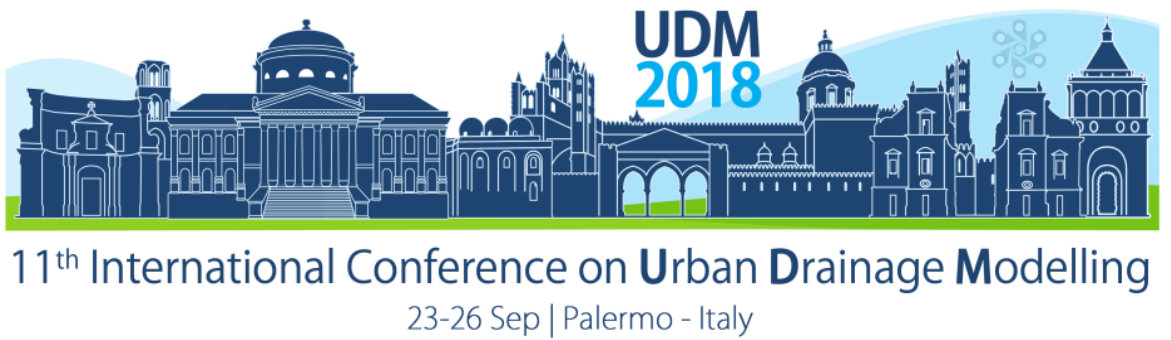

\section{RESULTS AND DISCUSSION}

A procedure to produce reliable results should include the following minimum standards:

1. Initial conditions must be known (soil wetness, current capacity of the sewer system etc.).

2. The basic data for the event analysis should span the entire event, including at least 24 hours before damage occurrence in order to include a potential time of water accumulation on the ground and possible basin retention times.

3. Radar data are required with a time step of 5 or 6 minutes or less so that statistical assessments can be performed and a spatial resolution $1 \times 1 \mathrm{~km}$ or better.

4. Radar data must be quality controlled according to the state of the art of radar data processing. This includes corrections for clutter, blockage, attenuation, hail, bright band (if applicable), temporal interpolation and second trip.

5. Rain gauges must be used as ground reference for radar adjustment when reflectivity data are used. Adjustment must be performed according to national and international regulations. If available, stations close to the damage site of all operators shall be included. Because adjustment procedures are sensitive to rain gauge data, the measurements from rain gauges must be quality controlled as well. If the gauge network density is less than 1 gauge per $10 \mathrm{~km}^{2}$, a sensitivity analysis of the result is required, giving the $90 \%$-percentile of the adjustment procedure.

6. For the event classification as "exceptional" or "not exceptional", an extreme value statistics / design storms of locally representative stations (point or grid) are required. The classification is then performed for the highest value for each site representative pixel (a pixel above the damage site and upstream of the damage site) for different selected integration periods, ranging from 5 minutes to 24 hours for summer events.

\section{CONCLUSIONS}

The proposed procedure allows for the comparison of events, based on a comparable data quality standard.

Further work includes the formulation of detailed minimum requirements for this procedure as to become an internationally acknowledged guidance.

\section{References}

Einfalt, T., Pfeifer, S., Burghoff, O. (2012) Feasibility of deriving damage functions from radar measurements. 9th International Workshop on Precipitation in Urban Areas, St. Moritz, 6-9 December. ISBN 978-3-906031-21-7.

Frerk, I., Treis, A., Jessen, M., Einfalt, T. (2012) Ten years of quality corrected and adjusted radar precipitation data for North Rhine Westphalia - methods and objectives. 9th International Workshop on Precipitation in Urban Areas, St. Moritz, 6-9 December. ISBN 978-3-906031-21-7.

GDV (2015) Naturgefahrenreport 2015 [in German]

Winterrath, T., Junghänel, T., Walawender, E., Brendel, C., Weigl, E., Hafer, M., Becker, A. (2017) Starkregenanalysen für Hessen - Auswertungen radarbasierter Niederschlagsbestimmungen von 2001 bis heute. KLIMPRAX-Ergebnispräsentation - 30. März 2017 - Frankfurt 


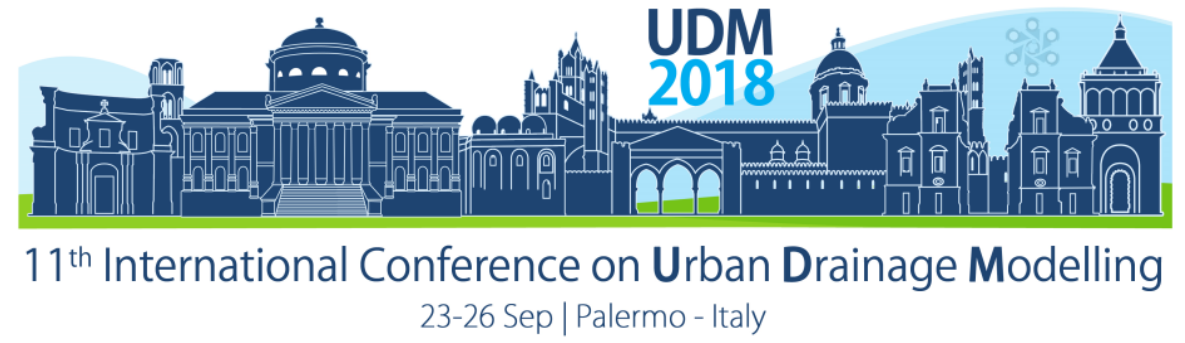

\title{
Influence of flood water contribution from multiple sources in extreme event statistics of urban flooding
}

\author{
Søren Thorndahl' ${ }^{1}$, Damian Murla-Tuyls' ${ }^{1}$, Rasmus Vest Nielsen ${ }^{1}$, Marc Schleiss $^{2}$, and Jonas Olsson ${ }^{3}$ \\ ${ }^{1}$ Aalborg University, Department of Civil Engineering, Aalborg, Denmark \\ ${ }^{2}$ Delft University of Technology, Department of Geoscience and Remote Sensing, Delft, Netherlands \\ ${ }^{3}$ Swedish Meteorological and Hydrological Institute, Research \& Development (hydrology), Norrköping, Sweden
}

\begin{abstract}
For pluvial flood risk assessment in urban areas it is important to be able to calculate how often a specific area is at risk of flooding. This is especially evident in urban areas subject to contribution from multiple sources, e.g. surcharging drainage system, surface runoff, overflowing rivers, etc. In this study extreme event statistics are assessed by simulation of rainfall impact and consecutive statistics of flood response in order to estimate return periods of flooding. The model applied is an integrated hydraulic model which includes relevant hydrological processes that contribute to urban flooding. The setup is analysed based on a small urban catchment in Aalborg Denmark. Results show that it is possible to estimate return periods of flood volume, flood extent and local water levels based on simulation and that rainfall and hydrological conditions critical to flooding can be identified.
\end{abstract}

Keywords: Urban flooding; extreme event statistics; integrated hydrological modelling

\section{INTRODUCTION}

Urban areas are at risk of flooding from multiple sources e.g. surcharging sewer or drainage systems, surface water runoff (rainfall not able to infiltrate), ground water, rivers or streams, storm surges, etc. Since contribution of flooding might come from multiple sources at the same time it is difficult to determine statistically how often flooding might occur.

In this study we focus on pluvial contributions to flooding from impervious areas (drainage system), pervious areas (direct runoff on surface); and stream bank overflow, since they are the dominant sources to flooding in the case study area (see section 2.1).

In management and design of urban infrastructure, it is important to be able to estimate the risk of flooding specific areas and to assess the return period of flood levels being exceeded (extreme event statistics). It is however difficult to determine the return periods accurately by simulating the flood response based on historical rainfall series. This is due to limited periods of observed rainfall, randomness in joint occurrences in flood contributions, e.g. high water level in stream at the same time as high saturation level in soil, and flood producing rainfall.

The objectives of the present study are: i) to set up an integrated flood model in an urban area in Denmark that includes contributions from multiple sources; ii) to identify rainfall and hydrological conditions critical to flooding from multiple sources; and iii) to estimate return periods for local flooding, which can be used as a management tool in flood risk assessment. 


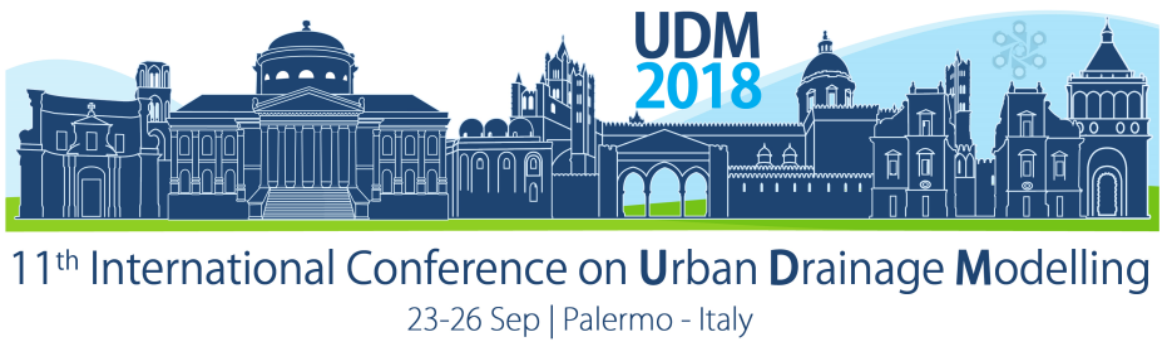

\section{MATERIALS AND METHODS}

\subsection{Case study area and urban flood model}

The applied flood model is a semi-distributed integrated 1D-2D urban drainage model covering a residential area of 60 ha (Kærby) and an industrial area of 38 ha (håndværkerkvarteret). The catchment has a partly combined partly separated drainage system. The case study area is bounded by three branches of the stream Østerå.

The integrated flood model, which is implemented in the MIKE model environment includes: i) the drainage system (1D) including pumps, combined sewer overflow structures, storage basins etc. which has contributions from the impervious parts of the catchment; ii) the stream branches (1D); iii) the surface runoff (2D) from pervious areas based on exceedance of soil infiltration capacity; and iv) an overland flood model (2D) based on a digital terrain model.

\subsection{Rainfall data and boundary conditions}

In order to derive extreme event statistics we need to consider historical rainfall series with long records. For this purpose we apply data from the Danish water pollution committee rain gauge network (Madsen et al., 2017). We develop a long-term (1979-2017) gridded dataset of $62 \times 38 \mathrm{~km}^{2}$ where hourly rainfall between a total of 73 gauges have been interpolated using ordinary kriging. This dataset will at a later point we applied to simulate rural catchment runoff (at a larger scale) with the HYPE model (Lindström et al., 2010) which again will be applied as an optimized boundary condition for the small scale model applied here. Since, we in this study focus on the urban hydrological processes at small scale, we need a finer temporal resolution and therefore apply rain gauge data from the dataset non-interpolated in space and in a $1 \mathrm{~min}$. resolution. We thus apply single rain gauges individually and neglect the spatial variability over the catchment. The rainfall is not representative of the true rainfall over the catchment, but another part of Denmark with similar climatological conditions and with long records, which makes it ideal for investigations of extreme event statistics of rainfall-flood response.

The selection of the most severe rainfall events is based on a two-step selection method explained by (Murla-Tuyls and Thorndahl, 2018). First, rainfall-runoff simulations are performed over the study area for the complete historical rainfall series. The second step consists in performing a hydraulic network simulation using the obtained rainfall-runoff results as input. From this the events with the largest number of surcharged manholes are selected and the 38 most severe events are simulated with the full flood model.

Boundary conditions for stream base flow are based on a seasonally varying average obtained from a few years of observations. Initial conditions of soil saturation and boundary condition for rainfall on the pervious areas contributing to flooding is based on a continuous simulation of infiltration from Green-Ampt (Rawls et al., 1983).

\section{RESULTS AND DISCUSSION}

Preliminary simulation results are presented in the following figures (further simulations are executed during spring of 2018). Figure 1 shows an estimation of return periods based on three output valuables from the model simulations: the number of flooded manholes, the max. flood area and the max. flood volume. 


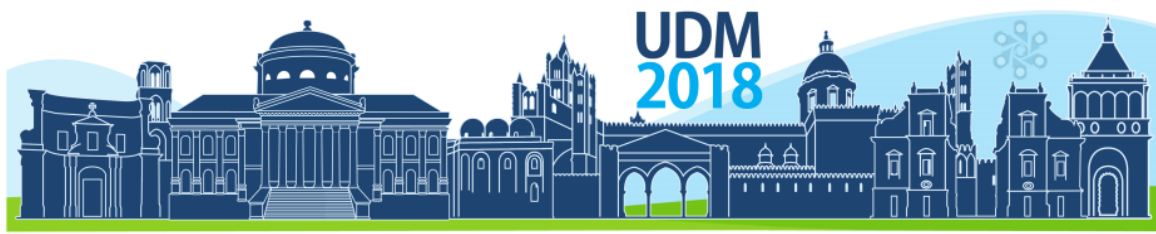

$11^{\text {th }}$ International Conference on Urban Drainage Modelling

23-26 Sep | Palermo - Italy
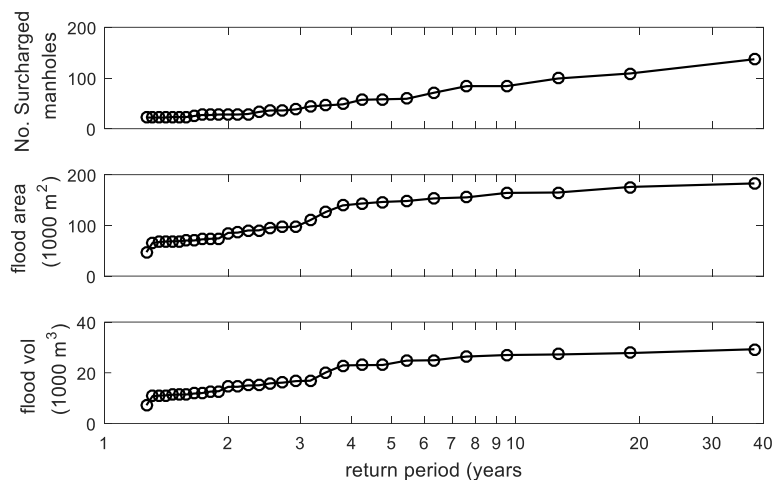

Figure 1. Simulated no. of surcharged manholes, flood area and flood volume as function of return period.
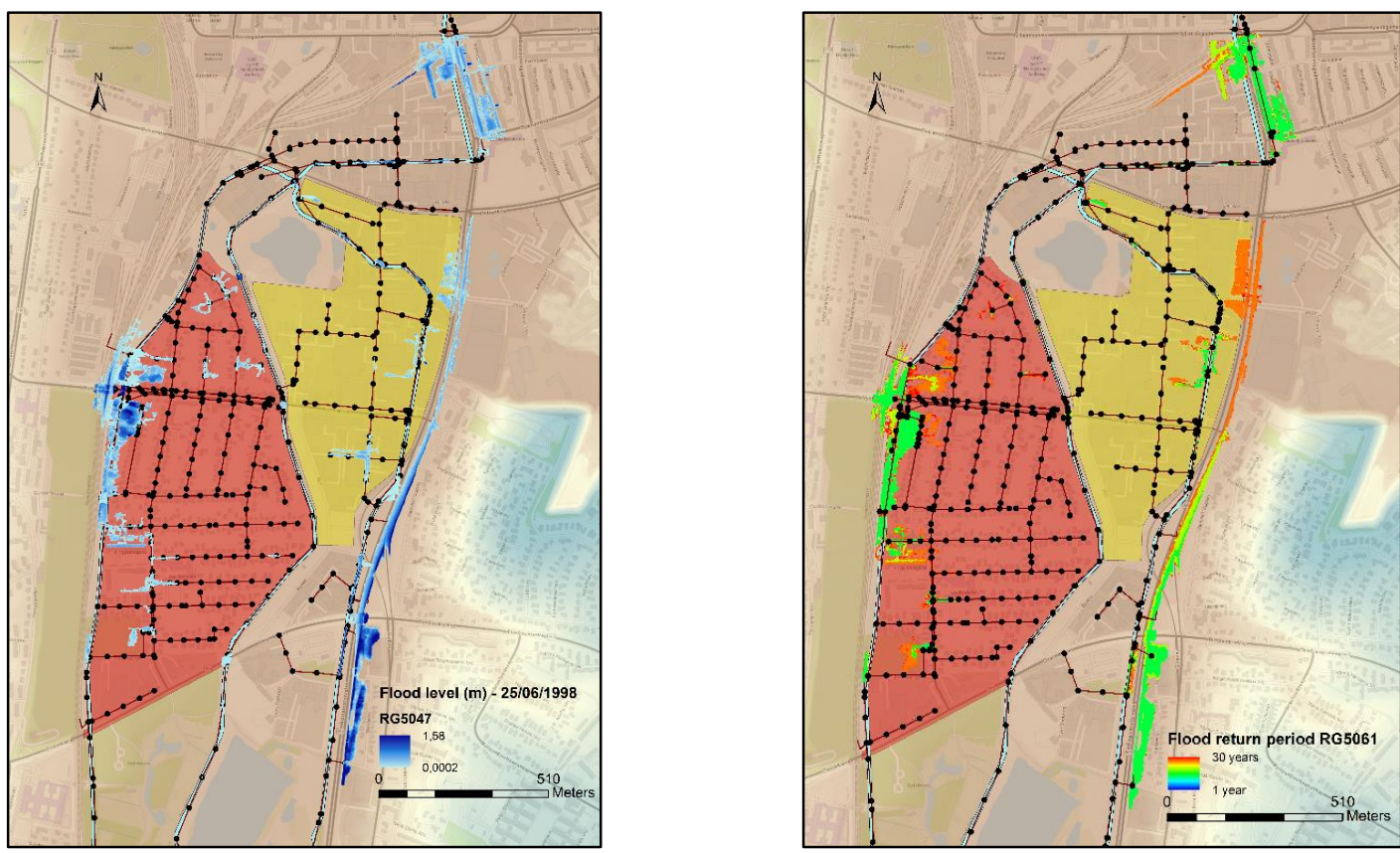

Figure 2. Left: Example of a simulated maximum flood levels for an event on 1998.06.25; and right: estimated return period of flooding based on ranking of flood levels.

Figure 2 (left) shows and example of a flood map for an event from June 1998. It is evident to see both flooding occurring from stream bank overflow in the eastern part of the catchment and a combination of drainage system flooding in the western part of the catchment. By ranking simulated water levels in each individual flooded cell, we can calculate the return period of flooding in a specific point. This is shown on figure 2 (right).

The flooding response time (figure 3 right), which can be considered a surrogate measure of the time of concentration, is estimated by correlating the maximum flood level in a given flood prone cell with the rainfall intensity aggregated over different durations. The flooding response time is selected for the rainfall duration with the largest correlation. (Murla-Tuyls and Thorndahl, 2018). From the values of the flooding response time it is possible to identify the rainfall characteristics which are on average the most critical for flooding of a specific point in the catchment. 


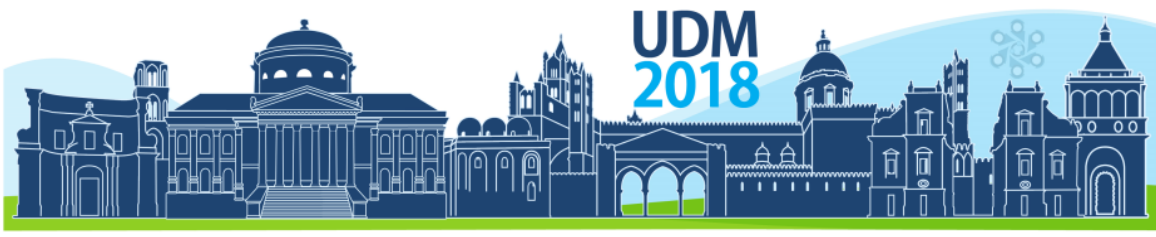

$11^{\text {th }}$ International Conference on Urban Drainage Modelling

23-26 Sep | Palermo - Italy

As an example Figure 3 right presents correlation between rainfall intensity and flood water level in a selected point shown in the black circle of figure 3, left, where parts of the urban area is flooded from stream bank overflow. The best correlation between rainfall intensity and simulated water level is found for an aggregated duration of $39 \mathrm{~min}$. Moreover, return periods of rainfall corresponding to the national Danish rainfall statistics (Madsen et al. 2017) are shown. From these simulations it is evident that the point will flood with a return period of approx. 1 year.
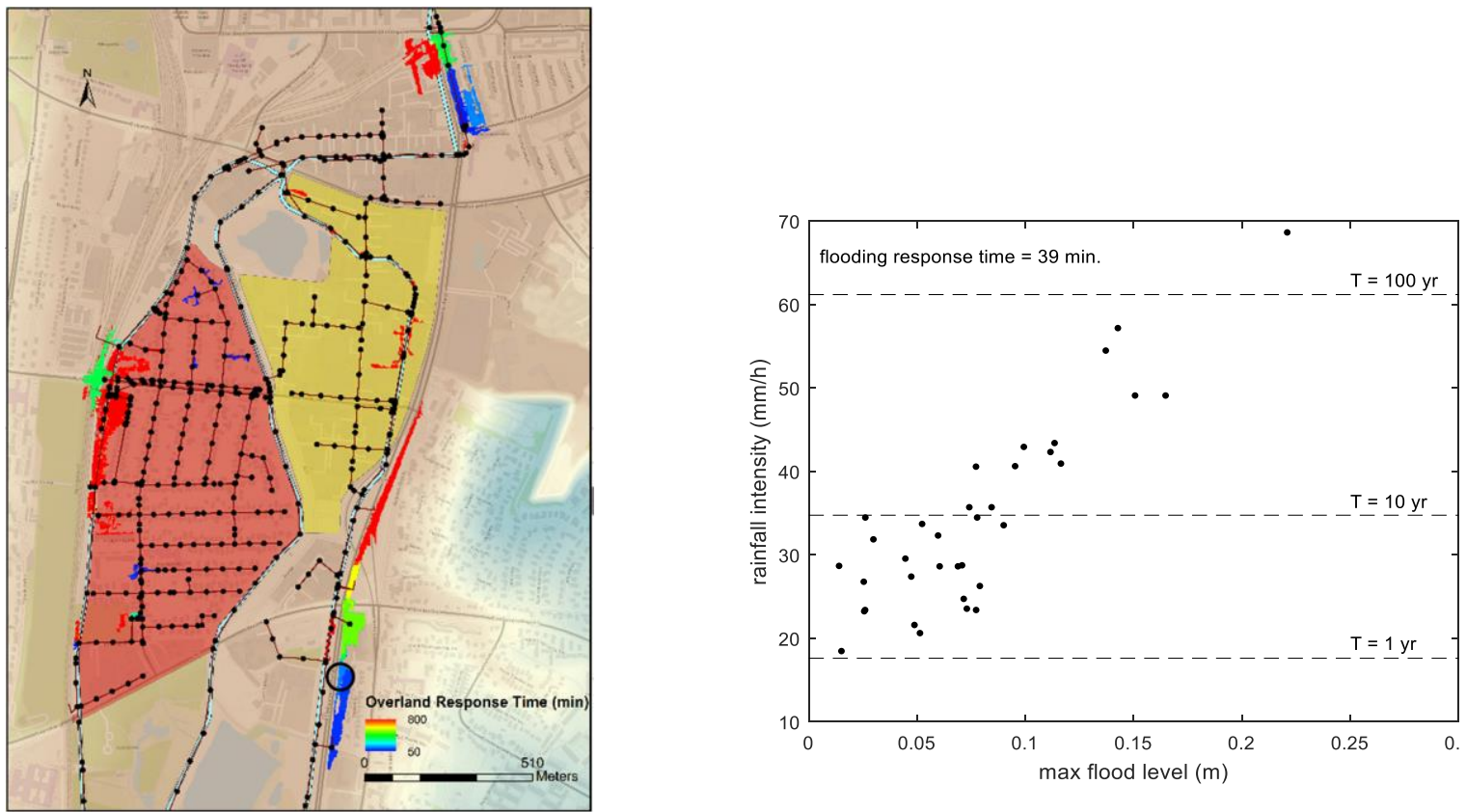

Figure 3. Left: Estimated average flooding response time; right: rainfall intensity aggregated over 39 min. durations plotted against max. simulated flood levels in a point within the black circle of the left figure.

\section{CONCLUSIONS}

The simulations show that it is indeed important to consider multiple sources of flood contributions in an integrated way in order to assess the return period of flooding in an urban area. In the analysis we have shown plausible ways to link rainfall statistics to flood statistics and to assess return periods of flooding locally. Further simulations and division of simulation results will show whether it is possible to assess return periods of flooding of individual cells based on their source.

\section{REFERENCES}

Lindström, G., Pers, C., Rosberg, J., Strömqvist, J., Arheimer, B. (2010) Development and testing of the HYPE (Hydrological Predictions for the Environment) water quality model for different spatial scales. Hydrology Research 41.

Madsen, H., Gregersen, I.B., Rosbjerg, D., Arnbjerg-Nielsen, K. (2017) Regional frequency analysis of short duration rainfall extremes using gridded daily rainfall data as co-variate. Water Science and Technology 75 (8) 1971-1981

Murla-Tuyls, D.M., Thorndahl, S., Rasmussen, M.R. (2018) Return period assessment of urban pluvial floods through modelling of rainfall-flood response. Submitted to Journal of Hydroinformatics, Oct. 2017. Revised Feb. 2018.

Rawls, W.J., Brakensiek, D.L., Miller, N. (1983). Green-Ampt Infiltration Parameters from Soils Data. Journal of Hydraulic Engineering 109, 62-70. 


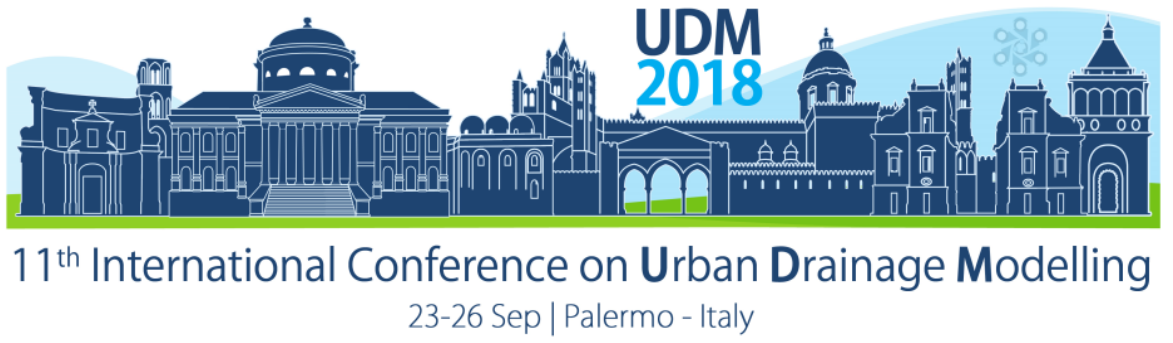

\title{
Investigation of Impacts of Spatial Variability and Motion of Rainfall in Urban Drainage Modelling
}

\author{
Christoffer B. Andersen ${ }^{1}$ and Søren Thorndahl ${ }^{1}$ \\ ${ }^{1}$ Aalborg University, Department of Civil Engineering, Aalborg, Denmark
}

\begin{abstract}
The topic of this paper is to investigate which knowledge can be acquired from weather radar systems on the case of spatial variability of storm events. Furthermore, it is investigated how this variation affects the results of an urban drainage model. The main focus of the study is to determine if the motion of a storm event has any impact on the runoff response in the drainage system. To do this a novel method is developed to rotate and relocate existing radar images and use the result as input to a selected model. At the moment the results show that the dominant direction of the storm has little to none effect on the outcome, but further research is being conducted to confirm this.
\end{abstract}

Keywords: Weather radar; Spatial variability; Urban hydrology

\section{INTRODUCTION}

Urban drainage models have become increasingly more complex which in return demands higher spatial resolution of precipitation data. Urban catchments consist of high internal spatial variability which make them very responsive to variability in precipitation, both regarding temporal and spatial variations, as discussed in e.g. Ochoa Rodriguez et al., (2015). Moreover, models are increasingly being set up to cover larger areas or whole cities, which also require accounting for spatial rainfall variability.

In Denmark a network of rain gauges has been established giving a good understanding of the temporal resolution of storm events (Madsen et. al, 2017). This network however still does not give a complete understanding of the spatial variability of storm events under all conditions.

This study strives to get an understanding how the spatial variation of rainfall impacts urban drainage systems. To accomplish this data from radars in Denmark is used to describe the spatial variation and use it as input to an urban drainage model. That way the effect of spatial distributed rain can be observed. More specifically it is investigated how rainfall coming from different directions impacts the response on the catchment in terms of peak flows, runoff volumes, combined sewer over flow volumes, and local surcharge of manholes. This is tested by a novel method where center of storms are relocated and rainfall fields are rotated.

\section{MATERIALS AND METHODS}

The research presented this paper is centred around developing and testing different way of using weather radar, in urban drainage modelling. A study area is thus selected near the capitol city of Denmark, Copenhagen, as presented in figure 1. 


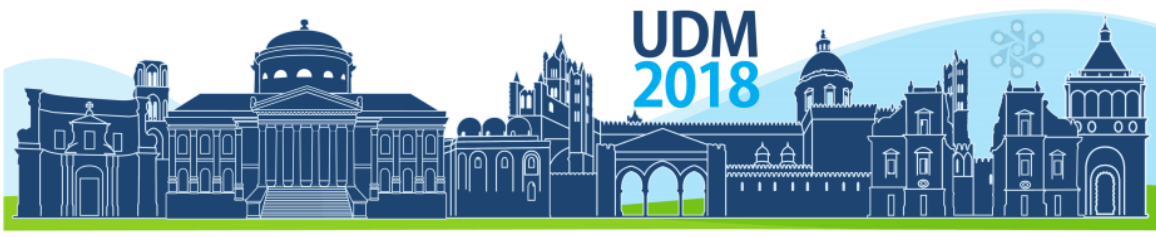

$11^{\text {th }}$ International Conference on Urban Drainage Modelling 23-26 Sep | Palermo - Italy

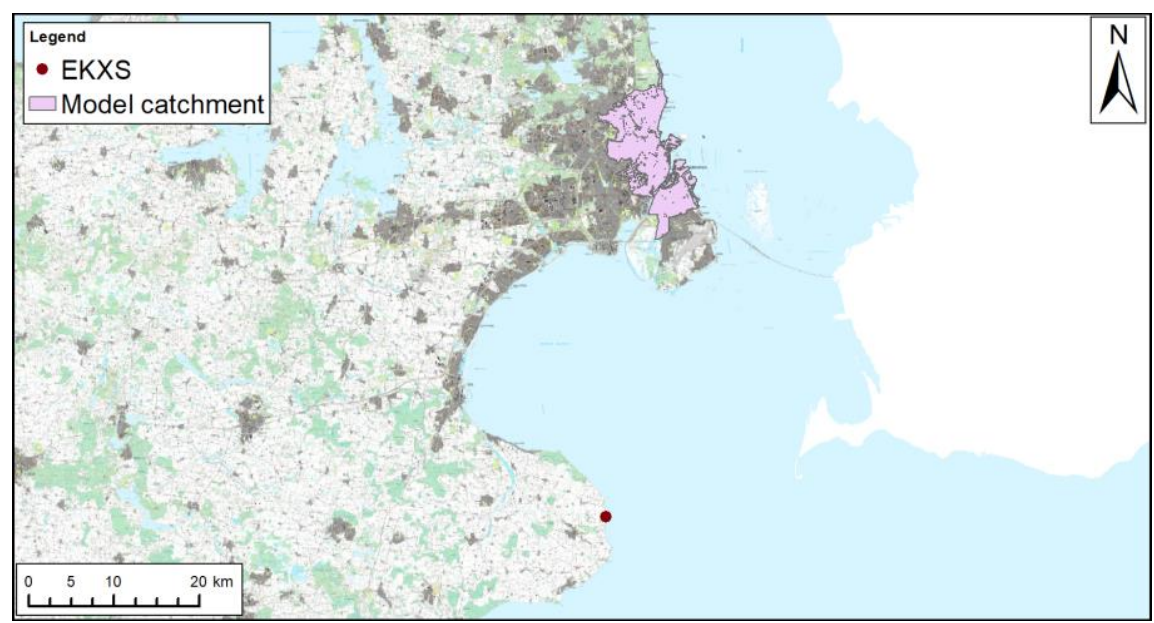

Figure 1 Overview of selected study area.

The chosen study area contains a C-band weather radar system (EKXS) operated by the Danish Meteorological Institute (DMI) and an urban drainage model covering the catchment of the wastewater treatment plant Lynetten. The following will describe how the data have been processed and how the model is set up.

\subsection{Data availability}

In this study data from the EKXS radar will be used. The radar is located at Stevns, about 40 $\mathrm{km}$ south of the city of Copenhagen. For technical specification of the radar and procedure for data sampling, please refer to (Thorndahl et. al., 2014). The radar data covers a period from 2002 to 2016. To increase the precision of the precipitation estimate the radar data undergoes two additional steps of data post-processing: The first step of increasing the validity of the precipitation estimate is to adjust the radar image against rain gauges within range of the radar. Daily mean field bias adjustment is used as described in Thorndahl et. al., (2014).

The temporal resolution of the original data is 10 minutes. This is deemed to be too coarse to be applied to a hydrological model. Using the methods described in Nielsen et. al., (2014), the data is interpolated to a resolution of 1 minute. The spatial resolution of the radar data is $500 \times 500 \mathrm{~m}^{2}$.

\subsection{Model for case area}

The urban drainage model used is developed by the capitol municipality (HOFOR) with the software pack MIKE Urban by DHI. The model covers the wastewater treatment plant Lynetten with a size of $82 \mathrm{~km}^{2}$. Table 1 displays catchment characteristics for the model.

Table 1 Specifications of the Lynetten model catchment. Numbers in parantehses display the standard deviation.

\begin{tabular}{ccc}
\hline Total area [ha] & Average sub-catchment area [ha] & Average imperviousness [\%] \\
\hline 8280 & $3.75( \pm 5.54)$ & $48.2( \pm 22.8)$ \\
\hline \hline
\end{tabular}




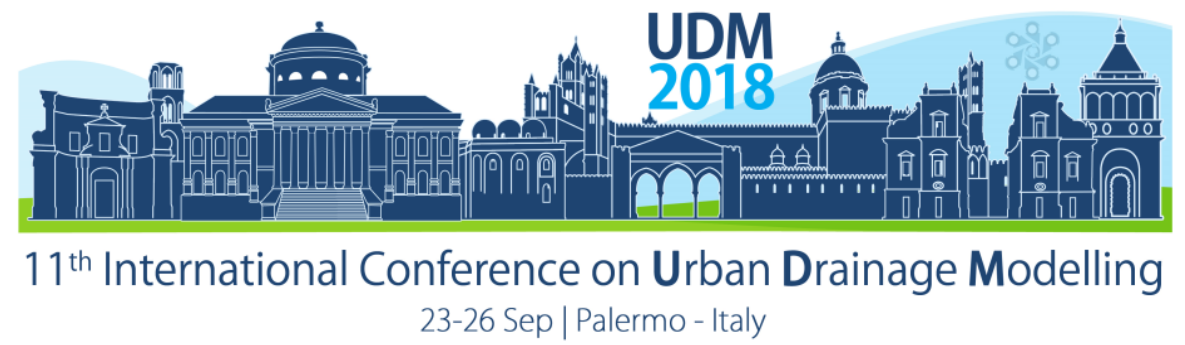

The radar is implemented in the model by connecting each pixel to each nearby sub catchment. This can be done since the average size the sub catchments is significantly smaller than the radar resolution.

\subsection{Methods}

To determine the motion of each storm the global vector estimation is applied. This method can be shortly summarized in the following steps:

1. Select the storm in question, which motions need to be determined.

2. Crop the radar image to avoid errors or noise in the image.

3. Spilt up the radar image in $t+d t$ pairs. The $d t$ is selected to be $10 \mathrm{~min}$ in this study.

4. Select cut of value and convert the image pairs, from step 3, to images with only two grayscale values. The cut of value was selected to be $0.1 \mathrm{~mm} /$ hour for this study.

5. Cross-correlate the image pairs, from point 4.

6. Determine motion from the result in point 5.

7. Determine dominant motion from the results in point 6 .

To ensure that results from the model can be considered comparable a method is developed to rotate selected radar images and keep the temporal dynamics. The method consists of determining the center of rotation. A center within the model area is selected at random and an area averaged rain series is determined. The rotated- and the original series is cross correlated to determine the similarity of the series. The maximum correlation at any given time delay is then chosen. This process is continued until a maximum is observed. This optimization is performed by applying the genetic algorithm (Schmitt, 2001). This creates a storm event that produces somewhat the same rainfall input with only the direction that have changed.

\section{RESULTS AND DISCUSSION}

Comparing the motion of the storm to results from the urban drainage model regarding: runoff volumes, combines sewer overflow volumes and surcharge of manholes, no affect of the storm direction is observed. Another analysis is then conducted to test the effect of the storm events motion. Hydrographs from the link upstream the wastewater treatment plant is extracted, an example of such is displayed on figure 2 .

15-10-2012

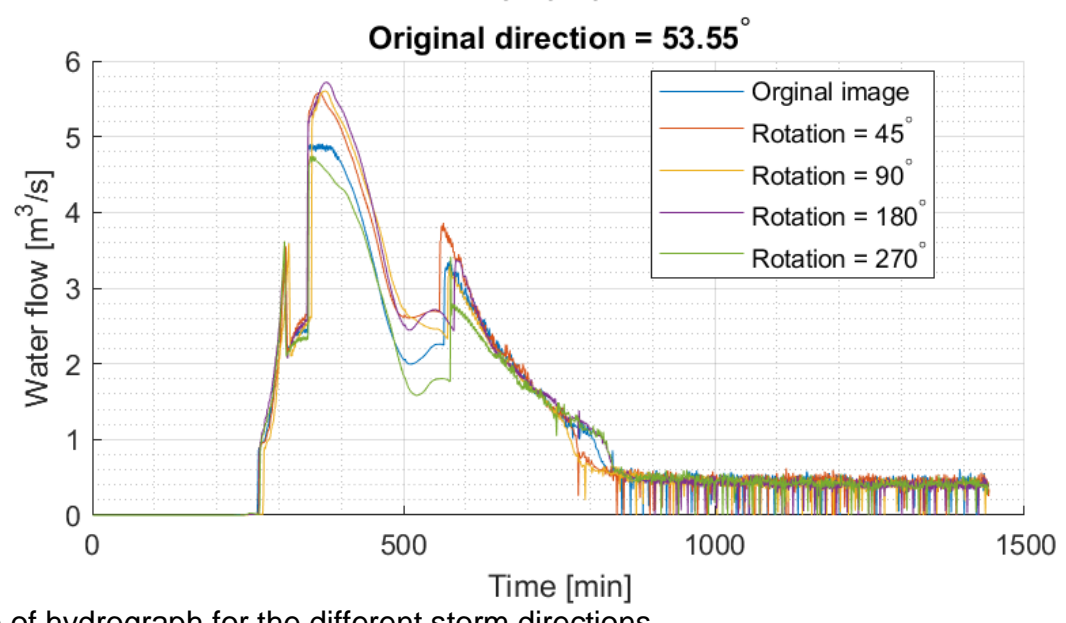

Figure 2 Example of hydrograph for the different storm directions. 


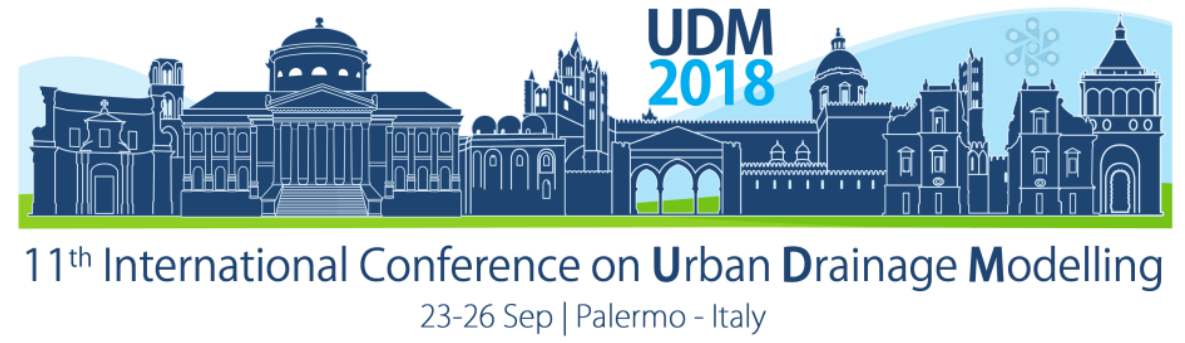

The results show that the difference between results seems minuscular. In table 2 values for when different volumes of water are observed at the specified location is listed.

Table 2 Results from figure 2. t10 defines the time it takes $10 \%$ of the volume to reach Lynetten, t25 is $25 \%$ and so forth. The value tMax defines at which time peak flow is observed.

\begin{tabular}{l|rrrrrrr}
\hline Direction & $\begin{array}{c}\mathrm{t} 10 \\
{[\mathrm{~min}]}\end{array}$ & $\begin{array}{c}\mathrm{t} 25 \\
{[\mathrm{~min}]}\end{array}$ & $\begin{array}{c}\mathrm{t50} \\
{[\mathrm{min}]}\end{array}$ & $\begin{array}{c}\mathrm{t75} \\
{[\mathrm{min}]}\end{array}$ & $\begin{array}{c}\mathrm{t} 90 \\
{[\mathrm{~min}]}\end{array}$ & $\begin{array}{c}\mathrm{tMax} \\
{[\mathrm{min}]}\end{array}$ & $\begin{array}{c}\text { Qmax } \\
{\left[\mathrm{m}^{3} / \mathrm{s}\right]}\end{array}$ \\
\hline Original & 347 & 398 & 535 & 706 & 1043 & 364 & 4,9 \\
45 deg & 349 & 399 & 522 & 684 & 1025 & 364 & 5,6 \\
$90 \mathrm{deg}$ & 353 & 400 & 508 & 676 & 988 & 373 & 5,6 \\
$180 \mathrm{deg}$ & 348 & 396 & 509 & 684 & 966 & 376 & 5,7 \\
$270 \mathrm{deg}$ & 345 & 397 & 532 & 721 & 1038 & 355 & 4,7 \\
\hline \hline
\end{tabular}

It seems that there is no clear distinction between the different motions At this time in the study only 10 storm events have been simulated and no one show signs of significant difference. The running hypothesis is that since the model is so large some averaging will happen during the system. Further analysis is being done at the moment to test if this is true.

Currently more simulations are being executed and the local impacts are studied more in detail.

\section{CONCLUSIONS}

At this time it seems that the direction of the storm event have no real impact on the response of the urban drainage system. The values in table 2 shows no significant difference depending on the direction of the storm. Further analysis needs to be conducted in order to confirm whether this is correct or not.

\section{References}

Madsen, H., Gregersen, I.B., Rosbjerg, D., Arnbjerg-Nielsen, K., (2017) Regional frequency analysis of short duration rain fall extremes using gridded daily rainfall data as co-variate. Water Science and Technology. 75(8) 1971-1981.

Nielsen, J.E., Thorndahl, S., Rasmussen, M.R. (2014) A numerical method to generate high temporal resolution precipitation time series by combining weather radar measurements with a nowcast model. Atmospheric Research. 138(14), 1-12.

Ochoa-Rodrigues, S., Wang, L., Gires, A., Pina, R.B, Reinoso-Rondinel, R., Bruni, G., Ichiba, A., Gaitan, S., Cristiano, E., Assel, J.A., Kroll, S., Murlá-Tuyls, D., Tisserand, B., Schertzer, D., Tchiguirinskaia, I., Onof, C., Willems, P., Veldhuis, M.T. (2015) Impact of spatial and temporal resolution of rainfall inputs on urban hydrodynamic modelling outputs: A multi-catchment investigation. Journal of Hydrology. 531(15), 389-407.

Schmitt, L.M., (2001) Theory of Genetic Algorithms. Theoreitcal Computer Science. 259(01), 1-61.

Thorndahl, S. Nielsen, J.E., Rasmussen, M.R. (2014) Bias adjustment and advection interpolation of long-term high resolution radar rainfall series. Journal of Hydrology. 508(14), 214-226. 


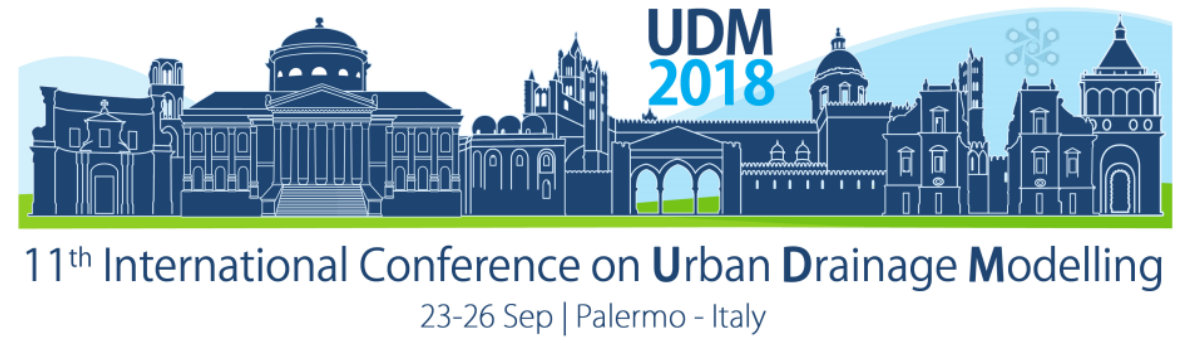

\title{
Performance of High-Resolution Numerical Weather Predictions with a Rapid Updating Cycle for Urban Runoff Forecasting
}

\author{
Jonas Wied Pedersen', Luca Vezzaro',2, Henrik Vedel ${ }^{3}$, Henrik Madsen ${ }^{4}$ and Peter Steen Mikkelsen ${ }^{1}$ \\ ${ }^{1}$ Department of Environmental Engineering, Technical University of Denmark, Kgs. Lyngby, Denmark \\ ${ }^{2}$ Krüger A/S - Veolia Water Technologies, Gladsaxe, Denmark \\ ${ }^{3}$ Danish Meteorological Institute, Technical University of Denmark, Kgs. Lyngby, Denmark \\ ${ }^{4}$ Department of Applied Mathematics and Computer Science, Technical University of Denmark, Kgs. Lyngby, \\ Denmark
}

\begin{abstract}
Rainfall forecasts based on numerical weather predictions are a fairly new tool within the urban drainage community. That is despite the fact that they provide longer forecast horizons than radar-based forecasts, which could be valuable for integrated management of urban drainage-wastewater systems. High-resolution numerical weather predictions with a high updating frequency are here used as forcing in a runoff model, which provides flow forecasts up to 10 hours ahead. Evaluation is done in terms of exceedance of a flow threshold. Results show trustworthy predictions on horizons less than two hours. For longer horizons, the True Positives Rate and the Positive Predictive Value decrease to around 0.2 and 0.3 , respectively.
\end{abstract}

Keywords: Numerical Weather Prediction; Urban runoff forecasting; Threshold exceedance evaluation

\section{INTRODUCTION}

Radar-based precipitation forecasts are skilful up to 3 hours ahead, the length depending strongly on the weather conditions (Thorndahl et al., 2017). However, many problems in integrated management of urban drainage-wastewater systems exist on time scales beyond this short horizon. Numerical Weather Predictions (NWP) can increase forecast horizons but at the expense of reduced spatial and temporal resolution. NWP is a fairly new tool within urban hydrology and there is thus little research into their performance as forcing for urban drainage models.

In this contribution, we investigate the use of a newly developed operational NWP nowcasting system at the Danish Meteorological Institute (DMI). The system assimilates additional observations of specific relevance to precipitation, including radar observations and cloud data, to improve the initial conditions (Korsholm et al., 2015). The NWP product is used to force a conceptual rainfall-runoff model for predictions of flow at the outlet of a sewer catchment with a forecast horizon up to 10 hours. The evaluation of skill is done in terms of predictions of high/low flow domains (Vezzaro et al, 2017).

\section{MATERIALS AND METHODS}

\subsection{Data and case study}

The case study for this contribution is the Dæmningen combined sewer catchment, which is located in Copenhagen, Denmark. The catchment is approximately $30 \mathrm{~km}^{2}$ and a flow gauge is located at its outlet, recording flow measurements at a two-minute resolution. Observed rainfall data are available from three rain gauges inside the catchment at one-minute resolution. Flow and rain gauge data are available for the calendar years of 2016 and 2017. 


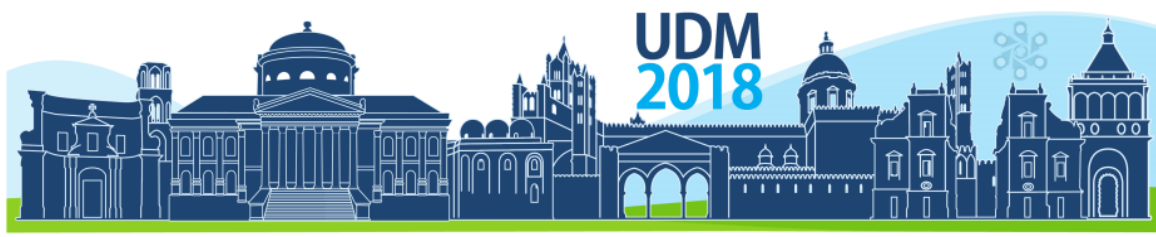

$11^{\text {th }}$ International Conference on Urban Drainage Modelling

23-26 Sep | Palermo - Italy

Figure 1 shows the sewer catchment boundary with the main sewer pipes, the location of the flow gauge, and the center of the NWP grid-boxes (i.e. where the NWP forecasts are available).

The NWP product is based on the HIRLAM model and it has a spatial resolution of approximately $3 \mathrm{~km}$ and a temporal resolution of 10 minutes. The forecast horizon is 10 hours and it has a rapid updating cycle as a new forecast is produced every hour. The NWP product comes with a half hour delay compared to the last observations assimilated into the model.

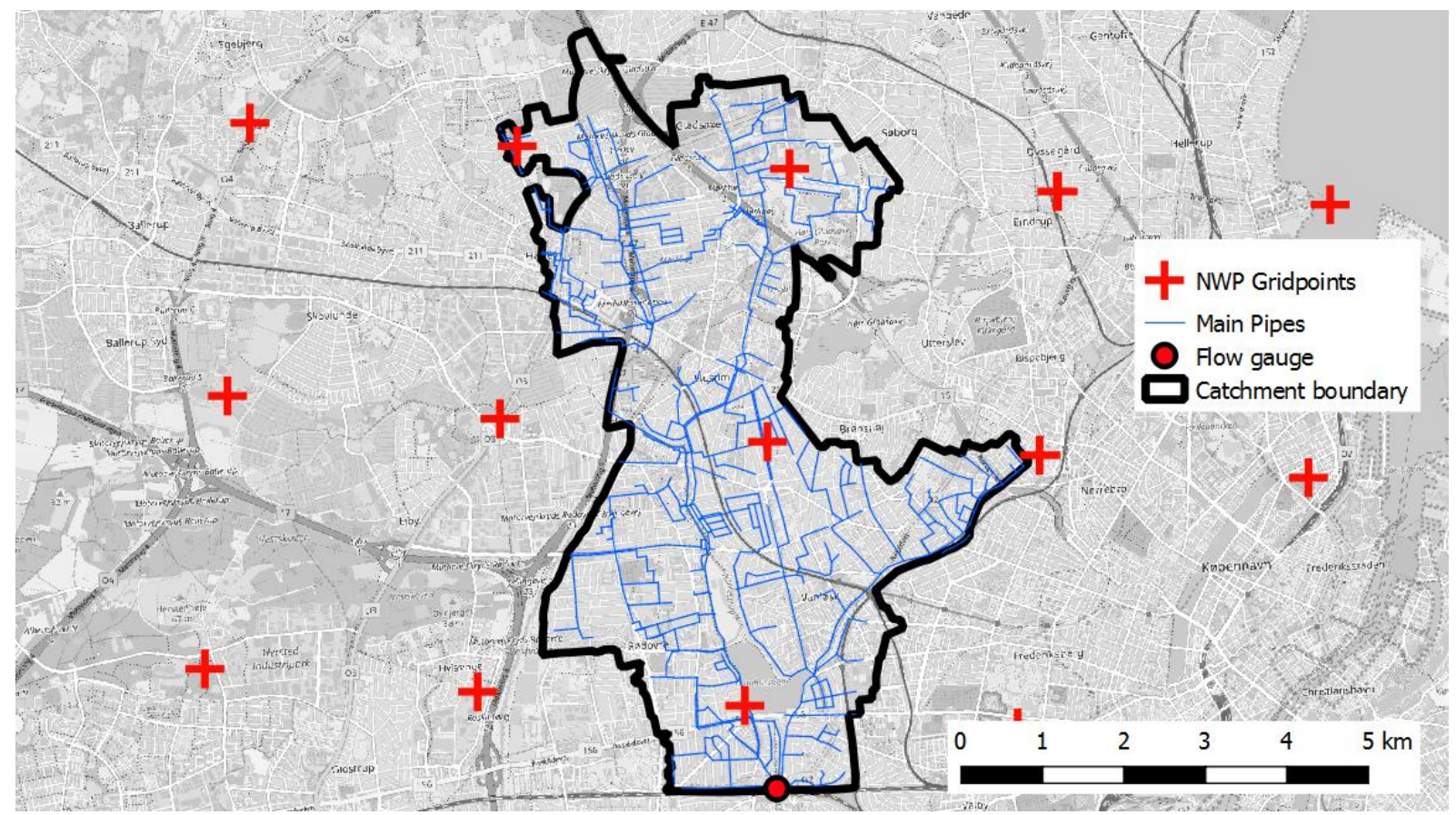

Figure 1. Overview of the Dæmningen sewer catchment including the center of the NWP grid points.

\subsection{Runoff model}

Stormwater flow is simulated with a conceptual model that consists of a Nash cascade with three linear reservoirs. This model contains two parameters: the effective area of the catchment and the reservoir time constant. The diurnal wastewater pattern from households and industry is simulated with a simple Fourier series as described in Equation 1:

$$
W W_{t}=a_{0}+a_{1} \cos (2 \pi t)+b_{1} \sin (2 \pi t)+a_{2} \cos (4 \pi t)+a_{2} \sin (4 \pi t)
$$

where $a_{0}, a_{1}, a_{2}, b_{1}$ and $b_{2}$ are parameters to be calibrated while $t$ is the time of day. The parameters are calibrated on data from 2016. Validation is then done on data from 2017.

\subsection{Forecast evaluation}

Flow forecasts are evaluated based on their ability to predict the exceedance of a flow threshold of $4000 \mathrm{~m}^{3} / \mathrm{h}$. This threshold signifies the difference between high and low flow domains as initially defined by Courdent et al. (2018) for the same case study. Threshold exceedance forecasts can be evaluated with a contingency table as illustrated in Table 1. From this table, the True Positives Rate (TPR) and the Positive Predictive Value (PPV) are calculated as given by Equations 2 and 3, respectively. TPR defines how many of the observed 


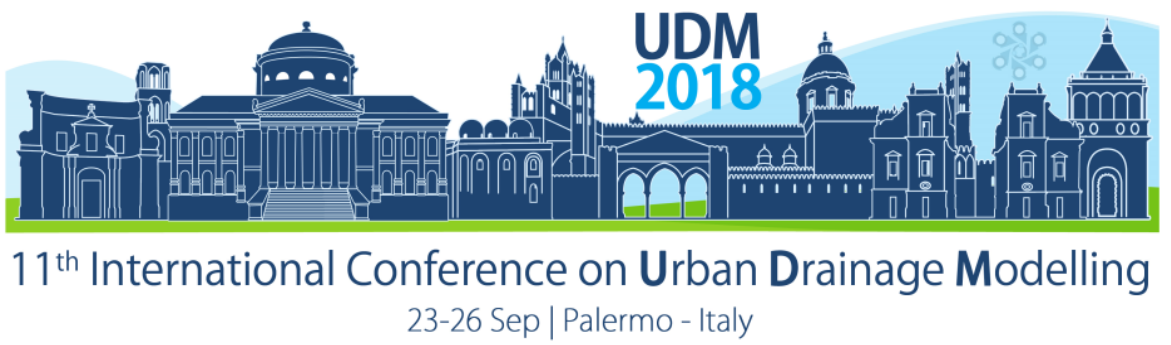

high flow time steps that were correctly predicted, while PPV defines how many of the predicted high flow time steps that actually came true. The evaluation is based on 2165 forecasts in MayJuly and October-December, 2017. The observed flow exceeds the high flow threshold around six percent of the time in this period.

Table 1. A contingency table that can be used for evaluating threshold exceedance problems. Here, positive means that a given threshold is exceeded in a time step while negative means that it is not.

\begin{tabular}{|l|c|c|}
\hline & Observation Positive & Observation Negative \\
\hline Forecast Positive & True Positive (TP) & False Positive (FP) \\
\hline Forecast Negative & False Negative (FN) & True Negative (TN) \\
\hline
\end{tabular}

$$
\begin{aligned}
& T P R=\frac{T P}{T P+F N} \\
& P P V=\frac{T P}{T P+F P}
\end{aligned}
$$

\section{RESULTS AND DISCUSSION}

\subsection{Example forecast}

Figure 2 shows an example of a high flow event on June 9-10, 2017. The figure shows four consecutive forecasts. It is thus possible to see the temporal evolution of the forecasts in the time leading up to the high flow event. Of the shown forecasts, the three earliest (T-10, T-6, and T-3) over-estimate the runoff volume and predict an increase in flow before it was observed in reality. Only the forecast produced an hour before the event $(T-1)$ manage to match the observed event, both in terms of timing and magnitude.

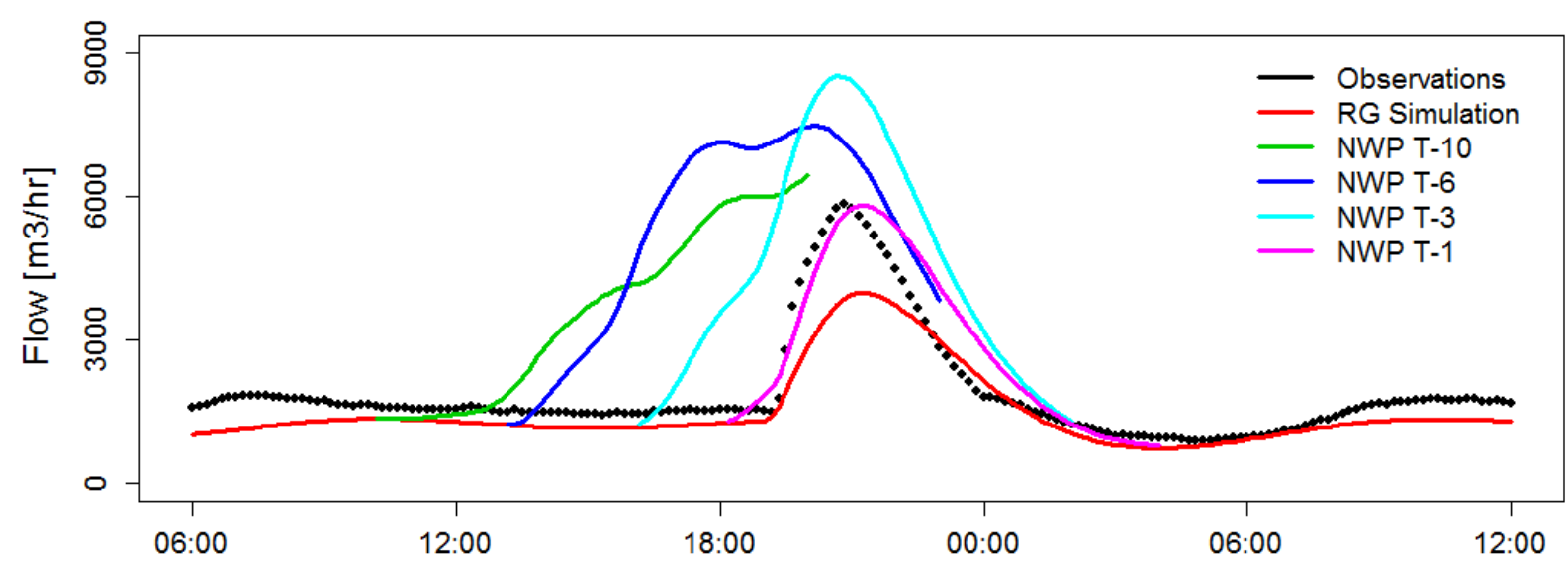

Figure 2. Example of four flow forecasts for an event on June 9-10, 2017. "T-" refers to the time before the onset of the event in hours, while "RG simulation" is flow simulated with observed rainfall for the event. 


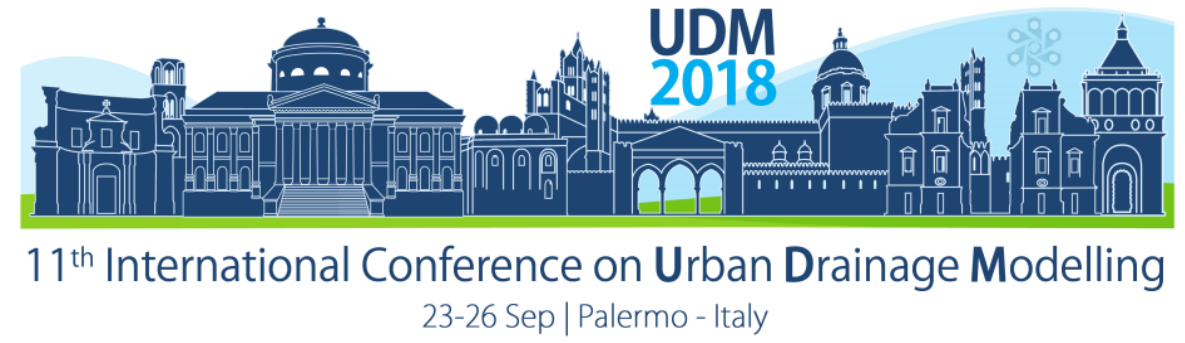

\subsection{Threshold exceedance evaluation}

Figure 3 shows TPR and PPV as a function of the forecast horizon. Both measures start at the level of the simulated runoff within the first hour and then decrease as the effect of the initial conditions in the runoff model fades out. TPR starts around 0.5 for short horizons less than two hours, which means that around half of all high flow observations are correctly predicted, while it drops to around 0.2 for horizons longer than four hours. The low TPR is mainly due to many events being under-predicted (not shown here). PPV starts at almost 1.0, which means that a positive prediction is very trustworthy as almost all high flow predictions eventually come true for horizons less than 1.5 hours. This drops to around $30 \%$ for horizons beyond four hours. These results highlight the issues linked to under-prediction of runoff events, which can significantly affect the performance of NWP for operation of integrated urban drainagewastewater systems. A possible solution could be the use of post-processing schemes as the one proposed by Courdent et al. (2018).
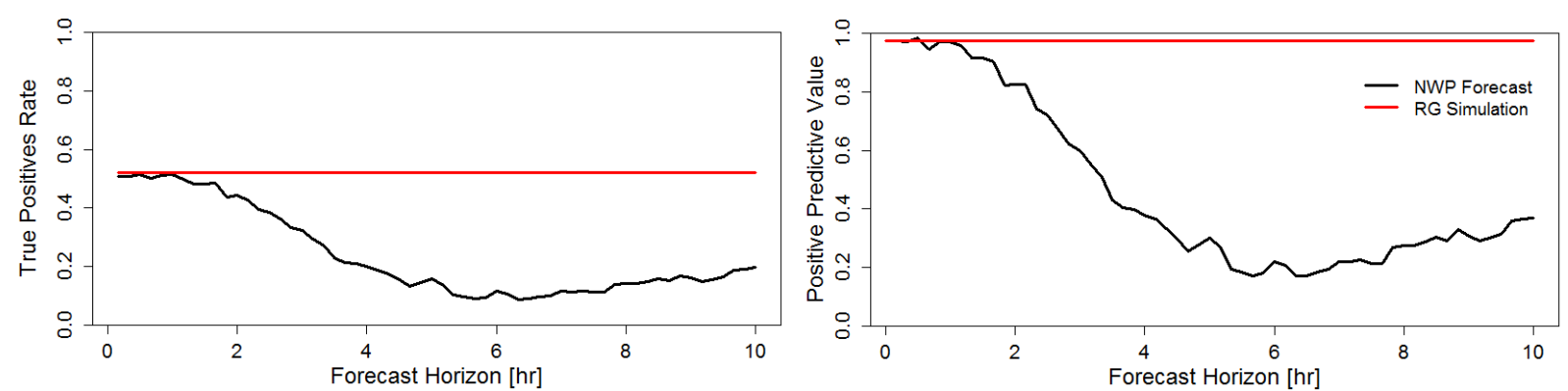

Figure 3. True positives rate (left) and positive predictive value (right) for the forecast driven by NWP and flow simulation with measured rainfall for the same period.

\section{CONCLUSIONS}

NWP models can provide realistic rainfall forecasts with longer time horizons than radar extrapolation, but suffer with regards to resolution in space and time. There is a need for more research into how NWP can be used as forcing for urban drainage models in a fruitful manner. In this contribution, we forecasted flow at the outlet of an urban drainage system with horizons up to 10 hours.

Evaluation of the ability to predict high flow events showed that the NWP-driven high flow predictions are very trustworthy on short horizons and then gradually worsen. Several events are under-predicted, which leads to only half of all high flow events being successfully forecasted on horizons less than two hours.

\section{References}

Courdent, V.A.T, Grum, M. and Mikkelsen, P.S. (2018). Distinguishing high and low flow domains in urban drainage systems 2 days ahead using numerical weather prediction ensembles. J. Hydrol. 556, 1013-1025.

Korsholm, U.S., Petersen, C., Sass, B.H., Nielsen, N.W., Jensen, D.G., Olsen, B.T., Gill, R. and Vedel, H. (2015). A new approach for assimilation of 2D radar precipitation in a high-resolution NWP model. Meteorol.Appl., 22, 48-59.

Thorndahl, S., Einfalt, T., Willems, P., Nielsen, J. E., ten Veldhuis, M.-C., Arnbjerg-Nielsen, K., Rasmussen, M. R. and Molnar, P. (2017). Weather radar rainfall data in urban hydrology. Hydrol. Earth Syst. Sc., 21, 1359-1380.

Vezzaro, L., Pedersen, J.W., Courdent, V.A.T., Löwe, R. and Mikkelsen, P.S. (2017). Towards a domain-based framework for use of rainfall forecasts in control of integrated urban wastewater systems. In Proceedings of 12th IWA Specialized Conference on Instrumentation, Control and Automation, Québec, Canada: IWA Publishing. 149-157. 


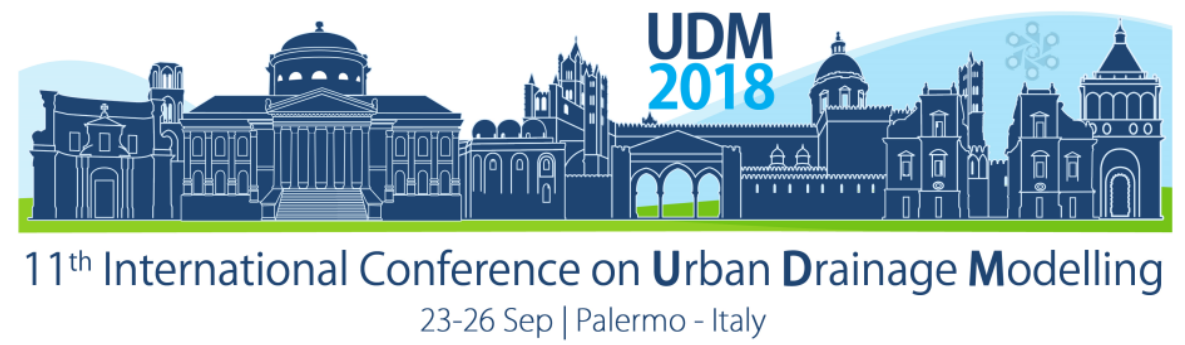

\title{
URBAN STORMWATER MONITORING AND MODELLING AT THE RIACHO FUNDO SUB-BASIN, BRASÍLIA - DF \\ Thays Mitsuko Tsuji ${ }^{1}$, Maria Elisa Leite Costa $^{1}$ and Sergio Koide ${ }^{1}$
}

\author{
${ }^{1}$ University of Brasília, Program of Environmental Technology and Water Resources, Brasília, Brazil \\ (thaysmitsuko@hotmail.com,mariaelisa@unb.br, skoide@unb.br)
}

\begin{abstract}
This research is aimed to evaluate the application of the PCSWMM model to an urban watershed in Paranoá Lake basin to verify if the hydraulic model correctly simulates the flow discharge, an important step to estimate the loads conveyed to the Lake. This study was carried out to evaluate the use of the SWMM model on small urban basins in central Brazil, based on rainfall and runoff monitoring during events. The modelling was carried out using observed rainfall as input to PCSWMM model with SCS method generation. It was confirmed that this model fits well to this type of watershed, however it can be improved by calibration to single events.
\end{abstract}

Keywords: Urban drainage; PCSWMM; runoff.

\section{INTRODUCTION}

The hydrological models allow predictions about the hydrological changes responses, which can provide support for decision-make, water resources planning and flood protection, for example (BEVEN, 2012).

Tsihrintzis and Sidan (2008) confirmed the necessity of stormwater modelling by asserting that accurate model is essential in the planning, design, and evaluation of stormwater management systems. Further, they stated that model development has been generally faster than proper model validation most previous studies concentrated in relatively large watersheds with mixed land uses. Thus, there is proven need for the endorsement of watershed models of various sizes and types in order to evaluate, and ultimately improve, stormwater management.

The Riacho Fundo River basin is the most urbanized in the Federal District. It is a Paranoá Lake tributary (as shows the Figure 1) and the lake reach formed by its waters the worst water quality is observed, as well as the most frequent and algae bloom (Pinto et al., 1999).

The Paranoá Lake is the most recent water supply source in the Federal District and it is very important to get better knowledge about the nutrients loads and sediments produced by the Riacho Fundo urban area and discharged to Paranoá Lake. And a model which provides a good efficiency simulating hydrograms also can supply the studies about non-point pollution.

The main objective of this study is to model process using the SWMM though the PCSWMM interface to generate the runoff because it may provide, after the calibration and verification, some predictions on the impacts which the Riacho Fundo sub-basin and it might supply the management about urban drainage water.

\section{MATERIALS AND METHODS}

\subsection{Monitoring}

Two rain gages were installed in the urban area (CBM and ETE) as shown on the Figure 2, as well as a level logger, installed at the downstream of the stormwater gallery. The stream flow was measured with an Acoustic Doppler Velocimetry - ADV. The results obtained with the monitoring were used in the calibration and verification process of modelling. 


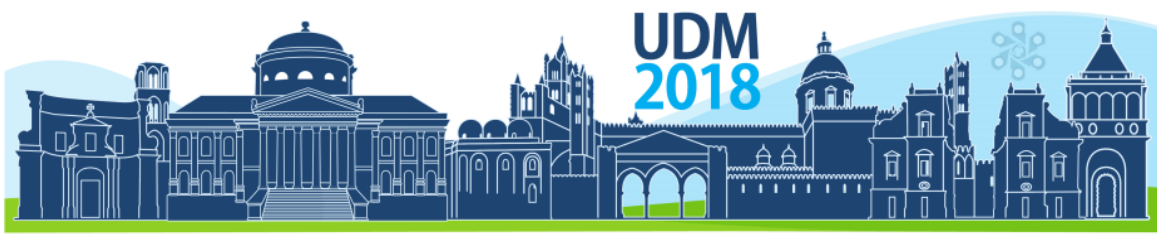

$11^{\text {th }}$ International Conference on Urban Drainage Modelling 23-26 Sep | Palermo - Italy

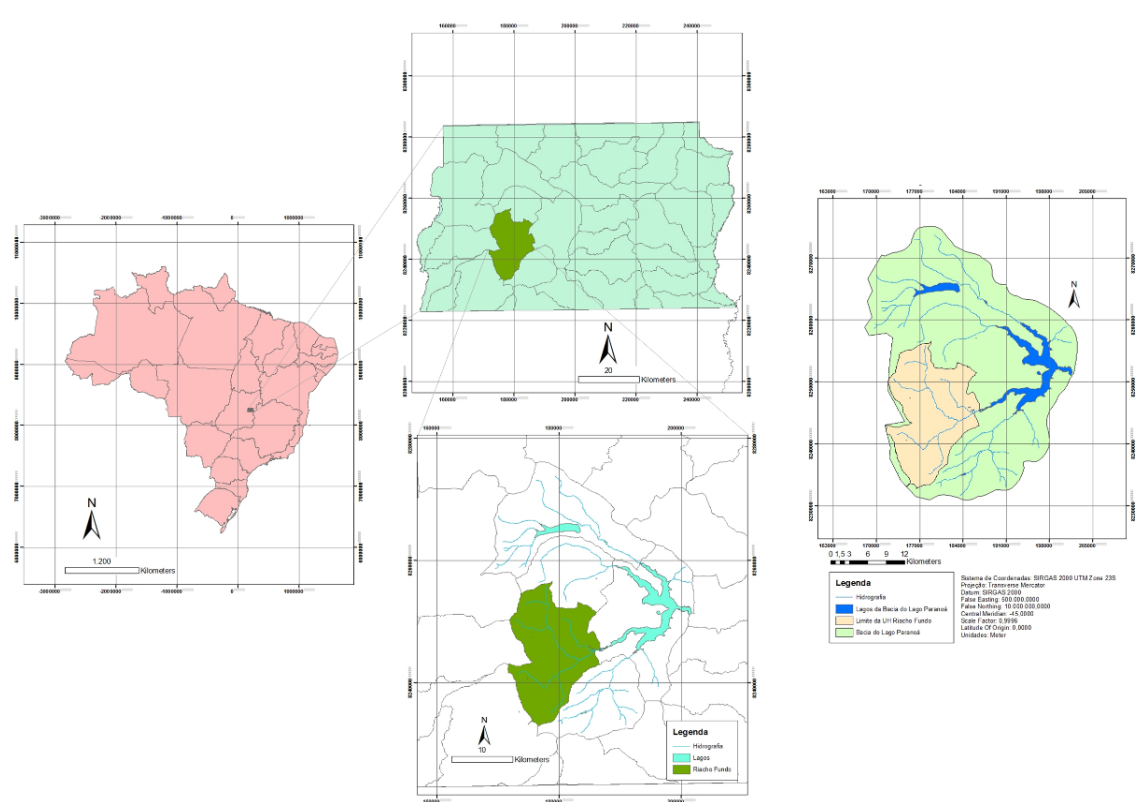

Figure 1. Riacho Fundo River location in a Paranoá Lake watershed context.

\subsection{Modelling}

For the modelling process, the studied area was divided in subcatchments by Voronoi decomposition and curve-numbers were attributed to each. The urban drainage network data and orthophotos with $0,24 \mathrm{~m}$ spatial resolution was supplied by NOVACAP, topography by SEGETH; and soil type was adopted as proposed by Reatto (2004).
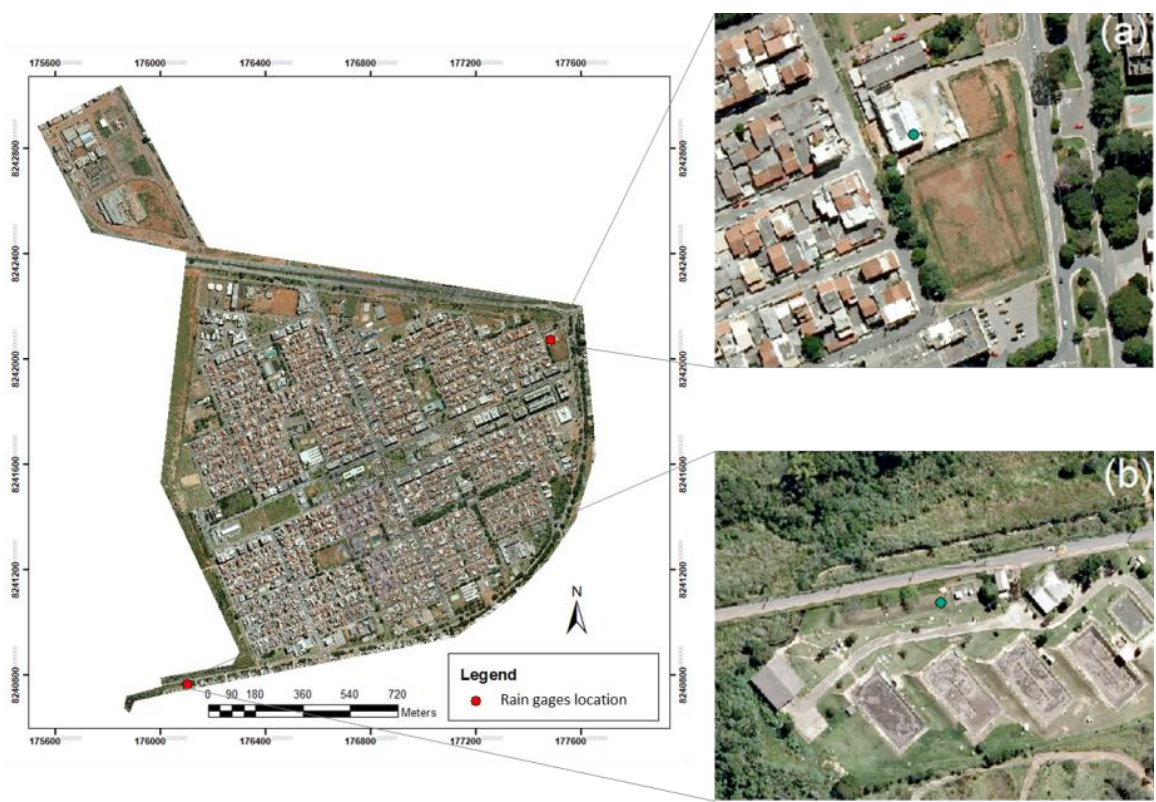

Figure 2. The rain gages location, (a) CBM and (b) ETE.

The simulations were carried out using the rainfall registered by the two rain gages. SCS curvenumber was adopted to evaluate infiltration and flood wave propagation was performed using dynamic wave theory (Saint-Venant equations). 


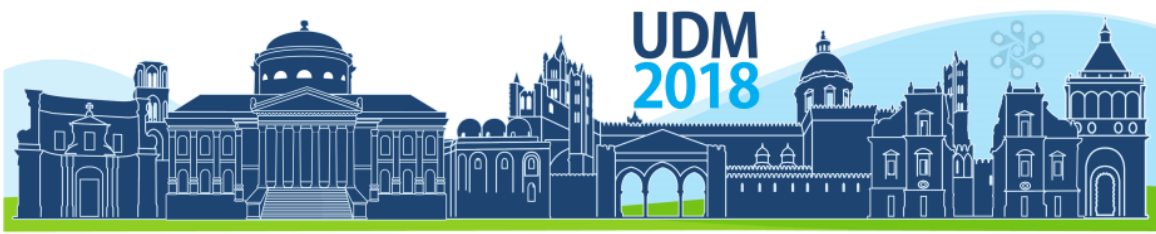

$11^{\text {th }}$ International Conference on Urban Drainage Modelling

23-26 Sep | Palermo - Italy

\section{RESULTS AND DISCUSSION}

The curve-number was chosen based on the land use and occupation and soil type. Curvenumber for each subcatchment was calculated by area weighting, and the results are shown in Figure 3.

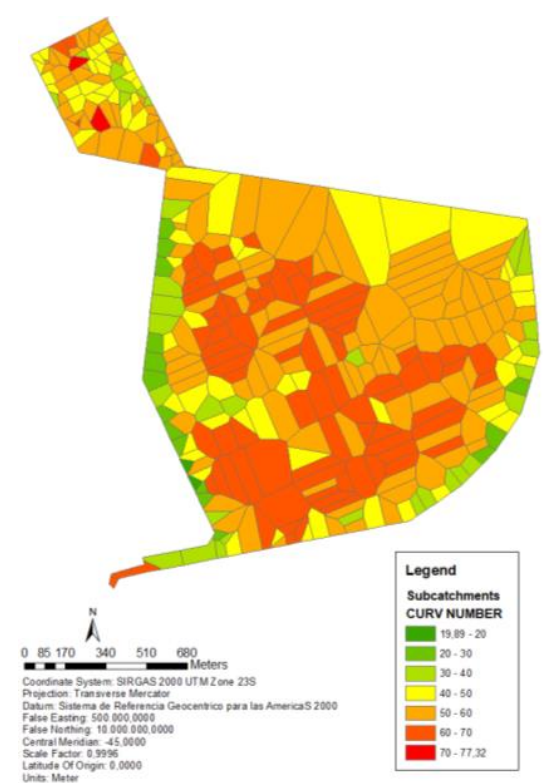

Figure 3. Studied area curve number values by subcatchment.

The simulations with PCSWMM were performed for the rainfalls occurred in 24th December 2017 and 3rd January 2018. The maximum value simulated for total inflow on the 24th December 2017 rainfall is about 1,200 L/s and for the 3rd January 2018 rainfall is about 1,250 $\mathrm{L} / \mathrm{s}$. All of these values are not calibrated yet. The hydrograms for the rainfall and the total inflow are shown on the Figure 4.

The error between the flow observed and simulated was evaluated by Nash-Sutcliffe efficiency (NSE) and coefficient of determination $\left(R^{2}\right)$, the model efficiency values means that for both rainfall event simulated the model without calibration could be improved to give better representations for the hidrograms, as shown on the Table 1 and Figure 5.

Table 1. Model efficiency

\begin{tabular}{|c|c|c|c|c|}
\hline \multirow{2}{*}{ Rainfall event } & \multicolumn{2}{|c|}{ Before calibration } & \multicolumn{2}{c|}{ After calibration } \\
\cline { 2 - 5 } & NSE & $\mathrm{R}^{2}$ & $\mathrm{NSE}$ & $\mathrm{R}^{2}$ \\
\hline 24th December 2017 & -0.437 & 0.0818 & 0.022 & 0.416 \\
\hline 3rd January 2018 & -3.06 & 0.514 & 0.641 & 0.722 \\
\hline
\end{tabular}


Proceedings of the 11th Int. Conference on Urban Drainage Modelling, 23-26 Sep. 2018, Palermo (ITALY). Ed. prof. Giorgio Mannina

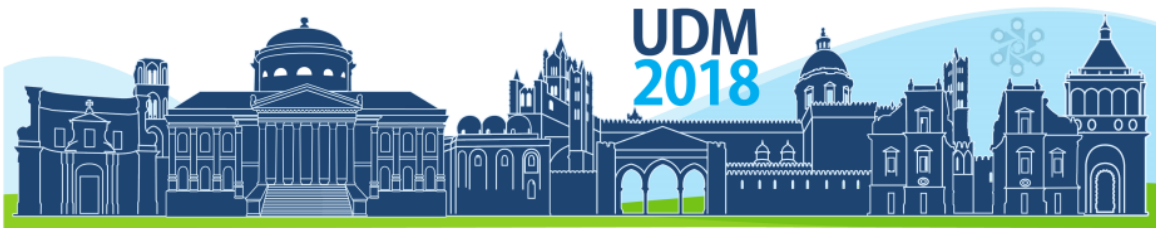

$11^{\text {th }}$ International Conference on Urban Drainage Modelling

23-26 Sep | Palermo - Italy
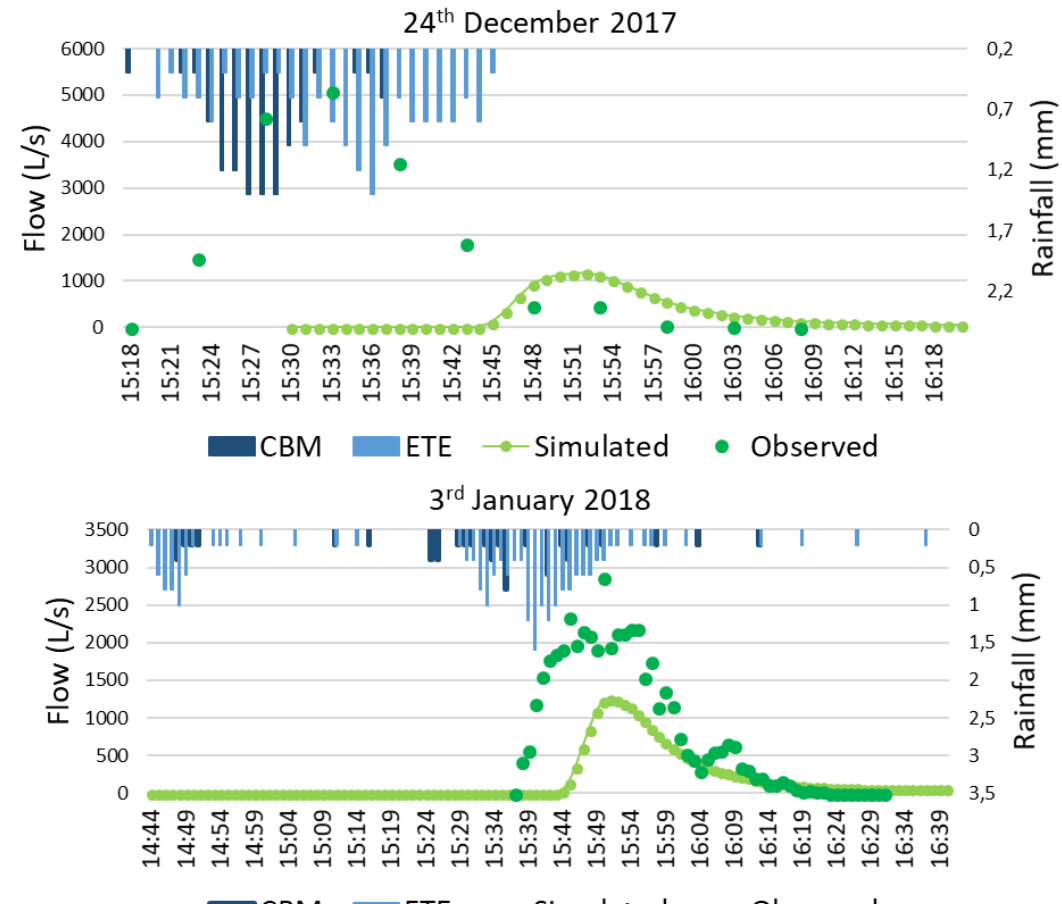

Figure 4. 24th December 2018 and 3rd january 2018 hydrograms .

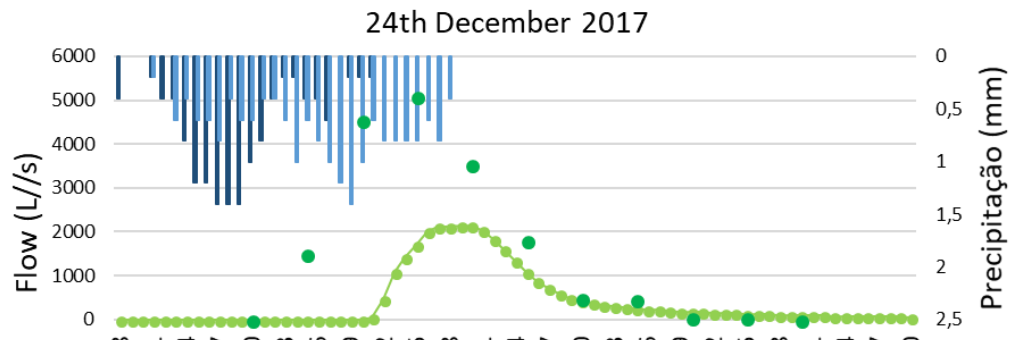

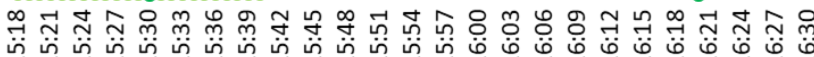

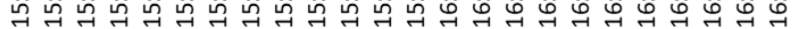

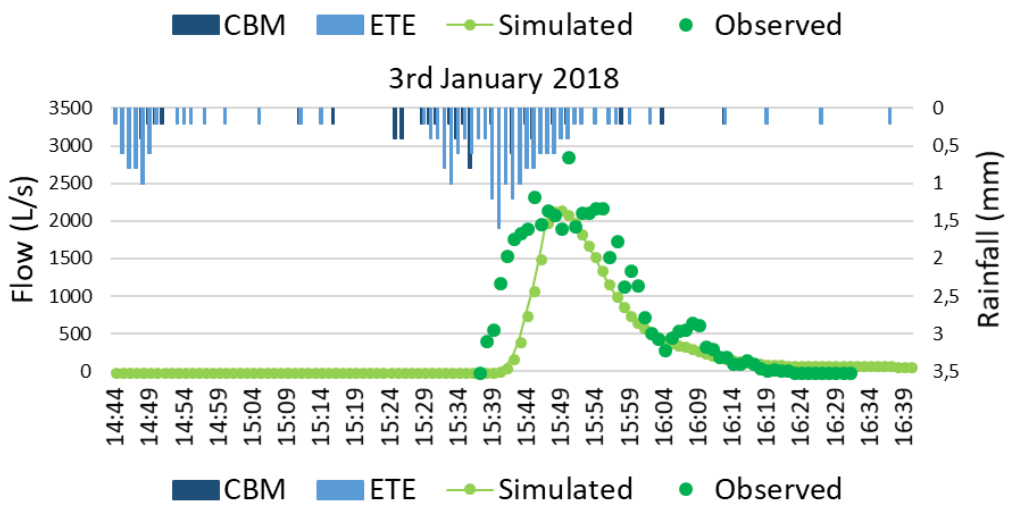

Figure 5. 24th December 2018 and 3rd january 2018 hydrograms with calibrated model. 


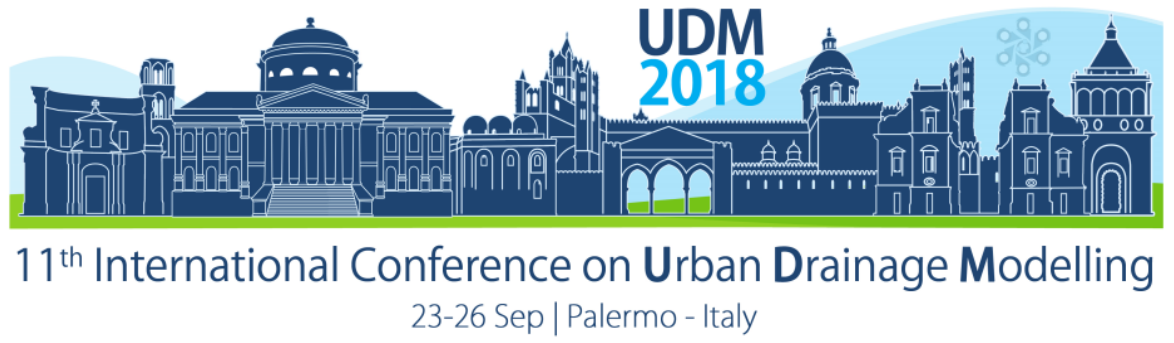

\section{CONCLUSIONS}

The SWMM model is a good tool to simulate the urban stormwater for small and very urbanized watersheds with characteristics closer to the Riacho Fundo sub-basin, but the calibration process is a very important step. Thereby, is reasonable affirm that SWMM could supply the management about urban drainage water on Lake Paranoá watershed. Furthermore, with this research was perceived that the PCSWMM interface turned the data input and calibration process easier and faster, and provided better simulations with the tools as Area Weighting, Voronoi Decomposition and the direct communication with GIS tools.

\section{REFERENCES}

APHA, AWWA e WPCF. (1985). Standard Methods for the Examination of Water and Wasterwater. 16a Edição, AWA, Washington, EUA.

BEVEN, K. J. (2012). Rainfall-runoff modelling: The primer. $2^{\text {nd }}$ ed.

CASTRO, N. (2006) A questão ambiental no Distrito Federal. SEBRAE: Brasília-DF. Available on: <http://intranet.df.sebrae.com.br/download/Backup/Questao\%20Ambiental.pdf>. Acesso em: 26 mar. 2017.

PINTO, M. T; CAVALCANTI, C. G; LUDUVICE, M. (1999). A evolução do processo de eutrofização do lago Paranoá - Brasília, após cinco anos de controle nas descargas de nutrientes. In: 20ํำ Congresso Brasileiro de Engenharia Sanitária e Ambiental. Available on: <http://www.bvsde.paho.org/bvsaidis/brasil20/v-047.pdf>. Acesso em: 05 de abr. 2017.

Porto, M.F. (1995) Aspectos qualitativos do escoamento superficial em áreas urbanas. In: Drenagem Urbana. Porto Alegre: ABRH e UFRGS, p. 387-414.Reatto, A., Martins, E.S., Farias, M.F.R., Silva, A.V., Carvalho Jr, O.A. (2004). Mapa Pedológico Digital - SIG Atualizado do Distrito Federal, Escala 1:100.000 e uma Síntese do Texto Explicativo. Empresa Brasileira de Solos (EMBRAPA), Planaltina-DF, 31p

TSIHRINTZIS, V. A., \& SIDAN, C. B. (2008). ILLUDAS and PSRM-QUAL predictive ability in small urban areas and comparison with other models. Hydrological Processes, 22(17), 3321-3336. 


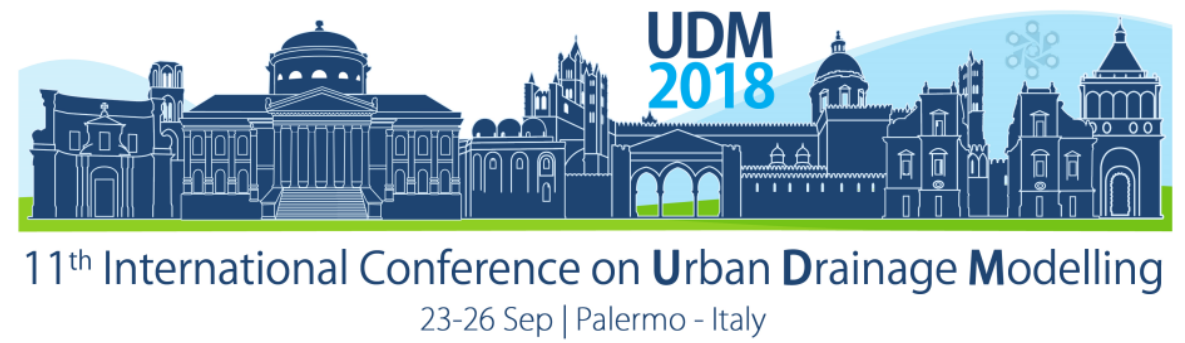

\title{
Rain Gauge vs. Radar Measurements - Modelling an Extreme Rain Event with High Spatial Variability
}

\author{
Tanja Vonach ${ }^{1 *}$, Thomas Einfalt ${ }^{2}$, Wolfgang Rauch ${ }^{1}$ and Manfred Kleidorfer ${ }^{1}$ \\ 1 University of Innsbruck, Department of Infrastructure Engineering, Innsbruck, Austria \\ 2 hydro \& meteo GmbH \& Co. KG, Lübeck, Germany \\ * corresponding author (tanja.vonach@uibk.ac.at)
}

\begin{abstract}
This work investigates the usage of both rain gauge measurements and radar data of a 500-year event that happened in Innsbruck in July 2016. The occurring intensities varied strongly, e.g. they could be classified into a return period of 500 and 25 years within a distance of $2 \mathrm{~km}$. The underlying research question is, whether a change of model performance can be expected due to a better representation of the spatial variability of this specific rain event. This further leads to the question, whether a spatially accurate representation of rain events is still decisive for model performance when modelling such intense rainfalls. For high return periods, other impacts may gain importance instead. Performance assessment is done by comparing simulated water levels to in-sewer measurements. Results show, that measured peak intensities and runoff volumes are significantly higher for radar measurements than for gauged precipitation which leads to a significant overestimation of water levels. Consequently, radar rainfall input did not improve the model performance. A reason could be found in the missing radar image at peak time, different temporal resolutions of the data sets, in the accuracy of the measuring methods during such heavy rainfall intensities or even in the underlying ideas of the initial model establishment.
\end{abstract}

Keywords: hydrodynamic modelling; extreme events; rainfall measurements

\section{INTRODUCTION}

Every cloud has a silver lining. This is also the case for a heavy rain event that happened on the $2^{\text {nd }}$ of July in Innsbruck, Austria. In the aftermath, it was classified as a 500-year event. Local floodings (pluvial and fluvial) occurred, causing further primarily financial and tangible damages. According to local newspaper reports, the municipal fire brigade had to march out about 300 times during one weekend. The biggest shopping centre of the city had even to be evacuated and temporarily closed.

Now the positive aspect is the rare possibility to learn from such a rare event, e.g. from the perspective of urban drainage modelling. The sewer system failed to drain the surface runoff in some areas of the city. Consequences such as ponding and flooding were reported numerously in public and social media. A collection of videos and photos from private persons is provided by the local newspaper (Tiroler Tageszeitung, 2016).

Although a hydrodynamic model of the underlying urban drainage system is available and has been investigated in a manifold of studies (e.g. Mikovits et al. (2017)) the model's ability to represent the runoff behaviour under a such a high level of exposure is questionable. For this specific event, Kleidorfer et al. (2018) already conducted a study to compare simulated to measured behaviour (expressed as flow depth). For this, rainfall measurements from precipitation gauges were used as the input to the hydrodynamic drainage model. For 35 water 


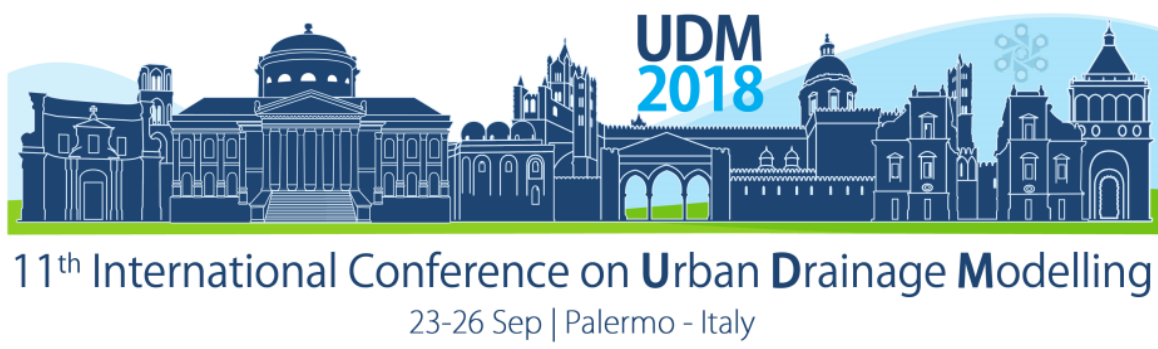

level measurements in total, the findings of Kleidorfer et al. (2018) showed wide-ranging agreements between simulated and measured water levels during the event. In some cases, measurements and simulations fit surprisingly well, while in other parts of the drainage system the model failed to mimic the real system behaviour. Amongst others, the study concluded with the insight that a higher resolution of rainfall data would possibly improve the system's performance for this rain event. An enhanced knowledge about predicting the behaviour of an urban drainage system under such extreme conditions is helpful for the development of water sensitive cities (Stokman et al., 2015).

As a very strong spatial variability of the rainfall intensities were apparent, a measurement density of approx. 1 gauge per $5 \mathrm{~km}^{2}$ might be too coarse for a local extreme event. This has already been stated in Schilling (1991) and corroborated in several other studies (i.e. OchoaRodriguez et al. (2015)).

One possibility to increase the available data resolution is the usage of radar rainfall data. Having its beginnings about 40 years ago (Austin \& Austin, 1974; Bachoc et al., 1984; Verworn, 1991), its applications in urban hydrology is very popular by now (Einfalt et al., 2002; Krämer \& Verworn, 2008; Schellart et al., 2012; Rico-Ramirez et al., 2015). Nevertheless, the tenor amongst researchers in this field is that radar rainfall data must be handled with care. As any measurement data, they are tainted with uncertainties (Rico-Ramirez et al., 2015). Especially when radar beams meet high rainfall intensities, attenuation occurs and any radar echoes beyond the high intensity rainfall are underestimated (Schellart et al., 2012). A comprehensive summary of what to consider when using radar rainfall data is given in Einfalt et al. (2004). Nevertheless, the usage of radar data combined with rain gauge measurements help to improve model predictions (Schellart et al., 2012).

This work aims at comparing the usage of rainfall data from rain gauges to radar measurements for the hydrodynamic simulation of an urban drainage system. Focus is laid on the model's ability to predict in-sewer water levels and the occurring of pluvial floodings due to a spatially highly variable heavy rain event.

\section{MATERIALS AND METHODS}

The main subject of this work is a rain event that happened in the afternoon of the $2^{\text {nd }}$ of July 2016. For this, two kinds of rainfall measurement data are used as an input to the hydrodynamic urban drainage model of Innsbruck in Tyrol, Austria. First, there are measurements from six rain gauges spread all over the municipal area (boxes on Figure 1a) and b)). Second, radar data is available for the investigation area.

Measurement data to validate the model outputs are available from 35 in-sewer water level measurements (dots on Figure 1).

The model is simulated with both rainfall inputs separately. Results are then considered from three perspectives:

1. Water level predictions compared to measurements

2. Prediction of flooded areas compared to occurrences according to citizen reports

3. Differences of simulated combined sewer overflow volumes (no measurement data available)

\subsection{Rain gauge measurements}

Figure 2 shows the rainfall intensities measured with the six rain gauges. Apparently, rain gauge $\mathrm{KRI}$ measured a peak more than twice as high than its neighboring gauge ARA. The 


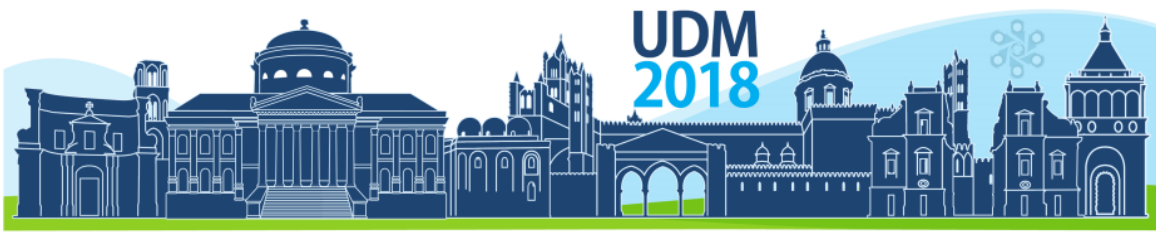

$11^{\text {th }}$ International Conference on Urban Drainage Modelling

23-26 Sep | Palermo - Italy

peak at $\mathrm{KRI}$ with $8.7 \mathrm{~mm}$ within one minute leads to a classification as a rain event with a return period of 500 years. Only $2 \mathrm{~km}$ of distance away, the return period decreases to not more than 25 years at measurement station ARA with a peak of $4 \mathrm{~mm} / \mathrm{min}$. At the same time, station FHI measured intensities with a return period of only 1 year.

\subsection{Radar data}

The Patscherkofel radar of the Austrian weather radar network is located in the vicinity of Innsbruck at $2246 \mathrm{~m}$ a.s.I. Data from this radar are used to get a more detailed insight into the event of $2^{\text {nd }}$ July 2016. Particular challenges for such extreme events are that radar measurements have to be postprocessed with care so that e.g. attenuation effects can be corrected for, and that the radar is situated literally above the city and does not look downwards. The spatial resolution of the data is $1^{\circ} \times 1 \mathrm{~km}$, and the temporal resolution 5 minutes.

Unfortunately, the radar image of the peak is subject to hail extinction and could not be used. Thus, the peak cannot be distinct as sharp as with gauge data.

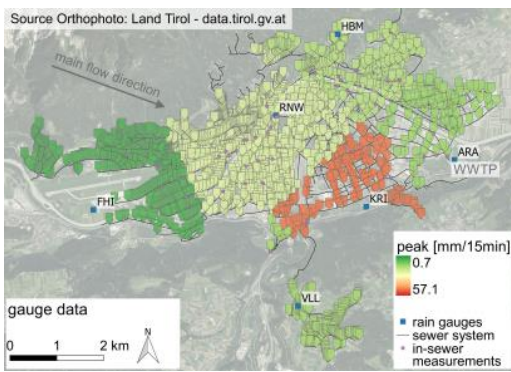

(a)

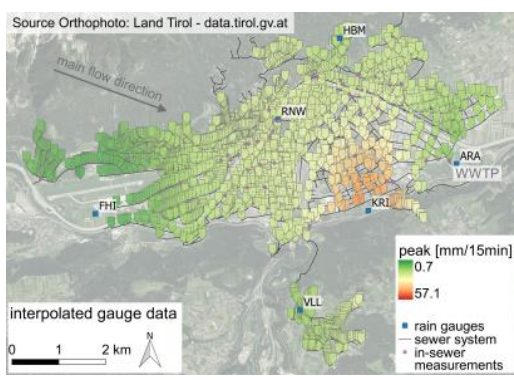

(b)

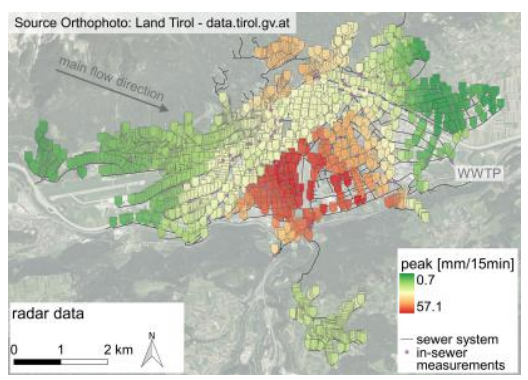

(c)

Figure 1. Measurement stations within the catchment and measured rainfall quantities between 16:47 and 17:02 (peak at station $\mathrm{KRI}$ ) on the subcatchments for different rain series: (a) rain gauge measurements, (b) interpolated rain gauge measurements, (c) radar measurement data

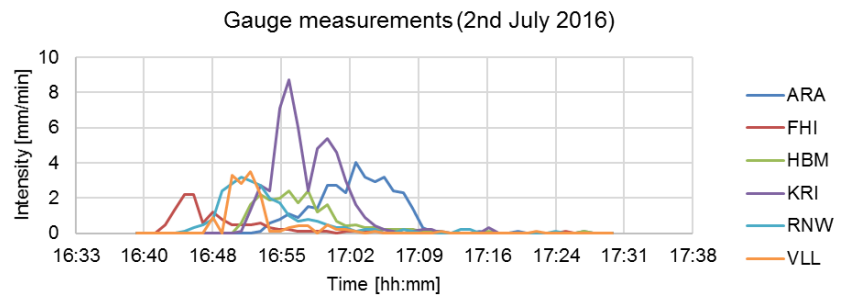

Figure 2. Rain gauge measurement data

\subsection{Model of the case study}

The case study city Innsbruck is located at an average altitude of approx. $600 \mathrm{~m}$ above sea level. By March 2018, about 150.000 permanent and non-permanent inhabitants are registered. The habitable area amounts to 3.000 ha, from which approx. two thirds are connected to the combined urban drainage system, leading to one wastewater treatment plant in the east of the city.

Modelling and simulation is done with the software SWMM (Version 5.1009) (Gironás et al., 2010). $250 \mathrm{~km}$ of sewer pipes (shown in Figure 1), 34 CSO's, 6 stormwater outlets and 2500 subcatchments are included in the hydrodynamic model with an impervious connected area of about 800 ha. 


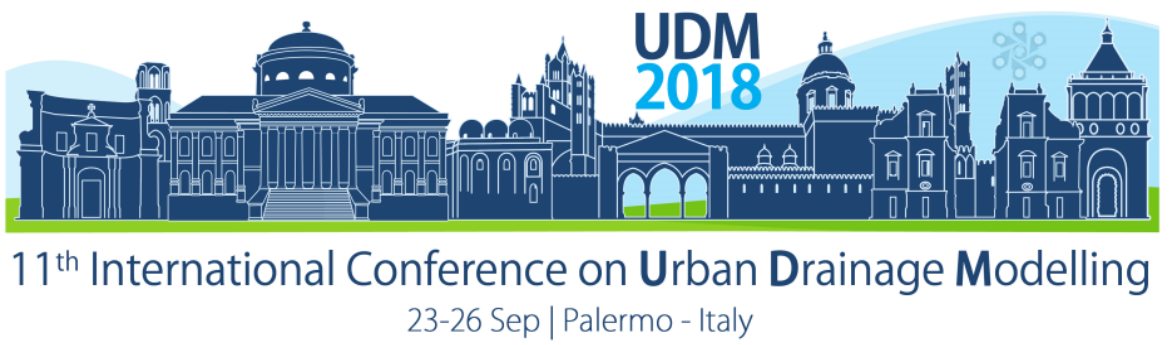

\section{RESULTS AND CONCLUSION}

A local shift of $2 \mathrm{~km}$ in a westward direction for the occurring event peak is obvious for radar measurement data compared to the interpolated rain gauge measurements. Summed up with the effect of an already higher spatial resolution, this might influence model outputs even more. Results show significantly inferior model performances when using radar rainfall data instead of gauge measurements or interpolated rainfall intensities as model input.

The agreement of simulated to measured water levels at 34 points within the sewer are shown in Figure 3. The Nash-Sutcliffe-Efficiency (NSE) is used to express the agreements. A clear shift of the cumulative frequency distribution plot to more negative values can be seen for the usage of radar measurement data as model input. Simulations with radar data tend to overestimate water level peaks within the system significantly (e.g. Figure 3b)).

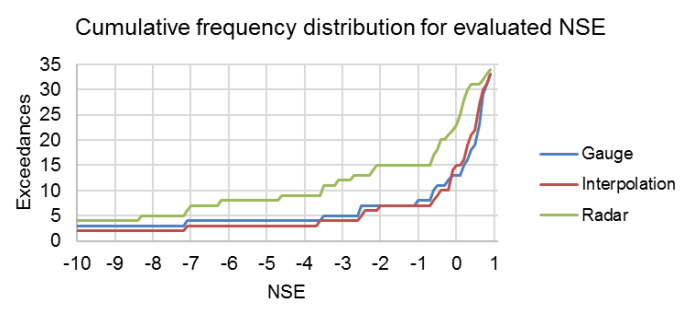

(a)

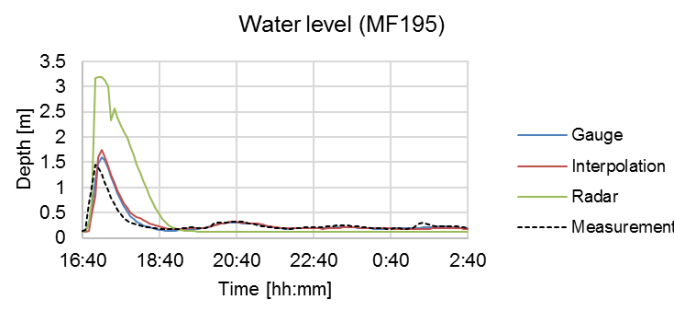

(b)

Figure 3. Agreement between simulated and measured water levels (a) cumulative frequency distribution for NSE (34 out of 35 measurement stations were possible to evaluate due to one occurring constant measurement) (b) exemplary comparison of water level measurements and simulation results for junction MF195 (NSEgauge $=0.748$, NSE interpolated $=0.581, \mathrm{NSE}_{\text {radar }}=-6.22$ )

Table 1 gives an overview on different evaluations to compare the three model input scenarios. Regarding the mean value of all agreements, interpolated rainfall inputs seem to reproduce the measurements the most appropriate, whereas gauged rainfall input is better when looking at the median and the number of positive values for NSE. Results further show that despite the different rainfall series do not differ a lot in their total precipitation quantities, high deviations occur for their simulated CSO and flooding volumes. Using radar rainfall as a model input would even quadruplicate the flooding volumes from using interpolated rainfall series.

Anticipated improvements in the model's ability to reproduce in-sewer measurement data could not be verified. The following key insights could be gained:

- Occurring peak intensities in rainfall data and simulated runoff volumes are significantly higher when using data from radar measurements than from rain gauges.

- The artificially increased spatial resolution of punctual rain gauge measurements by data interpolation seem to outweigh the benefits of a higher spatial resolution of radar measurements, but with a gap in time. Therefore, the model performs superior when using (interpolated) gauge data instead of high-resolution radar data. Consequently, further uncertainty analyses will be performed on the radar data.

- Possible reasons for the inferior model performance when using radar data could be the measurement data themselves or, more generally, the initial model set up. A higher temporal resolution of gauged data $(1 \mathrm{~min})$ compared to radar data with 5 min and varying precisions of measurement methods especially for heavy rain events (in this case in particular the failing radar image during the peak) might shift the results. Another possible explanation is that the model was initially set up for monitoring purposes during rain events with low return periods and the model was not aimed at predicting system behaviour under such rare events. 


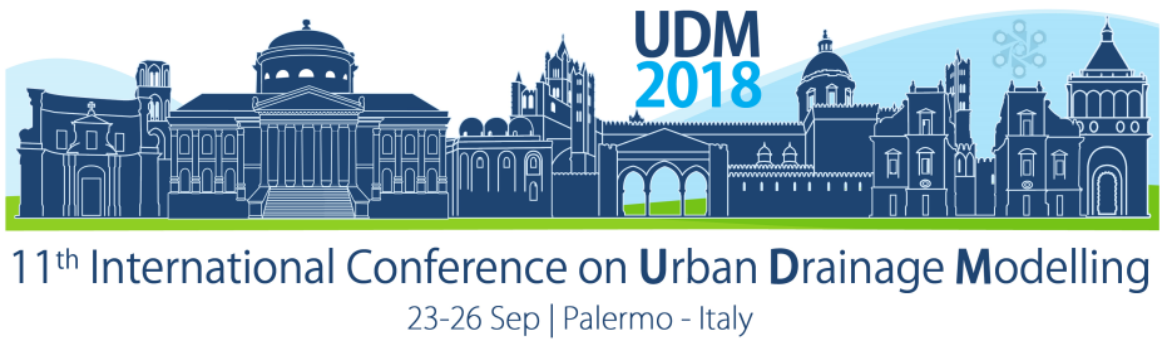

Table 1. Comparison of three different rainfall inputs to hydrodynamic simulation (NSE evaluated for water levels and measurement data of 34 junctions)

\begin{tabular}{lcccc}
\hline & & Gauge & Interpolated & Radar \\
\hline Total precipitation & {$[\mathrm{mm}]$} & 39.068 & 40.299 & 39.574 \\
Surface runoff & {$[\mathrm{mm}]$} & 14.4 & 14.1 & 18.6 \\
Max. rainfall intensity & {$[\mathrm{mm} / 15 \mathrm{~min}]$} & 48.5 & 44.53 & 57.14 \\
NSE mean / median & {$[-]$} & $-6.24 / 0.33$ & $-4.42 / 0.23$ & $-8.94 /-0.60$ \\
Number of NSE $>0$ & {$[-]$} & 21 & 19 & 11 \\
CSO volume & {$\left[\mathrm{m}^{3}\right]$} & 209473 & 205695 & 314760 \\
Flooding volume & {$\left[\mathrm{m}^{3}\right]$} & 94461 & 58654 & 206327
\end{tabular}

\section{References}

Austin G. L., \& Austin L. B. (1974). The use of radar in urban hydrology. Journal of Hydrology, 22(1-2), 131-142. doi:10.1016/0022-1694(74)90100-0

Bachoc A., Delattre J. M., Jacquet G., \& Frérot A. (1984, 4-8 June 1984). Hierarchical monitoring of sewer systems. A case study: the Seine Saint Denis County. Paper presented at the Third International Conference on Urban Storm Drainage, Göteborg.

Einfalt T., Arnbjerg-Nielsen K., Golz C., Jensen N.-E., Quirmbach M., Vaes G., \& Vieux B. (2004). Towards a roadmap for use of radar rainfall data in urban drainage. Journal of Hydrology, 299(3-4), $186-202$. doi:10.1016/j.jhydrol.2004.08.004

Einfalt T., Arnbjerg-Nielsen K., \& Spies S. (2002). An enquiry into rainfall data measurement and processing for model use in urban hydrology. Water Science and Technology, 45(2), 147-152.

Gironás J., Roesner L. A., Rossman L. A., \& Davis J. (2010). A new applications manual for the Storm Water Management Model (SWMM). Environmental Modelling \& Software, 25(6), 813-814. doi:10.1016/j.envsoft.2009.11.009

Kleidorfer M., Tscheikner-Gratl F., Vonach T., \& Rauch W. (2018). What can we learn from a 500-year event? Experiences from urban drainage in Austria. Water Science \& Technology. doi:10.2166/wst.2018.138

Krämer S., \& Verworn H. R. (2008, 31st August - 5th September 2008). Improved C-band radar data processing for real time control of urban drainage systems. Paper presented at the 11 th International Conference on Urban Drainage, Edinburgh, Scotland.

Mikovits C., Rauch W., \& Kleidorfer M. (2017). Importance of scenario analysis in urban development for urban water infrastructure planning and management. Computers, Environment and Urban Systems. doi:10.1016/j.compenvurbsys.2017.09.006

Ochoa-Rodriguez S., Wang L.-P., Gires A., Pina R. D., Reinoso-Rondinel R., Bruni G., . . . ten Veldhuis M.-C. (2015). Impact of spatial and temporal resolution of rainfall inputs on urban hydrodynamic modelling outputs: A multi-catchment investigation. Journal of Hydrology, 531, 389-407. doi:10.1016/j.jhydrol.2015.05.035

Rico-Ramirez M. A., Liguori S., \& Schellart A. N. A. (2015). Quantifying radar-rainfall uncertainties in urban drainage flow modelling. Journal of Hydrology, 528, 17-28. doi:10.1016/j.jhydrol.2015.05.057

Schellart A. N. A., Shepherd W. J., \& Saul A. J. (2012). Influence of rainfall estimation error and spatial variability on sewer flow prediction at a small urban scale. Advances in Water Resources, 45, 65-75. doi:10.1016/j.advwatres.2011.10.012

Schilling W. (1991). Rainfall data for urban hydrology: what do we need? Atmospheric Research, 27(1-3), 5 - 21.

Stokman A., Hoppe H., Massing C., Brenne F., \& Deister L. (2015). Starkregenereignisse als Motor einer wassersensitiven Stadtentwicklung. Korrespondenz Abwasser, 62(2), 122-129. doi:10.3242/kae2015.02.002

Tiroler Tageszeitung. (2016, 04.07.2016). Starkregen und Hagel: Aufräumen nach der Sintflut in Innsbruck. Tiroler Tageszeitung. Retrieved from http://www.tt.com/panorama/wetter/11714577-91/starkregen-und-hagelaufr\%C3\%A4umen-nach-der-sintflut-in-innsbruck.csp

Verworn H. R. (1991). Hydrological Relevance of Radar Rainfall Data. In I. D. Cluckie \& C. G. Collier (Eds.), Hydrological applications of weather radar (pp. 531-540). London: Ellis Horwood. 


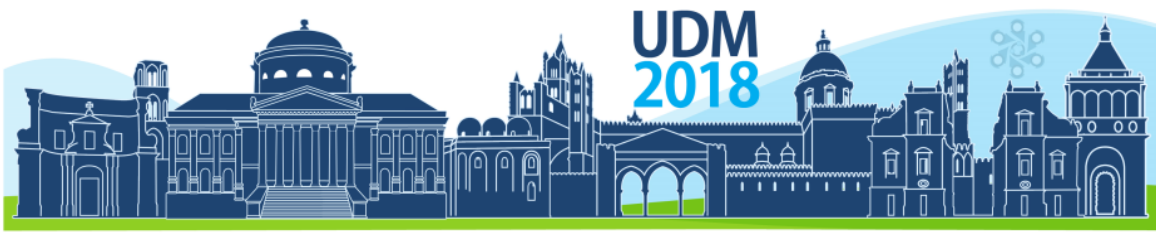

$11^{\text {th }}$ International Conference on Urban Drainage Modelling

23-26 Sep | Palermo - Italy

\title{
System-Wide Real Time Control Strategies for Overflow Volume Reduction - Extrapolating Annual Performance Indicators
}

\author{
Luca Vezzaro ${ }^{1,2}$ \\ ${ }^{1}$ Technical University of Denmark, Deparment of Environmental Engineering (DTU Environment), Bygningstorvet, \\ building 115, 2800 Kongens Lyngby, Denmark, luve@env.dtu.dk \\ 2 Krüger A/S, Veolia Water Technologies, Gladsaxevej 363, 2860 Søborg, Denmark
}

\begin{abstract}
Advanced real time control strategies of sewer networks can provide a significant contribution to the reduction of overflow volumes. Before full-scale implementation, these strategies need to be tested over long-time periods to calculate key performance indicators, such as yearly reduction in overflow volumes. This evaluation is often hindered by lack of sufficiently long data series. A new method was proposed to extrapolate yearly CSO reduction performance by using simulations of a limited number of CSO events. This article evaluates the precision of this extrapolation method by testing its precision in estimating CSO volumes yearly reduction for a synthetic example and a case study in Copenhagen (Denmark). The results showed a minor difference $(2-3 \%)$ in the estimated CSO reduction for the synthetic example. However, the method overestimated the yearly CSO reduction for the real case study, mainly due to yearly variation and to nonlinearity in the performance of control strategies. These preliminary results suggested that the extrapolation method converges with a lower number of CSO events compared to a simple sum of CSO volumes. Both the methods are thus suggested to obtain a more precise estimation of the yearly performance of advanced real time control strategies.
\end{abstract}

Keywords: Real Time Control, Model Predictive Control, Key Performance Indicators

\section{INTRODUCTION}

The digital transformation of the water sector is creating great opportunities for the implementation of new online control strategies, which ranges from local controls to systemwide optimization strategies (García et al., 2015; Lund et al., in press). System-wide Real Time Control (RTC) and Model-Predictive-Control (MPC) strategies, have been implemented at full scale (Mollerup et al., 2017) and in few cases a long-term evaluation of their environmental benefits is available (Fradet et al., 2011). Model-based evaluation of control strategies is therefore required by existing guidelines for control implementation (see for the example the German M180 guidelines - Schutze et al., 2008).

Given the highly spatial and temporal variability of rainfall, performance assessment of control strategies requires long-term simulations, i.e. the evaluation cannot be limited to few event in order to fully represent inter-event variability. Also, performance indicators are often expressed on a yearly basis (e.g. yearly reduction in Combined Sewer Overflows (CSO) volume), rather than on an event basis.

Van Daal et al. (2017) presented a comprehensive framework for model-based assessment of RTC strategies. However, the proposed framework relies on extensive measurements which are difficult to obtain for complex full-scale systems. Lack of data is exacerbated when looking at MPC strategies, which also requires rainfall forecast data. Löwe et al. (2016), for 


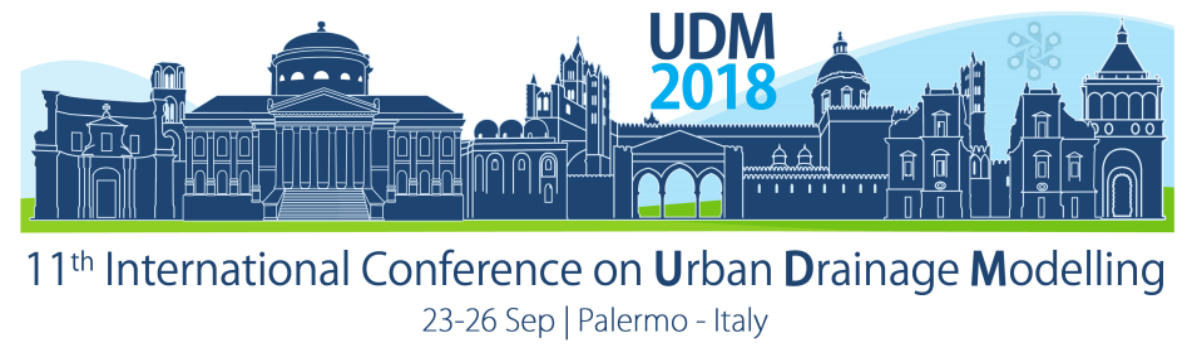

example, starting from a total of 422 rains events, identified 130 CSO events, where only 98 were included in the control evaluation due to issues in the dataset.

Excessive simulation time is also a recognized issue that limits the number of simulated events. For example, Meneses et al. (2018) used a detailed hydrodynamic model to evaluate a MPC strategy and limited their analysis to 46 selected events over a 5-year period. In order to extrapolate long-term (yearly) performance indicators based on a limited number of simulations, Meneses et al. (2018) applied a method originally applied for estimation of Expected Annual Damages in urban flood risk assessment (Zhou et al., 2012; Olsen et al., 2015). This article aims at assessing the applicability of this method for evaluating RTC and MPC strategies (based on CSO volume reduction). Firstly, the extrapolation method is tested on a synthetic example. Results from the system presented in Löwe et al. (2016) are then used to assess the validity of the proposed method.

\section{MATERIALS AND METHODS}

\subsection{Extrapolation method}

The proposed extrapolation method relies on the calculation of a CSO density curve $f_{\mathrm{CSO}}$ (Figure 1), which is calculated by dividing the CSO volume for each event ( $\left.V_{C S O}\right)$ by its return period. The CSO volume can either be defined for a single discharge point or as a sum of discharges across a defined catchment. The return period should be based on the CSO frequency, but this requires the availability of long time series of overflow events. Since this is rarely available, the rainfall return period can also be used (as in Meneses et al., 2018). However, it should be underlined that the non-linear nature of overflow events does not necessarily ensure a direct relationship between rainfall and CSO frequency.

After calculating $f_{\mathrm{CSO}}$ for different scenarios (baseline and control strategy), the relative reduction in yearly CSO volume $(\triangle C S O)$ can be estimated as:

$$
\Delta \text { CSO }=1-\frac{\int f_{\text {CSO,RTC }}(u) \mathrm{d} u}{\int f_{\text {CSO,baseline }}(u) \mathrm{d} u}
$$

where $f_{\mathrm{CSO} \text {,baseline }}(u)\left[\mathrm{m}^{3} /\right.$ year] is the CSO density curve for the baseline scenario; $f_{\mathrm{CSO}, \mathrm{RTC}}(u)$ $\left[\mathrm{m}^{3} /\right.$ year] is the CSO density curve for the control scenario, and $u$ is the logarithm of the return period.

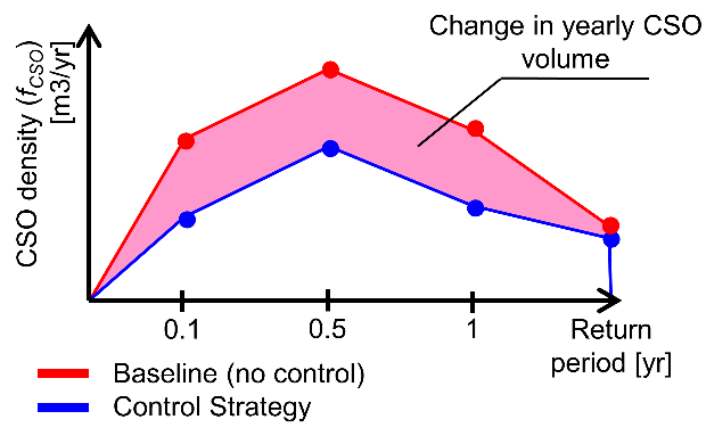

Figure 1. Schematization of the extrapolation method (adapted from Meneses et al., 2018)). 


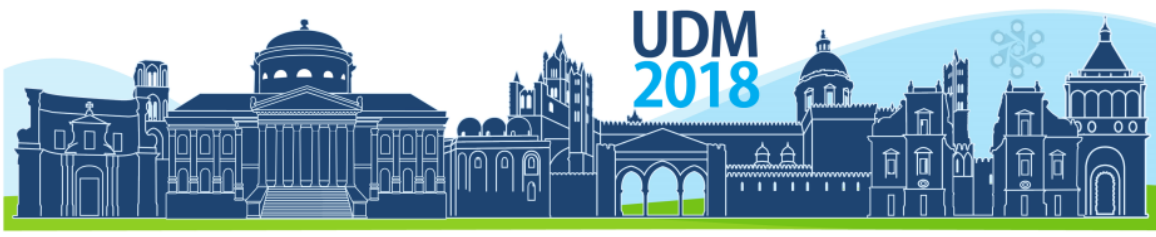

$11^{\text {th }}$ International Conference on Urban Drainage Modelling

23-26 Sep | Palermo - Italy

\subsection{Case Studies}

Synthetic Example. A total of 1,000 CSO volumes for the baseline scenario ( $\left.V_{\text {cso,baseline }}\right)$ were generated by sampling from a lognormal distribution (Figure 2 - left) and then randomly subdivided into 10 different years (i.e. there were 100 events for each year). The CSO volume for the control scenario $\left(V_{C S O, R T C}\right)$ was then calculated by assuming a non-linear relationship, defined based on the pattern observed in real case studies (Löwe et al., 2016; Meneses et al., 2018). According to this pattern, control is able to avoid all small events (reduction close to $100 \%$ ), while it does not have a significant reduction effect on big events (i.e. where the magnitude of the event is bigger than the system storage capacity).

Lynetten integrated MPC. Simulated CSO volumes from the Lynetten catchment, located in the city centre of Copenhagen (Denmark) were used. The sum of discharges from 9 CSO structures was used to evaluate the control performance. The CSO volumes were simulated by using rainfall data from the period 2000-2013. These rain data resulted in 921 CSO events over 13 years (ranging from a minimum of 54 to a maximum of 84 CSO events per year). The integrated MPC strategy described in Löwe et al. (2016) was applied to the catchment, resulting in the CSO volumes shown in Figure 2 (right). It should be noted that for few events the control strategy resulted in an increased CSO volume compared to the original discharges.

\subsection{Comparison Methodology}

For each case study the following steps were followed:

(a) yearly CSO reduction is calculated by using the whole available dataset ("true" CSO reduction);

(b) a subsample of CSO events is selected from a specific year (representing the situation where only limited event time series are available). The yearly reduction in CSO is extrapolated according to the methodology described in 2.1 ;

(c) step (b) is repeated with an increasing size of the subsample;

(d) the extrapolated CSO reduction is compared against the value obtained by using a simple sum of CSO volumes.

Points (b-d) were repeated 100 times in order to get a better overview of the precision and accuracy of the proposed methodology.
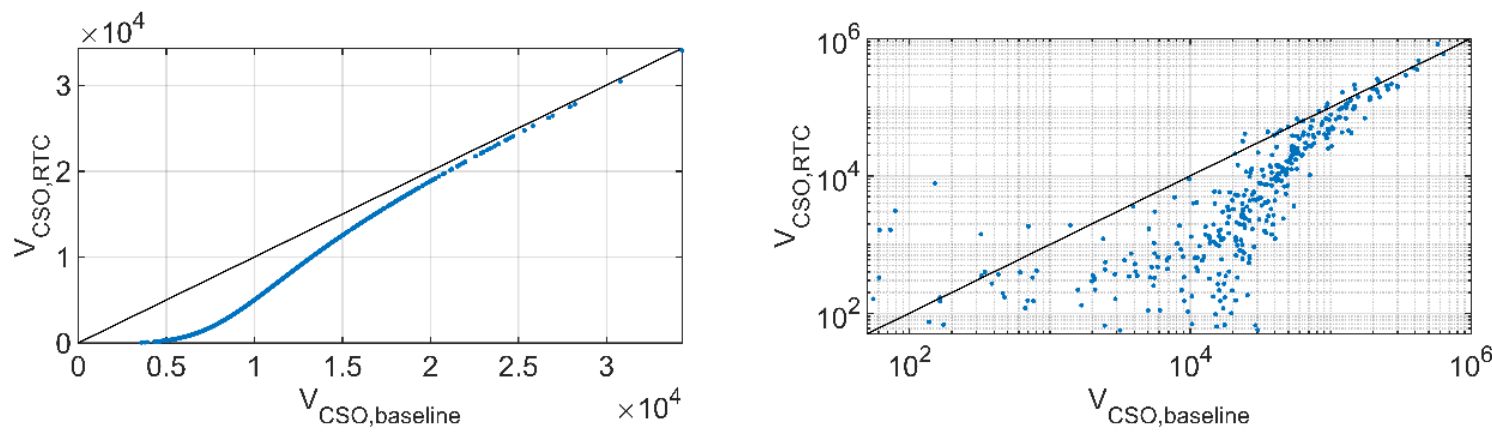

Figure 2. Comparison between CSO volumes without control (x-axis) and with control (y-axis) for all the analysed events. (left) Synthetic example. (right) Results for an integrated MPC strategy in the Lynetten catchment. 


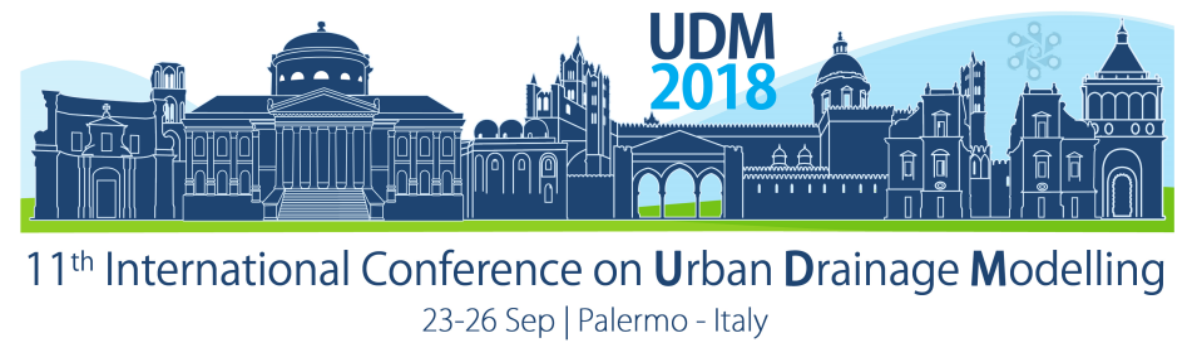

\section{RESULTS AND DISCUSSION}

Synthetic Example. Figure 3 shows how the extrapolation method quickly converged to a CSO reduction with a limited subsample of CSO events (10-15). The traditional method, based on the simple sum of volumes, showed a lower accuracy and tended to a greater underestimation of the removal potential. Overall, the extrapolation method resulted in a slight overestimation of the yearly CSO reduction ("true" 38\% - simulated 39\%).

Lynetten integrated MPC. Figure 4 highlights the high variability in CSO volumes for the different years, resulting in different yearly reductions (ranging from a minimum of $11 \%$ to a maximum of $64 \%$, with an average over the 13 year of $41 \%$ ).

The tendency to overestimate CSO reduction shown in the synthetic example was exacerbated for this case. This bias is mostly due to the assumption in a monotone, linear relationship between CSO volume and its reduction. Since the control performance are not linearly proportional to the event magnitude (e.g. in the case of coupled rain events), the integral of the function $f_{\mathrm{CSO}, \mathrm{RTC}}$.is not monotone. Since the term $\int f_{\mathrm{CSO}, \mathrm{RTC}}(u) \mathrm{d} u$ was calculated by using a trapezoidal integration rule

Nevertheless, the extrapolation method seems to converge to the final value more rapidly compared to simple arithmetic sum of CSO volumes. Also, the extrapolation method is less sensitive to the bias due to subsamples taken in years that are characterized by lower performance compared to the average value. For example, the control performance for 2007 and 2010 (Figure 4) were quite low $(12.5 \%$ and $11.5 \%$, respectively, against the $41 \%$ average), since these years where characterized by low-return period events. Nevertheless, the extrapolation method suggested an overall removal performance of around 20-30\% (2007 data) and 40-30\% (2010 data).

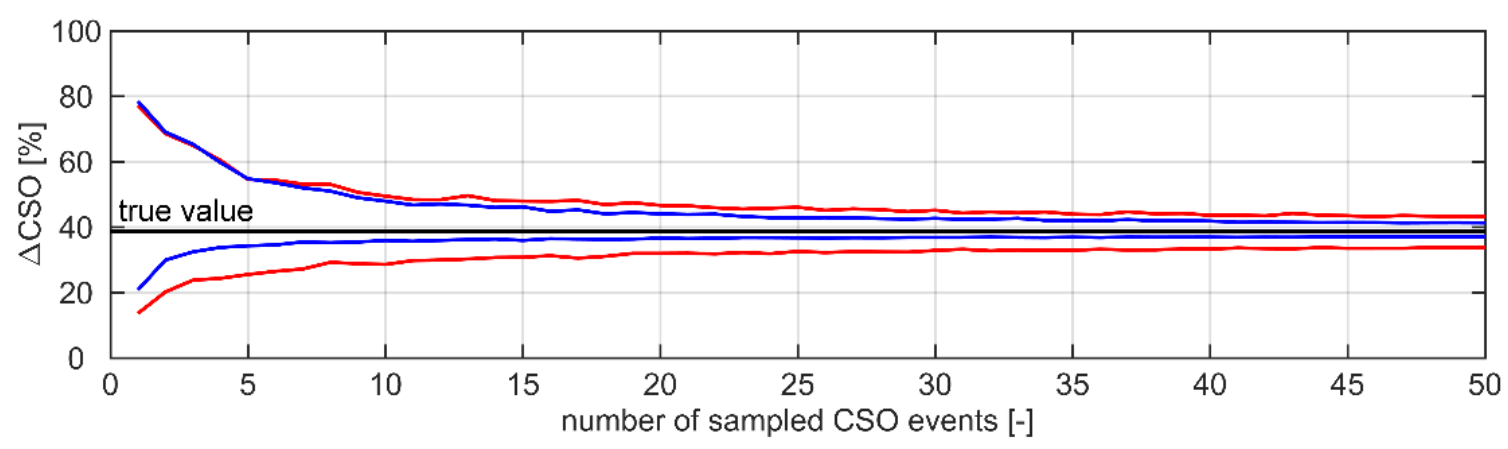

Figure 3. Estimated yearly reduction in CSO volume for the synthetic example by using the simple sum of CSO volumes (red) and the extrapolation method (blue) as function of number of sampled events. The lines shows the 5-95 percentiles for the 100 realizations. 


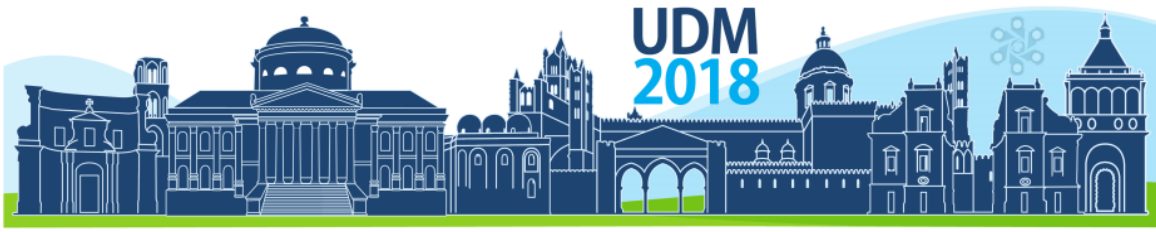

$11^{\text {th }}$ International Conference on Urban Drainage Modelling 23-26 Sep | Palermo - Italy

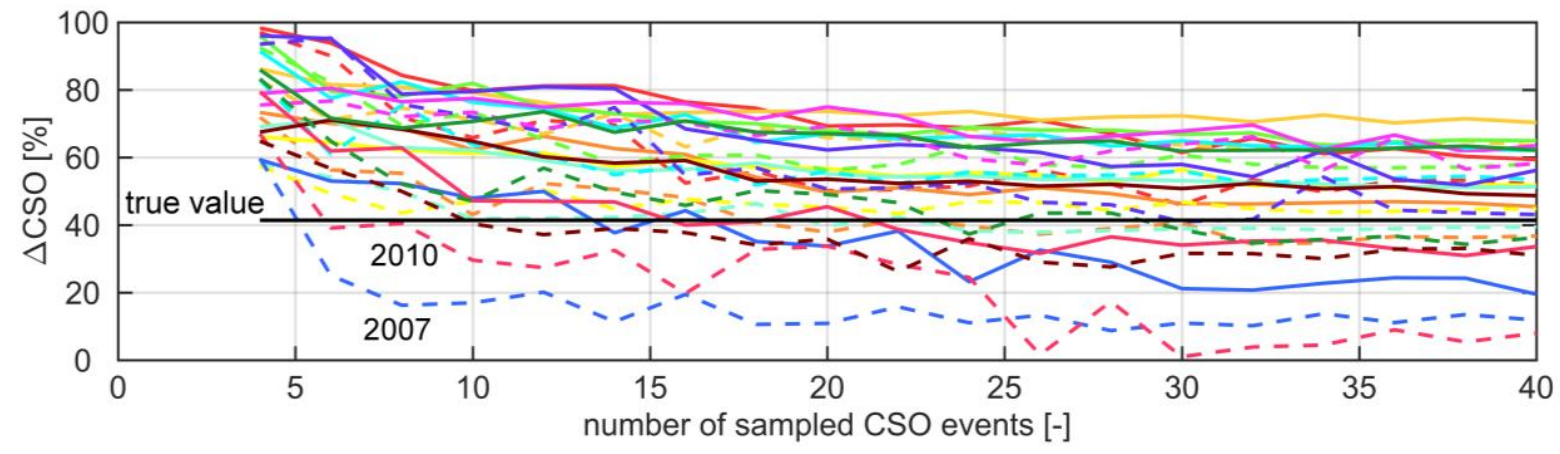

Figure 4. Estimated yearly reduction in CSO volume for the Lynetten example by using the simple sum of CSO volumes (dashed line) and the extrapolation method (solid line) as function of analysed events. Different years are visualized by using different colours. Lines shows the median value for the 100 realizations.

\section{CONCLUSIONS}

This preliminary assessment of the performance extrapolation method showed promising results in terms of convergence to the yearly performance indicator. However, the observed bias in CSO reduction, highlighted the need for further developments for accounting in the non-linearity of performance of RTC-MPC strategies. Also, further estimation of the method's accuracy compared to the simple sum of volumes is needed.

\section{References}

van Daal, P., Gruber, G., Langeveld, J., Muschalla, D., Clemens, F. (2017) Performance evaluation of real time control in urban wastewater systems in practice: Review and perspective. Environ. Modell. Softw., 95, 90101.

Fradet, O., Pleau, M., Marcoux, C. (2011) Reducing CSOs and giving the river back to the public: innovative combined sewer overflow control and riverbanks restoration of the St Charles River in Quebec City. Water Sci. Technol., 63(2), 331-338.

García, L., Barreiro-Gomez, J., Escobar, E., Téllez, D., Quijano, N., Ocampo-Martinez, C. (2015). Modeling and real-time control of urban drainage systems: A review. Adv. Water Res., 85, 120-132.

Lund, N. S., Falk, A. K. V., Borup, M., Madsen, H., Mikkelsen, P. S. (in press) Model predictive control of urban drainage systems: a review and perspective towards smart real-time water management. Crit. Rev. Env. Sci. Tec.

Löwe, R., Vezzaro, L., Mikkelsen, P. S., Grum, M., Madsen, H. (2016) Probabilistic runoff volume forecasting in risk-based optimization for RTC of urban drainage systems. Environ. Modelli. Softw., 80, 143-158.

Meneses, E. J., Gaussens, M., Jakobsen, C., Mikkelsen, P. S., Grum, M., Vezzaro, L. (2018) Coordinating rulebased and system-wide model predictive control strategies to reduce storage expansion of combined urban drainage systems: The case study of Lundtofte, Denmark. Water, 10(1).

Mollerup, A. L., Mikkelsen, P. S., Thornberg, D., Sin, G. (2017) Controlling sewer systems - a critical review based on systems in three EU cities. Urban Water J., 14(4), 435-442.

Olsen, A., Zhou, Q., Linde, J., Arnbjerg-Nielsen, K. (2015) Comparing Methods of Calculating Expected Annual Damage in Urban Pluvial Flood Risk Assessments. Water, 7(12), 255-270.

Schutze, M., Erbe, V., Haas, U., Scheer, M., Weyand, M. (2008) Sewer system real-time control supported by the M180 guideline document. Urban Water J., 5(1), 67-76.

Zhou, Q., Mikkelsen, P. S., Halsnæs, K., Arnbjerg-Nielsen, K. (2012) Framework for economic pluvial flood risk assessment considering climate change effects and adaptation benefits. J. Hydrol., 414-415, 539-549. 


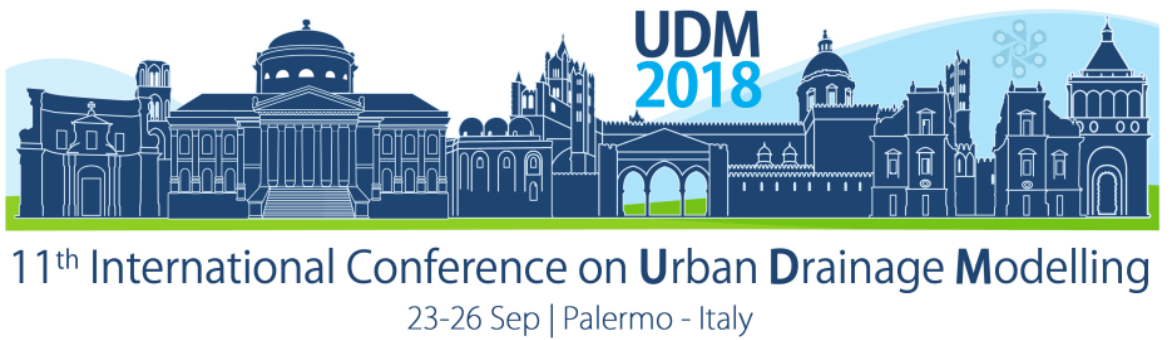

\title{
Influence of dynamic properties of rainfall on urban drainage infrastructure
}

\author{
Mrowiec M. ${ }^{1}$, Ociepa E. ${ }^{1}$, Malmur R. ${ }^{1}$ \\ ${ }^{1}$ Czestochowa University of Technology, Faculty of Infrastructure and Environment, Czestochowa, Poland
}

\begin{abstract}
Temporal and spatial variability of rainfalls have a significant impact on the operation of urban drainage systems. Stormwater storage reservoirs are particularly sensitive to these variations. This paper presents the results of research on the impact of the direction and speed of rainfall movement over an urban catchment of total area 560 ha on required volume of the storage tank. Simulations (using SWMM5 software) showed that movement of rainfall cells has a moderate impact on the peak-flows (around $20 \%$ increase in comparison to static variant), however, significantly affect the volume of stormwater accumulated in storage tanks. The most unfavorable variant is the rainfall moving in the direction and with velocity close to the general direction and average velocity of stormwater flow in the drainage system. The estimated increase of the unit volume of stored stormwater resulting from the dynamic properties of rainfall is about 6.5 to $8.0 \mathrm{~m}^{3}$ per hectare of impervious surface in comparison to static scenario.
\end{abstract}

Keywords: urban drainage, rainfall movement; storage reservoirs

\section{INTRODUCTION}

Since majority of rainfall measurements, apart from radar observations, supply point values while runoffs an areal process, assessments of areal rainfall values are necessary. Design storms, and even historical rainfalls used in hydrodynamic simulations, are almost always taken from one-point data (IDF relationships). When a design storm is applied, the movement of a storm is not considered - rainfall simply rapidly appear over whole catchment and also rapidly disappear after time $t_{d}$ (rain duration). Therefore the rainfall frequency provided by IDF relationships does not correspond to the observed runoff frequency (Jakubiak et al., 2014, Smith et al 2004, Bell and Moore 2000). In urban drainage systems the storage facilities are specially sensitive for spatial variability of rainstorms because required storage volume is estimated based by calculating the differences between inflow and outflow hydrograph. In literature only few works concernig the significance of rainfall movement for applications such as the design of urban drainage systems (conduits, reservoirs, CSOs etc.) (Niemczynowicz and Bengtsson 1996, Borga et al., Vaes et al. 2010). Abovementioned studies emphasized impact of local climatic conditions (i.e. predominant directions of wind, annual precipitation depth) on characteristics of rainfalls (duration, range, max. intensities etc.) (Berne et al. 2004, Morin et al. 2006). In most hydrological calculations we are dealing with inadequate and insufficient rainfall data: temporal resolution, spatial resolution and specially duration of collected data with sufficient resolution (Fletcher et al). Rigorous requirements of space and time resolution of gauge network that would resolve spatial and temporal variability of the convective rainfall process can, for practical reasons, never be satisfying (Schilling 1991, Zocatelli et al. 2010, Krajewski and Smith, 2002). 


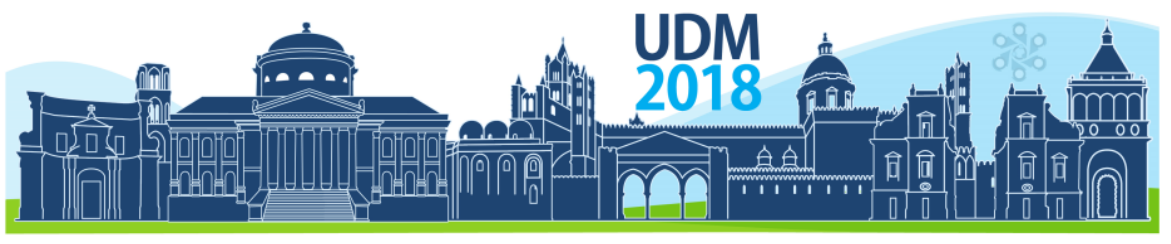

$11^{\text {th }}$ International Conference on Urban Drainage Modelling

23-26 Sep | Palermo - Italy

\section{MATERIALS AND METHODS}

Examination of the impact of the rainfall movement on drainage systems based on a hydrodynamic model of large urban catchment located in the central part of Czestochowa. The total area of the catchment (560ha) was divided into 200 subcatchments based on a DEM with a resolution of 5 meters. Model of drainage network includes of 415 conduits, 410 nodes, and the total length of over $35 \mathrm{~km}$. Maximum outflow-rates from the catchment reach over $10 \mathrm{~m} / \mathrm{s}$ during intensive rainfalls. The presented model has been calibrated taking into account 25 rainfall events recorded at 5 raingauges during $2011 \div 2012$ years. The flow-rates in channels was measured using two PCMPro flow meters. Average value of relative error regarding stormwater volume was equal to $6.1 \%$, for particular events it was ranged from 2.2 to $23.7 \%$. Because SWMM5 software do not contain a routine for direct simulating moving rainstorms, therefore whole catchment area was divided into a sectors of dimensions $600 \times 600 \mathrm{~m}$. Rainfall movement was simulated by lagging the uniformly distributed rainfall (block rain) stepwise over the subcatchments, with a time shift chosen in accordance with required storm velocity. For given rainfall velocities $v_{r}=2 \mathrm{~m} / \mathrm{s} ; 5 \mathrm{~m} / \mathrm{s}$ and $10 \mathrm{~m} / \mathrm{s}$ the time of rain cell travelling over the sector is equal $5 \mathrm{~min}, 2 \mathrm{~min}$, and $1 \mathrm{~min}$ respectively. Relationships between intensity and rain duration were estimated using IDF equation developed by Institute of Meteorology and Water Management (precipitation data recorded during years 1960-1990 on 20 raingauges.

\section{RESULTS AND DISCUSSION}

\subsection{Influence of rainfall movement on maximum flow-rates}

Based on the previously mentioned studies it was expected that the peak flow-rates at the outlet will be obtained for the direction of rainfall movement consistent with the general direction of stormwater flow in conduits. This was confirmed in results of the simulations as the largest flow-rates in the outlet section was recorded for rainfall td=20 min at speed of the $2 \mathrm{~m} / \mathrm{s}$ in East direction. The flow rate is about $12 \%\left(1.27 \mathrm{~m}^{3} / \mathrm{s}\right)$ higher than the intensity obtained for static conditions. For example, a 10-minute rainfall moving in south direction $\left(\mathrm{v}_{r}=2 \mathrm{~m} / \mathrm{s}\right)$ results in an $Q_{\max }=10.7 \mathrm{~m}^{3} / \mathrm{s}$ while the 30 -minute rainfall moving in West with analogous velocity results in a flow-rate $20 \%$ smaller.

Table. 1. Maximum flow-rates $\left[\mathrm{m}^{3} / \mathrm{s}\right]$ In outlet cross-section for static and dynamic variants of rainfalls.

\begin{tabular}{|c|c|c|c|c|c|c|c|c|}
\hline \multirow{2}{*}{$\begin{array}{c}\mathrm{v}_{\mathrm{r}} \\
{[\mathrm{m} / \mathrm{s}]}\end{array}$} & \multicolumn{8}{|c|}{ Rain duration } \\
\hline & \multicolumn{2}{|c|}{$10 \mathrm{~min}$} & \multicolumn{2}{|c|}{$20 \mathrm{~min}$} & \multicolumn{2}{|c|}{$30 \mathrm{~min}$} & \multicolumn{2}{|c|}{$45 \mathrm{~min}$} \\
\hline \multirow[t]{3}{*}{ static } & \multicolumn{2}{|c|}{9.06} & \multicolumn{2}{|c|}{10.92} & \multicolumn{2}{|c|}{10.76} & \multicolumn{2}{|c|}{9.18} \\
\hline & \multicolumn{8}{|c|}{ Direction of rainfall movement } \\
\hline & $\mathrm{E}$ & W & $\mathrm{E}$ & W & $\mathrm{E}$ & W & $\mathrm{E}$ & W \\
\hline 2 & 11.65 & 6.74 & 12.18 & 7.74 & 11.15 & 8.34 & 9.23 & 8.50 \\
\hline 5 & 10.84 & 7.73 & 11.92 & 9.37 & 11.10 & 9.71 & 9.22 & 9.05 \\
\hline \multirow[t]{2}{*}{10} & 9.68 & 8.31 & 11.30 & 10.23 & 10.93 & 10.33 & 9.21 & 9.13 \\
\hline & $\mathrm{S}$ & $\mathrm{N}$ & $\mathrm{S}$ & $\mathrm{N}$ & $S$ & $\mathrm{~N}$ & $\mathrm{~S}$ & $\mathrm{~N}$ \\
\hline 2 & 10.69 & 6.91 & 11.62 & 8.41 & 10.93 & 9.05 & 9.17 & 8.34 \\
\hline 5 & 9.55 & 8.13 & 11.55 & 10.02 & 10.94 & 9.96 & 9.20 & 9.11 \\
\hline 10 & 9.07 & 8.54 & 11.16 & 10.50 & 10.87 & 10.46 & 9.19 & 9.16 \\
\hline
\end{tabular}




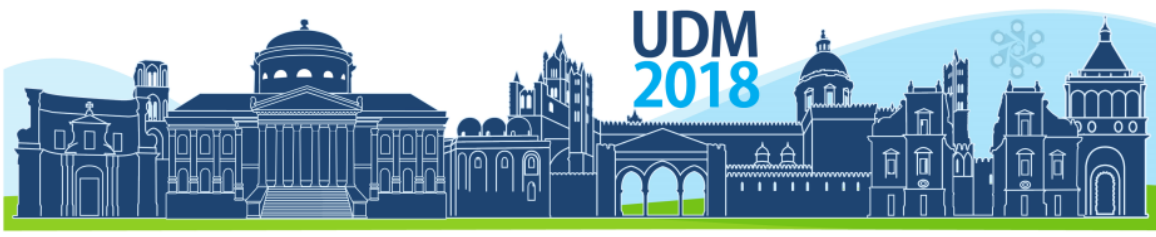

$11^{\text {th }}$ International Conference on Urban Drainage Modelling

23-26 Sep | Palermo - Italy

\subsection{Influence of rainfall movement on storage volumes}

Analyzing the shape of the hydrographs its obvious that rainfall movement is an important parameter while required volume is estimated. The influence is directly related to outflow-rate $\left(Q_{0}\right)$. thus simulations were performed for following unit outflow-rates from the storage tank $\left(q_{0}\right): 12.5 \mathrm{l} / \mathrm{s} \cdot h a .25 \mathrm{l} / \mathrm{s} \cdot \mathrm{ha} .37 .5 \mathrm{l} / \mathrm{s} \cdot \mathrm{ha}$ and $50 \mathrm{l} / \mathrm{s} \cdot \mathrm{ha}$. Modeled storage tank is equipped with a side weir (discharge to storage chamber) and a flow regulator to fix quasi-constant outflow rate. Figure 1 shows the unit volume of stored stormwater obtained using static as well as dynamic rainfall data for variable value of outflow-rate $Q_{0}$. For the dynamic conditions only minimum and maximum values were marked. In all the analyzed cases. the maximum value of $V_{R}$ has been obtained for variant precipitation moving in $E$ direction at velocity $V_{r}=2 \mathrm{~m} / \mathrm{s}$. These volumes were larger than average stored volume obtained in static variant by $700 \div 1100 \mathrm{~m}^{3}$ depending on the rain duration $t_{d}$. In relative terms. this means potentially underestimating the required retention capacity by: $3.1 \%$ for $q_{0}=12.5 \mathrm{l} / \mathrm{s} \cdot \mathrm{ha}, 9.5 \%$ for $\mathrm{q}_{0}=25$ $\mathrm{l} / \mathrm{s} \cdot \mathrm{ha}, 26.0 \%$ for $\mathrm{q}_{0}=37.5 \mathrm{l} / \mathrm{s} \cdot \mathrm{ha}, 55.5 \%$ for $\mathrm{q}_{0}=50.0 \mathrm{l} / \mathrm{s} \cdot \mathrm{ha}$. Considering minimum values of storage volume for dynamic conditions the differences are clearly larger and in all cases were obtained for rainfall movement in $N$ direction at velocity $v_{r}=2 \mathrm{~m} / \mathrm{s}$.

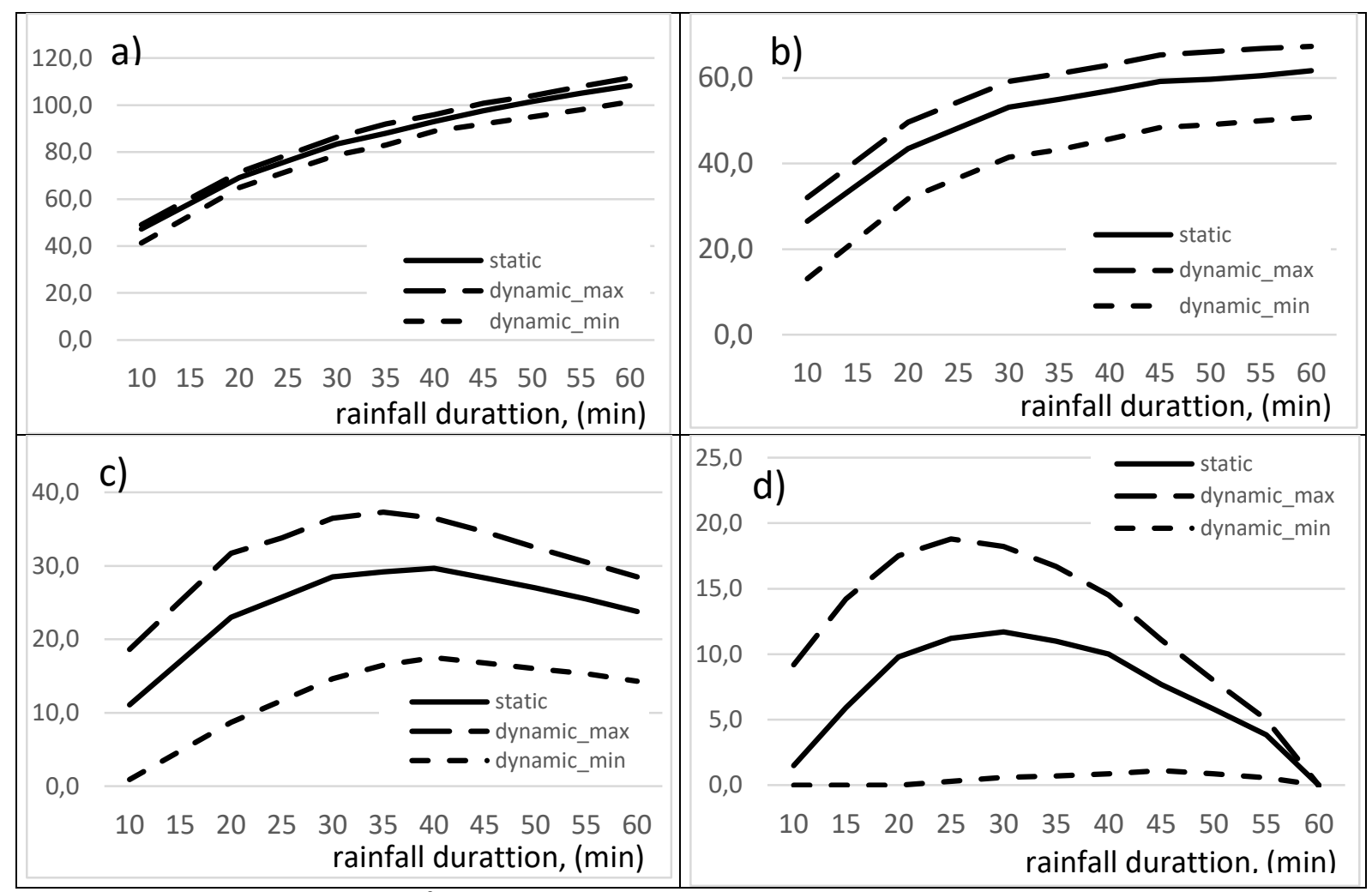

Figure 5. Unit storage volumes ( $\mathrm{m}^{3} / \mathrm{ha}$ ) for static and dynamic (maximum i minimum) conditions: a) $\mathrm{Q}_{0}=12.5 \mathrm{l} / \mathrm{sha}$. b) $Q_{0}=25 \mathrm{l} / \mathrm{sha}$. c) $Q_{0}=37.5 \mathrm{l} / \mathrm{sha}$. d) $Q_{0}=50 \mathrm{l} / \mathrm{sha}$.

It should be noted that the relative increase in maximum flow rates (Table 1) usually does not translate into direct growth of investment costs. because it does not necessarily result in a change to a larger diameter of a conduit. When dimensioning storage tanks this relation is simplified - increase of required storage volume usually results in proportional increase of investment costs. 


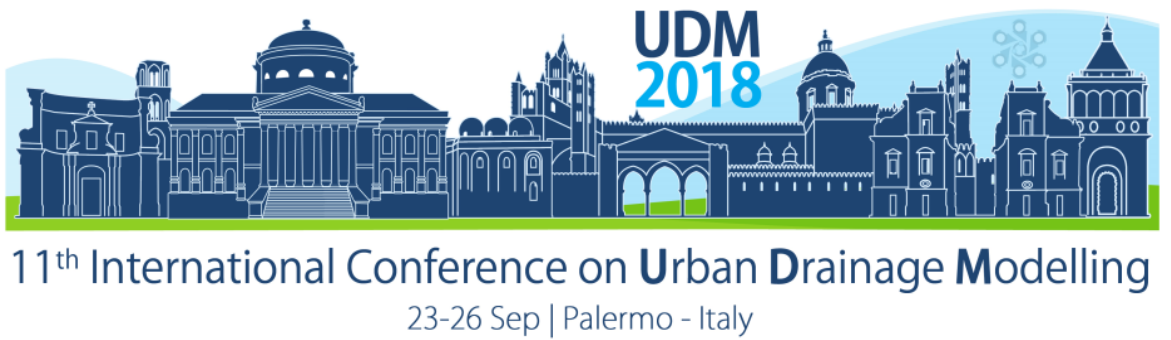

\section{CONCLUSIONS}

Results presented in this article are recommendations when the dynamic properties of rainfalls should be considered in calculations aimed to estimation of storage capacity. Following factors influence on the results: size of the catchment area (for small areas the dynamic properties of rainfall can be negligible). configuration of the drainage system (average slopes. shape of a catchment etc.) and also local rainfall characteristics. The following conclusions can be drawn from the present study:

- the maximum peak flow-rates for the dynamic conditions can be larger from a few percent to $30 \%$ (depending on the $t_{d}$ and $v_{r}$ ) higher than for the stationary variant,

- influence of the direction and speed of rainfall movement on the shape of inflow hydrograph to the reservoir is significant.

- the impact of the movement of precipitation on stored volume is closely related to outflow rate from retention reservoir (i.e. for $q_{0}=12.5 \mathrm{l} / \mathrm{sha}$ the difference between static and dynamic variants is less than $10 \%$ while for $q_{0}=50 \mathrm{l} / \mathrm{sha}$ it reach over $90 \%$ ).

- the maximum volume of stored stormwaters occurs with rainfalls whose velocities are close to flow velocity in the conduits $(2 \mathrm{~m} / \mathrm{s})$ and parallel to general direction of flow in the drainage system.

- relative differences in volume between static and dynamic ranged from $3 \%$ to $55 \%$ depending on $q_{0}$ (as absolute values it's about $700 \div 1100 \mathrm{~m}^{3}$. and expressed as unit volume: $6.5 \div 8.0 \mathrm{~m}^{3} / \mathrm{ha}$ of impervious area).

\section{References}

Bell V. A. and Moore R. J., "The sensitivity of catchment runoff models to rainfall data at different spatial scales", Hydrol. Earth Syst. Sci, 4, (2000), pp 653-667.

Berne A., Delrieu G., Creutin J. D., and Obled C., "Temporal and spatial resolution of rainfall measurements required for urban hydrology", J Hydrol., 299(3-4), (2004), pp 166-179.

Borga M., Anagnostou E. N., Bloschl G., and Creutin J. D., "Flash Floods: observations and analysis of hydrometeorological controls", J. Hydrol., (2010), 394(1-2), pp 1-3.

Clemens F., "Hydrodynamic models in urban drainage: Application and calibration, doctoral dissertation", TU Delft, Delft University Press, (2001).

De Lima J. L. and Singh V. P., The influence of the pattern of moving rainstorms on overland flow, Adv. Water. Res, 25(7), (2002), pp 817-828(12).

Fletcher T.D., Andrieu H., Hamel P., Understanding, management and modelling of urban hydrology and its consequences for receiving waters. A state of the art, Adv. Water Resour., (2013), 51, 261

Jakubiak, B. Licznar, P. Malinowski, S. P., (2014), Rainfall estimates from radar vs. raingauge measurements. Warsaw case study, Environment Protection Engineering, vol. 40, nr 2, 159-170,

Krajewski W. F. and Smith J. A., "Radar hydrology-rainfall estimation", Adv. Water Resources, 25, (2002), pp 13871394.

Morin E., Goodrich D. C., Maddox R. A., Gao X. G., Gupta H. V. and Sorooshian, S., "Spatial patterns in thunderstorm rainfall events and their coupling with watershed hydrological response", Adv. Water Res., 29, (2006), pp 843-860.

Niemczynowicz J. and Bengtsson L., "What practitioners need from theoreticians?" Atmospheric Research, 42, (1996), pp 5-17.

Schilling W., "Rainfall data for urban hydrology: what do we need?", Atmospheric Resources, vol. 27, (1991), pp 521.

Singh V. P., "Effect of the direction of storm movement on planar flow", Hydrol. Process., 12, (1998), pp 147-170.

Smith M., Koren V., Zhang Z., Reed S., Pan J. and Moreda F., "Runoff response to spatial variability in precipitation: an analysis of observed data", J. Hydrol., 298, (2004), pp 267-286.

Vaes G., Willems P. and Berlamont J., "Areal rainfall correction coefficients for small urban catchments", Atmospheric Research, 77, 2005, pp 48- 59.

Zoccatelli D., Borga, M., Zanon, F., Antonescu, B. and Stancalie, G., "Which rainfall spatial information for flash flood response modelling?, A numerical investigation based on data from the Carpathian range, Romania", J. Hydrol., 394(1-2), (2010), pp 148-161. 


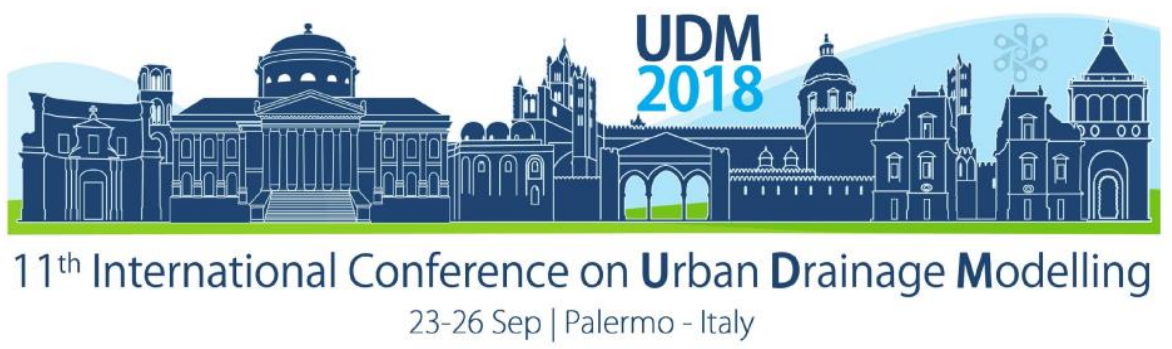

\title{
Modeling Infiltration Wells in SWMM and Comparing Its Performance with a Real-Scale Well
}

\author{
Anaí Floriano Vasconcelos ${ }^{1}$, Thays Santos Ferreira ${ }^{1}$, Maria Fernanda Nóbrega dos Santos ${ }^{1}$ and Ademir \\ Paceli Barbassa ${ }^{1}$ \\ ${ }^{1}$ Federal University of São Carlos (UFSCar), Department of Civil Engineering, São Carlos, Brazil
}

\begin{abstract}
The low impact development (LID) controls are increasingly encouraged to control the urbanization drainage impacts. A particularly interesting LID control for densely urbanized areas is an infiltration well (IW), as it occupies a small area and is efficient in recharging groundwater. The Storm Water Management Model (SWMM) is a hydraulichydrological modeling software program for urban areas that has been widely used and accepted. Its most recent versions already allow the modeling of some LID controls. However, despite their importance, IWs have not been studied yet. In this context, the goal of this article is to present a way to model the IW in SWMM using the available tools. For this purpose, infiltration trench (IT) input parameters were used. They were adapted to represent the IW stored volume and outflow. The water levels (WLs) calculated by the proposed model were compared to the WLs from a real-scale IW in the city of São Carlos, Brazil. The WLs were measured in the field by six controlled tests. The results showed a good fit between the WLs obtained by SWMM and the monitoring data, with an $\mathrm{R}^{2}$ between 0.96 and 0.97 and a Nash-Sutcliffe efficiency coefficient (NS) between 0.79 and 0.84 . These results validate the procedures adopted, which allows the IW modeling in the current version of SWMM.
\end{abstract}

Keywords: Infiltration well; Storm Water Management Model (SWMM); low impact development (LID)

\section{INTRODUCTION}

The Storm Water Management Model (SWMM) is a widely used and accepted software program for urban drainage modeling (Senior et al, 2018). It combines quantity and quality, hydraulic and hydrologic modeling, and considers low impact development (LID) controls (Rossman, 2015).

The runoff source control measures have been studied for more than three decades (Fletcher et al, 2014), and there is evidence of its efficiency in reducing urban drainage problems on a catchment scale (Tarigan, 2016). Several LID controls are being used around the world, and SWMM 5.1, the latest version of the software, includes eight types: BioRetention Cell, Rain Garden, Green Roof, Infiltration Trench, Permeable Pavement, Rain Barrel, Rooftop Disconnection, and Vegetative Swale (Rossman, 2015). Although explicitly predicting these eight types of LID, the software is not limited to them. The input data in SWMM is layer driven (Surface, Pavement, Soil, Storage, Drain, and Drain Mat) and the software predicts for each type of LID a specific combination of layers. Thus, any other LID control that can be described by these layers, and their input data, can be modeled by SWMM. This feature makes the tool even more powerful and flexible.

A recommended LID control for sites with a minimal area available for the controls' implementation is an infiltration well (IW). An IW consists of a well that receives the runoff 


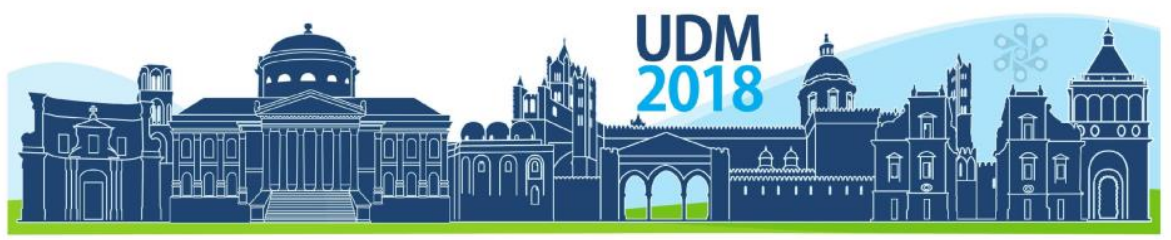

$11^{\text {th }}$ International Conference on Urban Drainage Modelling

23-26 Sep | Palermo - Italy

from the contribution area and infiltrates it into the soil through its bottom and walls (Ferreira, 2016). The infiltration area and the area occupied by the LID control are highly related in an IW, guaranteeing the efficiency of water infiltration into the soil (Prasetia, 2014).

The SWMM, however, does not include an IW in its range of LID control modeling possibilities. Despite the possibility of using any of the layers combinations available, none of them properly represents the IW characteristics, especially the infiltration through its bottom and walls and the empty storage volume combined. To enable the modeling of an IW in SWMM and to extend the applications of this powerful tool in densely urbanized catchments, this paper presents a way to represent it without new software features and, for validation, it compares the calculated results with in situ measured data from a real-scale IW built in the city of São Carlos, Brazil.

\section{MATERIALS AND METHODS}

\subsection{Real-scale IW and its monitoring}

The monitored IW is located on the São Carlos campus of the Federal University of São Carlos (UFSCar), Brazil and is built as represented in Figure 1.
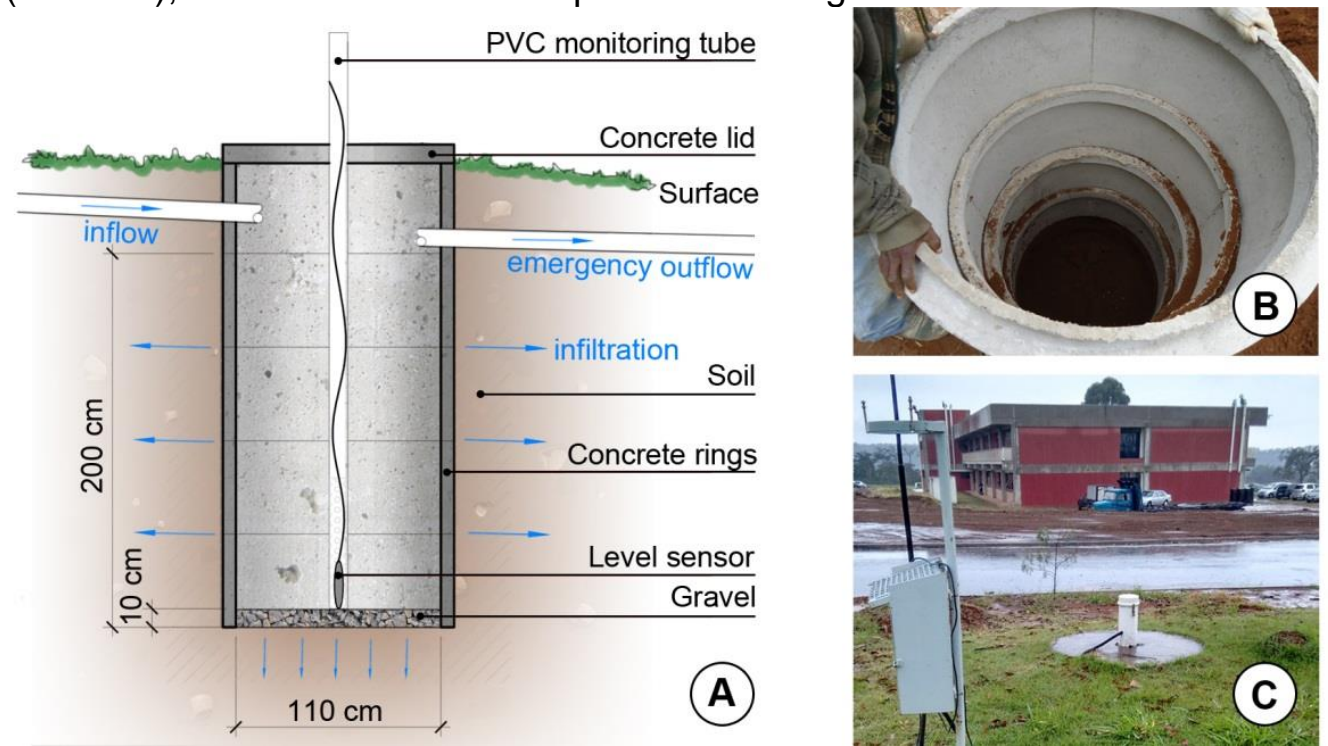

Figure 1. A) Real-scale IW section. B) Real-scale IW interior. C) Real-scale IW view and its monitoring system.

The IW was submitted to six artificial rainfall events, each with $1.71 \mathrm{~m}^{3}$ of water and a known inflow hydrogram. The WL inside the IW was monitored every minute with an OTT electronic level sensor, Orpheus Mini model.

\subsection{SWMM modeling strategies}

The SWMM LID control input data are separated by layers: Surface, Pavement, Soil, Storage, Drain, and Drain Mat. Each type of LID control uses a layer combination, depending on its characteristics (Rossman, 2015).

The LID control available in SWMM that best adapts its layers to the IW is the infiltration trench (IT). In this way, IT was adopted as a starting point and the necessary adaptations 


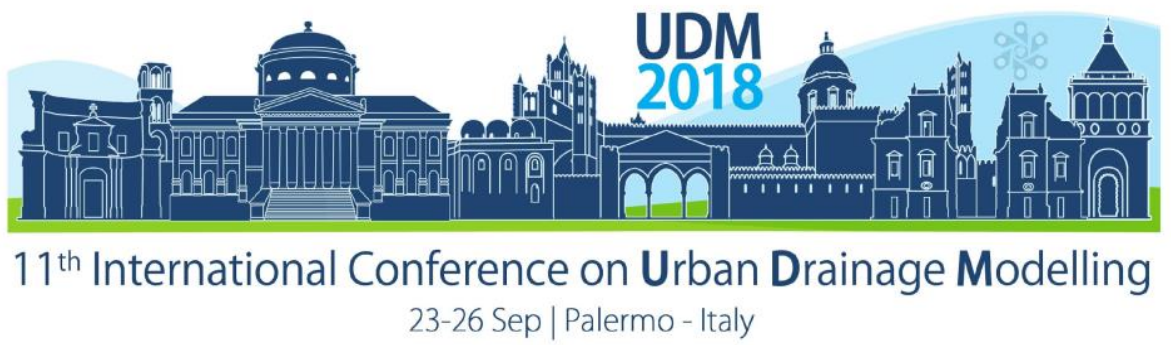

were made to represent the IW. The IT LID control requires the layers Surface and Storage, and it is also optional to use the Drain layer.

The Surface layer describes the LID control surface area and the flow on it. These characteristics are not important for the IW because its area is small, and its entrance structure ensures that all the received water can enter the storage volume. Thus, the adopted parameter values of this layer were zero.

The Storage layer characterizes how storage occurs in the structure. In general, the storage volume of an IT consists of a granular bed, which has a void ratio (VR = void volume / solid volume) smaller than 1. However, in the IW the storage volume is not filled by solids; thus, a VR value of 1000 was adopted, practically zeroing the volume of solids. In addition to the storage, it is in this layer that the constant infiltration rate by the bottom of the IT is defined. In this study case, the adopted value was $360 \mathrm{~mm} / \mathrm{h}$, obtained by Ferreira (2016), for the location where the monitored IW was installed.

The Drain layer is used in case of an auxiliary drain adoption for the IT drainage. The outflow through the drain is given by Formula 1.

$$
\mathrm{q}=\mathrm{Ch}^{\mathrm{n}}
$$

where $q$ is the outflow $(\mathrm{mm} / \mathrm{h}), \mathrm{h}$ is the height of water in the storage layer over the drain $(\mathrm{mm})$, and $\mathrm{C}$ and $\mathrm{n}$ are the drain's coefficient and exponent, respectively.

In this study, a drain was adopted to simulate the infiltration through the IW walls. Thus, a fictitious lateral drain was considered near the IW bottom with $C$ and $n$ values that makes its flow equivalent to the infiltration flow through the walls. The relation between $q$ and $h$ was constructed by regression based on the soil and the geometric characteristics of the IW. It was considered that infiltration occurs from the well to the soil through its walls and bottom. The concrete rings provide structural stability to the well and do not block the passage of the water. This adaptation allows quantity modeling. The quality modeling was not considered.

The measured input hydrogram of the São Carlos IW was inserted into the SWMM, and the WLs were calculated inside the IW. The WLs measured in each time interval of the IW in situ were compared with those calculated by the SWMM with the proposed changes. The WLS measured in situ were also compared with that calculated by the SWMM using the IT without a drain, that means, disregarding the infiltration through the walls.

\section{RESULTS AND DISCUSSION}

Figure 2 shows the observed WLs for a typical simulated rainfall event and the SWMM calculated WLs with and without a drain. It also depicts the accumulated inflow volume of the event. 


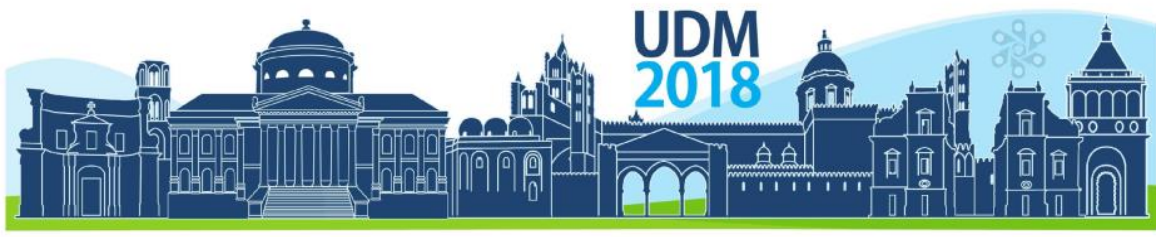

$11^{\text {th }}$ International Conference on Urban Drainage Modelling

23-26 Sep | Palermo - Italy

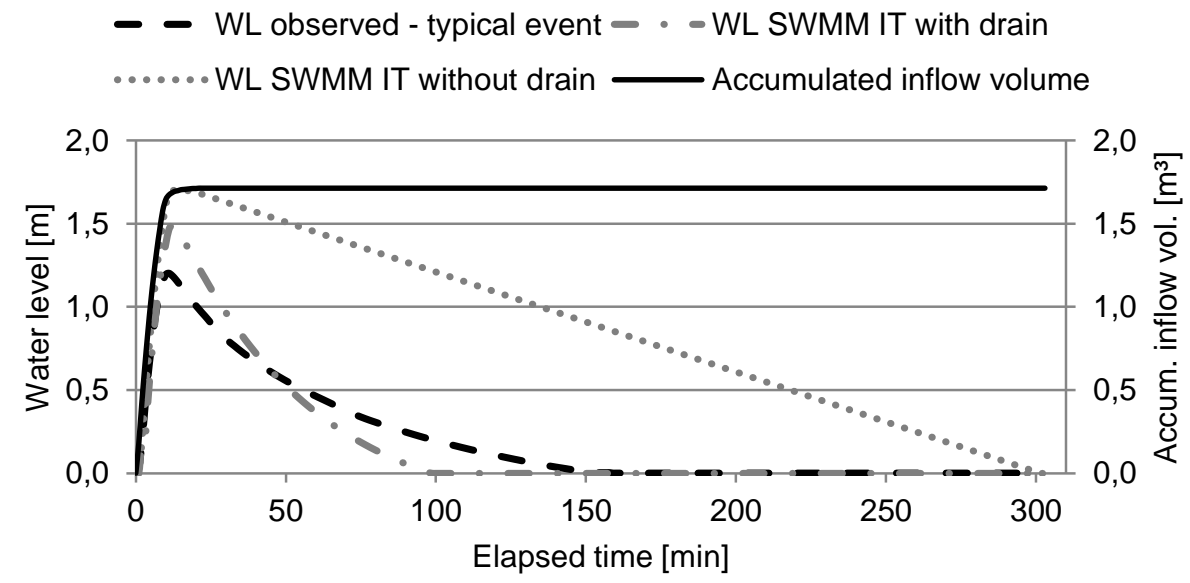

Figure 2. SWMM calculated WLs, typical observed WLs, and accumulated inflow volume.

Figure 2 shows that the IW modeled by SWMM without drain WLs obtained a poor fit with the observed WLs, with an $\mathrm{R}^{2}$ between 0.55 and 0.64 and a Nash-Sutcliffe efficiency coefficient (NS) between -6.19 and -4.18 . However, the IW modeled by SWMM with drain WLs showed good adjustments between the calculated and the observed WLs, with an $\mathrm{R}^{2}$ between 0.96 and 0.97 and an NS between 0.79 and 0.84 . In this case, the maximum calculated WL was $24 \%$ higher than the observed one. The observed IW operating time was $52 \%$ higher than the modeled one. Such differences may be related to the use of a constant infiltration rate to characterize water infiltration into the soil. This is the only currently available option in SWMM to describe the infiltration in LID controls. If it were possible to adopt a higher initial infiltration rate, which is generally associated with the dry soil, and a smaller value for the final infiltration rate, in the humid soil, these differences would likely decrease (Ferreira, 2016). The good adjustments observed in the modeling of the IT with drain also validate the hypothesis that the limiting factor for the water outflow from the well is the soil infiltration rate in the areas of wall and bottom and that the concrete rings do not block the passage of water.

The high field infiltration rates make this LID control efficient in the runoff control, as it is empty in less than 24 hours (Schueler, 1987). It should be noted that the local groundwater is about $10 \mathrm{~m}$ deep and there are no rainwater pollution sources at the site.

\section{CONCLUSIONS}

The results of this study indicated a good fit of the SWMM modeled WL with the observed ones, using an IT adaptation with a drain to simulate the IW infiltration flow through the walls. The relation between WLs and the infiltration flow through the walls, simulated by the drain, is easily obtained.

The procedures presented in this study enable an IW in SWMM to be modeled with the currently available tools. This extends the opportunities for software to face actual challenges in urban water modeling, such as the use of suitable to densely urbanized catchments LID controls. 


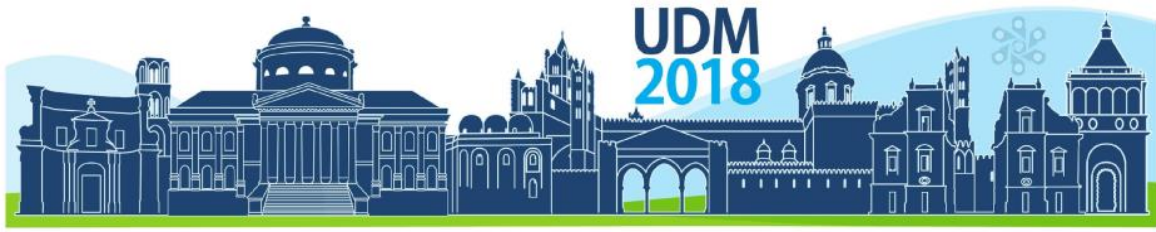

$11^{\text {th }}$ International Conference on Urban Drainage Modelling

23-26 Sep | Palermo - Italy

\section{Acknowledgements}

The authors would like to thank the National Council for the Improvement of Higher Education (CAPES) for the scholarship grant and financial support for research.

\section{References}

Ferreira, T.S. (2016) Avaliação do comportamento hidrológico de poços de infiltração de águas pluviais sob diferentes concepções [Evaluation of the hydrological behavior of rainwater infiltration wells under different conceptions]. M.Sc. thesis, Dept Civil. Eng., Federal Univ. of São Carlos, São Carlos, Brazil.

Fletcher, T.D.; Shuster, W.; Hunt, W.F.; Ashley, R.; Butler, D.; Arthur, S.; Trowsdale, S.; Barraud, S.; SemadeniDavies, A.; Bertrand-Krajewski, J.; Mikkelsen, P.S.; Rivard, G.; Uhl, M.; Dagenais, D. and Viklander, M. (2014) SUDS, LID, BMPs, WSUD and more - The evolution and application of terminology surrounding urban drainage. Urb. Wat. Jour. 12(7), 525-542.

Prasetia, I. (2014) Design of infiltration well in wetlands area that suitable for giving maximum groundwater recharge. Jour. Wetl. Env. Man. 2(2), 37-40.

Rossman, L.A. (2015) Storm Water Management Model user's manual version 5.1. U.S. Environmental Protection Agency, Cincinnati, United States of America.

Schueler, T.R. (1987) Controlling Urban Runoff: A Practical Manual for Planning and Design Urban BMPs. Metropolitan Council of Government, Washington, United States of America.

Senior, M.; Scheckenberger, R. and Bishop, B. (2018) Modeling catchbasins and inlets in SWMM. Journal of Water Management Modeling 26, C435.

Tarigan, S.D. (2016) Modeling effectiveness of management practices for flood mitigation using GIS spatial analysis functions in Upper Cilliwung watershed. IOP Conf. Series: Earth Env. Sci. 31, 012030. 


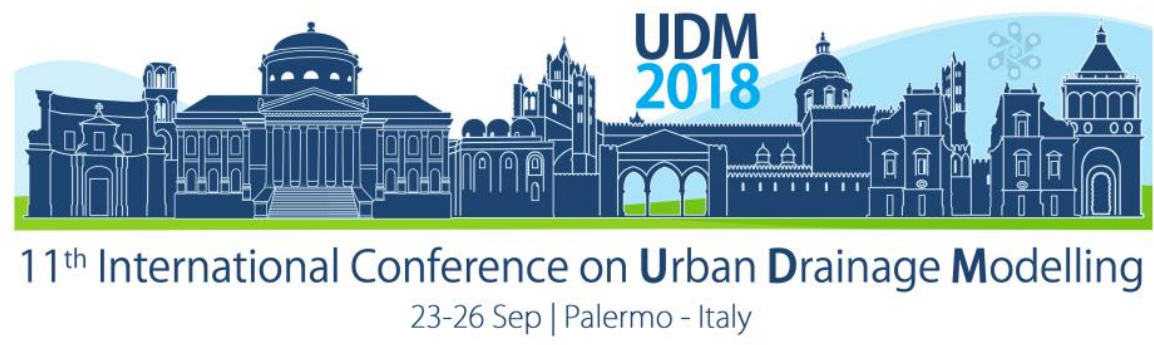

\title{
Modelling of storm precipitation
}

\section{Vitaly Ilinich ${ }^{1}$, Alexander Belolubtcev ${ }^{2}$, Alessandro Cavalli ${ }^{3}$, llyyas Veliev ${ }^{4}$ and Maxim Lapushkin $^{5}$}

\author{
${ }^{1}$ Russian state agrarian university - Moscow agricultural academy named after K.A. Timiryazev, Department \\ Meteorology, Moscow, Russia \\ ${ }^{2}$ Russian state agrarian university - Moscow agricultural academy named after K.A. Timiryazev, Department \\ Meteorology, Moscow, Russia \\ ${ }^{3}$ Russian state agrarian university - Moscow agricultural academy named after K.A. Timiryazev, Department \\ Meteorology, Moscow, Russia \\ ${ }^{4}$ Russian state agrarian university - Moscow agricultural academy named after K.A. Timiryazev, Department \\ Meteorology, Moscow, Russia \\ ${ }^{5}$ Russian state agrarian university - Moscow agricultural academy named after K.A. Timiryazev, Department \\ Hydrology, Moscow, Russia
}

(authors'addresses: vilinitch@gmail.com, belolyubcev@mail.ru, abcavall1993@gmail.com, cpp.sion@gmail.com, makslapushkin@gmail.com)

\begin{abstract}
The article is devoted to the stochastic modeling of maximum daily precipitation. Two approaches of Monte-Carlo methods are analyzed in respect to simulation of scenarios for dangerous precipitation during several days in a row. Such simulation is needed for modeling maximum runoff according to type of models "precipitation - runoff" in city conditions.
\end{abstract}

Keywords: storm precipitation; stochastic modeling, Monte-Carlo.

\section{INTRODUCTION}

Majority of observation on the meteorological stations showed increasing of storm precipitation, but not always (llinich and Larina, 2016; Sen Roy, 2009; Wilks, 1999). So we have to check this hypothesis in respect to of the Moscow regions. Then there is need to simulate storm precipitation according to last time of observation series which has more short duration but more reality due to climate changes for consideration a big amount of different scenarios of storm precipitation, which have essential impact on the maximum runoff in city conditions. The special methods of Monte-Carlo are analyzed for simulation of storm precipitation (Svanidze,1975).

The main hypothesis of the study - the proposed methods for simulation of scenarios of storm precipitation are adequate to observed in in respect to the statistical parameters of observed precipitation. So - the main statistic characteristics of the simulated scenarios should not differ substantially from similar characteristics of the observed scenarios.

\section{MATERIALS AND METHODS}

The studies were conducted on the base of data observation at the meteorological station of Moscow agricultural academy named after K.A. Timiryazev (Department Meteorology). The station is located in the northern district of Moscow and, it can be assumed, fairly objectively reflects the climatic characteristics and their changes in time relative to the region under 


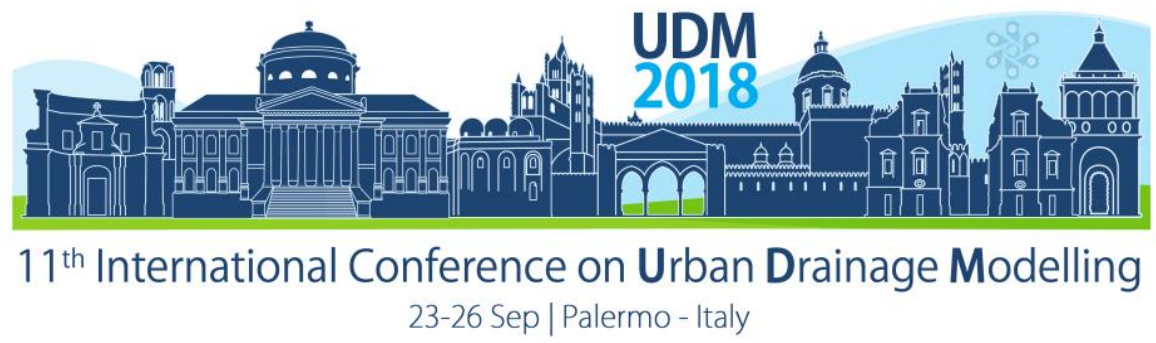

consideration. This station is a very representative basis for the design of hydraulic structures and general construction sites. The researches based on data observation of daily precipitation from 1897 until 2017 years. Precipitation of last years is differing from precipitation of XIX and XX centuries. So data observations were used for the last 20 years. However, such short time series can't give sufficient amount of different dangerous scenarios for period of a few days. 22 scenarios were chosen with total sum precipitations more 10 $\mathrm{mm}$, which include daily precipitation more $5 \mathrm{~mm}$. The scenarios were consisted by such order: every scenario had maximum value during 4 days. Some scenarios had 1 day only, others - not more 4 days because this it was maximum observed duration of dangerous precipitations (example is represented on fig.1). The sum of precipitation for every scenario was calculated.

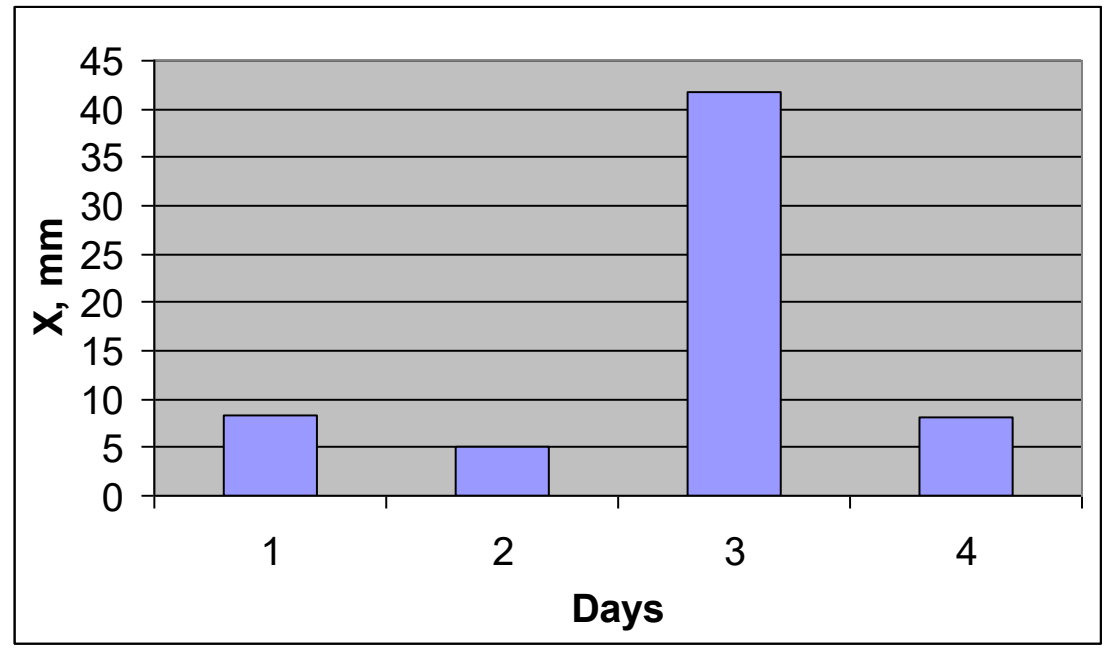

Figure 1. Fragment 7 of observed precipitation.

Then first variant of fragments formed. Every daily coefficient " $K$ " of the fragment was represented by ratio daily precipitation to its sum of precipitation (example is represented on fig.2).

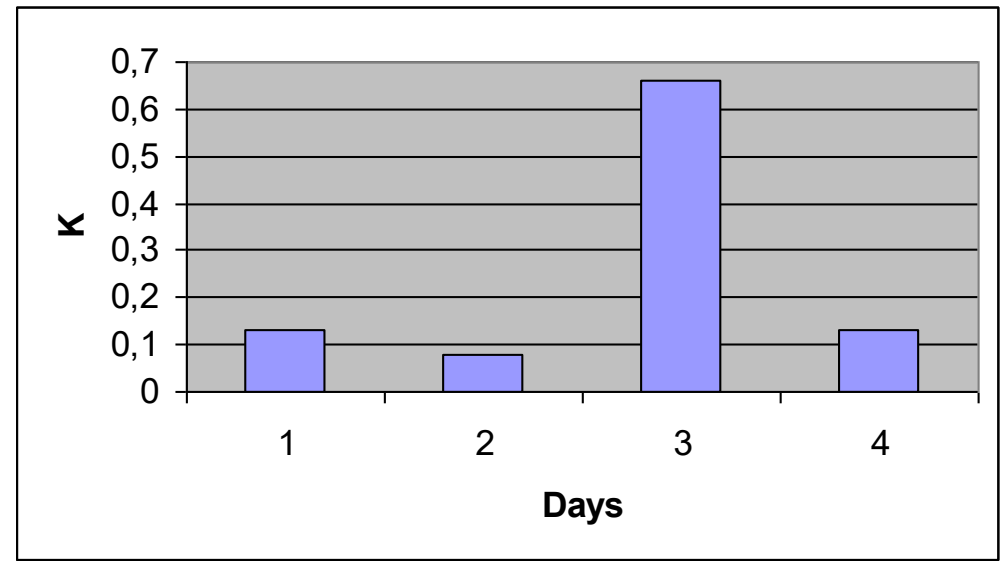

Figure 2. Fragment 7 for coefficients of daily precipitation in respect to sum of precipitation. 


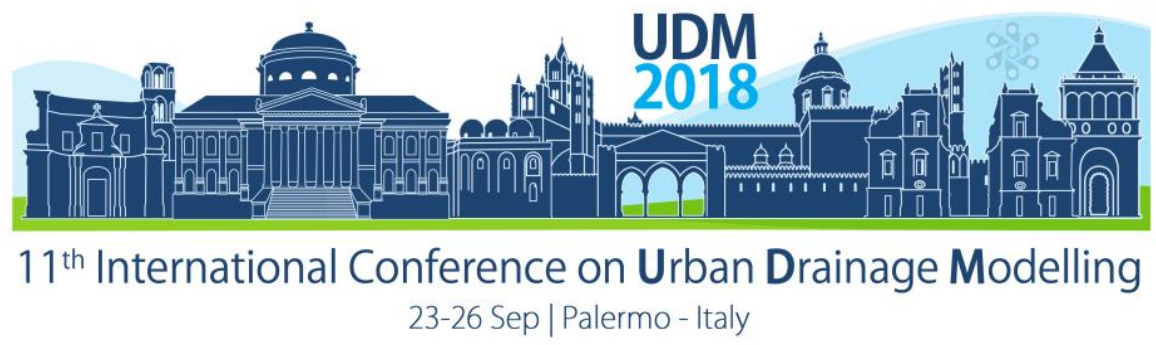

So, 22 fragments were formed. Second variant of the used fragments in simulation was obtained by calculation of ratio of every daily precipitation to the observed maximum daily precipitation during 4 days. So, other 22 fragments were determined too (example is represented on fig. 3).

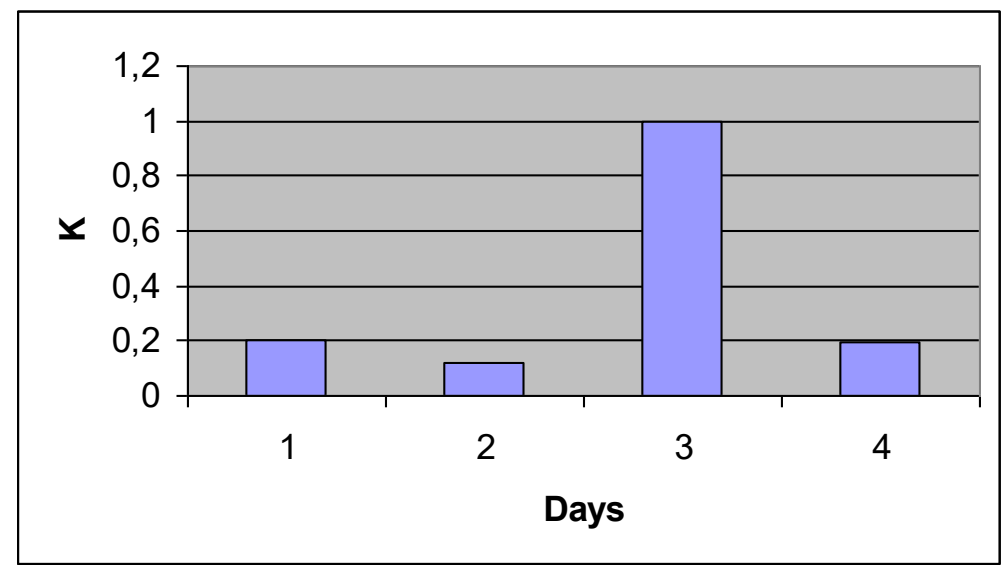

Figure 3. Fragment 7 for coefficients of ratio every daily precipitation to maximum daily precipitation.

It should notice that one fragment 7 has been represented on fig. 1-3.

Simulation of the artificial time series was done with help of the Fragment way of MonteCarlo method. The method uses twice modeling. At first, the ranks of the total precipitations for the 4 days were modeled by method Monte Carlo on the base of function of distribution of probability for random values according to statistical parameters of the total precipitations for the 4 days. Then within obtained series - daily values were modeled with help fragments, which were selected randomly (Monte Carlo method was used again).

Probabilities of summa of the total precipitations for the 4 days were modeled within interval $[0-1]$ according to formula (1):

$$
P_{[i+1]}=0,5+(\xi *[i]-0,5)
$$

Here:

$i$ - number for series of days with precipitation for artificial long time series $\left[i=1-I_{\text {end }}\right]$;

$I_{\text {end }}$ - total amount the series;

$P$ - probability within interval [0 - 1];

$\xi *[i]$ - the independent casual values which are modeled according to equal-distributed low within interval $[0-1]$;

Then the daily precipitations were modeled. Coefficients of fragment were multiplied on the modeled random value of the total precipitation for the 4 days. So, 500 scenarios of storm precipitation were modeled. 


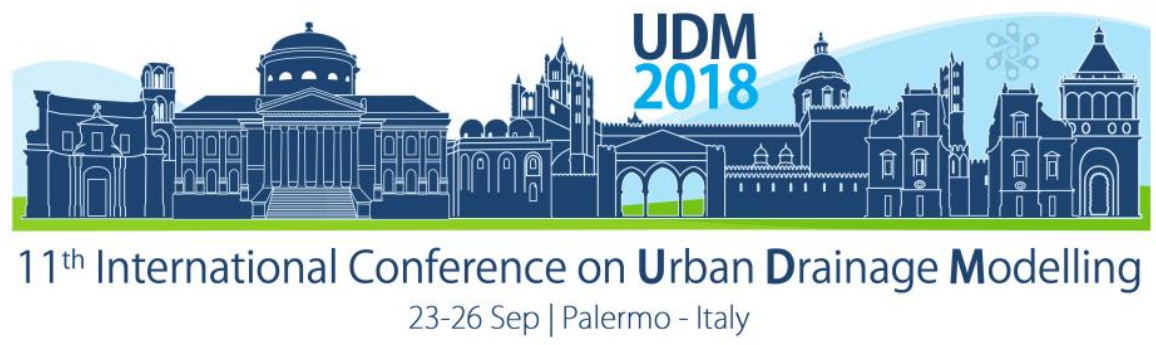

Other variant of simulation was analogic, but at first values of maximum daily precipitation were modeled according to their function distribution of probability for random values and statistical parameters. After that daily precipitation were modeled according to their fragments analogically.

\section{RESULTS AND DISCUSSION}

Analysis of adequacy of the methods for simulation of dangerous precipitations for city conditions in respect to data of observation was made on base of comparison of statistical characteristics for precipitation in respect to every day of fragment and of their sums. Results are represented in tables of 1 and 2 .

Table 1. Values of average for observed data (Source) and of simulated rows of model 1 and model 2.

\begin{tabular}{|c|c|c|c|c|c|}
\hline \multicolumn{5}{|c|}{ Values of average } \\
\hline & Day 1 & Day 2 & Day 3 & Day 4 & Sum \\
\hline Source & 0,955 & 2,859091 & 22,76364 & 5,013636 & 31,50455 \\
\hline Model 1 & 0,467596 & 5,897004 & 21,06409 & 4,350858 & 31,73984 \\
\hline Model 2 & 0,827048 & 2,584575 & 22,47 & 6,689382 & 32,57101 \\
\hline
\end{tabular}

Table 2. Values of variation coefficient for observed data (Source) and of simulated rows of model 1 and model 2.

\begin{tabular}{|c|c|c|c|c|c|}
\hline \multicolumn{7}{|c|}{ Values Cv } \\
\hline & Day 1 & Day 2 & Day 3 & Day 4 & Sum \\
\hline Source & 3,102631649 & 1,77127 & 0,515 & 1,282327 & 0,54984 \\
\hline Model 1 & 3,568166952 & 2,180655 & 0,680382 & 1,729937 & 0,546582 \\
\hline Model 2 & 3,805957056 & 2,060104 & 0,503402 & 1,37656 & 0,635369 \\
\hline
\end{tabular}

We can see that that second method of simulation of dangerous precipitation has less differences in respect to observed data.

\section{CONCLUSIONS}

The offered special method of Monte-Carlo for simulation of scenarios of dangerous storm precipitation is adequate in respect to observation data for Moscow city conditions. Second represented method gives more good results. The obtained scenarios of dangerous precipitation can serve for modelling of maximum runoff in city condition.

\section{References}

Ilinich, T.D. Larina. (2016). Evaluation of changes storm Precipitation during century for the modeling of floods. In the book: Sustainable Hydraulics in the Era of Global Change - Erpicum et al. (Eds.) Taylor \& Francis Group, London, ISBN 978-1-138-02977-4, p. 928 - 934.

Sen Roy S. (2009). A spatial analysis of extreme hourly precipitation patterns in India. International journal of climatology. Volume 29, Issue 3. Pages 345-355.

Svanidze G.G. (1975) Mathematical models of stream flow for water power (water management) calculation- In: Proceeding of Second World Congress, IWRA. Vol. 5. New Delhi, 17-24.

Wilks D.S. (1999): Inter annual variability and extreme-value characteristics of several stochastic daily precipitation models. - Agricultural and Forest Meteorology. 93(3):153-169. 


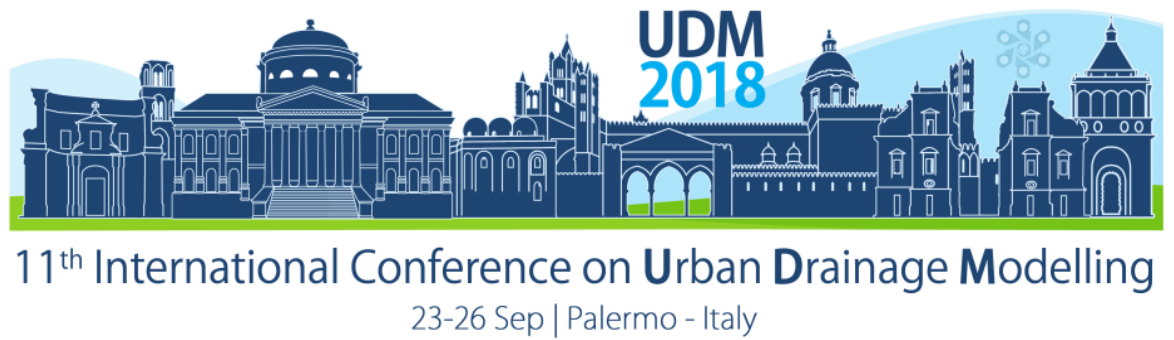

\title{
Real-time CSO spill control using existing in-sewer storage
}

\author{
Nuno Simões ${ }^{1}$, Luis Girão', Lucas Maluf ${ }^{1}$, Will Shepherd² Sonja Ostojin ${ }^{3}$, Alfeu Sá Marques ${ }^{1}$, Stephen \\ Mounce $^{2}$, Pete Skipworth ${ }^{3}$, Simon Tait ${ }^{2}$, João Paulo Leitão ${ }^{4}$ \\ ${ }^{1}$ INESCC, Department of Civil Engineering, University of Coimbra, Coimbra, Portugal \\ 2Pennine Water Group, Department of Civil and Structural Engineering, \\ University of Sheffield, Sheffield S1 3JD, UK. \\ ${ }^{3}$ Environmental Monitoring Solutions, Unit 7, President Buildings, Savile Street East, Sheffield, S4 7UQ, UK \\ ${ }^{4}$ EAWAG Überlandstrasse $133 \mathrm{CH}-8600$ Dübendorf Switzerland
}

\begin{abstract}
Increasing levels of urban development, together with climate change, are leading to an increase in the frequency and magnitude of stormwater flows. These changes may have a great impact on localised flooding and CSO discharges. The project CENTAUR developed an economical, decentralised and autonomous real-time control system that takes advantage of existing unused storage capacity in a drainage network to reduce urban flood risk. In this paper, the level based control algorithm developed in the CENTAUR project was adapted and applied in a sewer network to test the concept of local autonomous real time level based control to mitigate CSO discharges. This concept was tested using a sewer hydrodynamic model dynamically linked to a flow control algorithm. One year of continuous simulation was performed and the results presented show that if the flow control is properly located within a sewer network the autonomous level based control system can deliver a significant reduction in the number of CSO spills and their volume.
\end{abstract}

Keywords: Real-time control; CSO discharge; Fuzzy-Logic

\section{INTRODUCTION}

Development in urban areas and climate change are leading to an increase in the flow in many drainage systems. This change may cause an increase in the occurrence of both floods and combined sewer overflow (CSO) events that would have a detrimental impact on the quality of the receiving water.

In this context, the CENTAUR project - Cost Effective Neural Technique for Alleviation of Urban Flood Risk, aims to provide an economical, decentralised and autonomous real-time control (RTC) system that takes advantage of existing unused storage capacity in the drainage network. The CENTAUR system uses a Fuzzy Logic (FL) control algorithm to dynamically adjust the opening of a flow control device (FCD) to utilise spare capacity in the upstream part of the network and, therefore, influencing water depths both up and downstream of the FCD to reduce local flood risk at a target location.

In this study, this autonomous device and its control algorithm were adapted and tested using a calibrated hydrodynamic sewer network model to assess its ability to deliver a decrease in the volume and number of CSO discharges which occurred from CSOs, thus reducing the environmental impact on the receiving waters via a low cost intervention that requires minimal new infrastructure.

\section{MATERIALS AND METHODS}




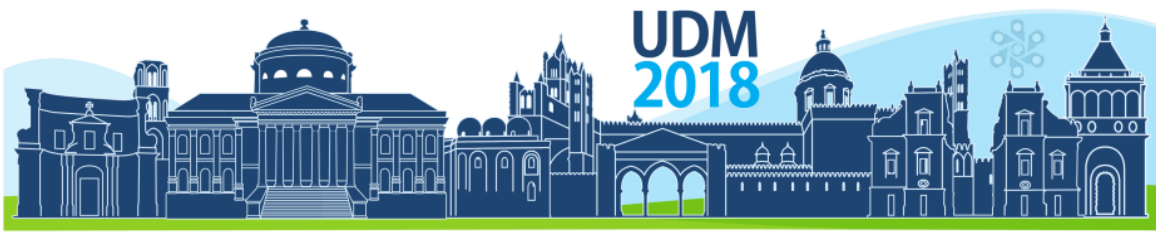

$11^{\text {th }}$ International Conference on Urban Drainage Modelling

23-26 Sep | Palermo - Italy

To test the concept of FL logic driven CSO control, an existing calibrated hydrodynamic sewer network model was linked with the control algorithm for the sewer network in Coimbra. Coimbra is a medium size city in the centre of Portugal. It is a highly urbanised catchment of approximately $1.5 \mathrm{~km}^{2}$. The drainage system of the Zona Central catchment is $34.8 \mathrm{~km}$ long and it is mostly a combined sewer network. A SWMM hydrodynamic model has been built, it comprises 911 subcatchments, 980 manholes and 1001 pipes. (Figure 1). At the downstream part of the catchment, a CSO separates the water that goes to the waste water treatment plant (WWTP) and to the receiving water without treatment (red circle in Figure 1). The CSO upstream pipe is in a $1700 \mathrm{~mm}$ diameter circular sewer, the CSO weir is located $0.6 \mathrm{~m}$ from the invert level and the continuation flow pipe diameter is $500 \mathrm{~mm}$. This CSO limits the flow peak to the treatment plant.

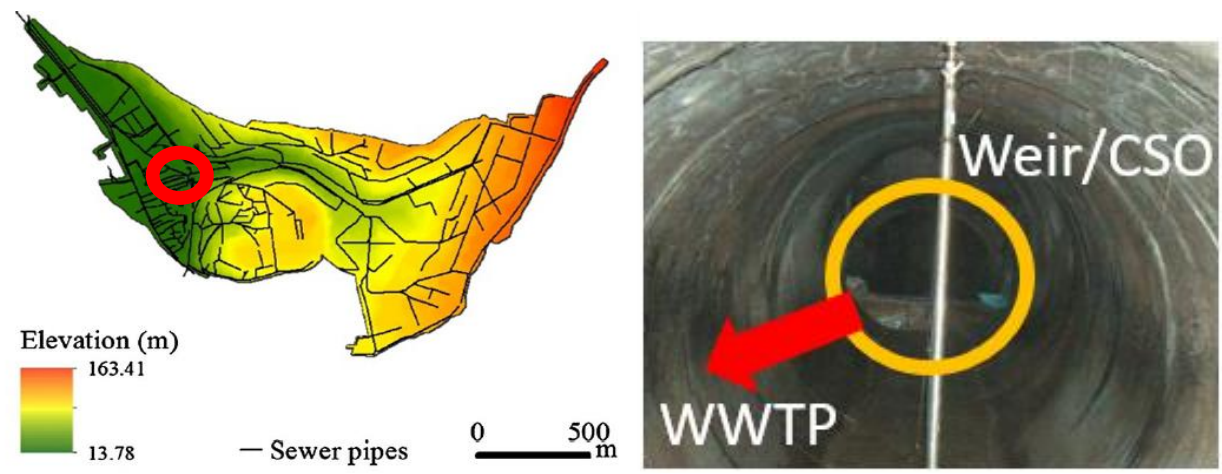

Figure 1. Zona Central catchments (left) and existing CSO (right).

To choose the location of the FCD, the CENTAUR.LOC (Leitão et al., 2018) software was used. The first manhole upstream of the CSO was selected due to the available volume., and the FCD was implemented in the SWMM model.

The FL algorithm was developed in Matlab and was implemented using the MatSWMM toolbox (Riano-Briceno et al., 2016). The algorithm was initially developed on a small sewer network to limit local flood risk as described in Shepherd et al. (2016), it was also applied to the Coimbra network for flood risk reduction (Maluf et al., 2017) and is now adapted and applied to the Coimbra network for CSO control. The input data for the algorithm is derived from level sensors at upstream and downstream locations in the network. When used for flood reduction, the downstream location is at the flooding site and the upstream locations is in the storage volume, here the downstream level sensor is in the CSO chamber. This data is an input to FL membership functions (MFs), which split the data into fuzzy categories. Each combination of MFs is assigned a rule which relates to a control action for the FCD (Shepherd et al, 2017).

\section{RESULTS AND DISCUSSION}

To test the benefits of the developed control system, a continuous simulation of 1-year duration was run using the 2016 rainfall data from Coimbra. In this year the total precipitation was $1218 \mathrm{~mm}$ (return period of $\sim 10$ years, average annual rainfall is $\sim 900 \mathrm{~mm}$ ). The maximum 1 hour precipitation is $19 \mathrm{~mm}$ which equates to a return period of $\sim 2$ years. 


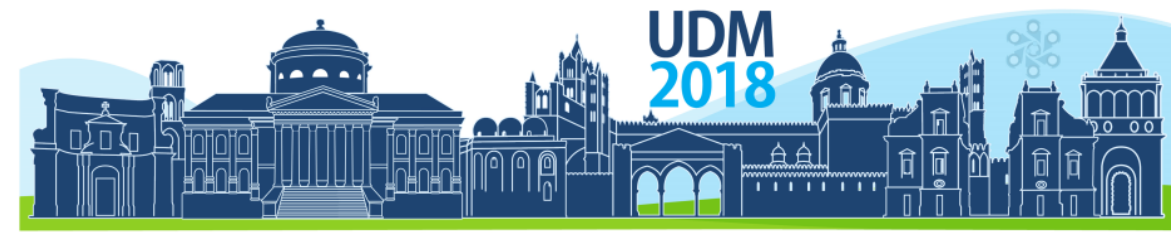

$11^{\text {th }}$ International Conference on Urban Drainage Modelling

23-26 Sep | Palermo - Italy

Table 1 presents simulation results of the total volume of wastewater that goes to the Wastewater Treatment Plant (WwTP) and the CSO discharge volume. It also presents the number of CSO spills. In this one year, it was possible to reduce the number of spills by $77.4 \%$, and the total volume reduction was $87.4 \%$ compared to the current system state in which no FCD is present.

Figure 2 presents the monthly volume of wastewater that goes to the WWTP and the CSO discharge volume both with the FCD (dark blue and orange bar) and without the FCD (light blue and yellow bar). In the rainiest months, it was possible to reduce the total volume by around $70 \%$ to $80 \%$, and in the spring and autumns months, with less rainfall, the reduction was almost $100 \%$. There is a small difference (error \% in Table 1) in the total volume to CSO and WWTP with and without FCD, due to numerical accuracy.

Table 1. Total annual volume of wastewater that goes to the WWTP, CSO discharge volume and number of CSO spills, with and without FCD.

\begin{tabular}{|c|c|c|c|c|c|c|c|c|c|}
\hline \multirow[b]{2}{*}{$\begin{array}{c}\text { Precipit. } \\
(\mathrm{mm})\end{array}$} & \multicolumn{3}{|c|}{ with FCD } & \multicolumn{3}{|c|}{ without FCD } & \multirow[b]{2}{*}{ Error \% } & \multirow[b]{2}{*}{$\begin{array}{l}\text { Number of } \\
\text { CSO spills } \\
\text { reduction }\end{array}$} & \multirow[b]{2}{*}{$\begin{array}{l}\text { CSO spills } \\
\text { volume } \\
\text { reduction }\end{array}$} \\
\hline & $\begin{array}{l}\text { Volume } \\
\text { to CSO } \\
\left(\mathrm{m}^{3}\right)\end{array}$ & \begin{tabular}{|l} 
Volume \\
to WWTP \\
$\left(\mathrm{m}^{3}\right)$ \\
\end{tabular} & $\begin{array}{l}\text { Number } \\
\text { of CSO } \\
\text { spills }\end{array}$ & $\begin{array}{l}\text { Volume } \\
\text { to CSO } \\
\left(\mathrm{m}^{3}\right)\end{array}$ & $\begin{array}{l}\text { Volume } \\
\text { to } \\
\text { WWTP } \\
\left(\mathrm{m}^{3}\right) \\
\end{array}$ & $\begin{array}{l}\text { Number } \\
\text { of CSO } \\
\text { spills }\end{array}$ & & & \\
\hline 1218 & 21048 & 1022972 & 30 & 109458 & 925731 & 127 & $1.1 \%$ & $77.4 \%$ & $87.4 \%$ \\
\hline
\end{tabular}

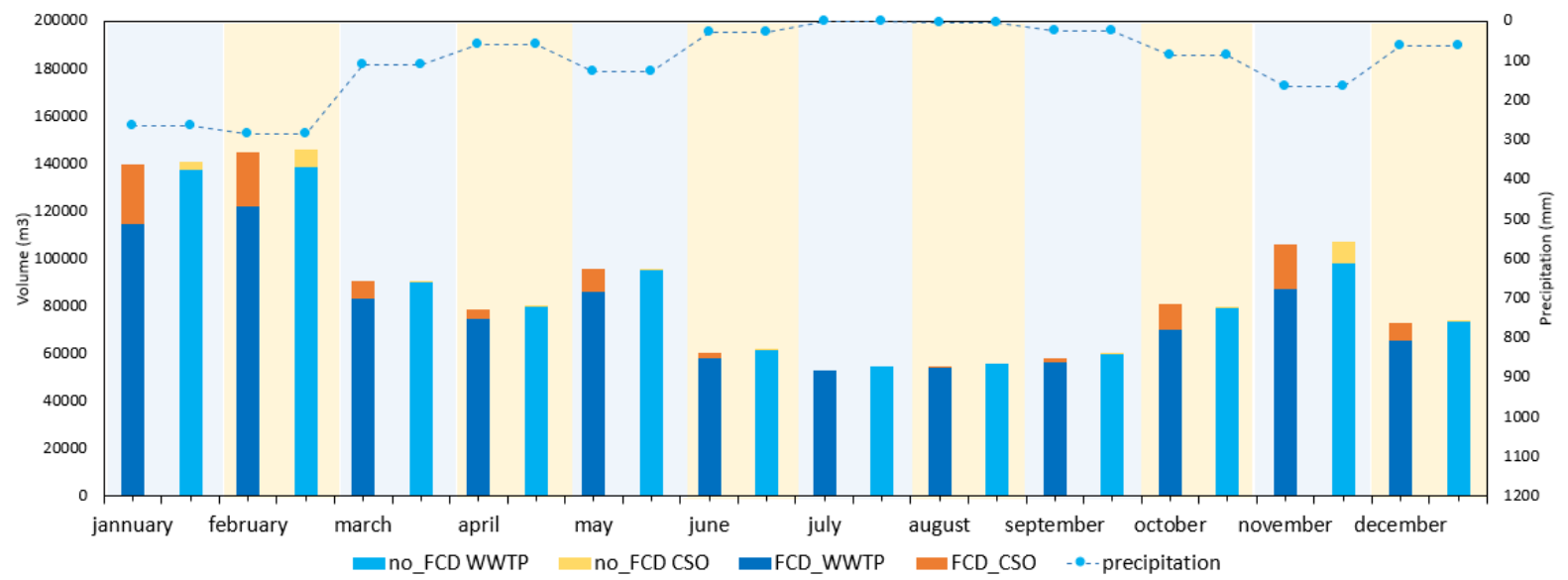

Figure 2. Monthly volume of wastewater that goes to the WWTP and the CSO discharge volume with FCD and without FCD.

Figure 3 shows one month of the CSO flow discharge continuous simulation with and without the FCD, here both the reduction in number of CSO spills, and the reduction of wastewater flow spilled from the CSO, can clearly be seen. 


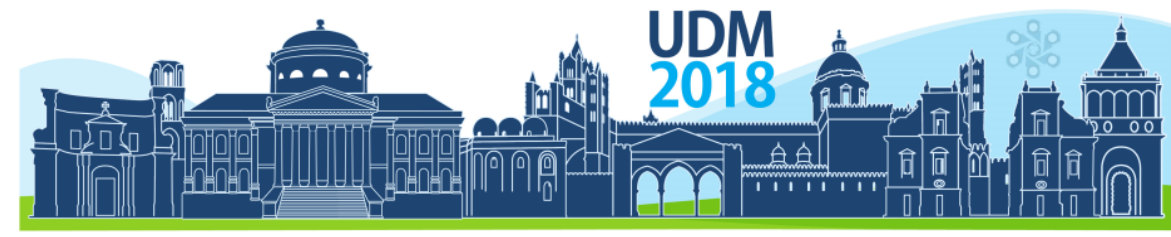

$11^{\text {th }}$ International Conference on Urban Drainage Modelling 23-26 Sep | Palermo - Italy

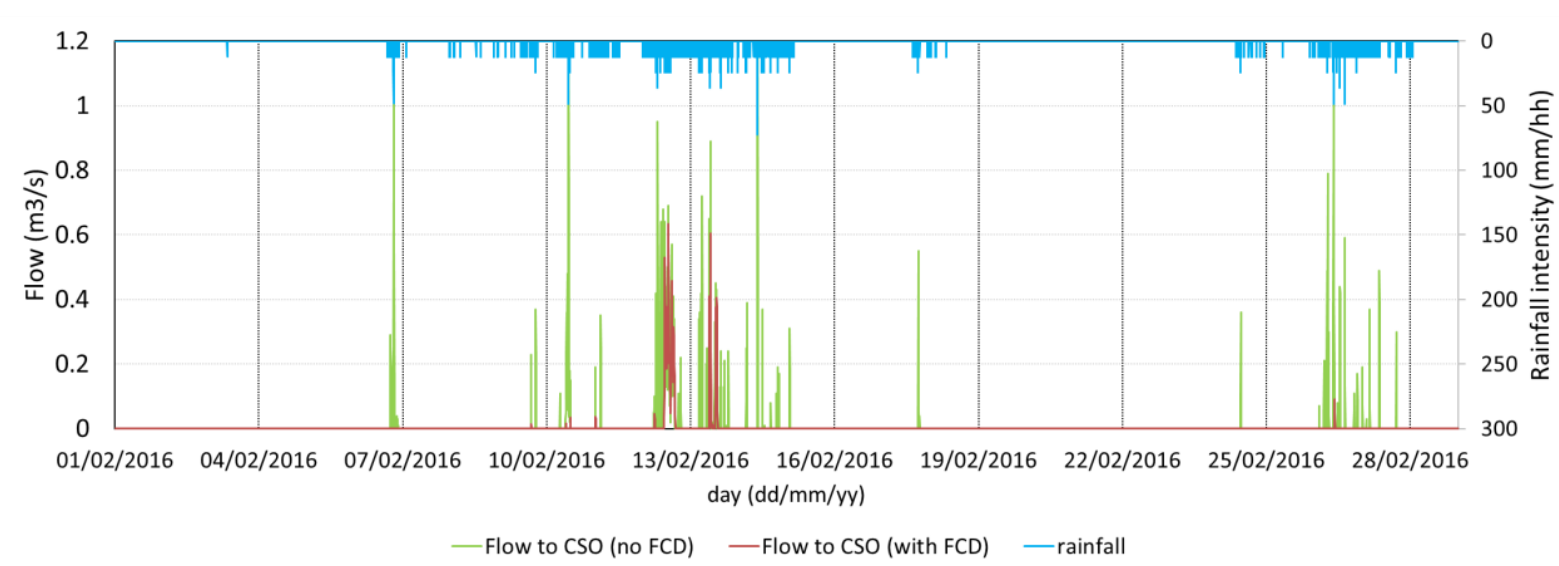

Figure 3. One months CSO flow discharge continuous simulation with and without FCD control.

\section{CONCLUSIONS}

The CENTAUR system uses FL based algorithms which use water level readings to operate a FCD to store water and reduce downstream flood risk. This concept was adapted to provide CSO spill reduction and implemented in a sewer network model in Coimbra, Portugal. A continuous 1-year simulation was run and the annual number of spills and volume discharged was reduced by over $70 \%$. This study demonstrates that locally based active flow control has the potential to offer significant reductions in environmental impact for low return period storms without the need for new large infrastructure such as storage tanks.

\section{ACKNOWLEDGMENTS}

This project has received funding from the European Union's Horizon 2020 research and innovation program under grant agreement No. 641931. Special thanks are due to AC, Águas de Coimbra, E.M., Coimbra, Portugal for providing rainfall and sewer data of the pilot location.

\section{References}

Leitão, J.P., Carbajal, J., Rieckermann, J., Simões, N., Sá Marques, J., Sousa, L., "Identifying the best locations to install flow control devices in sewer networks to enable in-sewer storage", Volume 556, January 2018, Pages 371-383. doi:10.1016/j.jhydrol.2017.11.020

Maluf, L., Shepherd, W., Ostojin, S., Simões, N., Sá Marques, A., Mounce, S., Skipworth, P., Leitão, J., Real-time flow control to utilise existing in-sewer storage, 14th IWA/IAHR International Conference on Urban Drainage (ICUD), Prague, Czech Republic, 2017. doi: 10.5281/zenodo.891133

Riano-Briceno G., Barreiro-Gomez J., Ramirez-Jaime A., Quijano N., Ocampo-Martinez C., "MatSWMM - An open-source toolbox for designing real-time control of urban drainage systems," Environ. Model. Softw. , vol. 83, pp. 143-154, 2016. doi: 10.1016/j.envsoft.2016.05.009

Shepherd W, Ostojin S, Mounce S, Skipworth P, and Tait S, "CENTAUR: Real time flow control system for flood risk reduction", Proceedings of CIWEM UDG conference, Blackpool, UK, 2016. doi: 10.5281/zenodo.400969

Shepherd, W. Mounce, S. R., Ostojin, S. Abdel-Aal, M. Schellart, A. Skipworth P. and Tait, S. "Optimising a Fuzzy Logic Real-Time Control System for Sewer Flooding Reduction using a Genetic Algorithm", Proceedings of CCWI conference, Sheffield, UK, 2017. doi: $\underline{10.15131 / \text { shef.data.5363572.v1 }}$ 


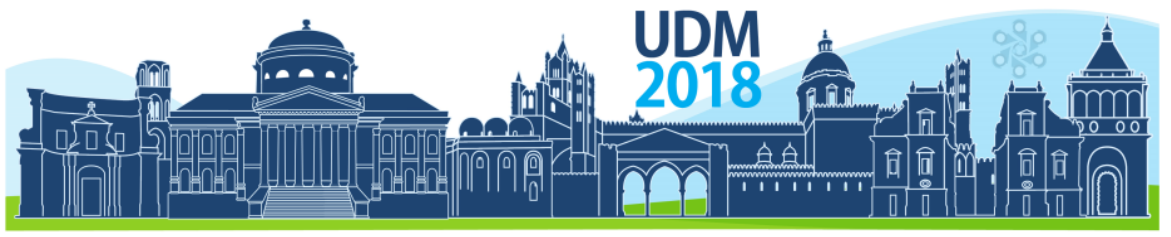

$11^{\text {th }}$ International Conference on Urban Drainage Modelling 23-26 Sep | Palermo - Italy

\title{
Type II (and Atlas 14) Storm Distribution Assumptions Yield Massive Over-estimates of Rainfall Intensity
}

\author{
John S. Tyner ${ }^{1}$ and Daniel C. Yoder ${ }^{1}$
}

${ }^{1}$ University of Tennessee, Department of Biosystems Engineering and Soil Science, Knoxville, Tenn., USA

\begin{abstract}
The Type II rainfall distribution is heavily utilized throughout most of the USA for modelling many types of rainfall based events. Its genesis stems from use of the Depth-Duration-Frequency (DDF) rainfall pattern method, which assumes a perfect correlation between the occurrences of rainfall intensities with the same return period, but from different durations. The manifestation of this assumption is that, for example, a 5-min 5-year event will be embedded within the 24-hr 5-yr event for a given locale. There is no apparent rationale for this assumption other than it is conservative in generating a very harsh hyetograph. In many locales where the Type II event is presumed to hold, weather patterns are such that the short duration highly intense storms (e.g., 5-min 5-year) generally occur in late spring and summer during afternoon convective thunderstorms, whereas the larger long duration storms (e.g., 24-hr 5-yr ) occur during fall and winter. In fact, data show that the assumption of a perfect positive correlation between say a 5-min 5-year event and the 24-hr 5-yr event is false. Indeed, a negative correlation exists. The result of making such an assumption often requires larger stormwater infrastructure to handle the erroneously large predicted runoff rates. The newer Atlas 14 rainfall distributions suffer from the same erroneous DDF assumption.
\end{abstract}

Keywords: Hyetograph, Type II, Atlas 14, Rainfall Distribution, DDF, stormwater

\section{INTRODUCTION}

Design storms are widely utilized in the prediction of runoff, stormwater routing, and flooding. A design storm will typically be an artificial hyetograph encompassing both total depth and intensity as a function of time. They function to test a stormwater design, for example, against generally a vigorous precipitation event, say a 5-yr 24-hr, which is meant to typify a rainfall event with a return period of 5 years and a duration of 24 hours.

Of course storm severity depends on both depth and intensity pattern. In some cases depth is more important than intensity, such as for extreme events over large areas. This is why the Soil Conservation Curve Number method (SCS-CN) for estimating large-event runoff volume works reasonably well without incorporating rainfall intensity (Mokus, 1964). Conversely, for smaller areas with lower-depth but high-intensity storms, it is largely the intensity and not the volume that controls localized flooding or routing issues. The Rational Method (RM) is often used to model such situations to predict maximum runoff rate from rainfall intensity without any knowledge of the total runoff depth (Kuichling, 1889). Thus the simple SCS-CN and RM stake out the intellectual endpoints of the importance of depth and intensity in defining a storm. In truth, however, runoff depth and rate throughout a storm are always a function of both precipitation depth and intensity pattern.

In the United States the most commonly employed design storm intensity distribution curve is known as the Type II. This is presented in almost all undergraduate engineering hydrology 


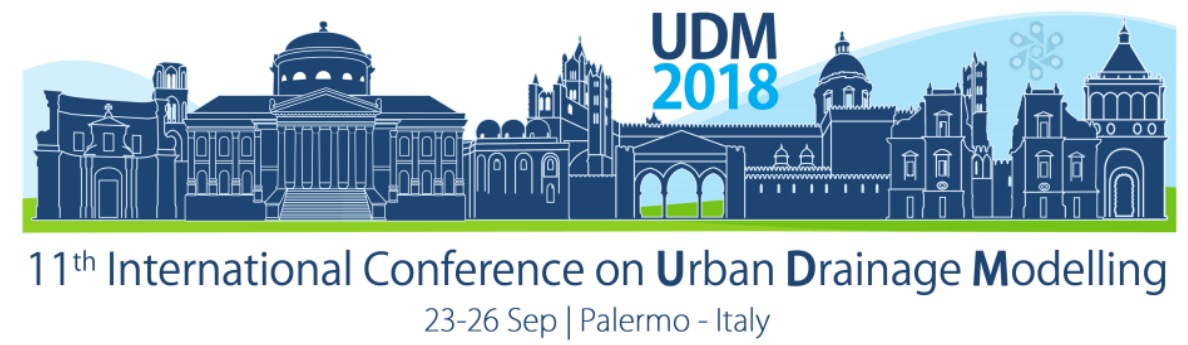

textbooks, but without describing its genesis or limitations. The Type II storm was developed by the Soil Conservation Service and first presented in TP-149 (SCS, 1973). This does not fully describe development of the Type II storm, and at least some of its original documentation is no longer available (NRCS, 2015). Haan et al. (1994) mention that the Type II was developed using a method similar to the Depth Duration Frequency (DDF) rainfall pattern.

A DDF rainfall pattern is particularly easy to generate and does not require significant computational resources, perhaps explaining its early use for the Type II. For example, to develop a 5-yr 24-hr rainfall distribution requires only the depths of rainfall corresponding to a 5 -yr return period for various durations, typically from 5 min up through $24 \mathrm{hrs}$. For the Type II the most intense period (usually the 5-min duration) is placed at the middle of the hyetograph at 12 hours. According to SCS (1973), this placement is "based on design consideration rather than meteorological factors", but those design considerations are not described. The next most intense duration-say the 10-min 5-yr event-is then placed either directly before or after the 5-min event, with subsequently longer durations (30-min, 1-hr, 2$\mathrm{hr}$, etc.) alternating to the front and then the back of the distribution until the entire 24 hours is filled up. Alternatively, instead of adding increasingly longer durations to the back and then the front of the existing distribution, each subsequent duration can be split in two, with half going before and half after the current distribution.

This approach includes the implicit assumption that the 5-yr 5-min event occurs within the 5yr 10-min event, which occurs within the 5-yr 15-min event, and so on up to the 5-yr 24-hour event, with the resulting hyetograph labeled the 5-yr 24-hr event. This yields a worst-case runoff scenario by combining very high intensity rainfall (from short duration events) and very large rainfall depth (from longer duration events) into a single hyetograph. The Type II originators had some understanding of this, stating "Type II represents regions in which the high rates of runoff from small areas are usually generated from summer thunderstorms" (SCS, 1973), but those areas clearly do not have summer thunderstorms lasting for upwards of 24-hrs as indicated for the Type II presented within TP-149. Further, the statement implies understanding of the seasonality of various types of events in the Type II areas, though this is not incorporated in the method.

The USDA National Resource Conservation Service (NRCS) is proposing to replace the Type II storm with Atlas 14 Rainfall Distributions (NRCS, 2015). They are generated using an approach very similar to that of the Type II, but from local historic rainfall data rather than applying a single storm distribution over a broad area. The Atlas 14 Rainfall distributions include the same nesting intensity assumption, resulting in distributions concurrently including extreme intensities and extreme depths, so the Atlas 14 hyetographs are very similar to the Type II.

The objectives of this research are to: 1) use precipitation data to assess the assumption of correlation between rainfall intensities of short and long durations with a common return period, and 2) discuss the effects of including DDF (intensity nesting) assumptions within a hyetograph when said hyetograph is utilized for various types of hydrologic modeling.

\section{MATERIALS AND METHODS}




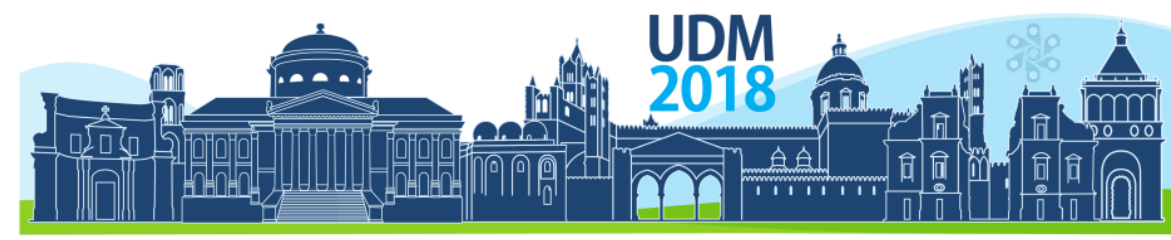

$11^{\text {th }}$ International Conference on Urban Drainage Modelling

23-26 Sep | Palermo - Italy

A 23-yr duration 5-min interval precipitation dataset with 1-mm resolution was obtained from the USA Oklahoma Mesonet (Brock et al., 1995). The data were imported into Matlab ${ }^{\circledR}$, and the beginning of individual storms were identified as precipitation following more than six hours without precipitation. This six-hour interval with no precipitation generally ensures that ensuing storms are statistically un-correlated (Huff, 1967).

The 5-min precipitation data from each storm were then accumulated into longer collection periods of $10 \mathrm{~min}, 15 \mathrm{~min}, 20 \mathrm{~min}, 30 \mathrm{~min}, 60 \mathrm{~min}, 2 \mathrm{hr}, 4 \mathrm{hr}, 6 \mathrm{hr}, 8 \mathrm{hr}, 12 \mathrm{hr}, 16 \mathrm{hr}, 20 \mathrm{hr}$, and $24 \mathrm{hr}$, yielding 14 precipitation series. Each value of the 14 series was then ranked to determine the resulting interval depths corresponding to the desired return periods of $0.25 \mathrm{yr}$ and $5 \mathrm{yrs}$. All storms were then examined, keeping as significant any storm that had at least one of its 14 intervals greater than the current return period. This resulted in two series of "significant events", one series exceeding the 0.25 -yr return period (177 events), and the other series exceeding the 5 -yr return period (17 events).

Finally, the 14 data series from the significant storms were used to calculate correlations between the 14 data series. The Type II hyetograph assumption is that these should all be perfectly correlated, since they are assumed to occur in the same event.

\section{RESULTS AND DISCUSSION}

Figure 1 displays the correlations between significant storms for the 0.25 -yr return period (left) and the 5-yr return period (right). The left graph shows moderate correlation between similar intervals, but little to no correlation as the intervals differ. For example, the 5-min interval coefficient of determination $\left(R^{2}\right)$ approaches zero for intervals of $12 \mathrm{hr}$ and longer, so knowing the 5-min interval precipitation provides no understanding of the 12-hr depth. The right graph shows an initially decreasing correlation between the 5-min interval and $4 \mathrm{hrs}$, but at longer duration intervals the $R^{2}$ increases. However, the sign of the 5-min correlation coefficient $(R)$ flips from positive to negative as duration increases beyond the 4-hr interval, indicating no predictive capacity.

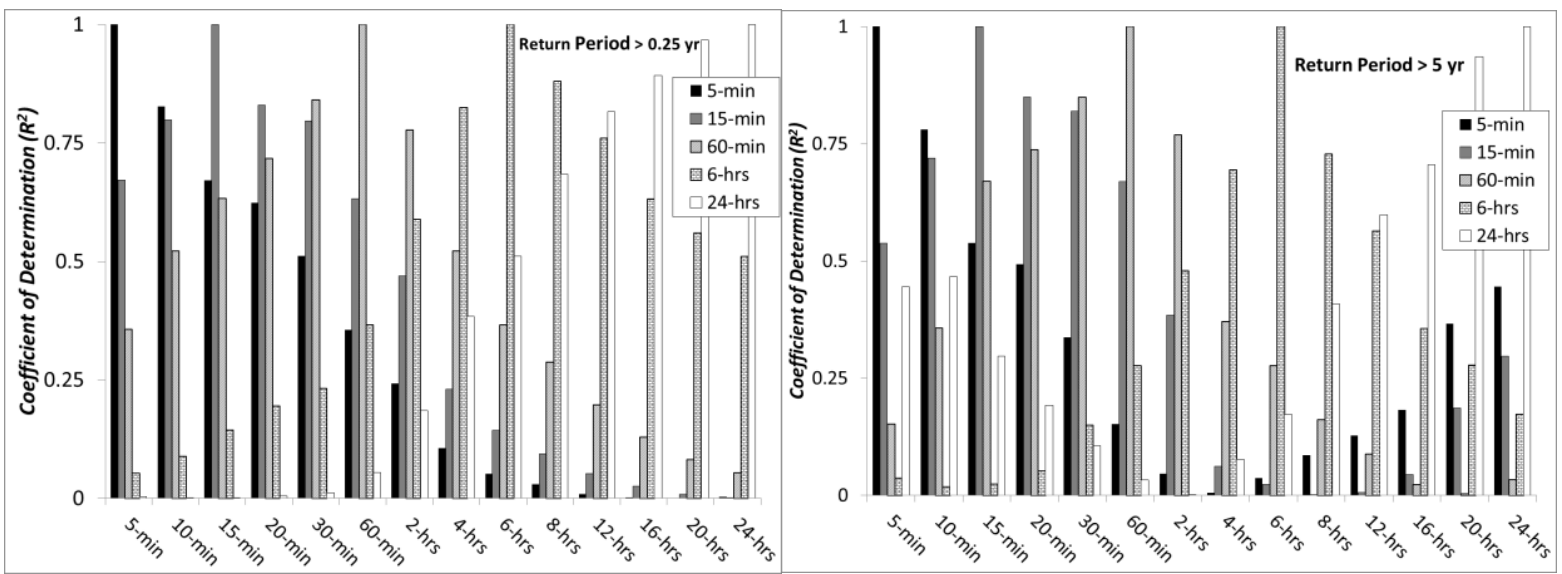

Figure 1. A comparison of the coefficient of determination $\left(R^{2}\right)$ between each of the 14 intervals for all storms with at least one interval having a return period greater than $0.25 \mathrm{yr}$ (left) and $5 \mathrm{yr}$ (right).

Figure 2 shows the maximum 5-min and 24-hr interval depths for the same two populations of storms. For the $0.25-\mathrm{yr}$ return period storms (left graph), zero correlation is predicted 


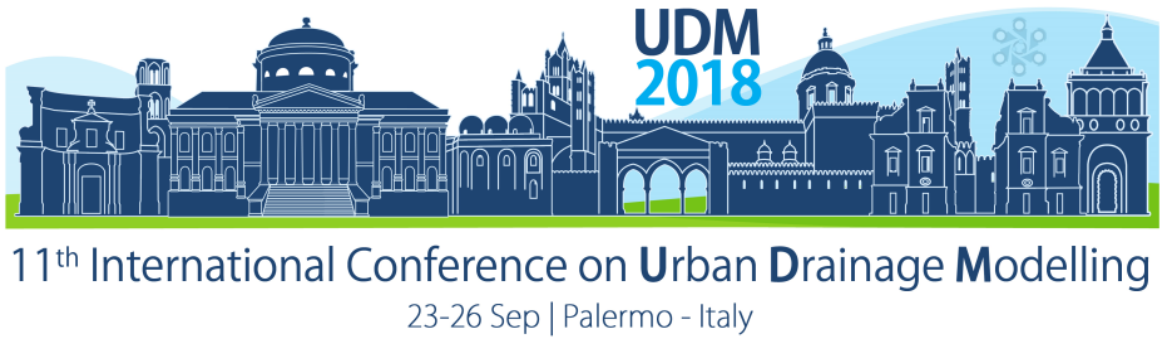

between the maximum 5-min and 24-hr depths for the same storms. For the 5-yr return period events (right graph), a moderately strong negative correlation is predicted. This suggests that as the maximum 24-hr depth increases, the maximum 5-min depth in that storm actually decreases relative to the entirety of the storm, and vice-versa. This clearly contradicts use of the DDF method to generate hyetographs such as the Type II and the Atlas 14.

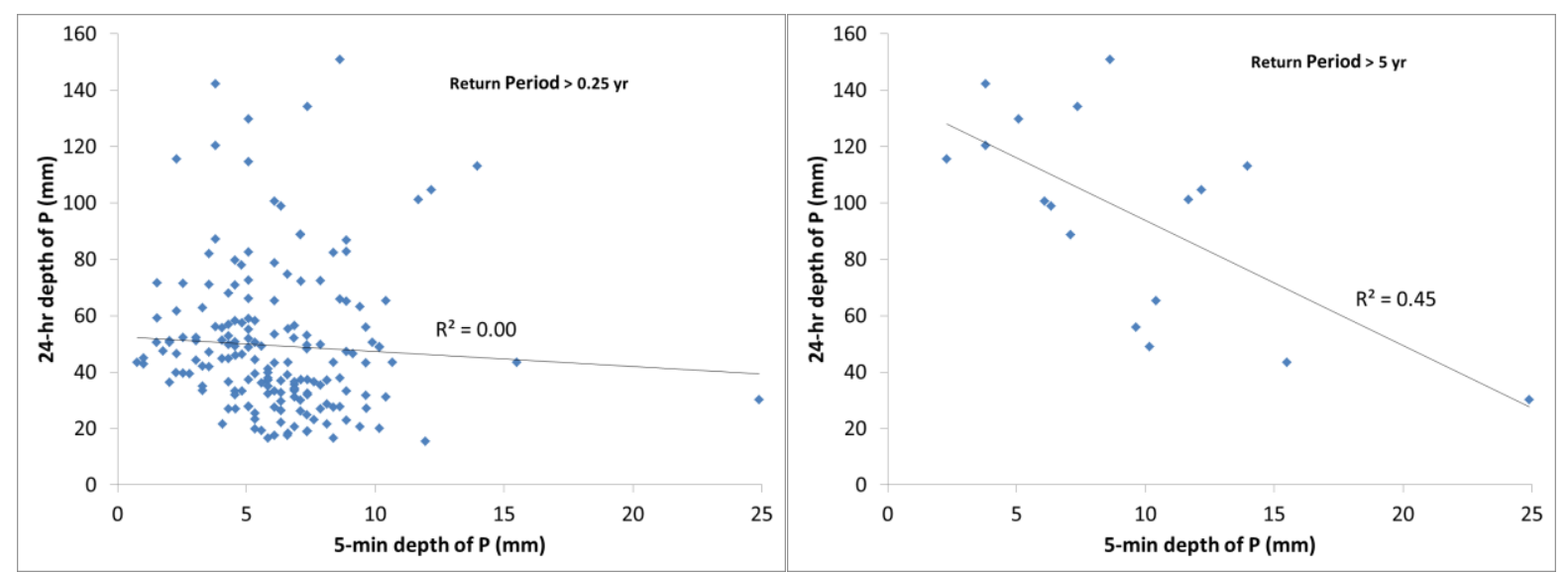

Figure 2. Comparison of the maximum 5-min and 24-hr interval depths from corresponding storms for all storms with at least one interval greater having a return period greater than $0.25 \mathrm{yr}$ (left) and $5 \mathrm{yr}$ (right).

\section{CONCLUSIONS}

This research concludes that the normal practice of nesting short-duration high-intensity rainfall intervals within increasingly longer intervals of the same return period to generate a hyetograph (i.e., the DDF method) makes a completely erroneous inherent assumption of a strong positive correlation between the different intervals. In truth, based on the preliminary evidence prepared for this short paper, as the return period increases the correlation is actually negative, forcefully contradicting a core assumption of the DDF method. This finding is consistent with precipitation being characterized by at least two distinct types of precipitation events: low-intensity long-duration rain resulting from large-scale frontal activity, and high-intensity short-duration rain resulting from summer convective thunderstorms.

\section{References}

Brock, F. V., K. C. Crawford, R. L. Elliott, G. W. Cuperus, S. J. Stadler, H. L. Johnson, and M. D. Eilts, 1995: The Oklahoma Mesonet: A technical overview. J. Atmos. Oceanic Technol., 12, 5-19.

Haan, C. T., B. J. Barfield, and J. C. Hayes 1994. Design Hydrology and Sedimentology for Small Catchments. Academic Press Inc. San Diego, CA.

Huff, F. A. 1967. Time distribution of rainfall in heavy storms. Water Resources Research, v. 3, n. 4, p. 10071019.

Kuichling, E. (1889). The relation between the rainfall and the discharge of sewers in populous districts. Transactions, American Society of Civil Engineers 20, 1-56.

Mockus, V. 1964, Personnel communication, Letter to Orrin Ferris dated March 5,1964.

National Resource Conservation Service 2015. "National Engineering Handbook, Chapter 4: Storm Rainfall Depth and Distributions (Draft)" NEH Part 630.04. U.S. Department of Agriculture, National Resource Conservation Service, Washington D.C.

Soil Conservation Service 1973. "A Method for Estimating Volume and Rate of Runoff in Small Watersheds" SCS-TP-149. U.S. Department of Agriculture, Soil Conservation Service, Washington D.C. 


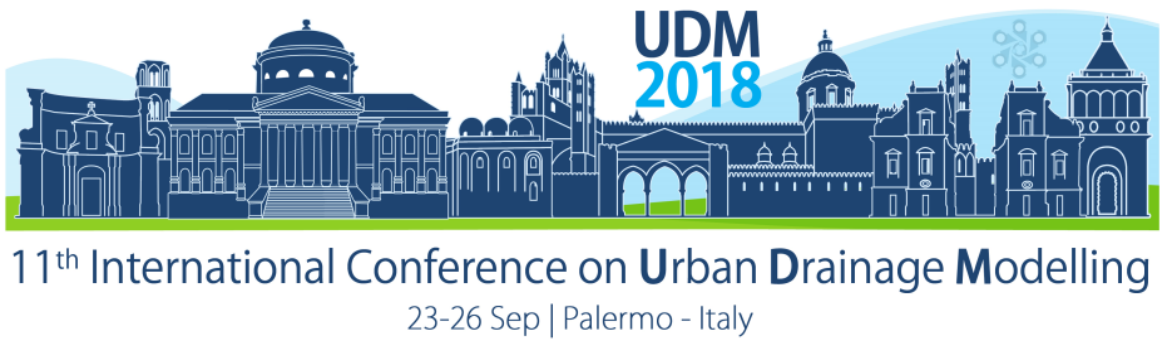

\title{
Efficient calibration and validation of physical stormwater quality modelling by meta-model based approach
}

\author{
Yi Hong ${ }^{1}$, Qinzhuo Liao², Celine Bonhomme', and Ghassan Chebbo' \\ ${ }^{1}$ LEESU, MA 102, École des Ponts ParisTech, 6-8 Avenue Blaise Pascal, 77455 Champs-sur- Marne, France \\ 2 KFUPM, Department of Petroleum Engineering, Dhahran, Saudi Arabia
}

\begin{abstract}
Model calibration and validation is still challenging for applications of physical stormwater quality model in the field of urban drainage modelling. In this context, this study aims to develop a new meta-model based framework for efficient calibration of complex and computationally intensive physically-based models. The proposed approach is applied to the physical FullSWOF-HR model for optimizing the washoff parameters. According to the average rainfall intensity, eight rainfall events are categorized into three groups for parameter optimisation, such as three light rains, three moderate rains and two heavy rains. After upscaling the original model, 77 parameter sampling experiments can be defined by a convergence analysis. Applying these 77 parameters series in FullSWOF-HR simulation runs, the interpolating polynomial of the original model is then generated by using the adaptive stochastic collocation method, which adopts sparse grid algorithm and selects the important parameters adaptively and automatically. Calibration process of the meta-model is based on the Markov chain Monte Carlo (MCMC) method. The optimized parameters are verified with the original model and then validated for different rainfall events. These promising results show that the proposed meta-model based approach can efficiently calibrate parameters for complex physical stormwater quality models. Our ongoing work focuses on the sensitivity/uncertainty analysis with this new meta-model based approach.
\end{abstract}

Keywords: Meta-model based approach; Calibration; Physically-based stormwater quality modelling; Adaptive stochastic collocation method; Markov chain Monte Carlo;

\section{INTRODUCTION}

Physically-based urban stormwater quality models have been increasingly used in view of developing advanced management tools and improving understanding of urban wash-off mechanisms (Fatichi et al., 2016; Hong et al., 2016a, 2016a; Refsgaard et al., 2010). Despite this trend towards physically-based modelling, several aspects still limit their applicability. Particularly for the issues linked with the considerable time expenses in calibration and validation, which may reduce the applicability of these modelling approaches (Beven and Binley, 1992; Dotto et al., 2012).

In order to efficiently achieve parameter optimization, recent studies have shown a growing interest in metal-model (or surrogate model) based approaches (Razavi et al., 2012). The basic idea of this method is to develop and analyze the cheaper-to-run "surrogate" of the original model, which is typically complex and computationally intensive. Meta-model based approach is hence particularly suitable for time-consuming physically-based models where hundreds or thousands of simulations become unaffordable. Currently, there are many metamodel based methods used in hydrological models (Razavi et al., 2012), however, very few applications of this method have been published in the urban drainage modelling field, 


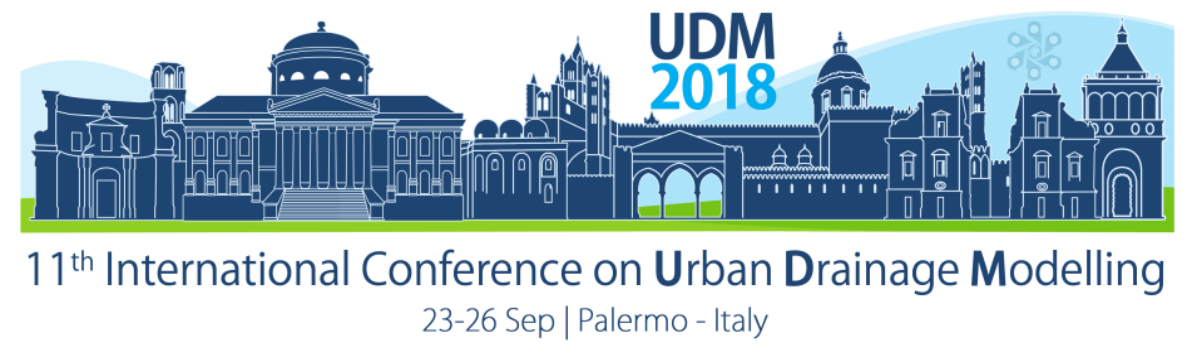

especially for the stormwater quality modelling. Therefore, the objective of this study is to (i) propose a new meta-model based approach for efficient calibration of physical stormwater quality models; (ii) apply this advanced method to an urban road catchment near Paris for calibrating parameters of a physically-based urban stormwater washoff model; (iii) verify the performance of the proposed calibration approach coupled with the physical urban wash-off model by comparing with measurements.

\section{MATERIALS AND METHODS}

\subsection{Physically-based urban stormwater washoff modelling}

The C++ code FullSWOF coupled with the Hairsine-Rose (HR) model (Hong et al., 2016b) is applied in this study for spatially distributed and physically-based modelling of urban stormwater runoff and washoff dynamics. The FullSWOF-HR model uses a finite volume scheme to solve bidimensional shallow-water equations for water flow simulations, while two types of washoff process are considered in the model: the rainfall-driven and flow-driven detachments of the deposited particles. Detailed modelling has been performed for a small urban catchment $\left(2661 \mathrm{~m}^{2}\right)$ represented by $1833 \times 515$ grid-cells of $10 \times 10 \mathrm{~cm}^{2}$ resolution. The parameters for water flow simulations have been calibrated and validated in the previous studies (Hong et al., 2016b). Six physical washoff parameters are analyzed in this study for different rainfall events.

Homogeneous rainfall is considered for the small urban catchment. According to the average rainfall intensity, 8 rainfall events are categorized into 3 groups for parameter optimisation. Such as (1) 3 light rains at an average intensity about $2 \mathrm{~mm} / \mathrm{hr}$; (2) 3 moderate rains at an average intensity around $3 \mathrm{~mm} / \mathrm{hr}$; and (3) 2 heavy rains at an average intensity more than 5 $\mathrm{mm} / \mathrm{hr}$. Characteristics of the studied rainfall events are listed in Table 1.

Table 1. Characteristics of the studied rainfall events

\begin{tabular}{lcccccc}
\hline \hline Rainfall events & Rain groups & $\begin{array}{c}\text { Average } \\
\text { intensity } \\
(\mathrm{mm} / \mathrm{hr})\end{array}$ & $\begin{array}{c}\text { Rain } \\
\text { depth } \\
(\mathrm{mm})\end{array}$ & $\begin{array}{c}\text { Duration } \\
(\mathrm{min})\end{array}$ & $\begin{array}{c}\text { Maximum 5-min } \\
\text { rainfall intensity } \\
(\mathrm{mm} / \mathrm{hr})\end{array}$ & $\begin{array}{c}\text { Antecedent } \\
\text { dry periods } \\
\text { (hours })\end{array}$ \\
\hline Oct. 6, 2014 & \multirow{2}{*}{ Light rain } & 2.14 & 4.50 & 126.3 & 6 & 178 \\
Nov. 14, 2014 & 2.14 & 7.10 & 199.5 & 6 & 168 \\
Nov. 15, 2014 & & 2.23 & 12.4 & 334.3 & 4.8 & 11 \\
\hline Oct. 8, 2014 & \multirow{2}{*}{ Moderate rain } & 3.16 & 6.19 & 117.7 & 8.4 & 7.5 \\
Nov. 7, 2014 & 3.26 & 3.20 & 58.8 & 6 & 77 \\
Feb. 28, 2015 & & 2.91 & 4.19 & 86.5 & 4.8 & 50 \\
\hline Oct. 7, 2014 & \multirow{2}{*}{ Heavy rain } & 5.22 & 1.60 & 18.4 & 9.6 & 3.7 \\
Dec. 27, 2014 & & 7.54 & 5.52 & 43.9 & 31.2 & 2.4 \\
\hline \hline
\end{tabular}

\subsection{Meta-model based framework}

As shown in Figure 1, we developed in this study a meta-model based framework for model calibration and validation. The main steps of this approach are as follows:

1. Upscale the high-fidelity fine resolution model to a lower-fidelity coarse resolution model;

2. Design parameter sampling experiments with the lower-fidelity model; 


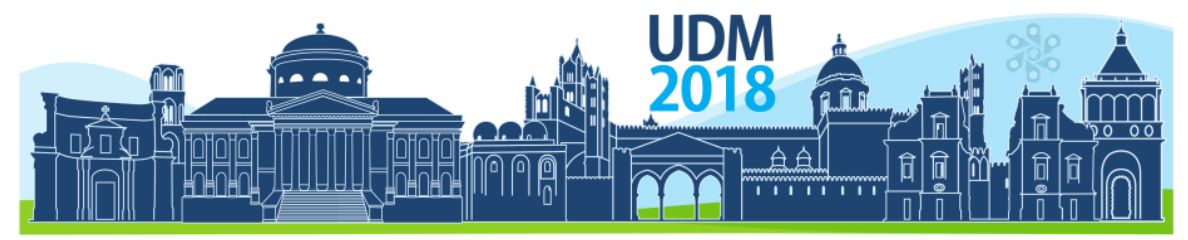

$11^{\text {th }}$ International Conference on Urban Drainage Modelling

23-26 Sep | Palermo - Italy

3. Using the defined parameter sampling experiments, construct the meta-model with highfidelity model simulations;

4. Calibrate parameters with the meta-model through assimilating the observed data;

5. Verify the optimized parameters with the high-fidelity model of the calibration rainfall event;

6. Validate the parameters with the high-fidelity model of different rainfall events.

The polynomial chaos/interpolation method is used in this study to construct the meta-model, for its accuracy and efficiency supported by solid mathematical foundation (Xiu and Karniadakis, 2003). More specifically, we used the adaptive stochastic collocation method, which adopts sparse grid algorithm and selects the important parameters adaptively and automatically (Liao et al., 2017). The calibration process is based on Bayesian inference, where the Markov chain Monte Carlo (MCMC) method is used to estimate the posterior probability distribution (Vrugt and Robinson, 2007).

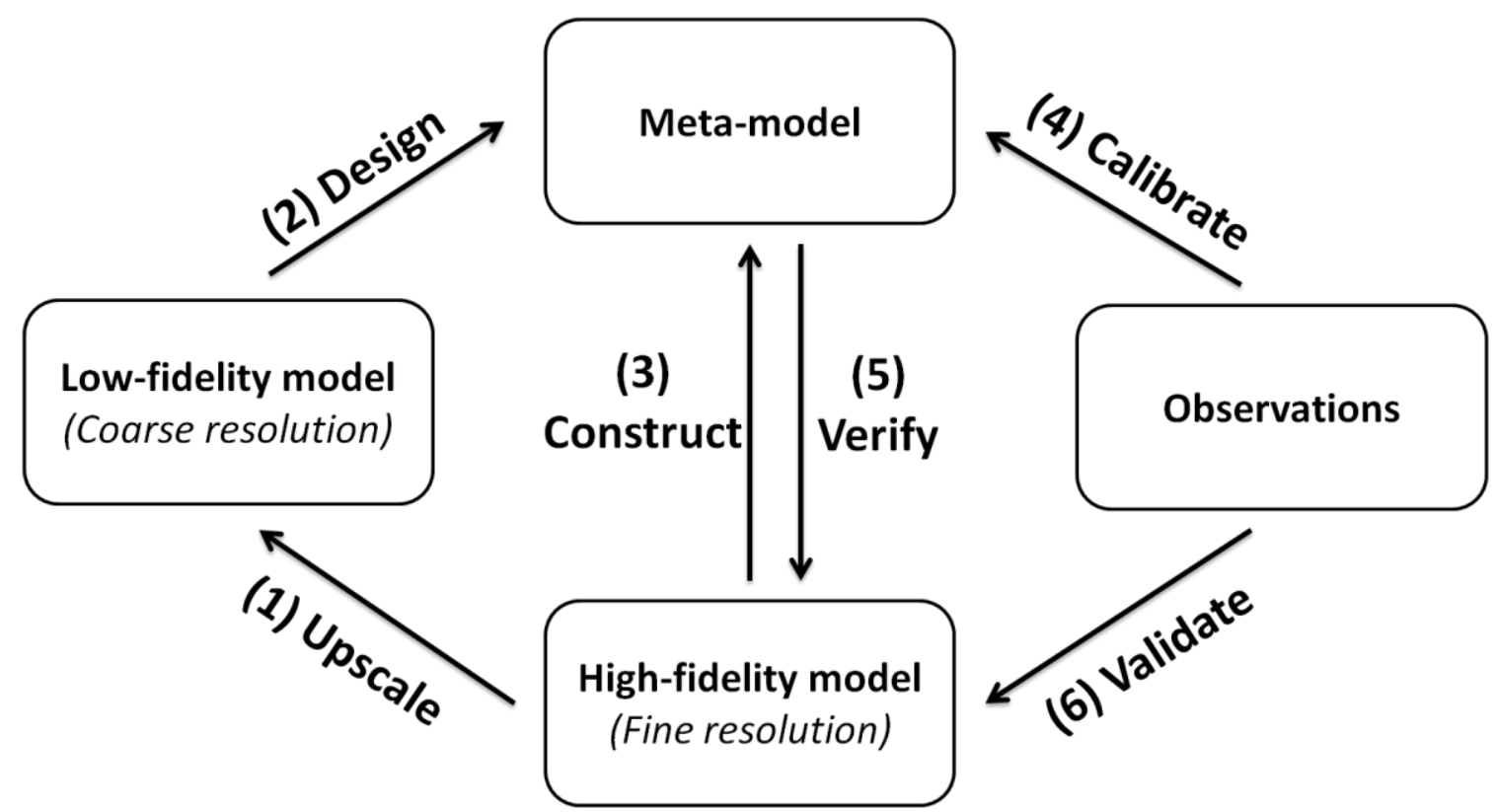

Figure 1. Illustration of the meta-model based framework.

\section{RESULTS AND DISCUSSION}

Using experimental design defined by the lower-fidelity surrogate, 77 series of parameters are selected. 77 FullSWOF-HR simulation runs are performed for each of the three rainfall events (Oct. 6, 2014, Oct. 8, 2014 and Oct. 7, 2014), to represent urban washoff dynamics in light rains, moderate rains and heavy rains, respectively. The interpolating polynomials of the original models are then generated. Comparing with the continuous observations of TSS concentration at the catchment outlet, parameter values are separately calibrated for the three indicated rainfall events, by applying the MCMC method on the surrogate polynomials. A very long Markov chain with 100,000 states is generated in just a few minutes thanks to the efficient meta-model.

The optimized parameters for each group of rainfall events are then verified and validated with the original FullSWOF-HR simulation runs (Figure 2). As illustrated in Figure 2, the 


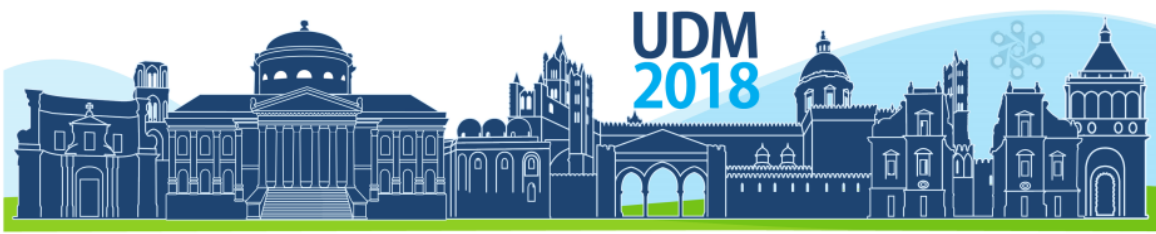

$11^{\text {th }}$ International Conference on Urban Drainage Modelling

23-26 Sep | Palermo - Italy

complex physical model FullSWOF-HR can be adequately calibrated by the proposed new meta-model based approach, for simulating washoff mechanisms in urban areas.

\section{CONSLUSION AND PERSPECTIVES}

In this work, we proposed a new meta-model based approach for efficient calibration of physical stormwater quality models. FullSWOF-HR model is applied to an urban road catchment near Paris to simulate the stormwater runoff and washoff dynamics. The set of parameter sampling points is designed by upscaling the original model. Proper meta-model can be then constructed by using the polynomial interpolation. Optimized Parameters are calculated by using the MCMC method with the meta-model, and then verified and validated with the original model. The results show that the proposed method can efficiently calibrate parameters for complex urban stormwater quality modelling. The sensitivity/uncertainty analysis with this new meta-model based approach is our ongoing work.

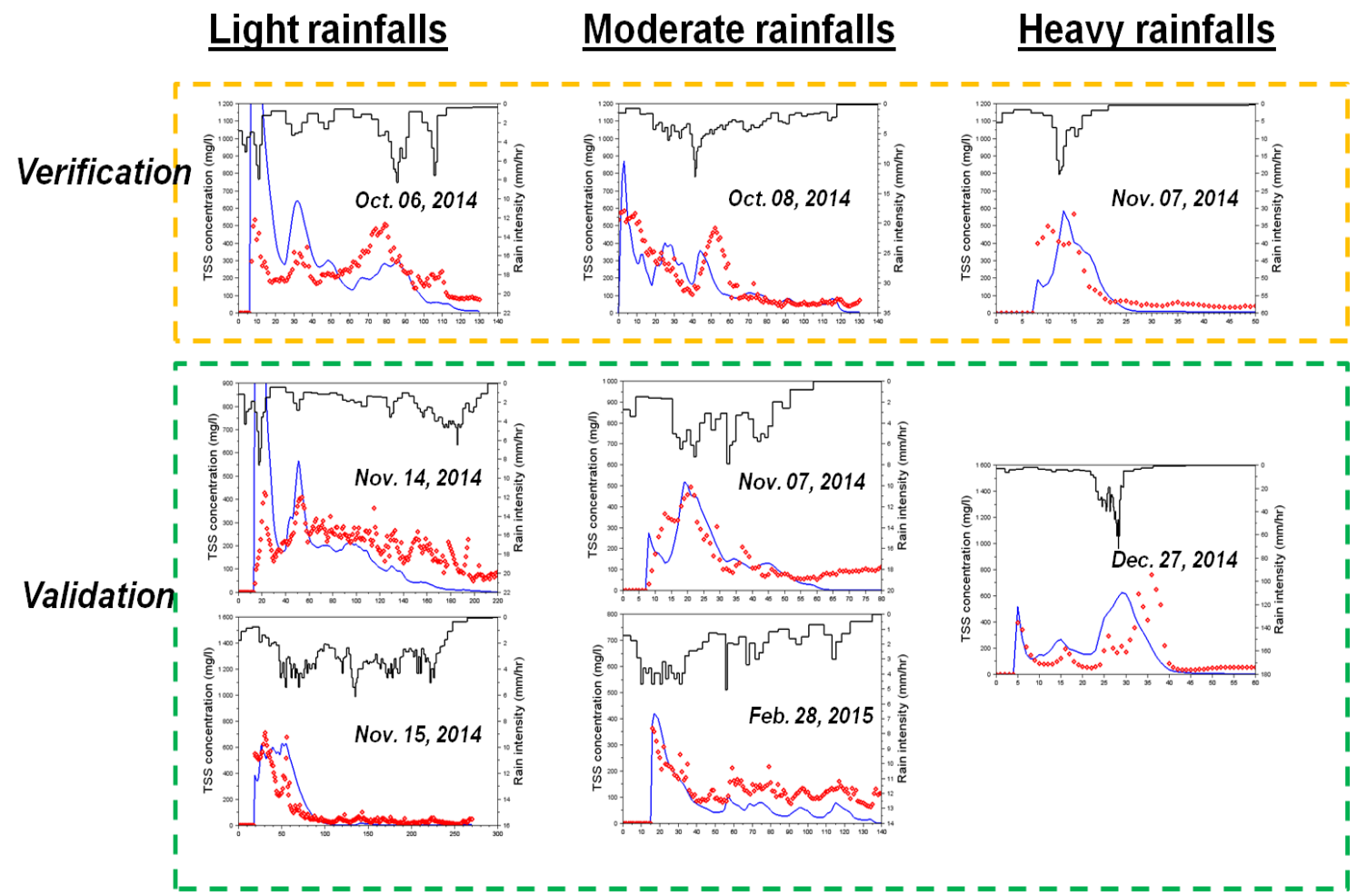

Figure 2. Model verification and validation for $\overline{3}$ light rains, $\overline{3}$ moderate rains and $\overline{2} \overline{\text { heavy }} \overline{\bar{r}}$ rains. Simulated $\overline{\mathrm{T} S S}$ concentrations (solid blue lines) are compared with observations (red dots); rains are plotted on the upper parts.

\section{References}

Beven, K., Binley, A., 1992. The future of distributed models: Model calibration and uncertainty prediction. Hydrol. Process. 6, 279-298. https://doi.org/10.1002/hyp.3360060305

Dotto, C.B.S., Mannina, G., Kleidorfer, M., Vezzaro, L., Henrichs, M., McCarthy, D.T., Freni, G., Rauch, W., Deletic, A., 2012. Comparison of different uncertainty techniques in urban stormwater quantity and quality modelling. Water Res. 46, 2545-2558. https://doi.org/10.1016/j.watres.2012.02.009

Fatichi, S., Vivoni, E.R., Ogden, F.L., Ivanov, V.Y., Mirus, B., Gochis, D., Downer, C.W., Camporese, M., Davison, J.H., Ebel, B., Jones, N., Kim, J., Mascaro, G., Niswonger, R., Restrepo, P., Rigon, R., Shen, C., Sulis, 


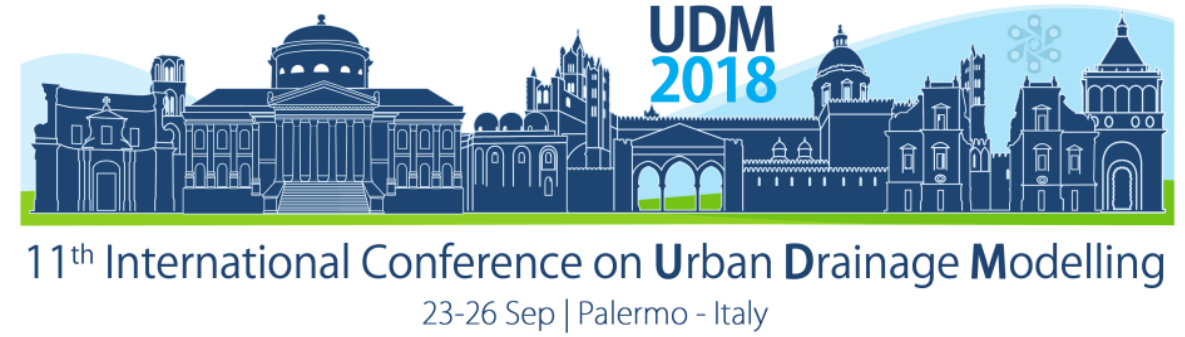

M., Tarboton, D., 2016. An overview of current applications, challenges, and future trends in distributed process-based models in hydrology. J. Hydrol. 537, 45-60. https://doi.org/10.1016/j.jhydrol.2016.03.026

Hong, Y., Bonhomme, C., Le, M.-H., Chebbo, G., 2016a. New insights into the urban washoff process with detailed physical modelling. Sci. Total Environ. 573, 924-936. https://doi.org/10.1016/j.scitotenv.2016.08.193

Hong, Y., Bonhomme, C., Le, M.-H., Chebbo, G., 2016b. A new approach of monitoring and physically-based modelling to investigate urban wash-off process on a road catchment near Paris. Water Res. 102, 96108. https://doi.org/10.1016/j.watres.2016.06.027

Liao, Q., Zhang, D., Tchelepi, H., 2017. A two-stage adaptive stochastic collocation method on nested sparse grids for multiphase flow in randomly heterogeneous porous media. J. Comput. Phys. 330, 828-845. https://doi.org/10.1016/j.jcp.2016.10.061

Razavi, S., Tolson, B.A., Burn, D.H., 2012. Review of surrogate modeling in water resources: REVIEW. Water Resour. Res. 48. https://doi.org/10.1029/2011WR011527

Refsgaard, J.C., Storm, B., Clausen, T., 2010. Système Hydrologique Europeén (SHE): review and perspectives after 30 years development in distributed physically-based hydrological modelling. Hydrol. Res. 41, 355377. https://doi.org/10.2166/nh.2010.009

Vrugt, J.A., Robinson, B.A., 2007. Treatment of uncertainty using ensemble methods: Comparison of sequential data assimilation and Bayesian model averaging: SEQUENTIAL DATA ASSIMILATION. Water Resour. Res. 43. https://doi.org/10.1029/2005WR004838

Xiu, D., Karniadakis, G.E., 2003. Modeling uncertainty in flow simulations via generalized polynomial chaos. J. Comput. Phys. 187, 137-167. https://doi.org/10.1016/S0021-9991(03)00092-5 


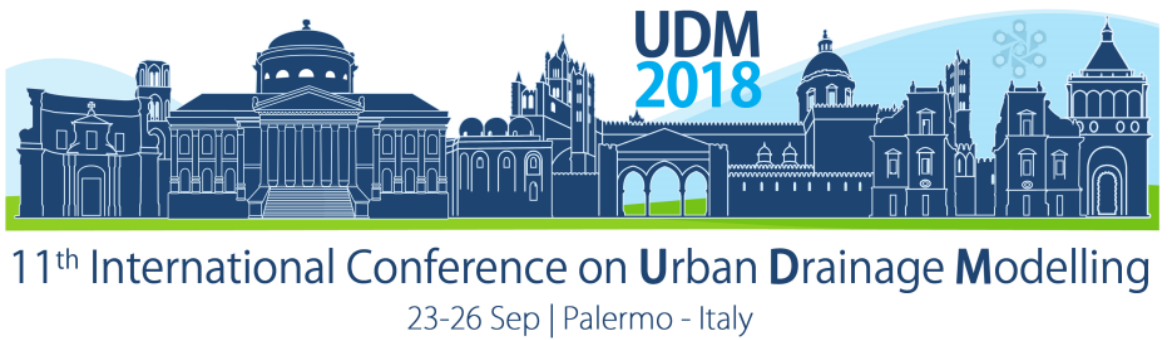

\title{
Automatic Calibration Approach for Multiple Rain Events in SWMM using Latin Hypercube Sampling
}

\author{
Benjamin Wagner', Julian David Reyes-Silva', Christian Förster', Jakob Benisch ${ }^{1}$, Björn Helm¹, \\ and Peter Krebs ${ }^{1}$ \\ ${ }^{1}$ Technische Universität Dresden, Institute of Urban Water Management, 01062 Dresden, Germany
}

\begin{abstract}
The present study aimed for the development and application of an automated calibration approach based on Latin Hypercube Sampling (LHS). The proposed methodology was used for calibrating an urban drainage model of a small sewer network of Dresden, implemented in EPA Stormwater Management Model (SWMM). Based on predefined ranges, LHS was applied to generate 1000 calibration parameter sets, which were used to simulate 24 different rain events. Nash-Sutcliffe Efficiency (NSE) was used to assess the goodness-of-fit of the results. NSE values were stored in an $m-b y-n$ matrix, where $m$ corresponds to the number of parameter sets and $n$ is the number of rain events and converted into 0 if they were below a defined threshold and 1 otherwise. For each row the sum of columns was calculated. The resulting number, referred to as degree, represents the amount of rain events for which the specific configuration yields a good NSE. Then, higher degrees imply a more robust set of parameters. By selecting a threshold of NSE $=0.75$ it was possible to determine 11 different configurations, for which 6 out of the 24 events fulfilled the threshold. Analysis of these positive solutions revealed that one of them, parameter set 18 (S18), consistently reported the best NSE values for all analyzed events, and therefore was selected as the best solution. Although, adequate validation results were obtained, additional improvements are needed. Moreover, this approach can also be used to perform sensitivity analyses and evaluate the influence of rain events on calibration efficiency.
\end{abstract}

Keywords: calibration; LHS; SWMM; parameter set degree

\section{INTRODUCTION}

The most widely used hydrologic-hydraulic simulation model to quantify the quality and quantity of runoff generated in urban areas is EPA Stormwater Management Model (SWMM) (Rossman, 2015). SWMM requires a considerable number of parameters to represent the complex relationships among rainfall, runoff, and catchments characteristics. In this context, automatic parameter estimation methods have been recognized to have the advantage of accelerating the model calibration process, minimize modeler bias, and increase the goodness of fit between simulated and measured values (Dent et al., 2004). The most common methodologies for SWMM are based on Genetic Algorithm (GA) approaches; see e.g. Dent et al., (2004), Jin et al., (2011) and Krebs et al., (2013). Eventhough good calibration results can be achieved with such methods, the obtained optimal parameter values are specific for the rain event or time frame, used for calibration, hence different results can be obtained for same parameters when calibrating for various events. In this context, the present study aimed for the development and implementation of an automatic calibration tool for SWMM, able to integrate data from different and independent rain events simultaneously, in order to determine a more robust set of optimal parameters. Incorporating multiple events in the calibration processes has been reported to decrease uncertainty bounds, reduce computational times and identify parameter sets with better generalization properties (di Piero et al., 2006; Gamerith et al., 2011; Arriero Shinnam \& Ribeiro Reis, 2014; Kim et al., 2015). The proposed methodology is 


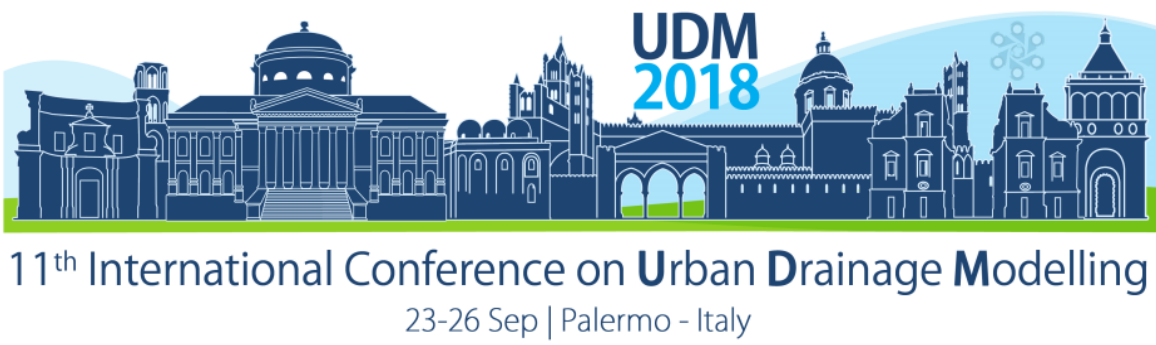

based on a Latin Hypercube Sampling (LHS), a stratified sampling method introduced by McKay et al (1979). LHS and other Monte-Carlo based approaches, e.g. Generalized Likelihood Uncertainty Estimation (GLUE), have been applied previously for uncertainty and sensitivity analyses in SWMM, e.g. Sun et al (2014) and Zhang \& Li (2015), but, to the extent of the authors knowledge, not for specific model calibration.

\section{MATERIALS AND METHODS}

\subsection{Study Case, Model Set-Up and Observed Data}

The study case corresponds to a separate sewer network located in the southeast region of the city of Dresden, Germany. A SWMM model was developed based on GIS data regarding sewer structure and surface characteristics. In total 60 subcatchments were identified. Initial values of area, width and slope were calculated based on GIS data, other sub-catchment parameters were set based on the recommended values in the SWMM manual (Rossman, 2015). Calibration and validation events and data were obtained from a high-resolution (5 minutes) rain and discharge time series between January 2016 and April 2018. Furthermore, 10 calibration parameters where selected based on reported sensitivity (Liong et al., 1991; Nguyen et al., 2000, Dent et al., 2004; Krebs et al., 2013; Zhang \& Li, 2015). These are: Impervious Area (IA), Width (W), Manning coefficient for pervious and impervious areas (nperv and n-imp), depression storage for pervious and impervious areas (s-perv, s-imp), slope (S), Initial Soil Moisture Deficit (IMD), soil saturated hydraulic conductivity (Ksat), and soil capillary suction (psi).

\subsection{Calibration Procedure}

The methodology proposed in this study can be divided into four main steps, presented below. All procedures and calculations were done by using Python version 3.6.4 and R 3.4.4.

1) Calibration parameters sampling and rain event selection. Rain events with precipitation height above $5 \mathrm{~mm}$ and at least 5 hours of dry-weather conditions before and after the event were selected. The ranges of parameters were determined based on literature values or $\pm 50 \%$ for the ones calculated using GIS data. Based on these ranges, LHS was applied to generate 1000 parameter sets.

2) Fitness evaluation and matrix development. Each parameter set was evaluated independently for each rain event, i.e. SWMM simulations for each event for all the 1000 configurations are carried out. Nash-Sutcliffe Efficiency (NSE) (Nash \& Sutcliffe, 1970 ) is used to assess the goodness-of-fit. NSE results are stored in an $m-b y-n$ matrix where $m$ corresponds to the set of parameters from the LHS and $n$ to the rain events.

3) Threshold selection and matrix arrangement. Values from the previous matrix are converted into 0 or 1 based on a user's defined threshold. If the NSE value is higher than the threshold it corresponds to 1 , otherwise is categorized as 0 .

4) Parameter set evaluation. For each row of the matrix, i.e. for each parameter set, the sum of the $1 \mathrm{~s}$ is calculated. The resulting number is an integer referred here as the degree of the parameter set. The main hypothesis of the proposed methodology is that the higher the degree of a parameter set the more robust it is, since it is able to provide good fitting results for different rain events. 


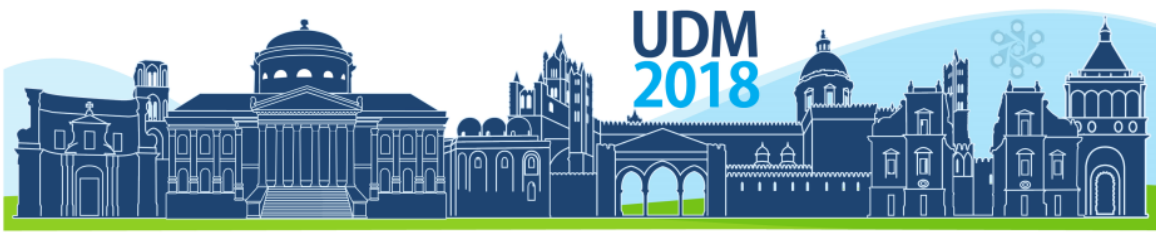

$11^{\text {th }}$ International Conference on Urban Drainage Modelling

23-26 Sep | Palermo - Italy

\section{RESULTS AND DISCUSSION}

In total, 24 rain events and their corresponding observed discharges were selected for calibration. The NSE distribution of the 1000 parameter sets evaluated for each of these events is presented in Figure 1A. From these results it becomes evident that the efficiency of a calibration procedure strongly depends on the selected rain event. For example, all 1000 configurations yielded good results (NSE higher than 0.8) for Event 4, while they were always inadequate (NSE lower than 0.3) for example in Event 15. The need for identifying a parameter set which yields good results for most of the events becomes obvious. In order to better understand the influence of the NSE threshold on the selection of optimal parameter sets, the procedure was conducted using different NSE values ranging from 0.5 to 0.9 . Figure $1 \mathrm{~B}$ shows the degree ranges of all sets for each threshold. As expected, lower thresholds implied that more parameter configurations were classified as "good", hence passing events, i.e. high degrees, were more frequent. Consequently, higher thresholds not only led to a decrease of the number of good parameter sets but also, these parameter sets were good for less rain events. Moreover, for thresholds equal or higher than 0.85 , almost all configurations yielded very good results for a specific rain event (see NSE distribution for Event 4 in Figure 1A), hence the number of good solutions increased significantly.
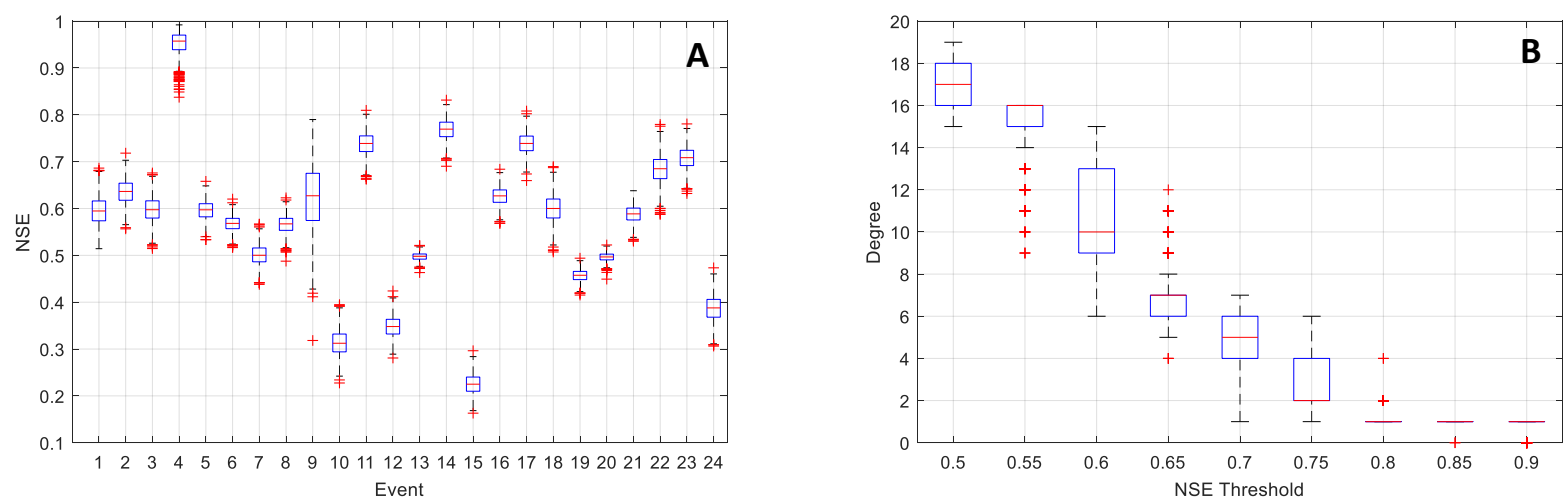

Figure 1: NSE values of 1000 model runs (A) and Degree distribution for different NSE thresholds (B)

In order to select an appropriate NSE limit value, the variations of the maximum parameter set degree and total number of good solutions with regard to different thresholds were analyzed (see Figure 2). Thresholds between 0.6 and 0.8 were found to yield a small amount of good parameter sets, between 2 and 13. As a rule of thumb, a good fitness is represented by an NSE equal or higher than 0.75 . In this context, although a smaller amount of good solutions was identified by using a threshold of 0.8 rather than 0.75 ( 2 and 11 respectively), a NSE of 0.75 was selected, since the maximum degree was higher, hence parameter sets were valid for a wider range of rain events (25\% in this case). Close analysis of the resulting 11 optimal solutions revealed that one of them, parameter set 18 (S18), consistently reported slightly better NSE values for all analyzed events, and therefore was selected as the best solution. Identification of a good parameter configuration can be improved by transitioning from the current single-objective multi-event calibration approach to a multi-objective multi-event methodology, as suggested by di Piero et al. (2006). 


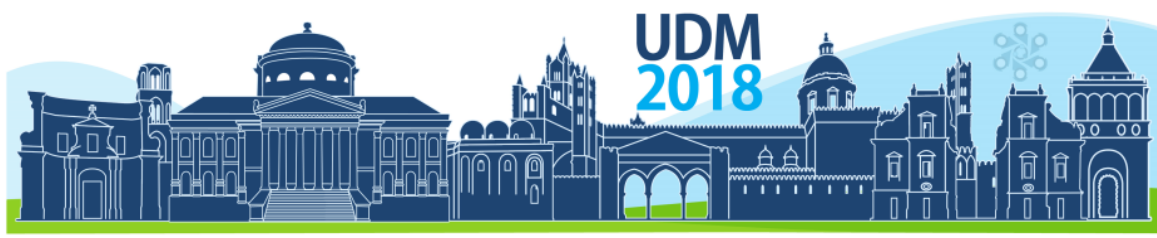

$11^{\text {th }}$ International Conference on Urban Drainage Modelling 23-26 Sep | Palermo - Italy

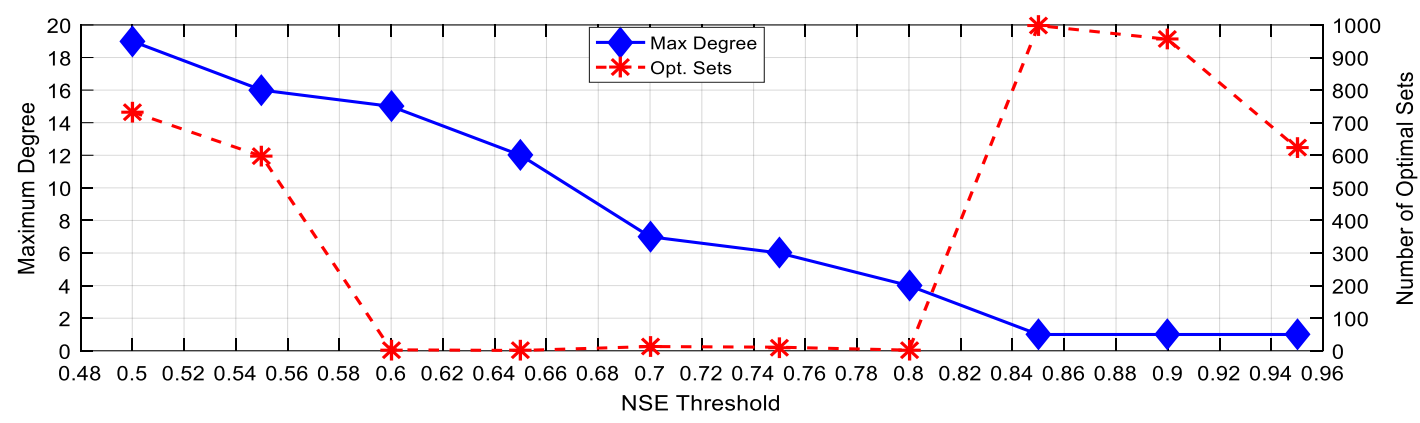

Figure 2. Variation of maximum degree and number of good solutions with regard to NSE thresholds

Validation results using the identified optimal parameter set, S18, showed that the proposed tool was able to achieve adequate results. In fact, NSE values for 5 out 7 validation events ranged from 0.59 and 0.66 , while the other two were not satisfactory, with NSE values of 0.28 and 0.34. In order to compare these results to the standard procedures, the same SWMM model was calibrated for the same 24 rain events using a genetic algorithm approach. Validation results in this case were higher than in the first approach, ranging from 0.59 to 0.8 for all events. In this context, several improvements can be done to enhance the performance of the proposed methodology. On one hand, sampling size can be increased in order to cover more possible solutions. This can be further developed by applying an improve version of the LHS, the orthogonal sampling, to assure that the parameter sets are not only independent but also represent the entire range of variation. On the other hand, improvements can be obtained by including more and diverse rain events into the analyses, in order to assess different hydrologic responses.

The proposed methodology can also be used for sensitivity analyses. Ranges of variation for a sensitive parameter are expected to decrease with regard to degree, i.e. sensitive parameters should converge to a certain value when they are good for a higher number of rain events (high degree). Conversely, ranges of values for an insensitive parameter do not change with higher degrees since their value does not affect the performance of the model. Figure 3 depicts an example of a sensitive parameter, Width (Fig. 3A), and an insensitive parameter nperv (Fig. 3B), for a given sub-catchment (Sub-48).
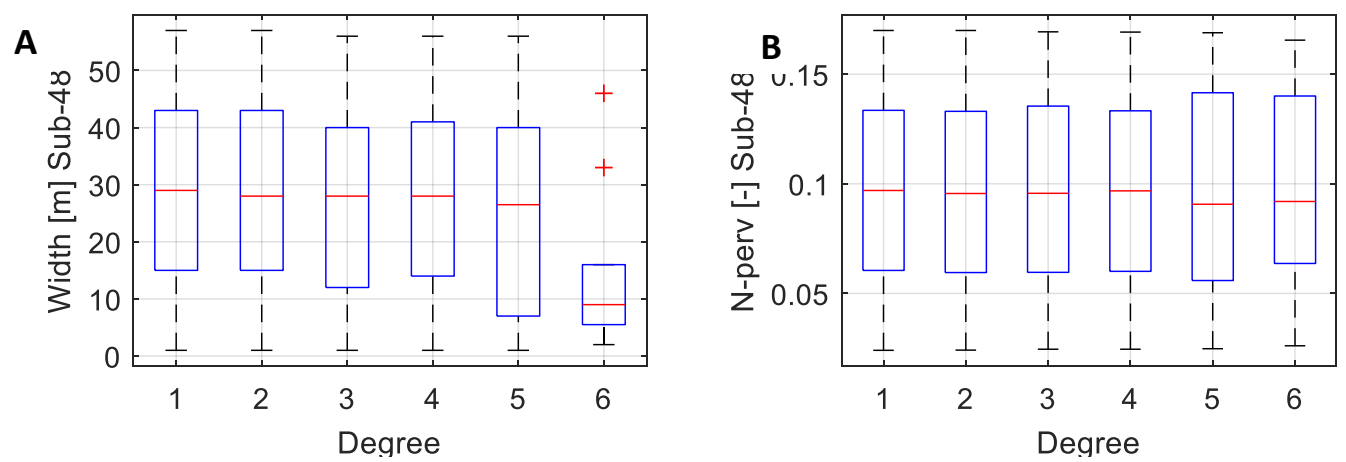

Figure 3. Parameter range of sub-catchment 48 Width and N-perv, based on NSE threshold of 0.75 


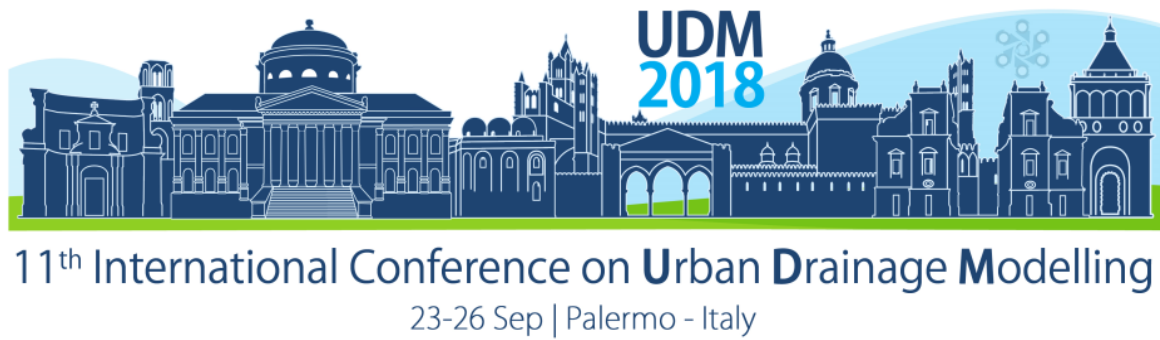

\section{CONCLUSIONS}

A single-objective multi-event automatic calibration tool was developed and tested for an EPA SWMM model of a small sub-catchment in Dresden, Germany. Although previous studies have already analyzed such approaches, the novelty of the presented methodology relies on the use of Latin Hypercube Sampling rather than genetic algorithm techniques. Main advantages of this approach are the considerable reduction of computational times and its straightforward implementation and results interpretation. Moreover, it can also be used to perform sensitivity analyses and evaluate the influence of rain events on calibration efficiency.

Although adequate results were achieved, suggesting that methodology has potential for identifying a robust set of parameters, further improvements can be done. Transitioning from a single-objective to a multi-objective multi-event approach could lead to a better identification of an optimal parameter set, which could be complemented by the use of an improved LHS procedure, the orthogonal sampling. A special consideration must be made regarding the selection of the NSE threshold. Equifinality problems can arise when using both low or high values. In the first case, more sets will be classified as good since the NSE requirements are too small. Moreover, some rain events will always fulfil the low threshold NSE value, independent from the parameter set used, and thus the approach is not selective. In contrary, higher thresholds will lead to solutions valid for a smaller number of rain events. In this context, it is recommended to perform a threshold analysis based on the events to be used for calibration, and a priori establish an acceptable range for the maximum degree, i.e. the amount of rain events for which the sets must be valid.

\section{References}

Arriero Shinnam, T. \& Ribeiro Reis, L. F., 2014. Incorporating multi-event and multi-site data in the calibration of SWMM. Procedia Engineering, Volume 70, pp. 75-84.

di Pierro, F., Khu, S.-T., Savić, D.,2006. From single-objective to multiple-objective multiple-rainfall events automatic calibration of urban storm water runoff models using genetic algorithms. Water Science and Technology, Volume 54 (6-7), pp. 57-64.

Dent, S., Hanna, R. B. \& Wright, L., 2004. Automated Calibration using Optimization Techniques with SWMMRUNOFF. Journal of Water Management Modeling, Volume R220-18, pp. 385-408.

Gamerith, V., Gruber, G., Muschalla, D., 2011. Single- and multievent optimization in combined sewer flow and water quality model calibration. Journal of Environmental Engineering, Volume 137 (7), pp. 551-558.

Jin, X., Jiang, Y., Wu, W. \& Jin, J., 2011. Automatic Calibration of SWMM Model with Adaptative Genetic Algorithm. International Symposium on Water Resource and Environmental Protection (ISWREP), pp. 891-895.

Kim, Y., Chung, E.-S., Won, K., Gil, K., 2015. Robust parameter estimation framework of a rainfall-runoff model using pareto optimum and minimax regret approach. Water (Switzerland), Volume 7 (3), pp. 1246-1263.

Krebs, G. Kokkonen, T. Valtanen, M. Koivusalo, H. Setälä, H., 2013. A high resolution application of a stormwater management model (SWMM) using genetic parameter optimization. Urban Water Journal, 10(6), pp. 394-410.

Liong, S. Y., Chan, W. T. \& Lum, L. H., 1991. Knowledge-Based System for SWMM Runoff Component Calibration. J. Water Resour. Plann. Manage, Volume 117, pp. 507-524.

McKay, M. D., Beckman, R. J. \& Conover, W. J., 1979. A Comparison of Three Methods for Selecting Values of Input Variables in the Analysis of Output from a Computer Code. Technometrics, 21(2), pp. 239-245.

Nash, J. E. \& Sutcliffe, J. V., 1970. River flow forecasting through conceptual models part I - A discussion of principles. Journal of Hydrology, 10(3), pp. 282-290.

Nguyen, V., Javaheri, H. \& Liong, S., 2000. On Automatic Calibration of the SWMM Model. Appl. Model Urban Water Sys., Volume 8, pp. 163-174.

Rossman, L. A., 2015. Storm water management model, user's manual, version 5.1. Cincinnati, OH: U.S. EPA.

Sun, N., Hong, B. \& Hall, M., 2014. Assessment of the SWMM model uncertainties within the generalized likelihood uncertainty estimation (GLUE) framework for a high resolution urban sewershed. Hydrological Processes, Volume 28, pp. 3018-3034.

Zhang, W. \& Li, t., 2015. The Influence of Objective Function and Acceptability Threshold on Uncertainty Assessment of an Urban Drainage Hydraulic Model with Generalized Likelihood Uncertainty Estimation Methodology. Water Resour Manage, Volume 29, pp. 2059-2072. 


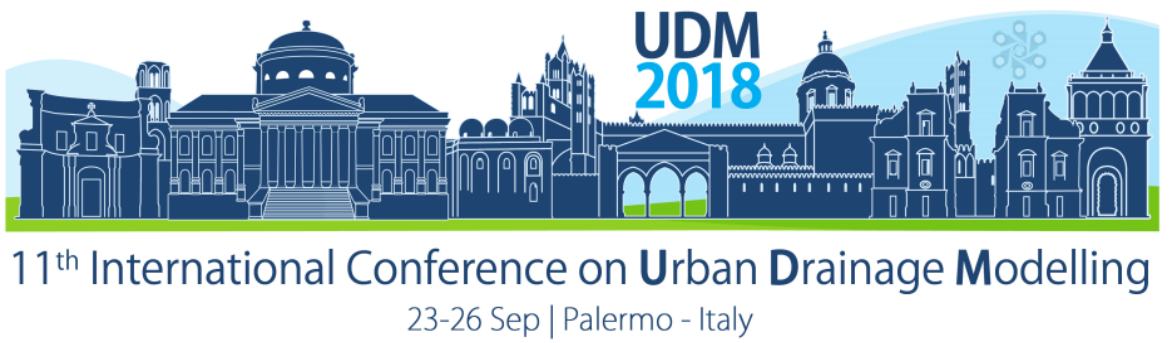

\title{
Commercial Microwave Links in Urban Drainage Modelling: On Deriving Precipitation Estimates for Various Link Lengths
}

\author{
Jaroslav Pastorek ${ }^{1}$, Martin Fencl',2, Jörg Rieckermann ${ }^{3}$ and Vojtěch Bareš1 \\ ${ }^{1}$ Czech Technical University in Prague, Department of Hydraulics and Hydrology, Prague, Czech Republic \\ ${ }^{2}$ Technical University of Denmark, Department of Environmental Engineering, Kongens Lyngby, Denmark \\ ${ }^{3}$ Eawag, Urban Water Management Department, Dübendorf, Switzerland
}

\begin{abstract}
It is currently unknown whether quantitative precipitation estimates (QPEs) from shorter or longer commercial microwave links (CMLs) are better suited to be used as input for urban drainage models. Short CMLs could deliver high spatial resolution, longer CMLs are probably less disturbed by systematic errors due to antenna wetting. We investigate the effect of various link lengths on urban runoff predictions using real-world CML data from an experimental catchment in Prague, Czech Republic. We run a rainfall-runoff model repeatedly, using QPEs from only a single CML (out of 19 available) every time and also their mean. We compare model predictions to observations at the drainage system outlet for 67 rainfall-runoff events from 3 summer seasons. We use i) unadjusted CML QPEs based on the power law between rainfall intensity and radio signal attenuation and ii) QPEs adjusted to 15-min rainfall data from distant rain gauges from a permanent network. We show that, when using the unadjusted CMLs, model performance is better for CMLs which do not provide overestimated QPEs, i.e. typically the longer ones. When using the adjusting-based method, we recommend using the mean of QPEs from all available CMLs. We could additionally benefit from CML QPEs if information about temporal dynamics of heavy rainfalls was not compromised when reducing the bias in these QPEs.
\end{abstract}

Keywords: Commercial microwave links; rainfall-runoff modelling; urban catchment.

\section{INTRODUCTION}

Commercial microwave links (CMLs) can provide path-integrated quantitative precipitation estimates (QPEs) derived from attenuation of radio waves by raindrops. Deriving QPEs from CMLs has already been examined by several studies, however, there has not been much research on using CML QPEs as inputs in urban drainage modelling. Stránský et al. (2018) concluded that CML QPEs adjusted to rain gauge data outperformed rain gauges used alone when reproducing runoff dynamics. Nevertheless, reliability of CMLs as rainfall sensors is variable and it is not well understood how different characteristics, especially length and frequency, determine the performance of CML QPEs when used in urban drainage models.

Lengths of CMLs typically range from hundreds to thousands of metres. From the point of view, shorter CMLs could theoretically provide more informative rainfall data, since their path lengths often correspond very well to spatial scales of small urban (sub)catchments. However, short CMLs (and those operating at low frequencies) are less sensitive to the attenuation by raindrops, and, thus, QPEs from these links are often compromised by systematic errors due to additional attenuation arising from antenna wetting at both end nodes (e.g. Leijnse et al., 2008) or due to quantization noise. 


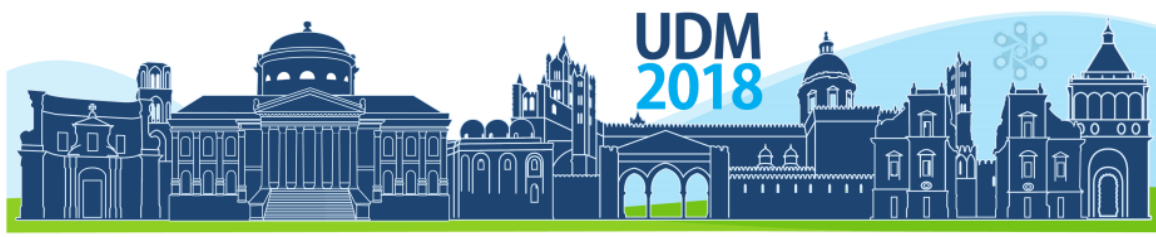

$11^{\text {th }}$ International Conference on Urban Drainage Modelling

23-26 Sep | Palermo - Italy

In the presented study, we aim to formulate recommendations on the suitability of CMLs of various lengths for deriving rainfall data for urban drainage modelling, and how to proceed when other rainfall measurements, typically from rain gauges, are (resp. are not) available in the catchment. We directly apply QPEs from a real-world CML network to rainfall-runoff modelling while using measured discharges as the reference. We do this while employing an extensive data set which was being collected for a period of 3 summer seasons and which contains data from $19 \mathrm{CMLs}$ located in a wider area of the studied urban catchment.

\section{MATERIALS AND METHODS}

The experimental urban catchment $\left(1.3 \mathrm{~km}^{2}\right)$ lies in Prague-Letňany, Czech Republic, and is drained by a separate sewer system. In a wider area of the catchment (Fig. 1), we monitored 19 CMLs between August 2014 and October 2016. Furthermore, observations from three tipping bucket rain gauges (operated by the municipal sewer authority, each in a distance of approximately $2.5 \mathrm{~km}$ from the catchment) were collected during the period. The CML QPEs were retrieved at 10-s resolution and aggregated to 1-min resolution to match the gauge data. In addition, we observed discharges at the outlet of the stormwater drainage system (Fig. 1) with an area-velocity flow meter (Triton, ADS).

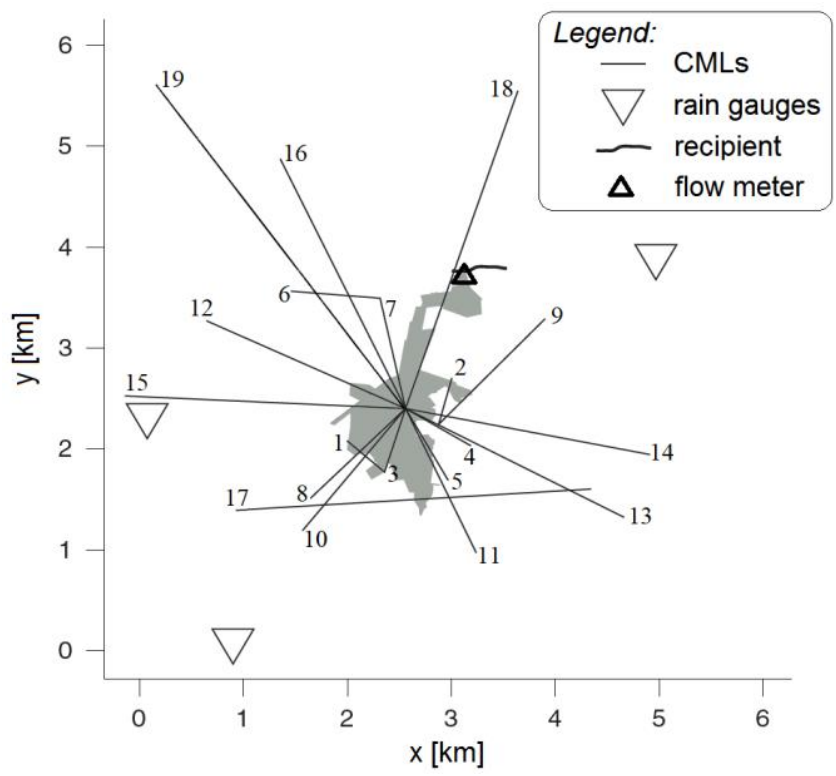

Figure 1. Location of the CMLs (with IDs denoted) and rain gauges in the area of the urban catchment. Note that the CML central node is close to the catchment's centroid and some of the CMLs reach far out of the catchment.

We use a calibrated EPA-SWMM model of the studied catchment to simulate discharges at the drainage system outlet. For all relevant (rainfall height over $2 \mathrm{~mm}$, in total 67) rainfallrunoff events which occurred during the monitored period, we compare the observed discharges with outputs of the rainfall-runoff model. We perform the modelling repeatedly, while altering input rainfall time series, using QPEs from one CML at a time (eventually using each of the 19 CMLs) and, moreover, the mean of the QPEs from all 19 CMLs. The mean of the instantaneous values from the three rain gauges is also used, representing referential traditional rainfall data. The precipitation input is always implemented as areal rainfall. To assess the model performance, we use the Nash-Sutcliffe efficiency (NSE, [-]) and the Pearson correlation coefficient (PCC, [-]), which is insensitive to linear bias. 


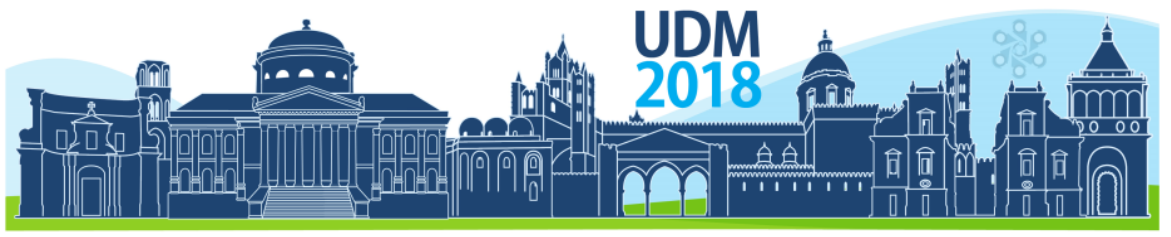

$11^{\text {th }}$ International Conference on Urban Drainage Modelling

23-26 Sep | Palermo - Italy

Moreover, we investigate two ways of retrieving CML precipitation estimates: i) using the power law between rainfall intensity and radio signal attenuation with parameters taken from literature and ii) adjusting to rainfall data from rain gauges. In the first approach, we apply wet antenna correction (as a constant offset) in accordance with Overeem et al. (2011). In the second method, the mean of the instantaneous values of three rain gauges, aggregated to 15-min time steps, is used for CML adjustment as proposed by Fencl et al. (2017). Baseline separation is for both approaches performed according to Fenicia et al. (2012).

\section{RESULTS AND DISCUSSION}

Firstly, we introduce results of the study by a single rainfall-runoff event (Fig. 2), which illustrates well the potential of using CML QPEs in urban drainage modelling. Discharges modelled using the CML QPEs adjusted to rain gauges fit the observations better than when using only the rain gauge data. However, when using the unadjusted CML QPEs, certain links provide rainfall estimates which capture also the first runoff peak, which is not present at all in the case of the rain gauge data. However, even if the hydrograph timing looks reasonable, the unadjusted CML data often lead to highly overestimated discharges.

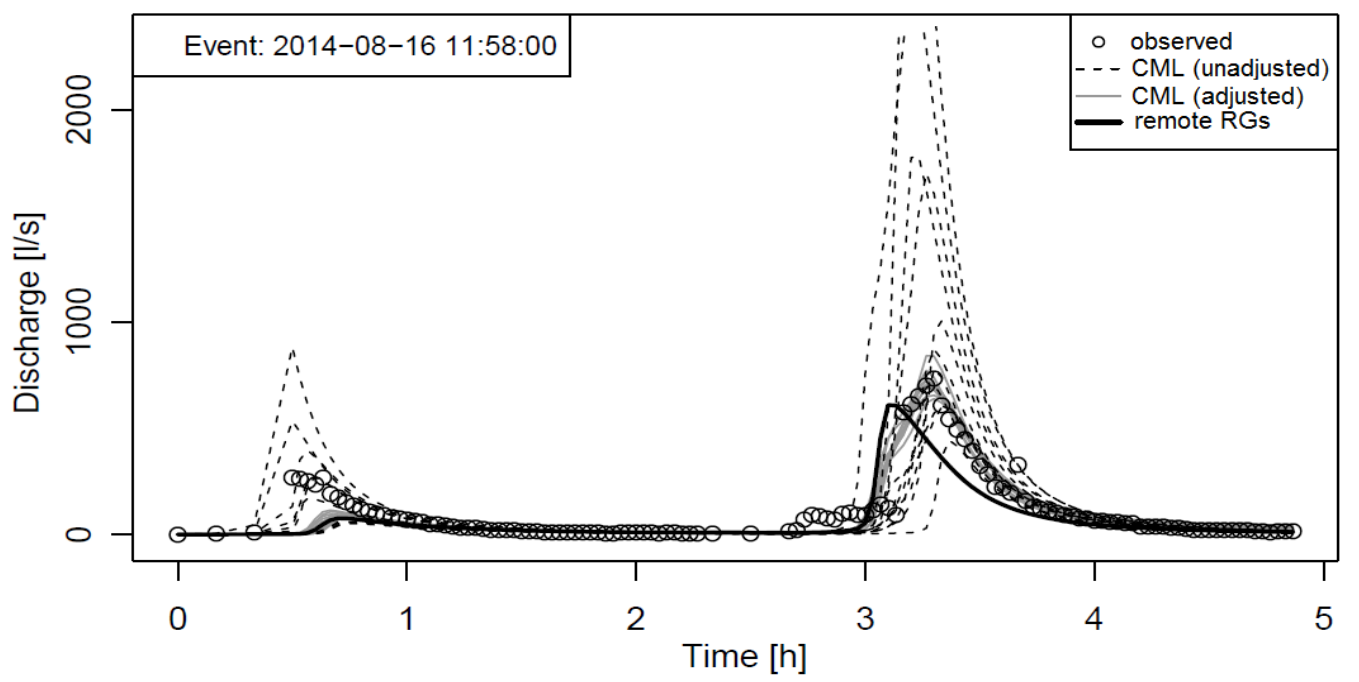

Figure 2. Modelled and observed discharges for a selected rainfall-runoff event. The values obtained with unadjusted CML QPEs reach up to $3800 \mathrm{l} / \mathrm{s}$.

When analysing all the simulated events, the results still differ substantially for the two CML QPE data sets. For the unadjusted CML QPEs, better NSE values (higher median, lower variability; not shown graphically) seem to correlate with higher CML lengths. Neither of the CML QPEs outperforms the rain gauges. Adjusting the CML QPEs substantially improves the results, especially in the case of short CMLs. All examined QPEs lead to very similar NSE values, the best of them is the mean over all the $19 \mathrm{CMLs}$. However, neither of them leads to NSE values substantially better than the data from rain gauges used alone.

The results are most interesting for the events with the maximal 10-minute precipitation rate over $12 \mathrm{~mm} / \mathrm{h}$ (approximately $30 \%$ of all events, further on referred to as heavy events). For unadjusted CML QPEs (Fig. 3 left), there still is a considerable dependency between the NSE values and CML length. However, it rather seems that the bias in CML QPEs is the chief determining factor of the NSE values. The best NSE values are obtained using the links which tend to underestimate the total discharged volumes, i.e. CMLs \#4, \#10 and \#19. And 


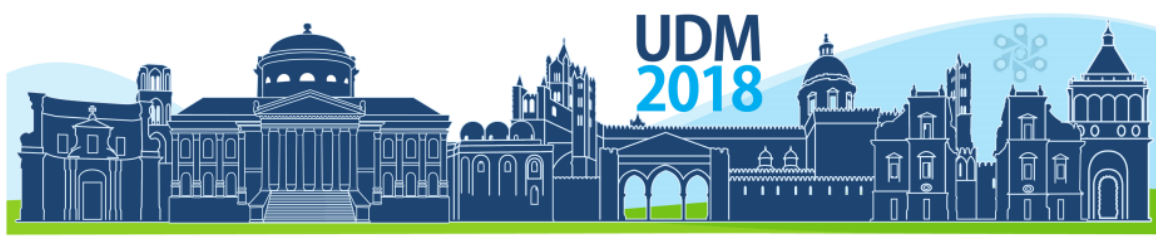

$11^{\text {th }}$ International Conference on Urban Drainage Modelling

23-26 Sep | Palermo - Italy

reversely, for the QPEs from CMLs leading to low NSE values, the discharged volumes are overestimated by $30-100 \%$ in median. For the adjusted CML QPEs (Fig. 3 right), the results vary much less for various CMLs. The highest NSE values are reached with the CMLs \#19 and \#16. Links \#4 and \#10 still perform better than the mean of the rain gauges. Interestingly, the same is true also for the mean of the QPEs from all available CMLs.
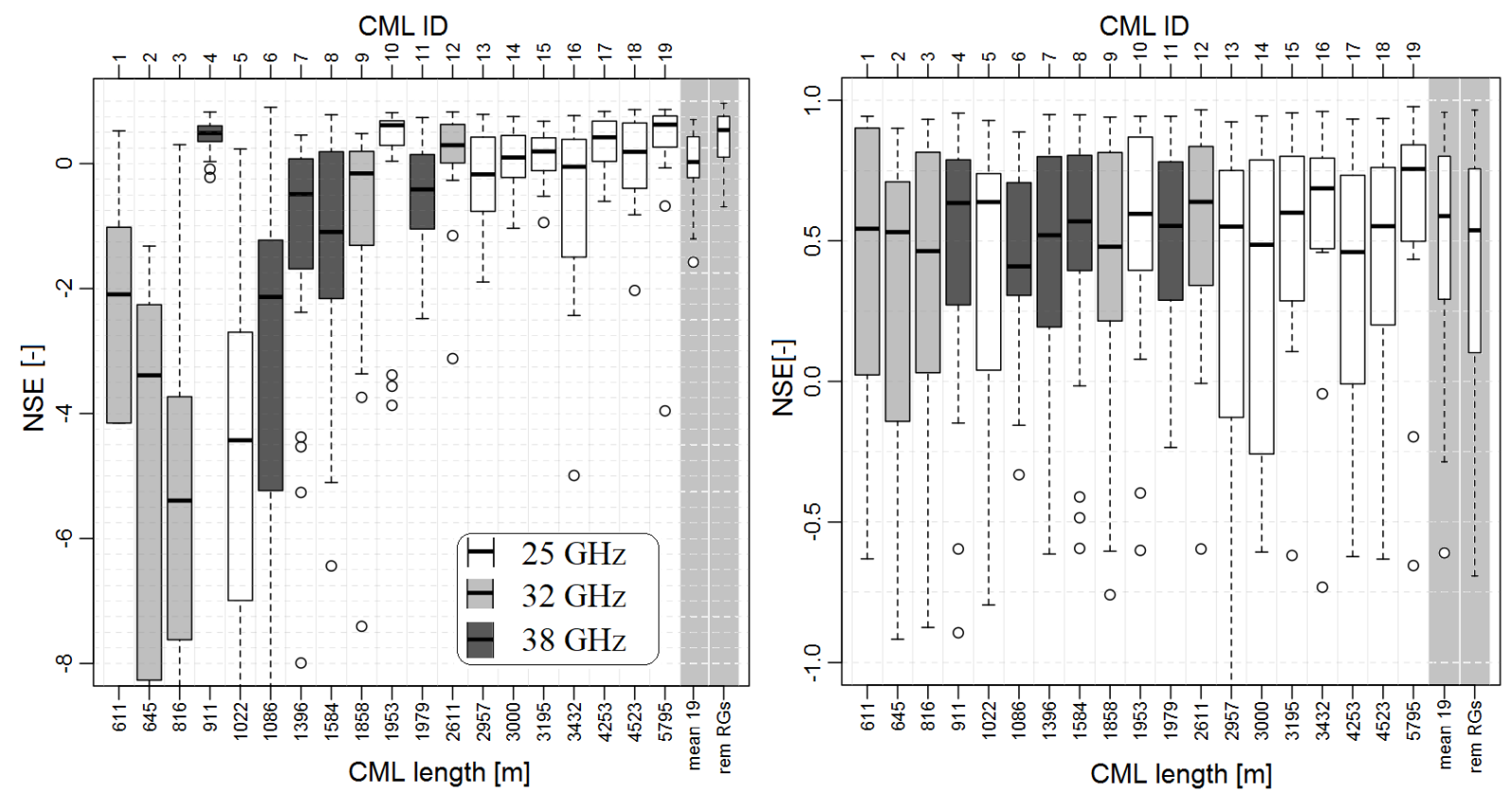

Figure 3. Boxplots of the NSE metric for CMLs of various lengths and frequencies for the heavy events and two investigated ways of using CML QPEs (left - no adjusting, right - adjusting to rain gauge data). Results for the mean of QPEs from all CMLs and for the rain gauges used alone are in both cases on the right.

The results for the heavy events look different when evaluated by the PCC metric. For the unadjusted CML QPEs (Fig. 4 left), there are considerable differences in the variance of the PCC values reached by different links. Low PCC values seem to be connected to the longer CMLs reaching out eastwards from the catchment (\#9, \#11, \#13, \#14, \#17 and \#18) and to those which tend to underestimate the QPEs (\#4, \#10 and \#19). For the CML QPEs adjusted to the rain gauges, the differences among various links are smaller. In general, including also the mean of the QPEs from all CMLs, the PCC values are, both in median and variability, similar to the values obtained when using only the rain gauge data. Interestingly, from all the examined rainfall data time series, the highest PCC values were reached using the mean of the unadjusted QPEs from all available CMLs.

\section{CONCLUSIONS}

Based on the presented results, if there are no additional precipitation data and no prior information about the bias in the QPEs from various CMLs available, we recommend using QPEs derived from longer CMLs. If we have no additional rainfall data but it is possible to learn about the bias in CML QPEs, e.g. from runoff measurements and rainfall-runoff modelling, we recommend using CMLs which do not provide substantially overestimated QPEs, primarily for heavy rainfall events, crucial for management of urban drainage systems. If traditional rainfall data (e.g. from a permanent rain gauge network) are available, then using CML QPEs adjusted to these data, instead of the traditional data alone, can be 


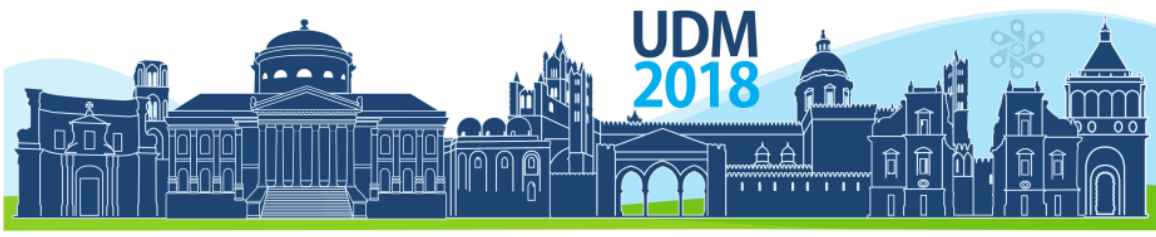

$11^{\text {th }}$ International Conference on Urban Drainage Modelling

23-26 Sep | Palermo - Italy

recommended chiefly for the heavy rainfalls. The mean of the adjusted QPEs from all available CMLs is a robust choice, however, certain CMLs can provide even better information. Since it is not clear how to recognize these CMLs beforehand, we encourage further research on efficient identification of such CMLs or their combinations.
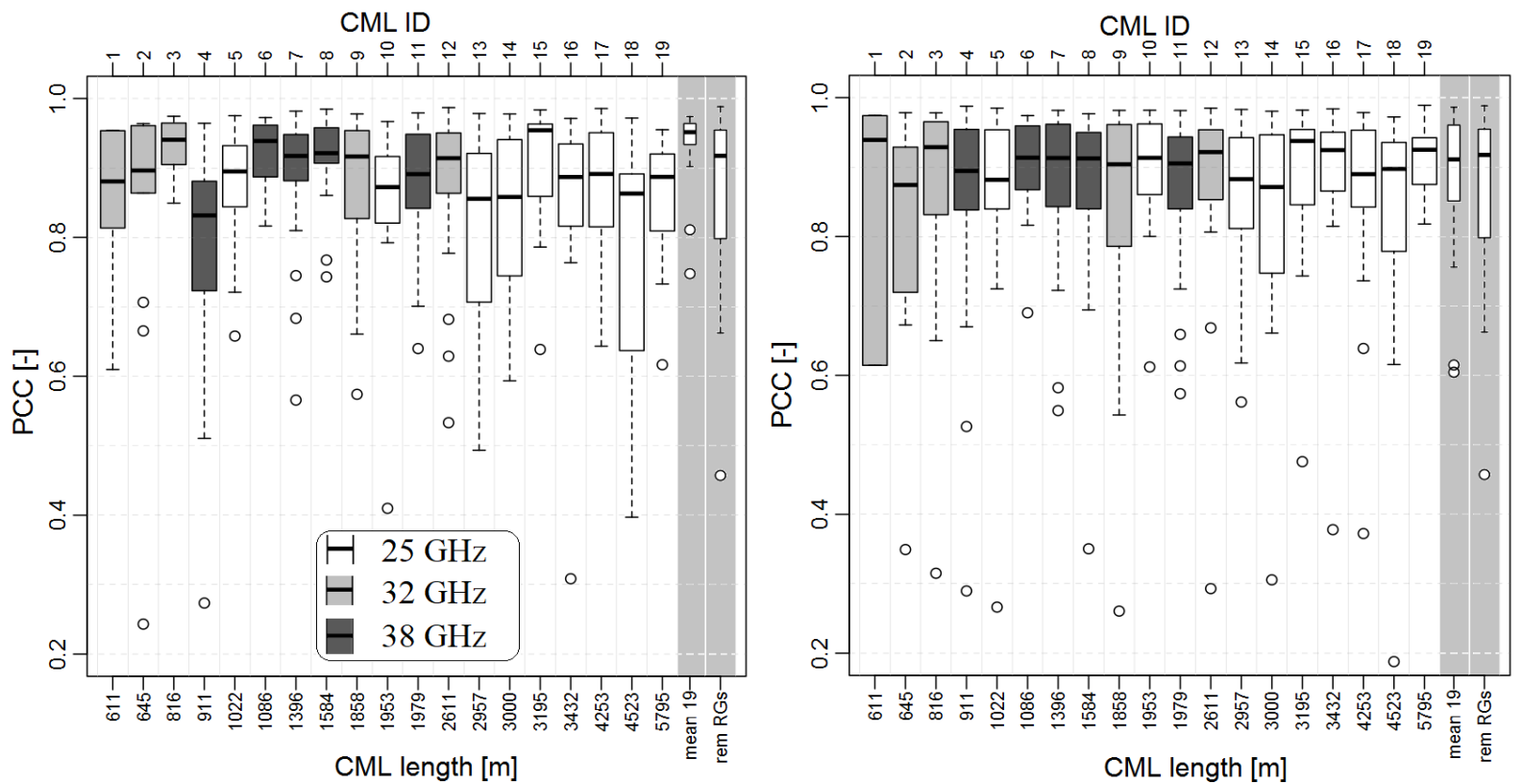

Figure 4. Boxplots of the PCC metric for CMLs of various lengths and frequencies for the heavy events and two investigated ways of using CML QPEs (left - no adjusting, right - adjusting to rain gauge data). Results for the mean of QPEs from all CMLs and for the rain gauges used alone are in both cases on the right.

The analyses of the PCC values shows that there is very valuable information about the temporal dynamics of heavy rainfalls included in the CML precipitation estimates, including those from short links. However, for the purposes of urban drainage modelling, we could additionally benefit from this information only if it was not compromised when reducing the bias in the QPEs. Therefore, further research should focus on improving the methods for bias reduction, potentially not using only additional rainfall data, but also runoff measurements.

\section{ACKNOWLEDGMENT}

This study was supported by the project no. 17-16389S of the Czech Science Foundation and by the project of the Czech Technical University in Prague no. SGS18/053/OHK1/1T/11.

\section{References}

Leijnse, H., Uijlenhoet, R., \& Stricker, J.N.M. (2008) Microwave link rainfall estimation: Effects of link length and frequency, temporal sampling, power resolution, and wet antenna attenuation. Advances in Water Resources 31, 1481-1493, doi:10.1016/j.advwatres.2008.03.004.

Fencl, M., Dohnal, M., Rieckermann, J., \& Bareš, V. (2017) Gauge-adjusted rainfall estimates from commercial microwave links, Hydrology and Earth System Sciences 21, 617-634, doi:10.5194/hess-21-617-2017.

Fenicia, F., Pfister, L., Kavetski, D., Matgen, P., Iffly, J.F., Hoffmann, L. \& Uijlenhoet, R. (2012) Microwave links for rainfall estimation in an urban environment: Insights from an experimental setup in LuxembourgCity. Journal of hydrology 464, 69-78, doi:10.1016/j.jhydrol.2012.06.047.

Overeem, A., Leijnse, H., \& Uijlenhoet, R. (2011) Measuring Urban Rainfall Using Microwave Links from Comercial Cellular Communication Networks. Water Resources Research 47, doi:10.1029/2010WR010350.

Stránský, D., Fencl, M. \& Bareš, V. (2018) Runoff prediction using rainfall data from microwave links: Tabor case study. Water Science and Technology 77, wst2018149, doi:10.2166/wst.2018.149. 


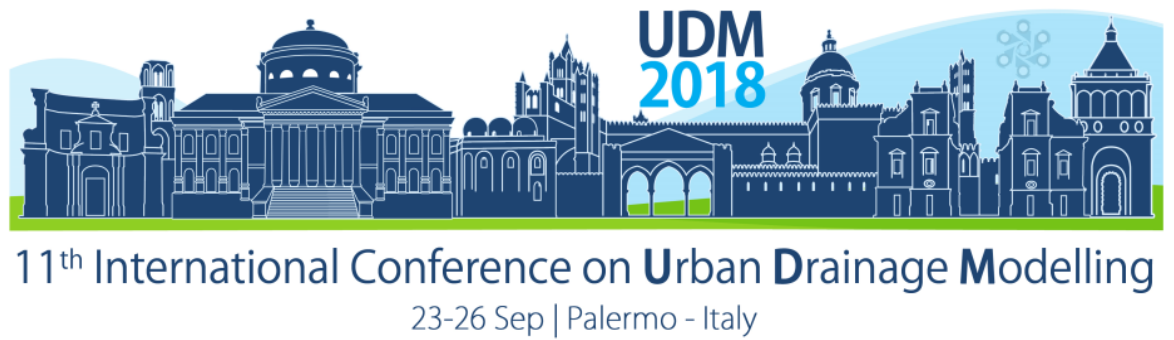

\title{
Flash floods in urban areas: case studies in Reggio Calabria (Italy)
}

\author{
Marcello De Franco ${ }^{1}$, Marianna Minniti ${ }^{1}$, Rosa Versaci ${ }^{1}$, Giandomenico Foti ${ }^{1}$, Caterina Canale $^{1}$ and \\ Pierfabrizio Puntorieri ${ }^{1}$ \\ ${ }^{1}$ Mediterranea University of Reggio Calabria, DICEAM Department, Reggio Calabria, Italy
}

\begin{abstract}
Flash flood is a precipitation of short duration and strong intensity which, generally, takes place in small portions of territory. Italy, due to climate, morphology and anthropization, is particularly subject to these phenomena. The major consequences of the flash floods occur in small basins, characterized by modest times of concentration and low storage capacity, especially if located close to urban areas. From this point of view, the development of alert systems can mitigate the impact of the phenomenon on the population. The paper will analyze the problems related to flash flood through two case studies near Reggio Calabria. It is a site of interest because it is located at the southern end of Calabria region, in the South of Italy, and is particularly prone to flash floods and environmental risks due to the morphological and climatic characteristics of its territory.
\end{abstract}

Keywords: Flash floods; urban drainage; hydrogeological instability, debris flow.

\section{INTRODUCTION}

Flash flood is usually defined as a sudden flood in a small catchment area, occurring after a short time since the start of high intensity rainfall (Braud et al., 2014). The Mediterranean region is prone to flash floods because summer events are usually local and of short duration, while in the autumn, the warmer sea surface temperature, as well as the large number of perturbations, can give rise to flash flood events (Jansà et al., 2014; Llasat et al., 2016). From this point of view, Italy (Fiori et al., 2014) and Calabria, due to their morphological and climatic characteristics, are territories particularly prone to hydrogeological instability phenomena such as flash floods, debris flow, sea storms (Arena et al., 2013; Barbaro et al., 2013) and coastal erosion (Barbaro et al., 2014; Borrello et al., 2017). The most critical aspects are observed when such phenomena occur in urban areas (Mahmood et al., 2017; Bronstert et al., 2018; Scionti et al., 2018), near road infrastructures (Vincendon et al., 2016) or in small ungaged mountain basins (Ragettli et al., 2017) or in the case of concomitant events (Barbaro et al., 2018; Destro et al., 2018), especially if close to the river mouths (Barbaro et al., 2012; Sicilia et al., 2013). Therefore, appropriate mitigation measures should be planned (Barbaro, 2016; Arlikatti et al., 2018) and improvement of the forecasting (Hardy et al., 2016; Lutoff et al., 2016) and alert (Barbaro et al., 2017; Simon et al., 2017) phases. The paper will analyze the problems related to flash floods through two case studies near Reggio Calabria.

\section{CASE STUDIES DESCRIPTION}

The case studies concern a flash flood, with concomitant debris flow, occurred in July 2017 in Scilla, and the flooding of the highway underpass in San Leo, caused by flash flood of November 2011 (Fig. 1). 


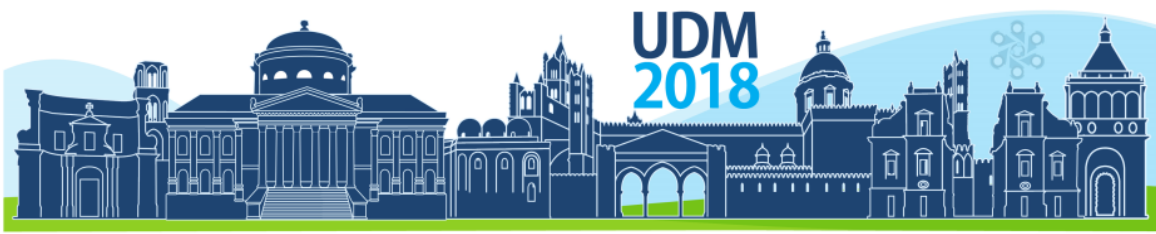

$11^{\text {th }}$ International Conference on Urban Drainage Modelling

23-26 Sep | Palermo - Italy

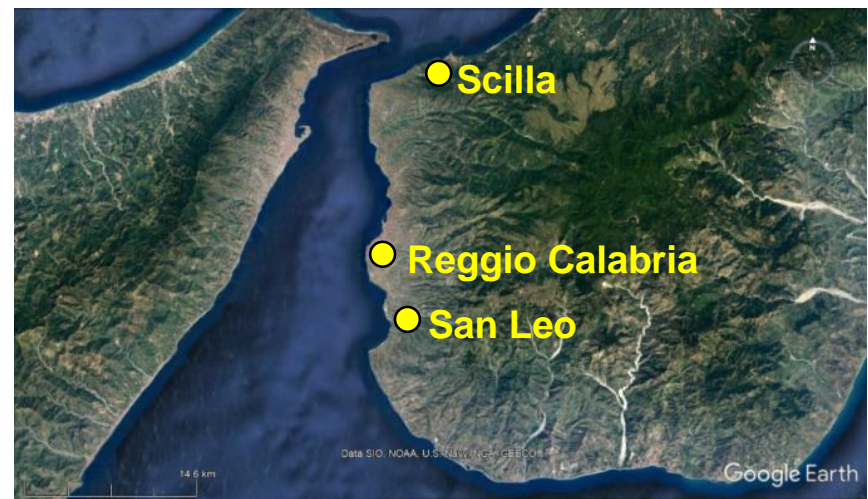

Figure 1. Location of the case studies.

About Scilla, it is a town located about $20 \mathrm{~km}$ North of Reggio Calabria, in a territory compressed between sea and mountain and often subject to phenomena of hydrogeological instability. The flash flood of 16 July 2017 involved the torrent called "Fosso Marina Grande", started at 7:00 am, lasted an hour with rainfall of over $75 \mathrm{~mm}$ (with peak of $12.2 \mathrm{~mm}$ from 7:40 am to 7:45 am) and caused a debris flow that affected the town near the river mouth (Fig. 2). The rainfall data were recorded by Scilla gauge.

The second case concerns the highway underpass in San Leo, which is located in a densely populated area a few kilometers South of Reggio Calabria and has been subject to several flooding since its construction. In particular, flash flood of 9 November 2011 has been analyzed. This flood lasted 20 minutes (from 2:40 pm to $3 \mathrm{pm}$ ) with an accumulation of 14.2 $\mathrm{mm}, 12$ of which are concentrated in 10 minutes (from $2.45 \mathrm{pm}$ to $2.55 \mathrm{pm}$ ), and caused flooding of the underpass with maximum water height exceeding $2 \mathrm{~m}$, indeed the truck shown in Fig. 2 is almost completely flooded. The rainfall data were recorded a few kilometers from the study area by Rosario Valanidi gauge. In the underpass do not flow natural river but collect water from streets and land, furthermore there are some orifices that clog almost totally during intense flood events due to the detritus of various nature carried by the current.

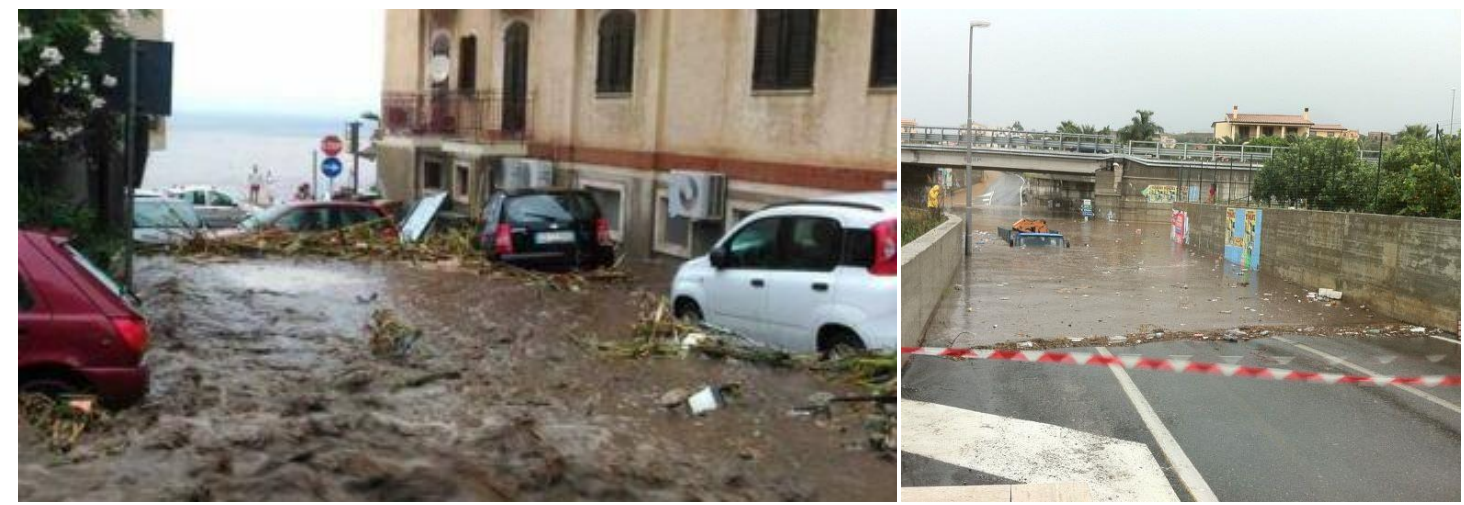

Figure 2. On the left: debris flow in Scilla. To the right: flooding of the highway underpass in San Leo.

\section{MODELING AND DISCUSSION}

In the first case study, the Scilla flash flood was modeled with HEC-HMS (for hydrological modeling, to evaluate the hydrograph generated by the rainfall event) and ADB-TOOLBOX (for debris flow modeling, using the application IDRA2D). The catchment area was perimeter 


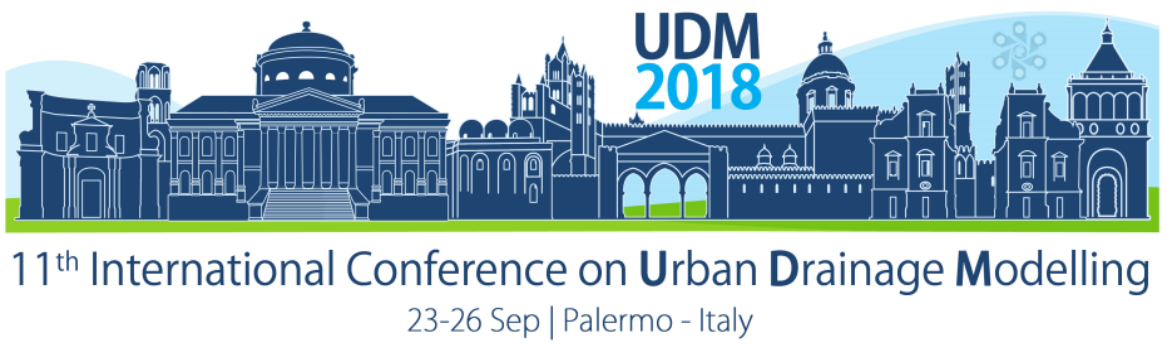

and characterized morphologically by MapWindow and QGIS and the cartographic data were taken from the Calabrian Geoportal. The basin has an area of just $1.3 \mathrm{~km}^{2}$ and a main stream lenght of just $2.3 \mathrm{~km}$. Furthermore, the basin is characterized by a considerable difference in height between the mouth and the mount $(676 \mathrm{~m})$ which, given the short longitudinal development, involves very high slope (above $50 \%$ ) and low concentration time (less than 20 minutes). All these factors increased the danger. About HEC-HMS, the hydrological losses were modeled by the SCS Curve Number Method and to evaluate the surface runoff was used the SCS Unit Hydrograph Method. Therefore, the rainfall event caused a peak discharge of about $7 \mathrm{~m}^{3} / \mathrm{s}$. About ADB-TOOLBOX, debris flow was modeled by the Egashira and Ashida Method and considering erodible bottom. The cartographic data are the LIDAR, with square mesh of $1 \mathrm{~m}$, of the National Geoportal, in which the shapefiles of buildings are also present. The parameters of the Egashira and Ashida Method was calibrated to obtain that the modeled values of debris flow shall agree with the real debris flow values (of the order of thousands of $\mathrm{m}^{3}$, Fig. 4).

In the second case study, the catchment area was perimeter and characterized morphologically by the analysis of the historical satellite imagery of Google Earth (the closest to the event is of 26 November 2011), using Path and Polygon functions. The flash flood was modeled using SWMM. In particular, the entire catchment area (about $400000 \mathrm{~m}^{3}$ ) was divided into 73 subcatchments, with homogeneous characteristics, and the streets was modeled as conduits of open rectangular shape (36 in total), connected by 37 nodes that collect the subcatchments runoff. In the simulation options, the Dynamic Wave was used as a Routing Model, while both the Horton and the Green-Ampt Model was tried as Infiltration Model, obtaining negligible differences between them and, finally, using the Horton Model. The model calibration phase mainly concerned the quantification of the permeable and impermeable areas of each subcatchments and the estimate of the storage depressions depth of both areas. At the end of the calibration phase was obtained a valid correspondence between the observed and the modeled water height, about $1.9 \mathrm{~m}$, in the underpass.
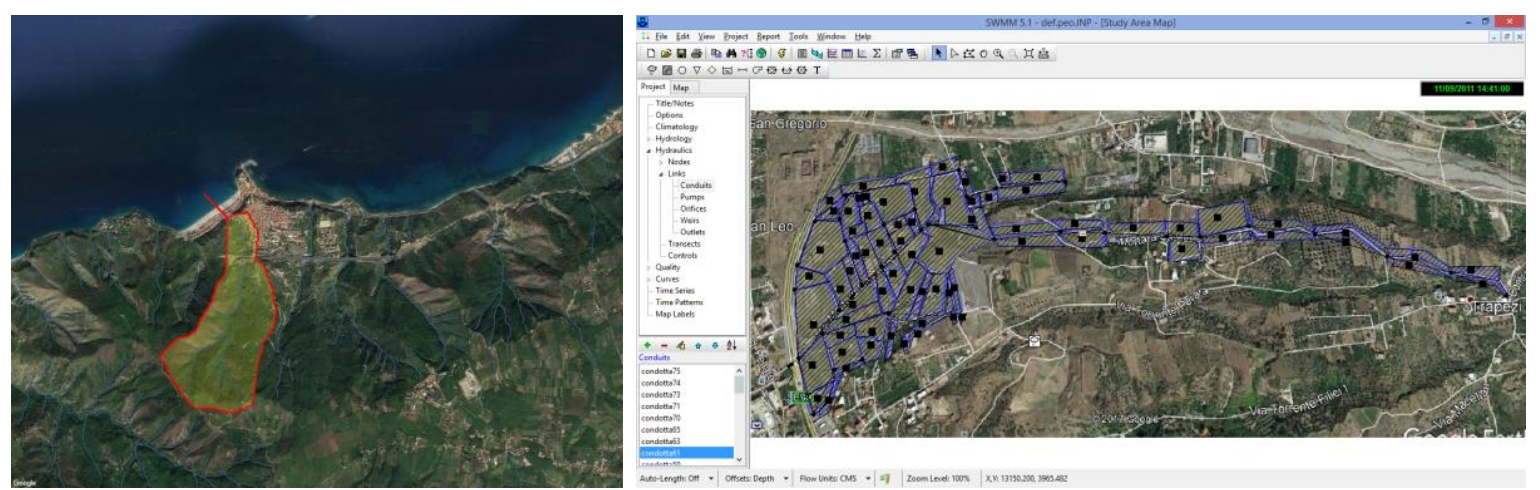

Figure 3. On the left: Fosso Marina Grande River basin. To the right: SWMM model prepared for highway underpass in San Leo. 


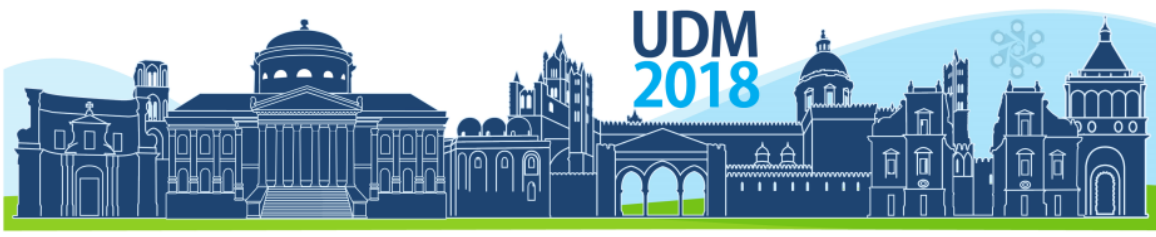

$11^{\text {th }}$ International Conference on Urban Drainage Modelling 23-26 Sep | Palermo - Italy

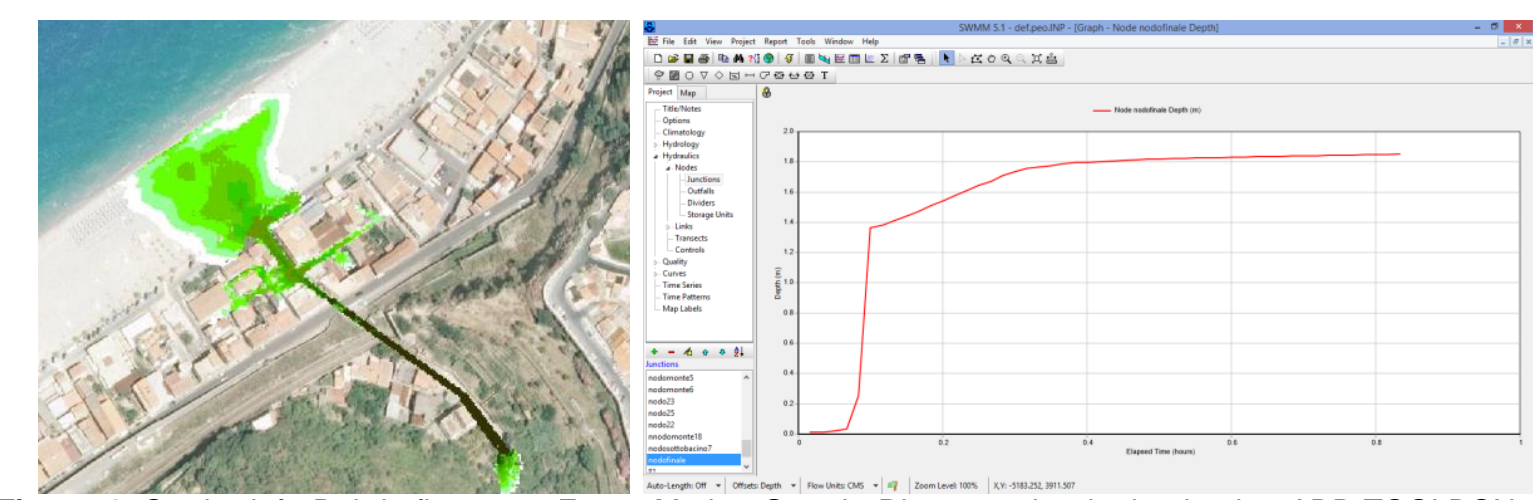

Figure 4. On the left: Debris flow near Fosso Marina Grande River mouth, obtained using ADB-TOOLBOX. To the right: Water depth obtained using SWMM in the node corresponding to the highway underpass in San Leo.

\section{CONCLUSIONS}

The Italian territory, due to its morphological and climatic characteristics and due to the anthropization, is particularly prone to hydrogeological instability phenomena such as flash floods and debris flow. The major consequences of the flash floods occur in small basins, characterized by modest times of concentration and low storage capacity, especially if located close to urban areas. The paper will analyze the problems related to flash floods through two case studies near Reggio Calabria. For the first case study, the Scilla flash flood and debris flow was modeled using MapWindow, QGIS, HEC-HMS and ADB-TOOLBOX. The basin has a small area and a considerable difference in height between the mouth and the mount which, given the short longitudinal development, involves very high slope and low concentration time: all these factors they increase the danger. The peak discharge was about $7 \mathrm{~m}^{3} / \mathrm{s}$ and the modeled values of debris flow, obtained using ADB-TOOLBOX with the Egashira and Ashira Method, shall agree with the real debris flow values (of the order of thousands of $\mathrm{m}^{3}$ ). For the second case study, in the San Leo highway underpass do not flow natural river but collect water from streets and land and there are some orifices that clog almost totally during intense flood events, like the one analyzed in this paper, due to the detritus of various nature carried by the current. In particular, flash flood of 9 November 2011 has been modeled using Google Earth and SWMM. The entire catchment area (about $400000 \mathrm{~m}^{3}$ ) was divided into 73 subcatchments, with homogeneous characteristics, and the streets was modeled as conduits of open rectangular shape (36 in total), connected by 37 nodes that collect the subcatchments runoff. Using the Dynamic Wave as a Routing Model, and the Horton as Infiltration model, have been obtained a valid correspondence between the observed and the modeled, about $2 \mathrm{~m}$, water height in the underpass. The paper, also, shows that modeling plays a fundamental role in understanding phenomena like flash floods and debris flow. Furthermore, the analysis of the phenomena that have occurred allows us to properly calibrate the models.

\section{References}

Arena, F., Barbaro, G. and Romolo, A. (2013a) Return period of a sea storm with at least two waves higher than a fixed threshold. Mathematical Problems in Engineering, 1-6.

Arlikatti, S., Maghelal, P., Agnimitra, N. and Chatterjee, V. (2018) Should I stay or should I go? Mitigation strategies for flash flooding in India. International Journal of Disaster Risk Reduction, 27, 48-56.

Barbaro, G. (2016) Master Plan of solutions to mitigate the risk of coastal erosion in Calabria (Italy), a case study, Ocean \& Coastal Management, 132, 24-35.

Barbaro, G., Foti, G. and Malara, G. (2013) Set-up due to random waves: influence of the directional spectrum. International Journal of Maritime Engineering, 155, A105-A115. 


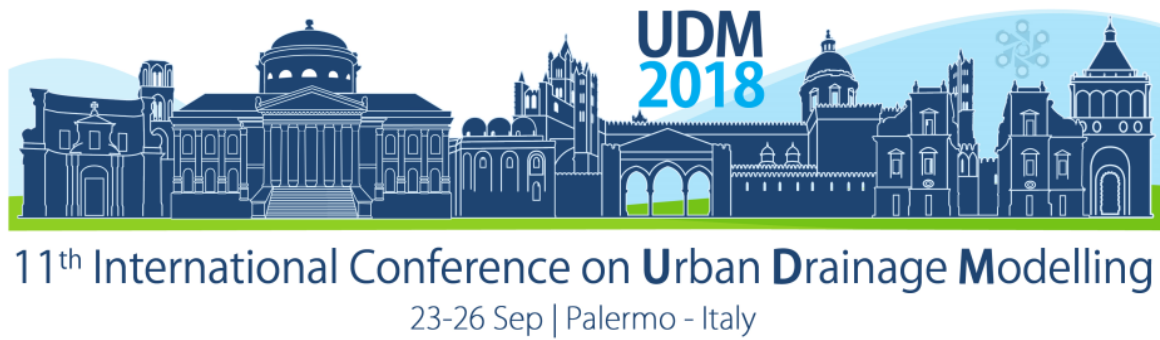

Barbaro, G., Foti, G., Mandaglio G., Mandaglio, M. and Sicilia, C. L. (2012) Estimate of sediment transport capacity in the basin of the Fiumara Annunziata (RC). Rendiconti Online Società Geologica Italiana, 21(1), 696-697.

Barbaro, G., Foti, G. and Sicilia, C.L. (2014) Coastal erosion in the South of Italy. Disaster Advances, 7, 37-42.

Barbaro, G., Gangemi, M.D. and Foti, G. (2017) An agent-based tsunami alert system. Prooceding of the $18^{\text {th }}$ Internationl Workshop "From Objects to Agents" (WOA), Scilla, Italy.

Barbaro, G., Petrucci, O., Canale, C., Foti, G., Mancuso, P. and Puntorieri, P. (2018) Contemporaneity of floods and storms. A case study of Metropolitan Area of Reggio Calabria in Southern Italy. Prooceedings of New Metropolitan Perspectives (NMP), Reggio Calabria, Italy.

Borrello, M.M., Foti, G. and Puntorieri, P. (2017) Shoreline evolution near the mouth of the Petrace River (Reggio Calabria, Italy). Proceedings of the $9^{\text {th }}$ International Conference on River Basin Management, Prague, Czech Republic.

Braud, I., Bouvier, C., Branger, F., Delrieu, G., Le Coz, J., Nord, G., Vandervaere, J.-P., Anquetin, S., Adamovic, M., Andrieu, J., Batiot, C., Boudevillain, B., Brunet, P., Carreau, J., Confoland, A., Didon-Lescot, J.-F., Domergue, J.-M., Douvinet, J., Dramais, G., Freydier, R., Gérard, S., Huza, J., Leblois, E., Le Bourgeois, O., Le Boursicaud, R., Marchand, P., Martin, P., Nottale, L., Patris, N., Renard, B., Seidel, J.-L., Taupin, J.-D., Vannier, O., Vincendon, B. and Wijbrans, A. (2014) Multi-scale hydrometeorological observation and modelling for flash flood understanding. Hydrological and Earth System Science, 18, 3733-3761.

Bronstert, A., Agarwal, A., Boessenkool, B., Crisologo, I., Fischer, M., Heistermann, M., Kohn-Reich, L., LopezTarazon, J.A., Moran, T., Ozturk, U., Reinhardt-Imjela, C. and Wendi, D. (2018) Forensic hydrometeorological analysis of an extreme flash-flood: The 2016-05-29 event in Braunsbach, SW Germany. Science of Total Environment, 630, 977-991.

Destro, E., Amponsah, W., Nikolopoulos, E.I., Marchi, L., Marra, F., Zoccatelli, D. and Borga, M. (2018) Coupled prediction of flash flood response and debris flow occurrence: Application on an alpine extreme flood event. Journal of Hydrology, 558, 225-237.

Fiori, E., Comellas, A., Molini, L., Rebora, N., Siccardi, F., Gochis, D.J., Tanelli, S. and Parodi, A. (2014) Analysis and hindcast simulations of an extreme rainfall event in the Mediterranean area: The Genoa 2011 case. Atmosferic Research, 138, 13-29.

Hardy, J., Gourley, J.J., Kirstetter, P.E., Hong, Y., Kong, F. and Flaming, Z.L. (2016) A method for probabilistic flash flood forecasting. Journal of Hydrology, 541, 480-494.

Jansa, A., Alpert, P., Arbogast, P., Buzzi, A., Ivancan-Picek, B., Kotroni, V., Llasat, M.C., Ramis, C., Richard, E., Romero, R. and Speranza, A. (2014) MEDEX: a general overview. Natural Hazards and Earth System Sciences, 14, 1965-1984.

Llasat, M.C., Marcos, R., Turco, M., Gilabert, J. and Llasat Botija, M. (2016) Trends in flash flood events versus convective precipitation in the Mediterranean region: The case of Catalonia. Journal of Hydrology, 541, 2437.

Lutoff, C., Creutin, J.D., Ruin, I. and Borga, M. (2016) Anticipating flash floods: multi-scale aspects of the social response. Journal of Hydrology, 541, 626-635.

Mahmood, M.I., Elagib, N.A., Horn, F. and Saad, S.A.G. (2017) Lesson learned from Kharthoum flash flood impacts: An integrated assessment. Science of Total Environment, 601-602, 1031-1045.

Ragettli, S., Zhou, J., Wang, H., Liu, C. and Guo., L. (2017) Modeling flash floods in ungauged mountain catchments in China: A decision tree learning approachfor parameter regionalization. Journal of Hydrology, 555, 330-346.

Scionti, F., Miguez, M.G., Barbaro, G., De Sousa, M.M., Foti, G. and Canale, C. (2018) Integrated methodology for urban flood risk mitigation in Cittanova (Italy). Journal of Water Resources, Planning and Management (in press).

Sicilia, C.L., Foti, G. and Campolo, A. (2013) Protection and management of the Annunziata river mouth area (Italy). Journal of Air, Soil and Water Research, 6, 107-113.

Simon, E., Vincendon, B. and Ducrocq, V. (2017). Ensemble-based flash-flood modeling: Taking into account hydrodynamic parameters and initial soil moisture uncertainties. Journal of Hydrology (in press).

Vincendon, B., Edouard, S., Dewaele, H., Ducrocq, V., Lespinas, F., Delrieu, G. and Anquetin, S. (2016) Modeling flash floods in Southern France for road management purposes. Journal of Hydrology, 541, 190-205. 


\section{Part E - Urban hydrologic and hydraulic processes}




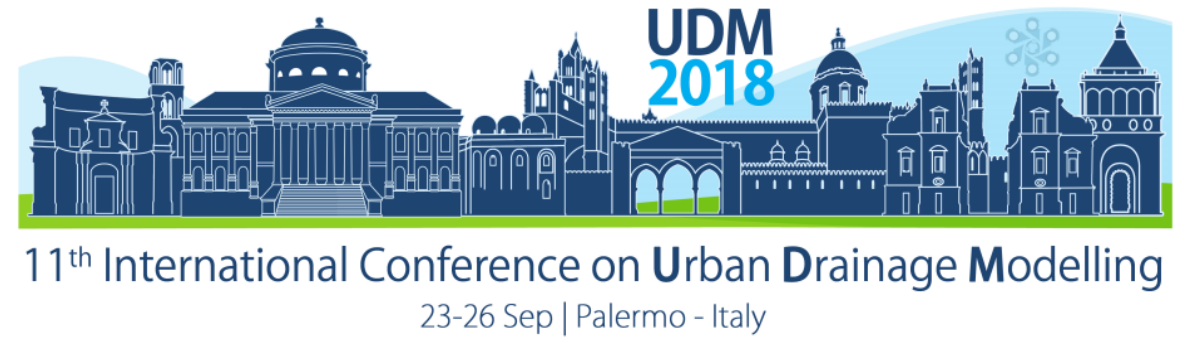

\title{
Automatic Discretization and Parameterization of watersheds using a digital elevation model
}

\author{
Karen Finney ${ }^{1}$, Rob James ${ }^{2}$, Nandana Perera ${ }^{3}$ and Tiehong Xiao ${ }^{4}$ \\ ${ }^{1} \mathrm{CHI}$, karen@chiwater.com, Engineering, Guelph, Ontario, Canada \\ 2 CHI, rob@chiwater.com, CEO, Guelph, Ontario, Canada \\ ${ }^{3} \mathrm{CHI}$, nandana@chiwater.com, Engineering, Guelph, Ontario, Canada \\ ${ }^{4} \mathrm{CHI}$, tiehong@chiwater.com, Programming, Guelph, Ontario, Canada
}

\begin{abstract}
Characterization of overland and channelized flow is crucial for understanding runoff. This paper examines the SWMM setup and parameterization of an existing model and one highly discretized using a watershed delineation/parameterization tool.
\end{abstract}

Keywords: Hydrology, Discretization, Hydraulics

\section{INTRODUCTION}

Modelling large watersheds requires the characterization of both overland and channelized flow. It is essential that these two types of flow are distinguished from one another. This can be achieved by creating a higher resolution model that better accounts for the watershed processes, particularly in headwater areas, by better representing additional processes occurring on watershed surfaces. Due to common project time and budget constraints, model discretization is limited, both in the required data collection and model development time. Thus, watersheds are generally divided into a small number of coarse subcatchments with resolutions of 100 - 400 ha and parameters such as slope, imperviousness and infiltration averaged across each subcatchment.

Calibrating coarse watershed models to match observed flows at downstream locations can result in calibrating parameters beyond their reasonable bounds thus producing unrealistic head water hydrographs. While it is never possible to completely characterize watershed hydrological processes, separating sheet flow from concentrated flow and groundwater can better account for the overland processes without having to artificially change parameters to meet observed flows.

\section{MATERIALS AND METHODS}

\subsection{Watershed delineation tool (WDT)}

PCSWMM's watershed delineation tool was used to re-delineate subcatchments for an existing SWMM5 model and increase the level of discretization in the hydraulic portion using a digital elevation model (DEM).

The watershed delineation tool uses sequential computations of flow direction, flow accumulation, and stream definition based on a threshold and watershed delineation (Jenson and Domingue, 1988; Maidment, 2002). The results of each process are saved to a grid layer for review by the user. All created grid layers are saved to the same folder as the selected DEM layer in Arcinfo binary grid format (FLT). 


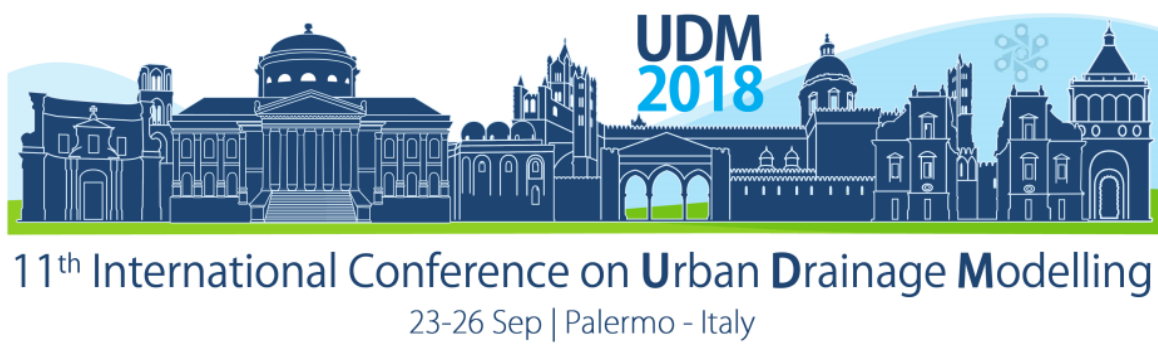

To estimate flow length, the WDT uses the Guo and Urbonas (2009) method that applies a kinematic wave approach to convert irregular shaped subcatchments to equivalent rectangular planes. Using this method, subcatchment length values are estimated using a kinematic shape factor assigned based on the stream location in relation to the subcatchment and longitudinal elevation drop of the receiving concentrated flow channel. Thus, application of the WDT helps to avoid excessively long overland flow paths that violate the sheet flow approximation and helps to overcome rectangular subcatchment shape limitations.

\subsection{Case Study}

The following case study compares two similar models of the Don River watershed. Situated in Southern Ontario, the Don River watershed has an area of 36000 ha and is home to 1.2 million residents. The first model, referred to heron in as the original model, has a coarse resolution with 67 subcatchments, 2842 conduits and 2472 junctions. The second model was built using the WDT and had a significantly higher resolution, specifically in the hydrology portion of the model, with 475 subcatchments, 2938 conduits and 2581 junctions.

The hydraulic network in the original Don River SWMM5 model was assembled using 35 existing HEC-RAS basin models, with some modifications based on stormwater infrastructure updates. The hydrology portion of the model was based on a subcatchment layer and the attribute values were estimated using area-weighting operations from a soils and land-use map. The remaining subcatchment attributes were estimated using a provided digital elevation model (DEM). The model was calibrated using observed rainfall and flow monitoring data to a level suitable for predicting the peak flows for large events.

The second model was built using the WDT and allowed every subcatchment to have an outlet node directly downstream. In this model, the original hydraulics were kept, and additional branches were added to the upstream areas of the watershed. Lumped stormwater ponds from the original model were edited to match the resolution of the new WDT subcatchments. Hydrology parameters were assigned using the same soils and land-use layers used in the original model. Both sets of model parameters were calibrated separately and optimized to best match observed flows, using the same level of effort.

\section{RESULTS AND DISCUSSION}

\subsection{Minor headings}

A total of 10 events were selected for the comparison and ranged from $10.2 \mathrm{~mm}-51.8 \mathrm{~mm}$. In all event hydrographs comparisons, the peak flows in the detailed model better match the observed flows when compared to the coarse model. In addition, both the receding limbs and climbing limbs were improved in the detailed model. Figure 1 shows the resultant hydrograph for one of the largest events. In this plot the observed hydrograph is shown in red, the course model results are shown in purple and the course model is shown in green. 
Proceedings of the 11th Int. Conference on Urban Drainage Modelling, 23-26 Sep. 2018, Palermo (ITALY). Ed. prof. Giorgio Mannina

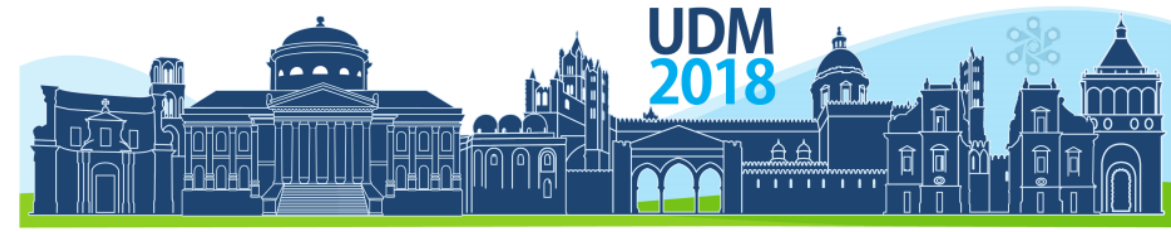

$11^{\text {th }}$ International Conference on Urban Drainage Modelling

23-26 Sep | Palermo - Italy

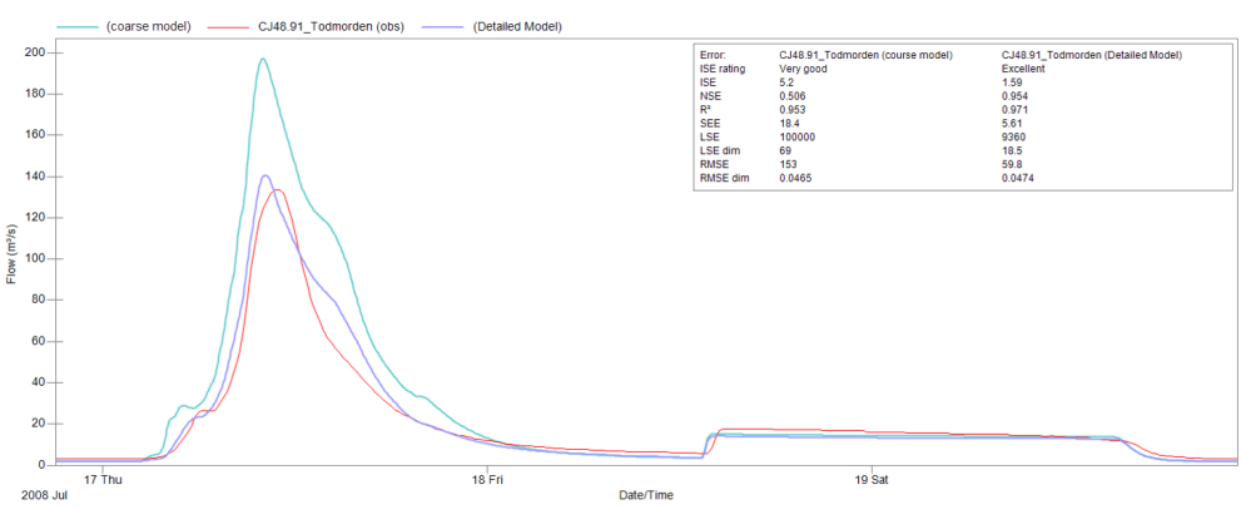

Figure 1. Event 1 comparison showing hydrographs for both the coarse and detailed models

Figures 2 and 3 show the event comparison plots for the event peak and totals.

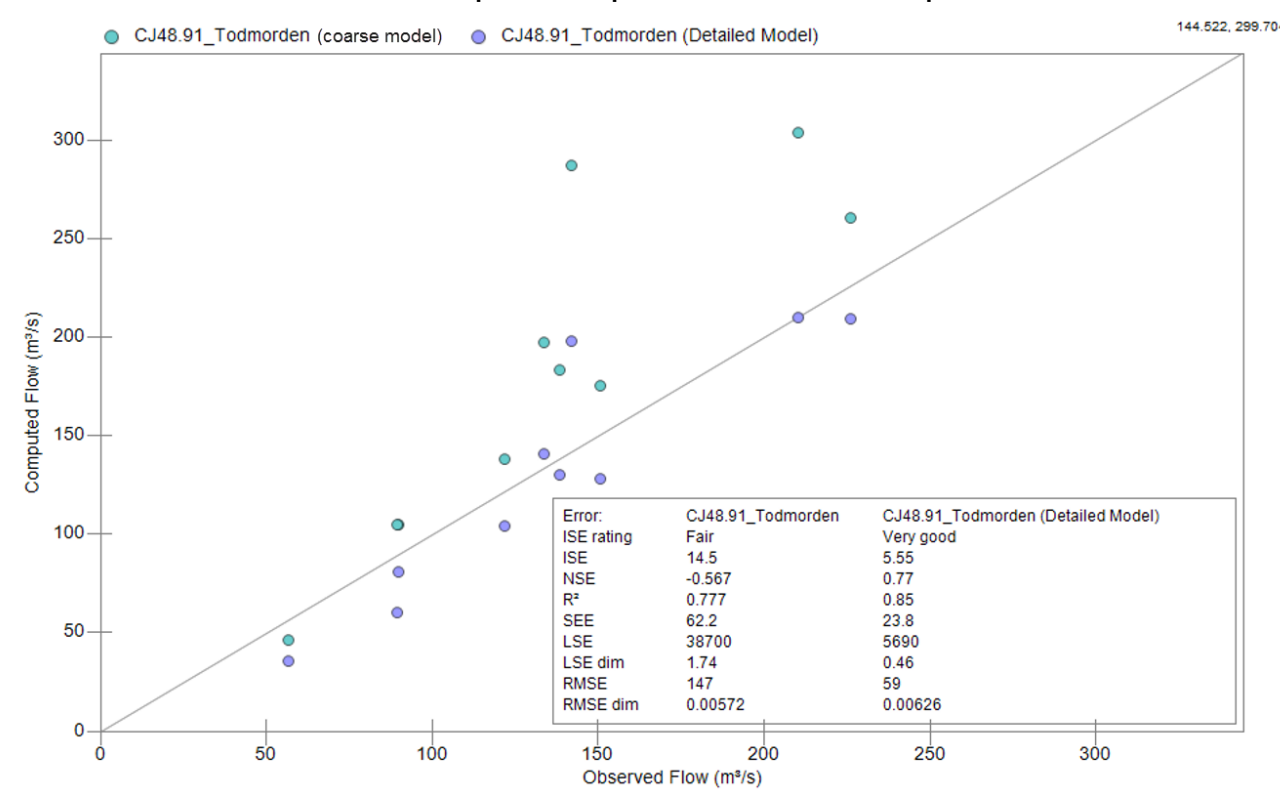

Figure 2. Peak flow event comparison for coarse and detailed models 


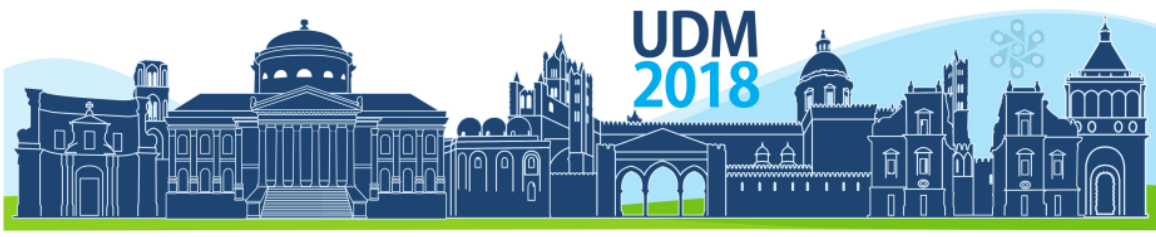

$11^{\text {th }}$ International Conference on Urban Drainage Modelling 23-26 Sep | Palermo - Italy

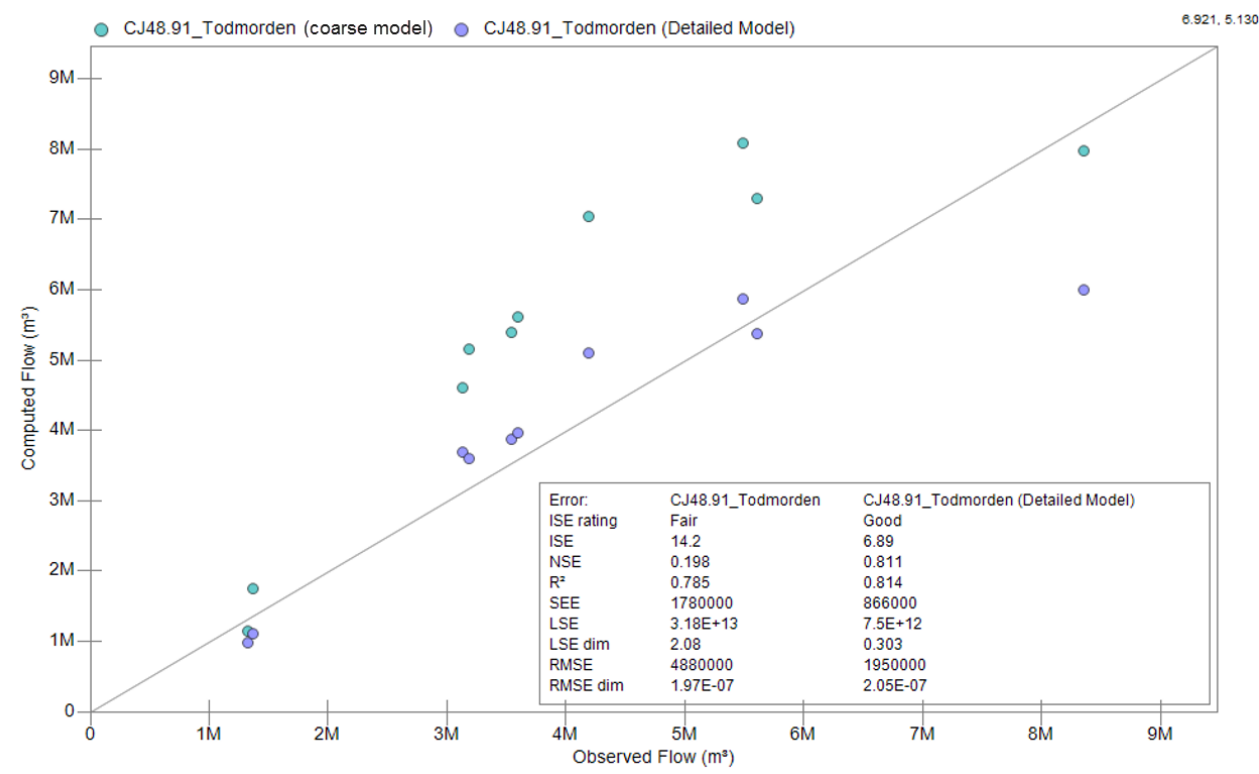

Figure 3. Total flow event comparison for coarse and detailed models

In both comparisons it was found that by increasing the resolution of the hydrology and hydraulic components in the Don River watershed, the hydrograph peaks and overall shape of the flow response were better captured.

\section{CONCLUSIONS}

The WDT automatically generates subcatchments and parameterizes elevation-based attributes such as slope and overland flow length using a DEM layer and a user-defined target discretization value. By further discretizing the watershed, the processes involved with channelized flow and sheet flow can be better represented.

Although limited modelling budgets and short time lines are still common, the technology and the data resources to improve model calibration and validation is available.

Creating a higher resolution model that better accounts for the watershed processes, particularly in headwater areas, result in a reliable tool that can be used for future applications.

Significant infrastructure expenditures are based on the application of stormwater models and it is therefore important to have a model capable of predicting flows for a variety of events. For the modeler, the benefits of a high-resolution calibrated / validated model include: better understanding of the modelled system; improved confidence and reliability in model results, model credibility and wider acceptance of engineering recommendations.

\section{References}

Guo, J.C.Y. and B. Urbonas. 2009. Conversion of natural watershed to kinematic wave cascading plane. Journal of Hydraulic Engineering. 14(8): 839-846

Jenson, S. K., and J. O. Domingue. 1988. Extracting Topographic Structure from Digital Elevation Data for Geographic Information System Analysis. Photogrammetric Engineering and Remote Sensing, 54 (11): 15931600

Maidment, D.R. 2002. Arc Hydro: GIS for Water Resources. ESRI Press. 


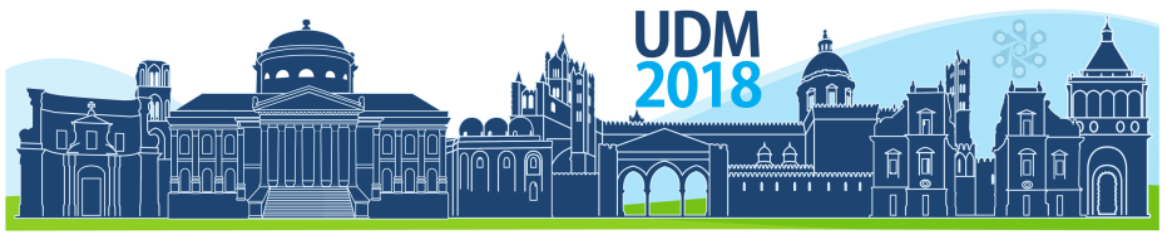

$11^{\text {th }}$ International Conference on Urban Drainage Modelling

23-26 Sep | Palermo - Italy

\title{
Determination of pluvial flood hazards for critical infrastructures and buildings taking in account impacts of grid resolution in grid- based flood models
}

\author{
Michael Jeskulke ${ }^{1,3}$, André Liebscher ${ }^{2}$, Holger Hoppe ${ }^{1}$ and Theo G. Schmitt ${ }^{3}$ \\ ${ }^{1}$ Dr. Pecher AG, Klinkerweg 5, 40699 Erkrath, Germany \\ ${ }^{2}$ Technical University Kaiserslautern, Department of Mathematics, 67653 Kaiserslautern, Germany \\ 3 Technical University Kaiserslautern, Department of Civil Engineering, 67653 Kaiserslautern, Germany
}

\begin{abstract}
The identification of flood hazards and flood risks (spatial overlay of flood hazards and potential damage) are basic tasks of flood risk management. Due to a lack of data for a comprehensive assessment of potential damage in urban areas, flood risks are often only determined for buildings (based on the building use from real estate cadastres). Therefore, building-related statements about flood hazards are required to assess flood risks. In practice, flood hazards for buildings are usually determined from results of hydrodynamic 2D surface runoff models using simple methods. These methods do not take into account the fact that building structures in the model may differ from the data of the underlying cadastre. This is particularly relevant for grid-based models, where the structure of a building in the model depends on the resolution of the calculation grid. To avoid inaccuracies inherent to these methods, we introduce a new algorithm. It first evaluates the results of a grid-based model on the basis of the calculation grid and then links them to the underlying building structures from the cadastre. Thus, differences between the rasterized buildings and their structure in the cadastre are taken into account. In addition we investigate the dependence of the results of the algorithm on the resolution of the calculation grid.
\end{abstract}

Keywords: pluvial flood risks, risk management, buildings, urban flooding

\section{Determining flood risks - background, difficulties and solutions}

The Intergovernmental Panel on Climate Change (IPCC) assumes that heavy rainfall events in middle latitudes will increase in frequency and intensity over the next few decades as a result of climate change (IPCC, 2014). To avoid property damage and personal injury caused by heavy rainfall in urban areas, efficient flood prevention will become indispensable.

Flood prevention comprises three tasks, namely, risk management, water-sensitive urban design and public relations (Jeskulke et al., 2017). According to this division, risk management includes the ascertainment of flood hazards ${ }^{1}$, the spatial overlay of flood hazards and potential damage (flood risks ${ }^{1}$ ) and the development of protective measures. While flood hazards can be calculated using hydrodynamic 2D surface runoff models or interlinked 1D/2D sewer network and surface runoff models, the estimation of potential damage is more difficult due to the lack of available data (DWA, 2016). Therefore, flood risks are assessed for individual buildings only. Based on building use information from official real

${ }^{1}$ The terms "flood hazard" and "flood risk" are defined according to the understanding of the European Union (EU, 2007). 


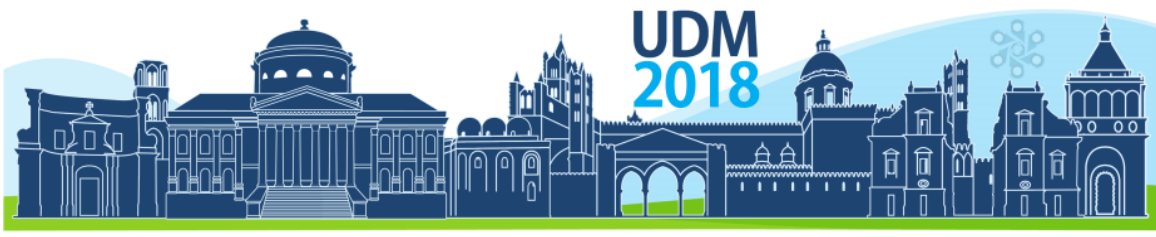

$11^{\text {th }}$ International Conference on Urban Drainage Modelling

23-26 Sep | Palermo - Italy

estate cadastres, damage can at least be estimated in a simplified way. The German Association for Water, Wastewater and Waste (DWA) recommends carrying out corresponding evaluations on the basis of building structures from the official real estate cadastre called ALKIS (DWA, 2016).

If the potential damage is determined for each building, it is also necessary to make a statement on the building-related hazard. In practice, flood hazards are usually determined by simply checking the distance between buildings and calculated floodplains or by evaluating the water levels in a certain radius around a building (Fig. 1). However, these methods disregard that the building structures in the model may differ from those of the underlying data from the cadastre. This is particularly true for grid-based (surface) models, where the structure of the buildings at the model level ("model building") depends on the resolution of the calculation grid. Especially at low resolutions (e. g. $5 \mathrm{~m} \times 5 \mathrm{~m}$ ) the structures in the model may deviate from the structures in ALKIS ("ALKIS building") (Fig. 1). Even flow obstacles may arise that significantly influence the drainage process (Fig. 2).

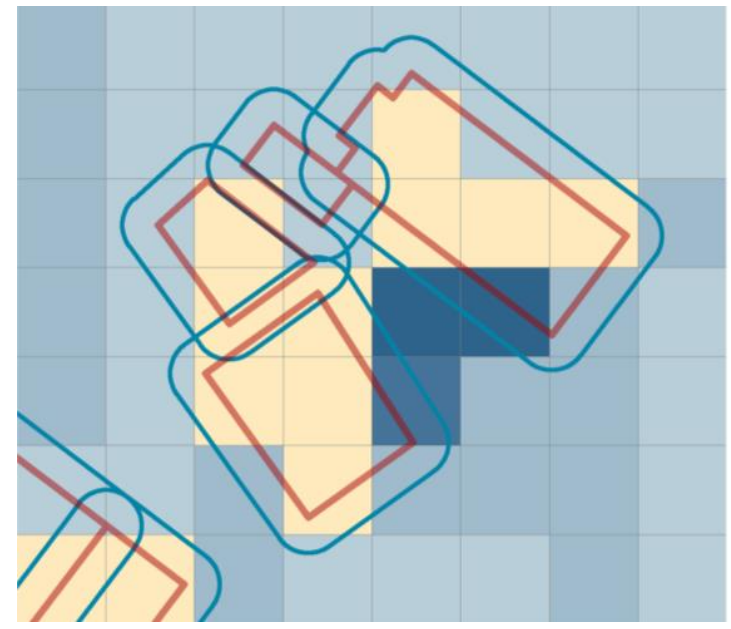

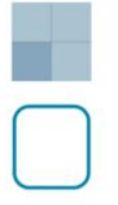

calculated water levels

search radius for the determination of a building-related water level based on the ALKIS structure

discretization of the ALKIS building

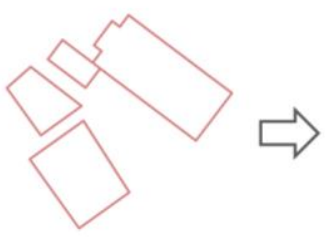

ALKIS building

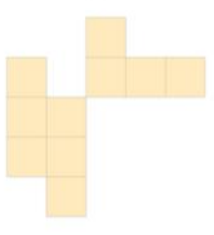

model building

Figure 1.Differences between the building structure in the official real estate cadastre ALKIS (ALKIS building) and the building structure in a grid-based 2D surface runoff model (model building)

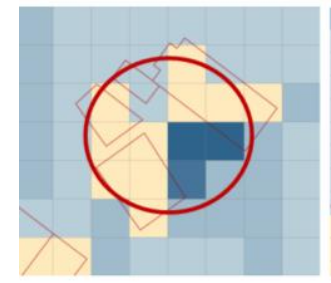

$5 \mathrm{~m} \times 5 \mathrm{~m}$ grid

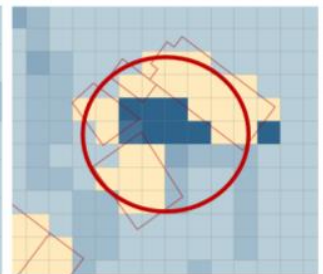

$3 \mathrm{~m} \times 3 \mathrm{~m}$ grid

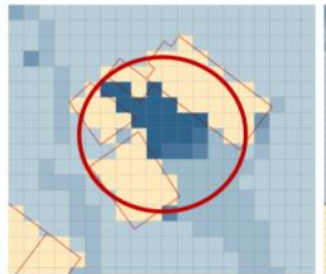

$2 \mathrm{~m} \times 2 \mathrm{~m}$ grid

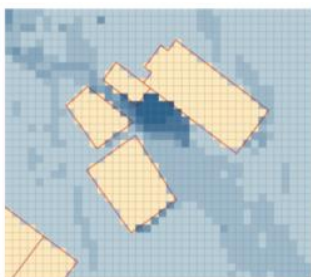

$1 \mathrm{~m} \times 1 \mathrm{~m}$ grid

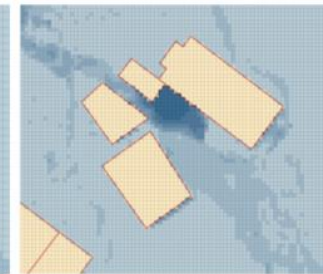

$0,5 \mathrm{~m} \times 0,5 \mathrm{~m}$ grid

Figure 2.Development of flow obstacles at low resolution of the calculation grid

To avoid inaccuracies arising from sole evaluations based on ALKIS buildings, we present a new algorithm. It first evaluates the results of the grid-based runoff model and then links these results to the underlying building structures from ALKIS. In contrast to the simplified GIS analyzes described above (Fig. 1), the algorithm takes into account for the first time differences between the respective building structures. Hints on similar methods for the 


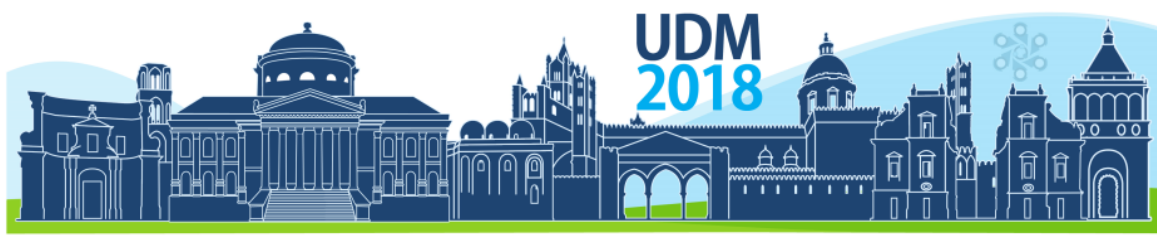

$11^{\text {th }}$ International Conference on Urban Drainage Modelling

23-26 Sep | Palermo - Italy

evaluation of 2D grid-based models have not been found despite extensive literature research. The following section describes the algorithm in more detail. In section 3 we study the influence of the resolution of the calculation grid on the results of the algorithm.

\section{Determining flood hazards for buildings}

Our algorithm evaluates the results of grid-based flood models and works with GIS-tools included in many open source and commercial software solutions. Simple application and transferability is thus guaranteed. The algorithm determines a maximum water level for each ALKIS building. This value serves as input for the identification of flood risks. Determining a maximum water level takes into account that for pluvial flooding the water levels around a building may differ substantially. This is contrary to fluvial flooding, where a building is entirely surrounded by water and thus only one water level needs to be accounted for.

The computation of the maximum water level comprises two steps (Fig 3). The first step is carried out at the model level. For each cell of a model building the maximum water level is determined from the eight surrounding cells of the calculation grid $\left(w_{\max , 1}\right)$. In the second step the algorithm links the model results to the ALKIS buildings. For each ALKIS building, the maximum value $\left(\mathrm{w}_{\max , 2}\right)$ is calculated from the cells of the model building $\left(\mathrm{w}_{\max , 1}\right)$ that overlap with the area of the ALKIS building.

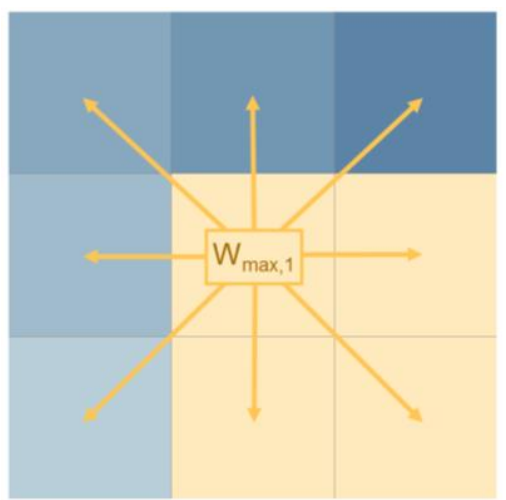

step 1

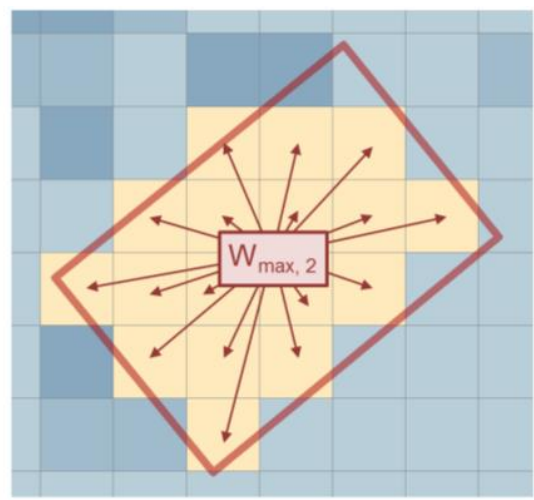

step 2

Figure 3.Determination of a maximum water level for an ALKIS building in two steps

The algorithm was implemented and tested with the Software ArcGIS from ESRI. In order to use vector-based tools, the raster data (buildings and water levels) were first converted to vector data (polygons). With the help of Spatial Joins the water levels $W_{\max , 1}$ and $W_{\max , 2}$ could be determined in the second step. The simplification of this approach using zonal statistics is currently under investigation.

\section{Impact of the grid resolution}

The resolution of the calculation grid has a high influence on the calculation results of surface runoff models (De Almeida et al., 2018; Hsu et al., 2016; Néelz et al., 2009). To study the effect of the grid resolution on the results of the algorithm, we chose a reprehensive catchment area in the city of Bornheim (Germany) with 2297 buildings. For each building, we 


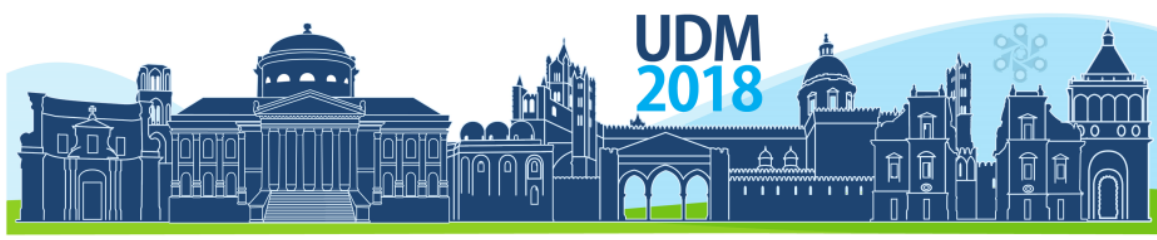

$11^{\text {th }}$ International Conference on Urban Drainage Modelling

23-26 Sep | Palermo - Italy

calculated the maximum water level using a 2D surface runoff model at eight resolutions, that is, at a grid size of $0.125^{2} \mathrm{~m}^{2}, 0.25^{2} \mathrm{~m}^{2}, 0.5^{2} \mathrm{~m}^{2}, 1^{2} \mathrm{~m}^{2}, 2^{2} \mathrm{~m}^{2}, 3^{2} \mathrm{~m}^{2}, 4^{2} \mathrm{~m}^{2}$ and $5^{2} \mathrm{~m}^{2}$. To assess the influence of resolution, we assume that the water level computed at a grid size of $0.125^{2} \mathrm{~m}^{2}$ gets closest to the "true value" and thus serves as reference.

We describe the influence of the grid resolution by the proportion $\mathrm{P}_{\delta}$ of buildings whose maximum water level deviates by more than a fixed value $\delta$ (in $\mathrm{m}$ ) from the reference value. The value $\delta$ characterizes the maximum tolerable error in water level with respect to a chosen grid size. Hence, $P_{\delta}$ increases with decreasing $\delta$ for a fixed grid size as illustrated in Fig. 4. At a resolution of $1 \mathrm{~m} \times 1 \mathrm{~m}$, for example, the deviation of the water levels is less than $10 \mathrm{~cm}$ for more than $80 \%$ of the buildings and less than $15 \mathrm{~cm}$ for $90 \%$ of the buildings.

The influence of the grid size is defined by $\mathrm{P}_{\delta}$ for fixed $\delta$ and follows the model

$$
\mathrm{P}_{\delta}(x)=a(\delta) \cdot \tanh (b(\delta) \cdot x)+c(\delta)
$$

where $x$ denotes the grid size and $a(\delta), b(\delta)$ and $c(\delta)$ are polynomials in $\delta$ fit by piecewise linear regression (Muggeo, 2003) using the parameters of individual nonlinear fits of $P_{\delta}$ for fixed $\delta$ ranging (in steps of $0.025 \mathrm{~m}$ ) from $0.05 \mathrm{~m}$ to $0.45 \mathrm{~m}$ as input data.
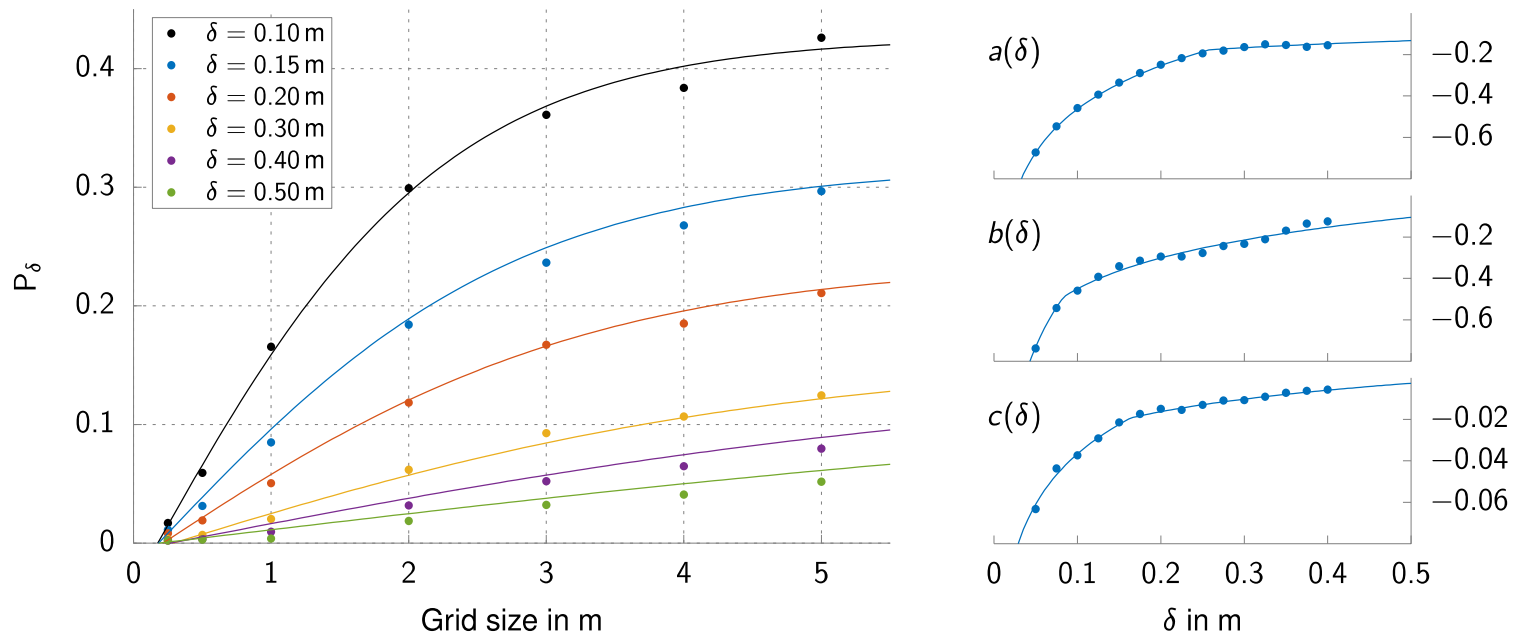

Figure 4. Proportion $\mathrm{P}_{\delta}$ of buildings whose maximum water level deviates by more than $\delta$ from the reference grid (left) along with a visualization of the parameters $a(\delta), b(\delta)$ and $c(\delta)$ of the model given in equation (1) (right).

\section{CONCLUSIONS}

The presented algorithm enables the identification of building-related flood risks while simultaneously accounting for possible differences between the building structure at the model level and its structure in the underlying cadastre. Therefore, our algorithm avoids the inaccuracies of simpler evaluation methods without that feature. Further investigations have shown that the resolution of the calculation grid of the hydrodynamic runoff model has a significant influence on the resulting water levels. Consequently, it is necessary to consider the resolution of the grid when assessing flooding risks. Based on the presented results, a grid resolution of at least $1 \mathrm{~m} \times 1 \mathrm{~m}$ is recommended for building-related statements on flood risk. Such results are useful, for example, to inform homeowners about flood risks to strengthen their own preparedness or to identify flood risks for critical infrastructures. 


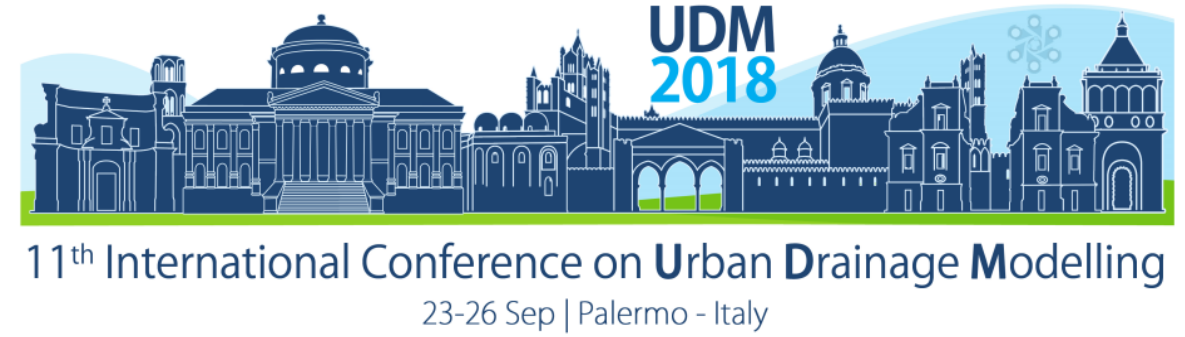

\section{References}

De Almeida, G.; Bates, P.; \& Ozdemir, H. (2016) Modeling urban floods at submeter resolution: challenges or opportunities for flood risk management?. Journal of Flood Risk Management, DOI: 10.1111/jfr3.12276

DWA (2016) Risk management in municipal flooding prevention for drainage systems in heavy rain. Advisory leaflet DWA-M 119, German Association for Water, Wastewater and Waste, December 2016, Hennef

EU (2007) Directive 2007/60/EC of the European Parliament and the Council of 23 October 2007 on the assessment and management of flood risks. Official Journal of the European Union, L288/27, 06.11.2007

Hsu, Y.-C.; Prinsen, G.; Bouaziz, L.; Lin, Y.-J.; Dahm, R. (2016) An Investigation of DEM Resolution Influende on Flood Inundation Simulation. 12th International Conference on Hydroinformatics, HIC 2016

IPCC (2014) Climate Change 2014: Synthesis Report. Contribution of Working Groups I, II and III to the Fifth Assessment Report of the Intergovernmental Panel on Climate Change [Core Writing Team, R.K. Pachauri and L.A. Meyer (eds.)]. IPCC, Geneva, Switzerland, 151 pp., ISBN 978-92-9169-143-2

Jeskulke, M.; Hoppe, H.; Massing, C.; Stokman, A.; Koch, M.; Behnken, K.; Gatke, D.; Thielking, K.; Wurthmann, J. (2017) Flood risks in urban areas - data analysis, communication and mitigation. FIG Working Week 2017, 31. May 2017, Helsinki, Finnland

Néelz, S.; Pender, G. (2009) Grid resolution dependency in inundation modelling: A case study. Flood Risk Management: Research and Practice - Samuels et al. (eds). Taylor \& Francis Group, London, ISBN 978-0415-48507-4

Muggeo, V. (2003) Estimating regression models with unknown break-points. Statistics in Medicine 22, p. 3055

Von Horn, J.; Bonnet, C.; Schäfer, K.; Koch, M.; Thielking, K.; Gatke, D.; Jeskulke, M.; Hoppe, H. (2018) Determining flooding risks using simplified and detailed hydrodynamic models - A practical guide to terms, calculation methods, basic and influencing factors. Korrespondenz Abwasser, Abfall 2018 (65), No. 2, p. 130. 


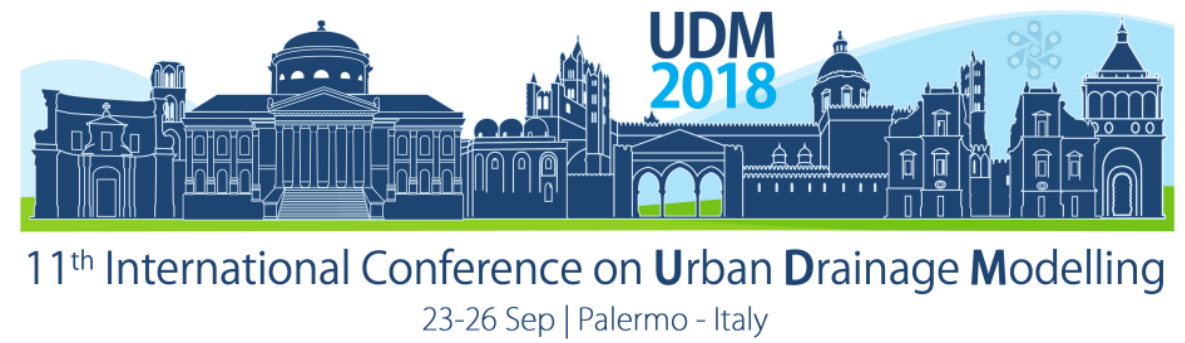

\title{
Seasonal variations in green roof hydrology
}

\author{
Simon De-Ville ${ }^{1}$ and Virginia Stovin ${ }^{2}$ \\ ${ }^{1}$ Loughborough University, School of Architecture, Building \& Civil Engineering, Loughborough, UK \\ ${ }^{2}$ The University of Sheffield, Department of Civil and Structural Engineering, Sheffield, UK
}

(S.De-Ville@lboro.ac.uk, v.stovin@sheffield.ac.uk)

\begin{abstract}
Green roofs can potentially contribute to urban stormwater management through two hydrological processes, the retention of rainfall and the detention of runoff. In temperate climates it is well known that green roofs tend to retain a higher proportion of rainfall in summer, when there is typically less rainfall and warmer conditions are more favourable for plant growth and evapotranspiration. What is not clear from existing studies, however, is whether seasonal changes affect the roof's fundamental hydrological properties such that the same storm falling on a roof with the same initial moisture content might produce a different runoff response in summer compared with winter. Seasonal variations in potential hydrological performance have been identified by monitoring four differently-configured extensive green roof test beds over a period of 6 years in Sheffield, UK. Temporal variations in maximum potential retention were identified through physical monitoring of substrate field capacity over time. An independent evaluation of temporal variations in detention performance was undertaken through the fitting of reservoir-routing model parameters. The maximum seasonal variation in potential retention was more than $8 \mathrm{~mm}$. For vegetated roof configurations, seasonal variation in detention performance was up to $63 \%$.
\end{abstract}

Keywords: Detention; Green roof; Retention; Seasonal variation.

\section{INTRODUCTION}

Green roofs can potentially contribute to urban stormwater management through two hydrological processes, the retention of rainfall and the detention of runoff. In temperate climates it is well known that green roofs tend to retain a higher proportion of rainfall in summer, when there is typically less rainfall and warmer conditions are more favourable for plant growth and evapotranspiration (Elliott et al., 2016). What is not clear from existing studies, however, is whether seasonal changes affect the roof's fundamental hydrological properties such that the same storm falling on a roof with the same initial moisture content might produce a different runoff response in summer compared with winter.

Many conceptual green roof models assume that the initial losses (or retention) due to a green roof will be equal to the difference between the substrate's field capacity and its moisture content at the start of a storm event. Therefore, if field capacity changes with time, the maximum possible potential retention capacity will also change. The first objective of this study was to determine whether field capacity varies seasonally.

In the case of detention, the substrate's hydraulic conductivity is the primary control on the time it takes runoff to pass through the green roof. Therefore the second objective was to determine whether hydraulic conductivity changes seasonally.

The work described here is part of a broader study (De-Ville et al., 2018) which considered both long-term evolutions and seasonal variations in the physical properties that determine potential hydrological performance. 


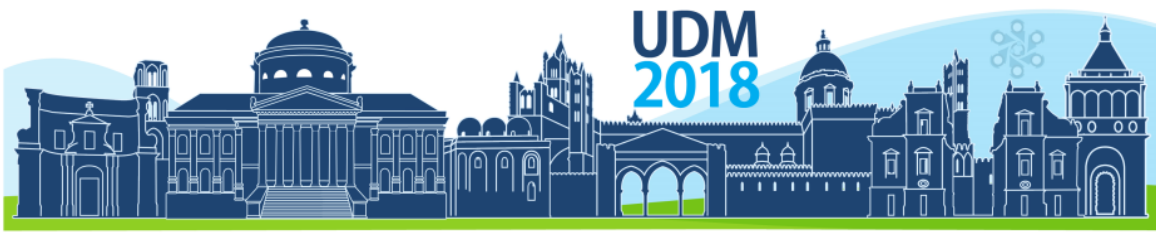

$11^{\text {th }}$ International Conference on Urban Drainage Modelling

23-26 Sep | Palermo - Italy

\section{MATERIALS AND METHODS}

The results reported here are part of a comprehensive long-term monitoring programme involving nine differently-configured extensive green roof test beds over a period of 6 years in Sheffield, UK (De-Ville et al., 2018). New approaches have been developed to track changes in both field capacity and apparent hydraulic conductivity in these test beds over time.

Retention. Four of the test beds, TB1, TB2, TB3 and TB7, were instrumented with moisture content probes. TB1, TB2 and TB3 are all vegetated with typical green roof sedum vegetation, whereas TB7 is unvegetated. TB1, TB2 and TB7 all have brick-based growing media (substrate), either ZinCo Heather with Lavender Substrate (HLS) or Sedum Carpet Substrate (SCS), whereas TB3 had a LECA (Light Expanded Clay Aggregate)-based substrate.

Data from the moisture content probes was used to determine changes in field capacity over time. Each bed contains three moisture probes, positioned in a vertical profile.

Figure 1 presents rainfall, runoff and moisture content profiles for a sample storm event. It may be seen that the substrate moisture content increases following the onset of rainfall, but then it tends to reach a plateau level. It was assumed that the plateau level - specifically the moisture content recorded two hours after the end of rainfall - corresponded to field capacity. Field capacity $\left(\theta_{\mathrm{FC}}\right)$ was determined for each bed for all storm events that resulted in runoff.

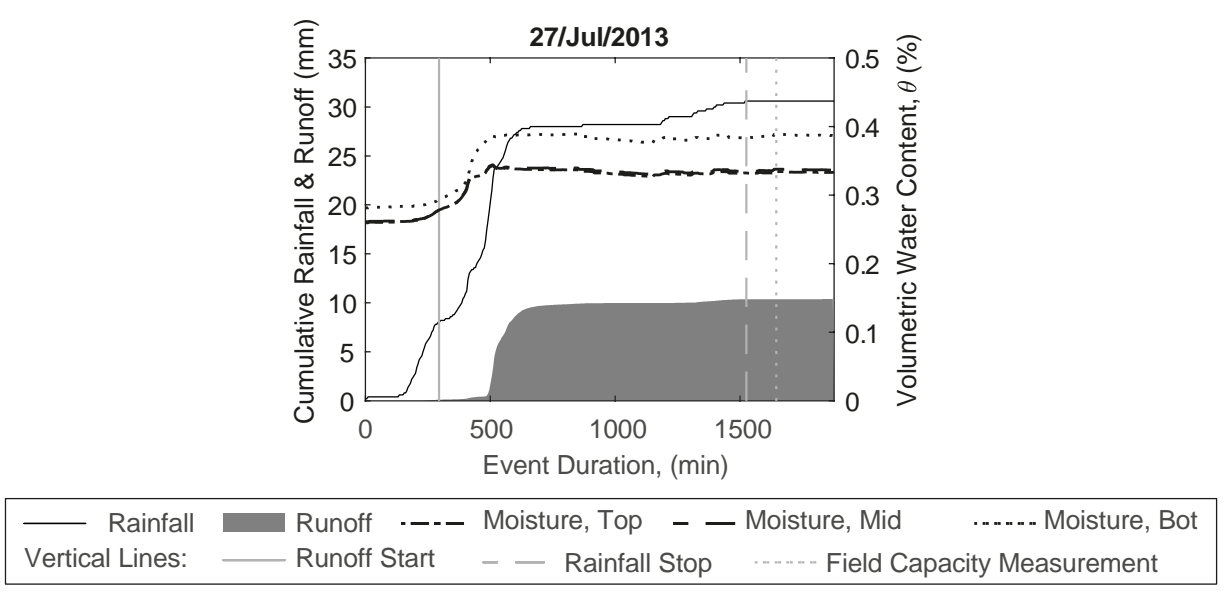

Figure 1. Moisture content profiles for TB1 during the 27 July 2013 storm event.

Detention. Direct, continuous, measurement of hydraulic conductivity was not feasible. Instead, an independent evaluation of temporal variations in detention performance was undertaken through the fitting of reservoir-routing model parameters to the observed net rainfall and runoff profiles. Runoff at time $t\left(Q_{t}\right)$ is related to the depth of rainfall temporarily stored in the green roof substrate $(h)$ via the equation $Q_{t}=D_{S} h_{t-1}^{D_{E}}$, in which $D_{S}$ and $D_{E}$ are the reservoir routing scale and exponent respectively. $D_{E}$ was assumed to take a constant value of 2.0, whilst $D_{S}$ was identified by fitting the modelled outflow profile to the observed outflow for all storm events that resulted in more than $2 \mathrm{~mm}$ runoff. Higher values of $D_{S}$ indicate a faster runoff response, or a higher apparent hydraulic conductivity.

In both cases the data were plotted as a function of day of the year, and Fourier series models were fitted to describe any annual cycles that were observed. 


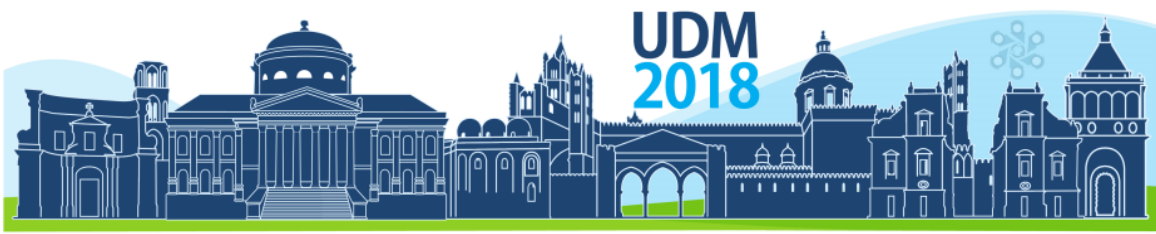

$11^{\text {th }}$ International Conference on Urban Drainage Modelling

23-26 Sep | Palermo - Italy

\section{RESULTS AND DISCUSSION}

\subsection{Retention}

Figure 2 shows a clear annual cycle in the monitored field capacity, which is consistently lowest in July and August (summer) and highest in winter. The biggest difference was observed in TB3, which has a LECA-based substrate. For TB3, the field capacity in the top and middle portions of the substrate is $11 \% \mathrm{v} / \mathrm{v}$ greater in winter compared with summer. For a substrate depth of $80 \mathrm{~mm}$, this equates to a difference of more than $8 \mathrm{~mm}$ in the maximum potential retention capacity (or initial losses).
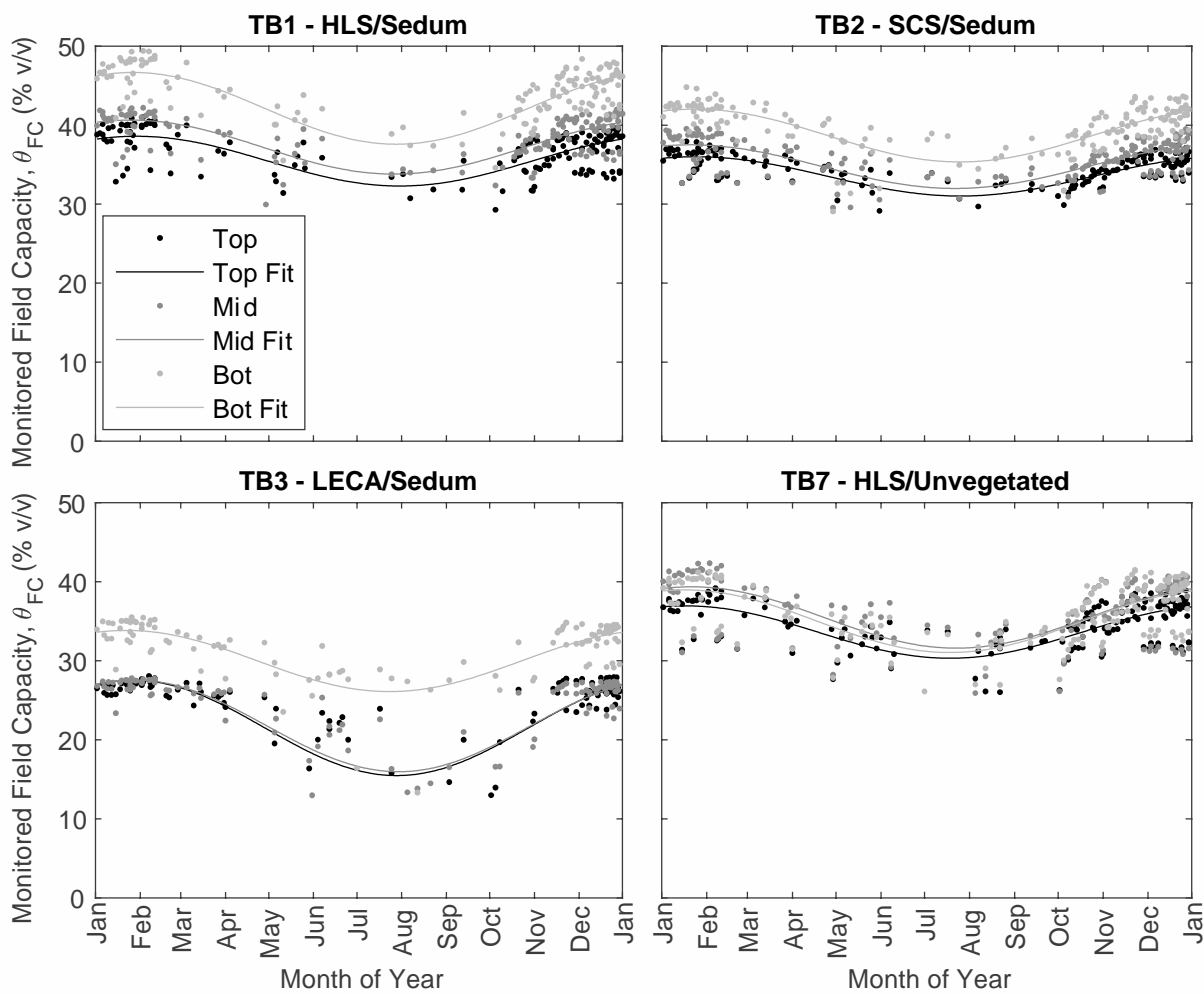

Figure 2. Monitored $\theta_{\mathrm{FC}}$ over time including Fourier series model fit (lines).

\subsection{Detention}

Figure 3 suggests that an annual cycle may also be observed in the detention characteristics of the green roof test beds, with less-effective detention (higher values of $D_{S}$ ) in the summer months. The highest variations are evident in TB3 (LECA-based substrate) and TB7 (unvegetated). Considering a 1-in-30-year design storm event with 0-days Antecedent Dry Weather Period (i.e. no retention), TB3 would provide $63.2 \%$ Peak Attenuation in winter compared with $40.5 \%$ in summer. To some extent this will be compensated by the greater levels of retention that can typically be expected in the summer due to higher rates of evapotranspiration. 


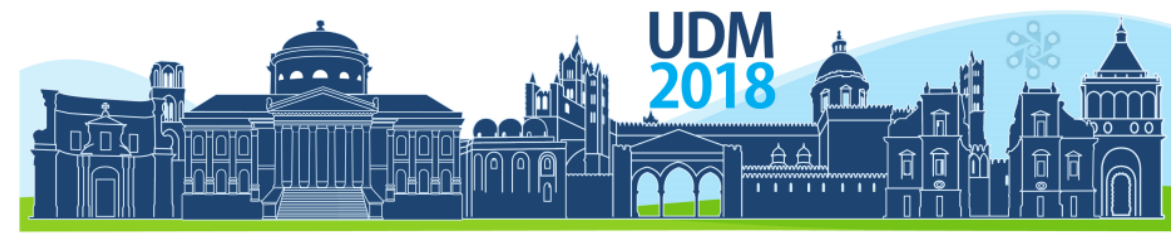

$11^{\text {th }}$ International Conference on Urban Drainage Modelling

23-26 Sep | Palermo - Italy

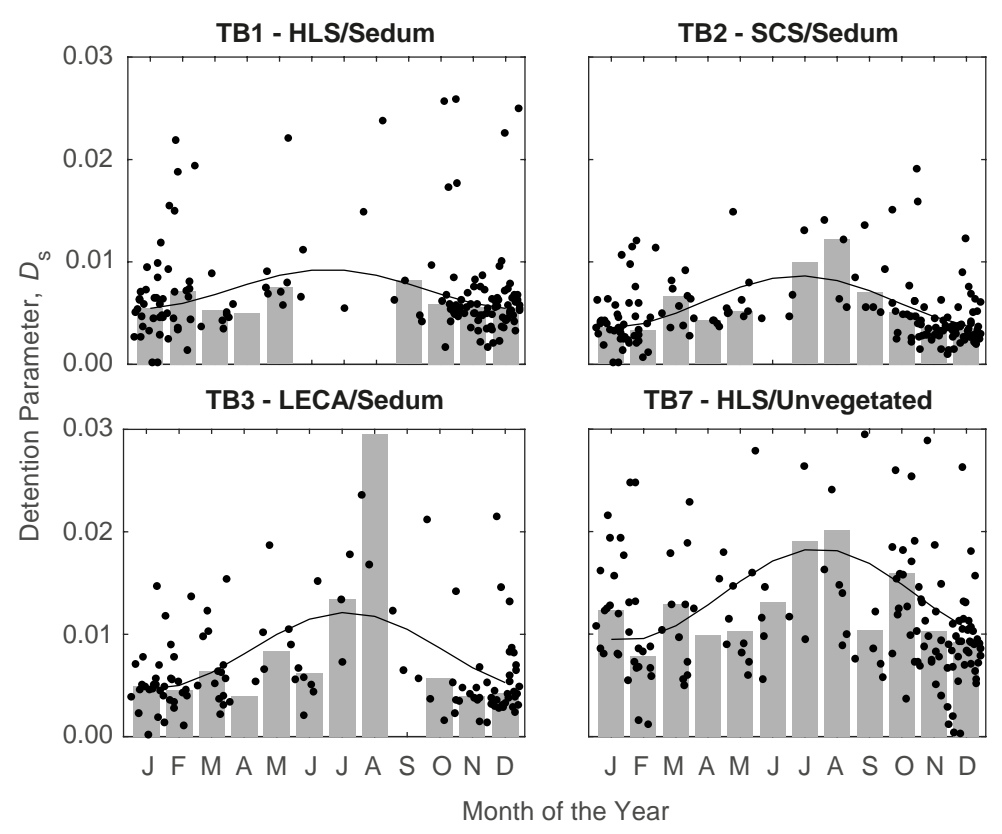

Figure 3. Scatter plot of model parameter $D_{s}$ over time including monthly median values (bars) and best fit Fourier series model (line).

\subsection{Discussion}

It is interesting to note that thse seasonal variations in hydrological performance characteristics were observed to be far greater than any longer-term year-on-year variations.

The green roof configurations that reflect industry good practice (such as TB1 and TB2 here) generally showed far greater hydrological stability compared with the less-conventional options such as the unvegetated TB7 or TB3 with its LECA-based substrate.

The observed annual cycles are believed to relate to seasonal changes in plant root activity and soil faunal activity, which impact on the substrate's physical properties (e.g. pore size distribution and hydraulic conductivity).

\section{CONCLUSIONS}

New methods have been developed that enable temporal variations in key hydrological properties that control retention and detention in green roof systems to be identified from monitored rainfall, runoff and moisture content profiles. Significant annual variations are evident in both retention and detention characteristics. These seasonal variations are far more pronounced than long-term changes, although standard configurations seem to offer greater stability compared with non-standard options.

\section{References}

De-Ville, S., Menon, M. and Stovin, V. (2018), Temporal variations in the potential hydrological performance of extensive green roof systems, J. Hydrology, 558, 564-578.

Elliott, R.M., Gibson, R.A., Carson, T.B., Marasco, D.E., Culligan, P.J., McGillis, W.R. (2016), Green roof seasonal variation: comparison of the hydrologic behavior of a thick and a thin extensive system in New York City. Environ. Res. Lett., 11 (7), 074020. 


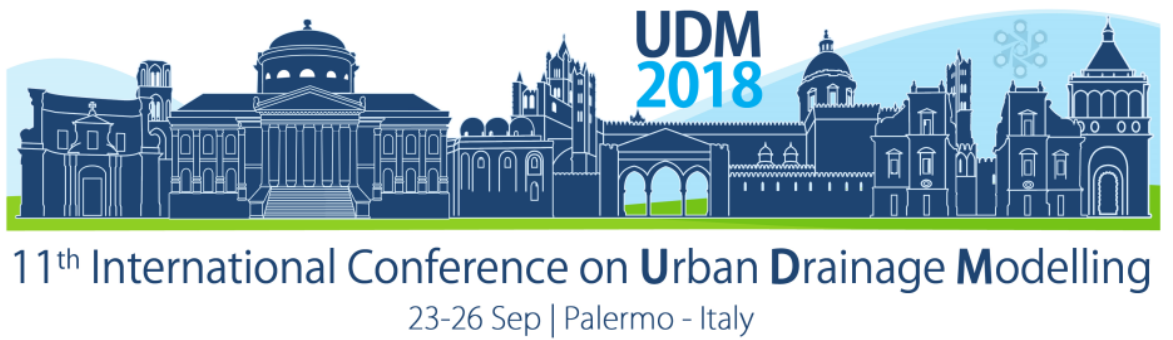

\title{
Analysing the cause of urban pluvial flooding in a hillside settlement
}

\author{
Lena Simperler ${ }^{1}$, Florian Kretschmer ${ }^{1}$ and Thomas ErtI ${ }^{1}$ \\ ${ }^{1}$ University of Natural Resources and Life Sciences, Vienna, Institute of Sanitary Engineering and Water Pollution \\ Control, Vienna, Austria
}

\begin{abstract}
Pluvial flood risk is increasing in urban and rural areas due to changes in precipitation patterns and urbanization. Pluvial flooding is often associated with insufficient capacities of the sewer system or low drainage efficiency of urban areas. In hilly areas hillside runoff additionally affects the risk of pluvial flooding. In the presented case study the cause of pluvial flooding at two selected sites in a settlement is investigated. To investigate all effects of pluvial flooding a coupled 1D-2D model of the whole catchment of the settlement is necessary. The results show that even though bottlenecks in the sewer system are important the effect of low drainage efficiency and hillside runoff greatly influence pluvial flooding. The knowledge of different causes of flooding can be further used for selecting and positioning appropriate adaption measures.
\end{abstract}

Keywords: pluvial flooding; 1D-2D coupled modelling; hillside runoff

\section{INTRODUCTION}

Pluvial flood risk is increasing in European cities due to changes in precipitation patters and increased urbanization (Skougaard Kaspersen et al., 2017; Zahnt et al., 2018). Pluvial flooding in urban areas can result from bottlenecks in sewer systems, low drainage efficiency of urban areas or overland flow (Palla et al., 2018; Sörensen and Mobini, 2017)

Hydrodynamic modelling is state of the art in detecting bottlenecks in sewer systems that lead to pluvial flooding (OEWAV, 2008). The runoff from the drainage areas can be connected to the sewer system through hydrographs or by a hydrodynamic 2D overland flow (Chang et al., 2015). However, with the first method the effects of insufficient drainage efficiency of surface areas cannot be detected (Palla et al., 2018). Furthermore the drainage area modelled is usually limited to the settlement area, while large undeveloped areas adjacent to settlements are not considered in this approach (OEWAV, 2008).

We suggest, however, that, especially in hilly areas, the contribution of hillside runoff is essential to understand the origin of pluvial flooding and needed for sustainable adaptation of existing drainage systems. In alpine regions in Austria an increase in damage by and number of pluvial flood events has been identified (Zahnt et al., 2018). In this case study we analyse the contribution of three sources to pluvial flooding namely bottlenecks in the sewer system, low drainage efficiency of urban areas and hillside runoff. With this analysis the knowledge on the influence of evaluating the whole catchment area in hilly areas to understand the causes of pluvial flooding is expanded. This results can be further used to find appropriate locations for flood mitigation measures. 


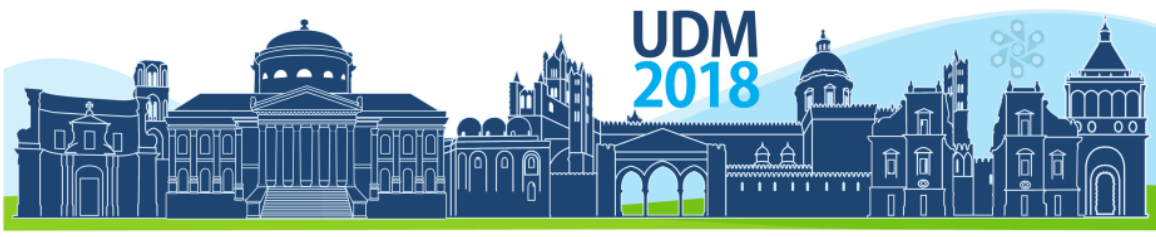

$11^{\text {th }}$ International Conference on Urban Drainage Modelling

23-26 Sep | Palermo - Italy

\section{MATERIALS AND METHODS}

\subsection{Study area}

The study area is located in a valley in Lower Austria, where pluvial flooding from surface runoff is a known problem. The catchment has an area of around 120 ha. About half of the area is covered in pasture and forest, the other half is covered by a settlement. The elevation of the modelled area ranges between $330 \mathrm{~m}$ and $630 \mathrm{~m}$ with a slope ranging between 10 and $90 \%$ uphill of the settlement.

\subsection{Model concept}

The contribution of the three sources to pluvial flooding is analysed using a coupled 1D-2D hydrodynamic model covering the whole catchment area of the settlement. Different design storm events are used in the model.

The 1D hydrodynamic drainage model was set up in MIKE URBAN (DHI, 2017). The pipe network was built according to existing data. Minor adjustments to the system were made, where data was missing (diameters from 5 storm sewer pipes). The roof tops were connected directly to the drainage systems whereas all other areas drain into the sewer system through the 2D overland flow model.

The 2D overland flow simulation was carried out in the MIKE URBAN environment as well as using the MIKE21 model (DHI, 2017). The model has a resolution of $1 \times 1 \mathrm{~m}$ derived from a digital elevation model (DEM) with the same resolution. The elevation of raster cells representing buildings was raised by $5 \mathrm{~m}$ to create a barrier. The friction value of the surface was determined according to land use information from the provincial government of Lower Austria and the Manning's roughness coefficient $n$ value for different surfaces (Chow, 1988).

Both, the sewer model and the 2D surface model, were set up as relatively simple models. As the prediction of specific water depths and flow rates is not the goal of this study an uncalibrated model was used. In the authors' opinion the simplified models are sufficient to give a general overview on sources of pluvial flooding.

For precipitation data 30 minute Euler type II design storms (OEWAV, 2008) were calculated for different return periods (1, 2, 3, 5 and 10 years) with data from the Austrian hydrographic service (BMNT, n.d.). The rainfall intensity is changing every 5 minutes with the peak value after 10 minutes. The total simulation time was 1 hour. The variation in rainfall intensity over time for the 1 year and 10 year return period design storms is represented in Figure 1.
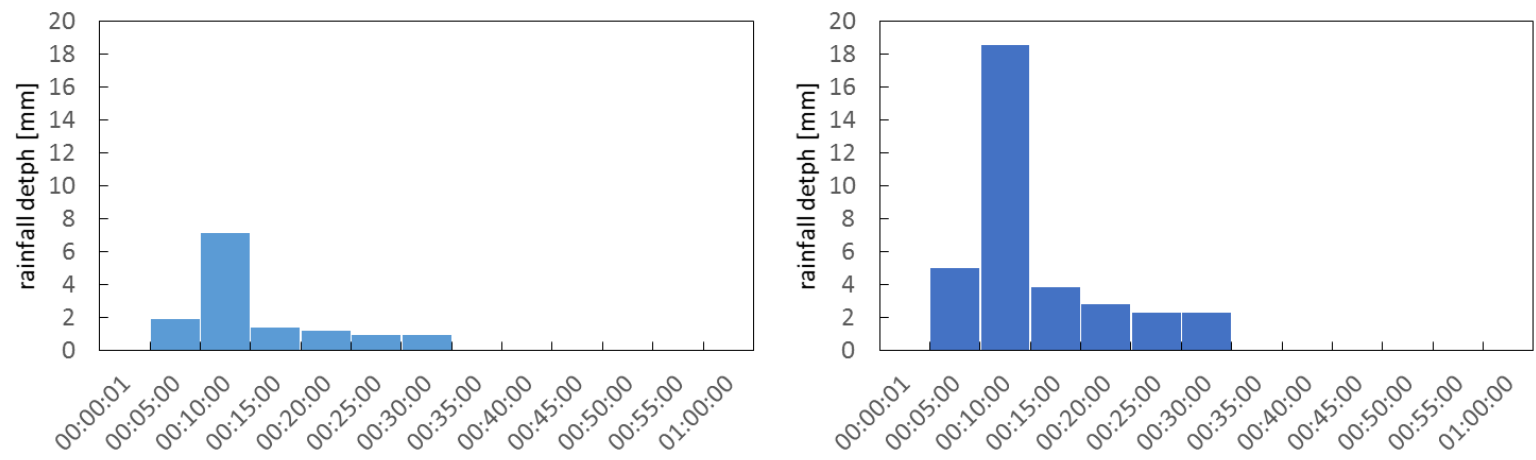

Figure 1 Hyetographs of design storms with 1 year (left) and 10 years (right) return period 


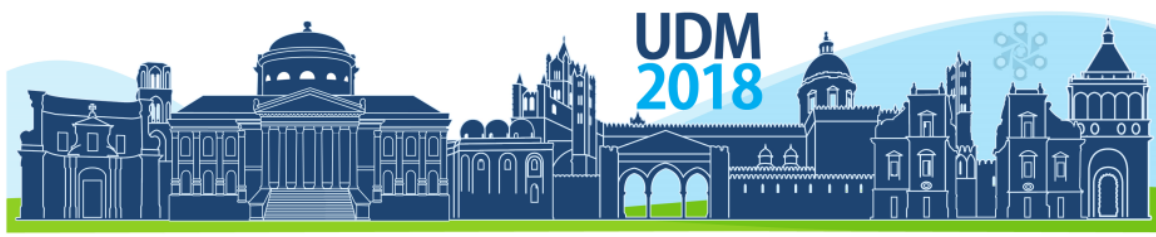

$11^{\text {th }}$ International Conference on Urban Drainage Modelling

23-26 Sep | Palermo - Italy

The results of the model for the different return periods have been evaluated visually to identify flooded manholes as well as flooded surface area. For surface flooding a minimum water depth of $5 \mathrm{~cm}$ was used as the lower limit to be considered flooding and a minimum of $5 \mathrm{~m}^{2}$ needed to be covered. The river at the border of the settlement was excluded from the flooding analysis. The flooded manholes were retrieved from the software. The main causes of flooding were characterized in three ways:

- Sewer bottleneck: pipe fully filled and surcharge from manhole

- Low drainage efficiency: no surcharge from manhole, inundation constant or decreasing after rain event

- Hillside runoff: no surcharge from manhole, inundation increasing after rain event

\section{RESULTS AND DISCUSSION}

In Figure 2 water depths after 1 hour are illustrated for two exemplary return periods, 1 and 10 years respectively. The location of the flooded areas are roughly the same in the two scenarios only the water depth and extent of the flood are varying, indicating no significant changes in flooding pattern with increasing rainfall intensity. Areas A and B (Figure 2) will be analysed in detail on the causes of pluvial flooding. Even tough sewer bottlenecks are important in the analysed system, other sources have significant influence on pluvial flooding in the study area as well.

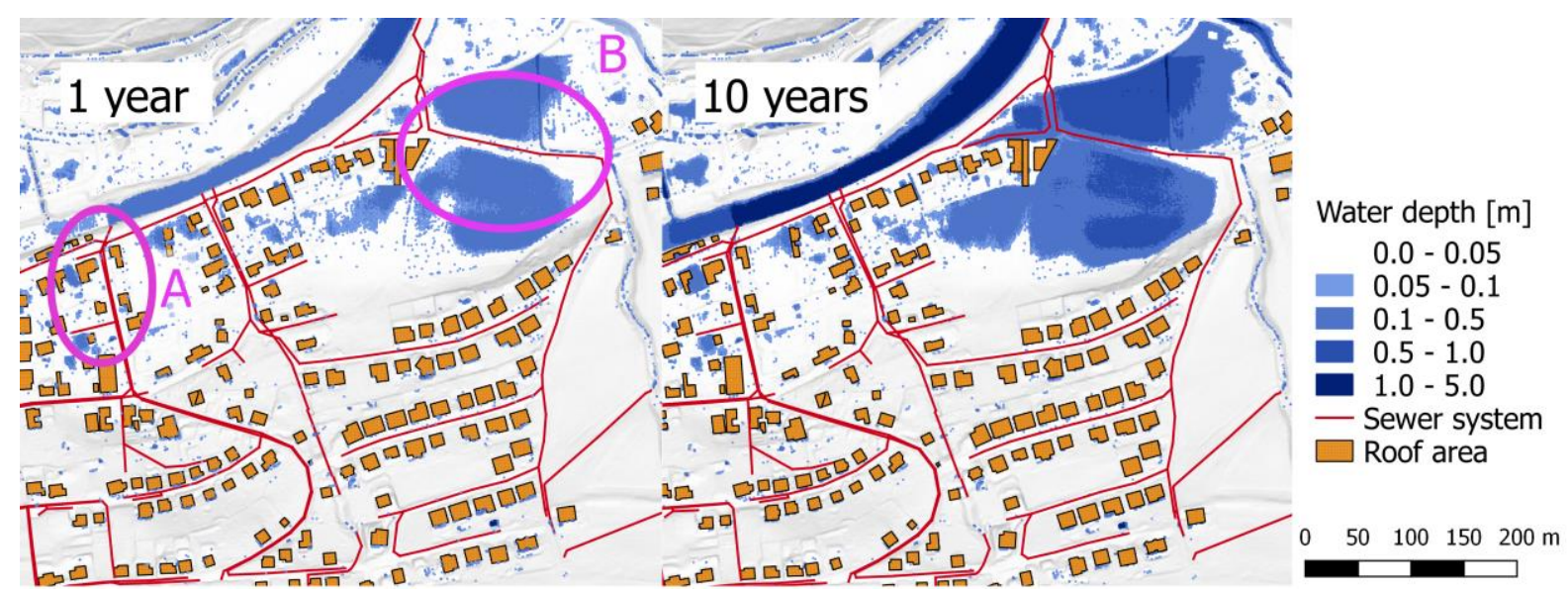

Figure 2 Water depth after 1 hour of simulation for rainfall return periods of 1 year and 10 years.

In area $A$ the water level in the sewer, shown in Figure 3, at the same time step as above indicates that even though there is capacity in the pipe the accumulated water on the surface cannot be drained due to low drainage efficiency of this area. The inundation area is, however, decreasing slightly after the rain event. The prevailing of water on the surface could, nevertheless, also result from misrepresentation of the existing surface conditions by the DEM. A more detailed model of the surface would improve the prediction of flooding in this area. 


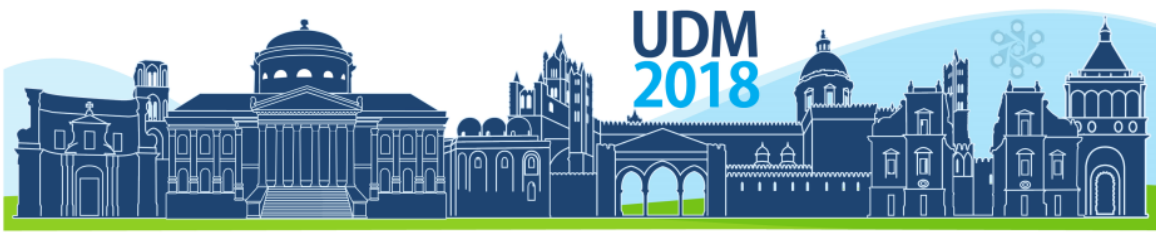

$11^{\text {th }}$ International Conference on Urban Drainage Modelling 23-26 Sep | Palermo - Italy

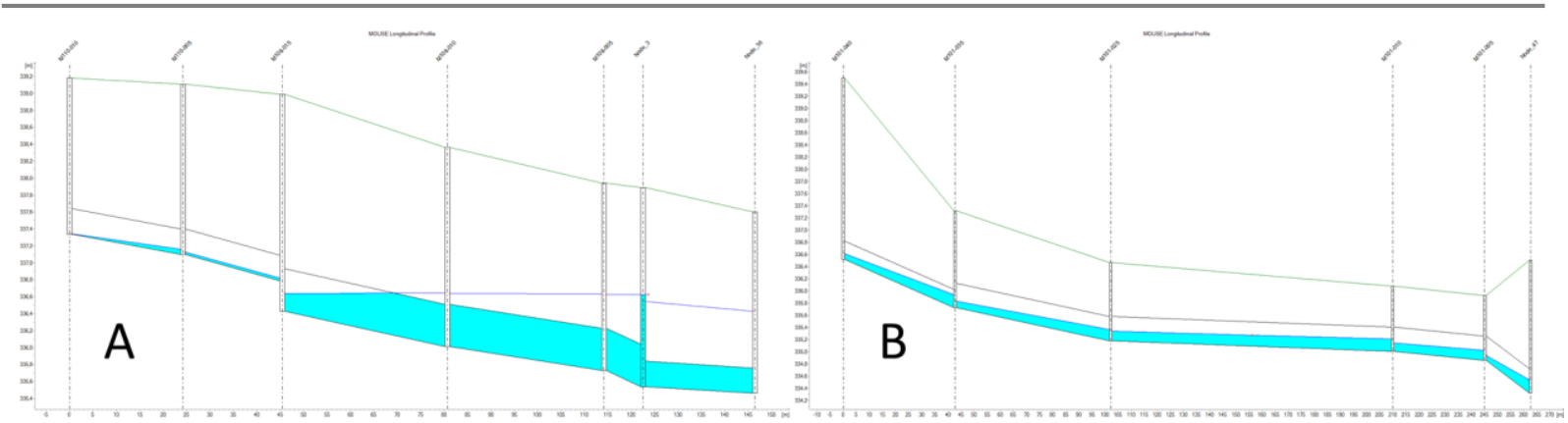

Figure 3 Water level in selected sewer sections after 1 hour of simulation for the return period of 1 year

In area $B$ the inundation area covers mainly undeveloped land in the 1 year scenario, however, when looking at the 10 year scenario also the settlement area is seriously affected. In this area low drainage efficiency as well as hillside runoff are major contributors to flooding. As seen in Figure 3 the manholes in the surrounding are not flooded indicating that the flooded area cannot be drained by the sewer system. Another cause of flooding in this area is hillside runoff as seen on the right edge of the selected area in Figure 2. This runoff is generated outside of the developed area and would therefore not be considered in studies focusing only on settlement areas. However, the contribution to urban pluvial flooding is significant as the inundation area is still increasing after the rain event has ended and when drainage capacity is available in the sewer.

The knowledge gained about the causes of pluvial flooding ca be further used to determine appropriate locations for flood mitigation measures. Within urban catchments it has been shown that sustainable urban drainage systems (SUDS) can be applied to reduce the flow during flood events (Viavattene and Ellis, 2012). In areas were hillside runoff has a major impact on pluvial flooding the different flood mitigation measures can be implemented.

\section{CONCLUSIONS}

Three causes of pluvial flooding were identified in the case study and their contribution to flooding was evaluated. Bottlenecks in the sewer are of significant importance during the rain event. In addition low drainage efficiency of some areas contribute to flooding. In those areas SUDS could be positioned in the settlement to prevent pluvial flooding. The largest flooded area in the case study is, however, caused by hillside runoff. This shows the importance of modelling not only urban areas, but also adjacent rural areas to properly assess causes for pluvial flooding in hilly areas.

\section{Acknowledgement}

We thank the provincial government of Lower Austria for providing the spatial data used in this study.

\section{References}

BMNT, n.d. Design rainfall events (in German) [WWW Document]. URL http://ehyd.gv.at/\# (accessed 2.10.18).

Chang, T.-J., Wang, C.-H., Chen, A.S., 2015. A novel approach to model dynamic flow interactions between storm sewer system and overland surface for different land covers in urban areas. J. Hydrol. 524, 662-679. https://doi.org/10.1016/j.jhydrol.2015.03.014

Chow, V.T., 1988. Open-channel hydraulics, Reissued. ed, McGraw-Hill classic textbook reissue series. McGrawHill, Boston, Mass. 
Proceedings of the 11th Int. Conference on Urban Drainage Modelling, 23-26 Sep. 2018, Palermo (ITALY). Ed. prof. Giorgio Mannina

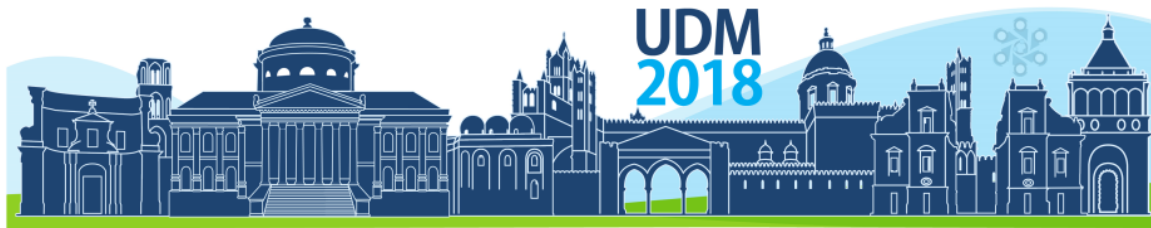

$11^{\text {th }}$ International Conference on Urban Drainage Modelling

23-26 Sep | Palermo - Italy

DHI, 2017. MIKE URBAN. Collection System - Modelling of storm water drainage networks and sewer collection systems. User guide.

OEWAV, 2008. ÖWAV Regelblatt 11 - Richtlinien für die abwassertechnische Berechnung und Dimensionierung von Abwasserkanälen (Guidelines for the calculation, dimensioning and design of sewers). Österreichischer Wasser- und Abfallwirtschafsverband, Vienna.

Palla, A., Colli, M., Candela, A., Aronica, G.T., Lanza, L.G., 2018. Pluvial flooding in urban areas: the role of surface drainage efficiency: The role of surface drainage on pluvial flooding. J. Flood Risk Manag. 11, S663-S676. https://doi.org/10.1111/jfr3.12246

Skougaard Kaspersen, P., Høegh Ravn, N., Arnbjerg-Nielsen, K., Madsen, H., Drews, M., 2017. Comparison of the impacts of urban development and climate change on exposing European cities to pluvial flooding. Hydrol. Earth Syst. Sci. 21, 4131-4147. https://doi.org/10.5194/hess-21-4131-2017

Sörensen, J., Mobini, S., 2017. Pluvial, urban flood mechanisms and characteristics - Assessment based on insurance claims. J. Hydrol. 555, 51-67. https://doi.org/10.1016/j.jhydrol.2017.09.039

Viavattene, C., Ellis, J.B., 2012. The management of urban surface water flood risks: SUDS performance in flood reduction from extreme events. Water Sci. Technol. 67, 99. https://doi.org/10.2166/wst.2012.537

Zahnt, N., Eder, M., Habersack, H., 2018. Herausforderungen durch pluviale Überflutungen - Grundlagen, Schäden und Lösungsansätze (Challenges caused by pluvial flooding - basic principles, damage and solution approaches). Österr. Wasser- Abfallwirtsch. 70, 64-77. https://doi.org/10.1007/s00506-017-0451-7 


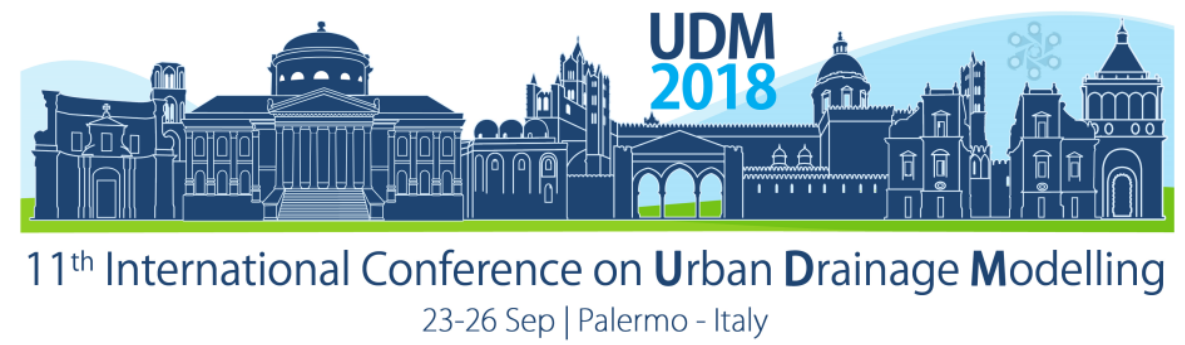

\title{
Implementation of GIS and Hydrologic/Hydraulic Modelling for Integrated Floodplain/Stormwater Management
}

\author{
Paul A. DeBarry, P.E., P.H., GISP, D.WRE1, Gerald W. Longenecker, P.E. ${ }^{2,}$, Ryan Burrows, P.E., CSI ${ }^{3}$ \\ 1 Technical Director of Watersheds and Geospatial Technologies, NTM Engineering, Inc, Dillsburg, PA, USA \\ ${ }^{2}$ Executive Vice President of Engineering Services, Skelly-Loy, Harrisburg, PA, USA \\ ${ }^{3}$ Design Engineer, NTM Engineering, Inc, Dillsburg, PA, USA
}

\begin{abstract}
A very unique stormwater and flooding issue presented itself in Carlisle Borough, Pennsylvania, USA. The Letort Spring Run traversed the town and its watershed had become substantially developed causing excessive runoff, and a series of low capacity bridges caused subsequent flooding. An existing storm sewer conveyance system became submerged during significant rain events, causing a surcharge of the system, which overflowed inlets and flooded local streets, residences and businesses. The Borough also needed to address water quality from stormwater runoff to meet their National Pollutant Discharge Elimination System (NPDES) permit requirements. The analysis was complex due to flat surfaces and storm sewer system profiles, a complex system of multiple open channels with low banks, culverts, bridges, ditches, little documentation of the existing storm sewer system, backwater, and the timing of peak flows that create backwater. The problem required a unique GIS and modelling analysis through development of detailed GIS data, field survey and hydrologic and hydraulic modelling using WMS, HEC-RAS, SWMM, PeakFQ and StreamStats. Data developed in the GIS was exported into the HEC-RAS and SWMM input file formats. Various scenarios were modelled to determine storm frequency and durations that caused the most damage so that various alternative solutions could be determined. The low impact development options were also run in SWMM to evaluate alternative solutions.
\end{abstract}

Keywords: Flooding, stormwater, GIS, SWMM, WMS, HEC-RAS, PEAKFQ, StreamStats, NPDES

\section{INTRODUCTION}

Drainage/flooding problems in the area the Borough of Carlisle, Pennsylvania disrupted traffic and caused significant economic damage. In addition to the flooding issue, water quality for the National Pollutant Discharge Elimination System (NPDES) compliance was an additional concern. To solve the problem, the source of the problem had to first be determined and if the cause of the flooding problems was from storm sewer backwater from Letort Spring Run, inadequate storm sewer or inlet capacity, or surface runoff volume (or a combination thereof).

Therefore, the stream and storm sewer system were hydrologically and hydraulically modelled to determine the cause of problems and proposed solutions. The process involved data collection of problem areas, use of LiDAR data, survey of the storm sewers, Geographic Information System (GIS) analysis and hydrologic and hydraulic modelling of the watersheds and storm sewers. The analysis determined that the flooding was caused by a combination of the Letort Spring Run backwater caused by a stressed impervious watershed, low banks causing localized stream flooding, and backwater caused by low clearance bridges which in turn surcharged the storm sewer system. A combination of solutions were presented which included flood control bridge rehabilitation, storm system upgrades and watershed low impact development (LID) measures. The project established an expandable working model and procedures were established which are customizable to any municipality that wants to create 


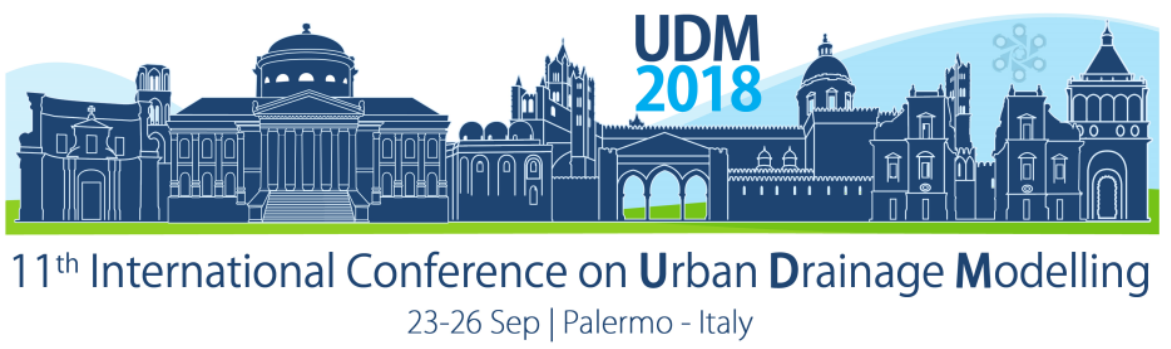

a solution for flooding, stormwater and water quality problems.

\section{MATERIALS AND METHODS}

\subsection{Software / Models}

There had been a Federal Emergency Management Agency (FEMA) Hydrologic Engineering Center River Analysis System (HEC-RAS) model developed for the Letort Spring Run channel, it is a steady flow backwater model, and was performed on the channel only. The ability to model storm sewer surcharging, reverse flow and ponding was required, therefore it was decided that the U.S. Environmental Protection Agency (EPA) Stormwater Management Model (SWMM) model would be the most appropriate model for this complex situation since it has the ability to dynamically determine backwater and evaluate low impact development (LID) alternative solutions.

The SWMM model requires specific input data in order to generate runoff, including rainfall data, subarea (catchment) drainage area, basin width, percent slope, percent impervious area, Manning ' $n$ ' value for impervious and pervious area, catchment storage, curb length, travel time, etc. SWMM has several infiltration routines including the Horton, Modified Horton, Green-Ampt, modified Green-Ampt, and NRCS curve number method however, the NRCS curve number was chosen since the parameters to compute it (land cover, soils) were readily available for the GIS and it is the preferred method by most engineers in the area.

This type of data for a complex analysis and modelling system is best obtained using GIS processing. The analysis, therefore, included complex procedures involving various software and modelling packages including ESRI's ArcGIS, The Watershed Modelling System (WMS) U.S. Army Corps of Engineers River Analysis System (HEC-RAS) and U.S. EPA'S Stormwater Management Model (SWMM) models. HEC-RAS data (cross sections, Manning ' $n$ ' value, bridge data, etc.) was imported into SWMM for the channel backwater analysis. ArcGIS was utilized by importing the various layers required for problem solving and analysis such as flood limits, surveyed problem areas, the storm sewer system, streets, curbs, land cover, soils, potential LID and other solution locations, etc. WMS was utilized for the actual GIS data overlaying and computations to develop the SWMM input data described above.

The (SWMM) model was then utilized to generate flows to compute stream elevations and storm sewer backwater conditions. This aided in the analysis of whether flooding was caused by excess runoff, inadequate inlet capacity, inadequate storm sewer capacity, or backwater from the Letort Spring Run and/or the storm sewers themselves. This also allowed for siting and analysis of potential low impact development scenarios and stormwater management facilities' impact to reducing flood flows.

\subsection{Data Collection}

Data required for the analysis included FEMA floodplains, problem areas, field survey of the storm sewers, (which included information on pipe size, location, dimensions, inverts, material, inlets, manholes, top of grate elevation), and cross sections and profile of the stream. The GIS data was imported into ArcGIS for processing. Layers were overlaid to assess drainage patterns and floodplains in relation to problem areas, evaluate attributes of 


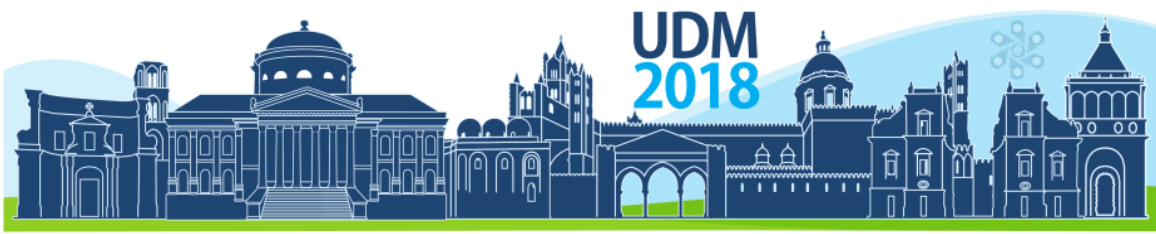

$11^{\text {th }}$ International Conference on Urban Drainage Modelling

23-26 Sep | Palermo - Italy

pipes, and verify connectivity. The digital data brought in to the WMS program for watershed processing included digital elevation models (DEMs), soils, land cover

LiDAR DEMs - The LiDAR data is a high-resolution (1-meter pixel equivalent) bare earth elevation raster GeoTIFF DEM of Pennsylvania. The LiDAR DEM was utilized to determine subwatersheds in the storm sewered area where street curb and gutters may also influence drainage patterns.

USGS (NED) DEMs - The National Elevation Dataset (NED) of The National Map 1/3 arcsecond 10-meter DEM was utilized for delineation of the entire Letort Spring Run watershed as shown in Figure 1 which also depicts the raw DEM as seen in ArcGIS and WMS and the resultant DEM delineated subwatersheds in the storm sewered portion of the watershed.
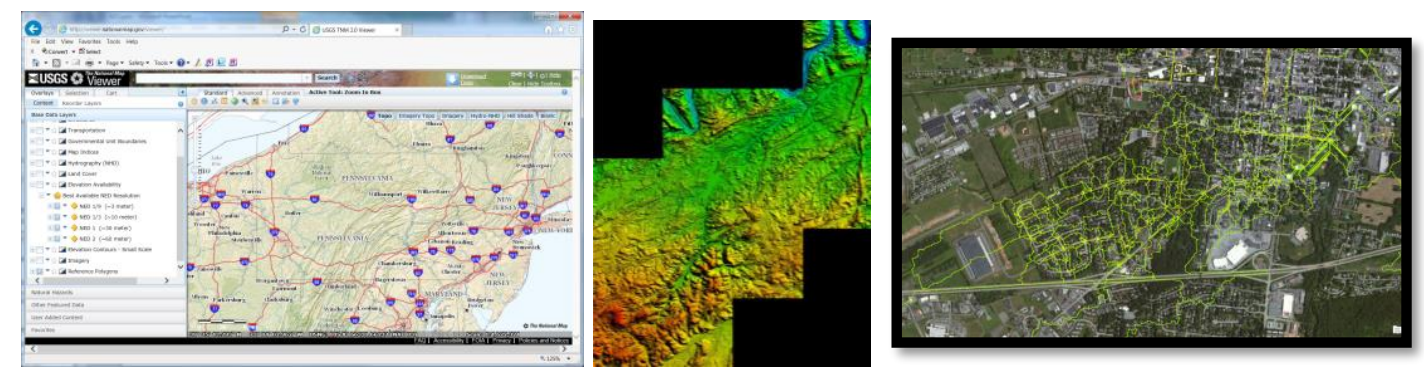

Figure 1. USGS NED data download site, final product imported into ArcGIS and WMS and delineated subwatersheds in the storm sewered portion of the watershed (with storm sewer shown in yellow).

USGS NLCD - The 2006 National Land Cover Dataset (NLCD) 30-meter satellite image raster "land cover on the ground" was processed in WMS. The Multi-Resolution Land Characteristics (MRLC) Consortium Viewer web site and the LULC classifications are shown in Figure 2.

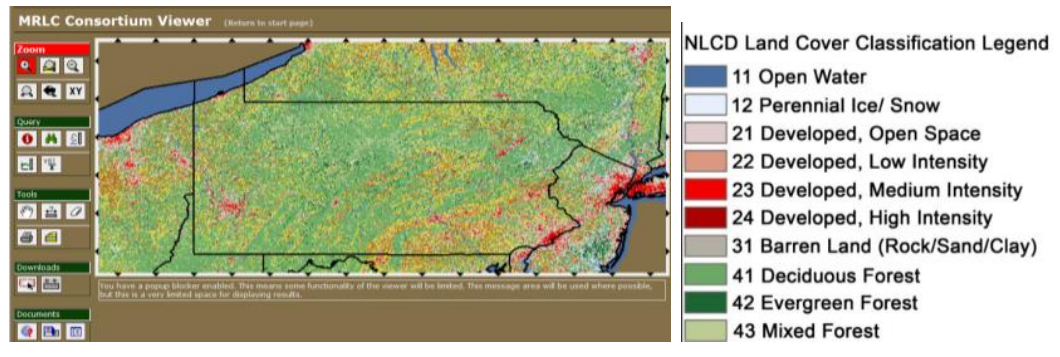

Figure 2. MRLC LULC download page and LULC classifications.

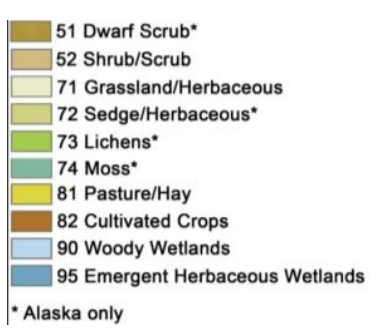

- Alaska only

NRCS (SSURGO) Soils - The Soil Survey Geographic (SSURGO) database provided the most detailed level of soils information available as shown in Figure 3. Utilizing the soil hydrologic soils groups (HSGs) attributes and the LULC data layer, the NRCS curve numbers $(\mathrm{CNs})$ for the infiltration routine were determined. 


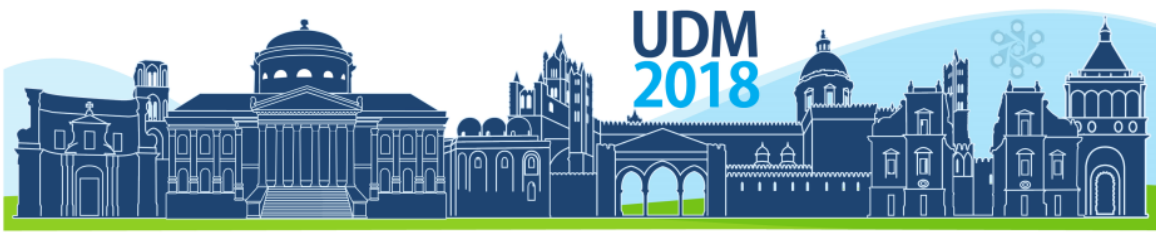

$11^{\text {th }}$ International Conference on Urban Drainage Modelling

23-26 Sep | Palermo - Italy
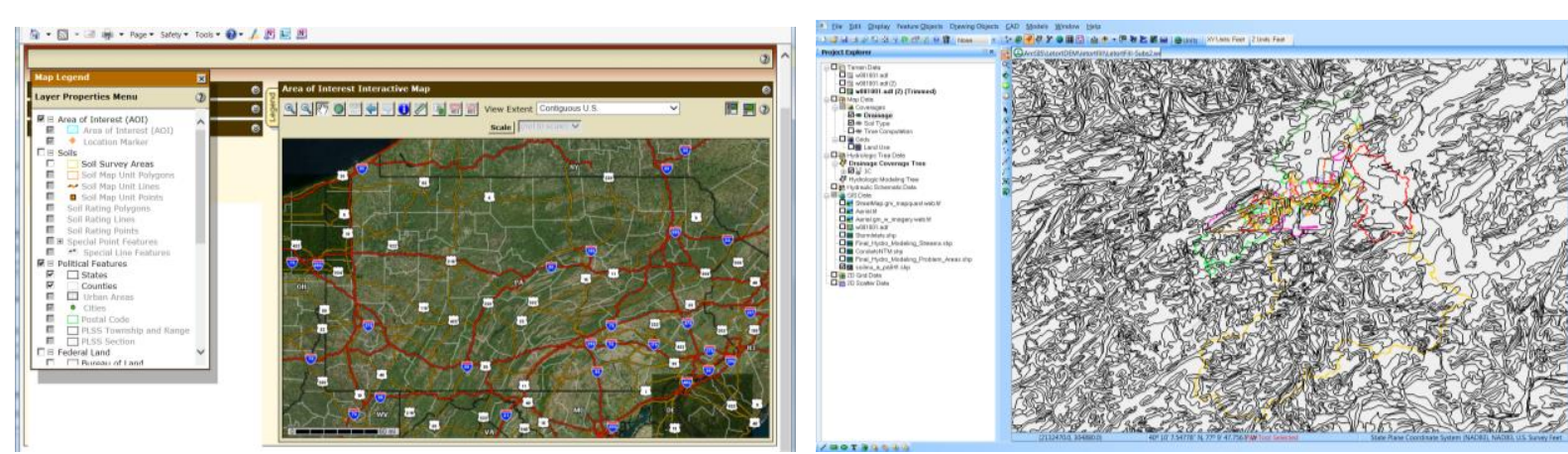

Figure 3. NRCS's Web Soil Survey Home Page and SSURGO data imported into WMS.

\section{RESULTS AND DISCUSSION}

\subsection{Detailed Model}

Utilizing the DEMs, subwatersheds (subbasins) and drainage areas were delineated for the system in WMS based on sewer trunk lines, inlet locations, outfalls and various locations. Points for watershed delineation were chosen to represent the drainage area and resultant flow contributing to each conduit. WMS also utilized to compute subwatershed ID, corresponding rain gage, drainage area, subbasin centroid $(X, Y)$, basin slopes, average width, length, shape factor, sinuosity, percent impervious, Manning ' $n$ ', mean elevation and outlet ID, which are all required input for the SWMM model. The surveyed storm sewer data (diameter, material, inverts in and out, etc.), street, channel and stream cross section data and rainfall data were all input into SWMM as well.

SWMM model was utilized to generate flows and SWMM and HEC-RAS used to compute stream elevations and storm sewer backwater conditions. This aided in the analysis of whether flooding was caused by excess runoff, inadequate inlet capacity or storm sewer capacity, or backwater from the Letort Spring Run and/or the storm sewers themselves. This also allowed for siting and analysis of potential LID scenarios and stormwater management facilities' impact to reducing flood flows.

\subsection{Calibration}

In order to utilize a model with confidence and reliability, it must be calibrated. A United State Geological Survey (USGS) stream gage, which had 34 years of data (1976-2009) recorded annual peak flows. A Log Pearson Type III analysis of actual stream gage data using USGS PEAKFQ computer program was performed and compared to the USGS statistical regression equations (SIR 2008-5102) within StreamStats. The SWMM model was run and input parameters adjusted, until the model replicated the various typical return periods, i.e. 2, 5-, 10-, 25-, 50-, and 100-year events. The dynamic wave method was utilized with slope and Froude normal flow, Hazen-Williams force main flow, curve number infiltration, variable time steps, and 0.005 head convergence tolerance with ponding allowed. Once SWMM was calibrated, individual hydrographs were developed within SWMM as shown in Figure 4, and compared to the peak flows generated from the methods described above. Once the flows were calibrated, the SWMM model was run and the profiles of conduits were analyzed for 


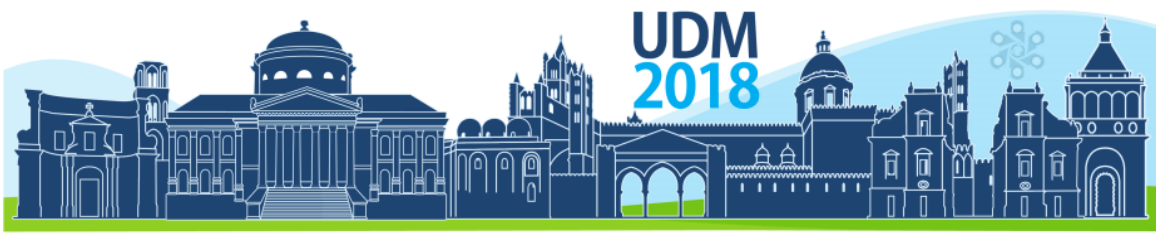

$11^{\text {th }}$ International Conference on Urban Drainage Modelling

23-26 Sep | Palermo - Italy

surcharge and flooding and to pinpoint the problem areas also shown in Figure 4, and to determine the potential cause of that problem.
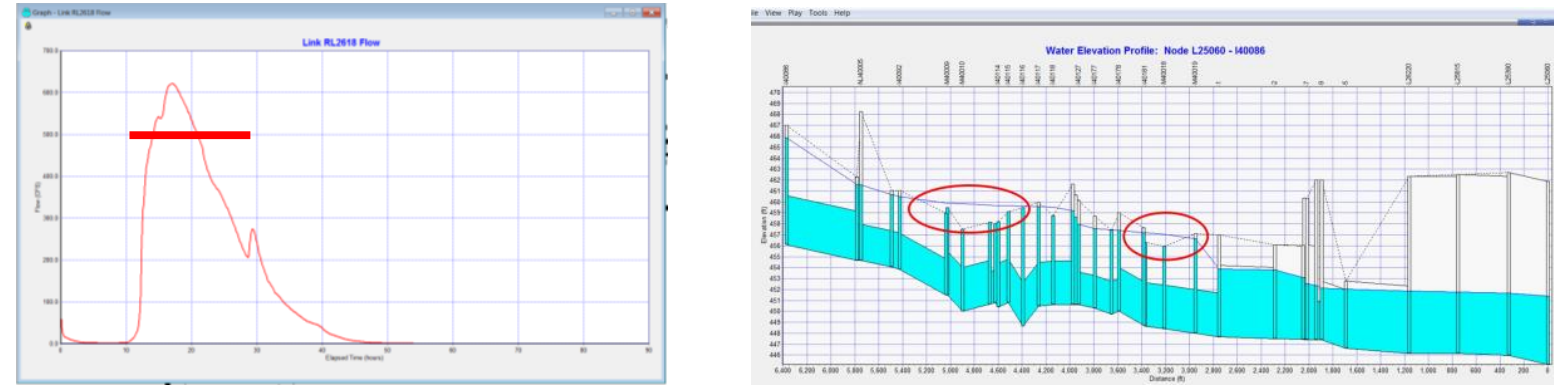

Figure 4. SWMM hydrograph, flow at which flooding occurs and SWMM profile showing surcharge areas.

\section{CONCLUSIONS}

Highly effective, accurate, hydrologic and hydraulic models were developed through survey, GIS processing and WMS, HEC-RAS and SWMM model development and calibration. The final product, the SWMM model, allows evaluation of backwater and storm sewer surcharge which confirmed noted problem areas, and allowed an analysis of the cause of the problem, (insufficient inlet or pipe capacity, pipe or stream backwater, surcharge or simply too much runoff peak or volume). The results showed one solution does not solve all, but requires a series of planned improvements over time. This can be attributed to factors such as development without stormwater BMPs and enclosing tributaries within the storm sewer, mild basin slope and karst geology of the region.

\section{References}

Aquaveo (2017) - Watershed Modelling System version (WMS) Version: 10.1.15 (64-Bit)

ESRI, ArcGIS (2017). Redlands California version 10.2

U.S. EPA Stormwater Management Model version 5 (SWMM5)

U.S. Army Corps of Engineers Hydrologic Engineering Center (2016) HEC-RAS version 4.1.0 


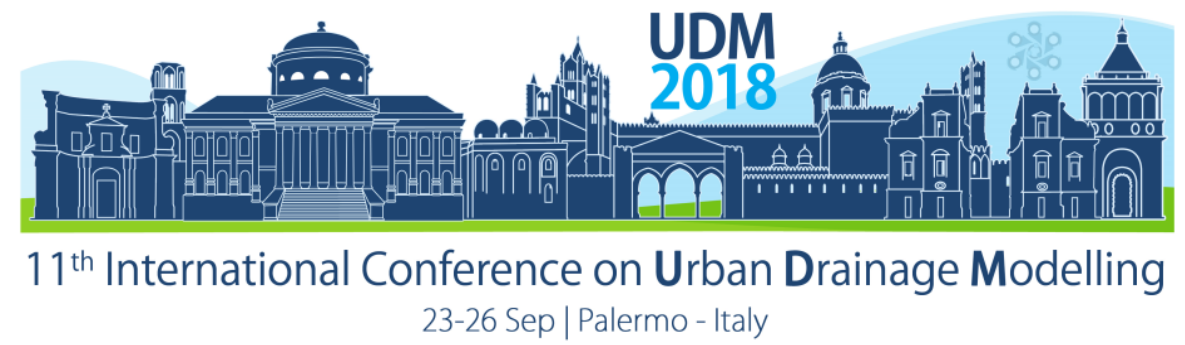

\title{
Uncertainty Quantification of Flood Damage Estimation for Urban Drainage Risk Management
}

\author{
Masaru MORITA ${ }^{1}$ and Yeou Koung TUNG ${ }^{2}$ \\ ${ }^{1}$ Shibaura Institute of Technology, Department of Civil Engineering, Tokyo, Japan \\ ${ }^{2}$ Natinal Chio-Tung University, Disaster Prevention and Water Environmental Research Center, Hsinchu, Taiwan
}

\begin{abstract}
The study presents an inundation damage estimation method which quantifies the uncertainty in inundation damage statistical data for urban drainage management. The flood damage is usually estimated by multiplying inundated asset value by damage rate determined by the inundation depth. The dispersions of the asset values and the damage rates related to the uncertainty were expressed quantitatively using probability distributions for the actual flood damage data surveyed by the national government. Monte Carlo simulation was utilized to calculate the damage from the two parameters with probability distributions. Thus the simulations brought about the monetary flood damage not in deterministic but in probabilistic form.
\end{abstract}

Keywords: Uncertainty; Flood damage estimation; Monte Carlo simulation

\section{INTRODUCTION}

Flood damage estimations, together with flood inundation calculations, are two essential processes in urban drainage risk management. There exist uncertainties that are unavoidable in the estimation and calculation processes (Beven and Hall, 2014; Apel et al., 2014). The various parameters used in damage estimations, such as asset value and damage rate, are based on the flood damage statistics and they often times possess greater uncertainty than those in hydraulic inundation calculations. Many studies have been done to analyse the uncertainty in flood inundation calculations. However, very few studies deal with explicit uncertainty quantification of flood damage estimations using actual flood damage statistics. Thus, this study focuses only on uncertainty quantification of flood damage estimation based on the national survey statistics of flood inundation damages in Japan (PWRI, 1995).

\section{UNCERTAINTY IN FLOOD DAMAGE ESTIMATION}

\subsection{Flood damage prediction model (FDPM)}

Flood damage prediction model (FDPM) estimates flood inundation damage in monetary terms for any given storm. FDPM, a GIS based flood damage prediction model, consists of two modules. Module-1 calculates inundation depths for input rainfall hyetograph and Module-2 estimates flood inundation damage from the inundation depths calculated by Module-1. For Module-1, the study used the software XP-SWMM 1D/2D to calculate the spatial distribution of inundation depths on a 50-m square grid for a given hyetograph. 


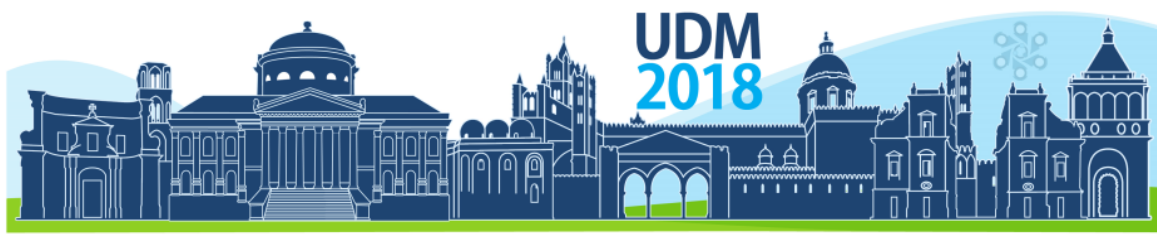

$11^{\text {th }}$ International Conference on Urban Drainage Modelling

23-26 Sep | Palermo - Italy

Monetary value of inundation damage is estimated by Module-2 as a function of inundation depth (Morita, 2008; Morita, 2013). In this study inundation damages specifically considered direct damage caused by physical contact with floodwater for eleven types of items: houses, household articles, business buildings, corporation assets and so forth. Direct damage is estimated by the inundation depth calculated by Module-1.

\subsection{Uncertainty in flood damage estimation}

Module-2 estimates the monetary inundation damage. To calculate the amount of direct damage, the asset value of each item is multiplied by the damage rate (i.e., percentage of damage) determined from the inundation - damage rate curve for a given inundation depth. For the eleven types of damage items considered, each has its own inundation - damage rate curve. These inundation - damage rate curves were derived using the inundation depth and damage rate data of the flood damage statistics surveyed by the national government (PWRI, 1995).

Inundation damage can be estimated by multiplying asset value with damage rate determined from the inundation depth calculated from Module-1. Figure 1 shows an example of inundation - damage rate relation for the domestic articles of a private house. The fitted relation is done by a logistic curve that describes the general behavior of inundation - damage rate characteristics quite reasonably. The logistic curve (the solid line) shown in Figure 1 can be used for deterministic flood damage estimation without giving regard to the scatteredness of the data. However, Figure 1 clearly shows that the variability of data is too significant to be ignored. Therefore, it is warranted to adopt a probabilistic flood damage estimation model that captures the

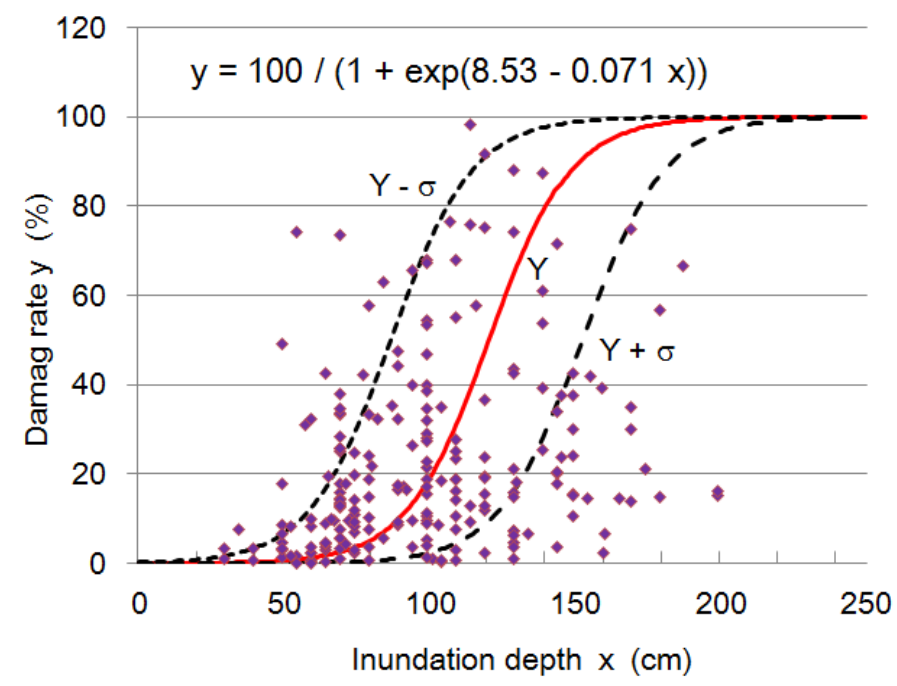

Figure 1. Example of Inundation - damage rate curves (logistic curve): curve for household articles. The damage remains small for low inundation and increases markedly over a certain threshold value such as the first floor level.

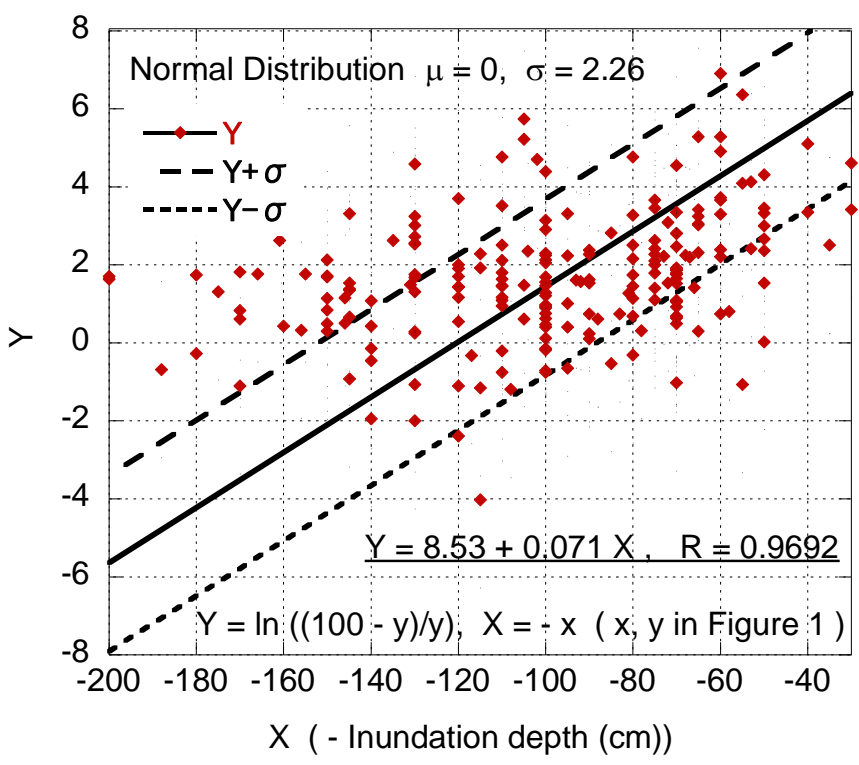

Figure 2. Dispersion of damage rates around the straight line for the method of least squares. The differences between the plotted data and the straight fitted line should be quantitatively treated using probability distribution. 


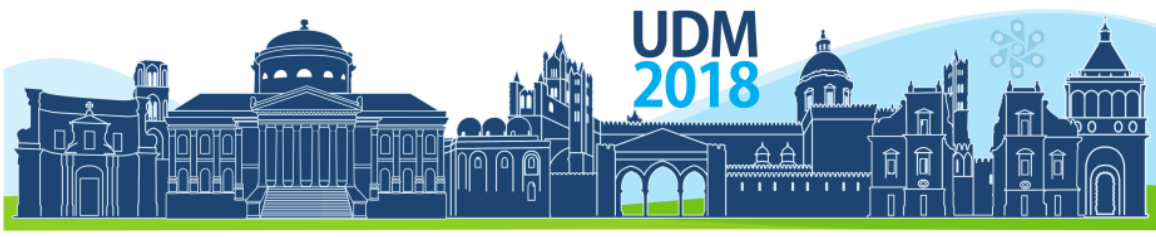

$11^{\text {th }}$ International Conference on Urban Drainage Modelling

23-26 Sep | Palermo - Italy

intrinsic variability of the data. To do so, the dispersion of data can be quantitatively treated using a probability distribution. The fitted curve in Figure 1 was obtained by the method of least squares using the transformed data shown in Figure 2.

To quantify the uncertainty in damage rate, we determined the probability distribution for the differences around the solid straight line in Figure 2. The normal distribution was adopted herein to quantify the dispersion. The straight lines of $Y, Y+\sigma, Y-\sigma$, in Figure 2 corresponds to the logistic curves of $Y, Y+\sigma, Y-\sigma$, in Figure 1, respectively. Not only the damage rate but also the dispersion of the asset value data should be treated for their uncertainty with some probability distribution. The logarithmic normal distribution was applied to the asset value data. The uncertainties of the two parameters, asset value and damage rate, were considered in the inundation damage calculation. The monetary inundation damage can then be calculated by multiplying the probabilistic assets values by the probabilistic damage rates. In this study, Monte Carlo simulation was applied to calculate direct damage for the eleven types of damaged household and business items.

\section{RESULTS AND DISCUSSION}

\subsection{Application of FDPM to Urban Drainage Area \\ FDPM was applied to a typical urban catchment area, the Zenpukuji River basin in the Tokyo Metropolis. The basin has an area of $18.3 \mathrm{~km}^{2}$ and is densely populated with high concentration of assets.}

The inundation calculations were carried out on a 50-m square grid for a design hyetograph (Morita, 2013). As an example, Figure 3 shows flood inundation calculations for 30-year storm under the present catchment condition. The calculated results are superposed with GIS data developed by the Tokyo Metropolitan Government. The database includes asset data organized for a 50-meter square grid which is identical to the calculation grid.

\subsection{Quantification of uncertainty in flood damage estimation}

For flood damage estimations, the software Crystal Ball was adopted for Monte Carlo simulation. A thousand (1000) repetitions of Monte Carlo Simulations for one chosen storm return period were carried out in which the asset values and the damage rate are randomly generated. The flood damage was estimated for rainstorms with 14 different return periods: 1-, 2-, 3-, 4-, 5-, 15-, 30-, 50-, 70-, 100-, 150-, 200-, 300-, 500-year. The input hyetographs were created based on IDF curves for storms with these return periods using the alternating 


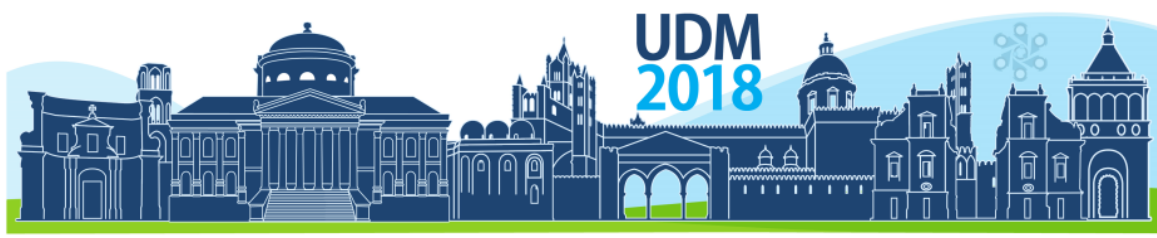

$11^{\text {th }}$ International Conference on Urban Drainage Modelling

23-26 Sep | Palermo - Italy

block method. The total flood damage for the Zenpukuji River basin was described as a relationship between flood damage percentile and return period (see Figure 4).

In Figure 4, the heavy solid curve in the middle denotes the median value of flood damage. The probabilistic calculation results are shown as a series of curves with different percentiles. The uncertainty of flood damage is expressed as a reliability area such as $20 \%, 40 \%, 60 \%$, and $80 \%$ center around the median value.

The reliability area is narrower for small return periods and broader for larger return periods. This can be explained by the smaller dispersion of damage rate for the lower inundation depth as shown in

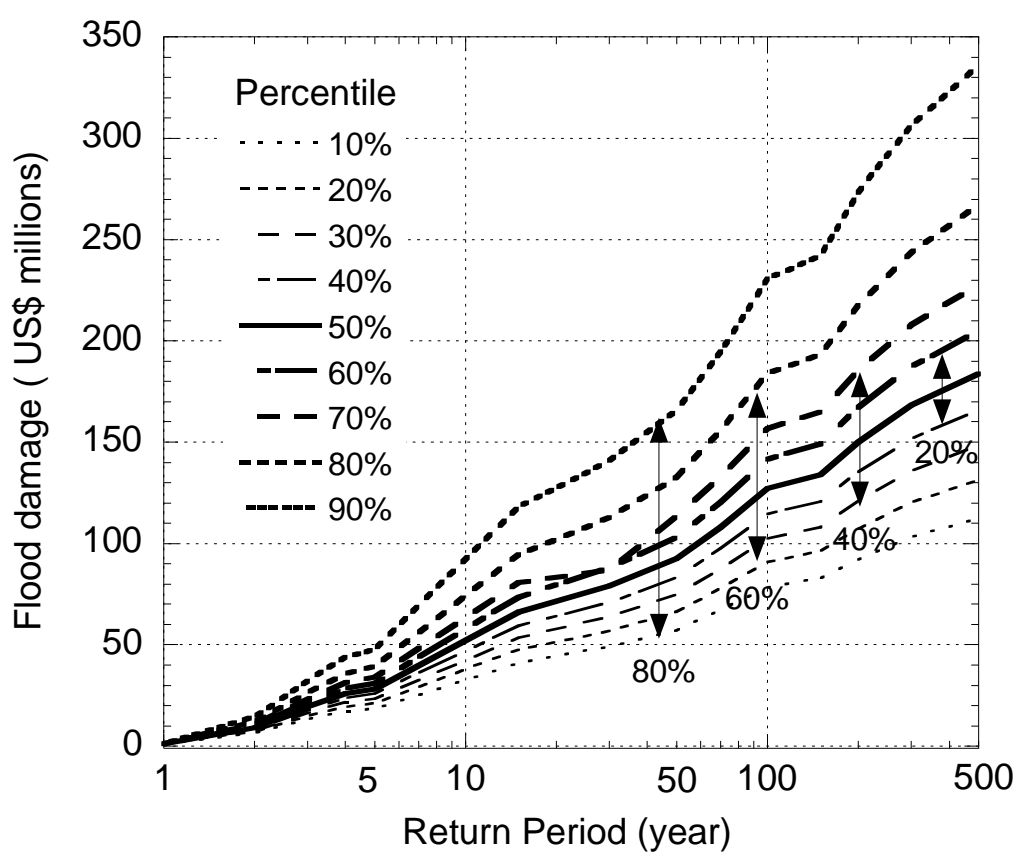
Figure 1.

Figure 4. Damage potential curves: relation between flood monetary damage and return period as a probabilistic calculation.

\section{CONCLUSIONS}

(1) A flood damage prediction model (FDPM) combined with GIS considering the uncertainty in flood damage estimation was presented.

(2) Monte Carlo simulation was implemented to deal with the uncertainties in asset value and damage rate in flood damage estimation using actual surveyed inundation data.

(3) The flood damage potential curve for the flood risk managenment in urban drainage areas can be transformed to the flood damage area chart with reliability values.

\section{References}

Apel,H., Thiken, A.H., Merz, B., and Blosh, G.(2006) A probabilistic modelling system for assessing flood risks, Natural Hazards, 38, 79-100.

Beven, K. and Hall, J. (2014) Applied uncertainty analysis for flood risk management, Imperial College Press, London.

Morita, M. (2008) Risk analysis and decision-making for optimal flood protection level in urban river management, The European Conference on Flood Risk Management, FLOODrisk 2008, Oxford UK.

Morita, M. (2013) Risk assessment method for flood control planning considering global climate change in urban river management, IAHS Publications, No. 357, pp. 107-116.

PWRI (1995) Estimation of damage rate for private and public properties based on an actual damage investigation, Public Works Research Institute of the Construction Ministry. 


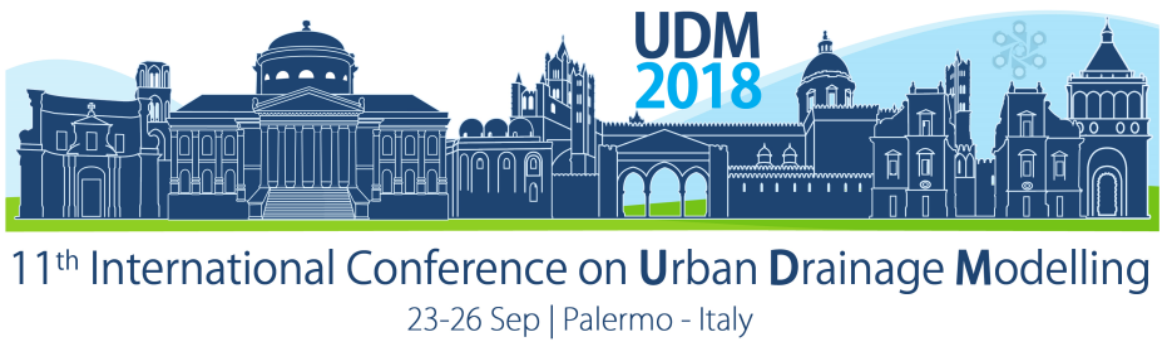

\title{
Hydrological Modelling of a Road-side Vegetated Filter Strip: Validation of a Coupled 2D Subsurface Flow and 1D Overland Flow Model
}

\author{
Tala Kanso ${ }^{1,2}$, Marie-Christine Gromaire ${ }^{1}$, David Ramier ${ }^{3}$ and Ghassan Chebbo ${ }^{1,2}$ \\ 1'LEESU, UMR MA 102, École des Ponts ParisTech, AgroParisTech, UPEC, UPE, Champs-sur-Marne, 6-8 avenue \\ Blaise Pascal, Cité Descartes, 77455 Marne-la-Vallée Cedex 2, France \\ ${ }^{2}$ Faculty of Engineering III, Lebanese University, Beirut, Lebanon \\ ${ }^{3}$ Cerema, DTer Ile-de-France, 12 rue Teisserenc de Bort, 78190 Trappes, France
}

\begin{abstract}
Vegetated filter strips (VFS) are commonly employed as a best management practice to treat road runoff. In order to understand the long-term hydrologic behaviour of a road-side VFS, a coupled HYDRUS 2-D subsurface and 1D overland flow model was used. This model was validated over an 8 months period based on five soil moisture sensors readings. Results show good agreement between simulations and measurements for some sensors. Conversely, a discrepancy was identified for other sensors at particular periods. This outcome leads to a better understanding of the actual hydrological performance, such as a probable occurrence of preferential flow.
\end{abstract}

Keywords: Filter strip; Hydrological performance; Preferential flow

\section{INTRODUCTION}

Impervious surfaces such as pavements and roofs increased by urbanization have strong negative impacts on the hydrological water cycle, leading to high runoff generation and water quality degradation (Davis et al., 2012). In the aim of reducing these effects, source control measures are employed as an effective and appealing solution (Han et al., 2005). Among these measures, are vegetated filter strips (VFS). They consist of a vegetated area with a moderate slope, aligned perpendicularly to the flow direction and adopted to improve water quality and hydrological characteristics of the flow. VFS are of wide application near wetlands, in agricultural fields, but are also considerably being used in urban areas, as a pre-treatment or a treatment practices. They are commonly implemented along highways, to reduce pollutant concentrations through filtration, sedimentation, infiltration and biological and chemical activity (Barrett et al., 1998). Beyond these water treatment aims, VFS allow for runoff infiltration into vegetated soils and thus are of interest to mimic the natural hydrological cycle.

Modelling of vegetated filter strips mainly focused on sediment trapping efficiency (GRASSF (B. J. Barfield et al., 1979); CREAMS (Knisel, 1980)), omitting the accurate description of hydrological processes. One-dimensional (horizontal) single-event models have been developed later, like VFSMOD (Muñoz-Carpena et al., (1999) and TRAVA (Deletic, 2001), providing an improved handling of the overland-flow and infiltration processes. These models are relevant for design purposes. However, their application is limited for water balance estimation that depends on the soil initial conditions and dry periods, thus requires a long-term modelling (Flanagan et al., 2017). In addition the roadside context is problematic for the modelling approach. For instance, the characteristics of the inflow and the road structure base that can be found under the filter strip medium, necessitate a precise description of the infiltration process. Therefore, a physically-based two dimensional model will help improve the modelling accuracy of hydrological processes. 


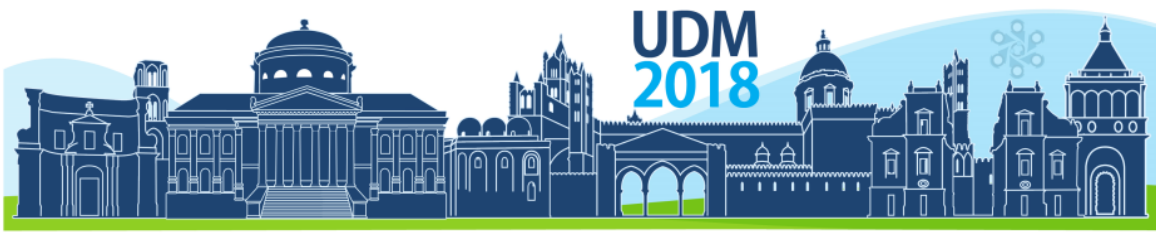

$11^{\text {th }}$ International Conference on Urban Drainage Modelling

23-26 Sep | Palermo - Italy

The purpose of this research is to understand and describe the hydrological behaviour of a VFS. Thus, a vegetated filter strip situated along a roadside in the suburbs of Paris, was equipped with soil moisture sensors and modelled. The adopted model, HYDRUS-2D coupled with the overland flow module, was validated over eight months, using soil moisture sensors readings.

\section{MATERIALS AND METHODS}

\subsection{Study site}

A roadside vegetated filter strip (Figure 1) in the Paris region (France), surrounded by an extremely industrial zone was chosen as the study site. It was constructed in 2012, with a width of $1.9 \mathrm{~m}$, a length of $50 \mathrm{~m}$, and a $5 \%$ slope. The runoff reaching the VFS is generated from a highly traffic road of $10.5 \mathrm{~m}$ width, and a $2 \%$ slope. The media of the VFS consists of the existing soil, classified as silt loam (USDA), with the following texture: $9.5 \%$ sand, $66.6 \%$ silt and $23.9 \%$ clay. The average soil bulk density, $1.48 \mathrm{~g} \cdot \mathrm{cm}-3$, was calculated from measurements performed over 3 equidistant points in length. The soil was equipped with 5 capacitive soil moisture sensors, four EC5 and one 5TE, from the ECH2O series (METER Group, 2018a, 2018b), at different depths varying between 6 and $21 \mathrm{~cm}$, and at different distances from the road $(30$ to $155 \mathrm{~cm}$ ). A road structure subbase was found under the filter media. This base is made of a soil treated with hydraulic binders, extended for about 1 to $2 \mathrm{~m}$ from the roadway sides. In highways supporting heavy-vehicle traffic, this base leads to an increase in the bearing capacity of the soil.

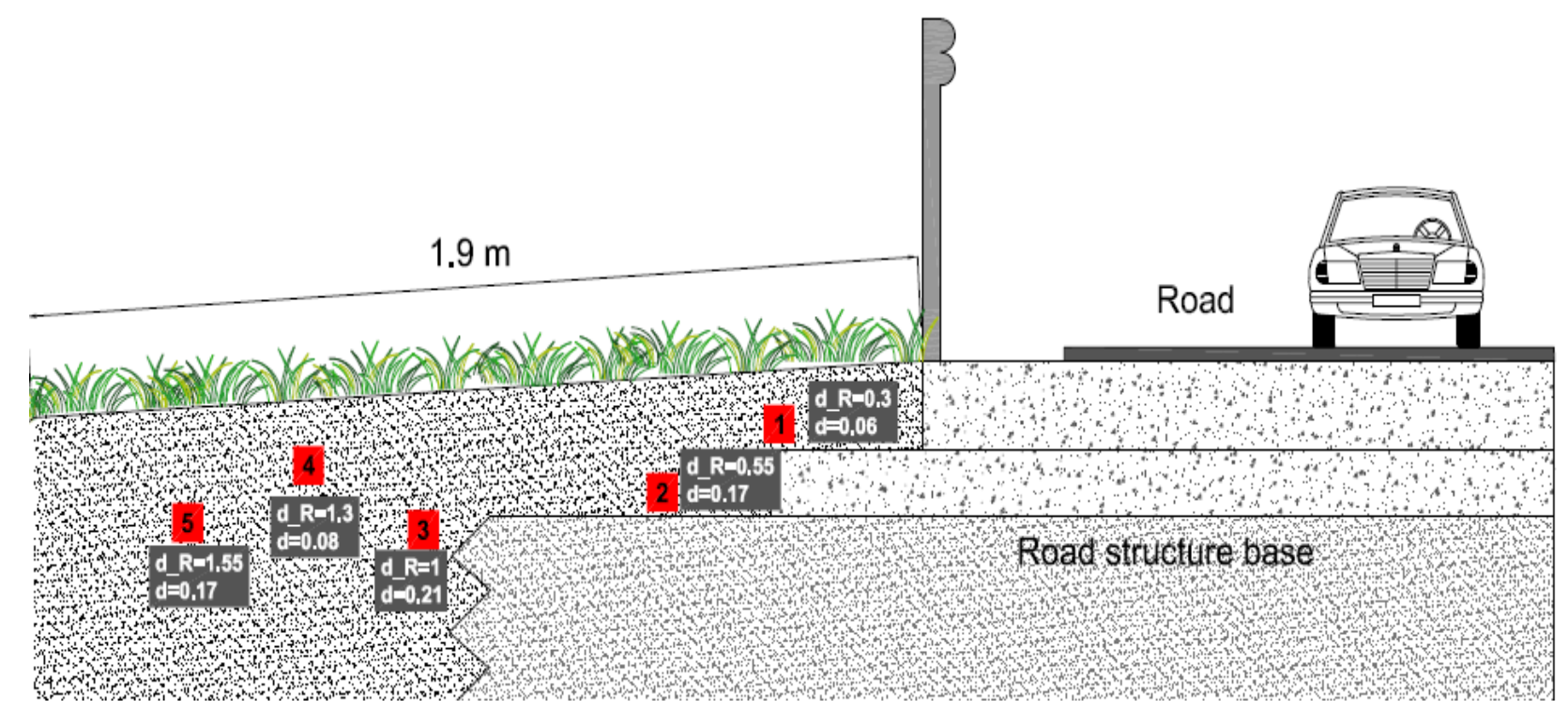

Figure 1. Transversal view of the roadside vegetated filter strip including sensors locations, with d_R (m) the distance from the road and $\mathrm{d}(\mathrm{m})$ the depth in the soil.

\subsection{Modelling and validation approach}

A coupled surface-subsurface flow model based on HYDRUS-2D (Šimůnek et al., 2016) was evaluated. Sub-surface flow is described using the 2-D Richards equation, while the overland flow is simulated using the 1-D kinematic wave equation (Köhne et al., 2011). The upper 


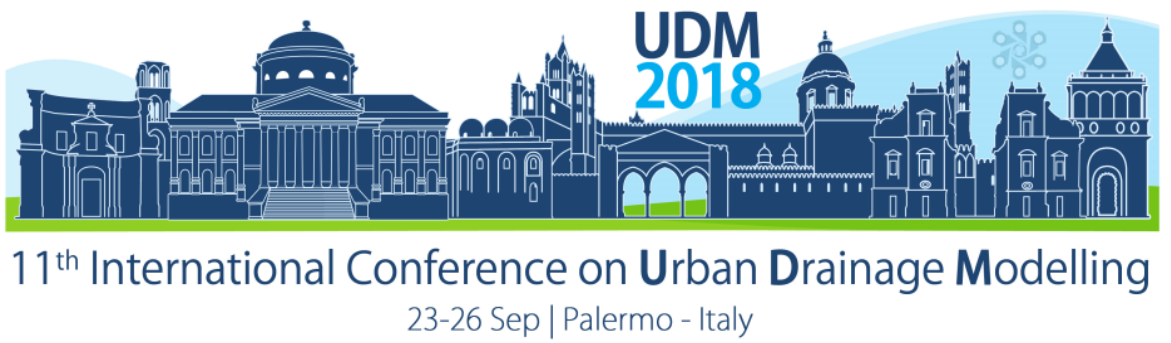

boundary condition applied to the VFS and the road surface, consists of the overland flow module coupled with atmospheric condition, for which an eight months series at a 6 min time step of rainfall and potential evaporation data in the Paris region was accorded. When the infiltration capacity of the soil is exceeded, runoff is generated, then water moves to the lower parts of the slope where it can again infiltrate. Manning's roughness coefficient is equal to 0.01 for the road and 0.03 for the VFS. The base layers of the road structure were considered as a complete impervious surface, thereby a no flux boundary condition was placed on their circumferences. The lower boundary condition, where there is no subbase, was chosen as a free drainage located at $1.15 \mathrm{~m}$ depth. The parameters of the van Genuchten-Mualem relationships were estimated using Rosetta predictions (based on the fraction of sand, silt and clay, and the measured bulk density of soil). For the domain spatial discretization, $5 \mathrm{~cm}$ triangular finite element meshes are used. The model was validated based on soil moisture sensors readings, which in turn are calibrated both in laboratory and in-situ. Soil moisture data are recorded at a 30 min time step.

\section{RESULTS AND DISCUSSION}

The results of the HYDRUS-2D simulation are shown in Figure 2. They represent the variation of the soil volumetric water content over a period of 8 months from 31/07/2016 to 31/03/2017. The measured and the simulated data were plotted for the five sensors at five different locations.

Two periods can be clearly identified: summer-autumn (July to November) and winter-spring (December to March). A considerably different range of variation in soil water content is noticed. As for the first period VWC vary from 20 to more than $40 \%$, while for the second this variation is less important (30 to $40 \%$ ). This may be due to longer dry periods inter-events in summer-autumn. At first, most peaks and troughs are well reproduced, and the root mean square errors are relatively good ( $<9$ Vol. \%) for all sensors. However for the sensors 4 and 5 , the most distant from the road, simulations predict better the volumetric water content in winterspring days. Thus the highest RMSE values $>5 \mathrm{Vol}$. \% are a result of the deviation during the dry season. To illustrate, the lowest values of VWC for sensor number 3 , are comparable to VWC values for sensors 4 and 5 . Nevertheless, the latter two sensors do not react to some rainfall events, mostly for the dry season, showing a strong deviation between measured and simulated value.

Therefore, an unusual functioning of VFS is identified. During summer-autumn period, the soil becomes dryer, which apparently contributes to the creation of cracks and fractures between road structure and soil media. These fractures were manifested as a preferential flow, hence water reaches sensor number 3 without reaching sensors 4 and 5 .

At a second stage the model will be validated based on the drained flux at the bottom of the vegetated filter strip. This validation would be of interest to verify and confirm the global performance of the model. The rainfall resolution could also have an impact on the outputs, especially for small impervious catchment. Yet in this study the 6 min rainfall resolution is sufficient to predict soil water dynamic recorded at a 30 min time step. 


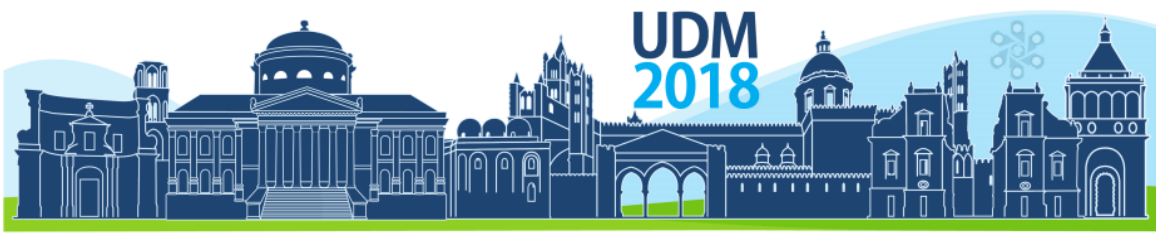

$11^{\text {th }}$ International Conference on Urban Drainage Modelling 23-26 Sep | Palermo - Italy
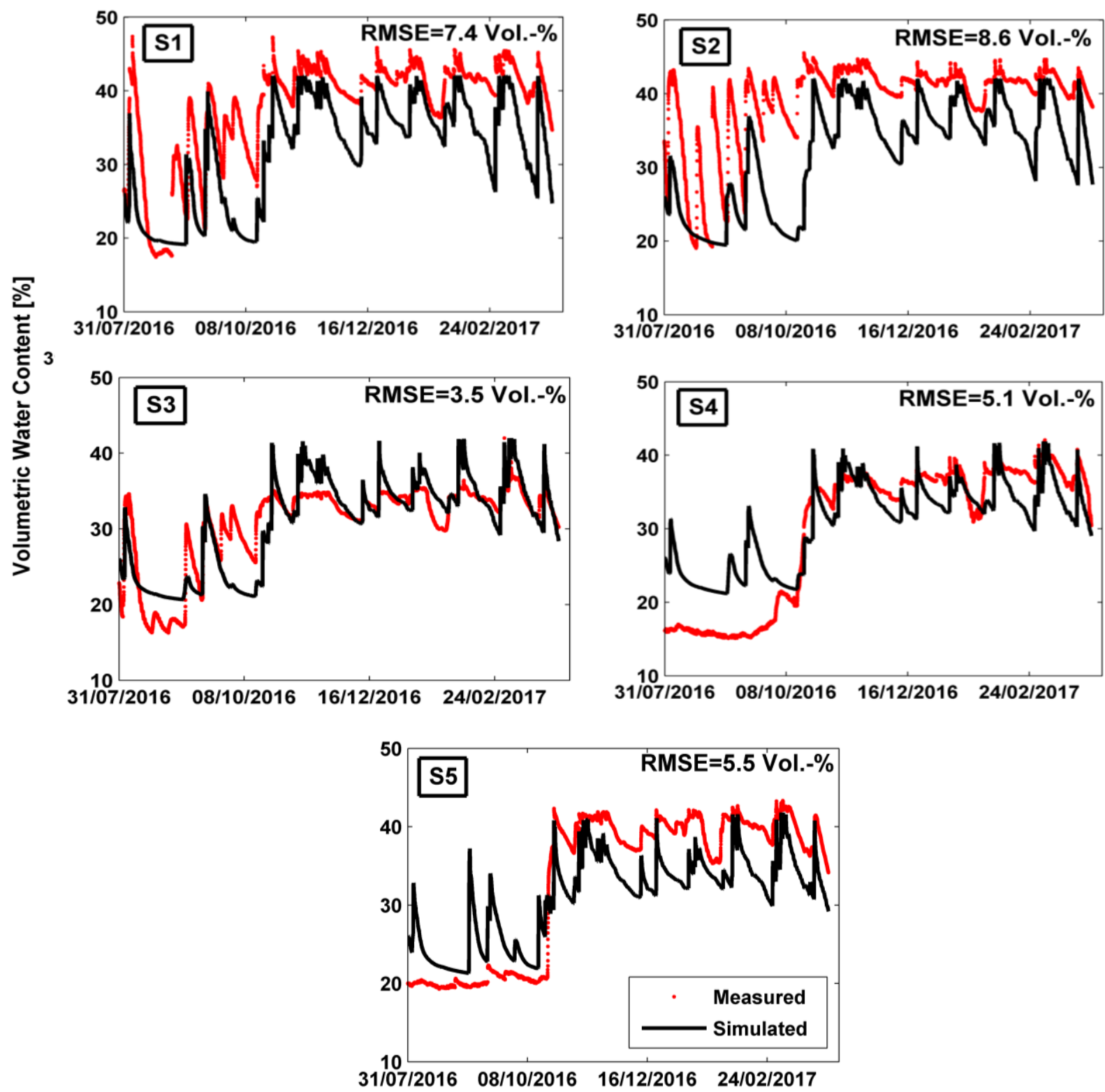

Figure 2. Measured and simulated volumetric water content (\%) for the five sensors implemented in the VFS. 


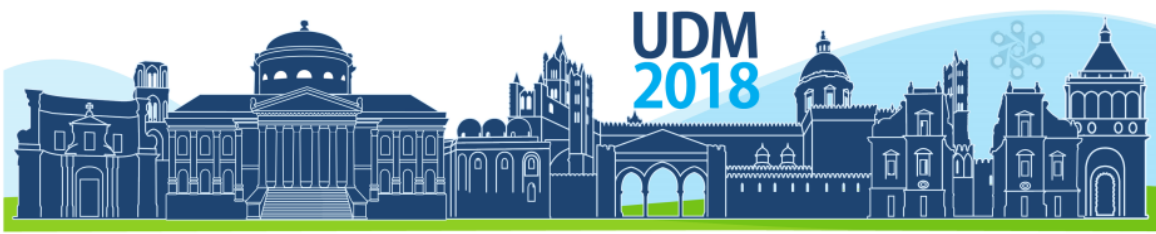

$11^{\text {th }}$ International Conference on Urban Drainage Modelling

23-26 Sep | Palermo - Italy

\section{CONCLUSIONS}

A HYDRUS-2D model coupled with an overland flow submodel was tested and validated on a road-side vegetated filter strip in the Paris region. The validation of the model was assessed based on an 8 months duration of volumetric water content measurements. Results revealed good agreement between simulations and measurements, for some soil moisture sensors. Conversely, simulations diverge from the measured data for the other sensors, particularly in the dry season (summer-autumn). This could be probably due to a preferential water flow caused by cracks creation between soil media and the road subbase. Given its high level of detail, this tool can be adapted to model and predict multiple hydrological performance including preferential flow and non-uniform inflow amongst others. This will yield a better understanding of long-term hydrological behaviours occurring in such systems. Additionally, this model could be used in the future to predict the efficiency of road-side vegetated filter strip as a treatment practice under various designs and climate.

\section{References}

B. J. Barfield, E. W. Tollner, and J. C. Hayes (1979). Filtration of Sediment by Simulated Vegetation I. Steady-State Flow with Homogeneous Sediment. Trans. ASAE 22, 0540-0545.

\footnotetext{
Barrett, M.E., Walsh, P.M., Jr., J.F.M., and Charbeneau, R.J. (1998). Performance of Vegetative Controls for Treating Highway Runoff. J. Environ. Eng. 124, 1121-1128.
}

Davis, A.P., Stagge, J.H., Jamil, E., and Kim, H. (2012). Hydraulic performance of grass swales for managing highway runoff. Water Res. 46, 6775-6786.

Deletic, A. (2001). Modelling of water and sediment transport over grassed areas. J. Hydrol. 248, 168-182.

Flanagan, K., Branchu, P., Ramier, D., and Gromaire, M.-C. (2017). Evaluation of the relative roles of a vegetative filter strip and a biofiltration swale in a treatment train for road runoff. Water Sci. Technol. 75, 987-997.

Han, J., Wu, J.S., and Allan, C. (2005). Suspended Sediment Removal by Vegetative Filter Strip Treating Highway Runoff. J. Environ. Sci. Health Part A 40, 1637-1649.

Knisel, W.G. (1980). CREAMS: a field scale model for Chemicals, Runoff, and Erosion from Agricultural Management Systems [USA]. U. S. Dept Agric. Conserv. Res. Rep. USA.

Köhne, J.M., Wöhling, T., Pot, V., Benoit, P., Leguédois, S., Bissonnais, Y.L., and Šimůnek, J. (2011). Coupled simulation of surface runoff and soil water flow using multi-objective parameter estimation. J. Hydrol. 403, 141-156.

METER Group (2018a). ECH2O 5TE Manual (Pullman WA, USA).

METER Group (2018b). ECH2O EC-5 Manual (Pullman WA, USA).

Muñoz-Carpena, R., Parsons, J.E., and Gilliam, J.W. (1999). Modeling hydrology and sediment transport in vegetative filter strips. J. Hydrol. 214, 111-129.

Šimůnek, J., van Genuchten, M.T., and Šejna, M. (2016). Recent Developments and Applications of the HYDRUS Computer Software Packages. Vadose Zone J. 15, 0. 


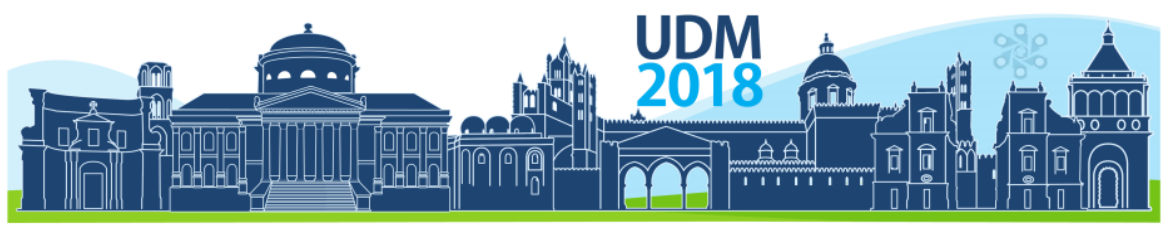

$11^{\text {th }}$ International Conference on Urban Drainage Modelling

23-26 Sep | Palermo - Italy

\title{
CA-ffe - a Cellular Automata Fast Flood Evaluation Model
}

\author{
Behzad Jamali ${ }^{1}$, Luke Cunningham², Peter M. Bach ${ }^{1,3}$ and Ana Deletic ${ }^{4}$ \\ ${ }^{1}$ Department of Civil Engineering, Monash University, Clayton, Australia \\ 2 Water Technology Pty Ltd, 15 Business Park Drive Notting Hill, Australia \\ ${ }^{3}$ Swiss Federal Institute of Aquatic Science \& Technology (Eawag), Switzerland \& ETH Zurich \\ ${ }^{4}$ School of Civil and Environmental Engineering, University of New South Wales (UNSW), Sydney, Australia
}

\begin{abstract}
We developed a new fast 2D flood inundation model by adapting algorithms for rapid flood inundation into a cellular automata (CA) approach. Rapid inundation models rely only on topographic depressions and the water balance equation. Through a CA approach, we improved this method by firstly eliminating the time consuming pre-processing step (for identification of depressions and their specific information) and, secondly, by solving the issue of not wetting flow path areas in between depressions. We tested our model by comparing its results to the HEC-RAS 2D and TUFLOW model in two small case studies in Melbourne. Results showed that our model is able to predict flood inundation depth and extent with sufficient accuracy for flood planning and management and within seconds or several minutes.
\end{abstract}

Keywords: cellular automata; urban flood; HEC-RAS; rapid flood inundation models; direct rainfall

\section{INTRODUCTION}

Different flood modelling packages have different levels of complexity, temporal and spatial scale of input and output variables, prediction accuracy, computational demand, and simulation run time. Simulation run time becomes an important factor when the study area is large or a large number of flood simulations is required (e.g. Apel et al., 2016; Simões et al., 2015). Models that solve the Shallow Water Equations (SWEs) (e.g. MIKE-FLOOD and TUFLOW) or their approximations (e.g. LISFLOOD-FP Bates and De Roo, 2000) are widely used to simulate detailed flood dynamics. Even in their simplified form, SWEs are complex mathematical formulas and computationally expensive operations (Guidolin et al., 2016). Parallel computing and the application of graphics processing units (GPUs) have been introduced recently to improve their simulation speed. Concurrently, recent development in flood models have also focussed on improving simulation speed by implementing simpler formulation of flood dynamics. We categorise these models into two groups:

Cellular Automata (CA) based models: which divide the flood calculation domain into grid of (rectangular) cells with a number of states (e.g. water level) and transition rules to represent the spatio-temporal evolution of flooding. These models generally use Manning's and critical flow formulas to calculate/limit flow fluxes among cells (Dottori and Todini, 2011). Ghimire et al. (2013) applied a simple method that ranked neighbour cells according to their water level. Water flow between cells was limited to the transferrable volume calculated by the Manning's and critical flow equations. Guidolin et al. (2016) further simplified this method using a weightbased approach that calculates intercellular flow transfer by applying the Manning's and critical flow equations only once per central cell.

Models based on topographic depressions (Rapid Flood Models RFMs): which divide the calculation domain into primary areas that represent topographic depressions. These models can also be considered as CA based models. However, they represent the flooding process 


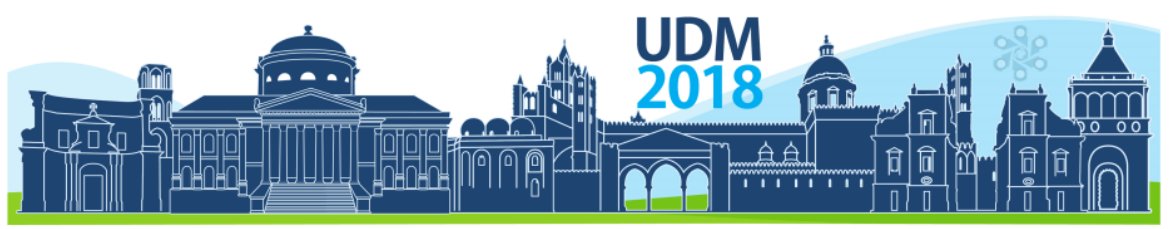

$11^{\text {th }}$ International Conference on Urban Drainage Modelling

23-26 Sep | Palermo - Italy

only using topographic depressions and the continuity equation (no Manning's or critical flow equations are applied). Therefore, they disregard the temporal evolution of flooding and only predict the final and maximum flood depth but not flow velocities (e.g. Gouldby et al., 2008; Krupka, 2009; Lhomme et al., 2008). These models have a shorter simulation run time (usually within seconds). Identification of the depression cells and extraction of their attributes (e.g. volume elevation relationship, neighbours and the communication levels) from DEM (preprocessing step) is computationally expensive and usually requires the user to choose a number of parameters (minimum cells depth/area). Additionally, these models do not wet flow path areas in between depressions especially in flat areas or in areas with uniform slope.

In this study we developed a Cellular Automata Fast Flood Evaluation Model (CA-ffe) on the concept of RFMs. We introduced a new algorithm that uses a regular grid of square cells instead of depressions. This enabled us to eliminate the pre-processing step, and also solve the issue of dry flow path areas. Similar to the RFMs, CA-ffe can be used to predict inundation originating from point sources (such as a drainage network manholes or a breach point in channels). Additionally, it is well-suited for the application of the direct rainfall (or rainfall-ongrid) approach, which has become popular in recent years. The model and its graphical user interface (GUI) is developed using the Python programming language and GDAL libraries. We tested CA-ffe in several case studies, differing in size, grid resolution, slopes and flood sources (direct rainfall and point sources) and compared the modelled inundation to those predicted by HEC-RAS 2D and TUFLOW models (we only presented the HEC-RAS model results and the TUFLOW results will be provided in the full paper).

\section{MATERIALS AND METHODS}

We adopted the RFM algorithm implemented in Lhomme et al. (2008) in the form of a CA algorithm. Our model uses Digital Elevation Model (DEM) grids as the lattice of CA cells. The algorithm starts by assigning rainfall and point source flood volumes to the CA cells as a column of 'excess volume' (Figure 1). We define excess volume as the flood volume temporarily stored in a cell and, depending on the state of the cell, it will raise water level of that cell or move to its neighbouring cells. At this stage, we do not simulate or account for hydrological losses (e.g. interception and infiltration) in the model and therefore, we use excess rainfall instead (i.e. the volume of rainfall available for direct surface runoff). At the start of the simulation, water level of each cell is equal to its ground elevation (i.e. zero water depth). The algorithm iterates through those cells that have excess volume and spreads excess volume according to the following four transition rules (see Figure 1):

Rule 1: raise water level in the central cell if it is in a depression;

Rule 2: share the excess volume between the five neighbouring cells (including the central cell) if they have equal water level (water levels will not change in this condition);

Rule 3: raise water level in the central cell by a constant increment value (and remove equivalent volume from the central cell's excess volume) if water level in the central cell is equal to or lower than neighbours; and

Rule 4: Divide the excess volume between neighbours based on their weights if water level in the central cell is higher than at least one neighbour. The weight of each cell is calculated based on the water level difference between the neighbour and central cells.

We tested CA-ffe model in 6 different case studies located in Melbourne, Australia and by comparing the results with two detailed hydrodynamic models: HEC-RAS and TUFLOW using four performance indicators (Table 1). 


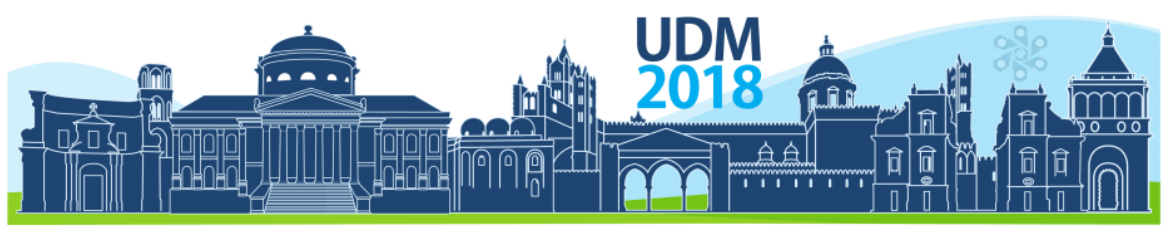

$11^{\text {th }}$ International Conference on Urban Drainage Modelling

23-26 Sep | Palermo - Italy

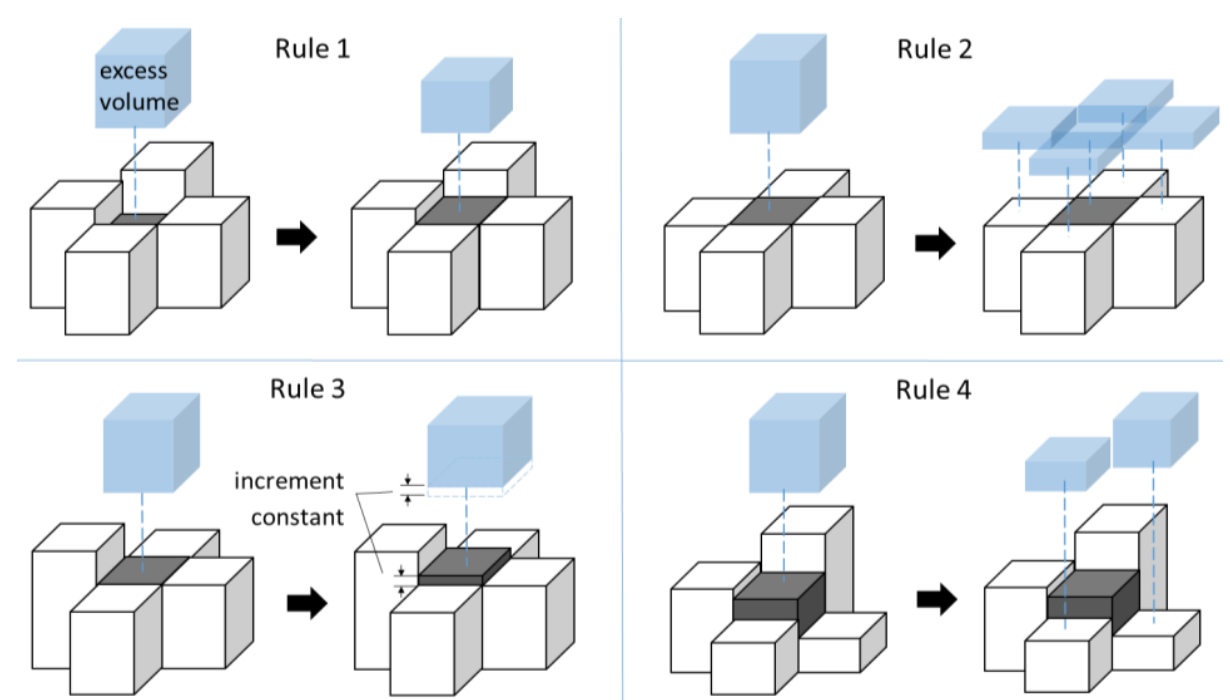

Figure 1. Description of the CA rules used in the 2D fast flood inundation algorithm. The cell with excess volume will be assumed as the central cell (in dark colour).

Table 1. Performance indexes used for testing the fast 2D flood model against HEC-RAS 2D

\begin{tabular}{lll}
\hline Performance index & Formula & range \\
\hline Hit Rate & $H R=\frac{\text { Hits }}{\text { Hits }+ \text { Misses }}$ & $\begin{array}{l}0-1 \text { (higher is } \\
\text { better) }\end{array}$ \\
False Alarm Rate & $F A R=\frac{\text { False alarms }}{\text { Hits }+ \text { False alarms }}$ & $0-1$ (lower is better) \\
Critical Success Index & $C S I=\frac{\text { Hits }}{\text { Hits }+ \text { Misses }+ \text { False alarms }}$ & $0-1$ (higher is better) \\
Root Mean Square Error & $R M S E=\sqrt{\frac{\sum_{i=1}^{p}\left(Y_{i}^{b}-Y_{i}^{T}\right)^{2}}{p}}$ & (lower is better) \\
\hline
\end{tabular}

\section{RESULTS AND DISCUSSION}

Here we present the predicted flood extents caused by a point source in two small case studies. CA-ffe was able to correctly predict the general flow path. The HR and FAR indexes were 0.78 and 0.05 respectively for the first test case (Figure 2a) and 0.75 and -0.06 for the second (Figure $2 \mathrm{~b}$ ). Simulation time for both test cases were less than 10 seconds. HEC-RAS simulations took around 10 hours on the same computer (full momentum equations with 0.5 second time step and 8 hours from the start of simulation).It should be mentioned that HECRAS run times could dramatically change depending on computing power. The full paper will represent a thorough comparison of our model with TUFLOW for different case studies.

\section{CONCLUSIONS}

Our fast 2D flood inundation model can predict the final flood extent and depth with sufficient accuracy and in a short time (within seconds or a few minutes depending on the study area and grid resolution). It is an easy model to setup and can be used for: assessment of flood risks especially in large urban areas; quickly finding hotspots and problem areas and then, if required, applying a detailed flood model and; flood emergency management when we need to run multiple scenarios for decision making (we can very quickly test the sensitivities of models and terrain changes like sand bag levees). 
Proceedings of the 11th Int. Conference on Urban Drainage Modelling, 23-26 Sep. 2018, Palermo (ITALY). Ed. prof. Giorgio Mannina

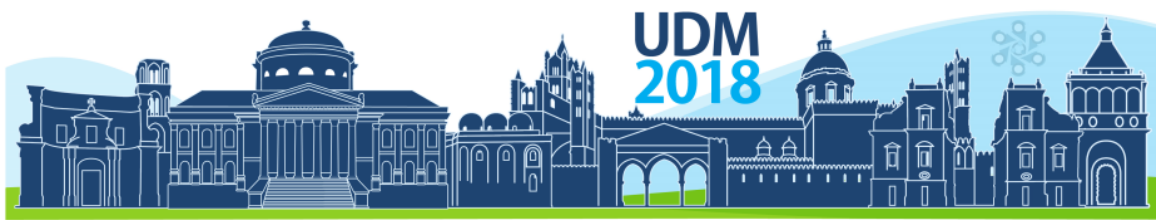

$11^{\text {th }}$ International Conference on Urban Drainage Modelling

23-26 Sep | Palermo - Italy
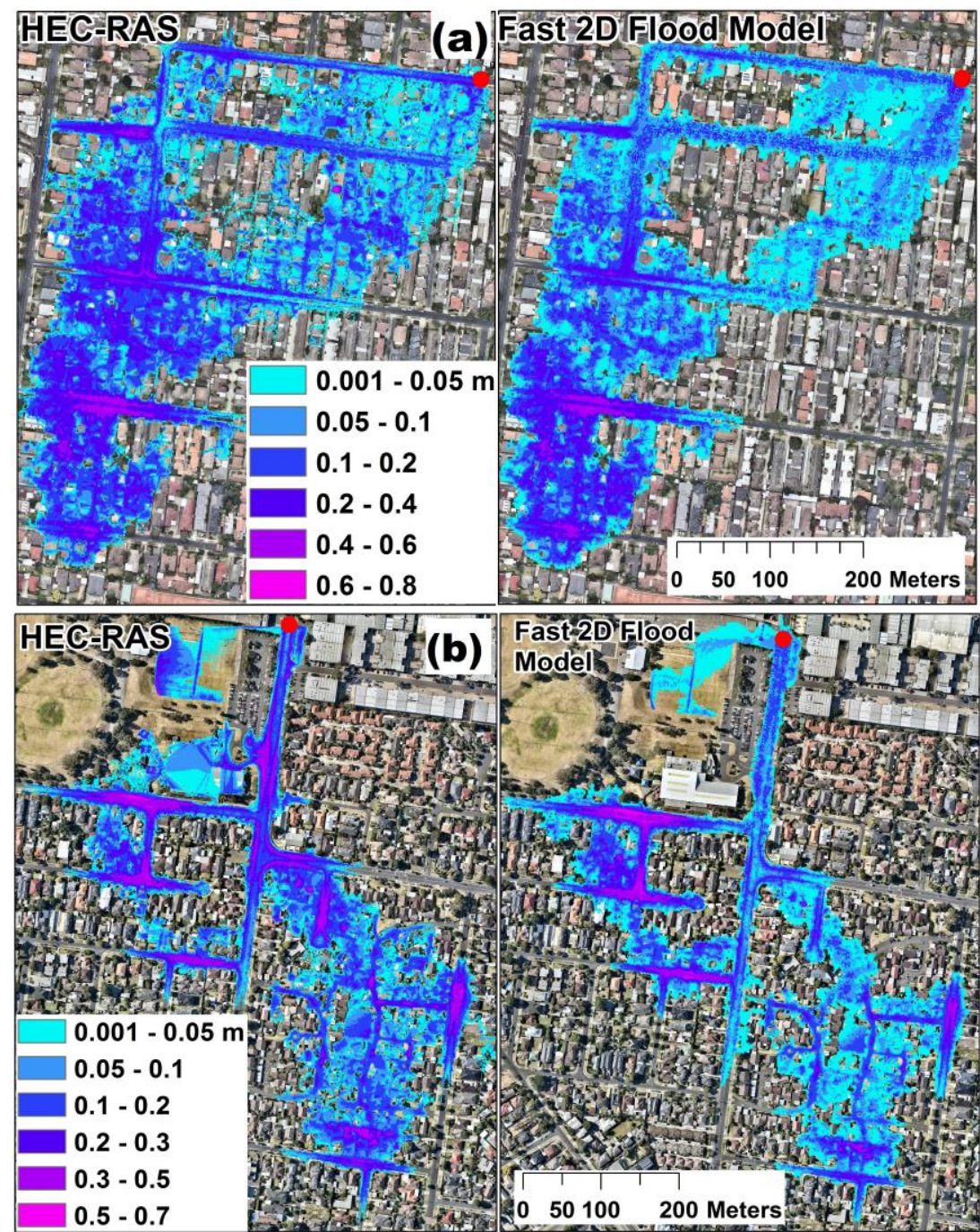

Figure 2. Flood inundation predicted by HEC-RAS 2D (left) and our CA-ffe model (right). Flooding is originated from a point source (red point) with a total volume of $8,000 \mathrm{~m}^{3}$.

\section{References}

Apel, H. et al., 2016. Combined fluvial and pluvial urban flood hazard analysis: concept development and application to Can Tho city, Mekong Delta, Vietnam. Nat. Hazards Earth Syst. Sci., 16(4): 941-961.

Bates, P.D., De Roo, A.P.J., 2000. A simple raster-based model for flood inundation simulation. Journal of Hydrology, 236(1): 54-77.

Dottori, F., Todini, E., 2011. Developments of a flood inundation model based on the cellular automata approach: Testing different methods to improve model performance. Physics and Chemistry of the Earth, Parts A/B/C, 36(7): 266-280.

Ghimire, B. et al., 2013. Formulation of a fast 2D urban pluvial flood model using a cellular automata approach. Journal of Hydroinformatics, 15(3): 676-686.

Gouldby, B., Sayers, P., Mulet-Marti, J., Hassan, M.A.A.M., Benwell, D., 2008. A methodology for regional-scale flood risk assessment. Proceedings of the Institution of Civil Engineers - Water Management, 161(3): 169-182.

Guidolin, M. et al., 2016. A weighted cellular automata 2D inundation model for rapid flood analysis. Environmental Modelling \& Software, 84: 378-394.

Krupka, M., 2009. A rapid inundation flood cell model for flood risk analysis, Heriot-Watt University.

Lhomme, J. et al., 2008. Recent development and application of a rapid flood spreading method.

Simões, N. et al., 2015. Stochastic Urban Pluvial Flood Hazard Maps Based upon a Spatial-Temporal Rainfall Generator. Water, 7(7): 3396. 


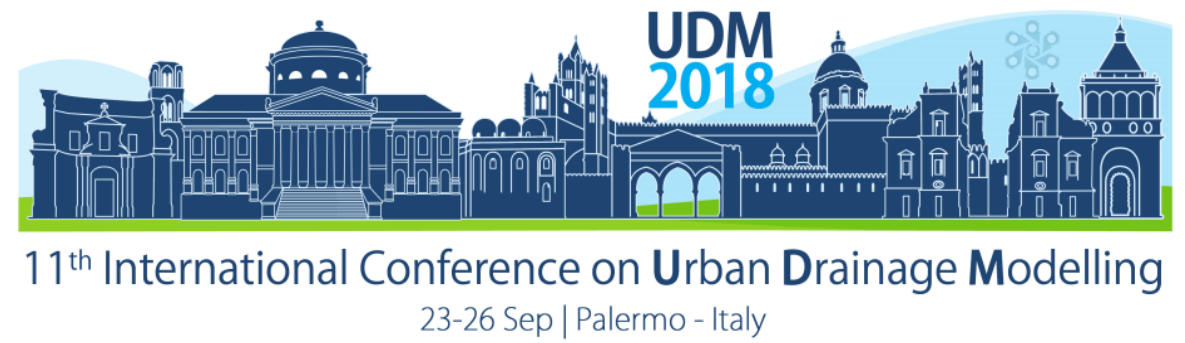

\title{
Importance of Subdivision Resolution of Surrogate Models for Emulating Catchment Response and Surcharge
}

\author{
Cecilie Thrysøe ${ }^{1}$, Morten Borup ${ }^{1}$ and Karsten Arnbjerg-Nielsen ${ }^{1}$ \\ ${ }^{1}$ Technical University of Denmark, Department of Environmental Engineering, 2800 Kgs. Lyngby, Denmark
}

\begin{abstract}
State-of-the-art urban drainage modelling applies high-fidelity physically based distributed models. However, high computational demands of such models limit the usage. In this study a conceptual surrogate model is set up to emulate the output of a Mike URBAN model. The surrogate model is a volume-based model, which models discharges from a user-defined compartment to downstream compartment(s) as well as to the surface. Training data is created by extracting steady state volume-discharge points from Mike URBAN and applying a piecewise linear interpolation between the points. Two surrogate models are set up for the Elster Creek catchment in Melbourne, Australia. The first consists of one compartment and the second subdivides this into 17 smaller compartments. Results show that both surrogate models perform very well in emulating the compartment volume and discharge from Mike URBAN. The surcharge is more difficult to model as its behaviour is more dynamic and hence most different from the steady state training data. Increasing compartment resolution shows an overall improvement of all results - especially in capturing surcharge behaviour. The results show that even surcharging urban drainage systems can be modelled sufficiently accurate for many purposes with the proposed surrogate models.
\end{abstract}

Keywords: Modelling resolution, Conceptual Modelling, Computation Time, Surcharging

\section{INTRODUCTION}

Due to climate change and urban development the need for fast and accurate urban drainage models are increasing. State-of-art models are high fidelity physically based distributed models such as Mike Urban (MU) and Mike Flood (MF). However, the usage of such models is limited due to large computation times. Many attempts have been made to reduce computational requirements while still assuring an accepting level of accuracy. Besides increasing the numerical efficiency of the computation by e.g. parallelization, cloud computing etc., this work can be divided in (i) simplified physically based models and (ii) conceptual models. (i) reduce the physical accuracy by e.g. simplifying the Saint-Venant equation or the computational grid e.g. Fewtrell et al. (2011). (ii) seek to model the desired response without including any of the original physical terms e.g. Wolfs et al. (2013). An example of the latter is a surrogate model (SM), which aims to emulate the output of a higher fidelity model. Hence, the output of the high-fidelity (HiFi) model is used to train and validate the surrogate model instead of observed data which may be unavailable.

This study aims to investigate the performance of a simple surrogate model which should be applicable for both planning and real time control usage in the urban drainage modelling context. The surrogate model will be varied in size to examine the influence.

\section{MATERIALS AND METHODS}




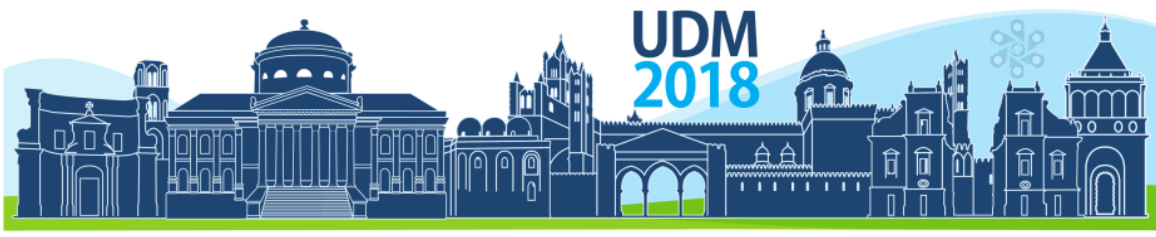

$11^{\text {th }}$ International Conference on Urban Drainage Modelling

23-26 Sep | Palermo - Italy

\subsection{Conceptual model}

The surrogate model is setup by lumping sections of a HiFi model into compartments. The volume of water within each compartment is modelled as a simple mass balance of the inand outgoing discharges. The outgoing discharges are governed by unambiguous volumedischarge rating curves which accounts for non-linearity's in the system. The SM engine applied is presented in Borup et al. (2017) with the difference that water can surcharge to the surface. In Figure 1 compartment $b$ receives water from an upstream compartment, $Q_{i n, b}$, and from rainfall runoff, $Q_{r u n, b}$. From here the water can be discharged downstream to compartment $c$ and it can surcharge to the surface, $Q_{\text {spill,b. }}$. Discharge to the surface and to downstream compartments are modelled in the same way and are unidirectional.

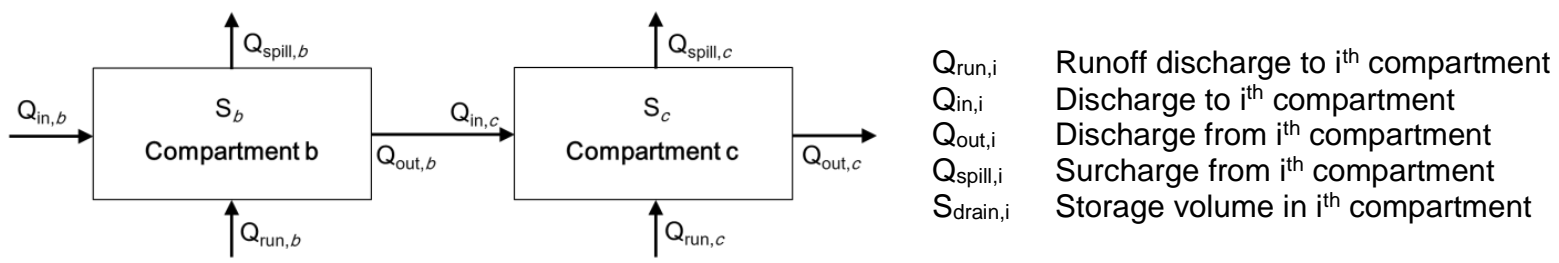

Figure 1. Conceptual setup for an example of a surrogate model containing two compartments, a and b.

\subsection{Training and validation data}

The governing volume-discharge relationships are derived from MU model results. For achieving a simple set of training data, steady state data are computed for a range of different rain intensities. The model is run with rain intensities ranging from 0 to $10 \mu \mathrm{m} / \mathrm{s}$. Each intensity level is kept constant for four hours to ensure close to steady state in the system. Afterwards steady state volume and discharge values are extracted for each compartment and used as parameters for the SM. The SM then interpolates linearly between these points when it simulates discharges. For the validation data a rain series covering the period 1979-2015 from Melbourne is applied (Bureau of Meteorology, 2015). From here $3 x$ 15 events covering the largest depth, intensity over $30 \mathrm{~min}$ and $180 \mathrm{~min}$ are extracted.

\subsection{Case study}

The case study area is the Elster Creek Catchment located in Melbourne, Australia. A Mike Urban model of the area is provided and shown in Figure 2 left (Davidsen et al., 2017).
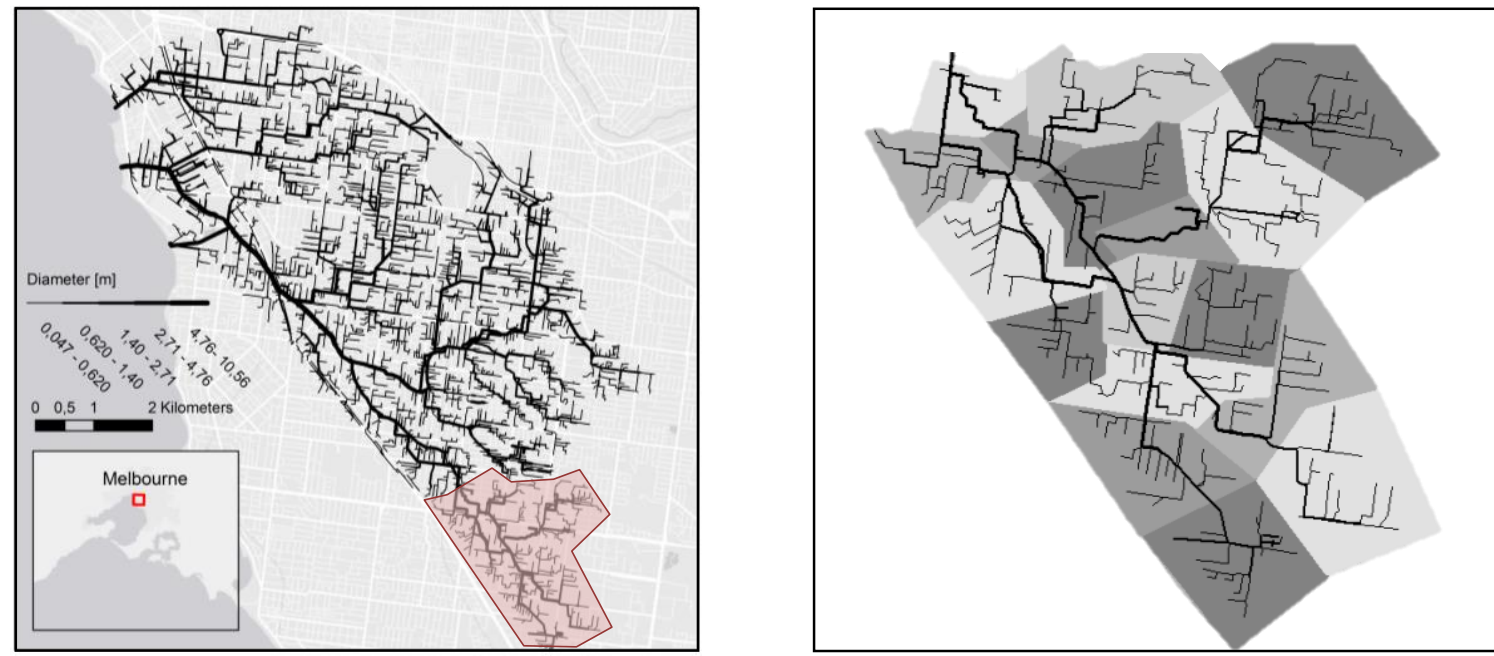

Figure 2. Elster Creek Catchment. Figure left shows compartment SM1 and right shows compartments SM1 div. 


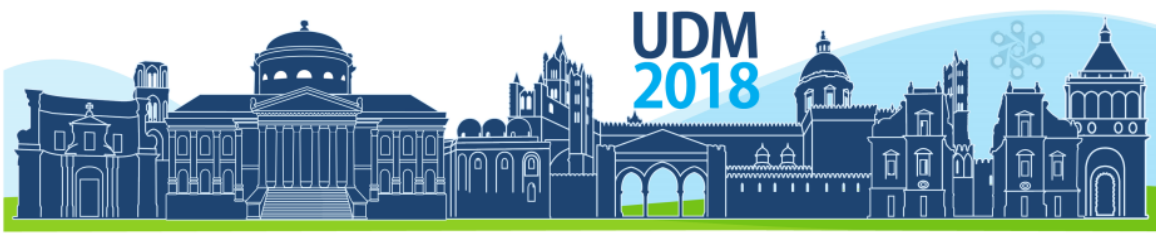

$11^{\text {th }}$ International Conference on Urban Drainage Modelling

23-26 Sep | Palermo - Italy

We will focus on the most upstream part of the catchment marked in the figure to the left. This area will be lumped to one compartment, SM1. To examine the influence of compartment resolution we subdivide this compartment further into 17 small compartments shown in Figure 2 to the right. Results from these compartments will be noted SM1 div.

\section{RESULTS AND DISCUSSION}

Figure 3 shows the MU model and the two SMs for an extracted rain event. The pink band shows the margin of $\mathrm{MU}$ when the discharge is varied with $\pm 23 \%$ corresponding to the overall uncertainty of pipe discharge according to Hansen and Liu (2004).
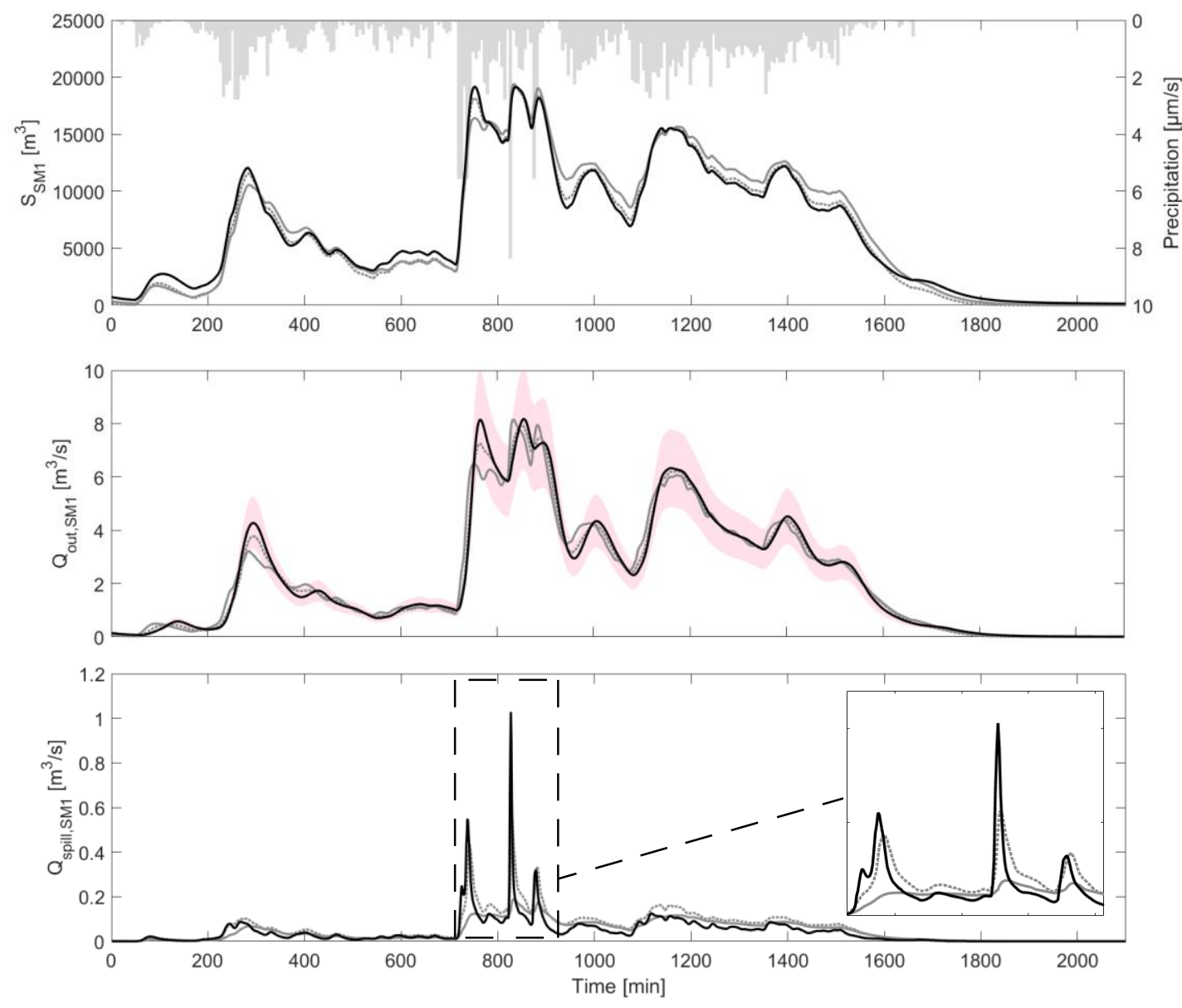

- MU, $-\mathrm{SM}_{\mathrm{ss}}, \cdots \mathrm{SM}_{\mathrm{div}}, \quad$ Precipitation, $\mathrm{MU}_{ \pm 23 \%}$

Figure 3. Comparison of Mike Urban model with surrogate model SM1 and surrogate model SM1div.

Both SMs fit very well to the MU model for the volume and discharge, but an overall better fit is obtained when subdividing the compartments. Both SMs discharge are mostly within the MU uncertainty band. The behaviour of the surcharging is more difficult to emulate, which demonstrates the limitations of applying steady state training data to describe a dynamic process. However, it is seen that by subdividing the single compartment to multiple compartments a much better fit is obtained. 


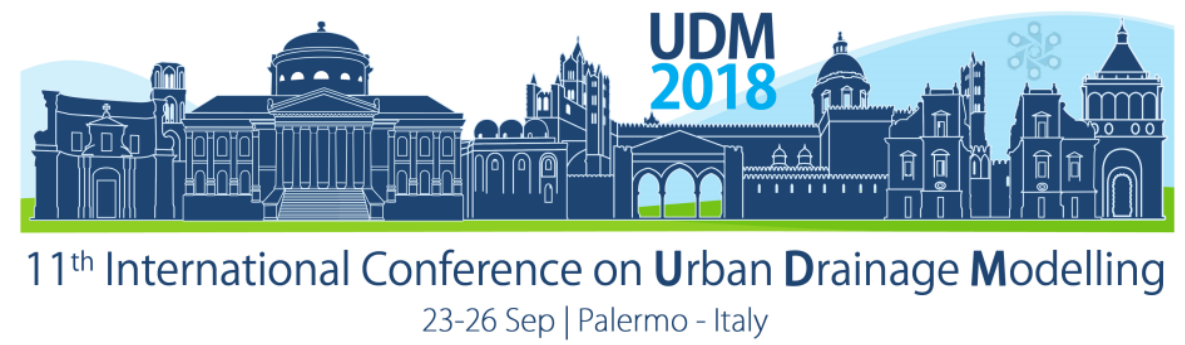

NSE (Nash-Sutcliffe-Efficiency), PEP (Peak-Error-Percentage) and PDIFF (peak difference in time) presented in Bennett et al. (2013) is used to evaluate the performance of the surrogate models for all 15x3 events. Results can be seen in Table 1 . The results confirm the visual inspection. The overall performance of both surrogate models is very good with NSE values above 0.9 for volume and discharge, while for surcharging it is 0.620 for SM1. When subdividing the surrogate model to $S M 1_{\text {div }}$ the NSE value is improved to 0.837 . This improvement can also be seen in PEP, where the error is overall reduced. For surcharging it is reduced most from $24.9 \%$ to $-1.57 \%$. Since PEP is negative for $\mathrm{SM} 1$ div the model generally overestimates the peaks while SM1 underestimates as also seen in Figure 3. Furthermore, timing of the surcharge peak is improved from $-8.15 \mathrm{~min}$ for SM1 to 3.76 minutes for $\mathrm{SM} 1_{\text {div }}$. Computation time was reduced approximately 700,000 times for the surrogate model.

Table 1. Measures of performance for the two surrogate models.

\begin{tabular}{|c|c|c|c|c|c|c|c|}
\hline & \multicolumn{3}{|c|}{$\begin{array}{c}\text { NSE } \\
{[-]}\end{array}$} & \multicolumn{3}{|c|}{$\begin{array}{c}\text { PEP } \\
\text { Mean / Median [\%] }\end{array}$} & $\begin{array}{l}\text { PDIFF } \\
\text { [min] }\end{array}$ \\
\hline & $S$ & Qout & $Q_{\text {spill }}$ & $S$ & Qout & $Q_{\text {spill }}$ & $Q_{\text {spill }}$ \\
\hline SM1 & 0.978 & 0.948 & 0.620 & $4.30 / 2.06$ & 7.62 / 4.26 & 24.9 / 23.7 & -8.15 \\
\hline SM1 div & 0.991 & 0.990 & 0.837 & $0.823 / 0.810$ & $5.79 / 4.30$ & $-1.57 /-2.04$ & -3.76 \\
\hline
\end{tabular}

\section{CONCLUSIONS}

Two simple surrogate models with different compartment resolutions were set up for Elster Creek catchment in Melbourne, Australia. Both models were able to sufficiently accurate emulate the volumes and discharges from a high-fidelity Mike URBAN model. The surcharge was more difficult to mimic as this is a more dynamic process and only steady state data was used for training. Subdividing the surrogate model achieved an overall improvement especially regarding surcharging. This study shows the great potential of surrogate models for further use in urban drainage modelling - even for surcharging systems.

\section{Acknowledgement}

This research has been financially supported by the Australian Government through the CRC for Water Sensitive Cities. The catchment data was kindly provided by Melbourne Water and City of Port Philip.

\section{References}

Bennett, N.D., Croke, B.F.W., Guariso, G., Guillaume, J.H.A., Hamilton, S.H., Jakeman, A.J., Marsili-Libelli, S., Newham, L.T.H., Norton, J.P., Perrin, C., Pierce, S.A., Robson, B., Seppelt, R., Voinov, A.A., Fath, B.D., Andreassian, V., 2013. Characterising performance of environmental models. Env. Mod. Softw. 40, 1-20.

Borup, M., Thrysøe, C., Arnbjerg-Nielsen, K., Righetti, F., Mikkelsen, P.S., 2017. A fast surrogate model tailormade for real time control. 14th IWA/IAHR Int. Conf. Urban Drain.

Bureau of Meteorology, 2015. Rain data extracted from eWater MUSIC for Melbourne Australia.

Davidsen, S., Löwe, R., Thrysøe, C., Arnbjerg-Nielsen, K., 2017. Simplification of one-dimensional hydraulic networks by automated processes evaluated on 1D/2D deterministic flood models. J. Hydroinf 19, 686-700.

Fewtrell, T.J., Duncan, A., Sampson, C.C., Neal, J.C., Bates, P.D., 2011. Benchmarking urban flood models of varying complexity and scale using high resolution terrestrial LiDAR data. Phys. Chem. Earth 36, 281-291.

Hansen, A. C. \& Liu, L. 2004 Risk-Based Design of Drainage Systems Uncertainty Analysis. Master's thesis, Technical University of Denmark, Kongens Lyngby, Denmark.

Wolfs, V., Villazon, M.F., Willems, P., 2013. Development of a semi-automated model identification and calibration tool for conceptual modelling of sewer systems. Wat Sci. Tech. 68, 167. 


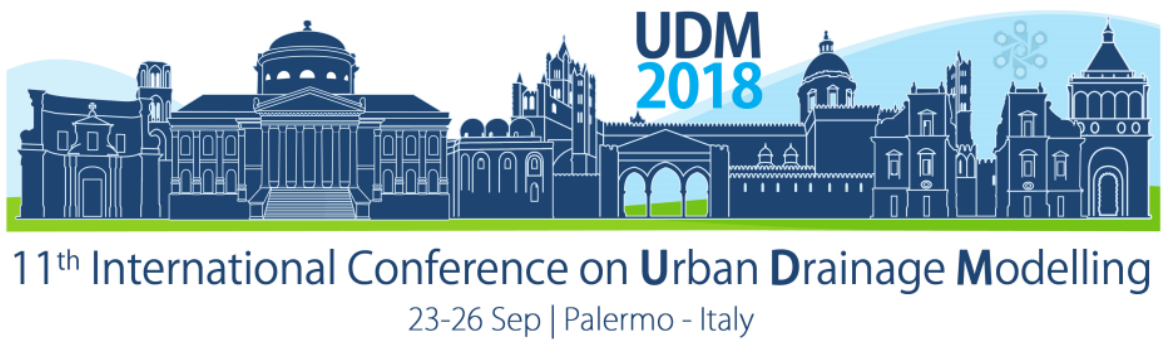

\title{
Hydrologic performance simulation of green infrastructures: why data-driven modelling can be useful?
}

\author{
Yang Yang ${ }^{1}$ and Ting Fong May Chui ${ }^{1}$ \\ ${ }^{1}$ The University of Hong Kong, Department of Civil Engineering, Hong Kong SAR, China \\ (Room 6-18A, Haking Wong Building, The University of Hong Kong, Pokfulam Road, \\ Hong Kong; Corresponding to Chui: maychui@hku.hk)
}

\begin{abstract}
Green infrastructures are decentralized semi-natural solutions for managing stormwater runoff. To assess their effectiveness in urban drainage, many process-based hydrological models have been developed. However, these models sometimes fail to deliver satisfactory results due to inadequate representations of the involved hydrological processes or due to limited field measurements for model setup. Data-driven modelling simulates directly the connections between the state variables of the system (such as the input variable and the output variable), and thus reduces the need for hydrological process characterization. Yet the usefulness of this modelling approach in green infrastructure related studies has not been fully explored. To demonstrate its effectiveness, two bioretention systems in the U.S. are studied. The designs of these two systems are unique, making them difficult to be modelled directly using the standard process-based models. In one site, the observations are also censored, i.e., only the overflow/no overflow binary outcomes are being monitored, with which the model calibration is inhibited. We showed that using the state-of-the-art data-driven modelling framework (e.g., CARET and MXNET), the occurrence or the outflow discharge rate of the bioretention systems at a given time can be accurately simulated only using the rainfall, evapotranspiration and the inflow time series. We conclude that data-driven modelling can be useful for simulating the hydrologic performance of green infrastructures, especially when the existing process-based models are inadequate in representing the design variabilities or the data for model setup is limited.
\end{abstract}

Keywords: Green infrastructures; data-driven modelling; machine learning

\section{INTRODUCTION}

Green infrastructures (GI), also known as sustainable drainage systems or low impact development practices, are decentralized small-scale landscape solutions that aim to manage stormwater close to its source (Ahiablame et al., 2012). GI were found to be effective in surface pollutant removal, groundwater recharge, runoff volume mitigation, and peak flow reduction, etc. The commonly used Gl include bioretention cells, green roofs, and porous pavement, etc. Gl overall have been receiving increasing attention in stormwater management.

To access their effectiveness in urban drainage, multiple process-based hydrological models have been developed. The most widely used ones include EPA SWMM and HYDRUS-2D, etc. In these models, various physically-based or empirical equations are used to characterize the involved hydrological processes. There are, however, often difficulties in applying these models in practice. For instance, various model parameters need to be determined for representing the physical properties of the modelled system; but not all the parameters are measurable or can be measured at low costs. Another issue is that the design variabilities of 


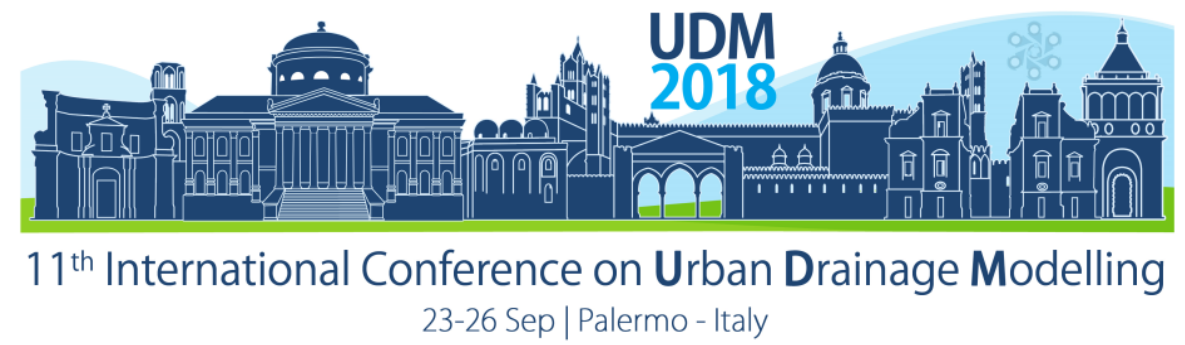

GI may not be adequately represented by the standard models. This is because innovative GI designs have been constantly proposed in recent years (e.g., bioretention cells with gravel surface layer for promoting infiltration, and various Gl treatment train configurations), models that specifically designed for these practices may not exist.

Data-driven modelling (DDM), also known as statistical learning or machine learning, seeks to use the observed data of the studied system to find the connections between the system state variables, e.g., the input and the output (Solomatine and Ostfeld, 2008). DDM commonly does not require the involved hydrological processes to be explicitly characterized; it thus reduces the effort in model setup, including model development and physical properties measurement. DDM has been used in many areas in the field of hydrology, e.g., streamflow prediction and groundwater modelling. However, the application of DDM in Gl related studies is currently limited. The goal of this study is to explore the application of the state-of-the-art data-driven models and DDM framework in simulating the hydrologic performance of Gl.

\section{MATERIALS AND METHODS}

\subsection{Methods}

This study employs two state-of-the-art DDM frameworks which are available in the $\mathrm{R}$ programming language, namely the MXNET package (Chen et al., 2015) and the CARET package (Kuhn, 2008). The MXNET is a flexible DDM library that enables various types of artificial neural network to be constructed easily. MXNET is available across multiple operating systems and allows for GPU and distributed computing. CARET is an R package that streamlines the application procedures in DDM, such as pre-processing, resampling, hyperparameter tuning and model evaluation. Currently, more than 200 data-driven models are supported by CARET.

In this study, MXNET is used to construct a simple single layer neural network to predict if overflow occurs in the bioretention system at given time. This is the so-called classification problem. CARET in this study is used to build data-driven models for predicting the outflow discharge rate of bioretention systems at a given time using the inflow time series. This is known as the regression problem.

\subsection{Study sites}

The first study site locates in Central Kitsap County Campus (CKCC), Kitsap County, WA, U.S., where multiple bioretention cells and a porous pavement system are implemented in a catchment of $9,290 \mathrm{~m}^{2}$. The overflow occurrence in two representative bioretention cells was monitored from October 2011 through September 2012 at a 5-min interval. The binary observations can be considered as censored and can inhibit the model calibration process. The climate condition was monitored in situ. A total of 162 single layer neural networks with different configurations (i.e., number of hidden nodes, types of activation function, batch sizes and epochs) are constructed using MXNET, where the output is a single binary outcome (i.e., overflow occurrence condition at a given time) and the input is a numerical vector of length 288 (i.e., the 5-min resolution rainfall time series in the previous 1 day). These neural networks differ in the number of hidden nodes, types of activation function, batch sizes and epochs. 


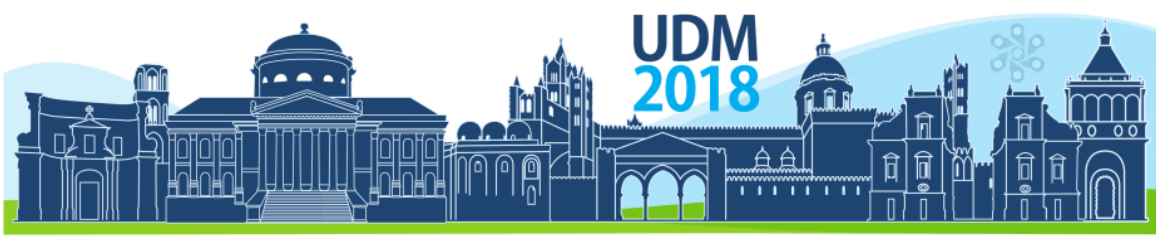

$11^{\text {th }}$ International Conference on Urban Drainage Modelling

23-26 Sep | Palermo - Italy

The second study site locates in St. Francis Apartments, Queen City Avenue, Cincinnati, $\mathrm{OH}$, U.S., in which two bioretention cells were constructed in series on a slope. The upper bioretention cell treats stormwater runoff from a car park and an upstream wooded area and drains its underdrain flow to the lower bioretention cell. The inflow and the underdrain flow of the upper cell and the outflow of the lower cell were measured at every 2 minutes during runoff events from 2011 to 2015. The climate condition was also monitored. In this site, the output of the data-driven models is the discharge rate of the underdrain flow out of the upper cell at a given time, and the input is the aggregated inflow variables (e.g., accumulative volume in the past 2 hours) and aggregated evapotranspiration variables. Using CARET, multiple types of the classic data-driven models, e.g. cubist regressions (cubist) and random forest regressions (RF), are built. The hyperparameters of the models are tuned using cross-validation. The resampling is performed by grouping the observations from the same rainfall event and then using each group either for training or testing at each cross-validation iteration. In this way, more objective estimates on the model's generalization performance can be obtained.

\section{RESULTS AND DISCUSSION}

\subsection{Case study 1}

In this site, overflows occurred only during the cooler months (from November to March). This suggests seasonality may exist in the performance of the GI. To eliminate this effect, only the observations during the rainfall events in the cooler months are used for modelling, i.e., 10996 observations distributed in 66 rainfall events. Figure 1 shows the prediction accuracy and the kappa statistics for the training set (46 events) and the test set (20 events). These neural networks generally perform well (more than $96 \%$ accuracy for both the test and training sets). The good performance is also confirmed by the kappa statistics which accounts for the class distributions. Considerable variations can be detected when different neural network configurations are used, which indicates that good network architecture can result in good model performances. The variation of the performance in the test set is higher than in the training set, which is common. To obtain a better estimation of the generalized performance, repeated data split and training/test iterations are recommended.

$$
\text { Training set }
$$

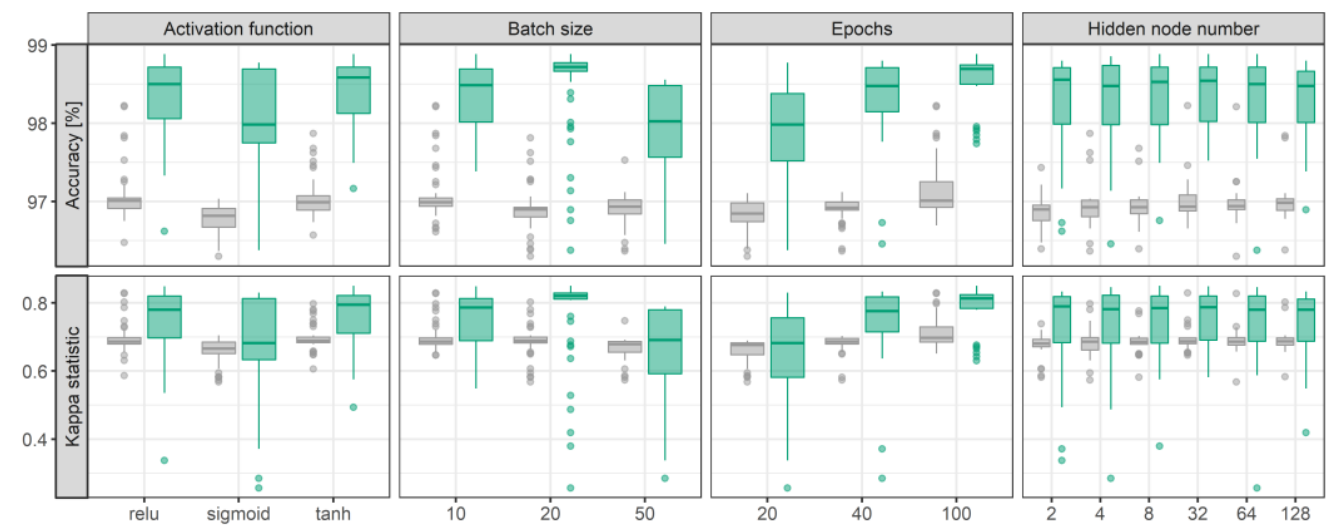

Figure 1. Distributions of the accuracy and the kappa statistics of 151 neural networks in the training and the test set; subplot labels indicate the configuration of the networks. The 11 networks with fitting error are not shown.

\subsection{Case study 2}




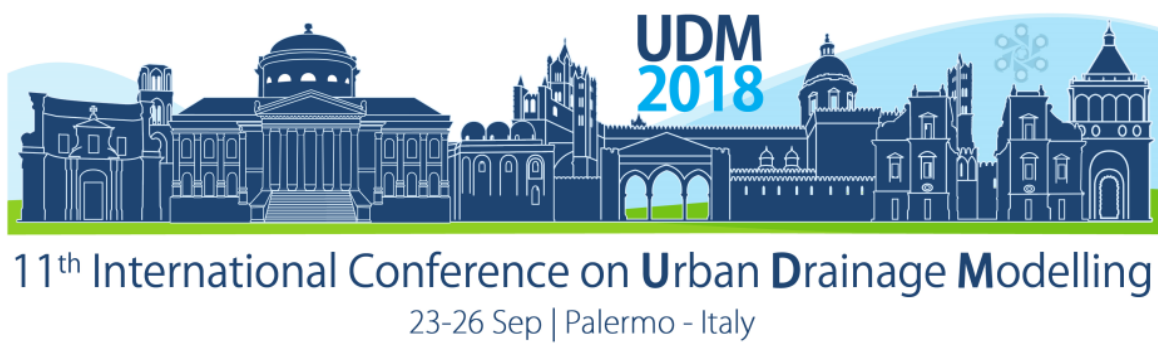

To reduce the number of predictors and to make it more feasible to achieve fitting, the predictors are aggregated, e.g., only the accumulative inflow depth in the past 20 minutes is used as predictor instead of using the original 10 inflow depths measured at every 2 minutes in the same periods; 12 aggregated inflow predictors and 9 evapotranspiration predictors are used. The data observed in 2014 is used for modelling. The performance of various tuned and calibrated data-driven models are shown in Figure 2. Considerable performance variations can be detected among models, while some models have good performances. Notice that some simpler models (such as partial least squares regression, pls) may be able to produce comparable or better results as compared to the more complex models (such as random forest regression, RF). These simpler models may be selected as the final model due to the high interpretability. Because the optimal model for a specific problem is rarely known beforehand, we recommend to evaluate multiple models in order to identify the best one.
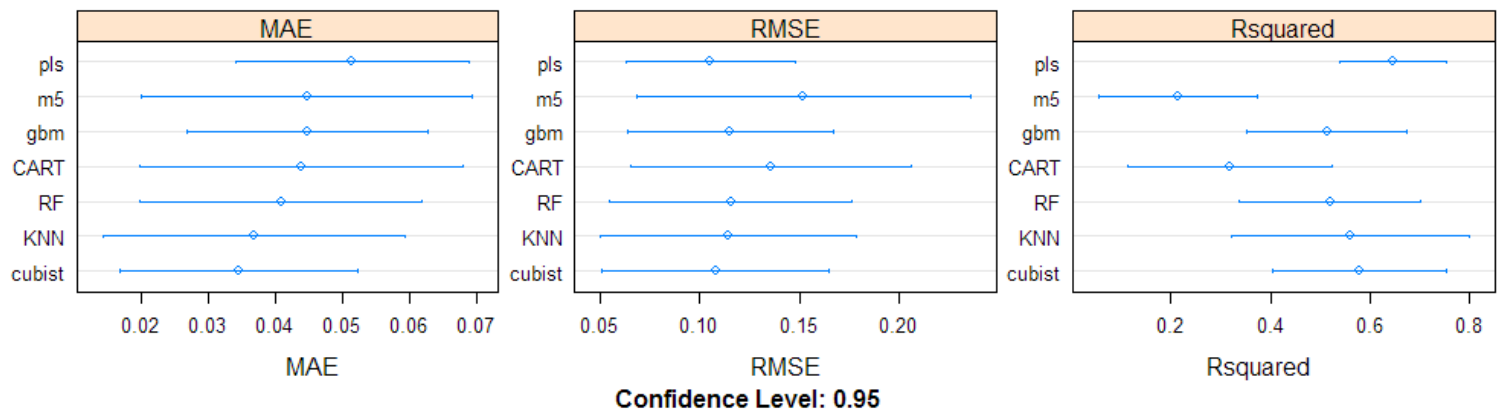

Figure 2. Confidence interval of the mean absolute error (MAE, in L/S), root mean squared error (RMSE, in L/S) and $\mathrm{r}^{2}$ (Rsquared) of multiple tuned data-driven models using the resampling results

\section{CONCLUSIONS}

In this study, we demonstrate that DDM can be useful for predicting the hydrologic performance of GI. DDM is recommended for sites where process-based models are unavailable or restricted due to limited field measurements or censored data. However, we also show that the performance of DDM is significantly affected by the input variables, the model being used, and the associated hyperparameters. To obtain the "best" data-driven model, or to estimate a model's generalization performance, formal DDM procedures, including feature section, performance estimation, and model selection must be practiced. We suggest future research to present more applications of DDM relevant to Gl performance simulation and to improve or modify any of the steps for DDM to be more suitable for GI related applications.

\section{Acknowledgments}

This study was supported by a grant from the Research Grants Council of the Hong Kong Special Administrative Region, China (Project No. HKU17255516). We would like to thank Robert A. Darner from the U.S. Geological Survey for providing site information on the St. Francis Apartments site.

\section{References}

Ahiablame, L.M., Engel, B.A. and Chaubey, I., 2012. Effectiveness of low impact development practices: literature review and suggestions for future research. Water, Air, \& Soil Pollution, 223(7): 4253-4273.

Chen, T., Li, M., Li, Y., Lin, M., Wang, N., Wang, M., Xiao, T., Xu, B., Zhang, C. and Zhang, Z., 2015. Mxnet: A flexible and efficient machine learning library for heterogeneous distributed systems. arXiv preprint arXiv:1512.01274.

Kuhn, M., 2008. Caret package. Journal of statistical software, 28(5): 1-26.

Solomatine, D.P. and Ostfeld, A., 2008. Data-driven modelling: some past experiences and new approaches. Journal of hydroinformatics, $10(1): 3-22$. 


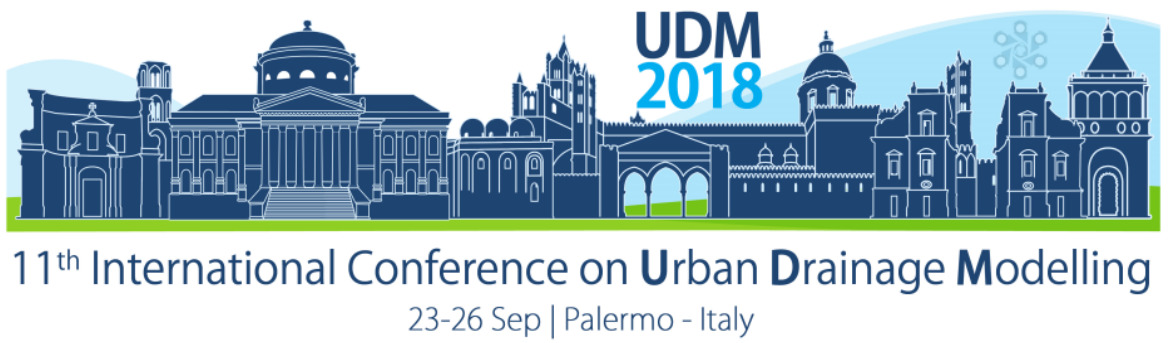

\title{
The Use of an Autocorrelation Function to Determine Urban Hydrological Catchment Characteristics
}

\author{
Andrew Bailey ${ }^{1}$, Alma Schellart ${ }^{1}$ \& Simon Tait ${ }^{1}$ \\ 1 University of Sheffield, Department of Civil and Structural Engineering, Sheffield, UK
}

\begin{abstract}
Urban hydrological modelling for the replication of surface and infiltration processes is a key component in the calibration and verification of urban drainage models. However, models can often be selected based on modeller preference rather than based the physical hydrological processes in the catchment. This paper presents an objective method of establishing catchment hydrological characteristics based on calculation of autocorrelation coefficients for a range of time differences. Case study examples are provided for the evaluation of resultant correlograms for three catchments. These catchments have produced different distinct correlograms, with the more impermeable catchment showing higher correlation at different lags, whilst a mixed residential and parkland catchment shows a quick drop in correlation at lags of the order of $k=100-200$ ( $3-6$ hours). Extension of the autocorrelation to additional datasets and longer term data could be a useful means of identifying key catchment processes and the significance of seasonal variation as well as informing flow monitoring strategy.
\end{abstract}

Keywords: Urban runoff, autocorrelation, urban hydrology, sewer asset management

\section{INTRODUCTION}

The modelling of urban hydrological surface runoff and infiltration processes is a key element in the calibration and verification of urban drainage models against observed flow survey datasets (Mannina 2005). In turn, the level of calibration and verification achieved will impact on model confidence and the model's predictive outputs when extrapolated to rainfall return periods of interest to urban drainage engineers for the investigation of catchment risks, and subsequent design of new assets (Hailegeorgis and Alfredsen 2017).

In order to attempt to reduce the model uncertainties associated with the modelling of urban surface runoff and infiltration processes, a number of different hydrological models have been developed over the past $30+$ years as computational urban drainage design has advanced, as highlighted in the review by (Zoppou 2001). It is highlighted that there is currently no single hydrological model that is considered suitable for representing the full spectrum of physical processes that interact on urban surfaces and in the underlying substrata.

It can be considered that there is significant progress to be made in the development of hydrologic models that better describe the underlying physical hydraulic and hydrological processes that occur in urban surfaces and soils. As a precursor to the development of improved modelling approaches, there is a need to understand urban catchment hydrologic storm responses objectively in order to identify the key parameters controlling conveyance in a given part of a catchment. For example, is infiltration a significant issue, or are surface processes dominant?

Hence the present paper outlines an approach developed to assess catchment characteristics based on the calculation of autocorrelation coefficients for observed flow monitoring survey data. A case study catchment is presented and analysed to demonstrate the effectiveness of the approach in identifying different catchment types. 


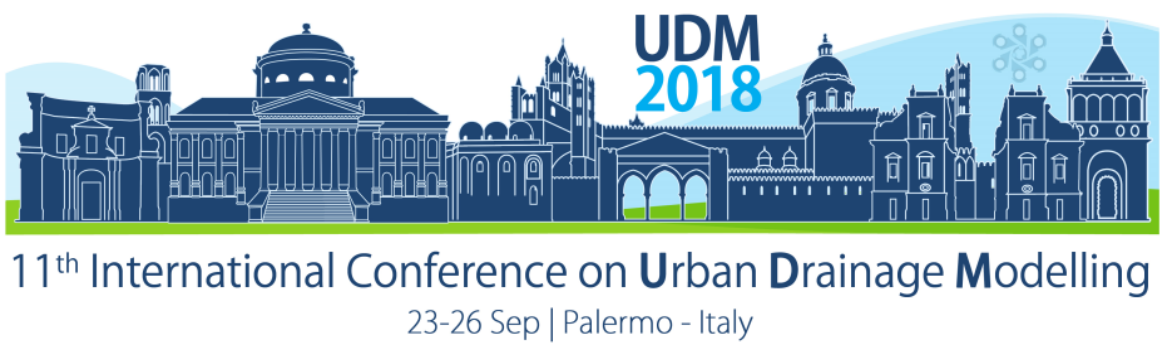

\section{MATERIALS AND METHODS}

\subsection{Flow survey autocorrelation coefficient calculation}

Currently the selection of runoff models is generally based on the preference of an individual modeller, or predefined in the modelling specification of a water authority. This often leads to a runoff modelling approach being predetermined by the modeller prior to considering the catchment characteristics as indicated in observed flow monitoring survey data. To this end, it is often a trial and error approach undertaken of using an impermeable surface model only initially and adding additional permeable and infiltration models on an ad-hoc basis to a catchment model, or simply calibrating to a specific element of observed hydrographs only, such as fitting the peak flow rather than the volume. Although ideally a model should be built for a specific purpose, in reality hydraulic models are often utilised for multiple purposes, such as e.g. assessing flood risk, CSO spill performance, receiving water quality prediction or catchment growth. Such limitations in the model calibration and verification can have significant impact on model predictions when extrapolated to design scenarios.

In order to identify data patterns suggestive of infiltration or permeable surface processes being significantly present in a catchment, calculation of the change in correlation for individual flow monitor locations over a range of time scales was considered as a method of potentially objectively defining catchment classifications. This has been calculated through the calculation of autocorrelation coefficients for a range of time differences (lag $\mathrm{k}$ ), which are considered to be of physical significance to urban hydrological processes.

It was hypothesised that for catchments dominated by impermeable surface processes, there would be a stronger degree of correlation with increasing lag due to the reduced variability in impermeable area runoff response to rainfall due to catchment wetness. Whereas for catchments containing increasing levels of permeable surface and infiltration characteristics, a high correlation would only be observable in a correlogram for small lag values (i.e. for the first few hours after rainfall only), and significantly reduced correlation at higher lags due to permeable processes being more susceptible to variance due to initial conditions, soil heterogeneity in urban catchments and inherently more non-linear processes. To this end, autocorrelation coefficients have been calculated based on the formulation given in (Chatfield 1975) for a large number of observations, as shown in Equation 1.

$$
R_{k}=\frac{\sum_{t=1}^{N-k}\left(x_{t}-\bar{x}\right)\left(x_{t+k}-\bar{x}\right)}{\sum_{t=1}^{N}\left(x_{t}-\bar{x}\right)^{2}}
$$

Where $\mathrm{R}_{\mathrm{k}}=$ autocorrelation coefficient at lag $\mathrm{k}, \mathrm{N}=$ number of observations, $\mathrm{k}=$ lag between observations, $\mathrm{x}_{\mathrm{t}}=$ individual observation and $\bar{x}=\sum_{t=1}^{N} x_{t} / N$.

Through calculation of the autocorrelation coefficient at lag $k\left(R_{k}\right)$ over a range of lag values (k), a correlogram can then be plotted of $R_{k}$ against lag, $k$ in order to identify patterns in the data collected by the flow monitor.

\subsection{Case study catchment}

For this study, data collected at flow monitoring locations was extracted from a modelling study of a large city in the north of the UK, which was completed in 2011-2013. The catchment is composed of a mixture of land use types and topographies. Although the full catchment flow survey was comprised of over 1000 flow monitor sites, for the purposes of these initial investigations, three subsets of data were extracted from separate parts of the city. Details of these catchments are summarised in Table 1. The flow monitors recorded at 


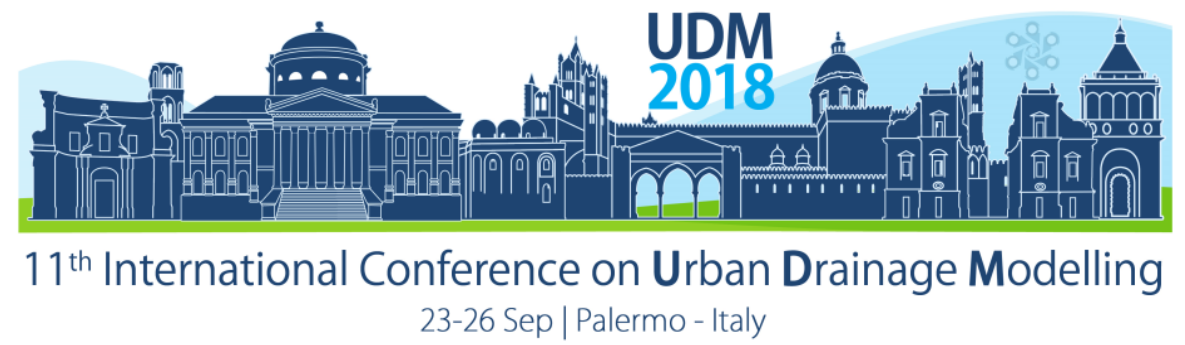

2-minute time intervals. It is noted that for catchment ' $\mathrm{B}$ ' that only 8 of the 20 available flow monitor datasets were utilised in this study due to data quality issues limiting the suitability of the full period dataset to be used for the autocorrelation calculations. It is further noted that analysis of a new dataset (catchment $\mathrm{C}$ ) is currently ongoing at the time of writing, but provides a much more substantial dataset both in terms of numbers of flow monitors and the duration of their installation period.

Table 1: Descriptions of catchments and flow monitor datasets used in initial testing

\begin{tabular}{|c|c|c|c|}
\hline $\begin{array}{l}\text { Catchment } \\
\text { Reference }\end{array}$ & $\begin{array}{c}\text { Flow survey } \\
\text { period }\end{array}$ & $\begin{array}{l}\text { Number of flow } \\
\text { monitors utilised }\end{array}$ & Catchment description \\
\hline $\bar{A}$ & $\begin{array}{c}13 / 09 / 2012- \\
01 / 12 / 2012\end{array}$ & 11 of 11 & $\begin{array}{c}\text { City centre area. Comprised mainly of commercial buildings and } \\
\text { significant proportion of impermeable area, with some residential } \\
\text { and parkland area. }\end{array}$ \\
\hline B & $\begin{array}{l}11 / 05 / 2012- \\
30 / 06 / 2012\end{array}$ & 8 of 20 & $\begin{array}{c}\text { Typical residential area comprised of housing with gardens, } \\
\text { parkland and isolated commercial estates }\end{array}$ \\
\hline C & $\begin{array}{l}28 / 02 / 2011- \\
24 / 12 / 2011\end{array}$ & 20 of $100^{*}$ & $\begin{array}{c}\text { Mixture of commercial city centre area and surrounding residential } \\
\text { area, spread over a large proportion of the city }\end{array}$ \\
\hline
\end{tabular}

*Quality of this dataset has not been fully reviewed at the time of writing and so only 20 of the 100 sets of flow monitor data have been analysed to date.

\section{RESULTS AND DISCUSSION}

The full period datasets were utilised in the calculation of $R_{k}$ for a range of lag $k$ values from 1 to 3,600 . As the provided data is in 2-minute time steps, this equates to lags ranging from 2 minutes to 5 days. These values were chosen initially due to urban hydrological models in current use generally having been derived to replicate processes over such time scales.

The correlograms calculated for catchments $A, B$ and $C^{1}$ are illustrated in Figure 1. From this it is evident that there is a distinct variation between the two correlograms over the same lag ranges. For catchment $A$ it can be observed that $R_{k}$ values in excess of 0.6 are calculated up to lag $k$ values of 500 ( 16 hours) and correlation is only slowly lost up to lag k values of 3600 (5 days). It is considered that this is due to the predominantly impermeable surfaces within this part of the catchment and hence a more consistent response of such surfaces to rainfall events. For catchment B, however, it is highlighted from Figure 1 that with the exception of one of the evaluated flow monitors, $R_{k}$ values are reduced to 0.4 or less within 100 lag steps ( $<2$ hours) at two flow monitors and for the remaining sites within 500 lag steps (16 hours). This is considered to be due to this catchment being a typical residential area with a mixture of impermeable and permeable urban surfaces as well as parkland. As such, it could be considered that this due to increased variability of permeable surfaces and infiltration flow responses as a function of catchment wetness. From the data for catchment $C$ in Figure 1, it is highlighted that the change in the calculated autocorrelation coefficients shows a mixture of responses between those calculated for catchments $A$ and $B$. As such, approximately half suggest a response similar to catchment $A$, with limited reduction in autocorrelation coefficient (i.e. residual $R_{k}$ values at 3,600 lags greater than 0.7 ), with the other half suggesting more rapid decays similar to those calculated from data collected in catchment $\mathrm{B}$.

\footnotetext{
${ }^{1}$ For the first 20 flow monitors from this dataset
} 


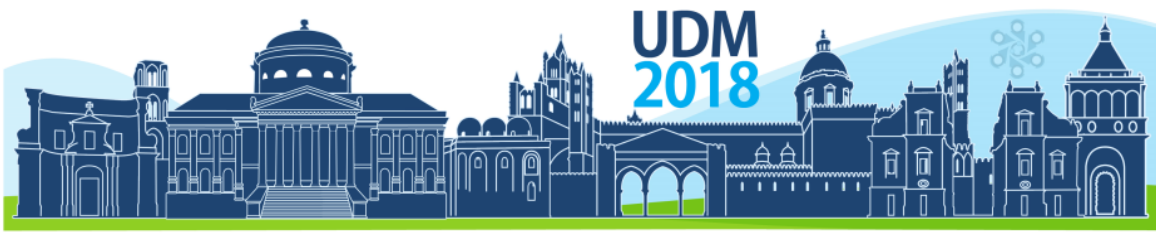

$11^{\text {th }}$ International Conference on Urban Drainage Modelling 23-26 Sep | Palermo - Italy
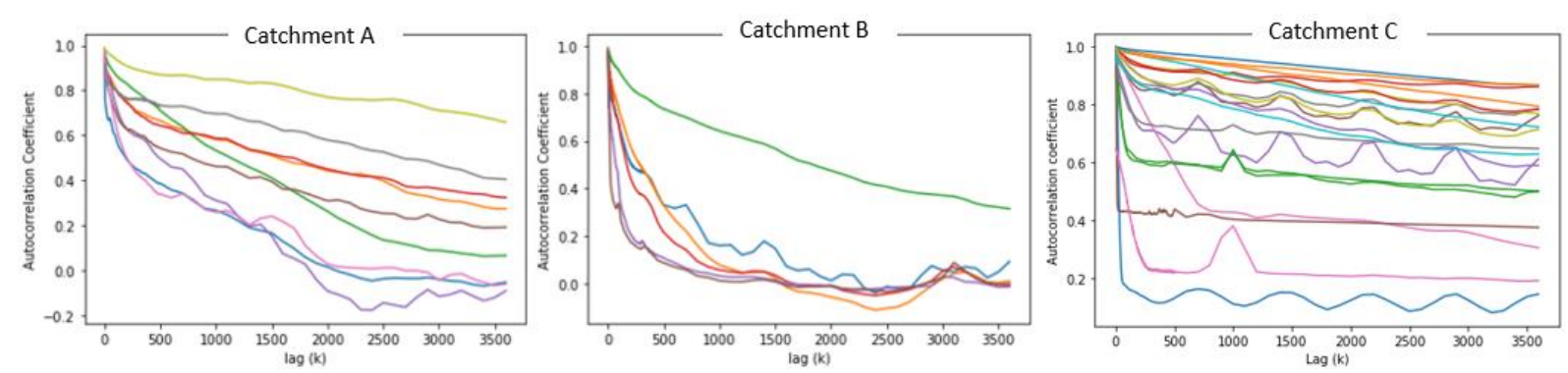

Figure 1: Correlograms calculated for catchments A, B \& $C^{2}$ for lag values up to 3600 (5 days)

From these results, it was hypothesised that the shape of a correlogram plotted from flow monitor data is an indicator of the hydrological nature of its upstream catchment. A test for evaluation of this hypothesis is considered from comparing the residual autocorrelation coefficient for a given monitor site (i.e $R_{k}$ at lag 3,600) with the average catchment permeability. Therefore, from the data presented, the residual $R_{k}$ value has been extracted as defined above and compared with the catchment permeability. As a full hydrodynamic InfoWorks model is available for the test catchment, the measure of permeability has been deduced from extracting the modelled subcatchments upstream of each flow monitor location, summing up the modelled impermeable areas within these subcatchments (runoff areas $1-3$ of the provided model), and dividing this total against the total areas of these modelled subcatchments.

The results of the abovementioned assessments are graphed in Figure 2. From this graph, it is evident that there are other factors influencing the residual autocorrelation coefficient calculation, with significant scatter in the plotted points, but interestingly, the majority of the data points from catchment $B$ are clustered with low residual $R k$ values and percentage impermeability, and the same clustering is apparent for catchment $A$, though with a broader scatter. The data from catchment $C$ is largely plotted between these two groups. Although it is very weakly indicated from the data plotted thus far, it could be suggested that there is a potential relationship between catchment permeability and a correlogram of flow monitor data.

As the correlogram plot for the full catchment $C$ dataset appears from initial testing to show a similar spread of residual $\mathrm{Rk}$ values as the initial 20 flow monitors evaluated, there is a potential that any relationship could become more apparent though the addition of this data to the plot in Figure 2. This work is currently ongoing.

\footnotetext{
${ }^{2}$ For the first 20 flow monitors in this dataset
} 


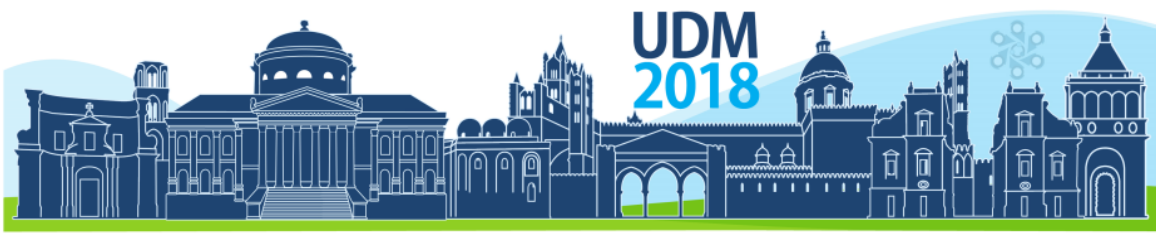

$11^{\text {th }}$ International Conference on Urban Drainage Modelling 23-26 Sep | Palermo - Italy

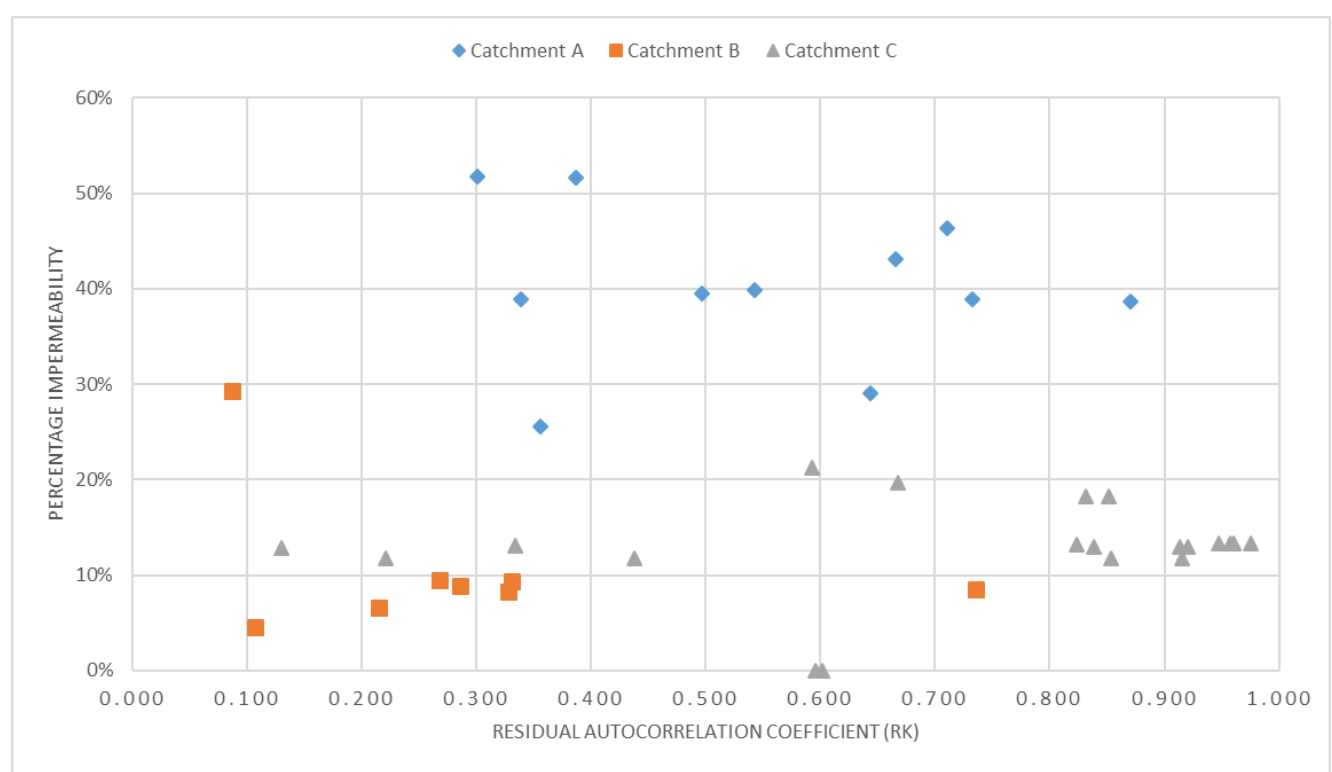

Figure 2: Plot of the percentage of catchment impermeability against calculated residual autocorrelation coefficients for catchments $A, B$ and $C^{3}$

\section{CONCLUSIONS}

This work has demonstrated an approach to objectively define key hydrological catchment characteristics for urban areas based on collected flow monitor datasets. From the initial analysis undertaken for the trial catchments the following points are concluded:

- there are distinctly different patterns in the calculated correlograms. This suggests the use of autocorrelation to be of potential value in defining catchment processes objectively prior to selection of appropriate runoff and infiltration modelling tools.

- Through the application of the technique to additional datasets it may be possible to further define the 'signatures' of different dominating processes in a monitor catchment. This work is currently ongoing.

- An extension of the process to lag intervals of seasonal / yearly scales could be useful in objectively determining seasonal variation in a catchment.

- Mapping the correlograms for networks of flow monitors could be a tool for determining the numbers of flow monitors required to effectively monitor a catchment. As such, monitors with very similar correlograms may indicate that multiple monitors are returning the same data not providing useful additional data for its given cost. Resultantly the monitoring strategy for a catchment could be reassessed.

\section{References}

Chatfield, C. 1975. The Analysis of Time Series: Theory and Practice. 1st ed. London, UK: Chapman \& Hall/CRC.

Hailegeorgis, Teklu T., and Knut Alfredsen. 2017. "Analyses of Extreme Precipitation and Runoff Events Including Uncertainties and Reliability in Design and Management of Urban Water Infrastructure." Journal of Hydrology 544. Elsevier B.V.: $290-305$. doi:10.1016/j.jhydrol.2016.11.037.

Mannina, Giorgio. 2005. "Integrated Urban Drainage Modelling with Uncertainty for Stormwater Pollution Management." Universita di Catania.

Zoppou, Christopher. 2001. "Review of Urban Storm Water Models." Environmental Modelling Software 16 (3): 195-231. doi:10.1016/S1364-8152(00)00084-0.

\footnotetext{
${ }^{3}$ For the first 20 flow monitors from this dataset
} 


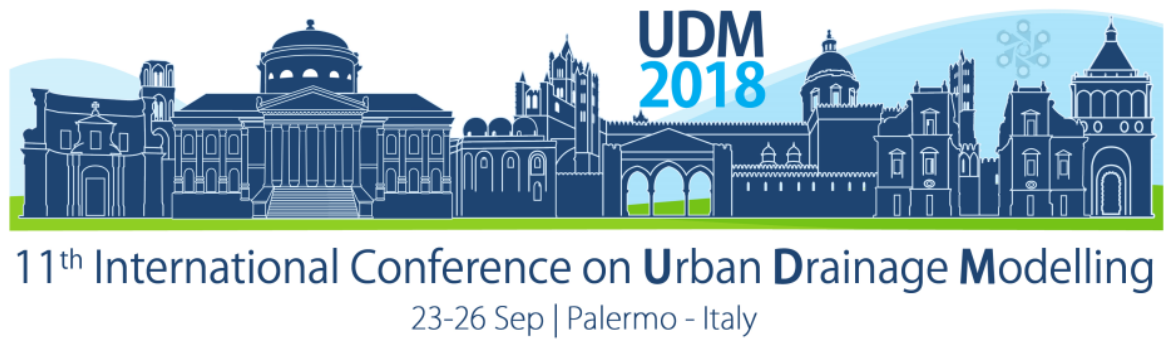

\title{
Assessing cost-effectiveness of different system structural characteristics in enhancing resilience of urban drainage systems
}

\author{
Zhiwei Xu' ${ }^{1}$, Yinan Zhao ${ }^{1}$, Xin Dong ${ }^{1}$ and Pengfei Du ${ }^{1}$ \\ ${ }^{1}$ Tsinghua University, School of Environment, Beijing, China
}

\begin{abstract}
Different urban drainage system structural characteristics such as topological structure, return period of pipe-sizing, green infrastructures and grey infrastructures are both significant in designing and managing urban drainage systems. These characteristics can somehow influence the resilience of systems and research is required to determine their cost-effectiveness. This study uses 1000 virtual drainage systems to evaluate the effect of each system structural characteristic on enhancing resilience. The results show that it is more cost-effective to enhance resilience in planning stage especially by finding better topological structure. In operational stage, building storage tanks is more costeffective than building LID, but considering the feasible site for storage tanks, it has limited effect on enhancing resilience.
\end{abstract}

Keywords: Resilience; urban drainage systems; virtual case study; cost-effectiveness analysis.

\section{INTRODUCTION}

Nowadays, urban drainage systems not only have to cope with the normal rainfall, but also need to adapt the extreme weather that exceed the design standards. As such, the concept of resilience of urban drainage systems was developed to evaluate the ability to mitigate, adapt to and recover from the failure caused by extreme rainfalls (Butler et al., 2014).

A set of system structural characteristics such as topological structure, return period of pipesizing, green infrastructures like LID, grey infrastructures like storage tanks can influence the resilience of urban drainage systems. There is need to explore the relationship between system structural characteristics and resilience, and further to figure out the costeffectiveness of system structural characteristics in enhancing resilience (Sweetapple et al., 2018).

Resilience of urban drainage systems is a topic of current research interests, the definition and assessment framework of resilience is diverse (Mugume et al. 2015, Dong et al., 2017). Due to the difficulty in collecting enough real case data, we generated 1000 virtual drainage systems using the boundary conditions of a real case area. Based on the resilience assessment framework and the systems we generated, we evaluate the effect of different system structural characteristics on enhancing resilience.

\section{MATERIALS AND METHODS}

\subsection{Overview of case study area}

The case study area is a typical urban area in China. It covers an area of $42.1 \mathrm{~km}^{2}$. The area is generalized by using the Storm Water Management Model (Rossman, 2010). We use the 


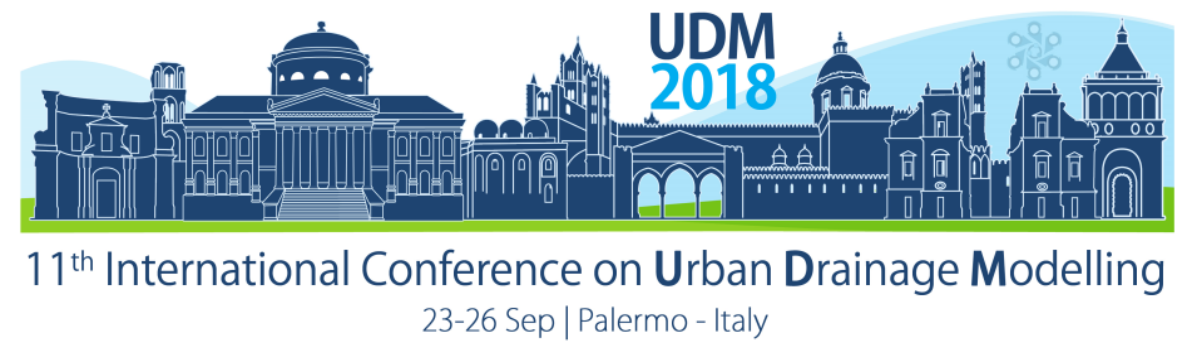

boundary conditions including elevation, land use, area and slope of each parcel to generate massive virtual drainage systems for further analysis.

\subsection{Resilience assessment}

We use resilience indexes developed by Mugume to evaluate the resilience of urban drainage systems (Mugume et al.,2015). It can be calculated by equation (1).

$$
\text { Res }=1-\frac{V_{T F}}{V_{T I}} * \frac{t_{f}}{t_{n}}
$$

where Res is the resilience of the urban drainage systems, $V_{T F}$ is the total flooding volumes, $\mathrm{V}_{\mathrm{TI}}$ is the total inflow volumes. The average flooding durations are called $\mathrm{t}_{\mathrm{f}}$, and the total simulation time is $t_{n}$.

\subsection{System attributes scenarios}

In this work, we change system structural characteristics including topological structure, return period of pipe-sizing, green infrastructures and grey infrastructures to improve resilience of urban drainage systems.

Topological structure is an important attribute of urban drainage systems. As all the subcatchments settle, different way to link all the sub-catchments give us possibilities for improving resilience. Massive virtual drainage systems with different topological structures are generated by using virtual drainage system generation model, which use a random spanning tree algorithm to generate drainage system layout and designs the pipes according to standard values.

Return period of pipe-sizing is a significant parameter to characterize the pipe capacity to withstand corresponding return period of rainfall. Because the diameter of pipes is mainly determined by the flux of rainwater collected by upstream sub-catchments, this parameter has a positive correlation with the diameter of pipes. We take 7 scenarios including return period of $3,4,5,10,20,50,100$ years to estimate its effect in the improvement of resilience.

Green infrastructures improve the resilience of urban drainage systems in multiple ways. A typical green infrastructure is low impact development (LID). LID such as green roof, bioretention tank and permeable pavement are taken into account in this study for improving resilience. We set up 4 scenarios of building the LID with the $5 \%, 10 \%, 15 \%, 20 \%$ of total area of each sub-catchment.

Storage tanks are grey infrastructure constructed to mitigate the urban flooding. We set up 8 scenarios with total volume of storage tanks varying from $800 \mathrm{~m}^{3}$ to $8000 \mathrm{~m}^{3}$ built at feasible sites to evaluate its effect on improving resilience

\section{RESULTS AND DISCUSSION}

\subsection{Effect comparison of system structural characteristics in enhancing resilience}

By using our virtual drainage system generation model, we generate 1000 urban drainage systems with different topological structure. Figure 1 depicts the Res and costs of these systems. Interestingly, there is not significant correlation between Res and cost (Pearson correlation coefficient $<0.05$ ). That is to say, by changing the topological structure of systems, we can find out that some systems with better resilience, however, have a considerable low 


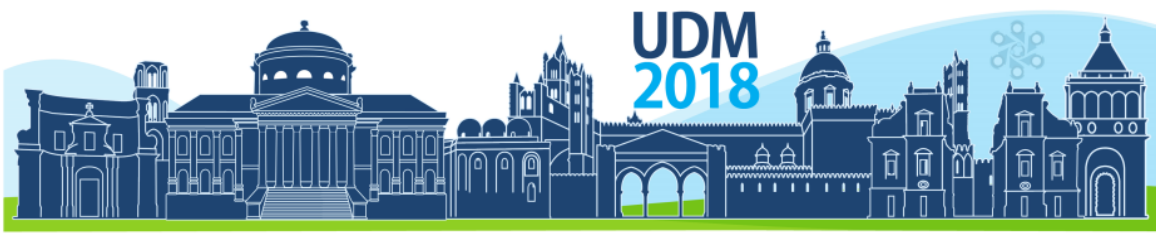

$11^{\text {th }}$ International Conference on Urban Drainage Modelling

23-26 Sep | Palermo - Italy

cost. As shown in the red circle in Figure 1, these systems are cost-effective. Therefore, different from the other three characteristics, finding a better topological structure give us chance to make system become both resilient and economical.

We take one of the cost-effective systems in Figure 1 as the benchmark system in further analysis. We normalize the resilience index into 0-1 according to the benchmark system. As shown in Figure 2, we change system structural characteristics including return period of pipe-sizing, percentage of LID, total volume of storage tanks. The increasing of return period of pipe-sizing is more effective in Res enhancing when it is small, and the return period of 20 years is the turning point. The percentage of LID and volume of storage tanks seem to have linear positive correlation with Res enhancement.

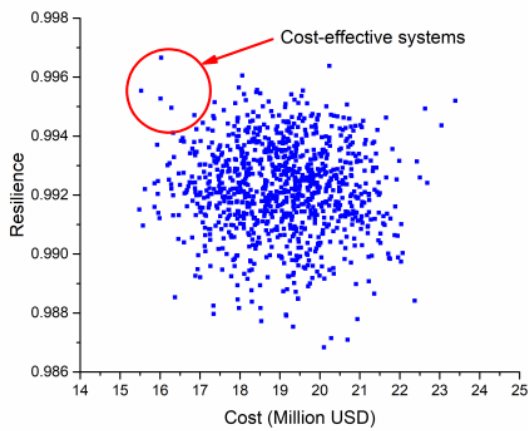

Figure 1. Relationship between resilience and costs in changing topological structure of urban drainage systems.

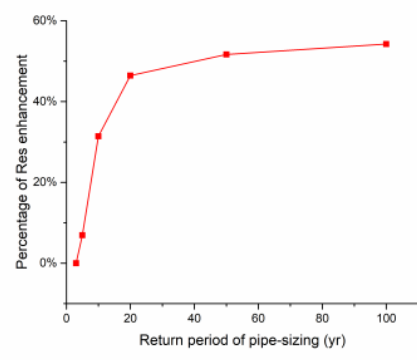

(a)

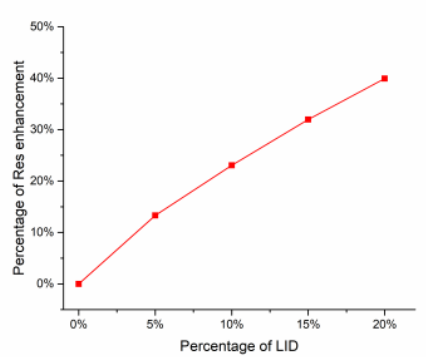

(b)

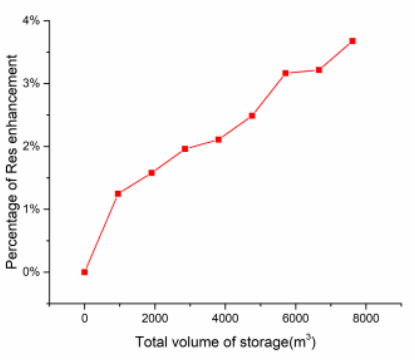

(c)

Figure 2. Effect of structural characteristics on enhancing resilience. (a)pipe-sizing, (b)LID, (c)storage tanks.

\subsection{Trade-off between cost and resilience enhancement}

By considering the extra cost of changing each structural characteristic compared to the benchmark systems, Figure 3 demonstrates the result of cost effect analysis for pipe-sizing, LID and storage tanks. We find out that building storage tanks is the cheapest but only increase the resilience by less than $5 \%$. Increasing return period of pipe-sizing and building LID have similar effect on enhancing resilience. The former is cheaper, however, it needs to be implemented in planning stage. 


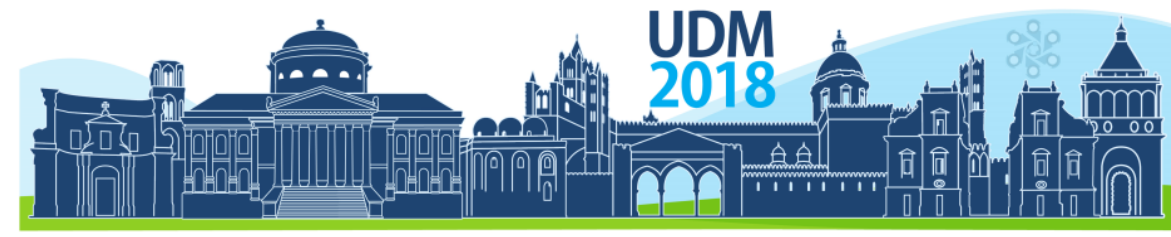

$11^{\text {th }}$ International Conference on Urban Drainage Modelling 23-26 Sep | Palermo - Italy

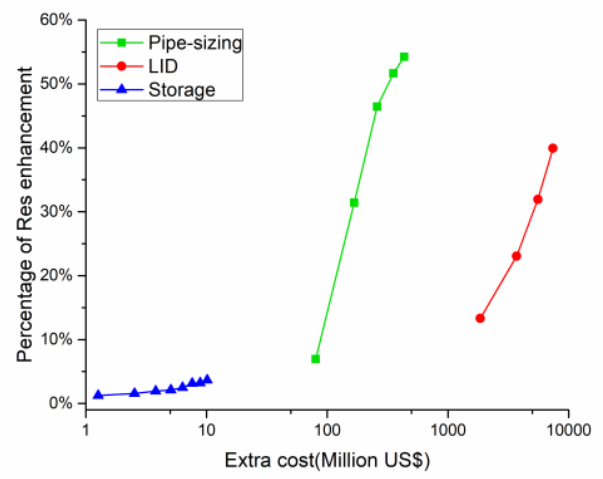

Figure 3. Cost effect analysis of system structural characteristics including pipe-sizing, LID and storage tanks.

To compare the cost-effectiveness of each system structural characteristic, we define the effectiveness of cost as the percentage of resilience enhancement per million USD, and the result is shown in Figure 4. Comparing the effectiveness of cost, building storage tank is the most cost-effective with nearly $1 \%$ of resilience enhancement per million USD, while building LID is the lowest cost-effective with only $0.01 \%$ of resilience enhancement per million USD. Therefore, in operational stage, building storage tanks is more cost-effective.

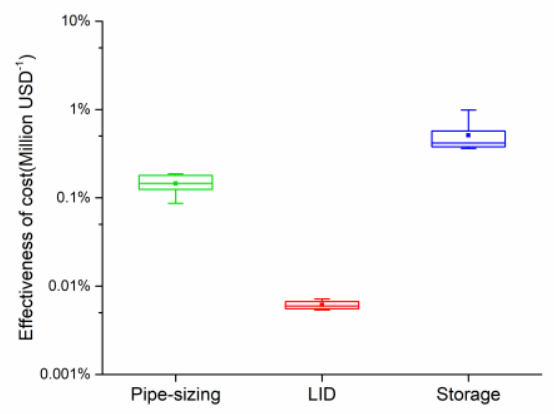

Figure 4. Effectiveness of cost for each system structural characteristic.

\section{CONCLUSIONS}

Based on the cost effect analysis of system structural characteristics in enhancing resilience of urban drainage system, our main findings are listed as follows:

- Finding better topological structure of urban drainage systems is the most cost-effective in enhancing resilience. It gives us chance to find a resilient system without increasing cost.

However, it is only suitable for a system in planning stage.

- Increasing return period of pipe-sizing is also a cost-effective approach in planning stage. It can bring over $50 \%$ of resilience enhancement.

- In operational stage, building storage tanks is more cost-effective than building LID, but it has limited effect on enhancing resilience.

In conclusion, it is more cost-effective to enhance resilience in planning stage especially by finding better topological structure. Therefore, future work may focus on exploring the topological structure features of resilient systems to help us finding better structure. 


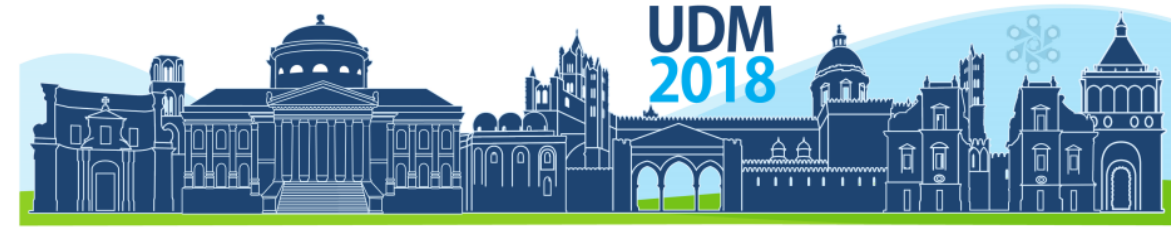

$11^{\text {th }}$ International Conference on Urban Drainage Modelling

23-26 Sep | Palermo - Italy

\section{ACKNOWLEDGEMENT}

This work was supported by National Key Research and Development Program of China (2016YFC0401401).

\section{References}

Butler, D., Farmani, R., Fu, G., Ward, S., Diao, K., \& Astaraie-Imani, M. (2014). A new approach to urban water management: Safe and sure. Procedia Engineering, 89, 347-354.

Dong, X., Guo, H., \& Zeng, S. (2017). Enhancing future resilience in urban drainage system: Green versus grey infrastructure. Water research, 124, 280-289.

Mugume, S. N., Gomez, D. E., Fu, G., Farmani, R., \& Butler, D. (2015). A global analysis approach for investigating structural resilience in urban drainage systems. Water research, 81, 15-26.

Rossman, L. A. (2010). Storm water management model user's manual, version 5.0. Cincinnati: National Risk Management Research Laboratory, Office of Research and Development, US Environmental Protection Agency.

Sweetapple, C., Fu, G., Farmani, R., Meng, F., Ward, S., \& Butler, D. (2018). Attribute-based intervention development for increasing resilience of urban drainage systems. Wat. Sci. Tech. 2018070. 


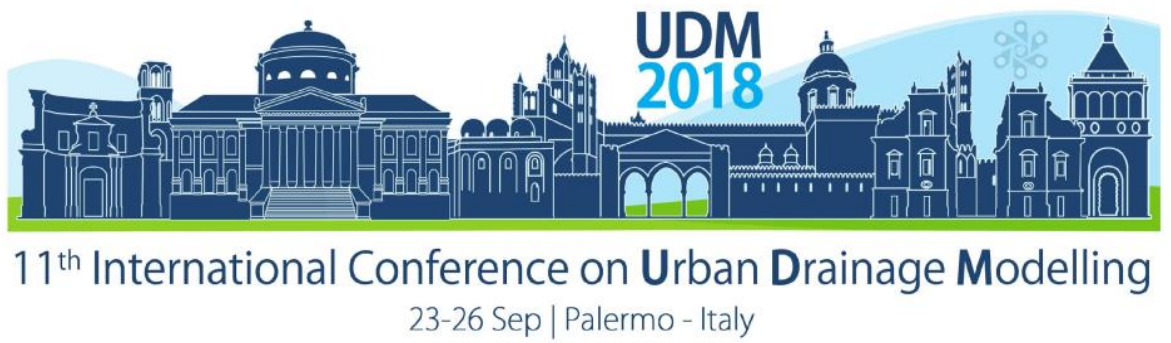

\title{
Multilayer Modelling as a Supporting Tool for Flood Diagnosis and Drainage System Design
}

\author{
Marcelo Gomes Miguez ${ }^{1,2}$, Fernanda Dias Radesca ${ }^{1}$, Aline Pires Veról ${ }^{1}$, Matheus Martins de Sousa ${ }^{1}$, \\ Laurent Feu Grancer Silva Oliveira ${ }^{2}$ \\ ${ }^{1}$ Universidade Federal do Rio de Janeiro, PEC-COPPE/UFRJ, Rio de Janeiro, Brazil \\ 2Universidade Federal do Rio de Janeiro, Escola Politécnica, Rio de Janeiro, Brazil
}

\begin{abstract}
The use of dual drainage models have increased significantly in the past decades, mostly because of advances in mathematical and GIS tools methods. This type of modelling provides precise diagnosis and can be applied to evaluate storm water infrastructure and diverse drainage alternatives. This study aimed to analyse minor and major drainage relations in Dona Eugênia River Basin, located in the metropolitan area of Rio de Janeiro, Brazil. Two alternatives were simulated using MODCEL. The first one considered only the terrain surface layer, while in the second the layer containing a designed storm sewer was introduced. The results provided information on where minor drainage gaps were located and on the effects of the storm sewer network discharges in the major drainage system.
\end{abstract}

Keywords: dual drainage, drainage system design, multilayer modelling, flood diagnosis, MODCEL

\section{INTRODUCTION}

The design of an urban drainage system must comprehend the different interactions occurring between minor and major drainage networks. It's important to assure that they function in an integrated way since the first should locally collect the distributed rainwater over the watershed and direct these discharges to the latter, which is supposed to properly convey the concentrated watershed flows (Miguez et al., 2015). Failures in the minor drainage system may lead to local flooding spread over the watershed, while major drainage failures can produce overflows that occupy the flood plains and affect large urban areas. Flooding in the urban environments can cause significant property losses and threaten human lives. Minor and major drainage failures, especially when combined, can contribute to aggravate the risks to cities (Randall et al., 2017).

Given the situation where the minor drainage network was correctly designed and implemented, but the major system has no conditions to absorb this contribution, large areas spread over the watershed can be affected. The city, in this case, can be flooded due to backwater, surcharging and reverse flow in the storm drains. On the other side, if the minor drainage is poorly designed or is found to be clogged or obsolete (or even non-existent), local floods and surface ponding tend to appear in lower and mild slope areas. In extreme events, when surpassing the major drainage design standards, both systems can fail, leading to major flooded areas (Miguez et al., 2015), along the floodplains and conflicting with urban occupation. This situation points to dual drainage models as useful decision supporting tool to provide a precise diagnosis of storm water infrastructure and its interaction with fluvial systems, as well as these models can help to predict design alternatives behaviours (Bertsch et al., 2017; Nanía et al., 2014). 


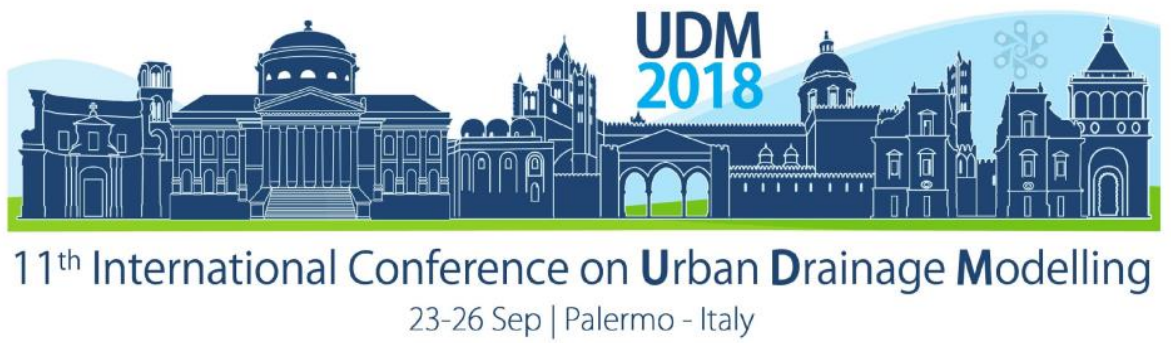

When reviewing of the history of dual drainage models, Smith (2006) highlighted that the beginning of related researches occurred in the late 1970's and early 1980's. Important advances were made by Djordjević et al. (1991), whose work developed a mathematical method to model storm sewers and street flows simultaneously. In the same year, Djokic and Maidment (1991) used GIS tools to typify the drainage network and the surface terrain in an urban environment model. Nasello and Tucciarelli (2005) formulated a model to simulate dual drainage in two overlapping cells, linked through vertical nodes. Recent works present novel approach to couple 1D/2D models and enhance drainage network and surface flow interaction (e.g. Chang et al., 2015; Rubinato et al., 2017). Quasi 2D-models can also be used to fulfil this aim, as it can be seen in Miguez et al. (2017).

In this study, we propose an assessing method to diagnose minor and major drainage functional status, in a preliminary way and for small urban catchments, avoiding field inspections and using a quasi 2D-model to identify major and minor drainage failures to map and compare co-related flooded areas. In this way, we intend to individualize what areas are flooded by minor drainage or major drainage failures. Note that we are considering the application of this method to small river catchments, with a drainage area similar to the size of the city itself. In these cases, the river tends to be incorporated into the major drainage system acting as its main channel. A case study related to Dona Eugênia River, in the city of Mesquita, located in the metropolitan area of Rio de Janeiro, Brazil, is used to exemplify the proposed method.

\section{MATERIALS AND METHODS}

\subsection{Modelling tool}

In a previous research made on the case study area (Veról, 2013; Miguez \& Veról, 2017), flood mitigation projects were developed with the aid of flood maps produced with MODCEL, a quasi2D hydrodynamic model. This model is based on the original work of Zanobetti et al. (1970) and assumes that the watershed can be subdivided into various types of flow-cells, which interact with each other through 1D flow equations. Additionally, MODCEL represents the dual drainage approach since surface flow, open channels and storm sewers can be linked, so the flow can occur simultaneously on a superficial layer and on an underground layer. More detailed description of MODCEL can be found in Mascarenhas \& Miguez (2002); Miguez \& Veról (2017) and Miguez et al. (2017).

\subsection{Modelling procedure}

The calibration of the model was performed by Veról (2013), when this author compared the model results with flooding points surveyed in a field campaign and with discharges in two river sections (in the middle of the basin and in its mouth). The diagnosis of the current situation of the watershed major drainage system showed several river overflows and a very significant flooded area. Pre-assessment of the minor drainage system showed that it was almost nonfunctional, so this diagnosis represented the superficial layer, simulating the rainfall-runoff transformation, the interactions between the generated flows and the surface of the watershed and its main channels. The data of four rain gauges were used to define a design storm event of 25-year return period, with a total of $83 \mathrm{~mm}$ in 108 minutes. It is important to note that $A$ flood map was produced, enveloping the worst possible results, referred to major drainage failure and insufficient and clogged minor drainage operation. 


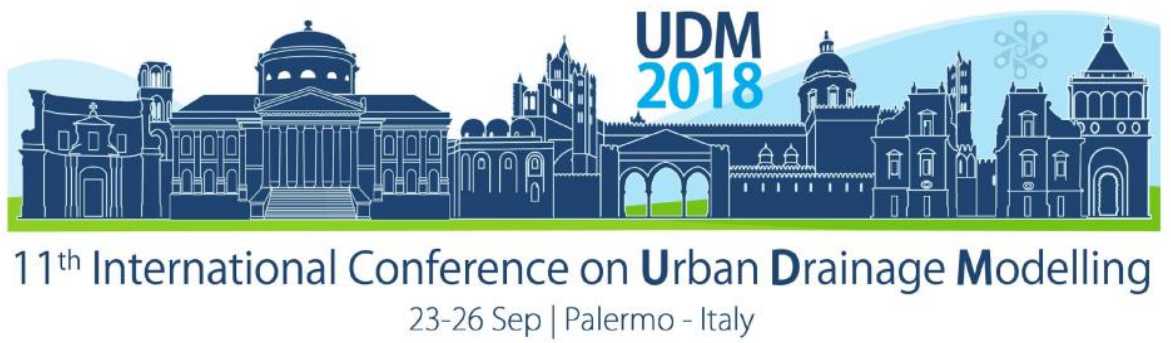

Departing from this previous study, we perceived that, by comparison, if an ideal minor drainage could be implemented and adequately put to work, the remaining flooded areas could be credited to the major drainage failure. In this way, the results would allow individualizing the participation of each system (minor and major drainage) in the observed flooding of the city of Mesquita. Therefor, in our work, the layer containing the minor drainage system was introduced to establish the relations between surface flows and storm drains. Initially, in order to make the surface sub-catchments compatible with the storm sewer network inlets, the cell division made by Veról (2013) was revised and the model was re-calibrated, taking the preceding results as reference. After that a new hypothetical situation was created by considering the layer composed by the minor drainage system as completely functional. This configuration implies that storm drains are in place, and maintenance is up to date, without any functional problem. In terms of minor drainage performance, this is the expected ideal situation, and it is usually not observed in practice. Therefore, using these two simulations referring to real flooding and hypothetical exclusive major drainage flooding (with minor drainage completely functional), it is possible to identify and individualize minor drainage deficiencies and make efforts to solve these problems.

\section{CASE STUDY}

Dona Eugênia River watershed is situated between two cities of the Baixada Fluminense region, in the metropolitan region of Rio de Janeiro, Brazil. The river runs inside an environmental preservation area in its upstream reaches, in Nova Iguaçu, and then crosses the urban area of Mesquita, where it is channelized and becomes degraded. This region has several problems related to intense and irregular settlements, discharge of sewage and solid waste into the river, and recurrent flooding problems. The average annual temperature is $22^{\circ} \mathrm{C}$ and the annual rainfall is approximately $1700 \mathrm{~mm}$ (COPPETEC, 2009).

\section{RESULTS AND DISCUSSION}

Figure 1 shows the hydrographs in the mouth of Dona Eugênia River for the two situations modelled. Comparison between the surface flow scenario (in the new model, but omitting the minor drainage) and the original data shows the re-calibration adjustment. Comparison between the dual drainage alternative and the surface flow alternative shows how minor drainage can contribute to diminish part of the flooded areas, while it also anticipates and increases flood peaks.

Errore. L'origine riferimento non è stata trovata. illustrates the cell division and the flood maps obtained in the two modelling alternatives for the urban areas of the watershed. The results obtained with the simulation of the surface layer show the severe flooding situation in the watershed. It is possible to observe numerous areas of surface ponding due to the functional minor drainage system failures (Figure 2(a)). On the other hand, the dual drainage alternative, representing the hypothetical ideal minor drainage operation, shows an impressive reduction on the surface flooded areas, but major drainage failures continues to occur, indicating that the flooding problems in the watershed are caused by insufficiency of both systems. The river overflowed in downstream areas and caused surcharge in the near storm drains network. The increase of peak flow and velocity promoted by the minor drainage flow also contributed to flooding new areas that were not affected in the previous scenario. This results shows the necessity to maintain (or recover) the minor drainage system almost everywhere on the urban watershed, as well as implementing complementary measures to reorganize the river flows. 


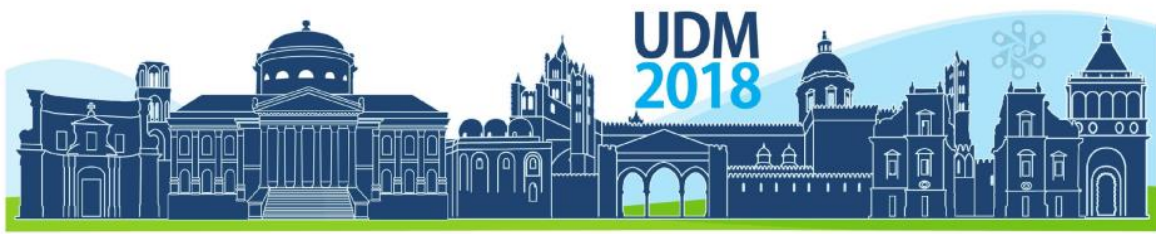

$11^{\text {th }}$ International Conference on Urban Drainage Modelling

23-26 Sep | Palermo - Italy

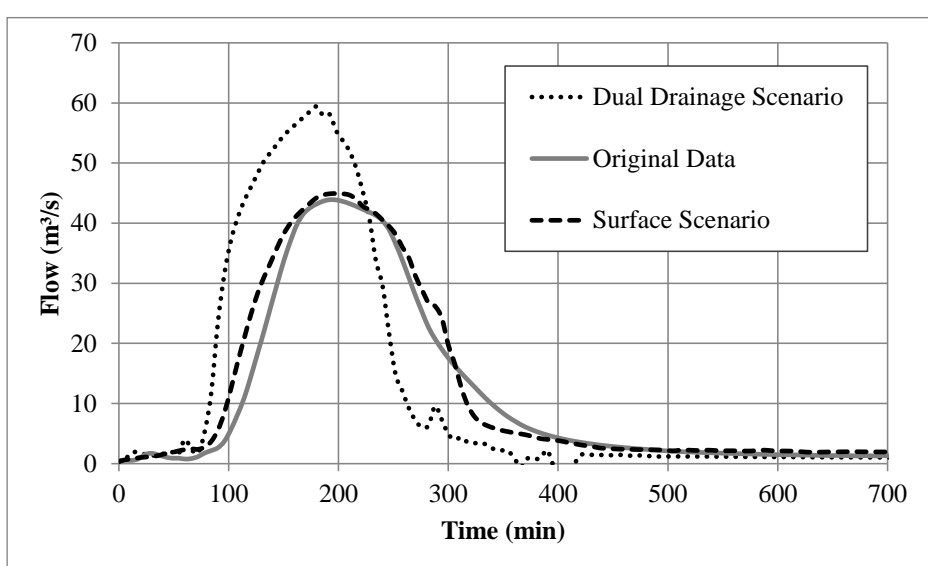

Figure 1. Hydrograph at the mouth of Dona Eugenia River.

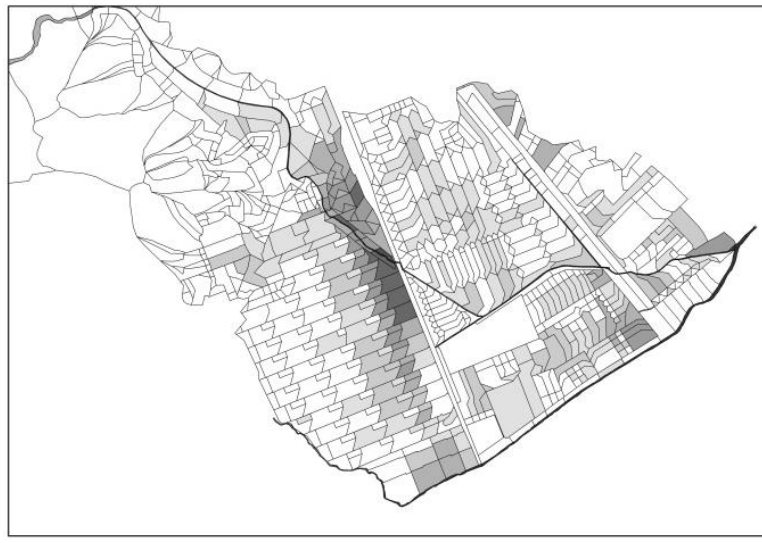

(a) Surface Alternative

Maximum Water Depth
$\square 0.00<\mathrm{h}<=0.15$
$0.15<\mathrm{h}<=0.30$

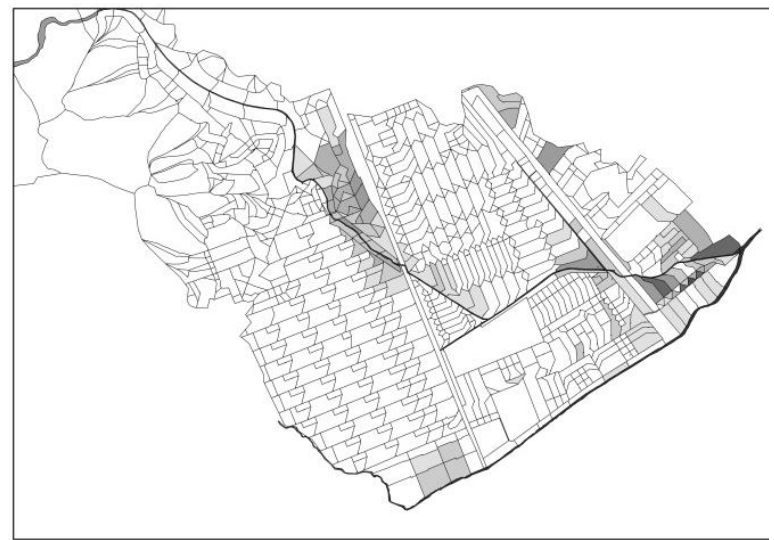

(b) Dual Drainage Alternative

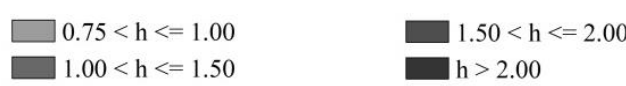

Figure 2. Flood maps of the urbanized area.

\section{CONCLUSIONS}

It is worth to emphasize that, especially in developing countries, it is frequent the situation in which maintenance is postponed, the storm drains do not cover the entire watershed, and urbanization has grown uncontrolled, stressing the system with greater discharges than that originally expected. Generally, it is not easy to identify the network reaches that are in need of maintenance. Nevertheless, the proposed comparison of results of the two alternatives provides support to identify, firstly, where minor drainage gaps are located. Consequently, it helps to direct efforts to the most critic regions and to optimize operation and minimize maintenance costs. Secondly, it can be used to properly evaluate the effects of the storm sewer network discharges in the major drainage system, leading to better design of drainage infrastructure. Besides that, it avoids (at least in a first moment of planning) the costly inspections inside the existing storm drains networks, allowing to direct efforts to critical regions mapped by mathematical modelling.

\section{References}

Bertsch, R., Glenis, V., and Kilsby, C. (2017) Urban flood simulation using synthetic storm drain networks. Wat. $\mathrm{CH}$ 


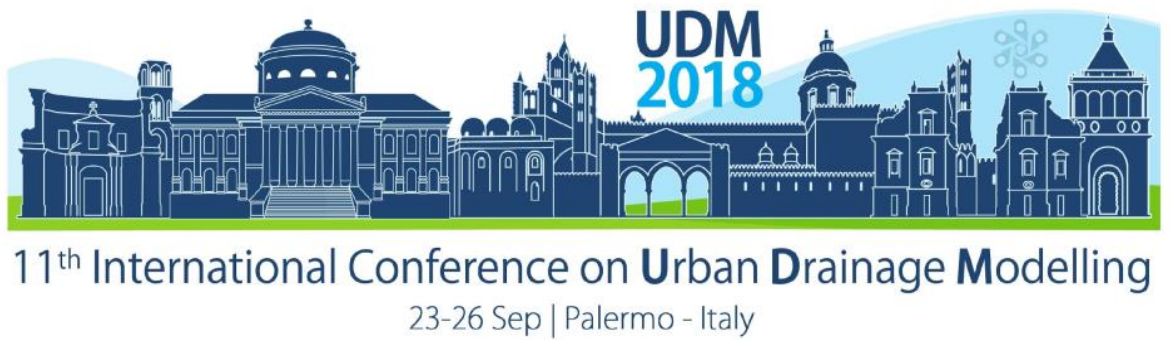

$9(12)$.

Chang, T. J., Wang, C. H., and Chen, A. S. (2015) A novel approach to model dynamic flow interactions between storm sewer system and overland surface for different land covers in urban areas. J. Hydrol. 524, 662-679.

COPPETEC (2009) Plano Diretor de Recursos Hídricos, Recuperação Ambiental e Controle de Inundacões da Bacia do Rio Iguaçu-Sarapuí. Rio de Janeiro, Brazil: Laboratório de Hidrologia e Estudos do Meio Ambiente, COPPE/UFRJ (in Portuguese).

Djokic, D. and Maidment, D. R. (1991) Terrain analysis for urban stormwater modelling. Hydrol. Processes 5(1), $115-124$.

Djordjevic, S., Ivetic, M., Maksimovic, C., Rajcevic, A. (1991) An approach to the simulation of street flooding in the modeling of surcharged flow in storm sewers. In: Maksimovic, Cedo (Ed.), Proceedings: New Technologies in Urban Drainage UDT '91. Elsevier Publishers, pp. 101-108.

Mascarenhas, F. C. B. and Miguez, M. G. (2002) Urban flood control through a mathematical cell model. Wat. Internat. 27(2), 208-218.

Miguez, M. G., Veról, A. P., Rezende, O. M. (2015) Drenagem Urbana: Do Projeto Tradicional à Sustentabilidade. 1 ed. Rio de Janeiro: Elsevier-Campus, p. 384 (in Portuguese).

Miguez, M. G., Battemarco, B. P., De Sousa, M. M., Rezende, O. M., Veról, A. P., and Gusmaroli, G. (2017) Urban flood simulation using MODCEL-an alternative quasi-2D conceptual model. Wat. $\mathrm{CH}$ 9(6).

Miguez, M. G.; Veról, A. P. (2017) A catchment scale Integrated Flood Resilience Index to support decision making in urban flood control design. Environ. and Planning. B: Urban Analyt. and City Sci. 44(5), 925-946.

Nanía, L. S., Leon, A. S., and García, M. H. (2014) Hydrologic-Hydraulic Model for Simulating Dual Drainage and Flooding in Urban Areas : Application to a Catchment in the Metropolitan Area of Chicago. J. Hydrol. Eng. 20(2005), 1-13.

Nasello, C. and Tucciarelli, T. (2005) Dual Multilevel Urban Drainage Model. J. Hydraul. Eng. 131(9), 748-754.

Randall, M., Perera, N., Gupta, N., and Ahmad, M. (2017) Development and Calibration of a Dual Drainage Model for the Cooksville Creek Watershed, Canada. J. Wat. Manag. Modeling 1-9.

Rubinato, M., Martins, R., Kesserwani, G., Leandro, J., Djordjević, S., and Shucksmith, J. (2017) Experimental calibration and validation of sewer/surface flow exchange equations in steady and unsteady flow conditions. J. Hydrol. 552, 421-432.

Smith, M. B. (2006) Comment on "Analysis and modeling of flooding in urban drainage systems." J. Hydrol. 317(34), $355-363$.

Veról, A.P. (2013) Requalificação Fluvial Integrada ao Manejo de Á guas Urbanas para Cidades mais Resilientes. PhD Thesis, COPPE/UFRJ, Rio de Janeiro, RJ, Brazil.

Zanobetti, D., Lorgeré, H., Preissman, A., Cunge, J. A. (1970) Mekong Delta Mathematical Program Construction. J. Waterw. Harb. Div. ASCE 96, 181-199. 
Proceedings of the 11th Int. Conference on Urban Drainage Modelling, 23-26 Sep. 2018, Palermo (ITALY). Ed. prof. Giorgio Mannina

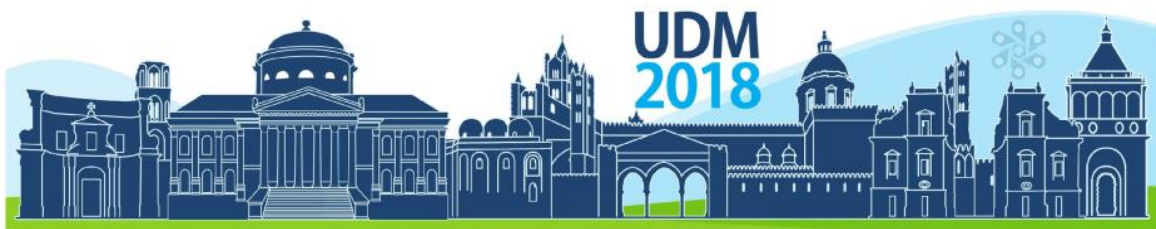

$11^{\text {th }}$ International Conference on Urban Drainage Modelling 23-26 Sep | Palermo - Italy 


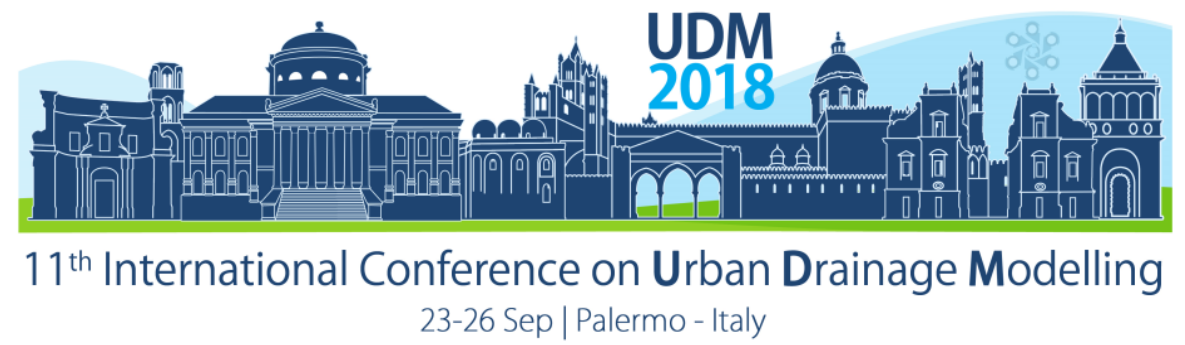

\title{
A data analysis and modelling approach to understand the role of urbanization features on the hydrological regime
}

\author{
Guido Petrucci ${ }^{1,2}$, Kevin De Bondt ${ }^{2}$ and Philippe Claeys ${ }^{3}$ \\ ${ }^{1}$ PROLOG INGENIERIE, Paris, France, petrucci@prolog-ingenierie.fr \\ 2 Vrije Universiteit Brussel, AMGC, Brussels, Belgium
}

\begin{abstract}
The impact of urbanization on the hydrological regime is complex and depends on different urban features. Increased imperviousness is the most studied one, but the reduction of buffers (river bed, ponds), increased drainage efficiency, or underground infrastructure interacting with subsurface flows can also be relevant. Classical assessment methods use data analysis on coupled catchments: they are limited by case-studies availability and cannot discriminate between different urban features. We associate here data analysis on 6 catchments in Brussels to detailed modelling, allowing to assess separately the role of different features of urbanization, i.e. imperviousness and ponds filling.
\end{abstract}

Keywords: urban hydrology, data analysis, physical modelling, urban growth, urban impact

\section{INTRODUCTION}

The impact of urbanization on the hydrological regime is complex and depends on different urban features. Increased imperviousness is the most studied one, and the most considered in water management, but other elements of urbanization can be relevant: e.g., reduction of natural buffers and storage (river bed, ponds), increased drainage efficiency, interaction of subsurface flows with underground infrastructure. Also, the impact of these features can be different if one considers storm events (high flows) or baseflow (Leopold et al., 1964; Meierdiercks et al., 2010; Braud et al., 2013; Bhaskar et al., 2016; Salavati et al., 2016).

Classical assessment methods of the urbanization impact rely on data analysis on coupled catchments: they are limited by case-studies availability and cannot discriminate between different urban features (Salavati et al., 2016). In this research we combine data analysis with a detailed modelling approach, in order to distinguish the role of different urban features on the hydrological regime.

\section{MATERIALS AND METHODS}

We consider the Woluwe catchment in the Brussels region, where a double network (river and combined sewer) drains an area of about $50 \mathrm{~km}^{2}$. Discharge measurements are available at different points of the two networks, and allow identifying 6 nested catchments: three urban and three non-urban (Fig. 1). Data include rainfall and discharge measurements over 8 to 11 years. For urban catchments, discharge is filtered to distinguish wastewater, stormwater and parasitic groundwater components (Braud et al., 2013). Data analysis performed includes monthly runoff and flow duration curves analysis (Meierdiercks et al., 2010; Petrucci et al., 2014). A SWMM model of 3 catchments (two urban, one non-urban) is realized and calibrated/validated against data. The models are used to simulate scenarios with variable impervious cover (3\%-30\%) and with or without natural ponds (150 m3/ha). 
Proceedings of the 11th Int. Conference on Urban Drainage Modelling, 23-26 Sep. 2018, Palermo (ITALY). Ed. prof. Giorgio Mannina

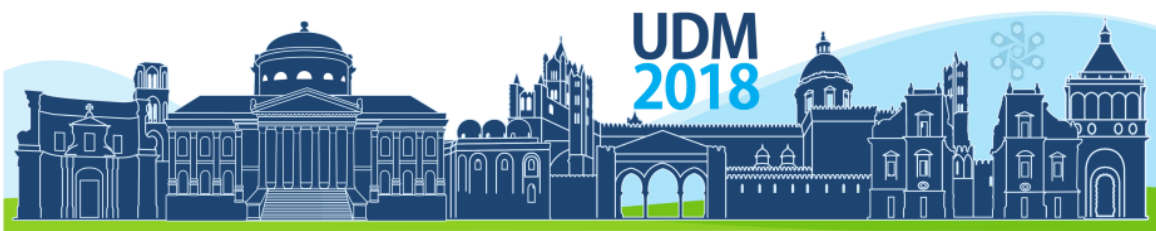

$11^{\text {th }}$ International Conference on Urban Drainage Modelling

23-26 Sep | Palermo - Italy

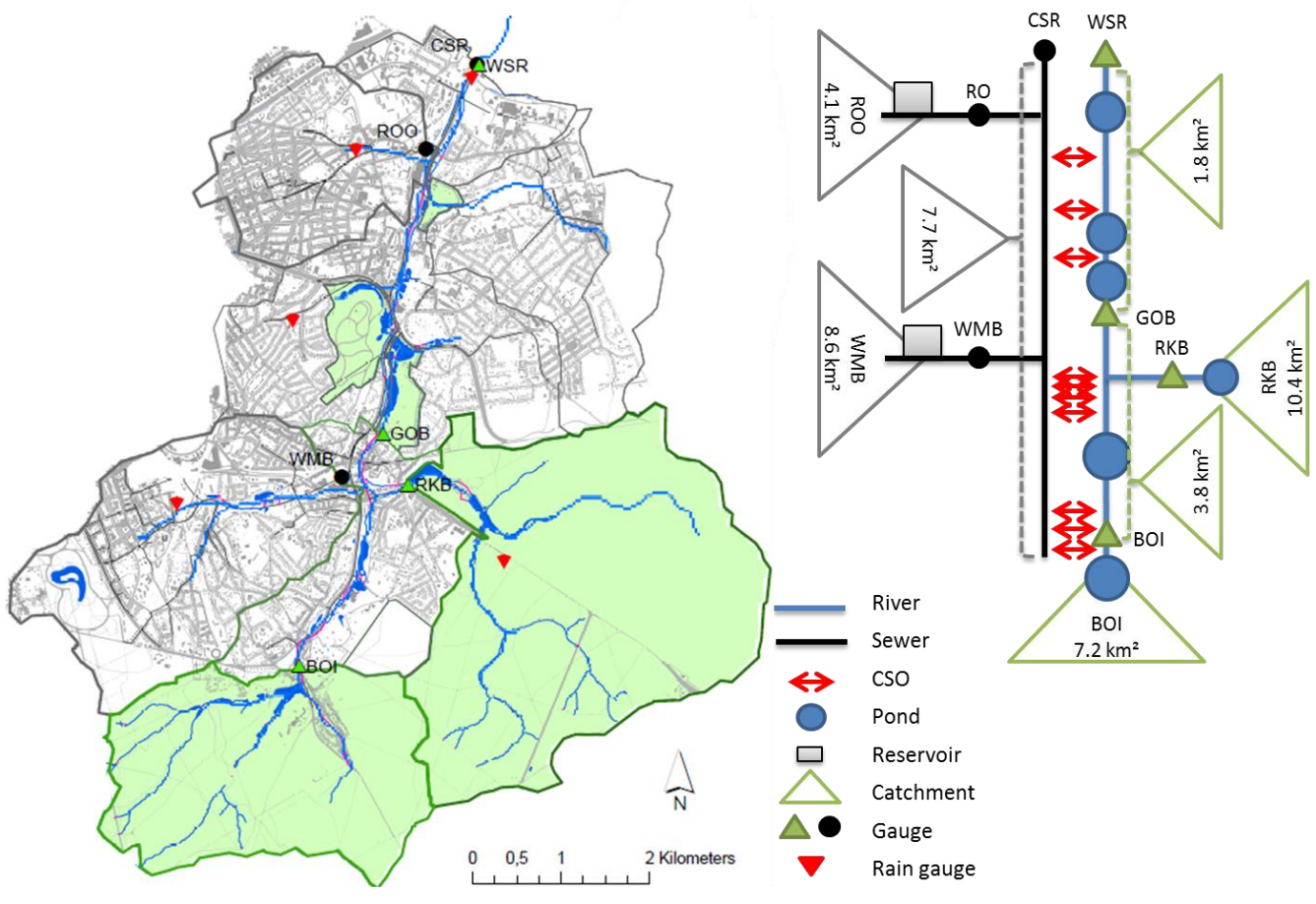

Figure 1. Map (left) and scheme (right) of the Woluwe catchment in the Brussels region. In the map, blue lines identify the "topographical" river network: the actual river in the urban areas is present only in the valley bottom.

\section{RESULTS AND DISCUSSION}

Data analysis (Fig. 2) shows that non-urban catchments have specific discharge variability, both inter- and intra-catchment, much smaller than urban ones.

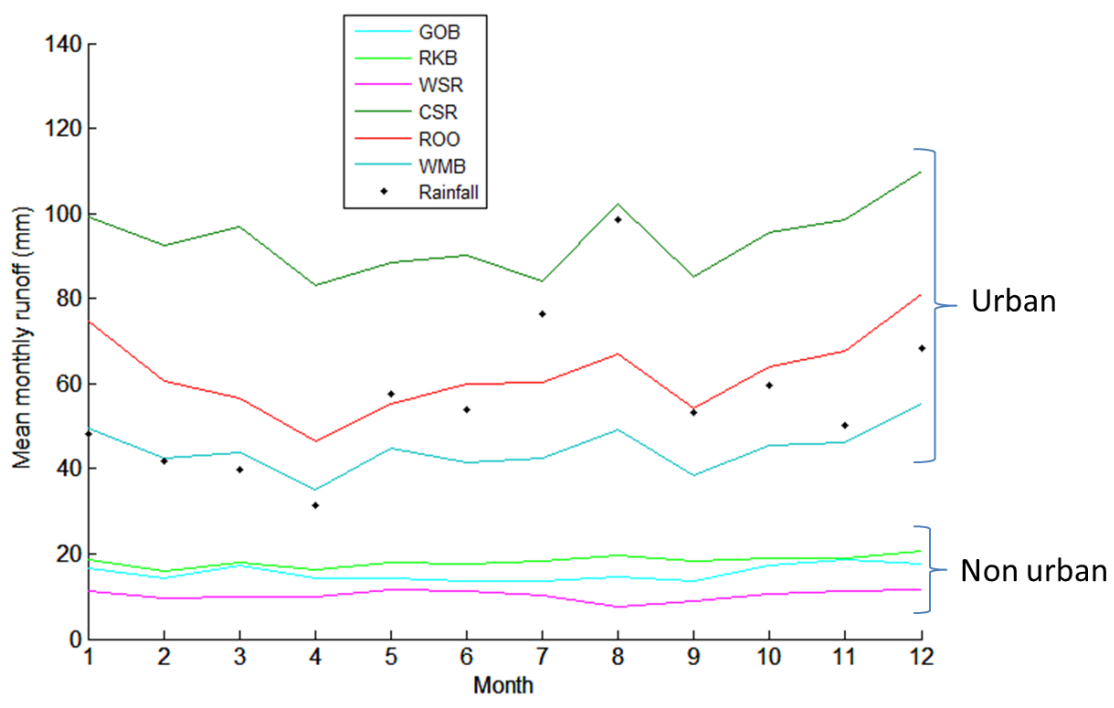

Figure 2. Example of data analysis. Mean monthly runoff for the six catchments considered. 


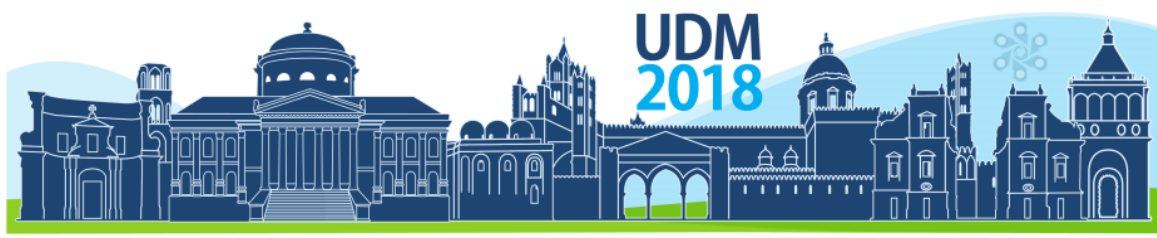

$11^{\text {th }}$ International Conference on Urban Drainage Modelling

23-26 Sep | Palermo - Italy

Fig. 3 shows that, for urban catchments, the intra-catchment variability (i.e. for one catchment, the difference between low and high flows discharge) is mainly due to the stormwater component. Conversely, inter-catchment variability (difference between catchments) is only partially due to stormwater: in particular, one catchment (CSR) has massive intakes of parasitic groundwater, making its flow regime significantly different from the two other urban catchments. The reason is linked to infrastructure: in the valley bottom, a deep drain is coupled to the sewer system. Although this result is site-specific, it clearly demonstrates how the physiography (i.e. valley bottom vs lateral valleys) can affect the hydrologic behavior of urban areas at least as much as imperviousness.

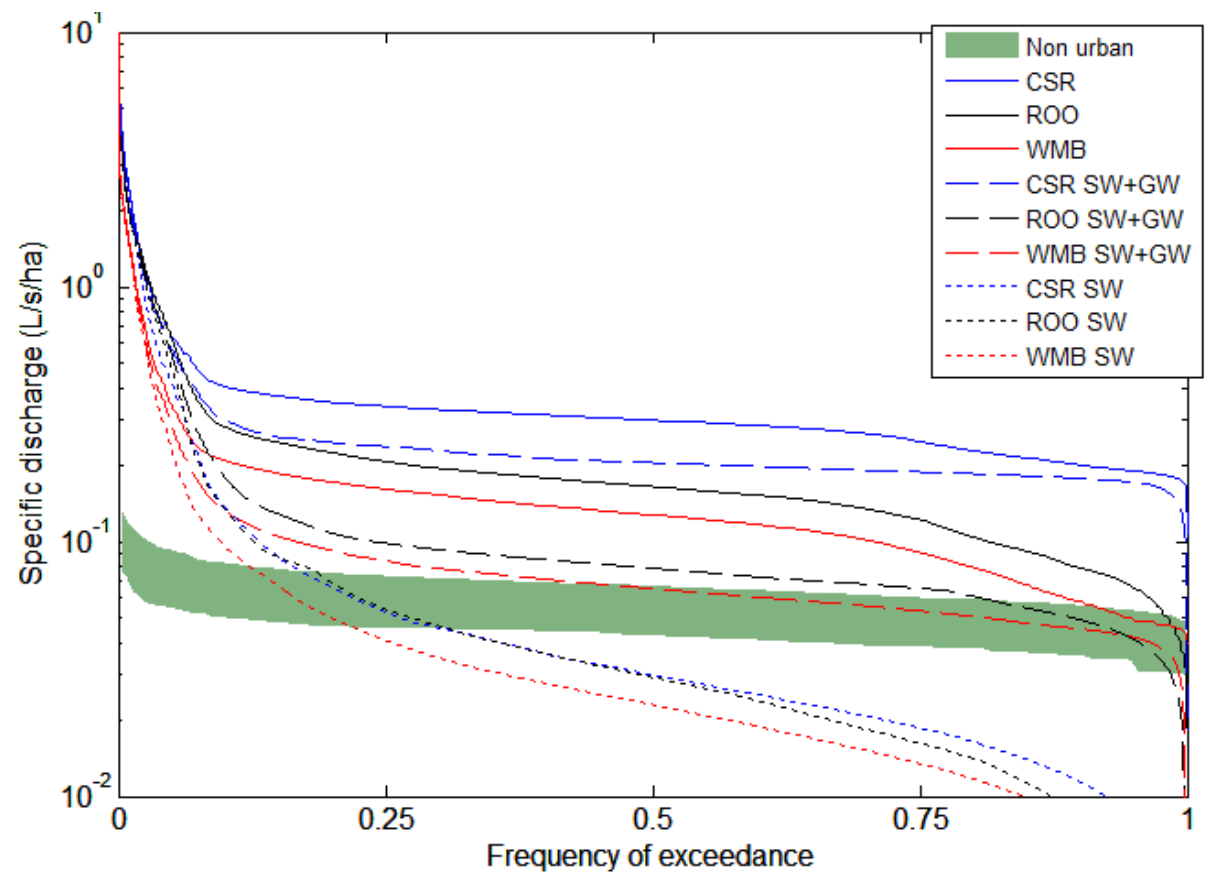

Figure 3. Flow duration curves for urban catchments discharge, stormwater (SW) and groundwater (GW) components

Scenario simulation on the model (Figure 4) allows distinguishing the impact of imperviousness and ponds removal on high flows. Starting from the green lines (non-urban: low impervious cover, ponds present), both removing the ponds (red lines) and increasing imperviousness (cyan lines) increases the specific high flows of about one order of magnitude. Even if imperviousness has a stronger impact, only the combination of the two effects fully explain the hydrological behavior of the urban catchments. This result is not only relevant to forecast the evolution of urbanizing watersheds, but also to plan mitigation measures in already urban catchments.

\section{CONCLUSIONS}

This work demonstrates how coupling physical modeling to data analysis can deepen our understanding of the hydrology of urban areas. It also allows reconsidering some classical assumption in urban water management: 


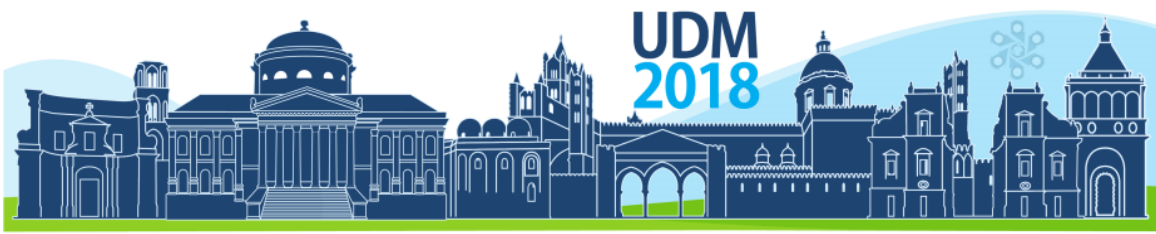

$11^{\text {th }}$ International Conference on Urban Drainage Modelling

23-26 Sep | Palermo - Italy

1. imperviousness is not the only, and sometimes not even the most important, variable to control;

2. urban catchments, even in the same city, can have extremely different regime, and physiography remains a fundamental driver of their hydrological behavior. In terms of water planning and management the consequence is that different areas, even close to each other, may require different actions and regulations;

3. impervious cover and buffer removal have complementary impacts: effective mitigation measures should address both, for instance by integrating impervious cover reduction and disconnection policies with blue/green network restoration actions.
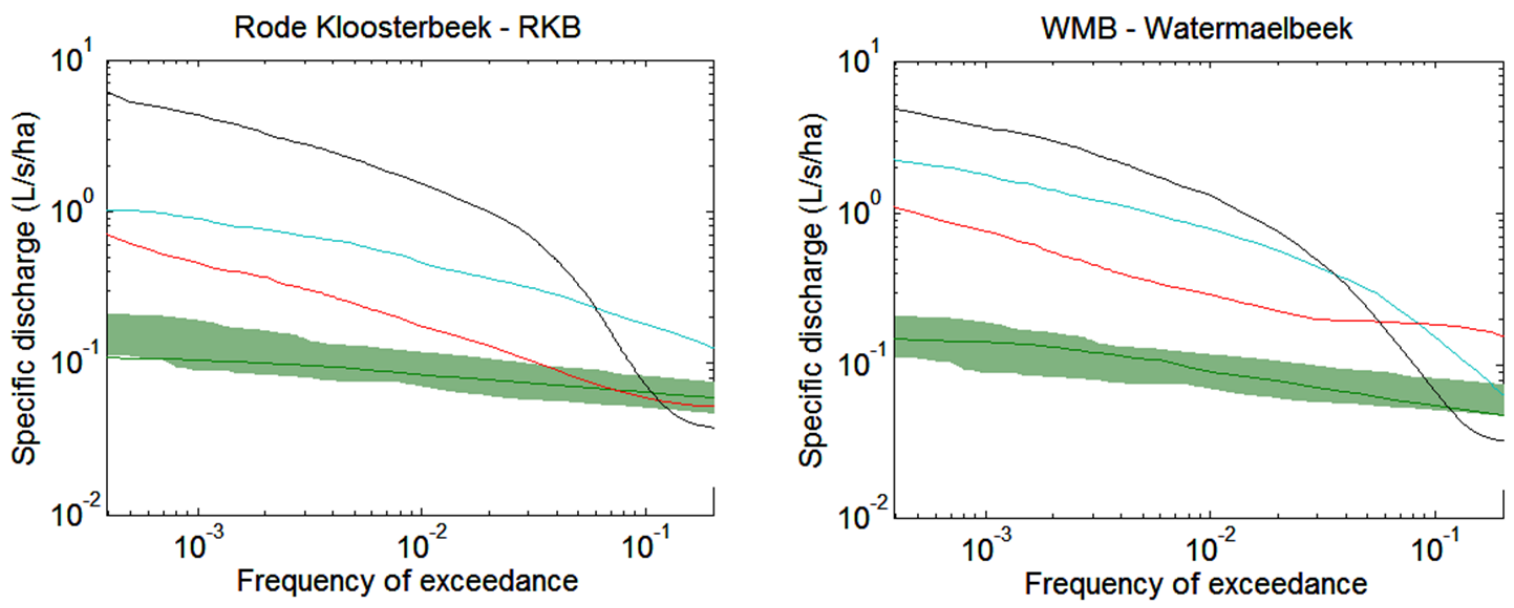

Figure 4. Scenario simulations: Flow duration curves for a natural (left) and an urban (right) catchments.

\section{Acknowledgments}

This work was supported by grants from Innoviris. Support from the VUB Strategic Research fund is also acknowledged. The authors wish to thank Vivaqua, IBGE-BIM and SBGE for providing the data used in this work.

\section{References}

Bhaskar, A.S., Beesley, L., Burns, M.J., Fletcher, T.D., Hamel, P., Oldham, C.E., Roy, A.H., 2016. Will it rise or will it fall? Managing the complex effects of urbanization on base flow. Freshwater Science 35, 293-310.

Braud, I., Breil, P., Thollet, F., Lagouy, M., Branger, F., Jacqueminet, C., Kermadi, S., Michel, K., 2013. Evidence of the impact of urbanization on the hydrological regime of a medium-sized periurban catchment in France. Journal of Hydrology, Hydrology of peri-urban catchments: processes and modelling 485, 5-23.

Leopold, L.B., 1968. Hydrology for urban land planning: A guidebook on the hydrologic effects of urban land use. US Government Printing Office.

Meierdiercks, K.L., Smith, J.A., Baeck, M.L., Miller, A.J., 2010. Heterogeneity of Hydrologic Response in Urban Watersheds1. JAWRA Journal of the American Water Resources Association 46, 1221-1237.

Petrucci, G., Rodriguez, F., Deroubaix, J.-F., Tassin, B., 2014. Linking the management of urban watersheds with the impacts on the receiving water bodies: the use of flow duration curves. Water Science \& Technology 70 , 127.

Salavati, B., Oudin, L., Furusho-Percot, C., Ribstein, P., 2016. Modeling approaches to detect land-use changes: Urbanization analyzed on a set of 43 US catchments. Journal of Hydrology 538, 138-151. 


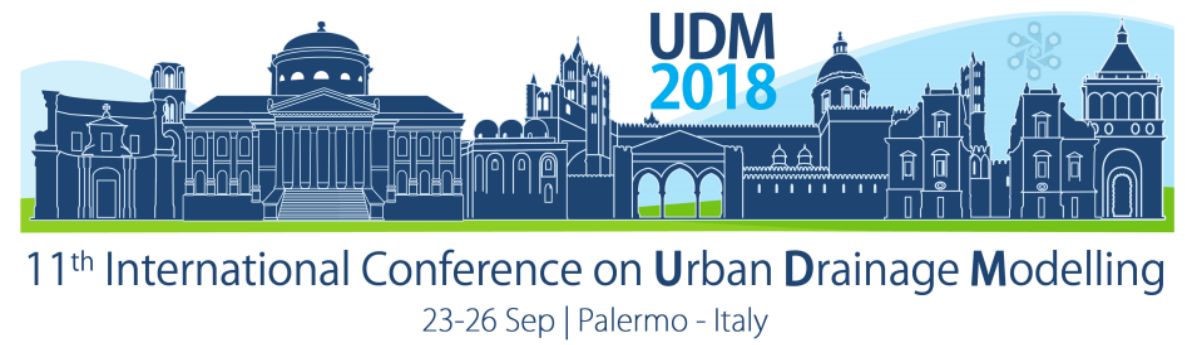

\title{
Sensitivity of water balance components to green roof parameters
}

\author{
Johannes Leimgruber, Gerald Krebs and Dirk Muschalla \\ Graz University of Technology, Institute of Urban Water Management and Landscape Water Engineering, \\ Stremayrgasse 10/l, 8010 Graz, Austria (Email: leimgruber@tugraz.at)
}

\begin{abstract}
Low Impact development (LID) strategies, e.g. green roofs, aim to mitigate the adverse impacts of urbanization like the increase of runoff and the decrease of evapotranspiration. Hydrological simulations are a reasonable option to evaluate the LID performance with respect to the complete water balance. Several modeling tools, e.g. SWMM, are suitable for this purpose. The sensitivity of the water balance components to LID parameters is an important knowledge for the modeling process as well as for the planning process of LIDs. This contribution presents the results of a global sensitivity analysis of the water balance components to the parameters of an extensive green roof. The analysis shows that most of the parameters are non-influential to runoff and evapotranspiration while the soil thickness is the most influential parameter.
\end{abstract}

Keywords: low impact development; sensitivity analysis; stormwater management

\section{INTRODUCTION}

Urbanization increases the imperviousness of formerly natural surfaces. This process considerably influences the water balance (Shuster et al., 2005). The runoff increases whereas evapotranspiration and groundwater recharge decrease, resulting in several negative impacts like larger runoff volumes and higher runoff peak rates, increase of runoff and potentially flooding events, urban heat islands, etc. (Fletcher et al., 2013).

Low impact development (LID) is a currently widely discussed and implemented concept in stormwater management, which aims to mitigate the adverse impacts of urbanization. The main goal of LID strategies is to maintain or restore the pre-development hydrologic regime (US EPA, 2000; Eckart et al., 2017).

Hydrological simulations are a reasonable option to evaluate the performance of LID strategies with respect to the water balance. Therefore, the pre- and post-development hydrological conditions of a site are analyzed. Commonly, only the runoff component of the water balance is considered. Evapotranspiration and infiltration/groundwater recharge are neglected, although they play an important role regarding the heat island effect or groundwater mounding due to artificial groundwater recharge (Goebel et al., 2007; Fletcher et al., 2013). However, holistic approaches considering all components of the water balance should be preferred in order to restore or at least to approximate the pre-development hydrological conditions.

Several modeling tools provide the possibility to simulate the hydrological processes of LIDs in order to evaluate their performance; of these, the US EPA Stormwater Management Model SWMM (Rossman, 2015) was used for this work.

This contribution presents a global sensitivity analysis (GSA) of the complete water balance to the parameters of an extensive green roof. By identifying non-influential parameters and parameters that highly affect the particular water balance component, the results are valuable for the planning process of LIDs in order to restore/approximate the pre-development hydrological conditions, which should be a main goal in stormwater management. 


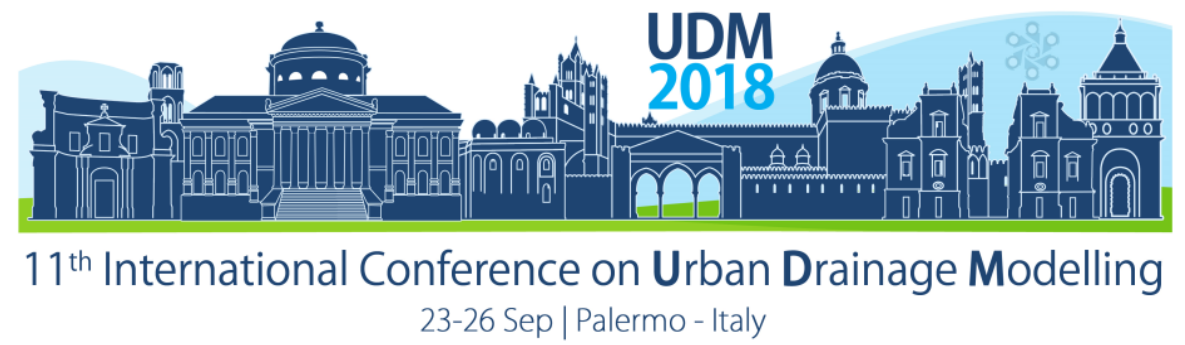

\section{MATERIALS AND METHODS}

The LID toolbox in SWMM comprises different layers, e.g. surface, soil, and drainage mat for a green roof, and the corresponding parameters. An overview of the parameters and their ranges (see (Rossman \& Huber, 2016) and (FLL, 2008)) used for the sensitivity analysis can be found in Table 1. The green roof has a dimension of $20 \mathrm{~m} \times 20 \mathrm{~m}(0.04 \mathrm{ha})$.

SWMM simulates LIDs with a soil moisture model considering the processes of runoff, infiltration, and evapotranspiration. Consequently, the water balance can be calculated:

$$
\begin{gathered}
\frac{d S}{d t}=P-E T-R \\
\text { (P... Precipitation, R... Runoff, ET... Evapotranspiration, S... Storage) }
\end{gathered}
$$

According to (Saltelli et al., 2005), with a number of input factors less than 20 and a CPU time per run less than $1 \mathrm{~min}$, the variance-based method of Sobol' (Sobol, 1993) is used to calculate the first-order sensitivity index $S_{i}$ as well as the total effect sensitivity index $S T_{i}$.

The first-order index $S_{i}$ represents the main effect contribution of each factor $X_{i}$ to the variance of the output. It indicates by how much one could reduce, on average, the output variance if $X_{i}$ could be fixed. $S_{i}$ can be used for the "factor prioritization" setting finding the most influential parameter that one should measure first in order to reduce the variance. The total effect index $S T_{i}$ accounts for the total contribution to the output variation due to factor $X_{i}$, thus, it summarizes its first-order effect plus all higher-order effects due to interactions. A total effect index of $S T_{i}=0$ implies that $X_{i}$ is non-influential and can be fixed anywhere in its distribution without affecting the variance of the output. Consequently, $S T_{i}$ can be used for the "factor fixing" setting.

For the implementation of the sensitivity analysis, the open-source Python library for Sensitivity Analysis SALib (Herman \& Usher, 2017) was used.

\section{RESULTS AND DISCUSSION}

Figure 1 shows an exemplary result of the 15000 simulations conducted for the extensive green roof. The runoff component ranges between $18 \%$ and $63 \%$ depending on the value of the green roof parameters. The scatter-plots for the different parameters indicate that the runoff is highly dependent on the soil thickness. A larger soil thickness results in smaller values of the runoff component as more water can be retained in the green roof. To a much smaller extent a similar behavior can be seen for the parameters porosity, field capacity and conductivity slope.

Table 1 shows the result of the sensitivity analysis. As already indicated by Figure 1, the runoff is highly sensitive to the soil thickness $(\mathrm{Si}=0.79, \mathrm{STi}=0.796)$. The simulation results are also sensitive to the porosity, the field capacity and the conductivity slope but with partly very small values (compare values in Table 1). The remaining parameters have a total effect index STi of 0 . That implies that these parameters are non-influential. Considering the values of the firstorder index $\mathrm{Si}$ for a factor prioritization, the soil thickness is the most influential parameter, followed by the porosity and with large distance by the field capacity and the conductivity slope. The findings described for the runoff component are also valid for the evapotranspiration (see Table 1). The values for the sensitivity indices are similar, thus, the results for the factor prioritization as well as for the factor fixing are identical. This is not surprising as the runoff is interacting with the evapotranspiration: the more water evapotranspirates, the less water can 
Proceedings of the 11th Int. Conference on Urban Drainage Modelling, 23-26 Sep. 2018, Palermo (ITALY). Ed. prof. Giorgio Mannina

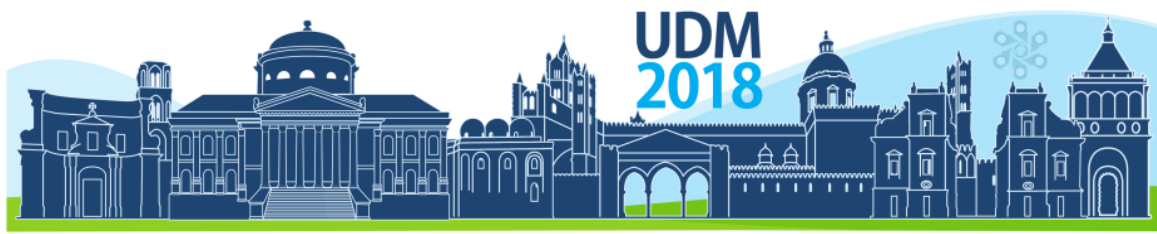

$11^{\text {th }}$ International Conference on Urban Drainage Modelling

23-26 Sep | Palermo - Italy

run off. Therefore, if the runoff is sensitive to a parameter also the evapotranspiration should be sensitive to it and vice versa.

As the storage change of the green roof water balance should be approximately zero for the long-term observation, no sensitivity analysis is presented for this component.
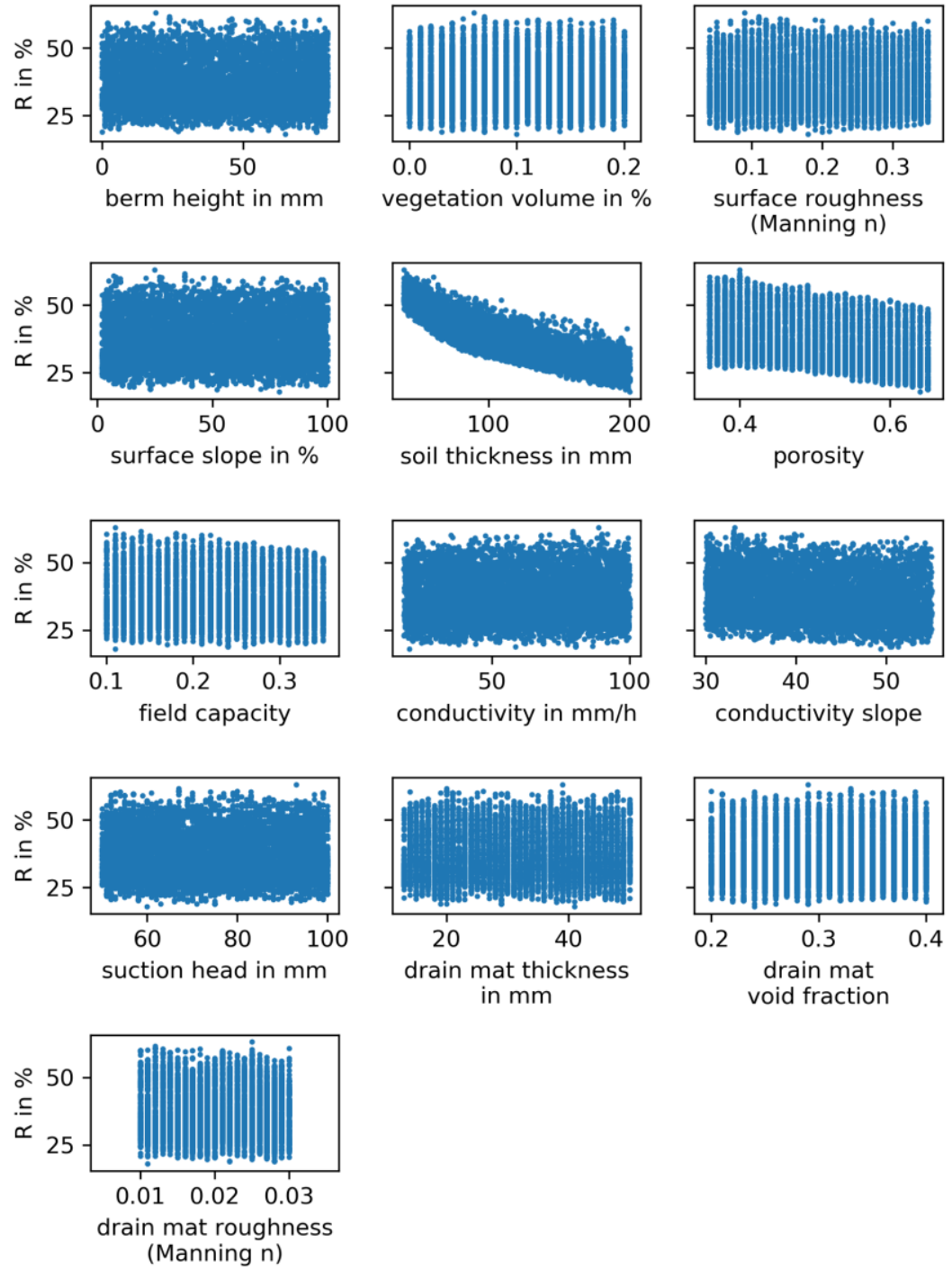

Figure 1. Result of the simulations for the extensive green roof (15000 simulations): Runoff $(R)$ in \% depending on the value of the 13 parameters 


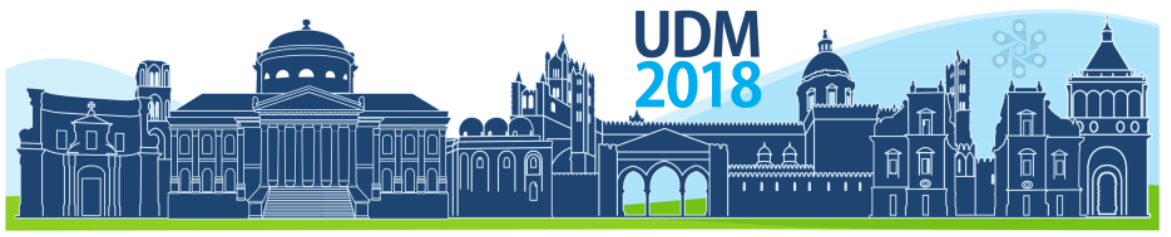

$11^{\text {th }}$ International Conference on Urban Drainage Modelling

23-26 Sep | Palermo - Italy

Table 1. Result of the sensitivity analysis for the green roof and parameter ranges for the GSA

\begin{tabular}{l|c|c|c|c|c|c|c} 
& \multicolumn{2}{|c|}{ Runoff } & \multicolumn{2}{c|}{$\begin{array}{c}\text { Evapo- } \\
\text { transpiration }\end{array}$} & \multicolumn{2}{c|}{$\begin{array}{c}\text { Ranges for } \\
\text { GSA }\end{array}$} & \\
\hline Parameter i & $S_{i}$ & $S_{i}$ & $S_{i}$ & $S_{i}$ & min & max & Unit \\
\hline Berm height & 0.000 & 0.000 & 0.000 & 0.000 & 0 & 80 & $\mathrm{~mm}$ \\
\hline Vegetation volume & 0.000 & 0.000 & 0.000 & 0.000 & 0 & 0.2 & $\%$ \\
\hline Surface roughness & 0.000 & 0.000 & 0.000 & 0.000 & 0.04 & 0.35 & Manning's $\mathrm{n}$ \\
\hline Surface slope & 0.000 & 0.000 & 0.000 & 0.000 & 2 & 100 & $\%$ \\
\hline Soil thickness & 0.795 & 0.804 & 0.798 & 0.807 & 40 & 200 & $\mathrm{~mm}$ \\
\hline Porosity & 0.168 & 0.188 & 0.166 & 0.186 & 0.36 & 0.65 & volume fraction \\
\hline Field capacity & 0.003 & 0.030 & 0.003 & 0.030 & 0.1 & 0.35 & volume fraction \\
\hline Conductivity & 0.001 & 0.004 & 0.001 & 0.004 & 18 & 100 & $\mathrm{~mm} / \mathrm{h}$ \\
\hline Conductivity slope & 0.022 & 0.024 & 0.021 & 0.023 & 30 & 55 & - \\
\hline Suction head & 0.000 & 0.000 & 0.000 & 0.000 & 50 & 100 & $\mathrm{~mm}$ \\
\hline Drain mat thickness & 0.000 & 0.000 & 0.000 & 0.000 & 13 & 50 & $\mathrm{~mm}$ \\
\hline Drain mat void fraction & 0.000 & 0.000 & 0.000 & 0.000 & 0.2 & 0.4 & fraction \\
\hline Drain mat roughness & 0.000 & 0.000 & 0.000 & 0.000 & 0.01 & 0.03 & Manning's $\mathrm{n}$
\end{tabular}

\section{CONCLUSIONS}

The restoration of the natural water balance should be one of the main goals in stormwater management. Following a holistic approach and not only focusing on the runoff, this work shows the sensitivity of all water balance components to green roof parameters.

The results of the GSA show that 9 of 13 parameters are non-influential and can be fixed anywhere in their range as the total-order index STi is 0 . The first-order index Si indicates that the runoff as well as the evapotranspiration is highly affected by the soil thickness. Smaller sensitivities were found for the porosity, the field capacity and the conductivity slope.

In further steps, sensitivity analyses are going to be conducted for other LID tools, e.g. bioretention cells or infiltration trenches. Furthermore, the influence of storm event characteristics is going to be investigated by determining a storm event-based water balance and performing the appropriate sensitivity analyses.

\section{References}

Eckart K., McPhee Z., \& Bolisetti T. (2017) Performance and implementation of low impact development - A review. Science of The Total Environment, 607(Supplement C), 413-432.

Fletcher T. D., Andrieu H., \& Hamel P. (2013) Understanding, management and modelling of urban hydrology and its consequences for receiving waters: A state of the art. Advances in Water Resources, 51, 261-279.

FLL (2008) Dachbegrünungsrichtlinie - Richtlinie für die Planung Ausführung und Pflege von Dachbegrünungen, Forschungsgesellschaft Landschaftsentwicklung und Landschaftsbau e.V., Bonn.

Goebel P., Coldewey W. G., Dierkes C., Kories H., Meßer J., \& Meißner E. (2007) Impacts of green roofs and rain water use on the water balance and groundwater levels in urban areas. Grundwasser, 12(3), 189-200.

Herman J. \& Usher W. (2017) SALib: An open-source Python library for Sensitivity Analysis. The Journal of Open Source Software. [online] http://joss.theoj.org (Accessed March 1, 2018).

Rossman L. (2015) Storm Water Management Model - User's Manual Version 5.1.

Rossman L. \& Huber W. (2016) Storm Water Management Model Reference Manual - Volume III - Water Quality.

Saltelli A., Ratto M., Tarantola S., \& Campolongo F. (2005) Sensitivity Analysis for Chemical Models. Chemical Reviews, 105(7), 2811-2827.

Shuster W. D., Bonta J., Thurston H., Warnemuende E., \& Smith D. R. (2005) Impacts of impervious surface on watershed hydrology: A review. Urban Water Journal, 2(4), 263-275.

Sobol I. M. (1993) Sensitivity estimates for nonlinear mathematical models. Mathematical Modelling and Computational Experiments, 1(4), 407-414.

US EPA (2000) Low Impact Development (LID) - A Literature Review, US EPA Office of Water (4203), Washington, DC, USA. 


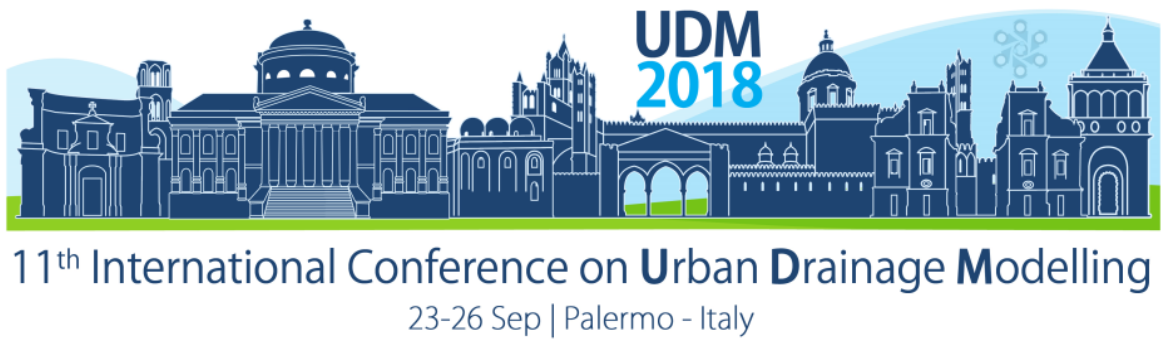

\title{
Transport capability of intake vortices at horizontal intake structures
}

\author{
Nina Voßwinkel ${ }^{1}$, Jörg Steinhardt ${ }^{2}$, Andreas Schlenkhoff ${ }^{3}$ and Rainer Mohn ${ }^{1}$ \\ ${ }^{1}$ Muenster University of Applied Sciences, IWARU, Muenster, Germany \\ 2 Steinhardt Wassertechnik GmbH, Taunusstein, Germany \\ ${ }^{3}$ University of Wuppertal, Hydraulic Engineering Section, Wuppertal, Germany
}

\begin{abstract}
Transport capability of intake vortices at horizontal intake structures was investigated by small-scale physical model tests on a scale of 1:5. The intention was to develop a prediction model which allows an evaluation of the transport capability of intake vortices on the basis of a calculated probability for various floating solids for a given geometry of intake structure. It could be demonstrated that the transport capability of intake vortices under constant geometrical boundary conditions can be determined on the basis of (i) the present hydraulic boundary conditions and (ii) the characteristics of the floating solids (density and diameter). A prediction model developed on this basis allows an estimation of the transport of floating solids for the present boundary conditions.
\end{abstract}

Keywords: intake vortex; prediction model; transport capability

\section{INTRODUCTION}

Scientific studies of vortex formations were mostly carried out in the context of pump-intake configurations in which air entrainment can cause a discharge reduction, vibrations, noises and even mechanical damage. Therefore, vortex cores are usually investigated with the objective of defining optimal conditions for intakes, for which an air core should not occur (i.e. (Anh 2004), (Chen et al. 2007) (Werth and Frizzell 2009) (Möller 2013)).

However, in this study an air core vortex should be precisely induced and reinforced by using a specific vortex plate. Such a vortex plate $\left(\right.$ HydroSpin ${ }^{\circledR}$ Steinhardt Wassertechnik $\left.\mathrm{GmbH}\right)$ can be used in a separation structure. A complete retention of floating substances cannot be guaranteed by the baffles above the overflow weir in the separation structure. The problem is that floating solids accumulate during an overflow event and are transported into the connected waters through vortex structures in front of the baffle. The entry of floating solids means a material and also aesthetic pollution for the connected water bodies. The vortex plate installed in the separating structure initiates and strengthens intake vortex. As a result, floating solids are continuously transported into the throttle and the risk of these pollutants entering the connected water body is significantly reduced.

It is known that a vortex can transport floating matter after reaching a certain level of strength - and this level is lower than required for the transport of air. The strength of an inlet vortex depends not only on the geometric boundary conditions (e.g. asymmetries), but also on the hydraulic boundary conditions defined by the flow rate and the water level above the intake

The objective of the investigation described here is to develop a prediction model for the transport of specific floating solids depending on the hydraulic boundary conditions and the characteristics of the solids for a given geometry of the intake structure. 


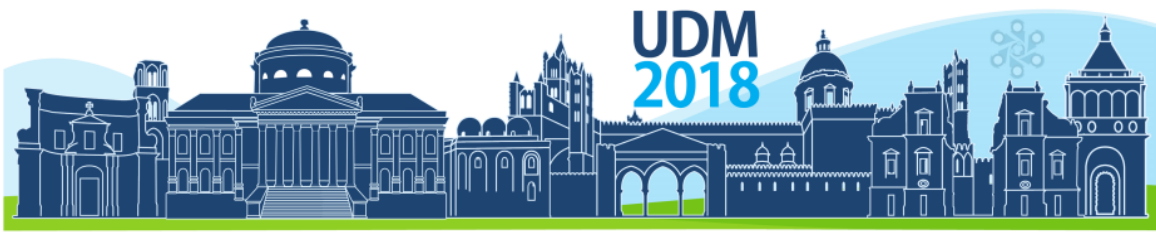

$11^{\text {th }}$ International Conference on Urban Drainage Modelling

23-26 Sep | Palermo - Italy

\section{MATERIALS AND METHODS}

\subsection{Configuration and boundary conditions}

In this investigation a small-scale physical model (scale 1:5) was used consisting of three main components: an inflow tank, a chamber and an outlet tank. Figure 1 shows a schematic illustration of the physical model.

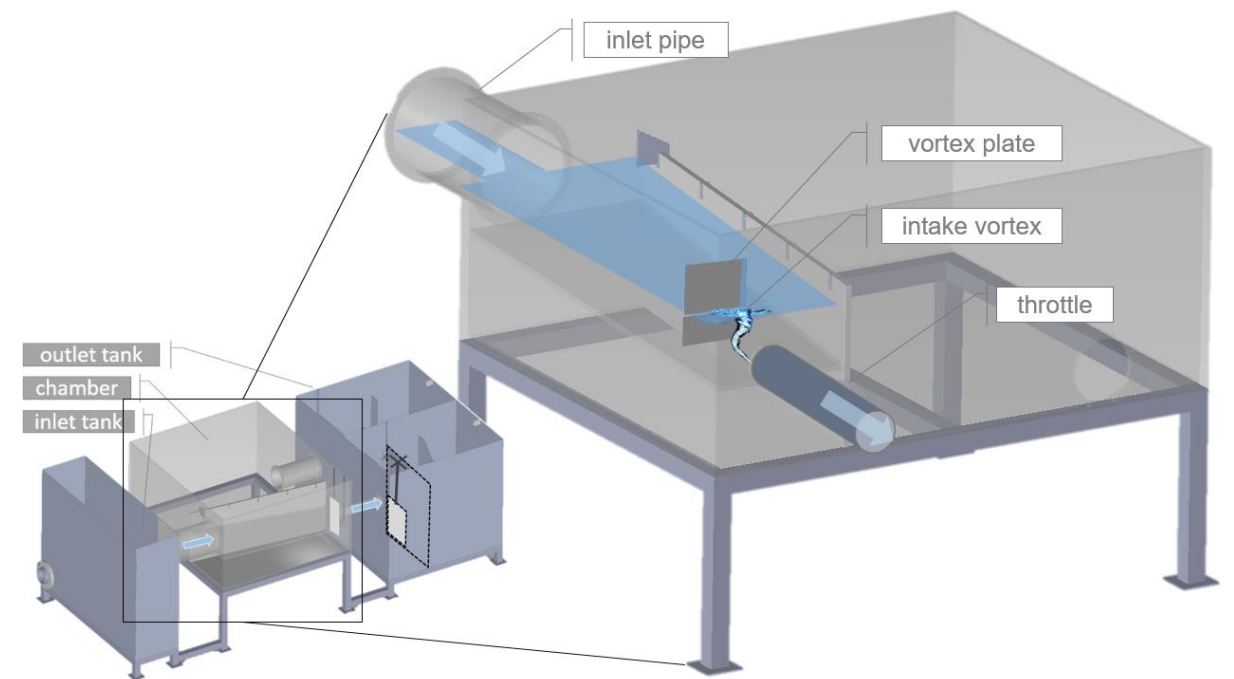

Figure 1: Configuration of the small-scale physical model (1:5) of the overflow structure (Vosswinkel 2017)

The chamber is $1.16 \mathrm{~m}$ long, $0.33 \mathrm{~m}$ high and is made of acrylic glass. The vortex plate is attached to the side wall of the chamber. This vortex plate is designed to reinforce and stabilize the intake vortex induced by the inflow into the throttle.

By regulating the downstream water level $\left(h_{\mathrm{u}}\right)$ in the outlet tank, the flow rate $(\mathrm{Q})$ and the water level in the chamber $\left(h_{\circ}\right)$ can be regulated independently of each other. A total of 49 different combinations of water level ( $h_{0}$, from $0.06 \mathrm{~m}$ to $0.31 \mathrm{~m}$ ) and flow rate $(Q$, from $2.0 \mathrm{l} / \mathrm{s}$ to $9.7 \mathrm{l} / \mathrm{s})$ were investigated in the physical model. The so-called intake Froude-number $\operatorname{Fr}_{E}(-)$ is used to describe the hydraulic boundary conditions: $F_{E}=\frac{v}{\sqrt{g * h_{0}}}(-)$; with: $g=$ gravit $\left.\left(m^{3^{*}} \mathrm{~kg}^{-1 *} \mathrm{~s}^{-2}\right)\right)$; $v=$ intake velocity $(\mathrm{m} / \mathrm{s}) ; h_{0}=$ water level (chamber) $(\mathrm{m})$.

\subsection{Floating Solids}

A total of 19 spherical floating solids were tested in the physical model. These are distinguished in terms of their different combinations of density and size. An important characteristic of floating solids is the difference between the buoyancy force $F_{A}(N)$ and the gravity force of a particle $F_{G}(N)$. This residual buoyancy force $F_{\text {Rest }}(N)$ needs to be overcome by the flow in order to transport the floating solids downwards to the intake. The residual buoyancy force is calculated by the following formula: $F_{\text {Rest }}=\left(F_{A}-F_{G}\right)(N)$.

\subsection{Evaluation methods}

For each of the 49 combinations of boundary conditions the occurring vortices were documented using a single lens reflex camera (by video and single photos). All floating solids 


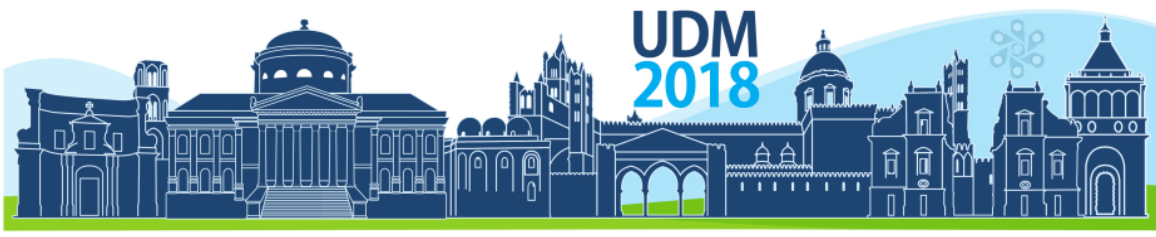

$11^{\text {th }}$ International Conference on Urban Drainage Modelling

23-26 Sep | Palermo - Italy

are added individually into the sphere of influence of all vortices by hand. A quality criterion $\mathrm{G}_{w}$ $(-)$ is defined which allows a comparison of the transport capability of the vortices regarding the 19 floating solids used here. For this purpose, the number of solids transported into the throttle is counted $\left(\mathrm{n}_{P, \text { transported }}(-)\right)$ and compared to the total number of used solids $\left(\mathrm{n}_{\mathrm{P}, \text { total }}(-)\right): G_{W}=\frac{n_{P, \text { transported }}}{n_{P, \text { total }}} * 100(-)$

By means of regression analyses, the correlation between the hydraulic boundary conditions as well as the properties of the particles (independent variables) and the transport of floating solids (dependent variable) is to be investigated. Since it was only registered in the physical model whether a specific floating solid was transported or not, the dependent variable is nominally scaled in which case a logistic regression is recommended. The logistic regression determines a probability for the transport of a specific solid.

\section{RESULTS AND DISCUSSION}

Measurement results (quality criterion $\mathrm{G}_{w}$ ) for the transport of floating solids depending on the hydraulic boundary conditions $\mathrm{Fr}_{\mathrm{E}}$ and $\mathrm{h}_{\mathrm{O}} / \mathrm{d}$ are represented in Figure 2 (left graphic). The solution field was created using a Thin Plate Spline. The shown solution field is clearly separated into four domains. The classification of those domains is based on obvious changes in the contour lines.
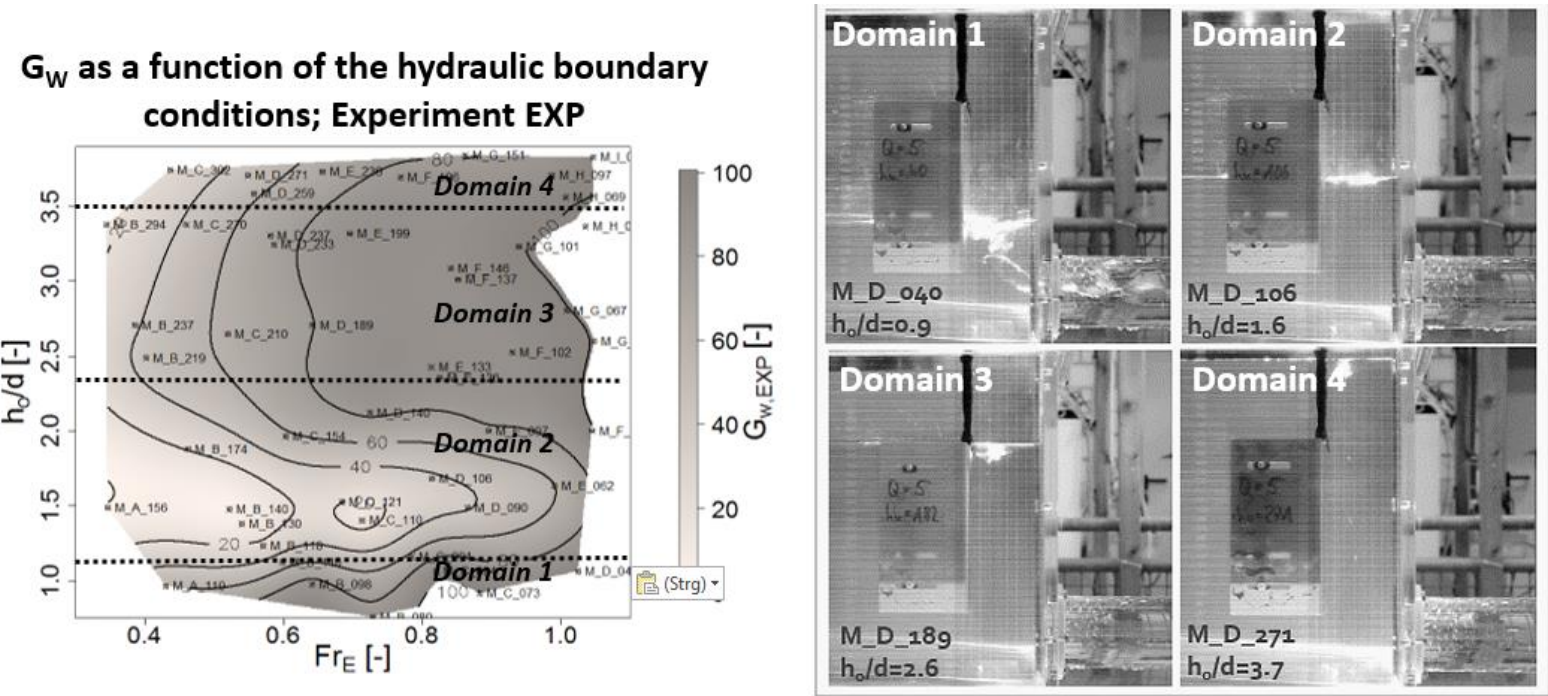

Figure 2: Left: Floating solid transport (quality criterion $\mathrm{G}_{w}(\%)$ ) depending on boundary conditions $\mathrm{Fr}_{\mathrm{E}}(-)$ and $h_{0} / d(-)$; Right: vortex formation at $Q=5(1 / s)$ in combination with different water levels $h_{0} / d(-)$ (Vosswinkel 2017)

Domain 2 shows different characteristics compared to the other ones, significantly less solids are transported, and the vortices are less strong. In the other domains, the transport of solids as well as the vortex strength gradually deteriorate with constant flow and increasing water levels. This behaviour was initially expected for all domains. Vortex formation observed in the experiment is shown in Figure 2 (right side). It is clearly noticeable that the vortex formation in domain 2 is almost completely suppressed. The cause for the different characteristics of the flow in this domain could be identified by using numerical simulations. The underflow of the vortex plate at certain water level heights creates a secondary vortex with a horizontal axis. 


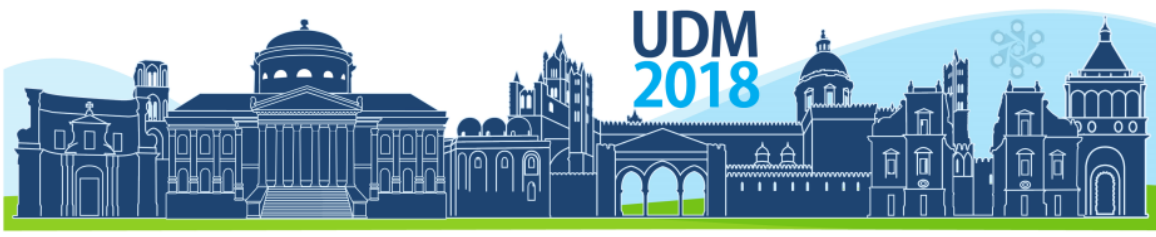

$11^{\text {th }}$ International Conference on Urban Drainage Modelling

23-26 Sep | Palermo - Italy

This weakens the formation of the primary intake vortex and thus hinders the transport of floating material.

Due to the very different characteristics of the four domains, a regression analysis (called EMP_RB_1) for the entire solution field was not successful. Therefore, a separate regression analysis was carried out for each of the four domains using a logistic regression (so called EMP_RB_2). As independent variables, the boundary conditions $\mathrm{Fr}_{E}(-)$ and $h_{0} / d(-)$ as well as the residual buoyancy force $\mathrm{F}_{\text {Rest }}(\mathrm{N})$ of the floating solids are included in the logistic regression. The dependent variable is defined by the quality criterion $\mathrm{G}_{w}$.

Predicted transport of floating solids (quality criterion $\mathrm{G}_{w}$ ) as determined by the regression model is shown in Figure 3 (left side). It is well comparable with the solution field of the results from the experiment in Figure 2. In addition, the deviations between the measured transport and the transport forecasted by the regression function for all 49 examined cases are displayed in the diagram (Figure 3, right side). In more than $90 \%$ of the cases, the regression function determines a correct prediction which can be considered a good fitting of the model.

\section{$\mathbf{G}_{\mathrm{W}}$ as a function of the hydraulic boundary} conditions; Regression EMP_RB

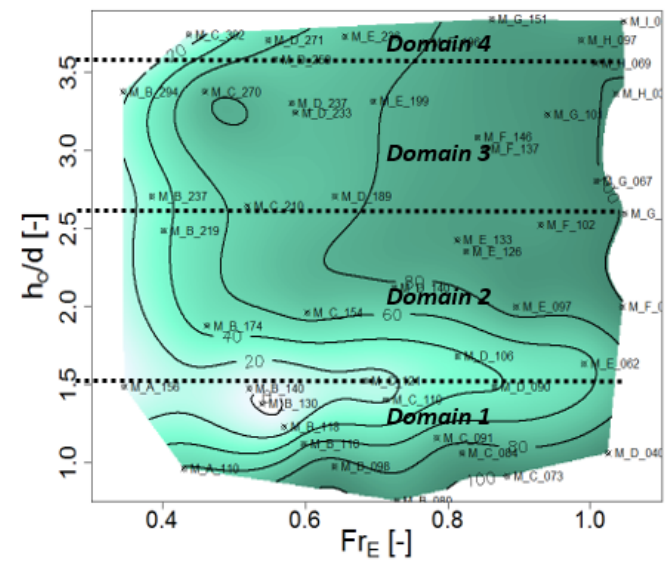

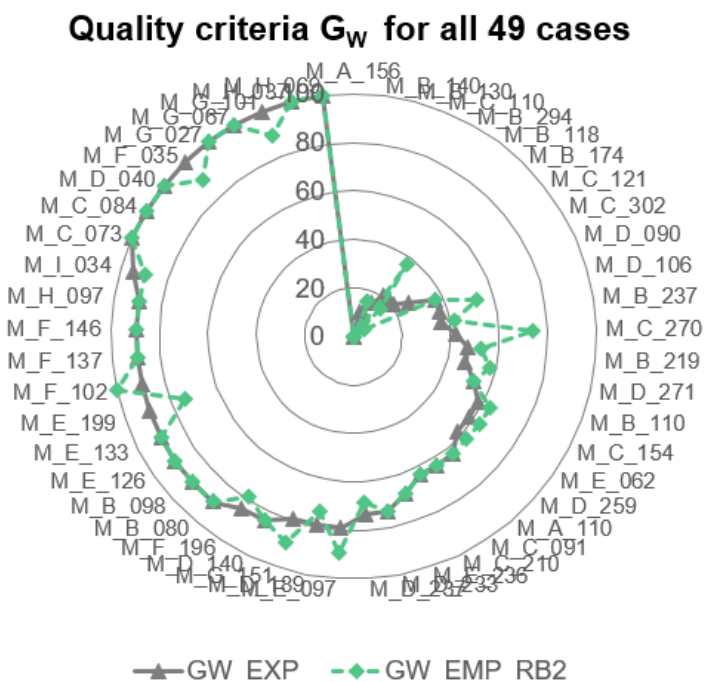

Figure 3: Left: Floating solid transport (quality criterion $\mathrm{G}_{w}(\%)$ ) depending on boundary conditions $\mathrm{Fr}_{\mathrm{E}}(-)$ and $h_{0} / d$ (-); Right: Deviations between the measured transport and the transport forecasted by the regression function for all 49 examined cases (Vosswinkel 2017)

\section{CONCLUSIONS}

The transport of floating solids through intake vortices depends on both the characteristics of the used solids (combined in the residual buoyancy force $F_{\text {Rest }}$ ) and the strength of the intake vortex itself. The latter is influenced by the geometric as well as the hydraulic boundary conditions. Under constant geometric boundary conditions, it can be determined that the lower the water level and the higher the intake velocity are, the higher is its ability to transport floating solids. The prediction model developed here is able to evaluate the transport of floating solids with good accuracy. However, it applies solely to the geometric boundary conditions investigated here. 
Proceedings of the 11th Int. Conference on Urban Drainage Modelling, 23-26 Sep. 2018, Palermo (ITALY). Ed. prof. Giorgio Mannina

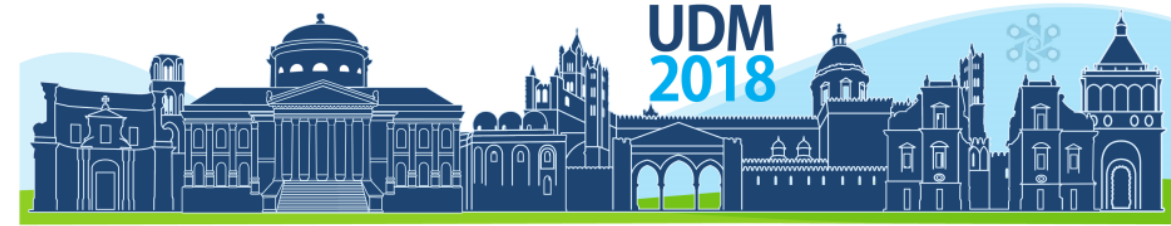

$11^{\text {th }}$ International Conference on Urban Drainage Modelling

23-26 Sep | Palermo - Italy

\section{References}

Anh, T. N. (2004): Free Surface Profile Analysis of Flows with Air-core Vortex. In: Journal of Applied Mechanics, 7, S. 7.

Chen, Y. L., Wu, C., Ye, M., und Ju, X. M. (2007): Hydraulic characteristics of vertical vortex at hydraulic intakes. In: Journal of Hydrodynamics, 19(2), S. 143-149.

Möller, G. (2013): Vortex-induced air entrainment rate at intakes. Dissertation. Eidgenössische Technische Hochschule ETH Zürich, Zürich.

Vosswinkel, N. (2017): Transport von Einlaufwirbeln. Bd. 21, Aachen: Bergische Universität Wuppertal.

Werth, D. and Frizzell, C. (2009): Minimum pump submergence to prevent surface vortex formation. In: Journal of Hydraulic Research, 47(1), S. 142-144. 


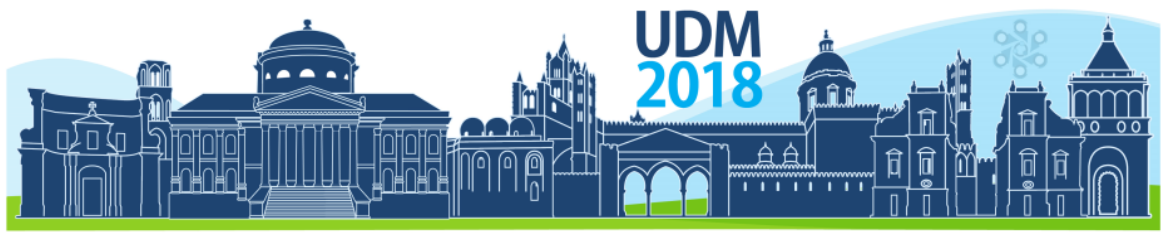

$11^{\text {th }}$ International Conference on Urban Drainage Modelling

23-26 Sep | Palermo - Italy

\title{
Uncertainty analysis of pollutant-hydrograph model in assessing inflow and infiltration of sanitary sewer system
}

\author{
Moran Wang, Mingkai Zhang and Yanchen Liu* \\ 1, State Key Joint Laboratory of Environment Simulation and Pollution Control, School of Environment, Tsinghua \\ University, Beijing, China, 100084 (E-mail: liuyc@mail.tsinghua.edu.cn)
}

\begin{abstract}
Infiltration and inflow is a very severe problem in the sanitary sewer system. There are many method to evaluate the RDII, of which a novel conductivity-based method for estimating RDII was proposed. However, the reliability such as uncertainty and accuracy are seldom evaluated. In this paper, the uncertainties of model parameters were estimated using the generalized likelihood uncertainty estimation (GLUE) method. The parameter uncertainty was considered in three types of rainfall events and two different system characteristic. The proposed method exhibits distinct advantages, compared to the traditional flow-based methods, in estimating RDII and overflow particularly when the two processes happen simultaneously.
\end{abstract}

Keywords: Sewerage system; Inflow and infiltration; Uncertainty;

\section{INTRODUCTION}

Infiltration/inflow (I/I) problems have long been the primary focus related to public sewer lines of collection facilities. Quantifying rainfall-derived inflow and infiltration (RDII) in a sanitary sewer is difficult when RDII and overflow occur simultaneously. This study a novel conductivitybased method for estimating RDII was proposed in our previous study. The method decomposes rainfall-derived inflow (RDI) and rainfall-induced infiltration (RII) separately based on conductivity measurement. There are two things we most concern about when use the proposed method, the uncertainty and the accuracy. Aiming at these two concerns, we conducted the uncertainty analysis for the proposed method.

\section{MATERIALS AND METHODS}

\subsection{Model of inflow and infiltration with instantaneous unit hydrograph in wet weather flow}

Inflow and infiltration can be simulated as the final outflow of a series of cascaded linear reservoirs. The outflow from the cascaded linear reservoirs is (Nash 1957):

$$
\mathrm{u}(0, t)=\frac{1}{K \cdot \Gamma(N)} \cdot\left(\frac{t}{K}\right)^{\mathrm{N}-1} \cdot e^{-\frac{t}{K}}
$$

where $u(0, t)$ is the instantaneous unit hydrograph, which represents the RDII flow as the result of unit instantaneous rainfall. $\mathrm{N}$ is the number of linear reservoirs, $\Gamma(N)$ is the gamma function of $\mathrm{N}$, and $\mathrm{K}$ is the storage coefficient of the linear reservoir. Rainfall are always continuous rather than instantaneous. So, the instantaneous unit hydrograph should be 


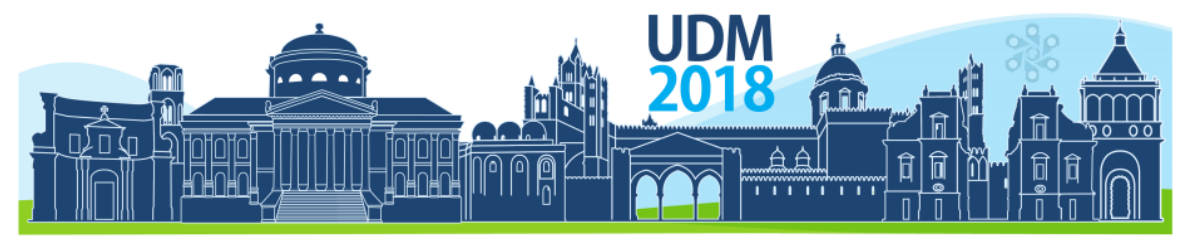

$11^{\text {th }}$ International Conference on Urban Drainage Modelling

23-26 Sep | Palermo - Italy

converted to a temporal unit hydrograph, which is used to describe the RDII process produced by per unit rainfall in the record time span ( $\Delta \mathrm{t}$, which is 10 minutes in our study):

$$
u(\Delta t, t)=\frac{1}{\Delta t}\left[\int_{0}^{t} u(0, \tau) d \tau-\int_{\Delta t}^{t} u(0, \tau-\Delta t) d \tau\right]
$$

where $\Delta t$ is the record time interval of rainfall, $u(\Delta t, t)$ represents the outflow as the results of unit rainfall in the period of $\Delta \mathrm{t}$.

Parameter $\mathrm{R}$ was used to represent the fractions of rainfall volume that enter the sewer system as RDII. The whole monitoring time can be divided into $n$ parts by the record time interval, $i$ is the ordinal number from 1 to $\mathrm{n}$. Pi is the rainfall depth per unit time (rainfall record time interval), the net rainfall entering into the sanitary sewer system could be presented as the product of $R$ and $\mathrm{Pi}$ in each unit time. $\mathrm{F}$ is the sub-catchment area upstream the monitoring site. By summing the $u(\Delta t, t)$ produced by each net rainfall, the discharge of RDIl can be expressed as:

$$
Q(t)=F \sum_{i=1}^{n} R \cdot P_{i} \cdot u_{i}(\Delta t, t)
$$

The inflow (RDI) and infiltration (RII) are described using the same principle of cascading linear reservoirs to reduce the computational complexity. For the inflow process, use RRDI, KRDI, NRDI substituting for $\mathrm{R}, \mathrm{K}, \mathrm{N}$ in equation (1) and(3), $u(\Delta t, t)$ in equation (2) and $\mathrm{Q}(\mathrm{t})$ in equation (3) will be correspondingly substituted by $u_{R D I}(\Delta t, t)$ and QRDI(t). In the same way, substituting RRII, KRII, NRII for $\mathrm{R}, \mathrm{K}, \mathrm{N},{ }^{u(\Delta t, t)}$ will be $u_{R I I}(\Delta t, t)$ and $\mathrm{Q}(\mathrm{t})$ will be $\mathrm{QRII}(\mathrm{t})$. RRDI and RRII represent the ratio of rainfall that enters the sewer system as RDI and RII, respectively, KRDI and KRII represent the storage coefficients of RDI and RII, respectively, and NRDI and NRII represent the number of linear reservoirs of RDI and RII, respectively. Then the wet weather flow QWWF(t) is the sum of the dry weather flow QDWF(t), RDI flow QRDI(t) and RII flow QRII(t), as equation (4) shows.

$$
Q_{W W F}(t)=Q_{D W F}(t)+F \sum_{i=1}^{n} R_{R D I} \cdot P_{i} \cdot u_{R D I_{i}}(\Delta t, t)+F \sum_{i=1}^{n} R_{R I I} \cdot P_{i} \cdot u_{R I I_{i}}(\Delta t, t)
$$

\subsection{Methodology of uncertainty analysis}

The uncertainty of model and $90 \%$ confidence interval of parameters was evaluated with generalized likelihood uncertainty estimation (GLUE) method (Beven and Binley 1992). The GLUE method adopts the concept of equifinality of models, parameters and variables. This methodology consists of three steps (Jensen 2003): First, determine the prior distribution for the parameters, which is typically discrete or continuous uniform distribution. Second is stochastic simulation based on the parameters defined previously, with Monte Carlo method to do a random sample of the parameter sets. Third, rate the simulation and the corresponding parameter sets according to the degree to which they fit observed data for every single 


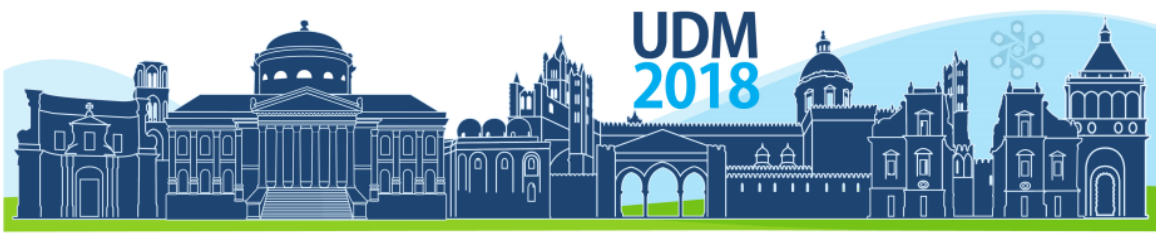

$11^{\text {th }}$ International Conference on Urban Drainage Modelling

23-26 Sep | Palermo - Italy

simulation. If the simulated results are "close" to the observed values, the simulation and this parameter set are accepted as having a given likelihood (NS value in our case), otherwise this simulation and parameter set will be rejected. Repeat these three steps until iterations reach the set point (5000 iterations in our case). Calculate the cumulative distribution function (CDF) for all the accepted parameters, the value corresponding to $5 \%$ and $95 \%$ of the CDF will be the $90 \%$ confidence interval of the parameters. The model uncertainty is revealed through the CDF of the accepted simulation results.

\section{RESULTS AND DISCUSSION}

\subsection{Comparison of MCMC and GLUE}

The MCMC and GLUE method were applied into medium rainfall event to conduct uncertainty analysis. The relationship of parameters were constrained as: RRDI $>R R I I, K R D I<K R I I$, NRDI<NRII. The cumulative distribution function of parameters were shown in Fig. 1,
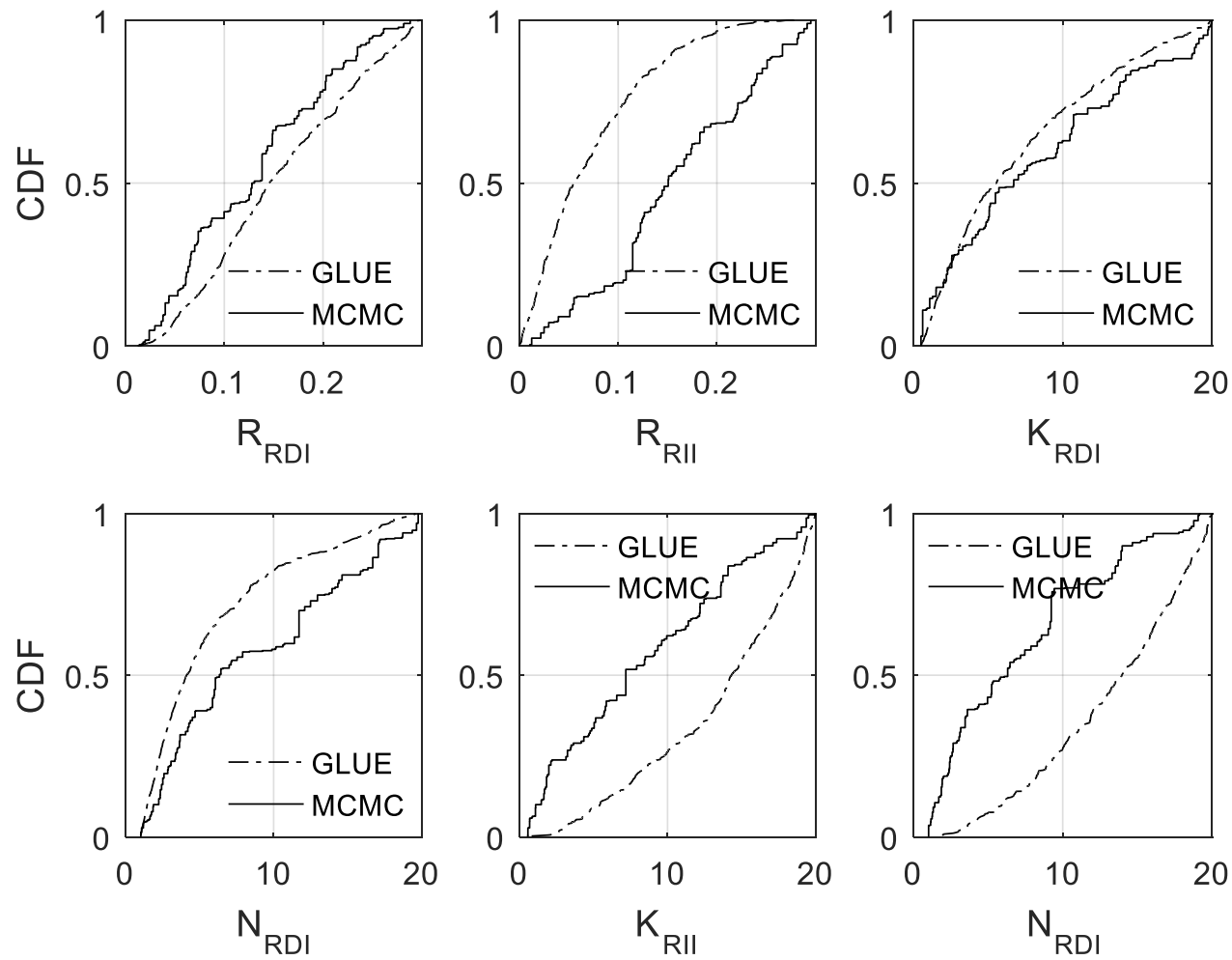

Fig. 1 Comparison of GLUE and MCMC

\section{2 Uncertainty analysis of model output}

The distribution of the six parameters in the wet weather model shown in figure 2.The parameters RRDI and RRII exhibited approximately normal distributions, NRDI and NRII 


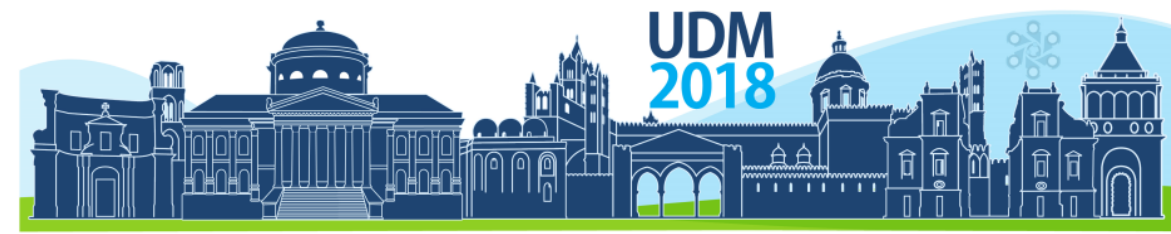

$11^{\text {th }}$ International Conference on Urban Drainage Modelling 23-26 Sep | Palermo - Italy

exhibited skewed distributions, and KRDI and KRII exhibited approximately uniform distributions.
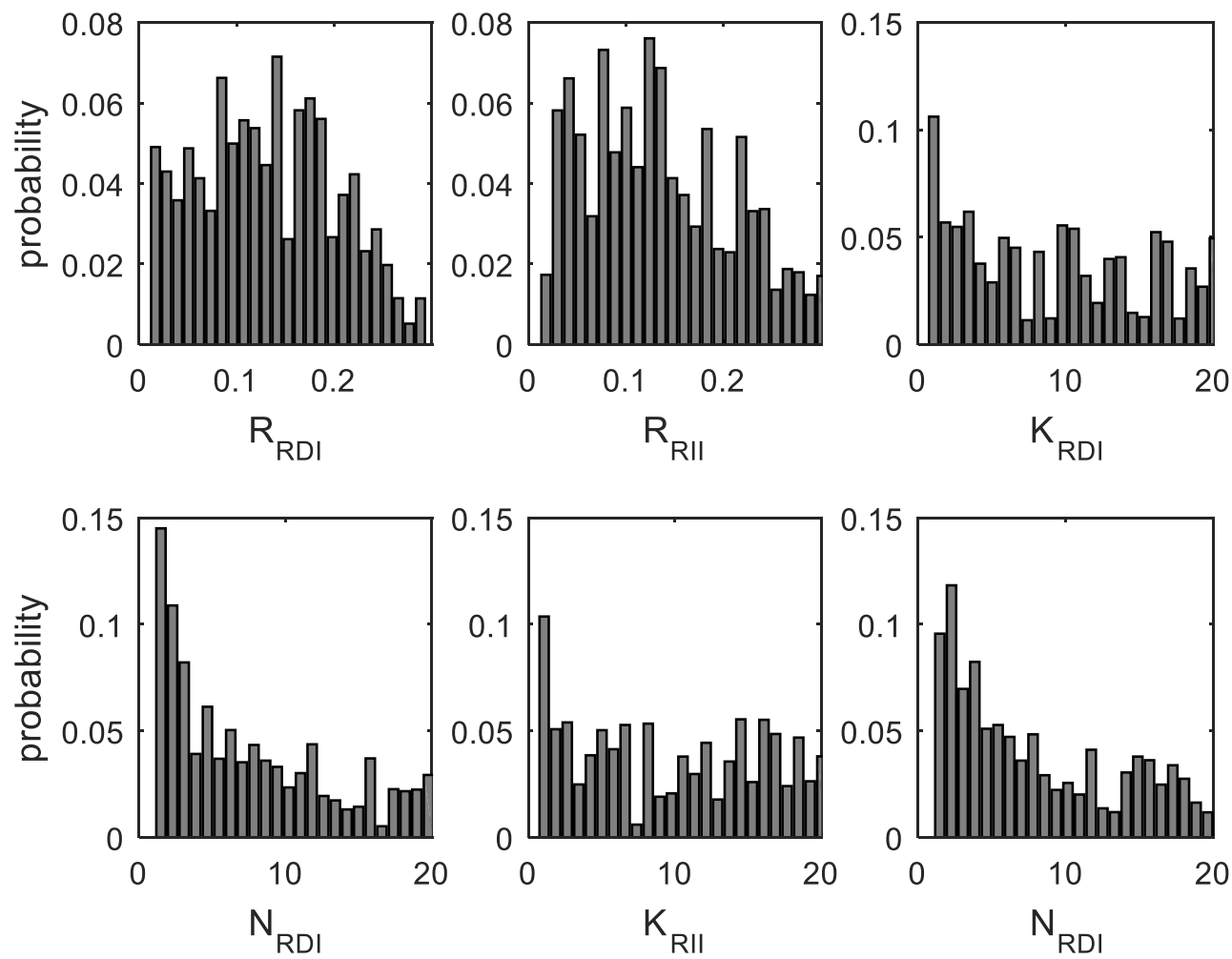

Figure 2. Distributions of the six parameters of the medium rainfall event with the GLUE method Parameters RRDI and RRII exhibited approximately normal distributions, NRDI and NRII exhibited skewed distributions, and KRDI and KRII exhibited approximately uniform distributions.

\section{CONCLUSIONS}

The parameter uncertainty was considered in three types of rainfall events and two different system characteristic. The result shows that there are some parameters are not sensitive and can affect others. The proposed method exhibits distinct advantages, compared to the traditional flow-based methods, in estimating RDII and overflow particularly when the two processes happen simultaneously. 


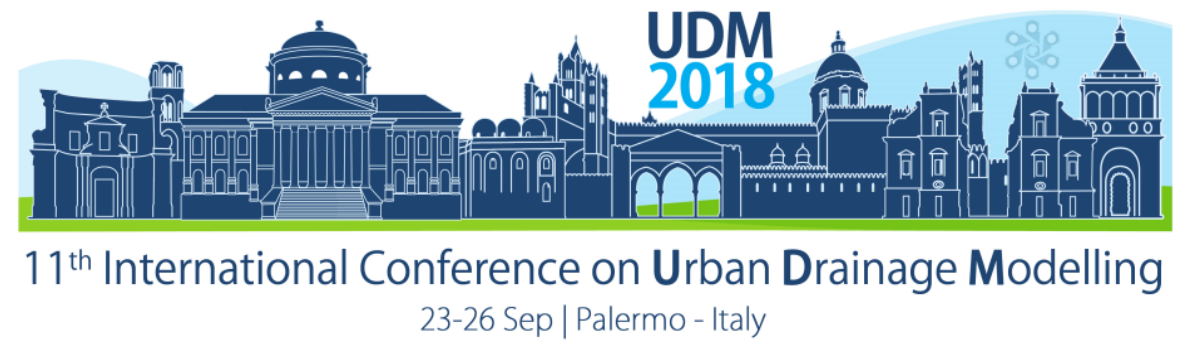

\title{
Integration of green areas into a suburban flood model
}

\author{
Boris Richter $^{1}$, Christine Stapel ${ }^{1}$, and Jens Tränckner ${ }^{1}$ \\ ${ }^{1}$ University of Rostock, Department of Water Management, Rostock, Germany
}

\begin{abstract}
As a result of urbanization, suburban areas are growing. The catchment of this areas is characterized by different land use and sealing types. Due to climate change, there is a tendency towards more intense precipitation events, which causes a respectable increase of overland flow on permeable surfaces (green area). For a detailed flood management a coupled model of runoff, sewer transport and overland flow which also integrate green areas is much more powerful. Available software is usually built as semi-distributed (SD) models whereof the $2 \mathrm{D}$ surface module can only convey but not generate grid cell runoff. Fully distributed (FD) models solve this problem but are often not applicable due the required detailed object data. This paper describes a method to integrate green areas into an existing sewer (SD) model by virtual networks. The runoff module is founded on the kinematic wave computation, which includes a module for the infiltration capacity based on the Horton equation. Therefore the additional runoff of the green areas is predictable and the results shows more representative expression of the flood situation. Otherwise, the natural retention effect of green areas is directly implemented and is therefore also quantifiable.
\end{abstract}

Keywords: flood; suburban; green area, Horton, infiltration, pervious area

\section{INTRODUCTION}

Urbanization is steadily increasing. Large cities are formed by so-called suburban areas. The catchment of these areas is characterized by a patchwork of natural, agricultural and urbanised surface (Braud et al. 2013). Due to climate change, there is a tendency towards more intense precipitation events, with a spatial and temporal variability (Cubasch et al. 2000). Especially during strong rain events with a long return period larger than 10 years, the runoff of permeable areas becomes more relevant for the sewer system according to impermeable surfaces (Davidsen et al. 2018). Both types of rainfall could overload the infiltration capacity of the soil - short rain events with a high intensity and long events with a great volume.

Experience with severe rain events in the city of Rostock lead to the development of coordinated flood prevention and control measures. In several cases, flood events were obviously not only caused by overloaded sewer and river systems, but at least aggravated by surface runoff from surrounding fields and garden areas. For detailed flood risk assessment and development of control measures, these processes must be appropriately described in integrated sewer and 2D flood models. However, available software is usually built as semidistributed (SD) models (sewer, overflow runoff) whereof the 2D runoff model can only convey but not generate grid cell runoff. Fully distributed (FD) models, e.g. proposed by (Pina et al. 2016) solve this problem but are often not applicable due the required detailed object data. This paper describes a pragmatic and efficient solution for integrated flood modelling, including outer areas using an SD approach.

\section{MATERIALS AND METHODS}

The method is developed and demonstrated for the semi-distributed -model combination MIKE Urban/MIKE flood, including modules for rainfall-runoff, sewer transport and overland flow. The 


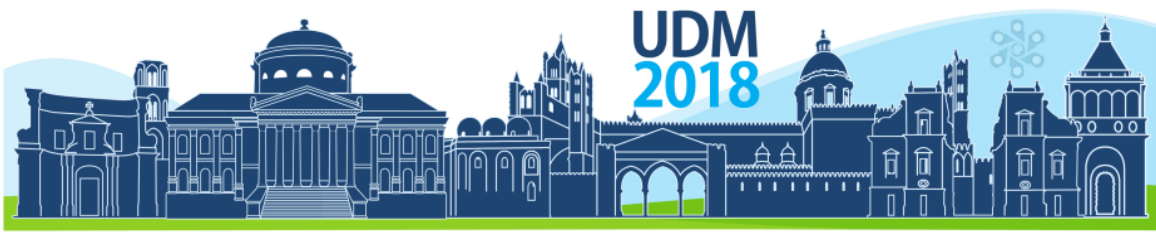

$11^{\text {th }}$ International Conference on Urban Drainage Modelling

23-26 Sep | Palermo - Italy

runoff module is based on the kinematic wave approach. Infiltration capacity is calculated by a modified Horton's equation. When rainfall intensity exceeds infiltration rate, runoff is generated in the respective time step $\Delta t$. Each sub catchment includes five different surface types with specific hydrologic parameters. Pipe flow is computed by a numerical solution of the SaintVenant-equation. Overland flow is calculated applying two-dimensional shallow water equation using finite differences approach with rectangular grids.

\subsection{Implementation of green area by virtual manholes}

Since semi distributed models like MIKE URBAN FLOOD are not able to generate grid cell runoff (Pina et al. 2016), the 2D runoff model needs external input to generate flood. Typically, they are coupled by links with one-dimensional transport models for rivers and sewer systems.
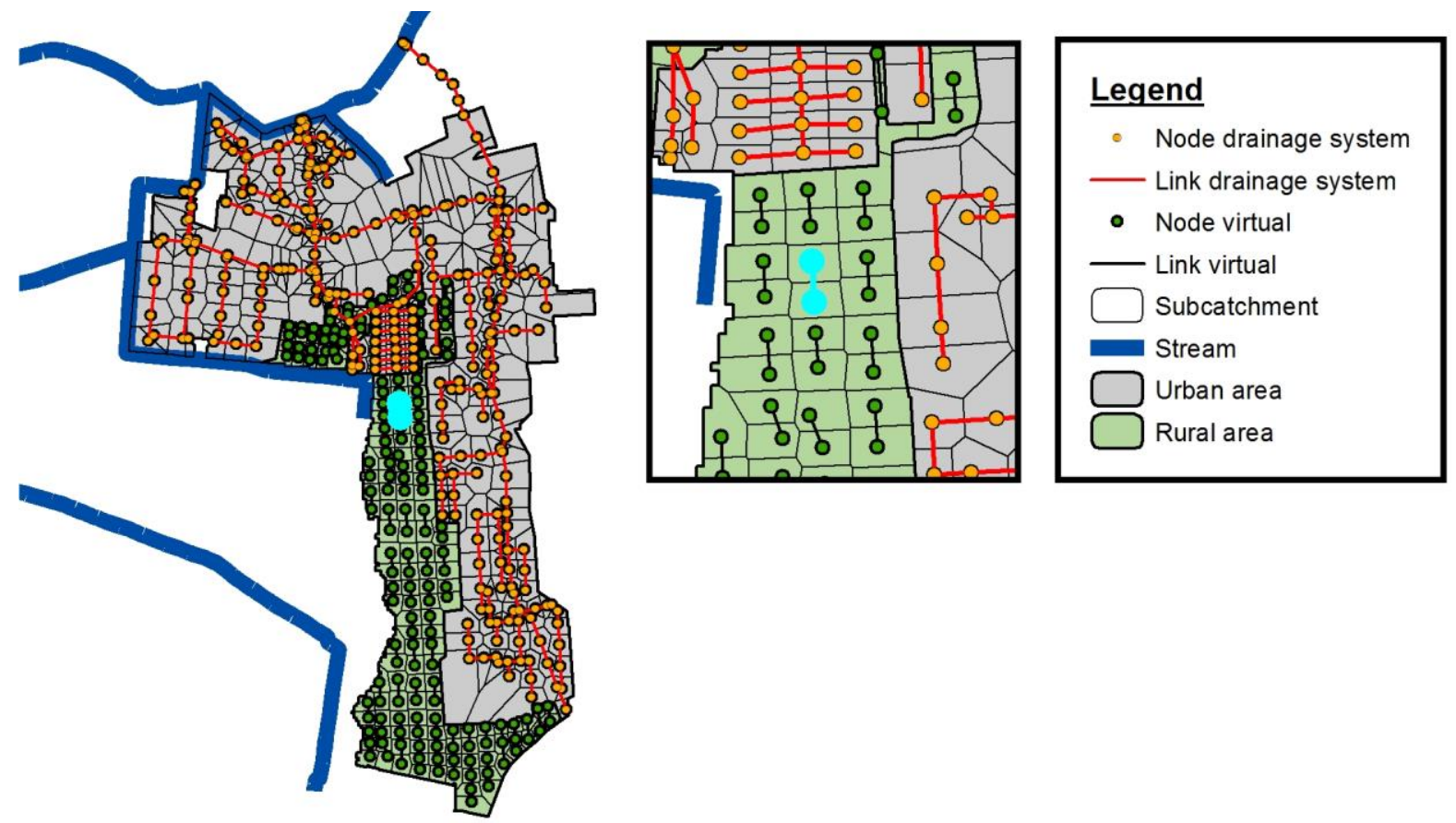

Figure 1. Overview map of the hydrological and urban catchment area, as well as the model approaches for the sewer network (urban area) and the virtual network (green area)

Accordingly, it is not yet possible to include runoff from non-connected green areas in these models. In this study virtual nodes (manholes) are used to connect the runoff model directly to the overland flow model. The software forces a minimum of two manholes inside a network system, therefore several small network systems without outflow are created (Figure 1). According to the model structure runoff is conveyed to the only manhole of the sub-catchment. When the volume of the virtual network system is filled, surface runoff starts. This approach has been tested for an exemplary area of investigation with known flooding problems from outer areas. It is characterized by two major catchments. - The green area is the permeable "outer area" which was formed by a GIS-based analysis of the watersheds. The border of the catchment "urban area" was defined by the land use type. Each node is connected to one subcatchment, which are formed by Thiessen-polygons.

\subsection{Elimination of volume error}

By implementing the virtual nodes into the sewer system model, total volume is artificially increased. To minimise the resulting retention effect of the virtual drainage system, the virtual 


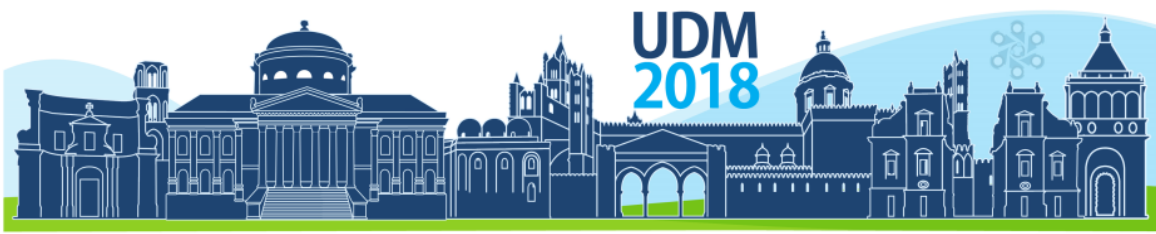

$11^{\text {th }}$ International Conference on Urban Drainage Modelling

23-26 Sep | Palermo - Italy

nodes were pre-filled (initial state) before running the actual simulation. All manholes are defined as "spilling" nodes. Otherwise the flood-volume from default nodes would be saved in an artificial basin above the node.

\subsection{Calibration of the model}

The model was designed to simulate flooding that has a statistical recurrence interval of 50 to 100 years. Therefore, a calibration with real data is extremely difficult since there is no permanent measurement station in the investigation area. The subsequent calibration (Figure 2) was performed on data collected during a measurement campaign as part of a research project.
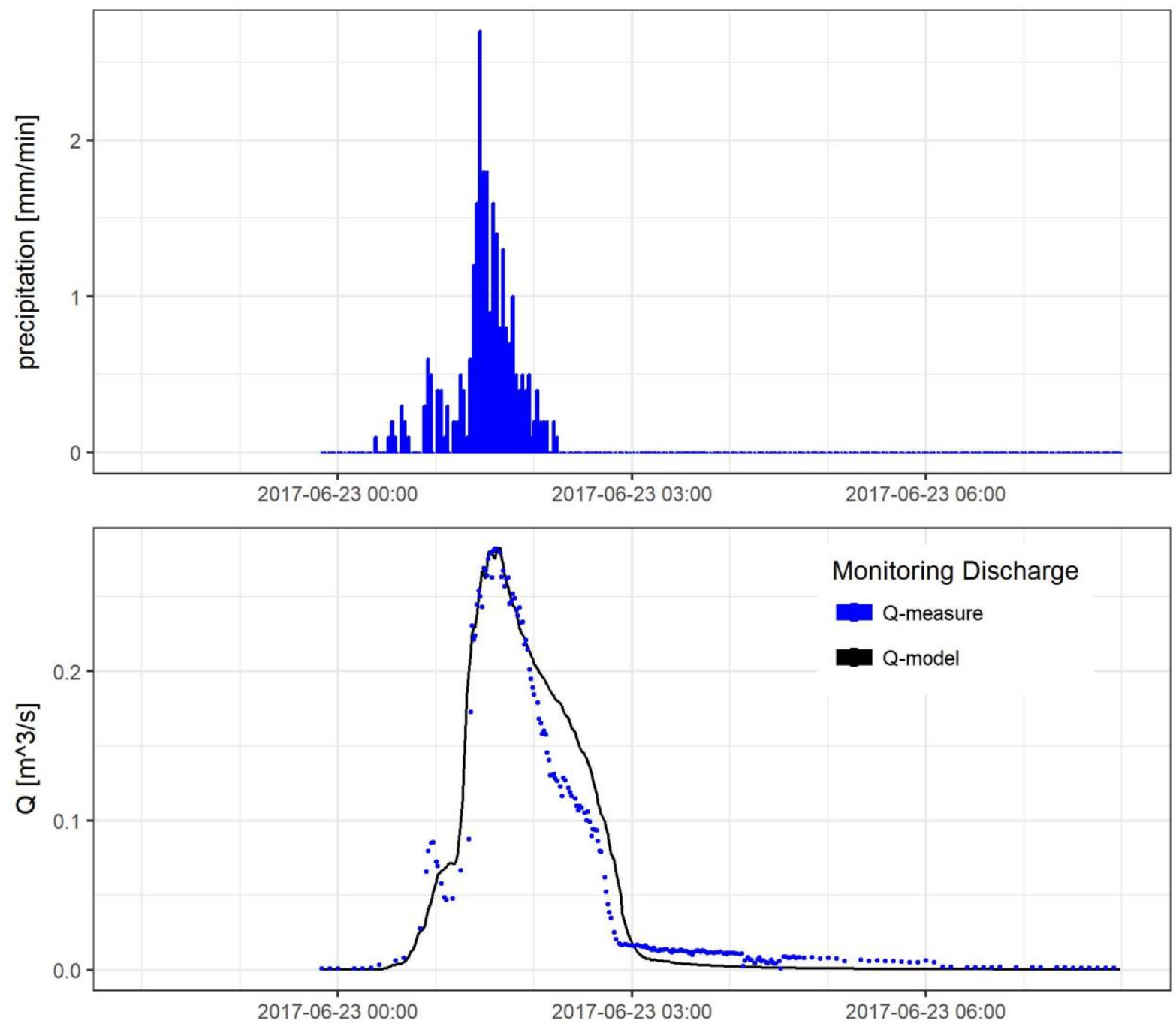

Figure 2: Calibration of the model

The calibration was performed based on the strongest event measured by a flowmeter places on the area outlet. Peak-Error (1\%), Volume-Error (5.5\%) and Nash-Sutcliffe efficiency (0.94) confirm a well fitted model. The shown precipitation is classified as a 5 -year event. To investigate the ability of the model even for rarer events, the measurement campaign is extended beyond the project duration. 


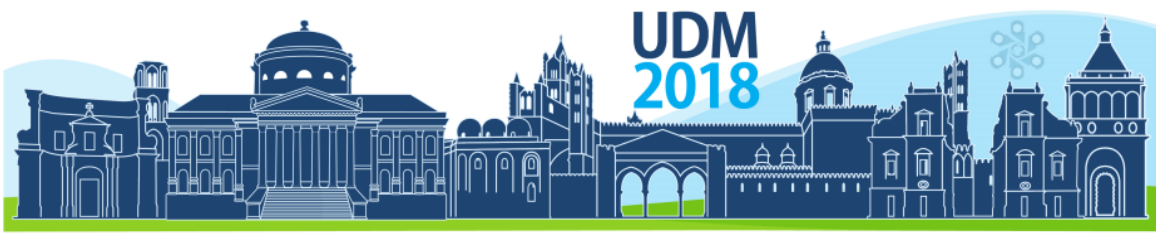

$11^{\text {th }}$ International Conference on Urban Drainage Modelling 23-26 Sep | Palermo - Italy

\section{RESULTS AND DISCUSSION}

Figure 3 shows the flood situation of the investigation area for a statistic rainfall event with a return period of 100 years and a duration of 1 hour.

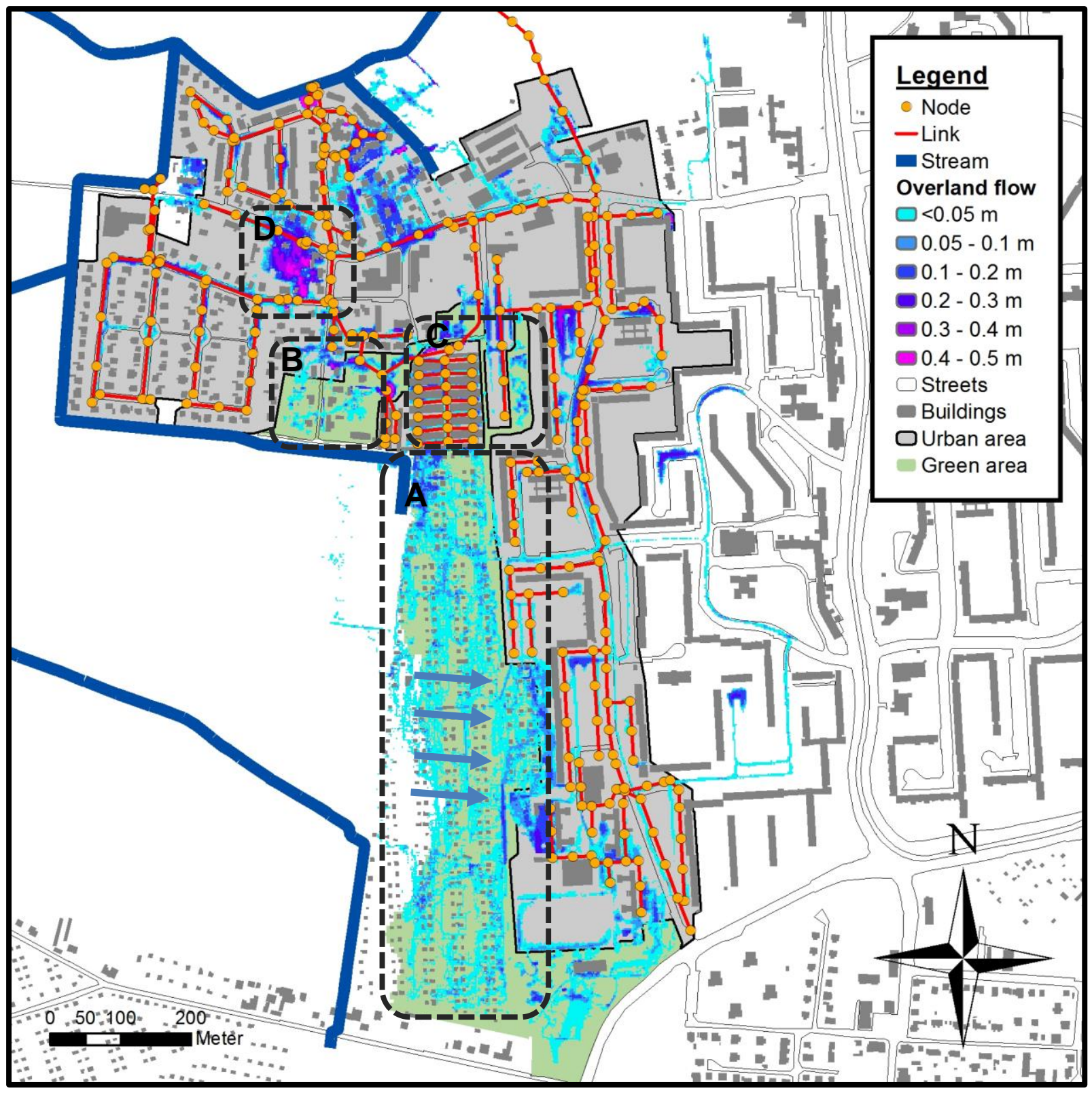

Figure 3. Flooding map of the study area with selected hotspots

The southwest (spot A) produces a significant flood volume, which flows east into the settlement and increases pressure on the drainage system. In the centre are several properties (spot B), where no drainage system is provided. These are flooded by their own generated runoff and affect surrounding areas, too.

But also the retention effect of green areas is mappable by the model. For example the parking area in spot $\mathrm{C}$ is relieved by surface flow into the nearby green area. The area with the highest 


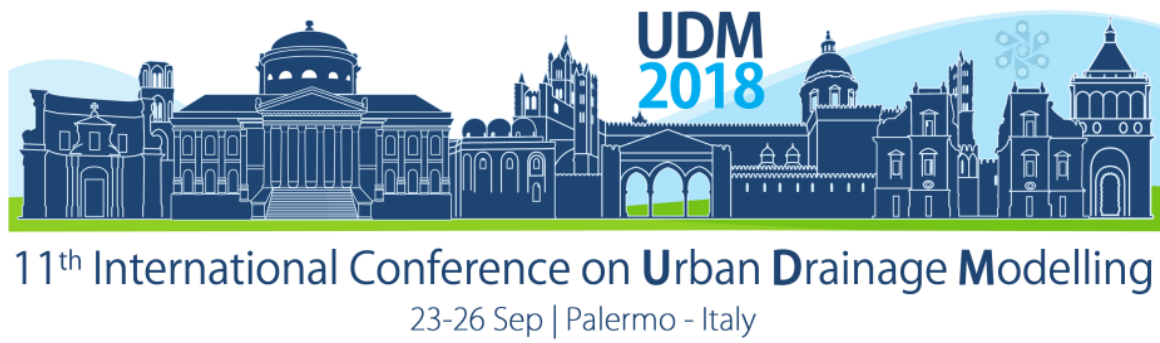

overflow level (spot D) is located in the northwest of the investigation area. In this case the approach makes planning errors obvious. Here, natural sinks were designated by the municipality as development area, which is now extreme exposed by heavy rain flooding. This model has already been used to evaluate measures that should mitigate this congestion situation. So far, the stakeholder prefer measures with classic urban drainage solutions, for which the model showed only a slight improvement. This aspect is of relevance, because this approach can be used as a tool to detect unnecessary investments in an early planning phase.

The reliability of the method is difficult to prove. As comparison, there is only a documentation of several extreme events (return period > 100 years) from 2011 (Miegel et al. 2014), which was created based on interviews of residents. This documentation and the statements of the authorities confirm as far as possible the results of the modelling.

\section{CONCLUSIONS}

The integration of green areas into an existing sewer network model by virtual networks has several advantages. Generation of surface runoff as function of rainfall intensity and infiltration rate is covered by the available model structures (here the Horton approach). The additional load of the drainage system, caused by surface runoff from not connected areas can be quantified, providing a more realistic flood situation especially for very strong events. The natural retention effect of green areas is directly implemented through this holistic consideration. And for this purpose, the approach offers also a good basis for evaluating specific measures that support this retention effect. The approach is also applicable for subcatchments with mixed land use. For this case a preliminary parametrization procedure is required, to mimic the probable interaction of impermeable and permeable surfaces (will be part of the oral presentation).

\section{Acknowledgment}

This work is part of the research project KOGGE (Common development of urban waterbodies at local government level), which is funded by the German Federal Ministry of Education and Research (BMBF, FKZ 033W032A). Special thanks to the sewer operator EURAWASSER Nord GmbH and the water and soil association "Untere Warnow-Küste" for a good cooperation.

\section{References}

Braud, I., Fletcher, T. D. and Andrieu, H. 2013 Hydrology of peri-urban catchments: Processes and modelling. Journal of Hydrology, 485, $1-4$.

Cubasch, U., Voss, R. and Mikolajewicz, U. 2000 Precipitation: A parameter changing climate and modified by climate change. Climatic Change, 46(3), 257-276.

Davidsen, S., Löwe, R., Ravn, N. H., Jensen, L. N. and Arnbjerg-Nielsen, K. 2018 Initial conditions of urban permeable surfaces in rainfall-runoff models using Horton's infiltration. Water science and technology : a journal of the International Association on Water Pollution Research, 77(3), 662-669.

Miegel, K., Mehl, D., Malitz, G. and Ertel, H. 2014 Unusual rainfall events in Mecklenburg-Vorpommern during the summer of 2011 and their hydrological consequences - Part 1: Hydrometeorological event appraisal. HYDROLOGIE UND WASSERBEWIRTSCHAFTUNG, 58(1), 18-28.

Pina, R., Ochoa-Rodriguez, S., Simões, N., Mijic, A., Marques, A. and Maksimović, Č. 2016 Semi- vs. FullyDistributed Urban Stormwater Models: Model Set Up and Comparison with Two Real Case Studies. Water, 8(12), 58 . 


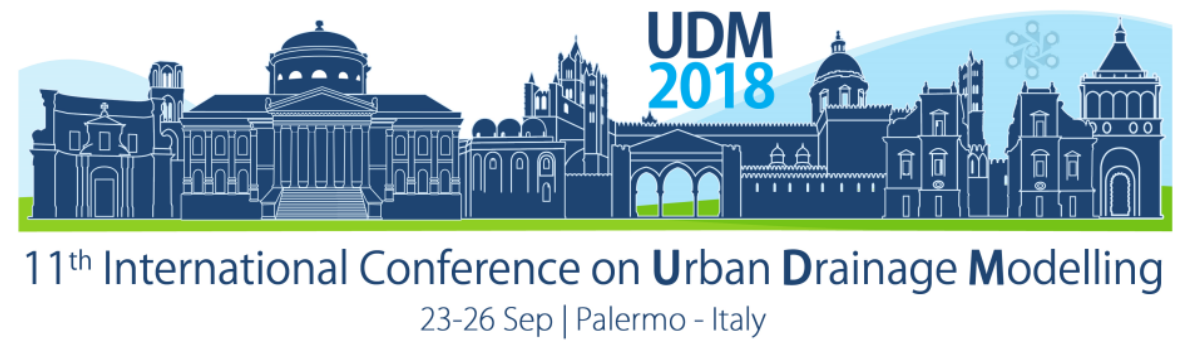

\title{
Modelling Road Transport Congestion Due to Flooding
}

\author{
Katya Pyatkova ${ }^{1}$, Albert S. Chen ${ }^{1}$, David Butler ${ }^{1}$ and Slobodan Djordjević ${ }^{1}$ \\ ${ }^{1}$ University of Exeter, Centre for Water Systems, Exeter, United Kingdom
}

\begin{abstract}
Transportation is essential for the normal flow of the economy because it is responsible for the movement of people and goods to planned locations. Therefore, traffic disruptions can have detrimental effects on multiple services. Road transportation is vulnerable to many threads, but flooding has the potential to lead to significant road network capacity reductions for a prolonged period of time. To assess the potential impacts of flooding on road transport, a detailed microscopic traffic model (SUMO) is integrated with an InfoWorks 1D-2D flood model. The traffic model simulates individually each vehicle in the network and has an adequate description of congestion, which makes it suitable for representing knock-on effects in transport systems. As both flooding and transport systems exhibit dynamic characteristics in space and time, dynamic model integration is carried out. Depending on the flood characteristics, a flooded road can undergo either a speed limit reduction or a complete closure. Once a road has been closed for traffic, vehicles that originally pass through it are forced to choose alternatives route to reach their unique destinations. That reroute will put an additional strain on a system already suffering reduced network capacity. The most congested roads in the network are identified after a comparison of the traffic conditions under normal conditions and flood conditions. The results suggest that the traffic delays in a dysfunctional network are more significant flood impact than the increased travel distance.
\end{abstract}

Keywords: flood impacts; microscopic traffic modelling; model integration; traffic disruption

\section{INTRODUCTION}

The total number of flood events globally has been steadily increasing in the past century (Munich RE, 2017). Coping better with floods stems from an improved understanding of complex interactions between the hazard characteristics and the inherent vulnerabilities of the system. Flood conditions can result from complex interactions between different sources (coastal, pluvial, and fluvial) and causes (natural, operational, social). In addition to the hazard complexity, floods can also cause a variety of consequences. The impact of flooding is often classified according to the contact of a subject with the flood. Direct flood impacts occur when the exposed element has a physical contact with the flood water. Indirect impacts develop after the flood affects certain dynamics in the system, while the receptors of the indirect impacts do not have physical contact with flood waters. These impacts typically evolve into a larger area and for a longer period of time than the flood itself (Messner et al., 2007). Traffic delays due to congestion can be considered lost opportunity, whereas the impact is distributed among the many users of the transport system.

To describe the interactions between the two complex systems previous research in that area has employed many simplifications. Suarez et al. (2005) concluded that climate change could potentially double both travel time and travel distance, whereas Chang et al. (2010) considered traffic delays as more significant. It is intuitive to expect that urban environment has many rerouting options, so the travelled distance should not be increased as much as the travel delays due to congestion. Balijepalli and Oppong, (2014) assessed the vulnerability and the robustness of the traffic system in York, UK. Nine roads were considered prone to flooding 


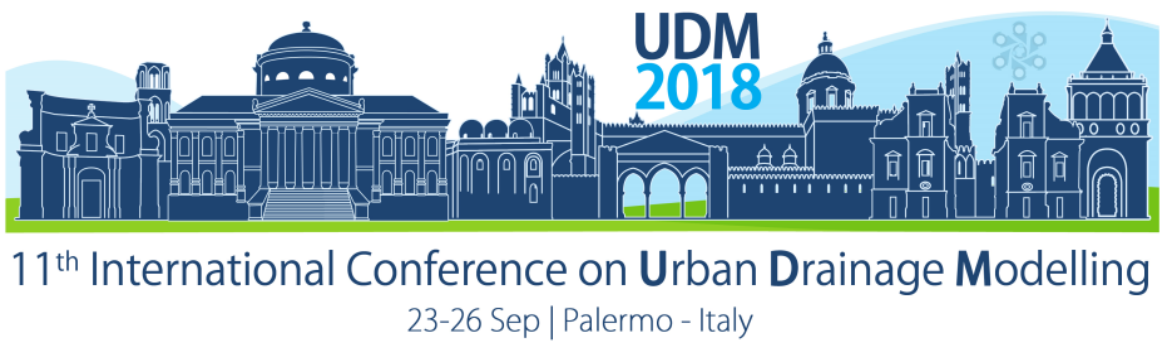

and were either closed for traffic or with reduced capacity. The vulnerability and robustness indices were calculated assuming each flooded street is independent. This rarely happens, because usually, flooding affects larger areas than just one street. However, the research identified the most vulnerable streets and also suggested that traffic delays are the most significant impact. All three studies employ a macroscopic traffic model, which only poorly represents congestion or diversions. Furthermore, the information about flood hazard in these studies is coarse with no representation of drainage system, which is essential for a correct spatial description of urban floods (Butler and Davies, 2011; Chen et al., 2007; Djordjevic et al., 2011).

Pregnolato et al., (2017) had a different approach to assessing impacts - they proposed a flood depth - speed reduction function after carrying out video analysis. They also compared traffic counter data between dry conditions and flood conditions in several locations in Newcastle. The traffic counts registered less traffic on the flooded roads although it was unclear whether the roads were blocked, or drivers chose to delay their journeys. Unfortunately, the actual flood depth from the event was not recorded, therefore the study could not validate the proposed function with real data.

Previous research has outlined the potential problems of transport networks during flood events but has not addressed in detail the issue of congestion. By integrating a detailed flood model and a microscopic traffic model (SUMO), the research presented in this paper aims to develop a novel approach to the problem of queueing. This can give an insight into the behaviour of the traffic system under time-varying flood conditions/traffic supply reductions.

\section{MATERIALS AND METHODS}

\subsection{Methodology}

To capture the complex dynamics of the flood and the traffic systems, a full integration of the models was carried out. The flood maps obtained from hydraulic modelling results are translated into a timely traffic model inputs. The rationale is that flood severity (extent and depth) and its propagation over time govern the situation on the road (Pyatkova et al., in press). To ensure a dynamic and comprehensive communication between both models, we have developed a tool that provides a consistent and homogeneous approach to combining the temporal variation of both flooding and network capacity. Figure 1 describes the workflow of the integration tool - it performs one-way communication between the flood and traffic models. Depending on the flood depth, some roads will endure slower traffic and others must be closed for traffic. The criteria to distinguish shallow from deep waters has been based on research about stability thresholds of flooded vehicles. Martínez-Gomariz et al. (2017) confirmed previous experimental studies that small vehicles lose stability in $0.3 \mathrm{~m}$ standing water. To ensure uniformity this minimum safety requirement will be applied as a criterion for street closures. Once a street is closed for traffic, the vehicles that are originally passing are rerouted just before reaching the road closure, by choosing the shortest path from their current location to their destinations. Streets with shallow flood depth (less than $0.3 \mathrm{~m}$ ) suffer speed reductions.

Flood Model

Flood depth
0.1-0.3 m - Reduced speed limits

Above $0.3 \mathrm{~m}$ - Closed streets

Figure 1. The general outline of the flood and traffic integration tool 


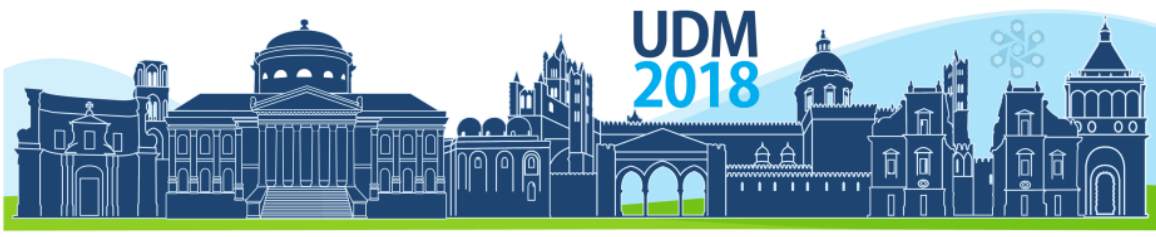

$11^{\text {th }}$ International Conference on Urban Drainage Modelling

23-26 Sep | Palermo - Italy

\subsection{Application}

InfoWorks 1D-2D model was run with design rainfall for return period of 100 years in the Spanish city of Marbella. The city lies between the Mediterranean Sea to the south and a very hilly area to the north. The catchment is very responsive due to the steep slopes and the intense rainfalls. The flood maps are fed into the integration tool, which identifies the streets with speed reduction or closure and writes the input files for the traffic model. All traffic models consist of two main components - traffic supply and traffic demand. The traffic supply describes the capacity of the infrastructure (road network and the rules to operate the traffic). The traffic demand represents the 'behaviour of consumers of transport services and facilities' (Ben-Akiva and Lerman, 1985). To compensate for the lack of traffic data, an activity-based traffic demand model is set to predict the attributes of trips (purpose, origin, destination and timing) based on detailed statistical and specific spatial data. The route assignment is represented by a dynamic user equilibrium which is run iteratively to minimize the cost function of travel time. The traffic model is run with different demand input for the morning and the evening peak and the off-peak afternoon traffic. This allows the analysis of how demand structure affects the impacts of unchanged flood characteristics.

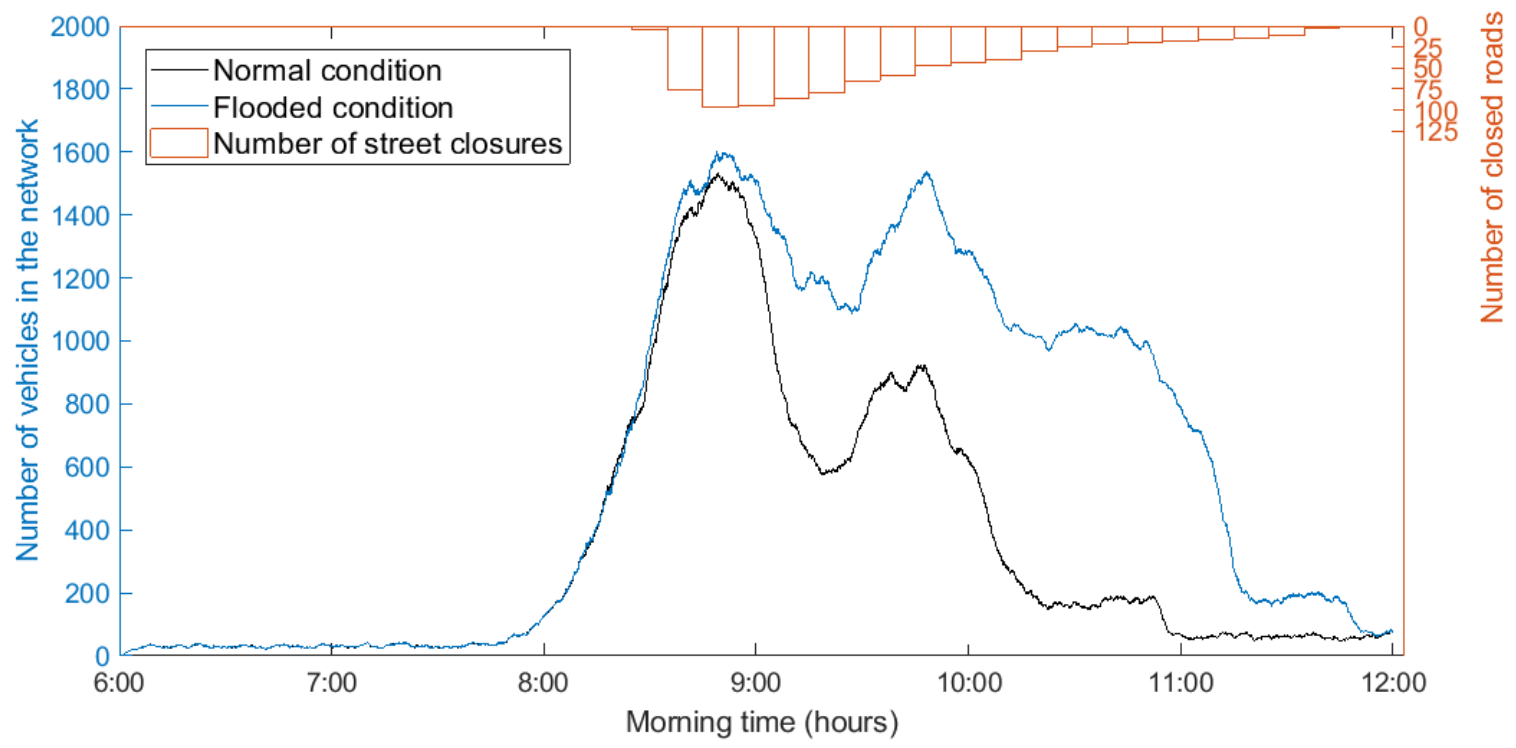

Figure 2. Number of vehicles in the network under normal and flooded condition. Top - road closures per 10min

\section{RESULTS AND DISCUSSION}

The number of vehicles in the network is an indicator of the performance of the transportation system. Once a vehicle reaches its destination, it leaves the network, so the lower number of vehicles generally means more vehicles have completed their journeys and the system is less congested. Figure 2 depicts the change of the number of vehicles over time under normal and flood conditions, and the number of individually closed streets per $10 \mathrm{~min}$. Although the number of road closures is the greatest at the beginning of the food propagation, the transport system is initially capable of absorbing the network capacity reductions. Despite the initial ability of the system to absorb shock, its performance quickly deteriorates after it is unable to complete routes on time. Due to delays, the number of vehicles in the network under flood condition is fivefold of the one under normal condition. The difference reaches tenfold around $11 \mathrm{AM}$. If we assume that congested streets have a speed reduction of more than 30 or $40 \mathrm{~km} / \mathrm{h}$ after the flood, Table 1 reveals that the number of congested streets is increasing in time despite 


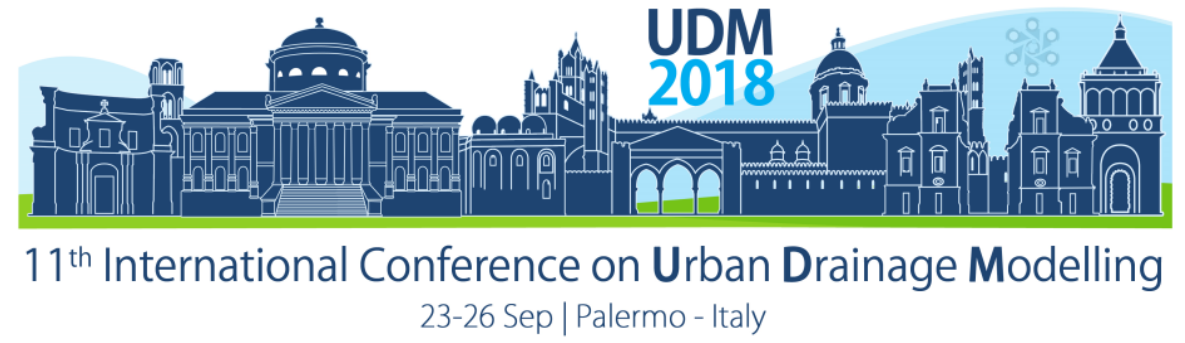

the significant decrease in closed streets towards the end of the simulation. Moreover, the total duration of the trips has increased by $15 \%$ compared to a $2 \%$ increase in travelled distance. Results also indicate that the indirect impact to the whole system is significant, after $17 \%$ of the vehicles were rerouted, while $22 \%$ of the vehicles during the simulation had more than doubled travel time.

Table 1. Number of streets with delayed traffic per speed reduction and time interval

\begin{tabular}{lcccc}
\hline Speed & \multicolumn{5}{c}{ Time of the day } \\
\cline { 2 - 5 } Reduction $(\mathrm{km} / \mathrm{h})$ & 8 to 9 AM & 9 to $10 \mathrm{AM}$ & 10 to $11 \mathrm{AM}$ & 11 to $12 \mathrm{AM}$ \\
\hline-30 & 21 & 33 & 49 & 93 \\
-40 & 11 & 19 & 30 & 57 \\
\hline
\end{tabular}

\section{CONCLUSIONS}

This research described an interdisciplinary approach to integrating flood and traffic models to assess the impact of flooding on urban traffic congestion. The results suggest that congestion does not evolve proportionately with the reduction of traffic supply and the knock-on effect on the traffic system may be revealed with a delay. Future developments in this research include the assessment of the performance of the system if different ex-ante mitigations or ex-post interventions are implemented.

\section{Acknowledgement}

Research on the PEARL (Preparing for Extreme And Rare events in coastaL regions) project is funded by the European Commission through Framework Programme 7, Grant No 603663.

\section{References}

Balijepalli, C., Oppong, O., 2014. Measuring vulnerability of road network considering the extent of serviceability of critical road links in urban areas. J. Transp. Geogr. 39, 145-155.

Ben-Akiva, M.E., Lerman, S.R., 1985. Discrete Choice Analysis: Theory and Application to Travel Demand. MIT Press.

Butler, D., Davies, J., 2011. Urban Drainage, Third Edition. CRC Press.

Chang, H., Lafrenz, M., Jung, I.-W., Figliozzi, M., Platman, D., Pederson, C., 2010. Potential Impacts of Climate Change on Flood-Induced Travel Disruptions: A Case Study of Portland, Oregon, USA. Ann. Assoc. Am. Geogr. 100, 938-952. https://doi.org/10.1080/00045608.2010.497110

Chen, A.S., Djordjevic, S., Leandro, J., Savic, D., 2007. The urban inundation model with bidirectional flow interaction between 2D overland surface and 1D sewer networks. NOVATECH 2007.

Djordjevic, S., Vojinovic, Z., Dawson, R., Savic, D.A., 2011. Uncertainties in Flood Modelling in Urban Areas, in: Applied Uncertainty Analysis for Flood Risk Management. IMPERIAL COLLEGE PRESS, pp. 297-334.

Martínez-Gomariz, E., Gómez, M., Russo, B., Djordjević, S., 2017. A new experiments-based methodology to define the stability threshold for any vehicle exposed to flooding. Urban Water J. 14, 930-939.

Messner, F., Penning-Rowsell, E., Green, C., Meyer, V., Tunstall, S.M., Veen, A. van der, 2007. Evaluating flood damages: guidance and recommendations on principles and methods (No. T09-06-01), T09-06-01.

Munich RE, 2017. Overview of natural catastrophe figures for 2016.

Pregnolato, M., Ford, A., Wilkinson, S.M., Dawson, R.J., 2017. The impact of flooding on road transport: A depthdisruption function. Transp. Res. Part Transp. Environ. 55, 67-81.

Pyatkova, K., Chen, A.S., Djordjevic, S., Butler, D., Vojinović, Z., Abebe, Hammond, M.J., in press. Flood impacts on road transportation using microscopic traffic modelling technique, Lecture Notes in Mobility. Springer.

Suarez, P., Anderson, W., Mahal, V., Lakshmanan, T.R., 2005. Impacts of flooding and climate change on urban transportation: A systemwide performance assessment of the Boston Metro Area. Transp. Res. Part Transp. Environ. 10, 231-244. 


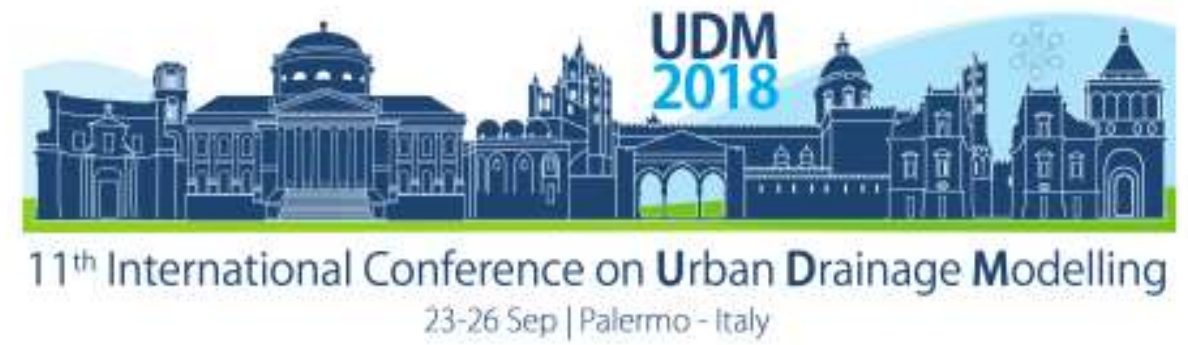

\title{
How important is the Physical interpretation and the role of the model user in urban flooding simulation?
}

\author{
Matheus Martins de Sousa ${ }^{1}$, Antonio Krishnamurti Beleño de Oliveira ${ }^{1}$, Bianca Maria Gomes da Silva ${ }^{2}$ and \\ Marcelo Gomes Miguez ${ }^{1,2}$ \\ 1 Universidade Federal do Rio de Janeiro, Programa de Engenharia Civil, Rio de Janeiro, Brazil \\ ²Universidade Federal do Rio de Janeiro, Escola Politécnica, Rio de Janeiro, Brazil
}

\begin{abstract}
Computational models for flood simulation were consolidated in recent years as a design tool. Due to technological evolution, the use of $2 \mathrm{D}$ mathematical models has become more frequent. However, the choice of $2 \mathrm{D}$ models is not always accompanied by an actual physical based demand that justifies this process, and often the problem that is solved does not need a 2D approximation or even does not actually configure a 2D solution surface. This study aims to present an alternative modelling in order to bring back the physical interpretation and highlight the modeller role as key elements in the interpretation and representation of the real systems. We used a Quasi-2D flow-cell model that solves 1D equations, constructed in a conceptual and interpretive way, as an alternative to the use of $2 \mathrm{D}$ models, showing the possibility of maintaining the same degree of representativeness. The Quasi-2D model was subjected to a test proposed by the British Environmental Agency. The results have demonstrated the importance of the modeller, emphasizing that the knowledge of the physical reality, of the hypotheses and simplifications adopted in the model construction, guarantees an optimized simulation and the quality of the results.
\end{abstract}

Keywords: Quasi-2D; Urban Floods; ModCel.

\section{INTRODUCTION}

With the diffusion of 2D models, the demand for information to use and calibrate these models became the main constraint for their application. The Light Detection and Ranging (LiDAR) technology is becoming the usual way to represent terrain details in the modelling process, allowing to refineme the modelling mesh with higher resolution information, but it is more expensive and more difficult to be processed. Moreover Abdullah et al. (2017) compared many LiDAR filtering algorithms and found that none of them is fully reliable in capturing some important urban features. Problems related with 2D models in urban regions are pointed out by Abily et al. (2013) that highlighted rapid changes in the flow regime and numerical problems with the drying and flooding of mesh elements modelled throughout the simulation. Almeida et al. (2016) find that small changes in the representation of the urban landscape are not observed in resolutions greater than 1 meter. However large basins do not support this refined mesh (JAMIESON et al, 2012). The computational cost makes it unfeasible. Leandro et. al. (2016) point out that the surface flows in urban areas are highly complex due to the interaction with artificial structures, which makes the application of a $2 \mathrm{D}$ model more complex. After confronting problems in calculating flow velocities and suggesting more detailed meshes, Néelz and Pender (2013) affirmed that simple mesh refinement is not a viable solution, since it can make modelling impracticable in computational terms, overcoming the ability to perform multiple simulations, quantify uncertainties, perform risk studies, calibrate models and so on.

By observing trends in the modelling process more comprehensively, Abbott and Vojinovic (2009) point out that currently the application of numerical models undergoes a major change 


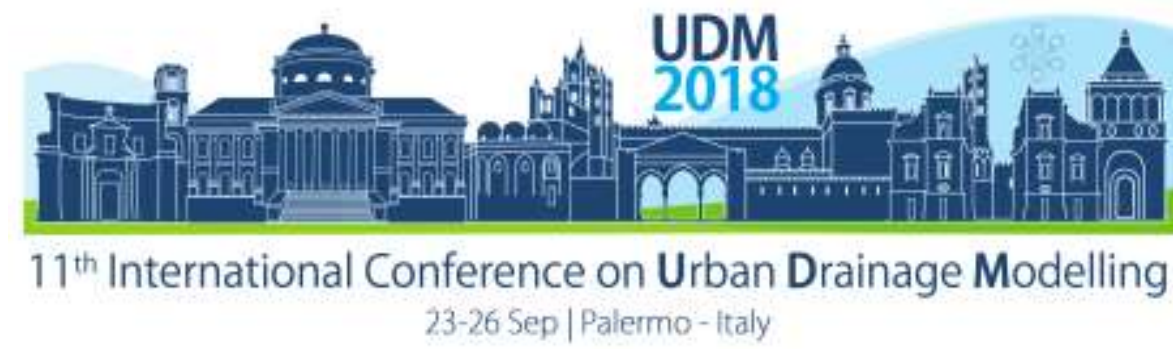

influenced by the way that knowledge is currently produced and used in society. This change, representative of the shift from modernity to postmodernity, or using Bauman's (2001) words from "solid modernity" to "liquid modernity", is marked by the shift from a society of knowledge providers to a society of knowledge consumers. In this context, Abbott and Vojinovic (2009) divided the hydrodynamic numerical models into five generations. The authors highlight that until the $3^{\text {rd }}$ generation there was practically no difference in modelling knowledge between users and developers. However, a relatively large gradient appeared in the $4^{\text {th }}$ generation, and it is even larger in the $5^{\text {th }}$ generation of models, where modelling is developed as a service and offered electronically encapsulated over the internet, what lead to a user that is distant from the modelling process and not really aware of model potentials and limitations. Cunge (2014) pointed out that except for very simple situations, the model user must be aware of basic hypotheses and physical laws that were considered in the software. Only then the user will be able to distinguish coherent modelling results from results completely incompatible with the physical reality of the system.

This article offers a counterpoint to the tendency of indiscriminately move towards more sophisticated models that use more input data but forgets to interpret physical reality. The current facilities tend to be used in a mechanical way, not always demanded by a technical question that could justify this process. In addition, this work seeks to stress the importance of the modeller as a key element in the modelling process, highlighting the physical interpretation and the importance of knowing model hypothesis and simplifications. The novelty of this article falls on demonstrating that a quasi-2d model associated with physical interpretation procedures and supported by simple integrated information can represent a real system with the same fidelity of (and faster than) a complete 2D model using sophisticated terrain information

This alternative way starts with a detailed preliminary analysis of the system to be modelled, and a clear question to be answered, seeking its comprehension, listing the main points that need to be represented and evaluating the necessary spatial scale for the model to present the answers that are sought. To couple with this approach, we chose an interpretive Quasi-2D model called MODCEL (Miguez et al., 2017), which can represent the flow in several directions in the two-dimensional plane, but which uses widely tested one-dimensional equations. Moreover, this model is completely dependent on physical interpretation. It is important to highlight that MODCEL cannot function by a blind automatic application. In fact, its application has to be preceded by several decisions on how to represent the terrain, the flow paths and the hydraulic behaviour of the modelled element. It rather obliges the modeller to investigate and understand how the real system works. This apparent weakness turns into strength, once this process inevitably leads the user to know more about the problem under investigation.

\section{MATERIALS AND METHODS}

\subsection{The Flow-Cell Model for urban basins - MODCEL}

MODCEL, developed by Miguez (2001), represents the urban space through homogeneous compartments, called cells. The concept of flood cells was initially developed by Zanobetti and Lorgeré (1968) and enshrined by Cunge et al (1980). MODCEL is detailed in Miguez (2017). These cells cover the whole space of the basin forming a flow network, interconnected by onedimensional equations. MODCEL is also integrated with a hydrological module that performs the rain-flow transformation in each cell, through the rational method. Thus MODCEL can represent the two-dimensional characteristics of the river watershed, but it only uses 1D equations. The model is capable of describing natural and artificial watercourses and detailed 


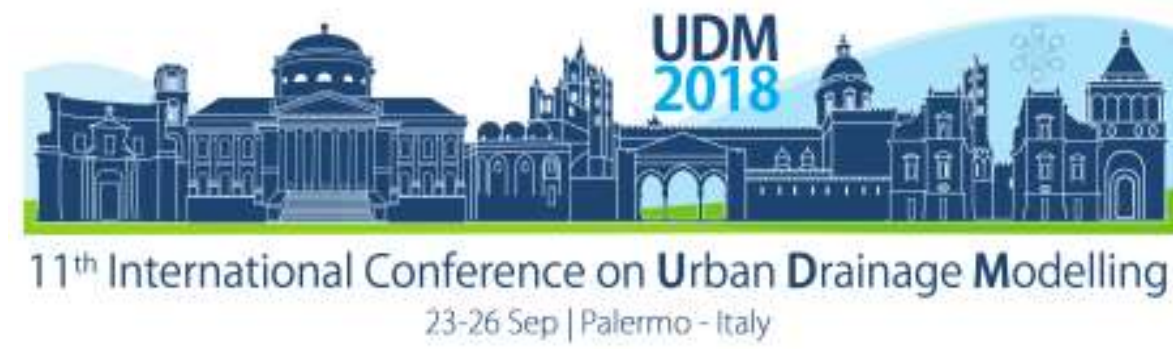

elements of the urban fabric (streets, squares, roofs, etc.), the flow in the underground storm drains, and the mutual connections between theses layers, including possible surcharges and overflows. Different hydraulic equations can represent the connections between each two cells, from the classical Saint-Venant dynamic equation to hydraulic links like weirs, orifices, pumps, flap etc. By rendering the flow through 1D equations written for predefined flow paths, the model preserves simplicity and saves computational time, in a quasi-2D approach. In a particular interpretation, because of the superficial and underground vertically linked layers, MODCEL can be seen as a quasi-3D model. On the other hand, the 1D equations are one of the weaknesses of this representation, since they cannot accurately model real extensive 2D flow surfaces, while not considering the cross-influences of flow velocities on the $x, y$-Cartesian axis.

\subsection{The Case Study}

A test proposed by the British Environment Agency (NÉELZ \& PENDER, 2013) was used to evaluate the application of the interpretative model concept. This benchmarking exercise involves 10 test cases and one of the objectives of this research is to provide a set of data against which a model can be evaluated by its developer. Test 8 , in particular, was designed to compare urban flood models and is divided into two parts, $8 \mathrm{~A}$ and $8 \mathrm{~B}$. In this paper, we used test $8 \mathrm{~A}$ as reference. which assumes that the flood arises from two sources: a uniformly distributed rainfall event applied to the modelled area; and a point discharge source occurring over a time base of approximately $15 \mathrm{~min}$, reaching a peak of $5 \mathrm{~m}^{3} / \mathrm{s}, 35 \mathrm{~min}$ after the rainfall event begins.

\subsection{Modelling Alternatives}

To evaluate the performance of the interpretive modelling proposition, MODCEL was applied in two ways. In the first alternative application, it was applied as a RASTER model, where the study region was divided into a mesh of cells of identical dimensions and linked to each other by the dynamic equation of Saint-Venant, without considering the inertia terms. The Rasterscale cell model was constructed with 43148 square cells of $9 \mathrm{~m}^{2}$ each. Following the test requirements, a Manning coefficient of 0.02 was set in the paved areas, and of 0.05 , in the other areas. This first representation follows the current trend of using a great mesh, mainly focusing on detailing the terrain model. In the second alternative application, the region was divided into a mesh of cells 163 cells (Figure 1) considering the physical interpretation presented in Figure 2, recognizing how the flow net functions.

\section{RESULTS AND DISCUSSION}

The Figure 3 shows the results obtained with MODCEL, respectively for first application Called "MODCEL - RASTER", and for the second application, called "MODCEL - QUASI-2D", compared with the published results (NÉELZ \& PENDER, 2013). Time of simulation using MODCEL to obtain these results was 3 days for first application and 3 minutes and 10 seconds for second application, and the simulation time step gave answers at each 1s. In fact, the proactive and interpretative behaviour of the modeller allowed to reach these results, saving computational time, without losing quality 


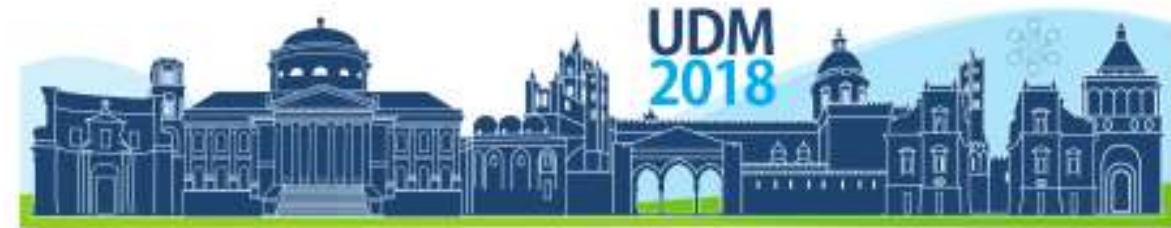

$11^{\text {th }}$ International Conference on Urban Drainage Modelling 23-26 Sep|Palemo-italy

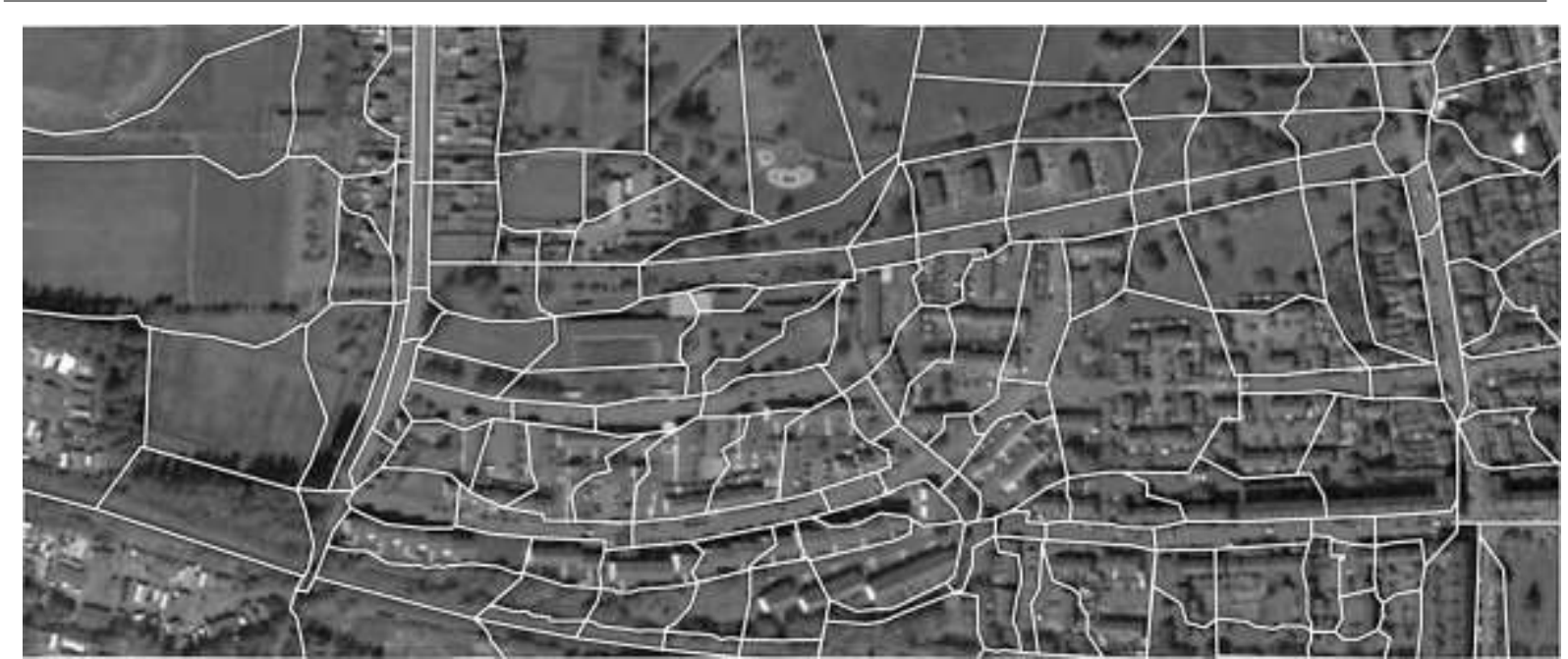

Figure 1. Cell division for the modelled area in Test 8.

The first step is to represent the possible
paths of flow through streets and thalwegs.
In the figure these paths are represented
by black arrows in the streets and white
arrows in urban thalwegs.

Figure 2. Cell division methodology. 


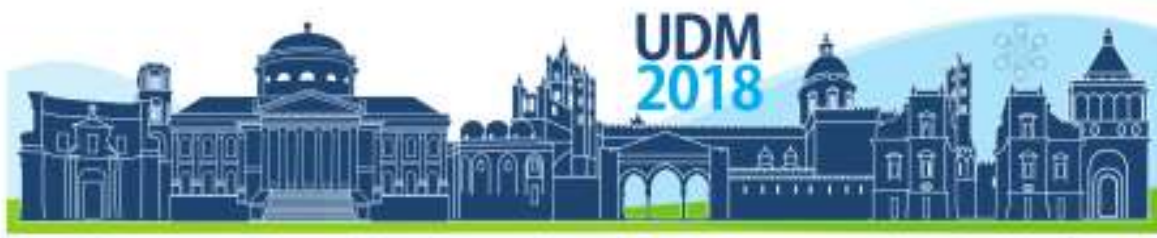

$11^{\text {th }}$ International Conference on Urban Drainage Modelling 23-26 Sep | Palermo-italy

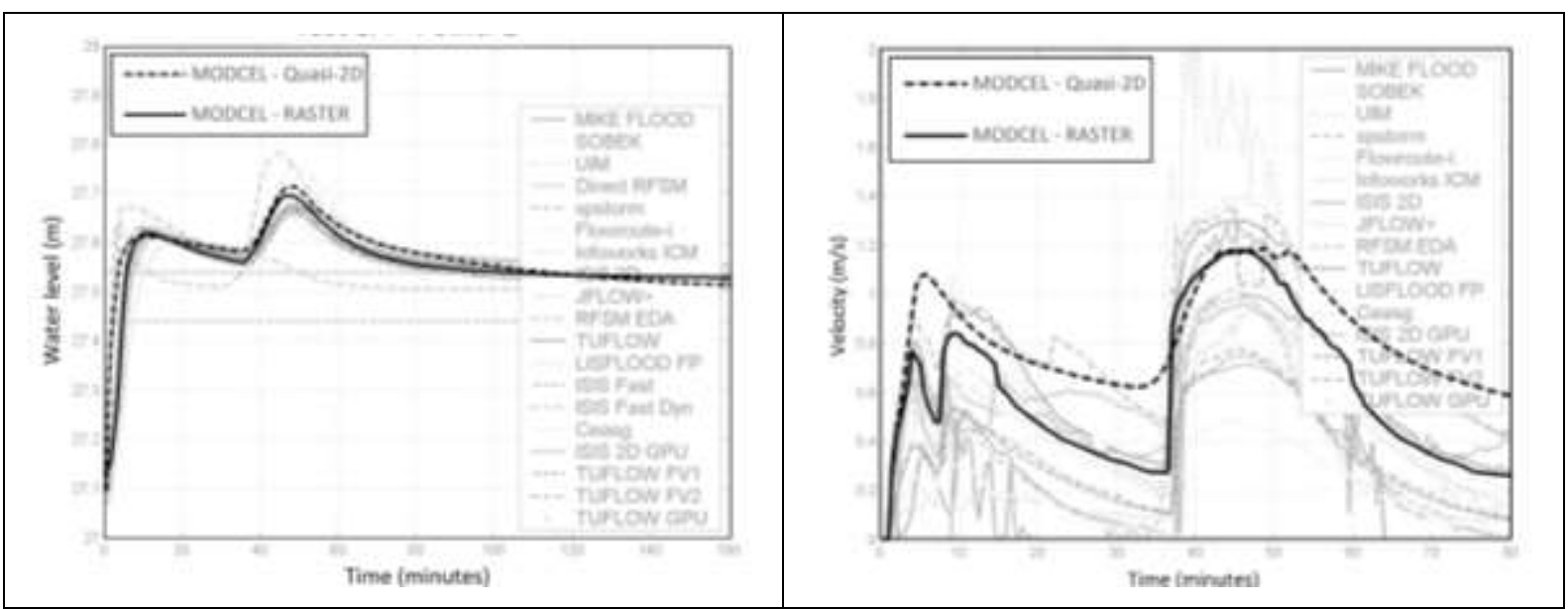

Figure 3. MODCEL results in points 1 and 6 respectively.

\section{CONCLUSIONS}

MODCEL is a conceptual and physically interpreted based model. Its application imply in an iterative process, where modelling evolves gradually while actual understanding of the system responses to causal factors are gradually understood and key factors are translated into model elements (cells) and links (hydraulic relations). An advantage from this approach refer to less data needs - conventional topography and city maps are sufficient, without any need of a LiDAR survey or similar detailed inputs. Computational processing times are also much lower. Considering the tests conducted in this research, it is possible to conclude that the interpretative approach reached satisfactory results, when compared to other models tested by the British Environmental Agency, revealing the importance of modeller actions. In fact, the final results were obtained with much fewer elements (163 vs. 43148 elements) and much lower computational cost (1350 times lower).

\section{References}

Abbott, M. B., \& Vojinovic, Z. (2009). Applications of numerical modelling in hydroinformatics. Journal of Hydroinformatics, 11(3-4), 308-319.

Abdullah, A. F., Vojinovic, Z., \& Meesuk, V. (2017). Modeling Flood Disasters: Issues Concerning Data for 2D Numerical Models. In MATEC Web of Conferences (Vol. 103, p. 04008). EDP Sciences.

Abily, M., Duluc, C. M., Faes, J. B., \& Gourbesville, P. (2013). Performance assessment of modelling tools for high resolution runoff simulation over an industrial site. Journal of Hydroinformatics, 15(4), 1296-1311.

Almeida, G. A., Bates, P., \& Ozdemir, H. (2016). Modelling urban floods at submetre resolution: challenges or opportunities for flood risk management?. Journal of Flood Risk Management, 11(S2).

Bauman, Z. (2001). Liquid modernity. Jorge Zahar.

Cunge, J. A., Holly, F. M., \& Verwey, A. (1980). Practical aspects of computational river hydraulics.

Cunge, J. A. (2014). What do we model? What results do we get? An anatomy of modelling systems foundations. In Advances in Hydroinformatics (pp. 5-18). Springer, Singapore.

Jamieson, S. R., Lhomme, J., Wright, G., \& Gouldby, B. (2012). A highly efficient 2D flood model with sub-element topography. In Proceedings of the Institution of Civil Engineers-Water Management (Vol. 165, No. 10, pp. 581595). Thomas Telford Ltd.

Leandro, J., Schumann, A., \& Pfister, A. (2016). A step towards considering the spatial heterogeneity of urban key features in urban hydrology flood modelling. Journal of hydrology, 535, 356-365.

Miguez, M. G. (2001). Modelo Matemático de Células de Escoamento para Bacias Urbanas. Doctoral Thesis COPPE/UFRJ, Rio de Janeiro.

Miguez, M.G., Battemarco, B.P., Sousa, M.M., Rezende, O.M., Veról, A.P., \& Gusmaroli, G. (2017). Urban Flood Simulation Using MODCEL-An Alternative Quasi-2D Conceptual Model. Water, 9(6), 445. 
Proceedings of the 11th Int. Conference on Urban Drainage Modelling, 23-26 Sep. 2018, Palermo (ITALY). Ed. prof. Giorgio Mannina

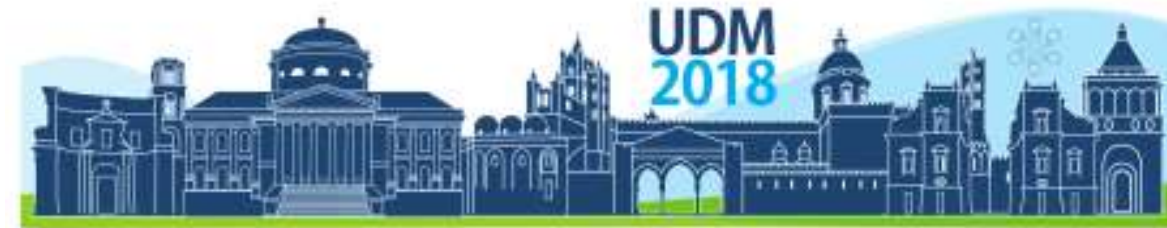

$11^{\text {th }}$ International Conference on Urban Drainage Modelling

23-26 Sep|Palermo-italy

Néelz, S., \& Pender, G. (2013). Delivering benefits thorough evidences: Benchmarking the Latest Generation of 2D Hydraulic Modelling Packages. Report-SC120002.

Zanobetti, D., \& Lorgeré, H. (1968). Le modèle mathématique du Delta du Mékong. La Houille Blanche, (5), 363378. 


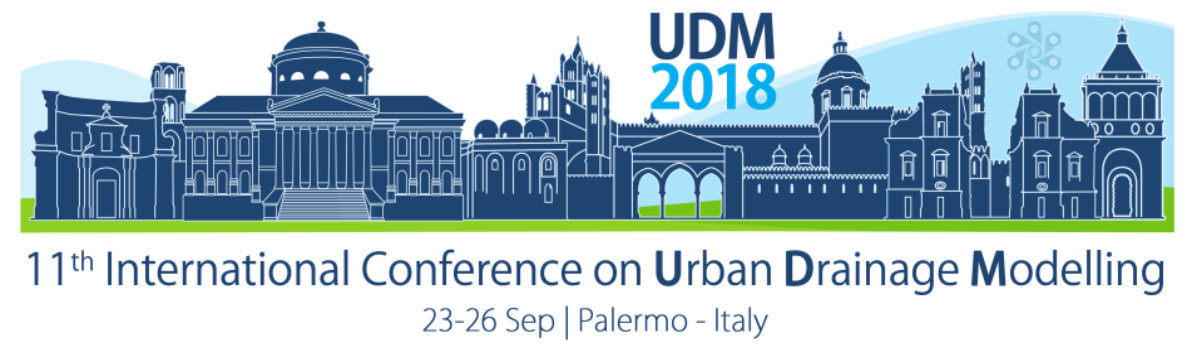

\title{
Integrated urban flash flood risk assessment
}

\author{
Stefan LEITNER ${ }^{1}$, Roman MAIER ${ }^{1}$, Axel SAUER ${ }^{2}$, Cornelia JÖBSTL ${ }^{3}$, Regine ORTLEPP ${ }^{2}$, Rudolf HORNICH ${ }^{3}$ \\ and Dirk MUSCHALLA ${ }^{1}$ \\ ${ }^{1}$ Institute of Urban Water Management, Graz University of Technology, Graz, Austria \\ ${ }^{2}$ Leibniz Institute of Ecological Urban and Regional Development, Dresden, Germany \\ ${ }^{3}$ Department of Water Management, Resources and Sustainability, Office of the Styrian Government, Graz,
} Austria

\begin{abstract}
In the last couple of years, a number of flash flood events have been observed in central Europe. The probability for the occurrence of such events will most likely increase in the future due to climate change, urbanization, demography, etc. To understand the dynamics of flash floods in urbanized areas, models are a helpful tool. 1D-2D hydrodynamic models for urban areas (1D sewer models and 2D surface-flow models) and 2D hydrodynamic river models represent the state of the art of urban flash flood and fluvial flood risk assessment. Beyond that, the analysis of urban areas surrounded by or located in hilly areas further ask for the consideration of hillsides and of the hydraulic connections between these hillsides, urban and fluvial areas. Besides the calculation of surface flow, the runoff generation becomes another dominating process. This leads to an integrated modelling approach considering three subsystems i) hill sides, ii) urban rivers and iii) urban areas with sewer systems; two model domains i) hydrology and ii) hydrodynamics and multiple uni- and bidirectional connections. The results of such an integrated model represent the flash flood hazard component. Integrated risk maps can then be derived via the GIS-based analysis of the spatially differentiated exposure of vulnerable receptors such as people, buildings, and infrastructure taking into account their specific sensitivities represented for example by depth-damage- or velocity-damage-functions.
\end{abstract}

Keywords: flash flood; integrated modelling; risk assessment

\section{INTRODUCTION}

The hazards of flash flood events concern scientists, planning engineers, stakeholders and the public. One of the most intensive recent events took place in Berlin on June 2017 (RAINMAN, 2017). Within 24 hours an amount of $150-247$ millimetres of rain has been measured in the greater Berlin area. That is about the average precipitation height of the whole month of June in that area (Davies, 2017). Standard methods to assess and reduce risks of flash floods are stated by the EU Flood Directive (European Parliament, 2007). Focus of the recently started Interreg Central Europe Project RAINMAN is integrated heavy rain risk management including risk assessment. The project aims to develop new methods and measures to improve the flash flood risk assessment for urban and rural areas. The focus is on the development of five main points: i) a risk assessing and mapping tool; ii) a guide for risk reduction measures; iii) recommendations for flood risk management plans; iv) awareness building and stakeholder involvement tools and v) a catalogue of good-practise examples for integrated reduction of flash flood risks. The presented methodology in this paper is part of the RAINMAN toolbox. It provides a tool for integrated flash flood risk assessment in urban, hilly regions based on leading edge modelling and GIS technologies. 


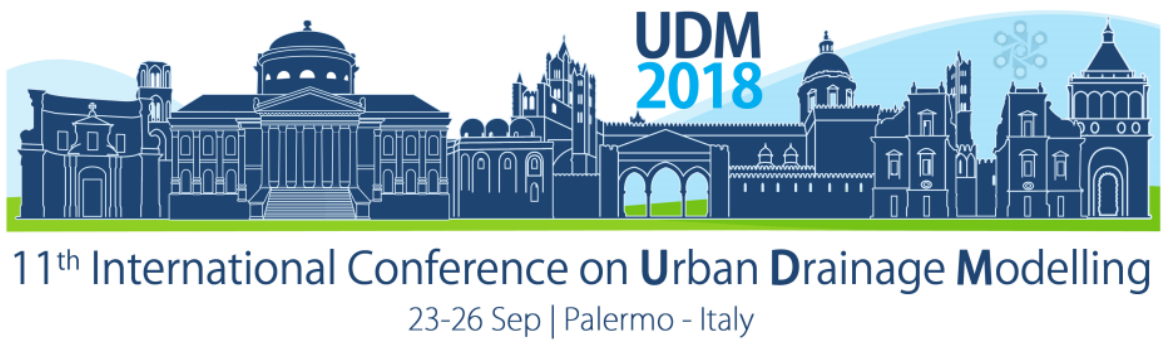

\section{MATERIALS AND METHODS}

\subsection{Major sub-systems, processes and models}

Figure 1 shows the three main systems that influence the generation of urban flash floods in hilly or mountainous regions: i) hillsides, ii) urban rivers and iii) urbanized areas. It also illustrates the uni- and bi-directional hydraulic connections between these systems. In hilly or mountainous regions, the boundaries of urban catchments are often hillsides. Hillsides can generate high surface runoff rates (slope water) during heavy rain events, which feed the runoff of creeks and urban rivers. Overloaded creeks can cause fluvial flooding in urban areas. Direct linkages between hillsides and urban areas are further sources of urban flooding. Another cause for urban flooding are heavy local storm events that result in overloaded sewers or flooded areas from surface runoff (pluvial flooding). The overlapping of slope water, fluvial and pluvial floods as well as the hydraulic interaction of the mentioned systems further increases the intensity of urban flood hazards. For the assessment of flooding in urban areas all three sub-systems have to be considered resulting in an integrated hydrological-hydraulic modelling approach including all important hydrological and hydraulic processes and connections, see figure 2 .

This paper presents a novel integrated modelling approach that includes hydrological and hydraulic sub-models for each of the considered subsystems. Every surface area (hillside and urban area) is represented by a grid-based two-layer concept. The hydrological layer calculates the effective precipitation $\left(P_{\text {eff }}\right)$ for each subarea as input for the corresponding surface hydraulic layer. Urban rivers are considered including the geometry of their river banks. The sewer system is represented including all important manholes and pipes.

Figure 2 shows all connections between the sub-systems. All sub-models are implemented reflecting the dominating hydrological and hydraulic processes of the modelled sub-system. For the hydrology, a 2D raster model (hillside) and a spatially detailed model based on hydrological response units - HRUs (urbanised areas) are used. The models include runoff generation from natural and urbanized areas including infiltration models. All hydrological models have a unidirectional connection to the corresponding surface hydraulic models and sewer system model in the urbanized subarea respectively. Different hydraulic models exist to model hydraulic surface runoff and the flow in conveyance systems (in our application sewers and urban rivers). To address the most important processes of urban rivers in the context of urban flooding 2D hydrodynamic models are state of the art. For the runoff concentration on hillsides and urbanized areas a wide range of models is available - from lumped models using Nash cascades to highly detailed models using the 2D shallow water equations. Only the later provides the needed state variables - water level and velocity - in a sufficient quality. For the sewer system a detailed model using the DeSaint-Venant-Equations has to be selected to provide accurate flow rates in sewer pipes and water levels in manholes - a prerequisite to simulate overflowing manholes and to include the influence of surface water levels on sewer flow rates. The connection between the applied hydraulic models are unidirectional or bidirectional. The connection between hillsides and rivers and hillsides and urban surfaces is unidirectional. The urban surfaces hydraulic models have two connections: i) with the urban rivers ii) with the sewer system, both are bidirectional connection. Sewer overflows represent a connection between sewer models and river models which is bidirectional if no flap gates are installed. The setup of a model that contains all described sub models and connections results in an integrated 1D/2D hydrological and hydraulic model for urbanized areas including hillsides and urban rivers. 


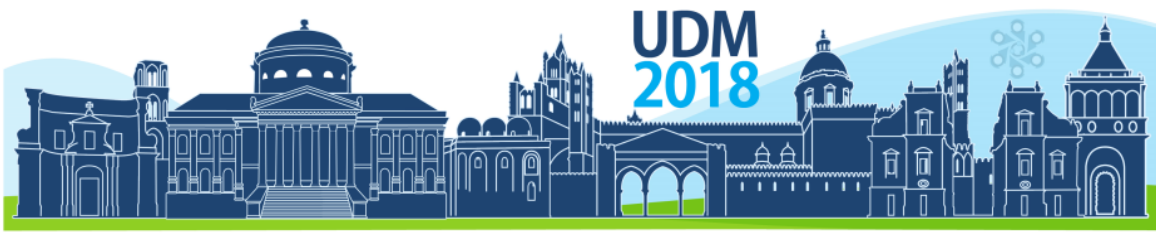

$11^{\text {th }}$ International Conference on Urban Drainage Modelling

23-26 Sep | Palermo - Italy

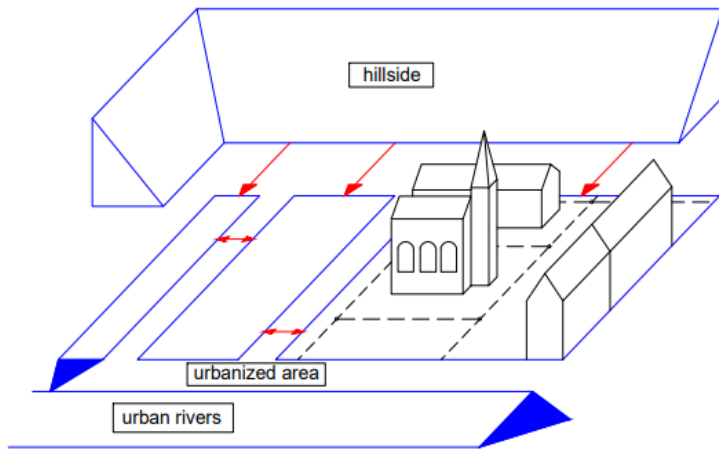

Figure 1: Major subareas of an integrated flash flood hazard assessment

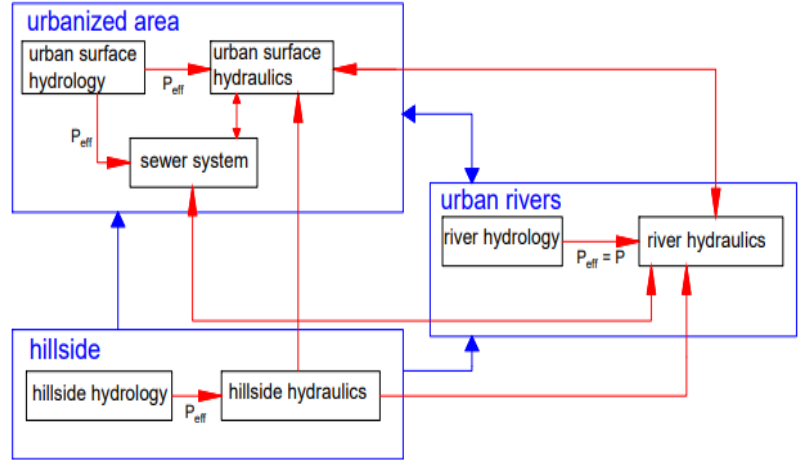

Figure 2: Linkage between major subareas and hydrology and surface hydraulics

\subsection{Vulnerability and risk analysis}

The results of the above mentioned integrated model represent the flash flood hazard component. Integrated risk maps can be derived via the GIS-based analysis of the spatially differentiated exposure of vulnerable receptors such as people, buildings, and infrastructure (e.g. roads, railways, trams, ...) taking into account their specific sensitivities represented for example by depth-damage- or velocity-damage-functions (e.g. Schinke et al., 2018) or depth-velocityclasses (e.g. Priest, 2009). Vector data from digital topographic maps, digitized objects from aerial images as well as landuse data from CORINE Land Cover are used to extract and classify vulnerable objects with the help of specific geoprocessing techniques such as buffering, overlaying and selecting based on attribute values. In a next step values are assigned to these objects to classify them according to their relevance and damage potential.

\section{RESULTS AND DISCUSSION}

The described integrated 1D/2D model approach is tested in a case study in Graz, Styria, Austria. The catchment includes three different subsystems - hillside, urban rivers and urbanised area including a sewer system.

\subsection{Integrated 1D/2D hydrological/hydraulic analysis}

Figure 3 shows the maximum surface water levels for a small part of the case study calculated with the integrated 1D/2D hydrological and hydraulic model and the underlying elevation model. The calibration of this model was challenging, because accurate data of measured water depth in case of flash flood events are usually not available. A plausibility check was done by comparing the simulation results with documented damages of past flood events (sewer operator, social media, fire department, etc.). 

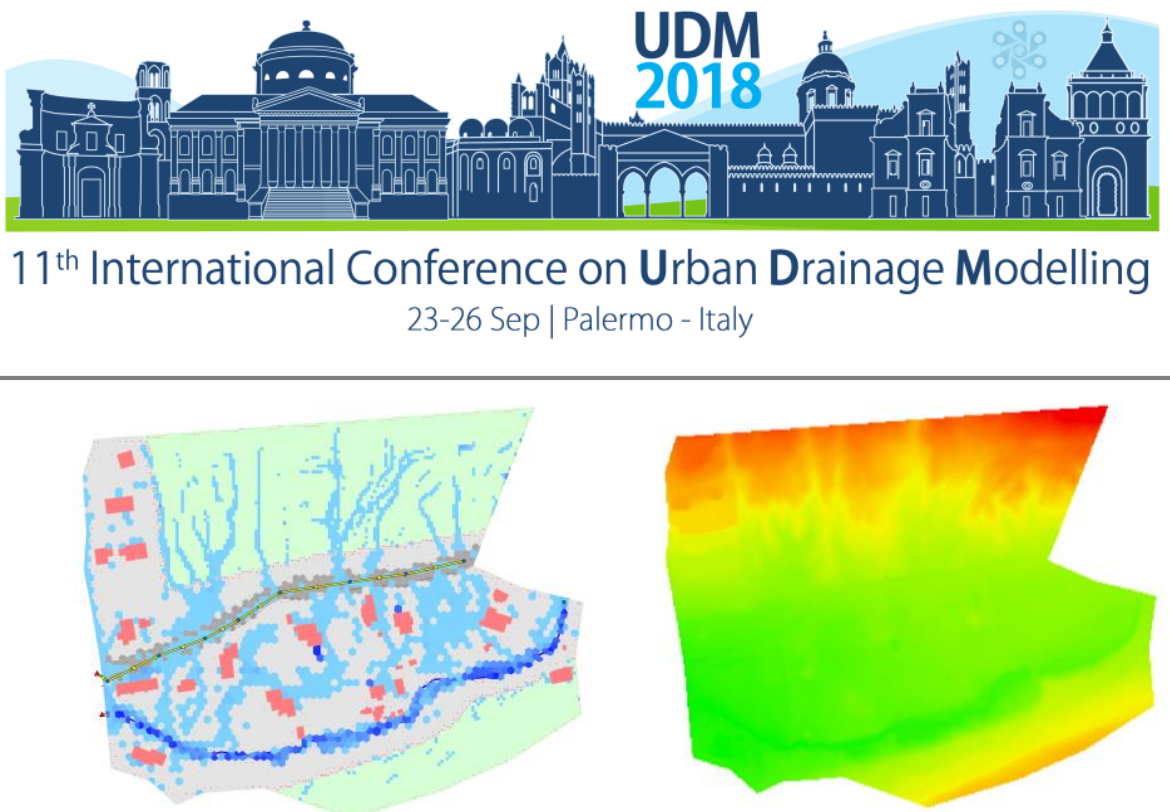

Figure 3: Simulation results for a part of the case study area. Left side - maximum water level calculated by the surface runoff simulation, light blue lowest, dark blue highest water levels, red buildings, grey streets, light green hill sides, yellow sewer. Ride side - catchment's topography, green lowest, red highest altitudes.

\subsection{Vulnerability and risk analysis}

The final result of the integrated flash flood risk assessment are risk maps for urban flash flood events for different receptors. Risk maps are prepared for three different flash flood hazard/precipitation events: a frequent event (approx. 5-10 years return period), a rare event (100 year return period), and an extreme event (probable maximum precipitation). Risk for built-up areas is expressed via the number of threatened buildings and a classification of the building value as well as its utilization. Risk for roads is expressed as inundated length and a classification of its traffic relevance (e.g. major road). Risk to people is mapped for all potentially accessible areas outside of buildings and expressed on a classified depth-velocity scale (see Priest, 2009).

\section{CONCLUSIONS}

The presented integrated hydrological and hydraulic modelling approach including 2D surface and river flow provides a sound basis for urban flash flood risk assessment. Three different subareas - hillside, urban rivers and urbanised areas with sewer systems - are considered together with all important connections. The simulation results of the surface runoff model together with the identification of potential receptors with their sensitivities are necessary to derive risk maps. Because the calibration of a 2D surface runoff model without accurate water depth measurement of flood events is normally not possible, information like existing damage documentation must be used to check the simulation results. All these tools (models, GIS tools and data analysis) are essential for generating reliable urban flood risk maps, which are the final output of an urban flash flood risk assessment.

\section{Acknowledgements}

We want to thank the partners of the project "RAINMAN" for their great work and input. Part of this work was funded by Interreg Central Europe Project CE968 RAINMAN.

\section{References}

Davies Richard (2017), Germany - Berlin Streets Under Water After 150mm of Rain in 24 Hours“ http://www.floodlist.com, http://floodlist.com/europe/germany-berlin-flood-june-2017.

European-Community (2007). „Directive 2007/60/EC of the European Parliament and of the Council of 23 October 2007 on the assessment and management of flood risks“. Official Journal of the European Union, Nr. L288: 27-34.

Priest, Sally; Tapsell, Sue, Penning-Rowsell, Edmund; Viavattene, Christophe, Wilson, Theresa (2009) Building models to estimate loss of life for flood events. FLOODsite report T10-08-10. http://www.floodsite.net/html/partner_area/project_docs/T10_08_10_Risk_to_Life_ExecSum_V1_3_P01.pdf

RAINMAN, integrated heavy rain risk management (2017), Newsletter\#1, http://www.interregcentral.eu/Content.N/RAINMAN-Newsletter-1-EN-1.pdf

Schinke, Reinhard; Kaidel, Anna; Golz, Sebastian; Naumann, Thomas; López-Gutiérrez, José Santos; Garvin, Stephen (2016) Analysing the effects of flood-resilience technologies in urban areas using a synthetic model approach. ISPRS International Journal of Geo-Information 5(11), 202, doi:10.3390/ijgi5110202 


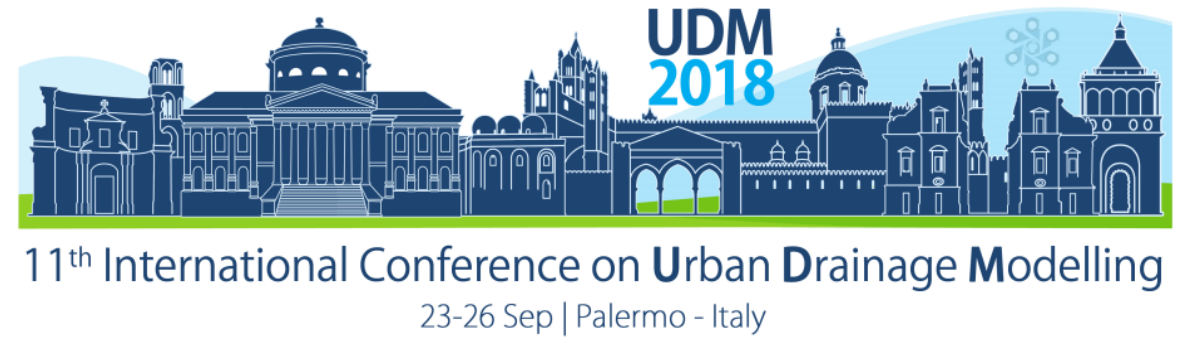

\title{
Numerical and CFD-based modelling of concentrated domestic slurry in turbulent flow through circular pipes
}

\author{
Dhruv Mehta ${ }^{1}$, Adithya Krishnan Thota Radhakrishnan ${ }^{1}$, Jules van Lier ${ }^{1}$ and Francois Clemens ${ }^{1,2}$ \\ ${ }^{1}$ Delft University of Technology, Sanitary Engineering, Delft, the Netherlands \\ ${ }^{2}$ Stichting Deltares, Delft, the Netherlands
}

\begin{abstract}
The concentration of domestic slurry has two advantages, it promotes resource recovery (nutrients and biomass) and saves water. But the design of a relevant sewerage requires a clear understanding of the frictional losses incurred during the transport of the slurry. This abstracts describes numerical \& CFDbased methods to estimate losses while the concentrated slurry flows through circular pipes in a fully-turbulent flow. To model turbulent flows through circular pipes, one can rely on either the Newtonian Moody Charts appropriate for engineering applications or a computational fluid dynamics (CFD)-based analysis, made possible through the Newtonian universal law of the wall. However, our studies reveal that concentrated domestic slurry behaves like a non-Newtonian fluid, of the Herschel-Bulkley type. Therefore, the analysis of such a slurry would require modifications to both, existing engineering models and CFD methods. This abstract summarises a modified law of the wall suitable for Herschel-Bulkley fluids, which has been validated against experiments on concentrated domestic slurry. It further details possible non-Newtonian numerical engineering models that could be modified to assess frictional losses incurred by Herschel-Bulkley fluids. The latter will be a quicker and perhaps reliable alternative to computationally expensive CFD-analyses.
\end{abstract}

Keywords: concentrated domestic slurry; urban drainage; Herschel-Bulkley fluid; non-Newtonian flow; computational fluid dynamics; turbulence

\section{INTRODUCTION}

Unlike a Newtonian fluid, the viscosity of a non-Newtonian fluid not only depends on the temperature and pressure but also on the flow itself. The simple constitutive relation of a Newtonian fluid reads,

$$
\tau=\mu \dot{r},
$$

where $\tau$ is the shear stress, $\mu$ is the molecular viscosity and $\dot{\gamma}$ is the shear rate. In contrast, the constitutive relation of a non-Newtonian fluid of the Herschel-Bulkley type reads (Herschel \& Bulkley, 1923),

$$
\tau=\left(\frac{\tau_{y}}{|\dot{r}|}+m\left(\dot{r}^{n-1}\right)\right) \dot{r}
$$

where, $m$ is the consistency index, $n$ is the behaviour index and $\tau_{y}$ is the yield stress. If $n=$ 0 , the fluid is a Bingham plastic and if $\tau_{y}=0$, the fluid is a power-law fluid (Chhabra \& Richardson, 1999); both of which are non-Newtonian fluids.

Heywood \& Cheng, 1984 and Skelland, 1967 summarise a range of numerical methods that could be used to predict frictional losses experienced by the above-mentioned non- 


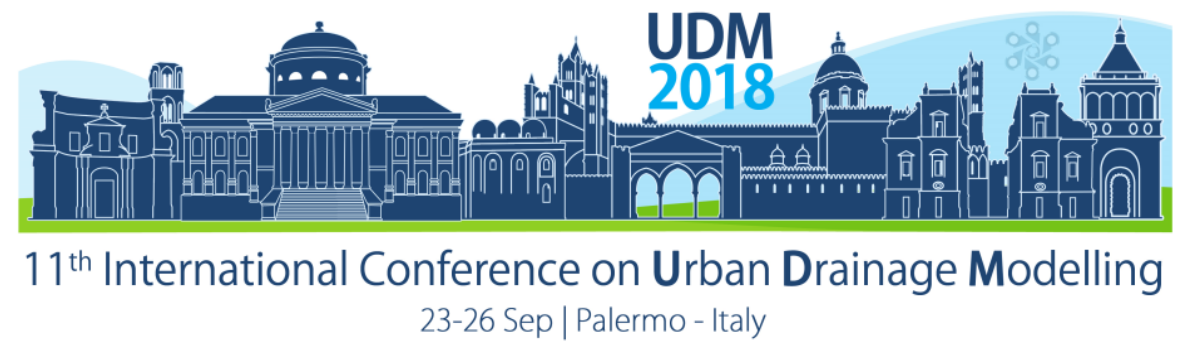

Newtonian fluids in turbulent flows. Each method has its range of accuracy and limitations. Based on a range of experiments, Slatter, 1995 proposed a simple numerical model suitable for Herschel-Bulkley fluids. Thomas \& Wilson, 1987 also proposed a numerical model but based on the theoretical nature of turbulent dissipation.

Malin, 1998 on the other hand, illustrates a computational fluid dynamics (CFD)-based analysis of turbulent flows of Herschel-Bulkley fluids. Malin, 1998 uses the $K-\varepsilon$ ReynoldsAveraged Navier-Stokes (RANS) model while replacing the molecular viscosity with an apparent viscosity calculated using the constitutive relations mentioned above.

On using the above-mentioned numerical methods, we noticed a discrepancy between the numerical predictions and the experimental observations on the flow of concentrated domestic slurry, as regards to the pressure losses in circular horizontal pipes. Further, using both $\mathrm{K}-\varepsilon$ and the Reynolds Stress Model (RSM) with non-Newtonian viscosity alone, led to poor predictions of the pressure losses.

\section{MATERIALS AND METHODS}

Concerning CFD, it is known that the universal law of the wall (Launder \& Spalding, 1974) is used to model the presence of a wall boundary (the pipe's wall in this case) for enabling accurate yet affordable simulations of wall-bounded flows. This law was developed and has been validated for Newtonian fluids alone.

The law of the wall for Newtonian fluids reads,

$$
\frac{u}{\left(\frac{\tau_{w}}{\rho}\right)^{1 / 2}}=\frac{1}{K} \ln \left(E \frac{\rho y \tau_{y}}{\mu}\right)
$$

where $K$ and $E$ are constants, $\rho$ is the density of the fluid, $y$ is distance from a wall boundary and $u$ is the velocity parallel to the wall at a distance $y$ from it. Using this law, one can determine the wall shear stress $\tau_{w}$ through an appropriate CFD simulation. However, this law when used with a Herschel-Bulkley fluid will lead to erroneous predictions of the wall shear stress and hence, the pressure losses.

Instead, Mehta et al., 2018, proposed a modified law of the wall that was derived using an approach similar to Launder \& Spalding, 1974 and relevant numerical methods summarised in Skelland, 1967. The aim was to incorporate the effects of the yield stress and the fluid behaviour index in a single equation that could approximate the near-wall behaviour of Herschel-Bulkley fluids and enable the prediction of wall shear stress through a CFD simulation using the $\mathrm{K}-\varepsilon$ and the RSM RANS models.

The modified law of the wall reads,

$$
\frac{u}{\left(\frac{\tau_{w}-\tau_{y}}{\rho}\right)^{1 / 2}}=\frac{1}{n K} \ln \left(E \frac{\rho}{m} y^{n}\left(\frac{\tau_{w}-\tau_{y}}{\rho}\right)^{1-\frac{n}{2}}\right),
$$




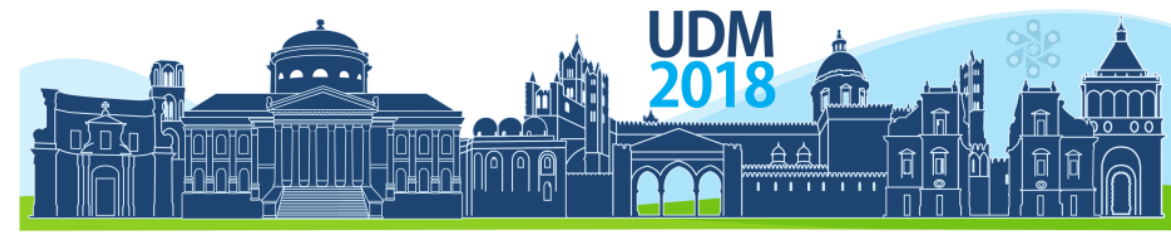

$11^{\text {th }}$ International Conference on Urban Drainage Modelling

23-26 Sep | Palermo - Italy

The above equation is referred to as $\psi_{1}$. On the other hand, there are semi-empirical relations that relate the wall shear stress and the flow properties, such as the one by Tomita (see Skelland, 1967) for power-law fluids,

$$
\sqrt{\frac{1}{f_{P}}}=4 \log \left(R e_{P} \sqrt{f_{P}}\right)-0.40
$$

where $\operatorname{Re}_{P}$ and $f_{P}$ are defined as follows.

$$
\begin{gathered}
f_{P}=\frac{\tau_{w}}{\rho V^{2}} \cdot \frac{8(2 n+1)}{3(3 n+1)} \\
\operatorname{Re}_{P}=\frac{D^{n} V^{2-n} \rho}{m} \cdot \frac{6\left(\frac{3 n+1}{n}\right)^{1-n}}{2^{n}\left(\frac{2 n+1}{n}\right)}
\end{gathered}
$$

$V$ is the average flow velocity through a pipe of diameter $D$. Various other approaches to model the pressure losses incurred by power law fluids have been proposed. However, Tomita (see Skelland, 1967) also derived an expression similar to the above, for Bingham plastic fluids. Given its completeness, we shall follow Tomita's approach to derive an expression for Herschel-Bulkley fluids, which combined the effect of Bingham plastic and power-law fluids.

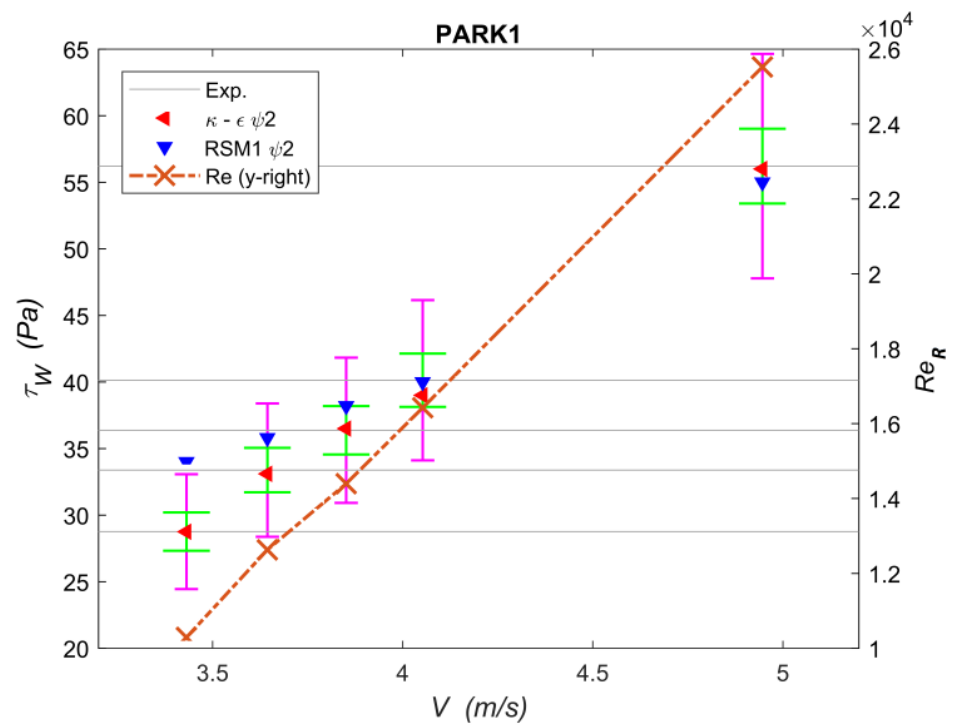

Figure 1. $m=0.0894, n=0.73, \tau_{y}=9.3 P a$ and $D=51 \mathrm{~mm}$. The accuracy of the modified law of the wall combined with $\mathrm{K}-\varepsilon$ and the RSM, is clearly visible.

The study will also include a thorough comparison of most existing numerical models, the CFD-based analysis using the modified law of the wall and experimental data, to ascertain which numerical (or CFD) method is most suited to our purpose. The next section summaries the results obtained through CFD using the modified law of the wall. 


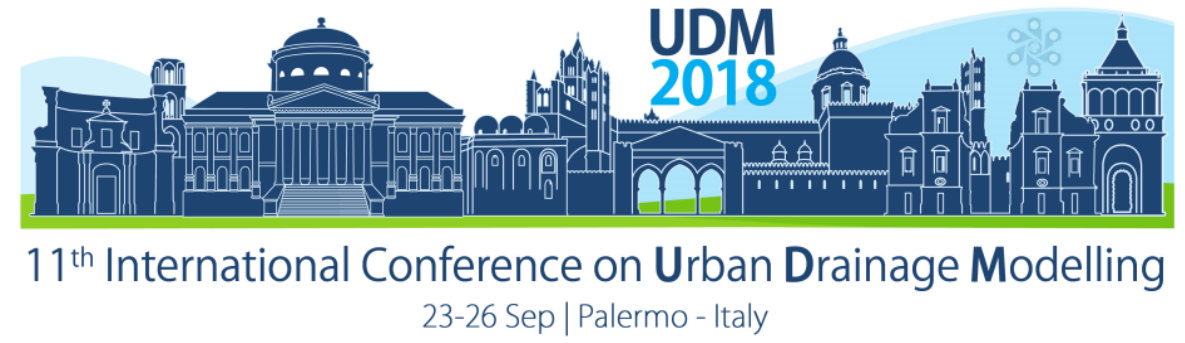

\section{RESULTS AND DISCUSSION}

Figure 1 contains two y-axes. The left $y$-axis represents $\tau_{w}$ while the right $y$-axis represents the Reynolds number $R_{R}$ (as proposed by Rudman et al., 2004). The x-axis represents the average flow velocity. The Reynolds number is shown with the crosses at each data point, whereas the experimental wall shear stress is shown with grey horizontal lines. Additionally, at each data point, the green error bar represents a 5\% deviation and the magenta error bar, a $15 \%$ deviation from the experimental data. Although we present only one result here, the modified law of the wall was used to simulate a range of test-cases from literature and those performed by the co-authors. The details can be found in Mehta et al., 2018.

\section{CONCLUSIONS}

The reported observations suggest that the proposed wall functions when combined with the standard $k-\varepsilon$ or RSM, provide reliable numerical predictions of the wall shear and hence, the pressure loss experienced by a Herschel-Bulkley fluid in turbulent flow through a circular horizontal pipe.

We are performing modifications of a few numerical models that have been proposed for power-law fluids and Bingham plastic fluids, the combined effect of which is seen in a Herschel-Bulkley fluid. We intend to present a comparison between the numerical methods that are currently being developing and the CFD analyses reported in the abstract, to ascertain if simple engineering models could replace CFD analyses for the turbulent flow of Herschel-Bulkley fluids.

\section{Acknowledgement}

This abstract is the result of the research carried out at the Delft University of Technology, Delft and funded by NWO-domain TTW, Foundation Deltares, Stowa, Foundation RIONED, Waternet, Waterboard Zuiderzeeland, Grontmij and XYLEM. We acknowledge the support of the funding bodies and their contributions to this research.

\section{References}

Chhabra, R.P. and Richardson, J.F. (1999) Non-Newtonian flow in the process industries. 1 ed., ButterworthHeinemann, Oxford, UK.

Herschel, W.H. and Bulkley, R. (1926) Konsistenzmessungen von Gummi-Benzollösungen. Kolloid Z. 39, 291300.

Heywood, N.I. and Cheng, D.C.H. (1984) Comparison of methods for predicting head loss in turbulent pipe flow of non-Newtonian fluids. T. I. Meas. Control 6, 33-45.

Launder, B.E. and Spalding, D.B. (1974) The numerical computation of turbulent flows. Comput. Method Appl. M. 3(2), 269-289.

Malin, M.R. (1998) Turbulent pipe-flow of Herschel-Bulkley fluids. Int. Commun. Heat Mass 25, 321-330.

Mehta, D., Thota Radhakrishnan, A.K., van Lier, J. and Clemens, F. (2018) A wall boundary condition for the simulation of a turbulent non-Newtonian domestic slurry in pipes. Water 10(2), 124.

Park, J.T., Mannheimer, R.J., Grimley, T.A. and Morrow, T.B. (1989) Pipe flow measurements of a transparent non-Newtonian slurry. J. Fluid Eng. 111, 331-336.

Rudman, M., Blackburn, H.M., Graham, L.J.W. and Pullum, L. (2004) Turbulent pipe flow of shear-thinning fluids. J. Non-Newton Fluid 118, 33-48.

Skelland, A.H.P. (1967) Non-Newtonian flow and heat transfer. John Wiley \& Sons.

Slatter, P.T. (1995) Transitional and turbulent flow of non-Newtonian slurries in pipes. PhD thesis, Department of Civil Engineering, University of Cape Town, Cape Town, South Africa.

Thomas, A.D. and Wilson, K.C. (1987) New analysis of non-Newtonian turbulent flow-yield power-law fluids. Can. J. Chem. Eng. 65, 335-289. 


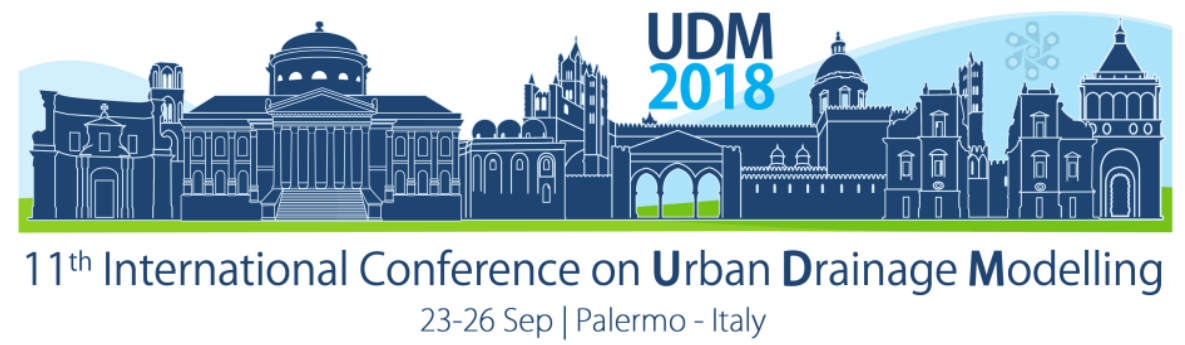

\title{
A Framework to Assess Urban Floods Resilience
}

\author{
Osvaldo Moura Rezende ${ }^{1}$, Anna Beatriz Ribeiro da Cruz de Franco², Antonio Krishnamurti Beleño de \\ Oliveira ${ }^{1}$, Ana Caroline Pitzer Jacob ${ }^{1}$ and Marcelo Gomes Miguez ${ }^{1,2}$ \\ ${ }^{1}$ Universidade Federal do Rio de Janeiro, COPPE/UFRJ, Rio de Janeiro, Brazil \\ 2 Universidade Federal do Rio de Janeiro, Escola Politécnica, Rio de Janeiro, Brazil
}

\begin{abstract}
Urban flooding is still often treated as a straight consequence of excess rainfall, without considering the watershed as an interdependent system connected with the development of its territory. The traditional approach implies continuous corrective interventions, usually of local character and resulting from post-events responses. This process requires increasingly large investments to implement structures capable to accommodate the runoff generated by urbanization. These efforts have not prevented floods from continuing to cause major damage worldwide, indicating the need for a change in storm water management strategy, shifting from a simple cost-benefit analysis to a risk management approach, with residual risk internalization, regarding inherent uncertainties, such as climate change and fast and uncontrolled urban growth. This paper proposes a multi-criteria index, the Urban Flood Resilience index-UFRI, to quantitatively measure resilience to floods, supported by a hydrodynamic mathematical model and socio-economic indicators, resulting in spatialized maps. A case study for an urban watershed in Rio de Janeiro is used to demonstrate UFRI potential.
\end{abstract}

Keywords: Sustainable Storm Water Management; Distributed Flood Control Measure; Flood Risk Management; Flood Resilience

\section{INTRODUCTION}

Despite the growing concern about the correct treatment of urban water, facing changes caused by the urban development process, flood events continue to cause great damage worldwide, even in central countries, where there is already considerable progress in the management of cities towards sustainability. This background indicates the need for a change in flood management strategy, leaving the simple cost-benefit analysis of structural flood control works to assume a flood risk management approach, in order to internalize residual risk. To make it possible, it should be considered the various uncertainties inherent in the process of flooding formation, such as climate change and urban development. This challenge is addressed in this paper that aims to offer practical analysis alternatives, which can provide support tools for territorial planning. These tools are designed to be able to consider storm water management as a factor of urban space structuring, offering more resilient solutions. Thus, the paper proposes a methodological process that allows to demonstrate possible advantages of the articulation between flood risk integrated management and the territorial planning of the city. In this way, two conceptions of interventions (concentrated and distributed) in the urban drainage system of an urban catchment with consolidated occupation are opposed.

\section{MATERIALS AND METHODS}

This paper aims to present a framework of methodological procedures that allows a systemic evaluation of flood resilience in an urban catchment, considering that the design of flood control measures should be guided by a reasoning of risk management and not just by a damage reduction evaluation. This is possible by internalizing residual risk and evaluating the resulting 


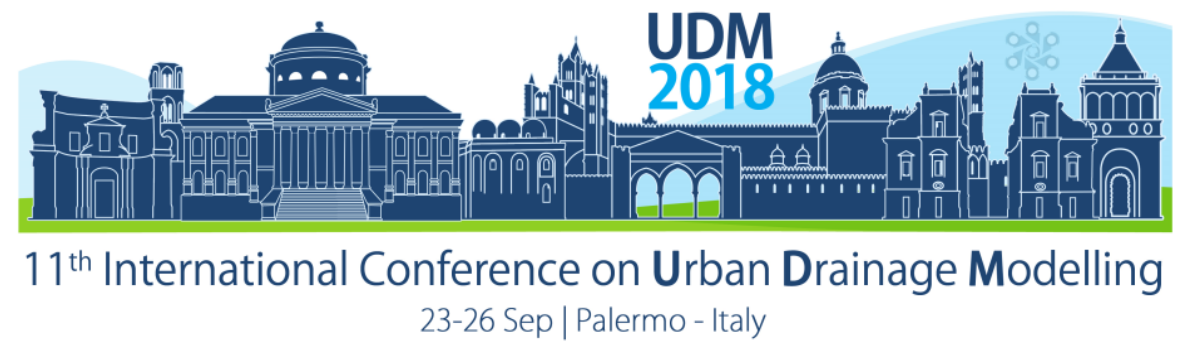

resilience of the system, from the consideration of hydrological scenarios with return periods greater than that of the reference design event in a given horizon of planning.

\subsection{Computational modelling system}

In order to obtain information on flood scenarios, hydrological and hydrodynamic modelling tools are used to support predictions using different rainfall design events for a set of varied return periods, involving the representation of representative points in the proper probabilistic curve. In this case, this information was obtained by using the Flow Cell Model - MODCEL (Mascarenhas \& Miguez, 2002; Miguez et al 2017). This model was based on the original work of Zanobetti (1970) and assumes that the watershed can be subdivided in various types of flow-cells, which interact with each other through 1D flow equations. MODCEL can be described as an urban flow cell model, which integrates hydrological processes observed in each cell into a looped hydrodynamic model, creating a spatial representation that interconnects surface flow, channel flows and storm drains. Therefore, a dual drainage approach supports this model, so the flow can occur simultaneously on both layers - surface and underground (SILVA, 2017).

\subsection{Urban Floods Resilience Index - UFRI}

To support the discussion on residual risk and support the methodology proposed here, an index is developed to support the planning and design of urban drainage solutions, adopting a methodology that starts from the concept of risk and consolidates a Resilience Index, acting to reduce risk consequences over time (SAYERS et al., 2013) regarding the losses materialization. The Urban Flood Resilience Index - UFRI, initially presented in Tebaldi et al. (2015) and Bertilsson \& Wiklund (2015), combines three sub-indexes, as showed by equation in the Figure 1. Each sub-index considers hazard-related indicators in its composition, covering maximum flood depths, water flow velocities and flood permanence time.

\begin{tabular}{|c|c|c|}
\hline \multicolumn{3}{|c|}{$U F R I=a \cdot\left(1-S i_{R}\right)+b \cdot\left(1-S i_{C}\right)+c \cdot\left(1-S i_{F}\right)$} \\
\hline $\begin{array}{l}S i_{R} \text { - Sub-index of Risk to } \\
\text { Resistance Capacity } \\
\text { - } I_{e} \text { - Indicator of Building Exposure } \\
\text { - } I_{I_{i}} \text { - Indicator of Urban } \\
\text { Infrastructure Exposure } \\
\text { - } I_{H} \text { - Indicator of Flood Depth }\end{array}$ & $\begin{array}{l}i_{C}-\text { Sub-index of Risk to } \\
\text { Material Recovery Capacity } \\
\text { - } I_{r v} \text { - Indicator of Relative Value } \\
\text { - } I_{S} \text { - Indicator of Building } \\
\text { Susceptibility } \\
\text { - } I_{S v} \text { - Indicator of Social } \\
\text { Vulnerability } \\
\text { - } I_{v p} \text { - Indicator of Vulnerability of } \\
\text { People } \\
\text { - } I_{F V} \text { - Indicator of Velocity Factor }\end{array}$ & $\begin{array}{l}i_{F}-\text { Sub-index of Risk to } \\
\text { Maintenance of the Operation } \\
\text { - } I_{R M} \text { - Indicator of Mobility Risk } \\
I_{r h} \text { - Indicator of Road } \\
\text { Hierarchy } \\
I_{n r t} \text { - Indicator of Non-Rail } \\
\text { Transport Service } \\
I_{P F}-\text { Indicator of Permanence } \\
\text { Factor } \\
\text { - } I_{d a} \text { - Indicator of Aid Access } \\
\text { Difficulty }\end{array}$ \\
\hline
\end{tabular}

Figure 1. The Urban Flood Resilience Index - UFRI.

\subsection{Proposed methodological framework to measure urban flood resilience}

The steps required to evaluate urban flood resilience with Urban Flood Resilience Index UFRI, through multi-events criterion (Rezende, 2018), are shown in Figure 2. Starting from the urban catchment evaluation, physical and socioeconomic data need to be collected. The physical data, mainly topography, hydrography, pluviometry, land use and urban patterns, are used to build the mathematical modelling basis. The results of the hydrodynamics modelling are used to fulfil the hazard indicators that are used to compose the higher orders indicators. That is, the hydrodynamic model provides $I_{H}, I_{F V}$ e $I_{P F}$. These indicators are inserted in the formulation of the UFRI index, for each flooding simulation result, considering the several hydrological events. At this stage, each event results in a partial UFRI map, with values of 


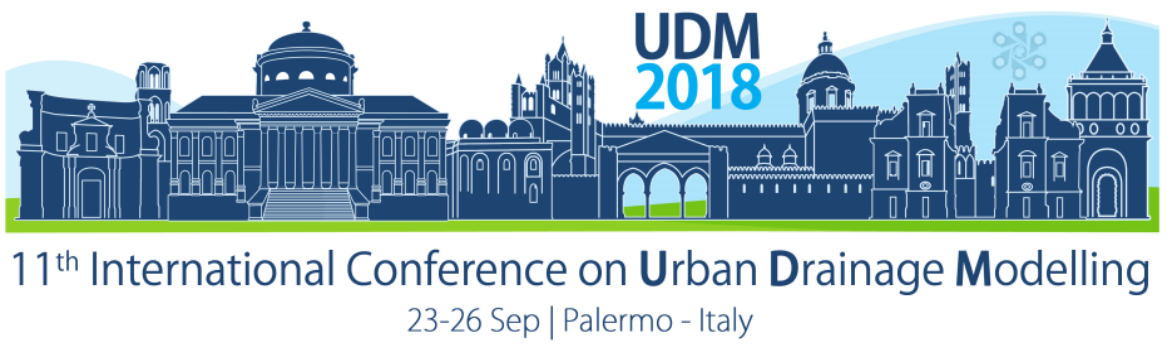

resilience for all cells. The second set of data referring to socio-economic information is used to build the indicators $I_{e}, I_{e i}, I_{r v}, I_{S}, I_{s v}, I_{v p}, I_{r h}, I_{n r t}$ e $I_{d a}$. Finally, the function of UFRI and its probability of occurrence on each cell are integrated, forming the Urban Resilience Map. The detailed composition of indicators and indexes can be found in Rezende (2018).

It is important to highlight that MODCEL is able to represent different watershed scales, since it performs the rainfall runoff transformation, simulates the superficial flows before entering the minor drainage network, then joins minor drainage.(including storm drains) into major drainage and ends up including river simulation. In fact, these scales may be too different and depending on the interest, the simulation may be diverse from one aim to another. However, we are considering here, as the main study object, the urban watersheds where small rivers are included in the major drainage system as its main channels.

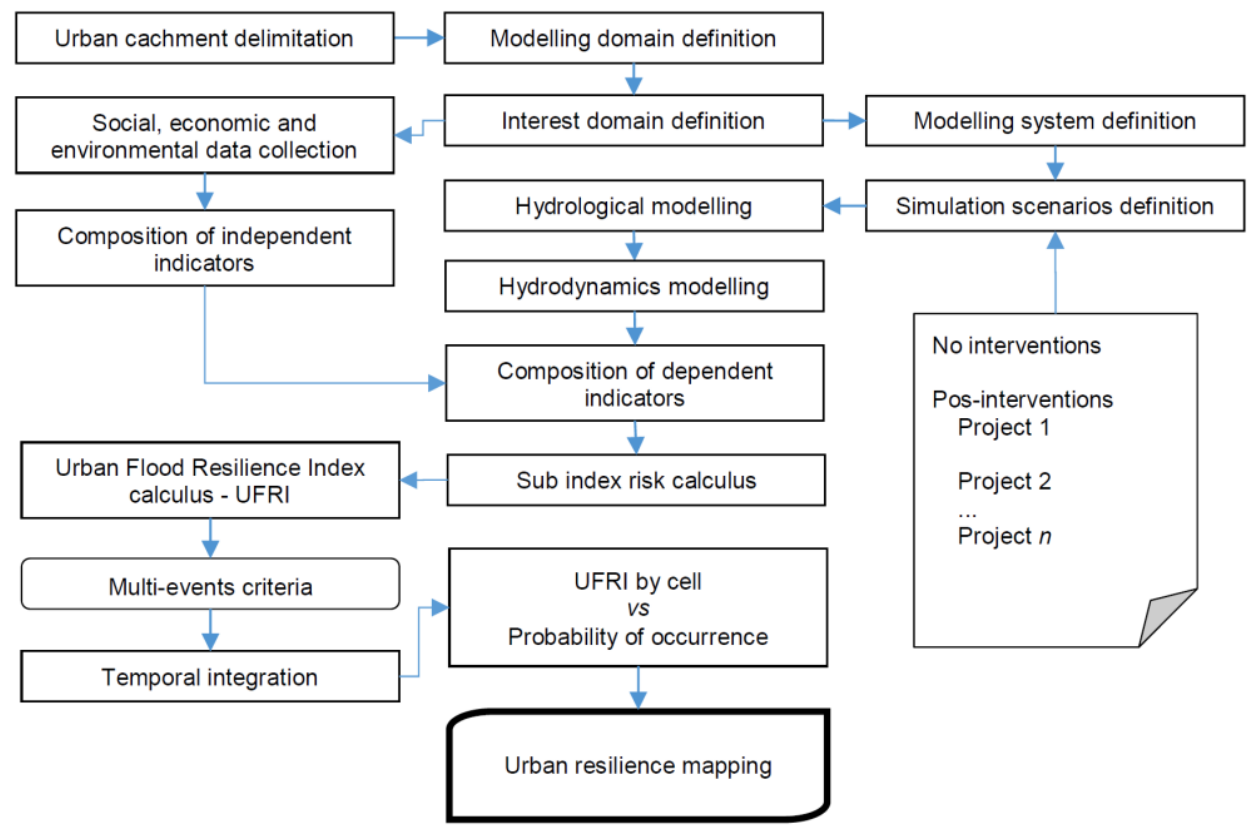

Figure 2. Methodological framework to map urban flood resilience.

The use of the multi-events criterion aims to internalize residual risk in the urban resilience evaluation, from the analysis of system response to several hydrological events. This criterion offers the possibility to create a spatial UFRI map, by integrating the function UFRI versus probability of occurrence of the events in each basic evaluation unit of the model, which are defined by the cells. After the construction of the mathematical model bases, simulations are performed considering several hydrological events with different return periods. The return periods (RP) adopted are: 01, 05, 10, 25, 50, 100, 500 and 1000 years. This choice aims to cover of the whole probabilistic curves, considering from ordinary events (01 year) to highly rare events (1000 years).

For each cell, the results of mathematical modelling, represented by flooding depths, flow velocities and flood permanence times, are used to feed a spreadsheet to calculate the indicators, the sub-indexes and, finally, the UFRI. This activity is performed for each hydrological scenario. Partial UFRI values are plotted against the probability of occurrence of a given event (or higher) over a 25-year horizon (taken as a planning reference horizon). For each cell, the UFRI function (UFRI vs probability) is integrated in order to estimate the final 


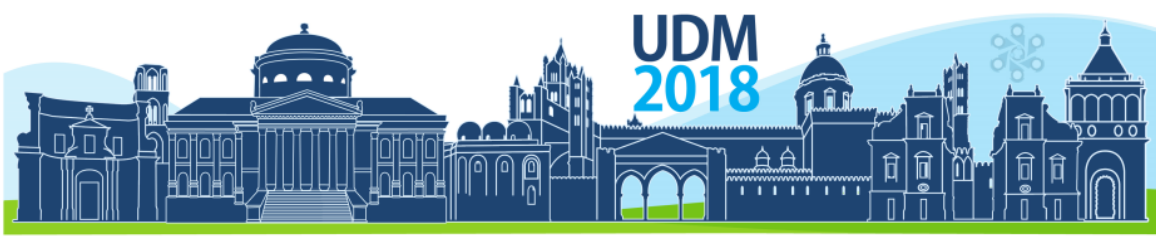

$11^{\text {th }}$ International Conference on Urban Drainage Modelling

23-26 Sep | Palermo - Italy

UFRI, which considers the probability of occurrence of several hydrological events over a period of 25 years. At the end, the basin resilience map is elaborated, with UFRI integrated for each cell on all simulated events. Since the impacts of events with more severity than that of the design event are considered in this UFRI integration process, one can conclude that the residual risk is internalized in the estimation of the urban basin resilience.

\subsection{Case study and Simulation scenarios}

The Canal do Mangue catchment was chosen as a case study to exemplify the discussion carried out in this work. This catchment is located in the city of Rio de Janeiro, in a highly urbanized area with a consolidated occupation. In this kind of situation, control actions are necessary based on urban drainage compensatory techniques. The proposed scenarios aim to provide a well operation of the basin drainage system in response to several hydrological events, considering three conditions of the drainage infrastructure system: CO - without interventions; C1 - with concentrated interventions; C2 - with distributed interventions over the watershed. For each drainage system condition, the hydrodynamic modelling was performed for the selected hydrological events, resulting in a spatial assessment of flooding hazard on the urban area. Three aspects of flooding were mapped each time: flood depth; surface flow velocity; permanence time of flooding.

The model considered the whole watershed, including hills upstream and the urban plains, the rivers and channels network and the storm drains greater than one square meter of cross section. Thus, the mapped flooding referred both to river flooding and storm water network surcharges and consequent overflows, using the main features of MODCEL.

\section{RESULTS AND DISCUSSION}

Figure 3 presents the distributed UFRI result spatialized in the Canal do Mangue catchment, resulting from the simulations with the three drainage network conditions.

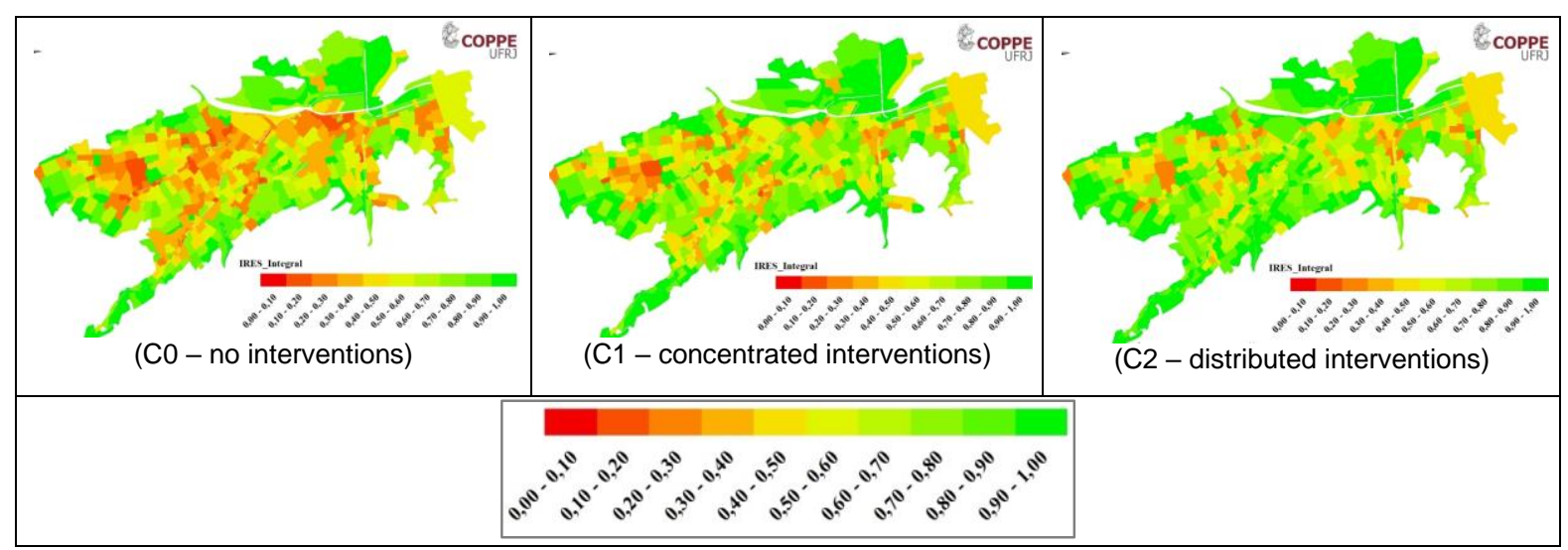

Figure 3 - UFRI mapping for the three drainage system conditions

A comparative evaluation of the final results of UFRI mapping in the basin can be carried out by analysing the potential of reducing areas with low resilience and increasing areas with high resilience. With this evaluation, it is possible to observe a sensitive impact of the interventions in the reduction of the area with very low resilience and in the increase of the areas with high and very high resilience. As seen in Figure 4. 


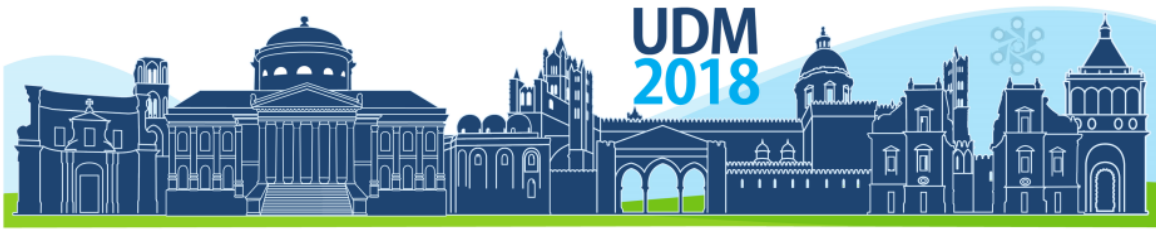

$11^{\text {th }}$ International Conference on Urban Drainage Modelling

23-26 Sep | Palermo - Italy

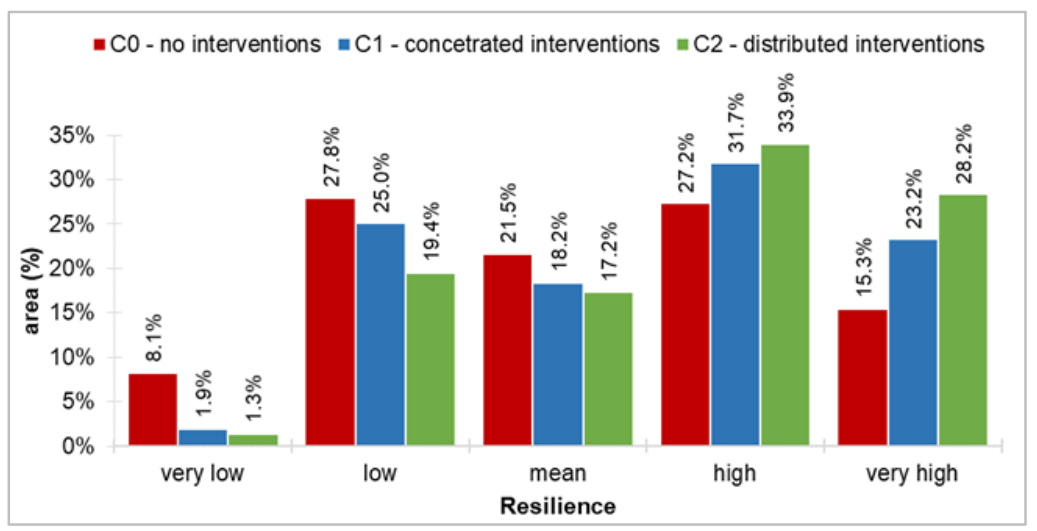

Figure 4 Distribution by area in the basin of the resilience bands, for each simulated condition.

\section{CONCLUSIONS}

The paper presents an alternative path for the evaluation of flood risk management plans, creating an approach focused on increasing resilience to floods in the urban system. The resilience-based approach prioritizes adaptive measures that seek to harmonize the relationship between the city and the flood cycle. The application of UFRI makes it possible to demonstrate spatially distributed results obtained by different approaches. The results showed an improvement in the response of the basin as more distributed the flood control interventions are. Resilience mapping can be used as a supporting tool for hierarchizing interventions, defining the locations that produce the greatest positive impacts on the system as a whole, and thus addressing a systemic assessment. The proposed criterion also allows an ecosystemic evaluation.

\section{References}

Bertilsson, L., Wiklund, K., 2015. Urban Flood Resilience: A case study on how to integrate flood resilience in urban planning. Dissertation (Master of Science in Division of Water Resources Engineering) Lund University, Sweden.

Mascarenhas, F.C.B., Miguez, M.G., 1994, Modelação de Grandes Planícies de Inundação por um Esquema de Células - Aplicação ao Pantanal de Mato-Grosso. Revista Brasileira de Engenharia (RBE), Caderno de Recursos Hídricos, v.12, n.2.

Mascarenhas, F.C.B.; Miguez, M.G.; 2002. Urban Flood Control through a Mathematical Cell. In: Water International Resources, Vol. 27, № 2, págs. 208-218, Junho 2002; Illinois, E.U.A.

Miguez, M.G., 2001, Modelo Matemático de Células de Escoamento para Bacias Urbanas. Tese de D.Sc., COPPE/UFRJ, Rio de Janeiro, RJ, Brasil.

Miguez, M.G.; Battemarco, B.P. ; Sousa, M.M.; Rezende, O.M. ; Veról, A.P. ; Gusmaroli, G. 2017. Urban Flood Simulation Using MODCEL-An Alternative Quasi-2D Conceptual Model. Water, v. 9, p. 445, 2017.

Rezende, O.M., 2018. Análise Quantitativa da Resiliência a Inundações para o Planejamento Urbano: Caso da Bacia do Canal do Mangue no Rio de Janeiro. Tese de D.Sc., COPPE/UFRJ, Rio de Janeiro, RJ, Brasil.

Samuels, P.; Gouldby, B., 2009. Language of Risk - Project Definitions (Second Edition). Integrated Flood Risk Analysis and Management Methodologies, FLOODSite. Disponível em: <www.floodsite.net>

Sayers, P.; LI Y.; Galloway, G.; Penning-Rowsell, E.; Shen, F.; Wen, K., Chen, Y. e Le Quesne, T., 2013. Flood Risk Management: A Strategic Ap-proach. Paris, UNESCO.

Silva, B.M.G. da; Sousa, M.M.; Rezende, O.M.; Jacob, A.C.P.; Ribeiro, L.B,F.; Miguez, M.G.; Arrais, C.M., 2017. Uso de Modelo Multicamadas para Avaliação de Cheias Urbanas, Proceedings of XXII Simpósio Brasileiro de Recursos Hídricos, Florianópolis, November 26 - December 01, 2017, [in portuguese].

Tebaldi, I., Miguez, M. G., Battemarco, B. P., Rezende, O. M., Veról, A. P., 2015. Índice de resiliência a inundações: Aplicação para a sub-bacia do rio Joana, Rio de Janeiro, RJ. In: XXI Simpósio Brasileiro de Recursos HídricosSBRH, 2015, Brasília, DF/Brasil.

Zanobetti, Dino et al. 1970. Mekong delta mathematical model program construction. Journal of the Waterways, Harbors and Coastal Engineering Division, v. 96, n. 2, p. 181-199. 


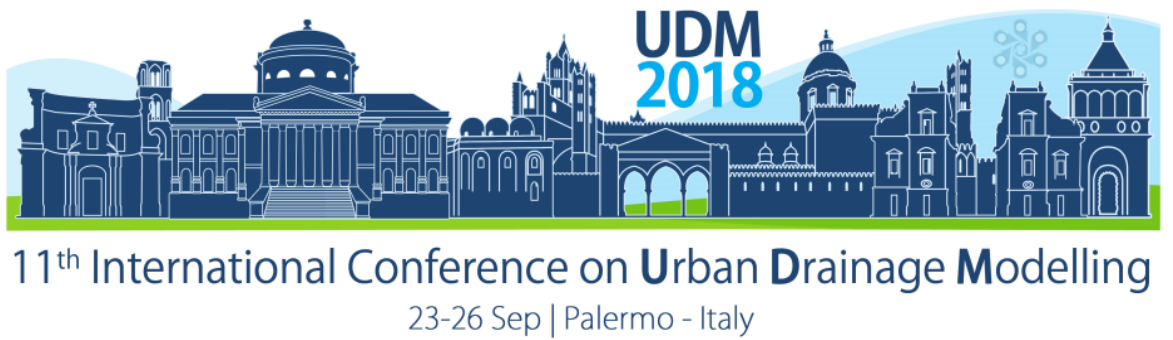

\title{
Challenge of Transport: Exploring the Limit of Gravity Sewers to Transport Concentrated Domestic Slurries
}

\author{
Adithya Thota Radhakrishnan ${ }^{1}$, Jeroen Langeveld ${ }^{1,2}$, Jules van Lier $^{1}$ and Francois Clemens ${ }^{1,3}$ \\ ${ }^{1}$ Delft University of Technology, Department of Water Management, Delft, The Netherlands \\ 2 Partners 4 Urban Water, Nijmegen, The Netherlands \\ ${ }^{3}$ Deltares, Department of Industrial Hydrodynamics, Delft, The Netherlands
}

\begin{abstract}
Novel sanitation systems produce wastewater streams with a high concentration of total suspended solids. Although pressurised pipe transport may be the key, it is instructive to know the limit of the conventional gravity based pipe system. A model is developed to describe the transport of these slurries in a partially filled pipe with a gravity based drive. This model depends on the pipe diameter, volumetric inflow, inclination of the pipe and concentration of the slurry. As it incorporates the change of rheological parameters through the dependence of concentration, the flow of slurries at various concentrations can be explored. On a case by case basis, by choosing the appropriate values for the variables, a moody chart showing the relationship between the friction factor and Reynolds number can be plotted. This chart shows the possible flow characteristics, and thereby determining the limits of the system.
\end{abstract}

Keywords: Novel sanitation, partially filled pipe model, gravity flow

\section{THE CHALLENGE}

Novel sanitation systems equipped with source separation, vacuum toilets and food waste disposers have known to produce wastewater streams with a high concentration of organic solids (Thota Radhakrishnan et al., 2017a). These slurries demand a higher load carrying capacity on the pipe transport systems from their collection to treatment. An answer to this is the already established pressurised pipe systems. But before that it is instructive to know the limits of the conventional gravity based sewer system.

To understand gravity based systems, it is intuitive to develop a model that describe these systems. This study deals with the development of this model and a case to elucidate its use. Two regimes occur in gravity based pipeline transport, a partially filed pipe or a fully filled pipe flow. A fully filled pipe flow can be directly extended from a pressurised pipe flow situation. Therefore, this paper will only deal with partially filled pipe flows.

\section{THE MODEL}

\subsection{Partially filled pipe flow}

Describing the flow in a partially filled pipe is akin to describing flow as an open channel. Thereby, both laminar and turbulent regimes need to be modelled. For deriving the wall shear stress and the friction factor, and thus velocity a hydraulic radius $R_{h}$ is used to represent the region of the pipe being considered.

The hydraulic radius is defined as $R_{h}=A / P$, where $A$ is the cross-sectional area of the flow and $P$ is the wetted perimeter of the channel. 


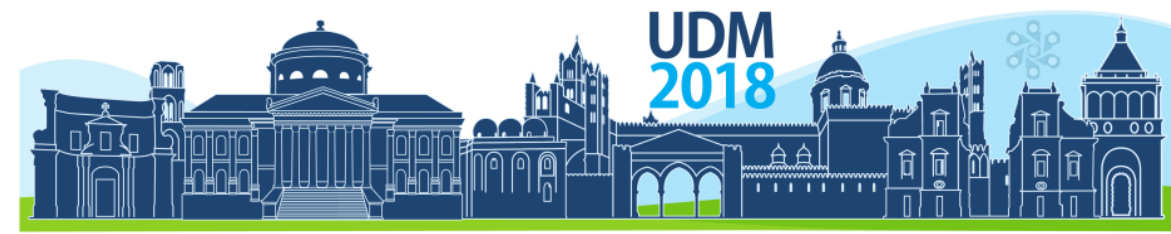

$11^{\text {th }}$ International Conference on Urban Drainage Modelling

23-26 Sep | Palermo - Italy
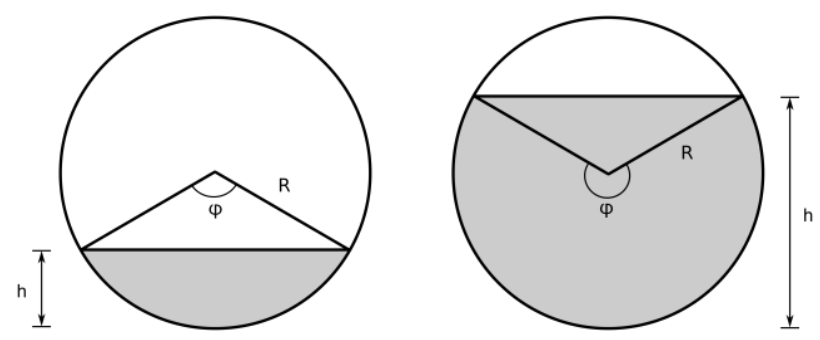

Figure 1. Partially filled pipe flow (shaded region) represented as a segment of a circle.

The partially filled flow as represented in figure 1, can be used to derive the parameters $A$ and $P$ as $A=D^{2}(\varphi-\sin \varphi) / 8$ and $P=D(\varphi / 2)$ with $\varphi=2 \cos ^{-1}(1-2 h / D)$, Where the diameter of the pipe is taken as $D$ and the flow height in the pipe (Figure 1) is considered to be $h$.

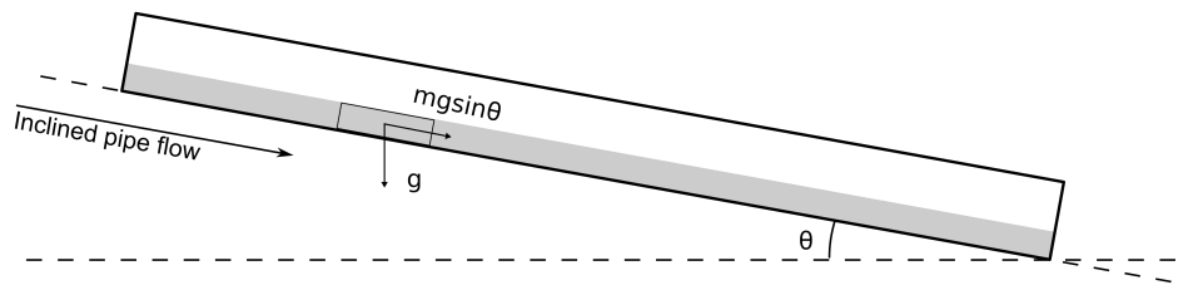

Figure 2. Representation of flow in an inclined pipe, with angle of inclination $\theta$.

In considering the flow in an inclined pipe (Figure 2), by equating the gravitational force to the difference in pressure along the pipe, the wall shear stress $\tau_{w}$ can be derived as:

$\tau_{w}=\frac{A}{P} \rho g \sin \theta=R_{h} \rho g \sin \theta$

Laminar flow. A recent review by Burger et al. (Burger et al., 2014) of the available laminar models, showed that the friction factor model incorporating the Reynolds number proposed by Haldenwang et. al. (Haldenwang et al., 2002) was the most appropriate.

The model follows as $f=16 / R_{H}$. The friction factor is used as $f=2 \tau_{w} / \rho V^{2}$, with the Haldenwang Reynolds number given as:

$R_{H}=\frac{8 \rho V^{2}}{\tau_{y}+k\left(\frac{2 V}{R_{h}}\right)^{n}}$

Where the average flow velocity is $V, \rho$ being the density of the fluid and the rheological parameters of the slurry under study is given by $\tau_{y}$ for the yield stress, $k$ for the consistency index and $n$ for the behaviour index. 


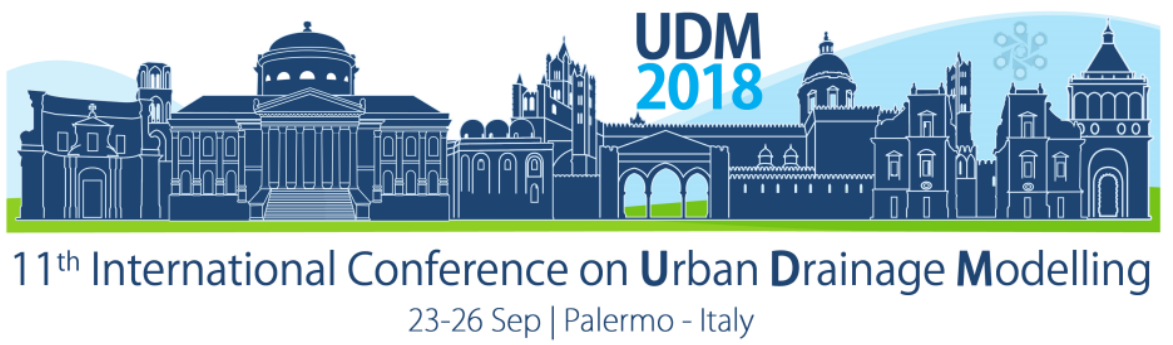

Turbulent flow. The Turbulent flow model is also the one proposed by Haldenwang (Burger et al., 2014), as this is shown to give the best results. The model describes the smooth wall turbulent velocity as:

$V=\sqrt{g h \sin \theta}\left[2.5 \ln \left(\frac{2 R_{h}}{e}\right)-76.86 \eta_{\operatorname{app}(500)}-9.45\right]$

Using $\eta_{a p p(500)}$ the apparent viscosity at a shear rate of $500 s^{-1}$.

\subsection{Rheology}

Rheology of concentrated domestic slurry that describes the flow characteristics is obtained from a previous work of the authors (Thota Radhakrishnan et al., 2017b). The rheology is obtained for the slurries from a pilot project employing vacuum toilets and source separation. The rheology used is a function of concentration, and therefore by varying the concentration of the slurry, the dependent rheology changes. Therefore, slurries at varies dilutions can be studied.

\section{RESULTS AND DISCUSSION}

A Moody chart like diagram is useful in studying pipe involving fractional losses. By solving the fraction factor equations (equation 2 and 3 ) for laminar and turbulent flow regimes one and plotting them, a Moody chart can be derived. As a representative diagram, the plot of friction factor $\mathrm{f} v \mathrm{vs}$. Haldenwang Reynolds number $\mathrm{R}_{\mathrm{H}}$ is shown in figure 3 for a pipe inclination of $2^{\circ}$ in a pipe of $400 \mathrm{~mm}$ diameter for a concentrated domestic slurry with a total suspended solid content of $2.8 \%$ (wt./wt.).

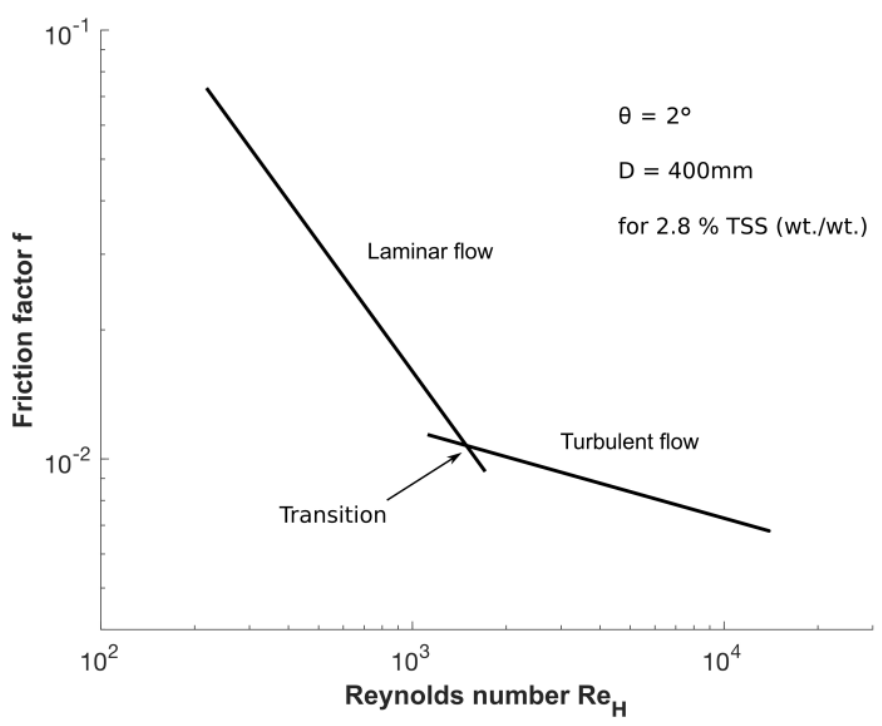

Figure 3. Friction factor vs. Haldenwang Reynolds number for a 400mm pipe diameter.

The preferable regime of operation is in that of turbulent. The transition to turbulence is approximately identified using the intersection of the laminar and turbulent curves. Using this curve and fixing an appropriate velocity, the limit of the gravity sewers can be determined. 


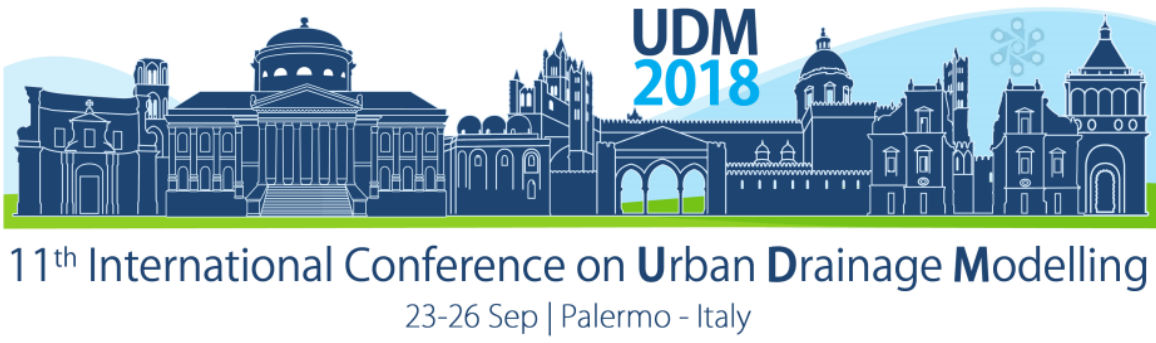

In practise. Let's consider a case where a small community of 25 houses have novel sanitation implemented in them. Considering an average of 4 persons per household, the community would consist of 100 inhabitants. To understand the limit of gravity aided pipe transport for the transport of concentrated domestic slurry containing mainly faeces, a peak case must be evaluated. This peak would be that $50 \%$ of the inhabitants make use of the sanitation facility at the same time (early morning peak, with respect of faecal discharge). With an average of $250 \mathrm{~g} / \mathrm{cap} /$ day (Rose et al., 2015; Nishimuta et al., 2006) faecal discharge per person per day and the use of 1 litre of flush water in the vacuum toilets, a maximum flow of $1.25 \mathrm{l} / \mathrm{cap}$ with a $2.3 \%$ TSS (wt./wt.) is generated. A total of $0.0625 \mathrm{~m}^{3} / \mathrm{s}$ of slurry must be handled by a gravity aided pipe system. In practise, taking a limit with a lower flow velocity of $0.7 \mathrm{~m} / \mathrm{s}$, a maximum transport length of $200 \mathrm{~m}$ can be achieved with a $400 \mathrm{~mm}$ pipe with $69 \%$ of the pipe filled. The limits to this calculation is taken as follows: (a) maximum underground laying depth cannot exceed $5 \mathrm{~m}$ (b) minimum flow velocity is $0.7 \mathrm{~m} / \mathrm{s}$ (c) flow must be in turbulence.

Note: Several cases will be elucidated and discussed in the full paper, as it is out of the scope of an extended abstract.

\section{CONCLUSIONS}

A model is developed to describe the flow of concentrated domestic slurry in a gravity based partially filled pipe system. This model can be controlled through several variables such as the pipe inclination, inflow rates, diameter of the pipe, and concentration of the slurry. Depending on the case, by choosing the appropriate values of the variables a moody chart can be created. This describes the possible flows in the system, thereby setting the limits of the system to these possible flows.

\section{References}

Burger J. H., Haldenwang R., \& Alderman N. J. (2014) Laminar and turbulent flow of non-newtonian fluids in open channels for different cross-sectional shapes. Journal of Hydraulic Engineering, 141(4), 4014084.

Haldenwang R., Slatter P. T., \& Chhabra R. P. (2002) "Laminar and transitional flow in open channels for nonNewtonian fluids" in BHR Group.

Nishimuta M., Inoue N., Kodama N., MORIKUNI E., YOSHIOKA Y. H., MATSUZAKI N., SHIMADA M., SATO N., IWAMOTO T., \& OHKI K. (2006) Moisture and Mineral Content of Human Feces-High Fecal Moisture Is Associated with Increased Sodium and Decreased Potassium Content-. Journal of nutritional science and vitaminology, 52(2), 121-126.

Rose C., Parker A., Jefferson B., \& Cartmell E. (2015) The characterization of feces and urine: a review of the literature to inform advanced treatment technology. Critical reviews in environmental science and technology, 45(17), 1827-1879.

Thota Radhakrishnan A., van Lier J., \& Clemens F. (2017a) Rheological characterisation of concentrated domestic slurry. Manuscript submitted for publication.

Thota Radhakrishnan A., van Lier J., \& Clemens F. (2017b) Rheology of un-sieved concentrated domestic slurry: a wide gap approach. Manuscript submitted for publication. 


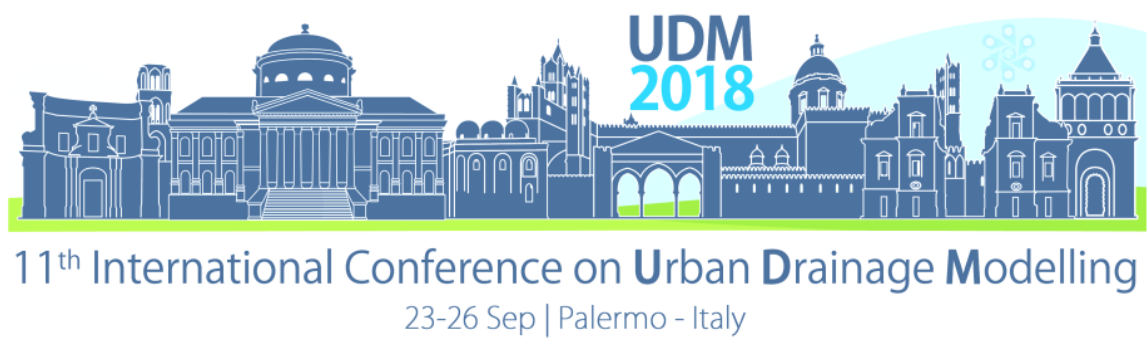

\title{
Impact of urbanization (trends) on hydrological behaviour of Belo Horizonte watersheds (Brazil)
}

\author{
Martin SEIDL ${ }^{1}$, Luiz Palmier ${ }^{2}$, Guido Petrucci ${ }^{1}$ and Nilo Nascimento ${ }^{2}$ \\ ${ }^{1}$ ENPC, LEESU, University Paris-Est, Marne-la-Vallée, France \\ 2 UFMG, EHR, Belo Horizonte, Brazil \\ (martin.seidl@enpc.fr,palmier@ehr.ufmg.br, guido.petrucci@leesu.enpc.fr, niloon@ehr.ufmg.br)
}

\begin{abstract}
The paper presents an analysis of runoff behaviour of four, small urban catchments between the city of Belo Horizonte and Contagem in Brazil, linked to their landuse. Two year of on- line measurements of hydrological and basic water quality data, combined with spatial analysis, made it possible to compare urban catchment with different land use and urbanization and support the generally admitted hypothesis that more dense urbanization generate faster and bigger discharges, accompanied by stronger solid fluxes. These findings contribute to better understanding of the urbanization trends of Pampulha watershed and to predict measures of mitigation if actual trends go on.
\end{abstract}

Keywords: urban catchment, land use, wet weather discharge, run-off, urbanization

\section{INTRODUCTION}

Brazil, as several other developing countries, suffers from fast urbanization, accompanied by impermeabilization and deficient infrastructures. Cities with a dense hydrographical network like the two and half million inhabitants counting Belo Horizonte, meets therefore everlasting difficulties linked to wet weather management like flooding, sediment built up, sewer overflows and diffuse pollution - in most of its urban rivers (Aroeira et al., 2010; Aroeira, 2012).

Urbanization and intensive land use can have a negative impact on the water cycle and a better knowledge of their relationship can help a more sustainable and integrated water management (IWM) at the catchment scale (Miller et al., 2014). The IWM together with sustainable drainage systems can helps to mitigate the impact of urbanization and climate change (Dudula and Randhir, 2016).

After previous study on quality of urban runoff in small urban watershed in Belo Horizonte (Seidl et al., 2014) the aim of this work is focused on the relationships between land use and quantitative and qualitative runoff characteristics in small urban watershed of lake Pampulha, experiencing fast urbanization to improve the water quality of the receiving water body.

\section{MATERIALS AND METHODS}

Originally, the lake Pampulha was built to supply drinking water to the city of Belo Horizonte, however, since the 1970s; the water quality has degraded as a consequence of the rapid watershed urbanization with neither sanitation infrastructure nor erosion control. Nowadays, lake silting and water eutrophication with episodes of cyano-bacteria blooms are the main problems to be tackled. Despite its poor water quality, the lake is an important tourist spot 


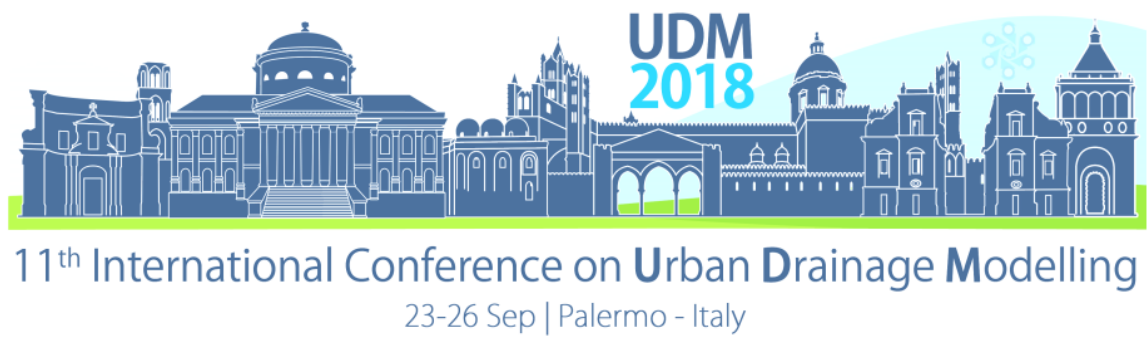

and recreational area for inhabitants and contributes to prevent flooding downstream (Friese et al., 2010).

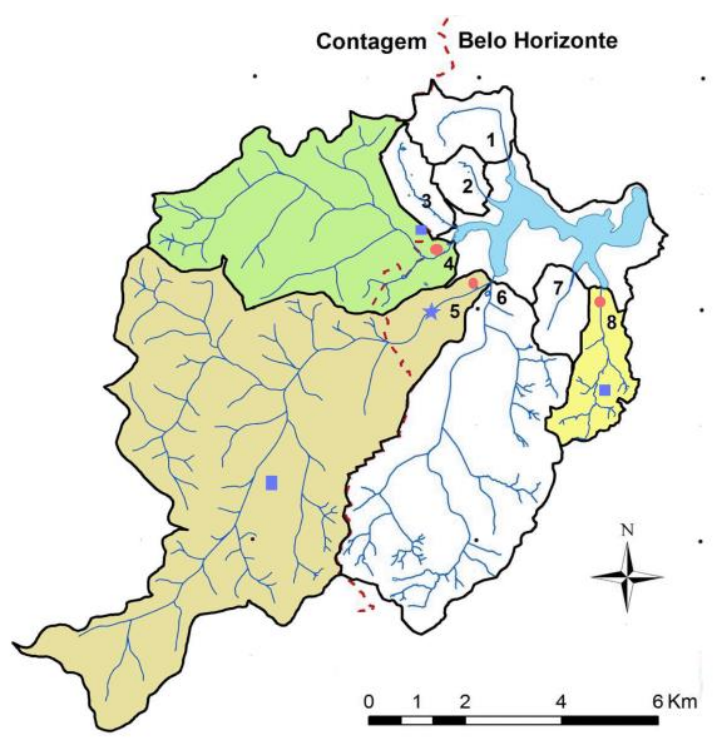

Figure 1: Studied watersheds (adapted from (Silva, 2014). Red dots: river level (including basic water quality parameters) and ground water level measurements, blues squares: rain gauges, blue star: third party rain gauge and level measurements. Lake coordinates: $19^{\circ} 55^{\prime} \mathrm{S}, 43^{\circ} 56^{\prime} \mathrm{W}$.

The catchment of the lake Pampulha (Figure 1) extends on $98 \mathrm{~km}^{2}$ (figure 1) and is drained by eight small creeks : (1) Olhos d'água ; (2) AABB ; (3) Bráunas ; (4) Água Funda ; (5) Sarandi ; (6) Ressaca; (7) Tijuco and (8) Mergulhão. To cover the major part of the catchment discharge (Friese et al., 2010; Resck et al., 2007; Silva, 2014), the watersheds of Agua Funda (4), Sarandi (6) and Mergulhao (8) were monitored over two hydrological periods, running from September (2016) to May (2018) at the outlet of each watershed. The river water level and basic water quality (conductivity, turbidity and oxygen) were monitored at 5 minute interval using a multi-parameter probe (Aquaread) and separate level probe (Campbell), in rectangular concerted sections. The precipitation was monitored separately in each basin, together with groundwater level (Sollinst). Flow velocity during rain events, were estimated in situ with floaters, in sections of $1 \mathrm{~km}$, ahead of the monitoring points. For the Ressaca (5) watershed data were obtained from the hydrological monitoring network of city of Belo Horizonte (Carvalho and Aroeira, 2012). - The water level data were transformed to flow using standard equation and channel geometry. The hydrological response of the watershed was in the first place characterized with peak flow, discharge coefficients basin discharge and mean concentrations (Tarboton, 2003). In the second place existing GIS data, combined with old and recent satellite images were used to build a numerical model within EPA SWMM (Rossman, 2015). For each basin a specific series of 20 rain events was used to calibrate its model, using a Matlab automated procedure with genetic algorithm (Petrucci, 2012; Silva et al., 2016). The hydrological behaviour of the watersheds was thereafter compared using calibrated SWMM model, applying identical rain event to all watersheds. Were tested events with monthly and annual return period. In the final paper these results are linked to land use data and a run-off prevision is proposed based on evaluating of historical data of urbanization. 


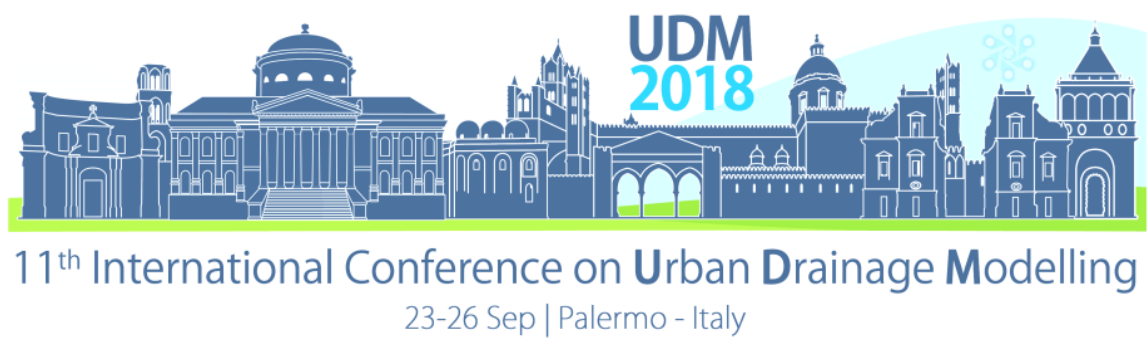

\section{RESULTS AND DISCUSSION}

The evaluation of concomitant rain events (table 1) can give some valuable information. First we observe an important watershed rainfall heterogeneity leading to apparently same discharge coefficient $(\mathrm{L} / \mathrm{s} / \mathrm{ha})$ for the small as for the big one. Though if we compare the maximum discharge to a theoretical average discharge (Qth) we observe a net difference between A.Funda and Mergulhao on one hand and Sarandi on second hand. The first are pervious for roughly $50 \%$, while the last only for $25 \%$.

Table 1: Example of the rain of 12 January 2017 event data, with rough estimates of maximum flows. The Qth is theoretical average flow generated at the basin outflow.

\begin{tabular}{|c|c|c|c|c|c|c|c|c|}
\hline & $\begin{array}{l}\text { A_catch } \\
\left(\mathbf{k m}^{2}\right)\end{array}$ & $\underset{(\mathrm{m})}{\text { d_river }}$ & $\begin{array}{c}\text { h_rain } \\
(\mathrm{mm})\end{array}$ & $\begin{array}{l}\text { t_rain } \\
\text { (h) }\end{array}$ & $\begin{array}{c}\text { Qmax } \\
(\mathrm{m} 3 / \mathrm{s})\end{array}$ & $\begin{array}{r}\text { Qth } \\
\text { (m3/s) }\end{array}$ & $\begin{array}{l}\text { Qmax/ } \\
\text { Qth }\end{array}$ & $\begin{array}{c}\text { Qmax } \\
\text { (L/s/ha) }\end{array}$ \\
\hline Sarandi & 44 & 8 & 14,2 & 1,25 & 32 & 1,39 & 23 & 7,3 \\
\hline A. Funda & 15 & 6 & 34,2 & 1,75 & 12 & 0,81 & 99 & 8,0 \\
\hline Mergulhao & 5 & 3 & 32,6 & 3 & 0,4 & 0,15 & 99 & 0,8 \\
\hline
\end{tabular}

A more refined analysis of hydrological behaviour of the watershed is done by SWMM. For the simulation of Mergulhao and Ressaca watershed the coefficient de Nash-Sutcliffe between 0.81 and 0.83 were obtained (Figure 2). The comparison with a rain event with a monthly return period ( $25.8 \mathrm{~mm}$ on 6 February 2017), shows clearly the positive impact of green (or pervious) surface on the watershed discharge, the green Mergulhao watershed (left) being slower and lower than the far more urbanized Resaca watershed. Mergulhao accounts for $1.37 \mathrm{l} / \mathrm{ha} / \mathrm{sec}$ in average while Ressaca is $7.56 \mathrm{I} / \mathrm{ha} / \mathrm{sec}$. This higher flux does not lead necessary to higher solid flux. More natural space can lead to higher erosion and solid loss than more urbanised watershed. Reversely more urbanised watershed has more diffuse pollution especially waste water leading to higher conductivity of the run-off (results not shown).
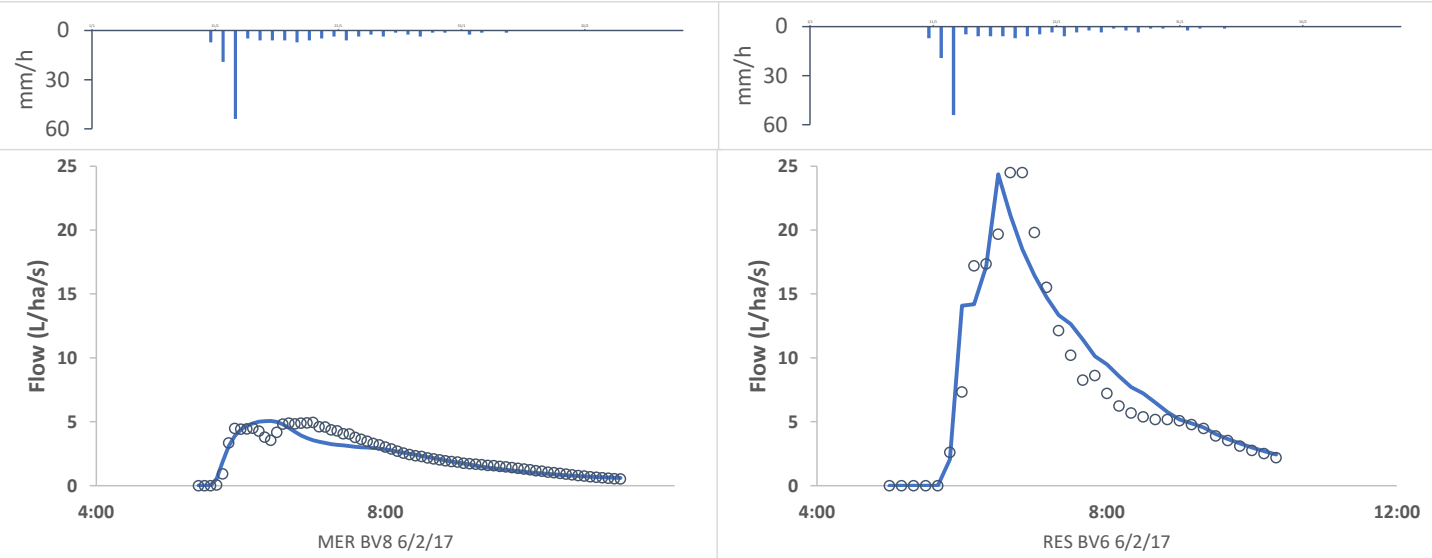

Figure 2. Example of simulation of an equivalent rain event for two watersheds with opposite land use. Left $40 \%$ open green space (Mergulhao). Right less than 10\% open green space (Resaca) 


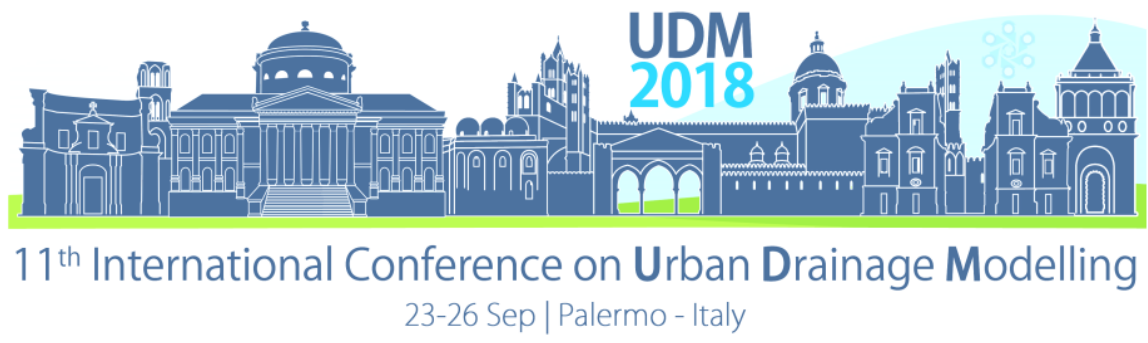

\section{CONCLUSIONS AND PERSPECTIVES}

One year of on-line measurements of hydrological and basic water quality data, combined with spatial analysis, made it possible to support the generally admitted hypothesis that more dense urbanization generate faster and bigger catchments discharges, accompanied by stronger solid fluxes (Fritsch, 2013; Salvadore et al., 2015). These findings will contribute to better understand and evaluate the effects of urbanization in the Belo Horizonte watershed and facilitate the restoration of lake Pampulha. The rain season 2017/2018 will serve to consolidate the previous runoff data and improve the hydrological analysis, allowing to predict the trend for the Pampulha watershed if actual urbanization trend will be maintained.

\section{ACKOWLEDGMENTS : The project was financially supported by FINEP CT Hidro as a part of project BRUM and by FAPEMIG through different scholarships.}

\section{References}

Aroeira, R., 2012. O Plano Diretor de Drenagem de Belo Horizonte - Desafios na Implantação do Sistema de Monitoramento Hidrológico e Alerta contra Inundações. PBH.

Aroeira, R., Arantes Braga, R., Donária Pereira, M., Carvalho Aguiar, I., 2010. The Municipal Sanitation Plan for the Municipality of Belo Horizonte. NOVATECH 2010.

Bhaskar, A.S., Welty, C., 2012. Water Balances along an Urban-to-Rural Gradient of Metropolitan Baltimore, 2001-2009. Environ. Eng. Geosci. 18, 37-50. https://doi.org/10.2113/gseegeosci.18.1.37

Carvalho, I., Aroeira, R., 2012. Política de Combate a Inundações de Belo Horizonte. PBH SUDECAP.

Dudula, J., Randhir, T.O., 2016. Modeling the influence of climate change on watershed systems: Adaptation through targeted practices. J. Hydrol. 541, 703-713. https://doi.org/10.1016/j.jhydrol.2016.07.020

Friese, K., Schmidt, G., de Lena, J.C., Arias Nalini, H., Zachmann, D.W., 2010. Anthropogenic influence on the degradation of an urban lake - The Pampulha reservoir in Belo Horizonte, Minas Gerais, Brazil. Limnol. Ecol. Manag. Inland Waters 40, 114-125. https://doi.org/10.1016/j.limno.2009.12.001

Fritsch, F.E.D., 2013. Influência do uso e ocupação do solo nas vazões de pico na bacia hidrográfica do alto rio ligeiro, Pato Branco-PR (B.S. thesis). Universidade Tecnológica Federal do Paraná.

Miller, J.D., Kim, H., Kjeldsen, T.R., Packman, J., Grebby, S., Dearden, R., 2014. Assessing the impact of urbanization on storm runoff in a peri-urban catchment using historical change in impervious cover. J. Hydrol. 515, 59-70. https://doi.org/10.1016/j.jhydrol.2014.04.011

Petrucci, G., 2012. La dffusion du controle a la source des eaux pluviales urbaines.Confrontation des pratiques a la rationalite hydrologique.

Resck, R.P., Neto, J.F.B., Coelho, R.M.P., 2007. Nova batimetria e avaliação de parâmetros morfométricos da Lagoa da Pampulha (Belo Horizonte, Brasil). Rev. Geogr. 3, 24-37.

Rossman, L.A., 2015. Storm Water Management ModelUser's Manual Version 5.1 (No. EPA/600/R-14/413b Revised September 2015www2.epa.gov/water-research). EPA, National Risk Management Laboratory Office of Research and Development U.S. Environmental Protection Agency.

Salvadore, E., Bronders, J., Batelaan, O., 2015. Hydrological modelling of urbanized catchments: A review and future directions. J. Hydrol. 529, 62-81. https://doi.org/10.1016/j.jhydrol.2015.06.028

Seidl, M., Petrucci, G., Lorgeoux, C., Nilo, D.O.N., 2014. Assessment of dry and wet weather pollutant fluxes in a small urban watershed of Belo Horizonte (Brazil), in: ICUD 2014,13th International Conference on Urban Drainage, Sarawak, Malaysia, 7-12 September 2014.

Silva, T., 2014. Suivi et modélisation de la dynamique des cyanobactéries dans les lacs urbains au sein de leur bassin versant (phdthesis). Université Paris-Est.

Silva, T.F. das G., Vinçon-Leite, B., Giani, A., Figueredo, C.C., Petrucci, G., Lemaire, B., Sperling, E.V., Tassin, B., Seidl, M., Khac, V.T., Viana, P.S., Viana, V.F.L., Toscano, R.A., Rodrigues, B.H.M., Nascimento, N. de O., 2016. Modelagem da Lagoa da Pampulha: uma ferramenta para avaliar o impacto da bacia hidrográfica na dinâmica do fitoplâncton. Eng. Sanit. E Ambient. 21, 95-108. https://doi.org/10.1590/S1413-41520201600100125692

Tarboton, D.G., 2003. Rainfall-runoff processes. Utah State University. 


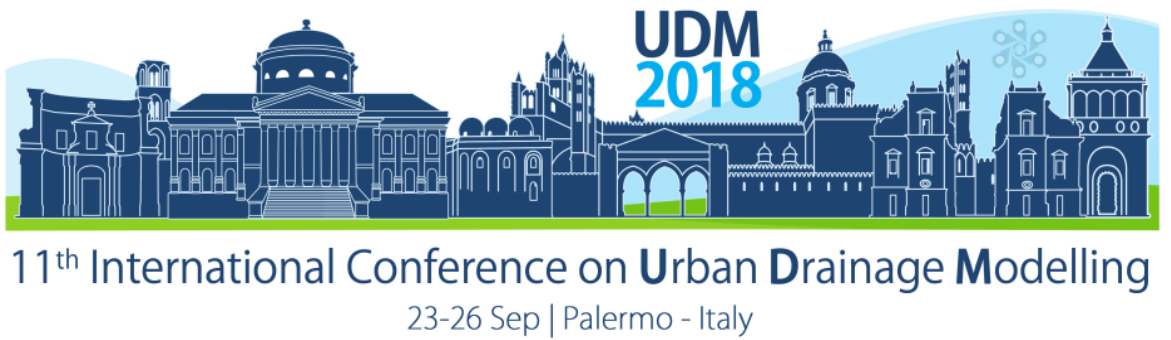

\title{
Urban Flood Management Based on Ensemble Precipitation Forecasts
}

\author{
Thomas Einfalt ${ }^{1}$, Sandra Hellmers ${ }^{2}$ and Alrun Jasper-Tönnies ${ }^{1}$ \\ ${ }^{1}$ hydro \& meteo GmbH \& Co. KG, Lübeck, Germany \\ 2 Technical University of Hamburg, Hamburg, Germany
}

\begin{abstract}
Sophisticated strategies are required for flood warning in urban areas regarding convective heavy rainfall events. An approach is presented to improve short-term precipitation forecasts by combining ensembles of radar nowcasts with the numerical weather predictions COSMO-DE-EPS of the German Weather Service. The combined ensemble forecasts are produced operationally every $5 \mathrm{~min}$. Applications involve the Flood Warning Service Hamburg ( $\mathrm{WaBiHa})$ and real-time hydrological simulations with the model KalypsoHydrology. Ensemble forecast flood hydrographs for the urban catchment Kollau are presented in this work. The range and quantiles are illustrated for a convective storm event in summer 2016. A flood management measure is improved by using precipitation forecasts in a flood control reservoir.
\end{abstract}

Keywords: ensemble forecast; online simulation; basin control; flood warning

\section{INTRODUCTION}

The high variability of local intense rainfall events and the short response time of flow in urban catchments require improved methods for flood warning and flood prevention. The presented work is part of the German research project StucK "Long term drainage management of tideinfluenced coastal urban areas with consideration of climate change". A key aspect of this project is to improve short term forecasts of heavy rainfall by combining ensembles of radar nowcasts with numerical weather prediction ensembles (Jasper-Tönnies et al., 2018).

In this paper we present the results of a case study of runoff simulations using ensemble precipitation forecasts as input to illustrate the potential of combined ensemble forecasts for urban water management and flood prevention based on reservoir control in Hamburg.

\section{MATERIALS AND METHODS}

\subsection{Ensemble precipitation forecasts}

Numerical Weather Predictions. Numerical weather predictions produced by the German Weather Service (DWD) are used: COSMO-DE is a non-hydrostatic model with a horizontal resolution of $0.025^{\circ}(2.8 \mathrm{~km})$. The deterministic forecasts COSMO-DE and the ensemble forecasts COSMO-DE-EPS (Kühnlein et al. 2014) are provided every $3 \mathrm{~h}$ with a lead time of $27 \mathrm{~h}$. COSMO-DE forecasts are currently used as input data for flood warnings by the Flood Warning Service Hamburg (WaBiHa: http://www.wabiha.de).

Ensemble Precipitation Nowcasts. The basis of the nowcasts are

- Radar data from 4 DWD radar stations: Boostedt, Rostock, Hannover and Emden. The radar product (DX) is a PPI with a resolution of $1 \mathrm{~km} \times 1^{\circ}$ and $5 \mathrm{~min}$.

- Rain gauge measurements of 400 stations (Hamburg/ Northern Germany, dt 5 min $-1 \mathrm{~h}$ ) 


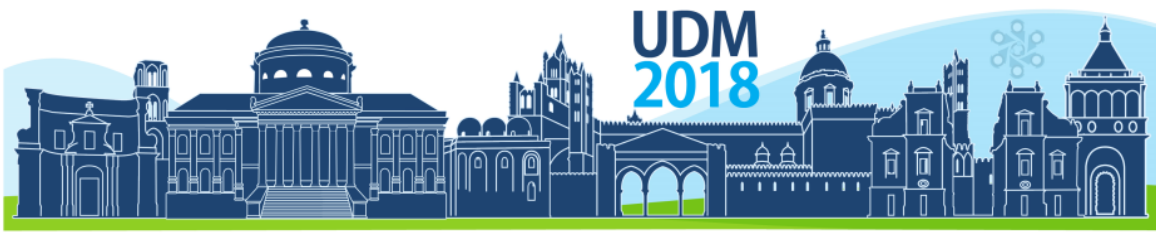

$11^{\text {th }}$ International Conference on Urban Drainage Modelling

23-26 Sep | Palermo - Italy

- The radar data are processed and corrected with the software SCOUT, using several filter and correction methods (Jasper-Tönnies \& Jessen, 2014). The rain gauge measurements are continuously used for the adjustment of radar measured rainfall sums, based on data of the past $3 \mathrm{~h}$. A composite with a resolution of $1 \mathrm{~km} \times 1 \mathrm{~km}$ is produced every $5 \mathrm{~min}$ from the data of the four radar stations. An example of the adjusted composite is shown in Fig. 1 .

- The radar composites of the last 30 min serve as input for calculating nowcasts with a lead time of 1-3 $\mathrm{h}$. The method is a further development of the nowcast described by Tessendorf and Einfalt (2012).

- Ensemble nowcasts are generated by variation of the forecast parameters. The size of the variation depends on the variance of the parameters found by cell-tracking and on assumptions about potential changes of the wind field and measurement errors.

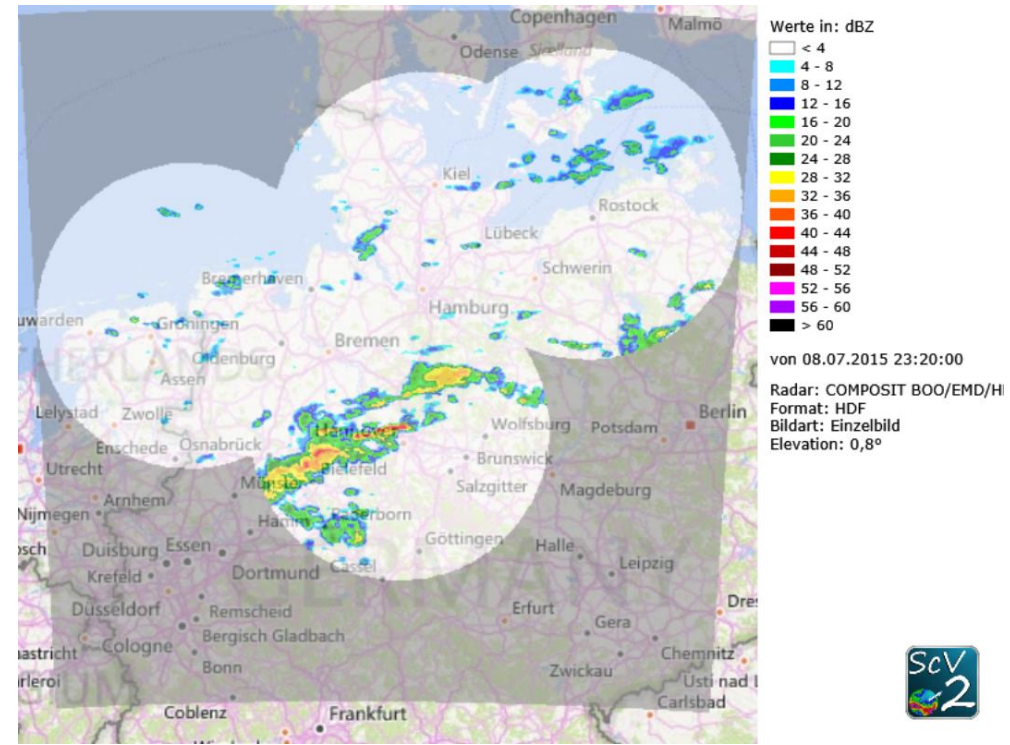

Figure 1. Operational North German composite from four radars Boostedt, Emden, Hannover, Rostock in dBZ

\subsection{Ensemble flood forecasts}

The precipitation forecasts are input to the semi-distributed rainfall runoff model KalypsoHydrology and the calculation core KalypsoNA to model the flow in the Kollau catchment, Hamburg (Figure 2, size: $33.6 \mathrm{~km}^{2}$; lag time: 1 hour). The model supports the simulation of the hydrological processes on the surface and the main processes in the subsurface (TUHH, 2013 and Hellmers \& Fröhle, 2017).

The radar data is assigned to each element of the hydrological model as the area weighted mean of all radar grid cells based on the intersection with the hydrological spatial element, as illustrated in Fig. 2 (right).

The simulation of the initial soil moisture is performed over the past 3 years to obtain the most recent soil moisture conditions. The operational forecast model starts four days before the current time, using radar measured precipitation data extended by ensemble forecasts as input. For each ensemble member, the flood hydrograph is computed at each node of the river 


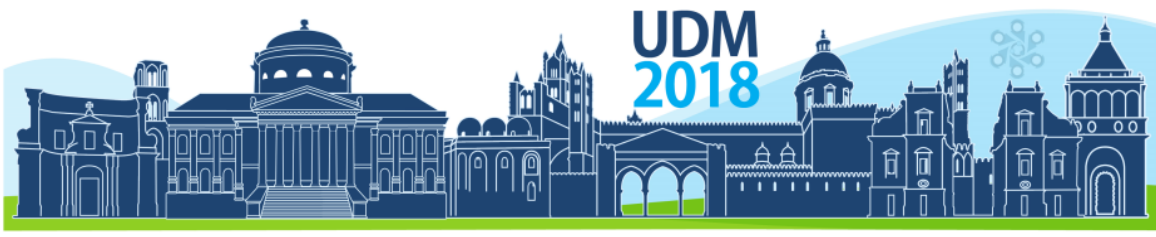

$11^{\text {th }}$ International Conference on Urban Drainage Modelling

23-26 Sep | Palermo - Italy

network and transferred to water levels for a comparison with the measured water levels. The simulations are updated every $15 \mathrm{~min}$.

The hydrological model has been extended with control system functions for advanced flood management. The setpoints for flow from flood management devices (retention ponds, flood gates etc) are defined by an automatic control system. To increase the potential retention volume for storm water, the devices can be pre-emptied before the event. The setpoints for the outlet valve of the device are modified according to forecasted rainfall amounts.

The flood control reservoir (FCR) "Steinwiesenweg" with a volume of $30400 \mathrm{~m}^{3}$ has been extended with a throttle valve which is controlled by rainfall forecasts. The location of the flood control reservoir is illustrated in Figure 2 (left).
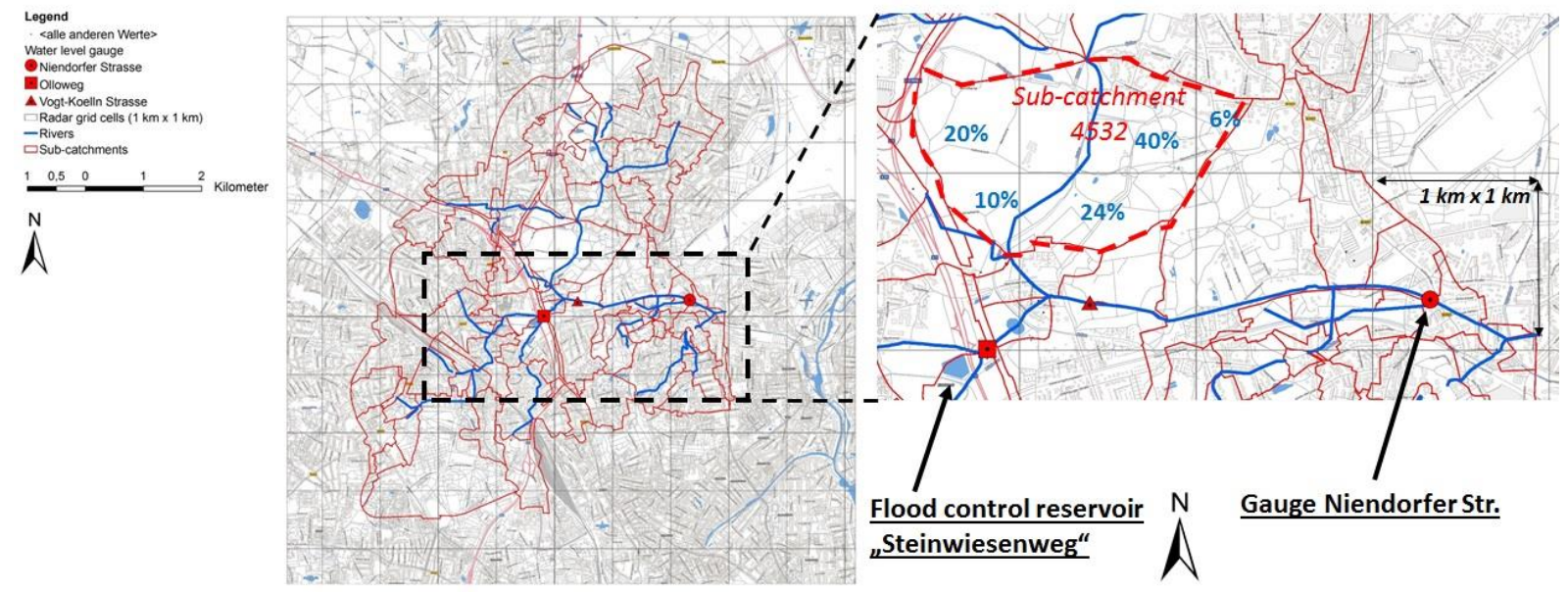

Fig. 2. Map of the Kollau catchment $\left(33.6 \mathrm{~km}^{2}\right)$, location of water level gauges, illustration of the intersection of precipitation data with hydrological elements and the location of the FCR 'Steinwiesenweg'.

\section{RESULTS AND DISCUSSION}

The runoff simulations of the convective precipitation event on 28 Aug 2016 in the Kollau catchment are evaluated in more detail as an example for using the ensemble nowcasts as model input. The precipitation came from two intensive rain cells which moved over the catchment between 14:00 and 16:00 UTC. The simulated flood hydrographs and water level measurements of the event are presented in Fig. 3 as quantile plot. The simulated water levels based on radar are shown in blue, the measured water level data in red. The moderate warning level at $620 \mathrm{~cm} \mathrm{NHN}$ is exceeded at the gauge station at 19:45 UTC.

In the Kollau catchment, out of 22 FCR with an overall volume of about $153513 \mathrm{~m}^{3}$ only the FCR 'Steinwiesenweg' is a retention pond constructed as bypass. The FCR is designed for large storm events with a return period of about once in 100 years. In this paper, this design is modified (1) by installing an automatic valve which is reducing the outflow according to the forecasted precipitation and (2) enabling an earlier inflow at lower inflow rates to the FCR from upstream. The results are presented for the convective rainfall event August 2016. The peak water level at the downstream gauge 'Niendorfer Str.' can be reduced by $6 \mathrm{~cm}$ (Fig. $3 \mathrm{~b}$ ). This result shows the potential for the improvement by actively controlling further FCR. 


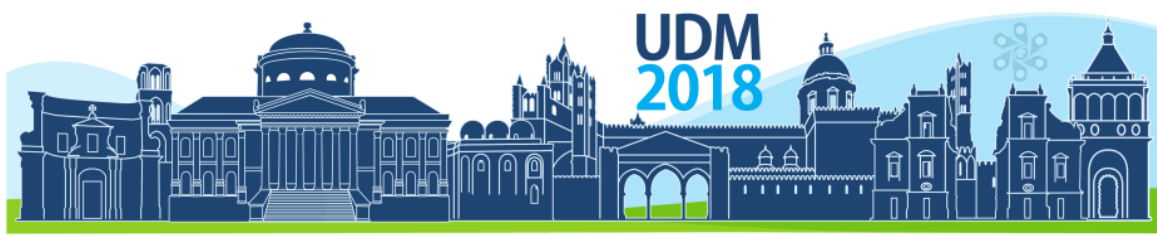

$11^{\text {th }}$ International Conference on Urban Drainage Modelling

23-26 Sep | Palermo - Italy

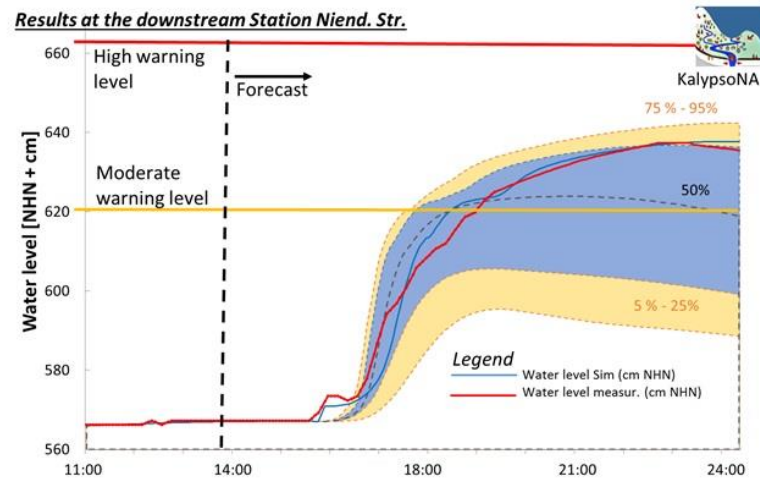

(a) Flood hydrographs in $\mathrm{cm} \mathrm{NHN}$

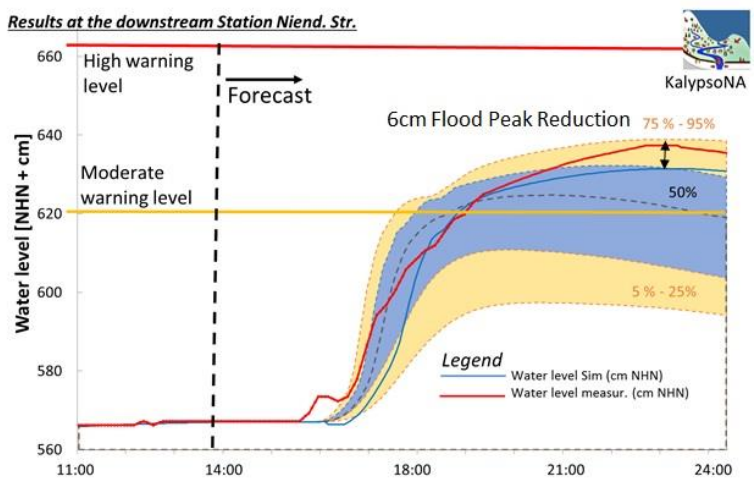

(b) With adjusted flood control reservoir Steinwiesenweg

Fig. 3. (a) Quantile plot of the flood hydrographs of 10 ensembles member runs in $\mathrm{cm}$ NHN of the rainfall event 28 August 2016 at the station Niendorfer Str.. Flood hydrographs based on radar measurements (blue) and water level measurements (red). (b) Plotted flood hydrograph results of the adjusted FCR Steinwiesenweg illustrating the reduction of $6 \mathrm{~cm}$ in peak water level.

\section{CONCLUSIONS}

The results show the integration of combined precipitation forecasts of radar nowcasts and COSMO-DE-EPS into the operational flood warning system. A real-time implementation of runoff simulations with the software KalpysoHydrology using the ensemble precipitation forecasts was realised in 2017 and shall improve warnings of the Flood Warning Service Hamburg.

The improvement of a flood management measure by using precipitation forecast and the active control of the flood control reservoir Steinwiesenweg is described. The results illustrate the potential to improve the flood retention management as well for small events by enabling a larger flexibility to use control systems coupled with precipitation forecasts.

\section{ACKNOWLEDGEMENTS}

StucK (www.stuck-hh.de) is a joint project in the framework "Regional Water Resources Management for Sustainable Protection of Waters in Germany" (ReWaM) sponsored by the German Federal Ministry of Education and Research (BMBF). The authors gratefully acknowledge this support.

\section{References}

Hellmers, S., Fröhle, P. Integrating Local Scale Drainage Measures in Meso Scale Catchment Modelling. Water 2017, 9, 71. (doi:10.3390/w9020071)

Jasper-Tönnies, A., Hellmers, S., Einfalt, T., Strehz, A., Fröhle, P. (2018) Ensembles of radar nowcasts and COSMO-DE-EPS for urban flood management, Water Science and Technology, DOI: 10.2166/wst.2018.079

Jasper-Tönnies, A., Jessen, M. (2014) Improved radar QPE with temporal interpolation using an advection scheme. Proc. ERAD, Garmisch, 1-5 September 2014.

Kühnlein C., Keil C., Craig G. C. \& Gebhardt C. 2014 The impact of downscaled initial condition perturbations on convective-scale ensemble forecasts of precipitation. Q.J.R. Meteorol. Soc.. doi: 10.1002/qj.2238

Tessendorf, A., Einfalt, T. (2012). Ensemble radar nowcasts - a multi-method approach. IAHS Publ. 351, p. 305310

TUHH 2013 Software-Entwicklung Niederschlag-Abfluss-Modell KalypsoNA [in German]. http://www.tuhh.de/wb/forschung/software-entwicklung/kalypso/kalypso-na.html (accessed 20 Sep 2017) 


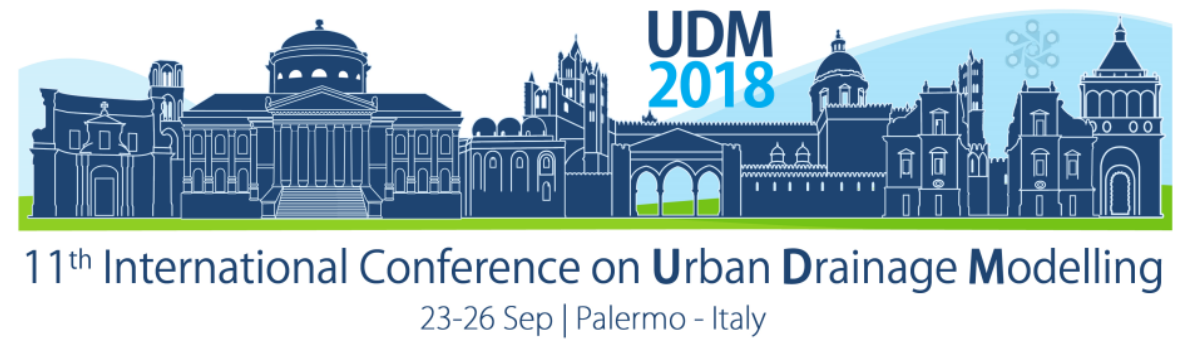

\title{
Hydrology of Green Walls: Factor Assessment and Water Balance Modelling
}

\author{
Veljko Prodanovic ${ }^{1}$, Ankun Wang ${ }^{2}$ and Ana Deletic ${ }^{1}$ \\ ${ }^{1}$ University of New South Wales (UNSW), School of Civil and Environmental Engineering, Sydney, Australia \\ ${ }^{2}$ Monash University, Department of Civil Engineering, Melbourne, Australia
}

\begin{abstract}
Green walls are rapidly becoming a popular green infrastructure choice in densely built urban environments, due to its multiple benefits and space saving feature. Additionally, green walls have been recently designed to treat greywater, making them valuable urban drainage assets. However, high and vastly variable water requirements of these systems are preventing its widespread. Only small number of studies have examined water needs of green walls, even though this can help to design more optimal systems with increased benefits. The knowledge on interactions between plant uptake and climate conditions (temperature and humidity) is lacking. The aim of this study was to understand how factors such as plant variation, position on the wall, seasonality, temperature and humidity, influence green wall water uptake. Dominant factors were further used to create simple water uptake estimation model. The experimental results showed that during summer, dominant water uptake process is transpiration, while during winter, evaporation was dominant. Positioning on the green wall showed high correlation with water uptake. Temperature and humidity changes during seasons varied. While temperature was found to be the major factor across most designs, humidity had lesser effect. Simplified evapotranspiration model forms a basis for water balance of these systems, while plant, position and seasonality factors are estimated from available data. Further model validation is conducted on discrete and continuous measurement.
\end{abstract}

Keywords: plants; temperature; seasonality; water uptake

\section{INTRODUCTION}

Green walls are rapidly becoming popular green urban infrastructure in dense environments. They can be implemented on most vertical surfaces, saving valuable horizontal space, and offer multiple benefits, such as cooling, energy savings, acoustic isolation and liveability increase (Perini and Rosasco, 2013). However, these systems have highly variable water needs $\left(1-20 \mathrm{~L} / \mathrm{m}^{2}\right.$ per day, (DEPI, 2014)), which causes widespread implementation issues (Medl et al., 2017). While some studies have tried to assess green wall water uptake (Urrestarazu et al., 2017) and irrigation scheme (Pérez-Urrestarazu et al., 2014), their scopes have been limited and there is a lack of understanding how plant species and climate conditions (temperature, humidity, seasons, etc.) effect green wall water uptake. This knowledge would present a valuable input for efficient green wall design, but also estimation of its cooling properties (Malys et al., 2016). Firstly, key green wall water uptake factors need to be understood.

Recently, green walls have been developed into greywater treatment systems (Masi et al., 2016) making them valuable urban drainage asset. This introduced a new challenge of understanding hydrological performance of green walls operating under overwatering conditions (high irrigation rate to create extra treated water for reuse). Hence, it is not clear how traditional hydrological water balance models can be adapted for water uptake estimation of such novel system. However, there is a significant need for simple water uptake estimation 


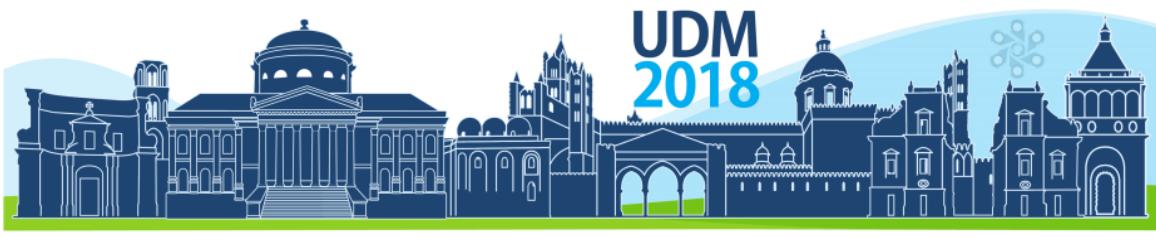

$11^{\text {th }}$ International Conference on Urban Drainage Modelling

23-26 Sep | Palermo - Italy

models, as these can further inform pollutant removal models for such systems and give crucial design parameters.

The overall aim of this work is to: (1) understand key factors (plant variation, position, seasonality, temperature, humidity, etc.) that influence water uptake in overwatered green wall systems, and (2) propose simple and robust model for water uptake estimation.

\section{MATERIALS AND METHODS}

\subsection{Experimental setup}

This study used Gro-wall ${ }^{\circledR} 4$ green wall (Atlantis, Australia), with every pot occupied by a single plant (Figure 1). Three vertical pots, containing the same plant species created a single test configuration. After dosing the top pot, water would trickle into subsequent levels (middle and bottom levels). This was done to test the effect of multi-level green wall design on water retention and plant uptake. To test how different plant species influences water requirements of the green wall, five different plants and non-vegetated control were used. Air temperature and humidity were continuously measured. While green wall was watered daily for a full year with two times greater volume than maximum estimated for experimental region, total of 18 days of water balance measuring campaigns were conducted during winter period, and 12 during summer. Water uptake was calculated by subtracting the weight of each individual green wall pot between two dosing days, and water retention by subtracting weight after and before dosing within a single day.
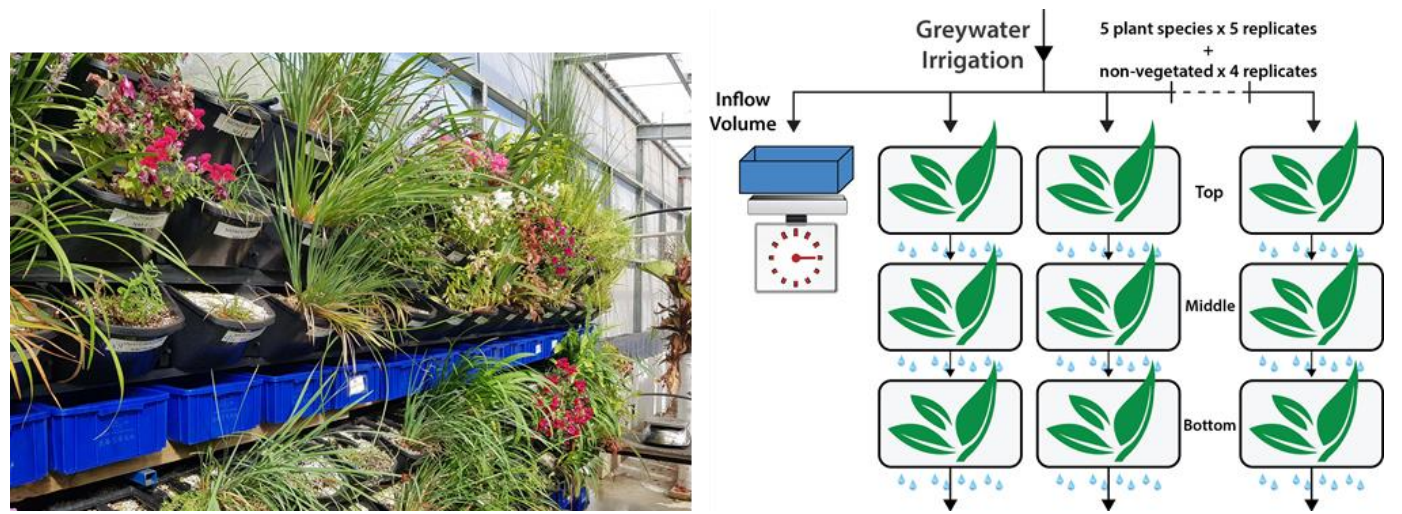

Figure 1. Illustration of three-level green wall design used in this experiment. Individual pots weighted before and after each test (not shown on the figure)

\subsection{Water balance modelling}

The basis for water uptake estimation is the calculation of evapotranspiration (ET) using the Penman-Monteith equation:

$$
E T=\frac{\Delta\left(R_{n}-\mathrm{G}\right)+\rho_{a} c_{p} \frac{\left(e_{s}-e_{a}\right)}{r_{a}}}{\Delta+\gamma\left(1+\frac{r_{s}}{r_{a}}\right)}
$$

where $R_{n}$ is the net radiation, $G$ is the soil heat flux, $\left(e_{s}-e_{a}\right)$ is vapour pressure deficit of the air, $\rho_{a}$ is the mean air density, $c_{p}$ is the specific heat of the air, $\Delta$ represents the slope of the saturation vapour pressure temperature relationship, $\gamma$ is the psychrometric constant, and $r_{s}$ and $r_{a}$ are the (bulk) surface and aerodynamic resistances. 


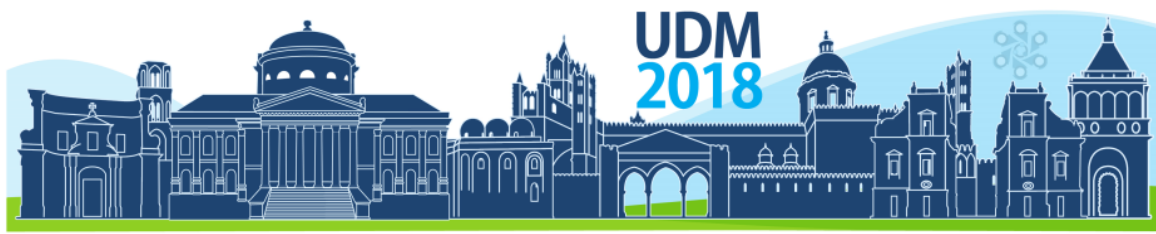

$11^{\text {th }}$ International Conference on Urban Drainage Modelling

23-26 Sep | Palermo - Italy

\section{RESULTS AND DISCUSSION}

\subsection{Factors influencing water uptake}

Plant species and seasonality. The results point to high variability of water uptake across selected plant species during seasons (Figure 2). While some plants like $O$. japonicus had similar water uptake to non-vegetated control, significantly greater uptake was observed across others. Summer uptake was three to four times higher than winter across all designs. While transpiration was dominant in summer, during winter evaporation was primary process.

ब Top Middle $\square$ Bottom

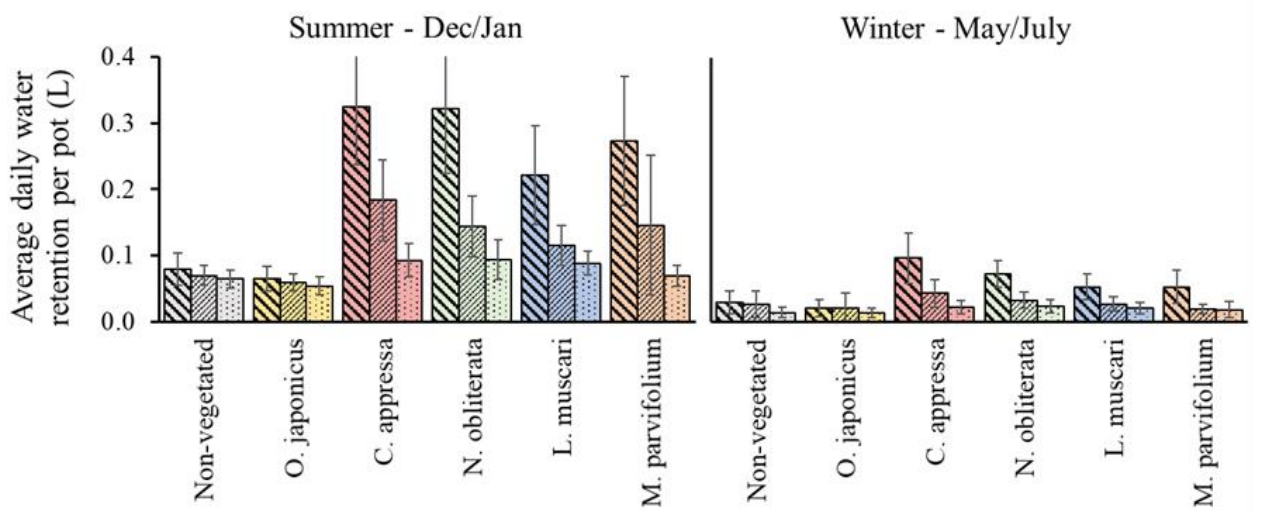

Figure 2. Comparison of average daily water retention for each level of the three-level green wall design, across two seasons. Values are presented in litres of retained water, with standard deviation shown as error bars.

Position on the green wall. Water retention within a three-level green wall system highlighted that most water is being lost at the top levels due to increased plant activity, while up to four times less water was loss at the bottom level, contributed to evaporation (Figure 2).

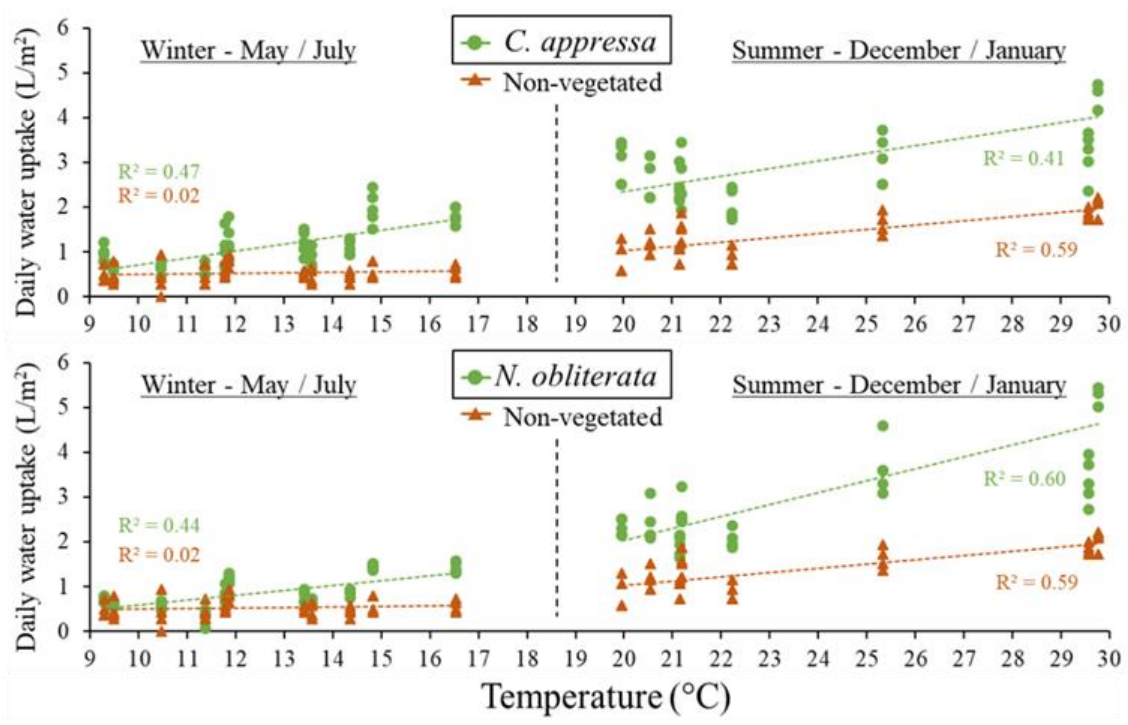

Figure 3. Relationship between daily water uptake and temperature, across selected plant species and seasons (winter and summer). Results compared against non-vegetated design

Air temperature. Temperature changes within different seasons pointed to high plant activity and reactiveness to different temperatures in winter months of the $C$. appressa plant (Figure 


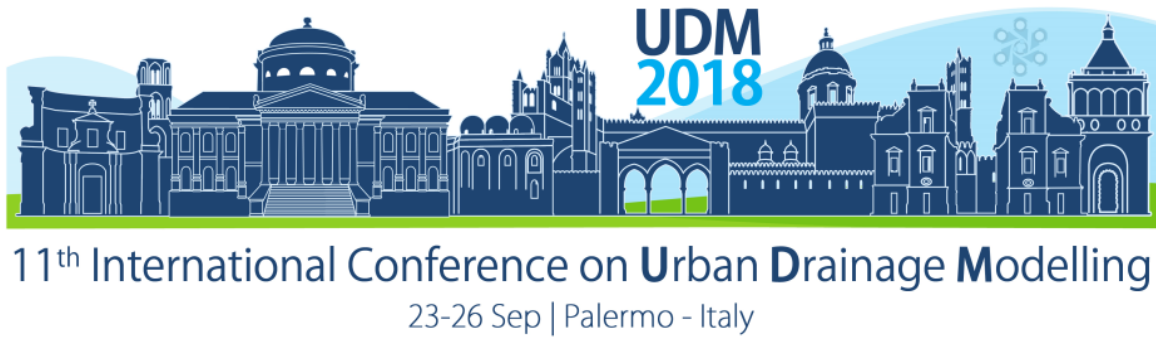

3). However, same was not observed for summer period. Similar winter trend (to a lesser degree) was detected for $N$. obliterata, while during summer this plant showed rise in plant water needs with temperature increase. These findings suggest that plant seasonality and growth cycles have a major role in determining their water requirements across the year.

Relative humidity. The changes in relative humidity across the seasons had no effect on water uptake of non-vegetated design. Some plants (C. appressa, $N$. obliterata and $L$. muscari) showed slight ability to absorb moisture from the high humidity air. However, this was limited and it is not expected that humidity will be a dominant factor.

\subsection{Model development}

The knowledge gathered from the experimental stage will further inform development of the robust hydrological green wall model. Sensitivity of the ET factors in Penman-Monteith equation will be assessed in the green wall context, with the aim of producing simplified water uptake estimate $\left(E T_{s}\right)$, for non-vegetated system. It is expected that $E T_{s}$ will depend on temperature and solar radiation based on geographic position $\left(R_{a}\right)$ as main factors. Based on the experimental findings, for estimation of total green wall system uptake (U), further parameters will be assessed: plant species coefficient $\left(k_{p l}\right)$, position on the wall coefficient $\left(k_{p o}\right)$ and seasonality coefficient $\left(\mathrm{k}_{\mathrm{s}}\right)$.

$$
\begin{gathered}
E T_{s}=f\left(T, R_{a}\right) \\
U=k_{p l} k_{p o} k_{s} E T_{s}
\end{gathered}
$$

This model will be calibrated and validated on both discrete and continuous measurement.

\section{CONCLUSIONS}

There is a significant need to understand water uptake of green wall systems due to their great wastewater treatment potential. Through experimental research, this work managed to understand the underlying factors that govern water uptake processes. Factors such as air temperature, seasonality, plant species type and position on the wall were found to play significant roles. These findings are further used to develop, calibrate and validate simple and robust green wall water uptake model.

\section{References}

DEPARTMENT OF ENVIRONMENT AND PRIMARY INDUSTRIES 2014. Growing Green Guide: A guide to green roofs, walls and facades in Melbourne and Victoria, Australia. In: ENVIRONMENT, D. O. (ed.). Victoria, Australia.

MALYS, L., MUSY, M. \& INARD, C. 2016. Direct and indirect impacts of vegetation on building comfort: A comparative study of lawns, greenwalls and green roofs. Energies, 9.

MASI, F., BRESCIANI, R., RIZZO, A., EDATHOOT, A., PATWARDHAN, N., PANSE, D. \& LANGERGRABER, G. 2016. Green walls for greywater treatment and recycling in dense urban areas: A case-study in Pune. Journal of Water Sanitation and Hygiene for Development, 6, 342-347.

MEDL, A., STANGL, R. \& FLORINETH, F. 2017. Vertical greening systems - A review on recent technologies and research advancement. Building and Environment, 125, 227-239.

PÉREZ-URRESTARAZU, L., EGEA, G., FRANCO-SALAS, A. \& FERNÁNDEZ-CAÑERO, R. 2014. Irrigation Systems Evaluation for Living Walls. Journal of Irrigation and Drainage Engineering, 140, 04013024.

PERINI, K. \& ROSASCO, P. 2013. Cost-benefit analysis for green façades and living wall systems. Building and Environment, 70, 110-121.

URRESTARAZU, M., CARRASCO, G. \& ÁLVARO, J. E. 2017. Design of a modular vegetative unit and fertigation management for noise-abatement walls in a semiarid climate. Journal of Irrigation and Drainage Engineering, 143. 


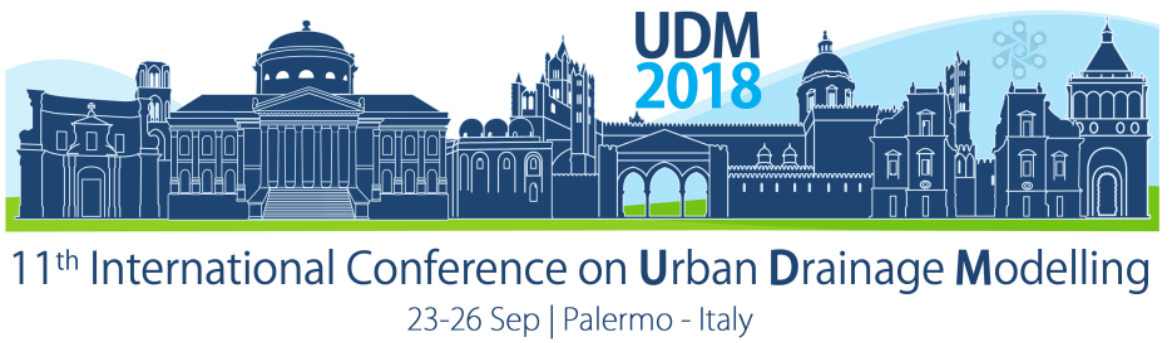

\title{
Modelling runoff in watershed without calibration using PCSWMM
}

Daniela Junqueira Carvalho' ${ }^{1}$, Maria Elisa Leite Costa ${ }^{1}$, Jeferson da Costa ${ }^{2}$ and Sérgio Koide ${ }^{1}$

${ }^{1}$ University of Brasília, Program of Environmental Technology and Water Resources, Brasília, Brazil

2 Federal District's Water, Energy and Basic Sanitation Regulatory Agency (ADASA), Brasilia, Brazil (d.junqueirac@gmail.com; mariaelisa@unb.br,jeferson.costa@adasa.df.gov.br, skoide@unb.br)

\begin{abstract}
Urbanization process changes the runoff generation, essential factor for drainage systems design. Unfortunately, it is very common in Brazil and in underdeveloped countries the lack of rainfall and field data, being frequently adopted the rational method for runoff estimation. To improve runoff estimation, it is growing the use of hydrodynamics models performed with computer programs, such as PCSWMM ${ }^{\mathrm{TM}}$ (SWMM with GIS integrated), but, most of the times model parameter values have to be assumed based on default values or developers' recommendations. In this study, PCSWMM was used for calculation of drainage system of Riacho Fundo's urban area in Federal District in Brazil, in preparation for future analysis of LID implementation. The main objective is to analyze the PCSWMM use in a watershed without data for calibration using the SCS method, implementing PCSWMM recommendations and comparing them with the rational method in terms of peak flow results. The results showed that adopting PCSWMM recommendation only for the Imperv (\%) parameter for subcatchments characteristics is the simulated scenario which is closest to rational method, while other modifications from the default values alter substantially the peak flow value.
\end{abstract}

Keywords: peak flow; rational method; SCS curve number method.

\section{INTRODUCTION}

Urbanization process causes the reduction of permeable areas in the cities, what leads to significant changes in the destination of stormwater and impacts the whole natural hydrological water cycle. Two of the modification in natural processes that can be mentioned are the increase of surface runoff and soil infiltration reduction.

To reduce the impacts, sustainable urban drainage management practices have been used to reduce the damage caused by soil impermeabilization, runoff, peak flows and concentration time reduction (Gonçalves et al., 2016). Low Impact Development (LID) practices can promote storm water flows reduction to reestablish the natural hydrological processes. According to Shamsi (2010) these practices aim to maintain a site's predevelopment hydrologic cycle with a distributed and decentralized approach. Such effort also involves urban planning and adaptation (Baptista et al., 2014).

Therefore, the study of drainage network designed or already constructed is very important in the search for more sustainable alternatives in urban stormwater management that can mitigate or even avoid the runoff quantity problems commonly faced in these areas such as flooding.

Sangal and Bonema (1994) had already stated that computer simulation models of stormwater systems could predict the hydrologic response of a watershed and evaluate the capacities of hydraulic conveyance systems becoming a well known tool. Unlike the Rational Method and design event modelling approaches, analyses made possible by modern computing are able to consider the full range of meteorological conditions (Thoman and Adams, 1998). However, a computer analysis depends on available and good quality data and the relation obtained by 


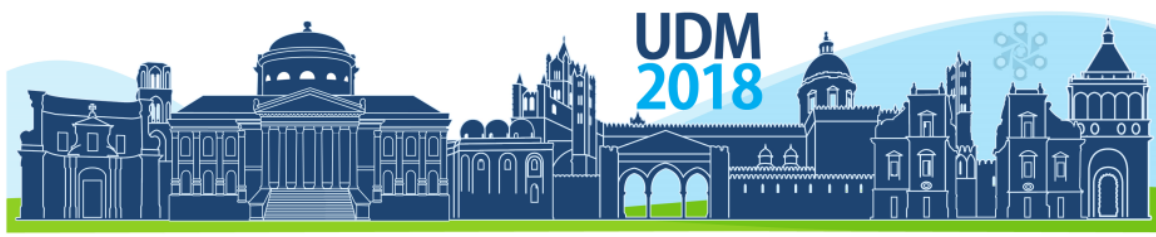

$11^{\text {th }}$ International Conference on Urban Drainage Modelling

23-26 Sep | Palermo - Italy

calibration between the response of the computer model and the watershed and drainage system behaviors (Sangal and Bonema, 1994).

Aiming the development of a framework to future studies that will evaluate the reduction of the maximum peak flow with the use of LID practices, this paper has as an objective the simulation of the constructed drainage network in an urban area in the PCSWMM software. The maximum peak flows were obtained for different values of three model parameters, considered the most significant and subject to uncertainty in order to observe their influence on the network flows. The drainage system is ungaged and thus is not possible to properly perform model calibration.

\section{MATERIALS AND METHODS}

The studied area corresponds to the urbanized portion of a city of the Federal District, in the center of Brazil. Riacho Fundo is a region composed by an urban center surrounded by a rural area, totaling more than 40,000 inhabitants. It is inserted in one of the most important subcatchments that contribute to the Paranoá lake. Concerning the urban infrastructure, Riacho Fundo has $82.9 \%$ of the area attended by the stormwater drainage system, according to a 2015 government survey. Figure 1 shows the area of study that drains into the network that will be analyzed.

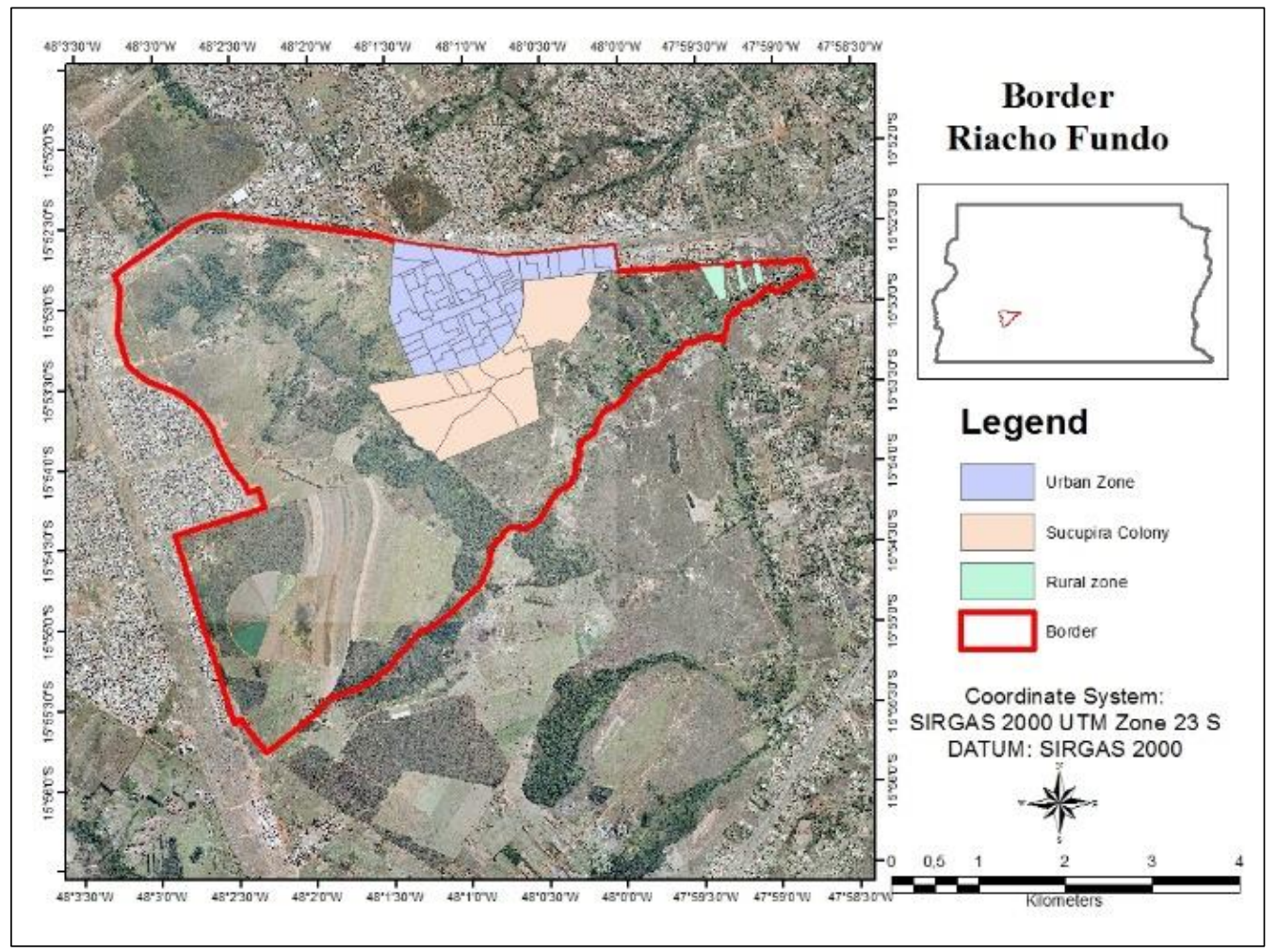

Figure 1. Urban center of the Riacho Fundo region, area served by the stormwater drainage network. (Silva et al, 2017).

It is relevant to point out that the of Riacho Fundo area was created in 1990 to eradicate irregular occupation that was taking place in the region and is located near an area of environmental preservation that includes springs of several streams. The Ecological Park of Riacho Fundo is within this area. 


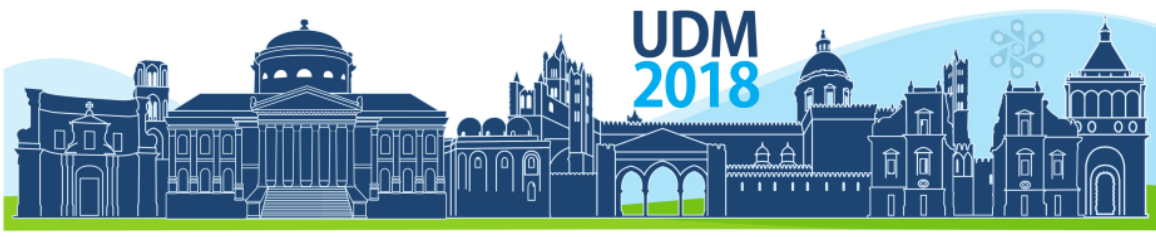

$11^{\text {th }}$ International Conference on Urban Drainage Modelling

23-26 Sep | Palermo - Italy

The area was chosen due to the availability of the network project and the access to a previous study in the same area. From the 235 subcatchments that compose the contribution zone to the registered drainage network, comprising an area of $1.91 \mathrm{~km}^{2}$, the last 15 subcatchments, near to the outfall, were selected to perform the simulations. This selected sector has an area of approximately $0.15 \mathrm{~km}^{2}$ and is shown in Figure 2.

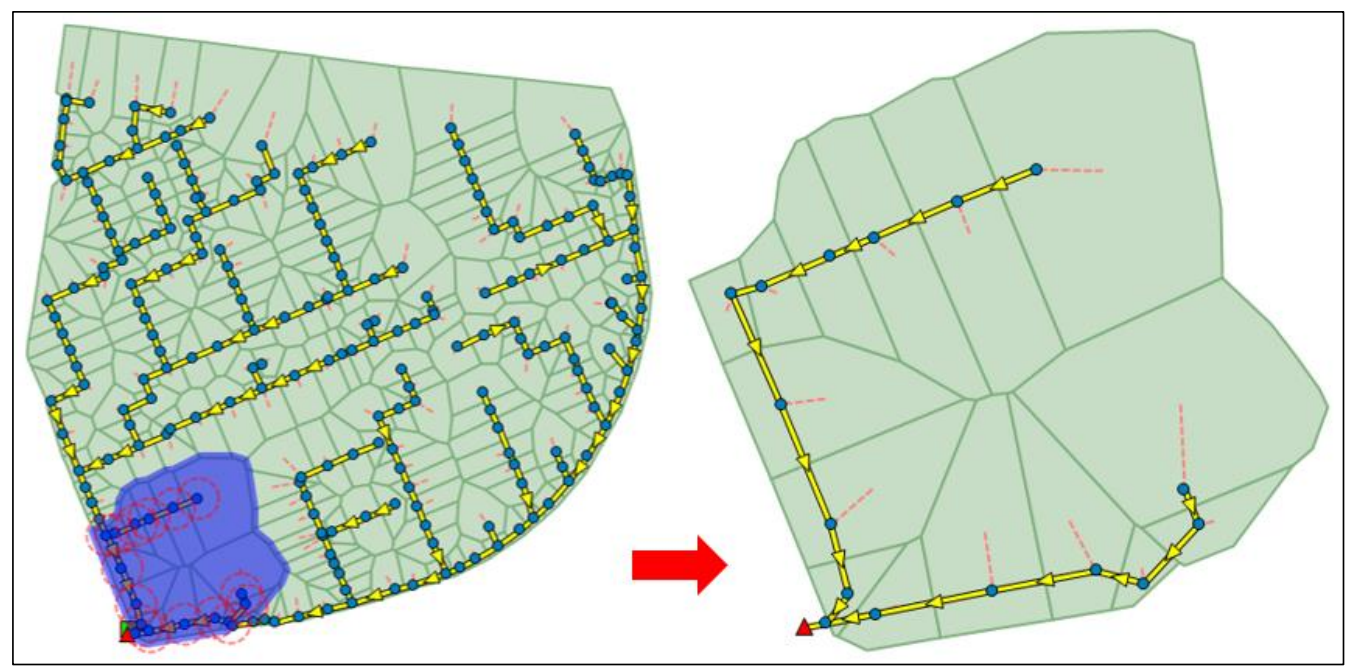

Figure 2. Study area selection within the subcatchments of the urban portion of Riacho Fundo, represented in the PCSWMM software.

The network was coded in the program and as well as information about the characteristics of the study area, such as land use and occupation, soil type and topography. The data about land use and occupation was classified manually using the ArcGIS software and this information was used to attribute Curve Number coefficient $(\mathrm{CN})$ for each subcatchment. For the subcatchments' average surface slope it was adopted the default value of $0.5 \%$. All the other parameters for the subcatchments that were not involved in the study were left as the default value.

The CN used in the SCS infiltration method was calculated by weighted arithmetic mean. Table 1 brings the values of the $\mathrm{CN}$ for each soil use or occupation considering the soil from the area studied is classified in the Hydrological Soil Group A and considering a medium condition for the initial soil moisture.

Table 1. Coefficients used for each type of land use and occupation.

\begin{tabular}{cc}
\hline Use/occupation & CN \\
\hline Paved driveways & 98 \\
Exposed soil & 68 \\
Vegetation and gardens & 45 \\
Residential lots & 77
\end{tabular}

Simulations of the network operation were carried out in the PCSWMM with the variation of the subcatchments' input data. The attributes that were varied are the ones specified in the PCSWMM Reference Manual as the parameters that have recommended values to be adopted if the Curve Number method is used for the infiltration calculation, them being: the percentage of the impervious area (Imperv); the Manning's roughness coefficient for the pervious area (Nperv); and the depth of depression storage on pervious area (Dstore perv) (Rossman and Huber, 2016). Thus, the simulations resulted in the creation of five scenarios, 


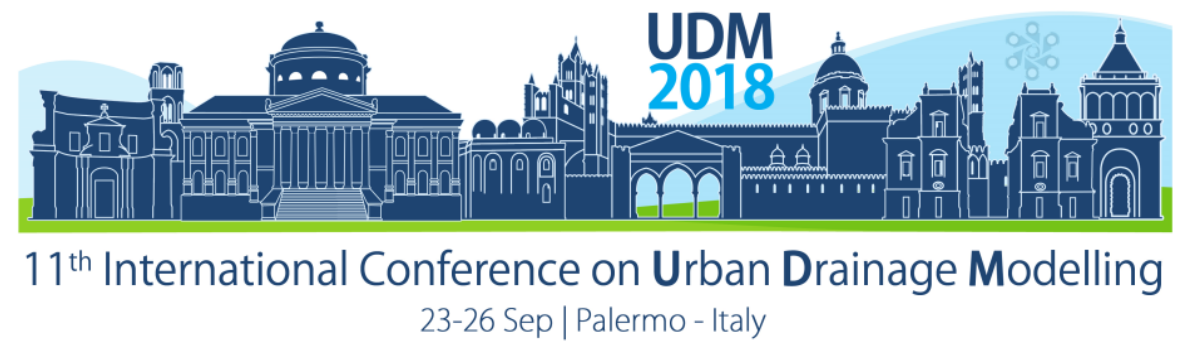

one with the initial default values for the paremeters and the others varying one parameter at a time. Table 2 presents the set of the parameters used for each scenario.

Table 2. Parameters values used on the scenarios.

\begin{tabular}{cccc}
\hline Scenario & $\begin{array}{c}\text { Imperv } \\
(\%)\end{array}$ & Nperv & $\begin{array}{c}\text { Dstore perv } \\
(\mathrm{mm})\end{array}$ \\
\hline 1 & 25 & 0.1 & 0.05 \\
2 & 0 & 0.1 & 0.05 \\
3 & 0 & 0 & 0.05 \\
4 & 0 & 0 & calculated \\
5 & 0 & 0.1 & calculated \\
\hline
\end{tabular}

One of the recommendations for the implementation of the Curve Number method as the infiltration model is to calculate the storage depth on pervious areas for each subcatchment instead of using a general value. It was indicated to calculate this parameter from the soil moisture storage capacity (S), given by Equations 1 and 2 presented in SI units.

$$
\begin{aligned}
& S=\frac{25,400}{C N}-254 \\
& \text { Dstore perv }=0.2 \cdot S
\end{aligned}
$$

Since there was no measured data to calibrate the model, it was used the value for the peak flow calculated by the Rational Method to compare with the results by the modelling without calibration. Despite all limitations of this method, it is acceptable to use the Rational Method to estimate the peak flow when dealing with small watersheds, which is the case. Sometimes due to the unavailability of good equipment, the deficiency in stormwater monitoring and the consequent lack of data, the simplified method becomes useful.

\section{RESULTS AND DISCUSSION}

Simulating the scenarios with these parameter values, the results showed a variation in peak flow at the outlet, as can be seen in Table 3. For scenario 4 all recommendations from the PCSWMM Reference Manual were considered. The scenario that led to the peak flow closest to the result calculated by the rational method was the scenario 2 . The calculation by the rational method led to a peak flow value of $3.2 \mathrm{~m}^{3} / \mathrm{s}$ and was used as a comparison method, considering that there is no data for the calibration and that for such small areas it usually produces good results.

Table 3. Peak flow discharged for each scenario.

\begin{tabular}{cc}
\hline Scenario & Flow $\left(\mathrm{m}^{3} / \mathrm{s}\right)$ \\
\hline 1 & 4.6 \\
2 & 3.2 \\
3 & 5.5 \\
4 & 4.9 \\
5 & 2.2 \\
\hline
\end{tabular}

By the evaluation of the peak flow results for the different scenarios it is possible to notice that the highest peak flow occurred in the scenario 3 , in which the percentage of the impervious area and the Manning's coefficient for the pervious area were assumed according to the recommended values by the Manual for the utilization of the Curve Number method. In scenario 5 the default value of Manning's coefficient for the pervious area was adopted and 


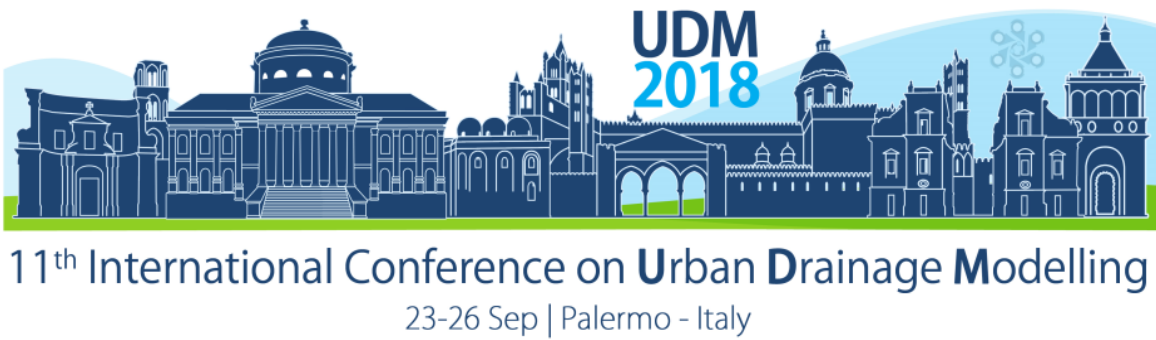

the other two parameters were adjusted to the recommendations. The peak flow generated had the lowest value among all scenarios $\left(2.2 \mathrm{~m}^{3} / \mathrm{s}\right)$. The difference between the peak flows for the scenarios 3 and 5 is greater than $3 \mathrm{~m}^{3} / \mathrm{s}$ and, therefore, it is interesting to notice how the set of values adopted for the parameters, although default or recommended, change so significantly the results for the peak flow obtained by the simulation.

The scenario that led to the result almost identical to the rational method was the scenario 2 , in which only one of the parameters was set in accordance with the PCSWMM Reference Manual's recommendations. Default values were adopted for the other two parameters. It is also interesting to note that adopting all PCSWMM recommendations led to the second highest peak flows (scenario 4).

\section{CONCLUSIONS}

The three input parameters studied in this paper, that refer to characteristics of the land use and occupation, presented high influence on the peak flows generated by the drainage network. However, it was not possible to establish a pattern for the variation of the peak flow in means of the number of parameters adopted as the default value or as the recommended from the Reference Manual, what can be exemplified by the large difference between the peak flows from scenarios 3 and 5.

Another aspect that can be observed in the results is related to the peak flows from scenarios 1 and 4 , which have very close values. In scenario 1 all parameters were set with the default values and in scenario 4 all the recommendations were assumed.

The study showed that the use of more elaborated models, in spite of being more consistent, it can bring uncertainty to the results, indicating needs for monitoring and calibration with field data. Nevertheless, the determination of a scenario in which the peak flow resulted in the simulation is close to the value calculated with a simplified method can be very useful for an area where calibration is not possible.

Other parameters used in the PCSWMM software are to be considered when performing further investigations about the process of modelling without calibration. In addition, if data is available in the future, the calibration can be performed in the area so that the assumptions raised in this study can be improved.

\section{References}

Baptista, L.S.F; Gonçalves, L.M. and Barbassa, A.P. (2014) A Concepção e Aplicação Sustentável do LID (Low Impact Development) sob a Ótica Ambiental, Hidrológica e Urbana. Livros de Actas do 6 Congresso LusoBrasileiro para Planejamento Urbano, Regional, Integrado e Sustentável, 2433-2441.

Gonçalves, L.M; Baptista, L.F.S. and Ribeiro, R.A. (2016) O Uso de Técnicas Compensatórias de Drenagem para Controle dos Impactos da Urbanização. Fórum Ambiental da Alta Paulista 12 (n.1), 92-106.

Rossman, L. A. and Huber, W. C. (2016). Storm water management model reference manual. Volume I - Hydrology (Revised). Cincinnati, OH: US Environmental Protection Agency, 231p.

Sangal, S. and Bonema, S.R. (1994). A Methodology for Calibrating SWMM Models. Journal of Water Management Modeling R176-24. doi: 10.14796/JWMM.RI76-24.

Shamsi, U.M. (2010). Low Impact Development for Stormwater Quantity and Quality. Journal of Water Management Modeling R236-13. doi: 10.14796/JWMM.R236-13.

Silva, C.C., Costa, M.E.L., Koide, S. (2017) Urban drainage: a hydrologic simulation of the drainage system in Riacho Fundo - Brasília - DF, Brazil. 14th ICUD - International Conference on Urban Drainage.

Thoman, G. and Adams, B.J. (1998). Sensitivity and Cross-Calibration of Two Types of Continuous Stormwater Models. Journal of Water Management Modeling R200-1 0. doi: 10.14796/JWMM.R200-10. 


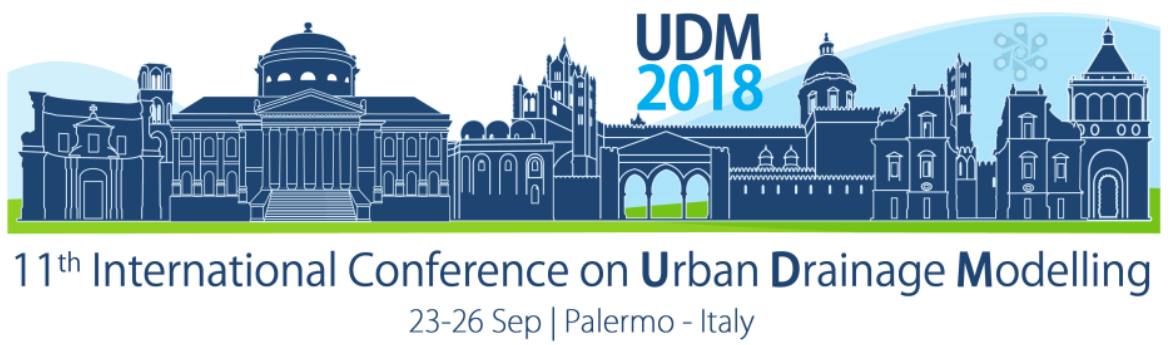

\title{
Modelling Urban Drainage in Taquari - Federal District in Brazil \\ Tamara J. Brandão', Maria Elisa Leite Costa ${ }^{1}$ and Conceição de Maria Albuquerque ${ }^{1}$ ${ }^{1}$ University of Brasilia, Department of Environmental and Civil Engineering, Brasília, Brazil. (tamarajouly@gmail.com, mariaelisa@unb.br, calves@unb.br)
}

\begin{abstract}
Taquari is a recent neighbourhood in Brasília, Federal District in Brazil, that started be occupied in 2002, with prevision more three phases to total occupation, however many impacts can be caused in water body receptor because the changes in land use. Therefore, this study investigated these variations in hydrology parameters, such as peak flow, with the objective of analysing in other to avoid possibilities impacts in Paranoá Lake, the new reservoir to water supply in the city. It was been used the PCSWMM software to analyse the differences before the urban system network implementation and after it. The results showed that the peak flow increased more than $300 \%$ mainly because all the discharged were concentred in two principal outfalls while, in the natural scenario were more distributed with more than 40 outfalls. It was possible to conclude that the new projects have to be design to natural scenario about hydrologic parameter because of several impacts in runoff volume, water quality and erosion process caused to hydric resources. This objective can be achieve though using LIDs, storing the excess runoff in the lot itself.
\end{abstract}

Keywords: PCSWMM; Runoff; Peak flow.

\section{INTRODUCTION}

Elements that are part of the urbanization process such as roofs, parking lots, sidewalks and other impervious surfaces are responsible for increasing peak flows, frequency of runoff and total volume of stormwater surface runoff when compared to pre-urbanization environmental conditions (UDFCD, 2016). Therefore, the evaluation of responses from small urban watersheds using modelling is of great interest for the urbanization impact estimation, risk analysis and all projects involving these environments (Beling et al, 2011).

Taquari is a recent urban development neiborhood of Brasília, Brazil. It drains its natural flows into the Paranoa Lake $\left(441 \mathrm{hm}^{3}\right)$ which will be a new water supply reservoir in a near future. The Taquari neighborhood has been developed since 2002. In 2009, during the studies of the Urban Drainage Plan of the Federal District the government realized that some conduits of the drainage system of the city were already working on its full capacity. Due to the expected expansion of economic activity in the area, there is high risk of increased stress on the drainage system in the next few years.

In the past fifteen years the area went through a major change, replacing the natural drainage with typical urban land use and drainage system: complex networks of curbs, gutters and surface and underground conduits. The present study evaluates the main consequences of the urban sprawl in the hydrologic behaviour represented by the peak flow changes (in volume, duration and frequency).

\section{MATERIALS AND METHODS}

The impacts of urbanization on the hydrological processes were evaluated through the drainage modelling using PCSWMM. The Soil conservation Service method to estimate the runoff was selected and the Curve Number $(\mathrm{CN})$ was defined according to the area's characteristics (land use and pedology), classifying the soil into the Hydrological Soil Group D. 


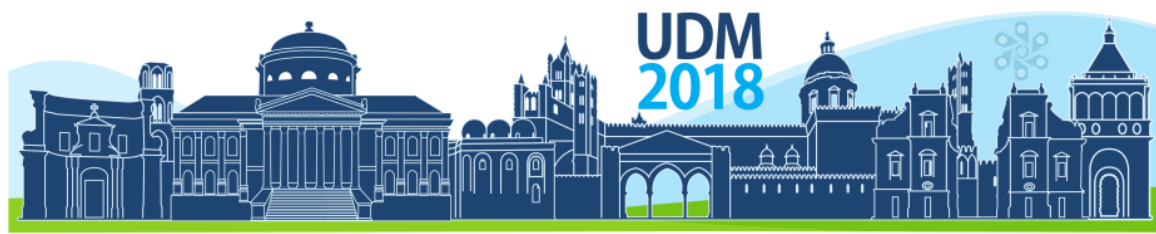

$11^{\text {th }}$ International Conference on Urban Drainage Modelling

23-26 Sep | Palermo - Italy

Besides the Curve Number parameter, the following elements were necessary for modelling: rainfall rate, sub catchment areas and drainage system elements (pipes size, manholes, outfalls). The Intensity-Duration-Frequency curve (IDF) was used to synthesize a rainfall rate with a 24-hour duration and return period of 10 years. The Figure 1 shows a diagram of the modelling steps.

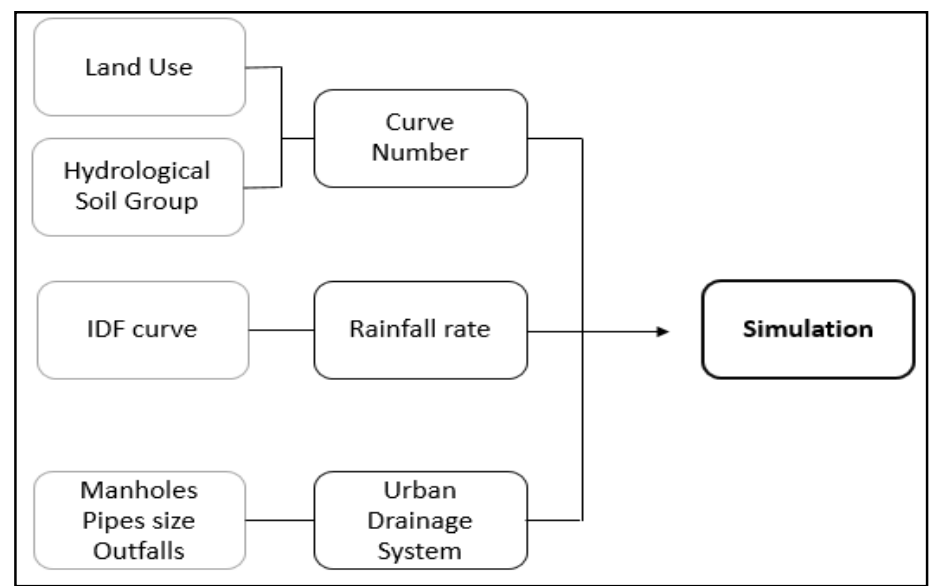

Figure 1 - Hydrological modelling steps for PCSWMM.

In order to compare the area natural drainage process with the drainage system implanted, two different scenarios were simulated. The first scenario estimated the runoff resulting from the natural land cover conditions and topographically natural outfalls. The second scenario quantified the runoff considering the area's current land use and the urban drainage system operation.

\section{RESULTS AND DISCUSSION}

The Figure 2 showed the difference between the two scenarios` land use.

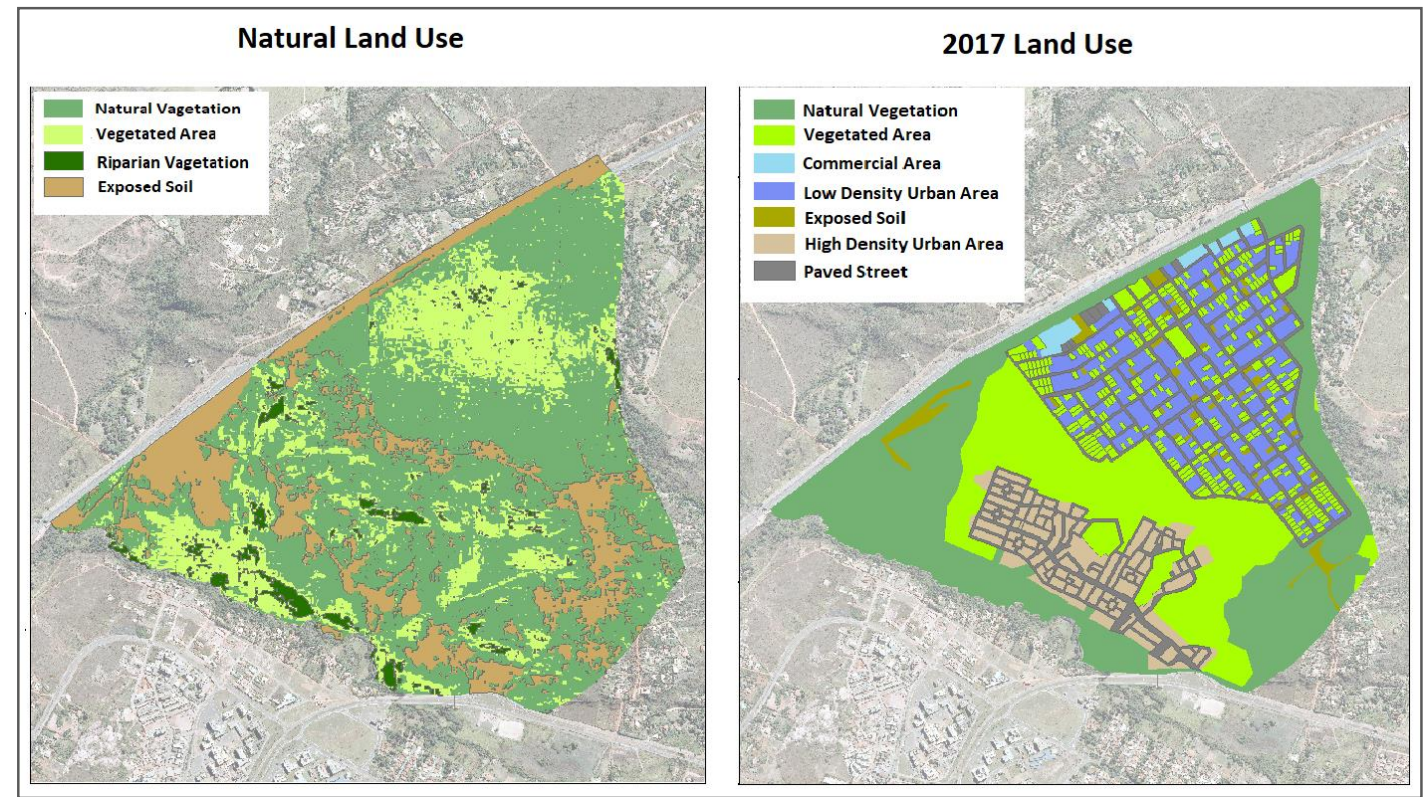

Figure 2 - Taquari`s different land use scenarios. 


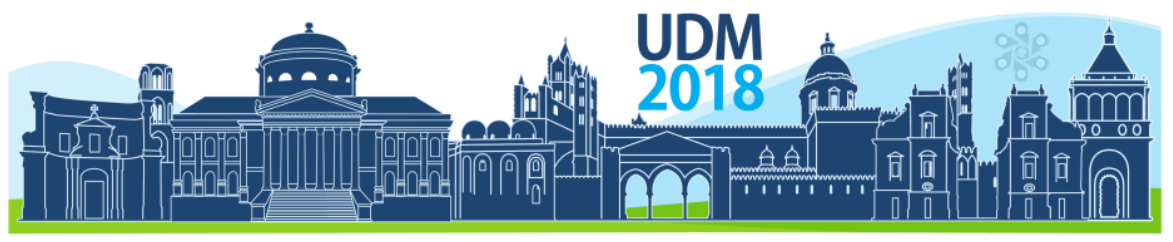

$11^{\text {th }}$ International Conference on Urban Drainage Modelling

23-26 Sep | Palermo - Italy

The natural drainage scenario (Figure 3 ) showed that there were 46 natural outfalls for Taquari's area. The flow direction ran towards two different water bodies: Torto's Riverside (right side) and an intermittent stream flow (left side). In opposite, the designed urban drainage system had a large reduction on the number of outfalls when compared to the natural scenario, presenting only 7 outfalls.

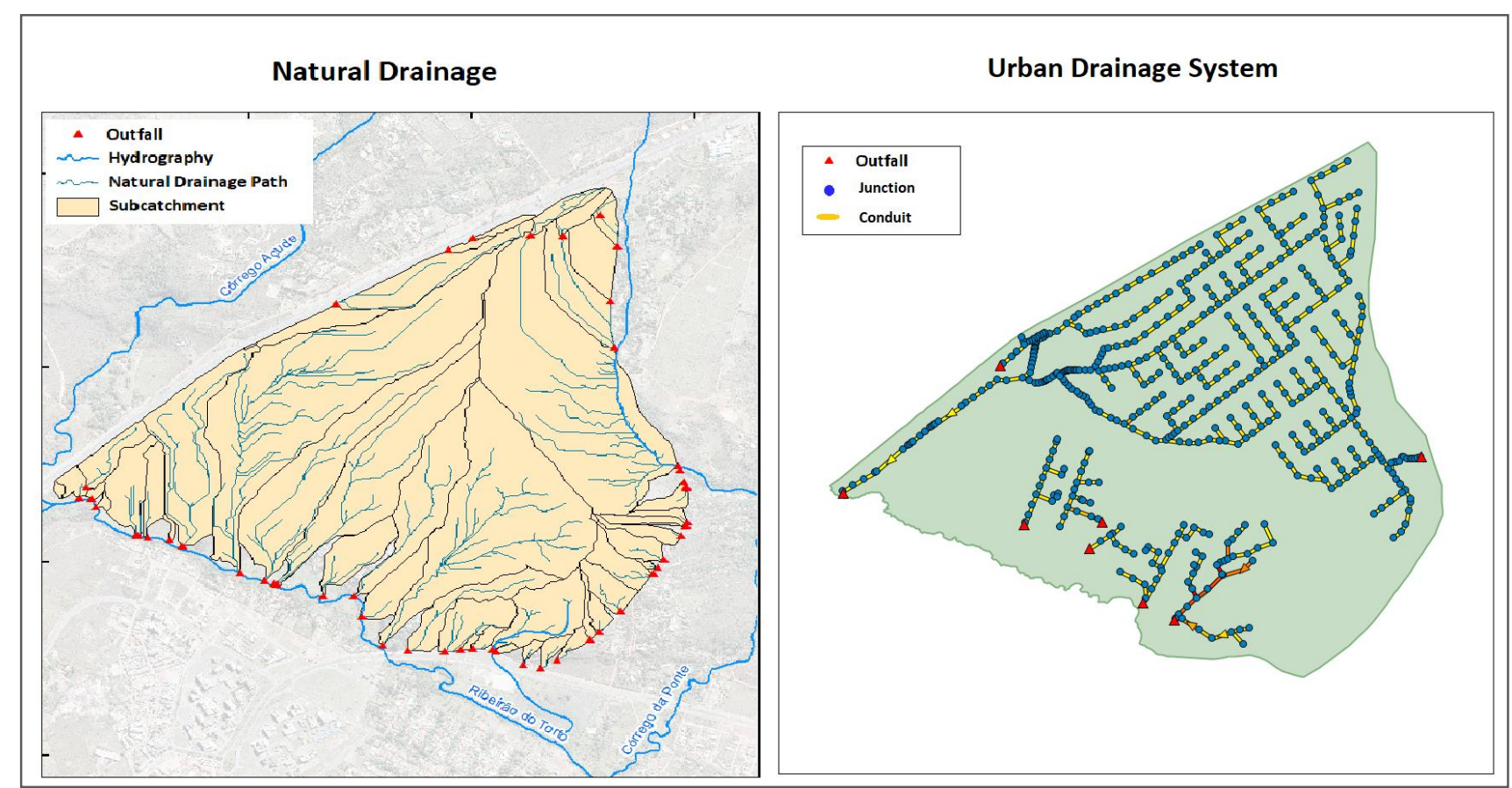

Figure 3 - Taquari’s Drainage System for different scenarios.

Besides the differences between the natural drainage system and the designed system, there was a significant change in the area`s land use. Initially there was mostly vegetated areas, with minors $\mathrm{CN}$ values and higher soil capability of infiltration. The current land cover is mainly constituted by urban structures with low infiltration rates and higher $\mathrm{CN}$.

This decreased number of outfalls and the land use changes resulted in two different flow rates as expected. One outfall flow was selected from each scenario, showing its highest peak flow observed from both results. The Figure 3 showed the highest peak flow of $6.6 \mathrm{~m} / \mathrm{s}$ for the natural scenario (Figure 4). There is a significant increase of this value on the second scenario, in which the peak flow is $23.1 \mathrm{~m}^{3} / \mathrm{s}$ (Figure 4), more than $300 \%$.

This increase can cause deterioration in water quality to water body receptor, because of the wash off of pollutants in urban land use occupation and erode the soil carrying more sediments.

One option to reduce these impacts is the use of LID - Low impact development. These practices are based on local treatment, attenuation, reuse, retention, and infiltration of surface runoff promoting flood control whilst also contributing to aesthetics, social, and environmental values in the urban area. The use of stormwater LIDs in new development areas is possibly less expensive and involves fewer effects than retrofitting consolidated areas, considering that they do not require demolition costs or other costs related to relocating people or economic activities. For example, bioretention and porous pavements can ensure a greater longevity for 


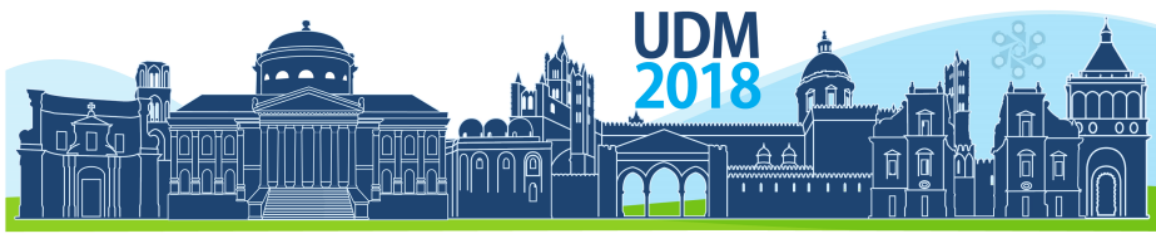

$11^{\text {th }}$ International Conference on Urban Drainage Modelling

23-26 Sep | Palermo - Italy

drainage infrastructure and avoid future investments in the implementation of stormwater ponds, which have expected drawbacks in maintenance and operation (Moura et al, 2014).
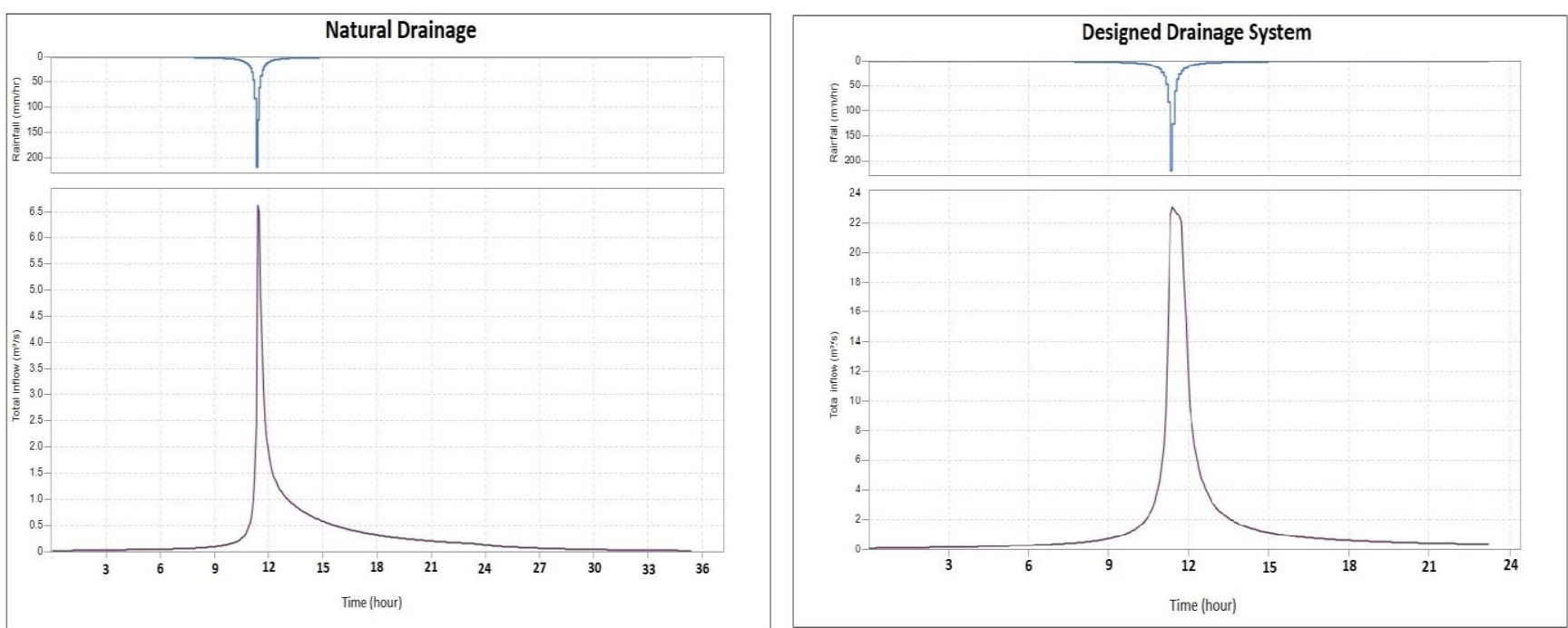

Figure 4 - Peak flow scenarios.

\section{CONCLUSIONS}

The changes in the land use's area and reduced infiltration rate affected the runnof's peak flow, causing a big variation between the scenarios. The other factor responsible for this variation is the reduced number of outlets that are part of the designed drainage system, which canalize a bigger water flow amount (resulting from urbanization process) through lesser outlets.

Therefore, these results are important to show the impacts in water receptor that can have its quality injured.

\section{References}

Beling, F. A., Garcia, J.I.B, Paiva, E. M. C. D., Bastos, G. A. P., Paiva, J. B. D.Analysis of the SWMM Model Parameters for Runoff Evaluation in Periurban Basins from Southern Brazil. 12nd International Conference on Urban Drainage, Porto Alegre/Brazil, 11-16 September 2011.

GOVERNO DO DISTRITO FEDERAL - GDF. Urban Drainage Manual. Master Plan of Urban Drainage of the Federal District, v. 2, 2009.

Moura, N.C.B., Pellegrino, P.R.M., Martins, J.R.S., 2015. Best management practices as an alternative for flood and urban storm water control in a changing climate. J. Flood Risk Manag. n/a-n/a. doi:10.1111/jfr3.12194.

Urban storm drainage criteria manual. Denver, CO: Urban Drainage and Flood Control District.2016. 


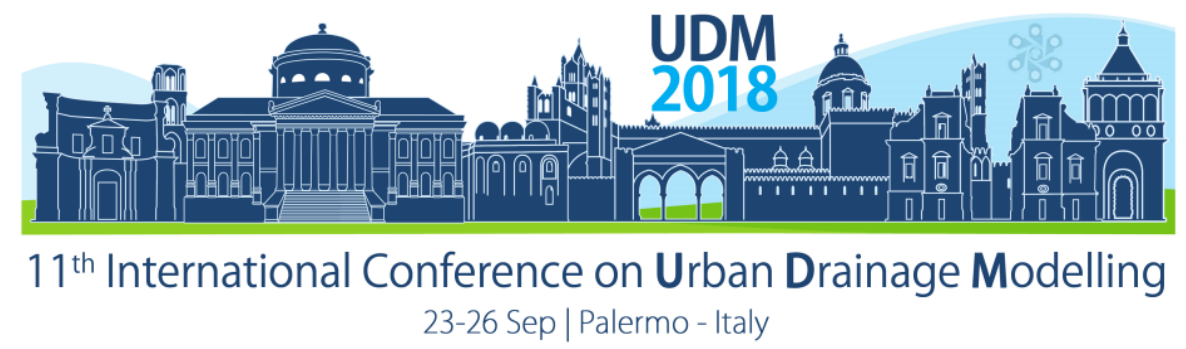

\title{
Evaluation of urban flooding hazard through the application of Bayesian Modelling Ensemble
}

\author{
Gabriele Freni ${ }^{1}$ and Vincenza Notaro ${ }^{1}$ \\ ${ }^{1}$ Università degli Studi di Enna "Kore" - Cittadella Universitaria - 94100 Enna, Italy
}

\begin{abstract}
The estimation of flood hazard frequency statistics for an urban catchment is of great interest in practice. The expected flood damage can be evaluated by an a priori estimation of potential damage caused by flooding or by interpolating real damage data. With regard to flood hazard appraisal several procedures propose to identify some hazard indicator $(\mathrm{HI})$ such as flood depth or the combination of flood depth and velocity and to assess the flood hazard corresponding to the analyzed area comparing the $\mathrm{HI}$ variables with user-defined threshold values or curves (penalty curves or matrixes). However, flooding data are usually unavailable or piecemeal allowing for carrying out a reliable flood hazard analysis, therefore hazard analysis is often performed by means of mathematical simulations aimed at evaluating water levels and flow velocities over catchment surface. As results a great part of the uncertainties intrinsic to flood risk appraisal can be related to the hazard evaluation due to the uncertainty inherent to modeling results and to the subjectivity of the user defined hazard thresholds applied to link flood depth to a hazard level. In the present work, a statistical methodology was proposed for evaluating and reducing the uncertainties connected with hazard level estimation. The methodology has been applied to a real urban watershed as case study.
\end{abstract}

Keywords: Urban flooding, flood hazard, flood risk, expected flood damage, statistical analysis

\section{INTRODUCTION}

Due to the hydraulic failure of urban drainage systems to collect zenithal storm waters, several cities in the world have to face with frequent and severe flood events causing high damages for people and goods. The increased runoff caused by the growing urbanization occurring in the last century and the effects of climate change combined with the aging sewer infrastructures represent the main causes of the urban drainage systems failures. In the last decades, assessing flood hazard frequency statistics for an urban catchment is of great interest in practice, as it provides the evaluation of potential flood risk and related damage ${ }^{1,2}$, and supports decision making for flood risk management ${ }^{3}$.

According to a proactive management of natural disasters, the European Directive $2007 / 60 / \mathrm{EC}^{4}$ (on the assessment and management of flood risks) invited Member States to identify the basins at risk of flooding and to draw up the related flood hazard and risk maps including detail on the flood extent, depth and level for several risk scenario by 2013 . The Flood Risk Directive only defines general requirements and invites member states to decide themselves on the appropriate methods needed for its implementation.

The terminology of flood risk analysis is still not uniform worldwide and also not within Europe. In literature flood risk is usually defined as function of the probability (flood hazard) of an event occurring, which comes from the rainfall ensemble, and the effects of the event (expected flood damage) taking into account both the exposure and the vulnerability of the 


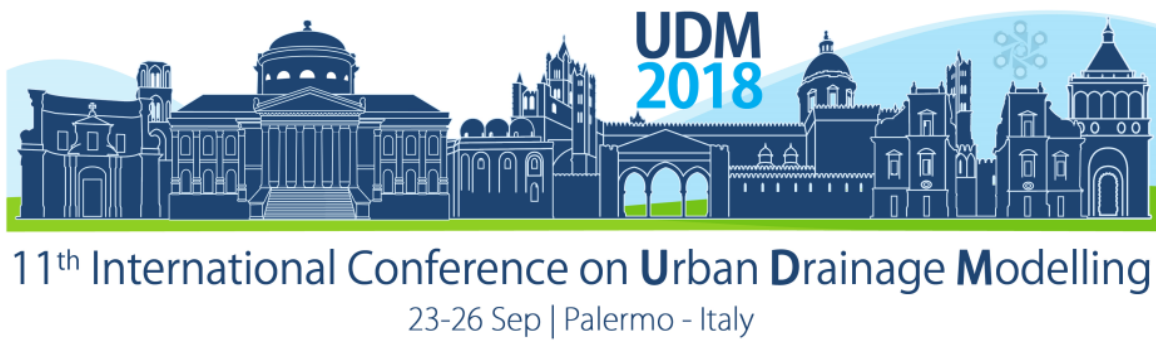

goods at risk. Several procedure evaluate the expected damage related to a flooding event by means of a-priori estimations of potential flood damage or by interpolating real damage data relating to the analyzed area,6,7,8. With regard to flood hazard, its appraisal is generally obtained defining some hazard indicators $(\mathrm{HI})$ synthetically representing the flooding frequency and magnitude such as the flooding depth on surface watershed or the combination of flooding depth and velocity. However, the historical series of flood data are often unavailable (or only available in piecemeal form) for carrying out a reliable assessment of urban flood hazard. Conversely, rainfall data are often easily accessible. Therefore, many standardized approaches indirectly estimate urban flood features (e.g., location, duration, water depth and velocity) by simulating via more or less complex numerical hydrodynamic tools ${ }^{9,7,10}$ urban drainage system behavior and adopting long historical rainfall series with different data resolution in time and space ${ }^{11,12}$ or synthetic rainfall hyetographs ${ }^{13}$ as input. Both approaches require that the numerical model undergo calibration over the available historical flooding data ${ }^{10}$. To link flooding data with a hazard level, each $\mathrm{HI}$ value is then compared with related threshold values or curves (penalty curves or matrixes) usually built consistent with a rule (e.g. as flooding depth or flooding depth per velocity increases, the flood hazard increases). However, the threshold values are user-defined depending often on user subjective perception of the system behavior, user personal experiences and on specific features of the analyzed urban watershed. In the present work, a statistical methodology is proposed for evaluating and reducing the uncertainties connected with hazard level estimation. The methodology robustness was tested on a real case study.

\section{MATERIALS AND METHODS}

\subsection{Bayesian Modelling Averaging Ensemble}

The uncertainty linked to mathematical model simulations has been extensively investigated in recent years. It can be reduced by means of: a robust model calibration ${ }^{10}$; a consistent definition of the rainfall events chosen as input of urban drainage system simulations ${ }^{12,13}$; and operational methods aimed at minimizing the uncertainty linked to mathematical model structure such as Bayesian Model Averaging ${ }^{14}$. Therefore, in the present paper a statistical analysis to quantify the uncertainty arising from the subjective selections of the penalty curve adopted to assess the hazard level related to a given $\mathrm{HI}$ value was proposed. The theoretical framework for the proposed analysis relies on Monte Carlo Simulations (MCS) and on the Generalized Likelihood Uncertainty Estimation methodology ${ }^{15}$.

As preliminary step the methodology requires employing an urban drainage mathematical model consistent with the hazard analysis needs. To this aim a dual drainage model ${ }^{16}$, able to simulate the surface runoff generation and propagation as well as the flow dynamic interactions between the underground urban drainage system (sewer conduits and manholes) and the surface drainage system (streets, pedestrian lawns, etc.), should be used ${ }^{7}$. Model simulations have to be run using long time series of historical or synthetic rainfall events as rainfall input, as long as the rainfall events are statistically independent ${ }^{17}$ in order to obtain a robust statistical analysis of flood hazard.

For each simulation, the maximum flood depth on sewer manhole (or the combination of flood depth and velocity) could be identified as hazard indicator (HI). Thus, a hazard level linked to each $\mathrm{HI}$ value is assigned by means of a selected penalty curve, and the global system flood hazard appraisal is achieved by a global function such as a weighted average where each 


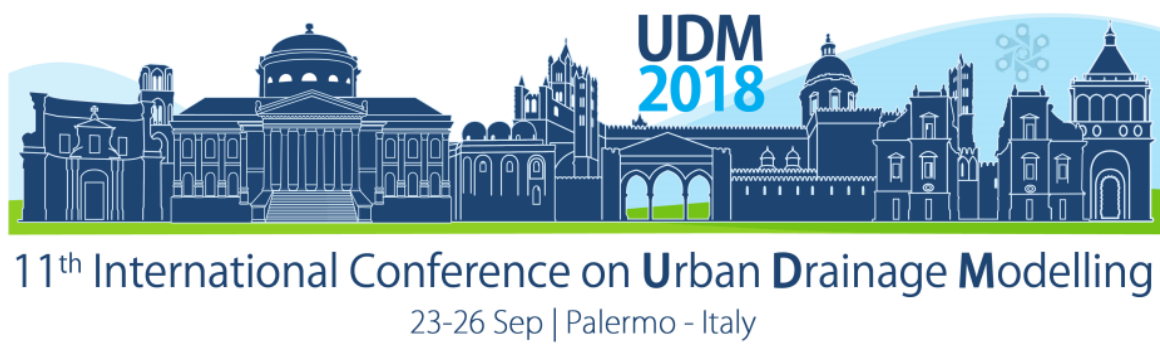

manhole is weighted in terms of its inlet and outlet pipes volume. Finally, a hazard probability relationship is obtained by fitting the global system hazard values with a suitable probability distribution function.

In order to investigate the influence of the penalty curve choice on the flood hazard assessment, a consistent sample of hazard threshold values or penalty curve shapes have to be defined by means of a uniform and randomly sampling strategy and for each one a flood hazard analysis have to be carry out. The number of penalty curve shape used, has to be decided by a preliminary analysis aimed at investigating the significance of the adopted random sample and the consequent reliability of the analysis results ${ }^{18}$. The uncertainty degree linked to penalty curve chosen by the operator can be obtained by evaluating the mean square error $\left(\mathrm{MSE}_{\mathrm{pc}}\right)$ values related to the $5^{\text {th }}$ and $95^{\text {th }}$ percentiles of the random sample with respect to the sample mean respectively. Similarly the $\mathrm{MSE}_{\mathrm{h}}$ related to the $5^{\text {th }}$ and $95^{\text {th }}$ percentiles of the hazard cumulative distribution functions CDFs can be assessed to quantify the uncertainty propagation through the hazard appraisal methodology. The comparison between $\mathrm{MSE}_{h}$ and $M S E_{p c}$ values allows to quantify the reduction or the increase of the uncertainty related to the operator subjective selections in applying the hazard analysis procedure ${ }^{15}$.

\subsection{The case study}

The proposed hazard analysis was applied to a case study: the "Centro Storico" of Palermo (Italy). The case study watershed is the oldest part of the city, strongly urbanized and with a very old drainage system; local surface flooding due to the system's surcharge, often occurs even for high-frequency rainfalls. To simulate the urban drainage-system behavior, a numerical model adopting a dual drainage approach ${ }^{7,16}$ was employed. Model calibration was carried out on the flood levels and volumes measured by Municipal Fire Brigades during 28 small flood events occurring in the studied area between 1993-2008 ${ }^{13}$. Simulations have been carried out using as input 102 statistical independent historical rainfall events, recorded at the Parco d'Orléans rain gage located into the analyzed area, operational since 1993 with a temporal resolution of 1 minute.

A random sample of 10.000 penalty curves was generated, (Fig. 1(a)) and for each one a flood hazard analysis was carried out. Figure 2(b) shows the related mean, $5^{\text {th }}$ and $95^{\text {th }}$ percentiles: the uncertainty connected with the operator choice of penalty curve shape is high, according to the wide distance between $5^{\text {th }}$ and $95^{\text {th }}$ percentile curves and the consequent high values of

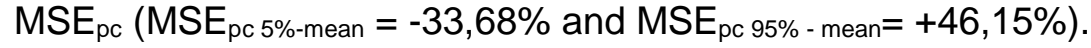

\section{RESULTS AND DISCUSSION}

The significance of the adopted random sample and the resulting reliability of the hazard analysis were investigated analyzing the variation of the uncertainty boundaries width of global system hazard for different sample sizes, varying from 100 to 100.000 realizations ${ }^{18}$. The analysis showed that the uncertainty boundaries width became insensitive to the sample size over 10.000 realizations. 


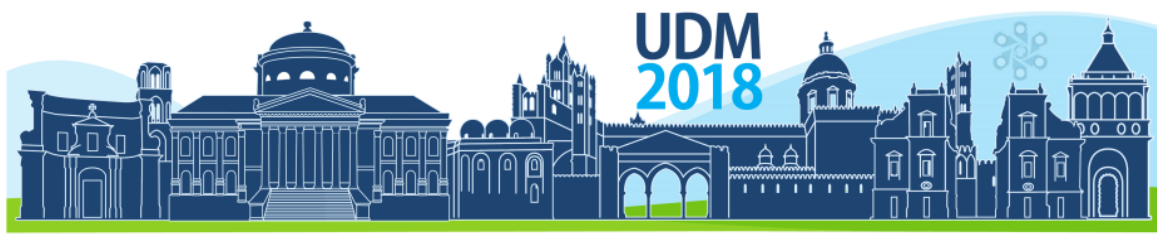

$11^{\text {th }}$ International Conference on Urban Drainage Modelling 23-26 Sep | Palermo - Italy
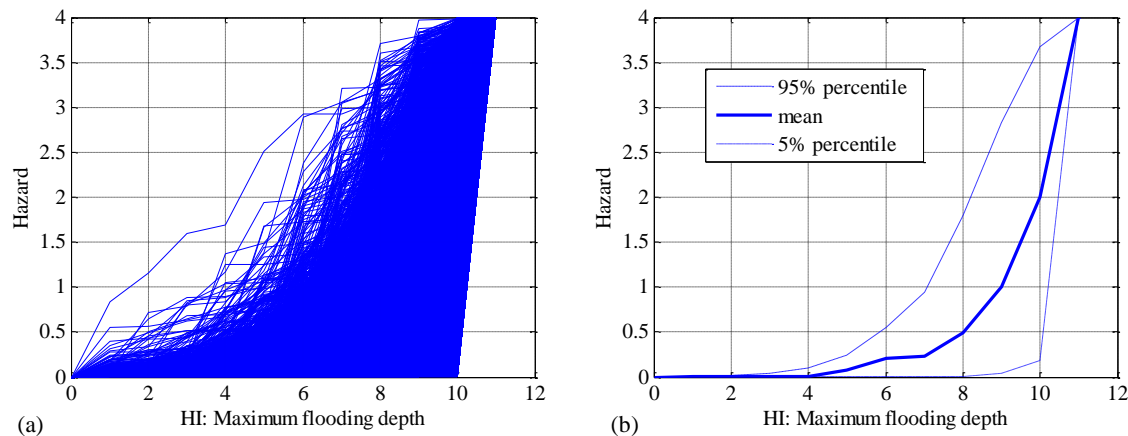

Figure 1. (a) Random sample of 10.000 hazard penalty curves; (b) Mean, $5^{\text {th }}$ and $95^{\text {th }}$ percentiles penalty curves

For each penalty curve of the sample the global system hazard linked to each simulated rainfall event was evaluated and a hazard-probability relationship was obtained by fitting with a Beta probability distribution function the 102 global system hazard values related to the simulated rainfalls; since Beta arguments has to be range in [0;1[ interval, a normalized hazard has been used. Figure 3 shows the global system hazard uncertainty boundaries obtained plotting $5^{\text {th }}$ and $95^{\text {th }}$ percentiles of the hazard CDFs. The uncertainty band is very narrow with low values

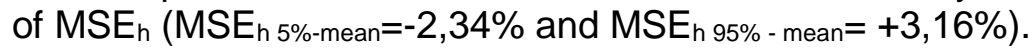

The comparison of Figures 1 (b) and 2 clarifies how the uncertainty linked to global system hazard appraisal is lower than the uncertainty related to the choice of the penalty curve shape. The $\mathrm{MSE}_{\mathrm{h}}$ related to the $5^{\text {th }}$ and $95^{\text {th }}$ percentiles shows a width of uncertainty band less then $6 \%$ while the uncertainty connected with the level of hazard associated with a single $\mathrm{HI}$ value can vary in a range of about $80 \%$ depending on the selected penalty curve. The robustness of the described statistical approach is confirmed by the analysis of Beta distribution parameters. Figures 3(a) and (b) show the distribution of the $\alpha$ and $b$ parameter of Beta probability distribution function, respectively. The distributions are very steep, demonstrating a low parameter variability with the selected penalty curve.

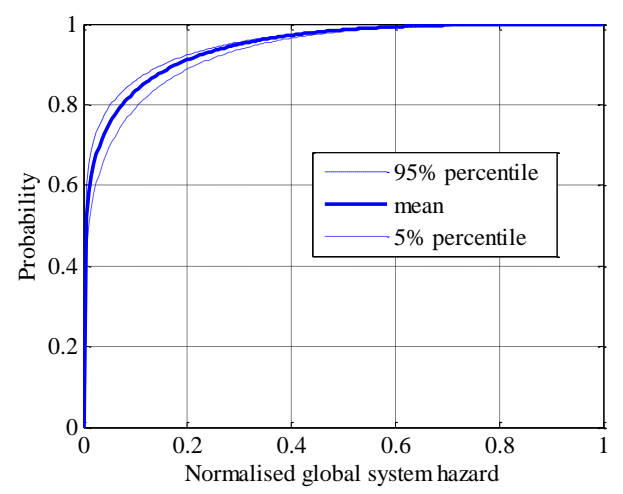

Figure 2. Mean, $5^{\text {th }}$ and $95^{\text {th }}$ percentiles curves related to Beta CDFs of the global system hazard

This consideration can increase the confidence of the user in applying statistical hazard analysis also for comparing different systems and different temporal conditions without reducing the reliability of the analysis response. 


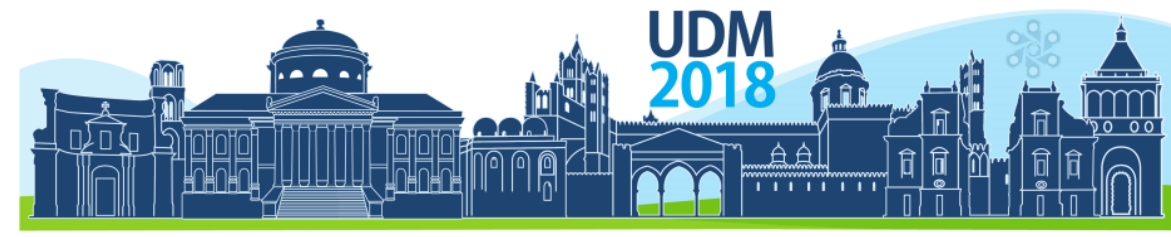

$11^{\text {th }}$ International Conference on Urban Drainage Modelling 23-26 Sep | Palermo - Italy
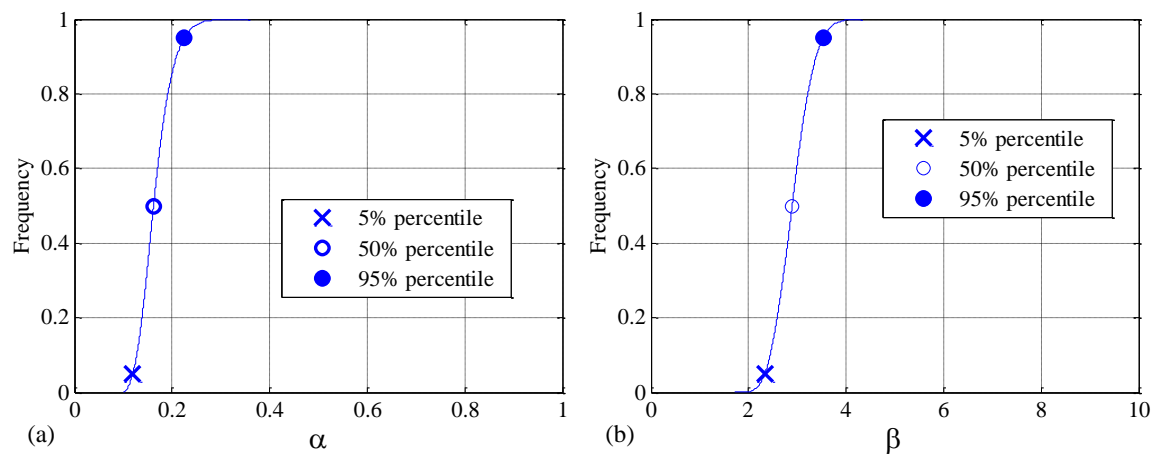

Figure 3. Likelihood $5^{\text {th }}, 50^{\text {th }}$ and $95^{\text {th }}$ percentiles related to $\alpha(a)$ and $\beta$ (b) parameters of Beta CDF

\section{CONCLUSIONS}

The hazard analysis reliability is highly dependent on the choice of penalty curves; this aspect reflects on analysis results that can be adopted mainly for comparing different scenarios in the same context. The statistical approach guarantees higher robustness dumping the uncertainties coming from the selection of penalty curves. Even if computationally onerous, the proposed statistical analysis increases the robustness of the method and allows for some general considerations about the user-dependency of the classical hazard assessment methodology and for increasing the user confidence in the method results.

\section{References}

1. G. Fu and K. Kapelan, Journal of Hydroinformatics., 15(3), 687-699 (2013).

2. J. Ahn, W.K.T. Cho, H. Shin and J.H. Heo, Water 6(12), 3841-3863 (2014).

3. V. Notaro, C.M. Fontanazza, G. La Loggia and G. Freni, "Identification of the best flood retrofitting scenario in an urban watershed by means of a Bayesian Decision Network" in: Urban Water II, edited by S. Mambretti and C.A. Brebbia, 2014 pp. 341-352

4. Directive 2007/60/EC of the European Parliament and of the Council of 23 October 2007 on the assessment and management of flood risks, European Parliament, Council, 2007.

5. R. J. Dawson, L. Speight, J. W. Hall, S. Djordjević, D. Savić, and J. Leandro, J. of Hydroinformatics, 10(4) 275-288 (2008)

6. S.N. Jonkman, M. Bočkarjovab, M. Kokc, P. Bernardinid, Ecological Economics, 66, 77-90 (2008)

7. G. Freni, G. La Loggia, V. Notaro, Water Science \& Technology 61, 2979-2993 (2010).

8. V. Notaro, M. De Marchis, C.M. Fontanazza, G. La Loggia, V. Puleo, G. Freni, Procedia Engineering 70, 1251-1260 (2014).

9. G. T.Aronica, G. Freni, and E. Oliveri, Hydrological Processes, 19(5), 1055-1071 (2005).

10. V. Notaro, C. M. Fontanazza, G. Freni, and V. Puleo, Water Science \& Technology 68(9), 1984-1993 (2013)

11. S. Thorndahl and P. Willems, Water Research, 42(1-2), 455-466. (2008).

12. C.M. Fontanazza, G. Freni, G. La Loggia, and V. Notaro, Water Science \& Technology, 63(11), 2641-2650 (2011)

13. C.M. Fontanazza, G. Freni and V. Notaro, Water Science \& Technology, 66(8), 1669-1677 (2012).

14. V. Notaro, C.M. Fontanazza, G. Freni and G. La Loggia, Procedia Engineering 89, 788 - 795 (2014)

15. K.J. Beven and A.M. Binley, Hydrological Processes 6(3): 279-298 (1992).

16. J. Leandro, A.S. Chen, S. Djordjević, and D.Savić, Journal of Hydraulic Engineering 135(6), 495-504 (2009)

17. H. Lei Jian and W. Schilling, Water Science and Technology 33(2), 79-90 (1996).

18. J. L. Bertrand-Krajewski, S. Barraud, J. P., Urban Water 4, 163-179 (2002) 


\section{Part F - Tools, techniques and analysis in urban drainage modelling including Real-Time Control}




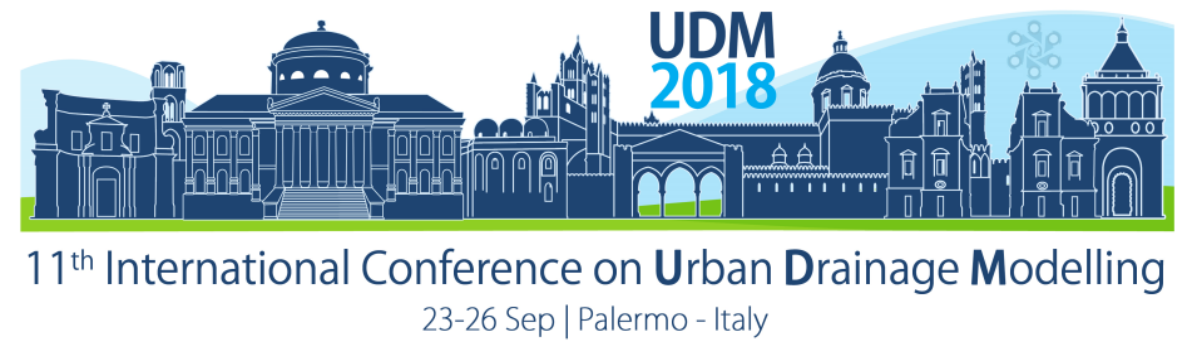

\title{
Uncertainty in environmental water quality modelling: where do we stand?
}

\author{
Anthony Jakeman', Barry Croke ${ }^{1,2}$, Baihua Fu' \\ ${ }^{1}$ The Australian National University, Fenner School of Environment and Society, Canberra, Australia \\ 2 The Australian National University, Mathematical Sciences Institute, Canberra, Australia
}

\begin{abstract}
The physical and biochemical processes that underpin the generation and transport of water quality constituents are extremely complex, as are the social and institutional processes that determine how human activities impact the landscape. Any models attempting to represent these processes will therefore be fraught with huge overall uncertainty. It is incumbent on developers and users of water quality models to manage the sources of uncertainties and reduce the critical ones that affect the clarification of decisions. This paper documents ten sources of uncertainties and suggests nine ways in which uncertainty in a model might be handled. Model conceptualisation is a major source of uncertainty that is all too often not reported nor justified. Commonly used process-based models are often non-identifiable, thus issues concerning the selection of scales and detail of model representation need more rigorous treatment. While parameter fixing is often undertaken to address over-parameterisation, seldom do we see the increasing use of sensitivity and uncertainty analyses leading to model structure improvements. Formal methods of uncertainty analysis are hindered by the many required assumptions. One way around this is to utilise exploratory modelling to identify conditions and assumptions under which certain objectives are met and not met. Methods of robust decision and risk analysis also have much to offer in this respect. Another known source of uncertainty is errors in the data. The paper advocates more attention to understanding one's data and the signals therein before embarking on any modelling. It also proposes complementary uses of empirical modelling when warranted by the problem context.
\end{abstract}

Keywords: Empirical; process based; diffuse sources; exploratory modelling; sensitivity analysis; Monte Carlo; emulation; identifiability; management

\section{INTRODUCTION}

It seems that progress in the science of water quality modelling has somewhat stalled. There is just a handful of models being applied for a majority of the applications for supporting management and policy. The main process-based ones being used, however, are heavily and arbitrarily over-parameterized with respect to the problem context, data and prior knowledge available, and tend to be applied with insufficient rigor that considers and prioritizes the various sources of uncertainty. These features present problems for uncertainty assessment of predictions despite the availability and increasing use of algorithms that attempt to characterize model sensitivities and uncertainties. On the other hand empirical approaches are still much applied in practice and justifiably represent an alternative, even complementary, paradigm. However there are still pervasively committed assumptions with the empirical approach that require justification and less presumptive uncertainty analysis. In addition there needs to be more hypothesizing in model structure 


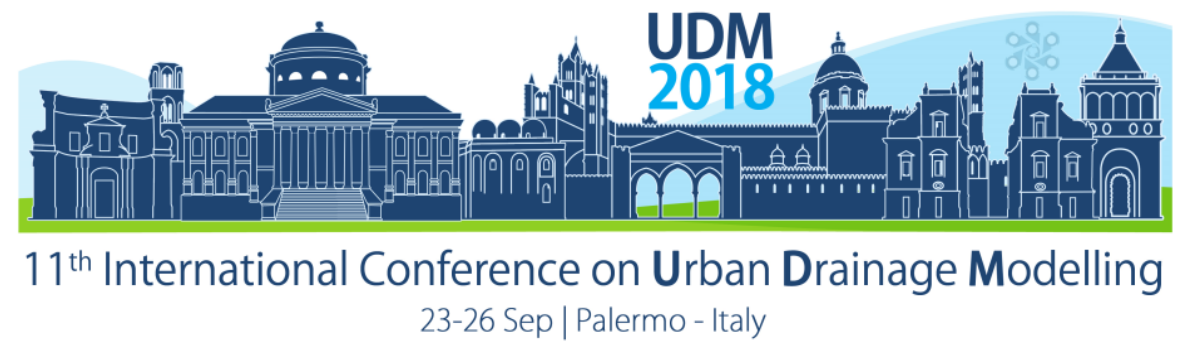

assumptions and comparison with alternatives, especially so when extrapolation of models beyond calibrated conditions such as flow range is required.

Employing an uncertainty lens, the paper attempts to articulate the factors that need to be addressed in developing and applying models and the steps that can be taken. There is a strong case for a more holistic approach to uncertainty assessment for the specific quantities of interest, including quantitative and qualitative methods and adherence to a fulsome emphasis on the technical and social aspects of the modelling procedure adopted.

There is also an issue with the available water quality data not being adequate in many situations. There is a need for more event-based water quality data collection, particularly for larger events.

\section{SOURCES OF UNCERTAINTY IN WATER QUALITY MODELLING}

Usually in the literature when sources of uncertainty are referred to, data, model structure and parameters are the main ones mentioned. However a more comprehensive list is warranted if we are to truly capture and address sources of uncertainty. There are ten distinct items to consider:
a. Data
b. Conceptualisation of the model
C. Future forcing conditions
d. Parameters and/or initial boundary conditions
e. Prior knowledge
f. Model family and its structure (empirical, physical, hybrid)
g. Model purpose and/or objectives
h. Verification/validation process and uncertainty assessment (including qualitative aspects)
i. Model code and numerical implementation
j. Communication process and modelling workflows

\subsection{Considerations for uncertainty sources in a-j above}

Data

Errors in data affect calibration of a model and their misspecification can also hinder more formal probabilistic approaches to uncertainty assessment. Errors also affect model outputs when using a model in the forward sense i.e. in predictive or simulation mode. Improved practice here would include undertaking preliminary data analysis to understand system response and represent errors and correlation relationships between data variables.

\section{Conceptualisation of the model}

It is all too tempting for those applying models to move to an available model/software and neglect this major step, one which needs strong consideration as to what quantities of interest 


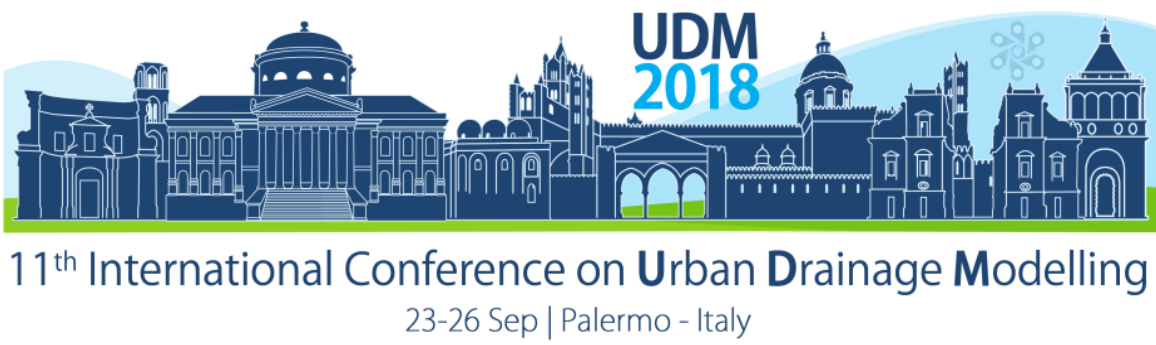

(see Model purpose and objectives below) are required and what drivers and relationships need to be represented and at what approximate level of detail. It is also in the interests of facilitating transparency and communication in a project to report on this step and document who was involved as part of the workflow.

\section{Future forcing conditions}

There are many factors that can influence how water quality may evolve in the future. Chief among these is climate but land use, land use practices and source and pathway management conditions will also be important to consider. The various assumptions and errors associated with representing such inputs need to be taken into account.

\section{Parameters and/or initial boundary conditions}

These quantities obviously affect the uncertainty of predictions or simulations from the model. Care needs to be taken in the methods selected to estimate parameters and especially in the fixing of some if this is invoked. The objective function(s) used to estimate parameters should be related to the purpose of the modelling and the errors to be minimised.

\section{Prior knowledge}

Whilst prior knowledge can be used to constrain parameters in a model structure, inappropriate constraints may underestimate or overestimate uncertainty, leading to underestimates of model output uncertainty and conservative estimates, respectively. One needs to appreciate the effects of such assumptions.

\section{Model family and its structure}

Here the choice should depend upon objectives of the modelling and the information available. Empirical/statistical approaches may be valuable for instance in situations where nonstationarity is not a major issue and resources are limited for building a process-based model. A key, essentially neglected issue is that of non-identifiability. Most of the commonly used process-based models are over-parameterised so that there are multiple parameter sets that explain model outputs to the same degree, largely whatever the metric of explanation.

\section{Model purpose and/or objectives}

A first principle, especially judicious in the face of much uncertainty, is to simplify the problem by exacting the purpose and being specific about the objectives and modelling purpose. This entails consideration of the quantities of interest (Qol) to be predicted and the level of accuracy required. For example, do we wish to know the total maximum daily load of a contaminant or just whether water quality will be no worse than currently under a specific forcing/change, both to some, but perhaps different, degree of confidence. In particular the forms (mean, maximum, low order moments, pdf, etc.) and spatio-temporal scales (where and how often) of model output influence the selection of the Qol. For example, is it a flux over some long time period or a daily time series providing patterns that affect ecological impacts? 


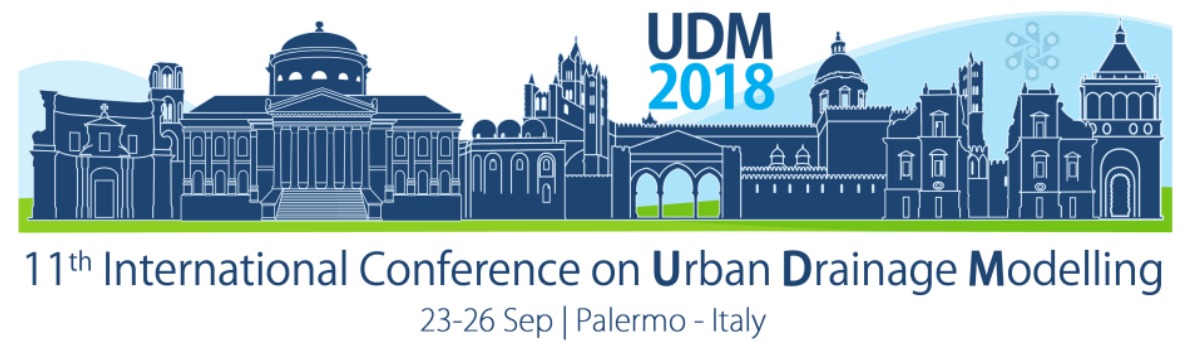

In addition to exacting the purpose of the deterministic model, one must also consider the purpose of the uncertainty analysis. For example, does one want to identify important parameters, predict mean behaviour or quantify risk?

It may also pay to consider concepts of vulnerability, risk and/or robustness when attempting to get a more definitive handle on uncertainties. These terms can apply to the formulation of the objectives/quantities of interest or they can apply to scenario analysis where one identifies uncertainties in inputs and parameters that lead to vulnerable, risky or robust outcomes.

\section{Verification/validation process and uncertainty assessment}

The less comprehensive this step, the less certain the model results. A glaring common deficiency is the absence of a cross-correlation analysis between model residuals and model inputs to assess if there is something missing or wrong in the model's explanation of outputs. Bennett et al. (2013) provide a compendium of methods and metrics to assess model performance. In the next section we will discuss techniques of uncertainty assessment that warrant more attention.

\section{Model code and numerical implementation}

This is another understated source of error. The likelihood of coding errors increases with coding complexity but errors in coding and poor algorithm selection can also produce errors. There are well-known methods in computer science that aim to verify and test model code, such as unit tests, but these are seldom reported upon.

\section{Communication process and modelling workflows}

The results presented to managers and decision makers can be too complex or too simple. There needs to be a balance between not being overwhelming and omitting vital information such as efficient uncertainty characterisation. See Bonneau et al. (2014) for a review of methods for uncertainty visualisation. In addition, communication within the modelling team and the legacy of the project benefit from adequate documentation of the workflow and version control.

\subsection{Methods currently available for exploring uncertainty in models}

In this section we mainly consider methods for addressing uncertainty in a model, rather than the broader issue of uncertainty in the modelling process and its ultimate predictions.

Sensitivity assessment (SA) (Norton, 2015) can be a useful procedure to explore the determinants of model outputs. It can be used to simplify a model calibration such as by fixing insensitive parameters and calibrating the remainder. Ideally it would also be used to understand model behaviour and improve model hypotheses and model structure. SA will not be further discussed here except to note that its limitations should be acknowledged. Shin et al. (2013) pose 10 questions that should be asked when performing SA. These include consideration of the impact on the analysis result of the parameter range, objective function, and input data used; as well as the length of analysis period, and the choice of SA method. The questions posed highlight two key issues: identifiability, and uncertainty in SA. 


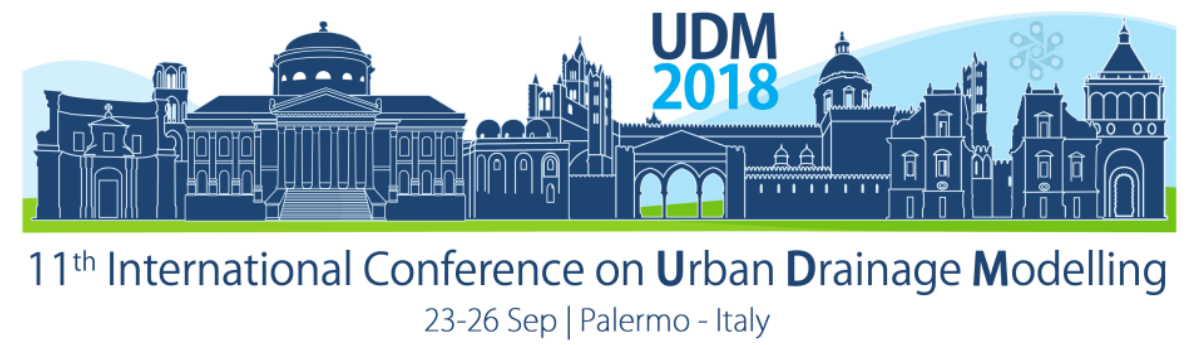

Bayesian inference methods yield a probabilistic description (posterior density) of the extent to which different realisations of parameters are consistent with observations (Kaipio and Somersalo, 2005). The discrepancy between the observations and the model simulations is encoded in the likelihood function. A major issue here is that model outputs are used to obtain posterior uncertainty distributions for model inputs. This is model dependent, i.e. estimated uncertainty for the same data used by two different models will most likely be different. This method needs informative priors (Renard et al., 2010) - i.e. one needs to have a good idea what the uncertainties in the model inputs are.

Generalized Likelihood Uncertainty Estimation (GLUE) is a popular Bayesian-like method for appreciating the uncertainties in a model (Beven and Binley, 1992). Here the likelihood is not a likelihood in the strict statistical sense but an objective function specified in a flexible manner so that posterior distributions are conditioned on the selection of the function. Approximate Bayesian Computation (e.g. Beaumont et al., 2002) is a similar approach.

Monte Carlo simulation is a general method for looking at uncertainties, of which Bayesian methods are a sophisticated example. The issue here is that one needs to set the uncertainties in the model inputs and parameters; the results will be predicated on those choices.

Algebraic methods of sensitivity and uncertainty analysis warrant more attention. Many of the processes represented in models can be differentiated so that one can get an idea of the relative effect of different parameters on outputs. Norton (2008) for example shows how algebraic analysis can provide informative results with little or no computing, with examples of a range of basic functions that occur in water quality models.

Exploratory modelling and analysis (EMA) in its broadest sense involves exploring scenarios about future conditions, model structure and parameter values. It can be used to search for scenarios that lead to good, poor and intermediate outcomes, or specified objectives such as robustness metrics (McPhail et al., 2018). EMA (e.g. Kwakkel and Pruyt, 2013) is related to robust decision making where computer-assisted reasoning is used as an adaptive decision support tool for complex systems with "deep uncertainty" (Lempert, 2002).

Crash testing the model refers to attempting to identify what parameter sets, observation periods and other conditions establish limitations or invalidate the model. This can involve examining the performance of the model through time and space. In a broader context, one can test multiple models (hypotheses) to explore uncertainties in model formulations. Bayesian model selection (Wasserman, 2000; Chipman et al., 2001) can also be used to formalise this based on the adopted (informative or non-informative) prior probability distributions.

Surrogate models or model emulation can be attractive when a model is extremely computationally expensive such that adequately understanding its behaviour and quantifying uncertainty can be computationally intractable for any of the aforementioned techniques. Various methods have been developed to produce surrogates of the model response to uncertain parameters. The most efficient are goal-oriented in nature and target very specific uncertainty measures. Generally speaking, surrogates are built using a small number of model simulations and are then substituted in place of the expensive simulation models in future analysis. Some of the most popular surrogate types include polynomial chaos expansions (Sudret, 2008), Gaussian processes (Rasmussen and Williams, 2006), and sparse grids (Bungartz and Griebel, 2004). 


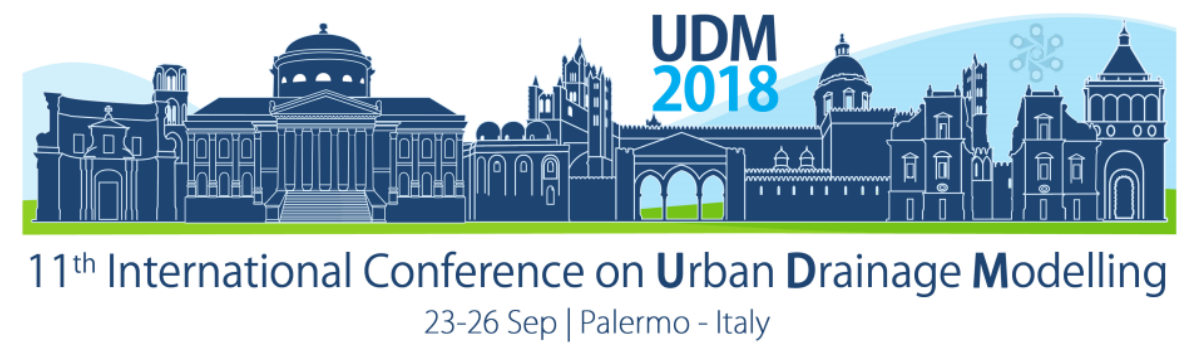

Qualitative approaches may be sufficient or at least a useful adjunct in some cases. The emphasis can be on how the prediction was produced, and the limitations involved in doing so. One way of approaching this is through quality assurance of the modelling process (Refsgaard et al. 2007) and its constituent assumptions, whilst another is to include qualitative judgements about the information and how it is produced (Van der Sluijs et al. 2005).

\section{BACK TO BASICS WITH MORE EMPIRICAL APPROACHES: REGRESSION ANALYSIS}

Empirical approaches require adequate data. While high frequency observations enable the use of tools like spectral analysis (e.g. Kirchner and Neal, 2013) to gain more understanding of the dynamics of water quality constituents, generally the high frequency observations necessary are not available at most locations. While "making do" with weekly, fortnightly or monthly water quality sampling results in a very limited view of the behaviour of the system (Kirchner et al., 2004), it is still the case that many sites have limited water quality data available. Until this lack of data can be corrected, ways of using the available data need to be employed. Due to the limitations in the available data, it is vital to develop an understanding of the uncertainties in the predictions, to report these, and to take them into consideration when making decisions.

Regression-based approaches are a fundamental method of converting observed water quality data into information that can be used in a water quality model (Letcher et al. 2002). This could relate the concentration of a constituent to flow (e.g. TSS), relate one constituent to another (e.g. particulate P to TSS), or compare different measurements of the same constituent (e.g. turbidity and TSS). Such regressions need to be adequately tested. Simply reporting the $R^{2}$ (i.e. the coefficient of determination for a linear regression) value is not sufficient. A common test is to use the $p$-value to assess statistical significance. In addition to this, it is advisable to record the uncertainty in the coefficients of the regression as this will give an idea of the confidence bounds in the model predictions. Further, recording of the range of data values used is helpful as the uncertainty will increase considerably when extrapolating beyond the limits of the available data (i.e. the choice of function that is fitted will have a considerable impact on the error under extrapolation, and this is not captured by the uncertainty in the coefficients).

The choice of function being fitted needs to be appropriate for the situation. The tendency is to use linear regression (extended using transformations to selected non-linear functions e.g. exponential, logarithmic, power laws, as well as breaking a non-linear response into linear sections: the "broken stick" approach). While transformations can be used to fit selected non-linear functions using linear regressions, care needs to be taken as there will be bias in the fitted result when transforming the y/ordinate-axis which will depend on the magnitude of the scatter in the data (Ferguson, 1986). While a linear regression is a straightforward calculation, non-linear regression requires an iterative approach, with selection of a convergence criteria.

When dealing with relationships between flow and concentrations or between two concentrations, frequently a linear regression to a power law is used. The problem is that the concentrations at high flows are driven by the flows, the concentrations at low flows are driven by localised activity (e.g. fish and birds sifting through bed sediments for food, land 


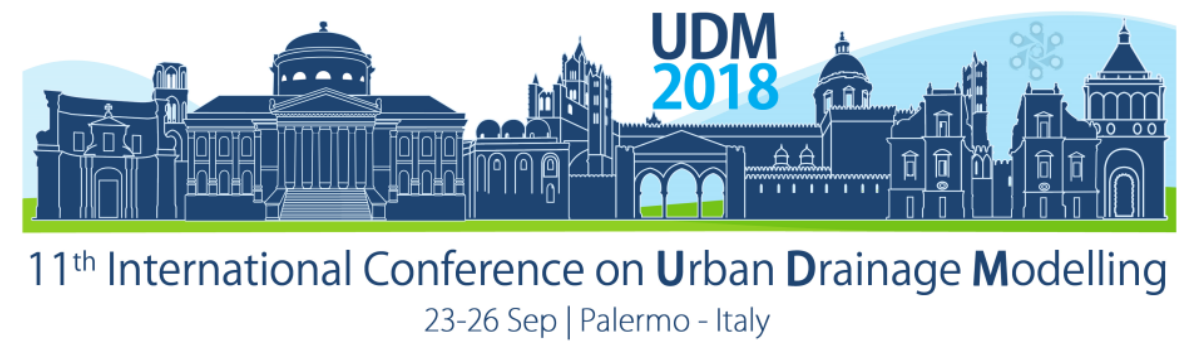

animals and birds wading through the water way, vegetation growth and decay). A single power law cannot capture these processes. As a result, there is a need for two different components. Easiest is a power law plus a constant:

$$
[x]=a Q^{b}+c
$$

where $[x]$ represents the concentration of the constituent of interest $(x), Q$ is the flow rate, and $a, b, c$ are the coefficients to be determined. Generally, the bulk of the available data is at low flows, which defines $c$ quite well. The result is that only the event-based data help with defining the values of $a$ and $b$, so these tend to have very large uncertainty. The uncertainty in these values are much less if a linear regression approach is used $(c=0)$, but doing this tends to result in a bias in the derived loads (in addition to that resulting from the use of the log transform) as the concentrations at high flows tend to be significantly under-estimated. Using the non-linear regression approach adds the complication of using an iterative approach, but avoids the bias issue (both due to the use of the log transform, and by selecting, hopefully, a more appropriate function).

Furthermore, care needs to be taken when extrapolating beyond the range of the available data. The uncertainty estimated using the uncertainty in the fitted parameters will underestimate the uncertainty in the predictions as the estimate hinges on the fitted function being a good representation of the relationship between the concentration of the constituent and flow.

Finally, for many constituents (those mobilized by rainfall events), the loads are dominated by the high flows. The uncertainty in these flow values is quite high as most stage height discharge rating curves are empirically based, and have little or no data at the highest flows (see point on extrapolation). Therefore, one needs to consider carefully the uncertainty in the observed flows (and the rating curve). Standard regression methods assume perfect data for the independent variable, with all the scatter attributed to the dependent variable. While this can work, care needs to be taken to ensure that this is not introducing a bias in the result, particularly when using the fitted function to estimate loads.

\section{WAYS FORWARD}

The primary need for improved water quality predictions in most cases is for better water quality data, especially targeted at high flow events. Selecting what observations are best taken should be based on the impact that the data will have on the uncertainty in model predictions, and should consider both spatial and temporal aspects. There is also a chasm in the literature for reporting better understanding of the quality of existing data as well as any new data collected, and how this impacts on the uncertainty in the model predictions. In addition, the uncertainty in observed and modelled flows should be considered and represented, and how these will impact on the estimates of constituent concentrations and loads.

There is also much room for more thorough testing and reporting of water quality models. This should not just be an analysis of the model residuals as these are a poor indicator of uncertainty in model predictions. Cross-correlation of residuals with model inputs, and the use of sensitivity and uncertainty analysis methods designed to adequately test the model's behaviour and suggest revised structural hypotheses, should be routine practices.

Opportunities in these respects abound. 


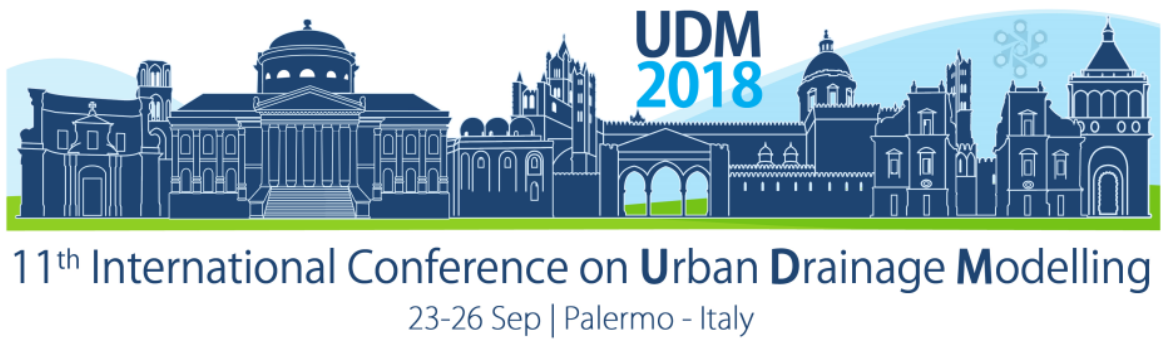

\section{References}

Beaumont, M.A., Zhang, W. and Balding, D.J. (2002) Approximate Bayesian computation in population genetics. Genetics, 162(4), 2025-2035.

Bennett, N.D., Croke, B.F.W., Guariso, G., Guillaume, J.H.A., Hamilton, S.H., Jakeman, A.J., Marsili-Libelli, S., Newham, L.T.H., Norton, J.P., Perrin, C., Pierce, S.A., Robson, B., Seppelt, R., Voinov, A.A., Fath, B.D. and Andreassian, V. (2013). Characterising performance of environmental models, Environmental Modelling and Software, 40, 1-20, doi: j.envsoft.2012.09.011.

Beven, K. and Binley, A. (1992) The future of distributed models: Model calibration and uncertainty prediction. Hydrological Processes, 6(3), 279-298.

Bonneau, G.P., Hege, H.C., Johnson, C.R., Oliveira, M.M. Potter, K., Rheingans, P. and Schultz, T. (2014) Overview and state-of-the-art of uncertainty visualization, in Scientific Visualization: Uncertainty,Multifield, Biomedical, and Scalable Visualization, ed. by C.D. Hansen, M. Chen, C.R., Johnson, A.E. Kaufman, H. Hagen (Springer, London, 2014), pp. 3-27.

Bungartz, H.-J. and Griebel, M. (2004) Sparse grids. Acta Numerica, 13,147-269.

Chipman, H., George, E.I., McCulloch, R.E. (2001) The Practical Implementation of Bayesian Model Selection. Model selection, Institute of Mathematical Statistics, Beachwood, OH, pp 65-116, doi:10.1214/Inms/1215540964. https://projecteuclid.org/euclid.Inms/1215540964.

Ferguson, R.I. (1986) River loads underestimated by rating curves, Water Resources Research, 22, 74-76.

Letcher, R.A., Jakeman, A.J., Calfas, >, Linforth, S., Baginska, B. and Lawrence, I. (2002) A comparison of catchment water quality models and direct estimation techniques. Environmental Modelling and Software, 17, 77-85.

Kaipio, J. and Somersalo, E. (2005) Statistical and Computational Inverse Problems. Springer

Kirchner, J. W., Feng, X., Neal, C. and Robson, A. J. (2004), The fine structure of water-quality dynamics: the (highfrequency) wave of the future. Hydrol. Process., 18: 1353-1359. doi:10.1002/hyp.5537.

Kwakkel, J.H. and Pruyt, E. (2013) Exploratory modeling and analysis, an approach for model-based foresight under deep uncertainty. Technological Forecasting and Social Change, 80(3), 419 -431. Future-Oriented Technology Analysis.

Lempert. R.J. (2002) A new decision sciences for complex systems. Proceedings of the National Academy of Sciences, 99(suppl 3), 7309-7313.

McPhail, C., Maier, H.R., Kwakkel, J.H., Giuliani, M., Castelletti, A. \& Westra, S. (2018). Robustness Metrics: How Are They Calculated, When Should They Be Used and Why Do They Give Different Results? Earth's Future, 6, 1-23.

Neal, C., Reynolds, B., Kirchner, J. W., Rowland, P., Norris, D., Sleep, D., Lawlor, A., Woods, C., Thacker, S., Guyatt, H., Vincent, C., Lehto, K., Grant, S., Williams, J., Neal, M., Wickham, H., Harman, S. and Armstrong, L. (2013) High-frequency precipitation and stream water quality time series from Plynlimon, Wales: an openly accessible data resource spanning the periodic table. Hydrol. Process., 27, 2531-2539, doi:10.1002/hyp.9814.

Norton, J.P. (2008) Algebraic sensitivity analysis of environmental models. Environmental Modelling and Software, 23, 963-972.

Norton J.P. (2015) An introduction to sensitivity assessment of simulation models, Environmental Modelling and Software, 69, 166-174, doi: j.envsoft.2015.03.020.

Rasmussen, C.E. and Williams. C. (2006) Gaussian Processes for Machine Learning. MIT Press.

Refsgaard, J.C., van der Sluijs, J.P., Hjberg, A.L. and Vanrolleghem, P.A. (2007) Uncertainty in the environmental modelling process a framework and guidance. Environ. Model. Softw. 22(11), 1543-1556.

Renard, B., Kavetski, D., Kuczera, G., Thyer, M. and Franks, S.W. (2010) Understanding predictive uncertainty in hydrologic modeling: The challenge of identifying input and structural errors, Water Resour. Res., 46, W05521, doi:10.1029/2009WR008328.

Sudret. B. (2008) Global sensitivity analysis using polynomial chaos expansions. Reliability Engineering \& System Safety, 93(7), 964-979, 2008.

Van Der Sluijs, J.P., Craye, M., Funtowicz, S., Kloprogge, P., Ravetz, J. and Risbey, J. (2005) Combining quantitative and qualitative measures of uncertainty in model-based environmental assessment: The nusap system. Risk Anal. 25(2), 481-492.

Shin, M.J., Guillaume, J.H.A., Croke, B.F.W. and Jakeman, A.J. (2013) Addressing ten questions about conceptual rainfall-runoff models with global sensitivity analyses in R, Journal of Hydrology, 503, 135-152, doi: j.jhydrol.2013.08.047.

Wasserman, L. (2000) Bayesian Model Selection and Model Averaging, Journal of Mathematical Psychology, 44, 92-107. doi:10.1006/jmps.1999.1278. 


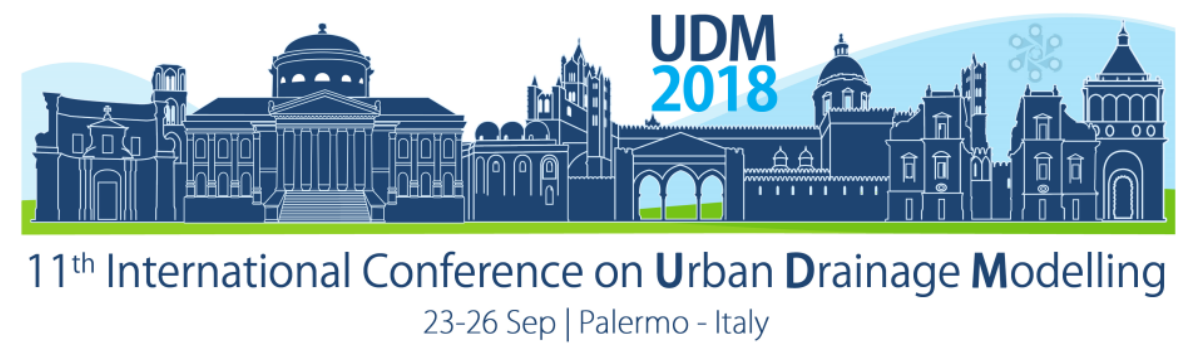

\title{
Integrated 1D/2D Urban Inundation Modelling with Refined Grid and OpenMP Parallelization
}

\author{
Seungsoo Lee ${ }^{1}$ \\ ${ }^{1}$ APEC Climate Center, Climate Application, Busan, Republic of Korea \\ (12 Centum 7-ro Haeundae-gu Busan Republic of Korea)
}

\begin{abstract}
Urban area consists of artificial structures such as buildings, roads, walls, parking lots etc. Therefore, the generation of fine meshes is a crucial component in depicting the complex urban features. However it accompanies huge amount of computational load with impractical calculation time. In this study, computational load reduction methods are tested using integrated 1D/2D urban inundation model based on refined grid with OpenMP parallelization technique. Refined grid $(10 \mathrm{~m}$ with $5 \mathrm{~m}$ resolution) was able to reduce surface grid 2.47 times compared with regular grid $(10 \mathrm{~m}$ resolution) and OpenMP parallelization shows 3.67 times running time reduction compared with serial code.
\end{abstract}

Keywords: Integrated 1D/2D; Refined grid; OpenMP Parallelization, Urban inundation modelling

\section{INTRODUCTION}

Urban inundation is one of the most common natural disasters and climate change exacerbates its effects by increasing its frequency and damages in the world(Liu and $\mathrm{Li}$, 2017). Integrated 1D/2D urban inundation model is widely used to analyse the causes of occurrence and establish the countermeasures. However, urban area consists of various artificial structures such as buildings, roads, walls, parking lots etc. with complex topography. In order to secure accurate simulation results, depiction of complex urban environmental in the modelling is a crucial component. Using appropriately fine grid or mesh may meet this requirement but this accompanies a lot of computational load with impractical calculation time. Therefore, it is necessary to secure appropriate calculation time with acceptable accuracy.

In this study, computational load reduction methods are tested using integrated 1D/2D urban inundation model based on refined grid with OpenMP parallelization technique. Regular grid case (case-1) using $5 \mathrm{~m}$ resolution DEM and refined grid case (case-2) using $10 \mathrm{~m}$ and $5 \mathrm{~m}$ resolution DEM are parallelized based on OpenMP technique and comparison simulations are conducted. Parallelization effect and computational load reduction impact by refined grid are evaluated.

\section{MATERIALS AND METHODS}

\subsection{Study area}

The study domain is the Oncheon river basin $\left(56.28 \mathrm{~km}^{2}\right)$ located in Busan, Republic of Korea(Fig. 1). The major land cover types include residential area, road, parking lot and mountain area. 596 sewer pipes and 556 manholes are considered as shown in Fig. 2. Total length of sewer pipes is $86.5 \mathrm{~km}$. 


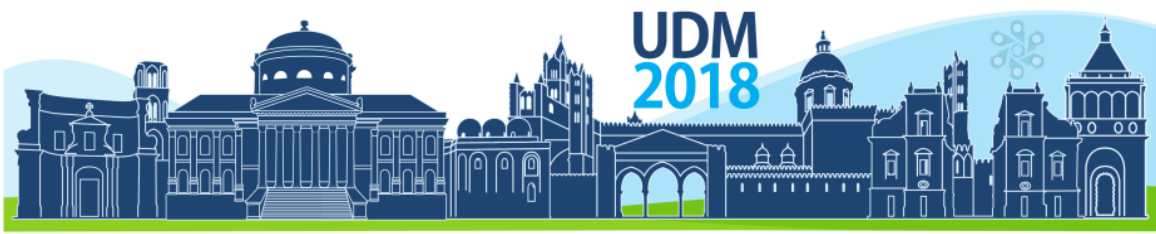

$11^{\text {th }}$ International Conference on Urban Drainage Modelling

23-26 Sep | Palermo - Italy

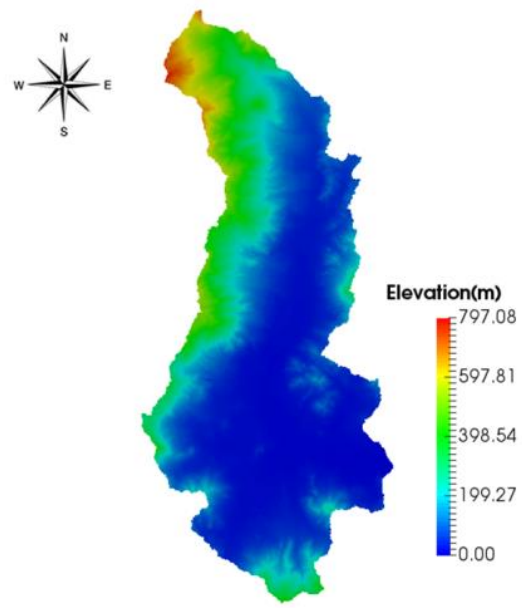

Figure 1. Basin map of study area

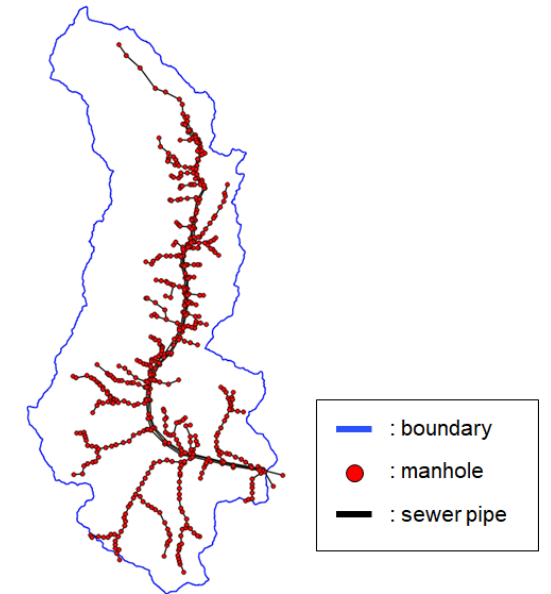

Figure 2. Sewer system data

\subsection{Governing equation}

The governing equations for storm water flow in two dimensional (2D) surface are as follows:

$\frac{\partial h}{\partial t}+\frac{\partial M}{\partial x}+\frac{\partial N}{\partial y}=r_{e}-q_{s t b}$

$\frac{\partial M}{\partial t}+\frac{\partial(u M)}{\partial x}+\frac{\partial(v M)}{\partial y}=-g h \frac{\partial H}{\partial x}-g n^{2} \frac{M \sqrt{u^{2}+v^{2}}}{h^{4 / 3}}$,

$\frac{\partial N}{\partial t}+\frac{\partial(u N)}{\partial x}+\frac{\partial(v N)}{\partial y}=-g h \frac{\partial H}{\partial y}-g n^{2} \frac{N \sqrt{u^{2}+v^{2}}}{h^{4 / 3}}$,

where, $h$ : water depth, $t$ : time, $M(=u h): x$-direction flux, $u$ : $x$-direction velocity, $N(=v h): y$ direction flux, $v$ : y-direction velocity, $r_{e}$ : rainfall intensity, $q_{s t b}\left(Q_{e t} / A_{s u r}\right)$ interacting discharge between the surface and drain box, $Q_{e}$ : calculated discharge from the water depth in surface and drain box using weir and orifice equation(Lee et al., 2016), $A_{\text {sur: }}$ area of surface grid, $g$ : gravitational acceleration, $\mathrm{H}$ : water elevation, $\mathrm{n}$ : Manning's roughness coefficient.

Pressimann slot model(Chaudhry, 1987) is applied to simulate storm water flow in sewer pipe and the governing equations are as follows:

$$
\begin{aligned}
& \frac{\partial A}{\partial t}+\frac{\partial Q}{\partial x}=q_{b t p}-q_{\text {man }}, \\
& \frac{\partial Q}{\partial t}+\frac{\partial(u Q)}{\partial x}=-g A \frac{\partial H_{p}}{\partial x}-g n^{2} \frac{Q|Q|}{R^{4 / 3} A},
\end{aligned}
$$

where, $A$ : wetted area of the sewer pipe, $Q$ : flow discharge, $q_{b t p}\left(Q_{e 2} / d x_{s w}\right)$ : interacting discharge between the drain box and sewer pipe, $Q_{e 2}$ : calculated discharge from the water depth in drain box and sewer pipe using weir and orifice equation $d x_{s w}$ : length of sewer pipe grid, $q_{\text {man }}\left(Q_{\text {man }} / d x_{s w}\right)$ : interacting discharge between the manhole and edge of sewer pipe per unit pipe length, $Q_{\operatorname{man}}$ interactive flow discharge between manhole and sewer pipe, $H_{p}\left(=z_{b}+\right.$ $\left.h_{p}\right)$ : piezometirc haed, $z_{b}$ : bottom elevation of sewer pipe, $h_{p}$ : water depth in sewer pipe, $R$ : hydraulic radius. 


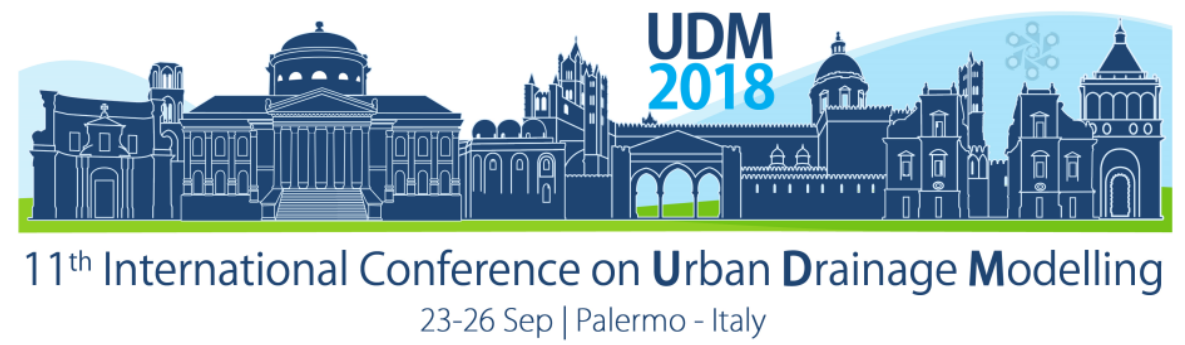

Water depth in drain box $\left(h_{d b}\right)$ is calculated based on the interactive discharge between sewer pipe and drain box as well as the interactive discharge between drain box and surface. The governing equation is as follow:

$\frac{\partial h_{d b}}{\partial t}=q_{s t b}-\frac{\sum_{i=1}^{n} Q_{e 2_{i}}}{A_{d b}}$,

where, $n$ : number of sewer pipe grids which are connected with the drain box. $A_{d b}$ : bottom area of drain box.

Water depth in manhole $\left(h_{\text {man }}\right)$ is calculated based on the interactive discharge between sewer pipe and manhole.

$\frac{\partial h_{\text {man }}}{\partial t}=\frac{\sum_{i=1}^{n} Q_{\text {man }_{i}}}{A_{\text {man }}}$,

where, $\mathrm{n}$ : number of edge of sewer pipes which are connected with the manhole. $A_{\text {man: }}$ : bottom area of the manhole. The details of the numerical model can be found in (Noh et al., 2016).

\subsection{Reduction calculation time}

Flow pathway in urban area can be determined by artificial structures as well as slope of topography. Therefore, the depiction of the urban landscape is a crucial component to achieve accurate simulation results. Fine meshes less then $10 \mathrm{~m}$ may overcome this obstacle but huge computational load is inevitable.

In order to reduce computation time while maintaining accuracy, the refined grid sizing is used and extended from the non-uniform but structured quadrilateral grid scheme(Liang, 2011) with OpenMP parallel computing technique(Chapman et al., 2007).

\subsection{Grid generation}

In this study, regular grid (case-1) using $10 \mathrm{~m}$ resolution DEM and refined grid (case-2) using $5 \mathrm{~m}$ and $10 \mathrm{~m}$ DEM are generated. In refined grid case, $5 \mathrm{~m}$ resolution DEM is used to depict road networks for distribution of storm drain or inlets and $10 \mathrm{~m}$ resolution DEM is used to depict other area. Total number of surface grid of case- 1 is 2,222,841 and 899,575 for case2. $1 \mathrm{~km}$ resolution radar observation data are used as input rainfall data and 3 hour simulations are conducted

\section{RESULTS AND DISCUSSION}

\subsection{Comparison of run time}

Comparison of running time between the case- 1 and the case- 2 by changing the number of cores was conducted to confirm the speed up ratio as shown in Fig. 3. Final running time (using 12 threads) was reduced by 3.16 and 3.67 times in case- 1 and case- 2 compared with a serial code, respectively. Interesting point in this result is that running time reduction ratio is varying for case-1 and case-2. In general, running time reduction ratio must show equal values under identical simulation condition although amount of computational load is not same. However, size of output file may cause delay time to restart calculation during the simulation and may affect the final simulation running time. 


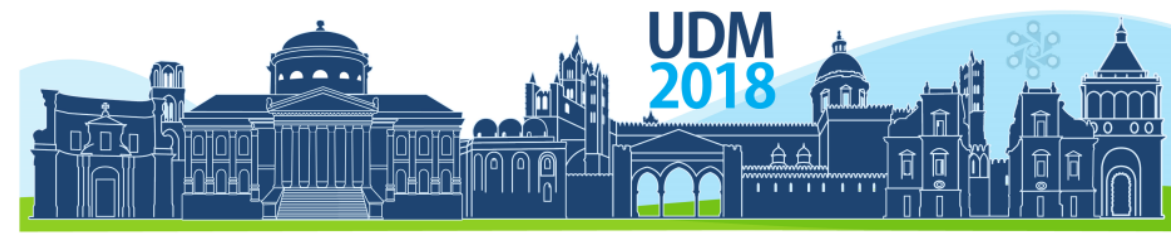

$11^{\text {th }}$ International Conference on Urban Drainage Modelling 23-26 Sep | Palermo - Italy

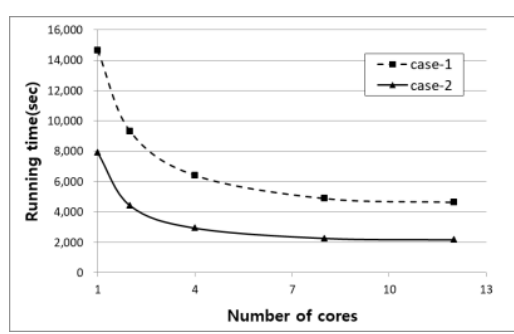

Figure 3. Comparison of calculation time reduction

\subsection{Comparison of simulation results}

Fig. 4 shows simulation result comparison between case- 1 and case-2. Both results show similar inundation area but different depth. The reason why both results show different water depth is presumed to be due to the discrepancy of elevation caused by differing DEM resolutions.

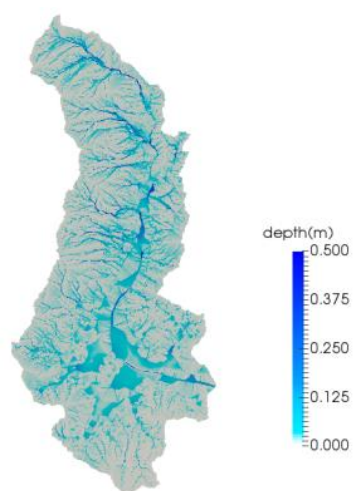

(a) Case-1

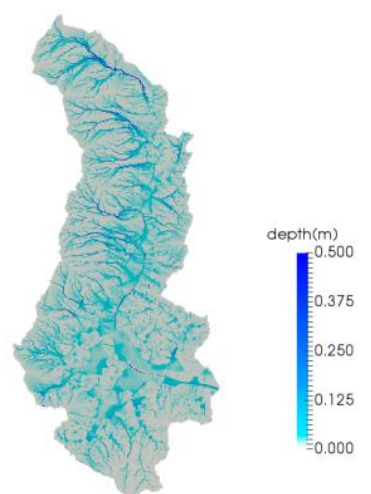

(b) Case-2

Figure 4. Comparison of inundation depth between regular and refined mesh

\section{CONCLUSIONS}

In this study, computational load reduction methods are tested using integrated 1D/2D urban inundation model based on refined grid with OpenMP parallelization technique. Refined grid ( $10 \mathrm{~m}$ with $5 \mathrm{~m}$ resolution) was able to reduce surface grid 2.47 times compared with regular grid (10m resolution) and OpenMP parallelization shows 3.67 times running time reduction compared with serial code.

\section{References}

Chapman, B., Host, G., Pas, R.V.D., 2007. Using OpenMP: Portable Shared Memory Parallel Programming. The MIT Press.

Chaudhry, M.H., 1987. Applied Hydraulic Transients, Subsequent edition. ed. Van Nostrand Reinhold, New York.

Lee, S., Nakagawa, H., Kawaike, K., Zhang, H., 2016. Urban inundation simulation considering road network and building configurations. J. Flood Risk Manag. 9, 224-233. https://doi.org/10.1111/jfr3.12165

Liang, Q., 2011. A structured but non-uniform Cartesian grid-based model for the shallow water equations. Int. J. Numer. Methods Fluids 66, 537-554. https://doi.org/10.1002/fld.2266

Liu, C., Li, Y., 2017. GIS-based dynamic modelling and analysis of flash floods considering land-use planning. Int. J. Geogr. Inf. Sci. 31, 481-498. https://doi.org/10.1080/13658816.2016.1207774

Noh, S.J., Lee, S., An, H., Kawaike, K., Nakagawa, H., 2016. Ensemble urban flood simulation in comparison with laboratory-scale experiments: Impact of interaction models for manhole, sewer pipe, and surface flow. Adv. Water Resour. 97, 25-37. https://doi.org/10.1016/j.advwatres.2016.08.015 


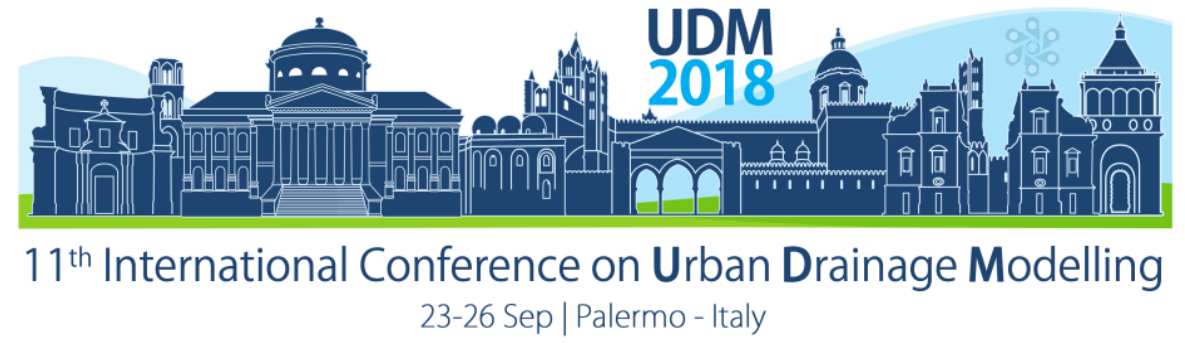

\title{
Multiple regression analysis as a comprehensive tool to model flood hazard in sewersheds
}

\author{
Daniel Jato-Espino ${ }^{1}$, Nora Sillanpää ${ }^{2}$, Ignacio Andrés-Doménech ${ }^{3}$ and Jorge Rodriguez-Hernandez ${ }^{1}$ \\ ${ }^{1}$ GITECO Research Group, Universidad de Cantabria, Av. de los Castros 44, 39005, Santander, Spain \\ 2 Department of Built Environment, Aalto University School of Engineering, P.O. Box 15200, 00076 Aalto, Finland \\ ${ }^{3}$ Instituto Universitario de Investigación de Ingeniería del Agua y del Medio Ambiente (IIAMA), Universitat \\ Politècnica de València, Cno. de Vera s/n, 46022 Valencia, Spain
}

\begin{abstract}
Flood modelling in urban areas is usually undertaken using stormwater tools, which are complex and time-consuming in terms of parametrization. To replace them, this research developed a methodology for predicting flooding probability in urban watersheds (sewersheds) through the modelling of peak flow rates from a set of watershed and sewer network-related factors relevant for the occurrence of floods. This was addressed through the stepped integration of Multiple Linear Regression (MLR), Multiple Nonlinear Regression (MNR) and Multiple Binary Logistic Regression (MBLR). A case study of a sewershed in Espoo (Finland) was used to validate the proposed approach and test it for future estimates, enabling the prediction of flooding probabilities under different Climate Change scenarios.
\end{abstract}

Keywords: Flood hazard modelling; Multiple Regression Analysis; Sewersheds

\section{INTRODUCTION}

The frequency and magnitude of floods are being exacerbated by increased urbanisation and Climate Change, as a result of daily anthropogenic activities that boost the presence of builtup surfaces and influence weather dynamics (Zeleňáková, 2015).

The modelling of these phenomena in sewersheds has been traditionally addressed with the support of stormwater management models (Kneb et al., 2005; Guan et al., 2015; Jato-Espino et al., 2017), which are complex and time consuming in terms of data characterisation and model calibration and validation.

Consequently, this research aimed at designing a methodology consisting of the replacement of stormwater models by three forms of Multiple Regression Analysis (MRA). This approach was validated through a real sewershed in Espoo, norther Finland.

\section{MATERIALS AND METHODS}

The modelling of flood hazard in sewersheds was addressed through the combination of three types of MRA: Multiple Linear Regression (MLR), Multiple Nonlinear Regression (MNR) and Multiple Binary Logistic Regression (MBLR).

The application of these statistical processes was based on a series of factors broken down according to the two components of sewershed: watershed and sewer network. Watershedrelated factors included the area, width, average slope and imperviousness of subwatersheds. The variables concerning the sewer network were the preceding, cumulative and subsequent length, diameter and slope of conduits, as well as the invert elevation of nodes. 


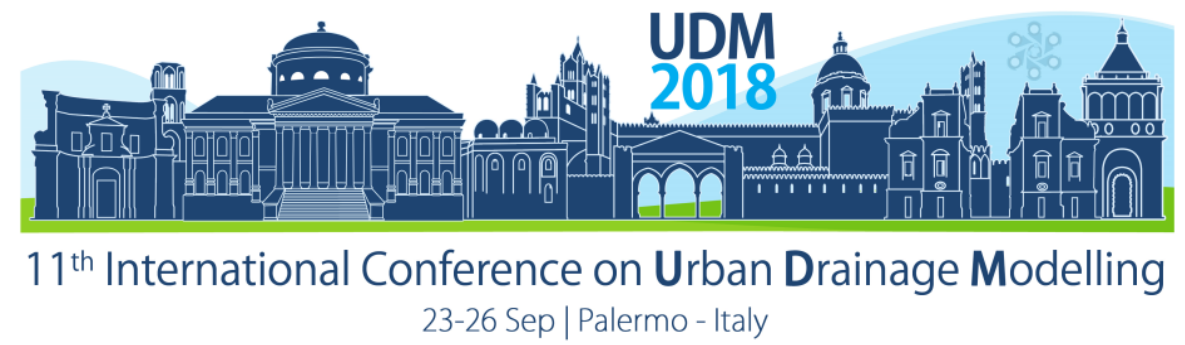

Watershed factors were expected to contribute to increasing the Maximum Lateral Inflow (MLI, $[\mathrm{l} / \mathrm{s}]$ ) in subwatersheds, whilst network variables represented the Maximum Total Inflow (MTI, $[\mathrm{l} / \mathrm{s}]$ ) in the nodes of the sewer network by integrating MLI and the amount of runoff conveyed by preceding nodes.

\subsection{Multiple Linear Regression (MLR)}

MLR was aimed at providing insight into the relationships between the abovementioned factors and the values of $\mathrm{MLI}$ and $\mathrm{MTI}$ in sewersheds as a consequence of severe rainfall events. The purpose of this technique was to identify which factors were the most influential in determining the magnitude of runoff in urban areas.

The strength of these relationships was measured under the consideration of a significance level of 0.05 , such that those factors having a $p$-value below this threshold were statistically significant for the prediction of MLI and MTI.

\subsection{Multiple Nonlinear Regression (MNR)}

The inclusion of MNLR sought to refine the modelling of MLI and MTI, taking into account only those significant factors identified in the previous step. In addition to the linear combinations analysed in MLR, this technique incorporated interactions and quadratic terms into the models, which enabled strengthening the precision of the estimates of MLI and MTI. To ensure the accuracy of MNLR models, their goodness-of-fit was double-checked through the predictive coefficient of determination (pred. $R^{2}$ ).

Since these models were intended to predict the amount of runoff produced by extreme storms, the factors included in the MNLR models obtained were expressed as a function of the rainfall intensity of different events through MLR.

\subsection{Multiple Binary Logistic Regression (MBLR)}

Unlike MLR and MNR, which enabled examining the linear and nonlinear joint relationships between the proposed factors and continuous variables (MLI and MTI), the response in MBLR models was dichotomous, indicating whether the nodes in the sewer network were flooded or not. This type of MRA enables the addition of the frequency, an intermediate element between the factors and the response indicating the probability of occurrence of floods. This term was defined as the division of MTI by MLI, in order to yield a value accounting for both direct and indirect flow contributions in the nodes, both at once and separately.

Given the nature of the response in MBLR models, the goodness-of-fit measures used to test their accuracy were the adjusted deviance $R^{2}\left(\operatorname{adj} . \operatorname{dev} . R^{2}\right)$, the Akaike Information Criterion (AIC) and the Hosmer-Lemeshow (H-L) test.

\section{RESULTS AND DISCUSSION}

The results were produced through the application of the MRA-based approach to a sewershed in Espoo (Finland) of 10.54 ha, formed of 79 subwatersheds and 80 conduits linking 75 nodes. Six real rainfall events and four Climate Change storms taken from Jato-Espino et al. (2017), where this sewershed was modelled and validated with field data using the computer program SWMM, were used to test the MRA models. The Climate Change scenarios considered were RCP4.5 and RCP8.5 (Moss et al., 2008), combined with return periods of 5, 25 and 50 years. 


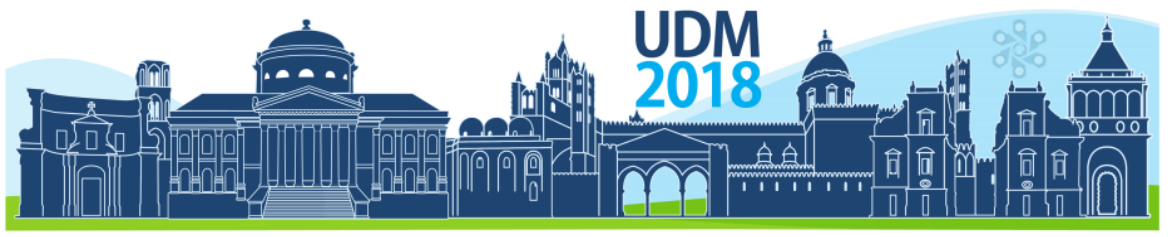

$11^{\text {th }}$ International Conference on Urban Drainage Modelling

23-26 Sep | Palermo - Italy

The use of MLR indicated that the area of the subwatersheds was the main contributor to MLI, followed by their imperviousness and average slope as the two other significant variables. In addition to these MLI-related factors, the cumulative preceding length of conduits was the only parameter proving to be statistically relevant for MTI.

All these factors were introduced in MNLR models to be tested through comparison with the SWMM-based results in Jato-Espino et al. (2017) for the aforementioned storm events. These models achieved values of pred. $\mathrm{R}^{2}$ of at least 0.92 , providing excellent replicates of MLI and MTI. The equations stemming from these models were expressed in terms of the intensity of the rainfall events under study, in order to facilitate their potential application.

Given the size of the sewershed, the combinations for the Climate Change scenarios RCP4.5 and RCP8.5 (Kawase et al., 2011) and a return period of 5 years were considered as the best representatives for this case. Figure 1 shows the fit between the values of MLI and MTI yielded by SWMM and MNR. The $\mathrm{R}^{2}$ coefficient reached was above 0.972 in all cases, which proved the reliability of the combination of MLR and MNR to reproduce peak flow rates in sewersheds.
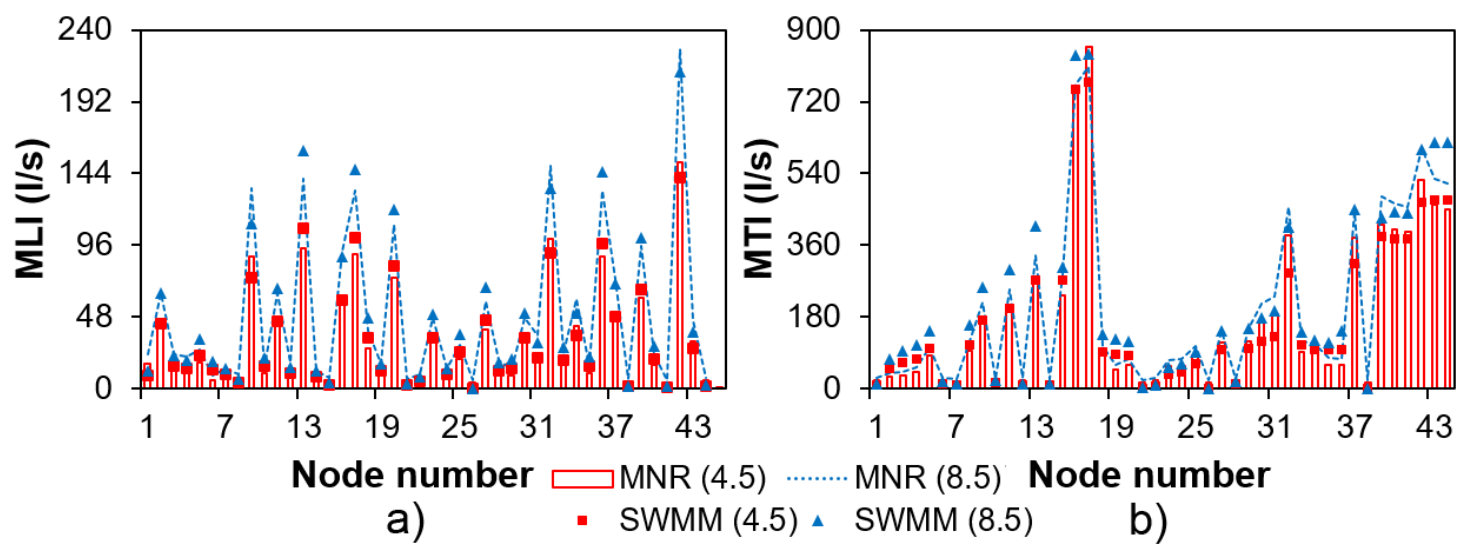

a)

- $\operatorname{SWMM}(4.5) \star \quad$ SWMM (8.5)

b)

Figure 1. Maximum Lateral Inflow (MLI) and Maximum Total Inflow (MTI) obtained using SWMM and Multiple Nonlinear Regression (MNR) for a 5-year return period and two Climate Change scenarios a) RCP4.5 b) RCP8.5

The combination of the watershed and sewer network factors with the values of MLI and MTI shown in Figure 1, representing the frequency of the MBLR models, produced estimates with adj. dev. $\mathrm{R}^{2}$ higher than 0.81 and $\mathrm{AIC}$ lower than 84 . Besides, the result of the H-L test was above the significance level in both cases, which further ensured the validity of the models.

Figure 2 depicts the values of MLI reached in the subwatersheds and the flood probability in the sewer network. The factors included in the MBLR-based models were the imperviousness of subwatersheds and the length of conduits, suggesting that increasing the diameter of pipes and depth of manholes would not make a significant difference in terms of flood mitigation. Instead, the relevance of permeability indicated that replacing built-up surfaces by Sustainable Urban Drainage Systems (SUDS) might contribute to reducing floods.

\section{CONCLUSIONS}

The results achieved through the analysis of the case study of Espoo (Finland) proved that the proposed MRA-based approach provides a comprehensive tool to predict flood probability in sewersheds based on monitored data, supporting the adoption of strategies for runoff control. 


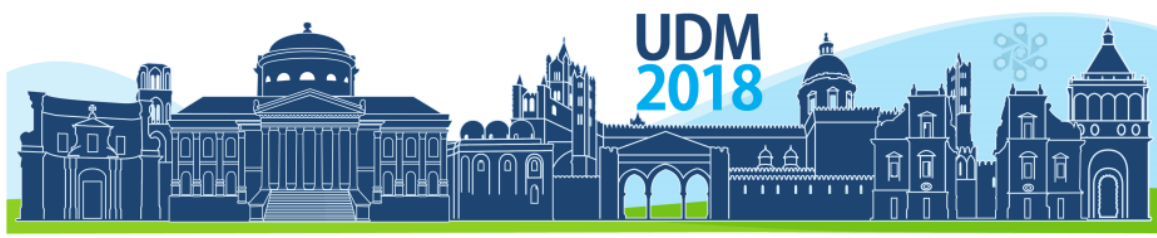

$11^{\text {th }}$ International Conference on Urban Drainage Modelling 23-26 Sep | Palermo - Italy
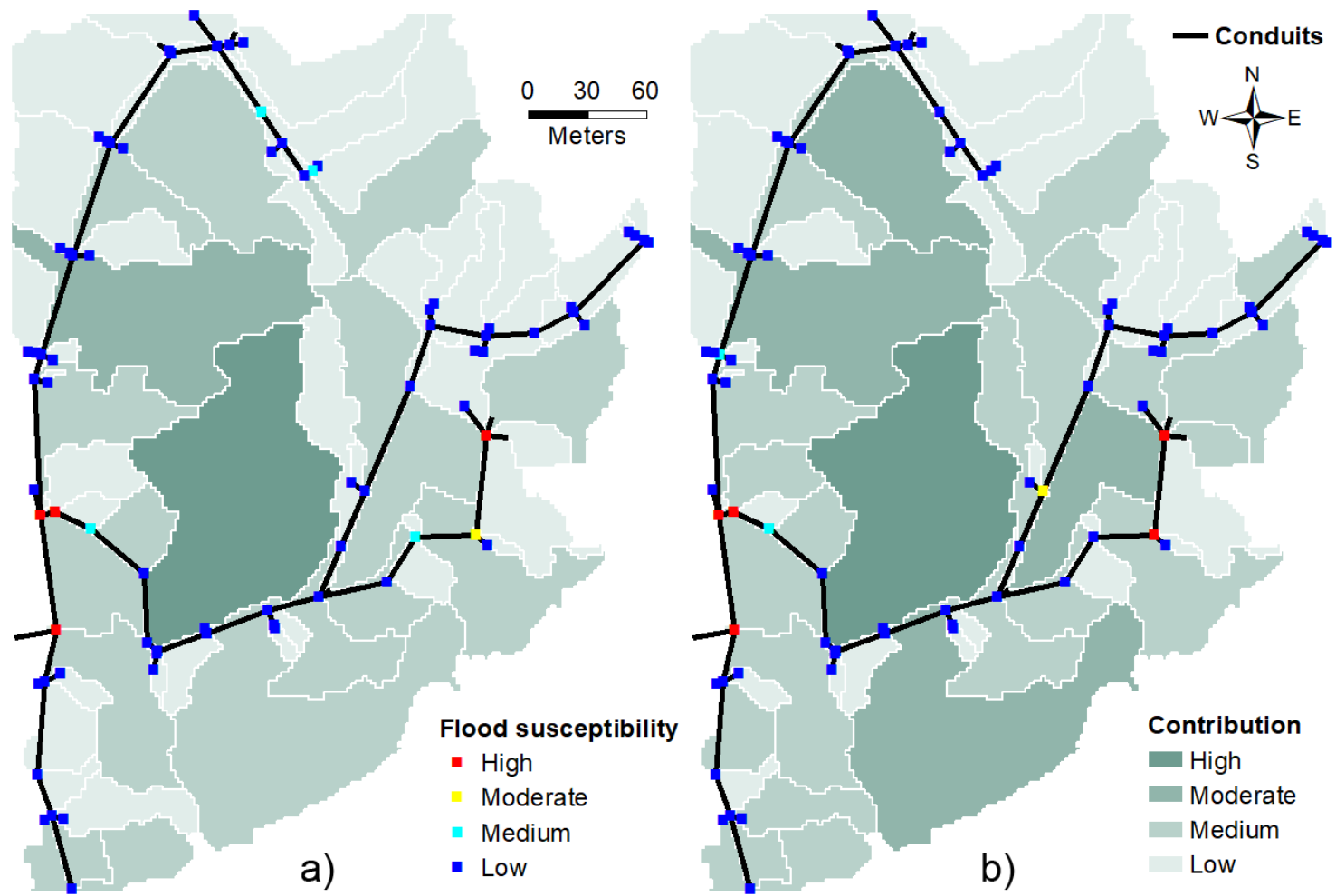

Figure 2. Flood susceptibility in the nodes of the sewer network and contribution from the subwatersheds for a 5 year storm and two Climate Change scenarios a) RCP4.5 b) RCP8.5

The findings stemming from this research indicated that future urban plans concerning flood management should strongly consider SUDS to boost the resilience of cities against drainagerelated phenomena.

To extend its potential implementation, this approach should be tested in other sewersheds with different climate regimes and degrees of development. In the end, this course of action might enable regionalising large areas using the models that best fit their characteristics.

\section{ACKNOWLEDGMENTS}

This research was funded through the research project SUPRIS (Ref. BIA2015-65240-C2 MINECO/FEDER, UE).

\section{References}

Guan, M., Sillanpää, N., Koivusalo, H. (2015) Modelling and assessment of hydrological changes in a developing urban catchment. Hydrol. Process. 29(13), 2880-2894.

Knebl, M. R., Yang, Z. -., Hutchison, K., Maidment, D. R. (2005). Regional scale flood modeling using NEXRAD rainfall, GIS, and HEC-HMS/ RAS: A case study for the San Antonio River Basin Summer 2002 storm event. J. Environ. Manage. 75(4), 325-336.

Jato-Espino, D., Sillanpää, N., Charlesworth, S. M., Andrés-Doménech, I. (2017) A simulation-optimization methodology to model urban catchments under non-stationary extreme rainfall events. Environ Modell. Softw. In Press, 1-15.

Kawase, H., Nagashima, T., Sudo, K., Nozawa, T. (2011) Future changes in tropospheric ozone under Representative Concentration Pathways(RCPs). Geophys. Res. Lett. 38(5), L05701.

Zeleňáková, M., Purcz, P., Hlavatá, H., \& Blištan, P. (2015) Climate change in urban versus rural areas. Procedia Engineer. 119(1), 1171-1180. 


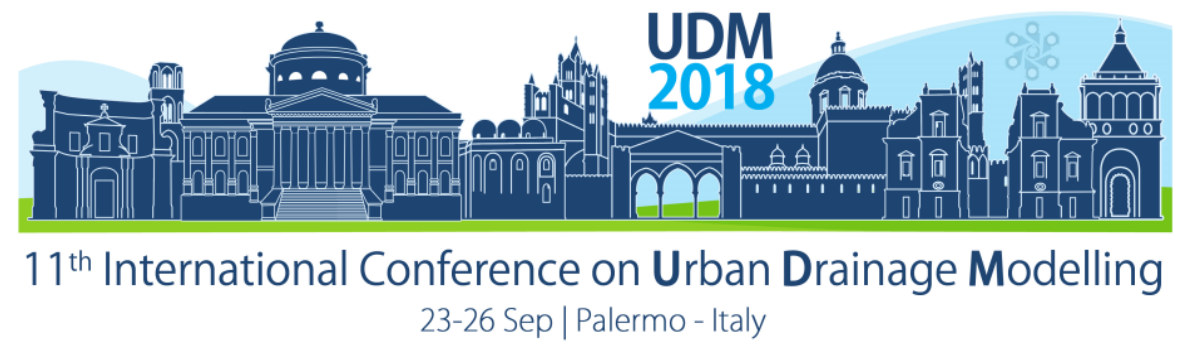

\title{
Generation of stormwater drainage networks using spatial data
}

\author{
Anneke Döring ${ }^{1}$ and Insa Neuweiler ${ }^{1}$ \\ ${ }^{1}$ Leibniz University Hanover, Institute for Fluid Dynamics and Environmental Physics, Hanover, Germany
}

\begin{abstract}
In this paper a tool to automatically design drainage systems for urban districts is provided. Since pipe networks typically follow public streets, the drainage network is placed below the existing streets. The presented approach supplies a complete workflow in $\mathrm{R}$, including an interface to hydraulic solvers implemented in the simulation software Stormwater Management Model. Algorithms to compute (1) subcatchments from land use data and (2) stormwater drainage networks from street polylines and topography are implemented. A test case, focussing on the stormwater drainage network on district scale, is setup. The stormwater network generator performs well for the small test case, however, some improvements on deriving the percentage of impervious surface cover have to be implemented. Further work includes the application to a more complex urban area, with pumps, combined sewer systems and multiple outfalls.
\end{abstract}

Keywords: urban water modelling; artificial drainage networks; RapidEye satellite imagery

\section{INTRODUCTION}

In urban drainage, new technologies, model approaches or strategies are often evaluated with case studies. While a lot of spatial data can usually be accessed, the access to drainage network data is limited. Sometimes only sections of the built drainage network are available. A variety of artificial drainage network generators was developed in the last years and is used for case studies. Some of these network generators include agent based cellular automata (Urich et al., 2010), others apply branching stochastic processes (Möderl et al., 2009) and some combine these methods (Sitzenfrei et al., 2010). Most of these approaches are meant to generate a high number of case studies; therefore, urban structures are simplified, especially when applying stochastic approaches. The positioning of pipes and the hydraulic dimensioning are usually of secondary importance. Blumensaat et al. (2012) presented a modular approach to representatively describe realistic networks. The main focus is to place pipes realistically in the urban environment.

Following the idea of Blumensaat et al. (2012) that pipe networks typically follow public streets, the drainage network is placed below the existing streets in this paper as well. Thus, real urban structures are preserved and the drainage network is rebuilt as close to reality as possible. While Blumensaat et al. (2012) realise the network construction in multiple steps, using several subroutines, the, in this paper presented, approach supplies a complete workflow in $\mathrm{R}$ (R Core Team, 2017), including an interface to hydraulic solvers implemented in the simulation software Stormwater Management Model, SWMM (Rossmann, 2010). Moreover, with the approach, described in this paper, we want to supplement available data, providing a tool to plan urban districts and later connect them to the existing drainage network. We combine the non-grid based drainage network generator with a grid based surface cover classification using multispectral RapidEye satellite imagery. Data from spectral and temporal band combinations of RapidEye images can be used to quantify vegetation cover in urban areas (e.g. Tigges et al., 2013). The approach and test case, described in this paper, focus on the stormwater drainage network on district scale. 


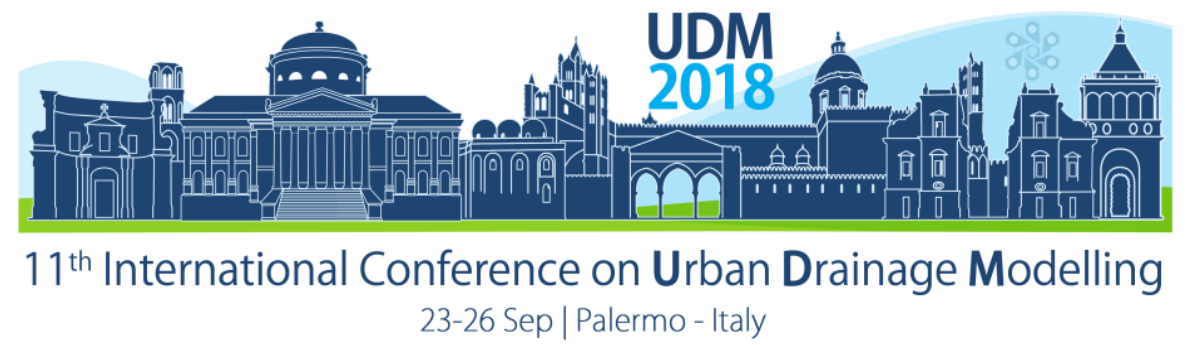

\section{MATERIALS AND METHODS}

An artificial stormwater drainage network is derived from existing urban structures, such as land use, topography and streets. Required input data are: Land cover derived from RapidEye satellite imagery, a digital terrain model and street polyline data, for example extracted from a digital landscape model. Three user defined sewer system parameters have to be set. Enabled by recent developments in R's spatial computing (sf - Pebesma, 2018), the presented approach is coded in R ( $R$ Core Team, 2017). Moreover, the interface package 'swmmr' can be used for pre- and postprocessing (Leutnant \& Döring, 2018). The result is a SWMM input file including a complete drainage network model with discharging surfaces, called subcatchments, junctions, conduits and outfalls. In the following, the implemented algorithms to compute (1) subcatchments and (2) stormwater drainage networks, are described.

\subsection{Computation of subcatchments}

Based on the sewer network (see 2.2) Thiessen polygons (Brassel \& Reif, 1979) are computed to define borders of discharging areas. For each junction node (centroid), a Thiessen polygon is defined, which is referred to as subcatchments in this work. The slope of each subcatchment is calculated using topography information given in the digital terrain model or a simpler topography raster. To complete this data set the percentages of pervious or impervious area per subcatchment area need to be specified. One way to do this is classifying urban land cover from multispectral RapidEye satellite imagery (2016), using training data and random decision forests. From this land cover classification pervious and impervious surfaces are obtained for a $5 \mathrm{~m} \times 5 \mathrm{~m}$ raster. The information from this land use raster are then transferred to the subcatchments.

\subsection{Computation of stormwater drainage networks}

Moving along the street polylines, given in the digital landscape model, junction nodes are defined. A junction is defined (1) if the direction of the street changes, (2) if a crossing between two polylines occurs, and (3) if the distance between two nodes exceeds a user-defined maximum distance. The maximum distance in the following test example is set to $50 \mathrm{~m}$. The height of the junction's top elevation is obtained from the digital terrain model. Conduits are defined following the street polylines and the topography. The flow direction within the conduits is given by the offset between the bottom heights of two connected junctions. The drainage network is tested for local sinks, loops or other slope errors. Errors are corrected, ensuring continuous flow paths from starting nodes to an outfall node. The bottom elevation of start junctions is calculated by subtracting a user-defined offset from the top elevation. In the following test example the offset is set to $2.5 \mathrm{~m}$. The remaining bottom elevations are adjusted, calculating the conduit slopes. Conduit slopes are determined by a user defined slope value, which is set to $1 \%$ in the following test example. An interface to SWMM is provided via input files. The conduit diameters are calculated and designed for a design rain (Euler Type II) of 2 years annuality and 15 min duration (DIN EN 752, DWA A 118).

\subsection{Test area}

A first test is conducted with a small research area in Lower Saxony, Germany. To validate the described approach a "near real world" model (A) is setup (Figure 1). For this domain the actually constructed drainage network is given. Rain and waste water are treated separately in the area; therefore, the rain water pipes can be analysed independently from the waste water sewers. This stormwater network is referred to as "real drainage network (rDN)" in the following. For all models only the stormwater drainage network is simulated. The actual land 


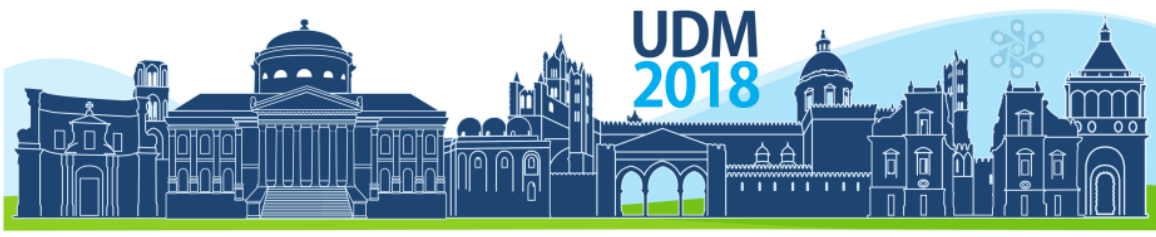

$11^{\text {th }}$ International Conference on Urban Drainage Modelling

23-26 Sep | Palermo - Italy

use is manually digitalized from aerial photographs taken in 2016, thus surface covers are represented accurately, with a high resolution. In SWMM buildings, sealed surfaces etc. are treated as separate subcatchments, resulting in 386 subcatchments. In a second model (B), subcatchments are aggregated using Thiessen polygons (see 2.1), to quantify the effect of this surface aggregation. Based on spatial data the artificial drainage network (aDN) is setup (see 2.2). In model (C) the artificial drainage network is combined with detailed Thiessen aggregated subcatchments with land use information obtained from model $A$, to be able to quantify the effect of the surfaces derived from RapidEye classification in model (D). The full artificial model (D), finally, consists of the Thiessen aggregated RapidEye classification (see 2.1) and the artificial drainage network (see 2.2). For all models (A-D) discharge is calculated performing hydrological-hydraulic simulations in SWMM (Figure 1). Simulations are run with a model rain event of a duration of 15 min and 2 years annuality.

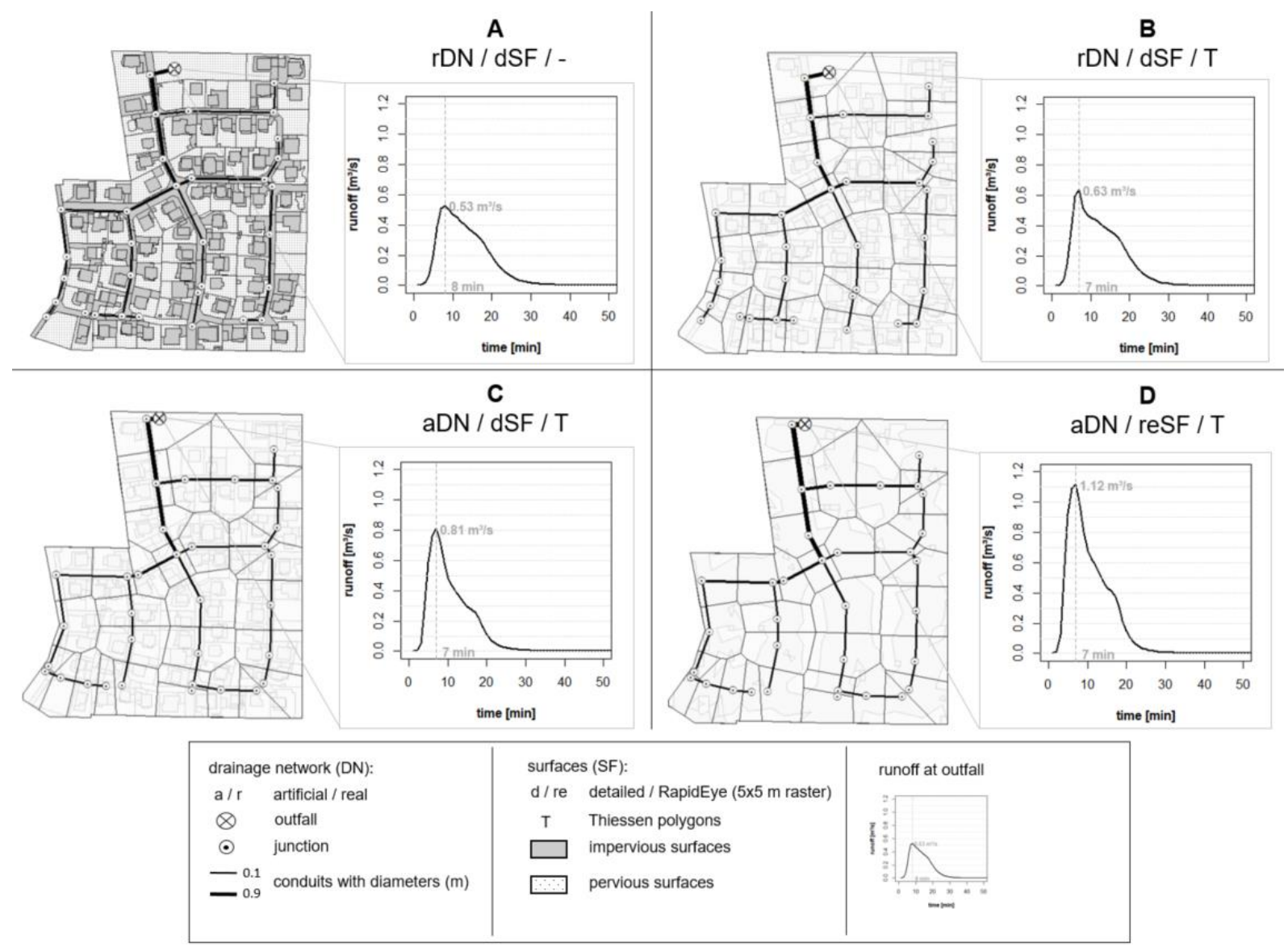

Figure 1. Model setup and discharge hydrograph at outfall nodes for the following models: $(A)$ detailed surfaces with real drainage network ( $\mathrm{rDN} / \mathrm{dSF} /-)$, (B) Thiessen aggregation of detailed surfaces with real drainage network (rDN/dSF/T), (C) Thiessen aggregation of detailed surfaces with artificial drainage network (aDN/dSF/T), and (D) Thiessen aggregation of RapidEye raster data with artificial drainage network (aDN/reSF/T/).

\section{RESULTS AND DISCUSSION}

The impervious area is overestimated by $48 \%$ through RapidEye classification. While in the detailed model (A) $50 \%$ of the total area is classified as impervious and $50 \%$ is classified as vegetated pervious surface, in the artificial model (D) $74 \%$ of the total area is classified as 


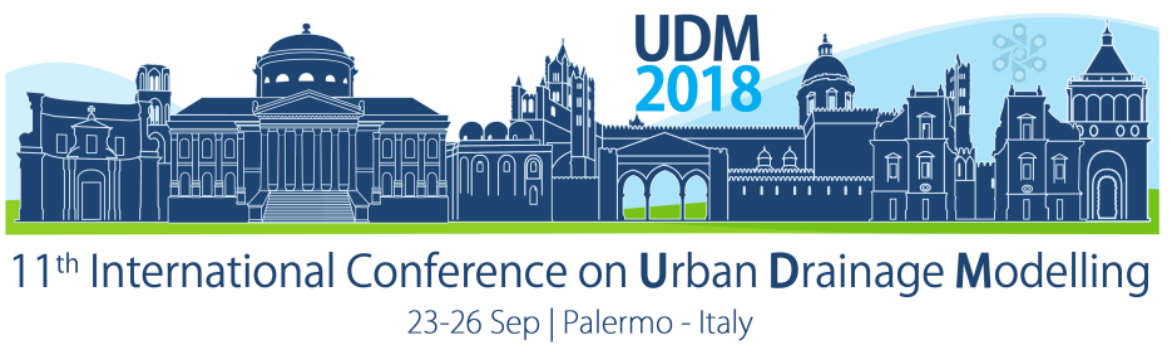

impervious and $26 \%$ is classified as vegetated surface (Table 1 ). It needs to be verified whether overestimations originate from the high percentage of the rather young vegetation in the test area. For a larger scale model with older vegetation, especially trees, RapidEye classification might have better results. Because of the discrepancy in impervious coverage, infiltration rates are smaller and surface runoff is higher in the artificial model (D) than in the detailed status quo model (A) (Table 1). Comparing the performance of the artificial drainage network (C) and the real drainage network $(B)$ with similar surface discretization, marginal differences in the water balances (Table 1) and peak flows at network outfalls occur (Figure 1). The maximum flow at the outfall is $32 \%$ higher and the system reacts slightly faster for the artificial drainage network (model C) than for the real drainage network (model B).

Table 1. Comparison of surface resolutions, drainage network parameters and model performances of the following models: $(A)$ detailed surfaces with real drainage network (rDN/dSF/-), (B) Thiessen aggregation of detailed surfaces with real drainage network (rDN/dSF/T), (C) Thiessen aggregation of detailed surfaces with artificial drainage network (aDN/dSF/T), (D) Thiessen aggregation of RapidEye raster data with artificial drainage network (aDN/reSF/T). ${ }^{1}$ user defined value; ${ }^{2}$ varies with user defined depth of start junctions; r: real, a: artificial; d: detailed, re: RapidEye; T: Thiessen polygons

\begin{tabular}{|c|c|c|c|c|c|}
\hline & & (A) & (B) & (C) & (D) \\
\hline Surfaces (SF) & & dSF / - & $d S F / T$ & $d S F / T$ & reSF / T \\
\hline pervious & $(\%)$ & 50 & 51 & 52 & 26 \\
\hline impervious & $(\%)$ & 50 & 49 & 48 & 74 \\
\hline $\begin{array}{l}\text { Drainage } \\
\text { network (DN) }\end{array}$ & & rDN & $\mathrm{rDN}$ & aDN & aDN \\
\hline \multicolumn{6}{|l|}{ Conduits } \\
\hline Total length & $(\mathrm{m})$ & 1100 & 1100 & 1199 & 1199 \\
\hline $\begin{array}{l}\text { Mean length } \\
( \pm \text { std. dev. })\end{array}$ & $(\mathrm{m})$ & $34 \pm 19$ & $34 \pm 19$ & $34 \pm 18$ & $34 \pm 18$ \\
\hline $\begin{array}{l}\text { Mean slope } \\
( \pm \text { std. dev.) }\end{array}$ & $(\%)$ & $0.5 \pm 0.3$ & $0.5 \pm 0.3$ & $1^{1}$ & $1^{1}$ \\
\hline Diameter & $(\mathrm{m})$ & 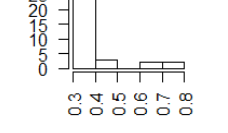 & 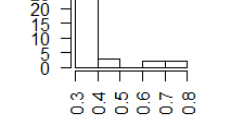 & 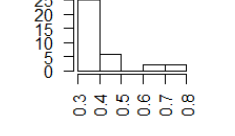 & 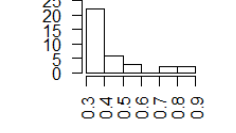 \\
\hline $\begin{array}{l}\text { Junctions } \\
\text { Mean Depth } \\
\text { ( } \pm \text { std. dev.) }\end{array}$ & $(\mathrm{m})$ & $1.56 \pm 0.30$ & $1.56 \pm 0.30$ & $3.35 \pm 0.96^{2}$ & $3.35 \pm 0.96^{2}$ \\
\hline $\begin{array}{l}\text { Water balance } \\
\text { (SWMM) }\end{array}$ & & rDN / dSF / - & $\mathrm{rDN} / \mathrm{dSF} / \mathrm{T}$ & $\mathrm{aDN} / \mathrm{dSF} / \mathrm{T}$ & $\mathrm{aDN} / \mathrm{reSF} / \mathrm{T}$ \\
\hline Infiltration & $(\%)$ & 50.4 & 46.7 & 47.4 & 23.6 \\
\hline Surface runoff & $(\%)$ & 50.1 & 53.7 & 53.0 & 77.0 \\
\hline Evaporation & $(\%)$ & 0.3 & 0.2 & 0.2 & 0.4 \\
\hline Continuity error & $(\%)$ & -0.8 & -0.6 & -0.6 & -1.0 \\
\hline
\end{tabular}




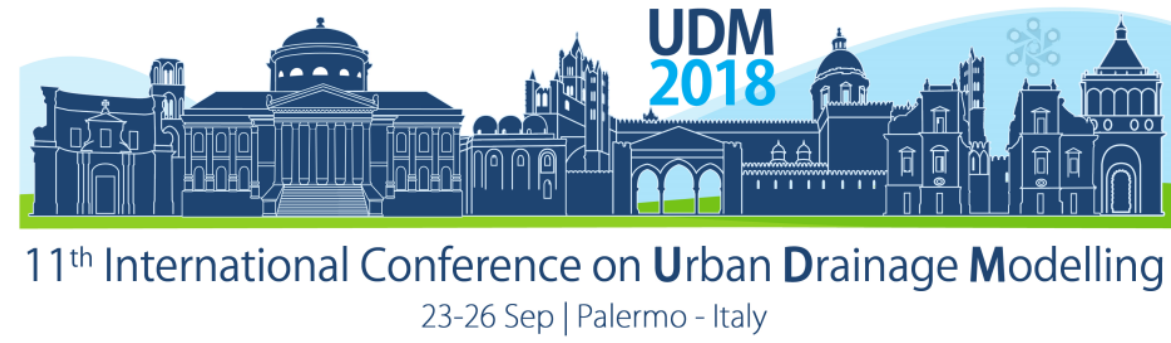

Comparing the structure of the sewer system some differences become apparent. The total length of conduits is higher in the artificial model $(C+D)$ (Table 1), here some improvements on the algorithm for linking junctions might be needed. The differences in pipe diameters in model $C$ and $D$ originate from the pipe sizing algorithm. With the higher percentage of drained surfaces in model $D$, the higher maximum pipe diameters seem to be consistent. For the test case the pipe sizing algorithm used here appears to perform better than the approach by Maurer et al. (2010) applied in Blumensaat et al. (2012).

\section{CONCLUSIONS}

With the presented approach stormwater drainage networks can be defined along street polylines given the topography and percentage of impervious surfaces. A full hydrologicalhydraulic SWMM model can be setup, with an automatic input generation. The approach is limited to stormwater pipes and a single system outfall at the moment. However, the results shown for the small scale test example are promising, although some improvements have to be implemented. Further work includes the application to a more complex urban area, with pumps, combined sewer systems and multiple outfalls. Interfaces to connect available drainage network data with artificial drainage network data are planned.

\section{Acknowledgements}

The work was funded by MWK Lower Saxony Niedersächsisches Vorab as part of the collaborative project "METAPOLIS" (Grant No. ZN3121). We thank Michael Strohbach and Andreas Dahlkamp from the METAPOLIS-Team for processing RapidEye data (RapidEye Science Archive Project-ID 00253).

\section{References}

Blumensaat F, Wolfram M, Krebs P (2012) Sewer model development under minimum data requirements. Environ Earth Sci. 65, 1427-1437. doi:10.1007/s12665-011-1146-1.

Brassel KE, Reif D. (1979) A Procedure to Generate Thiessen Polygons. Geogr Anal. 11(3), 289-303.

Leutnant, D., Döring, A (2018) swmmr: R Interface for US EPA's SWMM. R package version 0.8.0. https://github.com/dleutnant/swmmr.

Maurer M, Wolfram M, Herlyn A (2010) Factors affecting economies of scale in combined sewer systems. Water Sci Technol. 62(1), 36-41.

Möderl M, Butler D, Rauch W. (2009) A stochastic approach for automatic generation of urban drainage systems. Water Sci Technol. 59(6),1137-1143. doi:10.2166/wst.2009.097.

Pebesma, E. (2018) Sf: Simple Features for R. https://CRAN.R-project.org/package=sf.

R Core Team (2017) R: A Language and Environment for Statistical Computing. Vienna, Austria: R Foundation for Statistical Computing. https://www.Rproject.org/.

Rossman, L. A. (2010) Storm Water Management Model- User's Manual Version 5.0. Cincinnati, OH, USA: United States Environmental Protection Agency (US EPA).

Sitzenfrei R, Fach S, Kleidorfer M, Urich C, Rauch W. (2010) Dynamic virtual infrastructure benchmarking: DynaVIBe. Water Sci Technol Water Supply. 10(4), 600-609. doi:10.2166/ws.2010.188.

Tigges J, Lakes T, Hostert P. (2013) Urban vegetation classification : Benefits of multitemporal RapidEye satellite data. Remote Sens Environ. 136, 66-75. doi:10.1016/j.rse.2013.05.001.

Urich C, Sitzenfrei R, Möderl M, Rauch W. (2010) An agent-based approach for generating virtual sewer systems. Water Sci Technol. 62(5), 1090-1097. doi:10.2166/wst.2010.364. 


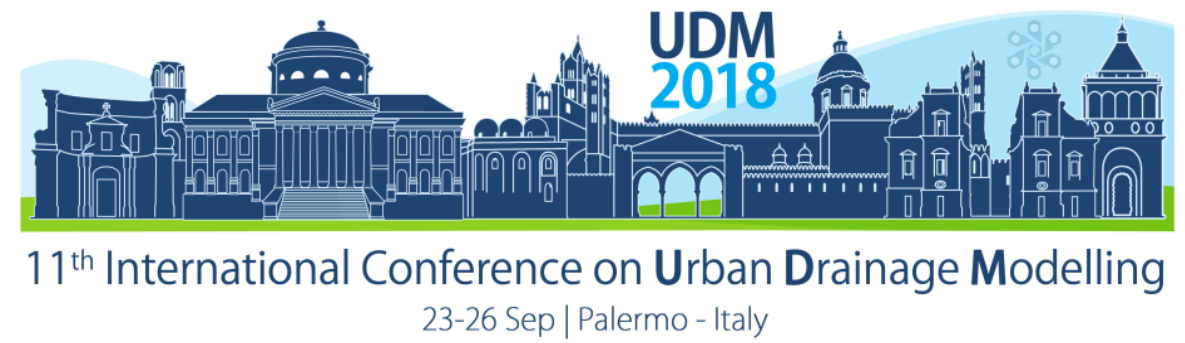

\title{
A new Saint-Venant solver for SWMM
}

\author{
Ben R. Hodges ${ }^{1}$, Frank Liu² and A. Charles Rowney ${ }^{1}$ \\ 1 University of Texas, Center for Infrastructure Modeling and Management, Austin, Texas, USA \\ 2 IBM Research Austin, Texas, USA
}

\begin{abstract}
The next generation of the public domain Storm Water Management Model (SWMM) code needs to be able to effectively use parallelization of $1000+$ threads for highresolution simulation of large urban drainage systems. We propose a new explicit solution technique using a "no-neighbour" finite-volume algorithm. A no-neighbour algorithm is strictly limited in the design of its time/space discretization stencil to limit the communication bandwidth issues that typically cause codes to lose efficiency when applied over large numbers of parallel threads. Returning SWMM to an explicit solver creates a number of challenges for implementing the solution technique, but also raises some new possibilities for how the model can be used. In this work, we briefly describe the proposed algorithm and examine its performance in simulating a steep urban stream.
\end{abstract}

Keywords: numerical algorithm; multi-threading parallel; Saint-Venant equations

\section{INTRODUCTION}

The next generation of computational models depend on a key question: How do we create efficient time-marching algorithms for multi-threading with 1000+ processors? This question is important because CPUs have not actually increased in clock speed since 2004 (Flamm, 2017); almost all our perceived speed-up for desktop computers over the last 15 years has been due to multi-threading on multi-core processors or clearing of other choke-points in the overall system. We expect this trend to continue and multi-thread performance will be increasingly important. Unfortunately, the Storm Water Management Model (SWMM) cannot obtain a speedup past $15 \mathrm{x}$ with parallel solutions, primarily due to Amdahl's Law (Amdahl, 1967) and the serial portions of the hydraulic solver (Burger et al., 2014). Our research team has been funded by the US EPA to develop the next-generation of the public-domain SWMM code, which we intend to be highly parallelizable, mass conservative, stable, and robust for both fine- and coarsely-resolved systems. The improved computational capabilities of the new SWMM code will open up new possibilities for how the model can be used and further developed by the community. Herein, we focus on the proposed upgrades to the open-channel flow solver, which are being tested in an open-source python code prior to actual implementation in SWMM.

\section{METHODS}

\subsection{Governing equations}

The present SWMM code uses a link-node approach with a finite-difference discretization. A problem for this method is that the solutions at abrupt geometrical changes or for rapid transitions between subcritical and supercritical are not always convergent or mass conservative. To address this issue, we believe the next generation SWMM solver should be based on a finite-volume algorithm that uses the volume $(V)$ and flowrate $(Q)$ of an element 


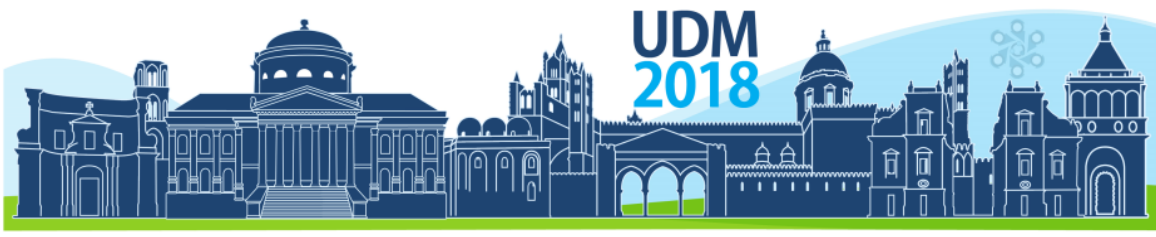

$11^{\text {th }}$ International Conference on Urban Drainage Modelling

23-26 Sep | Palermo - Italy

as the fundamental variables for the time-marching solution. A finite-volume representation of the classic Saint-Venant equations can be presented as:

$$
\begin{gathered}
\frac{\partial V_{e}}{\partial t}=Q_{u}-Q_{d} \\
\frac{\partial L Q_{e}}{\partial t}=Q_{u} U_{u}-Q_{d} U_{d}+g A_{u} \eta_{u}-g A_{d} \eta_{d}-g \eta_{e}\left(A_{u}-A_{d}\right)-g C V_{e} U_{e}^{2}
\end{gathered}
$$

where $U, A, \eta, L$, are the velocity, cross-sectional area, water surface elevation, and element length. The subscripts $(e, u, d)$ indicate (respectively) the element-averaged value, the value at the nominal upstream face, and the value at the nominal downstream face. The last term in eq. [2] represents the integrated effect of friction, where $C$ is a dimensional coefficient that is a function of the hydraulic radius $\left(R_{h}\right)$ and either Manning's $n$ or a friction factor, $f$ :

$$
\text { Darcy-Weisbach: } C=\frac{f}{8 g R_{h}} \quad ; \quad \text { Chezy-Manning: } \quad C=\frac{n^{2}}{R_{h}^{4 / 3}}
$$

With careful numerical discretization, we can create a model that handles abrupt transitions in geometry and disparities in adjacent cell sizes without developing instabilities or losing conservation. Note that the free-surface gradient terms in eq. [2] are somewhat different than typically presented, and are found from an integration over a finite volume that considers a free surface slope and bottom slope with either converging or diverging angles (Hodges, 2018). This new approach to the finite-volume formulation is substantially different than the CungeLiggett finite-volume equations for flow in natural channels (Cunge et al, 1980; Liggett, 1975).

\subsection{Numerical implementation}

For time-marching we use a Runge-Kutta 4th-order (RK4) explicit algorithm, which is compatible with a variety of spatial discretizations. We are interested in 1st and 2nd-order spatial discretizations that are consistent with the coarse grid resolution typically used in urban drainage modeling. Higher-order spatial schemes are often preferred for stability and accuracy in highly-resolved hydraulic simulations; however, such schemes typically involve larger time and space dependency (Figure 1).
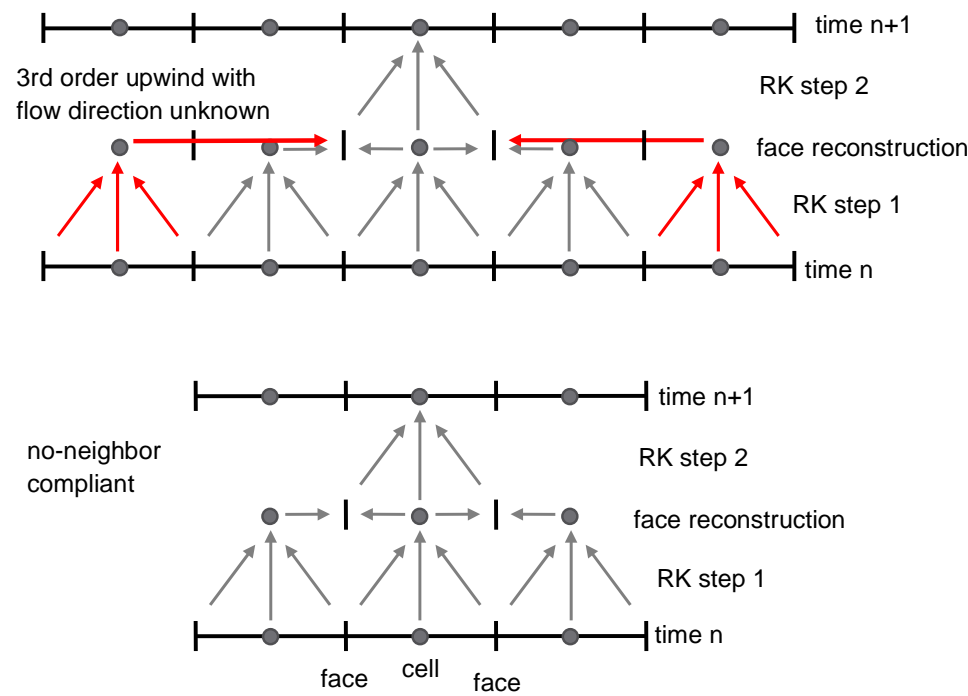

Figure 1. Comparison of time-space dependency for 3rd order upwind and no-neighbour 1st or 2nd-order reconstruction, shown with an RK2 time-march for simplicity. 


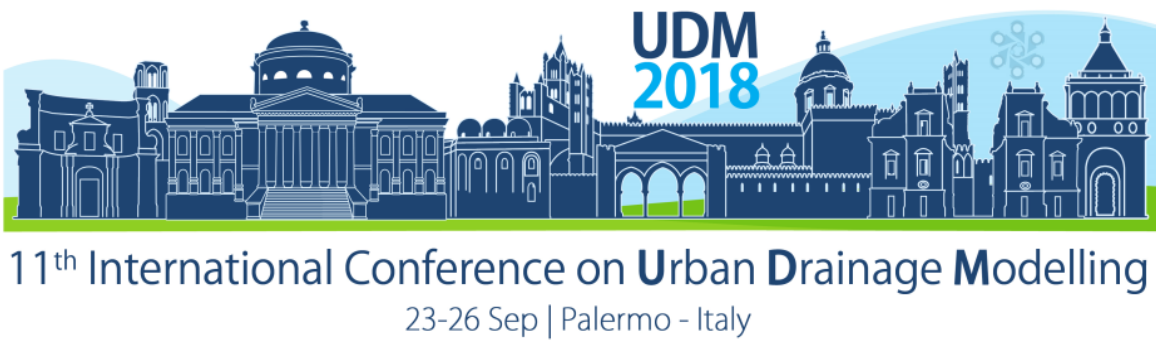

Face reconstruction with high-order schemes inherently involves "neighbour" cells that are not immediately adjacent to the face being reconstructed. This spatial dependency has two effects: (1) increasing the communication bandwidth required for a multi-threading solution, and (2) requiring smoothness in the solution field at a finer scale than typically used in a link-node models in SWMM. We propose the idea of a "no-neighbour" algorithm as one in which the solution in a finite-volume cell evolves over an RK subtime level with only information from itself and its adjacent faces, and a face reconstruction only requires information from the adjacent cells. The challenge for no-neighbour schemes is that they tend to have flowpressure coupling that can produce "checkerboard" grid-scale oscillations. We have found this problem to be tractable by introducing several approaches: (i) hydraulic time-scale interpolation for face reconstruction of $Q$, (ii) time-marching with a new friction-constrained RK4 algorithm, and (iii) inclusion of a small ad hoc kinetic energy damping term (Hodges and Liu, 2018). A test version of the algorithm for a single river reach has been coded in Python, which is not computationally efficient but allows rapid prototype testing of the algorithm. The opensource code is available at https://github.austin.utexas.edu/hodgesbr/SvePy .

\section{RESULTS AND DISCUSSION}

\subsection{Highly-resolved flow over a bump}

A laboratory-scale flow over a bump that transitions from subcritical to supercritical and back to subcritical has been extensively used as a challenging test case (e.g. Vázquez-Cendón, 1999) that is typically attributed to Ghoutal and Maurel (1997). The theoretical solution can be computed for frictionless flow using the Bernoulli equation to validate a model. Figure 2 shows results for the proposed no-neighbour finite-volume solver that tracks quite closely to the analytical solution. The simulation was started from a system at rest and evolved as an unsteady solution until the steady state was reached. Obtaining the correct depth before the jump effectively depends upon the grid resolution. This result shows that our no-neighbour finite-volume algorithm converges to the correct hydraulic solution.

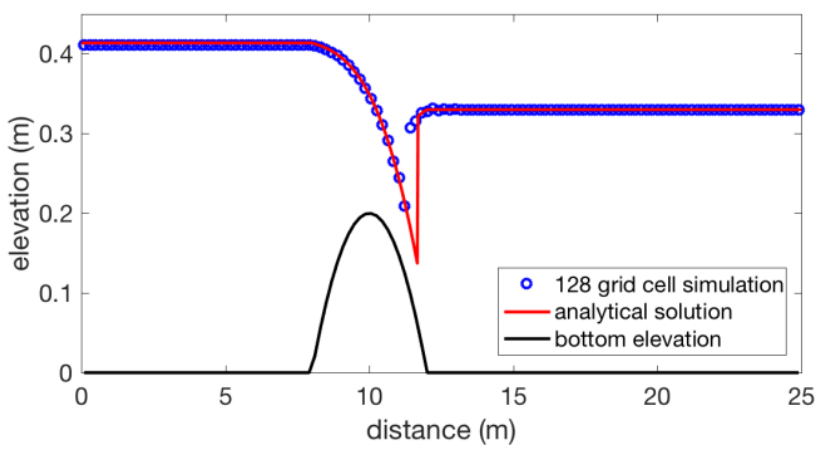

Figure 2. No-neighbour finite volume method and analytical solution for sub/super/sub-critical transitions in flow over a bump in a rectangular channel.

\subsection{Flow in a steep urban stream}

Waller Creek (Austin, Texas, USA) is a relatively steep urban stream (median slope of 0.008 over $10 \mathrm{~km}$ ) that has abrupt changes in geometry over relatively short distances (maximum slope of 0.84 and maximum adverse slope of -0.11 ) and provides a challenge for any SVE solver. At flow rates of $1.0 \mathrm{~m}^{3} \mathrm{~s}^{-1}$, the channel creates dozens of step-pool features with trans- 


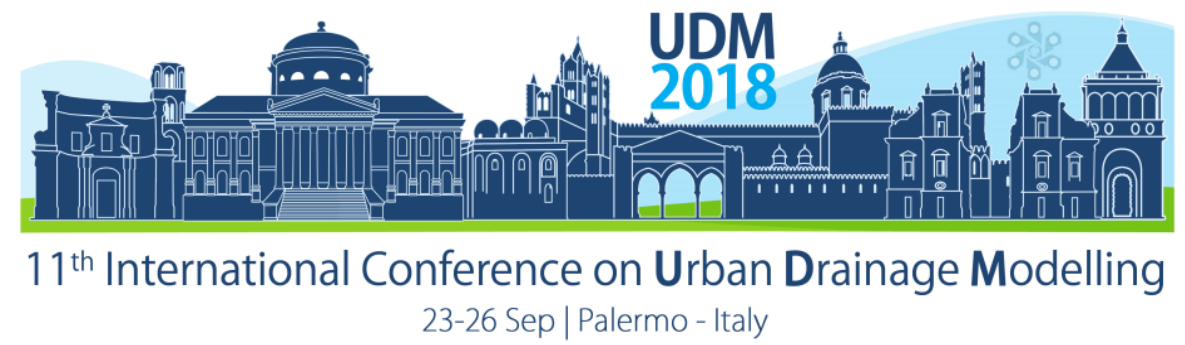

critical flows. Flow simulations are started with the water depth initially set to $0.5 \mathrm{~m}$ throughout the channel and initial flow rates equal to the steady upstream boundary inflow of $1.0 \mathrm{~m}^{3} \mathrm{~s}^{-1}$. The downstream boundary was held fixed at an elevation of $132 \mathrm{~m}$. Figure 3 shows a $1.0 \mathrm{~km}$ reach of the simulation domain that illustrates the typical solution after the unsteady evolution to steady state. Small grid-scale oscillations are present because of the abrupt geometry, but remain bounded. The simulation shown is with non-uniform grid based with a median cell length of $5.2 \mathrm{~m}$ and a standard deviation of $0.42 \mathrm{~m}$. We have achieved similar results using the coarser raw survey bathymetry for discretization, with a median cell length of $26.5 \mathrm{~m}$ and standard deviation of $59.9 \mathrm{~m}$.
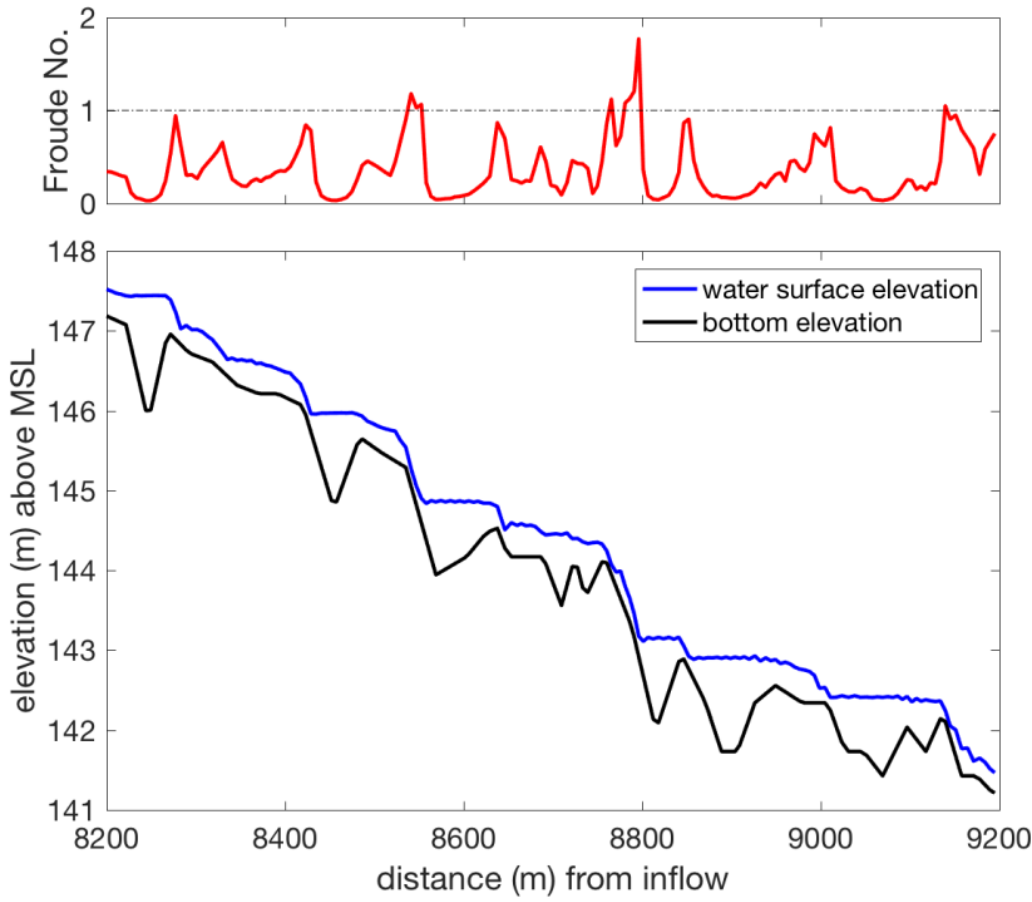

Figure 3. A short section of the Waller Creek high-resolution simulation showing the complexity of the channel geometry, the Froude number of the flow, and the water surface elevation.

\section{CONCLUSIONS}

A new "no-neighbour" finite-volume method is proposed as a foundation for the hydraulic solver in the next generation open-source SWMM code. The approach stable and robust for simulations at both fine resolution (as typical of other finite-volume models) and coarse resolution (as typical of link-node models). The solution approach is inherently mass conservative and has the desirable property of minimizes data transfer from neighbour cells compared to conventional higher-order finite-volume approaches.

\section{Acknowledgements}

This paper was developed under Cooperative Agreement No. 83595001 awarded by the U.S. Environmental Protection Agency to The University of Texas at Austin. It has not been formally reviewed by EPA. The views expressed in this document are solely those of the authors and do not necessarily reflect those of the Agency. EPA does not endorse any products or commercial services mentioned in this publication. 
Proceedings of the 11th Int. Conference on Urban Drainage Modelling, 23-26 Sep. 2018, Palermo (ITALY). Ed. prof. Giorgio Mannina

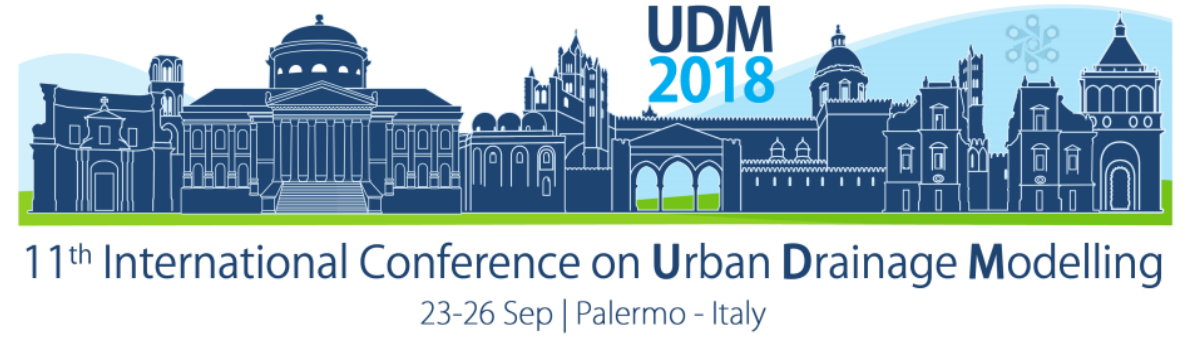

\section{References}

Amdahl, G.M. (1967) Validity of the single processor approach to achieving large scale computing capabilities. AFIPS Spring Joint Computer Conference (retyped and comments by Chen, G.) download March 16, 2018. http://www-inst.eecs.berkeley.edu/ n252/paper/Amdahl.pdf

Burger, G.; Sitzenfrei, R.; Kleidorfer, M.; and Rauch, W. (2014) Parallel flow routing in SWMM 5. Environmental Modeling \& Software 53 27-34.

Cunge, J. A., Holly, F. M., \& Verwey, A. (1980). Practical aspects of computational river hydraulics. Boston MA: Pitman Publishing Ltd.

Flamm, K. (2017) Has Moore's law been repealed? An economist's perspective. Computing in Science and Engineering, March/April, 29-39.

Ghoutal, N. and Maurel, F. (1997). Proceedings of the 2nd Workshop on Dam-Break Wave Simulation, Technical Report HE-43/97/016/A, Electricité de France, Département Laboratoire National d'Hydraulique, Groupe Hydraulique Fluiviale (as cited by Vázquez-Cendón, 1999; not available for review).

Hodges, B.R. (2018) Conservative finite-volume forms of the Saint-Venant equations for hydrology and urban drainage, Hydrology and Earth System Sciences, submitted May 2018.

Hodges, B.R. and Liu, F. (2018) No-neighbor discretization of a Saint-Venant model for unsteady open-channel flow," Journal of Hydraulic Research, submitted June 2018.

Liggett, J. A. (1975). Unsteady flow in open channels. Fort Collins, Colorado: Water Resources Publications.

Vázquez-Cendón, M.E. (1999) Improved treatment of source terms in upwind schemes for the shallow water equations in channels with irregular geometry. Journal of Computational Physics 148, 497-526. 


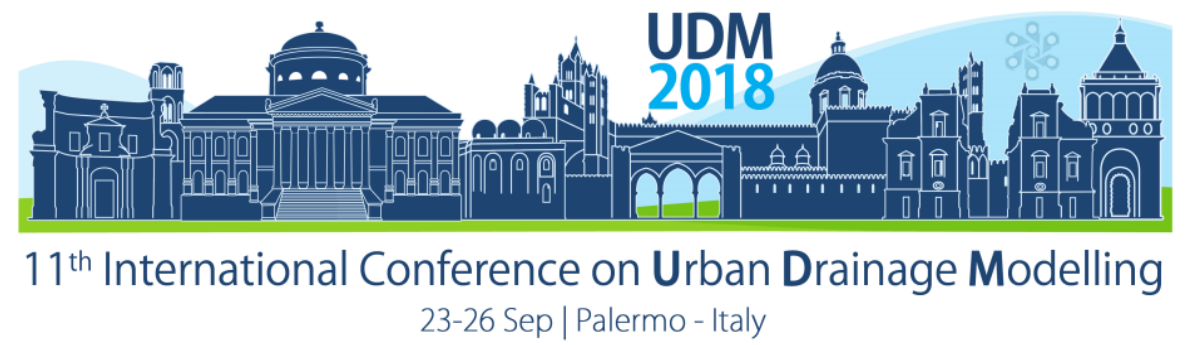

\title{
Benefits of Real Time Control for Catchment Scale Stormwater Harvesting in Cape Town, South Africa
}

\author{
John OKEDI ${ }^{1}$, Neil Philip ARMITAGE ${ }^{2 *}$ \\ ${ }^{1,2}$ Department of Civil Engineering, University of Cape Town, Private Bag X3, Rondebosch 7701, Cape \\ Town - South Africa \\ *corresponding author - Email: neil.armitage@uct.ac.za
}

\begin{abstract}
South Africa is a water stressed country with average annual rainfall of about $450 \mathrm{~mm}$ (well below $860 \mathrm{~mm}$ world average) and low stream flow. In Cape Town, limits of conventional water resources i.e. from reservoirs, have effectively been reached and in 2018, the city faced the prospect of taps running dry because of the prolonged exceptional drought that commenced in 2015. With no additional major dam sites available near Cape Town, the city is exploring alternative sources e.g. groundwater, wastewater treatment and reuse, and desalination of seawater. This study assessed the potential of harvesting stormwater from the existing, largely dry, ponds situated in the $100 \mathrm{~km}^{2}$ Zeekoe catchment. Storage is critical as Cape Town has a Mediterranean-type climate with short, wet winters and long dry summers. Since the potential storage capacity of the existing ponds is somewhat limited and their physical increase not practical due to land limitations in urban areas, an investigation was carried out into storage enhancement using Real-Time-Control (RTC) techniques that would safeguard the original purpose of the ponds which was largely flood-control. The envisaged RTC would dynamically manage pond outlets based on water levels and the expected inflow volume from rainfall so that ponds are pre-emptively drained just sufficiently to maintain their flood-control function before a storm event and end up full afterwards. An assessment was undertaken to compare demand met with and without RTC. It was determined that application of RTC on ponds and vleis would increase their effective yield by $113-290 \%$.
\end{abstract}

Keywords: Real-Time-Control; Stormwater Harvesting; Cape Town

\section{INTRODUCTION}

South Africa is a water stressed country with an average annual rainfall of only about $450 \mathrm{~mm}$ (well below $860 \mathrm{~mm}$ world average) and low stream flow. Surface water resources almost fully utilised and projected to have a gap between water demand and supply of some $17 \%$ by 2030 unless there is a significant change in water supply and use patterns (Addams et al., 2009). In Cape Town, the limits of conventional water resources i.e. from reservoirs have effectively been reached and in 2018 the city faced the prospect of the taps running dry because of the prolonged exceptional drought that commenced in 2015. With no additional major dam sites available near Cape Town, the city is exploring alternative sources e.g. groundwater, wastewater treatment and reuse, and desalination of seawater. In this study, the potential for harvesting stormwater from the existing, largely dry, ponds situated in the $100 \mathrm{~km}^{2}$ Zeekoe catchment was assessed. Storage is a critical issue as Cape Town has a Mediterranean-type climate with short, wet winters and long dry summers. Since the potential storage capacity of the existing ponds is somewhat limited and their physical increase not practical due to the availability of land in the city, an investigation was carried out into storage enhancement using 


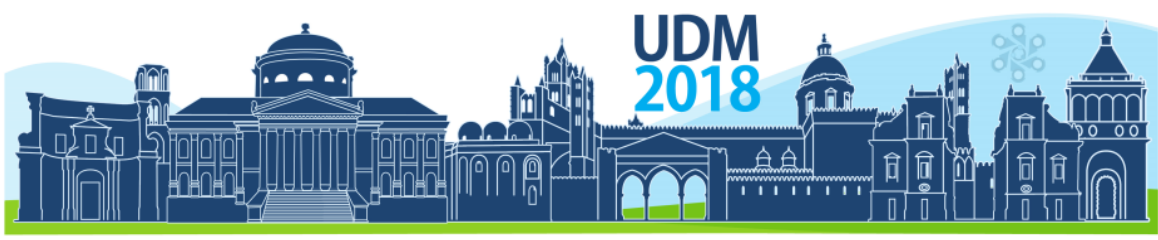

$11^{\text {th }}$ International Conference on Urban Drainage Modelling

23-26 Sep | Palermo - Italy

Real-Time-Control (RTC) techniques that would safeguard the original purpose of the ponds which was largely flood-control.

\section{MATERIALS AND METHODS}

The Zeekoe Catchment was chosen as study area as it had around 60 stormwater ponds and three reasonably large shallow lakes (labelled \#1, \#2 and \#3 in Figure 1) with the potential to be adapted for extended storage and water supply from stormwater harvesting.

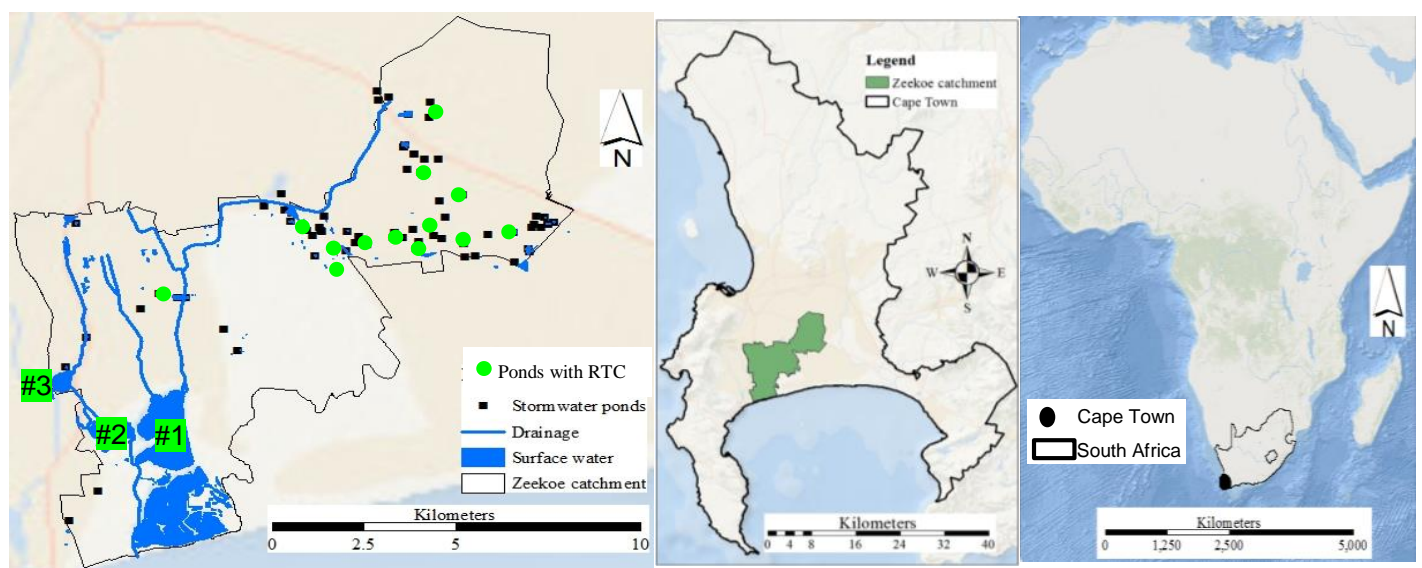

Figure 1 Location of Zeekoe Catchment in Cape Town, Souh Africa

The demand to be met by stormwater was initially limited to local non-potable water needs requiring little treatment, i.e. agriculture (Scenario 1, Sc1), garden irrigation and toilet flushing (Scenario 2, Sc2) and garden irrigation, toilet flushing and public parks (Scenario 3, Sc3). The estimated monthly demands from the various scenarios is indicated in Errore. L'origine

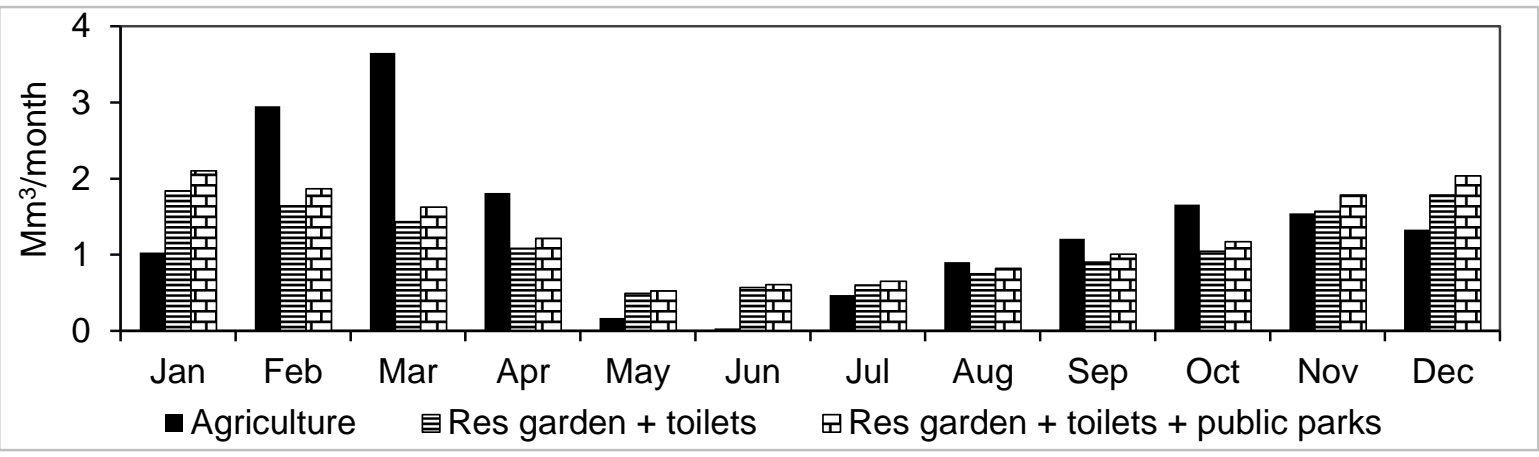

riferimento non è stata trovata..

Figure 2 Various non-potable water demands in the study area

PCSWMM ${ }^{\mathrm{TM}}$ was used to model the hydrological processes in the Zeekoe Catchment with a view to determining how to maximise the storage within the existing ponds and shallow lake system for stormwater harvesting from a limited number of points. The approach was informed by a similar study on smaller area nearby (Rohrer \& Armitage, 2017) which showed that a decentralised stormwater harvesting system, i.e. pumping from many ponds, was not as economic as pumping from a single point. This meant harvesting from the downstream shallow 


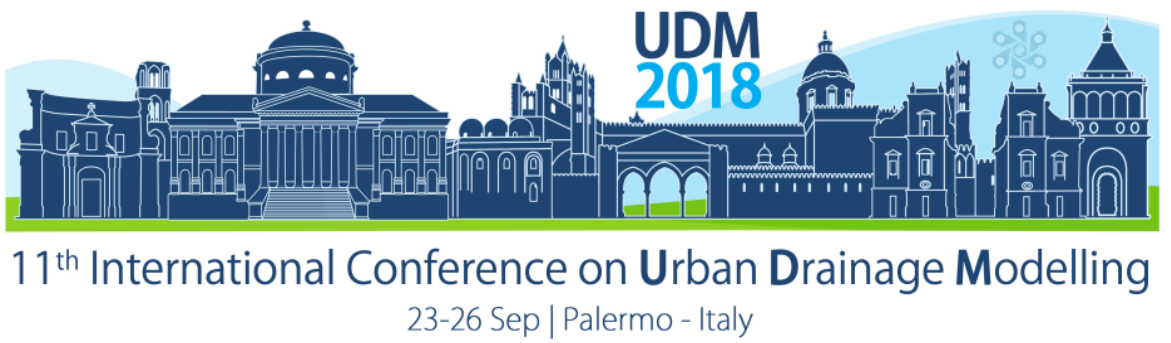

lakes labelled \#1 and \#2 in Figure 1. The three stormwater storage strategies considered in this study were as follows:

i. Strategy 1 - The baseline scheme where stormwater harvesting is done with no modification to the system i.e. ponds continue to function with temporary storage for flood control only. Abstraction was to be from the shallow lakes labelled \#1 and \#2 but from inflow only without supplementary storage.

ii. Strategy 2 - Stormwater harvesting was then enhanced through 'Real Time Control' (RTC) i.e. the use of real-time weather forecasts to manage the water levels in ponds so that they are pre-emptively emptied immediately before a storm event and just filled afterwards. In the application of RTC, the outlets from thirteen selected ponds were hypothetically modified to control outflow. The selected stormwater ponds are currently dry (detention) ponds, each greater than 1 ha plan area as these are the ones most able to provide significant storage. Another consideration was ponds with minimal risk of flooding nearby properties from a 20-year flood (a design requirement). Rainfall events in the study period $(2006-2015)$ were analysed for the selection of suitable storms to assess RTC. From this, it was determined that there was an average of 68 rainfall events per year. The average rainfall per event was $10 \mathrm{~mm}$ with $95^{\text {th }}$ percentile of $21 \mathrm{~mm}$. Two consecutive forecasted storms of about $20 \mathrm{~mm}$ each (Figure 3) were used to give an indication of the typical impact of rainfall on water levels in the ponds.

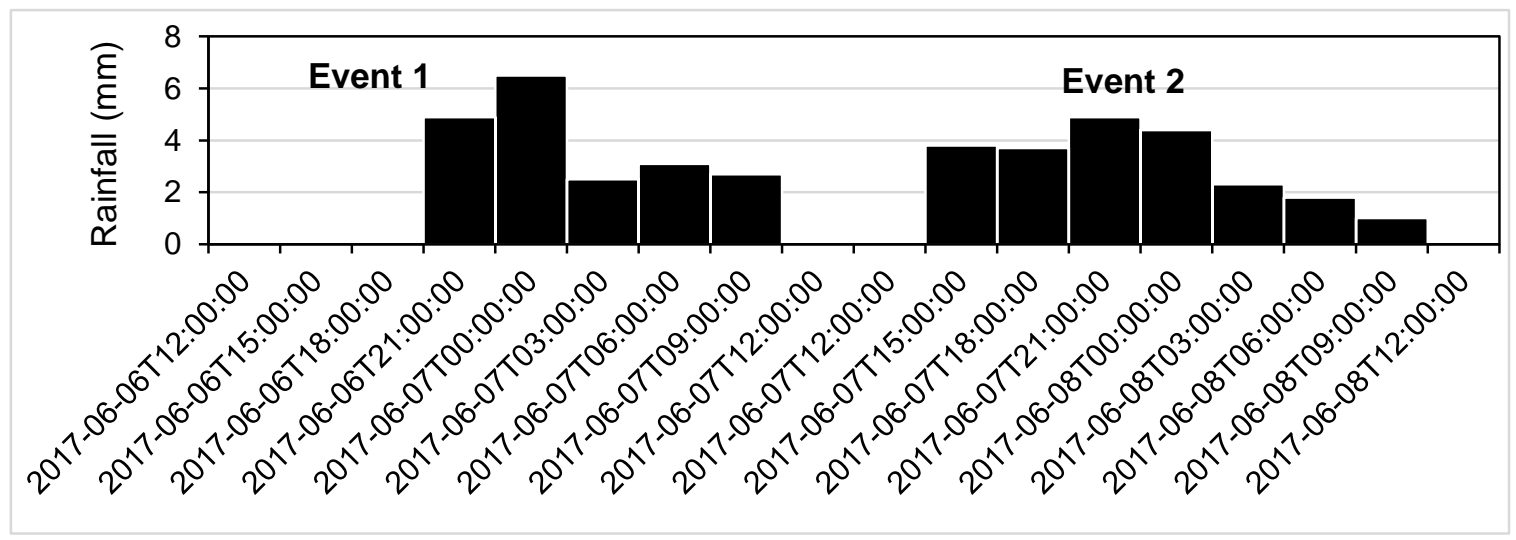

Figure 3 Two antecedent predicted storms over a 48 hour period

The inflow volume to the selected ponds from the forecasted rainfall was estimated in PCSWMM $^{\mathrm{TM}}$ and the ponds were determined to have sufficient capacity to contain generated flow from Event 1 with water levels ranging from $32-74 \%$ of total depths. With the additional inflow from Event 2, it was determined that capacity in most ponds was exceeded by $13-72 \%$ of the total storage volume. Only two ponds had capacity to contain the two storms with closed outlets. The findings from the event based method guided the selection of rules in continuous modelling over 10 years $(2006-2015)$ to coincide with the demand. The Proportional-Integral-Derivative (PID) controllers available in PCSWMM ${ }^{\mathrm{TM}}$ were then set such that the outlets of ponds were fully opened when the anticipated inflow was larger than available storage and thus threaten local flooding, or when there was sufficient storage capacity in the downstream vleis to receive the stormwater from the upstream ponds. Conversely, outlets of ponds were completely closed where anticipated inflow to the ponds was less or equal to the available storage. 


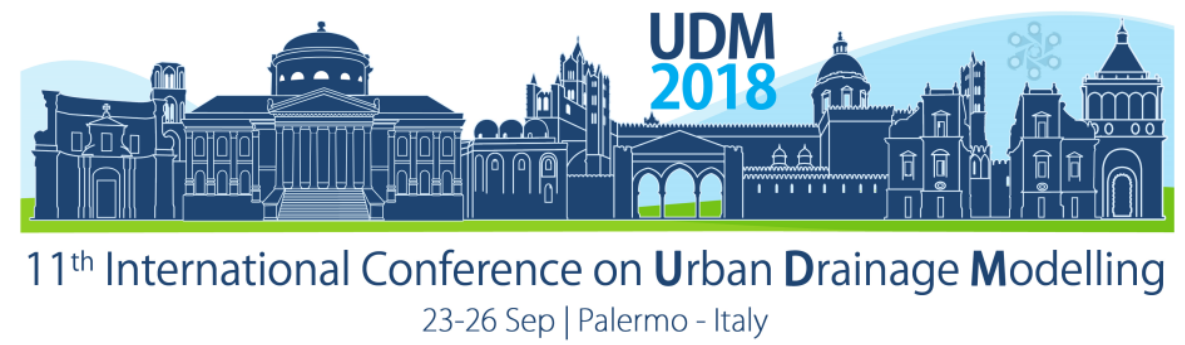

iii. Strategy 3 - Stormwater harvesting with RTC on the thirteen selected ponds in Strategy 2 with the lakes \#1 and \#2 providing additional storage. Since the lakes are used for other purposes e.g. recreational uses and ecology, some storage was reserved for these, with only $50 \%$ of their capacity i.e. $2.5 \mathrm{Mm}^{3}$ and $0.5 \mathrm{Mm}^{3}$ respectively considered for water supply.

The daily yield for the three strategies was modelled using rainfall data for the study period 2006 - 2015 for each of the three demand strategies i.e. Sc1 (agriculture only); Sc 2 (residential garden irrigation and toilet flushing); and Sc3 (residential garden irrigation, toilet flushing and public parks) and the 'demand met' and the 'loss from system' evaluated.

\section{RESULTS AND DISCUSSION}

The results are summarised as annual values in Figure 4. Depending on the demand scenario (i.e. Sc1, Sc2 or Sc3), application of RTC increased the effective yield by between 113 and $290 \%$ and significantly reduced the loss of the stormwater resource from system compared with the baseline strategy. Loss from system (Figure 4) includes water that fills the vleis and used for other purposes such as recreation and ecology.

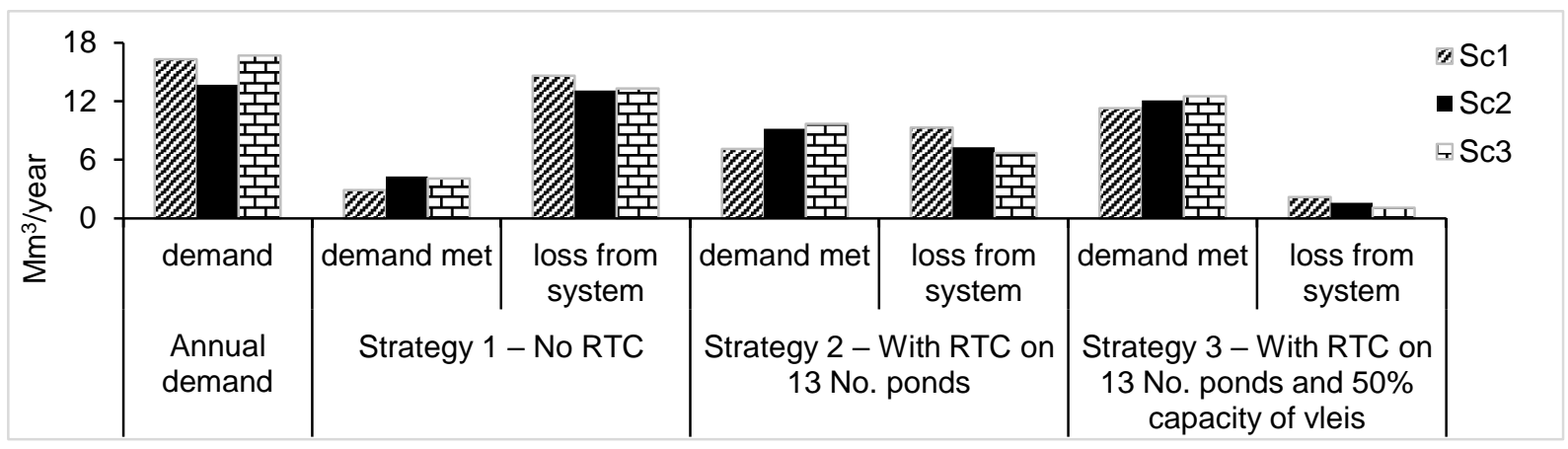

Figure 4 Supply to various demands and loss through spill

\section{CONCLUSIONS}

In regions with seasonal rainfall such as Cape Town, large storage is required if stormwater is to make a substantial contribution to water supply especially where the demands are mostly outdoor e.g. irrigation of agriculture, residential gardens and open parks. These non-potable demands were considered as they do not usually require full treatment to potable water standards, however they are highest in the dry summer months whilst the stormwater resource is largely only available in winter. This research investigated the viability of adapting the existing stormwater pond system - which consisted mainly of detention ponds designed for flood control but did include three small lakes - to provide some of the missing stormwater component with and without RTC methods to maximise their efficiency. Naturally, the water could be treated to potable water standards and used for all purposes but this introduces a significant treatment cost - although saving on reticulation. This is the subject of another study.

\section{References}

Addams, L., Boccaletti, G., Kerlin, M., \& Stuchtey, M. (2009). Charting our water future, economic frameworks to inform decision-making. The 2030 Water Resources Group.

Rohrer, A. R., \& Armitage, N. P. (2017). Improving the viability of stormwater harvesting 
Proceedings of the 11th Int. Conference on Urban Drainage Modelling, 23-26 Sep. 2018, Palermo (ITALY). Ed. prof. Giorgio Mannina

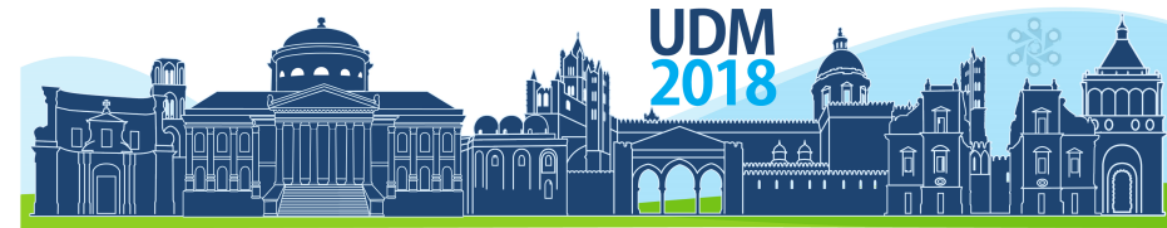

$11^{\text {th }}$ International Conference on Urban Drainage Modelling 23-26 Sep | Palermo - Italy

through rudimentary real time control. Water (Switzerland), 9(6). doi:10.3390/w9060371. ISSN:20734441. 


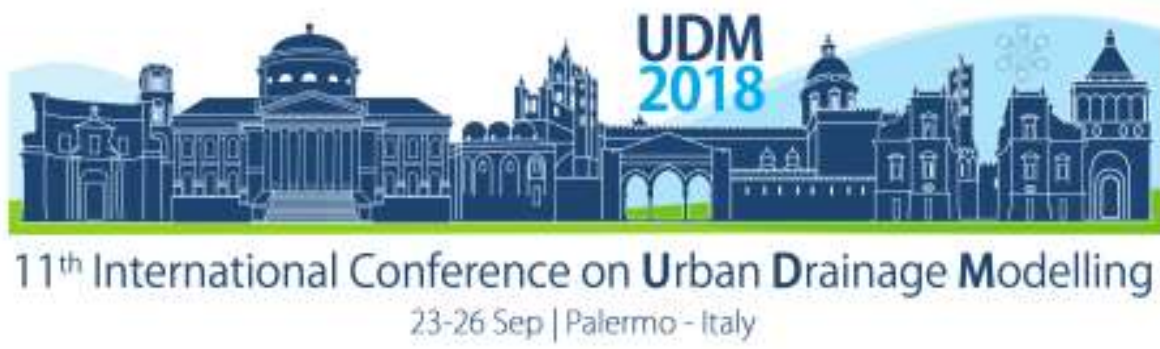

\title{
SWMM Model Data Management and Development Using FME Software
}

\author{
Leena Sänkiaho ${ }^{1}$ and Tiia Lampola ${ }^{2}$ \\ (Author Name Surname; 10pt, Arial, bold) \\ ${ }^{1}$ The Helsinki Region Environmental Authority (HSY), Helsinki, Finland \\ 2 SewCon Kuikka Oy, Nurmijärvi, Finland
}

\begin{abstract}
The Helsinki Region Environmental Authority (HSY) has been developing its own sewerage modelling process since 2014. This paper focuses on data management from different sources and the use of FME software as part of the data transformation process from several databases into a EPA SWMM-model.
\end{abstract}

Keywords: EPA SWMM; FME; Network information system NIS

\section{INTRODUCTION}

The Helsinki Region Environmental Authority (HSY) is responsible for the water and wastewater management of Helsinki Metropolitan area. The sewer network consists of around $2,400 \mathrm{~km}$ of pipes with 542 pumping stations, and it covers the wastewater flow of over 1.2 million inhabitants within Helsinki region. In modelling terms, this means approximately 70,000 links and nodes. In 2014 HSY started a development project to build a hydraulic model of the entire sewerage network. The aim of the project has been to build a hydraulic model for capacity, inflow and infiltration (I\&I), combined sewer overflow (CSO) management and long-term investment planning.

The aim has been to develop a standardised, repeatable, automated, documented and open data format model that is not totally relied upon by of any single supplier or consultancy (Yrjölä et al., 2015). Therefore EPA SWMM (EPA, 2015) was chosen as a model engine. Alongside the modelling project, the network information system (NIS) provider has been developing the ability to export data into EPA SWMM format, but is currently not able to combine data from other sources.

The aim of this paper is to discuss the different tools and methods that have been used to implement data from various sources and to discuss the tools chosen to manage the models in different scales and situations. For data management and transfer, FME software (Safe Software Inc) has played a critical role during the whole project. It is a licensed program which can read, transfer, analyse and join data from several formats either based on location or attributes.

The development criteria have been: How much we need manual labour compared to automated operations? If there are changes in data sources, what is the easiest way to change the data management process? How can we build models in different scales and aggregate data? Can we develop a user interface that does not need special NIS, GIS, programming or FME skills? 


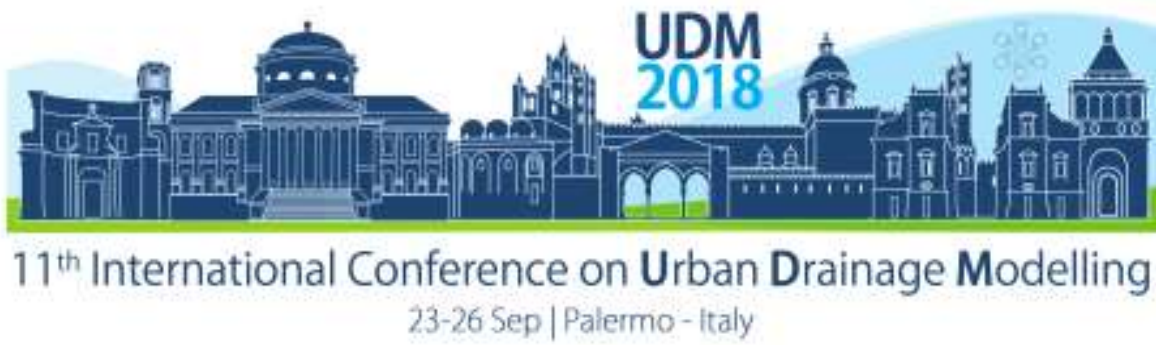

\section{FROM NETWORK DATA TO A FUNCTIONING MODEL}

Figure 1 shows an example of the different data sources used in modelling at HSY and how data is managed in the FME Workbench. Below is a description of how the data is acquired, corrected and transferred for the model. Some of the steps are still under development. During recent years a lot of work has been done to improve data quality and methods for data transfer.

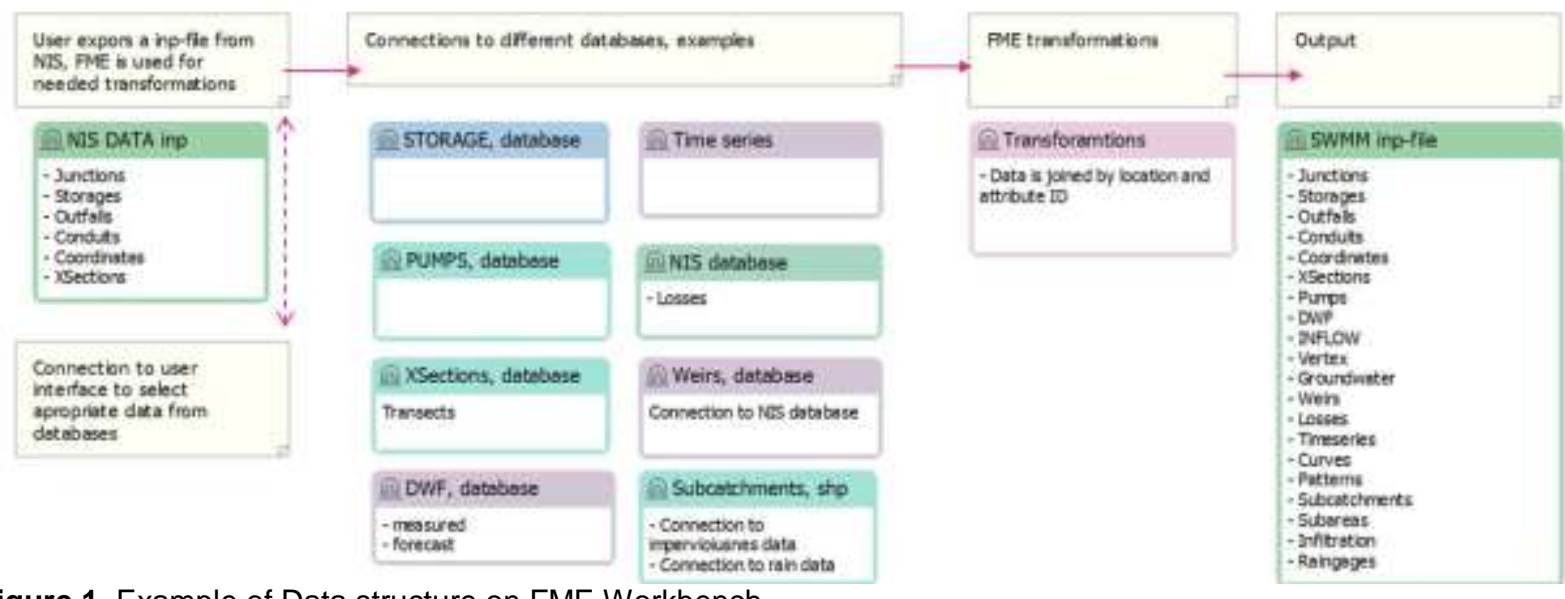

Figure 1. Example of Data structure on FME Workbench

\section{Network information system (NIS)}

The most time-consuming part of sewerage modelling is to find and replace incorrect network data. For links the most important network information is connections, types, elevations, diameters, cross-sections and materials, and for nodes it's elevations and types (manhole, storage and outlet). In previous modelling projects corrections have been done manually by consults in the modelling software and generally no records of the changes have been kept. At HSY a decision was made to use NIS as a place to store corrected data. Within NIS data is stored in several levels. Master data level consist of data that has been gathered by surveys after/during construction work or is digitized from old blueprints. Project data level consist of data that has been changed for the modelling purpose. Changes made in the master level overwrite data in project level.

The first step in data improvement was done by using a FME rule-based analysis to gather data from consecutive pipes and nodes, and digital elevation model. It took several trials before the right order of analysis was achieved. Caution must be paid when using FME so that the correct data is not lost in the process. The second step was the most laborious part in the process. Hundreds of hours were used to visually check and correct data even if there are tools in NIS to speed up the manual work. Also, several trials were done to develop a system to, i.e., connect links that do not have manholes between them, but are too short to be modelled as individual pipes.

From the NIS system, data can be exported either as shp- or inp-formats. In the beginning shp-format was used and data was transferred first into ArcGIS or Excel and then to SWMM by using inp.PINS- software (Pina et al. 2011). Using the inp-format in FME several data management steps can be avoided and the process becomes shorter and more automated. 


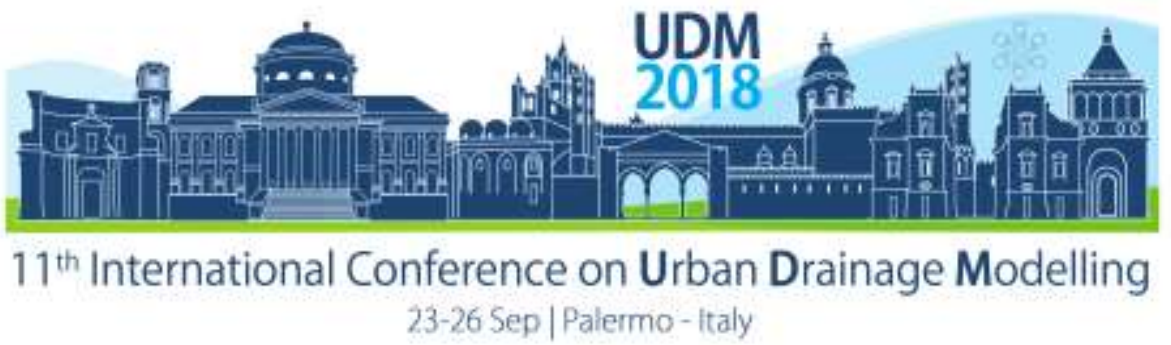

Figure 2 gives an example of the FME data transformation tools and the process. Yellow boxes represent a data source (reader) or results (writer). Blue boxes represent a transformation function such as a spatial join, conditional function or data format transformation.
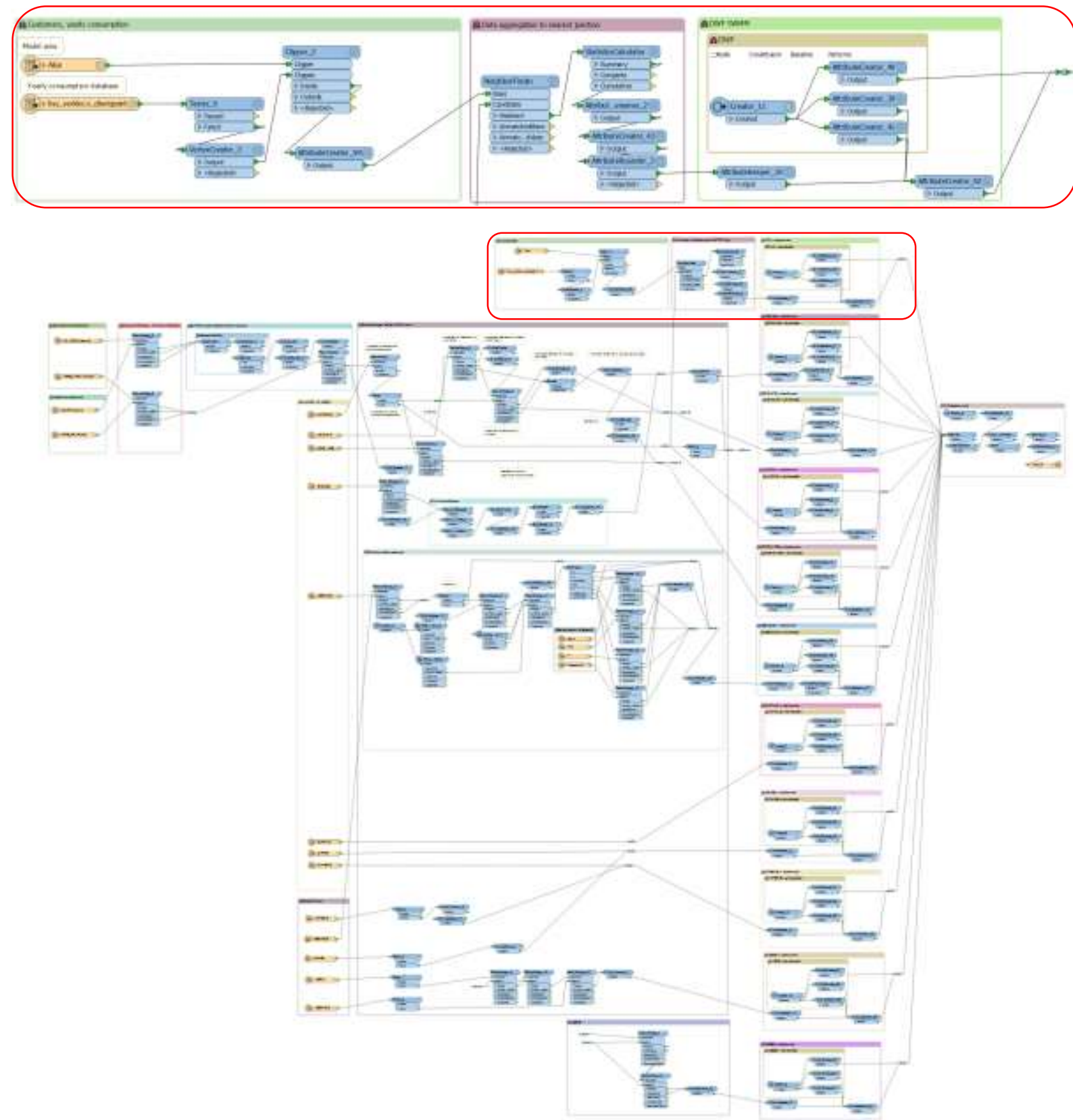

Figure 2. An example of a FME Workbench data transformation for an inp-file and different data source.

Pumping station data, Excel

Parallel to the modelling project pumping station data has been improved and a database for the model pumps and pumping stations has been developed. The master data is stored at AWR reporting system (Neocodex) and can be exported to excel. The plan is to develop a direct data connection between the FME and AWR reporting system. Also, the flow time 


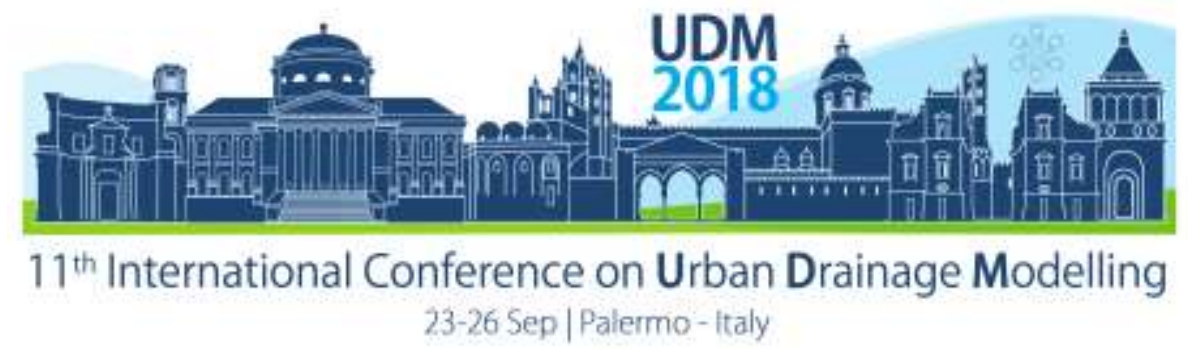

series are stored in AWR and is accessible through FME.

\section{Weirs}

Overflow structures are modelled mainly using weirs. The location and crest level are stored in the NIS, but other data is stored in databases. The database was collected by a consultancy.

\section{Transects}

There are around $90 \mathrm{~km}$ of sewerage tunnels in the Helsinki region. The tunnel locations are stored in NIS. A database of the tunnel transects was developed by a consult based on blueprints.

\section{Losses}

In the model each pipe will get its loss coefficients according to the type of the pipe and its connecting nodes (entry and exit losses). The data is stored in NIS database and is accessible through FME.

\section{Dry weather flow}

Wastewater flow is based on the metered water consumption data from the previous year. This data is stored in a geocoded database. Data is aggregated to the nearest sewerage junction. Curves for hourly, daily and monthly dry weather flow are estimated from the water distribution pressure zone data.

The cities in the Helsinki region have made a GIS dataset (500 m x $500 \mathrm{~m}$ grid) of the estimated future inhabitants and workplaces. For instance, this data can be used for future wastewater flow estimates.

\section{Flow time series}

There are several locations, for instance land fill sites, where wastewater flow is irregular but metered daily. In the user interface the user should be able to choose whether they want to use these time series. The plan is that in some cases pumping station data could be imported as time series.

\section{Catchment data}

The combined sewer system area has been divided into catchments based on a digital elevation model and an analysis done by a consultancy. HSY has developed an imperviousness GIS dataset based on land use, which is used as basis for imperviousness calculations in catchments.

\section{Rainfall data}

In the future the user should be able to choose if he/she wants to use radar data or design storm data for rainfall modelling. Rainfall radar data can be freely accessed from the Finnish Meteorological Institute and can be aggregated for the chosen area using FME. Design storms are stored as time-series files.

\section{Infiltration and inflow (I\&I)}

For I\&I, the development process is still under way. Until local calibration is achieved, infiltration can be estimated in relation to pipe lengths. 


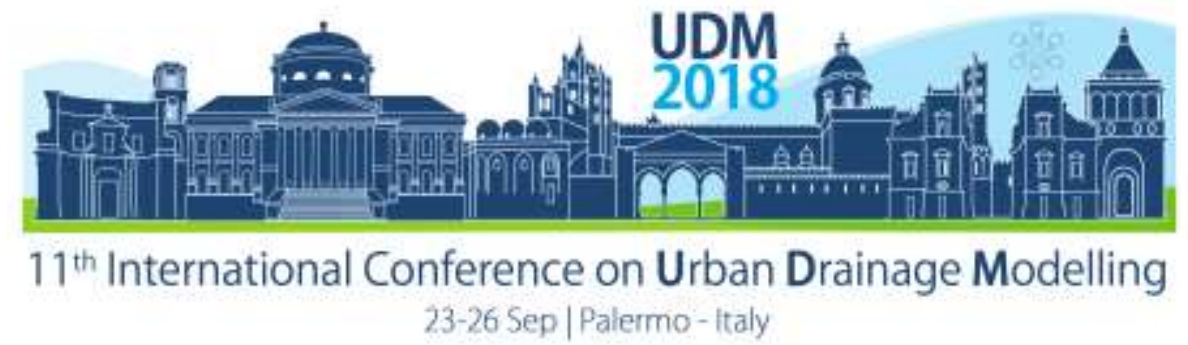

\section{RESULTS AND DISCUSSION}

The FME data management process has been developed and tested in spring 2018. During that time a lot of work has been done to improve data quality and connections in all databases. The process has been tested on several locations both on separate and combined sewers. With the FME most of the data transformation steps have been automated and work load has decreased significantly. For the modeller there are now only three steps to get a working model: 1. Export the network data from NIS into inp-file 2. Draw a polygon shape of the modelled dry and wet weather flow area 3. Import the inp-file and shp-files into the FME interface, choose the required data connections and run the transformation process.

\section{CONCLUSIONS}

Data quality and data transport methods are crucial when large sewerage models are developed. FME has proven to be a useful tool to minimize workload in data management. Also, it can be used to read data from a user interface.

Some of the steps could be avoided, if a commercial modelling program would have been used. On the other hand, the process chosen has improved the water utility staff's knowhow tremendously. With the chosen method, the water utility is also able to track changes made in the modelling data.

\section{References}

EPA U.S. Environmental Protection Agency (2015) Storm Water Management Model User's Manual Version 5.1. Pina, R. D.; Simões, N. E.; Sá Marques, A.; Sousa, J. (2011); Floodplain delineation with Free and Open Source Software, 12th International Conference on Urban Drainage, 12-15 September 2011, Porto Alegre, Brazil A. Yrjölä, T. Lampola, M. Heinonen, M. Sunela, T. Nikulainen (2015) Open Format Data in Sewer Modeling - Case HSY, Finland. Conference Nordiwa 2015, Proceedings 


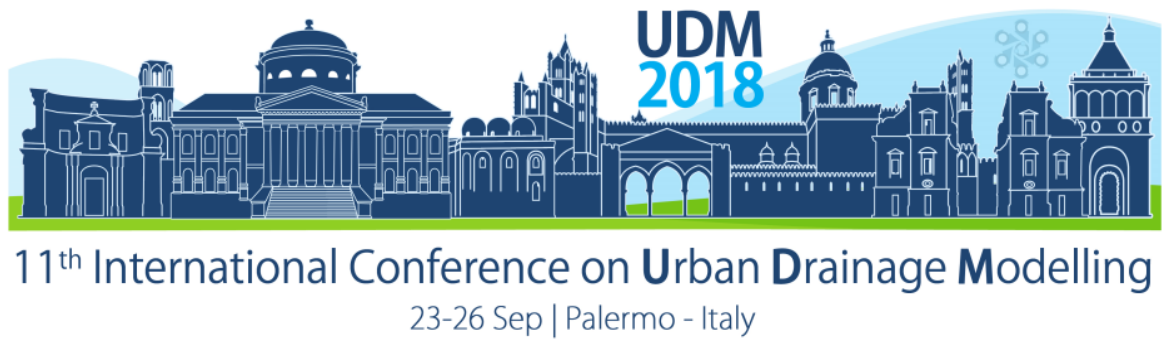

\title{
Emulation of a Detailed Urban Drainage Simulator to Be Applied For Short-Term Predictions
}

\author{
Mahmood Mahmoodian ${ }^{1,2}$, J. A. Torres-Matallana1, 3, Ulrich Leopold ${ }^{1}$, Georges Schutz ${ }^{4}$ \\ and Francois Clemens ${ }^{2,5}$ \\ ${ }^{1}$ Luxembourg Institute of Science and Technology (LIST), ERIN Department, Belvaux, Luxembourg \\ 2 Technical University of Delft, Sanitary Engineering Department, Delft, the Netherlands \\ ${ }^{3}$ Wageningen University, Soil Geography and Landscape Department, Wageningen, the Netherlands \\ ${ }^{4}$ RTC4Water, Belval, Luxembourg \\ ${ }^{5}$ Deltares, Hydraulic Engineering Department, Delft, the Netherlands
}

\begin{abstract}
The challenge of this study is to investigate on applicability of a data-driven Gaussian Process Emulator (GPE) technique to develop a surrogate model for a computationally expensive and detailed urban drainage simulator. The novelty is the consideration of (short) time series for the simulation inputs and outputs. Such simulation setup is interesting in applications such as Model Predictive Control (MPC) in which numerous, fast and frequent simulation results are required. Here, an emulator is developed to predict a storage tank's volume in a small case study in Luxembourg. Three main inputs are considered as the GPE's parameters: initial volume in the tank, the level in which the outlet pump of the tank must start to work, and the time series of expected rainfall in the upcoming 2 hours. The output of interest is the total volume of the storage tank for the next 24 hours. A dataset of 2000 input-output scenarios were produced using different possible combinations of the inputs and running the detailed simulator (InfoWorks ${ }^{\circledR}$ ICM). $80 \%$ of the dataset were applied to train the emulator and $20 \%$ to validate the results. Distributions of Nash-Sutcliffe efficiency and Volumetric Efficiency are presented as indicators for quantification of the emulation error. Based on the preliminary results, it can be concluded that the introduced technique is able to reduce the simulations runtime significantly while imposing some inevitable accuracy cost. More investigation is required to validate the more generic applicability of this technique for multiple outputs and interactions between different urban drainage components.
\end{abstract}

Keywords: Surrogate Model; Gaussian Process; Emulator; Urban Drainage, InfoWorks ${ }^{\circledR}$ ICM

\section{INTRODUCTION}

Acceleration of the model simulations while quantifying the uncertainty in the estimations, is still one of the challenges in the field of urban drainage modelling. Application of Gaussian Process Emulators (GPEs), as one of the promising surrogate modelling techniques, is gradually increasing to face this challenge. Among the most relevant and recent studies in this regard is a mechanism-based emulator, based on simulator's equations, which was introduced by Machac et al. (2016) for emulation of SWMM simulator. Later on, Carbajal et al. (2016) compared this mechanism-based GPE with a purely data-driven GPE. Based on the comparison results, it was asserted that data-driven GPE outperforms the mechanistic one in many applications. However, to the authors' knowledge, no data-driven GPE technique has been applied in the urban drainage modelling domain which can deal with inputs and outputs 


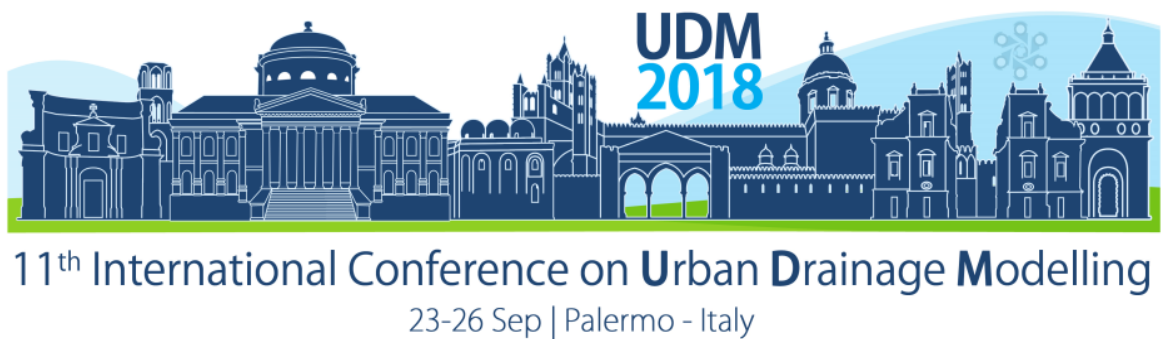

in time series format. The main reason for this is the high dimensionality problem in such case as a result of inclusion of numerous parameters. Although, in applications such as modelbased real-time control (RTC), the number of simulation inputs and outputs are limited. Hence, the main motivation in our study is to investigate on a data-driven emulation technique which has the potential to be applicable for simulators with inputs and outputs in time series format and use it for short-term predictions specifically for RTC purpose. The current document briefly presents the methodology applied in this regard together with illustration of some achieved results.

\section{MATERIALS AND METHODS}

\subsection{Emulation method}

The GPE method used in this study is based on (Olson, Chang, Keller, \& Haran, 2015). In this approach the model output of interest $(Y)$ can be formulated as a Gaussian process such that:

$$
Y \sim N\left(\mu_{\beta}, \Sigma\left(\xi_{y}\right)\right)
$$

where $\mu_{\beta}$ is a mean function which is considered linear in time, and $\xi_{y}$ is a vector of covariance matrix parameters. The GPE inputs should be prepared in terms of various simulation parameter sets and the corresponding outputs can be in times series format. An $R$ package named 'stilt' is used to develop the emulator in this study (Olson et al., 2015). Detailed information on the underlying mathematical framework of the method can be found in (Olson \& Chang, 2013).

\subsection{Candidate Simulator, Case Study and Data}

The candidate simulator subject to emulation in this study is InfoWorks $\AA^{\text {ICM }}$ which normally requires a detailed description of the structure and geometry of urban drainage networks together with numerous parameters and inputs. A small case study area from Haute Sûre catchment in Luxembourg, modelled by InfoWorks ${ }^{\circledR} I C M ~ 8.5$, is selected as the case study. The focus is to develop an emulator for short-term predictions of total storage volume in a combined sewer overflow (CSO) location in this case study. The introduced GPE method is able to map a set of parameters (inputs) to the desired outputs in times series format. It is observed that, in this case study, three inputs are playing the main role in changing the dynamics of the outputs of interest. These are including: the initial water volume in the storage tank (P1), the switch-on level for the fixed flow pump which controls the outflow of the tank (P2), and the expected rainfall event in the catchment. Since only short-term predictions are interested in this study, only short-term rainfall events are considered to test the applicability of the introduced GPE method. Hence, as an example, rainfall events with 2 hours duration and time steps of 10 minutes are taken into account. The rainfall intensity $(\mathrm{mm} / \mathrm{hr})$ in each time step is assumed as an individual parameter (i.e. 12 parameters: P3 to P14). The reason for consideration of rainfall time series as individual parameters is that the GPE technique applied in our research is only able to map individual discrete parameters (as input) to time series of the desired output. To our knowledge, taking into account continues time-series as input for GPE is very challenging due to high dimensionality problem in such case. 


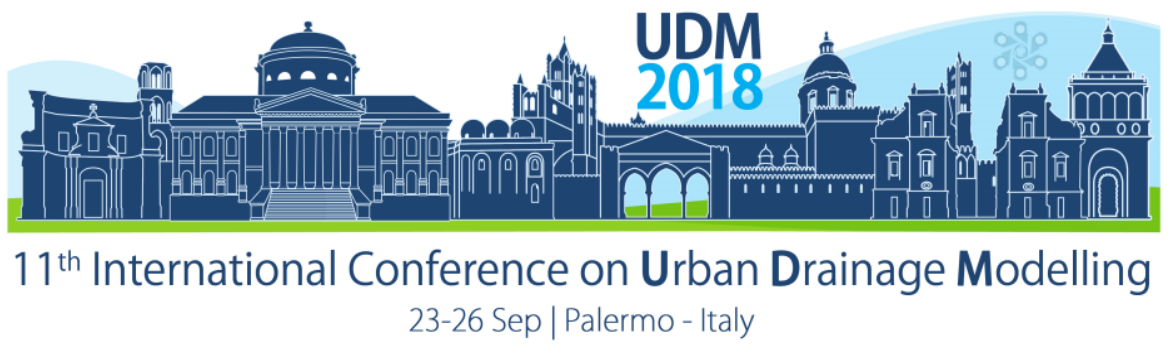

An ensemble of 100 rainfall time series were generated based on the observed rainfall time series in the case study area, consideration of different return periods and application of a multivariate autoregressive model and conditional simulation of rainfall time series (TorresMatallana, Leopold, \& Heuvelink, 2017). Afterwards, 2000 parameter sets are configured by various possible combinations of 4 samples for $\mathrm{P} 1,5$ samples for $\mathrm{P} 2$, and 100 samples for P3 to P14 (i.e. the 100 rainfall scenarios). Then, the parameter sets are used as input to run the InfoWorks ${ }^{\circledR}$ ICM simulator in order to build a dataset of 2000 input-output pairs to train and validate the emulator ( $80 \%$ for training, $20 \%$ for validation). Conditional Latin Hypercube Sampling (CLHS) technique, is implemented to sample the training and validation data from the ensemble dataset using the R package "clhs" (Roudier, 2017).

\section{VALIDATION RESULTS AND DISCUSSION}

Figure 1 illustrates comparison of the results produced by the emulator and the original simulator (InfoWorks $® I C M)$ regarding short-term predictions. Three random runs with different inputs are represented here as illustrative examples. Nash-Sutcliffe Efficiency (NSE) and Volumetric Efficiency (VE) are used as statistics for quantification of the emulation error. NSE or VE equal to 1 means a perfect match between the emulation and simulation time series. The results produced by the emulator and simulator are compared with each other using the validation dataset. Violin plots of NSE and VE are presented in figure 2 to visualise the kernel probability density of the data at different values.

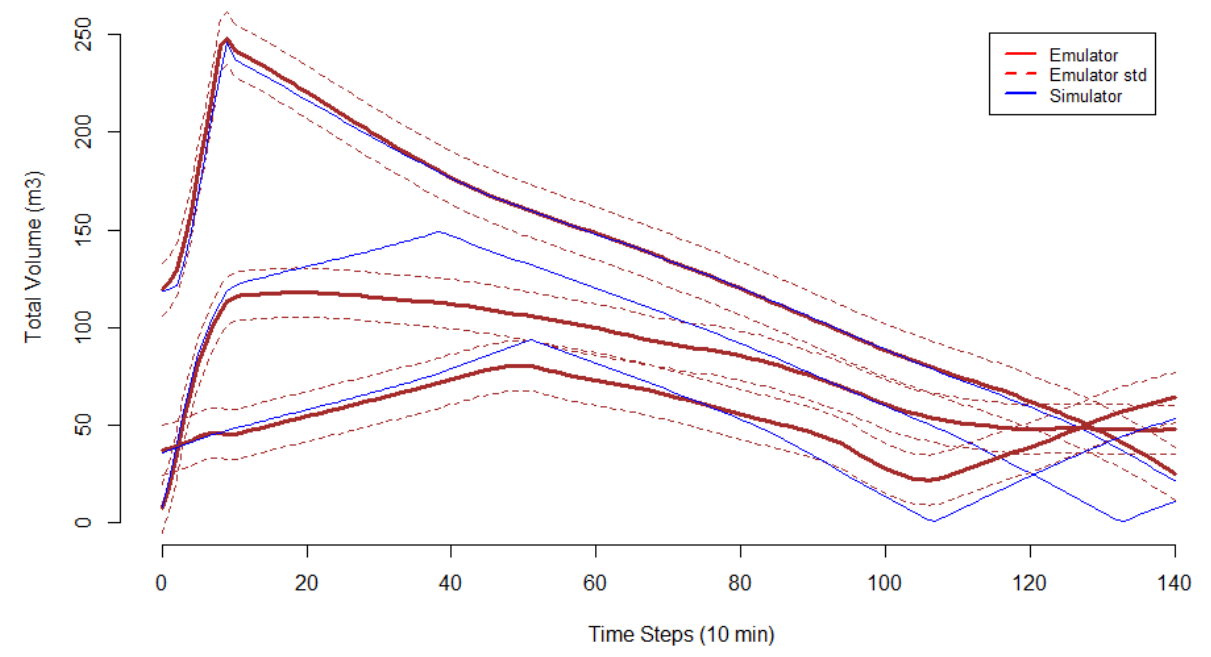

Figure 1. Comparison of emulator vs. simulator results for three random sample scenarios from validation dataset.

As it can be observed from Figure 2, the introduced GPE technique is capable of capturing the desired outputs in time series format with relatively high accuracy in comparison with the original detailed simulator. NSE and VE both are distributed towards $1\left(Q_{1}, Q_{2}\right.$ and $Q_{3}$ quantiles of both distributions are located between 0.8 and 1 in all cases). However, there are few cases in which the deviation between emulator and simulator is significantly beyond the $95 \%$ confidence interval. Moreover, it was observed that the emulator is approximately 300 times faster than the simulator in this small case study on the same computer. It should be noted 


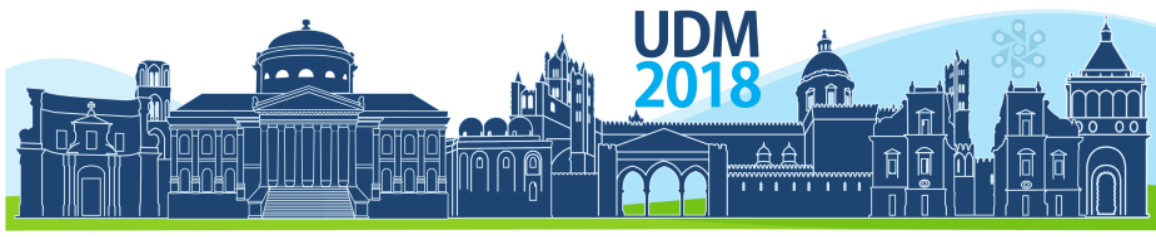

$11^{\text {th }}$ International Conference on Urban Drainage Modelling

23-26 Sep | Palermo - Italy

that, for runtime comparison solely the hydrodynamic simulation's runtime by InfoWorks ${ }^{\circledR}$ is considered (excluding wastewater quality modelling). This runtime acceleration is mainly obtained by reducing the complexity and the numerical approach behind the detailed simulator and fitting a model solely based on the data achieved from snapshots of the simulator runs.

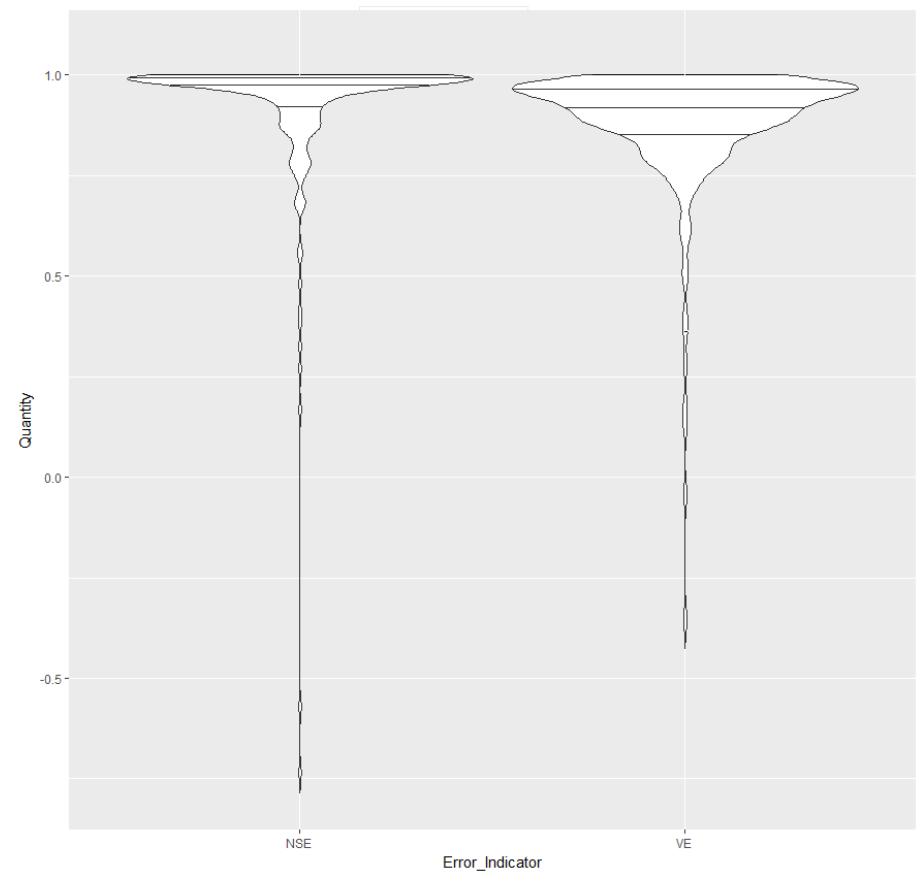

Figure 2. Distribution of NSE (left) and VE (right) for validation dataset (horizontal lines indicate the $0.25,0.5$ and 0.75 quantiles).

It should be mentioned that, the emulator fails to predict when the input parameters are beyond the training ranges. For instance, if the emulator is trained with rainfall intensities between 0 and $60 \mathrm{~mm} / \mathrm{hr}$, it cannot be used to predict the output for an intensity of $70 \mathrm{~mm} / \mathrm{hr}$. Besides, the emulator prediction results are worse (wider confidence interval) when there has not been sufficient training data in that range of inputs and outputs (data insufficiency). Hence, to achieve better emulation results, it is advised to implement a proper sampling design for the parameters to take into account a smoother coverage in the parameter space.

\section{CONCLUSIONS}

The main advantages of the introduced emulation technique are including: 1) its generic nonintrusive nature due to being solely based on data extracted from the simulator; 2) its applicability for inputs and outputs in (short) time series format; and 3) its capability for considerable simulation acceleration together with a low accuracy cost (if trained properly). However, this method can only be considered a proper surrogate modelling technique when a limited number of parameters are involved in changing the dynamics of the desired outputs. The future steps of this research will be investigation on the larger case study with various CSO locations and their interconnections; uncertainty quantification for rainfall input and its effect on emulation results; consideration of wastewater quality modelling; and finally application of such emulators in RTC of urban drainage systems. 


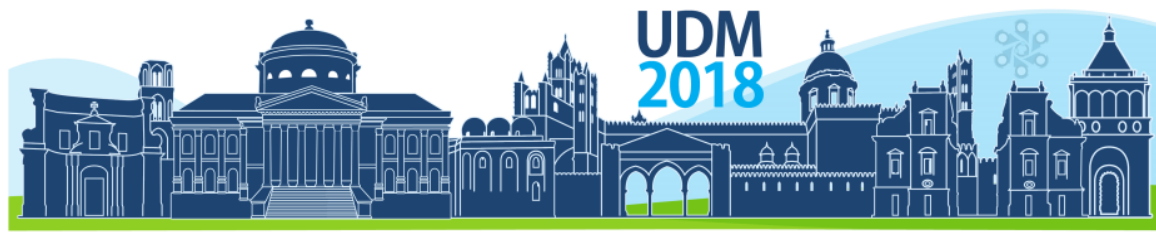

$11^{\text {th }}$ International Conference on Urban Drainage Modelling

23-26 Sep | Palermo - Italy

\section{Acknowledgements}

This research was done as part of the Marie Curie ITN - Quantifying Uncertainty in Integrated Catchment Studies (QUICS) project. This project has received funding from the European Union's Seventh Framework Programme for research, technological development and demonstration under grant agreement no. 607000.

\section{References}

Carbajal, J. P., Leitão, J. P., \& Albert, C. (2016). Appraisal of data-driven and mechanistic emulators of nonlinear hydrodynamic urban drainage simulators arXiv : 1609 . 08395v1 [ stat . ME ] 25 Sep 2016, 1-22.

Machac, D., Reichert, P., \& Albert, C. (2016). Emulation of dynamic simulators with application to hydrology. Journal of Computational Physics, 313, 352-366. https://doi.org/10.1016/j.jcp.2016.02.046.

Olson, R., \& Chang, W. (2013). Mathematical framework for a separable Gaussian Process emulator. Retrieved from www.geosc.psu.edu/ rtonkono.

Olson, R., Chang, W., Keller, K., \& Haran, M. (2015). R Package " stilt ." CRAN.

Roudier, P. (2017). R Package "clhs" - Conditioned Latin Hypercube Sampling. CRAN. https://doi.org/10.1201/b12728-46.

Torres-Matallana, J. A., Leopold, U., \& Heuvelink, G. B. M. (2017). Multivariate autoregressive modelling and conditional simulation of precipitation time series for urban water models. European Water, 57, 299-306. 


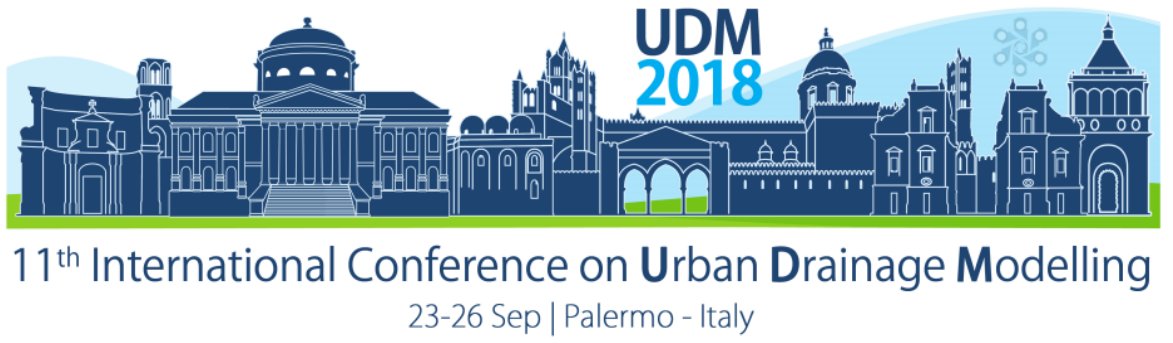

\title{
Automated Approach for Rainfall-Runoff Model Generation
}

\author{
Tero J. Niemi ${ }^{1}$, Gerald Krebs ${ }^{2}$ and Teemu Kokkonen ${ }^{1}$ \\ ${ }^{1}$ Aalto University School of Engineering, Department of Built Environment, Espoo, Finland \\ ${ }^{2}$ Graz University of Technology, Institute for Urban Water Management and Landscape Engineering, Graz, \\ Austria
}

\begin{abstract}
Manually constructing hydrological model descriptions for urban areas tends to be laborious due to the detailed mosaic land cover and the required high-resolution model setup. Here, the performance of a novel automated subcatchment generator with a detailed DEM-based surface flow routing is assessed against observations and manually constructed models. In general, the auto-generated models perform well against observations and comparably to manually constructed models regardless of the detail of land cover information input. The introduced inter-subcatchment connections may require previously acquired model parameters to be re-calibrated. This is due to the calibrated parameters in manually constructed models, even with high-resolution landuse, partly compensating for missing flow routes due to the larger scale used in subcatchment description.
\end{abstract}

Keywords: SWMM; flow routing; urban hydrological modelling

\section{INTRODUCTION}

Application of hydrological models is commonly the first step in assessing changes to hydrological cycle due to urbanization. With the recent increase of easily available highresolution data, such as remotely sensed land cover information and digital elevation models (DEMs), the bottleneck in model construction has been increasingly geared towards putting the data together and utilizing it in the model building process. This may require a considerable amount of manual labour unless the process can be automatized.

Recently, Warsta et al. (2017) developed an automated subcatchment generator tool (GisToSWMM5) for the Storm Water Management Model (SWMM) (Rossman, 2015) that aims to automate the tedious stages in the model construction process by connecting the subcatchments together and into the stormwater network. The tool is available from GitHub (https://github.com/AaltoUrbanWater). Niemi et al. (2018) improved the tool by adding an adaptive subcatchment generation routine, abandoning the earlier uniform grid approach and instead creating the subcatchments based on actual surface flow routes and landuse patterns.

In this study, the new adaptive subcatchment creation process is assessed against observations and simulation results from existing SWMM models on three urban catchments with two pre-existing landcover classifications of varying detail and previously calibrated SWMM parameter sets.

\section{MATERIALS AND METHODS}

\subsection{Study sites and data}

Three small urban catchments in Lahti, Finland, with varying landuse and various levels of imperviousness were studied. Catchments 1,2 and 3 have an area and fraction of impervious 


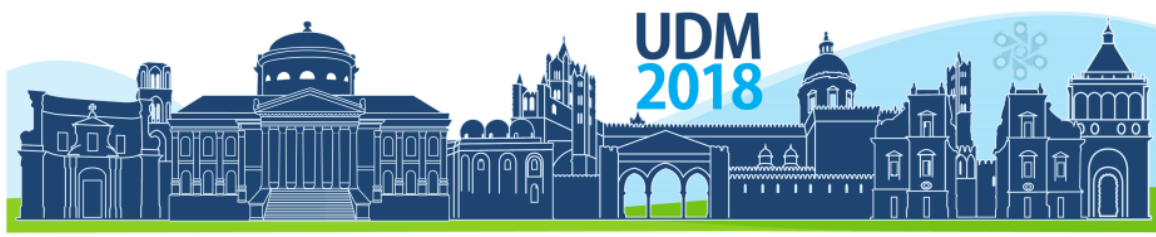

$11^{\text {th }}$ International Conference on Urban Drainage Modelling

23-26 Sep | Palermo - Italy

cover of 5.87 ha and $86 \%, 6.63$ ha and $54 \%$, and 12.59 ha and $19 \%$, respectively. Discharge was observed with 1 min resolution at the outlets of the catchments and rainfall with 1 min resolution using a rain gauge located at the outlet of catchment 2. An event of 9 Jul 2009 with a rainfall depth of $22.0 \mathrm{~mm}$ and a peak intensity of $1.73 \mathrm{~mm} / 5 \mathrm{~min}$ was studied. Details on the catchment description and observations are presented in Krebs et al. (2014).

\subsection{SWMM model setup}

Three SWMM model implementations were set up for each of the catchments. A manually constructed high-resolution model (HR) was based on land cover information collated from aerial images and site visits, and surface flow routing determined on-site (Krebs et al., 2014).

In addition to the HR model, two SWMM model descriptions for each catchment were created using the GisToSWMM5 tool with the adaptive subcatchment generation algorithm. A highresolution DEM raster was used for the automatically generated models. For the first set of models (HR-auto) the landuse information of the HR models was used. The landuse information for the second set (LR-auto) was based on low-resolution models from Krebs at al. (2016) relying on landcover information provided by the city of Lahti. HR-auto and LR-auto used the model parameter values calibrated for the HR models (Krebs et al. 2014, 2016).

Figure 1 presents an example of the tool with the raster input files and the resulting SWMM subcatchments. Warsta et al. (2017) and Niemi et al. (2018) present the details of the tool.
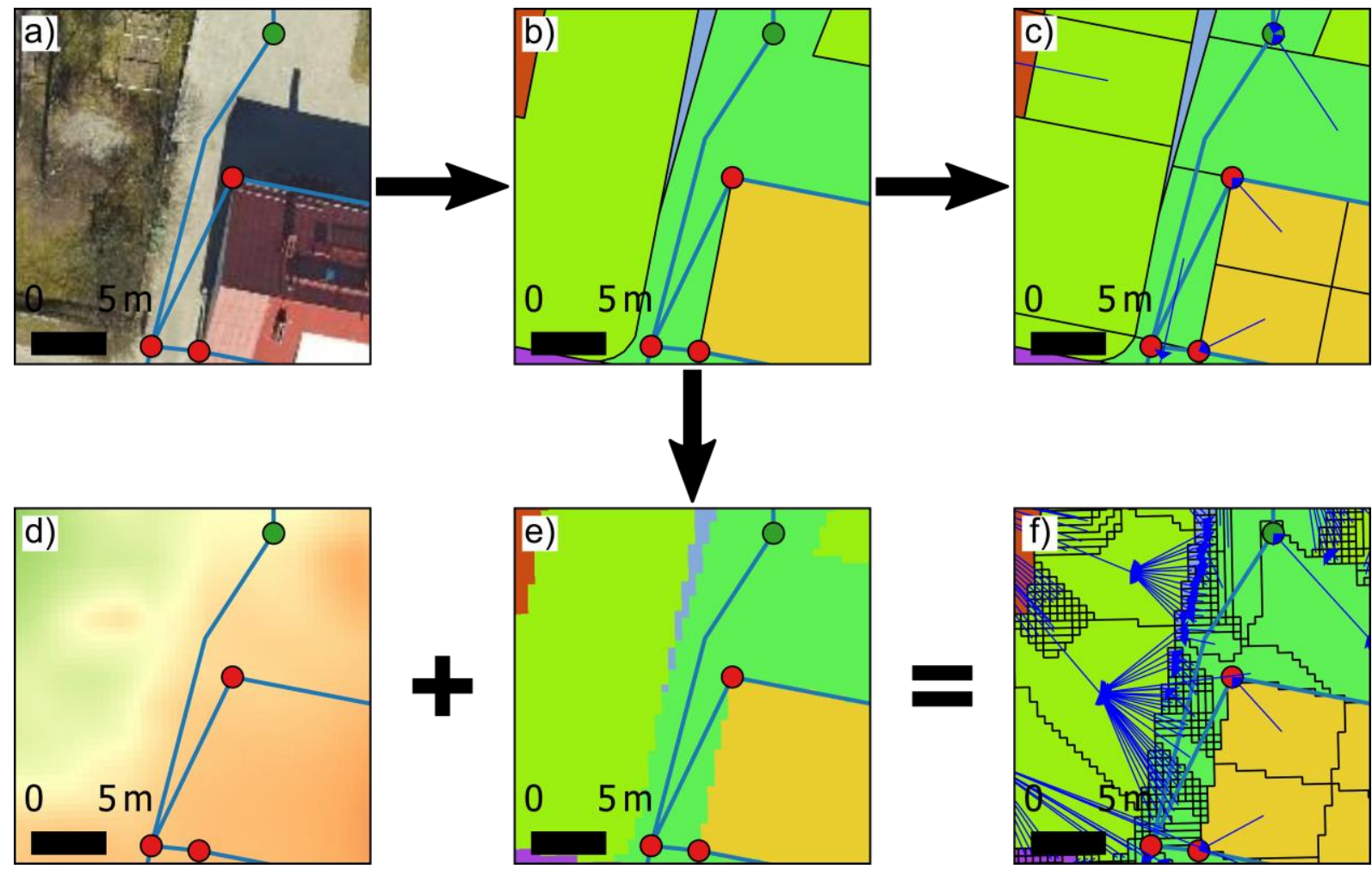

Figure 1. On the top row: a) an aerial image from catchment 2, b) the HR landuse classification for the corresponding area and c) the manually constructed HR model subcatchments for the area. On the bottom row: d) a high-resolution DEM for the area, e) the landuse from b) rasterized into the grid of the DEM and f) the HRauto model subcatchments for the area generated utilizing the DEM and the landuse rasters. Green and red circles refer to open and closed manholes, respectively, and the light blue lines depict the pipe network. The dark blue arrows present the subcatchment routing. 


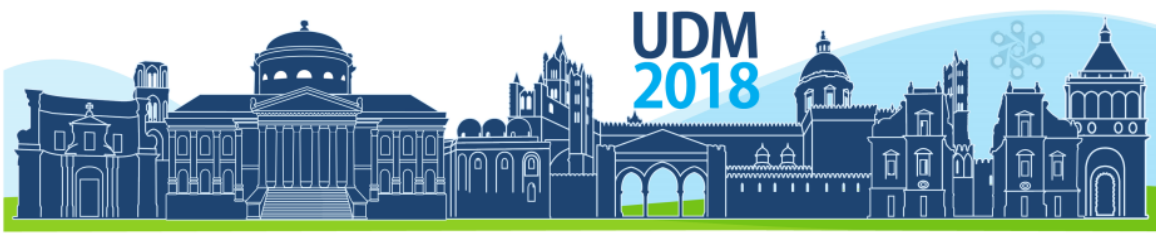

$11^{\text {th }}$ International Conference on Urban Drainage Modelling

23-26 Sep | Palermo - Italy

The input files for GisToSWMM5 include a DEM raster, as well as a landuse raster and a flow direction raster with the resolution and dimensions corresponding to those of the DEM. The basic workflow for preparing the input files proceeded as follows: 1) HR catchment boundaries were forced by raising DEM elevation outside the catchments; 2) A raster file was created with the index values describing the landuse information of each DEM raster cell inside the catchment boundaries; and 3) A flow direction raster was generated from the DEM raster. The tool then forms the subcatchments by combining cells with common landuse and shared outlet, and routes the water between the subcatchments as well as between subcatchments and the stormwater network.

\section{RESULTS AND DISCUSSION}

Figure 2 presents the HR and LR landuses, as well as the subcatchments for HR, HR-auto, and LR-auto models in catchment 2.
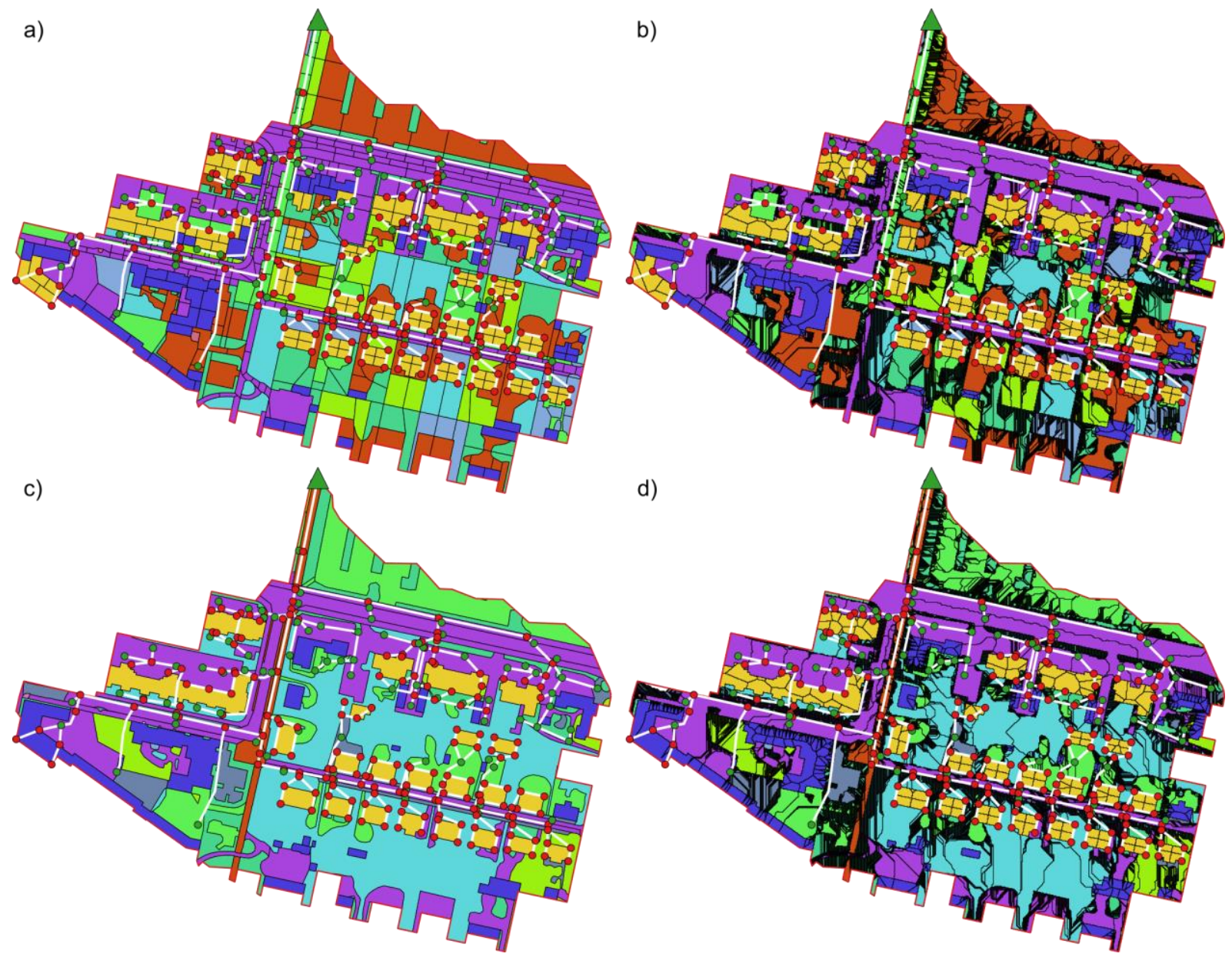

Figure 2. Landuses and subcatchments for catchment 2 according to a) HR, b) HR-auto, c) LR, and d) LR-auto. Different colours refer to unique landuse types and parameters. Green and red circles refer to open and closed manholes, respectively. White lines depict the pipe network and the green triangle the catchment outlet.

The HR-auto and LR-auto models retain the share and the distribution of the input data landuse, but the average subcatchment size for HR-auto $\left(6 \mathrm{~m}^{2}, 6 \mathrm{~m}^{2}\right.$, and $10 \mathrm{~m}^{2}$ for 1,2 , and 


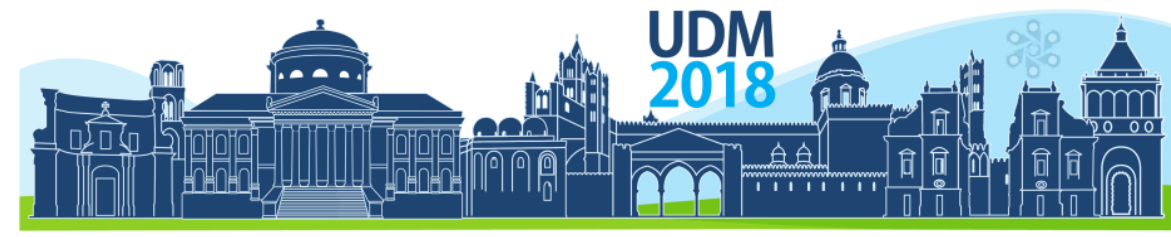

$11^{\text {th }}$ International Conference on Urban Drainage Modelling

23-26 Sep | Palermo - Italy

3, respectively) and LR-auto $\left(7 \mathrm{~m}^{2}, 6 \mathrm{~m}^{2}, 16 \mathrm{~m}^{2}\right)$ is considerably smaller than in the HR model $\left(85 \mathrm{~m}^{2}, 85 \mathrm{~m}^{2}, 153 \mathrm{~m}^{2}\right)$ due to the more detailed surface flow description between subcatchments.

Performance of the models was evaluated using Nash-Sutcliffe efficiency NSE (-), peak flow error PFE (\%), and volume error VE (\%) (Table 1) as well as by studying the hydrographs visually (Figure 3 ). The behaviour of high-resolution HR-auto and low-resolution LR-auto is similar in all catchments except for catchment 3 , indicating that the parameterization of urban hydrological models is not necessarily dependent on the very high detail of land cover information in terms of the number of land cover classes used in the models. The results are encouraging with respect to utilizing readily available land cover information data sets instead of laboriously collecting very high resolution land cover information via site visits, as the latter may not give much better results.

Table 1. Performance statistics NSE (-), PFE (\%), and VE (\%) for catchments 1, 2 and 3 in HR, HR-auto, and LRauto simulations.

\begin{tabular}{|c|c|c|c|c|c|c|c|c|c|}
\hline & \multicolumn{3}{|c|}{1} & \multicolumn{3}{|c|}{2} & \multicolumn{3}{|c|}{3} \\
\hline & $N S E$ & $P F E$ & $V E$ & $N S E$ & $P F E$ & $V E$ & $N S E$ & $P F E$ & $V E$ \\
\hline HR & 0.96 & 0.9 & -4.4 & 0.95 & -13.9 & -16.1 & 0.67 & -33.1 & -37.0 \\
\hline HR-auto & 0.95 & -0.9 & -11.4 & 0.84 & -29.0 & -30.5 & 0.61 & -39.7 & -44.5 \\
\hline LR-auto & 0.96 & -0.8 & -9.2 & 0.82 & -31.3 & -32.7 & 0.47 & -49.4 & -55.9 \\
\hline
\end{tabular}

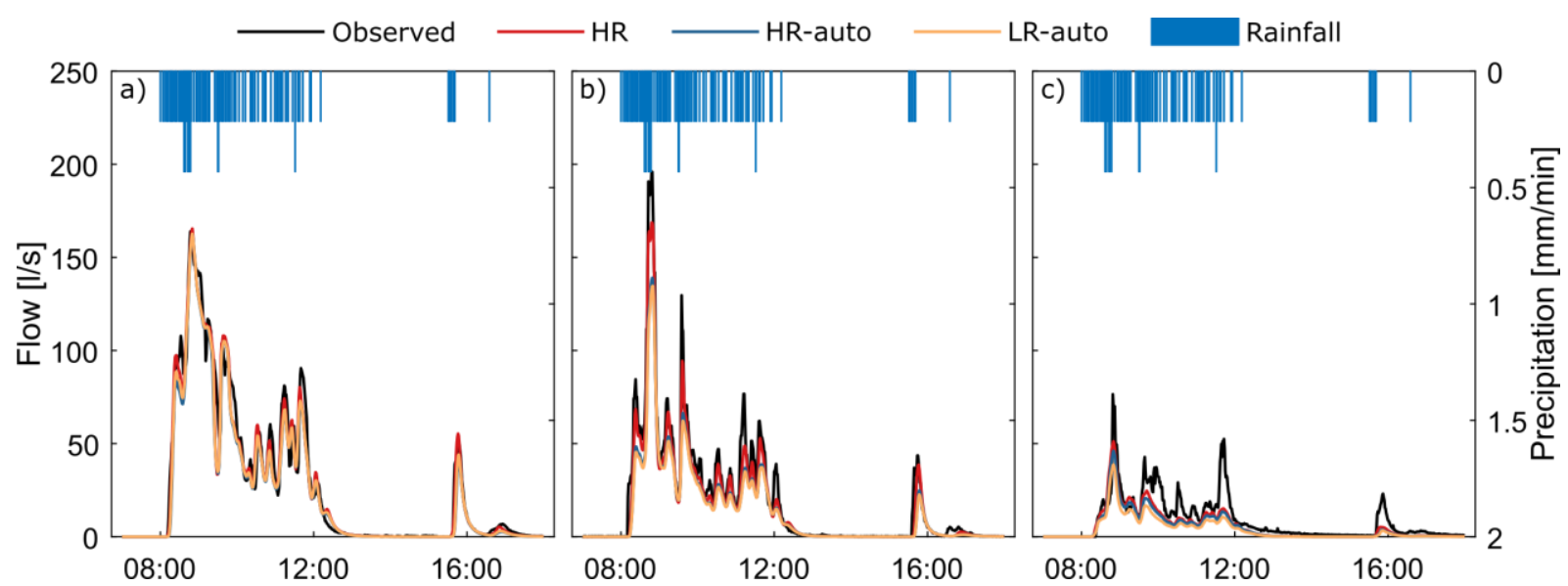

Figure 3. Observed and simulated HR, HR-auto, and LR-auto flows for catchments a) 1, b) 2, and c) 3.

When subcatchment flow is manually routed, impervious areas are usually routed as a whole either into the nearest inlet, on an adjacent impervious, or on an adjacent pervious surface. The runoff from a subcatchment is thus entirely routed to one recipient inlet or area. The detailed DEM-based surface flow routing in HR-auto and LR-auto allows routing water from impervious areas such as streets or parking lots partly onto pervious areas. Runoff from one surface can thus be automatically routed to several receiving subcatchments or inlets. 


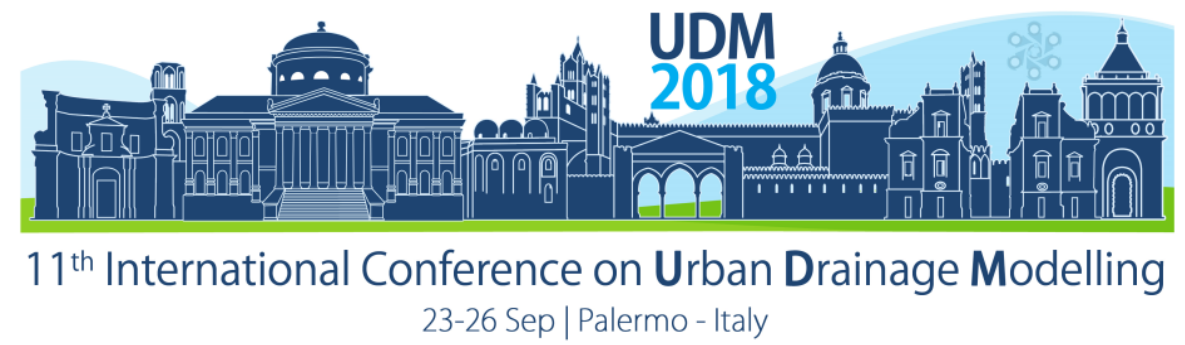

Compared to manually constructed models, the detailed surface flow routing of automatically generated models results in a different fraction of directly connected impervious areas. This explains the different behaviour of HR-auto and LR-auto models to that of HR model in catchment 2 compared to catchment 1 . In catchment 2 , with moderate imperviousness $(52 \%)$, pavement curbs are absent allowing street runoff to partly enter adjacent pervious areas. In catchment 1 (imperviousness 86\%), however, runoff is almost entirely reaching the drainage network, with little influence arising from the routing scheme. While the parameters have been obtained via calibrating a manual model, they partially compensate for the effect of missing flow routes from impervious to pervious surfaces due to assumption of lumped subcatchmnents in the calibration process. In catchment 3, effectively only the street areas contribute to the catchment runoff at the outlet, as the roofs of the catchment are connected to the yards where water infiltrates. None of the models perform particularly well, although the performance between HR and HR-auto is similar.

The results indicate a parameter dependence on the scale of the subcatchment description and flow routing. Parameters calibrated for lumped models compensate for missing flow routing details, and are not necessarily directly applicable when using high-resolution routing routines. The results imply that one should also consider the spatial detail of the respective models when regionalizating parameter values.

\section{CONCLUSIONS}

The novel automated adaptive subcatchment generator has the ability to create more accurate inter-subcatchment connections than what is typically present in manually constructed models. When accounting for the inter-subcatchment connections, parameter values calibrated for high-resolution landuse, but using lumped subcatchments, may not be directly applicable. On the other hand, as long as the inter-subcatchment connections are described accurately, lower resolution land cover information may have equivalent performance with higher resolution information.

\section{References}

Krebs, G., Kokkonen, T., Setälä, H., and Koivusalo, H. (2016) Parameterization of a Hydrological Model for a Large, Ungauged Urban Catchment. Water 8 (443).

Krebs, G., Kokkonen, T., Valtanen, M., Setälä, H., and Koivusalo, H. (2014) Spatial resolution considerations for urban hydrological modelling. J. Hydrol. 512, 482-497.

Niemi, T.J., Kokkonen, T., Sillanpää, N., Setälä, H., and Koivusalo, H. (2018) Automatized urban rainfall-runoff model generation with detailed land cover and flow routing information. Under review for Journal of Hydrology.

Rossman, L.A. (2015) Storm Water Management Model, User's Manual, Version 5.1 (No. EPA/600/R-05/040). U.S. Environmental Protection Agency, Cincinnati, OH, USA.

Warsta, L., Niemi, T.J., Taka, M., Krebs, G., Haahti, K., Koivusalo, H., and Kokkonen, T. (2017) Development and application of an automated subcatchment generator for SWMM using open data. Urban Water J. 14, 954963. 


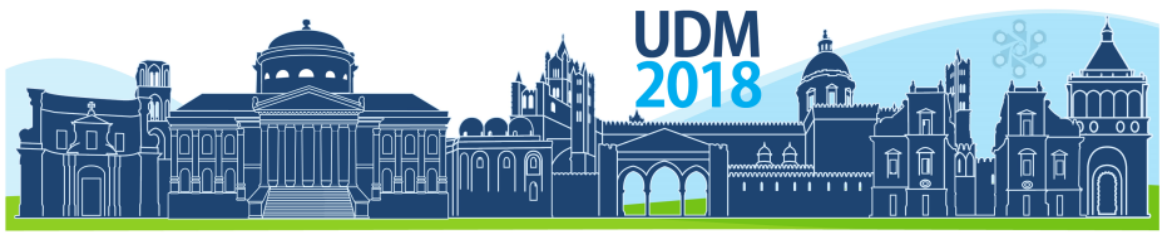

$11^{\text {th }}$ International Conference on Urban Drainage Modelling

23-26 Sep | Palermo - Italy

\title{
Comparison of Volume-based and Pollution-based Model-Predictive Controllers for Combined Sewer Network Regulation
}

\author{
Bernat Joseph-Duran', Thibaud Maruejouls², Duy Khiem Ly², \\ Jordi Meseguer ${ }^{1}$ and Gabriela Cembrano ${ }^{1,3}$ \\ ${ }^{1}$ Cetaqua, Water Technology Center, Cornellà de Llobregat, Spain. \\ ${ }^{2}$ Suez Eau France Research Center, LyRE, Bordeaux, France. \\ ${ }^{3}$ Institut de Robòtica i Informàtica Industrial (CSIC-UPC), Barcelona, Spain.
}

bjoseph@cetaqua.com, thibaud.maruejouls@lyonnaise-des-eaux.fr, khiem.ly.ext@suez.com, jmeseguer@cetaqua.com,cembrano@iri.upc.edu

\begin{abstract}
This work describes the application of Model Predictive Control (MPC) techniques to the regulation of Combined Sewer Networks. Two MPC controllers are compared to assess the pollutant load on receiving water bodies: a volume-based controller and a pollution-based controller. In the first case the simplified control model describes only the system hydraulics while in the second one Total Suspended Solids (TSS) transport is also included in the model. Both controllers are tested in closed-loop against a SWMM model extended with a TSS dynamics layer. Rainfall runoff and TSS forecasts generated by the SWMM-TSS model itself are used to feed the controllers.
\end{abstract}

Keywords: Real-Time Control; Integrated Model; Model-Predictive Control.

\section{INTRODUCTION}

The application of Real-Time Control (RTC) techniques to improve the performance of urban drainage systems during wet weather has been discussed in both academia and industry for many years now (Schütze et al., 2004). The classical approach, based on the most widely available instrumentation (sensors and actuators), focuses on the management of water flows and volumes (Gelormino \& Ricker, 1994; Cembrano et al., 2004; Marinaki \& Papageorgiou, 2005; Joseph-Duran et al., 2014), in order to avoid untreated water discharges to neighbouring urban or natural spaces. However, as early as almost twenty years ago now (e.g., Rauch \& Harremöes, 1999) another approach was developed, based on trying to evaluate the urban drainage system performance in terms of its pollution impact to receiving water bodies, rather than just spilled volume (Lau et al., 2002). With the improvement of sensor technology, process knowledge and modelling tools over the last 20 years, this latter approach, which initially remained mostly an academic one, has gained the attention of industry and policy-makers, especially in the light of the European Union Water Framework Directive 2000/60/EC.

In the context of the EU-funded project LIFE EFFIDRAIN (Joseph-Duran et al., 2016), comparison of volume-based and pollution-based controllers (Vanrolleghem et al., 2005) in two pilot sites is planned. These controllers are being developed to be tested using integrated models of the urban drainage system including the sewer network and the wastewater treatment plant (WWTP) and based on measurements of hydraulic variables and TSS concentrations.

This work presents preliminary results of the aforementioned approach applied to a sewer network model including a TSS transport and erosion/sedimentation dynamics model. The WWTP is not yet included in the control loop. 


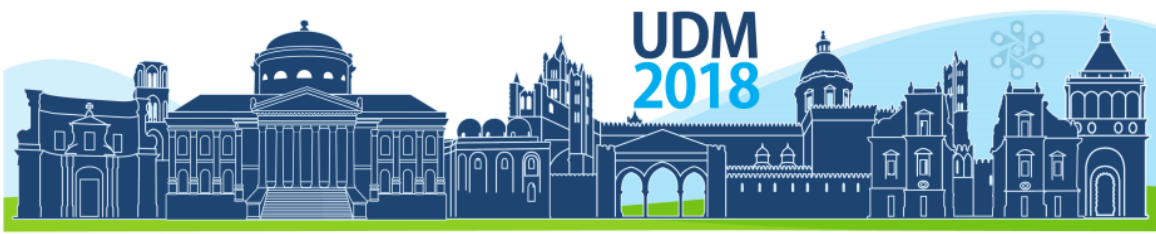

$11^{\text {th }}$ International Conference on Urban Drainage Modelling

23-26 Sep | Palermo - Italy

\section{MATERIALS AND METHODS}

To properly assess the performance of the proposed control algorithms a closed-loop simulation environment has been developed to sequentially execute sewer network model simulations and controller evaluations mimicking the information flow of a real application, as described in detail in Joseph-Duran et al. 2017. Figure 1 shows the main elements and information exchange of this algorithm.

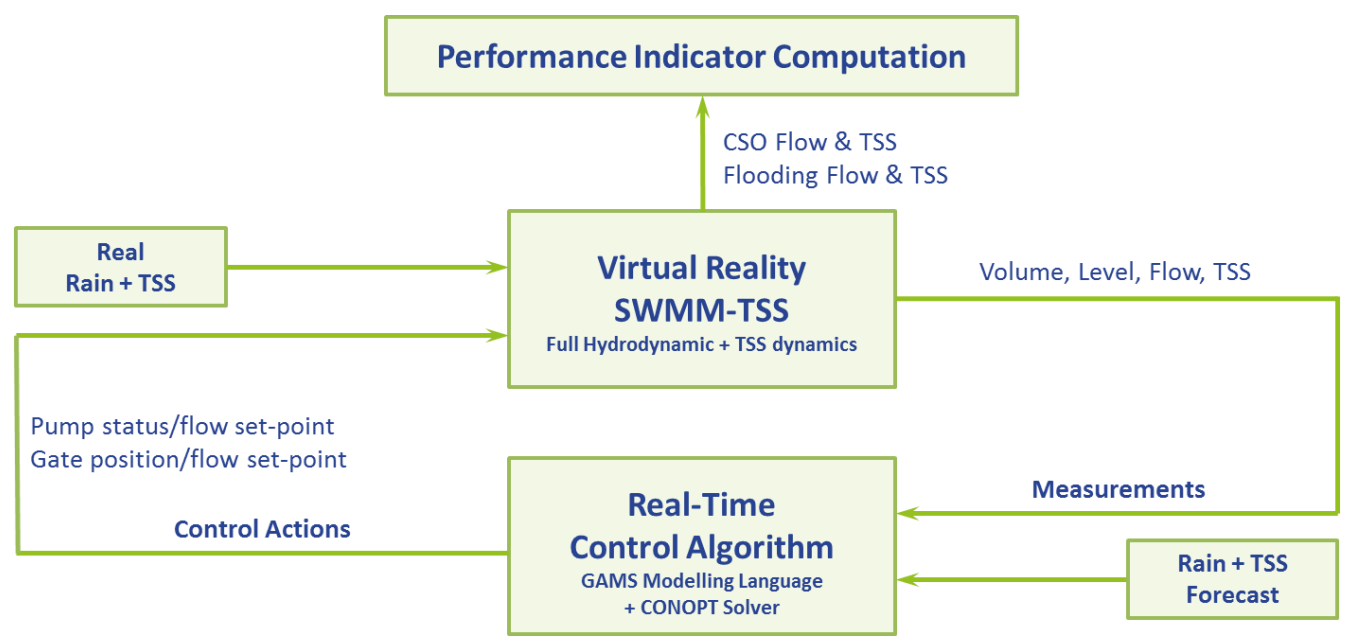

Figure 1. Diagram of the closed-loop simulation algorithm showing the different software elements.

The following subsections describe the software and models used in each step of this loop.

\subsection{SWMM Model}

The pilot site network studied in this work corresponds to an urban catchment in the French city of Bordeaux. It covers an area of 7,700 ha affecting a population of 300,000 inhabitants. The MPC controller covers five control stations connecting several catchments with the main collector, parallel to the Garonne River, and the Louis Fargue WWTP (Figure 2). The rest of the network tanks and actuators are managed through local control rules.
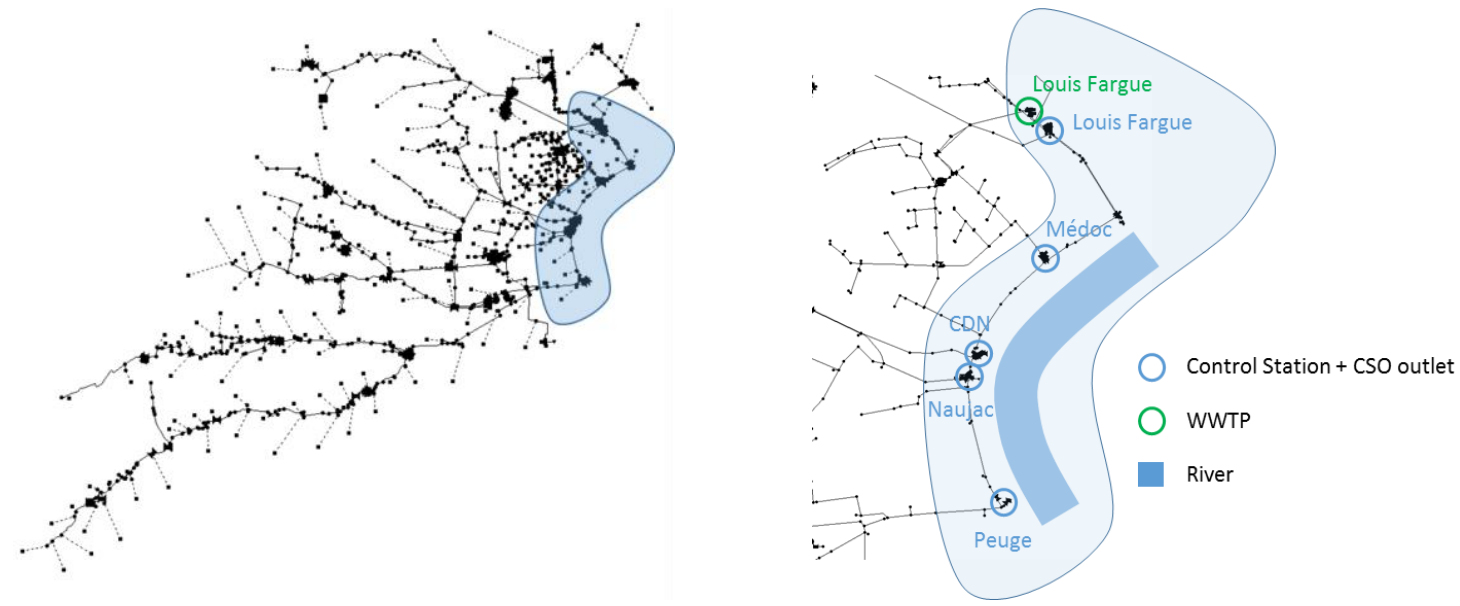

Figure 2. SWMM model of the pilot site network and detailed of the controlled area.

The network hydrology and hydraulics are described through an implementation using the wellknown simulation software SWMM5 (Rossman, 2015). 


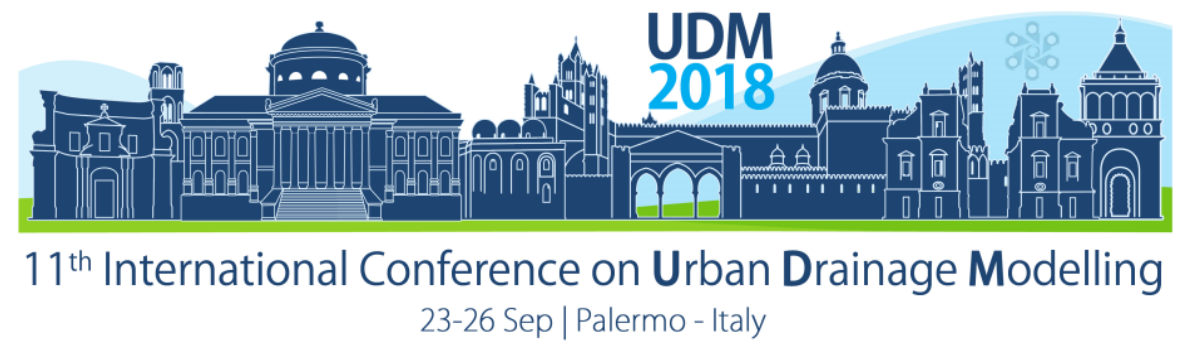

\subsection{SWMM-TSS Model}

To describe the TSS dynamics of the network a quality model to reproduce solids in sewers has been developed and integrated in the SWMM5 model library. This model includes the dynamics of buildup and washoff in catchments, erosion and sedimentation in sewers, and mass balance and sedimentation in tanks. Further details on these models and calibration results are provided in Montserrat et al., 2017.

\subsection{MPC Model}

Model Predictive Control (Camacho and Bordons, 2013) is a control technique based on solving finite-horizon Optimal Control Problems (OCP) based on a simplified model of the system under control. The accuracy lost in the simplification process is balanced by iteratively updating the model with system measurements and forecasts and by using short prediction windows.

\subsubsection{Hydraulic MPC Model}

As mentioned above, in the present case study two models have been used. First a purely hydraulic model, describing flow mass balances in junctions, tanks and hydraulic structures (weirs, pumping stations) and delays in sewers (Puig et al., 2009). In this case the control objectives are defined in terms of minimizing the flows at CSO structures.

\subsubsection{TSS Transport MPC Model}

To describe the TSS dynamics the hydraulic model has been extended. The hydraulic equations mentioned in the previous sections have been coupled with a TSS transport model, first outlined in Sun et al., 2017. In this work, the following discrete-time equations have been used as the simplified model for TSS transport:

- Transport in sewers:

$$
\operatorname{TSS}_{\text {out }}(t)=\operatorname{TSS}_{\text {in }}(t-\tau)
$$

- Mass balance in nodes:

$$
Q_{\text {out }}(t) \cdot T S S_{\text {out }}(t)=\sum_{i=1}^{n} Q_{\text {in }, i}(t) \cdot T S S_{\text {in }, i}(t)
$$

- Mass balance in tanks:

$$
m(t+1)=m(t)+\Delta t \cdot\left(Q_{\text {in }}(t) \cdot T S S_{\text {in }}(t)-Q_{\text {out }}(t) \cdot T S S_{\text {out }}(t)\right)
$$

- TSS concentration in tanks:

$$
\operatorname{TSS}_{\text {tank }}(t)=m(t) / V(t)
$$

Where $Q_{\text {in }}$ and $Q_{\text {out }}$ are the inflow and outflows $\left[\mathrm{m}^{3} / \mathrm{s}\right]$ at the corresponding element, $T S S_{\text {in }}$ and $T S S_{\text {out }}\left[\mathrm{kg} / \mathrm{m}^{3}\right]$ the corresponding inflow and outflow TSS concentrations, $V$ and $m$ the tank volume $\left[\mathrm{m}^{3}\right]$ and mass $[\mathrm{kg}], \Delta t$ the model discretization time-step [sec], $t$ the integer discrete time variable $[\Delta t]$ and $\tau[\Delta t]$ an integer time delay.

These equations are nonlinear and can lead to numerical problems such as divisions by zero or zero derivatives which difficult their use within optimization solvers. To avoid these problems the flow and volume terms have been replaced at every OCP by the corresponding values predicted at the previous iteration, turning the equations into linear ones. 


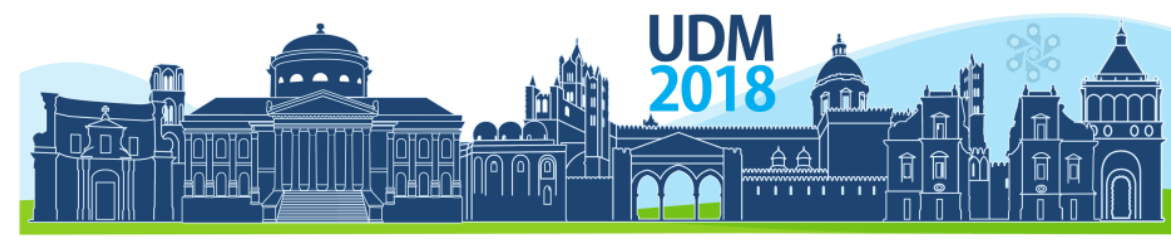

$11^{\text {th }}$ International Conference on Urban Drainage Modelling

23-26 Sep | Palermo - Italy

The previous TSS transport model allows to define the control objectives in terms of pollutant mass in CSO structures as:

$$
m_{C S O}(t)=\Delta t \cdot \sum_{k=t}^{t+H} T S S_{C S O}(k) \cdot Q_{C S O}(k)
$$

Where $m_{C S O}$ is the predicted discharged mass [kg] at time step $t$ along a prediction horizon of $H$ time-steps of $\Delta t$ seconds, $Q_{C S O}$ the CSO flow $\left[\mathrm{m}^{3} / \mathrm{s}\right]$ and $T S S_{C S O}$ is the CSO flow TSS concentration $\left[\mathrm{kg} / \mathrm{m}^{3}\right]$.

\subsection{Optimization Solver}

The Optimal Control Problems arising from the MPC controller have been implemented using GAMS optimization programming language (Rosenthal, 2013) and solved with CONOPT solver for nonlinear problems with discontinuous derivatives (Drud, 2010). To help the convergence of the nonlinear-model warm start techniques have been used in order to provide to each problem a good initial point, close to feasibility, generated at every iteration using the solution of the previous problem.

\section{RESULTS AND DISCUSSION}

\subsection{Comparison of PBMPC and VBMPC}

Preliminary results show the capability of the pollution-based controller to prioritize CSOs at those points where TSS concentrations are lower. This behaviour leads to a total CSO volume similar to that obtained with the volume-based controller but a lower total spilled mass, due to the lower concentration. Table 1 shows this behaviour for four different real rain events, where CSO Louis Fargue (near the WWTP) is reduced by the pollution-based controller at the expense of increasing CSO at almost all other locations, leading, however, to a reduction of the overall spilled mass.

Table 1. CSO Volume and CSO Mass variation obtained with the pollution-based MPC (PBMPC) with respect to that obtained with the volume-based MPC (VBMPC) for different rain events (RE). CSO Volume Variation [\%] CSO Mass Variation [\%]

\begin{tabular}{ccccccccc} 
CSO & RE1 & RE2 & RE3 & RE4 & RE1 & RE2 & RE3 & RE4 \\
\hline Louis Fargue & -51.8 & -27.8 & -57.7 & -68.7 & -55.3 & -5.8 & -56.5 & -60.3 \\
\hline Médoc & -0.2 & 131.3 & - & 2.6 & 237.1 & 26.2 & - & 1.7 \\
\hline CDN & 19.6 & 6.2 & 11.7 & 7.2 & 17.6 & 0.9 & 9.1 & 1.8 \\
\hline Naujac & 21.1 & -13.6 & 24.7 & 31.3 & 22.6 & -38.8 & 29.7 & 28.0 \\
\hline Peuge & 20.0 & 1.7 & 19.4 & 11.4 & 25.5 & 0.8 & 24.6 & 9.0 \\
\hline Total & -0.3 & -3.9 & -0.6 & 0.7 & -5.9 & -8.3 & -7.4 & -6.8 \\
\hline
\end{tabular}

\section{CONCLUSIONS}

Pollution-based and a volume-based MPC controllers have been implemented and tested on a real network described in SWMM5 with an additional TSS dynamics layer. Preliminary results show the ability of the pollution-based approach to reduce the total mass load to the receiving environment. Although the implementation of such controllers is still limited by the ability to measure quality on line at different points in the network, these results provide very valuable 


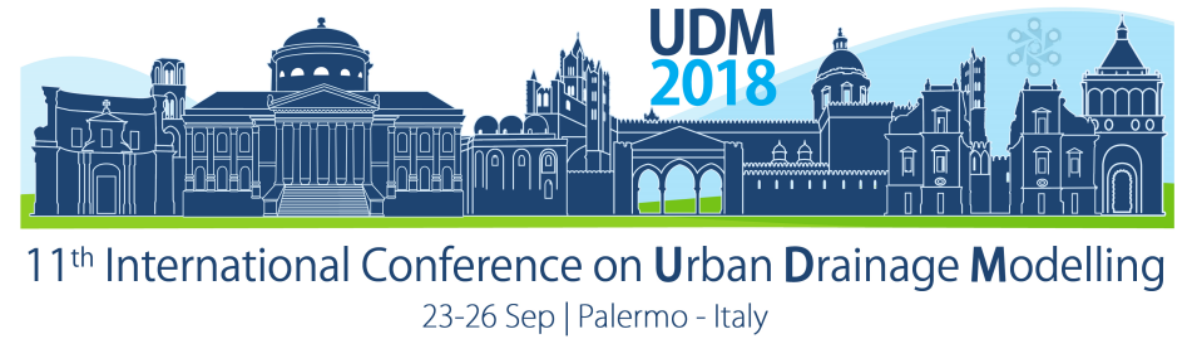

information on the network potential to reduce the pollution load of CSO discharges and for further planning and design of network infrastructure and real-time controllers.

\section{References}

Camacho, E. F., and Bordons, C. (2013). Model predictive control. Springer Science \& Business Media.

Drud, A. (2010). CONOPT. GAMS - The Solver Manuals, GAMS Development Corporation.

Joseph-Duran, B., Meseguer, J., Cembrano, G., Maruéjouls, T., Montserrat, A., Martínez, M., Guasch, R., and Rouge, P. (2016). LIFE EFFIDRAIN: Efficient Integrated Real-time Control in Urban Drainage Systems for Environmental Protection. Computing and Control for the Water Industry (CCWI), Amsterdam, the Netherlands, 2016.

Joseph-Duran, B., Meseguer, J., Cembrano, G., Maruejouls, T., Guasch, R., and Muñoz, E. (2017). Closed-loop Simulation of Real-time Controllers for Urban Drainage Systems using High Resolution Hydraulic Simulators. 14th IWA International Conference on Urban Drainage (ICUD). Prage, Czech Republic, 2017.

Joseph-Duran, B., Ocampo-Martinez, C., \& Cembrano, G. (2014). Hybrid modeling and receding horizon control of sewer networks. Water Resources Research, 50(11), 8497-8514.

Montserrat, A., Maruejouls, T., Litrico, X. and Binet, G. (2017). A quality model for combined sewer overflow and sediment description. 14th IWA International Conference on Urban Drainage (ICUD). Prage, Czech Republic, 2017.

Puig V., Cembrano G., Romera J., Quevedo J., Aznar B., Ramón G. \& Cabot J. (2009). Predictive optimal control of sewer networks using CORAL tool: application to Riera Blanca Catchment in Barcelona. Water Science \& Technology, 60(4): 869-878.

Rosenthal, R. (2013). GAMS - A User's Guide, GAMS Development Corporation.

Rossman, L.A. (2015). Storm Water Management Model User's Manual Version 5.1. Office of Research and Development, Water Supply and Water Resources Division. US Environmental Protection Agency.

Sun, C., Joseph-Duran, B., Maruejouls, T., Cembrano, G., Muñoz, E., Meseguer, J., and Puig, V. (2017). Efficient Integrated Model Predictive Control of Urban Drainage Systems using Simplified Conceptual Quality Models. 14th IWA International Conference on Urban Drainage (ICUD). Prage, Czech Republic, 2017.

Vanrolleghem, P. A., Benedetti, L., and Meirlaen, J. (2005). Modelling and real-time control of the integrated urban wastewater system. Environmental Modelling \& Software, 20(4), 427-442, doi: 10.1016/j.envsoft.2004.02.004. 


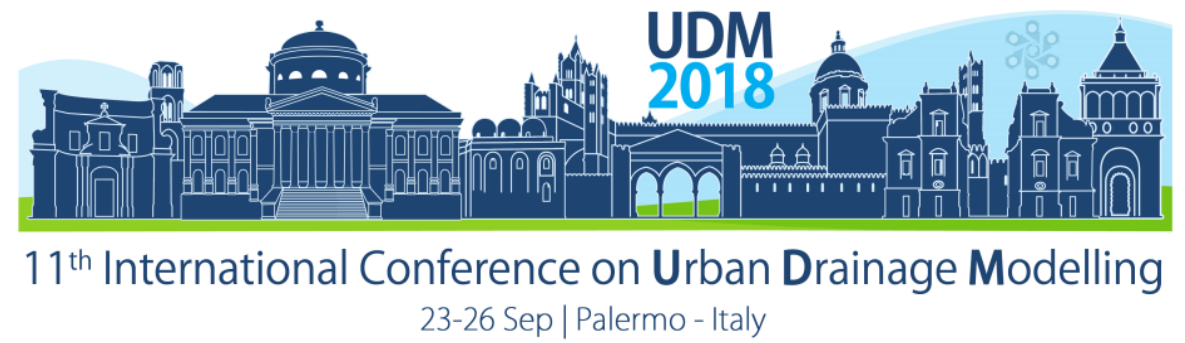

\title{
Revisiting conceptual stormwater quality models by alternative linear and non-linear formulations: an event-based approach
}

\author{
Santiago Sandoval ${ }^{1}$ and Jean-Luc Bertrand-Krajewski ${ }^{1}$ \\ 'Université de Lyon, INSA Lyon, DEEP, EA 7429, 34 avenue des Arts, F-69621 Villeurbanne cedex, France \\ (authors'addresses: santiago.sandoval-arenas@insa-lyon.fr;jean-luc.bertrand-krajewski@insa-lyon.fr)
}

\begin{abstract}
Different linear Transfer Functions (TFs) models are compared to the traditional non-linear Rating Curve (RC) model in a novel event-based exploratory frame. This approach aims to scrutinize for alternative representations of the stormwater TSS load dynamics at the output of a $185 \mathrm{Ha}$ urban catchment, when not considering explicitly a virtual state of available pollutant mass accumulated during the dry weather and subsequently washed by rainfall (simplification of the traditional accumulation/wash-off model). The advantages of using TFs remain unproved compared to the RC model, which show more performant results in terms of parsimony and simulation uncertainties with a data-set of 255 calibration and 110 verification online-monitored rainfall events. However, unreproducible rainfall events by means of Bayesian event-based calibrations, either with $\mathrm{RC}$ or TFs models, remain indistinguishable as a function of their antecedent dry weather conditions or further temporal variables. This suggests that a global deterministic process potentially missed by the RC or TFs descriptions (if there is one) might not be linkable to a dry weather build-up phenomenon, as assumed by the vast majority of the accumulation/wash-off models.
\end{abstract}

Keywords: Bayesian methods; model selection; transfer functions

\section{INTRODUCTION}

During the past 40 years, modelling the dynamics of stormwater Total Suspended Solids (TSS) loads at the outlet of urban catchments has been mainly addressed by the concept of accumulation/wash-off (see Sartor et al., 1974). These model structures are based on a state variable of total available pollutant mass $M[\mathrm{~kg}]$, accumulated during dry weather (build-up) and subsequently washed and transported by stormwater flowrate $Q(t)[\mathrm{L} / \mathrm{s}]$ to the outlet of the system. However, accumulation/wash-off models frequently exhibit unsatisfactory performances when implemented in real world applications, especially with large and complex urban catchments (e.g. Deletic et al., 2009). This can be explained by the nongeneralizable nature of the accumulation/wash-off concept to larger scales, where a virtual state variable of available pollutant mass $M$ representative for the entire catchment might be inexistent (Bonhomme and Petrucci, 2017). On the other hand, researchers have also argued about the benefits of adopting a simplified Rating Curve (RC) model (Huber et al., 1988), without including explicitly the pollutant mass $M$ process in the calculations (e.g. Kanso et al., 2005). Unexpectedly, studies testing further "inexistent $M$ ' models apart from the $R C$ remain limited.

During the past years, there has been an increasing interest in linear Transfer Functions (TF) models into environmental sciences due to their physical interpretability (Young, 2013). Therefore, the objective of this work is to explore different "inexistent $M$ " models (TFs and $\mathrm{RC}$ ) aimed to simulate TSS load pollutographs $[\mathrm{kg} / \mathrm{s}]$ at the outlet of the separate sewer in a 


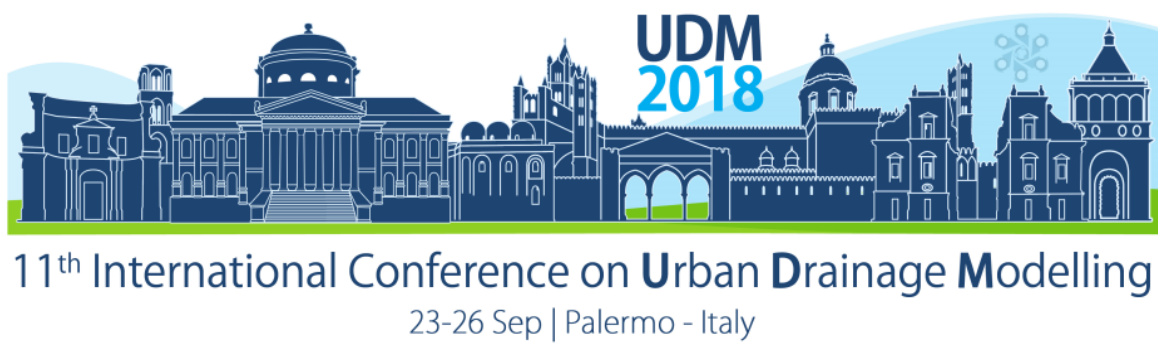

185 ha urban catchment (Chassieu, France), by means of a 2 min. time-step dataset of flow rate [L/s] and TSS load [kg/s] time series, measured from 2004 to 2011 . The potential benefits of the TFs compared to RC are assessed by two novel model selection methodologies, taking into account the inter-event variability for different performance indicators in 250 calibration events (Akaike, Bayesian and Young information criterion: AIC, BIC and YIC, resp.; Young, 2013) and 110 verification events (Nash-Sutcliffe efficiency and Average Relative Interval Length: NS and ARIL, resp.; Vezzaro and Mikkelsen, 2012). Results lead to revisit some postulates of the traditional accumulation/wash-off concept.

\section{MATERIALS AND METHODS}

\subsection{Transfer Functions (TFs) and Rating Curve (RC) models}

A linear TF can be expressed by the following equations (Young and Garnier, 2006):

$$
\operatorname{load}(t)=\frac{b_{0} s^{m}+b_{1} s^{m-1}+\cdots+b_{m-1} s+b_{m}}{s^{n}+a_{1} s^{n-1}+\cdots+a_{n-1} s+a_{n}} Q(t)
$$

where $s=d / d t$ is the derivative operator, $Q(t)[\mathrm{L} / \mathrm{s}]$ is the hydrograph and $\operatorname{load}(t)[\mathrm{kg} / \mathrm{s}]$ is the TSS load pollutograph, both at the outlet of the catchment. A model structure $T_{\mathrm{n}, \mathrm{m}}$ for this type of TFs models is defined from a pair of $n$ poles and $m$ zeros, including the parameters $\theta$ $=\left[a_{1}, . ., a_{n}, b_{0}, \ldots, b_{m}\right]$. The non-linear RC model can be expressed as load $=M_{0} \cdot Q(t)^{r}$ with the parameters $\theta=\left[M_{0}, r\right]$.

\subsection{Model selection for an event-based approach}

The model selection problem is commonly addressed by comparing the scores obtained by different candidate models, regarding a selected performance indicator PI (AIC, BIC, YIC for calibration data or NS, ARIL for verification data). This distinction is made as NS and ARIL are prone to report overestimated performances when calculated with calibration data (overfitting). In addition, AIC, BIC and YIC in verification tend to over-penalize the prediction capacity of models with a higher number of parameters. The $P I$ indicators are evaluated for the following $j=1$ : num str candidate model structures: RC (with 2 parameters) and TFs ( $n$ poles, $m$ zeros) $[0,0],[1,1],[2,1],[2,2],[3,2],[3,3]$ (with $1,3,4,5,6$ and 7 parameters), i.e. num_str $=7$. The PI scores are assessed comparing the observed and simulated TSS load pollutographs on an event basis, using rainfall events $i=1: 255$ for calibration and $i=256: 365$ for verification. Specifically, the AIC, BIC and YIC indicators are computed for each calibration event by means of the optimal value (max. likelihood) and uncertainty of $\theta_{i}$, obtained from a Bayesian event-based calibration (local to event $I$ ). The PI scores (i.e. NS or ARIL) for verification events are computed from a global estimation of $\theta$, provided by a group of representative $\theta$ s obtained in calibration (i.e. Bayesian event-based calibrations with NS > 0.8 ). For this purpose, each verification event is simulated by propagating the parametric uncertainties given by the global estimation of $\theta$, leading to obtain the mean and uncertainty bounds of the simulated pollutograph.

Indeed, the model with the highest (or lowest) score of $P I$ might be different from one event to another, under this event-based analysis. Therefore, two methodologies are proposed for selecting a single model among the different candidates, given the inter-event variability:

- Approach of selection 1 (S1): by using an ANOVA or Kruskal-Wallis (for non-normally distributed groups) statistical test. The model selection consists in evaluating if the interevent mean of a given indicator $P$, i.e. $\operatorname{mean}\left(P l_{1: 255}, j\right)$ (calibration) or $\operatorname{mean}\left(P l_{256: 365}, j\right)$ 


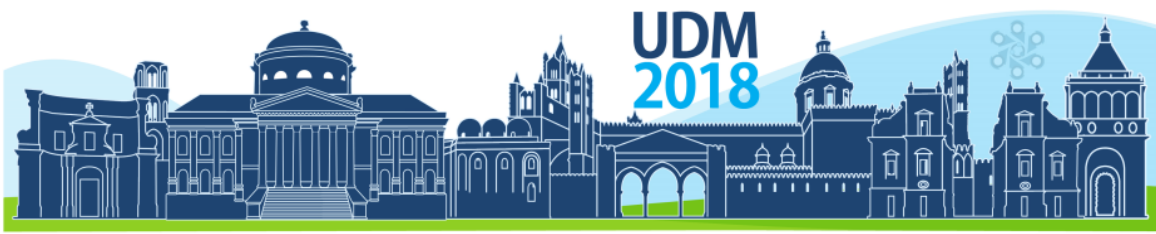

$11^{\text {th }}$ International Conference on Urban Drainage Modelling

23-26 Sep | Palermo - Italy

(verification) calculated for a model $j$, is significantly higher (or lower, if $P I$ should be min.) than the inter-event mean for the other model structures, i.e. $P l_{1: 255, \neq j}$ (calibration) or $\mathrm{Pl}_{256: 365 \text {, }}$ $\neq j$ (verification) (95\% significance level).

- Approach of selection 2 (S2): the model selection is based on the number of victories for a model structure $j$, i.e. the number of events in which: $P l_{1: 255, j}>P l_{1: 255, \neq j}$ or $P l_{1: 255, j}<P l_{1: 255, \neq j}$

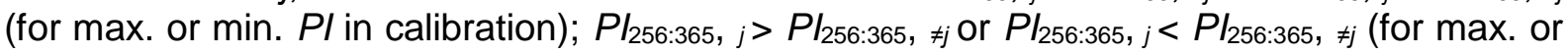
min. $P /$ in verification). This number of victories should be higher than the number of victories that might be obtained by chance. For a binomial distribution and a $95 \%$ significance level, this threshold is of 48 victories for cal. (255 events) and 23 for ver. (110 events), given that the probability of winning by chance for a model is $1 /$ num_struc $=1 / 7$.

\section{RESULTS AND DISCUSSION}

\subsection{Approach S1 and S2 for calibration: AIC, BIC and YIC}

a)

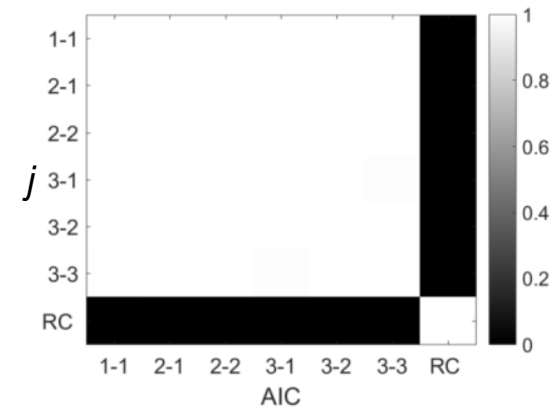

C)

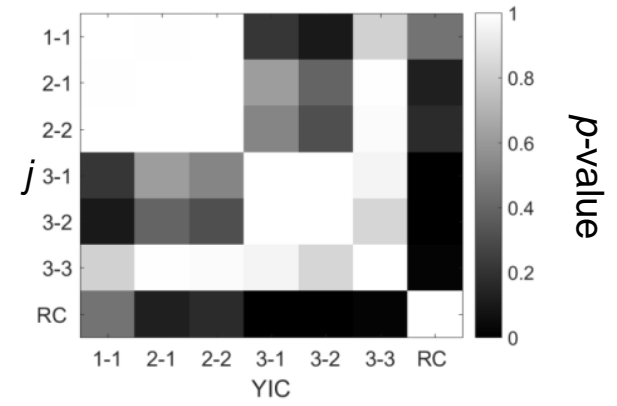

b)

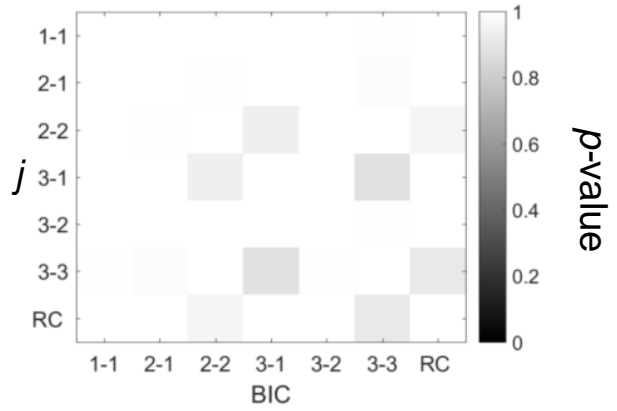

Figure 1. $p$-values of Kruskal-wallis test for comparisons of $\operatorname{groups} \operatorname{mean}\left(P /_{1: 255, j}\right)=\operatorname{mean}\left(P l_{1: 255, \neq j}\right)$ for all $j=$ 1:num_str in calibration, with PI: a) AIC b) BIC and c) YIC.

Kruskal-Wallis test (as groups are non-normally distributed) reported strong enough statistical evidence ( $p$-value < 0.05) that the AIC and YIC indicators for the RC model are significantly lower than for the TFs with the calibration data-set (black rows and columns in Figure 1a, c). This finding strengths the complementariness of the proposed indicators (AIC, $\mathrm{BIC}$ and $\mathrm{YIC}$ ), as e.g. analyses are not conclusive regarding exclusively the BIC (Figure 1b). One can conclude from this S1 approach in the calibration stage that $\mathrm{RC}$ is a promising model structure, which offers a suitable balance between performance, number of parameters and parametric uncertainties (NS > 0.6 for about $70 \%$ of the event-based calibration). No particular conclusions can be drawn from comparing the different TFs results. 


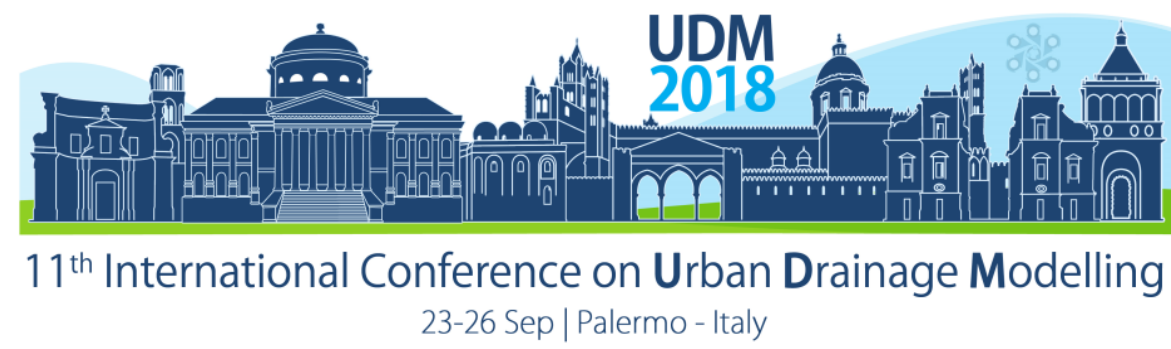

The S2 analysis confirmed the results obtained for the RC model by the $\mathrm{S} 1$ approach for the calibration data-set. This model is found to be successful more times (220) than what can be attributed to randomness regarding the AIC and YIC indicators (48 victories, for a significance level of $95 \%$ ). Therefore, the $\mathrm{RC}$ model can be a reasonable recommendation in case verification analyses are unfeasible.

\subsection{Approach S1 and S2 for verification: ARIL and NS}

A Kruskal-Wallis test (non-normally distributed groups) brings evidence that the ARIL values for the RC model in verification data are significantly lower than for most of the TFs ( $p$-value $<0.05$ ) (ARILs of about $400 \%$ and $800 \%$, resp.). No particular conclusions can be drawn from the results regarding comparisons of the NS values in verification, as the performances for all model structures are very similar (NS about 0.5). The S2 approach did not bring evidence towards recommending a best model from the analyzed model structures in verification, regarding the ARIL or NS indicators. From the obtained results, the advantages of using TFs including e.g. information from previous time-steps in the calculation of the load dynamics (Eq 1) remains unproved compared to the $\mathrm{RC}$ model. On the other hand, the RC model by itself can be still considered as unsatisfactory in verification (NS and ARIL of about 0.5 and $400 \%$, resp.), suggesting the lack of a key process in the model structure. However, this potentially missed process was found to be hardly linkable to a dry weather build-up phenomenon. The above, given that unreproducible rainfall events (NS $<0.6$ in local cal.), by either RC or TFs, remain indistinguishable as a function of their antecedent dry weather period or further temporal variables. Moreover, statistical tests strengthen that the occurrence of these unreproducible events is random in time.

\section{CONCLUSIONS}

Different linear Transfer Functions (TF) models are compared to the non-linear traditional Rating Curve (RC) model, aimed to scrutinize for alternative "inexistent accumulated/available mass" representations of the stormwater TSS load dynamics at the output of a 185 ha urban catchment. The advantages of using TFs remain unproved compared to the RC model. Unsatisfactory performances for either RC or TFs are found to be independent of antecedent dry weather conditions. Therefore, a potentially missed process (if there is one) in RC or TFs descriptions might not be linkable to a dry weather build-up phenomenon, as assumed by the vast majority of accumulation/wash-off models.

\section{References}

Bonhomme, C., and Petrucci, G. (2017). Should we trust build-up/wash-off water quality models at the scale of urban catchments? Water Research, 108, 422-431.

Deletic, A., Dotto, C., Fletcher, T. D., McCarthy, D. T., Bertrand-Krajewski, J.-L., Rauch, W., Kleidorfer, M., Freni, G., Mannina, G., and Tait, S. (2009). Defining uncertainties in modelling of urban drainage systems. In: 8th International Conference on Urban Drainage Modelling, Tokyo, Japan, $12 \mathrm{p}$.

Huber, W. C., Dickinson, R. E., Barnwell Jr, T. O., and Branch, A. (1988). Storm water management model; version 4. Environmental Protection Agency, United States.

Kanso, A., Tassin, B., and Chebbo, G. (2005). A benchmark methodology for managing uncertainties in urban runoff quality models. Water Sci. Technol., 51(2), 163-170.

Sartor, J. D., Boyd, G. B., and Agardy, F. J. (1974). Water pollution aspects of street surface contaminants. J. Water Pollut. Control Fed., 46, 458-467.

Vezzaro, L., and Mikkelsen, P. S. (2012). Application of global sensitivity analysis and uncertainty quantification in dynamic modelling of micropollutants in stormwater runoff. Environmental Modelling \& Software, 27, 40-51.

Young, P., and Garnier, H. (2006). Identification and estimation of continuous-time, data-based mechanistic (DBM) models for environmental systems. Environmental modelling \& software, 21(8), 1055-1072.

Young, P. (2013). Hypothetico-inductive data-based mechanistic modeling of hydrological systems. Water Resources Research, 49(2), 915-935. 


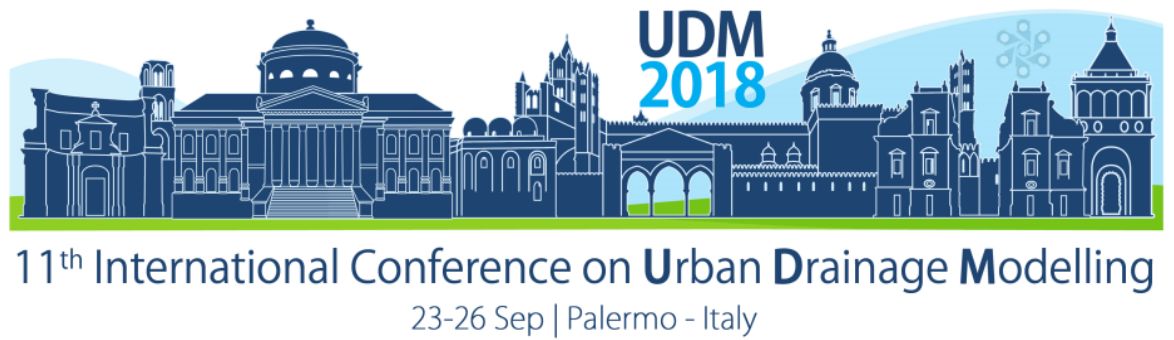

\title{
Real-time water level prediction based on artificial neural networks
}

\author{
Berkhahn Simon ${ }^{1}$, Neuweiler Insa ${ }^{1}$ and Fuchs Lothar ${ }^{2}$ \\ ${ }^{1}$ Institute of Fluid Mechanics and Environmental Physics in Civil Engineering, Leibniz Universität, Hannover, \\ Germany \\ 2 Institute for Technical and Scientific Hydrology (itwh GmbH), Hannover, Germany
}

\begin{abstract}
Urban flooding is often characterised by short lead times. In combination with the uncertainty in precipitation forecasting, the real-time forecasting of urban flooding is still challenging. Fast physically based models are still too slow for the usage in real-time forecasting. Data driven models are suitable to face this problem. The present study deals with testing an artificial neural network based model for the prediction of water levels with two dimensional spatial distributions at the catchment surface. The model was tested for synthetic rain events in a prior study. In the present study the model is successfully tested for spatially uniform distributed natural rain events.
\end{abstract}

Keywords: Urban flooding, neural network, real-time forecast

\section{INTRODUCTION}

Rain events with short duration and high precipitation rate can cause urban flooding. Considering the potential damage caused by an urban flood it is recommended to have early warning systems consisting of a rainfall forecast and a prediction of the water levels on the surface. Regarding the short lead times of the rain forecast and its uncertainty the water level prediction has to be fast to ensure a continuous adaption of the predicted water levels. Physically based models are usually to slow or have too many constraints for this purpose (Henonin et al. 2013). To solve this problem data driven models where used in several studies [e.g. Duncan et al. (2013) and Chang et al. (2014)]. The aim of data driven models is to find ways to reproduce the result of the physically based model with simpler and faster approaches. Data driven models can use measurements or results from physically based models. Data driven models run fast and can be used for real-time forecasting. Drawback of data driven models trained on physical model results is that in case of changes in the physical system the database has to be rebuild.

Artificial neural networks (ANN) have been used in the field of urban hydrology in several cases. The most often ANN where applied for the rainfall forecast [e.g. Chen et al. (2008), Hung et al. (2008) and Schellart et al. (2011)]. In Duncan et al. (2011) ANN where used for simulating a sewer system. In the present study a data driven model based on ANN was build up to predict maximum water levels in a medium sized urban catchment. The database for ANN training was generated by a hydrodynamic numerical model. In a prior study the model was successfully tested with synthetic rain events. In the present study natural rain events will be tested and evaluated.

\section{MATERIALS AND METHODS}

Artificial neural networks (ANN) are information processing models consisting of neurons and synapses. ANN can be trained by presenting samples of input and corresponding output to the 


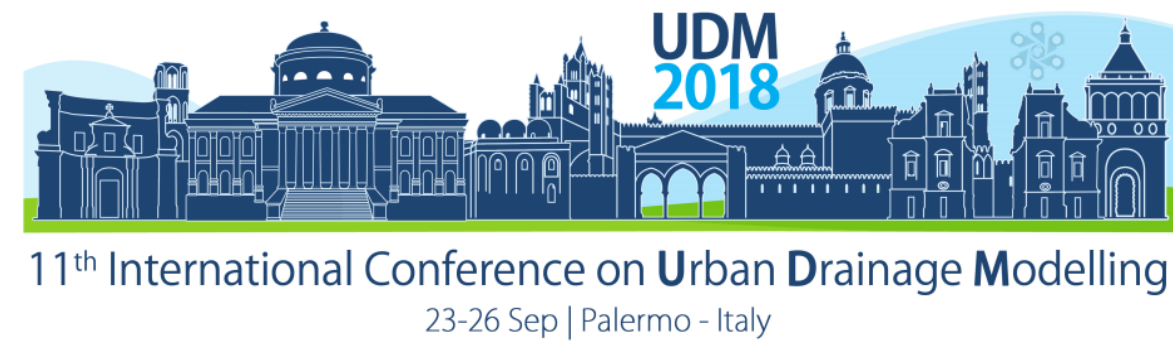

network. ANN have several layers, where the information is presented to the network via the input layer. Simulation results are returned in the output layer. In between those layers may be several hidden layers. The number of hidden layers and the number of neurons per layer is depending on the problem. The neurons process the information and send it to the next layer via the synapses. The synapses are weighted connections and can be adapted during the training phase. Similar to Berkhahn et al. (2017), the training of the present model is conducted with the resilient backpropagation algorithm. A thorough introduction on ANN can be found in Dalton \& Deshmane (1991).

The prediction-model for maximum water level consists of ANN using rain event as input and maximum water levels on the surface as output. The used ANN is a fully coupled feedforward network. As the input represents the rain event in 5-minute time distribution with a maximum duration of 2 hours, the vector of input neurons has the length of 24 . This length is a constant value. Rain events with a smaller duration than 2 hours have to be filled up with zero values. The length of the output vector is defined by the spatial discretisation of the catchment. To make the model applicable for catchments with different sizes the simulation area is divided into rectangular grid cells. For every grid cell an independent ANN is trained. With this approach the memory requirement can be reduced and also big catchments can be simulated. To improve the generalization of the prediction-model an ensemble approach is used. The ensemble approach was presented in Hansen et al. (1992) and was used for handwritten digit recognition. In the case of water level prediction, several ANN are trained with different initial weights to simulate water levels at the same points in the catchment. The output of the ensemble model is defined as the mean of every realisation. For one specific point $p$ the maximum water level $w l$ can be formulated as:

$$
w l_{p}=\frac{\sum_{i=1}^{n} w l_{p, i}}{n}
$$

where $i$ is the realisation and $n$ the ensemble size.

To find the number of hidden layers and the number of neurons per layer a pre-training is conducted with a field of different topologies. The number of hidden layers is tested in a range from 2 up to 20. The number of neurons per layer is tested in a range from 10 up to 100.

The urban catchment used in this study is an anonymized synthetic area derived from a real catchment. The approx. $6 \mathrm{~km}^{2}$ large study area has a mean slope of less than one percent. The sewer system consists of 1220 elements and has a total length of about 53 kilometres. The study area is divided into residential, commercial and industrial areas. The proportion of paved area is less than 50 percent.

The rain events used in this study are collected from historical events in northern Germany. Considering the limitation of the duration with respect to the input vector length only events with a duration from 15 minutes up to 2 hours are taken into account. With this constraint 529 rain events with return periods from 10 years up to over 100 years are used. The total intensity of the rain events is in a range from $17 \mathrm{~mm}$ to $76 \mathrm{~mm}$. The maximum peak per five minutes is in the range from $1.6 \mathrm{~mm}$ to $22 \mathrm{~mm}$.

The rain events are divided into two set, the training set and the test set. Rain events from the test set are only used to validate the trained model but never for the training. The rain events are separated randomly into sets with the same size. The training set has 265 members with total intensities in the range from $17 \mathrm{~mm}$ to $57.2 \mathrm{~mm}$. The test set has 264 members with total intensities in the range from $17.4 \mathrm{~mm}$ to $76.2 \mathrm{~mm}$. 


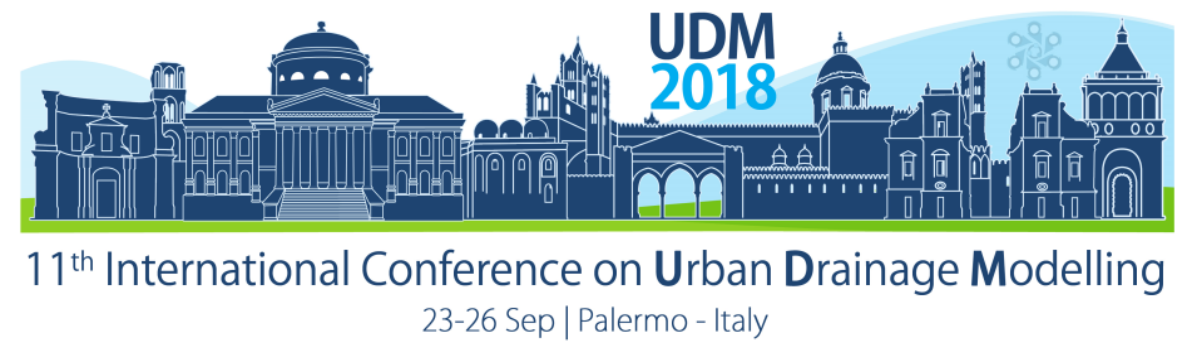

The maximum water levels per rain event were generated with the hydrodynamic numerical model HYSTEM-EXTRAN 2D (itwh, 2015). The physically based model represents the catchment surface with 1193222 triangles with an area in the range from $0.36 \mathrm{~m}^{2}$ to $6.31 \mathrm{~m}^{2}$. The mean size of the triangles is $3.06 \mathrm{~m}^{2}$. The buildings are represented by 2186 polygons with an area of $1.117 \mathrm{~km}^{2}$. The computation time is about 5 hours for a rain events with return period of 100 years and duration of 2 hours (i7, $3.60 \mathrm{GHz}, 32 \mathrm{~GB}$ RAM).

To use the results from the hydrodynamic model as output data for the ANN model several pre-processing steps are needed. The resolution for a real-time early warning system is not necessarily as high as for the physically based model. Therefor the resolution is decreased to a 6 by 6 -meter rectangular grid. The conversion of the grid is done by area related averaging. After decreasing the resolution every cell of the 6 by 6 -meter grid which has a maximum water level under a certain threshold in every event of the training set is neglected. With a threshold of $5 \mathrm{~mm} 9623$ cells are left for the simulation. The test area is divided in a grid of 25 subnets.

\section{RESULTS AND DISCUSSION}

To evaluate the prediction-model the Nash-Sutcliffe model efficiency coefficient (NSE) and the root mean squared error (RMSE) are used. The NSE and RMSE are defined as:

$$
\begin{aligned}
& N S E=1-\frac{\sum_{i=1}^{n}\left(w l_{\text {pred }, i}-w l_{\text {exp }, i}\right)^{2}}{\sum_{i=1}^{n}\left(w l_{\text {exp }, i}-\overline{w l}_{\text {exp }}\right)^{2}} \\
& R M S E=\sqrt{\frac{\sum_{i=1}^{n}\left(w l_{\text {pred }, i}-w l_{\text {exp }, i}\right)^{2}}{n}}
\end{aligned}
$$

where $\boldsymbol{i}$ marks the position of the water level. $\boldsymbol{w} \boldsymbol{l}_{\text {pred }}$ is the predicted and $\boldsymbol{w} \boldsymbol{l}_{\text {exp }}$ the expected water level and $\boldsymbol{n}$ is number of cells. The NSE is dimensionless and a value of 1 indicates a perfect match between predicted and expected values. The RMSE has the dimension of the examined values (in our case meters of water level on the surface). The lower the RMSE the better the prediction.

The results for every rain event in the test set are shown in figure 1. The graph shows that with increasing ensemble size the NSE is increasing and converging to a value of about 0.9 . According to Motovilov et al. (1999) values higher than 0.75 can be rated as 'good'. The RMSE for the ensemble size of 10 is about 0.02 meters.

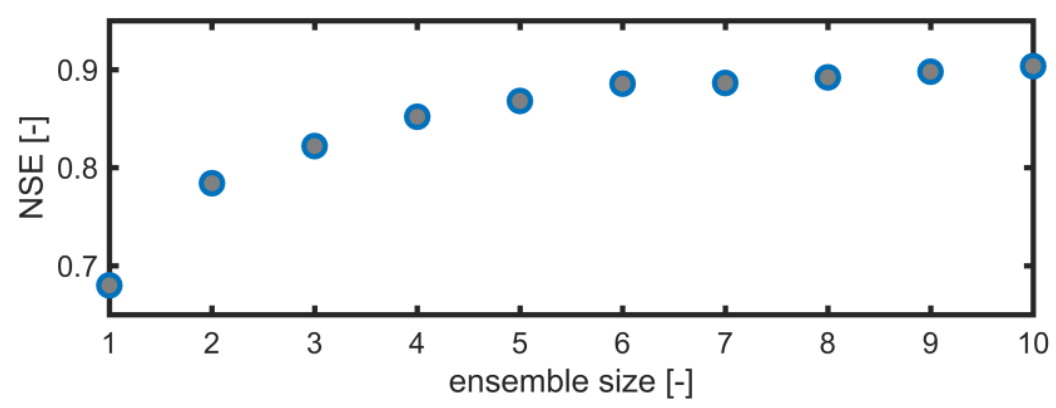

Figure 1. NSE for all test events over ensemble size.

The NSE was lower than 0.75 for 28 rain events in the test set. This may be caused by the wide spreading in the duration, which leads to a lot of zeros in the input vector. 


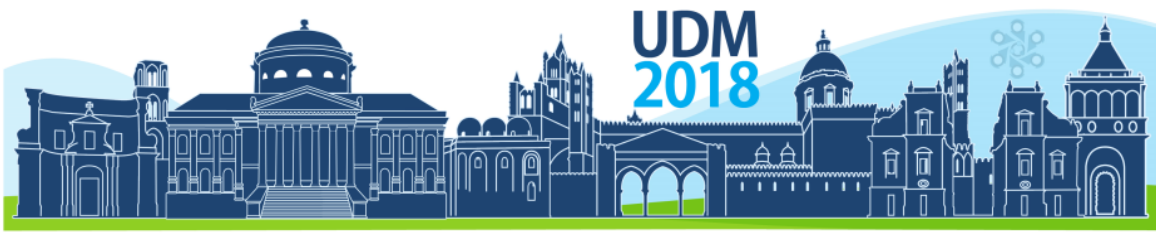

$11^{\text {th }}$ International Conference on Urban Drainage Modelling

23-26 Sep | Palermo - Italy

As shown in figure 2 the maximum water level distribution looks reasonable and no sharp borders are detected between the subnets. The computation time for the rain event with a return period of 100 years was less than 10 seconds ( $i 7,3.60 \mathrm{GHz}, 32 \mathrm{~GB}$ RAM). Thus the prediction model is 1800 times faster than the hydrodynamic approach.
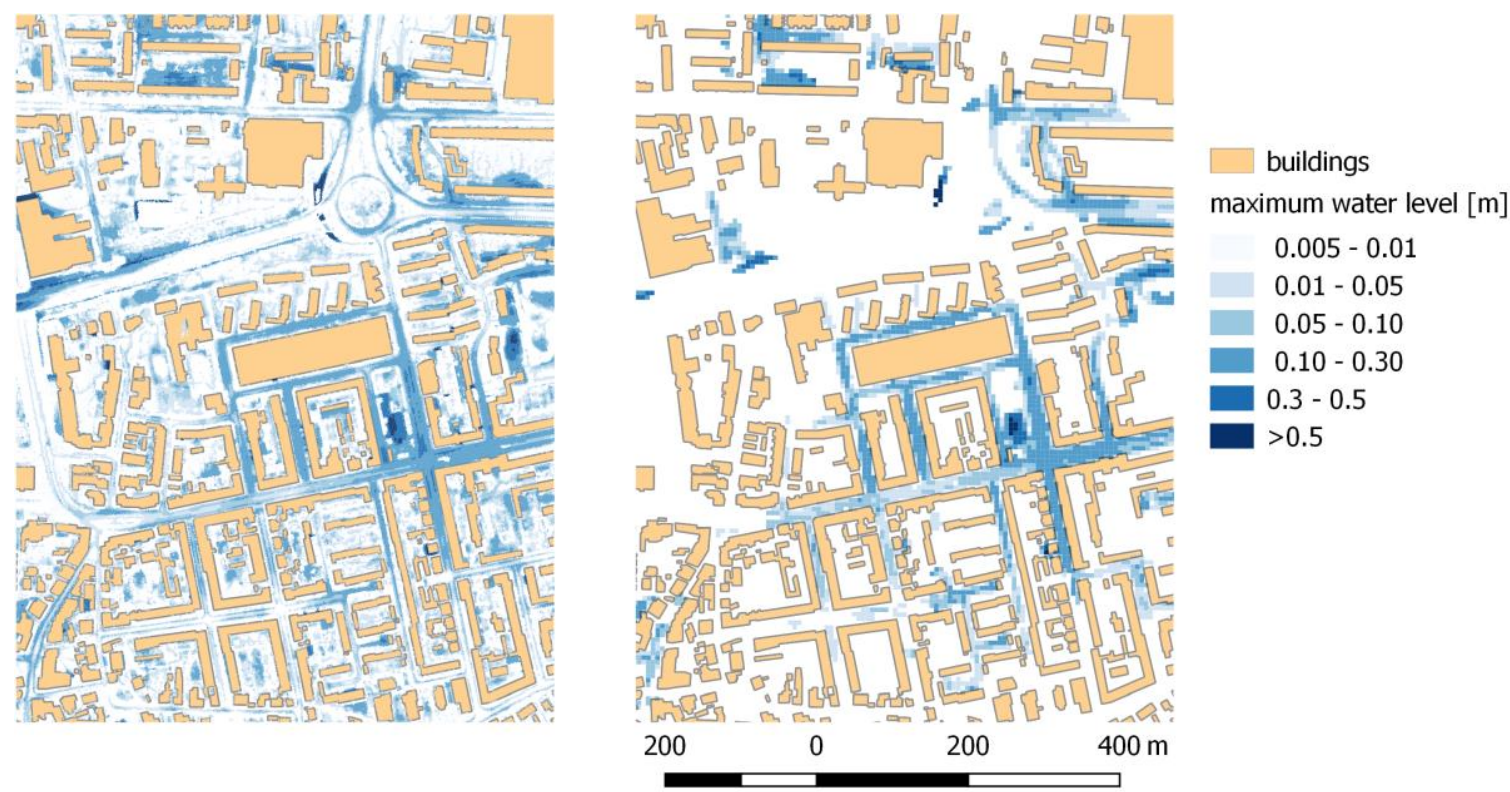

Figure 2. Max. water level maps for a rain event with return period of 100 years. Left: results from the hydrodynamic approach. Right: results from the ANN prediction.

\section{CONCLUSIONS}

The real-time prediction of maximum water level with an ANN ensemble model was successfully tested for natural rain events. The computation time with less than 10 seconds is suitable for real-time warning systems. The prediction-model needs further improvements to avoid the detected outliers.

\section{References}

Berkhahn, S., Fuchs, L., \& Neuweiler, I. (2017) Articial neural network for two-dimensional urban flood simulation and real-time forecasting. 14 th International Conference on Urban Drainage

Chang, F. J., Chen, P. A., Lu, Y. R., Huang, E., \& Chang, K. Y. (2014). Real-time multi-step-ahead water level forecasting by recurrent neural networks for urban flood control. Journal of Hydrology, 517, 836-846.

Chen, J. C., Shu, C. S., Ning, S. K., \& Chen, H. W. (2008). Flooding probability of urban area estimated by decision tree and artificial neural networks. Journal of Hydroinformatics, 10(1), 57-67.

Dalton, Jeff and Atul Deshmane (1991). Artificial neural networks. IEEE Potentials, 10(2), 33-36.

Duncan, A., Keedwell, E., Djordjevic, S., \& Savic, D. (2013). Machine Learning-Based Early Warning System for Urban Flood Management. International Conference on Flood Resilience 2013

Duncan, A., Chen, A. S., Keedwell, E., Djordjevic, S., \& Savic, D. (2011). Urban flood prediction in real-time from weather radar and rainfall data using artificial neural networks. IAHS Red Book, 351

Henonin, J., Russo, B., Mark, O., \& Gourbesville, P. (2013). Real-time urban flood forecasting and modelling-a state of the art. Journal of Hydroinformatics, 15(3), 717-736.

Hung, N. Q., Babel, M. S., Weesakul, S., \& Tripathi, N. K. (2008). An artificial neural network model for rainfall forecasting in Bangkok, Thailand. Hydrology and Earth System Sciences Discussions, 5(1), 183-218.

Itwh (2015) HYSTEM-EXTRAN 2D Modellbeschreibung (HYSTEM EXTRAN 2D model description), Institut für technisch-wissenschaftliche Hydrologie $\mathrm{GmbH}$, Hannover.

Schellart, A., Ochoa, S., Simões, N., Wang, L. P., Rico-Ramirez, M., Liguori, S., Duncan, A., Chen, A. S., Keedwell, E., Djordjevic, Savić, D., Saul, A. \& Maksimović, Č. (2011). Urban pluvial flood modelling with real time rainfall information-UK case studies. 12 th International Conference on Urban Drainage 


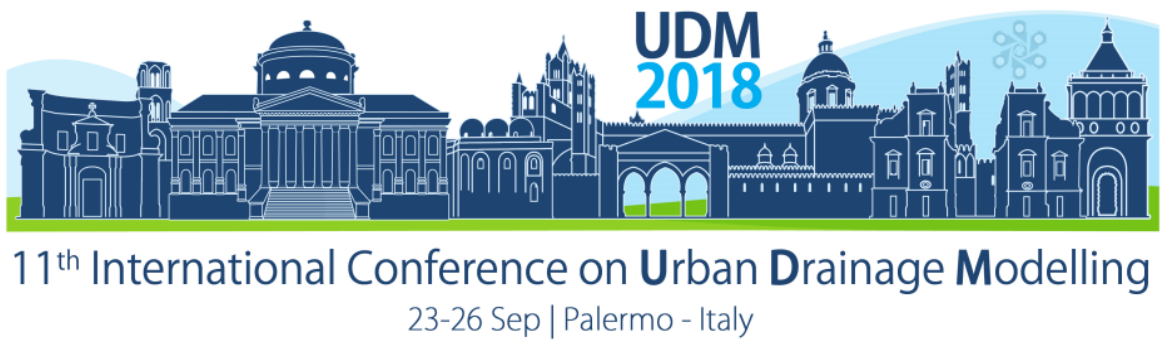

\title{
Selection of calibration events for modelling green urban drainage
}

\author{
Ico Broekhuizen ${ }^{1}$, Günther Leonhardt ${ }^{1}$, Jiri Marsalek ${ }^{1}$ and Maria Viklander ${ }^{1}$ \\ ${ }^{1}$ Luleå University of Technology, Department of Civil, Environmental and Natural Resources Engineering, Urban \\ Water Engineering, Luleå, Sweden \\ E-mail: ico.broekhuizen@ltu.se
}

\begin{abstract}
Urban drainage models are often calibrated using a limited number of rainfallrunoff events, which may be selected in different ways from a longer observation series. This paper compares 13 different single- and two-stage strategies for selecting events used to calibrate a SWMM model of a predominantly green urban area. Most led to successful calibration, but performance varied for various validation events. Most selection strategies were insensitive to the choice of Nash-Sutcliffe Model Efficiency or Root Mean Squared Error as the objective function. Calibrating impervious and green area parameters separately in two-stage strategies can help improve prediction of low-flow events in validation.
\end{abstract}

Keywords: event-based calibration, calibration event selection, green urban areas

\section{INTRODUCTION}

Calibration is often necessary to estimate parameters of urban drainage models representing specific catchments. Ideally this would be done using all data from a long record of field observations, but this is often infeasible because of the lack of data and the need to keep model run times short in the trial-and-error approach to calibration. Therefore, it is common to select a number of discrete rainfall events for calibration. Since each actual rainfall event is different, the choice of events will impact the results of the calibration. Previous research on this topic found: (i) large variations in calibration outcomes when different single events were used for calibration (Tscheikner-Gratl et al., 2016), and (ii) that using the five longest events required fewer flow measurement locations for successful calibration of CSO overflow volumes, than using the five highest peak events (Kleidorfer et al., 2009). The aforementioned papers examined a few strategies for selecting calibration events, but many more are available. They also focused on runoff processes on impervious surfaces, but the increasing use of green infrastructure suggests that runoff processes on green areas also need to be considered and studied (Fletcher, Andrieu and Hamel, 2013). This raised the research question addressed in this paper: what is the impact of different strategies for calibration event selection on the performance of a calibrated model for a predominantly green urban catchment?

\section{MATERIALS AND METHODS}

\subsection{Study site and data}

The study site is a 10.2 ha urban catchment in Luleå, Sweden. Twelve percent of the catchment area is impervious and connected directly to a storm sewer system, $25 \%$ is impervious but draining onto green areas, and the remaining $63 \%$ are green areas. Measurements of precipitation and drainage outflow (one observation/minute) were available for discrete rainfall events in 2013 - 2015, and continuous records were available in 2016 and 2017. 


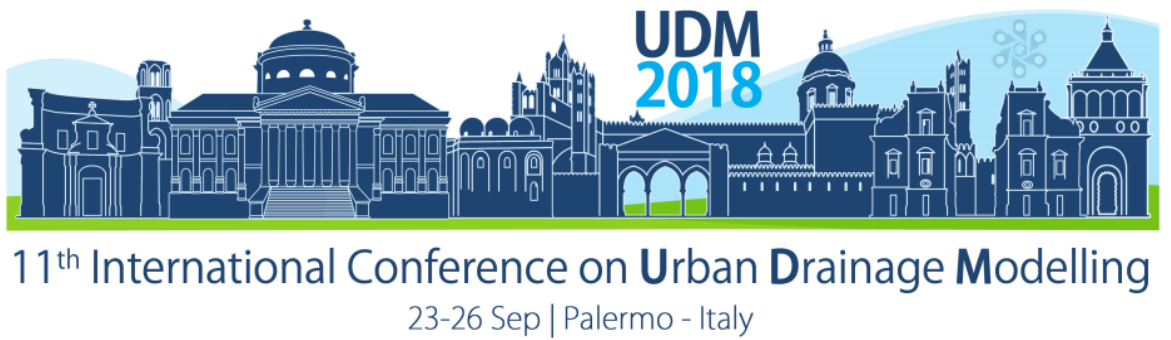

From the available precipitation record, rainfall events were extracted with a minimum interevent time of six hours. The resulting set of events was reduced to the events that were perceived suitable for calibration using the following criteria: (1) a minimum rain depth of $2 \mathrm{~mm}$, (2) $>90 \%$ rain and flow data availability, (3) water depths (at the flow sensor) $>10 \mathrm{~mm}$ at least $50 \%$ of the event duration and $>25 \mathrm{~mm}$ at least once during the event, (4) a peak flow rate $>2$ $\mathrm{l} / \mathrm{s}$, and (5) no snowfall or snowmelt during the event. The 2016 events (19 in total) were reserved for validation, while the remaining events (32 in total) were available for selection in calibration.

\subsection{Calibration scenarios}

Single- and two-stage calibration scenarios (CS) were considered. In single-stage CSs, the rainfall-runoff events with the highest value of a certain event characteristic were selected. The two-stage calibration scenarios assume that, for events with a smaller percentage runoff than the percentage of directly connected impervious area (12\% for this site), all runoff comes from these areas and no green areas or impervious areas draining onto green areas contribute. Consequently, events with less than $12 \%$ runoff are first used to calibrate parameters related to impervious areas; then, events with more runoff are used to calibrate the parameters related to green areas. Six events were used for each calibration scenario (split 3-3 for two-stage calibration).

For each available event, a number of rain and flow characteristics were calculated. For each characteristic, the top 6 and the top 3+3 events (two-stage calibration) were identified. From these calibration scenarios, we then selected seven single-stage and six two-stage calibration scenarios that (1) covered a range of different characteristics, and (2) did not have an identical set of events. In Table 1 and the following text, the names of calibration scenarios consist of: (1) "T6" for single-stage or "T32S" for two-stage scenarios; (2) the employed event characteristic (precipitation $\mathrm{P}$, precipitation intensity $\mathrm{PI}$, runoff flow rate $\mathrm{Q}$, flow volume $\mathrm{V}$; flow volume as percentage of rain perc_V, rainfall duration D_prec); and (3) the duration which the characteristics concern: sum, mean and max refer to the whole event; 30 and 60 min refer to the highest moving average for a 30- or 60-minute period within the event.

\subsection{Runoff model and calibration approach}

The US EPA Storm Water Management Model (SWMM, with the PCSWMM interface) was used with the Green-Ampt infiltration submodel. Based on GIS data and aerial images, the study area was divided into 146 subcatchments, each of which consisted of only a single land use (building, asphalt, grass area or swale). This approach has been shown to ease calibration (Petrucci and Bonhomme, 2014; Krebs et al., 2016). The area and slope of each subcatchment was estimated from the GIS data. The catchment width was estimated directly for small and disconnected roofs, but calibrated for other subcatchments. Other parameters were grouped based on land use, yielding a total of 13 hydrological model calibration parameters, the ranges of which were set on the basis of literature values (Rawls, Brakensiek and Miller, 1983; Krebs et al., 2016; Rossman and Huber, 2016). In addition, a rainfall multiplier was calibrated for each event to account for the fact that the rain gauge (located a few hundred metres outside the catchment) may not give an accurate measure of the catchment average precipitation.

The green nature of the study catchment required special attention to the initial conditions of the simulation. Assuming a worst-case scenario with large depression storage capacities and low infiltration rates, a continuous calculation of water in the depression storage and infiltration capacity was performed using the measured precipitation data. For each event, the last time point before the start of the rainfall where the depression storage was empty and the infiltration 


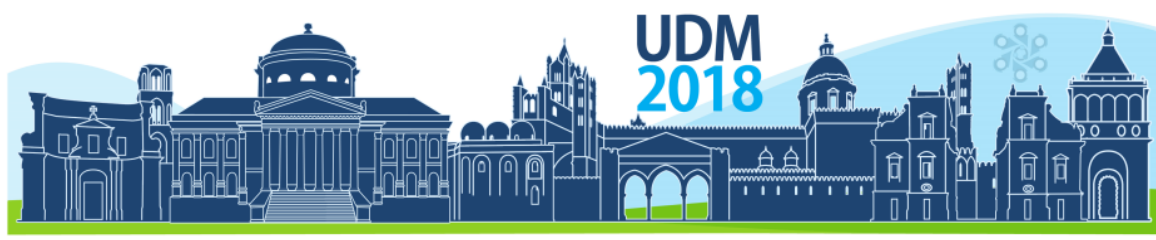

$11^{\text {th }}$ International Conference on Urban Drainage Modelling

23-26 Sep | Palermo - Italy

capacity fully recovered was then used as the start of the warm-up period of the simulation, so that the initial conditions were the same as they would be if a long-term continuous simulation had been used.

For each calibration scenario the optimal parameters were estimated using the SCE-UA algorithm (Duan, Sorooshian and Gupta, 1994) as implemented in SPOTPY (Houska et al., 2015). Each calibration scenario was run twice with mean of the Nash-Sutcliffe coefficients (NS) respectively the root mean square error (RMSE) calculated for each individual event as the objective function. To prevent low-flow periods (with high measurement uncertainties) from dominating the calibration, only hydrograph points with observed flow rates $\geq 1 \mathrm{l} / \mathrm{s}$ were considered.

\section{RESULTS AND DISCUSSION}

Table 1 shows results for different calibration scenarios. Calibrations were mostly successful (NS ranging from 0.55 to 0.80 ). The single-stage scenarios performed similarly, although T6_QV_ppP suffers somewhat from including a low-flow event where NS is low despite visually quite good results. Three of the two-stage scenarios performed somewhat less, but still with NS > 0.5. Two two-stage scenarios (T32S_PI_mean and T32S_P_sum) performed satisfactorily when using NS as objective function, but not when using RMSE. Except for these, there were only small differences between the two objective functions.

Validation shows mixed results: while T32S_Q_max and T32S_Q_60m failed in validation, the other CSs predicted nine to eleven of the validation events satisfactorily (NS $>0.5$, see Figure 1 a for an example). Yet, they also gave negative NS (i.e., worse performance than the average of the observations) for two to five events. Four of the validation events that are poorly predicted by most calibration scenarios have low peak flow rates (up to $7 \mathrm{l} / \mathrm{s}$ ). Such events will have a relatively low variance of the observations, which has a negative impact on NS and can make it sensitive to small changes in the simulated hydrographs. The fifth event was a short, intense event with a peak flow of $53 \mathrm{l} / \mathrm{s}$, which was overestimated by a factor of 2-3 and may have suffered from the often-reported high spatial variability of extreme rainfall. Undetected measurement errors may also influence the model performance.
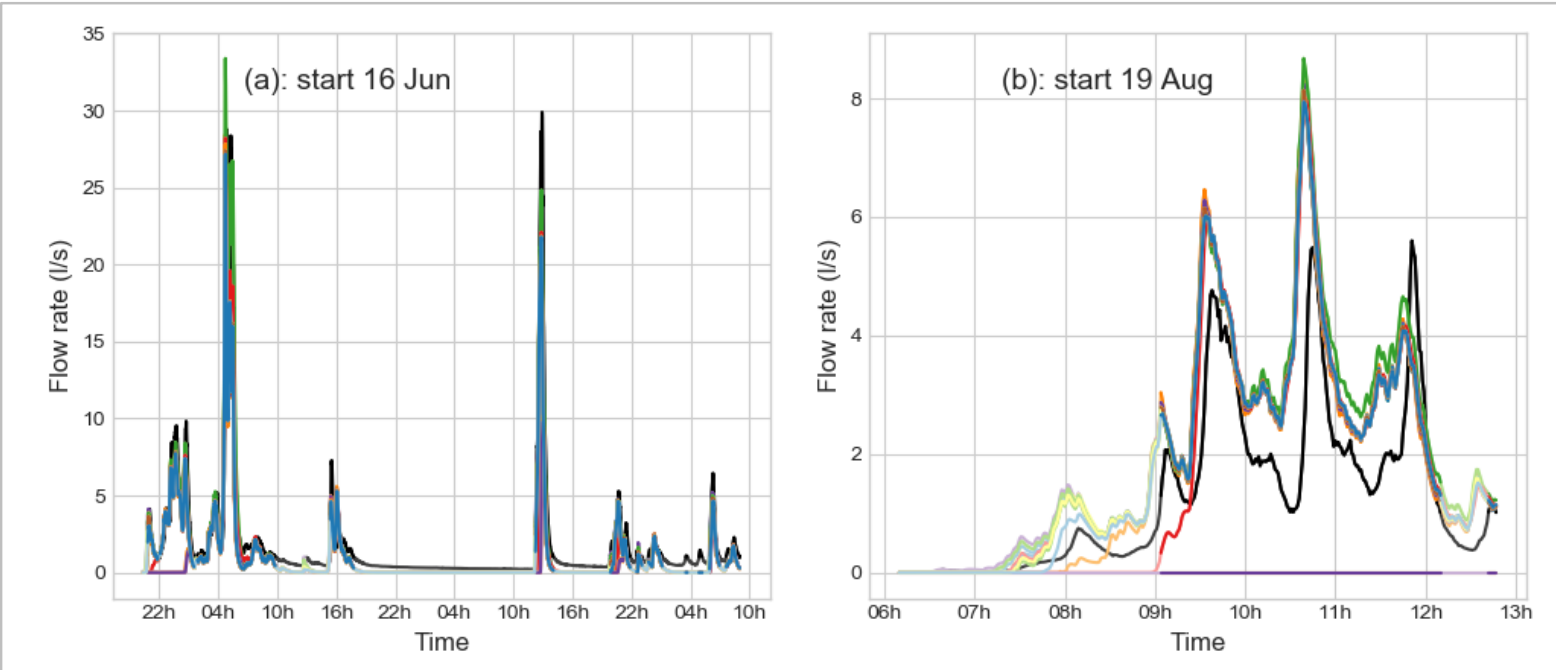

Figure 1. Examples of (a) good and (b) poor performance for all calibration scenarios (coloured lines) compared to observed values (black lines). Faded lines are used during the periods when the observed flow rate was $<1 \mathrm{l} / \mathrm{s}$. 


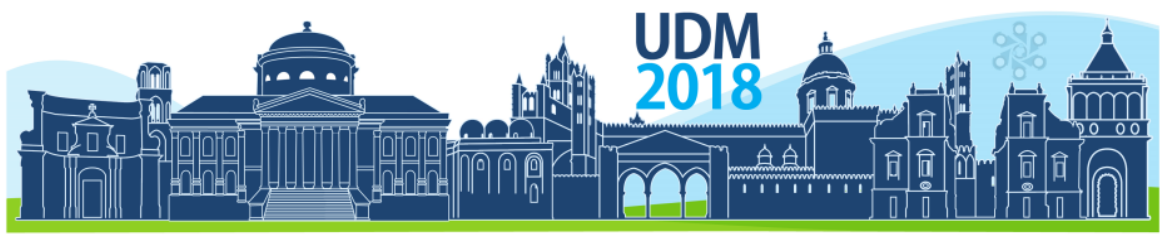

$11^{\text {th }}$ International Conference on Urban Drainage Modelling

23-26 Sep | Palermo - Italy

Table 1. Results for calibration and validation periods. NSclip is the mean NS after setting values $<-1$ equal to -1 . NSstack is the NS calculated after joining all events into a single time series. VEmean is the mean of the relative volume error for each event. Best score for each criterion is shown in bold font.

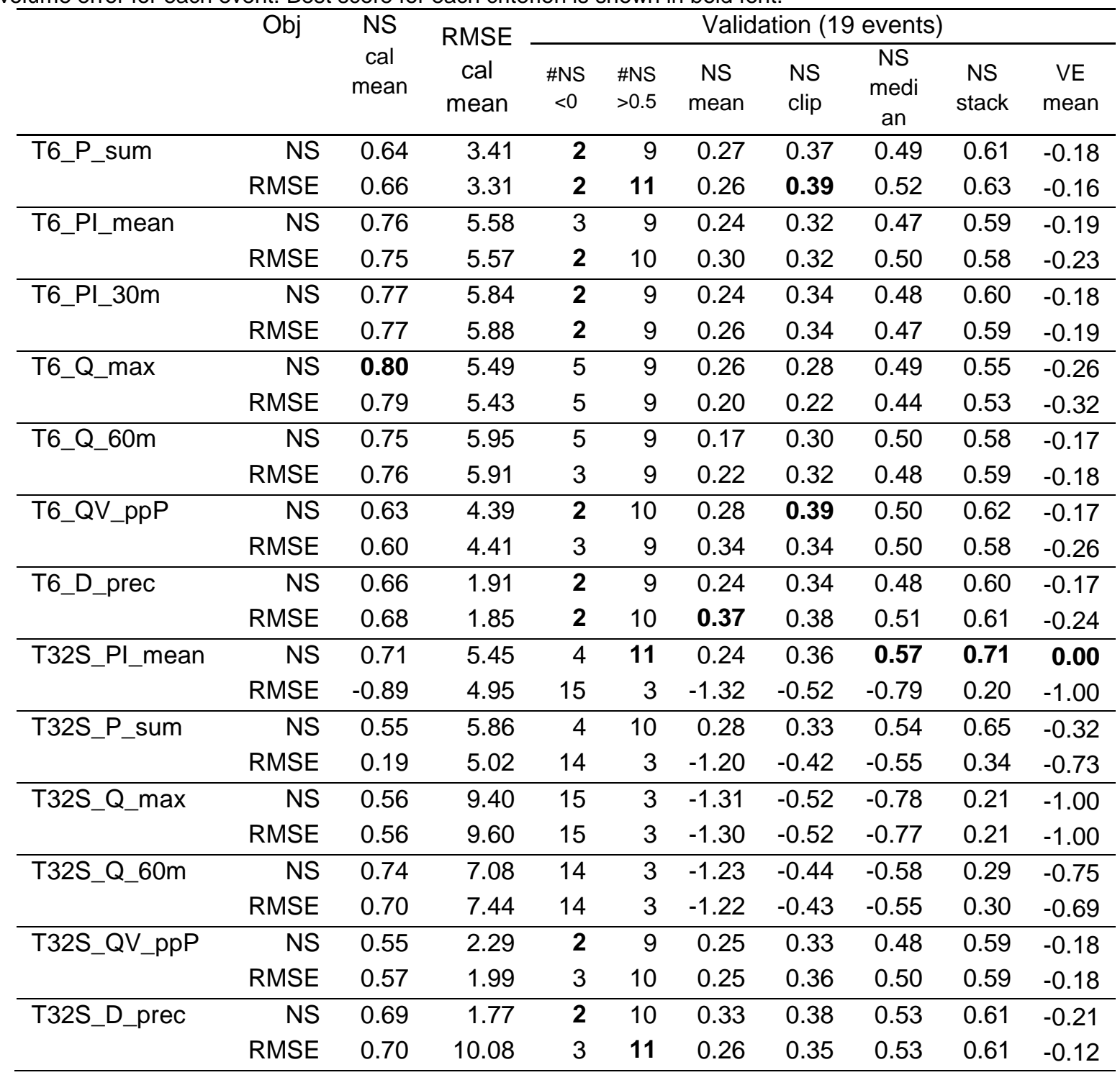

For overall performance, we consider different ways of combining the NS for the individual events. Simple use of the means shows unsatisfactory performance, which can be attributed to the possible range of $(-\infty ; 1]$ and the consequence that one poorly fitting model can cancel out several well-fitting models. To avoid this effect, we recalculated the mean NS after setting values $<-1$ to -1 . Although this limits the influence of poorly predicted events, the highest NS scores are still $<0.4$. The median NS (being insensitive to outliers) can be considered to give a better idea of a typical result. According to this metric, the top-three of CSs consists of twostage strategies. Finally, in a perhaps more typical approach, the outputs for all validation events were joined into a single time series prior to calculating NS. This metric shows satisfactory performance for all successfully calibrated CSs. The two-stage CSs that were 


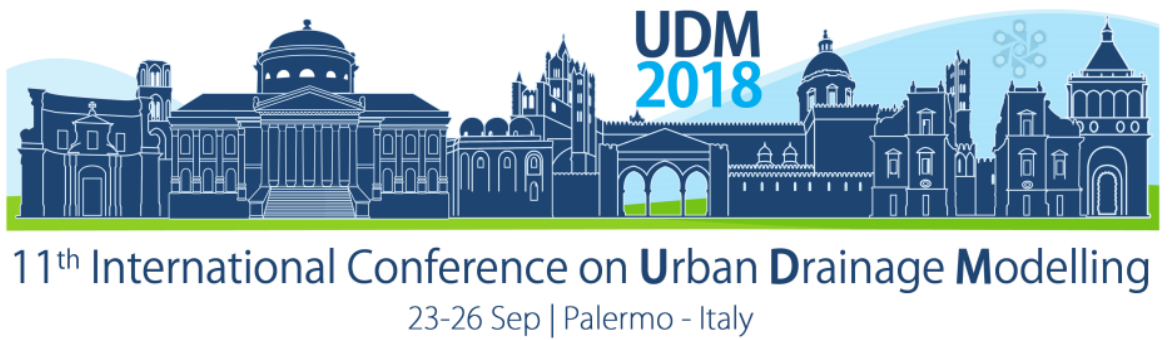

successful when switching to validation have less performance degradation in doing so than the two-stage CSs.

Whether or not two-stage calibration works better than single stage depends on the event characteristic used for event selection. For $P$ sum single-stage was more successful in calibration, but not so in validation; for PI_mean the two-stage two-stage NS performed better in validation; for $Q$ max and $Q \quad 60 \bar{m}$ all variants were calibrated satisfactorily, but the single-stage variants failed in validation; for $Q V \_p p P$ and $D \_p r e c$, both variants had similar performance throughout.

\section{CONCLUSIONS}

This paper investigated the impact of different calibration data selection strategies on calibrated model performance. Simply selecting the highest-ranking events according to different rainfall- and flow-based criteria results in models that calibrate well, but struggle to predict low-flow events in validation. Validation performance depends on how the results for individual events are combined, since a small number of poorly predicted events can cancel out a larger number of well-predicted events.

Calibrating impervious and pervious parameters in two consecutive steps can yield models that fit better for low-flow events in the validation period, leading to less performance degradation when switching to validation. However, when selecting events based on flow rates, the reduced information on less-intense events can lead to failure in validation.

\section{Acknowledgements}

This study is funded by the Swedish Research Council Formas (grant number 2015-121). The authors would like to thank $\mathrm{CHI} /$ HydroPraxis for providing PCSWMM. The authors would like to thank Helen Galfi, Ralf Rentz and Karolina Berggren for their work on the field measurements.

\section{References}

Duan, Qingyun, Soroosh Sorooshian, and Vijai K. Gupta. 1994. "Optimal Use of the SCE-UA Global Optimization Method for Calibrating Watershed Models." Journal of Hydrology 158 (3-4): 265-84. doi:10.1016/00221694(94)90057-4.

Fletcher, T. D., H. Andrieu, and P. Hamel. 2013. “Understanding, Management and Modelling of Urban Hydrology and Its Consequences for Receiving Waters: A State of the Art." Advances in Water Resources 51. Elsevier Ltd: 261-79. doi:10.1016/j.advwatres.2012.09.001.

Houska, Tobias, Philipp Kraft, Alejandro Chamorro-Chavez, and Lutz Breuer. 2015. "SPOTting Model Parameters Using a Ready-Made Python Package." PLoS ONE 10 (12): 1-22. doi:10.1371/journal.pone.0145180.

Kleidorfer, M., M. Möderl, S. Fach, and W. Rauch. 2009. "Optimization of Measurement Campaigns for Calibration of a Conceptual Sewer Model." Water Science and Technology 59 (8): 1523-30. doi:10.2166/wst.2009.154.

Krebs, Gerald, Teemu Kokkonen, Heikki Setälä, and Harri Koivusalo. 2016. "Parameterization of a Hydrological Model for a Large, Ungauged Urban Catchment." Water (Switzerland) 8 (10): 1-23. doi:10.3390/w8100443.

Petrucci, Guido, and Celine Bonhomme. 2014. "The Dilemma of Spatial Representation for Urban Hydrology SemiDistributed Modelling: Trade-Offs among Complexity, Calibration and Geographical Data." Journal of Hydrology 517. Elsevier B.V.: 997-1007. doi:10.1016/j.jhydrol.2014.06.019.

Rawls, Walter J., Donald L. Brakensiek, and Norman Miller. 1983. "Green-Ampt Infiltration Parameters from Soils Data." Journal of Hydraulic Engineering 109 (1): 62-70. doi:10.1061/(ASCE)0733-9429(1983)109:1(62).

Rossman, Lewis A., and Wayne C. Huber. 2016. "Storm Water Management Model Reference Manual Volume I Hydrology." www2.epa.gov/water-research.

Tscheikner-Gratl, Franz, Peter Zeisl, Carolina Kinzel, Johannes Leimgruber, Thomas Ertl, Wolfgang Rauch, and Manfred Kleidorfer. 2016. "Lost in Calibration: Why People Still Don't Calibrate Their Models, and Why They Still Should - a Case Study from Urban Drainage Modelling." Water Science and Technology, 395. doi:10.2166/wst.2016.395. 


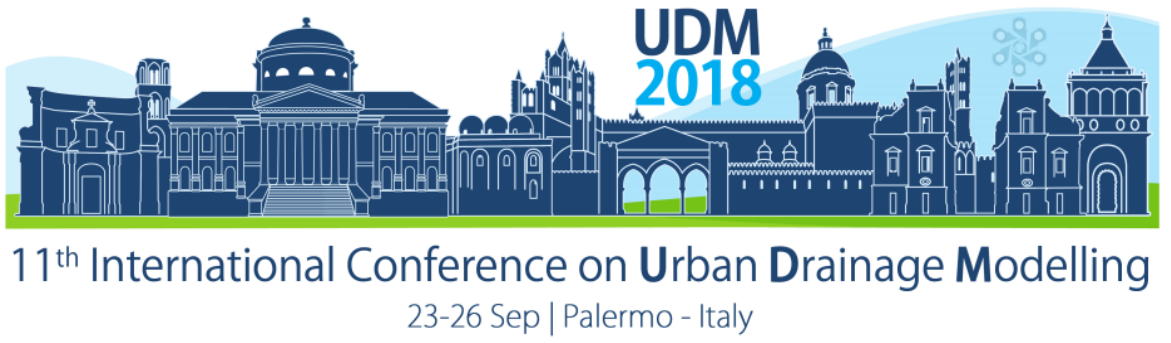

\title{
Potential of Using Mass-Volume Curve Prediction for Water Quality-based Real Time Control
}

\author{
Duy Khiem Ly', Thibaud Maruéjouls ${ }^{2}$, Guillaume Binet ${ }^{2}$, Jean-Luc Bertrand-Krajewski ${ }^{1}$ \\ ${ }^{1}$ University of Lyon, INSA Lyon, DEEP, EA 7429, F-69621 Villeurbanne cedex, France \\ ${ }^{2}$ Suez Eau France, LyRE, 43 rue Pierre Noailles, 33400 Talence, France
}

\begin{abstract}
This study implements two real time control (RTC) strategies on a small sewer network: water quality-based real time control (QBR) using mass-volume (MV) curves versus hydraulics-based RTC (HBR) and then compares their efficiencies. The network consists of a retention tank, a combined sewer overflow (CSO) structure and several actuators (valves and weir) for regulation. Initial results from the first demonstration on a rain event of $17.8 \mathrm{~mm}$ depth and 4-hour rainfall duration reveal the potential of the QBR. It offers a $10.7 \%$ reduction in CSO load while increasing CSO volume by $9.1 \%$, when compared to the HBR. The next step is being planned to characterize the types of rain events for which QBR offers the highest efficiency.
\end{abstract}

Keywords: mass-volume curve; real time control; combined sewer overflow

\section{INTRODUCTION}

Real time control (RTC) is considered as a cost-efficient technology to optimize the available capacity of an urban drainage system during wet weather and thereby alleviate the impact of combined sewer overflows (CSOs). The majority of RTC implementations are hydraulicsbased RTC (HBR), which aims at minimizing CSO volume through the use of online hydraulic measurements (Schutze et al., 1999, Pleau et al., 2005). Water quality-based RTC (QBR) was initiated more recently and has received increasing attention (Lacour et al., 2011; Vezzaro et al., 2014) due to advancements in wastewater quality sensors, modelling tools, and more rigorous adoptions of legislations to preserve receiving water bodies' ecological status, e.g. European Water Framework Directive and French Decree dated 21 July 2015 on the compliance of sewer networks. This study proposes the application of mass-volume (MV) curves (Bertrand-Krajewski et al., 1998) as a potential new approach for QBR and presents the results from its first demonstration on a small sewer network, in comparison to HBR.

\section{MATERIALS AND METHODS}

\subsection{Study area and modelling tool}

The urban catchment in this study is adapted from the Perinot catchment to facilitate quick and realistic RTC demonstration (Figure 1). In reality, Perinot is part of the Louis Fargue catchment, covering most of the urban areas in Bordeaux, France. Sewer hydraulics and water quality processes models are developed for control strategies using SWMM-TSS software, which contains an improved SWMM5.1.11 (USEPA) model library (Maruéjouls et al., 2012; Montserrat et al., 2017). The model applied for control strategies is extracted from a full-scale model developed for the whole 7700 ha Louis Fargue catchment, which is already calibrated and validated with long-term measurement data of turbidity, flow, and water level at four main 


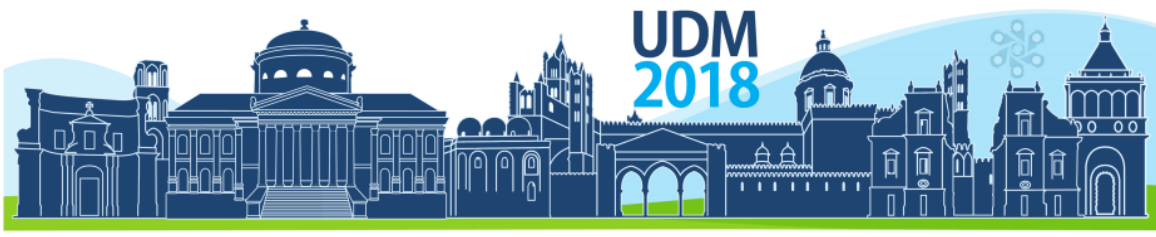

$11^{\text {th }}$ International Conference on Urban Drainage Modelling

23-26 Sep | Palermo - Italy

catchment outlets (Montserrat et al., 2017). Total suspended solids (TSS) is used as the quality state variable since it is the primary source of pollution transfer within the sewer pipes. TSS time series are obtained from turbidity time series by means of their correlation derived from several sampling campaigns during rain events (as presented in Maruéjouls et al., 2017). Rainfall data are extracted from a rain gauge located inside the catchment.

\subsection{Control elements}

Global control (see Figure 1) is based on regulating the weir $F$ to fill the tank or the valve $C$ to allow discharge through the CSO structure. Inlet offset of valve $C$ is at $0.54 \mathrm{~m}$, three times the maximum dry weather (DW) water depth at junction node D1. Valve $P$ settings depend on the water depth at junction node D2; once D2 depth reaches the threshold of $0.31 \mathrm{~m}$, opening of the valve should be minimal to ensure that the flow to waste water treatment plant (WWTP) remains always below $0.3 \mathrm{~m}^{3} / \mathrm{s}$, i.e. three times the maximum DW flow. Emptying of the tank is done after the rain event by adjusting valve $\mathrm{E}$ according to D2 depth too. All possible operational positions of the actuators are described below:

- weir F: 0 - no fill, 1 - fill.

- valve C: 0 - no CSO, 1 - CSO.

- valve P: 0.5 - D2 depth < $0.31 \mathrm{~m}, 0.033$ - otherwise.

- valve $\mathrm{E}$ : 0 - no empty, 0.05 - gradual empty if $\mathrm{D} 2$ depth $>0.31 \mathrm{~m}, 1$ - fast empty if equal to or lower than $0.31 \mathrm{~m}$.

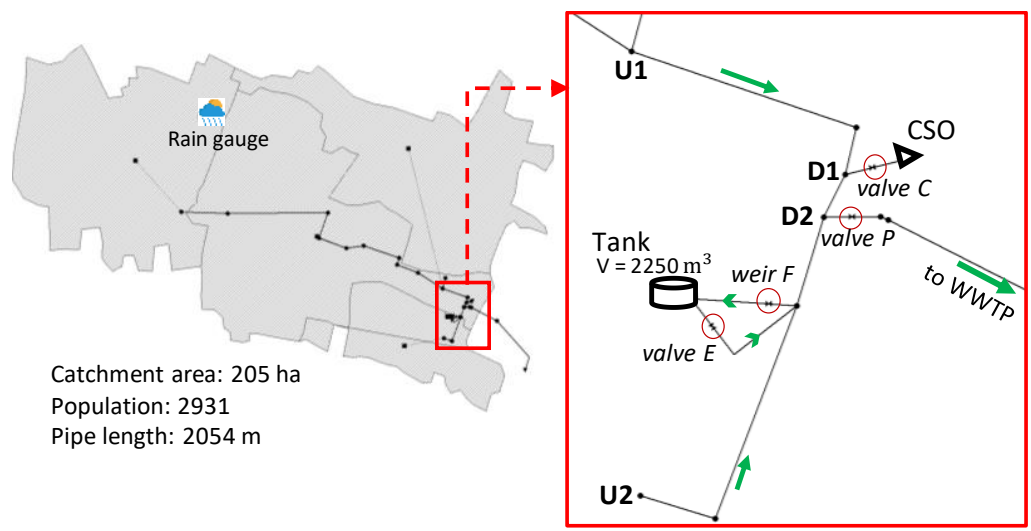

Figure 1. Adapted Perinot catchment and control elements.

\subsection{Control methods and performance measure}

Two control strategies are performed in this study: the QBR using MV curve versus the HBR. Both share the primary objective of avoid flooding in the network. The first strategy additionally targets reduction of CSO load while the second one focuses on reduction of CSO volume.

The diagram in Figure 2a illustrates the closed-loop simulation scheme implemented in both strategies. It involves using a controller to predict processes and solve the objective function within the incoming control time interval (CTI). The solution is then applied to the real system by means of actuator positions, letting the system evolves till the end of the CTI and measuring its states to set initial conditions for the next CTI. SWMM-TSS is applied to build both the model representing the virtual reality that provides measurements to the controller and the model for predictions in the controller. 


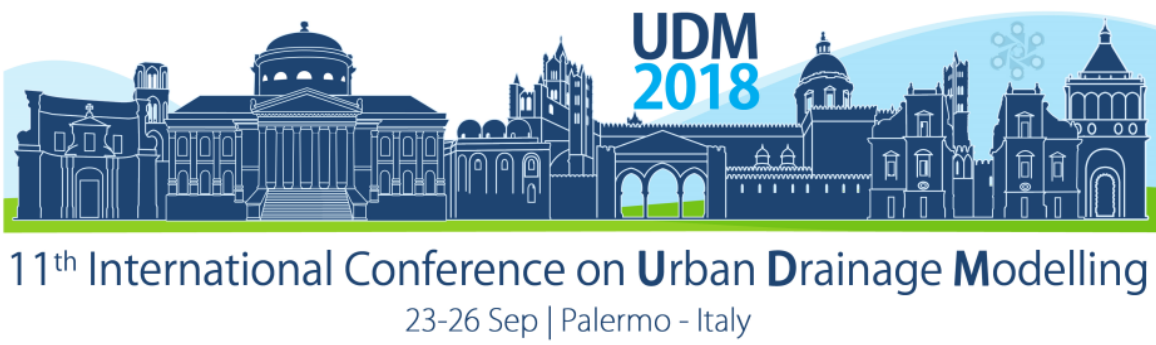

Strategy for QBR. The MV curve is a dimensionless way of representing the variation of the cumulative pollutant mass with respect to the cumulative volume during a rain event. Figure $2 \mathrm{~b}$ displays the upstream MV curve of the rain event selected for this study. It is derived from the simulated flow and TSS arriving at junction nodes U1 and U2. The SWMM-TSS model in the controller is run for the period between the beginning of the incoming CTI and the end of the rain event. Modelling outputs are used to predict the upstream MV curve. The rules for QBR are set as follows: should D1 depth be greater than $0.54 \mathrm{~m}$ during the incoming CTI, upstream MV slopes of this CTI and all further CTIs with D1 depth also greater than $0.54 \mathrm{~m}$ are picked and then sorted from largest to smallest one to determine the rank of the incoming CTI (e.g. rank k). Exceeding volume in each CTI from ranks 1 to k-1 can be obtained based on the difference between the simulated discharge upstream and three times its maximum DW discharge. If the sum of these volumes is less than the current tank capacity, exceeding volume of the incoming CTI needs to be stored in the tank. Otherwise, this volume is discharged through CSO.

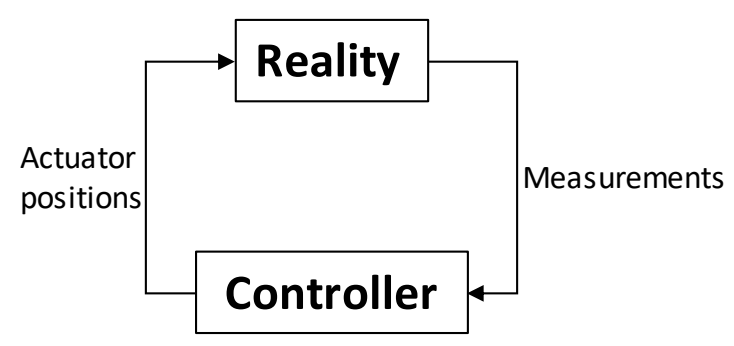

Figure 2. a) Closed-loop simulation scheme

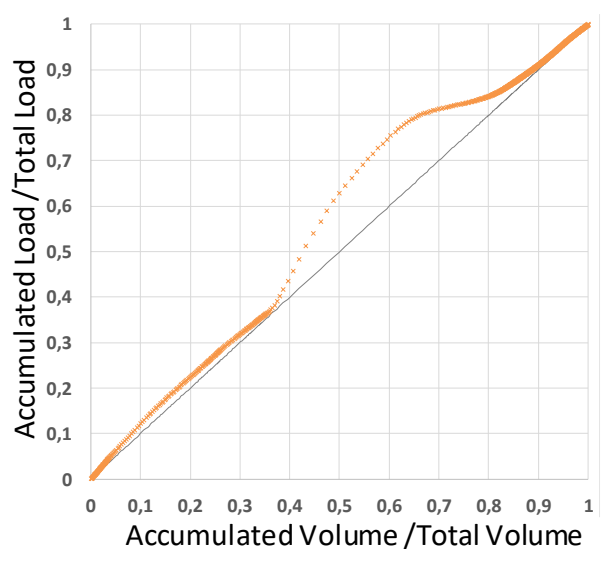

b) MV curve for the rain event on 23 April 2016

Strategy for HBR. During the incoming CTI, the tank is fed if D1 depth rises above $0.54 \mathrm{~m}$. If the tank is full, exceeding stormwater is spilled via CSO.

Performance measure. Total overflow loads and volumes in each strategy are estimated to evaluate their performances.

\section{RESULTS AND DISCUSSION}

The rain event used for demonstration has a return period of three months, with total depth of $17.8 \mathrm{~mm}$ and rainfall duration of approximately 4 hours. Figure 3 shows that QBR allows CSO discharges in the beginning and fills the tank mostly at the latter part of the event. This is in agreement with the evolution of the upstream MV curve in Figure $2 \mathrm{~b}$ and significantly different from the behaviour of HBR. The sharpest increase in the curve slope, representing the period containing the most polluted stormwater, is detected near the end of the event. On the other hand, HBR stores all the exceeding stormwater from the start to avoid CSO. Subsequently when the tank reaches full capacity, exceeding stormwater with higher concentration has to be spilled out. In total, the CSO load spilled by QBR during the rain event is $10.7 \%$ lower than by HBR although the CSO volume is $9.1 \%$ higher. 


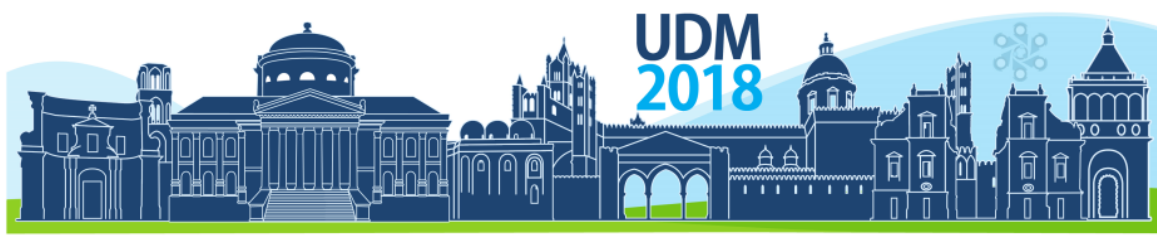

$11^{\text {th }}$ International Conference on Urban Drainage Modelling

23-26 Sep | Palermo - Italy

Furthermore, it takes longer time for exceeding stormwater to fill the tank through weir $\mathrm{K}$ than to spill through valve $C$. The depth at node D1 is thus usually higher in the case of HBR. There are times of fully pressurized flows and D1 depth increases rapidly, but still remains lower than the ground level. It is also observed that the downstream flow to WWTP is well maintained below the limit of $0.3 \mathrm{~m}^{3} / \mathrm{s}$.

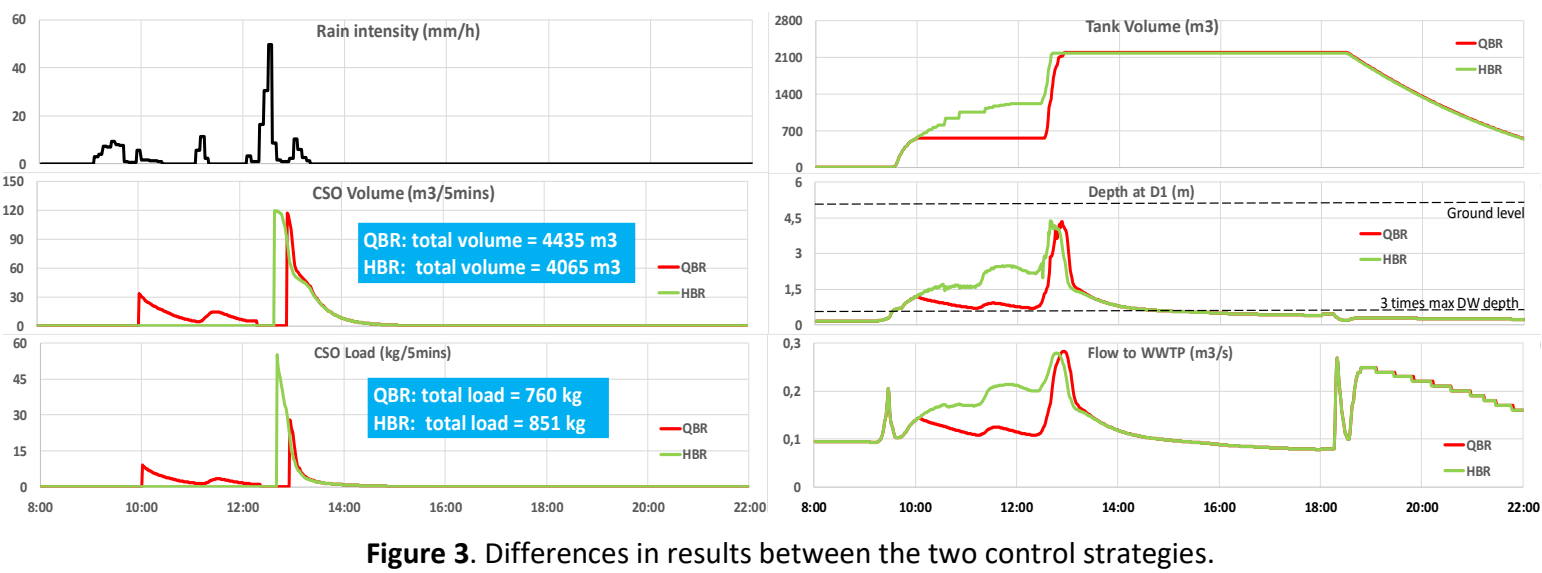

Another rain event is utilized to compare the two strategies but both provide identical actuator positions and performances. This is because the highest gain of MV slope occurs at the beginning of this rain event and along with the largest discharge of stormwater. The next step is to identify the types of rain events for which QBR offers the highest efficiency. This is planned to be presented in the conference later.

\section{CONCLUSIONS}

The results obtained from this study indicate the potential of using MV curves for QBR. Given the selected rain event, QBR using MV curves offers an obvious advantage in terms of CSO load reduction when compared to HBR. More detailed investigations are being carried out to further improve this newly proposed strategy and to characterize the types of rain events that can benefit from this approach.

\section{Acknowledgements}

The authors wish to thank the EU funding for LIFE EFFIDRAIN LIFE14 ENV/ES/00080 and the great technical and financial supports from Bordeaux Metropole and SGAC.

\section{References}

Bertrand-Krajewski, J. L., Chebbo, G., and Saget, A. (1998) Distribution of pollutant mass vs volume in stormwater discharges and the first flush phenomenon. Water Research 32(8), 2341-2356.

Lacour, C., Joannis, C., Schütze, M., and Chebbo, G. (2011) Efficiency of a turbidity-based, real-time control strategy applied to a retention tank: a simulation study. Water Science \& Technology, 64(7), 1533-1539.

Maruéjouls, T., Vanrolleghem, P. A., Pelletier, G., and Lessard, P. (2012) A phenomenological retention tank model using settling velocity distributions. Water Research, 46(20), 6857-6867.

Maruéjouls, T., Granger, D., Aouichat, F., Lafficher, C., Chadoutaud, E., Pouly, N. and Binet, G. (2017). Suivi de la qualité des eaux unitaires à l'échelle du bassin versant urbain par la mesure en continu (Online monitoring of combined wastewater quality at urban catchment scale). Techniques Sciences Méthodes, 10, 35-44. 
Proceedings of the 11th Int. Conference on Urban Drainage Modelling, 23-26 Sep. 2018, Palermo (ITALY). Ed. prof. Giorgio Mannina

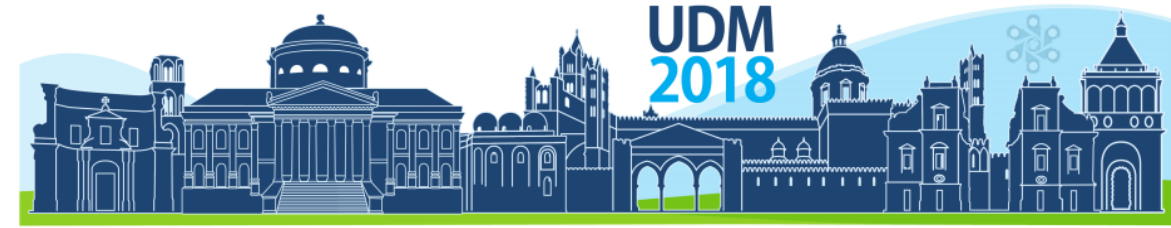

$11^{\text {th }}$ International Conference on Urban Drainage Modelling

23-26 Sep | Palermo - Italy

Montserrat, A., Maruéjouls, T., Litrico, X., and Binet, G. (2017) A quality model for combined sewer overflow and sediment description. In Proceedings of the 14th IWA/IAHR International Conference on Urban Drainage (pp. 373-376), Prague, Czech Republic.

Pleau, M., Colas, H., Lavallée, P., Pelletier, G., and Bonin, R. (2005) Global optimal real-time control of the Quebec urban drainage system. Environmental Modelling \& Software, 20, 401- 413.

Schütze, M., Butler, D., and Beck, M. B. (1999) Optimisation of control strategies for the urban wastewater system - An integrated approach. Water Science and Technology, 39(9), 209-216.

Vezzaro, L., Christensen, M.L., Thirsing, C., Grum, M., and Mikkelsen, P.S. (2014) Water quality-based real time control of integrated urban drainage systems: a preliminary study from Copenhagen, Denmark. Procedia Engineering, 70, 1707-1716. 


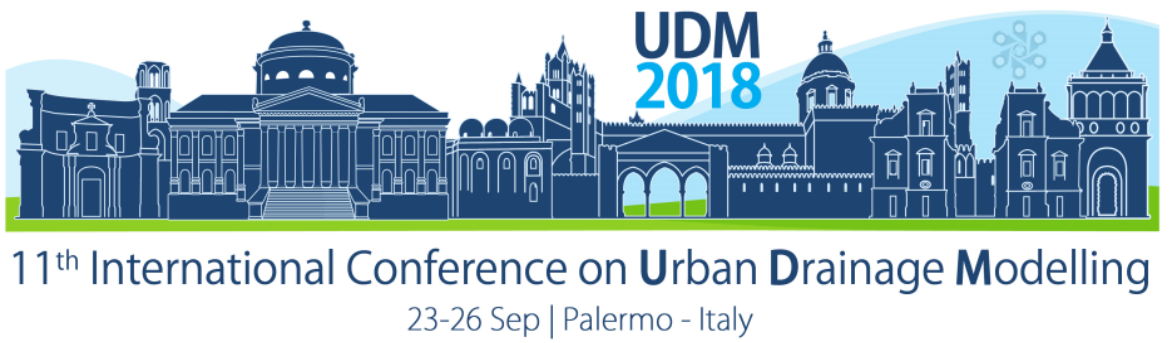

\title{
Conceptual Framework for Integrating Real-Time Control and Source Control Solutions for CSO Frequency Control
}

\author{
Marie-Ève Jean ${ }^{1}$, Sophie Duchesne ${ }^{1}$, Geneviève Pelletier ${ }^{2}$ and Martin Pleau ${ }^{3}$ \\ 1 Institut National de la recherche scientifique, Eau Terre Environnement Research Centre, Québec, Canada \\ 2 Université Laval, Department of Civil and Water Engineering, Québec, Canada \\ ${ }^{3}$ Tetra Tech CSO, Québec, Canada
}

\begin{abstract}
Combined sewer overflows (CSO) are associated with water quality degradation and health risks, but limited knowledge exists on the optimal solutions applicable to reach maximal overflow frequency targets as specified by some regulatory agencies. This study assesses the potential benefit of integrating source control with real-time control solutions based on hydrological/hydraulic modelling of urban catchments of the Province of Québec (Canada). Firstly, modelling procedures for volume sizing of CSO solutions are improved by determining the proper rainfall input among the three most common types of rainfall data (continuous simulation, historical rainstorms and IDF-derived storms) excluding winter months in the analysis to be aligned with Quebec legislation. Secondly, a methodological framework is developed to integrate source control and optimal real-time control solutions based on a cost-efficiency performance objective. Thirdly, two optimization software are coupled to iteratively solve for the best flow management strategy according to physical and operating constraints; iPOP for source control design and CSoft for dynamic control. Preliminary results showed that simulation of continuous rainfall series results in the most accurate volume estimations for sizing CSO solutions and IDF-derived design storms could serve as input data for initial optimization runs. Based on the determined appropriate rainfall data, source control optimization showed considerable solutions implementation cost reduction for acceptable runoff reduction. Future work includes refining the integrated solution framework and comparative analysis of modelling results under optimal implementation of source control and real-time control solutions.
\end{abstract}

Keywords: Combined sewer overflows; Source control; Real-time control; Rainfall data

\section{INTRODUCTION}

For many cities over the world, sanitary sewage and stormwater runoff are intercepted and transported together in a combined network toward a wastewater treatment plant. Per design, the capacity of this system will be surpassed during some wet weather events or thawing periods, causing discharge of untreated waters into receiving waters. These combined sewer overflows (CSOs) are one of the major causes of degraded water quality in urban rivers (Madoux-Humery et al., 2015) and the impact of climate change and urban land development are expected to exacerbate CSO-related problems (Yazdanfar and Sharma, 2015).

In the Province of Quebec (Canada), many municipalities are not achieving governmental overflow frequency targets to mitigate CSO impacts. For example, in the year 2013, a total of 36565 CSO events caused by rainfall or snowmelt events were recorded (MAMOT, 2014) contributing to aquatic life and environmental degradation, drinking water supply contamination and primary contact recreation restrictions. Municipalities are now required to demonstrate compensatory actions to avoid increasing the annual frequency of CSO under land development projects (MDDELCC, 2014). 


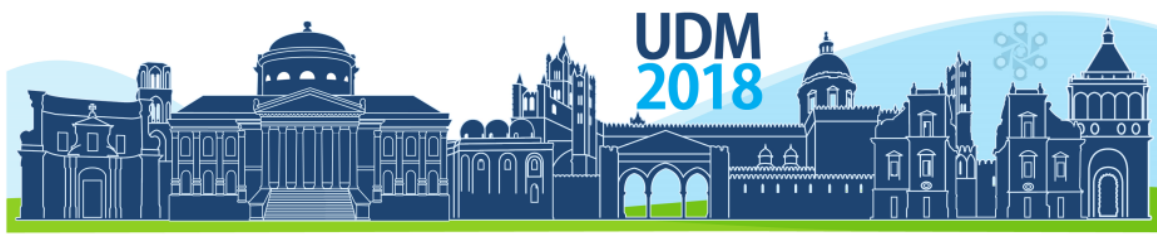

$11^{\text {th }}$ International Conference on Urban Drainage Modelling

23-26 Sep | Palermo - Italy

Implementation of CSO control measures presents significant challenges as only little knowledge exists on the adequate use of rainfall data for CSO analysis and the optimal choice of solutions to reach maximal annual overflow targets. To narrow these knowledge gaps, this research project aims at: 1) analysing the impact of rainfall inputs for sizing CSO mitigation measures; 2) elaborate an innovative methodological framework for integrating real-time and source control solutions optimization for CSO frequency reduction; and ultimately 3) evaluating how real-time control of the drainage network influences the design of source control practices at the watershed scale.

\section{MATERIALS AND METHODS}

\subsection{Study area}

The first case study is a 400 ha combined sewer catchment located in the southern part of Québec Province, Canada. The network was modelled using the hydrologic/hydraulic PCSWMM software (Computational Hydraulics International, 2016) and is schematised in Figure 1 with the ten overflow structures for which CSO frequencies and volumes were analysed (outfalls $A$ to $\mathrm{J}$ ). For this municipality, the provincial legislation imposes a maximum of seven CSOs during the wet weather season comprising May to November months.
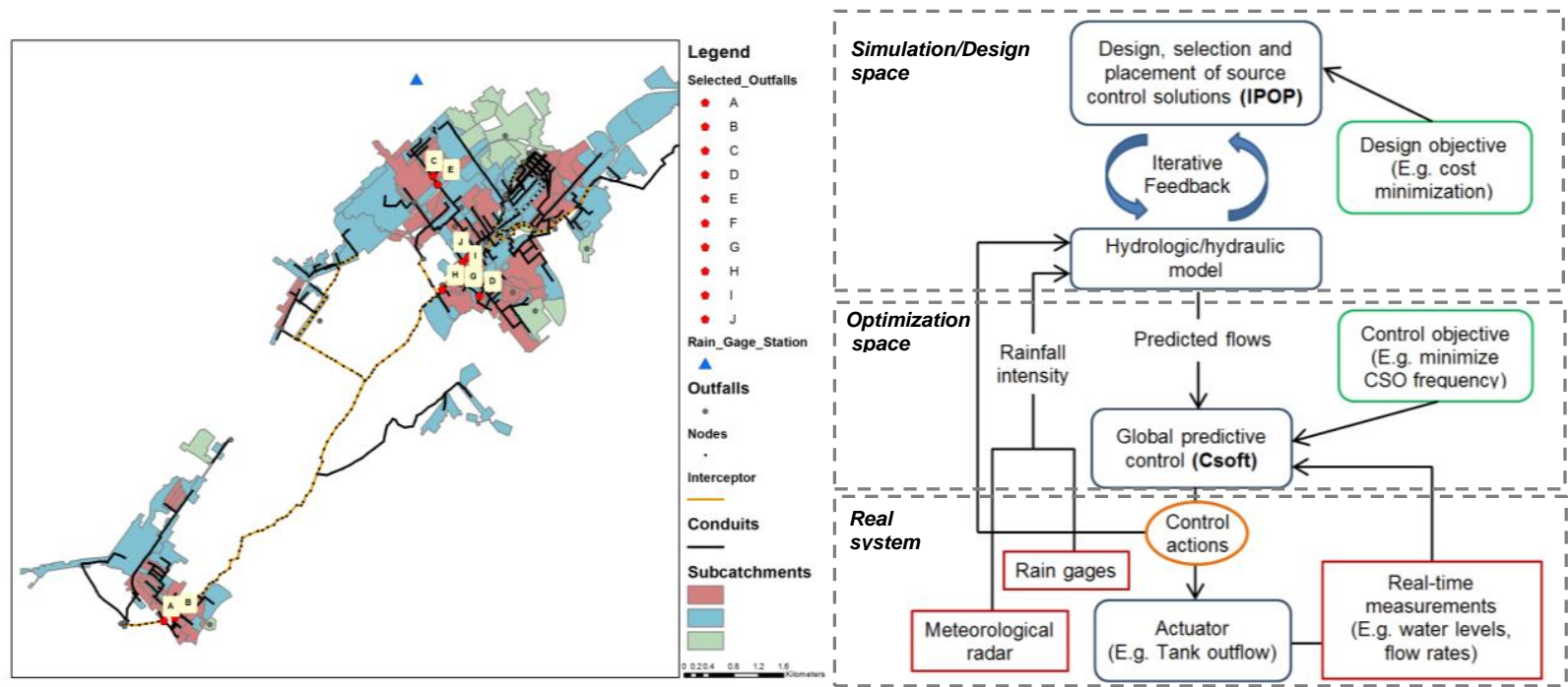

Figure 1. Combined sewer network and selected CSO structures

Figure 2. Optimization feedback loop between source control solutions and global predictive control

The second case study is a smaller combined sewer catchment of 102 ha located further south in Québec Province, Canada. The network comprises a deep tunnel of $2.1 \mathrm{~m}$ of diameter with one overflow structure located downstream.

\subsection{Rainfall data}

Different rainfall inputs were simulated to determine resulting impact on retention volume estimations for CSO frequency control. 


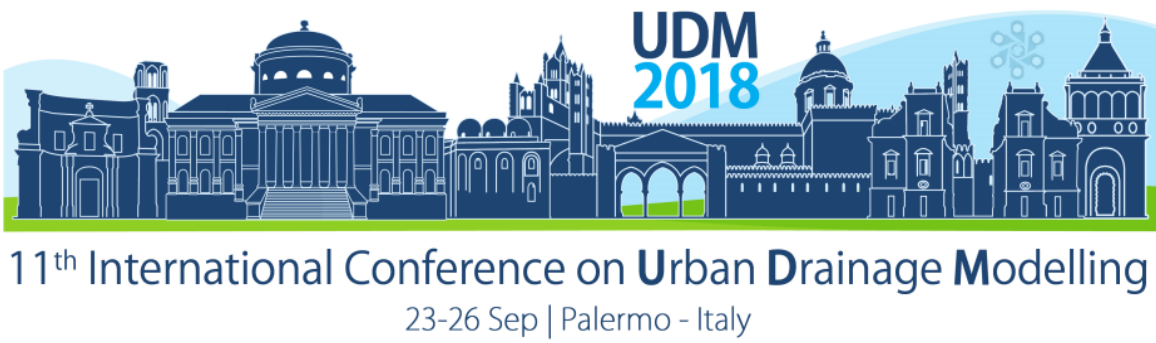

Continuous simulation. Nine years of seasonal 5-min rainfall data (May to November 20062009 and 2011-2015; since winter months are excluded from Quebec legislation).

Historical rainstorm events. A minimum inter-event time (MIT) criteria varying from 3, 6, 12 to $24 \mathrm{~h}$ was applied to the observed rainfall record. Historical design rainstorms were further selected among the MIT-separated series by frequency analysis, based on two rainfall event selection criteria: 1) total depth; and 2) maximal intensities over durations of 30,60, 120 and $180 \mathrm{~min}$. The selected events are exceeded, in depth or intensity, seven times a year maximum in order to achieve the annual CSO frequency target applicable at the case study location.

Intensity-Duration-Frequency (IDF) derived storms. IDF curves were constructed from daily maximum intensity values determined for durations varying from 5 to $1440 \mathrm{~min}$. From the IDF curves, the following synthetic storms were derived for a return period of seven times a year: 1) $1 \mathrm{~h}$, 3h and 6h Chicago storms (Keifer and Chu, 1957); 2) 1h Hydrotek storm (Watt et al., 1986); 3) 1h AES type 2 (Rousselle et al., 1990); and 4) 3h symmetrical triangular distribution.

\subsection{Conceptual framework for integrating solutions for CSO frequency control}

In order to assess the combined impact of applying real-time control and implementing source control practices, Figure 2 illustrates how the simulation, optimization and real system interact and the feedback loop linking global predictive real-time control of the network and source control solutions design. The methodology will further rely on the integration of two optimization software: Integrated Planning and Optimization Program (iPOP) and the Control of Sewer Overflow SOFTware (Csoft). iPOP is a software for optimizing the design of green and grey solutions for CSO abatement. It relies on SWMM 5 for sewer simulation and on a particle swarm optimization (PSO) or genetic algorithm (GA) for determining the optimal design (i.e. the alternative that enables to achieve the design objective(s) at the lowest cost or the most efficient options determined from Pareto front analysis). On the other hand, Csoft is a software dedicated to the operation of sewer systems. It enables to find the optimum setting of gates and pumps in order to minimize CSO frequencies and volumes. The optimal set points are determined using a Mix Integer Linear Programming algorithm.

The first step of the global methodology, is to apply iPOP and Csoft alone, which would provide comparison results for further assessing the combined benefit of integrating both design tools. In the case of source control optimization, the following procedure was followed for running iPOP: 1) Identification of land suitability for source control approaches based on detailed data on land uses, surface elevations, hydraulic soil conductivity and other geographical information, 2) Determination of the running parameters of SWMM (design rainfall event and simulation options), 3) Development of the optimization objective penalties and source control implementation cost functions, and 4) Selection of the iPOP optimization parameters including the optimization algorithm, population size, objective method (cost minimization or costefficiency curve), present worth analysis period and other economic considerations.

\section{RESULTS AND DISCUSSION}

\subsection{Rainfall input impact on the volume of CSO control solutions}

Figure 3 compares the design volume estimated with the different rainfall inputs for the study catchment. Volume determination is used as a point of comparison for rainfall data assessment, whereas the next research steps will include solution type, placement and operation. Continuous simulation of rainfall records led to solution sizing specific to each outfall 


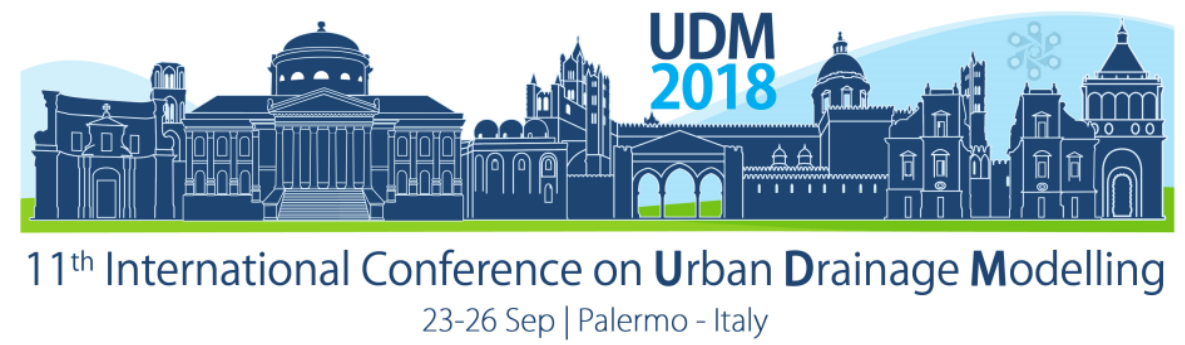

structures. However, reducing the number of years in the analysis rapidly impacted the estimated volumes (see Figure 4) as a consequence of inter-annual variability of rainfall data. For the historical design rainstorms based on total depth or maximal intensity, retention volume estimations demonstrated high inter-event variability, which is disputably applicable as design criteria for CSO control. Finally, event-based simulation of synthetic design storms derived from multiple IDF values such as Chicago storms should be prioritized over other standard storms as they resulted in volume estimations closer to those of continuous simulation. Synthetic design storms should serve as preliminary assessment of CSO control solutions and optimization runs, whereas continuous simulation for the final design and validation.
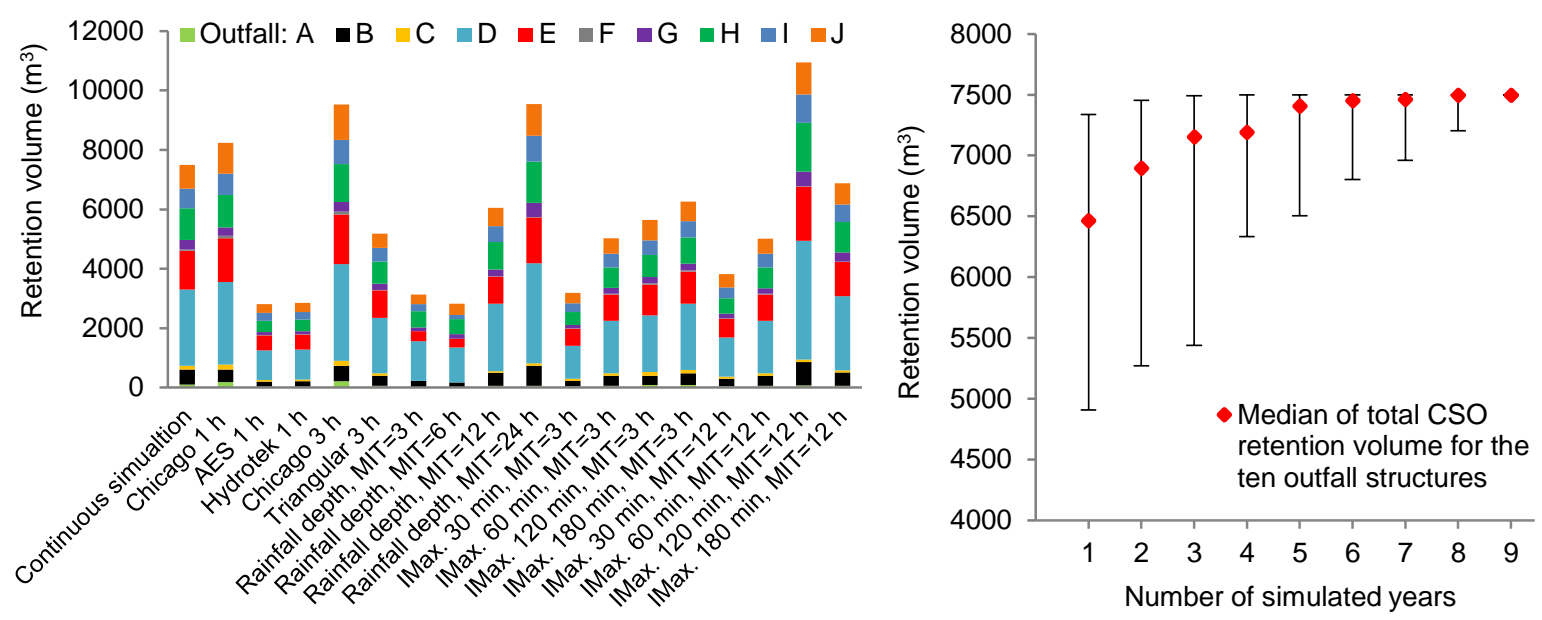

Figure 3. Retention volumes estimated to achieve a maximum of 7 CSOs per year under continuous simulation and event-based simulation

Figure 4. Sensitivity to the number of years of the total retention volumes computed for the 10 outfall structures to achieve a maximum of 7 CSOs per year

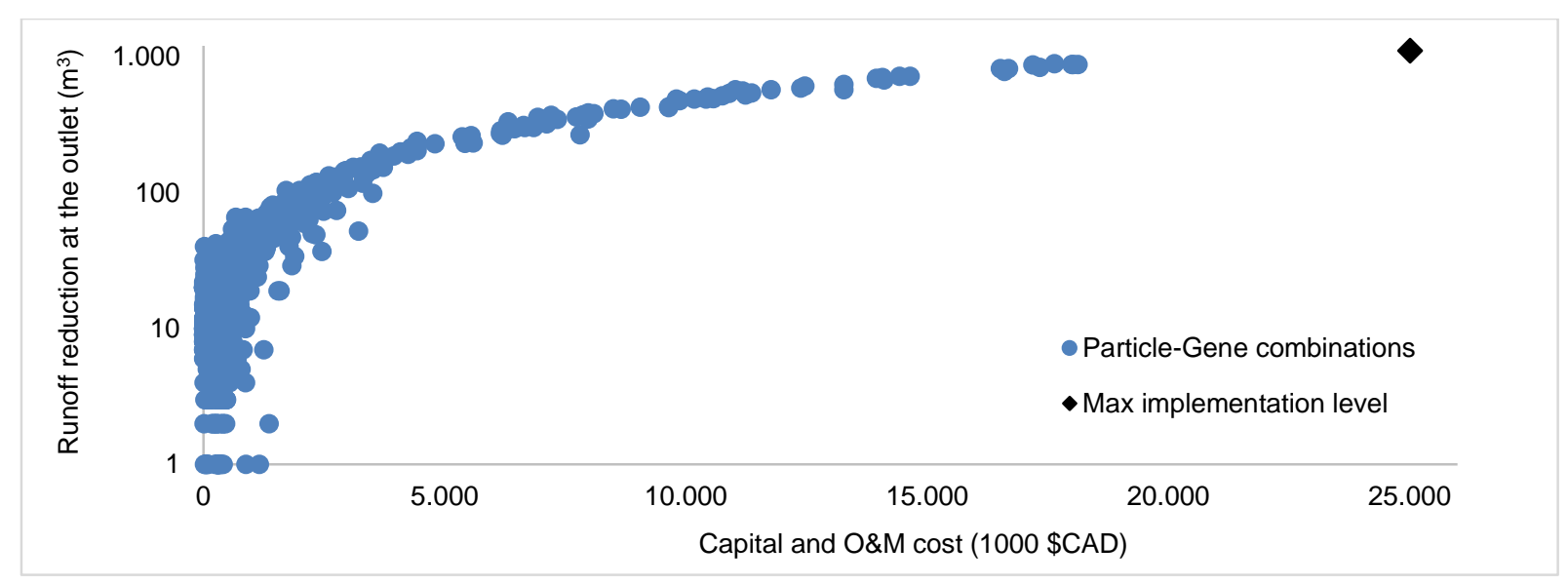

Figure 5. Cost-efficiency results for bioretention cells implementation

\subsection{Source control optimization}

Preliminary optimization results of bioretention cells quantity and placement at the watershed scale was conducted for the second case study under PSO. Figure 5 presents efficiency-cost 


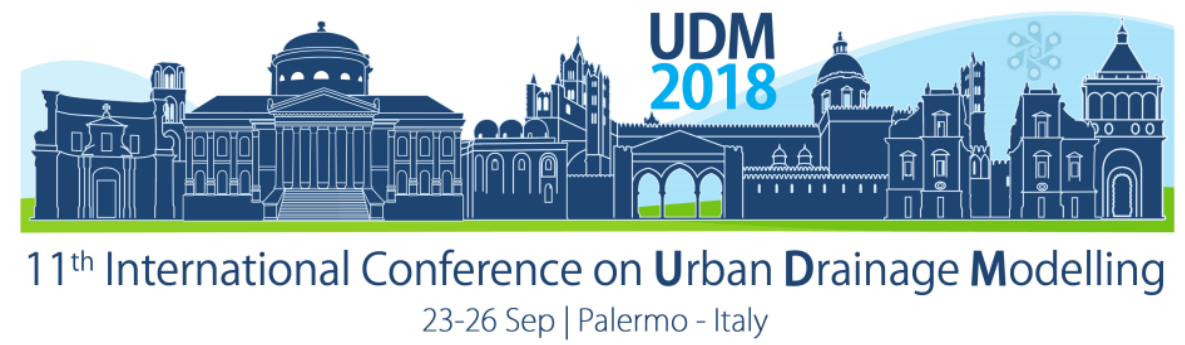

results based on a runoff reduction objective. The design rainfall event is selected according to the above analysis (Chicago storm of $3 \mathrm{~h}$ and a return period of 7 times a year) and has a frequency which corresponds to typical CSO frequency targets. Compare to the maximum implantation level, results demonstrated considerable capital, operation and maintenance cost reduction over the analysis period of 20 years for acceptable runoff reduction. Interestingly, the highest level of bioretention cells implementation is usually not located in the subcatchments having the greatest impervious surfaces. Further work will permit to determine optimal combination of multiple source control technologies (bioretention cells, permeable pavements, infiltration trench, etc.) to achieve CSO frequency targets in particular rather than only overall runoff reduction.

\section{CONCLUSIONS}

This study addresses the knowledge gaps of CSO frequency control. A better understanding of the impact of rainfall data on solution design is a prerequisite for improving modelling procedures for CSO analysis. Simulation of a continuous rainfall record results in the most accurate volume estimations for refining CSO solutions sizing, whereas IDF-derived design storms provide acceptable results for initiating optimization design. Based on adequate rainfall data selection method, the impact of integrating source control with online real-time control solutions can further be assessed. Preliminary results for source control quantity and placement optimization showed iPOP potential for reducing overall runoff while limiting investments. Future work will permit to apply both source control and real-time control optimization tools in integration to achieve CSO frequency targets. The research findings contribute to the advancement of knowledge concerning urban drainage system modelling for optimal solutions development for CSO control.

Acknowledgements: The authors gratefully acknowledge the technical support of James Brescol at Tetra Tech CSO and Véronique Guay from INRS, as well as the two municipalities who provides the data and Computational Hydraulics Int. for PCSWMM software license. This study was funded by the Natural Sciences and Engineering Research Council of Canada.

\section{References}

Computational Hydraulic International (2016). PCSWMM Version 6.2070, Toronto, Ontario.

Keifer, C. J., and Chu, H. H. (1957). Synthetic storm pattern for drainage design. J. Hydraul. Eng. 83(HY4), 13321133225.

Madoux-Humery, A-S., Dorner, S. M., Sauvé, S., Aboulfadl, K., Galarneau, M., Servais, P., and Prévost, M. (2015). Temporal analysis of microbiological and wastewater micropollutants loads from combined sewer overflows: implication for management. Environ. Sci.: Processes Impacts. 17(5), 965-974.

Ministère des Affaires municipales et de l'Occupation du territoire (MAMOT) (2014). Évaluation de performance des ouvrages municipaux d'assainissement des eaux pour l'année 2013. ISBN 978-2-550-70842-1. " Performance evaluation of municipal wastewater treatment facilities for the year 2013."

Ministère du Développement durable de l'Environnement et de la Lutte contre les changements climatiques (MDDELCC). (2014). Position sur l'application des normes pancanadiennes de débordement des réseaux d'égout municipaux. 〈http://www.mddelcc.gouv.qc.ca/eau/eaux-usees/ouvrages-municipaux/positionministere.htm〉 (Jan. 11, 2018). "Position on the application of the Canada-wide Strategy for the Management of Municipal Wastewater Effluent."

Watt et al. (1989). Hydrology of floods in Canada - a guide to planning and design, National Research Council Canada. Associate Committee on Hydrology, Ottawa, Canada.

Watt, W.E., Chow, K. C. A., Hogg, W. D., and Lathem, K. W. (1986) A 1-h urban design storm for Canada. Can. J. Civ. Eng. 13(3): 293-300.

Yazdanfar, Z., and Sharma, A. (2015) Urban drainage system planning and design--challenges with climate change and urbanization: a review. Water Sci. Technol. 72(2), 165-79. 


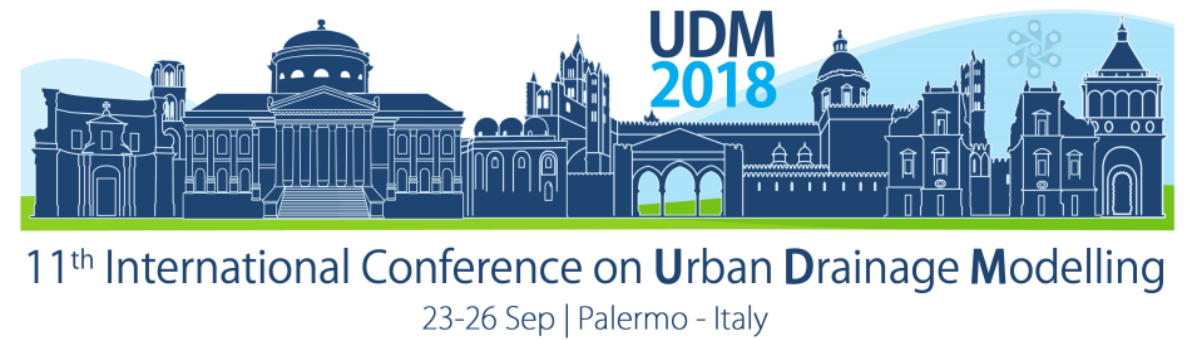

\title{
Using the Ensemble Kalman Filter to update a fast surrogate model for flow forecasting
}

\author{
Nadia Lund', Maurizio Mazzoleni' ${ }^{2}$, Henrik Madsen ${ }^{3}$, Ole Mark ${ }^{3}$, Peter Steen Mikkelsen ${ }^{1}$, Dimitri Solomatine ${ }^{2}$ \\ and Morten Borup' \\ ${ }^{1}$ Department of Environmental Engineering (DTU Environment), Technical University of Denmark, Bygningstorvet, \\ Building 115, 2800 Kgs. Lyngby, Denmark \\ 2Department of Integrated Water Systems and Governance, IHE Delft, Westvest 7, 2611AX Delft, the Netherlands
} ${ }^{3} \mathrm{DHI}$, Agern Allé 5, 2970 Hørsholm, Denmark

\begin{abstract}
Many cities face issues with rain induced flooding and combined sewer overflows, which can be addressed by using hydrodynamic models. These models are often simplified in a real-time setting to make them faster, and their performance can be improved by using data assimilation. In this study we use the Ensemble Kalman Filter to update a simplified model of a small area of Copenhagen, Denmark. The model is evaluated using perfect rain data for one summer month in 2016, and flow forecasts are used to quantify the performance of the update. We found that the 1-60 minutes forecast can be improved by updating the model. Having a small noise on the rain gives slightly worse results on a short forecast horizon and slightly better forecasts on a longer horizon. The forecast performance is also dependent on which model parts are updated.
\end{abstract}

Keywords: Data assimilation; surrogate model; flow forecasting

\section{INTRODUCTION}

Changes in precipitation patterns and increased urbanisation will often lead to increased runoff. This increase may result in more frequent bypasses at the wastewater treatment plants, flooding of streets and discharge of polluted mixed storm- and wastewater through combined sewer overflows (CSOs). Real-time urban drainage models, spanning from simplified models to detailed 1D hydrodynamic models (high-fidelity (HiFi) models), can be used to monitor the system and localize misbehaviours, forecast flooding or make a more optimal control of the system to reduce negative effects of the increased runoff. The reduction in computational cost is the main incentive to use simplified models. The uncertainty can be reduced by using measurements from the sewer system to update the real-time model every few minutes (also known as data assimilation). Data assimilation is well-known in many fields, but has not been used often within urban drainage (see Borup et al. 2011, 2014, 2015; Branisavljevic et al. 2014, Hansen et al. 2011; Hutton et al. 2014).

Model predictive control (MPC) of sewer systems typically employs a combination of various models (Lund et al., 2018), including models that produce flow inputs for the MPC. The fast and simple surrogate model by Borup et al. (2017) is developed for this purpose, and has the advantages of being thousands of times faster than the HiFi models they are constructed from, while maintaining the ability to predict key outputs. They furthermore do not have to rely on historical data for parameterization. The objective of this study is to quantify to which extent data assimilation can improve the forecast quality of these models by using downstream flow measurements. The update is done every minute using the Ensemble Kalman Filter (EnKF) since this works well with non-linear models and provides useful initial conditions for ensemble based forecasts, which is the long term goal of the proposed setup. 


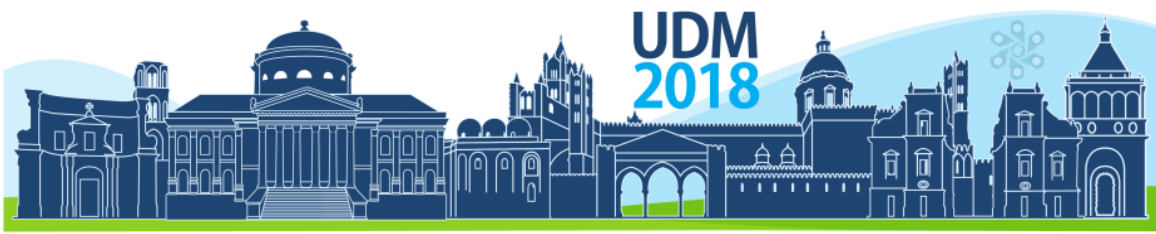

$11^{\text {th }}$ International Conference on Urban Drainage Modelling

23-26 Sep | Palermo - Italy

To our knowledge, the use of the EnKF to update fast surrogate models has not previously been studied within urban drainage.

\section{MATERIALS AND METHODS}

\subsection{Surrogate model and data}

We use a catchment of approximately $1.5 \times 1.6 \mathrm{~km}^{2}$ in Copenhagen, Denmark, as case study. The area is modelled using a surrogate model consisting of compartments, which each consists of one or more piecewise linear volume-discharge curves. These have been calibrated from a MIKE URBAN model (see Borup et al. (2017)). Figure 1 shows the setup of the compartment model. This area is of particular interest because it previously has been used in a MPC study (Lund et al. (2017)).

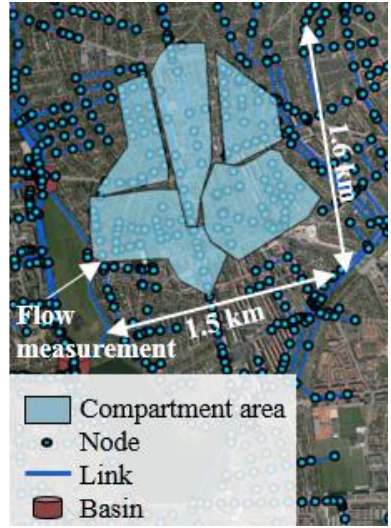

(a)

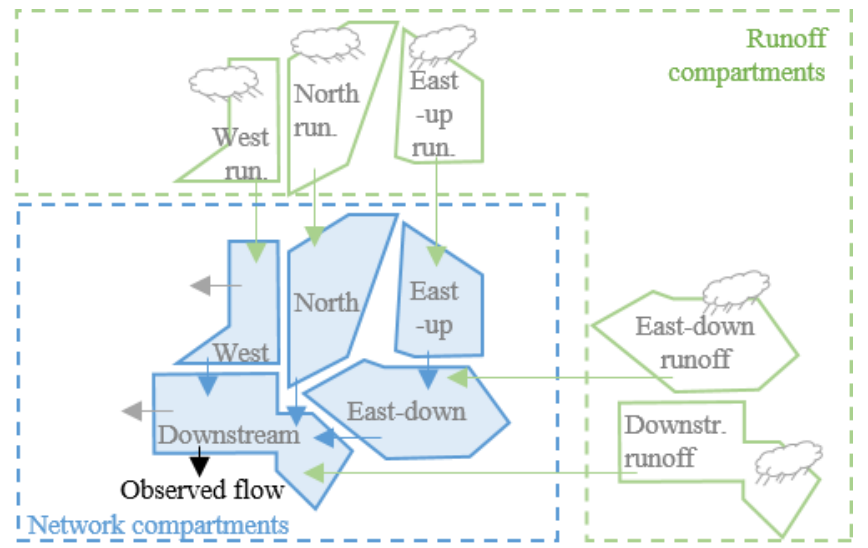

(b)
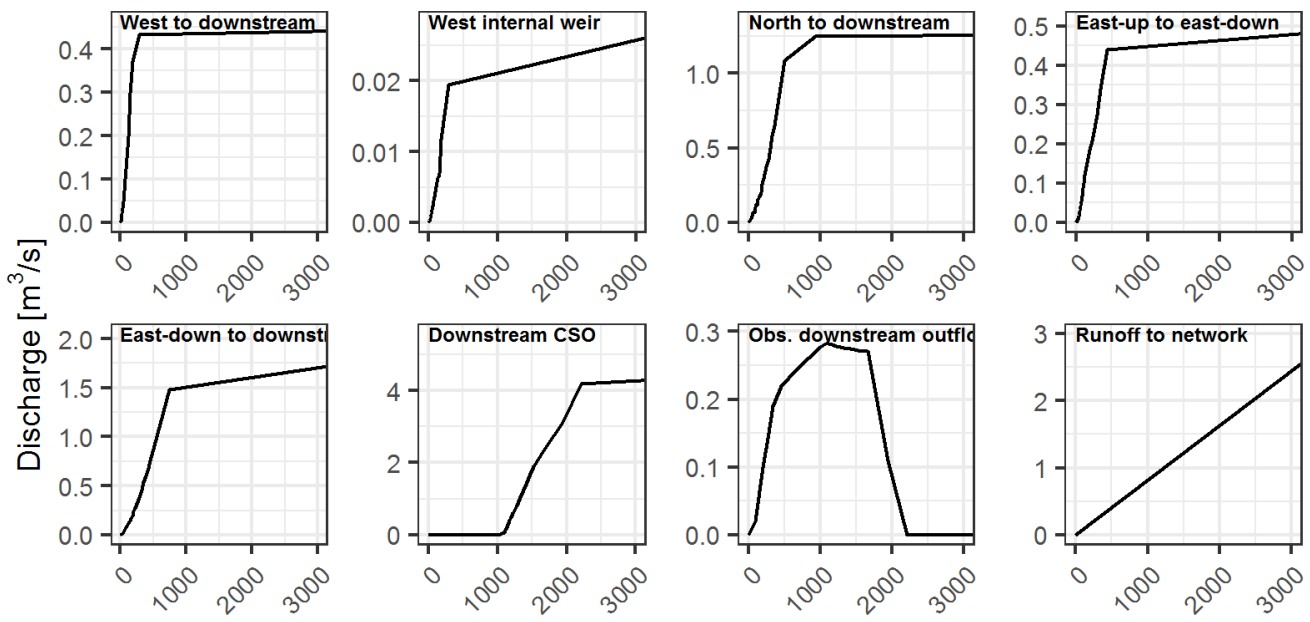

Volume $\left[\mathrm{m}^{3}\right]$

(c)

Figure 1. (a) MIKE URBAN model and its division into compartments; (b) Conceptualization of compartment model; (c) Volume-discharge curves for the network and the common curve for all runoff compartments.

The model is forced with one-minute rainfall data from June 16 to July 13,2016 . The rain measurements are obtained from the rain gauge SVK 5710 placed $0.5-2 \mathrm{~km}$ outside of the considered area. The surrogate model was constructed using synthetic rain data; thus, the 


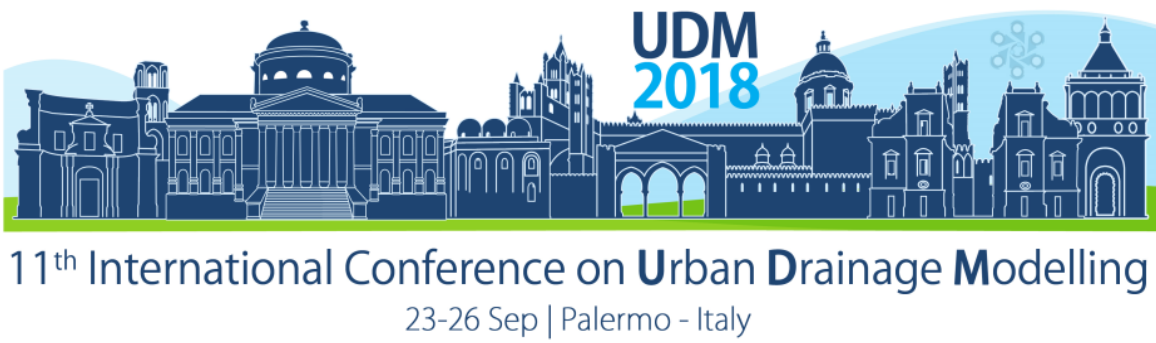

model itself does not compensate for any errors in the observed rainfall. The rain is translated to flow in the five runoff compartments simply by multiplying the rain intensity with the impermeable surface area of each compartment while a dry weather flow component is added to the downstream compartment. The runoff and network compartments mimic the runoff and network simulation of MIKE URBAN, respectively. Flow measurements are obtained from the outlet of a CSO structure located in the downstream end of the catchment for the same time period.

\subsection{The Ensemble Kalman Filter}

EnKF is a Monte Carlo implementation of the standard Kalman Filter in which an ensemble of models is used to represent the model uncertainty. Each model in the ensemble is represented by its state vector, which in the current example is a vector with all compartment volumes. The essence of the EnKF is that the ensemble is used to calculate the Kalman gain which then is used to adjust the values of the state vectors in the ensemble itself when new observations are available. In this way the information present in the observations is sequentially integrated into the ensemble and the ensemble mean is assumed to be the best estimate of the truth (more information can be found in Evensen (2003)).

In this study, we apply an ensemble size of 50 ensemble members. The relative error in the rainfall data is assumed uniformly distributed (Eq. 1) while the relative error in the observations is assumed normally distributed (Eq. 2)

$$
\begin{gathered}
I_{\text {ens }}(t)=I_{\text {obs }}(t) \boldsymbol{\varepsilon}_{\text {rain,perturb }}(t), \boldsymbol{\varepsilon}_{\text {rain,perturb }}(t) \sim U\left[\lim _{\min }, \lim _{\max }\right] \\
\boldsymbol{Q}_{\text {ens }}(t)=Q_{\text {obs }}(t) \boldsymbol{\varepsilon}_{\text {obs,perturb }}(t), \boldsymbol{\varepsilon}_{\text {obs,perturb }}(t) \sim N\left(1, \alpha Q_{o b s}\right)
\end{gathered}
$$

\subsection{Flow forecasts and performance evaluation}

Flow forecasts from the downstream compartment are compared to the flow measurements to examine the potential of using data assimilation in a forecast setting, for example, as input to MPC. Since we do not know the "truth" for the internal model states, the flow forecasts will also give an indication of the quality of the update of the internal states. In this study we assume "perfect rainfall forecast", i.e. the forecasted rainfall equals the measured rainfall in the forecast step. We apply deterministic forecasting, i.e. the mean of the ensemble is used as initial conditions in a surrogate model that is run up to 180 min into the future. The NashSutcliffe Efficiency (NSE) is used to evaluate the performance impact of different settings of data assimilation against the baseline scenario without data assimilation. The changes in settings include altering the assumed noise in the rainfall $\left(\lim _{\min }\right.$ and $\left.\lim _{\max }\right)$ and varying the set of compartments to be updated.

\section{RESULTS AND DISCUSSION}

When setting $\alpha=0.1$ for the noise in observations (Eq. 2) and updating all compartments, we first see that updating the model improves the forecasts 1-60 minutes ahead significantly. We also find that there is no significant difference between having a rain perturbation of $\mathrm{U}[0.5,1.5]$ and $\mathrm{U}[-2,4]$ (negative rain will practically remove water from the runoff compartments). Compared to these settings, the rain perturbation of $U[0.9,1.1]$ leads to slightly worse performance for shorter forecast horizons and slightly better for longer horizons. 


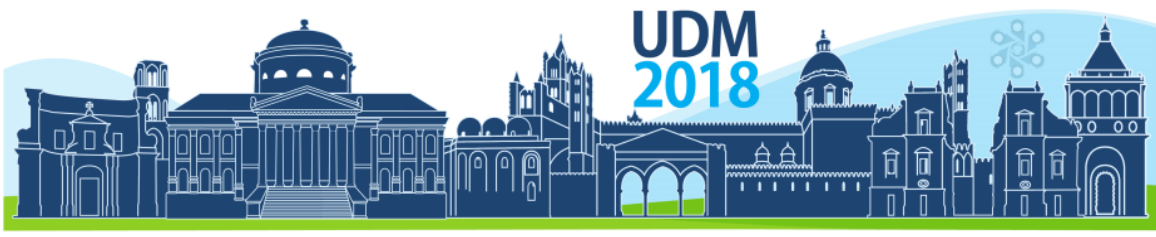

$11^{\text {th }}$ International Conference on Urban Drainage Modelling

23-26 Sep | Palermo - Italy

If we additionally change the set of compartments to update, we see that updating only the runoff compartments performs poorly. When using noise of $U[0.9,1.1]$ in the rain, there is no big difference between updating all compartments, network compartments or only the downstream network compartment. Updating the downstream network compartment thus outweighs the update of the other compartments. For a rain perturbation of $U[-2,4]$, forecasts horizons above 15 minutes benefit from not updating the runoff compartments, but is otherwise also dominated by the update of the downstream compartment. Future research will focus on incorporating time correlated noise in rainfall and compare the surrogate model forecast performance with the performance of the corresponding MIKE URBAN model.

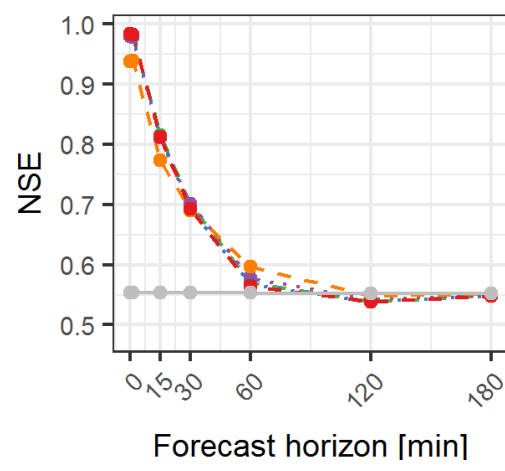

(a)

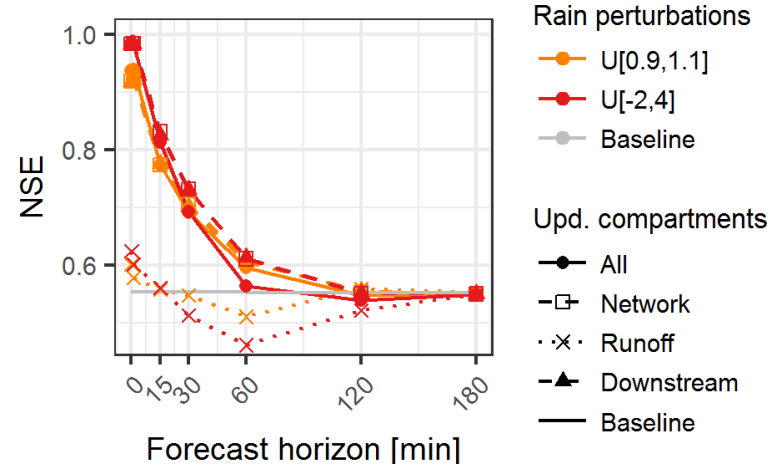

(b)

Figure 2. Nash-Sutcliffe Efficiency of flow forecasts by (a) varying the noise perturbations on the rain, and (b) varying which surrogate model compartments are updated.

\section{CONCLUSIONS}

We use the Ensemble Kalman Filter to update the volumes in a surrogate model of a $2.4 \mathrm{~km}^{2}$ catchment in Copenhagen, Denmark. We found that updating the model leads to improved 160 minutes forecasts. A small rain perturbation decreases the performance for short forecast horizons compared to a larger rain perturbation, and increases the performance for longer forecast horizons. We also found that the performance can be improved by not updating the runoff compartments, but that updating the downstream network compartment generally improved the performance. The immediate future research efforts will focus on including the time correlation of the noise in rainfall in the updating scheme and comparison of the performance with a MIKE URBAN model.

\section{References}

Borup, M., Grum, M., and Mikkelsen, P.S. (2011). Real time adjustment of slow changing flow components in distributed urban runoff models. Proceedings of the $12^{\text {th }}$ International conference on urban drainage, Porto Alegre, Brazil.

Borup, M., Grum, M., Madsen, H., and Mikkelsen, P.S. (2014). Updating distributed hydrodynamic urban drainage models. Proceedings of the 13th International conference on urban drainage, Sarawak, Malaysia.

Borup, M., Grum, M., Madsen, H., and Mikkelsen, P.S. (2015) A partial ensemble Kalman filtering approach to enable use of range limited observations. Stoch. Environ. Res. Risk Assess. 29, 119-129.

Borup, M., Thrysøe, C., Arnbjerg-Nielsen, K., Righetti, F., Mikkelsen, P.S. (2017). A fast surrogate model tailormade for real time control. Proceedings of the $14^{\text {th }}$ International conference on urban drainage, Prague, Czech Republic, 2486-2488.

Branisavljevic, N., Hutton, C., Kapelan, Z., Vamvakeridou-Lyroudia, L., and Savić, D.A. (2014). Real-Time Runoff Prediction Based on Data Assimilation And Model Bias Reduction. 11 th Int. Conf. Hydroinformatics, New York City, USA. 
Proceedings of the 11th Int. Conference on Urban Drainage Modelling, 23-26 Sep. 2018, Palermo (ITALY). Ed. prof. Giorgio Mannina

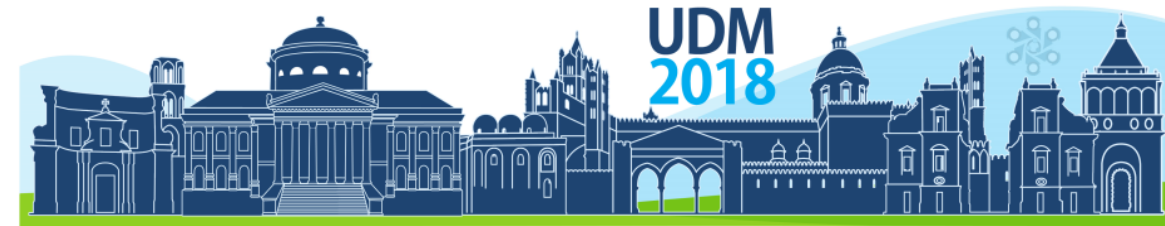

$11^{\text {th }}$ International Conference on Urban Drainage Modelling

23-26 Sep | Palermo - Italy

Evensen, G. (2003). The Ensemble Kalman Filter: theoretical formulation and practical implementation. Ocean Dynamics 53, 343-367.

Hansen, L.S., Borup, M., Møller, A., and Mikkelsen, P.S. (2011). Flow Forecasting in Urban Drainage Systems using Deterministic Updating of Water Levels in Distributed Hydraulic Models. Proceedings of the $12^{\text {th }}$ International conference on urban drainage, Porto Alegre, Brazil.

Hutton, C.J., Kapelan, Z., Vamvakeridou-Lyroudia, L., and Savić, D. (2014). Real-time data assimilation in urban rainfall-runoff models. Procedia Eng., 70, 843-852.

Lund, N., Borup, M., Halvgaard, R., Falk, A. K., Mark, O., Madsen, H., and Mikkelsen, P.S. (2017). Advancing from underground to aboveground model predictive control in urban drainage. Proceedings of the $14^{\text {th }}$ IWA/IAHR International conference on urban drainage, Prague, Czech Republic, 2486-2488.

Lund, N.S.V., Falk, A.K.V., Borup, M., Madsen, H., and Mikkelsen, P.S. (2018). Model predictive control of urban drainage systems: a review and perspective towards smart real-time water management. Critical Reviews in Environmental Science and Technology, 48(3), 279-339. DOI: 10.1080/10643389.2018.1455484 


\title{
Active Control of Combined Sewer Systems Based on Flow and Water Quality
}

\author{
Tiku T. Tanyimboh \\ School of Civil and Environmental Engineering, University of the Witwatersrand, Johannesburg, \\ Private Bag 3, WITS 2050, South Africa
}

\begin{abstract}
Discharges from urban wastewater systems are the main source of pollution for inland and coastal waters, and intermittent unsatisfactory discharges from combined sewer systems have been recognized as a major environmental concern. The aim of the research was to investigate active system control of an interceptor sewer system. The dynamic multiobjective optimization approach developed considered the unsteady flow and pollution load in the sewers and wastewater treatment costs. Contrary to previous approaches in the literature, the combined effect of the various primary contaminants was addressed by means of the effluent quality index.
\end{abstract}

Keywords: Combined sewer systems, active system control, combined sewer overflows, effluent quality index, constrained multiobjective evolutionary optimization, wastewater treatment cost, effluent quality

\section{INTRODUCTION}

Discharges from urban wastewater systems are the main source of pollution for inland and coastal waters, and intermittent unsatisfactory discharges from combined sewer systems have been recognized as a major environmental concern. The aim of the research was to investigate active system control of an interceptor sewer. The methodology considers the unsteady flow and pollution load in the sewers and wastewater treatment costs. This article extends the dynamic optimization approach in Rathnayake and Tanyimboh (2015) to the case of two consecutive storms. Contrary to previous approaches in the literature, the combined effect of the various primary contaminants is addressed by means of the effluent quality index. The article's focus is the entire system's optimization, an aspect of the real time control of urban drainage systems. The problem is really complex and multi-faceted. Information on the other aspects such as flow measurement, water quality analyses, control of the wastewater treatment works, etc. is available elsewhere.

\section{OPTIMIZATION PROBLEM FORMULATION}

The pollution load was modelled as in Eq. 1. The subscripts $t$ and $i$ represent the time steps and overflow chambers, respectively; $N_{t}=$ number of time steps; $N_{i}=$ number of overflow chambers; $E_{i, t}=$ pollution load from overflow chamber $i$ during time step $t ; f_{1}$ is the total pollution load to the receiving water for the entire duration of the storm.

$$
f_{1}=\sum_{t=1}^{N_{t}} \sum_{i=1}^{N_{i}} E_{i, t}
$$

Eq. 1 accounts for the changes in the concentrations of the contaminants in the wastewater throughout the duration of a storm, based on the effluent quality index. The effluent quality index considers the effects of several important wastewater contaminants in aggregate and includes the total suspended solids (TSS), chemical oxygen demand (COD), five-day biochemical oxygen demand (BOD), total Kjeldahl nitrogen (TKN) and nitrates/nitrites ( $\left.\mathrm{NO}_{x}\right)$ (Kim et al. 2006, Lee et al. 2006).

A generic indicative cost model for wastewater treatment based on various models and data in the literature was adopted (Hernandez-Sancho and Sala-Garrido 2008, United Nations 2003, Rathnayake and Tanyimboh 2015). The cost model used in Eq. 2 is for the total operating cost, i.e. treatment, personnel, energy, maintenance, etc. Any alternative cost function may be used instead. In Eq. 2, $C_{t}$ is the wastewater treatment cost for time step $t$ and $f_{2}$ is the total cost for the entire duration of the storm.

$$
f_{2}=\sum_{t=1}^{N_{t}} C_{t}
$$


The decision variables of the optimization problem were the control settings for the CSO (combined sewer overflow) chambers that regulated the flow rates to the interceptor sewer system. An orificebased system of control was assumed, and the aim of the optimization was to determine the timevarying optimal orifice settings (heights) for the duration of the storm, considering the flow and pollution load in the sewer. The objective functions $f_{1}$ and $f_{2}$ were minimised subject to the constitutive equations including the conservation of mass and energy that were satisfied externally in the hydraulic simulation model used (SWMM 5.0) (Rossman 2009). The maximum flow rate constraints for the various sewer sections were included, along with the relevant controls for the CSO chambers.

\section{COMPUTATIONAL SOLUTION METHODOLOGY}

The SWMM 5.0 (storm water management model) (Rossman 2009) hydraulic simulation model was linked to NSGA II (nondominated sorting genetic algorithm) (Deb et al. 2002) using C. Wastewater flow from the CSO chambers to the interceptor sewer was controlled using an orifice at the bottom of the CSO chamber. The orifice openings at the first time step of the storm were initially generated randomly. In this way, the initial values of the decision variables, i.e. the flow rates through the interceptor sewer sections, were generated. Next, a full hydraulic simulation, including water quality routing was carried out for the first time step. The results obtained from the hydraulic simulation were used to evaluate the fitness based on the objective function values.

Depending on the sewer network's actual priorities based on any financial, economic or environmental constraints, one or more optimal solutions may be selected from the Pareto optimal front from the first time step. Thus the control settings for the selected optimal solutions were obtained, and these solutions provided options for the starting point for the next time step. Next, the optimization algorithm was executed to find the Pareto-optimal solutions for the second time step. The same process was carried out until the last time step, to yield the control settings for the entire duration of the storm.

The flow continuity and energy conservation equations were automatically satisfied in the hydraulic simulation model. The maximum flow rate constraints were addressed using the constraint dominance approach in NSGA II (Deb 2000, Deb et al. 2002). For both the single and two consecutive storms, the population size used was 100, with 100 generations and a crossover probability of 1.0. The distribution indices for the crossover and mutation operators were 20 . The mutation probability was 0.6 , based on preliminary testing (Rathnayake and Tanyimboh 2012). Optimization runs with independent random seeds were conducted.

\section{CASE STUDIES}

The interceptor sewer system investigated (Rathnayake and Tanyimboh 2012) is shown in the schematic diagram in Figure 1. Additional details are available in Rathnayake and Tanyimboh (2015) and Thomas (2000). The flow rates in the sewers C1 to C3 and C4 to C7 were limited to the respective capacities, i.e. $3.26 \mathrm{~m}^{3} / \mathrm{s}$ and $7.72 \mathrm{~m}^{3} / \mathrm{s}$. The on-line storage tanks T8 and T9 were controlled in SWMM 5.0 to ensure there were no overflows from these tanks. The details of the hydrographs for a single storm are available in Thomas (2000). A medium pollution level, i.e. TSS = $220 \mathrm{mg} / \mathrm{L}, \mathrm{COD}=500 \mathrm{mg} / \mathrm{L}, \mathrm{BOD}=220 \mathrm{mg} / \mathrm{L}, \mathrm{TKN}=25 \mathrm{mg} / \mathrm{L}$ and $\mathrm{NO}_{\mathrm{x}}=40 \mathrm{mg} / \mathrm{L}$ was assumed, and pollutographs (Figure 2) based on different land-uses were applied (Rathnayake and Tanyimboh 2015).

The routing time-step in SWMM 5.0 was 30 seconds, and the optimization problem was solved using time steps of 15 minutes. The two extreme solutions highlighted in Figure 3 (solid circles), that respectively represented the minimum pollution load to the receiving water and minimum wastewater treatment cost, were selected from the Pareto optimal front. The control settings, i.e. the orifice heights, were obtained for the selected solutions. These settings were used in the hydraulic model as the two starting points for the next optimization time step. It is worth noting that hydraulic simulation of 
the sewer system is integral to the formulation and solution of the optimization problem. Hence, the details of the storage tanks, CSO chambers, etc. are not discussed here as space is limited. For example, Chen et al. (2013) described a CSO chamber and its modelling in detail.

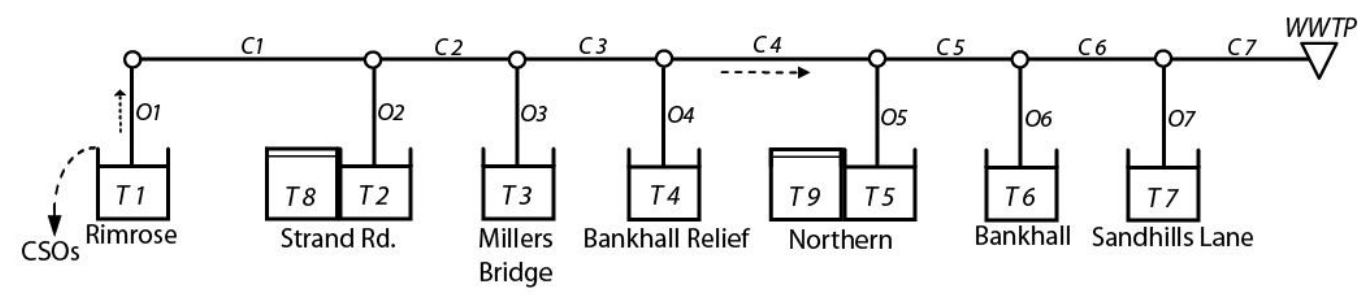

$$
\begin{aligned}
& \text { T1 - T7: Sewer chambers } \\
& \text { T8-T9: Storage tanks } \\
& \text { C1-C 7: Interceptor sewer conduits } \\
& \text { O1 - O7: Orifices } \\
& \text { WWTP: Wastewater treatment plant } \\
& \rightarrow-\rightarrow-\rightarrow \text { Flow directions }
\end{aligned}
$$

Figure 1. Interceptor sewer system

\section{RESULTS AND DISCUSSION}

Figure 3 shows the Pareto-optimal front achieved at 00:15:00 hours, i.e. 15 minutes. Results from the hydraulic simulations for the minimum pollution load solution are presented in Table 1, and the flow rates in the various sewer sections satisfied the maximum flow rate constraints.

For two consecutive storms, runoff hydrographs and pollutographs for two consecutive storms, as shown in Figure 2, were fed to the CSO chambers. The same sewer flow rate constraints and controls of the storage tanks were used in the optimization. Separate optimization runs were performed using 15 minute time steps for the minimum pollution load and minimum treatment cost. Table 2 shows the resulting wastewater flow rates in the interceptor sewer for the duration of the storm.

Additional extensive verification considering the quality of the solutions in terms of the feasibility and optimality of the solutions suggested that the methodology proposed yielded good results consistently. The solution procedure used provided results for the minimum pollution load and minimum treatment cost. Only solutions for the minimum pollution load have been presented due to the limitations of space. The combined sewer overflow rates and pollution loads along with the depths of water at the CSO chambers and storage tanks were investigated in detail using the hydraulic simulation model and the results were deemed to be satisfactory. These results would inform real-time control decisions.

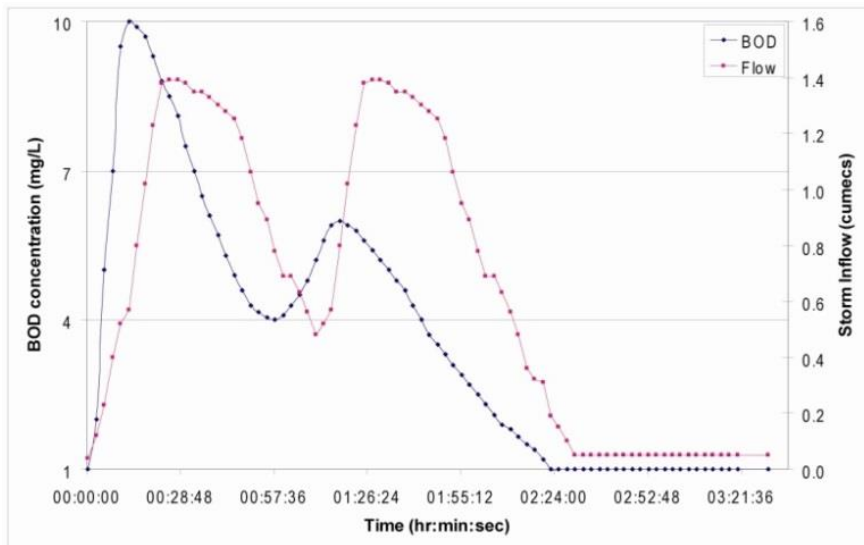

Figure 2. Two-storm pollutograph for Millers Bridge

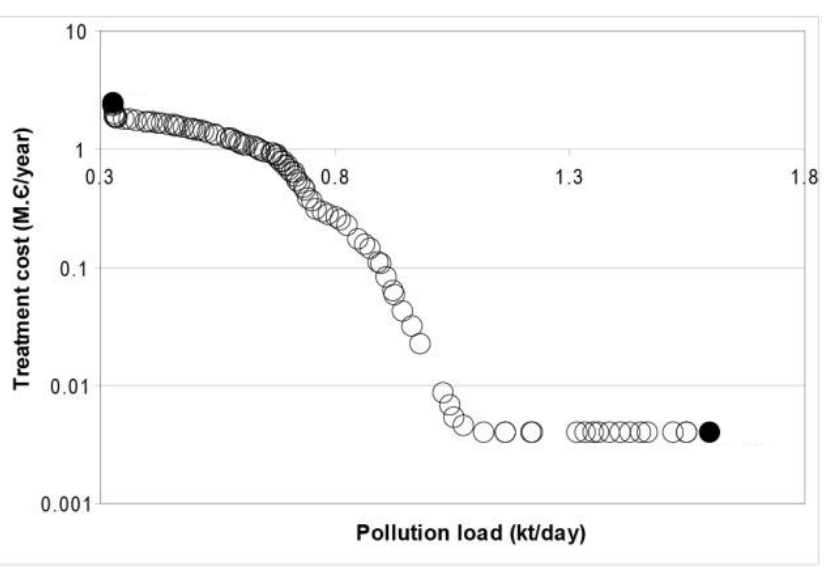

Figure 3. Pareto optimal front after 15 minutes 
Table 1. Flow rates through sewer sections for minimum pollution load from a single storm

\begin{tabular}{cccccccc}
\hline & \multicolumn{7}{c}{ Interceptor sewer flow rates $\left(\mathrm{m}^{3} / \mathrm{s}\right)$} \\
\cline { 2 - 8 } Time & C1 & C2 & C3 & C4 & C5 & C6 & C7 \\
\hline 00:15:00 & 2.74 & 1.66 & 3.24 & 5.84 & 4.89 & 3.02 & 1.81 \\
00:30:00 & 1.73 & 3.24 & 3.19 & 5.14 & 5.42 & 7.70 & 7.59 \\
00:45:00 & 3.20 & 3.16 & 3.21 & 3.20 & 3.15 & 4.10 & 7.69 \\
$01: 00: 00$ & 3.24 & 3.25 & 3.24 & 3.30 & 3.29 & 5.62 & 7.69 \\
$01: 15: 00$ & 1.20 & 1.43 & 3.22 & 3.32 & 3.57 & 5.95 & 7.66 \\
$01: 30: 00$ & 1.99 & 2.00 & 3.21 & 3.43 & 6.48 & 7.55 & 7.60 \\
$01: 45: 00$ & 2.28 & 2.26 & 3.24 & 3.33 & 7.49 & 7.42 & 7.39 \\
$02: 00: 00$ & 2.92 & 2.87 & 3.19 & 3.21 & 7.05 & 7.67 & 7.70 \\
$02: 15: 00$ & 3.07 & 3.19 & 3.26 & 3.22 & 7.56 & 7.59 & 7.56 \\
$02: 30: 00$ & 1.53 & 1.69 & 3.26 & 4.02 & 7.27 & 7.58 & 7.71 \\
\hline
\end{tabular}

Table 2. Flow rates through sewer sections for minimum pollution load from two consecutive storms

\begin{tabular}{cccccccc}
\hline & \multicolumn{7}{c}{ Interceptor sewer flow rates $\left(\mathrm{m}^{3} / \mathrm{s}\right)$} \\
\cline { 2 - 8 } Time & C1 & C2 & C3 & C4 & C5 & C6 & C7 \\
\hline 00:15:00 & 2.72 & 1.65 & 3.24 & 5.82 & 5.82 & 3.01 & 1.80 \\
00:30:00 & 1.73 & 3.24 & 3.19 & 5.15 & 5.42 & 7.67 & 7.56 \\
00:45:00 & 3.20 & 3.16 & 3.21 & 3.20 & 3.15 & 4.09 & 7.69 \\
01:00:00 & 3.24 & 3.25 & 3.24 & 3.30 & 3.29 & 5.62 & 7.69 \\
01:15:00 & 1.19 & 1.42 & 3.25 & 3.34 & 3.54 & 5.87 & 7.64 \\
01:30:00 & 1.40 & 3.20 & 3.07 & 3.03 & 3.52 & 5.76 & 7.71 \\
01:45:00 & 3.13 & 3.19 & 3.07 & 3.04 & 2.95 & 4.99 & 7.27 \\
02:00:00 & 3.12 & 3.15 & 3.15 & 3.15 & 3.16 & 5.46 & 7.65 \\
02:15:00 & 1.15 & 1.38 & 3.25 & 3.33 & 3.52 & 5.60 & 7.71 \\
02:30:00 & 1.90 & 1.84 & 3.00 & 3.20 & 7.52 & 7.36 & 7.59 \\
02:45:00 & 2.13 & 2.11 & 3.25 & 3.27 & 6.76 & 7.25 & 7.27 \\
$03: 00: 00$ & 3.04 & 2.99 & 3.26 & 3.24 & 6.66 & 7.48 & 7.44 \\
03:15:00 & 2.92 & 3.01 & 3.15 & 3.19 & 6.76 & 7.52 & 7.52 \\
03:30:00 & 1.50 & 1.68 & 3.20 & 3.26 & 6.87 & 7.40 & 7.51 \\
\hline
\end{tabular}

\section{References}

Chen, Z., Han, S., Zhou, F.-Y., Wang, K. (2013) A CFD modeling approach for municipal sewer system design optimization to minimize emissions into receiving water body. Water Resources Management, 27, 2053-2069.

Deb, K. (2000) An efficient constraint handling method for genetic algorithms. Computer Methods in Applied Mechanics and Engineering, 186, 311-338.

Deb, K., Pratap, A., Agarwal, S., Meyarivan, T. (2002) A fast and elitist multiobjective genetic algorithm: NSGA II. IEEE Transactions on Evolutionary Computation, 6(2), 182-197.

Hernandez-Sancho, Sala-Garrido (2008) Cost modelling in wastewater treatment processes: An empirical analysis for Spain. Dangerous Pollutants in Urban Water Cycle, 4, 219-226.

Kim, J., Ko, J., Lee, J. et al. (2006) Parameter sensitivity analysis for activated sludge models No. 1 and 3 combined with one-dimensional settling model. Water Science and Technology, 53, 129-138.

Lee, S., Ko, J., Poo, K. et al. (2006) Practical approach to parameter estimation for ASM3+bio-P module applied to five-stage step-feed EBPR process. Water Science and Technology, 53, 139-148.

Rathnayake, U., Tanyimboh T.T. (2012) Multi-objective optimization of urban wastewater systems. 10th International Conference on Hydroinformatics, ISBN 978-3-941492-45-5, Hamburg, Germany, 14-18 July, 2012.

Rathnayake, U.S., Tanyimboh, T.T. (2015) Evolutionary multi-objective optimal control of combined sewer overflows. Water Resources Management, 29(8), 2715-2731.

Rossman, L.A. (2009) SWMM 5.0 User's Manual. US EPA, Water Supply and Water Resources Division, National Risk Management Research Laboratory, Cincinnati, USA.

Thomas, N.S. (2000) Optimal pollution control models for interceptor sewer systems. PhD thesis, Department of Civil Engineering, University of Liverpool, Liverpool, UK.

United Nations (2003) Wastewater Treatment Technologies: A General Review. 


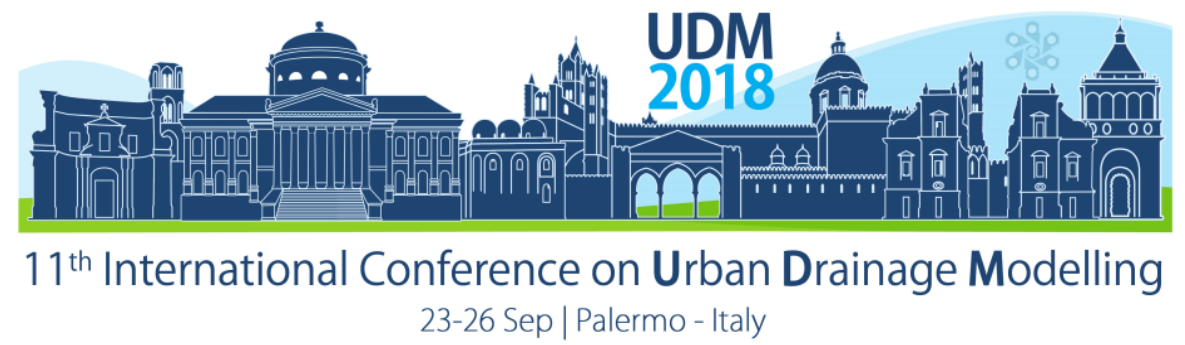

\title{
Long wave oscillations in a canal explained by a dynamic (PC)SWMM model.
}

\author{
Nelly Peyron ${ }^{1}$ and William James ${ }^{2}$ \\ ${ }^{1}$ HydroPraxis, Montpellier, France \\ ${ }^{2} \mathrm{CHI}$ (Computational Hydraulics International), Guelph, Canada
}

\begin{abstract}
One of the most important treatment plants in France is being rehabilitated in order to increase its capacity - a further biofiltration system is being added to the existing two biofiltration schemes. Because of the overall system and operational and construction complexity, it is important to ensure that water pressures remain reasonable during wave oscillations resulting from rapid pump stoppage and valve closure, as caused by an unexpected electrical outage. (PC)SWMM was successfully used to evaluate the wave oscillations.
\end{abstract}

Keywords: Wave oscillations; dynamical 1D model; canal flow

\section{INTRODUCTION}

Because of important environmental requirements for better water quality control in Europe, a major city in France decided to extend its treatment plant. One of the steps being undertaken is to add an additional biofiltration system to the existing treatment complex.

While the capacity of the current incoming canal to the existing two biofiltration systems is sufficient in terms of expected regular gradually-varied flow variations, a question arises relating to transient flow when an electrical outage occurs. In an outage, three pumps leading to the biofiltration systems stop abruptly and valves are shut, stopping water entering the canal. Oscillation waves will then be created making it necessary to:

- check that these waves will not endanger the existing canal, by subjecting it to unexpected pressure variations, and

- $\quad$ suggest possible solutions to avoid such problems.

\section{METHOLOGY AND APPLICATION}

\subsection{Approach}

To address the concern, a dynamic model is required to simulate the transient flow conditions under the stated constraints.

(PC)SWMM, a widely-used international model, was selected to conduct the study in 3 phases:

- model setup of the canal,

- calibration for steady state conditions, and

- implementation of the pump stoppage.

\subsection{Model development}

The model developed integrated the necessary hydraulic elements:

- the canal with the following dimensions:
$\circ$ length $\rightarrow 530 \mathrm{~m}$
$\circ \quad$ width $\rightarrow 8.4 \mathrm{~m}$ 


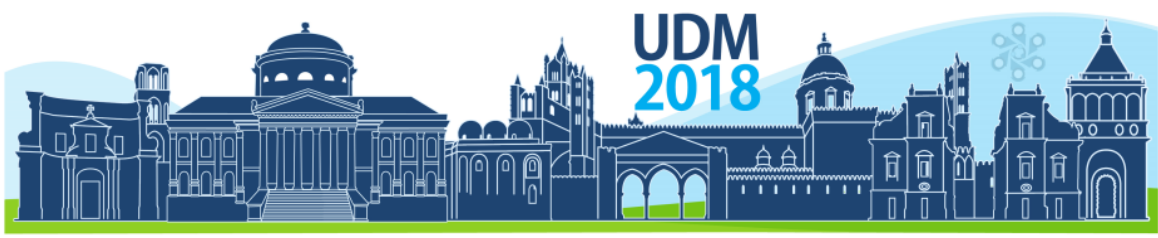

$11^{\text {th }}$ International Conference on Urban Drainage Modelling 23-26 Sep | Palermo - Italy

$\circ$ height $\rightarrow$ from 4.6 to $5.1 \mathrm{~m}$ with part at $2.4 \mathrm{~m}$

- abrupt simultaneous stoppage of the 3 pumps, and

- closure of the upstream valve diverting incoming water to a canal bypass

Figure 1 presents the model construction plan.

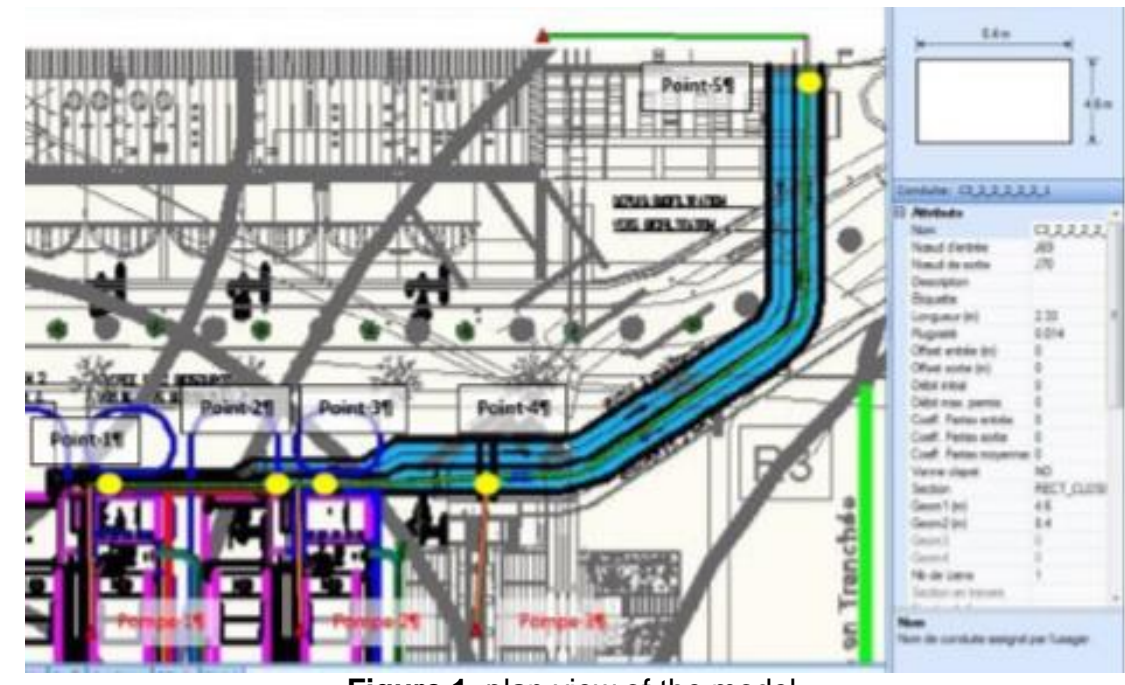

Figure 1. plan view of the model.

The model was calibrated against steady state data for roughness and head, and the model was deemed to represent observed flows within the canal very well, as shown in Figure 2.

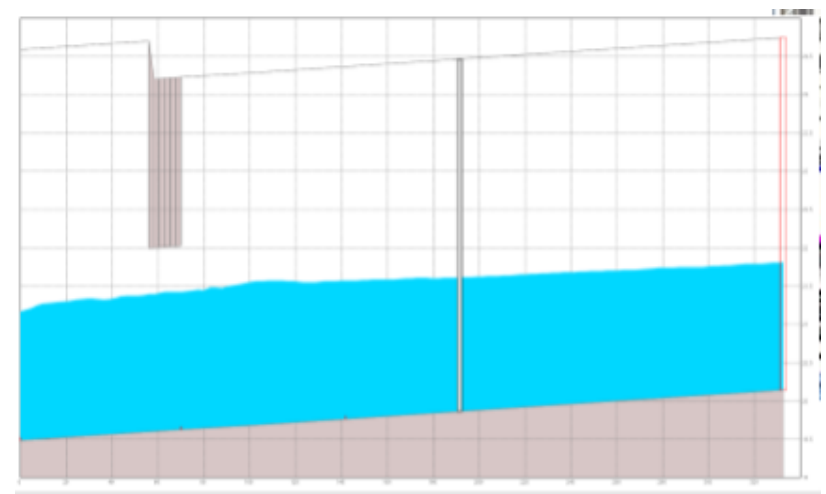

Figure 2. canal and flow profile.

\section{RESULTS AND DISCUSSIONS}

\subsection{Dynamic video}

The results are presented dynamically such that the three waves arising from the 3 pumps stoppage are visible. Figure 3 is derived from the video and illustrates the flow behaviour. 
Proceedings of the 11th Int. Conference on Urban Drainage Modelling, 23-26 Sep. 2018, Palermo (ITALY). Ed. prof. Giorgio Mannina

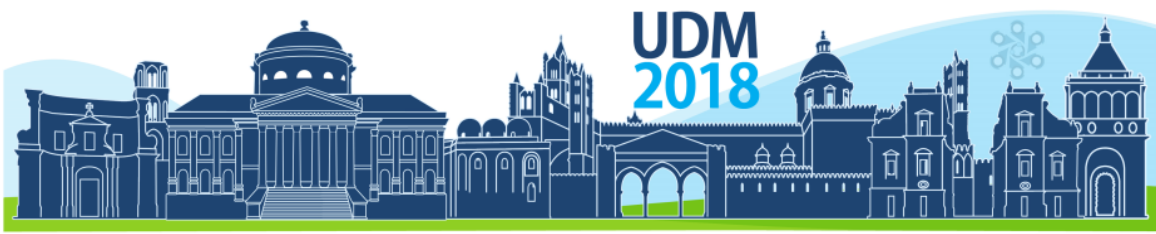

$11^{\text {th }}$ International Conference on Urban Drainage Modelling 23-26 Sep | Palermo - Italy

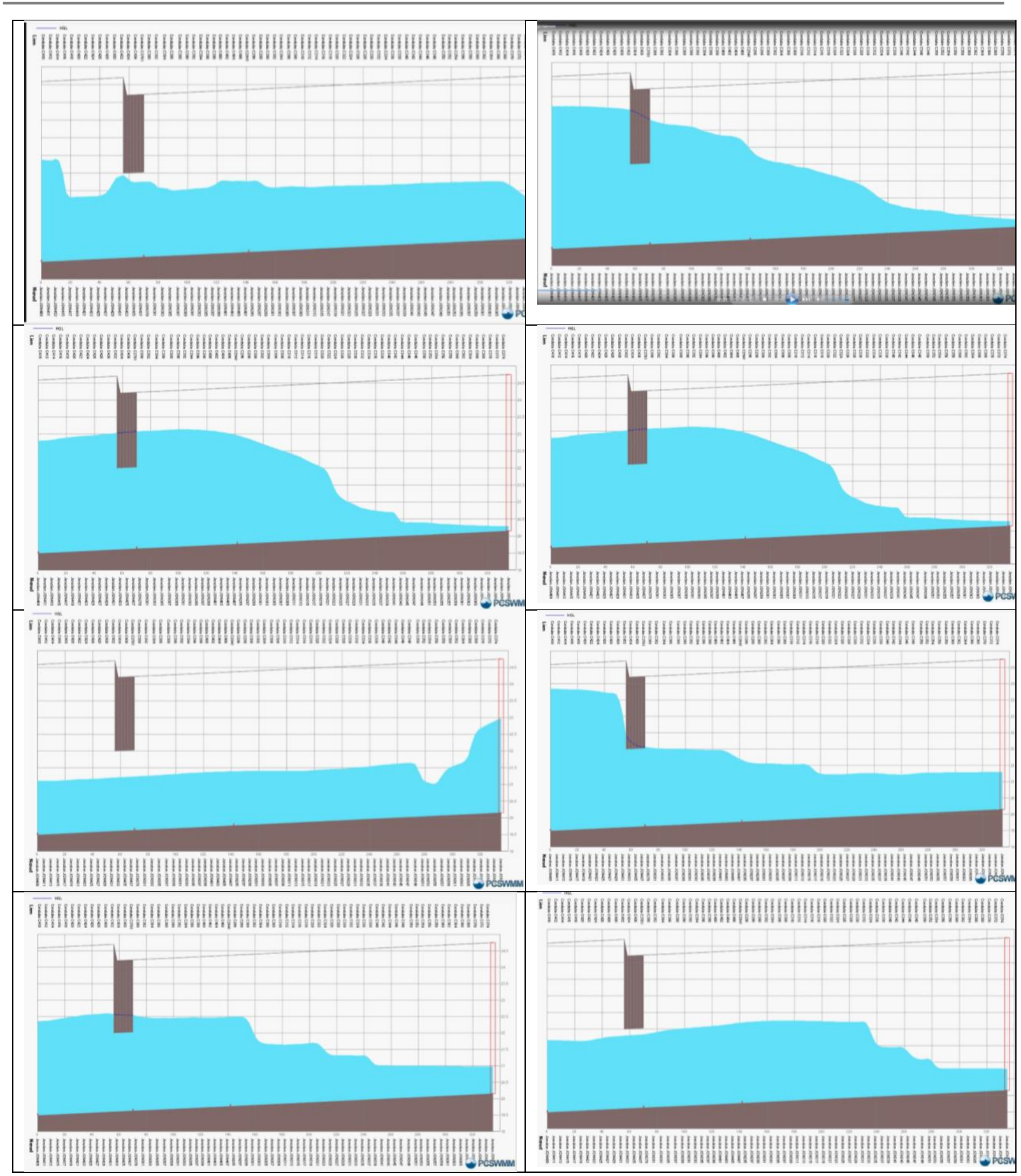

Figure 3. canal transition water flow after the electrical breakdown

\subsection{Discussion}

In addition to an improved understanding of the transient water behaviour under stoppage conditions, the model proved useful for evaluating the effect of roughness on the wave heights, as illustrated in Figure 4. 


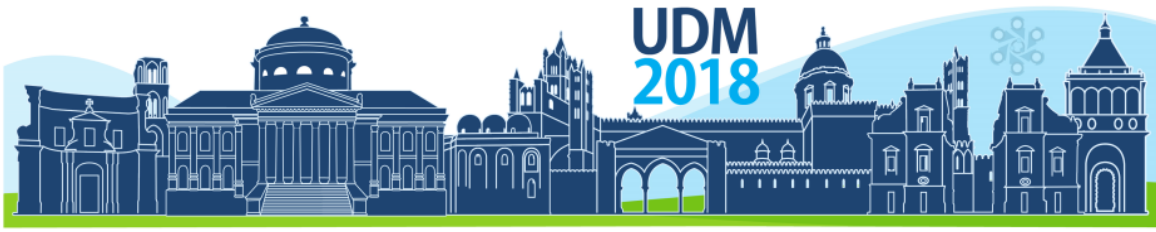

$11^{\text {th }}$ International Conference on Urban Drainage Modelling 23-26 Sep | Palermo - Italy

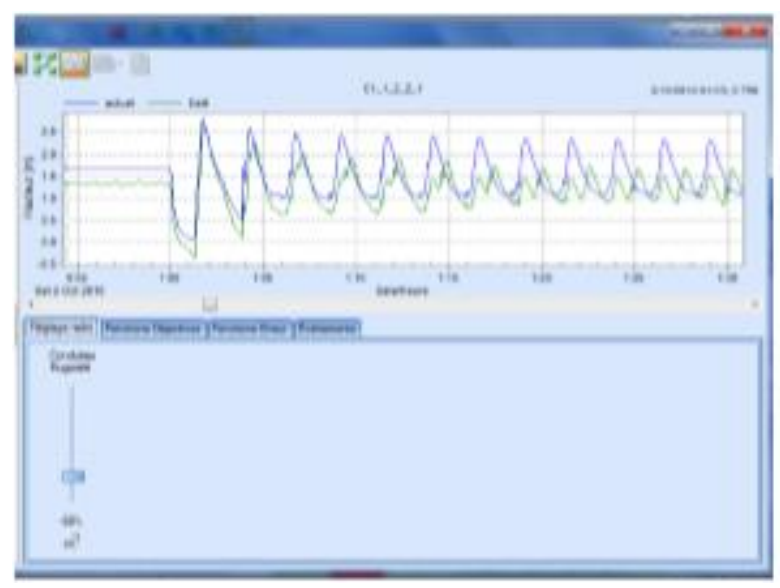

Figure 4. roughness sensitivity analysis

(PC)SWMM was easy to implement, producing useful results for complex transient flows.

\section{CONCLUSIONS}

The approach taken, based on a 1D dynamical model, successfully represented flow behaviour following an electrical outage.

The (PC)SWMM model could allow the engineer to:

- better understand the sewer water flow in critical conditions,

- conduct a sensitivity analysis that could estimate the impact of roughness,

- communicate the results clearly and hence inform decision-making.

\section{References}

Chocat B (1997). Encyclopédie de l'hydrologie urbaine et de l'assainissement. Technique et Documentation, Londres, New York, Paris

Huber, W.C. and Dickinson, R.E. (1988) Stormwater management model, User's manual, Version 4, EPA/600/388/001a (NTIS PB88-236641/AS), U.S. Environment Protection Agency, Athens, GA

James, W. (2003) Rules for responsible modelling, Computational Hydraulics International, Guelph, ON

James, W., Rossman, L.E. and James, W.R.C (2010) User Guide to SWMM5, Computational Hydraulics International, Guelph, CA

Linsley, R.K., Kohler, M.A. and Paulhus, J.L.H. (1982) Hydrology for engineers, McGraw-Hill, New York, NY

Rivard, G. (1998) Gestion des eaux pluviales en milieu urbain, Alias Communication Design, Sainte Dorothée, QC Ven Te Chow (1959) Open channel hydraulics, McGraw-Hill, New York, NY 


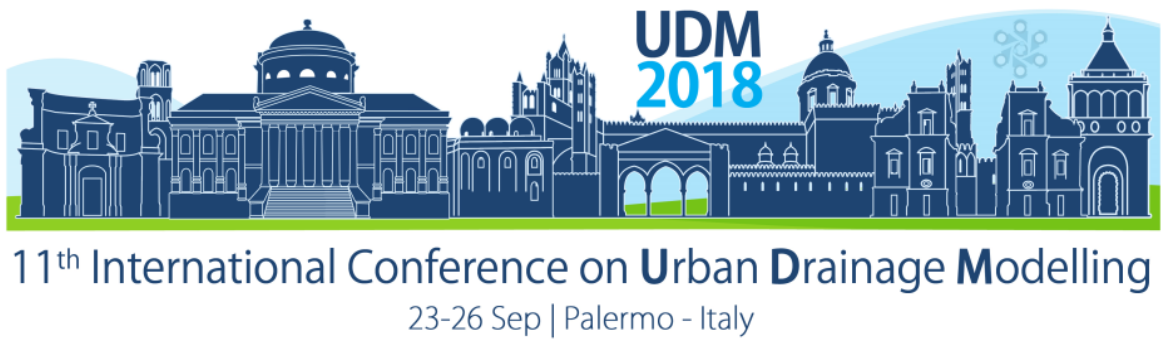

\title{
Can a surface overflow model predict particulate matter separation of unit operations?
}

\author{
Subba-Srikanth Pathapati ${ }^{1}$, John Sansalone \\ ${ }^{1}$ University of Florida, Engr. School of Sustainable Infrastructure \& Environment, Gainesville, FL, 32611, USA \\ 2 University of Florida, Engr. School of Sustainable Infrastructure \& Environment, Gainesville, FL, 32611, USA
}

\begin{abstract}
Worldwide there are now many types of unit operations (UO) utilizing high rate gravitational separation (discrete Type I settling) for separation of urban drainage particulate matter (PM) and the PM-bound chemicals and pathogens. Such units do not replace volumetric detention/retention systems that provide hydrologic and PM control but the small size of such units can allow greater application in urban locations and facilitate the frequent maintenance needs. In this study a basic surface overflow rate (SOR) model is compared to computational fluid dynamics (CFD) to predict PM separation during unsteady runoff events and steady design flows utilizing three particle size distributions (PSDs) of the same $\mathrm{d} 50 \mathrm{~m}$ but differing size dispersivity. The model comparison is made for three classes of "hydrodynamic separators" (HS), baffled (BHS), combination (CHS), and screened (SHS). The concept of a 'design flow rate' for each HS is investigated using residence time analyses. With a physically-validated CFD model as the control, results indicate the potential of increasing error in SOR predictive capability for PM separation as the PSD becomes increasingly hetero-disperse. Additionally, the SOR model consistently over predicted PM separation for unsteady flows for all HS units and PSDs, with larger error for the CHS and SHS, compared to the more quiescent BHS. CFD-modeled residence times are significantly larger than theoretical (ideal) residence time calculations for the SHS and CHS, due to flow mixing. Furthermore, the concept of a design flow can be ambiguous, and utilizing a target effluent PSD as the criteria for design is recommended.
\end{abstract}

Keywords: Best Management Practice; Computational fluid dynamics; Clarification

\section{INTRODUCTION}

Urban drainage transports a complex heterogeneous mixture of PM, as well as PM-bound chemicals and pathogens. Separation and management is challenged by urban land use constraints and existing infrastructure resulting in smaller, less volumetric unit operations (UO) for PM clarification such as hydrodynamic separator (HS) units which have proliferated to over 50,000 in North America. HS units are essentially small volumetric tanks of lower residence times, can have some degree of baffling, screening or hydrodynamic modification and are predominately non-ideal discrete Type I gravitational settling units (Wilson et al 2009).

Traditionally, a surface overflow rate (SOR) approach (Tchobonoglous et al 2003) is the basic foundation for designing a Type I settling UO. Since an SOR is resolved into units of length/time, as an overflow velocity, a design particle diameter or a critical particle size with a settling velocity can be compared to an SOR at a design flow rate or any flow rate. Prior to the last decade, incorporating an entire PSD in design has been less common. However, the dispersivity (shape) and scaling (coarseness) of a PSD as quantified in a two-parameter gamma distribution of PSD can have a significant impact on UO behavior and modeling thereof (Dickenson and Sansalone 2009). PSDs and hydrodynamics not withstanding; the assumption of discrete PM separation is more reasonable for small-footprint UOs with shorter residence 


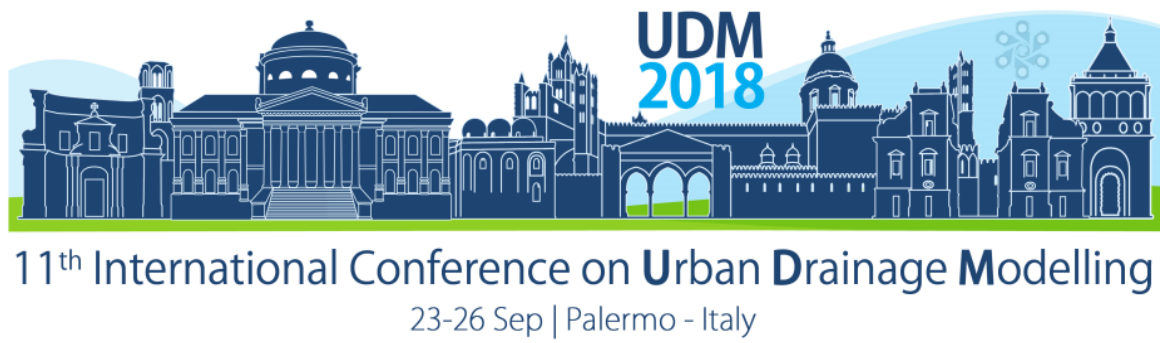

times (minutes) and coarser non-cohesive PM of higher specific gravity which is typical of urban drainage.

In contrast to SOR and semi-empirical model developments over the last century, CFD has emerged as a comprehensive design and analysis tool to predict the fate of PM transported in unsteady multiphase flows (Sansalone and Pathapati 2009). As with any model there are advantages and disadvantages to SOR and CFD. Therefore the question arises if a model such as SOR that can be executed in an iterative spreadsheet or through writing conventional coding given the data requirements and can accurately reproduce the behavior of HS units. To address this question this study compares the predictive capability of SOR as a model of PM separation by three classes of HS units of similar influent design flow rates for a series of three influent PSDs of equal $d_{50 m}$ with differing hetero-dispersivity. These SOR results are compared with a physically-validated CFD model of these HS units at design flow rates. An unsteady flow comparison between SOR and CFD is made utilizing a hydrograph with peak flow rate equal to the design flow rate of the HS units. The concept of a 'design flow rate' is then examined with the aid of residence time analyses.

\section{MATERIALS AND METHODS}

The HS units were screened (SHS), baffled (BHS), and combination (CHS). The SHS consists of two concentric cylindrical chambers separated by a static screen. In comparison, the BHS had a horizontal baffle designed for inlet/outlet control and oil/grease separation and a lower more quiescent chamber. The combined HS (CHS) consists of three separate chambers; a cylindrical settling chamber and two settling basins separated by baffles.

Three influent PSDs of the same $\mathrm{d}_{50 \mathrm{~m}}(75 \mu \mathrm{m})$ and differing size dispersivity are chosen as inputs; a mono-(uniform), a medium-, and a hetero-disperse PSD. The PSDs as \% finer by mass are modeled as a two parameter (shape, $\gamma$ and scaling, $\beta$ ) cumulative gamma distribution, to express the PM mass as a function of PM diameter. At a constant $\gamma$, an increasing $\beta$ indicates a coarser PSD while for a constant $\beta$, an increasing $\gamma$ indicates a finer PSD. The dispersivity values are $0.11,1.03$ and 2.63 for the mono-, medium-, and heterodisperse PSDs. Dickenson and Sansalone (2010) defined discretization number (DN) as the number of individual particle size ranges that are integrated over to obtain the PSD and recommended a DN range of 8 - 16 for accurate results. In this study the DN ranged from 11 to 17. To transport the PSDs, an influent hydrograph based on a Soil Conservation Service Type II distribution was constructed.

The SOR model assumed Type I settling (discrete PM settling) and used Newton's Law for settling velocity $\left(v_{p}\right)$ across all particle sizes. The PM separation determined for each particle size at each flow rate is provided as follows (Tchobonaglous et al 2003).

$$
\text { PM separated }=\left(1-X_{c}\right)+\int_{0}^{X_{c}} \frac{v_{p} A}{Q} d x
$$

In this equation the first term is the mass fraction of particles with velocity, vp greater than $\mathrm{Q} / \mathrm{A}$ (the critical velocity of the unit) at a given flowrate and the second term is the mass fraction of particles with velocity vp less than $Q / A$. PM separated was calculated at discrete flow rates across the entire storm, and integrated across the PSD to obtain the total PM separated for the entire rainfall-runoff event for the entire PSD. 


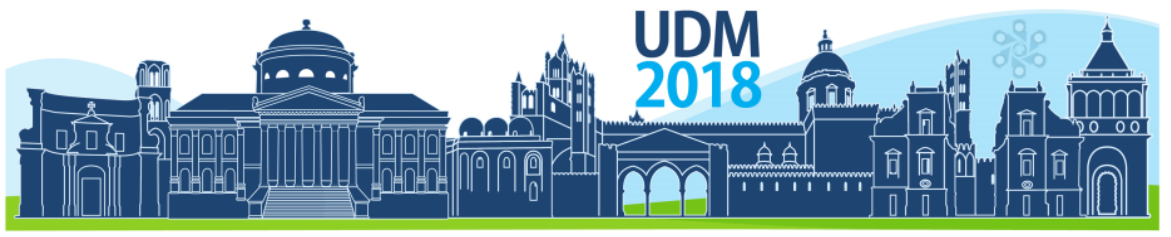

$11^{\text {th }}$ International Conference on Urban Drainage Modelling

23-26 Sep | Palermo - Italy

For the CFD model a 3-D approach is required to characterize the hydrodynamics and particle dynamics of each HS unit. The mass and momentum conservation (Navier-Stokes equations) for incompressible flows were utilized (Dickenson and Sansalone 2010). The standard $\mathrm{k}-\varepsilon$ model is used to model flow conditions. All the physical boundaries in each HS are set as impermeable walls. The free surface of flow is modeled as a shear-free boundary. A Eulerian-Lagrangian approach was used for the dilute (particle volume fraction < 10\%) PMladen flow. In this approach, the flow field is solved using the Eulerian approach.

Subsequently, particles are tracked using a Lagrangian Discrete Phase Model (DPM). The tracking length of $P M$ is determined based on hydraulic residence times calculated for neutrally buoyant tracer 'particles'. DPM boundary conditions included a 'reflect' boundary condition at all physical wall boundaries, and 'escape' boundary condition at the effluent outlet. The computational geometry of each HS units is meshed using an unstructured scheme with tetrahedral elements and used a finite volume method (FVM). A cell-centered scheme was used in discretization and a second-order upwind scheme was utilized for computing values at cell faces The SIMPLE (Semi-Implicit Method for Pressure Linked Equations) algorithm is utilized and accounts for pressure-velocity coupling. The criterion for iterative convergence was set at $1 \times 10^{-3}$ for all simulations.

\section{RESULTS AND DISCUSSION}

Table 1 summarizes the comparisons between the SOR and CFD approaches for PM separation for each of the three influent PSDs. The mono-disperse PSD generates the most consistent and largest PM separation for each HS unit. In contrast, the hetero-disperse PSD generates the lowest PM separation for each HS unit. These trends are consistent for the steady and unsteady flow results. For a given HS unit, results in Table 1 demonstrate a range of deviation in PM separation between PSDs of the same $d_{50 m}$ yet of differing size dispersivity.

Table 1. Comparison of predicted PM separation using a surface overflow rate (SOR) model and a computational fluid dynamics model (CFD). RPD is the relative percent difference.

\begin{tabular}{|c|c|c|c|c|c|c|c|c|c|c|}
\hline \multirow{4}{*}{$\begin{array}{l}\text { Influent } \\
\text { PSD }\end{array}$} & \multicolumn{10}{|c|}{$\%$ PM separated as a function of dispersivity(non-uniformity) of influent PSD } \\
\hline & \multirow{3}{*}{ Flow } & \multicolumn{3}{|c|}{ SHS } & \multicolumn{3}{|c|}{ BHS } & \multicolumn{3}{|c|}{$\mathrm{CHS}$} \\
\hline & & \multicolumn{2}{|c|}{ Method } & \multirow{2}{*}{ RPD } & \multicolumn{2}{|c|}{ Method } & \multirow{2}{*}{ RPD } & \multicolumn{2}{|c|}{ Method } & \multirow{2}{*}{ RPD } \\
\hline & & SOR & CFD & & SOR & CFD & & SOR & CFD & \\
\hline \multirow{2}{*}{$\begin{array}{c}\text { Mono- } \\
\text { disperse }\end{array}$} & Steady, $Q_{d}$ & 74.8 & 78.9 & 5.2 & 78.8 & 81.8 & 3.7 & 74.2 & 79 & 6.1 \\
\hline & Unsteady, $Q_{R}=Q_{d}$ & 88.6 & 64.1 & -38.2 & 89.1 & 79.2 & -12.5 & 87.5 & 71.8 & -21.9 \\
\hline \multirow{2}{*}{$\begin{array}{l}\text { Medium- } \\
\text { disperse }\end{array}$} & Steady, $\mathrm{Qd}$ & 65.7 & 69.9 & 6 & 69 & 73 & 5.5 & 65 & 67.7 & 4.3 \\
\hline & Unsteady, $Q_{R}=Q_{d}$ & 75.3 & 58.8 & -28.1 & 79.6 & 75.9 & -4.9 & 75.3 & 64.1 & -17.5 \\
\hline \multirow{2}{*}{$\begin{array}{l}\text { Hetero- } \\
\text { disperse }\end{array}$} & Steady, $Q_{d}$ & 58.7 & 47 & -24.9 & 60 & 55 & -9.1 & 58 & 45 & -28.9 \\
\hline & Unsteady, $Q_{R}=Q_{d}$ & 68.4 & 53.2 & -28.6 & 68.7 & 65.9 & -4.2 & 68.4 & 55.3 & -23.7 \\
\hline
\end{tabular}

A comparison of predicted effluent PSDs for the SHS, BHS and CHS from SOR and CFD models for SCS Type II hydrographs with a peak flow rate equal to the design flow rate of individual HS units are shown in Figure 1 in the left plots. Range bars illustrate the range in SOR predicted effluent PSDs for the three HS units. The plots on the right illustrate the deviation of a validated CFD model of residence times from theoretical (ideal) residence times. 


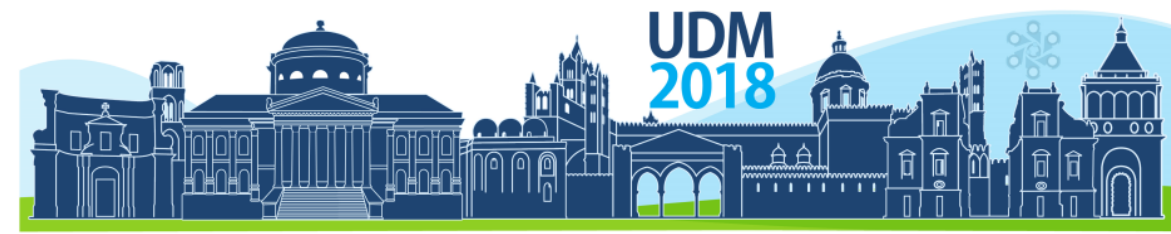

$11^{\text {th }}$ International Conference on Urban Drainage Modelling

23-26 Sep | Palermo - Italy
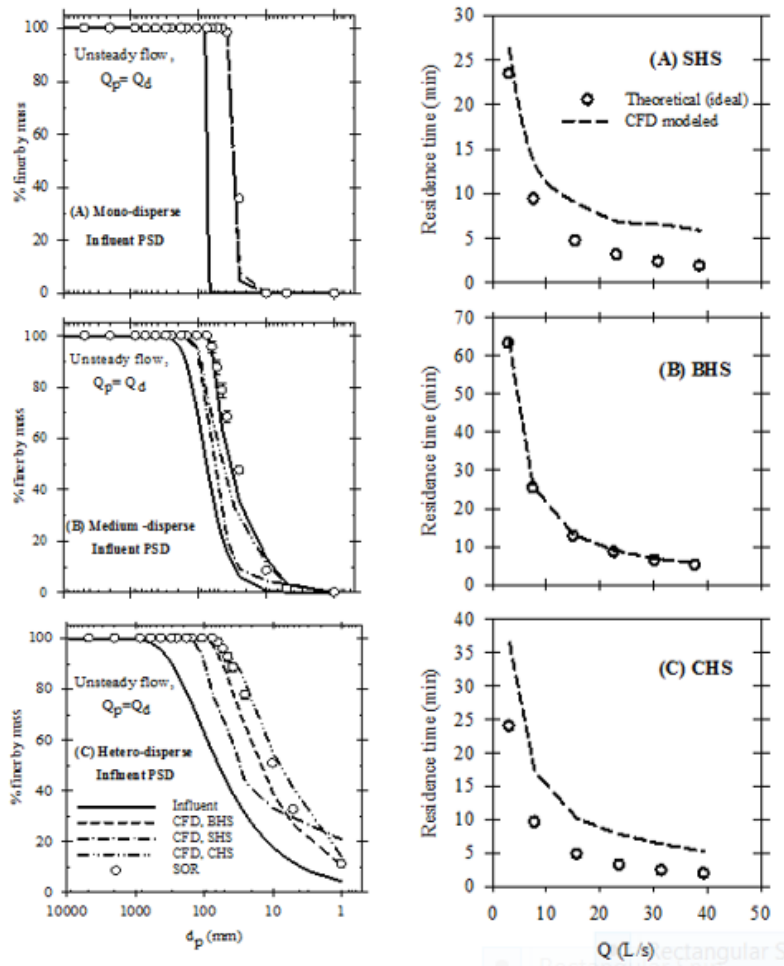

Figure 1. Plots on left are SOR and CFD models of PSDs and the plots on the right illustrate the deviation of a validated CFD model of residence times from theoretical residence times.

\section{CONCLUSIONS}

The SOR model generally did not replicate PM separation for transient flows, for all three units and influent PSDs. Results illuminate the inaccuracies in predictions when a singular influent particle characteristic such as a $d_{50 m}$ is used in lieu of an entire PSD. Due to similar surface areas and flow rates, the SOR approach predicts very similar effluent PSDs for the mechanistically different UOPs. The concept of a design flow rate was investigated for all the HS units. The design flow rate is an ambiguous term and does not accurately represent the hydraulics and size of any unit. This is bolstered by the large differences in percent separation for three UOPs with similar manufacturer specified design flow rates. Predicted residence times from CFD were generally different from mean residence times. The design flow rate should be replaced with a target effluent PSD for unit design.

\section{References}

Dickenson J. and Sansalone J. (2009). "Discrete Phase Model Representation of Particulate Matter (PM) for Simulating PM Separation by Hydrodynamic Unit Operations."Environ. Sci. and Technol., 43(21), 8220-8226, 2009.

Sansalone J.J. and Pathapati S.(2009) "Particle Dynamics of a Hydrodynamic Separator Subject to Transient Rainfall-Runoff." Water Res., 45, W09408, doi:10.1029/2008WR007661.

Tchobanoglous G., Burton F. L and Stensel H. D (2003). Wastewater Engineering: Treatment, Disposal, and Reuse, 4th Ed., Metcalf and Eddy, McGraw Hill, New York.

Wilson, M.A., Mohseni, O., Gulliver, J.S, Hozalski, R.M, H.S. Stefan, H.S. (2009), Assessment of hydrodynamic separators for storm-water treatment, 2009, J Hyd. Engrg., 135 (5), 383-392. 


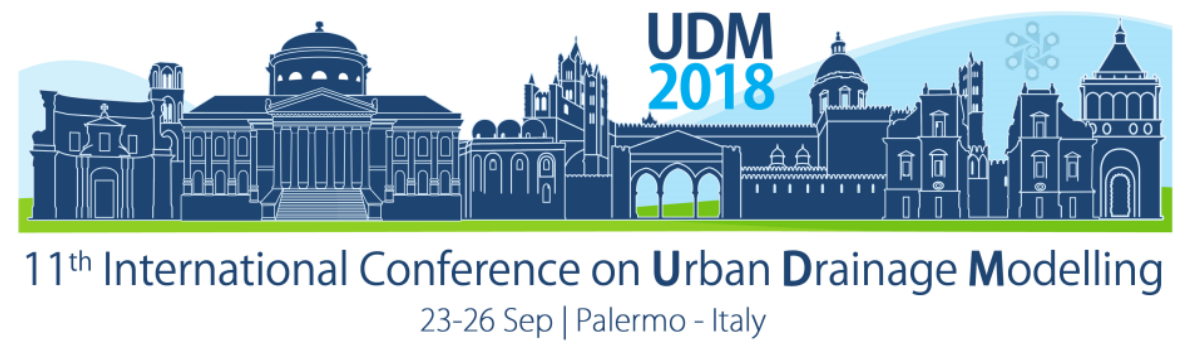

\title{
Experimental design to support water quality modelling of sewer systems
}

\author{
Julia M. Ledergerber ${ }^{1,2^{\star}}$, Thibaud Maruéjouls ${ }^{3}$ and Peter A. Vanrolleghem ${ }^{1,2}$ \\ ${ }^{1}$ modelEAU,Université Laval, Québec, Québec, Canada \\ ${ }^{2}$ CentrEau, Centre de recherche sur l'eau, Université Laval, Québec, Québec, Canada \\ ${ }^{3}$ Le LyRE, Suez Eau France SAS, Talence, France \\ *julia-margrit.ledergerber.1@ulaval.ca
}

\begin{abstract}
The paper proposes a model-based experimental design to calibrate a sewer water quality model for the Clos de Hilde catchment in Bordeaux, France. In order to carry out an experimental design, a preliminary calibrated model is developed and the influential parameters are identified. Subsequently the model is used to select the most informationrich experiment for calibration of the final model. This is done by simulating proposed experiments and evaluating the Fisher Information Matrix that quantifies the experiment's information content. The selected experiment will be carried out during the upcoming measurement campaign in summer 2018.
\end{abstract}

Keywords: Conceptual sewer model; model calibration; optimal experiment; particle settling velocity distribution

\section{INTRODUCTION}

Recent developments in legislation are increasingly asking to consider not only water quantity, but also quality. Therefore, water quality modelling at catchment and sewer level is of growing interest. Even though gains from water quality modelling are known, for instance for control of overflow structures (Schütze et al., 2004), water quality modelling in sewers is still relatively new and remains challenging, especially for total suspended solids (TSS).

To predict water quantity as well as quality at key points throughout the sewer system, such as overflow structures, a model has been developed. The chosen modelling approach for catchments and sewers combines conceptual, also known as hydrological, modelling with the PSVD (particle settling velocity distribution) approach for particulate water pollution (Maruéjouls et al., 2015). This approach allows for fast calculations and is easily extendable to the integrated level taking the water resource recovery facility (WRRF) into account.

However, water quality modelling in sewers remains challenging. A major part of the challenge is obtaining the water quality data necessary for model calibration. Indeed, in many cases, flow data are available, but extensive water quality data are missing. Moreover, obtaining the required quality data in a measurement campaign requires a non-negligible amount of time and resources. Especially the manual cleaning of the sensors is very time consuming and needs to be done on a regular basis.

It is known that not every data point contains the same level of information and therefore not all data has the same value for model calibration (Dochain \& Vanrolleghem, 2001). It is also known that often experiments are conducted which unfortunately deliver data of too low quality resulting in a model calibration with very uncertain and correlated parameters (De Pauw \& Vanrolleghem, 2006). It is therefore important to measure under experimental conditions that provide data containing the most information possible (data of high information content). For 


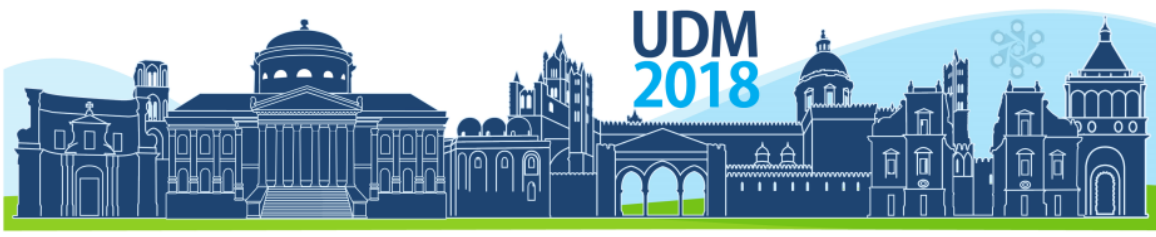

$11^{\text {th }}$ International Conference on Urban Drainage Modelling

23-26 Sep | Palermo - Italy

this, an experimental design (ED) is applied using a preliminary model, which aims at an experiment resulting in high quality data (De Pauw \& Vanrolleghem, 2006).

The aim of this work is to evaluate different proposed experiments with a preliminary model. The results are used to design a measurement campaign in Bordeaux, France planned for the summer of 2018. The measurement campaign is strictly limited to three months and two water quality measurement stations. For the two measurement locations, experience shows that, for practical reasons, a measurement period is best limited to $12 \mathrm{~h}$. The experimental design will select the most information-rich period to obtain the best data possible for further model improvements.

\section{MATERIALS AND METHODS}

\subsection{Software and Modelling Approach}

The model is implemented in WEST by DHI (Horsholm, DK). The catchment model used is the KOSIM-WEST model with the extensions proposed by Pieper (2017). It is a coupled model that includes sub-models for flow and pollutant generation during wet weather flow (WWF) and dry weather flow (DWF). The sewer model uses the PSVD linear reservoirs in series that include settling and resuspension for ten different particle classes (Maruéjouls et al., 2015).

\subsection{Case Study}

The studied catchment "Clos de Hilde" is located in Bordeaux, France. Key structures, such as retention tanks, pumping stations and overflows are mainly located along the Garonne river (see Figure 1). The catchment covers about 8000 ha and is a typical urban catchment consisting of both housing and industrial areas. It is drained with a combined sewer system in the older parts while separate sewers are found in the newer neighbourhoods. Preliminary water quality data have been collected at the pumping station Noutary and the inlet of the WRRF Clos de Hilde (Figure 1). During summer 2018, a second measurement campaign is conducted at the same two locations to collect data for improvements of the preliminary model.

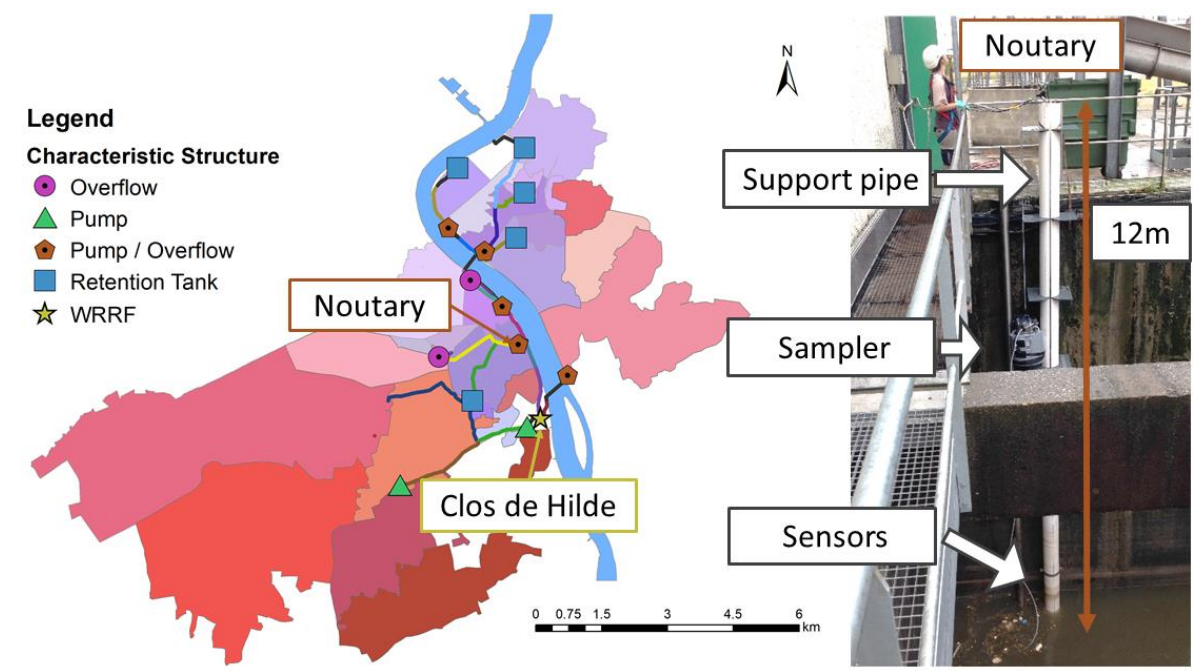

Figure 1. The left figure shows the Clos de Hilde catchment with key structures, the two measurement locations (Noutary and Clos de Hilde) are highlighted. The right figure shows the measurement location at the pumping station Noutary with the sensors and the sampler used for sensor calibration. 


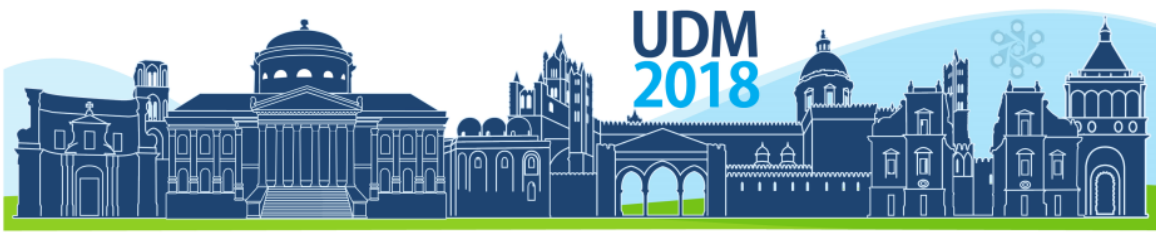

$11^{\text {th }}$ International Conference on Urban Drainage Modelling

23-26 Sep | Palermo - Italy

\section{RESULTS}

\subsection{Results Preliminary Model}

The model results for the validation period of the preliminary model are illustrated in Figure 2 and compared to measurement values for the two water quality measurement locations: inlet WRRF Clos de Hilde and pumping station Noutary.

The water quantity model has initially been calibrated $(\mathrm{NSE}=0.94)$ and validated $(\mathrm{NSE}=0.95)$ on an existing Mike Urban by DHI model. Only the DWF parameter have been recalibrated on actual flow measurements. The upper part of Figure 2 compares the model results with the flow measurements and shows a good performance at both locations during the validation period (Clos de Hilde: $\mathrm{NSE}=0.79$, RMSE $=0.068 \mathrm{~m}^{3} / \mathrm{s}$; Noutary: NSE $=0.41$, RMSE $=0.018$ $\mathrm{m}^{3} / \mathrm{s}$ ). A conceptual shortcoming is the rainfall-derived inflow and infiltration (day 61 - 65) which was not considered in the Mike Urban model. This will be considered in a next model version.

The second row in Figure 2 shows the water quality results of the preliminary model during the validation period. Some shortcomings are still visible: At the WRRF the dynamics of the DWF are generally overestimated $(\mathrm{NSE}=0.05, \mathrm{RMSE}=51.2 \mathrm{mg} / \mathrm{l})$, whereas they are underestimated at the pumping station Noutary (NSE=0.39, RMSE $=59.8 \mathrm{mg} / \mathrm{l}$ ). Since the available data was limited, some of the quality parameters of the preliminary model were obtained from external sources or were not differentiated for different sub-catchments and sewers. Nevertheless, knowing that this is still a preliminary model, the results are in the right order of magnitude and the dynamics resemble the measured ones. This model can therefore be used for the experimental design, which will allow getting the most information-rich data during a subsequent measurement campaign for improvement of the model.
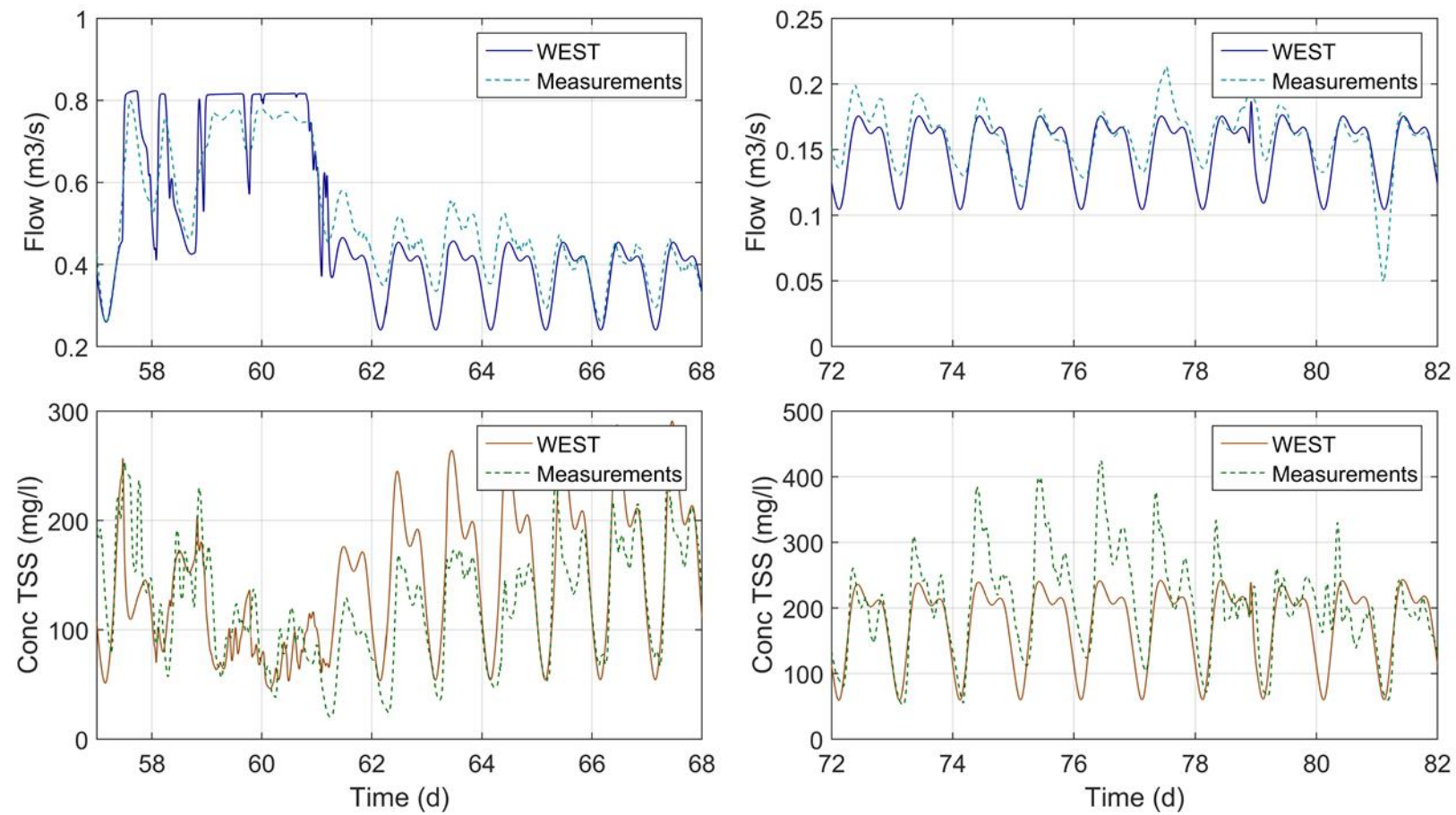

Figure 2. Model results in comparison to the measurements of flow and TSS at the inlet of the WRRF Clos de Hilde during WWF (left side) and at the inlet of the pumping station Noutary during DWF (right side) during the model validation period. 


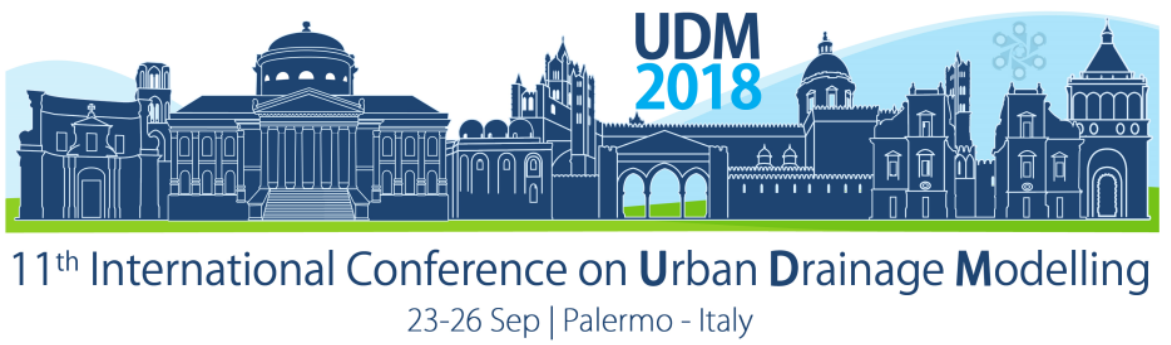

\subsection{Results Experimental Design}

As mentioned above, obtaining water quality data from sensors in a sewer system remains challenging (Ledergerber et al., 2017). A series of existing rain data, including series of DWF and WWF days, was used to calculate the sensitivity, which forms the basis of model-based experimental design. In total 37 parameters affecting water quality were considered, resulting in 74 model runs. Each of the parameters was changed by $+/-1 \%$ of its calibrated value.

Within the calculated series, a total of 7 different periods were identified to calculate the Fisher Information Matrix (FIM) (Dochain \& Vanrolleghem, 2001). Each period last for $12 \mathrm{~h}$, as ample experience with the measurement stations at the site has shown that no sensor failing occurs within that period after a clean start. Four reoccurring DWF conditions and three WWF conditions were differentiated. For DWF, both a day period (09:00 to 21:00), respectively a night period, were identified. Both day and night were analysed, once following a series of DWF days (DD1, DN1) and once following a rain event (DD2, DN2). Additionally, a period of an entire small rain event (SRB) was chosen, respectively two distinct periods for the beginning, respectively the tail of a big rain event (BRB, BRT). It is noted that each rain event is different and prediction of rain events remains uncertain. Nevertheless, suitable rain events that actually happened during the simulated period, were chosen. For the big rain event, one period was analysed for which the campaign started during the rain event. To capture the tail of a rain event, on site intervention of the sensors during the event would thus be necessary, which is not without security risks. Nevertheless, this scenario was added as a possible measurement period to evaluate its value in terms of information content.

The 7 different periods are compared using the Modified A-optimal design criterion to evaluate the FIM. The higher the value of this criterion, the richer the given data period is (Dochain \& Vanrolleghem, 2001). The results for the different measurement periods are summarized in Table 1. Generally, measurement data during a rain event appear to be richer in information than during dry weather flow. This is unsurprising as under such conditions in the model both DWF and WWF parameters are influential. However, during a DWF period, only DWF parameters are influential. Logically, collected data during such a period is unable to contain information for WWF parameters. It is, however, interesting to notice that the beginning of a big rain event contains more information than the end. For the DWF conditions, it is interesting to notice that data is information-richer during night than during day, and that a DWF day after a series of dry weather contains more information than a day following a rain event.

Table 1. Evaluation of the FIM using the modified A-optimal design criterion.

Abbr. Description Mod. A-optimal Evaluation

\begin{tabular}{ccccc}
\hline & DD1 & Day after long DWF period & 1730 & Best DWF \\
& DN1 & Night after long DWF period & 3050 & 830 \\
DD2 & Day following WWF & 2570 & Best overall \\
DN2 & Night following WWF & 8050 & \\
\hline & SRB & Entire small rain event & 28300 & 11400 \\
\hline
\end{tabular}




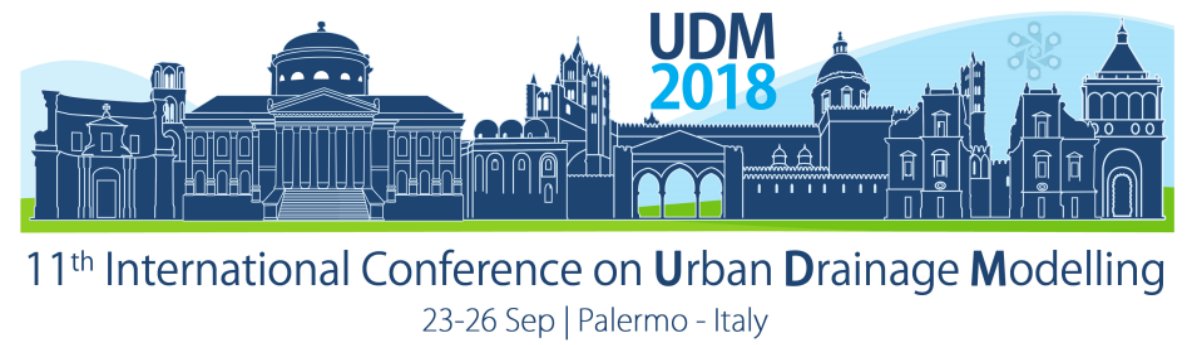

\section{DISCUSSION AND CONCLUSIONS}

Having a preliminary model allows comparing different data periods and identifying which data collection effort contains the most information. This allows then to plan the interventions on site in a way that there is a higher chance that the sensors are working during a period where the measurements are valuable.

It is obvious that the weather conditions as such cannot be influenced. But the results showed that during DWF night measurements contain more information than day measurements. It is therefore concluded that the measurement campaign with clean sensors is ideally started in the late afternoon, before leaving the site. This allows focusing on the night measurements instead of the day measurements that would follow a morning start.

The results also show that WWF measurements contain more information. However, it is also known that these are not only the more unpredictable conditions, but also the more difficult and dangerous to measure. Despite their intrinsic uncertainties, existing tools, such as radar and weather forecasts, can be used to optimally prepare for an upcoming rain event. It is more interesting to see, however, that the information at the beginning of a rain event contains more information than towards the end. Experience shows that sensors often fail during a rain event due to the particularly rough conditions. The results show that, fortunately, then the important data has already been collected. Going on site during a rain event is considered a major security risk and, given the results of the experimental design, does not seem to be necessary.

It has been shown that the experimental design gives valuable insights for the definition of the relevant measurement periods and allows therefore to better plan the necessary interventions. Using an experimental design does, however, not only result in information-rich data for a later improvement of the preliminary model, but also structures model calibration as well as the measurement campaign and results therefore in a more efficient overall modelling procedure.

\section{Acknowledgements}

The authors acknowledge the financial support by a Collaborative Research and Development grant of the Natural Sciences and Engineering Research Council (NSERC) and Suez Treatment Solutions Canada. The authors thank Bordeaux Metropole and SGAC for technical and financial support. Peter Vanrolleghem holds the Canada Research Chair in Water Quality Modelling.

\section{References}

De Pauw, D. J. W. and Vanrolleghem, P. A. (2006). Designing and performing experiments for model calibration using an automated iterative procedure. Wat. Sci. Tech. 53(1), 117-127.

Dochain, D. and Vanrolleghem, P. A. (2001). Dynamical modelling and estimation in wastewater treatment processes. IWA Publishing, London, UK.

Ledergerber, J. M., Leray, E., Maruéjouls, T. and Vanrolleghem, P. A. (2017). Optimization of installation and maintenance of water quality sensors in combined sewers. In Proceedings of the $14^{\text {th }}$ IWA/IHAR International Conference on Urban Drainage. Prague, Czech Republic, September 10-15 2017.

Maruéjouls, T., Lessard, P. and Vanrolleghem, P. A. (2015). A particle settling velocity-based integrated model for dry and wet weather wastewater quality modeling. In Proceedings of the WEF Collection Systems Conference. Cincinnati, Ohio, United States, April 19-22 2015.

Pieper, L. (2017). Development of a model simplification procedure for integrated urban water system models Conceptual catchment and sewer modelling. M.Sc. thesis, Université Laval, Québec, Québec, Canada.

Schütze, M., Campisano, A., Colas, H., Schilling, W. and Vanrolleghem, P. A. (2004). Real time control of urban wastewater systems - where do we stand today? J. Hydrology 299(3), 335-348. 


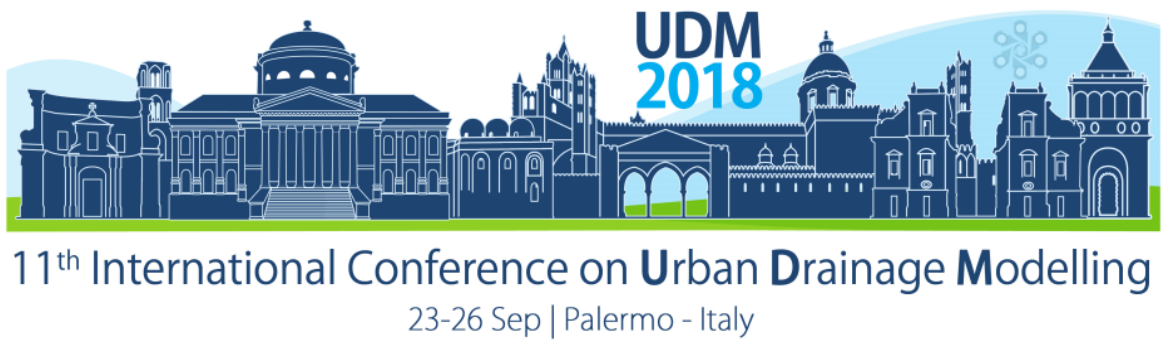

\title{
Robust model for estimating pump characteristics and sewer flows from pumping station data
}

\author{
Martin Fencl', Morten Grum², Morten Borup ${ }^{1}$ and Peter Steen Mikkelsen ${ }^{1}$ \\ ${ }^{1}$ Technical University of Denmark, Department of Environmental Engineering, Urban Water Systems Section, \\ Lyngby, Denmark \\ ${ }^{2}$ WaterZerv, Copenhagen, Denmark
}

\begin{abstract}
Flow data represent crucial input for reliable diagnostics of sewer functions and identification of potential problems such as unwanted inflow and infiltration. Flow estimates from pumping stations which are integral part of many of the middle sized and larger separate sewer systems might help in this regard. A robust model and an associated optimization procedure is proposed for estimating inflow to a pumping station using only registered water levels in the pump sump and power consumption. The model is suitable for identification of pump capacity and volume thresholds for switching the pump on and off. These are parameters which are required for flow estimation during periods with high inflows or during periods with flow conditions triggering pump switching on and off at frequencies close to the temporal resolution of monitored data. The model, however, requires further development to provide reliable inflows during time steps within which the pump switches on or off.
\end{abstract}

Keywords: Pumping stations; flow measurements; control rules

\section{INTRODUCTION}

Flow data represent crucial input for reliable diagnostics of sewer functions and identification of potential problems such as unwanted inflow and infiltration. An efficient planning and evaluation of rehabilitation/replacement actions requires long-term flow data (Staufer et al., 2012), however, such data is often not available as flow monitoring is challenging and often costly in harsh conditions occurring in sewers.

Pumping stations which are integral part of most of the middle sized and larger separate sewer systems might help in this regard. Pumping stations mostly consist of pump submerged in a pump sump. The pump switches on when pump sump is filled to some predefined level and then switches off again when the pump sump is emptied. Pump sumps are usually equipped with level gauges which measure water level in the pump sump. Furthermore, the electrical power consumption of the pump is measured. These data are collected for pumping diagnostics, however, they represent valuable sources of proxy flow data as:

$$
Q_{\text {in }}=\left(\Delta V(h)+Q_{p} * T p\right) / \Delta t
$$

where $Q_{i n}$ is the average inflow into the pump sump within the time step $\Delta t, Q_{p}$ is the pump capacity, $T p$ duration of pumping (time when the pump is on), and $\Delta V$ is the change of water volume in the pump sump which is a function of measured water level $h$ given by pump sump geometry. However, pumping stations are not primarily optimized for flow monitoring and data is often collected with insufficient temporal resolution. Thus, exact times of pumping are often unknown as well as the exact pump capacity and control rules which govern the 


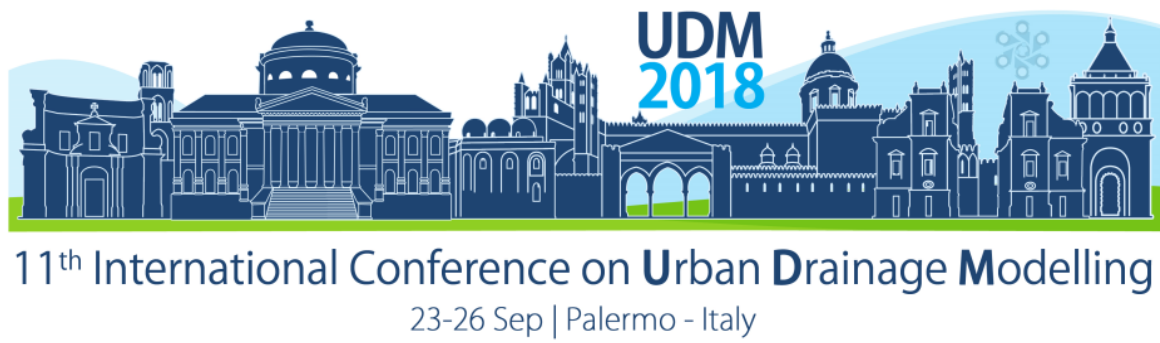

switching of the pump on and off. This causes uncertainties in inflow estimation during high flow rates when the pump is constantly running for a long period or during flow conditions triggering pump switching on and off at frequencies close to the temporal resolution of monitored data. Furthermore, control rules and pump capacity is needed for flow estimation from downstream pumping stations where the pumping is often triggered by dynamic flow pulses from an upstream pump, and neglecting of inflows during pumping period leads to systematically biased inflow estimates.

In this contribution, we suggest a pumping station inflow model with pump rate and control rules as model parameters. Furthermore, we propose a procedure to fit the model using pumping station data only. This enables us to estimate the pump capacity as well as the control rules, i.e. parameters needed for reliable pump sump inflow estimation during periods with high flows.

\section{MATERIALS AND METHODS}

\subsection{Taarnby catchment}

The pumping station used in this study is a part of a combined sewer system in a small urban catchment located in Taarnby, Denmark. The pumping station serves a subcatchment with approx. 400 inhabitants and a pipe length of about $2 \mathrm{~km}$. The volume of the pump sump is $24 \mathrm{~m}^{3}$, however, it is mostly operated within the approximate range $2-5 \mathrm{~m}^{3}$. The nominal pump capacity is $9 \mathrm{l} / \mathrm{s}$. The exact pumping capacity and level resp. volume thresholds for switching the pump on and off are unknown. Level data and electrical power consumption data are sampled at irregular time steps of $\Delta t \approx 5 \mathrm{~min}$. In addition, rainfall from a single rain gauge located in the catchment is available at 10 minute resolution. One month of observations from May to June 2017 is used for this study. This period was characterised by dry weather with only very few light rain events.

\subsection{Pumping station inflow model}

The pumping station inflow model is proposed to be capable of estimating flow from pump sump data during both filling (no pumping) and emptying periods (pumping). Fig. 1 shows a time series of volume and electrical power consumption observations during dry weather. The pump sump is being filled for about 5 time steps $(\approx 25 \mathrm{~min})$ and emptied within one or two time steps. The records, when the pump is on are indicated by a positive electrical power consumption $I$. Nevertheless, the state of the pump between the records is not known and thus the exact time of pumping is unknown as well. For example, the first pumping on the figure can last only five minutes from 19:20 to 19:25, but also almost 15 minutes from any time after 19:15 (last record with no pumping) to any time before 19:30 (first record with no pumping). We suggest using electric power consumption information from consecutive time steps $i$ and $i-1$ to estimate the exact pumping times. Four pump states (A-D) are, therefore, defined (Fig. 1):

A: pump sump filling: $l_{i-1}=l_{i}=0$

B: transition between filling and emptying period: $I_{i-1}=0 \wedge I_{i}>0$

C: pump sump emptying: $I_{i-1}>0 \wedge I_{i}=0$

D: transition between emptying and filling period: $l_{i-1}>0 \wedge l_{i}=0$ 


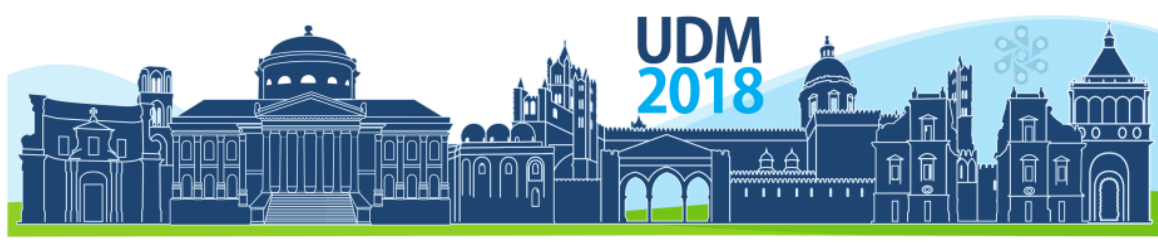

$11^{\text {th }}$ International Conference on Urban Drainage Modelling 23-26 Sep | Palermo - Italy

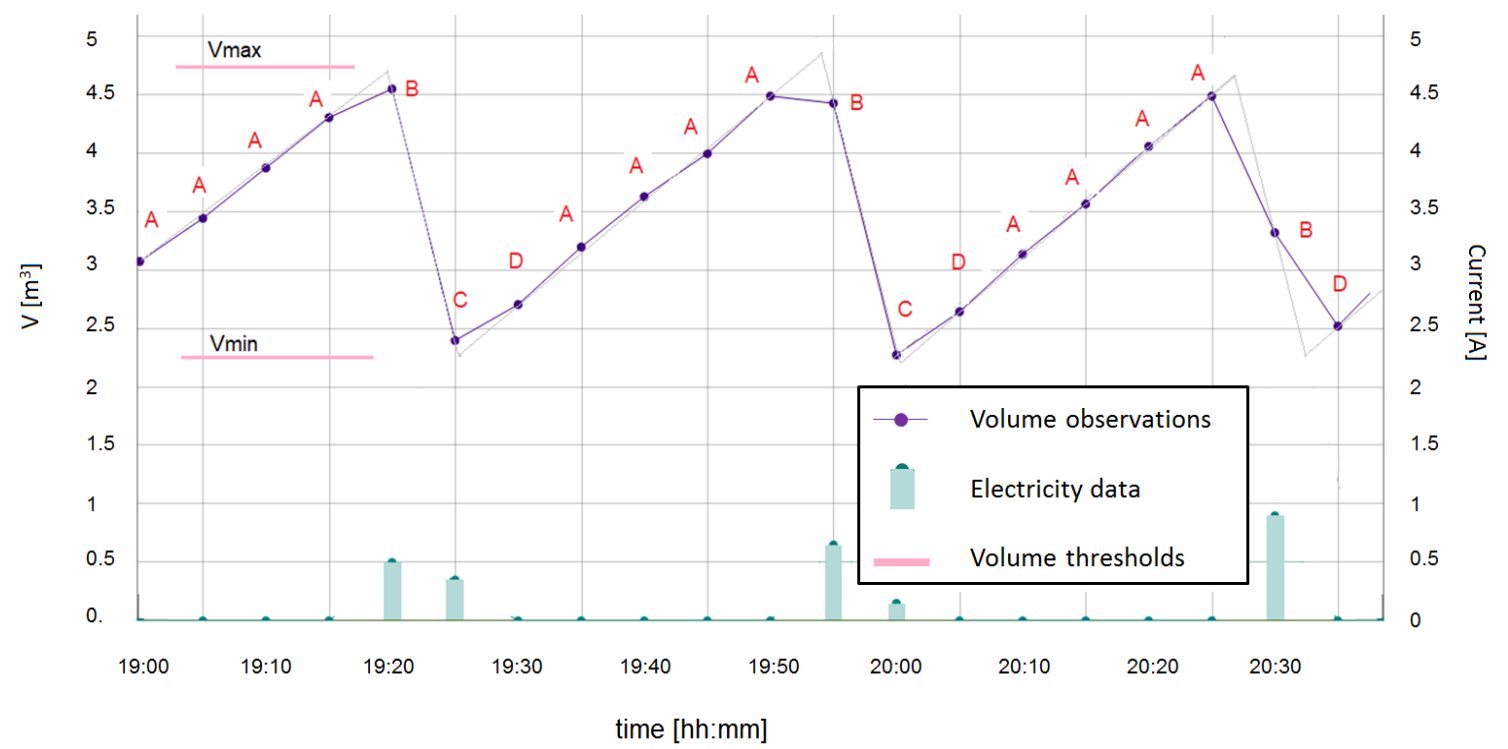

Figure 1. Volume and power consumption data obtained from the most upstream pumping station in the Taarnby catchment. Red labels over volume records denote pump states A-D. Grey lines were added manually to the figure to indicate differences between continuous and discrete volume time series sampled at raw resolution.

The pumping times $(T p)$ within state $A$ equal zero and within state $C$ they are equal to the time step $\Delta t$. The pumping times within state B are estimated assuming constant inflow $Q_{i}$ during the time step $\Delta t_{i}$. The period before the threshold $V_{\max }$ is reached $\left(T f_{i}\right)$ and the period the pump is on $\left(T p_{i}\right)$ can be then expressed as follows:

$$
\begin{aligned}
& T f_{i}=\left(V_{\text {max }}-V_{i-1}\right) / Q_{i} \\
& T p_{i}=\left(V_{\text {max }}-V_{i}\right) /\left(Q_{p}-Q_{i}\right) \\
& \Delta t=T p_{i}+T f_{i}
\end{aligned}
$$

where $V_{i-1}$ is the last volume record when the pump was off, $V_{i}$ the first record with pump being on and thus labelled as $\mathrm{B}$, and $Q_{p}$ is the pump capacity.

Similarly, the pumping time during state $D$ is estimated by expressing the period during pumping $\left(T p_{i}\right)$ and after it has stopped $\left(T f_{i}\right)$ using the volume threshold $V_{\min }$ :

$$
\begin{aligned}
& T p_{i}=\left(V_{i-1}-V_{\text {min }}\right) /\left(Q_{p}-Q_{i}\right) \\
& T f_{i}=\left(V_{i}-V_{\text {min }}\right) / Q_{i}
\end{aligned}
$$

The pump capacity $Q_{p}$ and volume thresholds $V_{\max }$ and $V_{\min }$ are regarded as model parameters and assumed to be constant within the whole experimental period. The model is fitted to the flows estimated during pump sump filling (1). The parameters are optimized separately: the pump capacity $Q_{p}$ is optimized by minimizing the sum of absolute differences between the inflow estimated for state $C$ using (1) and the closest observation of inflow during state $\mathrm{A}$. The $V_{\max }$ and $V_{\min }$ thresholds are optimized for state $\mathrm{B}$ and $\mathrm{D}$ by minimizing the sum of absolute differences between the observed $\Delta t$ and $\Delta t$ estimated from equations (2-6). The optimization is performed by a combination of golden section search and successive parabolic interpolation (Brent et al. 1973) implemented in the optimize() function available within the statistical computing language $R$ (R Core Team, 2017). 


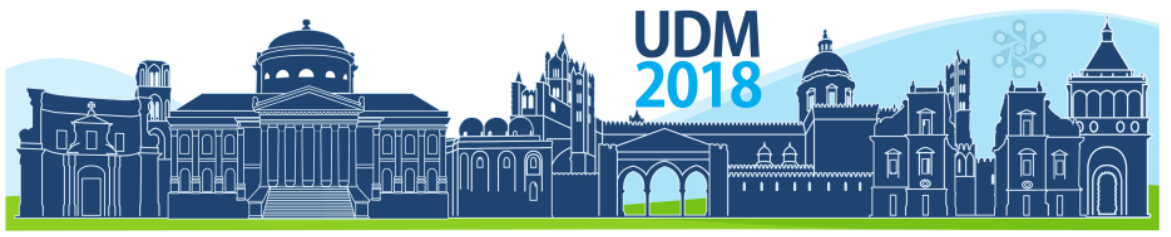

$11^{\text {th }}$ International Conference on Urban Drainage Modelling

23-26 Sep | Palermo - Italy

\section{RESULTS AND DISCUSSION}

The parameter space of the model was inspected to evaluate if the optimization converges towards unique values. Fig. 2 shows the parameter space of pump capacity $Q_{p}$ evaluated for states $\mathrm{C}$ and volume thresholds $V_{\max }$ and $V_{\min }$ evaluated for states $\mathrm{B}$ and D. All the parameters converge to well-defined minima.

The optimal value for pump capacity was found to be $8.6 \mathrm{l} / \mathrm{s}$, which is close to the nominal pump capacity. The maximal and minimal volume thresholds for switching the pump on and off were found to be $4.84 \mathrm{~m}^{3}$ and $2.21 \mathrm{~m}^{3}$. These values correspond to the rough threshold estimates marked in the Fig. 1 and indicate that the suggested optimization procedure is conceptually correct. The exact thresholds are unknown and we, unfortunately, do not have data to check these values. This is however a common situation for many pumping stations, which is why we postulate that the developed estimation procedure has great practical value.
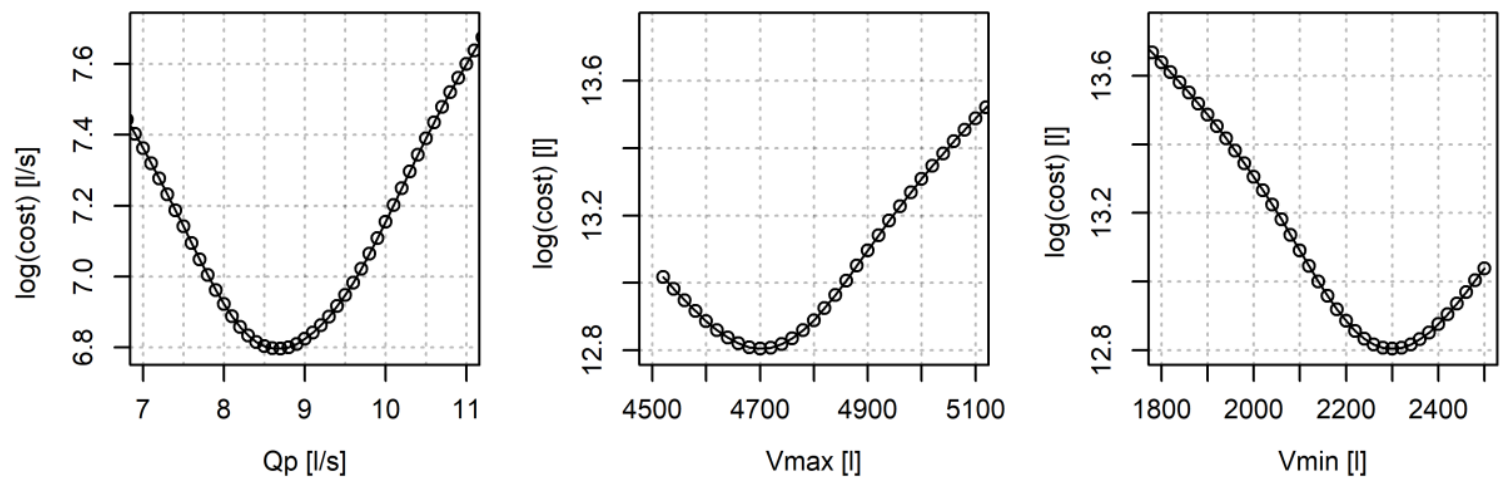

Figure 2. Cost functions of all three model parameters exhibit clear minima.

\section{CONCLUSIONS}

A model for estimating inflows to pumping stations was proposed and an optimization procedure was suggested to identify the pump capacity and volume thresholds for switching the pump on and off. The model performance was successfully tested on one month of data from a pumping station operated within a small urban catchment with a separate sewer system in Taarnby, Denmark.

The model is suitable for estimating pump capacity and thresholds for switching the pump on and off, which is valuable for pumping diagnostics. Reliable identification of pump sump capacity is also valuable for estimating inflows into pump sumps during periods with high flow rates when the pump is on for a long period. The model is, however, sensitive within the state $B$ and $D$ both on the observation errors in volume and inflow variability. Further work is therefore concentrating on reformulating the problem to a state space model (Carstensen et al., 1996), which will gain from considering the autocorrelation structure of flow time series estimated during pump sump filling periods.

\section{References}

Brent, R. (1973) Algorithms for Minimization without Derivatives. Englewood Cliffs N.J.: Prentice-Hall

Carstensen, J., Harremoës, P., Strube, R., (1996). Software sensors based on the grey-box modelling approach. Water Sci. Technol., Sensors in Wastewater Technology 33, 117-126.

R Core Team (2017). R: A language and environment for statistical computing. R Foundation for Statistical Computing, Vienna, Austria. URL https://www.R-project.org/

Staufer, P., Scheidegger, A., Rieckermann, J., (2012). Assessing the performance of sewer rehabilitation on the reduction of infiltration and inflow. Water Res. 46, 5185-5196. 


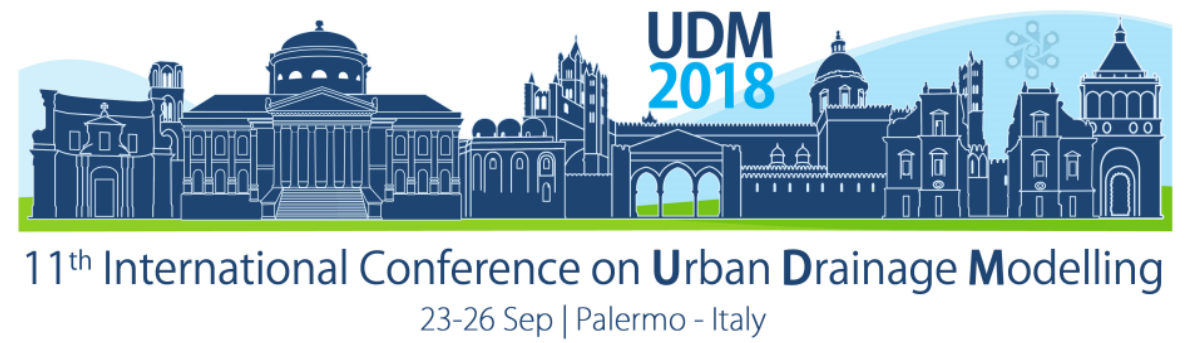

\title{
A graph-theory based algorithm to generate decentralized urban drainage layouts
}

\author{
Amin E. Bakhshipour ${ }^{1}$, Milad Bakhshizadeh ${ }^{2}$, Ulrich Dittmer ${ }^{1}$, Wolfgang Nowak ${ }^{3}$ and Ali Haghighi ${ }^{4}$ \\ ${ }^{1}$ University of Stuttgart, Institute for Sanitary Engineering, Water Quality and Solid Waste Management, Stuttgart, \\ Germany \\ ${ }^{2}$ Columbia University, Department of Statistics, New York, USA \\ ${ }^{3}$ University of Stuttgart, Institute for Modelling Hydraulic and Environmental Systems (LS3), Stuttgart, Germany. \\ ${ }^{4}$ Shahid Chamran University of Ahvaz, Department of Civil Engineering, Faculty of Engineering, Ahvaz, Iran.
}

\begin{abstract}
Recently, the implementation of centralized urban drainage networks, has increasingly been questioned. The main reasons are the lack of capital especially in developing countries, environmental-ecological concerns, the risk of failure, rapid change and high uncertainty in a developing country context. Latest investigations suggest a transition from centralized urban water management to decentralized or hybrid schemes. Therefore, there is a need for methodologies to evaluate the difference in performance of all feasible systems, from purely centralized to purely decentralized. For this purpose, the current study introduces the hanging gardens algorithm based on graph theory to generate all possible layouts for optimization purposes. The focus of this study is to find the optimum configuration of the pipe networks (grey infrastructures) considering different number and location of outlets. The algorithm starts with generating a centralized layout using an arbitrarily selected outlet, than another randomly nominated outlet among all candidates is added to the current layout. In the next step, the only path between new and old outlet is systematically found. Employing a randomly generated variable a pipe in the path is chosen to cut and decentralize the layout. A real case study, the stormwater collection network of a part of Ahvaz city in Iran is designed using the proposed approach. The number and location of the outlets, the layout configuration of each part and the size of the pipes are used as optimization variables. $A$ single-objective optimization for the cost is done and obtained results are discussed.
\end{abstract}

Keywords: Decentralization; Graph theory; Urban drainage; layout design; Optimization

\section{INTRODUCTION}

Recently, traditional implementation of centralized urban drainage networks has increasingly been questioned (Eggimann et al. 2015; Poustie et al. 2014). The main reason for questioning the traditional centralized approach is the lack of capital especially in the developing countries, where most governments do not have enough resources to build, maintain and rehabilitate such infrastructures. Besides the economic reasons, there are other objectives, which question the sustainability of the centralized infrastructures. The main are as follow: environmental-ecological concerns, the risk of failure, rapid change and high uncertainty in a developing country context, system vulnerability to climate change and failing to adequately address the human livability (Dhakal and Chevalier 2016; Hyunju Jeong 2013; Poustie et al. 2014; Reymond et al.).

Newly, investigations suggest a transition from centralized urban water management to decentralized or hybrid schemes (Poustie et al. 2014). Although, researchers suggest a transition from centralized infrastructures to decentralized one but a number of restrictions 


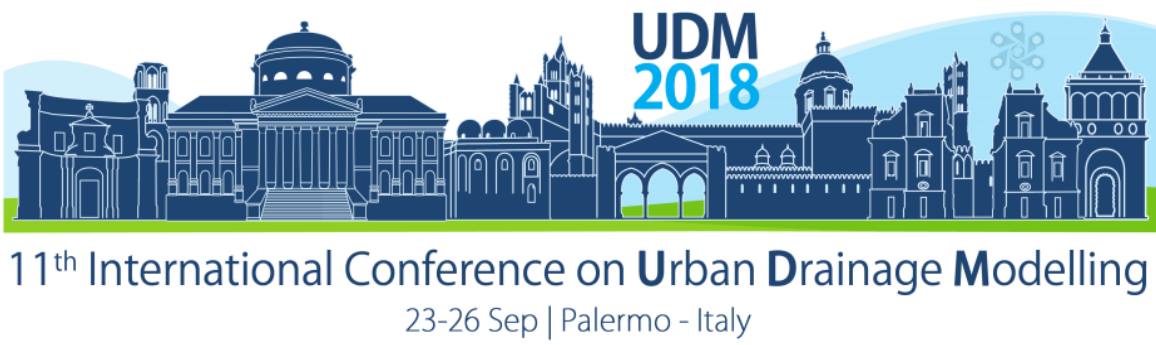

make the implementation of a fully decentralized system almost impossible especially in developing countries and pipe networks will still play a significant role in the field of urban drainage. Regarding separate sewage collection systems, hybridization could be obtained through a modular approach. Instead of investing for the large treatment plants and connecting a heavily centralized network of pipes to it, several smaller plants or on-site measures (e.g., on-site greywater reclamation system with small-scale MBRs) can be employed (Hyunju Jeong 2013; Porse 2013). Regarding separate stormwater management systems, besides the modular opportunity (dividing a centralized network into different parts by releasing stormwater in the different location of water body), hybridization may obtain through green infrastructure or low-impact development.

To find the optimal degree of centralization considering grey alternatives (the network of pipes), this work introduces hanging gardens algorithm based on graph theory to generate all possible urban drainage schemes from purely centralized to purely decentralized to find the optimum configuration. The proposed algorithm is applicable for designing both sewage collection and stormwater networks.

\section{HANGING GARDENS ALGORITHM}

To do a sewer network optimization systematically, it is primarily required to have a layout generator model able to satisfy all constraints while extracting layout alternatives from an initial base graph. A centralized feasible layout is a directed spanning tree with an outlet. In flat areas, there is no significant natural ground slope to help the designer to sketch an appropriate layout. The number of feasible layouts especially in such areas exponentially grows with the network size and number of outlet candidates. Hence, the efficiency and capability of the layout generator play a major role in the whole design process (Haghighi 2013). To generate a feasible layout considering several alternatives as outlets, the current study introduces a so-called hanging gardens algorithm which starts with generating a centralized layout and then adds another outlet from candidates to the generated graph and divides it into two parts. To generate a centralized layout with an arbitrarily selected outlet, loop by loop cutting algorithm proposed by Haghighi (2013) is employed. As the output of loop-by-loop cutting algorithm is a directed spanning tree, when a new root is added to a spanning tree, there will be one and just one path between two roots. Therefore, the problem is to find the path and cut it to generate two separate spanning trees. To find the path and cutting point, an innovative approach is proposed in this paper. Suppose the generated layout (e.g. fig. 1 a) is a system of ropes and balls (the nodes in the spanning tree are the balls and the edges are the ropes with similar lengths). If this system is hanged down from its root, the result would looks like fig. $1 \mathrm{~b}$. By doing that, it is possible to sort the nodes of the layout in a hierarchical way. Depth of each node, the distance between each node and root, is used for sorting purpose. Nodes are sorted according to their depth from lowest to highest in another matrix, so-called H-matrix (fig. $1 \mathrm{~b}$ ). To find the path between the new root and old root, it is enough to follow the direction of the pipes from upstream to downstream. After that, using an optimization variable a pipe in the path is selected to cut. After separating the layout, the H-matrix also has to be separated and updated. In this step, elements which are contributing in each part and their connectivity must be recognized. To do that, the algorithm starts from the first node in the new part which is the upstream node of cup pipe (e.g. node 9 in fig. $1 \mathrm{c}$ ). As this node has the lowest level among all nodes contributing in the new part in the initial $\mathrm{H}$-matrix (fig. $1 \mathrm{~b}$ ), going against the flow direction leads to discovering all the nodes in the new part. For the new part, all nodes must be redirected into the new outlet. After that, the obtained directed layout must be sorted again according to the distance 


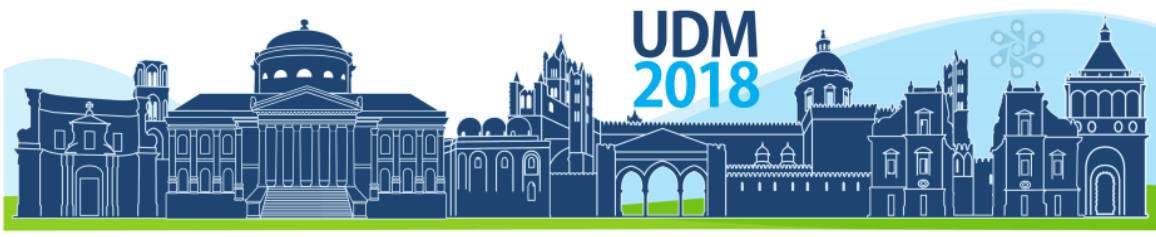

$11^{\text {th }}$ International Conference on Urban Drainage Modelling

23-26 Sep | Palermo - Italy

between nodes and the root, as explained before, by hanging down the new tree form its root (fig. $1 \mathrm{c}$ ).

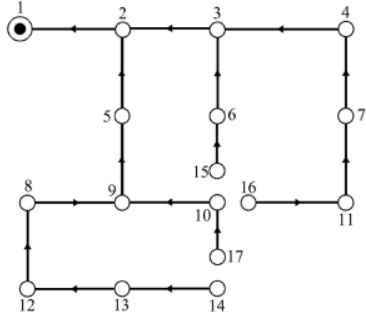

(a) An example centralized generated layout
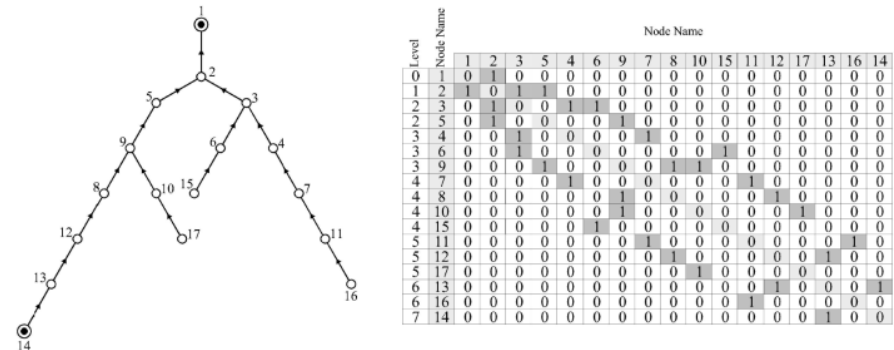

(b) Hanging Down the generated tree and constructing H-Matrix
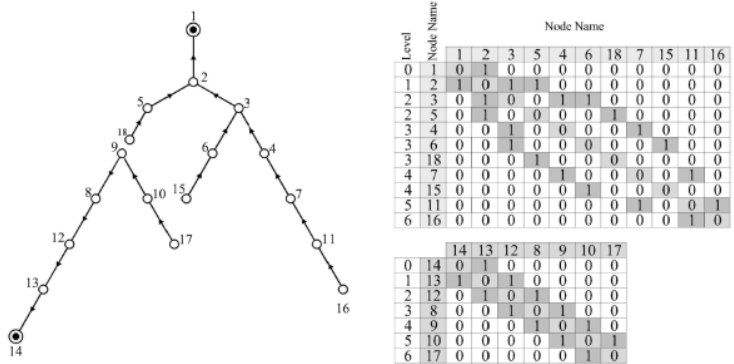

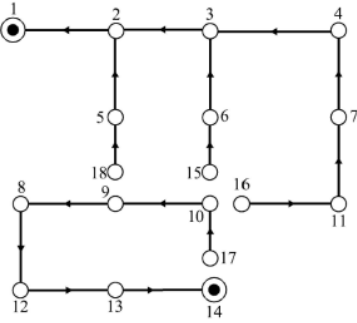

(d) Final decentralized generated layout with 2outlets

(c) Adding the second outlet and Updating $\mathrm{H}$-matrixes

hanging gardens algorithm

Using the proposed algorithm, it is possible to separate any directed tree into two directed trees. By introducing a new root to the system, firstly, the algorithm searches to find out in which part the new root exists and then uses the described modules to divide it. This procedure is iterated until all the possible roots are included in the final layout. As a final step, all the changes are applied to the real layout before hanging down (fig. $1 \mathrm{~d}$ ). As there is no limitation in the number of the roots, the hanging gardens algorithm is capable to generate all kind of layouts from fully centralized to fully decentralized.

\section{CASE STUDY AND DISCUSSION}

The proposed algorithm is applied to design the stormwater network of a part of Ahvaz city in Iran. Ahvaz is located in the southwest of Iran with more than one million populations. The city has a desert climate with long and very hot summer and mild short winters. The area under design has about 500-hectare highly urbanized drainage area and more than 100,000 population. Fig.2 a shows the base graph of the case study. It has 181 loops, 530 pipes, and 10 candidate outlets. Karun River, most Affluent River in Iran, passes through the city and provides the opportunity to drain the stormwater in different locations. Annually, urban flooding due to lack of a stormwater collection system imposes several problems during the winter. The dynamic wave approach in SWMM is used with a 5-years design storm (2 hours duration) for the hydraulic simulation. Surcharging is allowed to use the full capacity of pipe networks. Maximum allowable velocity in the pipes must be less than $4 \mathrm{~m} / \mathrm{s}$ and maximum allowable excavation depth was fixed at $5 \mathrm{~m}$. A genetic algorithm is used as optimization engine to find an initial solution then Tabu search is employed to improve the optimum solution. Number and location of outlets, the pipe configuration in each part, pipe diameters and slopes are optimization variables. Fig. $2 \mathrm{~b}$ presents the optimum design found by the 


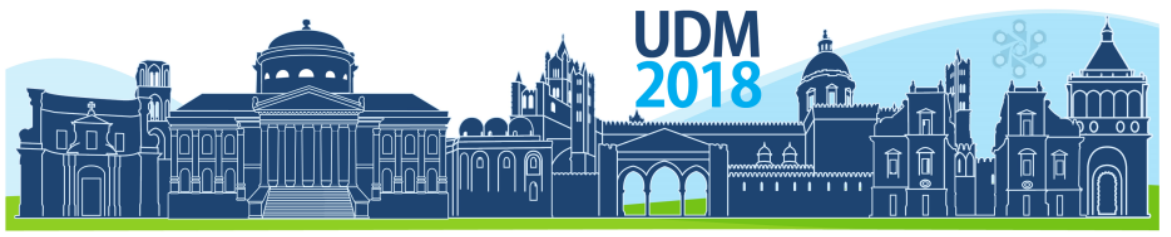

$11^{\text {th }}$ International Conference on Urban Drainage Modelling

23-26 Sep | Palermo - Italy

proposed algorithm. Seven outlets from ten candidates are selected in the suggested layout. The maximum invert elevation is $4.45 \mathrm{~m}$ (no pumping station is required) which is desirable for this area with a very flat topography. More design information is shown in the fig. $2 \mathrm{~b}$.

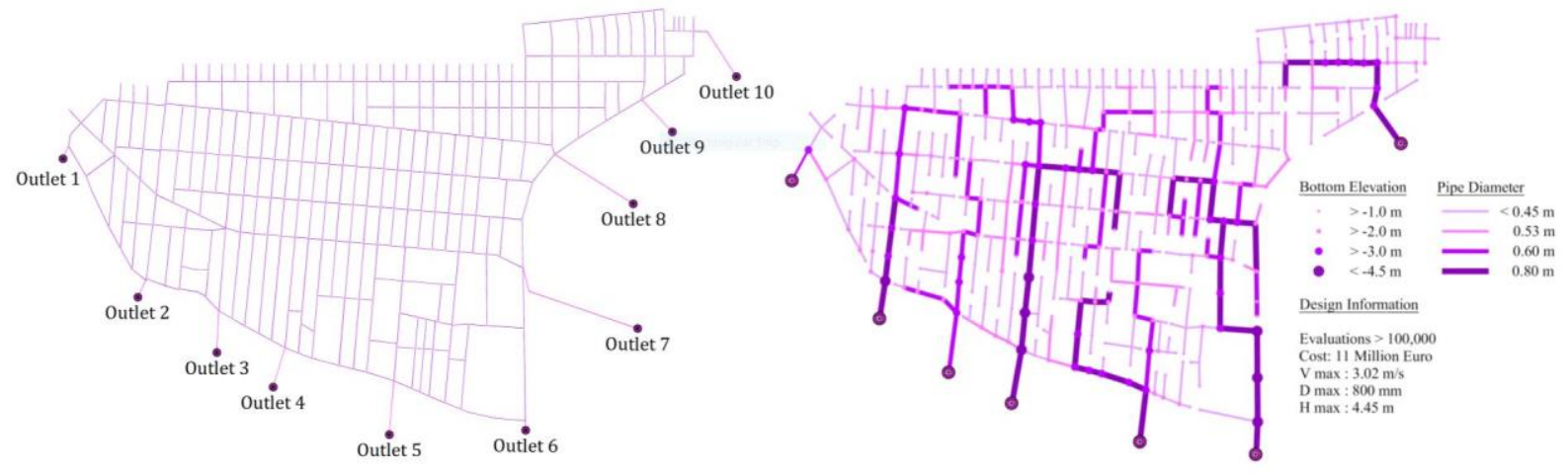

Figure 2. a) Base graph of case study b) Optimized decentralized layout

\section{CONCLUSION AND OUTLOOK}

This work introduced a graph theory based algorithm to generate decentralized urban drainage layout for optimization purposes. The proposed algorithm was applied successfully against a real case study with about 500-hectares serving area and very flat topography. For further studies, other alternatives for decentralization (e.g., green infrastructures) or finding optimal degree of centralization of sewage collection systems considering pipe network and treatment facilities besides other objective functions (e.g., reliability, resilience and sustainability of each alternative) could be considered.

\section{References}

Dhakal, K. P., and Chevalier, L. R. (2016). "Urban Stormwater Governance: The Need for a Paradigm Shift." Environmental Management, 10.1007/s00267-016-0667-5, 1112-1124.

Eggimann, S., Truffer, B., and Maurer, M. (2015). "To connect or not to connect? Modelling the optimal degree of centralisation for wastewater infrastructures." Water Res, 10.1016/j.watres.2015.07.004, 218-231.

Haghighi, A. 2013 Loop-by-Loop Cutting Algorithm to Generate Layouts for Urban Drainage Systems. J. Water Resour. Plann. Manage., 139(6), 693-703.

Hyunju Jeong (2013). Feasibility And Life Cycle Assessment Of Decentralized Water, Wastewater, And Stormwater Alternatives For Residential Communities With A Variety Of Population Densities, School of Civil and Environmental Engineering.

Libralato, G., Volpi Ghirardini, A., and Avezzu, F. (2012). "To centralise or to decentralise: an overview of the most recent trends in wastewater treatment management." Journal of Environmental Management, 10.1016/j.jenvman.2011.07.010, 61-68.

Makropoulos, C. K., and Butler, D. (2010). "Distributed Water Infrastructure for Sustainable Communities." Water Resour Manage, 10.1007/s11269-010-9580-5, 2795-2816.

Porse, E. (2013). "Stormwater Governance and Future Cities." Water, 10.3390/w5010029, 29-52.

Poustie, M. S., Deletic, A., Brown, R. R., Wong, T., Haan, F. J. de, and Skinner, R. (2014). "Sustainable urban water futures in developing countries: The centralised, decentralised or hybrid dilemma." Urban Water Journal, 10.1080/1573062X.2014.916725, 543-558.

Reymond, P., Renggli, S., and Lüthi, C. "Towards Sustainable Sanitation in an Urbanising World.".

Sitzenfrei, R., Moderl, M., and Rauch, W. (2013). "Assessing the impact of transitions from centralised to decentralised water solutions on existing infrastructures--integrated city-scale analysis with VIBe." Water Res, 10.1016/j.watres.2013.10.038, 7251-7263.

Sitzenfrei, R., and Rauch, W. (2014). "Investigating Transitions of Centralized Water Infrastructure to Decentralized Solutions - An Integrated Approach." Procedia Engineering, 10.1016/j.proeng.2014.02.171, 1549-1557.

Zhang, D., Gersberg, R. M., Ng, W. J., and Tan, S. K. (2015). "Conventional and decentralized urban stormwater management: A comparison through case studies of Singapore and Berlin, Germany." Urban Water Journal, 10.1080/1573062X.2015.1076488, 1-12. 


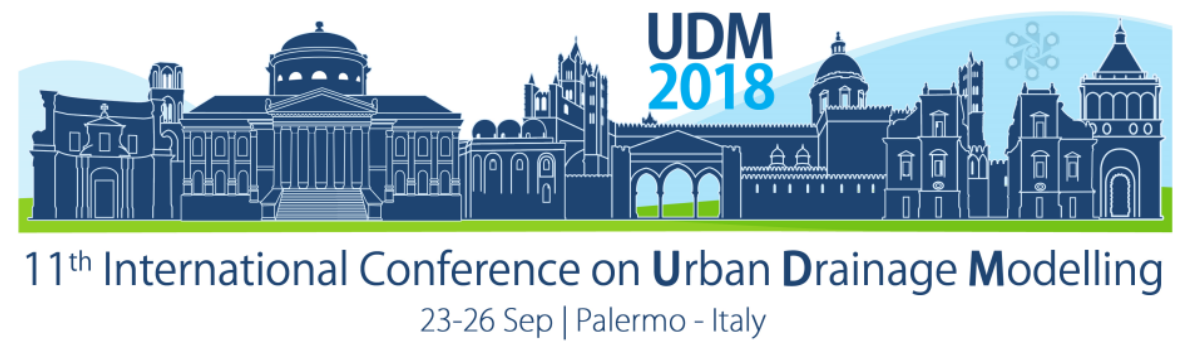

\title{
Supporting the needs and necessity for urban green stormwater infrastructure - a novel planning-support system
}

\author{
Martijn Kuller ${ }^{1}$, Peter M Bach ${ }^{1,2}$, Simon Roberts $^{3}$, Dale Browne ${ }^{3}$ and Ana Deletic ${ }^{1,4}$ \\ ${ }^{1}$ Monash Infrastructure Research Institute, Department of Civil Engineering, Monash University, Clayton, Australia \\ ${ }^{2}$ Swiss Federal Institute of Aquatic Science \& Technology (Eawag) / ETH Zürich, Switzerland \\ ${ }^{3}$ E2DesignLab, Melbourne, Australia \\ ${ }^{4}$ School of Civil and Environmental Engineering, University of New South Wales Sydney, Australia
}

\begin{abstract}
Planning of green urban drainage infrastructure known as Water Sensitive Urban Design (WSUD) is often opportunistic and ad-hoc. To improve the planning outcomes, a novel planning support system was developed. The spatial multi-criteria tool uses a novel WSUD suitability framework that incorporates ecosystem services and community needs as well as biophysical and urban form criteria, to add rigour to decision making. The framework identifies two sides to spatial suitability: 'WSUD needs a place'; describing spatial opportunities for WSUD, and 'A place needs WSUD'; describing spatial needs for WSUD. The tool was tested for the case study of Darebin City Council (Melbourne, Australia), by comparing its outputs to the outcomes of a manual urban planning process carried out by a local consulting firm. It was found that tool outputs correspond to the outcomes of a manual planning process. These results are promising for the tool, demonstrating its potential to support WSUD planning and improve the strategic outcomes of green infrastructure.
\end{abstract}

Keywords: Water Sensitive Urban Design; GIS-MCDA; Suitability assessment

\section{INTRODUCTION}

Water Sensitive Urban Design (WSUD) approaches often lead to the construction of distributed and green stormwater management systems such as raingardens, urban wetlands, swales and green roofs. Because these WSUD assets are an integral part of the urban landscape, their planning requires careful consideration of the urban biophysical and socio-economic context as well as urban form. Furthermore, strategic planning is required to optimise the benefits derived from WSUD. However, current planning practices have often proven to be adhoc and opportunistic (Kuller et al. 2018).

The application of Planning Support Systems (PSS) have the potential to significantly improve the planning practice and outcomes. They enable a deeper understanding of the planning complexity through their capacity to combine, analyse and present diverse spatial information (Klosterman 1997). In particular GIS based Multi-Criteria Decision Analysis (GIS-MCDA) has the capacity to respond to the need to address the multi-faceted nature of WSUD in urban planning. However, no rigorous and comprehensive GIS-MCDA PSS for WSUD planning are available to date.

This study aims to develop a PSS that automates spatial suitability assessment for the placement of WSUD in urban environments. This is achieved by (i) operationalising a novel and comprehensive WSUD suitability framework (Kuller et al. 2017), (ii) advancing spatial WSUD suitability mapping by applying a mix of GIS-MCDA techniques, (iii) developing a userfriendly spatial software integrating the above and (iv) testing the PSS on an existing casestudy in Melbourne for which spatial suitability analysis was previously performed (Roberts et al. 2017). 


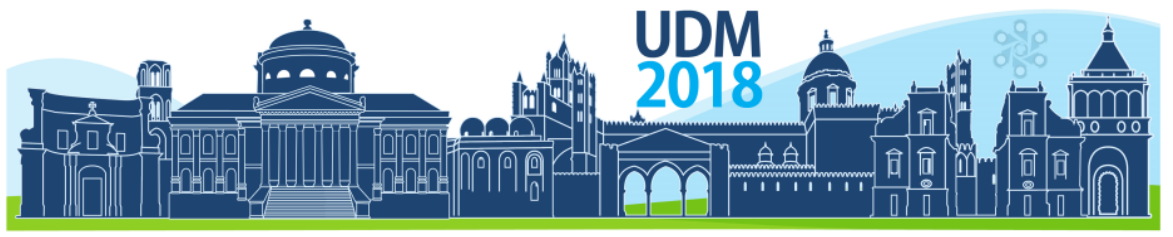

$11^{\text {th }}$ International Conference on Urban Drainage Modelling

23-26 Sep | Palermo - Italy

For the first time, this PSS systematically integrates ecosystem services and community needs with biophysical, socio-economic and urban form criteria underlying suitability for WSUD. The automation of advanced GIS-MCDA techniques enables planners to perform in-depth suitability analysis. The PSS produces output that is easy to interpret by experts as well as lay people, thereby facilitating deeper collaboration between all stakeholders in the urban planning process.

\section{MATERIALS AND METHODS}

\subsection{Tool structure}

The PSS was built as a python add-in to the ArcMap GIS software by ESRI. Its user interface appears as a toolbar with several buttons, dropdown menus and combo boxes in ArcMap. Its workflow follows four steps, as described by Malczewski and Rinner (2015).

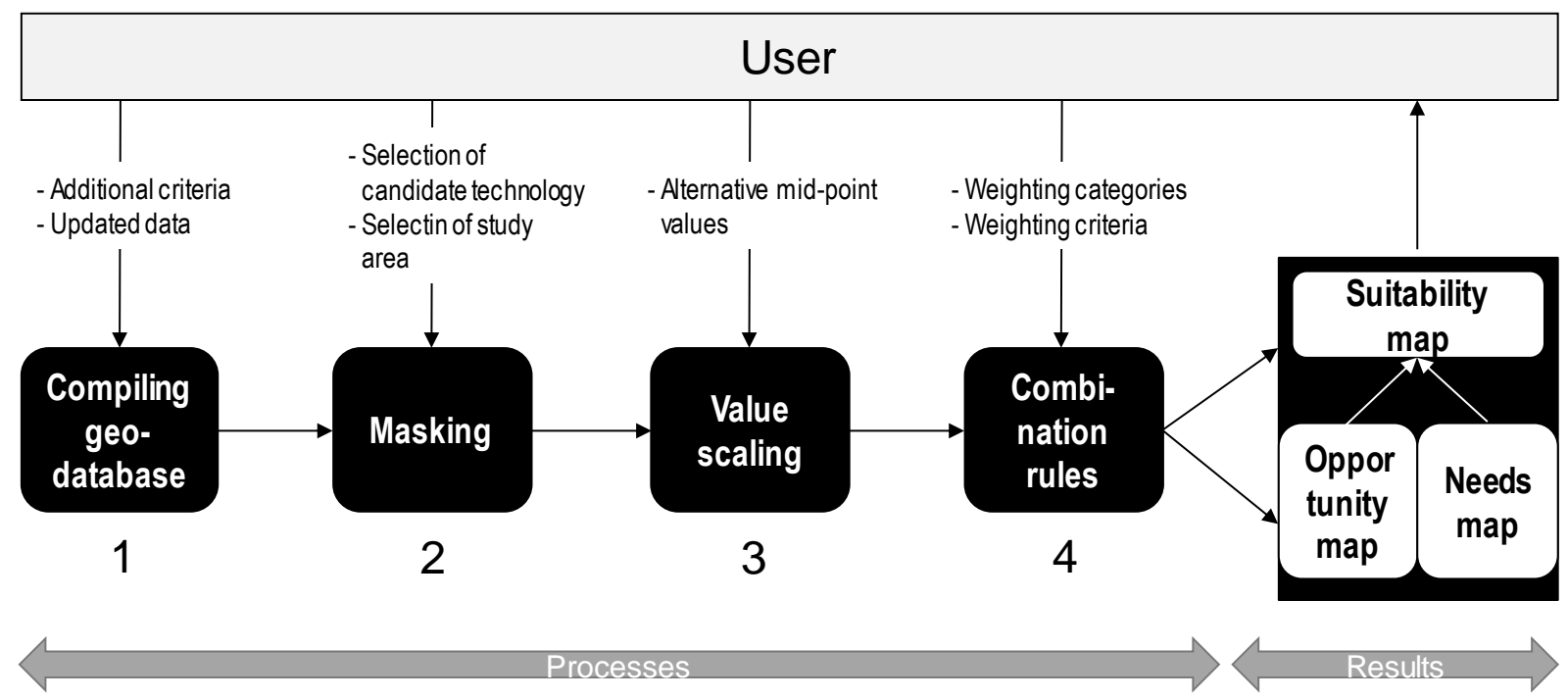

Figure 1 Work flow of our GIS-based Multi-Criteria Decision Analysis tool. For each process step, the input from the user is specified.

The suitability framework on which the tool is built, defines suitability in two ways: 'WSUD needs a place' and 'A place needs WSUD'. The former relates to biophysical, socio-economic and urban form factors, while the latter relates to ecosystem services provision, regulation, cultural and habitat. Both sides of suitability are organised into a hierarchy of criteria which, in turn, are linked to measurable indicators (Kuller et al. 2017). In the first step from Figure 1, the suitability framework is operationalised by compiling a geodatabase that contains the data underlying the framework's indicators. All data is made spatially explicit, while for some indicators that are not directly measurable, proxies are used (e.g. percentage of green votes as a proxy for environmental awareness). After the user has selected an area of interest and WSUD type (e.g. wetlands), the tool applies masking. During this second step, all areas where the selected WSUD type cannot be located are removed from the map. For example, slopes of over $8 \%$ prohibit the implementation of swales. The third step is value scaling, which transforms the data of the individual indicators into a suitability value that is uniform across all criteria, using a 'value function'. We have adopted value functions of the piecewise linear form, as described by Pereira and Duckstein (1993). Based on the selected WSUD technology, the tool automatically selects the relevant criteria to include in the analysis. 


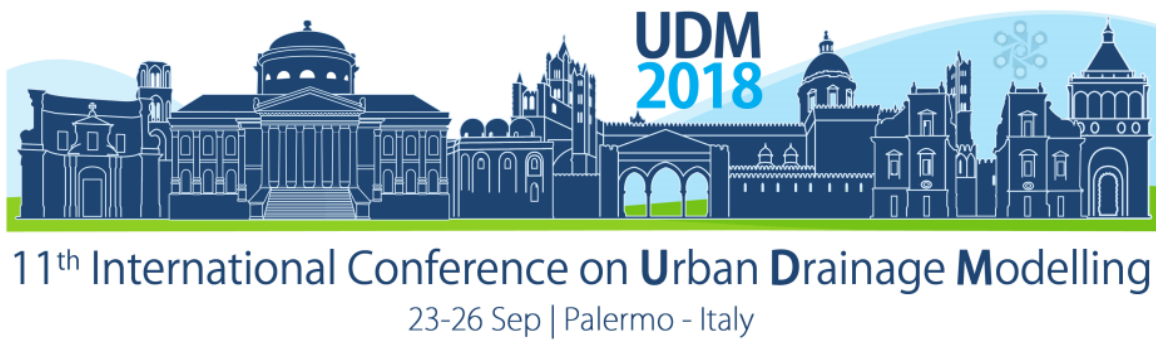

The fourth, and most important step is combination rules. During this process, the suitability layers that were generated in steps 1-3 are combined to produce the final suitability map for the selected area of interest and WSUD type. The tool uses weighted linear combination (Malczewski and Rinner 2015) and offers a mix of options to apply weighting of the different criteria. The first option allows the user to directly apply criteria weights through rating. The second option allows the user to weight criteria through a hierarchical system, where criteria are organised in categories as reflected in the suitability framework. The third option is entropybased weighting, where criteria weights are calculated based on the variability of data contained within the selected datasets (i.e. high variability means low entropy, thus high information content and high weight). This third option can be combined with the previous two options, to generate balanced criteria weights.

The tool then produces three output maps: an 'opportunities map', 'needs map' and an overall 'suitability map' which combines the former two. On these maps, suitability is represented on a scale from 0 (low suitability) to 100 (high suitability). The maps are interactive, allowing the user to click on any location to get a numerical summary of the causes for the suitability value at that particular location. Besides these maps, the tool produces a number of summary statistics to capture some descriptive characteristics of the area, like mean suitability and the total area of reasonably to highly suitable locations.

\subsection{Application and testing}

We ran our tool for the case study of the municipality of Darebin, north-east of Melbourne city centre. Darebin is situated between the inner city and outer fringes, has an area of $53 \mathrm{~km}^{2}$ and a population just shy of 150,000 . For simplicity, we applied equal weighting to all criteria. 'Bioretention and rain gardens' were selected as our WSUD asset type.

To test and validate the tool, the outputs of this run were then compared to the findings and recommendations of a recent prioritisation study that was carried out for Darebin City Council by E2DesignLab, a local engineering consulting firm (Roberts et al. 2017). This study resulted in a spatial layout for 68 priority systems (wetlands and rain gardens), and a further 110 optional locations for small scale systems.

\section{RESULTS AND DISCUSSION}

The mapped outputs of the tool are presented in Figure 2. The priority sites used for the tool testing are an overlaid in the final suitability map of Figure 2c. The proposed sites from E2DesignLab seem to follow the greener (more suitable locations) on the map relatively well for the priority sites. This is confirmed when we compare the mean values for Darebin to the mean values at the priority sites. Mean suitability values for Figure $2 a, 2 b$ and $2 c$ are 53.6, 70.6 and 62.1 respectively, while the corresponding values at the priority sites are $62.5,76.2$ and 69.3. Notable detail is that the difference between means is greater for Figure $2 a$ than for $2 \mathrm{~b}$, meaning that the opportunity map corresponds to priority sites slightly better than the needs map.

The run presented in this paper is only one of many possible run options. We've used equal weighting for conceptual simplicity. However, expert-driven weight assignment will be applied for further tool validation. Furthermore, the sensitivity of different weighting methods and criteria weights will be assessed in a sensitivity analysis. 


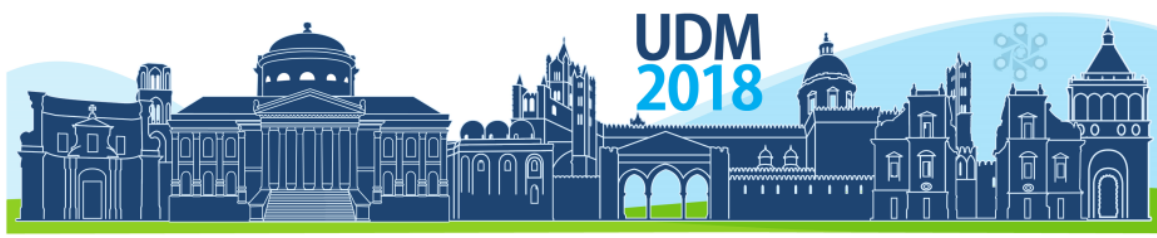

$11^{\text {th }}$ International Conference on Urban Drainage Modelling 23-26 Sep | Palermo - Italy
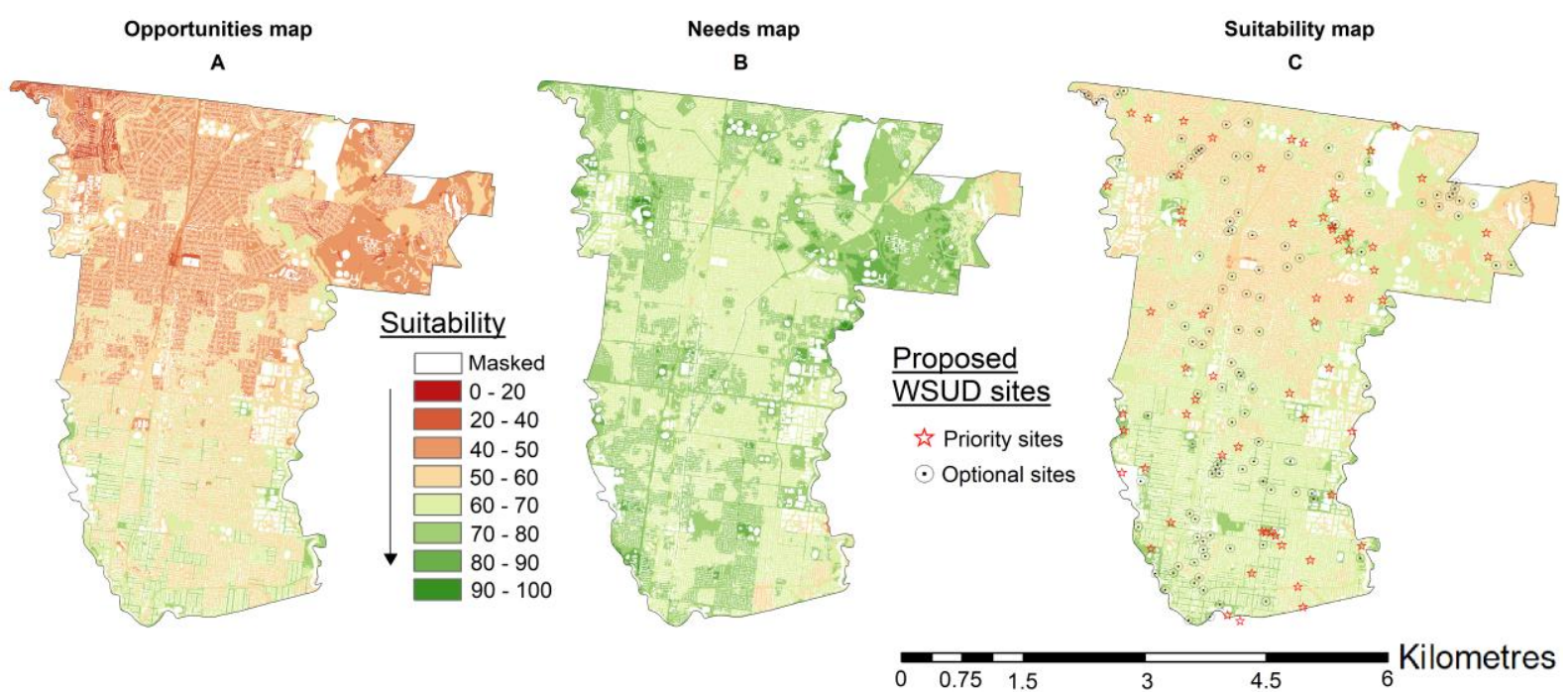

Figure 2 Outputs of the tool run with the sites for WSUD proposed by E2DesignLab overlaid in 2c for testing.

\section{CONCLUSIONS}

This paper presents a novel planning support tool to improve strategic planning of distributed green stormwater infrastructure in the urban environment. The tool applies a suitability framework which, for the first time, integrates ecosystem services and community needs with the more commonly used criteria such as biophysical factors and urban form.

The tool was successful at reproducing general outcomes comparable to the results of a manual urban planning decision making process, carried out by a consulting firm for Darebin City Council in Melbourne. Priority WSUD sites identified by the consulting firm corresponded well with highly suitable areas identified by the GIS-based Multi-Criteria Decision Analysis tool.

This tool has the potential to support urban planners to rigorously assess suitability for green urban drainage infrastructure. Thus, it will increase the strategic outcomes of their decisions and improve the operation of, and benefits derived from green urban drainage infrastructure.

\section{References}

Klosterman, R.E. (1997) Planning support systems: a new perspective on computer-aided planning. Journal of Planning education and research 17(1), 45-54.

Kuller, M., Bach, P.M., Ramirez-Lovering, D. and A., D. (2018) What drives the location choice for water sensitive infrastructure in Melbourne, Australia? Landscape and Urban Planning.

Kuller, M., Bach, P.M., Ramirez-Lovering, D. and Deletic, A. (2017) Framing water sensitive urban design as part of the urban form: A critical review of tools for best planning practice. Environmental Modelling \& Software 96, 265-282.

Malczewski, J. and Rinner, C. (2015) Multicriteria Decision Analysis in Geographic Information Science, Springer, New York.

Pereira, J.M.C. and Duckstein, L. (1993) A multiple criteria decision-making approach to GIS-based land suitability evaluation. International Journal of Geographical Information Systems 7(5), 407-424.

Roberts, S., Browne, D. and Lloyd, S. (2017) Priority Stormwater Projects for a Water Sensitive Darebin, E2DesignLab, Unpublished. 


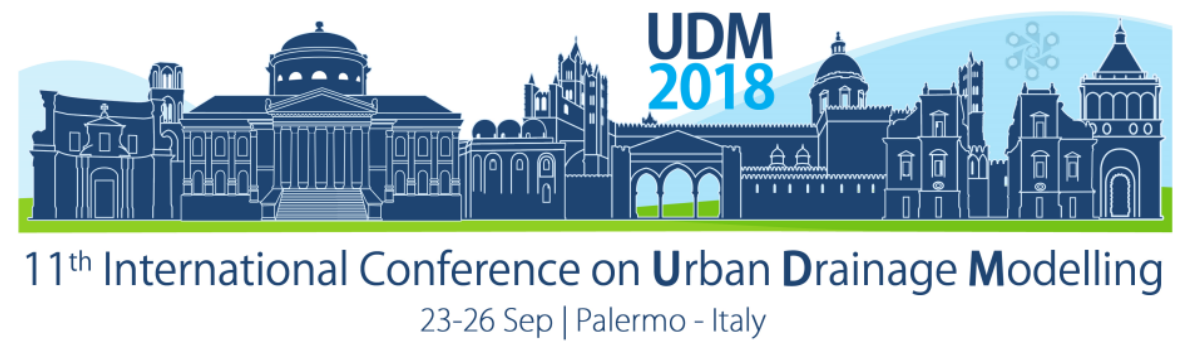

\title{
Electro-Magnetic Velocity meters: Assessment of the (Missing) Technical Parameters
}

\author{
Damjan Ivetic ${ }^{1}$, Dusan Prodanovic ${ }^{1}$ and Luka Stojadinovic ${ }^{1}$ \\ ${ }^{1}$ University of Belgrade, Faculty of Civ. Eng., Bul. kralja Aleksandra 73, Belgrade 11000, Serbia \\ (divetic@grf.bg.ac.rs - corresponding author, dprodanovic@grf.bg.ac.rs, st luka@hotmail.com )
}

\begin{abstract}
Flow measurements in Urban Drainage Systems are essential for the pollution control. Since the accuracy of the Acoustic Doppler Velocimeters is impeded by several factors, this research is focused on the alternative or a supplemental Electro-Magnetic Velocity (EMV) meters. EMV meters are more robust and reliable and can provide accurate measurements of low flows or even under a porous sediment cover. However, the downside of their usage is the small control volume (CV) where the flow velocities are integrated in a non-linear manner to obtain a single one-dimensional velocity measurement. To provide accurate mean flow velocity it is necessary to determine the size of the CV and to understand the non-linear integration principle within the $\mathrm{CV}$. These valuable data are typically not provided by the manufacturer. In this paper, an experimental methodology is proposed for defining the size of the CV and the one-dimensional (1D) weighting function, used to describe the sensor's integration principle. In the experiments, bed-mounted flat DC2 EMV probe was used. The size of the CV and 1D weighting function were determined based on the results of the EMV operation under sand cover of varying depth. It was shown that the reach of the $\mathrm{CV}$ for the used device is $6 \mathrm{~cm}$ from the electrodes of the sensor.
\end{abstract}

Keywords: Flow measurements; Electro-Magnetic Velocity meter; Weighting function

\section{INTRODUCTION}

Accurate flow measurements in Urban Drainage Systems (UDS) are essential for estimating pollutant loads and a better understanding of impacts on the urban aquatic environment. Flow measurements in UDS present a challenging task since they are designed to operate with partially filled pipes, commonly characterized by hostile environmental conditions. The VelocityArea (VA) method with a bed-mounted Acoustic Doppler Velocimeters (ADV) are frequently used (Larrarte et al., 2008). However, it was shown that the ability of the ADV to provide accurate velocity measurements in UDS is impeded by several factors (Aguilar et al., 2016). Hence an investigation on alternative or a supplement sensor is needed. In this paper, the flat bed-mounted Electro Magnetic Velocity (EMV) meter/sensor is analyzed.

Due to its operating principle, the EMV meters are inherently more robust and reliable when compared to the ADV. It was shown that EMV meter can provide linear measurements of the flow velocity even under porous sediment cover of few centimeters (Ivetic et al., 2018 - in preparation). Additionally, EMV meter has good performance in flows with low depths (smaller than $5 \mathrm{~cm}$ ) and very low velocities (below $\mathrm{cm} / \mathrm{s}$ ), making it a valuable measuring device in the combined sewer systems where a dramatic difference is observed between dry and wet weather flows (Harramoes et al., 1993). The downside of the EMV meter is the small control volume ( $\mathrm{CV}$, flow volume contributing to the sensor's output signal), hence the velocity measurements are more "local" when compared to the ADV. Furthermore, velocity measurements are a result of the non-linear integration of the flow velocity distribution within the CV (Shercliff, 1962). Hence, to provide accurate mean flow velocity measurements with 


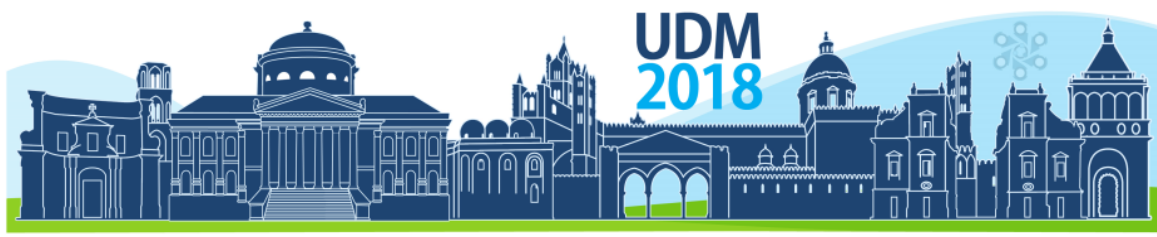

$11^{\text {th }}$ International Conference on Urban Drainage Modelling

23-26 Sep | Palermo - Italy

the EMV sensor, it is necessary to know the size of the CV and to understand the velocity integration principle within the CV. As the manufacturers of EMV meters are typically not providing the user with these valuable data, a suitable methodology for describing these features of the EMV meter is needed.

The focus of this research is to establish an experimental framework for defining the EMV's technical parameters, the size of the $\mathrm{CV}$ and the sensitivity of the measured velocity to the velocity distribution within the CV. The aim is to improve the accuracy of the VA flow measurements in UDS, by including additional technical parameters of the EMV sensor in the measurement.

\section{MATERIALS AND METHODS}

\subsection{Flat EMV}

In the research presented in this paper, a bed mounted flat DC2 EMV probe (Svet instrumenata, 2012), designed by a local SME for one-dimensional velocity measurements, was used. Flat EMV probe is shaped to minimize the flow disturbances. Two flat excitation coils are integrated into the robust inox housing of the probe, with the dimensions of $L=280$ $\mathrm{mm}, \mathrm{W}=160 \mathrm{~mm}$ and $\mathrm{H}=23 \mathrm{~mm}$ (Fig. 1A.). The manufacturer specifies that the accuracy of the DC-2 EMV device is $\pm 1 \%$, precision $0.001 \mathrm{~m} / \mathrm{s}$, and the operating range $\pm 15 \mathrm{~m} / \mathrm{s}$. The induced voltage shows a linear relationship with the measured velocity.
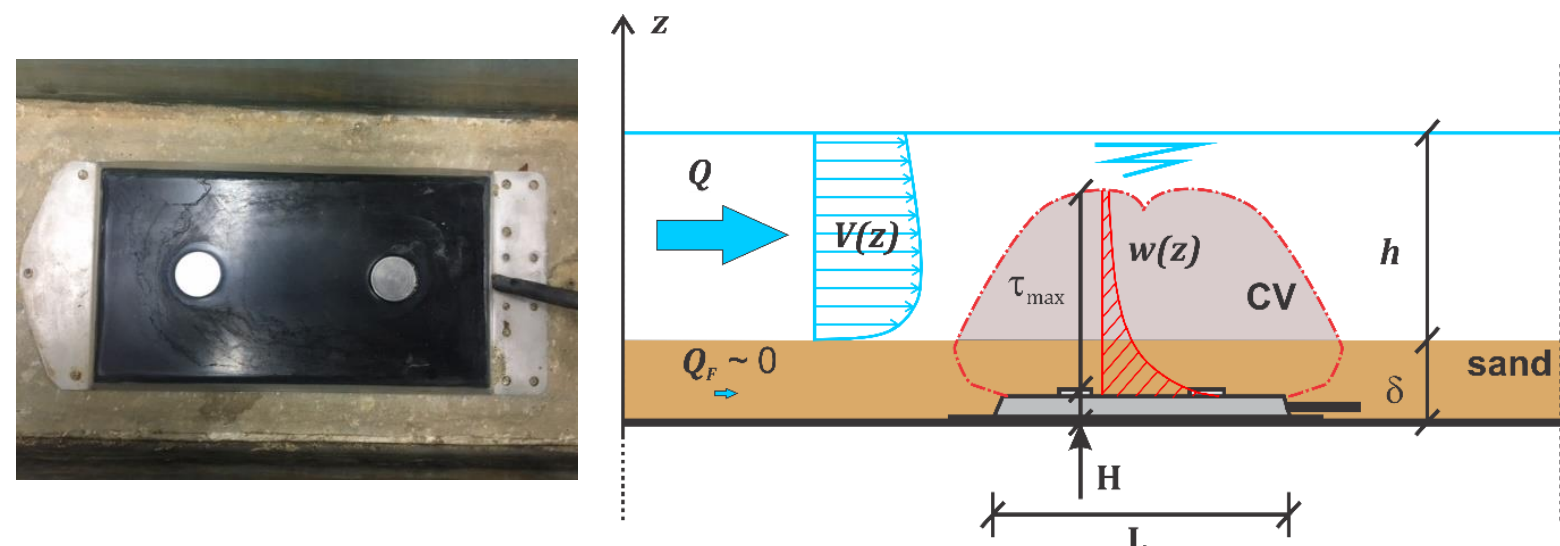

Figure 1. Left (A): Top view of flat DC2 EMV meter in a lab flume; Right (B): Illustration of the Flat EMV operation under sand cover with parameters significant to the analysis

In general, the EMV operating principle is based on the Faraday's law of induction, where the output signal (voltage $E$ ) is generated by the motion of the conductive fluid (water) through a transversal magnetic field (Shercliff, 1962). Although the general sensitivity was described as the cross product of the velocity $\vec{V}$ and the magnetic field $\vec{B}$, Shercliff (1962) proposed a simple equation to describe how each part of the flow contributes to the voltage $E$ through the weight function $w$ :

$$
E=\int_{\tau} w \cdot \vec{V} d \tau
$$




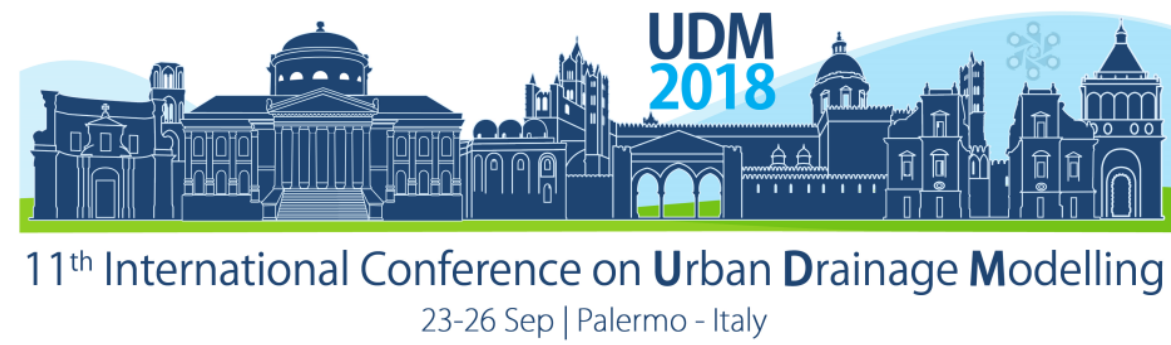

where $\tau$ is the control volume (CV) of the EM sensor (Fig. 1B). The CV is physically described as a volume (3D), yet for the practical purposes, it can be represented by a single parameter $\tau_{\max }-$ i.e. the reach of the CV or the upper limit of integration in eq. (1).

In the bed-mounted EMV application, $\tau$ is a variable, dependent on several factors: excitation current, distribution of the $\vec{B}$, conduits geometry and water depth $h$ (when the $h$ is bellow $\tau_{\max }$, otherwise $\tau=\tau_{\max }$ ). Since the excitation coils of the flat EMV probe are relatively small and power consumption is kept low (coil excitation current $80 \mathrm{~mA}$ during the $10 \mathrm{~s}$ sampling period), the reach of the produced magnetic field is limited to the vicinity of the EMV (Figure 1B). The goal of this research is to experimentally derive, one-dimensional $w$ and the maximum limits of the integration (the $\tau_{\max }$ ).

\subsection{Sand cover experiments}

To derive the weighing function, the relationship between the size of the CV and the EMV output voltage needs to be experimentally assessed. It is necessary to systematically exclude certain zones of the $\mathrm{CV}$ (in the $z$ direction) but still allow the contact between the conductive fluid and the electrodes (Fig. $1 \mathrm{~B}$ ). It is assumed that if the flat EMV is covered with the porous material (e.g. sand) of varying thickness $\delta$, this effect can be achieved. The zones occupied by sand, within the $\mathrm{CV}$, will not contribute to the output voltage as the filtration $\left(Q_{F}\right)$ velocity is negligible compared to the bulk flow $(Q)$ and the sand will not influence the magnetic field. The reduction of the CV in this manner, will lead to the proportionally smaller output voltage.

Previous flume experiments (Ivetic et al., 2018) have shown that the systematic effect of the sand cover, on the velocity measurements, can be minimized with the use of linear Correction Function Model (CFM), as long as the sand surface is flat. A part of the adapted lab flume, in the Faculty of Civil Engineering, University of Belgrade (Serbia), accommodating the free surface flow in an $8 \mathrm{~m}$ long and $0.25 \mathrm{~m}$ wide rectangular channel, has been used. Within these experiments, uncertainty benchmarking procedure (Aguilar et al., 2016) was utilized for assessing the velocity measurements acquired with the flat EMV under 16 different sand sediment depths $\delta=\{0,5,10,15,20,23,25,30,35,40,45,50,55,60,65,70,80 \mathrm{~mm}\}$. It was observed that the bias uncertainty increases with the increase of $\delta$ hence the parameters of the CFM model are dependant on the value of $\delta$. CFM is defined with two parameters, slope $\alpha$ representing the amplification of the output signal, and intercept $\beta$ corresponding to the zerodrift. Here, only the amplification of the signal $\alpha$ is considered, as the $\beta$ was proven to be constant for varying $\delta$. Based on the obtained CFM for sand, a power model for $\alpha$ (against $\delta$ ) was derived and plotted on Fig. 3A. The amplification $\alpha$ describes how the exclusion of the certain zones of the CV, starting from the EMV's upper surface $\left(z_{\text {sur }}\right)$, will reduce the strength of the output signal (Fig. 2A). 


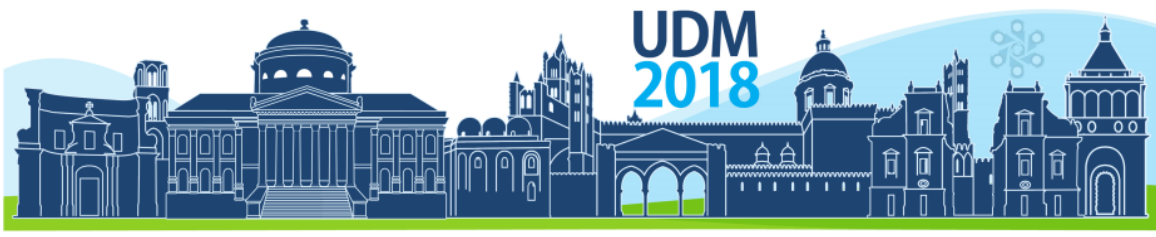

$11^{\text {th }}$ International Conference on Urban Drainage Modelling 23-26 Sep | Palermo - Italy
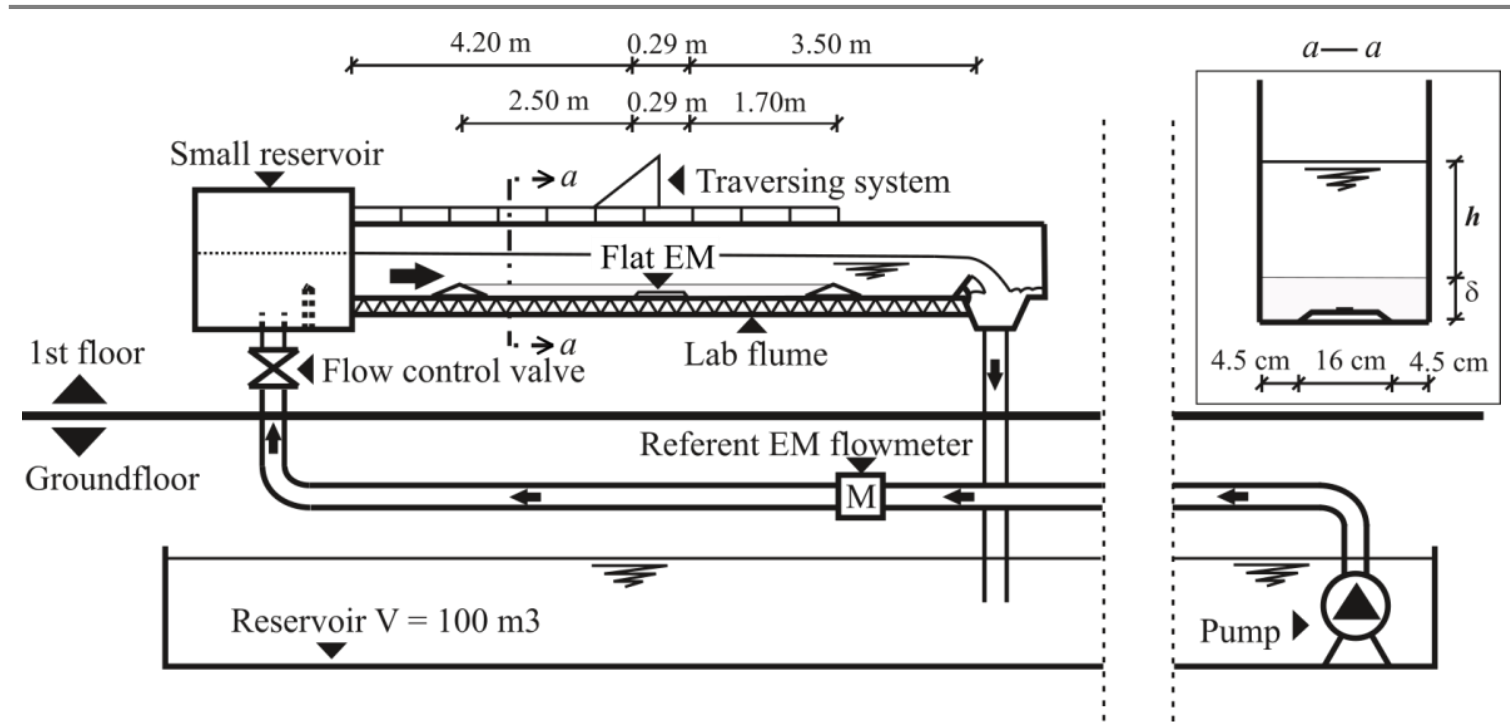

Figure 2. A schematic illustration of the adapted laboratory flume setup as part of the closed circulation system

For defining the one-dimensional $w$, a vertical velocity distribution within the bulk flow is needed. As the upstream length of the sand cover in the experiments was over few meters (length/width > 10), and the width/depth ratio was relatively low, the velocity distribution was approximated by the log-law extension proposed by Bonakdari et al. (2008). Next, it is necessary to discretise the vertical distance from $z_{\text {sur }}$ to $z_{\text {upp }}=z_{\text {sur }}+\tau_{\max }$, by arbitrary $d z$, defining $i=1 \rightarrow N$ number of vertical distances $z_{i}=z_{u p p}+i d z$. Finally, for each of the $z_{i}$, numerically approximated eq. (1), corresponding to the case of $\delta=z_{i}$, in form of a sum of squares can be written:

$$
N \alpha_{i} V=\sum_{i=1}^{N} w_{i} u_{i}
$$

where $V$ is the mean flow velocity. In total $N$ equations (2) can be defined, where for each equation $\alpha_{i}$ corresponds to the reduction of the $V$ for $\delta=z_{i}$. Furthermore, due to the presence of the sediment cover, for each of the $N$ equations (2) the distribution of the $u_{i}$ needs to be defined in accordance to the value $\delta=z_{i}$.

\section{RESULTS AND DISCUSSION}

The $N$ equations (2) form the system of linear equations with a lower diagonal matrix of unknown coefficients $w_{i}$ due to the fact that $Q_{F} \sim 0$. Solving this system leads to the experimentally defined one-dimensional weighting function $w$ (Fig. 3B). As $\tau_{\max }$ was not known a priori, it was varied until the smoothly receding $w$ was not computed. Finally, after verification with measured results, it was assumed that $\tau_{\max }$ is equal to $60 \mathrm{~mm}$. 


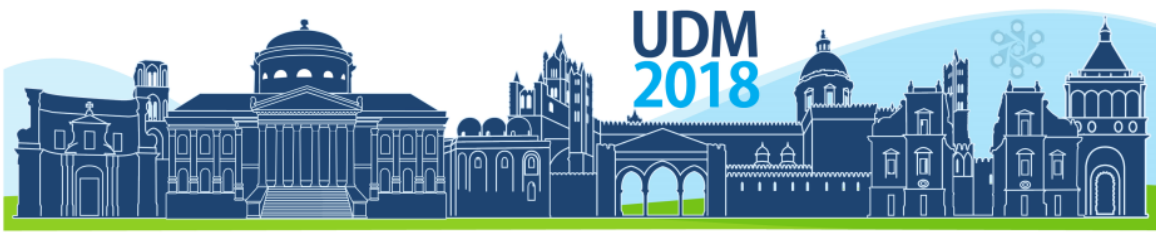

$11^{\text {th }}$ International Conference on Urban Drainage Modelling 23-26 Sep | Palermo - Italy
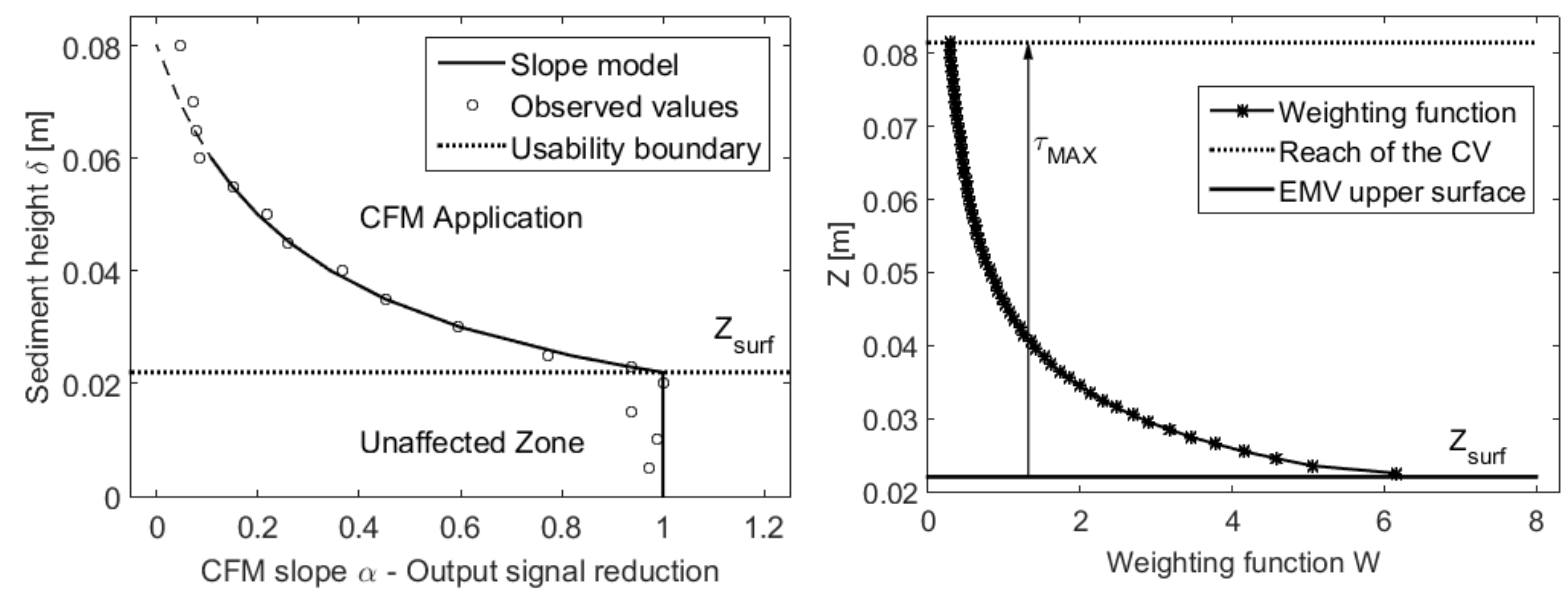

Figure 3. Left (A): CFM slope model based on the "observed" values of the correction function slopes for varying sand cover height; Right (B): One-dimensional Weighting function and the reach of the CV, derived from the sand cover experiment

\section{CONCLUSIONS}

EMV meters can be considered as a supplement or an alternative to commonly used ADVs for velocity measurements in the UDS. Technical parameters, such as weighting function and the reach of the EMV meter's CV are essential for accurate mean velocity estimation. In this paper, a methodology for the experimental derivation of these parameters is given. For flat EMV meter, used in the experiments, it is shown that the control volume is limited to $6 \mathrm{~cm}$ from the sensor electrodes. Additionally, a corresponding one-dimensional weighting function is derived. With these technical parameters of the EMV meter, it is possible to improve the accuracy of the VA flow measurements in the UDS, based on the knowledge of the site-specific hydraulic and geometric characteristics. Further field investigations, probably supported by CFD analysis, are needed for assessing the potential for VA flow measurement improvement.

\section{Acknowledgement}

The authors are grateful to the Serbian Ministry of Education, Science and Technological Development for its financial support, project No. TR37010.

\section{References}

Aguilar, M. F., McDonald, W. M., \& Dymond, R. L. (2016). Benchmarking laboratory observation uncertainty for inpipe storm sewer discharge measurements. Journal of Hydrology, 534, 73-86.

Bonakdari, H., Larrarte, F., Lassabatere, L., \& Joannis, C. (2008). Turbulent velocity profile in fully-developed open channel flows. Environmental Fluid Mechanics, 8(1), 1-17.

Harremoës, P., Capodaglio, A. G., Hellström, B. G., Henze, M., Jensen, K. N., Lynggaard-Jensen, A.,Otterpohl, R. \& Søeberg, H. (1993). Wastewater treatment plants under transient loading-Performance, modelling and control. Water Science and Technology, 27(12), 71.

Ivetic, D., Prodanovic, D., Stojadinovic, L. (2018). Submitted to the Journal of Hydrology, HYDROL27705.

Larrarte, F., Bardiaux, J. B., Battaglia, P., \& Joannis, C. (2008). Acoustic Doppler flow-meters: A proposal to characterize their technical parameters. Flow Measurement and Instrumentation, 19(5), 261-267.

Shercliff, J. A. (1962). The theory of electromagnetic flow-measurement. CUP Archive.

Svet instrumenata, 2012. Flat DC2.34 EMV. Product Datasheet (In Serbian). Retrieved from < http://www.si.co.rs/>. 


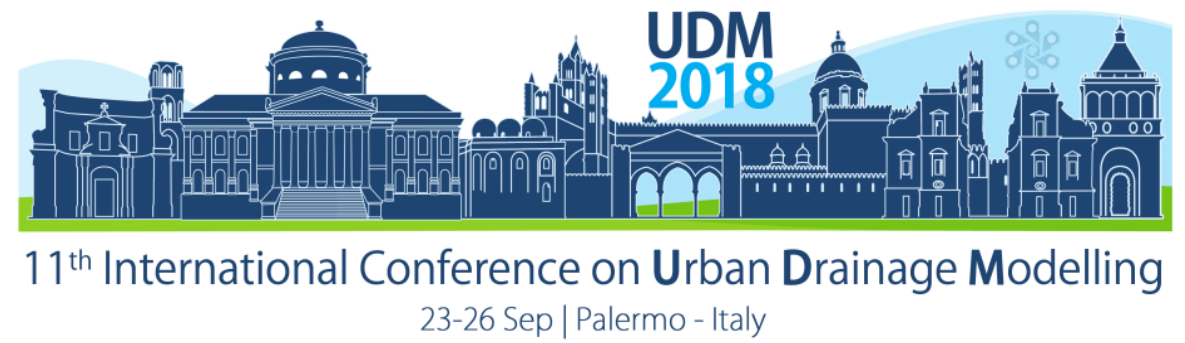

\title{
Urban Flooding and Adaptation to Climate Change in Sukhumvit Area, Bangkok, Thailand
}

\section{Sanit Wongsa ${ }^{1}$, Varameth Vichiensan ${ }^{2}$, Napaporn Piamsa-nga ${ }^{3}$ and Shinichiro Nakamura ${ }^{4}$}

${ }^{1}$ King Mongkut's University of Technology Thonburi, Department of Civil Technology Education, Bangkok, Thailand

${ }^{2}$ Kasetsart University, Department of Civil Engineering, Bangkok, Thailand

${ }^{3}$ Kasetsart University, Department of Water Resources Engineering, Bangkok, Thailand

${ }^{4}$ Nagoya University, Department of Civil Engineering, Nagoya, Japan

\begin{abstract}
Flooding in urban areas is an inevitable problem for many cities in the world. In Thailand, Bangkok has serious problems related to urban flooding. The situation was highlighted in May 2017, when residences experienced ankle to knee-deep flood water on the streets. Daily activities in parts of the city were nearly paralyzed and heavy traffic jams occurred due to stagnant water on the streets. The study has depended on a combined approach of physically based modeling and GIS. The urban drainage is structured by iRIC software for the basis of two networks, one simulating the two-dimension free-surface flow over the streets and one for the pumping/canal/pipe system. The interaction between street and pumping/canal/pipe system is modeled in a simple way. In 2017, ADAP-T project carried out a pilot study about urban flooding and adaptation modeling for Sukhumvit area, Bangkok Metropolitan. This study is performed as an extension and improvement of pilot study in terms of analyzing drainage system on effect of flood hazard, vulnerability, risk map and adaptation under the issue of climate change in Sukhumvit area, Bangkok, together with suggestion of alleviation scenarios to relieve flood problems.
\end{abstract}

Keywords: Urban flooding; Climate change adaptation, iRIC software

\section{INTRODUCTION}

Bangkok Metropolitan Administration (BMA) has experienced water logging for the last few years. Even a little rain may cause severe problems for certain city areas, which are inundated for several days. The water depth in some areas may be as much as $20-50 \mathrm{~cm}$, which creates large infrastructure problems for the city and huge economical losses in production together with large damages of existing traffic system, infrastructures, properties and goods. The BMA is protected from river flooding by an encircling embankment. Most of the time during the monsoon season, the water level in the Chao Phraya River remains about 2-3 m higher than the water level inside the city area, consequently the city drainage depends very much on the water levels of the peripheral river systems. The situation becomes worse when monsoon runoff generated from short duration and high intensity rainfall combines with high water level in river system. The main causes of floods in BMA can be classified into two types. The first one results from high water level of Chao Phraya River, canals system and the other caused by heavy rainfall.

The BMA has been struggling to divert floodwater out of the city because its water drainage system was developed mainly for handling localised flooding caused by heavy rainfall, not massive flood water from the upstream areas. BMA invested heavily in its water drainage infrastructure after 1983 when major flooded hit the city. Since then, canals and tunnels have 


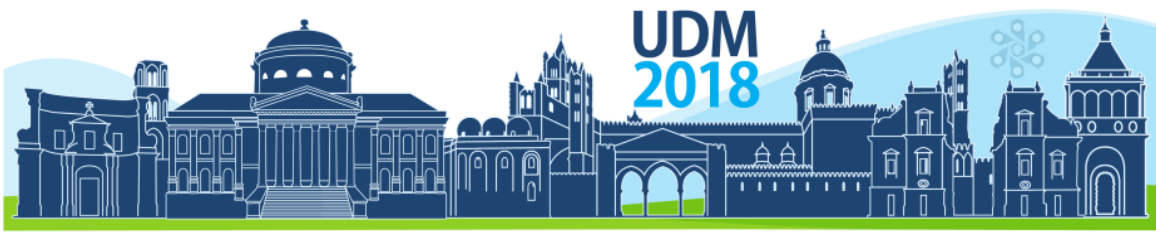

$11^{\text {th }}$ International Conference on Urban Drainage Modelling

23-26 Sep | Palermo - Italy

been dug, retention ponds designated, and pump stations constructed to help drain the flood water. Polder systems have been developed mainly in inner Bangkok, the western side of the city, and the eastern side. In inner Bangkok, a large polder has major roads and railways cutting through the Ramkhamhaeng and Phetchaburi areas, acting as its main dykes. The polder is divided into more than 20 sub-polders where drainage canals and tunnels and pumps help drain water out from the protected areas inside them. This study focus on water management Area-13 (Sukhumvit-North sub-polder), which includes the most important commercial areas of BMA, hence most of areas are impervious. Collected storm water from each sub-catchment is drained by sewer pipes/canals to Saen Saep, Ton and Phra Kanong canals and finally it is drained to main river system by pumps and canals at the basin in front of the sluice gate, as shown in Figure 1.

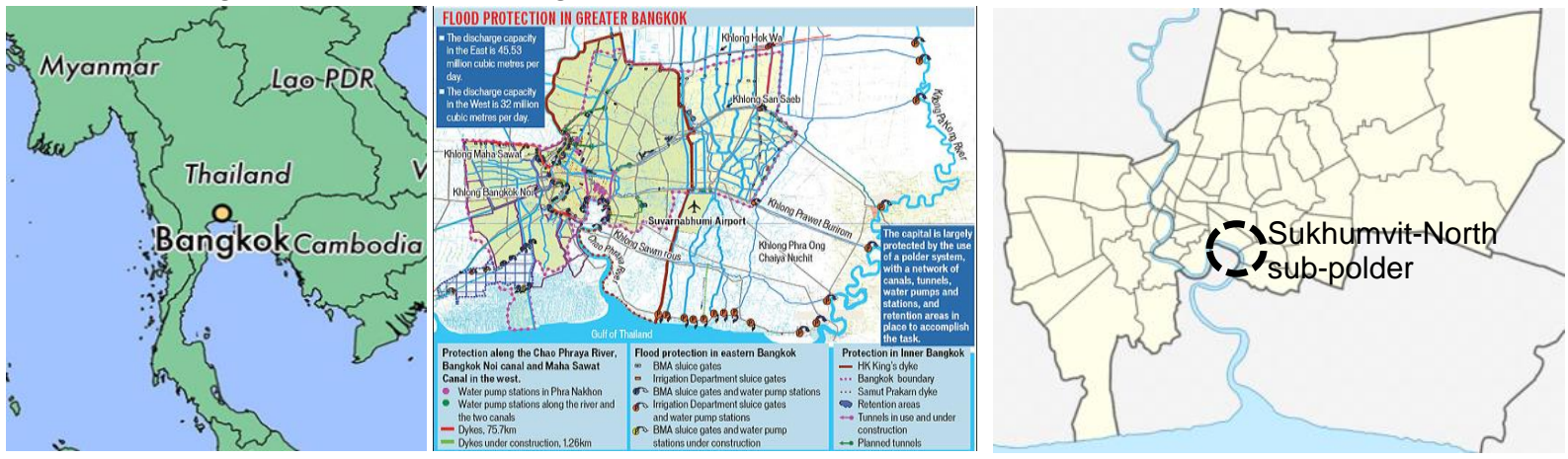

Figure 1. Bangkok's water drainage system and water management Area-13 Sukhumvit-North sub-polder drainage system. (Department of Drainage and Sewerage: DDS).

\section{IRIC SOFTWARE AND MODEL SETUP}

\section{1 iRIC software}

The iRIC software is public domain interface for calculating flow, sediment transport and morphodynamics in rivers and other geophysical flows. This interface is completely free to any users and includes 13 models ranging from simple one-dimensional models through three-dimensional models. Tools for creating these systems are supplied in iRIC webpage (http://i-ric.org/en/).

\subsection{Model setup}

For model simulation, grid size $5 \mathrm{~m} \times 5 \mathrm{~m}$ with totaling of 177,141 grids were adopted, with time step and manning's roughness parameter are $\Delta t=0.05 \mathrm{~s}$ and $n_{m}=0.03$, respectively. For model simulation, rainfall at station D29, and water level at pond/canal were adopted for input data and initial conditions, respectively. The 15 minute interval rainfall data recorded at D29 automatic rain gauge stations, extremes event during May 16, 2017, with totaling $93 \mathrm{~mm}$ are utilized to study the characteristic features of urban flood in Bangkok. The simulated flooding depths have been traced for several selected locations along with the available real flood marks to provide a general idea on how the simulated flood depths. However, overall flood depth, areas and flow direction tends to underestimate the water depths. For simulation with building block, it took a lot of computation times, since there are many small building blocks in computation domains. By grouping DEM from $5 \mathrm{~m}$ to $15 \mathrm{~m}$ and building blocks, which gives with better estimation, and more robust. Therefore, DEM $15 \mathrm{~m}$ with grouping building blocks have been adopted in this study. 


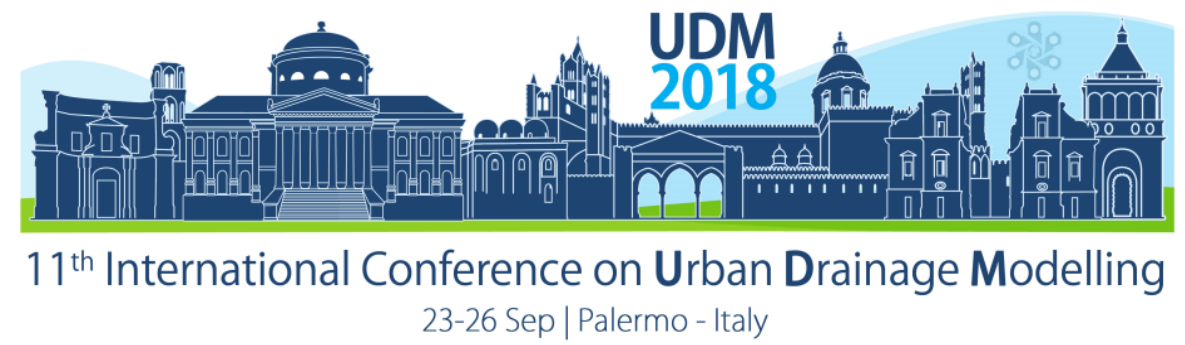

\section{RESULTS AND DISCUSSION}

\subsection{Simulation of May 16, 2017 Flooding (present condition)}

All consisting conditions of major canals, roads, pumps and sewer system have been included in the model. Then, the model has been properly calibrated for the surface roughness and runoff coefficient. It was found that manning's roughness $n_{m}=0.03$ and runoff coefficient $\mathrm{C}=0.8$ have been used in entire simulation domain. Good matching of model results and observed data ensures that the model was able to reproduce the actual flooding situation. Overall flood duration and areas at 4 selected locations are similar. But, flood depth are 4-6 cm, tends to underestimate the water depths slightly. The differences are larger at the main road, due to the different levels of traffic surface with walkways and garbage clogged the road drainage, which smaller grid sizes are required (Figure 2).

\subsection{Simulation of improve present flooding condition}

The analyses of the present urban flooding problem and the development of the technical solution for the problem alleviation have been carried out based on May 16, 2017 rainfall events. In 2017, canals dredging, giant tunnel and pumping station could not be implemented at some locations due to land dispute problem between the government and public. As an extension of present flooding condition, the drainage system has been improved by complete construction of canal dredging, giant tunnel and pumping station. The results of simulations of improve present flooding condition have shown a pronounced effective in drainage capacity which results in flooding of smaller areas, depths and shorter inundated duration as shown as flood inundation map in Figure 3. It can be seen that depth and duration of flooded decreased $1.0-1.5$ times. The reason of significant local flooding and flows in the streets is due to an insufficient drainage capacity of sewer and pumping systems. However, results of simulation can be founded that storm water cannot drained, flooded water were intermittently dry-out in some areas by pumping. Hence, increasing the pipe diameter and realigning of pipes and canals at flooded locations should be carried out.

\subsection{Simulation of climate change scenario}

This study assessed the potential impact of changed rainfall extreme on drainage systems in the BMA Area-13. The design storms for the study area were re-calculated from observed rainfall data and employing as time series rainfall input for the study area in present infrastructure scenario. It was found that overall flood depths, duration and areas are increased more than $1.5-2.0$ times in study areas. For flood depths in Sukhumvit21 (Asok Montri Rd.) and Khlong Toei (Rama 4 Rd.) are increased from $0.025-0.040 \mathrm{~m}$ to $0.04-$ $0.06 \mathrm{~m}$, due to an insufficient drainage capacity of sewer and pumping systems (Figure 4). The results show an increase in design storm depths under projected climatic change scenarios that suggest an update of current standard for designing is needed.

\section{CONCLUSIONS}

The study of urban flooding in Area-13 (Sukhumvit-North sub-polder), BMA, Thailand by using iRIC software. This study explored the potential simulation for 3 scenarios; (1) present condition, (2) improve present condition and (3) future impact of climate change. The results show that improved the drainage capacity locally, such as, sewer and pumping systems can 


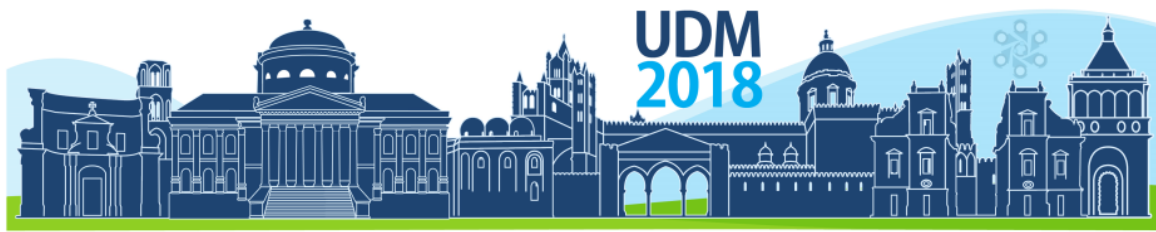

$11^{\text {th }}$ International Conference on Urban Drainage Modelling

23-26 Sep | Palermo - Italy

reduce present flood condition. For projected climatic change scenarios, it was found that overall flood depths, duration and areas are increased 1.5-2.0 times. Overall, the urban storm water management infrastructures designed based on current climate condition will not be able to cope with the increased design storm depth under future climate condition, an update of current standard for designing is needed. The findings of this study would encourage municipalities and other stakeholders for considering climate change impact in planning and designing of storm water management infrastructures to ensure that they will work effectively in future.
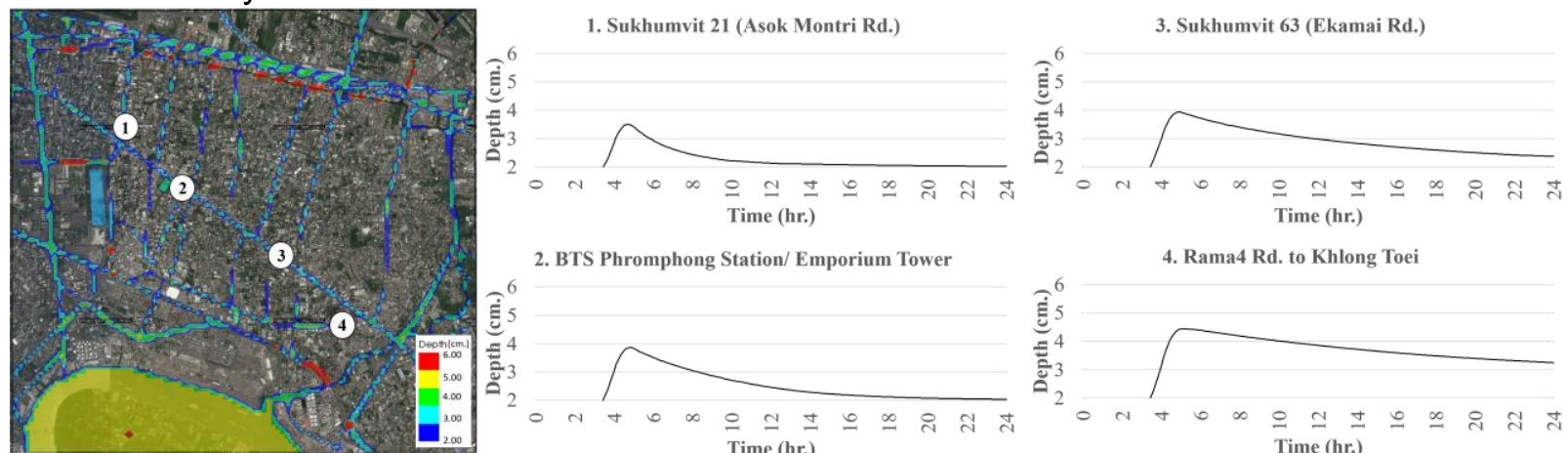

2. BTS Phromphong Station/Emporium Towe

4. Rama4 Rd. to Khlong Toei
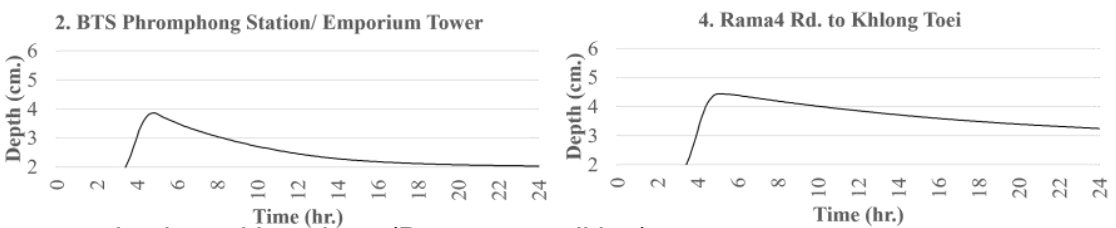

Figure 2. Time series flood depth at several selected locations (Present condition).
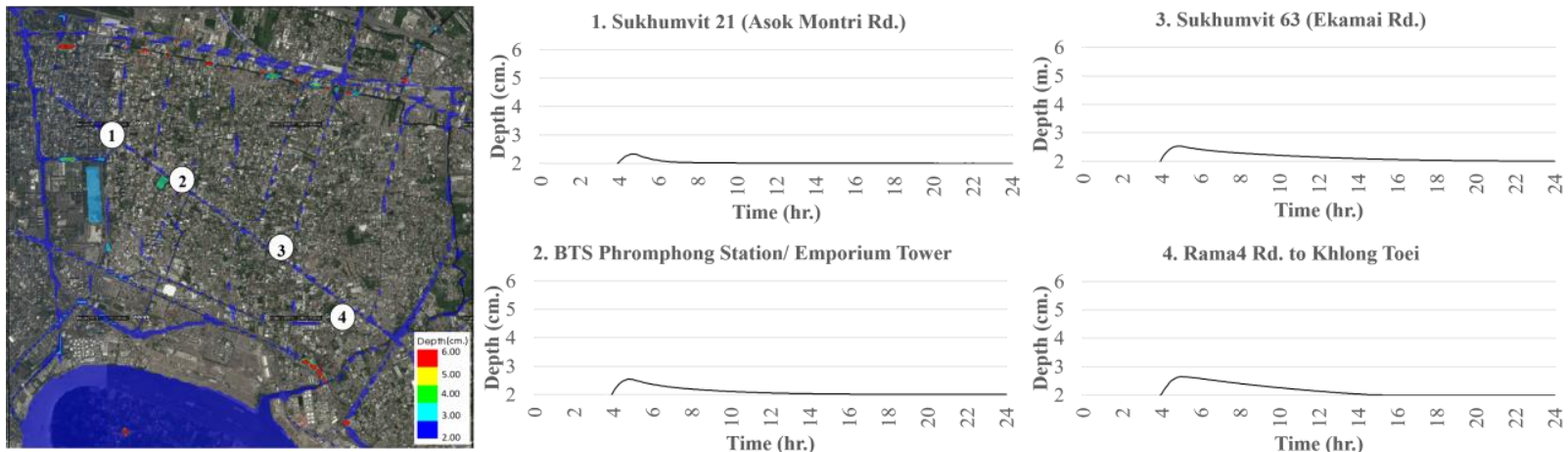

2. BTS Phromphong Station/ Emporium Tower

4. Rama4 Rd. to Khlong Toe

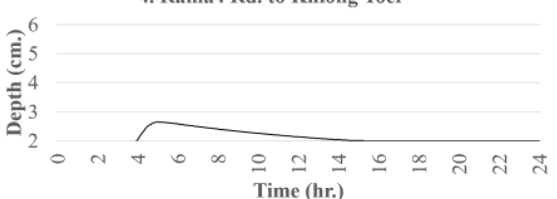

Figure 3. Time series flood depth at several selected locations (Improve present flooding condition).
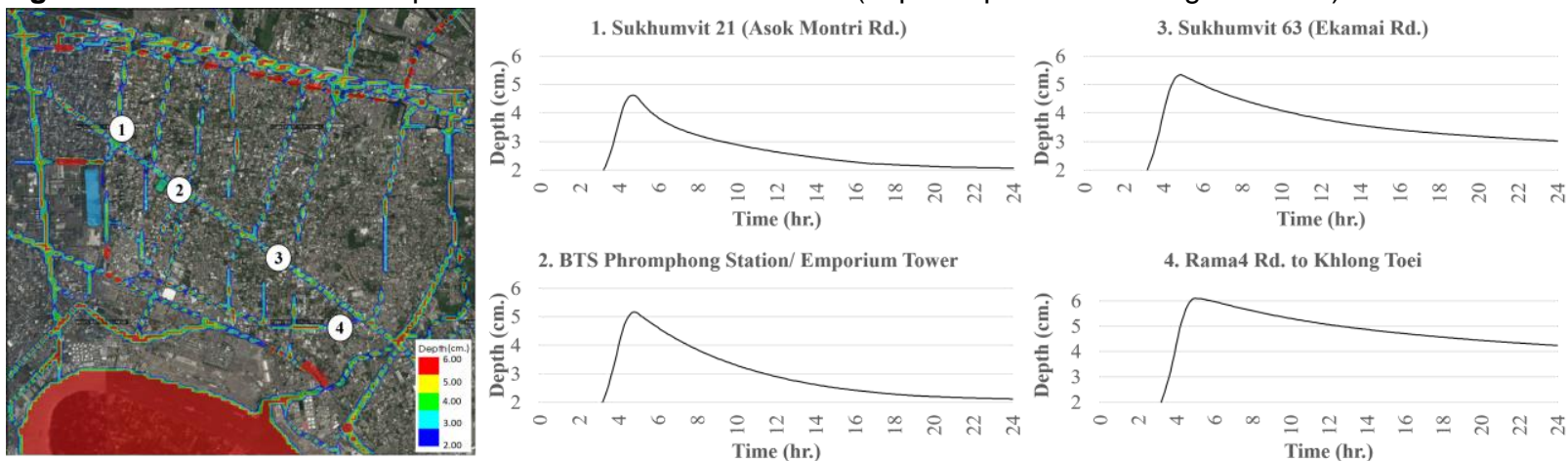

Figure 4. Time series flood depth at several selected locations (Climate change scenario).

\section{Acknowledgements}

This research was supported by "Advancing Co-design of Integrated Strategies with Adaptation to Climate Change in Thailand (ADAP-T)" supported by the Science and Technology Research Partnership for Sustainable Development (SATREPS), JST-JICA. We are also indebted to Department of Drainage and Sewerage (DDS: BMA) and Ms. Komkong T. (RA) for providing some fields and calculation data. 
Proceedings of the 11th Int. Conference on Urban Drainage Modelling, 23-26 Sep. 2018, Palermo (ITALY). Ed. prof. Giorgio Mannina

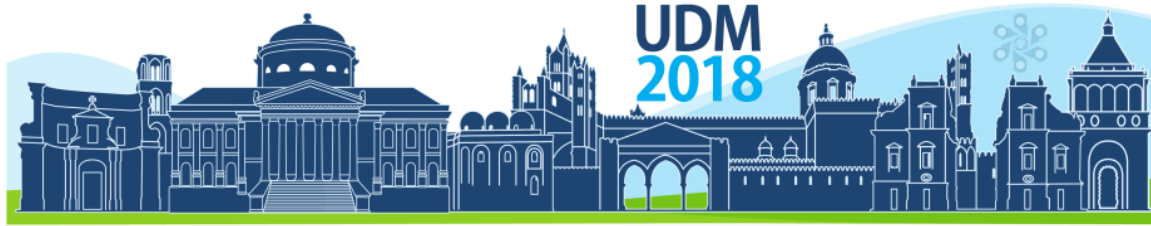

$11^{\text {th }}$ International Conference on Urban Drainage Modelling

23-26 Sep | Palermo - Italy

\section{review1:}

-This research did not use the existing software, but we are co-developer with the iRIC's team, Hokkaido University, Japan.

-Flood characteristic is very difference; flash flood in Japan, long-term flood in Thailand.

-This software originated from river morphodynamics simulation. We have developed/modified source code (Fortran) to simulate the Thailand great flood in 2011.

-Now, we created a lot of new features (rainfall, pump, hydraulic structure, pond, retard basin, building block, etc.,) for urban flood model.

\section{Review2:}

-The iRIC Nay2dFlood is a fully 2D model. Since the abstract is limited only 4 pages, we cannot describe model design and philosophy. Anyway, we will describe in a full article and our presentation.

-For climate change is in hydrology part. We analyze 15 minutes rainfall for 15 years cover Bangkok Metropolitan area, and design new IDF curve with climate change effect. Unfortunately, we will submit these results for national conference. Anyway, we will show in our presentation.

-We will improve Figures 2-4.

\section{Review3:}

-We choose Sukhumvit area, Bangkok, because it is a very problematic area, for both flood and traffic. We will also analyze the damage/impact of floods on traffic and logistic.

-Since the abstract is limited only 4 pages, we will describe the model theory in a full article and our presentation.

We will improve the extended abstract and re-submit

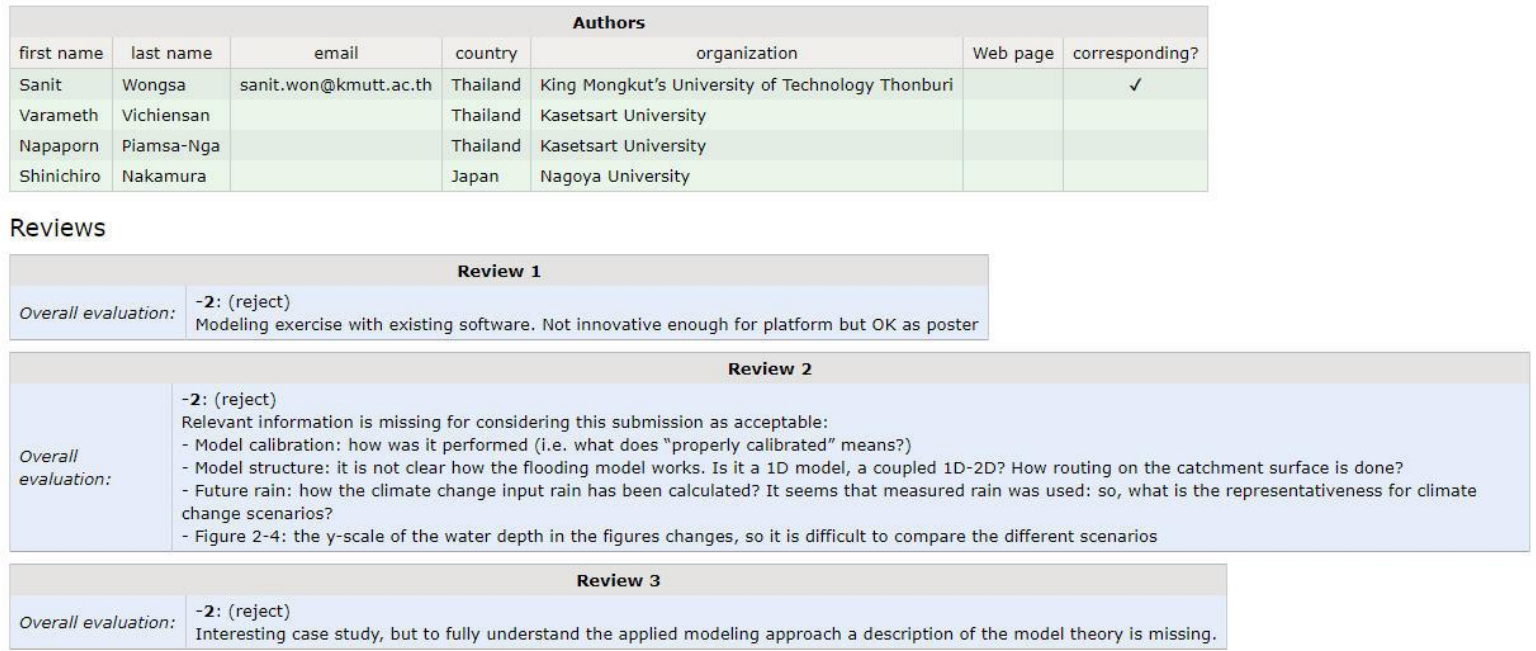




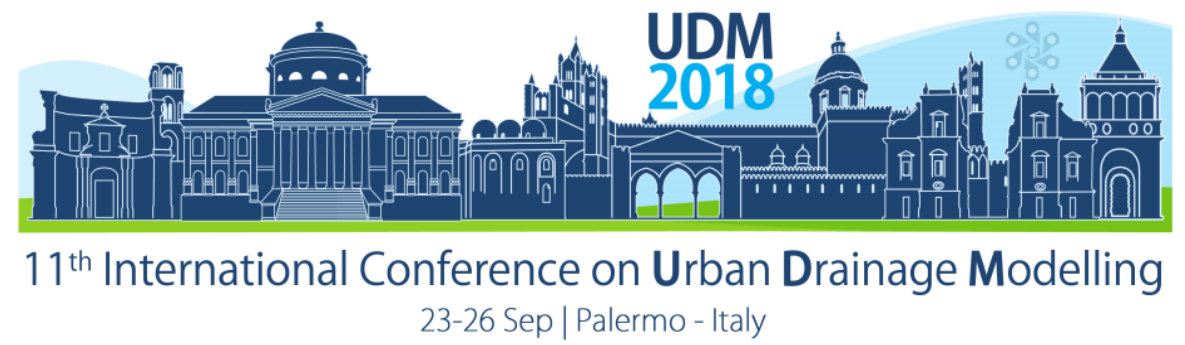

\title{
Hydrological Modelling and Detention Ponds Evaluation at Paranoa Lake - Brazil.
}

\author{
Fernanda Pereira de Souza ${ }^{1}$, Maria Elisa Leite Costa $^{2}$ and Sergio Koide ${ }^{3}$ \\ 1,2,3 University of Brasilia, Technology Faculty, Brasilia, Brazil \\ (eng.amb.fernanda@gmail.com; mariaelisa@unb.br; skoide@unb.br)
}

\begin{abstract}
Paranoá Lake is an urban lake and since last year Brasilia started to use its waters for human consumption. Until the 1990's algae and cyanobacteria blooms occurred and improvements on wastewater treatment plants brought the water quality to very good conditions in the 2000's. Recently water quality is starting to deteriorate mainly due to diffuse pollution. Thus, the evaluation of urban drainage waters entering the lake and the proposition of technological alternatives to minimize impacts are important for the analysis of diffuse urban pollution flowing into the lake. Quantitative and qualitative behaviour of the urban drainage waters were analysed by means of monitoring the precipitation amount and runoff flow and quality. Mathematical modelling using the SWMM and PCSWMM programs was carried out, and good results were obtained for flow modelling. However, in water quality simulations, poorer response was obtained. It was also evaluated the implementation of 13 alternatives of detention ponds to study the effects of their location on the removal of pollutants, as well as influences on the network flow support. It was observed that ponds allocated in the downstream part of the network are more efficient, but requireconstruction in environmentally and urbanistically problematic areas and high commercial value. Alternatives with smaller volumes in areas areas near the center ofthe basin can meet flooddamping needs of the presently constructed drainage network.
\end{abstract}

Keywords: LID; SWMM; Detention Basis

\section{INTRODUCTION}

Paranoa Lake composes the Lake Paranoa watershed. This basin is entirelly located in the Federal District territory and this allows control over the pollution sources that contribute to this lake. We need to understand the hydrological response of the different city areas to minimize the risks associated with the rainy events that occur in the region.

Hydrological models can help to understand hydrological dynamics, as well as to study and analyze alternatives of mitigation, changes in hydrological basin conditions, and are used mainly to anticipate events and allow the evaluation of preventive and/or remedial measures (Tucci, 2005).

Among the computational hydrological models, Storm Water Management Model - SWMM can simulate the quantity and quality of surface runoff in urban basins. This tool allows applications such as design and dimensioning of drainage network components, design of detention structures, diffuse pollution modelling and of Best Management Practices - BMP efficiency evaluation. (USEPA, 1999)

The SWMM represents the drainage system behaviour through a water flow series among the main environment compartments, as: atmospheric, where precipitation and deposition of pollutants occurs on the surface of the soil; the soil receives precipitation in the form of rain or snow; the transport compartment that exports the flow of water infiltration through runoff and 


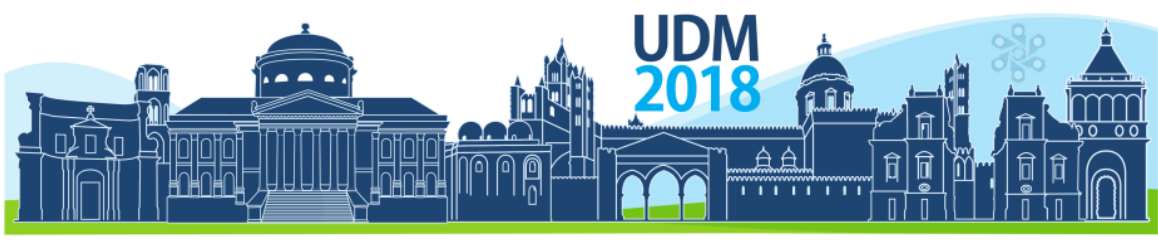

$11^{\text {th }}$ International Conference on Urban Drainage Modelling

23-26 Sep | Palermo - Italy

transport of pollutants; groundwater that receives the infiltration of the soil surface, and can transfer part of it to the transport compartment.

SWMM also allows the introduction of Low Impact Development Practices (LID) controls. They are represented by the combination of vertical layers whose properties are defined by area units. It can model five different generic types of LID: bioretention cells, porous pavement, infiltration trench, cisterns and vegetated ditches, and it can be combined in the same subbasin (Rossman, 2010).

In this work, it was tested different combinations of detention ponds in order to evaluate the hydrological and hydraulic processes in the sub-basins inserted in the Paranoa basin, using the SWMM program.

\section{MATERIALS AND METHODS}

Brasilia was created within the cerrado biome, which has about 10 biota that coexist without mixing or permeating in phytophysiognomy transition bands, and its biodiversity can be compared to the Amazon (Ferrante et al., 2001) . It is the highest region of the Brazilian Central Plateau, with springs of water courses of three great Brazilian hydrographic regions: of Paraná, São Francisco and Araguaia/Tocantins.

The study area is a sub-basin inserted in Brasilia central area, occupied by avenues, business buildings, residential and commercial areas. In this work drainage network, land use and occupation, soil pedology, climatological regime and flow were characterized /monitored. Flow monitoring allowed model calibration and simulation of the 13 LID implementation alternatives, described in Table 1.Layout of the ponds are shown in Figure 1.

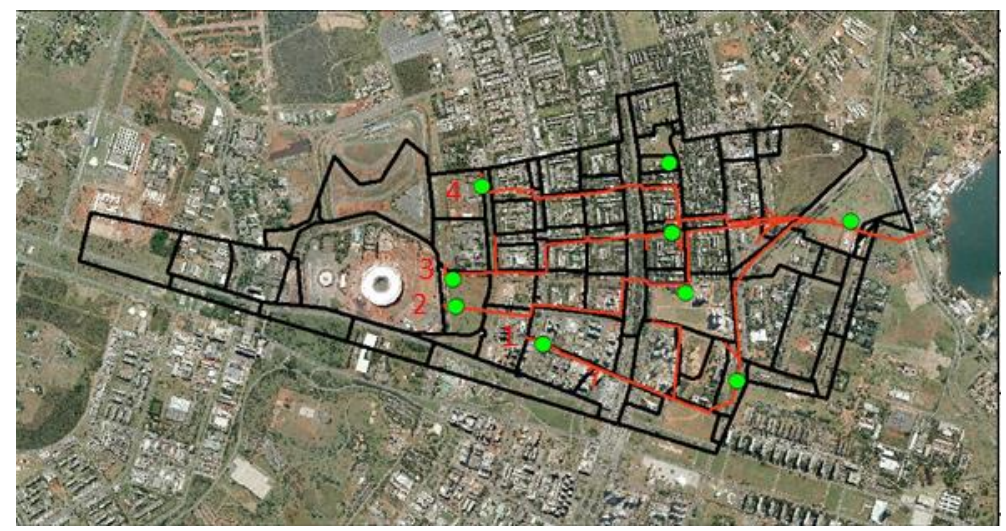

Figure 1. Drainage network position and location of the detention ponds in the galleries numbered 1 to 4. 


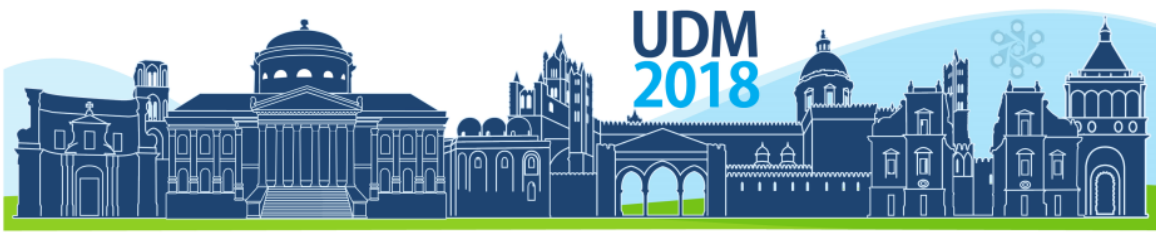

$11^{\text {th }}$ International Conference on Urban Drainage Modelling

23-26 Sep | Palermo - Italy

Table 1. Detention Basis Layout

\begin{tabular}{lcccc}
\hline & Localization & Quantity (unit) & Volume $\left(\mathrm{m}^{3}\right)$ & Elevation $(\mathrm{m})$ \\
\hline Alternative 1 & Upstream gallery 1 & 1 & $79.079,52$ & 6 \\
\hline Alternative 2 & Downstream gallery 1 & 1 & $79.079,52$ & 6 \\
\hline Alternative 3 & Upstream gallery 2 & 1 & $79.079,52$ & 6 \\
\hline Alternative 4 & Downstream gallery 2 & 1 & $79.079,52$ & 6 \\
\hline Alternative 5 & Upstream gallery 3 & 1 & $79.079,52$ & 6 \\
\hline Alternative 6 & Downstream gallery 3 & 1 & $79.079,52$ & 6 \\
\hline Alternative 7 & Upstream gallery 4 & 1 & $79.079,52$ & 6 \\
\hline Alternative 8 & Downstream gallery 4 & 1 & $79.079,52$ & 6 \\
\hline Alternative 9 & Downstream gallery 1 and 2 & 2 & $39.539,76$ & 5 \\
\hline Alternative 10 & Downstream gallery 2 and 3 & 2 & $39.539,76$ & 5 \\
\hline Alternative 11 & Downstream gallery 3 and 4 & 2 & $39.539,76$ & 5 \\
\hline Alternative 12 & Downstream gallery 1, 2 and 3 & 3 & $26.359,84$ & 5 \\
\hline Alternative 13 & Macrogallery & 1 & $79.079,52$ & 6 \\
\hline
\end{tabular}

The project developed in this area was divided into stages that included: (1) the qualitative and quantitative water monitoring; (2) water monitoring data processing; (3) modeling basin and sub-basins characterization; (4) simulations of flow rates, water quality and detention basins using SWMM; (5) deployment site evaluation; (6) qualitative and quantitative impacts.

To determine the contribution sub-basins, the slope map and the land use map were used, through which they identified the common characteristics to generate the map of the contribution sub-basins. The micro drainage survey was done in loco, with the marking of each manhole and verification well, to insert in the GIS software.

More than 50 events was monitored in the study basin, of which 20 allowed to perform the calibration and verification of the gallery flow and water quality simulation in PCSWMM.

\section{RESULTS AND DISCUSSION}

The current network has several pressure points, especially in gallery 1 , where the conduit junctions are drowned, Figure 2, which may be a reflection of the existing waterproofing area, with a cluster of public buildings, bus station and an open area which is quite compact since it is often used as parking lot.

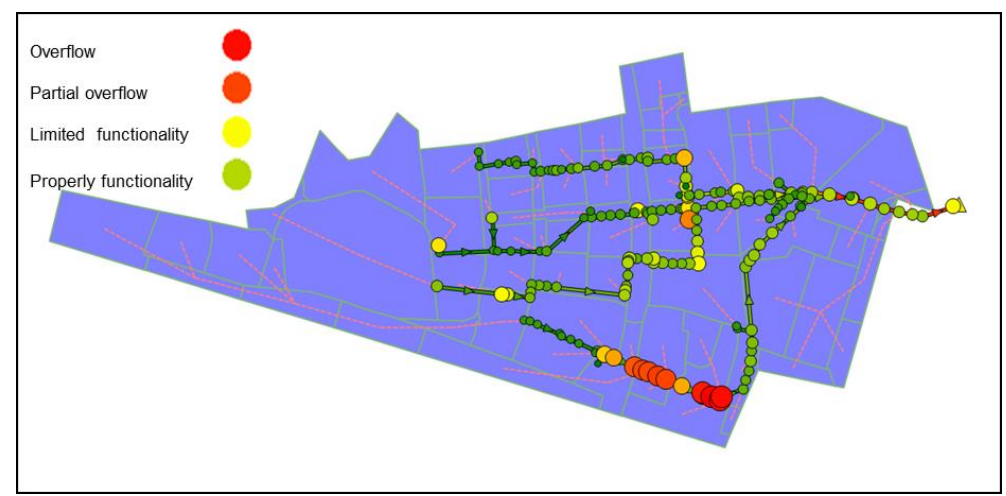

Figure 2. Drainage network behavior without interventions 


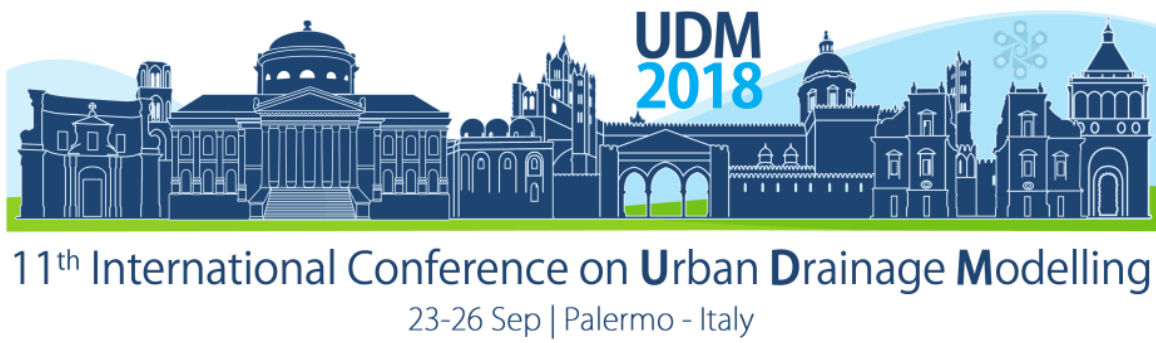

Analysing the network behaviour and comparing to the alternative without the LID implementation, the alternatives 9, 12 and 13 for each proposed event presented the best results in reducing the flow to the gallery outfall. The differences among the other alternatives are essentially based on the magnitude of the peak flow, with only the alternative 13 having the largest peak reduction, but all the other alternatives presented similar behaviours.

The detention basins modelled, besides promoting the regularization of flows, also allowed the control of pollutants. The removal efficiency of this technique is associated not only with the size of the basin in relation to the river basin, but also with the collection basin characteristics. As expected, larger detention ponds led to reduced peak flows and improved water quality due to the larger detention time.

The combined ponds, alternatives $9,10,11$ and 12, also promoted pollution load reductions, and, in spite of their smaller size, no overflow ocurred, thus all the flow passed through the process of pollution load reduction.

The combined basins, alternatives $9,10,11$ and 12, also promoted reductions of significant pollutants loads, in spite of their smaller size, there was no overflow, thus considering that all the flow passed through the process of reduction of pollutant loads

But, analyzing the percentage of removal of each pollutant for the different alternatives, it was observed that only alternative 13 reached the typical removal values for detention ponds related by Schueler (1997).

\section{CONCLUSIONS}

Simulating 13 detention ponds alternatives it was observed that that the detention ponds located at the upstream part of the basin had little effect on the final flow, but they contributed to the improvement of the drainage network by reducing the drainage system overflow locally. It was also observed that the detention ponds would have the same flow damping efficiency if they were reduced to the size of $70 \%$ of the original size, because their storage capacity was oversized.

In the detention basins located downstream part of the basin, the response in the final flow of the basin was more significant. The reductions achieved were $10 \%$ to $30 \%$ of the peak of the flow, and it would be possible to reduce the volume by $20 \%$, considering that the detention ponds did not reach their maximum level for the critical rainfall.

Implementing detention ponds can be an alternative to resizing the drainage network that has several points operating at their capacity limit. The alternatives that considered the combination of detention ponds implementation were the ones that presented the best reduction in the peak downstream of the basin, reaching values of $30 \%$ to $60 \%$ reduction.

In future works it is important to evaluate the combined implementation of LID to increase the reduction of flow in the system and of pollutants that reach Lake Paranoá. It's also important evaluate costs and avoid large-scale impacts within the basin. 
Proceedings of the 11th Int. Conference on Urban Drainage Modelling, 23-26 Sep. 2018, Palermo (ITALY). Ed. prof. Giorgio Mannina

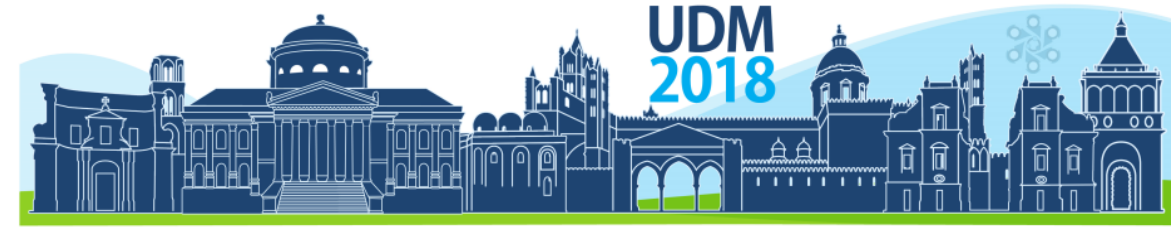

$11^{\text {th }}$ International Conference on Urban Drainage Modelling

23-26 Sep | Palermo - Italy

\section{References}

Rossman, L. A. (2010) Storm water management model users' manual version 5.0.Rep. No. EPA/600/R-05/040, U.S. Environmental Protection Agency, Water Supply and Water Resources Div., National Risk Management Research Laboratory, Cincinnati.

Tucci, C.E.M. (2005). Modelos hidrológicos. ABRH, Porto Alegre-RS.

USEPA - United States Environmental Protection Agency, (1999). Preliminary Data Summary of Urban Storm Water Best Management Practices. Office of Water (4303) EPA-821-R-99-012. Washington, DC. 1999

Zoppou, C., (2001). Review of urban storm water models. Environmental Modelling\& Software, Volume 16, Issue 3, abril 2001, p. 195-231.

Ferrante, J. E. T.; Rancan, L.; Barbosa Netto, P. Meio físico. In: Fonseca, F. O., (2001). Olhares sobre o lago Paranoá. Brasília, DF: GDF/SEMARH, 2001 


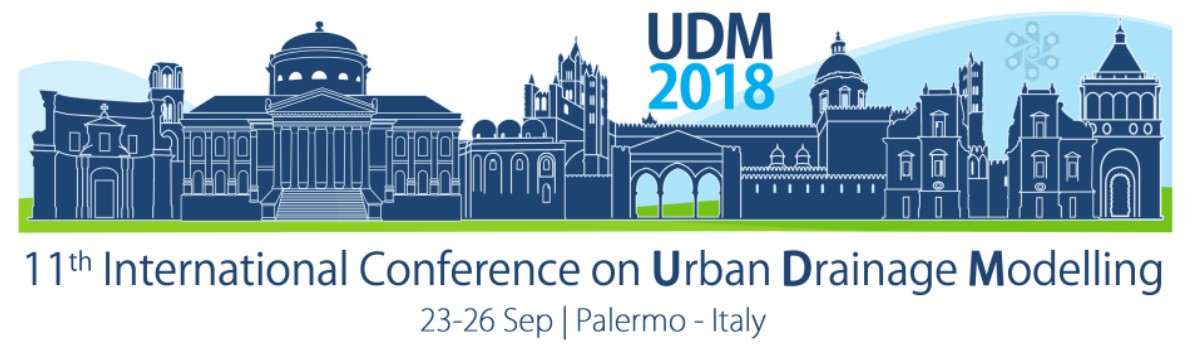

\title{
Using Precipitation and Combined Sewer Overflow Data for Predicting Hygienic Contaminations in Bathing Waters - A Data Analysis
}

\author{
Anna Bachmann-Machnik ${ }^{1}$, Ulrich Dittmer ${ }^{1}$ and Annika Schönfeld ${ }^{2}$ \\ ${ }^{1}$ Institute for Sanitary Engineering, Water Quality and Solid Waste Management (ISWA), University of Stuttgart, \\ Bandtaele 2, 70569 Stuttgart, Germany \\ 2 Ruhrvervand, Kronprinzenstraße 37, 45128 Essen, Germany
}

\begin{abstract}
Rivers and lakes in urbanised areas are increasingly appreciated for their high ecological and recreational value. The demand for bathing sites is growing. However, in many German rivers as the Ruhr River, bathing has been prohibited for decades. At Lake Baldeney, an impounded lake of the Ruhr River, located in a densely populated area in North-Rhine-Westphalia, the first bathing place was opened in 2017. Receiving water from combined sewer overflows during heavy rain events, the hygienic quality of the water body could be affected. Due to that an extensive monitoring programme of quality parameters along the Ruhr River has been carried out during the last years and an early warning system has been established to assure a safe bathing environment at all times in a previous research project. In this article highly resolved precipitation data from six rain gauges, overflow data from four combined sewer overflow (CSO) tanks and one storage sewer as well as flow data from the River Ruhr was analysed together with daily measurements of Escherichia coli (E. coli) and intestinal enterococci (Int. E.) to assess the prediction capacity of hygienic contaminations at the bathing site during three swimming seasons. Data evaluation showed a good predictive capability of precipitation data. Overflow data showed less predictive performance when using overflow information from one tank only, indicating that single overflow events not necessarily lead to hygienic contaminations above critical thresholds.
\end{abstract}

Keywords: Combined Sewer Overflow; Bathing Water Quality; Hygienic Water Quality

\section{INTRODUCTION}

Rivers and lakes are precious locations within urban environments and are more and more valued for their ecological and recreational value (Nescovic and Hein, 2015). The demand for bathing sites at urban waters is increasing. However, swimming in urban water bodies can cause infections as gastroenteritis or cercarial dermatitis (e.g. Kistemann et al., 2012; Soldánová et al., 2013). Therefore, bathing water quality in Europe is regulated by the European Bathing Water Directive (EU, 2006). Herein indicator organisms which can be used as representatives for numerous different species are defined to determine the fecal contamination of surface waters.

Important sources of microbial contamination of rivers are point sources as effluents of wastewater treatment plants, combined sewer overflows as well as diffuse sources as precipitation runoff from agricultural areas or wildlife (e.g. Donovan et al., 2008; Kistemann et al., 2012; Ottoson et al., 2006; Tondera et al., 2016).

The lower Ruhr River, located in North Rhine-Westphalia in western Germany passes through a densely populated area with large industrial cities. The watershed is administrated by the Ruhrverband. A century ago the hygienic and water quality in this river in the centre of a highly industrialised area was very low. The comprehensive development of modern wastewater treatment plants and combined sewer overflow treatment facilities has significantly improved 


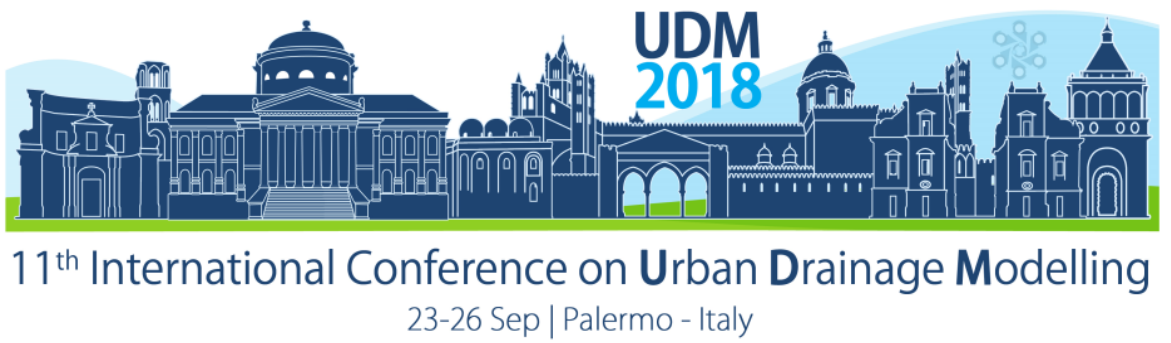

the water quality of the Ruhr River and nowadays secures high water quality standards (Raskob and Jardin, 2018). Calling for "good ecological status" the EU Water Framework Directive (EU, 2000) has also contributed to the significant improvement of the water quality. However, this "good ecological status" does not mean that the hygienic contamination of the river is suitable for bathing. (Kistemann et al., 2016) Especially after rain events the hygienic quality of the river can be decreased (Gasse et al., 2009; Tondera et al., 2016) so potentially harmful conditions could occur for bathing.

In order to prevent the public from harmful bathing conditions a simple early warning system has been set up in a previous research project. Data collected within this research project has been analysed for applicability of different model approaches for a hygiene early warning system by Mälzer et al., 2016. They showed that although artificial neural networks allow the most accurate prediction of bacterial concentrations in the lower Ruhr River, a simple binary model considering daily precipitation would be easier to implement still providing acceptable prediction results. This strategy has been implemented by the Ruhrverband and the first river bathing site "Seaside Beach" at Lake Baldeney in North-Rine Westphalia was opened in May 2017. Using a rather conservative daily precipitation threshold of $5 \mathrm{~mm} / \mathrm{d}$ for an evaluation period of three days resulted in more bathing prohibitions than actual hygienic contaminations defined by the Bathing Water Ordinance of North Rhine-Westphalia (1.800 MPN/100 ml E. coli and $800 \mathrm{MPN} / 100 \mathrm{ml}$ Int. E.) (Raskob and Jardin, 2018).

To improve the early warning system overflow data from five CSO structures within the catchment of the Lake Baldeney as well as flow data of the Ruhr River could be used in addition to the precipitation data. Therefore, an analysis of the predictive capacity of the online precipitation and overflow data was conducted. Different strategies for predictions of hygienic bathing water quality were assessed.

\section{MATERIALS AND METHODS}

\subsection{Study area and data}

Lake Baldeney is the biggest impounded lake of the lower Ruhr River. An overview of the study area is given in figure 1. Most probable numbers (MPN)/100 ml of E. coli and Int. E. were determined by the Ruhrverband in daily water samples during swimming season for 226 days from 2015-2017 at the bathing site. Furthermore, online data from six rain gauges, five CSO structures (in 2017; 2015-2016 four CSO structures) and four river flow measurements provided by the Ruhrverband was used for data analysis.

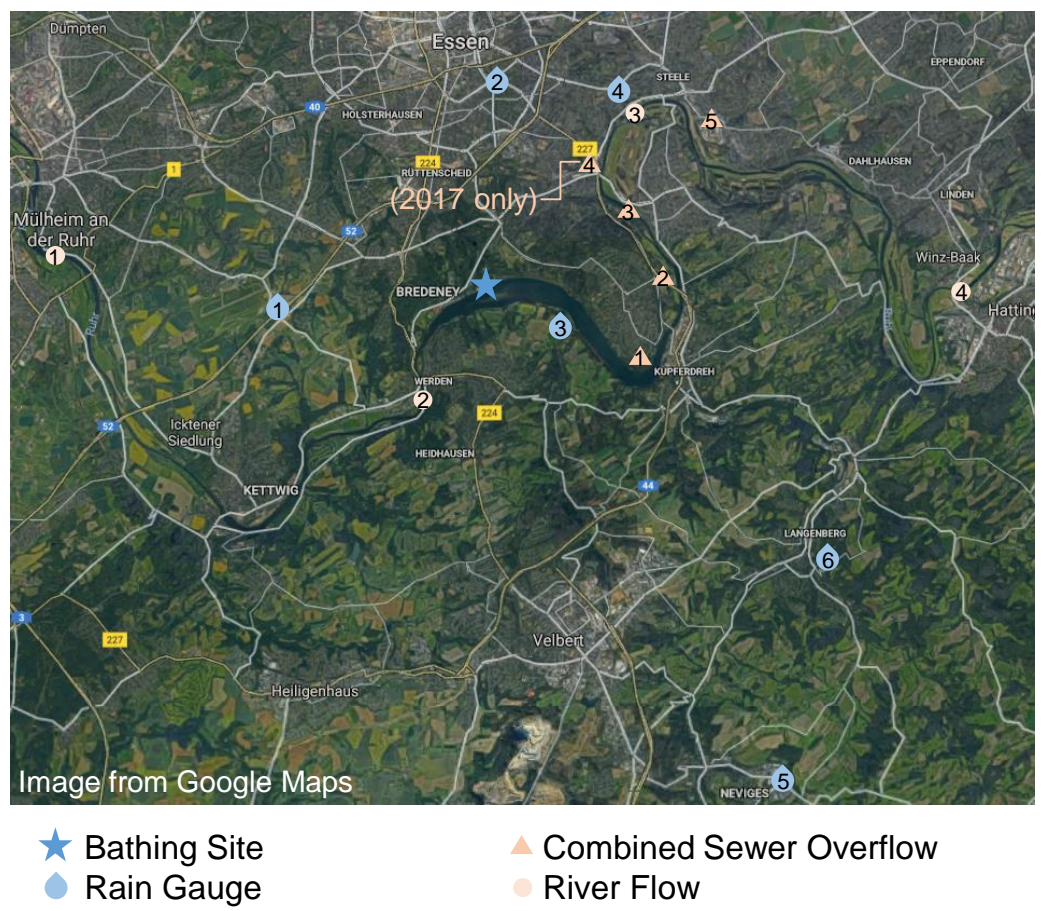

Figure 1. Study area and measurement stations 


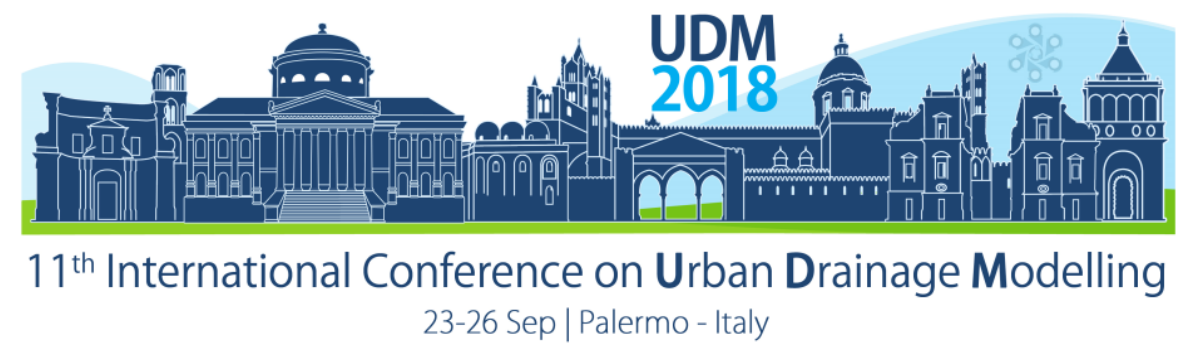

\subsection{Methods}

Correlations between daily precipitation sum, river flow, CSO duration and concentration of E. coli and Int. E. were assessed. Different time delays (one or two days) were taken into account. For assessment of different early warning strategies hygienic data has been converted into binary values (exceedance of threshold value of $1.800 \mathrm{MPN} / 100 \mathrm{ml}$ for $E$. coli and $800 \mathrm{MPN} / 100 \mathrm{ml}$ for Int. E.). Also CSO data as well as daily precipitation sums have been converted into binary data (with varying daily precipitation sum and event duration as thresholds) assessing different threshold values for optimal prediction of exceedance of hygienic pollution.

\section{RESULTS AND DISCUSSION}

With none of the assessed time lags significant correlations between the assessed parameters and the quantity of hygienic parameters could be obtained. All correlation coefficients were below 0.3 (for example see figure 2).
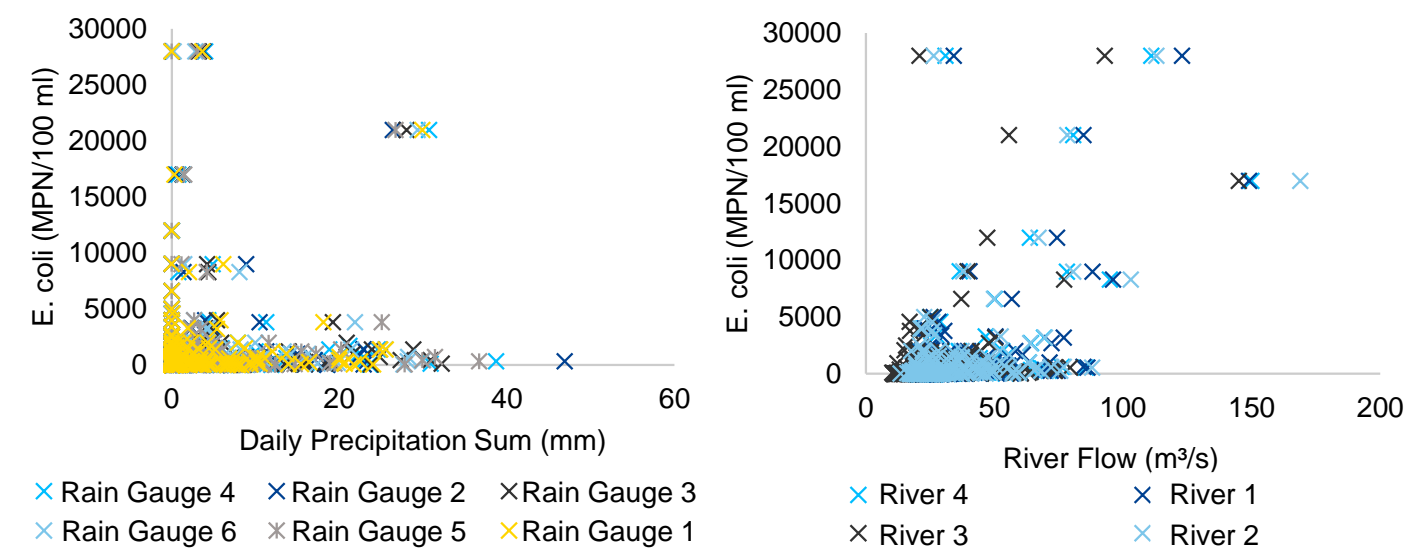

$\begin{array}{rr}\times \text { Rain Gauge } 4 & \times \text { Rain Gauge } 2 \\ \times \text { Rain Gauge } 6 & \text { * Rain Gauge } 3 \\ & \times \text { Rain Gauge } 1\end{array}$

Figure 2. Correlation of $E$. coli concentration and daily precipitation sum [left] and correlation of $E$. coli concentration and river flow [right]

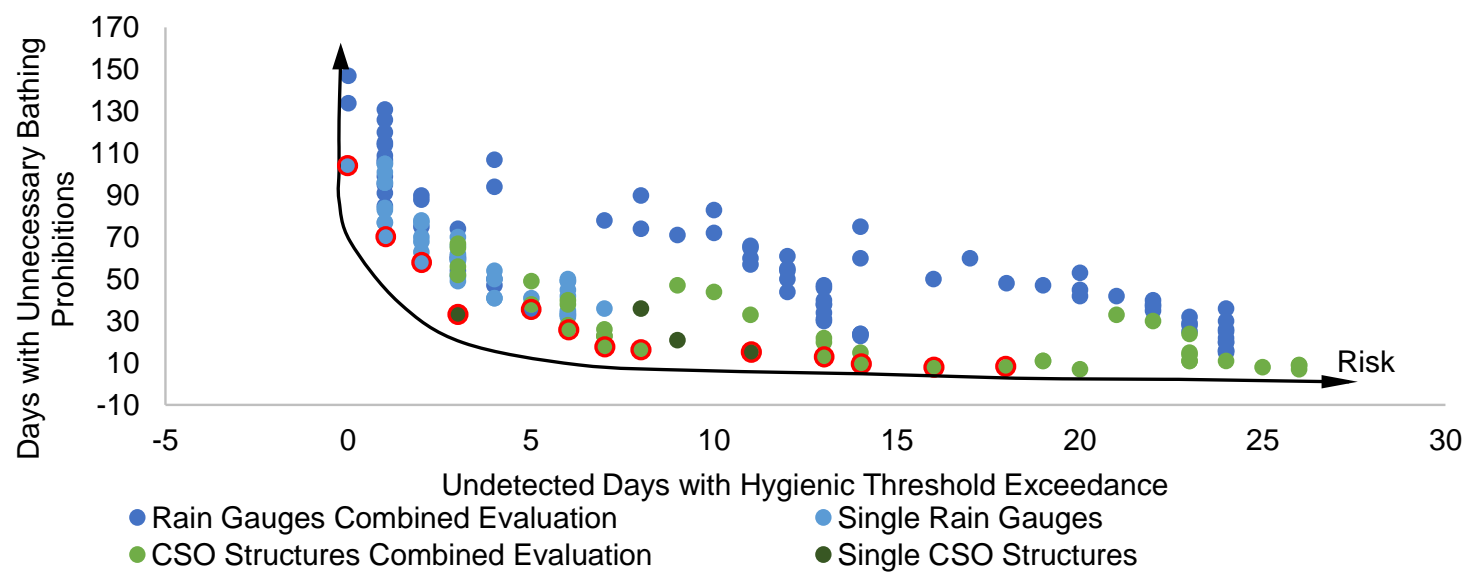

Figure 3. Overview of different forecasting strategies 2015-2016. Beneficial forecasting strategies with red circle.

The CSO tanks overflowed between 9 and 25 times in 2015, between 17 and 35 times in 2016 and between 20 and 48 times in 2017 . Overflow patterns were plausible. In $83 \%$ of the evaluated days in 2017 no CSO occured, in $8 \%$ of the days exactly one tank overflowed, in $10 \%$ of the days more than one CSO occured throughout the system. 


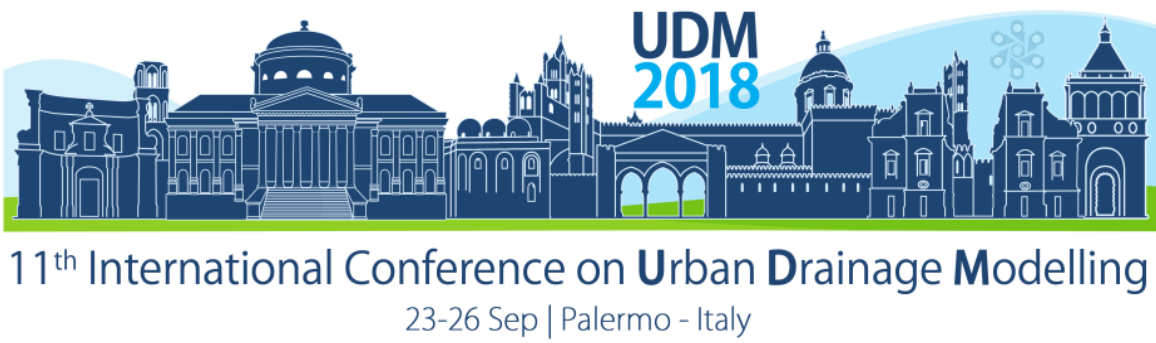

The predictive capacity of the precipitation data was better than the capacity of the CSO data for 2015 and 2016 (see figure 3). However, only four CSO tanks were taken into account for 2015-2016 due to data availability. In 2017 with data from five CSO tanks the predictive capacity of the joint CSO structures was in a similar range than the capacity of the rainfall data. The ratio of false positives (unnecessary bathing prohibitions) to false negatives (undetected hygienic threshold exceedances) under the assessed early warning strategies for the bathing seasons 2015 and 2016 ranges at the pareto front from 7:20 to 104:0 leaving a variety of suitable solutions.

\section{CONCLUSIONS}

Data evaluation has shown that overflow events at single CSO structures do not necessarily result in an exceedance of hygienic threshold values. Therefore, using data from single CSOstructures for prediction of hygienic contaminations is not the best early warning strategy. Regionalised information e.g. precipitation data from rain gauges or joint overflow data seems more suitable for prediction of critical hygienic conditions.

An evaluation as shown within this study can depict interrelations within the observed data. It can be used to derive pareto fronts of suitable forecasting strategies for different scenarios and their ability to predict exceedances of hygienic threshold values with a specific number of unnecessary bathing prohibitions (see figure 3). However, the forecasting strategy to be implemented has to be chosen by the responsible decision-makers based on their willingness to accept risk. A conservative strategy always causes more unnecessary bathing prohibitions. The results of the data evaluation could imply that the background levels of hygienic parameters may already exceed hygienic threshold values without the emissions from combined sewer overflows in this catchment. This would mean that CSOs are not the relevant sources for hygienic critical conditions, although their contribution is certainly high. Simple binary signals from CSOs (overflow yes/no) can be used for prediction of hygienic critical conditions of the bathing site, but it is necessary to not only rely on data from one single CSO tank but to use joint data from different CSO structures throughout the system. More data evaluation from the upcoming bathing season is needed to verify these findings.

\section{Acknowledgements}

Part of the analysed data was collected within the research project "Flusshygiene" funded by the German Federal Ministry of Education and Research (BMBF).

\section{References}

Donovan, E., Unice, K., Roberts, J.D., Harris, M., Finley, B. (2008). Risk of gastrointestinal disease associated with exposure to pathogens in the water of the Lower Passaic River. Appl. Environ. Microbiol. 74(4), 994-1003.

EU (2000). Directive 2000/60/EC - European water framework directive, $72 \mathrm{pp}$.

EU (2006). Directive 2006/7/EC of the european parliament and of the councel of 15 February 2006 concerning the management of bathing water quality and repealing Directive 76/160/EEC.

Gasse, J., Steinmetz, H., Krampe, J. (2009). Untersuchungen zur hygienischen Qualität kleiner Fließgewässer. Österreichische Wasser- und Abfallwirtschaft (11-12/09), 178-181.

Kistemann, T., Rind, E., Koch, C., Claßen, T., Lengen, C., Exner, M., Rechenburg, A. (2012). Effect of sewage treatment plants and diffuse pollution on the occurrence of protozoal parasites in the course of a small river. Int. J. Hyg. Envorin. Health 215(6), 577-583.

Kistemann, T., Schmidt, A., Flemming, H.-C. (2016). Post-industrial river water quality-Fit for bathing again? Int. J. Hyg. Envorin. Health 219(7 Pt B), 629-642.

Mälzer, H.-J., Beek, T. aus der, Müller, S., Gebhardt, J. (2016). Comparison of different model approaches for a hygiene early warning system at the lower Ruhr River, Germany. Int. J. Hyg. Envorin. Health 219(7 Pt B), 671-680. 
Proceedings of the 11th Int. Conference on Urban Drainage Modelling, 23-26 Sep. 2018, Palermo (ITALY). Ed. prof. Giorgio Mannina

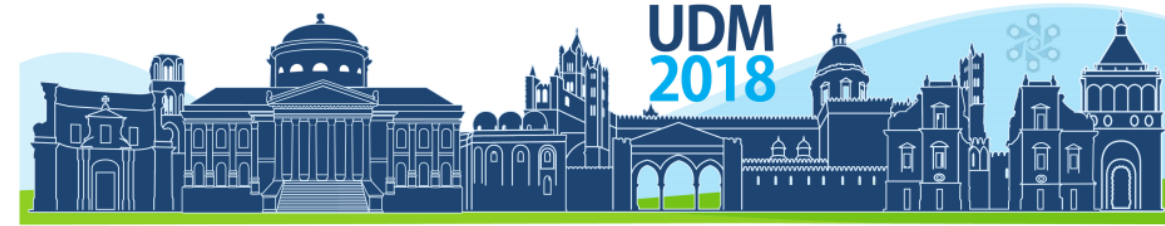

$11^{\text {th }}$ International Conference on Urban Drainage Modelling

23-26 Sep | Palermo - Italy

Nescovic, M., Hein, A. (2015). Rivers as social assets in urbanised areas: A cost-benefit analysis for b athing in the river Ruhr using contingent valuation method, in: Cities of the Future Conference Transitions to the Urban Water Services of Tomorrow (TRUST), Compendium.

Ottoson, J., Hansen, A., Björlenius, B., Norder, H., Stenström, T.A. (2006). Removal of viruses, parasitic protozoa and microbial indicators in conventional and membrane processes in a wastewater pilot plant. Wat. Res. 40(7), 14491457.

Raskob, S., Jardin, N. (2018). Baden im Baldeneysee - Erfahrungen mit der ersten Flussbadestelle in NRW, in: 51. Essener Tagung für Wasserwirtschaft, Essen. 14.-03.-16.03.2018, Aachen, 18/1-18/13.

Soldánová, M., Selbach, C., Kalbe, M., Kostadinova, A., Sures, B. (2013). Swimmer's itch: Etiology, impact, and risk factors in Europe. Trends Parasitol. 29(2), 65-74.

Tondera, K., Klaer, K., Roder, S., Brueckner, I., Strathmann, M., Kistemann, T., Schreiber, C., Pinnekamp, J. (2016). Developing an easy-to-apply model for identifying relevant pathogen pathways into surface waters used for recreational purposes. Int. J. Hyg. Envorin. Health 219(7 Pt B), 662-670. 


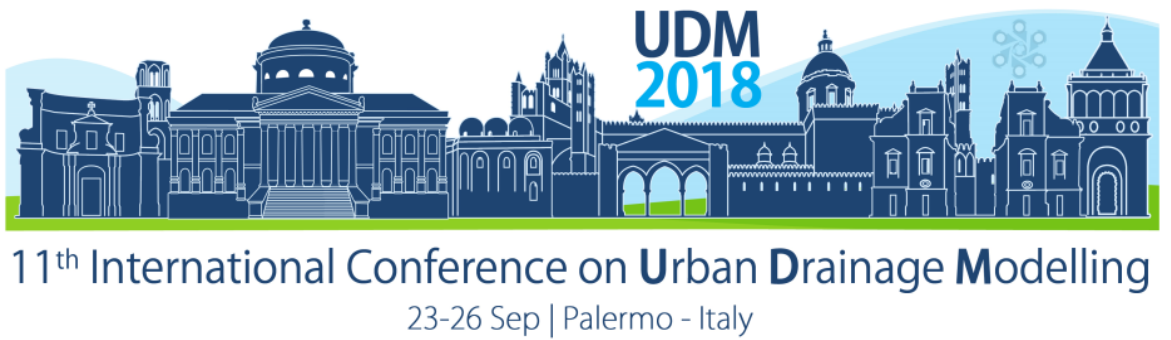

\title{
FloodCitiSense: Early Warning Service For Urban Pluvial Floods For And By Citizens and City Authorities
}

\author{
Boud Verbeiren ${ }^{1,2}$, Solomon Dagnachew Seyoum ${ }^{1}$, Ihab Lubbad ${ }^{1}$, Tian Xin ${ }^{3}$, Marie-Claire ten Veldhuis ${ }^{3}$, \\ Christian Onof ${ }^{4}$, Li-Pen Wang ${ }^{4,5}$, Susana Ochoa-Rodriguez ${ }^{6}$, Carina Veeckman7, Michelle Boonen7, Linda \\ $\mathrm{See}^{8}$, Dominique Nalpas ${ }^{9}$, Barry O'Brien ${ }^{10}$, Andy Johnston ${ }^{10}$ and Patrick Willems ${ }^{1}$ \\ ${ }^{1}$ Vrije Universiteit Brussel, Hydrology and Hydraulic Engineering, Brussels, Belgium \\ 2 Brussels Company for Water Management (SBGE/BMWB), Direction Exploitation, Brussels, Belgium \\ ${ }^{3}$ Delft University of Technology, CITG, Delft, The Netherlands \\ ${ }^{4}$ Imperial College London, Department of Civil and Environmental Engineering, London, UK \\ ${ }^{5}$ RainPlusPlus Ltd, Derby, UK \\ ${ }^{6}$ RPS Group, Environmental Management, Derby, UK \\ ${ }^{7}$ Vrije Universiteit Brussel, iMEC-SMIT, Brussels, Belgium \\ ${ }^{8}$ International Institute for Applied Systems Analysis, Ecosystems Services and Management, Laxenburg, Austria. \\ ${ }^{9}$ Etat Généraux des Eaux à Bruxelles, Brussels, Belgium \\ ${ }^{10}$ Local Government Information Unit, Birmingham, UK
}

\begin{abstract}
FloodCitiSense aims at developing an urban pluvial flood early warning service for, but also by citizens and city authorities, building upon the state-ofthe-art knowledge, methodologies and smart technologies provided by research units and private companies. FloodCitiSense targets the co-creation of this innovative public service in an urban living lab context with all local actors. This service will reduce the vulnerability of urban areas and citizens to pluvial floods, which occur when heavy rainfall exceeds the capacity of the urban drainage system. Due to their fast onset and localized nature, they cause significant damage to the urban environment and are challenging to manage. Monitoring and management of peak events in cities is typically in the hands of local governmental agencies. Citizens most often just play a passive role as people negatively affected by the flooding, despite the fact that they are often the 'first responders' and should therefore be actively involved. The FloodCitiSense project aims at integrating crowdsourced hydrological data, collaboratively monitored by local stakeholders, including citizens, making use of low-cost sensors and web-based technologies, into a flood early warning system. This will enable 'citizens and cities' to be better prepared for and better respond to urban pluvial floods. Three European pilot cities are targeted: Brussels - Belgium, Rotterdam - The Netherlands and Birmingham - UK.
\end{abstract}

Keywords: Urban pluvial flooding, Citizen science, Flood Early Warning System

\section{INTRODUCTION}

The hydrological response in (peri-)urban catchments is dependent on (1) rainfall and (2) the urban landscape. Besides rainfall intensity, rainfall spatial distribution is of great importance as it determines where the rain hits the urban landscape. The rainfall-runoff response at the urban surface is mainly determined by the land cover, with a very distinct behaviour in case of manmade materials (characterised by high sealed surface cover) or urban green. In case of extreme rainfall, fast and abundant runoff from sealed surfaces is the dominating mechanism which can quickly lead to exceedance of the system's drainage capacity, ultimately resulting in urban pluvial flooding. Due to the fast onset and localised nature of this type of flooding, occurring at small temporal and spatial scales, high resolution models and data are needed 


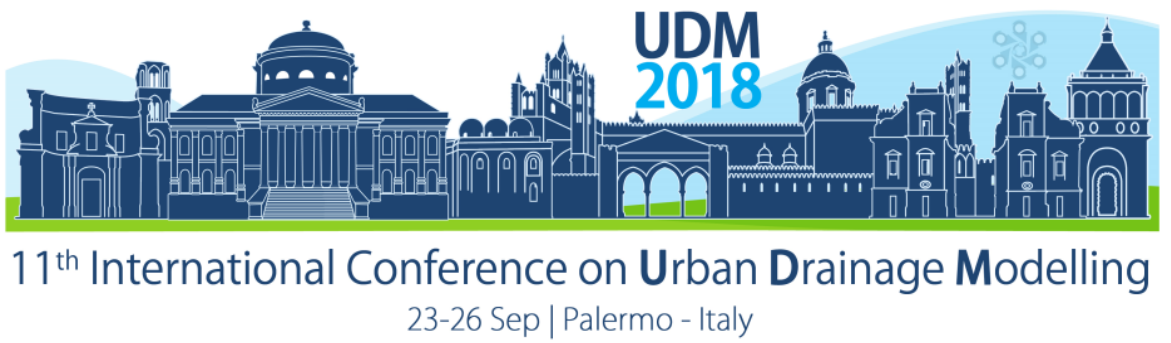

(Jacobsen, 2011; Bruni et al. 2014; Ochoa-Rodriguez et al. 2015b). This also demands a fast simulation of flood forecasts.

Contrary to what would be expected, these specific monitoring and modelling needs for pluvial flood analysis in urban catchments are not translated into a denser monitoring network of rainfall and/or hydrological response. Most urban catchments remain poorly gauged - even ungauged (Rodriguez et al., 2005). The main reason is the relatively high cost for installation and maintenance of dense sensor networks (Lowry \& Fienen, 2013). In the case of rainfall, recent developments in radar technology have made it possible to obtain spatially-continuous, high resolution rainfall estimates (Bruni et al, 2014; Veldhuis ten et al., 2014). However, the accuracy of radar estimates is often insufficient because they only provide an indirect measurement of rainfall. As such, these measurements need to be complemented by direct rainfall measurements on the ground (Wang et al., 2013, 2015).

In recent years, crowdsourcing or citizen science has gained popularity as an alternative data collection technique. Crowdsourcing refers to the involvement of citizen scientists and/or the use of "mass" data to fulfil the need for spatially distributed measurements (Muller et al., 2015). With respect to rainfall, several crowdsourcing initiatives exist, based on voluntary rain gauging and/or smart sensing (CoCoRaHs.org, Rainlog.org, etc.). Though some question the accuracy and usefulness of crowdsourced data (Riesch \& Potter, 2014), others clearly demonstrate the potential of crowdsourcing (Lowry \& Fienen, 2013) and smart sensing techniques (Overeem et al., 2013). Very good examples in the field of flood monitoring is the development of Citizen Water Observatories within the framework of the ongoing WeSenselt.eu project or the citizenbased reporting within the framework of the US FLOCAST project or the P+ Taiwan disaster reduction platform. These projects, however, do not focus on urban areas, where the response and lead times are typically much shorter. Smith et al. (2015) demonstrated that crowdsourced information on floods, harvested from social media, could successfully be used for validation of a real-time flood model.

While research seems to have been exploring widely the potential of citizen interaction in the field of flood monitoring (of non-urban areas), efforts have remained relatively limited at the level of public citizen interaction services by governmental agencies. The DIANE-CM project explored the potential of collaborative modelling where different stakeholders (including water managers, local authorities, emergency services and citizens) were involved in order to initiate public dialogue and come to more informed and shared decision-making to support flood risk management (Evers et al., 2012). Ochoa-Rodriguez et al. (2015a) reviewed pluvial flood warning approaches in England. Despite the rapid progress that has been made in recent years in improving forecasting, warning and management of this type of flooding, a number of major drawbacks remain, including insufficient accuracy and resolution of rainfall estimates and forecasts, simulation time still too long in relation to the typical short lead times of pluvial floods, lack of capacity at the local authorities level and low level of (public) awareness on this type of floods. These challenges will be tackled in FloodCitiSense by bringing local stakeholders together and jointly creating flood observatories and flood warning tools.

\section{MATERIALS AND METHODS}

The FloodCitiSense project proposes an interactive and cooperative framework (Figure 1) consisting of citizens, local authorities, research units and industrial partners aiming at improving the monitoring and management of urban pluvial flooding. Citizens are no longer considered as passive, potential "victims" of urban pluvial floods, but are engaged as active 


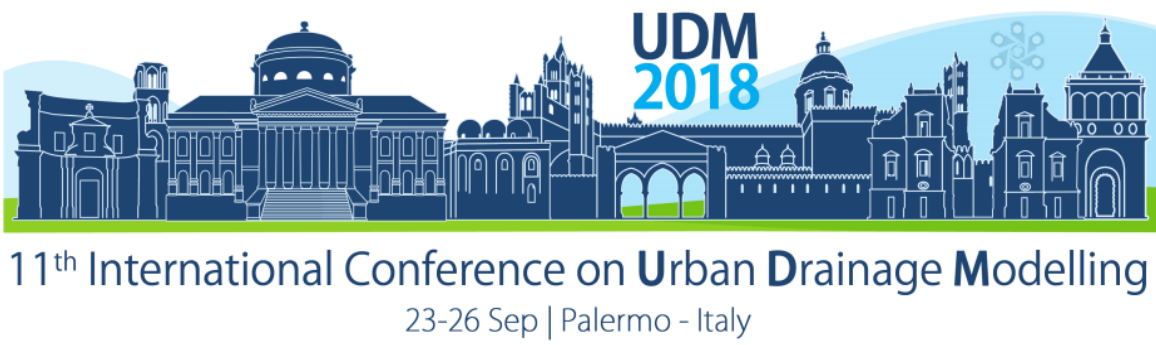

contributors in the process of pluvial flood monitoring and mapping, enabling better simulation and forecasting of flood events while enhancing awareness and ultimately resilience. Moreover, the proposed framework aims at establishing strong ties between research and public management, enabling the transfer of the latest state-of-the-art technologies in the monitoring and modelling of pluvial flooding. Both citizen science and smart sensing will play a central role in the envisaged urban pluvial flood early warning service. The service will consist of an intelligent algorithm enabling early detection of threshold levels/volumes triggering potential pluvial flood events and will support better preventive communication to the public

\section{FloodCitiSense}

Early Warning Service Urban pluvial Flooding

\section{Urban living labs}

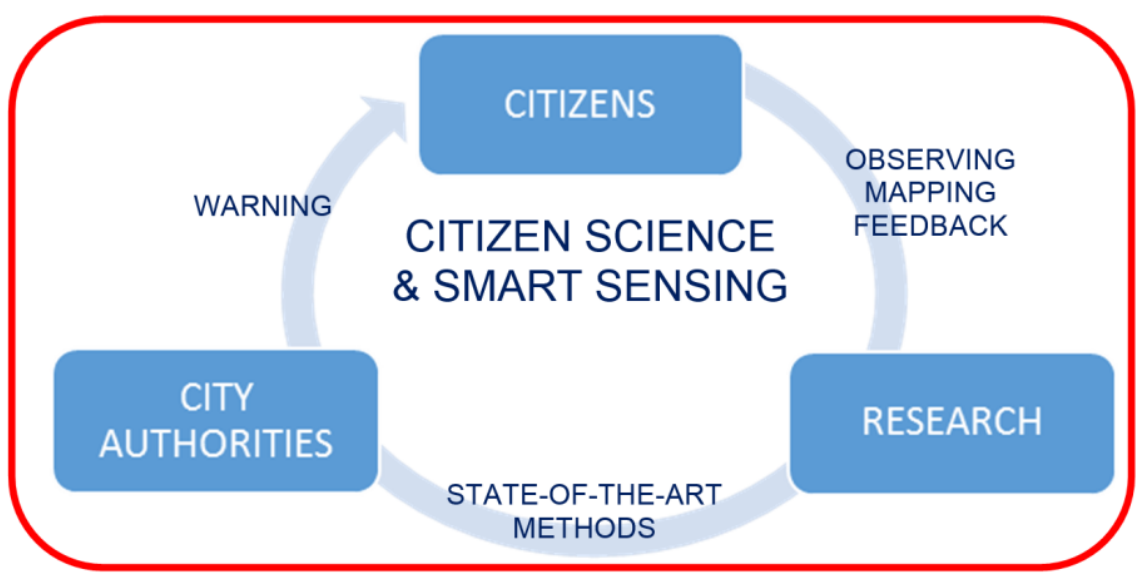

Figure 1: Concept of FloodCitiSense project

The main outcome will be an urban pluvial flood early warning service for, but also by citizens and city authorities, built upon the state-of-the-art knowledge, methodologies as well as smart technologies provided by research units and private companies. The targeted co-creation of this new, innovative public service is realized by bringing together all actors in urban living labs. The overall design of Living Lab experiments is based on principles of 'transition experiments' (Hoogma et al., 2002). In contrast to traditional innovation experiments aimed at testing and demonstrating, transition experiments focus on broad stakeholder involvement, cocreation, and strategic learning to achieve systemic change (Kemp \& van den Bosch 2006).

\section{RESULTS AND DISCUSSION}

In total, nine co-creation workshops with citizens and city stakeholders, were set-up between October 2017 and March 2018 that consisted of multiple creative exercises and group discussions to elicit user and data requirements about the FloodCitiSense solution, i.e. a social sensing application and low-cost rainfall sensor network (Veeckman \& Boonen, 2018).

Some small differences between the pilots could be noticed. First of all, the city stakeholders in Birmingham are a bit more reluctant towards citizens' contributions, and rely more on the high-density data retrieved from sensors. Brussels and Rotterdam perceived the citizens' contributions as highly valuable, and would like to position this as part of a greater awareness raising campaign around water management and sustainability in the city. Secondly, for the engagement strategy of citizens in Rotterdam and Brussels, some concerns were expressed 


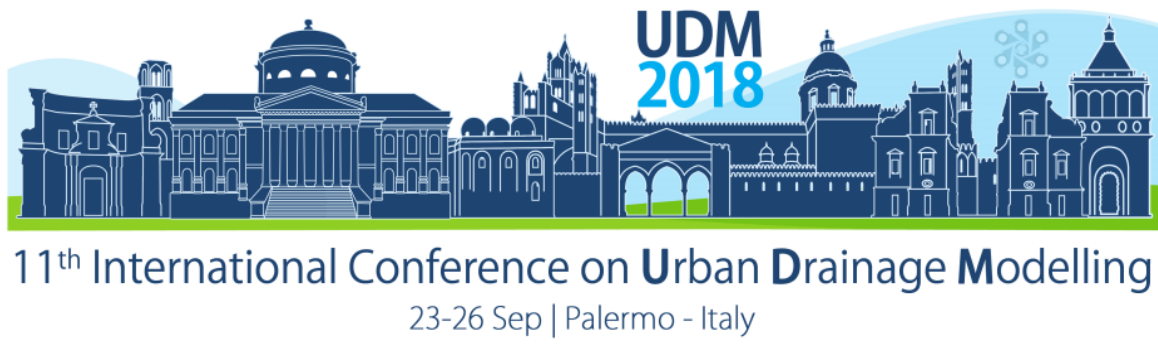

on how to motivate users in the long-term, as flooding events only happen rarely. As a solution, Rotterdam suggested to integrate FloodCitiSense with the Buitenbeter application, as this system already has a solid basis of frequent users. Brussels suggested to reach out to already existing strong local communities, and to invest in advertising campaigns with support of local media. Since Birmingham already has a large volunteering community through the Flood Action Group, less issues are expected for continued participation of citizens.

\section{CONCLUSIONS}

FloodCitiSense explores the potential of citizen science and low-cost sensing via co-creation of a flood early warning service in a Urban Living Lab context.

\section{References}

Bruni, G, Reinoso Rondinel, RR, Giesen, NC van de, Clemens, FHLR \& Veldhuis, JAE ten (2014). On the sensitivity of urban hydrodynamic modelling to rainfall spatial and temporal resolution. Hydrology and Earth System Sciences Discussions, 11(6), 5991-6033

Evers, M., Jonoski, A., Maksimovič, Č., Lange, L., Ochoa Rodriguez, S., Teklesadik, A., Cortes Arevalo, J., Almoradie, A., Eduardo Simões, N., Wang, L., and Makropoulos, C. (2012). Collaborative modelling for active involvement of stakeholders in urban flood risk management, Nat. Hazards Earth Syst. Sci., 12, 2821-2842, doi:10.5194/nhess-12-2821-2012

Goormans, T., Willems, P. (2013). Using local weather radar data for sewer system modelling: case study in Flanders, Belgium. Journal of Hydrologic Engineering, 18(2), 269-278

Hoogma, R., R. Kemp, J. Schot and B. Truffer (2002) Experimenting for sustainable transport: the approach of strategic niche management, Spon Press, London, ISBN 0-415-27116-9.

Jacobson C.R. (2011). Identification and quantification of the hydrological impacts of imperviousness in urban catchments: A review. J. of Environ. Management, 92(6): 1438-1448

Kemp, R. and Van den Bosch, S. (2006). Transitie-experimenten. Praktijkexperimenten met de potentie om bij te dragen aan transities. Delft/Rotterdam: KCT.

Lowry, C. S. and Fienen, M. N. (2013). CrowdHydrology: Crowdsourcing Hydrologic Data and Engaging Citizen Scientists. Ground Water, 51: 151-156

Muller, C.L., Chapman, L., Johnston, S., Kidd, C., Illingworth, S., et al. (2015), Crowdsourcing for climate and atmospheric sciences: current status and future potential. Int. J. Climatol., Jan 2015

Ochoa-Rodríguez, S., Wang, L.P., Thraves, L., Johnston, A. and Onof, C. (2015a). Surface water flood warnings in England: overview, assessment and recommendations based on survey responses and workshops. Journal of Flood Risk Management: n/a-n/a.Overeem, A.,Leijnse, H., and Uijlenhoet, R.(2013). Country-wide rainfall maps from cellular communication networks. Proc.Natl.Acad.Sci.U.S.A. 110, 2741-2745

Ochoa-Rodriguez, S. et al. (2015b). Impact of spatial and temporal resolution of rainfall inputs on urban hydrodynamic modelling outputs: A multi-catchment investigation. Journal of Hydrology, 531, 389-407.

Riesch, H. and Potter, C. (2014).Citizen science as seen by scientists: methodological, epistemological and ethical dimensions. Public Underst.Sci. 23, 107-120

Rodriguez F, Cudennec C, Andrieu H. (2005). Application of morphological approaches to determine unit hydrographs of urban catchments. Hydrological Processes, 19 (5): 1021-1035

Smith, L., Liang, Q., James, P. and Lin, W. (2015). Assessing the utility of social media as a data source for flood risk management using a real-time modelling framework. Journal of Flood Risk Management: doi: $10.1111 /$ jfr3.12154

Veeckman, C. \& Boonen M. (2018). Deliverable 1.3 - Scenario specification of FloodCitiSense V2, 48p. Available at floodcitisense.eu.

Veldhuis, JAE ten, et al. (2014). Weather radar for urban hydrological applications: lessons learnt and research needs identified from 4 pilot catchments in North-West Europe. Proceedings of the international symposium weather radar and hydrology, 1-10

Wang, L.-P., Ochoa-Rodríguez, S., Simoes, N., Onof, C. \& Maksimović, Č. (2013). Radar-raingauge data combination techniques: a revision and analysis of their suitability for urban hydrology. Water Science \& Technology, 68 (4), 737-747.

Wang, L-P., Ochoa-Rodriguez, S., Van Assel, J., Pina, R.D., Kroll, S., Pessemier, M., Willems, P., Onof, C. (2015). Enhancement of radar rainfall estimates for urban hydrology through optical flow temporal interpolation and Bayesian gauge-based adjustment. Journal of Hydrology, 531, 408-426. 


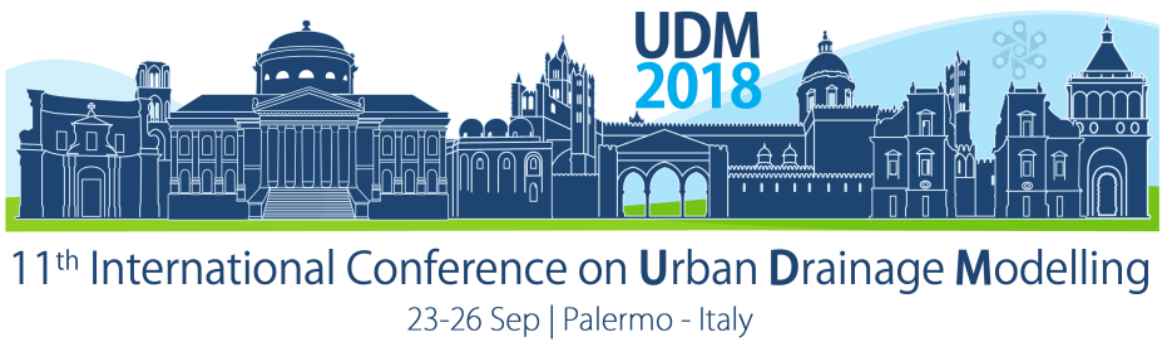

\title{
Mitigation of Urban Surface Runoff through LID solutions: Case study in Mediterranean Area
}

\author{
Francesca Principato ${ }^{1 *}$, Aldo Pedro Ferrante ${ }^{1}$, Ferdinando Frega ${ }^{1}$, \\ Manuela Bartolo ${ }^{1}$, Patrizia Piro ${ }^{1}$ \\ 1 University of Calabria, Department of Civil Engineering, Arcavacata di Rende (CS), Italy \\ ( ${ }^{*}$ Corresponding Author email: francesca.principato@unical.it)
}

\begin{abstract}
Here we investigate the influence of Low Impact Development (LID) practices implementation at urban catchment scale, by applying SWMM model to a densely urbanized area of the city of Cosenza, using monthly storms events. Among the source-control measures, Green Roofs and Permeable Pavements were chosen, being particularly suitable for highly urbanised areas already equipped with an underground drainage system. The main objective of this study is to assess how the implementation of LID techniques in urban areas can be an effective solution to improve stormwater management and restore the natural flow regime. With this aim, different conversion scenarios have been simulated and compared to the existing condition of the catchment, before LIDs implementation at catchment scale. Results reveal that combined LID techniques perform better than single LID practices in terms of both runoff reduction and increase in total infiltration.
\end{abstract}

Keywords: LID; Rainfall-Runoff; Stormwater Management; Green Roofs; Permeable Pavements; Modelling; SWMM.

\section{INTRODUCTION}

The ongoing surface sealing, due to urbanization growth, combined with climate change, resulted in increased vulnerability of urban areas and an alteration of the natural water cycle. An important hydrological effect that results from these changes are variations in the rainfallrunoff relation; during heavy rainfall events, infiltration and evapotranspiration rates are significantly reduced, and therefore the crucial issue is the increasing in the amount of surface runoff, which incrementing the runoff coefficient.

Retrofit the built-up areas in a water sensitive way, by implementing decentralized measures such as Low Impact Development (LID) techniques - can help to alleviate flooding and, at the same time, support the recovery of biodiversity and ecosystems (Bacchin et al., 2014; Maiolo et al., 2017). The fundamental approach of LID is the antithesis of conventional stormwater management: to manage water directly at the source (above ground rather than below) following an ecologically-based approach. Particularly in developing cities, where the pace of urbanization vastly reduces the availability of natural green areas, LID implementation could not only control stormwater runoff, but also restore the ecological environment, contributing to the sustainable development of cities (Mao et al., 2016).

Despite countless benefits of these practices, their implementation in Italy still find many impediments; for instance, despite several experimental studies have been conducted at local scale, there is still a general lack in implementation on an urban catchment scale.

Before implementing the sustainable techniques in an urban watershed, it is important and necessary to establish which could be the most suitable typologies, their size, characteristics and placement, which would accomplish the overall objectives. Nowadays, several existing hydrologic/hydraulic models are capable of modelling LID devices and provide assistance to investigate their hydrological implications (Elliott \& Trowsdale, 2007). Among them, EPASWMM software allows the modelling and simulation of LID that are considered as features of 


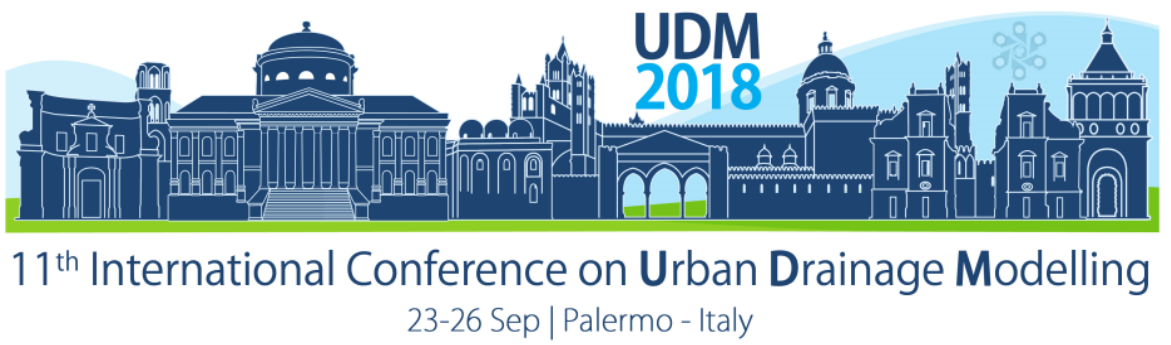

a given sub-catchment. The software can explicitly model LID measures that capture surface runoff and provide a combination of detention, infiltration, and evapotranspiration (Rossman, 2010; 2015).

In this framework, the main objective of the following study is to investigate the hydrologic response of a selected urban area, after the implementation of Low Impact Development systems (LIDs) as a source control solution, by comparing different land use conversion scenarios - after the installation of Green Roofs and Permeable Pavements - complementary to the actual urban drainage system.

\section{MATERIALS AND METHODS}

The results reported here are part of a broader study (in progress), which takes into account simulations at different spatial and temporal scale, in order to evaluate urban runoff mitigation related to LID implementation.

\subsection{Study Area description}

In this work, the study area is given by a portion of an urban catchment (the Liguori catchment), located in the city of Cosenza, a municipality in the Calabria Region, in Southern Italy. The selected area is a highly urbanized area with a total surface of about 102.4 ha, which is served by the combined drainage system. This is mostly a commercial and residential area, where more than half is impervious ( $33 \%$ buildings, $57.4 \%$ roads and parking) and only the remaining $9.6 \%$ is covered by green spaces. Table 1 shows the main land cover types and percentages of impervious/pervious areas, calculated based on landscape analysis.

Table 1. Land use of the study area

\begin{tabular}{cc|cc|ccc}
\hline Area & Total Areas & Tot. Impervious & Tot. Pervious & Built Area & Paved Area & Green Spaces \\
\hline$[$ ha] & 102.4 & 92.6 & 9.8 & 33.8 & 58.8 & 9.8 \\
{$[\%]$} & 100 & 90.4 & 9.6 & 33 & 57.4 & 9.6 \\
\hline
\end{tabular}

Considering the limited availability of free spaces within the selected area, Green Roofs (GRs) and Permeable Pavements (PPs) have been selected as the most suitable LID options for retrofit interventions.

\subsection{LID Simulation Scenarios}

In order to reduce the impact of imperviousness at catchment scale, and evaluate the effect of LID techniques on the quantitative runoff characteristics, the overland flow network of the study area has been retrofitted through the hypothetical implementation of a certain percentage of GRs and PPs. To assess the effect of the chosen source-control measures on surface runoff mitigation, different conversion scenarios have been applied and compared: in Scenario 1, extensive GRs were selected to replace $50 \%$ building's rooftops (about 35.4 ha $-3.5 \%$ of the total sub-area); in Scenario 2 impervious surfaces have been substituted with PPs (about 18.5 ha $-1.8 \%$ of the total sub-area); and for Scenario 3 the combined effect of GRs and PPs was evaluated (about 53.9 ha $-5.4 \%$ of the total sub-area). The current configuration, which corresponds to the existing condition, is assumed as the reference scenario (Scenario 0 ) in order to measure the impact of the LID application.

In this study, the SWMM model was used for the analysis of various scenarios. 


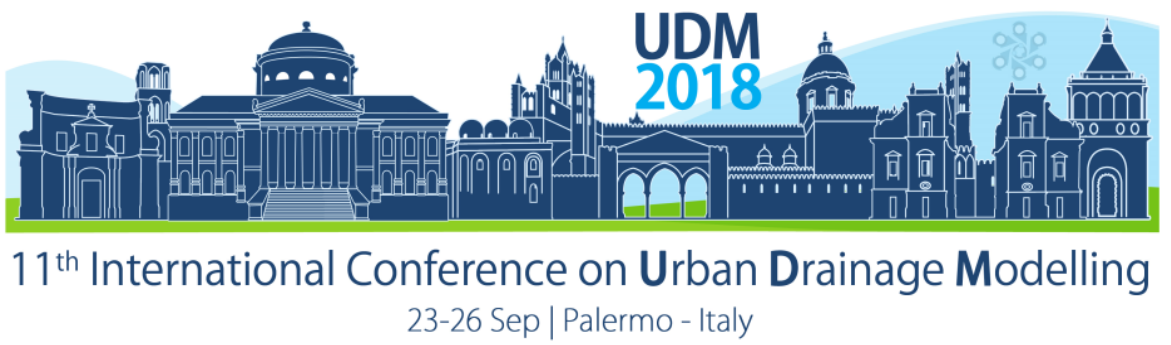

\subsection{The SWMM modelling framework setup}

As preliminary phase, it was necessary to split the selected area into sub-catchments for the modelling of the conversion scenarios. The whole study area was divided into 223 subcatchments, each of which is characterized by specific fractions of pervious and impervious areas and it is considered as a hydrologic unit of land that directs runoff to a single outlet point. The site information, together with the sewer data set and input parameters, were reported into EPA-SWMM (Version 5.1; Rossman, 2015) in order to represent hydrologic characteristics of each sub-catchment and simulate the hydrologic response of the study area to rainfall events. LID techniques were integrated using LID Control Editor, an additional module of the SWMM software, implemented to add any type of "source control technologies" to a specific subcatchment and simulate its hydrological behavior. In this study, to define LID properties, we used the parameters and the stratigraphy of the experimental sites installed at University of Calabria and developed during the Project PON01_02543 (Garofalo et al., 2016; Brunetti et al., 2016). The model was tested using rainfall data at monthly scale, collected between October 2015 and March 2016; the chosen of the period is based on the pluviometric features of Cosenza, which presents the rainiest months during autumn and winter seasons.

\section{RESULTS AND DISCUSSION}

The criterion chosen for locating LID techniques was to place them in the sub-catchments where the nodes and conduits of the drainage system were overloaded in the preimplementation scenario (Scenario0): these first simulations therefore highlighted the inadequacy of the drainage system and revealed the need for an effective approach to reduce risk of flooding. Therefore, the preselected LIDs were distributed - in different percentages depending on available built and/or paved areas - in the area that turned out more vulnerable from the hydraulic point of view.

The incidence of LIDs implementation was analyzed in terms of surface runoff, for whole study area and each considered months (Table 2).

Table 2. Total Surface Runoff $(\mathrm{mm})$ on a monthly basis

\begin{tabular}{|c|c|c|c|c|c|}
\hline & & Scenario 0 & Scenario 1 & Scenario 2 & Scenario 3 \\
\hline & $\begin{array}{c}\text { Rainfall Depth } \\
(\mathrm{mm})\end{array}$ & $\begin{array}{l}\text { Runoff } \\
(\mathrm{mm})\end{array}$ & $\begin{array}{l}\text { Runoff } \\
(\mathrm{mm})\end{array}$ & $\begin{array}{l}\text { Runoff } \\
(\mathrm{mm})\end{array}$ & $\begin{array}{l}\text { Runoff } \\
(\mathrm{mm})\end{array}$ \\
\hline Oct-15 & 308.4 & 301.7 & 289.9 & 286.2 & 276.5 \\
\hline Nov-15 & 154.9 & 150.5 & 144.2 & 142.7 & 137.3 \\
\hline Dec-15 & 12.2 & 11.0 & 10.3 & 10.3 & 9.7 \\
\hline Jan-16 & 175.5 & 170.8 & 164.1 & 162.1 & 156.4 \\
\hline Feb-16 & 186.4 & 182.5 & 175.3 & 173.2 & 167.2 \\
\hline Mar-16 & 170.9 & 163.2 & 156.2 & 154.3 & 148.3 \\
\hline
\end{tabular}

At the urban catchment scale, simulation results reveal that in the current situation almost all the rainwater is turns into surface runoff, clearly confirming the negative impacts of urbanization, instead this fraction decreases in presence of GRs and PPs. The effectiveness of the LID techniques is better highlighted by the graphical comparison of the percentages of runoff volume reduction and infiltration increasing, compared with the Scenario 0 (Fig. 1).

The results obtained from SWMM simulations reveal that the increase of permeable surfaces, obtained by LID implementation, provides beneficial effects in terms of both runoff volume reduction and increase in total infiltration volume, confirming the role of the LID solutions in restoring the critical components of the natural flow regime at the urban catchment scale. 


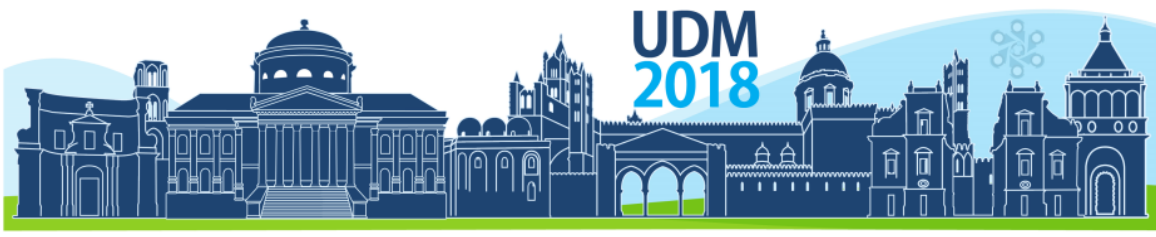

$11^{\text {th }}$ International Conference on Urban Drainage Modelling

23-26 Sep | Palermo - Italy

From a more detailed analysis, it is possible to note that the Scenario2, despite it affected a smaller conversion area, proves to be more effective in terms of total runoff reduction, instead of Scenario1; the PPs, indeed, were implemented only in 17 sub-catchment, against the 32 in which the building roofs were converted in GRs.

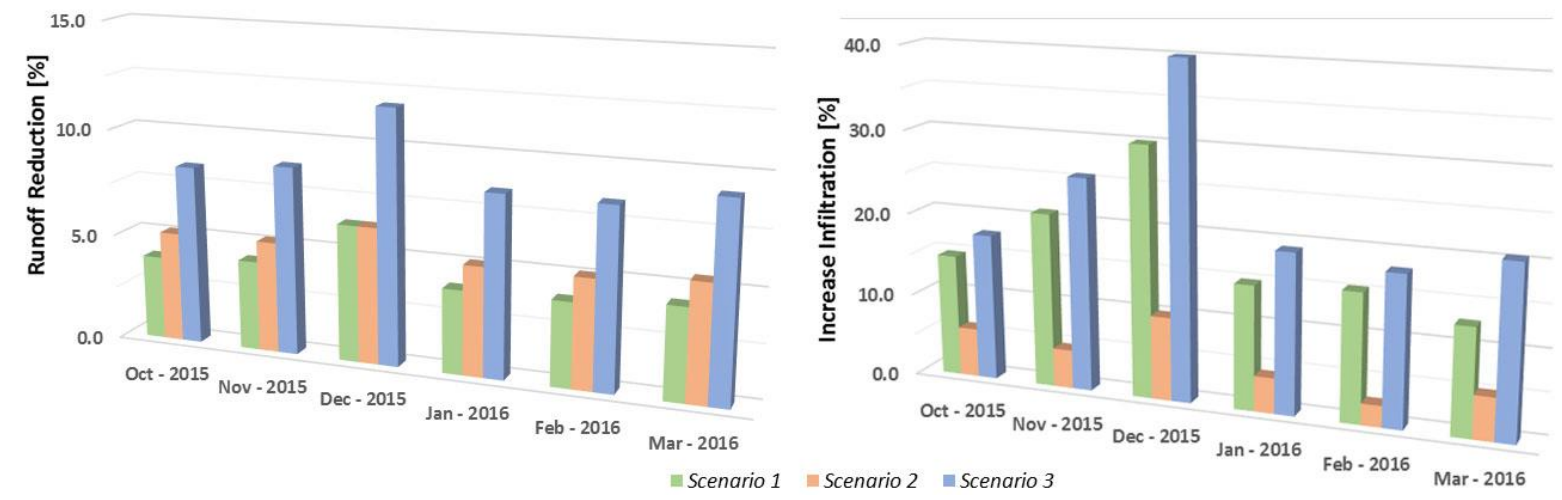

Figure 1. Runoff Reduction (\%) and Infiltration Increasing (\%) for the LID-implemented Scenarios

Even more, simultaneous presence of GRs and PPs (Scenario3), which has produced greater benefits than the implementation of individual LIDs, confirm the importance of the integrated approach that provides beneficial effects to the overall hydraulic performance of the network, offering a valid solution for controlling flooding in urban areas.

\section{CONCLUSIONS}

In this study the hydrologic response of an urban catchment, under different conversion scenarios have been investigated in order to evaluate LID implementation performances in stormwater management. The study reveals that also by converting only a small percentage of the entire catchment in LID system, can be reach beneficial effects in terms of runoff reduction and therefore decrease of surface runoff coefficient. Future studies will analyze also the performance in the individual sub-basins, in which the LID are located, revealing more relevant results, also in terms of surface runoff coefficient and peak flow reduction.

\section{References}

Bacchin, T.K., Ashley, R., Sijmons, D., Zevenbergen, C., Van Timmeren, A. (2014) Green-blue multifunctional infrastructure: an urban landscape system design new approach. In $13^{\text {th }}$ International Conference on Urban Drainage, Sarawak, Malaysia, 7-12.

Brunetti, G., Principato, F., Piro, P. (2016) Numerical analysis of the hydrologic performance of a permeable pavement. In Proceedings of XXXV National Conference of Hydraulics and Hydraulic, IDRA 2016, Bologna, IT, pp. 1203-1206, DOI: 10.6092/unibo/amsacta/5400.

Elliott A.H. \& Trowsdale S.A. (2007) A review of models for low impact urban stormwater drainage. Environmental Modelling \& Software, 22, 394-405.

Garofalo, G., Palermo, S.A., Principato, F., Theodosiou, T., Piro, P. (2016) The influence of hydrologic parameters on the hydraulic efficiency of an extensive green roof in Mediterranean Area. Water, 8(2):44, 2016, DOI: 10.3390/w8020044

Maiolo, M., Carini, M., Capano, G., Piro, P.(2017). Synthetic sustainability index (SSI) based on life cycle assessment approach of low impact development in the Mediterranean area. Cogent Engineering, 2017

Mao, X., Jia, H., Shaw, L.Y. (2017) Assessing the ecological benefits of aggregate LID-BMPs through modelling. Ecological modelling, 353, 139-149

Rossman, L.A. (2010). Storm Water Management Model User's Manual. Version 5.0. EPA/600/R-05/040.

Rossman, L.A. (2015) Storm Water Management Model - User's Manual, Version 5.1. EPA- 600/R-14/413b. 


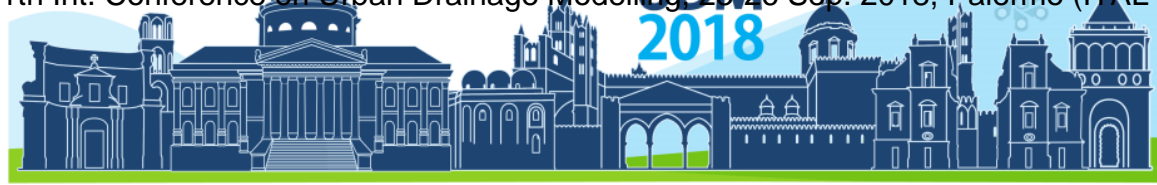

$11^{\text {th }}$ International Conference on Urban Drainage Modelling

23-26 Sep | Palermo - Italy

\title{
GESTOR: a new tool for the proactive management of sewer systems
}

\author{
Oriol Gutierrez ${ }^{*}$, Lluis Corominas ${ }^{1}$, Silvia Busquets ${ }^{1}$, Lluis Bosch1, Javier Garcia-Garcia², Pedro José \\ Martinez ${ }^{2}$, Oscar Macias ${ }^{2}$, Isabel Tormos ${ }^{2}$, Jose Guillermo Berlanga ${ }^{2}$, Narcis $\mathrm{Pi}^{3}$, Agustí-Pere Figueres ${ }^{3}$, \\ Oscar Soria ${ }^{3}$ \\ 1 Technologies and Evaluation Department, Catalan Institute for Water Research, ICRA \\ 101 Emili Grahit, Girona, Spain. \\ ${ }^{2}$ FACSA, Fomento Agrícola Castellonense Sociedad Anónima. 53, Avda. del Mar, Castellón de la Plana, Spain. \\ ${ }^{3}$ AMB Engineering. 50 Avda. Països Catalans, Riudellots de la Selva, Girona, Spain \\ * Corresponding author
}

Keywords: sewer systems, asset management, CSO, infiltration, corrosion

\begin{abstract}
GESTOR is a new management tool, being designed and under development, to upgrade current sewer-asset-management putting special emphasis on 3 specific issues: 1) online low-cost detection of combined sewer overflows, 2) Infiltration and exfiltration due to malfunction-leak of sewer pipes. 3) lifespan reduction and collapse due to induced corrosion generated by exposition to sulfide (H2S). GESTOR combines extensive monitoring campaigns of relevant data, modelling tools (such as GISWater and SWMM) coupled to advanced decision support systems and lifecycle assessment techniques. The development of the tool is being carried out in a case study in the sewer system of Peñiscola (Spain). Results to date show promising improvements in the monitoring of the 3 topics that will be incorporated to the final tool.
\end{abstract}

\section{INTRODUCTION}

Sewers are a crucial part of the integrated urban wastewater management which deals with the collecting and transport wastewater and stormwater to the treatment facilities or the natural media respectively. The main objectives of sewer systems are:

1) Hygienist: to avoid focus of contamination or diseases associated with the septicity of wastewater.

2) Protectionist: to avoid or reduce floods and their impact in relation to the protection of people and urban properties. In conditions of heavy rains, the sewerage has the mission of absorbing surface precipitation as much as possible, avoiding its accumulation in urban areas. This objective is related to the protection of people and urban properties.

3) Environmentalist: to avoid/reduce impacts to the receiving environment, preventing wastewater discharges. In times of heavy rain, combined sewer systems cannot absorb the peak flows of mixed storm-sewage and produce combined sewer overflows (CSO) direct spills to the receiving environment (rivers, beaches, etc).

In this work we present the status of the GESTOR project, a recently obtained Spanish national project within the frame of "Retos Collaboration" call which aims to promote the cooperation between companies and research organizations, in order 
Proceedings of the 11th Int. Conference on Urban Drainage Modellob23126 Sep. 2018, Palermo (ITALY). Ed. prof. Giorgio Mannina

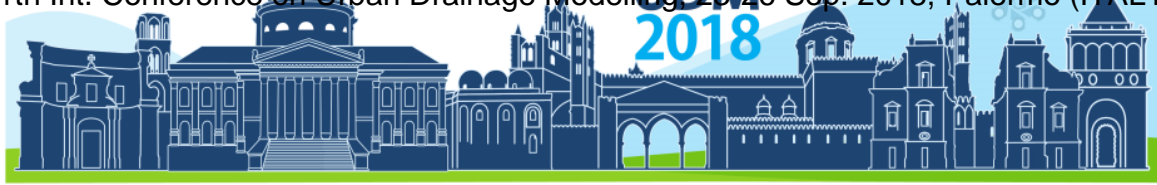

$11^{\text {th }}$ International Conference on Urban Drainage Modelling

23-26 Sep | Palermo - Italy

to developing new technologies in applied research. Within GESTOR, the partners FACSA, ABM and ICRA are working together with the objective of upgrading current sewer-asset-management tools putting the focus on 3 specific issues:

1) Combined sewer overflows: online low-cost detection and monitoring tools.

2) Infiltration and exfiltration due to malfunction-leak of sewer pipes.

3) Lifespan reduction and collapse due to induced corrosion generated by exposition to sulfide $\left(\mathrm{H}_{2} \mathrm{~S}\right)$.

The final objective is to provide an instrument with the capacity to anticipate problems and to provide as early as possible solutions to the studies issues.

\section{MATERIALS AND METHODS}

The work is carried out by a combination of extensive monitoring campaigns of relevant data, modelling tools (such as GISWater and SWMM) coupled to advanced decision support systems and lifecycle assessment techniques. Figure 1 presents the structure of the project with 3 workpackages, each one dedicated to the specific issued to address (WP2 CSO advanced techniques, WP3 Underground water Infiltration detection and WP4 new corrosion estimation techniques). All information will be compiled in the GESTOR software (WP5) which will integrate technical, social environmental and economic criteria.

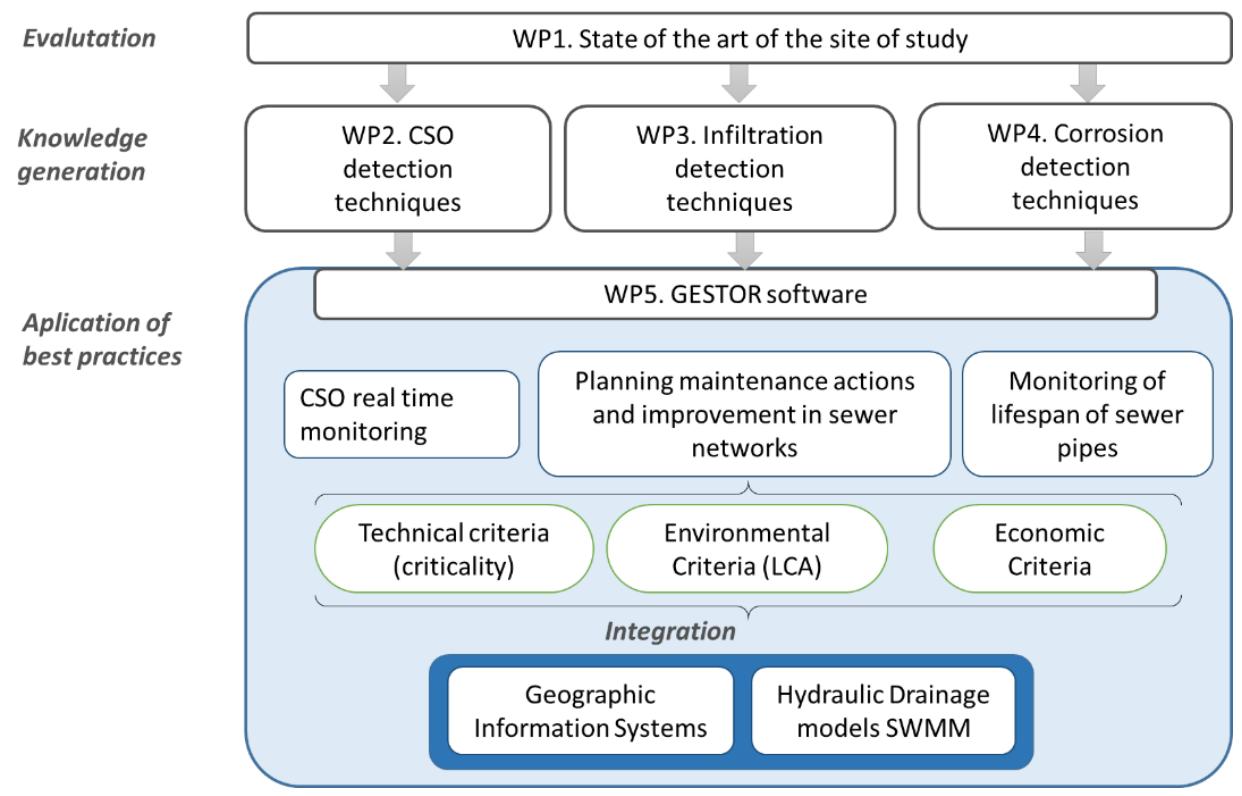

Figure 1. Structure of the GESTOR project.

The project is carried out in the case study at full scale in the sewer system of the municipality of Peñiscola (East Cost of Spain) Figure 2. Peñiscola is a Mediterranean touristic town, with high seasonality and variation of population, from 7000 to 100.000 inhab. Its sewer system has $\approx 80 \mathrm{~km}$ of pipes $(19.71 \mathrm{Km}$ of stormwater pipes, $58.24 \mathrm{Km}$ of sewerage system, 19 pumping stations, 4 combined sewer overflow points and 35 discharging points from stormwater network. 
Proceedings of the 11th Int. Conference on Urban Drainage Modellob23126 Sep. 2018, Palermo (ITALY). Ed. prof. Giorgio Mannina

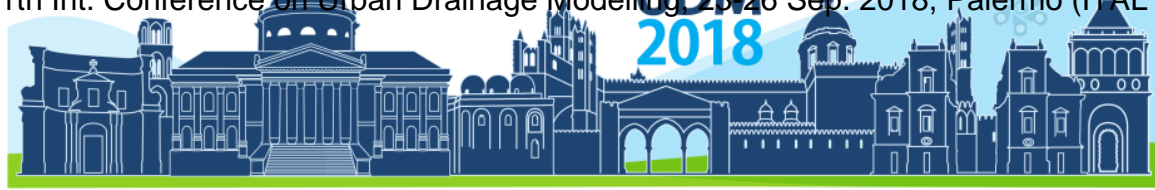

$11^{\text {th }}$ International Conference on Urban Drainage Modelling

23-26 Sep | Palermo - Italy
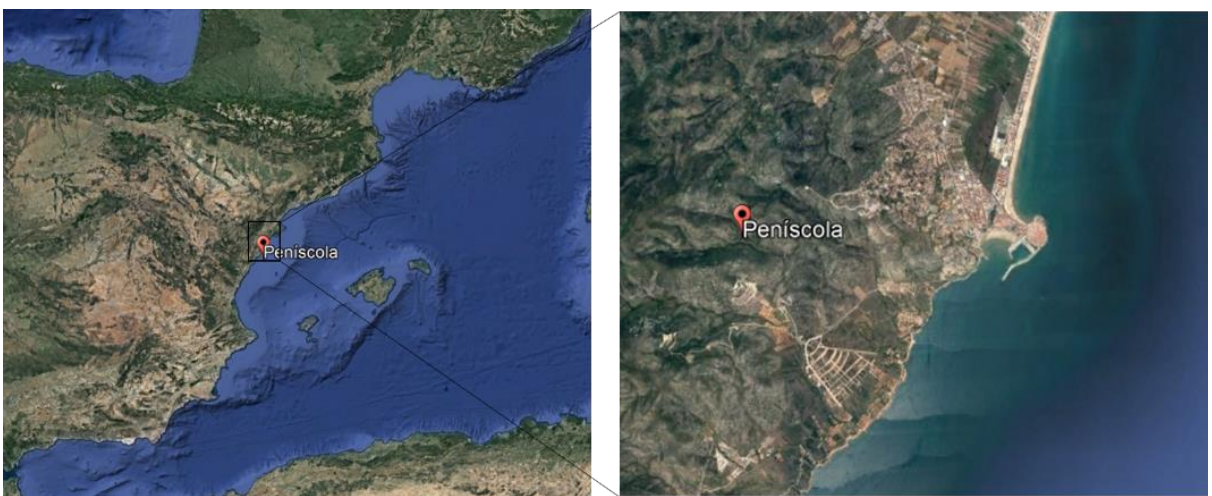

Figure 2. Location of Peñiscola, the case study of the GESTOR project.

\section{RESULTS AND DISCUSION}

1.5 years into the project, the main tasks carried out so far are related to the equipment of the sewer network with the tools to monitor CSO and infiltration, and to generation data-information which will be latter feed into the final tool.

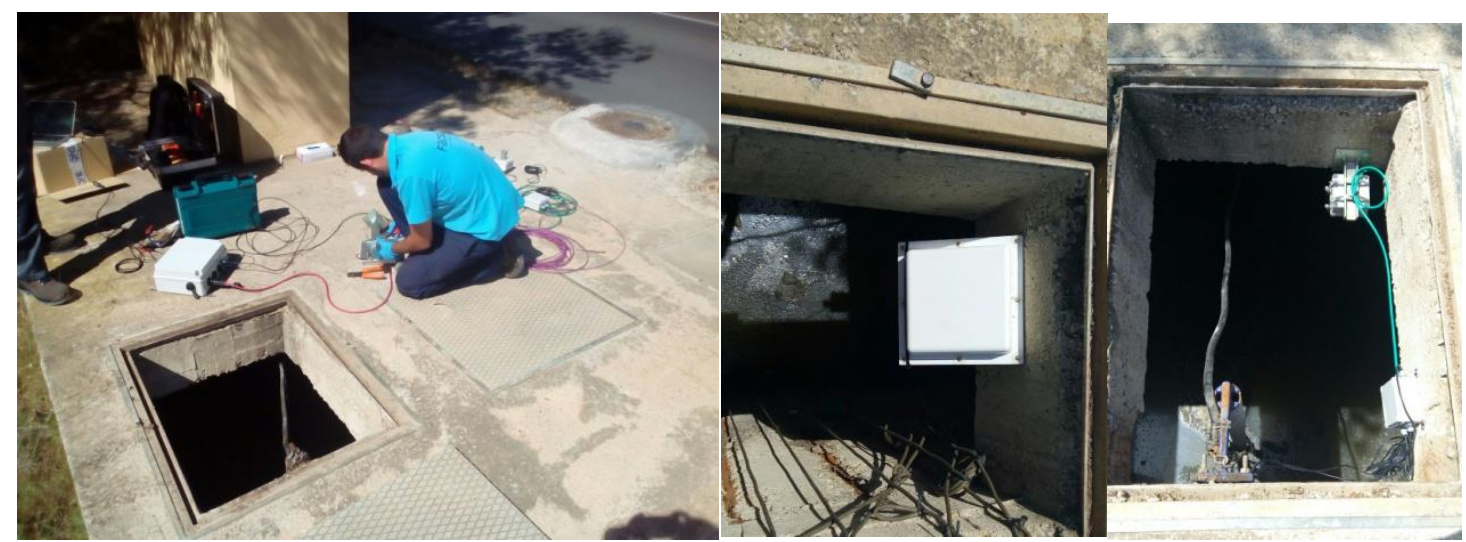

Figure 3. Installation of the low-cost CSO detectors in a pump station of the studied system.

With regards to the CSO detection, a very short number of CSO events were detected due to the extremely dry weather that ocurred in the last months $(<5 \mathrm{~mm}$ acumulated). Figure 4 presents an example of the few CSO detection data obtained. The precision in CSO detection was very satisfactory with detection of all occurred events. 
Proceedings of the 11th Int. Conference on Urban Drainage Modellob23126 Sep. 2018, Palermo (ITALY). Ed. prof. Giorgio Mannina

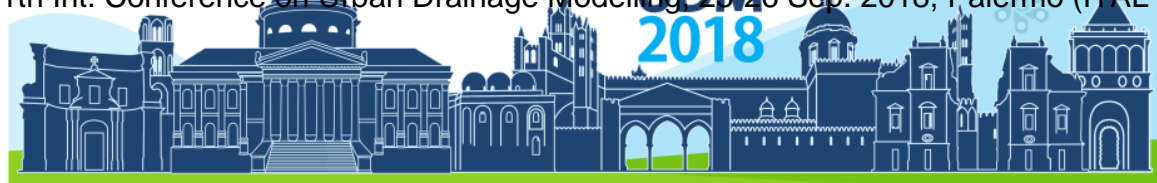

$11^{\text {th }}$ International Conference on Urban Drainage Modelling 23-26 Sep | Palermo - Italy

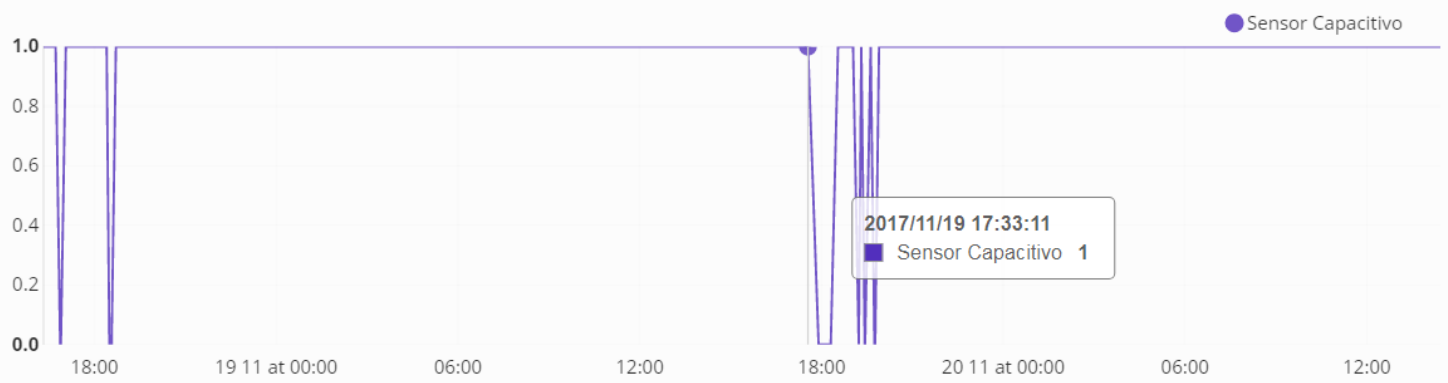

Figure 4. Data of the CSO event. Value $=1$ means no overflow; Value $=0$ means potential overflow occurring.

Within WP3, a series of techniques are being applied to detect infiltration of groundwater into the sewer network. Notably, Distributed Temperature Sensors (Temperature measurements through optical fiber) have been deployed to test the efficiency of this accurate technique in measuring infiltration in typical Mediterranean conditions. Initial results obtained are promising with a precise detection of small infiltration points.

Full set of results corresponding to the data and information generated by the time of the conference will be presented then. Also the integration and functioning of the final GESTOR tool. 


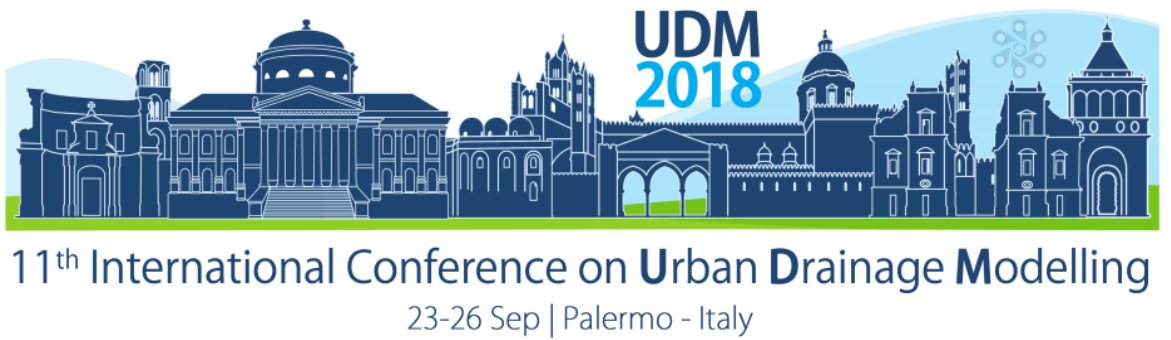

\title{
Urban Flood Area Delimitation using Reverse Water Local Flow Paths
}

\author{
Sergio Rosim ${ }^{1}$, João Ricardo de Freitas Oliveira' ${ }^{1}$ Monica De Martino ${ }^{2}$, Alfonso Quarati ${ }^{2}$ and \\ Alexandre Copertino Jardim ${ }^{3}$ \\ ${ }^{1}$ National Institute for Space Research (INPE), Image Processing Division (DPI), Sao Jose dos Campos, Brazil \\ Av. dos Astronautas, 1758 \\ ${ }^{2}$ Institute for Applied Mathematics and Information Technologies "Enrico Magenes" (IMATI), Genoa, Italy \\ Via de Marini 6, Genova \\ ${ }^{3}$ National Center for Natural Disaster Monitoring and Alert (CEMADEN), Sao Jose dos Campos, Brazil \\ Rodovia Presidente Dutra km40
}

\begin{abstract}
South America is vulnerable to flood disasters, which must be prevented and managed, especially in the urban area close to the rivers. Different terrain descriptors (e.g. hydrographic network, altimetry) are taken into consideration to identify area with potential risk of flooding. INPE has developed tools to process and manage hydrological information. This paper aims to improve such tools proposing a method to study urban flood area delimitation starting from a raster elevation representation of the urban area with high resolution and water level information. In particular, the proposed method considers the water behaviour assuming that water flood happens in the part of the river having altimetry higher than the surrounding surface. The use of such water behaviour information results in the improvement of the accuracy of the study of urban area with risk of flooding.
\end{abstract}

Keywords: DEM, Flood Area, water value, location flow

\section{INTRODUCTION}

Delimitation of flood urban areas has become increasingly important. In the last decades in Brazil, many cities have grown significantly in a disorderly way. This has caused anthropic actions in naturally flooded areas, such as the expansion of urban areas near the riverbed. In addition, mineral extraction activities near urban areas caused large floods (Agurto-Detzel et al., 2016) (Nunes, 2011). For example, on 5 November 2015 one of the worst mining accidents in the history of Brazil happened which caused the flooding of small villages and the mud spill devastated the ecosystem of the Doce River (Agurto-Detzel et al., 2016). Tools that can assist specialists and decision makers in the analysis and mitigation of urban floods and their effects are increasingly needed. (Savage et al., 2014) (Marzocchi et al., 2014) present twodimensional models used to estimate flooded areas.

The Image Processing Division at INPE has developed HAND, the Height Above the Nearest Drainage algorithm, as a prompt low-cost alternative in the absence of detailed hydrological and hydraulic data. It calculates a terrain descriptor that define the correlation between soil water conditions, like classes of water table depth, and topography (Renno et al., 2008) and may be used to delineate potential flooding area (Rosim et al.,2014). The algorithm computes a grid map where each cell value is the difference of elevation between the surface value of a cell of the digital elevation model (DEM) and the riverbed cell to which it drains. HAND defines the flooding zone and a water depth grid within this zone. Such results rely on the DEM resolution, the drainage network and the local flow (LDD) where LDD is generated from the DEM and indicates the water flow of each cell respect to its eight neighbor. All these information 


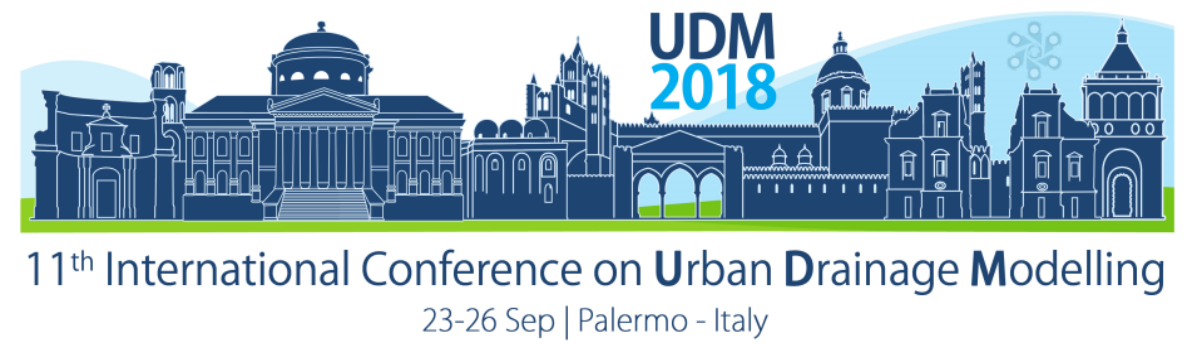

are used as input for HAND processing. (Speckhann et al., 2018) presents F2HAND a flood mapping technology combining HAND and flow frequency analysis to define flood hazards and determines the equivalency between HAND grid and the location where the water level was measured.

In this paper, we aim at improving the identification of the flood area calculated with HAND by exploiting the river water level information and inundation extent. It is assumed that water flood happens in the part of the river having altimetry higher than the surronding surface, flows according to LDD but in a reverse direction. The idea is to modify the original DEM adding the water level value to the DEM cells corresponding to the river and to calculate the flood by processing the modified DEM.

The water levels are generated by the hydrodynamic model Mike 11 (DHI, 1998) and assigned to some cells of the river grid. The missing water level information for the other river cells are calculated by interpolation between two consecutive available level values, and are added to the corresponding altimetry value in the original DEM.HAND is executed by processing the LDD, the river map and the modifyed DEM. The algorithm computes a grid map where each cell value is the elevation difference between the DEM cell and the stream bed cell to which it drains. All cells with negative value are flooded cells. The result is a thematic map showing the rivers and the flood area delimitation.

The contribution of the paper is to enhance the accuracy of the forecasted flooding in urban regions, when water behaviour have been taking into account

\section{MATERIALS AND METHODS}

The materials used in this work are the area DEM representing the relief of the geographic region, the hydrographic network and the water levels of rivers. The method exploits some tools developed at INPE: SPRING (Camara el al.,1996), TerraHidro (Freitas Oliveira et al., 2016) and HAND.

\subsection{Materials}

The study area is the region di Paraná State in south of Brazil: the urban area near Padilha river and its tributaries is considered. In particular, the geographical area is located in the metropolitan region of Curitiba, between longitudes 494738.98 and 484250.67 and latitudes s 255144.14 and s 251638.09 , in the UTM / SAD69 projection. We used a DEM of $5 \mathrm{~m}$ resolution. It was generated by isolines and isolated points extracted from altimetry maps of the region.

The values related to the water level is generated for some points of the river by the hydrodynamic model MIKE11, and were stored in a file. This file is a matrix containing for each row three kinds of information: the river names, the water level values, and the position of the water levels on the rivers provided as distance from the most downstream point.

The hydrographic network of $5 \mathrm{~m}$ resolution represented in Fig. 1 related to the Padilha river and five of its tributaries is used. It represents the base for positioning the water levels, It is important to note that each river should be represented by a single object. This object will have an attribute that will contain the name of the river, information necessary to link each river to the corresponding set of water level filed in its own file. The following tools are used to processing and generate data. 


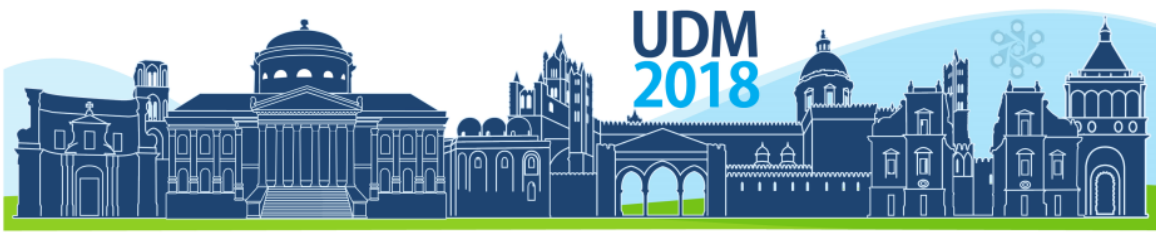

$11^{\text {th }}$ International Conference on Urban Drainage Modelling

23-26 Sep | Palermo - Italy

SPRING is a GIS and remote sensing image processing system with an object-oriented data model, which provides the integration of raster and vector data representations in a single environment (www.spring-gis.org/). TerraHidro is a distributed hydrological system created to develop water resource applications, using regular grid DEM as the surface and elevation structure for extracting hydrological information (e.g. drainage networks and watershed datasets)(http://wiki.dpi.inpe.br/doku.php?id=terrahidro/). HAND algorithm, provided by TerraHidro, determines the areas with greatest potential for flooding. The algorithm computes a grid map where each cell value is the elevation difference between the DEM surface cell and the stream bed cell to which it drains.

\subsection{Methods}

The proposed methods is characterised by the following steps:

- DEM generation. GIS SPRING is used to create the altimetry grid from the isolines and isolated points;

- River map transformation from vector to grid: the hydrographic map in vector format is transformed in grid. By GIS SPRING a grid is generated to identify the position of the river where cells with value is 1 represent river cells and value is 0 for others.

- Water levels processing. It consists on the association of the water level generated by the hydrodynamic model to the proper cell in the river grid map and calculation for the missing river values by interpolating the available water levels. It is done with GIS SPRING system.

- Modified DEM generation. The original DEM is modified by adding the water value to the altimetry for each river grid cell.

- LDD generation. TerraHidro is used to generate the local flow grid from the original grid.

- Flood map generation. HAND is used to determine the flood cells. HAND calculates, for every DEM cell, the altimetry difference between this cell and the nearest cell belonging to the drainage network, following the local drain directions. It's important to highlight that HAND uses the modified altimetry. The negative difference means that the flood altimetry value over the river is greater than the altimetry of the cell. Then this cell will potentially be flooded, assuming that the flow leaves the river and move in the opposite direction to the grid of local flows. Figure 1 shows HAND process. The grid of the rivers and the local flow grid are merged together.

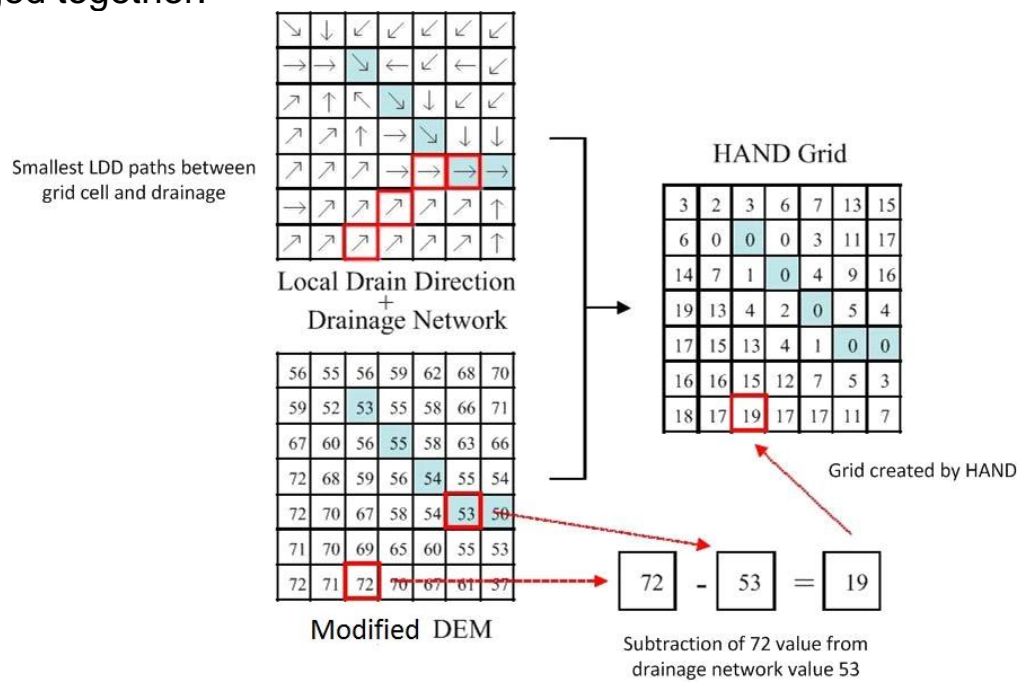

Figure 1. HAND process applied to modify the DEM with the water value added to the river cells. 


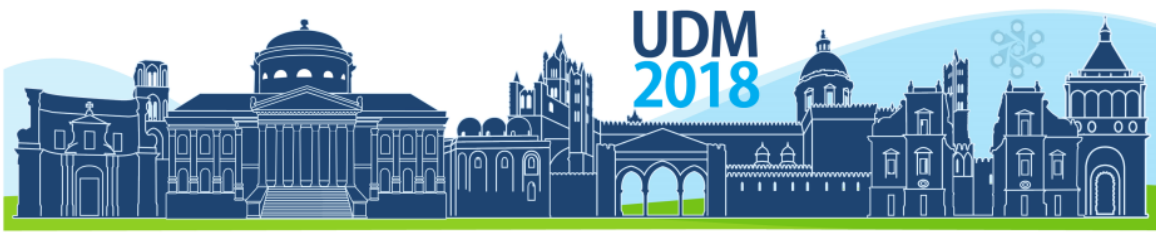

$11^{\text {th }}$ International Conference on Urban Drainage Modelling

23-26 Sep | Palermo - Italy

\section{RESULTS AND DISCUSSION}

We applied the method to the study area and the result is a raster map whose grid cells with negative or positive values: the negative values indicate the flooded areas. The greatest flood value outcome is $-4.57 \mathrm{~m}$. HAND grid may be sliced to highlight the flooded areas according with the flood values contour. Figure 2a presents the river (blue line) and the outcome of the flood areas (yellow colour)with one slice between -4.57 and 0.0 . Figure $2 b$ shows a zoom of a small area. The overlapping of the flood areas on the study region raster map highlights that significant urban area could be flooded according with this simulation. This method can be replicated in any city as long as the DEM with adequate resolution for urban region and the availability of water levels are supplied.

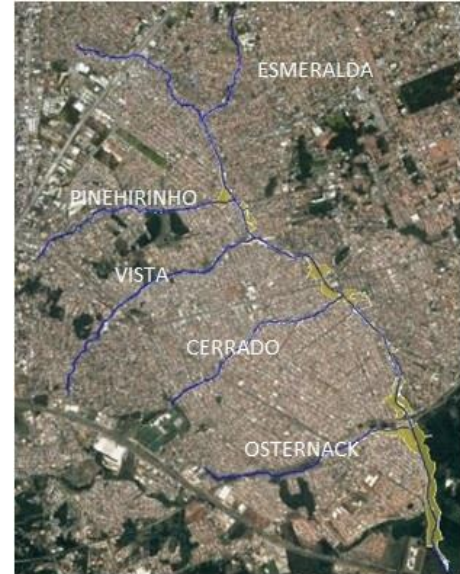

(a)

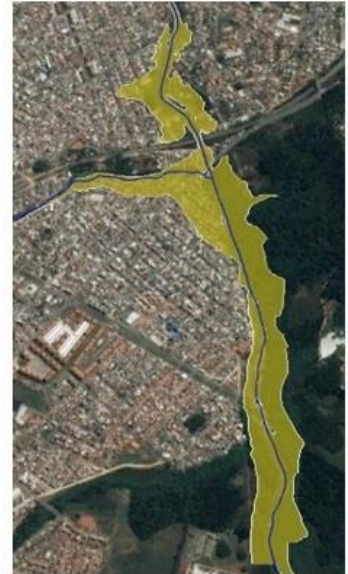

(b)

Figure 2. Flooded area (yellow area) considering Padilha river and its tributaries (blue lines).

The results validation require to compare simulation outcomes with satellite images taken at the same date of the events documenting the water flow level, that presents high cloud incidence levels. On-going work is developing a method for optical image cloud elimination to assist the verification of the results yield by the algorithm presented.

\section{CONCLUSIONS}

This paper proposes an urban flood area determination method based on physical water behaviour. It employs a 5 meters resolution DEM, the Padilha river and its 5 tributaries represented by vector format, the local flow grid and water level generated by Mike 11 hydrodynamic model. Preliminary evaluation of the outcome shows the consistency respect to the urban surface used. Future work foresees a deep validation considering the comparison with real data of flooding events.

\section{References}

Agurto-Detzel, H.; Bianchi, M.; Assumpo, M.; Schimmel, M.; Collao, B.; Ciardelli, C.; Barbosa, J.R. and Calhau, J. (2016) The tailings dam failure of 5 november 2015 in se brazil and its preceding seismic sequence, Geophysical Research Letters, vol. 43, no. 10, pp. 4929-4936.

Camara, G.; Souza, R.C.M.; Freitas, U.M.; Garrido, J. (1996) SPRING: Integrating remote sensing and GIS by object-oriented data modelling Computers\& Graphics, 20: (3) 395-403.

DHI (1998) Mike 11 GIS a flood management system for rivers and floodplains, version 2.1, Reference and User Manual, Danish Hydraulic Institute.

Freitas Oliveira, J.R. Rosim, S.; Jardim, A.C. (2016) Assessment of the drainage network extracted by the TerroHidro system using the CCM2 ;drainage as reference data. In: http://ccm.jrc.ec.europa.eu/documents/ workshop2016/2016_ricardo_rosim_jardim_great_britain_assesment_terrahidro.pdfWorkshop: CCM2 River 
Proceedings of the 11th Int. Conference on Urban Drainage Modelling, 23-26 Sep. 2018, Palermo (ITALY). Ed. prof. Giorgio Mannina

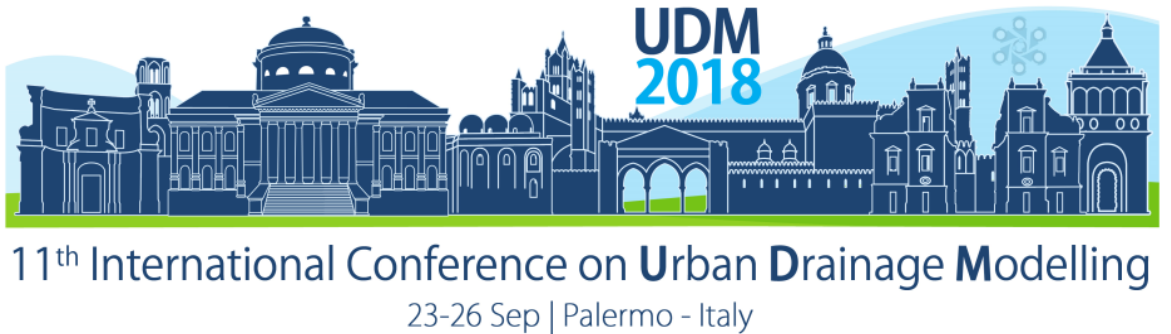

and Catchment Database for Europe - Applications. AGILE Conference - Association of Geographic Information Laboratories in Europe. Helsinki.

Marzocchi, M.; Federici, B.; Cannata, M.; Cosso, T.; Syriou, A. (2014) Comparison of one-dimensional and twodimensional GRASS-GIS models for flood mapping, Applied Geomatics, 6: 245, https://doi.org/10.1007/s12518014-0140-1

Nunes, L.H. (2011) An overview of recent natural disasters in south america,Meddedelingen der Zittingen (Bulletin des Seances), vol. 57, no. 1, pp. 409-425.

Renno, C.D.; Nobre, A., Cuartas, L.; Soares, J.; Hodnett, M.; Tomasella, J. and Waterloo, W. (2008) HAND, a new terrain descriptor using SRTM-DEM: Mapping terra-firme rainforest environments in Amazonia. Remote Sensing of Environment, vol. 112, no. 9, pp. 3469-3481.

Rosim S.; Freitas Oliveira, J.R.; Oliveira Ortiz, J.; Cuellar, M.Z.; Jardim, A.C. (2014) Drainage network extraction of Brazilian semiarid region with potential flood indication areas, Proc. SPIE 9239, Remote Sensing for Agriculture, Ecosystems, and Hydrology XVI, 923919; doi:10.1117/12.2066906

Savage, J.; Paul Bates, P.; Freer, J.; Neal, J. (2014). The impact of scale on probabilistic flood inundation maps using a 2D hydraulic model with uncertain boundary conditions. In: M. Beer, S.-K. Au, and J.W. Hall, eds, Vulnerability, Uncertainty and Risk: quantification, Mitigation, and Management (ICVRAM Proceedings, 13-16 July 2014, Liverpool). American Society of Civil Engineers, 279-289.

Speckhann, G.A.; Chaffe, P.L.B.; Goerl, R.F., Abreu, J.J.; Flores, J.A.A. (2018) Flood hazard mapping in Southern Brazil: a combination of flow frequency analysis and the HAND model, Hydrological Sciences Journal, 63:1, 87-100, DOI: 10.1080/02626667.2017.1409896 


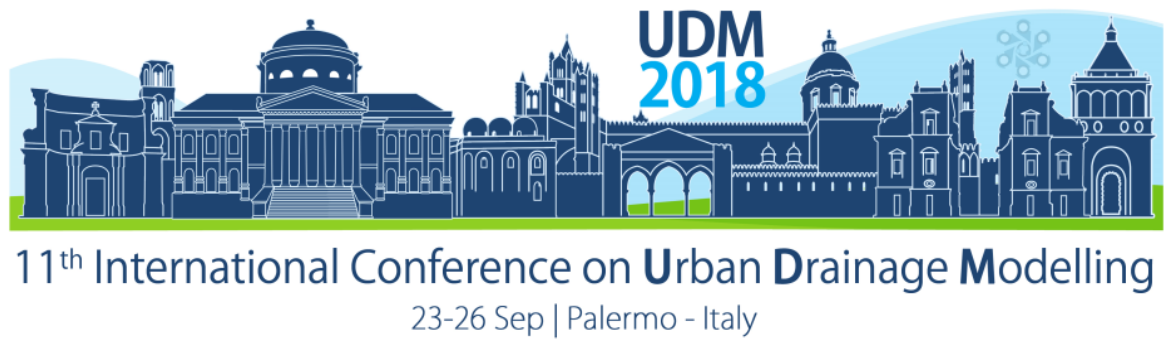

\title{
Numerical Unsaturated Flow Model of Railway Drainage Systems
}

\author{
Legaire Pinedo Ortiz de Mendivil, Christian Berretta and Andrew Sleigh \\ University of Leeds, School of Civil Engineering, Leeds, United Kingdom
}

\begin{abstract}
Substandard drainage assets are considered to be a major cause of flooding, earthwork failures, and deficient track geometry. Considering the deterioration of track materials due to cyclic loads and tamping forces, the impact of more frequent extreme rainfall events is likely to lead towards higher rates of hydraulic overloads in the drainage system, earthwork failures, and service disruptions. Therefore, the development of a numerical model could be able to describe the ageing track bed materials and provide an alternative tool for the simulation of the flow through the porous media used in the construction of railway tracks. In this paper the model HYDRUS is tested to simulate the drainage of trackbed materials under laboratory controlled conditions prior its application on actual railway drainage case studies.
\end{abstract}

Keywords: railway drainage systems; unsaturated flow; railway flooding

\section{INTRODUCTION}

Ballast and subballast track layers must be able to transmit the loads to the subgrade as much as allowing the efficient drainage of water entering in to the tracks. The efficient infiltration of water through the trackbed layers is essential for the delivery of an appropriate transportation service. Substandard drainage assets are a major cause of flooding, earthwork failures, and deficient track geometry.

The currently available railway drainage guidelines in the UK - based on agricultural methodsare not able to describe the flow processes in these porous media or neither address the changes in its hydraulic properties over time (Network Rail, 2010). Other approaches have been based on the application of the Dupuit-Forchheimer assumptions (Youngs and Rushton, 2009; Rushton and Ghataora, 2009). However, this theory may not be applicable in all the railway drainage typologies or describe transient flow (Kong et al., 2016).

In order to avoid inaccuracies on the groundwater table level (Kong et al., 2016), applying a physically based variably saturated-unsaturated flow model could appeal describe fouled ballast (Cui, 2016), and the subsurface flow mechanisms involved. This paper presents preliminary results of the simulation of railway drainage system materials under laboratory conditions using a physically based variable saturated flow model.

\section{MATERIALS AND METHODS}

The model used in this study is HYDRUS 2D/3D version 2.05. Due to the lack of data of the hydraulic properties of the track materials at the stations, a preliminary calibration and validation of the model was performed using the results and layers characteristics of a flume test under steady state conditions (Heyns, 2000) These soil parameters will be used for future simulations of the drainage outfall at Garforth and Newbury Park (UK). 


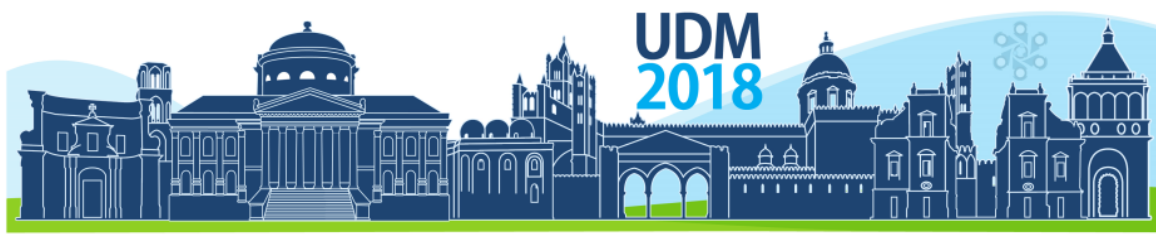

$11^{\text {th }}$ International Conference on Urban Drainage Modelling

23-26 Sep | Palermo - Italy

\subsection{Governing equations}

HYDRUS solves the modified form of the Richards' equation for variable saturated flow conditions:

$$
\frac{\partial \theta}{\partial t}=\frac{\partial}{\partial x_{i}}\left[K\left(K_{i j}^{A} \frac{\partial h}{\partial x_{j}}+K_{i j}^{A}\right)\right]-S
$$

Where $\theta$ is the volumetric water content $\left[\mathrm{L}^{3} \mathrm{~L}^{-3}\right], h$ is the pressure head $[\mathrm{L}], S$ is a sink term $\left[\mathrm{T}^{-1}\right], x_{i}(\mathrm{i}=1,2)$ are the spatial coordinates $[\mathrm{L}], t$ is time $[\mathrm{T}], K_{i j}^{A}$ are components of a dimensionless anisotropy tensor $\mathrm{K}^{\mathrm{A}} . \mathrm{K}$ is the unsaturated hydraulic conductivity function $\left[\mathrm{LT}^{-1}\right]$, and it is given by:

$$
K(h, x, y, z)=K_{s}(x, y, z) K_{r}(h, x, y, z)
$$

Where $K_{r}$ is the relative hydraulic conductivity and $K_{s}$ the saturated hydraulic conductivity $\left[\mathrm{LT}^{-1}\right]$.

Van Genuchten -Mualem model was used to define the soil hydraulic functions, given by the following expressions:

$$
\begin{gathered}
\theta(h)=\theta_{r}+\frac{\theta_{s}-\theta_{r}}{\left(1+|\alpha h|^{n}\right)^{m}} \text { for } \mathrm{h}<0 \\
\theta(h)=\theta_{s} \text { for } \mathrm{h} \geq 0 \\
K(h)=K_{s} S_{e}^{l}\left(1-\left(1-S_{e}^{1 / m}\right)^{m}\right)^{2} \\
S_{e}=\frac{\theta-\theta_{r}}{\theta_{s}-\theta_{r}} \\
m=1-\frac{1}{n} ; \mathrm{n}>1
\end{gathered}
$$

Where $\theta_{r}$ and $\theta_{s}$ denote residual and saturated volumetric water contents [ $\left.\mathrm{L}^{3} \mathrm{~L}^{-3}\right]$, respectively; $S_{e}$ is the effective saturation $[-], \alpha\left[\mathrm{L}^{-1}\right]$, and $n[-]$ are retention curve shape factors, and $I$ is a pore connectivity parameter [-].

\subsection{Flume test description}

During the flume tests performed by Heyns (2000) the flow processes of a rail track formed by a ballast layer and a subballast layer of 127 and $152.4 \mathrm{~cm}$, respectively, were observed. Six piezometers at the bottom of the flume (Figure 1) recorded the water table level under a different rainfall conditions (13 to $75 \mathrm{~mm} / \mathrm{h}$ ). Different slopes between the ballast and the subballast were also tested $(0,1,3$, and $5 \%)$. The draining characteristics of several subballast material were evaluated adding fines (Table 1)

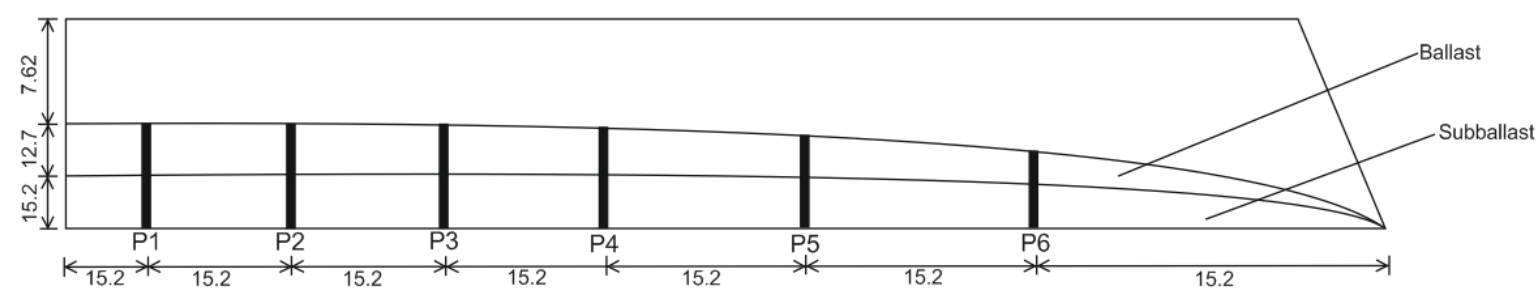

Figure 1. Description of Heyn's experiments with dimensions in $\mathrm{cm}$. Position of the piezometers is indicated in bold as well as the approximate position of ballast and subballast layers. The flume was $35.4 \mathrm{~cm}$ wide. Rainfall was simulated over $188 \mathrm{~cm}$ at the top of the flume. 


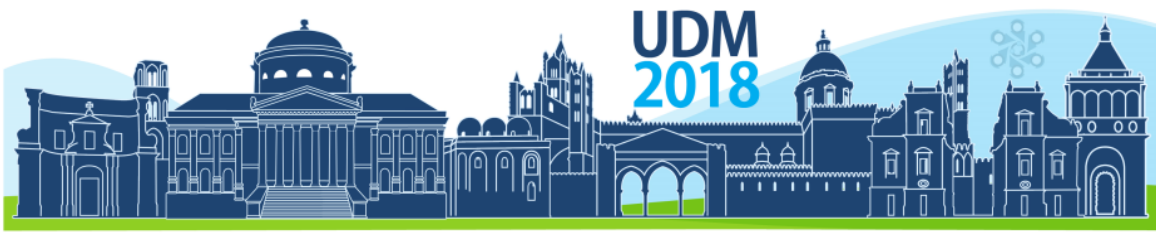

$11^{\text {th }}$ International Conference on Urban Drainage Modelling

23-26 Sep | Palermo - Italy

Table 1.Information provided about the materials used during Heyns' tests (Heyns, 2000).

\begin{tabular}{cccccc}
\hline $\begin{array}{c}\text { Subballast } \\
\text { Type }\end{array}$ & Description & $\begin{array}{c}\text { Fine content } \\
(\%)\end{array}$ & $\mathrm{K}_{\mathrm{s}}\left(\mathrm{m} \mathrm{s}^{-1}\right)$ & $\begin{array}{c}\text { Specific } \\
\text { retention }(\%)\end{array}$ & $\begin{array}{c}\text { Dry Unit Weight } \\
\left(\mathrm{kg} \mathrm{m}^{-3}\right)\end{array}$ \\
\hline Subballast 1 & Gravel & 0 & $5.8 \times 10^{-4}$ & 15.8 & 1938 \\
Subballast 2 & Gravelly sand & 10 & $7.5 \times 10^{-5}$ & 15.9 & 1954 \\
Subballast 3 & Gravelly sand & 18 & $6.6 \times 10^{-6}$ & 15.9 & 1986 \\
\hline
\end{tabular}

\subsection{Boundary conditions}

A time-variable atmospheric boundary condition was applied to include the rainfall intensities; no flow boundary conditions were added at the sides of the flumes and are also considered at the limits of the drainage area. A seepage boundary condition was included at the flume outlet during the Heyn's experiments simulation.

\subsection{Model calibration and validation}

The initial Van-Genuchten parameters used in the calibration were based on data from the literature (Filipović et al., 2014; Thoma et al., 2014). The Heyns' experiments data were used to calibrate $\alpha$ and $n$ over the cumulative outlet depths of events with 0.762 and $1.168 \mathrm{~cm} / \mathrm{h}$ rainfall intensities. Ballast representation was assumed to be similar to subballast 1 due to the open structure of American ballast (Rushton and Ghataora, 2009). Nash-sutcliffe Efficiency coefficient (NSE) was determined to assess the accuracy on the prediction of cumulative outflow depths. The Relative Percentage Difference (RPD) was used to evaluate the difference between the simulated and the observed cumulative depth.

\section{RESULTS AND DISCUSSION}

The resulting parameters of the calibration are reported in Table 2. Comparison of preliminary HYDRUS results with the flume test yield similar cumulative outflow depths and provided confidence on the Van Genuchten parameters used. The NSE coefficients for the validation events with $0.635 \mathrm{~cm} / \mathrm{h}$ and $0.559 \mathrm{~cm} / \mathrm{h}$ rainfall intensity were 0.998 and 0.963 , respectively (Figure 2). The RPD of the total cumulative depths showed a good prediction of the outfall values with ratios of $1.34 \%$ and $2.29 \%$.

Table 2. Calibrated Van Genuchten parameters for ballast and subballast 1 media.

\begin{tabular}{lcccccc}
\hline Track material & $\theta_{r}\left(\mathrm{~cm}^{3} \mathrm{~cm}^{-3}\right)$ & $\theta_{s}\left(\mathrm{~cm}^{3} \mathrm{~cm}^{-3}\right)$ & $\alpha\left(\mathrm{cm}^{-1}\right)$ & $\mathrm{n}$ & $K_{s}\left(\mathrm{~cm} \mathrm{~h}^{-1}\right)$ & $l$ \\
\hline Ballast & 0.005 & 0.4 & 0.2 & 3 & 2088 & 0.5 \\
Subballast 1 & 0.005 & 0.4 & 0.2 & 3 & 208.8 & 0.5 \\
\hline
\end{tabular}



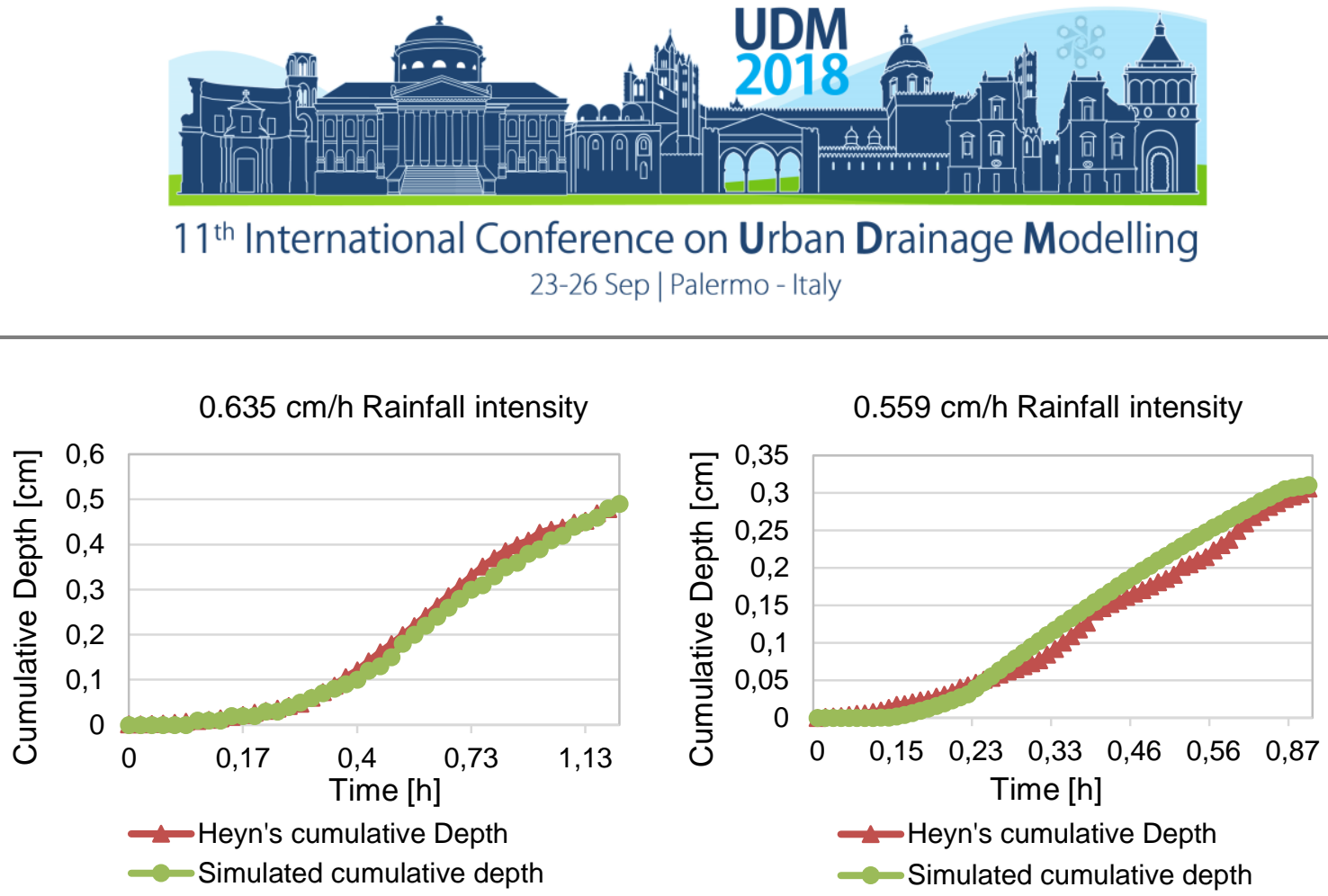

Figure 2. Comparison of cumulative outflow depth during Heyn's experiments and simulation results provided by HYDRUS.

\section{CONCLUSIONS}

The unsaturated flow model used in this study describes satisfactorily the steady state flow within the railway track media. The proposed soil hydraulic parameters provide confidence on the description of the hydraulic processes. Therefore, these will be used to apply the model to describe the drainage of Newbury Station in London and Garforth Station in Leeds (UK).

The use of a variably saturated-unsaturated model constitutes a novel approach for the simulation a railway drainage system, allowing to simulate the changes on ballast and subballast media over time. However, the limitations on studies available and the difficulties of the hydraulic characterisation of the track layers are the main challenge in the application of a physically based model.

\section{References}

Barber, M.E., King, S.G., Yonge, D.R. and Hathhorn, W.E. 2003. Ecology ditch: A best management practice for storm water runoff mitigation. Journal of Hydrologic Engineering. 8(3), pp.111-122.

Cui, Y.-J. 2016. Unsaturated railway track-bed materials. In: E3S Web of Conferences: EDP Sciences, p.01001.

Dan, H.C., Xin, P., Li, L. and Lockington, D. 2012. Capillary effect on flow in the drainage layer of highway pavement. Canadian Journal of Civil Engineering. 39(6), pp.654-666.

Filipović, V., Mallmann, F.J.K., Coquet, Y. and Šimůnek, J. 2014. Numerical simulation of water flow in tile and mole drainage systems. Agricultural water management. 146, pp.105-114.

Heyns, F.J. 2000. Railway track drainage design techniques. PhD thesis, University of Massachusetts Amherst.

Kong, J., Shen, C., Luo, Z., Hua, G. and Zhao, H. 2016. Improvement of the hillslope-storage Boussinesq model by considering lateral flow in the unsaturated zone. Water Resources Research. 52(4), pp.2965-2984.

Network Rail. 2010. Railway Drainage Systems Manual Part 2B:Hydraulic design of new Drainage Systems (NRL/L3/CIV/005/2B).

Roe, C. 2009. Barkingside Station: Interpretive Report.

Rushton, K.R. and Ghataora, G. 2009. Understanding and modelling drainage of railway ballast. PROCEEDINGS OF THE INSTITUTION OF CIVIL ENGINEERS-TRANSPORT. 162(4), pp.227-236.

Thoma, M.J., Barrash, W., Cardiff, M., Bradford, J. and Mead, J. 2014. Estimating unsaturated hydraulic functions for coarse sediment from a field-scale infiltration experiment. Vadose Zone Journal. 13(3).

Van Genuchten, M.T. 1980. A closed-form equation for predicting the hydraulic conductivity of unsaturated soils. Soil science society of America journal. 44(5), pp.892-898.

Youngs, E.G. and Rushton, K.R. 2009. Steady-state ditch-drainage of two-layered soil regions overlying an inverted V-shaped impermeable bed with examples of the drainage of ballast beneath railway tracks. Journal of Hydrology. 377(3), pp.367-376. 


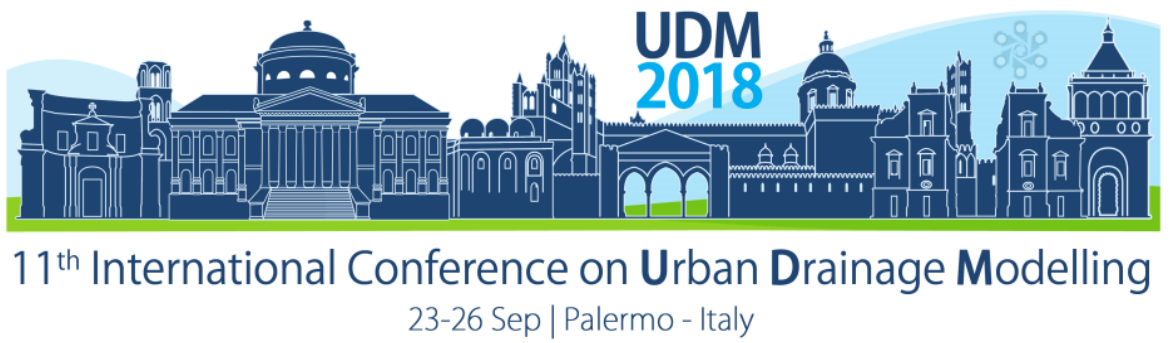

\title{
Characterization of the Dynamics of Microbiological and Chemical Contaminants in an Urban Catchment in South of France: From Field Data Collection to Modelling
}

\author{
Marlène Rio, Marie-George Tournoud, Christian Salles, Chrystelle Bancon-Montigny, \\ Patrick Monfort, Claire Rodier, Mylène Toubiana, Pierre Marchand
}

HSM, Univ Montpellier, CNRS, IRD, Montpellier, France

\begin{abstract}
Densely urbanized areas generate a wide range of contaminants exerting pressures on the quality of downstream rivers. As urban areas are in permanent extension, assessing the potential evolution of water quality and the effects of mitigation measures is a real challenge. Modelling tools could be helpful in decision making but require sound field data for calibration steps. The present study focuses on the urban river Lez that crosses the area of Montpellier city. Due to the Mediterranean climate, extreme precipitations intensify the transfer of contaminants by generating land runoff and significant sewer overflow. The spatiotemporal variability in microbiological and chemical contamination of the Lez river and its tributaries is characterized through field campaigns. Three low flow campaigns and a flood event are presented here, with a focus on the most urbanized subcatchment: Verdanson. Hydrological conditions are shown to have a strong impact on the water quality in terms of concentrations of fecal indicator bacteria, organotins, trace metals and polycyclic aromatic hydrocarbons. As a first step towards the modelling of the water quality during a flood event, a sensitivity analysis was performed to test how land cover could be properly be taken into account in the modelling process. The analysis reveals that discretizing the catchment into land cover-homogeneous subcatchments enhances the suitability of water quality model outputs, keeping good outputs of the hydrological model. Consequently, a rigorous description of land cover is required to properly assess the impacts of territorial dynamics on water quality.
\end{abstract}

Keywords: Urban catchment; Water quality modelling; Organotins; Trace metals; Fecal indicator bacteria

\section{INTRODUCTION}

Urban areas have been widely shown to impact the water quality of rivers during rainfall events, by transferring a wide range of contaminants released on impervious surfaces and into drainage and sewage networks (Mancini et al., 2005). Since urban development is rapid and sometimes associated with mitigation measures, it is important to design and deploy reliable water quality models to support water managers in their decision processes, particularly in a Mediterranean context, where extreme rainfall intensities strengthen the transfer of contaminants into the receiving environment (Rio et al., 2017). Yet modelling is inextricably linked to monitoring, for calibration and validation purposes, and a well-designed monitoring network is essential (Di Modugno et al., 2015). Our aim is to build a model and a sound monitoring network able to reproduce the dynamics of microbiological and chemical contaminants in highly urbanized rivers subject to Mediterranean climate. In this paper, we present the first steps of the study: (1) the monitoring network is explored through its ability to well-characterize the spatio-temporal variability of surface waters contamination; (2) the water-quality model is applied to a highly urbanized sub-catchment and sensitivity analysis test is run on the influence of land cover representation in water quality modelling. 


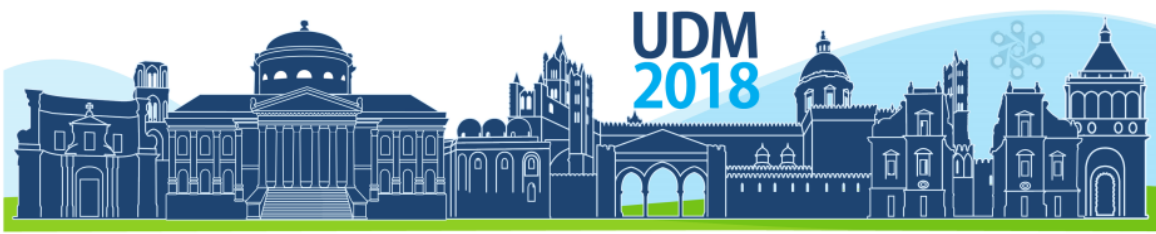

$11^{\text {th }}$ International Conference on Urban Drainage Modelling

23-26 Sep | Palermo - Italy

\section{MATERIALS AND METHODS}

\subsection{Study site}

Located in the Lez catchment $\left(709 \mathrm{~km}^{2}\right)$ in the south of France, the urban area of Montpellier has a population of 590000 inhabitants. At a catchment scale, predominant urban conditions share land use with agricultural and natural areas (Figure 1). The climate is Mediterranean, presenting semi-arid conditions with average rainfall of $676 \mathrm{~mm} /$ year. Crossing through Montpellier, the Lez river is a highly urbanized river of $29.5 \mathrm{~km}$ flowing into the Mediterranean sea. Its main tributary is the Verdanson river, a $7.5 \mathrm{~km}$ long watercourse within an entirely urbanized catchment of $16 \mathrm{~km}^{2}$, with a global imperviousness of $50 \%$.

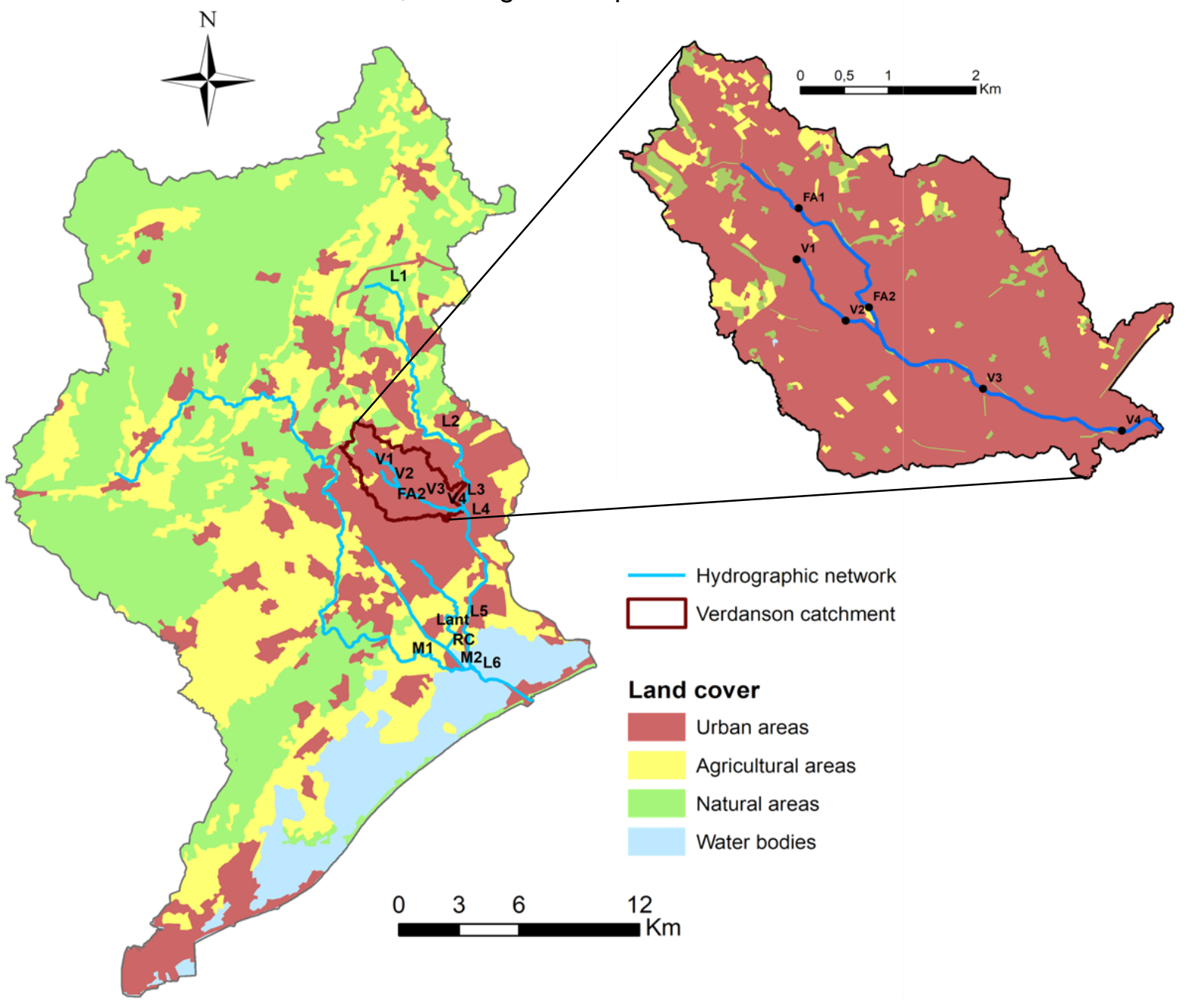

Figure 1. Description of the Lez-Mosson catchment and the Verdanson sub-catchment (France) and the monitoring network

\subsection{Sampling campaigns}

Water quality data were collected in 16 sampling sites along the Lez River and its tributaries to characterize contamination levels (Figure 1). Six sampling sites are located along the Lez river, from the spring (L1), the entrance of the urban area (L2), and the sites L3 to L5 


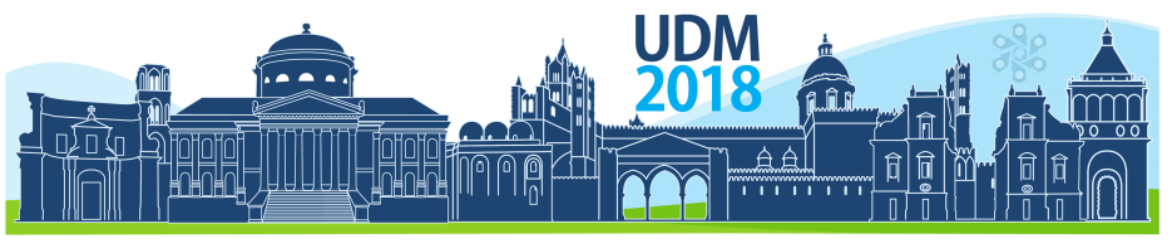

$11^{\text {th }}$ International Conference on Urban Drainage Modelling

23-26 Sep | Palermo - Italy

gradually integrating the contaminant inputs from urban and peri-urban zones, up to L6 close to the mouth in the Mediterranean sea. In the Verdanson tributary, the sampling locations were determined to assess the influence of residential areas (V1, V2, V3, and V4) and a hospital area (FA1, FA2). Water quality was also assessed in the tributary of the Mosson (M1, M2) and downstream of peri-urban areas, in the Rieu-Coulon (RC) and the Lantissargues watercourses (Lant). For each sampling site, physico-chemical parameters were measured in-situ and a velocity profiler was used to determine the flow. Water and sediment samples were collected for chemical and microbiological analyses. Here are presented results about: suspended matter, trace metals (As, $\mathrm{Cu}, \mathrm{Cr}, \mathrm{Zn}, \mathrm{Pb} \ldots$..), organostannic compounds (MBT, DBT, TBT), polycyclic aromatic hydrocarbons (PAHs) and fecal indicator bacteria. During the flood campaigns, suspended solids were collected by centrifugation and analyzed in terms of trace metals, organotins and PAHs.

In this study, the characterization of the level and dynamics of the contamination of the Lez urban river is described through three sampling campaigns conducted in low flow conditions, two in spring (D1 and D3) and one in winter (D2). The dry antecedent periods of these three campaigns were longer than 10 days. Additionally, a spring flood campaign at the outlet of the Verdanson catchment (V4) is discussed.

\subsection{Modelling}

The PCSWMM software was used to model water quality in the most urbanised tributary of the Lez river: Verdanson. This paper is focused on the sensitivity analysis performed on an upstream sub-catchment of the Verdanson river. Land cover was classified into seven categories: parking areas, roads, pedestrian areas, flat roofs, sloped roofs, natural fields and water bodies. Within the SWMM model, two catchment discretizations were compared (Figure 2). Firstly, the seven categories of land cover were represented as percentages of the surface of the entire catchment. Secondly, the catchment was discretized in seven fictive sub-catchments representing the land cover categories and connected to a single outlet. To model the concentration of total suspended solids, the exponential equation was used to describe build-up and wash-off processes. The parameters were defined according to the values collected in the literature (Chow et al., 2012).

(a)

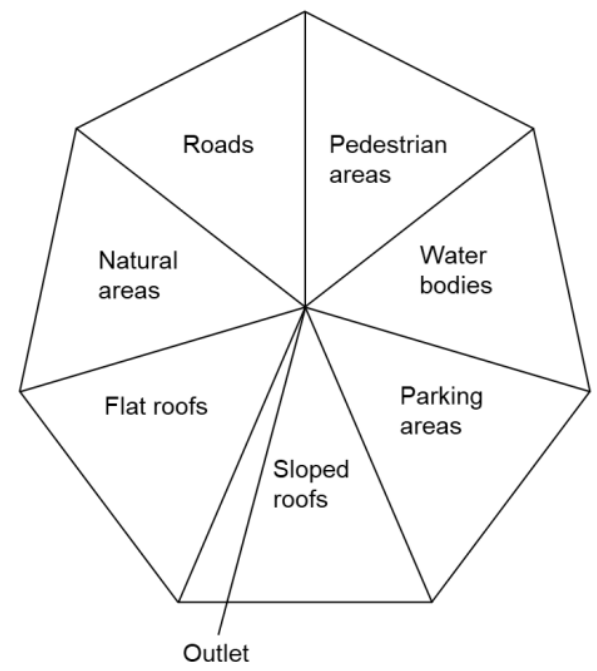

(b)

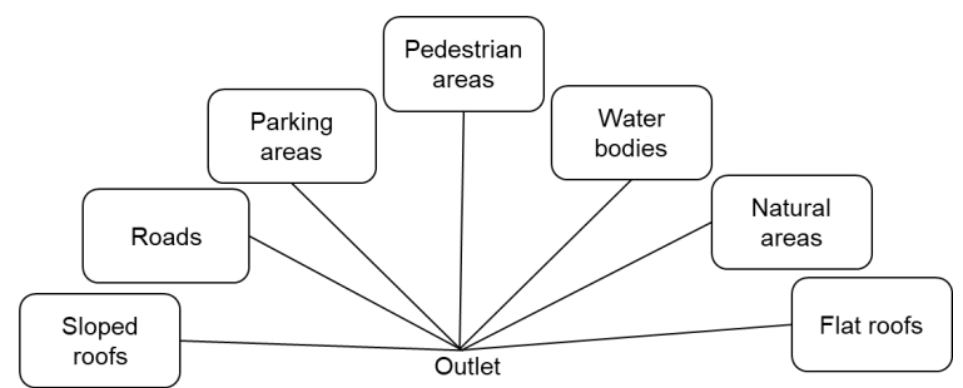

Figure 2. Schematic description of the two catchment discretizations used for land cover representation; (a) a single heterogeneous catchment, (b) subcatchments discretization according to the seven land cover 


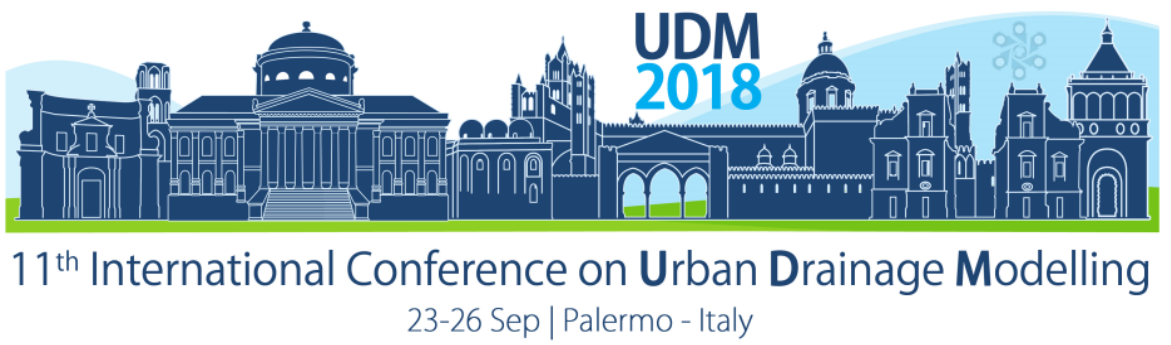

\section{RESULTS AND DISCUSSION}

\subsection{Contamination levels}

Spatial variations of trace metals concentrations $(\mathrm{Cu}, \mathrm{Cd}, \mathrm{Pb} \ldots)$ are observed among the sampling stations; a progressive increase in the Lez river flowing through the city of Montpellier reveals the influence of urban activities. During the dry weather campaigns, organostannic compounds were systematically observed in the waters sampled in the Lez river and its tributaries. The concentrations in Tributyltin (TBT), a priority hazardous substance, were widely higher (2 to 15 times) than the environmental quality standards set by the European water framework directive for the campaigns D2 and D3. As the organostannic compounds do not exist in the natural environment, but are widely used in domestic products, the results highlight a non-point source "background level of contamination" of several ng per litre. Regarding the concentrations of fecal indicator bacteria, higher levels of contamination were observed in the tributaries, and notably in the Verdanson watercourse, than in the Lez river. These results indicate a good representation of the spatial variations in microbiological and chemical contaminations of surface waters along the Lez river and its tributaries.

During the flood event, the concentrations of fecal indicator bacteria, trace metals, organostannic compounds and PAHs were significantly higher in the dissolved and particulate phases than under dry weather conditions. While in low flow conditions the level of TSS at V4 was lower than $1 \mathrm{mg} / \mathrm{L}$, it reached $700 \mathrm{mg} / \mathrm{L}$ during the flood event. A moderate first flush effect was observed (Figure 3), as $58 \%$ of the total mass was transported in the first $25 \%$ of runoff (Hathaway and Hunt, 2011).

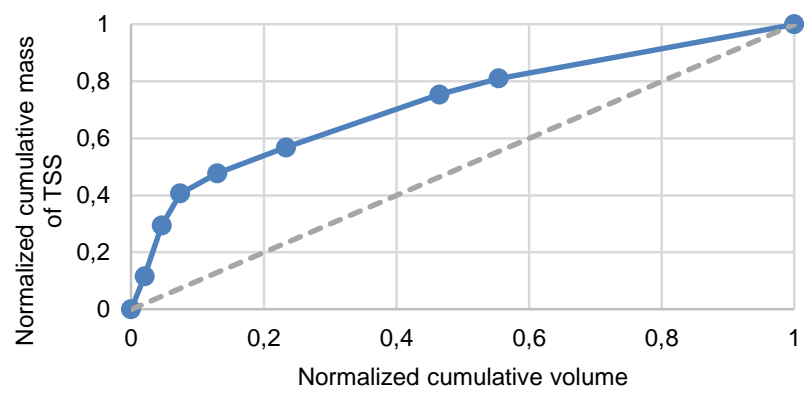

Figure 3. First flush effect observed during the flood event at the outlet of the Verdanson catchment (V4)

\subsection{Catchment discretization in water quality modelling}

As a first step towards the modelling of the contaminant dynamics within the Verdanson river, a sensitivity analysis has been performed in an upstream sub-catchment to assess the influence on the model outputs of the catchment discretization according to land cover. From the two model outputs presented, a minor influence appears on the hydrograph (Figure 4a), as the timing and magnitude of the flood peak are equal. The total volume is slightly higher from the entire catchment $(+4.85 \%)$, even though the fictive sub-catchments seem more reactive. Regarding the TSS concentrations, a significant difference is observed (Figure 4b). The response of the fictive sub-catchments is more rapid and the total mass of TSS is higher $(+15.7 \%)$. The event mean concentration is also higher at the outlet of the fictive subcatchments (EMC $=25 \mathrm{mg} / \mathrm{L}$, against $19.78 \mathrm{mg} / \mathrm{L}$ at the outlet of the entire catchment). Conclusively, the representation of the land cover within SWMM has a strong influence on event concentration, pollutograph dynamic, event load and therefore water quality outputs. 


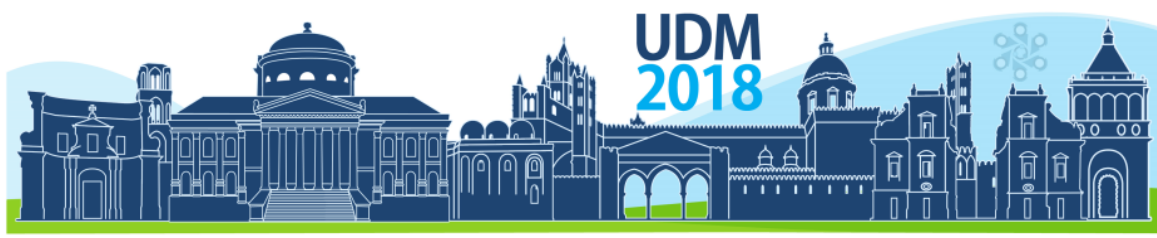

$11^{\text {th }}$ International Conference on Urban Drainage Modelling 23-26 Sep | Palermo - Italy

(a)

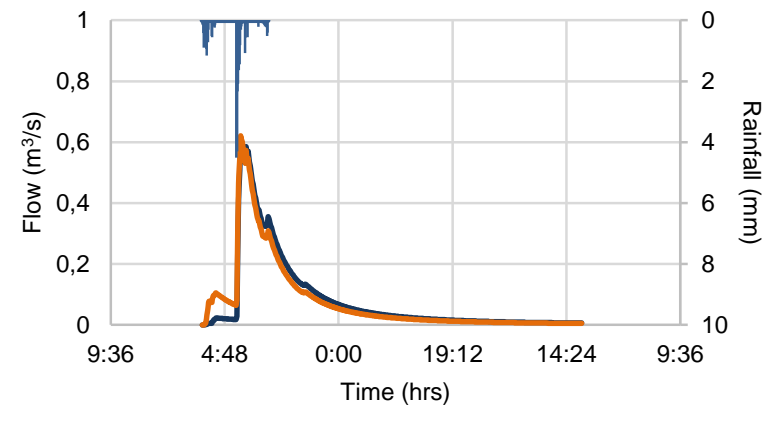

Entire catchment _ Fictive sub-catchments _ Rainfall (b)

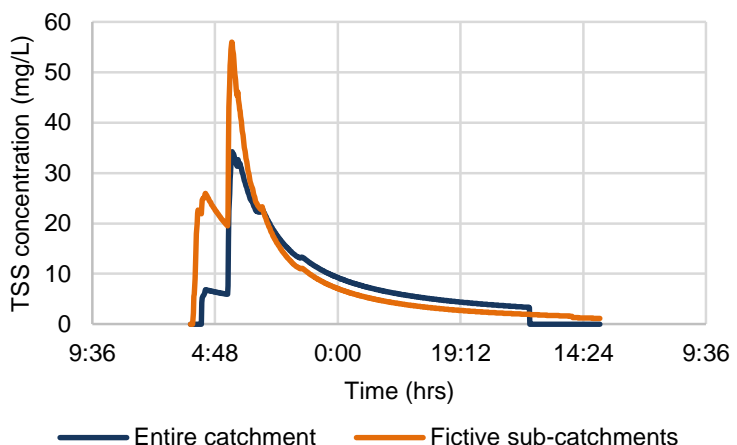

Figure 4. Comparison of the simulated hydrograph (a) and pollutograph (b) for a rainfall event, considering the land cover categories as percentages of the entire catchment or as fictive sub-catchments.

\section{CONCLUSIONS}

Focusing on a highly urbanized river in a Mediterranean context, this paper presents the first steps of the modelling of microbiological and chemical contaminant dynamics. As the calibration and validation processes require appropriate field data, a monitoring protocol has been implemented in the Lez river and its tributaries. Strong temporal variations of contaminant concentrations have been observed in relation to hydrological conditions. Also, a good representation of the spatial distribution of contamination levels has been achieved with a large number of sampling stations (16) distributed along the Lez river and the tributaries. A moderate first flush effect of TSS was observed during a flood event at the outlet of the Verdanson tributary. A water quality model has been developed in an entirely urbanized sub-catchment, and a sensitivity analysis emphasizes the influence of land cover description on water quality outputs. Further to this study, the perspectives are to integrate into the water quality model possible scenarios of urban land use planning in order to assess their potential impacts on surface water quality.

\section{Acknowledgments}

This work was supported by funding provided by a doctoral fellowship (Marlène Rio) from the the Labex DRIIHM, French programme "Investissements d'Avenir" (ANR-11-LABX-0010) which is managed by the ANR.

\section{References}

Chow, M.F., Yusop, Z., Toriman, M.E. (2012) Modelling Runoff Quantity and Quality in Tropical Urban Catchments Using Storm Water Management Model. International Journal of Environmental Science and Technology 9 (4): 737-48.

Di Modugno, M., Gioia, A., Gorgoglione, A., lacobellis, V., la Forgia, G., Piccinni, A.F., Ranieri, E. (2015) BuildUp/Wash-Off Monitoring and Assessement for Sustainable Management of First Flush in an Urban Area. Sustainability. 7(5):5050-5070.

Hathaway, J.M., Hunt, W.F. (2011) Evaluation of First Flush for Indicator Bacteria and Total Suspended Solids in Urban Stormwater Runoff. Water, Air, \& Soil Pollution 217 (1-4): 135-47.

Mancini, L., Formichetti, P., D’Angelo, A.M., Pierdominici, E., Sorace, A., Bottoni, P., Laconelli, M., Ferrari, C., Tancioni, L., Rossi, N., Rossi, A. (2005) Freshwater Quality in Urban Areas: A Case Study from Rome, Italy. Microchemical Journal. 79 (1-2):177-83.

Rio, M., Salles, C., Rodier, C., Cantet, F., Marchand, P., Mosser, T., Cernesson, F., Monfort, P., Tournoud, M-G., (2017) An empirical model to quantify fecal bacterial loadings to coastal areas: application in a Mediterranean context. CR Geosciences. 349:299-309. 


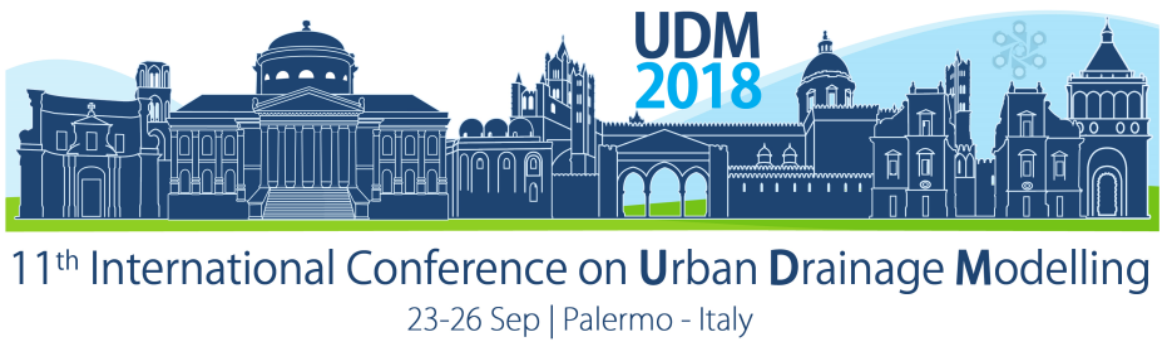

\title{
A Water Quality-Quantity Model for Avcılar Campus of Istanbul University Incorporating LID Implementation
}

\author{
Sezar Gülbaz ${ }^{1}$, Abdulsamed Yıldırım², Cevza Melek Kazezyılmaz-Alhan³ \\ 1,2,3 İstanbul University, Civil Engineering Department, Hydraulics Division, Istanbul, Turkey
}

\begin{abstract}
Rainwater management practices are implementations for improvement of storm water quality and quantity. Implementation of these practices in urban areas is vital because urbanization results in low percentage of permeable soil and cuts off the ground water recharge. Over impermeable surfaces, rain quickly turns into surface runoff and causes flooding. With urbanization, contaminants, which accumulate over the surface, increase and therefore, the contamination of the surface runoff also increases. A number of precautions and control mechanisms are needed to remove these contaminants from the surface runoff which are called as Low Impact Development (LID) Best Management Practices (BMP). LIDBMPs serve for protection of the hydrologic cycle, ecological balance, reduction of the flood risk and improvement of surface water quality. In this study, first, a hydrological model for Avcılar Campus of Istanbul University is developed by using Environmental Protection Agency Storm Water Management Model (EPA SWMM). Then, the water quality model is integrated into the hydrological model by defining various land use types such as low-density residential, high-density residential, highway commercial and highway, and pollution parameters such as total suspended solid (TSS) and lead (Pb). Finally, several LID implementations such as green roof, permeable pavement, bioretention, rain garden, and rain barrel, are defined into the model according to the settlement type on the campus. The impact of the LID implementations on the water quality and quantity are observed. Model results show that the LID implementations greatly reduce the peak discharge. Moreover, LID implementations also decrease pollutant concentrations in surface runoff.
\end{abstract}

Keywords: Best Management Practices (BMP); Low Impact Development (LID); Water Quantity; Water Quality

\section{INTRODUCTION}

Improvement of storm water quality is significant in order to ensure environmental sustainability, protect water resources and save human health. For this purpose, various nature based solutions are used in storm water treatment. These natural and effective methods are called as Low Impact Development Best Management Practices (LID-BMPs). LID-BMPs reduce the harmful effects of surface runoff by reducing the peak flow of surface water which results in flooding in urban areas (Jia et al., 2012; Tillinghast et al., 2011; Davis, 2008; Haifeng et al., 2012; Lee et al., 2012). Moreover, they also improve water quality by removing pollutants in storm water (Zhang and Guo, 2014; Gülbaz and Kazezyılmaz-Alhan, 2014).

EPA SWMM is a watershed hydrological and water quality model which can simulate surface runoff quantity and quality from primarily urbanized regions (Huber and Dickinson, 1988). EPA SWMM is capable of simulation of LID implementation including bioretention, rain garden, green roof, infiltration trench, permeable pavement, rain barrel, and vegetative swale. In order 


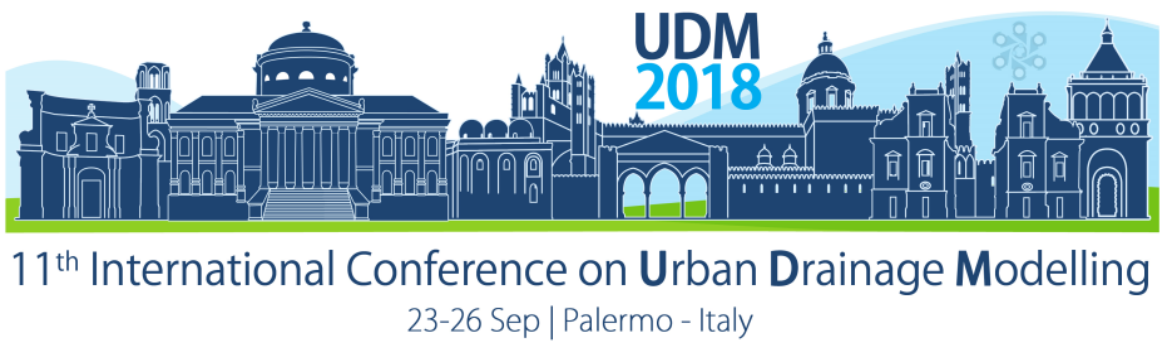

to model water quality, EPA SWMM involves buildup and washoff functions. Various pollutant accumulation (Pollutant Buildup) functions such as power, exponential and saturation function, and various Pollutant washoff functions such as exponential, rating curve, and event mean concentration are defined in EPA SWMM (Rossman, 2015).

The aim of this study is to develop a hydrologic and water quality model and integrate LIDs into the model. For this purpose, first, a hydrologic model by using for Avcllar Campus of Istanbul University is developed. Second, water quality model is integrated into the model by defining various types of land uses and pollutants. Finally, several types of LIDs are incorporated into the water quality-quantity model by considering appropriate settlement types on campus. Surface runoff and pollutant concentrations in surface runoff are computed before and after LID implementations to observe the impacts of LID implementations on the water quality and quantity.

\section{MATERIALS AND METHODS}

Avcılar Campus of Istanbul University is located on the European Continental side of Istanbul in Turkey and has a geographical coordinate of latitude 4059'13.2936 and longitude $28^{\circ} 43^{\prime} 34.4856$. The campus area is about 133 hectares. Avcılar Campus of Istanbul University was founded in 1978 and is the largest campus of Istanbul University. Engineering, veterinary, business administration, transportation and logistics faculties and vocational schools are located on campus in addition to social facilities and kindergarten. The hydrological model of the campus was generated by defining 230 subcatchments, 57 junctions, 56 conduits, and a rain gauge. For this purpose, the topographical map of the modeled area and rainfall data obtained from Florya Meteorological Station in Istanbul are used and parameters such as Manning's roughness coefficient for pervious and impervious areas, depth of depression storage on pervious and impervious areas, Manning's roughness coefficient for conduits, and hydraulic conductivity, are selected according to their typical values reported in the literature (Huber and Dickinson, 1988; Temprano, 2006). In order to develop the water quality model in EPA SWMM, power function is used for pollutant buildup and rating curve function is used for pollutant washoff in this study (Rossman, 2015). The quality input parameters, which belong to these buildup and washoff functions, are calculated based on a publication by Tsihrintzis and Hamid (1998) and presented in Table 1. These values are calculated for pollutant types of TSS and $\mathrm{Pb}$ and for four land use types for the selected rainfall. Finally, different types of LID such as green roof, permeable pavement, bioretention, rain garden, and rain barrel are integrated into the water quality-quantity model. The properties of surface, pavement, soil, storage and drainage layers for these LID types are defined into the model according to their typical values reported in the literature (Rossman, 2015).

Table 1. Calculated SWMM quality input parameters for TSS and $\mathrm{Pb}$ for different land uses.

\begin{tabular}{lcccccccc}
\hline & \multicolumn{2}{c}{$\begin{array}{l}\text { Time Exponent } \\
\text { (dimensionless) }\end{array}$} & \multicolumn{2}{c}{$\begin{array}{c}\text { Buildup Rate } \\
\text { Constant } \\
\left(M / T L^{2}\right)\end{array}$} & $\begin{array}{c}\text { Washoff } \\
\text { Exponent } \\
\text { (dimensionless) }\end{array}$ & $\begin{array}{c}\text { Washoff } \\
\text { Coefficient } \\
\left(M / L^{3}\right)\end{array}$ \\
\hline Low-Density Residential & 1.0579 & $\mathrm{NA}$ & 1.0969 & $\mathrm{NA}$ & 1.9739 & $\mathrm{NA}$ & 55.39212 & $\mathrm{NA}$ \\
\hline High-Density Residential & 1.3661 & 0.0953 & 1.3780 & 0.1299 & 2.3392 & 0.3313 & 376.442 & 0.1728 \\
\hline Highway & 1.4454 & 0.1283 & 1.5742 & 0.1306 & 2.2703 & 0.7551 & 244.77905 & 0.7027 \\
\hline Commercial & 1.4347 & 0.2442 & 1.5148 & 0.2243 & 2.3723 & 0.5339 & 310.675 & 0.6180 \\
\hline
\end{tabular}

NA: Not Applicable. 


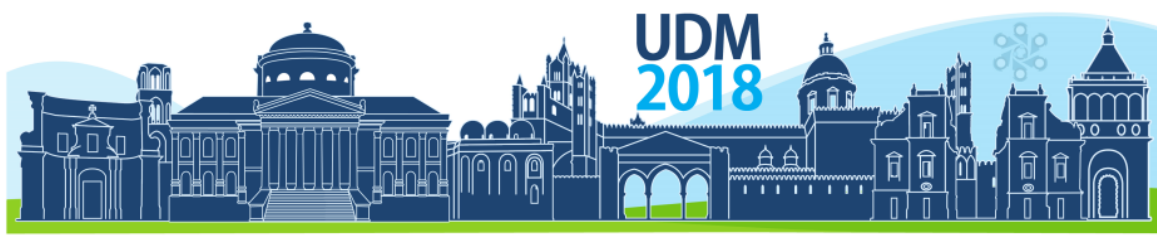

$11^{\text {th }}$ International Conference on Urban Drainage Modelling

23-26 Sep | Palermo - Italy

\section{RESULTS AND DISCUSSION}

In this part of the study, effects of LID implementation on water quantity and quality are observed. As it can be seen in Figure 1, the peak flowrate decreases from $56 \mathrm{~L} / \mathrm{s}$ to $41 \mathrm{~L} / \mathrm{s}$ after LID implementation. Therefore, the reduction percent in flowrate after LID implementation is $7.65 \%$. Figure 2 shows the predicted TSS concentration at the outlet of the modelled area. The peak TSS concentration decreases from $461 \mathrm{mg} / \mathrm{L}$ to $309 \mathrm{mg} / \mathrm{L}$. In other words, when LID is implemented into the modelled area, the peak of the TSS concentration decreases $33 \%$. Figure 3 shows the predicted $\mathrm{Pb}$ concentration at the outlet which decreases from $1.75 \mathrm{mg} / \mathrm{L}$ to $1.12 \mathrm{mg} / \mathrm{L}$. Thus, the peak of the $\mathrm{Pb}$ concentration decreases $36 \%$ after LID implementations.

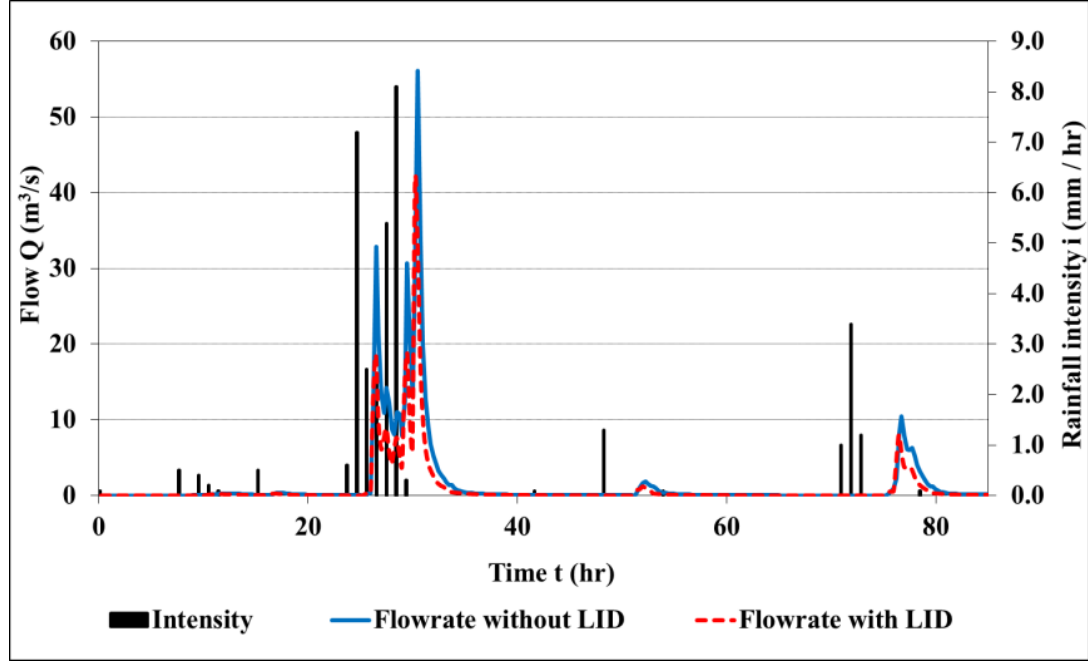

Figure 1. Predicted flow rate versus time at the outlet of the modelled area with LID BMPs and without LID BMPs during storm event observed between July 9-12, 1995.

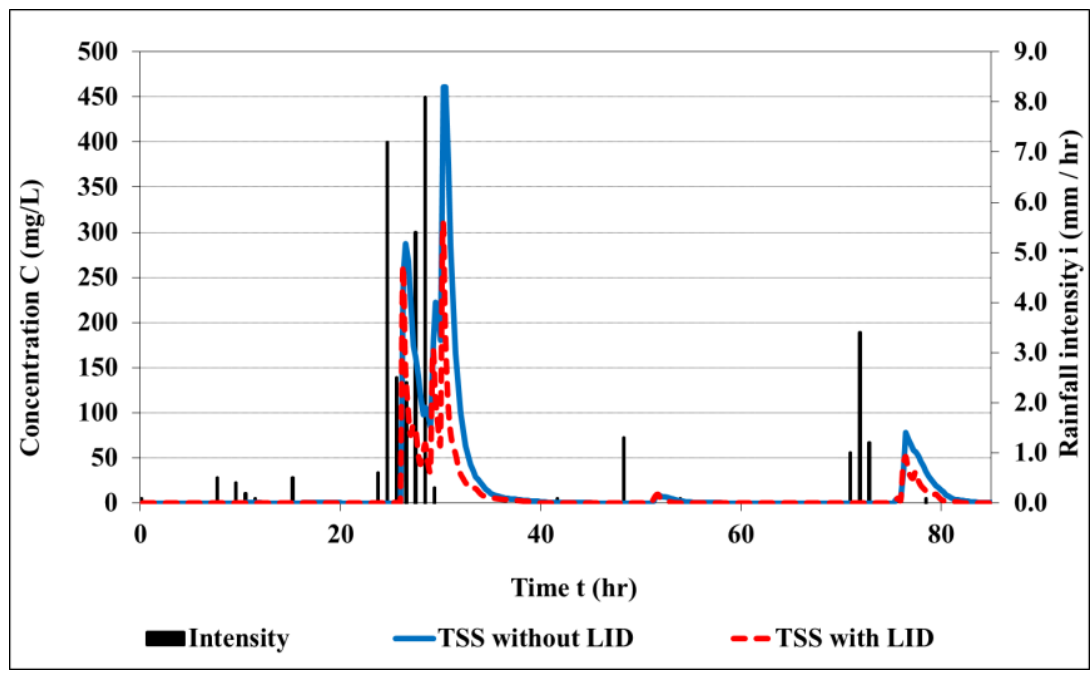

Figure 2. Predicted TSS concentration versus time at the outlet of the modelled area with LID BMPs and without LID BMPs during storm event observed between July 9-12, 1995. 


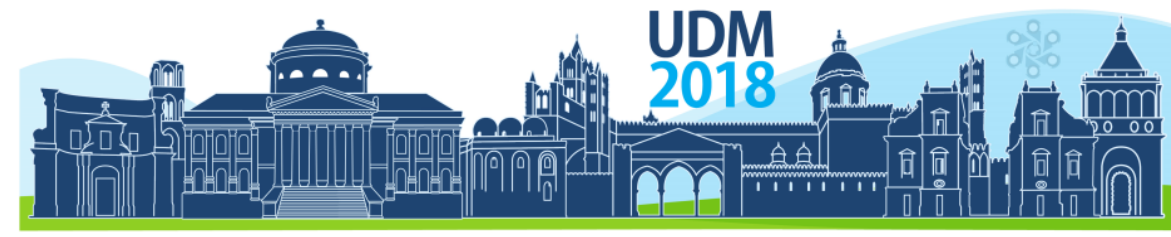

$11^{\text {th }}$ International Conference on Urban Drainage Modelling

23-26 Sep | Palermo - Italy

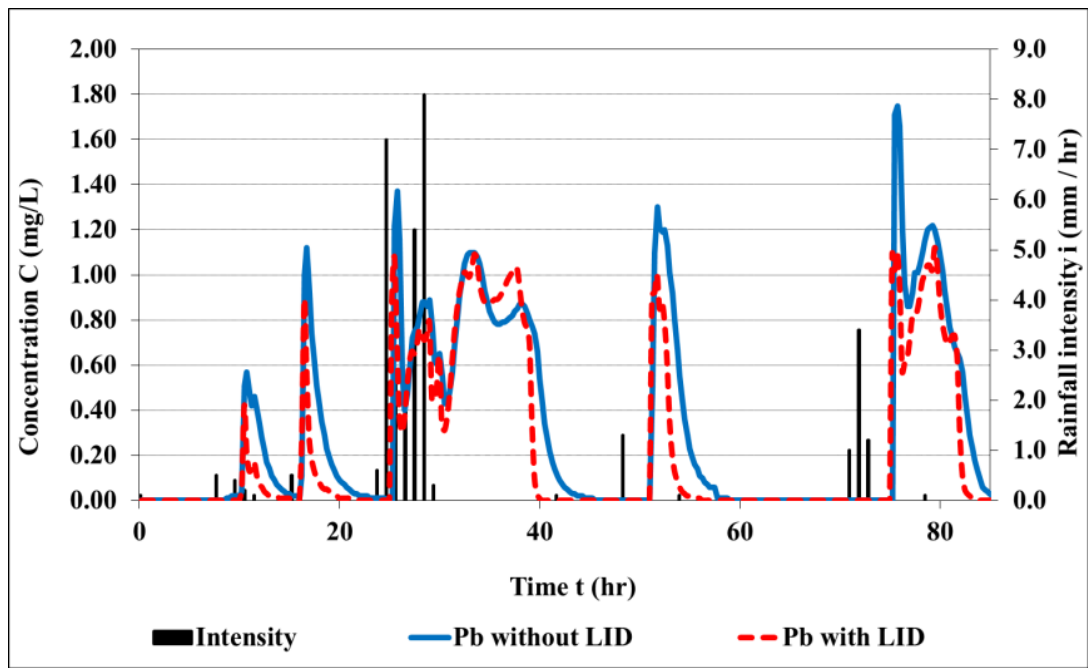

Figure 3. Predicted $\mathrm{Pb}$ concentration versus time at the outlet of the modelled area with LID BMPs and without LID BMPs during storm event observed between July 9-12, 1995.

\section{CONCLUSIONS}

In this study, a water quality-quantity model is developed for Avcilar Campus of Istanbul University in Istanbul, Turkey by using EPA SWMM. Then, change in flow rate, TSS and Pb concentration are predicted with and without LID implementations such as green roof, permeable pavement, bioretention, rain garden, and rain barrel. After implementing LIDs, flow rate, TSS and $\mathrm{Pb}$ concentrations with LIDs and without LIDs are compared. It is found that LID BMP implementations on the campus results in a decrease in the peak of the hydrograph and pollutographs (TSS and $\mathrm{Pb}$ ). Thus, LID implementation controls surface runoff and water quality considerably in the campus area.

\section{References}

Davis, A.P. (2008) Field Performance of Bioretention: Hydrology Impacts, Journal of Hydrologic Engineering, 13(2), pp.90-95.

Gülbaz, S. and Kazezyılmaz-Alhan, C.M. (2014) Investigating Effects of Low Impact Development on Surface Runoff and TSS with a Calibrated Hydrodynamic Model, Houille Blanche-Revue Internationale De L Eau, 3, 77-84.

Haifeng, J., Yuwen, L., Shaw, L. Y. and Yurong, C. (2012) Planning of LID-BMPs for urban runoff control: The case of Beijing Olympic Village, Separation and Purification Technology, 84 (SI), pp.112-119.

Huber, W.C. and Dickinson R.E. (1988) Storm Water Management Model, Version 4, User's Manual. Athens, GA. Environmental Research Laboratory, Office of Research and Development, U.S. Environmental Protection Agency (EPA)

Jia, H., Lu, Y., Yu, S.L. and Chen, Y. (2012) Planning of LID-BMPs for urban runoff control: The case of Beijing Olympic Village, Separation and Purification Technology, 84, pp.112-119.

Lee, J., Hyun, K., Choi, J, Yoon, Y. and Geronimo, F.K.F. (2012) Flood reduction analysis on watershed of LID design demonstration district using SWMM5, Desalination and Water Treatment, 38, pp.326-332.

Rossman, L.A. (2015) Storm Water Management Model, User's Manual, Version 5.1, National Risk Management

Laboratory Office of Research and Development U.S. Environmental Protection Agency 26 Martin Luther King Drive Cincinnati, OH 45268, U.S. Environmental Protection Agency, EPA/ 600/R-14/413b.

Tsihrintzis, V.A. and Hamid, R. (1998) Runoff quality prediction from small urban catchments using SWMM. Hydrological Processes, 12 (2), 311-329.

Temprano, J., Arango, O., Cagiao, J., Suarez, J. and Tejero I. (2006) Stormwater quality calibration by SWMM: A case study in Northern Spain, Water SA, 32(1), 55-63.

Tillinghast, E.D., Hunt, W.F. and Jennings, G.D. (2011) Stormwater control measure (SCM) design standards to limit stream erosion for Piedmont North Carolina, Journal of Hydrology, 411, pp.185-196.

Zhang, S. and Guo, Y. (2014) Stormwater Capture Efficiency of Bioretention Systems, Water Resources Management, 28 (1), 149-168. 


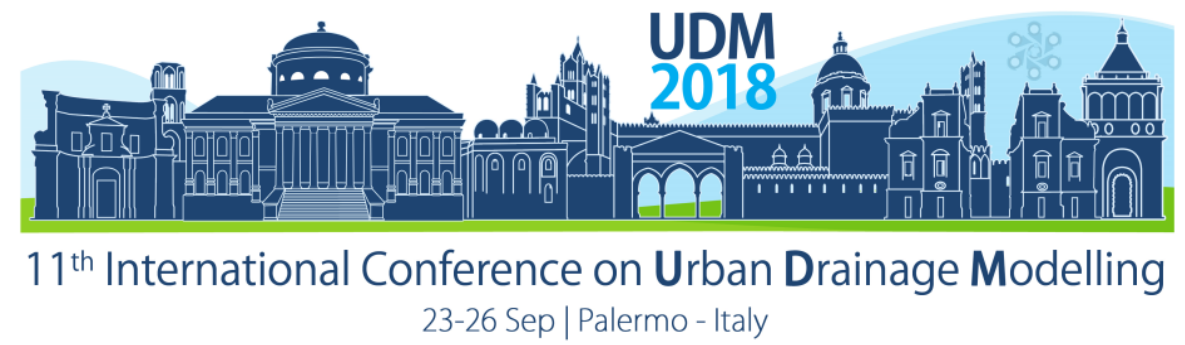

\title{
Combined Sewer Flow Prediction Using Hybrid Wavelet Artificial Neural Network Model
}

\author{
Zolal Ayazpour ${ }^{1}$, Amin E. Bakhshipour ${ }^{1}$, Ulrich Dittmer ${ }^{1}$ \\ 1 University of Stuttgart, Institute for Sanitary Engineering, Water Quality and Solid Waste Management, Stuttgart, \\ Germany
}

\begin{abstract}
This study presents a hybrid model for the prediction of dry and wet-weather flows in a combined sewer system. For this aim, a model based on wavelet transformation and artificial neural network (WANN) is developed. A high-resolution data set of rainfall and combined sewer flow from a catchment in Germany is used in the hybrid model. To simulate the combined sewer flow, the dry-weather flow is firstly modelled employing Artificial Neural Network (ANN). Subsequently, another ANN is applied and fed with rainfall time series, dryweather flow simulated in the previous step and lagged combined sewer flow time series as the main input variables to simulate the combined sewer flow. In modeling both the dryweather flow and the combined sewer flow, the wavelet transformation is firstly applied to extract the temporal and the spectral features of the measured sewer flow time series before using them in the ANN. To improve the WANN hybrid model result, different mother wavelet functions and decomposition levels, various lagged values for input variables, several training functions and network structures are implemented in the model and their influence on the hybrid model is investigated. According to this study, the proposed hybrid model can identify the complicated and dynamic nature of the combined sewer systems and thus provide accurate results.
\end{abstract}

Keywords: Combined sewer flow; Artificial neural network; Wavelet transformation

\section{INTRODUCTION}

Combined sewer flow prediction is a very important and challenging task for the optimal operation of the combined sewer systems. Combined sewer flow is varying all the time since it is influenced by daily wastewater inflow, infiltration and precipitation. Modelling the dynamic and nonlinear behaviour of combined sewer systems is difficult. There are two approaches for the combined sewer systems modelling: physical modelling and data-driven modelling (Troutman et al., 2017).

Physical models require large numbers of parameters to be defined and specified to characterize all parts of the system (e.g., land use, soil types, sewerage system characteristics and less well-defined parameters such as roof drain pipe connections). In complex and largescale models, measuring and updating all parameters is difficult and expensive, which limits the use of physical models (Troutman et al., 2017). In contrast, data-driven models are significantly reliant on the training data set and it is not required to specify the system characterization for them (Breinholt, 2012). However, it is obvious that the quality of the training data set plays an important role in building an accurate data-driven model such as ANN.

Recently, data-driven approaches are applied widely as a powerful tool for modelling hydrological problems to increase the prediction accuracy (Peng et al., 2017). In addition, the wavelet transformation is applied to extract the invisible features from the nonstationary time series (Alizadeh et al., 2017). The combination of wavelet transformation and data-driven models has been implemented in many water-related fields such as precipitation modelling, water quality modelling, flow forecasting, rainfall-runoff prediction and groundwater modelling (Nourani et al., 2014). 


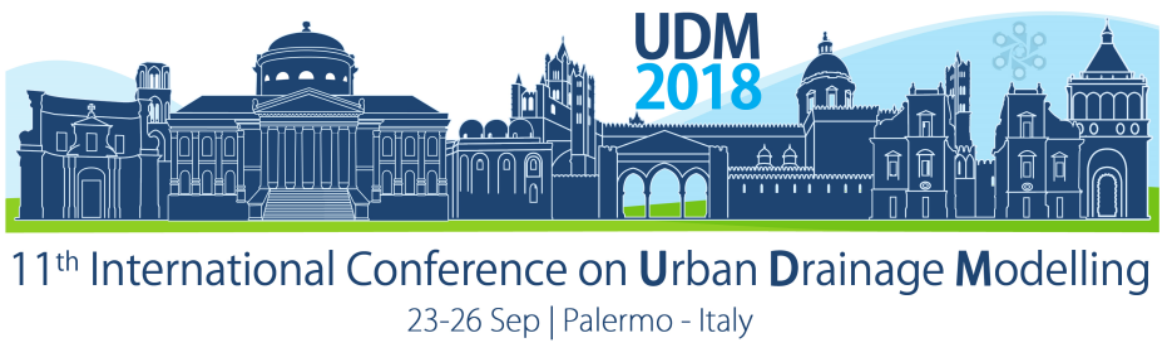

This study proposes a hybrid wavelet artificial neural network model for the prediction of dry and wet-weather flows in a combined sewer system.

\section{MATERIALS AND METHODS}

\subsection{Study area and data}

In the current study, Gondelsheim is selected as the study area to evaluate the performance of the proposed model. Gondelsheim is a small town located in the state of BadenWürttemberg in Germany. Precipitation, temperature and combined sewer flow time series are the data set used for the model development. All data are measured from the beginning of July to the end of December 2017, at a 5-minute time resolution.

\subsection{Wavelet transformation}

The wavelet transformation is introduced by Grossmann and Morlet (1984) in the twentieth century; however, its application has increased in the last decade (Solgi et al., 2017). It is applied to extract the temporal and spectral features of the measured time series which are not visible in the raw data. It also helps to remove redundant noises from the measured time series before using them in a model. Wavelet transform can be applied in two types, continuous wavelet transform $(C W T)$ and discrete wavelet transform $(D W T)$. It is more difficult to exploit the $C W T$ than the DWT because computing the CWT requires more time and data. They are defined as (Mallat, 1989; Shoaib et al., 2015):

$$
\begin{aligned}
& C W T_{a, b}(t)=\int_{-\infty}^{+\infty} f(t) \frac{1}{\sqrt{a}} \psi^{*}\left(\frac{t-b}{a}\right) d t \\
& D W T(a, b)_{D}=2^{-j / 2} \int_{j=1}^{j=J} \psi^{*}\left(2^{-\frac{j}{2}}-k\right) f(t) d t
\end{aligned}
$$

In Eq. (1), $f(t), \psi^{*}(t), a$ and $b$ are representing the continuous time signal, the complex conjugate of the mother wavelet function, the scale parameter and the temporal translation of the wavelet function, respectively. In Eq. (2), $j$ is controlling the wavelet scale and $k$ is controlling the translation.

\subsection{Artificial neural network}

The artificial neural network is an artificial intelligence method which is provided with the input and the target data set to identify the relationship between them and build a data-driven model. Each ANN has three distinguished layers: the input layer, the hidden layer and the output layer. Every layer includes several nodes (neurons) connected with the neurons in the following layer and each connection has its own weight which controls the connection strength. The input data set forward propagates through all the layers of the ANN to reach the output layer. The network error is calculated by comparing the network output and the observed target and the calculated error backward propagates to modify the weights and reduce the network error (Alizadeh et al., 2017). The output of the ANN can be calculated as Jeong and Kim (2005):

$$
o_{k}=g_{2}\left[\sum_{j=1}^{M} w_{k j} g_{1}\left(\sum_{j=1}^{N} w_{j i} x_{i}+w_{j o}\right)+w_{k o}\right]
$$

Where $\boldsymbol{x}_{\boldsymbol{i}}$ is the input value to node $\boldsymbol{i}$ and $\boldsymbol{O}_{\boldsymbol{k}}$ is the output value at node $\boldsymbol{k} . \boldsymbol{g}_{1}$ and $\boldsymbol{g}_{2}$ represent the activation functions for the hidden layer and output layer respectively. $\boldsymbol{w}_{\boldsymbol{j}}$ is the biases of the $\boldsymbol{j}_{\boldsymbol{t} \boldsymbol{h}}$ neuron in the hidden layer and $\boldsymbol{w}_{\boldsymbol{k} \boldsymbol{o}}$ is the biases of the $\boldsymbol{k}_{\boldsymbol{t} \boldsymbol{h}}$ neuron in the output layer. $\boldsymbol{w}_{\boldsymbol{j} \boldsymbol{i}}$ is the weight between the input node $\boldsymbol{i}$ and the hidden node $\boldsymbol{j}$ and $\boldsymbol{w}_{\boldsymbol{k} \boldsymbol{j}}$ is the weight between 


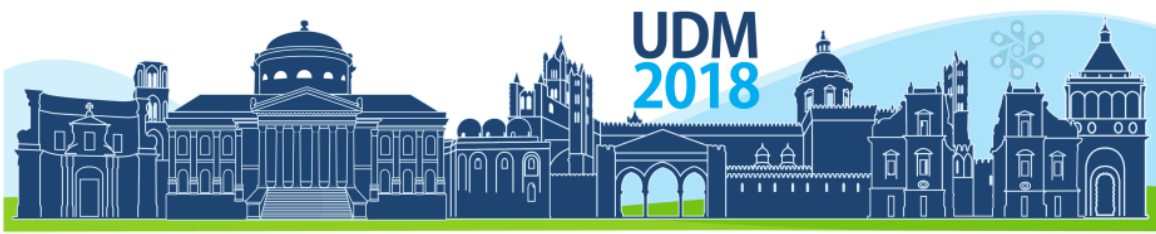

$11^{\text {th }}$ International Conference on Urban Drainage Modelling

23-26 Sep | Palermo - Italy

the hidden node $\boldsymbol{j}$ and the output node $\boldsymbol{k} . \boldsymbol{N}$ and $\boldsymbol{M}$ denote the number of neurons in the input layer and the hidden layer, respectively.

\subsection{Proposed hybrid WANN model}

To simulate the combined sewer flow, a hybrid WANN model with the algorithm illustrated in Fig. 1 is developed. Firstly, the measurement time span is separated into the wet-weather time span (with rainfall events) and the dry-weather time span. The dry-weather time span is extracted from the measured data set to obtain the dry-weather flow time series. Secondly, the dry-weather flow time series is decomposed by the wavelet transformation and it is turned to the time sub-signals. Thirdly, an ANN is exploited using the output of the wavelet transformation as the target vector to simulate the dry-weather flow and complete the dryweather flow data set for the entire measurement time span. In this step, time and temperature data set form the input vector. Fourthly, the combined sewer flow at the wet-weather time span is decomposed to the sub-signals by the wavelet transformation. Finally, another ANN is applied to model the combined sewer flow, using the transformed combined sewer flow time series (obtained from the fourth step) as the target vector and the rainfall time series, the dryweather flow time series (obtained from the third step) and the lagged combined sewer flow time series as the input vector. The rainfall time series and combined sewer flow time series measured at a 5-minute time resolution, which are used in this study, are shown in Fig. 2.

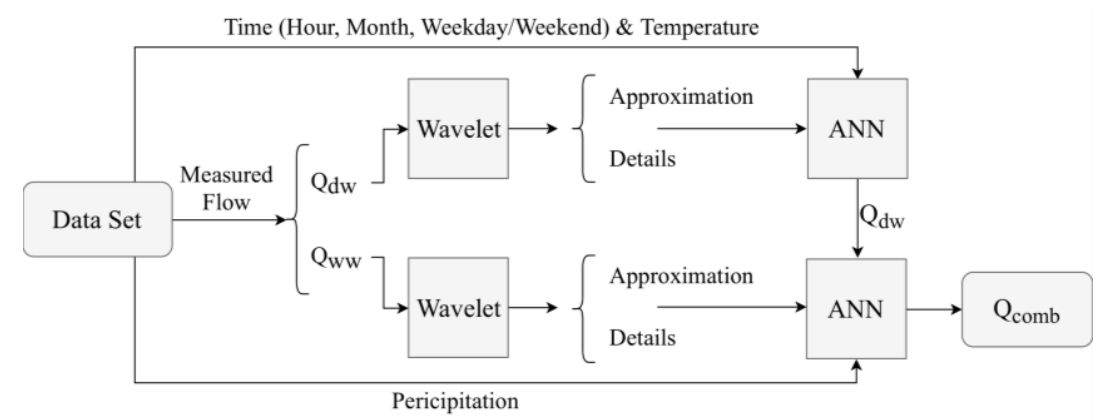

Figure 1. Flow chart of the proposed WANN model ( $Q_{d w}$ : dry-weather flow, $Q_{w w}$ : wet-weather flow and $Q_{\text {comb: combined sewer flow) }}$

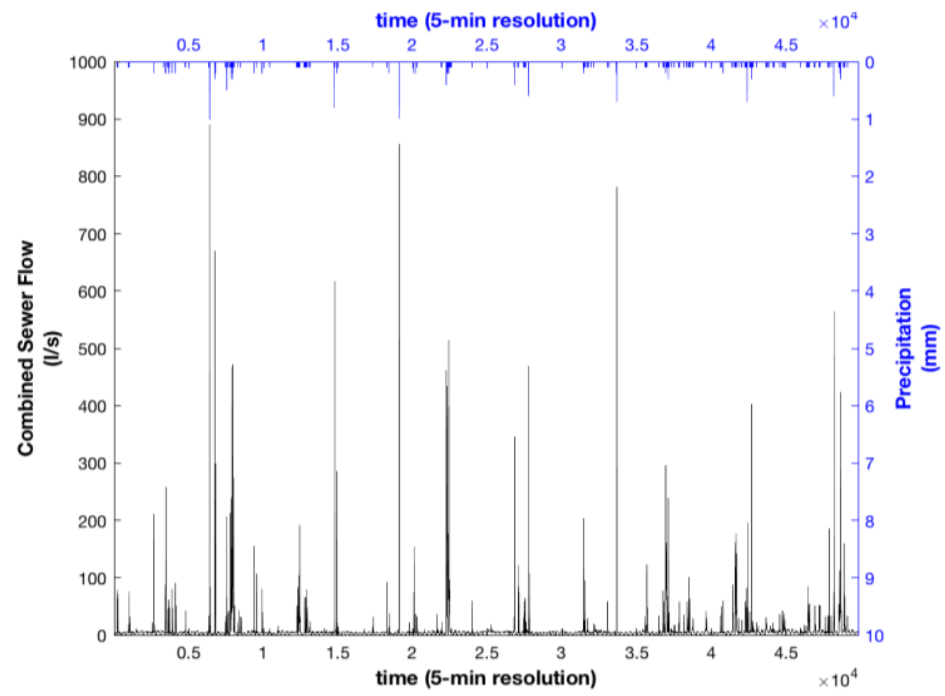

Figure 2. Precipitation and combined sewer flow data set 


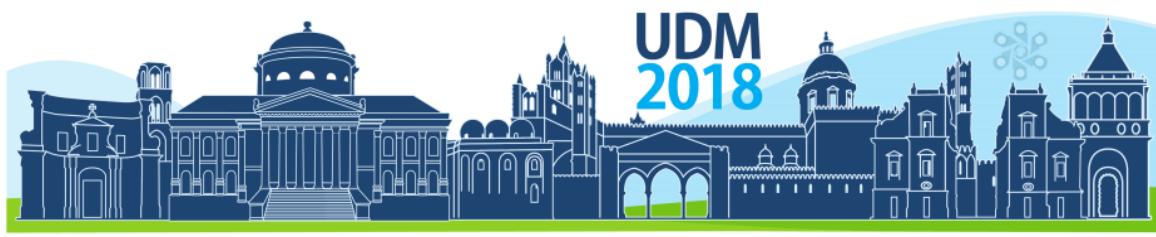

$11^{\text {th }}$ International Conference on Urban Drainage Modelling

23-26 Sep | Palermo - Italy

\section{RESULTS AND DISCUSSION}

\subsection{Dry-Weather Flow}

Fig. 3 shows the simulated dry-weather flow in a time span of 14 days and compares it with the observed one. As Fig. 3 displays, the hybrid model could well simulate the dry-weather flow. The increase in the wastewater flow at the weekend is identified by the model and the model can capture the daily and seasonal wastewater flow fluctuations.

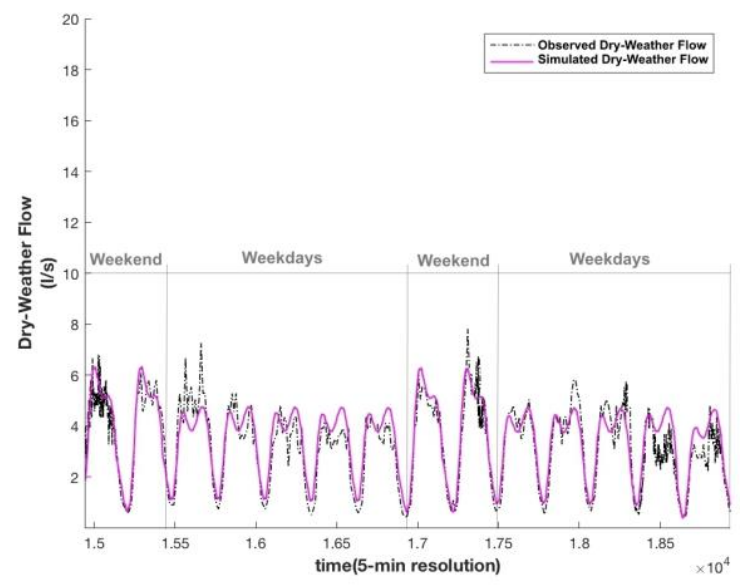

Figure 3. Simulated dry-weather flow, compared to the observed dry-weather flow

\subsection{Combined Sewer Flow}

The simulated combined sewer flows at the time of two different precipitation events are shown in Fig. 4. This figure illustrates the satisfying performance of the model in simulating the combined sewer flow. It is indicated that the model output matches the observed combined sewer flow and the complicated and non-linear behaviour of the combined sewer flow is understood by the model.

Table 1 displays the influence of the wavelet transformation on the model performance. According to this study, applying the wavelet transformation increases the $R$ (coefficient of correlation) and significantly decreases the RMSE (root mean square error), so it improves the model performance.

Table 1. Influence of the wavelet transformation on the model performance

\begin{tabular}{llcc}
\hline & & Simple ANN model & Hybrid WANN model \\
\hline \multirow{2}{*}{ Train } & $\mathrm{R}$ & 0.952 & 0.998 \\
& $\mathrm{RMSE}(\mathrm{l} / \mathrm{s})$ & 14.94 & 1.68 \\
\hline \multirow{2}{*}{ Test } & $\mathrm{R}$ & 0.929 & 0.998 \\
& $\mathrm{RMSE}(\mathrm{l} / \mathrm{s})$ & 20.46 & 1.75 \\
\hline
\end{tabular}

To improve the combined sewer flow prediction, several hybrid WANN model with different structures are executed. Various ANN training functions are employed in the ANN to obtain a more accurate prediction. In addition, different lagged values for the input variables are tested in the model to find the most effective one. Furthermore, various mother wavelet functions and decomposing levels for the data transformation are applied to gain a better performance. As a result of this study, applying the Bayesian Regularization as the ANN training function, considering the lagged values of 75 minutes for the precipitation and dry-weather flow time 


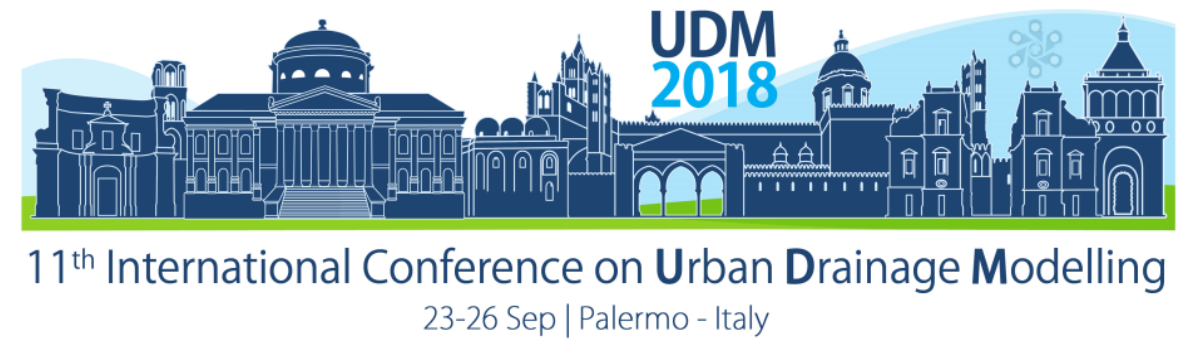

series and 90 minutes for the combined sewer flow time series, employing the $\mathrm{db} 4$ as the mother wavelet function with 3 levels of decomposition lead to the best model performance.
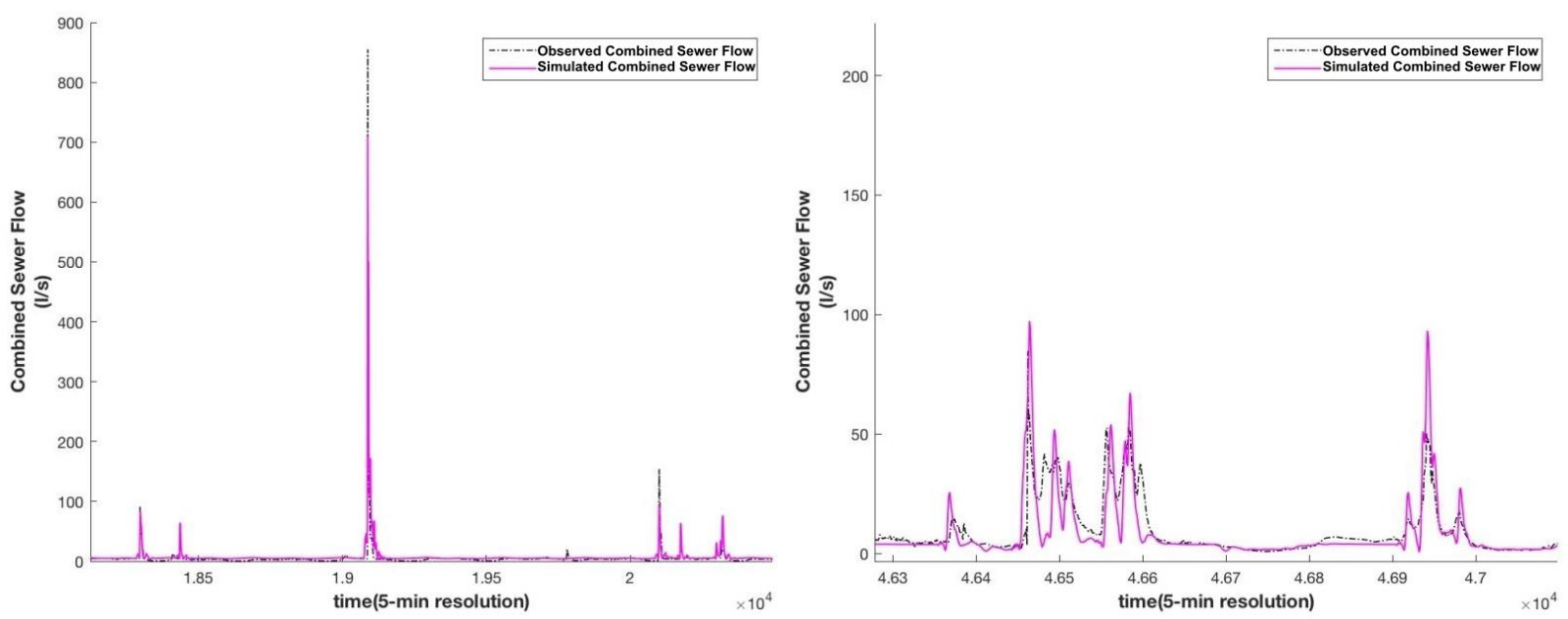

Figure 4. Simulated combined sewer flow, compared to the observed combined sewer flow

\section{CONCLUSIONS}

In this study, the hybrid WANN model is applied to simulate and predict the combined sewer flow as a substitute for hydrological-hydraulic models. Using high-resolution preciselymeasured data set allows us to apply this data-driven approach since training the WANN model with a high-quality data set leads to building a good model and results in accurate predictions in the future. The proposed hybrid model shows better performance in comparison with the simple ANN model. It has the ability to learn about the complex and nonlinear nature of the combined sewer systems and can identify its dynamics, so it is a powerful tool for the prediction of combined sewer flow.

\section{References}

Alizadeh, M.J., Kavianpour, M.R., Kisi, O. \& Nourani, V. (2017) A new approach for simulating and forecasting the rainfall-runoff process within the next two months. J. Hydrol. 548, 588-597.

Breinholt, A. (2012) Uncertainty in prediction and simulation of flow in sewer systems.

Grossmann, A. \& Morlet, J. (1984) Decomposition of Hardy Functions Into. SIAM J. Math. Anal. 15(4).

Jeong, D.-I. \& Kim, Y.-O. (2005) Rainfall-runoff models using artificial neural networks for ensemble streamflow prediction. Hydrol. Process. 19, 3819-3835.

Mallat, S.G. (1989) A Theory for Multiresolution Signal Decomposition: The Wavelet Representation. IEEE Trans. Pattern Anal. Mach. Intell. 11, 674-693.

Nourani, V., Hosseini Baghanam, A., Adamowski, J. \& Kisi, O. (2014) Applications of hybrid wavelet-Artificial Intelligence models in hydrology: A review. J. Hydrol. 514, 358-377.

Peng, T., Zhou, J., Zhang, C. \& Fu, W. (2017) Streamflow Forecasting Using Empirical Wavelet Transform and Artificial Neural Networks. Water 9, 406.

Shoaib, M., Shamseldin, A.Y., Melville, B.W. \& Khan, M.M. (2015) Runoff forecasting using hybrid Wavelet Gene Expression Programming (WGEP) approach. J. Hydrol. 527, 326-344.

Solgi, A., Zarei, H., Nourani, V. \& Bahmani, R. (2017) A new approach to flow simulation using hybrid models. Appl. Water Sci. 7, 3691-3706.

Troutman, S.C., Schambach, N., Love, N.G. \& Kerkez, B. (2017) An automated toolchain for the data-driven and dynamical modeling of combined sewer systems. Water Res. 126, 88-100. 


\section{Part G - Modelling interactions and integrated systems}




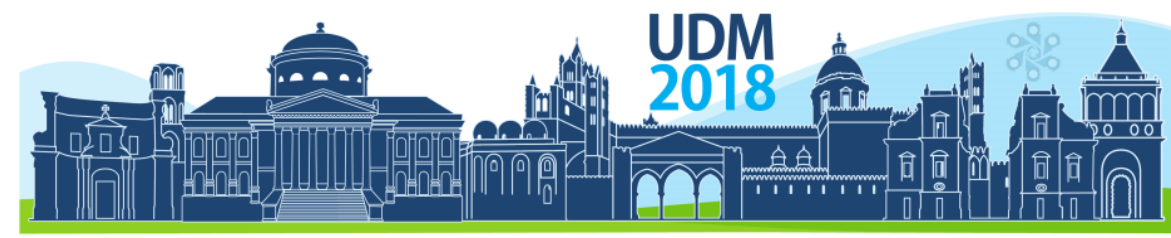

$11^{\text {th }}$ International Conference on Urban Drainage Modelling

23-26 Sep | Palermo - Italy

\title{
FRONTIERS IN INTEGRATED MODELLING
}

\author{
Wolfgang RAUCH \\ University Innsbruck, Department of Infrastructure - Technikerstr. 13, 6020 Innsbruck, Austria
}

\begin{abstract}
Bibliometric analysis indicates that integrated modelling in the context of urban drainage systems has reached maturity. Yet, up to now the approach failed to be adopted as mainstream in practice. This article discusses briefly frameworks, semantics and options of model integration and then embarks on the question: what are the obstacles of the approach? Last some recent examples are discussed with different perspectives of modelling aim that could indicate the way forward
\end{abstract}

Keywords: Integrated model, urban drainage, urban water system, modelling.

\section{Introduction and historic development}

Integrated modelling (IM) in the water sector has been introduced already in the 1970, and the interest in and application of the approach has increased substantially ever since (see Zare et al., 2017). The bulk of the articles found in the literature are linked with the term "Integrated Water Assessment Modelling IWAM" which is defined according to Laniak et al. (2013) as "an analytical approach that brings together knowledge from a variety of disciplinary sources to describe the cause-effect relationships by studying the relevant interactions and crosslinkages." As seen in Figure 1 Left, more than 13000 publications have been found by bibliometric analysis (Zare et al., 2017), indicating a stage of maturity for the IWAM approach reached by app. 2010.
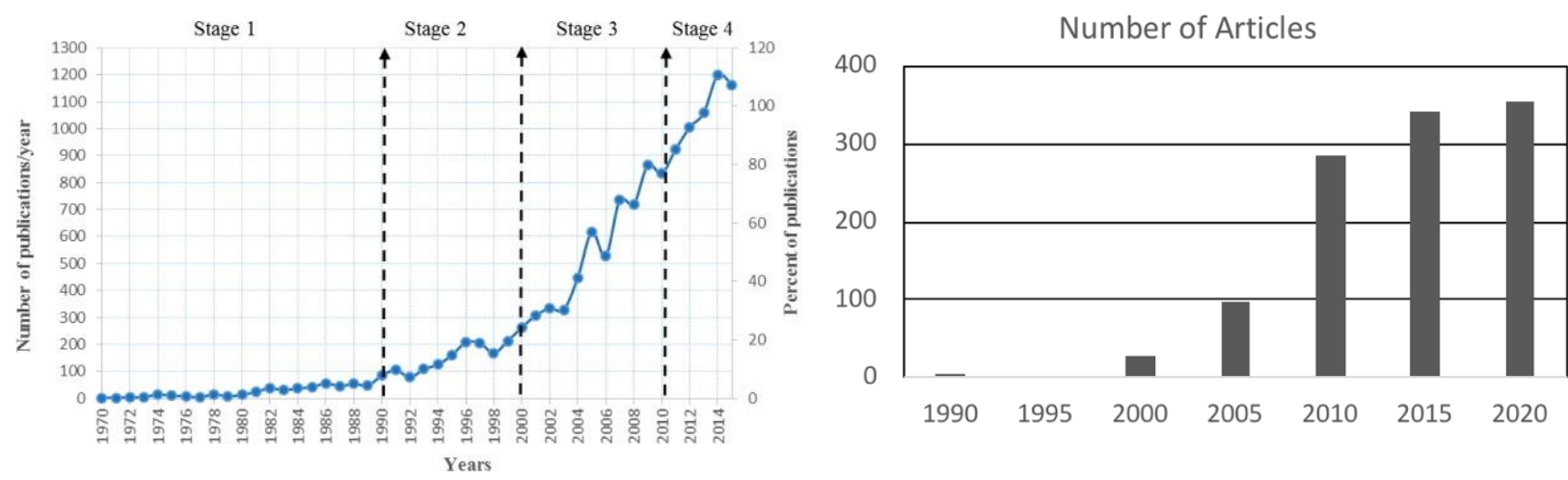

Figure 1. Publishing trends. Left: Area Integrated water assessment and modelling (reprinted from Zare et al., 2017) and Right: for the keywords "integrated urban drainage" AND "model". Source: Google Scholar. Period 2015 - 2020 is extrapolated from data until 07/2018.

Integrated modelling in connection with urban drainage systems (integrated urban drainage modelling - IUDM) can be seen as a subset of the earlier mentioned theme "integrated 


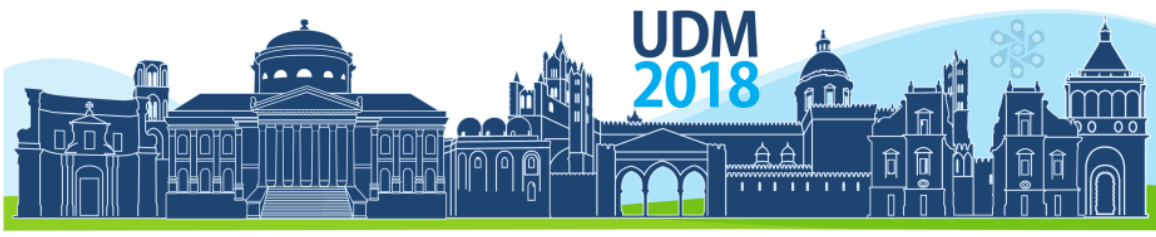

$11^{\text {th }}$ International Conference on Urban Drainage Modelling

23-26 Sep | Palermo - Italy

environment modelling" or IWAM, respectively and is clearly resulting in a smaller number of publications (app 10\% of thereof - see Fig. 1 Right). Bach et al. (2014) have reviewed the development of the field - see Fig. 2 - and found similar characteristics in the historical development.

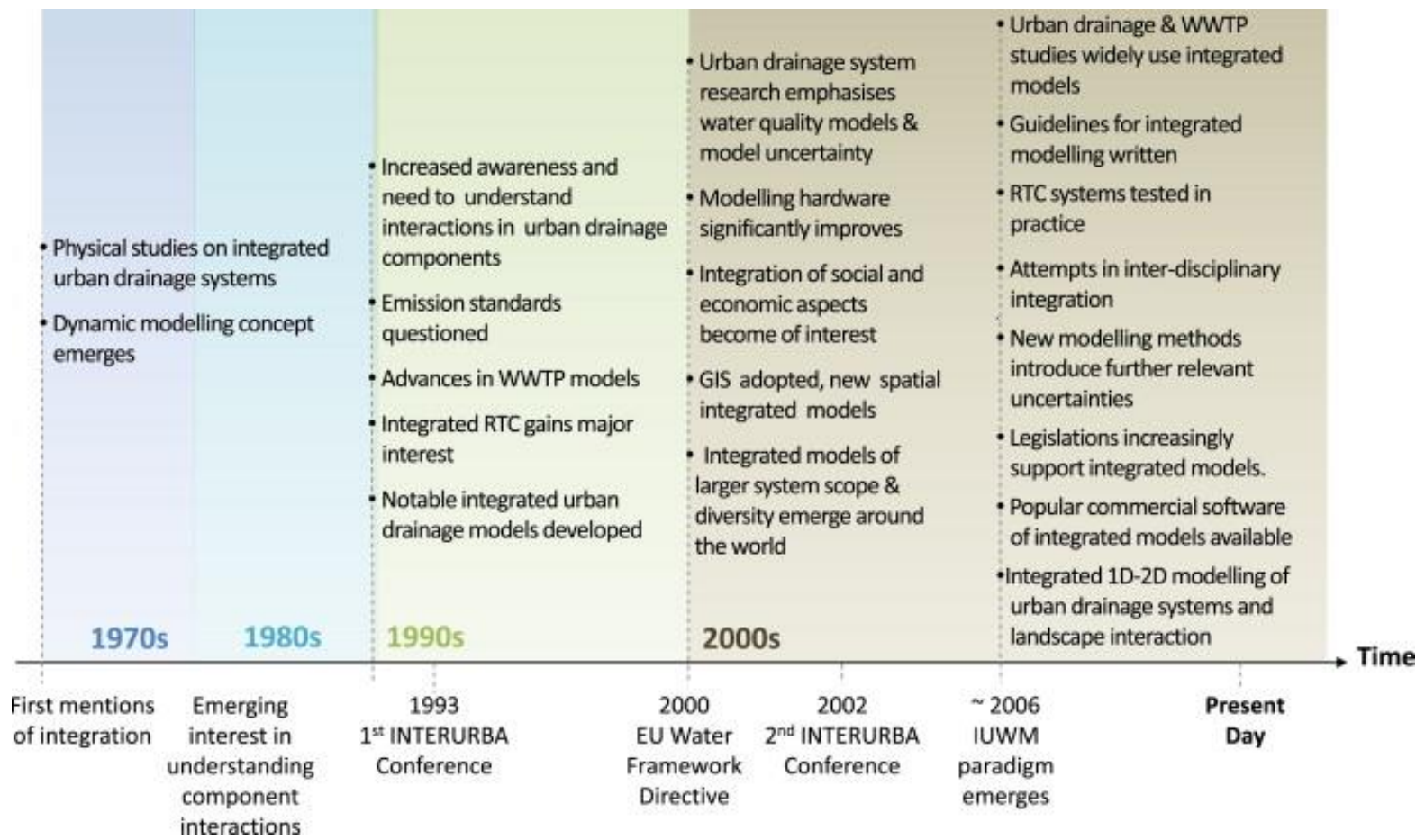

Figure 2. Historical evolution of integrated modelling research from an urban drainage perspective (reprinted from Bach et al., 2014)

While the above strongly indicates that the theme integrated modelling in the context of urban drainage systems has reached maturity in scientific perspective, the approach is still not adopted as mainstream in practice. This article discusses briefly frameworks, semantics and options of model integration and then embarks on the question: what are the obstacles of the approach? Last some recent examples are discussed with different perspectives of modelling aim that could indicate the way forward.

\section{Perception and Practice versus Definition and Options}

Integrated modelling is a term indicating multidisciplinary and completeness in the analysis of the problem at hand (Rauch et al., 2005). While this gives a thoroughly positive impression one still has to ask himself: why are we integrating? What is the problem statement that we aim to address and what are the system components that are actually needed to be considered? Frequently this fundamental step seems to be omitted and authors of studies arrive directly at integrated models. The reasoning for that is ranging from trivial (an overarching integrated model is available while a dedicated model of the investigated component is not) to ignorance (since the system is not understood at all, the most complex model available is used in the hope of enlightenment). Again, the merger of knowledge and 


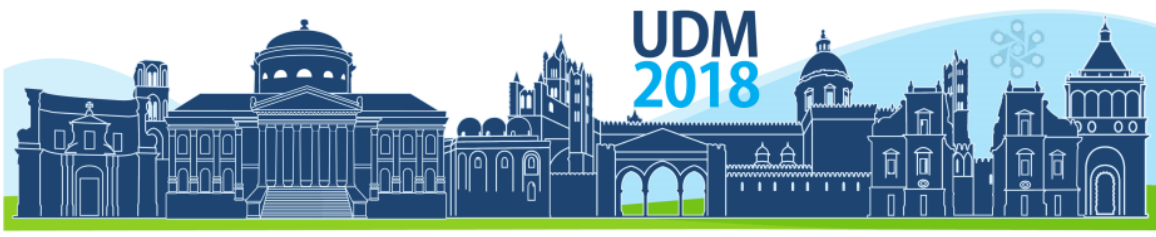

$11^{\text {th }}$ International Conference on Urban Drainage Modelling

23-26 Sep | Palermo - Italy

expertise from different fields (social, economic, engineering and natural science) is a noble task but does not automatically help to solve a problem.

Once the problem statement is clear the task is to define the model components (i.e. submodels that describe relevant aspects of systems dynamics) and establish the information flow between the components. Laniak et al., (2013) point out the necessity of "conceptual compatibility among the components (ontology) and specification of the information to be exchanged between components (semantics)."Blindly linking existing software has a high risk to create ugly constructs - so called "integronsters" (Voinov and Shugart, 2013).

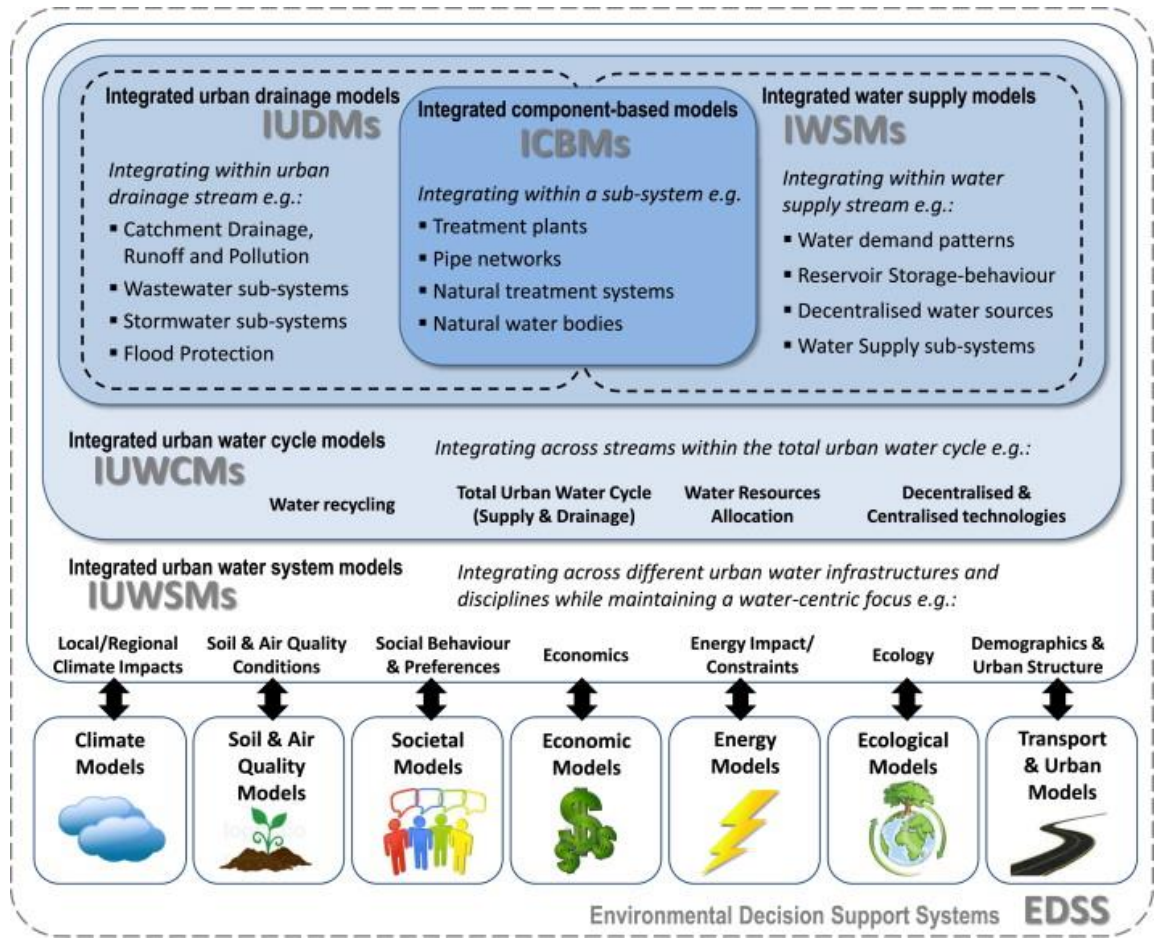

Figure 3. Suggested typology for classifying integrated urban water models (reprinted from Bach et al., 2014)

Bach et al., (2014) discuss a typology of IUDM's that allows a classification of thereof, based on the type of components linked together (see Fig. 3). In a simplistic view, at the heart of the IUDM there are one or more components of the drainage system, such as catchment and sewer model, linked with wastewater treatment, river and/or water supply models, respectively. Already at this core level the integration of multiple disciplines is necessary. The core model of the urban water system is then related with other components that can conveniently be classified as follows:

- Spatial integration: the linked components have a spatial context, such as urban planning, transport, influence of demographic changes, natural watershed, etc.

- Discipline integration: the components are adding an additional discipline such as economic consideration, energy, societal behavior, etc.

- Process integration: Integration can happen at different levels of complexity and could likewise aim at increasing the understanding rather than broadening the view. The 


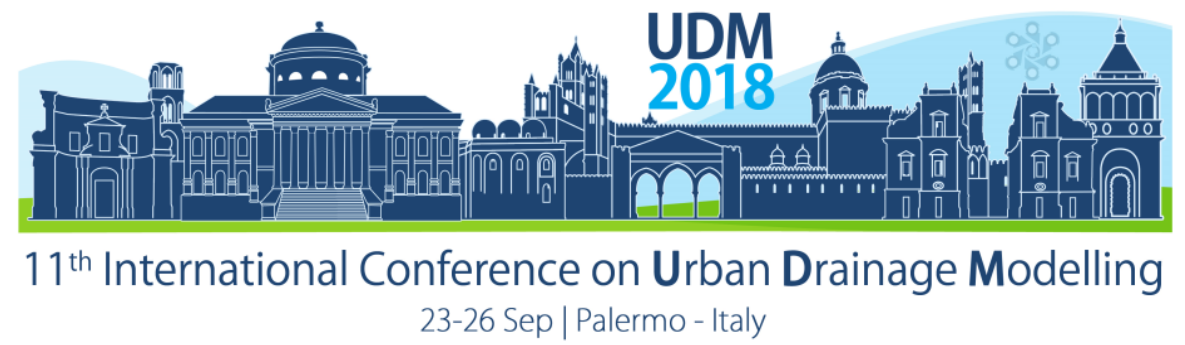

linked components thus provide more detailed and accurate description of a specific process.

\section{Obstacles}

In a historic context, integrated urban drainage modelling has been established in research already 2 decades ago, with basic frameworks of the key systems components (drainage/sewer, treatment plant and river) firmly in place as well as the required toolboxes for systems analysis. In spite of significant developments (also in the later years), practice was slow to pick up the approach.

Until recently the reluctance to make use of IM in urban drainage practice could have been attributed to technical issues, as surveillance, data transmission and management, computational speed and "user-friendliness" of the software lagged behind model development.

The other possible reason against the adoption of integrated modelling is the notion of "expertise" and scale of knowledge. Both scientist and practitioners have a knowledge background (discipline) where they are experts in. But integration spans wider and adopting an integrated view also results in being exposed to own ignorance - when dealing with aspects of other disciplines. There are 2 possible solutions to this: First, to establish multidisciplinary experts with insight knowledge over several fields. The detriment is as follows: according to Gladwell (2008) a rough estimate of the timeframe to be an expert in any field amounts to 10 000 hours of focus and practice (which is app. 7 years fulltime work - alike the duration of MSc $+\mathrm{PhD})$. Inevitably such multidisciplinary experts are a rare species and - if all - found more among the experienced ones. The second pathway is collaboration. Albeit logical and meaningful also this avenue takes time and devotion to achieve the necessary understanding among a group of experts. And again, the expertise is linked to persons not institutions and thus is neither easily established nor replaced.

Summarising, it is possible and reasonable to adopt an integrated view on problems as long it is a bird view angle but once going into details multidisciplinary knowledge is required that does not come easily. As planers, operators and other stakeholders are feeling more save in their own field of expertise integrated approaches tend to be avoided in practice.

\section{Some examples}

In the following 3 examples of integration are given following the earlier classification into spatial, disciplinary and process integration. Such examples are to be seen as an indication where integrated modelling could evolve in the near future.

The first example is the integration of urban water systems with the city dynamics and the societal system. E.g. Rauch et al. (2017) presented an integrated model for predicting transitions in the water sector - here towards decentralised drainage solutions. The spatially explicit model, denoted DAnCE4Water, integrates urban development patterns, water infrastructure changes and the dynamics of socio-institutional changes. 


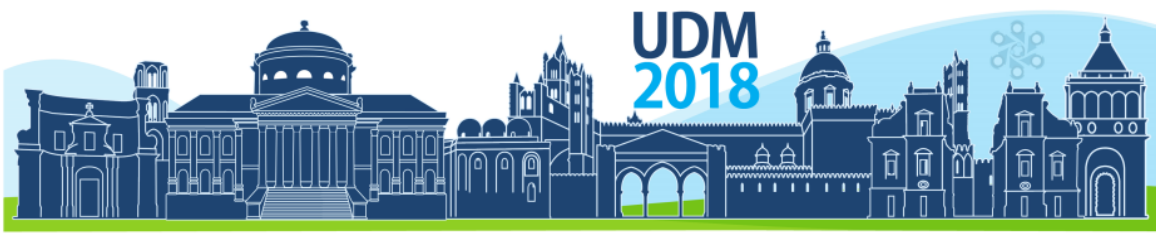

$11^{\text {th }}$ International Conference on Urban Drainage Modelling 23-26 Sep | Palermo - Italy

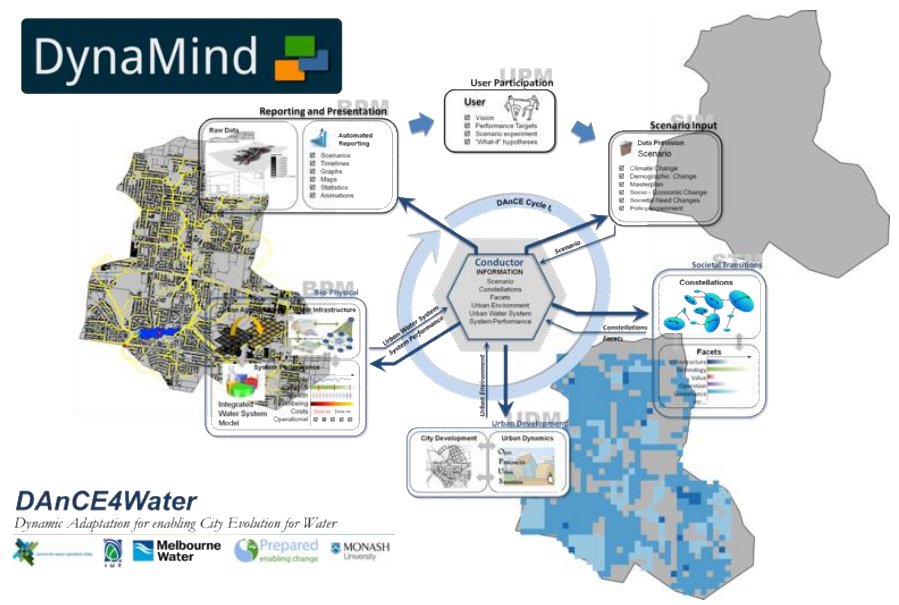

Figure 4. Dance4Water framework as an example of a spatially integrated model

Second, there are many studies integrating other disciplines to the urban drainage field focussing e.g. on economic and/or societal considerations. A topic already established in the wider context of the "energy, water and food nexus" is the energy balance (Bazilian et al. 2011). Models for energy use and production are currently integrated in whole plant modelling and water supply, giving a new perspective to the climate change debate. In a similar context, Mannina et al. (2018) discuss greenhouse gas emissions from the integrated drainage system.

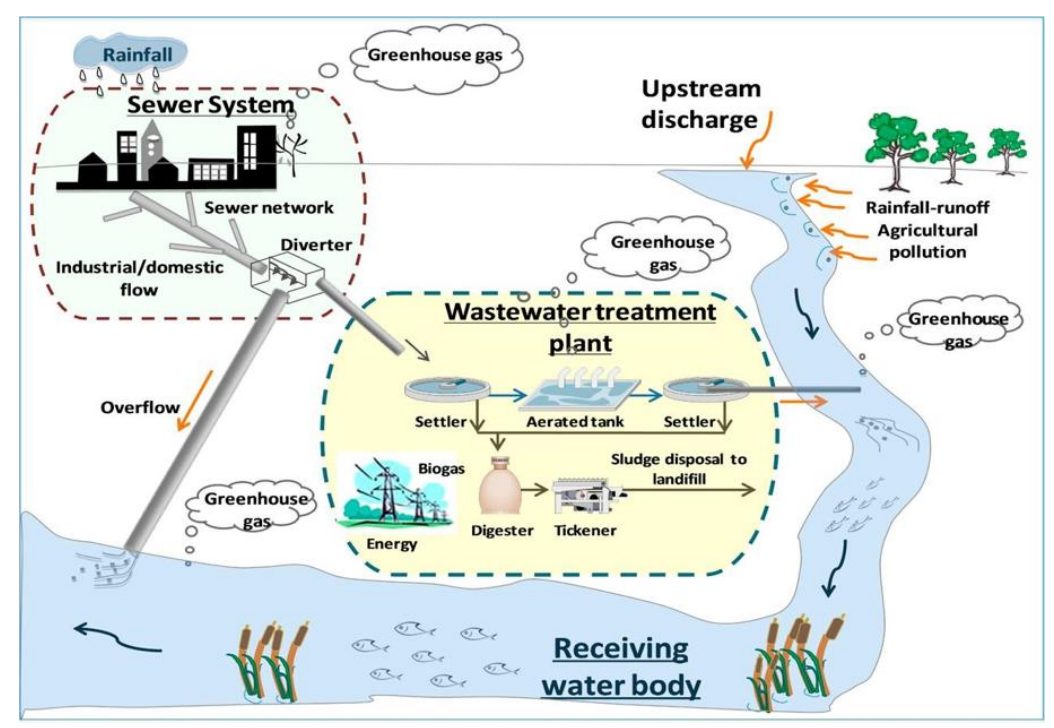

Figure 5. Framework for greenhouse gas emissions in the integrated system (reprinted from Mannina et al., 2018)

Last to be mentioned is the integration in terms of processes, meaning to couple core models of the integrated urban drainage system with models that offer a deeper understanding in a relevant issue. A typical example has been presented by Winkler et al., (2018) where a detailed computational fluid dynamics simulation of urban flooding has been used as virtual reality experiment to reach out to risk communication (see Figure 6). 


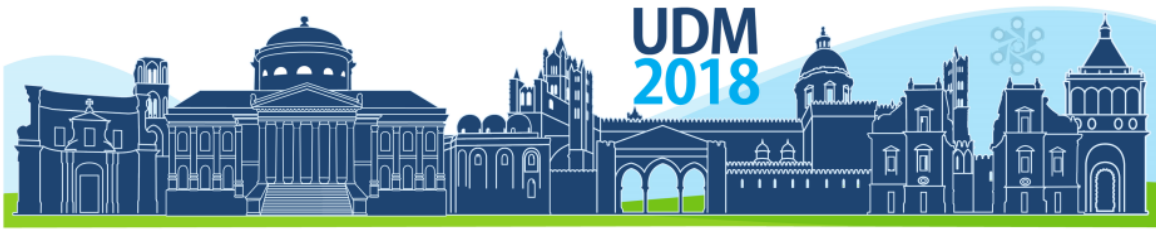

$11^{\text {th }}$ International Conference on Urban Drainage Modelling 23-26 Sep | Palermo - Italy

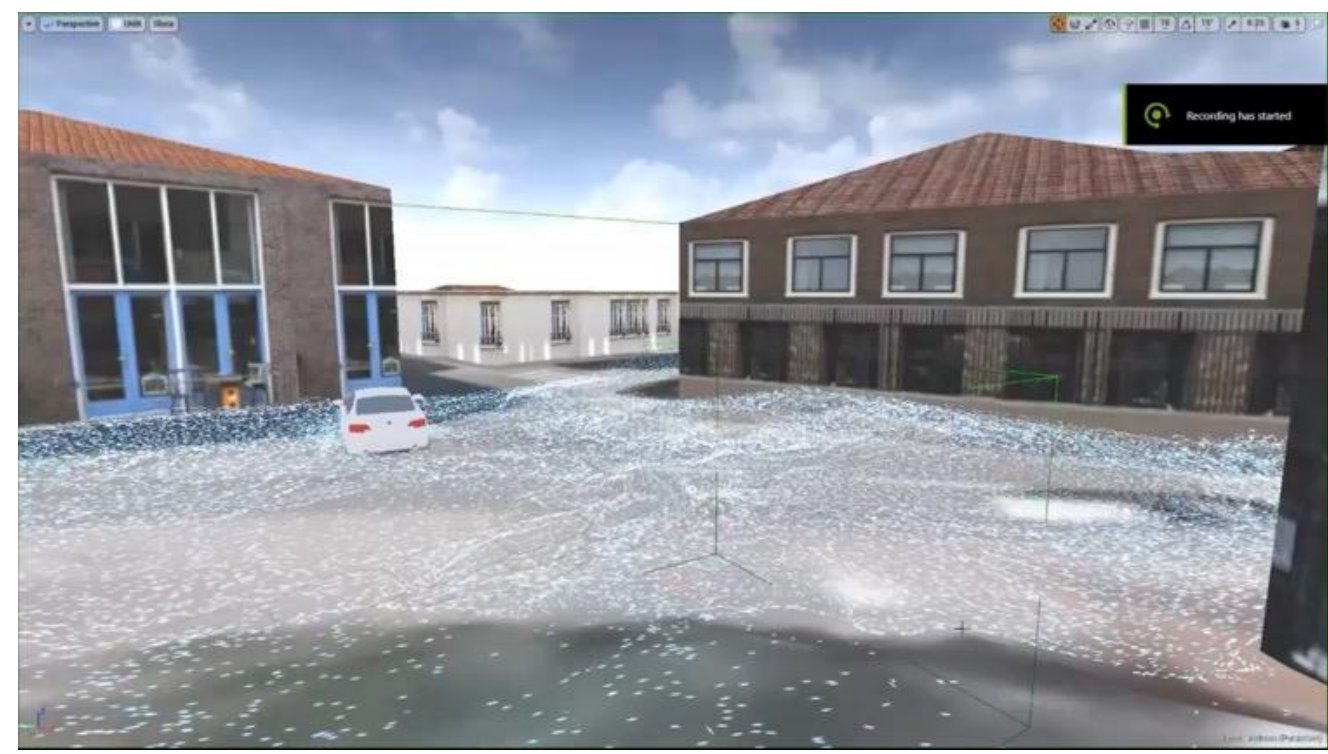

Figure 5. Virtual Reality for flood risk communication - linking urban drainage with computational fluid dynamics (Winkler et al., 2018)

\section{References}

Peter M. Bach, Wolfgang Rauch, Peter S. Mikkelsen, David T. McCarthy, Ana Deletic (2014): A critical review of integrated urban water modelling - Urban drainage and beyond, Environmental Modelling \& Software, 54, 2014, 88-107

Morgan Bazilian, Holger Rogner, Mark Howells, Sebastian Hermann, Douglas Arent, Dolf Gielen, Pasquale Steduto, Alexander Mueller, Paul Komor, Richard S.J. Tol, Kandeh K. Yumkella (2011): Considering the energy, water and food nexus: Towards an integrated modelling approach, Energy Policy, 39/12, 2011, 7896-7906.

Gerard F. Laniak, Gabriel Olchin, Jonathan Goodall, Alexey Voinov, Mary Hill, Pierre Glynn, Gene Whelan, Gary Geller, Nigel Quinn, Michiel Blind, Scott Peckham, Sim Reaney, Noha Gaber, Robert Kennedy, Andrew Hughes (2013): Integrated environmental modeling: A vision and roadmap for the future, Environmental Modelling \& Software, 39, 2013, 3-23

Malcolm Gladwell (2008): Outliers - the story of sucess, 2008 Hachette Book Group, Inc. ISBN 978-0-316-036696

Giorgio Mannina, David Butler, Lorenzo Benedetti, Ana Deletic, Harsha Fowdar, Guangtao Fu, Manfred Kleidorfer, David McCarthy, Peter Steen Mikkelsen, Wolfgang Rauch, Chris Sweetapple, Luca Vezzaro, Zhiguo Yuan, Patrick Willems (2018): Greenhouse gas emissions from integrated urban drainage systems: Where do we stand?, Journal of Hydrology, 559, 2018, 307-314

Rauch, W., Seggelke, K., Brown, R. and Krebs (2005): Integrated approaches in urban storm drainage: where do we stand? Environmental Management (2005) 35: 396

W. Rauch, C. Urich, P.M. Bach, B.C. Rogers, F.J. de Haan, R.R. Brown, M. Mair, D.T. McCarthy, M. Kleidorfer, R. Sitzenfrei, A. Deletic (2017): Modelling transitions in urban water systems, Water Research, 126, 2017, $501-514$

Alexey Voinov, Herman H. Shugart (2013): 'Integronsters', integral and integrated modeling, Environmental Modelling \& Software, 39, 2013, 149-158

Daniel Winkler, Jonatan Zischg, Wolfgang Rauch; Virtual reality in urban water management: communicating urban flooding with particle-based CFD simulations. Water Sci Technol 29 January 2018; 77 (2): 518-524

Fateme Zare, Sondoss Elsawah, Takuya Iwanaga, Anthony J. Jakeman, Suzanne A. Pierce (2017): Integrated water assessment and modelling: A bibliometric analysis of trends in the water resource sector, Journal of Hydrology, 552, 2017, 765-778 


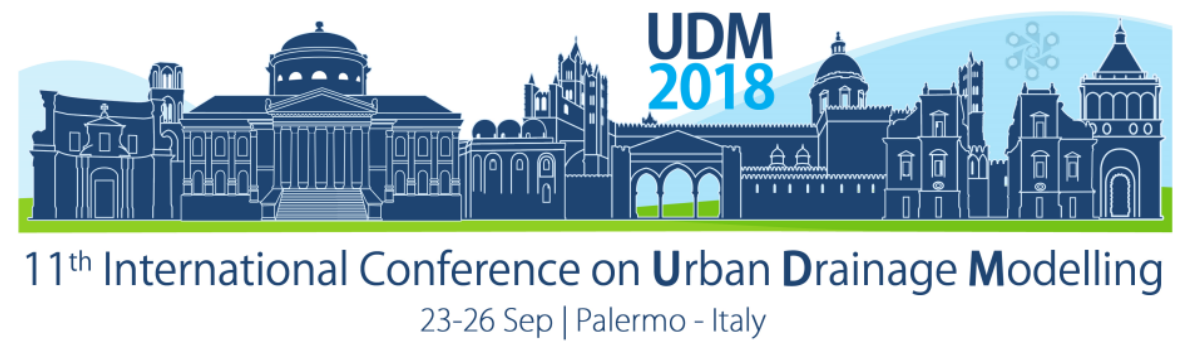

\title{
From unknown to uncertain: A statistical model on gully pot silting
}

\author{
Matthijs Rietveld ${ }^{1}$, Jeroen Langeveld ${ }^{1,2}$, Nadia Mobron ${ }^{1}$ and Francois Clemens ${ }^{1,3}$ \\ ${ }^{1}$ TU Delft, Sanitary Engineering, Delft, the Netherlands \\ ${ }^{2}$ Partners4UrbanWater, Nijmegen, the Netherlands \\ ${ }^{3}$ Deltares, department of Hydraulic Engineering, Delft, the Netherlands
}

\begin{abstract}
Gully pots are not only designed to transport water to the sewer system, but also to retain inflowing solids. Therefore, gully pots contain a so-called sediment trap, which gradually silts and needs to be cleaned frequently. The cleaning frequency applied by Dutch municipalities seems to be based on the available budget rather than to control the silting and solids management This could lead to on the one hand redundant cleanings and on the other hand clogged gully pots. This paper uses a statistical model, based on field measurements, to determine the influence of several physical phenomena on gully pot silting. Five factors that affect gully pot silting are identified: size of surface area connected to a gully pot, inlet type, sediment trap depth, presence of trees and rainfall volume. Municipal maintenance departments can avoid clogged gully pots and redundant cleanings by basing their cleaning frequency on these factors.
\end{abstract}

Keywords: Gully pot; Maintenance; Generalised Linear Model

\section{INTRODUCTION}

Cleaning roadside gully pots is a vital asset management task to safeguard a healthy environment in our modern cities. These gully pots link impervious areas to sewers and storm water infiltration facilities.. The sewers and storm water systems drain the excess storm water to prevent health risks and nuisance.

The runoff entering the gully pots does contains a large variety of solids. These solids are a potential source of pollution (e.g. Fulcher, 1994). Therefore, gully pots usually contain a sediment trap, which is designed to retain these solids, in order to reduce solid deposition in sewer systems, safeguard wastewater treatment plant efficiency, and protect the quality of receiving water bodies, see Bolognesi et al. (2008).

The silting rate depends on the load of solids flowing into the gully pot and on its solid retention efficiency. Butler and Karunaratne (1995) showed in lab experiments that this efficiency depends on the type of solids, the gully pot geometry, and the rainfall intensity. Post et al. (2016) showed in an extensive field experiment that the efficiency drops over time.

Post et al. (2016) monitored the silting process in 300 gully pots over a period of 15 months and found that a small amount (approximately 5 percent) of the gully pots got clogged in this period, whilst the solid level in the remaining gully pots reached a stable level. It is unknown what physical phenomena cause the difference between the two observed silting regimes.

Nonetheless, in both cases the gully pots should be cleaned. In the first case cleaning is required because gully pot flooding could occur and in the second case the solids are 


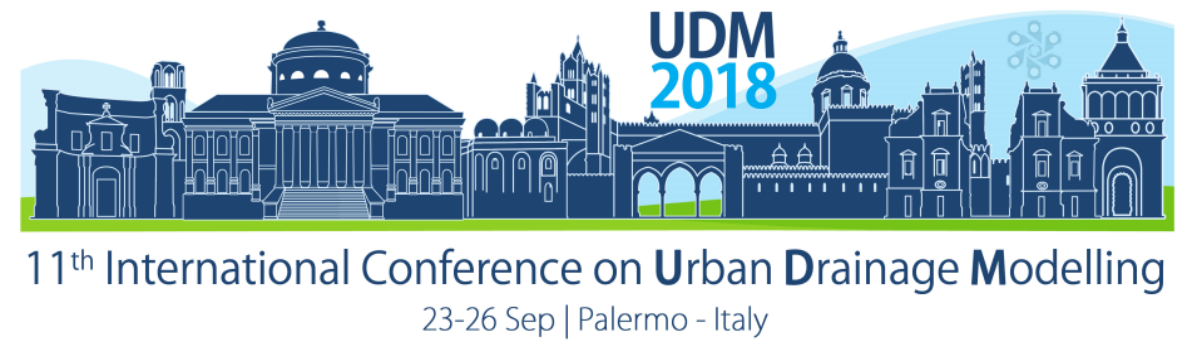

transported to other parts of the sewer system where they could form deposits. So, in both cases it is good practise to clean the gully pots.

Most municipalities in the Netherlands clean their gully pots on average once a year in residential areas and two to four times a year at vulnerable places like markets (Ten Veldhuis and Clemens, 2011). Generally, municipalities don't define the cleaning frequency on physical parameters correlated with silting rate. Therefore, redundant cleanings and late cleaning of gully pots occur.

Post et al. (2016) developed a statistical model that relates the filling rate of the sediment trap with time. It was not possible to take variable processes, like leave fall and rainfall, into account in that model on total silting. Therefore, another model on silting rate is needed. Moreover, Post et al. (2016) based their model on measurements in just one catchment. Measurements in more heterogeneous environments are needed to apply a model to areas in which no measurements are done.

Therefore, the study presented here uses field measurements to determine the silting rate. This is coupled with factors related to the inflow of solids, such as rainfall, traffic intensity, road type and traffic intensity and factors related to the gully pot efficiency, such as inlet type and sediment trap depth. We propose a statistical model based on these field measurements to estimate the silting level in gully pots. This can be used as a starting point to optimise the cleaning frequency of gully pots.

\section{MATERIALS AND METHODS}

The Ordinary Least Square method was used to analyse the silting rate in gully pots. The model includes several explanatory variables that are related to either the inflow of solids or to the retention of solids in gully pots. The following sections explain how the silting rate and the explanatory variables are determined.

\subsection{Determination of silting rate}

Measurements were performed in the cities of Rotterdam and The Hague, the Netherlands. The pots were measured once in 3 to 4 weeks from November 2017 until May 2018. The gully pots had been cleaned out prior to the measurement period.

Figure 1 shows at the left the method to determine the thickness of the solid layer. The measurement device was similar to the one used by Post et al. (2016). It consisted of a disk with a vertical hollow cylinder and a movable rod inside the cylinder. The disk was used to compress the solids until no more air escaped from the bed. The thickness of the solid layer was determined by pushing the movable rod through the solids to the bottom of the gully pot. The tapeline on the rod showed the solid layer thickness.

The solid volume was determined by multiplying the thickness of the solid layer by the cross section of the gully pot. The silting rate has been calculated by subtracting 2 consecutive measurements divided by the days in between these measurements.

\subsection{Determination of explanatory variables}

The parameters used in this research are related to both the inflow of solids and to the retention of solids in gully pots. 8 parameters are used, namely: size of area connected to a gully pot, traffic intensity, road type, inlet type, sediment trap depth, maximum rainfall intensity, rainfall volume and contribution of trees. 


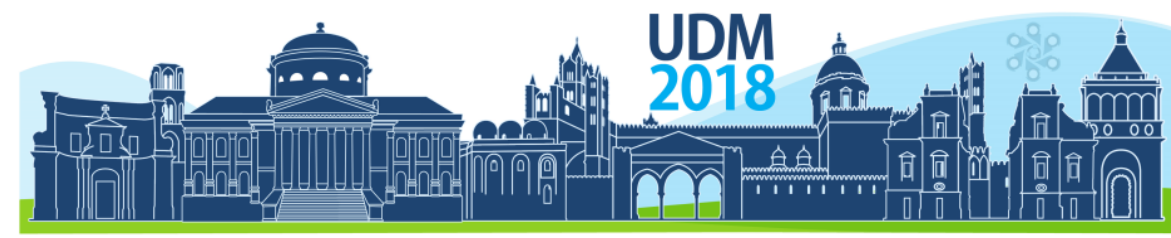

$11^{\text {th }}$ International Conference on Urban Drainage Modelling

23-26 Sep | Palermo - Italy

Trees contribute to the silting rate through the leaves and litter that flow into the gully pot. However, it is not feasible to count the number of leaves present in a street. Therefore, an easy estimator is needed to take this phenomenon into account. Therefore, a factor is introduced as an estimator of the amount of leaves/biomass per unit length of the street.

The amount of leaves per tree are estimated by multiplying the height of the tree (htree) with the diameter squared (Dtree). The tree volume is seen as the key driver explaining the available amount of biomass/leaves. In future research, also the type of tree may be taken into account, but in this first attempt only the tree volume was taken into account. The tree volume was estimated by a multiplication of the height of the tree $\left(h_{\text {tree }}\right)$ with the diameter of the tree squared $\left(D_{\text {tree }}\right)$. The summation of these values for all trees in a street is divided by the length of the street $\left(L_{\text {street }}\right)$. The tree factor can mathematically by written as:

$$
T_{f}=\frac{1}{L_{\text {street }}} \Sigma_{\mathrm{i}} h_{\text {tree }}(i) D_{\text {tree }}^{2}(i)
$$

\section{RESULTS AND DISCUSSION}

\subsection{Data exploration}

The data showed that both municipalities had made a mistake once by cleaning the gully pots in one of the monitored streets. Therefore, the data points of one period had to be removed. Next to that, data points were removed from some gully pots that did not function well hydraulically or contained irregular materials such as stones in their sediment trap. Figure 1 shows at the right the histogram of the cleansed data, which consist of 1271 data points.
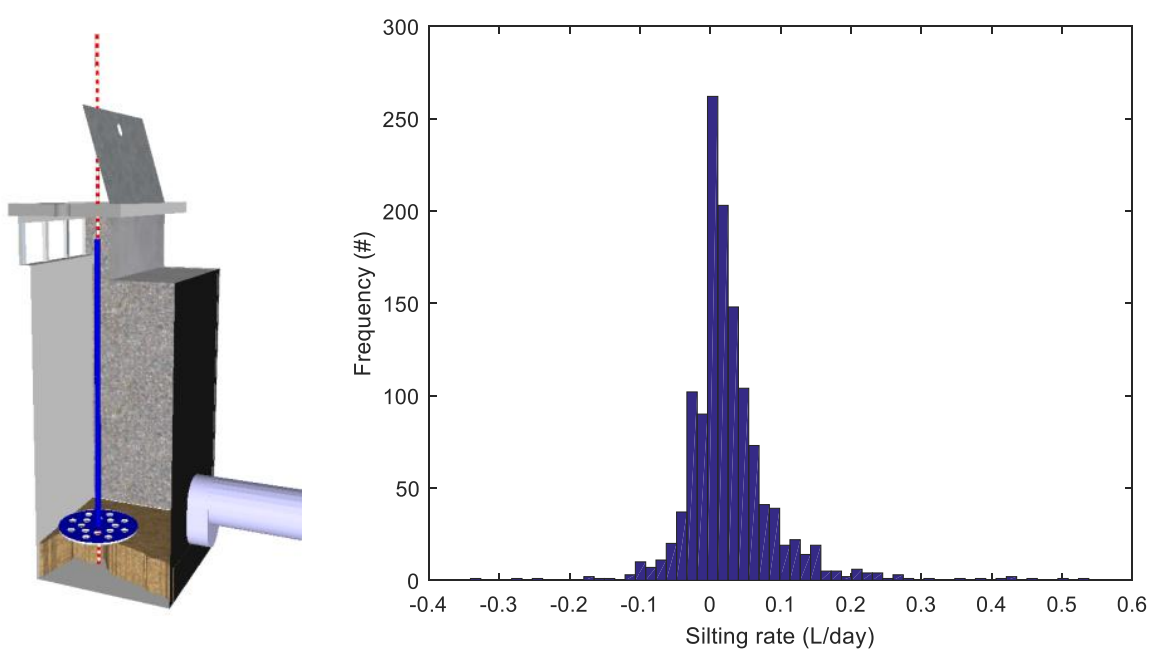

Figure 1. Left: Solid depth measurement, Right: Histogram of the measurement data.

\subsection{Model outcome}

The Ordinary Least Square model is used to analyse the data. The p-values of the included explanatory variables showed that some of them have an insignificant contribution $(p>0.05)$. 


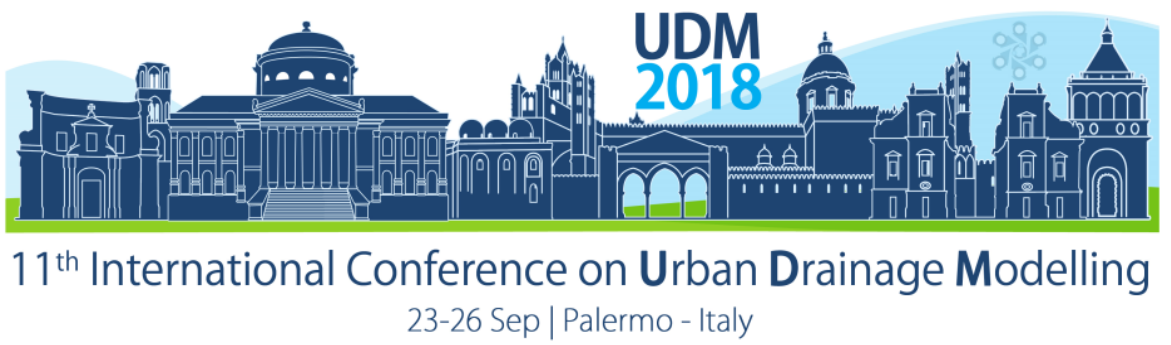

Therefore, the procedure is to remove step by step these variables to identify the important ones.

In this way, firstly the type of road, secondly the traffic intensity and lastly the rainfall intensity were removed. The 5 remaining variables are thus: connected area, sediment trap depth, inlet type, tree factor and rainfall volume. Table 1 shows the properties of these variables.

Positive $\beta$-values mean that there is a positive correlation between that value and the solid silting rate.

Table 1. The characteristics of the explanatory variables used in the model.

\begin{tabular}{lcccc}
\hline & $\beta$ & $p$-value & Range & Units \\
\hline Connected area & $7.2 \cdot 10^{-5}$ & $8.5 \cdot 10^{-5}$ & {$[6.0 \ldots 793.5]$} & $\mathrm{m}^{2}$ \\
Sediment trap depth & $1.9 \cdot 10^{-3}$ & $6.3 \cdot 10^{-4}$ & {$[16.5 \ldots 30.5]$} & $\mathrm{Cm}$ \\
Side inlet & $-1.1 \cdot 10^{-2}$ & $3.2 \cdot 10^{-3}$ & {$[$ Yes/No $]$} & - \\
Tree factor & $1.6 \cdot 10^{-4}$ & $5.3 \cdot 10^{-7}$ & {$[0 \ldots 167.9]$} & $\# \mathrm{~m}^{2}$ \\
Rainfall volume & $5.6 \cdot 10^{-3}$ & $1.6 \cdot 10^{-5}$ & {$[0.65 \ldots 5.64]$} & $\mathrm{mm} /$ day \\
\hline
\end{tabular}

The transport of solids is considered to be mainly done by road runoff. The model outcome shows that there is indeed a positive relation between the rainfall volume and the silting rate. This was also identified by Ellis and Harrop (1984).

The connected area is positively correlated with the silting rate. The size of the connected area relates to the amount of solids available for transport from the street, but also to the magnitude of the discharge of water. The first phenomenon has a positive relation with silting rate, while the second has a negative relation, because it induces resuspension. However, the positive beta value shows to the first effect is stronger than the second. These findings are in line with the observations of Post et al. (2016).

The model outcome suggests that the geometry of the gully pot is important. Table 1 shows that gully pots with a side inlet silt slower than ones with another type of inlet. Next to that, the sediment trap depth has a positive beta value. This means that the deeper the remaining part of the sediment trap, the faster it silts, which is in line with Memon and Butler (2002).

\section{CONCLUSIONS}

The "tree factor" appeared to have a significant relation with the silting rate. It might mean that leaf fall and the transport of leaves can be predicted with this factor. The strength of this relation is expected to increase during autumn and possibly during spring when blossom occurs. This will be checked in upcoming research.

The type of inlet could have a relation with the solid deposition in two ways. The inlet has an influence on the flow pattern in the pot, but also on the amount of inflow. Further research is needed to determine which of these is the dominant process. 


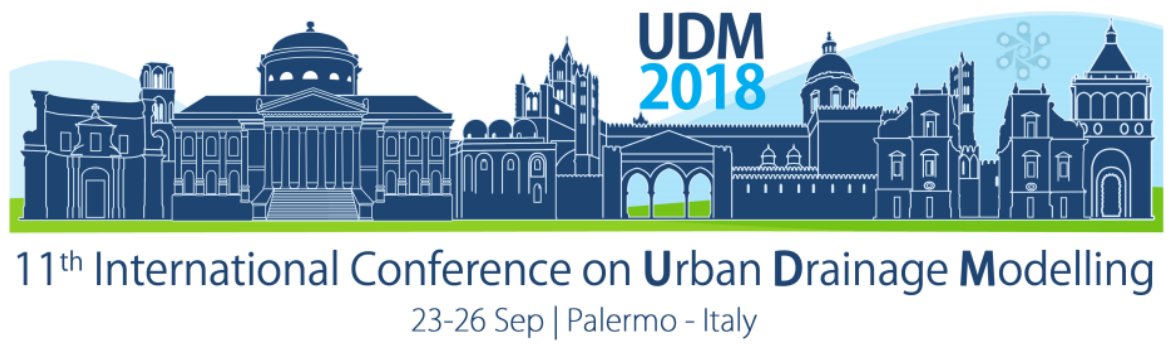

Furthermore, the positive correlation of the sediment trap depth could also be interpreted in different ways. It could either mean that less resuspension occurs in deeper gully pots or there is less sedimentation. Further research in the hydraulic lab of Deltares will be conducted to answer this question.

The transport of solids to the gully pot could be limited by the availability of solids on the street or by the transport capacity of the water. The relation of the rainfall volume with the silting rate shows that the transport capacity of the water is the limiting factor.

The proposed statistical model shows that both factors related to the geometry and the environment affect the silting rate in gully pots. Municipal maintenance departments can optimise their cleaning strategy with this information.

\section{REFERENCES}

Butler, D. and Karunaratne, S.H.P.G. (1995) The suspended solids trap efficiency of the roadside gully pot. Water research $29(2), 719-729$

Bolognesi, A., Casadio, A. Ciccarello, A., Maglionico, M. and Arina, S. (2008) Experimental study of roadside gully pots efficiency in trapping solids washed off during rainfall events. Proc. of the $11^{\text {th }}$ ICUD

Ellen, J.B. and Harrop, D.O. (1984) Variations in solids loadings to roadside gully pots. Science of the Total Environment 33 (1-4), 203-211

Fulcher, G.A. (1994) Urban stormwater quality from a residential catchment. Science of the Total Environment 146-147, 535-542

Memon, F.A. and Butler, D. (2002), Identification and modelling of dry weather processes in gully pots. Wat. Res. 36Butler and Parkinson (1997), 1351-1359.

Post, J.A.B., Pothof, I.W.M., Dirksen, J., Baars, E.J., Langeveld, J.G. and Clemens, F.H.L.R. (2016) Monitoring and statistical modelling of sedimentation in gully pots. Wat. Res. 88 245-256.

Ten Veldhuis, J.A.E. and Clemens, F.H.L.R. (2011) The efficiency of asset management strategies to reduce urban flood risk. Wat. Sci. Tech. 64 


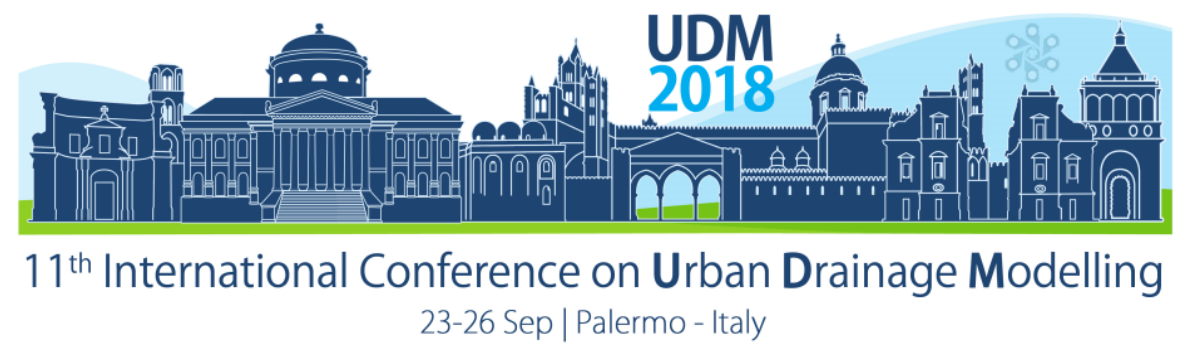

\title{
Forecasting pollution transport in drainage water
}

\author{
Robert Sämann ${ }^{1}$, Insa Neuweiler', Thomas Graf ${ }^{1}$ \\ ${ }^{1}$ Institute of Fluid Mechanics and Environmental Physics in Civil Engineering, Leibniz University, Hanover, \\ Germany
}

\begin{abstract}
The EVUS project (www.pluvialfloods.uni-hannover.de) has developed a concept for a real time forecasting system for urban flood damages. During heavy rainfall events the capacity of urban drainage systems can be exceeded, resulting in complex flow interactions between surface and pipe system via manholes and street inlets. The flow patterns of accidently spilled hazardous substances can be quite complex. In this study, we implemented a particle based transport model for fast prediction of travel paths of contaminants after a spill during a flash flood. The model calculates mixing and dispersion in the pipe system and on the surface by using a random-walk approach. It is applied to an urban catchment of $5 \mathrm{~km}^{2}$. Influence of pipe to surface coupling due to the additional transport paths is demonstrated. The model is based on pre-calculated flow fields and can forecast potential contaminated areas within less than one minute.
\end{abstract}

Keywords: real time prediction; solute transport; particle model

\section{INTRODUCTION}

The presented work addresses the question of contaminant transport after a spill of hazardous substances during a pluvial flash flood event. It is part of the EVUS project (www.pluvialfloods.uni-hannover.de). The aim of this project is an online real-time service for disaster management authorities that can forecast spreading of contaminants. Due to low visibility and high water levels during a heavy rainfall, the risk of accidents in traffic and mobilization of potentially dangerous substances is increased. Because water can interchange between pipe system and ground surface through manholes and street inlets, solutes can travel long distances on complex flow paths (Fuchs, 2013).

For an early warning, concentration peaks and spreading at contaminated locations have to be calculated within a few minutes.

\section{MATERIALS AND METHODS}

In contrast to Eulerian approaches, like in (Pathirana et al., 2011), the solute transport in the drainage network and on the surface is calculated using a Lagrangean based particle model that meets the requirements for a fast forecasting simulation. In this model each particle represents a particular mass of a substance and can easily be tracked on their way through the drainage flow field. This approach fulfils conservation of mass and prevents numerical diffusion, which would lead to underestimation of critical concentrations.

Real time calculation of flow with a finite volume model takes a long time and is therefore not applicable for the forecasting system. Instead, a variety of precipitation patterns is simulated in advance with the hydrodynamic HYSTEM EXTRAN 2D model (itwh, 2017) and the resulting time series of pipe and surface flow fields are stored in a database. To select the best flow field from this set, a Nearest-Neighbour approach (Lall \& Sharma 1996) is used for extracting the best matching results based on an actual rainfall event. 


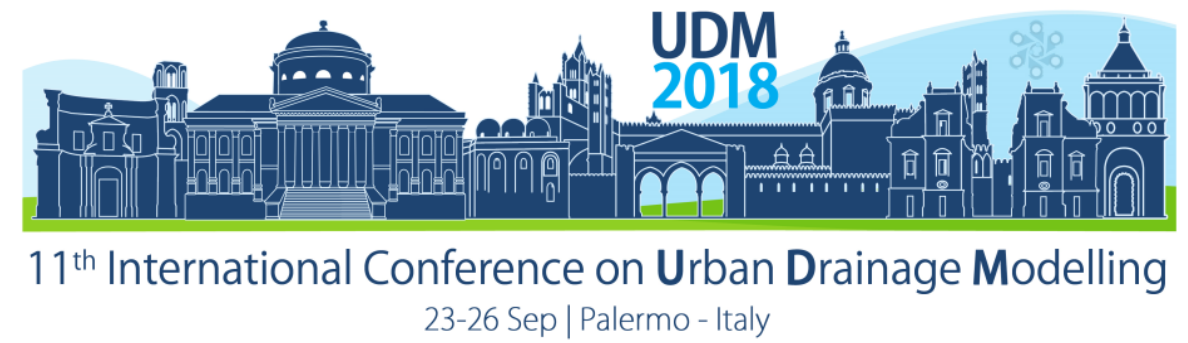

The particle based transport model uses 2D continuum movement on a 2D surface lattice and 1D movement in the pipe domain with a random walk approach that takes mixing and dispersion into account (Banton et al., 1997). Each particle is driven by the mean advection velocity. An additional random jump scaled with the square root of a dispersion factor for the internal mixing is applied. Inside the pipe system the magnitude of dispersion is $2 \mathrm{~m}^{2} / \mathrm{s}$ according to (Schlütter \& Mark, 2006). For the surface it is calculated as in (Lin \& Falkoner, 1997 ) with a longitudinal value of $0,5 \mathrm{~m}^{2} / \mathrm{s}$ on streets. Routing is performed proportional to outgoing fluxes in manholes with multiple outgoing pipes and spillout flow when surcharging is detected. Transfer of particles between pipe and surface domain is activated if the flooding status of manholes and street inlets is positive. For the surface all particles can move freely on a triangular lattice. A localization algorithm keeps track of particles, interpolates velocity and checks for boundary collision.

The range of time discretization can be varied without restriction to CFL criterion (Courant et al., 1967), because all particles are registered and handled individually by calculating the cell transit time (Pollock, 1988). Mixing and diffusion are locally independent and are therefore not subject to restrictions. The particle transport has been verified against an analytical solution as well as a high resolution finite volume model of a transport scenario during a flood wave in a pipe with length of several kilometres.

For the soil domain the spreading of solute from leakage pipes above the groundwater level is computed. A stationary groundwater flow map with respect to leakage in- and outflow was produced by Peche et al. (in Preperation). The transport simulation in the soil is carried out after the simulation in the pipes and on the surface as it uses timesteps of several days and does not need to be coupled directly to the pipe and surface transport.

For demonstration, scenarios with spilled solute in an urban drainage system during a pluvial flood event are performed to analyse the role of surface transport on the spreading of substances. Particle traces are recorded to identify effective ways of contaminant embankment for future events.

A rainfall scenario with a precipitation of 50 year return period is selected to demonstrate the model applicability. The test domain is an urban area of $5 \mathrm{~km}^{2}$ with a drainage pipe network length of $50 \mathrm{~km}$. The transport model is run with 20,000 particles.

\section{RESULTS AND DISCUSSION}

If only taking the pipe system into account and neglecting surface flow, the simulation finishes after 30 seconds. When the surface is coupled to the pipe system, the simulation runs 45 seconds. Loading velocity data from the database is already included in this duration. Pure computation time is 9 , respective 20 seconds. The travel distance for each particle from the injection location to one of 7 outlets to receiving waters is about $6 \mathrm{~km}$. Time step size is one second.

At several locations in the network solute is carried from pipes to the surface through surcharged manholes. Transport paths on the surface mainly follow the streets slope. For high water levels, contaminant transport paths on the surface create shortcuts connect pipes to the contamination that were not connected without flooding (Fig. 1).

Spreading on the surface does not only expand the number of contaminated pipes and areas. If particles are flushed to the surface and stored in ponds until the surcharge vanishes, the distribution is interrupted. Pipes that were contaminated in the pipe system-only run may not be affected in a coupled simulation (Fig. 2).

Ponded solute also changes the shape of solute breakthrough curves. If solute is spilled to the 
Proceedings of the 11th Int. Conference on Urban Drainage Modelling, 23-26 Sep. 2018, Palermo (ITALY). Ed. prof. Giorgio Mannina

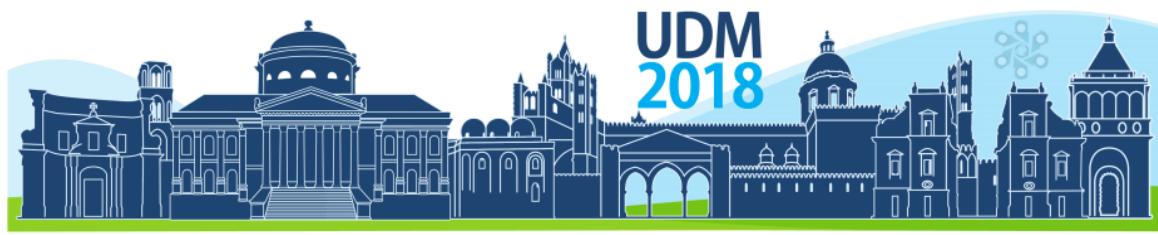

$11^{\text {th }}$ International Conference on Urban Drainage Modelling

23-26 Sep | Palermo - Italy

surface, transport paths are much slower and surcharged manholes and inlets prevent from re-entering the fast pipe system. Such breakthrough curves typically show much lower peak concentration and a wide range in time with several peaks compared to breakthrough curves in a pipe system alone (Fig. 3). This information is needed when the expected end of a contamination event has to be calculated for isolation of hazardous substances.

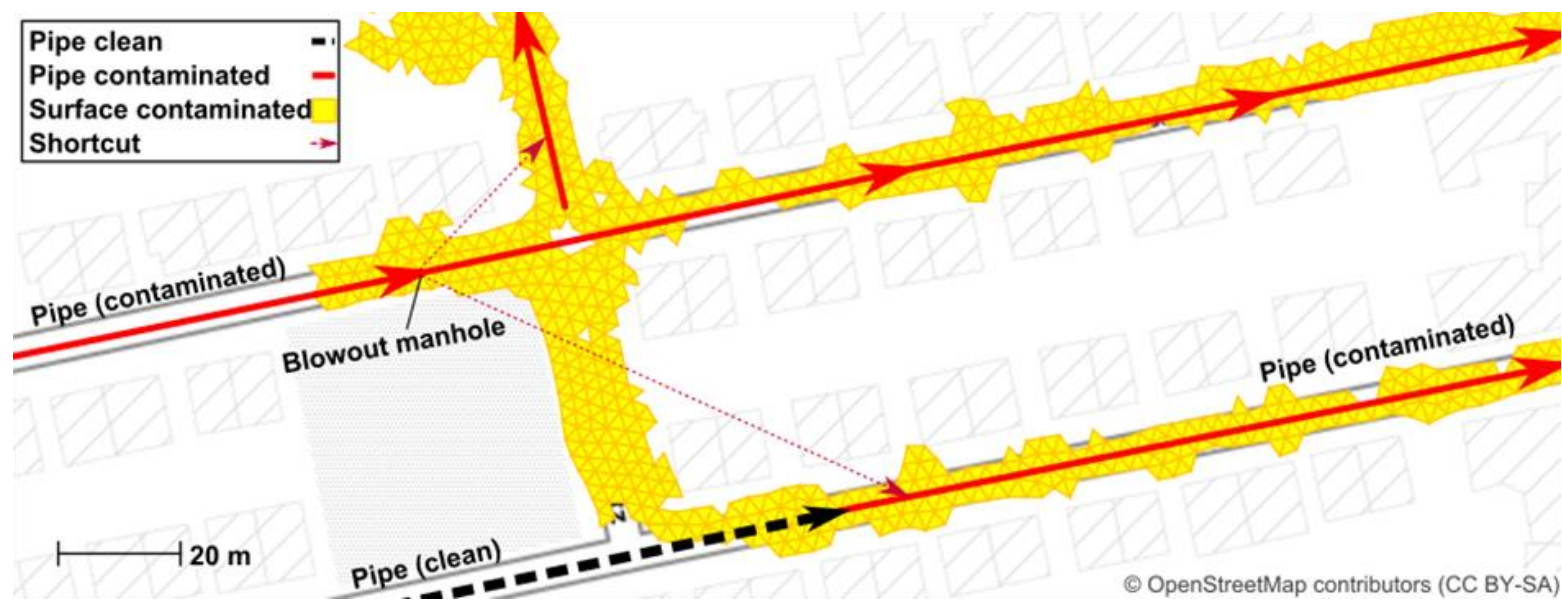

Figure 1. Contaminant spreading on surface leads to contamination of separated pipes

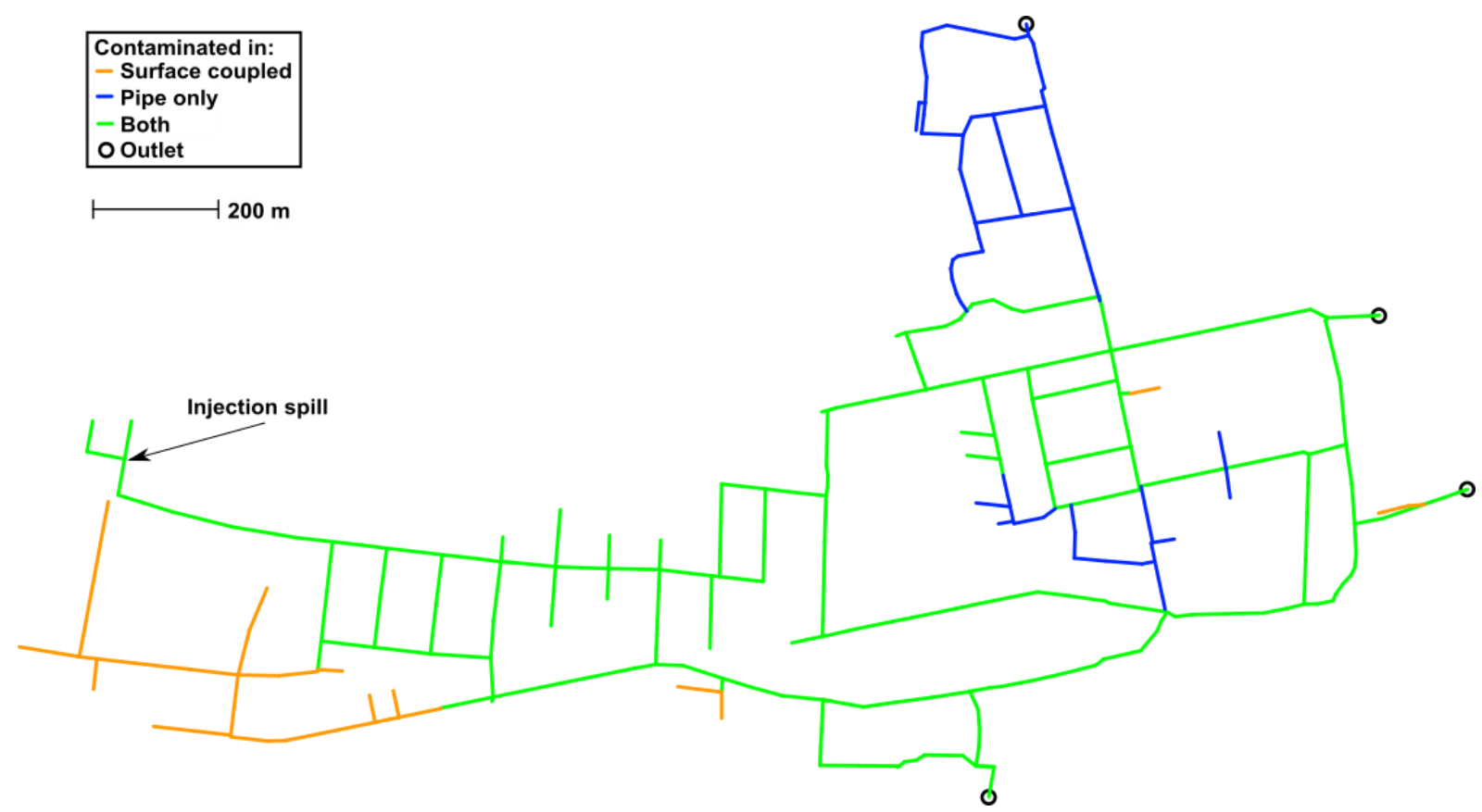

Figure 2. Different contaminated pipes with and without coupling to surface 


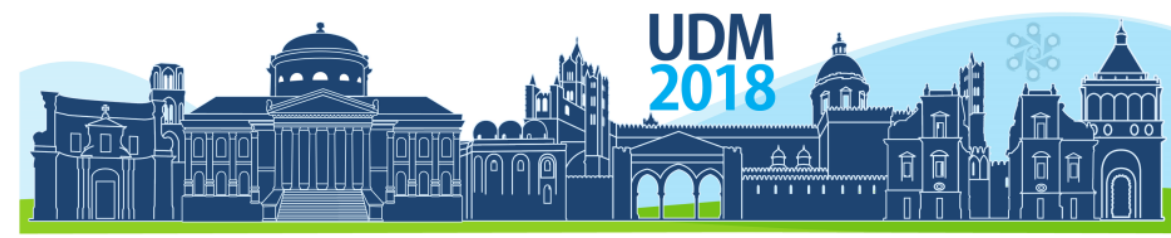

$11^{\text {th }}$ International Conference on Urban Drainage Modelling

23-26 Sep | Palermo - Italy

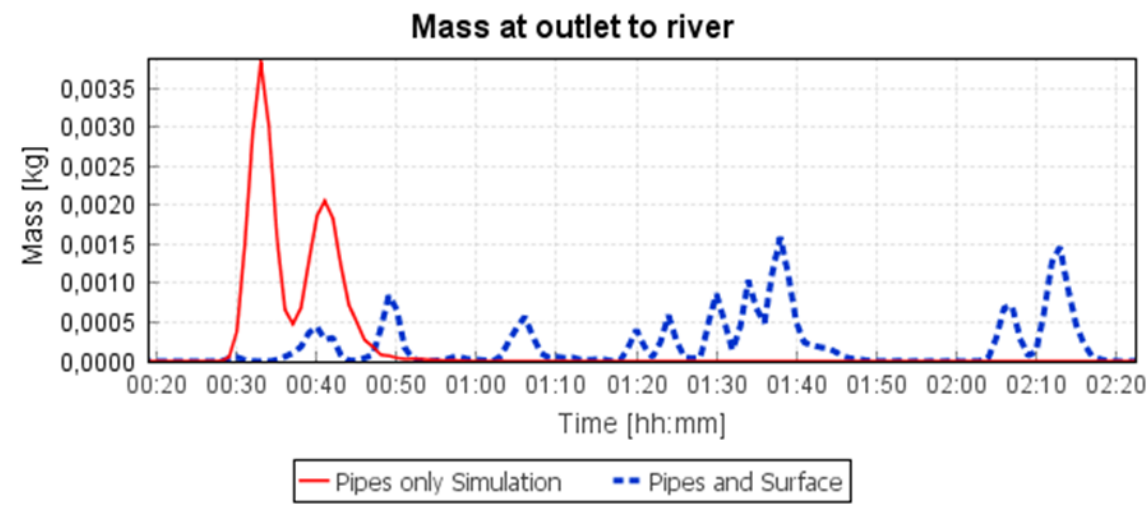

Figure 3. Breakthrough curve of solute particle mass at an pipe outlet to a river

\section{CONCLUSIONS}

When calculating contaminant spreading during a pluvial flooding event the surface flow has to be taken into account to compute realistic travel time distributions. The developed particle model is precise and fast. Demand of precise shapes for affected area and concentration peaks can be achieved.

Real time forecasting of pollutant spreading is possible with lead times below one minute per simulation in a catchment of a size of several square kilometres.

We plan to release the code of this software framework to open access and are searching for input to validate and to improve the functionality of the model.

\section{Acknowledgement}

This work is part of the EVUS Project within the GEOTECHNOLOGIEN framework funded by the Federal Ministry of Education and Research - BMBF, Germany. (project \# 03G0846A)

\section{References}

Banton, O., Delay, F., \& Porel, G. 1997 A New Time Domain Random Walk Method for Solute Transport in 1-D Heterogeneous Media. Ground Water, 35(6), 1008-1013.

Courant, R., Friedrichs, K., \& Lewy, H. 1967 On the partial difference equations of mathematical physics. IBM journal, 11(2), 215-234.

Fuchs, L. 2013 Gefährdungsanalyse zur Überflutungsvorsorge kommunaler Entwässerungssysteme. Sanierung und Anpassung von Entwässerungssystemen-Alternde Infrastruktur und Klimawandel, Österreichischer Wasserund Abfallwirtschaftsverband, Wien, ISBN, 978-3.

Itwh, 2015 HYSTEM-EXTRAN 2D Modellbeschreibung (Description of model for HYSTEM EXTRAN 2D)

Lall, U., Sharma, A., 1996 A nearest neighbor bootstrap for resampling hydrological time series. Wat. Resour. Res., 32: 679-693.

Lin, B., \& Falconer, R. A. 1997 Tidal flow and transport modeling using ULTIMATE QUICKEST scheme. Journal of hydraulic engineering, 123(4), 303-314.

Pathirana, A., Maheng Dikman, M., \& Brdjanovic, D. 2011. A Twodimensional pollutant transport model for sewer overflow impact simulation. In Proceedings: 12th International Conference on Urban Drainage, Porto Alegre/Brazil (pp. 10-15).

Peche, A., Graf, T., Fuchs, L., \& Neuweiler, I. (In preparation). Physically-based modeling of stormwater pipe leakage in an urban catchment.

Pollock, D. W. 1988 Semianalytical computation of path lines for finite-difference models. Ground Water, 26(6), 743-750.

Schlütter, F., \& Mark, O. 2003 Dynamic modelling of pollutants from CSOs. Water Science and Technology, 47(4), 149-156. 


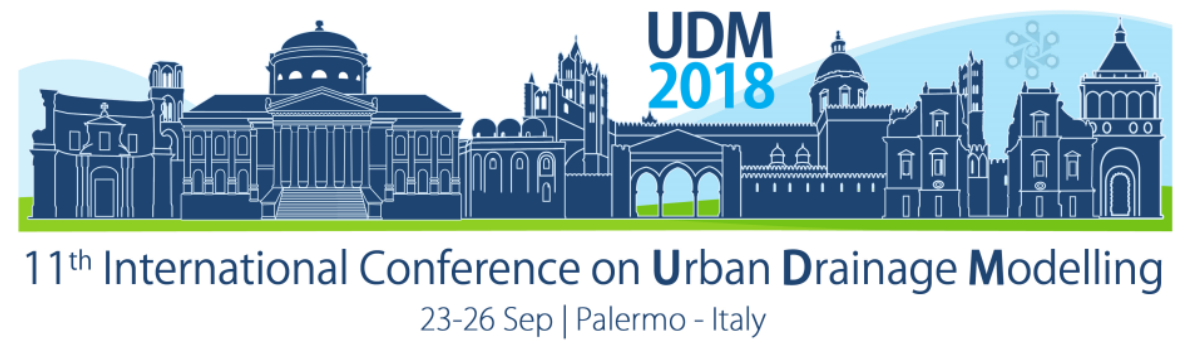

\title{
Impact evaluation of Wet-weather Events on Influent Flow and Loadings of a Water Resource Recovery Facility
}

\author{
Sina Borzooei ${ }^{1}$, Ramesh Teegavarapu², Soroush Abolfathi ${ }^{3}$, Youri Amerlinck ${ }^{4}$, Ingmar Nopens ${ }^{4}$ and Maria \\ Chiara Zanetti ${ }^{1}$ \\ ${ }^{1}$ Politecnico di Torino, Department of Civil and Environmental Engineering, Torino, Italy \\ 2 Florida Atlantic University, Department of Civil, Environmental and Geomatics Engineering, Florida, United \\ States \\ ${ }^{3}$ Coventry University, Flow Measurement \& Fluid Mechanics Research Centre, Coventry, United Kingdom \\ ${ }^{4}$ Ghent University, Department of Mathematical Modelling, Statistics and Bio-informatics, Gent, Belgium
}

\begin{abstract}
Since the introduction of environmental legislation and directives in Europe, the impact of combined sewer overflows (CSO) on receiving water bodies has become a priority concern in water and wastewater treatment industry. Timeconsuming and expensive local sampling and monitoring campaigns have been carried out to estimate the characteristic flow and pollutant concentrations of CSO water. This study focused on estimating the frequency and duration of wet-weather events and their impacts on influent flow and wastewater characteristics of the largest Italian water resource recovery facility (WRRF) in Castiglione Torinese. Eight years (viz. 2009-2016) of routinely collected influent data in addition to the arithmetic mean daily precipitation rates (PI) of the plant catchment area, were elaborated. Relationships between $\mathrm{PI}$ and volumetric influent flow rate $\left(Q_{i n}\right)$, chemical oxygen demand (COD), ammonium concentration $\left(\mathrm{N}^{-} \mathrm{NH}_{4}\right)$ and total suspended solids (TSS) are investigated. Time series data mining (TSDM) method is implemented for segmentation of time series by use of sliding window algorithm to partition the available records associated with wet and dry weather events based on the daily variation of $\mathrm{PI}$ time series. Appling the methodology in conjunction with results obtained from data reduction techniques, a wet-weather definition is proposed for the plant. The results confirm that applied methodology on routinely collected plant data can be considered as a good substitute for time-consuming and expensive sampling campaigns and plant monitoring programs usually conducted for accurate emergency response and long-term preparedness for extreme climate conditions.
\end{abstract}

Keywords: Wet weather; wastewater; rainfall, combined sewer system

\section{INTRODUCTION}

Combined sewer systems (CSSs) are sewage collection systems designed to collect surface runoff in addition to municipal and industrial wastewater. During heavy precipitation events when the volume of wastewater in CSSs exceeds the capacity of the collection system or treatment plant, combined sewer overflows (CSOs) discharge directly to surface water bodies (Burian et al., 1999). Significant chemical, physical and biological impacts of CSOs on receiving water bodies are well documented (e.g. Field and Sullivan, 2001). The adaptation of urban water and wastewater framework directives (CEC, 1996;1991) made these untreated or partially treated wastewater streams, a priority concern for the municipalities across Europe (Mostert, 2003). To study the adverse impacts of CSO on the receiving water quality, attentions have been focused on the qualitative and quantitative analysis of wet-weather flow (WWF) and its influence on treatment plant performance (Clark et al., 2007). The quality and quantity of 


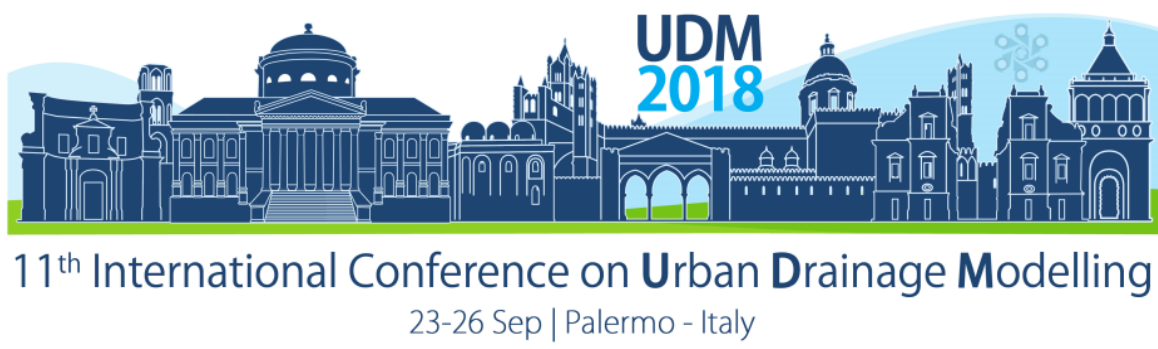

WWF depends on several factors including the size and layout of the sewer system, land use and contours, duration, intensity and areal extent of precipitation events (Kothandaraman, 1972). Since considering all of these parameters is not a straightforward task, an analysis of historical, routinely collected data of the WWTPs can be a potential alternative providing this crucial information for managing the fluctuating load during wet-weather events (Suarez and Puertas, 2005). Several studies have focused on elucidating empirical relationships between precipitation intensity $\left(P_{1}\right)$, influent flowrate $\left(Q_{i n}\right)$, and wastewater characteristics (among others, Berthouex and Fan, 1986; Giokas et al., 2002; Karagozoglu and Altin, 2003; Mines et al.,2007; Rouleau et al., 1997).

The majority of the reviewed studies were focused on seasonal and monthly average $P_{1}$ for investigating the impact of wet-weather on different influent parameters of WRRFs, while little attention has been paid to daily variability of rainfall quantities. Two main reasons stop researchers to consider daily $P_{1}: 1$ ) High incidence of zero values in rainfall records 2) Nonidentified minimum amount of precipitation which can affect specific plant influent data $\left(\mathrm{P}_{\text {th }}\right)$ and plant upset time ( $\left.\mathrm{t}_{\mathrm{u}}\right)$ after each wet-weather event (Oliveira-Esquerre et al., 2004).

In this study, a quantitative analysis of daily precipitation impacts on influent flowrate and associated water quality constituents for the Castiglione Torinese WRRF was performed on 7 years of historical data. Application of Segmentation of time series by use of Sliding Window algorithm was studied and a plant specific wet-weather definition is proposed.

\section{MATERIALS AND METHODS}

Castiglione Torinese WRRF is located about $11 \mathrm{~km}$ Northeast of Turin, capital of Piedmont, Northwest of Italy. From 2009 to 2015, 2440 consecutive days, wastewater quality parameters were measured by 24 hours composite sampling from the plant's influent. Inlet $\mathrm{N}-\mathrm{NH}_{4}{ }^{+}$ concentration (IAC) and concentration of COD and TSS were determined based on CNR-IRSA methodology (IRSA, 1994). Influent flowrate of the plant was continuously measured with 5minute interval by ultrasonic flowmeters installed at the entrance of each module of the plant. Precipitation data used in this study was provided by Piedmont Environmental protection agency (Arpa Piemonte, 2016). Eight meteorological stations (Bauducchi, Torino Vallere, Pino Torinese, Rivoli La Perosa, Turin via della Consolata, Torino Reiss Romoli, Castagneto Po, Caselle) equipped with tipping bucket rain gauges were selected in the catchment area to collect the daily precipitation data from 2009 to 2015. An arithmetic mean method was adapted to convert point precipitation values at different meteorological stations into a uniform value for the whole catchment area. All collected data sets (except $P_{I}$ ) were screened to identify missing elements, detect and exclude outliers. To minimize the loss of data, a statistical parametric approach of generalized extreme studentized deviate (GESD) method (Rosner, 1983) was adapted to determine the outliers of each univariate data set.

In this study, 5 time series of the recorded variables were considered as a sequence of time dependent values arranged by chronological order in successive time period of a day. Symbolically, each of the time series $(\mathrm{T})$, as a set of 2428 pairs of data is represented as follows:

$$
T_{v}=\left\{\left(v_{1}, t_{1}\right),\left(v_{2}, t_{2}\right), \ldots,\left(v_{i}, t_{i}\right)\right\}
$$

where for $i=1,2, \ldots, n=2428$ as a number of available observations, $v_{i}$ is the value of observed variables $\left(\mathrm{P}_{1}, \mathrm{Q}_{\mathrm{in}}, \mathrm{COD}\right.$, TSS and $\left.\mathrm{N}-\mathrm{NH}_{4}\right)$ and $t_{i}$ is the time (day) in which the value was recorded. In the segmentation process, each time series is divided into series of segments as consecutive portions of time series. Each segmentation (S) represents the time series (T) in a form of a set of $m$ consecutive segments as follows: 


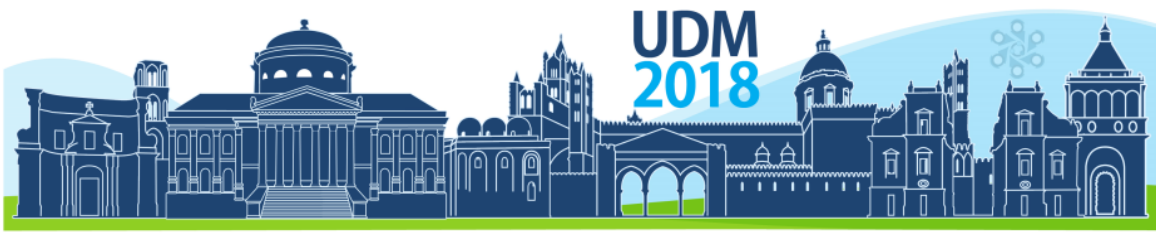

$11^{\text {th }}$ International Conference on Urban Drainage Modelling

23-26 Sep | Palermo - Italy

$$
S=\left\{S_{1}, S_{2}, \ldots, S_{j}\right\}
$$

Where for $j=1,2, \ldots, m$, each segment, $S_{j}$, consists of a certain number of pairs of data from the original time series. A sliding window algorithm (SWA) (Fig.1) method was implemented for segmentation of each time series.

Initial window

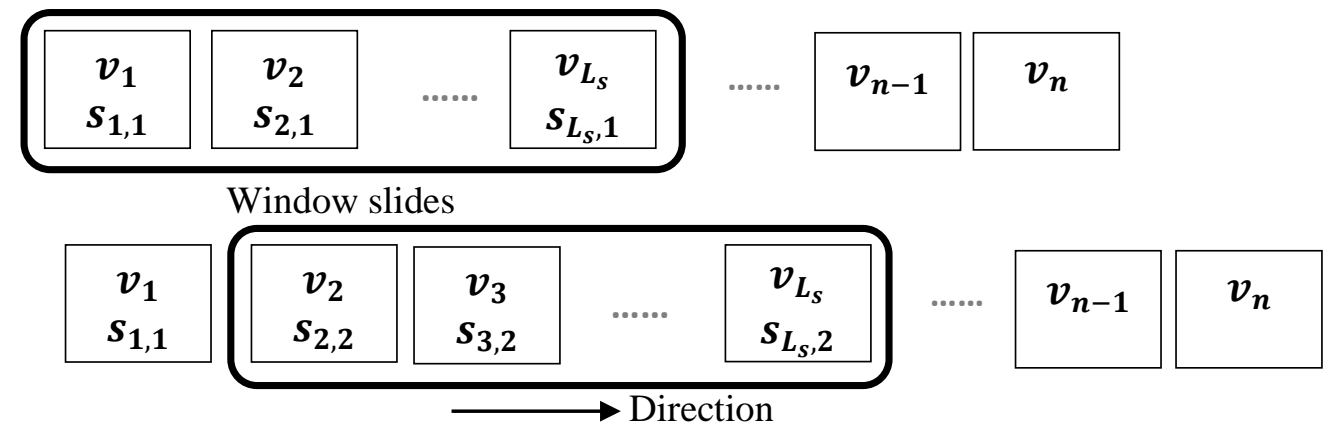

Figure. 1 Schematic description of sliding window algorithm

Integrating the results obtained from regression analysis of the treated time series with the sliding windows methodology, the best weather partitioning scenario was determined as a scenario which results in the highest coefficient of determination of positive correlation between $P_{s}$ and $Q_{\text {in }}$ of wet-weather data. For identification of the best combination of the $L_{s}$ (length of windows) and $\mathrm{P}_{\text {th }}$ (threshold precipitation) parameters, 25 scenarios with different values of $P_{\text {th }}(0,1,2,3,5 \mathrm{~mm} /$ day $)$ and $L_{s}(1,2,3,5,7$ days $)$ were developed and datasets were partitioned accordingly. Assuming the linear relation between $P s$ and $Q_{i n}$, the partitioning scenario with highest coefficient of determination of positive correlation between $P_{s}$ and $Q_{i n}$ of wet-weather data was selected and wet weather definition was proposed accordingly.

\section{RESULTS AND CONCLUSIONS}

From 25 developed scenarios for identification of the best combination of the LS and Pth parameters, the best correlation between $P s$ and $Q_{\text {in }}\left(R^{2}=0.35\right)$ was obtained for the scenario with $P_{t h}=3 \mathrm{~mm}$ and $L_{s}=2$ days. Therefore, for the Castiglione Torinese WWTP, wet-weather condition was defined as an event with accumulated precipitation rate $(\mathrm{Pa})$ greater than $3 \mathrm{~mm}$ which occurs at least 48 hours after previous measurable wet-weather. Further, according to the wet-weather definition, the data sets were partitioned to wet and dry weather data. From total number of 2728 data, 991 observations (36\%) were identified as wet-weather and the remaining as dry weather data. Further, statistical analyses were conducted to identify significant differences in the influent loadings and concentrations under wet and dry flow conditions. Kernel density estimation (KDE) was performed to estimate and compare the probability density functions of the dry and wet sets of observations. In KDE a Gaussian kernel was used as a weighting function and the probability density functions (PDF) were assessed by computing the geometric mean of kernel functions for all data sets. Given the importance of optimally chosen bandwidth of the kernel on the resulting estimate, normal distribution approximation method proposed in Silverman (2018) was implemented to identify the optimum bandwidths. Figure. 2 demonstrates the Kernel density estimations of wet and dry weather data sets. As anticipated, the influent flowrates in wet-weather condition are higher by $15-25 \%$ than those of dry weather condition. On the other hand, the reduction of influent 


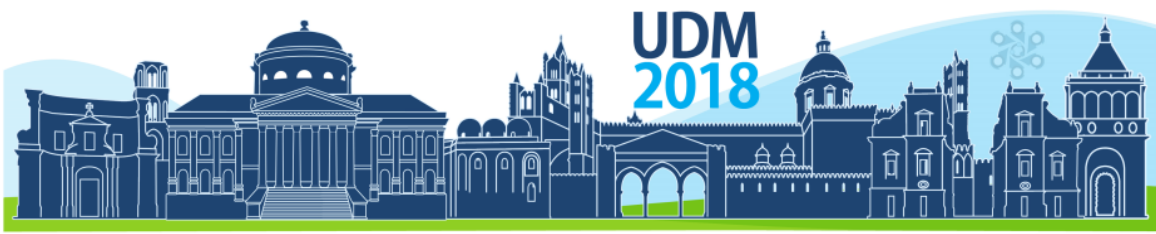

$11^{\text {th }}$ International Conference on Urban Drainage Modelling

23-26 Sep | Palermo - Italy

TSS, COD and N-NH4 in the wet-weather condition with dilution factors of $(0.06-0.08),(0.15-$ 0.17), (0.18-0.2) were observed (Figure. 2 a, b and c respectively).
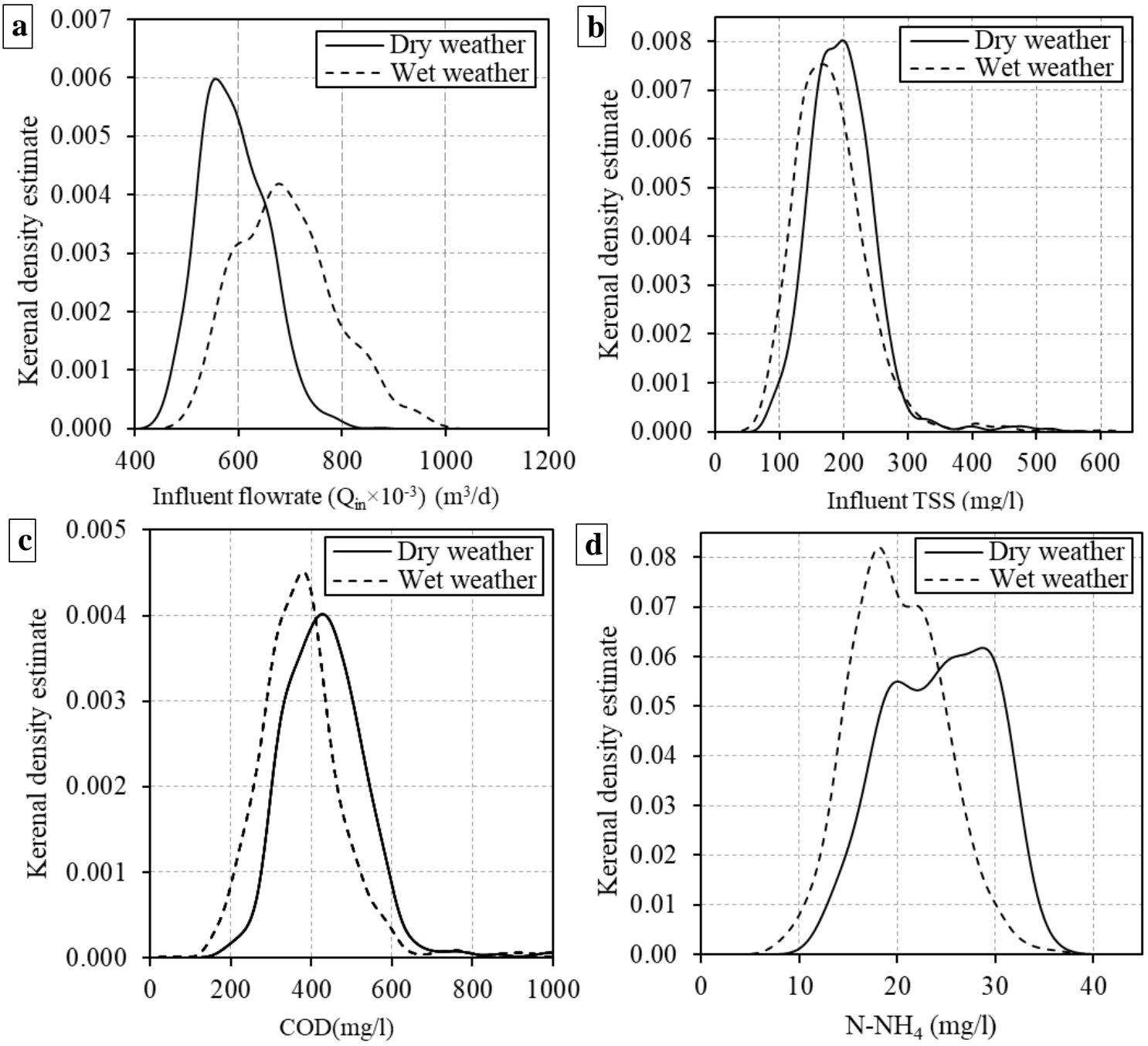

Figure. 2 Kernel density estimations of wet and dry weather Influent flow (a), TSS (b), COD (c) and N-NH4 (d)

\section{References}

Arpa Piemonte. (2016). Agenzia regionale per la protezione ambientale. [ONLINE] Available at: http://www.arpa.piemonte.gov.it/. [Accessed 1 February 2016].

Berthouex, P., and Fan, R. (1986). Evaluation of treatment plant performance: causes, frequency, and duration of upsets. J. Water Pollut. Control Fed. 368-375.

Bertrand-Krajewski, J.-L., Lefebvre, M., Lefai, B., and Audic, J.-M. (1995). Flow and pollutant measurements in a combined sewer system to operate a wastewater treatment plant and its storage tank during storm events. Water Sci. Technol. 31, 1-12.

Burian, S.J., Nix, S.J., Durrans, S.R., Pitt, R.E., Fan, C.-Y., and Field, R. (1999). Historical development of wetweather flow management. J. Water Resour. Plan. Manag. 125, 3-13.

CEC. (1996). Directive concerning integrated pollution prevention and control (96/61/EEC). Official Journal of the European Community, L 257, 26-40. 


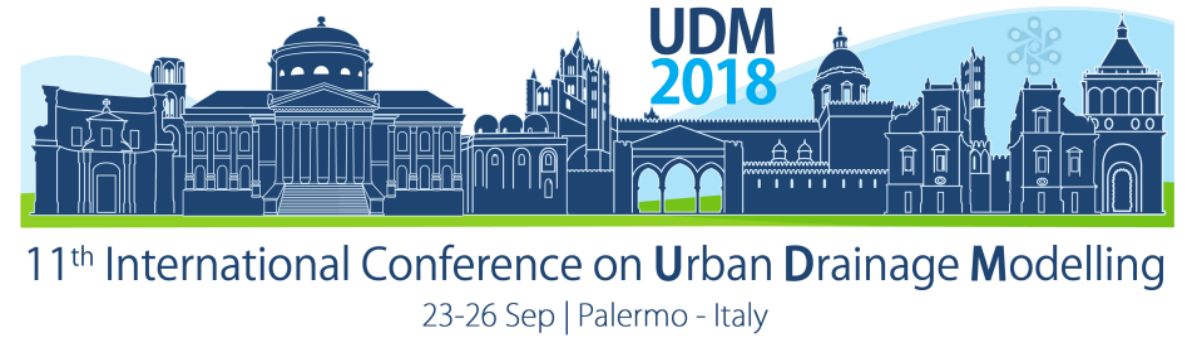

CEC. (1991). Directive concerning urban wastewater treatment (91/271/EEC). Official Journal of the European Community, L135, 40-52.

Clark, S.E., Burian, S., Pitt, R., and Field, R. (2007). Urban wet-weather flows. Water Environ. Res. 79, $1166-1227$.

Field, P.R., and Sullivan, P.D. (2001). Overview of EPA's wet-weather flow research program. Urban Water 3, 165169.

Franzblau, A.N. (1958). A primer of statistics for non-statisticians.

Giokas, D., Vlessidis, A., Angelidis, M., Tsimarakis, G.J., and Karayannis, M. (2002). Systematic analysis of the operational response of activated sludge process to variable wastewater flows. A case study. Clean Technol. Environ. Policy 4, 183-190.

IRSA, C., 1994. Metodi analitici per le acque. Ist. Poligr. E Zecca Dello Stato Roma.

Karagozoglu, B., and Altin, A. (2003). Flow-rate and pollution characteristics of domestic wastewater. Int. J. Environ. Pollut. 19, 259-270.

Kothandaraman, V. (1972). Water quality characteristics of storm sewer discharges and combined sewer overflows (Illinois State Water Survey).

Lovrić, M., Milanović, M., and Stamenković, M. (2014). Algoritmic methods for segmentation of time series: An overview. J. Contemp. Econ. Bus. Issues 1, 31-53.

Mines Jr, R.O., Lackey, L.W., and Behrend, G.H. (2007). The impact of rainfall on flows and loadings at Georgia's wastewater treatment plants. Water. Air. Soil Pollut. 179, 135-157.

Mostert, E. (2003). The European water framework directive and water management research. Phys. Chem. Earth Parts ABC 28, 523-527.

Oliveira-Esquerre, K.P., Seborg, D.E., Bruns, R.E., and Mori, M. (2004). Application of steady-state and dynamic modeling for the prediction of the BOD of an aerated lagoon at a pulp and paper mill: Part I. Linear approaches. Chem. Eng. J. 104, 73-81.

Rosner, B. (1983). Percentage points for a generalized ESD many-outlier procedure. Technometrics $25,165-172$.

Rouleau, S., Lessard, P., and Bellefleur, D. (1997). Behaviour of a small wastewater treatment plant during rain events. Can. J. Civ. Eng. 24, 790-798.

Suarez, J., and Puertas, J. (2005). Determination of COD, BOD, and suspended solids loads during combined sewer overflow (CSO) events in some combined catchments in Spain. Ecol. Eng. 24, 199-217. 


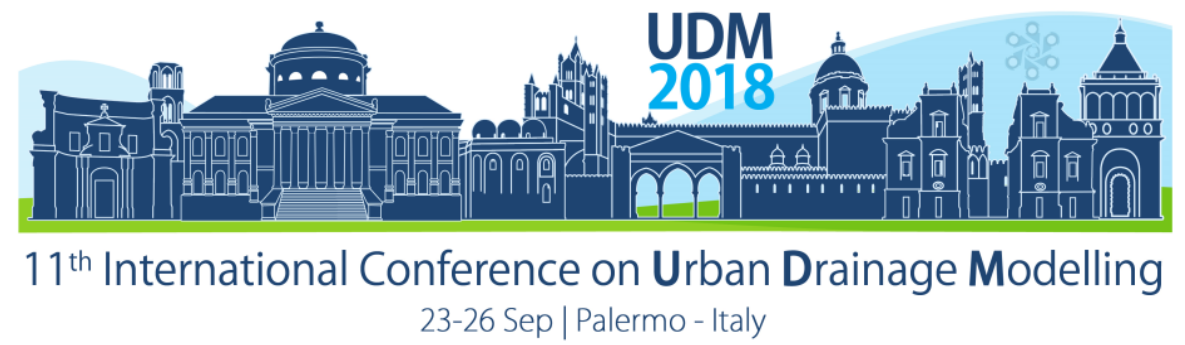

\title{
Modelling strategies to enable the uptake of decentralised water treatment technologies
}

\author{
Adam C. Castonguay1, Md Sayed Iftekhar², Christian Urich¹, Ana Deletic ${ }^{1,3}$ \\ ${ }^{1}$ Monash Infrastructure Research Institute, Department of Civil Engineering, Monash University 3800, Australia, \\ ${ }^{2}$ School of Agriculture and Environment, The University of Western Australia, Perth 6009, Australia, ${ }^{3}$ School of \\ Civil and Environmental Engineering, University of New South Wales, Sydney, 2052 Australia
}

\begin{abstract}
Nature-based solutions are considered as a flexible, fit-for-purpose and multifunctional approach to offset urban growth and the resulting increase of stormwater runoff and pollution. However, many uncertainties remain regarding the approach for the installation of decentralised stormwater treatment solutions, such as the economic evaluation of environmental benefits, the costs of systems over time, the property rights and maintenance responsibilities of such systems, etc. This paper presents an agent-based model to explore and simulate the decision-making and interactions of two types of agents: a local municipality and developers. The model is applied to evaluate policy mechanisms to increase the adoption of water sensitive urban design in a suburb of Melbourne. Policy mechanisms are evaluated by their capacity to achieve the municipality's pollution removal target by 2040 and by the cumulative net present value of installed assets over time. Results show that it is necessary to involve developers if the municipality hopes to achieve its pollution removal target, but mandatory installation of decentralised water treatment systems by developers is likely to yield greater costs than benefits.
\end{abstract}

Keywords: agent-based modelling, exploratory modelling, urban stormwater management, water infrastructure planning, water sensitive urban design

\section{INTRODUCTION}

Decentralised stormwater treatment technologies, also known as Water Sensitive Urban Design (WSUD) in Australia, Low Impact Development (LID) systems in the USA, or Sponge City technologies in China, have the potential to offset the negative impacts of urbanisation by providing a range of benefits, including stormwater treatment and harvesting, heat mitigation and flood risk reduction in a cost-effective and flexible way (Moore and Hunt 2012; Raymond et al. 2017). However, many uncertainties remain regarding the most effective approach to promote the installation of nature-based stormwater treatment solutions, such as the economic evaluation of environmental benefits, the various costs of systems over time, property rights, etc. (Roy et al. 2008; O'Donnell et al. 2017). Such decision-making under uncertainty can be investigated with an exploratory agent-based model, in which the decision-making of stakeholders or actors in the urban water system can be simulated autonomously.

The aim of this paper is to explore strategies available to local municipalities to enable the uptake of WSUD technologies. The objectives are to (1) evaluate strategies or policy mechanisms that can be used by municipalities to achieve its pollution removal target $(45 \%$ Total Nitrogen (TN) reduction by 2040), and (2) assess the efficiency of strategies by investigating the discounted benefits and costs over time of the installed technologies. 


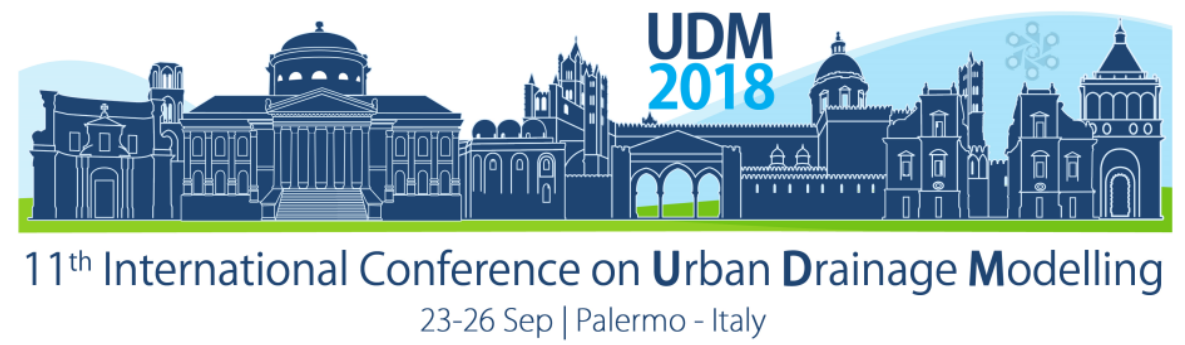

\section{MATERIALS AND METHODS}

\subsection{Modelling approach}

We apply an agent-based model that was developed to simulate the decision-making process of local governments to install WSUD systems, implemented in the DynaMind software (Urich et al. 2012). The model has been previously applied and validated with historical uptake of raingardens, constructed wetlands and ponds in the Kingston council for the period 2005-2012 (Castonguay et al. 2018a). In this paper, the model includes two types of agents, i.e., a local government and developers, and is applied for exploratory analysis to assess strategies to offset the impact of urban development and achieve pollution removal targets at the municipality scale. We selected a simulation period from 2016 to 2040 , therefore 25 time steps, as the Kingston city council has the objective to achieve its target pollution removal $(45 \%$ TN reduction) by 2040 (AECOM 2012). The urban development is simulated at parcel scale according to the urban development model based on Urich and Rauch (2014).

\subsection{Simulated strategies}

We investigate different strategies or policy mechanisms available to the local government to achieve its pollution removal target more efficiently. The model tests three scenarios of budget allocated for the installation of WSUD assets (B) and three scenarios of interactions with developers to offset the impervious areas generated by new developments (I), therefore generating nine model combinations:

- B1: Current allocation - The council allocates $250,000 \$$ annually for the installation of WSUD assets. This corresponds to the actual budget allocated to the installation of WSUD systems by the council as of 2017.

- B2: Medium allocation - The council allocates 500,000\$ annually for the installation of WSUD assets.

- B3: High allocation - The council allocates $1,000,000 \$$ annually for the installation of WSUD assets.

- 11: No interaction - Developers are not required to treat stormwater.

- 12: Target treatment - Developers are required to achieve the TN removal target (45\%) when a new house is built.

- 13: Full treatment - Developers are required to treat $100 \%$ of the impervious area generated by the new development or pay a stormwater offset to the council. The stormwater offset is calculated based on the current contribution set by the Kingston city council (Melbourne Water 2016):

$$
O_{a}=413.61 a^{0.5711}
$$

where $O_{a}$ is a unique contribution to be paid to the council in $\mathrm{AU} \$$ and $a$ is the impervious area generated by the new development in $\mathrm{m}^{2}$.

\subsection{Uncertainty assessment}

Due to the uncertainty related to several input parameters, such as costs, lifespans of system types and effective impervious area, a range was selected for sampling from uniform distributions. In total, 100 simulations were carried out for each of the nine model combinations. For more detail on the input parameters, see Castonguay et al. (2018a). 


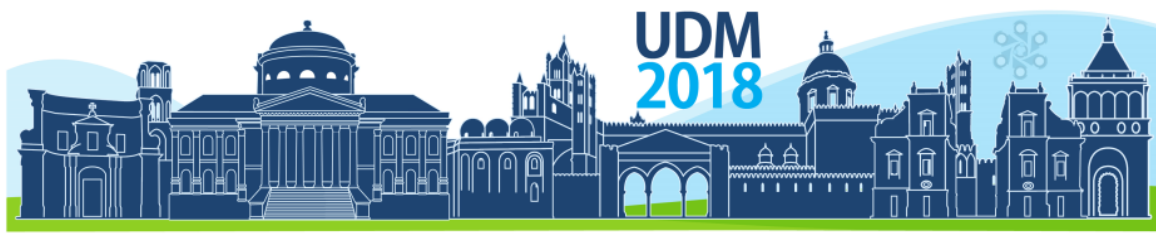

$11^{\text {th }}$ International Conference on Urban Drainage Modelling

23-26 Sep | Palermo - Italy

\section{RESULTS AND DISCUSSION}

\subsection{Pollution removal effectiveness of strategies}

Figure 1 shows the effectiveness of each strategy to achieve the pollution removal target set by the council by 2040. None of the strategies are able to achieve the target. Raising the budget (B1 to B3) increases the percentage of catchment treated but this strategy is relatively ineffective compared to interaction strategies (I). Interaction strategy I3: Full treatment is the most effective to remove pollution as developers are required to pay a contribution to the council, which is later reinvested in WSUD placement.

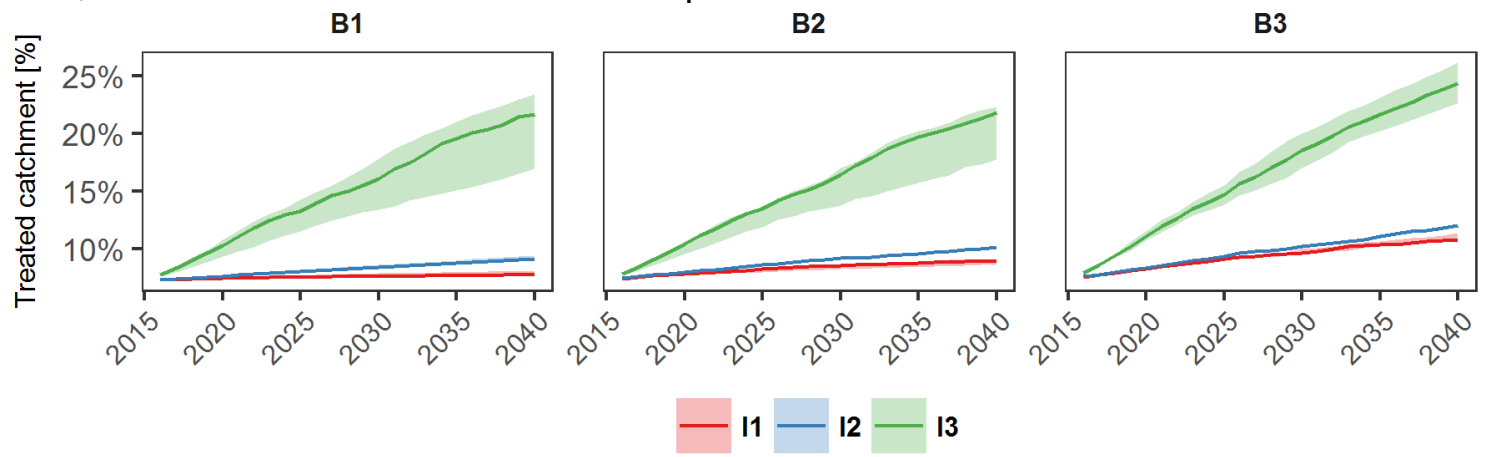

Figure 1. Effectiveness of policy mechanisms to achieve the council's pollution removal target according to the three budget $(B)$ and three interactions (I) scenarios.

\subsection{Net present value of strategies}

Figure 2 indicates that both strategies I1: No interaction and I3: Full treatment can provide a positive net present value (NPV) at the end of simulations under all budget (B) scenarios.

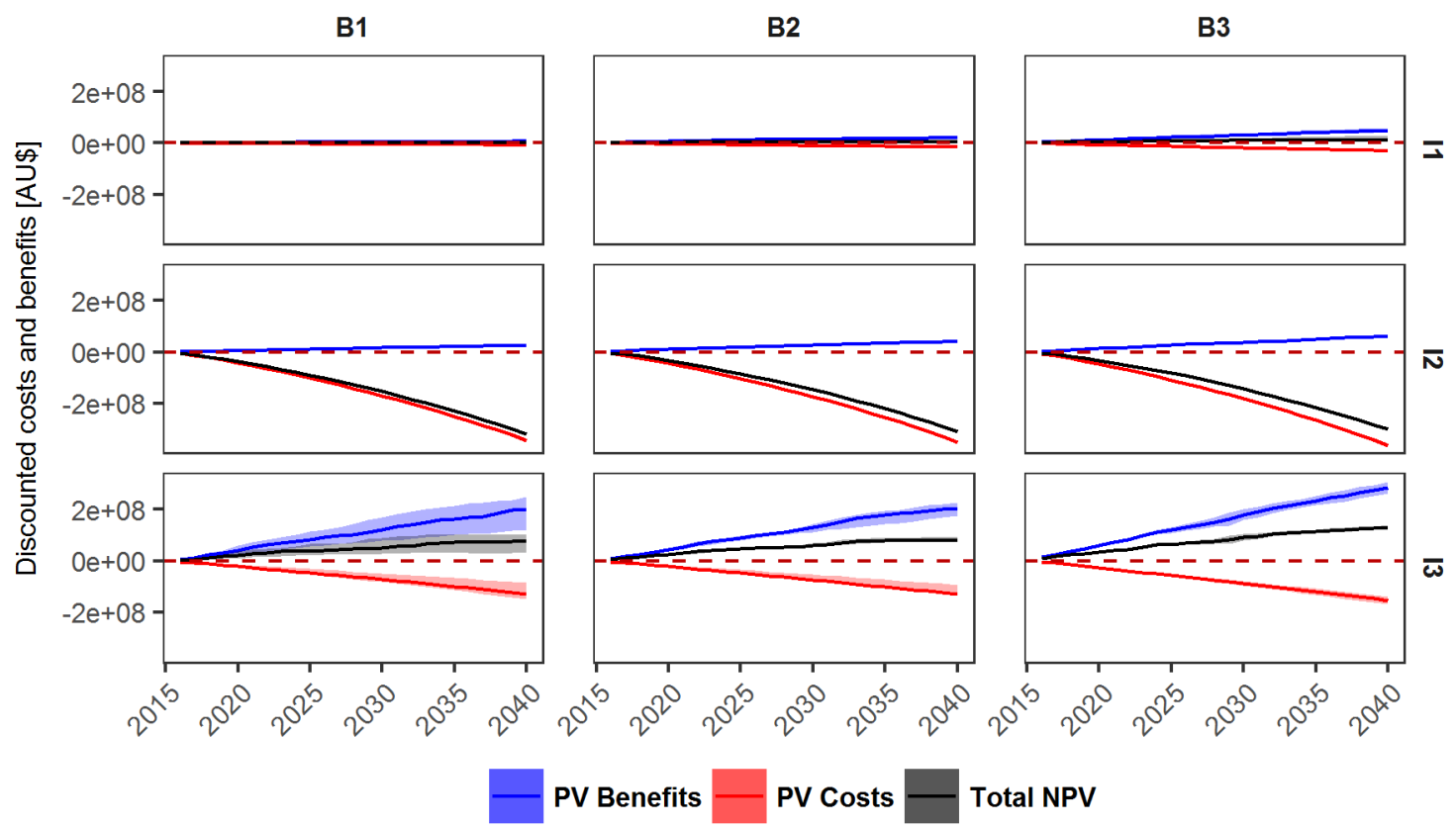

Figure 2. Comparison of the present value of TN removal benefits, present value of costs of WSUD assets and the total NPV according to the budget (B) and interactions (I) scenarios. The dashed line indicates the threshold for a positive NPV. 


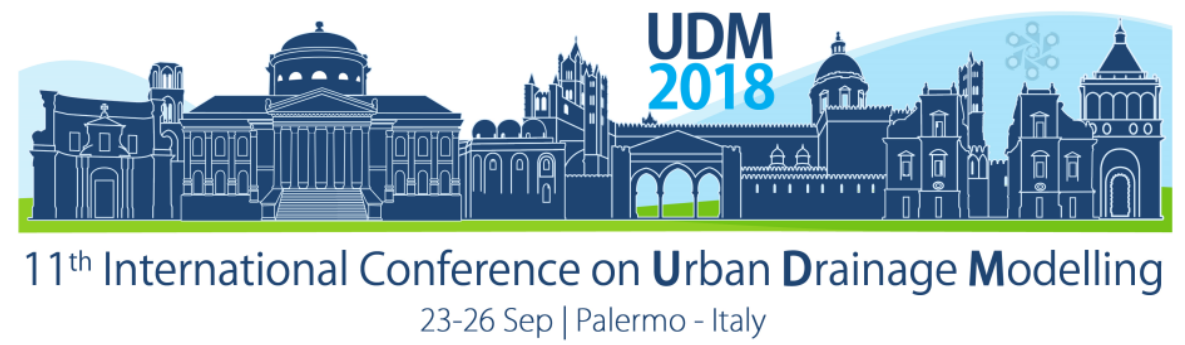

In contrast, 12: Target treatment simulations generate higher costs than benefits and therefore a negative cumulative NPV for all budget scenarios. This can be explain by the lack of economy of scale available to developers, as new developments in the simulations consist mainly of the subdivision of relatively small parcels. Therefore, for smaller developments, the payments of a contribution or stormwater tax from the developer to the council is more beneficial than the installation of a treatment system by the developer, as shown by the larger cumulative NPV for simulations with interaction scenario I3: Full treatment.

\section{CONCLUSIONS}

We presented a novel modelling approach to simulate strategies or policy mechanisms to offset the impact of urban development and achieve a pollution removal target by influencing the behaviour of developers. Results showed that only increasing the council's budget for WSUD allocation is likely to be insufficient to achieve its pollution removal target. Instead, involving developers by requiring a stormwater offset contribution yields greater pollution removal benefit in a cost-effective way. However, mandatory installation of decentralised water treatment systems by developers is likely to yield greater costs than benefits due to the lack of economy of scale.

The model could be improved to include other decentralised water technologies, such as green roofs and rainwater harvesting tanks (Castonguay et al. 2018b), which could provide private benefit of water savings and therefore appear more cost-effective to household. The model could also be used to test different strategies, such as spatially targeted requirements to attain environmental targets with a more spatially-explicit and cost-effective approach.

\section{References}

AECOM, 2012. Integrated water cycle strategy, Prepared for City of Kingston.

Castonguay A. C., Iftkhar M. S., Urich C., Bach P. M. and Deletic A., 2018a. Integrated modelling of stormwater treatment systems uptake. Water Res. Submitted.

Castonguay A. C., Urich C., Iftekhar M. S. and Deletic A., 2018b. Modelling urban water management transitions: a case of rainwater harvesting. Environ. Modell. Softw. Submitted.

Melbourne Water, 2016. Stormwater Quality - In-Lieu Developer Contributions. https://www.kingston.vic.gov.au/files/assets/public/strategic-planning/environmental-planning/stormwaterquality-in-lieu-contributions-brochure_v7.pdf.

Moore T. L. C. and Hunt W. F., 2012. Ecosystem service provision by stormwater wetlands and ponds - A means for evaluation? Water Res. 46(20), 6811-6823.

O'Donnell E. C., Lamond J. E. and Thorne C. R., 2017. Recognising barriers to implementation of Blue-Green Infrastructure: a Newcastle case study. Urban Water J. 14(9), 964-971.

Raymond C. M., Frantzeskaki N., Kabisch N., Berry P., Breil M., Nita M. R., Geneletti D. and Calfapietra C., 2017. A framework for assessing and implementing the co-benefits of nature-based solutions in urban areas. Environ. Sci. Policy 77, 15-24.

Roy A. H., Wenger S. J., Fletcher T. D., Walsh C. J., Ladson A. R., Shuster W. D., Thurston H. W. and Brown R. R., 2008. Impediments and solutions to sustainable, watershed-scale urban stormwater management: Lessons from Australia and the United States. Environ. Manage. 42(2), 344-359.

Urich C., Burger G., Mair M. and Rauch W., 2012. DynaMind-A Softwaretool for Integrated Modelling of Urban Environments and their Infrastructure. In: 10th International Conference on Hydroinformatics, Hamburg, Germany.

Urich C. and Rauch W., 2014. Exploring critical pathways for urban water management to identify robust strategies under deep uncertainties. Water Res. 66, 374-389. 


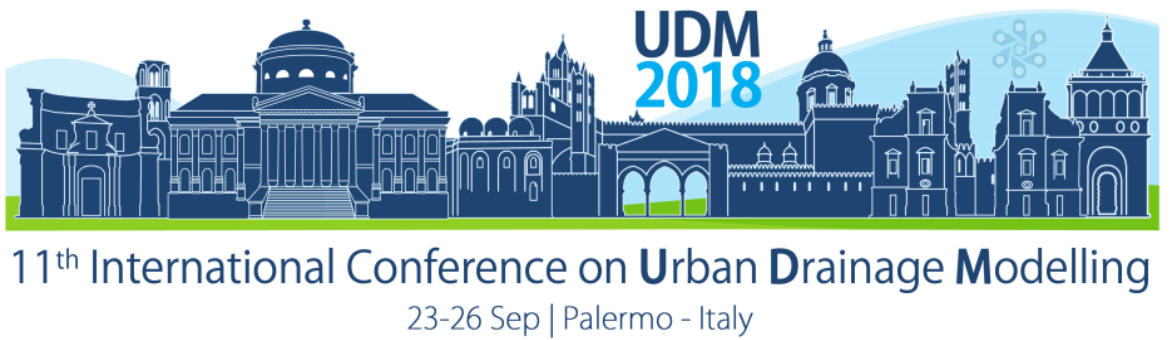

\title{
Wastewater System Ventilation - a Friend or Adversary?
}

\author{
Steve Adkins ${ }^{1}$, Slobodan Djordjević ${ }^{1}$ and Dragan A. Savić ${ }^{1}$ \\ ${ }^{1}$ University of Exeter, Centre for Water Systems, Exeter, United Kingdom
}

\begin{abstract}
Wastewater systems and their designs have been documented for thousands of years. However, little written evidence exists of the potential unpleasant odours that can be associated with drainage systems until the mid-nineteenth century. This paper presents a holistic overview of historic ventilation systems and wastewater network designs. Modelling the ventilation and potential fugitive emissions from urban drainage systems is a significant challenge. Yet using a revised approach, in association with calibrated and verified case study data, reliable holistic modelling may be achieved. Modern fugitive emissions are discussed and opportunities are further examined with the ventilation and gas in headspace model. This key predictive information may potentially extend asset life and therefore enable cost benefit analysis if the correct corrosion abatements solutions are applied.
\end{abstract}

Keywords: sewer networks, ventilation, corrosion abatement

\section{INTRODUCTION}

Wastewater systems ventilation has a checkered history; literature records the presence of sewage systems since before $3000 \mathrm{BC}$ (De Feo et al., 2014). However, there is little written evidence regarding the foul smells associated with sewer and urban wastewater systems until the nineteenth century (Faraday, 1855; Eassie, 1876; Halliday, 2013). Once ventilation practices were accepted as a necessary part of wastewater design criteria, many studies and techniques quickly became adopted (Oldright, 1883; Boyle, 1899; Donaldson, 1932).

Sadly, several of these practises were applied only after a catastrophe or occupational health and safety incidents had occurred, for example in Los Angeles where several manhole covers were catapulted via a sewer explosion (Knowlton, 1932). After the inspections of a substantial concrete trunk sewer main, it became apparent that it was necessary to evaluate the asset more thoroughly. The specific pipe design of this particular concrete infrastructure was of oviform cross section and the whole design criteria was to maintain a totally sealed system (Wong, 1999). This process may have succeeded in mitigating potential odour complaints, but the lack of ventilation exacerbated internal sulphide concrete corrosion. The subsequent report detailed the necessity to ventilate this wastewater system and reduce concrete corrosion by hydrogen sulphide (Brown, 1937). This analysis was the first ever undertaken anywhere in the world regarding large concrete sewer assets that had been attacked by sulphide corrosion.

\section{A HOLISTIC OVERVIEW OF SEWER VENTILATION}

Literature from the late 19th century suggests that the medical profession was taking a keen interest in sewer smells, alleged miasmas (Chadwick, 1842), appropriate traps (water seals) and wastewater systems ventilation (Lancet, 1870). Further references to natural and forced ventilation experiments are discussed in (Lancet, 1911). This particular article referenced the use of water seals with natural and forced ventilation of branch drains to eliminate street odours. This well documented project has no direct measurement records for sulphide gas in 


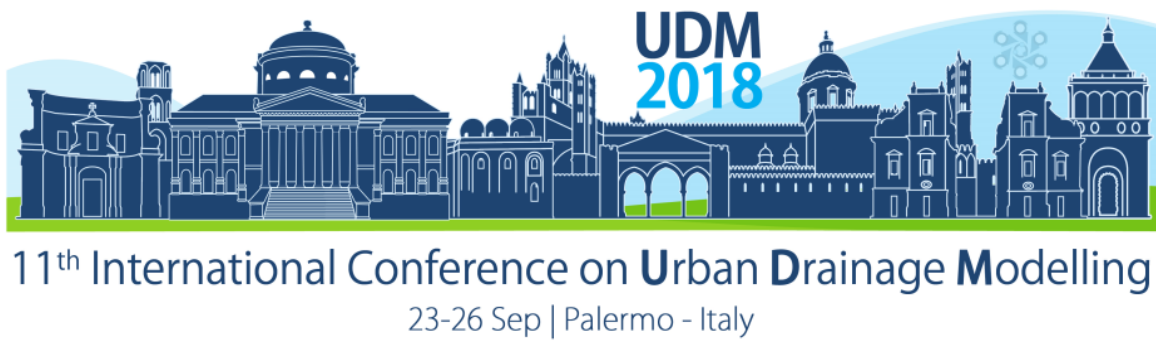

the sewer headspace, but basic measurements of ventilation infrastructure and associated pipework are provided and therefore capacities of available airflow and $\mathrm{CO}_{2}$ gas within the associated vents and sewers were documented, which is of historical importance. Changes in regulations over the years has cast a shadow over current vent designs and practice.

Nowadays odour complaints are taken very seriously by urban water utilities and councils. Legislation has ensured safety concerns for the public and wastewater maintenance workers wellbeing takes a high priority. Additional pressure may also be exerted via the associated utility regulator and the relevant environmental protection agency may also add weight to ensure responsible action is taken to mitigate odour complaints with the asset owner (DEFRA, 2006). There are many different vapours emitted from wastewater networks and, as such, these fugitive emissions are completely wastewater catchment dependant. For example, a catchment that only receives domestic wastes in the network will behave completely differently (biologically) than a mixed industrial and domestic catchment and associated drainage system that may also contain additional high strength trade waste material entering the sewer.

The design of the network also has implications. While the geographical location may predict specific civil engineering techniques, the age and capacity of the sewer network may present other challenges. For example, low asset gradients are associated with low flow velocity. Therefore, due to the long wastewater residence times within large pipes, the asset becomes a slow-moving sewage storage system. This large volume of effluent then mimics a shifting micro wastewater treatment facility, as gravity transfer will take protracted amounts of time for the sewage to reach a treatment works. Consequently, the biological activity and chemical changes to the wastewater should not be underestimated (Warith et al., 1998). Any biological activity may deplete available dissolved oxygen in wastewater and has the potential for fugitive emissions to contaminate sewer headspace if the network is not adequately ventilated.

The lack of available oxygen may also promote the growth of sulphide producing bacteria. In systems with low velocities, these biological process have the potential to generate large amounts of hydrogen sulphide and other gases while the wastewater is technically in transit (Liu et al., 2016). Most biological processes need oxygen to support their function, but when the available dissolved oxygen is depleted, the microbiology will adapt and encourage anaerobic micro bacterial change (Hvitved-Jacobsen et al., 2013).

\section{VENTILATION}

Focussing on just the ventilation aspects of gravity drainage systems, surface drag has the potential to increase airflow and therefore enhance the wastewater systems air in headspace transfer capacity. The empirical approach was originally developed by the research performed by Pescod and Price (1982). Their method was broken down into three primary considerations: (i) where ventilation inlets or inducts provided a source of fresh air, stacks or educts were used as primary exhausts and therefore, wind velocity passing over these stacks or educts due to the stack effect has the potential to suck out foul air (Brocard et al. 2012), (ii) the second variable observes the air and wastewater boundary - the drag creates a frictional interface and induces airflow in the direction of the wastewater flow, (iii) the final variable is barometric pressure - the differential air pressure in the network creates a pressure gradient to sustain an airflow (Edwini-Bonsu and Steffler, 2006). 


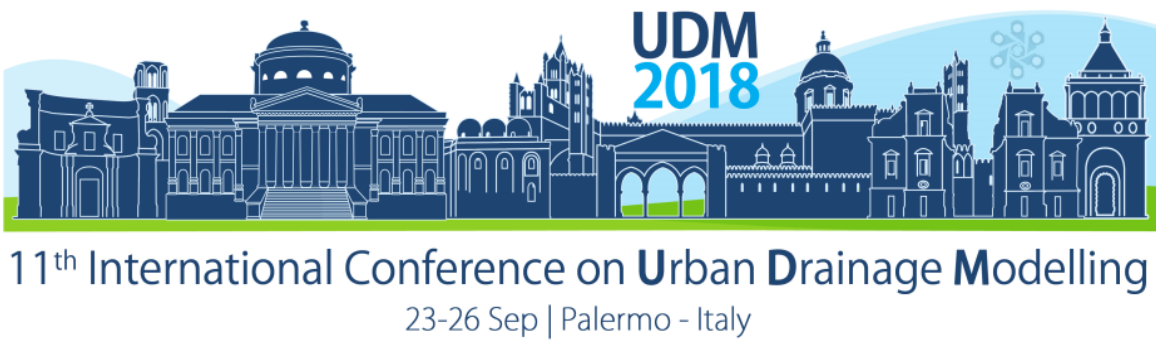

Since this time, others including WREF (2007), Wang et al. (2011), Hentz et al. (2013) and Lowe (2016), suggest there is a general consensus that the higher the surface velocity of the wastewater flow, the greater the drag coefficient and hence higher airflow. However, this scenario is not without certain caveats due to air introduced into the infrastructure via forced air ventilation, atmospheric vents and free path obstructions. Generally, sewer systems are associated with hydrogen sulphide gas, sometimes termed as "Sewer Gas" or a 'rotten eggs' odour (Pennell et al., 2013). $\mathrm{H}_{2} \mathrm{~S}$ gas is toxic (OSHA, 2006), in large concentrations flammable and has the potential to destroy concrete infrastructure. Australasian Corrosion Association (2015) produced a report specifically for the water industry, suggesting that costs directly apportioned to concrete corrosion were somewhere between 3-5\% of GDP.

A question may then be asked regarding potential benefits to a wastewater system via appropriate ventilation and associated odour mitigation? If it were possible to model potential hydrogen sulphide generation, is it then appropriate to apportion a reduction in sulphide production and hence indicate the potential cost savings in lower asset damage and potential rehabilitation expenditure? If so, it is suggested that specific odour generation and ventilation modelling may have the capacity to predict cost savings, project asset life and deliver a direct cost benefits analysis to water utilities if appropriate ventilation measures are applied.

The measurement of wastewater levels is reasonably straightforward. However, the effluent velocity parameter can be difficult to accurately measure due to several variable events. For example, two situations which in many circumstances cannot be forecast include very low flow velocities with low turbulence, which can challenge the sensors accuracy, and increased flows. In certain circumstances, high flows exhibit extreme variance in effluent surface turbulence. During several case studies, field systems have been developed to use Doppler radar to map the surface velocity of wastewater, but when the velocities are low, typically below $0.23 \mathrm{~m} / \mathrm{s}$ (Hach, 2012) errors may occur.

When only level data is available, open channel flow may be described by Saint-Venant equations, but may also be simplified with the judicious use of Manning formula. From these computations, using the Pescod and Price approach, air velocity may be calculated. It should be noted that the air velocity is normally less than the effluent velocity. Average air velocities are typically $5 \%$ to $30 \%$ of the average wastewater velocities (Pescod and Price, 1982).

\section{CONCLUSIONS AND FUTURE RESEARCH}

Besides the integration of wastewater flow, air / gas in headspace and differential air pressure variance, recent significant developments in microbiology regarding the specific process of bacterial sulphide production in urban sewer systems ( $\mathrm{Li}$ et al. 2017) need to be incorporated with existing knowledge to produce a completely new modelling approach. In the past, most research has been focused on flow or sulphide specific modelling. Little focus has been applied to a wholly optimised holistic approach, fully embracing flow, airspace / ventilation, the potential biological production of fugitive emissions and odour control. Nevertheless, while methane production within an urban drainage system has been acknowledged (Eijo-Río et al., 2015), with current global warming and the significant effects of methane release into the atmosphere as a greenhouse gas should also be accommodated within this methodology. This model development is 'work in progress' and will be reported at a later date. 


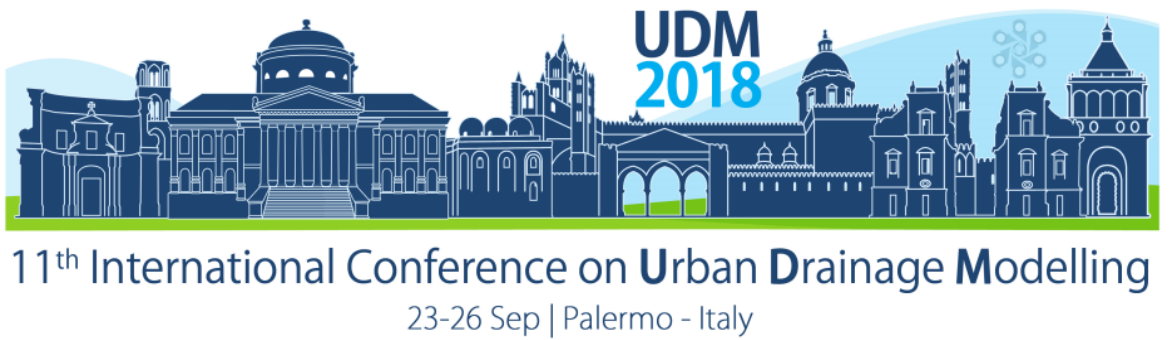

\section{References}

Australasian Corrosion Association, A. (2015) Cost of Urban Water Infrastructure Failure [press release], available: https://pacetoday.com.au/cost-of-urban-water-infrastructure-failure/ [accessed 9th November 2017].

Boyle, R. (1899) Natural and Artificial Methods of Ventilation, London: Robert Boyle \& Son Limited.

Brocard, D., McMasters, F. and Thomas, D. (2012) 'Air Flow in Sewers', Proceedings of the Water Environment Federation, 2012(16), 949-955.

Brown, R.F. (1937) 'North Outfall Sewer Inspection, City of Los Angeles', Sewage Works Journal, 9(3), 446-454.

Chadwick, E. (1842) Report on the sanitary condition of the labouring population og Great: Britain: supplementary report on the results of special inquiry into the practice of interment in towns, HM Stationery Office.

De Feo, G., Antoniou, G., Fardin, H., El-Gohary, F., Zheng, X., Reklaityte, I., Butler, D., Yannopoulos, S. and Angelakis, A. (2014) 'The Historical Development of Sewers Worldwide', Sustainability, 6(6), 3936.

DEFRA (2006) Nuisance smells: how councils deal with complaints, DEFRA, London https://www.gov.uk/government/uploads/system/uploads/attachment data/file/645288/pb11833sewageodour-cop.pdf [accessed 15th November 2017].

Donaldson, D. (1932) 'Sewer ventilation, why and how?', Sewage Works Journal, 108-113.

Eassie, W. (1876) Healthy Houses: A Handbook to the History, Defects, and Remedies of Drainage Ventilation, Warming, and Kindred Subjects; with Estimates for the Best System in Use, London: D. Appleton.

Edwini-Bonsu, S. and Steffler, P. (2006) 'Dynamics of air flow in sewer conduit headspace', Journal of Hydraulic Engineering, 132(8), 791-799.

Eijo-Río, E., Petit-Boix, A., Villalba, G., Suárez-Ojeda, M.E., Marin, D., Amores, M.J., Aldea, X., Rieradevall, J. and Gabarrell, X. (2015) 'Municipal Sewer Networks as Sources of Nitrous Oxide, Methane and Hydrogen Sulphide Emissions: A Review and Case Studies', Journal of Environmental Chemical Engineering, 3(3), 2084-2094.

Faraday, P.M. (1855) 'Observations on the filth of the Thames', The Times.

Hach (2012) 'Flo-Dar § AV Sensor', 1-4.

Halliday, S. (2013) The great stink of London: Sir Joseph Bazalgette and the cleansing of the Victorian metropolis, Stroud, Gloucestershire, UK: Sutton Publishing.

Hentz, L., Eftekharzadeh, S. and Atoulikian, R., P.E (2013) Ventilation and Odor Control for Sewers and Tunnels.

Hvitved-Jacobsen, T., Vollertsen, J. and Nielsen, A.H. (2013) Sewer Processes: Microbial and Chemical Process Engineering of Sewer Networks, Second Edition, CRC Press.

Knowlton, W.T. (1932) 'Explosions in Sewers and Sewer Maintenance', Sewage Works Journal, 4(1), 114-118.

Lancet, T. (1870) 'Reviews and Notices of Books', The Lancet, 96(2468), 855-857.

Lancet, T. (1911) 'Experiments in Sewer Ventilation at Leicester', The Lancet, 177(4566), 618-620.

Li, X., Kappler, U., Jiang, G. and Bond, P.L. (2017) 'The Ecology of Acidophilic Microorganisms in the Corroding Concrete Sewer Environment', Frontiers in Microbiology, 8(683).

Liu, Y.C., Tugtas, A.E., Sharma, K.R., Ni, B.-J. and Yuan, Z. (2016) 'Sulfide and Methane Production in Sewer Sediments: Field Survey and Model Evaluation', Water research, 89(Supplement C), 142-150.

Lowe, S. (2016) 'Sewer Ventilation: Factors Affecting Airflow and Modeling Approaches', Journal of Water Management Modeling, DOI: 10.14796/JWMM.C395.

Oldright, W. (1883) 'The overhead ventilation of sewers', Public health papers and reports, 9, 233-237.

OSHA (2006) Toxicological Profile for Hydrogen Sulfide, Washington, D.C., USA: Occupational Safety and Health Administration, U.S. Department of Labor, available: http://www.atsdr.cdc.gov/toxprofiles/tp114.pdf [accessed 17th March 2018].

Pennell, K.G., Scammell, M.K., McClean, M.D., Ames, J., Weldon, B., Friguglietti, L., Suuberg, E.M., Shen, R., Indeglia, P.A. and Heiger-Bernays, W.J. (2013) 'Sewer Gas: An Indoor Air Source of PCE to Consider During Vapor Intrusion Investigations', Groundwater Monitoring \& Remediation, 33(3), 119-126.

Pescod, M.B. and Price, A.C. (1982) 'Major Factors in Sewer Ventilation', Journal Water Pollution Control Federation, 54(4), 385-397.

Wang, Y., Nobi, N., Nguyen, T. and Vorreiter, L. (2011) 'A dynamic ventilation model for gravity sewer networks', Water Science and Technology, 65(1), 60.

Warith, M., Kennedy, K. and Reitsma, R. (1998) 'Use of Sanitary Sewers as Wastewater Pre-Treatment Systems', Waste Management, 18(4), 235-247.

Wong, A. (1999) 'Colonial Sanitation, Urban Planning and Social Reform in Sydney, New South Wales 1788 - 1857 ', Australasian Historical Archaeology, 17, 58-69.

WREF (2007) 'Plain English guidance with odours and corrosion in wastewater collection systems', WREF, Minimization of Odors and Corrosion in Collection Systems. 


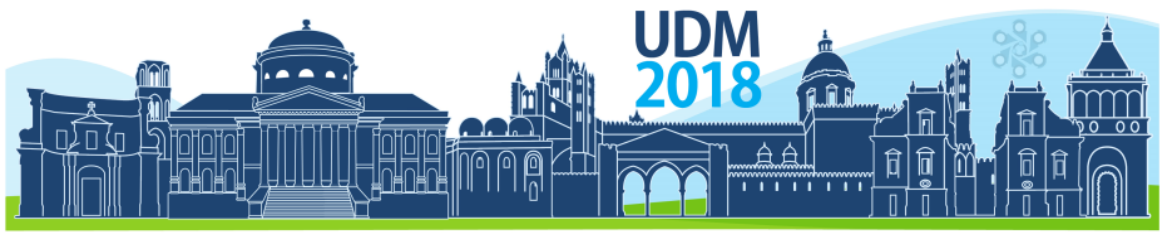

$11^{\text {th }}$ International Conference on Urban Drainage Modelling

23-26 Sep | Palermo - Italy

\title{
Influence of drainage network and compensatory techniques on urban flooding susceptibility
}

\author{
Jakcemara Caprario ${ }^{1}$, Aline Schuck Rech ${ }^{2}$, Fabiane Andressa Tasca ${ }^{3}$ and Alexandra Rodrigues Finotti ${ }^{4}$ \\ 1, 2, 3, 4 Federal University of Santa Catarina, Department of Sanitary and Environmental Engineering, \\ Florianópolis, Santa Catarina, Brazil. E-mails: jakcemara@hotmail.com; aline.schuck@unc.br; \\ fabitasca@gmail.com; alexandra.finotti@ufsc.br
}

\begin{abstract}
The occurrence of urban flooding due to the accelerated urbanization process and resulting drainage problems has become a worldwide issue and has been the subject of several studies in recent decades. In this sense, the goal of this study is to assess the influence of the drainage network associated with compensatory techniques on susceptibility of the urban flooding occurrence in Campeche District (Florianópolis - Brazil). To achieve this goal, the following methodological steps were used: (1) data collection and preparation; (2) application of the AHP method and consistency analysis; and (3) overlapping influence parameters considering two scenarios. The results show that the introduction of a drainage system decrease the degree of susceptibility of the urban flooding occurrence in approximately $27 \%$ of the areas of the Campeche District. It should be noted that, although costly, interventions for implementation of a drainage infrastructure associated with compensatory techniques make is extremely important for sustainable development.
\end{abstract}

Keywords: Urban drainage; Flooding susceptibility; Analytic Hierarchy Process

\section{INTRODUCTION}

The flooding resulting from the accelerated urbanization process have gained notoriety in the last 30 years. Due the influence of climate change and accelerated urbanization, extreme rainfall events has been intensifying the problem of urban flooding worldwide (Tucci 2004; Duan et al. 2016). According to Duan et al. (2016) the United Nations Office for Disaster Risk Reduction (UNISDR) reported more than 100 urban flooding events worldwide between 1980 and 2008, resulting in approximately 6700 deaths. In an analysis carried out by Jonkman (2005), in the universe of global flooding occurred during 1975 to 2001 period, for each serious flooding event approximately 12 deaths are associated with urban drainage problems, it's due to the lack of infrastructure capacity or even lack of infrastructure.

The urban drainage system in Brazil still is based on the assumption that "drain is necessary", draining runoff through conduits, as quickly as possible, increasing the magnitude and frequency of downstream flooding (Souza et al. 2013). Garcia and Paiva (2006) mention that a large number of Brazilian municipalities face problems due to lack of planning and investment in the drainage sector. According to National Plan for Basic Sanitation (PNSB) prepared by IBGE (2000), only $78.6 \%$ of Brazilian municipalities contain urban drainage systems, not considering the coverage index and infrastructure efficiency.

So, to support the decision-making process of urban planning, it's necessary to determine the influence that a sustainable drainage system generates on the flooding susceptibility of a 


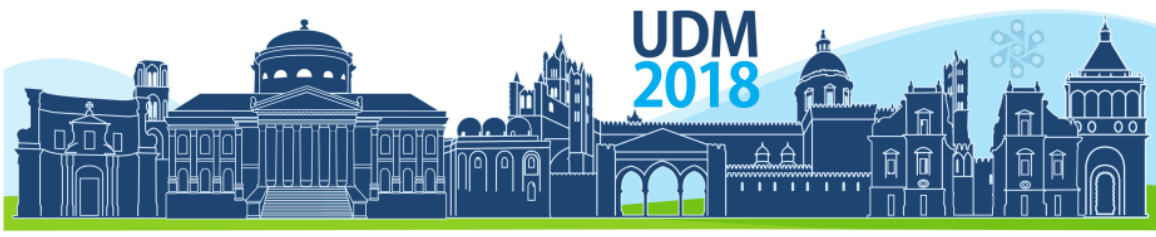

$11^{\text {th }}$ International Conference on Urban Drainage Modelling

23-26 Sep | Palermo - Italy

region. Therefore, the goal of this study is to assess the influence of the drainage network associated with compensatory techniques on susceptibility of the urban flooding occurrence in Campeche District (Florianópolis - Brazil).

\section{MATERIALS AND METHODS}

The methodology of this study is organized in three large steps: (1) data collection and preparation; (2) application of the AHP (Analytic Hierarchy Process) method and consistency analysis; and (3) overlapping parameters for each scenario. Two distinct scenarios were adopted: (1) partial existence of drainage network associated with compensatory techniques and (2) complete drainage system.

In the first step, data referring to six influence parameters of the study area were collected and prepared to GIS input as display in Table 1. For the classes of each parameter, a rate (i) is assigned, varying between 1 and 10, representing the relative importance between them according to the degree of flooding susceptibility and contribution to the runoff process.

Table 1. Data used for creation of influence parameters.

\begin{tabular}{llll}
\hline Data type & Source & Data & Produced parameter \\
\hline Aerial Photography & SDS & 2010 & Land use $(U)$ \\
Topographical curves & IPUF & 2000 & Altimetry $(A)$ \\
Topographical curves & IPUF & 2000 & Slope $(S)$ \\
Drainage network projects & PMF & 2013 & Drainage network $\left(D_{p, t}\right)$ \\
Drainage network projects & PMF & 2013 & Compensatory Techniques $(C)$ \\
Soil type map & EMBRAPA & 2011 & Land type $(T)$ \\
\hline
\end{tabular}

SDS - Secretaria de Estado do Desenvolvimento Sustentável (State Secretary for Sustainable Development) IPUF - Instituto de Planejamento Urbano de Florianópolis (Urban Planning Institute of Florianópolis) PMF - Prefeitura Municipal de Florianópolis (Department of Public Works of the Municipality of Florianópolis) EMBRAPA - Empresa Brasileira de Pesquisas Agropecuárias (Brazilian Agricultural Research Corporation)

In the second step, the AHP method, developed by Saaty (1977), was used to determine statistical weights of the influence parameters and generate a mathematical model of flooding susceptibility. The model was constructed based on the generic model introduced by equation 1.

$$
\text { Susceptibility index }=W_{1}(T)+W_{2}(U)+W_{3}(A)+W_{4}(S)+W_{5}\left(D_{p ; f}\right)+W_{6}(C)
$$

where $W_{1}, W_{2}, W_{3}, W_{4}, W_{5}$ e $W_{6}$ refers to the statistical weights of the influence parameters adopted in each scenario. Refer to Figure 1 adapted from Siddayao et al. (2014) for the general AHP scheme.

Also at this step, we perform the consistency analysis $(C R)$ of the determined weights, ensuring the conformity of the judgments made during the application of the AHP method.

The AHP method was selected based on three considerations. First, the method use a hierarchical structure, allowing the systematic definition of high-level objectives and strategies, where the judgment scale well defined. Additionally, the consistency analysis process ensures greater prediction of the hypothetical scenarios. Finally, the method is simple and versatile, being spread worldwide. 


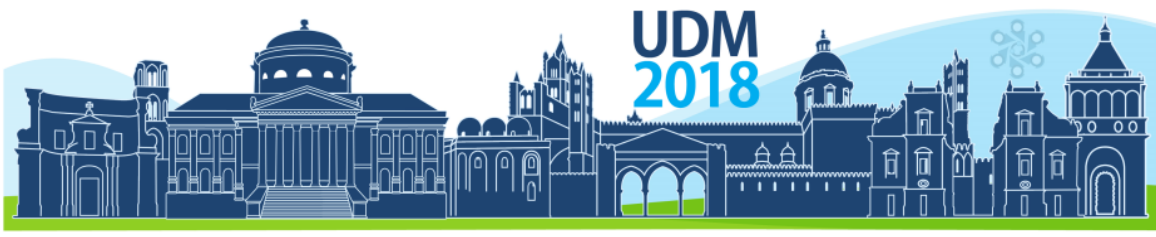

$11^{\text {th }}$ International Conference on Urban Drainage Modelling

23-26 Sep | Palermo - Italy

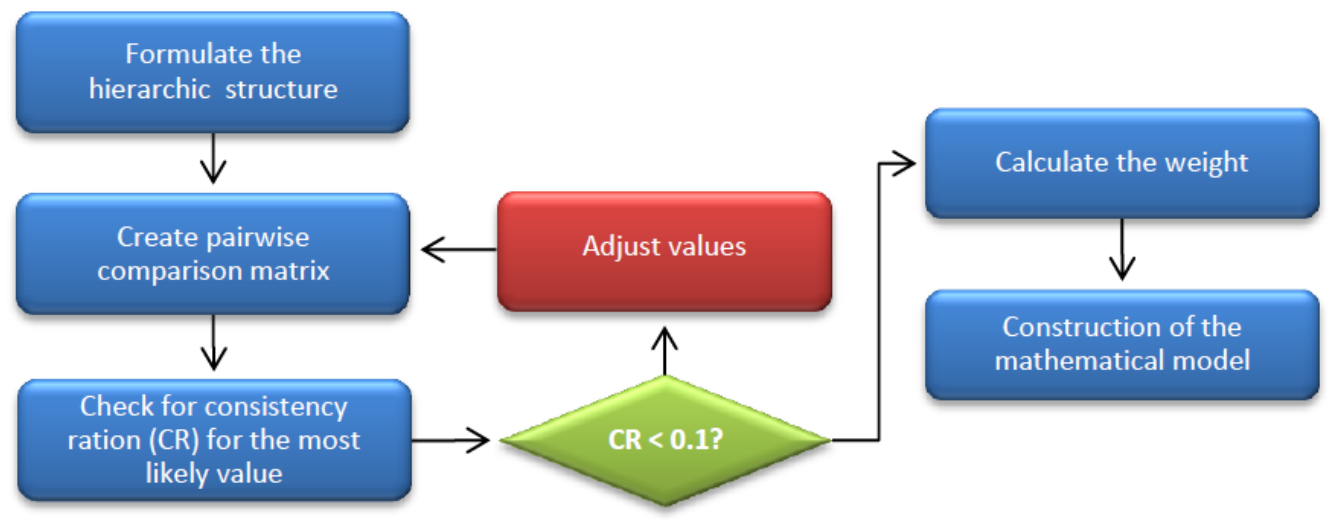

Figure 1. Analytic Hierarchy Process (AHP) Scheme.

Finally, in the third step of the study, the urban flooding suscetibily map of each scenario was generated. For the execution of this step, the influence parameters of each scenario were overlapped according to the mathematical model constructed by AHP method. For the drainage network and compensatory techniques factor were considered beyond the road surface areas, all the runoff contribution areas, these being defined by planialtimetric survey. The prepared and overlapping of the influence parameters were performed using traditional geoprocessing software.

After overlapping influence parameters, the results were classified using natural breaks Jenks method into four classes of urban flooding susceptibility: Low; Moderate; High and Extremely high.

The area adopted in this study corresponds to the Campeche District, located in the south portion of the Florianópolis Island, Santa Catarina - Brazil. With an area of $34.91 \mathrm{~km}^{2}$, the district is located in a sedimentary plain, being considered as the biggest floodable area of the island, rich in marshy ecosystems and the presence of a superficial unconfined aquifer. Besides these characteristics the area is distinguished by the presence of several compensatory techniques, represented by wells and swales.

\section{RESULTS AND CONCLUSIONS}

The graphical representation and the rates assigned for each class of influence parameters used to obtain the urban flooding susceptibility are display in Figure 2.

As result of the application of the AHP method to the influence parameters of each scenario, a consistent mathematical model was obtained. The model describes the two scenarios using six factors, ensuring $95 \%$ confidence in the results. The weights of the influence parameters for each scenario, as well as the consistency ration of the model constructed by the AHP method are provided in Table 2. 


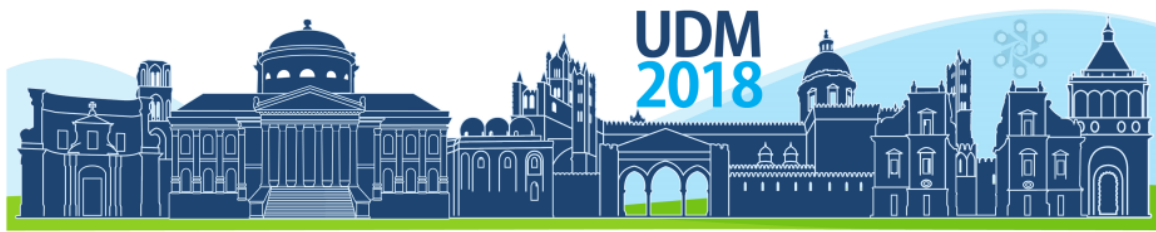

$11^{\text {th }}$ International Conference on Urban Drainage Modelling 23-26 Sep | Palermo - Italy

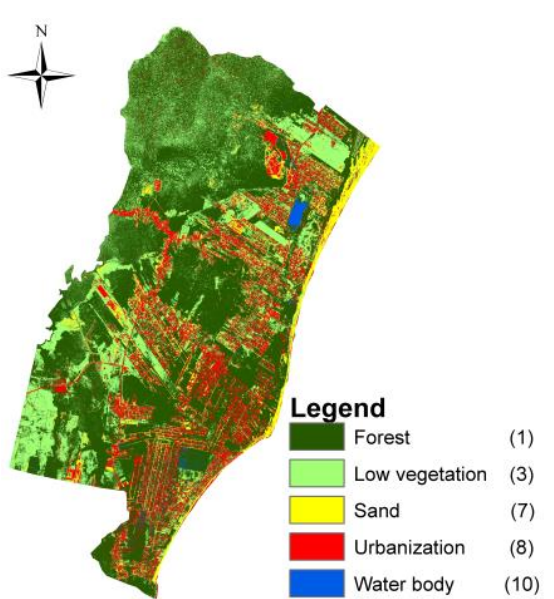

(a) Land use

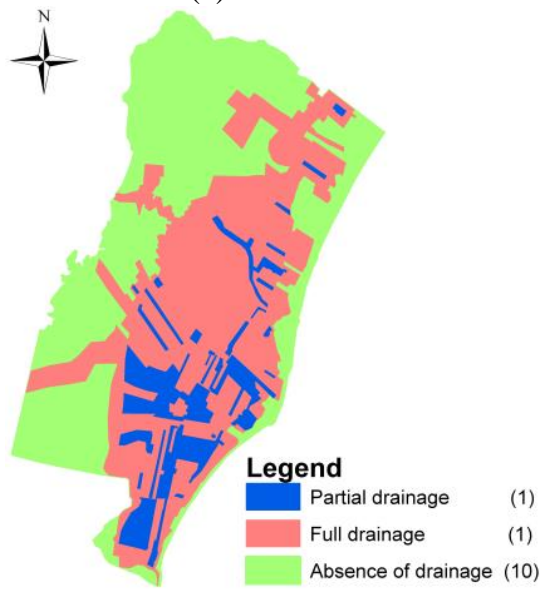

(d) Drainage network

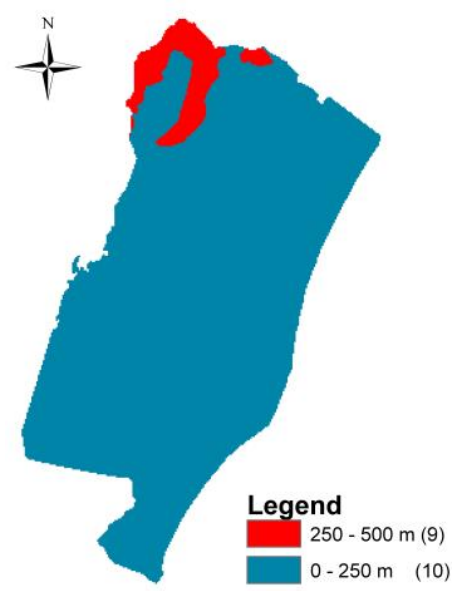

(b) Altimetry

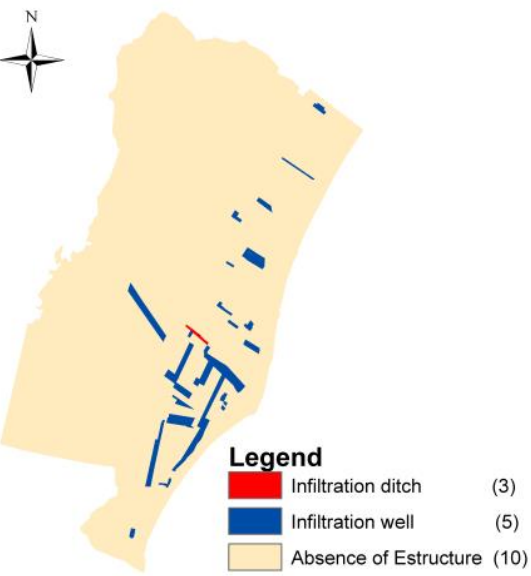

(e) Compensatory Techniques

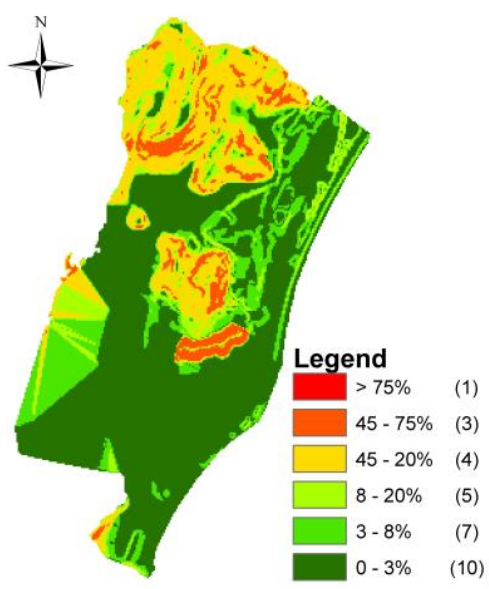

(c) Slope

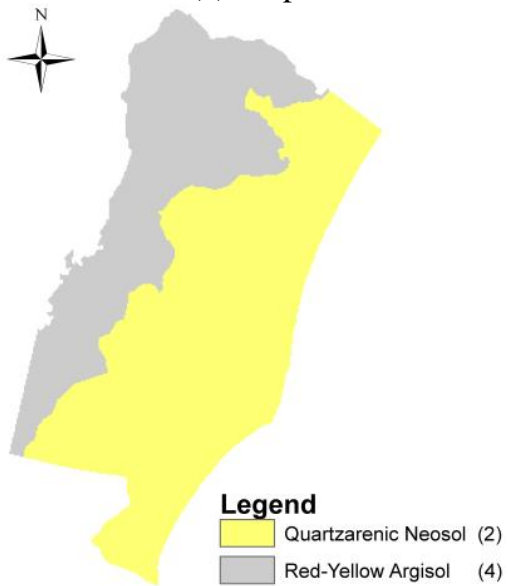

(f) Land type

Figure 2. Influence parameters and relative importance rates.

Table 2. Influence parameters weight determined by AHP method.

\begin{tabular}{lcc}
\multicolumn{1}{c}{ Influence parameter } & \multicolumn{2}{c}{ Weight $\left(W_{i}\right)$} \\
\cline { 2 - 3 } Landl type $(T)$ & Scenario 1 & Scenario 2 \\
Land use $(U)$ & 0.0297 & 0.0297 \\
Altimetry $(A)$ & 0.0804 & 0.0804 \\
Slope $(S)$ & 0.1300 & 0.1300 \\
Partial drainage network $\left(D_{p}\right)$ & 0.1300 & 0.1300 \\
Full drainage network $\left(D_{f}\right)$ & 0.2743 & - \\
Compensatory Techniques $(C)$ & - & 0.2743 \\
$C R$ & 0.2743 & 0.2743 \\
$C R$ ch stands for razão de consistência. & 0.0252 & 0.0252 \\
\hline
\end{tabular}

When comparing the results obtained by the overlapping of the influence parameters of the two scenarios (Figure 3 and Table 3 ), it's observed that an increase $87 \%$ in the drainage network would lead to a $27.24 \%$ decrease in the susceptibilities classified as high and extremely high class where the reduction would reach $14.40 \%$ of the susceptibility. Considering the current state of Campeche District infrastructure consolidation, where only $13 \%$ of roads are integrated into a drainage network, it's estimated that, although costly, 


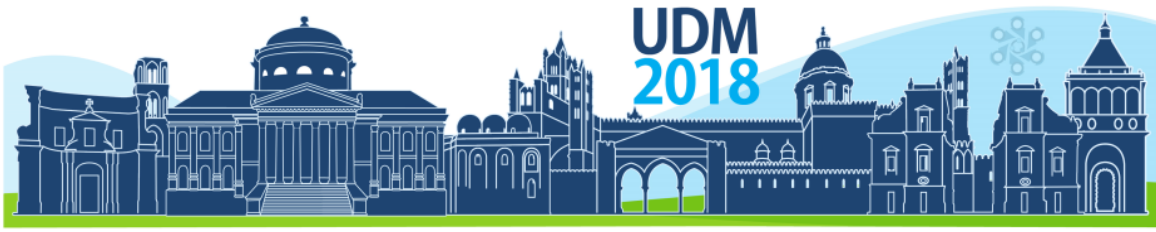

$11^{\text {th }}$ International Conference on Urban Drainage Modelling 23-26 Sep | Palermo - Italy

interventions for implementation of a drainage infrastructure associated with compensatory techniques make is extremely important for sustainable development.

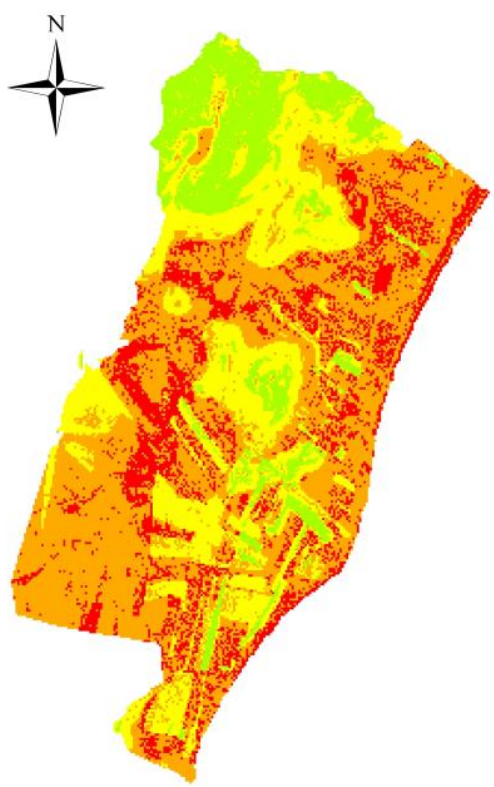

Scenario 1

UTM - SIRGAS 2000

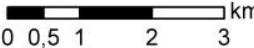

\section{Legend}

Figure 3. Comparison between the flooding susceptibility maps for each scenario.

Table 3. Flooding susceptibility class for each scenario.

\begin{tabular}{lrrrr}
\hline \multirow{2}{*}{ Susceptibility } & \multicolumn{4}{c}{ Area } \\
\cline { 2 - 5 } & \multicolumn{2}{c}{ Scenario 1 } & \multicolumn{2}{c}{ Scenario 2 } \\
\cline { 2 - 5 } & $\mathrm{km}^{2}$ & $\%$ & $\mathrm{~km}^{2}$ & $\%$ \\
\hline Low & 4.48 & 12.83 & 7.12 & 20.39 \\
Moderate & 8.70 & 24.94 & 15.57 & 44.61 \\
High & 15.88 & 45.48 & 11.39 & 32.64 \\
Extremely high & 5.85 & 16.76 & 0.82 & 2.36 \\
\hline
\end{tabular}

\section{References}

Duan, H.F; Li, F; Yan, H. (2016) Multi-Objective Optimal Design of detention tanks in the urban storm water drainage system: LID implementation and analysis. Water Resour Manage. 30(13), 4635-4648.

Garcia, J.I.B. and Paiva, E.M.C.D. (2006) Análise das áreas de risco de inundações para cenários futuros em uma bacia urbana. Recursos Hídricos: Jovem Pesquisador 2005. 1(1): 197-217.

IBGE, Instituto Brasileiro de Geografia e Estatística (2000) Pesquisa Nacional de Saneamento básico: 2000. Ministério do Planejamento, Orçamento e Gestão, Rio de Janeiro - Brasil.

Jonkman, S.N. (2005) Global perspectives on loss of human life caused by floods. Natural Hazards 34, 151-175.

Saaty, T.L. (1977) Scaling Method for priorities in hierarchical structures. Journal of mathematical psychology. 15, 234-281.

Siddayao, G.P; Valdez, S. E; Fernandez, P.L. (2014) Analytic Hierarchy Process (AHP) in spatial modeling for floodplain risk assessment. International Journal of Machine Learning and Computing. 4(5), 450-457.

Souza, V.C.B; Moraes, L.R.S; Borja, P.C. (2013) Déficit na drenagem urbana: buscando o entendimento e contribuindo para a definição. Revista Eletrônica de Gestão e Tecnologias Ambientais. 1(2), 162-175.

Tucci, C.E.M. (2004) Gerenciamento integrado das inundações urbanas no Brasil. Rega. 1(1), 59-73. 


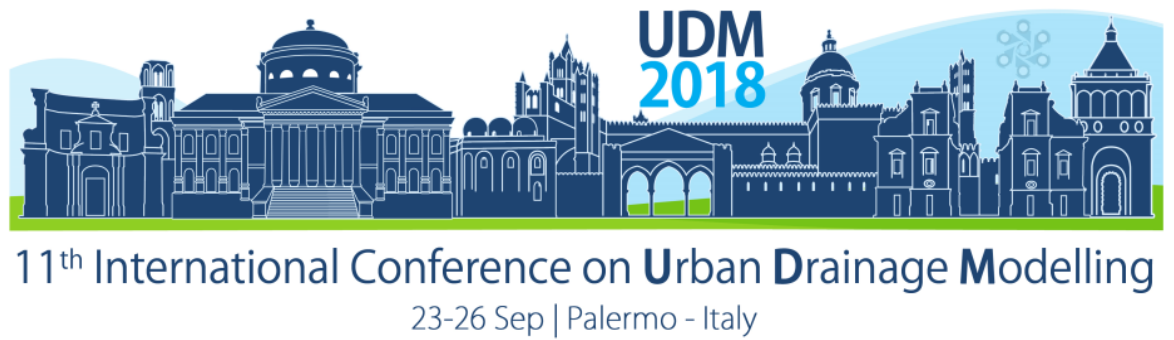

\title{
An integrated model to develop and optimize wet weather strategies for river water quality in Odense (DK)
}

\author{
Justine Hénonin', Lorenzo Benedetti², Annette Brink-Kjær ${ }^{1}$, Elliot J. Gill ${ }^{3}$, Peter Rasch ${ }^{4}$, Per Hallager ${ }^{1}$ and \\ Per Henrik Nielsen ${ }^{1}$ \\ ${ }^{1}$ VCS Denmark (VandCenter Syd), Odense, Denmark \\ 2 Waterways, Lekenik, Croatia \\ 3 Jacobs, Swindon, United Kingdom \\ ${ }^{4}$ Informetics, Copenhagen, Denmark
}

\begin{abstract}
Over the last 4 years, VCS Denmark has been developing an integrated urban watershed model for the city of Odense. The integration in one single model allows to represent the interconnected nature of all parts of the system, e.g. the impact of the wastewater collection system on the wastewater treatment facilities and on the rivers. Even though it includes all major components of the urban watershed system, the model is sufficiently fast to simulate dynamically both water quantity and quality on a continuous basis for several years. This allows for rapid assessment of various management strategies to help secure good quality ecosystems in the rivers while ensuring system optimization and sustainable investments.
\end{abstract}

Keywords: Urban drainage; integrated modelling; collection systems; river water quality; stormwater; wet weather; wastewater treatment

\section{INTRODUCTION}

VCS Denmark is the water utility for Odense, Denmark's third city, and for the northern part of the island of Funen. Odense's wastewater system is complex, with 112 combined sewer overflows (CSOs), more than 350 stormwater outfalls (SSOs) and three water resource recovery facilities (WRRFs). These have three main river recipients, all leading to Odense Fjord: Odense river, Stavis river and Lindved river. The utility is required to secure that wet weather impacts are controlled to help ensure that the receiving water bodies meet the water quality standards required under the European Union's Water Framework Directive (WFD). Currently, such requirements are mainly based on a maximum tolerated frequency of overflow events per year, as well as a maximum total overflow volume per area and per year. However, this does not reflect the capacity of the recipients to cope with a given overflow event and meeting these requirements do not necessarily guaranty the protection of said recipients. Hence, VCS Denmark has decided to use an integrated modelling approach to better understand the interactions between the different parts of the complex system (see Benedetti et al. (2013) for further examples). The model is helping to engage in constructive dialogue with the regulator and to reach a common level of understanding of the urban watershed behaviour.

\section{MODEL DEVELOPMENT AND VALIDATION}

The integrated model is developed using WEST (www.mikepoweredbydhi.com). Such model allows for simulation over the course of several years while retaining a small influent time step 


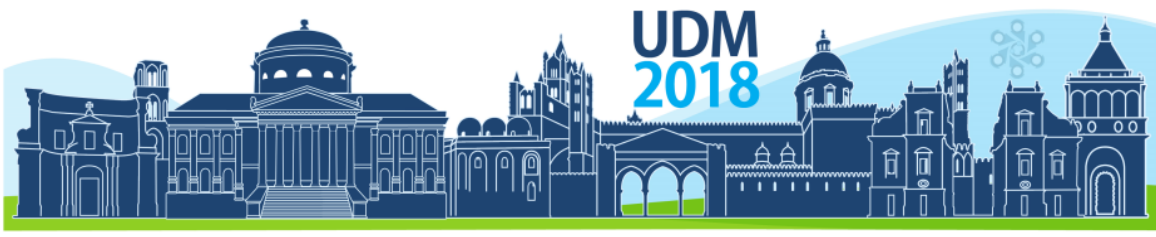

$11^{\text {th }}$ International Conference on Urban Drainage Modelling

23-26 Sep | Palermo - Italy

(1 minute) for detailed analysis of each significant rainfall event. An 8.5 years simulation of the full integrated system in Odense, with water quantity and quality analysis, runs currently in less than 12 hours on an average computer.

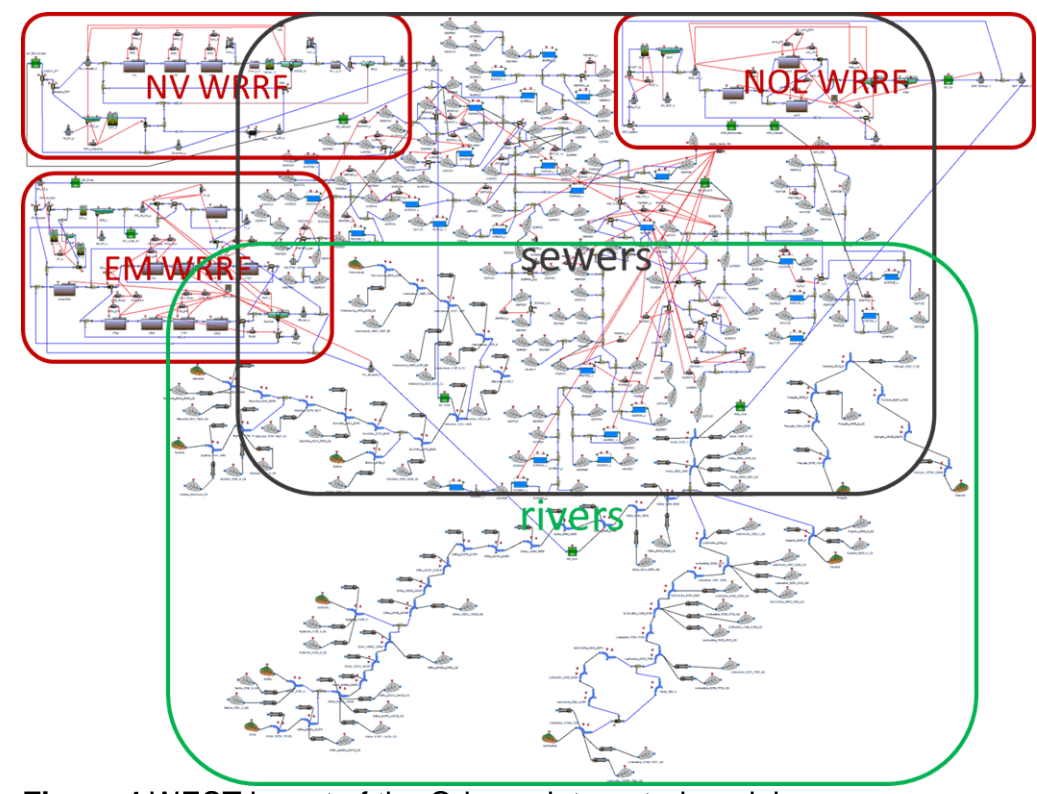

Figure 1 WEST layout of the Odense integrated model,

\subsection{Rivers}

The river network is modelled by representing river reaches as tanks with a regular gradient and trapezoidal shape derived from an existing detailed river model and field observations. Modelled flow is then calibrated against gauged data at five locations. The water quality model includes processes for dissolved oxygen (consumption by 5 types of BOD and reaeration), for nitrification and algae activity. Water quality in rivers is calibrated and validated against continuous measurements of oxygen and ammonium from 16 online monitoring stations.

\subsection{Collection system and stormwater system}

The collection system is modelled as "tank in series", with each CSO structure connected to a river stretch and receiving dry and wet flow from its upstream catchment. Input parameters are derived from a MIKE URBAN (www.mikepoweredbydhi.com) detailed model, e.g. storage capacity, transport time, controls and pumping. The WEST model is then validated against results from the MIKE URBAN model, checking that the CSOs dynamics, spill volumes and frequencies are consistent, as well as against measured frequencies at key overflow structures. Sewer water quality is generated in the catchments for dry weather using average loads and daily profiles, and in wet weather by accumulation and wash-off. Routing of pollutants in the sewer includes sedimentation and resuspension of particulates. The quality model is validated against measured data at the WRRFs. The stormwater system is more simplified than the collection system, with SSOs being grouped and represented as catchments with storage volume. Grouping mainly depends on their location along river stretches.

\subsection{Wastewater treatment facilities}




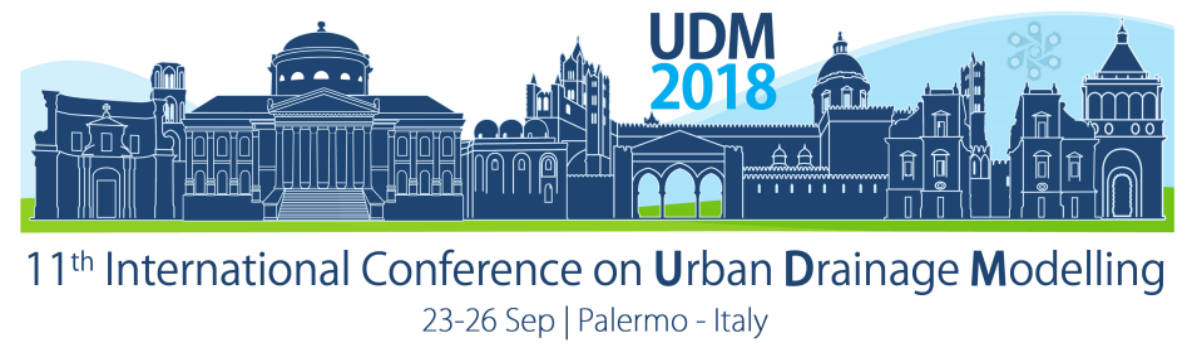

WRRFs are fully represented in the model, including all units of the wastewater treatment line (i.e. primary settling, activated sludge, secondary settling, effluent filters, etc.) including all controllers for aeration and recycles. They are calibrated against online and lab measurements at each significant step of the treatment processes. The model is configured to enable calculation of operating costs of the sewer system and the WRRFs, including pumping, aeration, chemicals and sludge treatment.

\section{RESULT ASSESSMENT AND DISCUSSION}

Such an integrated model faces many challenges, among which the upkeep of a proper calibration and consistency with current real systems. Furthermore, results should be assessed through a method understood and accepted by all stakeholders.

\section{Online measurements:}

Maintaining a river measuring system with 16 online stations is very costly in terms of equipment and time. The same can be stated for other measuring systems in sewers and treatment facilities. Hence the need to ensure that the raw data is processed and used to its maximal potential. To that effect, data web interfaces have been developed to view and manage measured data. One such portal focuses on river water monitoring, allowing users to consult and download online data for model calibration, as well as to see maintenance periods and results from lab analysis. Technicians in charge of maintaining the measuring stations also use this portal as a logbook and to schedule their maintenance according to potential drifts in the measurements. Alarms can be sent automatically to warn for peaks above given thresholds. The regulator has also access to the river data portal and can also log comments regarding operations potentially affecting the area. Data processing options are under development.

Update and consistency of the model:

Update of the integrated model is primarily driven by actual changes in the sewer system and WRRFs operation. Changes in the sewer system are first translated into the detailed MIKE URBAN model, against which these changes are tested before being built. The integrated model is then updated on a yearly basis to account for major changes in the system and tested against the MIKE URBAN model. A "model" web interface has been developed to focus on model comparison and result analysis. This web interface allows for the comparison of uploaded WEST results against a MIKE URBAN online model or offline model results, as well as against selected measured data. Further reporting and statistical analysis options are under development.

\section{River quality assessment with UPM:}

Compliance with WFD standards is assessed by using the United Kingdom developed Urban Pollution Management (UPM) Fundamental Intermittent Standards (FIS) (FWR 2013). These are concentration/duration/frequency standards for dissolved oxygen and unionised ammonia that are designed to test the long term ( $>1$ year) wet weather impact of urban wastewater systems on water quality of their recipients. To facilitate the use of UPM for status and scenario assessment and comparison, the "model" portal has been further developed to analyse WEST results with the UPM method, as seen in 


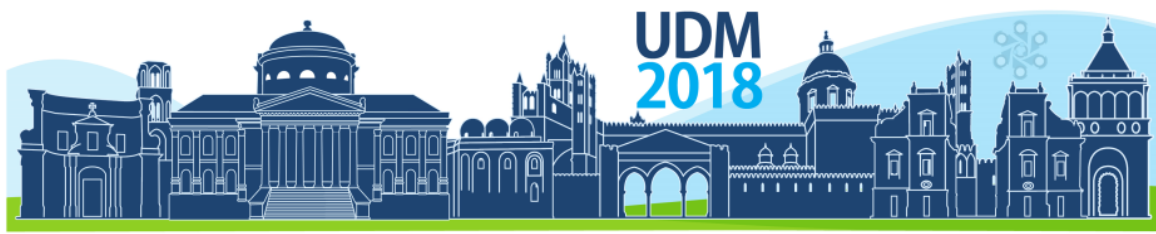

$11^{\text {th }}$ International Conference on Urban Drainage Modelling 23-26 Sep | Palermo - Italy

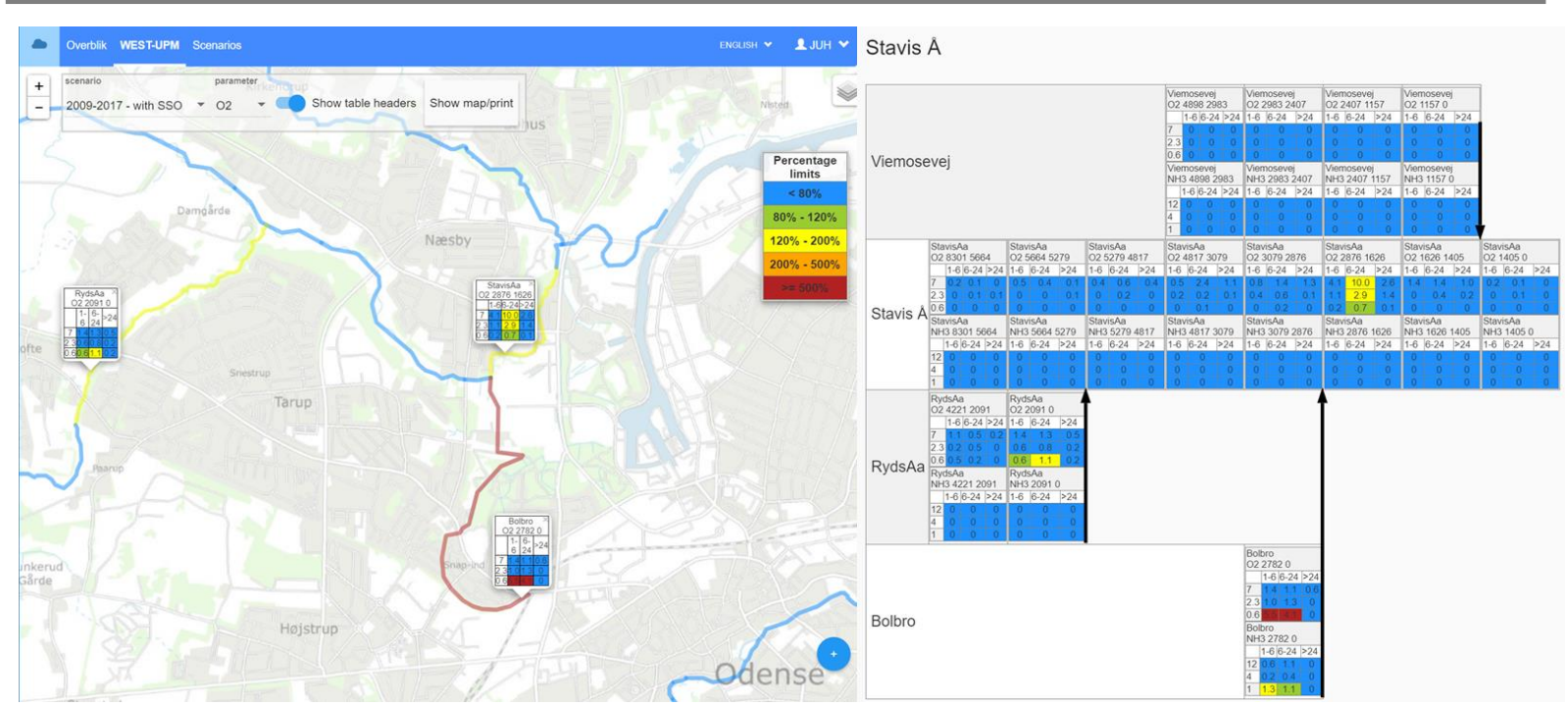

Figure 2.

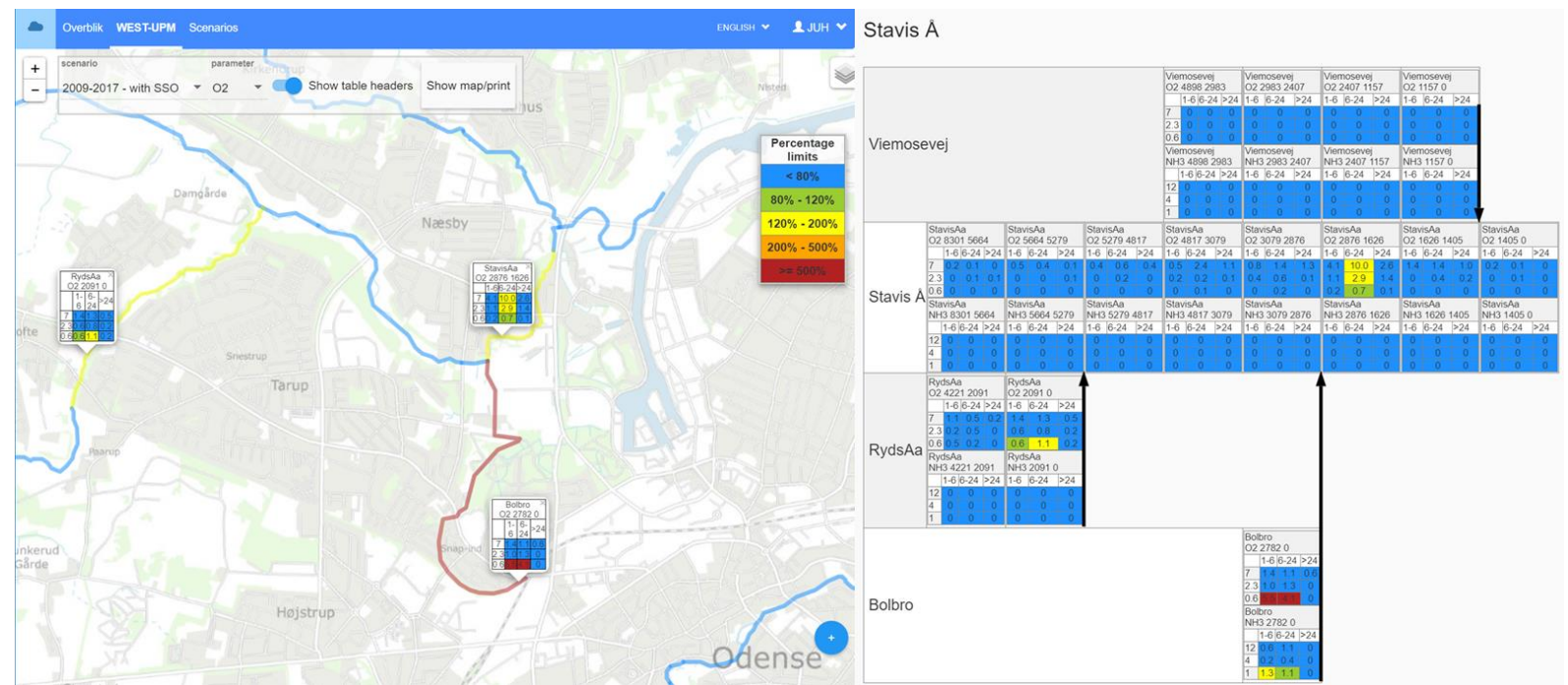

Figure 2 UPM assessment on the model web interface - map (left) and diagram (right) view

The feasibility of adaptation of UPM in Denmark has been discussed with the regulator, and academic experts have been commissioned to advise on such feasibility, particularly on the concentration thresholds to be used. Quality of Danish rivers is currently officially assessed through the Danish Stream Fauna Index (DVFI, using kick sampling and hand picking for identification of key macroinvertebrates to qualify stream environmental status). The integrated model has been used to assess the status of the river network through a UPM analysis covering 8 years of simulation up to 2017. First results have proven consistent with existing DVFI observations, increasing confidence in the model predictions, allowing for predictions of water quality in stretches where no DVFI measurement is available.

\section{CONCLUSIONS}

Preliminary results show the benefits of taking a catchment-wide approach to urban wastewater planning and of integrated modelling to better understand interactions and 


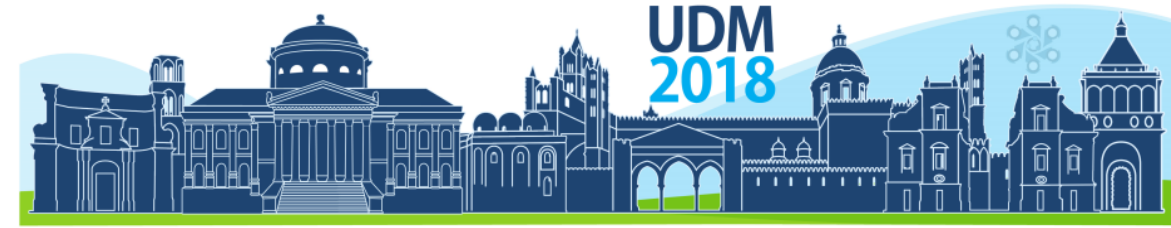

$11^{\text {th }}$ International Conference on Urban Drainage Modelling

23-26 Sep | Palermo - Italy

dynamics within systems usually modelled separately. Used as both a communication and analysis tool, the integrated model is helping all stakeholders (utility and regulator) to formulate a joint sustainable strategy aiming at the most cost-effective investments to protect both the receiving water bodies and wastewater system assets. Further developments will aim at improving the robustness of measurements as well as enhancing data processing and analysis to improve the usability of the model.

\section{References}

Benedetti, L., Langeveld, J.G., Comeau, A., Corominas, L., Daigger, G.T., Martin, C., Mikkelsen, P.-S., Vezzaro, L., Weijers, S. and Vanrolleghem, P.A. (2013) Modelling and monitoring of integrated urban wastewater systems: Review on status and perspectives. Water Science and Technology 68(6), 1203-1215.

FWR (2013). Urban pollution management Manual 3rd edition. Viewed at: www.fwr.org/UPM3/ 


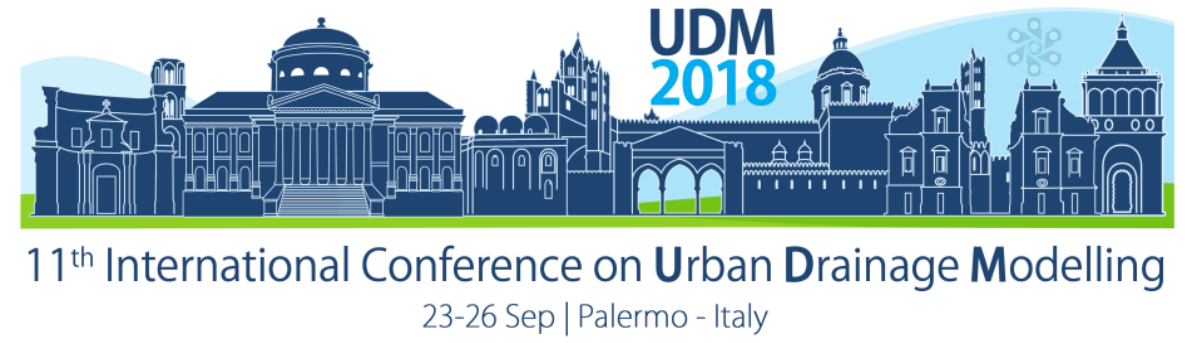

\title{
Sensitivity Analysis of an Integrated Urban Flood Model
}

\author{
Rasmus Nielsen ${ }^{1}$, and Søren Thorndahl' \\ ${ }^{1}$ Aalborg University, Dept. of Civil Engineering, Aalborg, Denmark
}

\begin{abstract}
In this paper, the model parameter sensitivity of an integrated urban flood model, including groundwater system, overland flow, sewer network, and river network, is investigated. The sensitivity analysis quantifies how influential the individual and correlated model parameters are to the simulated flood depth and area for an urban catchment in Aalborg, Denmark. The key parametric contributors to output sensitivity are analyzed by: i) identify the most sensitive model parameters using a Morris screening; ii) using the generalized Sobol' method to investigate the sensitivity of the individual input parameters and the interaction between each parameter. The results indicate that the groundwater system, overland flow, and river network contribute most to the flood depth and as such, they need to be considered in urban flood modelling.
\end{abstract}

Keywords: Integrated hydrological modelling; Global sensitivity analysis; Urban flooding

\section{INTRODUCTION}

Urban flood models are an important tool to help decision-makers plan management of flood risks (Mark \& Djordjević, 2006). The current state of the art urban flood models routes rainfall through a $1 \mathrm{D}$ sewer network model to a $2 \mathrm{D}$ surface model (1D-2D dual drainage model). 1D2D dual drainage models do not include a complete representation of the urban water cycle.

However, including more hydrological processes, such as riverine and groundwater systems, introduces more model parameters and requires a lot of data for calibration and validation, which most often is not available. The justification for using integrated flood models instead of a 1D-2D dual drainage model is case dependent, as the presence and impact of the hydrological processes vary.

It is useful to be able to predict if one needs to consider more hydrological processes and which ones are the most important. Prior knowledge about the most sensitive parameters allows the modeller to focus on gathering data for calibrating and validating the most important hydrological processes.

Sensitivity analysis (SA) is the typical approach to investigate the most significant and sensitive model parameters. SA are generally grouped into two categories: local and global analyses. Local SA changes one parameter at a time and is often used when no interaction between parameters is present. Global SA changes multiple parameters at a time, and is considered to be more appropriate for more physically-based models, where linear or non-linear parameter interaction is present.

In this study, the model parameter interaction in an integrated urban flood model is investigated, including streams, drainage system, and groundwater processes. The model parameter sensitivity of the integrated flood model is determined by: 1) Morris screening (Morris, 1991); (2) sensitivity analysis using the Sobol' method (Sobol, 1993). 


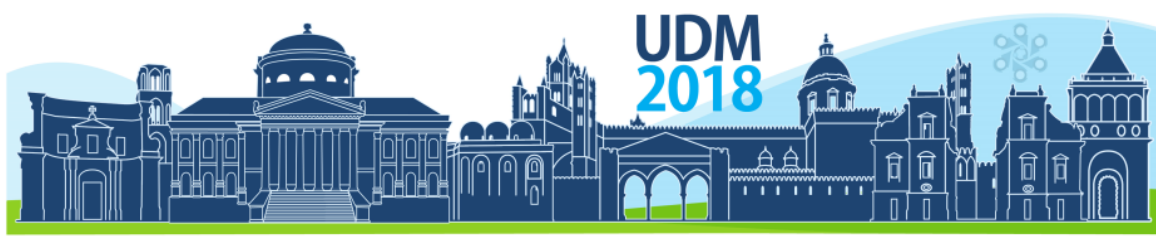

$11^{\text {th }}$ International Conference on Urban Drainage Modelling

23-26 Sep | Palermo - Italy

\section{MATERIALS AND METHODS}

\subsection{Methodology}

The Morris method screens for insensitive model parameters effectively with a small number of model runs (Morris, 1991). This is done as a preliminary step to exclude non-sensitive model parameters from any further analysis thereby decreasing the number of simulations needed. The Morris method calculates elementary effects from the ratio between the model output and change in input parameter value using (1).

$$
E E\left(x_{i}\right)=\frac{y\left(x_{1}, x_{2}, \ldots, x_{i-1}, x_{i}+\Delta, x_{i+1}, \ldots, x_{k}\right)-y\left(x_{1}, x_{2}, \ldots, x_{i}, \ldots, x_{k}\right)}{\Delta}
$$

Where $E E\left(x_{i}\right)$ is the elementary effect for parameter $x_{i}$ given a change of $\Delta$. For each parameter $R$ trajectories of $k+1$ sample points are generated, resulting in $R(k+1)$ elementary effects. Based on the calculated elementary effects for each parameter a mean, $\mu_{i}^{*}$, and a standard deviation, $\sigma_{i}$, is calculated using (2) and (3).

$$
\begin{gathered}
\mu_{i}^{*}=\frac{1}{R} \sum_{j=1}^{R}|E E(j)| \\
\sigma_{i}=\sqrt{\frac{1}{R-1} \sum_{j=1}^{R}\left[E E(j)-\frac{1}{R} \sum_{j=1}^{R} E E(j)\right]^{2}}
\end{gathered}
$$

$\mu_{i}^{*}$ is a proposed modification of the original mean from (Morris, 1991) presented in (Campolongo, et al., 2007), which uses the absolute elementary effects to avoid the cancellation of opposing signs. $\mu_{i}^{*}$ estimates the overall effect of a parameter and $\sigma_{i}$ estimates the interaction between parameters and non-linear effects.

Finally, the generalized Sobol' method is used to investigate how sensitive the flood depth in multiple points is to: the effects of each input parameter individually (first-order), the interaction between the parameters in pairs of two (second-order), and the combined effects (total-order). Assuming model parameters are independent and uncorrelated, the total variance of the model output is the sum of the composed variance from the individual parameters and the variances from the cooperative parameters. Therefore the variance decomposition can be expressed as (4).

$$
V(y)=\sum_{i=1}^{n} V_{i}+\sum_{i \leq j \leq n}^{n} V_{i j}+\cdots+\sum_{i \leq n}^{n} V_{1 \ldots n}
$$

Where $V(y)$ is the total variance of the model output, $V_{i}$ is the first order contribution effects of the $i$ th parameter, $V_{i j}$ is the second-order effects of the $i$ th and $j$ th parameters, and $n$ is the number of parameters. The Sobol indices, $S$, are evaluated as (5) by dividing (4) with total variance, $V(y)$. Hence, the first- and second-order sensitivity indices for each input can be evaluated as (6).

$$
\begin{gathered}
\sum_{i=1}^{n} S_{i}+\sum_{i \leq j \leq n}^{n} S_{i j}+\cdots+\sum_{i \leq n}^{n} S_{1 \ldots n}=1 \\
S_{i}=\frac{V_{i}}{V(y)} ; \quad S_{i j}=\frac{V_{i j}}{V(y)}
\end{gathered}
$$




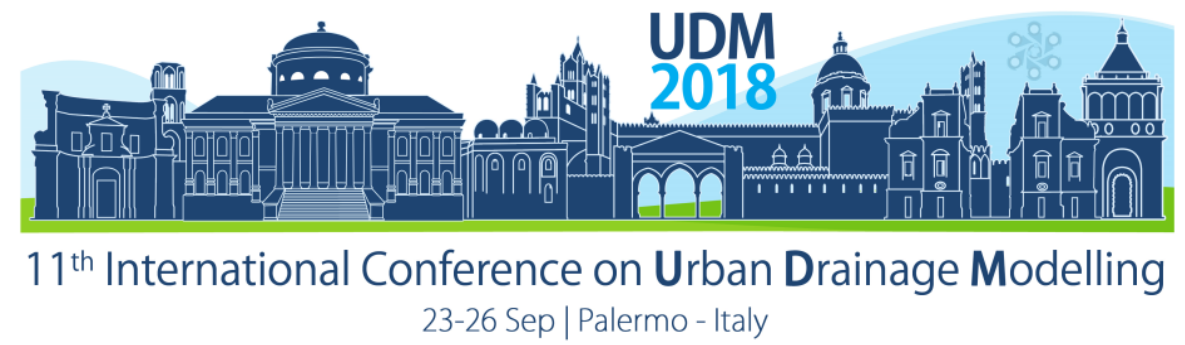

Sobol indices vary between 0 and 1, as a measure of the percentage of variance that can be attributed to an input parameter. The total effect index, $S_{T i}$, can be expressed as (7), where $S_{\sim i}$ denotes first- and second-order indices for all parameters except for the $i$ th parameter.

$$
S_{T i}=1-S_{\sim i}
$$

\subsection{Study site and model setup}

The study location is a residential and industrial area in Aalborg, northern Denmark. $59 \%$ of the total area of 98 ha is covered by impervious surfaces, mainly industry, streets, and pavement. The pervious surfaces consist of parks, gardened plots, and football fields. Rainfallrunoff is collected by the sewer network, which discharges the combined waste- and stormwater overflow to the tree branches of the stream Østerå.

The model setup consists of an integrated hydrological coupled with a hydraulic sewer drainage model. The hydrological model is a national model of the freshwater cycle in Denmark (Henriksen, et al., 2003). The following processes are included: overland flow (2D), groundwater system (3D), vertical unsaturated flow (1D), river network (1D), and sewer network (1D). The model parameters considered in this study and their chosen ranges are in Table 1.

Table 1. Ranges of the input parameters. ${ }^{1}$ Vertical hydraulic conductivity. ${ }^{2}$ Horizontal hydraulic conductivity, where the vertical hydraulic conductivity forced to be a factor of 10 lower $\left(K_{x} / K_{z}=10\right) .{ }^{3}$ Constant to control the exfiltration and infiltration between sewer pipes and groundwater. ${ }^{4}$ Adds an additional loss of water from the river system to the groundwater. ${ }^{5}$ The drain time constant is used in conjunction with a drainage level to calculate the amount of water drained from each cell.

\begin{tabular}{|c|c|c|c|}
\hline Input parameter & Symbol & Unit & Range \\
\hline Hydraulic conductivity, fractured clay ${ }^{1}$ & $K_{\text {frac,clay }}$ & $\mathrm{m} / \mathrm{s}$ & $2.50 \cdot 10^{-8}-4.42 \cdot 10^{-8}$ \\
\hline Hydraulic conductivity, quaternary clay² & $K_{\text {quat,clay }}$ & $\mathrm{m} / \mathrm{s}$ & $2.65 \cdot 10^{-7}-2.88 \cdot 10^{-7}$ \\
\hline Hydraulic conductivity, quaternary sand ${ }^{2}$ & $K_{\text {quat,sand }}$ & $\mathrm{m} / \mathrm{s}$ & $1.41 \cdot 10^{-4}-1.53 \cdot 10^{-4}$ \\
\hline Hydraulic conductivity, silt ${ }^{2}$ & $K_{\text {silt }}$ & $\mathrm{m} / \mathrm{s}$ & $1.43 \cdot 10^{-5}-2.43 \cdot 10^{-5}$ \\
\hline Hydraulic conductivity, quarts sand ${ }^{2}$ & $K_{\text {quar,sand }}$ & $\mathrm{m} / \mathrm{s}$ & $8.31 \cdot 10^{-4}-1.28 \cdot 10^{-3}$ \\
\hline Hydraulic conductivity, limestone ${ }^{1}$ & $K_{\text {limestone }}$ & $\mathrm{m} / \mathrm{s}$ & $1.46 \cdot 10^{-4}-1.61 \cdot 10^{-4}$ \\
\hline $\begin{array}{l}\text { Pipe leakage coefficient }{ }^{3} \\
\text { Surface Manning number }\end{array}$ & $\begin{array}{l}L C \\
M_{S}\end{array}$ & $\begin{array}{c}{[-]} \\
m^{-\frac{1}{3}} \cdot s^{-1}\end{array}$ & $\begin{array}{c}1.10^{-6}-1 \cdot 10^{-7} \\
20-40\end{array}$ \\
\hline Pipe Manning number & $M_{p}$ & $m^{-\frac{1}{3}} \cdot s^{-1}$ & $50-85$ \\
\hline River Manning number & $M_{r}$ & $m^{-\frac{1}{3}} \cdot s^{-1}$ & $5-16$ \\
\hline $\begin{array}{l}\text { River leakage constant }{ }^{4} \\
\text { Drain time constant }{ }^{5} \\
\text { Root zone depth }\end{array}$ & $\begin{array}{l}R_{c} \\
d_{t} \\
d_{l}\end{array}$ & $\begin{array}{c}s^{-1} \\
m / s \\
m \\
\end{array}$ & $\begin{array}{c}3.74 \cdot 10^{-7}-4.84 \cdot 10^{-7} \\
3.20 \cdot 10^{-7}-4.50 \cdot 10^{-7} \\
0-1\end{array}$ \\
\hline
\end{tabular}

Rainfall data is gathered from the Danish water pollution committee rain gauge network (Madsen, et al., 2017). The rainfall events are chosen based on the critical conditions for different hydrological processes based on the belief that different types of events could cause different model parameter sensitivities. 


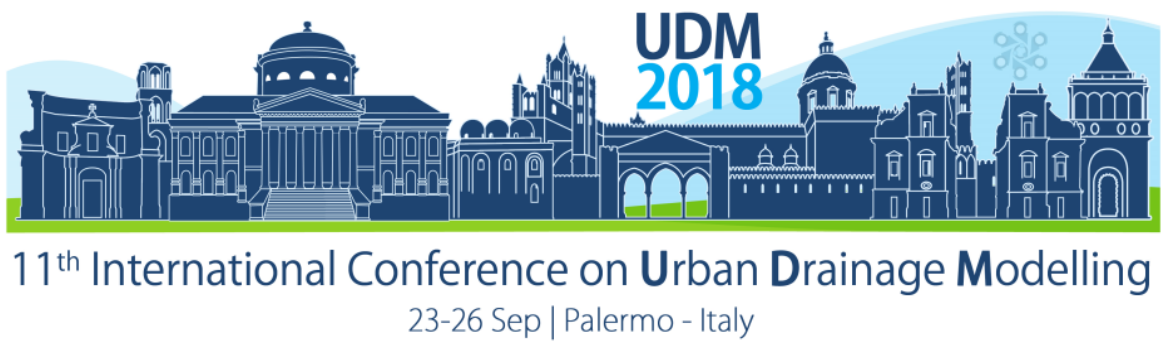

\section{RESULTS AND DISCUSSION}

Simulation results for the Morris screening and Sobol' method are presented in the following section for one of the selected rain events and the sensitivity for flood depth in one point. The results from the Morris Screening are illustrated in Figure 5, where $L C, M_{r}$, and $M_{s}$ are the most sensitive parameters and $K_{\text {frac,clay }}, M_{p}$, and $R C$ are less sensitive. The rest of the model parameters are grouped up in the lower left corner displaying a low sensitivity. It is decided to use $L C, M_{r}, M_{s}, K_{\text {frac,clay }}, M_{p}$, and $R C$ for further sensitivity analysis, reducing the number of varied model parameters from 13 to 6 .

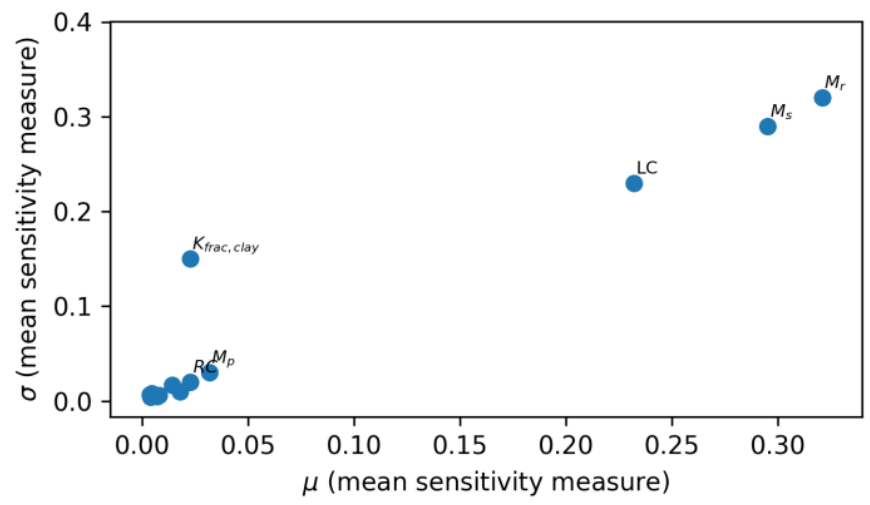

Figure 1. Mean and standard deviation from the Morris Screening. $\mu$ reflects the parameters sensitivity and a large $\sigma$ show a strong non-linear or interactive relationship with other parameters.

In Table 2 the sum of the first-order sensitivity indices contributes $89 \%$ to the total sensitivity, indicating a weak interaction between the parameters. The most sensitive parameters are: $M_{r}$, $M_{s}$, and $L C$, contributing with $25 \%, 32 \%$, and $34 \%$ of the total model output variance, respectively.

Table 2. Total effects and first-order sensitivity indices on the flood depth.

\begin{tabular}{lcc}
\hline Parameter & Total effects & First-order indices \\
\hline$K_{\text {frac,clay }}$ & 0.00 & 0.00 \\
$L C$ & 0.25 & 0.23 \\
$M_{s}$ & 0.32 & 0.29 \\
$R C$ & 0.03 & 0.02 \\
$M_{p}$ & 0.05 & 0.03 \\
$M_{r}$ & 0.34 & 0.32 \\
\hline Sum & 1.00 & 0.89 \\
\hline
\end{tabular}

The high total effects of $M_{r}, M_{s}$, and $L C$ is believed to be caused by two main factors: high temporal variation in rain intensity, and leakage of groundwater into the sewer system. Interestingly, the effects of $K_{\text {frac,clay }}$ and $R C$ are limited. The reason for the limited effects of $K_{\text {frac,clay }}$ and $R C$ is probably due to the large total rain depth of the rainfall event, where the water movement in the upper soil layers and water transfer between the streams and groundwater is insignificant. In Table 3 the sensitivity indices for the input parameters are grouped into four groups, representing the input parameters for the groundwater, overland surface, sewer network, and river models respectively. 


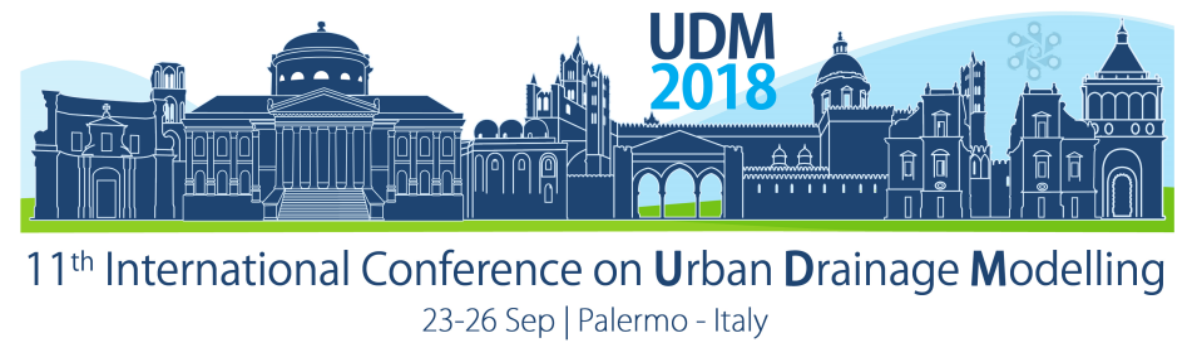

Table 3. Grouped total effects of the model input parameters on the flood depth.

\begin{tabular}{llc}
\hline Model & Parameters & Total effects \\
\hline Groundwater & $K_{\text {frac,clay }}, L C$ & 0.25 \\
Overland & $M_{s}$ & 0.32 \\
Sewer & $M_{p}$ & 0.09 \\
River & $R C, M_{r}$ & 0.34 \\
\hline
\end{tabular}

The input parameters for the river, overland surface, and groundwater models have the largest effects on the model output variance, whereas the model output is less sensitive to the input parameters for the sewer network model.

The apparent effects of the temporal variation in rainfall on the sensitivity of the input parameters suggest that more rainfall events should be included with different characteristics in the form of high and low intensities, durations, etc.

\section{CONCLUSIONS}

A global sensitivity analysis of an integrated flood model was evaluated and presented in this paper. The sensitivity analysis was performed using the generalized Sobol' method for a single rainfall event. The analysis indicates that the flood depth is mostly affected by the river, surface drainage, and groundwater system, where each contributes roughly $30 \%$ to the total output sensitivity. The sewer network model is accounting for $10 \%$ of output sensitivity.

The findings of this paper indicate that there is a need to consider the river and groundwater systems in the study case. However, further analysis of including multiple rainfall events are needed to fully understand the interactions between the hydrological systems and flooding in urban areas.

\section{REFERENCES}

Beven, K., \& Binley, A. (1992). The future of distributed models: Model calibration and uncertainty prediction. Hydrological Processes, 6(3), 1099-1085.

Campolongo, F., Cariboni, J. \& Saltelli, A., 2007. An effective screening design for sensitivity analysis of large models. Environmental modelling \& software, 22(10), pp. 1509-1518.

Henriksen, H. J., Troldborg, L., Nyegaard, P., Sonnenborg, T. O., Refsgaard, J. C., \& Madsen, B. (2003). Methodology for construction, calibration and validation of a national hydrological model for Denmark. Journal of Hydrology, 280(1), 52-71.

Madsen, H., Gregersen, I., Rosbjerg, D. \& Arnbjerg-Nielsen, K., 2017. Regional frequency analysis of short duration rainfall extremes using gridded daily rainfall data as co-variate. Water Science and Technology, 8(75), pp. 19711981.

Mark, O., \& Djordjević, S. (2006). While waiting for the next flood in your city. Nice, France, 7th International Conference on Hydroinformatics.

Morris, M. D. (1991). Factorial Sampling Plans for Preliminary Computational Experiments. Technometrics, 33(2), 161-174.

Sobol, I. M., 1993. Sensitivity Estimates for Nonlinear Mathematical Models. Mathematical modelling and computational experiments, 1(4), pp. 407-414. 


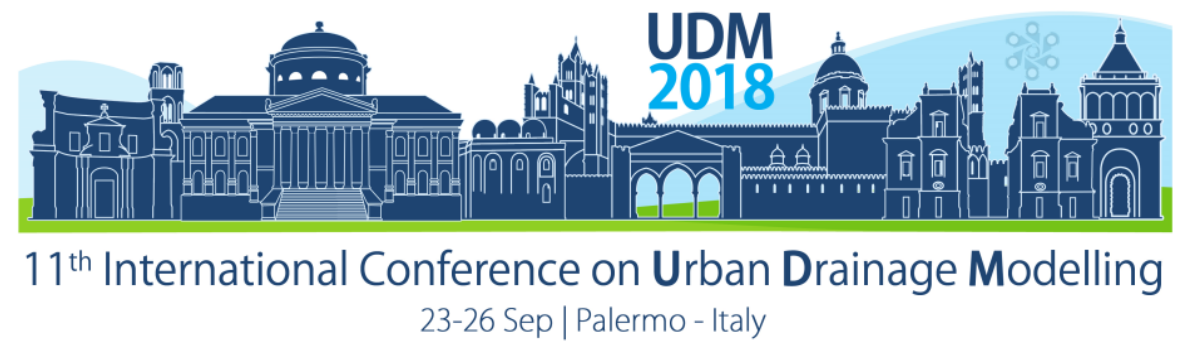

\title{
Quantifying Benefits of Permeable Pavement on Surface Runoff, an Agent-Based-Model with NetLogo
}

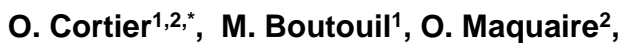 \\ ${ }^{1}$ COMUE NU - ESITC, ESITC Caen, 1, rue Pierre et Marie Curie, F-14610, Epron, France \\ ${ }^{2}$ Normandie Univ, UNICAEN, CNRS, LETG, Campus 1, Bâtiment A, Esplanade de la Paix, 14032 Caen, France \\ * Corresponding author's e-mail: olivier.cortier@esitc-caen.fr
}

\begin{abstract}
Permeable pavements benefits are large and well-studied all over the world by the scientific community however they are still not yet frequently used in urban projects. In order to explore permeable pavement benefits an Agent-Based-Model (ABM) was built. The model addresses the impact of the soil occupation of an urban catchment on its hydrological response. Specifically, it aims at quantifying the impacts of permeable pavement on runoff. ABM allows for exploring global phenomena by the integration of local processes. In this model, a simple micro-scale rule (move to the adjacent cell with the lowest piezometric level) performed by all the agents Drops gives a very relevant flow simulation at catchment-scale. This conceptual model is GIS-based and does not require important hydraulic data. Results show that turning $2.5 \%$ of the impervious cover into permeable pavements can reduce the runoff by $8.3 \%$. Model exploration highlights where and in which proportion permeable pavements should be used to be the most efficient.
\end{abstract}

Keywords: Agent-based-modeling; Hydrological behavior; GIS; Netlogo; Permeable pavement; Runoff

\section{INTRODUCTION}

The long term process of urbanization, hand in hand with the demographic growth, have resulted in the alteration of the natural hydrological cycle. Indeed, the increase of impervious surfaces in urban catchment leads to the increase of surface runoff through the decreased of infiltration and evaporation capacity (Braud et al., 2013; Haase, 2009; Jacobson, 2011; Miller et al., 2014). Meanwhile, climate change is likely to lead to an increase of the frequency of extreme rainfall events that will be accompanied by a more frequent occurrence of short duration floods (Yin et al., 2016). Over the past decades, alternative approaches known as Low Impact Development (LID) have been developed to address these issues. Among them, permeable pavements are particularly well adapted for urban planning in dense urban areas. They are well studied all over the world by the scientific community (Brunetti et al., 2016; Illgen et al., 2007). However, permeable pavements are still not yet frequently used in urban projects. The development of a new pervious concrete formulation at the ESITC laboratory (Nguyen et al., 2014) highlighted the need for tools to help local authority and stakeholder to use these techniques. In this context, modeling permeable pavement benefits on runoff in an urban setting, is increasingly relevant given their high potential benefits. Authors underline also the need for model that integrated the individual component and the urban water cycle at catchment scale (Fletcher et al., 2013; Salvadore et al., 2015). However, building an integrated model at a fine space and temporal resolution is often compromised by the complexities of urban environment and the hydraulic data needed (Chen et al., 2009). One solution is the use of simplified approaches based on cellular automata (Webber et al., 2018). This paper describes the development and test of an Agent-Based-Model (ABM). The model is GIS-based and is applied to an urban catchment in Normandy. This model will help to explore the benefits of permeable pavements on surface runoff with high spatial $\left(1 \mathrm{~m}^{2}\right)$ and time (1 minute) resolution. The final goal of this work is to give recommendations on where and in which proportion permeable pavements should be used to be the most efficient. 


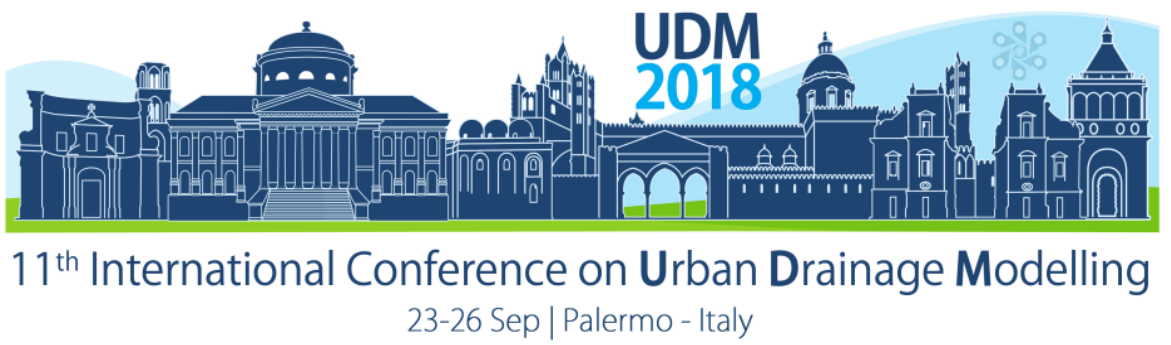

\section{MATERIALS AND METHODS}

\subsection{Catchment description}

Ouistreham is located in the North-West of France, in the region of Normandy $\left(49^{\circ} 17^{\prime} \mathrm{N}\right.$ $0^{\circ} 16^{\prime} \mathrm{W}$ ). The climate is oceanic with rainfalls all year long and a little seasonality variability. The average annual temperature is $11.6^{\circ} \mathrm{C}$ and the average annual precipitation is $679 \mathrm{~mm}$. The catchment consists of a district of Ouistreham, named Riva Bella, built by the sea from the year 1960. This 48.3 hectare catchment is built on a dune, sandy soil, and has the particularity of not having any storm water sewage network. Indeed rainfalls were historically infiltrated into the dune as all sidewalks and parts of the road were not covered. In the past few years, with the waterproofing of roads and sidewalks, flooding started to occur during heavily rainfall events. To deal with the runoff infiltration wells have been dug at strategic localizations but they require regular maintenance as the sand clogs them quickly.

Topography was obtained from a Lidar database (Litto3D®) with a horizontal resolution of 1 meter and a vertical precision of 20 centimeters. Land use was defined from aerial photography and field observation, Figure 1.

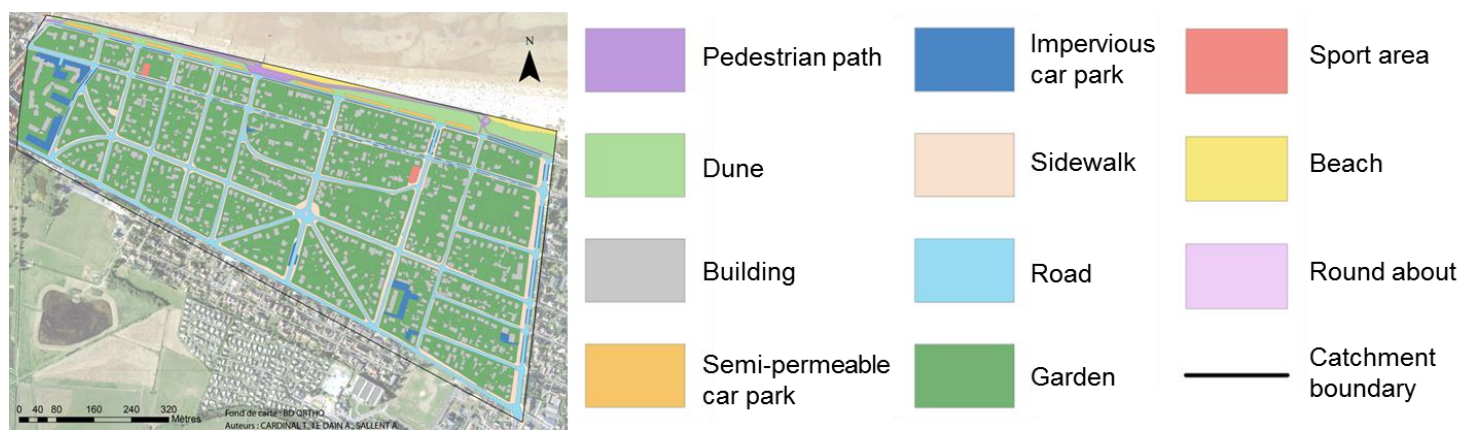

Figure 1. Land use of the 'Riva Bella' catchment.

\subsection{Model development}

\section{Entities, state variables, and scales}

The model is developed with NetLogo which is a multi-agent programmable modeling environment. ABM consists of two major elements: cellular automata (cells) and agents. First ArcGIS is used to develop land use and topography rasters. Next, NetLogo applies the rasters information to a grid of cells of $1 \mathrm{~m}^{2}$ dimension. Then, from its land use attribute, each cell gets hydrological attributes in terms of interception (in $\mathrm{mm}$ ) and infiltration (in $\mathrm{mm} / \mathrm{min}$ ). Two other attributes are used in case the cell is turned into permeable pavement, the flow in (in $\mathrm{mm} / \mathrm{min}$ ) giving the maximum water flow that can enter into the pavement, and the storage (in litres) giving the maximum storage allowed inside the pavement before the drainage. These attributes are obtained from a previous physical-based-modeling of hydrological processes of permeable pavements (Cortier et al., 2017). Two agents are used in the model, Drops and Waters. They are used respectively to simulate the water flow at the surface and inside the permeable pavement structure. They have one attribute, their size. Four parameters are used for the permeable pavement generation: the ratio of permeable pavement surfaces other impervious surface (in \%), their surface area (in $\mathrm{m}^{2}$ ), the land use localization (car park, road, sidewalk, etc.) and the elevation localization (top, bottom). Finally the user selects the rainfall profile and return period and the evapotranspiration value. 


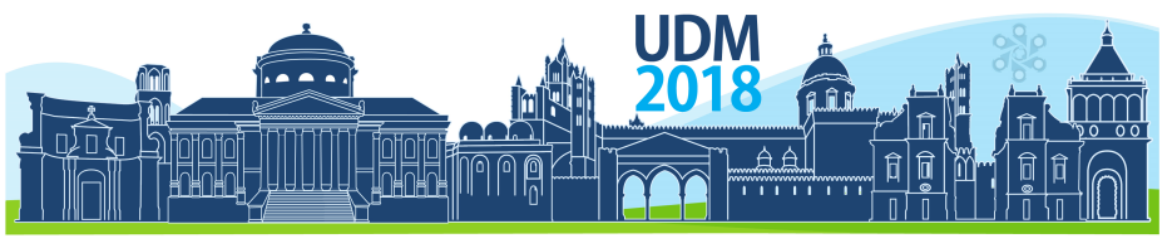

$11^{\text {th }}$ International Conference on Urban Drainage Modelling

23-26 Sep | Palermo - Italy

\section{Process overview and scheduling}

After a setup process, the model runs the simulation following the same processes at each step (one step corresponds to one minute) and for each cell, figure 2 . These processes are repeated until the end of the simulation corresponding to the end of the runoff discharge.

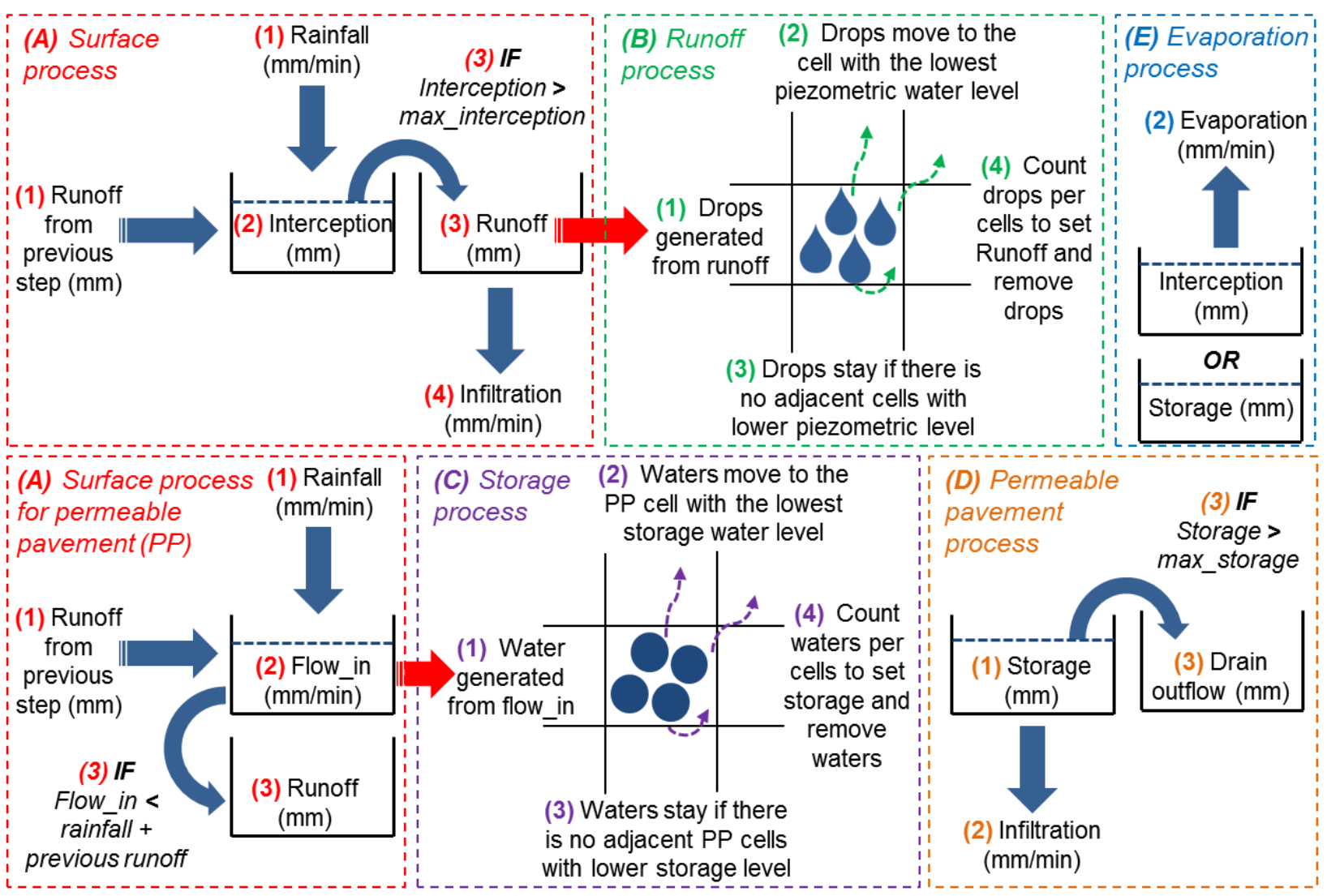

Figure 2. Schematic of the model processes for one step. Procedures (A), (B), and (E) are run for each cell, procedures $(C)$ and $(D)$ are only run for permeable pavement cells.

\section{RESULTS AND DISCUSSION}

\subsection{Model sensitivity analysis}

A sensitivity analysis was conducted on each model parameters to both asses the model robustness and identify the key attributes. First, the number of agents Waters and Drops created at each step was tested from 1 to 9 (per cell). Results show, first that using only 1 agent per cell does not allow for accurate runoff and storage simulation, second that using from 2 to 9 agents only slightly increases the model accuracy. These parameters were set to 4 as a compromise between accuracy and computation time. Second, the hydrological parameters were tested in a range of realistic value for each. A multi-linear regression analysis was run on the results. This analysis shows that soil permeability is the most influent parameter (normalized coefficient of -0.44 and +0.87 on runoff and infiltration respectively). Interception parameters only have a significant impact on interception, and permeable pavement storage parameter only impacts the repartition between storage and drain outflow. 


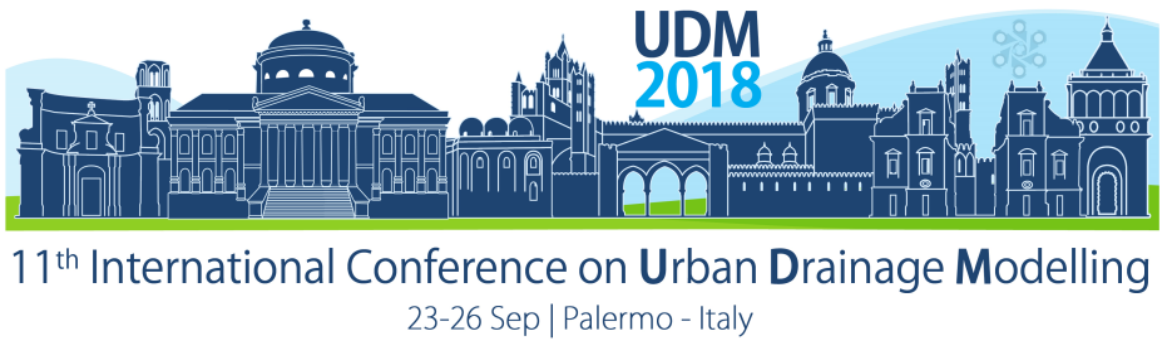

\subsection{Main results on permeable pavements benefits}

In order to explore the influence of permeable pavement ratio, size and localization on their benefits 72 simulations were conducted combining the four permeable pavement generation parameters. Results, obtained for a 100 years return period event, reveal that the ratio of permeable surface is the most influential parameter (table 1). Results also highlighted that; (a) permeable pavement area does not have a significant impact, (b) permeable pavement are slightly more efficient when located at the bottom than at the top of the catchment and (c) they are more efficient when located on car parks than on roads (for this specific catchment).

Table 1. Average values of runoff peak reduction for the main localization parameters (in $\%$ of the runoff peak).

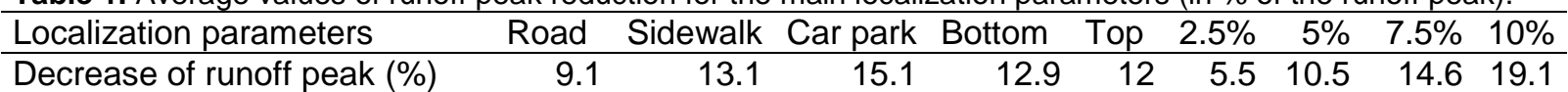

\section{CONCLUSIONS}

This study presents an agent-based-model built for the quantification of permeable pavement impacts on urban runoff. Sensitivity analysis revealed that the soil permeability is the most influent parameter on the runoff. An exploration of permeable pavement benefits according to their ratio, size and localization was conducted. Results reveal that, with the right localization, ratio of $2.5 \%$ and $10 \%$ of permeable surface can respectively reduce the runoff peak by $8.3 \%$ and $24.4 \%$ and increase the infiltration by $8.8 \%$ and $30.3 \%$ (for a 100 years return period event). Further model exploration will allow for better understanding permeable pavement impacts. Such study could help promote a widespread and right use of this LID technique.

\section{Authors wish to thanks the Normandy Regional Council for the funding provided.}

\section{References}

Braud, I., Breil, P., Thollet, F., Lagouy, M., Branger, F., Jacqueminet, C., Kermadi, S., Michel, K., 2013. Evidence of the impact of urbanization on the hydrological regime of a medium-sized periurban catchment in France. J. Hydrol., Hydrology of peri-urban catchments: processes and modelling 485, 5-23.

Brunetti, G., Šimůnek, J., Piro, P., 2016. A comprehensive numerical analysis of the hydraulic behavior of a permeable pavement. J. Hydrol. 540, 1146-1161.

Chen, J., Hill, A.A., Urbano, L.D., 2009. A GIS-based model for urban flood inundation. J. Hydrol. 373, 184-192.

Cortier, O., Boutouil, M., Maquaire, O., 2017. Modeling of the hydrological behaviour of pervious pavements, a physically based approach with FlexPDE, Presented at the 14th ICUD, Prague, pp. 2562-2567.

Fletcher, T.D., Andrieu, H., Hamel, P., 2013. Understanding, management and modelling of urban hydrology and its consequences for receiving waters: A state of the art. Adv. Water Resour., Issue 51, 261-279.

Haase, D., 2009. Effects of urbanisation on the water balance - A long-term trajectory. Environ. Impact Assess. Rev. 29, 211-219.

Illgen, M., Harting, K., Schmitt, T.G., Welker, A., 2007. Runoff and Infiltration characteristics of permeable pavements - Review of an intensive monitoring program. Presented at the Novatech, p. 8.

Jacobson, C.R., 2011. Identification and quantification of the hydrological impacts of imperviousness in urban catchments: A review. J. Environ. Manage. 92, 1438-1448.

Miller, J.D., Kim, H., Kjeldsen, T.R., Packman, J., Grebby, S., Dearden, R., 2014. Assessing the impact of urbanization on storm runoff in a peri-urban catchment using historical change in impervious cover. $J$. Hydrol. 515, 59-70.

Nguyen, D.H., Sebaibi, N., Boutouil, M., Leleyter, L., Baraud, F., 2014. A modified method for the design of pervious concrete mix. Constr. Build. Mater. 73, 271-282.

Salvadore, E., Bronders, J., Batelaan, O., 2015. Hydrological modelling of urbanized catchments: A review and future directions. J. Hydrol. 529, 62-81.

Webber, J.L., Gibson, M.J., Chen, A.S., Savic, D., Fu, G., Butler, D., 2018. Rapid assessment of surface-water flood-management options in urban catchments. Urban Water J. 15, 210-217.

Yin, J., Yu, D., Yin, Z., Liu, M., He, Q., 2016. Evaluating the impact and risk of pluvial flash flood on intra-urban road network: A case study in the city center of Shanghai, China. J. Hydrol. 537, 138-145. 


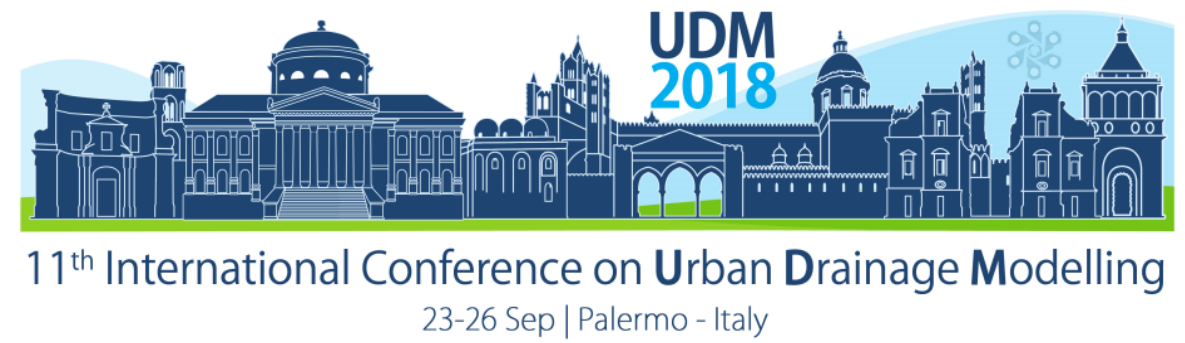

\title{
Estimating flows in urban creeks - two case studies in Finland
}

\author{
Lauri Harilainen ${ }^{1}$, Perttu Hyöty ${ }^{2}$, Tiina Okkonen ${ }^{3}$ and Adam Lunden-Morris ${ }^{4}$ \\ $1,3,4$ Sitowise, Water Services, Espoo, Finland \\ 2 Sitowise, Water Services, Tampere, Finland
}

\begin{abstract}
In this paper we present two urban flood study cases in Southern Finland. For larger, rural areas, methods and standard practices of estimating flood extent and flows of annually occurring post winter snow-melts have been developed over a long period of time. However, no such widely adopted procedures or regulations have been developed for urban watersheds. Thus, planners must judge the most appropriate method for obtaining results based on the needs on a case-by-case basis. This lack of regulations or agreed common standards is becoming a critical industry issue as the emergence and availability of detailed GIS and remote sensing data has given rise, in particular to the possibility of more accurate and detailed estimates of catchment runoff. In this paper, two cases are presented in which the most recent set of land cover data has been used. In first case the traditional run-off coefficient method was used, whereas in second a SWMM- model was introduced to compute runoff values. In both cases land cover information was available as detailed vectorized land use data, which was classified based on aerial image interpretation and Lidar data.
\end{abstract}

Keywords: Flow estimates, storm water modelling; land use; flooding

\section{INTRODUCTION}

Rapidly growing availability of remote sensing data and other open source GIS- information and the development of relevant tools is having a substantial impact on the assessment of urban hydrology. More detailed and freely available data gives new possibilities that didn't exist before. However, these new possibilities require development and implementation of new practices and methods. This paper demonstrates two cases in Finland where flood flow estimates were produced using the latest available land cover data sets. Flood estimates were calculated using two different methods. In the first case a traditional run-off coefficient method was employed to estimate runoff values in a perennial urban waterway $\left(F 24,4 \mathrm{~km}^{2}\right)$.

In second case a Storm Water Management Model (SWMM) was built for a smaller watershed ( $\left.F 2,1 \mathrm{~km}^{2}\right)$ to estimate design storm flooding events as part of a waterway channel relocation project. In both projects a recent land cover dataset covering the Helsinki metropolitan area was used. This dataset is based on aerial imagery interpretation and is further classified into impervious and pervious surfaces. This paper aims to demonstrate current procedures in the evaluation of urban runoff in Finland (1), discuss the challenges in modern storm water related engineering tasks (2) and give recommendations to improve urban drainage modelling practices (3).

\section{MATERIALS AND METHODS}

Datasets commonly known as the Regional Land Use Data have been produced for the Helsinki metropolitan area in both 2014 and updated in 2016 (Helsinki Region Environmental Services Authority, HSY. 2014 and 2016). The dataset is intended to be updated every 2 years 


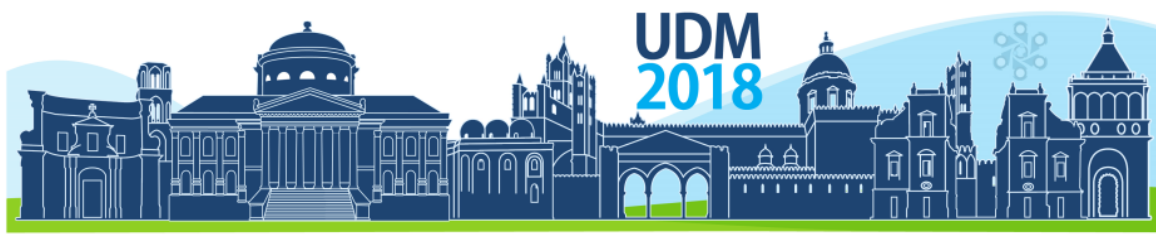

$11^{\text {th }}$ International Conference on Urban Drainage Modelling

23-26 Sep | Palermo - Italy

in order to keep up with the land use changes being experienced in Helsinki region. This data set was chosen to estimate the proportion of impervious surfaces due to its high level of detail. Land use categories are divided to paved and unpaved roads, roofs, other impervious surfaces, open fields, areas with low vegetation coverage, forested areas (sub divided by average tree height), rocky outcrops, bare ground and water bodies. The data set is vectorized and available in a $50 \times 50 \mathrm{~cm}$ raster format. Other similar land use data sets such as Urban Atlas and the spatially less detailed CORINE are commonly used in hydrological analysis and storm water studies in Finland.

Both studied catchments were divided in to sub-catchments with each sub-catchment being analysed using the open source QGIS-software to determine the proportion of each land use category on the basis of area. Runoff values were calculated for each sub-catchment based on the determined TIA (Total Impervious Area) value either using roughly calibrated runoff coefficients (Case 1) or the SWMM-model (Case 2) and verified against the Finnish Meteorological Institute's own rainfall radar data and other field observations.

\subsection{Case 1 -Gräsanoja 'Gräsa Creek'}

Gräsanoja is a $5 \mathrm{~km}$ long urban creek in the city of Espoo with catchment area of $24,4 \mathrm{~km}^{2}$ (Fig. 1). Storm events causing severe flooding have occurred within the last two years resulting in traffic interruptions and flood damage to nearby industrial buildings. Run-off coefficients were estimated for each sub-catchment based on the determined TIA values, average depression depth and total rainfall accumulation in order to determine of flow estimates for a master planning phase project, whilst being acutely aware of the limitations of run-off coefficient methods in determining accurate values in large watersheds. Run-off coefficients were further calibrated against actual documented flood observations from September 2016.

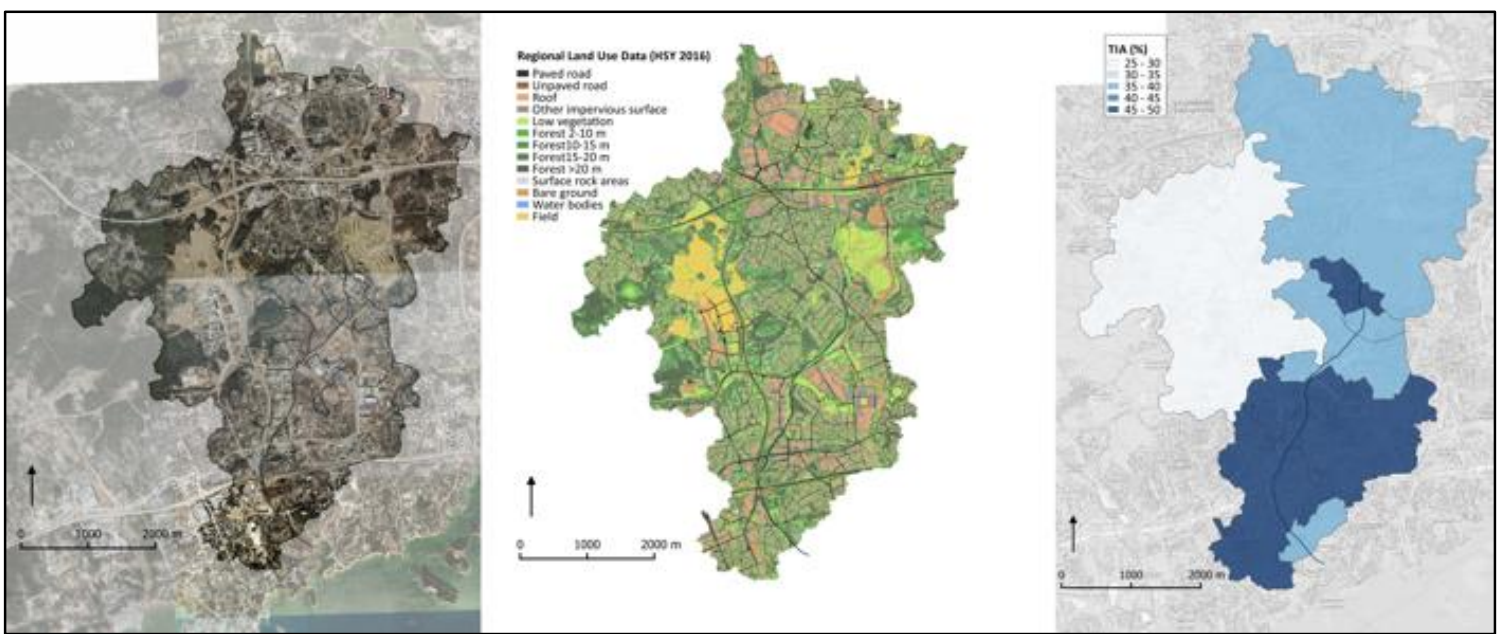

Figure 1. Studied catchment area Gräsanoja (1a) Land Use Data (1b), and estimates of TIA values of subcatchments (1c).

\subsection{Case 2 - Pellaksenoja 'Pellas Creek'}

Pellaksenoja, situated in city of Vantaa, is a relatively small urban creek of $2,2 \mathrm{~km}$ in length $(\mathrm{F}$ $2,1 \mathrm{~km}^{2}$ ). Part of the stream (approximately $350 \mathrm{~m}$ ) is to be relocated due to the space 


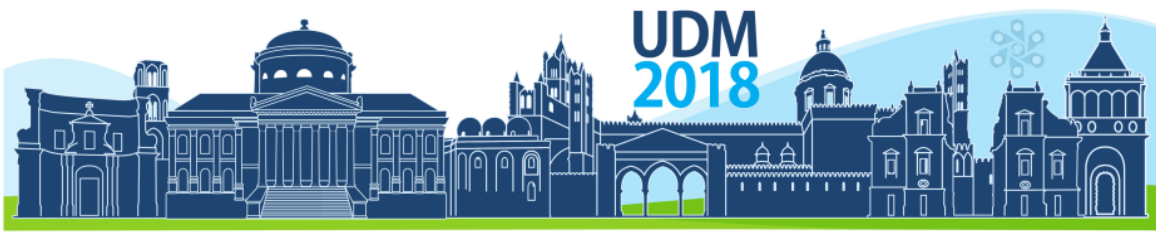

$11^{\text {th }}$ International Conference on Urban Drainage Modelling

23-26 Sep | Palermo - Italy

constraints brought about by the implementation of a new road alignment. A SWMM -model was chosen to analyze storm events and estimate dimensioning flows in order to determine the cross-sectional profile of the modified waterway. Modelling also made it possible to estimate the flow capacity of the stormwater drainage network operating within the local watershed. Sub-catchments were parametrized using the Regional Land Use Data (Fig 1.) for TIA, depression depths, manning values and impervious areas with no depression storage i.e. roof area. The Green-Ampt method was used for infiltration and soil types were determined from the municipal geological data set covering the study area. A SWMM-model was used to estimate future flows over a 20-year interval. Known land use plans and their subsequent impact on the catchment flow regime were modelled by augmenting the proportion of TIA values in certain sub-catchments to represent the expected development. Future flow scenarios were used to design the new channel reach. A HEC-RAS model was then set up in the detailed planning phase for determine detailed design of the channel and cross-sections.

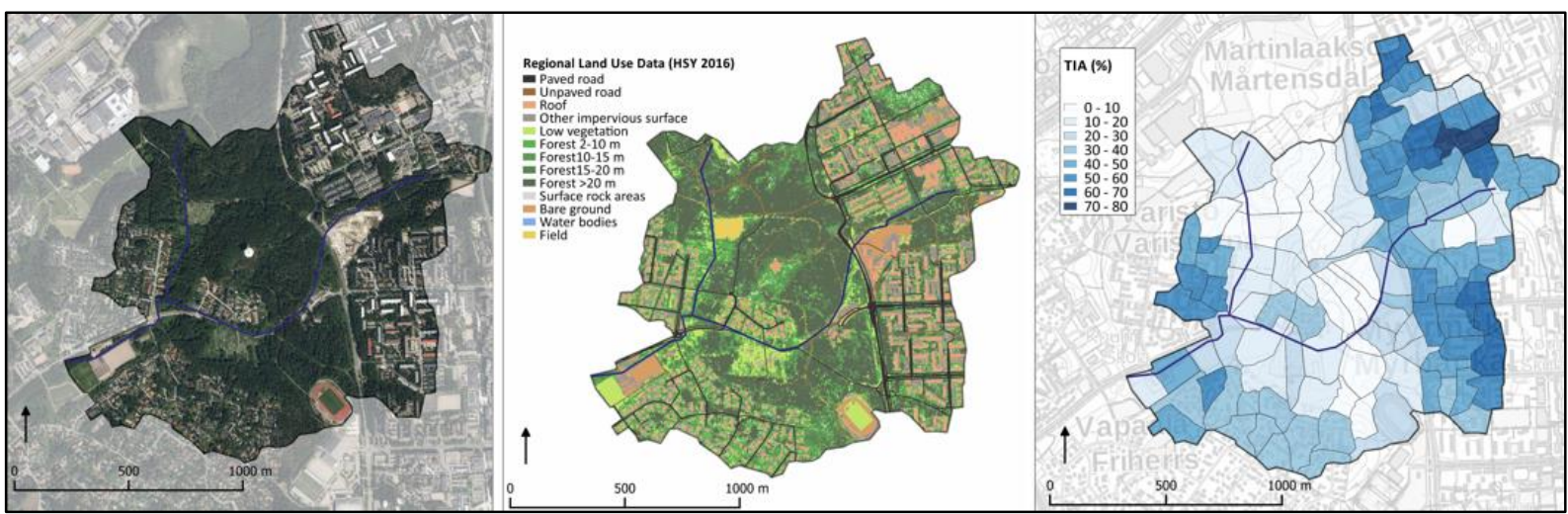

Figure 2. Studied catchment area of Creek Pellaksenoja (2a) Land Use Data (2b), and estimates of TIA values of subcatchments (2c).

\section{RESULTS AND DISCUSSION}

\subsection{Case 1-Gräsanoja}

Run-off coefficients estimated from the TIA values for each sub-catchment are presented in Table $1(\mathrm{C} 1)$. Coefficients were calculated from TIA values taking into account the estimated depression storage in each catchment. Applying these values to the meteorological radar rainfall intensity data suggested that the calculated flows (Flow, calculated) were higher than estimated flows (Flow, observed) during the September 2016 flood event. Run-off coefficients were then reduced by $35 \%$ in order to correspond with the observed values. These roughly calibrated run-off coefficients (C2) were then applied to obtain dimensioning flow values for a 100 year rainfall event.

Total rainfall accumulation during September 2016 flood event was $61 \mathrm{~mm}$ with the fairly steady rain fall intensity during the 9 hour long event being equivalent to an intensity of 19 $\mathrm{l} / \mathrm{s} / \mathrm{ha}$. The aim was to determine preliminary flood flow estimates for the sizing flow of 100 year event which corresponded to a total rainfall accumulation of $81 \mathrm{~mm}$ and intensity of $25 \mathrm{l} / \mathrm{s} / \mathrm{ha}$. The September flood event was estimated to be approximately a 25 year flood event. The applied method was relatively straight-forward but it produced the necessary information in order to evaluate the requirements of preliminary flood mitigation measures at the master planning phase of the project. 


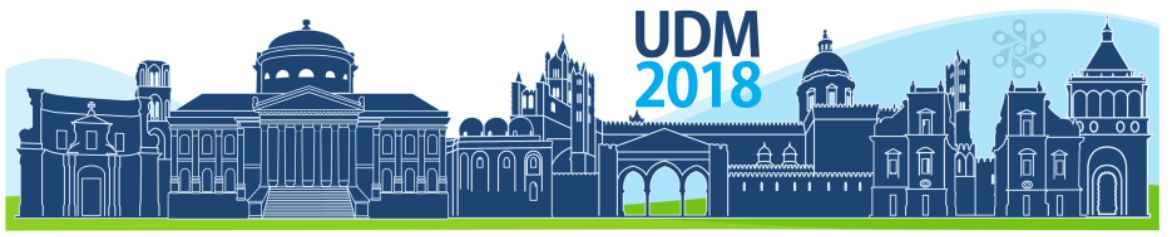

$11^{\text {th }}$ International Conference on Urban Drainage Modelling

23-26 Sep | Palermo - Italy

Table 1. Example of sub-catchments and parameters

\begin{tabular}{cccccccc}
\hline $\begin{array}{c}\text { Sub- } \\
\text { catchment \# }\end{array}$ & $\begin{array}{c}\text { Area } \\
\text { (ha) }\end{array}$ & $\begin{array}{c}\text { TIA } \\
(\%)\end{array}$ & C1 & $\begin{array}{c}\text { Flow, } \\
\text { calculated }\end{array}$ & $\begin{array}{c}\text { Flow, } \\
\text { observed }\end{array}$ & C2 & $\begin{array}{c}\text { Sizing flow } \\
1 / 100 \mathrm{a}\end{array}$ \\
\hline 1.01 & 820 & 40 & 0.35 & 5.4 & 3.5 & 0.23 & 4.7 \\
1.02 & 45 & 47 & 0.41 & 0.3 & 0.2 & 0.27 & 0.3 \\
1.03 & 30 & 39 & 0.34 & 0.2 & 0.1 & 0.22 & 0.2
\end{tabular}

\subsection{Case 2 -Pellaksenoja}

Actual observed or gauged flow measurements, which could be used to understand a catchment's rainfall response are rarely obtained, especially in small waterways. However, fortunately a significant rainfall event occurred within the 5-month project timeframe, which allowed for rudimentary field observations and a subsequent an estimate of flow to be made.

These estimates were then able to be correlated against rainfall data obtained from the Finnish meteorological Institute allowing for modification of the SWMM model. Subsequent simulations of a $10 \mathrm{~min}$ interval a correlated well with the modelled flow of $260 \mathrm{l} / \mathrm{s}$ compared with the measured flow of $240 \mathrm{l} / \mathrm{s}$.

\section{CONCLUSIONS}

Due to the availability and increase in the accuracy of spatial information, it is becoming more feasible for engineers to use modelling as an estimation and design tool in more varied and larger projects than previously. One current urban drainage challenge is that no guidelines or standards exist in relation to best practice in the use of new data sources and the application of this data in modelling parametrization. For large catchments, constructing a detailed storm water model can be time consuming so therefore with limited time and funding, the need for a more robust and suitable approach, such as Case 1, must be considered.

As such, a risk is that it is possible to obtain variations in outcome due to varied approach in the application of identical datasets. Therefore, common guidelines are essential in order to improve the reliability and transparency of modelling outcomes so that modelling outcomes can be confidently applied to further planning stages giving more value to completed studies. For example, a standard set of base parameters to be used amongst planners would greatly improve the usability of models. For Finnish conditions extensive studies on suitable parameters have already been carried out (Krebs 2016; Krebs 2014; Krebs 2013) and could serve as a good basis for developing such a data set. However, the best way to uniformly apply and estimate model parameters must be considered.

Further, in what types of catchments and drainage environments is modelling a valid option must be considered carefully? This can be highly dependent upon the project scale, objectives and budget, as well as specific catchment characteristics. Guidelines for parameter estimation and in sub catchments delineation according to heterogenous or homogenous land use would have a positive impact on the accuracy and reliability of modelling outcomes and also allow better integration of validation and calibration tools thus improving the overall reliability of results and to ensure that model results are realistic and plausible. 
Proceedings of the 11th Int. Conference on Urban Drainage Modelling, 23-26 Sep. 2018, Palermo (ITALY). Ed. prof. Giorgio Mannina

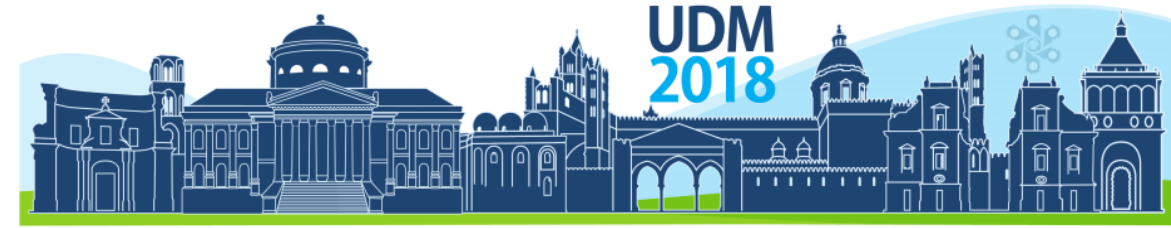

$11^{\text {th }}$ International Conference on Urban Drainage Modelling

23-26 Sep | Palermo - Italy

\section{References}

Krebs, G. 2016. Spatial resolution and parameterization of an urban hydrological model: Requirements for the evaluation of Low Impact Development strategies at the city scale. Aalto University publication series DOCTORAL DISSERTATIONS 78/2016. ISBN 978-952-60-6779-7. 172 p.

Krebs, G., Kokkonen, T., Valtanen, M., Koivusalo, H., Setälä, H. 2013. A high resolution application of a stormwater management model (SWMM) using genetic parameter optimization. Urban Water Journal, 10(6): 394-410.

Krebs, G., Kokkonen, T., Valtanen, M., Setälä, H., Koivusalo, H. 2014. Spatial resolution considerations for urban hydrological modelling. Journal of Hydrology, 512: 482-497 


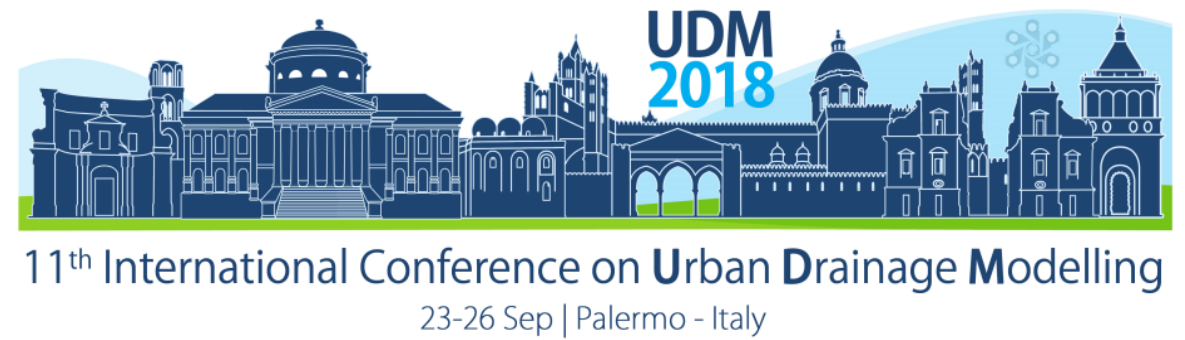

\title{
Coupling Urban Water and Energy Budgets with TEB-Hydro: Case Study on the French Catchment Pin Sec
}

\author{
Stavropulos-Laffaille Xenia ${ }^{1}$, Chancibault Katia ${ }^{1}$, Andrieu Hervé ${ }^{1}$, Lemonsu Aude ${ }^{2}$ and Masson Valéry² \\ ${ }^{1}$ IFSTTAR, GERS, EE, F-44344 Bouguenais, France \\ ${ }^{2}$ CNRM UMR 3589, Météo-France/CNRS, F-31057 Toulouse CEDEX 1, France
}

\begin{abstract}
In view of climate change and demographic pressure in cities, Sustainable Urban Drainage Systems (SUDs) have become essential to urban planners. Understanding their influence on the urban microclimate (energy and water budgets) at city scale is essential for developing adaptation strategies to global change. The hydro-microclimate model TEBHydro enables treating the water and energy budgets with the same level of detail. Its hydrological component has been improved recently and the hydrological processes have been evaluated. However, it has not yet been investigated how those changes affect the energy component of the model. Therefore, the model is applied to a long-term instrumented urban catchment in Western France, allowing its evaluation on water and energy fluxes. The comparison of the simulated total sewer discharge to observations shows a correct KGE criterion of 0.79 , with a tendency of overestimation of the model. The maximal daily observed latent heat fluxes, on the contrary, are mostly underestimated. However, taking into account a source area analysis of the observed turbulent heat fluxes achieves better results while comparing them to simulation.
\end{abstract}

Keywords: Hydro-microclimate modelling; Urban hydrology; Water and energy balance; Heat fluxes

\section{INTRODUCTION}

Climate and demographic changes are major drivers for future management strategies in cities. Integrating Nature Based Solutions (NBSs) and SUDs as adaption and mitigation strategies to global change in urban planning are promoted. Such features usually result in an increase of local water storage and thus might influence evapotranspiration and consequently the urban microclimate. As both the water and the energy cycles are impacted, future adaptation scenarios at city scale need to be evaluated by appropriate numerical tools, taking into account the coupling between the water and energy budgets (Fletcher et al., 2013, Bach et al. 2014, Salvadore et al., 2015).

In view of this, a hydro-microclimate model (TEB-Hydro) was developed by Chancibault et al. (2015) and its hydrological component was recently improved (Stavropulos-Laffaille et al., 2018). Contrary to other hydro-microclimate models, it takes into account both water and energy budgets with the same level of detail. Now, as this new model version is calibrated in a hydrological way, it is essential to assess the impacts on its energy component. Thus, this study presents an evaluation of hydro-microclimatic aspects of the model, comparing simulated and observed water and heat fluxes in the urban catchment Pin Sec (France) before a deeper analysis of their interactions.

\section{MATERIALS AND METHODS}

This section presents the hydro-microclimate model TEB-Hydro, the experimental site to which the model is applied and its configuration for simulation. 


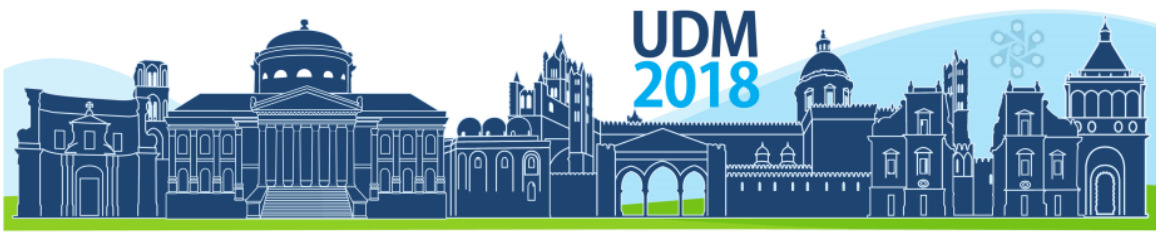

$11^{\text {th }}$ International Conference on Urban Drainage Modelling

\subsection{The hydro-microclimate model TEB-Hydro}

TEB-Hydro is an urban surface scheme of SURFEX (Masson et al. 2013), which couples the model TEB (Masson 2000) for urban surfaces and ISBA-DF (Boone et al. 2000) for natural ones. The urban environment is represented by the canyon approach (Oke 1987) based on three compartments: "buildings", "roads" and "gardens". Explicit water and energy exchanges between the urban sub-soil, the surface and the atmosphere are calculated for each of them. The model allows treating the energy and water budgets at the same level of detail considering respectively latent heat fluxes and evapotranspiration. The radiation and energy budgets of the model are presented in Lemonsu et al. (2012) and Masson (2000), and the hydrological processes of the model are described in detail in Stavropulos-Laffaille et al. (2018).

\subsection{Case Study - Pin Sec}

The Pin Sec catchment is located in the Eastern part of Nantes (Le Delliou et al., 2009) (Figure 1). The climate is temperate with a mean annual total rainfall of about $800 \mathrm{~mm}$. The residential catchment of 31 ha is occupied by single housing with private gardens in the North, and by shared housing and public parks in the South. Impervious surfaces represent $50 \%$ of the catchment area. The sewer network is separated. The catchment has been being instrumented since 2006 and disposes of a complete database of observations (precipitation rate, discharge in the sewer systems, soil moisture, ground water level and turbulent heat fluxes).

Table 1. Model parameters describing the Pin Sec catchment

\begin{tabular}{|ll|ll|}
\hline Urban cover & & Natural cover & \\
\hline Fraction of buildings & 0.19 & Fraction of gardens & 0.49 \\
Fraction of roads & 0.32 & Fraction of high vegetation & 0.25 \\
Mean building height $(\mathrm{m})$ & 9.33 & Fraction of low vegetation & 0.38 \\
Roughness length for momentum z0 & 0.93 & Fraction of bare soil & 0.37 \\
\cline { 2 - 4 } Stormwater sewer length $(\mathrm{m})$ & 3911.0 & Soil properties & \\
\cline { 2 - 3 } Wastewater sewer length $(\mathrm{m})$ & 6972.7 & Number of soil layers & 12 \\
Mean sewer depth $(\mathrm{m})$ & 1.5 & Fraction of clay & 0.08 \\
Fraction of impervious surfaces connected to sewer & 0.61 & Fraction of sand & 0.51 \\
\hline
\end{tabular}




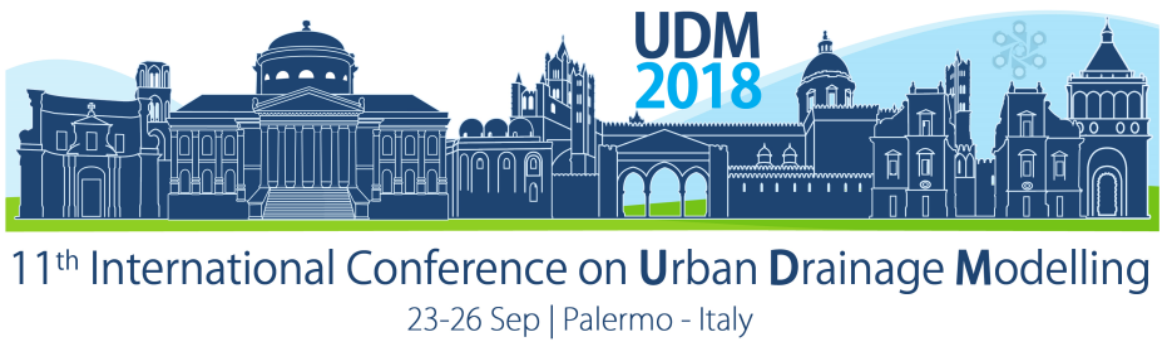

\subsection{Model configuration}

The Pin Sec catchment is represented by a single grid cell. The model parameters, describing the catchment properties, are defined in Table 1. The model is forced by meteorological observations at a time step of $60 \mathrm{~min}$. The numerical time step of the model is $5 \mathrm{~min}$. The simulation period is 2 years and a half between May 2010 and December 2012. The model was calibrated on the catchment by Stavropulos-Laffaille et al. (2018) and a first hydrological validation was performed on both the total stormwater discharge and the contribution of groundwater infiltration. Thus, the simulation performed hereafter, corresponds to the best configuration of parameters determined following this study.

\section{RESULTS AND DISCUSSION}

The results of the simulation are presented for two consecutive hydrological years from $1^{\text {st }}$ of September 2010 to $31^{\text {st }}$ of August 2012. The first four months are removed from the analysis due to the initialisation period of the model. The simulation outcome variables are then compared to observations and the statistic efficiency criteria KGE (Gupta et al. 2009) is calculated. First the modelled discharge at the basin outlet is confronted to the observed storm sewer discharge due to surface runoff. Second, the simulated latent and sensible heat fluxes are discussed. Therefore, a source area analysis (footprint) of the measured fluxes is taken into account, according to Schmid (1994).

\subsection{Sewer discharge}

Comparing the observed total sewer discharge to simulation for the simulation period gives a correct KGE-criterion of about 0.79 . This outcome is influenced by three components: the correlation ( $r$ ) between simulated and observed discharge peaks is of about 0.86 , the variability $(\alpha)$ of 1.15 and the bias $(\beta)$ of 0.98 . However, the model tends to overestimate the observed total sewer discharge (Figure 2a). This is due to the parameter describing the total fraction of impervious surfaces connected to the sewer, to which the model is very sensitive. In case this parameter is not known the model has to be calibrated on it. However, a detailed field survey on half of the Pin Sec catchment was conducted aiming to determine this parameter. Therefore, it was extrapolated on the whole catchment surface rather than considered for the calibration process. Furthermore, the simulated sewer discharge due to soil water infiltration is evaluated against observations, and will be presented at the conference.

\subsection{Turbulent heat fluxes}

The turbulent heat fluxes are evaluated considering a time step of $30 \mathrm{~min}$ in order to approach a steady state during the interval. The results according to the latent heat fluxes are discussed here (the sensible heat fluxes will be presented at the conference). The model seems to underestimate the maximal daily observed latent heat fluxes and to overestimate the nocturnal ones. Especially, the observed condensation at night, is not well reproduced by the model. A possible explanation could be a slowed down cooling process of built-up surfaces during night time. However, this needs further investigation. For the year 2012 the coefficient of determination (R2) is 0.49 . However, considering only the ones having their source areas mainly located on the catchment enables improving the coefficient of determination (R2) to 0.59 (Figure 2b). This approach will allow discussing more precisely the influence of the recent model developments on the heat fluxes and broadening the insight into the processes of coupling the water and energy budgets. 


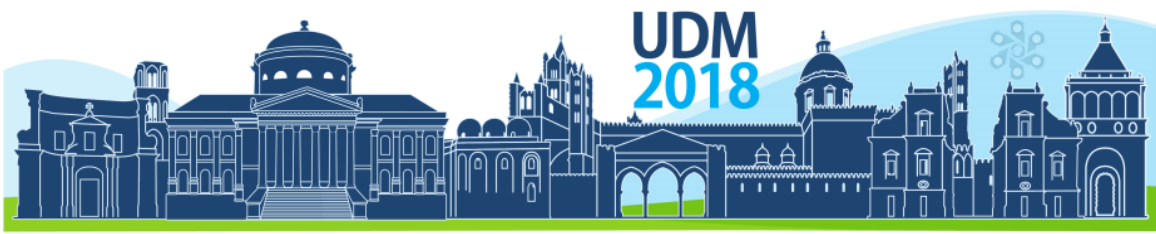

$11^{\text {th }}$ International Conference on Urban Drainage Modelling 23-26 Sep | Palermo - Italy
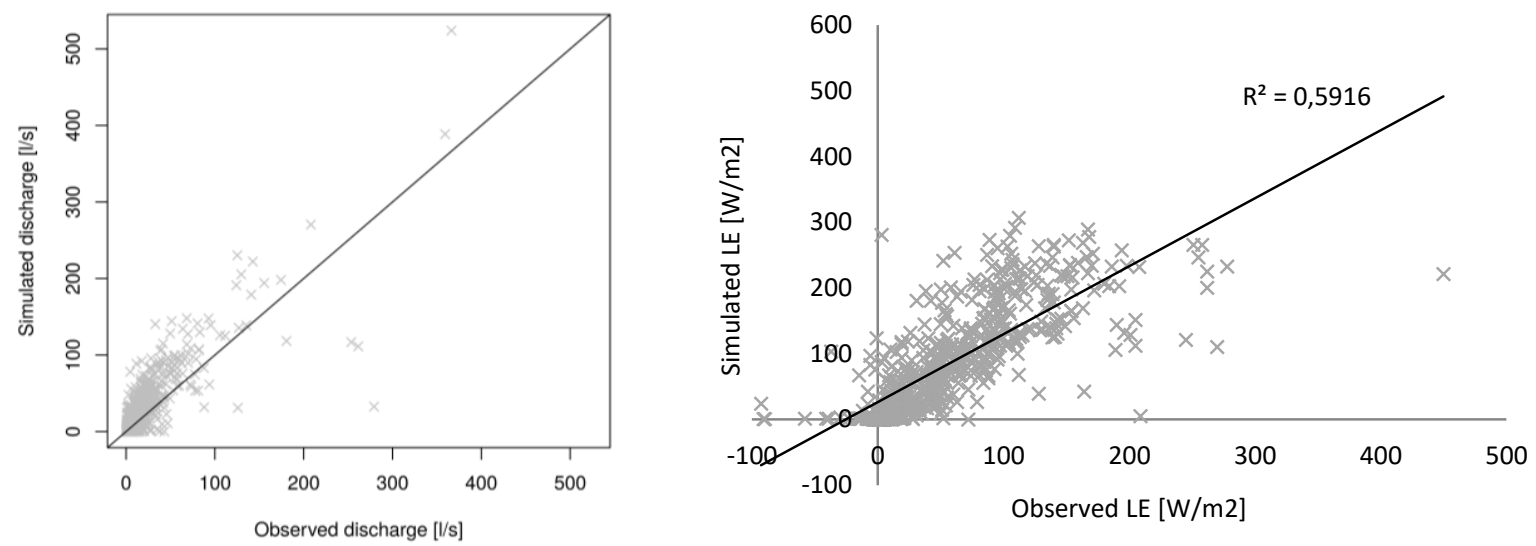

Figure 2. a) Comparison of simulated and observed total sewer discharge [l. $\left.\mathrm{s}^{-1}\right]$ from September 2010 to September 2012, b) Comparison of simulated and observed latent heat fluxes [W.m-2] in 2012 by taking into account their source areas mainly located on the catchment.

\section{CONCLUSIONS}

The recently improved hydro-microclimate model TEB-Hydro has been applied to the urban catchment Pin Sec in Nantes (France). Its simulated water and energy fluxes, with the emphasis on sewer discharge due to urban runoff and soil water infiltration and on latent and sensible heat fluxes, are compared to observations. Thus, the hydro-microclimate evaluation of the model on a small urban basin can be presented. Furthermore, the outcomes will be compared to the same simulation without TEB-Hydro, with the aim of analysing the impact of the hydrological processes and calibration on heat fluxes. Finally, the interactions between hydrological and energy processes will be discussed.

\section{References}

Bach, P. M., Rauch, W., Mikkelsen, P. S., McCarthy, D. T., \& Deletic, A. (2014) A critical review of integrated urban water modelling - Urban drainage and beyond. Environmental Modelling \& Software, 54, 88-107.

Boone, A., Masson, V., Meyers, T. \& Noilhan, J. (2000) The Influence of the Inclusion of Soil Freezing on Simulations by a Soil-Vegetation-Atmosphere Transfer Scheme. Journal of Applied Meteorology, 39, 1544-1569.

Chancibault, K., Brun, J.-M., Allard, A., Andrieu, H., Lemonsu, A., De Munck, C., \& Masson, V. 2015 Improving the water budget in the urban surface scheme TEB for a better evaluation of greening strategies for adaptation purposes. ICUC9 20-24 July 2015, Toulouse, France.

Fletcher, T., Andrieu, H., \& Hamel, P. (2013) Understanding, management and modelling of urban hydrology and its consequences for receiving waters: A state of the art. Advances in Water Resources, 51, 261-279.

Gupta, H. V.; Kling, H.; Yilmaz, K. K. \& Martinez, G. F. (2009) Decomposition of the mean squared error and NSE performance criteria: Implications for improving hydrological modeling, Journal of Hydrology, 377, 80-91.

Le Delliou, A.-L.; Rodriguez, F. \& Andrieu, H. (2009) Modélisation intégrée des flux d'eau dans la ville - impacts des réseaux d'assainissement sur les écoulements souterrains. La Houille Blanche, 152-158.

Lemonsu, A.; Masson, V.; Shashua-Bar, L.; Erell, E. \& Pearlmutter, D. (2012) Inclusion of vegetation in the Town Energy Balance Model for modeling urban green areas. Geoscientific Model Development, 5, 1377-1393.

Masson, V. (2000) A Physically-Based Scheme For The Urban Energy Budget In Atmospheric Models. BoundaryLayer Meteorology, 94(3), 357-397.

Masson, V.; Le Moigne, P.; Martin, E.; Faroux, S.; Alias, A.; Alkama, R.; Belamari, S.; Barbu, A.; Boone, A.; Bouyssel, F.; Brousseau, P.; Brun, E.; Calvet, J.-C.; Carrer, D.; Decharme, B.; Delire, C.; Donier, S.; 
Proceedings of the 11th Int. Conference on Urban Drainage Modelling, 23-26 Sep. 2018, Palermo (ITALY). Ed. prof. Giorgio Mannina

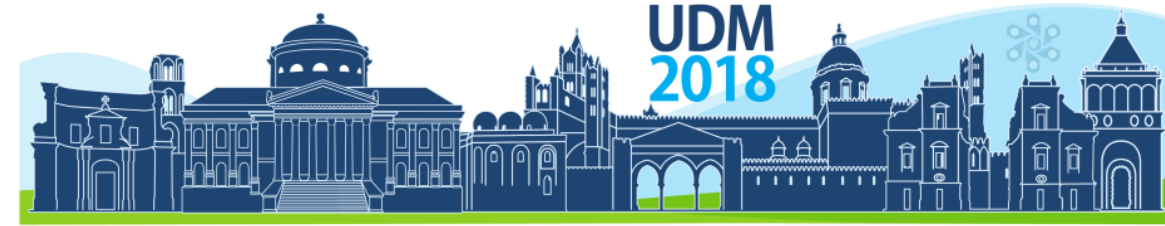

$11^{\text {th }}$ International Conference on Urban Drainage Modelling

23-26 Sep | Palermo - Italy

Essaouini, K.; Gibelin, A.-L.; Giordani, H.; Habets, F.; Jidane, M.; Kerdraon, G.; Kourzeneva, E.; Lafaysse, M.; Lafont, S.; Lebeaupin Brossier, C.; Lemonsu, A.; Mahfouf, J.-F.; Marguinaud, P.; Mokhtari, M.; Morin, S.; Pigeon, G.; Salgado, R.; Seity, Y.; Taillefer, F.; Tanguy, G.; Tulet, P.; Vincendon, B.; Vionnet, V. \& Voldoire, A. (2013) The SURFEXv7.2 land and ocean surface platform for coupled or offline simulation of earth surface variables and fluxes, Geoscientific Model Development, 6, 929-960.

Oke, T. (1987) Boundary Layer Climates 2d ed. Routledge.

Schmid, H. P. (1994) Source areas for scalars and scalar fluxes Boundary-Layer Meteorology, 67, 293-318.

Stavropulos-Laffaille, X.; Chancibault, K.; Brun, J.-M.; Lemonsu, A.; Masson, V.; Boone, A. \& Andrieu, H. (2018) Improvements of the hydrological processes of the Town Energy Balance Model (TEB-Veg) for urban modelling and impact assessment, Geoscientific Model Development, (paper submitted for publication).

Salvadore, E., Bronders, J., \& Batelaan, O. (2015) Hydrological modelling of urbanized catchments: A review and future directions. Journal of Hydrology, 529, Part 1, 62-81. 


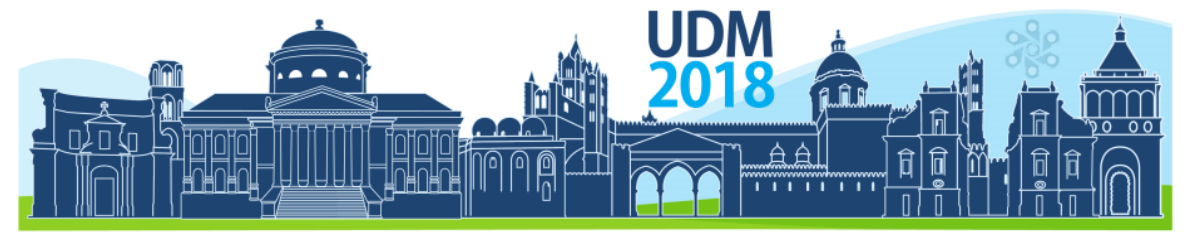

$11^{\text {th }}$ International Conference on Urban Drainage Modelling

23-26 Sep | Palermo - Italy

\title{
Calculation of the hydraulic capacity of grate inlets with supercritical surface flow and unsurcharged drainage flow conditions
}

\author{
Svenja Kemper ${ }^{1}$ and Andreas Schlenkhoff ${ }^{1}$ \\ ${ }^{1}$ University of Wuppertal, Hydraulic Engineering Section, Wuppertal, Germany
}

\begin{abstract}
According to an increasing number of heavy rainfall events, the managing of urban flooding requires new design approaches in urban drainage engineering. With bidirectional coupled numerical models the surface runoff, the underground sewer flow and the interaction processes between both systems can be calculated. Most of the numerical models use a weir equation to calculate the surface to sewer flow with unsurcharged flow conditions, but uncertainties still exist in the representation of the real flow conditions. Street inlets, existing in different types, are the connecting elements between the surface and the underground system. In the present study, an empirical formula was developed based on physical model test runs to estimate the hydraulic capacity of grate inlets with supercritical surface flow. The influencing hydraulic parameters are the water depth and flow velocity upstream of the grate and in addition different geometrical parameters are taken into account such as the grate dimensions or the orientation of the bars (transverse, longitudinal or diagonal).
\end{abstract}

Keywords: dual drainage flow, grate inlet, grate capacity

\section{INTRODUCTION}

With regard to an increasing number of heavy rainfall events, potentially caused by the climate change (IPCC, 2014), managing urban flooding becomes more important in the future. In order to localize inundation areas and to develop new design approaches information about the surface runoff as well as the underground sewer flow and the interaction processes between both systems is necessary. Bidirectional coupled numerical models (dual drainage models, 1D pipe flow model and 2D surface flow model) are capable of representing urban flooding under extreme flow conditions (Butler and Davies, 2011), but uncertainties in calculating the interaction processes still exist (Rubinato et al., 2017).

The present paper focuses on the surface flow to unsurcharged sewer flow conditions with grate inlets as intake structures. Common dual drainage models often use the free weir equation by neglecting the velocity head to determine the inflow from the surface to the sewer when the hydraulic head in the sewer network is less than the surface elevation (Rubinato et al., 2017). In Kemper (2018) it was found, that with supercritical surface flow conditions, the water depth and the flow velocity are the main influencing hydraulic parameters on the efficiency of grate inlets. With 2D surface flow models flow depths as well as flow velocities are known upstream of the grate and could be taken into account for calculating the surface to sewer flow.

Several investigations deal with the grate efficiency by neglecting the system below, e.g. Spaliviero et al. (2000), Despotovic et al. (2005), Gomez and Russo (2005), Brown et al. 


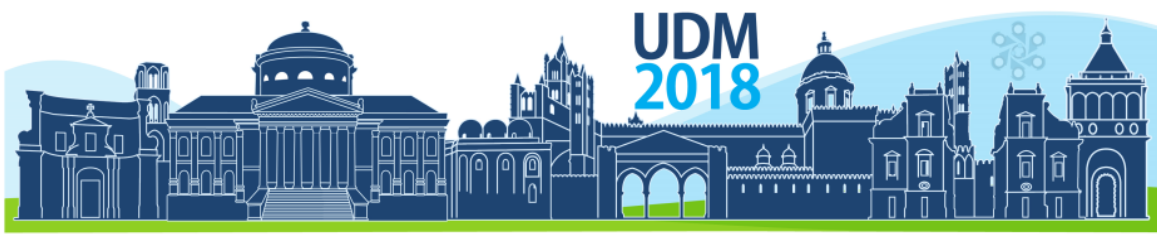

$11^{\text {th }}$ International Conference on Urban Drainage Modelling

23-26 Sep | Palermo - Italy

(2009) and Guo and MacKenzie (2012). Almost all of the published empirical equations to calculate the grate efficiency depend on parameters that are not immediately known from the 2D surface flow model and first need to be calculated or estimated.

In the presented study an empirical calculation formula to estimate the hydraulic grate efficiency with supercritical flow conditions was developed using results of physical model test runs.

\section{PHYSICAL MODEL SETUP}

The measurements were done in a flume made of acrylic glass with $L_{\text {Flume }}=10.00 \mathrm{~m}$ in length and $W_{\text {Flume }}=1.50 \mathrm{~m}$ in width with variable slope in longitudinal $\left(S_{L}\right)$ and transverse $\left(S_{T}\right)$ direction. The bottom roughness is approximately $k=1.5 \mathrm{~mm}$ (roofing paper). The grate of street inlets can be integrated in a 1:1 scale at the downstream end of the flume (Figure 1).

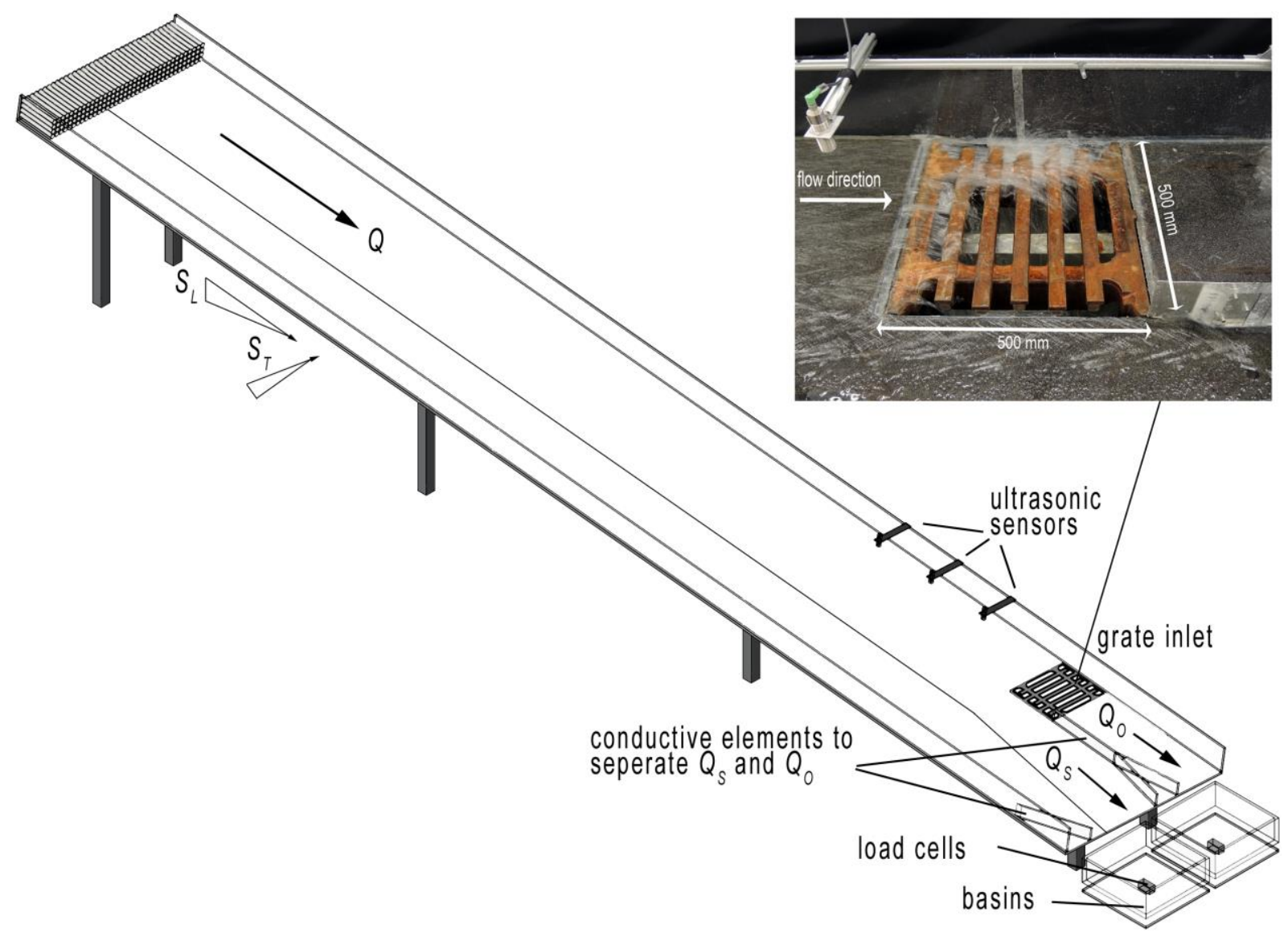

Figure 1. Physical model sketch 


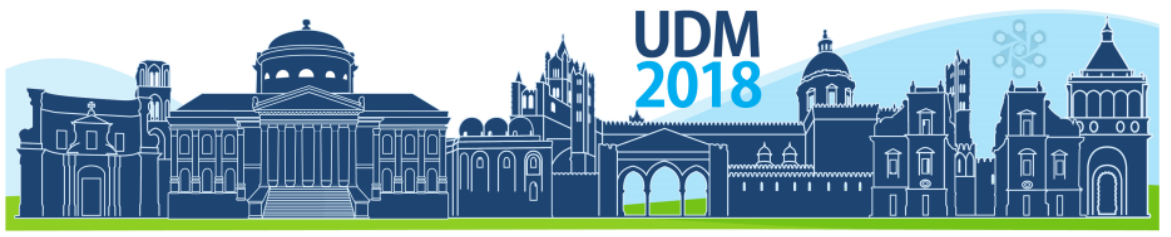

$11^{\text {th }}$ International Conference on Urban Drainage Modelling

23-26 Sep | Palermo - Italy

Six different grate geometries with transversal, longitudinal or diagonal orientated bars were tested (Figure 2). The grate width is $W_{G}=500 \mathrm{~mm}$ and the grate length between $L_{G}=500$ $\mathrm{mm}$ and $780 \mathrm{~mm}$.
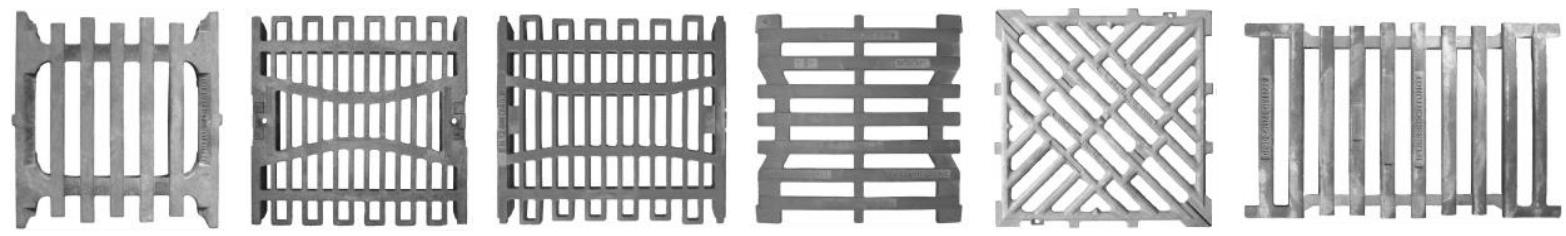

Figure 2. Investigated grate inlets with $W_{G}=500 \mathrm{~mm}$ (flow direction: left to right).

The investigation program is given in Table 1. In total, 28 different combinations of longitudinal slope and discharge were investigated with each of the six grate inlets (168 combinations). The transverse slope was fixed to $S_{T}=2.5 \%$. Only supercritical flow conditions occur, therefore, no backwater effects at the lower boundary of the model arise (free outflow). Uniform flow conditions were reached upstream of the street inlet with water spread widths less than $W_{\text {Flume }}=1.50 \mathrm{~m}$. Therefore, no influence due to the model limitations such as length and width occur. After reaching steady state conditions, the measurements were done with a measurement period of 30 seconds. The water depths upstream of the grate inlet were measured with three ultrasonic sensors (position of the sensors: see Figure 1 ). Using the continuity equation the mean flow velocity was calculated with $v_{m}=Q / A$. Using platform load cells the volume of the water intercepted by the grate $Q_{\text {, }}$, the water flowing beside the grate $Q_{s, L a b}$ and the water flowing over the grate $Q_{0}$ was measured over the time. Each model setup defined by longitudinal slope, discharge and grate inlet type was repeated five times (six model runs for each combination). The final results were calculated as the mean values of the six model runs.

Table 1. Investigation program

\begin{tabular}{ll}
\hline Longitudinal slope $S_{L}$ & $2,5 \%-10,0 \%$ with $\Delta S_{L}=2,5 \%$ \\
Transverse slope $S_{T}$ & $2,5 \%$ \\
Total Discharge $Q$ & $3 \mathrm{l} / \mathrm{s}-21 \mathrm{l} / \mathrm{s}$ with $\Delta Q=3 \mathrm{l} / \mathrm{s}$
\end{tabular}

\section{RESULTS AND DISCUSSION}

The grate capacity is defined as the quantity of the intercepted flow rate $Q_{l}[1 / \mathrm{s}]$ whereas the total hydraulic grate efficiency $E$ is described as a percentage of the approaching flow rate with $E=Q / Q$. In addition, the type-specific efficiency $E_{T}$ is defined. Therefore, the frontal flow on the width of the grate $Q_{F}$ with $Q_{F}=Q-Q_{S}$ (see Figure 3 ) is taken into account only:

$$
E_{T}=\frac{Q_{I}}{Q_{F}}
$$




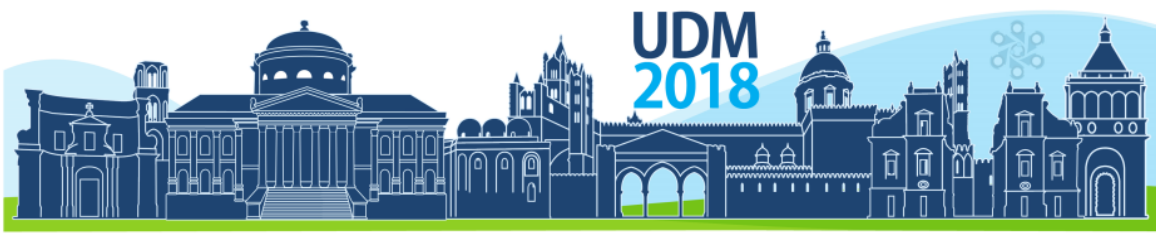

$11^{\text {th }}$ International Conference on Urban Drainage Modelling

23-26 Sep | Palermo - Italy
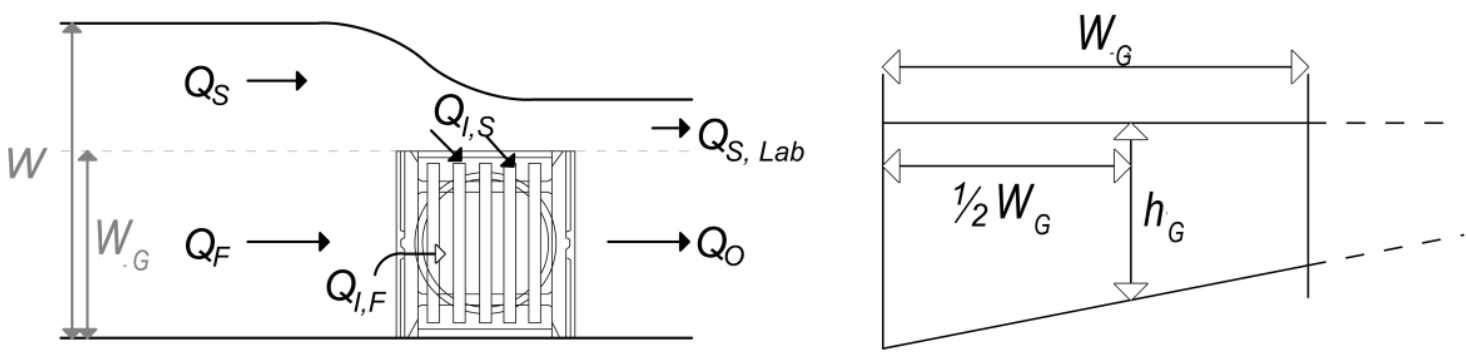

Figure 3. Schematic sketch (left: plan view, right: flow cross section)

The type-specific efficiency decreases with increasing water depth and flow velocity and is between $E_{T} \approx 0.8-1.0$ for the given boundary conditions such as discharge, grate geometry and street geometry (longitudinal and transverse slope). The percentage of the lateral intercepted discharge $Q_{l, S}$ is negligible small and it is $Q_{l} \approx Q_{l, F}$. The results of the physical model test runs are given exemplarily for one grate geometry depending on the flow depth and mean flow velocity in Figure 4.
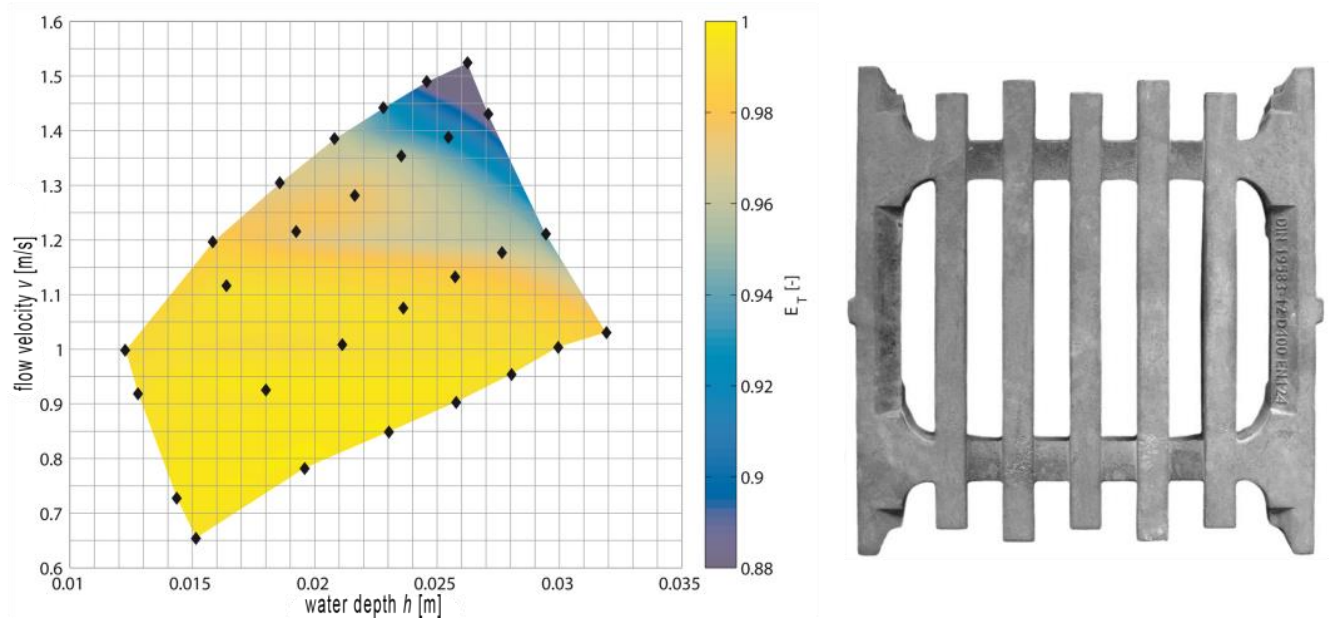

Figure 4. Type-specific efficiency $E_{T}$ depending on the flow depth and flow velocity (physical model results)

With respect to the known information of the 2D surface flow model, the main influencing hydraulic parameters water depth $h_{G}$ and flow velocity $v_{G}$ (mean value with regard to the width of the grate) are taken into account in the developed calculation formula. In addition, geometric parameters such as dimensions of the grate (length $L_{G}$ and width $W_{G}$ ), the opening area $A_{0}$ and the orientation of the bars $S$ are considered. The calculation formula to estimate the type-specific efficiency is developed by using numerical curve fitting methods as follows:

$$
E_{T}=1-F r_{G}^{9.5} \cdot\left(\frac{h_{G}^{1.5} \cdot W_{G}}{\sqrt{L_{G}} \cdot A_{0}}\right)^{S}
$$




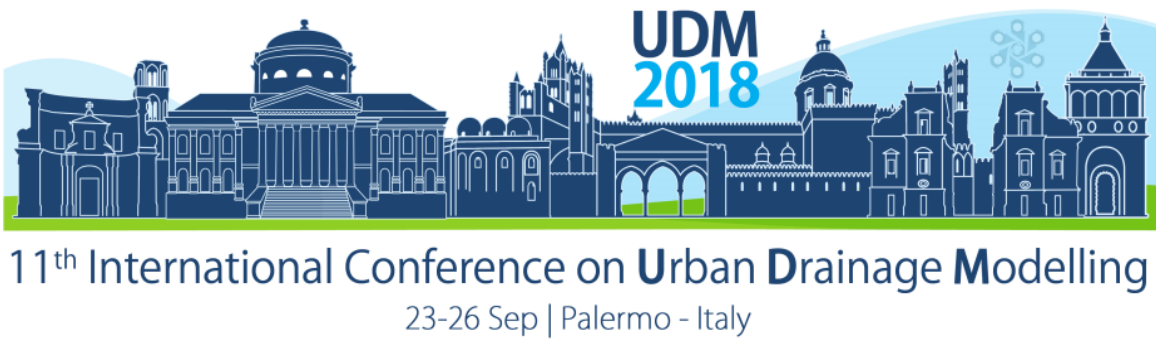

with $S=$ parameter for the orientation of the bars (Table 2) with $B_{X}=$ width of the bar openings in flow direction and the Froude number $F r_{G}=v_{G} /\left(g \cdot h_{G}\right)^{0.5}$. The formula is limited to supercritical flow conditions with no backwater effects caused by the underground drainage system and the hydraulic boundary conditions of the physical model test runs with $0.006 \mathrm{~m} \leq$ $h_{G} \leq 0.026 \mathrm{~m}$ and $0.66 \mathrm{~m} / \mathrm{s} \leq v_{G} \leq 1.68 \mathrm{~m} / \mathrm{s}$ (see Figure 4). Good agreement between estimated and measured results could be proven with relative deviations less than $1 \%$.

Table 2. Parameter $S$

\begin{tabular}{ll}
\hline Orientation of the bars & $\mathbf{S}$ \\
\hline Transversal bars $\left(B_{X}>0,03 \mathrm{~m}\right)$ & 3,6 \\
Transversal bars $\left(B_{X}<0,03 \mathrm{~m}\right)$ & 3,8 \\
Longitudinal bars & 4,1 \\
Diagonal bars & 4,1 \\
\hline
\end{tabular}

\section{CONCLUSIONS}

Bidirectional coupled models (dual drainage models) which consider the interaction between the underground drainage flow and the surface runoff are still employed in practice. To represent the interaction processes more realistic information about the hydraulic capacity of the connecting elements must be known. In the presented study the hydraulic capacity of grate inlets with supercritical surface flow and unsurcharged drainage flow conditions was investigated with physical model test runs. The type-specific efficiency was defined by taking the frontal flow on the width of the grate into account. The main influencing hydraulic parameters on the grate capacity are the water depth and flow velocity when supercritical surface flow conditions exist. With increasing water depth and flow velocity the type-specific efficiency decreases. Depending on both of the hydraulic parameters as well as on geometrical parameters such as grate dimensions and orientation of the bars an empirical calculation formula was developed to estimate the hydraulic capacity or type-specific efficiency of grates with supercritical surface flow conditions.

\section{References}

Butler, D. and Davies, J.W. (2011) Urban Drainage, Third Edition, Spon Press (imprint of the Taylor and Francis Group), Abingdon.

Brown, S.A., Schall, J.D., Morris, J.L., Doherty, C.L., Stein, S.M. and Warner, J.C. (2009) Urban Drainage Design Manual - Hydraulic Engineering Circular 22 (HEC-22), Third Edition, FHWA-NHI-10-009, U.S. Dept. of Transportation, Federal Highway Administration, Washington, D.C., National Highway Institute, Virginia.

Despotovic, J., Plavsic, J., Stefanovic, N. and Pavlovic, D. (2005) Inefficiency of storm water inlets as a source of urban floods. Water Science and Technology, 51(2), 139-145.

Gomez, M. and Russo, B. (2005) Comparative study of methodologies to determine inlet efficiency from test data. HEC-12 methodology vs UPC method. Water Resource Management 2005, Algarve, Portugal.

Guo, J.C.Y. and MacKenzie, K. (2012) Hydraulic efficiency of grate and curb-opening inlets under clogging effect. Report No. CDOT-2012-3, Final Report. Colorado Department of Transportation, Denver.

IPCC (2004) Climate Change 2014: Synthesis Report. Contribution of Working Groups I, II and III to the Fifth Assessment Report of the Intergovernmental Panel on Climate Change [Core Writing Team, R.K. Pachauri and L.A. Meyer (eds)]. IPCC, Geneva, Switzerland.

Kemper, S. (2018) Hydraulische Leistungsfähigkeit von Straßenablauf-Aufsätzen. Ph.D. thesis, Hydraulic Engineering Section, University of Wuppertal (in German).

Rubinato, M., Martins, R., Kesserwani, G., Leandro, J., Djordjevic, S. and Shucksmith, J. (2017) Experimental calibration and validation of sewer/surface flow exchange equations in steady and unsteady flow conditions. Journal of Hydrology, 552, 421-432.

Spaliviero, F., May, R.W.P. and Excaramela, M. (2000) Spacing of Road Gullies - Hydraulic performance of BS EN 124 gully gratings and kerb inlets. Report SR 533, HR Wallingford. 


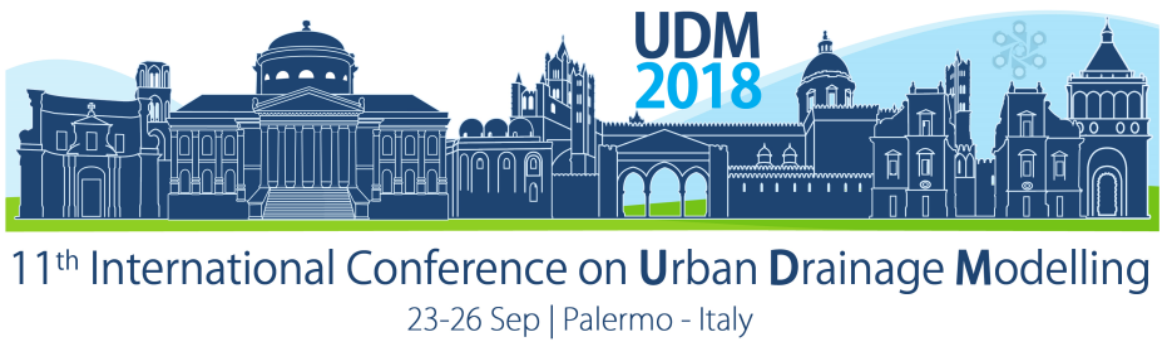

\title{
An Alternative Model Calibration Strategy for Watersheds Lacking Proper Data Records: Case Study of Riohacha, Colombia.
}

\author{
Antonio Krishnamurti Beleño de Oliveira1, Osvaldo Moura Rezende ${ }^{1}$, Matheus Martins de Sousa ${ }^{1}$ and \\ Marcelo Gomes Miguez ${ }^{1,2}$ \\ ${ }^{1}$ Universidade Federal do Rio de Janeiro, Programa de Engenharia Civil, Rio de Janeiro, Brazil \\ 2Universidade Federal do Rio de Janeiro, Escola Politécnica, Rio de Janeiro, Brazil
}

\begin{abstract}
The city of Riohacha presents a disorganized development model that added to recurrent events of intense rains, cause increasingly flood disasters. Due to the complexity and the hydrographic density of the region and the need to propose systemic solutions to flood problems, it was used mathematical modelling tools. Within the modelling process, calibration and validation are two fundamental actions that must precede the use of the hydrodynamic model. However, most of the river basins around the world lack hydrometeorological information, indispensable for calibration process. The present work develops a new approach for the calibration process, based on interviews and retrieval of historical information by flood marks. This new approach enables calibration in a scenario where there is a lack of information for the calibration process. Thus, the result of this work can be used as a conceptual basis of support in the calibration process for future hydrodynamic models in places where there is little or no information to support the process.
\end{abstract}

Keywords: Hydrodynamic Modelling; Urban Flood Simulation; Calibration

\section{INTRODUCTION}

Urban flooding is increasingly present problem in urban centres. Disorderly urban growth and lack of infrastructure coupled with unpredictable climate change have worsened the global picture of flood disasters statistics. This problem is aggravated when the countries of Latin America and the Caribbean are observed. According to the United Nations, the population of these countries would increase $25 \%$ by 2061 reaching its peak of 793 million ( United Nations Department of Economics and Social Affairs Population Division, 2015).

In this context, this work discusses the role of mathematical modelling and its calibration to simulate urban floods in the city of Riohacha, located in the northernmost Caribbean Region of Colombia. The city has a great historical importance and a high environmental potential; however, it presents a history of disordered growth and fast population increase. According to the Demographic Census (DANE 2005), the municipality presented a population growth of more than $100 \%$ in 11 years. This rapid urbanization development raises imperviousness rates and consequently worsens floods in the city, especially for the recurrent events of extreme rains that have been intensified by the La Niña phenomenon. Besides that, the local topography and hydrography contribute to this situation, once Riohacha has several natural terrain depressions and lagoons. These natural ponds act as storage compartments for water, during the rainy season. After reaching a certain water level, they start to connect with each other, composing a superficial drainage net, sometimes using the streets as channels. In addition, the whole city lies on elevations close to the mean sea level, hindering the rainwater flow. The depressions that appear in the urban area of Riohacha and one of the most important ponds (La Esperanza) can be seen in Figure 1. 


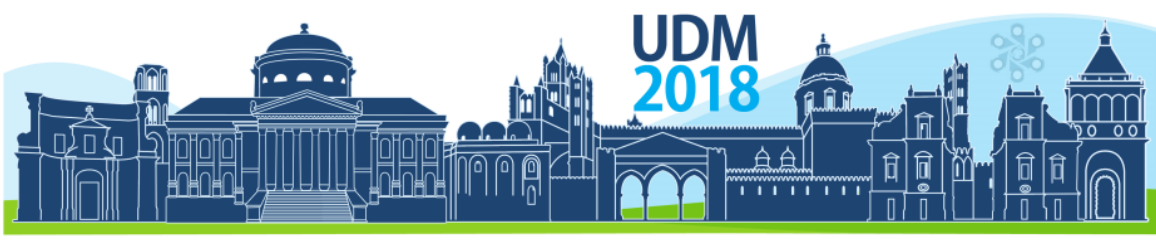

$11^{\text {th }}$ International Conference on Urban Drainage Modelling 23-26 Sep | Palermo - Italy

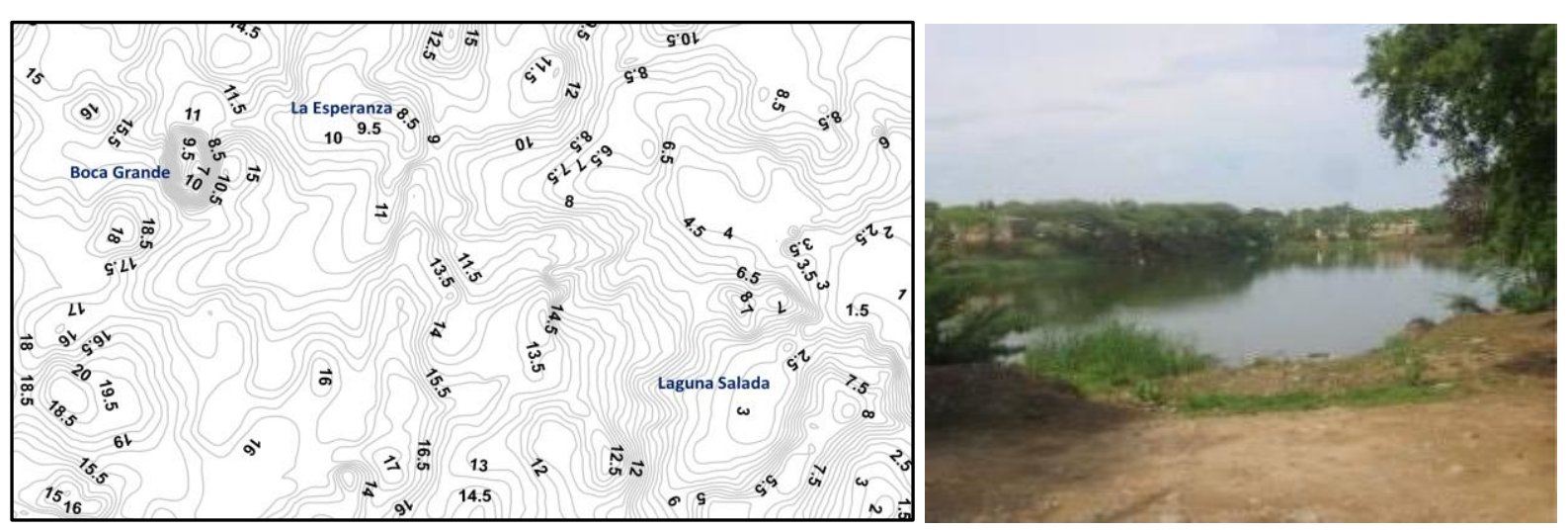

Figure 1 - Map with the urban topography of Riohacha and La Esperanza pond.

Due to the complexity and the natural drainage density of the region and the need to approach the watershed as a whole, a mathematical modelling tool was used to assess flooding problems and to aid in the design process. Key questions in mathematical modelling refer to understanding the physical reality, identifying data needs and gaps, defining basic hypothesis and simplifications, as well as defining dimension and model scale. Definition of scale is a modeller responsibility when analysing the proposed problem and it is one of the most important aspects of the modelling studies (SINGH \& KUMAR, 2017). Riohacha does not have detailed topographic data. This lack is a problem that can be solved by an experienced user; however, it also limits the use of some modelling resources which need extensive data.

Within the modelling process, calibration and validation are two fundamental actions that must precede the hydrodynamic simulation for forecasting purposes (TEJASWINI \& SATHIAN, 2018). In order to properly simulate the hydrodynamic behaviour in a watershed, calibration and validation are both vital to improve the consistency and confidence of the model and to reduce parameters uncertainty (WANG et al., 2017). However, most of the river basins around the world (especially small urban catchments) lack hydrometeorological information (LÓPEZ et al., 2017), which is an indispensable input for the calibration and validation processes. This scenario is frequent in Latin American countries, where the lack of reliable hydrometeorological information is a crucial problem for application of hydrodynamic models and execution of urban drainage projects (Santos Júnior \& Santos, 2014).

Given the difficulty of calibration in the context of the case study, the aim of this article is to develop and present an alternative and innovative strategy of modelling, calibrating and validating a physical system, based on interviews and field inspections to retrieve flooding historical information. Flood levels obtained from interviews or flood marks as well as flow paths and flow characteristics (flood path or flood ponding) were taken as the basic information for calibration and validation processes. The data generated a Georeferenced Database that allowed to reproduce a flooding surface and a network of flow directions.

The model chosen to represent this situation is particularly useful in urban environments without detailed topographic data. The hydrodynamic model called MODCEL simulates the physical situation through a set of flow-cells, which are compartments capable to represent average characteristics of the urban surface, store water and communicate with each other through hydraulic links, composing a flow network of ponds and flood paths. The flood surface retrieved from the field strategy can be used to calibrate the water levels (ponds) and 


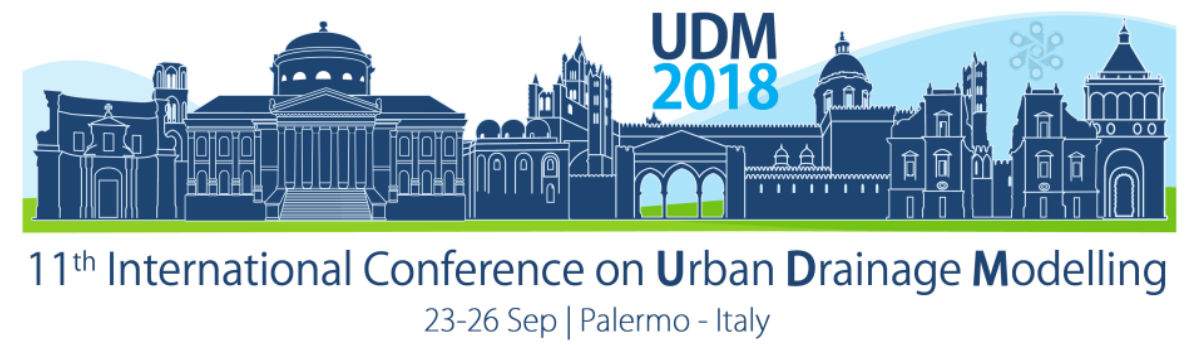

water depths (flood paths) in MODCEL simulation. On the other hand, it is expected that the flows resulting from the simulation have the same orientation and sense of the flow that the local population identified, also serving as a subsidy for calibrating the mathematical model.

Thus, the result of this work and the proposed methods, can be used for supporting the calibration process of hydrodynamic models in places where there is little or no information available.

\section{MATERIALS AND METHODS}

Considering the peculiarities of the case study, flow-cell model - MODCEL (MIGUEZ, 2001 and MIGUEZ et al., 2017) was chosen. MODCEL is a Quasi-2D hydrodynamic model in which the watershed is discretised in flow-cells, as previously introduced: such cells are homogeneous compartments that represent a portion of the terrain (natural or urbanised) and function in an integrated way, hydraulically communicating with each other only by onedimensional equations.

MODCEL is suitable for simulation of the particular "flattened egg box" Riohacha topography. A similar application was performed by Sousa (2017) who carried out tests proposed by the UK Environment Agency, through the comparison of MODCEL with several mathematical models (NÉELZ \& PENDER, 2009 and NÉELZ \& PENDER, 2010). One of the tests consisted in modelling a square region of a $2000 \mathrm{~m}$ by $2000 \mathrm{~m}$, with topography shaped like a "flattened egg box". MODCEL showed satisfactory results for the test compared to other models. Water levels and flow velocities were reproduced consistently, using a much lower number of elements, when compared with 2D hydrodynamic models using digital terrain models (DTM), proving that detailed topographic data does not limit the use of this model.

Considering the lack of data for the calibration process, several surveys of flood records were carried out in houses related to two intense rainfall events: Sep/2011 (Calibration); and Nov/2011 (Validation). In particular, a key feature was the ability to transport the flood depth inside houses to the local flood elevation referred to streets, since these field surveys were only able to recover flooding information from house owners.

After the detailed analysis and comparison of each house, it was observed that some elevations or depths of water would be physically impossible to occur. Some responses were inaccurate due to memory weakness or overstatements (for example, sometimes, one house was neighboured by 2 or 3 others that consistently reported a certain water level, while the first house reported a much higher inundation). Then, a reliability analysis was performed for the calibration and validation process, crossing spatially the information obtained. The criteria for not considering a certain information were:

1) if the reported value represents a high water depth at a point of high slope or small contribution basin;

2) if the reported value has a water depth very different from most points nearby;

3 ) if an information point deforms the resulting water surface produced (with local peaks);

4) if water was reported only inside the house, without water records on the street.

Classification was performed by comparing the surveyed and processed data with the simulated results. However, considering the natural characteristics of the watershed, a complementary distinction was made: reference information gathered in the surveys referred to "storage ponds" or "flow paths". "Storage ponds" were used to compare flooding in ponds and flat urban areas with depressions, where water behaviour is governed by storage effects (that is, where storage was the main characteristic of the cell representing a certain terrain 


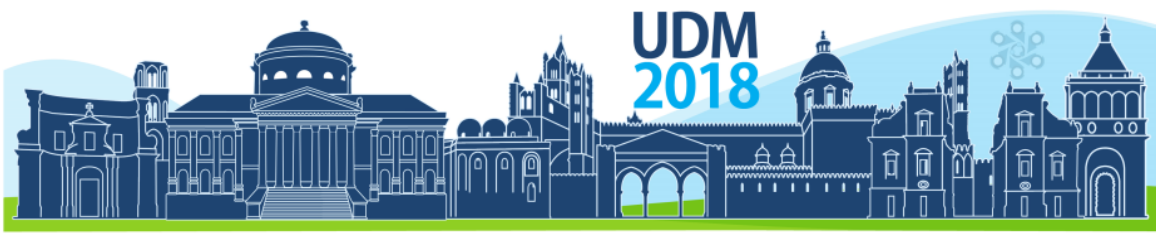

$11^{\text {th }}$ International Conference on Urban Drainage Modelling

23-26 Sep | Palermo - Italy

portion). Such regions are characterized by not having water in motion (at least, this is not the predominant effect) and presenting irregular terrain levels; thus, comparing water depths could result in significant errors just by slightly moving the position of the reference information point. "Flow paths" were used in places where local slope and urbanization patterns indicated predominantly running waters, without important storage effects (where cells represented a clear flow path). Considering MODCEL features, in general terms, "storage ponds" comparisons were made inside cells, taking the water level in the cell centre as a horizontal reference to the whole cell area, while "flow paths" comparisons referred to cell links, using water depths between each two cells.

\section{RESULTS AND DISCUSSION}

The flow network obtained from the field survey allowed to obtain the expected flows at the border of the cells. Observing

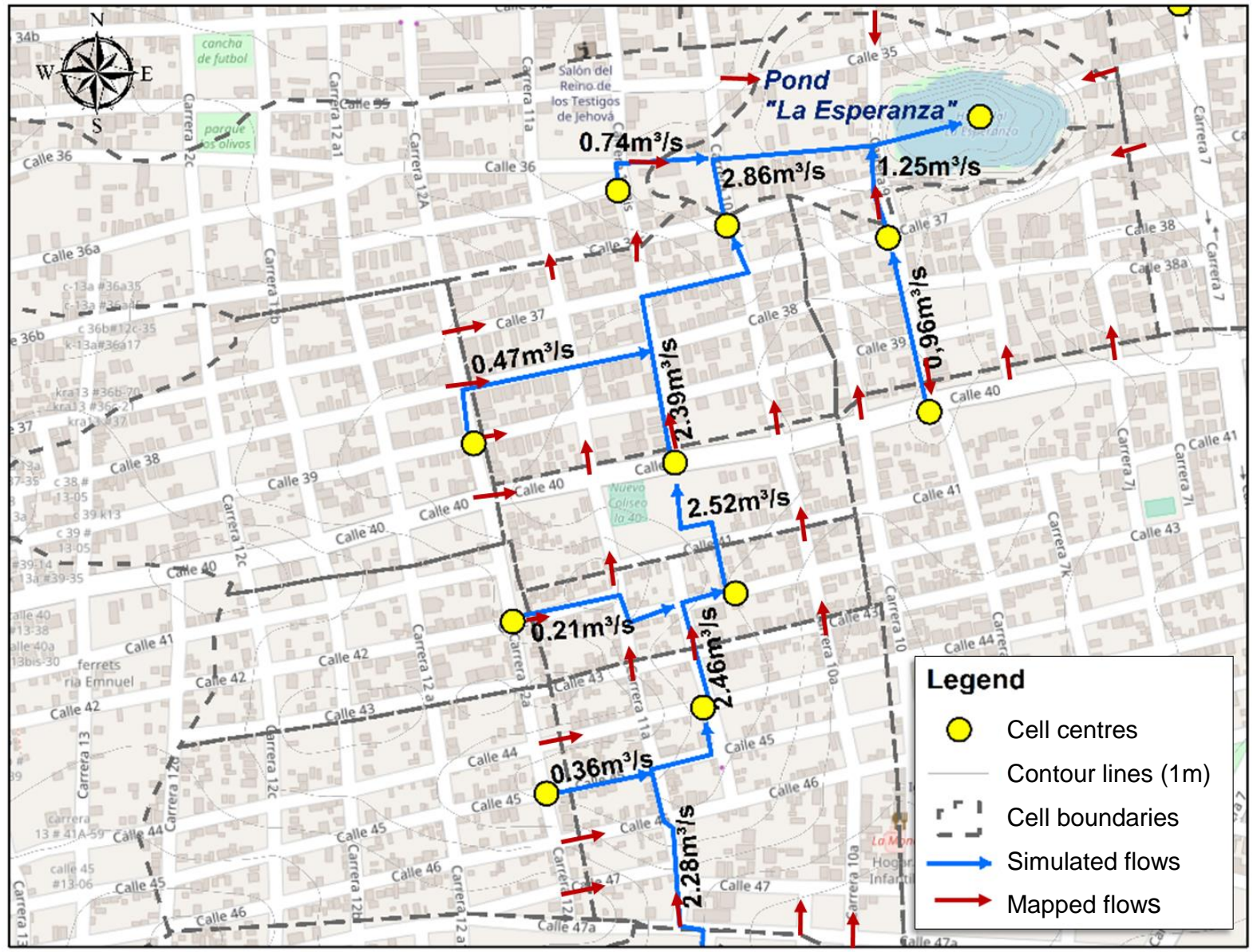

Figure 2, we realize that, in general, the model adequately represented the flows between cells. Therefore, the general flow behaviour simulated by MODCEL is preliminarily calibrated. The 
Proceedings of the 11th Int. Conference on Urban Drainage Modelling, 23-26 Sep. 2018, Palermo (ITALY). Ed. prof. Giorgio Mannina

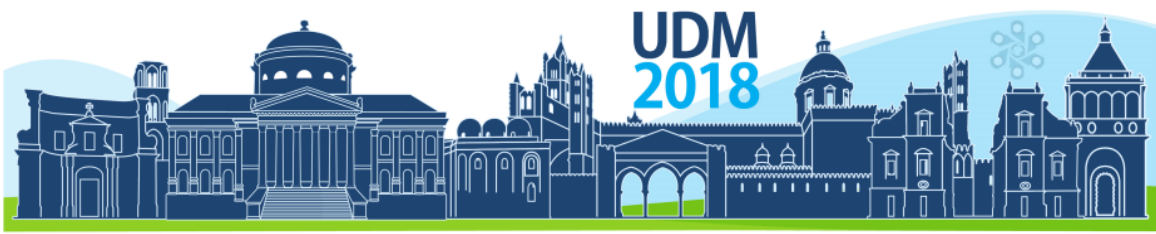

$11^{\text {th }}$ International Conference on Urban Drainage Modelling 23-26 Sep | Palermo - Italy

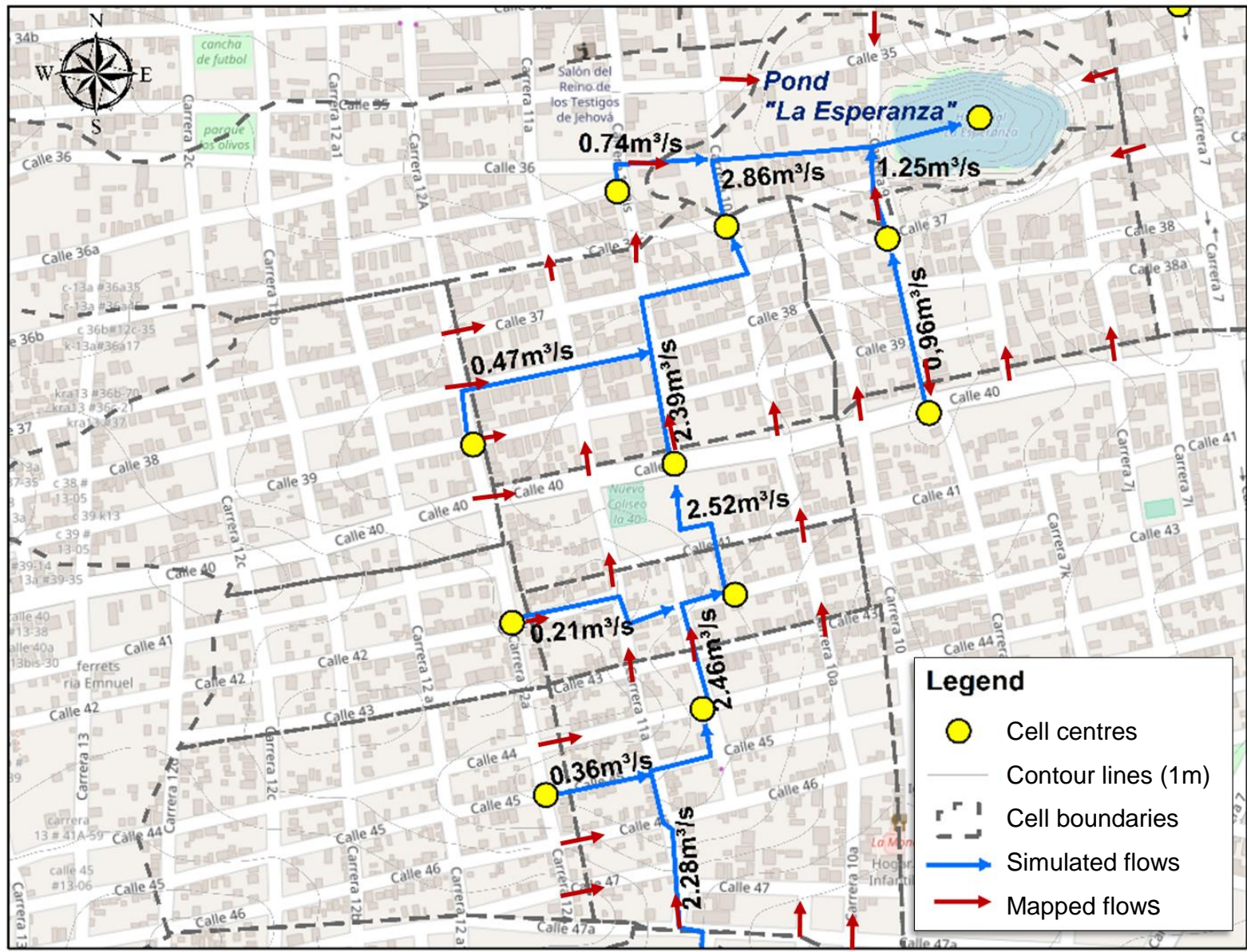

Figure 2 also shows the magnitude of the discharges between cells. 


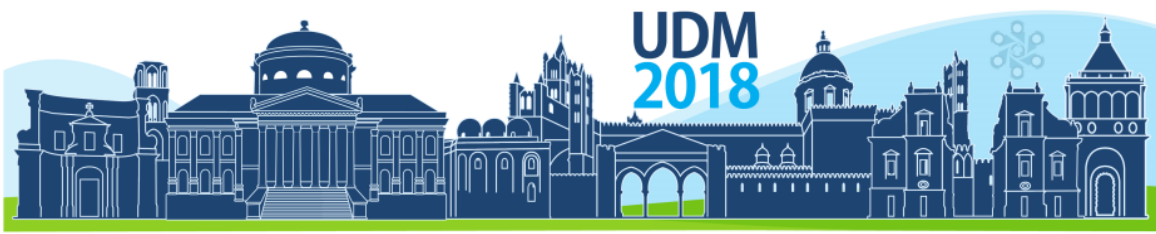

$11^{\text {th }}$ International Conference on Urban Drainage Modelling 23-26 Sep | Palermo - Italy

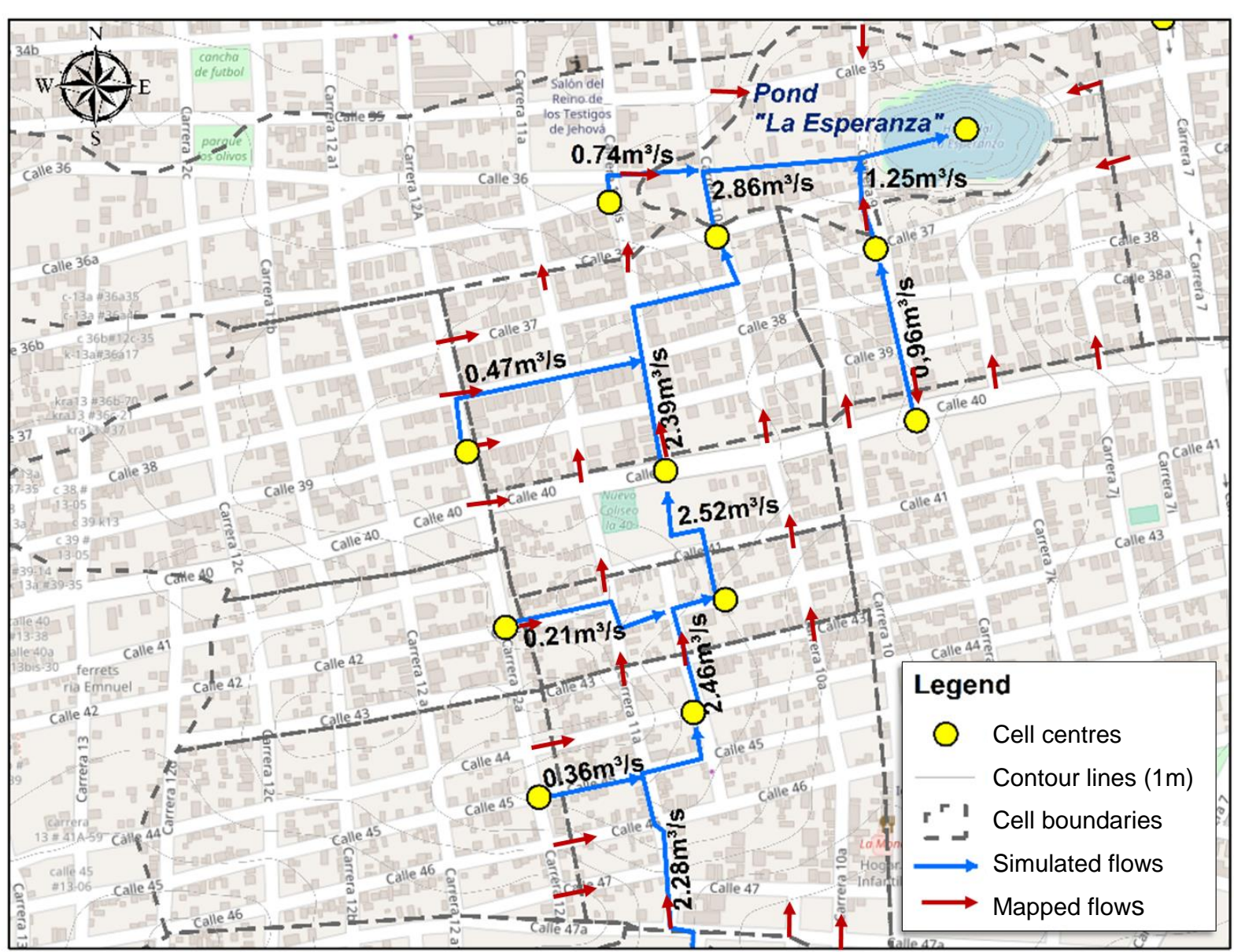

Figure 2 - Comparison between flow directions obtained by polls and simulated whit MODCEL.

In the formal calibration process, 16 "storage ponds" and 21 "flow paths" were compared. Water depths in some ponds may reach a few meters. A point was considered calibrated if an absolute difference of no more than $0.15 \mathrm{~m}$ appears between the surveyed point and the modelled result in the same point. The calibration results can be seen in Figure 3. Considering the validation process, 13 points were compared by the "storage ponds" criterion and 43 points by the "flow paths" criterion. The average of all difference between the modelled and interview value for the validation event resulted in $14 \mathrm{~cm}$.
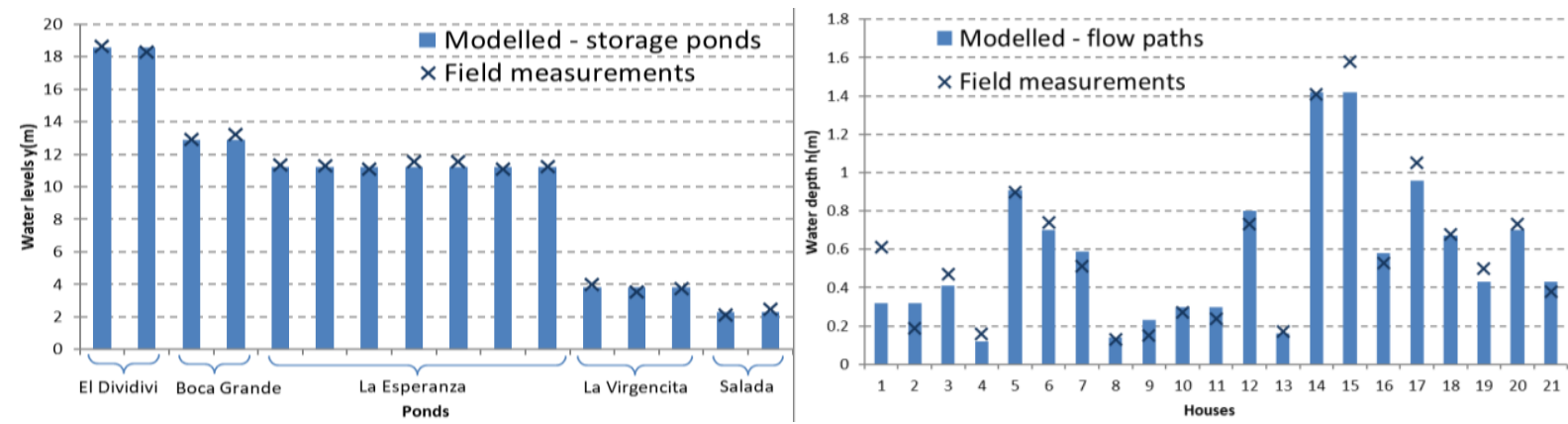

Figure 3 - Calibration results for "storage ponds" and "flow paths" 


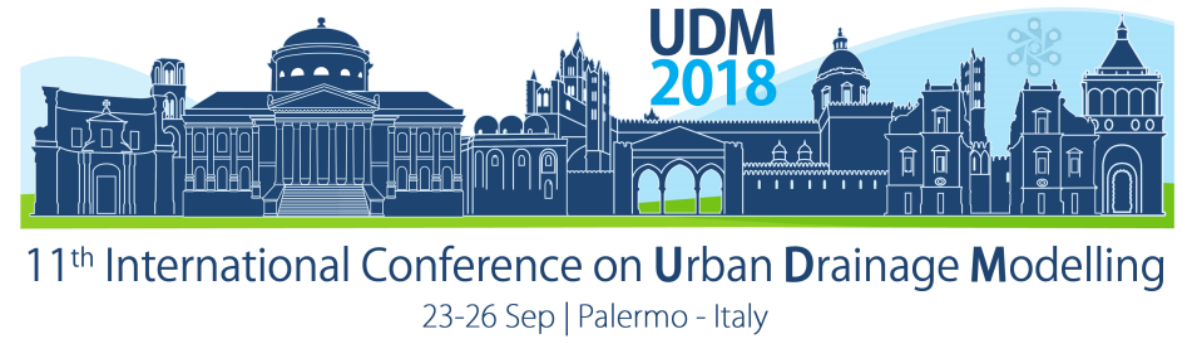

Good results are seen for the calibration and validation events. Taking into account that the events have the highest rainfall intensity and were the ones that caused the most damage to population, it was expected (and apparently it was confirmed) that residents would have the most recent flood levels in memory, presenting the best records for comparison.

\section{CONCLUSIONS}

Despite the lack of proper and formal information for model calibration, a field campaign, oriented by a structured questionnaire, supported by a local topography survey and the search for watermarks in the urban structures, allowed to reproduce the flooding surface of past events, recovering information that was previously unavailable.

Considering this information and using a quasi-2D model, capable to represent the local topography in an interpretative way (avoiding the need of a detailed DTM), a calibration process was successfully held and the differences between the calculated events and the recovered information were acceptable. Validation was also considered successful. Thus, it is possible to conclude that the model choice and the calibration procedures prepared the model to properly respond to simulation of intense rainfall events for design purposes, making reliable predictions in an area where data availability is low.

\section{References}

DANE (Departamento Admnistrativo Nacional de Estadística). (2005). XVII censo nacional de población y VI de vivenda, Santafé de Bogotá, DC, DANE

López, P. L., Sutanudjaja, E. H., Schellekens, J., Sterk, G., \& Bierkens, M. F. (2017). Calibration of a large-scale hydrological model using satellite-based soil moisture and evapotranspiration products. Hydrology and Earth System Sciences, 21(unknown), 3125-3144.

Miguez, M. G. (2001) Modelo Matemático de Células de Escoamento para Bacias Urbanas. [thesis] COPPE/UFRJ, Rio de Janeiro.

Miguez, M., Peres Battemarco, B., Martins De Sousa, M., Moura Rezende, O., Pires Veról, A., \& Gusmaroli, G. (2017). Urban Flood Simulation Using MODCEL-An Alternative Quasi-2D Conceptual Model. Water, 9(6), 445.

Néelz, S. (2009). Desktop review of 2D hydraulic modelling packages. Bristol: Environment Agency.

Néelz, S., \& Pender, G. (2010). Benchmarking of 2D hydraulic modelling packages.

Santos Júnior, V. J., \& Santos, C. O. (2014). A evolução da urbanização e os processos de produção de inundações urbanas. Estação Científica (UNIFAP), 3(1), 19-30.

Singh, G., \& Kumar, E. (2017). Input data scale impacts on modeling output results: A review. Journal of Spatial Hydrology, 13(1).

Sousa, M. M. (2018). Avaliação Comparativa de Metodologias de Modelagem Hidráulica 2D e seu Impacto na Interpretação e Avaliação de Ondas de Cheia [thesis]. COPPE/UFRJ, Rio de Janeiro.

Tejaswini, V., \& Sathian, K. K. (2018). Calibration and Validation of Swat Model for Kunthipuzha Basin Using SUFI-2 Algorithm. Int. J. Curr. Microbiol. App. Sci, 7(1), 2162-2172.

United Nations Department of Economics and Social Affairs Population Division (2015). World Population Prospects: The 2015 Revision.

Wang, L., van Meerveld, H. J., \& Seibert, J. (2017). When should stream water be sampled to be most informative for event-based, multi-criteria model calibration?. Hydrology Research, 48(6), 1566-1584. 


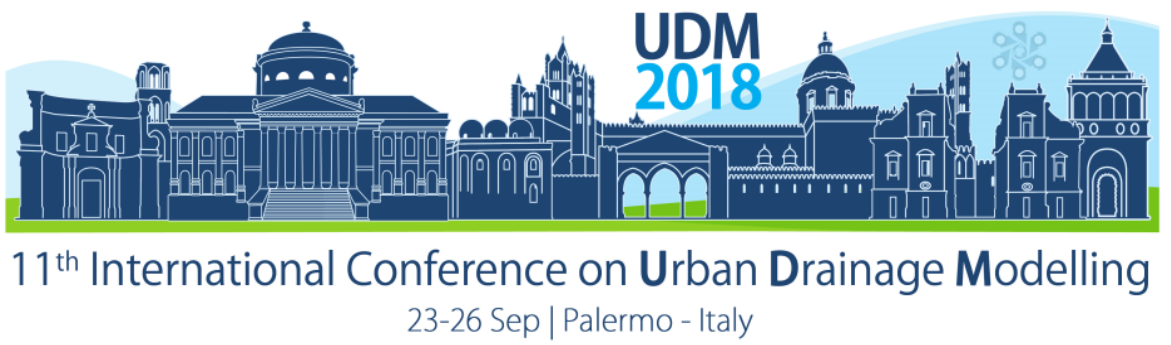

\title{
Model based assessment of sanitation systems for the integrated management of industrial discharges
}

\author{
Luis M. García1, Jesús A. Pelegino, Luis Sancho,2, Alberto Ciriza ${ }^{3}$, Mónica Gutiérrez4, and \\ Tamara Fernández-Arévalo ${ }^{1}$
}

\author{
${ }^{1}$ Ceit-IK4, Paseo Manuel Lardizabal № 15 (20018) San Sebastián, Spain. \\ ${ }^{2}$ Tecnun (Universidad de Navarra), Paseo Manuel Lardizabal № 13 (20018) San Sebastián, Spain. \\ ${ }^{3}$ Consorcio de Aguas Bilbao-Bizkaia, Maestro José, Sestao, 49810. \\ ${ }^{4}$ Azti-Tecnalia, Astondo Bidea, Edificio 609, Parque Tecnológico de Bizkaia, E-48160 Derio, Spain.
}

\begin{abstract}
This work presents a global model of sanitation system that integrates different simulation tools. The main objective of this work is to manage, in a controlled way, high salinity industrial discharges to ensure the stability of the sewer network and the municipally wastewater treatment plant.
\end{abstract}

Keywords: integrated modelling of sanitation system; control; industrial discharges; sulphates

\section{INTRODUCTION}

One of the main challenges in sewer network management is guaranteeing the correct operation of wastewater treatment plants (WWTPs) after incorporating industrial wastewater into the municipal sanitation system. The incorporation of these streams with high concentrations of pollutants can produce problems in ensuring effluent quality in the WWTP due to an increase in the organic load to be treated or by inhibiting biological processes involved in plant operation. Some of the compounds that can generate these problems are sulphates or sulphur-derived compounds, that can contribute to inhibit biological processes in WWTP such as nitrification and biological phosphorus removal and can cause corrosion problems. These components can be found in the sewer network due to the existence of industrial discharges, but also due to saline water infiltrations into the network. These identified effects can be intensified when the discharges or infiltrations generate sudden changes in concentration in the network, or especially, in the WWTP influent. For this reason, the key to integrating these currents in the sanitation system can be carrying out a controlled discharge that guarantees the stability of the system, while also considering uncontrolled additions such as infiltrations. For the fast and rigorous assessment of this integration, mathematical modelling is a very useful tool.

In recent years, the most complex challenge has been to integrate the whole system. A complete review of the state of the art of the integration of both systems can be found in Benedetti et al. (2013). In this research, the importance of WWTP influent generation techniques is highlighted, which can also be seen more specifically in the work of Keupers \& Willems (2015). The control rules incorporated and analysed in these integrated system studies (Gutierrez et al., 2010) have focused mainly on salt dosage to minimize the effects of corrosion.

This work considers the problem from a global perspective, considering the sanitation network, the WWTP, the saline discharges of the industrial sector. The goal of this work is to propose a flexible modelling methodology that considers the whole system from the discharges of the industrial sector to the WWTP, as well as the development of simple control laws for global management of the system. To achieve this goal, it is important to use compatible models that 


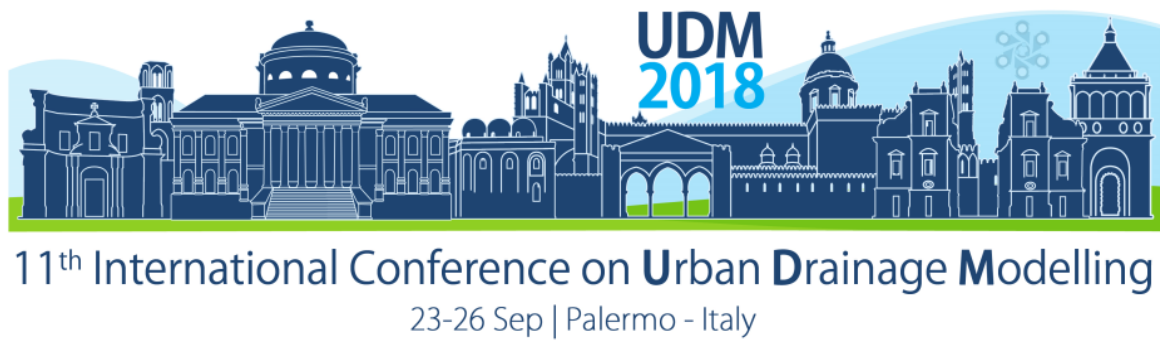

guarantee mass and charge continuity throughout the system, as can be achieved with the Plant-Wide Modelling (PWM) methodology (Grau et al., 2007; Fernández-Arévalo et al., 2014, 2017; Lizarralde et al., 2015).

The application case is part of the European project LIFE VERTALIM (http://www.azti.es/vertalim). The project's main objective is the development of a holistic solution for controlled integration of the discharges from small fish canning companies into the urban sanitation system, particularised for the case of various canning plants that discharge to the Galtzuaran WWTP (Ondarroa, Bizkaia, Spain). These discharges, together with saline infiltration in the sewer network, generate high conductivity concentrations that cause inhibition problems in biological processes in the WWTP, together with operational problems due to the generation of sulphides in the WWTP.

\section{STUDY CASE}

The sewer network analysed in this project is located in the region of Bizkaia and includes the entire sewerage system of the municipalities of Ondarroa and Berriatua. As a result of the increasingly need to integrate industrial discharges into the urban sanitation network, various small industries in the canning sector (one of the most important in the area) are being incorporated into the existing sewer network. So far, these industries have been dumping their wastewater to the river, but with the new integration, there is a complex problem. On the one hand, although individually each company located in the area is able to comply with the discharge regulations, if all of them dump simultaneously, the WWTP would not be able to cope with this high load. On the other hand, the high saline load contained in the discharges of these companies produces problems related to inhibition in the biological treatments mentioned above due to the presence of sulphur compounds. Four canning industries have been incorporated to the network; three are grouped within an industrial estate, and the fourth belongs to Berriatua. In order to properly manage their discharges, each one has a wastewater lamination tank that allows them to store the spill for a longer or shorter period of time.

The problem caused by the spills from the canning industries can be aggravated by the existence of seawater infiltrations that can occur in the network, due to the deterioration of the pipes caused by the passage of time. In this case, the existence of infiltration points in the municipality of Ondarroa brings into the network of large amounts of saline water in times of high tides, increasing the problem in biological treatments.

\section{METHODOLOGY}

\subsection{Simulation platform}

To carry out the proposed integrated modelling, three different tools are used: MIKE URBAN ${ }^{\circledR}$ for the sewer network modelling, WEST ${ }^{\circledR}$ to reproduce the behaviour of the WWTP, and a reduced model based on virtual tanks programmed in $\mathrm{C}++$ to implement the different control laws (this is a simpler language to implement the control in SCADA).

To model the hydraulic and pollutant transport behaviour in the sewage network (see Figure 1a) Saint-Venant and transport phenomena equations were used. It should be mentioned that the modelling of the sewer network only includes the transport of pollutants, so it is assumed that during the water transport there is no biological transformation. The mathematical model 


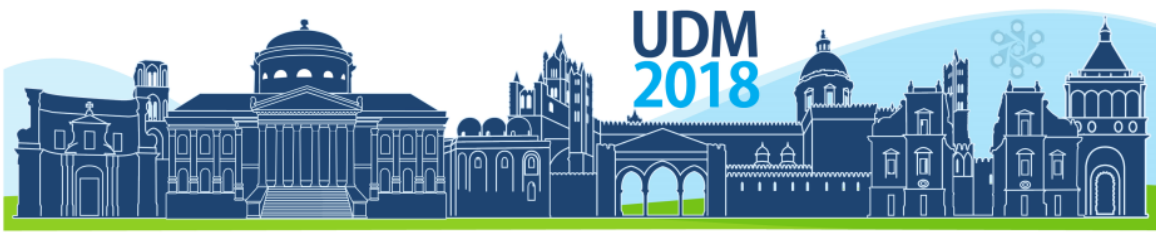

$11^{\text {th }}$ International Conference on Urban Drainage Modelling

23-26 Sep | Palermo - Italy

of the WWTP was built on the WEST ${ }^{\circledR}$ simulation platform under the Plant-Wide Modelling (PWM) methodology developed by Ceit-IK4 (Figure 1b). For this specific case, the CNPS_AnD category was selected to reproduce the organic matter, nitrogen, phosphorus, and sulphur removal in aerobic, anaerobic and anoxic conditions. For the compatibility and the direct connection of the two platforms (sewer network and WWTP), the definition of sewer network contaminants in the components of the mathematical model to be used in the WWTP (CNPS_AnD category) would be necessary. This step will guarantee mass and charge continuity in the whole system and will facilitate the simulation. Finally, the reduced model consists of taking a sector of the sewer network which incorporates hydraulic modelling (Martínez, 2010) and pollutant transport as a virtual tank (Sun et al., 2016). In addition to these virtual tanks, the model also includes the real tanks that exist in the network. The main reason why the reduced model is used is that this is the most appropriate way to program the control rules in the SCADA software, using $\mathrm{C}++$.

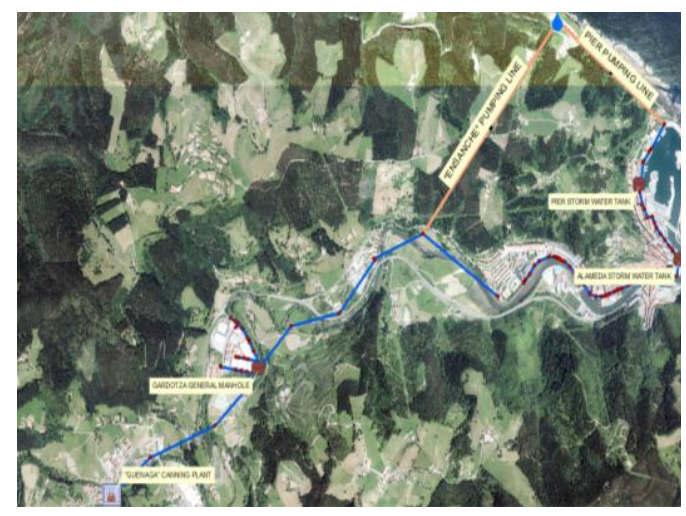

(a)

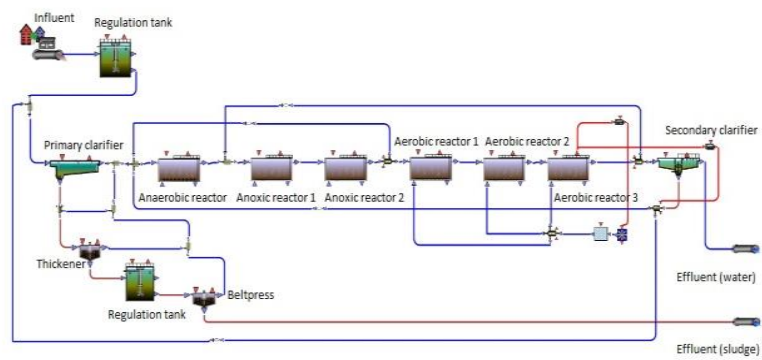

(b)

Figure 1. Layout of: (a) sewer network; (b) WWTP.

\subsection{Modelling sequence}

The modelling sequence consists of the following stages (Figure 2):

1. Data collection and processing. To model in MIKE URBAN ${ }^{\circledR}$ it is necessary to know the data related to the sewer network (dimensions, hydraulic, characterisation of the canning plant and urban inflows), while for the modelling in WEST ${ }^{\circledR}$ it is necessary to know the data of the WWTP (equipment, yields, water characterisation, etc.).

2. Calibration of the integrated model. The simulation of the WWTP and the sewer network is carried out simultaneously, using the effluent from the network as an influent of the WWTP.

3. Scenario simulation. In order to fully understand the operation of the complete network (sewer network and WWTP), different scenarios are simulated, considering the high variation in the network (caused by the climate and the production of the canning industries). The conclusions obtained after the analysis of the different scenarios will allow plant operators to establish qualitative control measures that will be implemented.

4. Reduced model calibration. This stage can be carried out once the sewer network has been calibrated in MIKE URBAN ${ }^{\circledR}$, since the reduced model does not include the WWTP. 


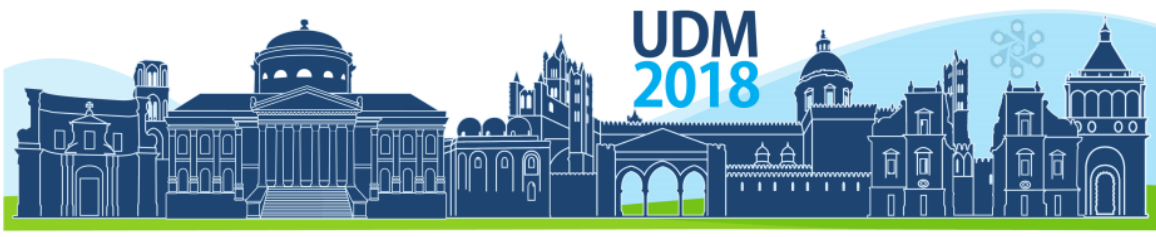

$11^{\text {th }}$ International Conference on Urban Drainage Modelling

23-26 Sep | Palermo - Italy

The objective here is to obtain a set of calibration parameters that will be useful for calibrating the equations of the reduced model.

5. Control rules implementation. This last stage tries to validate the different control rules designed during the scenario analysis by implementing them in the reduced model.

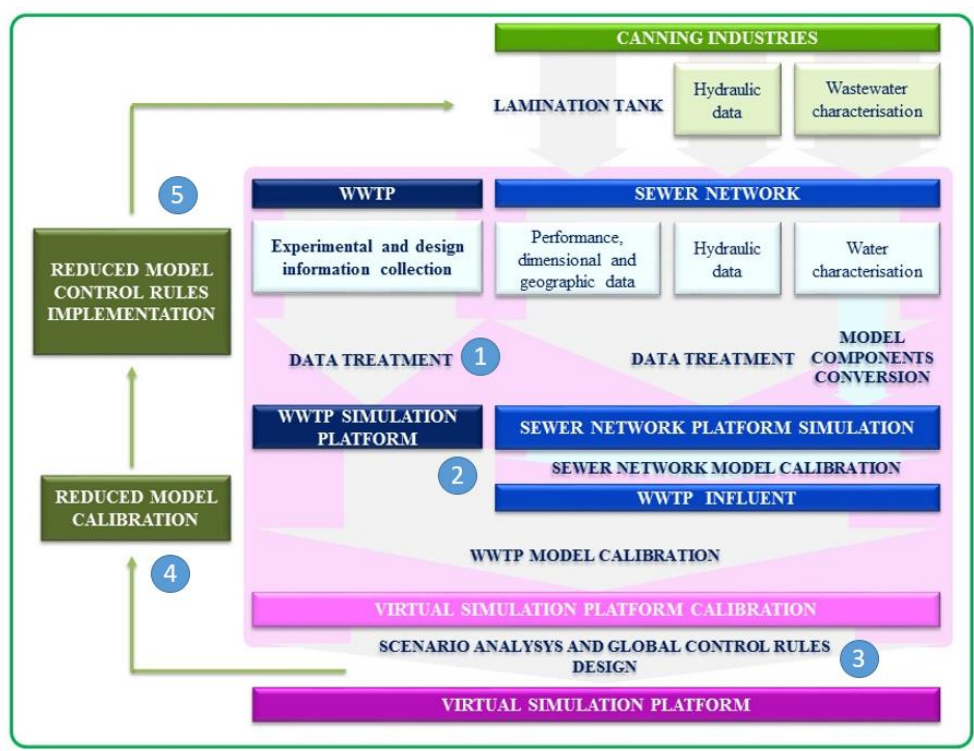

Figure 2. Modelling sequence of complete simulation platform.

\subsection{Calibration methodology}

The calibration methodology followed in each part of the model are presented below:

- Fish cannery effluent characterisation: To determine the quantity of each of these components, analytics that report information about the main indicators of water quality (total suspended solids, chemical oxygen demand, conductivity, $\mathrm{pH}$, etc.) were run. By applying the corresponding ratios to the analysed water quality, a complete characterisation of each wastewater was obtained.

- Sewer network calibration methodology: The first stage was based on reproducing the real hydraulic and pollutant transport behaviour along the sewer network using MIKE URBAN ${ }^{\circledR}$. The second stage used that postulate to calibrate the reduced model by determining a set of parameters that would define the reduced model equations. In this case, the results were compared with the simulations carried out in MIKE URBAN ${ }^{\circledR}$.

- WWTP calibration results: The sewage network effluent was used as an influent for the WWTP simulation and the one-year WWTP operational data used for its calibration.

\subsection{Scenario analysis and control rules implementation}

Once the complete model was calibrated, the scenario analysis allowed the behaviour of the network and the WWTP to be determined according to different input parameters: rainfall vs. dry periods; strong and normal tides; and canning industry production (high, average, and zero (due to stoppage)). 


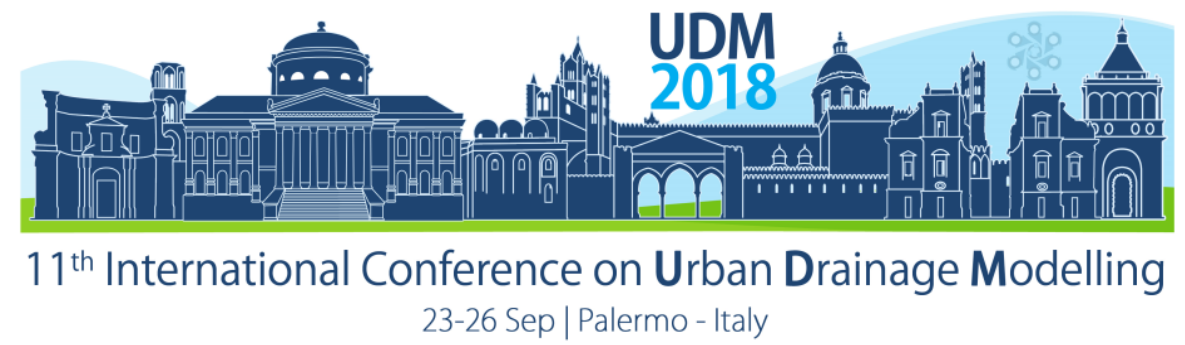

Using information obtained in these analysis, a qualitative control rules could be designed. The main objective of the control system developed in the project is to minimise the conductivity variation at the WWTP entrance that is the result of high variations in salt concentration, which can cause in inhibition biological processes (nitrification) and problems associated to sulphide generation. Because the WWTP has a big lamination tank at its entrance, eliminating high conductivity peaks allows the organic load to be regulated at the same time.

The control strategy is based on switching each canning plant's period of discharge to the network by using their lamination tanks. In turn, the pumping points of the network are also considered as actuators of this control system, allowing a greater or lesser amount of water to be retained in each pumping well. This control strategy will be limited by the different restrictions in the manipulated variables: the holding capacity of the tanks in the canneries, the holding capacity of the network's pumping wells, the available time periods for discharges, etc.

The control rules will be implemented as recommendations in the treatment plants' System Control and Data Acquisition (SCADA).

\section{CONCLUSIONS}

A series of modelling methodologies for sewer networks and WWTP has been integrated by considering the problems caused by the presence of sulphates in wastewater. This integration has been applied to a real case study, in which saline infiltrations and discharges from small canning plants create a problem for the treatment plant; this establishes, in a new way, control rules to minimise the problem.

The integral modelling developed in this project could be replicable in other regions where the lack of wastewater management in small industrial plants negatively affects WWTP operation.

Acknowledgments: This study was partially funded by Life EU programme under LIFE15 ENV/ES/000373 agreement.

\section{REFERENCES}

Benedetti, L., Langeveld, J., Comeau, A., Corominas, L., Daigger, G., Martín, C., Mikkelsen, P.S., Vezzaro, L., Weijers, S., and Vanrolleghem, P. (2013). Modelling and monitoring of integrated urban wastewater systems: review on status and perspectives. Water Science \& Technology, 1203-1215.

Fernández-Arévalo T., Lizarralde I., Fdz-Polanco F., Pérez-Elvira S.I., Garrido J.M., Puig S., Poch M., Grau P., and Ayesa E. (2017). Quantitative assessment of energy and resource recovery in wastewater treatment plants based on plant-wide simulations. Water Research, 118, 272-188.

Fernández-Arévalo T., Lizarralde I., Grau P., and Ayesa E. (2014). New systematic methodology for incorporating dynamic heat transfer modelling in multi-phase biochemical reactors. Water Research, 60, 141-155.

Grau P., de Gracia M., Vanrolleghem P., and Ayesa E. (2007). A new Plant-Wide modelling methodology for WWTPs. Water Research, 41(19), 4357-4372.

Gutierrez, O., Park, D., Sharma, K., and Yuan, Z. (2010). Iron salts dosage for sulfide control in sewers induces chemical phosphorus removal during wastewater treatment. Water Research 44, 3467-3475.

Keupers, I., and Willems, P. (2015). CSO water quality generator based on calibration to WWTP influent data. $10^{\text {th }}$ International Urban Drainage Modelling Conference, (stránky 97-104). Québec, Canada.

Lizarralde I., Fernández-Arévalo T., Brouckaert C. J., Vanrolleghem P. A., Ikumi D. S., Ekama G. A., Ayesa E., and Grau P. (2015). A new general methodology for incorporating physico-chemical transformations into multiphase wastewater treatment process models. Water Research, 74, 239-256.

Martínez, C.O. (2010). Model predictive control of wastewater systems. Barcelona: Springer.

Sun, C., Joseph-Duran, B., Maruejouls, T., Meseguer, J., Puig, V., \& Litrico, X. (2016). Real-Time Control-Oriented Quality Modelling in Combined Urban Drainage Networks. Barcelona. 


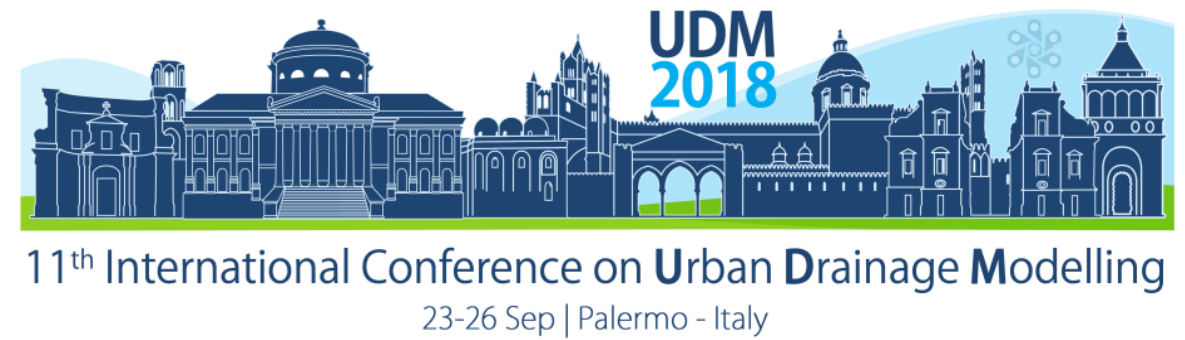

\title{
Effect of Aged Pipe Roughness's on Urban Flooding: Results from Sensitivity Tests with SWMM Model
}

\author{
Gourcerol Marinneㄹ, Moreno-Rodenas Antonio', Lepot Mathieu ${ }^{1}$ and Clemens François H.L.R. ${ }^{1,2}$ \\ ${ }^{1} \mathrm{TU}$ Delft, Watermanagement Department, Delft, The Netherlands \\ ${ }^{2}$ Deltares, Delft, The Netherlands
}

\begin{abstract}
Sewer modelling often assumes a constant roughness, corresponding to new pipe materials (typically Manning's $n$ of $0.011 s \cdot m^{-1 / 3}$ ). However, a few studies highlight that the actual roughness of aged pipes can be significantly higher (up to $0.015 \boldsymbol{s} \cdot \boldsymbol{m}^{\mathbf{- 1 / 3}}$ ). This actual roughness decreases the sewer discharge capacities but, at the same time, increases the duration the design storm (thus reducing the discharge capacity requirement). This study aims at balancing those two effects to determine whether or not the current design practice is conservative. Preliminary results show that an increased roughness leads to a longer concentration time and therefor a longer design storm duration. Furthermore, a rough system generates more combined sewer overflows (e.g. up to $25 \%$ more for a Manning's $n$ of 0.0149 $\left.s \cdot m^{-1 / 3}\right)$
\end{abstract}

Keywords: Urban Flooding; Roughness; Modelling

\section{INTRODUCTION}

Modelling is often used for the design or the diagnostic of sewer systems in order to check if they can deal with a rain event i.e. with a given return period. Pipe roughness's are usually assumed as new pipe roughness's (typically Manning's $n$ of $0.011 \mathrm{~s} \cdot \mathrm{m}^{-1 / 3}$ ). However, a recent study (Stanic et al., 2016) has shown that pipe roughness's can increase while aging (due to corrosion processes of the cement): e.g. a Manning's $n$ of $0.015 \mathrm{~s} \cdot \mathrm{m}^{-1 / 3}$ for a pipe after 89 years of servicing. Aged pipes can have two implications on the hydrodynamic behaviour of drainage systems: $i$ ) the reduction of the pipe discharge capacities and ii) the increase of the response time for a given system (i.e. reducing the critical rain intensity). At the catchment scale, aged and so rough pipes can lead to increasing flooding volumes (Tscheikner-Gratl et al., 2014).

On one hand, well-known established hydraulic equations clearly show that the intrinsic pipe capacity will decrease with an increasing roughness. On the other hand, the flow will slow down, leading to an increased response time (or concentration time), i.e. a lower rainfall intensity and a lower required discharge capacity for the same return period. The present study aims at investigating the effect of this increasing roughness on urban modelling forecast and the real return period for which the system is still operating as expected.

\section{MATERIALS AND METHODS}

\subsection{Plausible roughness's and their distribution}

Roughness values. Stanic et al. (2016) gave a range of Manning's $n$ for several pipes. Those data are quite rare, but Lipeme Kouyi (2018) confirms those values (Table 1). 


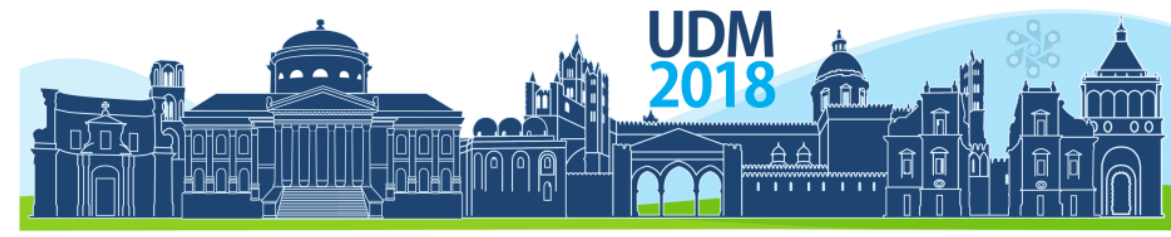

$11^{\text {th }}$ International Conference on Urban Drainage Modelling

23-26 Sep | Palermo - Italy

Table 1. Roughness found in the literature.

\begin{tabular}{|c|c|c|c|c|}
\hline \multirow{2}{*}{$\begin{array}{c}\text { Age of the pipes } \\
\text { (year) }\end{array}$} & \multicolumn{3}{|c|}{ Manning's $n\left[\mathrm{~s} \cdot \mathrm{m}^{-\frac{1}{3}}\right]$} & \multirow[t]{2}{*}{ Reference } \\
\hline & (crown) & (middle) & (invert) & \\
\hline 0 & \multicolumn{3}{|c|}{0.0114} & Stanic et al. (2016) \\
\hline 0 & \multicolumn{3}{|c|}{0.0119} & Pegram \& Pennington (1996) \\
\hline 0 & \multicolumn{3}{|c|}{0.0118} & \\
\hline 20 & \multicolumn{3}{|c|}{0.016} & \\
\hline 20 & \multicolumn{3}{|c|}{0.0186} & Jaromink et al. (2011) \\
\hline 30 & \multicolumn{3}{|c|}{0.0141} & \\
\hline 53 & \multicolumn{3}{|c|}{0.014431} & van Bijnen et al. (2018) \\
\hline 61 & 0.012 & 0.0129 & 0.012 & \\
\hline 61 & 0.0123 & 0.0122 & 0.0109 & \\
\hline 89 & 0.0177 & 0.0132 & 0.0117 & Stanic et al. (2016) \\
\hline 89 & 0.0187 & 0.0135 & 0.0114 & \\
\hline nc. & \multicolumn{3}{|c|}{$\begin{array}{l}\text { from } 0.0128 \text { to } 0.0154 \text { (average } \\
\text { of } 0.0139 \text { ) }\end{array}$} & Lipeme Kouyi (2018) \\
\hline
\end{tabular}

Roughness distribution model. A stochastic model is used to create a roughness joint probability distribution. The roughness model was build based on the following assumptions: A1, Pipe roughness values at a given drainage system are normally distributed (Fig.1). A2, the evolution of roughness's with age follows the general shape of deterioration model for sewer systems (Eq. 1, Fig. 1). A3, pipe roughnesses are spatially correlated. The literature does not report any information on the spatial distribution. However, even if corrosion processes can be very local, they are mainly due to flow characteristics, wastewater matrix and conditions, leading to a down-upstream correlation structure. Furthermore, pipe replacements often happen in batches, leading to stronger spatial correlation. Thus, an elicited model was created to reproduce a plausible pipe roughness correlation between nearby pipes.

The manning roughness of a pipe of certain age was modelled as:

$$
n\left(t_{\text {age }}\right) \sim N\left(\boldsymbol{\mu}=n_{f}+n_{s} \cdot\left(1-e^{-0.5 \cdot\left(\frac{t_{\text {age }}}{\tau_{\text {temp }}}\right)^{2}}\right), \boldsymbol{\sigma}=\sigma_{f}+k \cdot n_{s} \cdot\left(1-e^{-0.5 \cdot\left(\frac{t_{\text {age }}}{\tau_{\text {temp }}}\right)^{2}}\right)\right),
$$

were the mean of the process is described by a constant term $n_{f}$, or average from factory and an increasing component dominated by a temporal characteristic length $\tau_{\text {temp }}$, which stabilizes to some sill value $n_{s}$. The standard deviation is computed from an intial dispersion from factory $\sigma_{f}$ and a proportional component of the mean represented by $k$. The values at $t_{\text {age }}=0\left(n_{f}=\right.$ $0.011 \boldsymbol{s} \cdot \boldsymbol{m}^{-\frac{1}{3}}$ and $\sigma_{f}=0.00033 \boldsymbol{s} \cdot \boldsymbol{m}^{-1 / 3}$ ) were reported by Stanic et al. (2016) and Jaromink et al. (2011). The parameter values of $k=0.24, \tau_{\text {temp }}=10.7$ years and $n_{s}=0.005 \boldsymbol{s} \cdot \boldsymbol{m}^{-1 / 3}$ 


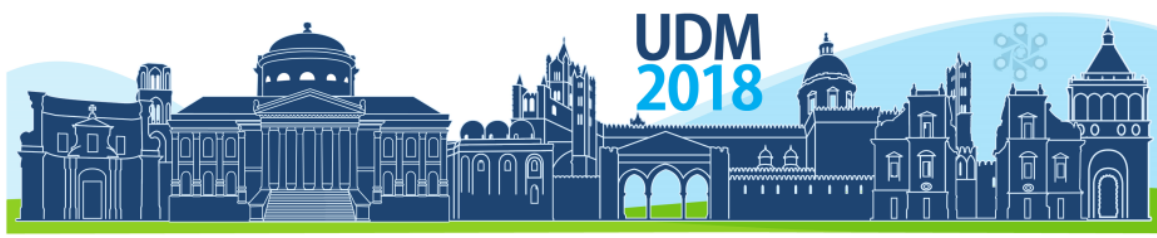

$11^{\text {th }}$ International Conference on Urban Drainage Modelling

23-26 Sep | Palermo - Italy

were computed by calibration from measured values of pipe age and manning's roughness reported in the literature (Table 1).

In order to characterize the spatial correlation, two assumptions have been proposed: i) the correlation of roughness's is distance dependent and it can be represented by a squared exponential correlation function (Eq. 2, Fig. 2), thus the pipe to pipe distances (distance matrix, $\boldsymbol{D M})$ it is possible to estimate the covariance matrix $(\boldsymbol{C})$, and ii) based on the network graph the connection between each pipe and its neighbours is calculated. While sorting the pipes (from down- to up-stream), the adjacency matrix represents the hydraulic connectivity matrix under dry weather conditions, this can encoded as a pipe connection matrix (PM).

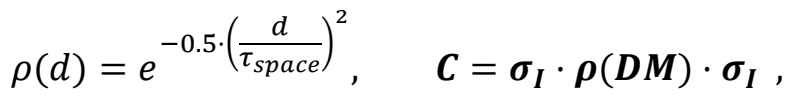

the correlation $\rho$ at distance $d$ is dependent in a characteristic length $\tau_{\text {space }}$. The covariance matrix $C$ is computed by multiplying a diagonal matrix with the individual pipe standard deviations $\sigma_{I}$ and the correlation matrix $\boldsymbol{\rho}(\boldsymbol{D} \boldsymbol{M}) \in \mathbb{R}^{N x N}$ were $\mathrm{N}$ is the number of pipes composing the system.

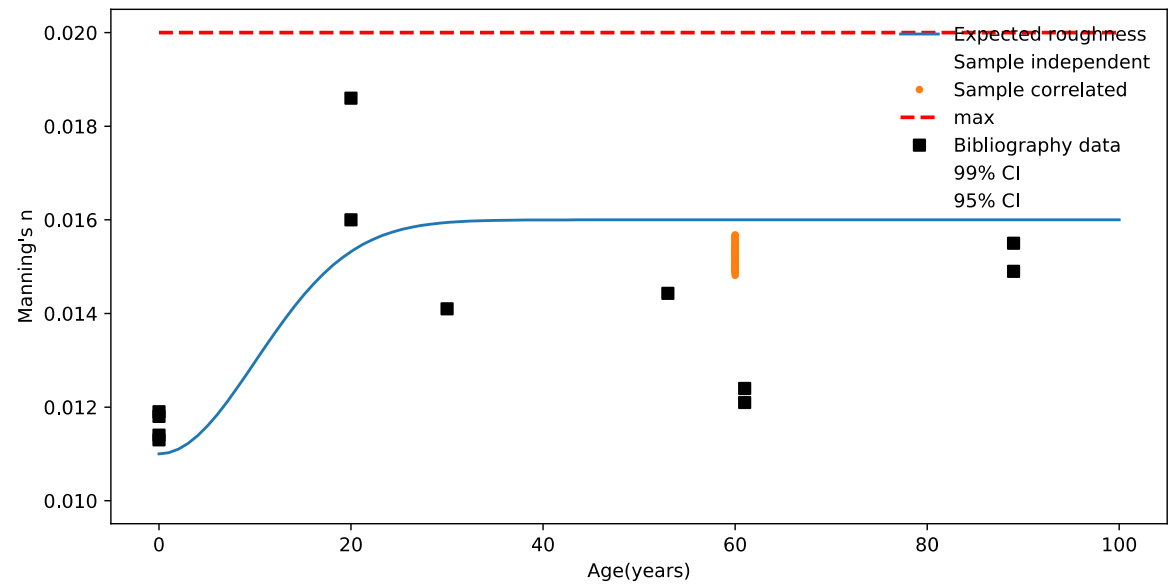

Figure 1. Evolution of the roughness and its distribution with age.

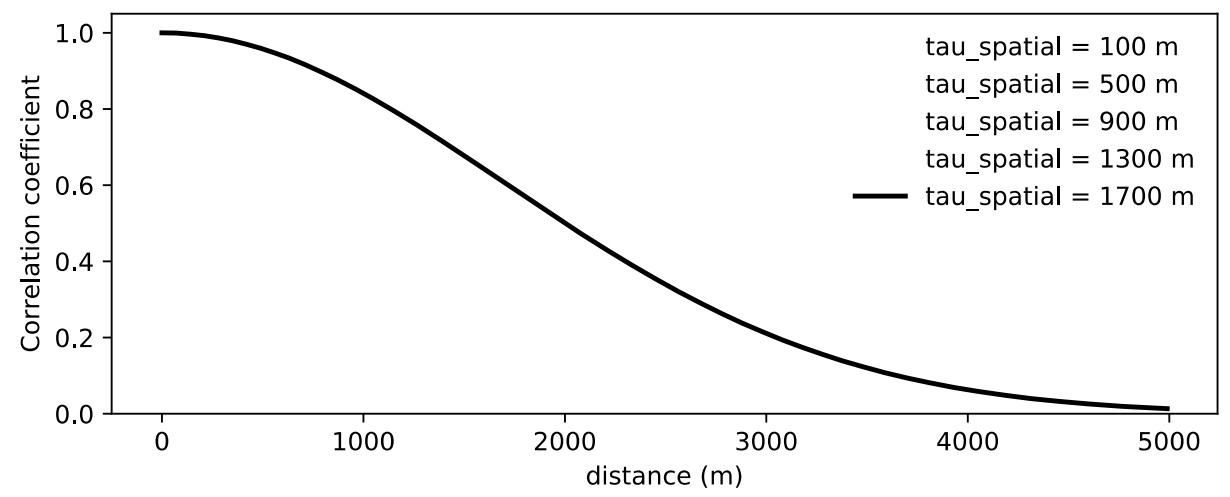

Figure 2. Spatial correlation structure. 


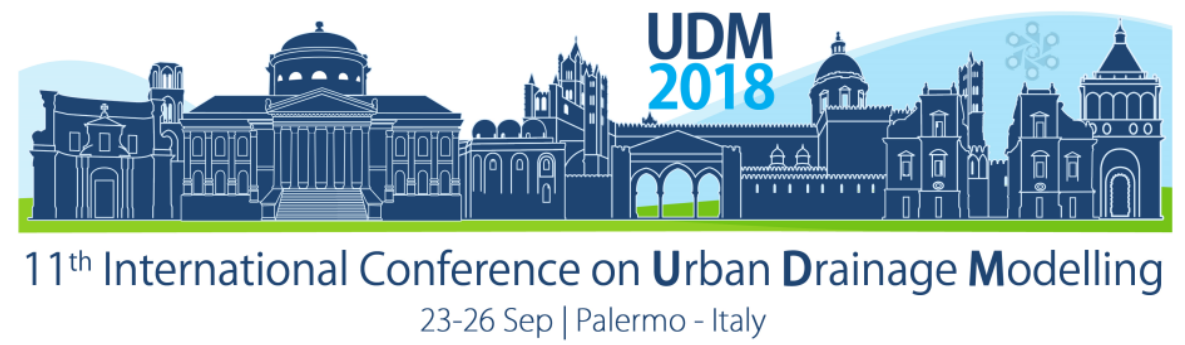

Equation 3 gives the corrected covariance matrix $\left(\boldsymbol{C}_{\boldsymbol{u d}}\right)$ between the pipe roughness's given the Eq. 2 and the established hydraulic connections between all the pipes.

$$
\boldsymbol{C}_{\boldsymbol{u d}}=\boldsymbol{P M} \cdot \boldsymbol{C}
$$

Sampling from the roughness model. The system is composed by $N$ pipes with an unknown roughness value. Samples from the roughness joint probability distribution (a multivariate Gaussian distribution with a given mean related to the age of the system and a certain correlation structure imposed) are drawn and propagated through the model.

Simulations. A base simulation using the mean pipe roughness for different ages is propagated through a Saint-Venant equation based representation of the drainage system (SWMM). Additionally, 100 samples are drawn at each of various levels of spatial correlation and pipe age combinations generating 24 scenarios (Table 2).

Table 2. Scenario to the be tested in SWMM.

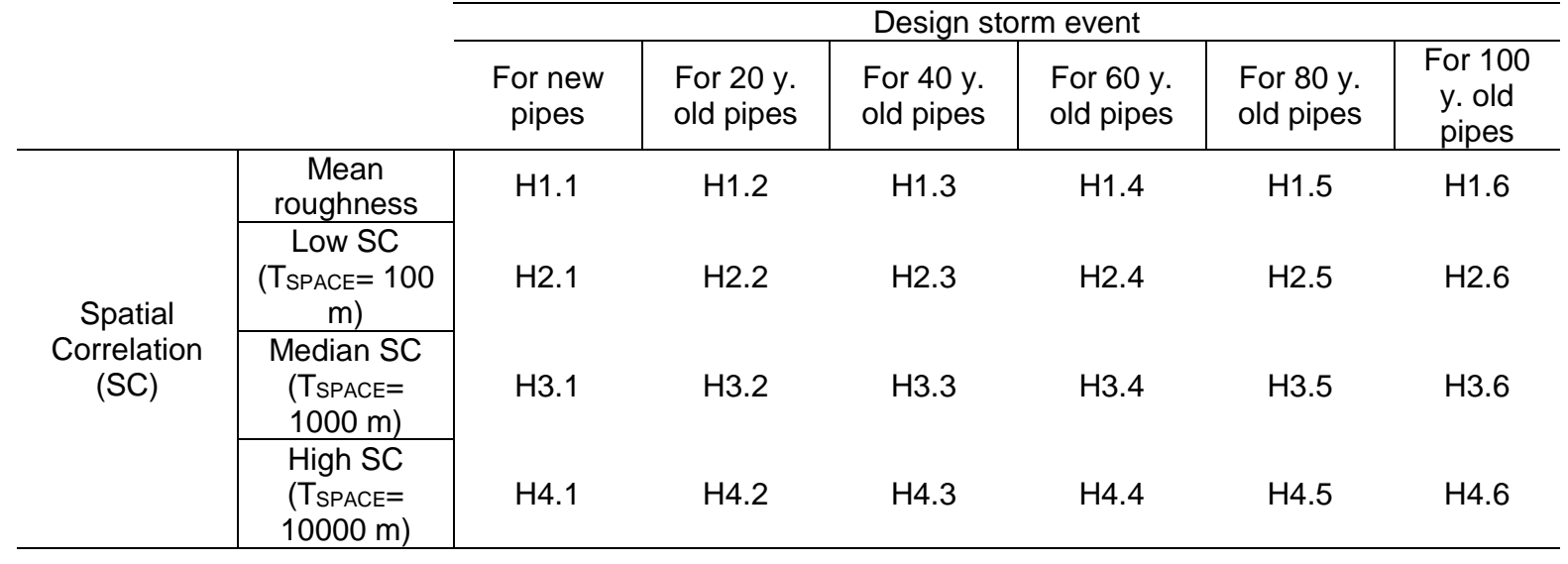

Results analysis. For the given 1806 simulations done according to the experimental matrix (Table 2), overflow volumes, flooding in manholes and concentration time have been compared for the following design storms:

- Roughness's of $n=0,0113$ for all pipes and the critical design storm (DS ${ }_{0.0113}$ ),

- Sampled roughness's and the critical design storm (DS 0,0113$)$,

- Sampled roughness's and its critical design storm (fitted for the given sampled roughness's)

\subsection{Case study: catchment of Loenen (The Netherlands).}

The case study is the sewer system of Loenen (see e.g. van Bijnen et al. 2018). The system is depicted in Fig. 3. 


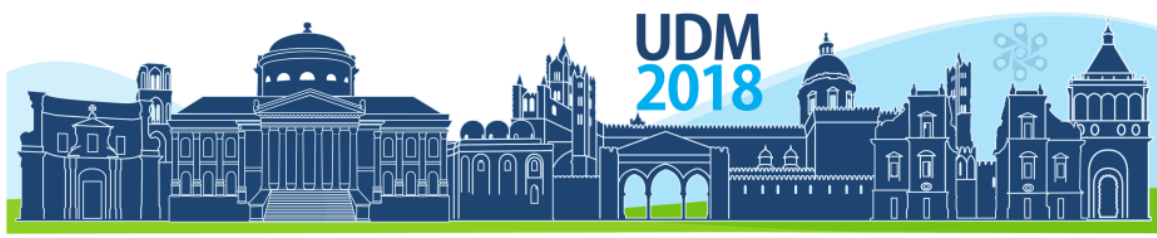

$11^{\text {th }}$ International Conference on Urban Drainage Modelling

23-26 Sep | Palermo - Italy

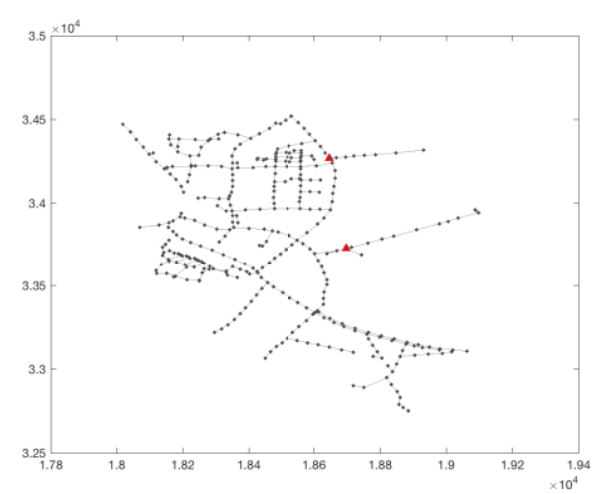

Figure 3. 2D (left) view of the Loenen catchment.

\section{RESULTS AND DISCUSSION}

The first results show a strong influence of the roughness's on sewer modelling. As an example, while assuming a constant roughness for all the pipe, the simulations give the following results. $\mathrm{DS}_{0.0113}(\mathrm{I}=66.48 \mathrm{~mm} / \mathrm{h})$ and $\mathrm{n}=0.0113$ : concentration time of $20 \mathrm{~min}$, $\mathrm{V}_{\mathrm{CSO}, \mathrm{DO} 1}=113.1 \mathrm{~m}^{3}, \mathrm{~V}_{\mathrm{CSO}, \mathrm{DO} 2}=7.7 \mathrm{~m}^{3} . \mathrm{DS}_{0.0113}(\mathrm{I}=66.48 \mathrm{~mm} / \mathrm{h})$ and $\mathrm{n}=0.0144$. Concentration time of $20 \mathrm{~min}, \mathrm{~V}_{\mathrm{CSO}, \mathrm{DO} 1}=111.8 \mathrm{~m}^{3}, \mathrm{~V}_{\mathrm{CSO}, \mathrm{DO} 2}=9.6 \mathrm{~m}^{3} . \mathrm{DS}_{0.0144}(\mathrm{I}=61.94 \mathrm{~mm} / \mathrm{h})$ and $\mathrm{n}=0.0144$. Concentration time of $22 \mathrm{~min}, \mathrm{~V}_{\mathrm{CSO}, \mathrm{DO} 1}=114.7 \mathrm{~m}^{3}, \mathrm{~V}_{\mathrm{CSO}, \mathrm{DO} 2}=9.6 \mathrm{~m}^{3}$.

For the same storm event $\left(\mathrm{DS}_{0.0113}\right)$ but different roughness's, the concentration time increases with the roughness, the CSO volume decreases of $1-2 \%$ for the DO1 and of $25 \%$ for the DO2. While comparing the two roughness's and their respective critical design storm, the concentration time increases of $2 \mathrm{~min}$ and the CSO volumes increase of few cubic meters.

\section{CONCLUSIONS}

The lack of literature studies on roughness's of pipe wall and its possible implications on sewer modelling clearly highlight that in situ measurements of roughness's are needed to better understand the hydrologic and hydraulic behaviour of sewer systems.

\section{References}

Van Bijnen, M., Korving, H., Langeveld, J., Clemense, F. (2018). Quantitative Impact assessment of sewer condition on health risk. Water

Jaromin, K., Jlilati, A., Widomski, M., Lagod, G. (2011). Materials, exploitation manners and roughness coefficient in gravitational sanitation conduits. Ecological Chemistry and Engineering $A, 18$

Lipeme Kouyi G. (2018). Personal communication.

Pegram, G.G.S., Pennington, M.S. (1996). A method for estimating the hydraulic roughness of unlined bored tunnels. Water Research Commission, Departmenent of Civil Engineering University of Natal

Stanic, N., Clemens, F.H.L.R. and Langeveld J.G. (2016) Estimation of Hydraulic Roughness of Concrete Sewer Pipes by Laser Scanning. J. of Hydrau. Eng. 143(2), https://doi.org/10.1061/(ASCE)HY.1943-7900.0001223

Tscheikner-Gratl F., Mikovits C., Rauch, W. and Kleidorfer M. (2014) Adaptation of sewer networks using integrated rehabilitation management. Wat. Sci. \& Tech. 70(11), $1847-1856$. 


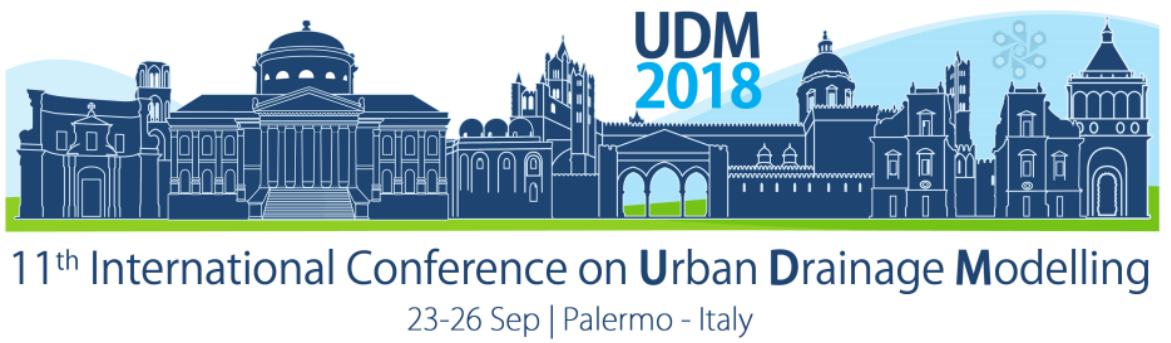

\title{
Implementing sustainable sanitation in an integrated Model - A straightforward approach for long-term simulation Claudia Campusano Garcia ${ }^{1,2}$ and Inka Kaufmann Alves ${ }^{2}$ \\ ${ }^{1}$ Institute of Urban Water Management, Department of Civil Engineering, University of Kaiserslautern, Paul-Ehrlich-Straße 14, 67663 Kaiserslautern, Germany \\ 2 Water and Urban Water Management, School of Engineering, Mainz University of Applied Sciences, Holzstraße 36, 55116 Mainz, Germany
}

\begin{abstract}
At present, increasingly requirements aiming resource efficiency and environmental sustainability demand more knowledge about the feasibility of implementation of such technologies in a large-scale as well as in the long-term. Even at modified sewage flows and compositions, water infrastructures must always remain reliable in order to guarantee a sustainable urban water management. Dimensioning methods and assessment variables must be adapted in order to achieve systems that are more flexible in the long-term. This paper aims to assess the actual impact of the implementation of sustainable sanitation systems in an existing sewage disposal system with means of a dynamic simulation. Various scenario simulations showed that the implementation of the module for BW/GW separation represents the investigated sustainable sanitation measures reliably with means of dynamic simulation. Moreover, the impact of the implementation of these measures and the consideration of population decline demand a more dynamical operational flexibility within the WWTP. To sum up, implementing this simplified approach for a stepwise integration of resource-oriented sanitation technologies allows a sewage system evaluation not only for dry weather conditions but also for stormwater conditions.
\end{abstract}

Keywords: sustainable sanitation; decentralization; stormwater management; integrated modeling

\section{INTRODUCTION}

As experiences in the water management sector demonstrate a growing incompatibility between the design concept of its infrastructures for long life spans and the hardly predictable factors, which influence their operation, it becomes more necessary to deeply understand how the different water and wastewater subsystems interact with one another. At present, increasingly requirements aiming at resource efficiency and environmental sustainability demand more knowledge about the feasibility of implementation of such technologies in a large-scale as well as in the long-term. By applying integrated dynamic modeling, it is possible to assess the effects of a stepwise implementation of sustainable sanitation measures (SuSan). In this matter, various studies have focused on decision-support solutions for water supply and wastewater discharge concepts as well as on optimization of operating strategies (cf. Schütze and Alex, 2014, Schmitt et al., 2014, Kaufmann Alves, 2013). Furthermore, some well-known assessments of new sanitation concepts based on integrated dynamic simulation have been developed for urban scenarios (cf. Penn et al., 2013, Urich et al., 2014).

Nonetheless, rural areas have not been extensively investigated using detailed modeling thus far. In Germany, areas with low population density have been coping with some core challenges over the years such as demographic decline, climate change, and stricter discharge standards. Since these challenges would translate in a slightly different implementation approach as for urban conglomerates it is the main goal of the research project linked to this study to gain a thorough understanding of the temporal behavior of water systems within a 


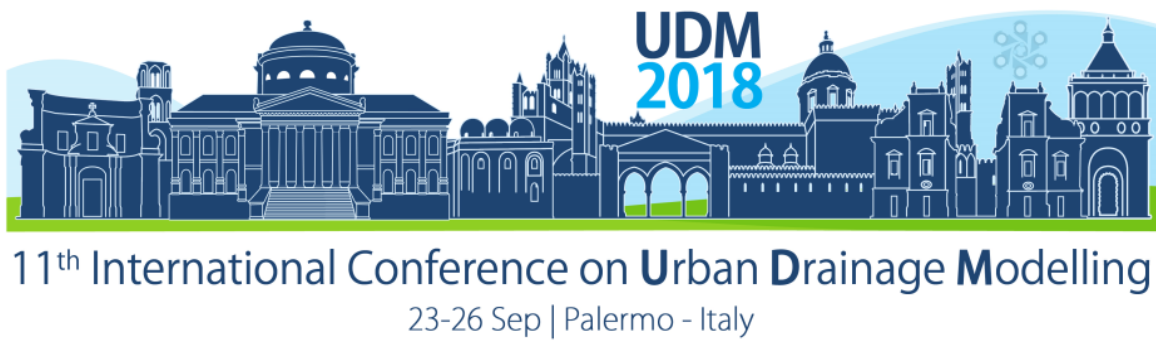

holistic approach using an integrated model. A simplified approach of wastewater separation into blackwater and greywater (BW/GW separation) was modeled as a component of the sewer network to assess the long-term operation and reliability of an existing wastewater plant (WWTP) under the timely implementation of various SuSan measures. Hence, the aim of this paper is the application of a straightforward concept for dynamic modeling to analyze the detailed behavior of the material flows in the sewer as well as to monitor their influence within the various receiving infrastructures of the effluent.

\section{MATERIALS AND METHODS}

\subsection{Study area and data model set-up}

The study area comprises a mostly combined sewer network and a wastewater treatment plant (WWTP) (21,000-population equivalents capacity) within a rural municipality in Southwest Germany. Table 1 shows some characteristic values of the catchment area.

Table 1. Dry weather flow and impervious area ratio distribution of the study area

\begin{tabular}{ccc}
\hline Municipality & $\begin{array}{c}\text { Percentage of total dry } \\
\text { weather flow [\%] }\end{array}$ & $\begin{array}{c}\text { Impervious area } \\
\text { ratio [\%] }\end{array}$ \\
\hline 1 & 20 & 7 \\
2 & 4 & 2 \\
3 & 34 & 15 \\
4 & 25 & 9 \\
5 & 6 & 3 \\
6 & 10 & 5.7 \\
7 & 1 & 0.3 \\
Total & 100 & 42 \\
\hline
\end{tabular}

An integrated data model was laid out with the SIMBA\# Version 2.1 (cf. Alex J., 2015). This software allows an integrative approach of pollutant modeling along the sewer network as well as the simulation of wastewater treatment within a single model.

The parameters COD, TKN, and $\mathrm{P}_{\text {tot }}$ describe the wastewater composition within the sewer. $A$ hydrological mathematical model represents the sewer network hydraulics of most part of the system. Moreover, a small subcatchment area was modeled using the hydrodynamic model from EPA SWMM. In the latter case, a detailed consideration of the sewer was carried out to examine the effects of the implemented measures under stormwater conditions. Furthermore, the activated sludge model ASM3 (cf. Gujer et al., 2000) was applied to describe the biological processes taking place within the WWTP. The structure of the integrated data model follows the recommendations of the Central European Simulation Research Group (cf. Muschalla et al., 2009).

\subsection{Implementation of SuSan measures}

A long-term assessment of the operational behavior water management subsystems and, their interactions was carried out with emphasis on examining the chronological and spatial implementation of resource-oriented sanitation systems within ten-year intervals from 2015 to 2065. For this study, the optimized solutions delivered by the decision-support tool SinOptiKom (cf. Schmitt et al., 2016) for various scenarios were implemented into the model. The objective 


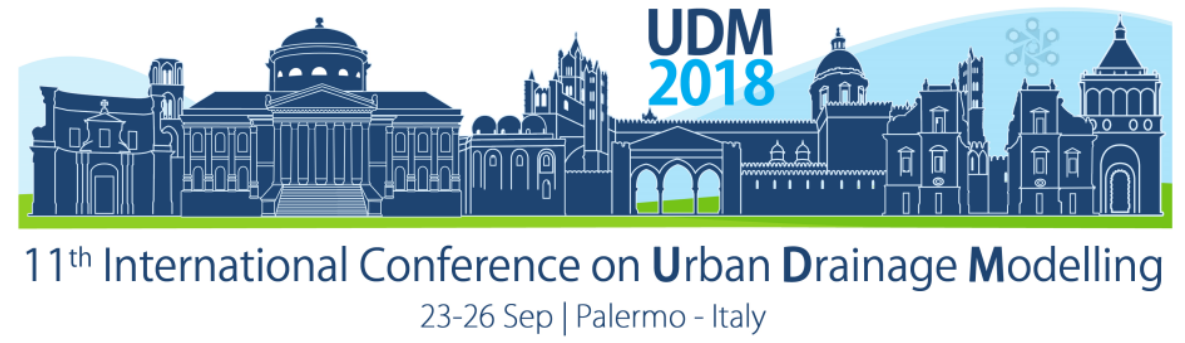

functions and the nature of the choice for the mentioned scenarios are fully discussed in Baron et al. 2017.

For this study, on the one hand, a BW/GW separation was programmed by means of a simplified mathematical approach, which considers the recommended values in DWA, 2014. The defining parameters of the source separation module are shown in Table 2.

Table 2. Distribution of material flows in wastewater (cf. Schmitt et al. 2016, DWA 2014)

\begin{tabular}{lcccc}
\hline & COD & $\mathrm{N}$ & $\mathrm{P}$ & water volume \\
\hline Wastewater in $\mathrm{g} /(\mathrm{l} \cdot \mathrm{d})$ & 120 & 12.9 & 1.8 & 1 \\
Proportion in blackwater & 0.52 & 0.92 & 0.75 & 0.33 \\
Proportion in greywater & 0.48 & 0.08 & 0.25 & 0.67 \\
\hline
\end{tabular}

On the other hand, a module for stormwater decoupling measures such as swales and surface infiltration systems were programmed as well. Furthermore, population decline was also considered for every calculation step.

The decentralization measures resulting from a selected transformation path proposed by Baron et al. 2017 are presented in Table 3.

Table 3. Implemented SuSan measures for two municipalities of a selected case scenario: 100\% Energy Efficiency, $50 \%$ Costs (own representation based on Baron et al. 2017). Implemented measures: Blackwater separation to cofermentation (BW Co-Ferm.), greywater separation to wastewater treatment plant (GW WWTP), surface infiltration (Sul), swale infiltration (Swl), roof greening (RG)

\begin{tabular}{|c|c|c|c|c|c|c|c|c|c|c|c|c|c|c|c|c|c|c|}
\hline \multirow{3}{*}{$\begin{array}{c}\begin{array}{c}\text { Mu- } \\
\text { nici- } \\
\text { pality }\end{array} \\
1 \\
(29 \% \\
\text { QDw1) }\end{array}$} & \multicolumn{18}{|c|}{ SuSan Measures } \\
\hline & \multicolumn{3}{|c|}{2015} & \multicolumn{2}{|c|}{2025} & \multicolumn{3}{|c|}{2035} & \multicolumn{3}{|c|}{2045} & \multicolumn{3}{|c|}{2055} & \multicolumn{4}{|c|}{2065} \\
\hline & - & - & Swl & $\begin{array}{c}\text { BW } \\
\text { Co- } \\
\text { Ferm }\end{array}$ & $\begin{array}{c}\text { GW } \\
\text { WWTP }\end{array}$ & $\begin{array}{c}\text { Sw } \\
1\end{array}$ & $\begin{array}{l}\text { BW } \\
\text { Co- } \\
\text { Ferm }\end{array}$ & $\begin{array}{c}\text { GW } \\
\text { WWTP }\end{array}$ & Swl & $\begin{array}{c}\text { BW } \\
\text { Co- } \\
\text { Ferm }\end{array}$ & $\begin{array}{c}\text { GW } \\
\text { WWTP }\end{array}$ & $\begin{array}{c}\text { Sw } \\
\text { I }\end{array}$ & $\begin{array}{c}\text { BW } \\
\text { Co- } \\
\text { Ferm }\end{array}$ & $\begin{array}{c}\text { GW } \\
\text { WWTP }\end{array}$ & Swl & $\begin{array}{c}\text { BW } \\
\text { Co- } \\
\text { Ferm }\end{array}$ & $\begin{array}{c}\text { GW } \\
\text { WWTP }\end{array}$ & Swl \\
\hline $\begin{array}{c}1 \\
(71 \% \\
\text { Q } \text { Qw1 } 1)^{\prime}\end{array}$ & - & - & Swl & $\begin{array}{l}\text { BW } \\
\text { Co- } \\
\text { Ferm }\end{array}$ & $\begin{array}{c}\text { GW } \\
\text { WWTP }\end{array}$ & $\begin{array}{c}\text { Sw } \\
\text { I }\end{array}$ & $\begin{array}{l}\text { BW } \\
\text { Co- } \\
\text { Ferm }\end{array}$ & $\begin{array}{c}\text { GW } \\
\text { WWTP }\end{array}$ & Swl & $\begin{array}{l}\text { BW } \\
\text { Co- } \\
\text { Ferm }\end{array}$ & $\begin{array}{c}\text { GW } \\
\text { WWTP }\end{array}$ & $\begin{array}{c}\text { Sw } \\
1 \\
\text { Sul }\end{array}$ & $\begin{array}{c}\text { BW } \\
\text { Co- } \\
\text { Ferm }\end{array}$ & $\begin{array}{c}\text { GW } \\
\text { WWTP }\end{array}$ & $\begin{array}{l}\text { Swl } \\
\text { Sul }\end{array}$ & $\begin{array}{c}\text { BW } \\
\text { Co- } \\
\text { Ferm }\end{array}$ & $\begin{array}{c}\text { GW } \\
\text { WWTP }\end{array}$ & $\begin{array}{l}\text { Swl } \\
\text { Sul }\end{array}$ \\
\hline $\begin{array}{c}2 \\
100 \% \\
\left.\text { Q }{ }^{2} 2\right)\end{array}$ & - & - & Swl & - & - & $\begin{array}{c}\text { Sw } \\
\text { I } \\
\text { Sul }\end{array}$ & $\begin{array}{l}\text { BW } \\
\text { Co- } \\
\text { Ferm }\end{array}$ & $\begin{array}{c}\text { GW } \\
\text { WWTP }\end{array}$ & $\begin{array}{l}\text { Swl } \\
\text { Sul }\end{array}$ & $\begin{array}{c}\text { BW } \\
\text { Co- } \\
\text { Ferm }\end{array}$ & $\begin{array}{c}\text { GW } \\
\text { WWTP }\end{array}$ & $\begin{array}{c}\text { Sw } \\
1 \\
\text { Sul }\end{array}$ & $\begin{array}{c}\text { BW } \\
\text { Co- } \\
\text { Ferm }\end{array}$ & $\begin{array}{c}\text { GW } \\
\text { WWTP }\end{array}$ & $\begin{array}{l}\text { Swl } \\
\text { Sul }\end{array}$ & $\begin{array}{c}\text { BW } \\
\text { Co- } \\
\text { Ferm }\end{array}$ & $\begin{array}{c}\text { GW } \\
\text { WWTP }\end{array}$ & $\begin{array}{l}\text { Swl } \\
\text { Sul }\end{array}$ \\
\hline
\end{tabular}

\section{RESULTS AND DISCUSSION}

The implementation of the module for BW/GW separation showed that the sustainable sanitation measure can be reliably represented by means of dynamic simulation. Figure 1 shows the time-dependent behavior of COD load and flow rate resulting from the simulated separation of BW/GW for dry weather conditions in a selected municipality. 


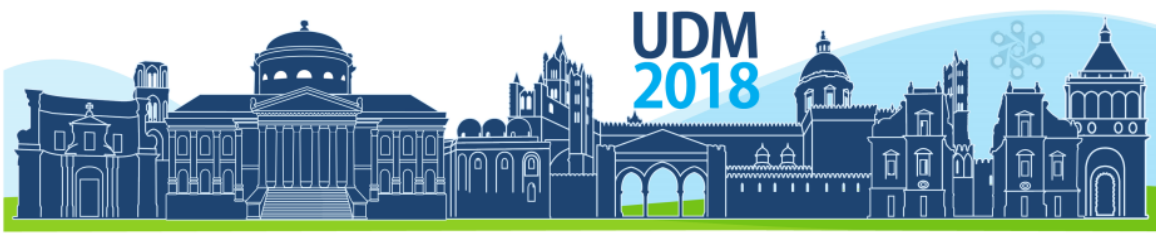

$11^{\text {th }}$ International Conference on Urban Drainage Modelling 23-26 Sep | Palermo - Italy
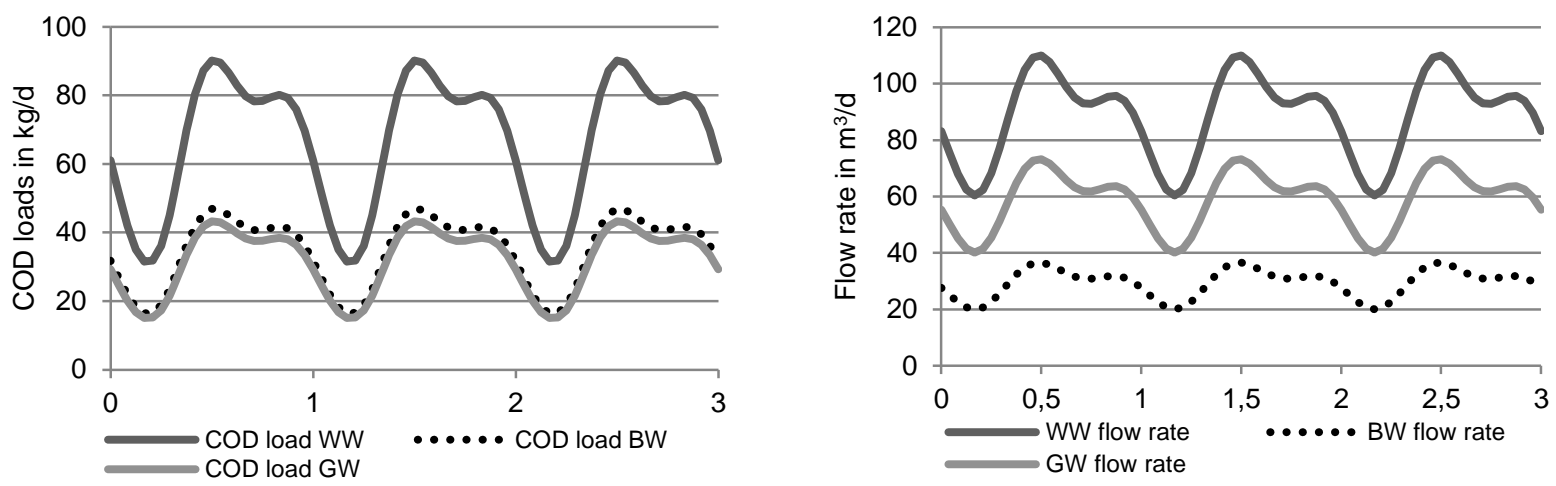

Figure 1. Comparison of three-day period COD load (left) and flow rate (right) distribution for household wastewater (dry weather) versus BW/GW separation for the settlement 2

The implementation of sustainable sanitation and the consideration of population decline lead to a more dynamical operation response from the WWTP. Figure 2 shows the course of pollutant loads within the combined sewer as well as the blackwater in 10-year steps at the inlet of the WWTP in the case of scenario "nutrient recovery". The blackwater is drained out with pressure pipelines into the WWTP for co-fermentation in the digestion tank.
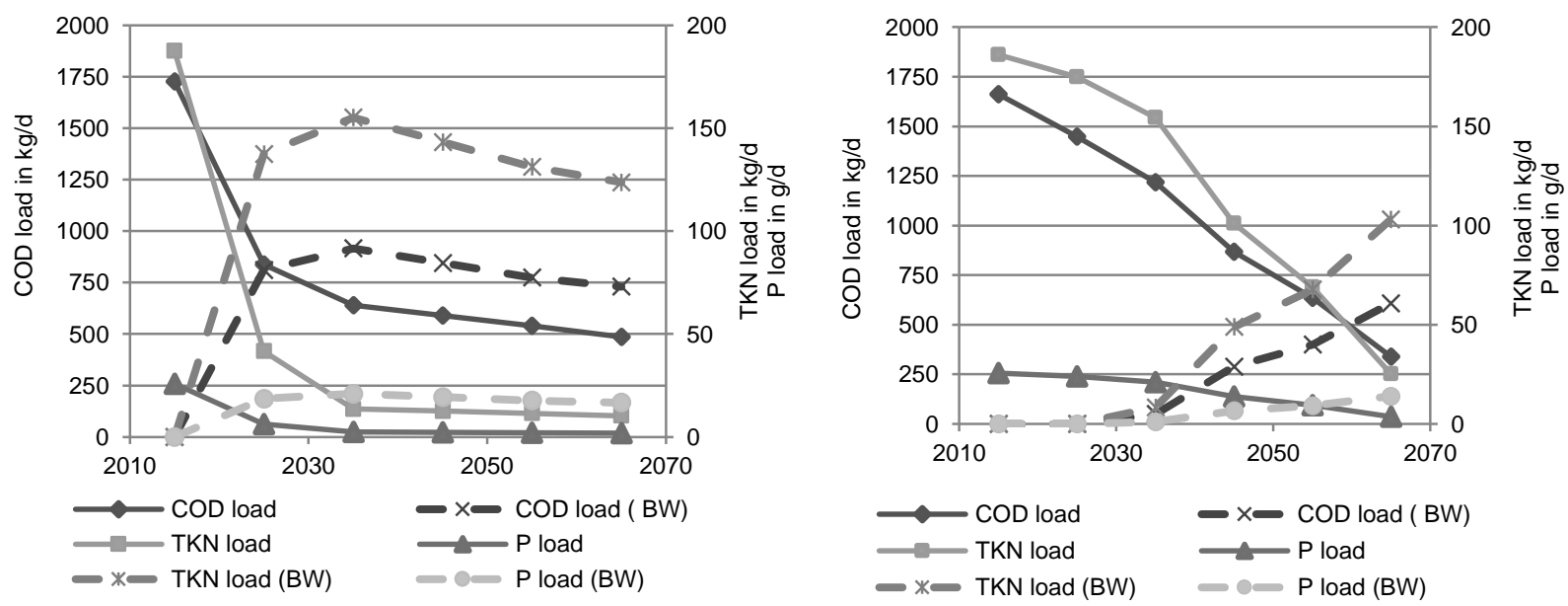

Figure 2. Pollutant loads at the inlet of the WWTP from wastewater and blackwater for co-fermentation loads for 100\% Energy Efficiency, 50\% Costs (left) and Nutrient Recovery (right) for years 2015 to 2065

\section{CONCLUSIONS}

The developed modules for adaptation measures and strategies within the data model showed to be successful with the aim of assess operational alternatives in various parts of the sewage disposal system. Moreover, implementing this simplified approach for a stepwise integration of resource-oriented sanitation technologies allows a holistic evaluation of the system not only for dry weather conditions but also for stormwater conditions. 


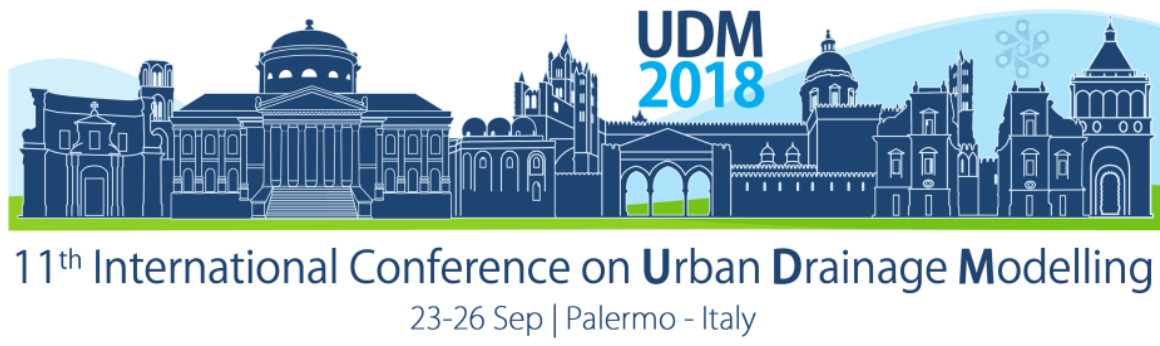

Furthermore, the progressive decrease of the discharge volume flows and pollutant loads, e.g. changes in COD:N ratio, demand indeed more flexible operational strategies at the WWTP to remain reliable. Without the consideration of further planning measures, initial results indicated some technical constraints within the WWTP. The type of implemented sustainable sanitation systems influences these constraints.

\section{ACKNOWLEDGMENTS}

The Foundation Carl Zeiss (Young Generation Sponsorship Program 2014 - 2017) and the Ministry of Higher Education, Science and Technology of the Dominican Republic (2017 2018) supported this research. Their contributions to the progress of the investigation are highly appreciated.

\section{References}

Baron S., Dilly, T. C., Kaufmann Alves, I. and Schmitt, T. G. (2017): Transformation of urban drainage systems in rural areas towards decentral and resource oriented systems. In: Proceedings of the "14th IWA/IAHR International Conference on Urban Drainage". 10 - 15 September, 2017, Prague, Czech Republic.

DWA (2014): Grundsätze für die Planung und Implementierung Neuartiger Sanitärsysteme. Arbeitsblatt DWA-A 272 (Principles for the planning and implementation of innovative sanitation systems. German Rules and Standards, A 272). Hennef (Sieg): Deutsche Vereinigung für Wasserwirtschaft, Abwasser und Abfall

Kaufmann Alves, I. (2013): A mathematical approach to find long-term strategies for the implementation of resourceorientated sanitation. Wat. Sci. Technol. 67 (7):1442-1454

Penn, R., Friedler, E., Ostfeld, A. (2013): Multi-objective evolutionary optimization for greywater reuse in municipal sewer systems. Water Research 47(15): 5911-5920

Schmitt, T. G., Worreschk, S., Kaufmann Alves, I., Herold, F. and Thielen, C. (2014): An Optimization and Decision Support Tool for Long-Term Strategies in the Transformation of Urban Water Infrastructure. CUNY Academic Works

Schmitt T.G., Wölle J., Dilly T., Baron S., Knerr H. et al. (2016): SinOptiKom - Sektorübergreifende Prozess-optimierung in der Transformation kommunaler Infrastrukturen im ländlichen Raum (Cross-sectoral optimization of transformation processes in municipal infrastructures in rural areas). Project Report (ref. no. 33W009). BMBF funding measure INIS "Smart and multifunctional infrastructural systems for sustainable water supply, sanitation and stormwater management"

Schütze, M., Alex J. (2014): A Simulator for Model-Based Participatory Integrated Urban Water Management. In: Proceedings of the "13th International Conference on Urban Drainage". 7 - 12 September, 2014, Sarawak, Malaysia

Urich, C., Sitzenfrei, R., Bach P. M., Kleidorfer, M., Mair, M., McCarthy, D. T., Deletic, A., Rauch, W. (2014): Modelling the Co-evolution of Cities and Their Water Infrastructures. In: Proceedings of the "13th International Conference on Urban Drainage". 7 - 12 September, 2014, Sarawak, Malaysia 


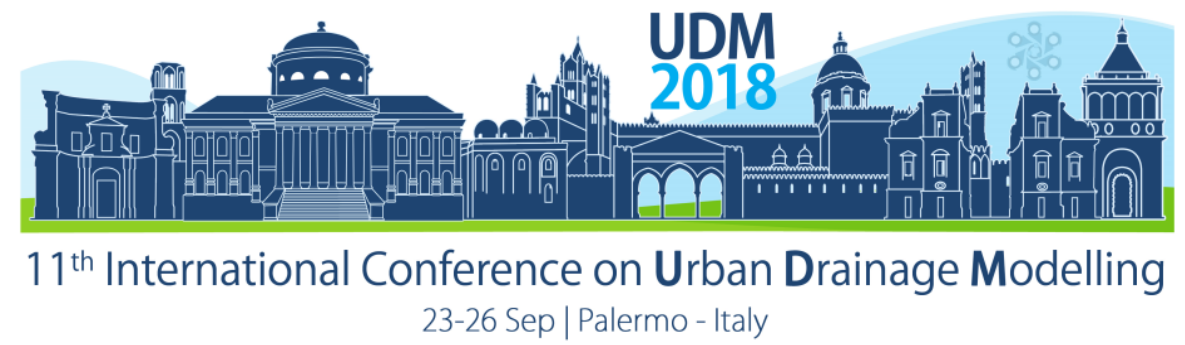

\title{
Cellular Automata Approach for 2D pollution transport modelling in urban groundwater
}

\author{
Miloš Milašinović ${ }^{1}$, Anja Ranđelović ${ }^{1}$, Nenad Jaćimović ${ }^{1}$ and Dušan Prodanović ${ }^{1}$ \\ ${ }^{1}$ Faculty of Civil Engineering, Department of Hydraulic and Environmental Engineering, Belgrade, Serbia
}

\begin{abstract}
Integrated modelling requires many simplifications in order to speed up long time calculations and simulations. Therefore, many non-traditional methods are being widely used. Cellular automata (CA) represents one of these methods. The paper presents the application of the CA approach in modelling of the contaminant transport in unsteady groundwater conditions. It compares the results obtained using the two CA models modified for groundwater problems. Results obtained in this paper show that CA approach can be successfully used for simulations of unsteady groundwater conditions, caused by surface-groundwater interaction, and pollution transport.
\end{abstract}

Keywords: Integrated modelling; Cellular Automata; contaminant transport, surface-groundwater interaction

\section{INTRODUCTION}

Water quality in urban catchments is one of the crucial problems that need to be addressed to assure high quality of life in cities. Particularly vulnerable to quality deterioration is the groundwater, often used for water supply, especially if the aquifer lies near or beneath the city. This creates a problem with groundwater resources pollution protection. Urban stormwater runoff is being categorized as one of the major pollution sources to receiving waters. Although build-up and wash-off mechanisms of pollution in highly urbanized areas have been subjects of numerous studies (Deletic, Maksimovic, \& Ivetic, 1997), interaction between groundwater and sewer systems should be further investigated. Old combined sewer systems (and even inadequately constructed separate ones) may leak underground. Sewer leakage combined with absence of a wastewater treatment system (Belgrade being such an extreme example), puts groundwater resources at a high risk of contamination. To assess various "what if' scenarios, particularly when there are water quality monitoring points, it is of outmost importance to develop a usable integrated model.

Due to the complexity of the commonly used physically based models, computation cost occurs as one of the main problems, especially in long term simulations. Combination of several numerical models in order to solve physically based models for interactions in a chain of models can, often, create an unsolvable problem. Hence, simplified models, such as the Cellular Automata (CA) have been a topic for many researchers in the last two decades, especially since they can speed up the computation. Additionally, with the development of parallel computing, CA models became highly exploited methods in different areas (Bandini, Mauri, \& Serra, 2001), including the water cycle modelling.

Development of flood inundation models based on CA approach started with Dottori \& Todini, 2010. They proposed a CA based model for representing diffusion dominated problems such as the flood inundation events. Guidolin et al., 2016 developed weighted cellular automata model for rapid flood inundation analysis. At the same time with development of the CA models for flood inundation and runoff problems (surface water problems), several researchers used this approach to solve problems in groundwater modelling. Ravazzani, 


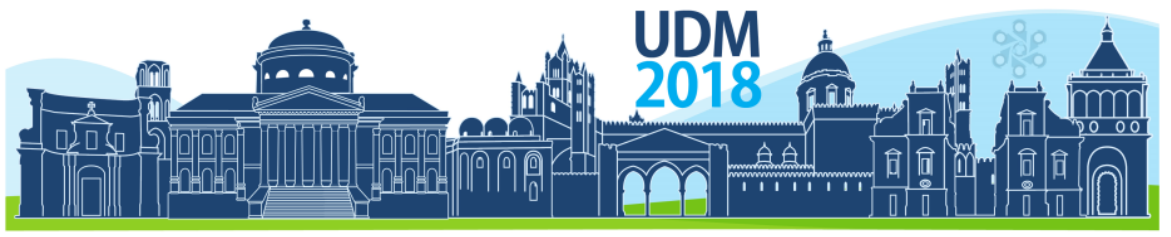

$11^{\text {th }}$ International Conference on Urban Drainage Modelling

23-26 Sep | Palermo - Italy

Rametta, \& Mancini, 2011 used CA for unsteady groundwater state modelling caused by constant pumping rate from a well. At the same time CA approach is used to model pollution (contaminant) and other transport processes, in atmosphere, surface water and groundwater. Modelling of air pollution transport was the subject of researches presented by Guariso \& Maniezzo, 1992. Palanichamy, Schüttrumpf, \& Palani, 2008 developed probabilistic CA model for two dimensional contaminant transport in groundwater in steady state conditions.

This paper presents development of a methodology that can be used to model pollution transport in unsteady groundwater conditions. The primary objective of this research is to analyse and compare the behaviour of the two CA-based models for contaminant transport from linear pollution source in unsteady groundwater conditions caused by infiltration. Analysis shows the CA based algorithm may be utilized for groundwater and diffusion dominant mechanisms of pollution transport modelling.

\section{MATERIALS AND METHODS}

Methodology is based on a two-layer (two-stage) modelling (Figure 1). First layer is used for hydrodynamic modelling of the unsteady groundwater conditions. In this layer, the two CA approaches are possible: the first one is weighted cellular automata, proposed by Guidolin et al., 2016, modified for groundwater conditions, and the second one the cellular automata model based on simple Darcy's law, proposed by Ravazzani et al., 2011. Second layer is used for modelling of the pollution (contaminant) transport using the velocity-field obtained in the first layer (hydrodynamic layer).

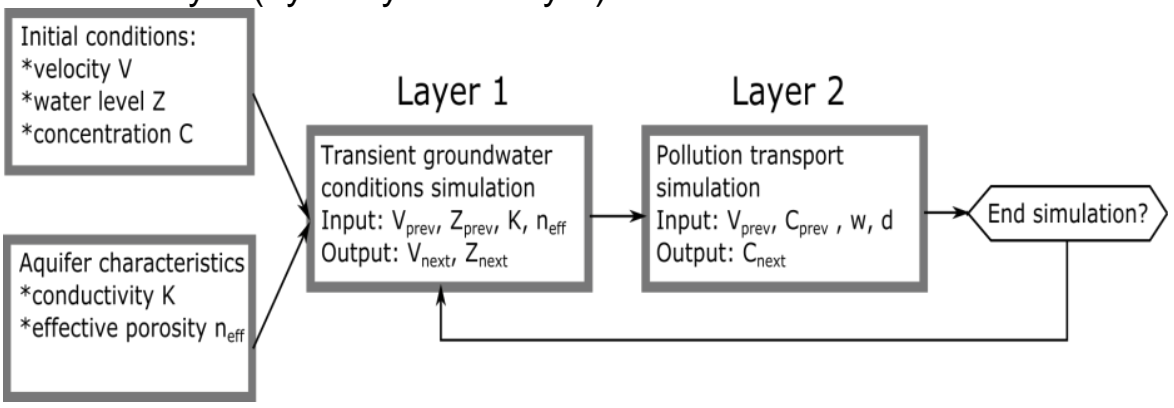

a)

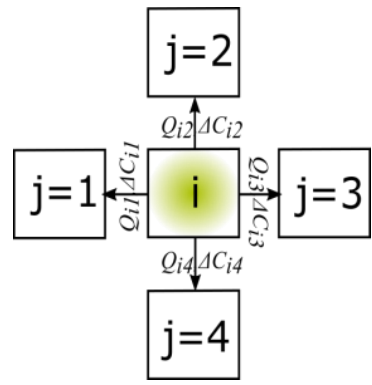

b)

Figure 1. a) Schematic view of the CA two-layer model: Layer 1 is computed either by WCAGW or by DCAGW; b) Cell local numeration

2.1 Weighted Cellular Automata for Unsteady Groundwater Flow Modelling - WCAGW The WCAGW model is developed by modifying the Weighted Cellular Automata (WCA2D) (Guidolin et al., 2016) so it can be used for the simulations in unsteady groundwater conditions. This method uses cellular weights, calculated on the basis of the head gradient. WCAGW differs from the original WCA2D in physical limitations of the maximum intercellular velocity (eq. 1) and the modification of the cells state update equation (eq. 2).

$$
v_{M}=\frac{4 \cdot K_{i} \cdot H_{i} \cdot K_{M} \cdot H_{M}}{\left(K_{i} \cdot H_{i}+K_{M} \cdot H_{M}\right) \cdot\left(H_{i}+H_{M}\right) \cdot d_{i M}}\left(H_{i}-H_{M}\right)
$$

$$
H_{i}^{n+1}=H_{i}^{n}-\frac{1}{n_{e f f}} \cdot \frac{\sum Q_{i j}^{n}}{A_{i}} \cdot \Delta t
$$

where $v_{M}$ represent max allowed velocity $(M$ is the index of max weighted cell, according to local numeration Fig $1 b$.), $K_{i}$ represent hydraulic conductivity of the central cell, $K_{M}$ represent hydraulic conductivity of an adjacent cell with max weight, $H_{i}$ represent water level in the central cell, $H_{M}$ represent water level in the max weighted adjacent cell and $d_{i M}$ represent boundary length between two cells. In equation (2) $n_{\text {eff }}$ represent effective porosity, $Q_{i j}$ 


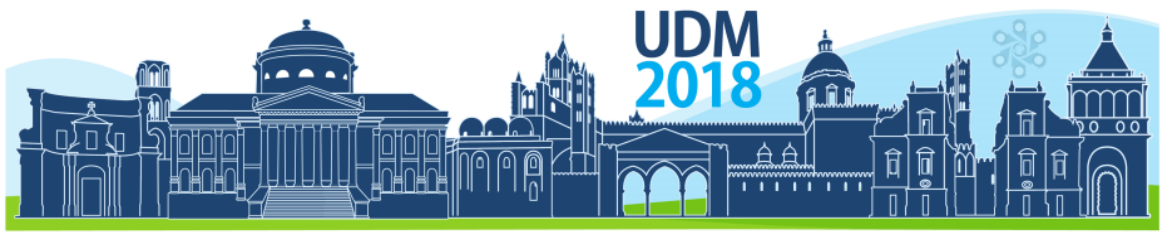

$11^{\text {th }}$ International Conference on Urban Drainage Modelling

23-26 Sep | Palermo - Italy

represents intercellular discharge and/or volume input/output (well or infiltration), $A_{i}$ is the area of the central cell basis and $\Delta t$ is time step.

\subsection{Darcy's law-based Cellular Automata for Unsteady Groundwater Flow Modelling - DCAGW}

Darcy's law-based Cellular Automata for Unsteady Groundwater Modelling (Ravazzani et al., 2011), originally developed for simulation of unsteady groundwater conditions due to the constant pumping rate from a well, was slightly modified so it can be used for simulations of unsteady groundwater conditions caused by homogeneous infiltration over the entire domain (eq. 3). Cell state update is calculated using equation (2).

$$
Q_{i j}^{n}=\frac{2 \cdot K_{i} \cdot H_{i}^{n} \cdot K_{j} \cdot H_{j}^{n}}{K_{i} \cdot H_{i}^{n}+K_{j} \cdot H_{j}^{n}}\left(H_{j}^{n}-H_{i}^{n}\right)
$$

\subsection{Cellular Automata for Pollution Transport Modelling - CAPT}

Pollution transport model uses velocity field calculated either by WCAGW or DCAGW. Pollution transport is calculated on the basis of the adjacent cells pollution state gradient, advection (convection) factor and diffusion factor (eq. 4). Updated cell pollution state presents the linear combination of adjacent cells state from the previous time step.

$$
C_{i}^{n+1}=C_{i}^{n}+\sum_{j=1}^{4}\left(-2 \frac{v_{j}^{n}}{n_{\text {eff }}} \cdot \frac{\left(C_{j}^{n}-C_{i}^{n}\right)}{\Delta x}+4 \cdot \alpha_{x(y)} \cdot v_{j}^{n} \cdot \frac{C_{j}^{n}-C_{i}^{n}}{\Delta x^{2}}\right) \cdot \Delta t
$$

Where $C_{i}^{n+1}$ is pollution concentration in central cell in the next step, $C_{i}^{n}$ is pollution concentration in central cell at the present time, $C_{j}^{n}(j=1,2,3,4)$ is pollution concentration at an adjacent cell at the present time, $v_{j}$ is velocity between cells, $\Delta x$ spatial resolution, $\Delta t$ temporal resolution and $\alpha_{x(y)}$ is longitudinal (transversal) dispersivity.

\subsection{Test case}

Initial methodology testing is performed on an artificial square domain. Boundary conditions include constant head $H=15 \mathrm{~m}$ on the west and the north boundaries and concentration set at $0 \mathrm{mg} / \mathrm{l}$ and Neumann boundary condition of zero velocity on the east and the south boundaries. The initial condition over the entire domain is a constant head of $H=15 \mathrm{~m}$ with no flow conditions and concentration of $C=0 \mathrm{mg} / \mathrm{l}$. The domain is assumed to be homogeneous with a hydraulic conductivity $K=1.25^{*} 10^{-5} \mathrm{~m} / \mathrm{s}$ and effective porosity $n_{\text {eff }}=0.26$. The domain is discretized in a $10 \times 10 \mathrm{~m}$ cellular grid. Pollution is set as a linear source pollution with constant concentration of $5 \mathrm{mg} / \mathrm{l}$ during the simulation period. Infiltration is represented by a constant rainfall intensity $i=0.1 \mathrm{~mm} / \mathrm{h}$ over 250 days with the time step $\Delta t=6 \mathrm{~h}$, spread homogeneously over the entire domain.

\section{RESULTS AND DISCUSSION}

Initial results of the simulation using coupled DCAGW/CAPT and WCAGW/CAPT models for pollution transport in unsteady groundwater conditions are presented in Figure 2 and Figure 3 , respectively, at one time frame: 250 days after infiltration start and as head and concentration time series at 4 observation points. Figure 2 includes water levels over the entire domain (top graphs) and pollution concentration distribution (bottom graphs) for 3 different models, DCAGW/CAPT, WCAGW/CAPT and MODFLOW, respectively.

DCAGW simulation shows better head matching with MODFLOW results with NRMSD (Normalised Root Mean Square Deviation - RMSE normalized inrelation to the difference between max and min value) changing between $0.0547 \%$ and $0.0668 \%$ for 4 observation points, while the NRMSD is between $0.5247 \%$ and $1.6209 \%$ when WCAGW model is used. Interestingly, when pollutant concentration are compared, coupled WCAGW/CAPT shows 


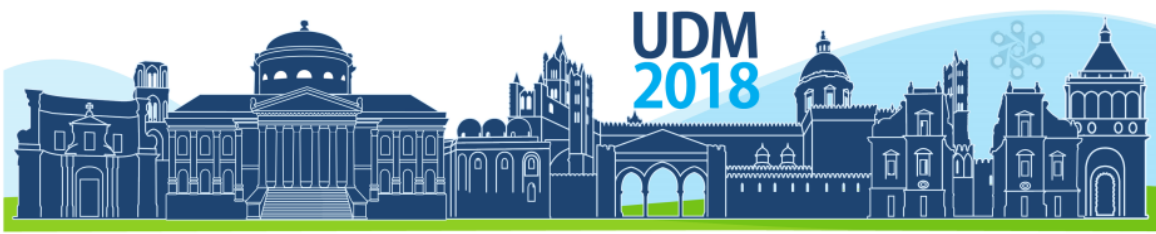

$11^{\text {th }}$ International Conference on Urban Drainage Modelling

23-26 Sep | Palermo - Italy

slightly better matching with MODFLOW than coupled DCAGW/CAPT model. NRMSD for pollutant concentration when WCAGW/CAPT is used are between $0.1681 \%$ and $4.3028 \%$ for 4 observation points. When DCAGW/CAPT model is used NRMSD is between $1.1843 \%$ and $5.6380 \%$.

\section{CONCLUSIONS}

CA approach was used to calculate pollution transport in unsteady groundwater conditions. Two models were tested and compared for simulation of the hydrodynamics effects (WCAGW, DCAGW) and one model was used for pollution transport modelling (CAPT). Analysis shows CA approach usage potential for pollution transport modelling when diffusion is dominant transport mechanism. Future work will include model testing with real scenarios and advection/convection dominant cases and comparison with standard models such as MODFLOW.

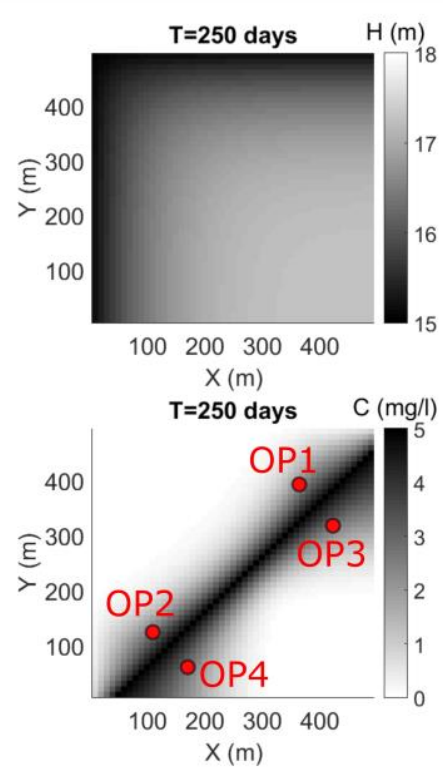

a)

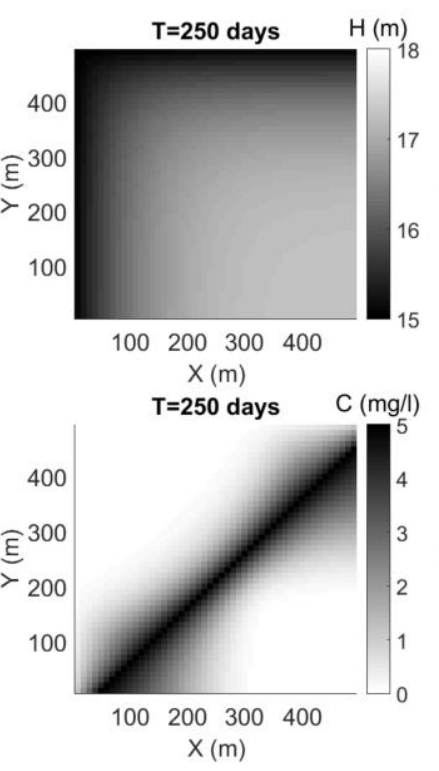

b)

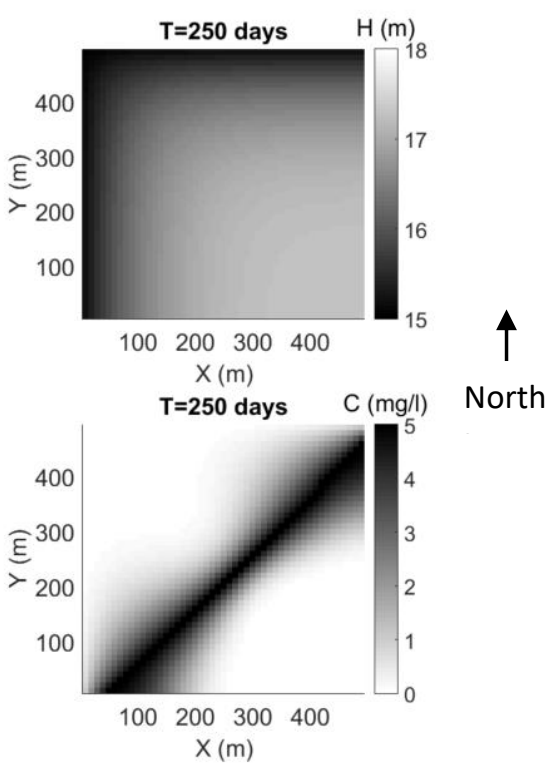

c)

Figure 2. a) Head $(\mathrm{H})$ and pollution concentrations $(\mathrm{C})$ over the entire domain using coupled DCAGW/CAPT simulation $\left(\alpha_{x}=1000 \mathrm{~m} ; \alpha_{y}=\alpha_{x}\right)$ and observation points (OP) marked as red dots; b) Head $(\mathrm{H})$ and pollution concentrations (C) over the entire domain using coupled WCAGW/CAPT simulation $\left(\alpha_{x}=1000 \mathrm{~m} ; \alpha_{y}=\alpha_{\mathrm{x}}\right)$; b) Head $(\mathrm{H})$ and pollution concentrations $(\mathrm{C})$ over the entire domain using MODFLOW $\left(\alpha_{x}=1000 \mathrm{~m} ; \alpha_{y}=\alpha_{\mathrm{x}}\right)$. 


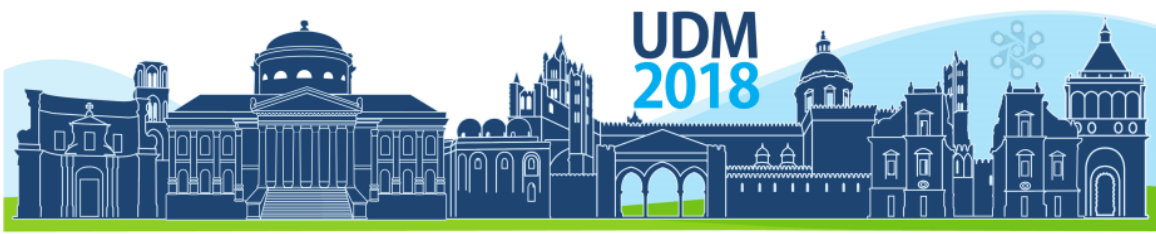

$11^{\text {th }}$ International Conference on Urban Drainage Modelling

23-26 Sep | Palermo - Italy

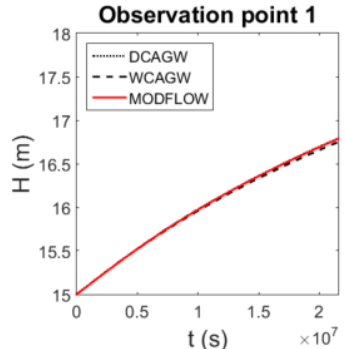

Observation point 3
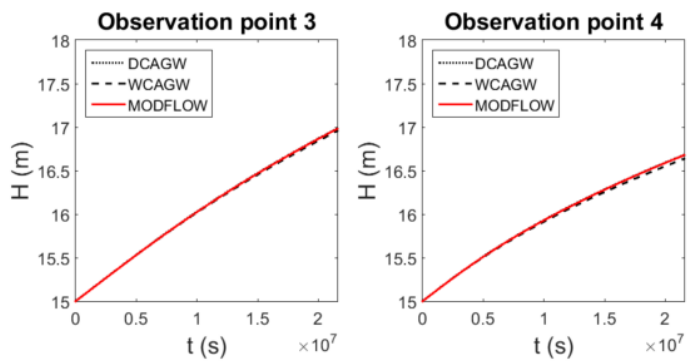

a)

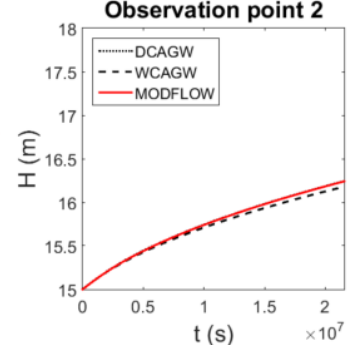

)
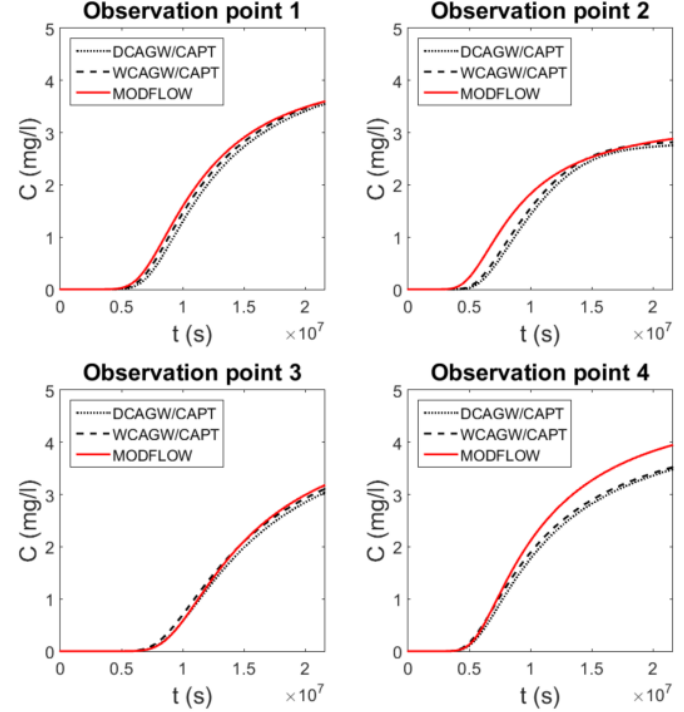

b)

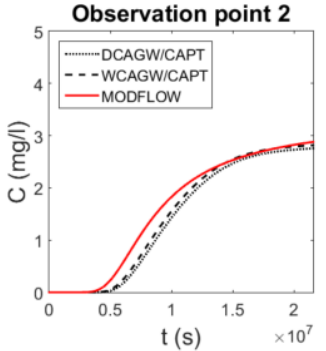

Figure 3. a) Head time series in four observation points marked in Figure 2a; b) Concentration time series in four observation points marked in Figure 2a.

\section{ACKNOWLEDGEMENT}

The authors are grateful to the Serbian Ministry of Education, Science and Technological Development for its financial support, project No. TR37010.

\section{References}

Bandini, S., Mauri, G., \& Serra, R. (2001). Cellular automata: From a theoretical parallel computational model to its application to complex systems. Parallel Computing, 27(5), 539-553. https://doi.org/10.1016/S01678191(00)00076-4

Deletic, A., Maksimovic, C., \& Ivetic, M. (1997). Modelling of storm wash-off of suspended solids from impervious surfaces. Journal of Hydraulic Research, 35(1), 99-118. https://doi.org/10.1080/00221689709498646

Dottori, F., \& Todini, E. (2010). A 2D Flood Inundation Model Based on Cellular Automata Approach. XVIII International Conference on Water Resources, (2), 1-8.

Guariso, G., \& Maniezzo, V. (1992). Air quality simulation through cellular automata. Environmental Software, 7(3), 131-141. https://doi.org/10.1016/0266-9838(92)90010-2

Guidolin, M., Chen, A. S., Ghimire, B., Keedwell, E. C., Djordjević, S., \& Savić, D. A. (2016). A weighted cellular automata 2D inundation model for rapid flood analysis. Environmental Modelling and Software, 84, 378394. https://doi.org/10.1016/j.envsoft.2016.07.008

Palanichamy, J., Schüttrumpf, H., \& Palani, S. (2008). A probabilistic cellular automaton for two dimensional contaminant transport simulation in ground water. Water Science and Technology, 58(11), 2083-2092. https://doi.org/10.2166/wst.2008.824

Ravazzani, G., Rametta, D., \& Mancini, M. (2011). Macroscopic cellular automata for groundwater modelling: A first approach. Environmental Modelling and Software, 26(5), 634-643.

https://doi.org/10.1016/j.envsoft.2010.11.011 


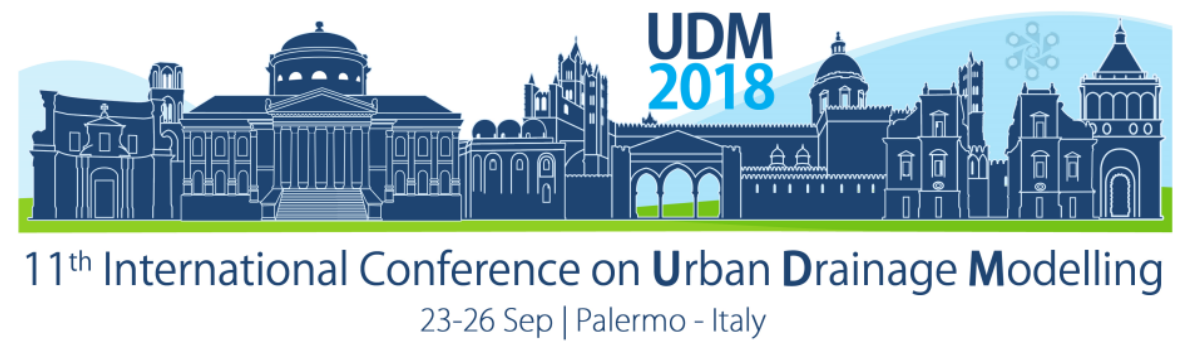

\title{
Numerical soil model for analysing sewer pipe-soil interactions
}

\author{
Irene C. Scheperboer ${ }^{1}$, Akke S.J. Suiker ${ }^{1}$, Emanuela Bosco', Francois H.L.R. Clemens 2,3 \\ ${ }^{1}$ Eindhoven University of Technology, Department of the Built Environment, Eindhoven, the Netherlands \\ 2 Delft University of Technology, Department of Civil Engineering and Geosciences, Delft, the Netherlands \\ ${ }^{3}$ Deltares, Department of Hydraulic Engineering, Delft, the Netherlands
}

\begin{abstract}
Determining the load bearing capacity of a deteriorated sewer is one of the important aspects to assess the overall condition of the sewer pipe system. Current indicators to achieve an impression of the residual bearing strength of the pipe are the age of the pipe and footage obtained by camera inspection (CCTV). However, these indicators have proven not to be very accurate, which makes the need for a reliable method to estimate the load bearing capacity of sewers high. The finite element method (FEM) is a suitable analysis tool for gaining a detailed understanding of the load bearing capacity of in-situ sewer pipes. The load bearing capacity does not only depend on the geometrical and material parameters of the pipe itself, but also on the deformation and failure behaviour of the soil structure supporting the pipe. The present contribution discusses the numerical implementation of an advanced soil model that can be used in a finite element analysis of a sewer pipe-soil system, which is a first step in the development of a computational model that is able to accurately predict the overall failure response of sewer pipe systems under arbitrary in-situ conditions.
\end{abstract}

Keywords: Sewer pipe-soil interaction; frictional sliding; granular compaction; isotropic and kinematic hardening

\section{INTRODUCTION}

The load bearing capacity of deteriorated sewer pipes is of vital importance for the ability of the sewer pipe to fulfill its function as a hydraulic system. The tools currently used for condition assessment of sewer pipes in general, and the load bearing capacity of buried pipes in particular, are not very accurate (Stanić et al., 2017). Decisions on maintenance and renewal are mainly based on information about the age of the pipe and footage obtained from Closed Circuit TeleVision camera inspection (CCTV), and these strategies often suggest premature and unnecessary interventions (van Riel et al., 2016). Insight into the failure mechanisms of sewer pipes is important to better estimate the residual load bearing capacity of the pipe, and numerical simulations can help to accomplish this goal. An important factor of influence on the residual strength of a sewer pipe, next to biochemical deterioration of the pipe itself, is the failure and deformation behavior of the soil layers supporting the pipe (Davies et al., 2001). This contribution treats the development of a finite element model for sewer systems, where the attention is focused on the elasto-plastic behavior of the surrounding soil structure.

\section{MATERIALS AND METHODS}

For the description of the interaction between a sewer pipe and the surrounding soil, the sewer pipe is initially assumed to be elastic. Extensions towards a more realistic constitutive behavior for the pipe will be considered in further research. The soil is modelled as elasto-plastic, in accordance with the formulation proposed in Foster et al. (2005). This model is implemented in the commercial finite element software package ABAQUS Standard through a User Material subroutine (UMAT). The main equations of this soil model are reviewed below. 


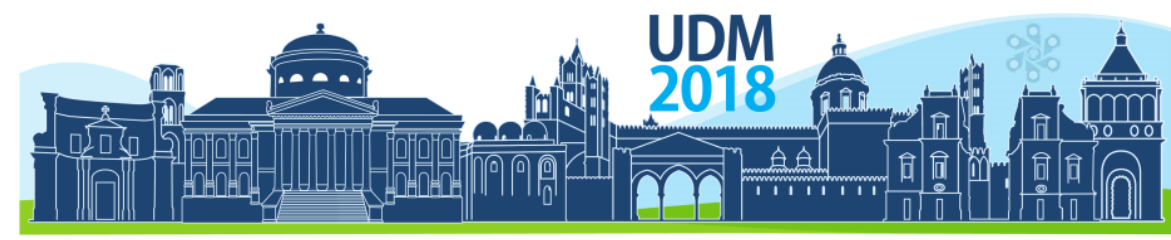

$11^{\text {th }}$ International Conference on Urban Drainage Modelling

23-26 Sep | Palermo - Italy

The soil model proposed in Foster et al., (2005) is based on a composite yield surface that consists of a part that simulates frictional failure

$$
F_{f}\left(I_{1}\right)=c_{1}-c_{3} \exp \left(c_{2} I_{1}\right)-\tan (\phi) I_{1},
$$

and a part describing granular compaction

$$
F_{c}\left(\kappa, I_{1}\right)= \begin{cases}1-\left(\frac{I_{1}-\kappa}{X(\kappa)-\kappa}\right)^{2}, & \text { if } I_{1} \leq \kappa \\ 1, & \text { otherwise }\end{cases}
$$

The frictional part, Eq.(1) accounts for the pressure dependency of the shear strength, and is dependent on the cohesion $c$, calculated as $c=c_{1}-c_{3}$, and the angle of internal friction $\phi$, see also Fig. 1a. The compaction part, Eq.(2), depends on the hydrostatic pressure $I_{1}$, an internal state parameter for volumetric hardening $\kappa$, and a pressure value $X(\kappa)$ at which the shear strength becomes zero, see Fig. $1 \mathrm{~b}$. The composite yield criterion is constructed as a combination of the frictional and compaction failure criteria, Eqs.(1) and (2), i.e.,

$$
f=J_{2} \Gamma^{2}-\left(F_{f}-N\right)^{2} F_{c},
$$

Where $J_{2}$ represents the second deviatoric stress invariant, $\Gamma$ accounts for the difference in triaxial extension and triaxial compression, and $N$ is a parameter for calibrating the tensile strength of the material. In order to account for non-associated plasticity, a plastic potential $g$ is constructed to determine the plastic deformations (Foster et al., 2005). The relation between the volumetric plastic strain $\epsilon_{v o l}^{p}$ and the internal variable $\kappa$ is given in rate form as

$$
\dot{\epsilon}_{v o l}^{p}=\frac{\partial \epsilon_{v o l}^{p}}{\partial X} \frac{\partial X}{\partial \kappa} \dot{\kappa},
$$

while the relation between the rate of $\kappa$ and that of the consistency parameter $\gamma$ reads

$$
\dot{\kappa}=\dot{\gamma} \frac{\partial g}{\partial I_{1}} /\left(\frac{\partial \epsilon_{v o l}^{p}}{\partial X} \frac{\partial X}{\partial \kappa}\right)
$$

for the case where the absolute value of $\kappa$ is increasing. For including kinematic hardening, the evolution of a back stress $\alpha$ needs to be taken into account through

$$
\dot{\boldsymbol{\alpha}}=c^{\alpha} G^{\alpha}\left(\frac{\partial g}{\partial \boldsymbol{\sigma}}-\frac{1}{3} \frac{\partial g}{\partial I_{1}} \boldsymbol{I}\right),
$$

where $c^{\alpha}$ represents the kinematic hardening modulus, $G^{\alpha}$ is the second invariant of the back stress, and $I$ is the second-order identity tensor. It is important to include kinematic hardening in the model, when realistic traffic loading will be included in a later stage of the research project.

The solution of the above model requires an incremental-iterative update scheme, whereby the updates for the stresses and the internal variables are computed using an implicit Euler backward algorithm. For this purpose, the stresses and internal parameters are included into a vector of unknowns $Z$, while the corresponding expressions for these parameters are assembled into a vector of residuals $R$, which for plane-strain conditions leads to

$$
\boldsymbol{Z}=\left[\begin{array}{llllllllll}
\sigma_{11} & \sigma_{22} & \sigma_{33} & \sigma_{12} & \alpha_{11} & \alpha_{22} & \alpha_{33} & \alpha_{12} & \kappa & \Delta \gamma
\end{array}\right]_{n+1}^{T},
$$




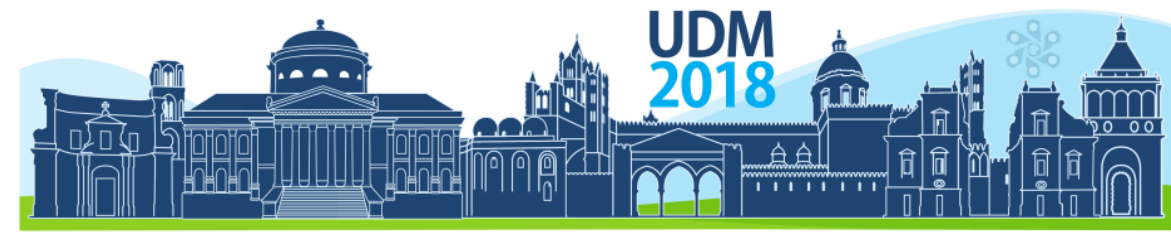

$11^{\text {th }}$ International Conference on Urban Drainage Modelling 23-26 Sep | Palermo - Italy

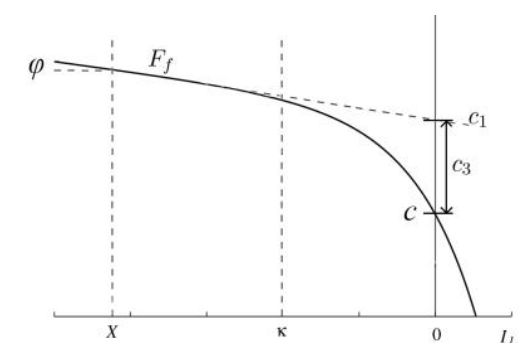

(a) Friction surface

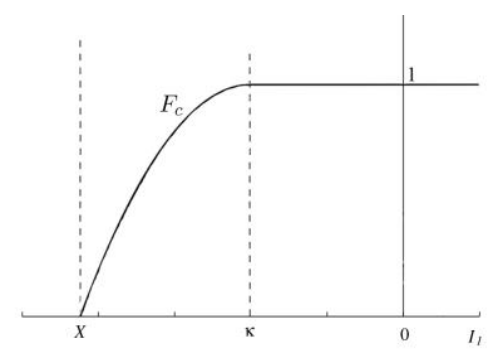

(b) Compaction surface

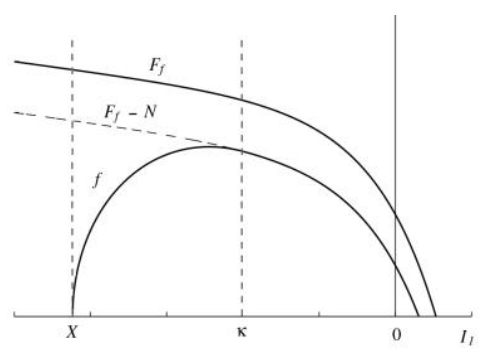

(c) Yield surface

Figure 1. Construction of the yield surface from a friction surface and a compaction surface

and

$$
\boldsymbol{R}=\left[\begin{array}{ccccc}
\Delta \gamma C_{11 k l}^{e} \frac{\partial g}{\partial \sigma_{k l}} & - & \sigma_{11} & + & \sigma_{11}^{\text {trial }} \\
\Delta \gamma C_{22 k l}^{e} \frac{\partial g}{\partial \sigma_{k l}} & - & \sigma_{22} & + & \sigma_{22}^{\text {trial }} \\
\Delta \gamma C_{33 k l}^{e} \frac{\partial g}{\partial \sigma_{k l}} & - & \sigma_{33} & + & \sigma_{33}^{\text {trial }} \\
\Delta \gamma C_{12 k l}^{e} \frac{\partial g}{\partial \sigma_{k l}} & - & \sigma_{12} & + & \sigma_{12}^{\text {trial }} \\
\Delta \gamma c^{\alpha} G^{\alpha}\left(\frac{\partial g}{\partial \sigma_{11}}-\frac{1}{3} \frac{\partial g}{\partial I_{1}}\right) & - & \alpha_{11} & + & \alpha_{11}^{\text {trial }} \\
\Delta \gamma c^{\alpha} G^{\alpha}\left(\frac{\partial g}{\partial \sigma_{22}}-\frac{1}{3} \frac{\partial g}{\partial I_{1}}\right) & - & \alpha_{22} & + & \alpha_{22}^{\text {trial }} \\
\Delta \gamma c^{\alpha} G^{\alpha}\left(\frac{\partial g}{\partial \sigma_{33}}-\frac{1}{3} \frac{\partial g}{\partial I_{1}}\right) & - & \alpha_{33} & + & \alpha_{33}^{\text {trial }} \\
\Delta \gamma c^{\alpha} G^{\alpha} \frac{\partial g}{\partial \sigma_{12}} & - & \alpha_{12} & + & \alpha_{12}^{\text {trial }} \\
\Delta \gamma \frac{\partial g}{\partial I_{1}} / \frac{\partial \epsilon_{v}^{p}}{\partial X} \frac{\partial X}{\partial \kappa} & - & \kappa & + & \kappa^{\text {trial }} \\
J_{2} \Gamma^{2}-\left(F_{f}-N\right) F_{c} & & &
\end{array}\right]_{n+1}=\mathbf{0}
$$

Where $g$ represents the plastic potential used for determining the plastic deformations, and the superscript trial indicates the (elastic) trial state of the corresponding parameter (Foster et al., 2005). Note that in Eqs.(7) and (8) all variables are evaluated at the new time instant $t_{n+1}$. The iterative update of the vector of unknowns within a time increment is carried out with a NewtonRaphson iteration,

$$
\boldsymbol{Z}^{i+1}=\boldsymbol{Z}^{i}-\left[\frac{\partial \boldsymbol{R}}{\partial \boldsymbol{Z}}\right]^{-1} \boldsymbol{R}^{i}
$$

where $i+1$ and $i$ are the current and previous iterations, respectively.

\section{RESULTS AND DISCUSSION}

The numerical implementation of the elasto-plastic soil model is tested in a case study of an in-situ concrete sewer pipe embedded in a soil trench, see Fig. 2. A displacement is incrementally applied at the top of the trench, which is assumed to be a simplification of traffic loading. At the sides and at the bottom of the trench the displacements are prescribed to be zero, simulating the confinement caused by the adjacent soil. The elastic material parameters of the concrete sewer pipe are $E=30 \mathrm{GPa}$ and $\nu=0.2$. The elastic properties of the sandy soil are taken from Stanić et al. (2017), while the isotropic hardening properties of the soil are 


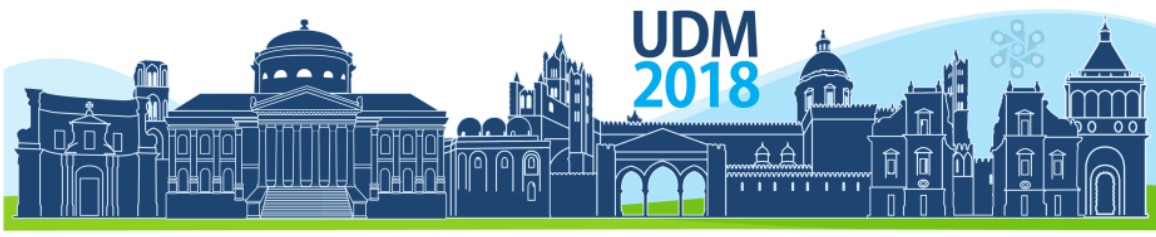

$11^{\text {th }}$ International Conference on Urban Drainage Modelling

23-26 Sep | Palermo - Italy

adopted from Foster et al. (2005). Kinematic hardening, which is only relevant under cyclic loading, is left out of consideration in this case study.

A plot of the maximum principal stresses (units of $\mathrm{MPa}$ ) is shown in Fig. 3 . The tensile strength of the concrete is taken as $\sigma_{t}=3 \mathrm{MPa}$. The light grey regions across the thickness of the sewer pipe, which are shown in red in the magnification shown in the inset of Fig. 3, indicate where the tensile strength is exceeded, which would correspond to the appearance of cracks. The tensile strength is first exceeded at the inside bottom of the sewer pipe, quickly followed by the inside top of the pipe. Subsequently, the tensile stress is reached at the left and right outer sides of the sewer pipe. This sequence of events is in correspondence with the crack formation observed in the large scale experimental tests reported in Stanić et al. (2017).

Plastic deformations in the soil emerge near the free surface, close to the location of the surface load. In practice, the sewer pipe is embedded in several layers compacted and uncompacted soil. In a later stage, the presented soil model can be used to simulate different material properties in these layers and plastic stresses are assumed to occur not only at the free surface, but also within the soil layers close to the sewer pipe.

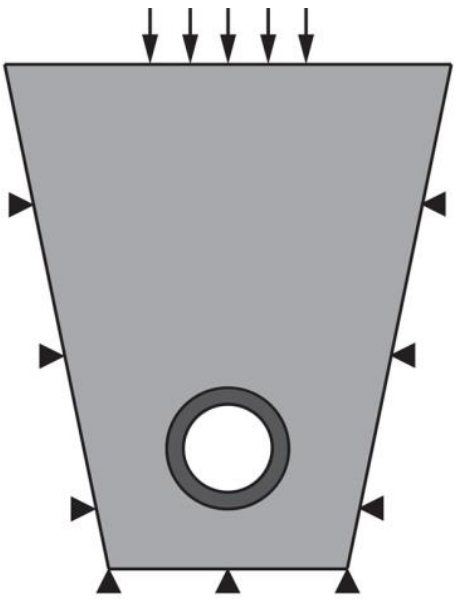

Figure 2. Schematic representation of a sewer pipe system

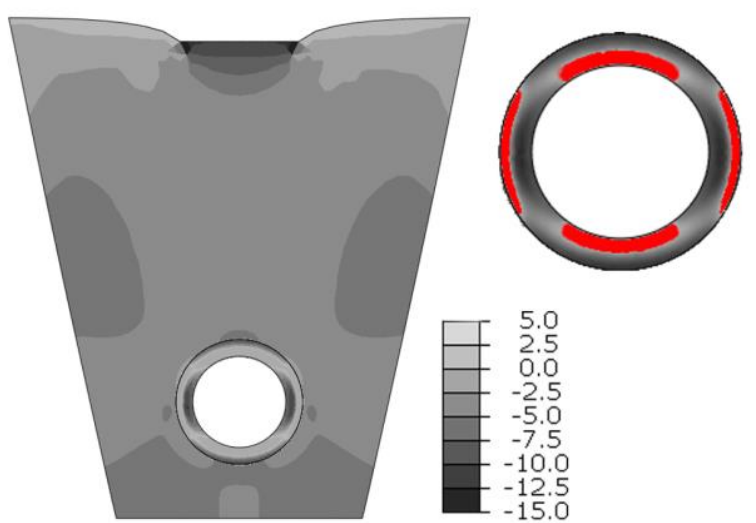

Figure 3. Distribution of the maximum principal stress (in $\mathrm{MPa}$ ) in the sewer pipe and soil trench

\section{CONCLUSIONS}

In this contribution, the numerical implementation of an advanced elasto-plastic soil model is treated, which is used in a finite element simulation of the response of an in-situ sewer pipe system. The benchmark problem simulated relates to a relatively simple 2D configuration, which gives a first indication at which location cracking may be expected in the sewer pipe. It is found that the locations indicated by the model described in this paper, are in agreement with experimental results, even when a highly simplified model of the concrete sewer pipe and the boundary conditions is used. The work presented here is part of an extended study in the numerical modelling of a sewer-soil interaction problem. The analysis will be extended in future work towards a 3D model in order to account for differential settlements in the longitudinal direction of the sewer pipe, which have been proven to be of importance in collapse of the sewer pipe (Xu et al., 2017). In addition, the effect of soil erosion due to ground water flow will be incorporated in the model. Soil erosion can lead to the formation of voids around the sewer pipe and may have a significant effect on its load bearing capacity(Davies et al., 2001). In 
Proceedings of the 11th Int. Conference on Urban Drainage Modelling, 23-26 Sep. 2018, Palermo (ITALY). Ed. prof. Giorgio Mannina

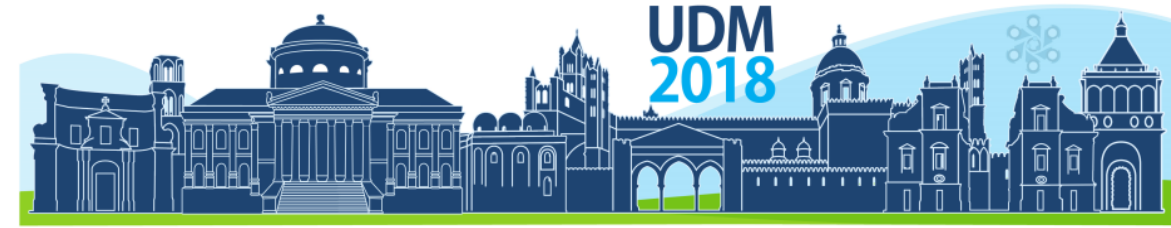

$11^{\text {th }}$ International Conference on Urban Drainage Modelling

23-26 Sep | Palermo - Italy

addition, the simple elastic model used for the sewer pipe will be extended with the effects of crack initiation and crack propagation, in accordance with the interface damage formulation presented in Cid Alfaro et al. (2009).

\section{References}

Cid Alfaro, M.V., Suiker, A.S.J., de Borst, R., Remmers, J.J.C., 2009. Analysis of fracture and delamination in laminates using 3D numerical modelling. Eng. Fract. Mech. 76, 761-780. https://doi.org/10.1016/j.engfracmech.2008.09.002

Davies, J.P., Clarke, B.A., Whiter, J.T., Cunningham, R.J., 2001. Factors influencing the structural deterioration and collapse of rigid sewer pipes. Urban Water J. 3, 73-89.

Foster, C.D., Regueiro, R.A., Fossum, A.F., Borja, R.I., 2005. Implicit numerical integration of a three-invariant, isotropic/kinematic hardening cap plasticity model for geomaterials. Comput. Methods Appl. Mech. Eng. 194, 5109-5138. https://doi.org/10.1016/i.cma.2005.01.001

Stanić, N., Langeveld, J., Salet, T., Clemens, F., 2017. Relating the structural strength of concrete sewer pipes and material properties retrieved from core samples. Struct. Infrastruct. Eng. 13, 637-651. https://doi.org/10.1080/15732479.2016.1187631

van Riel, W., van Bueren, E., Langeveld, J., Herder, P., Clemens, F., 2016. Decision-making for sewer asset management: Theory and practice. Urban Water J. 13, 57-68. https://doi.org/10.1080/1573062X.2015.1011667

Xu, M., Shen, D., Rakitin, B., 2017. The longitudinal response of buried large-diameter reinforced concrete pipeline with gasketed bell-and-spigot joints subjected to traffic loading. Tunn. Undergr. Space Technol. 64, 117132. https://doi.org/10.1016/j.tust.2016.12.020 


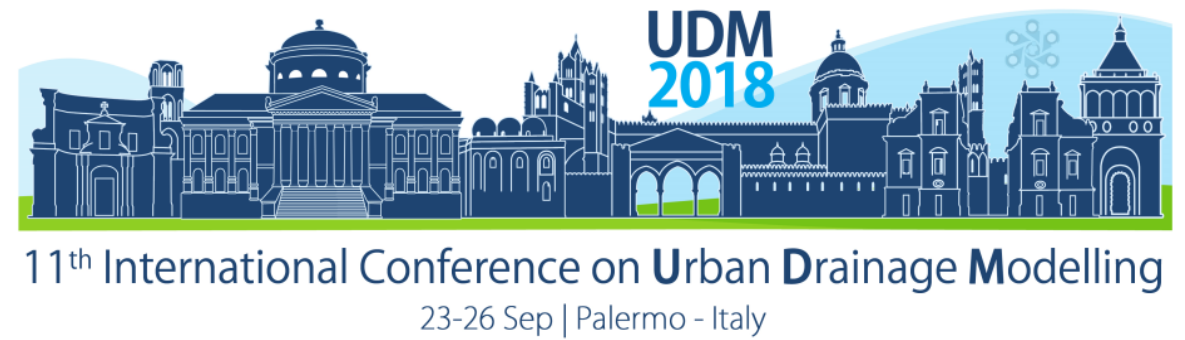

\title{
QUICS: how to deal with misconceptions in integrated model applications?
}

\author{
Franz Tscheikner-Gratl ${ }^{1}$, Vasilis Bellos ${ }^{2}$, Alma Schellart ${ }^{3}$, Jeroen Langeveld ${ }^{1}$, Francois Clemens ${ }^{1}$, Gerard \\ B. M. Heuvelink ${ }^{4}$, Lorenzo Benedetti ${ }^{5}$, Miguel Angel Rico-Ramirez ${ }^{6}$, Rita F. Carvalho ${ }^{7}$, Lutz Breuer ${ }^{8}$, James \\ Shucksmith ${ }^{3}$ and Simon Tait ${ }^{3}$

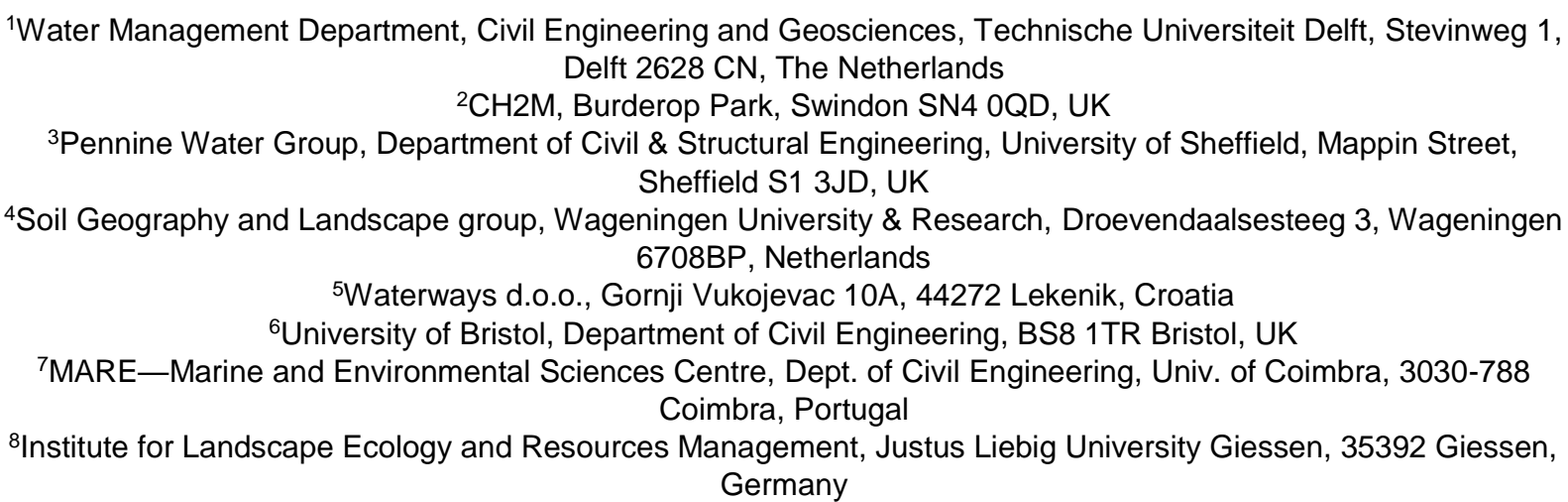

\begin{abstract}
This paper aims to stimulate discussion based on the experiences derived from the QUICS project (Quantifying Uncertainty in Integrated Catchment Studies). This paper will first briefly discuss the state of the art of knowledge of uncertainties in sub-models of integrated water quality models as well as the contributions delivered by the QUICS project. Furthermore, it discusses the challenges of linking different sub-models in contrast to building an integrated model from scratch and then calibrating it all at once. This discussion includes the subjects, whether we should shift our modelling uncertainty from uncertainties due to linkage, when using linked models, to uncertainties in model structure by necessary simplification or by using more parameters. This goes hand in hand with the remaining question if there is an increase in uncertainty by linking these models or if a compensation effect could take place. Finally, challenges and bottlenecks in the application of uncertainty analysis in integrated water quality models, as encountered in this project, are discussed and recommendations for future research areas are highlighted.
\end{abstract}

Keywords: Uncertainty; Integrated Catchment Modelling; water quality; challenges; practical implementation

\section{INTRODUCTION}

Deterministic integrated catchment water quality models are often the method of choice to predict surface water quality to assist in making decisions and designing solutions. In theory, such integrated models include and cross both urban and rural catchment spatial and temporal scales, although in practice studies considering contributions of both rural and urban and other origins (e.g. Honti et al. (2017)), remain rare.

Integrated models can simulate the interlinked dynamics of the catchment system, enable the assessment of a range of alternative responses (infrastructural/regulatory) and allow the identification of an "optimal" response (i.e. the lowest cost or highest value), although the impact of any response could be quite remote from the location of its implementation. Significant asset investment and detailed water management strategies are based on the outputs of such modelling studies. However, there is increasing concern that these 


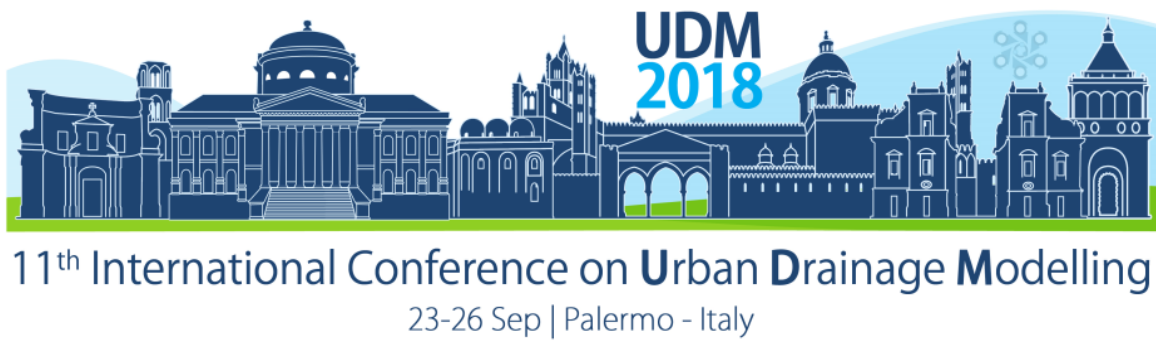

deterministic models can lead to incorrect problem diagnosis and inefficient water quality and environmental management strategies (e.g. Schellart et al., 2010).

Unfortunately, the end users of integrated catchment models (ICMs) often neither have the knowledge nor the practical tools to estimate the levels of uncertainty associated with submodels of different spatial and temporal resolutions. There are currently, as far as the authors are aware, no practical tools available to describe how these uncertainties are propagated between sub-models and in which way they influence water quality predictions. Since modelling is an expensive and time-consuming process, information on predictive uncertainty needs to be provided to practitioners in a way that enables local authorities or utilities to evaluate the impact of these uncertainties on their investment decisions. Whether an uncertainty analysis tool is suitable is not only a function of the catchment, the model type, the available data and the water quality processes involved, but also of the interpretation of environmental legislation by the local regulator and the local industrial modelling code of practice. For example, rainfall spatial and temporal variability can add to the uncertainty, however, if the local regulator expects the use of a non-spatially varied design storm, then it is not possible to include rainfall related uncertainty in the uncertainty analysis (Sriwastava et al., 2018). This lack of suitable tools, able to propagate uncertainties across water quality models with widely different space and time scales, was the motivation of the QUICS project (Quantifying Uncertainty in Integrated Catchment Studies). In consequence, this paper aims to provide a discussion point based on the experience derived from the project.

\section{CHALLENGES OF LINKING DIFFERENT SUB-MODELS}

In integrated modelling studies, typically one wishes to simulate several systems and associated processes over a range of varying spatial and temporal scales. Including an increasing number of systems and processes tends to dramatically increase the need for input data (on geometry, boundary conditions, process parameters). The naive thought that adding more detail into a model leads more accurate results is paramount to this urge for more model integration, but the question remains if linking together different models can always deliver enhanced modelling results and how long it takes before we have an "Integronster" (Voinov and Shugart, 2013) or a "random number generator" (Willems, 2006). In this sense, a similarity with optimal tax theory is observed: "When the income tax percentage is $0 \%$, no tax income is generated, while when the income tax rate is $100 \%$ no tax income is generated as well", this latter observation is a strong simplification of the very complicated and long lasting discussions on optimal tax theory (see e.g. Mirrlees (1971)). There should be an optimum (at least seen from the perspective of a tax collector) between these two extremes, but what this exactly is, is hard, if not impossible to determine and depends largely on the context, subjective individual preferences and/or political viewpoints.

Given that an integrated model has a larger number of uncertainty sources within each of its sub-models, it is tempting for scientists to think that its output uncertainty will also be larger, while practitioners tend not to give much thought on this topic if legislative regulations are met by existing simulation results. This impression is reinforced by the belief that 'uncertainty propagation' is synonymous to 'uncertainty amplification', suggesting that in a chain of models the uncertainty can only grow. However, this is not generally true. In contrast, in many cases the output uncertainty will decrease when models are coupled because of a compensation effect. Thus, coupling models does not automatically lead to an increase in the size of uncertainty, but it depends on the case at hand and whether there are 


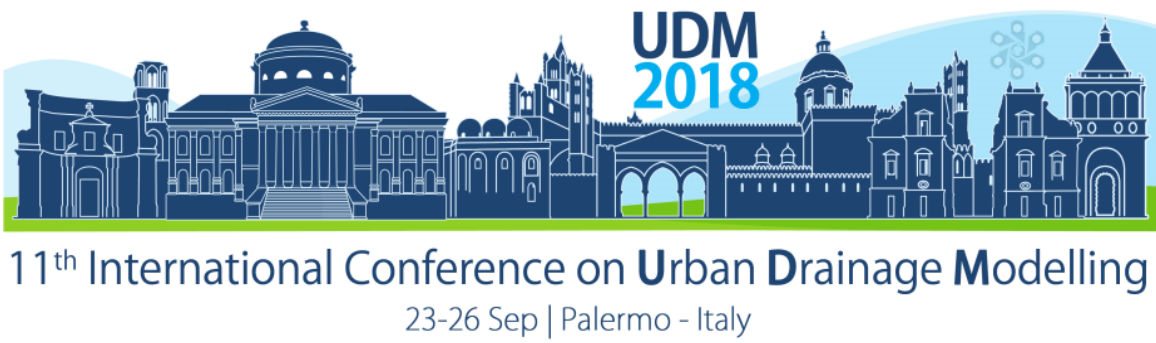

processes involved that occur only after certain thresholds are achieved, non-linear processes and processes where variability changes with space and time scale, such as rainfall.

Muthusamy et al. (2018) investigated the propagation of different sources of uncertainty, including rainfall uncertainty, in improved sediment wash-off modelling. It was concluded that the level of uncertainty in predicted wash-off load due to rainfall uncertainty can be smaller, similar or higher to the rainfall uncertainty depending on the rainfall intensity range and the "first-flush" effect. A study on uncertainty in sediment build-up in sewer systems (Schellart et al., 2010) showed that uncertainty in hydraulic roughness, particle size and uncertainty in coefficient in the sediment transport equation all contribute to uncertainty in predicted sediment build-up. Whereas a study on uncertainty in simulation of combined sewer overflow volume (Sriwastava et al., 2018) showed that the main contributor was uncertainty in runoff coefficient, with limited contribution from uncertainty in hydraulic roughness and weir crest level. This is thought to be due to the way they were simulated in these studies, sediment transport was a very non-linear process and rainfall runoff was not. Although neither of these two studies took uncertainty into rainfall into account, e.g. both studies looked at events large enough to cause sediment transport/ combined sewer overflow, in case rainfall uncertainty was considered, results may have been different depending on the spatial and temporal scales taken into consideration. Amongst others, Ochoa-Rodriguez et al. (2015) show the impact variation in impact of rainfall input resolution on flow simulation in urban drainage models in the order of magnitude of several square $\mathrm{km}$ areas, decreases significantly as catchment drainage area increases. Moreno-Rodenas et al. (2017) described that simulation of dissolved oxygen (DO) in an $800 \mathrm{~km} 2$ river catchment showed a negligible sensitivity to temporal aggregation of rainfall inputs. A recent comparison (Camargos et al., 2018) of highresolution local input data compared to global data products showed that hydrological target values from the widely used SWAT model were only minor affected by input data quality. However, it also showed that all these different model setups underestimated the model uncertainty, suggesting that additional sources of uncertainties should be considered simultaneously.

To be certain whether uncertainties amplify or cancel each other out, it is imperative that a sound and case-specific uncertainty propagation analysis is done, to demonstrate clearly the level of predictive uncertainty.

\section{CHALLENGES IN APPLICATION}

Despite considerable uncertainty, integrated models are important for effective decision support in major investment decisions for water utilities:

- Model outputs can be justified to a regulator in a transparent, comprehensible and repeatable way, especially when industrial modelling practice guidance is used in the creation of (sub-) models.

- Relative comparison between solutions is still useful to find the "best" alternative.

- They are cheaper than performing extensive and long-term measurements.

- There is a capability to simulate extreme events, although the calibration based on regular events may decrease the validity of the results.

Lee Jr. (1973) defined seven sins for large-scale models for urban planning and we would like to revisit them for integrated water quality models in the context of uncertainty, to highlight currently remaining challenges in application. Although defined 45 years ago some of these points may still ring true in the ears of integrated modellers. 


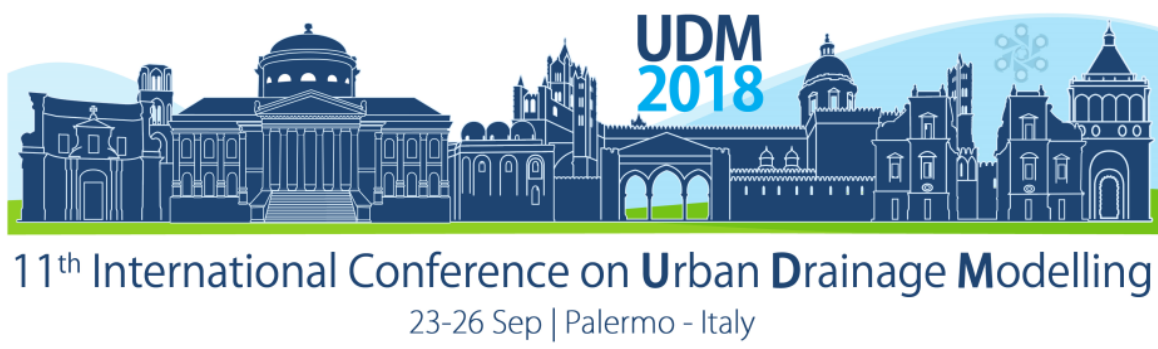

Hyper-comprehensiveness (1), defined as an overly complex model structure, and complicatedness (2) in terms of interactions between the model components are connected to the question of linking different sub-models. Also, Grossness (3), which means the level of detail for predictions may be too coarse for effective decision making, relates to this aspect. The objective of the modelling endeavour should be clarified and with it the scale and level of detail of the necessary results. The hungriness (4) for data is connected to this point in the way that an adequate amount of data is essential to define the model setup and to identify the model parameters (Muschalla et al., 2009). Mechanicalness (5), defined as errors caused by the computational representation of the model, could in times of increasing computational resources be expanded and reinterpreted as limitations in terms of availability, accessibility and computational cost. The problem of wrongheadedness (6) can be explained by the gap between the behaviour of the model which it was built for and what it is used for. This connects to the observation that perception of uncertainty on different inputs and parameters for existing model does not scale when used for several objectives, which may change the temporal and spatial extent of the project. If we translate all the limitations mentioned to a common metric, we end up at the sin of expensiveness (7). In practice addressing most of these issues requires monetary investments (e.g. for software, sensors, experienced modellers) as well as time resources.

\section{CONCLUSIONS}

Several frameworks were developed directed to a common uncertainty language and repository of methods for uncertainty analysis. Sriwastava and Moreno-Rodenas (2017) give an extensive overview of these frameworks and their applications. The theoretical uncertainty analysis findings are very difficult to be applied in commercial software and models preferred by practitioners, due to several reasons (e.g. computational burden, low accessibility in commercial software, problems in automatization, as well as the interpretation of environmental legislation by the local regulator (Sriwastava and Moreno-Rodenas, 2017) and local industrial code of practice (Bellos et al., 2018)). Some main findings are:

- A workflow for integrated catchment modelling (Tscheikner-Gratl et al., 2017) should be used.

- In decision support, there are no 'one size fits it all' modelling approaches.

- First step in modelling is always to clarify the objectives - not the tools.

- Think about what level of uncertainty the decision maker is willing to accept, and what uncertainty analysis method fits with the local interpretation of environmental legislation and locally accepted modelling code of practice.

- Communication of uncertainties is difficult but important.

Further research in uncertainty decomposition and model sampling acceleration is still required, to allow for the implementation of uncertainty analysis frameworks in practice. More research should also be carried out on how best to involve local environmental regulators and organisations providing industrial modelling code of practice guidance. Also, although modelling activity is highly tailored for each specific scenario, further discussion on details such as acceptable uncertainty degrees or sub-model linkage strategies is needed. Another important question for further research is about procedures to achieve user-specified confidence levels for water quality predictions and to objectively assess how additional expenditure of model development or data collection reduces the uncertainty of model predictions. 


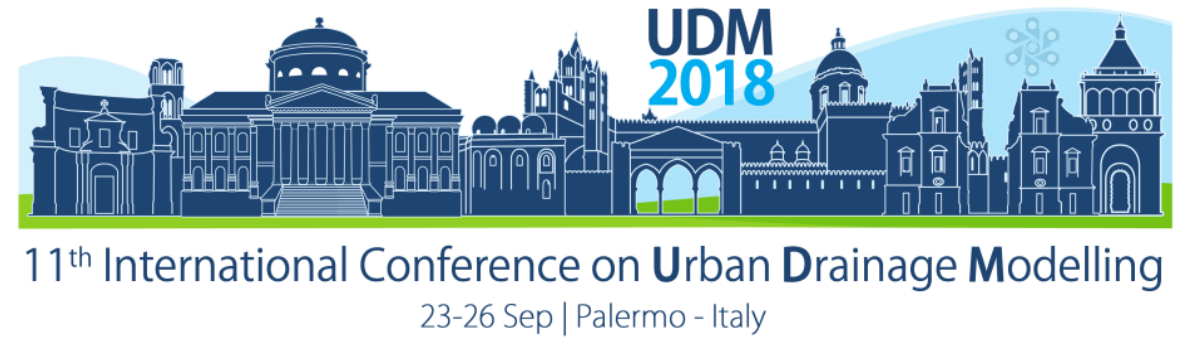

\section{References}

Bellos, V., Gill, E., Schellart, A. N. A., and Tait, S. J. (2018) QUICS: Quantifying Uncertainty in Integrated Catchment Studies - Good Practice Guidance: Incorporating Uncertainty in Integrated Catchment Studies, [online] https://www.sheffield.ac.uk/quics/dissemination/reports.

Camargos, C., Julich, S., Houska, T., Bach, M., and Breuer, L. (2018) Effects of input data content on the uncertainty of simulatingwater resources. Water (Switzerland), 10(5), 1-18. DOI: 10.3390/w10050621.

Honti, M., Schuwirth, N., Rieckermann, J., and Stamm, C. (2017) Can integrative catchment management mitigate future water quality issues caused by climate change and socio-economic development? Hydrology and Earth System Sciences, 21(3), 1593-1609. DOI: 10.5194/hess-21-1593-2017.

Lee Jr., D. B. (1973) Requiem for Large-Scale Models. AIP Journal, 163-178. DOI: 10.1080/01944367308977851.

Mirrlees, J. A. (1971) An Exploration in the Theory of Optimal Income Taxation. The review of economic studies, 38(2), 175-208.

Moreno-Rodenas, A. M., Cecinati, F., Langeveld, J., and Clemens, F. H. L. R. (2017) Impact of spatiotemporal characteristics of rainfall inputs on integrated catchment dissolved oxygen simulations. Water (Switzerland), 9(12). DOI: 10.3390/w9120926.

Muschalla, D., Schütze, M., Schroeder, K., Bach, M., Blumensaat, F., Gruber, G., Klepiszewski, K., Pabst, M., Pressl, A., Schindler, N., Solvi, A. M., and Wiese, J. (2009) The HSG procedure for modelling integrated urban wastewater systems. Water Science and Technology, 60(8), 2065-2075. DOI: 10.2166/wst.2009.576.

Muthusamy, M., Wani, O., Schellart, A., and Tait, S. (2018) Accounting for variation in rainfall intensity and surface slope in wash-off model calibration and prediction within the Bayesian framework. Water Research. DOI: 10.1016/j.watres.2018.06.022.

Ochoa-Rodriguez, S., Wang, L. P., Gires, A., Pina, R. D., Reinoso-Rondinel, R., Bruni, G., Ichiba, A., Gaitan, S., Cristiano, E., Van Assel, J., Kroll, S., Murlà-Tuyls, D., Tisserand, B., Schertzer, D., Tchiguirinskaia, I., Onof, C., Willems, P., and ten Veldhuis, M.-C. (2015) Impact of spatial and temporal resolution of rainfall inputs on urban hydrodynamic modelling outputs: A multi-catchment investigation. Journal of Hydrology, 531, 389407. DOI: $10.1016 /$ j.jhydrol.2015.05.035.

Schellart, A. N. A., Tait, S. J., and Ashley, R. M. (2010) Towards quantification of uncertainty in predicting water quality failures in integrated catchment model studies. Water Research, 44(13), 3893-3904. DOI: 10.1016/j.watres.2010.05.001.

Sriwastava, A. K. and Moreno-Rodenas, A. (2017) QUICS: Quantifying Uncertainty in Integrated Catchment Studies - Report on uncertainty frameworks and potential improvements, [online] https://www.sheffield.ac.uk/quics/dissemination/reports.

Sriwastava, A. K., Tait, S., Schellart, A. N. A., Kroll, S., Van Dorpe, M., Van Assel, J., and Shucksmith, J. D. (2018) Quantifying uncertainty in the simulation of sewer overflow volume. Journal of Environmental Engineering, 144(7), 1-10. DOI: 10.1061/(ASCE)EE.1943-7870.0001392.

Tscheikner-Gratl, F., Lepot, M., Moreno-Rodenas, A., and Schellart, A. N. A. (2017) QUICS: Quantifying Uncertainty in Integrated Catchment Studies - A Framework for the application of uncertainty analysis, [online] https://www.sheffield.ac.uk/quics/dissemination/reports.

Voinov, A. A. and Shugart, H. H. (2013) "Integronsters", integral and integrated modeling. Environmental Modelling and Software, 39, 149-158. DOI: 10.1016/j.envsoft.2012.05.014.

Willems, P. (2006) Random number generator or sewer water quality model? Water Science \& Technology, 54(67), 387. DOI: 10.2166/wst.2006.581. 


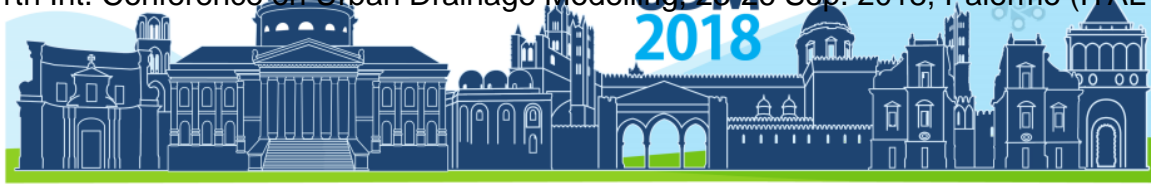

$11^{\text {th }}$ International Conference on Urban Drainage Modelling

23-26 Sep | Palermo - Italy

\title{
Longer pipes or smaller treatment plants? Impacts of connecting neighbouring sewer systems considering construction, detrimental emissions and its control strategies.
}

\author{
LI. Corominas*, S. Morera*, O. Gutierrez ${ }^{\star 1}$, \\ * Technologies and Evaluation Department, Catalan Institute for Water Research, ICRA \\ 101 Emili Grahit, Girona, Spain, email: Icorominas@icra.cat; email: smorera@icra.cat; email: \\ ogutierrez@icra.cat \\ ${ }^{1}$ Corresponding author
}

Keywords: Decentralised sanitation systems, Life cycle assessment, sewer emissions.

\begin{abstract}
Sanitation services are carried out either by means of centralised or decentralised systems. Decentralised wastewater treatment plants (WWTPs) allow to treat locally the wastewater, geographically close to the point of generation reducing investments in sewer networks and potentially allowing cost savings. Traditionally, the choice between centralised or decentralised was mainly driven by economic cost, but increase of environmental-social awareness combined with advanced tools such as Life cycle assessment (LCA) provided a broader scope to consider in the decision. In this work we apply LCA to analyse the impact of the construction of a long connection pipe $(11 \mathrm{kms})$ between the neighbouring sewer systems of Sant Pere Pescador and l'Escala (North East Spain). This centralised real scenario has been compared with a virtual-decentralised option of constructing two WWTPs, one for each system, with special emphasis on the impacts of detrimental emissions of $\mathrm{H}_{2} \mathrm{~S}$ and $\mathrm{CH}_{4}$ generated from sewer systems. Obtained results showed that $\mathrm{H}_{2} \mathrm{~S}$ emissions are significant in some LCA categories, such as terrestrial acidification impacts, and hence should be properly measured and included in LCA inventories. Also the study showed that there is not a clear winner between the options analysed. Thus depending on the aim and interest of the system managers, the centralised option would be still better than the decentralised.
\end{abstract}

\section{MOTIVATION}

Sanitation services in a region are provided by centralised or decentralised systems (Libralato et al. 2012). Decentralised wastewater treatment plants (WWTPs) enable waste water to be treated geographically close to the point of generation (Tchobanoglous and Leverenz 2013), making costly investments in sewer networks obsolete and potentially allowing cost savings. Traditionally, economic costs played the most critical role in the decision-making about which option to implement (centralised or decentralised). The recent work of Eggimann et al. (2016) proposes an approach for cost-based identification of decentralization levels in a given region. But the increase of environmental-social awareness combined with the development advanced analysis methodologies (notably Life cycle assessment, LCA) provided a broader scope of information and tools to consider in the decision.

In this work we apply LCA to analyse the impact of the construction of a long connection pipe (11kms) between the neighbouring sewer systems of Sant Pere Pescador and l'Escala (North East Spain). This centralised real scenario has been compared with a decentralised 


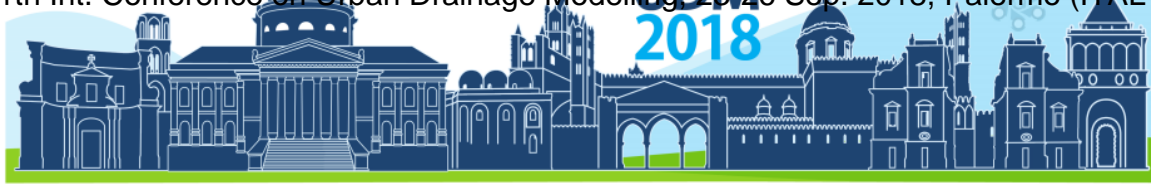

$11^{\text {th }}$ International Conference on Urban Drainage Modelling

23-26 Sep | Palermo - Italy

option of constructing two WWTPs, one for each system. The main novelty compared to previous LCA work on this topic is the inclusion in the analysis of detrimental emissions of sulfide $\left(\mathrm{H}_{2} \mathrm{~S}\right)$ and Methane $\left(\mathrm{CH}_{4}\right)$ from long connection pipes and the effects of dosing chemicals (Nitrate and Ferric) to control those emissions. $\mathrm{H}_{2} \mathrm{~S}$ is an odorous, toxic and highly corrosive gas, while $\mathrm{CH}_{4}$ is a greenhouse gas contributing to global warming. Despite being a common issue, $\mathrm{H}_{2} \mathrm{~S}$ and $\mathrm{CH}_{4}$ have hardly ever been considered in LCA analysis of sewer systems (Risch et al., 2015).

\section{MATERIALS AND METHODS}

The general LCA methodology described in the ISO 14040 and 14044 standards (ISO 14040, 2006; ISO 14044, 2006) was applied through the 4 following steps: Goal \& scope definition, inventory analysis, impact assessment and interpretation of results. A comprehensive inventory is provided for the construction and operation of the sewer systems (using the tool developed in Morera et al., 2015) and the WWTPs (Morera et al., 2017). We used ReCiPe on SimaPro. For H2S we took characterization factors from CML impact assessment method using the reference substance 1,4-DB.

Figure 1 presents the two scenarios analysed: A) 1 WWTP that treats sewage from l'Escala (10.000 to $50.000 \mathrm{Hab}$.) and also from Sant Pere Pescador (SPP-2.000-10.000 Hab.) which is pumped through a long pipe of $11 \mathrm{kms}$. Current situation, B) two WWTP's that treat separately wastewater from each municipality Modelled situation. Extensive sampling campaigns for $\mathrm{H}_{2} \mathrm{~S}$ and $\mathrm{CH}_{4}$ online monitoring were carried out at relevant points of the system in 2015 and later used on the LCA assessment. The required dosage of Nitrate and ferric to control $\mathrm{H}_{2} \mathrm{~S}$ and $\mathrm{CH}_{4}$ emissions in the system was calculated with the SeweX model (Sharma et al. 2012)
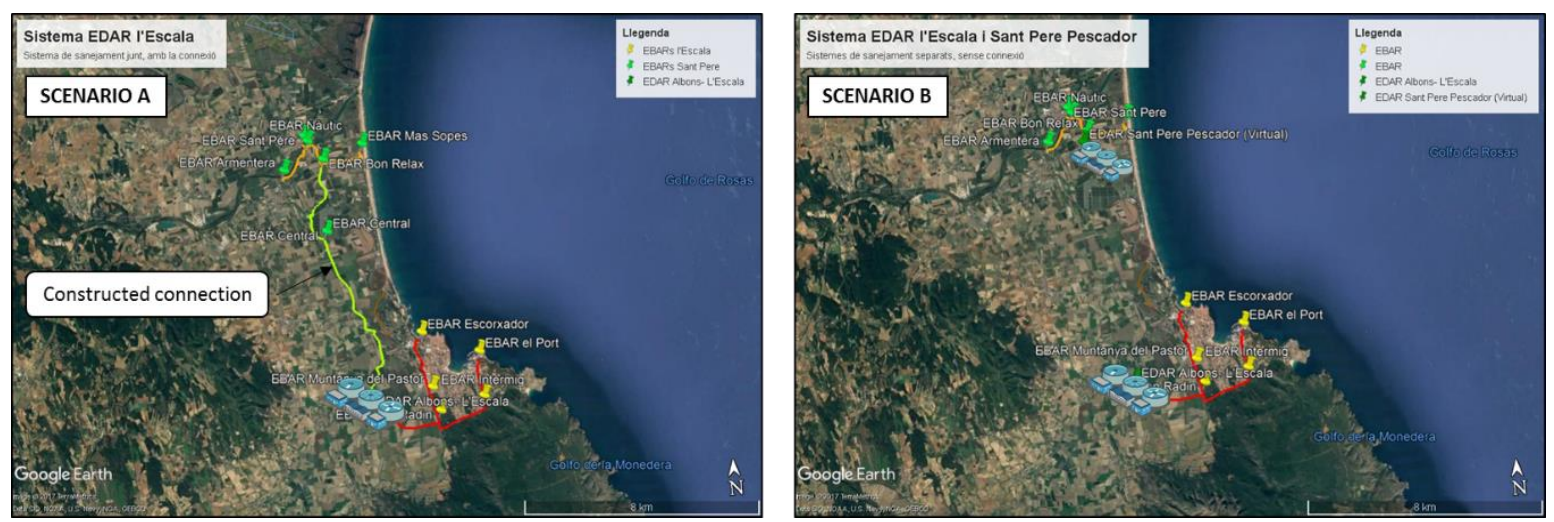

Figure 1. Layout of the system studied. Scenario A corresponds to the current situation where all sewage is treated in a central wwtp nearby l'Escala. Wastewater from Sant Pere Pescador is pumped $11 \mathrm{kms}$ the constructed connection. Scenario B corresponds to a virtual scenario where the connection does not exists and the sewage of SPP is treated locally in a smaller wwtp.

\section{RESULTS}

Figure 2 presents the comparison of Scenario B (no pipe connection; decentralised) with respect to Scenario $A$ (constructed pipe; centralised). Positive scores mean induced impacts due to the implementation of Scenario B; while negative scores mean avoided impacts due the implementation of Scenario B. The decentralised scenario shows a reduction of "terrestrial acidification" impacts by $\approx 30 \%$. In fact, the operation of the long pipe produced 
Proceedings of the 11th Int. Conference on Urban Drainage ModellobDB/26 Seb. 2018, Palermo (ITALY). Ed. prof. Giorgio Mannina

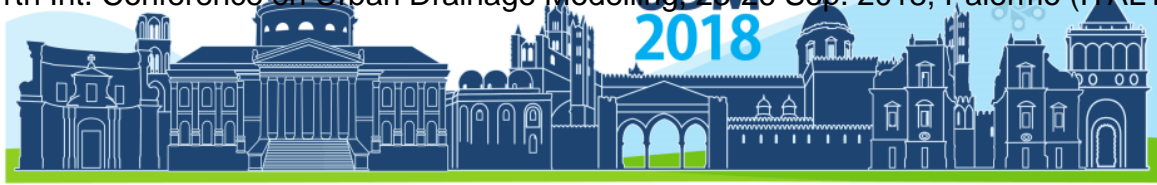

$11^{\text {th }}$ International Conference on Urban Drainage Modelling

23-26 Sep | Palermo - Italy

an increase of the detrimental emissions, mainly $\mathrm{H}_{2} \mathrm{~S}(160 \mathrm{KgS} /$ day) which has a large influence on terrestrial acidification. The generation of $\mathrm{CH}_{4}$ due to the connection did not had a significant impact in the overall GHG emisions (less than $5 \%$ of increase). Scenario $A$ shows some disadvantages compared to scenario B. For instance, the construction and operation of a new WWTP in the area of Sant Pere Pescador implies the consumption of resources (e.g. concrete and metals) and the operation implies the consumption of energy. Hence, we see an increase in the impact categories "human toxicity", "metal depletion", "water depletion" and "urban land ocupation".

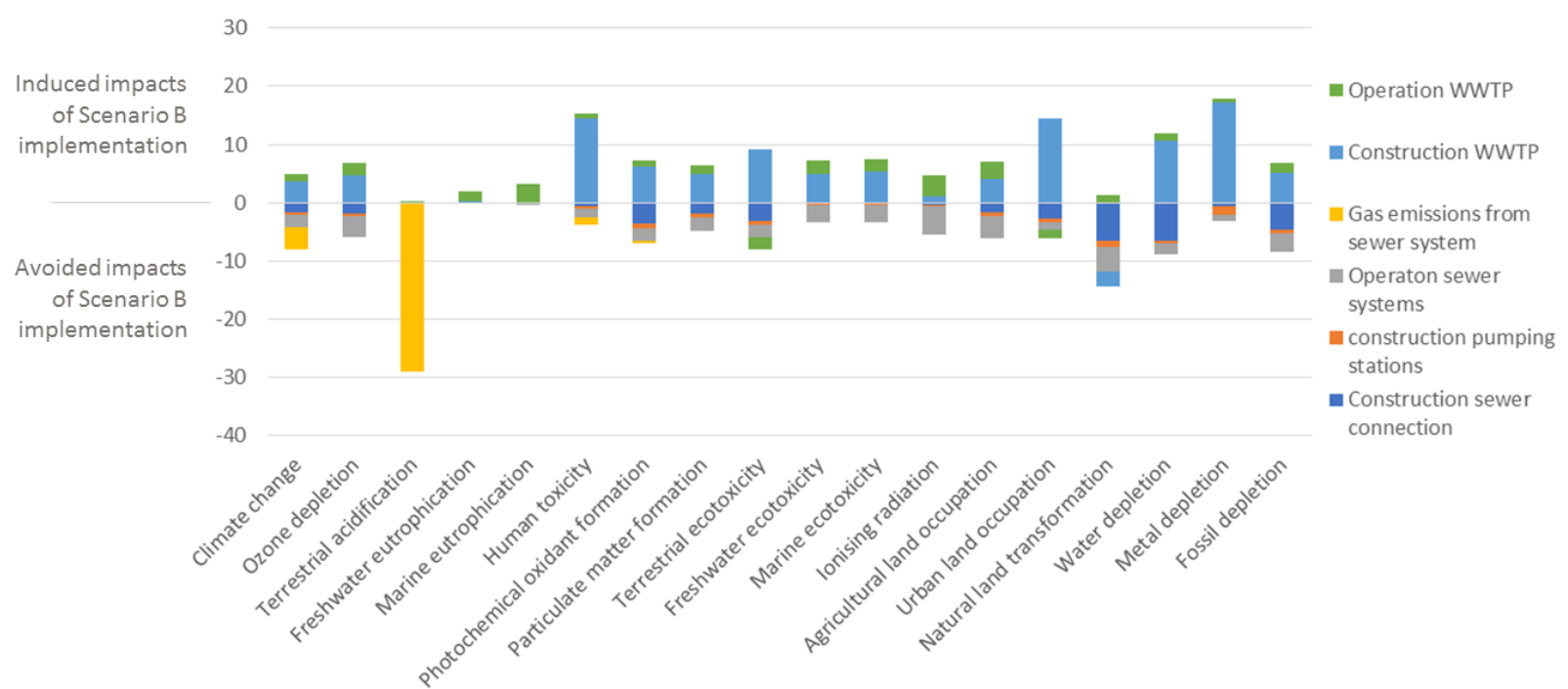

Figure 2. LCA results. Comparison of the produced (positive) and avoided (negative) impacts due to the application of the decentralised scenario. Scenario B.

\section{TAKE-HOME MESSAGE}

$\mathrm{H}_{2} \mathrm{~S}$ emissions dominate the terrestrial acidification impacts and hence should be properly measured and included in LCA inventories. With regards to the case-study there is not a clear winner between the options analysed. Depending on the aim and interest of the system managers, the centralysed option would be still better than the decentralyzed. Future work will include impacts of the corrosion produced by $\mathrm{H}_{2} \mathrm{~S}$ in the LCA of the system. It is widely known that $\mathrm{H}_{2} \mathrm{~S}$ is an inducer of corrosion which will dramatically decrease the life of service of pipes and installations of the system. Full set of results will be presented at the conference.

\section{REFERENCES}

Libralato, G., Volpi Ghirardini, A., Avezzù, F., 2012. To centralise or to decentralise: An overview of the most recent trends in wastewater treatment management. J. Environ. Manage. 94, 61-68. doi:10.1016/j.jenvman.2011.07.010

Maurer, M., Rothenberger, O., Larsen, T.A., 2005. Decentralised wastewater treatment technologies from a national perspective: At what cost are they competitive? Water Sci. Technol. Water Supply 5, 145-154.

Morera, S., Comas, J., Poch, M., Corominas, L., 2015. Connection of neighboring wastewater treatment plants: Economic and environmental assessment. J. Clean. Prod. 90, 34-42. 
Proceedings of the 11th Int. Conference on Urban Drainage Modellob23126 Sep. 2018, Palermo (ITALY). Ed. prof. Giorgio Mannina

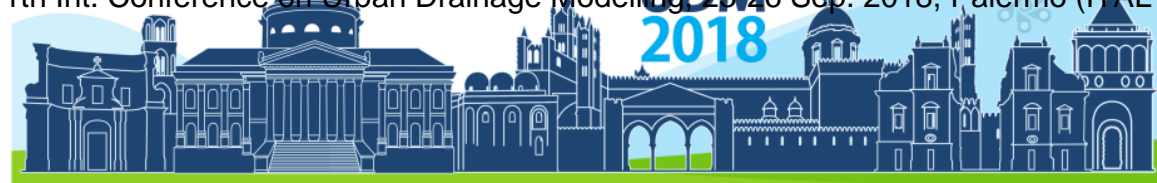

$11^{\text {th }}$ International Conference on Urban Drainage Modelling

23-26 Sep | Palermo - Italy

doi:10.1016/j.jclepro.2014.11.047

Risch, E., Gutierrez, O., Roux, P., Boutin, C., Corominas, L., 2015. Life cycle assessment of urban wastewater systems: Quantifying the relative contribution of sewer systems. Water Res. 77, 3548. doi:https://doi.org/10.1016/j.watres.2015.03.006

K. R. Sharma, S. Corrie and Z. Yuan. 2012 Integrated modelling of sewer system and wastewater treatment plant for investigating the impacts of chemical dosing in sewers. Water Science \& Technology 65.8 1399-1405. doi: 10.2166/wst.2012.019 


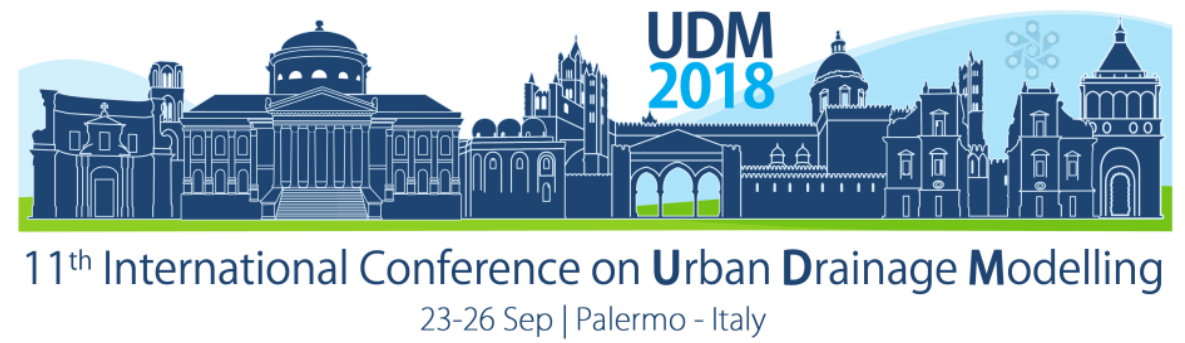

\title{
Sewer-groundwater Interaction in Urban Coastal Areas
}

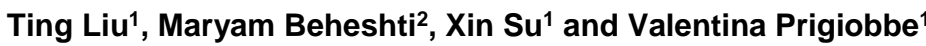 \\ ${ }^{1}$ Stevens Institute of Technology, Department of Civil, Environmental, and \\ Ocean Engineering, Hoboken, NJ, U.S.A. \\ ${ }^{2}$ Norwegian University of Science and Technology, Department of Hydraulic and \\ Environmental Engineering, Trondheim, Norway
}

\begin{abstract}
Fecal Indicator Bacteria (FIB) are the primary tools recommended by the U.S. EPA to monitor sewage contamination in waterways. Their concentration along one of the most populated area in the U.S. can exceed the EPA guidelines for water quality after a minor rain event or even in dry weather conditions. Here, we present a study to investigate the role of groundwater infiltration into damaged sewer pipes on combined sewer overflow (CSOs) after a minor rain event or even in dry weather. Groundwater and sewer modelling were combined with a statistical model accounting for weighted risk factors, such as, e.g., pipe material and size, and type of soil, for a coastal city (Hoboken, NJ) located in one of the most populated areas of the U.S.. A risk map of groundwater infiltration was then determined. Preliminary simulations of the groundwater accounting for the tide show that the large parts of the sewer network of the city may be submerged always by groundwater. Parts of the network present also high risk of failure, suggesting that they may be affected significantly by infiltration and may require, therefore, renovation or upgrading.
\end{abstract}

Keywords: Urban hydrology; Hydrologic modelling; Sewer infiltration

\section{INTRODUCTION}

The aging of sewer system on the eastern part of U.S. is an emerging engineering and societal issue. As the estimation from U.S. EPA (Mehan, 2002) approximately $23 \%$ of the sewer system will be in a very poor condition by 2020 . The replacement and rehabilitation of sewer is one of the most pressing issue in urban drainage (Koch et al., 2002). Structural damages may make a pipe potentially affected by infiltrations of groundwater and leakages (or exfiltration) of wastewater. It is common that the infiltration rate is much larger than the exfiltration rate (Eiswirth and Hötzl, 1997; Belhadj et al., 1995; Karpf and Krebs, 2011; Prigiobbe and Giulianelli, 2009). One of the negative consequences of infiltration is the large amount of discharged untreated wastewater, i.e., combined sewer overflows (CSOs), delivered to rivers and coastal waterways. Moreover, several documented cases of dry-weather Fecal Indicator Bacteria (FIB) events have been observed in some of the major waterways in the USA, in the recent years, e.g., at the estuary of the Hudson River (RiverKeeper, 2017). A recent study by Young et al. (2013) shows the occurrence of the antibiotic-resistant bacteria in the Hudson River Estuary nearby New York City metropolitan area and the presence of high concentrations of these contaminants was ascribed to CSOs. However, the reason of these high concentrations of bacteria has never been ascribed to the presence of infiltration of groundwater into aging infrastructure. In coastal urban areas, the water table of the shallow aquifer is sensitive to the tide and can change significantly, but with a larger period of the tide. This implies that during periods of low tide, the aquifer can be very shallow and submerged the sewer causing infiltrations into damaged pipes. Therefore, even in dry weather conditions and particularly during low tide, CSOs can occur. 


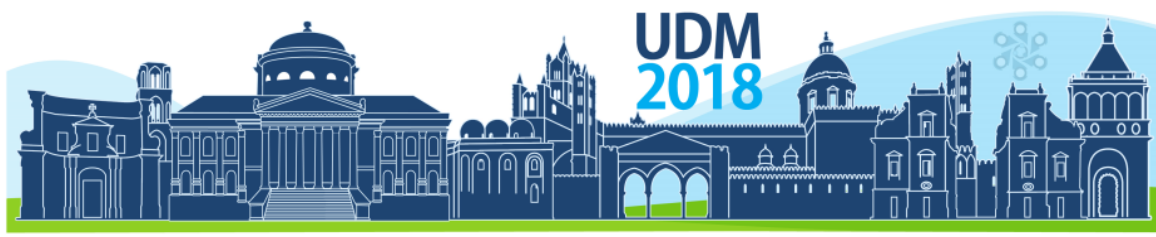

$11^{\text {th }}$ International Conference on Urban Drainage Modelling

23-26 Sep | Palermo - Italy

Here, a study of the interaction between an aging sewer network located in the city of Hoboken $(\mathrm{NJ})$ and the tidal groundwater is presented. Due to its low-elevation, it is subjected to both storm surge and rain flooding, sensitive to sea-level rise, and experiences disruptive cases of water infrastructure breakage. A framework to identify the part of sewer network that has potential of infiltration is described and the results provided in a visual manner.

\section{MATERIALS AND METHODS}

\subsection{Hydrological modelling of the sewer system}

The flow within the sewer network of the city of Hoboken was simulated using the open-source hydrological software (SWMM, U.S. EPA) (Gironás et al., 2010) with full dynamic wave flow routing option. The modelled area in SWMM covered approximately $2.89 \mathrm{~km}^{2}$ that was divided into 126 sub-drainage areas (Figure 1.a). The sewer system in south part of the city was fully implemented as these part is more prone to flooding; whereas north part with lower resolution.

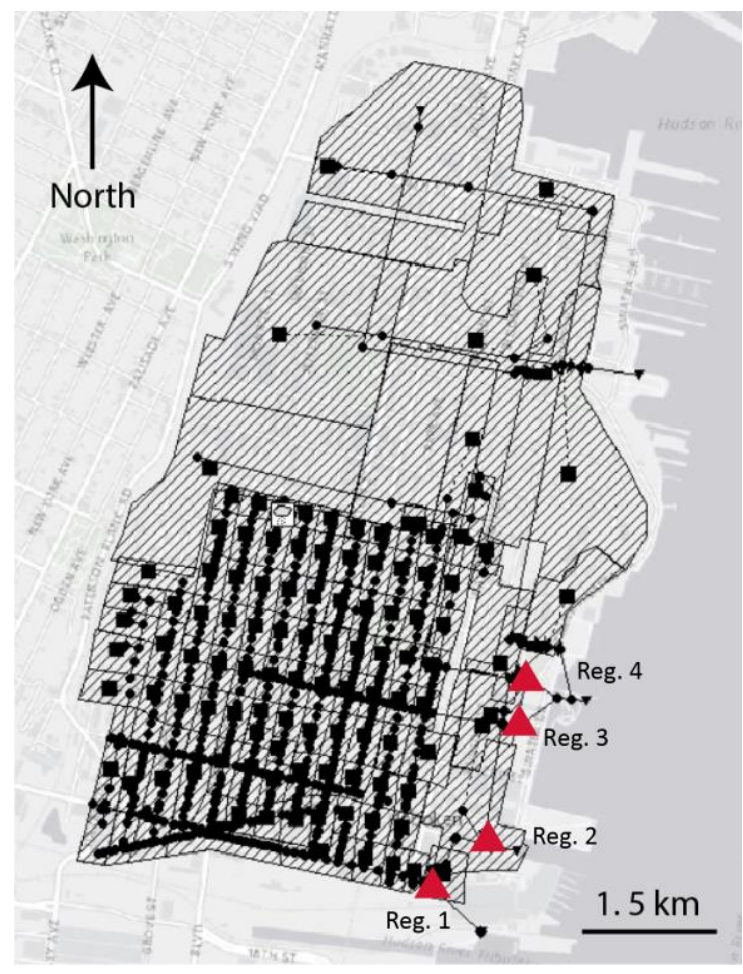

(a)

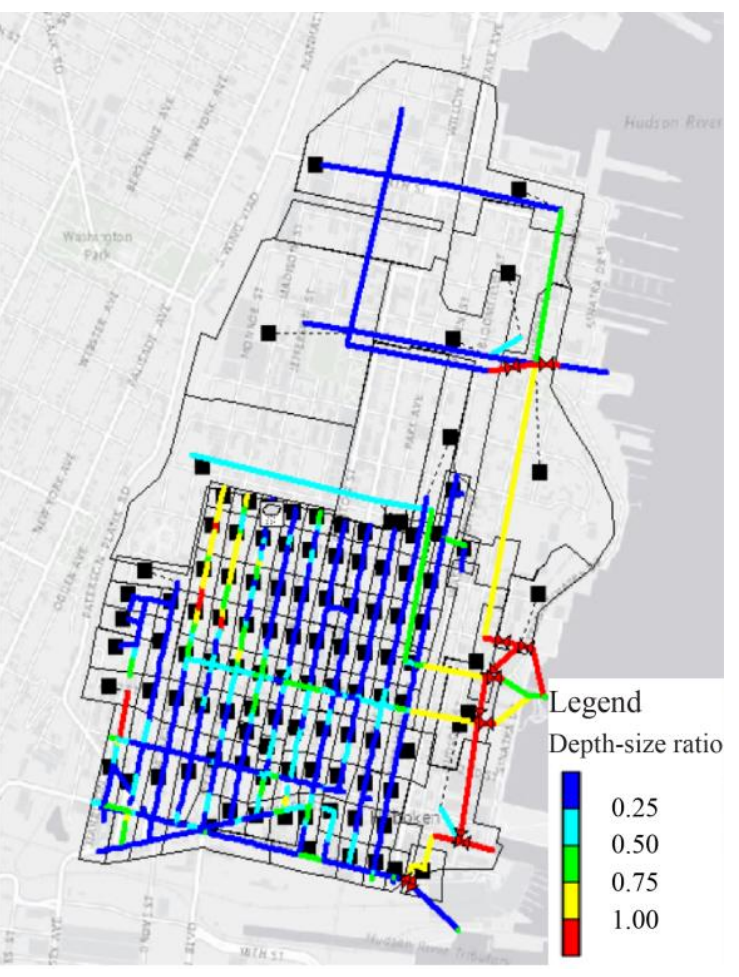

(b)

Figure 1. (a) Scheme of the sewer network of city of Hoboken as implemented in the sewer system model, and locations of regulators where calibration was performed; (b) simulation results of sewer flow at the dry weather flow peak condition expressed as the depth-size ratio of the pipe $\left(c_{p},-\right)$, i.e., the ratio between depth of water in the pipe and height of the pipe.

It was assumed that every local drainage area is connected to the nearest stormwater drainage inlet. The dry weather flow was calculated based on the daily water usage pattern (Mayer et al., 1999), the water consumption of Hoboken (SUEZ, 2016), and population of the drainage areas (U.S. Census Bureau, 2016). The inputs in wet weather conditions for SWMM included the stormwater system of the studied sub-catchment, represented by the street network, properties of the manholes, invert elevations, height to ground surface, and the gravity pipes network (provided by North Hudson Sewerage Authority). The outflow nodes towards the river 


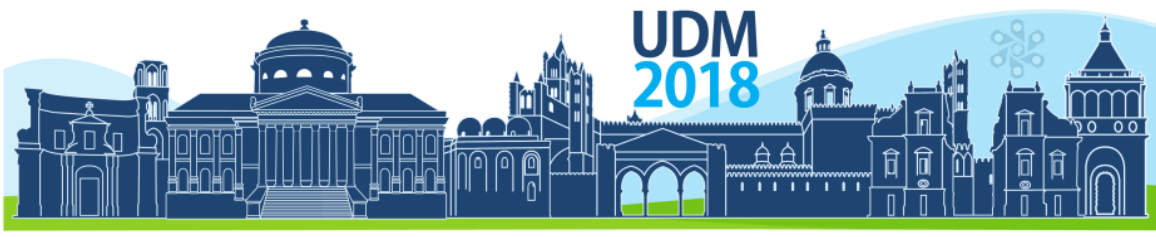

$11^{\text {th }}$ International Conference on Urban Drainage Modelling

23-26 Sep | Palermo - Italy

Hudson were in total five of which one belongs to a main sewer pipeline of a neighbouring city which delivers directly the sewage to the Hoboken's wastewater treatment plant (WWTP).

\subsection{Groundwater model}

The groundwater modelling was performed by USGS MODFLOW(Harbaugh et al., 2000) with the user interface provided by Groundwater Modelling System (GMS) (Aquaveo, 2007). The boundaries at the geographical borders of Hoboken were given to the model including the tide level record (NOAA, 2017) and groundwater level records at wells. The model includes 19,116 single vertical layer cells with hydraulic conductivity that were acquired from shallow geology conditions (NJDEP, 2002). The groundwater model simulated 7 months of groundwater which overlays the sewer simulation. Validations were based on groundwater levels in 3 wells located at the center of Hoboken.
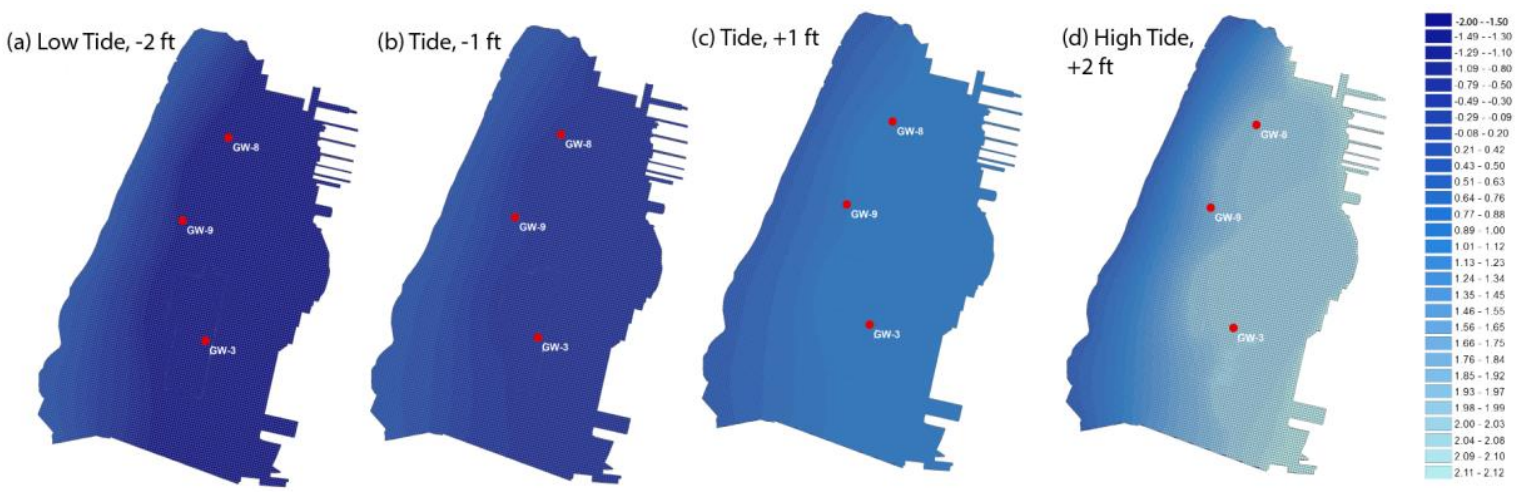

Figure 2. Scheme of the groundwater model and the simulated groundwater depth in low to high tide levels. The red dots in the figure are the locations of the wells that were used for validation.

\subsection{Failure model}

Following (Bach et al., submitted; Liu et al., submitted), a multiple-factor sewer failure model was built to estimate the potential risk for the damage of sewer pipe. The failure factors for structure pipe damage include: the ductility of pipe, the bedding foundation, the gradient of pipes, the joint condition of pipe, the traffic load on the surface, the groundwater condition, and the size and shape of pipes.

\section{RESULTS AND DISCUSSION}

\subsection{Results of dry weather simulation}

The sewer flow model was calibrated using measurements performed in 2011 in four locations shows in Figure 1.a along a pipe close to the Hoboken's waterfront (Dewberry, 2017). Recently, pumps have been installed along that pipes, but they have been neglected in the presented model. Therefore, the simulated sewer network represents a system as before the upgrading. The calibration results shows the coefficient of determination $\mathrm{R}^{2}$ equals to 0.50 , $0.29,0.63$, and 0.75 with respect of regulator 1-4.

A continuous 10 days' dry weather simulation was run to avoid the fluctuation of dry weather flow simulation results. Figure 1.b shows the simulation result of peak dry weather flow condition during the simulation. The figure shows the distribution of the depth-size ratio of the pipe $\left(c_{p},-\right)$, i.e., ratio between depth of water in the pipe and height of the pipe, where $c_{p}=0$ means no water is in the pipe, $c_{p} \geq 1$ corresponds to a full pipe. As the figure shows, the majority 


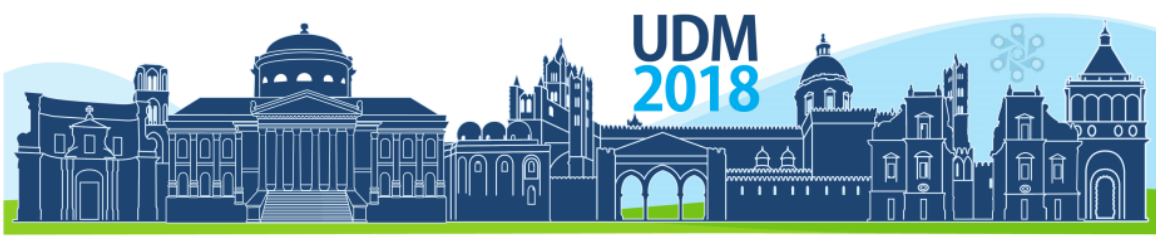

$11^{\text {th }}$ International Conference on Urban Drainage Modelling

23-26 Sep | Palermo - Italy

of the sewer system is under its full depth-size ratio, which indicates that no CSO should be expected in dry weather conditions.

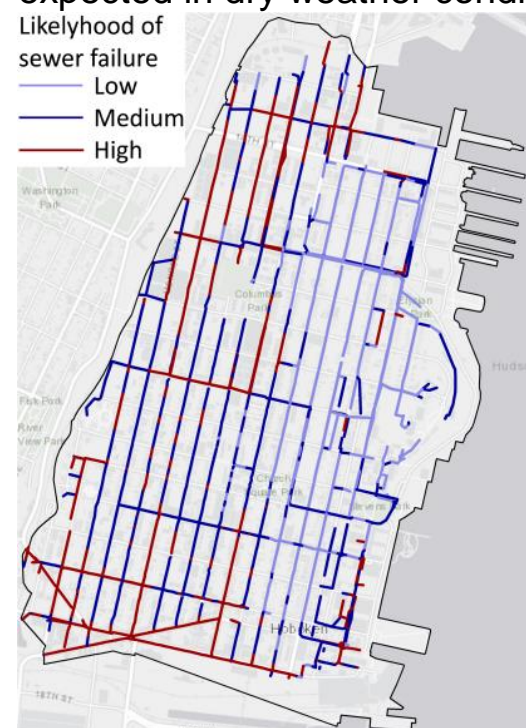

(a)

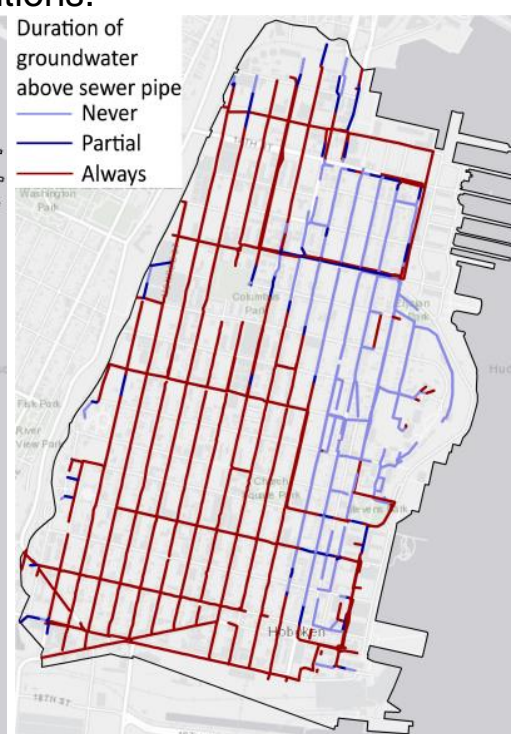

(b)

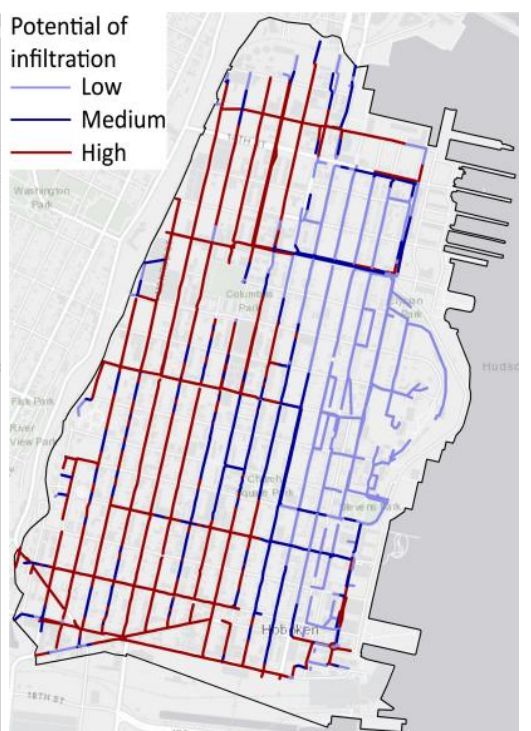

(c)

Figure 3. (a) Merged map for risk of failure; (b) location of pipes with respect to an average water table of the shallow aquifer during the simulation, as groundwater never, intermittently, or always above sewer pipe; (c) infiltration risk map upon combination of the maps in parts $a$ and $b$.

\subsection{Coupling visualization model and groundwater model}

Figure 3.a shows the merged map for risk of failure. By coupling the average groundwater simulation results (Liu et al., submitted) (Figure 3.b), the potential for infiltration of the sewer network in Hoboken was determined (Figure 3.c). The results show that the South-West part of system has the highest risk of sewer infiltration.

\subsection{Modelling groundwater infiltration}

In the sewer flow model, the groundwater infiltration was assumed to exist only at the high infiltration risk sewer pipes in Figure 3.c, and at sewer pipes with vertical levels below the groundwater level. It is known that the groundwater infiltration rate can be estimated from the head difference and the conductivity of damaged sewer pipe surfaces (Karpf and Krebs, 2011), however, these values could vary throughout the sewer network. Thus, the infiltration rate is simplified to be $50 \%$ of the average dry weather flow rate, which is within the range of observations in previous works (Bénédittis et al., 2005; Eiswirth and Hötzl, 1997; Prigiobbe and Giulianelli, 2009).

In the sewer model, the dry weather infiltration flow was added as direct inflow to manholes at the downstream of the pipes with infiltration. With fixed groundwater levels and river tide levels, simulations under four scenarios were performed, i.e., deep vs. shallow groundwater levels with low vs. high river tide levels. The results show that under the low tide level, both deep and shallow groundwater could lead to dry weather CSO discharge in a daily periodic pattern. However, the CSOs will not activate during dry weather under high tide regardless of groundwater levels. Such results indicate that the dry weather CSO discharge due to infiltration is more sensitive to the tide levels and less sensitive to groundwater levels.

\section{CONCLUSIONS}




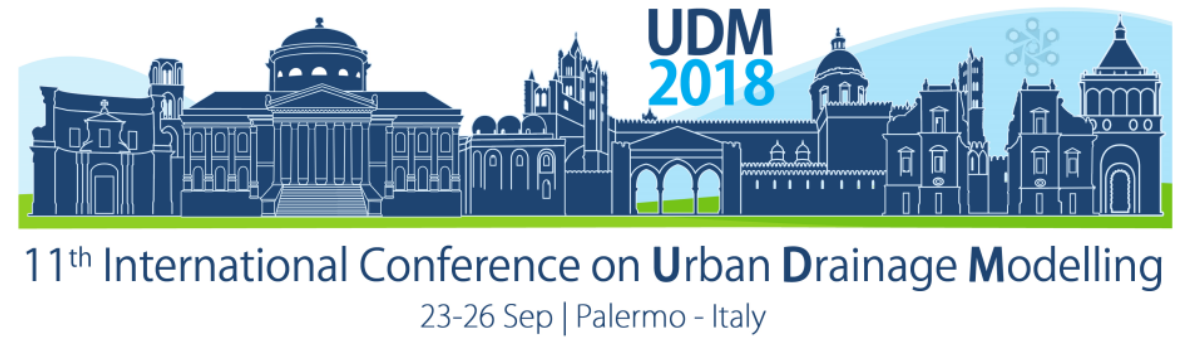

Through the combination of a hydrological model, assessment of risk of failure, and a hydrogeological model of the city of Hoboken, this work provides a framework to identify parts of a sewer network that could be subjected to groundwater infiltration, and analysed the scenarios that could cause dry weather CSO discharge. Future work will focus on the validation of the infiltration risk map with direct measurements, such as, e.g., CCTV images, sewer flow measurement, and isotropic characterization (Kracht et al., 2007; Prigiobbe and Giulianelli, 2009).

\section{ACKNOWLEDGMENTS}

The authors would like to acknowledge Dr. Firas Saleh for helping in setting the sewer network in an initial phase of the project and the students Martijn Kriebel and Robin Noordhoek from the University of Twente (The Netherlands) that during the exchange period at Stevens Institute of Technology helped to extend the network.

\section{References}

Aquaveo. (2007) Groundwater Modeling System Version 10.1, build date, 2015, UT, USA.

Bach, M. J. W., Hoving, N. B., Hartmann, A., Ramirez-Marquez, J. E., Vesonder, G. T., Washburn, A. \& Prigiobbe, V. (submitted) Method to assess and visualize the likelihood of sewer system failure. Urban Water J.

Belhadj, N., Joannis, C. \& Raimbault, G. (1995) Modelling of rainfall induced infiltration into separate sewerage. Water Sci. Technol. 32(1), 161-168.

De Bénédittis, J., \& Bertrand-Krajewski, J. L. (2005). Infiltration in sewer systems: comparison of measurement methods. Wat. Sci. \& tech., 52(3), 219-227.

Dewberry. (2017) Rebuild by Design - Hudson River Project, Hydrology and Flood Risk Assessment Report. NJDEP.

Eiswirth, M. \& Hötzl, H. (1997) The impact of leaking sewers on urban groundwater. Groundw. Urban Environ. 1, 399-404.

Gironás, J., Roesner, L. A., Rossman, L. A. \& Davis, J. (2010) A new applications manual for the Storm Water Management Model (SWMM). Environ. Model. Softw. 25(6), 813-814.

Harbaugh, Arlen W., et al. (2000) MODFLOW-2000, The U. S. Geological Survey Modular Ground-Water ModelUser Guide to Modularization Concepts and the Ground-Water Flow Process. Open-file Report. U. S. Geological Survey 92: 134.

Karpf, C., \& Krebs, P. (2004). Sewers as drainage systems-quantification of groundwater infiltration. NOVATECH 2004 "Sustainable Techniques and Strategies in Urban Water Management", Lyon, Proceedings Vol, 2, 969-975.

Karpf, C. and Krebs, P. (2011) Quantification of groundwater infiltration and surface water inflows in urban sewer networks based on a multiple model approach. Water Res. 45(10), 3129-3136.

Liu, T., Su, X., Prigiobbe, V. (Submitted) Groundwater-sewer interaction in urban coastal areas. Environ. Sci. Technol.

Kracht, O., Gresch, M. \& Gujer, W. (2007) A Stable Isotope Approach for the Quantification of Sewer Infiltration. Environ. Sci. Technol. 41(16), 5839-5845.

Burger, G., Sitzenfrei, R., Kleidorfer, M. \& Rauch, W. (2014) Parallel flow routing in SWMM 5. Environ. Model. Softw. 53, 27-34.

National Oceanographic and Atmospheric Administration (NOAA). (2017) Tide at The Battery, \{NY\} - Station \{ID\}: 8518750

New Jersey Department of Environmental Protection (NJDEP). (2002) Surficial Geology of the Elizabeth Quadrangle, Essex, Hudson, and Union Counties, NJ.

Mayer, P. W., DeOreo, W. B., Opitz, E. M., Kiefer, J. C., Davis, W. Y., Dziegielewski, B. \& Nelson, J. O. (1999) Residential end uses of water. Amer Water Works Assn.

Mehan, G. T. (2002) The clean water and drinking water infrastructure gap analysis. EPA-816-R-02-020.

Prigiobbe, V. \& Giulianelli, M. (2009) Quantification of sewer system infiltration using $\delta 180$ hydrograph separation. Water Sci. Technol. 60(3), 727-735.

RiverKeeper (2017) Hudson river estuary data. Available at: https://www.riverkeeper.org/water-quality/hudsonriver/

SUEZ. (2016) Your water quality information. Consumer confidence report.

U.S. Census Bureau. (2016) American FactFinder, Annual Estimates of the Resident Population: April 1, 2010 to July 1, 2016, 2016 Population Estimates, New Jersey. Retrieved from http://factfinder2.census.gov.

Xia, Y. et al. (2012), NCEP/EMC. (2012) NLDAS Noah Land Surface Model L4 Hourly 0.125 x 0.125 degree V002. Goddard Earth Sciences Data and Information Services Center (GES DISC). 


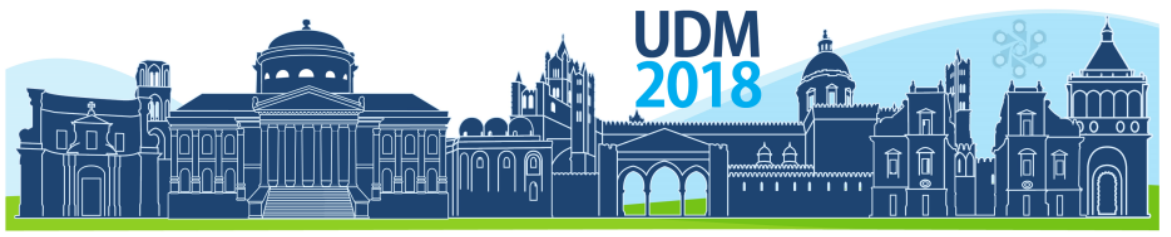

$11^{\text {th }}$ International Conference on Urban Drainage Modelling

23-26 Sep | Palermo - Italy

\title{
Validation of an unsteady flow numerical model for sediment transport induced by flushing operation in combined sewers
}

\author{
Gashin Shahsavari ${ }^{1}$, Alberto Campisano ${ }^{2}$, Carlo Modica² ${ }^{2}$ and Gilles Arnaud-Fassetta ${ }^{1}$ \\ ${ }^{1}$ Paris-Diderot University, PRODIG Lab., Paris, France \\ 2Dipartimento di Ingegneria Civile e Architettura, Università di Catania, Viale A. Doria 6, 95125, Catania, Italy
}

\begin{abstract}
An unsteady flow numerical model based on the solution of the 1-D De Saint Venant-Exner equations was developed and validated against the results of a field flushing experiment that was carried out in the year 2014 within a combined sewer trunk of the Paris sewer system. The comparison of numerical and experimental results showed that the model may reproduce in a proper way the erosional effects of the flush on the mobile bed of the sewer at the end of the experiment. Model results confirmed the potential erosive effect of the flush up to several hundreds meters downstream of the flushing device, with a significant reduction of the deposited sediments in the channel.
\end{abstract}

Keywords: Sewer flushing; Sediment transport modeling; Combined sewer

\section{INTRODUCTION}

The analysis of sediment transport induced by flushing operation in storm water/combined sewers has been the subject of several research studies in the recent years. Experiments have been carried out at both laboratory and field levels to explore the effects (i.e., the cleaning performance) of a number of flushing devices on the sediments deposited on the invert of sewer pipes (Lorenzen, 1996; Ristenpart, 1998; Dettmar and Staufer, 2005; Campisano et al., 2006; Creaco and Bertrand-Krajewski, 2009).

At the same time, other studies have focused on modelling aspects of sewer flushing, including sediment erosion and transport processes (e.g. Campisano et al., 2006; Shirazi et al., 2014). However, much of the developed models have not been extensively validated against experimental observations obtained through field tests.

Very recently, Shahsavari et al. (2017) have shown the results of field experiments aimed at investigating the impact of a single flush on the sediment bed of a combined sewer trunk in the municipality of Paris. The objective of the present paper is to show the preliminary results of the validation of a 1-D unsteady flow numerical model for the analysis of the cleaning performance of the performed flush. The analysis includes the comparison of experimental and model results concerning the evolution of both hydraulic and sediment-related parameters during the flush experiment.

\section{MATERIALS AND METHODS}

\subsection{Experimental data}

The results of an experimental campaign carried out during the year 2014 in a large combined sewer (Collecteur des Coteaux) of Paris city were used for the validation of the model. The scouring effects of a single flush were explored over a $1.1 \mathrm{~km}$ long channel trunk of the selected sewer. The trunk is characterized by a compound cross-section with central 


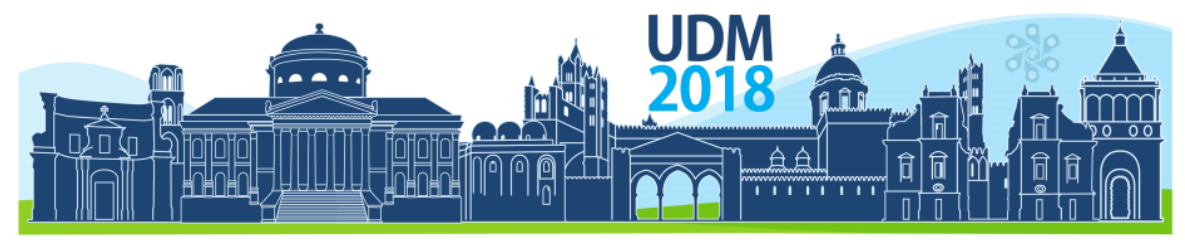

$11^{\text {th }}$ International Conference on Urban Drainage Modelling

23-26 Sep | Palermo - Italy

cunette and side-walkways. The relatively low value of the average longitudinal slope of channel $(\sim 0.09 \%)$ determines relevant problems of sedimentation in the sewer. Mean $d_{50}$ over the experimental channel is about $2.2 \mathrm{~mm}$. A moveable gate was used to perform the flush through initial storage and successive release of combined sewer flows. The sewer trunk was fully equipped with a set of measuring devices to monitor both flow and sediment transport during the flush experiment. Flow parameters were measured in five cross-sections both upstream and downstream the flushing gate. Moreover, sediment depths throughout the channel were measured by radar/sonar scan systems before and after the flush for consistent evaluation of the flush cleaning performance (Shahsavari et al., 2017).

\subsection{Description of the numerical model}

The adopted numerical model is based on the solution of the 1-D De Saint Venant equations for the unsteady flow description, and on the Exner equation for the sediment continuity. For a prismatic channel without lateral inflows and outflows, the following conservative vector form can be used:

$$
\frac{\partial U}{\partial t}+\frac{\partial F(U)}{\partial x}=D(U)
$$

where $U$ is the dependent variable vector, $F(U)$ is the flux vector, and $D(U)$ is the source term vector written as follows:

$$
U=\left[\begin{array}{l}
A \\
Q \\
A_{S}
\end{array}\right], \quad F(U)=\left[\begin{array}{l}
Q \\
V \cdot Q+\frac{F_{h}}{\rho} \\
\frac{1}{1-p} \cdot Q_{S}
\end{array}\right] \quad \text { and } \quad D(U)=\left[\begin{array}{l}
0 \\
g \cdot A \cdot(i-J) \\
0
\end{array}\right]
$$

being $x[\mathrm{~m}]$ and $t[\mathrm{~s}]$ the space and time independent variables; $A\left[\mathrm{~m}^{2}\right]$ the water crosssection; $Q\left[\mathrm{~m}^{3} / \mathrm{s}\right]$ and $V[\mathrm{~m} / \mathrm{s}]$ the flow discharge and the flow velocity respectively; $F_{h}[\mathrm{~N}]$ the hydrostatic force over the cross section; $\rho\left[\mathrm{kg} / \mathrm{m}^{3}\right]$ the water density; $g\left[\mathrm{~m} / \mathrm{s}^{2}\right]$ the gravity acceleration; $i$ the bed slope; $J$ the friction slope; $A_{s}\left[\mathrm{~m}^{2}\right]$ the sediment cross-section; $Q_{s}$ $\left[\mathrm{m}^{3} / \mathrm{s}\right]$ the volumetric sediment discharge; and $p$ the sediment porosity.

The friction slope is evaluated using the Strickler roughness equation (Strickler, 1923):

$$
J=\frac{Q^{2}}{k_{e q}^{2} \cdot A^{2} \cdot R^{4 / 3}} \quad \text { with } \quad k_{e q}=\left(\frac{P}{\sum \frac{P_{i}}{k_{i}^{3 / 2}}}\right)
$$

being $R[\mathrm{~m}]$ the hydraulic radius, $k_{e q}\left[\mathrm{~m}^{1 / 3} / \mathrm{s}\right]$ the composite roughness coefficient, $P[\mathrm{~m}]$ the wetted perimeter, $k_{i}\left[\mathrm{~m}^{1 / 3} / \mathrm{s}\right]$ the roughness coefficient of the part $P_{i}$ of the wetted perimeter. Coefficient $k_{i}$ for the sediment bed was calculated based on the sediment characteristic size using the well-known Strickler formula. Coefficient $k_{i}$ for the channel walls was calibrated based on water level and flow measurements under uniform flow conditions.

The system of equations is solved by using the "shock-capturing" TVD-McCormack scheme (Garcia-Navarro and Saviron, 1992). Meyer-Peter and Müller (1948) formula is used for the 


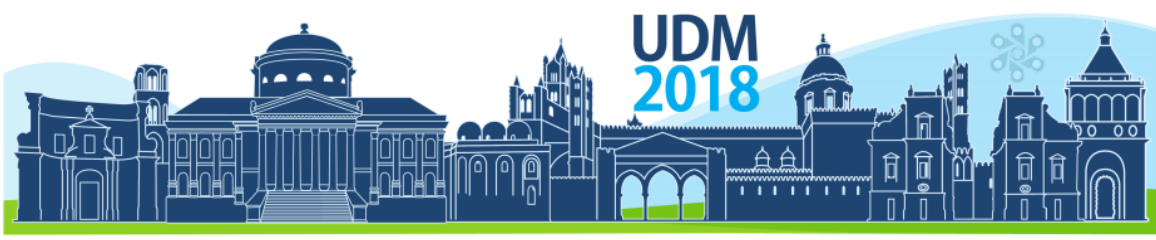

$11^{\text {th }}$ International Conference on Urban Drainage Modelling

23-26 Sep | Palermo - Italy

estimation of the sediment discharge $Q_{s}$ (bed load component) as a function of the flow and sediment characteristics. Moreover, the Velikanov approach (Velikanov, 1954) is used to evaluate the suspended load component.

Boundary conditions on the hydraulic variables (flow and water level) are prescribed at the upstream and downstream channel ends, as well as in correspondence of the gate as internal conditions. Additional boundary conditions for the sediment are also imposed at the two channel ends based on the information obtained by the experiments

\section{RESULTS AND DISCUSSION}

Simulations were extensively compared with the field data, including hydraulic parameters monitored during the experiment as well as sediment depths after the flush. Figure 1 shows examples of the comparison between simulated and experimental variables during the flush (i.e. flow discharge and water level) at sections $-5 \mathrm{~m}$ and $+50 \mathrm{~m}$ upstream and downstream of the gate, respectively. The graphs show that the model results are in relatively good agreement with the experiments, including the initial abrupt water level increase at section $+50 \mathrm{~m}$, subsequent to the transit of the flush wave front that propagates downstream. Results also show the water level at section $-5 \mathrm{~m}$ to drop down due to the flow release process upstream of the gate. Also, the model correctly reproduces the declining trend of the flow discharge after the flush peak.

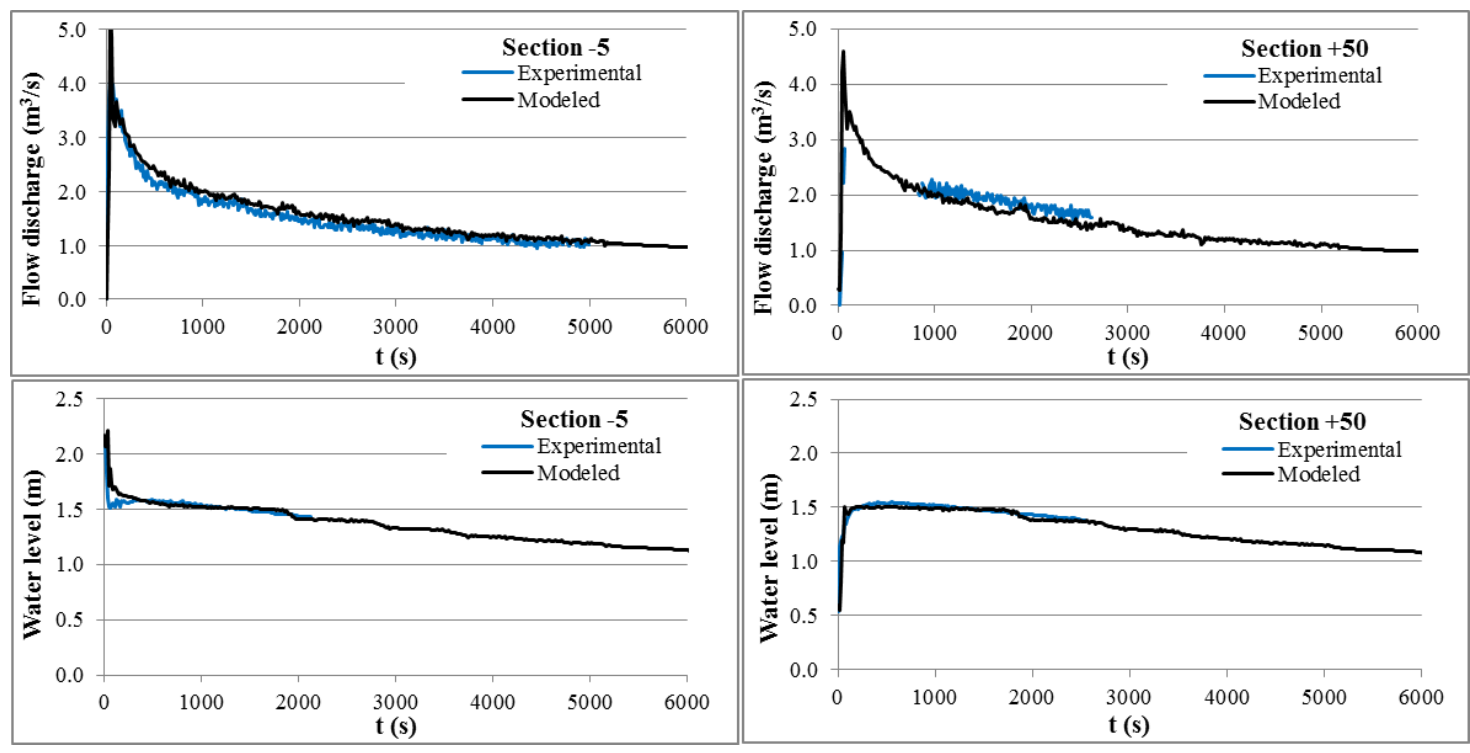

Figure 1 Comparison between experimental and numerical results at sections $-5 \mathrm{~m}$ and $+50 \mathrm{~m}$ from the gate.

Figure 2 shows the results in terms of bed erosion in the channel as induced by the flush. Due to the high energy of the flush, erosional effects were observed in the channel bed over a distance up to about $850 \mathrm{~m}$ downstream of the gate. Due to the relatively large size of $d_{50}$, the results of the used model for uniform sediments did reveal occurrence of bed load transport only. Although the comparison between observed and simulated values of the sediment depths at the end of the flush shows relatively large differences in some sections of the channel, a sufficiently small value of the RMSE $(0.044 \mathrm{~m})$ was obtained. Overall, a significant reduction of the sediments initially deposited on the trunk invert was obtained with the flush. The model results provided about $3.7 \mathrm{~m}^{3}$ of sediments washed out from the channel as compared with the $5.4 \mathrm{~m}^{3}$ measured through the experiments. 


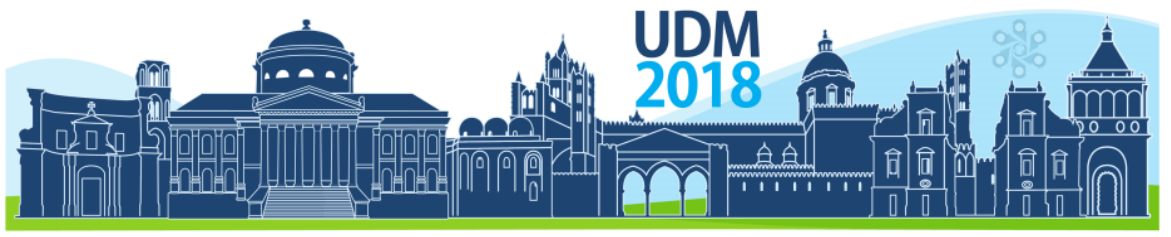

$11^{\text {th }}$ International Conference on Urban Drainage Modelling 23-26 Sep | Palermo - Italy

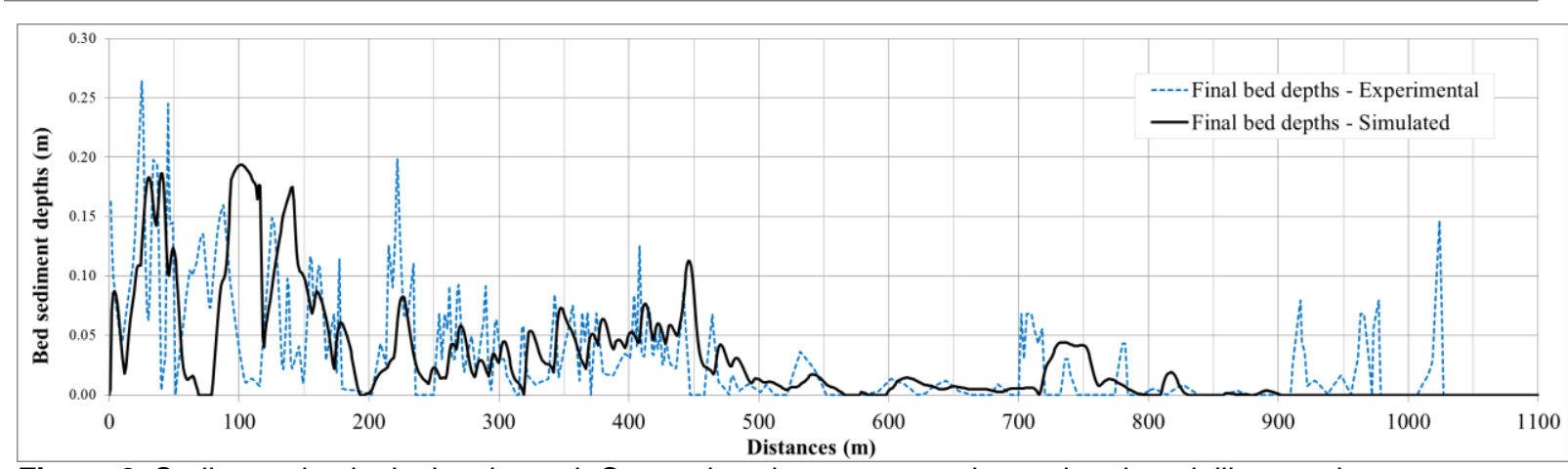

Figure 2. Sediment depths in the channel. Comparison between experimental and modelling results.

\section{CONCLUSIONS}

The results of the application of a numerical model for the evaluation of erosional effects of flushing in a combined sewer trunk of Paris sewer system were presented in the paper. The results were validated using the data derived from an antecedent field experimental analysis carried out in the same trunk. Overall, preliminary simulations showed a relatively good agreement between the model and experimental observations, including the ability of the model to correctly reproduce the main hydraulic processes. Globally, the uniform model showed appreciable erosional impact of the flush on the initial bed of sediments deposited over the channel invert. Improved modelling results are expected in the future with the use of a model for the transport of non-uniform sediments.

\section{References}

Bertrand-Krajewski, J.L., Campisano, A., Creaco, E. and Modica, C. (2005) Experimental analysis of the hydrass flushing gate and field validation of flush propagation modelling. Water Sci. Technol. 51(2): 129-37.

Campisano, A., Creaco, E. and Modica, C. (2006) Experimental analysis of the hydrass flushing gate and laboratory validation of flush propagation modelling. Water Sci. Technol. 54(6-7): 101-108.

Creaco, E. and Bertrand-Krajewski, J.L. (2009) Numerical simulation of flushing effect on sewer sediments and comparison of four sediment transport formulas. Journal of Hydraulic Research 47(2): 195-202.

Dettmar, J. and Staufer, P. (2005) Modelling of flushing waves for optimising cleaning operations. Water Sci. Technol. 52(5): 233-240.

García-Navarro, P. and Savirón, J.M. (1992) McCormack's method for the numerical simulation of onedimensional discontinuous unsteady open channel flow. Journal of Hydraulic Research 30(1): 95-104.

Meyer-Peter, E. and Müller, R. (1948) Formulas for Bed-Load Transport. IAHR-Meeting Stockholm, Zahlentabellen zu den Geschiebetriebsversuchen der Versuchsanstalt für Wasserbau und Erdbau an der ETH Zürich, unpublished supplement (in German).

Lorenzen, A., Ristenpart, E., Pfuhl, W. (1996) Flush cleaning of sewers. Water Sci. Technol. 33 (9): 221-228.

Ristenpart, E. (1998) Solids transport by flushing of combined sewers. Water Sci. Technol. 37(1): 171-178.

Shahsavari, G., Arnaud-Fassetta, G. and Campisano, A. (2017) A field experiment to evaluate the cleaning performance of sewer flushing on non-uniform sediment deposits. Water Research 118: 59-69.

Shirazi, R.H.S.M., Campisano, A., Modica, C. and Willems, P. (2014) Modelling the erosive effects of sewer flushing using different sediment transport formulae. Water Sci. Technol. 69(6): 1198-1204.

Velikanov M.A. (1954) Principle of the gravitational theory of the movement of sediments. Academy of Sciences Bulletin, Geophysical Series, Moscow, USSR 4, 349-359 (in Russian).

Strickler, A. (1923) Beiträge zur Frage der Geschwindigkeitsformel und der Rauhligkeitszahlen für Ströme, Kanäle und geschlossene Leitungen. Mitt. des Eidgenössischen Amtes für Wasserwirtschaft, 16, Bern (in German). 


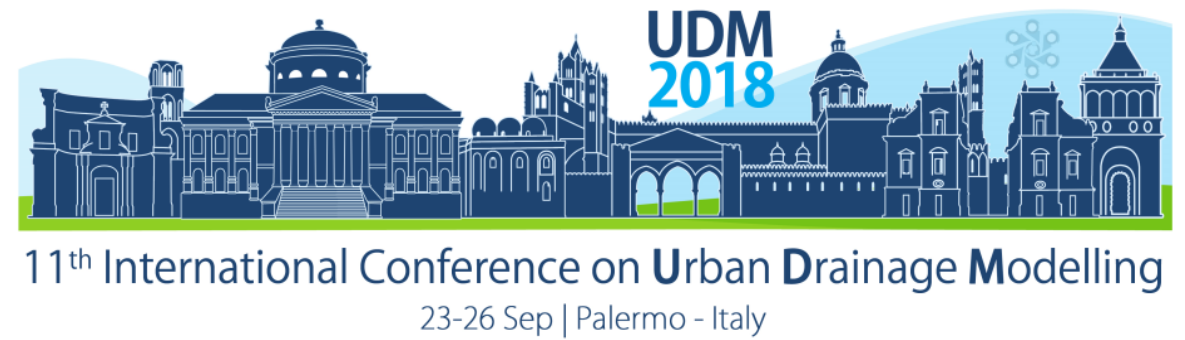

\title{
Smart Rain Barrels: Advanced LID management through measurement and control
}

\author{
Martin Oberascher ${ }^{1, *}$, Jonatan Zischg ${ }^{1}$, Stefania Anna Palermo ${ }^{1,2}$, \\ Carolina Kinzel ${ }^{1}$, Wolfgang Rauch ${ }^{1}$ and Robert Sitzenfrei ${ }^{1}$
${ }^{1}$ Unit of Environmental Engineering, Department of Infrastructure Engineering, University of Innsbruck, Austria 2Department of Civil Engineering, University of Calabria, Italy
${ }^{*}$ Corresponding author's e-mail: martin.oberascher@uibk.ac.at

\begin{abstract}
Rain barrels are micro-scale applications which are used as temporary storage and for rainwater harvesting. They can be easily implemented into existing stormwater infrastructure. Recent advances in the field of Internet of Things (IoT) have opened up new possibilities for real-time monitoring and control of such structures, that enable the reduction of urban flooding or combined sewer overflows. The special feature of our smart rain barrel is its integration into a pilot project for smart cities, where every water inflow and outflow of the university campus in Innsbruck (Austria) is measured. Weather forecasts and timecontrolled filling levels of different Low Impact Developments (LID) structures and the connected sewer system are used for real-time control (RTC). In a first step, the smart rain barrels are implemented into a SWMM-model with the objective of reducing the peak runoff rate by using the filling level in the main conduit as the control variable for real-time control. Results show that depending on the installation site and the storage volume of the rain barrel, a flood volume reduction of $18-40 \%$ can be achieved although only a simplified automatic control system has been implemented.
\end{abstract}

Keywords: LID; smart cities; real-time monitoring and control; peak flow reduction

\section{INTRODUCTION}

Low Impact Development (LID) practices are used to control runoff volumes, peak runoff rates, flow frequency/duration and to improve the water quality in receiving waters by increasing the intercepted runoff, water treatment, evaporation, infiltration and storage volume. In many cases, LIDs are micro-scale applications, including rain barrels and cisterns, which can be used as temporary storage and for rainwater harvesting (Prince George's County 1991). In Australia, on-site detention systems, consisting of controlled water tanks and placed on individual properties, have already been used since the 1990s to reduce stormwater runoff in the sewer system (O'Loughlin, Beecham et al. 1995) and were later completed with storage volumes for non-potable water usage (van der Sterren, Rahman et al. 2009). Further research on controlled water tanks show that discharge rates and water demands can be reduced by an average of $18 \%$ and $10 \%$ respectively by using daily time-steps for the analyses (MelvilleShreeve, Cadwalder et al. 2016). In particular, rain barrels require little space and can therefore be easily integrated into existing infrastructure. Nowadays, due to the technological advances of the Internet of Things (IoT), even in LID devices the water flow water can be measured, communicated and analysed in real-time, and as a result, the overall state of the water systems is known at any time. This information can be used for real-time control (RTC) which allows for an adaption of existing infrastructure to changing needs (Kerkez 2018). 


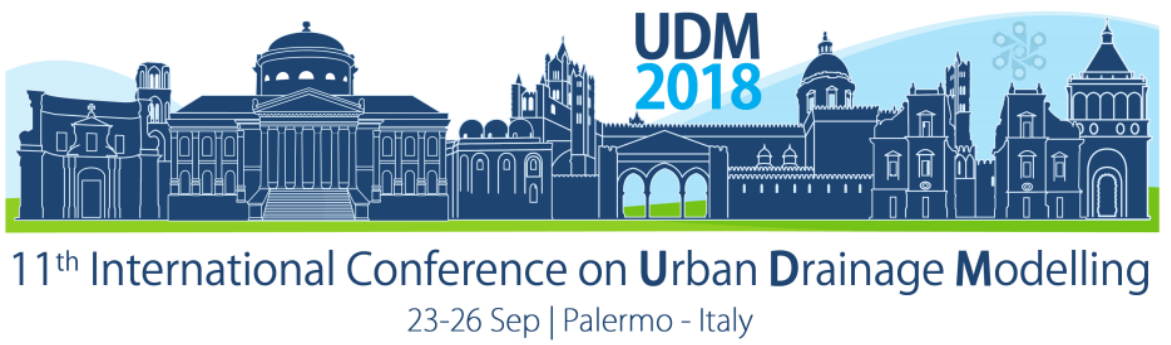

In this paper, loT and rain barrels are linked together, resulting in a smart rain barrel, which is real-time monitored and real-time controlled. The idea of a smart rain barrel is nothing new, as the large number of different publicly available products shows (RainGrid n.d., Sieker n.d.). Unlike these products, however, our smart rain barrels are integrated into a pilot project for smart cities, where LIDs will communicate among each other and are connected with the RTC system. Within the Smart Water Control project, every water inflow and outflow from the university campus in Innsbruck (Austria) is measured in real-time, including filling levels of different LIDs and the central sewer system. In combination with weather forecasts, these data are used for RTC of the smart rain barrels to optimize the efficiency of the above-mentioned LID aims. In a first step, a simplified smart rain barrel model is implemented in the existing stormwater infrastructure, by using only the filling depth in the sewer system as the control variable for RTC. The objective of this paper is to investigate the potential of peak runoff reduction and to estimate the future suitability of optimizing smart rain barrels.

\section{MATERIALS AND METHODS}

\subsection{Concept of the Smart Rain Barrel (SRB)}

The conceptual idea of the SRB is shown in Figure 1(a). The SRB is equipped with a controllable valve and a water level measurement and is placed within a network of SBRs. The SRBs communicate with each other without a central database (loT concept); instead, data is transmitted wirelessly and directly between the SRBs via Long Range Wide Area Network (LoRaWAN). The aims of the presented control strategy are the reduction of peak runoff rate and the reduction of potable water consumption for irrigation.
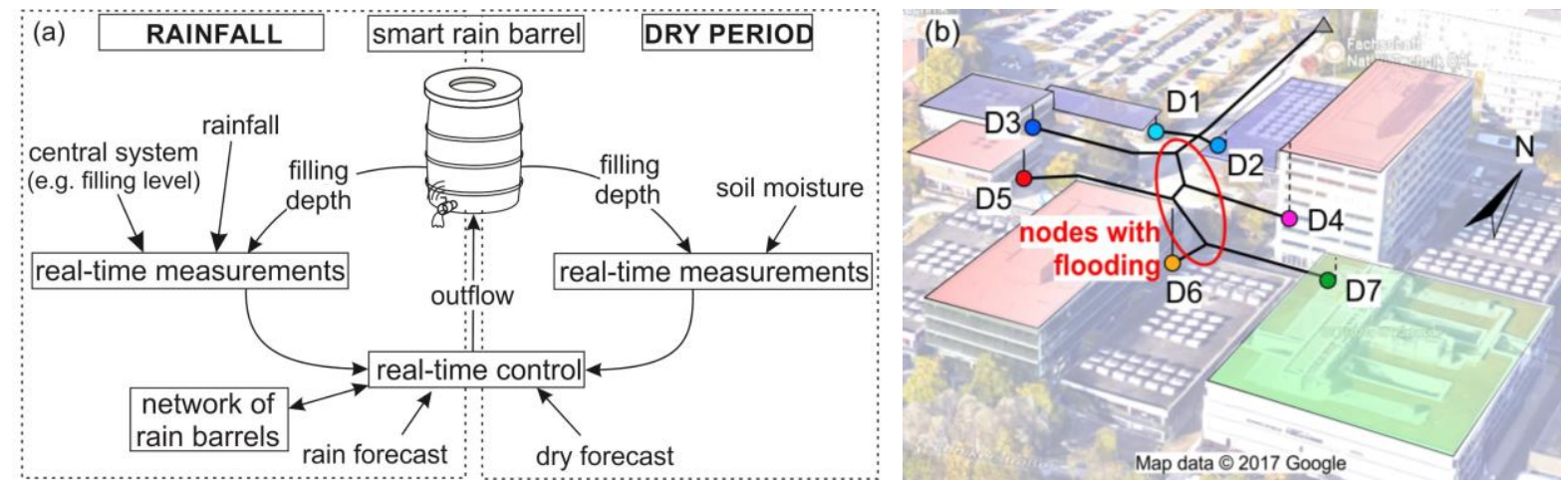

Figure 1. (a) Concept of a SRB: Different strategies for rainfall events or dry periods and (b) placement of 7 SRBS (D1 to D7) and their intercepted roof areas. The red coloured areas represent conventional roofs, the blue coloured areas are gravel roofs, and the green area corresponds to a green roof.

An important factor that influences the control of the SRB is the weather forecast with predicted amount and duration of precipitation. Depending on the weather forecast, three states of the control strategy can be distinguished: (i) the predicted rainfall exceeds the available storage volume, (ii) the predicted rainfall is less than the available storage volume, and (iii) dry weather period. If the predicted inflow to the rain barrel exceeds the total storage volume, the SRB empties completely just before the rainfall event. However, if the calculated inflow is less than the storage volume, the SRB is only partially emptied to ensure a fully filled barrel at the end of the rain event, e.g. for irrigation purposes. And for dry weather periods, the SRB reduces potable water consumption by using the stored water for irrigation. To reduce the uncertainties of the weather forecast, rainfall is measured in real-time and compared with the weather 


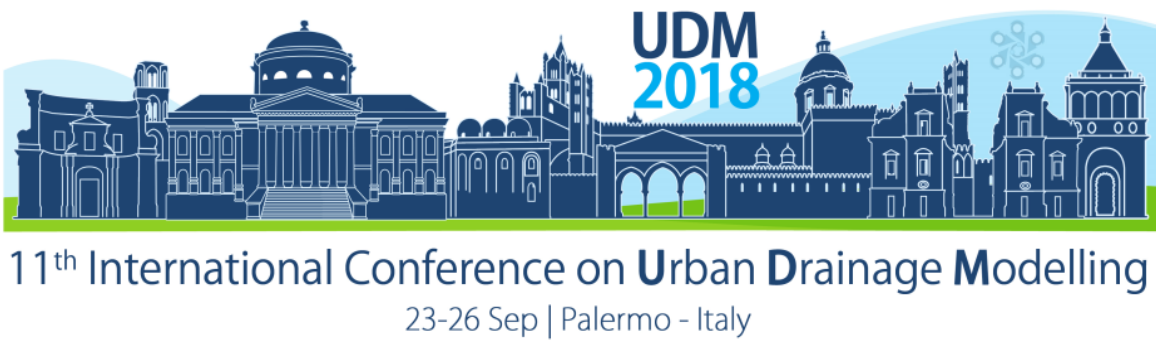

forecast to change the strategy if necessary. To find the ideal time for using the storage volume of the SRB, minimizing system flooding and discharges to receiving waters, the outflow of the SRB is real-time controlled by using data of the central drainage system. Furthermore, in dry weather periods, soil moisture is measured and plants are irrigated with the stored water to reduce the potable water consumption. As an example of the effects of the SRB, the impact of the rain barrel control on the reduction of stormwater runoff with a simple control strategy is presented.

\subsection{Case study}

The SRBs are implemented into the existing stormwater system at the university campus in Innsbruck (Austria). The Campus area is equipped with different measuring devices including water meters, rain gauges, ultrasonic sensors and soil moisture sensors. These devices measure water flows (e.g. water supply, rainfall, groundwater, sewer system etc.) to and from the campus area in real-time. These data are used for the development of RTC strategies such as SRBs.

The campus area can be divided into two different and currently independent systems. On the one hand, surface areas (e.g. pavements, streets, green spaces), that drain into decentralized LIDs (e.g. raingarden and infiltration trenches), on the other hand, roof areas which are connected to the central stormwater system. The latter system is used for the implementation of our SRBs. The SRBs can also be used to connect the central and decentral systems, either by discharging into the LIDs and fully utilizing their capacities, or by directly discharging to the central system. Figure 1(b) shows the campus area, object of this study, consisting of one green roof (green colour), three gravel roofs (blue colour) and three flat roofs without LIDs (red colour), with a total area of 0.71 ha. The main stormwater conduit has a total length of $270 \mathrm{~m}$ and consists of pipes with diameters from $200 \mathrm{~mm}$ to $500 \mathrm{~mm}$, which exceeds the design capacities. To show the advantages of the SRBs under design conditions, the diameters were artificially reduced to $200 \mathrm{~mm}$ and $300 \mathrm{~mm}$ to observe flooding when applying the design rain events. D1 to D7 indicate the locations of the implemented SRBs, which are independently investigated. This study is a modelling study to support the development of a prototypes of SRBs (e.g. choice of sizes and locations) which is currently under construction and will be situated at the campus area in the near future.

\subsection{Numerical Model}

For the hydrodynamic simulation, the EPA Storm Water Management Model SWMM (Gironás, Roesner et al. 2010) was used. In a first step, a simplified model for the SRBs was created, using the filling level in the sewer system for RTC. The objective was to reduce the peak runoff rate in the sewer system. The SRBs were implemented as additional storage volume and placed between the roof subcatchments and the inlet of the sewer system. The SRBs were controlled by rules consisting of a conditional clause (e.g. filling level of the sewer systems) and an action clause (e.g. different outflows from the rain barrel). In the model, the outlet from the SRBs was closed when the filling level at the closest manhole was higher than a predefined height. As an initial assumption, a filling level of $60 \%$ at the manhole was used for peak runoff reduction in the drainage system. When the storage volume of the SRB was full, the overflow was routed into the drainage system. To evaluate the reduction of peak runoff and the effect of the SRB's location, each building was individually equipped with a SRB (see Figure 1(b)). Furthermore, the additional storage of the SRBs was modified in a range from 0.1 to $6 \mathrm{~m}^{3}$. For the simulation, a 14-year rain series from a nearby weather station was used and an exact rain forecast was assumed. The 16 rain events that caused flooding were extracted from the rain 


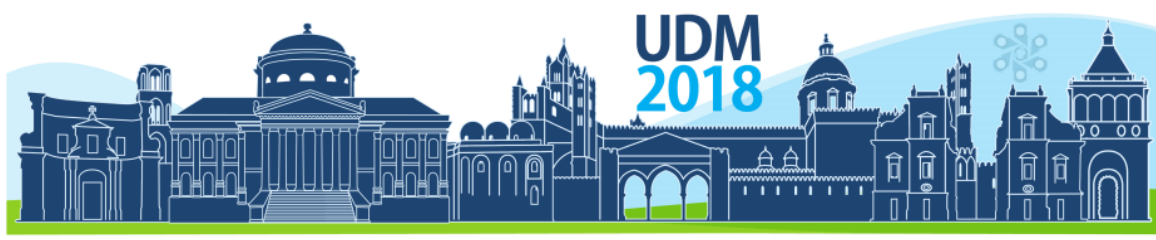

$11^{\text {th }}$ International Conference on Urban Drainage Modelling

23-26 Sep | Palermo - Italy

series and aggregated to reduce the simulation time. They were separated by an additional day without precipitation, which was used for emptying the SRBs. The rain data were available in 5 min steps and the rain events had maximum intensities from 3.3 to $11.5 \mathrm{~mm}$ in $5 \mathrm{~min}$ and a maximum total precipitation of 13 to $38 \mathrm{~mm}$. The total flood volume of the reference state was $214 \mathrm{~m}^{3}$ and was used for comparison of the different locations and SRB sizes.

\section{RESULTS AND DISCUSSION}

Figure 2 shows the simulation results for the implementation of SRBs of different sizes and at different locations as compared to the reference (actual) state without SRBs. The flood volume reduction depends on the barrel size and its location (same colour coding as in Figure 1(b)). It can be seen that the location of the SRB has a major impact on the reduction of the flooding volume. For example, SRBs located at D1 or D2 have no effect, while SRBs situated at all other locations clearly decrease the total flood volume of up to approximately $97 \mathrm{~m}^{3}$ which corresponds to a reduction rate of $40 \%$. The variations of the results can be explained by the fact that flooding primarily occurs in the marked area (see red circled area in Figure 1(b)), implying that not all SRB locations are efficient. Additional storage volumes at D1 or D2 are located downstream of the primary flooding area, so that the peak runoff rate that causes flooding is not reduced. All other nodes are located in upstream direction of the flooding area, resulting in a decrease of the flood volume by $18-40 \%$.

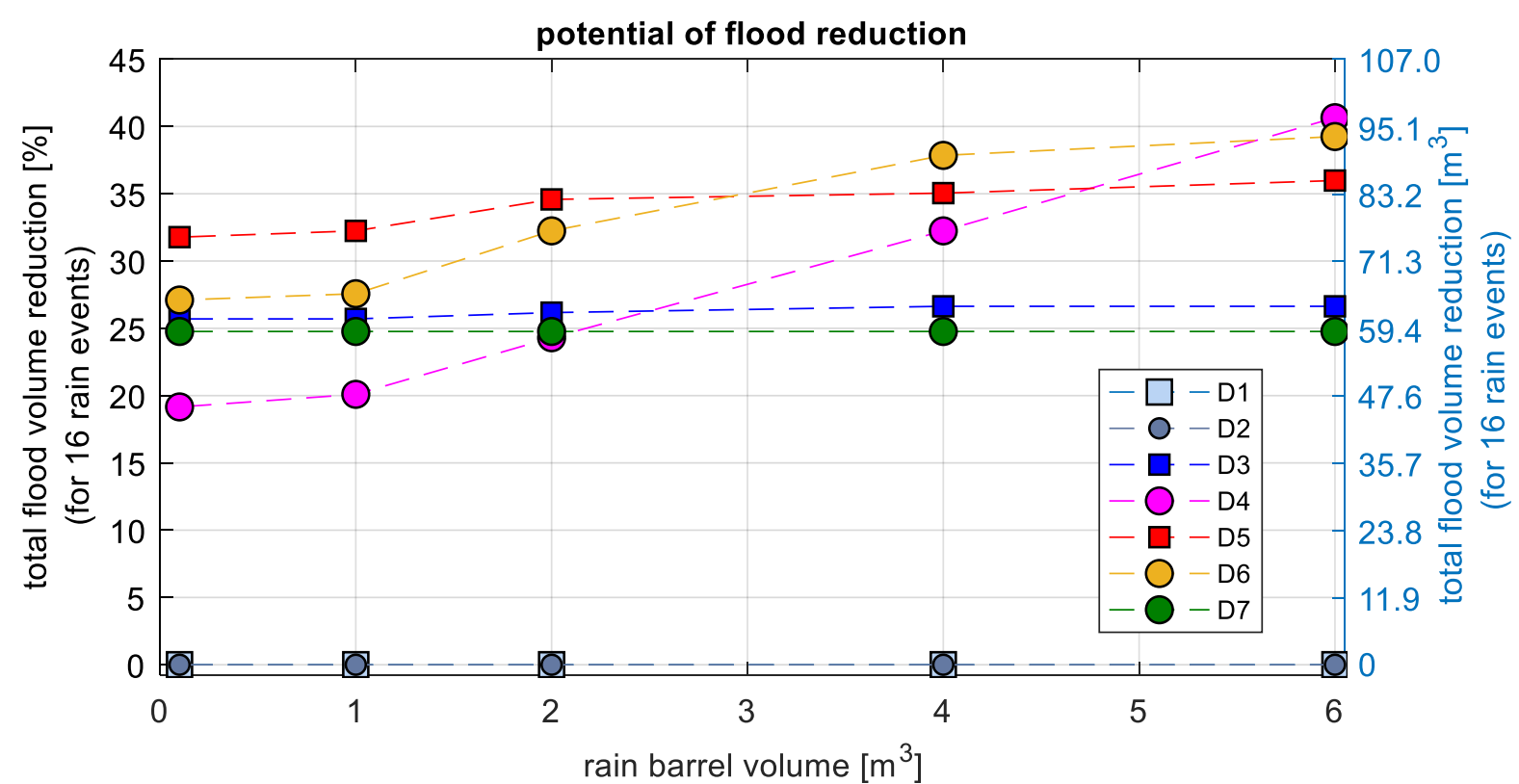

Figure 2. Results of the simulation showing the potential of flood reduction when implementing SRBs of different size at different locations compared to the reference state

It is particularly interesting to note that the size of SRBs located at a gravel roof (D3) or a green roof (D7) does not have any influence on the flood volume reduction, while for conventional roofs the flood volume reduction is greatly dependent on the available volume. Another important point is, that there is hardly any difference between rain barrels with storage volumes less than $1 \mathrm{~m}^{3}$ noticeable. By a more detailed exclamation, the effectiveness of storage volumes less than $1 \mathrm{~m}^{3}$ is mainly influenced by two main factors. The first factor is the relation between filling time of the SRB and the chosen report time steps in SWMM. For example, if 


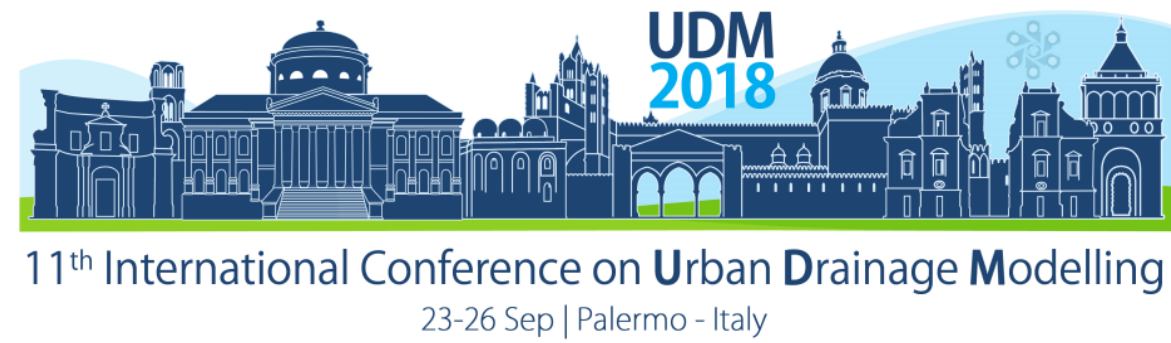

the SRB is filled in $10 \mathrm{~s}$ the report time step must be small enough to show effects in the flood reduction. The other point is, that the control strategy with the fixed filling level in the sewer system as input parameter is not suitable for minimising the flood volume. For example, in the worst case the SRB is already fully filled bevor flooding occurs. Although, the primary purpose of the SRB is not flood prevention, it can be seen that the accumulated flood reduction can reach up to $40 \%$ compared to the reference state. However, this reduction rates are not realistic because of SRB volumes of $6 \mathrm{~m}^{3}$.

\section{CONCLUSIONS}

This paper presented a concept for using real-time controlled smart rain barrels integrated into a smart city pilot project using weather forecasts and real-time measurements of rain, soil moisture and filling levels recorded in the LIDs and the sewer system. The smart rain barrels were implemented into a SWMM-model for a first evaluation of their effectiveness. In the current model setup, a simplified automatic control by using the filling level in the sewer system as the only control variable was applied. First results showed that accumulated flood volume reductions of $18-40 \%$ can be achieved and that the location of the smart rain barrel and the storage size are important factors to reduce flooding. However, the main purpose of a smart rain barrel is to reduce potable water consumption and not necessarily to increase flood robustness. If the uncertainty of the weather forecast is increased, the choice of appropriate weights for the two contradicting objectives of flood reduction and water savings for irrigation becomes more important. Based on the presented evaluations, smart rain barrels are installed and operated on campus. A further advantage of the proposed concept is that the structures can communicate with each other even without a central database (Internet of Things concept). Similar to the decentralised smart rain barrels, we want to achieve a decentralised real-time control system, which is desirable in the context of smart cities, and therefore the Internet of Things concept is most appropriate. The smart rain barrels can also be used to connect the central and decentral systems, either by discharging into the LIDs and fully utilizing their capacities, or by directly discharging to the central system.

\section{Acknowledgements}

This research was funded by the Climate and Energy Fund within the Smart Cities program (project number 858782).

\section{References}

Gironás, J., L. A. Roesner, L. A. Rossman and J. Davis (2010). "A new applications manual for the Storm Water Management Model (SWMM)." Environmental Modelling \& Software 25(6): 813-814.

Kerkez, B. (2018). "Building Smarter Water Systems." The Bridge Spring 2018: 7.

Melville-Shreeve, P., O. Cadwalder, W. Eisenstein, S. Ward and D. Butler (2016). Rainwater harvesting for drought management and stormwater control in the San Francisco Bay Area. 9th International Conference NOVATECH. Lyon.

O'Loughlin, G., S. Beecham, S. Lees, L. Rose and D. Nicholas (1995). "On-Site Stormwater Detention systems in Sydney." Water Science and Technology 32(1): 7.

Prince George's County (1991). Low-Impact Develompent Design Strategies: An Integrated Design Approach, Prince George's County, Maryland.

RainGrid. (n.d.). "Stormwater Smartgrids." Retrieved 26. March, 2018, from https://www.raingrid.com/stormwatersmartgrids/.

Sieker. (n.d.). "Smart Cistern - Efficient rainwater usage based on precipitation forecast."Retrieved 26. March, 2018, from http://www.sieker.de/en/products-and-services/product/smart-cistern-40.html.

van der Sterren, M., A. Rahman, S. Shrestha, G. Barker and G. Ryan (2009). "An overview of on-site retention and detention policies for urban stormwater management in the Greater Western Sydney Region in Australia." Water International 34(3): 362-372. 


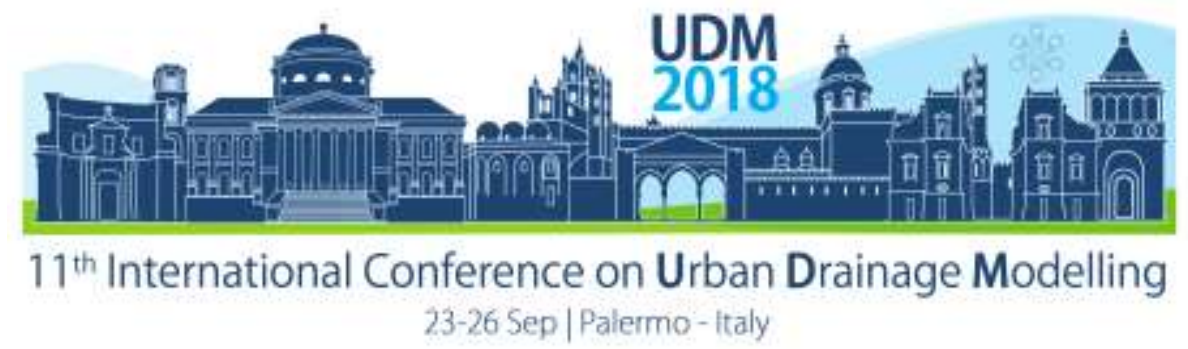

\title{
Numerical Modeling of Biogenic Sulphide Corrosion in Concrete Sewer Pipes
}

\author{
F.A.M. Rooyackers', E. Bosco', A.S.J. Suiker', F.H.L.R. Clemens ${ }^{2,3}$ \\ ${ }^{1}$ Eindhoven University of Technology, Department of the Build Environment, Eindhoven, the Netherlands \\ ${ }^{2}$ Delft University of Technology, Department of Civil Engineering and Geosciences, Delft, the Netherlands \\ ${ }^{3}$ Deltares, Department of Hydraulic Engineering, Delft, the Netherlands
}

\begin{abstract}
In order for concrete sewer pipes to properly fulfil their function, the load bearing capacity should be sufficient to withstand the loads experienced during operation. Sulphuric acid produced by the bacteria present in the sewer system may deteriorate the concrete pipe significantly, thereby affecting the load bearing capacity. This study presents a first step in the development of a numerical model for describing the chemical degradation processes in sewer pipes, which is done by coupling the diffusion processes of chemical components to a continuum damage model that mimics the resulting degradation. The model should be able to provide useful guidelines regarding the durability of concrete sewer pipes in engineering applications. The main results of a literature study on the chemical processes in concrete sewer pipes are presented, followed by an analysis of a basic two-dimensional benchmark problem in which three (diffusion-)reaction models are coupled to an isotropic damage formulation to simulate the chemical deterioration processes of a sewer system.
\end{abstract}

Keywords: Concrete, Biogenic Acid Attack, Diffusion-reaction model, Continuum Damage Mechanics, Finite Element Method.

\section{Introduction}

This contribution focuses on the numerical modeling of biogenic sulphide corrosion, which is a specific form of chemical attack on concrete sewer pipes. This chemical process can cause a severe reduction of the load bearing capacity of sewer systems; although the deterioration mechanism gradually builds up in time, it eventually may lead to catastrophic collapse of a sewer system. It is estimated that in the Netherlands alone, the expenses related to maintenance and repair of sewer systems are in the order of $€ 800$ million, although figures as high as $€ 1.45$ billion are also published (Oosterom \& Hermans, 2013). The development of mechanistic models is necessary for obtaining detailed insight into these complex processes, and for developing effective maintenance procedures. In the present modeling approach, diffusion-reaction models for the transportation mechanisms of corrosive products are developed, which are coupled to a continuum damage model to predict the structural degradation of concrete sewer pipes. The modeling approach should help to establish useful guidelines for predicting the durability of sewer pipes under practical circumstances.

\section{Methodology and chemical species}

The term biogenic sulphide attack refers to the deterioration mechanism of the cement matrix of concrete, resulting from chemical reactions of cement with sulphuric acid, produced by certain bacteria. Due to such chemical degradation processes, a concrete sewer pipe at some stage may no longer be able to carry the loading experienced during operation, as a result of which it may collapse. This problem occurs at a large scale, and therefore has significant economic consequences. In order to develop a model that predicts the chemical degradation of concrete sewer pipes, a literature study has been performed to identify and characterize the most relevant chemical processes. Subsequently, these processes are incorporated in a chemo-mechanical deterioration model, of which the main features are illustrated by means of a simple benchmark problem. 


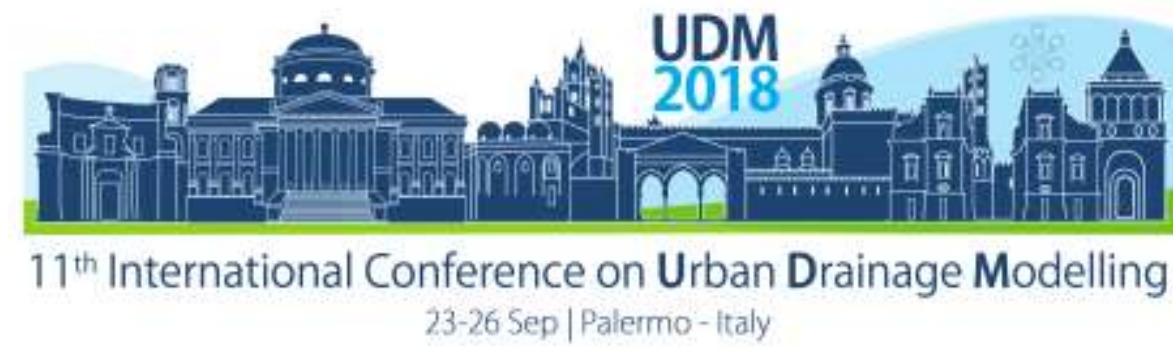

\subsection{Hydrogen Sulphide $\left(\mathrm{H}_{2} \mathrm{~S}\right)$ production}

The key factor in the chemical conversion of sulphates (present in the wastewater) to $\mathrm{H}_{2} \mathrm{~S}$ are the sulphate-reducing bacteria. In a sewer system, bacteria of the Desulfovibrio genus are very common, which favor an environment with high levels of organic material (Monteny et al., 2000). As a result of their metabolism, these bacteria consume sulphates and produce $\mathrm{H}_{2} \mathrm{~S}$, which is poorly soluble in water. In specific, the dissolved $\mathrm{H}_{2} \mathrm{~S}$ is chemically unstable in a solution with a pH of 6-7 and is therefore released from the sewage in a gaseous phase.

\subsection{Hydrogen Sulphide $\left(\mathrm{H}_{2} \mathrm{~S}\right)$ transport}

At the crown of a sewer pipe, the $\mathrm{H}_{2} \mathrm{~S}$ gas meets the layer of condensate present on the relatively cold, concrete inner surface. In alkaline conditions, $\mathrm{H}_{2} \mathrm{~S}$ gas is better soluble and therefore starts to dissolve in the condensate layer. In such solutions, the $\mathrm{H}_{2} \mathrm{~S}$ forms an $\mathrm{HS}^{-}$ ion and an $\mathrm{H}^{+}$ion (pKa1 $=7$ ), although in very alkaline environments it dissolves into $\mathrm{S}^{2-}$ and $2 \mathrm{H}^{+}$ions $(\mathrm{pKa} 2=14)$.

\subsection{Sulphuric acid $\left(\mathrm{H}_{2} \mathrm{SO}_{4}\right)$ production}

Neutrophilic sulphur-oxidizing micro-organisms of the Thiooxidans species can grow in the moisture layer present on the inner surface of a concrete sewer pipe (Parker, 1945). Initially the $\mathrm{pH}$ of the moisture layer is too high for bacterial growth; however, in practice the $\mathrm{pH}$ levels of moisture layers decrease with time. A global consensus on the underlying phenomenon has not been reached in the literature; most papers cite carbonation as the most obvious cause for the pH drop (Ismail et al., 1993; O'Connell et al., 2010; Davis et al., 1998), although dissolved $\mathrm{H}_{2} \mathrm{~S}$ (Ayoub et al., 2004; Vollertsen et al., 2008; Islander et al., 1991) and the presence of fungi (Cho \& Mori, 1995; Gu et al., 1998) in the condensate layer are also mentioned. In most experimental observation studies, the tidal zones are primarily corroded (Mori et al., 1991; Ismail et al., 1993), but some studies also report severe corrosion at the crown (Davis et al., 1998; Vincke et al., 2001). The acidic products of these neutrophilic bacteria accumulate in the condensate layer, the most important one being sulphuric acid, which diffuses into the pore structure of the cement matrix and chemically attacks several hydrates of cement. In the process, expansive products are created. This induces a mechanical stress, which leads to the formation of micro-cracks when the tensile strength is reached.

\subsection{Chemical reactions within the cement paste}

Concrete is composed of aggregates glued together by a cement matrix. Cement consists mainly of calcium hydroxide $(\mathrm{C}-\mathrm{H})$ and calcium-silicate-hydrate $(\mathrm{C}-\mathrm{S}-\mathrm{H})$. It is a porous material in which water or other liquids can only penetrate to a certain depth. The water penetrating the pore structure dissolves small amounts of $\mathrm{C}-\mathrm{H}$, resulting in a highly alkaline solution $\mathrm{pH} 11-$ 13). This is also the case for the thin moisture layer on the inner surface of a concrete sewer pipe. $\mathrm{C}-\mathrm{H}$ does not contribute to the structural properties of the cement directly. On the contrary, C-S-H is a gel like material, which affects the strength and stiffness of the cement paste (Alexander et al., 2013; Gutberlet et al., 2015). When $\mathrm{H}_{2} \mathrm{SO}_{4}$ penetrates into the pore structure of the cement matrix, $\mathrm{C}-\mathrm{H}$ dissolved in the pore solution reacts with $\mathrm{H}_{2} \mathrm{SO}_{4}$. In this process gypsum $\left(\mathrm{CaSO}_{4}\right)$ is formed (Alexander et al., 2013; Allahverdi \& Skvara, 2000):

$$
\mathrm{Ca}^{2+}(\mathrm{aq})+2 \mathrm{OH}^{-}(\mathrm{aq})+\mathrm{H}_{2} \mathrm{SO}_{4}(\mathrm{aq}) \rightarrow \mathrm{CaSO}_{4} \cdot 2 \mathrm{H}_{2} \mathrm{O}
$$

Due to the expansive nature of gypsum, tensile stresses in the cement matrix may induce micro-cracks, thereby increasing the porosity significantly. When $\mathrm{C}-\mathrm{H}$ is depleted in a specific region, the $\mathrm{pH}$ starts to drop, which affects the chemical equilibrium of $\mathrm{C}-\mathrm{S}-\mathrm{H}$ (Allahverdi \& Skvara, 2000). Consequently, C-S-H starts to dissolve and react with $\mathrm{H}_{2} \mathrm{SO}_{4}$ (Alexander et al., 


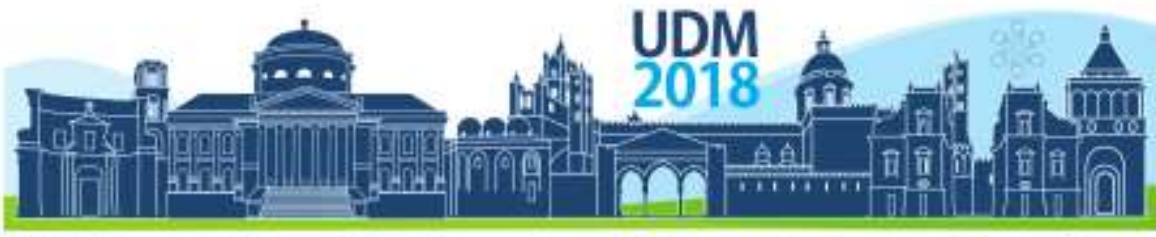

$11^{\text {th }}$ International Conference on Urban Drainage Modelling 23-26 Sep|Palemo-italy

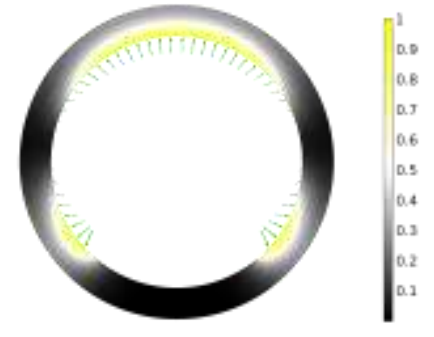

(a) Concentration of $\mathrm{H}_{2} \mathrm{SO}_{4}$ computed by a diffusion-reaction model. The boundary flux (green arrows) represents the bacterial layer density along the circumference of the pipe.

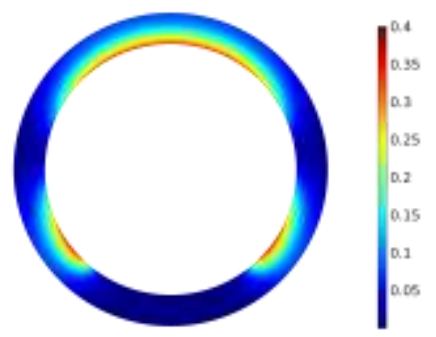

(d) Distribution of the damage parameter $d_{c}$ as a linear function of the gypsum concentration.

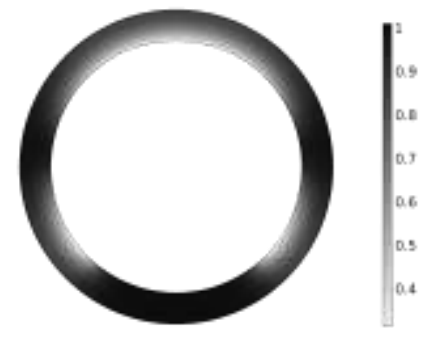

(b) Concentration of C-S-H computed by a reaction model, with the sink term being a function of the C-S- $\mathrm{H}$ and $\mathrm{H}_{2} \mathrm{SO}_{4}$ concentrations.

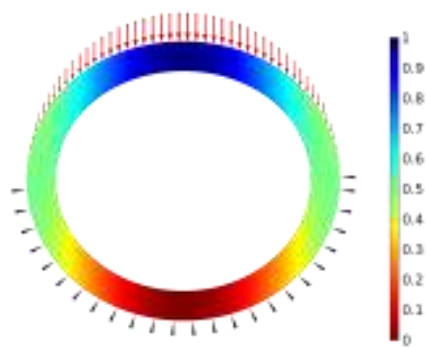

(e) Displacement profile of the damaged pipe supported by a spring foundation and loaded at the top. (c)

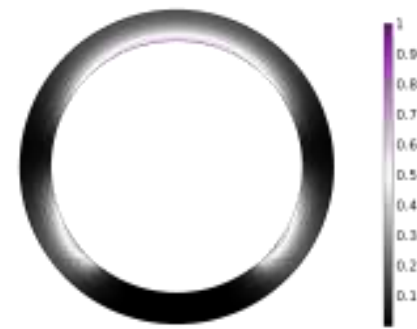

Concentration of gypsum $\left(\mathrm{CaSO}_{4}\right)$ computed by a reaction model, with the source term being dependent on the $\mathrm{H}_{2} \mathrm{SO}_{4}$ and $\mathrm{C}-\mathrm{S}-\mathrm{H}$ concentrations.

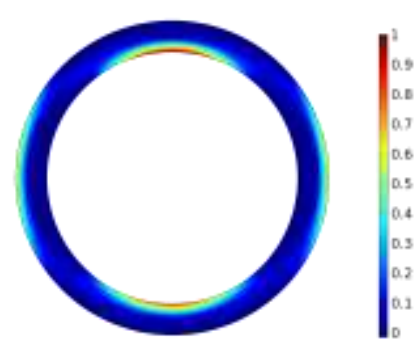

(f) Distribution of the maximum principal (tensile) stress.

Figure 1: Chemo-mechanical response of a concrete sewer pipe. Distributions of various concentrations (a-c) and the mechanical response (d-f). Every plot is normalized with respect to its maximum value.

2013; Monteny et al., 2000), affecting the strength of the concrete.

$$
\mathrm{CaO} \cdot \mathrm{SiO}_{2} \cdot \mathrm{H}_{2} \mathrm{O}+\mathrm{H}_{2} \mathrm{SO}_{4}(\mathrm{aq}) \rightarrow \mathrm{CaSO}_{4}+\mathrm{Si}(\mathrm{OH})_{4}+\mathrm{H}_{2} \mathrm{O}
$$

The gypsum layer has a low strength and stiffness, and has a higher porosity. Occasionally, investigators also emphasize the protective function of this layer (Gutberlet et al., 2015; Allahverdi \& Skvara, 2000; Mehta, 1985).

\section{Results and Discussion}

The chemical degradation of concrete sewer systems is driven by the transportation of specific chemical species and their reaction as a function of their location and time (Cefis \& Comi, 2014; Campos et al., 2015), as described by the diffusion-reaction equation:

$$
\frac{\partial C(x, y, t)}{\partial t}-D \nabla^{2} C(x, y, t)=Q_{r}(x, y, t),
$$

where $C$ is the concentration of the chemical specie, $D$ is the diffusion coefficient, $Q_{r}$ is the reaction term, and $\nabla^{2}=\partial^{2} / \partial x^{2}+\partial^{2} / \partial y^{2}$. Eq. (1) can further be coupled to diffusion models for other chemical species. This is demonstrated in Figure 1, in which the diffusion of sulphuric acid $\left(\mathrm{H}_{2} \mathrm{SO}_{4}\right)$ through the concrete wall and the chemical reaction with $\mathrm{C}-\mathrm{S}-\mathrm{H}$ to gypsum $\left(\mathrm{CaSO}_{4}\right)$ are simulated simultaneously. Here, the three (diffusion-)reaction models are coupled by their respective reaction terms $Q_{r}$, which appears as a (negative) sink or a (positive) source term. The magnitude of the flux term in the first diffusion-reaction equation $\left(\mathrm{H}_{2} \mathrm{SO}_{4}\right)$ relates to the number of bacteria present at the inner surface. A phase transition parameter $d_{c}$ takes into account the mechanical properties of gypsum, which represents the volumetric ratio of $\mathrm{C}-\mathrm{S}-\mathrm{H}$, 


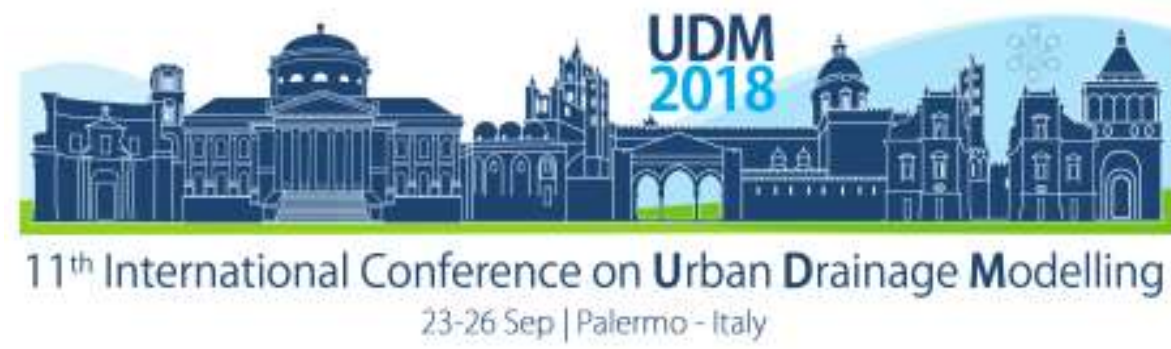

with $d_{c}=0$ representing the initial concentration of $\mathrm{C}-\mathrm{S}-\mathrm{H}$ and $d_{c}=1$ representing total depletion of $\mathrm{C}-\mathrm{S}-\mathrm{H}$. In addition, gypsum formed in the diffusion-reaction process occupies a higher volume than the original cement paste material, thereby inducing mechanical stresses. The formation of micro-cracks is accounted for effectively by means of an isotropic continuum damage model, whereby a damage parameter $d_{d}$ monitors the amount of damage generated in a material point of the structure, with $d_{d}=0$ representing the undamaged state and $d_{d}=1$ reflecting the fully-damaged state at which the integrity of the material is lost. The reduction in stress under the development of damage and chemical reaction occurs in accordance with the constitutive relation:

$$
\boldsymbol{\sigma}=\left(1-d_{d}\right)\left[\left(1-d_{c}\right){ }^{4} \boldsymbol{C}_{0}^{\mathrm{CSH}}: \boldsymbol{\varepsilon}^{e}+d_{c}{ }^{4} \boldsymbol{C}_{0}^{\mathrm{Gypsum}}: \boldsymbol{\varepsilon}^{e}\right],
$$

where $\boldsymbol{\sigma}$ and $\boldsymbol{\varepsilon}^{e}$ are the stress and elastic strain tensors, and ${ }^{4} \boldsymbol{C}_{0}$ is the fourth-order elastic stiffness tensor. For reasons of simplicity, ${ }^{4} \boldsymbol{C}_{0}^{\text {Gypsum }}$ is assumed to be equal to zero, as is the damage parameter $d_{d}$, which is currently under development. The phase transition parameter $d_{c}$ is proportionally linked to the concentration of $\mathrm{C}-\mathrm{S}-\mathrm{H}$ in the diffusion-reaction equation, Eq.(1), as can be observed from Figure 1d.

\subsection{Ongoing work on continuum damage modeling}

In order to evaluate the damage parameter $d_{d}$, a constitutive assumption is needed to define the equivalent strain as a function of the strain tensor to describe the material behaviour under progressive damage. A common assumption for quasi-brittle materials is:

$$
\tilde{\varepsilon}=\sqrt{\sum_{i=1}^{3}\left\langle\varepsilon_{i}\right\rangle^{2}},
$$

with $\varepsilon_{i}(I=1,2,3)$ being the principal strains and \langle\rangle the Macaulay brackets (Mazars and Pijaudier-Cabot, 1989). In addition, a softening law is needed to compute the amount of damage as a function of the equivalent strain, for which the following linear form is adopted:

$$
d_{d}(\kappa)=\frac{\kappa_{u}}{\kappa} \frac{\left(\kappa-\kappa_{0}\right)}{\left(\kappa_{u}-\kappa_{0}\right)} .
$$

The history parameter $\kappa$ tracks the maximum value of the equivalent strain during the simulation, which starts at an initial value of $\kappa_{0}$ and is limited by $\kappa_{u}$. In the quasi static analysis, the equivalent strain $\tilde{\varepsilon}_{n+1}$ at time $t_{n+1}=t_{n}+\Delta t_{n+1}$ is first determined and compared to the history parameter from the previous time step, from which the damage increment is computed:

$$
\Delta d_{d, n+1}=\left\{\begin{array}{cl}
\frac{\left(f_{n+1}-d_{d, n}\right) \Delta t_{n+1}}{\eta+\Delta t_{n+1}} & \text { for } \tilde{\varepsilon}_{n+1}>\kappa_{n} \\
0 & \text { for } 0 \leq \tilde{\varepsilon}_{n+1} \leq \kappa_{n}
\end{array}\right.
$$

In this equation, $\eta$ is a relaxation parameter, which is taken close to zero, and $f_{n+1}$ is the value of the damage loading function, which is equal to $d_{d}\left(\tilde{\varepsilon}_{n+1}\right)$. From this damage increment, the total damage parameter is evaluated. Using the inverse relation of the softening law given in Eq. (4), the history parameter is updated. In order to couple this model to the diffusion-reaction models, the total strain will be defined as $\boldsymbol{\varepsilon}=\boldsymbol{\varepsilon}^{e}+\boldsymbol{\varepsilon}^{c}$ where $\boldsymbol{\varepsilon}^{e}$ is the elastic strain tensor and $\boldsymbol{\varepsilon}^{c}$ is defined as:

$$
\boldsymbol{\varepsilon}^{c}=d_{c} \varepsilon^{g} \boldsymbol{I},
$$




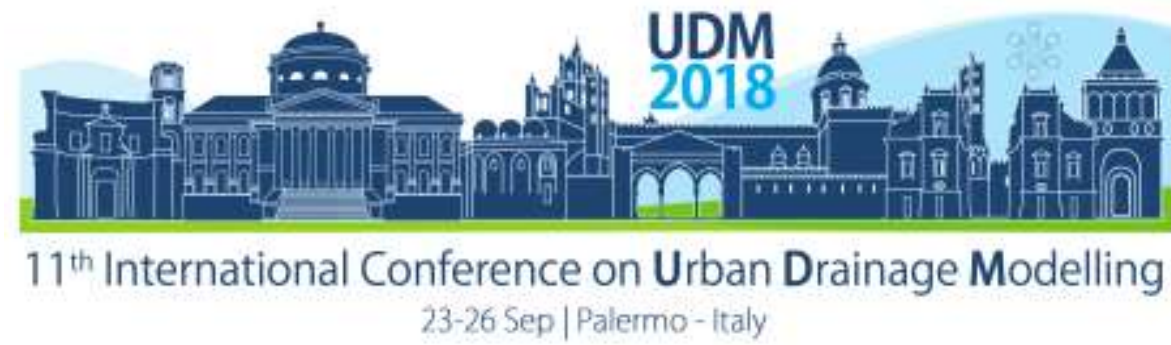

where $\varepsilon^{g}$ is the growth strain associated with the formation of gypsum and $I$ is the second order identity tensor. The continuum damage model is currently under development and will be benchmarked with other research and experiments.

\section{Conclusions}

The chemical-mechanical processes relevant to the biogenic sulphuric corrosion of concrete sewer pipes have been reviewed and numerically implemented in a coupled finite element model. The coupled formulation is based on linear diffusion laws and an isotropic continuum damage model. In future work, the chemo-mechanical model will be extended to take into account the effect of damage on the diffusion properties, and the flow of $\mathrm{H}_{2} \mathrm{~S}$ through the head space of the pipe will be simulated by means of a computational fluid dynamics model. Further, the coupling between the mechanical and chemical part needs to be adequately accounted for by means of a chemical strain related to gypsum precipitation. The model will be calibrated and validated with data from laboratory tests and in-situ experiments.

\section{References}

A.Campos, C.M.Lopez, \& A.Aguado (2015). Diffusion-reaction model for the internal sulfate attack in concrete. Construction and Building Materials, 102, 531-540.

Allahverdi, A., \& Skvara, F. (2000). Acidic corrosion of hydrated cement based materials; part 1 - mechanism of the phenomenon. Ceramics - Silikaty, 44, 114-120.

Ayoub, G., N.Azar, Fadel, M. E., \& B.Hamad (2004). Assessment of hydrogen sulphide corrosion of cementitious sewer pipes: a case study. Urban Water Journal, 1, 39-53.

C.D.Parker (1945). The corrosion of concrete. Australian Journal of Experimental Biology and Medical Science, 23, 81-98.

Cefis, N., \& Comi, C. (2014). Damage modelling in concrete subject to sulfate attack. Frattura ed Integrità Strutturale, 29, 222-229.

Davis, J., Nica, D., Shields, K., \& Roberts, D. (1998). Analysis of concrete from corroded sewer pipe. International Biodeterioration \& Biodegradation, 42, 75-84.

E.Oosterom, \& R.Hermans (2013). Riolering in beeld. Benchmark Rioleringszorg 2013, (pp. 1-144).

Gu, J., T.E.Ford, N.S.Berke, \& R.Mitchell (1998). Biodeterioration of concrete by the fungus fusarium. International Biodeterioration and Biodegradation, 41, 101-109.

J.Vollertsen, Nielsen, A., Jensen, H.,Wium-Andersen, T., \& Hvitved-Jacobsen, T. (2008). Corrosion of concrete sewers - the kinetics of hydrogen sulfide oxidation. Science of the Total Environment, 394, 162-170.

K.S.Cho, \& T.Mori (1995). A newly isolated fungus participates in the corrosion of concrete sewer pipes. Water Science and Technology, 31, 263-271.

M.Alexander, A.Bertron, \& de Belie, N. (2013). Performance of Cement-Based Materials in Aggressive Aqueous Environments. Springer.

M.O'Connell, McNally, C., \& Richardson, M. (2010). Biochemical attack on concrete in wastewater applications; a state of the art review. Cement \& Concrete Composites, 32, 479-485.

Monteny, J., Vincke, E., Beeldens, A., de Belie, N., Taerwe, L., van Gemert, D., \& Verstraete, W. (2000). Chemical, microbiological, and in situ test methods for biogenic sulfuric acid corrosion of concrete. Cement and Concrete Research, 30, 623-634.

N.Ismail, T.Nonaka, S.Noda, \& T.Mori (1993). Effect of carbonation on microbial corrosion of concrete. Journal of Construction Management and Engineering, 20, 133-138.

P.K.Mehta (1985). Studies on chemical resistance of low water/cement ratio concretes. Cement and Concrete Research, 15, 969-978.

R.L.Islander, J.S.Devinny, F.Mansfeld, A.Postyn, \& H.Shih (1991). Microbial ecology of crown corrosion in sewers. Journal of Environmental Engineering, 117, 751-770.

T.Gutberlet, H.Hilbig, \& R.E.Beddoe (2015). Acid attack on hydrated cement - effect of mineral acids on the degradation process. Cement and Concrete Research, 74, 35-43.

T.Mori, T.Nonaka, K.Tazaki, M.Koga, Y.Hikosaka, \& S.Noda (1991). Interaction of nutrients, moisture and ph on microbial corrosion of concrete sewer pipes. Water Research, 26, 29-37.

Vincke, E., Boon, N., \& Verstraete, W. (2001). Analysis of the microbial communities on corroded concrete sewer pipes a case study. Applied microbiology and biotechnology, 57, 776-785. 


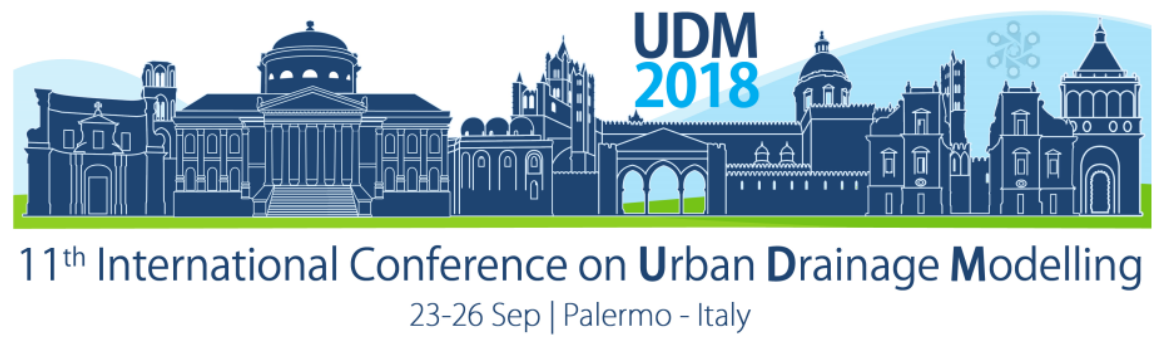

\title{
Virtual modelling of city defence from spring flood with help of water reservoir
}

\author{
Vitaly llinich ${ }^{1}$, Alex Perminov ${ }^{2}$ and Fidanna Khairullina ${ }^{3}$ \\ ${ }^{1}$ Russian Timiryazev State Agrarian University, Meteorology, Moscow, Russia \\ ${ }^{2}$ Russian Timiryazev State Agrarian University, Hydrology, Moscow, Russia \\ ${ }^{3}$ Russian Timiryazev State Agrarian University, Hydrology, Moscow, Russia
}

\begin{abstract}
The article is dedicated to research of possibility for defence of city from spring flood on the base of modelling of the flood mitigation with help flood control by virtual small water reservoirs located in different places of the river system. Reducing of the flooding occurs due to the limited hydraulic flow capacity of the water flow by dam spillways without flood control by people. Preliminarily the main river basin characteristics are evaluated on the base of GIS. Topographical dependences between water storages of virtual water reservoir and corresponded and levels are determined in respect to different dam location with help of GIS too. The offered model is represented on the example of concrete river basin. Results have showed relevance of the model for flood mitigation on the river basin.
\end{abstract}

Keywords: spring flood; city defend; water reservoir

\section{INTRODUCTION}

A significant territory of Russia and several of north European countries have a big spring flood which comes to inundation of different cities and other settlements. Especially often such facts have place on foothills with sun slopes where flood waters have a rapid concentration. In such cases a dam of water reservoir before city can defend of city territory and people from inundation. So, main aim of the research is to evaluate approach to decreasing of city inundation by placing new small water reservoir (pond) in river system with dam before city. Reducing the degree of inundation should occur due to the limited hydraulic flow capacity by spillway of the dam.

The approach requires the mathematical modeling of the following components:

- $\quad$ the surface of the river basin with its main physical and geographical characteristics using a GIS system;

- $\quad$ hydrological modeling of spring flood runoff to the virtual water reservoir;

- modeling of flood routing through spillway constructions of dam.

Modeling should provide:

- the possibility of obtaining the hydrographic characteristics of virtual reservoirs (dependence between water levels and volumes) with their various locations on the rivers of the entire river basin on the base of GIS;

- $\quad$ the possibility of analyzing flood control by water reservoirs located in different places of river system and having the dams with different sizes and location of spillways.

\section{MATERIALS AND METHODS}

The city Temyasovo on the river Sakmara was chosen as a research object. The river has feed by snowmelt water more $80 \%$. The square of the river catchment in Temyasovo is small and consists near $250 \mathrm{~km}^{2}$. However, the city is inundated almost every year. This occurs because 


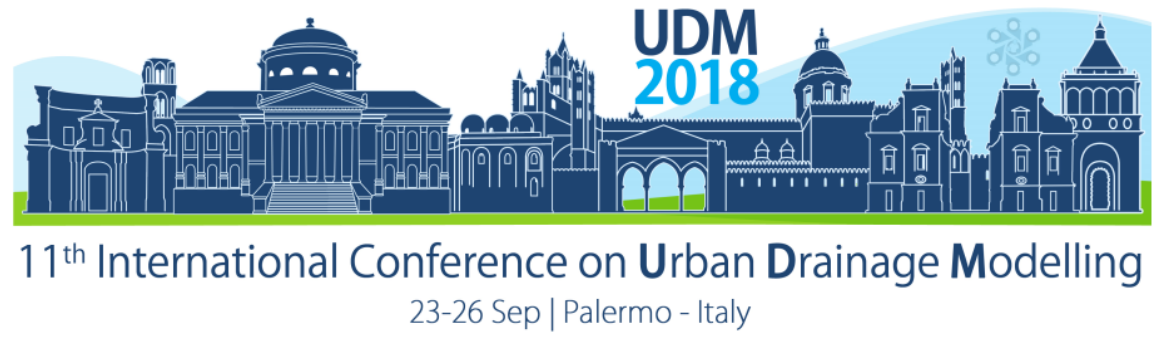

the catchment of the Sakmara is located in foothill of the South Ural mountain and its slopes are looking on sun and have significant gradient. So the snowmelt occurs quickly and time of runoff concentration is small. Accordingly we have very much water discharge almost every year.

Surface of catchment represented with help of Geoinformation system Golden Software Surfer. The GIS is currently the industry standard for constructing graphic images of the Earth's surface. The advantage of the program are the interpolation algorithms inherent in it, which, with the highest quality, allow the creation of digital surface models from spatially unevenly distributed data. The maps obtained with help of GIS represented on figures 1 and 2. A map was created with help of GIS (Golden Software Surfer v13). It allows determine hydro-graphic characteristics of any catchment area within the presented river system with needed scale. For example, there is possibility to determine: square of the concreate catchment and its average slope, length and slope of the river, which are needed for calculation maximum water discharge ac-cording to hydrological model

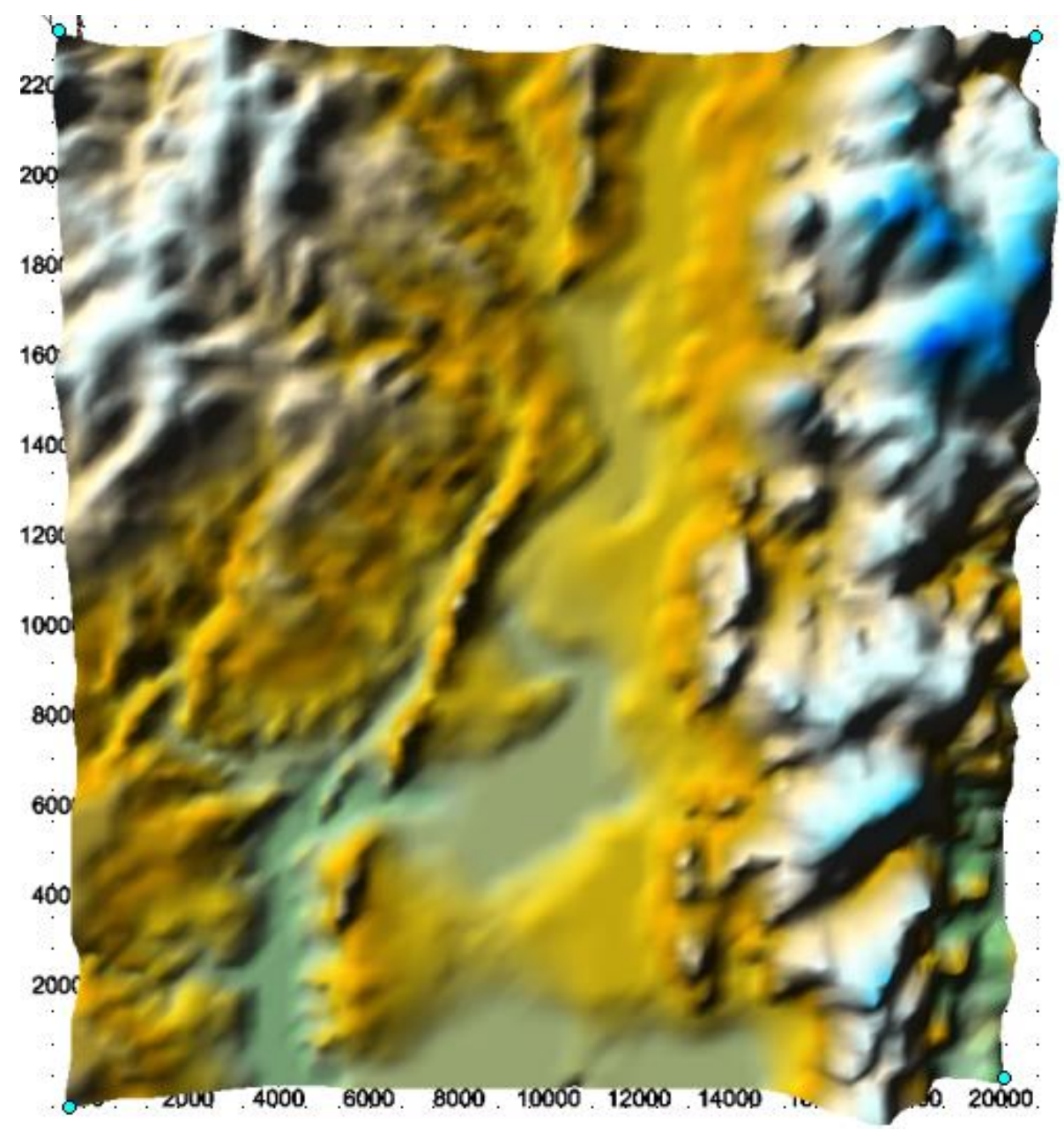

Figure 1. Part of catchment of river Sakmara. 


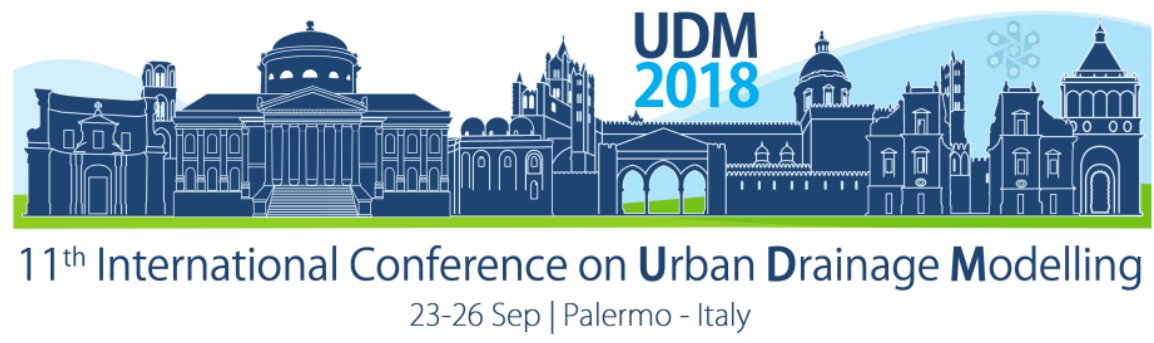

We can see on fig. 1 part of river basin Sakmara in 3D model. Fig.2 represents map where any catchment for virtual water reservoir may be imagined and the main catchment characteristics may be determined automatically with help of GIS.

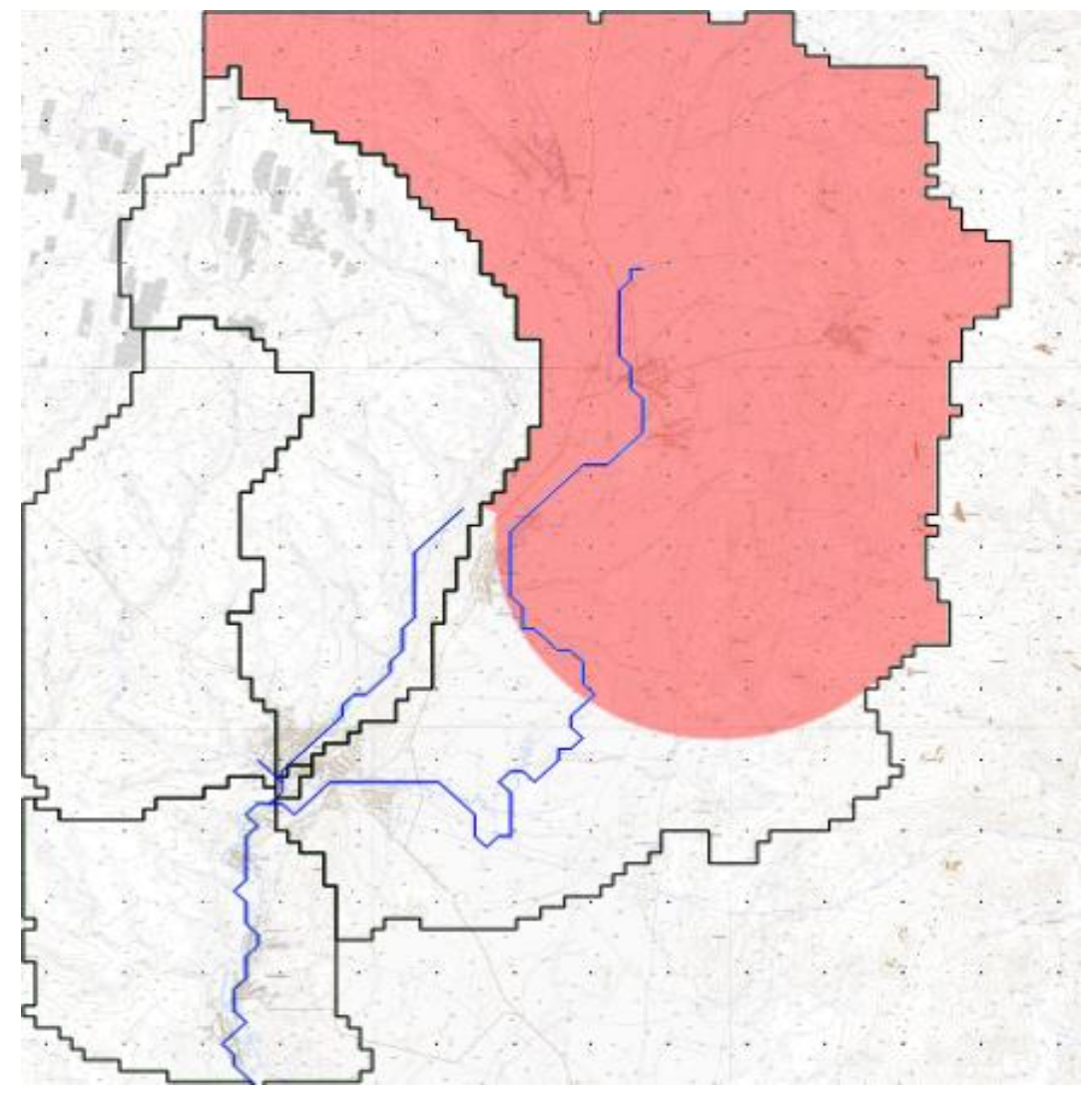

Figure 2. Part of river basin for the dam of virtual water reservoir.

Model of spring flood was represented by formula (1) in respect to the maximum water discharge. The formula is recommended by the regulatory documents (SP 33-101-2003, 2003) of the Russian Federation for projects of hydro technical constructions on small rivers.

$$
Q_{p \%}=q_{p \%} \cdot F=\frac{K_{0} h_{p \%} \mu \delta \delta_{1} \delta_{2}}{\left(F+F_{1}\right)^{n_{1}}} \cdot F, \mathrm{M}^{3} / \mathrm{c}
$$

Here: F- square of catchment; $\mathrm{q}_{\mathrm{p} \%}$ - modulus of flow; $\mathrm{K}_{\mathrm{o}}$ - parameter characterizes velocity of snowmelt and time of runoff concentration; $\mathrm{hp} \%$ - the depth $(\mathrm{mm})$ of all spring flood volume for probability $\mathrm{P} \% ; \mu$ - coefficient which accounts difference between statistical parameters of depth and water maximum discharge; $\delta, \delta_{1}, \delta_{2}$ - coefficients take to consideration the decreasing of water maximum discharges due to: lakes, forest and swamps on catchment; $F_{1}$ - the added square of catchment for the accounting of decreasing ratio $\mathrm{q} / \mathrm{h}$ with help of regional parameter $\mathrm{n}_{1}$

The parameters $\mathrm{K}_{\mathrm{o}}, \mathrm{h}_{\mathrm{p} \%}, \mu$ are determined according to regional maps and schemas (SP 33101-2003, 2003); parameters $F, \delta, \delta_{1}, \delta_{2}$ and several coefficients for determining of parameters $\mathrm{hp} \%$ and $\mu$ - are taken with the obtained GIS maps. 


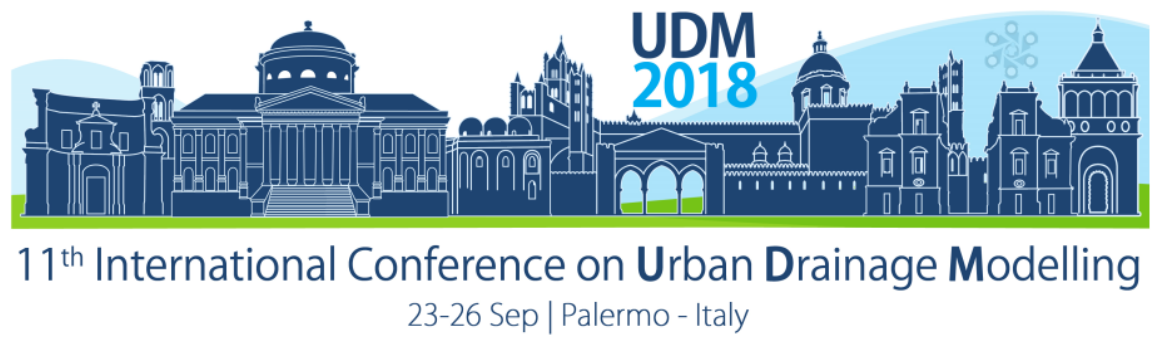

Values of maximum water discharges are calculated according to formula 1 for different locations of virtual reservoir dam. Hydrograph of runoff calculated according to maximum water discharge and special regional schema.

A hydrograph of the discharges through overflow spillway depends on form and sizes of dam spillway and place of its location on the river, that can be changed. Accordingly, the bathygraphical curve of water reservoir (dependence between water storages and water level $-V(Z)$ can be changed with help of GIS. Spillways were represented by complex of tube and straight drop spillway. Hydrograph of draft discharges through complex spillway was determined with help of Kocherin method. (Ovcharov E.E., llinitch V.V., Proschliakov I.V. and oth.,2008).

\section{RESULTS AND DISCUSSION}

The runoff hydrograph to water reservoir is represented on the fig. 3 by blue color. The hydrograph was obtained with maximum discharge $Q_{1 \%}=193 \mathrm{~m}^{3} / \mathrm{s}$ according to parameters determined on the base of GIS and according to requirements of documents [1].

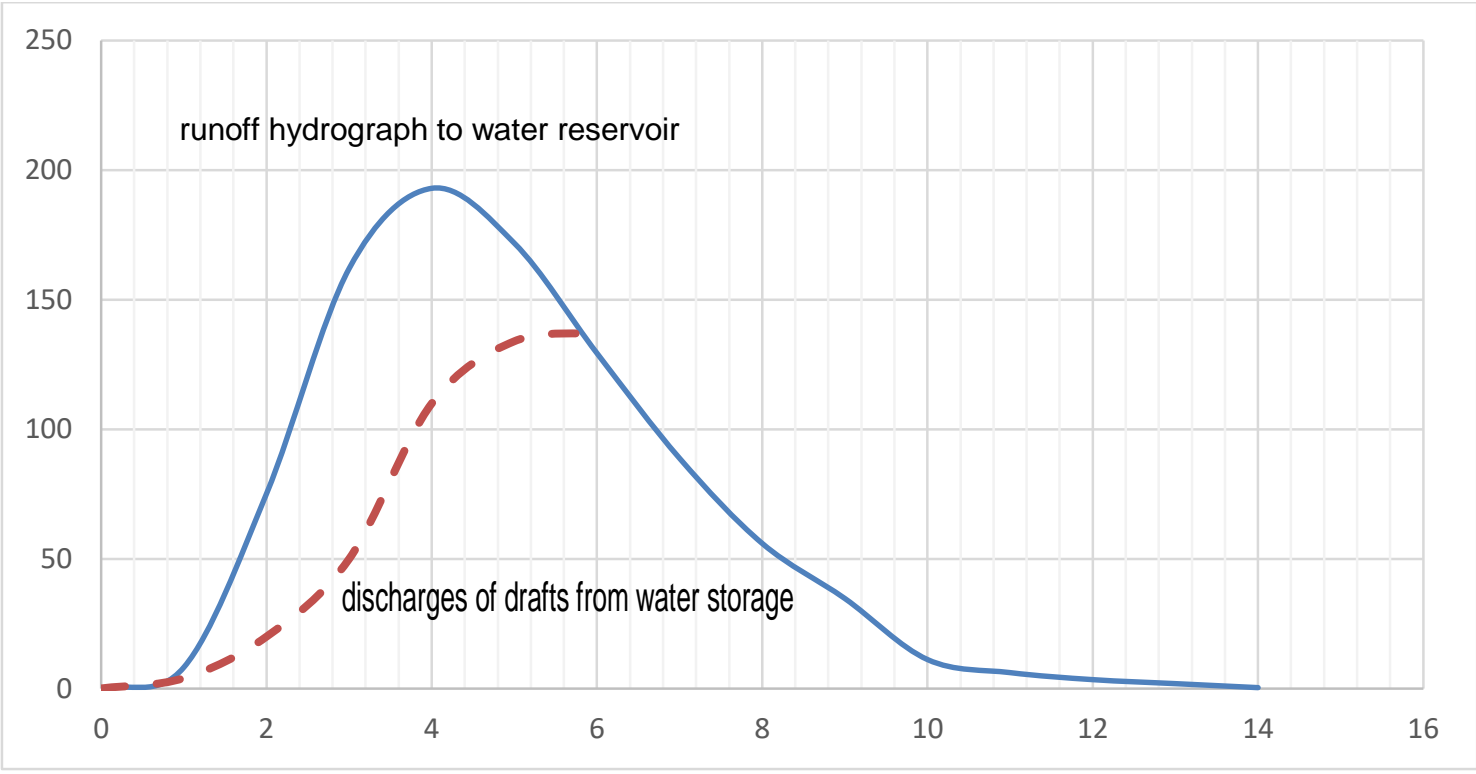

Figure 3. Graphs of runoff $\left(\mathrm{m}^{3} / \mathrm{s}\right)$ to water reservoir and of discharges of drafts from water storage in respect to time (dailies).

We can see on the fig.3 that maximum water discharge has been decreased significantly to $140 \mathrm{~m}^{3} / \mathrm{s}$. So, we have mitigation of city inundation.

\section{CONCLUSIONS.}

The represented approach provides a possibility to consider different variants of the locations of the flood-control reservoirs and parameters of its dam and spillways, and also corresponding variants of inundation on city territory. 
Proceedings of the 11th Int. Conference on Urban Drainage Modelling, 23-26 Sep. 2018, Palermo (ITALY). Ed. prof. Giorgio Mannina

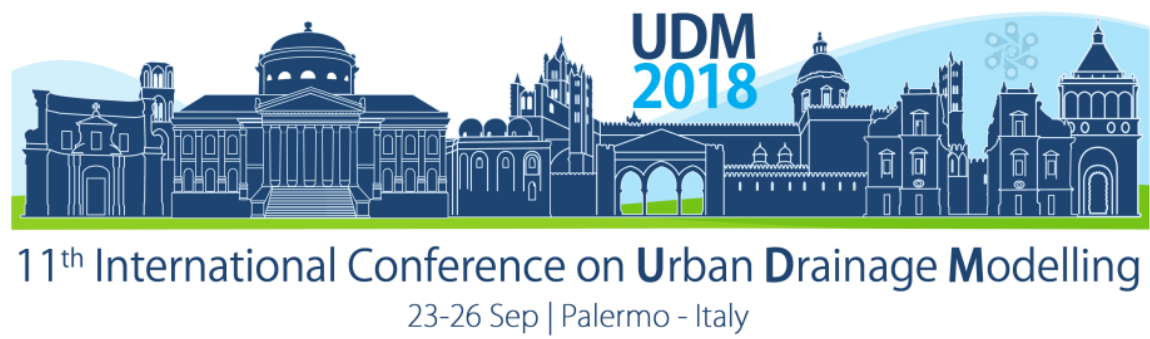

\section{References}

SP 33-101-2003. Determination of design hydrological performance, Moscow, 2003, P. 70 (Rus).

Ovcharov E.E., Ilinitch V.V., Proschliakov I.V. and oth..(2008) Testbook "Hydrology and regulation of ranoff", Minsk, 2008, p 242. 


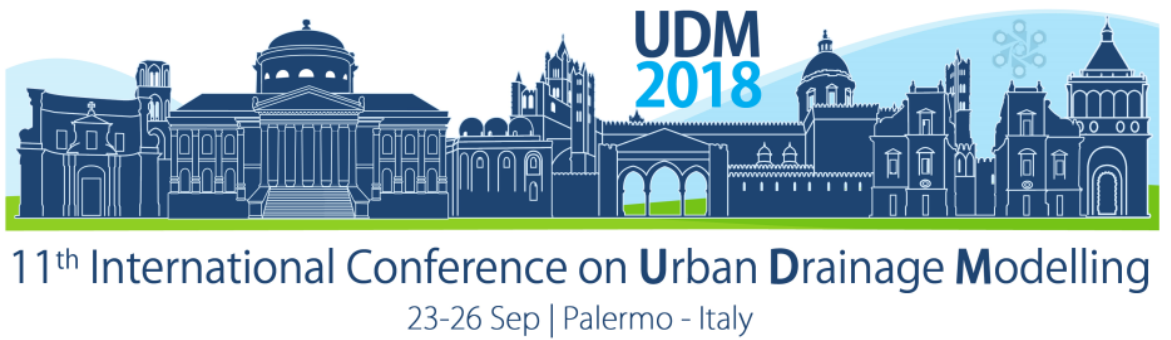

\title{
Visual Risk Communication of Urban Flooding in 3D Environments based on Terrestrial Laser Scanning
}

\author{
Rosa De Santis ${ }^{1}$, Francesco Macchione ${ }^{1}$, Pierfranco Costabile ${ }^{1}$ and Carmelina Costanzo ${ }^{1}$ \\ ${ }^{1}$ LAMPIT (Laboratorio di Modellistica numerica per la Protezione Idraulica del Territorio), \\ Environmental and Chemical Engineering, University of Calabria, 87036 Rende, Italy. \\ (rosa.desantis@unical.it, francesco.macchione@unical.it, pierfranco.costabile@unical.it,
} carmen.costanzo@unical.it)

\begin{abstract}
In this paper, attention is focused on the extension of the urban flood-mapping concept from an eminently cartographic context to a three-dimensional one, by applying techniques for the representations of urban flood inundation in a virtual environment for hazard communication purposes. In particular, visual risk communication of urban flooding in 3D environments, based on terrestrial laser scanning, has been analyzed here. Moreover, a web-based rendering of point clouds for the visualization of urban flooding has been explored in order to highlight its benefits in urban flood risk communication.
\end{abstract}

Keywords: Urban flood, visual risk communication, 3-D mapping

\section{INTRODUCTION}

Pluvial, fluvial and coastal flooding represent a major threat in urban areas. Risk mapping is currently designed for risk management. The state of art about the flood mapping comprehension reveals that this tool often does not provide a strong support to stakeholders in flood risk management (Leskens et al., 2014). Therefore, there is a big need for more research on the effectiveness of visual risk communication in terms of risk awareness, knowledge and behaviour. Since the importance of practitioners participation has been highlighted (Delgado-Galván et al., 2014; Maskrey et al., 2016), the development of new risk visual tools should simplify the identification of flood hazard and suggest feasible approaches to enhance flood hazard perception, to raise awareness in all stakeholders and influence behavior of people in emergency.

An effective tool might be represented by visualizations of flood inundation in a 3D virtual environment coping responses to flooding risks, improve the interpretability of disaster data and the effectiveness of decision making processes (Qiu et al., 2017). In this context, Macchione et al. (2018), De Santis et al. (2018) proposed a quick workflow for the representation of two-dimensional hydraulic simulations within a 3-D virtual reality environment, essentially based on the extrusion of building footprints from airborne LIDAR data and texture-mapping technique, to improve the realism of the building model façades (see figure 1). The hydraulic simulations have been carried out using a 2-D numerical model, previously developed and applied in several situations, based on the shallow water equations (Costabile et al., 2017; Macchione et al., 2016). The results obtained with this approach allow one to provide an overall look at a neighbourhood level, but not at the level of the individual buildings in detail. Therefore, for a correct geometrical description of façade features, terrestrial laser scanning (TLS) acquisition is required.

Another trend for disseminating and visualizing 3D data is the application of web visualisations. This reduces the need for tools at the user side because dissemination and visualisation are interconnected (Kehl, 2015). To promote this goal, the authors introduce a preliminary web- 


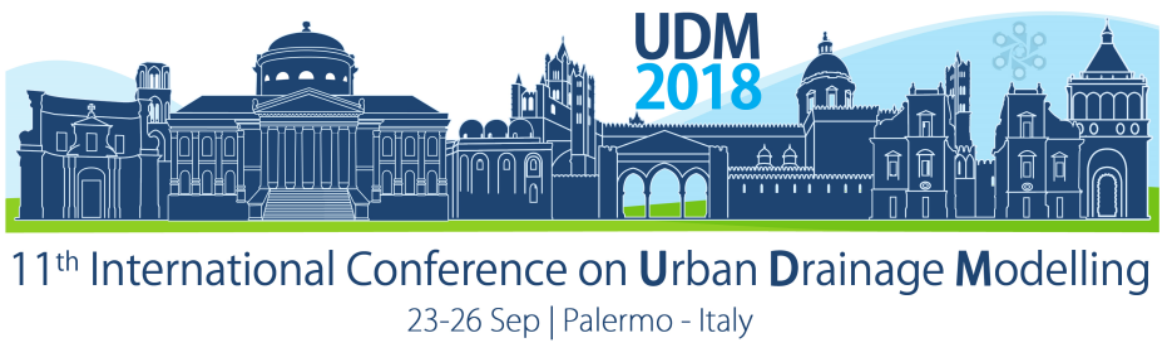

based rendering of large point cloud for visualizating flooding scenarios. In particular, these issues are discussed with reference to a hypothetical urban flooding of the old town of Cosenza (South of Italy) located at the confluence of the Busento and the Crati rivers.

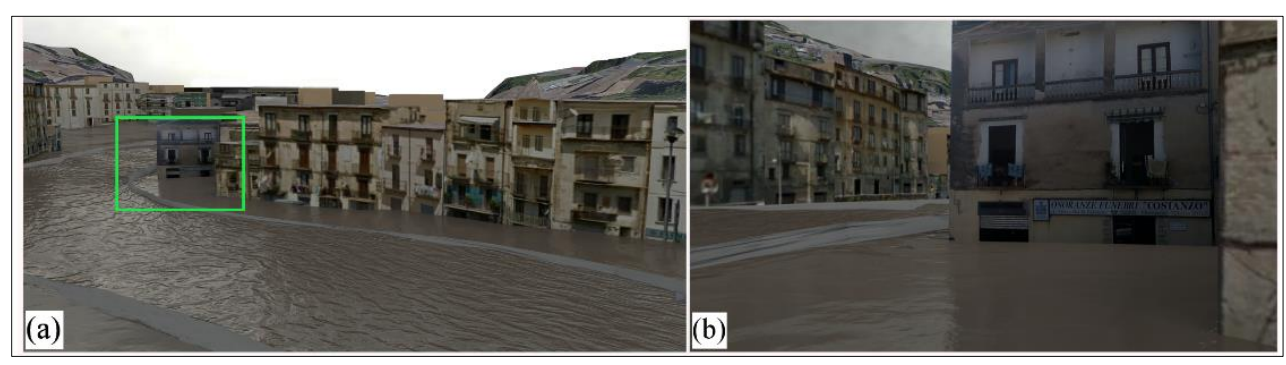

Figure 1. (a) An example of 3-D representation of the flood map using texture mapping; (b) visualization of the interaction between flood level and building façade highlighted in the green box (from De Santis et al., 2018).

Though these ideas are applied within the context of a fluvial urban flooding, they can be immediately extended to a pluvial urban flooding, in which the drainage system plays a significant role (Gómez et al. 2011).

\section{TERRESTRIAL LASER SCANNING SUPPORTING URBAN FLOOD MAP IN 3-D VIRTUAL ENVIRONMENTS}

To obtain a fully 3-D description of the environment of interest, laser-scanning technology has emerged in recent years as a leading source for automated acquisition of buildings, vegetation, terrain, etc., mainly due to the direct measurements of the surface topography both accurately and densely (Maragkogiannis et al., 2014; Wallace et al., 2016).

A local survey of the building façades, streets and levees was made in the area of interest. Generally, the terrestrial laser scanning procedure required some pre-processing steps, including: the project planning, scanning, registration/georeferencing, filtering and visualization (see De Santis et al., 2018). The raw data from each scanning location was georeferenced, registered and filtered using the Leica Cyclone 9.0 (Leica Geosystems, AG). Although preprocessing of large point datasets require some efforts, it can be done in a semi-automatic mode and the result can be visualised outside the processing software - in a dedicated virtual environment, over the web, on mobile device - enabling water experts to promote the discussions between practitioners and decision makers in developing efficient worst case scenario and evacuation plans. An initial screening level on the usability of terrestrial LiDAR surveys for flood hazard communication was carried out directly in the 3D point cloud processing software CloudCompare. The figure $2 \mathrm{a}$ shows the properties of point cloud scans, coupled to output of water depths in single band pseudo-colour. The user can determinate local building water level directly by picking points on façade, in order to display corresponding local $z$ coordinate (see the Figure $2 b$ ). Water surface is not realistically rendered into this $3 \mathrm{D}$ visualization because CloudCompare do not have a render engine. In addition, visualisation of large point clouds within the software is slow and non-intuitive.

\subsection{Web-based rendering of point clouds for the visualization of urban flooding}

The previous approach might be improved in a rendering system that combines large-scale LIDAR data and realistic water visualizations (Leskens et al.2017) with an interactive speed. To promote this goal, the authors explored the visualization of urban flooding scenarios using free open source WebGL based point cloud renderers. One of the main advantages of 3D web visualization of flood scenario is to allow end-users interactively navigating the modelling 


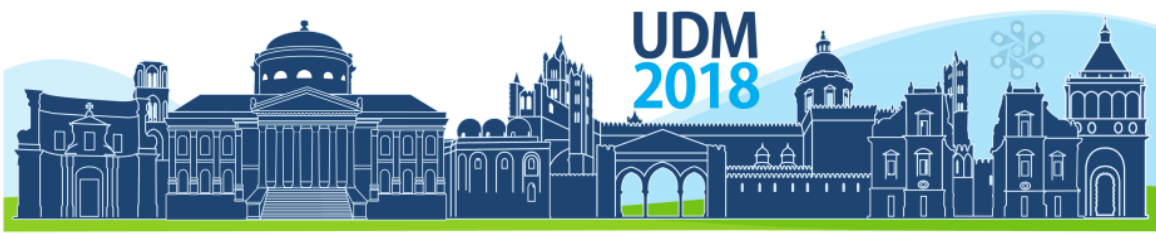

$11^{\text {th }}$ International Conference on Urban Drainage Modelling

23-26 Sep | Palermo - Italy

results using a standard browser without third-party applications. A user can easily explore the 3D space to investigate the flood impact to individual properties and their surroundings in detail. The flood risk managers can more effectively explain the impact of flooding to the stakeholders. This will improve the risk communication among participants such that better adaptation strategies can be developed, evaluated and visualised to support decision makings for strengthen the resilience to flooding (Chen et al., 2018).

The renderer implementation presented here has been based on Potree (www.potree.org) that uses standard web technologies such as WebGL, three.js and Javascript, and does not require additional plugins. Potree relies on the reorganization of the point cloud data into a multiresolution octree data structure and validates raw point cloud data without the need for a timeintensive and potentially costly meshing step. The focus on large point clouds and a variety of measuring tools also allows users to potentially analyse water depths as point vertex attribute. This tool might have a lot of benefits, especially for the visual analysis of evacuation paths.
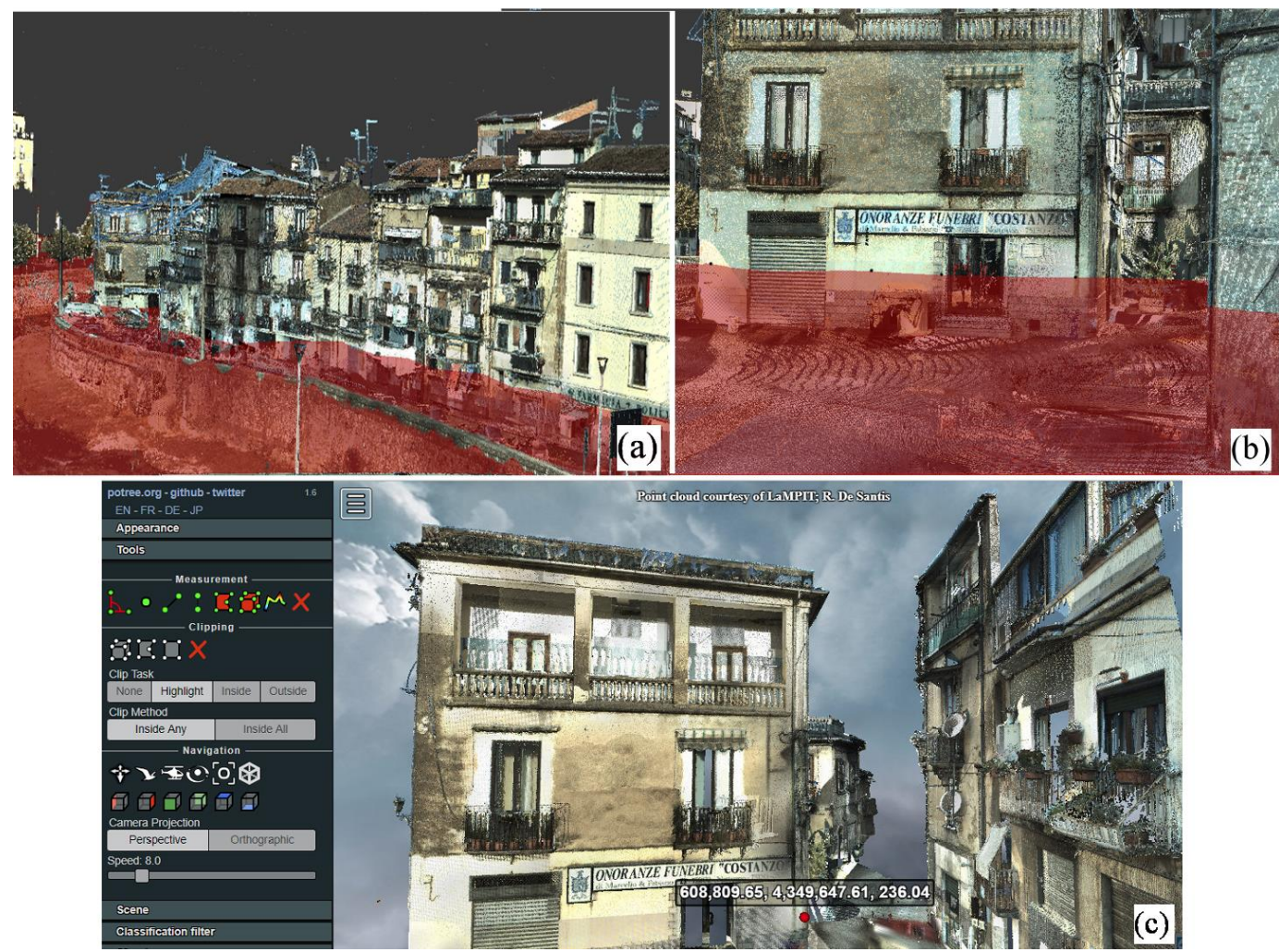

Figure 2. (a) An example of 3-D representation of the flood map using TLS data; (b) detail of visualization of the interaction between flood level and building façade (water surface depicted in red); (c) potree.html file opened in a local web server

Figure $2 \mathrm{c}$ shows the potree.html file opened in a local web server. Compared to figure $2 \mathrm{~b}$, it is evident that the potree viewer significantly improved the rendering of the building. In this preliminary step, water depths are not displayed on the user interface yet because the analysis of the Potree viewer has been limited to the evaluation of the point cloud web rendering. Obviously, the final goal is to create a product like similar to that shown in figure $2 a, b$ but reproducing a realistic rendering of water surface, in order to generate an accessible and usable web product for practitioner and lay-people. 


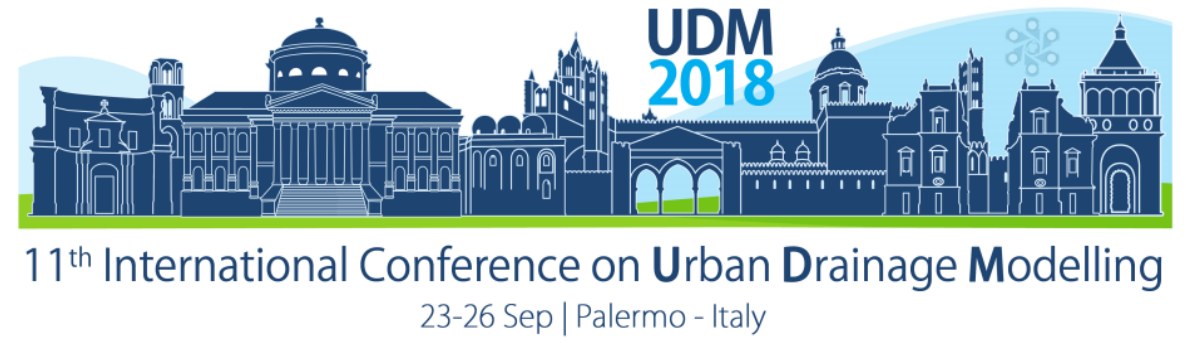

\section{CONCLUSIONS}

The traditional flood hazard maps do not allow a non-expert audience an immediate readability of flooding effects and, consequently, could be not helpful to all the stakeholders involved in urban flood risk management. In order to enhance flood hazard perception, a visual risk communication of urban flooding in 3D environments, based on terrestrial laser scanning, has been analyzed here. In particular, a web-based rendering of point clouds for the visualization of urban flooding has been explored. The challenge of this approach is to provide rapid visualisation, manipulation and analysis of complex scenes, overcoming the gap between large-scale mapping LiDAR data, realistic water visualization and software and hardware systems. Representations like those shown in the paper might be very useful to improve the global awareness of the flood severity and the related potential damages.

In the future, the authors will implement a WebGL -based computing framework that couples physically based shallow water models with real-time realistic rendering water simulation.

\section{References}

Costabile, P., Costanzo, C., and Macchione, F. (2017) Performances and limitations of the diffusive approximation of the 2-d shallow water equations for flood simulation in urban and rural areas. Applied Numerical Mathematics, 116: 141-156.

Chen, A. S., Khoury, M., Vamvakeridou-Lyroudia, L., Stewart, D., Wood, M., Savic, D. A. and Djordjevic, S. (2018) $3 \mathrm{D}$ visualisation tool for improving the resilience to urban and coastal flooding in Torbay, UK. Procedia Eng, 212, 809-815.

De Santis R., Macchione, F., Costabile, P. and Costanzo C. (2018) A comparative analysis of 3-D representations of urban flood map in virtual environments for hazard communication purposes. In: RiverFlow 2018. Accepted.

Delgado-Galván, X., Izquierdo, J., Benítez, J. and Pérez-García, R. (2014) Joint stakeholder decision-making on the management of the Silao- Romita aquifer using AHP, Environ. Model. Softw. 51, 310-322.

Gómez, M., Macchione, F. and Russo, B. (2011) Methodologies to study the surface hydraulic behaviour of urban catchments during storm events, Water Science and Technology 63 (11), 2666-2673.

Kehl C. (2015) Disseminating large-scale semantic 3D landscape models using open visualisation platforms. EJG 6(2), 51-68.

Leskens, J.G., Brugnach, M., Hoekstra, A.Y. and Schuurmans, W. (2014) Why are decisions in flood disasters management so poorly supported by information from flood models?, Environ. Model. Softw. 53, 53-61.

Leskens, J.G., Kehl, C., Tutenel, T., Kol, T., de Haan, G., Stelling, G. and Eisemann, E. (2017) An interactive simulation and visualization tool for flood analysis usable for practitioners. Mitig. Adapt. Strat GI. 22(2), 307324.

Macchione F, P. Costabile, C. Costanzo, R. De Santis. (2018) Moving to 3-D flood hazard maps for enhancing risk communication.. Under review.

Macchione, F., Costabile, P., Costanzo, C., Lorenzo, G.D., Razdar, B. (2016) Dam breach modelling: Influence on downstream water levels and a proposal of a physically based module for flood propagation software. J. Hydroinf., 18 (4) 615-633.

Maragkogiannis, K., Kolokotsa, D., Maravelakis, E. and Konstantaras, A. (2014) Combining terrestrial laser scanning and computational fluid dynamics for the study of the urban thermal environment. Sustain. Cities Soc. 13, 207-216.

Maskrey, S.A., Mount, N.J., Thorne, C.R. and Dryden, I. (2016) Participatory modelling for stakeholder involvement in the development of flood risk management intervention options. Environ. Modell. Soft. 82, 275-294.

Qiu, L., Du, Z., Zhu, Q. and Fan, Y. (2017) An integrated flood management system based on linking environmental models and disastersrelated data, Environ. Model. Softw. 91, 111-126.

Wallace, L., Gupta, V., Reinke, K. and Jones, S. (2016) An assessment of pre- and post fire near surface fuel hazard in an australian dry sclerophyll forest using point cloud data captured using a Terrestrial Laser Scanner. Remote Sens. 8(8), 679. 


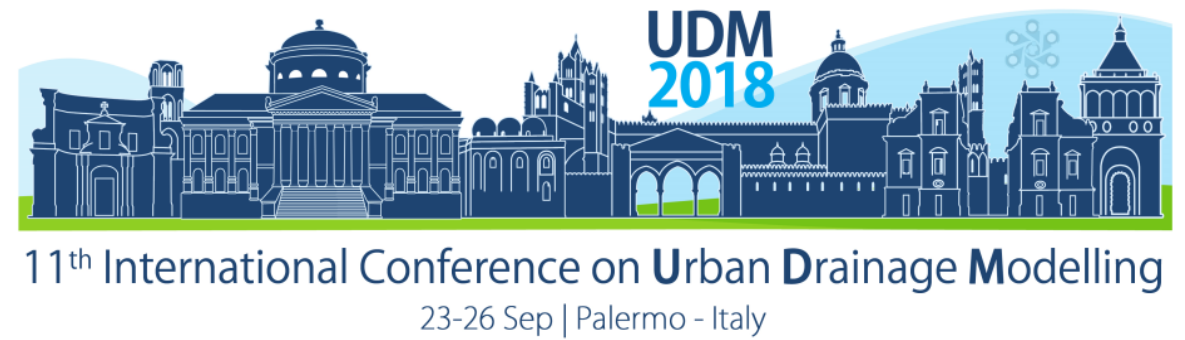

\title{
Water Quality Characterization of Irrigation and Storm Runoff for a Nursery
}

\author{
Mohammad Nayeb Yazdi ${ }^{1}$, David J. Sample1, Durelle Scott ${ }^{1}$, and James S. Owen ${ }^{2}$ \\ ${ }^{1}$ Virginia Polytechnic Institute and State University, Department of Biological Systems Engineering, Virginia \\ Beach, USA \\ ${ }^{2}$ Virginia Polytechnic Institute and State University, Department of Horticulture, Hampton Roads Agricultural \\ Research and Extension Centre, Virginia Beach, USA
}

\begin{abstract}
Commercial nurseries grow plants in containers on semi-permeable production areas. Fertilizer is added to the substrate or applied via irrigation to facilitate plant growth, the resulting runoff has increased levels of sediment, nitrogen and phosphorus compared to background. This runoff is often collected and recycled, but, if discharged, could negatively impact water bodies downstream. Several storm and irrigation runoff samples were collected from a mid-Atlantic nursery and analysed for $\mathrm{pH}$, electrical conductivity (EC), total suspended solid (TSS), total nitrogen (TN), and total phosphorus (TP). Samples were collected downstream of 5.2 hectare production area, which consisted of 1.82 ha in gravel roads and 3.38 ha in 26 pads, draining to a central ditch. The nursery was modelled using the Storm Water Management Model (SWMM), an urban drainage model, since runoff hydrographs behave similar to urban areas (i.e., flashy). A preliminary hydrologic and water quality calibration was performed with the limited dataset to assess the potential of using SWMM to characterize runoff. During irrigation, there was a direct relationship between runoff and TSS peaks, i.e., TSS peaks follow peak runoff, with a defined lag. In contrast, there was an inverse relationship between runoff peaks and concentrations of TN and TP. During irrigation, simulated event mean concentrations (EMCs) of TP, TN and TSS were 0.42, 2.77 and $36.0 \mathrm{mg} / \mathrm{L}$, respectively. SWMM was able to characterize the runoff well from the 5.2 ha area and can be potentially used to assess water quality treatment options if further calibrated data become available.
\end{abstract}

Keywords: Nursery, SWMM, urban drainage modelling, nonpoint source pollution, water quality

\section{INTRODUCTION}

Non-point source (NPS) water pollution is the most significant cause of surface water quality degradation (Chang et al., 2017). Precipitation, imperviousness, soil erosion, drainage, topography and land are examples of the many factors that influence NPS pollution (Chen et al., 2016; Guo et al., 2014). Agricultural runoff is one of the most important sources of NSP. Sixty percent of nursery crops are containerized'-grown above ground in containers using a porous growing media with little water or nutrient retention. Nurseries often locate on the fringe of urban areas for market reasons. Runoff from nurseries can contain significant loads of total phosphorous (TP), total nitrogen (TN) and total suspended solid (TSS), which can impair surface water if discharged (Majsztrik et al., 2017; White et al., 2011, 2010). Plants are grown on a semi-impervious surface known as a pad. Additionally, pads can be lined with impermeable liners to reduce leachate to groundwater and to facilitate runoff collection. Since pads occupy much of the land area of a typical nursery, they behave similar to an urban area (flashy hydrograph).

Despite the large scale of these operations, no studies are available that characterize nursery pad runoff quality. In order to address nursery runoff, a generalized model that characterizes 


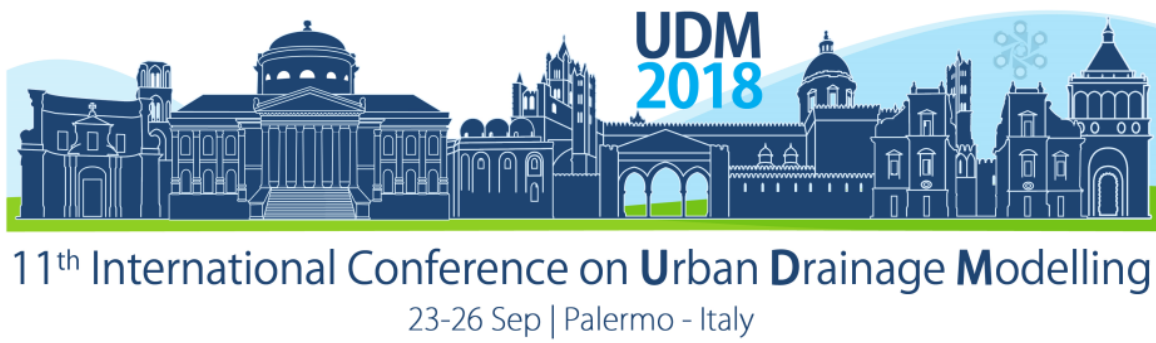

runoff using the pad as its smallest hydrologic response unit (HRU) is needed. The fate and transport of runoff pollutants such as TN, TP and TSS that occur during an irrigation or rainfall event depends on many of factors such as container substrate, pad soil characteristics and permeability, pad slope, precipitation, antecedent dry period and timing of rain/irrigation events. Pads at a typical nursery are normally less than $0.5 \mathrm{ha}$, and, due to the flashy nature of runoff, to capture runoff behaviour at this scale likely requires a sub hourly temporal resolution. The Storm Water Management Model (SWMM) (Rossman, 2010), which is an urban drainage model, is typically used at these scales.

The objectives of this study were (1) to characterize water quantity and quality from storm and irrigation runoff from a set of nursery pads in the mid-Atlantic region; (2) to estimate TSS, TN and TP loading during a variety of events; (3) and to assess the applicability of SWMM to simulate the site effectively. Using publically available geographic information system (GIS), a SWMM model was developed and calibrated to the collected data. Transport of TN, TP, and TSS was estimated, and the utility of using SWMM for this purpose was assessed.

\section{MATERIALS AND METHODS}

A nursery site in the Mid-Atlantic region was selected for this study. This site was chosen because of the proximity of a downstream collection channel that could accommodate installation of monitoring equipment. At the monitoring site, an $\mathrm{H}$-flume and an automatic sampler, ISCO (Lincoln, Nebraska) model 6712, an ISCO model 674 rain gage, and an ISCO model 730 bubbler flow meter were installed to measure flows and collect equal volume samples across runoff hydrographs. Water quality measurements was include TSS, TN, TP, $\mathrm{pH}$, and electrical conductivity. Sampling was conducted at the monitoring site for six irrigation events and four storm events. The maximum flow capacity for $\mathrm{H}$-flume at the outlet of monitoring site was $450 \mathrm{~L} / \mathrm{s}$. During all irrigation and storm events, runoff and a measurable water level was observed at the outlet; otherwise the outlet was dry. Precipitation frequency (PF) estimates for this case study were taken from the National Oceanic and Atmospheric Administration (NOAA) ATLAS 14 (NOAA, 2016);for 1-year, 1-hr and 3-hr, precipitation depths are expect to be $36 \mathrm{~mm}$ and $45 \mathrm{~mm}$, respectively. Thus, precipitation depths for our storm events were likely less than those for a 1-year return period.

Next, a SWMM Model was developed utilizing site and monitoring data. This included property boundaries, soils, land use, hydrography, and digital elevation models. Hydraulic system information (pipe inverts, diameters, ditch geometry, etc.) were taken using our own measurements. Precipitation data was measured on site using an ISCO model 674 rain gage. Runoff and water quality constituent loads and/or concentrations were the outputs of the SWMM model. We used generally accepted criteria for evaluating calibration, including coefficient of determination $\left(R^{2}\right)$, Nash Sutcliffe Efficiency (NSE), and Percent Bias (PBIAS). $R^{2}$ describe the degree of collinearity between simulated and observed data and ranges from 0 to 1 , values close to 1 indicate less variability (Nasr et al., 2007; Seong et al., 2015). $R^{2}$ greater than 0.5 is generally considered satisfactory. NSE is a normalized statistic which indicates how well the plot of observed versus simulated data fits when compared with that of a simple average (Nash and Sutcliffe, 1970). A value of NSE close to 1 is generally considered an excellent level of performance. Zero value of PBIAS indicates model's prediction accurately, while positive and negative values indicate under-estimation and over-estimation of model, respectively (Gupta et al., 1999). 


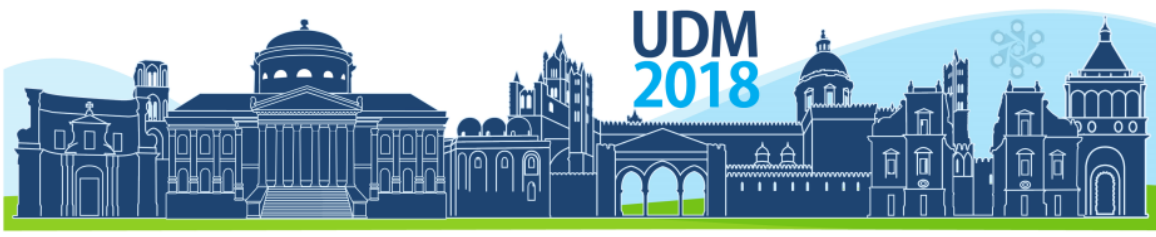

$11^{\text {th }}$ International Conference on Urban Drainage Modelling

23-26 Sep | Palermo - Italy

\section{RESULTS AND DISCUSSION}

\subsection{EMCs for Pollutants}

Event mean concentration (EMC) is commonly used to characterize runoff water quality. Runoff EMCs were estimated by field monitoring results. We calculated EMCs for TSS, TP, and TN in runoff from each irrigation and storm events (Table 1). The highest TSS, TP and TN EMCs were produced during storm events due to high intensities of rainfall. The mean and highest values of TSS concentrations during irrigation events were $30.44 \mathrm{mg} / \mathrm{L}$ and $41.61 \mathrm{mg} / \mathrm{L}$, respectively, while the corresponding EMCs during storm events were $216.40 \mathrm{mg} / \mathrm{L}$ and 308.62 $\mathrm{mg} / \mathrm{L}$, respectively. Storm runoff had roughly 7 times the TSS EMC of irrigation runoff, whereas TP and TN EMCs are comparable.

Table 1. Estimated EMCs and load flux of pollutants.

\begin{tabular}{|c|c|c|c|c|c|c|c|}
\hline Date & Period & $\begin{array}{c}\text { TSS } \\
(\mathrm{mg} / \mathrm{L})\end{array}$ & $\begin{array}{c}\mathrm{TP} \\
(\mathrm{mg} / \mathrm{L})\end{array}$ & $\begin{array}{c}\mathrm{TN} \\
(\mathrm{mg} / \mathrm{L})\end{array}$ & $\begin{array}{c}\text { TSS } \\
(\mathrm{kg} / \mathrm{d})\end{array}$ & $\begin{array}{c}\text { TP } \\
(\mathrm{kg} / \mathrm{d})\end{array}$ & $\begin{array}{r}\mathrm{TN} \\
(\mathrm{kg} / \mathrm{d}) \\
\end{array}$ \\
\hline 09/22/2017(I) & $5: 45-6: 45$ & 26.3 & 0.38 & 2.47 & 0.82 & 0.02 & 0.18 \\
\hline 09/29/2017(l) & $5: 30-6: 00$ & 26.3 & 0.35 & 2.96 & 0.68 & 0.006 & 0.05 \\
\hline 09/30/2017(l) & $5: 15-6: 15$ & 35.2 & 0.37 & 3.08 & 1.04 & 0.02 & 0.12 \\
\hline $10 / 01 / 2017^{(I)}$ & $5: 30-6: 00$ & 27.6 & 0.36 & 3.79 & 0.25 & 0.004 & 0.03 \\
\hline $10 / 02 / 2017^{(l)}$ & $5: 30-6: 00$ & 25.3 & 0.32 & 3.70 & 0.47 & 0.006 & 0.07 \\
\hline $10 / 05 / 2017^{(I)}$ & $5: 15-6: 15$ & 41.6 & 0.29 & 2.48 & 1.94 & 0.014 & 0.12 \\
\hline $10 / 24 / 2017^{(\mathrm{S})}$ & $1: 25-5: 10$ & 125.1 & 0.40 & 3.17 & 284.7 & 0.90 & 7.21 \\
\hline 08/07/2017(S) & $18: 10-19: 15$ & 308.6 & 0.55 & 3.91 & 580.4 & 0.52 & 1.94 \\
\hline
\end{tabular}

\subsection{Pollutograph during irrigation and storm}

SWMM was calibrated based on the 10 irrigation and storm events. $R^{2}$, NSE and PBIAS for these 10 events, were $0.73,0.69$ and $12.0 \%$, respectively. SWMM could properly simulate hydrology and water quality of the nursery. The hydrograph and the concentrations of water quality constituents for one irrigation and storm events are illustrated in Figure 1. During the irrigation and storm events, average peak flows were approximately 7 and $250 \mathrm{~L} / \mathrm{s}$, respectively. There was a direct relationship between runoff and TSS peaks, i.e., TSS peaks follow peak runoff, with a defined lag. The concentration of TSS and the flow reached the peak almost at the same time. After reaching the peak, the concentration of TSS declined due to dilution. With respect to rainfall, due to first-flush (initial runoff with high level of pollutants due to buildup during dry periods), the TSS peak happened prior to the peak. There was an inverse relationship between runoff peaks and concentrations of TN and TP. The lowest concentrations of TN and TP occurred after runoff peaks due to dilution. Phosphorus strongly 


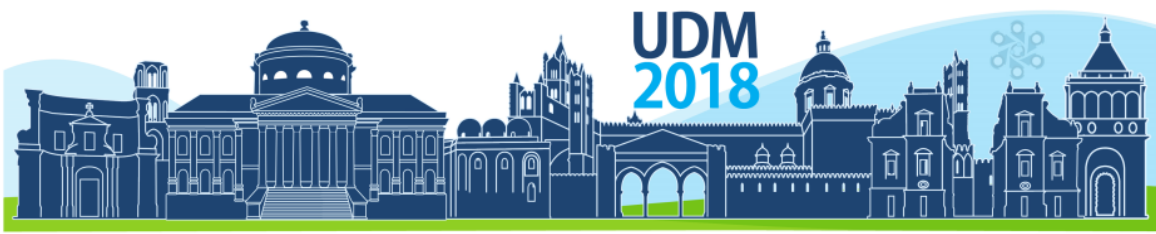

$11^{\text {th }}$ International Conference on Urban Drainage Modelling

23-26 Sep | Palermo - Italy

adheres to the surface and requires high kinetic energy for removal. This means during events with higher kinetic energy and longer duration, phosphorus wash-off increased significantly. Hence, concentration of TP during storm events was greater than irrigation events. During irrigation, SWMM simulated EMCs of TP, TN and TSS were $0.42,2.77$ and $36.0 \mathrm{mg} / \mathrm{L}$, respectively.

\section{CONCLUSIONS}

Water quality characterization for nursery irrigation and storm runoff were evaluated for this study. Since, the nursery was covered with semi-impervious area; it can be monitored and modelled like an urban area, using a model like SWMM. The results indicated that there is direct correlation between runoff peaks and TSS concentration, while there was an inverse relationship between runoff peak and concentration of TP and TN. During irrigation, SWMM simulated EMCs of TP, TN and TSS were $0.42,2.77$ and $36 \mathrm{mg} / \mathrm{L}$, respectively.
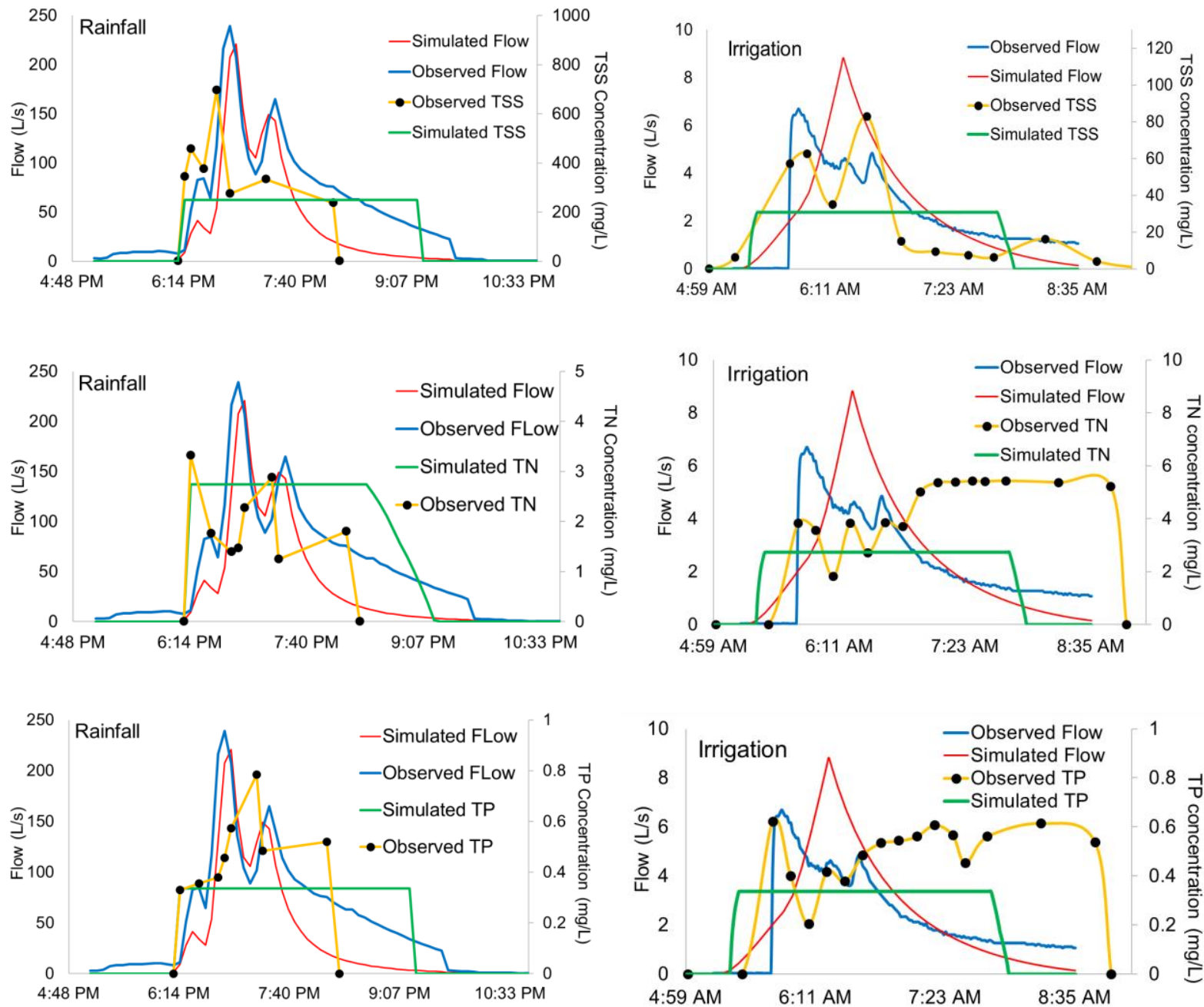

Figure 1. Pollutograph for irrigation and rainfall runoff for TSS, TN, and TP. 


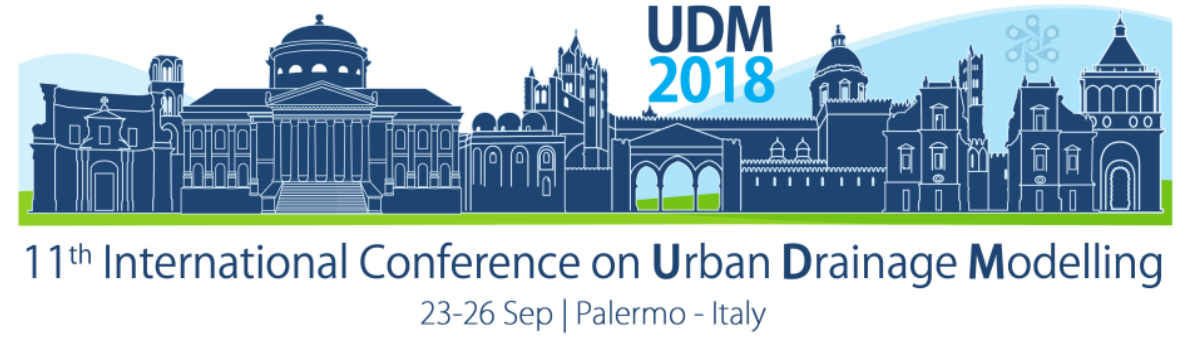

\section{References}

Chang, C., Sun, D., Feng, P., Zhang, M., Ge, N., (2017). Impacts of Nonpoint Source Pollution on Water Quality in the Yuqiao Reservoir. Environ. Eng. Sci. 34, 418-432. doi:10.1089/ees.2016.0124

Chen, L., Wang, G., Zhong, Y., Shen, Z., (2016). Evaluating the impacts of soil data on hydrological and nonpoint source pollution prediction. Sci. Total Environ. 563-564, 19-28. doi:10.1016/j.scitotenv.2016.04.107

Guo, W., Fu, Y., Ruan, B., Ge, H., Zhao, N., (2014). Agricultural non-point source pollution in the Yongding River Basin. Ecol. Indic. 36, 254-261. doi:10.1016/j.ecolind.2013.07.012

Gupta, H.V., Sorooshian, S., Yapo, P.O., (1999). Status of Automatic Calibration for Hydrologic Models: Comparison with Multilevel Expert Calibration. J. Hydrol. Eng. 4, 135-143. doi:10.1061/(ASCE)10840699(1999)4:2(135)

Majsztrik, J.C., Fernandez, R.T., Fisher, P.R., Hitchcock, D.R., Lea-Cox, J., Owen, J.S., Oki, L.R., White, S.A., (2017). Water Use and Treatment in Container-Grown Specialty Crop Production: A Review. Water. Air. Soil Pollut. 228. doi:10.1007/s11270-017-3272-1

Nash, J.E., Sutcliffe, J.V., (1970). River flow forecasting through conceptual models part I - A discussion of principles. J. Hydrol. 10, 282-290. doi:10.1016/0022-1694(70)90255-6

Nasr, A., Bruen, M., Jordan, P., Moles, R., Kiely, G., Byrne, P., (2007). A comparison of SWAT, HSPF and SHETRAN/GOPC for modelling phosphorus export from three catchments in Ireland. Water Res. 41, 10651073. doi:10.1016/j.watres.2006.11.026

NOAA, (2016). Precipitation Frequency Data Server. Natl. Ocean. Atmos. Adm. URL https://hdsc.nws.noaa.gov/hdsc/pfds

Rossman, L.A., (2010). Storm water management model user's manual, version 5.0. Cincinnati: National Risk Management Research Laboratory, Office of Research and Development, US Environmental Protection Agency.

Seong, C., Herand, Y., Benham, B.L., (2015). Automatic calibration tool for hydrologic simulation programFORTRAN using a shuffled complex evolution algorithm. Water. 7, 503-527. doi:10.3390/w7020503

White, S.A., Taylor, M.D., Albano, J.P., Whitwell, T., Klaine, S.J., (2011). Phosphorus retention in lab and fieldscale subsurface-flow wetlands treating plant nursery runoff. Ecol. Eng. 37, 1968-1976. doi:10.1016/J.ECOLENG.2011.08.009

White, S.A., Taylor, M.D., Chandler, S.L., Whitwell, T., Klaine, S.J., (2010). Remediation of nitrogen and phosphorus from nursery runoff during the spring via free water surface constructed wetlands. Environ. Hortic. 28, 209. 


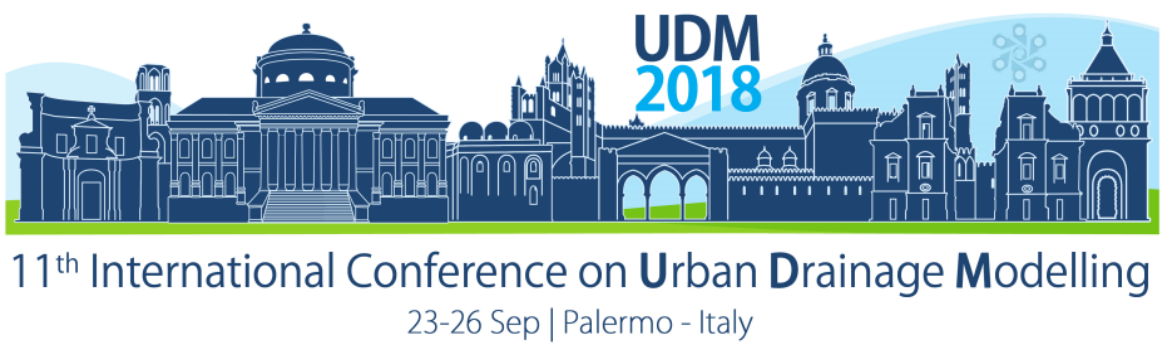

\title{
Sewer flow prediction at a large urban scale: influence of radar rainfall spatial resolution
}

\author{
Sara Simona Cipolla ${ }^{1}$, Giulia Paola Di Ventura ${ }^{2}$, Marco Maglionico², Pier Paolo Alberoni ${ }^{3}$ and Attilio \\ Castellarin ${ }^{2}$ \\ ${ }^{1}$ University of Bologna, CIRI-EC Interdepartmental Centre for Industrial Research in Building and Construction, \\ Bologna, Italy \\ 2 University of Bologna, DICAM Department of Civil, Chemical, Environmental, and Materials Engineering, \\ Bologna, Italy \\ ARPAE Regional Agency for Prevention, Environment and Energy of Emilia-Romagna, Italy
}

\begin{abstract}
There is a growing interest in using radar rainfall data to evaluate the performance of urban drainage systems in near real time. This paper describes a study based on a large $\left(55 \mathrm{~km}^{2}\right)$ urban catchment in northern Italy. Different spatial resolutions of radar data have been compared and used as input to a numerical hydrological-hydraulic model of the drainage system, constructed by means of Inforworks CS software. The results show that the spatial resolution of weather radar data plays a significant role when modelling the hydrological behaviour of the drainage system and using different resolutions may result in significant differences in peak flows and runoff volumes.
\end{abstract}

Keywords: CSOs; modeling; radar; rainfall; sewers.

\section{INTRODUCTION}

There is a growing interest in accurately evaluating the behavior of urban drainage systems for both the mitigation of urban flood risk and management of water quality issues. The numerical modelling of urban drainage systems is widely used to analyze the response of these systems to rainfall events in terms of both hydraulic and environmental aspects, and to evaluate the performance of different design configurations. Rainfall patterns and their spatial distribution are a key element in numerical modelling of sewer systems because represent the main input of the model. Spatial variation of rainfall may cause differences in terms of sewer flow peak, and volumes spilled from the combined sewer overflows (CSOs).

In recent years there is a growing interest in estimating rainfall intensities from weather radar data to better understand the response of urban catchments to extreme rainfall events or to predict the future performance of urban drainage systems (Schellart et al., 2012). Meteorological radar is a remote sensing system that provides rainfall estimations at high spatial and temporal resolutions (Morin et al., 2003). The use of rain gauges provide multiple single point measurements, on the contrary the use of radar provide spatial rainfall data over an entire region. Estimating rainfall intensities from radar data may be considered advantageous in particular in highly urbanized cities in which catchments have low concentration times.

The aim of this paper is to analyze how the spatial resolution of rainfall estimated from weather radar data influences the simulated peak flows and spilled volumes from combined sewer overflows (CSOs). The case study is the whole sewer system of the city of Bologna (Italy). 


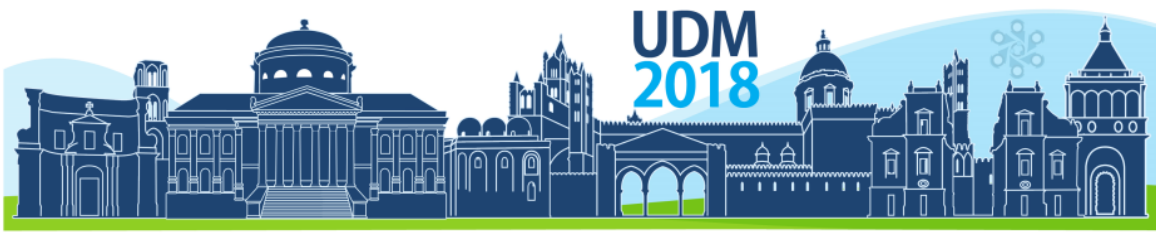

$11^{\text {th }}$ International Conference on Urban Drainage Modelling

23-26 Sep | Palermo - Italy

\section{MATERIALS AND METHODS}

\subsection{Case study}

The sewer system of Bologna, a city located in northern Italy, is mainly a combined system with a total length of about $728 \mathrm{~km}$ and with $122 \mathrm{CSOs}$. Therefore, during the rainfall events wastewater and stormwater are mixed (Cipolla et al., 2014) and when the sewage flow exceed the waste water treatment plant (WWTP) capacity, CSOs guarantee the overall hydraulic safety and the WWTP efficiency spilling the excess of wastewater directly into the water bodies (Casadio et al., 2010).

The hydraulic behavior of this system has been analyzed with a hydrodynamic model developed by means of Infoworks software (http://www.innovyze.com/products/infoworks cs/) version 9.5. It results in 18577 nodes, 18702 links, and 17224 subcatchments for a total of 5494 hectares drained. Fig. 1 shows the sewer network and the CSOs position.

The model, which was calibrated and validated based on some experimental measurements campaigns done in 2005 and 2006 (e.g. flow rate, volume spilled by CSOs, rainfall, etc) by local stakeholder (HERA SpA), has been used to simulate the drainage system using as input different precipitation patterns.

\subsection{Radar rainfall data}

ARPAE Agency (www.arpae.it) provided the radar data used for this study. They consists of images of cumulative precipitation at 5-minute time steps at two different spatial resolutions: $250 \mathrm{~m}$ and $1 \mathrm{~km}$, and overlying the entire city of Bologna. First, data errors caused by clutter (CL), WI-FI echoes, abnormal propagation (AP), and beam blocking (BB) have been identified and corrected. Subsequently, the correction of vertical profiles reflectivity (VPR), and the classification into convective and stratiform components have been done to properly tackle the reflectivity-rainfall conversion. The rainfall events recorded on $18^{\text {th }}$ November 2006 and on $13^{\text {th }}$ June 2014 have been selected to compare different radar resolution ( $250 \mathrm{~m}$ vs $1 \mathrm{~km})$. Fig. 1 shows the radar rainfall coverage used in this study for the event recorded on 13 June 2014 00:10 UTC at $250 \mathrm{~m} \mathrm{(a)} \mathrm{and} 1 \mathrm{~km} \mathrm{(b)} \mathrm{pixel} \mathrm{radar} \mathrm{resolution.}$

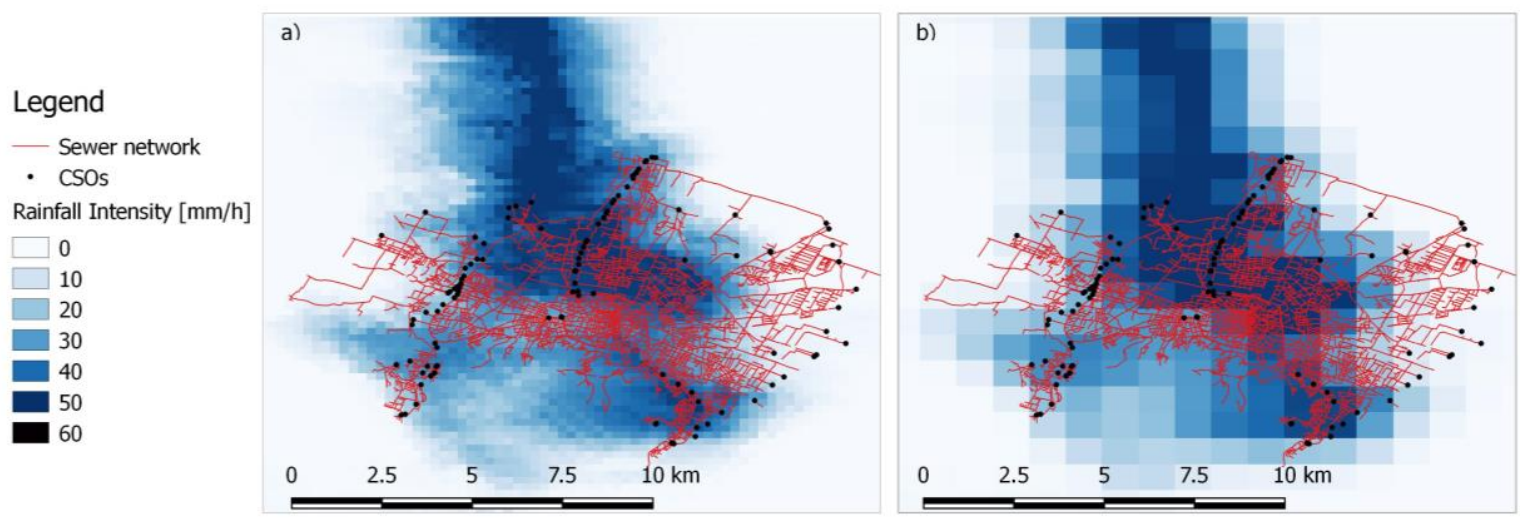

Figure 1. Layout of sewage network showing CSOs position (black dots), and map of the radar rainfall intensities at $250 \mathrm{~m}$ (a) and $1 \mathrm{~km}$ (b) resolution,13 $3^{\text {th }}$ June 2014 00:10 UTC. 


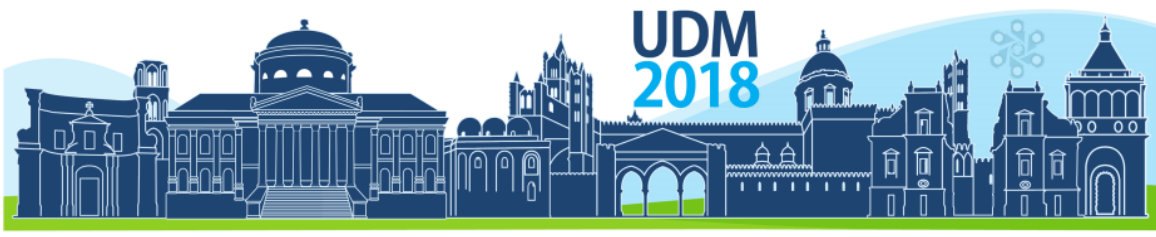

$11^{\text {th }}$ International Conference on Urban Drainage Modelling

23-26 Sep | Palermo - Italy

\subsection{Model simulation set-up}

Seven simulations were performed for each rainfall event, each one corresponding to a different precipitation scenario. Simulations enabled us to determine the differences in terms of sewer flow peak and volume spilled by CSOs. Rainfall scenarios have been created as following: a) a rainfall time series extracted for each sub-catchment (17'224) from $1 \mathrm{~km}$ resolution radar data; b) a rainfall time series extracted for each sub-catchment (17'224) from $250 \mathrm{~m}$ resolution radar data; c) 865 synthetic rain gauges located on a regular grid (size 250 $\mathrm{m}$ ) that overlaps the sub-catchments (Fig. 2a); d) 77 synthetic rain gauges located on a regular grid (1 km) that overlaps the sub-catchments (Fig. 2b); e) 15 synthetic rain gauges located on a regular grid $(2 \mathrm{~km})$ that overlaps the sub-catchments (Fig. 2c); f) a rainfall time series corresponding to the average rainfall intensity recorded during each time step over the entire area; $g$ ) a rainfall time series corresponding to the one that was recorded above the pixel where the maximum rainfall intensity occurred. Rainfall intensities for cases $c, d$ and $e$ are sourced from radar data at $250 \mathrm{~m}$ resolution, and each rain gauge has been associated with a subcatchment based on the minimum distance criteria.
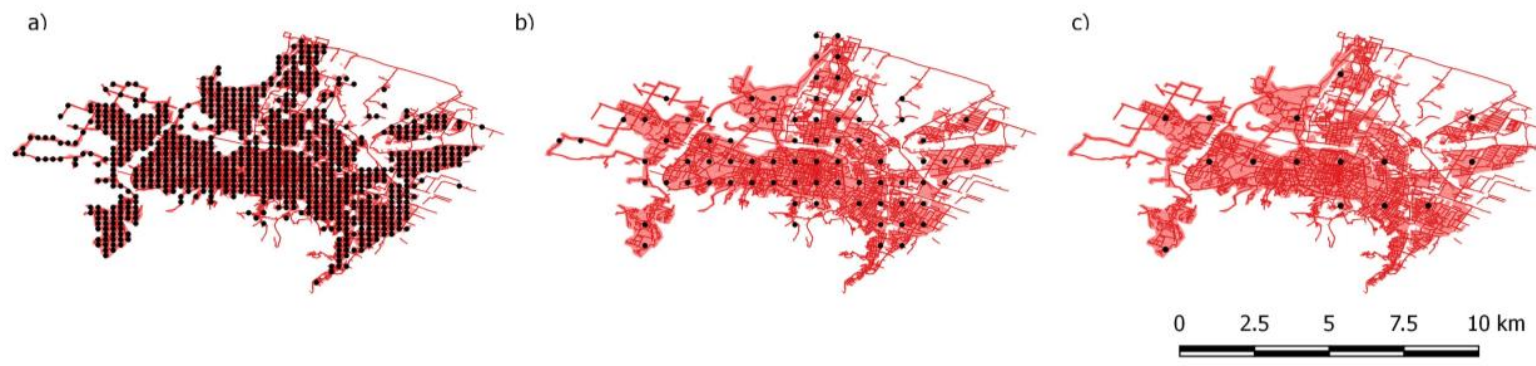

Figure 2. Position of the synthetic rain gauges on a regular mesh grid of: a) $250 \mathrm{~m}$ (865 points), b) $1 \mathrm{~km}$ (77 points), c) $2 \mathrm{~km}$ (15 points).

\section{RESULTS AND DISCUSSION}

\subsection{Comparison of simulated sewer flows}

The implications of the differences in rainfall distributions on sewer flow simulation have been studied by comparing simulated flows using the previously described rainfall scenarios for two locations described in table 1 . The simulation carried out with the radar data with mesh to 250 $\mathrm{m}$ (time series $b$ ) has been used as benchmark.

Table 1. Characteristics of the conduits monitored in terms of drained area, total length of conduits upstream, longest path, and population (adapted from Cipolla et al. (2014)).

\begin{tabular}{lcccc}
\hline Location & Drained area (ha) & Total lenght $(\mathrm{m})$ & Longest path $(\mathrm{m})$ & Inhabitants \\
\hline $\mathrm{A}$ & 276 & 24870 & 6310 & 12212 \\
$\mathrm{~B}$ & 1151 & 169300 & 12930 & 440795
\end{tabular}

Figure $3 a$ and $3 b$ compare the simulated sewer flows based on rainfall scenario for the two sewer positions described in Table 1 during the event recorded on June 132014 (cumulative rainfall $\approx 35.8 \mathrm{~mm}$, peak intensity $52 \mathrm{~mm} / \mathrm{h}$ ). Both figures show how space resolution of rainfall can significantly influence simulated sewer flows, especially peak flows, which is of key importance for understanding flooding and CSOs spills. It may be noticed how in the 


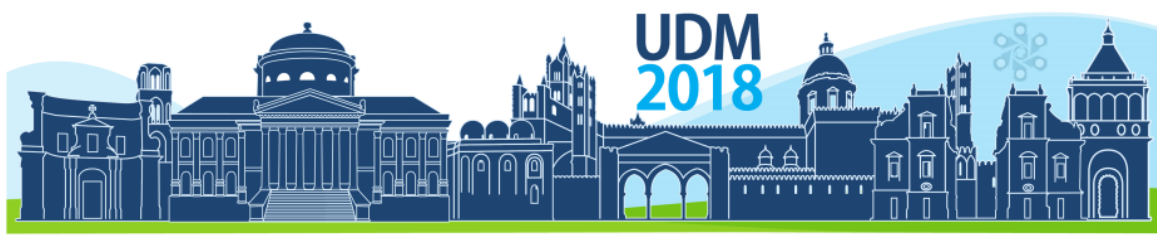

$11^{\text {th }}$ International Conference on Urban Drainage Modelling

23-26 Sep | Palermo - Italy

catchment, position $A$, the peak of flow rate and the volume drained increase as the spatial resolution of the precipitation decreases, while in position $B$ there is an inverse phenomenon. This demonstrates how a detailed knowledge of the spatial distribution of the rainfall event leads to a more precise estimation of the volumes drained by the sewer system. However, as the drained area increases, the differences between the hydrographs obtained from the various simulations are minimized due to the presence of CSOs. Fig. 4 shows the variation of the volumes spilled by CSOs as the spatial resolution of rainfall varies.
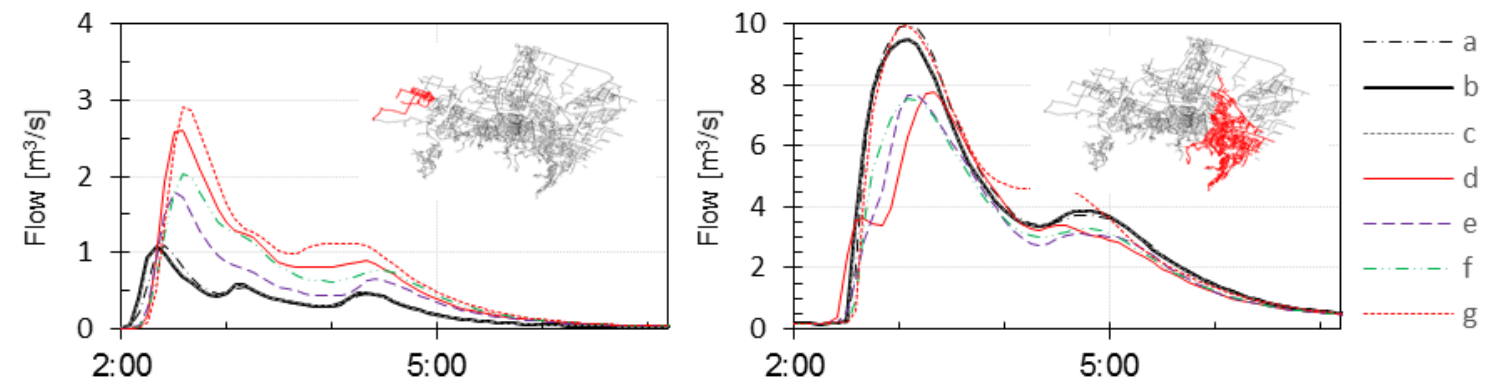

Figure 3. Comparisons of simulated flows for the event recorded on $13^{\text {th }}$ June 2014 , (a) location $A$; (b) location $B$
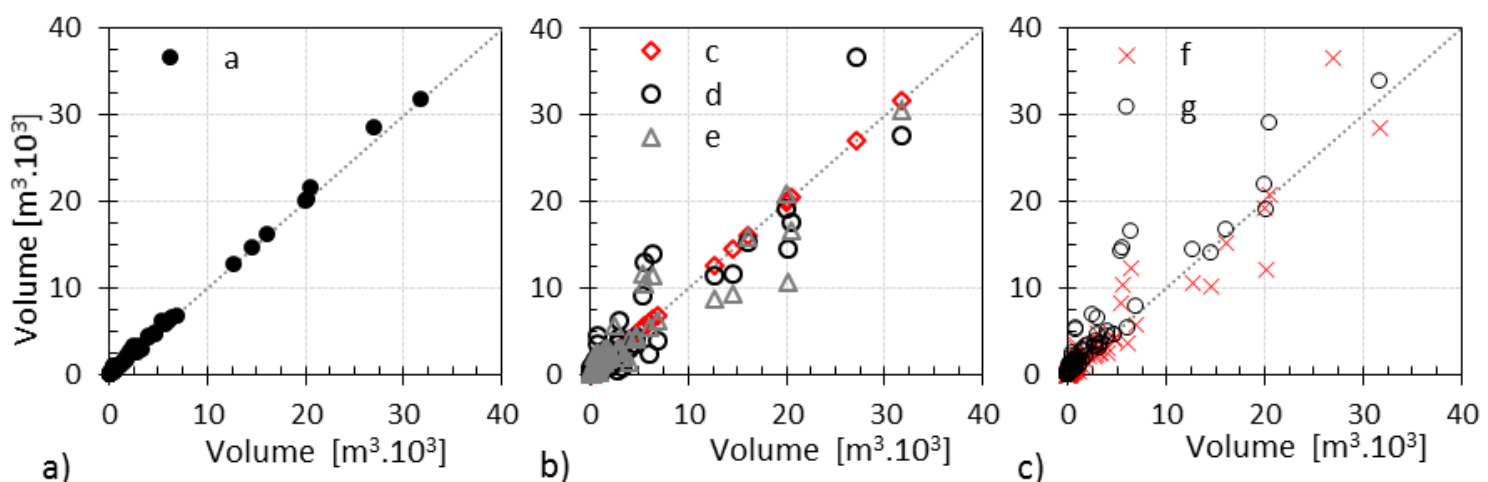

Figure 4. Comparisons of volume spilled from CSOs from scenario b and scenario $a(a)$, scenarios $c, d$, and $e$ (b), and scenarios $f$ and $g(\mathrm{c})$

\section{CONCLUSIONS}

This study describes the impact on the modelled hydrological-hydraulic behaviour of a large urban drainage system caused by different spatial resolution of weather data. A detailed numerical hydrological-hydraulic model was used for simulating runoff and sewer flows corresponding to a selection of storm events. The results show significant differences in predicted stormwater peak flows and overall runoff volumes and, consequently, in the prediction of the volume spilled by combined sewers over flows.

\section{References}

Casadio A, Maglionico M, Bolognesi A, Artina S (2010) Toxicity and pollutant impact analysis in an urban river due to combined sewer overflows loads. Water Sci Technol; 61, 207-15.

Cipolla SS, Maglionico M (2014) Heat recovery from urban wastewater: Analysis of the variability of flow rate and temperature. Energy Build 69, 122-130.

Morin E, Krajewski WF, Goodrich DC, Gao X, Sorooshian S. (2003) Estimating Rainfall Intensities from Weather Radar Data: The Scale-Dependency Problem. J Hydrometeorol 4, 782-97.

Schellart A, Shepherd WJ, Saul AJ (2012) Influence of rainfall estimation error and spatial variability on sewer flow prediction at a small urban scale. Adv Water Resour 45, 65-75. 


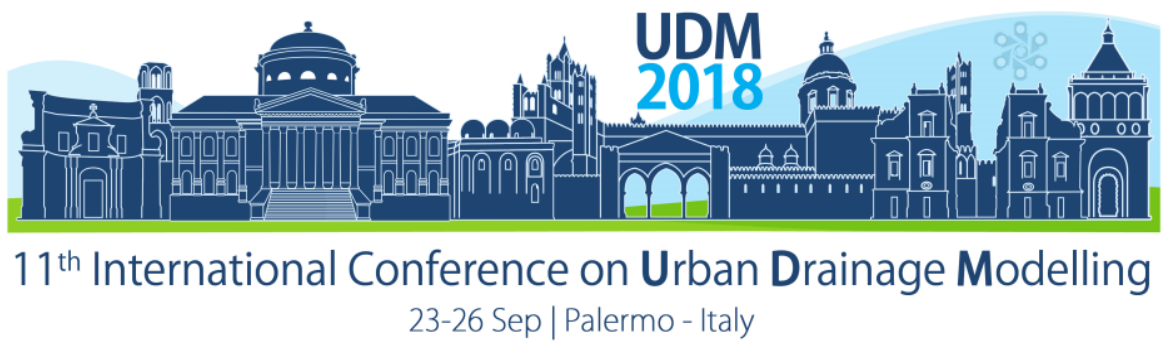

\title{
Integrated hydraulic and hydrological modeling of a constructed wetland for storm water management
}

\author{
Paola Aldana ${ }^{1}$, Néstor Mancipe ${ }^{1}$ and Andrés Torres ${ }^{2}$ \\ ${ }^{1}$ Universidad Nacional de Colombia, Civil and Agriculture Engineering Department, Bogotá, Colombia \\ ${ }^{2}$ Pontificia Universidad Javeriana, Civil Engineering Department, Bogotá, Colombia
}

\begin{abstract}
Large scale implementation of Constructed Wetlands(CW's) as a Sustainable Urban Drainage System (SUDS), may be prohibited due to the required investment and maintenance/operation costs. Integrated hydraulic and hydrological modeling is a relatively lowcost tool for simulating a CW behavior towards assessing its implementation viability. However, previous work has only focused on evaluating simplified models or hydraulic indexes instead of considering integrated modelling schemes. The objective of this study is to stablish if a verywell-known dynamic hydrology-hydraulic model has the capabilities to simulate the hydraulic behavior of a CW towards optimizing the CW localization and sizing as a function of their peak and volume runoff control capacity. The Storm Water Management Model (SWMM) is selected and two scenarios are considered: [1] a distributed hydraulic model performed open rectangular channels, and [2] a hydrologic aggregated model that represents the $\mathrm{CW}$ as a bio-retention cell at the subcatchment level. Water level collected by sensors and rainfall data obtained nearby rain gauges (disaggregated hourly through a Barlet-Lewis model) is used to construct the models. Simulation results suggests that neither the distributed hydraulic (St. Venant equations) model nor the hydrologic aggregated model accurately represent the flow dynamics through the CW. A coupled approach within SWMM between the St.Venant equations and DupuitForcheimer equations is being developed in order to represent in a better way the hydrodynamic process of the CW structure including porosity and hydraulic conductivity.
\end{abstract}

Keywords: Constructed wetland modelling; Porous media flow hydrodynamics; SUDS

\section{INTRODUCTION}

Flow management of storm water systems may satisfy the following criteria according to Sachs (2008): [1] sufficiency, focused on the reduction of flows and volumes to necessary levels and uses; [2] consistency, associated with their relation with the environment; and [3] efficiency of the system, which is only sought once the other criteria are met (Masi, Rizzo, \& Regelsberger, 2017). In this way SUDS's are developed as strategies which are capable to ensure these criteria.

CW's as a SUDS is a nature-based retention system that satisfy urban design objectives providing wildlife habitat, removing stormwater pollutants and ensuring flood control (Wong, et al., 1999). The integration of CW's in the urban areas would provide potential benefits increasing their implementation opportunities (Masi, Rizzo, \& Regelsberger, 2017).

Although, most of the CW's research has focused on water quality modelling (Hickey, et al., 2018, Pittman, 2011), there are few studies that assess the hydraulic and hydrodynamic performance of $\mathrm{CW}$ by either using hydraulic conceptual models (Mangangka, 2017) or simplified models (Fournela, et al., 2013). On the other hand, hydraulic indexes such as hydraulic residence time (HRT), Effective volume ratio, hydraulic efficiency have been appraised through different tracer methods (Chazarenc, Merlin, \& Gonthier, 2003; Bonner, et al., 2017) and computational fluid dynamics or numerical models (Rengers, et al., 2016; Jenkins \& Greenway, 2005). 


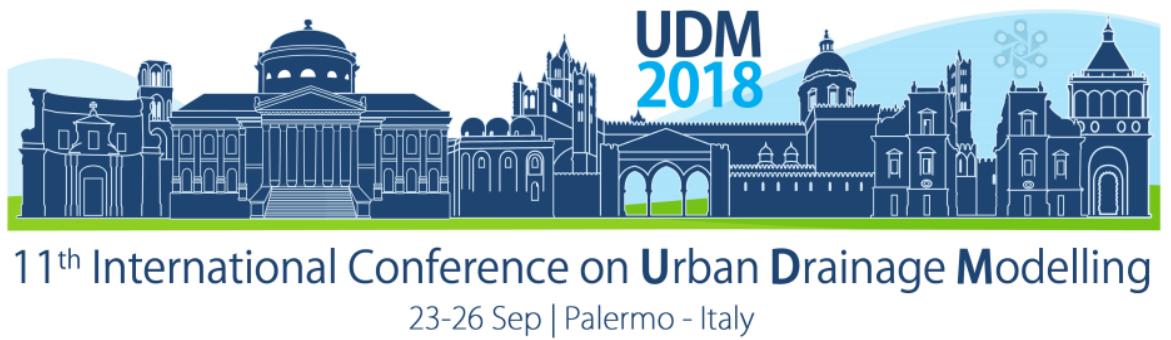

While, the main objective in the implementation of $\mathrm{CW}$ is the retention and removal of contaminants, the hydrodynamics of these structures has not been widely studied. It is considered essential for the compression of the processes of removal of pollutants, so it is expected that the configuration of an integrated hydraulic and hydrological model can be integrated with a model of water quality that allows obtaining better results.

Overall, integrated hydraulic and hydrological model is needed to accurately represent CW's hydrodynamics where design criteria for these systems could be established. An integrated CW's model would be useful to optimizing the size and localization of these SUDS's in the cities as a function of CW's capabilities on peak and volume runoff control, reducing unnecessary investments.

\section{MATERIALS AND METHODS}

To achieve the project's objective a dynamic hydrology-hydraulic software model is selected. The input data for the selected model is taken from an experimental CW located on Pontificia Universidad Javeriana (PUJ), Bogotá. Rainfall data and water level is preprocessed for temporal consistency. Finally, two scenarios are performed for verifying the software capabilities to represent this CW system.

\subsection{Selected modeling software}

SWMM is an analytical tool which use a Saint Venant equations in a one dimension, it is widely used and accepted to model urban drainage systems. Also, SWMM provides a LID module does not include a configuration for CW. Taking into account these limitations, the aim of this study is to evaluate the capability of SWMM to simulate the hydrodinamics of a complex structures such as CW.

SWMM is a worldwide free used model which is capable to represent hydraulic and hydrologic systems. Although, there are few modeling software, SWMM is chosen because it is one of the most dynamic hydrology-hydraulic model that work with geographic information systems.

\subsection{Constructed Wetland configuration}

\section{CW dimensions}

A CW with horizontal subsurface flow, collects storm water runoff from a parking lot $\left(3,776 \mathrm{~m}^{2}\right)$ within the PUJ. The underlying gravel bed was built with different gravel sizes to minimize possible clogging. The CW is divided in three horizontal zones with $1 \mathrm{in}, 3 / 4 \mathrm{in}$, and $1 / 2$ in gravel size, respectively (Galarza, et al., 2015).

\section{Sensors data}

Flow rate and water levels are monitored in the $\mathrm{CW}$ through two triangular sharp-crested weirs and ten ultrasonic level sensors. Water levels are recorded in time intervals of one minute by the ultrasonic level sensors which are distributed along the CW: one in front of each weir, seven in the CW and one in the reservoir tank (Galarza, et al., 2016).

\subsection{Rainfall information}

Daily rainfall data was obtained from the Bogotá metropolitan sewer district (EAB) hydrometeorological monitoring system. A daily to hourly disaggregation process is done for 


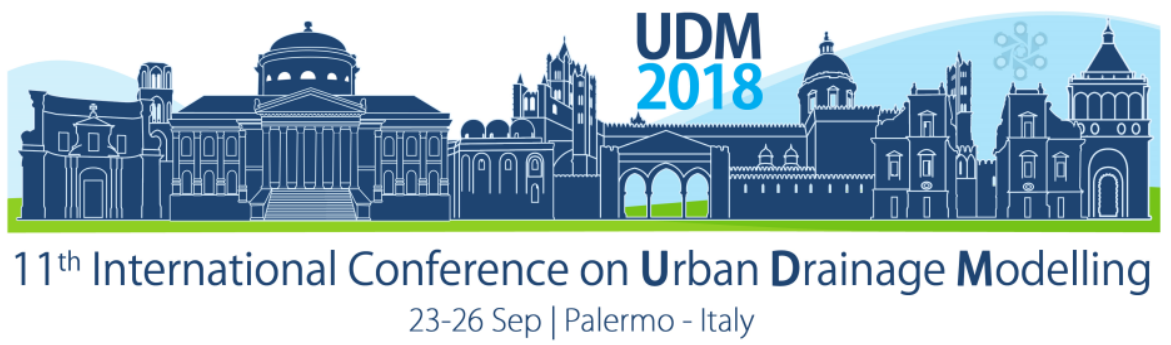

the rainfall data with a Barlet-Lewis based model using an $\mathrm{R}$ package called Hyetosminute. The disaggregation results are validated with one-minute rainfall data obtained from rain gauges installed behind the CW by the PUJ.

\subsection{Distributed and Aggregated models}

Two continuous simulation scenarios are tested to represent the hydraulic behavior of the CW in SWMM. The solution of St Venant's equations is developed by the dynamic wave method and validation process is carried out with the water level records.

The first scenario is a distributed model where the $\mathrm{CW}$ is represented by chambers as a series of links connected through orifices and weirs. This scenario may represent all the hydraulic conditions of the structures associated with the CW. The second scenario is an aggregated model where the CW is added to the drainage area through the "LID control" module in SWMM. A bio-retention cell is selected because this LID option considers the porous medium and the volumetric vegetation fraction.

\section{RESULTS AND DISCUSSION}

Taking into account the simulated process, the rainfall data pre-processing has significantly correlation with the model's output data. The same resolution should be defined to observe accurately their relationship. The results obtained show that the configurations established in SWMM are not be able to represent the CW's hydrodinamic.

\subsection{Information pre-processing}

Water level data for the continuous simulation period corresponds to May 26 to July 2, 2014. The information is aggregated hourly to work at an appropriate temporal resolution for decision making. Additionally, this resolution reduces the signal noise observed at one-minute resolution.

\subsection{Distributed model}

Chambers are represented by rectangular open channels connected through nodes each other's. Simulated weirs and orifices allow represent retention processes within CW's structure. The simulation results for this scenario demonstrated the effects on the attenuation of the flow peaks through the CW (Fig. 1a). Water level has a progressive increase corresponding to the impulses generated by the rainfall, however, the peaks are not effectively represented (Figure $1 \mathrm{~b}$ ). The results suggest that the displacement and reduction of the peaks in the simulation would be related with the displaced volume and the low water velocities in the porous medium.

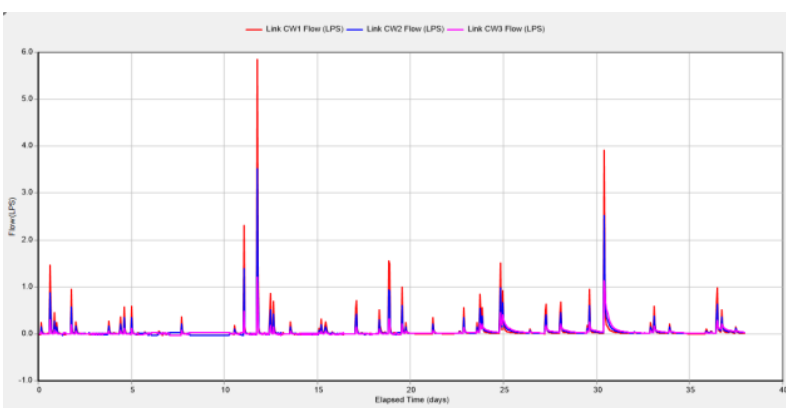

Figure 1a. Flow (lps) vs t (hours) in the channels.

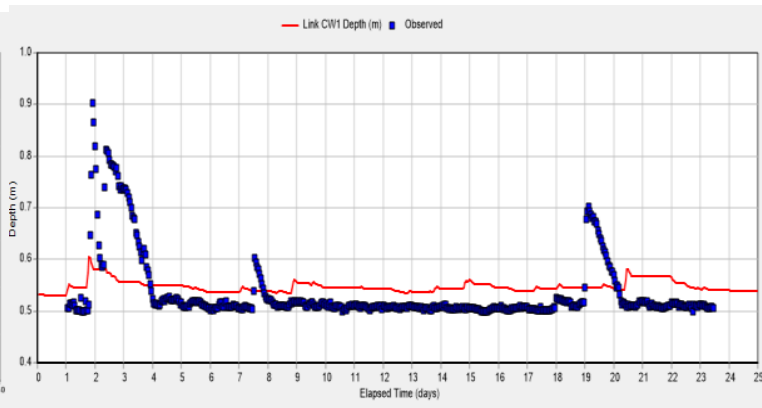

Figure 1b. Water depth vs. $t$ in the channels 


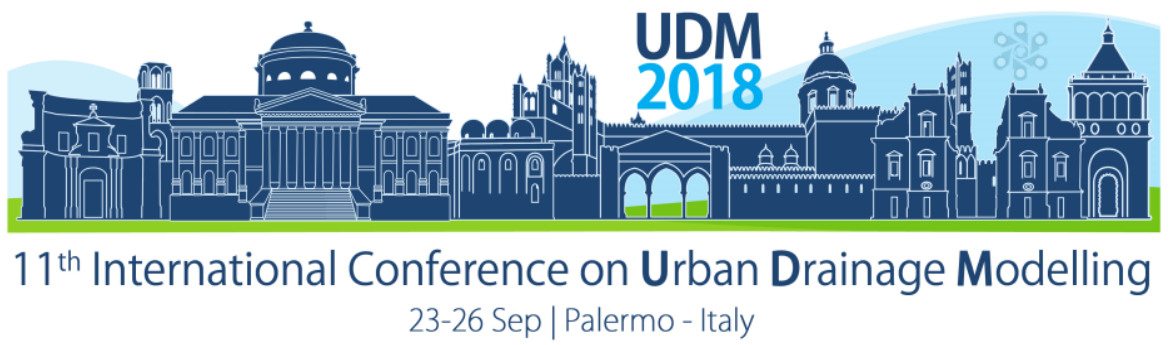

\subsection{Aggregated model}

The simulation results for this scenario demonstrated that the configured structure behaves like a typical tank model in which runoff is generated only until the defined level is reached. The attenuation of the first flow peaks is reflected in a greater output on days 18 and 31 approximately (Figure 2a). The method of estimating the output flow rate of the structure is associated with a mass balance that does not adequately represent the water depth within the structure. (Figure 2b).

\subsection{Overall assessment}

In general, it can be inferred that the St Venant equations (distributed model) and the mass balance carried out in the typical tank model (aggregated model) are not adequate to efficiently simulate the flow dynamics within a complex structure such as a CW.

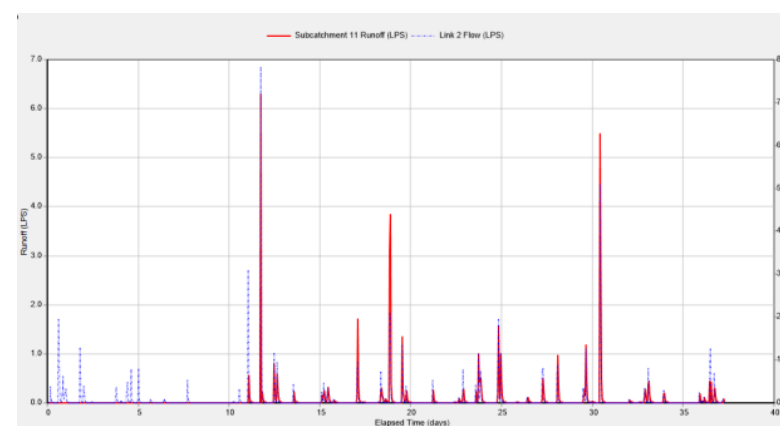

Figure 2a. Flow (Ips) vs t (hours) in the channels.

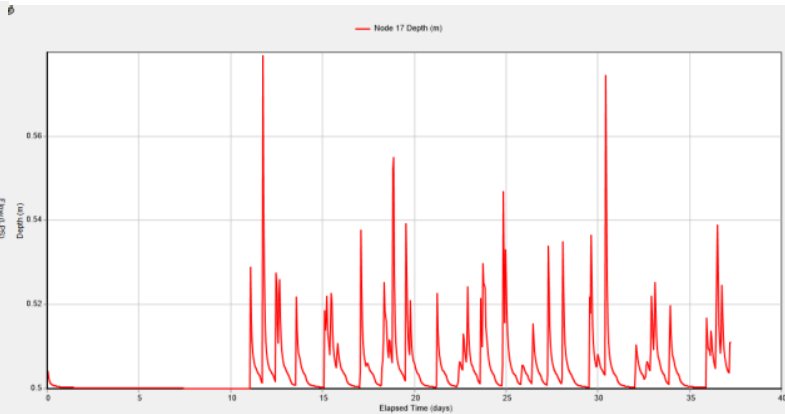

Figure $\mathbf{2 b}$. Water depth vs. $t$ in the channels

Considerations of flow in porous medium related not only with the gravel support medium but with the density of vegetation in the $\mathrm{CW}$, should be taken into account in the equations solution. Therefore, a coupled SWMM model (St Venant equations for continuity) with the Dupuit Forcheimer equation (flow in porous media) is proposed. The later method explains the movement of water in this type of horizontal flow wetlands (Kadlec \& Wallace, 2009).

A preliminary work has been done to incorporate parameters such as porosity and hydraulic conductivity into the system configuration and SWMM's solution method. The association of these parameters will be reflected in a water level increase both by displaced volume and by the low water velocities in the medium. It is expected this project will be concluded within a few months.

\section{CONCLUSIONS}

The results of this study indicate that the scenarios performed on SWMM are not capable to represent accurately the hydraulics behavior of a complex structure as a CW. Disaggregated model reproduce higher base water levels instead lower values for peaks. Aggregated model does not simulate properly the water depth in the control structure.

The CW's performance is strongly associated with the parameters of the porous media. Porosity, hydraulic conductivity and volumetric vegetation fraction should be included into the system configuration and SWMM's solution method to simulate a water level increase both by displaced volume and by the low water velocities in the medium.

Validation process in the Barlet-Lewis model is acutely relevant for the adequate representation of the output data of the CW. The calibration for the Barlet-Lewis model's 


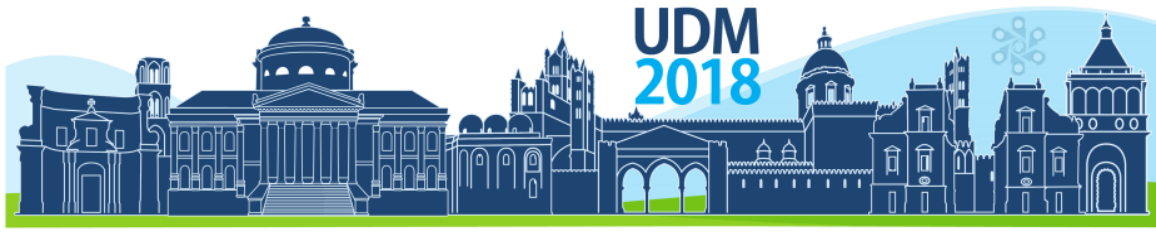

$11^{\text {th }}$ International Conference on Urban Drainage Modelling

23-26 Sep | Palermo - Italy

parameters improve the representation of the peaks into the $\mathrm{CW}$. This allows to affirm that the differences found between the observed data and the outputs of the model are related with hydraulic parameters.

\section{References}

Chazarenc, F., Merlin, G., \& Gonthier, Y. (2003). Hydrodynamics of horizontal subsurface flow contructed wetlands. Ecological engineering, 165-173.

Fournela, J., Forqueta, N., Mollea, P., \& Grasmickb, A. (2013). Modeling constructed wetlands with variably saturated vertical subsurface-flow for urban stormwater treatment. Ecological engineering, 1-8.

Galarza Molina, S., Torres, A., Lara, J., Solarte, L., González, J., \& González, L. (2015). Towards a constructed wetland/reservoir-tank system for rainwater harvesting in an experimental catchment in Colombia. 415-421.

Galarza, S., Gómez, A., Hernández, N., Burns, M., Fletcher, T., \& Torres, A. (2016). On-line equipment installed in a stormwater harvesting system: calibration procedures, first performance results and applications. Bogotá: Novatech.

Hickey, A., Arnscheidt, J., Joyce, E., O’Toole, J., Galvin, G., O'Callaghan, M., . . . Kavanagh, E. (2018). An assessment of the performance of municipal constructed wetlands in Ireland. Journal of environmental management, 263-272.

Jenkins, G., \& Greenway, M. (2005). The hydraulic efficiency of fringing versus banded vegetation in constructed wetlands. Ecological Engineering, 61-72.

Kadlec, R., \& Wallace, S. (2009). Treatment Wetlands. New York: CRC Press.

Mangangka, I. (2017). Modelling the hydraulic processes on constructed stormwater wetland. Civil Engineering Dimension, 21-28.

Masi, F., Rizzo, A., \& Regelsberger, M. (2017). The role of constructed wetlands in a new circular economy, resource oriented, and ecosystem services paradigm. Journal of environmental management, 1-10.

Pittman, J. (2011). Urban hydrology modeling with EPA's stormwater management model (SWMM) and analysis of water quality in a newly constructed stormwater wetland. Villanova University. 


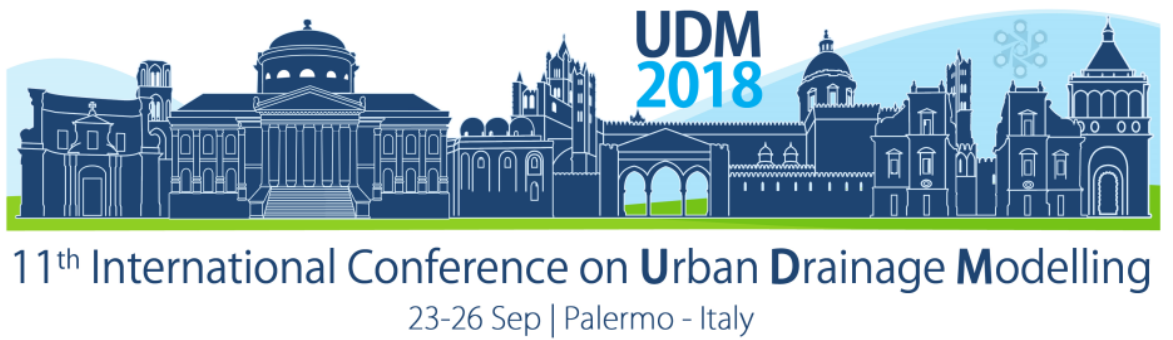

\title{
Uncertainty Propagation In Integrated Urban Water Quality Modelling
}

\author{
Giorgio Mannina ${ }^{1,2}$ \\ ${ }^{1}$ Dipartimento di Ingegneria Civile, Ambientale, Aerospaziale, dei Materiali, Università di Palermo, Viale delle \\ Scienze, Ed. 8, Palermo (IT), Italy \\ ${ }^{2}$ Department of Earth and Environmental Engineering, Columbia University, 500 West 120th Street, New York, \\ NY 10027, USA
}

\begin{abstract}
Sensitivity and uncertainty assessment of integrated urban drainage water quality models are crucial steps in the evaluation of the reliability of model results. Indeed, the assessment of the reliability of the results of complex water quality models is crucial in understanding their significance. In the case of integrated urban drainage water quality models, due to the fact that integrated approaches are basically a cascade of sub-models (simulating the sewer system, wastewater treatment plant and receiving water body), uncertainty produced in one sub-model propagates to the following ones in a manner dependent on the model structure, the estimation of parameters and the availability and uncertainty of measurements in the different parts of the system. Uncertainty basically propagates throughout a chain of models in which the simulation output from upstream models is transferred to the downstream ones as input. The paper presents the uncertainty assessment of an integrated urban drainage model developed in previous studies by means of the Generalized Likelihood Uncertainty Estimation (GLUE) methodology. A straightforward approach based on the analysis of the coefficient of variation (Rxy). Rxy is defined as the ratio between the standard deviation $(\alpha)$ and the average $(\mu)$ value of the model output of reference taken into account. The analysis has been applied to an experimental catchment in Bologna (Italy) which consists of a part of the Bologna sewer network and a reach of the Savena river. The results showed that the method can be a useful tool for uncertainty analysis and for guiding the operator in the choice of the modelling approach.
\end{abstract}

Keywords: Integrated urban drainage modelling; environmental water quality management; pollution evaluation; uncertainty analysis

\section{INTRODUCTION}

In the last years, the use of mathematical models has gained importance in urban drainage system management; indeed, such models enable a combined analysis of the different components that constitute a drainage system: sewer system, wastewater treatment plant, receiving water body (Rauch et al., 2002).

The effectiveness of an integrated approach has been widely demonstrated in the past and it is also presented in the WFD 2000/60/CE contents that furthermore introduce a new point of view regarding the water quality management of the whole system requiring a global analysis at catchment scale for the pollutant sources.

Indeed, the need of an integrated point of view is implicitly introduced and required by European Directives. Already fifteen years ago, CEE Directive 91/271 has overtaken the "emission standard" concept, that fixes discharge limits depending on polluting emission characteristics, substituting it with the "stream standard" concept, that fixes discharge limits for 


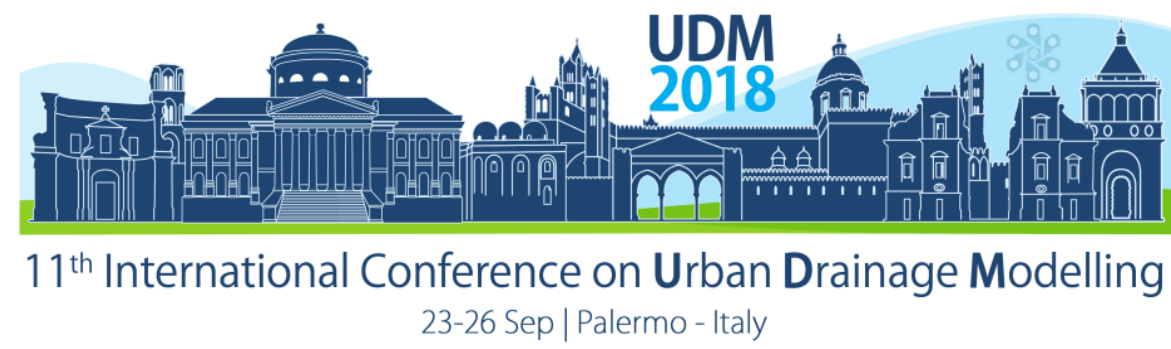

each polluting substance depending on self-depurative characteristics of the RWB. This Directive has had difficult application without an integrated perspective and efficient tools for simulating the whole system (urban catchment, SS, WWTP, RWB). These tools, commonly known as "integrated models", are aimed to the simulation of single drainage system components and their interactions. More recently, in the UE 2000/60 Directive (WFD: Water Framework Directive), receiving water bodies analysis became more complex, framing urban pollution in the wider range of catchment scale polluting sources making in fact necessary a wider integration of urban point discharge environmental impact with non point pollution coming from agricultural and productive activities. Although urban integrated modelling approach can be the best way for designing as well as managing the whole system (namely, sewer networks, WWTP and RWB) some difficulties prevent a straightforward application (Candela et al., 2012):

- The responsibilities for planning and managing the different sub-systems

- The models for the different sub-systems have been developed independently. Therefore, integrations between the different sub-systems are far to be straightforward.

- The data requirements increase dramatically with the inclusion of more and more sub-systems.

- The complexity of a given model introduces uncertainties in the modelling process that, sometimes, are not clearly identifiable and assessable (Mannina \& Viviani 2010).

Furthermore, despite such difficulties due to the fact that many sub-models are connected uncertainty propagation issues have generally to be faced. Therefore, uncertainty analysis is imperative and can be a good tool for selecting the right model approach. Despite the important role played by the uncertainty only few studies have been carried out. Indeed, assessing uncertainties in urban drainage models is not wide spread in practice and is usually an academic exercise (Dotto et al., 2012; Deletic et al., 2011). This is mainly because the techniques required for this analysis are so numerous, highly complex, poorly understood, and some are still highly underdeveloped. Clear and comprehensive comparisons of these techniques when applied to typical drainage models would therefore be desirable (Dotto et al., 2012).

In the light of the considerations discussed above, the paper is aimed to assess the uncertainty of an integrated model as well as to study its propagation in order to survey about results accuracy in case of scarce data availability. To accomplish such objects, a previously developed integrated model (Mannina et al., 2004; Mannina, 2005) and the GLUE methodology (Generalized Likelihood Uncertainty Efficiency) have been adopted (Beven and Binley, 1992).

\section{MATERIALS AND METHODS}

\subsection{The mathematical model}

An integrated bespoke model previously developed has been applied in the present study (Mannina, 2005). The key elements of the integrated model will be reported and the readers is referred to previous literatures for further details (Mannina et al, 2004; Mannina, 2005). 


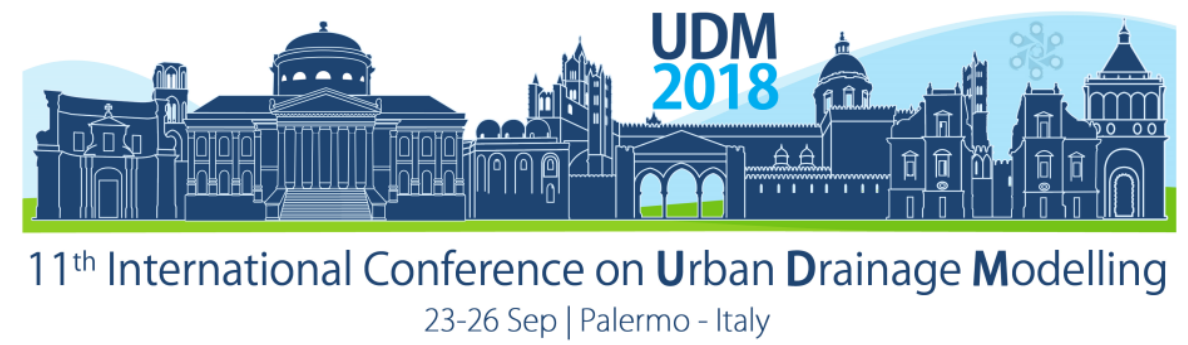

The urban drainage integrated model is made up of three sub-models. Each sub-model simulates one sub-system of the integrated system: SS, WWTP and RWB.

the SS sub-model, which is able to evaluate the quality - quantity features of SS outflows. Such sub-model allows for determining the hydrograph and pollutograph in the sewer for different pollutants (TSS, BOD and COD);

the WWTP sub-model, which is representative of the treatment processes. An activated sludge tank and a settler are simulated according to, respectively, Monod's theory and Takács models (Takács et al., 1991). The analysis was limited to such units since they represent the most sensitive in the WWTP during a storm event;

the RWB sub-model that simulates the pollutants transformations inside the water body.

The integrated urban drainage model has been developed in Fortran programming language; such aspect is important from the model computational time requirements especial in case of long term simulation analysis.

\subsection{Uncertainty assessment and propagation}

The GLUE procedure requires a large number of Monte Carlo simulations, where the random sampling of individual parameters from probability distributions is used to determine a set of parameter values. The performance of individual parameter sets are characterized by a likelihood weight, computed by comparing predicted to observed responses using some kind of likelihood measure. Parameter sets with poor likelihood weights are classified as nonbehavioral and can be rejected. All other weights from behavioral or acceptable runs are retained and re-scaled so that their cumulative total sums is equal to 1 . The cumulative likelihood weighted distribution of predictions can then be used to estimate quantiles for the predictions at any time step. The GLUE procedure thus transforms the problem of searching for an optimum parameter set into a search for the sets of parameter values that give reliable simulations. Following this approach there is no requirement to minimize (or maximize) any objective function, but information about the performance of different parameter sets can be derived from some indexes of goodness-of-fit (likelihood measures). The fundamental difference of this approach compared to other methods described is that the procedure is based on the concept that for a given model structure, not a single parameter set represents the observed reality, but a number of parameter set combinations may represent the observed reality behavior equally as well. This is the concept of equifinality, which maintains that due to the errors inherent in the model structure, (e.g. due to simplification and aggregation) errors in observed data and the difficulty in determining an exact error model, it is inappropriate to perform calibration based on an optimum set of parameters.

As in traditional calibration approaches, once the model structure and data for calibration have been determined, the definition of the likelihood measure must be chosen. Likelihood measure should be zero for all simulations that are considered to exhibit behavior dissimilar to the system under study, and it should increase monotonically as the similarity in behavior increases. Here, the Nash and Sutcliff efficiency index (1970) has been used as likelihood measure: 


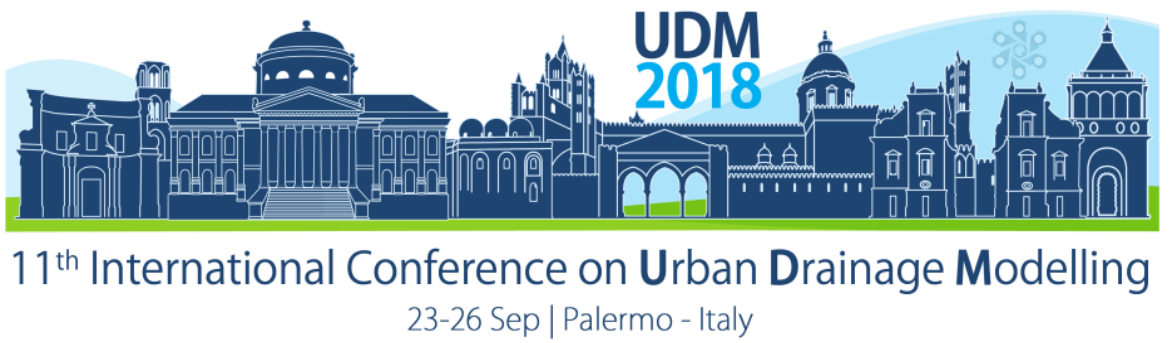

$E_{i, j}=1-\frac{\sigma_{e}^{2}}{\sigma_{o}^{2}}$

where $\sigma_{e}^{2}$ is the error variance, defined as the difference between the measured and simulated values, and $\sigma_{0}^{2}$ is the variance of the observations; the i subscript indicates different variables TSS, BOD, COD and dissolved oxygen (DO) while the $\mathrm{j}$ subscript indicates, alternatively, the SS, the combined sewer overflow (CSO) and the RWB. Like other likelihood measures, Nash - Sutcliff index is equal or lower then zero for all simulations that are considered to exhibit behavior dissimilar to the system under study, and it increases monotonically as the similarity in behavior increases with a limit value equal to 1 .

Once defined a likelihood index, the likelihood value associated with a set of parameters may be treated as a fuzzy measure that reflects the degree of belief of the modeler in that set of parameter values as a simulator of the system. The degree of belief is derived from the predicted variables arising from that set of parameter values. Treating the distribution of likelihood values as a probabilistic weighting function for the predicted variables, therefore allows an assessment of the uncertainty associated with the predictions, conditioned on the definition of the likelihood function, input data and model structure used.

A method of deriving predictive uncertainty bounds using the likelihood weights from the behavioral simulations has been shown by Beven and Binley (1992). The uncertainty bounds are calculated using the $5 \%$ and $95 \%$ percentiles of the predicted output likelihood weighted distribution. In the specific study, uncertainty connected with both quantitative and qualitative objective functions has been analyzed.

In order to evaluate the balance between different sub-models in terms of uncertainty generation and propagation a straightforward approach based on the calculation of the coefficient of variation (Rxy). Rxy is defined as the ratio between the standard deviation ( $\alpha$ ) and the average $(\mu)$ value of the model output of reference taken into account. Low Rxy values suggest that the modelled output is close to its average value.

\subsection{The case study}

The model has been applied to the catchment of the Savena river. The sewer system and the river studied in this work concerns a part of the sewer network of Bologna, studied within the European Union research project INNOVATION 10340I (Artina et al., 1999). The aim of the project was the "Application for the Urban Pollution Management Procedure to River Quality Protection in European Member States"; the Italian team was coordinated by CSDU (Centro Studi Idraulica Urbana) and it was constituted by ARPA Emilia-Romagna (Environmental Agency), Bologna University and Milan Polytechnic.

The Savena is a rural ephemeral river that passes through a number of small towns before entering the southern neighbourhood of Bologna. The catchment area of the Savena, at the downstream boundary of the studied river reach, is nearly $160 \mathrm{~km} 2$. The river is characterized by a very variable hydraulic regime with discharge usually ranging from few liters per second, during dry periods in summer period, up to several cubic meters per second during wet weather.

The studied river reach is about $6 \mathrm{~km}$ length receiving $6 \mathrm{CSO}$ discharges from the Bologna sewer network and 12 from the San Lazzaro sewer systems, a small centre in the surrounding 


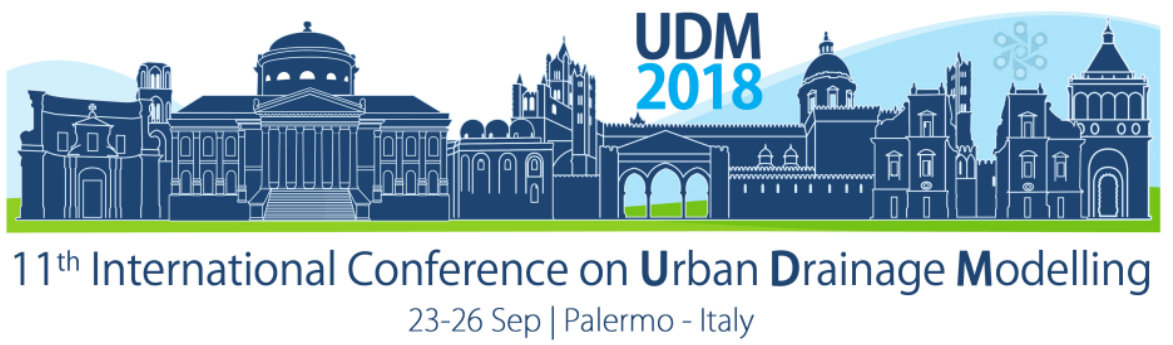

area of Bologna. The CSOs generally operates also during small intensity rainfalls and, in many cases, their discharge is of the same order of the river one.

The sewer network is a part of the combined system serving the whole city of Bologna, which can be considered as hydraulically divided into many independent catchments, all connected to a WWTP. The whole city of Bologna has about 500,000 inhabitants and an equivalent population of about 800,000 inhabitants. Only the part of this catchment which has directly or indirectly an effect on the studied reach of the Savena river has been taken into account. This part of Bologna has an area of more than 450 ha, with an impervious percentage of about $66 \%$ and about 60,000 inhabitants.

The six CSOs are installed in correspondence of collectors of different sizes and shapes ranging from egg shape $80 \times 120 \mathrm{~cm}$ up to polycentric shape $260 \times 208 \mathrm{~cm}$.

The sewer system of San Lazzaro, on the right side of the Savena river, has a catchment of about 120 ha with 10,000 inhabitants.

During experimental survey, carried out from December 1997 to July 1999, about 50 events have been recorded, but, for only 5 of these, water quality aspects have been analyzed regarding RWB, the CSO outlets and the SS. The analyzed parameters were: BOD5, NH4, TSS, COD, pH, DO, temperature and conductibility.

In this paper, only a part of the Savena river has been simulated (400 meters downstream the CSO No. 6) because the contribution of this CSO to river pollution has been determined much more relevant respect all the others. The contribution of other polluting sources has been considered by monitoring river pollution load in the first cross-section upstream of CSO No. 6 and introducing this information as input in the models.

\section{RESULTS AND DISCUSSION}

10,000 behavioral Monte Carlo simulations have been considered, varying both quantity and quality parameters: likelihood measures obtained for each sub-model have been related each other both considering flows and concentrations.

Analyzing only quantity modules (figure 1), it can be stated that uncertainty connected with RWB sub-model is negligible. The SS is thus responsible of the most part of the uncertainty propagated to the RWB flow output.

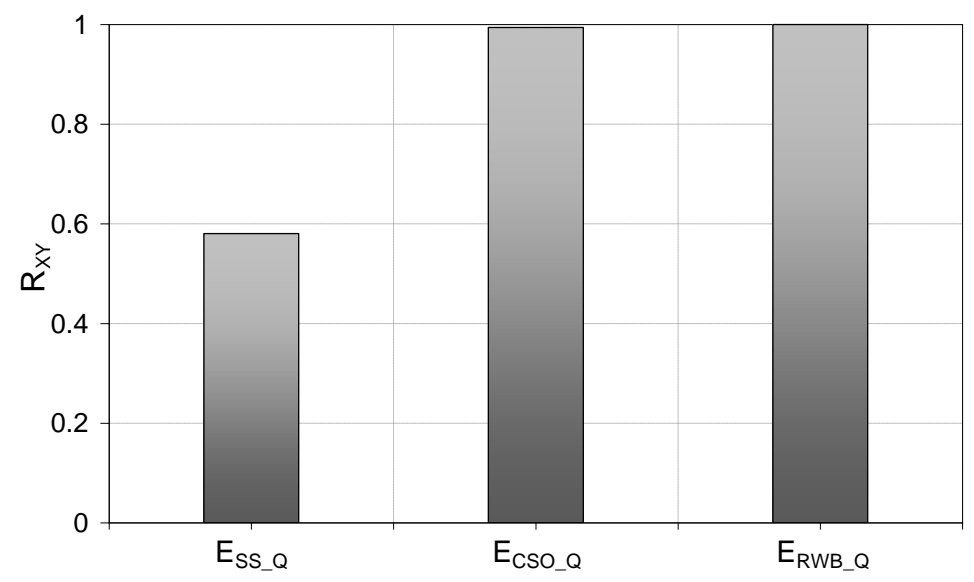

Figure 1. Rxy coefficients between RWB, SS and CSO for the quantity modules 


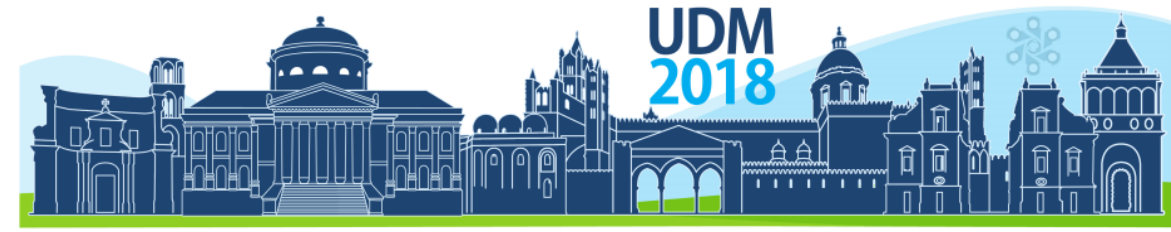

$11^{\text {th }}$ International Conference on Urban Drainage Modelling

23-26 Sep | Palermo - Italy

This analysis denotes a scarce balance among the quantity modules and it suggests the following modifications to the model structure:

- RWB sub-model complexity is not useful in the present application and it can be simplified probably using a conceptual model with lower computation needs;

- SS sub-model, on the contrary, is probably too simplified and it should be replaced by a more detailed one; probably distributed models should be investigated in order to add details to this part of the integrated approach.

A better balance can be found analysing the uncertainty propagated among the quality modules (figure 2).

(a)

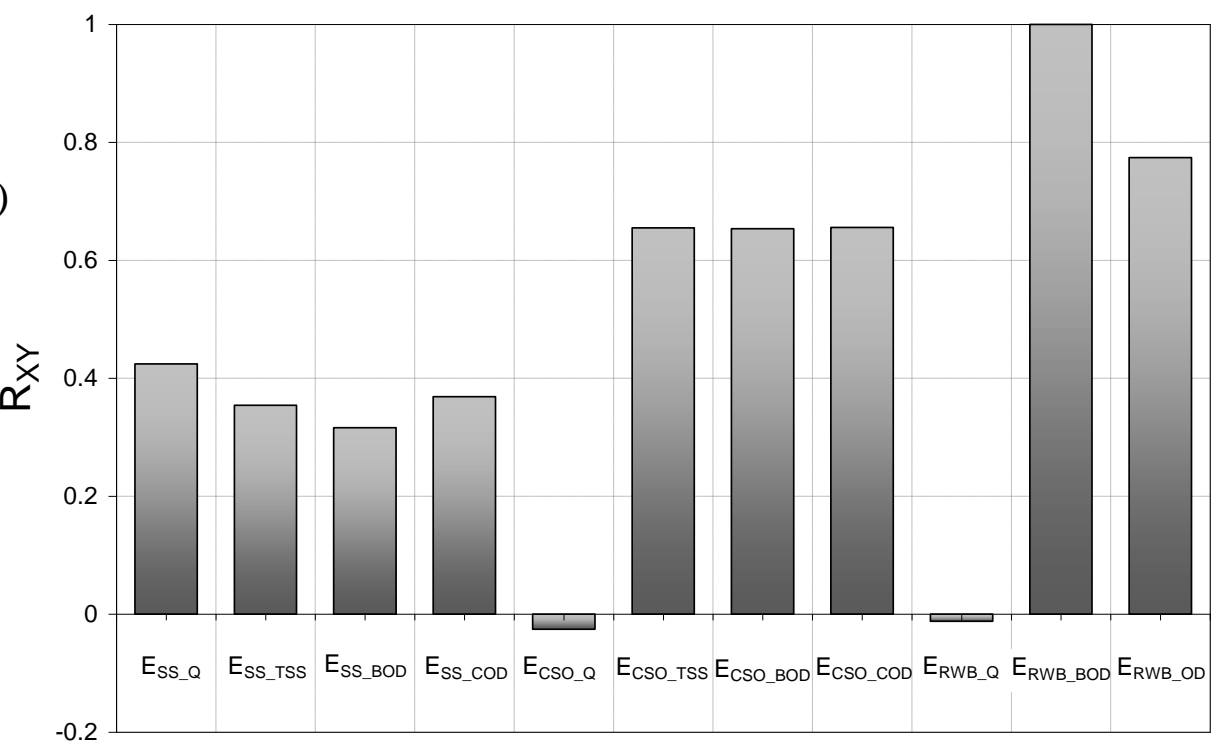

(b)

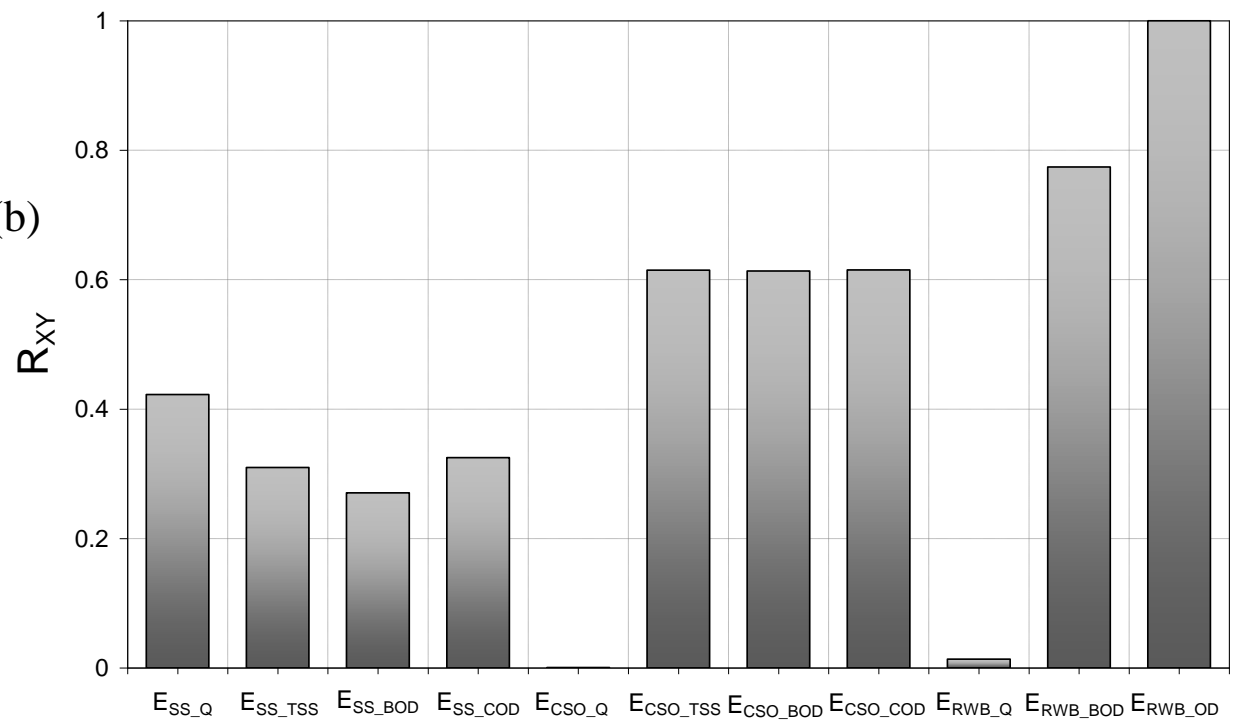




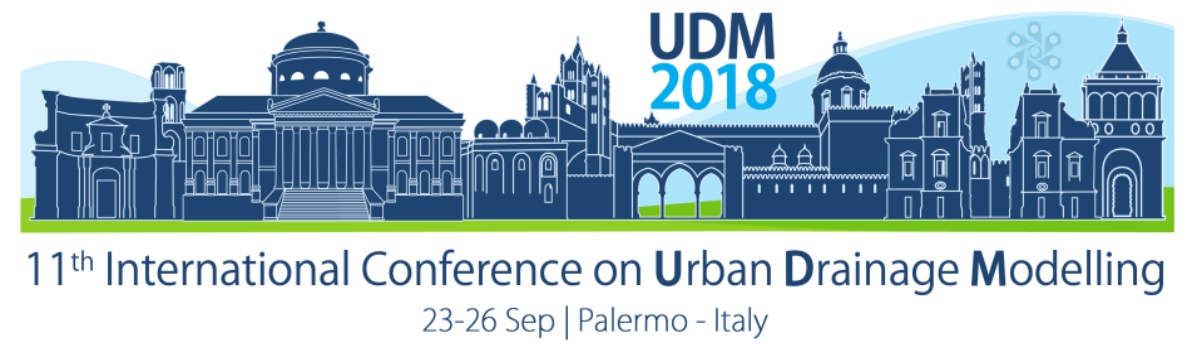

Figure 2 Rxy coefficients between RWB BOD (a) and OD (b) modeling efficiency indexes and upstream submodels ones both concerning quantity and quality modules

Even if the correlation analysis may provide qualitative information, the variation of Rxy index from one sub-model to the others can be considered as an indicator of the modeling noise introduced by each part of the integrated approach. The analysis of figure 2 enables to draw the following considerations:

- $\quad$ analyzing the quality features, RWB sub-model assumes a more relevant role in uncertainty propagation with respect to quantity modules. This result can be justified by the important role of reaeration and deoxygenation constants in the modification of BOD and DO in the RWB;

- $\quad$ SS, CSO and RWB contribute more uniformly to uncertainty propagation assuming approximately $1 / 3$ of the overall modeling uncertainty;

- $\quad$ there is no connection between uncertainties generated in RWB quantity and quality modules, demonstrating the different magnitude of the two uncertainty propagation processes;

- there is a good connection between modeling efficiencies in the evaluation of RWB concentrations and the efficiencies in the evaluation of SS discharge, while correlation attenuates considering CSO and RWB discharges; this fact can be explained by the relevant role assumed by SS hydrograph in the analysis of resuspension processes in the sewer system and the importance of such process in the evaluation of RWB polluting concentrations.

\section{CONCLUSIONS}

The present study analysed parametric and structural uncertainty of an urban drainage integrated model. As technical literature demonstrated in the last decade, this aspect has a relevant influence on the evaluation of modeling reliability and on the confidence that operators can put on its results. Integrated modeling uncertainty can depend on several factors like scarce data availability, especially when considering both water quantity and quality aspects. From the performed analyses some considerations can be drawn that partially confirm analytically what has been stated several times in literature, even if only with qualitative statements:

- the complexity of the integrated approach greatly modifies the propagation of uncertainties from one sub-model to the downstream one, so a dedicated analysis has been performed in order to aggregate the information coming from each sub-model and evaluate the weight of each of them in the definition of the overall modeling uncertainty;

- $\quad$ the adopted approach allowed for identifying unbalances in terms of uncertainty propagation among different quantity modules showing that uncertainty is mainly due to hydrological depletion module and to net rainfall - runoff propagation;

- $\quad$ on the other hand, quality modules resulted to be more balanced showing the relevant role assumed by water quality kinetic constants in uncertainty propagation in BOD and DO concentrations.

\section{References}




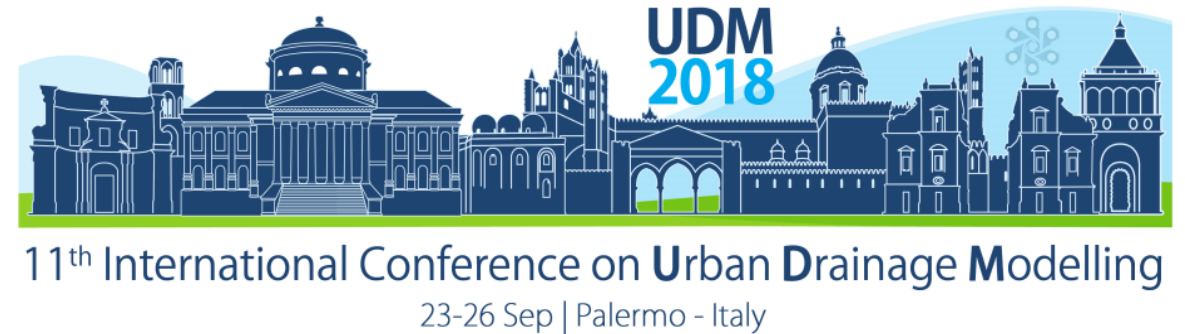

Artina, S., Bardasi, G., Borea, F., Franco, C., Maglionico, M., Paoletti, A., Sanfilippo, U. (1999). Water quality modelling in ephemeral streams receiving urban overflows. The pilot study in Bologna. Proc., 8th Int. Conf. on Urban Storm Drainage.

Beven, K.J., and Binley, A.M. (1992). The future of distributed models - model calibration and uncertainty prediction. Hydrological Processes 6(3), 279-298.

Candela, A., Freni, G., Mannina, G. and Viviani, G. (2012) Receiving water body quality assessment: an integrated mathematical approach applied to an Italian case study. Journal of Hydroinformatics, 14(1), 30-47.

Deletic, A. Dotto, C.B.S., McCarthy, D.T., Kleidorfer, M., Freni, G., Mannina, G., Uhl, M., Henrichs, M., Fletcher, T.D., Rauch, W., Bertrand-Krajewski, J.L., Tait, S. (2011) Assessing Uncertainties in Urban Drainage Models. Physics and Chemistry of the Earth., (in press).

Dotto, C. B. S., Mannina, G., Kleidorfer, M., Vezzaro, L., Henrichs, M., McCarthy, D.T., Freni, G., Rauch, W., Deletic, A. (2012) Comparison of different uncertainty techniques in urban stormwater quantity and quality modelling. Water Research, (in press).

Freni, G., Mannina, G., The identifiability analysis for setting up measuring campaigns in integrated water quality modelling. Physics and Chemistry of the Earth., (in press)

Mannina, G. (2005). Integrated urban drainage modelling with uncertainty for stormwater pollution management. Ph.D. thesis, Università di Catania, Italy.

Mannina, G., Viviani, G., Freni, G., (2004). Modelling the Integrated Urban Drainage Systems. Sewer Networks and Processes within Urban Water Systems Editor(s): J-L Bertrand-Krajewski, M Almeida, J Matos, S Abdul-Talib.

Mannina, G. and Viviani, G. (2010) An urban drainage stormwater quality model: Model development and uncertainty quantification. Journal of Hydrology, 381(3-4), 248-265.

Nash J.E., and Sutcliffe J.V. (1970). River flow forecasting through conceptual models. J. Hydrology.

Rauch, W., Bertrand-Krajewski, J. L., Krebs, P.,Mark, O., Schilling,W. and Schutze, M. 2002 Deterministic modelling of integrated urban drainage systems. Water Sci. Technol. 45(3), 81-94.

Takács I., Patry G.G., and Nolasco D.. (1991). A dynamic model of the clarification-thickening process. Water Resour., 25, 1263-1271. 


\section{Part $\mathrm{H}$ - Transport and sewer processes including Micropollutants and pathogens}




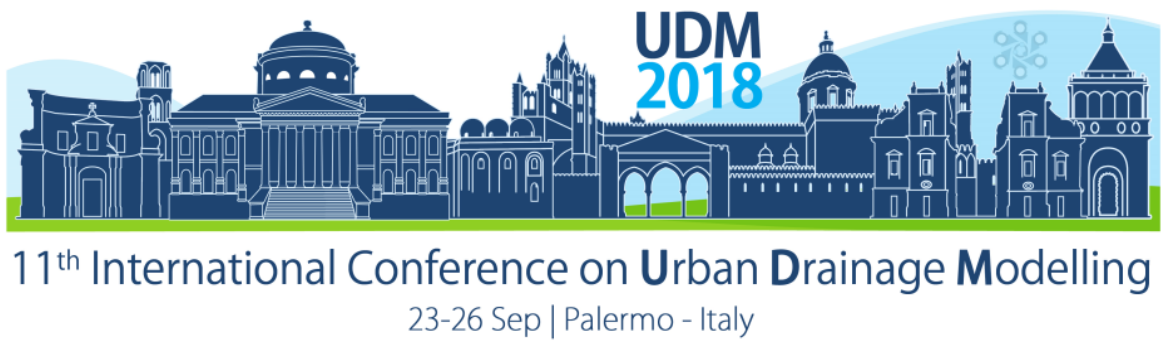

\title{
Percolation of Water from Surface Runoff - Case Studies
}

\author{
Martina Zeleňáková1, Petr Hluštík ${ }^{2}$, Gabriel Markovič² ${ }^{2}$ Gabriela Hudáková ${ }^{1}$ and Ladislav Tometz ${ }^{3}$ \\ ${ }^{1}$ Technical University of Košice, Department of Environmental Engineering, Košice, Slovakia \\ 2University of Technology, Department of Municipal Water Management, Brno, Country \\ ${ }^{3}$ Technical University of Košice, Department of Architectural Engineering, Košice, Slovakia \\ ${ }^{4}$ Technical University of Košice, Department of Geosciences, Košice, Slovakia
}

\begin{abstract}
At present great emphasis is placed on draining rainwater from town and village lands through percolation facilities, which represent a sustainable method of handling precipitation water from surface runoff. Therefore, the work is focused on experimental insitu analysis for resolving the percolation of rainwater from surface runoff. The study focused on determining the filtration coefficient, for which existing percolation facilities were used, socalled percolation shafts in two study areas, on the basis of confrontation of theoretical and practical analyses. The use of percolation facilities is demonstrated in the work; this represents an effective method of draining precipitation water from surface runoff for a specific project design.
\end{abstract}

Keywords: urban drainage; hydrogeology; percolation facility

\section{INTRODUCTION}

The science of urban hydrology has evolved with the aim of improving urban water management for public health and hygiene, for flood protection, as well as protection of the environment and the life-cycle of cities. Management of urban drainage requires several disciplines: engineering, environmental science, public health and sociology. Urban hydrology is not even close to being simple and requires the development of new technologies that point out the technical problems in towns and which correspond to the needs of urban communities (Butler and Davies, 2011; Beven, 2001; Stevenson, 1981). Management of precipitation water is an important activity not only in agriculture and water management, but also in the construction field. The percolation of precipitation water is a current and important issue, especially in the present in association with climatic change, when it is necessary to slow the runoff of water from land, support the percolation of water into soil and increase the retention capability of the ground (Zeleňáková et al. 2009; Vranayová et al. 2011). In construction engineering determination of the filtration coefficient is most often done using empirical calculations from grading curves. In hydrogeological practice, however, this basic hydraulic parameter is most exactly determined using field tests, so-called hydrodynamic tests. Depending on the presence of underground water these may be either pumping or ascending, and if the water is not present in the surveyed rocky environment, then filling (percolation) tests.

The paper presents the results of determining filtration coefficients for two study areas obtained from hydrodynamic tests, from grading curves and calculations according to empirical relations. 


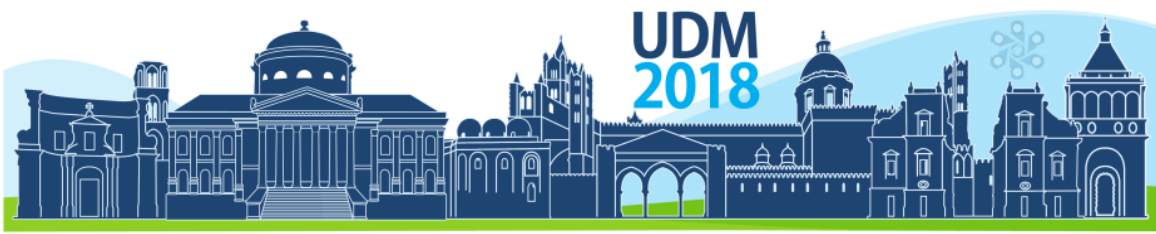

$11^{\text {th }}$ International Conference on Urban Drainage Modelling

23-26 Sep | Palermo - Italy

\section{MATERIALS AND METHODS}

\subsection{Study areas}

The territories where the field tests were conducted are located in two different regions of eastern Slovakia (Figure 1). Specifically, they are the cities of Košice (Study area I) and Prešov (Study area II).

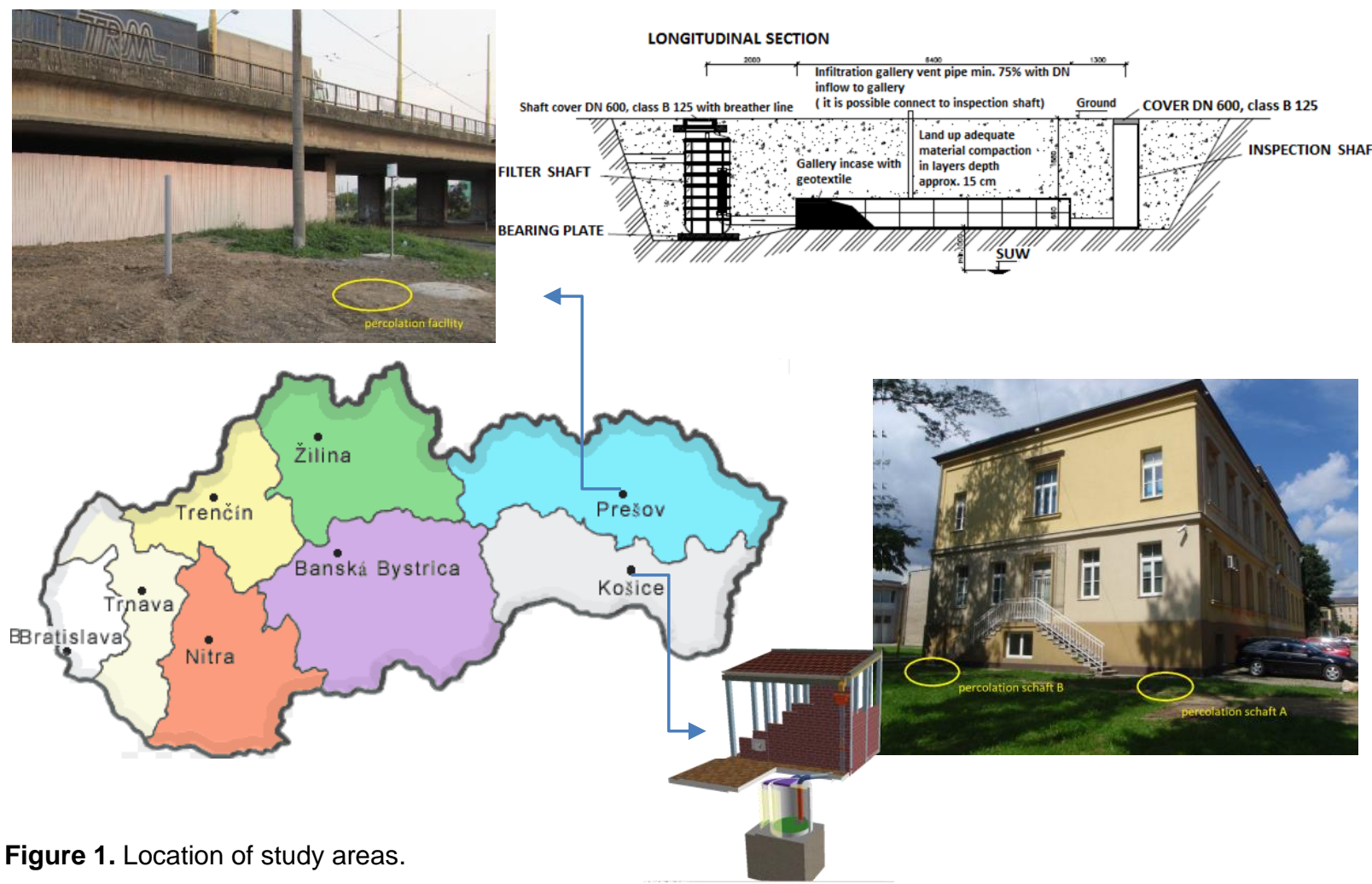

The first territory of interest is located in Košice (Study area I), specifically in the campus of the Technical University (TUKE). The research was carried out in two percolation shafts, where the rainwater is drained from the roof of nearby building depicted in Fig 1 . The second territory of interest is located in Prešov (Study area II), near the road bridge. After the reconstruction of the bridge the rainwater was drained from bridge to percolation facility depicted in Fig. 1.

\subsection{Measurements}

We have started the measurements in March 2011. The devices are placed in shafts as it is shown in Fig. 2. Measurements are focused on the amount of drained water by UV-sensor placed in the measuring channel, the height of the water level in the shaft by pressure sensor placed in the bottom of the shaft. The measured data from these measuring instruments are transmitted to the data telemetric unit M4016, which is located also in the shaft, and using the communication module the data is subsequently stored in the form of datahosting on the server. All the data are posted online for further processing. We are measuring also the parameters of water quality $-\mathrm{pH}$ and conductivity by multiparametric probe but these measurements are not object of this article. 


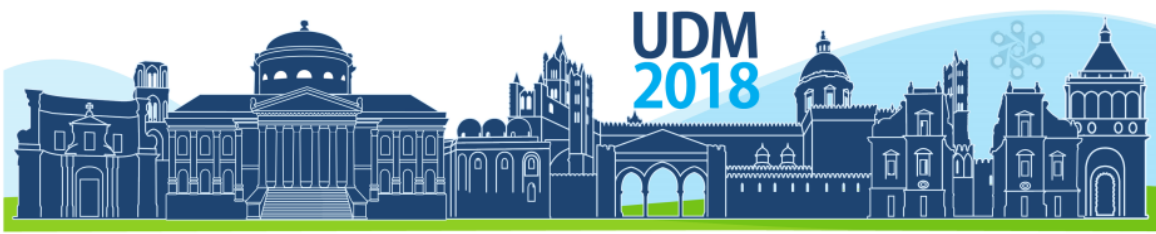

$11^{\text {th }}$ International Conference on Urban Drainage Modelling

23-26 Sep | Palermo - Italy
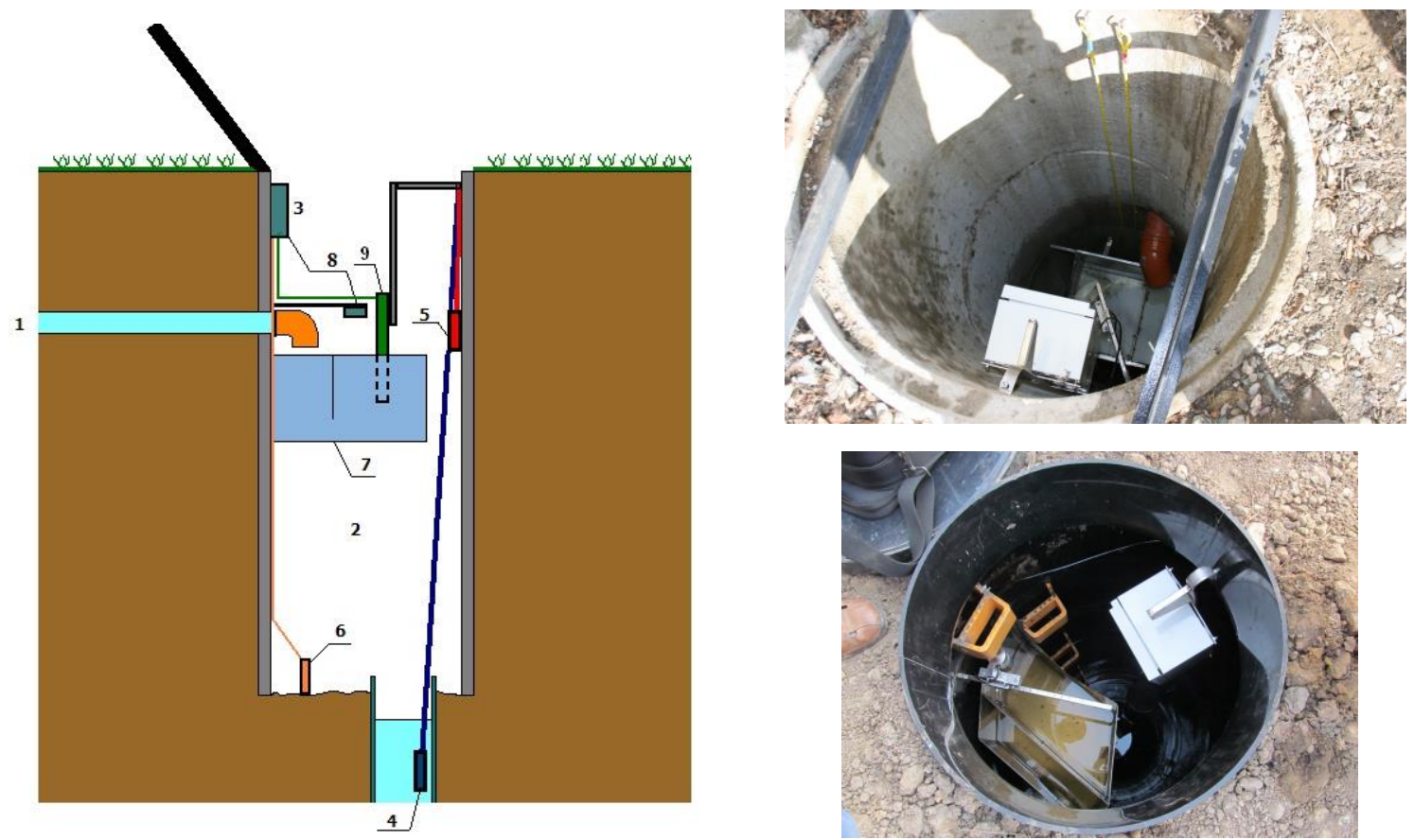

Figure 2. Percolation shaft: 1-drained rainwater; 2-percolation shaft; 3- data telemetric unit M4016; 4-levelogger; 5-barologger; 6- pressure sensor; 7-measuring channel; 8- UZV-sensor; 9-multiparameter probe.

\subsection{Determination of the filtration coefficient}

The percolation of precipitation waters into the rocky environment to a great measure depends on the local conditions, primarily from the measure of its permeability. The basic hydraulic characteristic of this measure is the filtration coefficient. Correctly determining its values represents a key question in the assessment of the percolation of water into rock or soil. Many different methods exist for its determination. In construction engineering determination of the filtration coefficient is most often done using empirical calculations from grading curves. Also empirical equations can be used for its determination. In hydrogeological practice, however, this basic hydraulic parameter is most exactly determined using field tests, so-called hydrodynamic tests. Depending on the presence of underground water these may be either pumping or ascending, and if the water is not present in the surveyed rocky environment, then filling (percolation) tests.

According to available provisions the bottom of percolation bodies should be situated minimally $1.0 \mathrm{~m}$, in the case of percolation wells minimally $1.5 \mathrm{~m}$, above the maximum level of the groundwater, and the permeability of the percolation layer should be in the range of $k_{f}=5.10^{-3}$ to $5.10^{-6} \mathrm{~m} \cdot \mathrm{s}^{-1}$.

\section{RESULTS AND DISCUSSION}

The bottom of a percolation well which is in the grounds of the TU Košice is located in a layer of gravels with a portion of fine-grained soil, for which $k_{\mathrm{f}}=1.10^{-3}$ up to $1.10^{-4} \mathrm{~m} \cdot \mathrm{s}^{-1}$. These are neogenic sediments, which create favourable conditions for concentrating a larger amount of groundwater. 


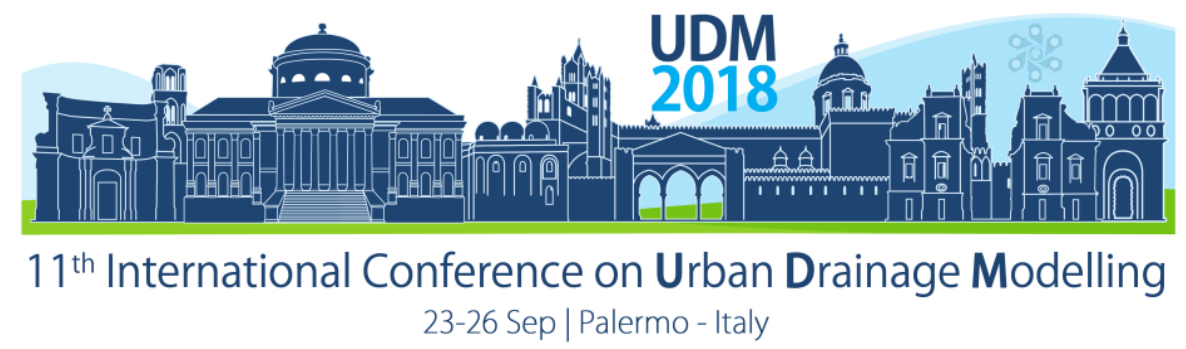

The filtration coefficient was determined from grading curves as follows. With calculation of the filtration coefficient the size of the gravel grain at a falling of $10 \%$ and $60 \%$ is important. The filtration coefficient for shaft $A$ is $1.58 .10^{-3} \mathrm{~m}_{\mathrm{s}} \mathrm{s}^{-1}$, and for shaft $B$ in Košice it is $1.89 .10^{-4} \mathrm{~m} . \mathrm{s}^{-1}$ and for Šarišské Lúky it is $4.84 .10^{-7} \mathrm{~m} . \mathrm{s}^{-1}$. This analysis was necessary for stating the efficiency of percolation facilities. The results of investigations proved that the percolation shafts in Study area I are suitable and efficient and in contrary the percolation facility in Study area II is not appropriate solution.

In conclusion it is necessary to state that the foundation of an optimally designed percolation system is certainly a quality geological and hydrogeological study. Determining not only the filtration coefficient or percolation coefficient of the first layer in contact with the built-in facility was shown to be important, but also the flow properties of the other soils.

The fact that Slovakia is lacking valid legislation which would exactly define the input requirements for the design of percolation facilities appears to be a problem. New legislation should thus resolve not only the determination of conditions for the percolation of rainwater but should also set the range and method of carrying out a geological and hydrogeological study.

\section{CONCLUSIONS}

In recent years advancements have developed in science as well as in practices of urban hydrology from the viewpoint of basic understanding and approaches to management. New technologies have been developed for recording, analysing and predicting precipitation in urban areas with the aim of pointing out the issues of small spatial and time benchmarks for the reaction to precipitation and runoff in towns as well as the percolation of water from surface runoff, with an emphasis on the retention capacity of a selected territory (Vranyova et al., 2011). With the development of constructions in big cities and in their surroundings dealing with the issue of overburdened sewerage networks is occurring more often (Zeleňáková et al., 2009; Markovič and Zeleňáková, 2017).

The variability and complexity of the precipitation runoff reaction in urban areas remains a field of active research, particularly in suburban areas with a complex mix of urban and rural landscape with multiple precipitation events, which complicate urban drainage. While runoff from an impermeable surface is relatively foreseeable, changes in permeable areas have as a consequence a change in the processes of surface and sub-surface runoff. And thus research and solutions to the percolation of water from surface runoff is further required.

\section{Acknowledgement}

This work was supported by project VEGA 1/0202/15 Sustainable and Safe Water Management in Buildings.

\section{References}

Beven, K.J. (2001) Rainfall-Runoff Modelling, The Primer. John Wiley \& Sons, Chichester. $360 \mathrm{~s}$.

Butler, D. and Davies, J. W. (2011) Urban Drainage, 3rd Edition, Spon Press an imprint of Taylor \& Francis, ISBN 978-0-415-45526-8

Stephenson, D. (1981) Stormwater hydrology and drainage. Elsevier Scientific Publishing Company.

Markovic, G., Zelenakova, M. (2017) Measurement and evaluation of percolation drainage systems capacity in real conditions. In: 1st International Conference on Advances in Environmental Engineering (AEE), Ostrava IOP Conference Series-Earth and Environmental Science. 92(012040)

Vranayová, Z., Karelová, Z., Očipová, D. (2011) Precipitation Monitoring Methodology at the Campus of Technical University of Košice. In: Selected Scientific Papers. Journal of Civil Engineering. 6(2).

Zeleňáková, M., Bálintová, M., Foraiová, K. (2009) Rain water management for the purposes of sustainable development. In: Zeszyty naukowe Politechniki Rzeszowskiej: Budownictwo i Inzynieria Srodowiska. 266 (54), 119-128. 


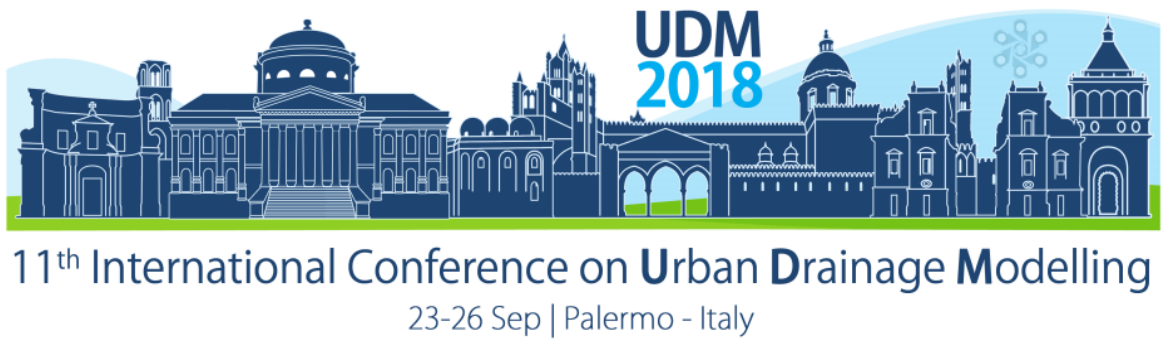

\title{
Mathematical Modelling of In-sewer Processes as a Tool for Sewer System Design
}

\author{
Giorgio Mannina ${ }^{1}$, Paolo S. Calabrò ${ }^{2}$ and Gaspare Viviani ${ }^{3}$ \\ ${ }^{1}$ Università di Palermo, Dipartimento di Ingegneria Civile, Ambientale, Aerospaziale, dei Materiali, Palermo, Italy \\ 2 Università Mediterranea di Reggio Calabria, Department of Civil, Energy, Environmental and Materials \\ Engineering, Reggio Calabria, Italy
}

\begin{abstract}
The objective of this paper is to evaluate the potential impact of in-sewer processes (COD components transformation and hydrogen sulphide production) on the design of sewer systems. The tool used for such analysis is a mathematical model derived from the WATS model (Wastewater Aerobic/anaerobic Transformation in Sewers) able to describe the processes occurring in the sewer system both under aerobic and anaerobic conditions. The model is applied to three synthetic catchments with, respectively, 10,000, 50,000 and 250,000 inhabitants connected to gravity sewer systems different in terms of type (separate or combined), slope, length, travel time, wastewater temperature. The simulation results enable to assess the effect of the in sewer transformations in terms of hydrogen sulphide formation and transformation of the biodegradable organic matter that is necessary for biological nutrients removal at the WWTP.
\end{abstract}

Keywords: Aerobic/anaerobic conditions; Sewer; Wastewater transformations; Biological nutrients removal

\section{INTRODUCTION}

The objective of this paper is to evaluate the potential impact of the in-sewer processes (COD components transformation and hydrogen sulphide production) on the design of sewer systems. The model has been applied to synthetic urban catchments with different characteristics in order to cover as much as possible the range of possible real cases occurring in engineering practice. The model results enabled to evaluate the characteristics of the sewer system that influence significantly the in-sewer processes both in terms of hydrogen sulphide production and of COD transformation. With regard to this latter, model outputs have been compared with the amount of biodegradable organic matter needed for biologic nutrients removal. In fact, according to Henze et al., 1999, considering typical composition of raw wastewater (Bonomo, 2008; Tchobanoglous et al., 2002; Henze et al., 1996) and the standard for discharge of treated wastewater in Italy (Gazzetta Ufficiale della Repubblica Italiana, 2006), about $90 \mathrm{mg} / \mathrm{l}$ of readily biodegradable organic matter are needed for phosphorus removal and approximately $425 \mathrm{mg} / \mathrm{l} \mathrm{COD}$ are needed for denitrification. As better explained below, in this paper influent COD concentration has been assumed equal to $530 \mathrm{mg} / \mathrm{l}$ following Henze et al., 1996, in this case the organic matter available for biologic nutrients removal is hardly higher than the minimum amount calculated above $(90 \mathrm{mg} / \mathrm{l}$ for $\mathrm{P}$ removal and $425 \mathrm{mg} / \mathrm{l}$ for $\mathrm{N}$ removal for a total of $515 \mathrm{mg} / \mathrm{l} \mathrm{COD)}$ ) and for this reason also a limited change in COD amount and composition due to in-sewer processes can negatively influence biologic nutrients removal. 


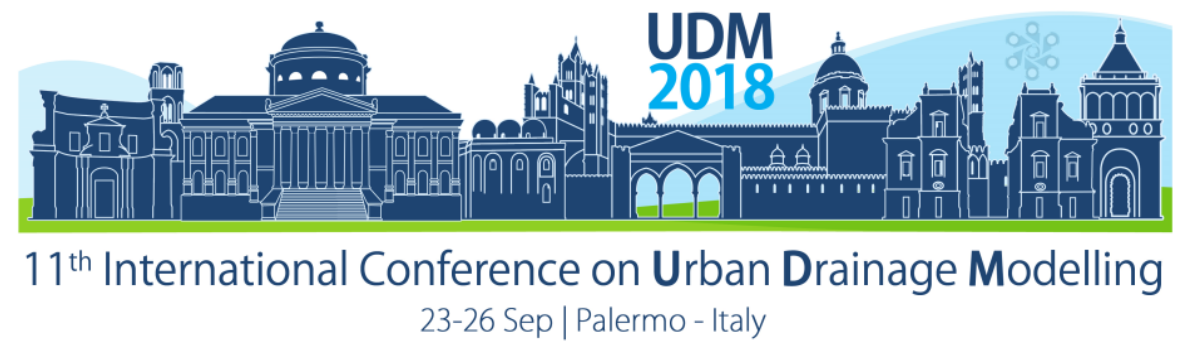

\section{METHODS: MODEL DESCRIPTION AND APPLICATION}

The adopted model (see Calabrò et al., 2009) simulates the main in-sewer processes and it is mainly based on the WATS model (Hvitved-Jacobsen et al., 1999). Similarly to the WATS (Tanaka and Hvitved-Jacobsen, 1998; Bruno et al., 2003), the quantity module is dynamic and it is therefore able to consider the variability of the flow during the day while the quality module is quasi-steady (Calabrò et al., 2009). It automatically switches between aerobic and anaerobic conditions according to the local environmental conditions (presence or absence of Dissolved Oxygen). The model consists of two modules, the first module deals with the flow propagation in the sewer system, it reproduces the dynamic conditions; as matter of a fact, such module considers the variations of parameters and control variables, such as discharge, water height and velocity in space and time. On the other hand, the second module describes the in-sewer transformations according to several differential equations which are based on mass balances. As the quantity module, the quality module reproduces dynamic conditions.

The developed model has been applied to three synthetic cases with different characteristics to cover as much as possible the range of possible real cases occurring in engineering practice. The catchments present a population of respectively 10,000, 50,000 and 250,000 inhabitants and are connected to gravity sewer systems with differences in terms of type (separate or combined), slope, length, travel time, wastewater temperature. Diameter ranges have been generated using Italian Best Practice Design Rules (see CSDU, 1997) and average specific water consumption. Separate and combined sewers have been considered because, during dry weather, under the same discharge, reaeration is significantly different due to the noticeable difference of the ratio between water depth and diameter.

The model parameters and the wastewater COD fractionations have been set at the same values coming from previous model applications (see Calabrò et al., 2009). Table 1 summarizes the values of the parameters used in the simulations. The simulations have been carried out considering a variation of the values of the parameter under investigation according to the range presented in Table 1 with the other parameters set at their default values. The model outputs chosen for the assessment were: COD, readily biodegradable COD (evaluated as the sum of SS and XS1) and SH2S at the outlet of the sewer.

Table 1. Parameters values considered in simulations.

\begin{tabular}{|c|c|c|}
\hline Parameter & \multicolumn{2}{|c|}{ Range of variation (Default value) } \\
\hline Catchment Population [inhabitant] & 50,000 & 250,000 \\
\hline Type & \multicolumn{2}{|c|}{ Separate, Combined } \\
\hline Specific Water Consumption [m³/in*day] & 0.350 & 0.450 \\
\hline Slope $[\mathrm{m} / \mathrm{m}]$ & \multicolumn{2}{|c|}{$0.0005-0.1(\mathbf{0 , 0 0 9 )}$} \\
\hline Diameter [m] & $\begin{array}{cc}0,32-1,6 & 0.7-3.5 \\
(\mathbf{0 . 3 2} \text { sep. }-1.6 \text { com.) } & (0.7 \text { sep. }-2.0 \\
\end{array}$ & $\begin{array}{l}1.3-6.7 \\
\text { ep. }-4.0 \text { com.) }\end{array}$ \\
\hline Length $[\mathrm{km}]$ & \multicolumn{2}{|l|}{$0-15$} \\
\hline Total COD [mg/l] (see Henze et al.1999) & \multicolumn{2}{|l|}{530} \\
\hline Most readily Biodegr. COD $\mathrm{S}_{\mathrm{s}}+\mathrm{X}_{\mathrm{S} 1}+\mathrm{X}_{\mathrm{S} 2}[\mathrm{mg} / \mathrm{l}]$ & \multicolumn{2}{|l|}{140} \\
\hline Temperature $\left[{ }^{\circ} \mathrm{C}\right]$ & \multicolumn{2}{|l|}{$5-25(20)$} \\
\hline
\end{tabular}

\section{RESULTS AND DISCUSSION}

The simulation results are summarized in Table 2; in particular, for each of the three synthetic catchments considered, the changes in the model outputs (Hydraulic Retention Time HRT), 


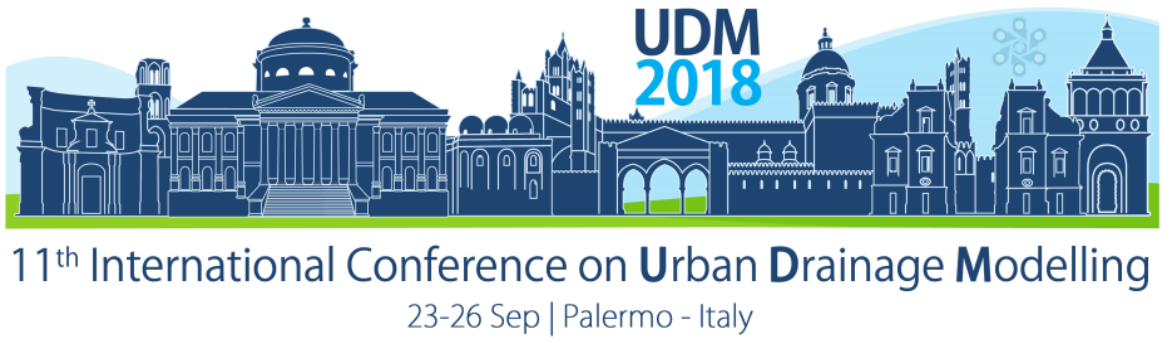

Total COD, Readily Biodegradable COD and H2S concentration) have been reported as a function of the sewer type, diameter, slope, length and wastewater temperature. Regarding, Total COD and Readily Biodegradable COD concentration, maximum, minimum and average values normalized respect to their initial value have been reported. On the other hand, concerning HRT and H2S instead of the normalized values their actual values have been reported.

Table 2. Synthesis of simulation results.

Minimum/Maximum - Average Value at the outlet of a sewer of length equal to $15 \mathrm{~km}$ (normalized respect to initial values)

\begin{tabular}{|c|c|c|c|c|}
\hline & $\mathrm{HRT}[\mathrm{h}]^{*}$ & COD total & $\mathrm{S}_{\mathrm{s}}+\mathrm{X}_{\mathrm{S} 1}$ & $\mathrm{~S}_{\mathrm{H} 2 \mathrm{~S}}\left[\mathrm{mg} / \mathrm{l}^{*}\right.$ \\
\hline & \multicolumn{4}{|c|}{ Separate Sewer } \\
\hline \multicolumn{5}{|c|}{ 10,000 INHABITANTS } \\
\hline Diameter [m] & $4.14 / 5.07-4.67$ & $0.960 / 0.980-\mathbf{0 . 9 7 3}$ & $0.762 / 1.003-0.918$ & $0.721 / 2.028-1.469$ \\
\hline Slope $[\mathrm{m} / \mathrm{m}]$ & $2.08 / 12.89-5.99$ & $0.943 / 0.973-0.959$ & $0.467 / 0.964-\mathbf{0 . 7 2 4}$ & $0.019 / 2.424-1.018$ \\
\hline Temperature $\left[{ }^{\circ} \mathrm{C}\right]$ & not applicable & $0.955 / 0.974-0.965$ & $0.684 / 1.010-0.849$ & $0.118 / 0.949-0.497$ \\
\hline Length ${ }^{\star \star}[\mathrm{km}]$ & $0.83 / 4.14-1.93$ & $0.992 / 0.960-0.982$ & $0.963 / 0.762-0.903$ & $0.120 / 0.721-0.303$ \\
\hline \multicolumn{5}{|c|}{ 50,000 INHABITANTS } \\
\hline Diameter [m] & $2.56 / 3.15-2.85$ & $0.986 / 0.993-0.990$ & $0.915 / 1.002-0.966$ & $0.028 / 0.663-0.473$ \\
\hline Slope $[\mathrm{m} / \mathrm{m}]$ & $1.25 / 7.90-4.00$ & $0.977 / 0.991-0.985$ & $0.781 / 1.030-0.908$ & $0.005 / 0.735-\mathbf{0 . 3 3 1}$ \\
\hline Temperature $\left[{ }^{\circ} \mathrm{C}\right]$ & not applicable & $0.984 / 0.991-0.987$ & $0.882 / 1.030-0.954$ & $0.087 / 0.359-0.216$ \\
\hline Length $^{\star \star}[\mathrm{km}]$ & $0.52 / 2.56-1.19$ & $0.997 / 0.986-0.993$ & $0.984 / 0.915-0.962$ & $0.056 / 0.289-0.132$ \\
\hline \multicolumn{5}{|c|}{ 250,000 INHABITANTS } \\
\hline Diameter [m] & $1.60 / 1.97-1.75$ & $0.994 / 0.997-0.996$ & $0.967 / 1.005-0.985$ & $0.105 / 0.215-0.148$ \\
\hline Slope $[\mathrm{m} / \mathrm{m}]$ & $0.34 / 2.13-1.08$ & 0.990/0.997-0.994 & $0.917 / 1.027-0.969$ & $0.007 / 0.236-0.113$ \\
\hline Temperature $\left[{ }^{\circ} \mathrm{C}\right]$ & not applicable & $0.994 / 0.996-0.995$ & $0.954 / 1.018-0.985$ & $0.047 / 0.130-0.086$ \\
\hline Length ** $[\mathrm{km}]$ & $.32 / 1.61-0.75$ & $0.999 / 0.995-0.998$ & $0.994 / 0.969-0.986$ & $0.021 / 0.106-0.049$ \\
\hline & \multicolumn{4}{|c|}{ Combined Sewer } \\
\hline \multicolumn{5}{|c|}{ 10,000 INHABITANTS } \\
\hline Diameter [m] & $4.14 / 5.07-4.67$ & $0.960 / 0.980-\mathbf{0 . 9 7 3}$ & $0.762 / 1.003-0.918$ & $0.721 / 2.028-1.469$ \\
\hline Slope [m/m] & $2.18 / 13.93-6.98$ & $0.956 / 0.991-0.976$ & $0.766 / 1.211-1.005$ & $0.300 / 3.687-2.032$ \\
\hline Temperature $\left[{ }^{\circ} \mathrm{C}\right]$ & not applicable & $0.977 / 0.986-0.982$ & $0.993 / 1.101-1.038$ & $0.952 / 2.450-1.658$ \\
\hline Length $^{\star *}[\mathrm{~km}]$ & $1.01 / 5.07-2.37$ & $0.996 / 0.980-0.991$ & 1.006/1.003-1.008 & $0.388 / 2.028-0.922$ \\
\hline \multicolumn{5}{|c|}{ 50,000 INHABITANTS } \\
\hline Diameter [m] & $2.56 / 3.15-2.85$ & $0.986 / 0.993-0.990$ & $0.915 / 1.002-0.966$ & $0.028 / 0.663-\mathbf{0 . 4 7 3}$ \\
\hline Slope [m/m] & $1.26 / 8.00-4.01$ & $0.981 / 0.996-0.990$ & $0.869 / 1.089-0.982$ & $0.067 / 0.899-0.497$ \\
\hline Temperature $\left[{ }^{\circ} \mathrm{C}\right]$ & not applicable & 0.990/0.994-0.992 & $0.963 / 1.042-1.000$ & $0.245 / 0.606-0.416$ \\
\hline Length $^{\star \star}[\mathrm{km}]$ & $0.63 / 2.91-1.36$ & $0.998 / 0.991-0.996$ & $0.996 / 0.979-0.991$ & $0.100 / 0.507-0.235$ \\
\hline \multicolumn{5}{|c|}{ 250,000 INHABITANTS } \\
\hline Diameter [m] & $1.60 / 1.97-1.75$ & $0.994 / 0.997-0.996$ & $0.967 / 1.005-0.985$ & $0.105 / 0.215-\mathbf{0 . 1 4 8}$ \\
\hline Slope [m/m] & $0.37 / 2.34-1.17$ & $0.992 / 0.999-0.996$ & $0.944 / 1.051-\mathbf{0 . 9 9 7}$ & $0.041 / 0.281-0.167$ \\
\hline Temperature $\left[{ }^{\circ} \mathrm{C}\right]$ & not applicable & $0.996 / 0.998-0.997$ & $0.988 / 1.022-1.004$ & $0.094 / 0.203-0.145$ \\
\hline Length ${ }^{\star *}[\mathrm{~km}]$ & $0.37 / 1.83-0.85$ & 0.999/0.997-0.998 & 0.999/0.995-0.998 & $0.034 / 0.170-0.079$ \\
\hline
\end{tabular}

From the results analysis emerges that there is only a slight total COD variation both in dependence of the diameter, the slope, the type of sewer and the temperature. However, ss explained above, this reduction in the available COD, although moderate, could negatively influence biologic nutrients removal and should be carefully considered on case by case basis. It is also interesting that the readily biodegradable COD in correspondence of limited oxygen availability (low reaeration due to limited values of slope and velocity or excessive filling rate) or limited biological activity due to low temperature, shows an increase respect to the initial value. This effect is obviously emphasized in combined sewer where, during dry weather, the 


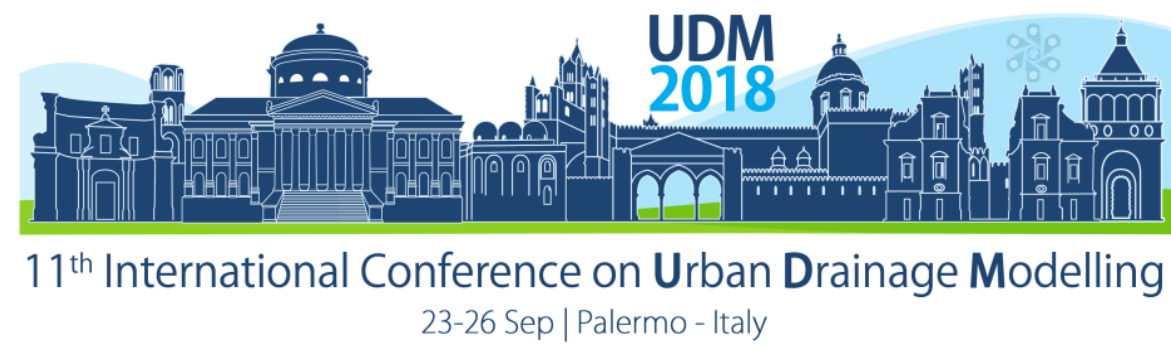

velocity is reduced. Reciprocally, a high level of hydrogen sulphide occurs in the same cases. Readly biodegradable COD reduction in smaller catchments with separate sewers and high average slopes could be high enough to reduce this component down to values non compatible with biological phosphorus removal.

Referring to the type of sewer, the change in readily biodegradable COD concentration is higher for separate sewer and, on the other hand, combined sewers are generally affected by higher levels of hydrogen sulphide. The wastewater temperature shows, as it could have been expected, a significant impact on in sewer processes. The model results analysis clearly shows that the most significant in sewer processes take place in the smallest of the three synthetic catchments tested that is also the one showing the highest HRTs. In most cases the dependence of the outputs with the various parameters tested seems linear but it has to be outlined that if sewer length is increased the trend could be very different.

\section{CONCLUSIONS}

The model results showed that the most significant results of in sewer processes in gravity sewers are hydrogen sulphide production and COD modification in terms of increase or decrease of readily biodegradable substrate. The most significant in sewer processes take place in the smallest of the three synthetic catchments tested that is also the one showing the highest HRTs. The in sewer processes are almost negligible for modest travel time and for sewer length lower than 3 to $5 \mathrm{~km}$; conversely, their impact is stronger if sewer length is around $10 / 15 \mathrm{~km}$ and HRT is of several hours.

At the end it is important to underline that since wastewater composition is highly variable, and, as discussed above the available biodegradable organic matter is often slightly sufficient for biologic nutrients removal, the possible negative influence of in-sewer processes on this process should be evaluated on case by case basis since it can not be excluded beforehand. For this reason, reliable models are needed to foresee such cases and to avert possible problems with an appropriate design of sewer systems or at least to to adopt appropriate countermeasures (e.g. change in WWTP lay-out, adoption of chemical P removal, use of additional carbon sources).

\section{References}

Bonomo, L. (2008). Trattamenti delle acque reflue. McGraw-Hill Companies, Milan.

Bruno, S., Viviani, G., Aronica, G., Freni, G. (2003). The sewer as a biological reactor: proposal and application of a mathematical model in a gravity sewer in Palermo (Italy). Proceedings of the 17th EJSW (European Junior Scientists Workshop) Dresden, Germany, pp. 179-188.

Centro Studi Deflussi Urbani (1997). Sistemi di Fognatura - Manuale di Progettazione.. Hoepli, Milan (Italy).

Gazzetta Ufficiale della Repubblica Italiana (2006). Decreto Legislativo, 3 aprile 2006, n. 152, Norme in materia ambientale. Gazzetta Ufficiale Serie Generale n.88 del 14/04/2006 - Suppl. Ordinario n. 96.

Henze, M., Harremoes, P., la Cour Jansen, J., and Arvin, E. (1996). Wastewater Treatment. Biological and chemical Processes. 2nd Edition. Springer (Berlin).

Hvitved-Jacobsen, T., Vollertsen, J. and Tanaka N. (1999). Wastewater quality changes during transport in sewers - an integrated aerobic and anaerobic model concept for carbon and sulfur microbial transformations, Wat. Sci. Tech., 39(2), 242-249.

Tanaka, N. and Hvitved-Jacobsen, T. (1998). Transformations of wastewater organic matter in sewers under changing aerobic/anaerobic conditions. Wat. Sci. Tech., 37(1), 105-113.

Tchobanoglous, G., Burton, F.L., Burton, F. and Stensel H.D. (2002). Wastewater engineering. Treatment and reuse, Metcalf \& Eddy, Inc., McGraw-Hill Company, New York, 2002. 


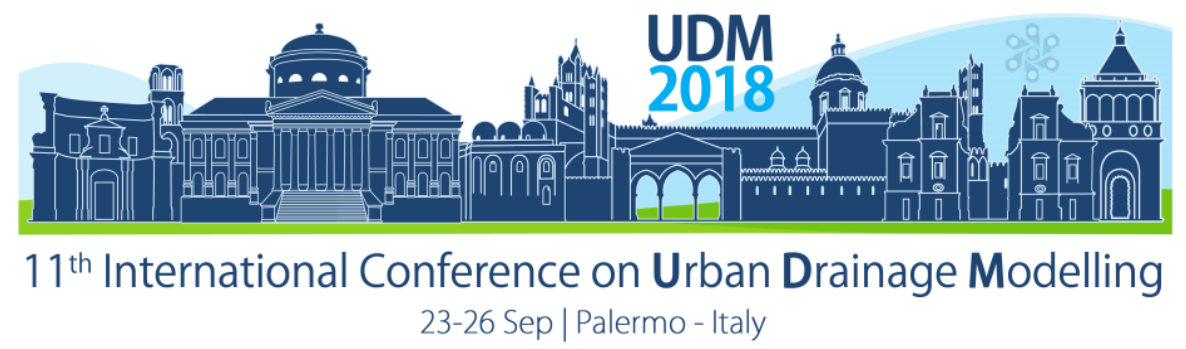

\title{
Detection of exfiltration in sewer systems with tracers
}

\author{
Bram Stegeman ${ }^{1}$, Jeroen Langeveld ${ }^{1,2}$, Thom Bogaard ${ }^{1}$ and François Clemens ${ }^{1,3}$ \\ ${ }^{1}$ Delft University of Technology, Water Management Department, Delft, The Netherlands \\ 2Partners4UrbanWater, Nijmegen, The Netherlands \\ ${ }^{3}$ Deltares, Delft, The Netherlands
}

\begin{abstract}
Due to the ageing of our underground wastewater infrastructure, leakage of sewers and pressure mains and subsequent infiltration or exfiltration are becoming an increasingly important issue. Herein, we present a novel method to detect and potentially quantify exfiltration from sewer systems under variable flow conditions; the DEST method. The DEST method is based on the principle of setting up a mass balance of a tracer substance. At an upstream point a tracer is injected in a sewer with a constant rate for a certain period, subsequently downstream high frequent time discrete grab samples are combined with discharge measurements to complete the mass balance. The method is applied on a sewer section in Loenen (NL) to investigate its feasibility. Two different tracers are used; Lithium chloride and Deuterium. Preliminary results indicate that both tracers show similar behaviour at the downstream measurement point. Final lab results are expected at the end of March, allowing in depth analysis of the experimental results with a focus on the measurement uncertainty.
\end{abstract}

Keywords: Exfiltration; Tracer; Leakage; Sewer; Field experiments; DEST

\section{INTRODUCTION}

Due to the ageing of our underground wastewater infrastructure, leakage of sewers and pressure mains and subsequent infiltration or exfiltration are becoming an increasingly important issue. Infiltration of groundwater in sewers below the groundwater level could lead to an unnecessary high hydraulic influent load of wastewater treatment works and a decreased treatment efficiency. Infiltration of groundwater might also result in sewer collapse, due to the ingress of soil into the sewer and the subsequent undermining of roads (Stanić, Langeveld, \& Clemens, 2014). Exfiltration from gravity sewers and pressure mains might also result in sewer collapse due to bedding erosion. In addition, exfiltration of sewage which contains pathogens and pharmaceuticals might have detrimental environmental effects and threaten groundwater quality used in drinking water production (Nakada et al., 2008). Even though many of these issues are well known, relatively little effort is spend by sewer operators to detect and repair leaks. This is partly a result of a lack of suitable inspection techniques and incentives. However, current focus on Asset Management and risk reduction has initiated new research into potential methods to detect, locate and quantify leakage from sewage systems and pressure mains.

In past decades there has been an increased interest in the problem of sewer leakage. In the APUSS project methods based on tracer experiments have been developed to measure infiltration and exfiltration in sewer systems. Exfiltration is measured in a reach with a pulse dosing method (QUEST) or a continuous dosing method (QUEST-C) (Rieckermann, Bareš, Kracht, Braun, \& Gujer, 2007). Since the need for a discharge measurement is canceled out, both methods produce most reliable results under steady flow conditions. 


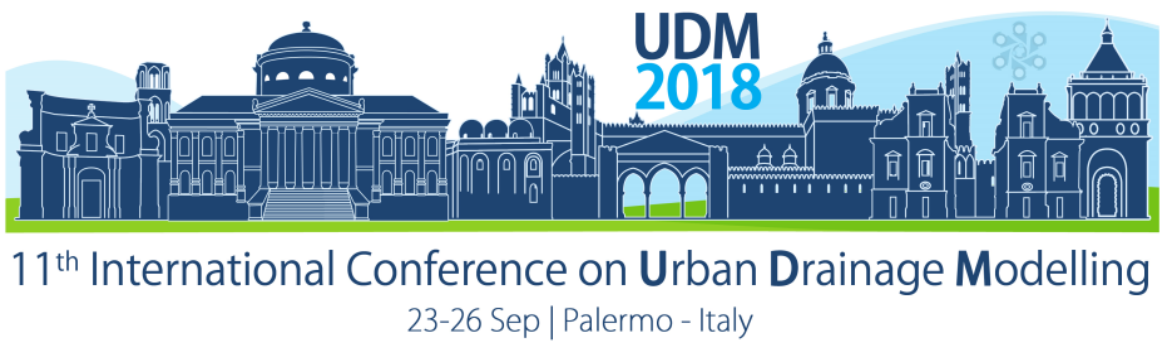

This is also why, ideally, these methods are applied in trunk sewers with a constant flow, suffucient length and no inflows. However, exfiltration also may occur in sewer networks with inflows and QUEST-C cannot be applied to this type of situations. Therefore an alternative method with tracers is developed and tested.

The proposed paper addresses the results of multiple field tests with the novel DEST (Detection of exfiltration with tracers) method to detect and potentially quantify exfiltration under variable flow conditions.

\section{MATERIALS AND METHODS}

\subsection{Exfiltration quantification and detection with tracers}

The principle of the DEST method is applying a mass balance of a tracer in a sewer reach or system (see figure 1). At a certain upstream point in the sewer system a well-known mass of tracer is injected. Consequently, the conservative tracer mixes with the sewer flow and exfiltration will result in a decrease of tracer mass. To complete the balance, downstream at the reach or system under investigation, the remaining tracer mass is determined. To this end, discharge is measured with an Electromagnetic Flow Meter and high frequent time discrete samples of wastewater are collected for lab analysis of the tracer substance.

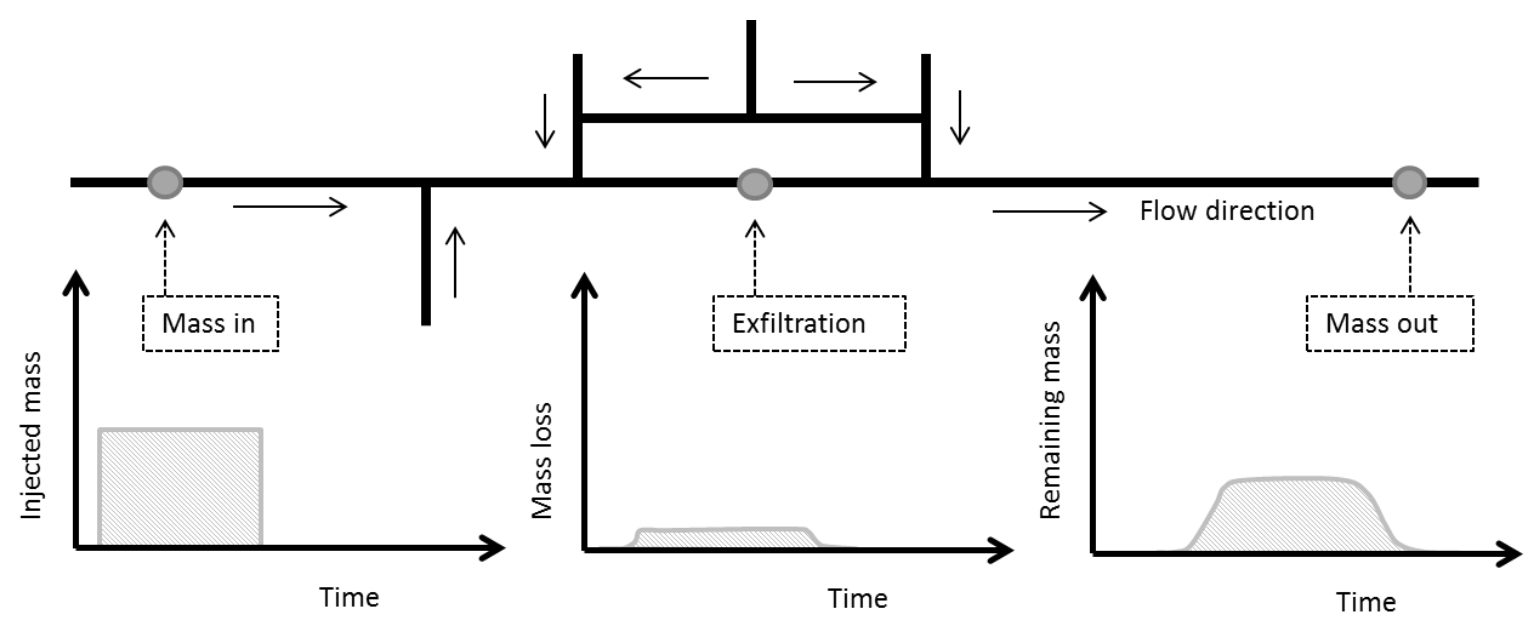

Figure 1. Conceptual scheme of DEST experiment.

Exfiltration is calculated by comparing the injected mass (massin) with the remaining mass (mass $\left.{ }_{\text {out }}\right)$. The injected mass is the product of the dosed volume $\left(\mathrm{V}_{\text {in }}\right)$ and concentration $\left(\mathrm{C}_{\text {in }}\right)$. The remaining mass is derived from the discharge $(\mathrm{Q})$ and concentration $(C)$, corrected background concentration $\left(\mathrm{C}_{0}\right)$ at time t. Exfiltration can be defined as:

$$
E=\frac{\operatorname{mass}_{\text {in }}-\text { mass }_{\text {out }}}{\text { mass }_{\text {in }}}=1-\frac{\int Q(t)\left(C(t)-C_{0}(t)\right) d t}{V_{\text {in }} C_{\text {in }}}
$$

When there is no additional sewer inflow between the injection and measurement point, formula 1.1 can be used to quantify the exfiltration. 


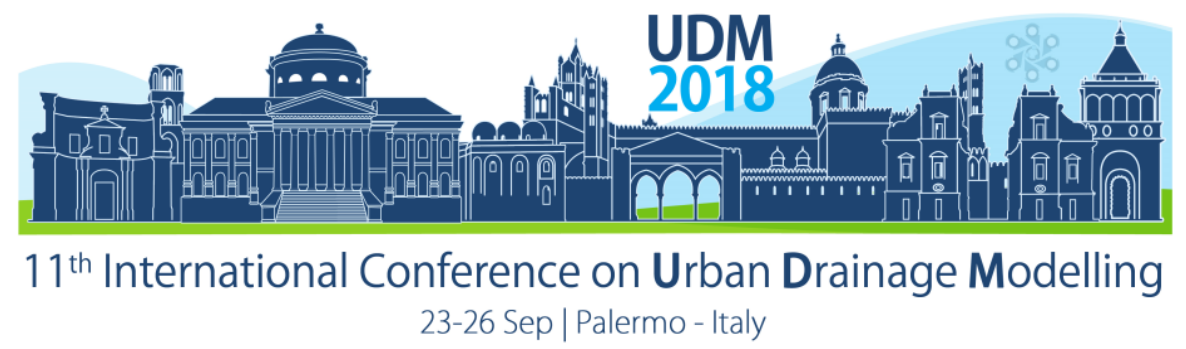

\subsection{Case study: Loenen (NL)}

The DEST method is applied in a sewer section in Loenen to investigate its feasibility. A description of this catchment can be found in Van Bijnen et al (2012). The investigated reach is about $640 \mathrm{~m}$ long with consecutively a diameter of 1250 and $500 \mathrm{~mm}$. At $70 \mathrm{~m}$ downstream from the dosing point there is a lateral inflow. Infiltration is also likely to occur. The investigation reach is the main sewer towards the pumping station with an average slope of $2.3 \%$. Groundwater level measurements confirm that the investigated reach is located below groundwater level. Consequently, exfiltration due to leakage can be excluded for this sewer, making it a suitable location for the experiment.

\subsection{Experimental setup}

In total 6 field experiments have been conducted. At the start of each experiment samples were collected to determine the background concentrations. At 3 out of 6 experiments an artificial exfiltration was introduced. At $247 \mathrm{~m}$ downstream from the dosing point a peristaltic pump in combination with a wastewater collection vessel (1000 I) was installed.

Subsequently the extracted volume was measured, and after mixing 3 samples were collected.

At the dosing point two tracers (Lithium chloride $(\mathrm{LiCl})$ and Deuterium $\left({ }^{2} \mathrm{H}\right)$ ) were injected in the sewer system using a peristaltic pump. The dosage rate was approximately $240 \mathrm{ml} / \mathrm{min}$ and the dosage time varied between 41 and 43 minutes. The experiments had a dosed $\mathrm{Li}^{+}$ concentration of around $10,5 \mathrm{~g} / \mathrm{L}$ and around $13 \mathrm{~g} / \mathrm{L}$ (4 out of 6 ). The ${ }^{2} z$ value of the 6 vessels need to be determined.

At the downstream measurement point a local bypass was created. The conduit was closed with a metal valve and a submergible pump with variable discharge was installed. At this point a pressure and conductivity sensor were also installed. The discharge from the diverted flow was measured and simultaneously time discrete samples were taken. The sampling interval is 5 seconds and composite samples are collected every 150 seconds. The samples were filtered and analysed with an ICP-OES for $\mathrm{Li}^{+}$and with a laser absorption spectrometer.

The start and stop of a single experimental run was initiated by two types of markers: one based on visual observation; ping-pong balls ( 5 white balls for the start and 5 pink balls for the stop). When these balls arrived at the artificial exfiltration location the pump was switched on or off. During the first two experiments these balls did not arrive at the downstream measurement point. Likely as a result of a submerged pipe at a manhole. Therefore, at the remaining experiments a pulse dose of $\mathrm{NaCl}$ solution (around $170 \mathrm{~g} / \mathrm{l}$ table salt) before the start and after the stop of the tracer dosing has been used as a marker. This resulting increase in conductivity was used as a sampling start and stop indicator.

\section{RESULTS AND DISCUSSION}

\subsection{Downstream tracer values}

Figure 2 presents the lithium concentration and ${ }^{2} \delta$ values in time for experiments 1 and 2 at the downstream measurement point. The correlation between the two time series in both experiments is $R^{2}>0.998$. 

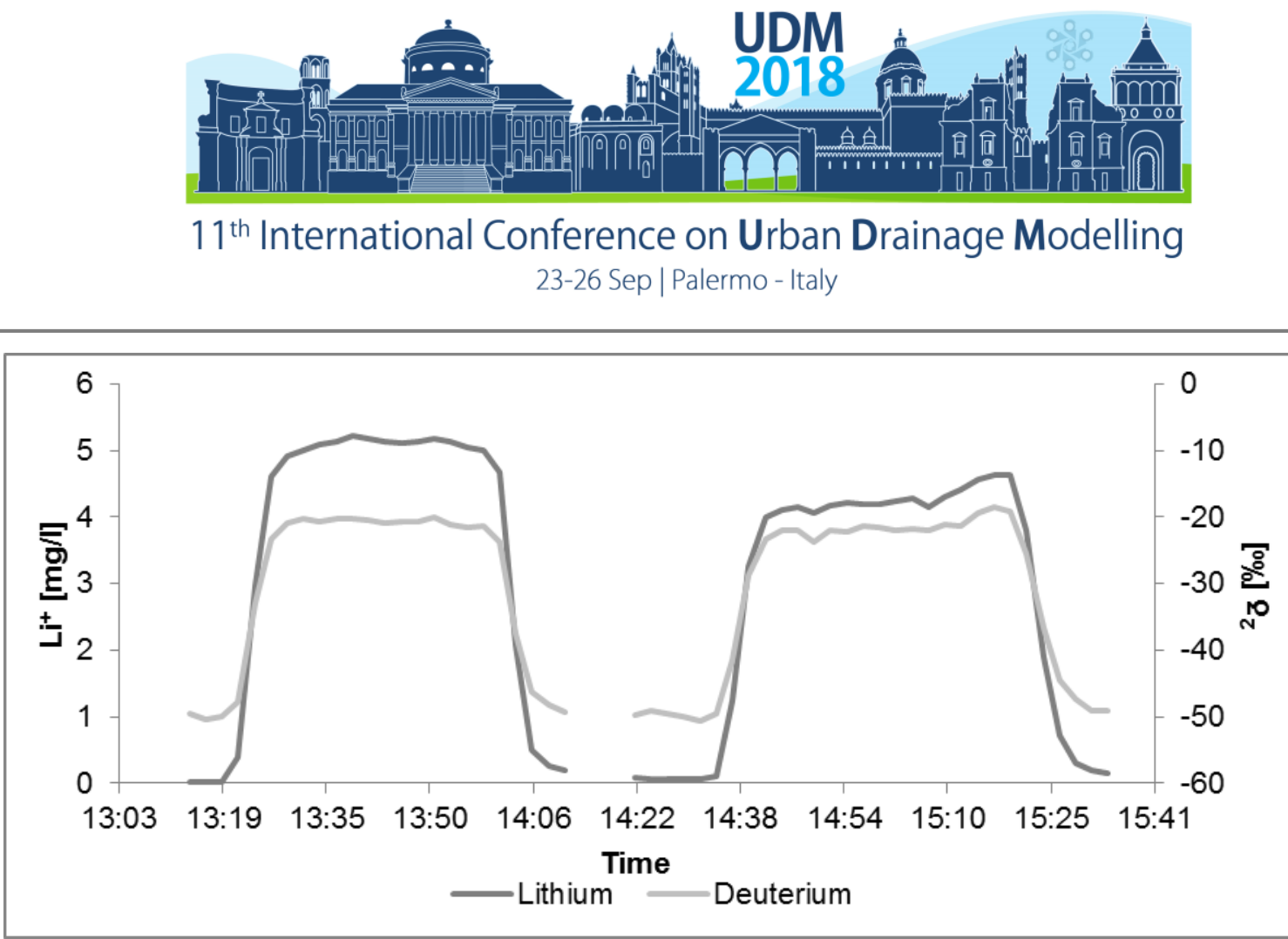

Figure 2. Lithium and Deuterium time series for experiment 1 and 2 at downstream measurement point.

\subsection{Expected results}

At the time of writing of the abstract, not all lab analyses have been finished. They will be available at the end of March. Once all data will be available, the data analysis will focus on the measurement uncertainty. This will include the analysis uncertainty of $\mathrm{Li}^{+}$and ${ }^{2} \mathrm{H}$ measurements and possible variability in background values. The uncertainty of the discharge measurements also has to be evaluated, in combination with sample volume and time of sampling. Since time series are used, the autocorrelation also have to be investigated. The influence of a long concentration tail and the resulting initial higher background concentration on an experiment will be quantified. The same holds for the observed small leakage at the closed valve.

\section{CONCLUSIONS}

The novel DEST (Detection of exfiltration with tracers) method to detect exfiltration in sewer systems has been tested on its feasibility in a field research. Two different tracers were applied; Lithium chloride and Deuterium. Results indicate that both tracers show similar behaviour at the downstream measurement point.

\section{References}

Nakada, N., Kiri, K., Shinohara, H., Harada, A., Kuroda, K., Takizawa, S., \& Takada, H. (2008). Evaluation of Pharmaceuticals and Personal Care Products as Water-soluble Molecular Markers of Sewage. Environ. Sci. Technol., 42, 6347-6353. https://doi.org/10.1021/es7030856

Rieckermann, J., Bareš, V., Kracht, O., Braun, D., \& Gujer, W. (2007). Estimating sewer leakage from continuous tracer experiments. Water Research, 41(9), 1960-1972. https://doi.org/10.1016/j.watres.2007.01.024

Stanić, N., Langeveld, J. G., \& Clemens, F. H. L. R. (2014). HAZard and OPerability (HAZOP) analysis for identification of information requirements for sewer asset management. Structure and Infrastructure Engineering, 10(11), 1345-1356. https://doi.org/10.1080/15732479.2013.807845

Van Bijnen, M., Korving, H., \& Clemens, F. (2012). Impact of sewer condition on urban flooding: An uncertainty analysis based on field observations and Monte Carlo simulations on full hydrodynamic models. Water Science and Technology, 65(12), 2219-2227. https://doi.org/10.2166/wst.2012.134 


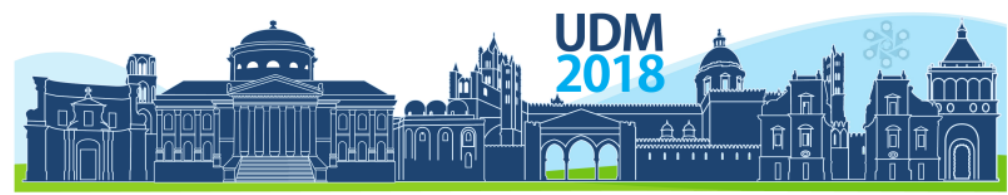

$11^{\text {th }}$ International Conference on Urban Drainage Modelling

23-26 Sep | Palermo - Italy

\title{
Improving the hydraulic integrity to separate the sewer system in hilly regions using a new manhole design
}

\author{
Alaa Abbas ${ }^{1}$, lacopo Carnacina1, Felicite Ruddock', Rafid Alkhaddar', Glynn Rothwell ${ }^{2}$ and \\ Robert Andoh ${ }^{3}$ \\ ${ }^{1}$ Liverpool John Moores University, Department of Civil Engineering, Liverpool, UK \\ 2 Liverpool John Moores University, Department of Maritime and Mechanical Engineering, Liverpool, UK \\ ${ }^{3}$ AWD Consult Inc. South Portland, ME, USA
}

\begin{abstract}
The design of the sewer system in hilly regions has a different concept from other areas due to the high flow velocity generated in the system that characterises a sloped system. The flow velocity of sewage or stormwater in the sewer system is limited by design criteria, using minimum velocity to avoid settlement of suspended solids in the pipes and maximum velocity to keep the solute homogeneous (fluid and suspended solids) and avoid pipe erosion. Maintaining these limits of the velocity within hilly regions is challenging and designers usually use steep cascade manholes to dissipate the fluid flow energy. This paper presents a new manhole design to mitigate stormwater flow energy, which is more critical than sewage flow in such areas, and using the traditional normal steps manhole for the sewage chamber. The new manhole design includes two chambers, an inner chamber used as in the traditional manhole for sewage and an outer chamber used for stormwater flow. The hydraulic properties of the new manhole have been explored using a physical model in laboratory conditions and compared with traditional manhole performance. The laboratory results are used for validation and are compared with computational fluid dynamic model outputs of the new design. The hydraulic performance of the new design reveals improvement in decrease in the flow energy of stormwater and increase in the capacity of storage for the stormwater network.
\end{abstract}

Keywords: Hilly regions, sewer system design, separate, storm, urban drainage.

\section{INTRODUCTION}

The traditional design of a sewer manhole has not been changed in the last century and is widely used in two types of sewer systems. In the combined sewer system, the sewage and stormwater are collected and conveyed through a single pipeline. A combined sewer system is more common in the UK and many European countries because it has a lower construction cost and requires less space to accommodate the pipelines compared with separate sewer systems, which use two sets of pipelines, one to collect and convey sewage and the other to collect and discharge stormwater. The combined sewer system and its management recently has been deemed responsible for serious environmental impact in watercourses as a result of the increased load on the system's capacity, due to population growth and the impact of climate change. Therefore, updated environmental regulations have banned these systems in all new developments, where sanitary networks are designed by a separate sewer system and a combined system can only be used to replace or extend the old existing combined system. This research presents a new design for a manhole to separate the sewer system and exploit the advantages of the combined system (decrease the construction cost and the footprint) and the traditional separate system in one system. The new design allows the separate sewer system to be used in regions where setting the traditional separate sewer system presents more challenges, such as in hilly regions (Pagliara et al. 2011).

The drop manhole is the old effective technique used to reduce the flow velocity in hilly regions; using the drop manhole allows designers to assign adequate slopes to the sewer pipe to maintain minimum and maximum velocity for the flow. The hydraulic performance of the 


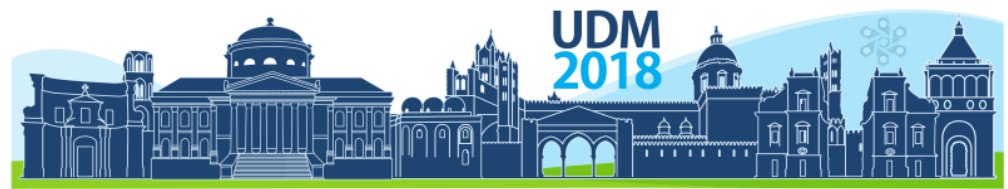

$11^{\text {th }}$ International Conference on Urban Drainage Modelling 23-26 Sep | Palermo - Italy

traditional manholes in hilly regions has been investigated by Carnacina et al. (2008); De Martino et al. (2002); Granata et al. (2011); Pagliara et al. (2011). Granata et al. (2014) tried to improve the hydraulic performance of the traditional drop manhole by proposing the installation of dissipative tools (two different types of jet-breaker) to the drop manhole and testing the effects of these tools on hydraulic behaviour by conducting experimental tests. This research presents a new manhole design to achieve two targets: it first allows the use of a separate sewer system in a narrow hilly street, and second it allows the required drop depth for the storm manhole chamber to be decreased, as the geometry of the new manhole provides appropriate dissipated flow energy for a storm flow. The hydraulic properties of the new design are investigated using a laboratory experimental model and computational fluid dynamic model.

\section{MATERIALS AND METHODS}

\subsection{The new manhole design}

The new manhole design combines storm and sanitary manholes in one structure and is proposed for a separate sewer system. The manhole shape is cylindrical with two separate chambers: the inner chamber is used as the traditional sanitary manhole and the external one is used for stormwater flow only. The level of the storm chamber is shallower than the sanitary chamber, and the range of depth of both chambers is changing according to the design level of the inlet/outlet sanitary pipes for the inner chamber and the storm pipe for the outer chamber. In general, it is laid between ( 1 and 6 metres) below the road surface. This system requires the storm pipe to be located over the sanitary pipe. The diameter of the sanitary chamber can range from 0.7 to 1 metre and for the external chamber from 2.1 to 2.5 metres, depending on the design depth of the manhole. Figure $1 \mathrm{a}$ and $\mathrm{b}$ demonstrates the details for the manhole design and the separation technique.

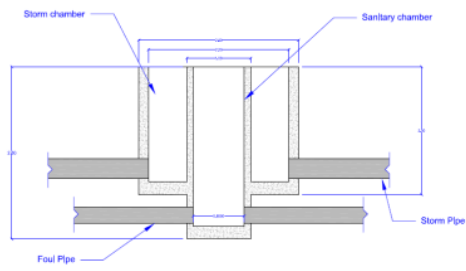

Figure 1 a. Cross section for the design of the new manhole.

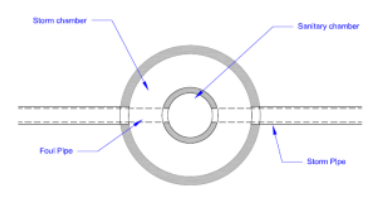

Figure 1 b. Top view of the new manhole.

The new manhole design generates high disruption of the storm flow and dissipates the flow energy inside the storm chamber. This allows the depth of the storm chamber to be decreased in steep streets and a high decline for the storm pipe to be used, roughly equivalent to the decline of the street. Figure 2 shows a section of a separate network in a hilly region using the new manhole design.

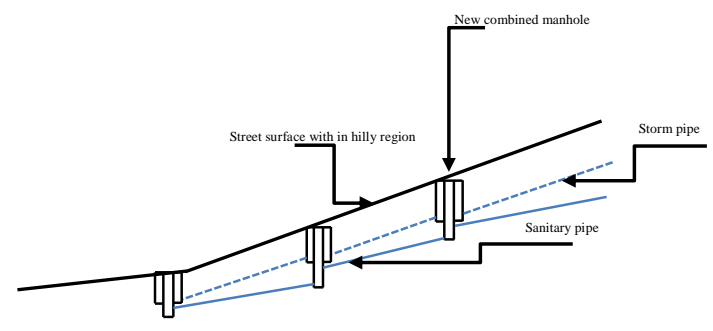




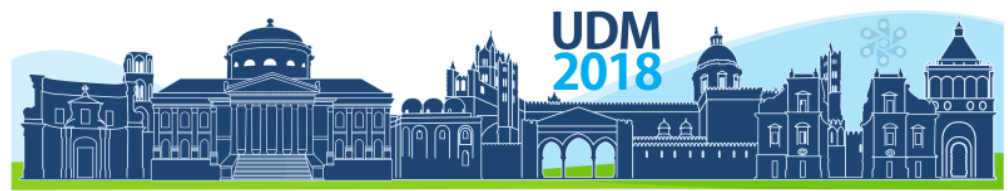

$11^{\text {th }}$ International Conference on Urban Drainage Modelling

23-26 Sep | Palermo - Italy

\subsection{Experimental setup}

The experimental runs are conducted in LJMU laboratory; the aim of these experiments is to find out the energy dispersion of storm flow through the new manhole design under different flow rates. A model of scale 1:5 simulates the new design, with an inner chamber made of plexiglass pipe with a $20 \mathrm{~cm}$ diameter and the outer chamber of $50 \mathrm{~cm}$ in diameter, both 80 $\mathrm{cm}$ in length.

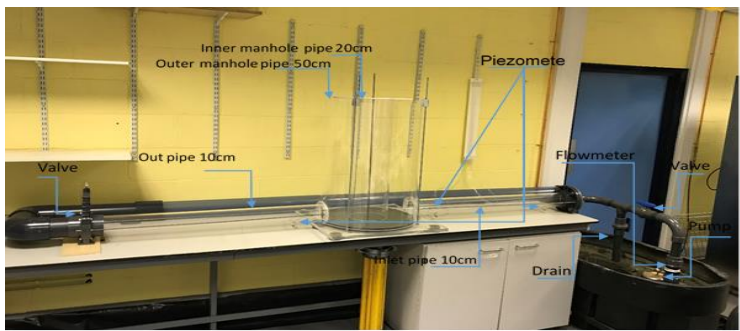

Figure 3. The setup of the physical model to test the hydraulic properties for the new manhole design

\subsection{Computational fluid dynamic CFD model}

The CFD model has been built to simulate the hydraulic properties inside the storm chamber. The same dimensions of the physical model are used in the CFD, as well as the boundary conditions established at the inlet of the system using different rates of flow and atmospheric pressure at the outlet pipe and the cover of the manhole.

\section{RESULTS AND DISCUSSION}

Three points can disrupt the flow and cause head loss in the storm chamber: the first one is the inner chamber wall which blocks the storm flow path and splits the flow into two paths; the second is where the two conduit bends inside the manhole; and the third is the entrance head loss at the outlet pipe. In contrast, the traditional storm manhole has only the entrance head loss at the outlet pipe and head loss of the friction with the manhole internal wall. The drop of pressure and the velocity were selected as factors to measure the head loss for the flow inside the new manhole design. The results are compared with head loss for the flow inside the traditional manhole design in Figure 4. The figure shows the change of the flow velocity between the new manhole design and the traditional manhole at different flow rates. Table 1 presents the pressure inside the new manhole and inside the traditional manhole and the drop of pressure that results from using the new design is calculated.

\begin{tabular}{c|ccccc}
$\begin{array}{c}\text { Flow Rate } \\
\left(\mathrm{m}^{3} / \mathrm{s}\right)\end{array}$ & 0.005 & 0.01 & 0.03 \\
\hline $\begin{array}{c}\text { New } \\
\text { Manhole }\end{array}$ & &
\end{tabular}

Figure 4. Comparison the flow velocity between the flow inside new manhole design and traditional manhole at different flowrates using CFD. 


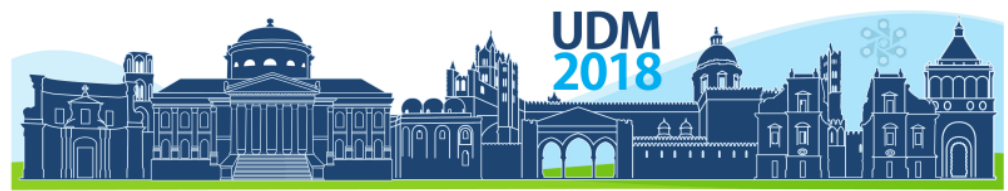

$11^{\text {th }}$ International Conference on Urban Drainage Modelling

23-26 Sep | Palermo - Italy

Table 1. CFD outputs for the pressure inside the new manhole and the traditional manhole and the drop of pressure between using the new manhole shape and the traditional manhole at different flow rates.

\begin{tabular}{|c|c|c|c|c|c|c|}
\hline \multirow{2}{*}{$\begin{array}{c}\text { Flow rate } \\
\mathrm{m} 3 / \mathrm{s}\end{array}$} & \multicolumn{2}{|c|}{$\begin{array}{l}\text { Pressure inside the new } \\
\text { manhole (pa) }\end{array}$} & \multicolumn{2}{|c|}{$\begin{array}{c}\text { Pressure inside a traditional } \\
\text { manhole }(\mathrm{pa})\end{array}$} & \multicolumn{2}{|c|}{ Drop in the pressure(pa) } \\
\hline & Inlet & Outlet & Inlet & Outlet & inlet & outlet \\
\hline 0.005 & 101282 & 101352 & 101310 & 101393 & 28 & 41 \\
\hline 0.01 & 101158 & 101439 & 101266 & 101603 & 108 & 164 \\
\hline 0.02 & 101157 & 101439 & 101089 & 102433 & 431 & 994 \\
\hline 0.03 & 99790 & 102066 & 100760 & 103851 & 970 & 1785 \\
\hline 0.04 & 98583 & 103278 & 100363 & 106496 & 1780 & 3218 \\
\hline 0.05 & 97090 & 104463 & 99876 & 109117 & 2786 & 4654 \\
\hline
\end{tabular}

The new manhole design achieved appropriate mitigation for the storm flow resulting from increasing the path of the flow and the disruption caused by the wall of the inner manhole to the stormwater flow. This head loss tends to increase when the flow rate increases. Figure 5 shows the pressure drop between the new design and traditional manhole design at different rates of flow from experimental results.

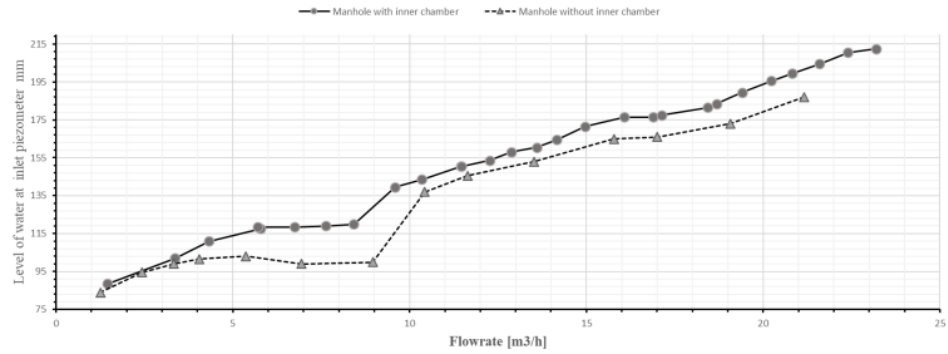

Figure 5. Comparison of the drop of pressure between the flow inside the new manhole design and the traditional manhole at different flow rates.

\section{CONCLUSIONS}

The design of a storm network is more challenging in hilly areas, due to the runoff quick time of concentration. Therefore, mitigating the flow energy and increasing the storage capacity and the retention time of the storm flow can improve the safety factor of the system to reduce flooding risk, especially downstream of the network. The new manhole shape disrupts the continuity of stormwater flow in the system and increases the detention time and path of stormwater flow through the storm chamber. This dissipation is about equivalent to the dissipation cause by the traditional drop manhole. The results showed that the head loss of the flow energy increased with high flow rate inside the new manhole, and the pressure head was less than the pressure inside the traditional manhole. These advantages allow the new manhole to be used in hilly regions area in shallower depths for the storm chamber rather than using a deeper drop manhole. The researcher are working to validate the CFD outputs with experimental results in the next step of this research.

\section{References}

Carnacina, I., Bernats, M., and Pagliara, S. (2008). "Overflow features in a particular combined sewer manhole." International Junior Researcher and Engineer Workshop on Hydraulic Structures, 2nd, ed. Pisa, Italy.

De Martino, F., Gisonni, C., and Hager, W. H. (2002). "Drop in Combined Sewer Manhole for Supercritical Flow." Journal of Irrigation and Drainage Engineering, 128(6), 397-400.

Granata, F., De Marinis, G., and Gargano, R. (2014). "Flow-improving elements in circular drop manholes." Journal of Hydraulic Research, 1-9.

Granata, F., de Marinis, G., Gargano, R., and Hager, W. H. (2011). "Hydraulics of Circular Drop Manholes." Journal of Irrigation \& Drainage Engineering, 137(2), 102-111.

Hager, W. H. (2010). Wastewater Hydraulics Theory and Practice, Springer, Verlag Berlin Heidelberg.

Pagliara, S., Carnacina, I., and Palermo, M. "Combined Sewer Network in Hilly Region: Field Survey and Pollutant Overflow Optimization." Springer Netherlands, 87-97. 


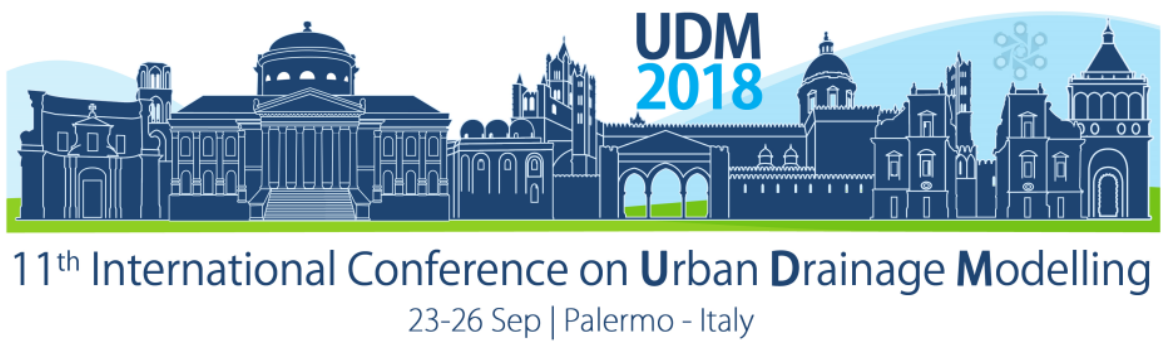

\title{
Dynamic Modelling and Comparison of $\mathrm{H}_{2} \mathrm{~S}$ Mitigation Strategies
}

\author{
Berislav Tomicic ${ }^{1}$, Morten Just Kjølby', and Mikkel Holmen Andersen ${ }^{1}$ \\ ${ }^{1}$ DHI, Urban Water, Hørsholm, Denmark
}

\begin{abstract}
Hydrogen sulphide $\left(\mathrm{H}_{2} \mathrm{~S}\right)$ formation is a growing problem for utility companies in many countries. Increased centralisation of wastewater management leads to prolonged retention times, higher $\mathrm{H}_{2} \mathrm{~S}$ production, and problems with odour and corrosion for the utility companies. A cost-effective tool for a city-wide dynamic simulation of $\mathrm{H}_{2} \mathrm{~S}$ in wastewater collection systems is presented. The $\mathrm{H}_{2} \mathrm{~S}$ modelling, based on the state-of-the-art Wastewater Aerobic/anaerobic Transformations in Sewers (WATS) conceptual model has been integrated into a fully dynamic hydraulic and advection-dispersion model MIKE URBAN. The paper demonstrates a desk-top analysis and testing of mitigation options involving management of pumping operation and chemical dosing strategies to prevent the formation of hydrogen sulphide.
\end{abstract}

Keywords: Hydrogen sulphide, model prediction, odour, corrosion, chemical dosing

\section{INTRODUCTION}

Formation of hydrogen sulphide $\left(\mathrm{H}_{2} \mathrm{~S}\right)$ is a serious problem in countless sewer systems all over the world. Firstly, $\mathrm{H}_{2} \mathrm{~S}$ can cause a significant loss of asset value due to corrosion of the sewer infrastructure. Secondly, $\mathrm{H}_{2} \mathrm{~S}$ is a serious odour nuisance to the general public living standards and usually a breach of the utilities' desired standards of services. Finally, the presence of $\mathrm{H}_{2} \mathrm{~S}$ in sewage leads to a hazardous work environment for the maintenance crew when present in the sewer atmosphere.

The corrosion of sewer infrastructure can necessitate premature repair or replacement of concrete pipes, manholes, wet wells, pump stations, pump equipment etc. According to relevant sources, costs related to the mitigation of corrosion and odour damages exceed $50 \%$ of the overall sewer maintenance and rehabilitation costs. Furthermore, the problem is increasing due to a combination of climate changes, water saving programmes, increased urbanization with separate sewer systems, centralised wastewater treatment with long rising mains resulting in higher retention times and anaerobic condition.

As $\mathrm{H}_{2} \mathrm{~S}$ is the primary source of corrosion and odour problems it is important to understand the dynamics of its formation and mitigation measures. $\mathrm{H}_{2} \mathrm{~S}$ is formed under anaerobic conditions, especially in rising mains, and is released into the sewer atmosphere at the rising mains terminal points and at pumping stations, where it gets converted into sulphuric acid, eventually leading to corrosion of concrete, pumps and other equipment.

In order to understand and tackle $\mathrm{H}_{2} \mathrm{~S}$ in a city-wide network, a biokinetic $\mathrm{H}_{2} \mathrm{~S}$ modelling approach has been developed and integrated into a fully dynamic hydraulic and advectiondispersion model. The implemented ECO Lab $\mathrm{H}_{2} \mathrm{~S}$ model has been based on the state-of-theart Wastewater Aerobic/anaerobic Transformations in Sewers (WATS) conceptual model (Hvidtved-Jacobsen et al. 2013) and is integrated with a MIKE URBAN hydraulic and advection-dispersion model. This paper presents a cost-effective tool for analysing and testing effective mitigation options involving management of pumping operations and chemical dosing strategies to prevent the formation of $\mathrm{H}_{2} \mathrm{~S}$. 


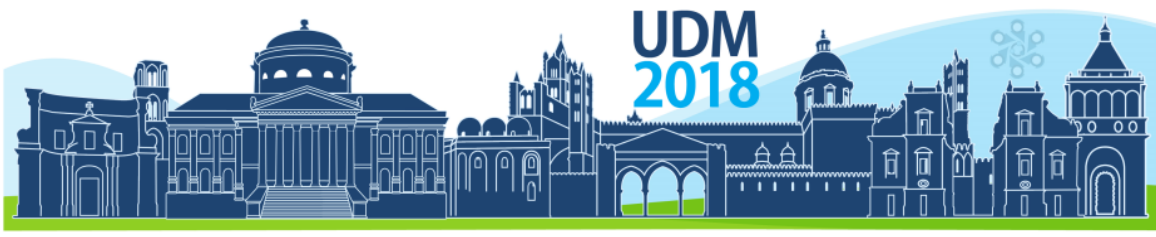

$11^{\text {th }}$ International Conference on Urban Drainage Modelling

23-26 Sep | Palermo - Italy

\section{MATERIALS AND METHODS}

\subsection{Modelling platform}

The WATS model concept for $\mathrm{H}_{2} \mathrm{~S}$ processes has been integrated in MIKE ECO Lab, a numerical laboratory for Ecological modelling. The WATS MIKE ECO Lab model describes the biological processes in the sewerage system in one single model. In this model the transformation of organic matter and electron acceptors (oxygen, nitrate, sulphate) is described with special emphasis on reactions to determine the degree of $\mathrm{H}_{2} \mathrm{~S}$ in the sewer liquid phase. The model results describe all the processes included in the WATS conceptual model as a function of time. In addition, a number of relevant derived variables are computed including water retention time. The WATS MIKE ECO Lab model was further integrated with the advection-dispersion module in MIKE 1D and describes the physical transport processes at each grid-point covering the area of interest. The data required to run the entire model are wastewater flows from pollution sources, concentrations of relevant wastewater constituents, water temperature, and $\mathrm{pH}$.

\subsection{Site description}

Application of the model is demonstrated on a wastewater collection system in Denmark, illustrated in Figure 1. The system collects wastewater from a hotel and a local rural community and transports it over a topographically challenging terrain towards a regional WWTP. It consists of two pumping stations and rising mains in series, with lengths of $1,850 \mathrm{~m}$ and 1,250 m.

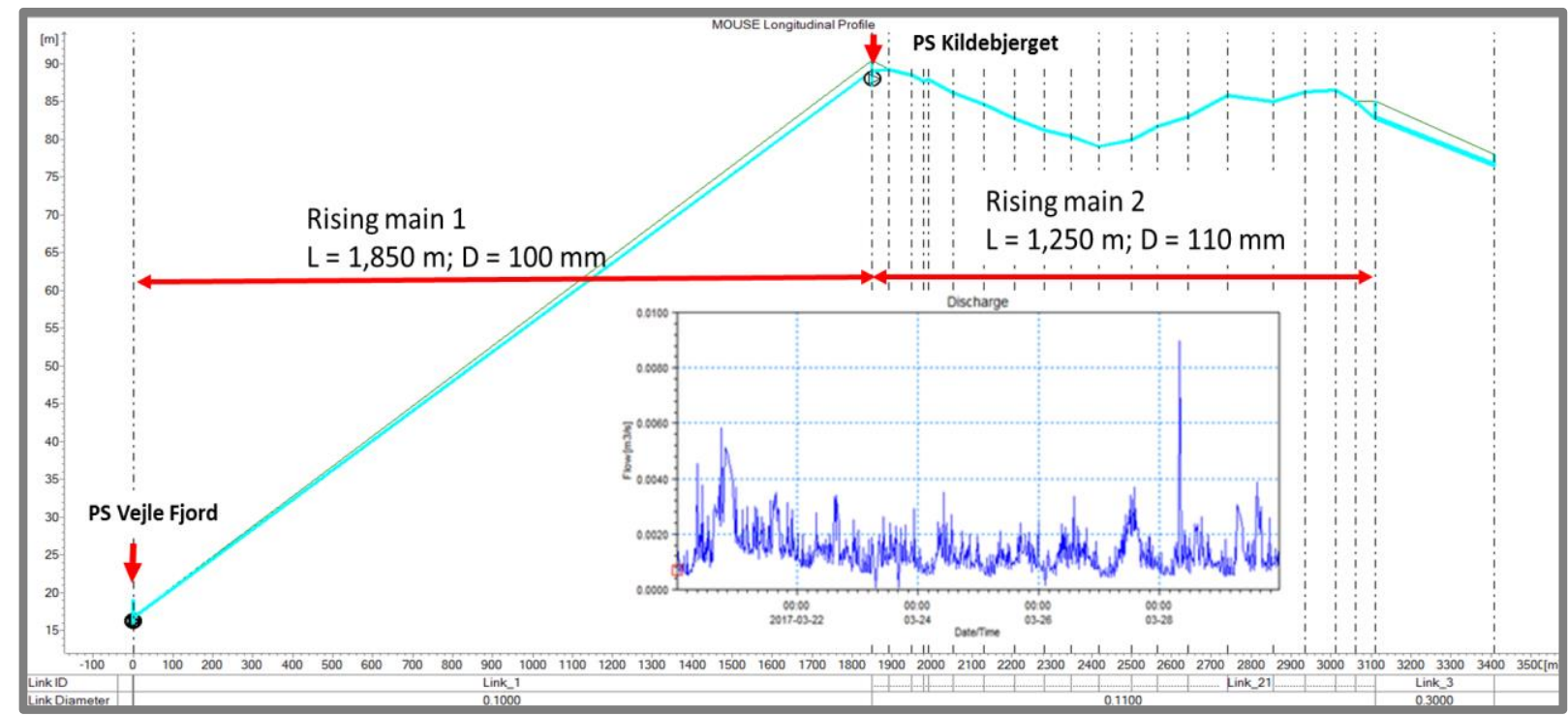

Figure 1. Longitudinal profile through the modelled system. The flow direction is from left to right. Wastewater is pumped from PS Vejle Fjord and further downstream from PS Kildebjerget.

In this small system, the flows oscillate erratically in wide limits, as shown in the time series insert in Figure 1. Probably, the water quality properties also oscillate in a similar manner. In low-flow periods (during night), resident time may exceed eight hours and $\mathrm{H}_{2} \mathrm{~S}$ builds up in the upper segment of the longer rising main and along entire lengths of the shorter rising main. 


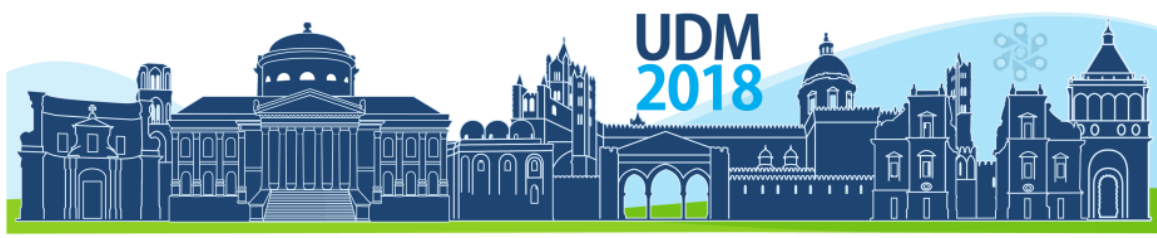

$11^{\text {th }}$ International Conference on Urban Drainage Modelling

23-26 Sep | Palermo - Italy

\section{RESULTS AND DISCUSSION}

\subsection{Simulation scenarios}

The study includes a number of scenarios featuring various measures for mitigation of sulphide, such as adding iron, nitrate, magnesium hydroxide, or aerating the sewage flow. This paper reports the results for the simulated effects of adding iron $\left(\mathrm{Fe}^{3+}\right)$ and nitrate $\left(\mathrm{NO}_{3}-\mathrm{N}\right)$ to the wastewater stream. The simulated scenarios are defined by the model's boundary conditions and the applied reactive control (Table 1). Simulations extend over a 2-day period $\left(20^{\text {th }}-23^{\text {rd }}\right.$ March 2017). The model is loaded with actual recorded wastewater flows.

Table 1. Simulated scenarios

\begin{tabular}{|c|c|c|c|}
\hline \multirow{2}{*}{ Boundary condition component } & \multicolumn{3}{|c|}{ Scenario } \\
\hline & Base & Dosing $\mathrm{Fe}^{3+}$ & Dosing $\mathrm{NO}_{3}-\mathrm{N}$ \\
\hline Wastewater Flow [m3/s] & As recorded & As recorded & As recorded \\
\hline Temperature [deg. C] & 20 & 20 & 20 \\
\hline $\mathrm{pH}$ & 7 & 7 & 7 \\
\hline Dissolved oxygen [mg/l] & 8 & 8 & 8 \\
\hline Sulphate $\mathrm{SO}_{4}[\mathrm{mg} / \mathrm{l}]$ & 140 & 140 & 140 \\
\hline Total COD [mg/l] & 600 & 600 & 600 \\
\hline SF (Fermentable/biodegradable products [mg/l] & 16 & 16 & 16 \\
\hline$S A$ (Fermentation products) $[\mathrm{mg} / \mathrm{l}]$ & 9 & 9 & 9 \\
\hline$X$ Bw (Heterotropic active biomass in water) $[\mathrm{mg} / \mathrm{l}]$ & 24 & 24 & 24 \\
\hline$X$ X1 fast hydrolysable substrate) $[\mathrm{mg} / \mathrm{ll}]$ & 72 & 72 & 72 \\
\hline X_S2 Fast hydrolysable products [mg/l] & 479 & 479 & 479 \\
\hline $\mathrm{Fe}^{3+}$ Dosing & - & $10 \mathrm{~kg} / 12$ hours & - \\
\hline $\mathrm{NO}_{3}-\mathrm{N}$ Dosing & - & - & RTC Flow-prop. \\
\hline
\end{tabular}

\subsection{Simulation results and discussion}

Results of the simulations are illustrated in Figure 2 (dosing of $\mathrm{Fe}^{3+}$ ) and Figure 3 (dosing of $\mathrm{NO}_{3}-\mathrm{N}$ ). In both scenarios simulated concentrations of $\mathrm{H}_{2} \mathrm{~S}$ in water phase are compared with the Base scenario.

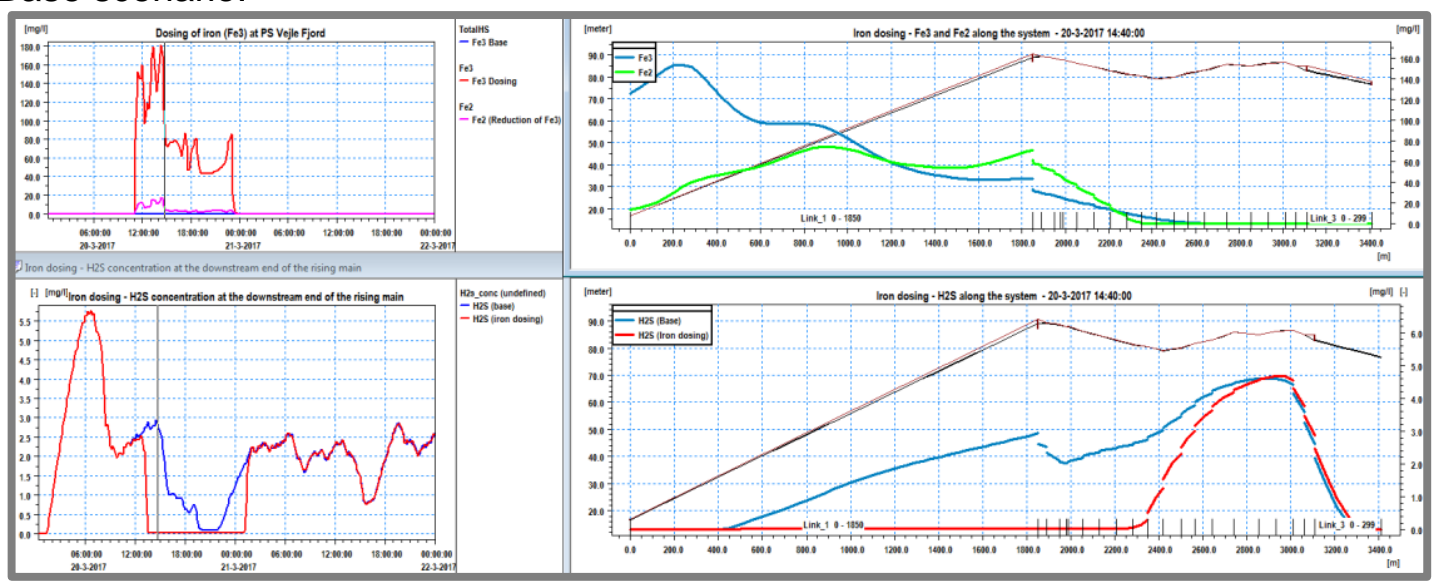

Figure 2. $10 \mathrm{~kg} \mathrm{Fe}^{3+}$ is added uniformly during a 12-hour period. The model simulates reduction of $\mathrm{Fe}^{3+}$ to $\mathrm{Fe}^{2+}$, as well as precipitation of sulfide as FeS. During the presence of $\mathrm{Fe}^{2+}$ in water, all sulphide is precipitated. Relevant variables can be shown in an animated presentation, providing a detailed insight into a highly dynamic situation. 


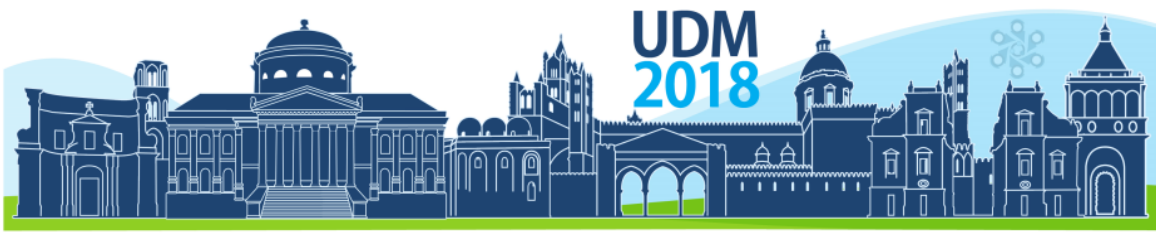

$11^{\text {th }}$ International Conference on Urban Drainage Modelling 23-26 Sep | Palermo - Italy

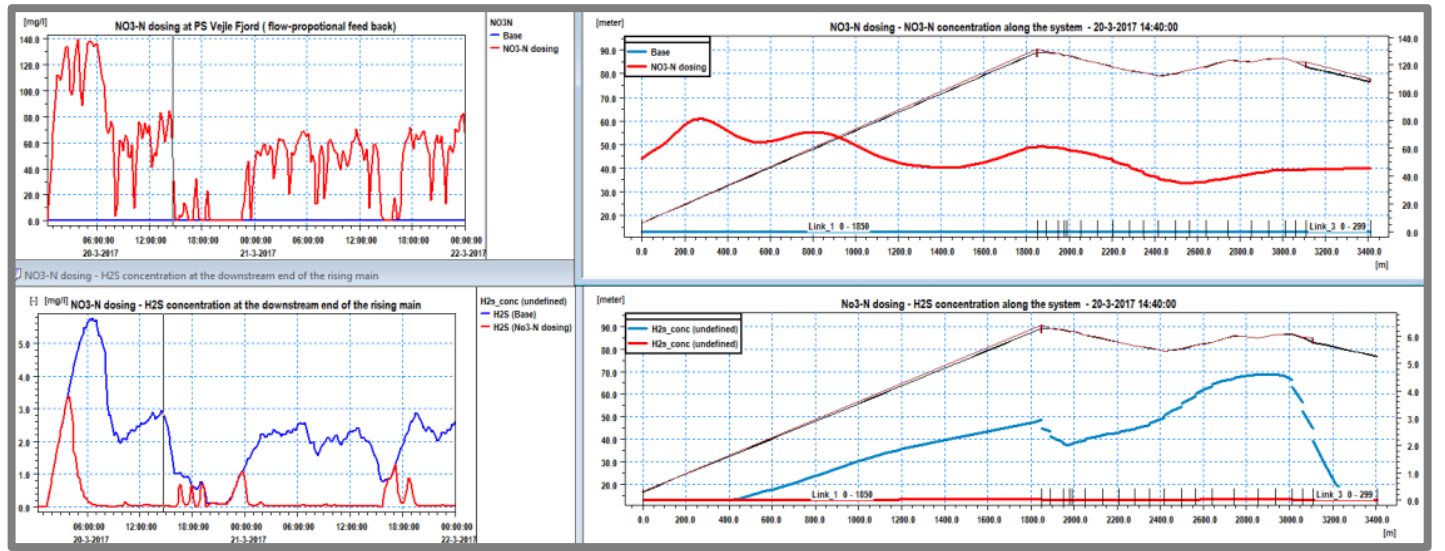

Figure 3. Automatic dosing of $\mathrm{NO}_{3}-\mathrm{N}$ at PS Vejle Fjord (flow proportional feedback) is simulated. $\mathrm{NO}_{3}-\mathrm{N}$ prevents effectively formation of sulphide, but a perfect upstream dosing is difficult to achieve due to the time offset by resident time. Obviously, $\mathrm{NO}_{3}-\mathrm{N}$ is overdosed in the simulated scenario, as a significant residual concentration is present at the downstream end of the system.

These examples demonstrate a high potential of the WATS MIKE ECO Lab simulation system in the fight against $\mathrm{H}_{2} \mathrm{~S}$ formation and its adverse effects in wastewater systems.

\section{CONCLUSION}

Dynamic simulations of hydrogen sulphide formation in sewers, including various mitigation measures, appear as a valuable contribution to a better understanding of causes and extent of the $\mathrm{H}_{2} \mathrm{~S}$ formation. In the present work, the hydrogen sulphide model was implemented in an open biokinetic modelling framework allowing users to modify and extent the hydrogen sulphide process model. Including $\mathrm{H}_{2} \mathrm{~S}$ modelling with existing MIKE URBAN hydraulic models enables a city-wide simulation and forecast of problematic hydrogen sulphide areas in the network. Using the combined model, various scenarios and mitigation options can be simulated and used to formulate an optimised mitigation control strategy. In this paper two chemical dosing mitigation options are included. Oxygen injection, base addition, and various advanced pump control strategies are also available. Having a dynamic $\mathrm{H}_{2} \mathrm{~S}$ simulation of formation as an integrated part of a well-established and proven modelling system for sewer hydraulics and pollution transport, sulphide-related simulations are readily available to scientists, consultants, and system operators for the purposes of sulphide problem diagnostics and prediction, mitigation measures design and testing etc.

\section{References}

Hvidtved-Jacobsen, Vollertsen, Haaning Nielsen (2013), Sewer Processes. Microbial and Chemical Process Engineering of Sewer Networks, CRC Press, $2^{\text {nd }}$ Edition. ISBN-13:978-1-4398-8178-1 


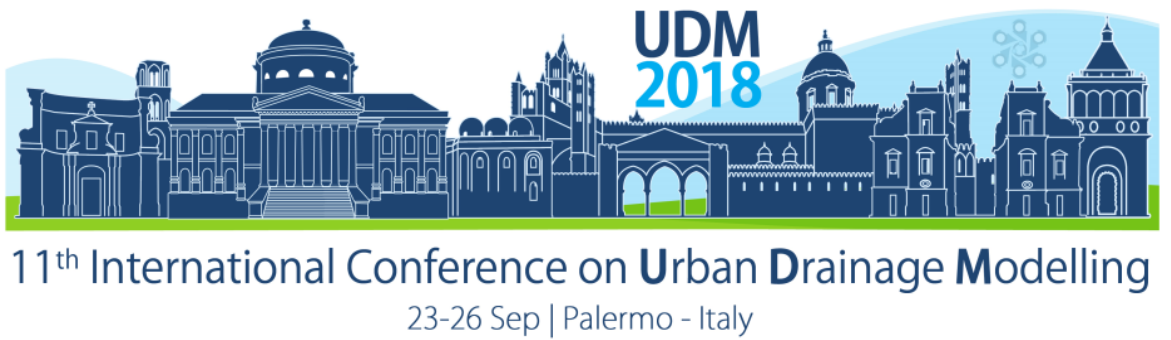

\title{
Testing new stormwater pollution build-up algorithms informed by genetic programming approach
}

\author{
Kefeng Zhang1, Peter Bach,3,4, David McCarthy², and Ana Deletic ${ }^{1}$ \\ ${ }^{1}$ Water Research Centre, School of Civil and Environmental Engineering, the University of New South Wales, \\ Sydney, Australia \\ ${ }^{2}$ Monash Infrastructure Research Institute, Department of Civil Engineering, Monash University Clayton 3800 \\ VIC, Australia \\ ${ }^{3}$ Swiss Federal Institute of Aquatic Science \& Technology (Eawag), Überlandstrasse 133, Dübendorf, Switzerland \\ ${ }^{4}$ Institute of Environmental Engineering, ETH Zürich, 8093, Zürich, Switzerland
}

(Authors' addresses: Vallentine Annex, Building H22, UNSW, Sydney NSW 2052, Australia)

\begin{abstract}
This paper uses the Genetic programming (GP) technique to explore new build-up algorithms by inclusion of various climate variables, e.g. antecedent dry weather period, temperatures, rainfall, etc. A range of stormwater quality models were then proposed by combing these new build-up algorithms and different washoff models. These proposed models were tested using data collected from two urban catchments in Melbourne, Australia and validation will be performed using separated catchments. Calibration results show that new proposed models with inclusion of both antecedent dry weather period (ADWP) and temperature as variables in the build-up algorithms performed better than the commonly used traditional pollutant build-up and wash-off models for simulating TN and TP concentrations. It is suggested that different build-up algorithms shall be used for different pollutants to increase the simulation accuracy. The results also show that the wash-off process can be sufficiently simulated using simple exponential decay, considering either rainfall or runoff intensity.
\end{abstract}

Keywords: build-up and wash-off; genetic programming; antecedent dry weather period; temperature

\section{INTRODUCTION}

Stormwater quality models are useful tools to assist urban stormwater management. Since 1970s, different types of mathematical stormwater quality models have been developed to predict urban stormwater quality. The basic build-up/wash-off model that was firstly developed by Sartor et al. (1974), has still been the most widely used model and is implemented in stormwater management software (e.g. SWMM Rossman, 2010). This models can well represent physical processes and provide decent performance (NashSutcliffe coefficient, E>0.5) for some specific catchments over short periods, the models may even fail at the same catchments over a different period (Sage et al., 2015), due to the complex natural of the build-up and wash-off processes, alongside with high temporal and spatial variations; hence the reliability of build-up/wash-off water quality models are often questioned at a urban catchment scale (Wijesiri et al., 2015).

To improve the modelling approaches, understanding the processes within stormwater pollution generation is important. The pollutant build-up may either be set as constant value regardless of cliamte conditions, or related to antecedent dry weather periods (ADWP), modelled in different ways - power accumulation function, linear, etc (Vaze and Chiew, 2003;Sage et al., 2015). Currently in most studies, ADWP is often considered as a reliable predictor of pollutants concentrations or loads in stormwater, it is often argued that using ADWP as a sole factor in estimating pollution accumulation is problematic (Sage et al., 2015). Nevertheless, rare studies have been looking into the impact of other exploratory variables on the build-up process, e.g. impact of temperatures and previous rainfall event. 


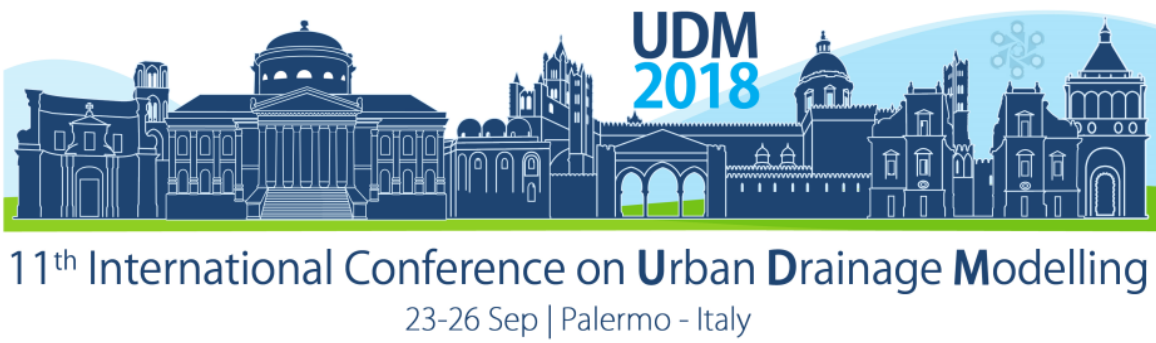

Moreover, the majority of the current studies are focusing on the accumulation of sediments, while the other pollutants are simply assumed to be attached and washed off via sediment or modelled using same general build-up and wash-off algorithems for different pollutants (Vaze and Chiew, 2003); however, it neglected the fact that different pollutants have distinct characteristics, and it will be worth investigating their specific accumulation characteristics.

In this study, different build-up algorithms of three inherent different pollutants (TSS, TN and TP) were investigated based on large monitoring dataset at two catchments, using statistical analysis and genetic modelling approach. These were then coupled with different wash-off equations to form new build-up and wash-off models to model stormwater quality at catchment scale. It is hypothesized that the accumulation are not just affected by ADWP and varies according to the type of pollutants.

\section{METHODS}

\subsection{Proposed Model}

The structure of a stochastic model developed by Daly et al. (2014) was adopted:

$$
C=C_{0} \exp (-k * V)
$$

where the often-used exponential decay of pollutants concentration $(C)$ was modelled as a function of runoff depth (V). $C_{0}$ is the starting concentration for each event; $k$ is the exponential decay coefficient.

Build-up algorithems. $\mathrm{C}_{0}$ in Equation 1 is the results of pollution build over the dry periods, hence in this study it assumed to be a function of various explanatory climate variables. This study firstly did correlation analyses between $C_{0}$ and a range of climate variables, including ADWP, average maximum air temperature over the past $x$ days $\left(T_{\max 1}, T_{\max 3}, T_{\max 7}-\right.$ standardised to room temperature $\left.15^{\circ} \mathrm{C}\right)$, minimum temperature $\left(T_{\min 1}, T_{\min 3}\right.$ and $\left.T_{\min 7}\right)$, rainfall amount within the previous $x$ days (Rain ${ }_{1}$, Rain $_{3}$ and Rain $n_{7} ; \mathrm{mm}$ ), and solar expose $\left(\right.$ Solar $_{1}$, Solar 3 and Solar 7 ; MJ $/ \mathrm{m}^{2}$ ). Genetic programming (GP) technique was then employed in this study to inform the best algorithms that describe the quantitative relationship between $C_{0}$ and the three most significantly correlated variables. GP is a "natural-selection" based machine learning approach (Koza, 1992), where mathematical expressions are treated as individual members in an evolving population. This was done by using a well-documented GP software Eureqa developed by Schmidt and Lipson (2013). Lastly, for each pollutant, the two best fit algorithms with maximum two coefficients (low complexity) were picked for further testing coupling with the typical wash-off models.

Wash-off models. The exponential decay coefficient $k$ was expressed in three ways: (1) as a calibration parameter, (2) as a power function of rainfall intensity $(I), l: k_{1} \times l^{k 2}$, and (3) as a power function of runoff rate $(R): k_{1} \times R^{k 2}$, where $\mathrm{k}_{1}$ and $\mathrm{k}_{2}$ are parameters as suggested by previous studies (Vaze and Chiew, 2003;McCarthy et al., 2013). Therefore, by coupling two different new build-up algorithms, six new build-up and wash-off stormwater models were proposed for each pollutant. In addition, a widely accepted build-up and wash-off model by Vaze and Chiew (2003) (originally used in SWMM) was also tested:

$$
L(t)=P(t)-P(t) \times e^{k_{1} R(t)^{k_{2}}}
$$

Where $L(t)=$ wash-off pollutant load during time step $t ; \mathrm{P}(\mathrm{t})$ accumulated surface load of pollutant; $\mathrm{R}(\mathrm{t})$ runoff rate at time step $t$; and $k 1, k 2,\left.P(t)\right|_{t=0}$ are calibration parameters.

\subsection{Model calibration and validation}

Field measurements carried out at two catchments of different sizes and land-uses in Melbourne: Gilby Road (GR; 28 ha, light industrial area) and Richmond (RICH; 89 ha, high 


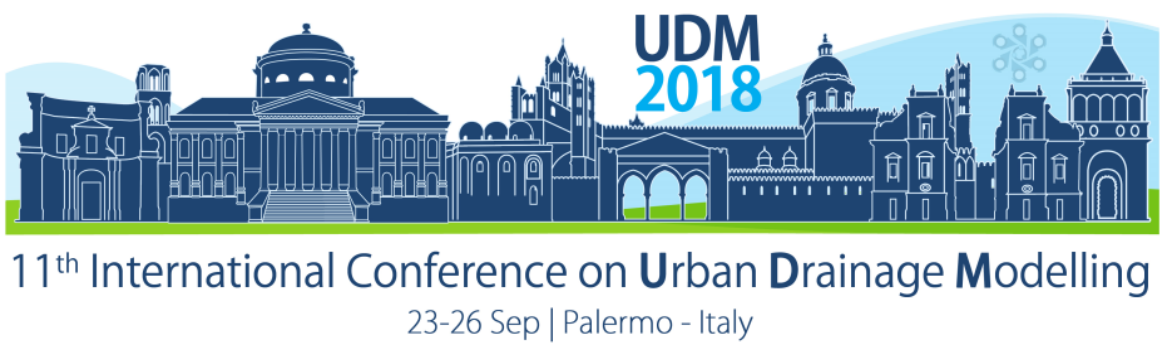

density residential area), have been used to calibrate the model. Data-sets from separate catchment will be used for model validation.

\section{RESULTS AND DISCUSSION}

\subsection{Build-up algorithm generation}

Correlation between starting concentration $\left(C_{0}\right)$ and climate variables. Correlation analysis revealed that the ADWP was the most significant factor than impacted the $\mathrm{C}_{0}$ of all pollutants $(p<0.1)$. This is as expected, as ADWP is often used as the parameter for estimating pollutant accumulation processes (Behera et al., 2006; Rossman, 2010). This analysis also shows that other variables are also influential $(p<0.1)$, e.g. Rain ${ }_{1}$ was found to be highly correlated to $\mathrm{C}_{0}$ of TSS; the correlation between $\mathrm{T}_{\min 1}$ and TP, and between $\mathrm{Rain}_{7}, \mathrm{~T}_{\min 3}$ and TN were also found to be significant.

Build-up Algorithms generation. Table 1 presents the algorithms suggested by the GP software Eureqa for estimation of $\mathrm{C}_{0}$ using the most significantly correlated climate variables. Although the algorithms generation is based on 'black-box' approach driven by the data, their physical meanings are apparent: linear accumulation which are one of the common build-up functions previously reported (Behera et al., 2006). Taking TN-A algorithm for example, the first term ' 2.35 ' represents the residual amount of TN (in this case concentration) after the previous event, while the second term '0.37*ADWP' indicates the accumulation with increasing ADWP. As it is often argued that using ADWP as a sole factor in estimating pollution accumulation is problematic (Sage et al., 2015), this study provides new insights into the inclusion of other important variables (e.g. temperature and rainfall) in estimation of pollution build-up using GP technique; e.g. TN-B and both TP algorithms reflect a positive impact of temperature on $\mathrm{C}_{0}$. For TSS, the previous rainfall amount (Rain ${ }_{1}$ ) was found to adversely impact the $\mathrm{C}_{0}$ values as indicated by TSS-A algorithm.

Table 1. Suggested algorithms for estimation of $\mathrm{C}_{0}$ using the most influential variables; two for each pollutant.

\begin{tabular}{|c|c|c|c|c|c|c|c|c|}
\hline & & Suggested algorithms & $\mathbf{R}^{2}$ & $\begin{array}{l}\text { Correlation } \\
\text { coefficient }\end{array}$ & $\begin{array}{l}\text { Max } \\
\text { Err. }\end{array}$ & $\begin{array}{l}\text { Mean Square } \\
\text { Err. }\end{array}$ & Mean abs. Err. & parameters \\
\hline TN & $\begin{array}{l}\mathrm{A} \\
\mathrm{B}\end{array}$ & $\begin{array}{l}\mathrm{C}_{0 \text { TN }}=2.35+0.37^{*} A D W P \\
\mathrm{C}_{0 \text { TN }}=1.77+0.0203^{*} A D W{ }^{*} \mathrm{~T}_{\min 3}\end{array}$ & $\begin{array}{l}0.03 \\
0.15\end{array}$ & $\begin{array}{l}0.34 \\
0.48 \\
\end{array}$ & $\begin{array}{l}9.8 \\
9.5\end{array}$ & $\begin{array}{l}13.4 \\
11.8 \\
\end{array}$ & $\begin{array}{l}2.40 \\
2.24\end{array}$ & $\begin{array}{l}2 \\
2 \\
\end{array}$ \\
\hline TP & $\begin{array}{l}\text { A } \\
B\end{array}$ & $\begin{array}{l}\mathrm{C}_{0 \text { TP }}=0.0054^{*} \mathrm{ADWP}^{*} \mathrm{~T}_{\min 1} \\
\mathrm{C}_{0 \text { TP }}=0.27+0.00356^{*} \mathrm{ADW} \mathrm{P}^{*} \mathrm{~T}_{\min 1}\end{array}$ & $\begin{array}{l}0.44 \\
0.42\end{array}$ & $\begin{array}{l}0.74 \\
0.74\end{array}$ & $\begin{array}{l}1.0 \\
1.2 \\
\end{array}$ & $\begin{array}{l}0.26 \\
0.27\end{array}$ & $\begin{array}{l}0.44 \\
0.43\end{array}$ & $\begin{array}{l}1 \\
2\end{array}$ \\
\hline TSS & $\begin{array}{l}A \\
B\end{array}$ & $\begin{array}{l}\mathrm{C}_{0 \_ \text {TSS }}=77.2+11.5^{\star} \text { ADWP } /\left(\text { Rain }_{1}\right) \\
\mathrm{C}_{0} \text { TSS }=70.1+15.0^{\star} \text { ADWP }\end{array}$ & $\begin{array}{l}0.42 \\
0.11\end{array}$ & $\begin{array}{l}0.74 \\
0.52\end{array}$ & $\begin{array}{l}797 \\
1011\end{array}$ & $\begin{array}{l}29231 \\
55464\end{array}$ & $\begin{array}{l}91 \\
142.3\end{array}$ & $\begin{array}{l}2 \\
2\end{array}$ \\
\hline
\end{tabular}

The proposed new build-up and wash-off models for the three pollutants are presented in Table 2, based on the generated build-up and selected wash-off models, with the specific numbers in the algorithms of Table 1 replaced by calibration parameters.

\subsection{Model calibration results}

Model performance assessed using Nash-Sutcliffe coefficient from calibration was presented in Figure 1. It can be seen that for TSS the all the proposed new models had relative poor performance $(E<0.28$ for Richmond and $<0.11$ for Gilby road) than the $M 0 \quad(E=0.36$ for Richmond and 0.19 for Gilby road). This indicates that the traditional build-up and wash-off model is good enough to capture the TSS accumulation and wash-off processes. TN and TP however, could be better simulated using some of the proposed models; e.g. highest $\mathrm{E}$ value was observed using Model M4 for TN, with $\mathrm{E}_{\mathrm{M} 4 \_ \text {Richmond }}(\mathrm{TN})=0.49$ and $\mathrm{E}_{\mathrm{M} 4 \text { _Gilby }}(\mathrm{TN})=0.40$ which is $6 \%$ and $110 \%$ higher than that using M0 (0.46 and 0.19$)$, respectively. As for TP, M1 had the best performance, with $E_{\mathrm{M} 1 \_ \text {Richmond }}(\mathrm{TP})=0.45$ and $\mathrm{E}_{\mathrm{M} 1 \_ \text {Gilby }}(\mathrm{TP})=0.56$; this was $30 \%$ and $126 \%$ higher than M0. The inclusion of temperature as a parameter in the better performing models indicates that it may be necessary to consider the temperature in 


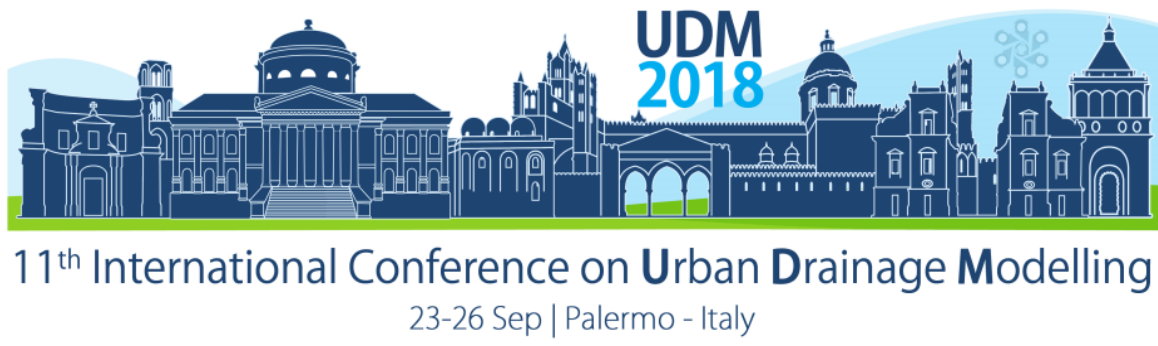

stormwater quality modelling for TP and TN. However, further studies are needed to explore how temperature impact stormwater nutrients pollution. The results also show that the washoff process can be sufficiently simulated using simple exponential decay, without considering either rainfall or runoff intensity. In addition, it is suggested that rather than using a same general model (e.g. M0) for all pollutants, different build-up algorithms shall be used for different pollutants.

Table 2. Proposed build-up and wash-off models to be tested

\begin{tabular}{|c|c|c|c|}
\hline & TSS & TP & TN \\
\hline Model 0 (M0) & & $\mathrm{L}(\mathrm{t})=\mathrm{P}(\mathrm{t})-\mathrm{P}(\mathrm{t}){ }^{\star} \mathrm{EXP}\left(\mathrm{k}_{1}{ }^{*} \mathrm{R}(\mathrm{t})^{\mathrm{k} 2}\right)$ & \\
\hline Model 1 (M1) & $C=\left(\alpha+\beta^{*} A D W P /\right.$ Rain $\left._{1}\right) / E X P\left(-V^{*} k\right)$ & $C=\left(\alpha+\beta^{*} A D W P^{*} T_{1}\right) / E X P\left(-V^{*} k\right)$ & $C=\left(\alpha+\beta^{*} A D W P\right) / E X P\left(-V^{*} k\right)$ \\
\hline Model 2 (M2) & $\mathrm{C}=\left(\alpha+\beta^{*} \mathrm{ADWP} / \mathrm{Rain}_{1}\right) / \mathrm{EXP}\left(-\mathrm{V}^{*} \mathrm{k}_{1}{ }^{*} \mathrm{I}^{0.293}\right)$ & $C=\left(\alpha+\beta^{*} A D W P^{*} T_{1}\right) / E X P\left(-\left.V^{*} k_{1}{ }^{*}\right|^{0.293}\right)$ & $C=\left(\alpha+\beta^{*} A D W P\right) / E X P\left(-\left.V^{*} k_{1}{ }^{*}\right|^{0.293}\right)$ \\
\hline Model 3 (M3) & $C=\left(\alpha+\beta^{*} A D W P /\right.$ Rain $\left._{1}\right) / \operatorname{EXP}\left(-V^{*} k_{1}{ }^{*} R l^{k 2}\right)$ & $C=\left(\alpha+\beta^{*} A D W P^{*} T_{1}\right) / E X P\left(-V^{*} k_{1}{ }^{*} R I^{k 2}\right)$ & $C=\left(\alpha+\beta^{*} A D W P\right) / E X P\left(-V^{*} k_{1}{ }^{*} R I^{k 2}\right)$ \\
\hline Model 4 (M4) & $C=\left(\alpha+\beta^{*} A D W P\right) / E X P\left(-V^{*} k\right)$ & $\mathrm{C}=\left(\alpha^{*} \mathrm{ADW} \mathrm{P}^{*} \mathrm{~T}_{1}\right) / \mathrm{EXP}\left(-\mathrm{V}^{*} \mathrm{k}\right)$ & $C=\left(\alpha+\beta^{*} A D W P^{*} T_{3}\right) / E X P\left(-V^{*} k\right)$ \\
\hline Model 5 (M5) & $C=\left(\alpha+\beta^{*} A D W P\right) / E X P\left(-\left.V^{*} k_{1}{ }^{*}\right|^{0.293}\right)$ & $C=\left(a^{*} A D W P * T_{1}\right) / E X P\left(-\left.V^{*} k_{1}{ }^{*}\right|^{0.293}\right)$ & $C=\left(\alpha+\beta^{*} A D W P * T_{3}\right) / E X P\left(-V^{*} k_{1}{ }^{*} I^{0.293}\right)$ \\
\hline Model 6 (M6) & $\mathrm{C}=\left(\alpha+\beta^{*} \mathrm{ADWP}\right) / \mathrm{EXP}\left(-\mathrm{V}^{*} \mathrm{k}_{1}{ }^{*} \mathrm{R}^{\mathrm{k} 2}\right)^{\prime}$ & $C=\left(a^{*} A D W P^{*} T_{1}\right) / E X P\left(-V^{*} k_{1}{ }^{*} R l^{k 2}\right)^{\prime}$ & $\mathrm{C}=\left(\alpha+\beta^{*} \mathrm{ADW} \mathrm{P}^{*} \mathrm{~T}_{3}\right) / \mathrm{EXP}\left(-\left.\mathrm{V}^{*} \mathrm{k}_{1}{ }^{*} \mathrm{R}\right|^{\mathrm{k} 2}\right)$ \\
\hline
\end{tabular}

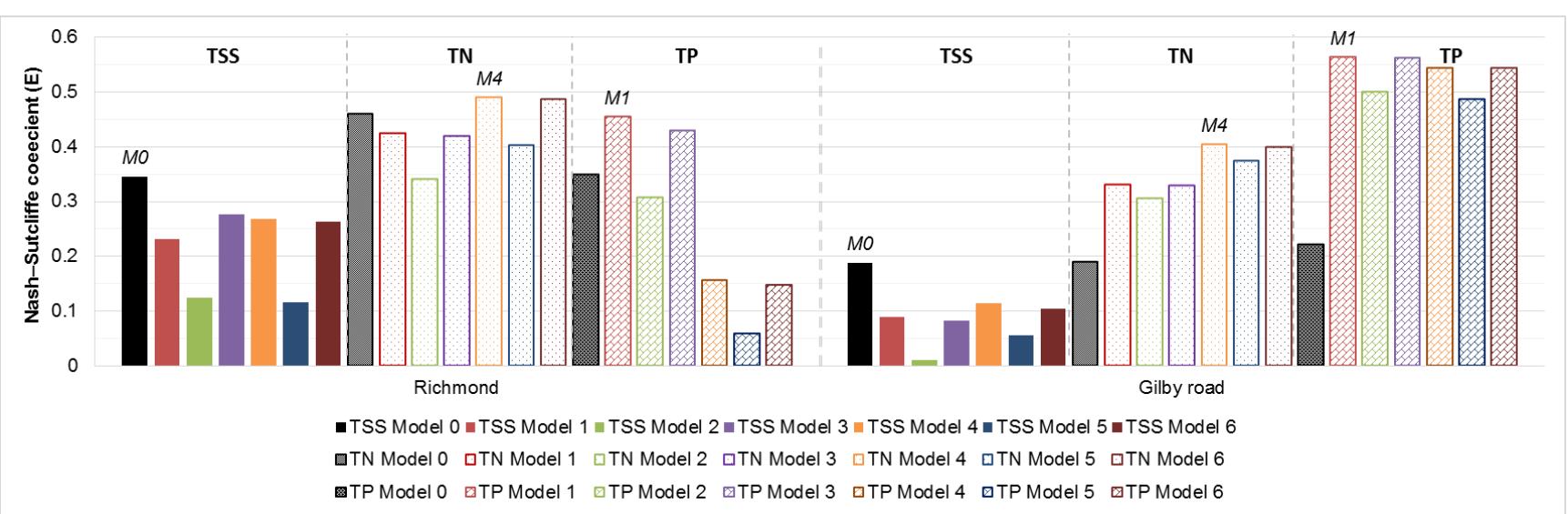

Figure 1. Calibration performance of all the models. The best models are indicated.

\section{CONCLUSIONS}

This paper uses a new approach that employs the genetic programming to suggest different stormwater pollutant build-up algorithms to be included in the build-up and wash-off models for estimating pollutant concentrations. Results show that inclusion of both antecedent dry weather period (ADWP) and temperature as variables in the build-up algorithms may improve the stormwater quality models for simulating TN and TP concentrations. Further model validation will be performed and presented in the conference.

\section{References}

Behera, P.K., Adams, B.J. and Li, J.Y., 2006. Runoff quality analysis of urban catchments with analytical probabilistic models. Journal of Water Resources Planning and Management 132(1), 4-14.

Daly, E., Bach, P.M. and Deletic, A., 2014. Stormwater pollutant runoff: A stochastic approach. Advances in Water Resources.

Koza, J.R., 1992. Genetic programming: on the programming of computers by means of natural selection. MIT press.

McCarthy, D.T., Deletic, A., Mitchell, V.G. and Diaper, C., 2013. Predicting between-event variability of escherichia coli in urban storm water. Journal of Environmental Engineering (United States) 139(5), 728-737.

Rossman, L.A., 2010. Storm water management model user's manual, version 5.0. National Risk Management Research Laboratory, Office of Research and Development, US Environmental Protection Agency Cincinnati.

Sage, J., Bonhomme, C., Al Ali, S. and Gromaire, M.-C., 2015. Performance assessment of a commonly used "accumulation and wash-off" model from long-term continuous road runoff turbidity measurements. Water Research 78, 47-59.

Sartor, J.D., Boyd, G.B. and Agardy, F.J., 1974. Water pollution aspects of street surface contaminants. Journal (Water Pollution Control Federation), 458-467.

Schmidt, M. and Lipson, H., 2013. Eureqa (version 0.99 .5 beta) [software]. [Available at www.eureqa.com.].

Vaze, J. and Chiew, F.H., 2003. Comparative evaluation of urban storm water quality models. Water Resources Research 39(10).

Wijesiri, B., Egodawatta, P., McGree, J. and Goonetilleke, A., 2015. Influence of pollutant build-up on variability in wash-off from urban road surfaces. Science of The Total Environment 527, 344-350. 


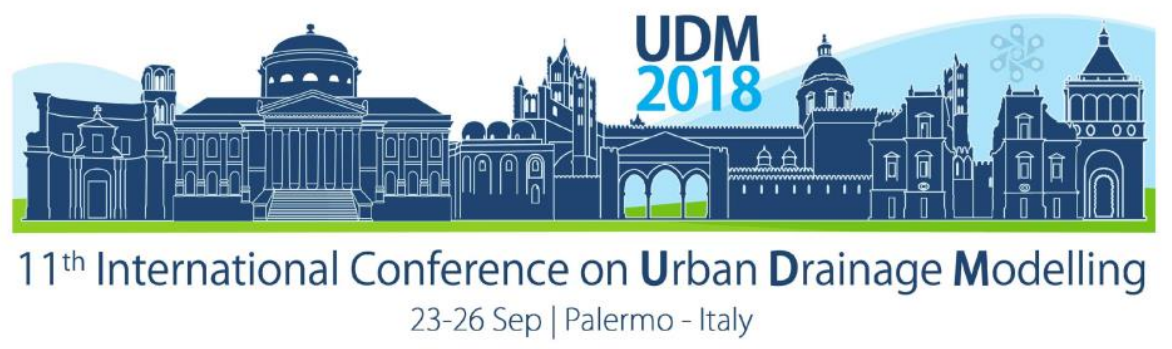

\title{
Estimation of Faecal Indicator Bacteria in Stormwater by Multiple Regression Modelling and Microbial Partitioning to Solids
}

\author{
Helen Galfi' ${ }^{1}$, Heléne Österlund ${ }^{1}$, Jiri Marsalek ${ }^{1}$, and Maria Viklander ${ }^{1}$ \\ Luleå University of Technology, Department of Civil, Environmental and Mining Engineering, Luleå 97187 , \\ Sweden
}

\begin{abstract}
Concerns about the contamination of sources of drinking water by stormwater motivated a sanitary survey of several urban catchments in the City of Östersund (Northern Sweden). A data subset from these surveys, comprising of faecal indicator bacteria (FIB) concentrations (E. coli and enterococci), measured for six storm events in three catchments, was used for investigating the feasibility of developing a FIB estimation procedure for the studied catchments by two approaches: (a) Multiple regression models, and (b) microbial partitioning to solids. In regressions, five explanatory variables (associated constituents) were derived from the literature and measured data: stormwater temperature and flow rate, and measurements of total suspended solids (TSS), total phosphorus (TP) and electric conductivity (EC). The obtained regression models were satisfactory for enterococci (regression of modelled FIBs on measured FIB was described by $R^{2}=0.7$ ), but less acceptable for $E$. coli $\left(\mathrm{R}^{2}=0.2\right)$. Microbial partitioning to stormwater solids from gully pots was found infeasible; the sediment sampled contained very low FIB counts. Hence, the former method is recommended for further refinement and applications.
\end{abstract}

Keywords: Faecal indicator bacteria (FIBs); sanitary surveys of storm sewers; statistical modelling of FIBs.

\section{INTRODUCTION}

Concerns about the microbiological quality of stormwater, typically described by concentrations of faecal indicator bacteria (FIBs), are driven by the public health risks associated with microbiological contamination of recreational waters, sources of drinking water, and stormwater used as a source of subpotable water (Marsalek and Rochfort, 2004). To minimize such risks, municipalities conduct sanitary surveys of urban catchments using FIB concentrations for assessing exposures. In these surveys, FIBs monitoring is often expanded by monitoring additional constituents (Hathaway et al., 2010; Galfi et al., 2016), with the goal of using such data for developing simple statistical models allowing FIB prediction on the basis of routinely collected quality data. In spite of limited accuracy of such tools, they are useful for planning remediation of FIB contamination (Tsanis et al., 1995; Sokolova et al., 2014) and future FIB data collection, and may offer a practical alternative to more complex FIB modelling approaches (McCarthy et al., 2011).

Another simple approach to assessing FIBs in stormwater is based on microbial partitioning of FIBs to suspended solids (Jeng et al., 2005), or settleable solids in stormwater (Characklis et al., 2005), with FIBs displaying fairly consistent behaviour in both cases and association of microorganisms with settleable particles (30-55\%). Hence, microbial partitioning coefficients could be applied to the sediment entering stormwater to estimate FIB concentrations in stormwater. 


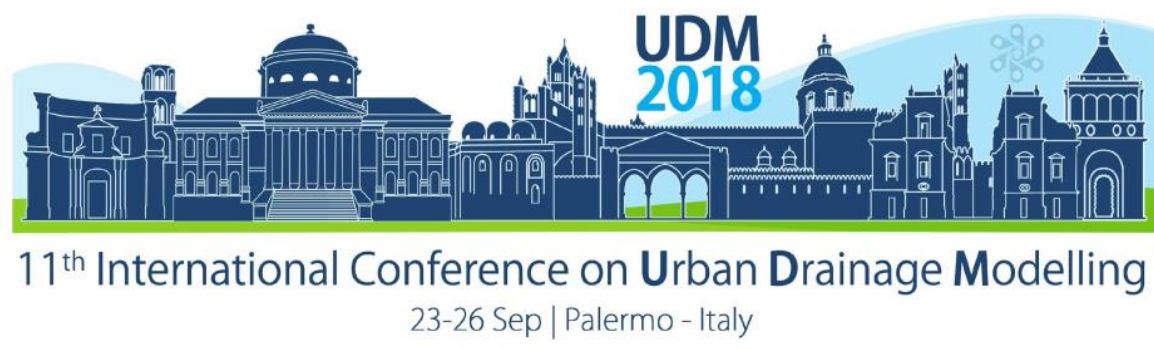

Potential impacts of FIB contamination on raw drinking water and recreational waters in the City of Östersund (Sweden) motivated a study of FIBs in stormwater from several urban catchments in the city (Galfi et al., 2016). Using a subset of such data and new data on $\mathrm{FIB} /$ solids partitioning, the purpose of the study described herein was to examine the feasibility of modelling the FIB data using two approaches: (a) FIB-associated stormwater quality constituents, and (b) microbial partitioning to stormwater settleable solids.

\section{MATERIALS AND METHODS}

\subsection{Study sites}

The field sampling of stormwater was conducted immediately upstream of the drainage outfalls of three Östersund sewersheds discharging stormwater into Lake Storsjön, in the general vicinity of the intake of the water treatment plant serving about 50,000 inhabitants. Characteristics of the catchments studied are listed in Table 1 and further details can be found in Galfi et al. (2016).

Table 1. Study catchment characteristics

\begin{tabular}{lcccc} 
& Land use & Area & Imperviousness & Slope \\
\cline { 2 - 5 } Catchment & & $(\mathrm{ha})$ & $(\%)$ & $(\%)$ \\
\cline { 2 - 5 } C1 & Low density residential & 19 & 21 & $1.6-17$ \\
C3 & High density residential & 23 & 47 & $0.01-3$ \\
& Highly imperviousness central & 2.2 & 85 & $0.5-1$ \\
\hline
\end{tabular}

\subsection{Sample collection and analysis}

Samples were collected manually by dipping clean bottles into the sewer flow. In total 120 flow-weighted stormwater samples were collected in the catchments studied and submitted for analysis of FIBs and associated constituents. Full listing of 20 constituents analysed and the analytical methods used can be found elsewhere (Galfi et al. 2016); for the purpose of this study, the list of constituents was reduced to seven: two common FIBs ( $E$. coli and enterococci) and five associated parameters identified by the literature survey (Hathaway et al., 2010; Chudoba et al., 2013) and multiple regressions of the collected data: stormwater temperature (T), discharge (Q), electrical conductivity (EC), total suspended solids (TSS), and total phosphorus (TP). For microbial partitioning to stormwater sediments, 52 composite sediment samples were collected after runoff events from the bottom of gully pots draining into the sewers studied. It was assumed that the sediment sampled represented that conveyed by stormwater in the adjacent sewers during the runoff events sampled.

\subsection{FIB statistical modelling}

The first modelling approach was based on the previous study of Galfi et al. (2016). Two constituents, TSS and total phosphorus, as well as runoff temperature and flow rate were identified as strongly correlated to FIBs in stormwater. Thus the model consisted of multiple regressions assuming the following functional relationship: $C_{F I B}=K f(T, Q, T S S, T P, E C)$, where $K$ is a regression constant, $f=$ function, and the five explanatory variables were described above in Section 2.2. In microbial partitioning, regressions of FIB concentrations in gully pot sediment on FIB concentrations in stormwater were produced for both E. coli and 


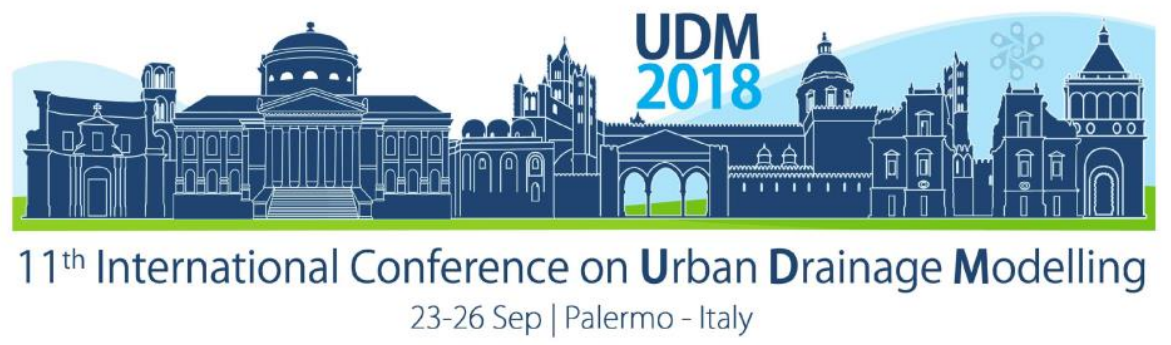

enterococci, and average FIB cfu (colony forming units) per $1 \mathrm{mg}$ of sediment were calculated and compared to an analogous ratio of FIB cfu per $1 \mathrm{mg}$ of TSS.

\section{RESULTS AND DISCUSSION}

The five constituents studied, T, Q, TSS, TP, and EC could explain, to a fair extent, the measured FIB concentrations in stormwater as shown in Table 2.

Table 2. Statistically modelled and measured FIB concentrations, in natural log (In) values, in runoff from the three catchments studied

\begin{tabular}{|c|c|c|c|c|c|c|c|}
\hline \multirow[b]{2}{*}{ Catchment } & \multirow[b]{2}{*}{ Events } & \multicolumn{2}{|l|}{$\ln ($ E. coli $)$} & \multirow{2}{*}{$\begin{array}{l}\text { Ratio } \\
M_{\text {mod }} / M_{\text {meas }}\end{array}$} & \multicolumn{2}{|c|}{ In(Enterococci) } & \multirow{2}{*}{$\begin{array}{l}\text { Ratio } \\
M_{\text {mod }} / M_{\text {meas }}\end{array}$} \\
\hline & & Modelled & Measured & & Modelled & Measured & \\
\hline \multirow[t]{6}{*}{ C1 } & 14.09 .2012 & 6.83 & 6.21 & 1.10 & 8.11 & 7.31 & 1.11 \\
\hline & 26.09.2012 & 5.65 & 5.70 & 0.99 & 7.42 & 7.82 & 0.95 \\
\hline & 04.10 .2012 & 5.58 & 4.61 & 1.21 & 7.26 & 7.31 & 0.99 \\
\hline & 09.05 .2013 & 3.85 & 4.09 & 0.94 & 6.02 & 5.14 & 1.17 \\
\hline & 03.06 .2013 & 5.98 & 7.65 & 0.78 & 7.85 & 8.10 & 0.97 \\
\hline & 13.06 .2013 & 6.84 & 7.41 & 0.92 & 8.18 & 7.97 & 1.03 \\
\hline Mean (M) & & 5.79 & 5.95 & 0.99 & 7.47 & 7.28 & 1.04 \\
\hline \multirow[t]{6}{*}{$\mathrm{C} 2$} & 14.09 .2012 & 6.71 & 5.65 & 1.19 & 7.91 & 7.89 & 1.00 \\
\hline & 26.09.2012 & 6.23 & 5.04 & 1.24 & 6.96 & 7.60 & 1.03 \\
\hline & 04.10 .2012 & 5.99 & 5.36 & 1.12 & 6.60 & 7.40 & 1.06 \\
\hline & 09.05 .2013 & 5.51 & 3.99 & 1.38 & 5.92 & 3.56 & 1.23 \\
\hline & 03.06 .2013 & 6.47 & 6.15 & 1.05 & 7.55 & 7.42 & 0.99 \\
\hline & 13.06.2013 & 6.47 & 6.85 & 0.94 & 7.36 & 7.67 & 0.94 \\
\hline Mean (M) & & 6.23 & 5.51 & 1.15 & 7.05 & 6.84 & 1.04 \\
\hline \multirow[t]{6}{*}{$\mathrm{C} 3$} & 14.09 .2012 & 7.67 & 5.70 & 1.35 & 7.57 & 7.89 & 0.96 \\
\hline & 26.09.2012 & 7.67 & 5.44 & 1.41 & 6.69 & 6.75 & 0.99 \\
\hline & 04.10 .2012 & 6.71 & 7.40 & 0.91 & 6.33 & 6.21 & 1.00 \\
\hline & 09.05 .2013 & 6.95 & 2.89 & 2.40 & 5.43 & 4.82 & 1.13 \\
\hline & 03.06 .2013 & 7.43 & 7.34 & 1.01 & 6.71 & 7.59 & 0.88 \\
\hline & 13.06 .2013 & 7.91 & 7.86 & 1.01 & 7.55 & 7.79 & 0.97 \\
\hline Mean (M) & & 7.39 & 6.11 & 1.35 & 6.71 & 6.84 & 0.99 \\
\hline
\end{tabular}

However, in C2 and C3, only one of the FIBs tested, either E. coli or enterococci, could be explained as a function of the above constituents (Table 3 ). 


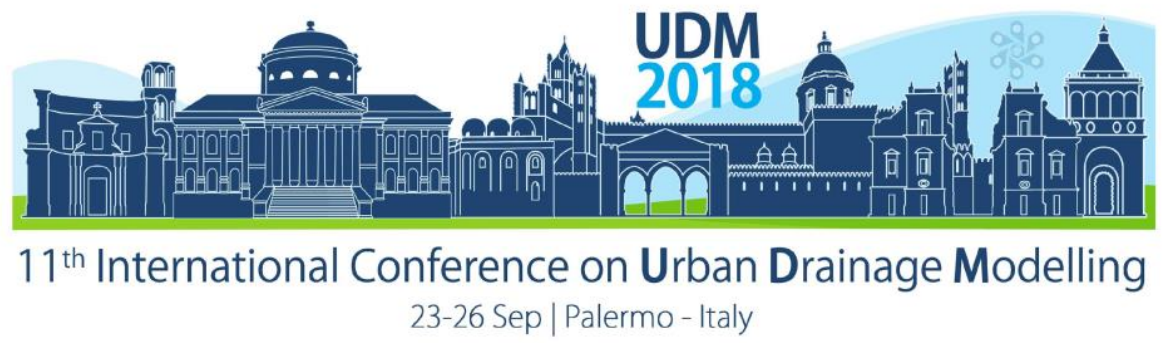

Table 3. Fitted regression models for geometric means of two FIBs in six rain runoff events in three catchments

\begin{tabular}{lcc}
\hline Catchment & Response variable & Explanatory variable equation \\
\hline C1 & E. coli & $0.51+0.5 \mathrm{~T}\left({ }^{\circ} \mathrm{C}\right)+0.004 \mathrm{TSS}(\mathrm{mg} / \mathrm{L})$ \\
& Enterococci & $3.56+0.36 \mathrm{~T}\left({ }^{\circ} \mathrm{C}\right)+3.28 \mathrm{TP}(\mathrm{mg} / \mathrm{L})-0.48 \mathrm{EC}(\mu \mathrm{s} / \mathrm{cm})$ \\
\hline C2 & E. coli & $4.07+0.24 \mathrm{~T}\left({ }^{\circ} \mathrm{C}\right)+0.02 \mathrm{Q}(\mathrm{L} / \mathrm{s})$ \\
\hline C3 & Enterococci & $-0.05+0.42 \mathrm{~T}\left({ }^{\circ} \mathrm{C}\right)+0.22 \mathrm{Q}(\mathrm{l} / \mathrm{s})$ \\
\hline
\end{tabular}

Averaging observed FIBs over individual catchments produced acceptable agreements of geometric means (ratios $M_{\text {mod }} / M_{\text {meas }}=0.99-1.35$ ), but the data in Fig. 1 indicate that the statistically modelled enterococci showed a much better fit $\left(R^{2}=0.7\right)$ than $E$. coli $\left(R^{2}=0.2\right)$ for a data set combining event means in all the three catchments.

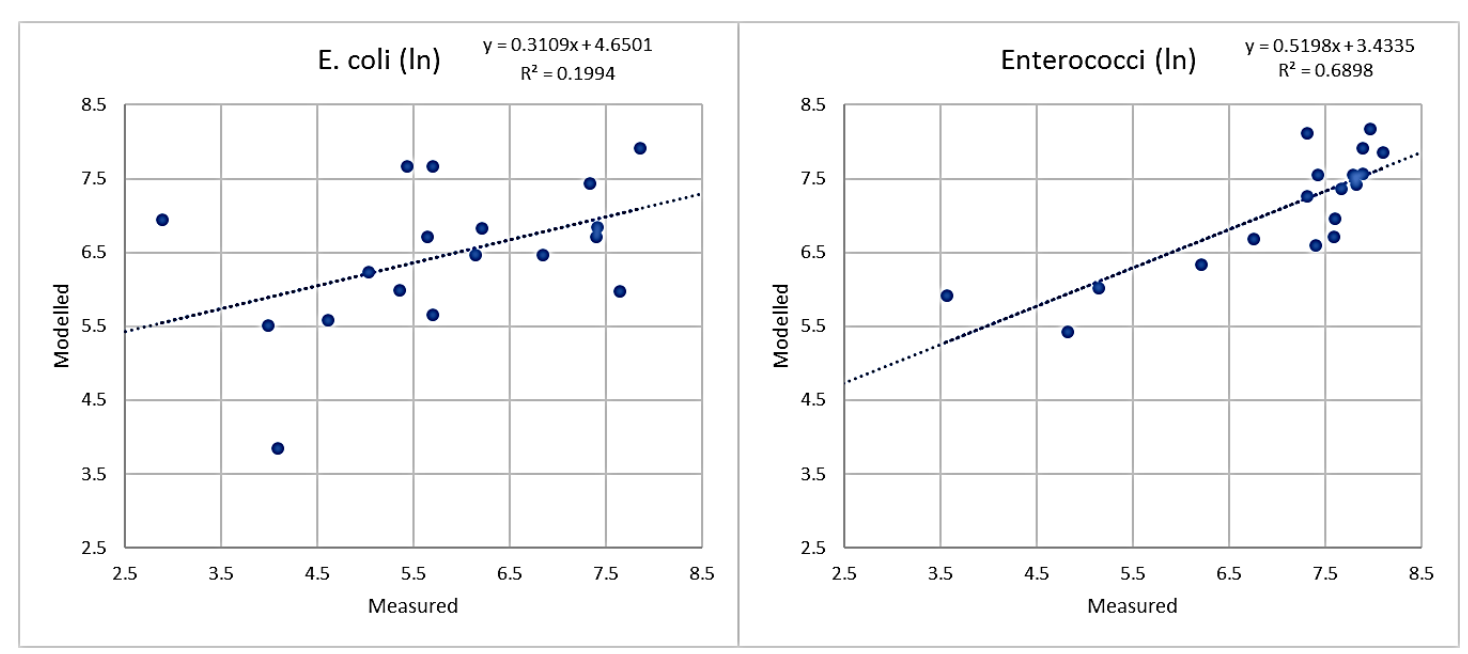

Figure 1. Measured and modelled E. coli and enterococci means for all the three catchments

In the partitioning approach, the measured FIB concentrations in water samples were plotted vs. the corresponding concentrations in the sediment in Fig. 2. The regression fit described by $\mathrm{R}^{2}=0.1$ and 0.35 , for $E$. coli and enterococci, respectively, was rather poor. In search for explanation, FIB counts per unit mass of the two types of solids, TSS and gully pot sediment, were calculated and compared in Table 4.

Table 4. (FIB counts) / (solids mass) ratio means in gully pot sediment and runoff TSS in catchments C1 - C3

\begin{tabular}{lcccc}
\hline \multirow{2}{*}{ Catchment } & \multicolumn{2}{c}{ E. Coli $(\mathrm{cfu}) /$ solids $(\mathrm{mg})$} & \multicolumn{2}{c}{ Enterococci (cfu) / solids $(\mathrm{mg})$} \\
\cline { 2 - 5 } & $\begin{array}{c}\text { Gully pot } \\
\text { sediment }\end{array}$ & $\begin{array}{c}\text { Stormwater } \\
\text { TSS }\end{array}$ & $\begin{array}{c}\text { Gully pot } \\
\text { sediment }\end{array}$ & $\begin{array}{c}\text { Stormwater } \\
\text { TSS }\end{array}$ \\
\hline C1 & 0.6 & 98 & 2.5 & 395 \\
C2 & 0.1 & 79 & 1 & 492 \\
C3 & 2 & 185 & 4.3 & 198 \\
\hline
\end{tabular}




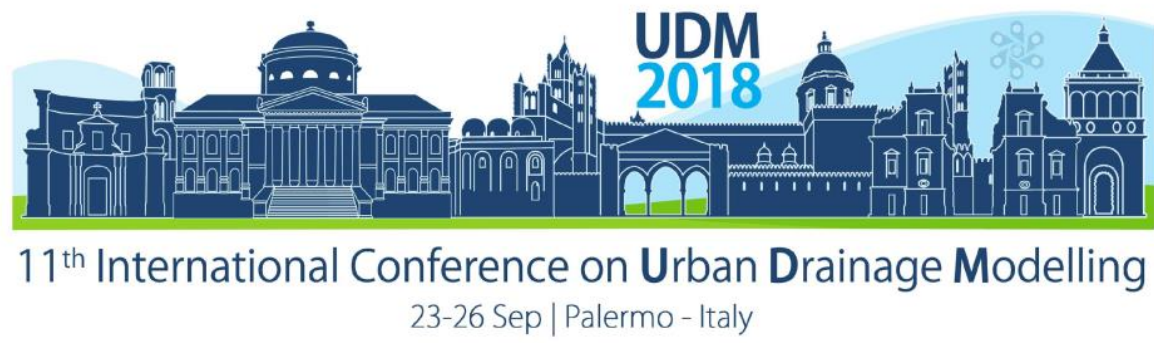

While for TSS the average counts per unit mass were 79-185 E. coli and 198-492 of enterococci cfu per $1 \mathrm{mg}$, respectively, the corresponding numbers for the gully pot sediment were just between $0.1-2$ and $1-4.3 \mathrm{cfu} / 1 \mathrm{mg}$ of sediment, respectively. Hence, as demonstrated in Fig. 2, the use of microbial partitioning was found infeasible (low $\mathrm{R}^{2}$-values), because much of the sampled sediment was inorganic material with low microbial presence.
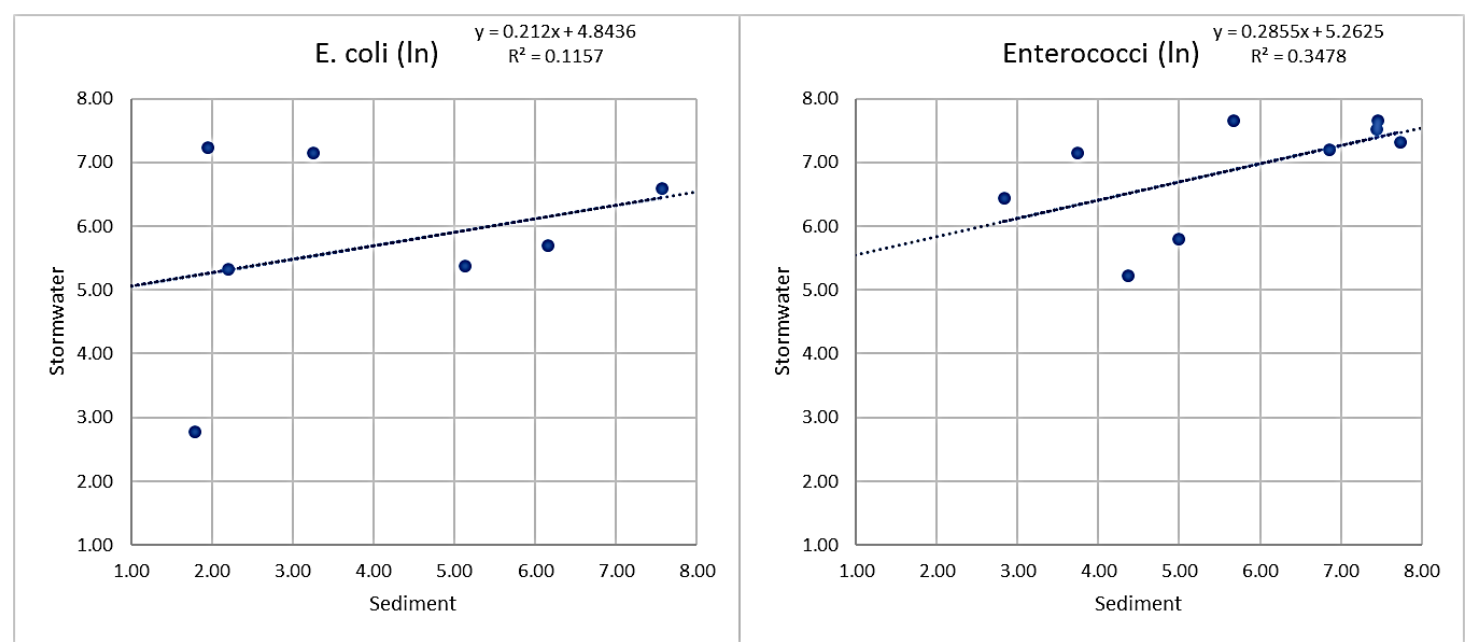

Figure 2. FIB concentrations in stormwater TSS vs. FIBs in gully pot sediment

\section{CONCLUSIONS}

Multiple regressions of $E$. coli and enterococci on associated stormwater constituents $(T, Q$, TSS, TP, and EC) produced practical statistical tools for estimating enterococci in stormwater $\left(R^{2}=0.7\right.$; for a combined set of three catchments and geometric event mean counts in six events); the corresponding value for $E$. coli was rather low, $\mathrm{R}^{2}=0.2$. The microbial partitioning of FIBs to stormwater solids sampled in gully pots has not produced satisfactory results, most likely because of low presence of FIBs in the sediments sampled.

\section{References}

Characklis, G.W., Dilts, M.J., Simmons, O.D., Likirdopulos, C.A., Krometis, L.-A. H., and Sobsey, M.D. (2005). Microbial partitioning to settleable particles in stormwater. Wat. Res. 39: 1773-1782.

Chudoba. E. A.. Mallin. M. A.. Cahoon. L. B.. Skrabal. S. A. (2013). Stimulation of fecal bacteria in ambient waters by experimental inputs of organic and inorganic phosphorus. Wat. Res. 47(10): 3455-3466.

Galfi. H. Österlund. H.. Marsalek. J. Viklander. M. (2016). Indicator bacteria and associated water quality constituents in stormwater and snowmelt from four urban catchments. Journal of Hydrology. 539: 125-140.

Hathaway, J.M., Hunt, W.F., and Simmons, O.D. (2010). Statistical evaluation of factors affecting indicator bacteria in urban storm-water runoff. J. Environ. Engng (ASCE), 136(12): 1360-68.

Jeng, H. C.. England. A. J. Bradford. H. B. (2005). Indicator organisms associated with stormwater suspended particles and estuarine sediment. Journal of Environmental Science and Health. 40(4). 779-791.

Marsalek, J. and Rochfort, Q. (2004). Urban wet-weather flows: Sources of fecal contamination impacting on recreational waters and threatening drinking water sources. J. Toxicol. and Environ. Health, 67(A):1765-77.

McCarthy. D. T. Deletic. A.. Mitchell. V. G. \& Diaper. C. (2011). Development and testing of a model for MicroOrganism Prediction in Urban Stormwater (MOPUS). Journal of hydrology. 409(1): 236-247.

Sokolova. E.. Pettersson. T. J. R.. Bergstedt. O. (2014). Hydrodynamic modelling and forecasting of microbial water quality in a drinking water source. Journal of Water Supply: Research and Technology - Aqua. 63(3): 189-199; DOI:10.2166/aqua.2013.216.

Tsanis, I.K., Wu, J., and Marsalek, J. (1995). Feasibility of modelling remedial measures for microbiological pollution of the St. Clair River at Sarnia Bay. J. Great Lakes Research, 21(1): 138-154. 


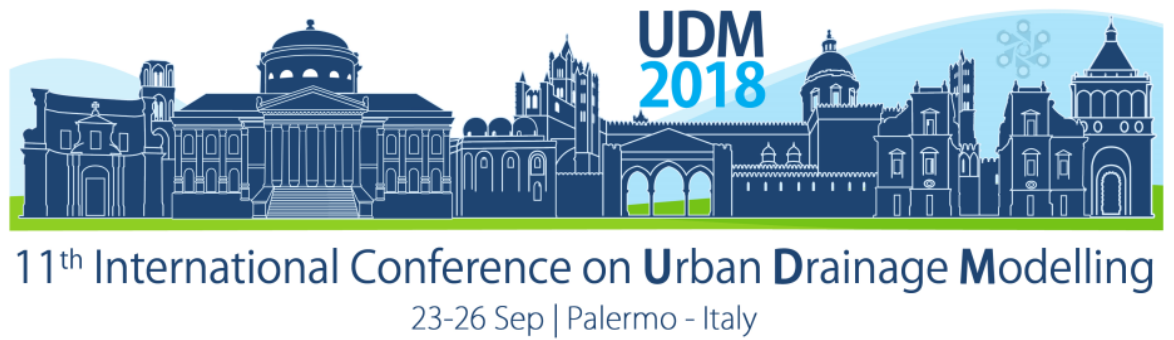

\title{
Illicit Connections and Antibiotic Resistant Bacteria in Urban Surface Water: What is Their Relation?
}

\author{
Rémy Schilperoort ${ }^{1}$, Hetty Blaak ${ }^{2}$, Heike Schmitt ${ }^{2}$, Arjo Hof ${ }^{3}$, Joan Meijerink ${ }^{4}$, Bert Palsma ${ }^{5}$ and Jeroen \\ Langeveld ${ }^{1,6}$ \\ ${ }^{1}$ Partners4UrbanWater, Nijmegen, the Netherlands \\ 2 National Institute for Public Health and the Environment (RIVM), Bilthoven, the Netherlands \\ ${ }^{3}$ Municipality of Almere, Almere, the Netherlands \\ ${ }^{4}$ Regional Water Authority Zuiderzeeland, Lelystad, the Netherlands \\ ${ }^{5}$ Foundation for Applied Water Research (STOWA), Amersfoort, the Netherlands \\ ${ }^{6}$ Delft University of Technology, Delft, the Netherlands
}

\begin{abstract}
Antibiotic resistant bacteria pose a threat to human health care. People may acquire such bacteria through contaminated surface waters. Known sources of contamination are WWTP effluent, combined sewer overflows (CSO) and run-off from agricultural lands. This study shows the wide-spread presence of ESBL-producing E.coli and ampicillin-resistant Enterococcus spp. in urban surface waters in the Netherlands that are not subject to these known sources. It studies the possible relation between these bacteria in surface water and any illicit connections in the storm sewers that discharge to the surface waters. The effect of illicit connections is assessed by sampling prior to and after the localization and removal of all illicit connections in an urban catchment area in the municipality of Almere, the Netherlands.
\end{abstract}

Keywords: Antibiotic Resistant Bacteria; Surface Water Quality; Illicit Connections

\section{INTRODUCTION}

Over the last decades, the prevalence of antibiotic resistant bacteria such as Extended Spectrum Beta Lactamase (ESBL)-producing Enterobacteriaceae has increased throughout Europe (Cantón et al., 2008). The current number of carriers in the Netherlands is estimated at $5 \%$ of the population (Huijbers et al., 2013). This poses a threat to human health care as infections caused by these bacteria are generally difficult to treat and require the use of lastresort antibiotics.

Several exposure routes for humans to antibiotic resistant bacteria are known, such as within health care settings, through contact with animal carriers (e.g. on farms) and through the consumption of contaminated foods. Increasingly, contact with faecally contaminated surface water, e.g. during recreation, is considered another possible exposure route. An important contributor of fecal bacteria to surface waters is the urban wastewater system via two sources: WWTP effluent and combined sewer overflows (CSO). Estimations indicate that in the Netherlands both sources contribute a significant and roughly equal number of (resistant) bacteria to Dutch surface waters (STOWA, 2018).

In earlier work (Blaak et al., 2017) we demonstrated that antibiotic resistant bacteria can also be present in urban surface waters in the Netherlands that are not under the influence of WWTP effluent or CSOs. One example was the surface water of a hydraulically isolated, 2300 ha urban catchment area in the municipality of Almere with around 85.000 inhabitants. The area was selected because of the complete absence of WWTPs and combined sewers 


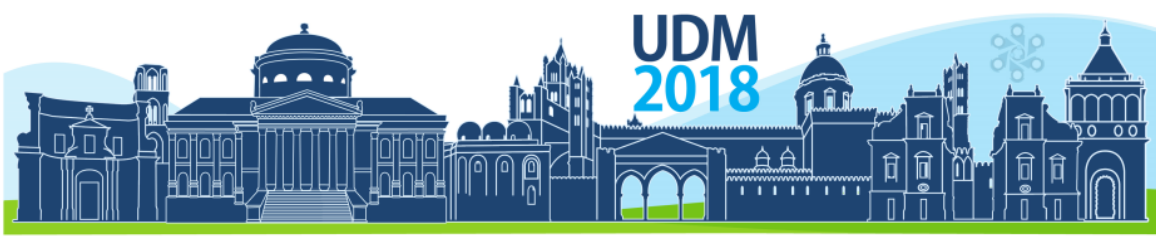

$11^{\text {th }}$ International Conference on Urban Drainage Modelling

23-26 Sep | Palermo - Italy

discharging to the water system; instead, the area has separate sewer systems only. A sampling campaign in the summer of 2016 from 15 randomly selected locations (see Figure 1 , left) during both wet and dry weather showed the abundant presence of ESBL-EC (a resistant variant of E.Coli) and ARE (a resistant variant of Enterococcus spp.) in the catchment area. In total, ESBL-EC was found in 17 samples (57\%) and ARE in 11 samples (37\%), see Figure 1 (right).
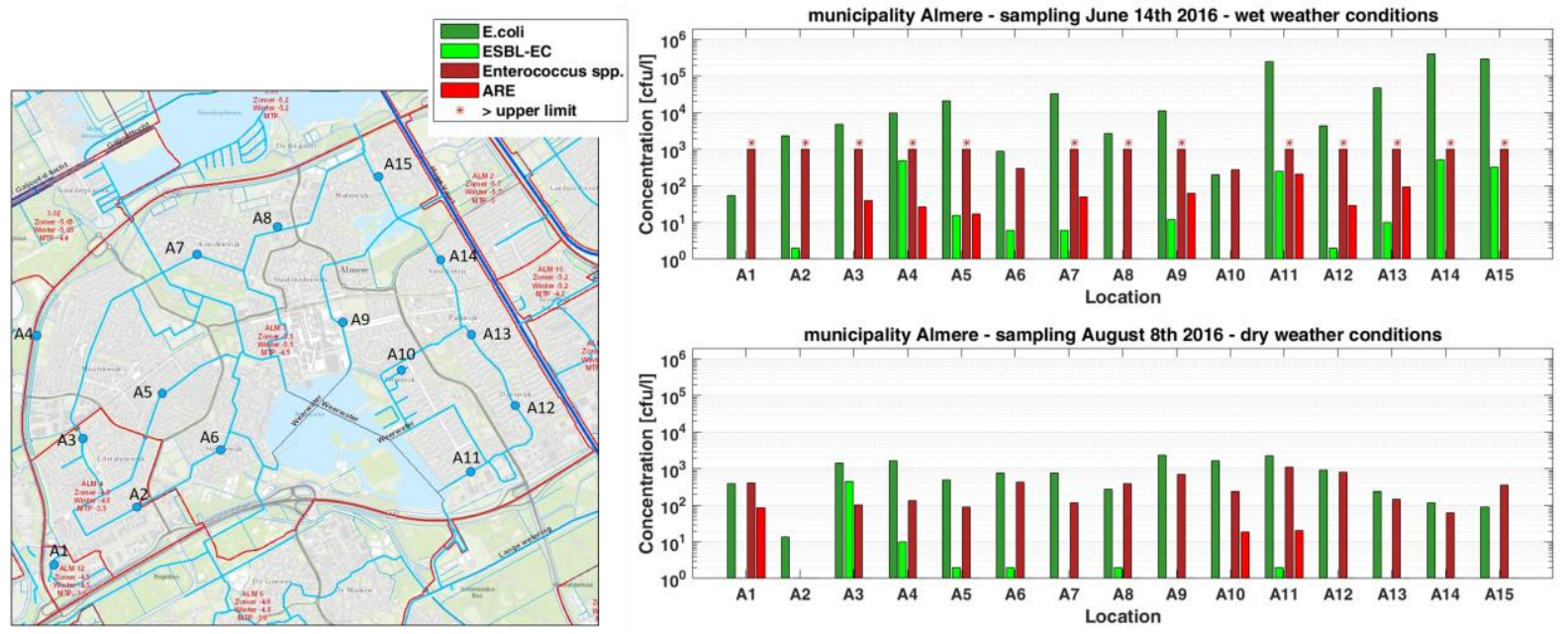

Figure 1. Sampling locations (left) and sampling results (right) for random sampling of E. coli, ESBL-EC, Enterococcus spp. and ARE in urban surface water in the municipality of Almere, June-August 2016.

Without WWTP effluent, CSOs and agricultural influences, the source(s) of these fecal bacteria and their resistant variants must be local. A possible source is human wastewater discharged to the surface water system via storm sewers due to illicit connections. On the one hand, this would be in line with the facts that (1) the bacterial concentrations in surface water increased significantly during wet weather (see Figure 1) and (2) illicit connections are a common phenomenon associated with separate sewer systems. On the other hand, the number of locations and, in some cases, the measured concentrations seem rather high compared to expectations. Based on an ESBL-EC prevalence of $5 \%$ among the common population (Huijbers et al., 2013) and an average of $2 \%$ illicit connections in the Netherlands (Schilperoort et al., 2011), 'only' 85 out of the 85.000 inhabitants are expected to discharge ESBL-EC to the local Almere surface water system via their wastewater. It seems improbable that this relatively small volume of wastewater can lead to the $57 \%$ positive samples with a widespread geographical distribution as presented in Figure 1. Possible explanations for this anomaly are (1) a higher ESBL-EC prevalence in the catchment, (2) more than $2 \%$ illicit connections in the area, and/or (3) other sources of (resistant) bacteria such as animal excrements in storm water run-off (birds, dogs, etc.) and excrements of waterfowl (ducks, geese and swans) in surface waters. Based on the 2016 results, no conclusions could be drawn on the origin of the (resistant) bacteria in the studied surface waters.

This extended abstract presents follow-up research that intends to address this anomaly and study more in depth the possible relation between illicit connections and the presence of antibiotic resistant bacteria in surface waters. 


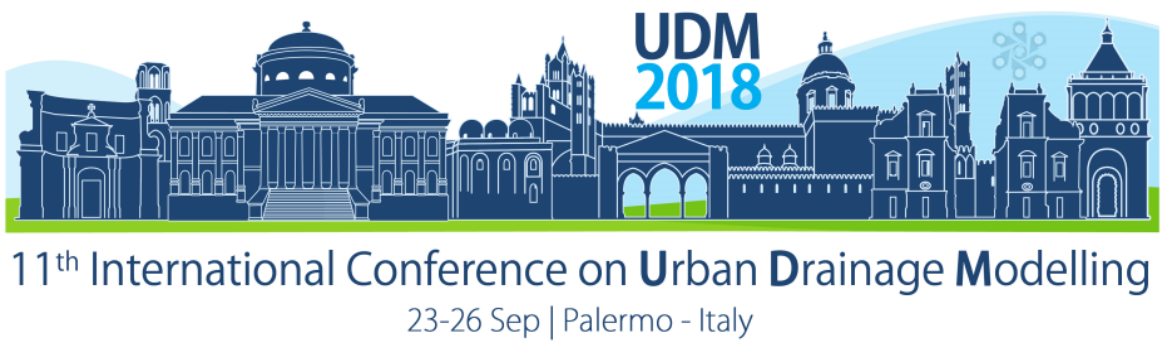

\section{MATERIALS AND METHODS}

\subsection{Study approach}

To (further) study the relation between illicit connections and bacterial contamination of surface water we use the following approach. In a selected catchment area we:

(1) apply random sampling in local surface water and in the storm sewer (December 2017);

(2) investigate the presence and locations of illicit connections (April/May 2018);

(3) sample the water, biofilm and sediment inside the storm sewer at and around the locations of illicit connections (May 2018);

(4) remove all illicit connections from the storm sewer and clean the storm sewer (June 2018);

(5) repeat the sampling in local surface water and in the storm sewer (June 2018).

Comparison of the sampling results of (1) and (5) will give an indication of the overall effect of the removal of illicit connections on the (bacterial) water quality in the storm sewer and in surface water. The sampling results of (3) will give a more detailed view on the fate and spread of bacteria around illicit connections.

\subsection{Research area}

The catchment area selected for the study is a 100 ha residential area in the municipality of Almere with around 5.400 inhabitants. The area has a separate sewer system with all storm sewers discharging to two central ponds in the neighbourhood. The ponds are not connected, and discharge in opposite directions. This gives the possibility to study two independent, hydraulically isolated surface water systems that are not influenced by WWTP effluent, CSOs and agriculture.
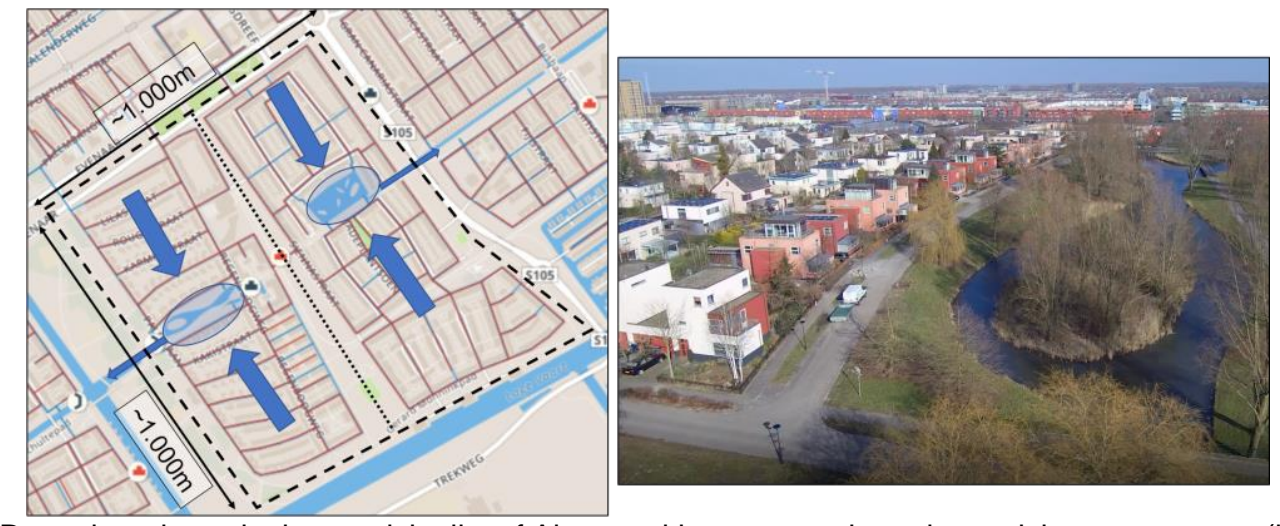

Figure 2. Regenboogbuurt in the municipality of Almere with two central ponds receiving storm water (left); aerial view of one of the central ponds (right)

\subsection{Methods}

Each sample is analysed for the fecal bacteria Escherichia coli (E.coli) and Enterococcus spp. as well as the antibiotic resistant variations "Extended-Spectrum Beta-Lactamase"-producing Escherichia coli (ESBL-EC) and ampicillin-resistant Enterococcus spp. (ARE). These bacteria have been selected as examples for clinically relevant resistant bacteria.

Illicit connections in the storm sewers are searched for using Distributed Temperature Sensing (DTS, see e.g. Nienhuis et al., 2013). DTS uses fibre-optic cables that measure in-sewer temperatures along the entire length of the storm sewer (14 km in total). The method yields individual readings for each cables section of $12,5 \mathrm{~cm}$ and for every 30 seconds. Locations 


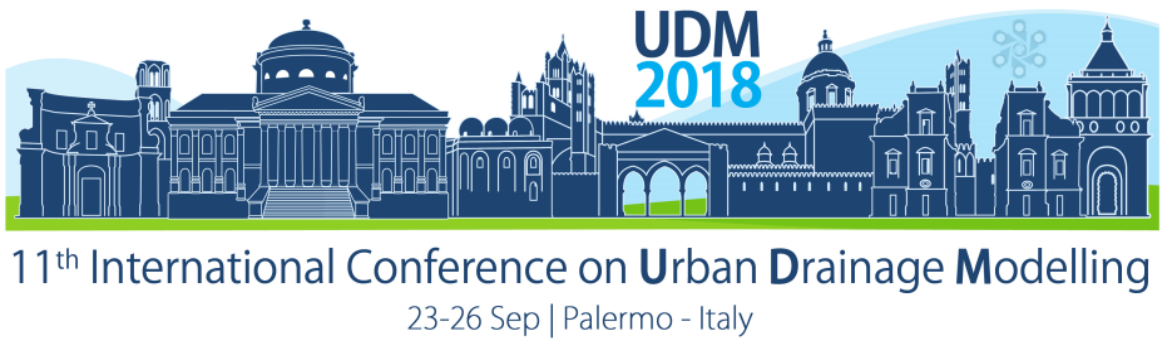

with temperature anomalies (e.g. sudden temperature increases due to the discharge of warm wastewater) are generally associated with illicit connections.

\section{RESULTS AND DISCUSSION}

\subsection{Results initial random sampling}

Random sampling of surface water and water inside the storm sewer in the Regenboogbuurt was done December $12^{\text {th }}, 2017$. In total 17 samples were collected, of which 5 samples from the western central pond in the area and 12 samples from storm sewer manholes randomly distributed over the area, see Figure 3 (left). In total, ESBL-EC was found in 5 samples (29\%) and ARE in 14 samples (82\%), see Figure 3 (right).
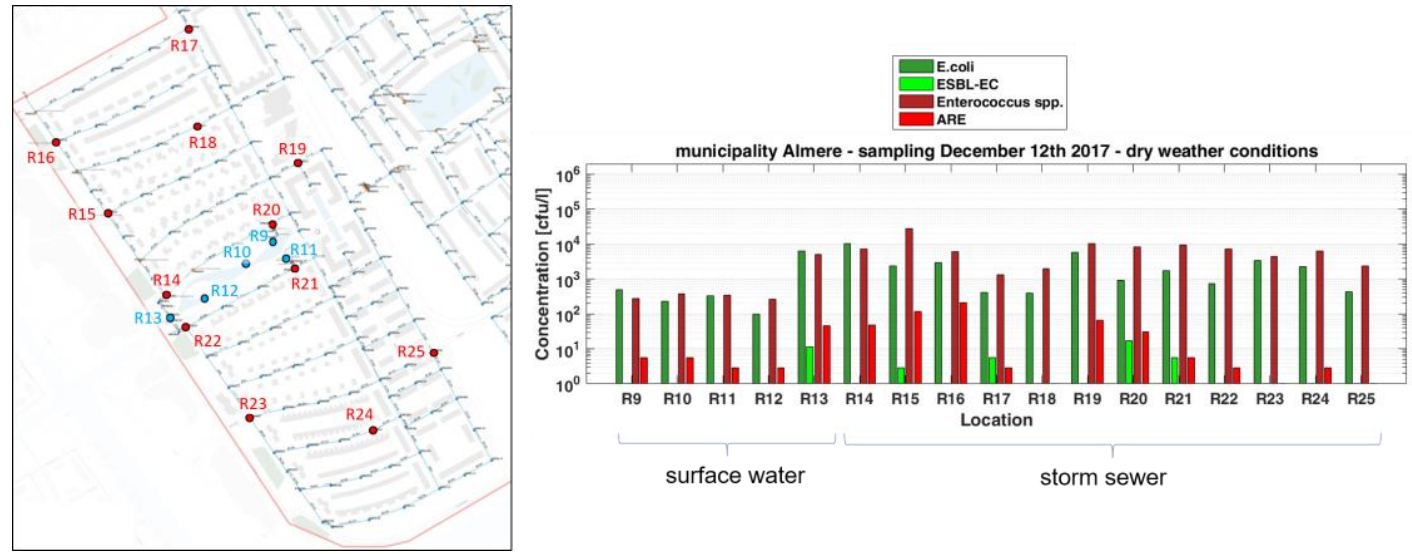

Figure 3. Sampling locations (left) and sampling results (right) for random sampling of E. coli, ESBL-EC, Enterococcus spp. and ARE in surface water (blue locations) and storm sewer (red locations) in Regenboogbuurt in Almere, December 2017.

\section{CONCLUSIONS - OUTLOOK}

The remainder of this study (searching for and repairing illicit connections and repeated sampling) is to be executed in April-June 2018. Results will be presented in the full paper.

\section{References}

Blaak, H., Schmitt, H., Schilperoort, R., Langeveld, J. and Palsma, B. (2017). Antibiotic Resistant Bacteria in Urban Surface Water and the Role of Misconnections. Water Matters, 2 (2017) via www.h2o-wattermatters.com.

Cantón, R., Novais, A., Valverde, A., Machado, E., Peixe, L., Baquero, F. and Coque, T.M. (2008). Prevalence and spread of extended-spectrum $\beta$-lactamase-producing Enterobacteriaceae in Europe. Clin. Microbiol. Infect. 14(Suppl. 1), 144-153.

Huijbers, P., de Kraker, M., Graat, E.A., van Hoek, A.H., van Santen, M.G., de Jong, M.C., van Duijkeren, E. and de Greeff, S.C. (2013). Prevalence of extended-spectrum $\beta$-lactamase-producing Enterobacteriaceae in humans living in municipalities with high and low broiler density. Clin. Microbiol. Infect. 19(6):E256-259.

Nienhuis, J., De Haan, C., Langeveld, J., Klootwijk, M., \& Clemens, F. (2013). Assessment of detection limits of fiber-optic distributed temperature sensing for detection of illicit connections. Water Science and Technology, $67(12), 2712-2718$.

Schilperoort, R., de Haan, C. and Langeveld, J. (2011). Opsporen en classificeren van foutaansluitingen (in Dutch: Detection and classification of illicit connections). Vakblad Riolering 18(dec2011), 14-15.

STOWA (2018). Rol van humaan afvalwater en dierlijke bronnen bij verspreiding van antibioticaresistentie (in Dutch: The role of human wastewater and animal sources in the spread of antibiotic resistance). Report 2018-11, STOWA, Amersfoort, the Netherlands. 


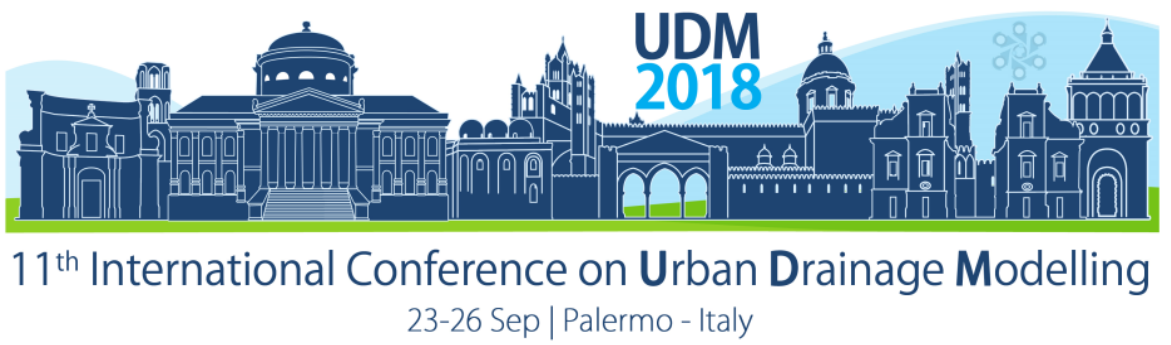

\title{
Evaluation of hydrogen sulphide formation in a mega-sized tunnel sewer system: experimental and modelling Investigations
}

\author{
Zhengsheng Liang ${ }^{1,2}$, Jianliang Sun', Feng Jiang ${ }^{1 *}$ \\ ${ }^{1}$ School of Chemistry \& Environment, South China Normal University, Guangzhou, China; \\ ${ }^{2}$ Guangzhou HKUST Fok Ying Tung Research Institute, Guangzhou, China; \\ ${ }^{*}$ Corresponding Author. E-mail: jiangfeng@m.scnu.edu.cn
}

\begin{abstract}
The sulphide formation in the mega-sized deep tunnel sewer systems which have a number of inlets are largely unknown. Taking a real Sewage Conveyance System (SCS) with 23.6 km-long and 130 m-deep tunnels in Hong Kong as a representative example, this study conducted experimental and modelling investigations to evaluate the sulphide formation in the SCS, with the consideration of the dynamics in the sewage flow and characteristics. In the field investigation, the remarkable variations in the concentrations of dissolved sulphide at the seven inlets and the outlet of the SCS were observed, due to the dynamic sewage flow and characteristics from the inlets. The overall sulphide production rate in the SCS was up to $1400 \mathrm{~kg} \mathrm{~S} / \mathrm{d}$. The results of the simulation using a sewer process mathematical model demonstrated that the profiles of dissolved sulphide concentrations in the SCS with multiple inlets were much different from those in the single-pipe sewer. For example, the maximum sulphide concentration was observed in a upstream tunnel rather than in downstream. Two tunnels with long HRTs and large flowrates contributed $89 \%$ of the total sulphide production in the SCS. This study reveals that sulphide was massively produced in the mega-sized tunnel sewer system, and the sewer process model can help get insight to the sulphide formation in tunnels, which will significantly benefit the development of measures and strategies of hydrogen sulphide control in sewer networks.
\end{abstract}

Keywords: Deep tunnel sewer systems; hydrogen sulphide; sewer modelling; sewer management

\section{INTRODUCTION}

Mega-sized deep tunnel sewer networks are usually used in large cities for stormwater and wastewater conveyance. However, during the long-distance and long-time transportation, hydrogen sulphide $\left(\mathrm{H}_{2} \mathrm{~S}\right)$ could be extensively formed in sewers and results in odour and corrosion problems. Moreover, the mega-sized deep tunnel sewer networks, which have a number of inlets, resulting in the substantial dynamics in the sewage flow and characteristics in different pipelines of the networks, is far more complex than single sewer pipelines (Hvitved-Jacobsen et al., 2013). Accurate and reliable evaluation of hydrogen sulphide formation and emissions, is difficult in such sewer systems. To develop optimal strategy for sulphide migration in mega-sized sewer systems, evaluation of sulphide formation and identification of the key influencing factors are essential for the sewer management.

Mathematical modelling is a useful and low-cost strategy to evaluate the hydrogen sulphide formation in sewers. Few models, such as InfoSWMM, WATS and SEWERX, have been developed and successfully applied to predict the sulphide formation in the single sewer pipelines and systems (Huisman and Gujer, 2002; Hvitved-Jacobsen, 2002; Sharma et al., 2008). However, the models aforementioned are based on the assumption of static sewer biofilm, and ignore the dynamics of sewer biofilms induced by the variations in the sewage flowrate and properties. They may not be applied to simulate the mega-sized sewer networks with multiple sewage inlets. Our previous study has developed a sewer biofilm model, which can well describe the dynamics in the sewer biofilm properties and sulphide formation (Jiang 


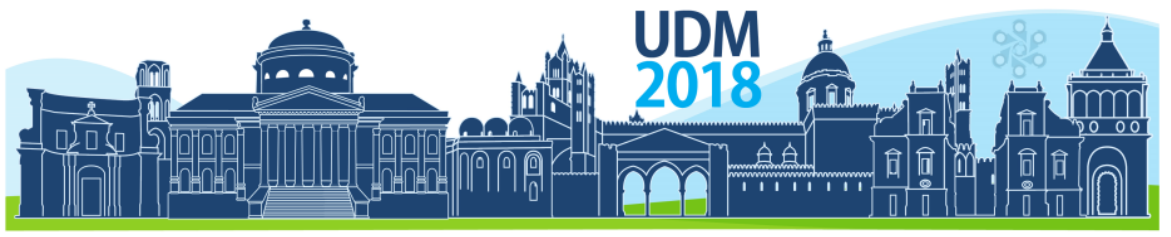

$11^{\text {th }}$ International Conference on Urban Drainage Modelling

23-26 Sep | Palermo - Italy

et al., 2009). The sewer process mathematical model (SPMM), which integrates the sewer biofilm model, the bulk sewage quality model and the gas emission model, is expected to be a reliable tool to predict the sulphide formation in mega-sized sewer networks.

Therefore, taking the Sewage Conveyance System (SCS) that consists of $23.3 \mathrm{~km}$-long and 130 m-deep tunnel systems in Hong Kong as an example, we conducted field experimental investigation and mathematical modelling works to evaluate the sulphide formation in the complex and dynamic mega-sized sewer networks.

\section{MATERIALS AND METHODS}

\subsection{Tunnel sewer system and field investigation}

The SCS collects and conveys about 1.14 million $\mathrm{m}^{3}$ of sewage per day from seven preliminary treatment works (including Chai Wan PTW (CW), Shau Kei Wan PTW (SKW), Tseung Kwan O PTW (TKO), Kwun Tong PTW (KT), To Kwa Wan PTW (TKW), Tsing Yi PTW (TY) and Kwai Chung PTW (KC)) on both sides of Victoria Harbour to the Stonecutters Island Sewage Treatment Works (SCISTW) (Figure 1). The system consists of 23.6-km interconnected sewage tunnels buried 70-160 $\mathrm{m}$ below the ground, including one pressurized-flow tunnel and six reverse-siphon-flow tunnels, with 1.2-3.5 $\mathrm{m}$ in diameter. The daily flowrates in the seven tunnels ranged from 58000 to $850000 \mathrm{~m}^{3} / \mathrm{d}$ and the maximum hydraulic retention time (HRT) was $4.1 \mathrm{~h}$.

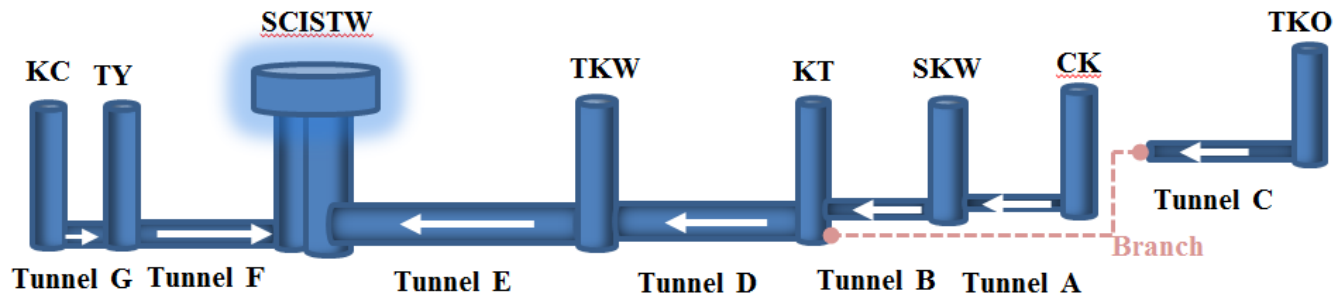

Figure 1. The schematic presentation of the SCS.

Seven-day field investigation was conducted in two stages (October 4-7 and October 4-11, 2015 , respectively). Sewage samples were collected every two hours at the seven inlets and the outlet of the SCS and subjected to the measurements of $\mathrm{SO}_{4}{ }^{2-}, \mathrm{S}^{2-}, \mathrm{SCOD}, \mathrm{TSS}$ and $\mathrm{pH}$.

\subsection{Modelling investigation}

A sewer process mathematical model, which developed from the sewer biofilm model (Jiang et al. 2009), was used to simulate the hydrogen sulphide formation and emissions in the mega-sized tunnel sewer networks using MatLab 2014 (Mathworks Inc., USA). The sewer process model has been tested and validated in real sewers in Hong Kong (unpublished data). Thus, after the sensitivity analysis, only three parameters, including maximum growth rate constant of SRB, oxygen inhibition constant for SRB and sulphide oxidation rate constant, were determined as the key parameters and calibrated in this study. The model calibration and validation were conducted using the data obtained in the Stages 1 and 2 of the field investigation, respectively. The model was used to reveal the dynamics in the sulphide formation in the SCS.

\section{RESULTS AND DISCUSSION}




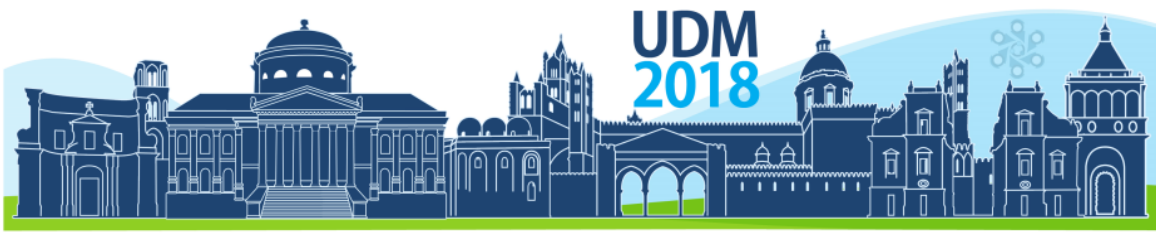

$11^{\text {th }}$ International Conference on Urban Drainage Modelling

23-26 Sep | Palermo - Italy

\subsection{Field investigation}

The results of the field investigation show that the concentrations of dissolved sulphide in the sewage at the seven inlets and the outlet of the SCS fluctuated significantly between 0 and $4.0 \mathrm{mg} / \mathrm{L}$ within $72 \mathrm{~h}$ (Figure $2 \mathrm{~A}$ ). The observed remarkable fluctuations in the sulphide formation in the SCS was due to the dynamics in the sewage flow and characteristics from the seven inlets. The average sulphide concentrations at the seven inlets were $0.2-1.6 \mathrm{mg} / \mathrm{L}$, and it was $1.82 \mathrm{mg} / \mathrm{L}$ at the outlet. On daily average basis, the corresponding sulphide inputs and output of the SCS were calculated and are shown in Figure 2B. The two major initial sulphide inputs were KTO PTW (228 kg S/d) and KT PTW (191 kg S/d), and the total sulphide output was up to $2089 \mathrm{~kg} \mathrm{~S} / \mathrm{d}$, giving a net sulphide production rate of $1410 \mathrm{~kg} \mathrm{~S} / \mathrm{d}$.

The findings of the field investigation demonstrate that substantial amounts of sulphide were generated during the sewage transportation in the SCS. However, the specific profiles of sulphide generation in each tunnel cannot be obtained from the field investigation, because sewage sampling inside the deep tunnels is impossible. Therefore, modelling evaluation is necessary to reveal the dynamics and profiles of sulphide formation in such a mega-sized sewer system with multiple inlets.
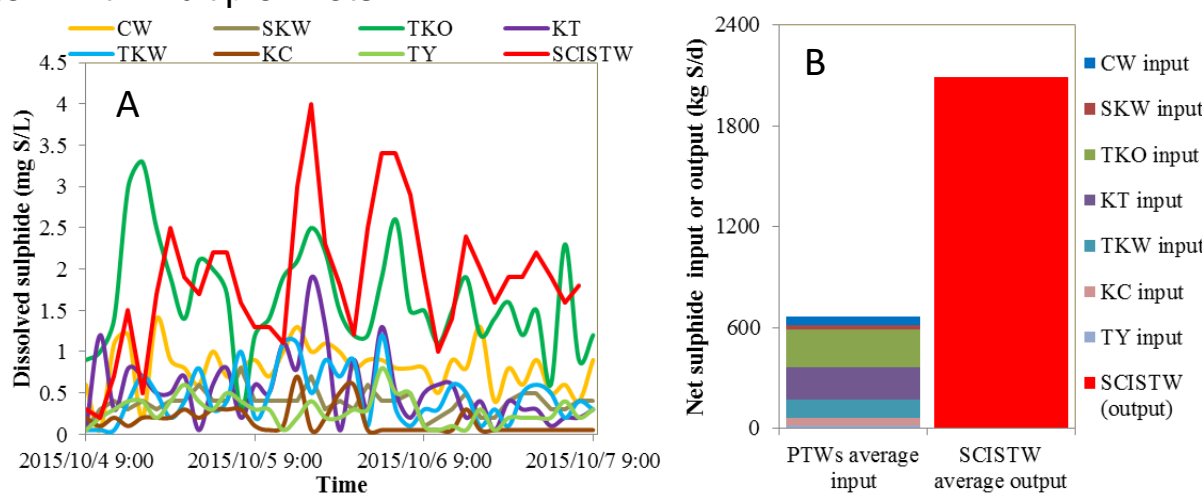

Figure 2. (A) The dissolved sulphide concentrations in the sewage at inlets and outlet of the SCS. (B) The daily sulphide inputs and outputs of the SCS.

\subsection{Model calibration and validation}

Figure 3A shows that the flow rates predicted by the SPMM without parameter adjustment can well reflect the measured flow rates at the outlet of the SCS, which were obtained in Stage 1 and 2 of the field investigation, which confirmed the validity of the SPMM.

After calibration, the sewer process model can well predict the sulphide transformation in the SCS. Figure 3B shows that the simulation results of the calibrated model agreed with the measured concentrations of dissolved sulphide at the outlet of the system in Stage 1 of the field investigation. With the data obtained in Stage 2 of the field investigation, the calibrated model was also able to well describe the dynamics in the dissolved sulphide concentrations except two extraordinary points, demonstrating the validity of the SPMM in predicting the dynamics in the sulfide formation in the SCS with multiple sewage inlets. 


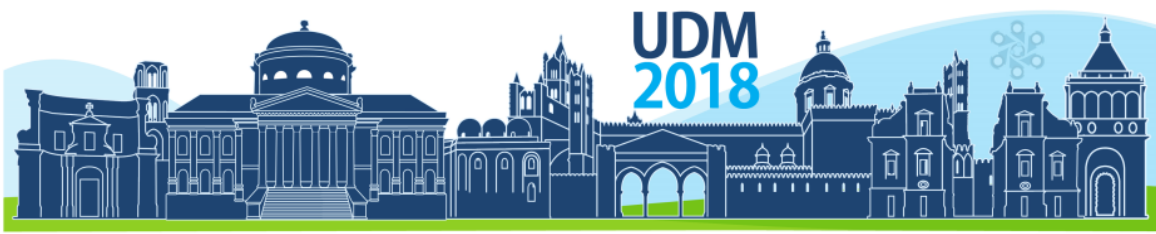

$11^{\text {th }}$ International Conference on Urban Drainage Modelling

23-26 Sep | Palermo - Italy
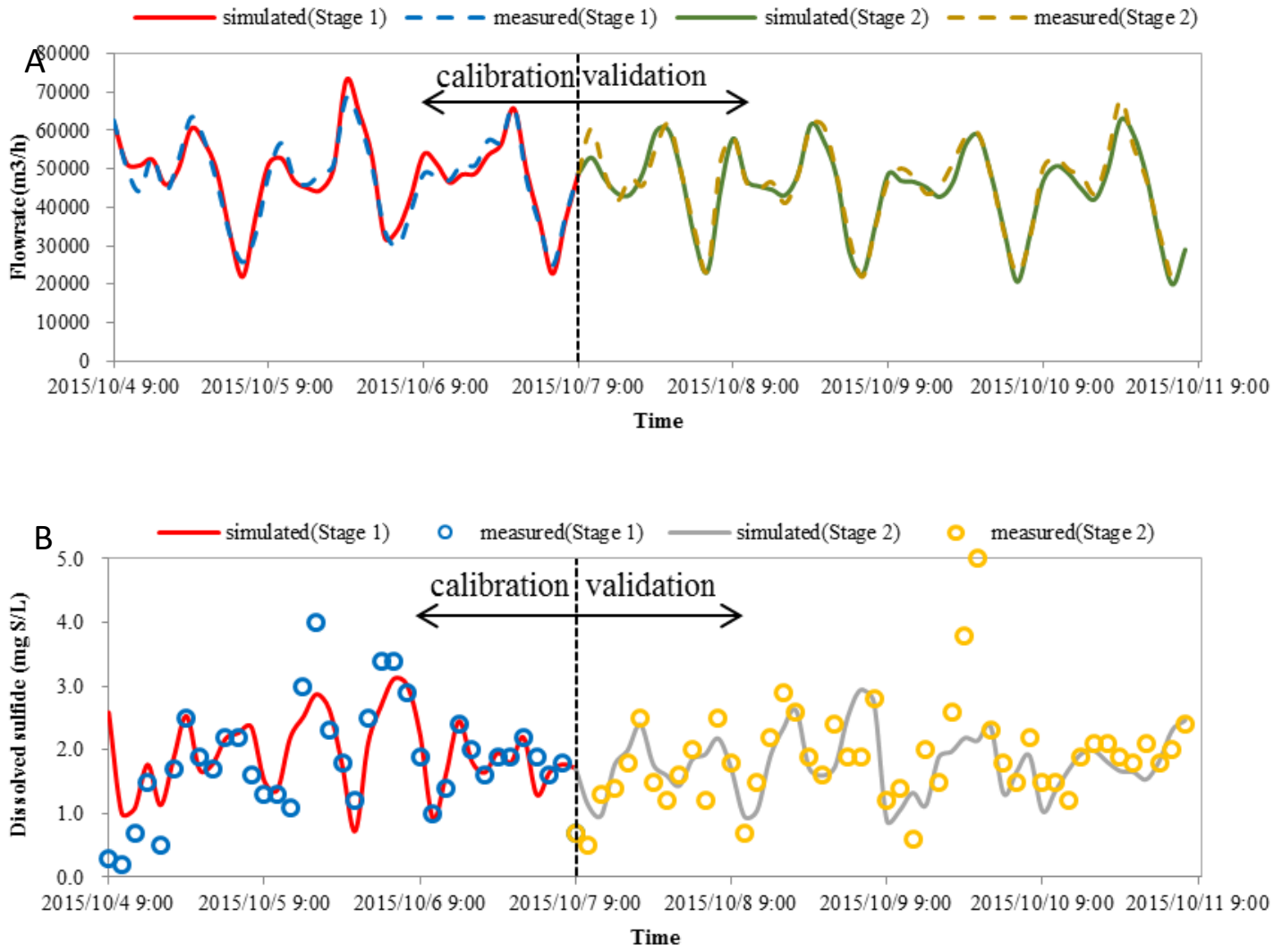

Figure 3. The sewage flow rates $(A)$ and the concentrations of dissolved sulphide (B) measured at the outlet of the SCS (SCISTW) and simulated by the SPMM model.

\subsection{Model-based evaluation of sulphide formation in SCS}

The calibrated and validated SPMM model was used to simulate the profiles of sulphide formation in the individual tunnels of the SCS. The concentration profiles of dissolved sulphide inside the seven tunnels of the SCS are shown in Figure 4A. Unlike the single-pipe sewer, in which the dissolved sulphide concentrations increased gradually and the maximum sulphide concentrations were often found at the outlets(Sharma et al., 2008), the seven sewage inlets resulted in the diverse profiles in the seven tunnels of the SCS, and the maximum sulphide concentration (about $3 \mathrm{mg} / \mathrm{L}$ ) was observed in the upstream tunnel (Tunnel C).

Interestingly, the changes in the concentrations of dissolved sulphide in each tunnel of the SCS exhibited similar trends, with obvious decreases within the first few hundred meters followed by gradual rebounds to the peaked values at the end points (Figure 4A). The decreases in the front segments of tunnels can due to the dilution by the upstream sewage from the inlets and also the oxidation of pre-existing sulphide in the upstream sewage. Dissolved oxygen can be introduced by the inlets at the entrances, where the waterfalls reoxygenate the sewage. After the complete consumption of dissolved oxygen by the sulphide oxidation and heterotrophic biochemical processes, the anaerobic conditions were re- 


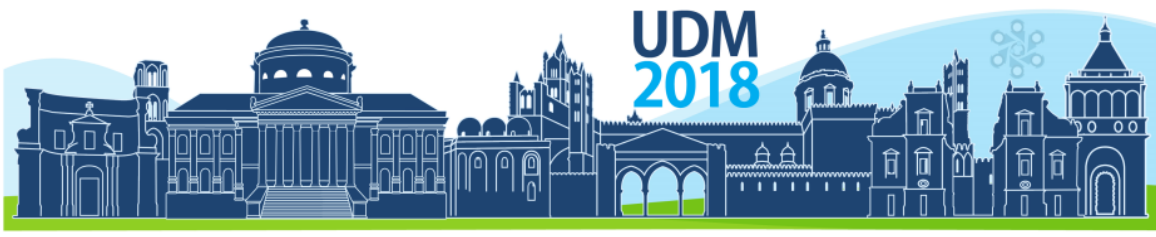

$11^{\text {th }}$ International Conference on Urban Drainage Modelling

23-26 Sep | Palermo - Italy

developed and the sulphide formation by SRB increased the dissolved sulphide concentrations in the middle-end segments of tunnels.

The specific net sulphide production rates in the seven tunnels of the SCS were also calculated using the SPMM. As shown in Figure 4B, Tunnel $E$ had the highest sulphide production rate $(43.35 \mathrm{~kg} \mathrm{~S} / \mathrm{h})$, followed Tunnel $\mathrm{F}(17.49 \mathrm{~kg} \mathrm{~S} / \mathrm{h})$, and they together contributed $89 \%$ of the total sulphide production in the SCS. The high sulphide production the two tunnels can be attributed to the long HRTs $(1.5$ and $1.3 \mathrm{~h})$ and large flow rates $(8.5$ and $2.9 \times 10^{5} \mathrm{~m}^{3} / \mathrm{d}$ ). The net sulphide loss was found in the Tunnel $\mathrm{G}$, because that the HRT was too short $(0.3 \mathrm{~h})$ and DO introduced by the inlet (KC PTW) was not complete depleted.
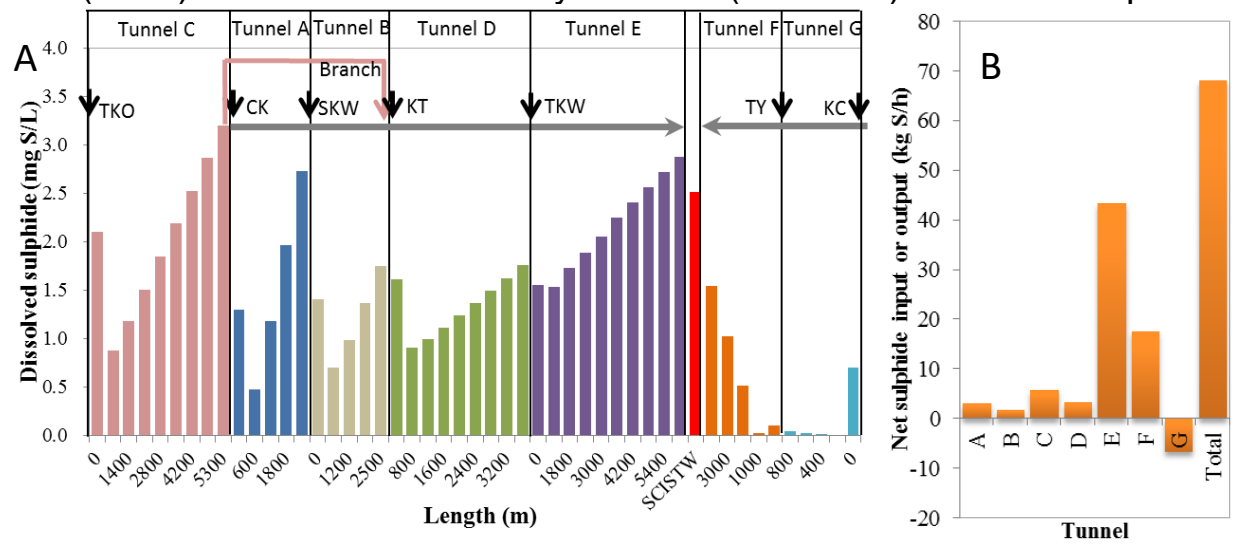

Figure 4. (A) The predicted profiles dissolved sulphide concentrations in different tunnels of the CSC. (B) The predicted sulphide production in the seven tunnels of the SCS.

\section{CONCLUSIONS}

By integrating the field experimental and modelling investigations, this study demonstrates that a large amount of sulphide is generated in the SCS, with a daily sulphide production rate of $1410 \mathrm{~kg} \mathrm{~S} / \mathrm{d}$, which can cause a number of problems, such as sewer corrosion, odour nuisance, secondary air pollution and health hazards to sewer workers. Though the Drainage Service Department of Hong Kong has implemented odour mitigation measures in SCISTW, more effective in-sewer control of sulphide formation in the SCS is necessary. The SPMM provided insight of sulphide formation in the tunnels of the SCS, which allows us to find out the key factors and develop the measures and strategies for hydrogen sulphide control in a mega-sized deep tunnel sewer system.

\section{References}

Huisman, J. and Gujer, W. (2002) Modelling wastewater transformation in sewers based on ASM3. Water Science \& Technology 45(6), 51-60.

Hvitved-Jacobsen, T. (2002) Sewer processes: microbial and chemical process engineering of sewer networks, CRC.

Sharma, K.R., Yuan, Z., de Haas, D., Hamilton, G., Corrie, S. and Keller, J. (2008) Dynamics and dynamic modelling of H2S production in sewer systems. Water research 42(10-11), 2527-2538.

Jiang, F., Leung, D.H.-w., Li, S., Chen, G.-H., Okabe, S. and van Loosdrecht, M.C.M. (2009) A biofilm model for prediction of pollutant transformation in sewers. water research 43(13), 3187-3198.

Hvitved-Jacobsen, T., Vollertsen, J. and Nielsen, A.H. (2013) Sewer processes: microbial and chemical process engineering of sewer networks, CRC press. 


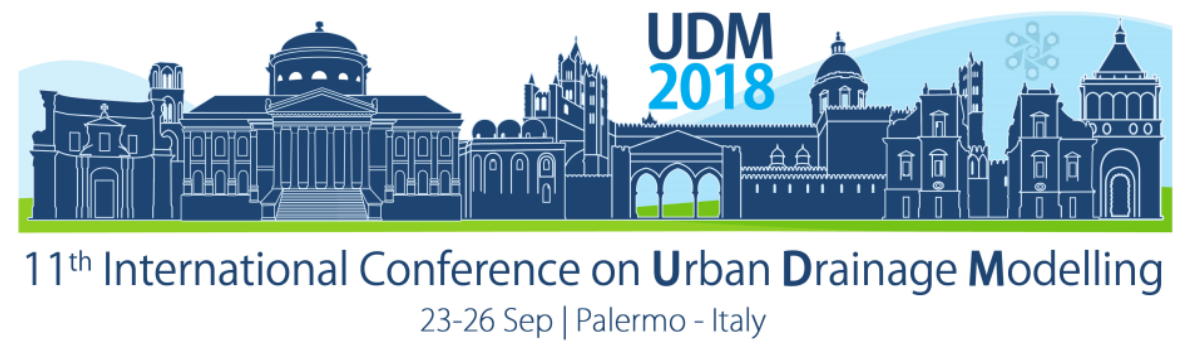

\title{
A Dynamic Pharmaceuticals Loads Source Generator
}

\author{
Tanguy Pouzol ${ }^{1}$, Yves Lévi ${ }^{2}$, Jean-Luc Bertrand-Krajewski ${ }^{1}$ \\ ${ }^{1}$ Univ. Lyon, INSA Lyon, DEEP, EA 7429, F-69621 Villeurbanne cedex, France \\ 2 Univ. Paris Sud, Faculté de Pharmacie, UMR 8079 CNRS-AgroParisTech, 92290 Chatenay-Malabry, France
}

\begin{abstract}
As pharmaceuticals and metabolites are assumed to reach the environment after human consumption and excretion, it is important to model their discharge in wastewater. Due to the difficulty to collect detailed data on pharmaceuticals sales and the diversity of processes influencing the fate of pharmaceuticals, modelling pharmaceutical fate is difficult and models in the literature struggle to accurately and reliably predict pharmaceuticals loads. In such a context, a new stochastic model is proposed. Pharmaceuticals loads in wastewater are predicted by modelling the discharge from sick persons in a catchment at a minute time step. Posology, time-use, metabolism and excretions are generated using different distributions. The model is tested for 9 molecules on an urban catchment (16 000 inhabitants), using monthly sales data. $24 \mathrm{~h}$ average samples and 24 consecutives $1 \mathrm{~h}$ average samples campaigns are used to assess the model performance. Results show that the model can predict with reasonable accuracy and reliability daily and hourly loads for an urban catchment.
\end{abstract}

Keywords: Stochastic modelling; Individual behaviour; Pharmaceuticals sales

\section{INTRODUCTION}

Pharmaceuticals in the environment are an important field of study and a great concern in terms of environmental and public health risks. Their modelling is paramount to fully understand their fate. However monitoring pharmaceuticals with analytical chemistry is difficult and costly. A significant part of pharmaceuticals reach the environment through human consumption and excretion (Heberer, 2002; Qian et al., 2015) and pharmaceuticals fate models almost always include a source model in which loads discharged into wastewater are proportional to sales data (Kümmerer et al., 1997; Heberer and Feldmann, 2005; Singer et al., 2016). The results of such models are difficult to interpret since, from one molecule to another and from one study to another, pharmaceuticals loads may be greatly over- or under- estimated (de Garcia et al., 2013). However, they are widely used because they are quick and easy to use and do not require detailed data, compared to other more elaborated models (e.g. Coutu et al., 2016). In this context, we propose and assess a new pharmaceuticals fate stochastic model in wastewater based on detailed pharmaceutical sales data and monitoring campaigns.

\section{MATERIALS AND METHODS}

\subsection{Experimental site and data}

The model is tested on the Bellecombe wastewater treatment plant (WWTP) (France) collecting effluents from 16000 inhabitants through $230 \mathrm{~km}$ of sewers which were previously modelled (Pouzol et al., 2015). Census data indicate that 14500 inhabitants are active people and that only 7000 jobs exist on the catchment; then other active people work out of the catchment during the day. Monthly pharmaceuticals sales over 2.5 years were collected. Nine molecules were monitored with state-of-the-art sampling strategy, method (materials and 


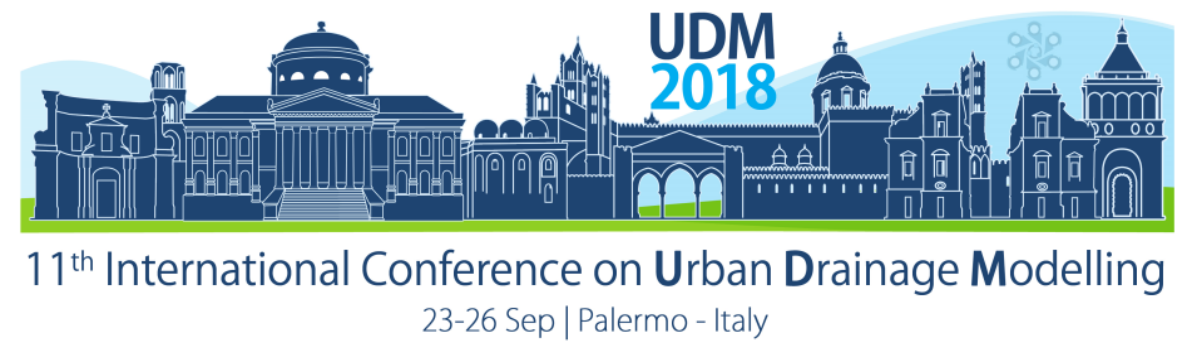

handling) and analyses (LC-MS/MS). Twenty $24 \mathrm{~h}$ average samples and four 24 consecutives $1 \mathrm{~h}$ average samples campaigns were performed between 2012 and 2016.

\subsection{Model}

The successive processes leading to the discharge of pharmaceuticals in sewers are stochastic by nature. The model thus aims generating discharges of sick persons over the catchment, who can be either inhabitants or outside persons who work in the catchment. Their number is determined by $i)$ the total mass $M$ of pharmaceuticals consumed in one day that is randomly picked according to sales data and ii) the standard individual posology. For each sick person, the model follows 4 steps:

Posology. It is determined according to pharmaceutical data and websites and consists of time consumption pattern, number of intakes, mass for each intake and duration between intakes. The last three values are randomly picked from literature distributions. The time consumption pattern consists of generic descriptions, e.g. "Awake and not out from household" for presence or " $33 \%$ chance for each meal" for intakes time.

Time-Use. Periods of time when the person is asleep, out of household and eating are generated according to time-use survey data. These periods are weighted according to the time consumption pattern and then all intakes are randomly picked.

Metabolism. Pharmaceuticals intakes are transformed into a mass of pharmaceutical stored in the bladder over time, according to medical literature. Fractions of pharmaceuticals are transferred through three "boxes" (gastro-intestinal system, blood and bladder) at certain rates (exponential decay). All parameters are randomly picked from medical literature distributions (e.g. www.eurekasante.vidal.fr, https://pubchem.ncbi.nlm.nih.gov/).

Excretion. When persons excrete urine in toilets, pharmaceuticals stored in the bladder are discharged. The times of toilet uses are randomly picked using the time-use generated in step 2 (see Pouzol et al., 2015 for details). For local inhabitants, it is assumed that excretion during "out of household" times are made outside the catchment. Conversely, for outside persons working in the catchment, these excretions are the only ones considered.

\section{RESULTS AND DISCUSSION}

\subsection{Daily loads}

Measured and modelled daily loads are compared using the ratio average modelled over average measured daily loads $(\mathrm{R})$. The results of the model for one molecule are considered satisfactory whenever the ratio $R$ is between 0.5 and 2 . Also, the model is considered reliable if it has satisfactory results for every molecule.

Eight out of the nine molecules show satisfactory ratios $\mathrm{R}$ (average: 1.3 , min: 0.5 , max: 2.19 ). Ketoprofen is the only molecule with an unsatisfactory ratio $\mathrm{R}$. However, its metabolic parameters are not well defined (wide range of excretion) and it is not sold solely as oral forms (Ketoprofen: $17 \%$ dermal forms), as such the fraction directly discharged into the sewer is not well known and approximated by the model (from 25 to $75 \%$ ). This leads to an over-estimation of its daily loads. 


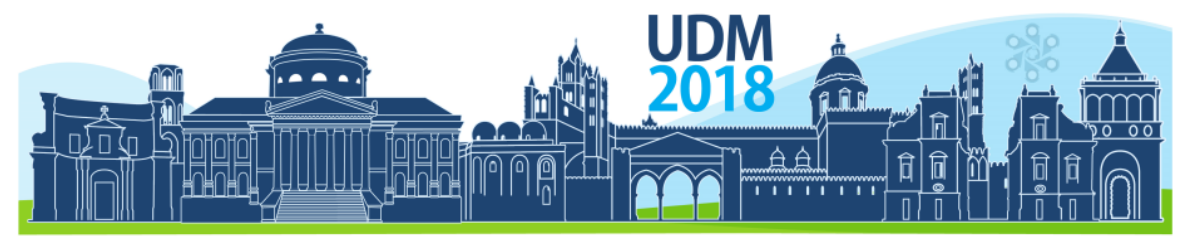

$11^{\text {th }}$ International Conference on Urban Drainage Modelling

23-26 Sep | Palermo - Italy

The ratios between the coefficients of variation of the modelled over the measured daily loads indicate that the model underestimates the dispersion of the daily loads (averagely 0.28 ). This seems to be mainly the result of the temporal scale used for the pharmaceutical sales. Indeed, daily sales derived from monthly data are understandably unable to represent daily sales and so daily consumption and loads in wastewater.

\subsection{Hourly loads}

Usually, measured and modelled hourly dynamics are compared using the Nash-Sutcliffe efficiency (NSE) indicator. However, as only 4 hourly loads campaigns are available, average normalized measured hourly loads time series are not sufficiently representative of the

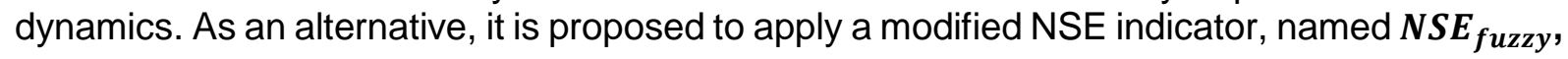
for each measured time series accounting for the distribution of all modelled time series. $\boldsymbol{N S} \boldsymbol{E}_{f u z z y}$ is calculated as follows and is interpreted like the usual NSE (satisfactory model performance if above 0.5):

$$
\begin{aligned}
& N S E_{\text {fuzzy }}=1-\frac{\sum_{t=1}^{T}\left(\tilde{L}_{\text {measured }}(t)-\tilde{L}_{\text {fuzzy }}(t)\right)^{2}}{\sum_{t=1}^{T}\left(\tilde{L}_{\text {measured }}(t)-\tilde{\tilde{L}}_{\text {measured }}\right)^{2}} \\
& \text { if } Q_{1}\left(\tilde{L}_{\text {modelled }}(t)\right) \leq \tilde{L}_{\text {measured }}(t) \text { then } \widetilde{L}_{\text {fuzzy }}(t)=Q_{1}\left(\tilde{L}_{\text {modelled }}(t)\right) \\
& \text { if } Q_{3}\left(\tilde{L}_{\text {modelled }}(t)\right) \leq \tilde{L}_{\text {measured }}(t) \text { then } \tilde{L}_{\text {fuzzy }}(t)=Q_{3}\left(\tilde{L}_{\text {modelled }}(t)\right) \\
& \text { else } \tilde{L}_{\text {fuzzy }}(t)=\tilde{L}_{\text {measured }}(t)
\end{aligned}
$$

With:

$t$ : time

$\tilde{L}_{\text {measured }}(t)$ : normalized measured pharmaceutical hourly load at time $t$

$\tilde{L}_{f u z z y}(t)$ : normalized modelled hourly load at time $t$ for $N S E_{f u z z}$

$\overline{\tilde{L}_{\text {measured }}}$ : average normalized measured hourly load at time $t$

$Q_{1}(X), Q_{3}(X)$ : first and third quartiles of a list of values $X$

$\tilde{L}_{\text {modelled }}(t)$ : distribution of the normalized modelled hourly loads at time $t$.

The model is considered reliable if it gives satisfactory results for every molecule.

Seven out of the nine molecules show satisfactory $N S E_{f u z z y}$ values (average: 0.5 , min: 0.18 , max: 0.72). Results for Ibuprofen are displayed in Figure 1. The low $N S E_{f u z z y}$ values for Atenolol (0.18) and Carbamazepine (0.19) can be explained by the combination of i) stochastic nature of pharmaceutical consumption and ii) low consumption levels (only a few patients per day for Carbamazepine in the entire catchment). More hourly campaigns would help to determine the average dynamics of hourly loads with more confidence. Assessing the model performance would then be less sensitive to random peaks in measured hourly loads which do reflect the average dynamics.

\section{CONCLUSIONS}

The proposed model is able to predict reliably both the daily and hourly loads of pharmaceuticals at the WWTP inlet with an acceptable accuracy considering the available data and the analytical uncertainties. Daily loads are either over or underestimated depending on 


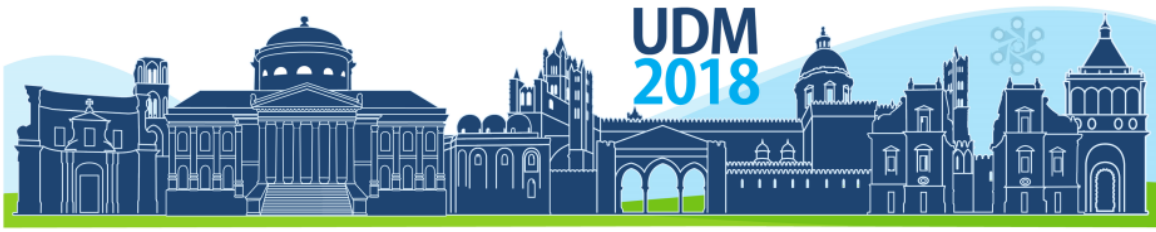

$11^{\text {th }}$ International Conference on Urban Drainage Modelling

23-26 Sep | Palermo - Italy

the molecule. The variability of the daily loads is under-estimated. Hourly loads are sensitive to random peaks due to the stochastic nature of the processes.

Future works should focus on: i) measuring more hourly loads in order to better determine the average dynamics of pharmaceuticals, ii) testing the model on other catchments and for more molecules and iii) simplifying the model structure in order to facilitate its implementation and use.

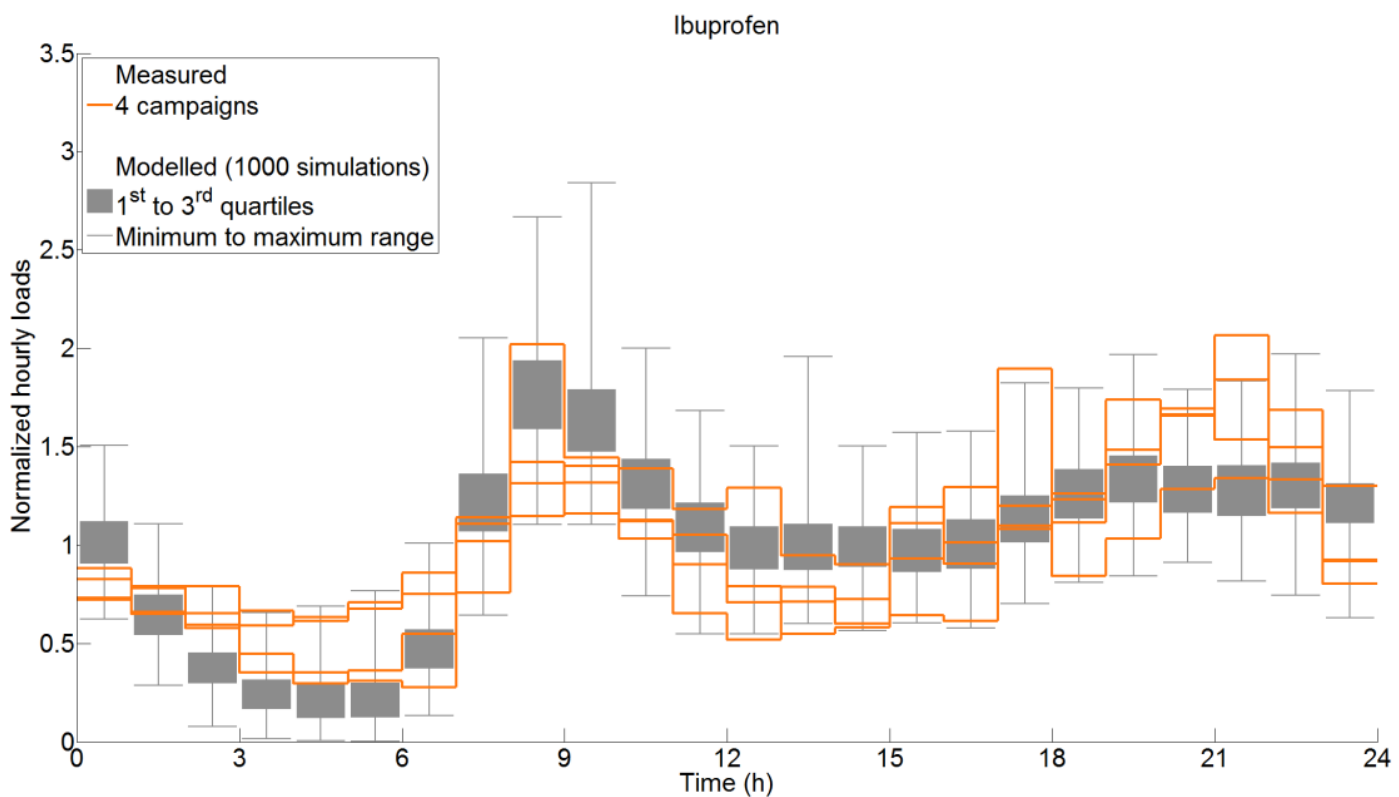

Figure 1. Comparison of the measured and modelled hourly loads.

\section{References}

Coutu S., Pouchon T., Queloz P., Vernaz N. (2016) Integrated stochastic modelling of pharmaceuticals in sewage networks. Stochastic Environmental Research and Risk Assessment, 30, 1087-1097.

de García S.O, Pinto G.P., Encina P.G., Mata R.I. (2013) Consumption and occurrence of pharmaceutical and personal care products in the aquatic environment in Spain. Science of the Total Environment, 444, 451-465.

Heberer T. (2002) Occurrence, fate, and removal of pharmaceutical residues in the aquatic environment: a review of recent research data. Toxicology Letters, 131, 5-17.

Heberer T., Feldmann D. (2005) Contribution of effluents from hospitals and private households to the total loads of diclofenac and carbamazepine in municipal sewage effluents - modelling versus measurements. Journal of Hazardous Materials, 122, 211-218.

Kümmerer K., Steger-Hartmann T., Meyer M. (1997) Biodegradability of the anti-tumour agent ifosfamide and its occurrence in hospital effluents and communal sewage. Water Research, 31, 2705-2710.

Qian S., Xuqi C., Shuguang L., Wentao Z., Zhaofu Q., Gang Y. (2015) Occurrence, sources and fate of pharmaceuticals and personal care products in the groundwater: A review. Emerging Contaminants, 1, 14-24.

Pouzol T., Bertrand-Krajewski J.-L., Lévi Y. (2015) Stochastic modelling of dry weather flow in an extensive sewer network using individual behaviour. $10^{\text {th }}$ International Urban Drainage Modelling conference, Canada.

Singer H. P., Wössner A E., McArdell C. S., Fenner K. (2016) Rapid Screening for Exposure to "Non-Target" Pharmaceuticals from Wastewater Effluents by Combining HRMS-Based Suspect Screening and Exposure Modeling. Environmental Science and Technology, 50, 6698-6707. 


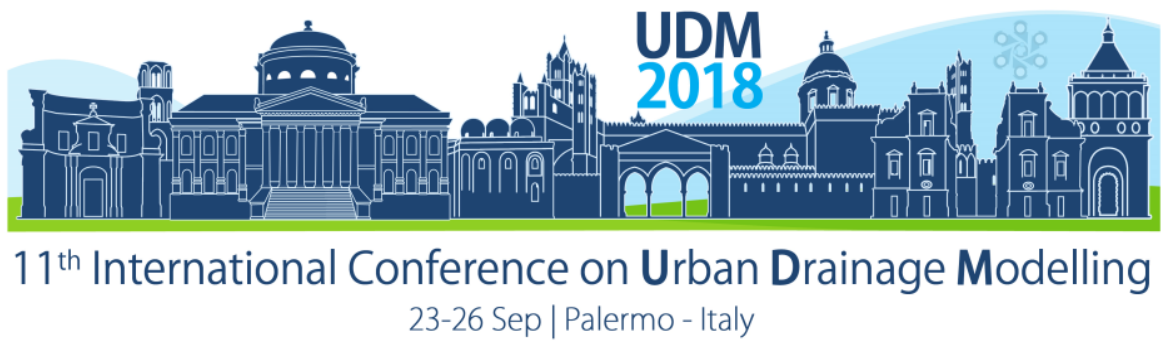

\title{
Developing and Validating a Model to Assess Sewer Sediment Issues from Changing Wastewater Inflows and Concentration
}

\author{
Madhu K Murali', 4, Matthew R Hipsey ${ }^{2,4}$, Anas Ghadouani', 4, and Zhiguo Yuan 3, 4 \\ ${ }^{1}$ The University of Western Australia, Department of Civil, Environmental and Mining Engineering, Perth, Australia \\ ${ }^{2}$ The University of Western Australia, School of Agriculture and Environment, Perth, Australia \\ ${ }^{3}$ The University of Queensland, Advanced Water Management Centre, Brisbane, Australia \\ ${ }^{4}$ Cooperative Research Centre for Water Sensitive Cities, Melbourne, Australia
}

\begin{abstract}
Sewers are critical for the maintenance of both public and environmental health in urban areas through their transport of wastewater for treatment. Despite significant costs associated with excess sewer solids deposition causing blockages and reduced hydraulic capacity, there are still gaps in our knowledge of sewer solids processes. This is particularly a concern with the implementation of Decentralised Water Recycling (DWR) and further reductions in per capita water consumption. This will reduce wastewater inflow to and increase the concentration of solids in sewers, leading to increased blockages and reduced hydraulic capacities in sewers. Sewer solids can be divided into two main groups based on their size: gross solids and sewer sediments. This paper details the development, initial calibration, and validation of a comprehensive sewer sediment transport model to assist in quantifying the impacts of changing wastewater inflows and concentration. This model aims to facilitate the transition to more sustainable cities by reducing the uncertainties in the implementation of sustainable water measures, such as DWR and water use reduction. OpenFOAM, an open-source computational fluid dynamics package, was used to develop the sewer sediment model. This model has components that model flow, suspended sediment transport, bedload transport, and deposited bed development. Model calibration, using a square hydraulic flume, shows model results for flow and sediment transport are promising. Model validation experiments in a pilot-scale sewer system show that reducing sewer inflows are going to be a concern for sewer solids, especially in non-ideal or ageing sewers.
\end{abstract}

Keywords: Sewers; Integrated Urban Water Management; Sewer Solids

\section{INTRODUCTION}

As cities move towards the sustainable management of their water resources, the implementation of measures to obtain local or "decentralized" sources of water, such as recycled wastewater and urban stormwater, and reduce per capita water usage is essential (OECD, 2013). These measures help replicate the natural water cycle in cities and reduce urban impacts on the surrounding environment, but they will likely reduce inflows to sewers and increase the concentration of the discharged wastewater (DeZellar and Maier, 1980) potentially leading to increased sewer blockages, overflows and corrosion (Marleni et al., 2012). Another concern is the introduction of treatment system concentrate or sludge from Decentralised Water Recycling (DWR) into sewers which will further increase wastewater concentration periodically. Modelling sewer solids effectively for several scenarios will assist in quantifying the impacts from reduced water use and the implementation of DWR on a wider scale.

Sewer solids is an all-encompassing term for any material transported in sewers besides 


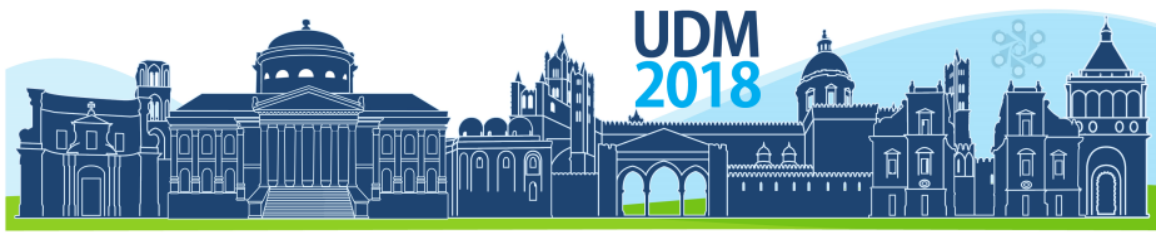

$11^{\text {th }}$ International Conference on Urban Drainage Modelling

23-26 Sep | Palermo - Italy

wastewater and stormwater liquids (Friedler et al., 1996), however, for ease of classification these can be divided into two categories: sewer sediments and gross solids. Gross solids have previously been defined as solids having dimensions greater than $6 \mathrm{~mm}$ in two directions and having a specific gravity close to 1 (Ashley et al., 2004). Sewer sediments on the other hand tend to be finer organic or inorganic particles; five types of sewer sediments (Types A, B, C, $D$, and $E$ ) based on their size, chemical composition, and deposition patterns have been proposed (Crabtree, 1989). Currently, sewer solids modelling, particularly in commercial software, has the capability to model sewer sediment transport processes effectively (Innovyze, 2014). However, the ability to model the development of the deposited bed and its sediment deposition/erosion processes may be lacking (Ashley et al., 2005, Banasiak et al., 2005). The ability to model gross solids transport is also often limited. This paper aims to outline the development and experimental validation of a comprehensive sewer sediment model. Such a model can be used to assess the impacts of different levels of DWR and water use reduction on sewer sediment processes in a local sewer. This model can also be simplified and implemented in an existing urban drainage model for use across wider scales.

\section{MATERIALS AND METHODS}

\subsection{Model Description}

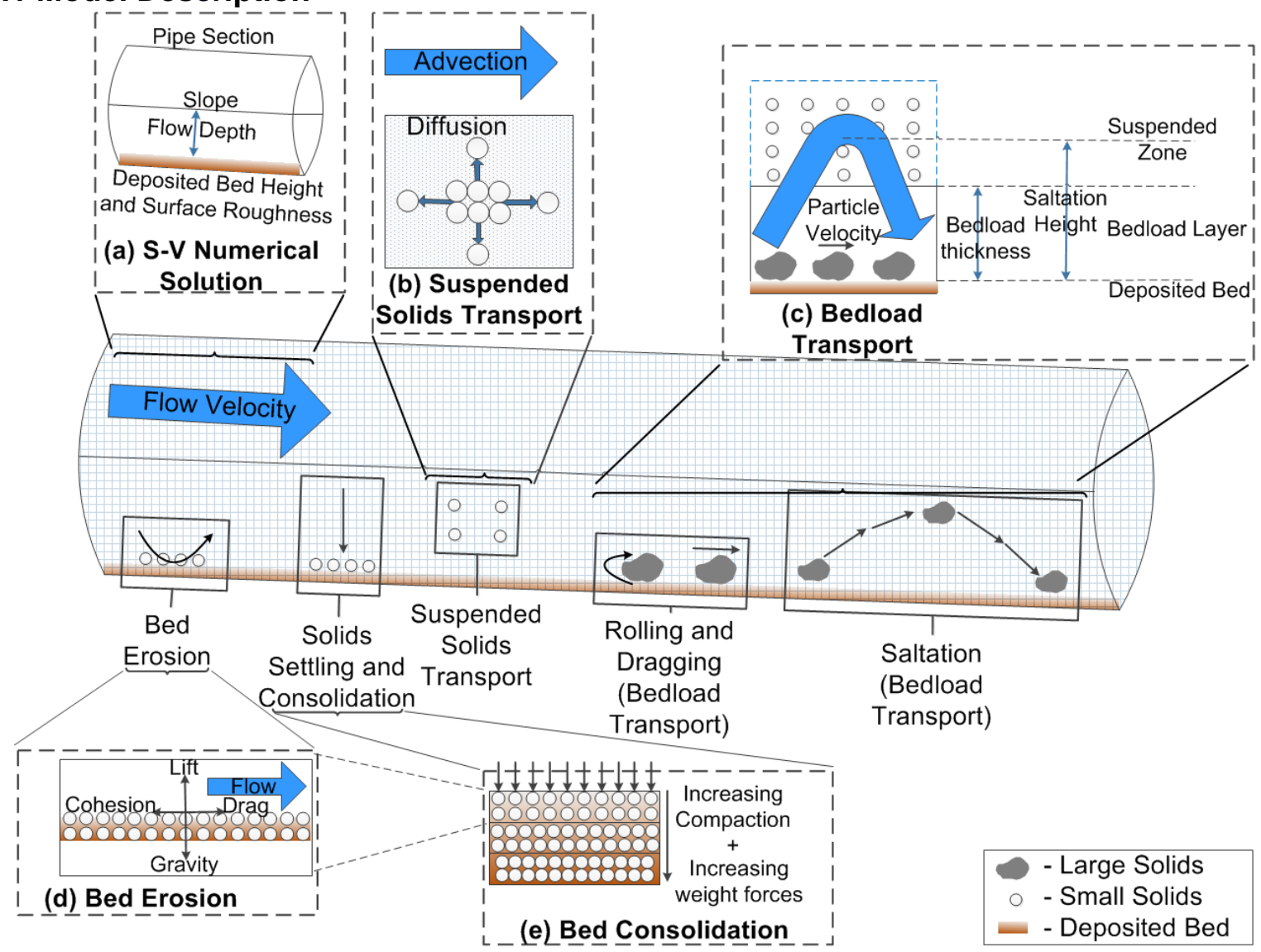

Figure 1. OpenFOAM sewer solids model with a summary of flow, solids transport and deposited bed processes. 


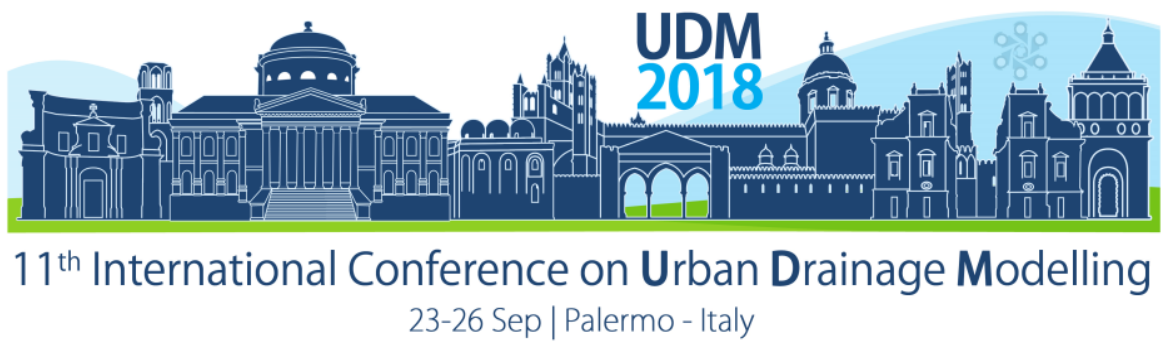

Modelling Platform and Flow. OpenFOAM, an open-source Computational Fluid Dynamics (CFD) package was used for model development. It has previously been used for modelling sediment transport applications in scour (Liu and Garcia, 2008) and surface water (Jacobsen and Fredsøe, 2014, Sattar et al., 2017) research. Flow in a partially-filled pipe or open channel is usually solved numerically using a subset of the Navier-Stokes equation, the Saint-Venant (S-V) equations (Butler and Davies, 2004).

Suspended Sediment Transport: An advection-diffusion type equation (a basic, onedimensional form in Equation 1) was used to model the concentration of sewer sediments that move in suspension with wastewater flow. Equation 1 was modified for use in three dimensions in OpenFOAM according to Jacobsen (2011).

$\frac{\partial C}{\partial t}=-u_{x} \frac{\partial C}{\partial x}+\frac{\partial}{\partial x}\left(\epsilon_{x} \frac{\partial C}{\partial x}\right)$

where, $C$ is the concentration of suspended sewer sediments, $u_{x}$ is the flow velocity and $\varepsilon_{x}$ is the diffusion coefficient.

Bedload Transport: The transport equation developed in Roulund et al. (2005) was used to model larger or denser sediment particles dragged or rolled along the bed as bedload (Equation 2).

$\mathrm{q}_{\mathrm{b}}=\frac{1}{6} \pi \mathrm{dp} \mathrm{p}_{\mathrm{ef}} \mathrm{u}_{\mathrm{b}}$

where $q_{b}$ is the bedload transport rate, $d$ is the mean sediment diameter, $p_{\text {ef }}$ is the probability of moving particles near the bed (calculated using the shear stresses and dynamic friction coefficient), and $u_{b}$ is the mean velocity of a bedload particle (calculated iteratively based on the forces on a bedload particle in motion).

Deposited Bed Height: The height of the deposited bed (h) was calculated using the Exner equation (Equation 3 ) before numerical filtering and smoothing to maintain equation stability (Jacobsen, 2011).

$\frac{\partial \mathrm{h}}{\partial \mathrm{t}}=-\frac{1}{1-\mathrm{e}_{\mathrm{d}}}\left[\nabla \cdot \mathrm{q}_{\mathrm{b}}+\mathrm{SS}_{\mathrm{E}}+\mathrm{SS} \mathrm{S}_{\mathrm{D}}\right]$

where $\nabla$ is the gradient operator, $e_{d}$ is the bed porosity, $S S_{E}$ is the erosion of suspended solids from the bed, and $S S_{D}$ is the deposition of suspended solids onto the bed. $S S_{E}$ and $S S_{D}$ are calculated based on sediment characteristics, applied shear stress and several other variables.

Bed Processes: The incorporation of other bed processes including sediment cohesion and consolidation, or self-weight compaction of the sediments in the bed, into the sediment model are also planned.

\subsection{Calibration and Validation Experiments}

Model Calibration. Flow velocity and sediment transport data was collected experimentally in a square hydraulic flume with a hydraulic jump using an Acoustic Doppler Velocimeter (ADV) and video camera, respectively. This data was then used to initially calibrate the flow and sediment models.

Model Validation. Two sections of a dual (control and experimental) $225 \mathrm{~mm}$ gravity sewer line were used to obtain data for validation experiments. These sections are part of a pilot-scale setup which consists of two $300 \mathrm{~m}$ long lines of gravity sewer with variable inflow of wastewater and Waste Activated Sludge (WAS) from a conventional activated sludge Wastewater 


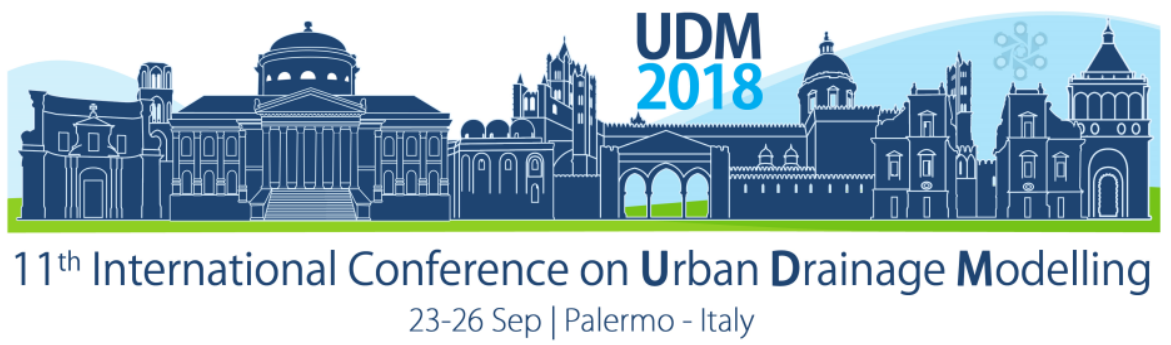

Treatment Plant (WWTP). Initially, scenarios to induce deposition were run by increasing wastewater solids concentration by adding WAS and reducing wastewater inflow to the lines; these were followed by high wastewater flow scenarios to erode the deposited solids (scenarios and results summarised in Table 1). Wastewater and WAS flowrates into the pilot plant were measured at regular intervals for all scenarios using flowmeters. Flow heights were also measured at the selected sewer sections for different flow rates to determine average flow velocity. Deposited bed height was measured before and after each scenario along with a reference photo.

\section{RESULTS AND DISCUSSION}

\subsection{Model Calibration}

Initial model benchmarking from experimental square channel and literature data showed a good fit between model and comparison results. The model can handle the complexities of the physical processes associated with modelling sewer solids.

\subsection{Model Validation}

The most clear result from the validation experiments (Table 1 ) is that the discharge of WAS had little to no impact on the deposited bed height in the pilot plant. There was no visible difference in the deposited bed in the control and experimental lines, even with the quantities of WAS added into the experimental line. However, a significant increase in bed height occurred in both lines with only a $10 \%$ reduction in flow leading to around a $200 \%$ increase in height. It is important to note that the sections measured represent a worst-case scenario, having non-design slopes after sagging issues in the pilot plant, and these increases are unlikely to occur in real-world conditions. These results seem to indicate that reducing sewer inflows is more of a concern for sewer solids deposition than the potential introduction of DWR treatment sludge. Modelling work is currently underway to verify this hypothesis.

Table 1. Pilot-scale validation experiment deposition scenarios and subsequent deposited bed height

\begin{tabular}{ccccccc}
\hline Scenario & $\begin{array}{c}\text { Wastewater } \\
\text { Flowrate } \\
(\mathrm{L} / \mathrm{min})\end{array}$ & $\begin{array}{c}\text { WAS Flowrate in } \\
\text { Experimental Line } \\
(\mathrm{L} / \mathrm{min})^{1}\end{array}$ & $\begin{array}{c}\text { Control Line } \\
\text { Intiial Avg. } \\
\text { Bed } \\
\text { Height } \\
\end{array}$ & $\begin{array}{c}\text { Final } \\
\text { Avg. Bed } \\
\text { Height } \\
(\mathrm{mm})\end{array}$ & $\begin{array}{c}\text { Avg. Bed } \\
\text { Height } \\
(\mathrm{mm})\end{array}$ & $\begin{array}{c}\text { Initial } \\
\text { Height } \\
(\mathrm{mm})\end{array}$ \\
\hline 1 & 200 & $12^{2}$ & 20 & 20 & 20 & 20 \\
2 & 200 & $12^{2}, 2.5^{3}$ & 20 & 20 & 20 & 20 \\
3 & 180 & $12^{2}, 2.5^{3}$ & 20 & 40 & 20 & 40
\end{tabular}

${ }^{1}$ No WAS was introduced to the Control Line.

${ }^{2}$ Intermittent flowrate where the pump was operational for $10 \mathrm{mins} /$ hour during the scenario period.

${ }^{3}$ Continuous flowrate where an additional pump was used continuously during the scenario period. 


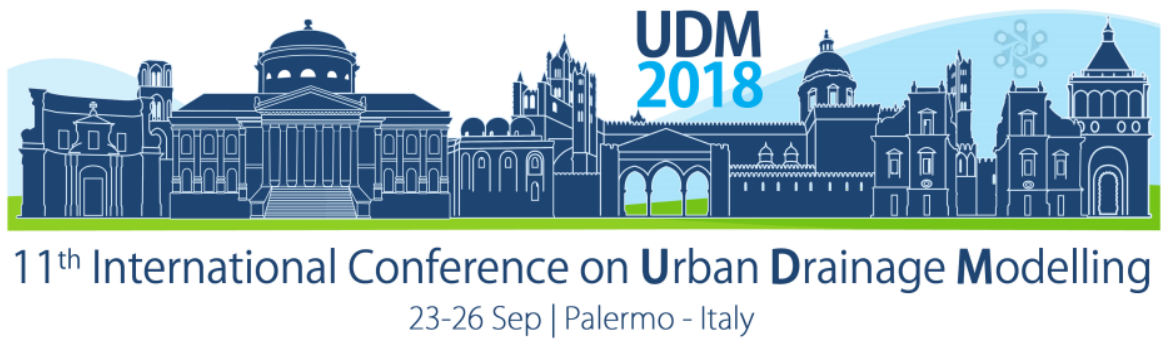

\subsection{Limitations}

Limitations. The main limitation in the validation experiments was the measurement of the deposited height. It was difficult to measure the bed accurately due to access issues and without disturbing the bed. Additionally, the erosion scenarios were not effective as the wastewater inflows to the pilot plant were not sufficiently high to generate critical flow velocities for erosion.

\section{CONCLUSIONS}

The impact of DWR measures and reduced per capita water use on sewer solids deposition can be significant. The significant costs associated with sewers make the quantification of such issues critical to ensure the transition to sustainable water systems. Results from this study indicate that reducing overall water use, which will lead to higher concentration wastewater, may have more of an impact on sewer sediment deposition than DWR sludge discharge to sewers.

\section{References}

ASHLEY, R., BERTRAND-KRAJEWSKI, J. L. \& HVITVED-JACOBSEN, T. 2005. Sewer solids-20 years of investigation. Water Sci Technol, 52, 73-84.

ASHLEY, R. M., BERTRAND-KRAJEWSKI, J. L., HVITVED-JACOBSEN, T. \& VERBANCK, M. A. 2004. Solids in Sewers: Characteristics, Effects and Control of Sewer Solids and Associated Pollutants, Cornwall, UK, IWA Publishing.

BANASIAK, R., VERHOEVEN, R., DE SUTTER, R. \& TAIT, S. 2005. The erosion behaviour of biologically active sewer sediment deposits: observations from a laboratory study. Water Res, 39, 5221-31.

BUTLER, D. \& DAVIES, J. W. 2004. Urban Drainage: Second Edition, London, Taylor and Francis.

CRABTREE, R. W. 1989. Sediments in Sewers. Water and Environment Journal, 3, 569-578.

DEZELLAR, J. T. \& MAIER, W. J. 1980. Effects of Water Conservation on Sanitary Sewers and Wastewater Treatment Plants. Journal (Water Pollution Control Federation), 52, 76-88.

FRIEDLER, E., BROWN, D. M. \& BUTLER, D. 1996. A study of WC derived sewer solids. Water Science and Technology, 33, 17.

INNOVYZE. 2014. 2D Suspended Sediment Modelling in Infoworks ICM [Online]. Available: http://blog.innovyze.com/2014/08/05/2d-suspended-sediment-modelling-in-infoworks-icm/ [Accessed 12th December 2015].

JACOBSEN, N. G. 2011. A Full Hydro- and Morphodynamic Description of Breaker Bar Development. PhD Thesis, DTU Mechanical Engineering.

JACOBSEN, N. G. \& FREDSØE, J. 2014. Formation and development of a breaker bar under regular waves. Part 2: Sediment transport and morphology. Coastal Engineering, 88, 55-68.

LIU, X. \& GARCIA, M. 2008. Three-Dimensional Numerical Model with Free Water Surface and Mesh Deformation for Local Sediment Scour. Journal of Waterway, Port, Coastal, and Ocean Engineering, 134, 203-217.

MARLENI, N., GRAY, S., SHARMA, A., BURN, S. \& MUTTIL, N. 2012. Impact of water source management practices in residential areas on sewer networks a review. Water Science and Technology, 65, 624.

OECD 2013. Water and Climate Change Adaptation, OECD Publishing.

ROULUND, A., SUMER, B. M., FREDSØE, J. \& MICHELSEN, J. 2005. Numerical and experimental investigation of flow and scour around a circular pile. Journal of Fluid Mechanics, 534, 351-401.

SATTAR, A. M. A., JASAK, H. \& SKURIC, V. 2017. Three dimensional modeling of free surface flow and sediment transport with bed deformation using automatic mesh motion. Environmental Modelling \& Software, 97, 303-317. 


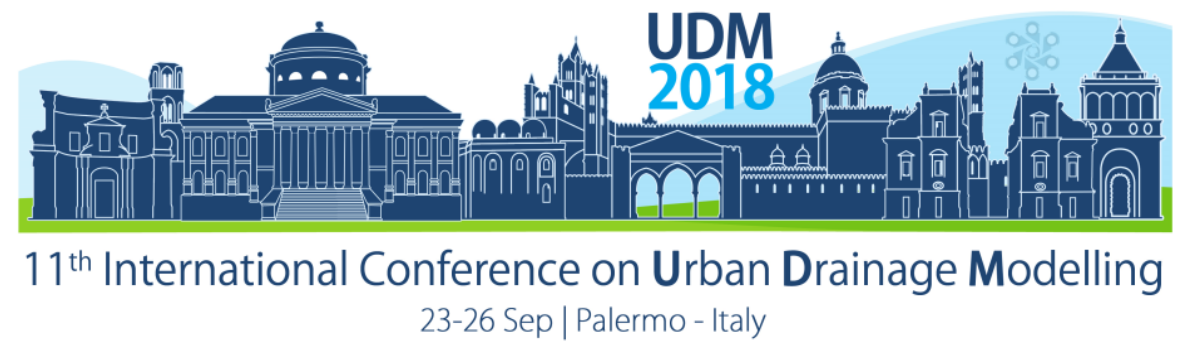

\title{
Using Mass-Volume-Curves to Assess the Empirical Pollutant Modelling Concept
}

\author{
Dominik Leutnant ${ }^{1}$, Dirk Muschalla ${ }^{2}$ and Mathias Uhl ${ }^{1}$ \\ ${ }^{1}$ Institute for Infrastructure, Water, Resources, Environment (IWARU), \\ Muenster University of Applied Sciences, Corrensstr. 25, Muenster 48149, Germany \\ ${ }^{2}$ Institute of Urban Water Management and Landscape Water Engineering, \\ Graz University of Technology, Stremayrgasse 10/l, 8010 Graz, Austria \\ (leutnant@fh-muenster.de; d.muschalla@tugraz.at; uhl@fh-muenster.de)
}

\begin{abstract}
Mass-Volume-Curves describe intra-event mass distribution and enable the analysis of the first-flush phenomenon. In the work presented, Mass-Volume-Curves of observed and simulated events from a small flat roof catchment are used to assess the goodness-of-fit of the exponential wash-off model of the stormwater management model SWMM. Model parameters for total suspended solids (TSS) build-up and wash-off were calibrated with different scenarios to respect the influence of different objective functions and parameter selection. For calibration based on a cumulative TSS event load distribution function, Kolmogorov-Smirnov and Anderson-Darling test statistics are used as objective functions. Furthermore, an event-based calibration approach using the Nash-Sutcliffe criterion was applied. Results from this comprehensive calibration study show that i) the exponential wash-off model generally underestimates observed TSS event loads and ii) the model error increases with higher TSS event loads. However, model calibration based on a cumulative TSS event load distribution function using the Kolmogorov Smirnov statistic yields to comparable results with regard to a conventional event-based approach. The MVCurve analysis indicate that the quality model concept is rarely capable to replicate intraevent characteristics.
\end{abstract}

Keywords: Exponential wash-off; SWMM; stormwater quality modelling; Mass-Volume-Curves

\section{INTRODUCTION}

Stormwater quality models are essential tools to support the implementation of cost-effective urban drainage strategies. However, available models only provide simplified model concepts to simulate the origin, accumulation and transport of pollutants (e.g. total suspended solids (TSS)) on urban surfaces which subsequently leads to uncertain model results (Sage et al. 2015). Modelling build-up and wash-off processes commonly employs exponential equations which provide parameters to be calibrated (Sartor et al. 1974, Egodawatta et al. 2007, Egodawatta et al. 2009). Because of their empirical origin, these concepts are not considered to be process-oriented. From a practical point of view however, there is great interest in their application, especially due to its simplicity. In particular, it is of interest whether these simplified concepts allow to realistically estimate TSS event loads and to generally approximate realistic intra-event characteristics.

\section{MATERIALS AND METHODS}

\subsection{Data}

Continuous stormwater quality runoff data comprising 65 storm events from a $50 \mathrm{~m}^{2}$ flat roof (bitumen sheeting) given in Leutnant et al. (2016) have been used for model calibration. The publication also provides grouped Mass-Volume-Curves (MV-Curves) which are used for model performance evaluation. Additionally, an approximated lognormal distribution function 


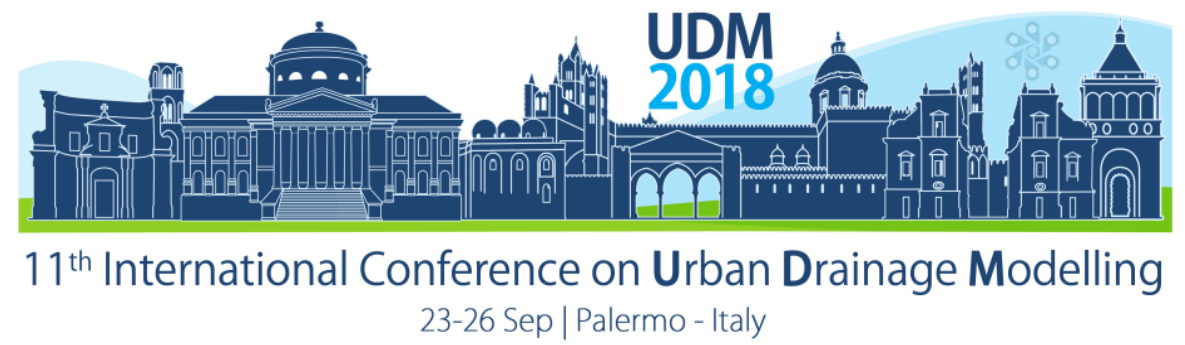

which statistically describe TSS event load distribution (Leutnant et al. 2018) from the experimental site is used as objective function.

\subsection{Modelling and calibration}

SWMM5 (Rossman 2010) is used to simulate stormwater runoff and quality processes. At first, runoff parameters were calibrated to subsequently enable the calibration of the exponential build-up and wash-off model parameters. In this study, model parameters to be calibrated are i) initial mass at simulation start, ii) max buildup at surface, iii) buildup coefficient, iv) washoff coefficient and v) washoff exponent. Three calibration scenarios are analysed and compared. Initially, the distance of simulated TSS event load distribution function and lognormal distribution function is minimized towards Kolmogorov-Smirnov (KS) and AndersonDarling (AD) test statistics. Furthermore, the sum of load weighted Nash-Sutcliffe-Efficiencies (NSE) of all events is applied as objective function. The calibration is performed with a differential evolution algorithm provided in the $R$ package DEoptim (Ardia et al. 2016). The optimisation generates 200 generations each with a population of 100 members. Parameter ranges are given in Table 1.

Table 1. Parameter ranges used for quality calibration

\begin{tabular}{|c|c|c|c|c|c|}
\hline Objective Function & $\begin{array}{c}\text { Initial } \\
\text { Build Up } \\
\left(\mathrm{kg} \mathrm{ha}^{-1}\right)\end{array}$ & $\begin{array}{l}\text { Build Up Coeff1 } \\
\qquad\left(\mathrm{kg} \mathrm{ha}^{-1}\right)\end{array}$ & $\begin{array}{c}\text { Build Up Coeff2 } \\
\left.\text { (days }{ }^{-1}\right)\end{array}$ & $\begin{array}{l}\text { Wash-Off Coeff1 } \\
(-)\end{array}$ & $\begin{array}{c}\text { Wash-Off Coeff2 } \\
(-)\end{array}$ \\
\hline \multicolumn{6}{|l|}{ KS } \\
\hline$A D$ & {$[10-50]$} & {$[0.001-50]$} & {$[0.001-5]$} & {$[0.001-5]$} & {$[0.001-5]$} \\
\hline NSE & & & & & \\
\hline
\end{tabular}

\subsection{Analysis of model performance}

The model performance is numerically assessed with respect to the total sum of TSS event loads. In addition, MV-Curves of observed and simulated events are visually compared to evaluate the model's ability to replicate intra-event dynamics. Best-fit parameter sets obtained through calibration are given as well as its uncertainty ranges. Data analysis and visualisation utilizes R (R Core Team 2017).

\section{RESULTS AND DISCUSSION}

\subsection{Results}

Table 2 compares the sum of TSS event loads of observed and simulated data. Corresponding estimated parameter values differentiated by the objective function applied are given in Table 3. Figure 1 depicts the cumulative distribution function of observed and simulated TSS event loads. The lognormal distribution function used for model calibration is highlighted as black solid line. Grouped MV-Curves of simulation and observation are shown in Figure 2.

Table 2. Total observed and simulated TSS event loads

\begin{tabular}{|c|c|c|c|}
\hline Observation & $\begin{array}{c}\text { Simulation } \\
\text { (best-fit KS) }\end{array}$ & $\begin{array}{l}\text { Simulation } \\
\text { (best-fit AD) } \\
\text { a) }\end{array}$ & $\begin{array}{c}\text { Simulation } \\
\text { (best-fit NSE) }\end{array}$ \\
\hline 113.1 & 87.5 & 53.2 & 94.5 \\
\hline
\end{tabular}


Proceedings of the 11th Int. Conference on Urban Drainage Modelling, 23-26 Sep. 2018, Palermo (ITALY). Ed. prof. Giorgio Mannina

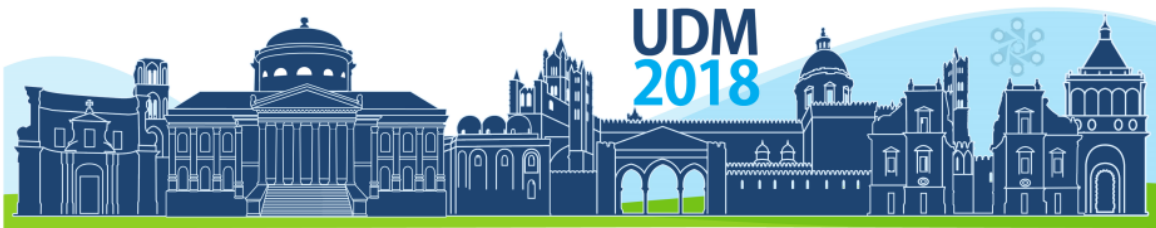

$11^{\text {th }}$ International Conference on Urban Drainage Modelling

23-26 Sep | Palermo - Italy

Table 3. Optimized parameter values

\begin{tabular}{cccccc}
\hline Objective Function & $\begin{array}{c}\text { Initial } \\
\text { Build Up }\end{array}$ & $\begin{array}{c}\text { Build Up } \\
\text { Coeff1 }\end{array}$ & $\begin{array}{c}\text { Build Up } \\
\text { Coeff2 } \\
\text { best-fit (mean;sd) }\end{array}$ & $\begin{array}{c}\text { Wash-Off } \\
\text { Coeff1 }\end{array}$ & $\begin{array}{c}\text { Wash-Off } \\
\text { Coeff2 }\end{array}$ \\
\hline KS & $\mathbf{2 6 . 0 9}$ & $\mathbf{1 7 . 9 0}$ & $\mathbf{0 . 0 2 5}$ & $\mathbf{0 . 0 0 1}$ & $\mathbf{2 . 8 1}$ \\
& $(28.12 ; 11.66)$ & $(9.52 ; 4.81)$ & $(0.11 ; 0.29)$ & $(0.24 ; 0.39)$ & $(2.46 ; 0.86)$ \\
AD & $\mathbf{4 3 . 9 0}$ & $\mathbf{4 3 . 4 3}$ & $\mathbf{0 . 0 1 9}$ & $\mathbf{1 . 5 9}$ & $\mathbf{0 . 0 0 3}$ \\
& $(30.8 ; 11.08)$ & $(24.96 ; 13.50)$ & $(0.14 ; 0.49)$ & $(1.66 ; 0.25)$ & $(0.07 ; 0.14)$ \\
NSE & $\mathbf{4 5 . 2 9}$ & $\mathbf{1 2 . 4 3}$ & $\mathbf{1 . 1 0}$ & $\mathbf{0 . 0 0 1}$ & $\mathbf{2 . 4 8}$ \\
& $(32.91 ; 9.38)$ & $(10.08 ; 2.74)$ & $(0.94 ; 0.73)$ & $(0.01 ; 0.02)$ & $(2.23 ; 0.27)$ \\
\hline
\end{tabular}

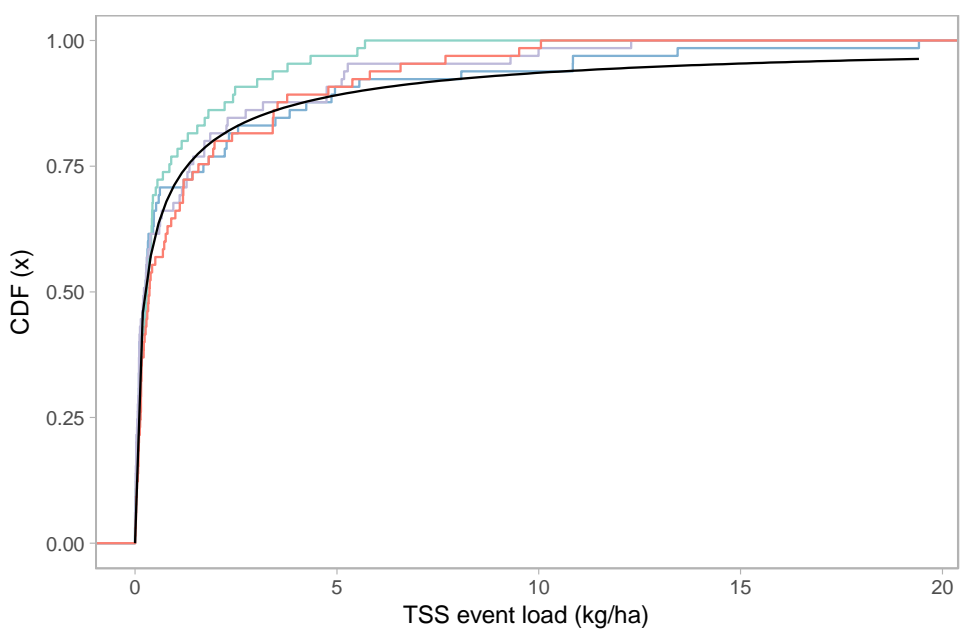

$$
\begin{aligned}
& \text { — lognorm } \\
& \text { - observation } \\
& \text { — simulation (best-fit AD) } \\
& \text { - simulation (best-fit KS) } \\
& \text { - simulation (best-fit NSE) }
\end{aligned}
$$

Figure 1. Observed and simulated TSS event load distribution functions

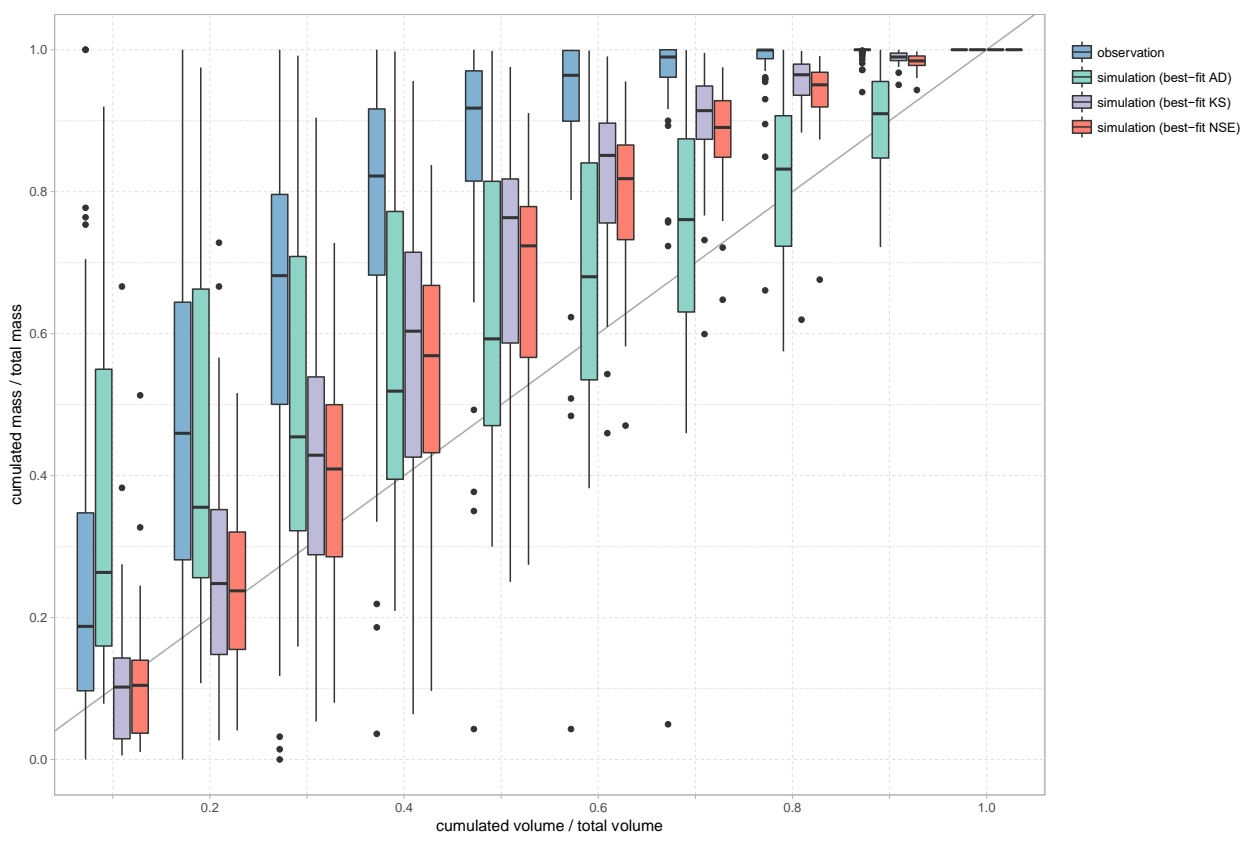

Figure 2. Grouped MV-Curves of observation and simulation with different objective functions 


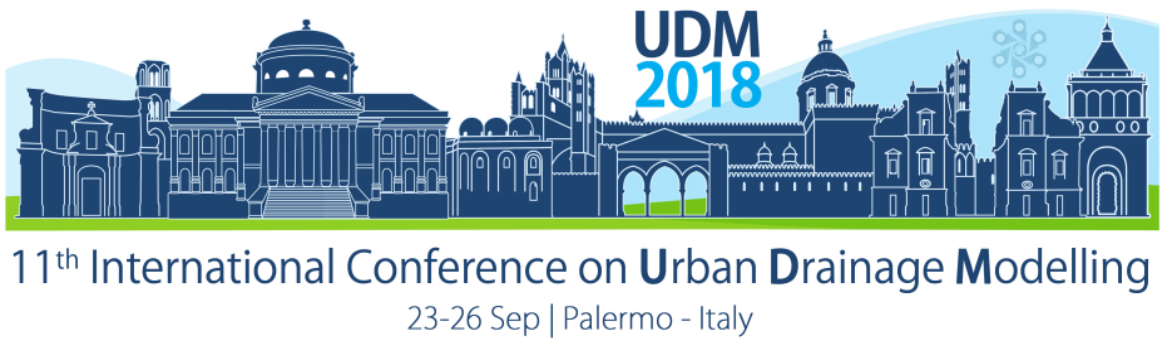

\subsection{Discussion}

Generally, the calibrated quality model underestimates the total sum of TSS event loads. Calibration with NSE yields to $15 \%$ less TSS event load, the error using the KS statistic is approx. $25 \%$. The AD calibration significantly fails to reproduce the TSS event loads (>50\% deviation). From the cumulative distribution function can be stated that the error mainly occurs due to poor fitting of events with high TSS loads. Because the NSE calibration was setup with load proportional weights for each event, the results of this approach are closer to the observed CDF. However, the difference between NSE and KS are less significant.

MV-Curves clearly demonstrate that the model concept analysed is rarely capable to replicate observed intra-event distributions. Both NSE and KS calibration approaches lead to parameter values, which result in more runoff proportional wash-off characteristics. Especially, the first runoff quantiles are poorly represented. Parameters obtained through AD-based calibration approach initially produce a more appropriate fitting, which noticeably decrease after $20 \%$ runoff volume.

\section{CONCLUSIONS}

The stormwater quality model SWMM was used to replicate runoff and quality processes of a flat roof. An event-based calibration approach accounting for the Nash-Sutcliffe efficiency was conducted and compared to a distribution-based calibration approach using KolmogorovSmirnov and Anderson-Darling test statistics. Results illustrate that the empirical quality model concept is rarely capable to replicate intra-event characteristics. In contrast, cumulative TSS event load distribution can be well fitted when using an appropriate objective function.

\section{References}

Ardia, D., Mullen, K. M., Peterson, B. G., and Ulrich, J. (2016): DEoptim: Differential Evolution in R.

Egodawatta, P., Thomas, E., and Goonetilleke, A. (2007): Mathematical interpretation of pollutant wash-off from urban road surfaces using simulated rainfall. In: Water Research, 41(13), S. 3025-3031.

Egodawatta, P., Thomas, E., and Goonetilleke, A. (2009): Understanding the physical processes of pollutant buildup and wash-off on roof surfaces. In: The Science of the Total Environment, 407(6), S. 1834-41.

Leutnant, D., Muschalla, D., and Uhl, M. (2016): Stormwater Pollutant Process Analysis with Long-Term Online Monitoring Data at Micro-Scale Sites. In: Water, 8(7), S. 299.

Leutnant, D., Muschalla, D., und Uhl, M. (2018): Statistical Distribution of TSS Event Loads from Small Urban Environments. In: Water, 10(6), S. 769.

R Core Team (2017): R: A Language and Environment for Statistical Computing. Vienna, Austria: R Foundation for Statistical Computing.

Rossman, L. A. (2010): Storm Water Management Model - User's Manual Version 5.0., S. 285, Cincinnati, $\mathrm{OH}$, USA: United States Environmental Protection Agency (US EPA).

Sage, J., Bonhomme, C., Al Ali, S., and Gromaire, M.-C. (2015): Performance assessment of a commonly used "accumulation and wash-off" model from long-term continuous road runoff turbidity measurements. In: Water Research, 78(0), S. 47-59.

Sartor, J. D., Boyd, G. B., and Agardy, F. J. (1974): Water pollution aspects of street surface contaminants. In: Journal of the Water Pollution Control Federation, 46(3). 


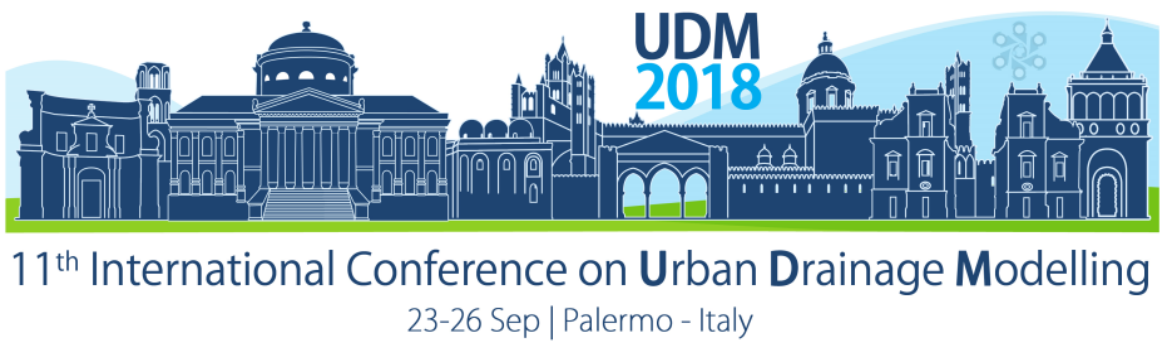

\title{
Conceptualizing the sewage collection system for integrated sewer-WWTP modelling and optimization
}

\author{
Lisha Guo ${ }^{1,2}$, Sovanna Tik ${ }^{3}$, Julia M. Ledergerber ${ }^{3}$, \\ Domenico Santoro ${ }^{2}$, Elsayed Elbeshbishy1, Peter A. Vanrolleghem ${ }^{3}$ \\ 1. Ryerson University, 350 Victoria Street, Toronto, ON, Canada M5B 2K3 \\ 2. Trojan Technologies, 3020 Gore Road, London, ON, Canada N5V 4T7 \\ 3. modelEAU, Département de génie civil et de génie des eaux, Université Laval, 1065 avenue de la Médecine, \\ Québec, QC, Canada G1V 0 A6
}

\begin{abstract}
In this paper, a new conceptual modelling approach and calibration method is proposed for integrating sewage collection system and wastewater treatment plant (WWTP) operations. The method consists of simplifying a complex sewer network into a computationally efficient (conceptual) model able to capture the sewer dynamics, both in terms of flow rate and water quality, entering the wastewater treatment plant. Biochemical process modelling was carried out on this conceptual model and compared with a wholenetwork biochemical model which covered all pipes of a sewer system. The conceptual biochemical model can achieve similar results as the whole-network model in terms of water qualities, but provides fast simulation speed and easy calibration. Those advantages mean that the conceptual biochemical model of a collection system can be used in an integrated model with which sewer and WWTP can be simulated simultaneously for long-term evaluation of optimization scenarios.
\end{abstract}

Keywords: sewer biochemical processes, integrated modelling, conceptual model, corrosion, wastewater quality

\section{INTRODUCTION}

Driven by an increasing interest in process intensification and resource recovery, an integrated management of sewer and wastewater treatment plant (WWTP) is becoming meaningful more than ever before. Therefore, studies on sewage collection systems are extending from sewer hydraulics to sewer biochemical processes. Indeed, modelling of pollutant transport and conversion in sewers relies on two categories of models: sewer flow models (transport term) and sewer biochemical process models (reaction term), Figure 1. Thanks to decades of efforts, the study of hydraulic or hydrologic modelling has achieved great success. On the other hand, the modelling of sewer biochemical processes is catching more attentions in recent years, with models proposed by modifying or adopting similar concepts as used in the biochemical models of WWTPs (Hvitved-Jacobsen et al., 2013; Jiang et al, 2009; Sharma et al., 2008).

However, to use those sewer biochemical models in sewer networks is not as easy as in WWTPs. Modelling large-scale sewer networks asks far more computational effort than WWTPs. This drawback severely restricts the application of sewer biochemical models and their integration with WWTP models. Coding and programming is the third pillar of the modelling task (Figure 1), because it has a great impact on simulation speed and the user's experience. Unfortunately, little efforts have been put on this topic so far.

The aim of this study was to break those barriers in sewer biochemical modelling in order to achieve real integrated modelling of water quality in sewer and WWTP, which means that sewer and WWTP models can be run simultaneously on one layout for long-term evaluation. Therefore, a new method is proposed in this paper, which can simplify a complex network into 


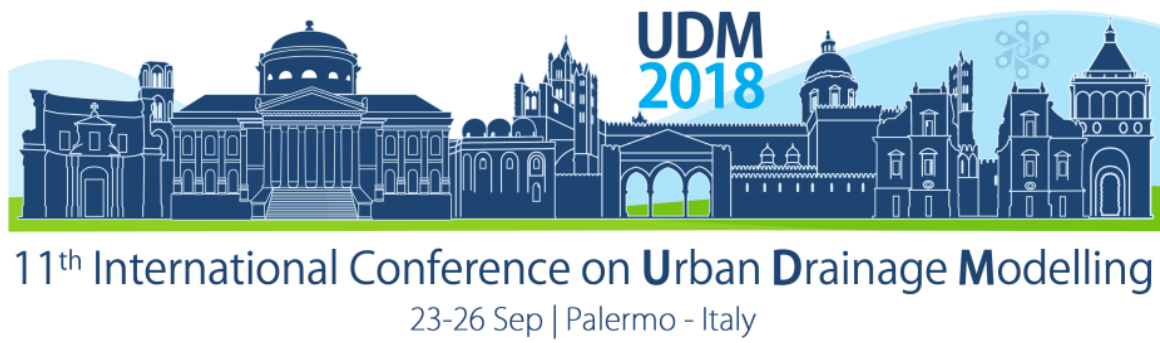

a conceptual model in view of biochemical modelling. A case study was carried out on a collection system in Quebec City, Canada.

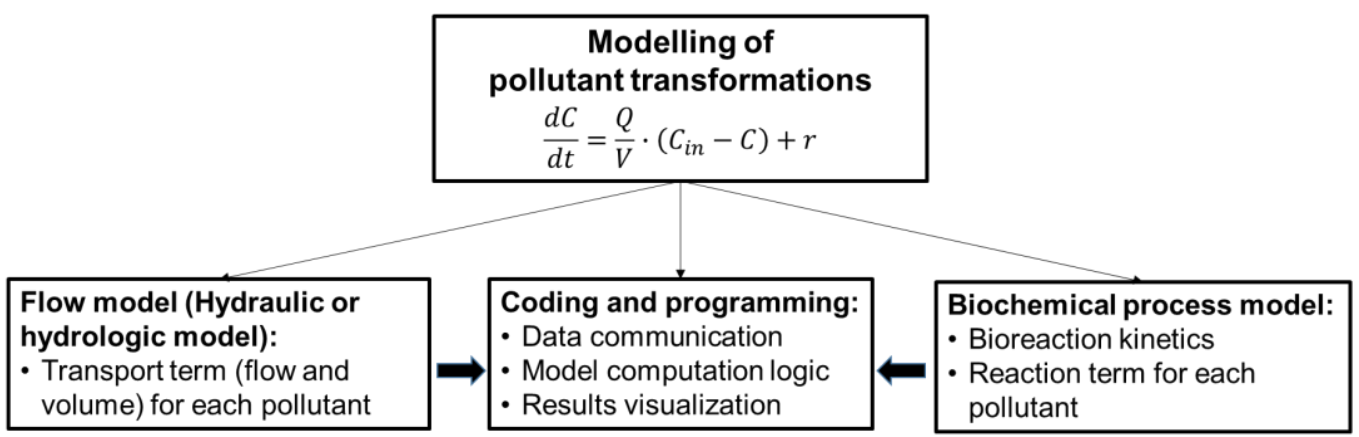

Figure 1. Scheme of pollutant transport and conversion modelling in sewers

\section{METHOD}

Originally, the approach of conceptual models was proposed as an alternative to traditional hydraulic models like SWMM, for its fast computation speed is an advantage in studying realtime control in stormwater management. For the modelling of sewer biochemical processes, this feature is even more advantageous, e.g. for integrated modelling and long-term simulation. However, although conceptual modelling is not a new concept, its application in sewer biochemical process modelling differs from that in sewer flow modelling.

\subsection{Identifying key elements and regions}

Before conceptualizing a big sewer network into a simple system, the first step is to identify which elements in the network play a crucial role and how to cut the big network into pieces. In the modelling of in-sewer biochemical processes, more interests are given to how those processes are going on under ordinary dry-weather conditions. Therefore, the storage tanks and pumping stations that are active under dry-weather conditions are picked out and included in conceptual modelling. Usually, those elements are also the accessible places where operation adjustments or chemical dosing strategies can be tested.

\subsection{Conceptualizing sewer network}

One vital question in conceptual modelling is calibration. In sewer system modelling, calibration is more focused on sewer flow. However, in order to model pollutant concentration changes, flow and volume are equally important (Figure 1). Therefore, two calibration targets are set: the total volume $\left(V_{\text {Target }}\right)$ and the final outflow $\left(Q_{\text {Target }}\right)$ of the target sewer network. Therefore, the calibration question can be stated as (Figure 2): knowing all inflows coming into the target network $\left(Q_{\mathrm{ln}, \text { Total }}\right)$ and assuming volume $(V)$ and flow $(Q)$ of each conceptual tank expressed in a relationship of: $Q_{i}=\mathrm{k} \cdot V_{\mathrm{i}}^{\mathrm{m}}$, find parameters: $\mathrm{n}$ (number of tanks), $\mathrm{k}$ and $\mathrm{m}$ of a tank-in-series system to meet $V_{\text {Target }}$ and $Q_{\text {Target }}$.

In most parameter optimization methods, the algorithm searches the best parameter set in a pre-defined parameter space. However, this kind of methods usually requires a good guess of the parameter ranges. The search can take a long time, and sometimes, it may end up only in a local optimum. For these reasons, a simple calibration procedure is proposed. First, one

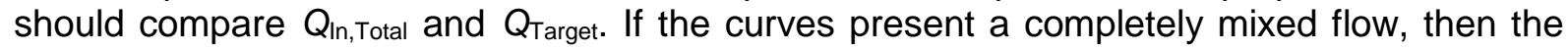
network can be simplified as one tank. Otherwise, one must shift $Q_{\text {Target }}$ forwards by a time 


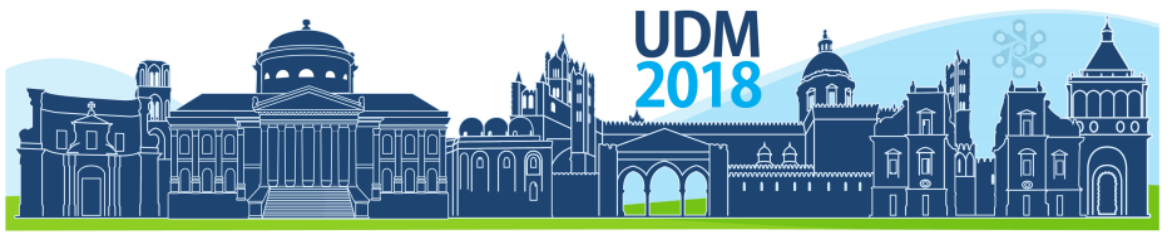

$11^{\text {th }}$ International Conference on Urban Drainage Modelling

23-26 Sep | Palermo - Italy

step (ts) to get a new data series, $Q_{\text {Target,ts, }}$ until finding the best match between $\ln \left(V_{\text {Target }}\right)$ and $\ln \left(Q_{\text {Target,ts }}\right): \quad \ln \left(V_{\text {Target }}\right)=\mathrm{a} \cdot \ln \left(Q_{\text {Target,ts }}\right)+\mathrm{b} . \mathrm{k}$ and $\mathrm{m}$ can be calculated as:

$$
\begin{array}{cc}
m=1 / a & \text { Eq. } 1 \\
k=n^{(1 / a)} / \exp (b / a) & \text { Eq. } 2
\end{array}
$$

$n$ depends on the flow type. For a clear plug flow, it is suggested to try $n \geq 10$.

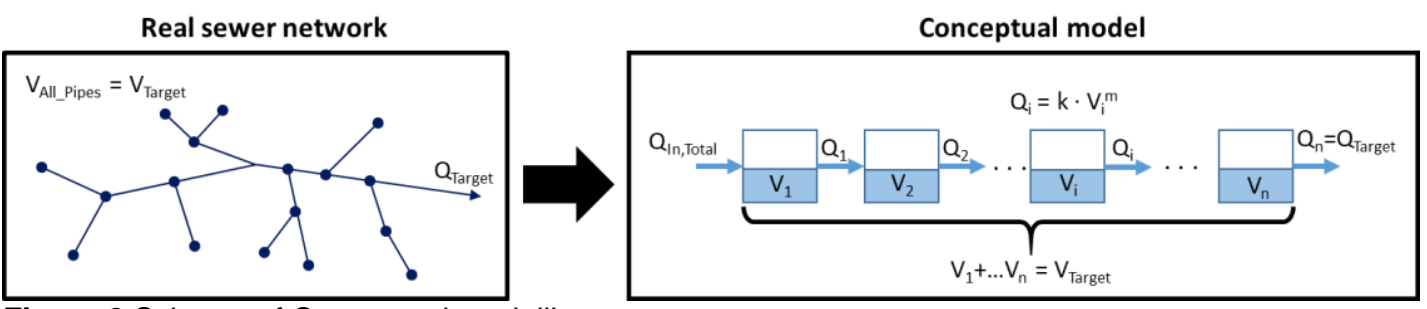

Figure 2 Scheme of Conceptual modelling

\subsection{Conceptualizing storage tanks}

The storage tanks controlled by pumping stations were modelled by applying pumping rules; otherwise, they were modelled as a non-linear tank using the equation $Q_{\mathrm{st}}=\mathrm{k} \cdot V_{\mathrm{st}}^{\mathrm{m}}$.

\subsection{In-sewer biochemical process modeling}

As shown in Figure 1, the modelling of sewer pollutant variations consists of choosing a combination among a set of sewer flow models and a set of biochemical process models. Therefore, a new modelling tool was developed, which couples sewer flow models, i.e. hydraulic models and conceptual models, with different biochemical models. The tool can easily handle large-scale networks and quickly deliver results. The tool offers a basis in which different biochemical models can be embedded. Currently, it incorporates two biochemical models: the SeweX model (Sharma et al., 2008) and a modified version of a simple biofilm model (Rauch et al., 1999). In this study, the SeweX model was selected, which is suitable for simulating conventional sewer processes including sulfide production, fermentation, and so on.

\section{RESULTS}

The studied sewage collection system is located in Quebec City, Quebec, Canada. The SWMM model of the sewer network (Wipliez, 2011) was calibrated based on real flow sensor data (Figure 3). The WWTP receives wastewater from two big regions. In this case, the collection system from the central region was investigated.

As explained above, the first step is to identify key elements and regions. As a result, the blue zone in Figure 3, which covers about 400 sewer pipes, is the region retained after excluding the key storage tanks and pumping stations. Clearly, this blue zone is the main target of the conceptual modelling in this case, because it covers almost the whole network.

The wastewater inflow to this blue zone can be categorized as two types based on their sources. First, the blue zone has a plenty of local inflow nodes. All those local inflow nodes are summed up into one input to the blue zone. Second, there are several small pieces of network consisting of storage tanks, pumping stations and pipes running short distance, which transport wastewater downstream to the blue zone. Since they only account for a small fraction of the whole network, at the first stage of the study the focus was given to the blue zone, and the 


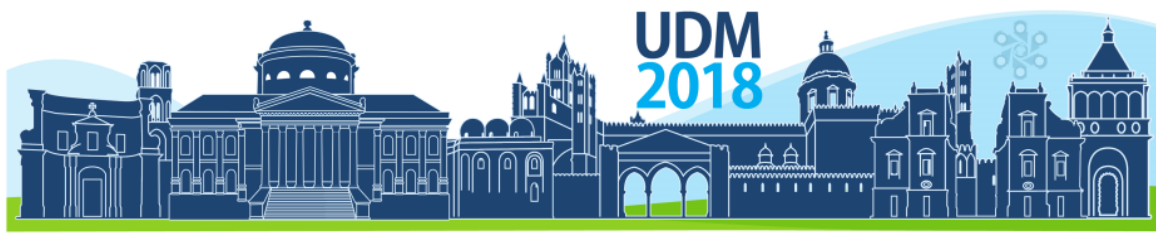

$11^{\text {th }}$ International Conference on Urban Drainage Modelling

23-26 Sep | Palermo - Italy

SWMM information of those small network pieces was directly used as an input. As a result, the sewer network covered by the blue zone was conceptualized and calibrated into a system of 20 tanks-in-series (Figure 4).

a. SWMM model

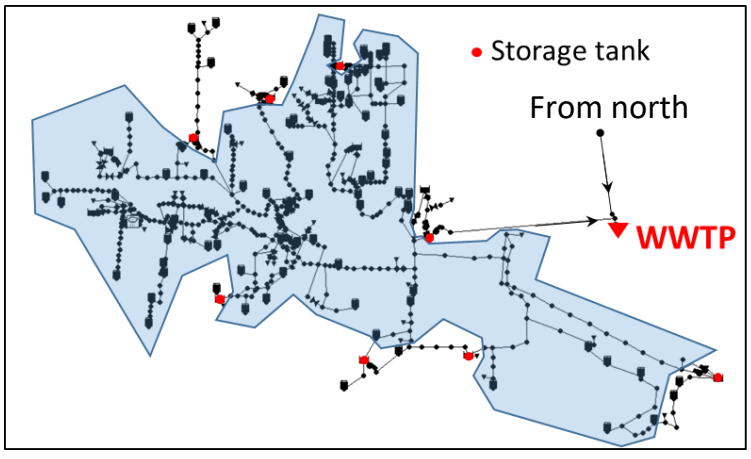

b. SWMM calibration results

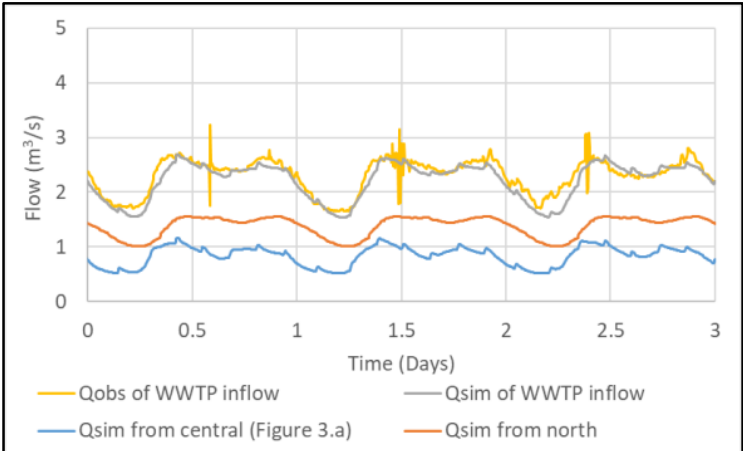

Figure 3. SWMM model of the studied case in Quebec City, Quebec, Canada
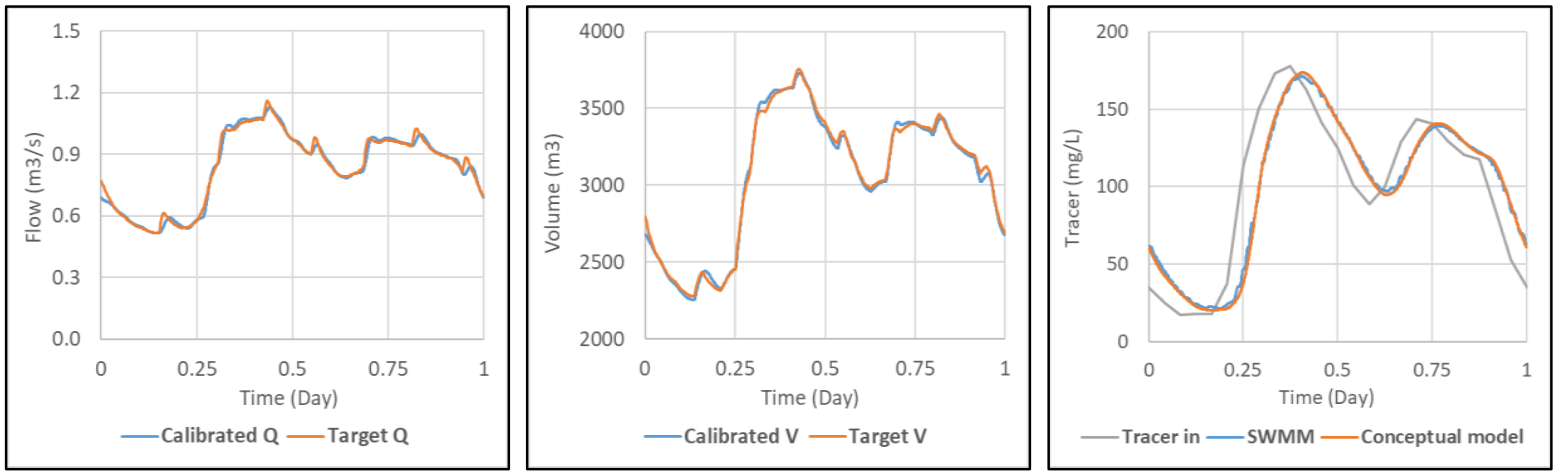

Figure 4 Calibration results of conceptual model $(n=20, k=30.0919, m=1.5449)$

After that, conceptual modelling of the collection system was further extended to storage tanks, pumping stations and small network pieces by using the method as described above. For the sewer network of those small pieces, most of them can be simplified as one conceptual sewer tank. In the end, the entire network of Figure 3.a was conceptualized as Figure 5. Sewer4 is the conceptual sewer of the blue zone in Figure 3.a. It consists of 20 tanks, receiving wastewater from two small branches (Sewer1 and Sewer 3) and local inflows (Inflow4).

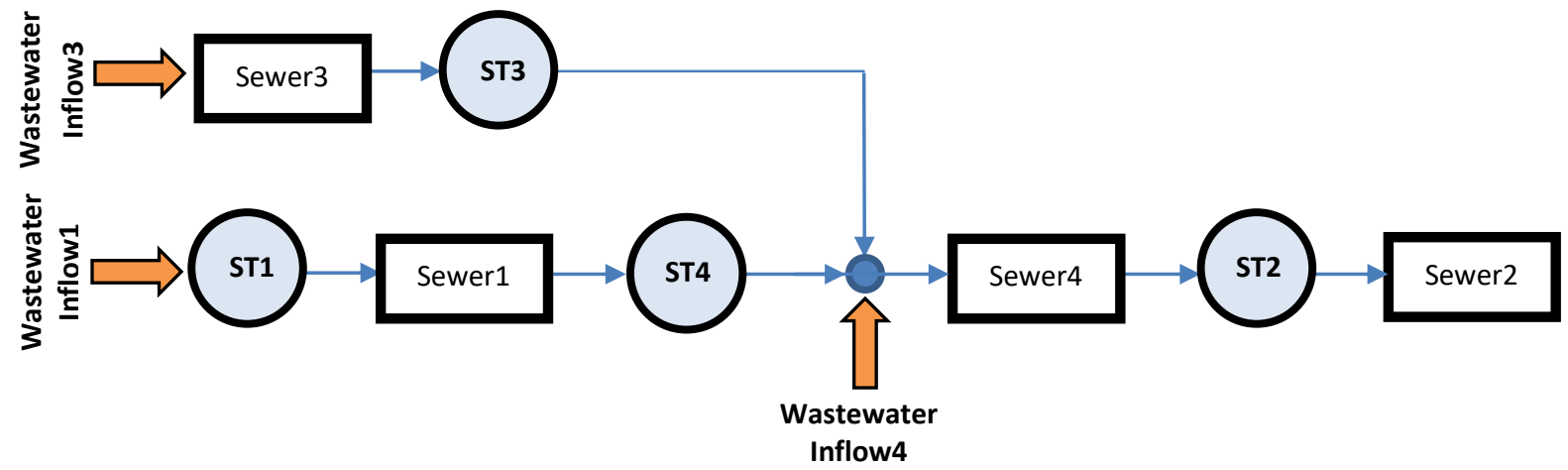

Figure 5 The schematic map of the conceptual collection system (Note: ST means storage tank) 


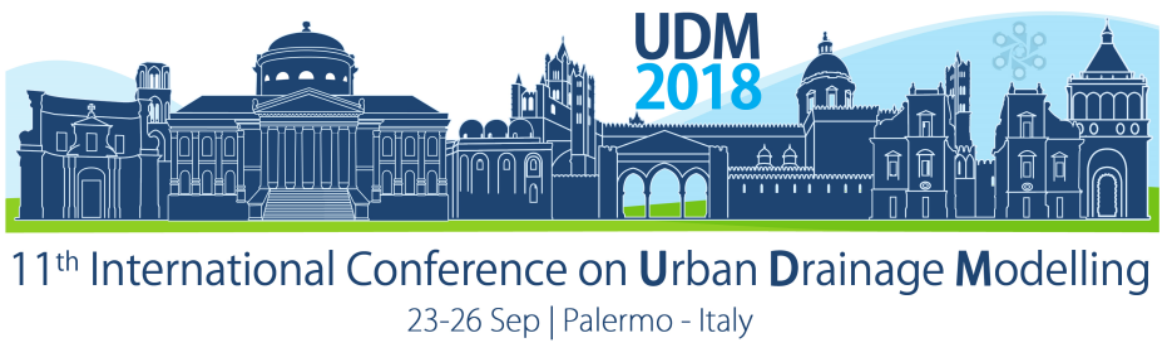

Then, by using the new modelling tool presented above the SWMM model and the conceptual model were coupled with the SeweX biochemical model, i.e. SWMM-SeweX set and Conceptual-SeweX set. As shown in Figure 6, the two show very similar results. Noticeably, the simulation with the conceptual model is significantly faster than with the SWMM (hours vs. minutes). The simulation speed of the sewer conceptual model is competitive with that of a full-scale WWTP model. Therefore, the sewer conceptual model can be connected to a WWTP model like the Benchmark Model No.2 (BSM2) to form a real integrated model, which means that sewer and WWTP can be run simultaneously on the same layout for long-term simulation. Also, the conceptual biochemical model is easier to be calibrated than the SWMM biochemical model because the system is simpler with fewer objects to be considered and the simulation is faster for quick result evaluation.

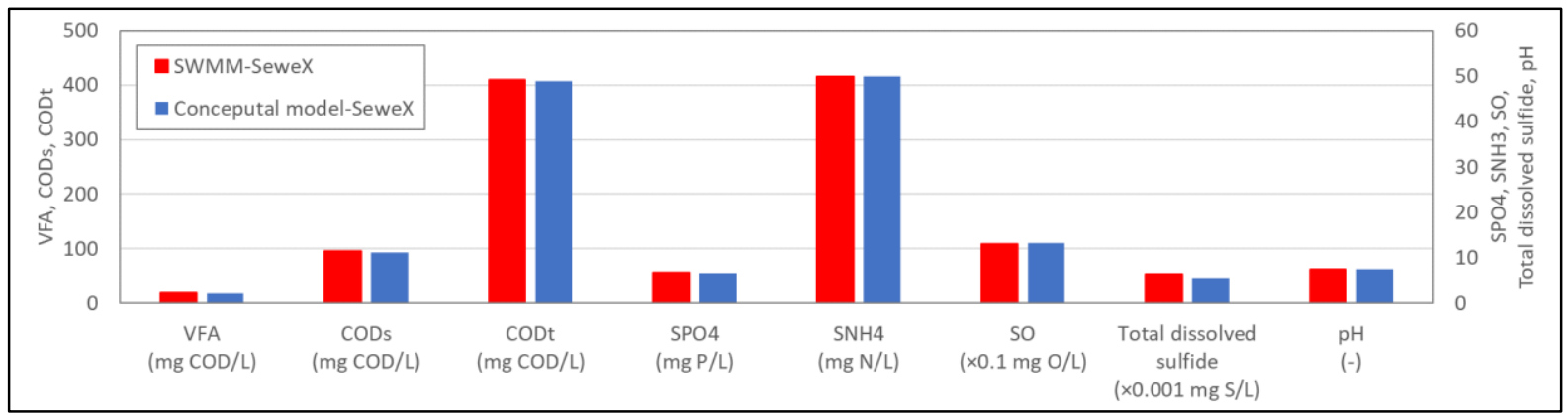

Figure 6. Comparison between whole-network and conceptual modelling in terms of biochemical processes

\section{CONCLUSION}

In this study, a conceptual modelling and calibration method was proposed for sewer biochemical modelling purposes. The method can quickly simplify a complex network into a series of conceptual tanks and satisfy calibration goals on sewer flow and volume. It serves as an important component to a new modelling tool, which is capable to handle different scales of collection systems and to incorporate different biochemical models. The whole-network (SWMM-based) modelling and the conceptual modelling have each their own advantages. In practice, the two methods can be selected or combined according to specific purposes. On the one hand, the whole-network modelling method runs simulations for all pipes of a sewer network to show the spatial distribution of pollutants throughout the system. This method can be used to identify hot spots in a large network. On the other hand, the conceptual modelling method shows advantages in terms of fast simulation and easy calibration. Given those reasons, it has a great potential in sewer-WWTP integrated modelling and long-term simulation.

\section{References:}

Hvitved-Jacobsen T., Vollertsen J. and Nielsen A.H. (2013) Sewer processes: microbial and chemical process engineering of sewer networks (2nd Edition). CRC press, US, 2013.

Jiang F., Leung D.H., Li S., Chen G.-H., Okabe S., and van Loosdrecht M.C.M. (2009) Biofilm model for prediction of pollutant transformation in sewers. Wat. Res. 43(13), 3187-3198.

Rauch W., Vanhooren H. and Vanrolleghem P.A. (1999) A simplified mixed-culture biofilm model. Wat. Res. 33(9), 2148-2162.

Sharma K. R., Yuan Z., de Haas D., Hamilton G., Corrie S. and Keller J. (2008) Dynamics and dynamic modelling of $\mathrm{H} 2 \mathrm{~S}$ production in sewer systems. Wat. Res. 42(10/11), 2527-2538.

Wipliez, B. (2011) Caractérisation et gestion de la vidange de réservoirs de rétention d'eaux unitaires. Master thesis, Université Laval, Québec, Canada (in French) 


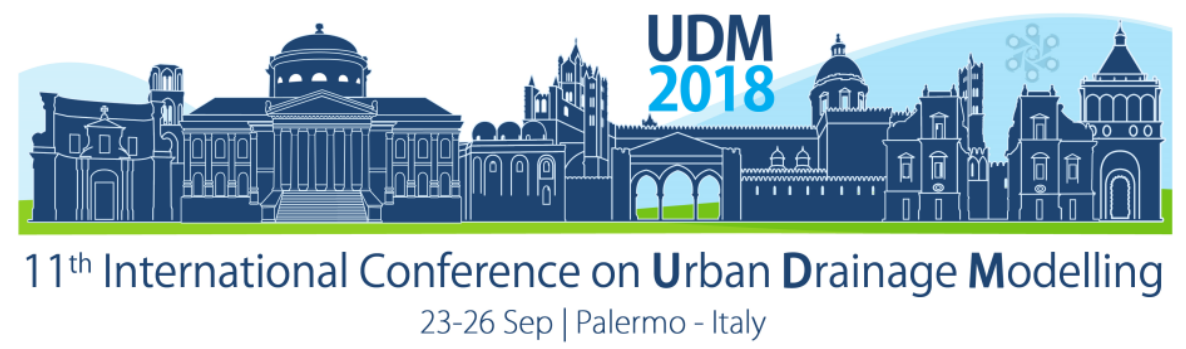

\title{
Modelling of heavy metals and PAHs concentration in urban stormwater runoff
}

\author{
Afshin Sadeghikhah ${ }^{1}$, Jin Zhang ${ }^{1}$ and Peter Krebs ${ }^{1}$ \\ ${ }^{1}$ Institute of Urban Water Management, Technische Universität Dresden, 01062 Dresden, Germany
}

\begin{abstract}
A separated drainage model of the city Dresden, Germany, is the base to comprehend urban surface run-off and pollutant transport. The complexity of processes challenges a robust calibration. We propose model adaptation with information of Roof Materials (RM), contamination classes of streets, in-situ build-up and wash-off coefficients. In summary, the calibrated drainage model implemented by Heavy metals (HMs) and PAHs concentration recorded from a measuring campaign done for entire city Dresden, shows acceptable correlation with lab results from analysing the samples from an automatic sampler during a moderate rain event. Due to proposed methods, online water quality parameters, the drainage model will be extrapolated and calibrated for entire city which Low Impact Development (LID) and cost analysis leads us to Best Management Practices (BMPs) for the city.
\end{abstract}

Keywords: Build-up; Heavy metals; Polycyclic Aromatic Hydrocarbons; Stormwater wash-off

\section{INTRODUCTION}

Rapid urbanization is a global phenomenon, which leads to an increase of impervious surfaces. Natural and anthropogenic pollutants are washed off the road and roof surfaces and are transported via urban drainage systems. In a seperated or combined drainage system, due to the sttructure or capacity limitation, during the wet weather period, these pollutants would be discharged into the receiving water bodies which poses a pollution risk to the adjacent receiving waters. Among these pollutants, polycyclic aromatic hydrocarbons (PAHs) and heavy metals (HMs) are known to be toxic, carcinogenic, mutagenic, and teratogenic. Due to the significant risk to the aquatic environment, some PAHs and HMs are listed as of the European Water Framework Directive (WFD) (Zhang, et al.,2017a; Zhang, et al., 2017b). Therefore, the best management practices (BMPs) consider street sweeping as a potential performance in eliminating PAHs and HMs from the street surface during the dry weather period. However, how to optimize the street sweeping strategy with the consideration of sweeping frequencies and the characteristics of precipitation event needs to be further investigated.

Accordingly, the main focuses of this study are (i) implement the spatial variabilities of roof and street in an urban stormwater drainage model, (ii) simulate the PAHs and HMs build-up and wash-off processes, and (iii) calibrate the proposed model by in-situ parameters. 


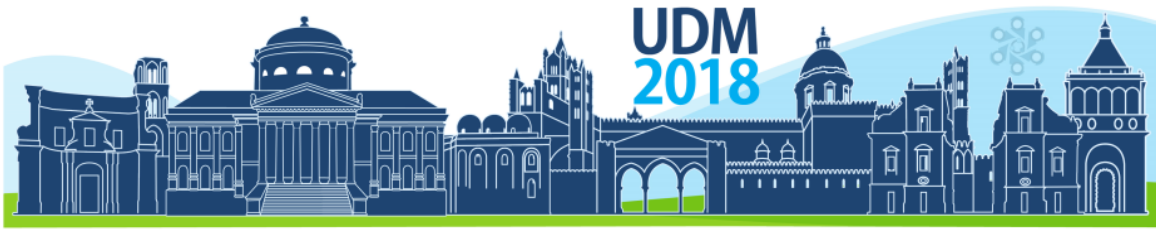

$11^{\text {th }}$ International Conference on Urban Drainage Modelling

23-26 Sep | Palermo - Italy

\section{MATERIALS AND METHODS}

\subsection{Model preparation}

The study area is in the Grosszschachwitz catchment of Dresden city, Germany. This urbanized 50 ha area is served by the separate drainage system as seen in Fig. 1. The software Stormwater Management Model (SWMM) was used to simulate the hydrological and hydraulic processes. Streets' information and hierarchy were implemented based on data from the traffic-analysis-management and optimization system (VAMOS) coupled with European Monitoring and Evaluation Program (EMEP). Roofs' information (area and mean slope) were implemented into the drainage model. Roof materials (RM) were detected by object based (OB) approach from ENVI software following the method described in our previous work (Sadeghikhah, et al., 2017). Due to relatively small study area including the stormwater system, streets contributing to the wash-off process are in the same category and all roofing materials are bitumen due to the new built area. Build-up and wash-off parameters were selected according to a sampling campaign done for the entire city of Dresden.

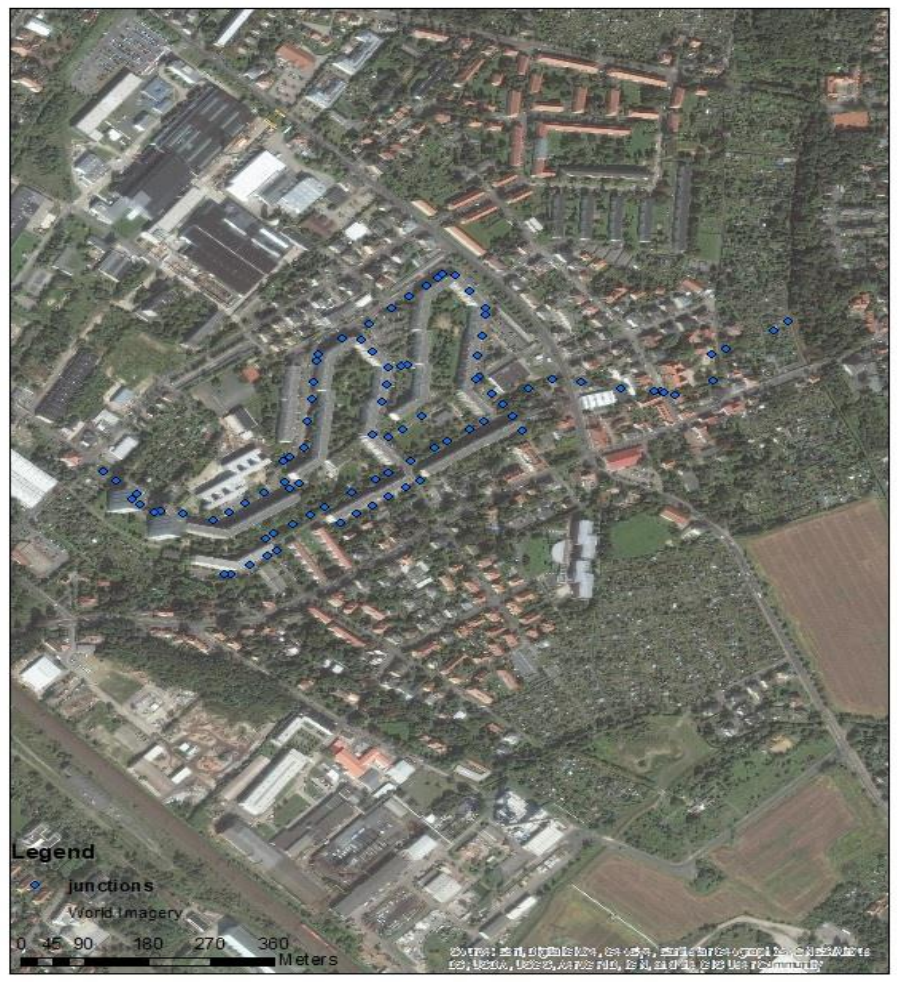

Figure 1. Study area with the seperated drainage system

\subsection{Model Calibration and Validation}

Due to high resolution observed data close to the outlet of the separated system, we were able to calibrate the model regarding the water quantity for 4 rain events from short to long return periods. Figure 2 illustrates the validation of data for a moderate rain event with the NashSutcliffe efficiency of 0.74 . 


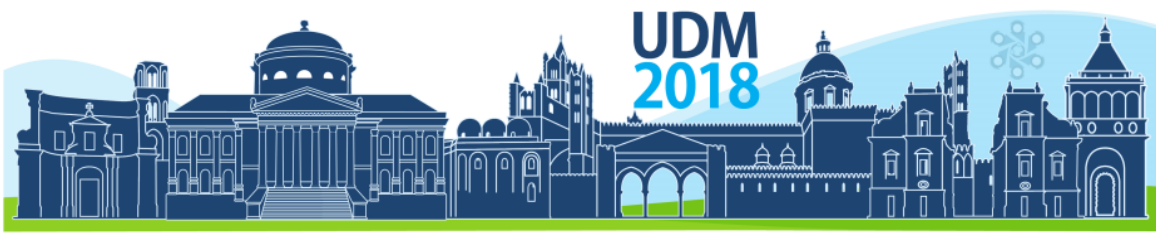

$11^{\text {th }}$ International Conference on Urban Drainage Modelling

23-26 Sep | Palermo - Italy

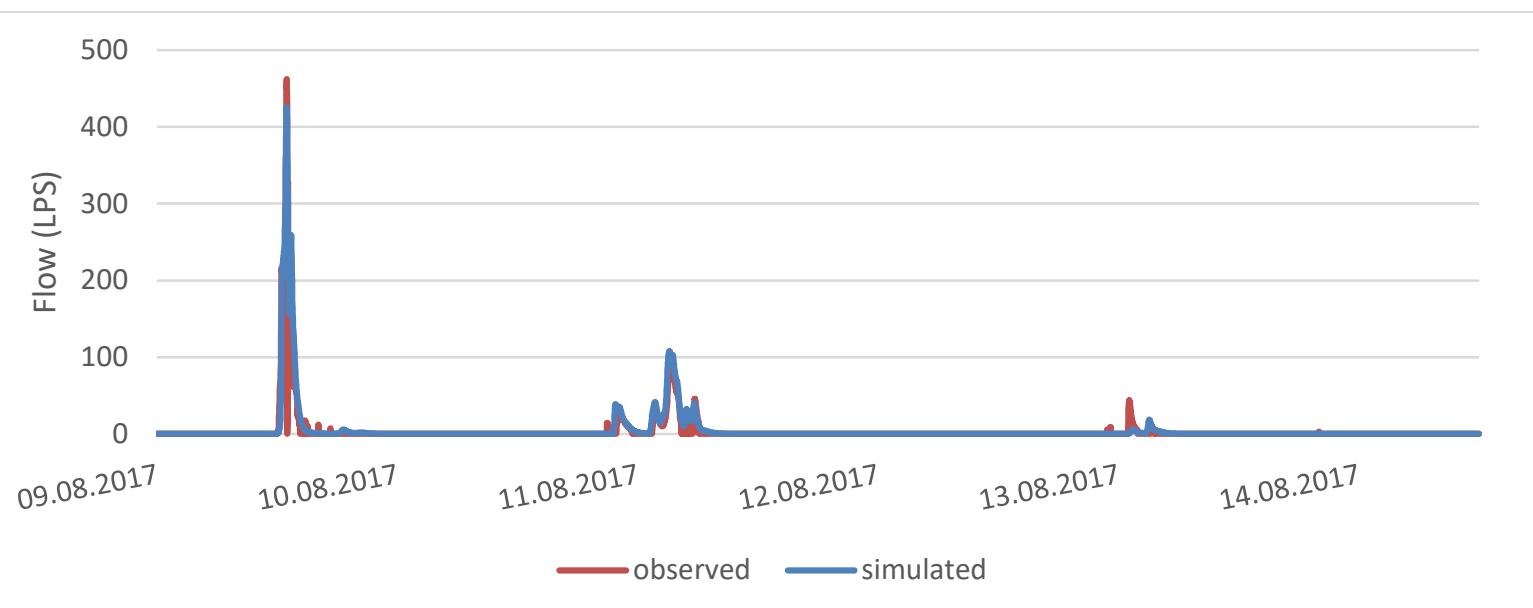

Figure 2 . Simulated and obsereved flow data comparison

\section{RESULTS AND DISCUSSION}

An automatic sampler, Maxx P6-L, was used during a rain event. Figure 3 shows the comparison between observed and modeled $\mathrm{Zn}$ concentration on $11^{\text {th }}$ of August 2017. Although the samples from the automatic sampler are limited to two hours, they prove a short time match which brings out the importance of repetitive sampling covering the flow time over different rain events.

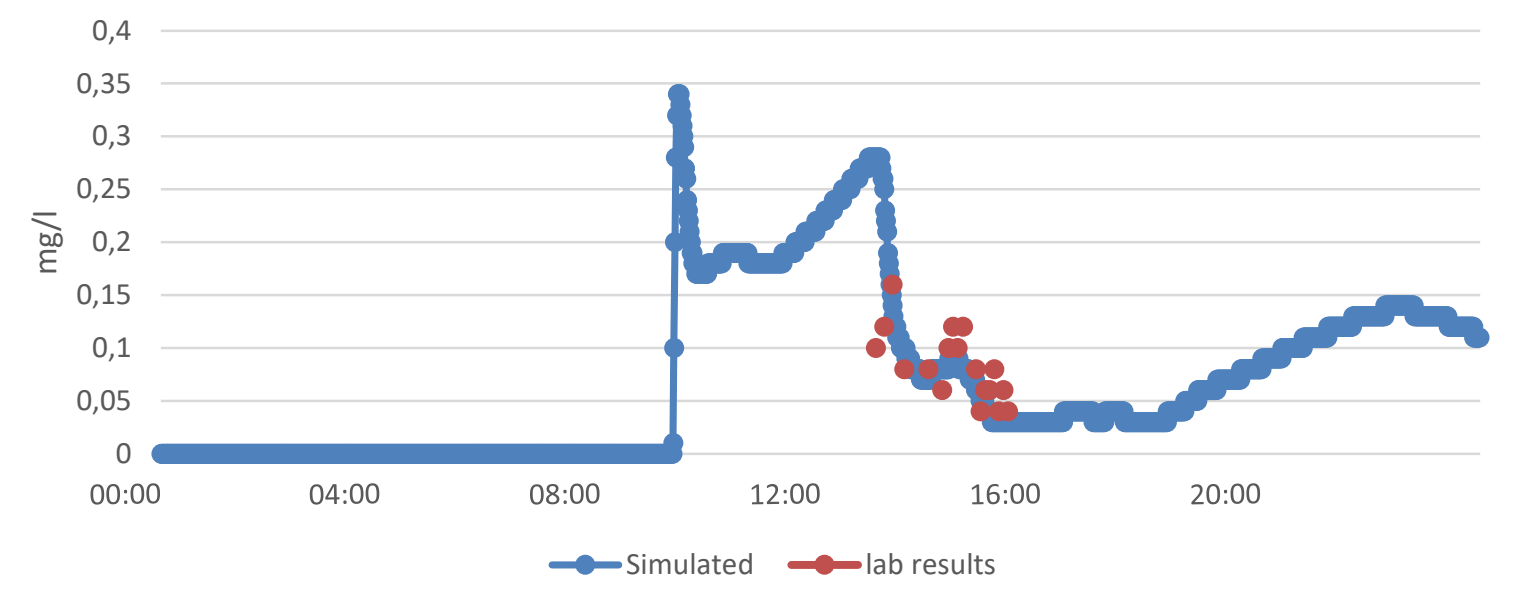

Figure 3. comparison between modelled and sampled Zn concentration

For same time period as data validation, Fig. 4 illustrates the $\Sigma_{16} \mathrm{PAHs}$ concentration washed off from impervious surfaces after 10 antecedent dry days. Considering the runoff and pollutant concentration shows the major wash-off load at first flush which brings out the importance of Low Impact Development (LID) implementation and cost analysis in order to reduce the first flush effect. 


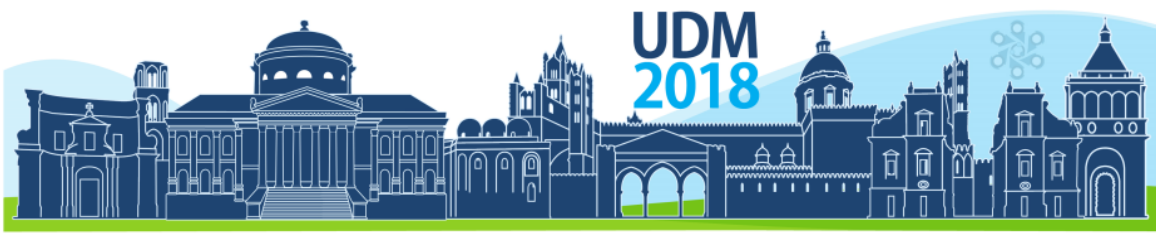

$11^{\text {th }}$ International Conference on Urban Drainage Modelling 23-26 Sep | Palermo - Italy

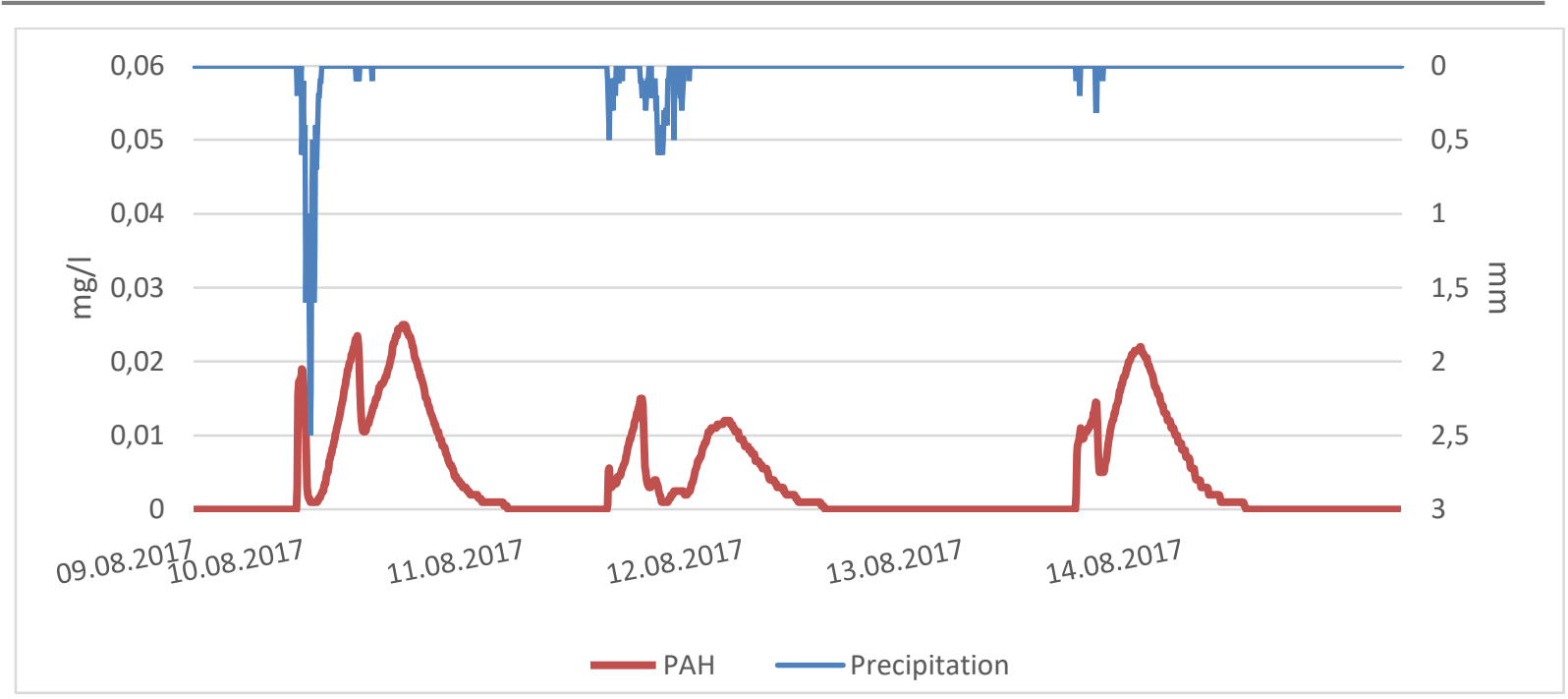

Figure 4. modelled PAHs concentration during a rain event

Furthermore, existing model will be calibrated regarding high frequency quality parameters recorded from measuring stations. Due to sampling campaign done for build-up and wash-off coefficients, dynamic sweeping calendar, the calibrated model will be ready for LID implementation for the entire city of Dresden which coupled with cost analysis, Best Management Practice (BMP) will be reachable.

\section{CONCLUSIONS}

In spite of relatively good correlation regarding the water quantity of the model, water quality calibration will be done due to high frequency measuring stations. Automatic sampler will be used flow proportionally in order to cover the entire rain event which would be beneficial for HMs and PAHs calibration. Furthermore, dynamic street sweeping calendar and LIDs would be implemented in to the drainage model for entire city which leads to the BPMs.

\section{References}

Sadeghikhah, A. Kaeseberg, T., Zhang, J., Pape, S., Mueller, M., Krebs, P.., 2017. Pollutant build-up and wash-off on city scale. Prague, International Conference on Urban Drainage.

Zhang, J., Hua, P. \& Krebs, P., 2017a. Influences of land use and antecedent dry-weather period on pollution level and ecological risk of heavy metals in road-deposited sediment.. Environmental pollutant, Volume 228, pp. 158-68.

Zhang, J. Wu, J.Fan, G.,Bai, Y., Kaeseberg, T. and Krebs, P. ., 2017b. Influence of land use on source apportionment and risk assessment of polycyclic aromatic hydrocarbons in road-deposited sediment.. Environmental pollutant, Volume 229, pp. 705-14. 


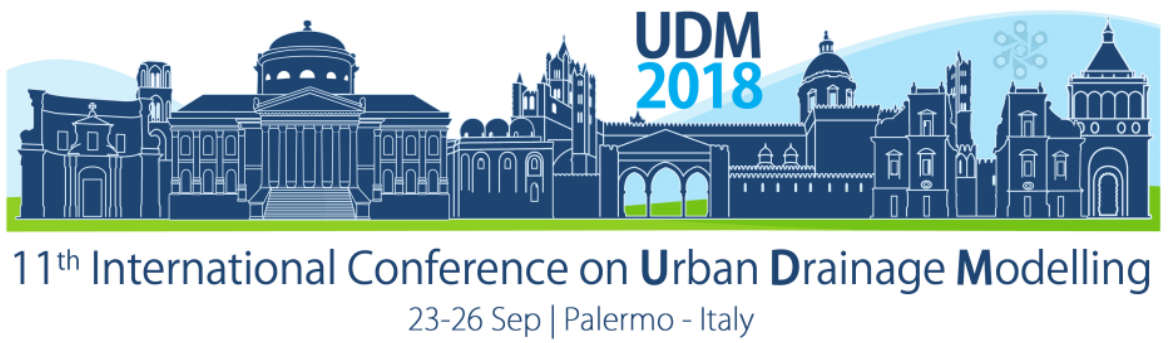

\title{
Multiphase CFD-Simulation of Transport Phenomena in Sewer Systems
}

\author{
Katharina Teuber ${ }^{1}$, Tabea Broecker ${ }^{1}$ Shibashish D. Jaydev ${ }^{1}$, Gebregziabher M. Goitom $^{1}$, Maria Sielaff ${ }^{2}$ \\ Daneish Despot ${ }^{3}$, Dietmar Stephan ${ }^{2}$, Matthias Barjenbruch ${ }^{3}$ and Reinhard Hinkelmann ${ }^{1}$ \\ ${ }^{1}$ Chair of Water Resources Management and Modeling of Hydrosystems, TU Berlin, Berlin, Germany \\ ${ }^{2}$ Chair of Building Materials and Construction Chemistry, TU Berlin, Berlin, Germany \\ ${ }^{3}$ Chair of Urban Water Management, TU Berlin, Berlin, Germany
}

\begin{abstract}
This paper presents different computational fluid dynamics applications using the multiphase solver interFoam which is implemented in the open source software OpenFOAM. The solver uses the volume of fluid approach. When modelling tracer transport in the proximity of the interface between two phases, the problem of non-physical tracer spreading across the interface has to be overcome. In this paper, two ways are presented to model such systems successfully. First, tracer transport around concrete probes in the headspace of a sewer pilot plant is considered. In this case a two-phase (water-air) system is assumed by describing an idealized water surface as a boundary condition and a passive tracer is applied. Second, flow in a complex sewer stretch containing a hydraulic jump is simulated and a tracer is applied in the water phase. A multiphase transport approach based on the Henry coefficient is used in this case and plausible results are obtained.
\end{abstract}

Keywords: Computational Fluid Dynamics (CFD); OpenFOAM; Multiphase modelling; Transport modelling

\section{INTRODUCTION}

In the field of hydraulic engineering, shallow water flow models using the depth-averaged Navier-Stokes equations are often suitable to analyse flow phenomena. However, in certain application areas where a hydrostatic pressure distribution within the flow field is not given, these models reach their limits and alternatives have to be looked for. In the field of urban drainage such structures can occur in complex sewer systems containing hydraulic jumps due to changes of the flow regime. A thorough description of transport in the different phases and mass transfer across the phase interface can be used to describe complex species transport and biochemical processes, for example the development of odour and corrosion due to hydrogen sulphide in sewer systems. Therefore, this study focuses on transport phenomena in multiphase (water-air) systems.

When a passive advection-diffusion tracer is applied in the nearfield of the interface, a nonphysical spreading across the interface between two phases can occur. Figure 1 illustrates the problem using the example of a rectangular pipe which is partially filled with water. After a few seconds the tracer spreads across the water surface into the air due to diffusion. Since the interFoam solver only distinguishes between phases by using an additional transport equation that modifies phase specific variables, a passive tracer can spread into the air phase. This paper presents two ways to overcome this issue by using different approaches.

In the first part the headspace of a sewer pilot plant is being investigated with a simplified single-phase approach, assuming an idealized water surface. 


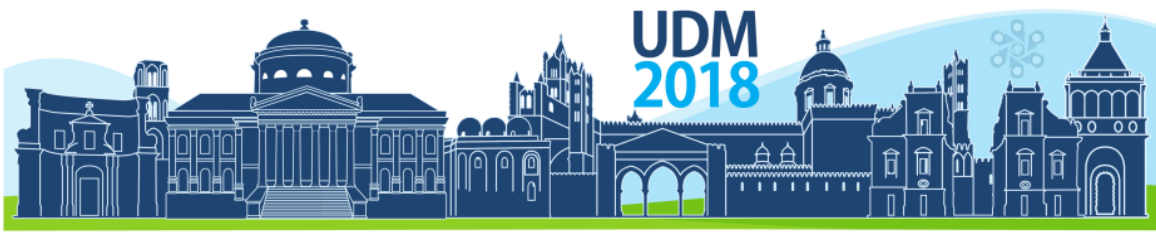

$11^{\text {th }}$ International Conference on Urban Drainage Modelling

23-26 Sep | Palermo - Italy

The second study presents tracer transport in a sewer stretch containing complex hydraulic flow phenomena. In this case the tracer is present in the water phase. A special formulation that regards the mass transfer depending on the Henry coefficient has been introduced by Haroun et al. (2010) and has been applied in this study.

\section{Standard transport equation}

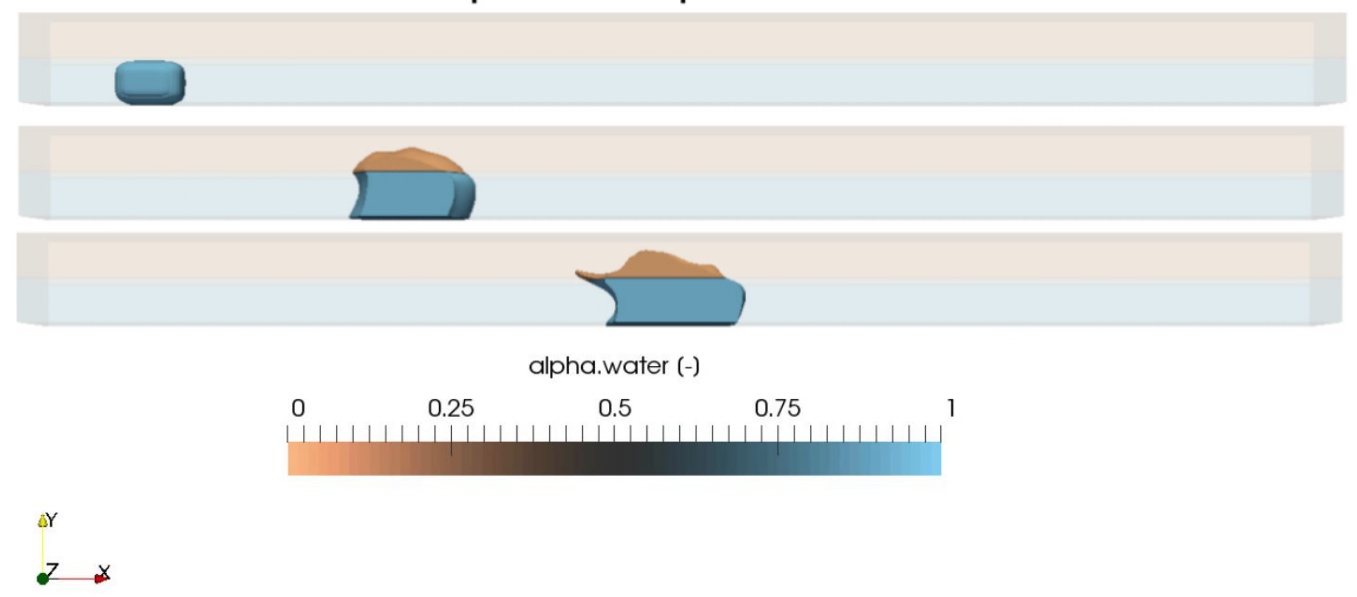

Figure 1. Tracer transport in water phase of rectangular pipe with non-physical spreading across water surface.

\section{MATERIALS AND METHODS}

\subsection{Hydrodynamic simulations}

Surface water and air flow is calculated by using the two-phase flow solver interFoam based on a volume of fluid approach for one- and two-phase flows as it is implemented in the open source model OpenFOAM. Both phases are considered as one fluid with rapidly changing fluid properties, therefore one set of Navier-Stokes-equations is solved. The phases are distinguished by an additional transport equation for the volume fraction which is used as a marker to describe the distribution of the phases throughout the domain. The governing equations can be found in Rusche (2002).

\subsection{Transport simulations}

For the first study, the transport of a passive tracer with a concentration $C$ is examined with an advection-diffusion equation that was implemented into the interFoam solver (see Eq. 1). The physical diffusivity $D_{\text {phys }}$ as well as the turbulent Schmidt number $S c_{\text {turb }}$, which defines the turbulent diffusivity coefficient $D_{\text {turb }}$, have to be defined by the user (Eq. 2):

with

$$
\frac{\partial C}{\partial t}+\nabla \cdot(C \vec{U})+\nabla \cdot\left(D_{\text {phys }}+D_{\text {turb }}\right) \nabla \cdot C=0
$$

$$
D_{\text {turb }}=\frac{\mu_{\text {turb }} / \rho}{S c_{\text {turb }}}
$$

\subsection{Mass transfer}




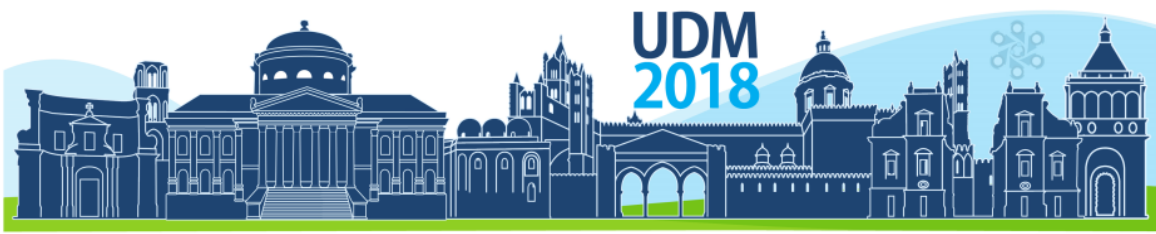

$11^{\text {th }}$ International Conference on Urban Drainage Modelling

23-26 Sep | Palermo - Italy

For the second study, the approach introduced by Haroun et al. (2010) as it has been implemented by Nieves-Remacha et al. (2015) has been used. The approach is based on the interFoam solver and adds a transport equation as outlined in Eqs. 1 and 2. At the interface the following boundary conditions have to be satisfied:

$$
\begin{gathered}
H e=\frac{C_{i}{ }^{L}}{C_{i}{ }^{G}} \\
D_{i}{ }^{L} \nabla C_{i}{ }^{L}=D_{i}{ }^{G} \nabla C_{i}{ }^{G}
\end{gathered}
$$

Where $D_{i}$ is the diffusivity and $C_{i}$ is the concentration in the respective phase. He denotes the dimensionless Henry coefficient and superscripts $L$ and $G$ denote the liquid and gas phase. To avoid spreading of the tracer across the water surface in the case presented in section 3.2 , the Henry coefficient has been set to $10^{-6}$ which prevents mass exchange across the water-air interface.

\section{RESULTS AND DISCUSSION}

\subsection{Spreading of hydrogen sulphide in headspace of sewer pilot plant (air phase)}

In the first part the headspace of a sewer pilot plant is being investigated. In the pilot plant, probes made of various types of concrete are installed to investigate their resistance against sulphuric acid corrosion. The diameter of the pipe is $400 \mathrm{~mm}$. The original setup of the pipe has a length of $25 \mathrm{~m}$, for the computational domain a length of $2 \mathrm{~m}$ has been chosen.

Simulations are performed to detect whether the concentration around the concrete probes is distributed homogeneously or whether peaks occur that might influence the corrosion rate locally. The simulations are being performed with a simplified single-phase approach, assuming an idealized water surface. Since the water surface is being described using a slip boundary condition, only the upper half of the pipe has to be discretized with the computational mesh. The computational domain is shown in Figure 2 and the resulting tracer concentration is illustrated in Figure 3. The results show an accumulation of the tracer around the probes in the rear part of the pipe.

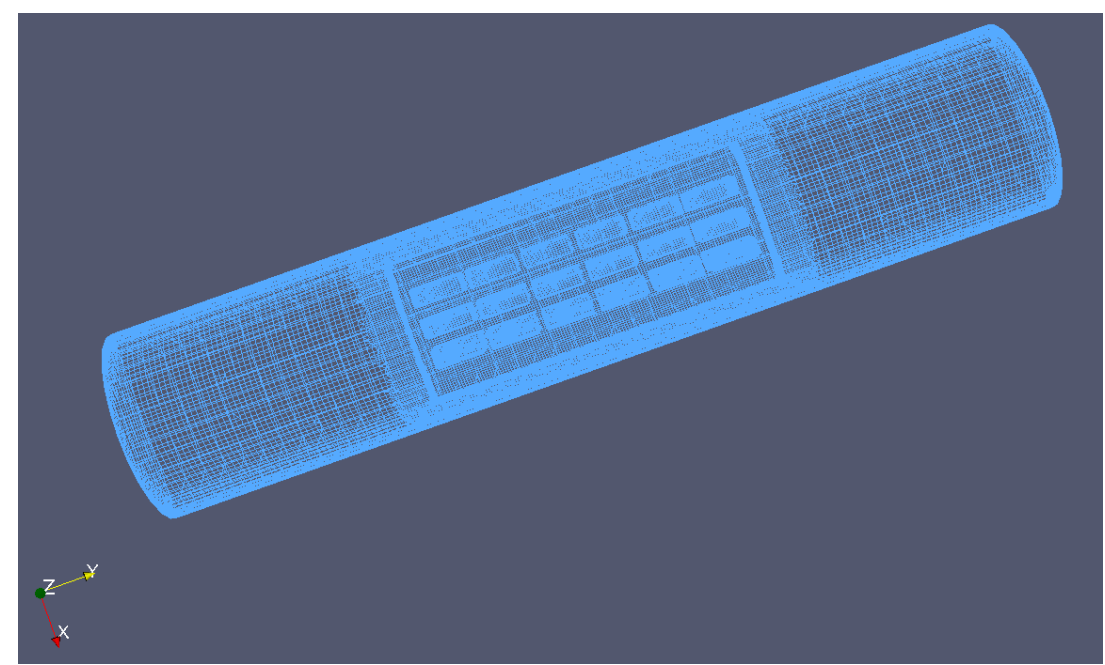

Figure 2. Top view of the model domain (pipeline containing the concrete probes). 


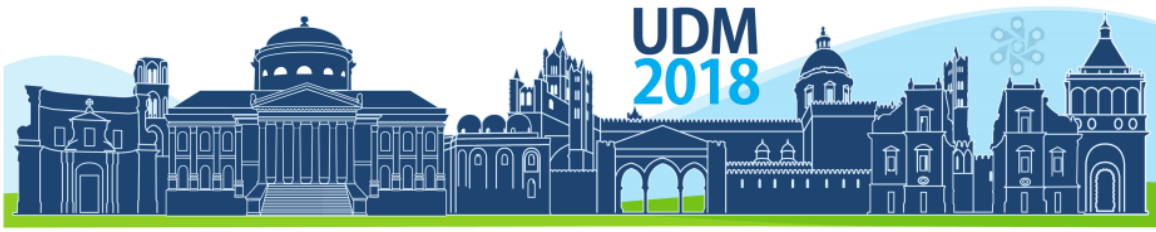

$11^{\text {th }}$ International Conference on Urban Drainage Modelling 23-26 Sep | Palermo - Italy

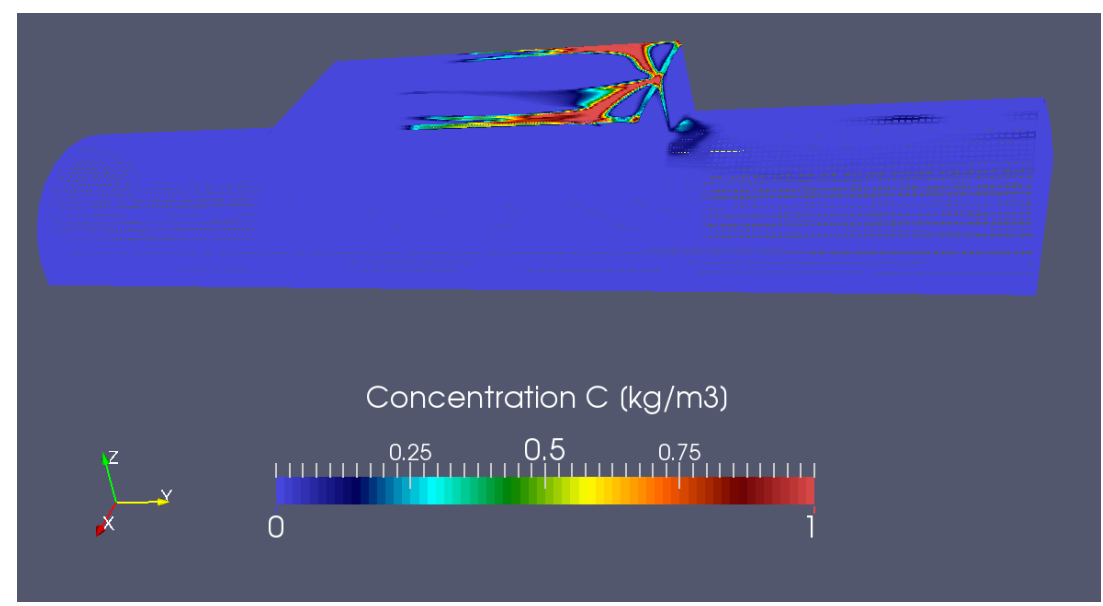

Figure 3. Resulting tracer distribution.

\subsection{Tracer transport in sewer pipe (water phase)}

In the second case, a complex sewer stretch containing a hydraulic jump has been analysed. The overall geometry has a length of roughly $90 \mathrm{~m}$ and the sewer pipe consists of different cross sections with widths up to $7.50 \mathrm{~m}$ and a maximum height of $5.63 \mathrm{~m}$ The detailed geometry has been outlined in Bayón et al. (2015). In this case the mass transfer formulation by Haroun et al. (2010) has been applied to keep the tracer in the water phase. Figure 4 shows that the tracer does not cross the water surface in the case of the simple rectangular geometry introduced in Section 1. Figure 5 illustrates the movement of the tracer along the complex sewer stretch and through the hydraulic jump. The results confirm that also in cases with high turbulence the tracer remains in the water phase.

Mass transfer equation (Haroun, 2010)

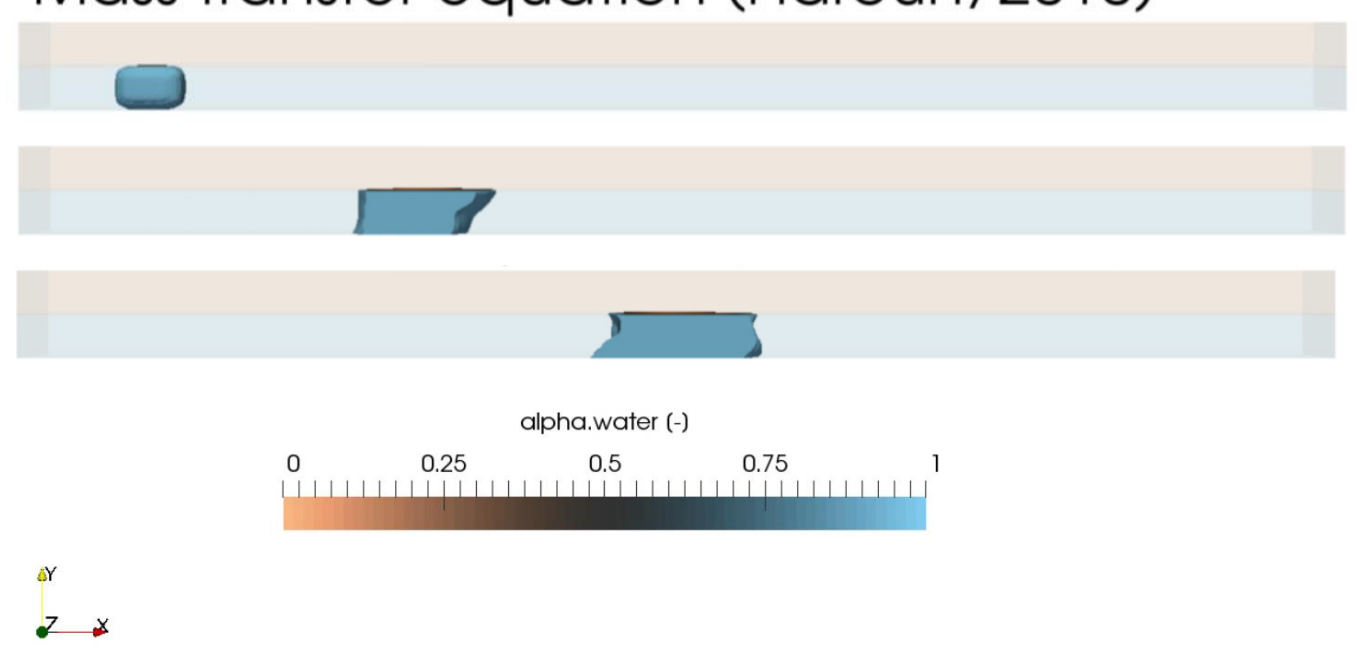

Figure 4. Movement and spreading of tracer along sewer. 


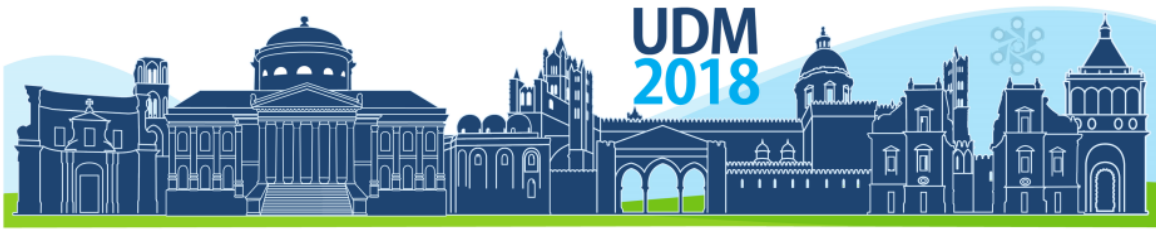

$11^{\text {th }}$ International Conference on Urban Drainage Modelling 23-26 Sep | Palermo - Italy
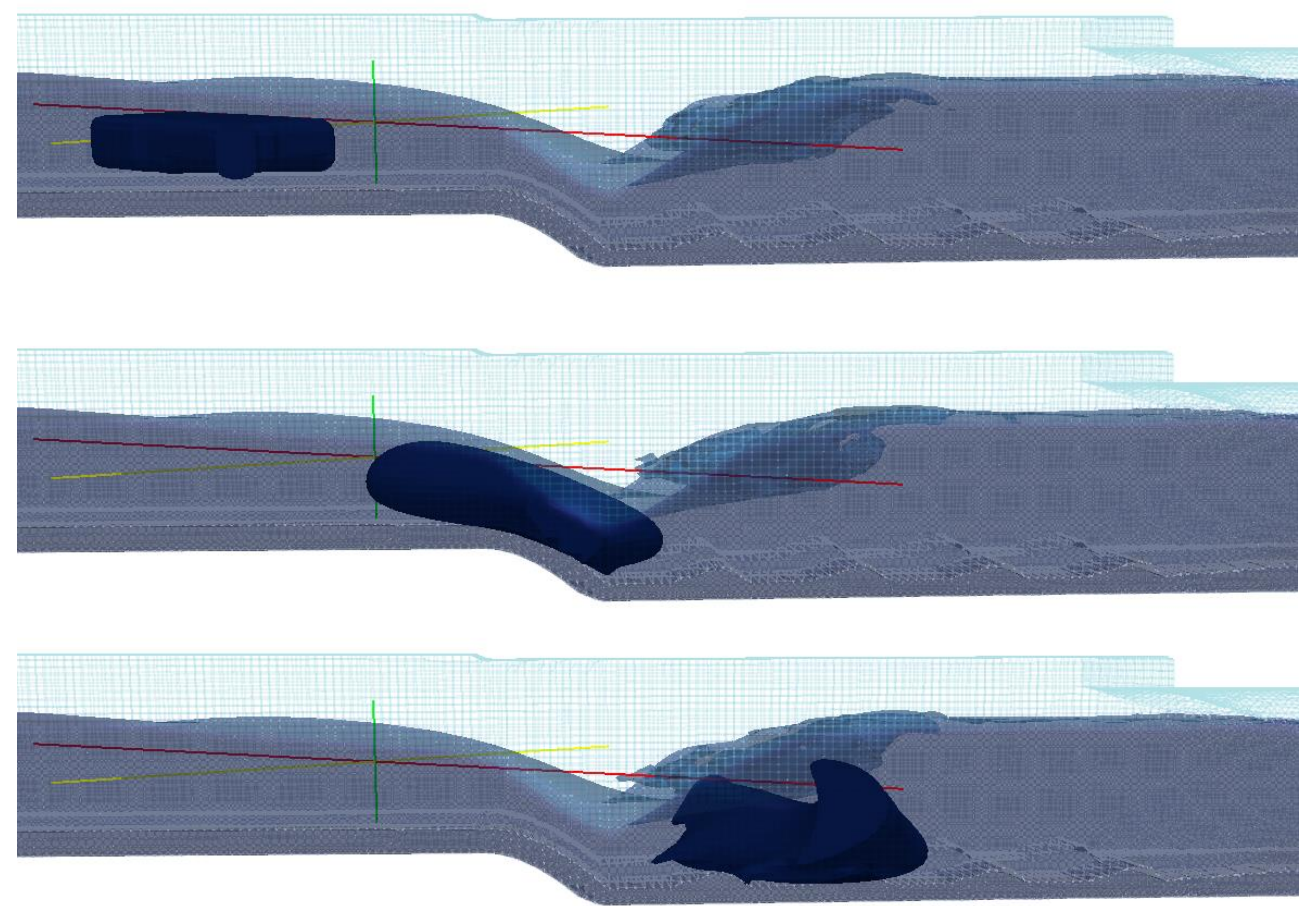

Figure 5. Movement and spreading of tracer along sewer.

\section{CONCLUSIONS}

Within this study three-dimensional two-phase (water-air) flow and transport simulations have been carried out in two different examples. These systems are difficult to model in a way that a passive advection-diffusion tracer can cross the barrier of the water surface without any physical constraints due to the formulation of the interFoam solver. In this paper, two ways are presented to overcome this obstacle. First, to model the air phase as a single phase system which can be valid for stratified flows in sewers and second, to use a mass transfer approach based on the Henry coefficient and modify the Henry coefficient in order to avoid mass transfer across the water surface.

\section{References}

Bayón, A., Valles-Morán, F. J., \& López-Jiménez, P. A. (2015). Numerical analysis and validation of South Valencia sewage collection system diversion. In 36th IAHR World Congress, The Hague, The Netherlands.

Edwini-Bonsu, S. and Steffler, P. (2006). Dynamics of air flow in sewer conduit headspace. Journal of Hydraulic Engineering, 132(8):791-799.

Haroun, Y., Legendre, D., \& Raynal, L. (2010). Volume of fluid method for interfacial reactive mass transfer: application to stable liquid film. Chemical Engineering Science, 65(10), 2896-2909.

Nieves-Remacha, M. J., Yang, L., \& Jensen, K. F. (2015). OpenFOAM computational fluid dynamic simulations of two-phase flow and mass transfer in an Advanced-Flow Reactor. Industrial \& Engineering Chemistry Research, 54(26), 6649-6659.

Rusche, H. (2002). Computational fluid dynamics of dispersed two-phase flows at high phase fractions, PhD Thesis. Imperial College London (University of London). 


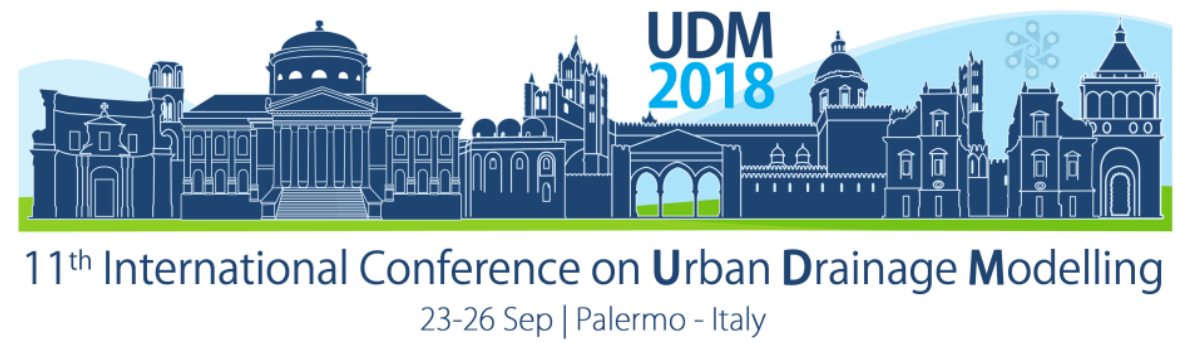

\title{
The efficiency of storm water sedimentation tanks for fine particles in urban run-off
}

\author{
Wietbüscher Maike ${ }^{1}$, Voßwinkel Nina ${ }^{1}$ and Mohn Rainer ${ }^{1}$ \\ ${ }^{1}$ Institute for Infrastructure - Water - Resources - Environment, Muenster University of Applied Sciences, \\ Department of Civil Engineering, Muenster, Germany
}

\begin{abstract}
The sedimentation process seemed to be a well-known process to treat the urban runoff before discharging it into a water body. The flow mechanisms in real-life sedimentation tanks have now been investigated closer to optimize them for finer particle fractions and interesting findings occurred. The aim of the study was to investigate the sedimentation efficiency of finer mineral particle fractions, which are suspected carriers of heavy metal loads, with the help of an induced flow characteristic. Preparatory studies showed that recirculation zones could have a positive effect on the settlement of finer particles, especially if the axis of the recirculation is horizontal and perpendicular to the flow direction. Therefore the ratio of inlet-height $\left(\mathrm{H}_{\text {Inlet }}\right)$ to the height of the sedimentation tank $\left(\mathrm{H}_{\text {Tank }}\right)$ was varied systematically to maximize the sedimentation efficiency $(n(-))$ of fine mineral particles. It was found that the particle behaviour is influenced by the shear-layer between the main flow and the various sizes of the circulation zone, which depends on the height-ratio at the inlet.
\end{abstract}

Keywords: sedimentation tank; particle efficiency; storm water run-off

\section{INTRODUCTION}

The aim of the Water Framework Directive is to achieve good ecological status for water bodies, including the protection of water bodies from pollution caused by storm water runoff which can have a harmful impact on the environment Ashley et al. (2004). Therefore, the aim of storm water treatment is to retain the fractions with the particle-bound high concentrations of pollutants such as heavy metals in sedimentation tanks. Research projects, e.g. Zhao et al. (2010), Adachi and Tainosho (2005) and Karlsson et al. (2010), have shown that the heavy metal concentrations are bound to fine particle fractions. Zhao et al. (2010) describe that $70 \%$ of the heavy metal load is bounded to the fraction with a diameter smaller than $44 \mu \mathrm{m}$.

The flow characteristics in sedimentation tanks has to be optimized for fine particles to retain them with a higher efficiency. Initially it was assumed that a uniform or rather a plug-flow characteristic in rectangular storm water tanks is a suitable characteristic for sedimentation processes Muth (1992). Current research indicates that the plug-flow characteristic is not ideal to retain this finer particle fraction.

The aim of this study was to investigate the sedimentation efficiency of finer mineral particle fractions. The influence of different inlet-heights in proportion to the height of the sedimentation tank was examined. Since the inlet is located only in the upper surface, a recirculation zone with horizontal axis forms directly behind the wall where the inlet is located and on the bottom of the tank (Fig. 1). This flow characteristic was induced because the effect of these recirculations and the effect of the shear layers between the inlet flow and the circulation flow as well as the streamline curvature showed in preparatory studies to influence positively the sedimentation behaviour of finer mineral particles. Other flow configurations with vertical or mixed axis recirculations showed less or contrary behaviour. 


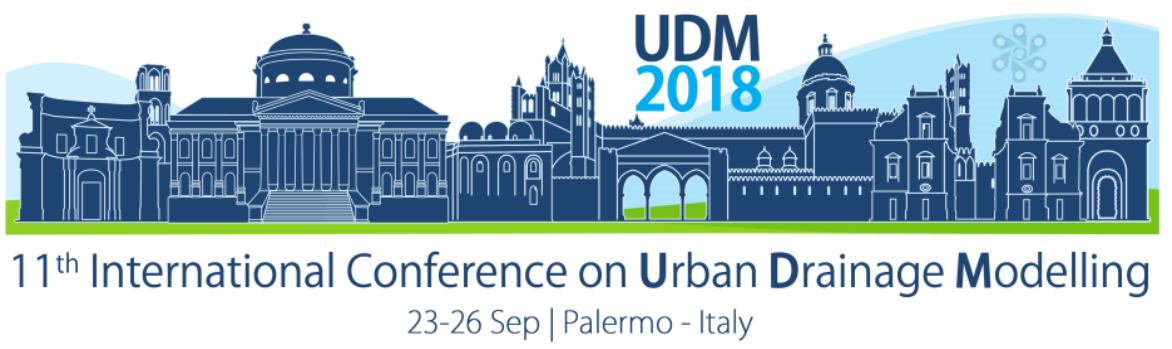

\section{MATERIAL AND METHODS}

This study was performed by three-dimensional numerical simulations using the finite volume code FLUENT, software package ANSYS Inc.

Numerous simplified geometries of sedimentation tanks have been investigated. The standard tank had dimensions of $\mathrm{L}=20.0 \mathrm{~m} \times \mathrm{W}=4.5 \mathrm{~m} \times \mathrm{H}_{\text {Tank }}=2.0 \mathrm{~m}$. The mesh consisted of 1.440 .000 hexahedra elements with $0.05 \mathrm{~m}$ cells. The tanks were simulated with a pseudotransient time step under use of the Reynolds-Stress-Turbulence-Model. This model is able to resolve anisotropic structures and models turbulent structures and circulations. The inlet boundary conditions were defined as a velocity-inlet with a block-shaped velocity-profile, and the outflow boundary conditions were set as a pressure-outlet. The efforts necessary to produce an uniform block profile between the sewer pipe and the model inlet are not addressed in this study. The free water surface was simplified by using a symmetry plane. The wall roughness is implemented with $0.005 \mathrm{~m}$. In this study the particle trajectories were modelled with the Discrete Phase Model (based on the Euler-Lagrangian method), which is completed by a random walk model for turbulent particle diffusion. The separation efficiencies of the particle fractions were analysed with a modification of the user defined function (UDF) given by Yan et al. (2014). For this study the critical bed shear stress according to van Rijn (2016) was subsequently implemented in this UDF. It decides whether a particle is trapped or reflected from the ground.

In this study, the ratio of inlet-height $\left(\mathrm{H}_{\text {Inlet }}\right)$ to the height of the sedimentation tank $\left(\mathrm{H}_{\text {Tank }}\right)$ was varied systematically for an ideal height-ratio (hr) to retain a maximum of fine mineral particles. A factor of 1.0 means a fully opened inlet, with the factor approaching zero, the inletheight decreases but the resulting velocities increase. As result a recirculation zone is induced with different sizes. The boundary condition, geometry and the scheme of flow characteristics of the sedimentation tank are illustrated in Figure 1, boundary conditions and parameters used for the simulation are shown in Table 1.

$$
\text { height }- \text { ratio } h r=\frac{H_{\text {Inlet }}}{H_{\text {Tank }}} ; \text { surface flow rate } q_{A}=\frac{\text { flow rate }}{\text { water surface }}
$$

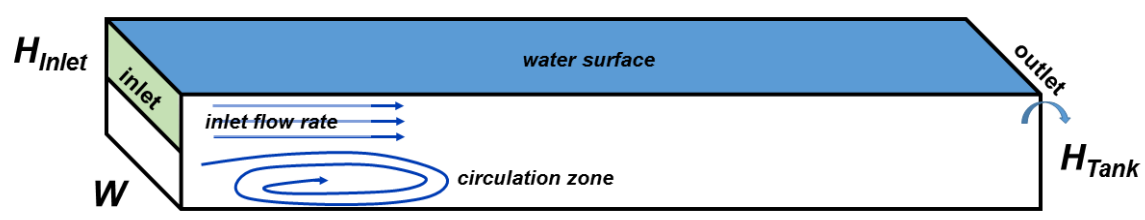

$L$

Figure 1. Boundary conditions, geometry of simulations and scheme of flow characteristics

Table 1. Boundary conditions

\begin{tabular}{lcc}
\hline & unit & value \\
\hline length $(\mathrm{L})$ & $\mathrm{m}$ & 20.00 \\
width $(\mathrm{W})$ & $\mathrm{m}$ & 4.50 \\
height $\left(\mathrm{H}_{\text {Tank }}\right)$ & $\mathrm{m}$ & 2.00 \\
height-ratios $(\mathrm{hr})$ & - & $1.0-0.0625$ \\
flow rate & $\mathrm{m}^{3} / \mathrm{h}$ & 0.25 \\
water surface & $\mathrm{m}^{2}$ & 90.00 \\
surface flow rate $\left(\mathrm{q}_{\mathrm{A}}\right)$ & $\mathrm{m} / \mathrm{h}$ & 10.00 \\
\hline
\end{tabular}




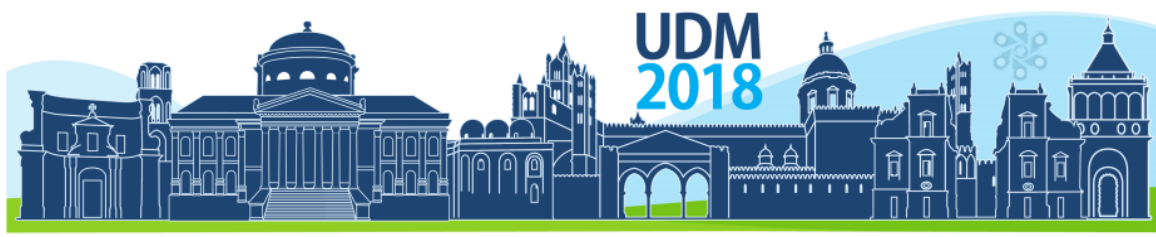

$11^{\text {th }}$ International Conference on Urban Drainage Modelling

23-26 Sep | Palermo - Italy

The separation efficiency $(n(-))$ is modelled for selected particle fractions. The results are compared with the theoretical efficiency based on the Hazen-Theory Hazen (1904) which is calculated for a plug-flow characteristic without any influence of wall, outflow structure or turbulence. The Hazen-Number is the quotient of the sedimentation velocity of the particle ( $v_{s}$ in $\mathrm{m} / \mathrm{h}$ ) and the surface flow rate $\left(\mathrm{q}_{\mathrm{A}}\right.$ in $\left.\mathrm{m} / \mathrm{h}\right)$. The surface flow rate represents the hydraulic load or surface-specific discharge intensity.

$$
\text { separation efficiency } \eta=\frac{\text { retained mass of a particle fraction }}{\text { induced mass of a particle fraction }}
$$

\section{RESULTS AND DISCUSSION}

The simulated streamlines in a defined geometry, with a height-ratio of 0.5 , are illustrated in Figure 2. The streamlines are coloured by velocity $(u)$ in main direction.

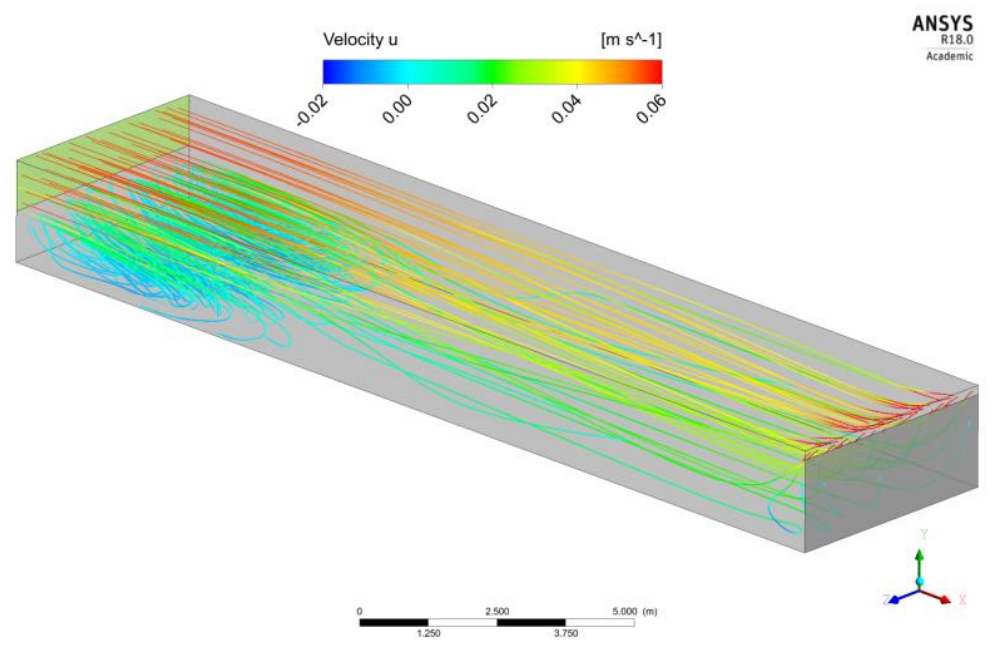

Figure 2. Streamlines visualize the flow characteristics with a height-ratio of 0.5

Flow visualization in Figure 2 shows the expected recirculation zone with a horizontal rotation axis on the bottom of the tank, right behind the inlet. The recirculation zone has low velocities (coloured blue). High velocities (coloured red) with a uniform flow are found above the recirculation zone. A rather uniform flow over the entire height could be oberserved in the rear of the basin before the flow is concentrated again for the outlet.

This simulation was carried out for different height-ratios (hr). The separation efficiencies for particle fractions for the dimensionless Hazen-Numbers have been plotted (Figure 3), where the particle diameter $(\mu \mathrm{m})$ were plotted on the secondary horizontal axis. The grey line describes the Hazen-Theory which describes the theoretical efficiency for particle fractions in an ideal laminar plug-flow. The green line illustrates the results of a ratio $\mathrm{hr}$ of 1.0 , representing a plug-flow, without recirculation zone, which is influenced only by the surrounding walls, the outlet structure and turbulence.

The blue lines in Fig. 3 show the separation efficiency of the particle fractions with ratios $\mathrm{hr}$ between 0.75 (dark blue) and 0.0625 (light blue). Most of the graphs are close to the green line, but the graph for the smallest height-ratio $\mathrm{hr}$ of 0.0625 (light blue with squares) has much better efficiencies for the finer fractions. However, the behavior of all separations 


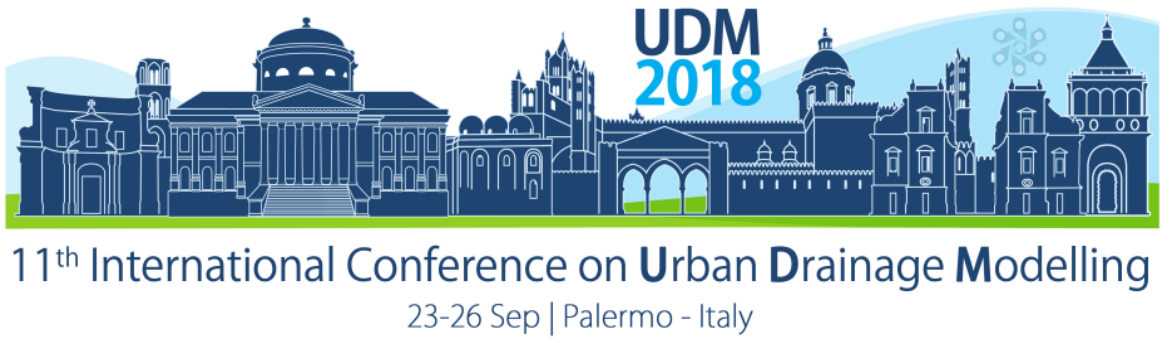

efficiencies are contrary. A point of return cannot be identified, but should be in proximity to a particle diameter of $57 \mu \mathrm{m}$ and a Hazen-Number of 0.75 . The efficiencies of the fine fractions increase with a decreasing height-ratio $\mathrm{hr}$, while they decrease for the coarse fraction. This behavior could occur due to the influence of the shear-layer between the main flow and the various sizes of the circulation zone, which depends on the height-ratio hr.

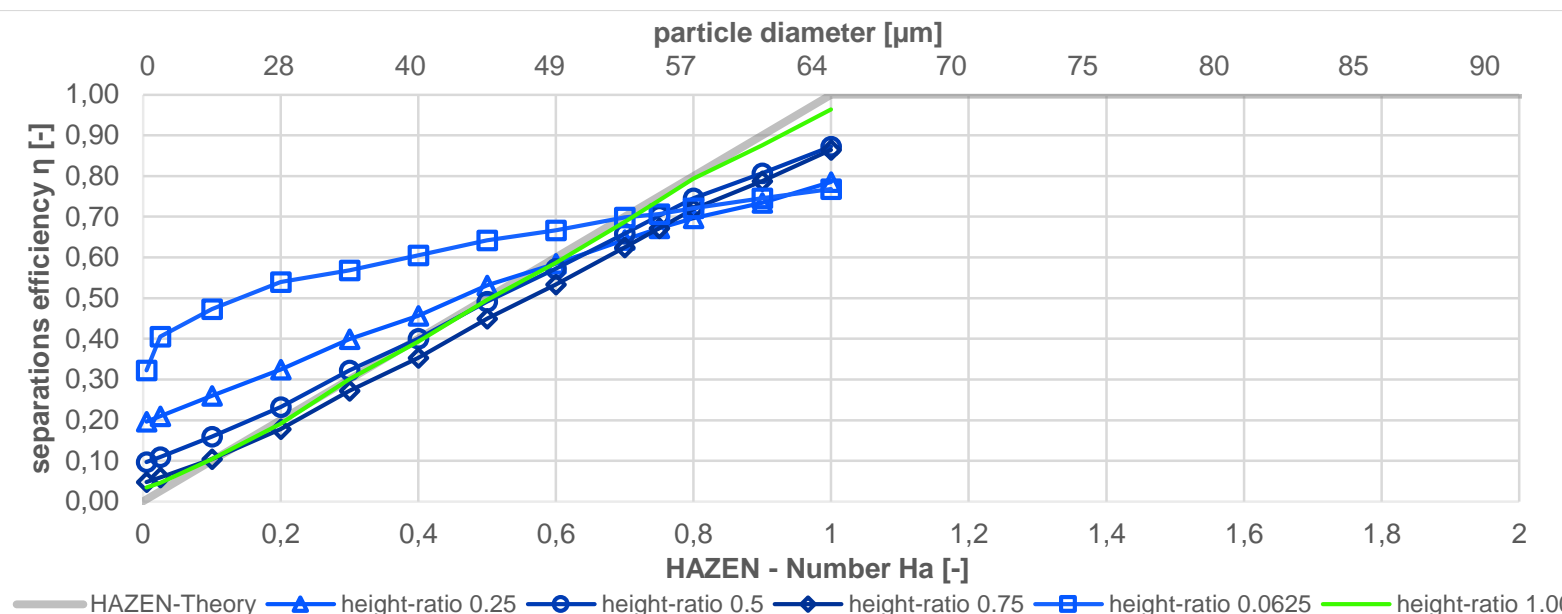

Figure 3. Chart for efficiencies of particle-fraction with simulations of different height-ratios

\section{CONCLUSIONS}

The currently harmful impacts on the environment by discharge of urban storm water run-off could be reduced by a modification of new or existing settling tanks that forms a controlled recirculation on the bottom behind the inlet. This configuration affects the sedimentation efficiency of fine particle fractions with the particle-bounded high concentrations of heavy metals. The influence of inlet-height on the separation efficiencies of different particle fractions was examined in this study. The results show a positive influence of recirculation zones on finer particle fractions, with an efficiency maximum for a height-ratio of 0.75 . Further research will be conducted on particle behavior in recirculation zones and in plug flow at the Muenster University of Applied Sciences, Institute for Infrastructure · Water · Resources · Environment (IWARU).

\section{References}

Adachi, K., Tainosho, Y., 2005. Single particle characterization of size-fractionated road sediments. Appl. Geochem. 20, 849859. https://doi.org/10.1016/j.apgeochem.2005.01.005

Ashley, R.M., Bertrand-Krajewski, J.-L., Hvitved-Jacobsen, T., Verbanck, M., 2004. Solids in Sewers - Characteristics, Effects and Control of Sewer Solids and Associated Pollutants, Scientific and Technical Report. IWA Publishing, London.

Hazen, A., 1904. On Sedimentation. ASCE Trans. 53, 45-71.

Karlsson, K., Viklander, M., Scholes, L., Revitt, M., 2010. Heavy metal concentrations and toxicity in water and sediment from stormwater ponds and sedimentation tanks. J. Hazard. Mater. 178, 612-618. https://doi.org/10.1016/j.jhazmat.2010.01.129

Muth, W., 1992. Regenüberlaufbecken - Strömungsuntersuchung an Durchlaufbecken. Korresp. Abwasser 39, $910-915$.

van Rijn, L.C., 2016. Initiation of motion and suspension of mud-sand mixtures.

Yan, H.X., Kouyi, G.L., Gonzalez-Merchan, C., Becouze-Lareure, C., Sebastian, C., Barraud, S., Bertrand-Krajewski, J.L., 2014. Computational fluid dynamics modelling of flow and particulate contaminants sedimentation in an urban stormwater detention and settling basin. Environ. Sci. Pollut. Res. 21, 5347-5356. https://doi.org/10.1007/s11356-013-2455-6

Zhao, H., Li, X., Wang, X., Tian, D., 2010. Grain size distribution of road-deposited sediment and its contribution to heavy metal pollution in urban runoff in Beijing, China. J. Hazard. Mater. 183, $203-210$. https://doi.org/10.1016/j.jhazmat.2010.07.012 


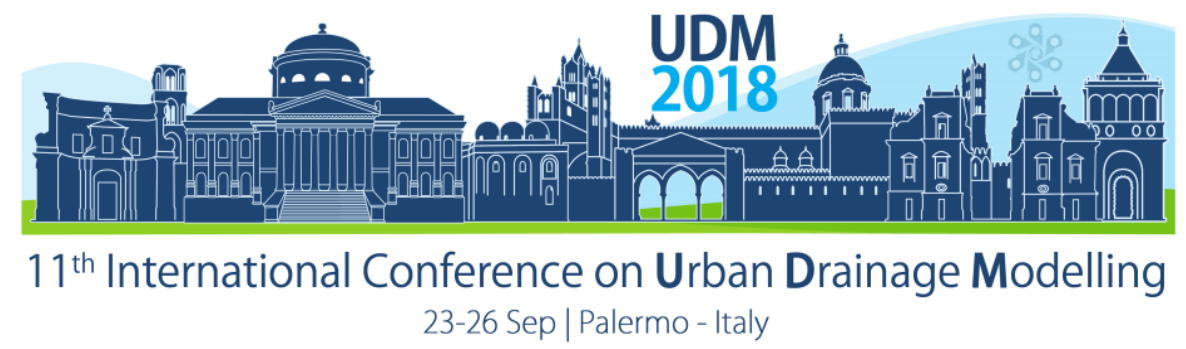

\title{
Relevance Of Different CSO Outlets For Bathing Water Quality In A River System
}

\author{
Mathias Riechel ${ }^{1}$, Wolfgang Seis ${ }^{1}$, Andreas Matzinger ${ }^{1}$, Erika Pawlowsky-Reusing ${ }^{2}$, Pascale Rouault ${ }^{1}$ \\ ${ }^{1}$ Kompetenzzentrum Wasser Berlin, Berlin, Germany \\ 2 Berliner Wasserbetriebe, Berlin, Germany
}

\begin{abstract}
Combined sewer systems are one of the major sources of microbiological contamination in urban water bodies. However, identification of hotspots for pathogen emissions is not straightforward, especially in large and complex drainage systems. To determine the relevance of different CSO outlets for bathing water quality a simple tracer approach which uses wastewater volume as a proxy for pathogen emissions has been developed and tested for the city of Berlin, Germany. The approach reveals that the average wastewater ratio in CSO varies largely between different river outlets (0 to 15\%). Hence, the outlets with the largest CSO volumes are not automatically the greatest wastewater emitters and assumed hotspots for pathogen contamination do not coincide with hydraulic hotspots. This is verified with own measurements that show enormous differences in pathogen concentrations between waste and stormwater of 4 orders of magnitude. As a result, wastewater which represents only $5 \%$ of the CSO volume contributes $>99 \%$ of the pathogen loadings to the river. The study highlights the relevance of wastewater volumes for the identification of point sources for the hygienic impairment of water bodies.
\end{abstract}

Keywords: CSO, Pathogens, Bathing water, Wastewater tracer

\section{INTRODUCTION}

The revised Bathing Water Directive (EU 2006) requests that member states take appropriate measures to achieve at least sufficient bathing water quality at European bathing sites. To comply with the regulation and allocate measures effectively it is necessary to first identify the sources of microbiological contamination.

Different authors found that combined sewer overflows (CSO) are one of the major reasons for hygienic impairment of urban water bodies (Bryan Ellis and Yu 1995; Passerat et al. 2011; Rechenburg et al. 2006). However, it is not straightforward to find the actual hotspots of pathogen emissions, especially in large combined sewer systems with a multitude of different CSO outlets. This is assumed to be partly due to the enormous differences in pathogen concentrations between waste and stormwater and the uneven distribution of wastewater flows in many combined sewer networks. The latter is particularly the case when parts of the combined sewer system also receive stormwater runoff of the separate sewer system as in Berlin.

This paper presents a simple tracer approach to identify the relevance of different CSO outlets for bathing water quality in the urban river system of Berlin, Germany. The tracer approach is implemented in a hydrodynamic model of the city's combined sewer system and is verified with measurements of Escherichia coli and somatic coliphages. 


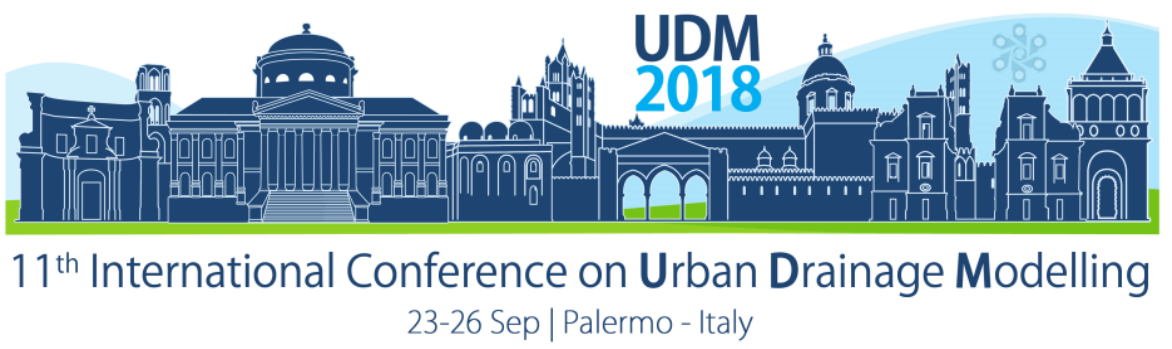

\section{MATERIALS AND METHODS}

\subsection{Study site}

The combined sewer system (CSS) of the city of Berlin covers an impervious area of $66 \mathrm{~km}^{2}$ and drains wastewater of 1.5 million inhabitants. The CSS has a total length of approx. $2000 \mathrm{~km}$ and is connected to the river system via 176 CSO outlets, discharging in case of heavy rainfall. The CSO outlets are located at the River Spree, its side-channels and the Lower Havel along a total distance of $\sim 50 \mathrm{~km}$. While the River Spree and its side channels are mostly used for shipping and recreation, the Lower Havel has different declared bathing sites $\sim 5 \mathrm{~km}$ downstream of the CSS. The typical flow time for that river stretch is 1 to 2 days.

\subsection{CSO emission model}

A hydrodynamic model of the combined sewer system was set up in the software InfoWorks and initially calibrated by Pawlowsky-Reusing et al. (2006). Since then the model was constantly refined and recently validated by Riechel et al. (2016). The model consists of 3210 subcatchments, 4810 conduits and 4621 manholes. For this study the InfoWorks ICM software package (Innovyze 2017, version 7.0) was used. InfoWorks solves the full St. Venant equations and thus accounts for backwater effects and reverse flow, both of which occur in the Berlin sewer system. Surface runoff is simulated with the Desbordes routing model under consideration of initial losses and evaporation. Domestic and commercial wastewater flow is represented in form of hydrographs.

\subsection{Tracer calculation}

Assuming a highly diverging microbiological contamination potential of the waste and stormwater portions of CSO, a wastewater tracer was simulated as a proxy for fecal pathogens. The tracer is transported advectively with the flow and is neither subject to sedimentation nor degradation. A concentration of $100 \mathrm{mg} \mathrm{L}^{-1}$ in domestic and commercial wastewater and of $0 \mathrm{mg} \mathrm{L}^{-1}$ in stormwater runoff was assigned to the tracer as constant values. The wastewater ratio at any point in the combined sewer network can be directly derived from the simulated tracer concentration (Example in Fig. 1).

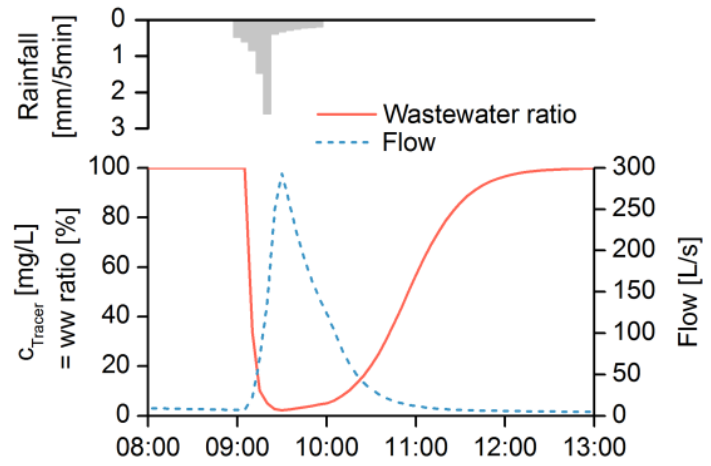

Figure 1. Rainfall, flow and wastewater ratio in a combined sewer.

To confirm the relevance of the wastewater portion in CSO for the microbiological contamination of urban rivers total loads of Eschericia coli and somatic coliphages originating from the waste and stormwater portion of CSO were calculated. Own measurements in stormwater runoff (Seis et al. 2016) and in raw wastewater (unpublished data) were used.

CSO volumes and wastewater ratios were simulated for the summer period of the year 2016 (May to October). Precipitation data of 9 rain gauges at a 5-min interval was considered with total rainfall ranging between 199 and $261 \mathrm{~mm}$.

\section{RESULTS AND DISCUSSION}

For the summer period 2016 a total CSO volume of 2.9 million $\mathrm{m}^{3}$ with $144,000 \mathrm{~m}^{3}$ discharged wastewater ( $5 \%$ of the CSO volume) is simulated. Wastewater ratios vary largely 


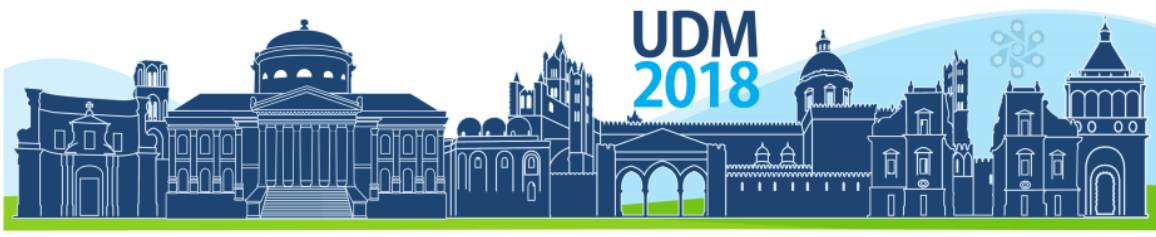

$11^{\text {th }}$ International Conference on Urban Drainage Modelling

23-26 Sep | Palermo - Italy

between different CSO outlets (Fig. 2). At 20 outlets, primarily those that receive additional surface runoff of the separate sewer system, only marginal wastewater portions $(<1 \%)$ are simulated. On the other hand, 12 outlets have a mean wastewater ratio $>10 \%$, typically in catchments with relatively large populations and a small specific storage capacity. Temporal variability is also very distinctive at some outlets. Highest wastewater ratios are typically observed in the beginning of a rainfall event when sewers are still filled with dry-weather flow. Figure 2 shows the frequency distribution of the wastewater ratio at three exemplary CSO outlets with mean wastewater ratios of $0.2 \%$ (a), $5.3 \%$ (b) and $13.1 \%$ (c).

a)

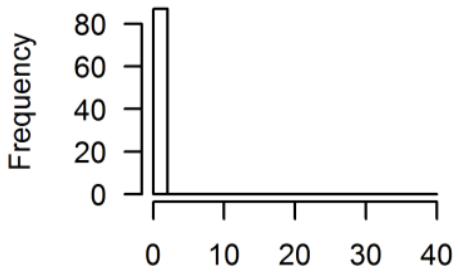

ww ratio [\%] b)

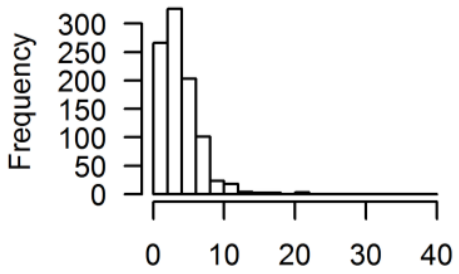

ww ratio [\%] c)

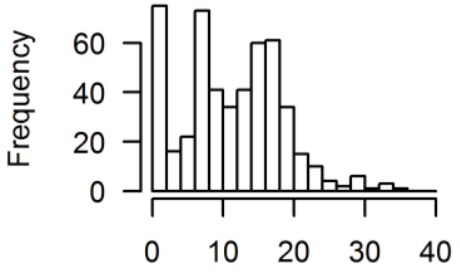

ww ratio [\%]

Figure 2. Distribution of simulated wastewater ratios at three exemplary CSO outlets located at Landwehrkanal km 1.6 (a), Landwehrkanal km 1.7 (b) and Spree km 6.0 (c).

Following the quantification of wastewater ratios and associated volumes, hotspots for wastewater discharges and potential microbiological contamination were mapped. Results show that the outlets with the largest CSO volumes (Fig. 3, left) are not necessarily the ones with the highest wastewater volumes (Fig. 3, right). Vice versa, the two outlets with the highest wastewater contribution (in sum $26 \%$ ) discharge only $13 \%$ of the total CSO volume and would eventully not have been detected with a solely hydraulic simulation approach.
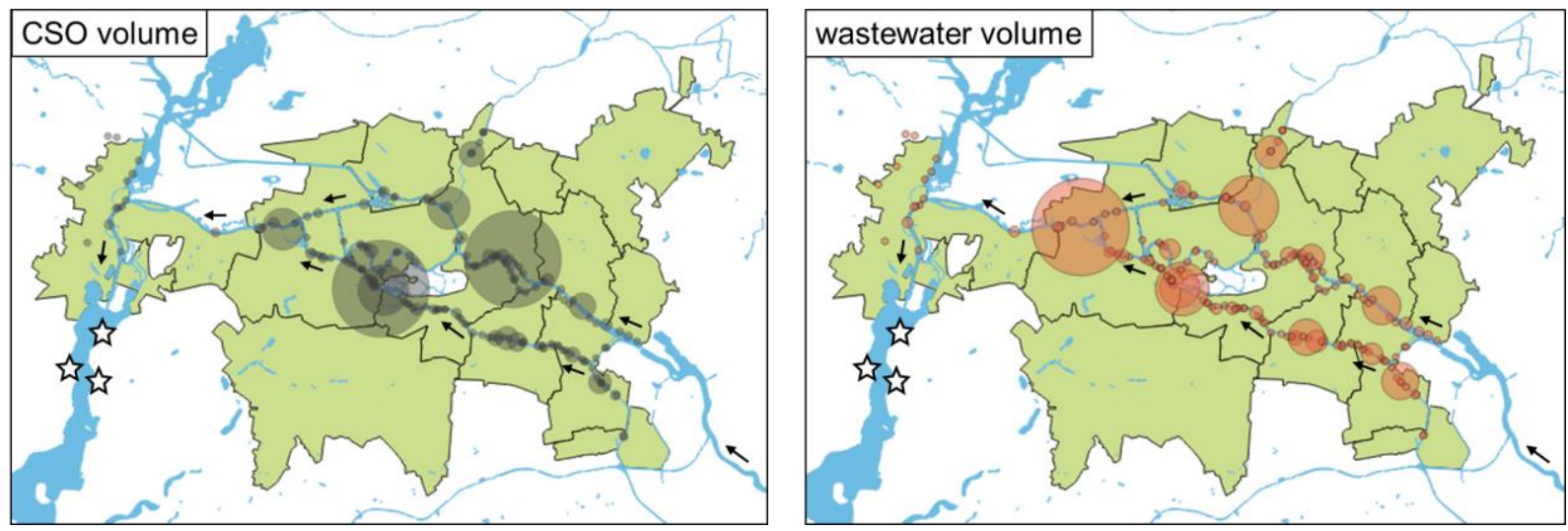

Figure 3. Locations of total CSO (left) and wastewater discharges (right) of the Berlin combined sewer system. The size of the circles is proportional to the simulated CSO and wastewater volumes. Arrows indicate the flow direction. The stars represent the downstream bathing sites.

Measurements indicate that pathogen concentrations in wastewater are approx. 4 orders of magnitude higher than in stormwater. As a consequence, wastewater which represents only $5 \%$ of the CSO volume contributes $>99 \%$ of the total pathogen loadings to the river (Table 1). This highlights the importance of simulating wastewater volumes when identifying point sources for the hygienic impairment of water bodies. 


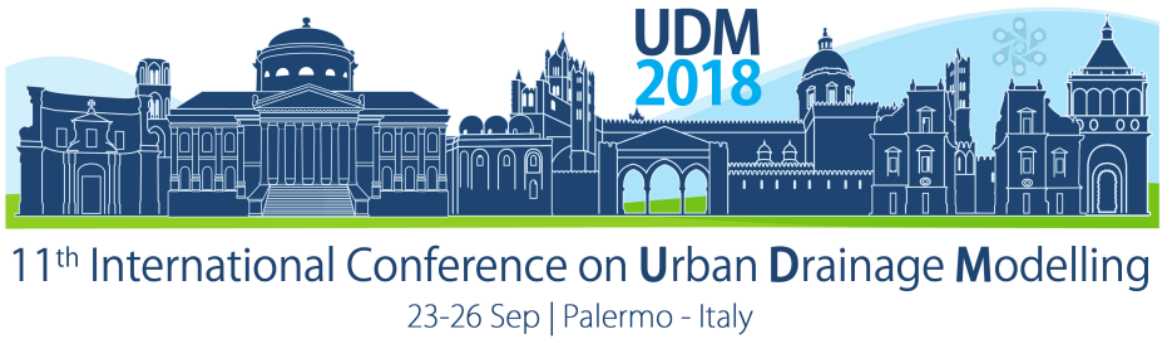

Table 1. Simulated CSO volume, measured concentrations for E. coli and somatic coliphages and resulting pathogen loadings via the storm and wastewater portions of CSO. Measurements refer to event mean concentrations for stormwater $(n=9)$ and single samples for wastewater $(n=11)$.

\begin{tabular}{lcccccc}
\hline & & \multicolumn{2}{c}{ E. coli } & & \multicolumn{2}{c}{ S. Coliphages } \\
\cline { 3 - 4 } \cline { 6 - 7 } & $\begin{array}{c}\text { Simulated } \\
\text { volume }\left[\mathrm{m}^{3}\right]\end{array}$ & $\begin{array}{c}\text { Concentration } \\
{[\mathrm{MPN} / 100 \mathrm{~mL}]}\end{array}$ & $\begin{array}{c}\text { Loading } \\
{[\mathrm{MPN}]}\end{array}$ & & $\begin{array}{c}\text { Concentration } \\
{[\mathrm{PFU} / 100 \mathrm{~mL}]}\end{array}$ & $\begin{array}{c}\text { Loading } \\
\text { [PFU] }\end{array}$ \\
\hline Wastewater & $1.4 \times 10^{5}$ & $1.4 \times 10^{8}$ & $2.1 \times 10^{17}$ & & $2.8 \times 10^{5}$ & $4.1 \times 10^{14}$ \\
Stormwater & $2.7 \times 10^{6}$ & $8.9 \times 10^{3}$ & $2.4 \times 10^{14}$ & & $5.1 \times 10^{1}$ & $1.4 \times 10^{12}$ \\
\hline
\end{tabular}

\section{CONCLUSIONS}

The following key conclusions can be drawn:

- A simple wastewater tracer can be used as a proxy for pathogen emissions from a combined sewer system.

- Hotspots for microbiological contamination do not necessarily correspond with the CSO outlets that discharge the largest volumes.

- For the improvement of bathing water quality mitigation measures may be implemented at different locations than measures to tackle other water quality goals, e.g. the elimination of severe oxygen deficits.

- The presented approach can be employed also for other contaminants which are primarily associated with wastewater such as paracetamol or ibuprofen (Weyrauch et al. 2010).

\section{Acknowledgments}

The presented paper highlights results of the project FLUSSHYGIENE funded by the German Federal Ministry of Education and Research (BMBF, grant number 02WRS1278A) and the Berlin water utility (BWB).

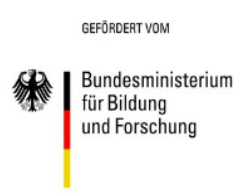

\section{References}

Bryan Ellis J. and Yu W. (1995) Bacteriology of urban runoff: The combined sewer as a bacterial reactor and generator. Water Science and Technology 31(7), 303-10.

EU (2006) Directive 2006/7/EC of the European Parliament and of the Council of 15 February 2006 concerning the management of bathing water quality and repealing Directive 76/160/EEC.

Innovyze (2017) InfoWorks ICM SE User Manual. Version 7.0. Wallingford.

Rechenburg A., Koch C., Claßen T. and Kistemann T. (2006) Impact of sewage treatment plants and combined sewer overflow basins on the microbiological quality of surface water. Water Science \& Technology 54, 95-9.

Passerat J., Ouattara N. K., Mouchel J. M., Vincent R. and Servais P. (2011) Impact of an intense combined sewer overflow event on the microbiological water quality of the Seine River. Water Research 45(2), 893-903.

Pawlowsky-Reusing, E., Schroeder, K., Meier, I., Mannel, R. (2006) ISM - Integrated Sewage Management Final Research Report. Kompetenzzentrum Wasser Berlin, p. 419.

Riechel M., Matzinger A., Pawlowsky-Reusing E., Sonnenberg H., Uldack M., Heinzmann B., Caradot N., von Seggern D. and Rouault P. (2016) Impacts of combined sewer overflows on a large urban river Understanding the effect of different management strategies. Water Research 105, 264-73.

Seis, W., Wicke, D., Caradot, N., Schubert, R., Matzinger, A., Rouault, P., Heinzmann, B., Weise, L., Köhler, A. (2016) Quantifying microbial contamination in urban stormwater runoff. $9^{\text {th }}$ International Conference NOVATECH. Lyon, France, 28 June-1 July 2016.

Weyrauch P., Matzinger A., Pawlowsky-Reusing E., Plume S., von Seggern D., Heinzmann B., Schroeder K. and Rouault P. (2010) Contribution of combined sewer overflows to trace contaminant loads in urban streams. Water Research 44(15), 4451-62. 


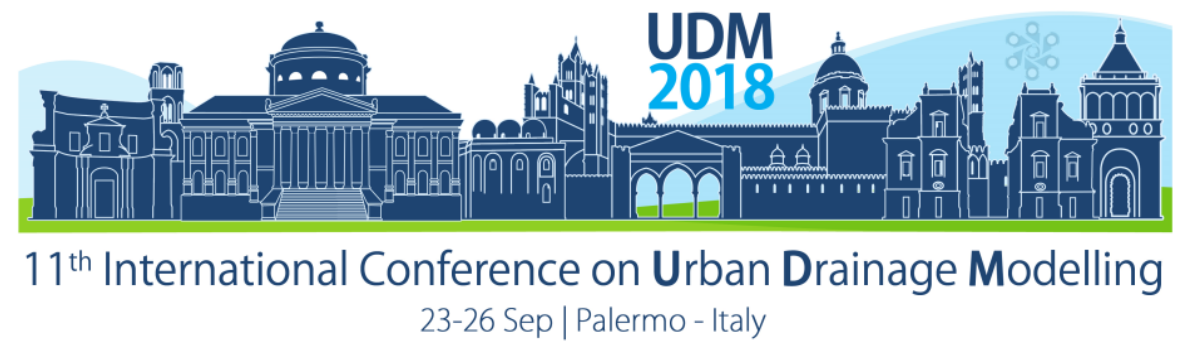

\title{
Pollutant loading of different particle size fractions compared to the pollutant loads of urban stormwater runoff events.
}

\author{
Baum Philipp ${ }^{1}$ and Dittmer Ulrich ${ }^{1}$ \\ ${ }^{1}$ Institute for Sanitary Engineering, Water Quality and Solid Waste Management (ISWA), University of Stuttgart, \\ Department of Urban Drainage, Stuttgart, Germany
} (Bandtäle 2, D-70569 Stuttgart, Germany)

\begin{abstract}
A stormwater monitoring campaign at a treatment facility is undertaken to further investigate the relationship of TSS removal and the reduction of micropollutant loads. Therefore the particle characteristics are investigated as well as the associated pollutants within different particle size fractions. First results in terms of pollutant loadings are used to calculate the respective PAH loads of the sampled rain events. Furthermore on the basis of the current monitoring campaign, TSS data of a preliminary investigation is used to also calculate the pollutant loads of this time period. The comparison reveals, that a difference between the two monitoring campaigns can be seen. In a next step, the loadings of different substances (flame retardants, plasticisers, pesticides) will be evaluated in the same way.
\end{abstract}

Keywords: stormwater treatment; particle characteristics; pollutant loads

\section{INTRODUCTION}

Urban stormwater runoff can be highly contaminated. It is recognized to have significant negative impact on aquatic ecosystems worldwide. To design effective treatment measures a realistic estimation of urban stormwater pollutant loads is required. Very often models are used to support the process of planning and the implementation of urban drainage strategies. However, due to the fact that usually models are based upon empirical equations or simple regression functions to simulate the complex reality of nature, model outputs can be highly uncertain (Dotto et al. 2010). In regards to the simulation of treatment processes or in-sewer processes, in depth knowledge of physical and chemical particle characteristics such as particle size distribution (PSD), organic content, settling velocities or pollutant loading etc. is very important.

In this abstract the pollutant loads of polycyclic aromatic hydrocarbons (PAHs) for different particle size fractions for 9 sampled rain events of an ongoing monitoring campaign are shown. The preliminary found pollutant loading (mass of pollutant per mass of total suspended solids) associated with particles in different size fractions is used to calculate the PAH loads of an earlier monitoring program at the same study site. The background of this ongoing study is to further investigate the hypothesis that with the removal of total suspended solids (TSS) a significant amount of particulate micropollutants can be removed as well. However, this hypothesis is strongly dependent on the characteristics of the particles in urban runoff and their associated micropollutants. If, as literature suggests, the fine fraction is contaminated the most (Xanthopoulos and Hahn 1990), as well as the amount of fine particles in urban runoff is about $70-80 \%$ of the total suspended solids (Fuchs et al. 2013), the hypothesis is doubtful. Due to the overall better removal efficiency of coarse particles, this less polluted fraction would be 


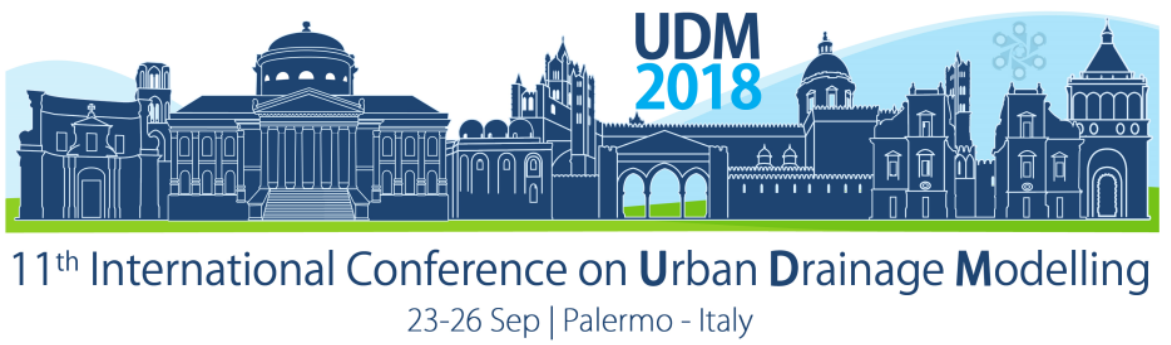

removed but the major part of pollutants would reaches the receiving waters with the fine fraction.

\section{MATERIALS AND METHODS}

\subsection{Study area and monitored treatment facility}

The catchment is located in the city of Freiburg in the south west of Germany. The area mainly consists of industrial and commercial buildings. It has a size of 110 ha with a degree of paving of 0.7 . The complete catchment is served by a separate system. At the outlet of the area the stormwater sewer has a diameter of $2 \mathrm{~m}$ and is part of the treatment facility located there. It is an underground concrete build facility. Due to a movable weir it is possible to discharge water after a certain sedimentation period (currently $6 \mathrm{~h}$ ) into the receiving water. The retained and after the sedimentation period highly polluted water is then directed to the waste water sewer.

\subsection{Sampling strategies and laboratory analyses}

Large volume sampling tanks with a volume of about $1000 \mathrm{~L}$ are used. Two submersible pumps fill these containers volume proportional to each discharge (treated water and retained waste water). After a sedimentation time of about 3 to 5 days the solids are taken out of the containers and brought to the laboratory for further analysis. The analysis includes the PSD $(<63 \mu \mathrm{m}, 63-$ $125 \mu \mathrm{m}, 125-250 \mu \mathrm{m}$ and 250-2000 $\mu \mathrm{m}$ ), the corresponding event mean concentrations (EMC) as well as the organic content of the particles in the respective size fractions. Furthermore the samples are analyzed for numerous micropollutants. The sample taking, the preparation of the samples and the analytical steps are modified from (Fuchs et al. 2013; Dierschke and Welker 2015). A more detailed description of the study area, and the sampling and laboratory analyses can be found in (Baum and Dittmer 2017).

\section{RESULTS AND DISCUSSION}

The obtained results so far, in terms of pollutant loading within different particle size fractions, show an almost similar loading for three size fractions (Baum and Dittmer 2017). This loading is the bases for the calculation of the following particulate PAH loads.

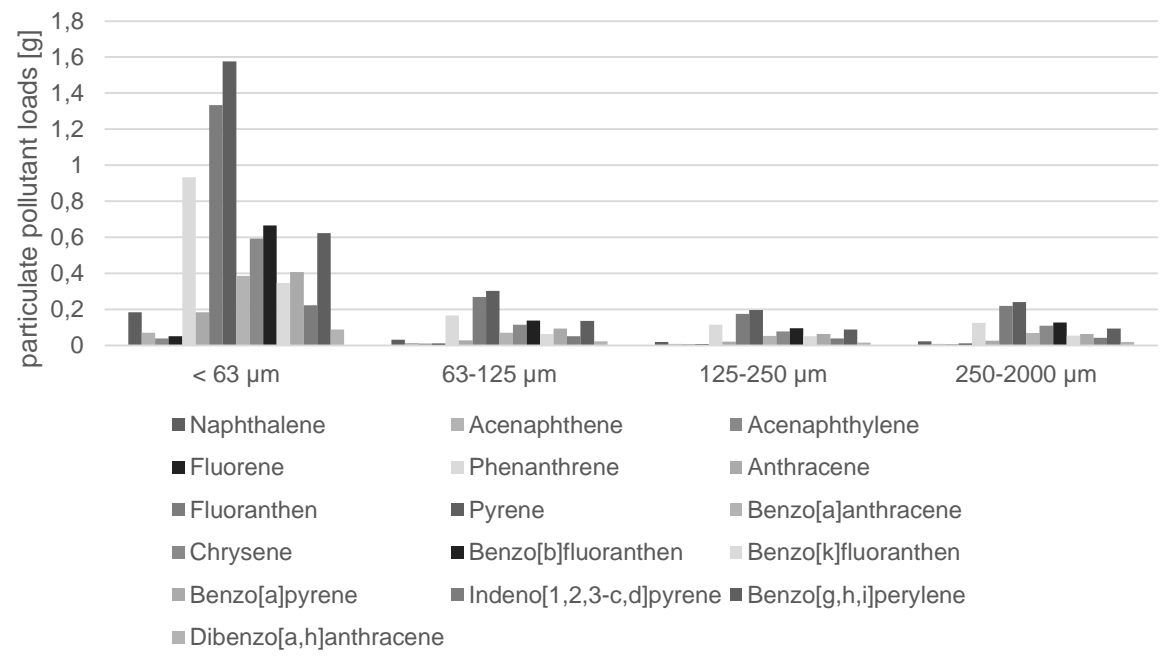

Figure 1. Total particulate load of the 16 EPA PAHs in different particle size fractions of 9 sampled rain events from February to May 2017 


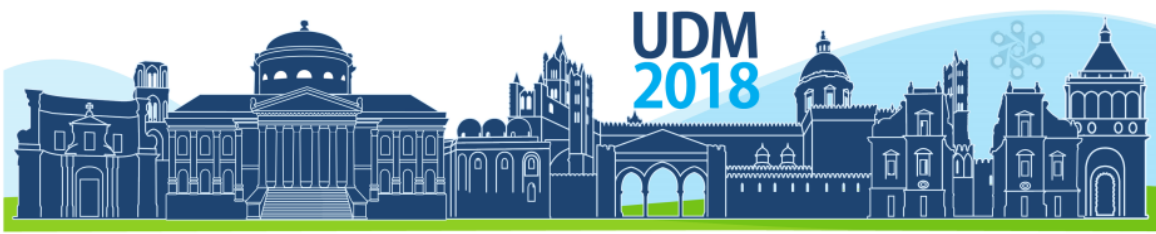

$11^{\text {th }}$ International Conference on Urban Drainage Modelling

23-26 Sep | Palermo - Italy

Figure 1 shows the loads of 9 sampled rain events from February to May 2017. It can be seen, that the smallest particle size fractions is associated with the highest particulate PAH loads for all of the 16 EPA PAHs.

With the assumption of the same PSD for the coarse size fraction, as in the current investigation, the monitored TSS loads of a preliminary study at the same side ( 23 rain events have been sampled from Nov.2015-Nov.2016) was used to calculate the associated PAH loads (figure 2). In figure 3, the coarse particle size fractions of the 9 sampled rain events (figure 1) are summed up. This allows a better comparison of the two different time periods. The loads in 2015/2016 are clearly higher than those in 2017.

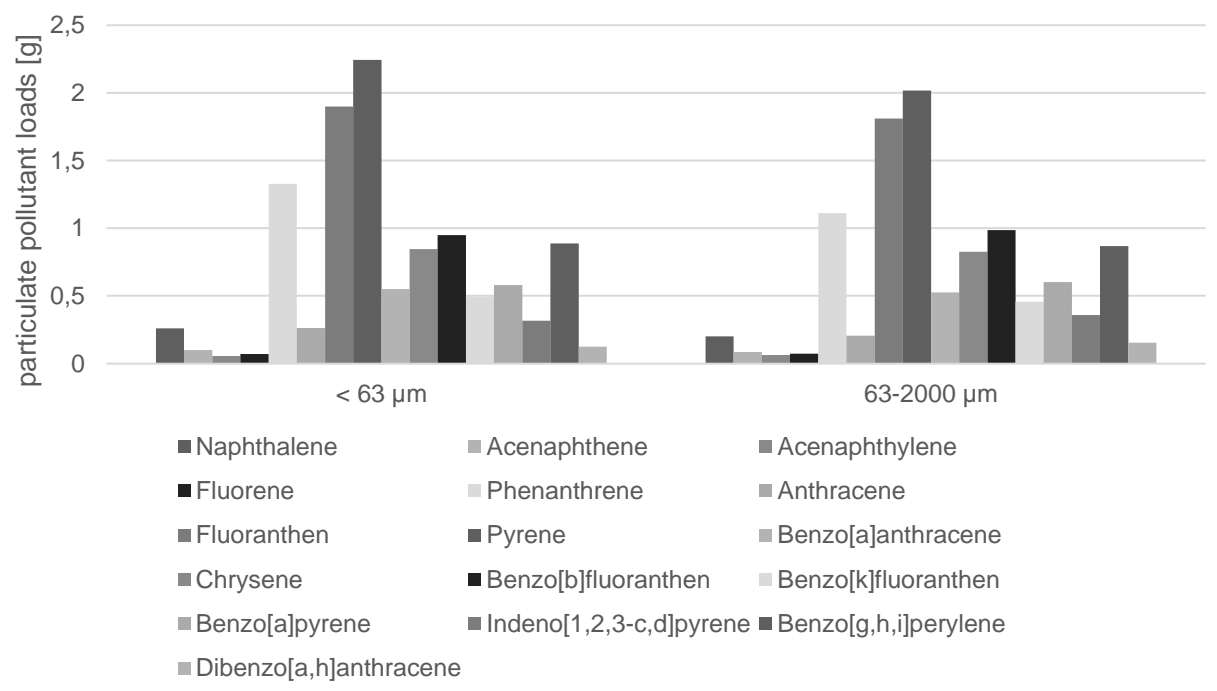

Figure 2. Total particulate load of the 16 EPA PAH in two different particle size fractions for 23 rain events from Nov.2015-Nov.2016. Calculated with the particle loading found in the current investigation, assuming the same PSD within the coarse size fraction as monitored in the current study.

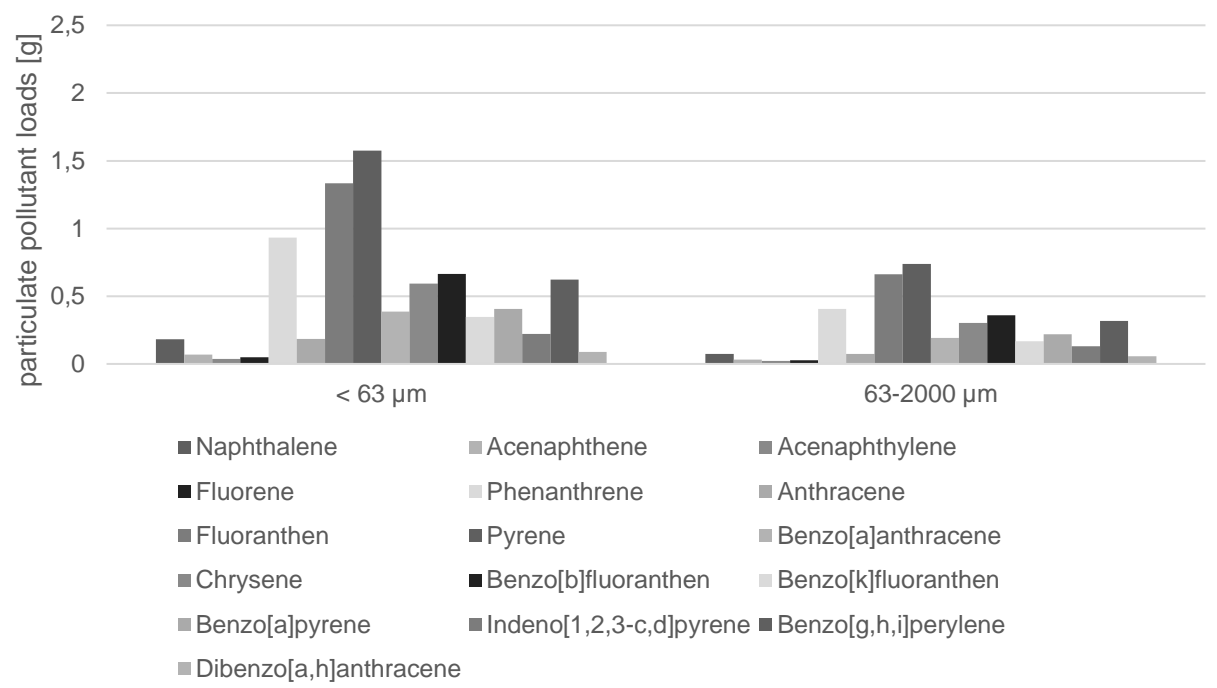

Figure 3. Total particulate load of the 16 EPA PAH in two different particle size fractions of 9 sampled rain events from February to May 2017.

By removing the better settable coarse particles in figure 2, almost $50 \%$ of the total PAH load can be removed as well. Bearing in mind, that most treatment facilities are more effective in 


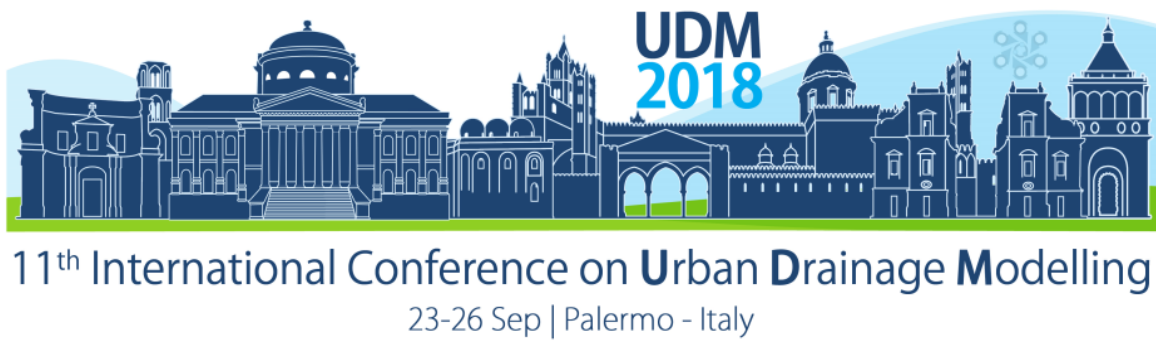

removing coarser stormwater particles. Regarding the sampled events in 2017 the overall tendency is similar. By removing the coarse particle fraction, about one third of the total amount of PAHs could be removed.

The obvious difference between the two time periods can be explained by different facts. First, there are underlying uncertainties that are associated with the sample taking as well as the laboratory analysis. Second, the calculated loads of the different time periods are based on a different amount of sampled volume. The 23 sampled rain events in 2015/2016 had a total volume of about $54,680 \mathrm{~m}^{3}$ and the 9 rain events from 2017 a volume of about 13,280 $\mathrm{m}^{3}$ Furthermore, the difference can be explained by the intervariability of rain events. This intervariability of rain events complicates the accurate extrapolation of the measured events to the whole years. However to compare the two time periods more accurate, an extrapolation of the 9 sampled rain events to the whole year of 2017 (total number of about 90 runoff events) as well as the extrapolation of the sampled events in 2015/2016 (total number of about 120 runoff events) is needed. The statistical method of bootstrapping can be a possible and useful tool to describe the intervariability of events.

\section{CONCLUSIONS AND OUTLOOK}

Referring to the issue behind the investigations (further investigation of the hypothesis, that with the removal of total suspended solids (TSS), a significant amount of particulate micropollutants can be removed as well) the obtained results so far suggest, that by reducing the TSS load, the pollutant load can be reduced significantly as well. At least in terms of PAH.

The data pool so far is rather small. However, the monitoring campaign is still ongoing, and in the upcoming months until the conference in September, further rain events will be sampled and evaluated. Furthermore additional substances (flame retardants, plasticisers, pesticides etc.) besides $\mathrm{PAH}$ will be evaluated in terms of their particulate loads in different size fractions. This will be done for the already sampled events as well as the events sampled in future. The method of bootstrapping will be applied and a more accurate extrapolation of the sampled events to the total number of runoff events in the respective time periods will be done.

\section{References}

Baum, P.; Dittmer, U. (2017) Characteristics of particles and associated micropollutants in stormwater runoff. ICUD 2017. 14th IWA/IAHR International Conference on Urban Drainage, Praque, Czech Republic, 527-534, 10.15.09.2017

Dierschke, M.; Welker, A. (2015) Bestimmung von Feststoffen in Niederschlagsabflüssen (Method for measuring suspended solids in runoff). In: gwf Wasser - Abwasser, S. 440-446.

Dotto, C.B.S.; Kleidorfer, M.; Deletic, A.; Fletcher, T.D.; McCarthy, D.T.; Rauch, W. (2010) Stormwater quality models: performance and sensitivity analysis. Water Sci Technol 62 (4), 837-843.

Fuchs, S.; Eyckmanns-Wolters, R.; Maus, C.; Sommer, M.; Voßwinkel, N.; Mohn, R. (2013) Reduktion des Feststoffeintrages durch Niederschlagseinleitungen - Abschlussbericht der Phase 1 (Reduction of sediment input due to stormwater treatment - final report phase 1). MKULNV NRW.

Xanthopoulos, C.; Hahn, H. H. (1990) Pollutants attached to particles from drainage areas. Science of the Total Environment 93, $441-448$. 


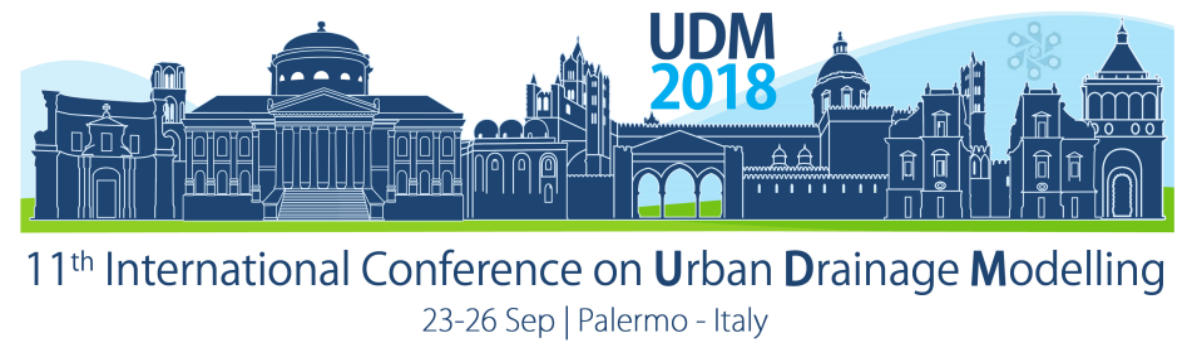

\title{
Spatiotemporal modelling of sediment-related blockages in the sewer system of Bogotá (Colombia)
}

\author{
Eliana Soriano Pulido', Carlos Valencia Arboleda1 and Juan Pablo Rodríguez Sánchez ${ }^{2}$ \\ ${ }^{1}$ Universidad de los Andes, Department of Industrial Engineering, Bogotá, Colombia \\ 2Universidad de los Andes, Department of Civil and Environmental Engineering, Bogotá, Colombia \\ (em.soriano10@uniandes.edu.co, cf.valencia@uniandes.edu.co, pabl-rod@uniandes.edu.co)
}

\begin{abstract}
The planning and scheduling of maintenance operations of large sewer systems generate a complex decision-making environment due to the difficulty in the collection of spatiotemporal information about the operational and structural condition of their components (e.g. pipes, gully pots and manholes). Thus, water utilities generally carry out these operations following a corrective approach. This paper estudies the spatiotemporal distribution of failure events, considering the stochastic process involved using a LogGaussian Cox process model. In addition, association of failure occurrences to environmental and sewer system covariates was assessed. The proposed method was applied to analyze sediment-related blockages in the sewer system of an operative zone of Bogotá (Colombia).
\end{abstract}

Keywords: Sediment-related blockages; Log-Gaussian Cox Process; Spatiotemporal Modelling

\section{INTRODUCTION}

In different studies it has been stated that blockage events account for a significant proportion of reported failures in sewer systems (Jin and Mukherjee 2010; Xie et al. 2017). These blockages are normally detected when a component of the system, or the system as a whole, stops performing its function as expected (Santos et al. 2017). Although many sewer system failures triggering mechanisms have been identified, sediment-related sewer blockages often appear random (Rodríguez et al., 2012).

The lack of knowledge of the current state of the sewer system is the reason why most of the water utilities carry out maintenance operations with a corrective approach. In the case of corrective maintenance, the system is exposed to overflows and flooding until the maintenance operation is effectively performed (Fontecha et al. 2016), and additionally generates several over costs with respect to preventive maintenance. Thus the prediction of blockages plays an important role in the management of the infrastructure of urban water systems. Although deterioration models of sewer systems can be classified into two main groups, physically-based and statistical models, most deterioration models are of the statistical type based on observations of failure events (Rodríguez et al. 2012).

Much of the research on sewer blockages has either focussed on predicting mean blockage rates and on examining how these failure rates change over time or representing the spatial distribution of sewer failures and/or flood hazards. Despite the fact that sediment-related blockages in sewer systems occur in a spatiotemporal context, to the best knowledge of the authors of this paper, there is not previous research in modelling the intensity of these failures and relative risk as continuous phenomena both in time and space. This paper studies the impact of spatiotemporal correlation between sediment-related blockages. In addition, this model identifies factors that are associated with clustering of failures, which 


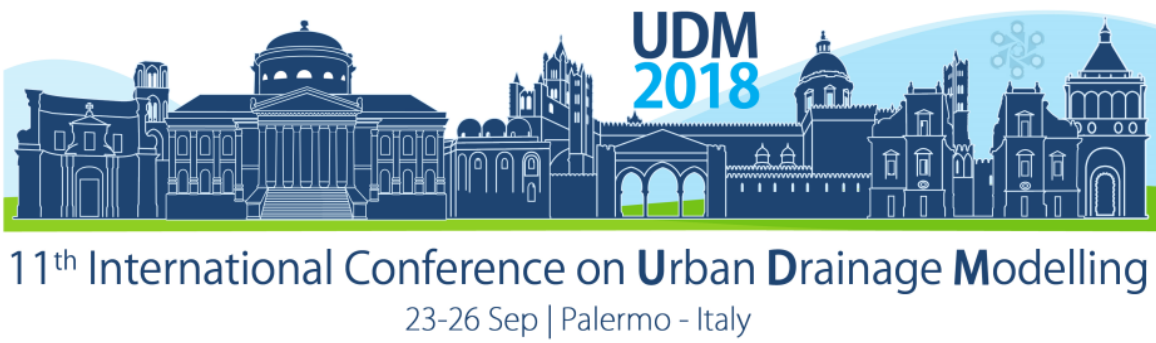

may be physical properties of the sewer system or characteristics of the location where the failure event occurred.

\section{MATERIALS AND METHODS}

\subsection{Log-Gaussian Cox Process}

The Log-Gaussian Cox process is a class of statistical models for point processes, both spatial and spatiotemporal. The spatiotemporal Log-Gaussian Cox Process is extremely flexible as it enables the presence of both fixed and random effects in capturing the spacetime behaviour (Taylor et al. 2013).

\subsection{Bayesian Inference}

There are three main methodologies for inference of Log-Gaussian Cox processes (Diggle et al., 2013): moment based estimation, maximum likelihood and Bayesian inference. The first one is considered a simplistic approach rarely used in applications. Both maximum likelihood and Bayesian estimation require the joint probability distribution of the data points, which considering the double stochastic nature of the model is not easy to optimize. We used Bayesian estimation: using a computational approximation of the posterior parametric distributions has several advantages, as being able to incorporate the predictive probability model of new data points and forecasting the process during the periods that follow the observational window. The Bayesian inference for the Log-Gaussian Cox process model were carried out using Monte Carlo Markov Chain (MCMC). Although there are several sampling methods to perform MCMC, we selected the Metropolis-adjusted Langevin algorithm (MALA), which mimics a Langevin diffusion process.

\subsection{Covariates}

Covariates are the factors that are suspected to be associated with the occurrence of sediment-related failures. They include sewer system properties as well as environmental factors. 21 covariates were available and considered for this study, of which 20 were of spatial type and the remaining was of temporal type (i.e. monthly precipitation). Models can also include other temporal explanatory variables, such as soil wetness, water consumption rates and pipe structural condition to simulate the time-dependence of hydraulic deterioration however (both in general and in this case study) such data is not available.

\subsection{Case study}

The water utility of the city of Bogotá, Empresa de Acueducto y Alcantarillado de Bogotá (EAAB-ESP), serves over 1.7 million residential users. In order to provide integral and efficient service to citizens, the water utility divided the city into five operative zones. Each zone is responsible for the operation and maintenance of water supply and sewage networks in a specific area of the city. In this research, the proposed statistical analyses methods are evaluated in the case study of sediment-related blockages in the sewer system of Zone 2, which drains an area of approximately $100 \mathrm{Km}^{2}$ by means of both combined and separate sewer systems. The record of sewer failures is obtained from a platform that collects and handles customer complaints, which is managed by the Bogotá's water utility. The customer complaints database available for testing the methods proposed in this research corresponds to a period of 7.3 years (from January 2004 to April 2011). For each reported failure, the following information is available: geographic coordinates where the failure was indicated, report date and the system component in which the failure was observed (i.e., pipe, gully pot, 


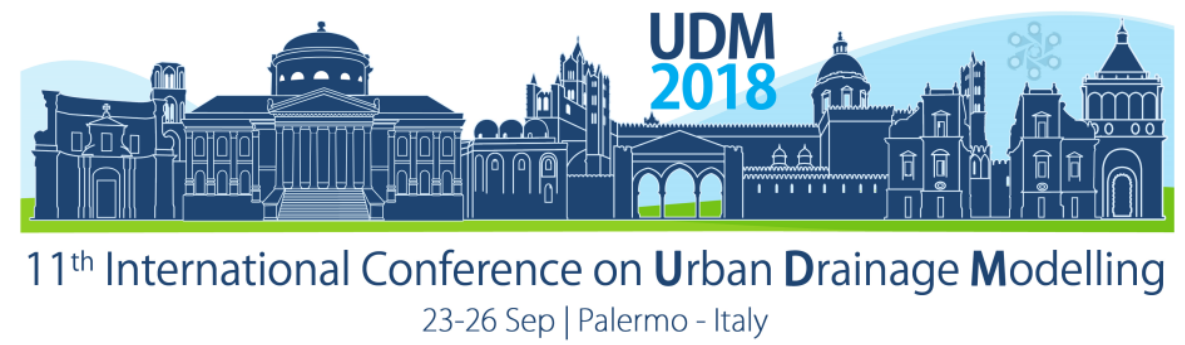

or manhole). The case study area contains 32,097 reports of sediment-related failures for the period of analysis. For a detailed description of the customer complaints database see Rodríguez et al. (2012).

\section{RESULTS AND DISCUSSION}

\subsection{Significant Covariates}

The model was first run with all 21 covariates. The decision on which covariates were to play a part in the analysis was based on their statistical significance. Of the 21 covariates considered, 5 were statistically significant. These were: population, monthly precipitation, sanitary and combined pipe length and sanitary and combined pipe material. Thus, the final model was run with these 5 covariates. These results show that estimated number of sediment-related failures was higher in places with higher population density. In addition, the estimated intensity was higher in those months in which the precipitation levels were greater. Each unit increase in sanitary and combined pipe length led to an increase in intensity of blockage. Finally, each unit increase in the proportion of sanitary and combined pipe length made from concrete or stoneware led to an increase in expected number of blockages with respect to other sanitary and combined pipe materials present in case study.

\subsection{Intensity and Relative Risk}

Figure 1 shows the predicted covariate-adjusted relative risk surfaces derived from the model for 6 months of the observation window (September 2010 to February 2011). Having considered covariates that were likely to have some correlation with the expected number of failures, allowed to set aside the variation in response variable that was predicted by these covariates, isolating the effect of spatiotemporal dependency on expected intensity of failures with greater precision. These plots reveal some small clusters of raised risk, which were probably formed as a consequence of the spatiotemporal correlation.

\section{CONCLUSIONS}

This study provides a statistical approach based on Log-Gaussian Cox processes to model intensity and relative risk of sediment-related blockages in sewer systems. The main contribution of this research is the prediction of the spatiotemporal variation in these response surfaces. In addition, this approach allowed to infer the effect of environmental and system covariates on the expected number of blockages.

\section{References}

Diggle, Peter J., Paula Moraga, Barry S. Rowlingson, and Benjamin M. Taylor. 2013. "Spatial and SpatioTemporal Log-Gaussian Cox Processes: Extending the Geostatistical Paradigm." Statistical Science 28 (4):542-63.

Fontecha, John E., Raha Akhavan-Tabatabaei, Daniel Duque, Andrés L. Medaglia, María N. Torres, and Juan Pablo Rodríguez. 2016. "On the Preventive Management of Sediment-Related Sewer Blockages: A Combined Maintenance and Routing Optimization Approach." Water Science and Technology 74 (2):302-8.

Jin, Yongliang, and Amlan Mukherjee. 2010. "Modeling Blockage Failures in Sewer Systems to Support Maintenance Decision Making." Journal of Performance of Constructed Facilities 24 (6). American Society of Civil Engineers:622-33. https://doi.org/10.1061/(ASCE)CF.1943-5509.0000126.

Rodríguez, Juan Pablo, Neil Mclntyre, Mario Díaz-Granados, and Cedo Maksimović. 2012. "A Database and Model to Support Proactive Management of Sediment-Related Sewer Blockages." Water Research 46 (15):4571-86. https://doi.org/10.1016/j.watres.2012.06.037. 


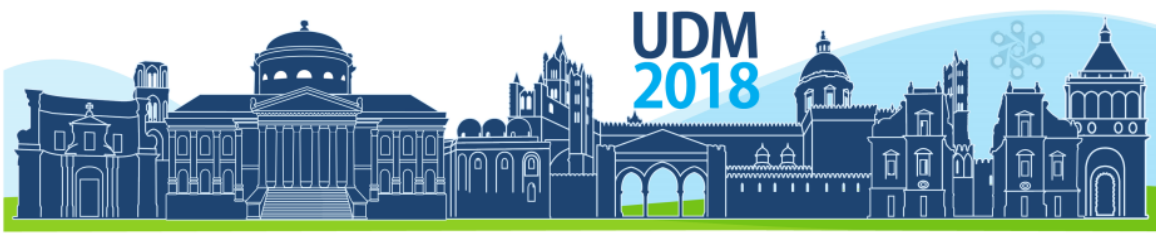

$11^{\text {th }}$ International Conference on Urban Drainage Modelling

23-26 Sep | Palermo - Italy

Santos, Pedro, Conceição Amado, Sérgio T. Coelho, and João P. Leitão. 2017. "Stochastic Data Mining Tools for Pipe Blockage Failure Prediction." Urban Water Journal 14 (4). Taylor \& Francis:343-53. https://doi.org/10.1080/1573062X.2016.1148178.

Taylor, Benjamin M., Tilman M. Davies, Barry S. Rowlingson, and Peter J. Diggle. 2013. "Igcp:An R Package for Inference with Spatial and Spatio-Temporal Log-Gaussian Cox Processes." Journal of Statistical Software 52 (4):1-40. https://doi.org/10.18637/jss.v052.i04.

Xie, Qiang, Chrianna Bharat, R. Nazim Khan, Andrew Best, and Melinda Hodkiewicz. 2017. "Cox Proportional Hazards Modelling of Blockage Risk in Vitrified Clay Wastewater Pipes." Urban Water Journal 14 (7):669-75.
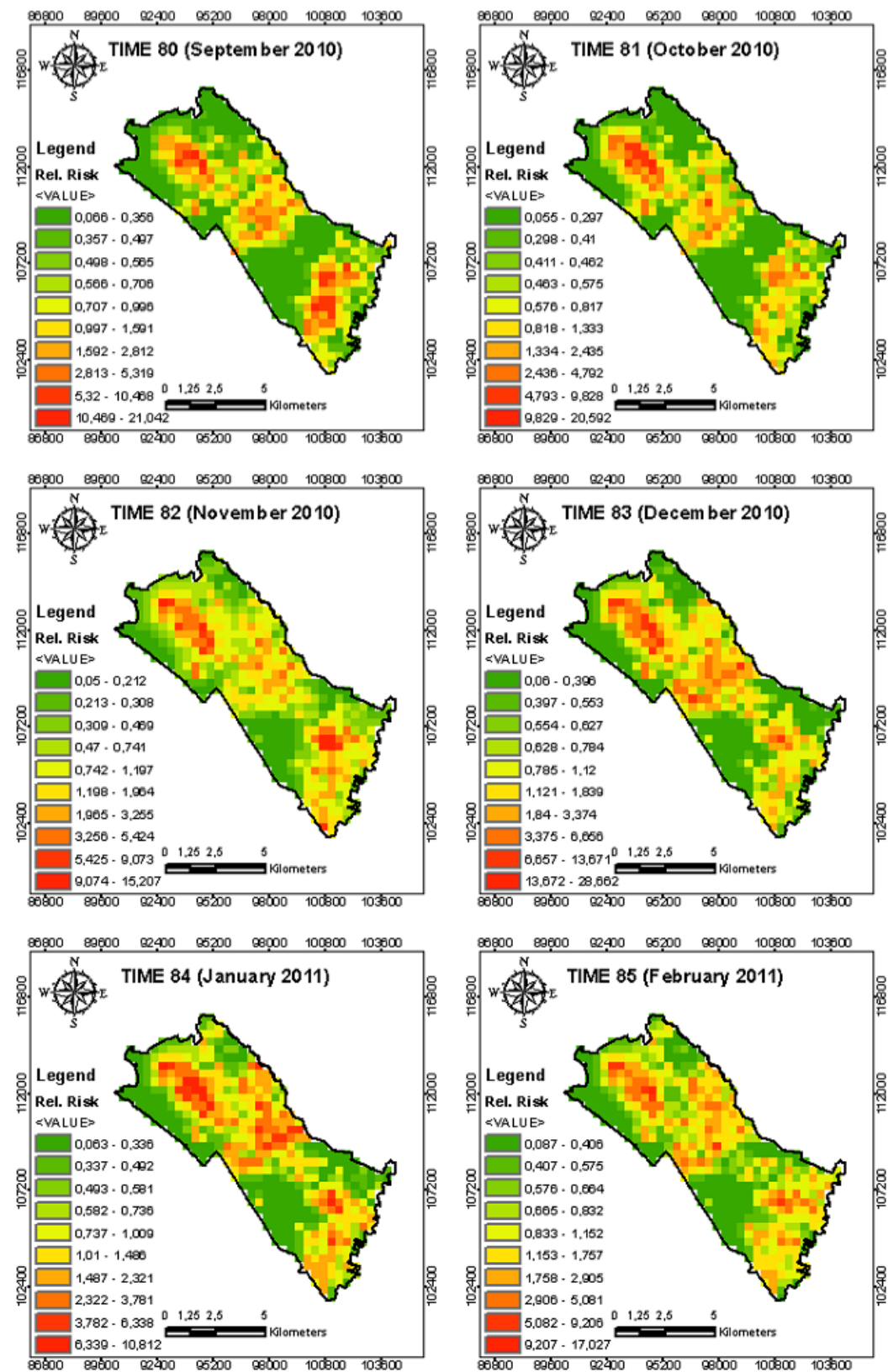

Figure 1. Predicted covariate-adjusted relative risk surfaces derived from the model for 6 months of the observation window (September 2010 to February 2011) 


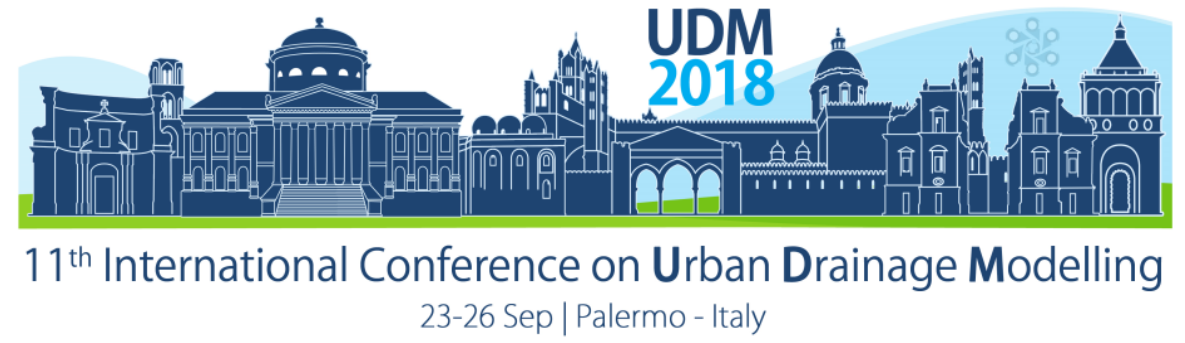

\title{
Modeling storm water pipe leakage: transient vs. steady-state groundwater flow
}

\author{
Peche Aaron ${ }^{1}$, Graf Thomas ${ }^{1}$, Kidmose Jacob², Christiansen Barlebo Heidi², Fuchs Lothar ${ }^{3}$, and Neuweiler \\ Insa ${ }^{1}$ \\ ${ }^{1}$ Institute of Fluid Mechanics and Environmental Physics in Civil Engineering, Leibniz University, Hanover, \\ Germany \\ ${ }^{2}$ Department of Hydrology, Geological Survey of Denmark and Greenland (GEUS), Copenhagen, Denmark \\ ${ }^{3}$ Institute for Technical and Scientific Hydrology (itwh) GmbH, Engelbosteler Damm 22, 30167 Hanover, Germany
}

\begin{abstract}
Storm water pipe leakage in an urban environment may lead to severe problems such as a reduced pipe system capacity. Detailed physically-based numerical models are necessary to understand leakage and mitigate risks. In the present study, we present the application of a physically-based pipe flow-groundwater flow model (full model) for storm water leakage in an urban catchment. We further present the application of a simplified model, in which the transient groundwater model is neglected and the soil domain is represented by a steady-state pressure distribution. We compare both models based on a series of simulations in the same urban catchment. We conclude that the simplified model is as accurate as the full model for the given setup. Comparing both models, the computation time could be reduced from several hours to one minute.
\end{abstract}

Keywords: Storm water pipe leakage; Catchment scale; Coupled model; OpenGeoSys; HYSTEM-EXTRAN;

\section{INTRODUCTION}

Storm water pipe leakage in an urban environment may evoke a series of problems, such as reduced pipe capacity (and subsequent increase in manhole overflow and surface flooding) [Weiss et al., 2002], land subsidence (Martinez et al., 2011), and subsurface and groundwater contamination.

The understanding of storm water pipe leakage is essential in order to take measures against these problems for risk and cost mitigation. Physically-based pipe flow - subsurface flow models are necessary to quantify leakage (Mohrlok et al., 2008). Drawback of such physicallybased models is the computational cost.

In the present study, we present the application of such a physically-based urban flow model including leakage, pipe and subsurface flow in an urban catchment. In order to reduce computational cost, we present a novel simplified model in which we calculate leakage using a steady-state soil water pressure distribution stemming from a calibrated groundwater model. The coupled transient urban flow model will be referred to as 'full model' and its steady-state simplification as 'simplified model'.

\section{MATERIALS AND METHODS}

\subsection{Full model}




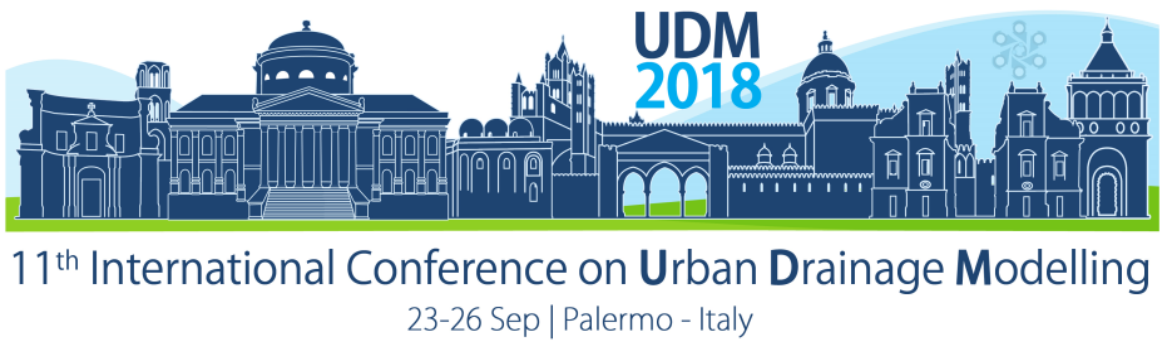

Storm water pipe leakage is simulated with the model OGS-HE (Peche et al., 2017). That coupled model consists of the pipe flow simulator HYSTEM-EXTRAN [HE] (itwh, 2014) and the groundwater flow simulator OpenGeoSys (Kolditz et al., 2012). Governing equations are the 1D Saint-Venant equations (Saint-Venant, 1871) for pipe flow and Richards' equation (Richards, 1931) with van Genuchten parametrization (van Genuchten, 1980) for threedimensional variably-saturated subsurface flow. Assuming a fully saturated surrounding of the pipe defect and a constant cross-sectional defect area, leakage in form of groundwater infiltration (GI) is calculated using a form of Darcy's law. Storm water exfiltration (SE) through a variably saturated colmation layer is calculated using a leakage function for storm water pipe leakage. This leakage function is derived as described in Peche et al. (2017).

\subsection{Simplified model}

In the simplified model for storm water pipe leakage, pipe flow is calculated according to section 2.1. GI and SE are calculated using Darcy's law, and a leakage function similar to the procedure in the full model, respectively. However, a steady-state (previously calculated) soil water pressure distribution was used as input for the calculation of leakage. Such a simplification may be realistic for small leakage and short simulation times.

The difference to the full model is that no transient groundwater model is required to calculate storm water pipe leakage. Both models calculate Gl when groundwater is above pipe water. When pipe water is above groundwater, SE is calculated.

\subsection{Test area and model setup}

The test area is an anonymous urban catchment in Germany. The storm water pipe system has a total length of $53 \mathrm{~km}$ and consists of 1211 pipes and 1142 manholes. It slopes towards the east with an average slope of $0.6 \%$, where it discharges into a river.

Groundwater flows towards the east into a hydraulically connected river. A Dirichlet-type boundary condition representing the river was set to the eastern boundary of the model domain. Remaining boundaries were set as Neumann no-flow boundary conditions. Using data from observation wells and values for groundwater recharge, the groundwater model was successfully calibrated for 5 permeability zones. A stationary soil water pressure distribution (stemming from this calibration) was used as initial condition for the full model. Local values of pressure were used as input of the simplified model.

Storm water pipe defects were included in the model as standard defect per meter pipe segment. The standard defect of the present pipe system (which is in good condition) was set to $A_{\text {defect }}=4 \cdot 10^{-7} \mathrm{~m}^{2}$. The presence of a colmation layer was assumed for all defects, where leakage in form of SE occurs. Colmation layers in the model have a constant thickness of 0.02 $\mathrm{m}$ and constant hydraulic properties (porosity: $\emptyset=0.02$; intrinsic permeability: $\kappa=1.33 \cdot 10^{-12}$ $\mathrm{m}^{2}$; van Genuchten parameter: $\left.\alpha=2 \mathrm{~m}^{-1}, m=0.291\right)$. The presence of a colmation layer was neglected for $\mathrm{Gl}$.

Synthetic rain events in form of Euler 1-type rains (E1) with durations from 1 to 10 hours and return periods of $1,2,5,10,20,50$, and 100 years (RP1,2,5,10,20,50,100) were used as input for both models. 


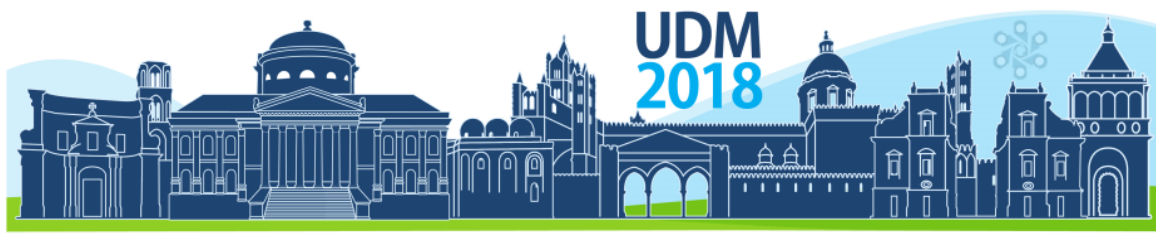

$11^{\text {th }}$ International Conference on Urban Drainage Modelling

23-26 Sep | Palermo - Italy

Simulation time was set to 4 hours, where the rain event starts after 30 minutes and drainage of the storm water pipe system in the following 3 hours.

\section{RESULTS AND DISCUSSION}

Exemplary results in form of absolute values of leakage (values for $\mathrm{Gl}$ are negative, values for SE positive) for each simulated time step calculated by both models are given in Figure 1.

Clearly, with a coefficient of determination $R^{2}>0.99$, results of the simplified model show high agreement to results of the full model. Outliers stem from different results for pipe flow and leakage in both models. Rising or falling pipe water levels close to the groundwater level result in a change from GI to SE (or vice versa). A defect might change from GI to SE and the presence of a colmation layer is switched on. This results in a change of absolute leakage of several orders of magnitude difference. Due to different flow characteristics in both models, this switch between GI and SE occurs few time steps earlier or later in one of both models creating large outliers in model results. However, there are few existing outliers, especially regarding the size of each data set with 437000 data points.

The number of outliers increases with increasing return period. This shows that the application of the simplified model may be chosen such that it depends on the return period of the rain event.

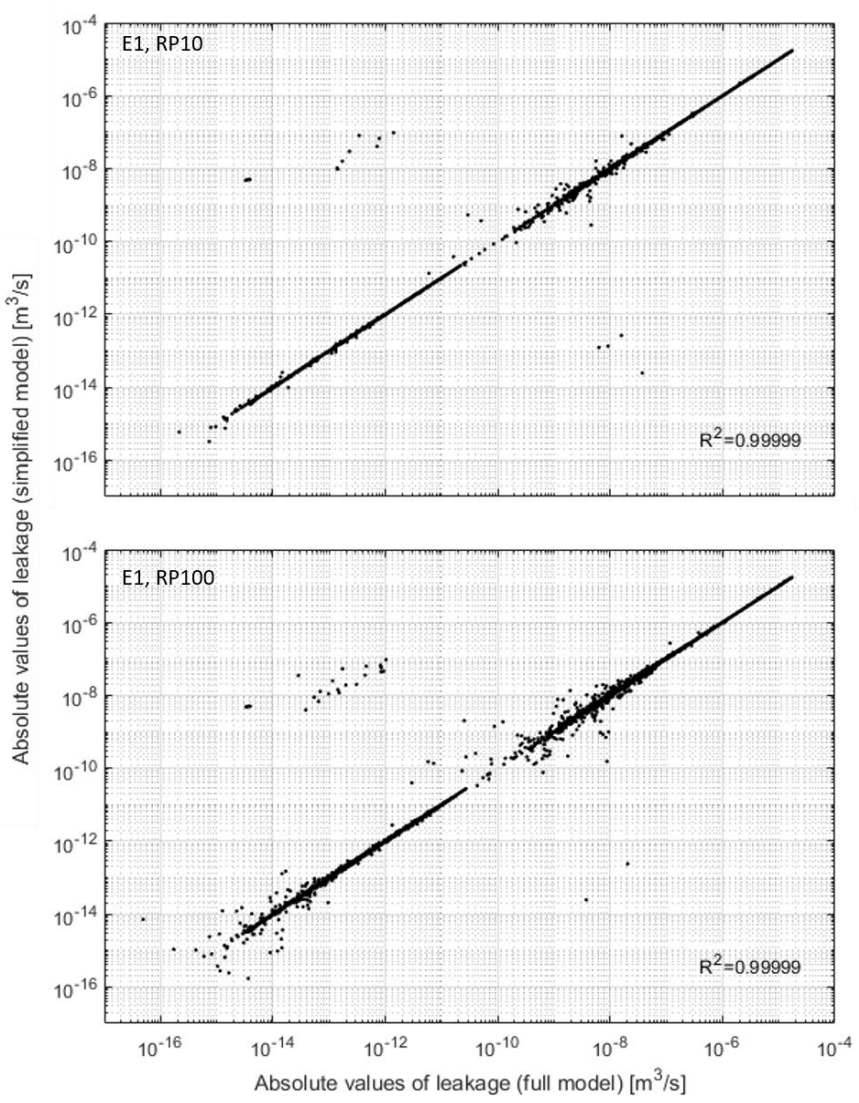

Figure 1. Absolute values of pipe leakage calculated with the full model and the simplified model. Above: Results for a Euler 1-type rain event of 1 hour duration with a return period of 10 years. Below: Results for a Euler 1-type rain event of 1 hour duration with a return period of 100 years. 


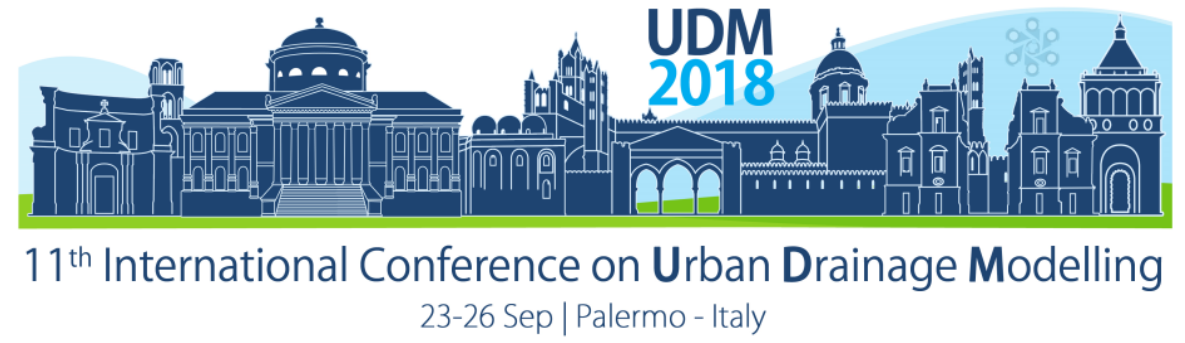

\section{CONCLUSIONS}

Clearly, a simplified model can be used for the simulation of storm water pipe leakage with the presented model setup.

By using the simplified model, the computation time (on a desktop PC with Intel Core i7-6700 processor) was reduced to 67 seconds compared to 50400 seconds ( $=14$ hours) for the full model. This is beneficial for real-time applications, where large-scale flow processes have to be simulated efficiently.

In future studies, the applicability of the simplified model will be further investigated. This includes simulation scenarios with more rain events with larger duration and larger standard defect sizes resulting in larger leakage (for which we assume an increased error from the simplified model).

\section{Acknowledgement}

This work is part of the EVUS Project within the GEOTECHNOLOGIEN framework funded by the Federal Ministry of Education and Research - BMBF, Germany.

\section{References}

itwh, (2014) Kanalnetzberechnung - Hydrodynamische Abfluss-Transport- und Schmutzfrachtberechnung. HYSTEM-EXTRAN 7 Modellbeschreibung, Institut für technisch-wissenschaftliche Hydrologie GmbH Hannover.

Kolditz, O., Bauer, S., Bilke, L., Böttcher, N., Delfs, J.O., Fischer, T., Görke, U.J., Kalbacher, T., Kosakowski, G., McDermott, C.I., Park, C.H., Radu, F., Rink, K., Shao, H., Sun, F., Sun, Y.Y., Singh, A.K., Taron, J., Walther, M., Wang, W., Watanabe, N., Wu, Y., Xie, M., Xu, W., Zehner, B. (2012). OpenGeoSys: an open-source initiative for numerical simulation of thermo-hydro-mechanical/chemical (THM/C) processes in porous media. Environmental Earth Sciences, 67 (2): 589-599. https://doi.org/10.1007/s12665-012-1546-x.

Martinez, S.E., Escolero, O. and Wolf, L. (2011). Total urban water cycle models in semiarid environments Quantitative scenario analysis at the area of San Luis potosi, Mexico. Water Resources Management, 25(1):239-263.

Mohrlok, U., Wolf, L., and Klinger, J. (2008). Quantification of infiltration processes in urban areas by accounting for spatial parameter variability. Journal of Soils and Sediments, 8(1):34-42, 2008.

Peche, A., Graf, T., Fuchs, L., and Neuweiler, I. (2017) A coupled approach for the three-dimensional simulation of pipe leakage in variably saturated soil. Journal of Hydrology 555, 569-585, https://doi.org/10.1016/i.jhydrol.2017.10.050.

Richards, L.A. (1931) Capillary conduction of liquids through porous mediums. Journal of Applied Physics, 1 (5): 318-333. https://doi.org/10.1063/1.1745010.

Saint-Venant, A., (1871) Théorie du mouvement non-permanent des eaux, avec application aux crues des rivières et à l'introduction des marées dans leurs lits [eng.: Theory of non-permanent water movement with application to river flooding and the introduction of the tides in their tidal beds]. Comptes Rendus Hebdomadaires des Séances de l'Académie des Sciences, ISSN 0001-4036; 73.

Van Genuchten, M.Th. (1980). A closed-form equation for predicting the hydraulic conductivity of unsaturated soils Soil Science Society of America Journal, 44(5): 892-898.

Weiss, G., Brombach, H., and Haller, B. (2002). Infiltration and inflow in combined sewer systems: long-term analysis. Water Science and technology, 45(7): 11-19. 


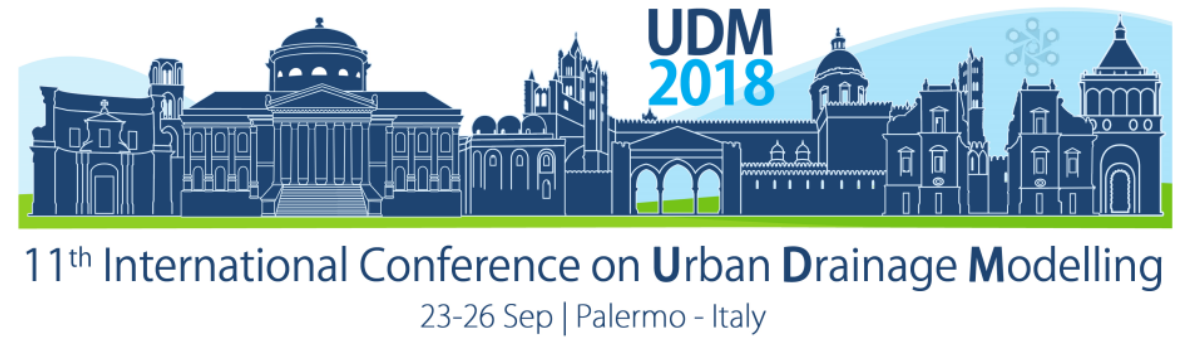

\title{
Just Suspended Speed For Solid Particle Transport In Torus Reactor
}

\author{
Alouache Ali ${ }^{1}$, Selatnia Ammar ${ }^{1,2}$, Halet Farid ${ }^{1,3}$, Abdelouhab Lefkir ${ }^{4}$, Houssem Eddine Sayah ${ }^{3}$ \\ and Nadjemi Boubekeur ${ }^{1}$ \\ ${ }^{1}$ Laboratoire d'Etude et de Développement des Techniques de Traitement et d'Epuration \\ des Eaux et de Gestion Environnementale - LEDTEGE Ecole Normale Supérieure Kouba,Algeria. \\ ${ }^{2}$ Département de Génie Chimique, Ecole Nationale Polytechnique, Algiers, Algeria. \\ ${ }^{3}$ Université M'HAMED BOUGARA de Boumerdes, Boumerdes, Algeria \\ ${ }^{4}$ Ecole Nationale Supérieure des Travaux Publics (ENSTP), Algiers, Algeria
}

\begin{abstract}
: the deposing velocity is an important parameter in the designing of solid transportation in pipe; it represents the lowest speed at which transportation can operate corresponding to no solid particles remains in the reactor or pipe bottom.

This minimal velocity has been investigated in several types of reactors in water treatment and solid transport. A Little importance has been given to loop reactors in liquid solid mixtures especially torus reactor which has significant advantages in chemical and biochemical process and mixing. In the present work solid-liquid suspension in torus reactor is investigated by the experimental determination of the just suspended speed Njs at which all the solid particles are completely suspended. For this purpose a modified method based on visual assessment have been used. The effect of solid loading (1-7\%) and particle size $(80-500 \mu \mathrm{m})$ and different solid density was carried out. The Njs is largely depending on concentration and density of solid particles, it presents a weak dependence on particles size. The determination of Njs seems necessary in solid transport and operations involving solid-liquid mixtures where the mass transfer is a limiting factor.
\end{abstract}

Keywords: Suspension; Solid transportation; torus reactor; just suspended speed.

\section{INTRODUCTION}

Several types of stirred reactors used in industrial processes for heterogeneous chemical reactions, and wastewater treatment, require working at low stirring speeds. Therefore, solid particle deposition may occur on the impeller and the reactor walls.

Manufacturers recommend increasing agitation speed to reach the complete suspension required for transport of solid particles (just suspended speed Njs). Below (Njs), the solidliquid exchange surface is partially used which causes decreasing of mass and heat transfer, while above this speed the increasing of solid-liquid mass-transfer is negligible, and the power consumption is significant. Researchers have focused on determining the minimum stirring speed which makes all the particles in suspension (Njs), and its dependence on the physical, geometrical parameters of the reactor, and the operating conditions (Baldi et al, 1978; Nienow et al, 1968; Raghava et al, 1988; Zwietering, 1958).

The minimum liquid velocity required to prevent deposition of solids in horizontal pipe for hydraulic transport of sand and water slurries was investigated by (Durand et al, 1952). The stirred tank and pipe have been fully explored in studying of solid-liquid mixing; many researchers have been published to determine experimentally the just suspended speed for complete suspension (Taghavi et al, 2014). Very little attention has been devoted to solidliquid suspension in loop reactor. It has potential application in biochemical reaction and processing of highly viscous liquids. the loop reactor was proposed by (Norwood, 1962) for the first time in a slurry polymerization of olefins. Researches containing solids suspension in torus reactor have been published (Laederach et al, 1984; Murakami et al, 1982; Nouri et al, 1997; SATO et al, 1979; Tanaka et al, 1989) all authors recommended to use a high Reynolds number (high agitation speed) to prevent deposition of solid particles at the reactor's wall and impeller. According to the literature, it does not appear that a minimal rotational speed determination was carried out in loop (torus) reactor, at which all the solid 


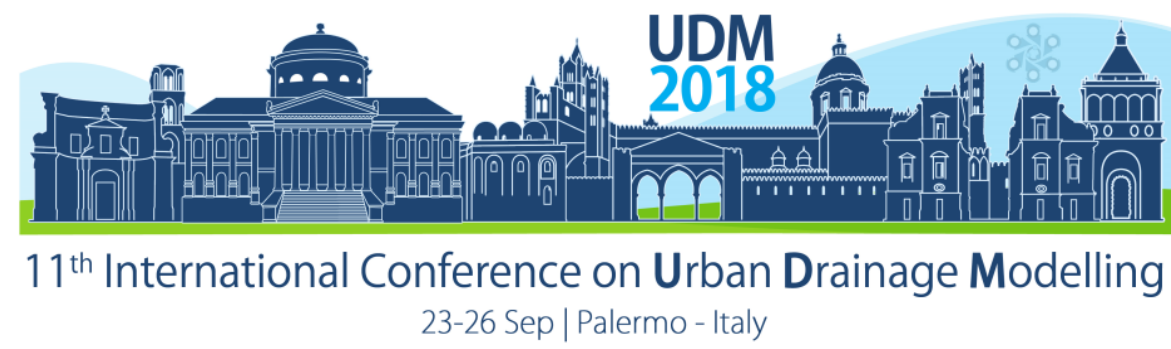

particles were suspended. The aim of this work is to determine experimentally the just suspended speed $\left(\mathrm{N}_{\mathrm{js}}\right)$ in torus reactor. For this purpose, a study of the $\left(\mathrm{N}_{\mathrm{js}}\right)$ dependence on solid mass concentration, and particles size, and density difference between liquid and solid, were investigated.

\section{MATERIALS AND METHODS}

\subsection{Description of the experimental device}

The torus reactor used in this study is similar at those used by (Belleville et al, 1992; Nasrallah et al, 2008; Nouri et al, 2008 ) presented in figure1 constructed from transparent pipe, of inner diameter $\left(D_{t}\right)$ of $50 \mathrm{~mm}$, the length of the torus reactor is $1400 \mathrm{~mm}$, which corresponds to a total volume of $2.9 \mathrm{I}$. The mixing was achieved by a marine screw impeller, driven by a variable speed motor (IKA-WERK RW20). This reactor was used by (Alouache et al. 2017). The characteristics of solid particles are present in Table 1.

\subsection{Measurement techniques and procedure}

The experiments were carried out using a transparent torus reactor fixed on a glass table under which a mirror is placed to give the image of the reactor bottom. Only visual observations were made using a simple digital camera for images acquisition. The average particles size (dp) ranging from 120 to $450 \mu \mathrm{m}$ were used for the experimental procedure. Number of papers on particle suspension were published, based on the visual method largely used by authors (Armenante et al, 1992; Brucato et al, 2010; Jirout et al, 2011; Kuzmanić et al, 2008; Legrand et al, 2007; Ravelet et al, 2013) for the just suspended speed assessment.

In order to determine experimentally $\left(\mathrm{N}_{\mathrm{js}}\right)$ an experimental method (the "steady cone radius method",SCRM) was proposed by (Brucato et al., 2010). In the present case, for $\mathrm{N}_{\text {js }}$ measurement a modified SCRM method based on visualization was used to identify the just suspended conditions in torus reactor. First, the solid particles are introduced into the reactor, and filling with water to reach the final volume, followed by a high agitation speed necessary to suspend the solid phase throughout the reactor circumference. By turning off the stirrer, all particles start to settle on the bottom circumference, forming a particles settling bed with an angle $\alpha_{0}=360^{\circ}$.

The increase in agitation speed leads to a decrease in the angle from $\alpha_{0}$ to $\alpha=0^{\circ}$ the measurement is made between the bed boundaries to give $\alpha$ value. The ratio $\mathrm{R}$ presented in Eq. (1) can be exploited to determine the agitation speed at which no particles remain steady on the reactor bottom, it corresponds to ratio $\mathrm{R}=0$. For all cases investigated here, a graph similar to that shown in Figure.2 was obtained, gives the experiment Njs values by extrapolation. All experiments were performed in duplicates with excellent reproducibility.

$$
R=\alpha / \alpha_{0}
$$

For each solid loading the just suspended speed $\left(\mathrm{N}_{\mathrm{js}}\right)$ is determined by varying agitation speed from $200 \mathrm{rpm}$ until the speed where the settling bed disappears, it corresponds to $\left(\alpha=0^{\circ}\right)$. Consequently the suspension was considered complete, that corresponds to no deposits particles remained on the reactor bottom for more than 1 or 2 seconds according to (Zwietering, 1958).

\section{RESULTS AND DISCUSSION}




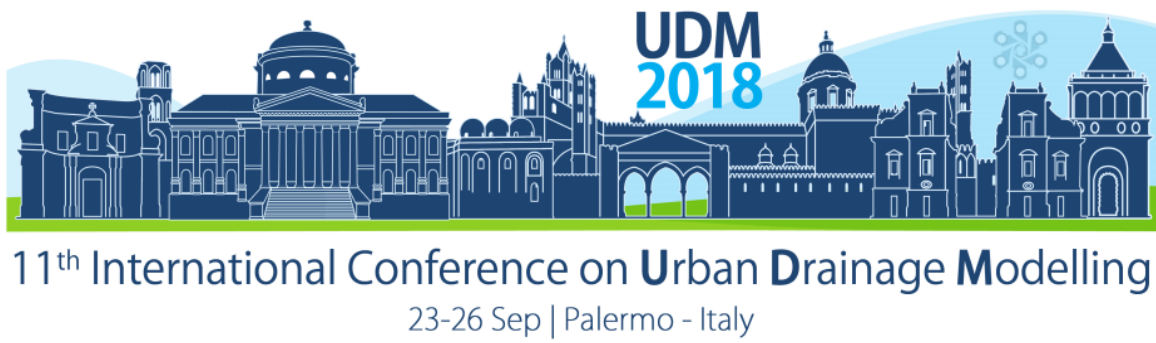

The characteristics of solid particles, liquid phase, reactor geometry, and agitation parameters influence the fluid-particles hydrodynamics and thus the suspension (Taghavi et al, 2014). The dependence of $N_{j s}$ on solid mass concentration of sand particles $\left(C_{v}\right)$ for different particles size is illustrated in Figure 3 . It can be seen that increasing $\left(\mathrm{C}_{\mathrm{v}}\right)$ increases the required $(\mathrm{Njs})$ to remove the settling bed and keep all particles in solution. This phenomenon can be interpreted by the two zones present in torus reactor. A well mixed zone as a constant stirred tank reactor upstream and downstream the impeller and a transport zone as a plug flow. A boundary exists between the two zones. When a variation of rotation speed occurs, not only the volumes of the zones vary but their location within the torus evolves counter-clockwise (Dieulot et al, 2005). For a positive variation in impeller speed, the volume of the well mixed zone increases whereas that of the transport zone decreases. The well mixed zone contains suspended particles in opposite of the transport zone which corresponds to a bed formed by the settling particles. At the just suspended speed (Njs), the volume of the transport zone tends to zero which corresponds to $\alpha=0^{\circ}$, then the torus reactor will be composed only by the well mixed zone. As a result an improvement of the mixture is obtained. The dependence of $\left(\mathrm{N}_{\mathrm{j} s}\right)$ on particles size is weaker than concentration; hence, it's important for industrials to use particles of large sizes in complete suspension condition without increasing the impeller speed and energy consumption, this is available only in the range size investigated here so extrapolation for large particle is risky and cannot be extended (Brucato et al., 2010). According to these results, we have studied other types of solid particles widely used in water treatment and environmental remediation namely activated carbon and biomass. The determination of $\left(\mathrm{N}_{\mathrm{js}}\right)$ for different particles concentration was found between $800 \mathrm{rpm}$ and $1000 \mathrm{rpm}$.

In complete suspension all solid particles will be surrounded by the liquid, (Brucato et al, 2010). Thus mass transfer will be promoted which may explain some kinetic reaction where mass transfer is a limiting factor. According to the curve represents (Njs) versus $\left(\Delta \rho / \rho_{l}\right)$ (not shown here), increasing the solid density increases the (Njs), which is largely dependent on the density difference between the solid particles and the liquid.

\section{CONCLUSIONS}

Solid-liquid suspension experiments in a torus reactor were performed. A modified experimental technique method (SCRM), based on the angular measurement of the settling bed was used for visual evaluation of the just suspended speed Njs required to maintain all solid particles suspended. The parameters affecting Njs such as particle concentration, particle diameter and particle density were investigated.

Summarizing it seems that the suspended speed in torus reactor is proportional to the concentration and density difference, whereas the dependence on the particle diameter is negligible which allows us to deduce that our results are similar to those obtained by authors. The SCRM method has the advantage of avoiding measurement subjectivity and was found to result into excellent reproducibility (Brucato et al., 2010) same remarks were observed for the modified SCRM method used in the torus reactor.

\section{Notation:}

$\mathrm{C}_{\mathrm{v}} \quad$ solid mass concentration $(\% \mathrm{w} / \mathrm{w})$, non-dimensional

$d_{p} \quad$ particles diameter

$\mathrm{N}$ agitation speed, RPM

$\mathrm{N}_{\mathrm{js}} \quad$ just suspended agitation speed, RPM 


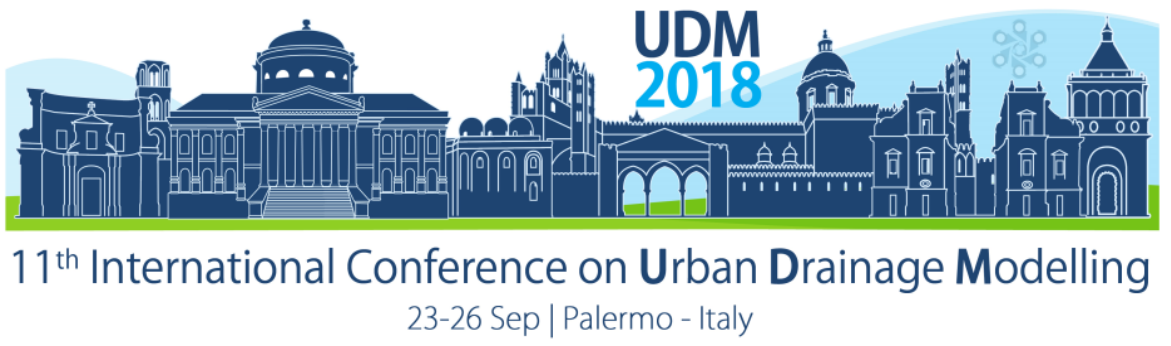

$\begin{array}{ll}D_{t} & \text { internal reactor diameter, } \mathrm{mm} \\ \mathrm{L}_{\mathrm{t}} & \text { reactor length, } \mathrm{mm} \\ \rho_{l} & \text { liquid density, } \mathrm{Kg} / \mathrm{m}^{3} \\ \rho_{s} & \text { soliid density, } \mathrm{Kg} / \mathrm{m}^{3} \\ \Delta \rho & \text { density diference, } \mathrm{Kg} / \mathrm{m}^{3} \\ \alpha_{0} & \text { circumference angle } \\ \alpha & \text { settling bed angle }\end{array}$

\section{References}

Armenante, P. M., Huang, Y.-T., \& Li, T. (1992). Determination of the minimum agitation speed to attain the just dispersed state in solid-liquid and liquid-liquid reactors provided with multiple impellers. Chemical Engineering Science, 47(9-11), 2865-2870.

Alouache A, Selatnia A, Halet F (2017) Frontiers in Wastewater Treatment and Modelling. doi: 10.1007/978-3319-58421-8

Baldi, G., Conti, R., \& Alaria, E. (1978). Complete suspension of particles in mechanically agitated vessels. Chemical Engineering Science, 33(1), 21-25.

Belleville, P., Nouri, L., \& Legrand, J. (1992). Mixing characteristics in the torus reactor. Chemical engineering \& technology, 15(4), 282-289.

Brucato, A., Cipollina, A., Micale, G., Scargiali, F., \& Tamburini, A. (2010). Particle suspension in top-covered unbaffled tanks. Chemical Engineering Science, 65(10), 3001-3008. doi: 10.1016/j.ces.2010.01.026

Brucato, A., Micale, G., \& Rizzuti, L. (1997). Determination of the amount of unsuspended solid particles inside stirred tanks by means of pressure measurements. Paper presented at the Rec Progr Genie des Proc.

Dieulot, J. Y., Petit, N., Rouchon, P., \& Delaplace, G. (2005). An arrangement of ideal zones with shifting boundaries as a way to model mixing processes in unsteady stirring conditions in agitated vessels. Chemical Engineering Science, 60(20), 5544-5554. doi: 10.1016/j.ces.2005.03.067

Durand, R., \& Condolios, E. (1952). The hydraulic transport of coal and solid material in pipes. Paper presented at the Proceedings of Colloquium on Hydraulic Transportation, France.

Jirout, T., \& Rieger, F. (2011). Impeller design for mixing of suspensions. Chemical Engineering Research and Design, 89(7), 1144-1151. doi: 10.1016/j.cherd.2010.12.005

Kuzmanić, N., Žanetić, R., \& Akrap, M. (2008). Impact of floating suspended solids on the homogenisation of the liquid phase in dual-impeller agitated vessel. Chemical Engineering and Processing: Process Intensification, 47(4), 663-669. doi: 10.1016/j.cep.2006.12.010

Laederach, H., \& Widmer, F. (1984). Le bioréacteur torique. Informations chimie(249), 157-160.

Legrand, A., Berthou, M., \& Fillaudeau, L. (2007). Characterization of solid-liquid suspensions (real, large nonspherical particles in non-Newtonian carrier fluid) flowing in horizontal and vertical pipes. Journal of Food Engineering, 78(1), 345-355. doi: 10.1016/j.jfoodeng.2005.10.002

Murakami, Y., Hirose, T., Ono, S., Eitoku, H., \& Nishijima, T. (1982). Power consumption and pumping characteristics in a loop reactor. Industrial \& Engineering Chemistry Process Design and Development, 21(2), 273-276.

Nasrallah, N., Legrand, J., Bensmaili, A., \& Nouri, L. (2008). Effect of impeller type on the mixing in torus reactors. Chemical Engineering and Processing: Process Intensification, 47(12), 2175-2183.

Nienow, A. (1968). Suspension of solid particles in turbine agitated baffled vessels. Chemical Engineering Science, 23(12), 1453-1459.

Norwood, D. (1962). Japan Patent. Shawa37-1 0 0, 87(1), 962.

Nouri, L., Legrand, J., Popineau, Y., \& Belleville, P. (1997). Enzymatic hydrolysis of wheat proteins Part 2: comparison of performance of batch-stirred and torus reactors. Chemical Engineering Journal, 65(3), 195-199.

Nouri, L. h., Legrand, J., Benmalek, N., Imerzoukene, F., Yeddou, A.-R., \& Halet, F. (2008). Characterisation and comparison of the micromixing efficiency in torus and batch stirred reactors. Chemical Engineering Journal, 142(1), 78-86. doi: 10.1016/j.cej.2008.01.030

Raghava Rao, K., Rewatkar, V., \& Joshi, J. (1988). Critical impeller speed for solid suspension in mechanically agitated contactors. AlChE journal, 34(8), 1332-1340. 
Proceedings of the 11th Int. Conference on Urban Drainage Modelling, 23-26 Sep. 2018, Palermo (ITALY). Ed. prof. Giorgio Mannina

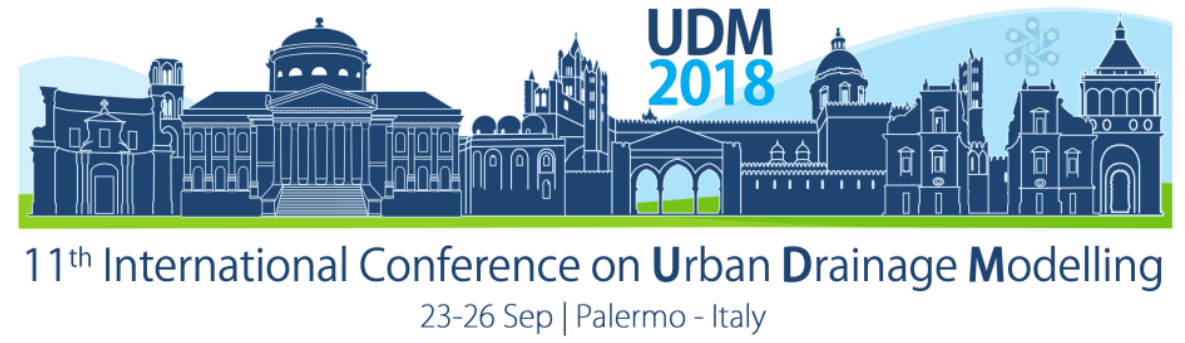

Ravelet, F., Bakir, F., Khelladi, S., \& Rey, R. (2013). Experimental study of hydraulic transport of large particles in horizontal pipes. Experimental Thermal and Fluid Science, 45, 187-197. doi: 10.1016/j.expthermflusci.2012.11.003

SATO, Y., MURAKAMI, Y., HIROSE, T., HASHIGUCHI, Y., ONO, S., \& ICHIKAWA, M. (1979). Flow pattern, circulation velocity and pressure loss in loop reactor. Journal of Chemical Engineering of Japan, 12(6), 448-453.

Taghavi, M., Ebrahimi, S., \& Moghaddas, J. (2014). Solid Particle Distribution in Centrifugal Impeller Contactors. Journal of Dispersion Science and Technology, 35(8), 1097-1105. doi: 10.1080/01932691.2013.833106

Tanaka, M., Hosogai, K., \& Sendai, T. (1989). Dispersion behaviour of droplets in circular loop reactors. Chemical engineering \& technology, 12(1), 205-212.

Zwietering, T. N. (1958). Suspending of solid particles in liquid by agitators. Chemical Engineering Science, 8(34), 244-253.

Table 1. characteristics of solid particles

\begin{tabular}{ccccc}
\hline Material & $\mathrm{d}_{\mathrm{p}}$ & Average $\mathrm{d}_{\mathrm{p}}$ & $\rho$ & Particles concentration \\
\hline & $(\mu \mathrm{m})$ & $(\mu \mathrm{m})$ & $\left(\mathrm{kg} / \mathrm{m}^{3}\right)$ & $(\% \mathrm{w} / \mathrm{w})$ \\
\hline Sand & $80-160$ & 120 & 2400 & $1-3-5-7$ \\
& $160-315$ & 237.5 & & $1-3-5-7$ \\
& $315-400$ & 357.5 & & $1-3-5-7$ \\
Siporex & $400-500$ & 450 & & $1-3-5-7$ \\
& $80-160$ & 120 & 1900 & $1-3-5-7$ \\
& $160-315$ & 237.5 & & $1-3-5-7$ \\
& $315-400$ & 357.5 & & $1-3-5-7$ \\
Biomass & $400-500$ & 450 & & $1-3-5-7$ \\
& $160-315$ & 237.5 & 1200 & $1-3-5-7$
\end{tabular}

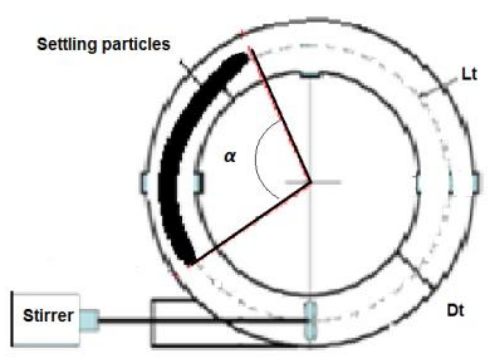

Figure1: sketch of torus reactor

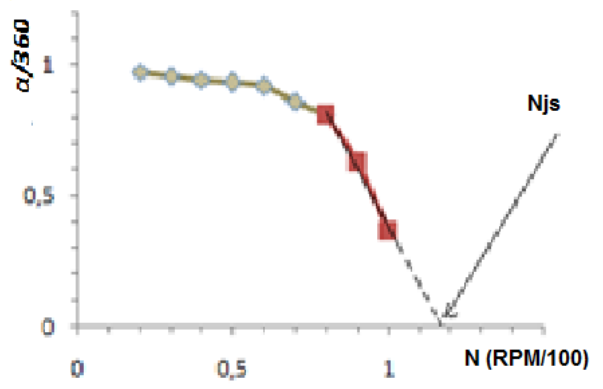

Figure 2: Typical trend

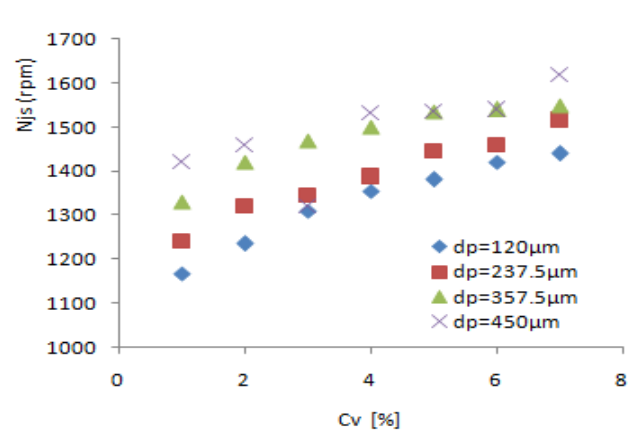

Figure 3: Dependence of Njs on solid mass concentration of sand for different particle size 


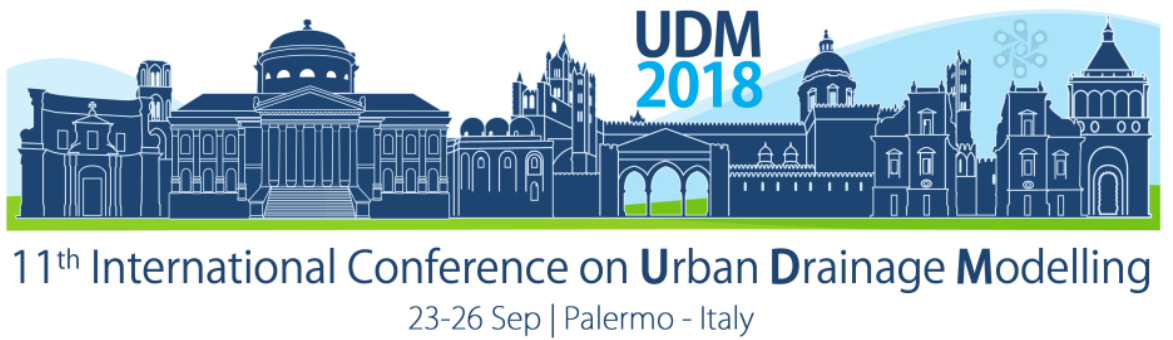

\title{
Stormwater Runoff Treatment Filtration System and Backwashing System
}

\author{
J.H. Lee', M.J. Lee ${ }^{2}$, S.H. Yang ${ }^{3}$ \\ ${ }^{123}$ Division of Civil, Environmental \& Urban-Transportation Engineering, Korea National University of \\ Transportation, 50 University Road, Chungju, Chungbuk, 27469, Korea
}

\begin{abstract}
This study has been carried out to evaluate the applicability of the pilot scale the hybrid type of stormwater runoff treatment systems (SFS) for treatment of combined sewer overflow. And, to determine the optimum operation parameter such as coagulation dosage concentration, effectiveness of coagulant usage, surface loading rate and backwashing conditions. The SFS system is consisted of hydrocyclone coagulation/flocculation with polyaluminium chloride silicate (PACS) and upflow filter to treat combined sewer overflows. There are two modes (without PACS use and with PACS use) of operation for STS system. In case of without coagulant use, the range of SS, turbidity removal efficiency were 72.0$86.6 \%$ (mean $80.0 \%$ ), 30.9-71.1\% (mean 49.3\%), respectively. And, the recovery rate of filter was $79.2-83.6 \%$ (mean $81.2 \%$ ) the rate of remained solid loading in filter media was $16.4-20.8 \%$ (mean $18.8 \%$ ) after backwashing. In case of SFS run with coagulant use, The range of influent flowrate and surface overflow rate were 6.8-8.0 m3/day (mean 7.2 $\mathrm{m} 3 /$ day), $163.2-191.8 \mathrm{~m} 3 / \mathrm{m} 2 /$ day (mean $172.4 \mathrm{~m} 3 / \mathrm{m} 2 /$ day), respectively. The influent turbidity, SS concentrations were 59.0-90.7 NTU (mean 72.0 NTU), 194.0- $320.0 \mathrm{mg} / \mathrm{L}$ (mean $246.7 \mathrm{mg} / \mathrm{L}$ ), respectively. The range of PACS dosage concentration was 6.0-7.1 $\mathrm{mg} / \mathrm{L}$ (mean $6.7 \mathrm{mg} / \mathrm{L}$ ). The range of SS, turbidity removal efficiency were 84.9-98.2 (mean $91.4 \%$ ), 70.7-96.3 (mean $84.0 \%$ ), respectively. It was found that removal efficiency was enhanced with PACS dosage. The recovery rate of filter was 92.0-92.5\% (mean 92.3\%) the rate of remained solid loading in filter media was $6.1-8.2 \%$ (mean $7.2 \%$ ) after backwashing. In case of coagulant use, the particle size of effluent is bigger than influent particle size. The results showed that STS with PACS use more effective than without PACS use in SS and turbidity removal efficiency and recovery rate of filter.
\end{abstract}

Keywords: stormwater; filtration; combined sewer overflow; backwashing; hydrocyclone

\section{INTRODUCTION}

During storm events, many wastewater treatment plants may not be able to achieve the requested effluent quality. In the worst case, untreated CSO may bypass the plant. To overcome and mitigate these problems related to CSO and stormwater runoff, engineers and others are constantly seeking best management practices (BMPs); filtration, sedimentation, chemical flocculation, and vortex separators. Among the BMPS, the upflow direct filtration system is quite outstanding for SSO and CSO treatment (Bernardo, 2006). Solid particles smaller than $30 \mu \mathrm{m}$ in diameter are not easily separated by conventional types of upflow filtation system. To overcome this problem, upflow filter combined with hydrocyclone flocculator has been applied to treatment of the micro particles in urban storm runoff. We have conducted a pilot scale studies on treatable potential of micro particles using stormwater filtration system (STS) which used rectangular shape media made of polypropylene and polyethylene materials. This study has been carried out to evaluate the applicability of the pilot scale SFS and determine the optimum operational parameter such as coagulation dosage concentration, effectiveness of coagulant usage, surface loading rate and backwashing conditions

\section{MATERIALS AND METHODS}

\subsection{Setup of the pilot scale stormwater filtration system}

The pilot scale stormwater filtration system (STS) was installed at the municipal wastewater plant serving the city of Cheongju (CWTP) Korea. CWTP has an average flow of 2.8 million cubic meter a day The STS influent submersible pump was installed at the existing grit chamber. The pilot scale stormwater filtration system (STS) used for experiments is shown in schematically in Figure 1. During a storm event, the discharge of untreated sewage and stormwater are inflow of CWTP. STS consisted of two hydrocyclones for coagulation and flocculation, filter column, backwash blower and pump, air flow meter, pressure gauge, valve fitting, centrifugal pump, submersible pumps, automatic switch controller, chemical flowrate 


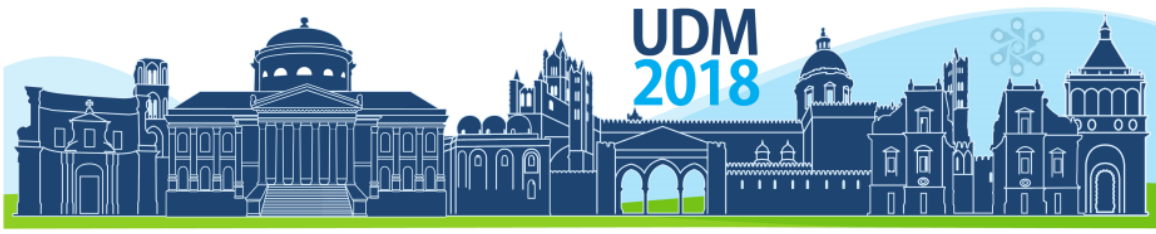

$11^{\text {th }}$ International Conference on Urban Drainage Modelling

23-26 Sep | Palermo - Italy

gauge, injection pump, electromagnetic flow meter, effluent and underflow storage tank. Influent submersible pumped from grit chamber was transfer to the storm water storage tank. Influent from storm water storage tank was injected to hydrocyclone with coagulant to hydrocyclone and underflow returned to the influent pipe to improve flocculation ballasting.

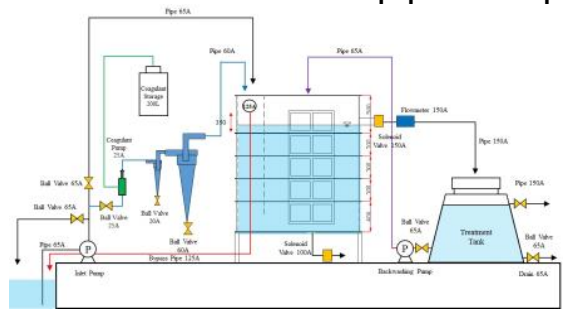

Figure 1. Schematic diagram and installed photo of the pilot scale stormwater filtration system.

\subsection{Process operation and measurement method}

Graded particle size $(<100 \mu \mathrm{m})$ materials were vigorously mixed with grit chamber wastewater and stored at storage tank and mixed continuously using a mixer in order to obtain homogeneity. A laser diffraction particle size analyzer (Shimadzu model SALD-2101) was used to determine the particle size and distribution. To determine the removal efficiency for various influent SS concentrations and turbidity (NTU), a series of tests were performed. The range of surface loading rate for filtration was 453.6-528.0 m3/m2/day (mean 496.0 $\mathrm{m} 3 / \mathrm{m} 2 /$ day), and the filtration retention time was $3.8-4.4 \mathrm{~min}$ (mean $4.1 \mathrm{~min}$ ). The influent SS concentrations, turbidy were varied ranging from 118.0 to $366.0 \mathrm{mg} / \mathrm{L}$ (mean $238.8 \mathrm{mg} / \mathrm{L}$ ), and 39.6 to 114.0 NTU (mean 76.2 NTU).

\section{RESULTS AND DISCUSSION}

\subsection{STS operation without coagulant}

The STS run without coagulant dosing had a total operation time of $14.8 \mathrm{hr}$. Through more than 6 experiments were carried out with various conditions such as different SS concentration. Results calculated in terms of SS and turbidity removal efficiency are shown in Table 1. Results showed that the range of SS, turbidity removal efficiency were $72.0-86.6 \%$ (mean $80.0 \%$ ), 30.9-71.1\% (mean $49.3 \%$ ), respectively. The variation of surface overflow rate, retention time, head loss, and SS solid loading rate were shown in Figure 3 . When solid loading increased, SS removal efficiency was rapidly decreased. The calculated average solid load was $12.4 \mathrm{~kg} / \mathrm{m} 2$. There has uncorrelated between removal efficiency and head loss were shown in Figure 4. A number of samples were analyzed for particle size distribution.

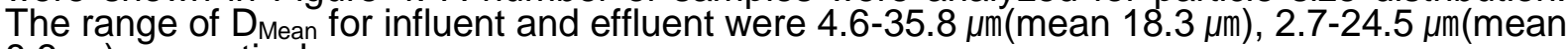
$8.3 \mu \mathrm{m})$ respectively.

Table 1. Summary results operation condition and SS and turbidity removal efficiency without coagulants

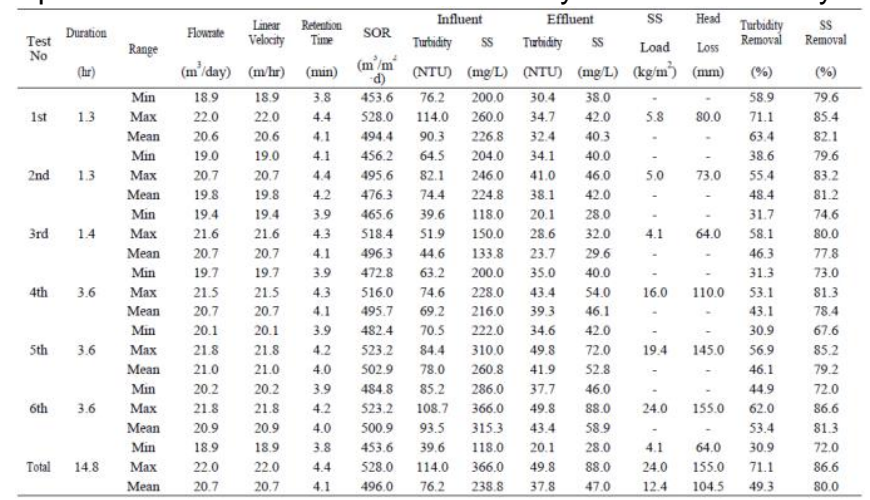




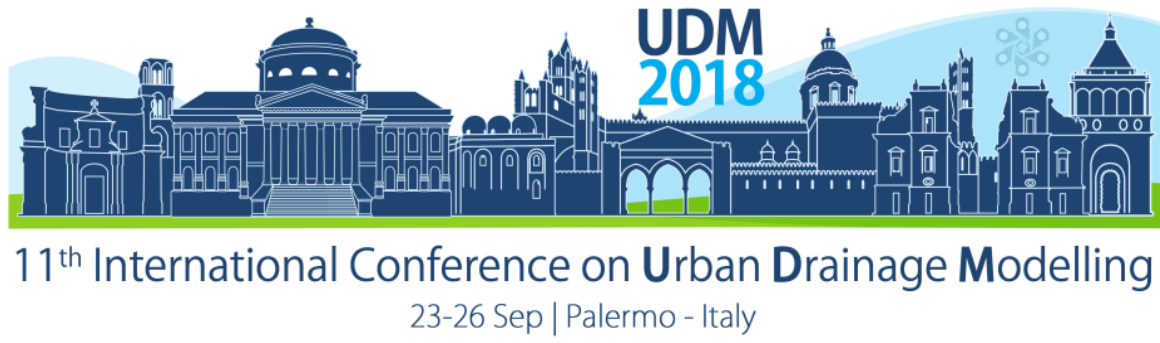

\subsubsection{Filter backwashing and solid mass balance in case of without coagulant use}

To backwash a filter, the influent value is closed, and drained whole wastewater. After drain colume as filled with effluent and 1st backwashing by blowing air $3 \mathrm{~min}$, and repeat twice in the same way. The SFS system was backwashed by blowing air with effluent water through for $3 \mathrm{~min}$ at a rate of $60 \mathrm{~m} 3 / \mathrm{m} 2 / \mathrm{hr}$ after two times backwash, whole drained wastewater was collected for mass balanced analysis. 6 series of backwashing experiments were conducted to determine the effectiveness of air blowing. The recovery rate of filter was $79.2-83.6 \%$ (mean $81.2 \%$ ) the rate of remained solid loading in filter media was $16.4-20.8 \%$ (mean $18.8 \%$ ) after backwashing.

\subsection{SFS operation with coagulant}

The SFS run with coagulant dosing had a total operation time of $4 \mathrm{hr}$. Among the several types of coagulants, polyaluminium chloride silicate (PACS) was selected for stormwater treatment. As the results of Jar test showed that PACS optimum dosage was $7.0 \mathrm{mg} / \mathrm{L}$, which these conditions left residual turbidity to less than 2.0NTU. Through more than 3 experiments were carried out with various conditions such as different SS concentration. The range of influent flowrate and surface overflow rate were 6.8-8.0 m3/day (mean $7.2 \mathrm{~m} 3 / \mathrm{day}$ ), 163.2$191.8 \mathrm{~m} 3 / \mathrm{m} 2 /$ day (mean $172.4 \mathrm{~m} 3 / \mathrm{m} 2 /$ day), respectively. The influent turbidity, SS concentrations were 59.0-90.7 NTU (mean 72.0 NTU), $194.0-320.0 \mathrm{mg} / \mathrm{L}$ (mean $246.7 \mathrm{mg} / \mathrm{L}$ ), respectively. The range of PACS dosage concentration was $6.0-7.1 \mathrm{mg} / \mathrm{L}$ (mean $6.7 \mathrm{mg} / \mathrm{L}$ ). As shown Table 3, results showed that the range of SS, turbidity removal efficiency were 84.9-98.2 (mean 91.4\%), 70.7-96.3 (mean 84.0\%), respectively. The range of DMean for influent and effluent were 13.1-27.2 $\mu \mathrm{m}$ (mean 18.6 $\mu \mathrm{m}$ ), 14.3-31.9 $\mu \mathrm{m}$ (mean $22.0 \mu \mathrm{m}$ ) respectively. The correlation coefficient (R2) between SS and turbidity was 0.90 as shown in Figure 3.

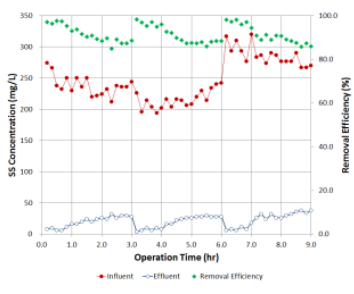

(a) SS

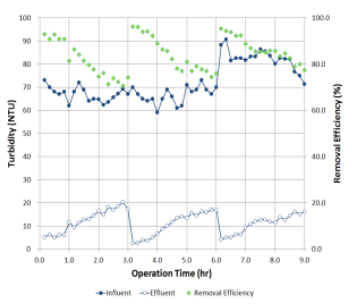

(b) Turbidity

Figure 2. The results of filtration pilot test in CWTP: with hydrocyclone coagulation.

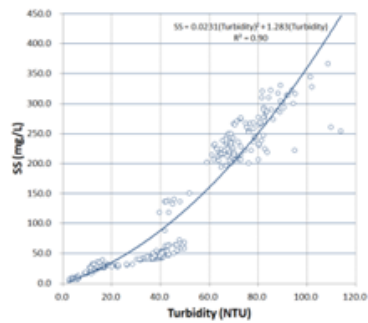

Figure 3. The correlation coefficient $\left(R^{2}\right)$ between $S S$ and turbidity

\subsubsection{Filter backwashing and solid mass balance in case of with coagulant use}

Backwashing begins when the drainage pipe valve at the filtration tank bottom is completely open (backwashing stage 1). Backwashing stage 2 was using air bubbles and water jet washing the media for 3 min and open the drainage valve. After backwashing stage 1,2 , $92.0-92.5 \%$ (mean 92.3\%) of SS loading was discharged from filtration tank. Figure 16 is shows that the accumulated floc formation inside filter media. 3 series of backwashing experiments were conducted to determine the effectiveness of air blowing. The results of 3 series of the backwashing experiments and SS loading mass balance analysis are summarized in Table 4 and Figure 17. The recovery rate of filter was 92.0-92.5\% (mean $92.3 \%$ ) the rate of remained solid loading in filter media was $6.1-8.2 \%$ (mean $7.2 \%$ ) after backwashing. 


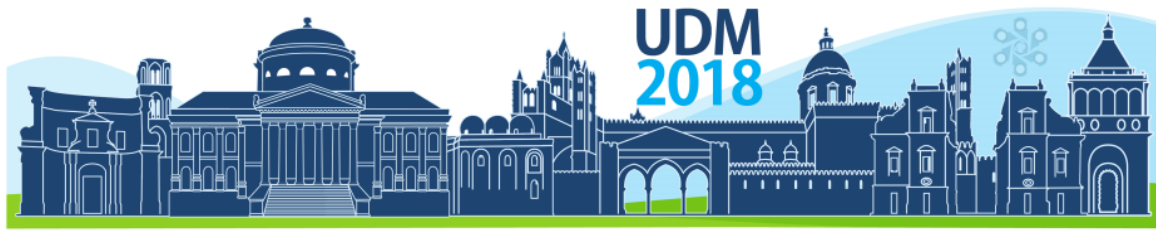

$11^{\text {th }}$ International Conference on Urban Drainage Modelling

23-26 Sep | Palermo - Italy

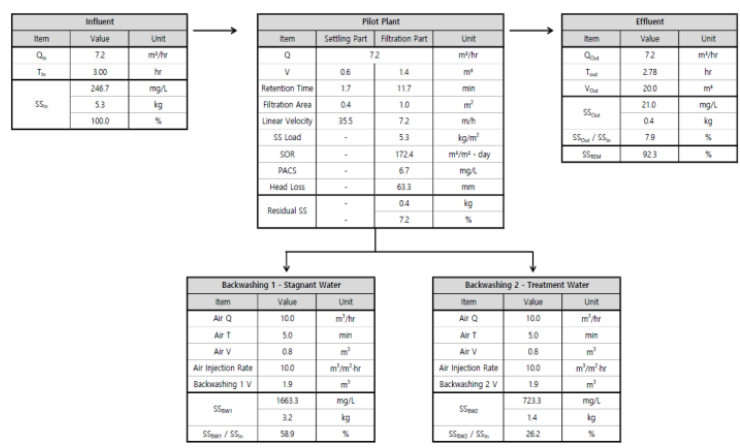

Figure 17. SS solid loading mass balance in case of coagulant use.

\section{CONCLUSIONS}

This study has been carried out to evaluate the applicability of the hybrid type of stormwater runoff treatment systems (SFS) and determine the optimum operational parameter such as coagulation dosage concentration, with or without coagulants, surface loading rate and backwashing conditions. The results of Jar test showed that PACS optimum dosage was $7.0 \mathrm{mg} / \mathrm{L}$, which these conditions left residual turbidity to less than 2.0NTU. In case of SFS run with coagulant use, The range of influent flowrate and surface overflow rate were 6.8-8.0 m3/day (mean 7.2 m3/day), 163.2-191.8 m3/m2/day (mean $172.4 \mathrm{m3} / \mathrm{m} 2 /$ day), respectively. The influent turbidity, SS concentrations were 59.0-90.7 NTU (mean 72.0 NTU), 194.0- 320.0 $\mathrm{mg} / \mathrm{L}$ (mean $246.7 \mathrm{mg} / \mathrm{L}$ ), respectively. The range of PACS dosage concentration was 6.0$7.1 \mathrm{mg} / \mathrm{L}$ (mean $6.7 \mathrm{mg} / \mathrm{L}$ ). The range of SS, turbidity removal efficiency were 84.9-98.2 (mean 91.4\%), 70.7-96.3 (mean 84.0\%), respectively. It was found that removal efficiency was enhanced with PACS dosage. The recovery rate of filter was 92.0-92.5\% (mean 92.3\%) the rate of remained solid loading in filter media was $6.1-8.2 \%$ (mean $7.2 \%$ ) after backwashing. In case of coagulant use, the particle size of effluent is bigger than influent particle size. The results showed that STS with PACS use more effective than without PACS use in SS and turbidity removal efficiency and recovery rate of filter. The SFS system, which came out to solve the problems of low efficiency of removing micro particles of upflow filtration type stormwater treatment devices, therefore SFS is considered as an alternative system.

\section{ACKNOWLEDGEMENTS}

This research was supported by Basic Science Research Program through the National Research Foundation of Korea(NRF) funded by the Ministry of Education(No. 2017R1D1A1B03033724).

\section{References}

Balmforth, D.J., (1990), The pollution aspects of storm-sewage overflows, Water and Environment Journal, 4(3), 219-226.

Chow, M.F., Yusop, Z.(2014), Characterization and source identification of stormwater runoff in tropical urban catchments, Water Science and Technology, 69(2), 244-251.

Chaters F.J. et al., (2015), Particle size distribution variance in untreated urban runoff and its implication on treatment selection, Water Research, 85, 337-345Sartor J.D., et al., (1974), Water pollution aspects of street surface contaminants, Journal of WPCF., 46(3), 458-467.

Ebeling J.M. et al, (2003), Evaluation of chemical coagulation-flocculation aids for the removal of suspended solids and phosphorus from intense recirculating aquaculture effluence discharge, Aquaculture Engineering, 29, 23-42.

El-Gendy, A.S., et al., (2008), Treatment of combined sewer overflow using retention treatment basin assisted with polymer chemical coagulation, Water Environment Research, 80(9), 774-763.

El Samrani A.G., et al., Chemical coagulation of combined sewer overflow: Heavy metal removal and treatment optimization, Water Research, 42, 951-960.

Filtration+Seperation, (March/April 2010). Wastewater treatment: Enhanced biological treatment of storm flows.

Ma Y., Zhu D.Z. (2014), Improving sediment removal in standard stormwater sumps, Water Science and Technology 69(10), 2099- 2104

Shimadzu Corporation, Particle Size Analyzer Model : SALD-2101.

Torres A., Bertrand-Krajewski J.L., (2008), Evaluation of uncertainties in settling velocities of particles in urban stormwater runoff, Water Science and Technology, 57(9), 1389-1395. 


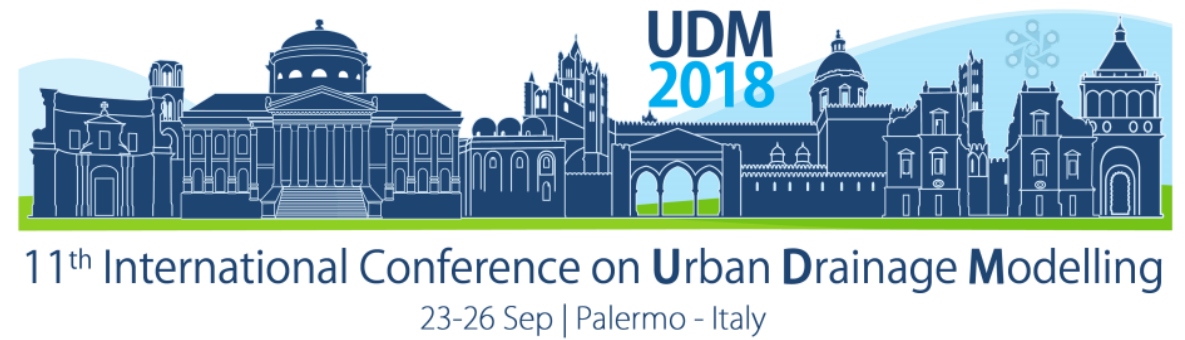

\title{
Microalgae Cultivation using Various Sources of Organic Substrate for High Lipid Content
}

\author{
Hesam Kamyab ${ }^{1,2^{*}}$, Shreeshivadasan Chelliapan ${ }^{1 *}$, Chew Tin Lee ${ }^{3}$, Shahabaldin Rezania ${ }^{4}$, \\ Amirreza Talaiekhozani ${ }^{5}$,Tayebeh Khademi ${ }^{6}$, Ashok Kumar ${ }^{7}$ \\ ${ }^{1}$ Department of Engineering, UTM Razak School of Engineering and Advanced Technology, Universiti Teknologi \\ Malaysia, Jalan Sultan Yahya Petra, 54100 Kuala Lumpur, Malaysia \\ ${ }^{2}$ Department of Mechanical and Industrial Engineering, University of Illinois at Chicago, 845 West Taylor Street, \\ Chicago, IL 60607, USA \\ ${ }^{3}$ Department of Bioprocess and Polymer Engineering, Innovation Centre in Agritechnology for Advanced \\ Bioprocessing (ICA), Universiti Teknologi Malaysia, 81310, Johor, Malaysia \\ ${ }^{4}$ Department of Civil and Environmental Engineering, Seoul National University, Seoul, Republic of Korea \\ ${ }^{5}$ Department of Civil Engineering, Jami Institute of Technology, Isfahan, Iran \\ ${ }^{6}$ Faculty of Management, Universiti Teknologi Malaysia, 81310 UTM Skudai, Johor, Malaysia \\ ${ }^{7}$ Department of Biotechnology and Bioinformatics, Jaypee University of Information Technology, Waknaghat, \\ Solan, 173215 H.P., India \\ *Corresponding Author: hesam_kamyab@yahoo.com; shreeshivadasan.kl@utm.my
}

\begin{abstract}
The ingredients of photosynthetic reactions can be exploited to increase algal culture productivity to effectively treat wastewater by significantly reducing the presence of organic and inorganic compounds. In this study, we introduced microalgae Chlorella pyrenoidosa ( $C$. pyrenoidosa) into four different wastewater samples, including Palm Oil Mill Effluent (POME), piggery, domestic, and mixed-kitchen wastes. The C. pyrenoidosa growth efficacy of POME and subsequent drop in nutrients were demonstrated. It was clearly seen that POME had the highest Chemical Oxygen Demand (COD) values at 700 $\mathrm{mg} \mathrm{L}^{-1}$. The Total Nitrogen (TN) ratio for the piggery sample was the highest at $590 \mathrm{mg} \mathrm{L}^{-1}$. Productivity was evaluated in terms of chlorophyll content, growth rate, biomass, and lipid content. POME and domestic wastes had the first and second highest chlorophyll a content of $3 \mathrm{mg} \mathrm{L}^{-1}$ and $2.5 \mathrm{mg} \mathrm{L}^{-1}$, respectively. The optimum growth rate for $C$. pyrenoidosa was observed when using POME as a substrate. This study confirmed that Cell Dry Weight (CDW) in POME was the highest with $500 \mathrm{mg} \mathrm{L}^{-1}$ after 20 days cultivation of $C$. pyrenoidosa, when compared to other substrates. Maximum lipid content was recorded for POME, domestic sample, piggery, and mixed-kitchen waste, at 182, 148, 0.99, and117 mg $\mathrm{L}^{-1}$, respectively. The above results revealed that POME was the best substrate choice for alga $C$. pyrenoidosa with the highest lipid production rate of the four substrates. It was established that POME (as a nutrient enriched media) assisted $C$. pyrenoidosa growth and considerably reduced the presence of organic and inorganic compounds.
\end{abstract}

Keywords: Chlorella pyrenoidosa; Wastewater; Lipid content; Organic substrate

\section{INTRODUCTION}

Palm Oil Mill Effluent (POME) is a thick, brownish, viscous nontoxic liquid waste with an unpleasant odour. It was proven that palm oil mills generate several environmentally harmful by-products [Ahmad et al.,2003]. This waste discharge (called POME) from the Malaysian palm oil industry is an affluent source of nutrients and carbon for exploitation in microalgae 


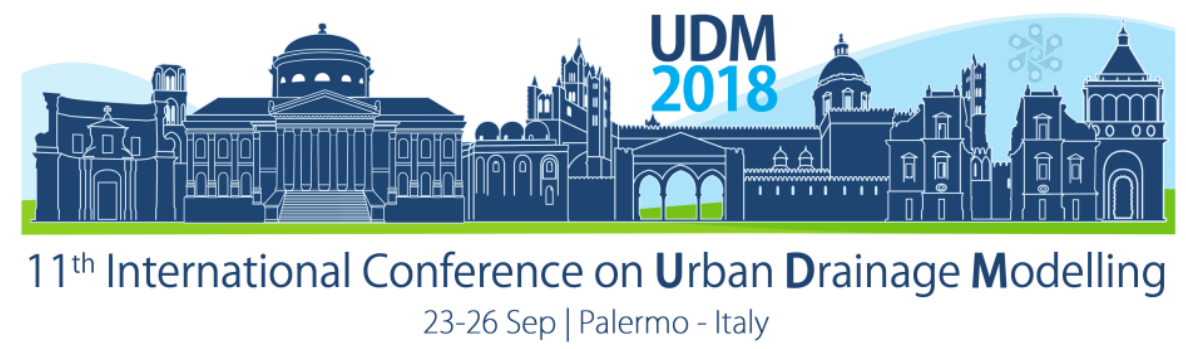

cultivation [Kamyab et al.,2016]. According to the Department of Environment (DOE) Malaysia, effluent produced by industries does not meet the standards and is not properly treated before being released into rivers and lakes [Resdi et al.,2016]. Recently, microalgae received considerable attention due to its potential in wastewater treatment and biomass production [Li et al.,2008]. Microalgae could be used as an active agent to uptake nutrients, components, and chemicals/toxic and discharged from industrial sections into rivers or lakes [Kamyab et al.,2016]. This method is based on the cultivation of microalgae using industrial waste, which is being discharged into the water to obtain high lipid microalgae content as a novel raw material for energy production. According to Kamyab et al., 2016, Chlorella pyrenoidosa (C. pyrenoidosa) is a promising agent that could be used to treat wastewater such as POME. The aim of this study is to analyse the biomass production, growth rate, and lipid content of cultured microalgae $C$. pyrenoidosa in various organic substrates such as POME, piggery, domestic, and mixed-kitchen waste.

\section{MATERIALS AND METHODS}

\subsection{Sample collection}

Palm Oil Mill Effluent (POME) as a carbon and mixed consortia of microalgae was obtained from facultative ponds at a Felda palm oil mill in Kulai (Johor, Malaysia). The collected POME was allowed to reach room temperature before sample preparation. Raw piggery (pig slurry), domestic, and mixed-kitchen wastes were collected from piggery industry in Malaysia and Universiti Teknologi Malaysia (UTM), Skudai, and Johor Bahru, respectively. The Desa Bakti River was chosen for domestic waste collection from a stabilisation pond used by UTM. Mixed-kitchen waste was collected from domestic restaurants in UTM as well. [Kamyab et al.,2015].

\subsection{Determination of Mixed Liquor Suspended Solids (MLSS) and Mixed Liquor Volatile Suspended Solids (MLVSS)}

Biomass was obtained by filtering the sample through a pre-dried $0.45 \mu \mathrm{m}$ Whatman filter paper, which was dried in an oven for $1 \mathrm{~h}$ at $103^{\circ} \mathrm{C}$. Suspended volatile solids were obtained by incinerating dried solids at $550^{\circ} \mathrm{C}$ in the furnace for $15 \mathrm{~min}$. All analyses were carried out according to the standard methods 2540.D;E for MLSS and MLVSS, respectively [Clesceri et al.,1989]. The formulas used for determining sample volume are shown below:

$\operatorname{MLSS}(\mathrm{mg} / \mathrm{L})=\frac{(4-\mathrm{B}) \times 1000}{\text { sample volume }(\mathrm{mL})}$
$\operatorname{MLVSS}(\mathrm{mg} / \mathrm{L})=\frac{(\mathrm{C}-\mathrm{D}) \times 1000}{\text { sample volume }(\mathrm{mL})}$

\section{RESULTS AND DISCUSSION}

\subsection{Mixed Liquor Suspended Solid (MLSS)/ Mixed Liquor Volatile Suspended Solid (MLVSS) and Chlorophyll a Content}

Figure 1 shows the value of mixed liquor suspended solids (MLSS) for C. pyrenoidosa cultivated in POME, piggery, domestic, and mixed-kitchen waste. Based on Figure 1, POME had the highest MLSS values of around $820 \mathrm{mg} \mathrm{L}^{-1}$ and the lowest growth rate. Domestic 


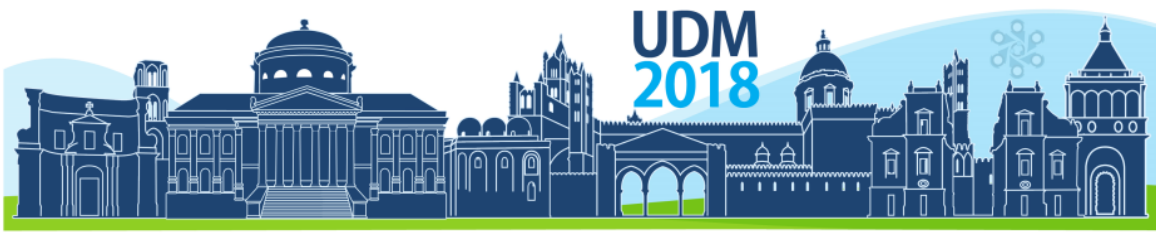

$11^{\text {th }}$ International Conference on Urban Drainage Modelling

23-26 Sep | Palermo - Italy

waste showed the greatest rate increment. Mixed-kitchen waste increased to around $700 \mathrm{mg}$ $\mathrm{L}^{-1}$. The MLSS of $C$. pyrenoidosa cultured in piggery waste increased slightly from day 0 to day 10 but dropped slightly after day 10 and was constant until day 20 showing that piggery samples entered have stationary phase. Mixed-kitchen waste showed a stationary phase of growth after culturing. Performance comparisons in terms of MLVSS/MLSS ratios and lipid content of $C$. pyrenoidosa using POME was stated by Kamyab et al., (2016). The correlation between MLVSS/MLSS ratio and lipid content was indicated for POME as a substrate, where lipid content increased with the MLVSS/MLSS ratio. This enhancement is primarily attributed to the consumption of substrates by $C$. pyrenoidosa, affecting both growth and lipid storage.

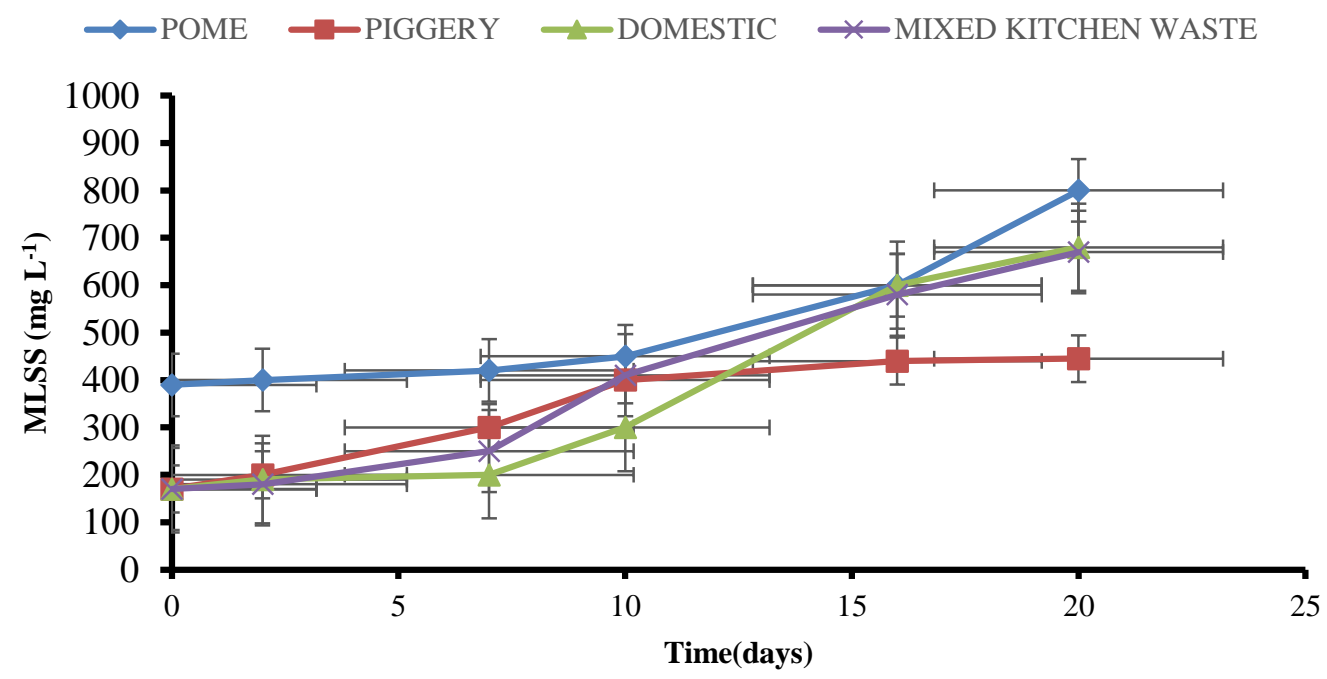

Figure 1: Mixed liquor suspended solid (MLSS) versus time for $C$. pyrenoidosa cultivated in POME, piggery, domestic and mixed-kitchen wastes

Figure 2 demonstrates a MLVSS for POME, piggery, domestic, and mixed-kitchen waste for cultured $C$. pyrenoidosa substrates. Figure 2 shows the rapid increment for POME, domestic, and mixed-kitchen waste, while a slight growth in MLVSS content was recorded in the same period of time (20 days). Results showed that POME had the highest MLVSS value compared to other substrates. This confirms that POME is the richest nutrient source for cultivating $C$. pyrenoidosa with a maximum MLVSS of about $750 \mathrm{mg} \mathrm{L}^{-1}$. The piggery sample had the lowest growth rate. The slight rise in the $C$. pyrenoidosa for the piggery sample shows a non-active substrate, which is unsuitable for cultivating any species of microalgae. The growth rate of $C$. vulgaris increased with the decreased concentrations of piggery wastewater in the culture media regardless of diluent type [Ji et al.,2013]. 


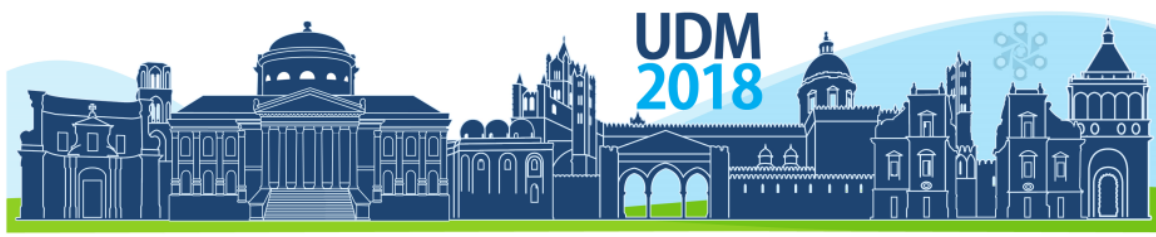

$11^{\text {th }}$ International Conference on Urban Drainage Modelling

23-26 Sep | Palermo - Italy

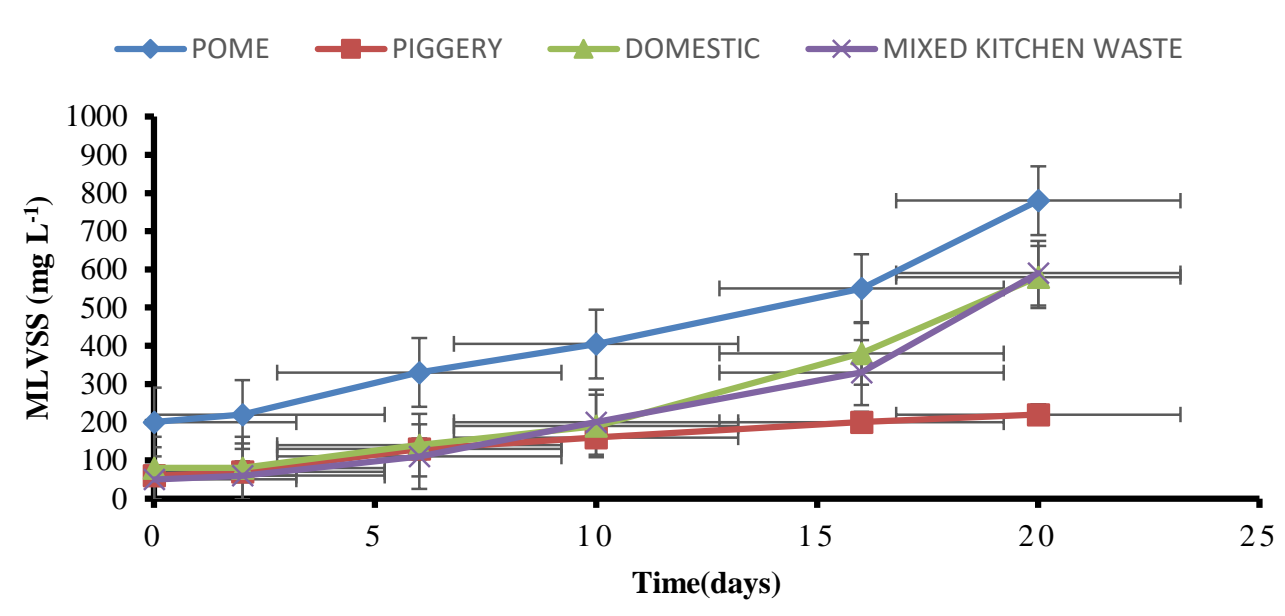

Figure 2: Mixed liquor volatile suspended solid (MLVSS) versus time in several sources of organic substrate

The lipid content production for $C$. pyrenoidosa cultivated in POME, piggery, domestic, and mixed-kitchen waste is illustrated in Figure 3. Based on Figure 3, C. pyrenoidosa produced lipids in all four waste samples. POME showed an increasing trend with lipid content values from $88 \mathrm{mg} \mathrm{L}^{-1}$ and to $182 \mathrm{mg} \mathrm{L}^{-1}$. This confirms that POME is the best substrate choice, with the highest lipid production rates compared to the other organic substrates used in this study. As for the domestic sample, an increase from $46 \mathrm{mg} \mathrm{L}^{-1}$ to 148 $\mathrm{mg} \mathrm{L}^{-1}$ shows that it is the second best choice for high lipid production for $C$. pyrenoidosa. The piggery and mixed-kitchen waste had similar increasing trends for lipid production with values between $25 \mathrm{mg} \mathrm{L}^{-1}$ and $117 \mathrm{mg} \mathrm{L}^{-1}$. Furthermore, piggery and mixed-kitchen waste are the third and fourth choice for the cultivation of high lipid content $C$. pyrenoidosa. Kamyab et al., (2016b) stated that the highest and lowest lipid content of $C$. sorokiniana and C. pyrenoidosa microalgae strains cultivated in POME produced were $2.68 \mathrm{mg} / \mathrm{mg} \mathrm{CDW}$ and $0.74 \mathrm{mg} / \mathrm{mg}$ CDW, respectively. Converti et al., (2009) acknowledged a drop in nutrient content from increased lipid concentrations. Moreover, ecological stresses such as nitrogen diminution led to the inhibition of cell division without an instant reduction in oil/lipid production. According to Kamyab et al. (2017), C. pyrenoidosa was found to be a dominant species in POME. Besides, the optimal lipid production was gained by $C$. pyrenoidosa at day 20 and lipid content at $56 \mathrm{mg} / \mathrm{L}$ was documented. 


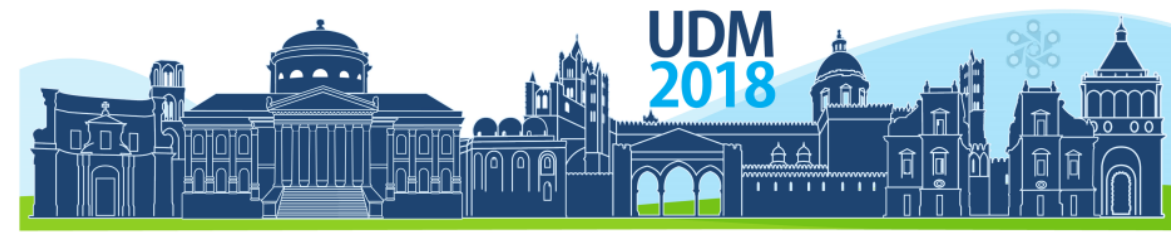

$11^{\text {th }}$ International Conference on Urban Drainage Modelling

23-26 Sep | Palermo - Italy

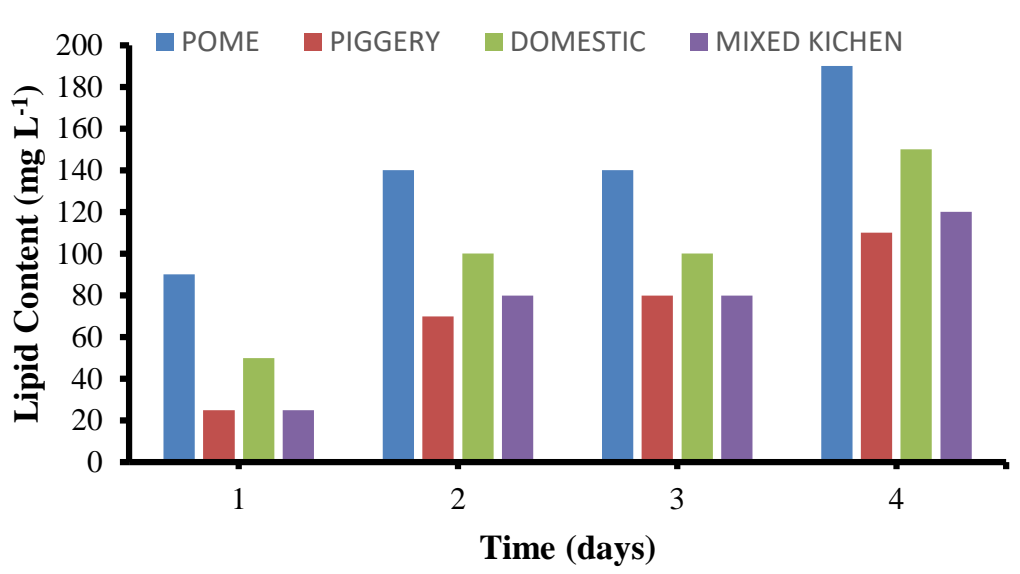

\section{CONCLUSIONS}

Environmental pollution, specifically water pollution, is alarming in both developed and developing countries. Algae growth and lipid production were determined by an indigenous strain using POME, piggery domestic, and mixed-kitchen waste substrates. It can be concluded that among all substrates the optimum growth rate of $C$. pyrenoidosa was observed when using POME. The above results revealed that POME is a suitable growth media for the algae $C$. pyrenoidosa for improving maximum lipid yield for biofuel production.

\section{References}

Ahmad, A. L., Ismail, S., \& Bhatia, S. (2003). Water recycling from palm oil mill effluent (POME) using membrane technology. Desalination, 157(1-3), 87-95.

Clesceri, L. S. A E Greenberg \& RR Trussell 1989 Standard Methods for the Examination of Water and Wastewater. American Public Health Association, Washington, DC.

Ji, M. K., Kim, H. C., Sapireddy, V. R., Yun, H. S., Abou-Shanab, R. A., Choi, J., \& Jeon, B. H. (2013). Simultaneous nutrient removal and lipid production from pretreated piggery wastewater by Chlorella vulgaris YSW-04. Applied microbiology and biotechnology, 97(6), 2701-2710.

Kamyab, H., Din, M. F. M., Ghoshal, S. K., Lee, C. T., Keyvanfar, A., Bavafa, A. A., \& Lim, J. S. (2016). Chlorella pyrenoidosa mediated lipid production using Malaysian agricultural wastewater: effects of photon and carbon. Waste and Biomass Valorization, 7(4), 779-788.

Kamyab, H., Md Din, M. F., Lee, C. T., Keyvanfar, A., Shafaghat, A., Majid, M. Z. A., \& Yun, T. X. (2015). Lipid production by microalgae Chlorella pyrenoidosa cultivated in palm oil mill effluent (POME) using hybrid photo bioreactor (HPBR). Desalination and water treatment, 55(13), 3737-3749.

Li, Y., Chen, Y. F., Chen, P., Min, M., Zhou, W., Martinez, B., \& Ruan, R. (2011). Characterization of a microalga Chlorella sp. well adapted to highly concentrated municipal wastewater for nutrient removal and biodiesel production. Bioresource technology, 102(8), 5138-5144.

Resdi, R., Lim, J. S., Kamyab, H., Lee, C. T., Hashim, H., Mohamad, N., \& Ho, W. S. (2016). Review of microalgae growth in palm oil mill effluent for lipid production. Clean Technologies and Environmental Policy, 18(8), 2347-2361 


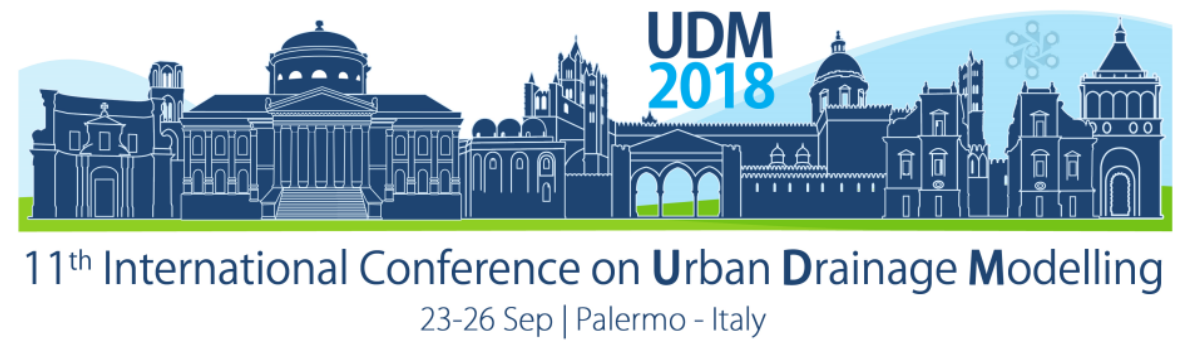

\title{
Partitioning of metals in urban drainage from paved source area catchments
}

\author{
Ilaria Gnecco', Anna Palla', John Sansalone ${ }^{2}$ \\ 11Department of Civil, Chemical and Environmental Engineering, University of Genova, Genoa, Italy \\ ${ }^{2}$ University of Florida, Engr. School of Sustainable Infrastructure \& Environment, Gainesville, FL, 32611, USA
}

\begin{abstract}
Representation of metal partitioning in urban drainage is required when determining loadings, treatment, maintenance and regulatory compliance. This is particularly the case for paved urban source areas where, if a first-flush exists, the design volumetric capture and treatment will be based on such regulatory requirements. However, such treatment for metals requires partitioning information if metals are to be effectively separated from flows from paved source areas. This study examined partitioning and transport of metals from paved surfaces of four differing land uses: highway, airside and landside within aviation site, commercial/tourism terminals within port area. Equilibrium concentrations of metals and particulate matter (PM) using a non-parametric analysis for a series of six paved surface area catchments were compared. In particular two American highway sites, and four Italian sites located in the Liguria Region (two port terminal sites and two aviation sites) were examined and compared with event based concentrations collected from catchments with similar land uses. The role of hydrology on mass transport and partitioning of aqueous and particulate-bound metal fractions was evaluated. Finally transport of metal phases on an event basis, thus relating hydrology and PM mass delivery impacting metal partitioning were examined. Partitioning, indexed through a partitioning coefficient, $\mathrm{K}_{d}(\mathrm{~L} / \mathrm{kg})$ accounts for hydrologic transport, PM transport and interactions with and between metals. $K_{d}$ can vary by orders of magnitude across a runoff event for the source area catchments of this study. Highway sites were more heavily loaded with PM and metals than airport sites. The metals results from the six sites of this study were compared to similar sites around the world. Based on the variability of partitioning, whether intra- or inter-event, results indicate that paved source area treatment requires a combination of sedimentation, filtration and adsorption mechanisms for in-situ unit operations and processes (UOP).
\end{abstract}

Keywords: Best Management Practices; Partitioning, Metals; Particulate Matter, Urban Drainage

\section{INTRODUCTION}

Anthropogenic activities in paved source areas such as modern transportation whether from vehicular, industrial or air traffic can be a significant source of particulate matter (PM) and metals that are mobilized and transported during runoff events. Metals transported in runoff partition between PM and dissolved fraction, favoring the dissolved fraction for low rainfall $\mathrm{pH}$ levels at low pavement residence times in terms of minutes (Sansalone and Buchberger 1997).

Partitioning of metals, in this study between dissolved and particulate phases of runoff, is complex. While partitioning can be described on an event basis, partitioning is likely to vary significantly between events, paved source areas and within events. The variable nature of partitioning is due to the variable PM concentrations, particle size distributions (PSDs), $\mathrm{pH}$, alkalinity, residence time, hydrologic phenomena and urban surface conditions. Partitioning is typically defined as an interaction between the dissolved metal fraction, and the 


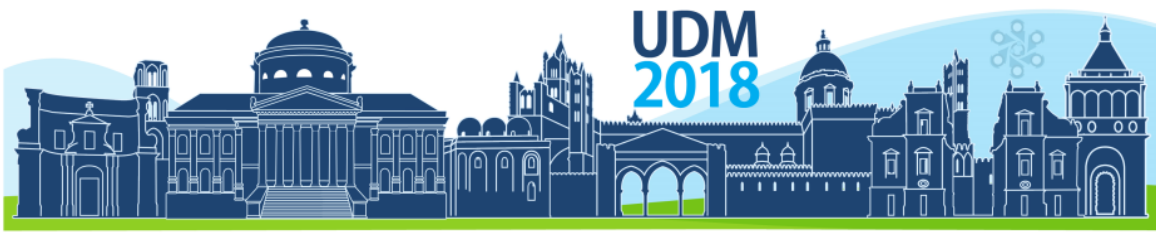

$11^{\text {th }}$ International Conference on Urban Drainage Modelling

23-26 Sep | Palermo - Italy

particulate-bound fraction; irrespective of the colloidal fraction. These interactions can be forward (nominally sorption) or reverse reactions (desorption) that occur during the partitioning reaction as shown conceptually in Figure 1. This is the conceptual model of partitioning in this study. This partitioning includes specific mass transfer mechanisms such as ion exchange, surface complexation and precipitation. Chemical species in complex environmental systems eventually attain different equilibrium concentrations in the phases comprising these systems. The concentrations in theory should be quantifiable as PM phase to aqueous phase partitioning and is a reasonable estimate of the distribution of a solute between two phases.

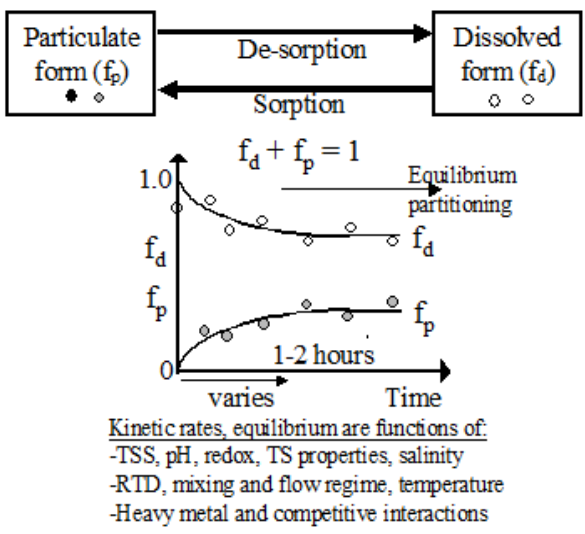

Figure 1. Two partition model of partitioning between dissolved and particulate metals

While partitioning in this study is examined through a two partition model, there is a very hetero-disperse PSD in source area runoff that varies from colloidal $(<1 \mu \mathrm{m})$ to suspended $(<25 \mu \mathrm{m}$, as total suspended solids, TSS) to settleable $(<75 \mu \mathrm{m})$ to sediment PM $(<4750$ $\mu \mathrm{m}$ nominally) with larger PM classified as gross solids. For urban paved source areas, on a gravimetric basis, the sediment fraction generally dominates, the colloidal fraction is less than several percent and the suspended fraction is in the range of 20 to $30 \%$ of the total. However, on a number basis the fine suspended fraction $(<10 \mu \mathrm{m})$ dominates all other PM fractions. While specific surface area $\left(\mathrm{m}^{2} / \mathrm{g}\right)$ of PM increases with decreasing PM diameter, the total surface area $\left(\mathrm{m}^{2}\right)$ is dominated by the sediment fraction because this fraction gravimetrically dominates PM transported in paved source areas.

Under conditions where a number of metals are present in runoff (common analytes are $\mathrm{Cu}$, $\mathrm{Cd}, \mathrm{Pb}$ and $\mathrm{Zn}$ ), the competitive order of partitioning (sorption) can be compared to bonding preferences as predicted using covalent theory, electrostatics, or hydrolysis followed by sorption. According to covalent theory for divalent metal ions, the bonding preference is $\mathrm{Cu}$ $>\mathrm{Pb}>\mathrm{Cd}>\mathrm{Zn}$ (McBride 1994). However, based on electrostatics, bonding preference for divalent metals is $\mathrm{Cu}>\mathrm{Zn}>\mathrm{Cd}>\mathrm{Pb}$ (McBride 1994). Finally, based on the tendency to hydrolyze, the bonding preference of selected metal ions is $\mathrm{Pb}>\mathrm{Cu}>\mathrm{Zn}>\mathrm{Cd}$ (McBride 1994).

Knowledge of the partitioning and the relative fractions of dissolved $\left(f_{d}\right)$ and particulate-bound $\left(f_{p}\right)$ mass delivered for treatment are of fundamental importance for in-situ treatments where residence times on the source area surface in the presence of entrained PM are on the order of minutes to less than an hour. In these urban paved sources areas, partitioning is competitive and with partitioning is the distribution of metal mass as a function of particle size 


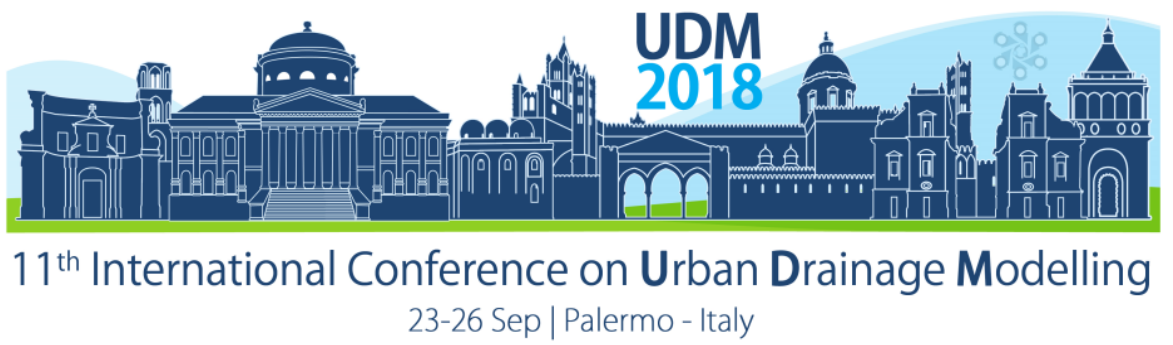

across the PSD. This study takes a 2-partition approach, lumping the metal distribution across the PSD as a single particle-bound partition; irrespective of distribution across the PSD.

\section{MATERIALS AND METHODS}

The partitioning model is based on Glenn (2002) who defined two partitions, for a given constituent, in the dissolved and particulate-bound fractions. The dissolved fraction is defined as $C^{\prime}{ }_{d}$ in $\left[M / L^{3}\right]$, where $M=$ mass of constituent and $L^{3}=$ volume of aqueous solution (or non-aqueous solution). The particulate form is defined as $C_{p}$ in $\left[M / L^{3}\right]$, where $M=$ mass of constituent and $L^{3}$ is the volume of PM plus water (the bulk volume). Therefore, the form $\mathrm{C}_{p}$ is the mass of the metal "sorbed" to PM relative to the volume of water (Thomann and Mueller 1987). For a given concentration of $P M, C_{p}$ can also be expressed as $C_{p}=C_{s}(m)$ where $m$ is the $P M$ concentration in $\left[M / L^{3}\right], L$ is the bulk aqueous volume with $P M, C_{s}$ is the metal concentration expresses on a dry weight basis [M/M] (i.e. mass of metal on or in the $\mathrm{PM} / \mathrm{mass}$ of dry $\mathrm{PM}$ ); Units for $\mathrm{C}_{\mathrm{s}}$ are typically $\mu \mathrm{g} / \mathrm{g}$; noting the $\mu \mathrm{g} / \mathrm{g}$ is equivalent to a part per million.

Assuming linear kinetics (Thomann and Mueller 1987), a representation of the partitioning balancing the mechanism of sorption of the metal to PM and desorption from the PM back into the dissolved phase is shown in Figure 2 and leads to $K_{d}$. The slope in Figure 2 is $K_{d}$ and represents the ratio of (metal mass/PM mass) to (metal mass/liquid volume).

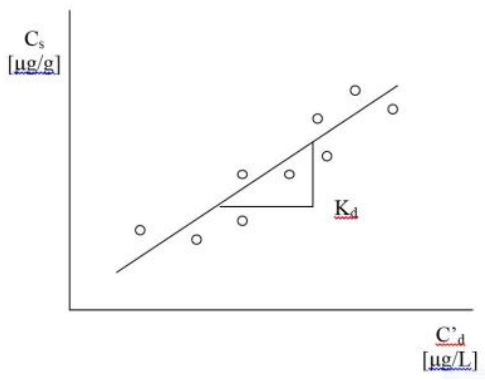

Figure 2. Definition of $K_{d}$ and conceptual relation of $P M$ and dissolved metals

In order to examine partitioning in paved source area runoff related to the different urban land-use activities, a series of six paved source area catchments were picked out including four differing land uses: highway, parking lot (landside) and apron terminal (airside) within aviation site, commercial/tourism terminals within the port area. These source areas are compared to similar areas around the world for metals and PM. A summary of paved source areas, methods and databases used with selected data obtained are summarized in Table 1. 


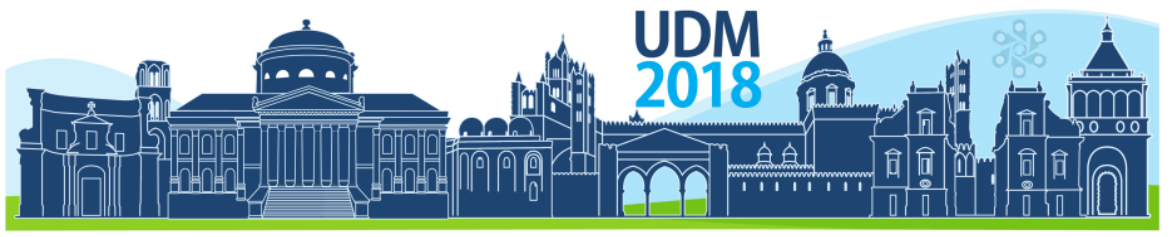

$11^{\text {th }}$ International Conference on Urban Drainage Modelling

23-26 Sep | Palermo - Italy

Table 1. Summary of paved source area catchment descriptions and sampling/analytical methodology employed for the measurement of PM and metals in runoff events.

\begin{tabular}{|c|c|c|c|c|c|c|c|c|c|c|c|c|}
\hline Location & Land-use & Area $^{a}$ & $\begin{array}{l}\text { Pave } \\
\text { ment }^{b}\end{array}$ & Imp. ${ }^{\circ}$ & Slope $e^{d}$ & $A D T^{\mathrm{e}}$ & $\begin{array}{r}\text { Monitoring } \\
\text { Period } \\
\end{array}$ & Rain & $n^{f}$ & $\begin{array}{c}\text { Sampling } \\
\text { methods }\end{array}$ & $\begin{array}{l}\text { Standard } \\
\text { Method }^{\text {h }}\end{array}$ & $R_{e f}$ \\
\hline & & $\mathrm{m}^{2}$ & & $\%$ & & $\times 10^{3}$ & & $\mathrm{~mm} / \mathrm{yr}$ & & & & \\
\hline Cincinnati $(\mathrm{OH}, \mathrm{USA})$ & Highway (I-75) & 300 & A & 100 & $<0.004$ & 117 & Oct 95 - June 97 & 1,020 & 11 & GS & APHA & (1) \\
\hline Baton Rouge (LA, USA) & Highway (I-10) & 544 & $\mathrm{C}$ & 100 & 0.0018 & 70 & Juan 02 - July 02 & 1,460 & 6 & GS & APHA & (2) \\
\hline Little Rock (AR, USA) & Highway (I-30) & 6,070 & A & 90 & n.a. & 42 & May 83 - May 84 & 1,237 & 17 & AS & APHA & (3a) \\
\hline Denver (CO, USA) & Highway (I-25) & 142,859 & A & 37 & n.a. & 149 & Aug 76 - July 77 & 376 & 16 & AS & APHA & $(3 b)$ \\
\hline Nashville (TE, USA) & Highway (I-40) & 225,013 & $\mathrm{C}$ & 37 & n.a. & 88 & Oct $76-$ Sep 77 & 1,143 & 21 & AS & APHA & $(3 c)$ \\
\hline Loire-Atlantique (France) & Highway (A-11) & 3,200 & $\mathrm{~A}$ & $\sim 100$ & n.a. & 12 & Mar 95-Feb 96 & 656 & 49 & AS & ISO & (4) \\
\hline Airport (Genova, Italy) & Apron Terminal & 10,000 & $\mathrm{C}$ & 100 & 0.003 & n.a. & Nov $05-$ Dec 06 & 1,035 & 10 & AS & APAT & (5a) \\
\hline Airports (Florida, USA) & Apron Terminal & 187,700 & $\mathrm{C}$ & 100 & 0.02 & n.a. & Sept $02-$ Nov 04 & 1,522 & $42^{1}$ & AS & APHA & (6a) \\
\hline Airports (Florida, USA) & Taxiway & 187,700 & $\mathrm{~A} / \mathrm{C}$ & 100 & 0.02 & n.a. & Sept $02-$ Nov 04 & 1,522 & $40^{1}$ & AS & APHA & $(6 b)$ \\
\hline Airport of Genova (Italy) & Parking lot & 14,000 & $\mathrm{~A} / \mathrm{C}$ & 100 & 0.002 & n.a. & Nov $05-$ Dec 06 & 1,035 & 12 & AS & APAT & $(5 b)$ \\
\hline Austin (TX, USA) & Low traffic density & 526 & A & 100 & n.a. & $\sim 9$ & Sept 93 - May 95 & 826 & 29 & AS & EPA & (7) \\
\hline Le Maris (Paris, France) & Urban streets & $<1,700$ & A & 90 & n.a. & n.a. & July 96 - May 97 & 2,250 & 26 & AS & APHA & (8) \\
\hline Albaro (Genova, Italy) & Residential area & 2,800 & A & 75 & $?$ & n.a. & $\operatorname{Jan} 02-\operatorname{Sep} 03$ & 1,147 & 12 & AS & APAT & (9) \\
\hline London (UK) & Urban roads & n.a. & A & 100 & n.a. & $<73$ & n.a. & 585 & 10 & GS & APHA & (10) \\
\hline Isfahan (Iran) & Urban catchment & $3,600,000$ & n.a. & 55 & 0.02 & n.a. & Dec $99-$ Mar 01 & 118 & 10 & GS & APHA & (11) \\
\hline Yalianfang (Macau, China) & Urban catchment & 140,000 & n.a. & 60 & n.a. & 20 & Aug $05-$ Nov 05 & & 5 & AS & APHA & (12) \\
\hline Port of Genova (Italy) & Tourism Terminal & 49,000 & $\mathrm{~A} / \mathrm{C}$ & 100 & $<0.005$ & n.a. & Feb $06-$ Nov 06 & 937 & 5 & AS & APAT & (13) \\
\hline Port of La Spezia (Italy) & Container Term. & 9,000 & A & 100 & 0.004 & n.a. & Apr $05-\operatorname{Jan} 06$ & 914 & 13 & AS & APAT & (14) \\
\hline Port of Savona (Italy) & Breakbulk Term. & 13,000 & A & 100 & 0.002 & n.a. & Sept 06 - June 07 & 954 & 7 & AS & APAT & (15) \\
\hline
\end{tabular}

a Monitored drainace area $\mathrm{b} A=$ asphalt $\mathrm{C}=$ concrete $\mathrm{A} / \mathrm{C}=$ mixture of asphalt and concrete; $\mathrm{c}$ Imperviousness on the monitored drainage area- $\mathrm{d}$ Mean slope of the drainag surface area; ${ }^{\mathrm{e}}$ Average daily traffic on the number of lanes monitored; ${ }^{\mathrm{f}}$ Number of rainfall events sampled (snow events not considered); ${ }^{\mathrm{g}} \mathrm{AS}=$ automatic sampler, GS $=$ manual grab sampling; h APHA (1972, 1992,1998), U.S EPA (1993), ISO (1993), APAT (2003); f (1) Sansalone 1997; (2) Sansalone (2008); (3) FHWA - Federal Highway Administration, 1990; (4) Legret and Pagotto, 1999; (5) Gnecco et al., 2008; (6) FDOT - Florida Department of Transportation, 2005; (7) Barrett et al., 1995; (8) Gromarie-Mertz et al., 1999; (9) Gnecco et al., 2005; (10) Memon and Butler, 2005; (11) Taebi and Droste, 2004; (12) Huang et al., 2007; (13) Gnecco et al., 2007; (14) Gnecco et al., 2006; (15) Gnecco et al., 2008; ${ }^{\text {i }}$ Number of collected samples.

\section{RESULTS AND DISCUSSION}

An example of partitioning results for metals in this study is shown in Figure 3 . Figure 3 illustrates a consistent increase in $\mathrm{K}_{d}$ for all metals across this source area runoff event. At the same time, PM illustrates a mass-limited washoff response; which is expected for a source area where PM and metal build up are dominated by traffic sources. Furthermore, the partitioning changes by orders of magnitude across this event, consistent with other results from the American source areas of this study. A $K_{d}$ condition in the range of $10^{4}$ to $10^{5} \mathrm{~L} / \mathrm{kg}$ appears to be approached for all metals as elapsed time (a surrogate for transported flow volume) increases despite variations in other parameters such as PM and flow. In fact, $\mathrm{K}_{d}$ values in the range of $10^{4}$ to $10^{5} \mathrm{~L} / \mathrm{kg}$ are typical for rivers and large lakes where the residence time is in terms of days and conditions such as PM and flow are constant. Finally, the variations in flow and PM are mirrored shortly afterwards by resulting changes in $\mathrm{K}_{\mathrm{d}}$. Finally, the variation in the relative magnitude of $\mathrm{K}_{\mathrm{d}}$ for $\mathrm{Zn}, \mathrm{Cd}, \mathrm{Cu}$ and $\mathrm{Pb}$ tends to follow similar trends that can be explained by covalent bonding theory or tendency of the metal to undergo hydrolysis.

\section{CONCLUSIONS}

A two-partition model is used to examine metal partitioning for a series of paved source areas in the USA and Italy. Metal results are compared to published data for similar paved source areas around the world. An example is illustrated for one source area dominated by traffic in Cincinnati. Results demonstrate that partitioning can vary by orders of magnitude across a runoff event, from largely dissolved to approaching a particulate-bound asymptote similar to receiving waters of much higher residence times. Results suggest that for on-line and real-time treatment of source area runoff, a combination of sedimentation, filtration and 


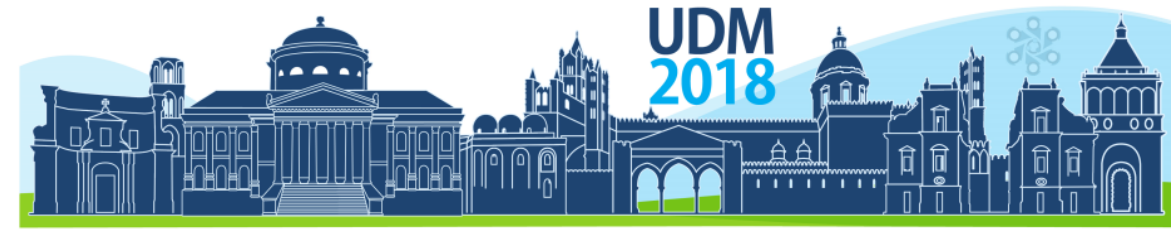

$11^{\text {th }}$ International Conference on Urban Drainage Modelling 23-26 Sep | Palermo - Italy

adsorption is required. For off-line storage and treatment before discharge, sedimentation and filtration may be sufficiently robust to achieve discharge goals.

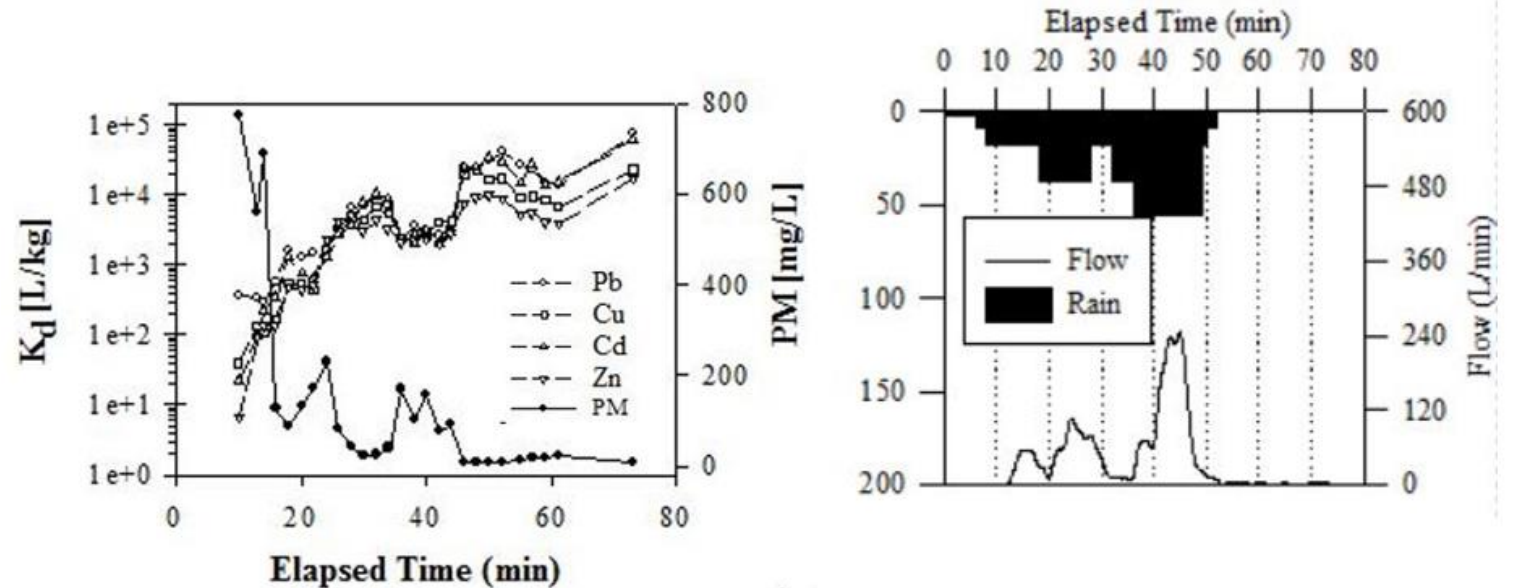

Figure 3. Metal partitioning, PM transport and hydrology for Cincinnati, $\mathrm{OH}(\mathrm{I}-75)$.

\section{References}

Glenn, Tre (2002) Heavy metal distribution for aqueous and solid phases in runoff, snowmelt and soils, Louisiana State University, Baton Rouge, LA USA.

McBride, M. (1994). Environmental Chemistry of Soils. Oxford University Press, New York, pp. 406.

Sansalone, J.J., and Buchberger, S.G. (1997) Partitioning and first flush of metals in urban rroadway storm water. Journal of Environmental Engineering, 123(2), 134-143.

Thomann, R., and Mueller, J. (1987) Principles of surface water quality modeling and control. Harper \& Row, Publishers, Inc., New York, NY, 1-644. 


\section{Part I - Water management, society and climate change}




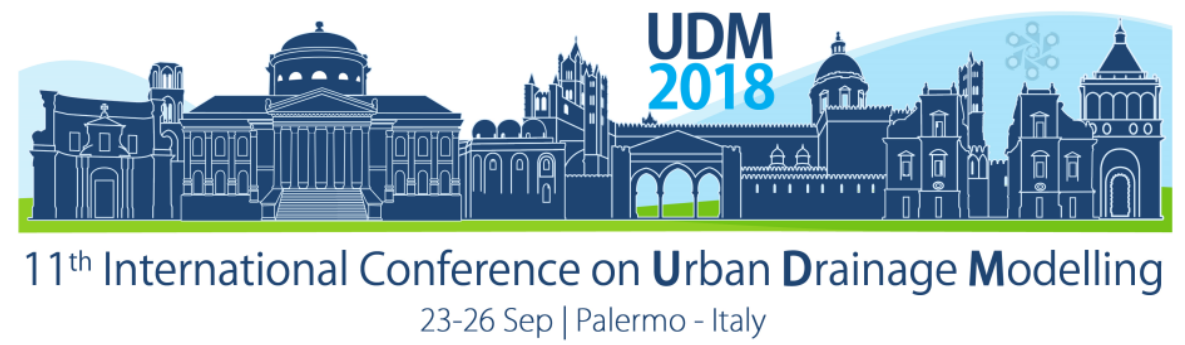

\title{
Advances in modelling particle transport in urban storm- and wastewater systems
}

\author{
Peter A. Vanrolleghem ${ }^{1,2}$, Sovanna Tik ${ }^{1,2}$ and Paul Lessard ${ }^{2}$ \\ ${ }^{1}$ modelEAU,Université Laval, Québec, Québec, Canada \\ ${ }^{2}$ CentrEau, Centre de recherche sur l'eau, Université Laval, Québec, Québec, Canada
}

\begin{abstract}
Suspended solids in sewers not only carry organic and inorganic pollution but are also the preferred vector for heavy metals, hydrocarbons, many hydrophobic micropollutants and pathogens that are preferentially attached to them. Their behaviour in sewer systems has thus been object of many studies, but, unfortunately the predictive power of the available models remains limited due to the complexity of the processes that determine their transport, sampling and measurement. This contribution summarizes 10 years of research at Université Laval that took advantage of the ViCAs measurement set-up that allows for characterizing the wastewater particles' settling velocity distribution (PSVD) to come up with a conceptual modelling framework of storm and wastewater transport systems in which mass balances are made of particle classes, each with a characteristic settling velocity. The models have been calibrated and validated for stormwater basins, combined sewer retention tanks, primary clarifiers and complete combined sewer systems, from sewer catchment to stormwater basins outlets, sewer overflows and primary clarifier effluents. The ViCAs experimental set-up is simple to build and work with, and has intrinsic quality control indicators that allow evaluating the quality of the obtained PSVD's.
\end{abstract}

Keywords: Conceptual sewer model; particle settling velocity distribution, ViCAs,

\section{INTRODUCTION}

Urban stormwater composition changes a lot from the moment it hits the ground to its discharge into the receiving water, both in combined and separate sewer systems. Water pollution can be split in soluble and particulate components, the latter often being characterized by the concentration of total suspended solids (TSS). TSS is often correlated with turbidity, which can be measured online, providing then continuous information on this aspect of water quality, and allowing development of controllers that take advantage of it. This paper focuses on particulate pollution of stormwater which is a key parameter to evaluate the stormwater's impact on the environment. Indeed, particulate material not only leads to visual pollution, but also contains considerable organic matter, leading to oxygen depletion, and nutrients, causing eutrophication. Moreover it carries adsorbed pollution (pathogens, heavy metals, hydrophobic micropollutants, ...). Despite years of efforts (Ashley et al., 2004), understanding the processes affecting particulate pollution in the system, especially in sewers, and predicting its fate remains a considerable challenge. This paper summarizes some of the salient results of the research conducted over the last ten years at Université Laval.

In view of improving the receiving water quality, it is essential to consider the integrated urban wastewater systems (IUWS) as a whole. Indeed, interactions between the sewers, the treatment plant (WWTP) and the receiving water bodies can be significant. When dealing with such complex systems, mathematical models have been proven particularly useful. Models allow scenario elaboration to simulate management strategies and their impact, enabling the engineer to better understand the system, yielding better informed decision-making. 


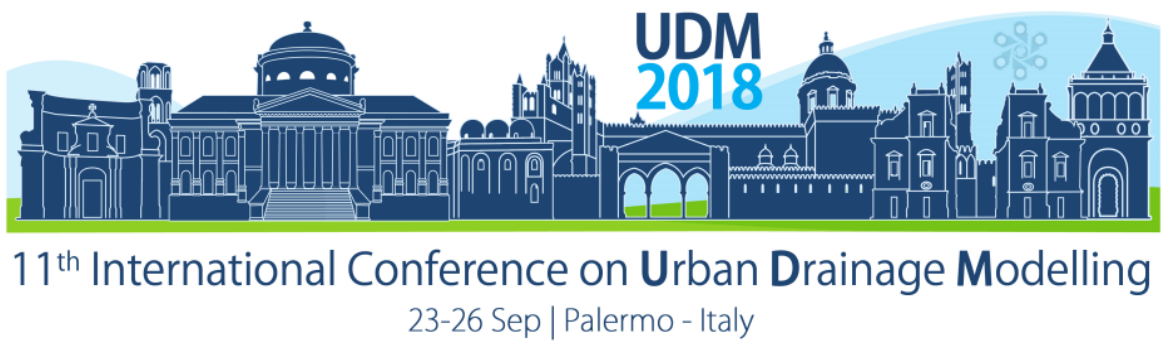

In this paper, particle settling velocity distribution (PSVD)-based models, using a relatively simple wastewater characterization method, the ViCAs method are presented. They allow better prediction of water quality in terms of TSS along the system. Anticipated benefits of water quality-based control in an integrated setting are briefly introduced.

\section{PSVD CHARACTERIZATION AND MODELLING CONCEPT}

\subsection{Software and Modelling Approach}

The ViCAs-TSS characterization protocol ("Vitesse de Chute en Assainissement", French for "Settling velocity in wastewater management", Chebbo and Gromaire, 2009) originally developed to characterize stormwater particulates was adopted in our work to characterize particulate matter throughout the urban wastewater system. A ViCAs lab experiment consists in filling a $60 \mathrm{~cm}$ column with $4.5 \mathrm{~L}$ homogeneous sample of storm- or wastewater, which is then subject to static settling. A series of cups is placed sequentially underneath the column to collect particles that settle from the column. At pre-determined instances (e.g. after 1, 3, 7, 15, $30,60,120$ minutes), a cup is withdrawn and substituted by another one. The TSS collected in each cup is weighed and the cumulative mass of settled TSS is interpreted to yield the socalled particle settling velocity distribution (PSVD) of the water sample (Figure 1). This PSVD enables assigning settling velocities (Vs) to different mass fractions of particles.

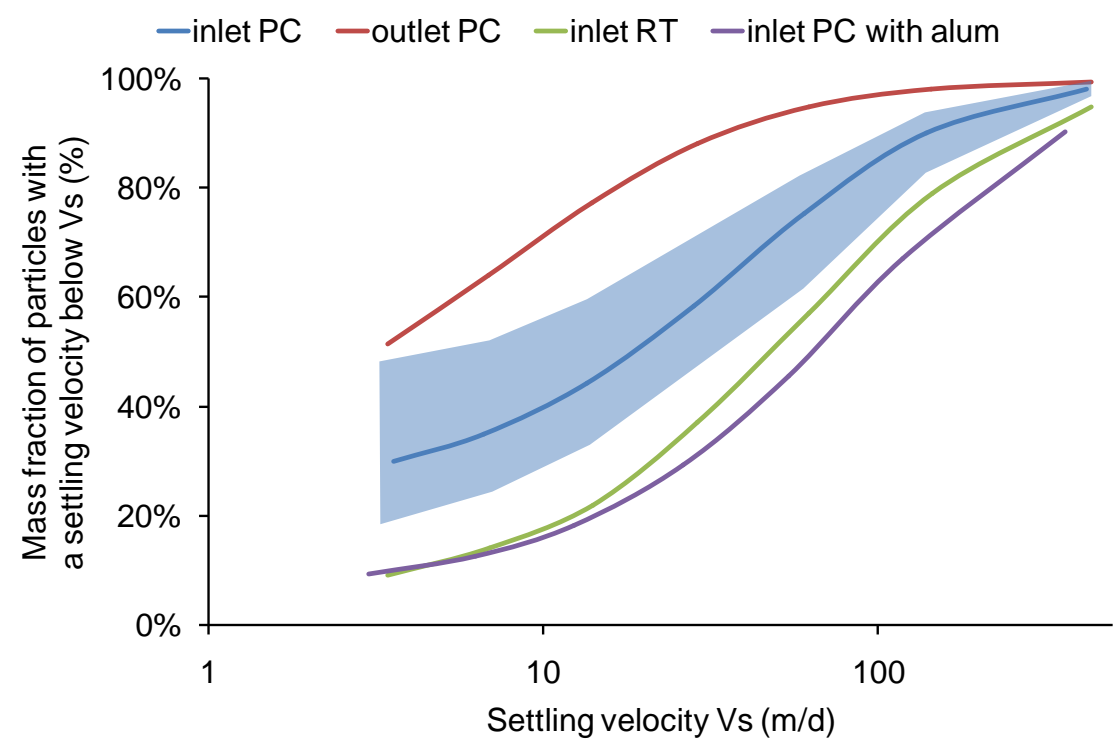

Figure 1. Examples of Particulate Settling Velocity Distributions (PSVD) along the IUWS and typical PSVD region observed at the inlet of the primary clarifier (PC). Alum addition 'lowers' the PSVD curve in a chemically enhanced PC (from blue to purple). Inlet RT (retention tank) curve characterizes combined wastewater during wet weather.

Over the last ten years, a large number of ViCAs experiments have been performed with samples collected at different locations within the urban storm and wastewater systems and this in different cities in Canada and Europe. Key information extracted from this extensive experimental work is that: 


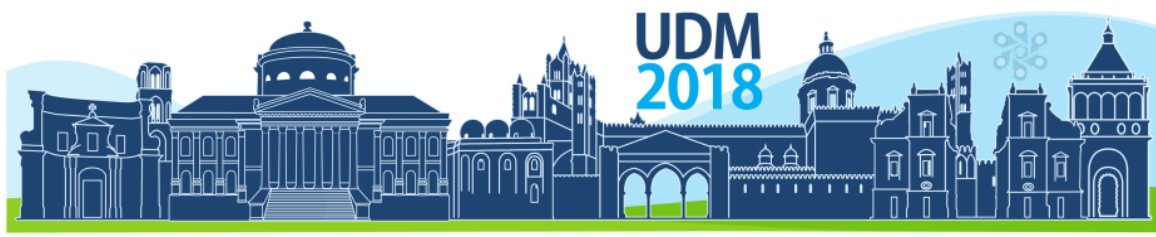

$11^{\text {th }}$ International Conference on Urban Drainage Modelling

23-26 Sep | Palermo - Italy

- the PSVD is not constant in space nor time. However, the PSVD of a sample taken under specific conditions (location, same operational conditions...) will be situated in typical regions (see, for instance, Figure 1 for the inlet primary clarifier region);

- within a specific region, the PSVD of a sample is quite well correlated with its TSS concentration (Bachis et al., 2015).

Settling is the most important process to consider when dealing with particulate pollution. Hence, the particle settling velocity is a key parameter to determine in view of modelling. Models that only consider a single, mean settling velocity to all particles do not allow embracing the heterogeneity of particulate pollution in storm- and wastewaters. The purpose of PSVDbased models is to improve the predictive capacity of models by fractionating TSS into a limited number of particle classes, each class defined by a mean settling velocity extracted from the relatively simple and inexpensive ViCAs experiments (Errore. L'origine riferimento non è stata trovata.). The models of the different systems described below use dynamic mass balances of the different particle classes to predict the evolution of their concentrations.

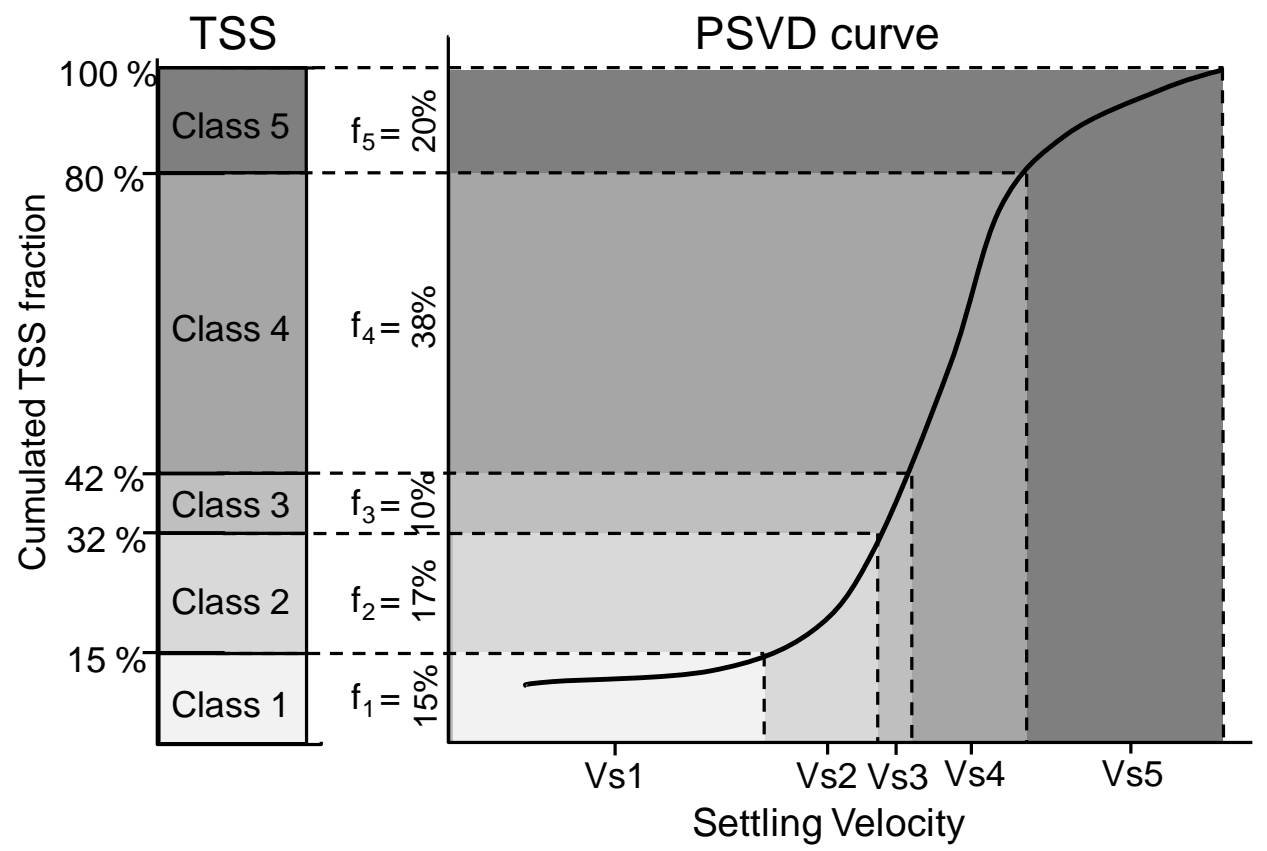

Figure 2. An example of TSS fractionation in five particle classes is presented (class delineation in dashed line). Each particle class, characterized by a mean settling velocity (Vs1 to Vs5) is associated with its TSS mass fraction ( $f_{1}$ to $\left.f_{5}\right)$.

\section{APPLICATIONS}

\subsection{Stormwater Basins}

In separate sewer systems, rain water is often discharged to the receiving water without treatment, even though it is not exempt of pollution. At some places, stormwater basins have been built to attenuate the hydraulic impact of a sudden wet weather discharge to the receiving water, causing increased erosion and sometimes even flooding. Although these facilities have not been designed with treatment in mind, improvement in water quality due to settling in the 


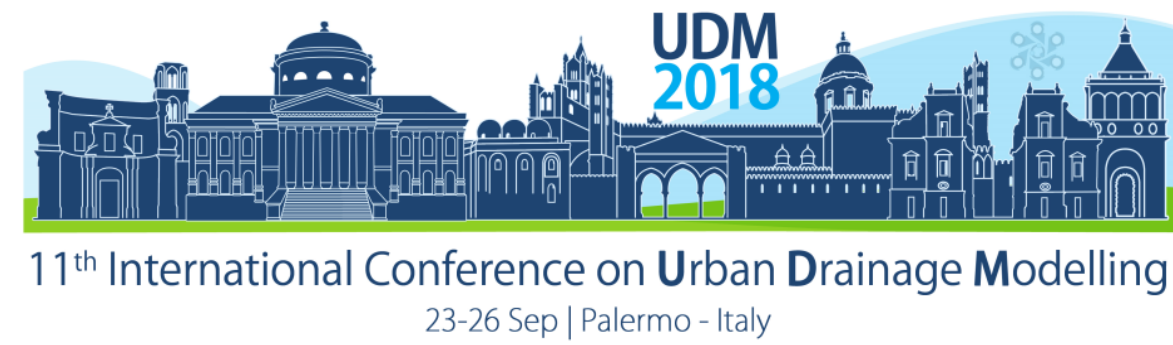

basins was observed (Carpenter et al., 2014). Hence, a better understanding of the phenomenon was deemed interesting to take advantage of. Vallet et al. (2014) developed a multi-layer stormwater tank model based on PSVD. The model has a varying volume and is able to reproduce settling and resuspension thanks to settling fluxes between the layers and a mixing model for resuspension. The model can reproduce both the particles' concentrations at the outlet of the tank and inside the tank. Indeed, the PSVD approach coupled with a discretization of the water column in layers enables to reproduce the TSS concentration gradient over the water column (Vallet et al., 2014).

Gaborit et al. (2013) also demonstrated that a prediction of the TSS arriving at the stormwater tank inlet could be improved by taking over the PSVD approach for build-up and wash-off phenomena. They observed that consecutive rain peaks were not resulting in the same TSS concentration. By implementing various build-up and wash-off rates depending on particle classes (and thus particle settling velocity), they could reproduce TSS wash-off peaks of consecutive rain events.

\subsection{Combined sewer retention tanks (RT)}

When combined sewage is prevented from overflowing by storage in retention tanks (RT), it is not surprising that PSVD has proven a key property to take into account when trying to model the fate of TSS as the water resides in the RT. Very few studies have been carried out characterizing the settling process in RT. Métadier et al. (2013) and Maruéjouls et al. (2013) both highlighted the interest in observing particulate pollutant behaviour in RT in order to better understand and predict effective TSS removal in these tanks.

The calibration/validation work of the RT model of Maruéjouls et al. (2014) has proven the superiority of a model considering multiple settling velocity classes rather than a single average settling velocity. An important characteristic of the model is that it can accommodate for the fact that the PSVD of the TSS is not constant, but depends on a number of factors such as the time of the day - low TSS waters have a different PSVD than high TSS waters - dry or wet weather conditions, .... This highly enhanced the model adaptability to different case studies all the while keeping the calibration work limited since the PSVD model's parameter values are the direct result of ViCAs measurements. The model performance was compared with a former existing RT model from Lessard and Beck (1991) and found to be improved using the PSVD approach.

\subsection{Primary clarifier and Chemically Enhanced Primary Treatment}

The PSVD-based primary clarifier model of Bachis et al. (2015) is similar to the above RT model, with the exception that the volume of water in the tank is now constant. It was shown that the vertical gradient of the concentration of each of the particle classes in the settler can be simulated. To describe the vertical gradient, the settler is divided into a number of layers and a mass balance is calculated around each layer for each of the classes. Five particle classes with different (constant) settling velocities make up the core of the model (Bachis et al., 2015). Again, ViCAs experiments allow simple calibration of the PSVD-based primary clarifier model.

Primary clarification is the first wastewater treatment process to suffer from the sudden changes in WWTP influent characteristics due to stormwater. To attenuate the negative impact of wet weather conditions, chemically enhanced primary treatment (CEPT) can be applied. Chemicals (usually alum as coagulant) is added to the primary clarifier influent, improving the TSS settling characteristics. By performing a ViCAs experiment on samples with and without alum addition, the impact of CEPT on the PSVD has been determined (Errore. L'origine 


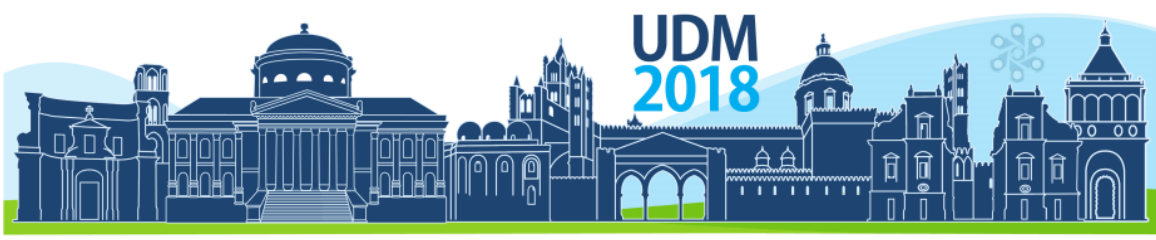

$11^{\text {th }}$ International Conference on Urban Drainage Modelling

23-26 Sep | Palermo - Italy

riferimento non è stata trovata.). CEPT tends to "lower" the PSVD curve implying that the fraction of particles with higher settling velocity is increased at the expense of classes with lower settling velocity. CEPT can thus be modelled by making the TSS fractionation dependent on the chemical concentration. The layer structure of the model enables reproducing the hydraulic conditions in the clarifier, which is essential to describe the observed delay between chemical addition and its effect on the outlet TSS concentration. Properly dealing with this delay is essential for the development of a chemical dosing controller which aims at reducing chemical addition without jeopardizing settling performance (Tik and Vanrolleghem, 2017).

\subsection{Integrated model and (water quality based) control possibilities}

All models presented above have been developed using the modelling and simulation platform WEST $^{\circledR}$ (mikebydhi.com), facilitating their combination in an integrated model. Based on data collected in the field, the system represented in Errore. L'origine riferimento non è stata trovata. has been modelled (Maruéjouls et al., 2015). It includes three catchment areas, each equipped with an off-line RT. These three catchments are connected to a main interceptor bringing combined sewage to the WWTP. The plant is modelled by a grit chamber, a primary clarifier with possibility of CEPT and three bypasses. Data have been collected at multiple locations along this system and the model performance is remarkable given the complexity of the processes affecting TSS.

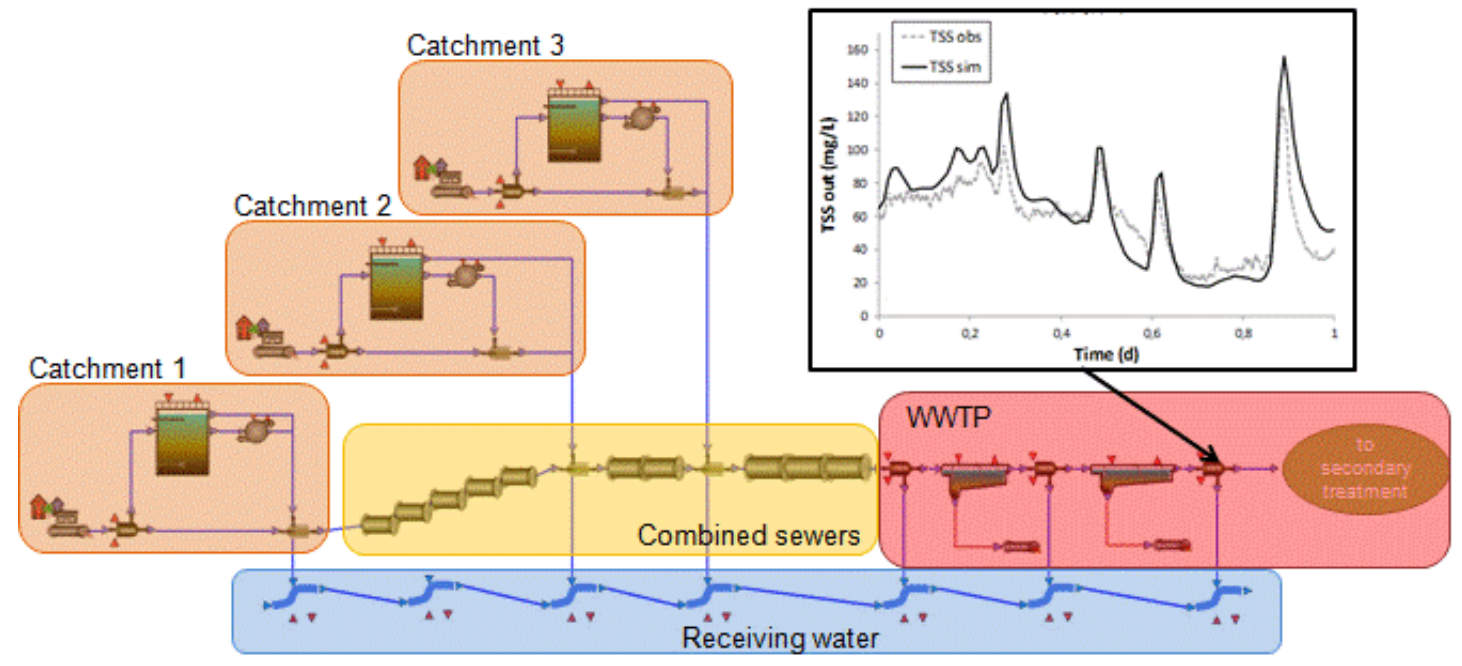

Figure 3. Integrated model configuration in WEST ${ }^{\circledR}$ (mikebydhi.com). Insert shows results of a validation of the primary clarifier PSVD-model (Bachis et al., 2015).

Using the integrated model, different control strategies have been evaluated (Tik et al., 2016). Scenarios were designed around the following control actions that only use water height, flow rate and turbidity data:

- retention tanks emptying flow rate

- activation of CEPT and chemical dosing flow rate

- flow rate sent to secondary treatment

The impact of each scenario, in terms of water volume and TSS load discharged in the receiving water vs. time to empty the RTs, have then been calculated (Tik et al., 2014). The results showed a significant reduction in volume of untreated or partially-treated wastewater discharged into the receiving water, but more importantly from an environmental protection 


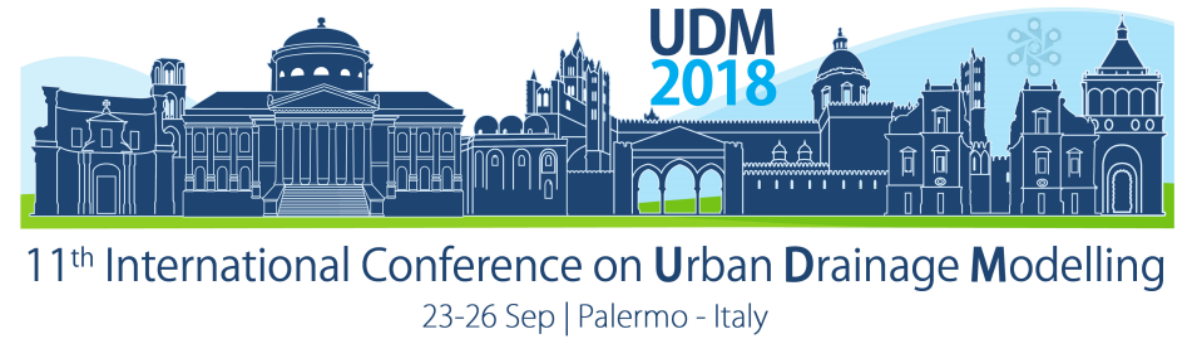

perspective, a percent-wise greater reduction of mass of suspended solids discharged. However, this indisputable benefit for the environment comes at the expense of an increase in RT emptying times. Weather predictions should therefore be used to prevent such slower emptying in case the retention capacity is needed for an upcoming rain event.

\section{CONCLUSIONS}

This paper presented PSVD-based models of the major subsystems involved in stormwater and wastewater transport and treatment. The PSVD approach allows significantly better prediction of water quality, in terms of TSS concentration, compared to the standard approach of assigning a mean settling velocity to all particles. By combining these models in an integrated model, the potential of improving system management has been evaluated. Results of relatively simple control strategies show that there is room for considerable reduction of environmental impact of discharged particles. Further real-time control ideas are currently examined.

\section{Acknowledgements}

Funding of the studies leading to the development of the PSVD modelling approach was provided by Québec City, Veolia Water Technologies, FRQNT and NSERC. Peter Vanrolleghem holds the Canada Research Chair on Water Quality Modelling.

\section{References}

Ashley, R., Bertrand-Krajewski, J., Hvitved-Jacobsen, T. and Verbanck, M. (2004). Solids in Sewers Characteristics, Effects and Control of Sewer Solids and Associated Pollutants. IWA Scientific \& Technical Report No 14, IWA Publishing, London, UK.

Bachis, G., Maruéjouls, T., Tik, S., Amerlinck, Y., Melcer H., Nopens, I., Lessard, P. and Vanrolleghem, P.A. (2015). Modelling and characterization of primary settlers in view of whole plant and resource recovery modelling. Wat Sci. Tech., 72(12), 2251-2261.

Carpenter, J.F., Vallet, B., Pelletier, G., Lessard, P. and Vanrolleghem, P.A. (2014). Pollutant removal efficiency of a retrofitted stormwater detention pond. Water Qual. Res. J. Can., 49(2), 124-134.

Chebbo, G. and Gromaire, M.-C. (2009). VICAS - An operating protocol to measure the distributions of suspended solid settling velocities within urban drainage samples. J. Environ. Eng., 135(9), 768-775.

Gaborit, E., Muschalla, D., Vallet, B., Vanrolleghem, P.A. and Anctil, F. (2013). Improving the performance of stormwater detention basins by real-time control using rainfall forecasts. Urban Water J., 10(4), 230-246.

Lessard, P. and Beck, M. (1991) Dynamic simulation of storm tanks. Water Res., 25(4), 375-391.

Maruéjouls, T., Lessard, P. and Vanrolleghem, P.A. (2015). A particle settling velocity-based integrated model for dry and wet weather wastewater quality modelling. In: Proceedings WEF Collection Systems Conference 2015. Cincinnati, OH, USA, April 19-22 2015

Maruéjouls, T., Vanrolleghem, P.A. and Lessard, P. (2014). Calibration and validation of a dynamic model for water quality in combined sewer retention tanks. Urban Water J., 11(8), 668-677.

Maruéjouls, T., Vanrolleghem, P.A., Pelletier, G. and Lessard, P. (2013). Characterisation of retention tank water quality: Particle settling velocity distribution and retention time. Water Qual. Res. J. Can., 48(4), 321-332.

Métadier, M., Binet, G., Barillon, B., Polard, T., Lalanne, P., Litrico, X. and de Bouteiller, C. (2013). Monitoring of a stormwater settling tank: How to optimize depollution efficiency. In: Proceedings $8^{\text {th }}$ International Conference Novatech, Lyon, France, June 23-27, 2013.

Tik, S., Maruéjouls, T., Lessard, P., and Vanrolleghem, P.A. (2014). Optimizing wastewater management during wet weather using an integrated model. In: Proceedings of the 13th International Conference on Urban Drainage (ICUD2014), Sarawak, Malaysia, September 7-12, 2014.

Tik, S., Maruéjouls, T., Lessard, P. and Vanrolleghem, P. A. (2016). Estimating and minimizing both CSO and WRRF discharge impact by water quality based control. In: Proceedings WEF Collection Systems Conference 2016. Atlanta, GA, USA, May 1-4 2016.

Tik, S. and Vanrolleghem, P.A. (2017). Chemically enhancing primary clarifiers: Model-based development of a dosing controller and full-scale implementation. Wat. Sci. Tech., 75(5), 1185-1193. 
Proceedings of the 11th Int. Conference on Urban Drainage Modelling, 23-26 Sep. 2018, Palermo (ITALY). Ed. prof. Giorgio Mannina

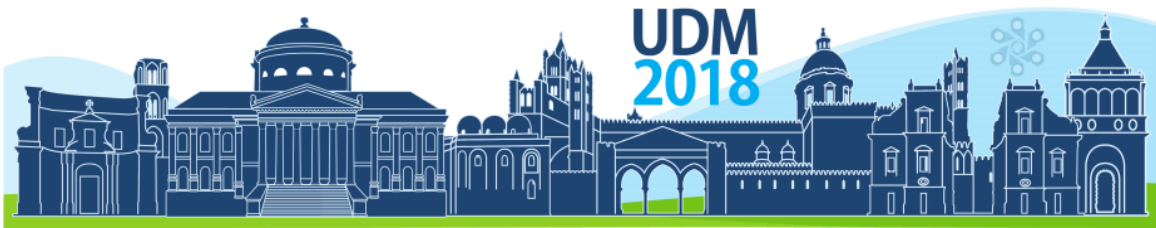

$11^{\text {th }}$ International Conference on Urban Drainage Modelling

23-26 Sep | Palermo - Italy

Vallet, B., Muschalla, D., Lessard, P., and Vanrolleghem, P.A. (2014). A new dynamic water quality model for stormwater basins as a tool for urban runoff management: Concept and validation. Urban Water J., 11(3):211220 . 


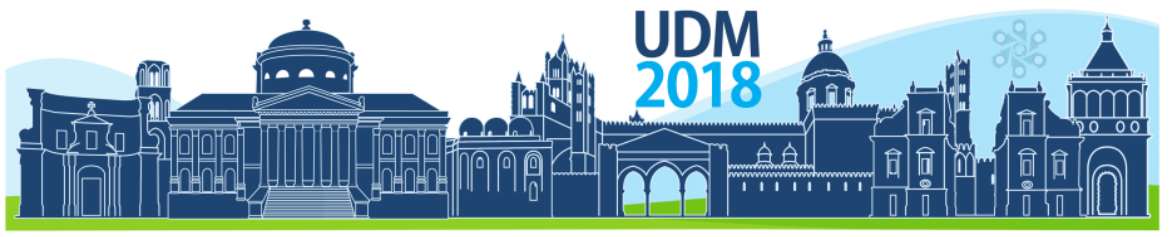

$11^{\text {th }}$ International Conference on Urban Drainage Modelling

23-26 Sep | Palermo - Italy

\title{
Redesign of water quality network for the urban rivers in Salitre in Bogotá, Colombia, using an artificial neural network
}

\author{
Carlos Peña-Guzmán ${ }^{1}$, Paula Balaguera ${ }^{1}$, Nathalia Hernandez ${ }^{1}$ and Ronal Sierra \\ ${ }^{1}$ Santo Tomas University, Environmental Engineering program, Bogotá, Colombia
}

\begin{abstract}
Bogotá is the biggest urban center in Colombia, and has the largest population in the country, with about eight million inhabitants. This has led to an impact on different natural resources, principally the water resource. This is why the city currently has a water quality network that allows measuring of the quality conditions of Bogotá's rivers. This network has been operating since the nineties, but has not been optimized, despite the dynamics of the city and the sanitation infrastructure. For this reason, a redesign of the network over the Torca and Salitre rivers was planned using an artificial neural network, which allowed us to optimize the measurement frequency (month and day) and the number of measurement points on each river.
\end{abstract}

Keywords: Redesign; Urban Rivers; Water Quality Network; Artificial Neural Network; Optimization.

\section{INTRODUCTION}

The increase in the degradation of water quality due to anthropogenic activities has generated impacts on different water sources. Therefore, it is necessary to identify and measure these changes in physical, chemical, and biological characteristics through monitoring. This is clearly seen in urban rivers, which has historically generated the need to structure water quality networks (RCH). At the same time, the information collected by these networks has allowed the optimization and redesign of these networks, allowing the improvement of the frequency, location, and quantity of measurement parameters (Harmancioglu et al., 1998; Sanders, 1983; Strobl et al., 2006). In addition, the RCH has the function of being a supply of technical information for decision-making in the city (Harmancioglu et al., 1998).

This case is not alien to the city of Bogotá, which is the capital of Colombia and the main geographical, political, industrial, economic, and cultural center of the country. This has brought with it an accelerated demographic growth, since at present there are about eight million inhabitants, which represents more than $17 \%$ of the total population of the nation.

This historical growth has generated negative environmental impacts on the water resource, since these bodies receive a large amount of discharge directly, drastically altering the quality and the potential use of rivers and wetlands of the city (Peña-Guzmán et al., 2016). This forced the design and operation of the Bogotá Water Quality Network (BWQN), in order to evaluate the state of the main rivers in the city; the Salitre, Torca, Fucha, and Tunjuelo.

This article presents the redesigned Salitre Water Quality Network (SWQN), optimizing the frequency measurement and monitoring points, through the implementation of an artificial neural network. 


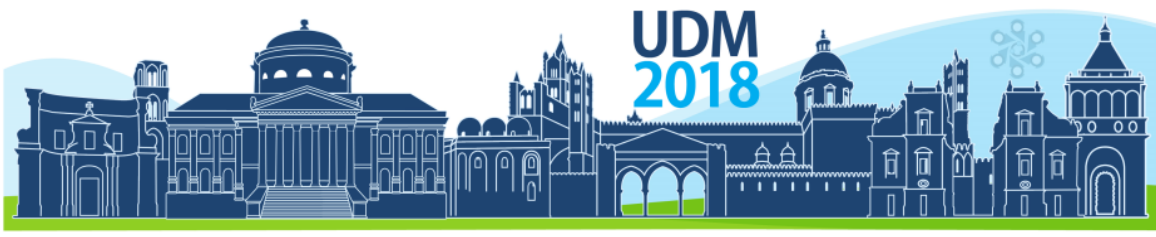

$11^{\text {th }}$ International Conference on Urban Drainage Modelling

23-26 Sep | Palermo - Italy

\section{MATERIALS AND METHODS}

\subsection{Geographic location}

The Salitre River rises in the eastern hills of Bogotá, and has a total length of $21.56 \mathrm{~km}$ from its source to its mouth in the Bogotá River. This river is located in the north-center of the city, which is characterized by having different land uses, however, residential use predominates. Currently, the SWQN has six monitoring stations on this river, which are in the order: Parque Nacional, Arzobispo, Calle 53, Avenida 68, TV 91, and Alameda, as seen in Fig. 1.

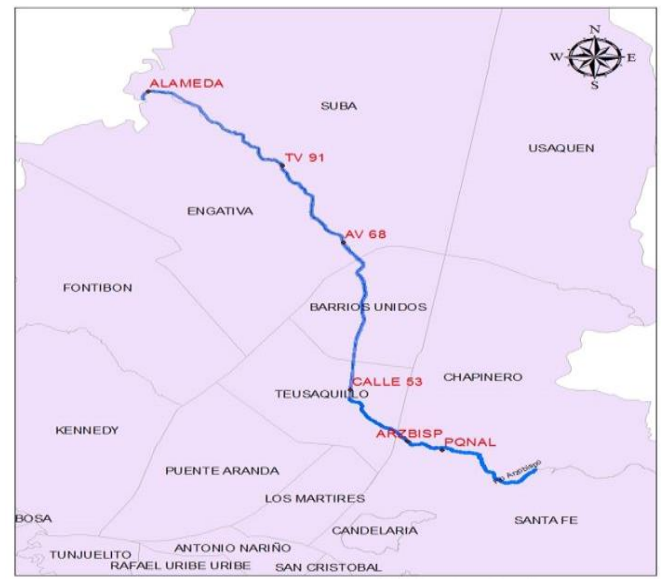

Figure 1. Salitre Water Quality Network.

\subsection{Data and analysis}

For the article, the measurements obtained from the monitors were carried out from 2009 to November 2013 (240 measurements) provided by the city's environmental authority. Within the analysis of the information, a certain monitoring frequency is not evident. For this case study, the analysis and exploration of methods to optimize and redesign the SWQN focused on the following quality determinants: Biological Oxygen Demand $\left(\mathrm{BOD}_{5}\right)$, Chemical Oxygen Demand (COD), Totals Suspended Solids (TSS), Total Nitrogen (TN), Total Phosphorus (TP), Methylene Blue Active Substances (MBAS), pH, Fats and Oils (F\&O), Fecal Coliforms, and Dissolved Oxygen (DO).

For the analysis of the data, a monthly multiannual evaluation was established, since with this election, the temporal variations generated by the population dynamics of the different areas and the climatic variations that occur at different times of the year are shown. For the development of the models, outliers were determined using the interquartile differences method.

\subsection{Artificial Neural Network (ANN)}

The artificial neural network back-propagation was used with the purpose of generating new classifications for the spatial (season) and temporal (month and day) variables. The neural network procedure was carried out in two steps; first the training of the network, in which the learning rate $(0.1$ to 1$)$ and the number of hidden layers (3 to 15) were calibrated. For the 


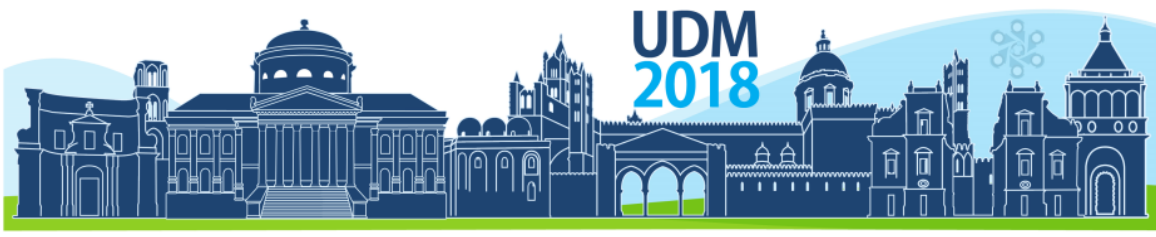

$11^{\text {th }}$ International Conference on Urban Drainage Modelling

23-26 Sep | Palermo - Italy

training, a random database with $70 \%$ of the information was generated. Subsequently, a validation of the neural network was carried out, for which $30 \%$ of the information was used.

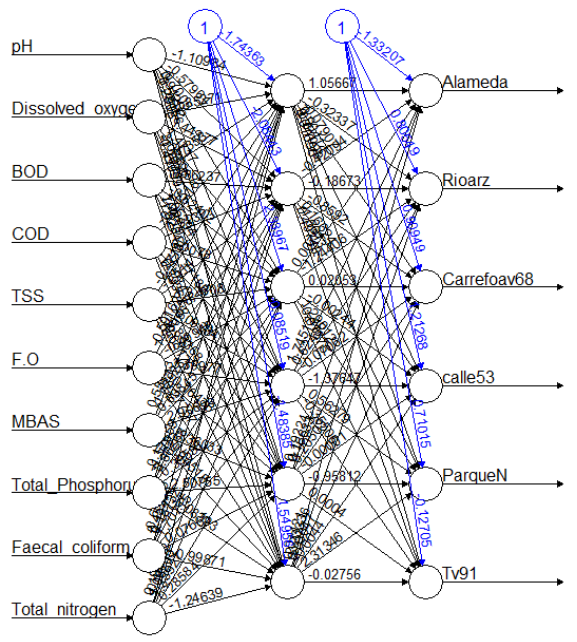

Figure 2. ANN Topology.

\section{RESULTS AND DISCUSSION}

Of the spatial variable (station) it was found that the stations Calle 53 and Avenida 68 show great similarity in the concentrations of the different determinants, indicating that the number of stations in the middle part of the river should be decreased. Although the ANN showed that the Alameda and Transversal 91 stations could be grouped into one, it is considered necessary to maintain them, since they are found before and after the Juan Amarillo wetland, so they can be considered as control stations.

For the monitoring frequency, the days of measurement were established, taking into account the range of variation of the parameter concentrations. For the SWQN, measurements of all parameters were taken on Monday, Wednesday, and Friday, because although the variation that occurs between days is not very marked, in those small differences between the ranges of change of the values recorded, it was determined that the days previously exposed, are the most optimal.

For the monthly variability, the bimodal behavior of the climate of the city was taken into account, since precipitation is one of the variables that most influences the changes in the concentration of the quality parameters. To this end, the ANN has as a variable information on the state of the climate when the sample was taken-cloudy, rainy, and sunny. According to this, the model showed that the measurements should be carried out mainly during the months of January and December, referring to the dry season and seasonal rains during the months of September and October. These results indicate that measuring in the last four months of the year can register the greatest variability in parameter measurements. As for the days, very little variation was found among them, indicating that the frequency of the day has no significant effect on the measurement, the only importance is observed in the TSS. The number of samples needed to control pollution on the Salitre River should be weekly in the days and months proposed. 


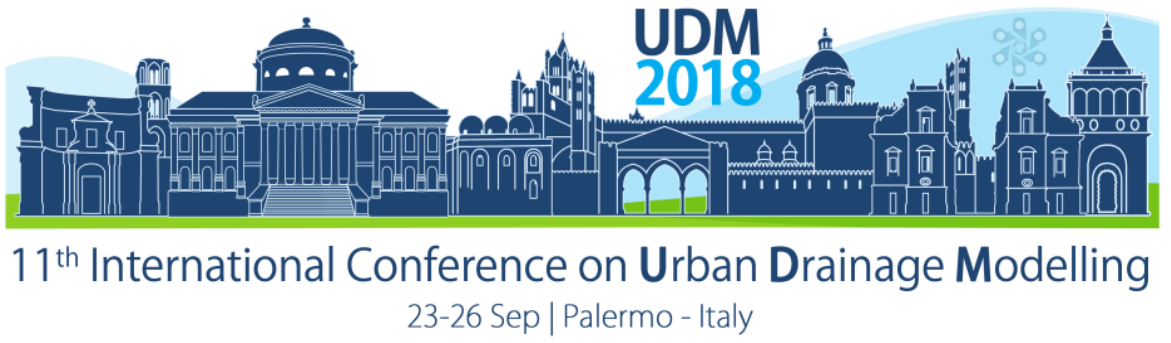

\section{CONCLUSIONS}

According to the above, a new design proposal of the SWQN can be presented below.

It is temporarily proposed that measurements be taken on Monday, Wednesday, and Saturday because, despite the small difference between days, it was determined that these days are the most optimal, taking into account the mainly industrial and commercial activities in the area. For the months of measurement, when taking into account the behavior of the climate of the city given by the ANN, this proposal includes the operation of the commercial and industrial sectors, which is why the following months are established: in the dry season, January, July, and December (January for industrial production and commercial activity, July for normal season in these sectors, and December for maximum industrial production as well as a growth in commercial use) and for the rainy season the months of April, September, and October. Regarding the number of stations on the river, it was determined that, in compliance with the water quality regulations, the city should have five stations, which are: Parque Nacional (as the reference point before the entrance of the urban perimeter), Arzobispo (because it is the entrance of the urban sector), Avenida 68 (because it is the central point of the basin), Transversal 91 (entrance to the Juan Amarillo wetland, the city's main ecological system), and Alameda (exit of the Juan Amarillo wetland system, and discharge to the Bogotá River).

Finally, in terms of cost, this has a significant impact, since it would achieve a reduction in the total investment of the network. Additionally, this reduction would allow investment in sanitation works, in pollution control, and recovery of the city's water resources.

\section{References}

Harmancioglu, N. B., Ozkul, S. D., Alpaslan, M. N. 1998 Water Quality Monitoring and Network Design. In: Environmental Data Management, Water Science and Technology Library, Harmancioglu, N.B., Singh, V.P., Alpaslan, M.N. (Eds.), Springer Netherlands, pp. 61-106. https://doi.org/10.1007/978-94-015-90563_4

Peña-Guzmán, C., Melgarejo, J., Prats, D. 2016 El ciclo urbano del agua en Bogotá, Colombia: estado actual y desafíos para la sostenibilidad. Tecnol. Cienc. Agua 7, 57-71.

Sanders, T. G. 1983 Design of Networks for Monitoring Water Quality. Water Resources Publication.

Strobl, R. O., Robillard, P. D., Shannon, R. D., Day, R. L., McDonnell, A. J. 2006 A Water Quality Monitoring Network Design Methodology for the Selection of Critical Sampling Points: Part I. Environ. Monit. Assess. 112, 137-158. https://doi.org/10.1007/s10661-006-0774-5 


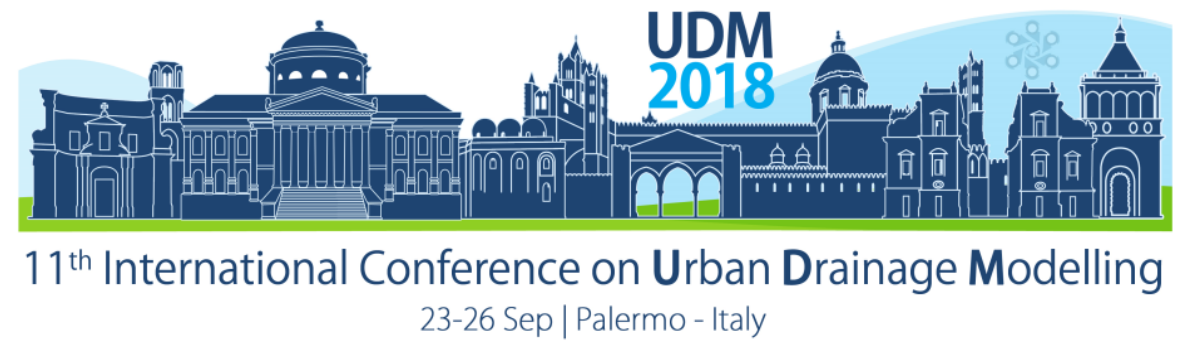

\title{
Uncertainties in estimating the economic benefits from blue and green stormwater infrastructure
}

\author{
Richard Ashley ${ }^{1,2}$, Berry Gersonius ${ }^{2}$, Bruce Horton ${ }^{3}$, Chris Digman ${ }^{4}$, and Paul Shaffer ${ }^{5}$ \\ ${ }^{1}$ EcoFutures Ltd., 3 Greendale Court Honley, West Yorkshire, HD9 6JW, UK. \\ ${ }^{2}$ IHE Delft, Institute for Water Education, 2611 AX, Delft, Netherlands \\ ${ }^{3}$ Stantec, Kelsey House, Papermill Drive, Redditch B98 8QJ UK \\ 3 Unit 2B, Block E, The Boulevard, Leeds Dock, Leeds, LS10 1PZ UK \\ ${ }^{5}$ Construction Industry Research and Information Association, Griffin Ct., 15 Long Ln., London EC1A 9PN, U.K.
}

\begin{abstract}
A number of tools have been developed to value the wide range of benefits that blue and green infrastructure (BGI) can provide when used to manage stormwater, many utilise the value that the benefits from Ecosystem Services (ES) can provide. These tools can help make comparisons to show that these approaches can provide multiple benefits when compared with using traditional urban drainage measures. A tool for valuing stormwater measures has been developed primarily for UK applications, the Benefits of SuDS Tool (B£ST), which has been applied to a number of case studies to maximise the value of using BGI for: flood alleviation schemes; combined sewer overflow pollution control; and neighbourhood regeneration in both the UK and the Netherlands. Uncertainty is included explicitly in the B£ST. The uncertainties associated with the use of the B£ST are throughout the process, in the various data, models, assumptions and user applications of the tool. These are outlined in this abstract, and the development of the uncertainty assessment processes in the B£ST is presented, together with case examples. Lessons are drawn regarding the relative uncertainties in using any BGI valuation tool for informing decisions about stormwater management.
\end{abstract}

Keywords: Benefits; blue-green; stormwater; economics

\section{INTRODUCTION}

Traditional piped drainage systems provide various benefits, including flood control and management of contaminated urban runoff. However, stormwater measures that utilise BGI provide many other additional benefits especially where these are surface-based. The benefits include adding to the stock of green infrastructure and natural capital, and ecosystem services (ES); reduce air pollution; and alleviate urban heat islands.. Efforts are being directed towards developing the means of financial valuation of aspects of BGI used in development in urban areas that are not readily seen in terms of market value (e.g. Ashley et al, 2018) and various $\mathrm{Gl}$ and associated assessment tools are available for this. This abstract focuses on a recently developed financial tool for valuing the benefits brought from using BGI for managing stormwater, known as the B£ST (Benefits of SuDS tool; CIRIA, 2016) and how B£ST deals with uncertainty. Benefits from BGI schemes are now being explicitly quantified in the various analytical tools emerging, and in B£ST more than 1000 credible sources have been used to build the database of values. However, to be confident about the value of the benefits being provided and to make reliable decisions regarding the greatest overall value for society of using GSI/BGI for stormwater measures, the uncertainties in the evaluation of the benefits need to be identified, included and assessed and the associated decision making risks taken into account. Despite this need, there is very little information about the uncertainties in valuing GSI using the available tools and analytical processes. This abstract briefly reviews the significant uncertainties based on cases and lessons learned and the methods for including uncertainties in the B£ST. 


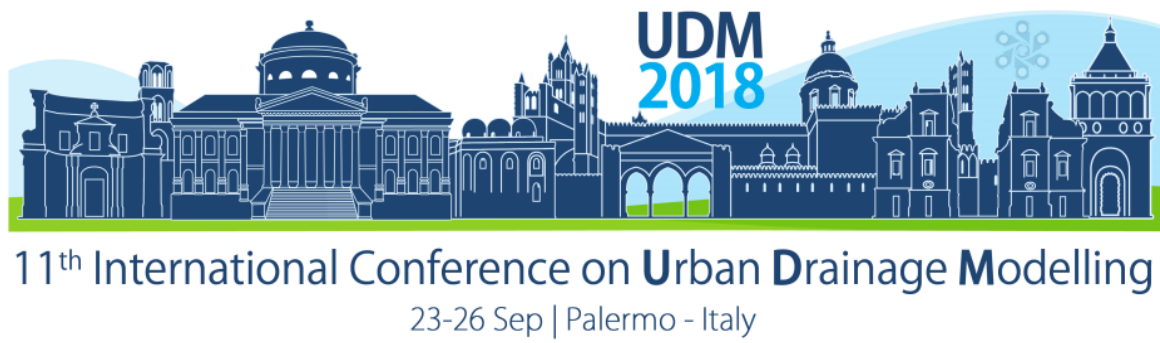

\section{MATERIALS AND METHODS}

Three main sets of information are required when using the B£ST: (i) the base physical data relating to performance of the $\mathrm{BGI}$ option for the various criteria; (ii) numerical values related to these criteria; and (iii) the monetisation or valuation of these data, e.g. where a new development using $\mathrm{BGl}$ is expected to sequester many tonnes of $\mathrm{CO}_{2}$ the physical data includes numerical data for the sequestered $X$ tonnes of $\mathrm{CO}_{2}$. The impact value of this may be determined by standardised nationally set monetary benefit estimation; monetisation of the benefits quantified by the physical data, i.e. $£$ per unit of $\mathrm{CO}_{2}$ sequestered, multiplied by the amount in $\mathrm{X}$ tonnes. The $\mathrm{B} £ S T$ is designed to evaluate the multiple benefits which are provided by the measures that use BGI or GSI, categorised in terms of both ES and a Triple-BottomLine (TBL) of economy/financial; environmental; and social values. Monetary valuation is based on a range of market and non-market approaches, the majority of which are based on the value transfer approach from the standard UK Flood and Coastal Erosion Risk Management assessments (Eftec, 2010), notwithstanding the known limitations of value transfer approaches (e.g. Schmidt et al, 2016). The B£ST can be also used to assess the benefits provided from traditional piped drainage systems (CIRIA, 2016). The B£ST uses standardised accounting procedures to help to minimise uncertainties and their implications.

There are uncertainties in the physical performance data and model results and in the way in which the predicted changes from an option under consideration are monetised. In each aspect of knowledge and understanding about BGI design, operation and performance (Meng et al, 2017). In developing uncertainty assessments in the B£ST, uncertainties were considered in 5 benefit groups: water quantity; water quality; amenity; biodiversity and ecology; financial assessment. B£ST uses ES assessment data, for which Hamel \& Bryant (2017) state that of 153 reported ES valuation assessments, only some 1/3rd included some form of uncertainty assessment. BGI valuations add further levels of complexity as explained here, and hence outcomes from the B£ST are likely to be even less certain than they are for ES assessments.

Confidence scoring and sensitivity analysis. In the B£ST, the uncertainties have not been explicitly assessed, i.e. there is no requirement to assess the uncertainty in for example, the quantified tonnage of $\mathrm{CO}_{2}$ sequestered, which may come from a separate analysis. Instead a user defined confidence and sensitivity approach is built into the B£ST spreadsheets, that can be informed by uncertainty analysis if this has been carried out. Confidence scoring was selected for the explicit inclusion of uncertainty as it confronted users with the need to consider uncertainty in the analysis process, rather than picking 'default' numbers from the data base, and users can input their own data where available. A confidence score ranging from $25 \%$ to $100 \%$, in steps of $25 \%$ is selected for both the physical data and also the monetary attribution to the physical changes provided by the BGI option. Both confidence scores are used together to factor the original financial value estimated from B£ST. Hence as an example, where the lowest physical data confidence score suggested might be $75 \%$, and the lowest financial valuation confidence score is $25 \%$, the overall benefit value is reduced by a factor of $0.75 \mathrm{x}$ $0.25(=0.19)$. This is presumed to be a pessimistic assessment and hence an underestimate of the true value of the benefits. The B£ST includes a sheet to help users undertake simple sensitivity analysis, and illustrate whether categories form $>20 \%$ or $10-20 \%$ of the total value of benefits (before confidence scores are applied). This uses the initial assessment and allows the user to alter the confidence scores $(25 \%, 50 \%, 75 \%, 100 \%, 125 \%)$. 


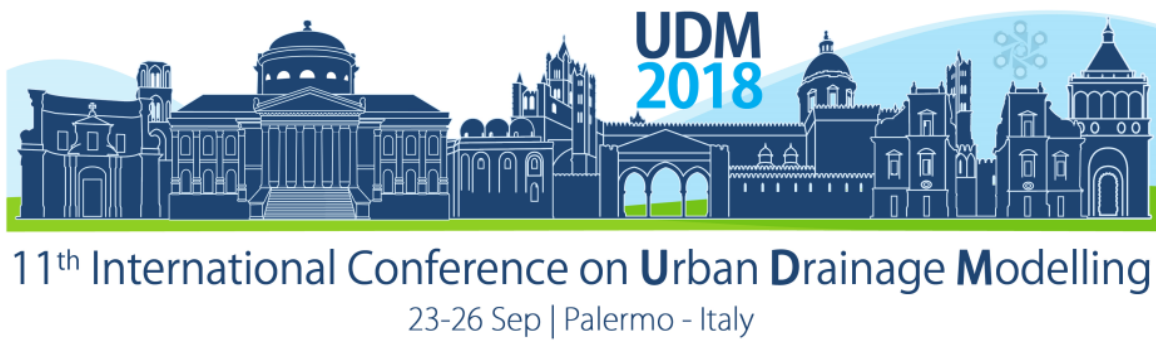

Leveraging. Marginal changes in a scheme may bring about significant changes in benefits. The assumptions about some of the benefits in the B£ST include both linear and non-linear changes in benefits in relation to the scale of the provision of individual BGI components. Even small changes in provision in numbers of trees may have a significant effect on the outcomes. This can be important: (i) to understand if there are key switching points, i.e. the extent to which variables used in the assessment of costs and benefits have to change for the NPV of the project or programme to switch from positive to negative; covered by the sensitivity testing outlined earlier; (ii) where other funders or stakeholders are likely to become interested in a project, especially where e.g., new health benefits are going to be created, potentially bringing interest to health providers who may then add funding to the project.

\section{RESULTS AND DISCUSSION}

A case example. This is used to illustrate some of the aspects of uncertainty when using the $\mathrm{B} £ S T$ for BGI valuation as a direct consequence of: (i) the assumptions used in the B£ST; and (ii) the way in which the tool is applied. Not all sources of uncertainty and assessment methods described earlier are included, however, some with the greatest potential to influence the results are outlined. The case is for a 46ha drainage catchment in Leeds, Yorkshire, UK which is currently discharging overflows from a number of combined sewers into a small watercourse (Ashley et al, 2018a). The overflows need to be reduced to preserve important habitats. The population in the area is some 4,700 and there is a mix of high to medium density urban spaces and a country park. A BGI option has been considered for the scheme and has the best overall PV of all of the options, although the costs are high. Further details of the B£ST analysis are in (Ashley et al, 2018a), here the focus is on the uncertainties in the analysis.

Confidence scoring and sensitivity analysis. Figure 1a shows the total benefits, together with the sensitivity analysis ranges. Figure $1 \mathrm{~b}$ shows the individual benefit categories and the uncertainties in their valuation. In the Figures, the only uncertainties are those related to the assumptions used in the assessments of the physical and the financial data. Even when only considering the user defined confidence scores, the variation in estimates (uncertainties) for the value of the overall benefits is large. The sensitivity analysis indicates that the PV may potentially be negative. Individual benefit categories each have more or less uncertainty as expressed in the selection of confidence scores (physical and financial together): Amenity 0.25 ; Flooding 0.5 ; Recreation 0.25 ; Water quality 0.5 . Of these, amenity is the largest value benefit comprising some $65 \%$ of the overall value, with flooding at some $28 \%$ and water quality some $5 \%$.

Leveraging. Leveraging value analysis shows that the benefits would change markedly with numbers of trees and this may be significant when linked to the potential changes in residents having an enhanced view of green spaces. Where both the numbers of trees are increased from 250 up to 1000 and the numbers of residents with a view are increased from 150 up to 500 , there is a large impact on the value of the consequential health benefits, rising from £0.6million to £3.5million. 


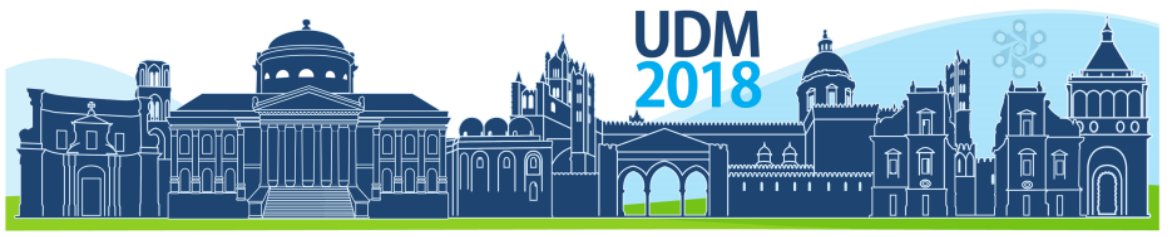

$11^{\text {th }}$ International Conference on Urban Drainage Modelling 23-26 Sep | Palermo - Italy
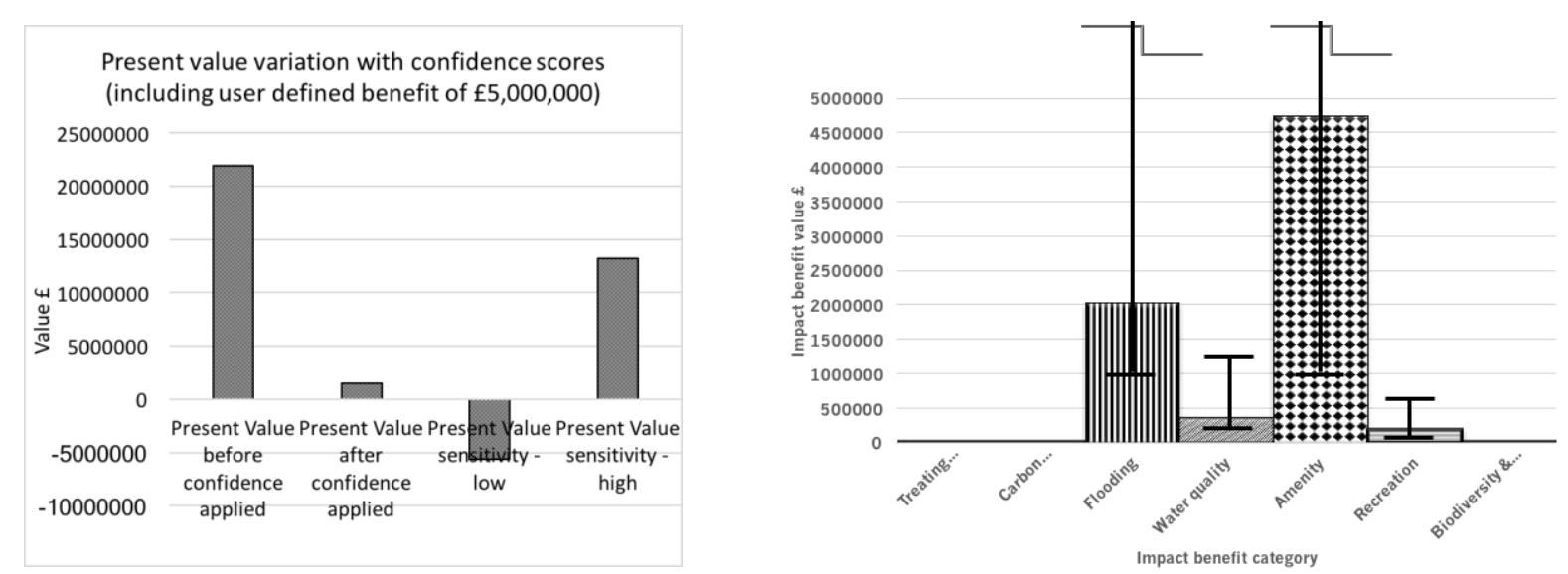

Figure 1. a) Main benefit value for BAU for the BGI option for the scheme lifetime of 2015-2095, and b) Sensitivity ranges for main benefits for $\mathrm{BAU}$ for the $\mathrm{BGI}$ option

\section{CONCLUSIONS}

This abstract has demonstrated the nature of uncertainties in estimating the multiple benefits of using BGI for stormwater management. The scale of these uncertainties is not unique to valuing BGI, it applies also to the analysis of the performance of traditional buried piped infrastructure. In the rush to demonstrate that multifunctional BGI is economically preferable to piped drainage systems, it is tempting to gloss over the uncertainties that really need to be clearly defined and brought to the attention of all stakeholders. Although there are clear subjectivities in certain aspects of the valuation of BGI, many of these also apply to 'hard' infrastructure valuation. Hamel \& Myers (2017) indicate that there is still a long way to go in valuing what may not be valuable in the conventional monetary sense; the systems and services provided by nature and natural systems. At the least, experts need to ensure that decision makers understand fully the uncertainties in the monetary bottom line for both benefits and costs for valuing BGI for stormwater management. The B£ST, in explicitly including uncertainty in a simple way, highlights how significant this can be.

\section{References}

Ashley R M., et al. (2018). Evaluating the longer term benefits of sustainable drainage. Proceedings of the Institution of Civil Engineers Water Management 171 April. Issue WM2 Pages 57-66 https://doi.org/10.1680/jwama.16.00118. Paper 1600118

Ashley R M., et al. (2018a). Demonstrating and monetizing the multiple benefits from using SuDS. American Society of Civil Engineers. Journal of Sustainable Water in the Built Environment. 2018, 4(2) 05017008. 1-8.

Brisley R. et al, (2015). Techniques for valuing adaptive capacity in flood risk management. Proc. Inst. Civil Engineers. Water Management. Paper 1400070 p1-9.

CIRIA (2016) Benefits of SuDS Tool. http://www.susdrain.org/resources/best.html

Eftec (2010) Flood and Coastal Erosion Risk Management: Economic Valuation of Environmental Effects. HANDBOOK for the Environment Agency for England and Wales.

Hamel P., Bryant B P. (2017). Uncertainty assessment in ecosystem services analyses: seven challenges and practical responses. Ecosystem Services 24, 1-15.

Meng, T.; et al. (2017). Green and Smart: Perspectives of City and Water Agency Officials in Pennsylvania toward Adopting New Infrastructure Technologies for Stormwater Management. J. Sustainable Water Built Environ., 2017, 3(2): 05017001.

Ossa-Moreno J, et al. (2017) Economic analysis of wider benefits to facilitate Suds uptake in London, UK. Sustainable Cities and Society 28: 411-419, https://doi.org/10.1016/ j.scs.2016.10.002.

Schmidt S., et al. (2016). Uncertainty of monetary valued ecosystem services - value transfer functions for global mapping. PLOS ONE, doi: 10.1371/journal.pone.0148524 March 3. 


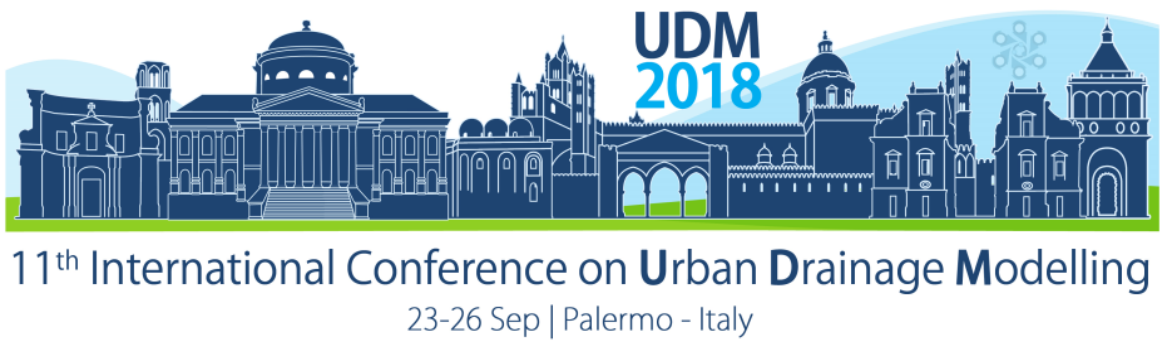

\title{
Evaluating city scale surface water management using a rapid assessment framework in Melbourne, Australia
}

\author{
James L Webber ${ }^{12}$, Matthew J Burns ${ }^{2}$, Guangtao Fu', David Butler ${ }^{1}$ and Tim D Fletcher ${ }^{2}$ \\ 1 University of Exeter, Centre for Water Systems, Exeter, UK \\ 2 University of Melbourne, Waterway Ecosystem Research Group, Melbourne, Australia
}

\begin{abstract}
This research develops application of a strategic surface water management screening framework to enhance decision support in cities. Decision support in cities is typically constrained by resource costs of detailed analysis, this new methodology overcomes this through applying a simplified option screening process to evidence strategy and direct future detailed modelling of promising options. This study advanced on previous research by developing the methodology through option evaluation using a real world case study in collaboration with key catchment stakeholders. Research included stakeholder engagement workshops to identify catchment flood hazards and design potential management strategies, followed by application of the fast flood assessment framework to assess the flood reduction potential of each strategy. Theoretical implications indicate that city scale interventions demonstrate effective performance at managing design standard flood events. Practical findings indicate the framework to be an effective stakeholder engagement tool due to fast analysis of collaborative strategies. The key benefit to readers is understanding that fast, simplified urban drainage modelling can provide an opportunity to collaboratively screen flood hazards and generate evidence for prioritising detailed modelling in urban catchments.
\end{abstract}

Keywords: Green infrastructure; Strategic design; Surface water management; Urban flooding.

\section{INTRODUCTION}

This study advances recent developments in simplified urban flood modelling to collaboratively assess the effectiveness of surface water flood management alongside key catchment stakeholders in Melbourne city centre. A range of strategies were collaboratively designed through catchment flood management workshops and then tested using a simplified representation of options as part of a rapid assessment framework.

Cities are uniquely vulnerable to surface water flooding due to extensive impermeable surfaces increasing runoff in combination with a concentration of social, economic and cultural function compounding potential impacts. Emerging threats of climate change, urban expansion and aging drainage infrastructure are predicted to worsen future flood hazard and highlight a need for effective urban management (Barbosa et al. 2012; IPCC 2014). Many management strategies are available, however evidencing selection of options can be limited by a resource intensive and technically demanding modelling process (Elliott and Trowsdale 2007). Option selection is further exacerbated by the complexity of urban environments and the many spatial permutations of management strategies possible in a catchment. Recent research has developed new methods to refine option selection through preliminarily screening using a fast, simplified comparison framework (Webber et al. 2018a; 2018b). This study advances the framework to real world application to identify and assess green infrastructure flood management strategies in collaboration with catchment stakeholders in Melbourne, Australia. Work outlines collaborative flood hazard screening, strategy design and initial results from analysis of city scale green infrastructure strategies. The key finding is that simplified urban drainage modelling techniques can engage collaborators in efficient strategy development 


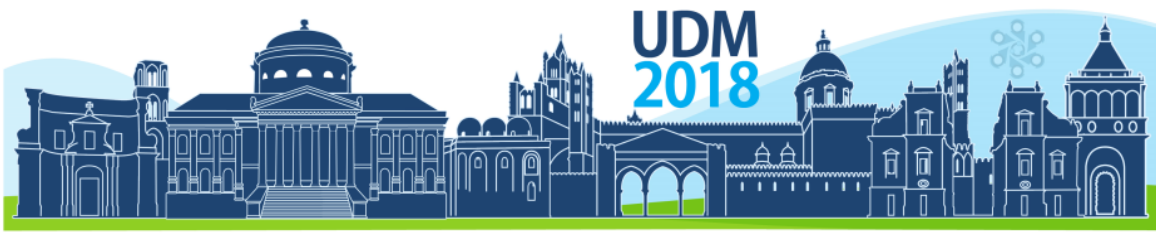

$11^{\text {th }}$ International Conference on Urban Drainage Modelling

23-26 Sep | Palermo - Italy

through fast analysis of options. This approach can be used as a preliminary tool to complement and support existing hydro-dynamic surface water management models.

\section{MATERIALS AND METHODS}

The fast assessment framework is decribed in detail in previous publications (Webber et al. $2018 \mathrm{a} ; 2018 \mathrm{~b})$. Figure 1 provides a brief summary of the approach. Speed of analysis is increased through a simplified representation of interventions using high level assumptions and application of a fast cellular automata flood routing model (CADDIES) (Guidolin et al. 2016). In simple terms, the model represents the urban catchment through parameters applied across a regular grid. Rainfall is applied to the grid as an input, and routed between grid cells based on a modified Manning's equation controlled by elevation, input, output and cell roughness. Land use types and interventions can be applied to the grid through modifying parameters. CADDIES 2D routing achieves similar accuracy to industry standard hydrodynamic models but requiring 5 to 20 times less calculations (Gibson et al. 2016). However, simplifications in representations of physical processes (for example removing the 1D network and representing the drainage system as an output rate per cell) mean that the approach is intended to act as a preliminary screening technique, and not for detailed design.

Water level controlled by weighting of adjacent cells

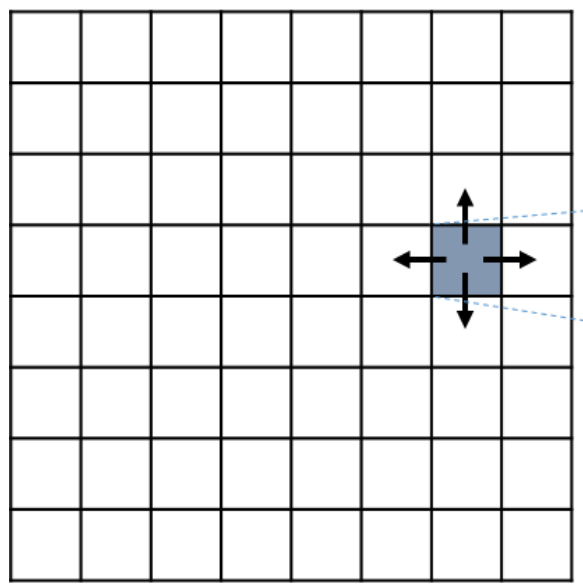

Parameters of each cell represent effects of land use and interventions

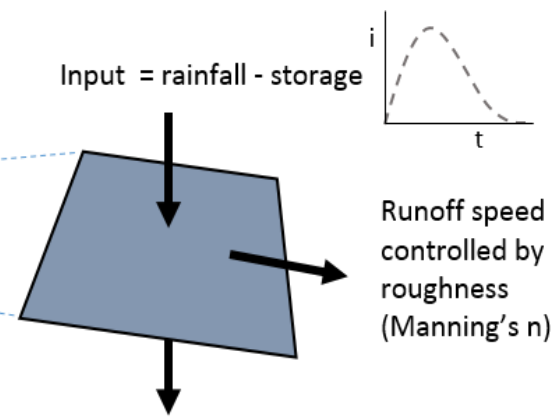

Output $=$ infiltration + evapotranspiration

Figure 1. Simplified surface water flood modelling using CADDIES (Webber et al. 2018a)

Catchment elevation was represented using $1 \mathrm{~m}$ resolution DTM. Land use types were classified at a $1 \mathrm{~m}^{2}$ resolution using local mapping and included urban space, buildings, vegetation cover (minimal, moderate, heavy) and transport infrastructure. Parameterisation of surface types was based on academic literature (Butler and Davies 2011). A full survey of the underlying drainage system was unavailable, so the system was represented using a constant infiltration rate of $15 \mathrm{~mm} /$ hour across all contributing land cells. This represented the system operating at full capacity during a design standard event. Assumptions were corroborated through workshops with the City of Melbourne and were validated using flood observations from previous events. 


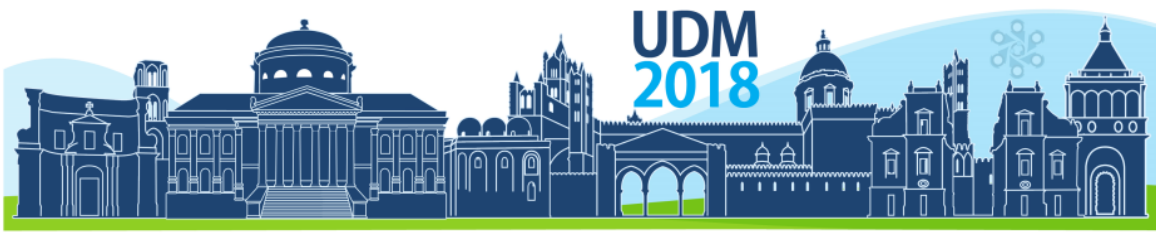

$11^{\text {th }}$ International Conference on Urban Drainage Modelling

23-26 Sep | Palermo - Italy

Rainfall was selected through analysis of storm durations (30,60, 120, 180, 270 and 480 min) at a $5 \%$ annual exceedance probability (AEP) rainfall intensity (equivalent to a 20 year return period). This analysis identified peak flooding during the one hour storm.

A range of strategies were identified and developed through catchment stakeholder workshops. Strategies were developed through collaborative generation of intervention location maps and intervention effect parameters. Figure 2 shows an example including three of the twelve intervention maps set up during stakeholder workshops. These identify the areas where intervention effects will be applied across the catchment.

Parameterisation of strategie effects was representative of an average impact across the area of application translated to each $1 \mathrm{~m}^{2}$ model cell within that area. For example, rather than identifying individual locations for raingardens to cover $10 \%$ of the suitable catchment area, $10 \%$ of the effect of a raingarden was applied across the entire suitable area. Hence, the averaged effect of some interventions (tree pits) is minimal in relation to application across a large area. This advantaged simulation through accelerating simulation setup time, but is only suitable for catchment scale strategic analysis and should not be used to simulate local detailed scale flood dynamics.
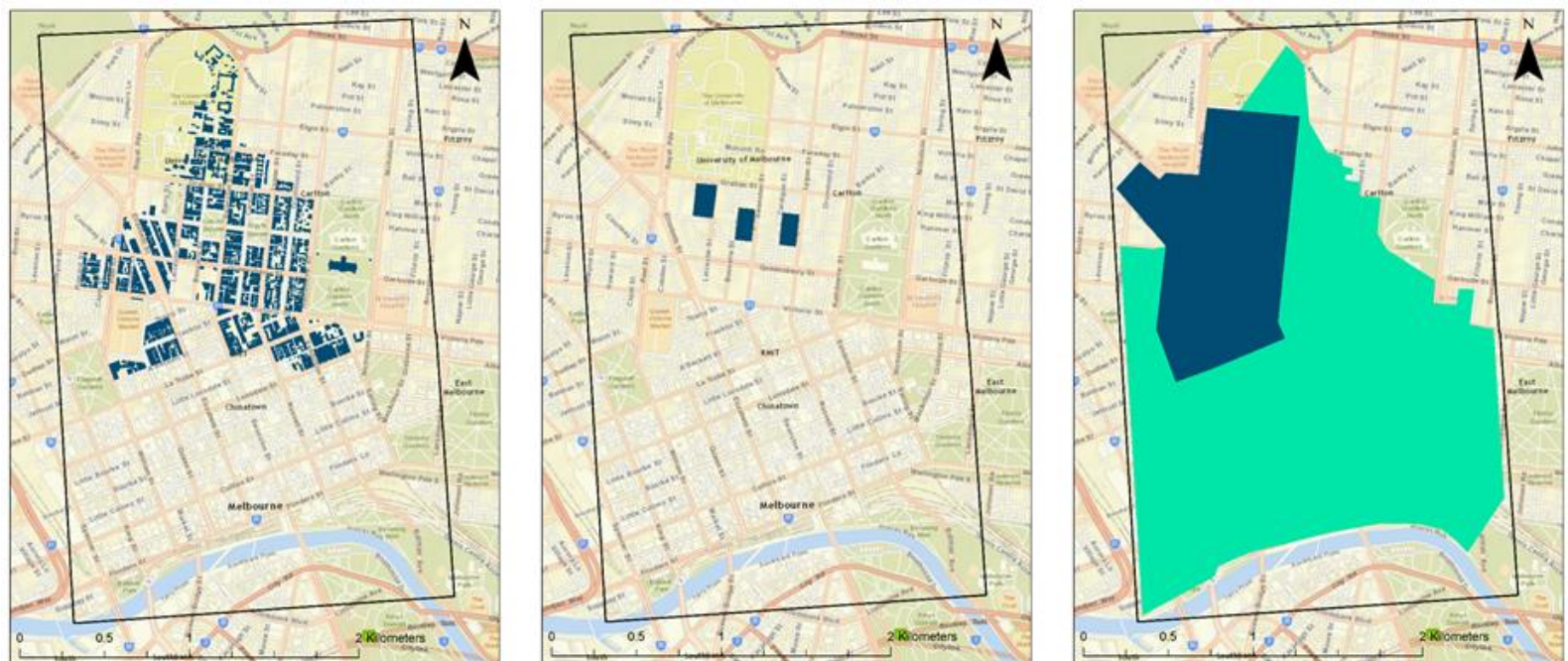

Figure 2. Examples of intervention strategy distribution across the upper Elizabeth Street catchment, showing proposed green roofs, urban parks and catchment storage zones (map credit: ESRI OpenStreetMap).

Strategies included catchment wide rainwater capture strategies with the following capacities in each $1 \mathrm{~m}$ by $1 \mathrm{~m}$ cell, indicated in the intervention maps: green roofs $\left(10 \mathrm{l} / \mathrm{m}^{2}\right)$, rainwater capture $\left(25 \mathrm{l} / \mathrm{m}^{2}\right)$, raingardens $\left(7 \mathrm{l} / \mathrm{m}^{2}\right)$, permeable paving $\left(10 \mathrm{l} / \mathrm{m}^{2}\right)$. As well as strategically targeted capture options: increasing park space $\left(10 \mathrm{l} / \mathrm{m}^{2}\right)$, green roofs $\left(7.5 \mathrm{l} / \mathrm{m}^{2}\right)$, storage zones $\left(8.1\right.$ and $\left.4.5 \mathrm{l} / \mathrm{m}^{2}\right)$, tree pits $\left(0.1 \mathrm{l} / \mathrm{m}^{2}\right)$ and storage at university buildings (ranging from 3.3 to $46 \mathrm{l} / \mathrm{m}^{2}$ ). Duplication of pipe sub-catchments was also included through doubling the output rate in corresponding cells to $30 \mathrm{~mm} /$ hour.

\section{RESULTS AND DISCUSSION}

Assessment was focused on a flood zone corresponding with a major street in the city centre (Figure 3). This was identified as the main area of flood hazard within the catchment. 


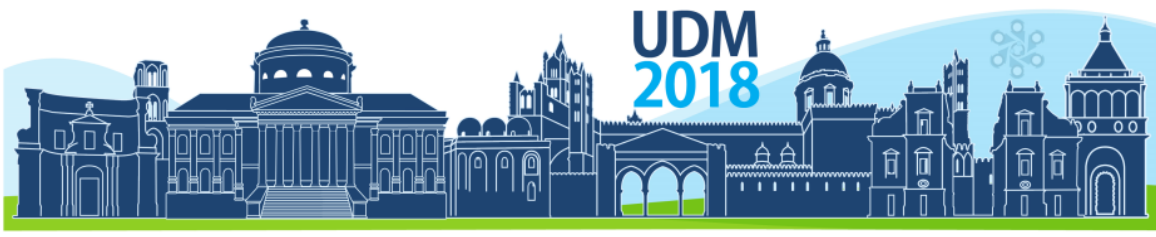

$11^{\text {th }}$ International Conference on Urban Drainage Modelling 23-26 Sep | Palermo - Italy
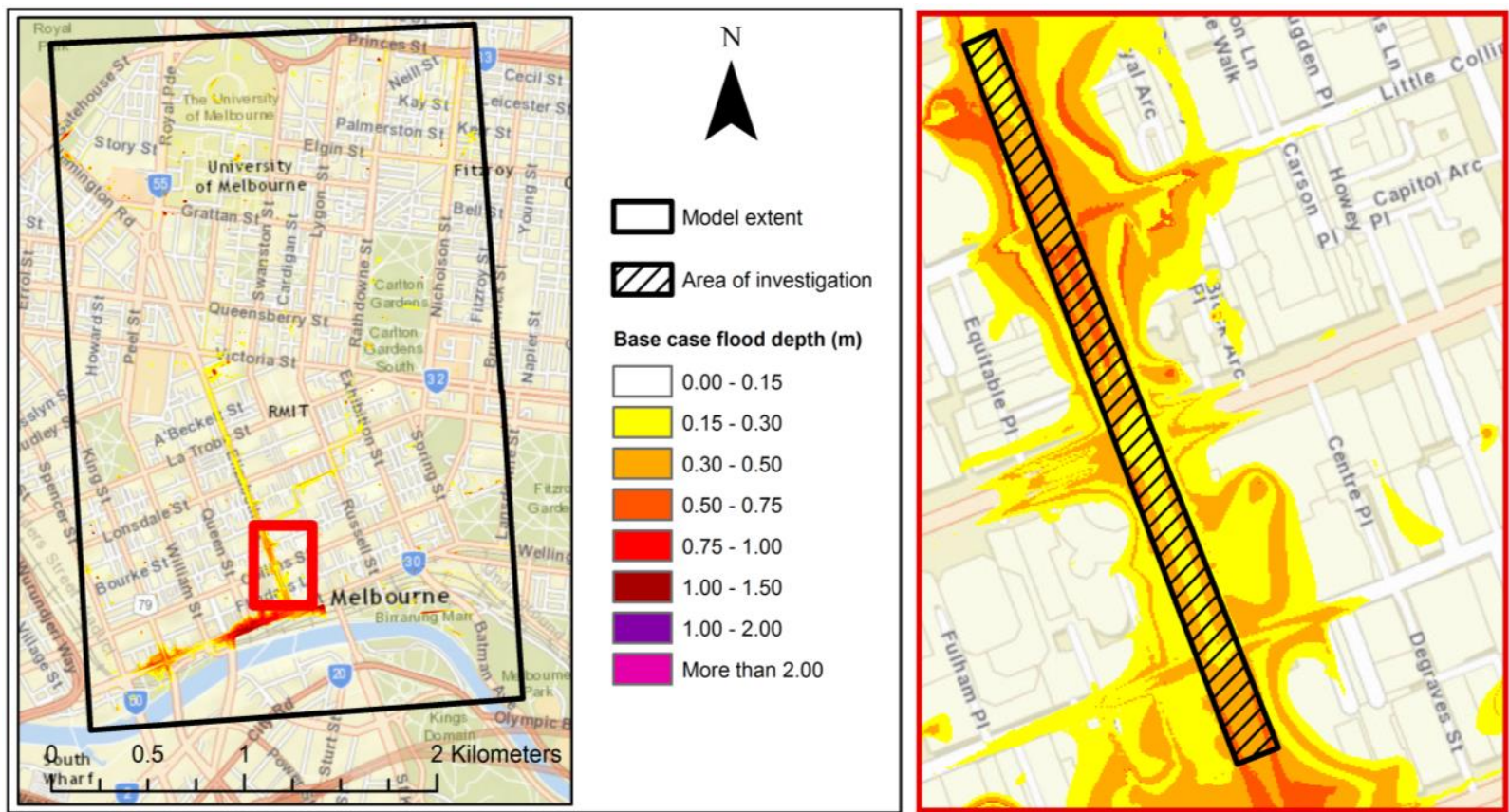

Figure 3. Peak flood depth during 'base case' 5\% AEP, one hour rainfall event. Area of investigation highlighted in cut-out extent (map credit: ESRI OpenStreetMap).

Figure 4 presents a distribution of peak flood depths from every grid cell within this zone during a one hour rainfall event when managed using the range of intervention strategies. The box represents the $75^{\text {th }}$, mean and $25^{\text {th }}$ percentiles and the vertical line represents the range of data, with outliers represented as dots. Surface water flooding was observed in all scenarios, indicating that no strategy totally prevented flooding in the area of investigation. All interventions demonstrate improved performance versus the base case scenario. The most effective interventions were those applied across large areas of the catchment, including rainwater capture, green roofs, permeable paving, drainage upgrades and introduction of enhanced storage in the upper catchment. Rainwater capture was consistently the most effective intervention, reducing the mean peak flood depth to less than $0.2 \mathrm{~m}$.

Tree pits and capturing runoff at City's universities demonstrated a negligible reduction in flood depth versus the base scenario. It is suggested that these interventions only capture enough rainfall to delay the timing of the flood peak, rather than reducing it. The apparent limited performance of certain localised or independent interventions should be considered in the context of an incremental development step towards a larger catchment management approach. In addition to this, although local strategies may not reduce the peak depth in downstream catchment, their local effect may facilitate more effective movement around areas of severe flooding which are consistent with large storms. 


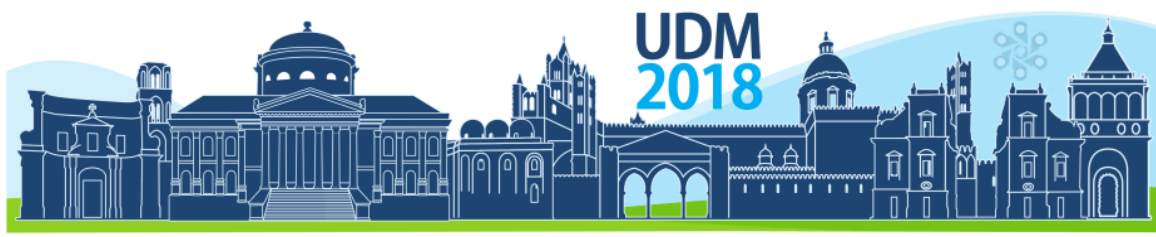

$11^{\text {th }}$ International Conference on Urban Drainage Modelling

23-26 Sep | Palermo - Italy

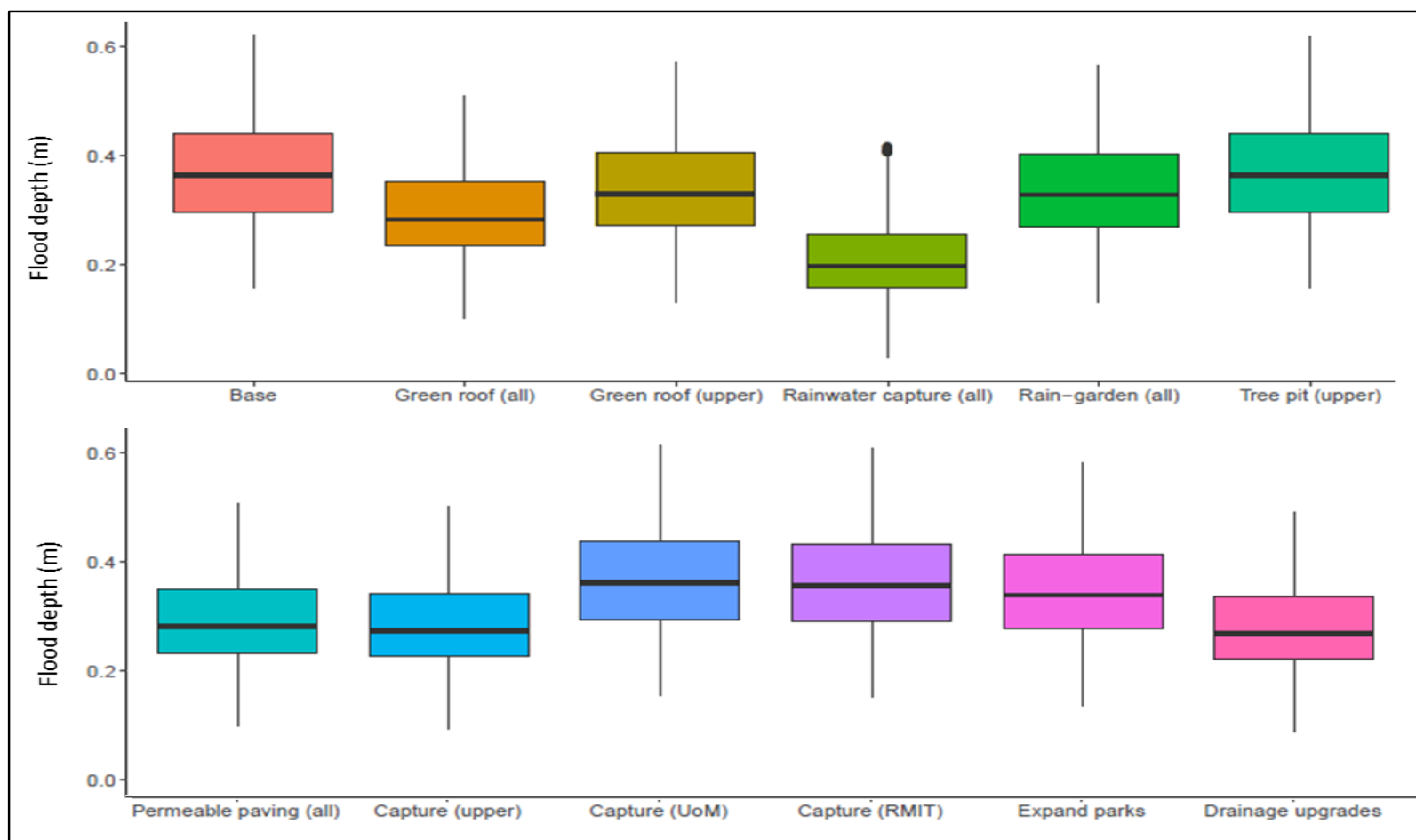

Figure 4. Flood depth in study transect during 5\% AEP, one hour rainfall event

\section{CONCLUSIONS}

The work concluded two main findings. Firstly, catchment scale management was effective at reducing peak flood depth across the downstream area of investigation, supporting future flood management building towards city scale strategies. Secondly, application of the rapid assessment framework proved an effective method for integrating stakeholder expertise to form an evidential basis to inform next steps. Future work should assess the effectiveness of green infrastructure strategies across a wider range of events and evaluate performance in low probability, high intensity rainfall.

\section{REFERENCES}

Barbosa, A.E., Fernandes, J.N. and David, L.M. (2012). Key issues for sustainable urban stormwater management. Water Research, 46(20), pp.6787-6798.

Butler, D. and Davies, J. (2011). Urban drainage. Third edition. SPON Press, Abingdon.

Elliott, A.H. and Trowsdale, S.A. (2007). A review of models for low impact urban stormwater drainage. Environmental Modelling and Software, 22(3), pp.394-405.

Gibson, M.J., Savic, D.A., Djordjevic, S., Chen, A.S., Fraser, S. and Watson, T. (2016). Accuracy and Computational Efficiency of $2 \mathrm{D}$ Urban Surface Flood Modelling Based on Cellular Automata. Procedia Engineering, 154, pp.801-810.

Guidolin, M., Chen, A.S., Ghimire, B., Keedwell, E.C., Djordjević, S. and Savić, D.A. (2016). A weighted cellular automata 2D inundation model for rapid flood analysis. Environmental Modelling \& Software, 84, pp.378-394.

IPCC. (2014). Climate Change 2014: Synthesis Report. Contribution of Working Groups I, II and III to the Fifth Assessment Report of the Intergovernmental Panel on Climate Change.

Webber, J.L., Fu, G. and Butler, D. (2018a). Rapid surface water intervention Derformance comparison for urban planning. Water Science and Technology, 77(8), 2084-2092.

Webber, J.L., Gibson, M.J., Chen, A.S., Fu, G. and Butler, D. (2018b). Rapid assessment of surface water flood management options in urban catchments. Urban Water Journal, 15(3), 210-217. 


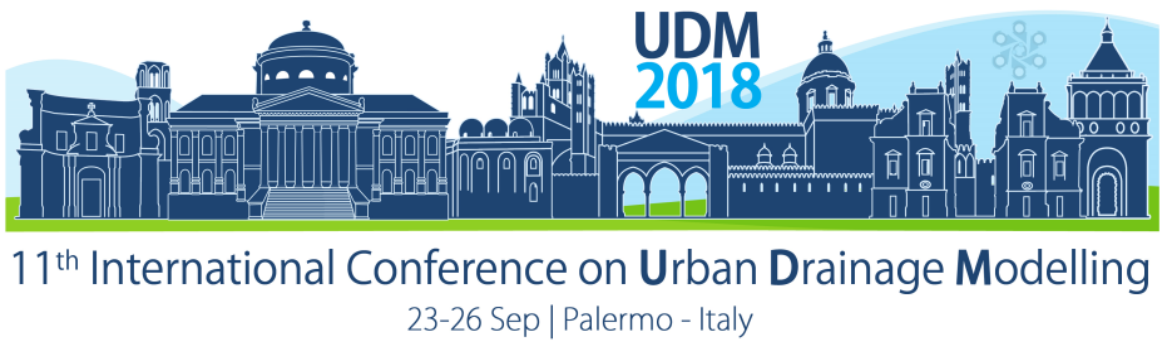

\title{
Optimizing SVM model as predicting model for sewer pipes in the two main cities in Colombia
}

\author{
Nathalie Hernández ${ }^{1}$, Nicolas Caradot ${ }^{2}$, Hauke Sonnenberg ${ }^{2}$, Pascale Rouault ${ }^{2}$ and Andrés Torres ${ }^{1}$
}

${ }^{1}$ Civil Engineering Department, Pontificia Universidad Javeriana, Bogotá, Colombia

${ }^{2}$ Kompetenzzentrum Wasser Berlin, Berlin, Germany

\begin{abstract}
As in most of the cities around the world, in the last 30 years Latin-American ones have focused on investing in building infrastructure to provide sewer and water services to the communities. However, these infrastructures are going aging day to day. The municipalities need to extend management activities by the development of support tools such as deterioration models to face the aging problem. In the literature of sewer asset management, SVM has been a useful tool to predict and forecast the structural condition of pipes. In this work, the use of differential evolution method as optimization tool was implemented to find the optimal hyper-parameters for SVM models. The SVM models were applied in the main cities of Colombia (Bogota and Medellin) given as a result that the optimized SVM model provides less than $5 \%$ of deviation in the prediction of structural conditions in both cities.
\end{abstract}

Keywords: Sewer asset Management, Support Vector Machines, Differential Evolution method, Optimization, deviation analysis.

\section{INTRODUCTION}

In the last 30 years, most municipalities have invested in sewer system expansion to meet growth and treatment plant upgrades. However, a relatively small proportion of the budget has been allocated to sewer rehabilitation (AWWA, 2012). According to the distribution of infrastructure investment by sector during the 2003-2012 period in Latin-America, water and sewer systems are the last ones of the infrastructures (less than 0.3 GDP) which are taken into account in the public budget (Larde \& Sánchez, 2014). As a result, most cities face the problem of aging infrastructure in need of extensive and ongoing repair, rehabilitation or renewal (Caradot et al., 2017).

The lack of information about sewer condition limits rehabilitation strategies. Therefore, deterioration models have been developed to forecast the evolution of the system according to its current and past state (Caradot et al., 2015). One of the generated deterioration models is based on learning machine approaches as support vector machines (SVM) (Hernandez et al., 2017a; Hernandez et al., 2017b; Mashford et al., 2010). The advantage of SVM in these experiences has been that, from its classification property, it could forecast the structural condition distribution to have a global overview useful for investments plans (Hernandez et al. 2017b). However, the incidence of different hyperparameters in the SVM model prediction results has not yet been explored in deep for sewer asset management purposes. Therefore, the main idea of this work is optimizing the hyper-parameters of SVM to improve their prediction performance using differential evolution (DE) as an optimization tool.

\section{MATERIALS AND METHODS}

\subsection{Cases studies: Sewer systems of Bogotá and Medellin}

For the city of Bogotá (8 million of inhabitants), after data clean-up, 5076 consistent inspections (representing $245 \mathrm{~km}$ ) were linked to 5031 sewer pipes. The structural condition of the 


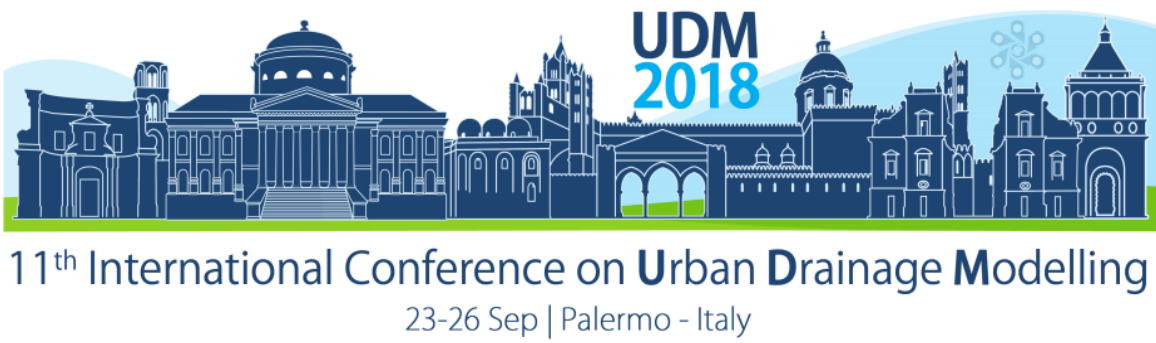

inspected pipes was evaluated using the local sewer assessment standard NS-058 (EAAB, 2001). Scores are given to each structural failure found in a pipe and subsequently added up to qualify its structural condition. These scores are ranked in 5 grades: from 1 to 5 , with 5 being the critical condition (total score $\geq 165$ points).

The database of Medellin (3,7 million of inhabitants), after data clean-up, 13.265 consistent inspections $(441 \mathrm{~km})$ were linked to 12.710 sewer pipes. The condition of the inspected pipes was evaluated using the local sewer assessment standard (EPM, 2010). Each structural or operational failure is qualified according to the type of damage and their localization into the pipe's perimeter. Then these failures are categorized in high, medium and low relevance in the sewer system. Finally, each condition (structural and operational) is calculated by adding up the product of failures' number and their score of each categorization of relevance in the sewer system divided by the length of the asset. The final scores are ranked in 5 grades: from 1 to 5 , with 5 being the critical condition (total score $\geq 21,6$ )

\subsection{Methods}

Support Vector Machines (SVM)

SVM is a learning machine method, which classifies data by hyperplanes: SVM generates hyperplanes, lines or non-linear curves, to separate and classify the data in some features space into different regions. The base of SVM classifiers is for solving binary classification problems where there are only two class labels and large predictor variables. When the type of classification is multiclass (more than two categories), it uses some methods such as "oneagainst-one" and "pairwise" methods (Betancourt, 2005). The aim of SVM is finding the optimal hyperplanes that maximize the separation margins between the classes. The hyperparameters depend on the kernel function chosen and soft margin parameter $\mathrm{C}$. C trades off misclassification of training examples against the simplicity of the decision surface and determines how much is the margin's width of the hyperplane. A low $\mathrm{C}$ value makes the decision surface smoother with a larger margin in comparison with a higher $C$ value, for which its margin is thinner (Hornik et al., 2006). The chosen kernel function was RBF (Gaussian/Radial basis function) which is the most suitable for classification tasks (Genton, 2002). The hyper-parameter related to RBF is gamma $\left(\gamma=\frac{1}{2 \sigma}\right)$ which represents the relationship of the deviation standard $(\sigma)$ of the Gaussian function: a small gamma value generates a higher variance, which implies that the model is too constrained and cannot capture the complexity of the shape of the data. On the other hand, a large gamma value generates a smaller variance, which implies that the radius of influence of the support vectors only includes the support vectors themselves and no amount of regularization with $\mathrm{C}$ will be able to prevent overfitting (Hornik et al., 2006).

Furthermore, the classes' weight was included as another parameter. This parameter assigns an asymmetric cost to each class. It could be especially important when one or more specific types of errors are more harmful than others or when there is a severe class imbalance that biases the model to the majority class (Gunn, 1998).

\section{Optimization Technique: Differential Evolution (DE)}

DE optimizes a problem by iteratively trying to improve a candidate solution with regard to a given measure of quality with particular characteristics such as: (i) few or no assumptions about the problem to optimize are proposed, and therefore it is a metaheuristic method; (ii) the optimization problem does not have to be differentiable as is required by classic optimization methods, and therefore it can be used to solve optimization problems that are not continuous, noisy and time changing; (iii) the optimization problem is treated as a black box that provides 


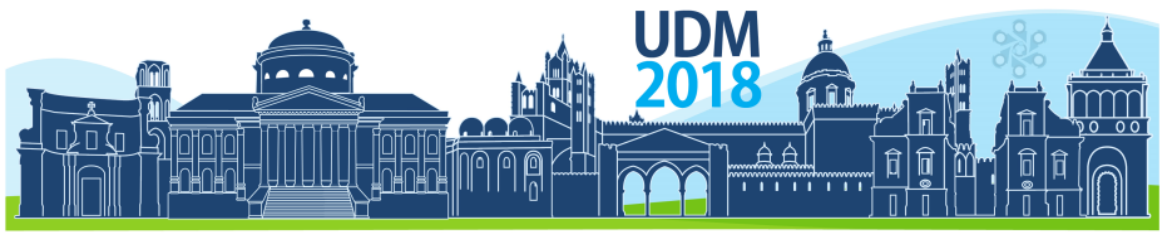

$11^{\text {th }}$ International Conference on Urban Drainage Modelling

23-26 Sep | Palermo - Italy

a measure of quality given a candidate solution and the gradient is therefore not needed (Torres et al., 2013; Price et al., 2006).

This method was used by the DeOptim package (Mullen et al., 2011) in R software (R Development Core Team, 2018). The optimization is carried out with only $2 / 3$ of the inspection data of each city, the given problem is the SVM model, and the objective function is the Knet metric, explained as follows.

\section{Performance metrics}

Model performance is traditionally evaluated by comparing model outcomes with observed data, i.e., the inspected sewer conditions. With each sewer, the inspected condition is compared with the predicted one. A set of performance metrics has been defined to benchmark and evaluate models' performances. The metrics need to be intuitive, self-explanatory and thus clearly understandable.

The metric assesses the model performance at the network level: it describes the deviation between the predicted and the inspected condition distributions, for the entire network (K1, K2, and K3 deviation of pipes in good (grade 1), Intermediate (grades 2,3 and 4), and critical (grade 5 ) conditions respectively) and for different age groups ( $\mathrm{K} 4, \mathrm{~K} 5$ and $\mathrm{K} 6$ ) deviations of pipes in good, medium and critical conditions respectively for a specific group of pipes that belong to the oldest period). The main idea of this metric is to indicate to which extent the model can predict the condition distribution of the network, i.e., the number of pipes in each condition. The Knet metric can summarise these six indicators (Equation 1):

$$
\text { Knet }=\sqrt{\frac{K 1^{2}+K 2^{2}+K 3^{2}+K 4^{2}+K 5^{2}+K 6^{2}}{6}} \quad \text { Equation (1) }
$$

\section{RESULTS AND DISCUSSION}

After a brief statistical analysis, redundancy concepts (Hernández et al., 2016) and Cramer's Test (Baker et al., 2008) were used to choose which factors (available physical and environmental characteristics of sewer assets) are related to sewer pipes deterioration.

According to these analyses, the chosen factors for Bogota dataset are: age, diameter, length, material of the pipes, sewerage and network that belongs to the pipe, depth, district, zone, land use and coordinates (latitude $-X$ and longitude $-Y$ ) where is located the pipe, as well as the road type and its material over the sewer pipe and the quality of data information.

On the other hand, the chosen factors for Medellin dataset are: age, diameter, length, slope, and material of the pipes, type of effluent (sewerage), depth and district that that pipe belongs. The hyper-parameters found by DE method are those shown in table 1. This table shows the hyper-parameter gamma, $\mathrm{C}$, the weights $(\mathrm{w})$ on each structural condition and the metric Knet obtained by DE after 100 iterations for each city.

Table 1. Optimal SVM hyper-parameters for both datasets.

\begin{tabular}{lcrrrrrrrr}
\hline \multirow{2}{*}{ dataset } & \multicolumn{8}{c}{ Hyper-Parameters } \\
\cline { 2 - 11 } & Sigma & C & \multicolumn{1}{c}{ w1 } & w2 & w3 & w4 & w5 & Knet \\
\hline Bogotá & 0,2078 & 115,787 & 1,169 & 4,923 & 4,087 & 5,050 & 4,2620 & 0,5468 \\
\hline Medellín & 0,6820 & 39,644 & 1 & 1 & 1 & 1 & 2,6582 & 0,5359 \\
\hline
\end{tabular}




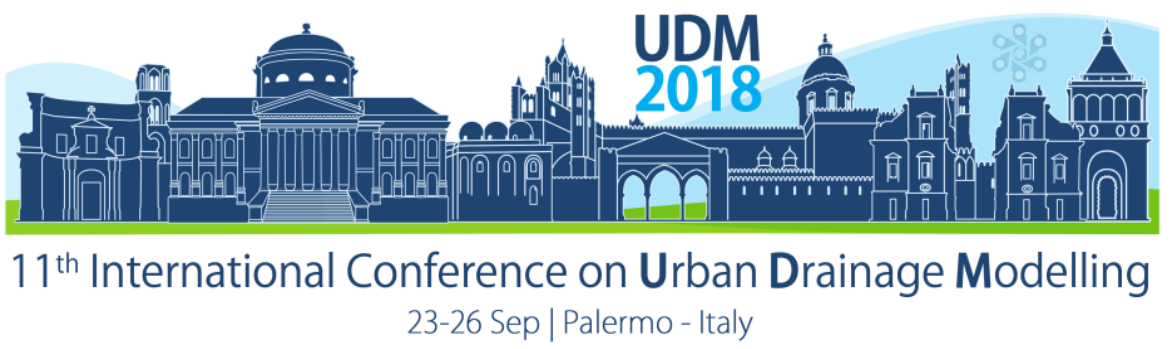

It is possible to observe in Table 1 that for Bogota dataset the five weights of the structural conditions were optimized, obtaining Knet close to zero (0.54). For Medellin, only the weight of those pipes in critical conditions was optimized, obtaining at the end similar Knet $(0,53)$.

With the hyper-parameters shown in Table 1, SVM models with RBF kernel function were trained with 2/3 of each dataset and tested with the rest. Table 2 shows the deviation results ( $\mathrm{K}$ indicators) and the Knet metric obtained in the test data for each city. The oldest period of age for the cities were: pipes with ages higher than 80 years for Bogota and pipes with ages higher than 50 years for Medellin.

Table 2. SVM models' performance results for both datasets

\begin{tabular}{lccccccc}
\hline \multirow{2}{*}{ dataset } & $\mathbf{7}$ Indicators in test data \\
\cline { 2 - 9 } & K1 & K2 & K3 & K4 & K5 & K6 & Knet \\
\hline Bogotá & $-4,65$ & 1,71 & 2,94 & $-1,15$ & $-2,08$ & 3,23 & 3,33 \\
\hline Medellín & 1,02 & $-1,3$ & 0,28 & $-3,4$ & 2,08 & 1,32 & 0,97 \\
\hline
\end{tabular}

According to the results shown in Table 2, the metric Knet for both datasets is lower than 3,33, and the $\mathrm{K}$ indicators show that deviation is lower than $5 \%$. Nevertheless, there are some differences: for Medellin deviation results ( $\mathrm{K}$ indicators) and Knet metric are lower than for Bogota, especially in the indicators K3 and K6 that represent the deviation in pipes with critical conditions. The deviation results of both cities are interesting, since the hyperparameters, optimized for Medellin's database, were less than for Bogota (see Table 1) getting lower deviation results: only the weight of critical conditions was optimized for Medellin while the five weights in the structural conditions were optimized for Bogota's database.

\section{CONCLUSIONS}

The use of differential evolution method (DE) as the optimization tool for identifying the suitable hyper-parameters for SVM Models was appropriate. However, this work is on development since it is necessary to explore other methods to select the proper covariates in the model, as well as, exploring other ways of condition grouping to obtain higher prediction's performance. Even though, SVM model for Bogota contains more information of the physical and environmental characteristics (covariates) and more hyper-parameters were optimized, it does not have a better prediction performance than the one for Medellin. Many circumstances could explain this issue: (i) Any of the chosen covariates (or their combination) for the Bogota's case could contain noise; (ii) The uncertainty in the data inspection could be higher for Bogota dataset than for Medellin one, since Medellin's municipality directly inspects the sewer pipes in the metropolitan area of Medellin, while Bogota's municipality outsources this activity to external companies using diverse devices and expertise.

\section{Acknoweledgements}

This research is supported by the program PROCOL, bilateral convention between DAAD in Germany (Proposal title: "Development of innovative tools to support efficient sewer asset management strategies in Germany and Colombia) and COLCIENCIAS in Colombia (Colciencias -Pontificia Universidad Javeriana "Contrato de Financiamiento de Recuperación Contingente de Movilidad Internacional No. 646 del 2015" and Project ID: 6725 - PRY ID - 6853- Proposal title: "Herramientas de gestión proactiva de alcantarillados adapatadas a diferentes contextos de gestión patrimonial")including funding from the German Federal Ministry of Education and Research (BMBF). 


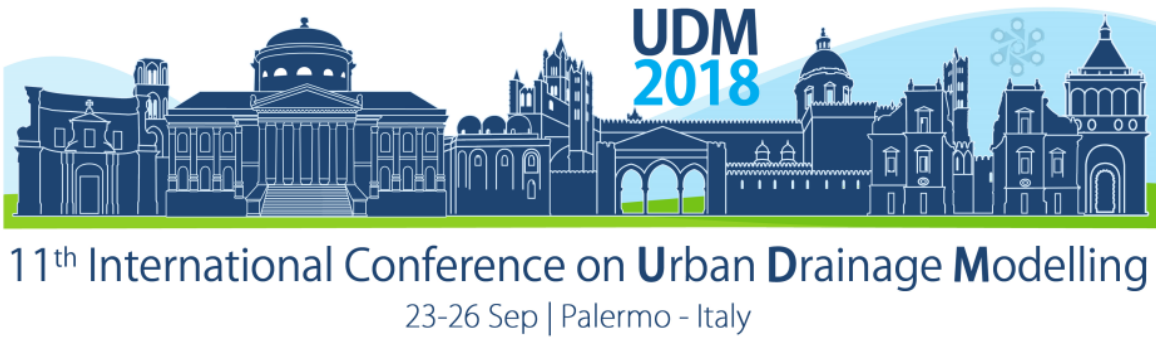

Furthermore, the authors would like to thank COLCIENCIAS and PUJ for supporting one of the authors in her PHD's studies ("Convocatoria 727 del 2015- Apoyo doctorados nacionales").

A special acknowledgement to EAB ("Empresa de Acueducto de Bogota") and EPM ("Empresas Públicas de Medellín) for supplying the database information used in this research.

\section{References}

AWWA (2012). Buried no longer: confronting America's water infrastructure challenge, AWWA's infrastructure financing report, Boulder, CO.

Baker, V. S., Imade, G. E., Molta, N. B., Tawde, P., Pam, S. D., Obadofin, M. O., ... \& Baker, M. (2008). Cytokineassociated neutrophil extracellular traps and antinuclear antibodies in Plasmodium falciparum infected children under six years of age. Malaria journal, 7(1), 41.

Caradot N, Sonnenberg H, Hartmann A., Kropp I, Ringe A, Denhez S., Timm M., Rouault P. The influence of data availability on the performance of sewer deterioration modelling. 10th International Urban Drainage Modelling Conference September 20 -23, 2015, Mont-Sainte-Anne, Québec, Canada.

Empresa de Acueducto y Alcantarillado de Bogotá EAAB. (2001). "NS - 058. Aspectos Técnicos para inspección y mantenimiento de redes y estructuras de alcantarillado", Bogotá, Colombia, EAAB-E.S.P.: 2001

Empresas Públicas de Medellin EPM \& INGENIERIA TOTAL LTDA (2010). Metodología para el diagnóstico y evaluación de redes de Alcantarillado con CCTV. Departamento de Diagnóstico e inspección de redes de alcantarillado; EPM E.S.P., Medellín, Antioquía, Colombia.

Caradot, N., Sonnenberg, H., Kropp, I., Ringe, A., Denhez, S., Hartmann, A., \& Rouault, P. (2017b). The relevance of sewer deterioration modelling to support asset management strategies. Urban Water Journal, 1-9.

Genton, M. G. (2002). Classes of kernels for machine learning: a statistics perspective. The Journal of Machine Learning Research, 2, 299-312.

Gunn, S. R. (1998). Support vector machines for classification and regression. ISIS technical report, 14(1), 5-16.

Hernandez, N., Obregón N. \& Torres, A. (2016). Identificación de factores de tipo categórico relacionados con la condición estructural de tuberías de alcantarillado de Bogotá a partir de conceptos de entropía de la información. Ingeniería solidaria, 12(19), 63-71.

Hernández N., Caradot N., Sonnerberg H., Rouault P and Torres A (2017a). Support tools to predict the critical structural condition of uninspected sewer pipes in Bogota D.C. The leading edge sustainable asset management of water and wastewater infrastructure conference. Trondheim, Norway 20-22 june 2017.

Hernández N., Caradot N., Sonnerberg H., Rouault P and Torres A (2017c). Support Vector Machines used for the prediction of the structural conditions of pipes in Bogota's sewer system. 14th International conference on urban drainage. Prague, Czech Republic 10-15 September 2017

Hornik, K., Meyer, D., \& Karatzoglou, A. (2006). Support vector machines in R. Journal of statistical software, 15(9), $1-28$.

Lardé, J., \& Sánchez, R. (2014). La brecha de infraestructura económica y las inversiones en América Latina.

Mashford, J., Marlow, D., Tran, D., \& May, R. (2010). Prediction of sewer condition grade using support vector machines. Journal of Computing in Civil Engineering, 25(4), 283-290.

Mullen K., Ardia D., Gil D., Windover D., Cline J. (2011). 'DEoptim': An R Package for Global Optimization by Differential Evolution. Journal of Statistical Software, 40(6), 1-26. http://www.jstatsoft.org/v40/i06/

Price K.V., Storn R.M., Lampinen J.A. (2006). Differential Evolution - A Practical Approach to Global Optimization. Heidelberg (Germany): Springer-Verlag.

R Development Core Team R (2017). A language and environment for statistical computing. Vienna (Austria): R Foundation for Statistical Computing,. ISBN 3-900051-07-0. http://www.R-project.org/.

Torres, A., Lepot, M., \& Bertrand-Krajewski, J. L. (2013, August). Local calibration for a UV/Vis spectrometer: PLS vs. SVM. A case study in a WWTP. In 7th International Conference on Sewer Processes \& Networks (pp. 18). 


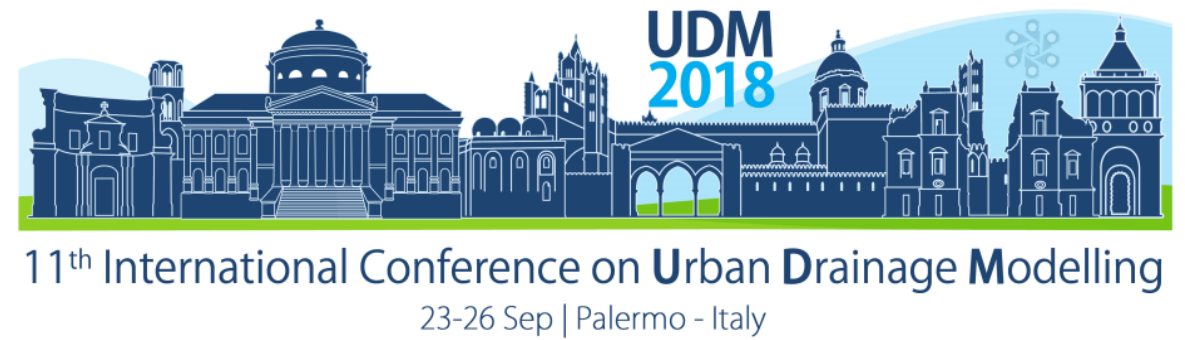

\title{
Climate Change Impact on Water Supply Demands: Case Study of the City of Skopje
}

\author{
Katerina Donevska ${ }^{1}$ and Angelco Panov ${ }^{2}$ \\ University Ss Cyrill and Methodius, Faculty of Civil Engineering, Partizanski odredi 24, Skopje, Republic of \\ Macedonia \\ 2 Pointpro Consulting, Maksim Gorki 16, Skopje, Republic of Macedonia
}

\begin{abstract}
The aim of the paper is to present climate chance impact on drinking water supply and assess availability of current water resources to meet the increasing demands in climate change conditions for the city of Skopje. Series of monthly precipitation and temperature data are generated up to 2050, using recorded data and data for predicted changes of air temperature and precipitation according to climate change scenarios developed for the Republic of Macedonia within the Third National Communication. Climate change impact on drinking water supply is assessed using statistical models for dependence of the water supply data to the main climate parameters: temperature and precipitation. Forecast of future water quantities includes implementation of multi regression models defined with a set of independent variables: number of population for time sets (t, t-1, t-2, t-3), precipitation and air temperature including predicted changes of the data under climate change conditions for the same time sets. Two scenarios are analysed: first - predicts the number of population until 2050 remains nearly the same as nowadays, second - predicts increase of number of population on average annual rate of increase of $0,58 \%$. Results are indicating shortage of available water resources for population and industry in climate change scenarios (increasing of temperatures and decreasing of precipitations) and increase of population. Understanding the vulnerability of both water resources and variability of drinking water demands for the city of Skopje results in identifying the most dominant factors that influence vulnerability. It is vital to ensuring sustainable water management in the region.
\end{abstract}

Keywords: drinking water supply; climate change; water management

\section{INTRODUCTION}

The paper presents analyses of the climate chance impact on water supply demands for the city of Skopje (capital of the Republic of Macedonia) and link them to the available water resources. The research presents a part of the project Climate Change Strategy for the City of Skopje Skopje (City of Skopje, 2017). Analyses include generation of series of monthly and annual temperature and precipitation data in compliance with the official climate change scenarios for Macedonia using data from the Third National Communication on Climate Change to UNFCCC (MoEPP, 2014) and analysis of the dependence of the water supply to the generated climate parameters in climate change conditions. The aim of the research is to link the demand of drinking water to the supply of drinking water for the forthcoming period in climate change conditions. 


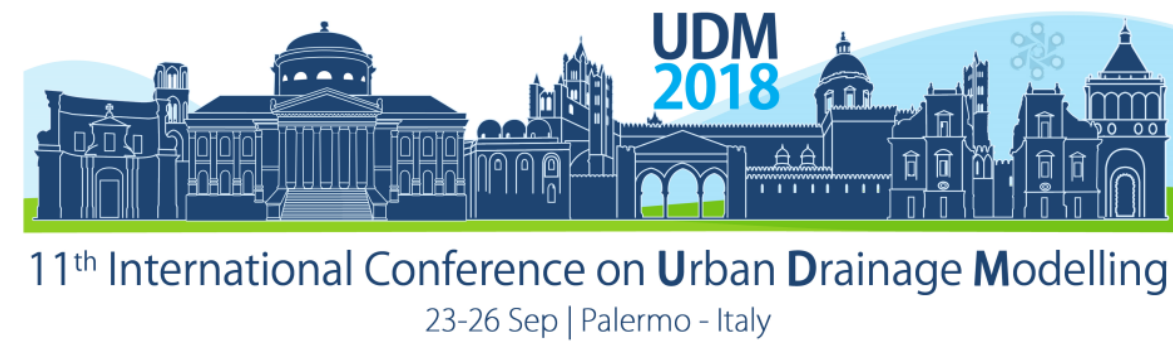

Understanding the vulnerability of both water resources and variability of drinking water demands is vital to identifying the most dominant factors influencing the vulnerability and consequently ensuring sustainable water management in the region. The availability of such an assessment provides the decision-makers with various alternatives to evaluate and modify existing policies/strategies and implement measures to improve water resources management.

\section{MATERIALS AND METHODS}

The data used in the research include: average monthly and annual temperatures and monthly and annual sum of precipitation for the main meteorological station Zajcev Rid in Skopje, for the period from 1978 to 2015; data for predicted changes of air temperature and precipitation according to climate change scenarios developed for the Republic of Macedonia within the Third National Communication; data for delivered water quantities for drinking water supply of population and industry for the period from 1990 to 2015 and data about available water resources: spring that supplies the city of Skopje with drinking water (spring Rasce) and ground water resources (wells).

Methodology of the research is mainly consisted of the following phases:

- Monthly and annual precipitation and temperature data series are generated up to 2050 using recorded precipitation and temperature data for the period 1978-2015 and data for predicted changes of air temperature (increase) and precipitation (decrease). Data about medium predicted changes of climate data are used according to official climate change scenarios for Macedonia developed within the Third National Communication on Climate Change.

- Data about delivered water quantities for drinking water supply of population and industry for the period from 1990 to 2015 are statistically analysed. For the particular case of delivered water quantities a multi regression model is defined with a set of independent variables, so the correlative relationship between the recorded and predicted climate data is stronger. The set of independent variables included precipitation and temperature data, so the model might be applied to forecast water consumption under climate change conditions. The regression model used for forecasting the future water consumption of population and industry was formed using data for independent variables such as: number of population for time sets (t, t-1, t-2, $\mathrm{t}-3$ ) and precipitation and average air temperature for main meteorological station Skopje for the same time sets ( $t, t-1, t-2$ and $t-3$ ). The application of multi regression models in hydraulics and hydrology is widely used for temporal and spatial simulation of hydrological events. The purpose of the multi regression analysis is formation plane in n-dimensional space, where " $n$ " is the number of independent variable sizes. The disadvantage of regression models, as well as most other models, is the inability to fully simulate the local peaks.

- According to statistical principles, normalization of the time series being used in the regression models in the range $(0,1)$ was done and transformed (normalized) model was created at the beginning of the statistical analysis. All statistical tests and analyses were performed on the transformed model. The series consisted of 300 data (period from year 1990 to 2015) is divided into two parts (first part is used for formingcalibration of the model, and the second part for testing-validation of the adaptability of the adopted regression model). 


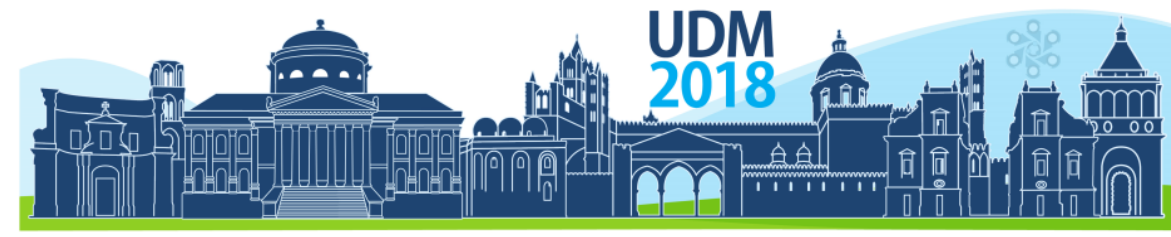

$11^{\text {th }}$ International Conference on Urban Drainage Modelling

23-26 Sep | Palermo - Italy

- Based on the adopted predictive multi-regression model WP $=f($ Population, $T, P, n$, $n-1, n-2, n-3)$, a calculation/forecast of future production of water for the population and industry is performed, as a function of previous number of population and climate data for the current year and the previous time sets (independent variables). The aim of linking the quantity of produced water and main climate data is to analyse the impact of future climate change on water production/demand. Two scenarios are analysed: first - assumes the number of population until 2050 remains nearly the same as today, second - assumes increase of number of population on average annual rate of increase of $0,58 \%$.

\section{RESULTS AND DISCUSSION}

Results of the analyses indicate the following:

- The applied models are evaluated in terms of regression coefficient and standard error of the models. The models show good adaptability, with extreme high correlation and relatively small error of the model.

- Graphical presentation of the measured and generated data (Figure 1 and Figure 2, data from 1990 to 2015) indicates that generated series don't fit the extremes of measured series. However, the simulation was performed for average monthly data, therefore the error of the model in terms of the peak may be considered as tolerant as the absolute error of the volume of the analysed series is minimal.

- For the first scenario, if the number of population until 2050 remains nearly the same as today, water production during period (2016-2050) shows nearly $12 \%$ increase compared to the analysed period 1990 to 2015 . The increase is due to the climate change conditions (Figure 1).

- For the second scenario, i.e increase of number of population on average annual rate of increase of $0,58 \%$, the results present an increase of nearly $26 \%$ of future water production during period (2015-2050) compared to the analyzed period from 1990 to 2015. The increase is mainly due to the increase of number of population (Figure 2).

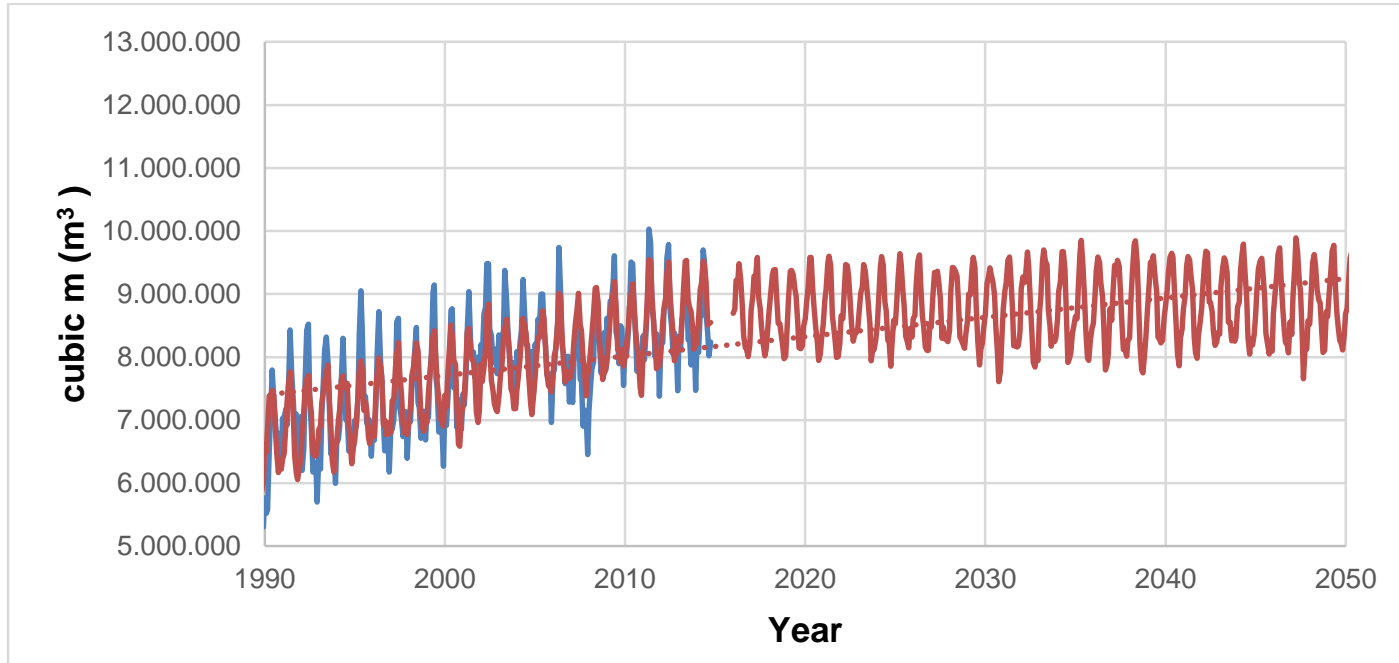

Figure 1. Dependency of the water production for period 2016 - 2050 year, scenario I: constant number of population, increase of temperatures and decrease of precipitation 


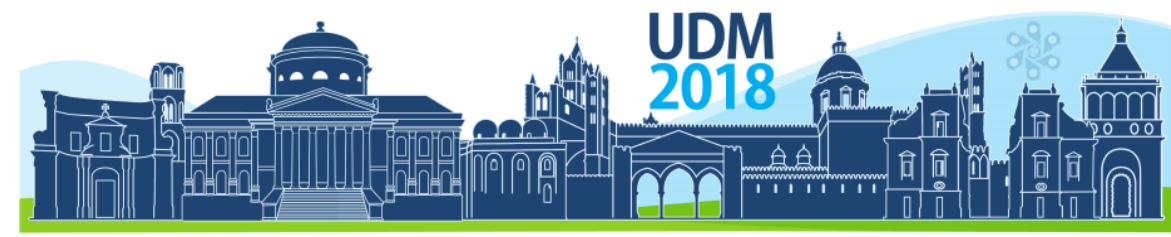

$11^{\text {th }}$ International Conference on Urban Drainage Modelling 23-26 Sep | Palermo - Italy

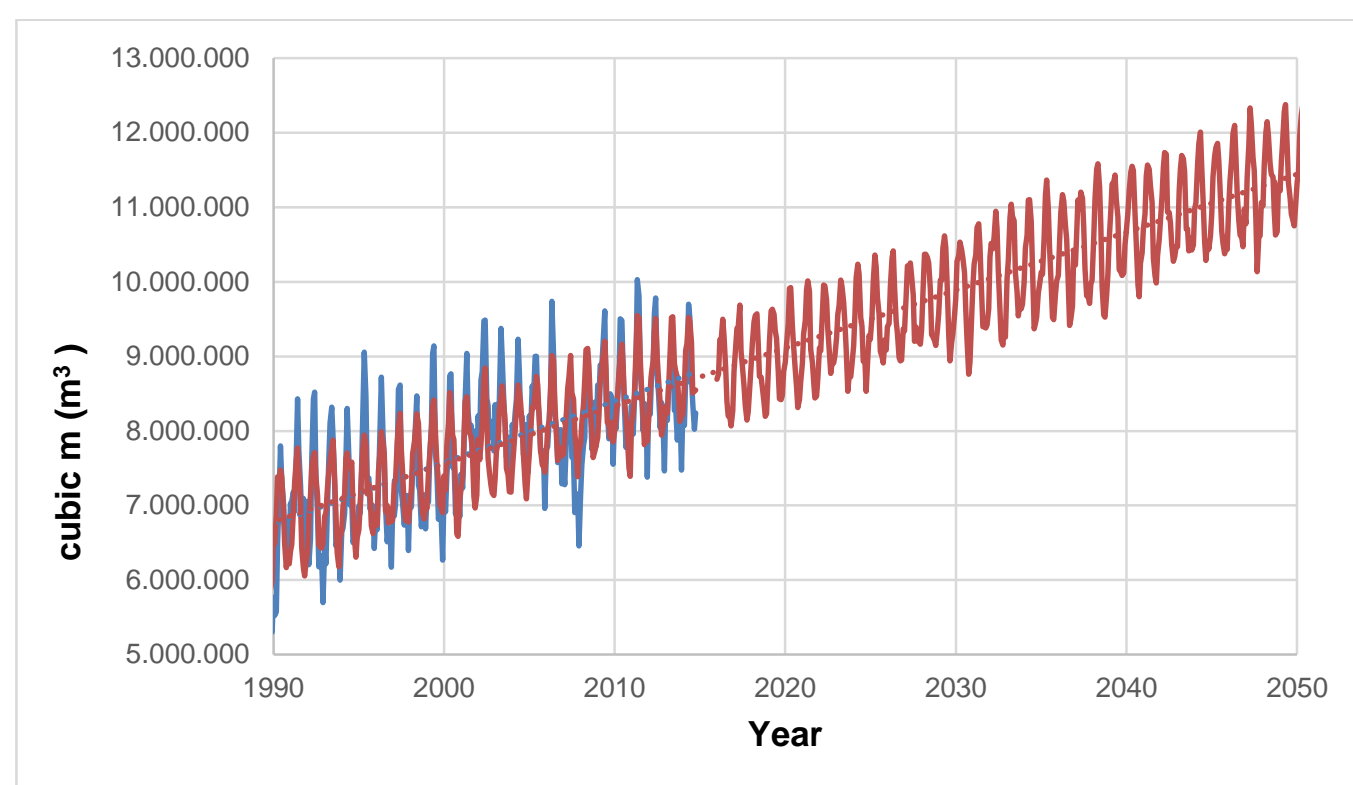

Figure 2. Dependency of the water production for period $2016-2050$ year, scenario II: increase of total number of population, increase of temperatures and decrease of precipitation

\section{CONCLUSIONS}

Taking into consideration average capacity of the spring that supplies the city of Skopje with drinking water (spring Rasce), as well as the yield of ground water wells used for water supply of the city, the forecasted water production for both scenarios using the historical pattern of water supply of consumers/produced water were linked with available water resources for the city water supply system. Results indicate that for the first scenario, i.e. in climate change conditions and no increase of number of population, the current pattern of water supply of consumers by the city water supply can be met. However, even increase of the number of population by $0,58 \%$ rate of increase, contributes towards using of maximal capacities of the spring Rasce and groundwater wells to meet the maximal forecasted production. In climate change conditions, predicting temperature increase, precipitations decrease and increase of the drought conditions, the frequency of occurring lower discharges/yield than the average both for the spring and groundwater is expected to be higher. These predictions are indicating the need for including uncertainties in future projections as of high importance.

\section{References}

City of Skopje (2017), Resilient Skopje, Climate Change Strategy.

Ministry of Environment and Physical Planning of the Republic of Macedonia (MoEPP) (2014), Third National Communication on Climate Change. 


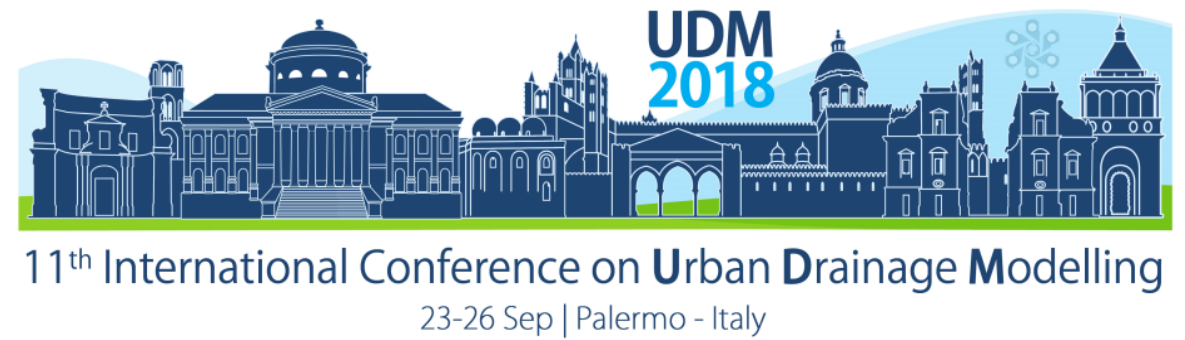

\title{
Impacts of in-sewer defects on human health risks compared with impacts of climate change
}

\author{
Hans Korving ${ }^{1,2}$, Marco van Bijnen ${ }^{3}$ \\ 1 Deltares, Delft, P.O. Box 177, $2600 \mathrm{MH}$, the Netherlands \\ 2 Delft Institute of Applied Mathematics, Delft University of Technology, Delft, P.O. Box 5031, 2600 GA, the \\ Netherlands \\ ${ }^{3}$ Department of Water Management, Faculty of Civil Engineering and Geo Sciences, Delft University of \\ Technology, Delft, P.O. Box 5048, 2600 GA, the Netherlands
}

\begin{abstract}
Exposure to urban pluvial flooding may pose health risks to humans due to a variety of contaminants in floodwater. In-sewer defects may increase pluvial flooding. This possibly increases health risks. This abstract addresses the impact of in-sewer defects on pluvial flooding and infection probabilities for humans. The impact of sedimentation is compared with the increase of infection probabilities due to climate change. The impact of in-sewer defects was assessed by means of Monte Carlo simulation. The catchment-wide average infection probability was calculated using Quantitative Microbial Risk Assessment (QMRA) and flooding frequencies from Monte Carlo simulations with a hydrodynamic model of the sewer system. For the 'Tuindorp' catchment (Utrecht, the Netherlands), it is concluded that the impact of climate change on infection probability is of the same order of magnitude as the shift due to sediment deposits in the current climate given current sewer cleaning intervals. Therefore, current serviceability levels of this sewer system can be maintained using a higher cleaning frequency despite climate change impacts.
\end{abstract}

Keywords: Health risk; Asset management; Climate change; Hydrodynamic modelling

\section{INTRODUCTION}

Exposure to urban pluvial flooding may pose a health risk to humans, since the floodwater may contain a variety of contaminants. These include human enteric pathogens (e.g. norovirus and enterovirus) from urban wastewater (Lodder and De Roda Husman, 2005), and Campylobacter, Giardia, and Cryptosporidium from both animal faeces and human wastewater (Koenraad etal., 1994; Schets etal., 2008). De Man et al. (2014) quantified risks of infection from exposure to urban floodwater using Quantitative Microbial Risk Assessment (QMRA). In-sewer defects affect the hydraulic performance of a sewer system and may cause increased pluvial flooding. Van Bijnen et al. (2012) demonstrated that in-sewer defects cause increased flooding with sedimentation as the predominant factor. As a result, annual infection risks will increase significantly due to higher flooding frequencies as was shown in Van Bijnen etal. (2018).

This abstract compares the impact of sedimentation on infection risks from exposure to urban floodwater with the increase of infection risks due to heavier rains as expected in climate projections. Impact is compared in terms of catchment-wide infection probabilities per year. The analysis is based on flooding frequencies from Monte Carlo simulations as presented by Van Bijnen et al. (2012) and infection probabilities due to the ingestion of urban floodwater from De Man et al. (2014). Climate change impacts on rainfall are based on the most recent climate projections for the Netherlands (Van den Hurk etal., 2014). 


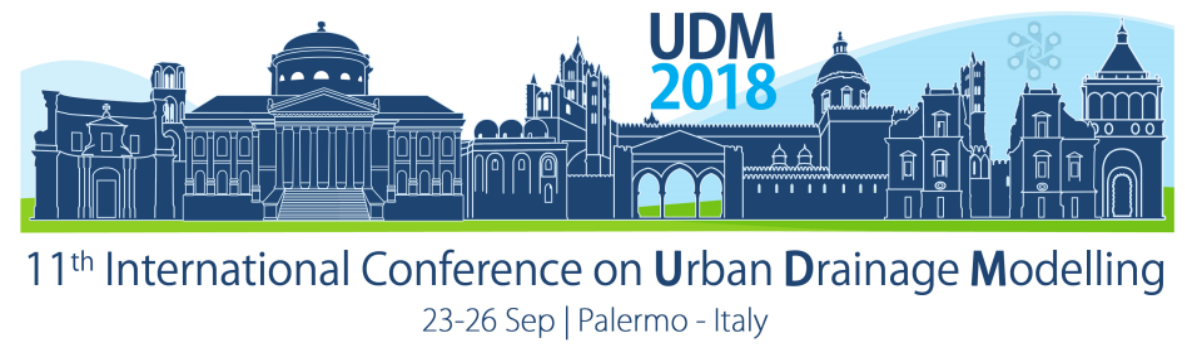

\section{MATERIALS AND METHODS}

\subsection{Research catchment}

The impact of sedimentation and climate change on infection risks is studied for the 'Tuindorp' catchment in Utrecht (the Netherlands). This catchment is a combined sewer system (see Figure 1). The catchment area is relatively flat (average surface slope $3.0 \mathrm{~mm} / \mathrm{m}$ ). It comprises a range of contributing area types, both roofs and pavements (total area $56.9 \mathrm{ha})$. The storage volume equals $4,669 \mathrm{~m}^{3}(8.2 \mathrm{~mm})$. The collected sewage is transported to the pumping station in the southern part of the catchment (pumping capacity $800 \mathrm{~m}^{3} / \mathrm{h}$, dry weather flow $157 \mathrm{~m}^{3} / \mathrm{h}$ ). The system contains five combined sewer overflow (CSO) structures. One CSO discharges into a storage-settling tank (volume $822 \mathrm{~m}^{3}$ ). There are no discharges to or inflows from adjacent systems in the catchment.

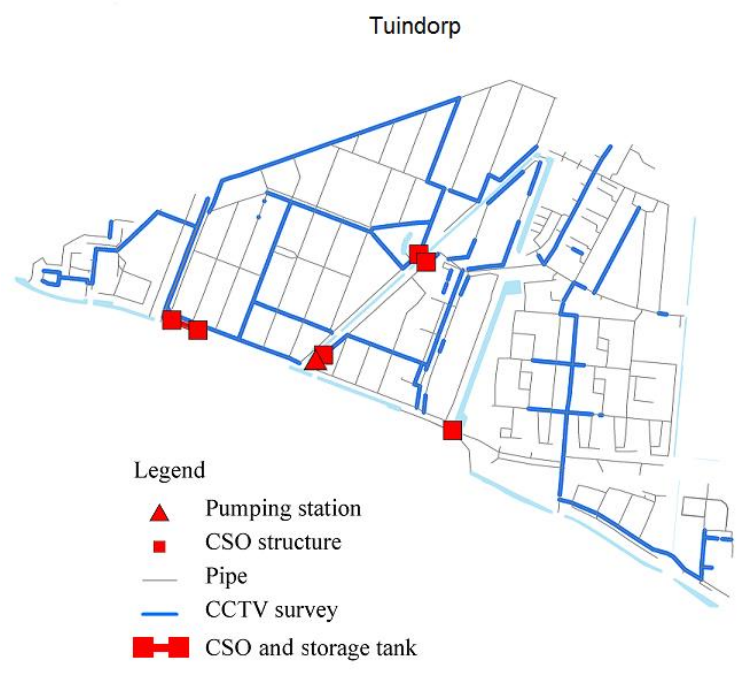

Figure 1. Layout 'Tuindorp' catchment.

\subsection{In-sewer defects}

Observed sediment depths were used to include sediment deposition in the model (for details see Van Bijnen etal., 2012). In Utrecht, sediment depths are registered by cleaning engineers prior to pipe jetting during the cleaning program. They are registered as a relative depth, i.e. ratio of observed depth and conduit height. A beta distribution function was fitted on observed depths for different classes of pipe shapes and heights. In the Monte Carlo simulations, sediment depths in the pipes were randomly drawn from these distributions and added to the model as permanent sediment deposits. As a result, the generated system states represent the current sewer cleaning strategy in Utrecht.

\subsection{Climate change}

For the analysis a 10-year rainfall series was used which was observed in De Bilt (the Netherlands). It comprises a continuous series of rainfall volumes with an interval of 15 minutes during the period 1955-1964. Usually, this series is used for evaluating design performance of sewer systems in the Netherlands. Climate change was included by perturbing the series with the WL scenario from the KNMl'14 scenarios using two time horizons: 2050 and 2085 (Van den Hurk etal., 2014; Bakker, 2015). 


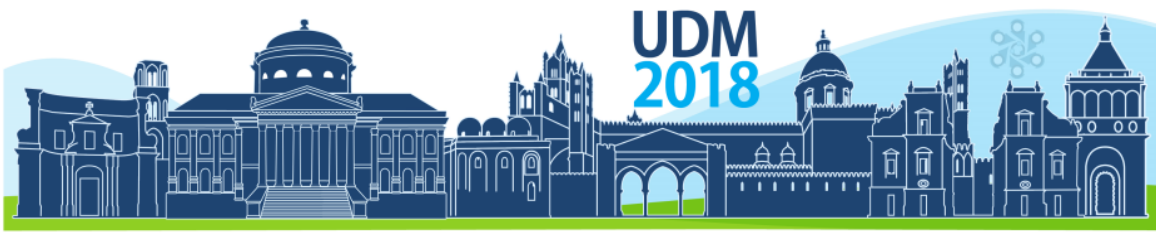

$11^{\text {th }}$ International Conference on Urban Drainage Modelling

23-26 Sep | Palermo - Italy

\subsection{Model set-up and validation}

An InfoWorks model was used for the hydraulic calculations with a 1D/1D approach describing the interaction between sewer network and surface flooding. This model concept was chosen in order to achieve faster calculations for the Monte Carlo simulations. A 1D/1D approach is acceptable for flat catchments such as 'Tuindorp'. The hydrodynamic model was validated and not calibrated (for details see Van Bijnen et al., 2018). For the validation, reported incidents from the call data of the municipality supplemented with interviews with residents were compared with model results in order to remove systematic errors.

\subsection{Monte Carlo simulations}

Monte Carlo simulations (750 runs) were used to evaluate the impact of sediments on flooding frequencies at each manhole. For the simulations, 322 independent storm events were filtered from the rainfall series using a filter based on in-sewer storage volume, pumping capacity and required dry periods between storm events. A single run in the Monte Carlo procedure is defined as a hydrodynamic simulation of the complete collection of the 322 selected storm events for a single system state. In each run, the relative sediment depth of each pipe was randomly drawn from the probability distributions. As a result, the network will have a different configuration in each run.

\subsection{Quantification of health risks}

In the 1D/1D approach modelling approach, floodwater is stored above ground in a 'cone' on top of each manhole. The shape of the flood cone determines the relationship between flood volume and water level above street (see Figure 2). The summed frequency of exceedances of threshold water levels at each manhole per system state per year is derived from the model calculations. The threshold level corresponds with a flooded area of $100 \mathrm{~m}^{2}$, since De Man et al. (2014) took samples of floodwater if the area was larger than this value.
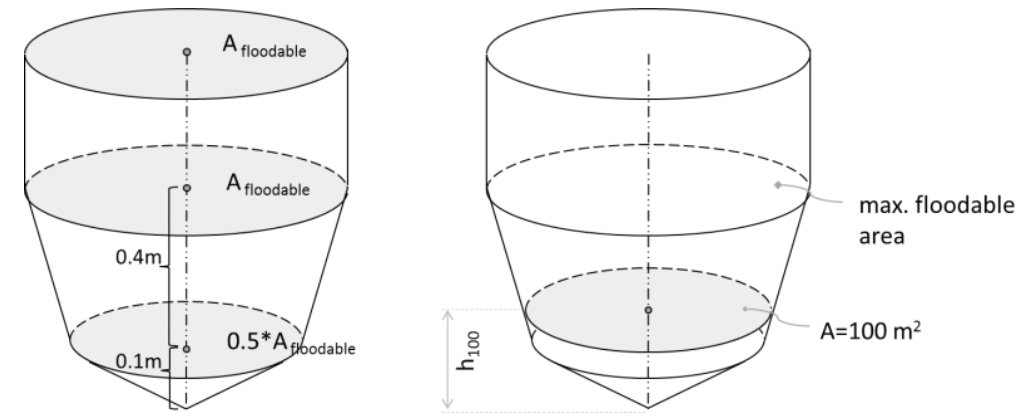

Figure 2. Flood cone on top of manhole storing water above street level: (left) relationship between flood volume and water level above the street; (right) threshold area $100 \mathrm{~m}^{2}$ and corresponding threshold water levels $\mathrm{h}_{100}$.

According to De Man et al. (2014) the overall infection probability for adults amounts $3.9 \%$ per flooding event. The infection probability per year at each manhole is calculated from the overall probability per exposure event and the frequency of flooding events as follows,

$$
\mathrm{P}_{\text {infection/year }}=1-\prod_{\mathrm{i}=1}^{\mathrm{n}}\left(1-\mathrm{P}_{\text {infection/event }}\right)=1-\left(1-\mathrm{P}_{\text {infection/event }}\right)^{\mathrm{n}}
$$

where $n$ is the frequency of flooding events per year. The catchment-wide infection probability per year equals a weighted average based on number of inhabitants per manhole. 


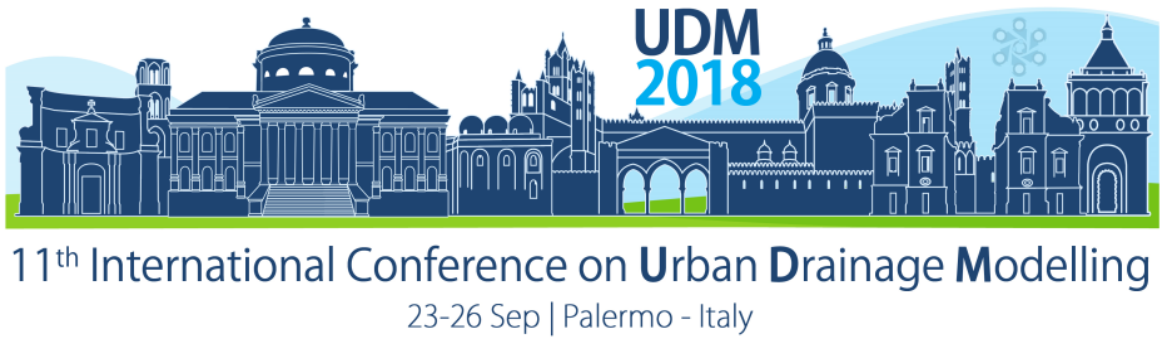

\section{RESULTS AND DISCUSSION}

The catchment-wide infection probability for the current climate increases due to sediment deposits with 2.5 (see Table 1). This shift is statistically significant (for details see Van Bijnen etal., 2018). The reference system (a) and the climate projections (c, d) represent a single run of the hydrodynamic model with the complete set of selected storm events for the sewer system without sediment deposits. The Monte Carlo simulation represents runs with 750 system states with randomly added sediment deposits. The increase of infection probability due to climate change falls within the $95 \%$ bandwidth of the shift due to sediment deposits in the current climate. This means that the impact of climate change on infection probabilities is of the same order of magnitude as the impact of sediment deposits in the current climate given current sewer cleaning intervals.

Table 1. Summary statistics of catchment-wide probability of infection per year for (a) clean system and current climate ('reference'), (b) system with sediments and current climate (MC simulation, $N=750$ ), (c) and (d) $\underline{\text { clean }}$ system and climate change ('WL 2050' and 'WL 2085).

\begin{tabular}{lcccc}
\hline & $\begin{array}{c}\text { (a) Reference } \\
\text { No sediment }\end{array}$ & $\begin{array}{c}\text { (b) MC simulation } \\
\text { With sediment }\end{array}$ & $\begin{array}{c}\text { (c) } \mathrm{W}_{\mathrm{L} 2050} \\
\text { No sediment }\end{array}$ & $\begin{array}{c}(\mathrm{d}) \mathrm{W}_{\mathrm{L}} 2085 \\
\text { No sediment }\end{array}$ \\
\hline Infection probability $\left(\times 10^{-3}\right)$ & 4.7 & 7.2 & 6.7 & 8.0 \\
$95 \%$ interval $\left(\times 10^{-3}\right)$ & - & $6.6-8.2$ & - & - \\
\hline
\end{tabular}

\section{CONCLUSIONS}

The objective of this abstract is to compare the impact of the impact of in-sewer defects on infection risks from exposure to urban floodwater with the increase of infection risks due to heavier rains as expected in climate projections. Calculation results show that the impact of climate change on infection probability is of the same order of magnitude as the shift due to sediment deposits in the current climate given current sewer cleaning intervals. This means that although the climate changes, for this sewer system current serviceability levels in terms of infection probability due to flooding can be maintained with a higher cleaning frequency.

\section{References}

Bakker, A. (2015). Time series transformation tool version 3.1: Description of the program to generate time series consistent with the KNMI'14 climate scenarios. TR 349. KNMI, De Bilt, the Netherlands.

De Man, H.; Van den Berg, H.H.J.L.; Leenen, E.J.T.M.; Schijven, J.F.; Schets, F.M.; Van der Vliet, J.C.; Van Knapen, F.; De Roda Husman, A.M. (2014). Quantitative assessment of infection risk from exposure to waterborne pathogens in urban floodwater. Water Res. 48, 90-99.

Koenraad, P.M.F.J.; Hazeleger, W.C.; Vanderlaan, T.; Beumer, R.R.; Rombouts, F.M. (1994). Survey of Campylobacter spp. in sewage plants in the Netherlands. Food Microbiol. 11, 65-75.

Lodder, W.J.; De Roda Husman, A.M. (2005). Presence of noroviruses and other enteric viruses in sewage and surface waters in The Netherlands. Appl. Environ. Microbiol. 71, 1453-1461.

Schets, F.M.; Van Wijnen, J.H.; Schijven, J.F.; Schoon, H.; De Roda Husman, A.M. (2008). Monitoring of waterborne pathogens in surface waters in Amsterdam, the Netherlands, and the potential health risk associated with exposure to Cryptosporidium and Giardia in these waters. Appl. Environ. Microbiol., 74, 2069-2078.

Van Bijnen, M.; Korving, H.; Clemens, F. (2012). Impact of sewer condition on urban flooding: an uncertainty analysis based on field observations and Monte Carlo simulations on full hydrodynamic models. Water Sci. Technol. 65, 2219-2227.

Van Bijnen, M.; Korving, H.; Langeveld, J.; Clemens, F. (2018). Quantitative impact assessment of sewer condition on health risk. Water 10(3), [245]. DOI:10.3390/w10030245.

Van den Hurk, B.; Siegmund, P.; Klein Tank, A. (2014). KNMl'14: Climate Change scenarios for the 21st Century - A Netherlands perspective. Scientific background report KNMI'14. Scientific report WR 2014-01. KNMI, De Bilt, the Netherlands. 


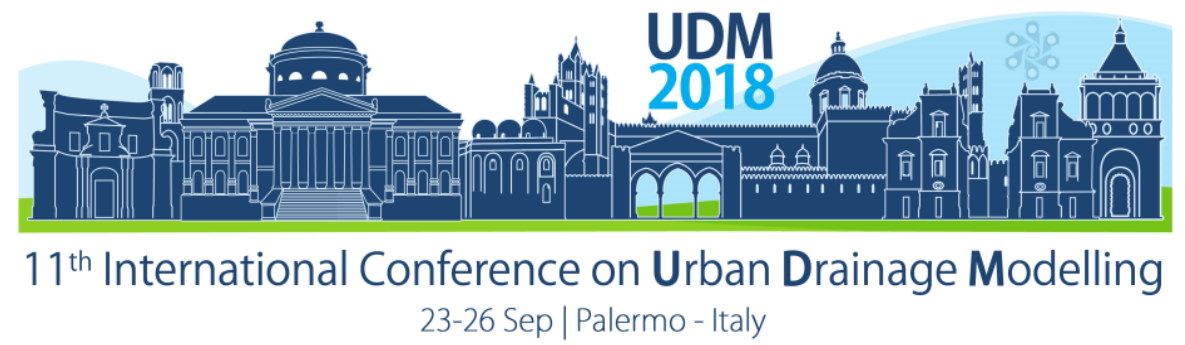

\title{
Combined sewer overflow management: proof-of-concept of a screening level model for regional scale appraisal of measures
}

\author{
Alberto Pistocchi ${ }^{1}$, Chiara Dorati ${ }^{1}$ \\ ${ }^{1}$ European Commission Joint Research Centre, Ispra, Italy \\ (via E.Fermi, 2749 - 21100 Ispra (VA) Italy, Alberto.pistocchi@ec.europa.eu)
}

\begin{abstract}
Combined sewer overflows (CSO) represent a potentially important source of pollution in several river basins. Yet, the quantification of CSO loads is still problematic, and their management may be consequently hampered. In this contribution we present a proof of concept for a simplified, screening level model to quantify CSO loads, for regional scale applications. The model has two parameters, a runoff coefficient of the drainage catchment and the effective dilution ratio at which CSO begins. These two parameters enable appraising the potentials associated with reduction of runoff (e.g. urban greening) and retrofitting of the sewer network. We present and discuss a preliminary calculation for the functional urban areas (FUA) of the European Union, highlighting the possibility to use the model in the screening of management options.
\end{abstract}

Keywords: Combined sewer overflows; screening model; regional scale.

\section{INTRODUCTION}

Combined sewer overflows (CSOs) may be a significant source of pollution; with progressing implementation of urban wastewater treatment, they may grow as a major pathway of urban pollution in many river basins (Milieu, 2016). Analysing CSOs is in principle straightforward at the local scale with standard urban drainage models, often requiring as input the geometry of the drainage network and the design parameters of the overflows, in addition to time series of overflow volumes for model calibration. As data on overflows and drainage characteristics are often scarce and sparse, assessing the overall impact of CSOs is a challenge when working at the regional scale. In this contribution we present a proof-of-concept of a simple model designed to quantify CSOs at the regional scale.

\section{MATERIALS AND METHODS}

For each urban area, as a first and rough approximation, we imagine the whole combined drainage network to have a single outlet, and we model a single "equivalent" CSO downstream of the latter. This approximation is acceptable for areas where runoff and wastewater collection in the sewer combined network are uniform within an urban area, and the less realistic, the higher the variability of $f, d$ and $P$ within it. We quantify the aggregated CSO water discharge for the urban area with the equation:

$$
Q_{C S O}=\max \left(0, f A_{U} R+(1-d) k P\right)
$$

where $A_{U}$ is the surface area served by combined sewer networks, $R$ is rainfall, $k$ the wastewater discharge per capita in the area, $\mathrm{P}$ the total population, $\mathrm{f}$ a runoff coefficient $(\%$ of rainfall on urban area $A_{\cup}$ which turns into runoff), and d the combined sewers' design dilution rate, i.e. a multiple of wastewater discharge (usually in the range $2 \div 10$ ) above which CSO begins. If we assume that urban runoff is initially free from pollution, the CSO mass discharge of a given pollutant can be computed as: 


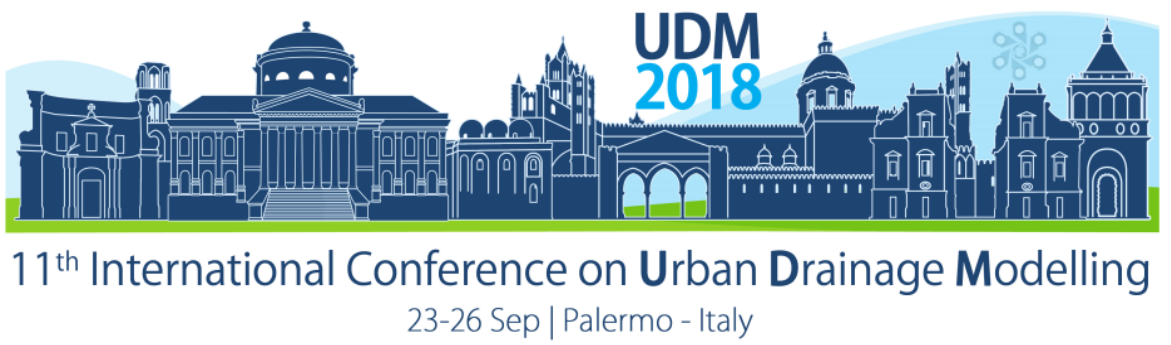

$$
L_{C S O}=C \frac{\max \left(0, f A_{U} R+(1-d) k P\right)}{1+\frac{f A_{U} R}{k P}}
$$

where $C$ is the concentration of the pollutant in wastewater. In the setup of the model, $A_{u}, k$ and $P$ can be regarded as known input parameters and $R$ is an external forcing, while two parameters remain to be calibrated, one representing land management (f), and the other representing the sewers'safety margin before CSO (d). If we set $\mathrm{C}=1$, equation [2] is numerically equal to the volumetric discharge of untreated wastewater corresponding to the CSO, i.e. its "untreated wastewater equivalent".

We apply the above equations to the $\sim 700$ Functional Urban Areas (FUA) identified across Europe (EEA, 2012). We calculate a time series of precipitation from the three-hourly MultiSource Weighted-Ensemble Precipitation (MSWEP) version 2.0 global dataset (Beck at al., 2017), from which grid cell values for each 3-hour step are averaged across each FUA.

This setup allows estimating the total CSO water and pollutant mass discharge from the FUA, if appropriate parameters $d$ and $f$ are provided. Population is estimated based on GEOSTAT $1 \mathrm{~km}^{2}$ population-grid of 2011 (EC, 2011), while $\mathrm{k}$ is set to $160 \mathrm{l} /$ (inhab.day). In this proof of concept, we also assume that $100 \%$ of urban areas are served by combined sewers. Furthermore, we assume $\mathrm{f}=1$ for impervious areas and $\mathrm{f}=0$ for non-imprevious areas within each FUA. The degree of imperviousness is estimated for each FUA based on Functional Urban Areas indicators from LUISA modelling platform (Lavalle et al. 2014). For the sake of a first exploration, we set a constant value for Europe of $d=3$. On average, about $30 \%$ of urban areas are expected to have separate sewersin Europe (Milieu, 2016). Consequently, CSO discharges are expected to be proportionally overestimated and represent "potential" discharges. The overestimation will depend on the actual share of the FUA served by separate sewers.

\section{RESULTS AND DISCUSSION}

Figure 1 shows an estimate of the load, in $\mathrm{m}^{3}$ of "wastewater equivalent" per hectare of impervious surface, discharged through CSO under the above assumptions. The map highlights that most of the FUA in Europe are expected to generate yearly around $100 \mathrm{~m}^{3} / \mathrm{ha}$ of volume equivalent to untreated wastewater, with higher values, up to $300 \mathrm{~m}^{3} / \mathrm{ha}$, driven either by high imperviousness (as typical of dense metropolitan areas), or high precipitation intensity (as typical e.g. of the Atlantic coast of Spain and Portugal, or Scotland). Maximum discharges may exceed $300 \mathrm{~m}^{3} /$ ha yearly at a few FUAs with particularly high precipitation (Scotland, Atlantic coast of the Iberian Peninsula). Apparently, the map provides a first screening and cannot capture the specific situation of individual FUAs, where the actual imperviousness of urban surfaces, rate of connection to combined and separate sewer networks, and design dilution factor of combined sewers may vary very significantly.

In order to explore the impact of $f$ and $d$ on the results, we conduct a sensitivity analysis by allowing each of these parameters to vary while keeping the other constant. We refer to six FUAs (Zagreb, Valencia, Gent, Lyon, Dresden, Milan) encompassing a broad variability of conditions in Europe. The results are shown in Figure 2. The volume of equivalent wastewater obviously decreases with increasing $d$ and increases with increasing $f$, following simple power laws. The volume changes are quite continuous, and it is not straightforward to identify "critical" threshold values of $f$ and $d$ allowing to stabilize the generated loads. Sensitivity to $f$ seems generally more pronounced than to $d$, implying that reducing urban imperviousness may be more effective than retrofitting sewer conveyance. 


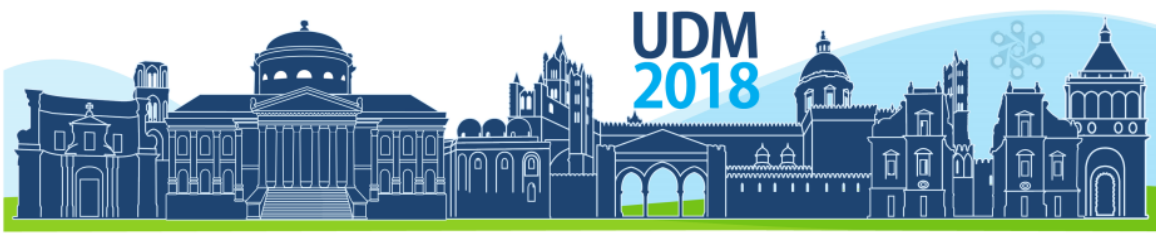

$11^{\text {th }}$ International Conference on Urban Drainage Modelling 23-26 Sep | Palermo - Italy

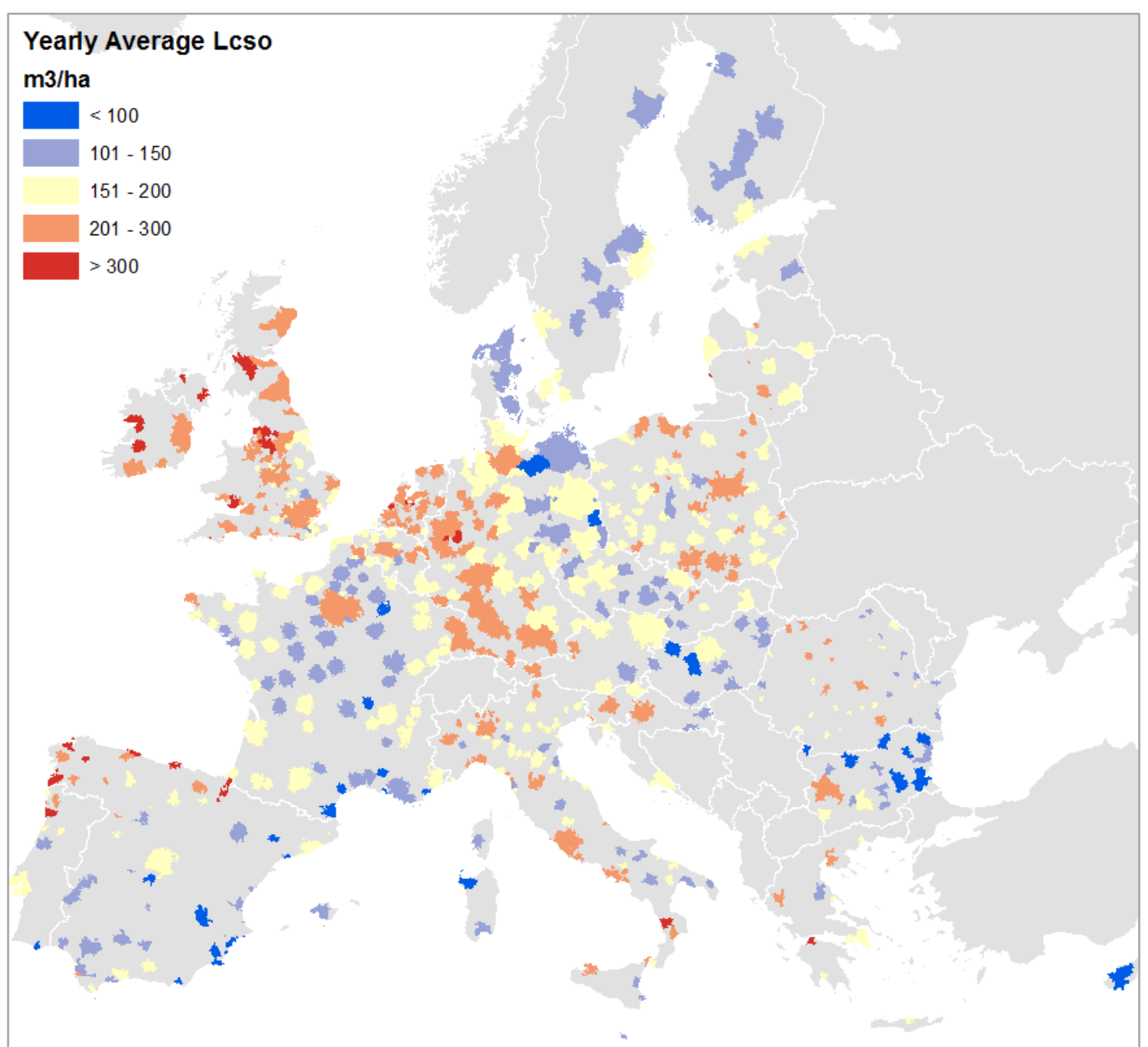

Figure 1. Average CSO "untreated wastewater equivalent" discharges ( $\mathrm{m}^{3} /$ year / ha of impervious area) for the FUAs of the European Union.

\section{CONSLUSIONS}

We present a proof-of-concept for screening-level model to quantify loads of wastewater from CSO, applicable at the regional scale. The model reflects the interplay of combined sewer conveyance (d) and urban land management (f), and is designed for the impact assessment of CSO management scenarios. In particular, the model is meant to quantify the reduction of CSO that can be associated with reductions in $f$ through multifunctional urban greening measures, such as green roofs or other natural water retention measures. The CSO volume predictions can be compared with records of overflows where available, hence parameters $f$ and $\mathrm{d}$ can be calibrated in specific urban areas in Europe. Additional work is required to compare model predictions with observations of CSO across Europe, in order to calibrate parameters $\mathrm{d}$ and $\mathrm{f}$. Also, the uniform distribution of precipitation assumed within a 3-hour step could be corrected by considering e.g. a symmetric triangular hyetograph within each step, in the absence of better temporal resolution data necessary to account for short-duration storm events. 
Proceedings of the 11th Int. Conference on Urban Drainage Modelling, 23-26 Sep. 2018, Palermo (ITALY). Ed. prof. Giorgio Mannina

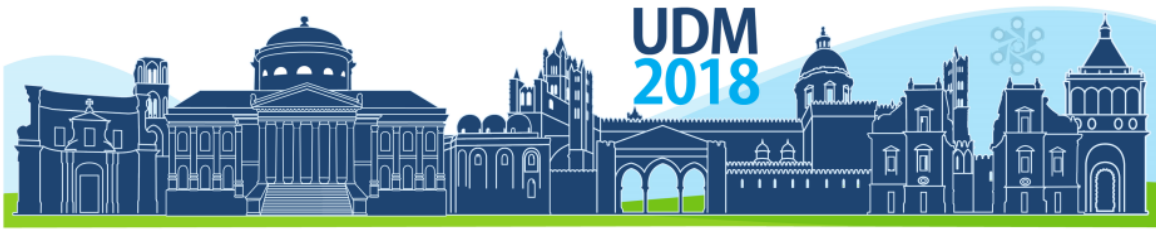

$11^{\text {th }}$ International Conference on Urban Drainage Modelling 23-26 Sep | Palermo - Italy

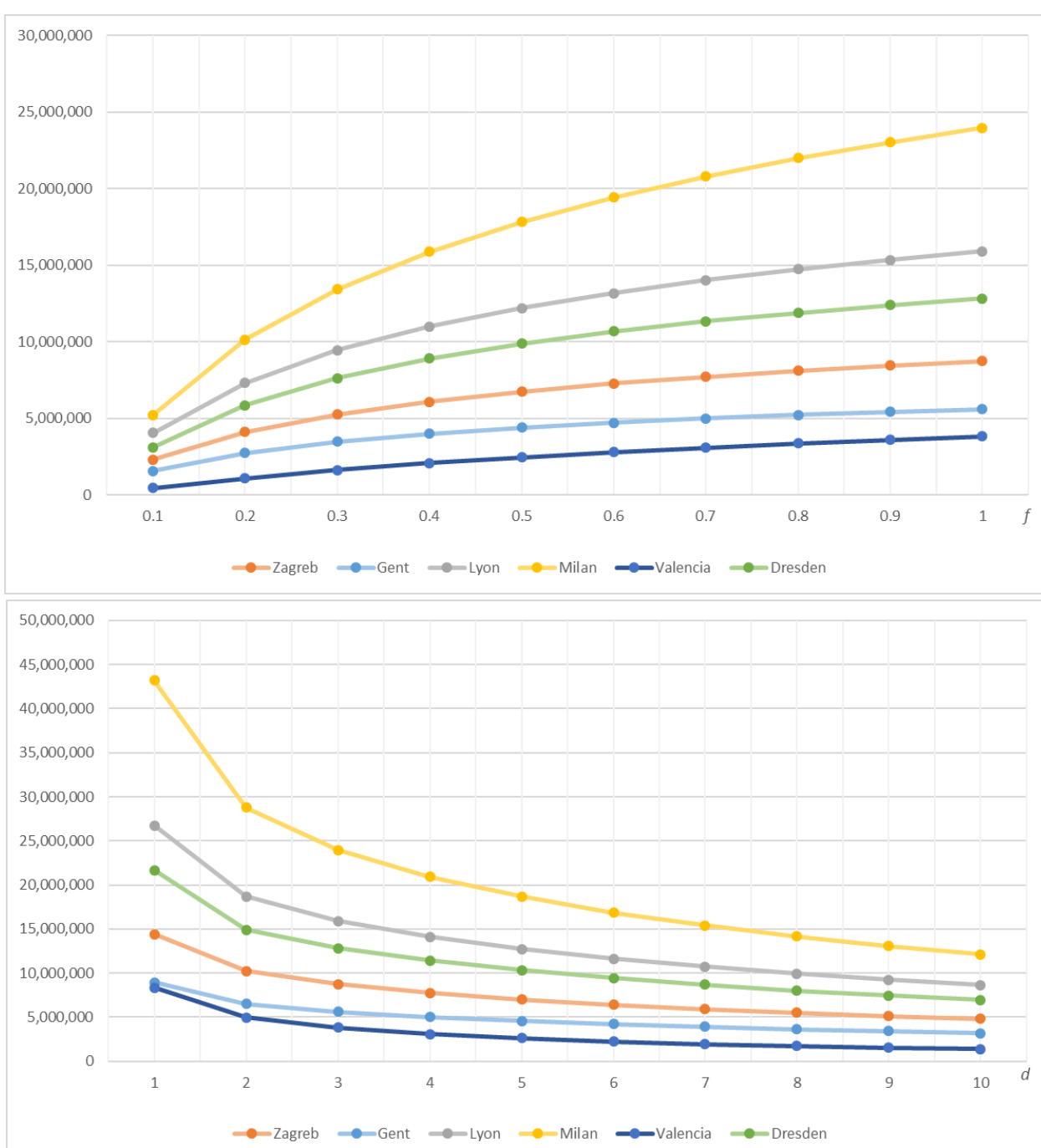

Figure 2. Sensitivity of yearly average CSO "untreated wastewater equivalents" ( $\mathrm{m}^{3} / \mathrm{year}$ ) to the dilution ratio (d) for $f=1$ (below), and runoff coefficient (f) for $d=3$ (above), for six selected European FUAs. Above:

\section{References}

Milieu (2016) Assessment of impact of storm water overflows from combined waste water collecting systems on water bodies (including the marine environment) in the $28 \mathrm{EU}$ Member States. European Commission Specific Contract No. 070201/2014/SFRA/693725/ENV/C.2. URL https://circabc.europa.eu/sd/a/c57243c9-adeb-40ceb9db-a2066b9692a4/Final\%20Report

Beck, H.E., A.I.J.M. van Dijk, V. Levizzani, J. Schellekens, D.G. Miralles, B. Martens, A. de Roo: MSWEP: 3-hourly $0.25^{\circ}$ global gridded precipitation (1979-2015) by merging gauge, satellite, and reanalysis data, Hydrology and Earth System Sciences, 21(1), 589-615, 2017a. Information on the dataset can be found at http://gloh20.org/

European Commission (Eurostat, Joint Research Centre and DG Regional Policy - REGIO-GIS), GEOSTAT population Grid 2011. Information on the dataset can be found at http://ec.europa.eu/eurostat/statisticsexplained/index.php/Population grids

European Environment Agency (EEA 2012) Copernicus Urban Atlas: https://land.copernicus.eu/local/urbanatlas/urban-atlas-2012?tab=metadata

Lavalle, Carlo; Kompil, Mert; Barbosa, Ana (2015): UI - Artificial Areas per Inhabitant (LUISA Platform REF2014). European Commission, Joint Research Centre (JRC) [Dataset] PID: http://data.europa.eu/89h/irc-luisa-ui-artareas-per-inh-ref-2014 


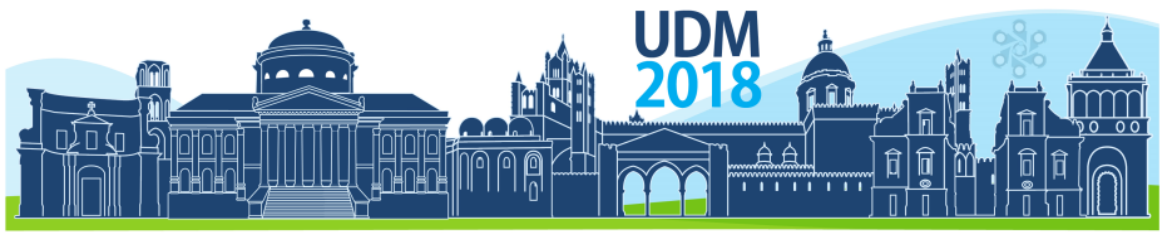

$11^{\text {th }}$ International Conference on Urban Drainage Modelling

23-26 Sep | Palermo - Italy

\title{
Early stage planning tools for stormwater quantity and quality management in Denmark and China
}

\author{
Ditte Marie Reinholdt Jensen ${ }^{1}$, Sara Maria Lerer ${ }^{1}$, Luca Vezzaro1, Hjalte Jomo Danielsen Sørup ${ }^{1}$, Karsten \\ Arnbjerg-Nielsen ${ }^{1}$, Xuyong $\mathrm{Li}^{2}$ and Peter Steen Mikkelsen ${ }^{1}$ \\ ${ }^{1}$ Technical University of Denmark, Department of Environmental Engineering, Lyngby, Denmark \\ ${ }^{2}$ Chinese Academy of Sciences, Research Centre for Eco-Environmental Sciences, Beijing, China
}

\begin{abstract}
In order to accommodate the increasing need for early phase planning and design tools that allows for a holistic approach to stormwater quantity and stormwater quality management, a new planning tool is suggested by adding a quality module onto an existing WSUD tool.
\end{abstract}

Keywords: Stormwater management; Stormwater quality; Planning tools; WSUD tool

\section{INTRODUCTION}

The increased frequency of extreme rain events in both China (Zhou et al., 2017) and Denmark (Gregersen et al., 2014) combined with growing urbanisation (United Nations Department of Economic and Social Affairs, 2014) has resulted in increasingly frequent occurrences of urban flooding. This has initiated infrastructural investments in stormwater management systems, which are coordinated through the Chinese Sponge City construction plans, (MOHURD, 2014), and the Danish Climate Change Adaptation and Cloudburst Management plans (City of Copenhagen, 2011; 2012).

The applied solutions have been decentralised stormwater control measures (SCMs), where water is stored for infiltration and evaporation or delayed in order to reduce peak flows. Emphasis has been on above-ground, nature based solutions, often referred to in literature as Water Sensitive Urban Design (WSUD), Low Impact Development (LID), Best Management Practices (BMPs) and Sustainable Urban Drainage Systems (SUDS) (Fletcher et al., 2015). These solutions help restoring the hydrological balance disturbed by the sealing of surfaces that comes with urbanisation (Henrichs et al., 2016) and hold great potential for retaining micro-pollutants (MP) and increasing liveability (Liu \& Jensen, 2017).

Compared with traditional underground drainage systems, planning of near surface, nature based SCMs to comply with goals concerning both stormwater quantity management and stormwater quality management, require collaboration across a broader spectrum of professions. Bridging the gap between different water officials sets requirements for planning and design tools to be intuitive in their application and easily understandable in their presentation of results. Additionally, they should consider stormwater quantity and quality holistically and be quick to use for the purpose of screening many possible solutions.

We have previously shown the benefits of using a simple, early phase planning tool for hydraulic and hydrological contexts. The WSUD tool presented by Lerer et al., 2015 emphasizes reducing complexity in order to help drainage engineers communicate their priorities to stakeholders. However, it is targeted at Danish planning context only and does not include water quality assessment. The objective of this study is to explore the possibility of developing a similar tool that also includes stormwater quality assessment to be used for screening in early planning and design phases. 


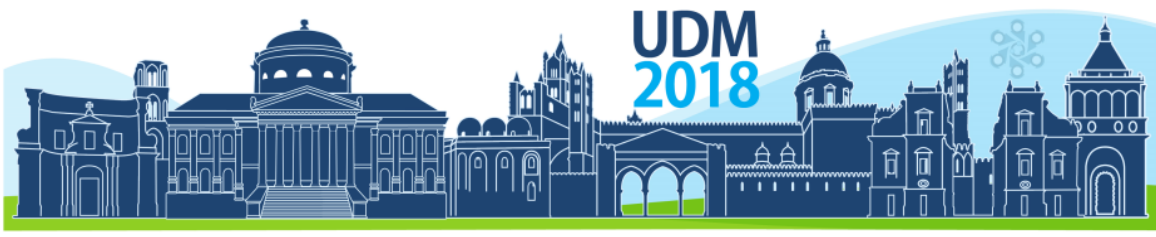

$11^{\text {th }}$ International Conference on Urban Drainage Modelling

23-26 Sep | Palermo - Italy

\section{MATERIALS AND METHODS}

\subsection{The Three Points Approach}

The Three Point Approach (3PA) suggested by Fratini et al. (2012) has proven useful to facilitate transdisciplinary collaboration on multipurpose stormwater control projects across different decision domains (Lerer et al., 2017). The 3PA addresses solutions on scales ranging from $(A)$ everyday rainfall and rainwater resource utilization, over $(B)$ design rain and urban drainage service levels, to $(C)$ extreme rainfall and pluvial flood mitigation.

\subsection{WSUD planning tool}

The WSUD tool described by Lerer et al. (2016) is a simplified planning tool for assessment of the hydrological performance of different WSUD elements based on few input parameter and uses look-up tables on simulations of detailed hydrodynamic models. The tool is based on Danish weather statistics, and it can currently be used to assess the performance of permeable paving, bio-retention units or local detention ponds. The results are presented in the context of the 3PA, as demonstrated in Figure 1. In addition, an annual water balance is provided to illustrate the potential for restoring a more natural hydrological cycle.
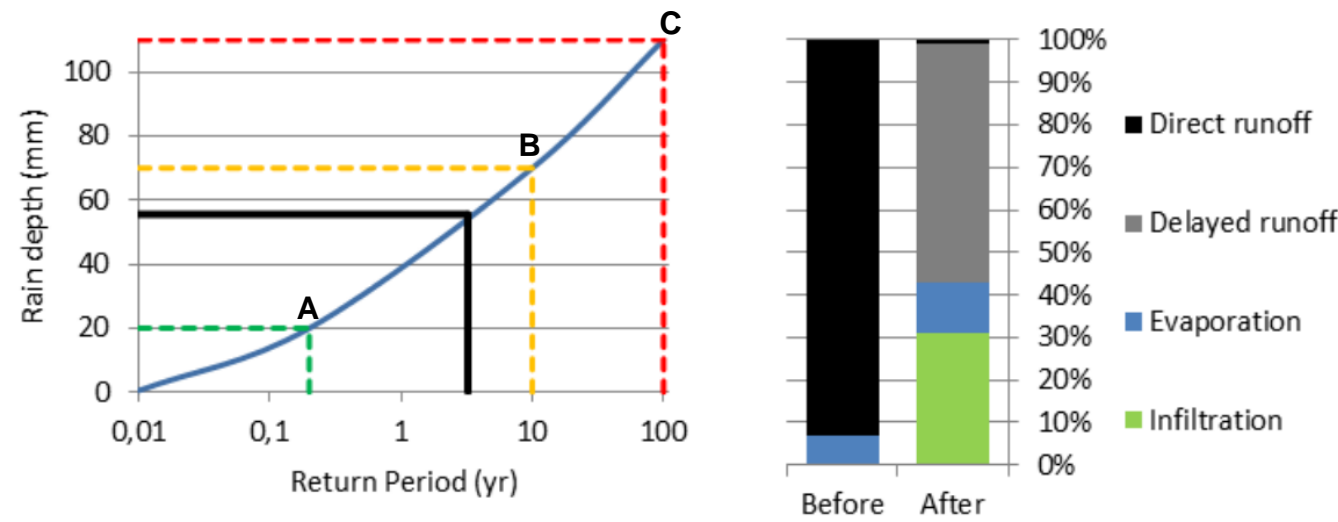

Figure 1: The WSUD tool presents (left) the maximum rainfall event depth that can be controlled by the SCM and the associated return period, and (right) the water balance before and after implementation. This example is edited from (Lerer et al., 2016).

For the tool to include assessment of both water quantity and water quality impacts of SCM installations, an additional module will have to be added, as illustrated in Figure 2.

\subsection{Quality modelling}

In order to create the quality module, we will be simplifying the wash-off and removal modelling procedure described by (Vezzaro et al., 2015). Based on existing literature and database systems (e.g. Lützhøft et al., 2012 or Revitt et al., 2013), values of MP release from different land uses can be applied to an accumulation-washoff-model to estimate 'before' loads, while the WSUD removal will be modelled by applying the Stormwater Treatment Unit model for MicroPollutants (STUMP) (Vezzaro et al., 2010).

As illustrated in Figure 2 the quality module should be able to display the amount of MP that is degraded in the WSUD as well as the accumulation within the important receiving compartments of the urban water system. 


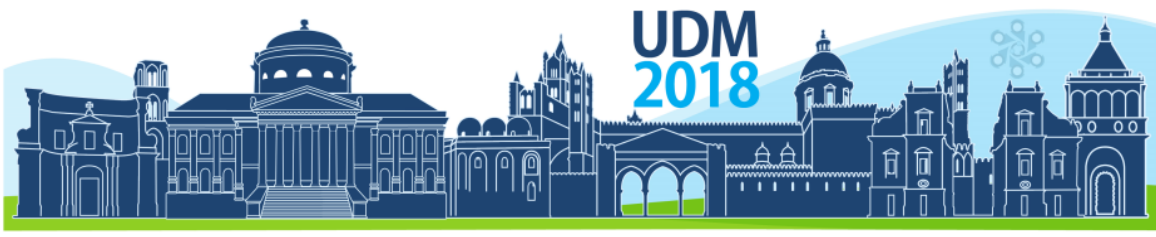

$11^{\text {th }}$ International Conference on Urban Drainage Modelling

23-26 Sep | Palermo - Italy

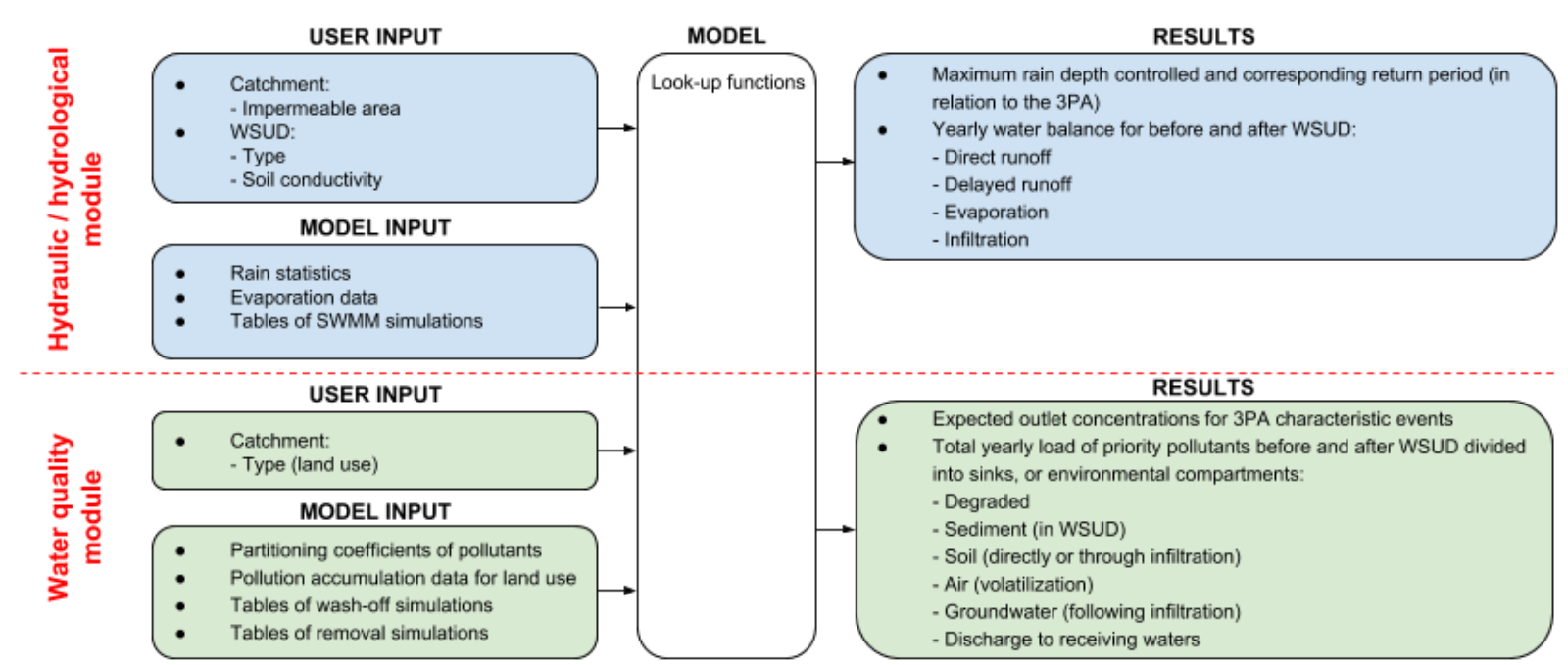

Figure 2: Conceptualisation of the existing WSUD tool with outline of additional inputs and model functions to create a water quality module.

\subsection{Case studies}

The development of the water quality module will be supported by data collected in a series of case studies, where the results from the simplified model can be compared to monitoring data and detailed modelling results. In 2018 two field studies will be established for this purpose: the Danish FUPARU project, where a HydroSeparator ${ }^{\circledR}$ SCM has been installed in Kærby to mitigate pollution loads into the natural water system, and the sponge city project in Shenzhen (southern China). Here the monitoring campaign is already in progress, collecting data before, during and after the construction of sponge city elements. Here the WSUD tool will have to be adjusted to local rain statistics before implementation.

\section{RESULTS AND DISCUSSION}

We argue that a simple tool that assesses both stormwater quantity and quality is needed, and that such a tool can be created by expanding the WSUD tool concept of Lerer et al. (2016). As the WSUD tool illustrates results by showing the percentage of the water balance that is managed, this will be very well suited for addressing the Chinese sponge city goals of controlling a certain fraction of the total yearly runoff. Also, the division into three event regimes using the 3PA will serve as a good communication tool in China, where distinction is already made between small, medium and large scale rain events.

The tool simplicity can benefit a planning situation without compromising early design decisions. The tool will be a steady state tool, and therefore increased pollutant emissions (as discussed by Ma et al., 2018) during construction phase are not considered in the presentation of results. Mitigation of this and many other considerations should be handled in a detailed design phase following the initial planning phase.

\section{CONCLUSIONS}

The results from this study are intended to be used for holistic evaluation of both water quantity and quality in early stage planning processes of stormwater management in Denmark and China. 


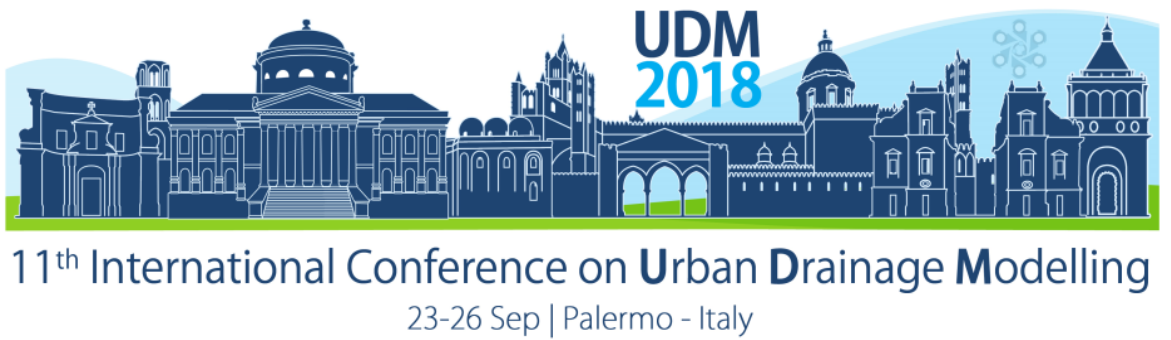

\section{References}

City of Copenhagen. (2011). Copenhagen Climate Adaptation Plan. Retrieved from http://kk.sites.itera.dk/apps/kk_pub2/pdf/1270_UEsoelrcLC.pdf

City of Copenhagen. (2012). Cloudburst Management Plan. Retrieved from http://kk.sites.itera.dk/apps/kk_pub2/pdf/1018_I9HA0rd2PF.pdf

Fletcher, T. D., Shuster, W., Hunt, W. F., Ashley, R., Butler, D., Arthur, S., ... Viklander, M. (2015). SUDS, LID, BMPs, WSUD and more - The evolution and application of terminology surrounding urban drainage. Urban Water Journal, 12(7), 525-542. https://doi.org/10.1080/1573062X.2014.916314

Fratini, C. F., Geldof, G. D., Kluck, J., \& Mikkelsen, P. S. (2012). Three Points Approach (3PA) for urban flood risk management: A tool to support climate change adaptation through transdisciplinarity and multifunctionality. Urban Water Journal, 9(5), 317-331. https://doi.org/10.1080/1573062X.2012.668913

Gregersen, I. B., Sunyer Pinya, M. A., Madsen, H., Funder, S., Luchner, J., Rosbjerg, D., \& Arnbjerg-Nielsen, K. (2014). Past, present, and future variations of extreme precipitation in Denmark: Technical report. Kgs. Lyngby: DTU Environment.

Henrichs, M., Langner, J., \& Uhl, M. (2016). Development of a simplified urban water balance model (WABILA). Water Science and Technology, 73(8), 1785-1795. https://doi.org/10.2166/wst.2016.020

Lerer, S. M., Righetti, F., Rozario, T., \& Mikkelsen, P. S. (2017). Integrated hydrological model-based assessment of stormwater management scenarios in Copenhagen's first climate resilient neighbourhood using the three point approach. Water (Switzerland), 9(11). https://doi.org/10.3390/w9110883

Lerer, S. M., Sørup, H. J. D., \& Arnbjerg-Nielsen, Karsten Mikkelsen, P. S. (2016). A new tool for quantifying the hydrological effects of LID retrofit designs - the power of simplicity. In 2016 International Low Impact Development Conference.

Lerer, S., Arnbjerg-Nielsen, K., \& Mikkelsen, P. (2015). A Mapping of Tools for Informing Water Sensitive Urban Design Planning Decisions-Questions, Aspects and Context Sensitivity. Water, 7(3), 993-1012. https://doi.org/10.3390/w7030993

Liu, L., \& Jensen, M. B. (2017). Climate resilience strategies of Beijing and Copenhagen and their links to sustainability. Water Policy, 19(6), 997-1013. https://doi.org/10.2166/wp.2017.165

Lützhøft, H. C. H., Donner, E., Wickman, T., Eriksson, E., Banovec, P., Mikkelsen, P. S., \& Ledin, A. (2012). A source classification framework supporting pollutant source mapping, pollutant release prediction, transport and load forecasting, and source control planning for urban environments. Environmental Science and Pollution Research, 19(4), 1119-1130. https://doi.org/10.1007/s11356-011-0627-9

Ma, Y., Gong, M., Zhao, H., \& Li, X. (2018). Influence of low impact development construction on pollutant process of road-deposited sediments and associated heavy metals. Science of the Total Environment, 613614, 1130-1139. https://doi.org/10.1016/j.scitotenv.2017.09.174

MOHURD (Ministry of Housing and Urban-Rural Development, C. (2014). 低影响开发雨水系统构建（试行）. Retrieved from http://www.mohurd.gov.cn/wjfb/201411/W020141102041225.pdf

Revitt, D. M., Lundy, L., Eriksson, E., \& Viavattene, C. (2013). Comparison of pollutant emission control strategies for cadmium and mercury in urban water systems using substance flow analysis. Journal of Environmental Management, 116, 172-180. https://doi.org/10.1016/j.jenvman.2012.12.007

United Nations - Department of Economic and Social Affairs. (2014). World Urbanization Prospects, the 2014 revision. Retrieved March 1, 2018, from https://esa.un.org/unpd/wup/CD-ROM/

Vezzaro, L., Eriksson, E., Ledin, A., \& Mikkelsen, P. S. (2010). Dynamic stormwater treatment unit model for micropollutants (STUMP) based on substance inherent properties. Water Science and Technology, 62(3), 622-629. https://doi.org/10.2166/wst.2010.316

Vezzaro, L., Sharma, A. K., Ledin, A., \& Mikkelsen, P. S. (2015). Evaluation of stormwater micropollutant source control and end-of-pipe control strategies using an uncertainty-calibrated integrated dynamic simulation model. Journal of Environmental Management, 151, 56-64. https://doi.org/10.1016/j.jenvman.2014.12.013

Zhou, X., Bai, Z., \& Yang, Y. (2017). Linking trends in urban extreme rainfall to urban flooding in China. International Journal of Climatology, 37(13), 4586-4593. https://doi.org/10.1002/joc.5107 


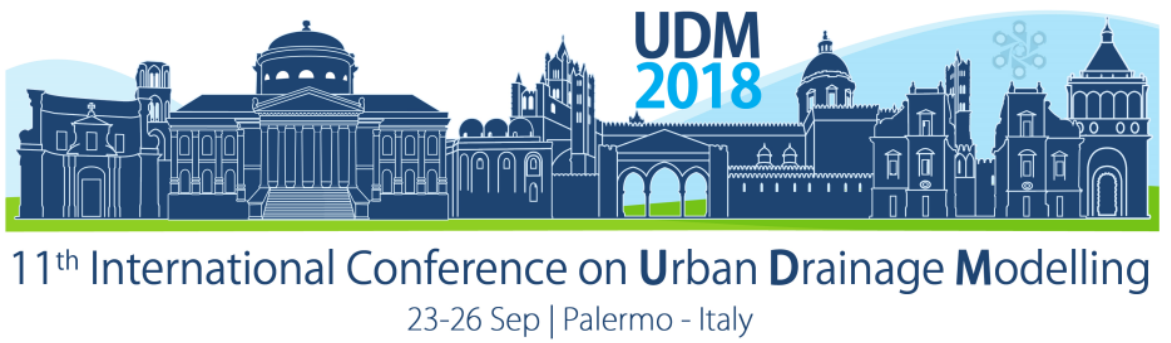

\title{
Selection of the Best Water Supply Scenario for Urban Demand based on the Risk Analysis in Decision-Making Model
}

\author{
Reza Javidi Sabbaghian ${ }^{1}$, Amir Pouyan Nejadhashemi² \\ ${ }^{1}$ Hakim Sabzevari University, Department of Civil Engineering, Sabzevar, Iran \\ 2 Michigan State University, Department of Biosystems and Agricultural Engineering, East Lansing, USA
}

\begin{abstract}
In recent years, inefficient water resources management has caused to serious crisis in supplying water for urban demand within the watersheds. Therefore, one of the most important challenges for urban decision-makers (DMs) is selecting the most desirable water supply scenario, satisfying the several sustainable development criteria. Accordingly, this paper has developed a risk-based multiple criteria decision-making (MCDM) model for selecting the best scenario based on the modified ordered weighted averaging (MOWA) operator. This operator considers the risk-taking degree of DMs, the criteria importance degree and the DMs' power weight, simultaneously. By use of this operator, the scenario scores have been calculated in several risk cases of decision-making, depending on the satisfaction of the number of criteria. This approach has been developed for Mashhad watershed in north-eastern Iran, to select the best water supply scenario for urban demand in 2040. The evaluation of scenarios has been performed with respect to the sustainable development criteria based on the urban watershed modelling. Finally, depending on each case of risk-taking degree, the most preferable scenario has been determined for satisfying the important criteria within the watershed. Development of this model is recommended for any watershed management modelling to supply urban demand.
\end{abstract}

Keywords: Water supply scenario; Risk analysis; Multiple criteria decision-making model

\section{INTRODUCTION}

In recent years, one of the most important complexities for urban watershed management, is the increase of sustainable development criteria including the environmental and socioeconomic criteria (Giri and Nejadhashemi, 2014). This has led to serious challenge among decision-makers (DMs) for selecting the best water supply scenario, which should satisfy the important criteria. Furtehrmore, the group of DMs may have several risk attitudes, which affect the final rank of water scenarios (Mianabadi et al., 2014). The risk attitude depends on the risktaking degree of DMs, which is expressed by some linguistic statements such as "select the best scenario for satisfying all criteria" for completely risk-averse viewpoint, "satisfying at least one criterion" for completely risk-prone standpoint, and the other risk attitudes. Consequently, a reliable risk-based multi-criteria decision-making (MCDM) model should be analyzed to evaluate several scenarios with respect to criteria (Bouzarour-Amokrane et al., 2015).

For solving the risk-based MCDM problems, several methods have been developed as some of the most important are demonstrated in the literature (Linkov and Steevens, 2013). One of the most frequently used methods is the ordered weighted averaging (OWA) operator (Emrouznejad and Marra, 2014). This operator has some limitations, which it does not consider the criteria weights, and the DMs' power weights. In this paper, these limitations are resolved by using the modified ordered weighted averaging (MOWA) operator. 


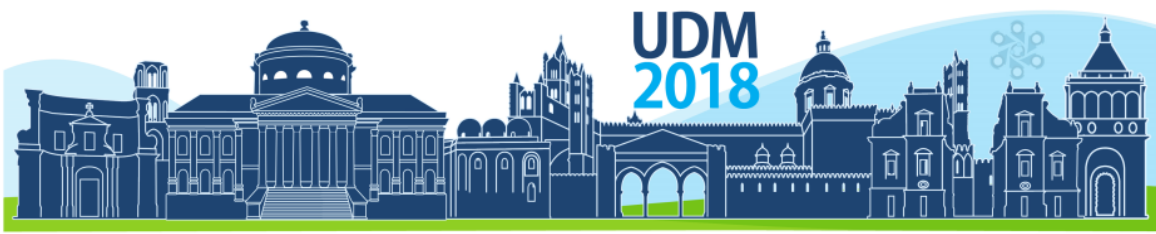

$11^{\text {th }}$ International Conference on Urban Drainage Modelling

23-26 Sep | Palermo - Italy

\section{MATERIALS AND METHODS}

\subsection{The risk-based MCDM process for urban watershed management}

The proposed flow diagram for the risk-based MCDM process has been presented in Fig. 1:

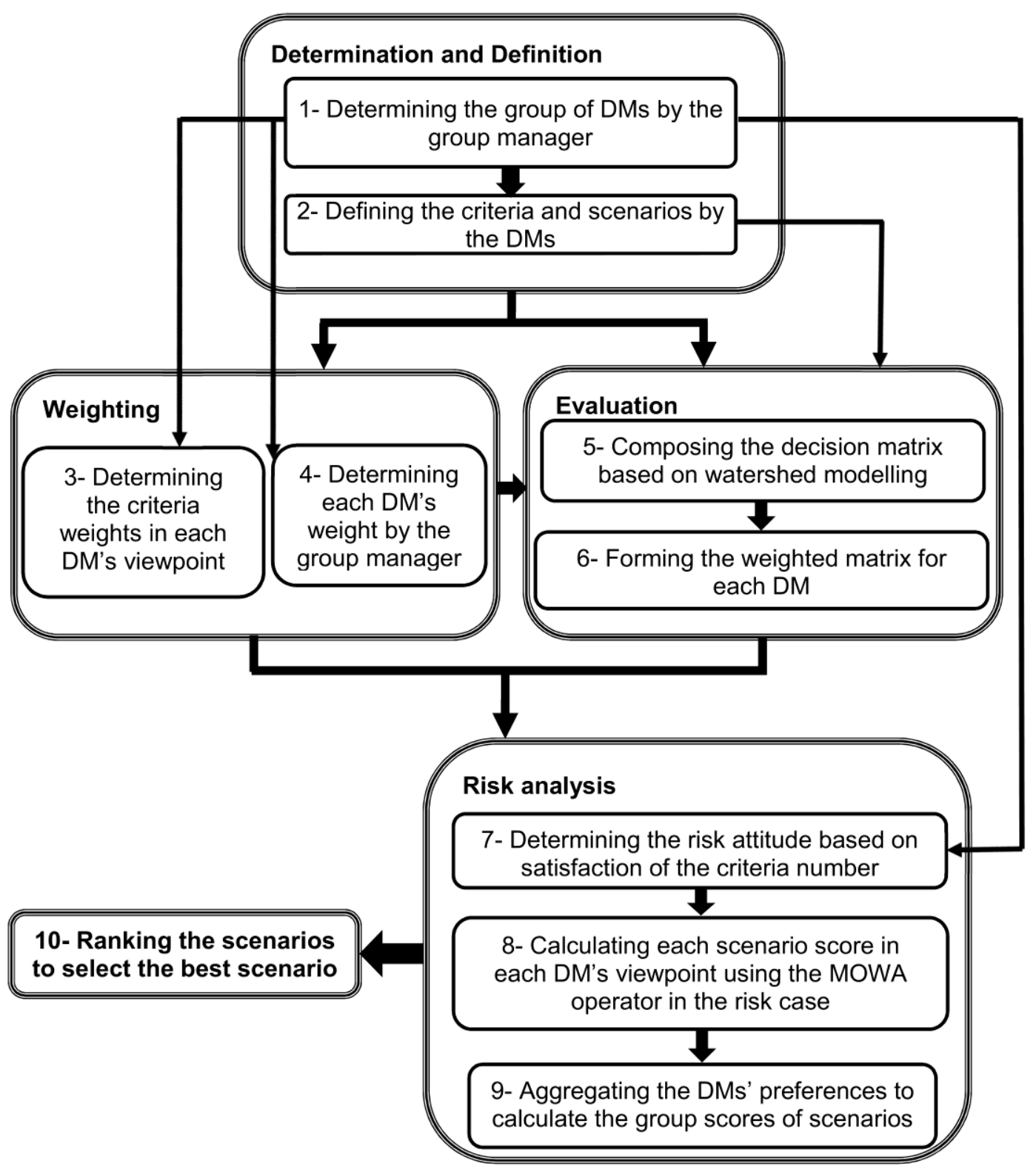

Figure 1. The proposed risk-based MCDM process for urban watershed management

\subsection{Materials of the study area}

This approach is performed for urban management of Mashhad watershed, which is located in the Quaraqum main watershed in north-eastern Iran (Fig. 2). 


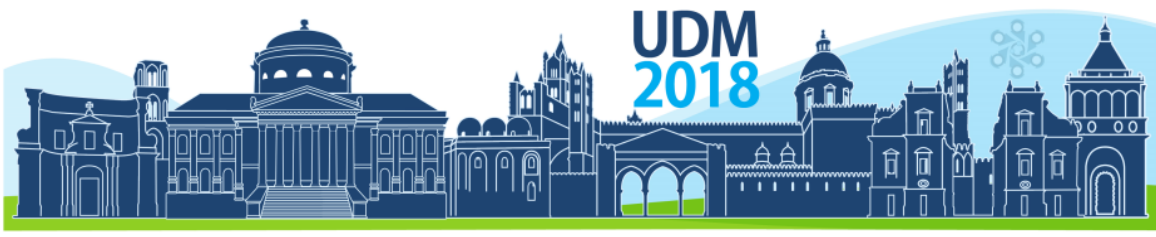

$11^{\text {th }}$ International Conference on Urban Drainage Modelling 23-26 Sep | Palermo - Italy

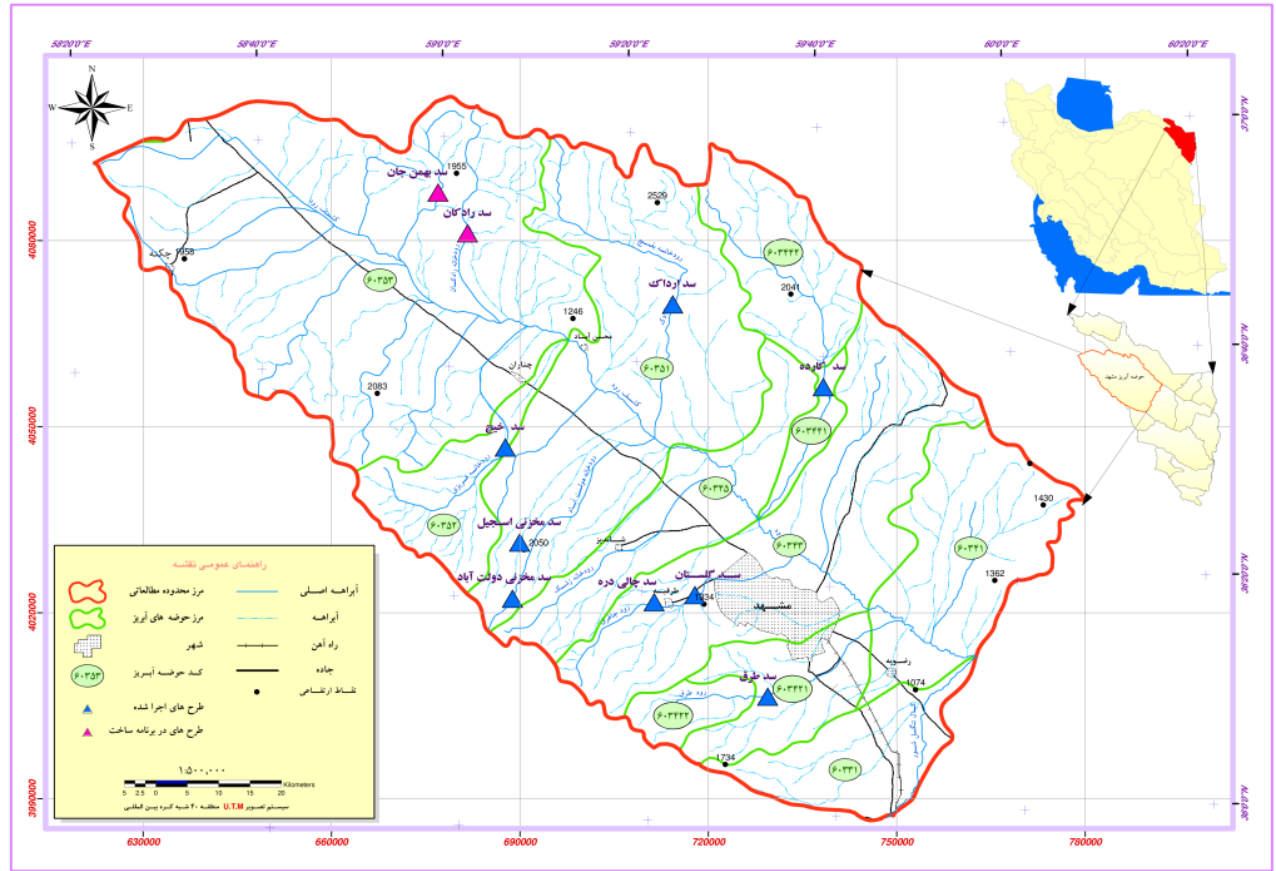

Figure 2. Location of Mashhad watershed in Quaraqum main watershed in the north-eastern Iran

The DMs, that have the effective role within the watershed, are including 6 organizations. The sustainable development criteria within the watershed, are the following 11 criteria:

$\boldsymbol{C}_{1^{-}}$Water stress ratio; $\boldsymbol{C}_{2^{-}}$Groundwater dependency; $\boldsymbol{C}_{3^{-}}$Supply percentage for urban demand; $\boldsymbol{C}_{4^{-}}$Supply percentage for environmental demand; $\boldsymbol{C}_{5^{-}}$Renewable water resources per capita; $\boldsymbol{C}_{6^{-}}$Reliability for water supply; $\boldsymbol{C}_{\boldsymbol{7}^{-}}$Groundwater unsustainability; $\boldsymbol{C}_{\mathbf{8}^{-}}$Refined sewerage ratio; $\boldsymbol{C}_{\boldsymbol{9}}$ - Environmental supply; $\boldsymbol{C}_{10}$ - Benefit per cost ratio; $\boldsymbol{C}_{11}$ - Social equity.

The importance degree of each criterion has been assigned by each DM, using the linguistic variables, then fuzzified and defuzzified (Linkov and Steevens, 2013). Finally, the criteria weights are aggregated and the group weights are determined, which presented in Table 1:

Table 1. The criteria weights in viewpoint of the group of DMs

\begin{tabular}{cccccccccccc}
\hline Criterion no. & $C_{1}$ & $C_{2}$ & $C_{3}$ & $C_{4}$ & $C_{5}$ & $C_{6}$ & $C_{7}$ & $C_{8}$ & $C_{9}$ & $C_{10}$ & $C_{11}$ \\
\hline Criterion weight & 0.112 & 0.109 & 0.074 & 0.070 & 0.098 & 0.090 & 0.106 & 0.087 & 0.073 & 0.082 & 0.098 \\
\hline
\end{tabular}

The five proposed scenarios are listed below:

Sc.1- Using just the existing projects (the groundwater resources and the operated dams);

Sc.2- Implementing the inter-basin transfer projects from the neighbor northern watershed;

Sc. . $^{-}$Utilizing the refined sewerage in agricultural lands;

Sc.4- Implementing the properly modified plants;

Sc.5- Implementing the inter-basin transfer projects, utilizing the refined sewerage in agricultural lands, and implementing the properly modified plants.

The scenarios are analyzed by use of the MODSIM watershed modelling, and the effect of each scenario is determined on each criterion as each decision matrix element. 


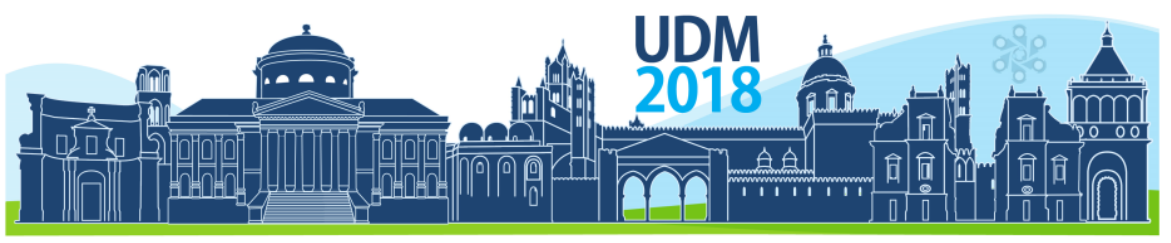

$11^{\text {th }}$ International Conference on Urban Drainage Modelling

23-26 Sep | Palermo - Italy

\subsection{The proposed MOWA methodology}

In the process, $S c .=\left\{S c_{\cdot 1}, \ldots, S c_{. j}, \ldots, S c_{\cdot m}\right\}$ is the set of $m$ water supply scenarios, which are evaluated based on the set of $n$ sustainable criteria $C=\left\{C_{1}, \ldots, C_{i}, \ldots, C_{n}\right\}$; in viewpoints of the $p$ DMs $D M=\left\{D M_{1}, \ldots, D M_{k}, \ldots, D M_{p}\right\} . \lambda=\left(\lambda_{1}, \ldots, \lambda_{p}\right)^{T}$ is the DMs' power weights vector, and $w^{(k)}=\left(w_{1}^{(k)}, \ldots, w_{n}^{(k)}\right)^{T}$ is the criteria weights vector in $k^{t h}$ DM's viewpoint, and $\sum_{i=1}^{n} w_{i}^{(k)}=1$. Each DM determines the importance degree of criteria by one of the linguistic members from the set of $S=$ NNone, Very low, Low, Slightly low, Medium, Slightly high, High, Very high, Perfect\}. The linguistic criteria weights are fuzzified with trapezoidal fuzzy numbers. Also, the DMs' power weights are determined based on their influence in the decision-making. The weights are defuzzified by using the centroid method (Linkov and Steevens, 2013).

In the first aggregation step, the scenario scores in each DM's opinion are calculated, using (1): $F_{M O W A}^{(k)}\left(S c_{\cdot j}\right)=\sum_{i=1}^{n}\left\{(i / n)^{(1 / \theta)-1}-(i-1 / n)^{(1 / \theta)-1}\right\} b_{i}^{(k)}, j=1,2, \ldots, m$

where $b_{i}^{(k)}$ is the $i^{\text {th }}$ largest value of the weighted normalized evaluation vector of $\left(w_{1}^{(k)} a_{1 j}^{(k)}, \ldots, w_{n}^{(k)} a_{n j}^{(k)}\right)$ associated with each DM. $a_{i j}^{(k)}$ is the element of the $k^{\text {th }}$ decision matrix, representing the evaluation of the $j^{\text {th }}$ scenario with respect to the $i^{\text {th }}$ criterion by the $k^{\text {th }}$ DM's viewpoint. Also, $F_{M O W A}^{(k)}\left(S c_{\cdot j}\right)$ is the score of the $j^{\text {th }}$ scenario in the $k^{t h}$ DM's viewpoint.

In the second aggregation step, the scenario scores in group opinion are calculated, using (2): $F_{\text {MOWA }}^{(G)}\left(S c_{\cdot j}\right)=\sum_{i=1}^{n}\left\{(i / n)^{(1 / \theta)-1}-(i-1 / n)^{(1 / \theta)-1}\right\} b_{i}^{(G)}, j=1,2, \ldots, m$

where $b_{i}^{(G)}$ is the $i^{\text {th }}$ largest value of vector of $\left(w_{1}^{(G)} a_{1 j}^{(G)}, \ldots, w_{n}^{(G)} a_{n j}^{(G)}\right)$ in the group aggregated matrix, where $a_{i j}^{(G)}=\sum_{k=1}^{p} \lambda_{k} a_{i j}^{(k)}$. Also, $F_{M O W A}^{(G)}\left(S c_{\cdot j}\right)$ is the group score of the $j^{\text {th }}$ scenario.

\section{RESULTS AND DISCUSSION}

After the calculations based on the risk-based MCDM process, the MOWA scenario scores in the group viewpoint are determined for several risk attitudes, as represented in Fig. 3:

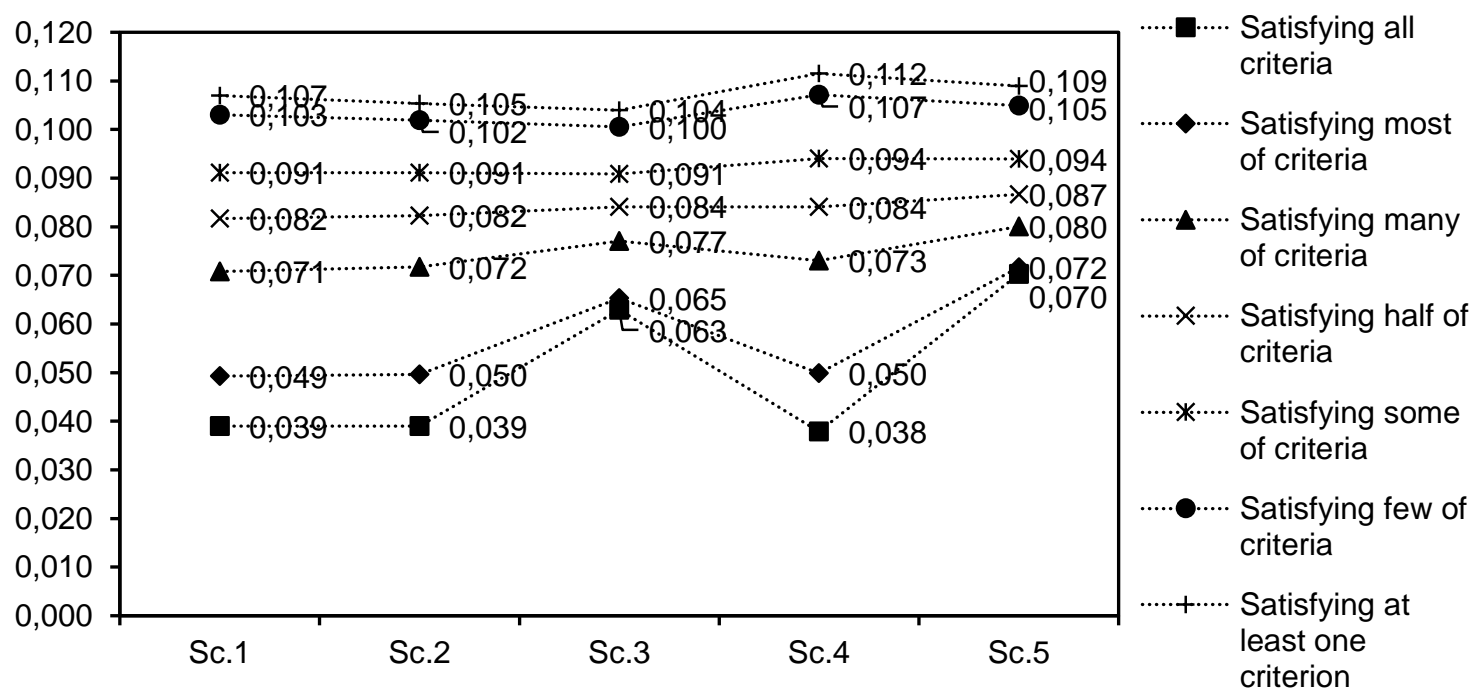

Figure 3. The urban water supply scenario scores in several risk attitudes of decision-making 


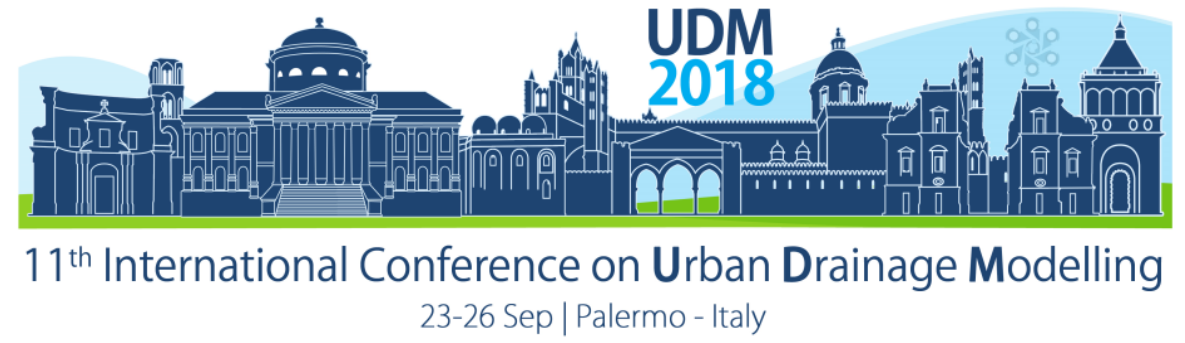

As the results of Figure 3, for each scenario, the score increases from the completely riskaverse viewpoint to the completely risk-prone standpoint. In the completely risk-averse viewpoint, the scenario $S c .5$ is selected by the group, while in the completely risk-prone standpoint, the scenario Sc. 4 is chosen.

\section{CONCLUSIONS}

In real-world group decision-making, there are various DMs and beneficiaries with several preferences, viewpoints and risk attitudes to select the most desirable scenario which satisfy the criteria. In this paper, we utilized the MOWA aggregation operator to calculate the group scores of various scenarios, for which the importance degree of criteria, the DMs' power weights, and the risk attitudes of the DMs have been considered, simultaneously. The final ranking of scenarios could be determined based on the risk-based scores for the scenarios. The results showed that the selected scenarios is depended on the risk-taking degree of DMs, the importance degree of criteria and the DMs' preferences in the decision-making process within the urban watershed management. This proposed risk-based MCDM solution is recommended for analyzing all types of water supply scenarios for urban demand, which can be run by the watershed modelling and analyzed with respect to several criteria.

\section{References}

Bouzarour-Amokrane, Y., Tchangani, A. and Peres, F. (2015) A bipolar consensus approach for group decision making problems. Expert Systems with Applications, 42(3), 1759-1772.

Emrouznejad, A., and Marra, M. (2014) Ordered weighted averaging operators 1988-2014: A citation-based literature survey. International Journal of Intelligent Systems, 29(11), 994-1014.

Linkov, I. and Steevens, J. (2013) A Detailed Analysis of the Theoretical Foundation of Different MCDA. Ch. 35, Appendix A: Multi-Criteria Decision Analysis.

Mianabadi, H., Sheikhmohammady, M., Mostert, E., and Van de Giesen, N. (2014) Application of the ordered weighted averaging (OWA) method to the Caspian Sea conflict. Stochastic Environmental Research and Risk Assessment, 28(6), 1359-1372.

Giri, S., and Nejadhashemi, A.P. (2014) Application of analytical hierarchy process for effective selection of agricultural best management practices. Journal of Environmental Management, 132, 165-177. 


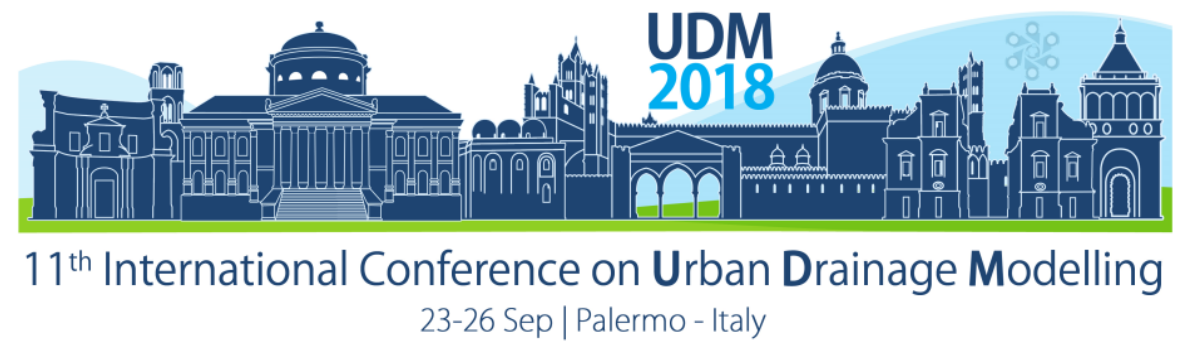

\title{
How to make our models relevant for decision-makers by using stakeholder analysis?
}

\author{
Julie Skrydstrup ${ }^{1}$, Herle Mo Madsen¹, Roland Löwe', Henrik Thorén ${ }^{2}$ and Karsten Arnbjerg- \\ Nielsen ${ }^{1}$ \\ ${ }^{1}$ Technical University of Denmark, Department of Environmental Engineering, 2800 Kgs. Lyngby, Denmark \\ 2 Rambøll Denmark, Water, Copenhagen, Denmark
}

\begin{abstract}
Urban water management is no longer an isolated discipline, but a contester for space in urban planning. New stakeholders with different objectives are requiring answers outside the scope of our models. This study aims to identity these answers to make water management relevant for other disciplines and easy communication. Stakeholder analysis, in the form of data screening of national literature and workshops, is used to systematically investigate planning objectives. Furthermore, indicators to quantify the achievement of these objectives are explored in national and global literature. Preliminary results show that planning objectives can be divided into four main categories; welfare, environmental protection, economic objectives and technical objectives. Even though planning objectives were derived in a national context, they cover objectives listed in similar studies performed in Switzerland and UK, suggesting relevance beyond national borders. The preliminary results even go beyond these studies by including more welfare objectives, e.g. mobility. Stakeholder preferences change over time, so their connection to planning objectives needs to be continuously modified in or models.
\end{abstract}

Keywords: Strategic planning; Indicators; Spatial planning; Stakeholders

\section{INTRODUCTION}

Urban space is a valuable resource and urban water management (UWM) is typically struggling for relevance in urban planning. When integrating UWM into city planning, it can no longer be considered an isolated discipline. Instead UWM becomes visible in society, which should be reflected on and utilized in planning for optimal outcomes, as described in Fletcher et al. (2013). Planning is no longer a serial approach, but a complex adaptive system happening on different spatial and temporal scales (Geldof and Stahre, 2004), and now includes new stakeholders with different objectives, funding and power (Fratini et al., 2012).

To ease communication with other stakeholders, and make water management relevant for other disciplines, we need to know what answers they expect. Lerer et al. (2015) made an overview of the model tools and the answers they can give. Most model tools within UWM answer questions related to hydraulic (e.g. MIKE URBAN (Roldin et al., 2012)), chemical (e.g. MUSIC (Burns et al., 2011)) and economic (e.g. SUSTAIN (Lee et al., 2012)) aspects of water (Bach et al., 2014; Lerer et al., 2015), but the link to the rest of society is missing. There are several examples where stakeholder analysis has been used to mitigate the link to society, but these studies only consider impacts by water infrastructure objectives (Lienert et al., 2015) or sustainable urban drainage systems (Horton et al., 2015).

This study aims to investigate which answers our models need to provide to facilitate dialogue between decision makers. For this purpose we systematically investigate planning objectives for both UWM and urban planning using stakeholder analysis. Furthermore, indicators to quantify these objectives are explored, so objectives can be documented and quantified. 


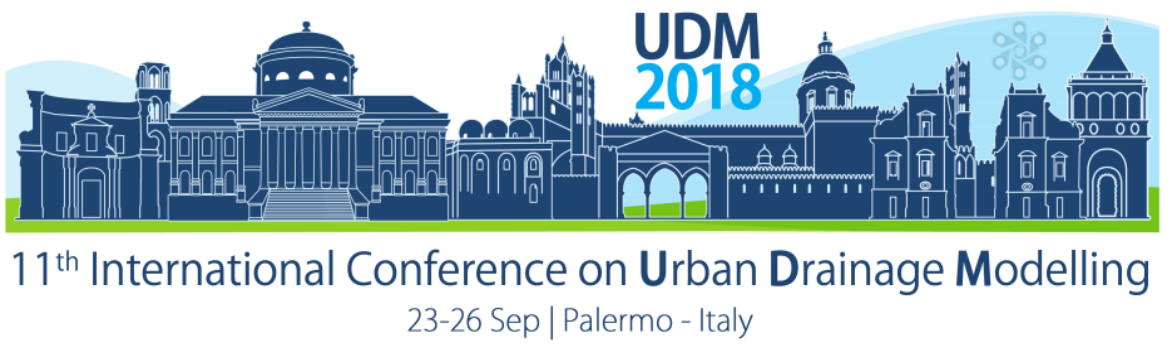

\section{MATERIALS AND METHODS}

The scope of our analysis is the planning environment as observed in Denmark to date. While this is a rather limited scope, similar stakeholder networks are expected in other Western countries. In addition, we link the results of our analysis to similar studies performed in Switzerland (Lienert et al. 2015) and the UK (Horton et al., 2015). Our methodology is illustrated in Figure 1. Starting from a review of Danish publications focusing on UWM and urban planning, we create an overview of the relevant stakeholders and their objectives with regards to urban planning in general and UWM in particular. The outcomes of this analysis are verified in a series of workshops and compared against results published in the international literature. Finally, indicators for the different planning objectives are identified in the literature and in dialogue with the relevant stakeholders. These indicators can be used to measure whether planning objectives are achieved and need to be quantified by models in the planning process. Planning objectives are structured in a hierarchy according to their abstraction level. For example, overall objectives has a high level of abstraction and low level of detail, where indicators has a higher level of detail and thus a lower abstraction level.

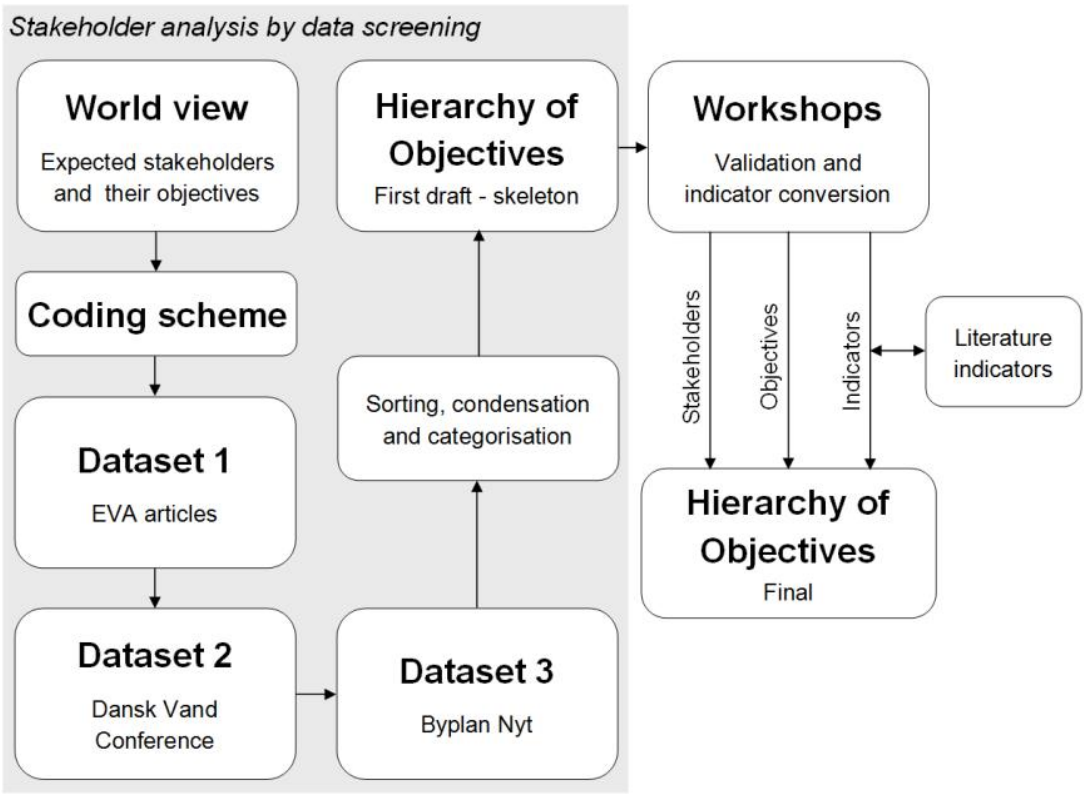

Figure 1. Overview of the methodology applied to find stakeholders, objectives and indicators to evaluate urban water management strategies.

\subsection{Stakeholder analysis by data screening}

Before screening the literature we defined a so-called coding scheme. The coding scheme consisted of a list of stakeholders and planning objectives that were expected before the analysis and ensured consistent naming and condensation of the data. The coding scheme was iteratively adjusted throughout the review process. 42 articles published between 2016 and 2018 were reviewed with respect to which stakeholders were involved in a project and which objectives they pursued (Dansk Byplanlaboratorium, 2016-2018; DANVA, 2016-2018.; EVA, 2016-2018). In addition, auxiliary information about, e.g., project types, spatial scales, time scales and stakeholder roles were collected. The screening stopped when no new information was obtained. The hierarchy of objectives was then created by sorting, condensing and categorising the obtained data. 


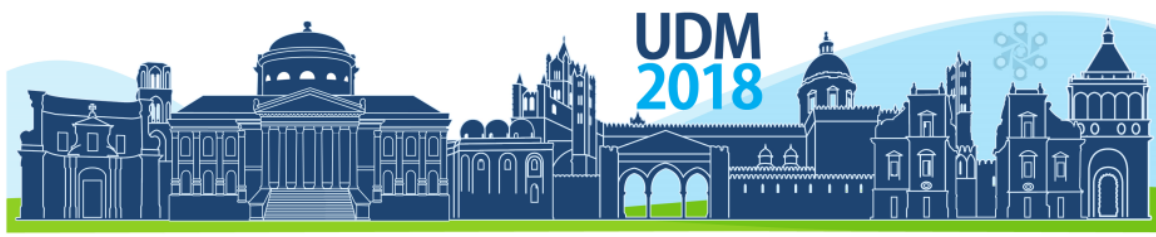

$11^{\text {th }}$ International Conference on Urban Drainage Modelling

23-26 Sep | Palermo - Italy

\subsection{Workshops as validation procedure}

A series of workshops are carried out during spring 2018 to validate the hierarchy of objectives (Figure 1). Workshop participants will primarily be professionals from municipalities and utilities working with water and environmental aspects, but participants working with urban planning, traffic and health will also be included to ensure a thorough testing of the hierarchy. Participants create their own list of planning objectives based on two pre-selected case studies, and convert the found objectives into indicators. The resulting hierarchy from the data screening will then be compared and modified accordingly.

\section{RESULTS AND DISCUSSION}

The preliminary results from literature screening suggest four main categories of planning objectives:

- Welfare

- Environment (Figure 2)

- Economic objectives

- Technical objectives

Many objectives are intertwined, especially when quantified with monetary indicators. For example, people's willingness-to-pay (WTP) for recreation is often used to measure the value of water with a good quality (Hasler et al., 2009). Recreation is typically considered an aspect of welfare, while good water quality is also an element of environmental protection. Another example is the objective of using energy more efficiently. This objective can be framed as both an environmental objective (Figure 2), but also as an economic one when aiming to reduce operational costs. Such interdependencies need to be considered when evaluating the performance of different management strategies to avoid double counting.

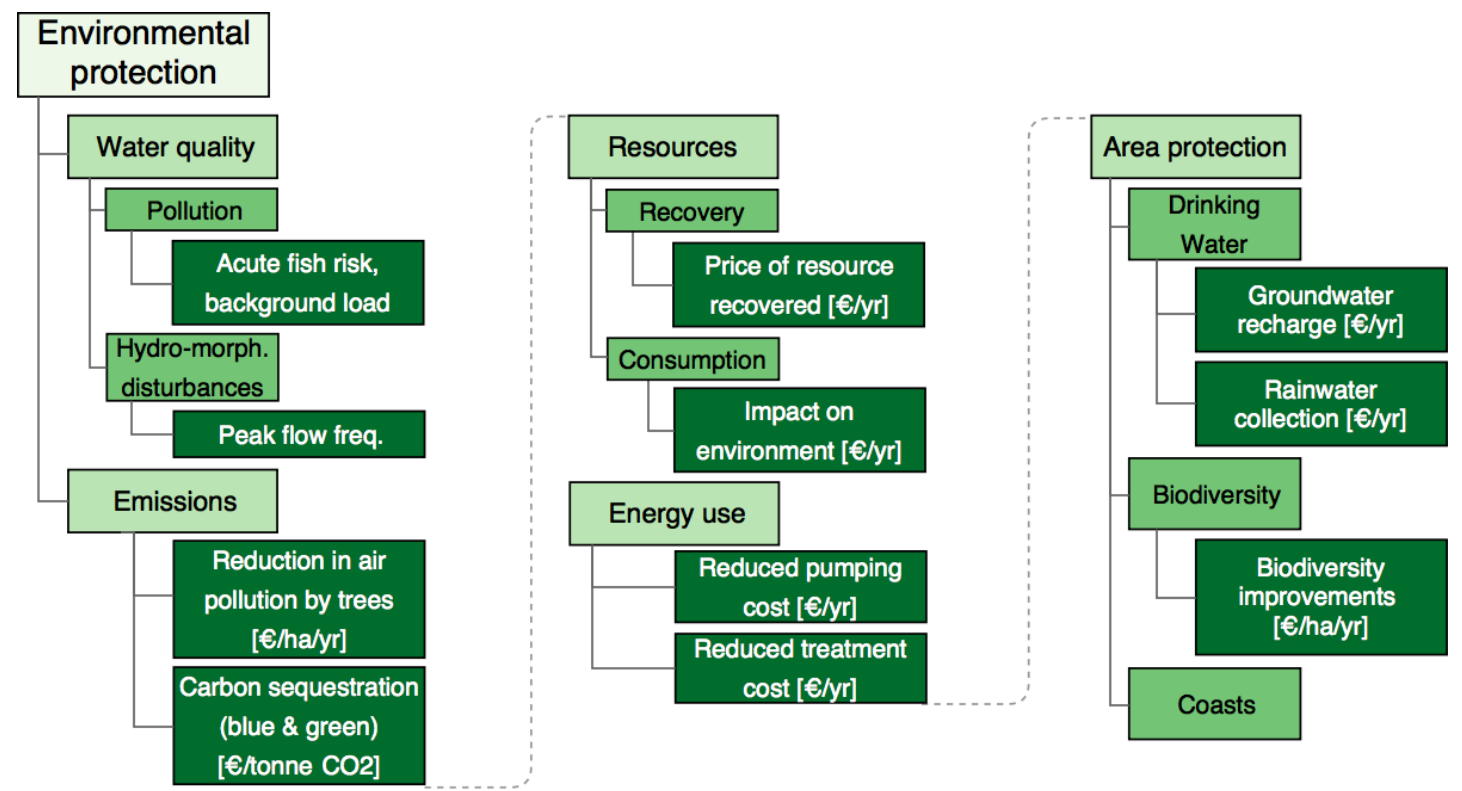

Figure 2. Preliminary planning objectives concerned with environmental protection. Potential indicators are given in dark green coloured boxes. 


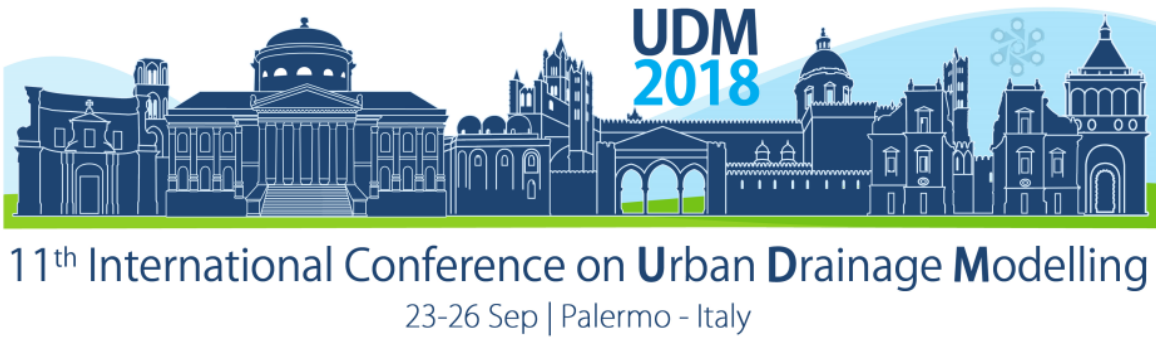

A major part of the screened literature does not consider any indicators for measuring whether the objectives of a project are achieved. This suggests that objectives are often assessed in a qualitative manner. However, indicators are important to compare different strategies and to communicate amongst different stakeholders. The next step of this analysis will therefore be to define indicators that link model results and planning objectives. Subsequently, the method will be applied in different case studies to identify how the planning objectives can be framed in different contexts.

\section{CONCLUSIONS}

Stakeholder analysis in the form of data screening and workshops were used to identify a full list of planning objectives for urban water management in Denmark. The list of objectives could be divided into four overall categories; welfare, environmental protection, economic objectives and technical objectives. The preliminary hierarchy of objectives cover objectives and indicators found in Switzerland and UK, but goes beyond by also including welfare objectives related to spatial planning, e.g. mobility. However, it is important to note that the composed hierarchy is a national snapshot, which needs to be revised continuously in the models.

\section{References}

Bach, P.M., Rauch, W., Mikkelsen, P.S., McCarthy, D.T., Deletic, A. (2014) A critical review of integrated urban water modelling - Urban drainage and beyond. Environ. Model. Softw. 54, 88-107.

Burns, M.J., Fletcher, T.D., Walsh, C.J., Ladson, A.R., Hatt, B.E. (2011) Hydrologic shortcomings of conventional urban stormwater management and opportunities for reform. Landsc. Urban Plan. 105, 230-240.

Dansk Byplanlaboratorium. (2016-2018) ByplanNyt (Danish journal for exchange of experience in city development). Dansk Byplanlaboratorium (Danish city planning lab), Copenhagen, http://www.byplanlab.dk/byplannyt overblik

DANVA. (2016-2018) Dansk Vand conference proceedings. DANVA (Danish water- and wastewater union), Copenhagen, http://old.danva.dk/Arrangementer/Afholdte-arrangementer.aspx

EVA. (2016-2018) EVA Bladet (Danish journal for exchange of experience amongst water engineers). IDA (Danish Engineering Association), Copenhagen, http://www.evanet.dk/bladet/

Fletcher, T.D., Andrieu, H., Hamel, P. (2013) Understanding, management and modelling of urban hydrology and its consequences for receiving waters: A state of the art. Adv. Water Resour. 51, 261-279.

Fratini, C.F., Elle, M., Jensen, M.B., Mikkelsen, P.S. (2012) A conceptual framework for addressing complexity and unfolding transition dynamics when developing sustainable adaptation strategies in urban water management. Water Sci. Technol. 66, 2393-2401.

Geldof, G.D., Stahre, P. (2004) The interaction between water and society. Enhancing Urban Environ. by Environ. Upgrad. Restor. 381-394.

Hasler, B., Brodersen, S.L., Christensen, L.P., Christensen, T., Hansen, H.E., Kataria, M., Martinsen, L., Nissen, C.J. (2009). Assessing Economic Benefits of Good Ecological Status under the EU Water Framework Directive . Testing practical guidelines in Odense River basin. AQUAMONEY.

Horton, B., Digman, C.J., Ashley, R.M., Gill, E. (2015) BeST ( Benefits of SuDS Tool ): W045c BeST - Technical Guidance. CIRIA, London.

Lee, J.G., Selvakumar, A., Alvi, K., Riverson, J., Zhen, J.X., Shoemaker, L., Lai, F.-H. (2012) A watershed-scale design optimization model for stormwater best management practices. Environ. Model. Softw. 37, 6-18.

Lerer, S., Arnbjerg-Nielsen, K., Mikkelsen, P. (2015) A Mapping of Tools for Informing Water Sensitive Urban Design Planning Decisions-Questions, Aspects and Context Sensitivity. Water 7, 993-1012.

Lienert, J., Scholten, L., Egger, C., Maurer, M. (2015) Structured decision-making for sustainable water infrastructure planning and four future scenarios. EURO J. Decis. Process. 3, 107-140.

Roldin, M., Fryd, O., Jeppesen, J., Mark, O., Binning, P.J., Mikkelsen, P.S., Jensen, M.B. (2012) Modelling the impact of soakaway retrofits on combined sewage overflows in a $3 \mathrm{~km} 2$ urban catchment in Copenhagen, Denmark. J. Hydrol. 452-453, 64-75. 


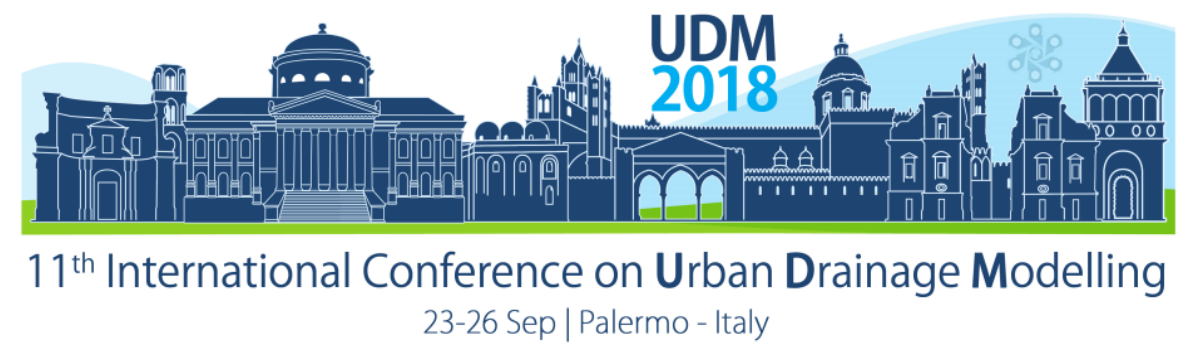

\title{
Impacts of urban development on urban water management at varying spatial and temporal scales
}

\author{
Roland Löwe' ${ }^{1}$, Michael Mair ${ }^{2}$, Agnethe N. Pedersen ${ }^{3}$, Wolfgang Rauch², Manfred Kleidorfer ${ }^{2}$ and Karsten \\ Arnbjerg-Nielsen ${ }^{1}$ \\ ${ }^{1}$ Department of Environmental Engineering, Section of Urban Water Systems, Technical University of Denmark \\ (DTU Environment), Miljøvej B115, Kgs. Lyngby, 2800, Denmark \\ ${ }^{2}$ Unit of Environmental Engineering, University of Innsbruck, Technikerstrasse 13, 6020 Innsbruck, Austria \\ ${ }^{3}$ VCS Denmark (Vandcenter Syd), Vandværksvej 7, 5000 Odense, Denmark
}

\begin{abstract}
We consider the impact of random variations in the location of urban development on urban water management. The municipal plan for a medium-sized city is implemented in a detailed, vector-based urban development model. Locations where new developments occur at a given time point are varied randomly, and the effect on urban water management is tested by evaluating changes in the building area, the number of buildings subject to flood risk and the number of residents at different scales. Urban development has substantial impact on these indicators, while random variations seem to impact urban water management mostly on the local spatial scales. This result is attributed to the short time horizon and the limited number of urban development locations considered in this work. On-going work focuses on simulating extended scenarios for urban development and on the inclusion of hydraulic modelling results.
\end{abstract}

Keywords: strategic planning; urban development; risk assessment

\section{INTRODUCTION}

Long-term planning of urban water management should consider potential impacts from urban development to derive robust strategies (e.g., (Urich and Rauch, 2014)). Models applied for simulating changes of the urban space generally range from highly detailed microsimulation setups that aim to model the effects of human decision making on an individual level (Waddell, 2002; Wegener, 2011) to raster-based blackbox models which extrapolate historical trends (Sekovski et al., 2015; Sanchez et al., 2014).

Considering an urban development model based on a detailed, vector-based representation of the urban space is appealing, because it simplifies communication with stakeholders and because simulated changes of the urban space can be directly translated into changes of the parameters of the hydrological models used for assessing impacts of urban developments. Detailed socio-economic data on an individual level are, on the other hand, often difficult to obtain and subject to privacy issues and modelling urban development on a micro-level can be tedious. Recent work has therefore considered a simplified representation of the urban development process where new urban developments are assumed to occur in pre-defined zones which are derived from, for example, municipal plans. Within these zones, new properties are then created either in a random manner or following a pre-defined pattern (Mikovits et al., 2017; Löwe et al., 2017).

One of the questions that so far went unanswered is what level of uncertainty we should expect from random variations in when and where urban development occurs in the city and how these variations affect the ability to project elements of the urban water cycle on different spatial and temporal scales, and thus also how reliable planning decisions can be made for different elements of urban water management. This question is the focus of this work. 


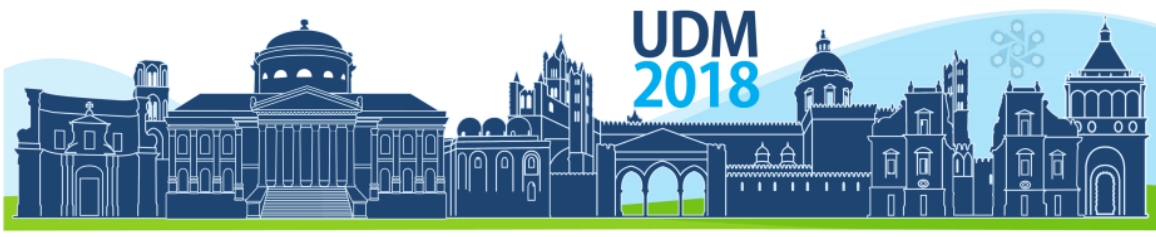

$11^{\text {th }}$ International Conference on Urban Drainage Modelling

23-26 Sep | Palermo - Italy

\section{MATERIALS AND METHODS}

\subsection{Data}

We consider the city of Odense in Denmark. The urban area has approximately 200,000 inhabitants. Odense has been subject to substantial urban sprawl over the last 3 decades (Kaspersen et al., 2017) and a population increase in the order of $10 \%$ is projected over the next 20 years. The municipality aims for a densification of the urban space by concentrating urban developments around local centres, but still also allows for new developments in rural areas (Odense Kommune, 2015). Figure 1 illustrates the areas where new urban developments are planned by the municipality until 2028, together with the location and catchments of wastewater treatment plants, as well as a number of subcatchments which the utility considers for planning purposes. For each of the development areas in Figure 1, the municipality has defined time points, types of developments and a number of residential units that are foreseen. Detailed data on existing buildings and parcels are available from municipal registers, while information on households and the number of inhabitants was obtained from national registers (Danmarks Statistik, 2016).

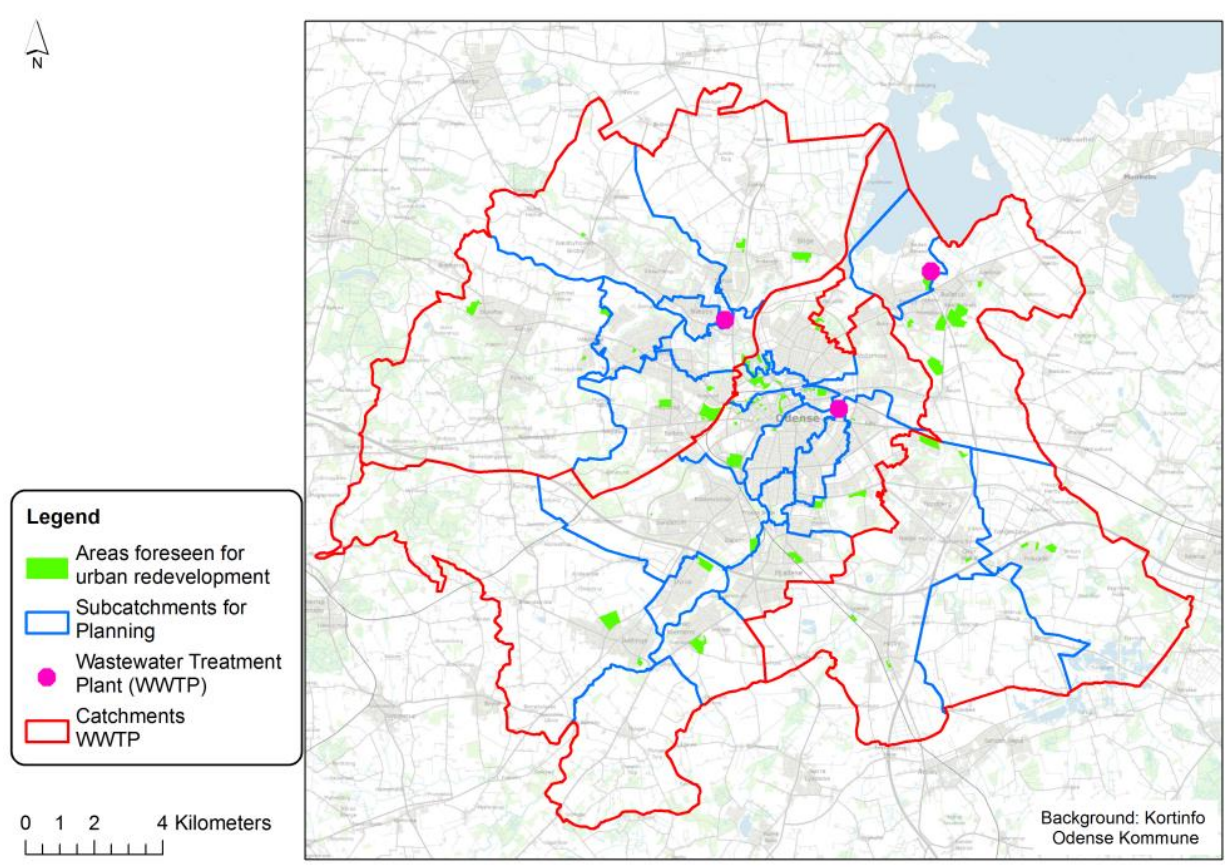

Figure 1. City .of Odense, Denmark. Highlighted are wastewater treatment plants (WWTP, purple), catchment area for each WWTP, subareas used for planning by the utility (blue) and locations where the municipality foresees urban developments in the period 2016-2028.

\subsection{Modelling Urban Development}

To evaluate how variations in urban development impact urban water management, we consider 2 scenarios. In Scenario 1, we simulate urban development exactly as foreseen by the municipality for the period from 2016 to 2028. In Scenario 2 the same number of residential units is developed in each year as in scenario 1, and the same locations are considered for urban development, but the time point when the different areas are developed is varied randomly. We create 10 realisations of the random process and test the effect of the variations in urban development on urban water management as described in Section 2.3. 


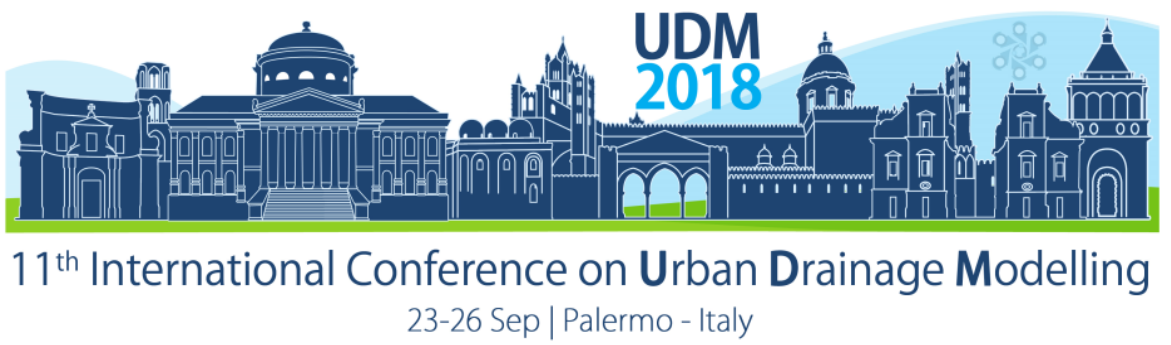

Urban development is in both scenarios implemented in a 2 step procedure:

1. Mark areas where development occurs and remove existing buildings that are not of residential type or younger than 25 years.

2. Merge the available parcel space into single polygons, subdivide into new parcels and create new buildings. This process requires a parametrization of the size of parcels and buildings that should be created, as well as the number of residential units in each new building. These parameters are derived from an analysis of the existing building stock in the city, considering median values for each building type.

The subdivision of parcels and the creation of new buildings is performed using the Dynamind framework (Urich et al., 2012), while all other GIS operations are performed using Spatialite (Furieri, 2015) through Python.

\subsection{Assessing Urban Water Management on Different Spatiotemporal Scales}

The hypothesis is that variations of urban development will limit predictions of the urban water cycle particularly on small scales, while larger scales are subject to little variation. Thus, we assess impacts on 3 different scales as shown in Table 1. The local scale corresponds to areas assigned to individual nodes in the detailed MIKE URBAN model for the city, having areas between $400 \mathrm{~m}^{2}$ and 1 ha. The subcatchment and catchment scale are considered as illustrated in Figure 1. We consider three different indicators, each of which relates to different planning tasks on different scales.

Table 1. Overview of planning indicators for urban water management and which planning tasks they affect at the different spatial scales.

\begin{tabular}{lccc}
\hline $\begin{array}{l}\text { Indicators for } \begin{array}{l}\text { Local scale (not } \\
\text { management }\end{array} \\
\text { Built-up area }\end{array}$ & $\begin{array}{c}\text { Feasibility of local } \\
\text { shown in Figure 1) } \\
\text { retention solutions }\end{array}$ & $\begin{array}{c}\text { Hydraulic load } \\
\text { (blue in Figure 1) }\end{array}$ & $\begin{array}{c}\text { Catchment scale } \\
\text { (red in Figure 1) }\end{array}$ \\
\hline Number of residents & CSO pollutant load & $\begin{array}{c}\text { Dimensioning of pumps } \\
\text { CSO pollutant load }\end{array}$ & Dimensioning of WWT \\
\hline $\begin{array}{l}\text { Number of buildings in } \\
\text { bluespots filled during } \\
>30 \mathrm{~mm} \text { rainfall }\end{array}$ & $\begin{array}{c}\text { Prioritization of } \\
\text { local protection }\end{array}$ & & Prioritizing investments \\
into flood protection
\end{tabular}

\section{RESULTS AND DISCUSSION}

Figure 2 illustrates how urban development is simulated for the centre of Odense in scenario 1. The simulated residential and building densities for this scenario are implemented exactly as defined by the municipal plan. New buildings are developed in the areas marked by yellow lines, and existing buildings are replaced as part of the redevelopment. The results highlight the limitations of generating projections that are solely based on planning documents, as rowhouses are developed with unrealistically high densities in the northwestern part of the area, while residential blocks are developed with unrealistically small building densities in the southern part of the area.

Considering the impact of urban development on water management, the simulated urban growth in scenario 1 leads to substantial variations of the number of residents on all 3 scales (5-9\% on the catchment scale, $0-50 \%$ on the subcatchment scale, $0-100 \%$ on the local scale). Similarly, the number of buildings in bluespots increases between 7 and $9 \%$ on the 


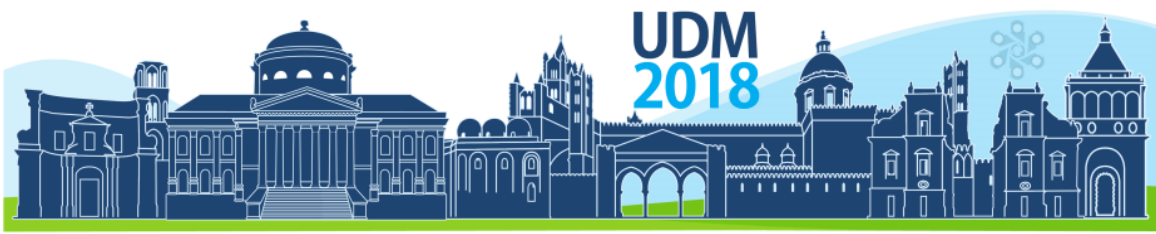

$11^{\text {th }}$ International Conference on Urban Drainage Modelling

23-26 Sep | Palermo - Italy

catchment scale, while the built-up area is subject to smaller variations (catchment scale: 0 $3 \%$, subcatchment scale: $4-9 \%$, local scale: $0-100 \%$ ).
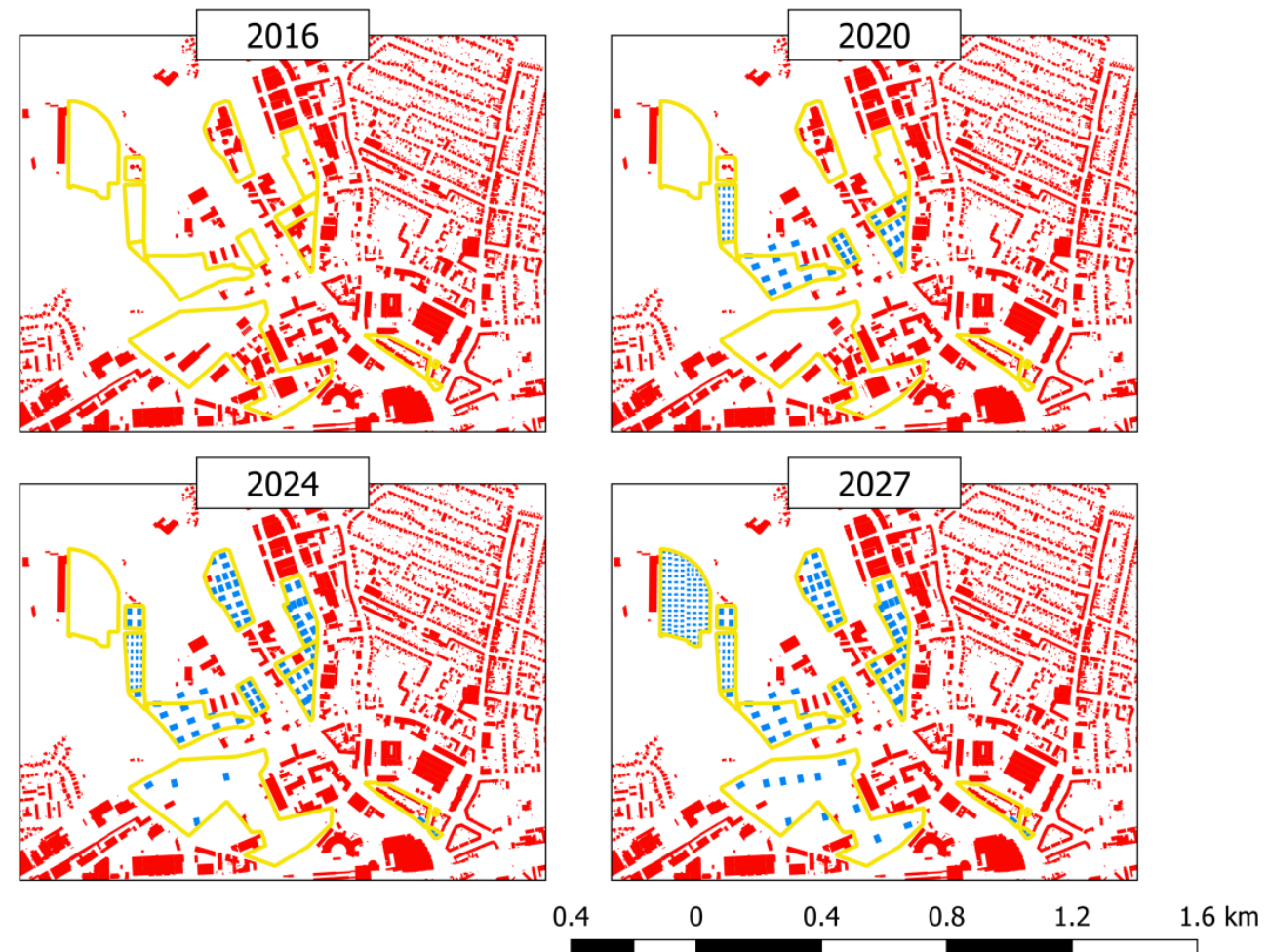

Figure 2. Example for urban development simulated for the centre of Odense in scenario 1. Areas where the municipality foresees developments are marked by yellow lines. Existing buildings are marked red, newly developed buildings are marked blue.

building area

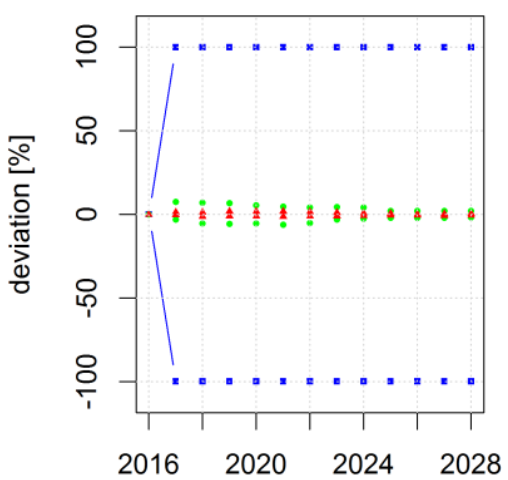

no. of residents

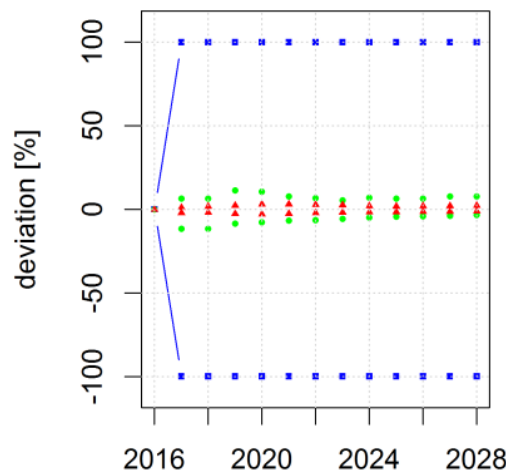

buildings in bluespots

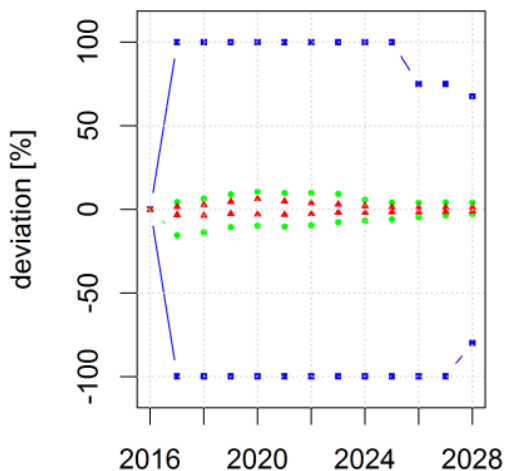

Figure 3. Deviations between water management indicators simulated in scenarios 1 and 2 . The figures show 2.5 and $97.5 \%$ quantiles for local scale (blue squares), subcatchment scale (green dots) and catchment scale (red triangles). Deviations $>100 \%$ and $<-100 \%$ are displayed as $100 \%$.

Figure 3 illustrates the degree to which the indicators describing impacts on urban water management vary between Scenarios 1 and 2, considering any time point of the simulated period from 2016 to 2028 . The deviations are generally substantial on the local scale and 


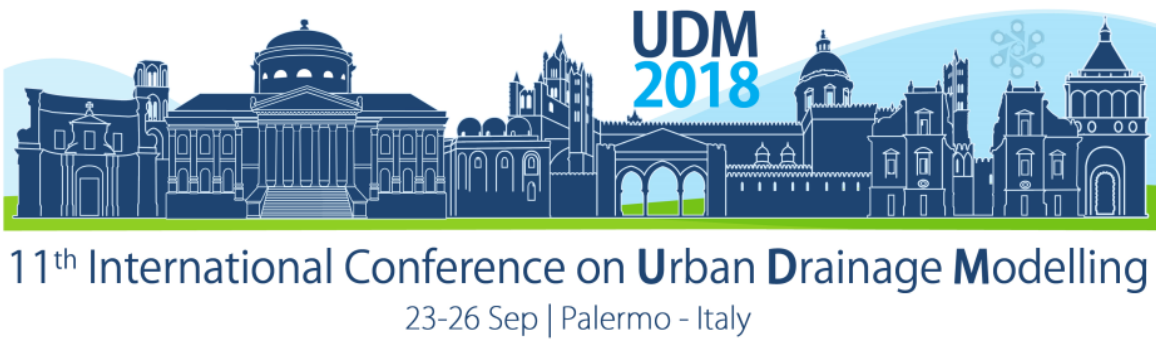

smaller on the larger scales. The deviations are biggest in the beginning of the planning horizon where most of the urban development occurs and the maximal observed deviations on the local scale do not approach 0 towards the end of the planning horizon, because some of the pre-defined developments spread out over large areas with small building densities. The exact location of the developed buildings cannot be foreseen in these cases.

\section{CONCLUSIONS}

Figure 3 suggests that random variations in urban development can lead to rather small variations in the order of $5-10 \%$ for urban water management indicators on larger scales. This result is an outcome of the small number of development zones defined by the municipality, where new developments are simulated in all zones in all scenarios. Many more potential locations where urban development may occur can be identified and developments will in reality only take place in a subset of these. Particularly on the subcatchment scale, we would expect levels of random variation which are similar to the total changes simulated for scenario 1 in this work.

Projections of population growth are deeply uncertain and, for Odense, range between 0 and $60 \%$ over a planning horizon of 40 years. It is thus likely that random variations in the location of urban development have substantial impacts on projections of the urban water cycle on shorter time horizons ( $<10$ years), while uncertainties of socio-economic development dominate projections of the urban water cycle on longer time horizons. These considerations are the subject of on-going work which also includes hydraulic simulations and the consideration of longer planning horizons.

\section{References}

Danmarks Statistik (2016) Statistikbanken. Household and Population Registers. [online] statistikbanken.dk/km5 Furieri, A. (2015) SpatiaLite. [online] https://www.gaia-gis.it/fossil/libspatialite/index.

Kaspersen, P. S., Ravn, N. H., Arnbjerg-Nielsen, K., Madsen, H., and Drews, M. (2017) Comparison of the impacts of urban development and climate change on exposing European cities to pluvial flooding. Hydrology and Earth System Sciences, 21(8), 4131-4147.

Löwe, R., Urich, C., Sto. Domingo, N., Mark, O., Deletic, A., and Arnbjerg-Nielsen, K. (2017) Assessment of Urban Pluvial Flood Risk and Efficiency of Adaptation Options Through Simulations - A New Generation of Urban Planning Tools. Journal of Hydrology, 550, 355-367.

Mikovits, C., Rauch, W., and Kleidorfer, M. (2017) Importance of scenario analysis in urban development for urban water infrastructure planning and management. Computers, Environment and Urban Systems,

Odense Kommune (2015) Forudsætningsredegørelse-Planstrategi 2015, Kommuneplan 2016-2028, Odense, DK.

Sanchez, A., Medina, N., Vojinovic, Z., and Price, R. (2014) An integrated cellular automata evolutionary-based approach for evaluating future scenarios and the expansion of urban drainage networks. Journal of Hydroinformatics, 16(2), 319.

Sekovski, I., Armaroli, C., Calabrese, L., Mancini, F., Stecchi, F., and Perini, L. (2015) Coupling scenarios of urban growth and flood hazards along the Emilia-Romagna coast (Italy). Natural Hazards and Earth System Sciences, 15(10), 2331-2346.

Urich, C., Burger, G., Mair, M., and Rauch, W. (2012) "Dynamind - a software tool for integrated modelling of urban environments and their infrastructure" in Proceedings of the 10th International Conference on Hydroinformatics., Hamburg, Germany.

Urich, C. and Rauch, W. (2014) Exploring critical pathways for urban water management to identify robust strategies under deep uncertainties. Water research, 66C, 374-389.

Waddell, P. (2002) UrbanSim - Modeling urban development for land use, transportation, and environmental planning. Journal of the American Planning Association, 68(May), 297-314.

Wegener, M. (2011) The IRPUD Model, Dortmund, Germany. 


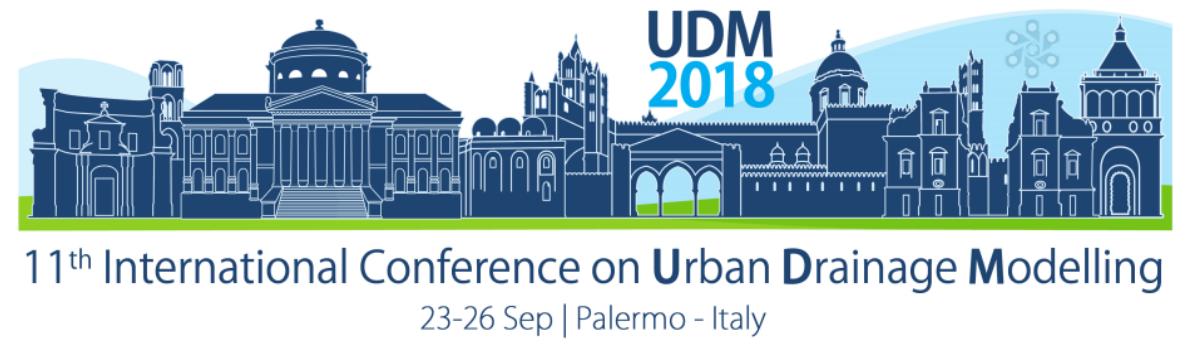

\title{
Rainwater harvesting system efficiency and economic assessment for different residential building typologies
}

\author{
Sara Corvaro ${ }^{1}$ \\ 1 Università Politecnica delle Marche, Dipartimento di Ingegneria Civile, Edile e Architettura (DICEA), Ancona, Italy
}

\begin{abstract}
The focus of the paper is the evaluation of the water saving efficiency and the payback period of domestic rainwater harvesting (DRWH) systems. The study was carried out with reference to different residential building typologies (flat and condominium) in subcoastal Italian climate regime. The buildings are characterized by different rooftop area, number of building floors and inhabitant number. The economical assessment is provided by comparing, along the design life span of the building, the capital costs and the savings due to the replacement of the water supply with the rainwater. In the present analysis the rainwater is used for both indoor and outdoor non-potable consumption.
\end{abstract}

Keywords: domestic rainwater harvesting; efficiency; water storage tank; costs and savings, payback period

\section{INTRODUCTION}

The use of collected rainwater systems to support human non-potable consumption is increasing in the last years. The primary reason for the use of domestic rainwater harvesting (DRWH) systems is the potable water supply substitution (Mitchell et al., 2008). It is widely recognized that rainwater can replace potable water for several less quality-demanding water uses, such as house toilet flushing, car washing, terrace cleaning or private garden watering. In the present study the rainwater is used for both indoor (toilet flushing and washing machine) and outdoor (garden irrigation) non-potable consumption. A significant amount (up to $30 \%$ ) of water in residential building (estimated currently to be $1501 /$ person/day) is typically used for toilet flushing, while about $12 \%$ for the washing machine. The water demand for an home garden irrigation is usually related to the square meter of the garden area. The economic feasibility of a DRWH system depends on a lot of variables, such as rainfall climate regime, rooftop and/or terrace surfaces, inhabitant number and water tariff, hence different results can be obtained depending significantly on the local condition. The tank storage capacity is commonly considered the most important cost in a DRWH system, however, in specific cases (e.g. condominium) the cost of the pump could also be significant, due to higher head and, hence, larger pump size. The main objective of this paper is to investigate the role of DRWH systems in terms of both efficiency and payback period by means of a parametric analysis, that takes into account of different rooftop area, building floors, inhabitant numbers and, hence, of both tank capacity and, as a novel parameter, pump size.

\section{MATERIALS AND METHODS}

\subsection{Test case description}

The residential buildings were assumed to be located in Ancona, a town at the east coast of Italy, classified as sub-coastal climate regime according to the Köppen-Geiger climate zoning map. Rainfall data were provided by the rainfall gauging station of Ancona-Torrette 


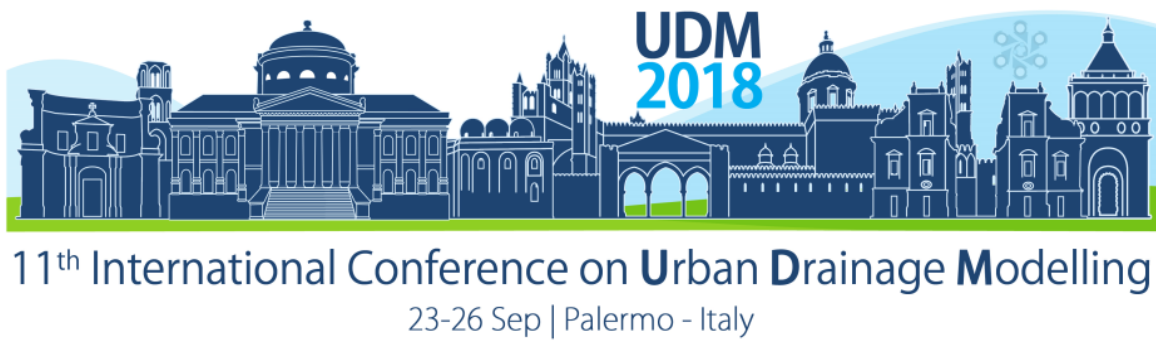

that operates since year 1946. The precipitation data has been elaborated in order to identify the "typical year", which corresponds to the year characterized by the minimum deviation of the observed data from the averaged ones. Water balance simulations were carried out choosing a daily time step, as recommended by Fewkes and Butler (2000).

Different domestic buildings typologies were considered which were characterized by different rooftop area, number of floors and inhabitant number. In order to study not only detached houses and to represent realistic and common building condition for an Italian town, the floor number was assumed to be in the range 1-3 (flat and condominium) and the rooftop area changed from $100 \mathrm{~m}^{2}$ to $400 \mathrm{~m}^{2}$. The inhabitant number was in the range $3-54$. Such value range has been obtained by following the Italian law about parameters for habitative and hygienic-sanitary suitability (D.M. 5/07/1975) which rules that for each inhabitant a minimum habitable surface must be ensured. Combinations of all these parameters have led to 46 different conditions. In order to point out also the significant role of the tank storage size $S$ on the efficiency and on the cost assessment ( $S$ has been evaluated as indicated in the German regulation DIN 1989-1:2002-04), for each case its capacity has been changed in the range $0.5 \mathrm{~S}, 1.0 \mathrm{~S}, 1.25 \mathrm{~S}, 1.50 \mathrm{~S}, 1.75 \mathrm{~S}, 2 \mathrm{~S}$ leading to a total number of test cases equal to 246 (only commercial tank size were taken into account).

The water demand to be supplied by rainwater is assumed to occur at a constant daily rate. The garden irrigation demand is not equal during the year because it is larger during the summer time and smaller in the winter time (about 100 days in a year). However, for simplicity, a constant water rate has been assumed by spreading the annual water irrigation demand over each day. The amount of irrigation demand is evaluated by considering a value of $51 / \mathrm{m}^{2}$ and a garden surface of $50 \mathrm{~m}^{2}$ for each family that lives at the ground floor (in the present study a family is assumed to be composed by 3 persons).

\subsection{Modelling and methodology analysis}

The DRWH system is sketched by the rooftop surface, pipes, storage tank and distribution component which includes the pipes, the pump system and other devices that move water from the storage to the point-of-use. The hydrologic-hydraulic modelling is undertaken using EPA SWMM. The DRWH systems were simulated in SWMM as catchment area (rooftop surface), conduits, storage unit, pumping system. Moreover, an additional outfall simulates the overflow discharged into sewer piping.

Tank water saving efficiency $E_{W S}(\%)$ and tank volumetric retention efficiency $E_{R}(\%)$ were here defined as proposed by Campisano and Modica (2015):

$$
E_{w s}=\frac{\sum Y}{D} ; E_{R}=1-\frac{\sum O}{\sum A P_{t}}
$$

where $Y$ is the volume of rainwater yielded from the storage tank, $D$ is the annual nonpotable water demand, $O$ is the volume discharged as overflow from the storage tank, $P_{t}$ is the precipitation of the "typical year" at the time step $t$ (in the present study $t$ corresponds to one day) and $A$ is the rooftop surface. For the sake of brevity, in the present paper only the results about the water saving efficiency were reported.

The economic assessment has been made by comparing the flow of costs and savings of the investment. The capital costs are due to the tank, pipes, pump (influenced by the number of inhabitants and building floors), devices, installation, maintenance, while the savings are 


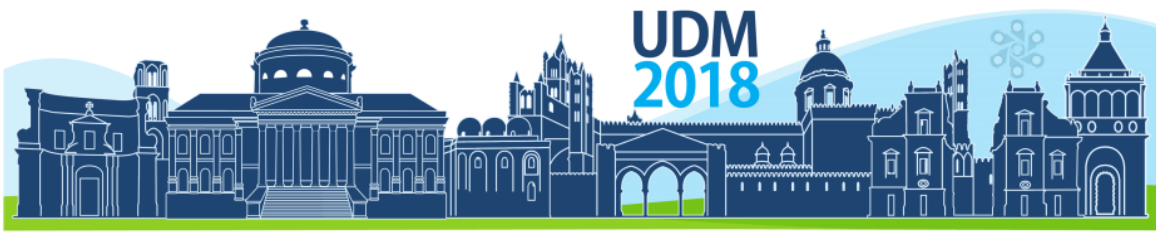

$11^{\text {th }}$ International Conference on Urban Drainage Modelling

23-26 Sep | Palermo - Italy

due to the water replacement, that is the primary benefit of such system. Therefore, in the economic analysis the water price is a key factor, savings for cost of water supplied by the rainwater. Predictions about future water tariff along the design life span are here taken into account, by means of a linear trend, in order to evaluate the payback period.

\section{RESULTS AND DISCUSSION}

\subsection{Water saving efficiency}

In Fig. 1 the numerical results about the temporal evolution of the water balance is shown for one test case: rooftop surface $A=200 \mathrm{~m}^{2}, 2$ floors and 12 inhabitants.

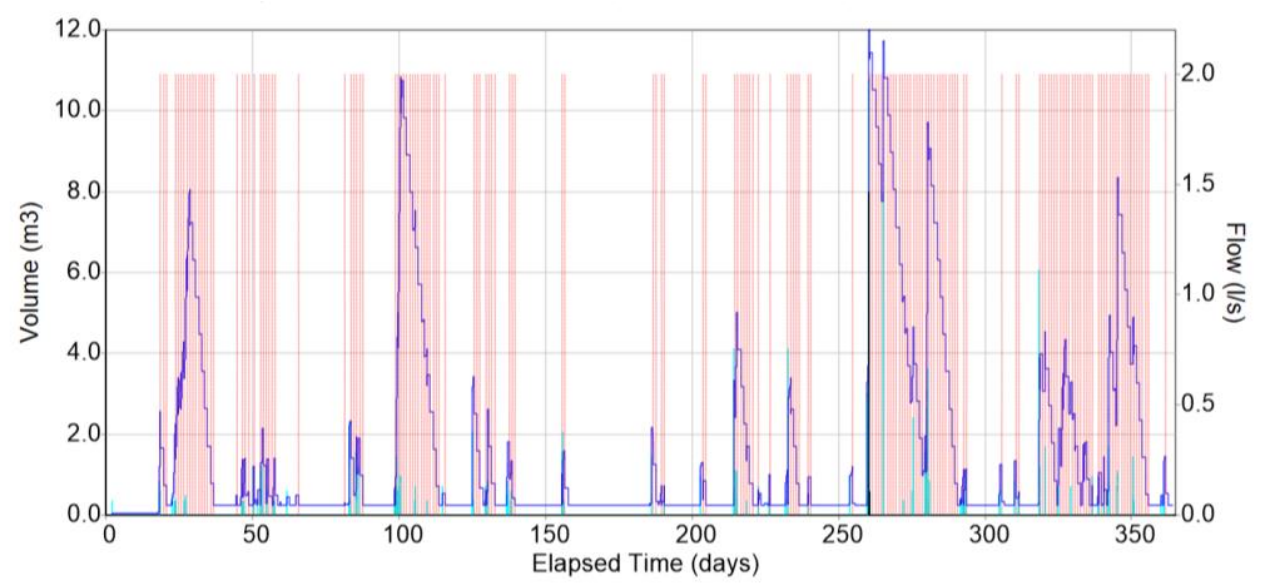

Figure 1. Harvested water volume (blue line), pumped water flow (red dotted line), runoff (cyan line), overflow (black line) for the test case with a rooftop surface $A=200 \mathrm{~m}^{2}, 2$ floors and 12 inhabitants.

To consider different combinations of demand $D$, storage capacity $S$, rooftop area $A$ and annual precipitation $P$, two dimensionless ratios are traditionally taken into account in the literature, namely demand fraction $d=D / A P$ and storage fraction $s=S / A P$. Figure 2 shows the influence of the water saving efficiency to such parameters. By analyzing the results of the simulations for all the test cases, the water saving efficiency $E_{w s}$ ranges between $20 \%$ to $80 \%$.

Inspection of Fig. 2 reveals also that the influence of the storage capacity on the water saving efficiency becomes more and more smaller with the increase of the demand fraction. Larger efficiency can be achieved with both small demand fraction (small water demand, strong rainfall regime or wide rooftop surface) and large tank storage capacity. In the latter case it is very important to evaluate not only the efficiency of a DRWH, but also its economic feasibility, as briefly reported in the following section, being important the tank storage cost.

\subsection{Economic assessment}

The economic assessment was based on the cost and saving flows by considering the future prediction of the costs along the design life span, in order to evaluate the payback period for each different test case. Fig. 2 shows that the payback periods changed in the range 1035years for the site-specific variables such as local rainfall and water tariff. A very weak influence of the demand fraction on the payback period has been found, while, as expected, the payback period is strongly influenced by the storage fraction. Note that in the economic 


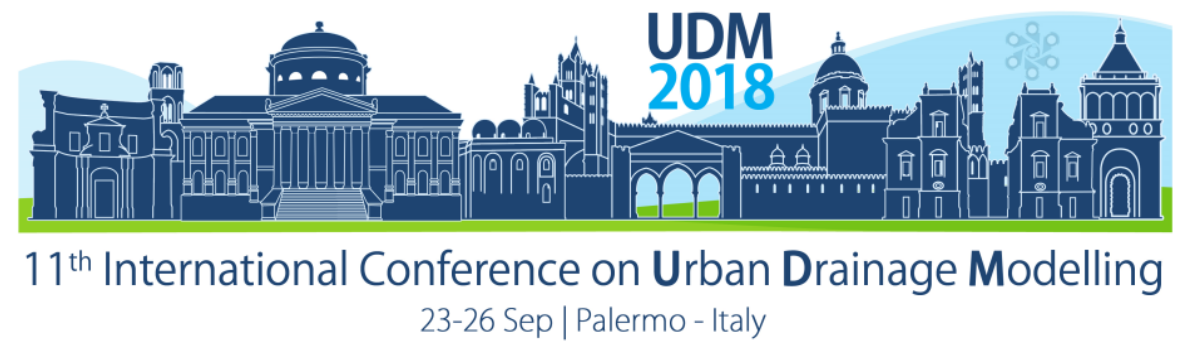

computations also other costs have been taken into account, in particular the pump costs became significant in the case of buildings with 2 or 3 floors and a large number of people. However, when only the influence of the tank storage size on the payback period is considered, a twice tank storage capacity led to an increase of the payback periods of about $20-30 \%$.
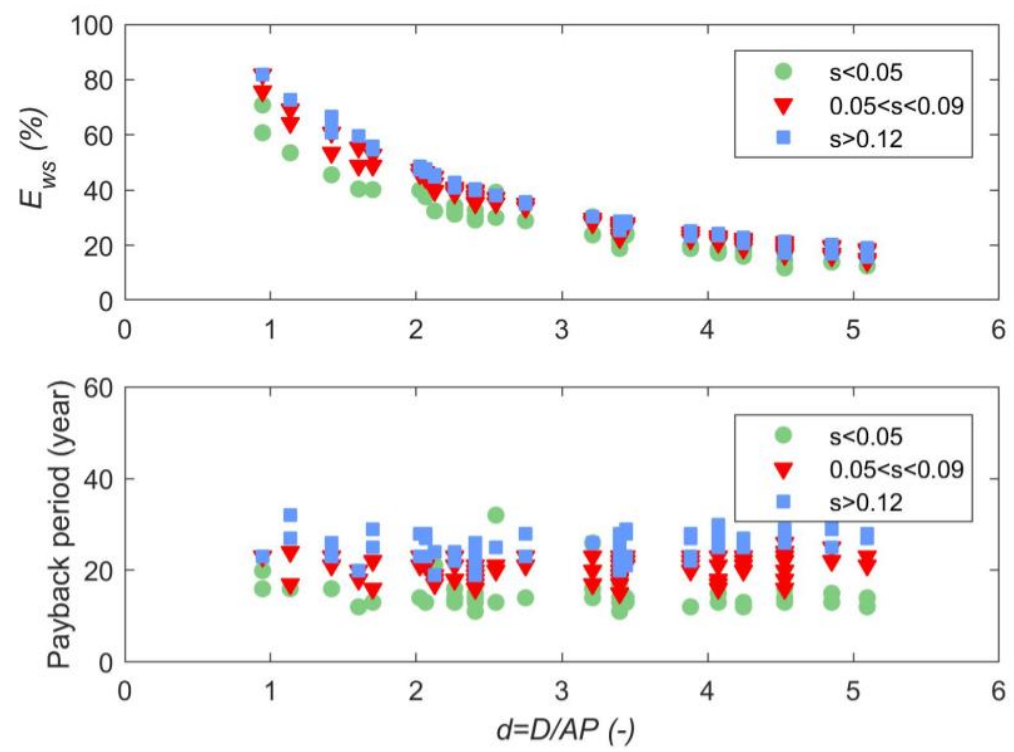

Figure 2. Influence of the water saving efficiency and of the payback period on the water demand fraction $d$ and storage fraction $S=S / A P$.

\section{CONCLUSIONS}

Several simulations on the performance of domestic rainwater systems were carried out in order to analyze both the efficiency and the payback period of different residential building typologies. The analysis has been performed in order to consider the combination of different parameters such as the rooftop surface, number of building floors, inhabitant number, water demand, tank storage and pump size. The tank size is the most important cost in a DRWH system cost, however in a building with more than one floor, the pump cost could be significant leading to $30 \%$ of the tank cost for a building with 3 floors and a rooftop area of about $150 \mathrm{~m}^{2}$. The water saving efficiency increases in the cases of small water demand fraction. The increase of the tank storage size of $100 \%$ leads to an increase of the efficiency of about $10-20 \%$, but, at the same time, a significant increase (about $20-30 \%$ ) of the payback period occurs. In conclusion, a parametric estimation of the DRWH system performance has been achieved for buildings in sub-coastal Italian climate regime, however the extension of the payback period results to other site condition should be verified and made with care due to the influence of the local water tariff.

\section{References}

Campisano, A. and Modica, C. (2015). Appropriate resolution timescale to evaluate water saving and retention potential of rainwater harvesting for toilet flushing in single houses. J. Hydroinform. 17(3); 331-346.

Fewkes, A and Butler, D. (2000). Simulating the performance of rainwater collection systems using behavioural models? Build. Serv. Eng. Res. Tec. 21(2); 99-106.

Mitchell, V.G., McCarthy, D.T., Deletic, A. and Fletcher T.D. (2008). Urban stormwater harvesting e sensitivity of a storage behaviour model. Environ. Modelli. Soft.. 23; 782-93. 


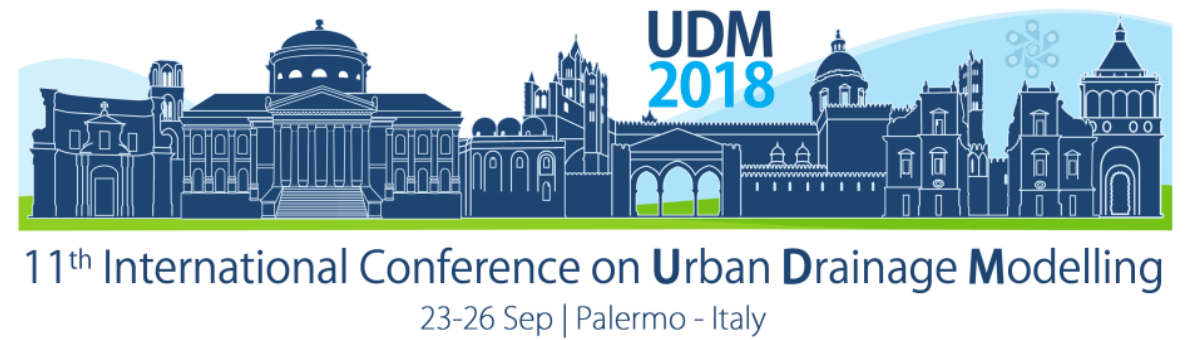

\title{
Model based estimation of a natural water balance as reference for planning in urban areas
}

\author{
Malte Henrichs ${ }^{1}$, Andreas Steinbrich ${ }^{2}$, Hannes Leistert ${ }^{2}$, Isabel Scherer ${ }^{1}$, Tobias Schuetz ${ }^{3}$, Mathias Uhl', \\ Markus Weiler ${ }^{2}$ \\ ${ }^{1}$ University of Applied Science Münster, Institute for Infrastructure.Water.Resources.Environment, Münster, \\ Germany \\ 2 University Freiburg, Hydrology, Faculty of Environment and Natural Resources, Freiburg im Breisgau, Germany \\ 3 University Trier, Faculty VI, Hydrology, Trier, Germany
}

\begin{abstract}
The water balance of urban areas differs considerably from the landscape water balance. Increased surface runoff, reduced groundwater recharge and evaporation change the hydrological regime, the morphology and ecology of water bodies close to the cities, the groundwater in the urban area and the urban climate. Today's urban drainage systems are designed to prevent, reduce, drain, seep away, evaporate or discharge precipitation into nearby surface waters with considerable delays. In doing so, it follows the principles of the German Water Resources Act (WHG) and the objectives of the relevant technical regulations DWA-A 102 to keep changes in the natural water balance by settlement activities as low as ecologically, technically and economically acceptable. A reference for the "natural" water balance has to be defined as a planning objective in order to quantify the hydrological changes in settlements. As a suitable reference, we propose to use the water balance of the landscape of the associated ecoregion with today's cultural land use without urban developments. This approach is more suitable to define local conditions than the water balance of the enclosed catchment. The presented calculation approach to define reference values of the water balance, uses soil and geological properties, precipitation and climate data and can be implemented and applied uniformly throughout Germany. The water balances in this study are simulated with the water balance model RoGeR. In this study, the developed approach is applied for five locations in Germany.
\end{abstract}

Keywords: WSUD, water balance modelling, RoGeR,

\section{INTRODUCTION}

The water balance in urban areas is heavily modified compared to cultural landscapes. The surface runoff increases with rising imperviousness while groundwater recharge and evaporation are reduced significantly (e.g. Fletcher et al., 2013). As a result, the hydrological regime, the morphology and ecology of urban streams, the groundwater level as well as the urban climate are affected. In the last decade, water sensitive urban design (WSUD) has become a more and more accepted strategy towards sustainable water management in urban areas. WSUD measures are well known and proven in practice.

Today's urban drainage systems are designed to prevent, reduce, drain, seep away, evaporate or discharge precipitation into nearby surface waters with considerable delays. In doing so, it follows the premises of the German Water Resources Act (WHG) and the objectives of the relevant technical regulations DWA-A 102 (2016) to keep changes in the natural water balance by urban developments as low as ecologically, technically and economically justifiable. Therefore, a reference state for the water balance (water balance of the pre-developed area) is needed (Henrichs et al. 2016). 


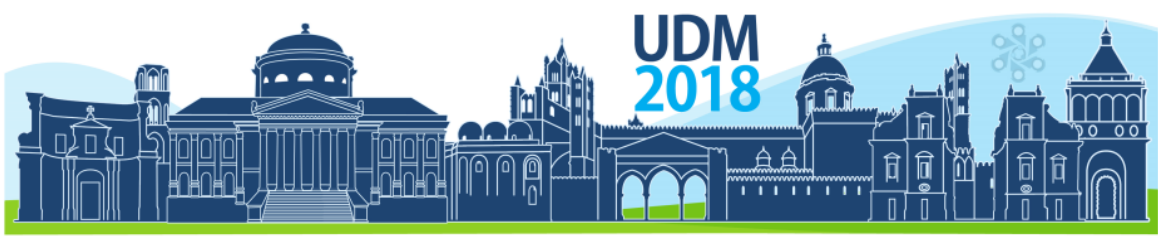

$11^{\text {th }}$ International Conference on Urban Drainage Modelling

23-26 Sep | Palermo - Italy

This study has the objective to answer the following research questions:

1. Which transfer concept can be used to derive reference values for the urban water balance from the near natural water balance?

2. What instruments and data are required?

3. Is the calculation approach feasible?

4. Are the results of the calculation approach valid?

\section{MATERIALS AND METHODS}

Transfer concept and data. The transfer concept is based on open data for landuse (Corine Land Cover data), soil data (BUEK 1:200.000), precipitation, and climate (evaporation) data from the DWD (German Weather Service). The workflow to define representative land uses and soils, as input for the water balance modelling approach for the planning area, is shown in Figure 1.

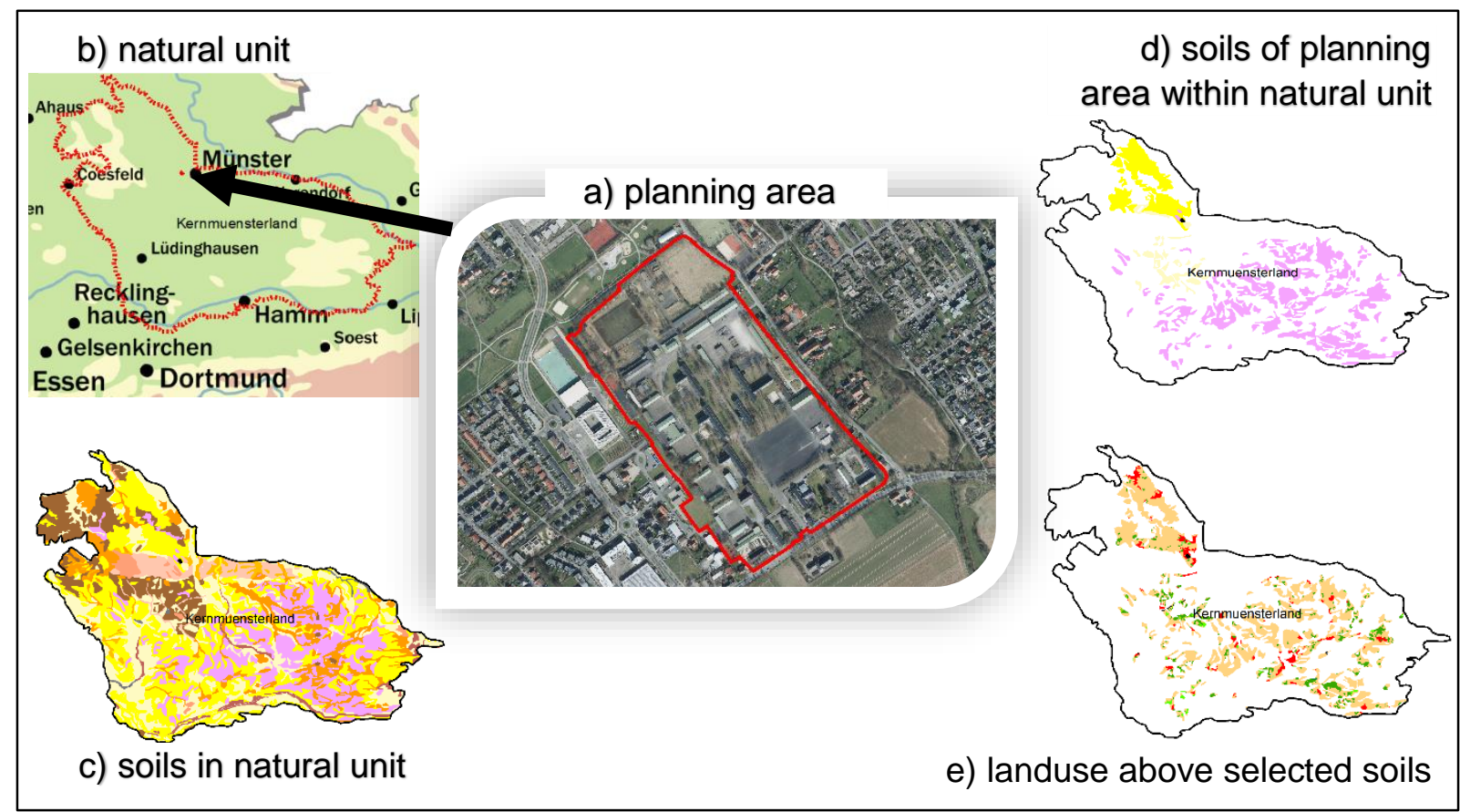

Figure 1. Work flow for the selection of the data basis for the planning and reference area/region. a) definition of the planning area, b) selection of the natural unit, c) existing soils within the natural unit, d) selections of relevant soils within the natural unit, e) analysis of landuses for selected soils

Simulation model. In this study the water balance simulations were carried out with RoGeRWBM (Steinbrich et al. 2016). However, the approach is not limited to the RoGeR model. RoGeR-WBM is a grid based water balance model with detailed representation of infiltration, preferential and subsurface flow and was validated using longterm lysimeter data for different landuses (gras, deciduous, and coniferous forest) (Steinbrich et al. 2018). Precipitation and evaporation timeseries are used as climate inputs. Steinbrich et al. (2018) developed transfer functions to estimate model parameters from soil and landuse properties. 


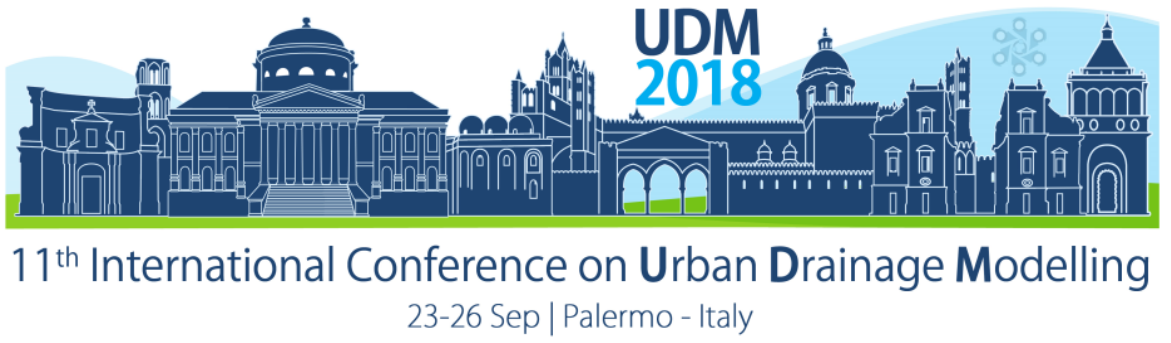

\section{RESULTS AND DISCUSSION}

Near natural water balance of urban areas. Table 1 lists the calculated water balances for five regions in Germany with varying annual precipitation. Figure 2 visualises the water balances using relative values in a triangular plot. It is obvious that direct runoff is below $10 \%$ of precipitation. Evaporation varies between 40 and $75 \%$ and groundwater recharge between 25 and $55 \%$. The locations Teltowplatte (Berlin) and Freiburger Bucht have very high proportions of evaporation, which can be explained by high groundwater levels and large potential evaporation yielding to a small or negative climatic water balance.

Table 1. Long-term simulated average water balance components from RoGeR-WBM for the reference regions (with P precipitation, ET evaporation, RD direct runoff, RS surface runoff, RI Interflow, GWN groundwater recharge).

\begin{tabular}{lccccccc}
\hline & $\mathrm{P}$ & $\mathrm{ET}$ & $\mathrm{RD}$ & $\mathrm{RS}$ & $\mathrm{RI}$ & $\mathrm{GWN}$ & $\mathrm{GWN}(+\mathrm{RI})$ \\
\cline { 2 - 8 } & 714 & 409 & 132 & 30 & 102 & 172 & 274 \\
\hline Kernmünsterland & 656 & 450 & 57 & 2 & 55 & 174 & 229 \\
Braunschweig & 856 & 606 & 81 & 16 & 65 & 166 & 231 \\
Freiburger Bucht & 1080 & 479 & 114 & 20 & 94 & 529 & 623 \\
Bergische Hochflächen & 556 & 490 & 80 & 9 & 71 & 108 & 179 \\
Teltowplatte & & & & & & & \\
\hline
\end{tabular}

The choice of current non-urban landuse in the reference area as a planning reference recognizes the reality of our cultural landscape. Therefore, unrealistic requirements for future planning are avoided in urban water management. At the same time, realistic planning goals increase the acceptance of investments and decrease possible restrictions associated with stormwater management measures. 


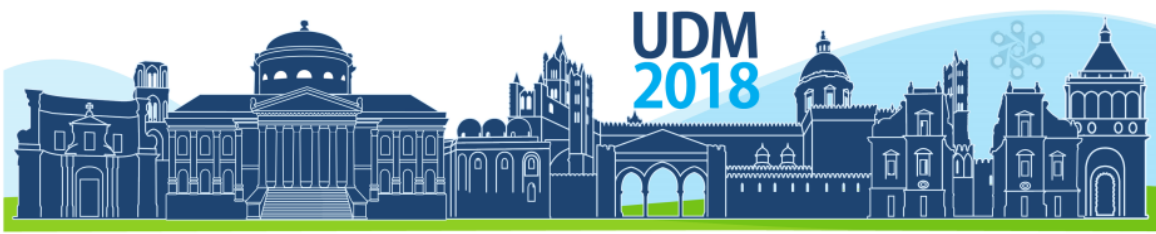

$11^{\text {th }}$ International Conference on Urban Drainage Modelling

23-26 Sep | Palermo - Italy

- Münster Oxford

- Hannover-Kronsberg

- Freiburg Vauban

- Bergisches Land NRW

- Berlin

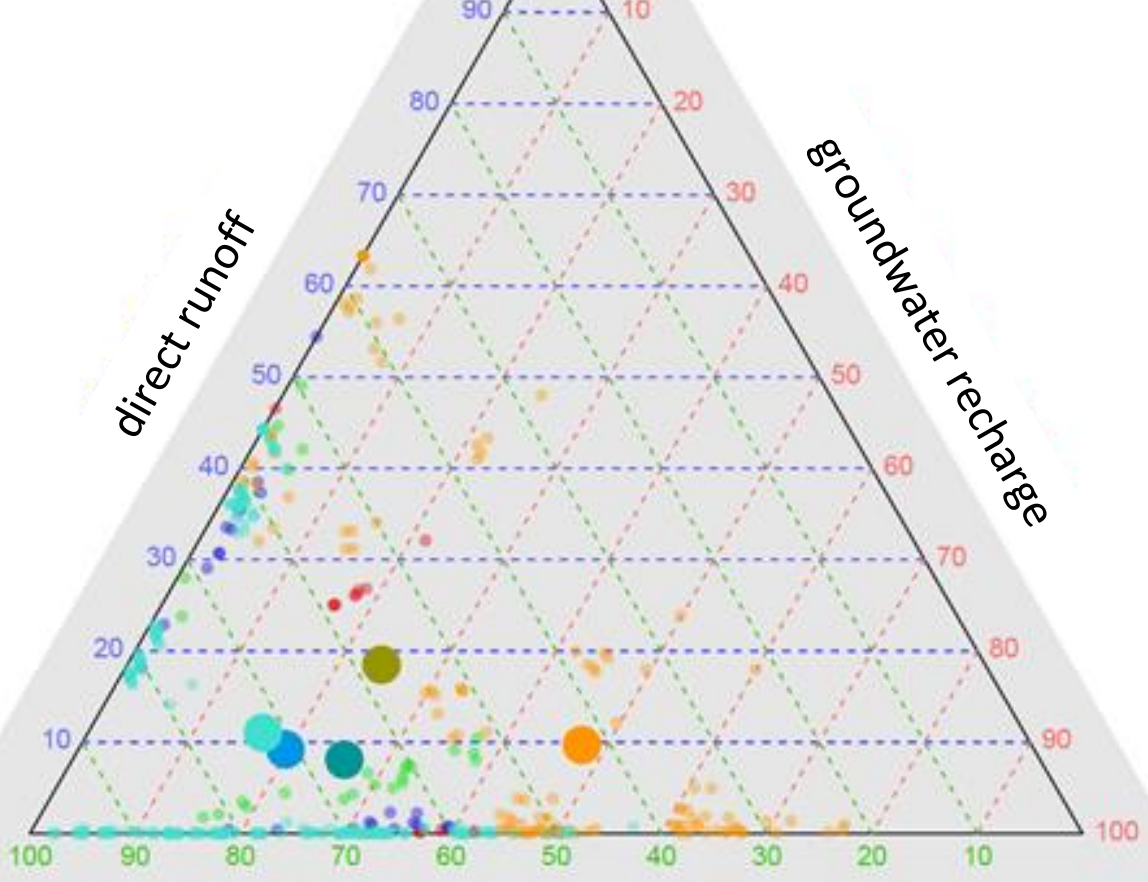

evaporation

Figure 2: Proportion of the water balance components for the five reference regions. Larger circles represent the mean values for the whole regions. Smaller circles represent the different areas assembling the reference regions (Steinbrich et al. 2018, modified).

\section{CONCLUSIONS}

One of the goals of sustainable urban drainage systems is to minimize the impact of urbanization on the water balance, respecting ecological, technical and economic aspects. A reference state has to be defined in order to compare and evaluate the water balance of the urban planning area with a reference area. However, there is currently no adequate method available to define the reference state. This state can be obtained by estimating the water balance for representative areas situated within the same physiographic unit. These representative areas should be defined by identical hydrogeological properties as the soils within the planning area, with the same mix of current land cover, excluding settlements, commercial and traffic areas. Readily available geo data and climate data should be used as input data. The simulation of the water balance can be performed with any appropriate water balance model. The model RoGeR-WBM, which was applied in this study, was validated by modelling the water balance of the large-scale lysimeter St. Arnold with three different types 


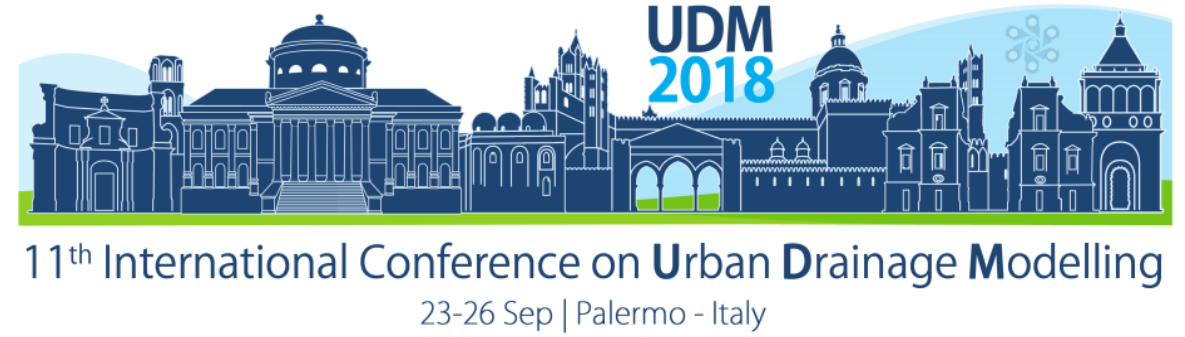

of land cover. The five case studies in Germany, presented in this study, showed that the method is applicable and leads to plausible results.

\section{Acknowledgement}

The research work and software development are part of the joint research project "Wasserhaushalt siedlungsgeprägter Gewässer" (WASIG, Scherer et al. 2017) and is supported by the German Federal Ministry of Education and Research (BMBF, FKZ 033W040C, Fördermaßnahme REWAM, Förderschwerpunkt NAWAM).

\section{References}

DWA-A 102 (2016): Niederschlagsbedingte Siedlungsabflüsse - Grundsätze und Anforderungen zum Umgang mit Regenwasser (Entwurf). DWA-Arbeitsblatt 100. Hennef: GFA-Gesellschaft zur Förderung der Abwassertechnik e. V. (in German).

Fletcher TD, Andrieu H, Hamel P (2013): Understanding, management and modelling of urban hydrology and its consequences for receiving waters: A state of the art. In: Advances in Water Resources, 51 (0), S. 261-279.

Henrichs M, Langner J, Uhl M (2016): Development of a simplified urban water balance model (WABILA). In: Water Science and Technology, 73(8), S. 1785-1795.

Scherer, I., Henrichs, M., Uhl M., Schuetz, T., Weiler, M., Hackenbroch, K., König, F. und T. Freytag (2017): Planungsinstrumente und Bewirtschaftungskonzepte für den Wasserhaushalt in Siedlungen, Korrespondenz Wasserwirtschaft, 4 (17), S. 221-228 (in German).

Steinbrich A, Leistert H, Weiler M (2016): Model-based quantification of runoff generation processes at high spatial and temporal resolution. Environmental Earth Sciences, 75 (1423), S. 1-16.

Steinbrich A, Henrichs M, Leistert H, Scherer I, Schuetz T, Uhl M, Weiler M (2018): Estimation of a natural water balance as reference for planning in urban areas. Hydrologie und Wasserbewirtschaftung, (submitted, in German). 


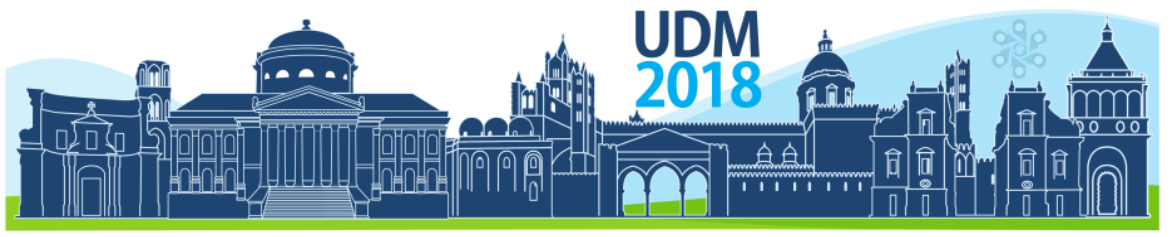

$11^{\text {th }}$ International Conference on Urban Drainage Modelling

23-26 Sep | Palermo - Italy

\title{
Preliminary analysis about the effects on the SPI values computed from different best-fit probability models in two Italian regions
}

\author{
Claudio Mineo', Benedetta Moccia', Federico Lombardo', Fabio Russo' and Francesco Napolitano \\ ${ }^{1}$ Sapienza Università di Roma, Dipartimento di Ingegneria Civile, Edile e Ambientale, DICEA, Rome, Italy
}

(claudio.mineo@uniroma1.it)

\begin{abstract}
Droughts are one of the most challenging issues in water resource management in urban areas due to their major socio-economic impacts. The identification and evaluation of droughts are commonly based on the Standardized Precipitation Index (SPI), which is estimated through easily accessible information (i.e., monthly rainfall). In this work, we show a preliminary analysis on the role played by the nature of the probability distribution in the calculation of the one-month SPI. Long-term rainfall time series from two Italian regions are investigated.
\end{abstract}

Keywords: Drought; Standardized precipitation index; Fitting performance.

\section{INTRODUCTION}

It is widely acknowledged that the study of droughts is of primary importance for freshwater planning and management. Over the years, a number of different indices have been developed to quantify droughts, each with its own pros and cons. One of the most used methods for analysing and monitoring droughts is the Standardized Precipitation Index (SPI) (McKee et al., 1993), which is probability based and allows for comparisons between different locations in different climate regimes. It requires precipitation as the only input parameter, and this is a significant advantage of the SPI over other drought indices due to greater availability of rainfall time series rather than other hydro-meteorological variables. In fact, rainfall is measured since a long time by traditional raingage stations and more recently by modern weather radars (Lombardo et al., 2006). McKee et al. (1993) assume rainfall data to follow a gamma probability distribution whose parameters are derived through a process of maximum likelihood estimation. Once the parameters are determined, the inverse standard Gaussian function is applied to the cumulative probability of an observed precipitation amount, thus yielding the SPI index, which can be computed for rainfall totals at various time scales. The monthly time scale (i.e., the one-month SPI) seems to be more appropriate for urban water supply, agricultural interests, and ground water abstractions (Mishra and Singh, 2010). Therefore, we refer to this particular time scale in this study, while other time resolutions will be investigated in a future work.

Clearly, the size of the data series has a significant impact on the SPI values due to the uncertainty in the estimation of the shape and scale parameters of the gamma distribution function (Wu et al., 2005). In addition, several researchers pointed out that SPI values may vary if we use different probability distributions to describe observed rainfall amounts instead of the gamma model (Guttman, 1999; Lloyd-Hughes and Saunders, 2002; Madsen et al., 1998; Todorovic and Woolhiser, 1976). In this paper we directly fit and compare the performance of four widely used probability distributions to several long-term rainfall records 


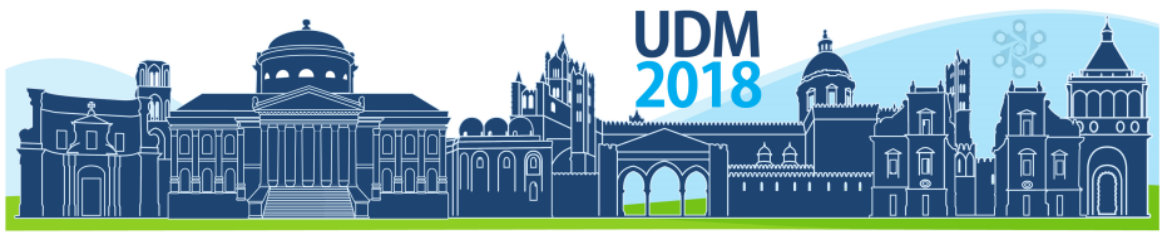

$11^{\text {th }}$ International Conference on Urban Drainage Modelling

23-26 Sep | Palermo - Italy

from two Italian regions (Lazio and Sicily) characterized by different climate regimes. In particular, we explore the relative performance of the classic gamma distribution compared to other distributions also used in the literature by means of a straightforward method (Papalexiou et al., 2013; Adirosi et al., 2015).

The preliminary results show that the gamma distribution fits well rainfall data series from both regions, even though other probability models provide better fitting results (see Table 2 below). Finally, we compare the one-month SPI values obtained by the standard approach to those calculated by the best-fit distributions selected through the above-mentioned method for two raingages, which are characterized by the longest records of our datasets. The use of different probability distributions does not seem to affect significantly the frequency distribution of the SPI values belonging to the eight categories suggested by the literature (see e.g. Lloyd-Hughes and Saunders, 2002).

\section{MATERIALS AND METHODS}

\subsection{Observational data}

The regional hydrographic offices of Lazio and Sicily provided the monthly rainfall data series used in this study. The datasets consist of 345 and 365 raingages with records of different length for the periods 1916-2015 and 1921-2013, respectively. In our analysis, we selected only raingages whose record length is greater than or equal to 50 years (see Table 1).

Table 1. Description of the datasets.

\begin{tabular}{|l|c|c|c|c|c|}
\cline { 2 - 6 } \multicolumn{1}{c|}{} & Period & $\begin{array}{c}\text { Number of } \\
\text { analysed } \\
\text { stations }\end{array}$ & $\begin{array}{c}\text { Minimum } \\
\text { sample size } \\
\text { [years] }\end{array}$ & $\begin{array}{c}\text { Average } \\
\text { sample size } \\
\text { [years] }\end{array}$ & $\begin{array}{c}\text { Maximum } \\
\text { sample size } \\
\text { [years] }\end{array}$ \\
\hline Lazio & $1916-2015$ & 72 & 51 & 66 & 95 \\
\hline Sicily & $1921-2013$ & 51 & 61 & 84 & 93 \\
\hline
\end{tabular}

\subsection{Methodology}

We fit and compare the performance of four common probability distributions to monthly rainfall data series. The candidate distributions are: (i) gamma $(G)$, which represents the distribution used by McKee et al. (1993) in the standard approach to the SPI estimation, (ii) lognormal (LN), (iii) Weibull (W) and (iv) Gaussian (N) distributions. This choice is driven by their simplicity, popularity and because they are all characterized by two parameters. In particular, we analyse the relative quality of each distribution (relative ranking) following the methodology proposed by Papalexiou et al. (2013). Such a method is suitable for large datasets and returns a performance score for each fitting. This fitting method requires the numerical minimization of a modified mean square error (MSE), N1, which measures the distance between the hypothetical and empirical exceedance probability functions (EPFs). This metric is defined as:

$$
N 1_{j}=\frac{1}{N} \sum_{i=1}^{N}\left(\frac{\bar{F}\left(x_{i, j}\right)}{\bar{F}_{N}\left(x_{i, j}\right)}-1\right)^{2}
$$

where $j=1, \ldots, 12$ denotes a specific month of the year, $N$ is the common sample size; $\bar{F}\left(x_{i, j}\right)$ and $\bar{F}_{N}\left(x_{i, j}\right)$ respectively denote the theoretical and empirical exceedance probabilities of the rainfall amount, $x_{i, j}$, for a given month $j$. As the performances of the four 


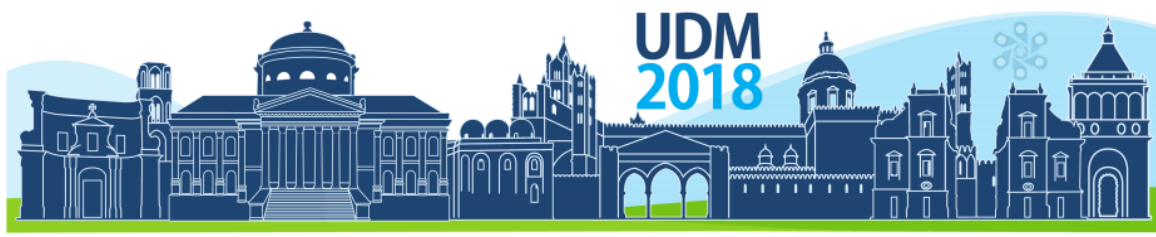

$11^{\text {th }}$ International Conference on Urban Drainage Modelling

23-26 Sep | Palermo - Italy

distributions are directly comparable according to the values given by eq. (1), the best fitting is provided by the distribution with the associated $N 1$ minimum value.

\section{RESULTS AND DISCUSSION}

The fitting performances of the considered theoretical distributions to both datasets are shown in Table 2. As expected, the Gaussian distribution shows the worst fit for both datasets, particularly for Sicily that is characterized by a dry climate with zero precipitation values, which have been properly accounted for (see e.g. Wu et al., 2007).

Table 2. Frequency of best-fit distributions for both datasets.

\begin{tabular}{|l|c|c|c|c|}
\cline { 2 - 5 } \multicolumn{1}{c|}{} & \multicolumn{4}{c|}{ Probability distribution } \\
\hline Dataset & Gamma & Lognormal & Weibull & Gaussian \\
\hline Lazio & $26 \%$ & $28 \%$ & $30 \%$ & $16 \%$ \\
\hline Sicily & $29 \%$ & $33 \%$ & $31 \%$ & $7 \%$ \\
\hline
\end{tabular}

\subsection{Evaluation of one-month SPI for the Subiaco (Lazio) and the Caltagirone (Sicily) stations}

For further analysis, we investigate here the raingages with the longest records of our datasets: Subiaco (in Lazio), and Caltagirone (in Sicily), with respectively 96 and 93 years of records. In Table 3, we report the best-fit distributions for each month of the year.

Table 3. Best-fit distributions for Subiaco and Caltagirone stations: Gamma (G), Lognormal (LN), Weibull (W) and Gaussian (N).

\begin{tabular}{|l|c|c|c|c|c|c|c|c|c|c|c|c|}
\cline { 2 - 14 } \multicolumn{1}{c|}{} & \multicolumn{10}{c|}{ Months } \\
\hline Station & Jan & Feb & Mar & Apr & May & Jun & Jul & Aug & Sep & Oct & Nov & Dec \\
\hline Subiaco & W & LN & W & G & N & G & LN & W & G & W & W & G \\
\hline Caltagirone & LN & G & W & G & G & W & LN & G & W & LN & G & N \\
\hline
\end{tabular}

Figure 1 depicts the frequency distribution of eight dry/wet categories resulting from the onemonth SPI values computed by using the standard approach (i.e., gamma-distributed monthly rainfall whose parameters are derived by maximum likelihood method) and our modified approach (i.e., monthly rainfall follows the best-fit distributions in Table 3).
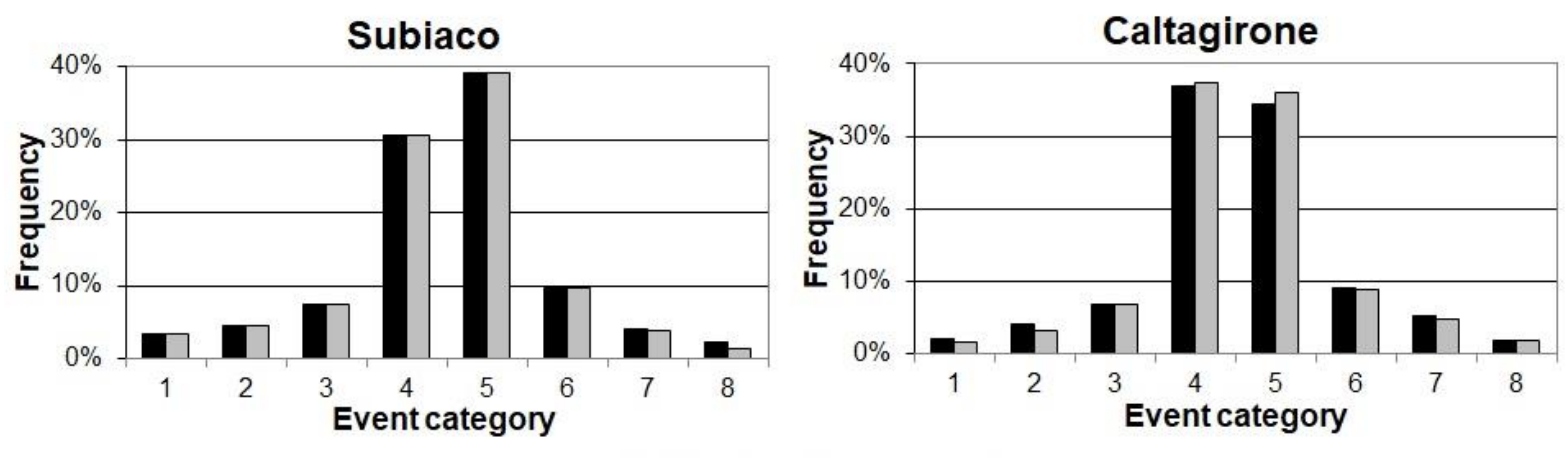

-modified approach

口standard approach 


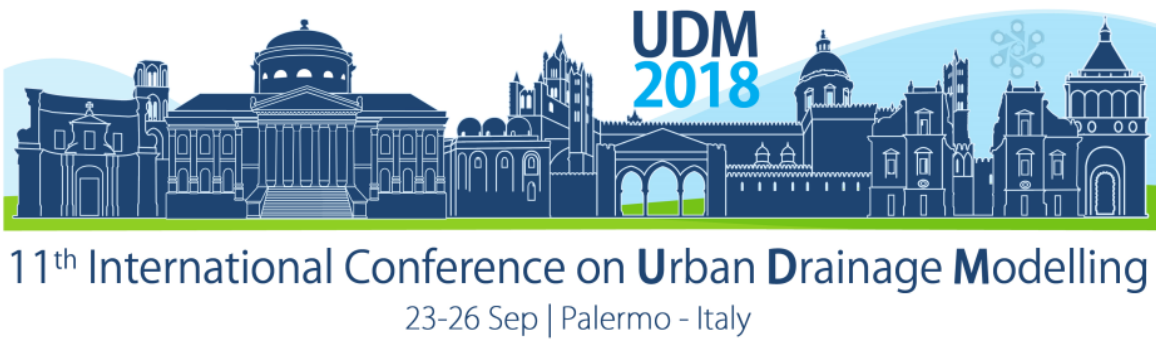

Figure 1. Frequency distribution plots of dry/wet events for the following SPI categories including: 1 denotes extremely dry (SPI $\leq-2) ; 2$ is severely dry $(-1.99<\mathrm{SPI} \leq-1.5) ; 3$ is moderately dry $(-1.49<\mathrm{SPI} \leq-1) ; 4$ is mildly dry $(-0.99<\mathrm{SPI} \leq 0) ; 5$ is mildly wet $(0<\mathrm{SPI} \leq 0.99) ; 6$ is moderately wet $(1<\mathrm{SPI} \leq 1.49)$; 7 is severely wet $(1.99$ $<\mathrm{SPI} \leq 1.5) ; 8$ is extremely wet $(\mathrm{SPI} \geq 2)$.

Results show good agreement between the two approaches, even though further analyses are required to generalize such findings.

\section{CONCLUSIONS}

In this work, we show a preliminary analysis on the role played by the nature of the probability distribution in the calculation of the one-month SPI. We compare the standard approach used in the literature (i.e., rainfall data following a gamma probability distribution whose parameters are derived by maximum likelihood method) to a different approach that assumes rainfall to be distributed according to different best-fit probability models, whose parameters and performance are determined by means of the straightforward method in eq. (1). Firstly, we use this method to fit and compare the performance of four candidate probability distributions to several long-term monthly rainfall records from two Italian regions (Lazio and Sicily) characterized by different climate regimes. The results show that the gamma distribution fits well rainfall data series from both regions, even though the Weibull and lognormal models provide better fitting results. Secondly, we compare the one-month SPI values obtained by the standard approach to those calculated by the best-fit distributions selected among the four candidates for two raingages, which are characterized by the longest records of our datasets. The use of different probability distributions does not seem to affect significantly the frequency distribution of the SPI values belonging to the eight categories suggested by the literature.

\section{References}

Adirosi, E., Baldini, L., Lombardo, F., Russo, F., Napolitano, F., Volpi, E., \& Tokay, A. (2015). Comparison of different fittings of drop spectra for rainfall retrievals. Advances in water resources, 83, 55-67.

Cancelliere, A., \& Bonaccorso, B. (2009). Uncertainty analysis of the Standardized Precipitation Index in the presence of trend. Hydrology Days, 1, 14-26.

Guttman, N. B. (1999). Accepting the standardized precipitation index: a calculation algorithm. JAWRA Journal of the American Water Resources Association, 35(2), 311-322.

Lloyd-Hughes, B., \& Saunders, M. A. (2002). A drought climatology for Europe. International journal of climatology, 22(13), 1571-1592.

Lombardo, F., Napolitano, F., Russo, F., Scialanga, G., Baldini, L., \& Gorgucci, E. (2006). Rainfall estimation and ground clutter rejection with dual polarization weather radar. Advances in Geosciences, 7, 127-130.

Madsen, H., Mikkelsen, P. S., Rosbjerg, D., \& Harremoes, P. (1998). Estimation of regional intensity-durationfrequency curves for extreme precipitation. Water Science and Technology, 37(11), 29-36.

McKee, T. B., Doesken, N. J., \& Kleist, J. (1993, January). The relationship of drought frequency and duration to time scales. In Proceedings of the 8th Conference on Applied Climatology (Vol. 17, No. 22, pp. 179-183). Boston, MA: American Meteorological Society.

Mishra, A. K., \& Singh, V. P. (2010). A review of drought concepts. Journal of hydrology, 391(1-2), 202-216.

Papalexiou, S. M., Koutsoyiannis, D., \& Makropoulos, C. (2013). How extreme is extreme? An assessment of daily rainfall distribution tails. Hydrology and Earth System Sciences, 17(2), 851-862.

Todorovic, P., \& Woolhiser, D. (1976). Stochastic Structures of the Local Pattern of Precipitation. Stochastic Approaches to Water Resources, 2.

Wu, H., Hayes, M. J., Wilhite, D. A., \& Svoboda, M. D. (2005). The effect of the length of record on the standardized precipitation index calculation. International journal of climatology, 25(4), 505-520.

Wu, H., Svoboda, M. D., Hayes, M. J., Wilhite, D. A., \& Wen, F. (2007). Appropriate application of the standardized precipitation index in arid locations and dry seasons. International Journal of Climatology, 27(1), 65-79. 


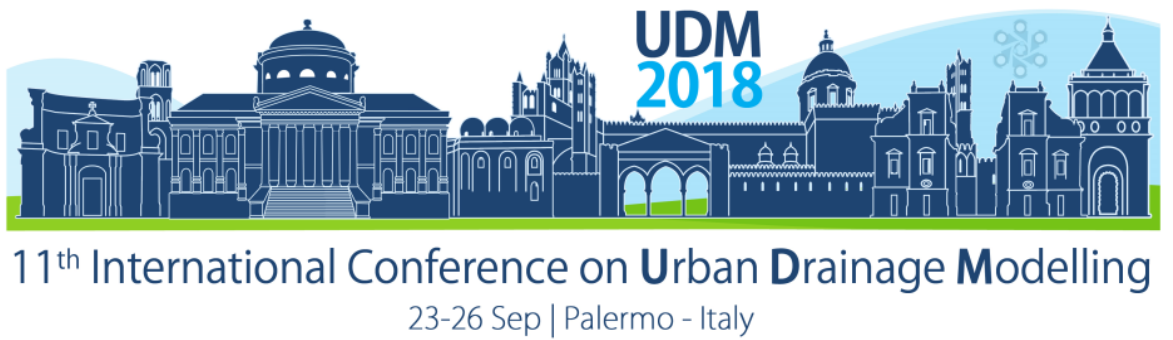

\title{
Energy Assessment of Seawater Toilet Flushing in Qatar
}

\author{
Hamish R. Mackey ${ }^{{ }^{*}}$, Saad Hafiz ${ }^{1}$ and Sami G. Al Ghamdi ${ }^{1}$ \\ ${ }^{1}$ Division of Sustainable Development, College of Science and Engineering, Hamad bin Khalifa University, Qatar \\ Foundation, Doha, Qatar. \\ *hmackey@hbku.edu.qa
}

\begin{abstract}
Seawater toilet flushing (SWTF) is an alternative water source that has been utilised in Hong Kong for economical water supply and demonstrated using other Asian case studies. Yet how the impact of SWTF translates to other regions with different water supply sources and wastewater discharge requirements remains unexplored. In this study, we look at SWTF for the water-scarce Middle East using Doha, Qatar as a case study. We demonstrate the importance of wastewater discharge conditions on the effectiveness of this technology and the role that corresponding water conservation efforts may play. Where water reuse is a baseline condition the effectiveness of SWTF is limited.
\end{abstract}

Keywords: Water resources; Scope boundary; Desalination

\section{INTRODUCTION}

Water scarcity is a severe economic and social stress for many countries and is ranked the most significant global risk with respect to impact over the coming decade (WEF, 2015). Such impacts will be especially severe in the Middle East which will include 14 of the 33 most waterstressed countries by 2040, including five countries with a water stress index of 5.0/5.0 (WRI, 2015). For this reason, this region is also the most reliant on energy-intensive desalination for water supply. Seawater toilet flushing (SWTF) is a potential technology that could benefit the regions coastal cities as an alternative to using desalinated water, as toilet flushing water requires only minimal treatment. SWTF has been utilised widely in Hong Kong for 60 years, and economically remains a preferred water supply option for the city (Tang et al., 2006; HKDEVB, 2014). Moreover, its environmental and energy benefits have been demonstrated in life cycle studies using a number of Asian cities as case studies (Liu et al., 2016). However, water supply sources and wastewater treatment and reuse regulations strongly influence the overall boundary conditions of any assessment, making outcomes of Asian case studies possibly inapplicable for other regions.

Qatar, located on a small hyper-arid peninsula within the Arabian/Persian Gulf, is one of the five countries with a predicted 2040 water stress index of 5.0/5.0. Already the municipal supply is $99 \%$ reliant on desalination (Kahramaa, 2017) and wastewater recycling is already widely implemented for landscaping and fodder crop irrigation but has limitations on further use due to social acceptance (Alhumoud \& Madzikanda, 2010). Paradoxically, the country has one of the highest levels of per capita water use globally at roughly $550 \mathrm{~L} / \mathrm{cap} / \mathrm{d}$ (Kahramaa, 2017) and intense efforts are underway to reduce this consumption. For these reasons, Qatar makes an interesting case study for seawater toilet flushing. Furthermore, Qatar, like many Gulf countries, prohibits the discharge of treated wastewater to the ocean in an effort to encourage reuse and to protect the shallow enclosed oceans, on which desalination is dependent, from eutrophication. Consequently, the increased salinity of wastewater caused by SWTF requires desalination of the resulting brackish wastewater, possibly offsetting benefits of avoiding initial 


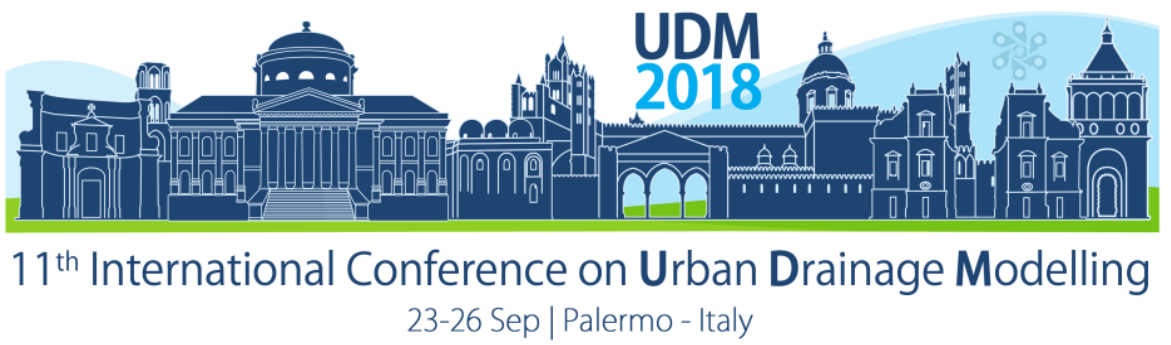

desalination. This study, therefore, assesses the suitability of seawater toilet flushing for the Middle East using Doha, Qatar as a case study.

The study focuses on the reduction in energy demand and water withdrawals that could possibly be achieved with SWTF in the region. Specific objectives assessed are understanding 1) the influence of the boundary conditions, particularly enforced wastewater reuse, on the effectiveness of SWTF compared with Asian case studies where ocean disposal and alternative water supplies were available; 2) the influence of changing household water demands on the effectiveness of SWTF, since water conservation could result in increased salinity of the wastewater if non-toilet uses are most conserved and; 3 ) the influence of desalination method as Qatar slowly shifts from thermal desalination processes to seawater reverse osmosis (SWRO) desalination.

\section{MATERIALS AND METHODS}

\subsection{Location and System Description}

In Doha, Qatar, 99\% of municipal water supply is by desalination, of which $94 \%$ is thermal technology (mainly multi-stage flash, MSF) (Kahramaa, 2017). This water is supplied from two desalination sites to the city where it is distributed to local neighbourhood pumping zones consisting of looped networks. Wastewater collected from the city is transported to one of three major wastewater treatment plants (WWTPs) and undergoes advanced treatment including ultrafiltration for irrigation purposes. Household water use for toilet flushing in Qatar and nearby regions is $11 \%$ due to high water usage for other activities (Al-Mohannadi, 2001, RTI \& EAA, 2009). The system diagram and boundary of the analysis are shown in Figure 1. As the existing wastewater treatment plant remains the same in all scenarios and data for its energy use was unavailable, it has been excluded from the analysis.

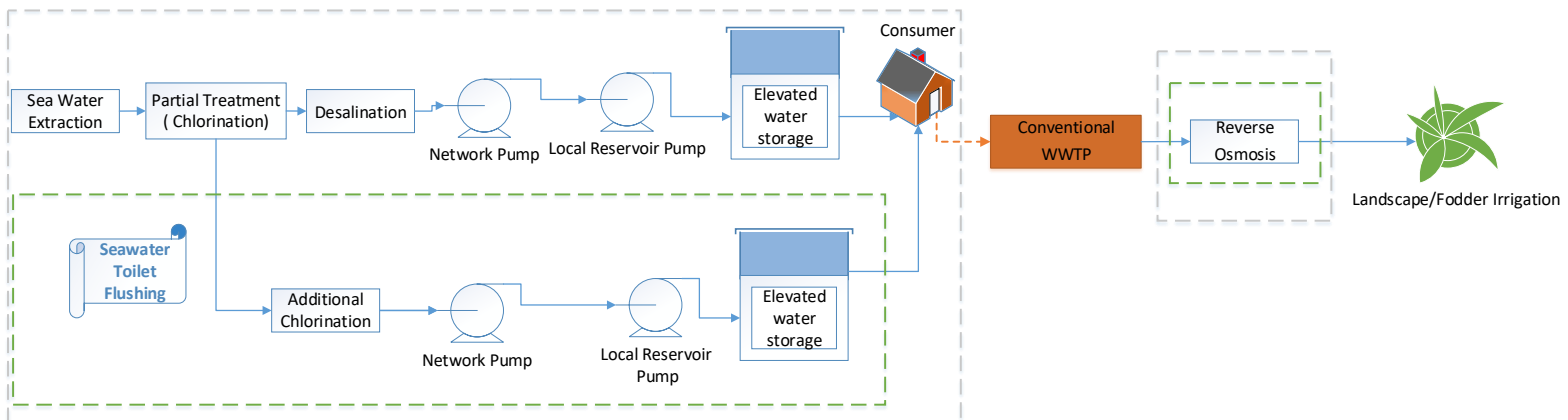

Figure 1. Schematic of the overall process. Grey-dotted lines indicate system boundary of analysis. Green-dotted lines indicate additional components in the SWTF scenario.

\subsection{Analysis Scenarios}

The study compares the existing use of MSF desalinated supply (Base-0) with the augmentation of SWTF (SWTF-0), and additionally SWTF if desalination is by SWRO (SWTF$0-R O)$. In all these cases toilet flushing is $11 \%$ of water demand. In the second stage of analysis, the impact of future water conservation efforts is considered under two extremes. In the first, all water savings occur for outdoor uses, denoted by "-O-X" where $\mathrm{X}$ is the percentage water saving. For example "SWTF-O-10" would be for the case with SWTF with a $10 \%$ water conservation based on reductions only to outdoor water use. In this case, both the salt load and volume of wastewater from the house remain constant assuming evaporation/infiltration 


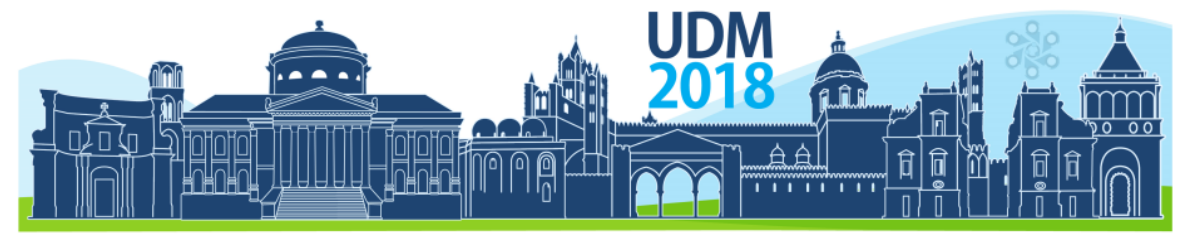

$11^{\text {th }}$ International Conference on Urban Drainage Modelling

23-26 Sep | Palermo - Italy

of all outdoor water. In the second case, all water savings were associated with indoor usage other than the toilet, causing the wastewater salinity to increase due to decreasing volume but constant salt load. This scenario was denoted by "-I-X" where X is again the percentage of water saving. The resulting flows and salinities of each scenario are given in Table 1, based on inventory data given in Section 2.3.

Table 1. Relative volumes of water for each stage of abstraction, use and disposal relative to the original Base-0 household use of $1 \mathrm{~m}^{3}$ of desalinated water.

\begin{tabular}{|c|c|c|c|c|c|c|c|c|}
\hline \multirow{2}{*}{$\begin{array}{l}\text { Water supply scenario } \\
\text { Conservation level }\end{array}$} & \multicolumn{3}{|c|}{ Base-O } & \multirow{2}{*}{$\begin{array}{l}\text { SWTF } \\
0 \%\end{array}$} & \multicolumn{2}{|c|}{ SWTF-O } & \multicolumn{2}{|c|}{ SWTF-I } \\
\hline & $0 \%$ & $10 \%$ & $20 \%$ & & $10 \%$ & $20 \%$ & $10 \%$ & $20 \%$ \\
\hline Water desalinated & 1.064 & 0.957 & 0.851 & 0.947 & 0.827 & 0.705 & 0.827 & 0.705 \\
\hline Seawater abstracted & 0 & 0 & 0 & 0.117 & 0.117 & 0.117 & 0.117 & 0.117 \\
\hline $\begin{array}{l}\text { In-house desalinated water } \\
\text { use }\end{array}$ & 1 & 0.9 & 0.8 & 0.89 & 0.79 & 0.69 & 0.79 & 0.69 \\
\hline In-house SWTF use & 0 & 0 & 0 & 0.11 & 0.11 & 0.11 & 0.11 & 0.11 \\
\hline To sewer & 0.550 & 0.550 & 0.550 & 0.550 & 0.550 & 0.550 & 0.495 & 0.440 \\
\hline Wastewater salinity (g/L) & 1 & 1 & 1 & 1.80 & 1.80 & 1.80 & 1.86 & 1.95 \\
\hline
\end{tabular}

\subsection{Data Inventory}

Data used in the project was from 2016 and 2017 and were collected from Qatar's sole water utility provider and Qatar's Ministry of Development Planning and Statistics.

Desalination. Energy requirements for MSF are $4 \mathrm{kWh} / \mathrm{m}^{3}$ electrical energy for mechanical equipment and $16 \mathrm{kWh} / \mathrm{m}^{3}$ electrical equivalent of thermal energy capable of driving a steam turbine (Darwish et al., 2016). Energy for SWRO is $4.5 \mathrm{kWh} / \mathrm{m}^{3}$ including pretreatment.

Transmission Main and Looped Network Conveyance. Desalinated water is conveyed from two locations via a connected ring transmission corridor consisting of $2 \times 1600 \mathrm{~mm}$ DN ductile iron pipes with a total length of $168 \mathrm{~km}$ per pipeline. Headloss was calculated using the Darcy Weisbach and Colebrook-White method using an estimated pumping velocity of $2.1 \mathrm{~m} / \mathrm{s}$ based on water demand (MDPS, 2017). Velocities were adjusted according to flow reductions caused by SWTF implementation. Pumps were assumed to have an efficiency of $85 \%$ and the static pressure requirement in the system was taken as $10 \mathrm{~m}$ head, which had negligible influence on the specific pumping energy. Pumping energy of $0.015 \mathrm{kWh} / \mathrm{m}^{3}$ was provided for by the local water utility for the looped distribution system within the city after it has been pumped to a neighbourhood reservoir. The total loss in the transmission and neighbourhood network is $6 \%$ (Kahramaa, 2017). For the SWTF system, a conceptual ring main was laid around Doha with a length of $60 \mathrm{~km}$ and with a design velocity of $2.1 \mathrm{~m} / \mathrm{s}$. Sensitivity analysis of the SWTF ring main design (data not shown) indicated no significant influence on the analysis outcomes.

Wastewater Treatment. The current fraction of household water supply entering the sewerage network is 55\%, with the remainder assumed to go to outdoor uses (MDPS, 2017). No data was available for the sewerage network or treatment plant design/operation that may influence energy use. Therefore these were excluded from the boundary. The primary consideration for the WWTP is the need for RO desalination for any further increase in wastewater salinity beyond the existing baseline of $1000 \mathrm{mg} / \mathrm{L}$ TDS. Energy requirements for the WWTP RO at 


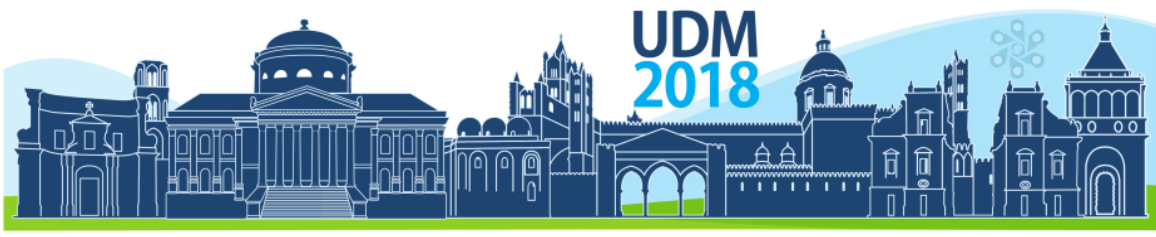

$11^{\text {th }}$ International Conference on Urban Drainage Modelling

23-26 Sep | Palermo - Italy

varying salinities was calculated using Hydranautics IMS Design software where the SWTF contribution is 42,000 mg-TDS/L-seawater based on Arabian Gulf salinity (Beltagy, 1983).

\section{RESULTS AND DISCUSSION}

\subsection{Total Energy Comparison}

All options relative to the base case provided an overall energy saving due to the significant contribution of thermal energy used in the MSF process that could otherwise be utilised for work to generate electrical energy (Figure 2). However, when only considering mechanical energy utilised in the processes SWTF no longer became advantageous compared to the base case, showing a small increase due to the WWTP RO. Water conservation efforts towards internal use were more effective than outdoor use due to the reduction in wastewater flows, despite causing a higher water salinity to the WWTP RO (Table 1). However, these differences were minute. The results also indicate that if SWRO is used for seawater desalination, then SWTF would not be advantageous, given the higher mechanical energy requirements of SWRO. In all cases, conveyance energy requirements were negligible compared to desalination both for supply and for wastewater treatment.

\subsection{Volumetric Energy Requirement}

In the case of outdoor water conservation SWTF led to increasing specific mechanical energy requirements with increasing water conservation due to the increase of salinity in the wastewater without a reduction in volume. When considering total energy, a small difference was observed in specific energy requirements between the options, with the difference for SWTF between indoor and outdoor conservation almost negligible. A change in the portion of water used inside the house (i.e. going to the sewer) led to little change in the overall energy comparison but led to significantly closer specific energy requirements (data not shown).
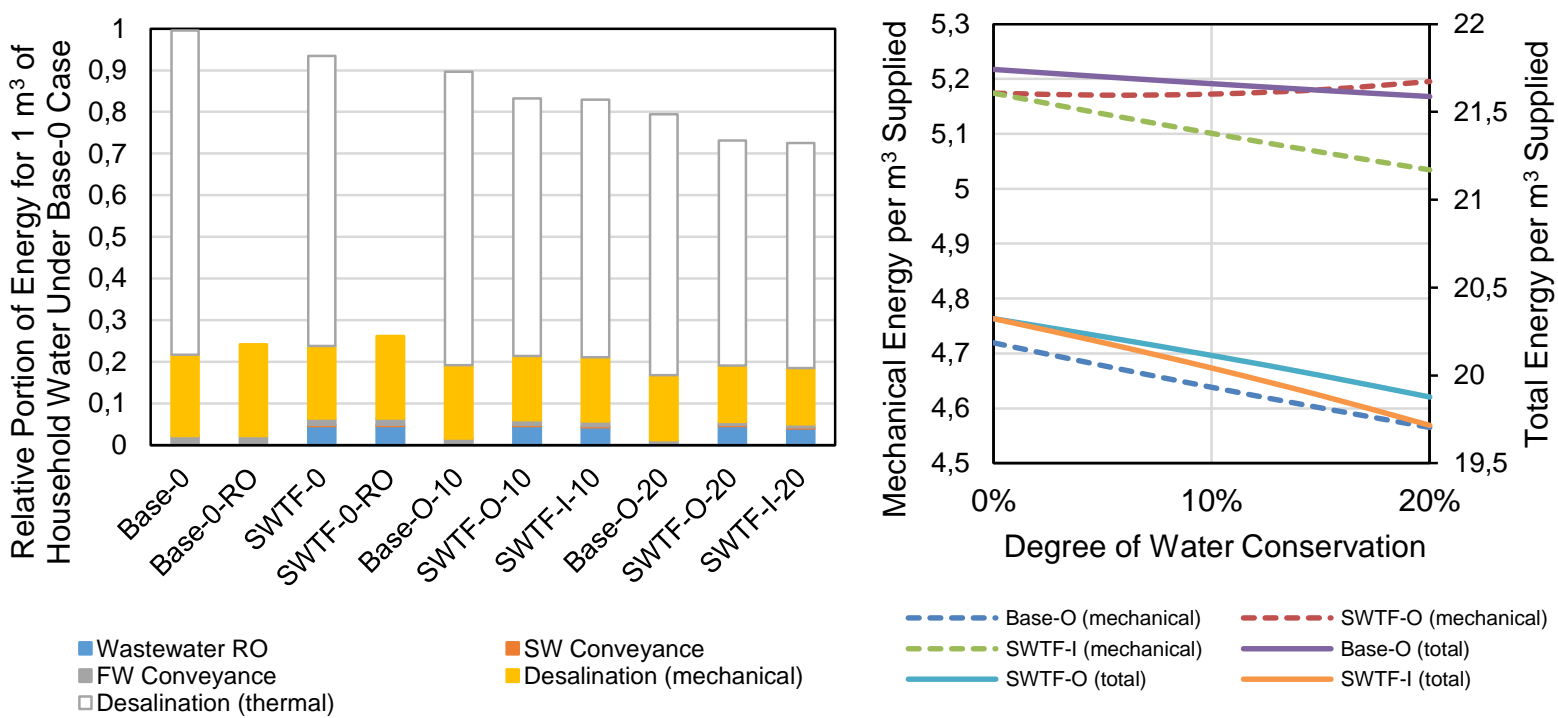

Figure 2. Comparison of the energy requirements for the different scenarios showing relative contributions to the base case from different system components (left) and absolute specific energy requirements (right). 


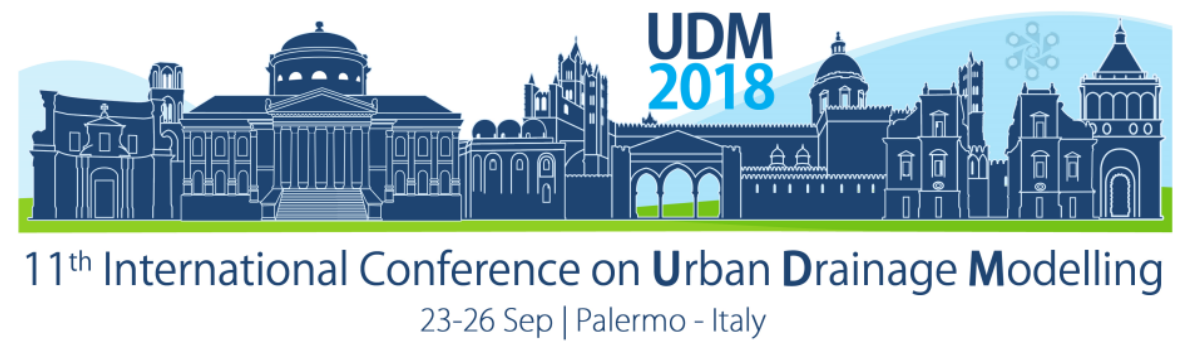

\subsection{System Boundary Considerations}

Existing studies demonstrating SWTF systems as environmentally and cost competitive have started with a base case of surface/imported water supply and ocean discharge of treated wastewater (Tang et al., 2006; Liu et al., 2016). However, for a city to consider a dual network for toilet flushing indicates high water-stress and therefore that existing desalination or water reuse is likely existing or also planned. In this study the MSF water supply system should favour SWTF, being the most energy intensive option available. Despite this, SWTF showed only minor improvements in total energy. When compared with SWRO, a more popular but still energy-intensive desalination process, it was more disadvantageous to co-implement SWTF than solely desalinate. Only in cases where water scarcity is less severe surface water or groundwater supplies may still exist, but in these scenarios SWTF is at an even higher energy penalty if water reuse is implemented. Another critical consideration of genuinely water-scarce cities is water availability which also does not favour SWTF. For instance, the water savings available through water reuse is considerably greater than that of SWTF as it makes use of all internal house water (55\% vs $11 \%$ in Qatar case). Thus, for very water-scarce cities, the choice of SWTF does not seem to be advantageous, especially in light of construction costs and additional maintenance requirements (Tang et al., 2006).

\section{CONCLUSIONS}

This work demonstrates the importance of existing wastewater discharge conditions on the effectiveness of proposed water supply strategies, namely SWTF. In the Middle East case, despite a reliance on high-energy thermal desalination for water supply, the case for SWTF does not appear strong due to energy requirements for water reuse RO. Water conservation efforts in conjunction with SWTF and water reuse create a tradeoff between reduced treatment volume and increasing salinity resulting in reduced benefits. It is therefore recommended to only focus on water reuse and conservation within severely water-stressed cities.

\section{References}

Al-Mohannadi, H.I. (2001) Water resources in the State of Qatar: toward holistic management. Doctoral thesis, University of Huddersfield.

Aluhumoud, J.M. and Madzikanda, M. (2010) Public perceptions on water reuse options: the case of Sulaibiya Wastewater Treatment Plant in Kuwait. Int. Bus. Econ. Res. J. 9(1), 141-158.

Beltagy, A.I. (1983) Some oceanographic measurements in the Gulf waters around Qatar Peninsula. Qatar Univ. Sci. Bull. 3, 329-341.

Darwish, M.A., Abdulrahim, H.K., Hassan A.S. (2016) Realistic power and desalted water production costs in Qatar. Desalin. Water Treat. 57(10), 4296-4302.

HK-DEVB (2014) Examination of estimates of expenditure 2014-2015, Question No 2504, Reply DEVB(W)121. Development Bureau, Hong Kong.

Kahramaa (2017) Annual statistics report 2017. General Electricity and Water Corporation, Doha, Qatar.

Liu, X., Dai, J., Jiang, F., Chen, G., Chui, H.-K., van Loosdrecht, M.C.M. (2016) Sustainable application of a novel water cycle using seawater for toilet flushing. Engineering 2, 460-469.

Luo, T., Young, R. and Reig, P. (2015) Aqueduct projected water stress country rankings. Technical Note. Water Resources Institute, Washington DC, USA.

MDPS (2017) Water statistics in the State of Qatar 2015. Ministry of Development Planning and Statistics, Doha, Qatar.

RTI \& EAA (2009) Demand-Side Management for Electricity and Water Use in Abu Dhabi, Report by RTI \& Executive Affairs Authority, Abu Dhabi, UAE.

Tang, S.L., Yue, D.P.T., Li, X.Z. (2006) Comparison of engineering costs of raw freshwater, reclaimed water and seawater for toilet flushing in Hong Kong. Water Env. J. 20, 240-247.

WEF (2015) Global risk report 2015. World Economic Forum, Switzerland. 


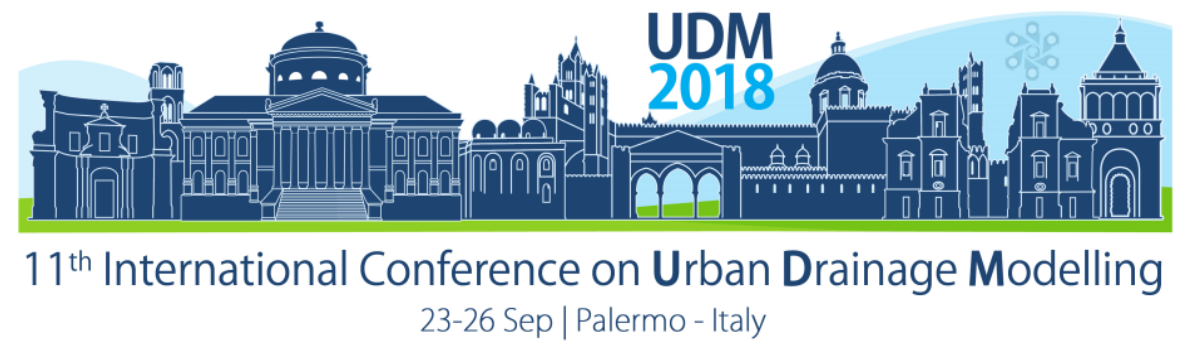

\title{
Modelling climate changes impacts in a subtropical urban drainage
}

\author{
César Ambrogi Ferreira do Lago', Marina Batalini de Macedo ${ }^{1}$ and Eduardo Mario Mendiondo ${ }^{1}$ \\ ${ }^{1}$ University of Sao Paulo, Sao Carlos School of Engineering, Sao Carlos, Brazil \\ Av. Trab. São-Carlense, 400, Parque Arnold Schimidt, São Carlos, SP, 13566-590.
}

\begin{abstract}
It is expected that climate changes will increase water insecurity, leading to many negative consequences to economy and human health. Therefore, it is important to estimate such impacts for a more precise water management. In this study, the runoff quality was estimated for four two different climate changes scenarios (RCP 4.5 and 8.5) in a subtropical urban catchment. Climate changes rainfall data were acquired thorugh Brazilian National Institute for Space Research (Inpe). This data was desegregated to a 5 minutes time resolution through modified Bartlett-Lewis to simulate runoff quantity. Then, the buildup/washoff model was used for runoff quality predictions, which was properly calibrated and validated. According to Inpe's data, it is expected that rainfall volume will decrease in $51 \%$ if RCP 8.5 scenario prevail. The decrease in rainfall volume will result in lower runoff volumes with higher concentration of pollutants. The impacts of climate changes on pollutants concentration depends on their buildup/washoff characteristics. Pollutants with low $w 1$ have softer concentration increase, such as nitrite $\left(\mathrm{NO}_{2}\right)$ with an increase around $4 \%$ until the end of the century. While pollutants with high w1, and low b2, have a more significant concentration increase, like iron (Fe) and total organic carbon (TOC) with an increase over $60 \%$ and $70 \%$ on their concentration, respectively. In addition to the rainfall volume decrease, and consequentially in water supply, climate change will also decrease the quality of water bodies in Sao Carlos. Preventive actions should be included in the urban planning of Sao Carlos, to avoid future water insecurity.
\end{abstract}

Keywords: Climate changes; subtropical urban catchment; runoff quality

\section{INTRODUCTION}

One of the main consequences of urbanization is the change in the hydrological cycle. It generates a soil imperviousness, resulting in an increase of the runoff volume (Guan, Sillanpää, \& Koivusalo, 2015), and consequently in higher risks of floods (Sun et al. 2017) with greater amount of pollutants carried (Flecther, Andrieu \& Hamel, 2013), compromising the quality of urban rivers.

Different climates also generate different hydrological responses that may interfere in the runoff generation. In tropical climates for example, high intensity rainfalls result in a faster runoff response (Piro \& Carbone, 2014), where the pollutants are washed faster. In these areas, especially, the phenomenon involved in stormwater quality need to be better understood for more assertive quality models (Obropta \& Kardos , 2007).

It is expected that climate change will increase water insecurity, reducing water supply. (Chou et al., 2014-a; Chou et al.; 2014-b; Lyra et al, 2017). This phenomenon may also alter precipitation regime, and therefore the runoff generation processes.

This study evaluated the impacts of two climate changes scenarios (RCP 4.5 and 8.5) on the runoff quality in a subtropical urban catchment, according to the buildup and washoff characteristics of the pollutant.

\section{MATERIALS AND METHODS}




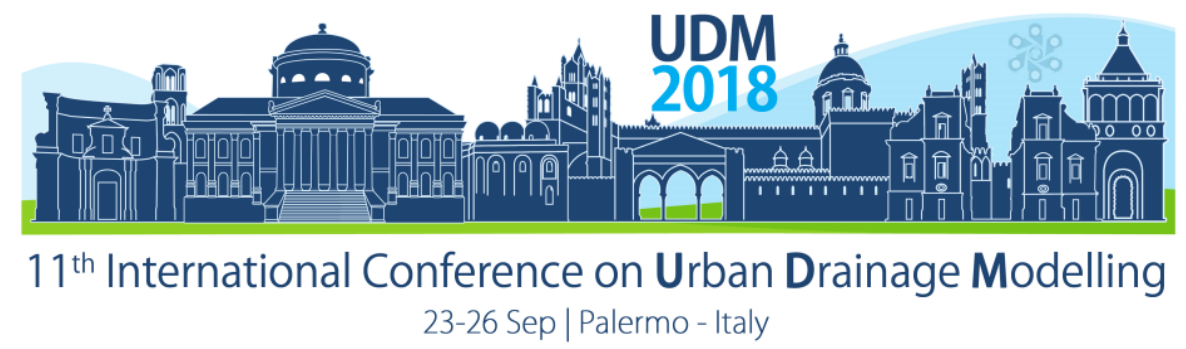

The studied catchment has a 2.3 ha area with $22 \%$ of imperviousness, located in Campus 2 at the University of São Paulo (USP), São Carlos- Brazil, with a Cfa climate classification as Köppen e Geiger.

Two climate changes scenarios were evaluated (the RCP 4.5 and 8.5) for four future timeslots (2020-2039, 2040-2059, 2060-2079, 2080-2099), which were compared to the present date from 1980 to 1999 . The climate changes scenarios were downscaled from HadGEM2-ES thorough $5 \times 5 \mathrm{~km}$ Eta model by Brazilian National Institute for Space Research (Inpe), acquired in projeta.cptec.inpe.br. (Chou et al., 2014-a; Chou et al.; 2014-b; Lyra et al, 2017).

The acquired rainfall data had a resolution 3 hours, which was desegregated by the modified Bartlett-Lewis model to a 5 minutes resolution. The desegregation process was calibrated with observed rainfall between 2013 and 2017. The desegregated rainfall series was used in SWMM for runoff quantity predictions and then the buildup/washoff model was used for quality.

Eleven monitored events were used to calibrate the runoff volume and pollutants mass, the quantity was simulated using PCSWMM software and quality with buildup/ washoff exponential equations. A load-based quality calibration was performed, as it presented better proximity between observed and predicted mass when compared to concentration-based. Six pollutants were analyzed: iron ( $\mathrm{Fe})$, nitrate $\left(\mathrm{NO}_{3}\right)$, nitrite $\left(\mathrm{NO}_{2}\right)$, total organic carbon (TOC), phosphate $\left(\mathrm{PO}_{4}\right)$ and zinc $(\mathrm{Zn})$. Table 1 presents each pollutant buildup and washoff coefficients.

Table 1: Pollutants washoff and buildup characteristics

\begin{tabular}{|c|c|c|c|c|}
\hline & Wasl & off & Bui & dup \\
\hline & $w 1$ & $w 2$ & $\begin{array}{c}b 1 \\
\text { (kg/ha) }\end{array}$ & $\begin{array}{c}b 2 \\
\text { (1/days) }\end{array}$ \\
\hline $\mathrm{Fe}$ & 0.36 & 0.67 & 0.36 & 0.029 \\
\hline $\mathrm{NO}_{3}$ & 0.011 & 0.45 & 0.82 & 0.0078 \\
\hline $\mathrm{NO}_{2}$ & 0.0012 & 0.86 & 0.08 & 0.024 \\
\hline TOC & 0.051 & 0.91 & 5.5 & 0.0046 \\
\hline $\mathrm{PO}_{4}$ & 0.12 & 1.07 & 0.012 & 0.033 \\
\hline $\mathrm{Zn}$ & 0.098 & 1.04 & 0.021 & 0.029 \\
\hline
\end{tabular}

\section{RESULTS AND DISCUSSION}

\subsection{Climate changes impacts}

Table 2 shows the climate change impacts on the temperature, precipitation, and runoff quantity and quality. For the less optimistic scenario, RCP 8.5, an increase of approximately $8^{\circ} \mathrm{C}$ in the average air temperature and a fall of $51 \%$ in the rainfall volume are expected. If the RCP scenario 4.5 occurs, it is estimated that the impacts will be milder, with an increase of almost $5^{\circ} \mathrm{C}$ in the air temperature and a fall of $13 \%$ in the precipitation.

Table 2: Temperature and precipitation in climate changes scenarios 


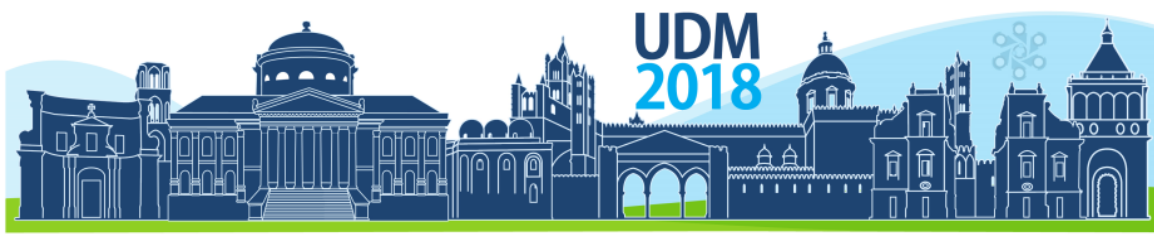

$11^{\text {th }}$ International Conference on Urban Drainage Modelling

23-26 Sep | Palermo - Italy

\begin{tabular}{|c|c|c|c|c|c|c|c|c|c|c|c|}
\hline & \multirow{2}{*}{$\begin{array}{l}1980- \\
1999\end{array}$} & \multicolumn{2}{|c|}{ 2020-2039 } & \multicolumn{2}{|c|}{ 2040-2059 } & \multicolumn{2}{|c|}{ 2060-2079 } & \multicolumn{2}{|c|}{ 2080-2099 } & \multicolumn{2}{|c|}{$\begin{array}{c}\text { Difference in } 1 \\
\text { century }\end{array}$} \\
\hline & & 4.5 & 8.5 & 4.5 & 8.5 & 4.5 & 8.5 & 4.5 & 8.5 & 4.5 & 8.5 \\
\hline Average Tem & 21.35 & 24.46 & 25.40 & 24.39 & 25.65 & 25.79 & 27.42 & 26.01 & 29.43 & 4.66 & 8.08 \\
\hline Total Precipitation (mm) & 38926 & 23394 & 20093 & 27548 & 26649 & 23938 & 23061 & 23031 & 18771 & $-41 \%$ & $-51 \%$ \\
\hline
\end{tabular}

\subsection{Runoff quantity and quality estimation}

Table 3 presents the effects of climate changes on runoff quantity and quality. The input runoff depth in the period between 1980 and 2000 is higher than all future periods for both scenarios. It falls to the 2020-2039 period, has an increment for the next period and continuously falls until 2080-2099. In 100 years, the drop in surface runoff is greater than the pollutants fall. The pollutant with the highest decrease was $\mathrm{NO}_{2}$ with low coefficient $\mathrm{w} 1$, tending to follow the decrease in runoff volume. Fe with the highest w1 was the pollutant with the second lowest percentage drop. TOC, with lower exponent buildup b2, had a drop of only $2.3 \%$ in 100 years in both scenarios.

Table 3: Estimated climate changes impact runoff and pollutants washoff.

\begin{tabular}{|c|c|c|c|c|c|c|c|c|c|c|c|}
\hline & \multirow{2}{*}{$1980-2000$} & \multicolumn{2}{|c|}{$2020-2040$} & \multicolumn{2}{|c|}{$2040-2060$} & \multicolumn{2}{|c|}{$2060-2080$} & \multicolumn{2}{|c|}{$2080-2100$} & \multicolumn{2}{|c|}{ Difference in 1 century } \\
\hline & & 4.5 & 8.5 & 4.5 & 8.5 & 4.5 & 8.5 & 4.5 & 8.5 & 4.5 & 8.5 \\
\hline Runoff (mm) & 7393.2 & 4296.5 & 3512.0 & 5267.9 & 4971.6 & 4551.3 & 4408.0 & 4153.4 & 3486.9 & $-43.8 \%$ & $-52.8 \%$ \\
\hline $\mathrm{Fe}(\mathrm{g} / \mathrm{ha})$ & 5425.1 & 5209.7 & 5060.8 & 5161.7 & 5216.6 & 4983.4 & 4964.3 & 5056.5 & 4948.7 & $-6.8 \%$ & $-8.8 \%$ \\
\hline NO3 (g/ha) & 2473.3 & 2181.4 & 2015.8 & 2210.6 & 2187.2 & 2076.0 & 2032.0 & 2092.3 & 1911.1 & $-15.4 \%$ & $-22.7 \%$ \\
\hline NO2 (g/ha) & 64.7 & 39.7 & 33.0 & 46.8 & 44.4 & 40.7 & 39.3 & 37.8 & 31.8 & $-41.6 \%$ & $-50.8 \%$ \\
\hline PO4 (g/ha) & 172.9 & 152.6 & 141.6 & 154.5 & 156.6 & 144.0 & 145.0 & 148.0 & 140.2 & $-14.4 \%$ & $-18.9 \%$ \\
\hline TOC (g/ha) & 14178.4 & 14271.7 & 13768.3 & 13891.7 & 14046.5 & 13687.7 & 13685.2 & 13858.0 & 13855.5 & $-2.3 \%$ & $-2.3 \%$ \\
\hline $\mathrm{Zn}(\mathrm{g} / \mathrm{ha})$ & 264.1 & 232.7 & 216.1 & 236.4 & 239.6 & 220.3 & 222.0 & 211.2 & 213.6 & $-20.0 \%$ & $-19.1 \%$ \\
\hline
\end{tabular}

Lower precipitation frequency on both scenarios results in higher pollutants accumulation, which tend to be washed more easily for those with higher w1. It explains why the pollutants with higher w1 has a lower decrease in climate changes scenarios.

TOC has the lowest decrease due to its small buildup recovery rate. With more frequent rainfall events from 1980 to 1999, it becomes harder to recover its maximum buildup. With climate changes, however, longer dry times allow this pollutant to reach higher buildup levels, explaining the lower mass drop of this pollutant in 100 years.

Since the pollutants mass decrease is softer than runoff volumes, their Event Mean Concentration (EMC) must increase with climate change, as shown in table 4 . The concentration of TOC is the most affected by climate change, while NO2 has the lowest growth.

A relation can be observed between runoff quantity and quality. The periods with greater runoff depths have the lower pollutants concentrations, which means that lower rainfall volumes generally results in higher pollutants EMC.

Dry period between rainfalls also influences the pollutants EMC. The dry periods between each rainfall event for both scenarios from 2020 to 2099 were measured for comparison.

The scenario 4.5 has an average of $48( \pm 115)$ hours of dry period between rainfall events and tend to have higher EMCs when compared to 8.5 , which has an average of 40 ( \pm 89$)$ dry hours 


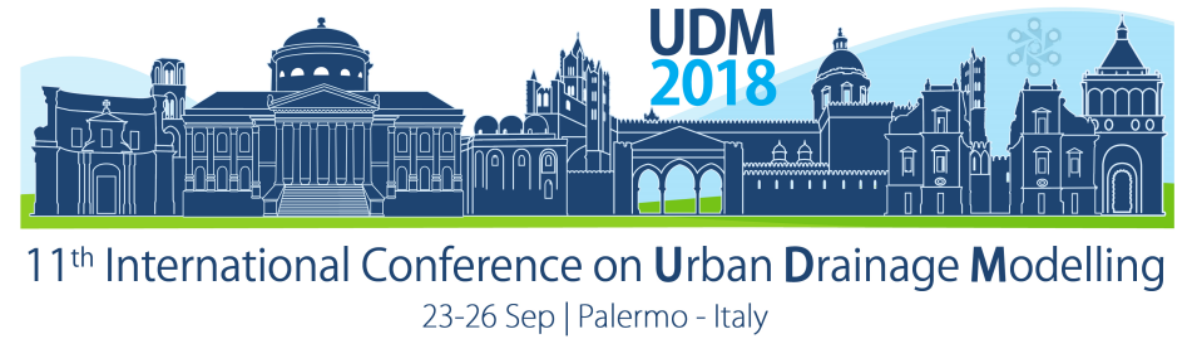

between events. This higher dry period between events in the 4.5 scenario was enough to result in poorer runoff quality.

Table 4: Pollutants EMC under climate changes

\begin{tabular}{|c|c|c|c|c|c|c|c|c|c|c|c|}
\hline & \multirow{2}{*}{$1980-2000$} & \multicolumn{2}{|c|}{ 2020-2040 } & \multicolumn{2}{|c|}{$2040-2060$} & \multicolumn{2}{|c|}{ 2060-2080 } & \multicolumn{2}{|c|}{$2080-2100$} & \multicolumn{2}{|c|}{ Difference in 1 century } \\
\hline & & 4.5 & 8.5 & 4.5 & 8.5 & 4.5 & 8.5 & 4.5 & 8.5 & 4.5 & 8.5 \\
\hline $\mathrm{Fe}(\mathrm{g} / \mathrm{ha})$ & 0.73 & 1.21 & 1.2 & 0.98 & 1 & 1.1 & 1.1 & 1.22 & 1.2 & $65.91 \%$ & $62.37 \%$ \\
\hline NO3 (g/ha) & 0.33 & 0.51 & 0.47 & 0.42 & 0.42 & 0.46 & 0.45 & 0.5 & 0.46 & $50.58 \%$ & $37.54 \%$ \\
\hline NO2 (g/ha) & 0.0088 & 0.0092 & 0.0077 & 0.0089 & 0.0084 & 0.0089 & 0.0086 & 0.0091 & 0.0091 & $3.95 \%$ & $3.95 \%$ \\
\hline PO4 (g/ha) & 0.023 & 0.036 & 0.033 & 0.029 & 0.03 & 0.032 & 0.032 & 0.036 & 0.034 & $52.35 \%$ & $44.41 \%$ \\
\hline TOC (g/ha) & 1.9 & 3.32 & 3.2 & 2.64 & 2.7 & 3.01 & 3 & 3.34 & 3.3 & $73.98 \%$ & $73.95 \%$ \\
\hline Zn (g/ha) & 0.036 & 0.054 & 0.05 & 0.045 & 0.045 & 0.048 & 0.049 & 0.051 & 0.051 & $42.35 \%$ & $43.96 \%$ \\
\hline
\end{tabular}

\section{CONSLUSIONS}

Rainfall volumes in Sao Carlos tend to decrease in the future, which may compromise the water supply in the region. In addition, it will result in higher pollutants concentration, degrading the water bodies quality, that will already have their discharges effected.

The correlation of the buildup and washoff characteristics of each to their EMCs changes over the years were briefly discussed. In summary, climate changes have lower impact on pollutants with low coefficient w1. The higher EMC increases were observe for those with higher w1 and smaller b2.

This study shows how climate changes raises water insecurity, not only quantitative but also in qualitative aspect. It also highlights the importance of using alternative technologies, such as low impact developments (LID) to ameliorate water quality in urban areas.

\section{References}

Chou, S. C., Lyra, A., Mourão, C., Dereczynski, C., Pilotto, I., Gomes, J., ... \& Campos, D. (2014). Evaluation of the Eta simulations nested in three global climate models. American Journal of Climate Change, 3(5), 438-454.

Chou, S. C., Lyra, A., Mourão, C., Dereczynski, C., Pilotto, I., Gomes, J., ... \& Campos, D. (2014). Assessment of climate change over South America under RCP 4.5 and 8.5 downscaling scenarios. American Journal of Climate Change, 3(5), 512-525.

Guan, M., Sillanpää, N., \& Koivusalo, H., 2015. Modelling and assessment of hydrological changes in a developing urban catchment. Hydrological Processes, 29(13), 2880-2894.

Fletcher, T. D., Andrieu, H., \& Hamel, P., 2013. Understanding, management and modelling of urban hydrology and its consequences for receiving waters: A state of the art. Advances in Water Resources, 51, 261-279.

Lyra, A., Tavares, P., Chou, S. C., Sueiro, G., Dereczynski, C., Sondermann, M., ... \& Giarolla, A. (2016). Climate change projections over three metropolitan regions in Southeast Brazil using the non-hydrostatic Eta regional climate model at 5-km resolution. Theoretical and Applied Climatology, 1-20.

Obropta, C. C., \& Kardos, J. S. (2007). Review of urban stormwater quality models: deterministic, stochastic, and hybrid approaches. JAWRA Journal of the American Water Resources Association, 43(6), 1508-1523.

Piro, P., \& Carbone, M. (2014). A modelling approach to assessing variations of total suspended solids (TSS) mass fluxes during storm events. Hydrological Processes, 28(4), 2419-2426.

Sun, S., Barraud, S., Branger, F., Braud, I., \& Castebrunet, H., 2017. Urban hydrologic trend analysis based on rainfall and runoff data analysis and conceptual model calibration. Hydrological Processes, 31(6), 1349-1359. 


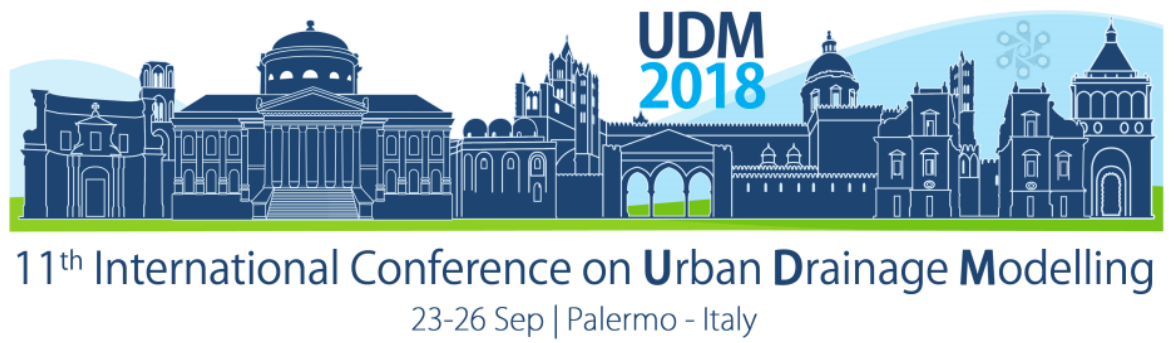

\title{
Heavy metals in wash-off from facade and road surface
}

\author{
Zhenyu Wang ${ }^{1}$, Pei Hua ${ }^{1}$, Afshin Sadeghikhah ${ }^{1}$, Jin Zhang ${ }^{2 \star}$, Peter Krebs ${ }^{1}$ \\ 1 Institute of Urban Water Management, Technische Universität Dresden, 01062 Dresden, Germany \\ *Corresponding author's e-mail: zhenyu.wang19@gmail.com, iin.zhang@hotmail.com \\ 2 Institute of Groundwater and Earth Sciences, Jinan University, 510632 Guangzhou, China
}

\begin{abstract}
Heavy metals adsorbed onto particles have been regarded as an important pollution sources in urban surface runoff. $\mathrm{Cu}$ (copper), $\mathrm{Zn}$ (zinc) and $\mathrm{Cd}$ (cadmium) on two different surface, facade and road, were determined in the study. Direct sucking (DS) and runoff $(\mathrm{RO})$ methods were used to collect the samples. Results found that DS method would collect more particles than RO method due to stronger suction power of the vacuuming collector and, therefore, DS method can be represented as wash-off process during strong storm event. Besides, the gravity force and different surface properties between road and facade yielded the result that more heavy metals accumulated on road than facade. Finally, the influence of non-melt snow on amount of surface heavy metals was also found in the study.
\end{abstract}

Keywords: Heavy metals; Road and facade; Wash-off

\section{INTRODUCTION}

Stormwater pollution has gained an increasing amount of attention since the high toxic pollutants mainly contributed by traffic activities are found in surface runoff. The priority pollutants regulated by EPA include heavy metals (Zhang et al., 2015a, b; Trujillo-González et al., 2016), polycyclic aromatic hydrocarbon (Liu et al., 2017), etc. Especially heavy metals are of great concern in stormwater pollution due to their toxicity, persistence and abiotic degradation in the environment and bioaccumulation in food webs (Al-Najjar et al., 2011; Dhanakumar et al., 2013). They can be accumulated on impervious surface during antecedent period of dry weather and be washed off by stormwater runoff from surface in precipitation events. Though there are large numbers of studies considering wash-off process of heavy metals, most studies only focus on road runoff pollution and neglect other potential surfaces like facade, which also contains priority pollutants. Besides, considering sampling collection, there are several wash-off sampling methods mentioned in many studies (Egodawatta et al. 2009; Amato et al., 2010; Davis. \& Birch, 2010; Zhang et al., 2017), which have pros and cons. The focuses of this study are, therefore, to (i) evaluate the pollution potential of heavy metals from both facade and road and (ii) compare different sample collection techniques regarding to wash-off process.

\section{MATERIALS AND METHODS}

\subsection{Study area}

The sampling area is located on George-Bähr-Straße within the campus of Technische Universität Dresden, Germany. All building facade along the street is made from the same materials, bricks and mortar, and the road is paved also with a uniform material, asphalt. The sampling street is near Bergstraße and Nürnberger str. with high traffic load which is $13600-$ 


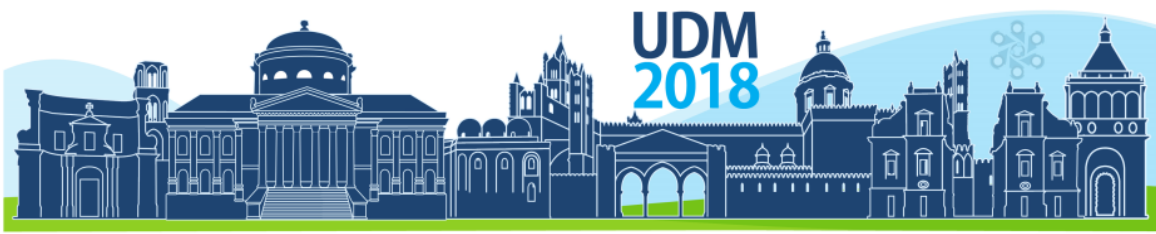

$11^{\text {th }}$ International Conference on Urban Drainage Modelling

23-26 Sep | Palermo - Italy

15000 vehicles mobilize per day (Landeshauptstadt Dresden, 2010). There are three sampling sites selected along George-Bähr-Straße (Fig. 1).

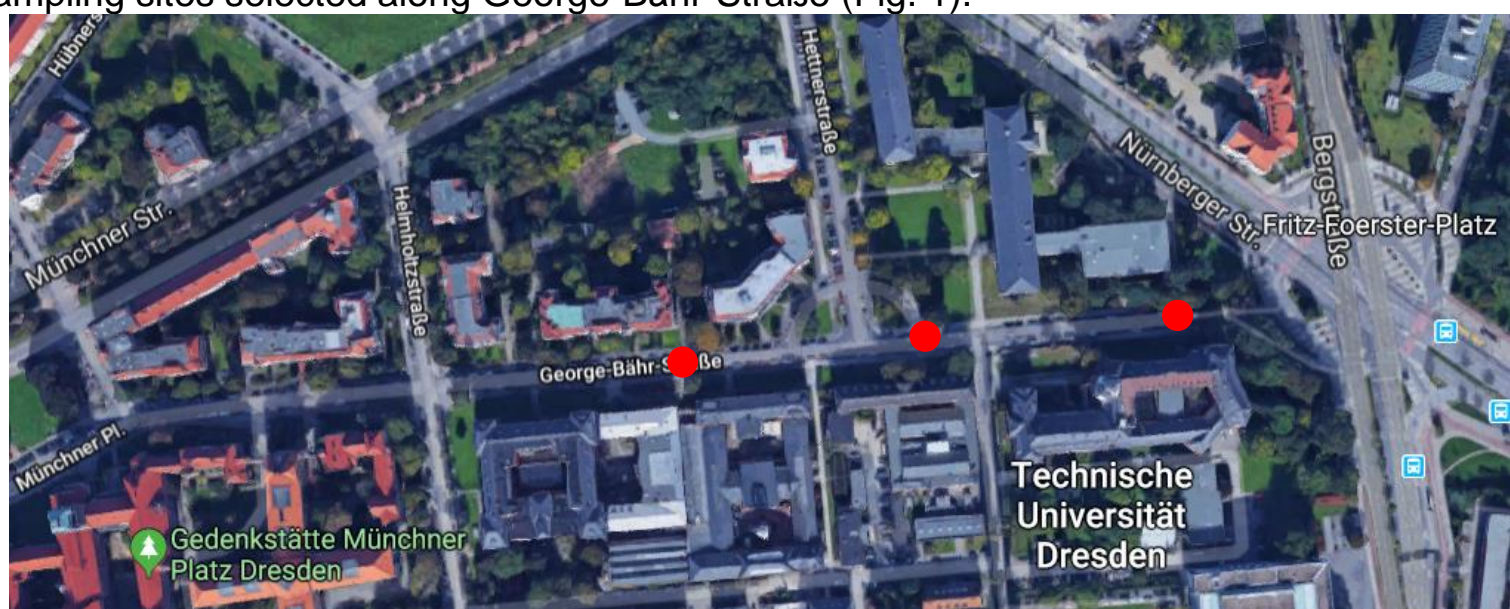

Figure 1. The map of study area. Red dots represent the sampling sites.

\subsection{Sample collection}

In each sampling site, facade sample was collected from 2 meters above ground level of the nearby university building and road sample was obtained from roadside curb areas, where most sediment is assembled (Sartor \& Boyd, 1972). The collection of wash-off particles was then performed by two sampling techniques, which are direct sucking method (DS) (Amato et al., 2010; Zhang et al., 2017) and runoff approach (RO) (Egodawatta et al.2009; Davis. \& Birch, 2010).

- DS: the particles within $1 \mathrm{~m}^{2}$ analysed surface were collected by vacuuming twice in different direction as the surface was sprayed with 1 litre of synthetic rainwater.

- RO: $1 \mathrm{~m}^{2}$ surface was sprayed uniformly with 1 litre of synthetic rainwater and the runoff was collected by vacuuming at outlet.

Puzzi 100 Super vacuum cleaner was used for vacuuming collection, and the synthetic rainwater was made with $1.35 \mu \mathrm{g} / \mathrm{L}$ of $\mathrm{NaCl}, 1.13 \mu \mathrm{g} / \mathrm{L}$ of $\mathrm{HNO}_{3}$ as well as $1.76 \mu \mathrm{g} / \mathrm{L}$ of $\mathrm{H}_{2} \mathrm{SO}_{4}$ with $\mathrm{CH}_{3} \mathrm{COO}$ - and $\mathrm{CH}_{3} \mathrm{COONa}$ as buffers, which was based on the methodologies previously used by Davis et al. (2001) and Zhang et al. (2016). A little $\mathrm{NaOH}$ solution was added to adjust the $\mathrm{pH}$ of raw synthetic rainwater (4.7-5) close to the $\mathrm{pH}$ for the rainwater in Dresden (5.3). Since the antecedent dry period (ADP) was not considered in the study, the sampling collection was performed on 25. Feb and 4. Mar 2016, which both had 2-day ADP. Due to the snowy weather on 2. Mar, there was still some snow covered on green area on 4. Mar.

\subsection{Chemical analysis}

A total of 24 samples were tested for $\mathrm{Cu}$ (copper), Zn (zinc) and $\mathrm{Cd}$ (cadmium). The analytical methods were all finished by following the norms and procedures established in the German Norm DIN 38406-7, DIN 38406-8, DIN EN ISO 5961 respectively. The concentrations of $\mathrm{Cu}$ and $\mathrm{Zn}$ were determined by using flame furnace atomic absorption spectrometry (FF-AAS), while graphite furnace atomic absorption spectroscopy (GFAAS) was used to analyse $\mathrm{Cd}$, which had relatively lower concentration. The limits of detection were $0.01 \mathrm{mg} / \mathrm{L}$ for $\mathrm{Cu}, 0.01 \mathrm{mg} / \mathrm{L}$ for $\mathrm{Zn}$ and $0.05 \mu \mathrm{g} / \mathrm{L}$ for $\mathrm{Cd}$ and the limits of quantitation were $0.03 \mathrm{mg} / \mathrm{L}$ for $\mathrm{Cu}, 0.03 \mathrm{mg} / \mathrm{L}$ for $\mathrm{Zn}$ and $0.1 \mu \mathrm{g} / \mathrm{L}$ for $\mathrm{Cd}$. 


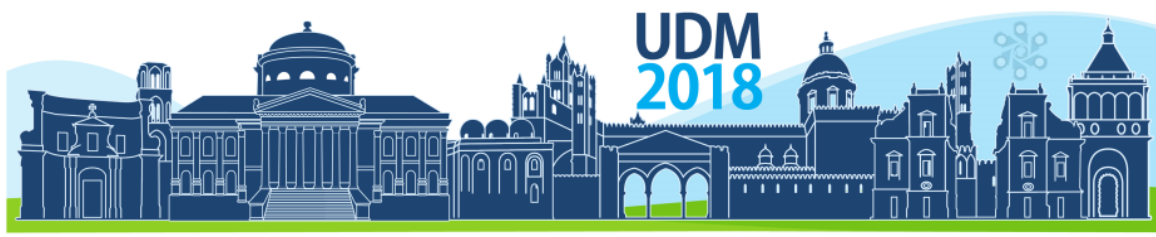

$11^{\text {th }}$ International Conference on Urban Drainage Modelling

23-26 Sep | Palermo - Italy

\section{RESULTS AND DISCUSSION}

\subsection{Snow influence on heavy metal concentration}

The concentration of $\mathrm{Cu}, \mathrm{Zn}$ and $\mathrm{Cd}$ is categorized into different sampling dates, sampling sites and surface properties and presented in Fig. 2. It is obvious that the concentration of all heavy metals was significantly higher on 25 .Feb than on 4.Mar. It is an interesting result because the snow covered on the surface on 4.Mar may absorb the heavy metals contributed by traffic activities, which mitigates the build-up rate in antecedent dry period after snow events compared to the period after general precipitation events.

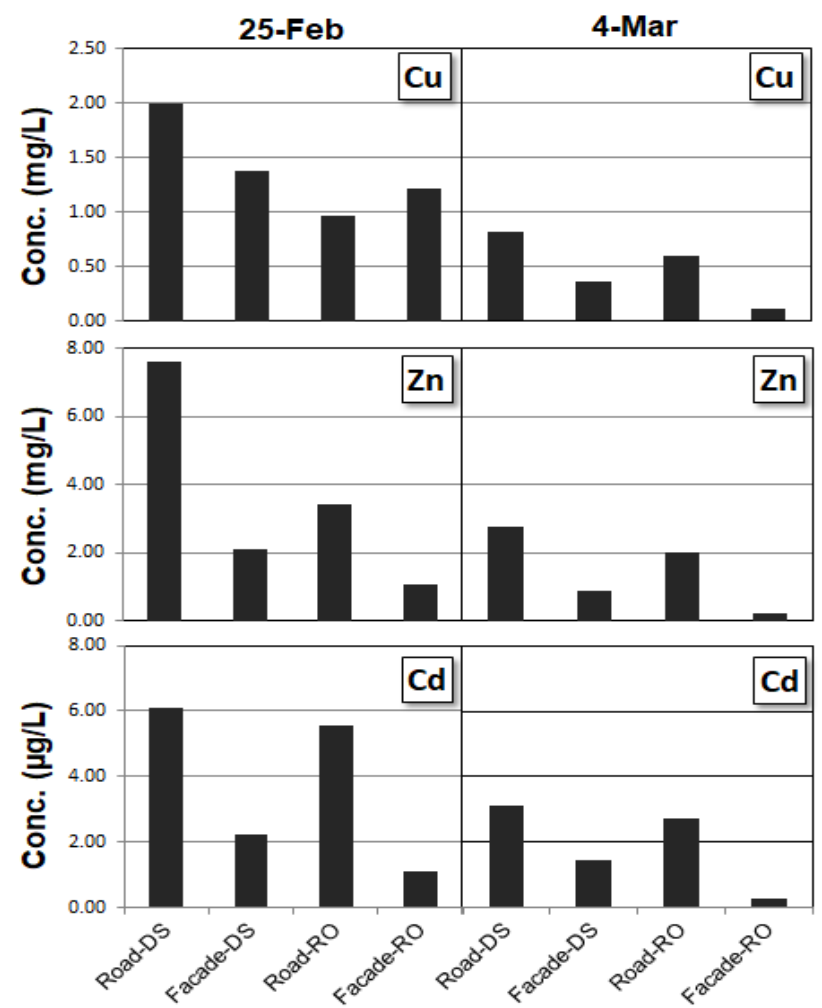

Figure 2. The concentration of $\mathrm{Cu}, \mathrm{Zn}$ and $\mathrm{Cd}$ collected from facade and road on 25.Feb and 4.Mar. DS is direct sucking method and $\mathrm{RO}$ is runoff method.

\subsection{Understanding the difference concentration between road and facade}

In comparison with the two analysed surfaces under the same sampling conditions, the concentration of heavy metals on facade is relatively lower than on road surface in most cases (Fig. 2). The gravity force and roughness property of facade cause the result that only the particles with strong adhesion capacity can be attached stably on facade. Besides, these on facade are actually mainly re-suspended fine particles coming from the road surface. Compared with $\mathrm{Zn}$ and $\mathrm{Cd}$, $\mathrm{Cu}$ has higher concentration ratio of facade to road and even more $\mathrm{Cu}$ concentration is found on facade than on road by $\mathrm{RO}$ collection on $25-\mathrm{Feb}$.

\subsection{Heavy metal assessment in different sampling methods}

As presented in Fig. 2, the samples collected by DS method show relatively higher heavy metal concentrations than RO method. This is an expected result due to the fact that the 


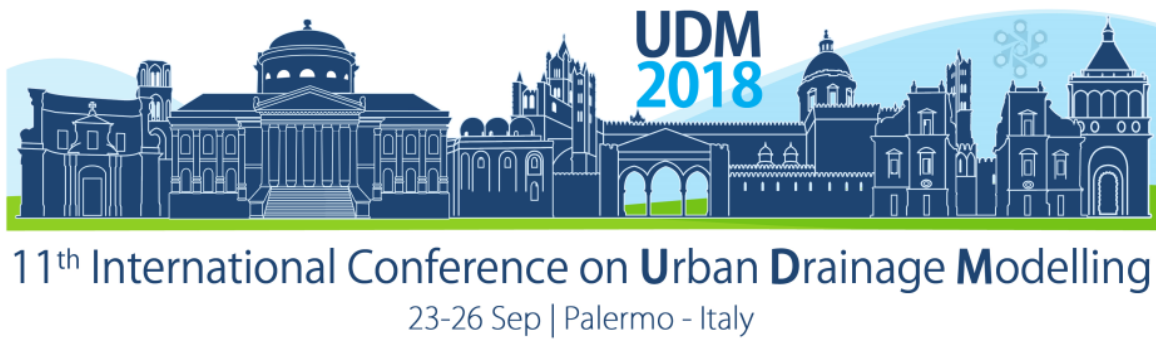

suction power of the vacuum leads to a detachment of particles with heavy metals which in normal conditions will not detach by runoff process. Interestingly, the higher concentration of heavy metals on road, especially $\mathrm{Cd}$, collected by DS method yields the larger concentration difference between DS method and RO method. It may be because the fine particles with pollutants can aggregate into larger size due to particle re-distribution if the amount of fine particles reaches the saturation value (Wijesiri, 2016), and larger particles are hard to be detached from surface by runoff with low discharge in $\mathrm{RO}$ method. The concentration on facade has no such effect, which is probably due to the finer particles on facade than on road. Therefore, DS method can represent the wash-off process in heavy storm event and RO approach is the runoff model during small precipitation.

\section{CONCLUSIONS}

The main focuses of this study are to evaluate the heavy metals pollution on road and facade and to compare two wash-off sampling techniques. Interestingly, the result shows that nonmelt snow can influence the build-up rate of heavy metals on both road and facade. Besides, the concentration of heavy metals on facade was lower than on road due to gravity and different surface properties. Compared to $\mathrm{Zn}$ and $\mathrm{Cd}$, the ratio of $\mathrm{Cu}$ concentration on facade to road was higher. Considering two sampling methods, DS method can simulate the washoff process in heavy storm event while $\mathrm{RO}$ method represents the process in small precipitation.

\section{References}

Al-Najjar, T., Rasheed, M., Ababneh, Z., Ababneh, A., \& Al-Omarey, H. (2011). Heavy metals pollution in sediment cores from the Gulf of Aqaba, Red Sea. Natural science, 3(09), 775.

Amato, F., Querol, X., Johansson, C., Nagl, C., \& Alastuey, A. (2010). A review on the effectiveness of street sweeping, washing and dust suppressants as urban PM control methods. Science of the Total Environment, 408(16), 3070-3084.

Davis, A. P., Shokouhian, M., \& Ni, S. (2001). Loading estimates of lead, copper, cadmium, and zinc in urban runoff from specific sources. Chemosphere, 44(5), 997-1009.

Davis, B., \& Birch, G. (2010). Comparison of heavy metal loads in stormwater runoff from major and minor urban roads using pollutant yield rating curves. Environmental Pollution, 158(8), 2541-2545.

Dhanakumar, S., Murthy, K. R., Solaraj, G., \& Mohanraj, R. (2013). Heavy-metal fractionation in surface sediments of the Cauvery River Estuarine Region, Southeastern Coast of India. Archives of environmental contamination and toxicology, 65(1), 14-23.

Egodawatta, P., Thomas, E., \& Goonetilleke, A. (2009). Understanding the physical processes of pollutant buildup and wash-off on roof surfaces. Science of the Total Environment, 407(6), 1834-1841.

Landeshauptstadt Dresden, S. u. T., 2010. Verkehrsmengenkarte 2009. Dresden: Autobahnamt Dresden

Liu, A., Duodu, G. O., Mummullage, S., Ayoko, G. A., \& Goonetilleke, A. (2017). Hierarchy of factors which influence polycyclic aromatic hydrocarbons (PAHs) distribution in river sediments. Environmental pollution, 223, 81-89.

Sartor, J. D., \& Boyd, G. B. (1972). Water pollution aspects of street surface contaminants (Vol. 81). US Government Printing Office.

Trujillo-González, J. M., Torres-Mora, M. A., Keesstra, S., Brevik, E. C., \& Jiménez-Ballesta, R. (2016). Heavy metal accumulation related to population density in road dust samples taken from urban sites under different land uses. Science of the Total Environment, 553, 636-642.

Wijesiri, B., Egodawatta, P., McGree, J., \& Goonetilleke, A. (2016). Understanding the uncertainty associated with particle-bound pollutant build-up and wash-off: A critical review. Water research, 101, 582-596.

Zhang, J., Hua, P., \& Krebs, P. (2015a). The build-up dynamic and chemical fractionation of Cu, $\mathrm{Zn}$ and $\mathrm{Cd}$ in road-deposited sediment. Science of the Total Environment, 532, 723-732.

Zhang, J., Hua, P., \& Krebs, P. (2015b). The chemical fractionation and potential source identification of $\mathrm{Cu}, \mathrm{Zn}$ and $\mathrm{Cd}$ on urban watershed. Water Science and Technology, 72(8), 1428-1436.

Zhang, J., Hua, P., \& Krebs, P. (2016). The influences of dissolved organic matter and surfactant on the desorption of $\mathrm{Cu}$ and $\mathrm{Zn}$ from road-deposited sediment. Chemosphere, 150, 63-70.

Zhang, J., Hua, P., \& Krebs, P. (2017). Influences of land use and antecedent dry-weather period on pollution level and ecological risk of heavy metals in road-deposited sediment. Environmental Pollution, 228, 158-168. 


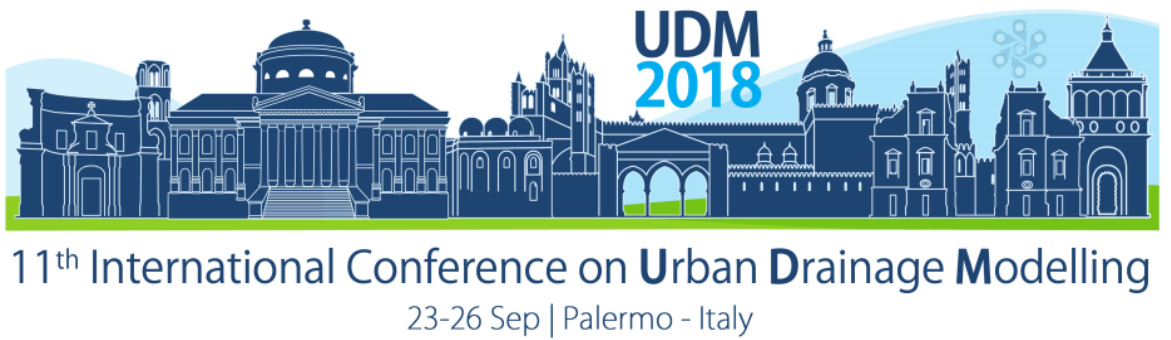

\title{
An assessment of per capita water consumption in Sirte, Libya
}

\author{
Iman Alharsha ${ }^{1}$, Fayyaz Memon ${ }^{1}$, Raziyeh Farmani ${ }^{1}$ \\ 1 Centre for Water Systems, University of Exeter, Exeter, Devon EX4 4QF, UK \\ iasa202@exeter.ac.uk
}

\begin{abstract}
Worldwide, where freshwater resources are limited, a major water scarcity problem occurs. Population growth, which leads to increased water consumption with high inefficiencies of household water use behaviour especially in developing countries, makes the problem worse. In this situation, a sustainable urban water management approach which considers household water consumption patterns is required. However, country specific water consumption data particularly for the developing countries is limited. This paper investigates per capita water consumption in Sirte city by evaluating the indoor and outdoor domestic water uses using a survey. The survey contains information about demographic, socio-economic and household water end use behavioural characteristics. The preliminary results suggest that water consumption varies with the type of dwelling and females tends to consume considerable more water in comparison to males. Household income does not seem to affect water consumption.
\end{abstract}

Keywords: Domestic water end-uses, Household Water consumption, Survey

\section{INTRODUCTION}

Water is considered as one of the principle needs of all living organisms. Human needs water in all his life activities. These include daily life practices (domestic needs), industrial and agricultural activities. In many countries water demands are continuously increasing due to population growth, urbanization and improved living standards (Domene et al. 2006; Kenney el at. 2008 and Lee el at. 2012). On the other hand, limited water resources and climate uncertainties magnify the water scarcity problem. Arnell (2004) reported that two-thirds of the world's population would be living in water stressed countries by 2025 . The gap between demand and availability of water resources is reaching critical levels in many countries in the world. Water demand management measures such as water reuse require detailed knowledge of water end-use behaviours and household's water use patterns to ensure efficient water resources management planning. In developed courtiers domestic water demand has been effectively analysed, but this is not the case in the developing countries (Nauges and Whittington 2009). Several studies have analysed end-use water consumption characteristics. In Australia, studies were done on water end-uses characteristics in terms of seasonal water consumption variability, frequency, duration, flow rate, peak demands and demand patterns (Loh and Coghlan 2003; Willis el at 2013; Beal 2013). A study by Wa'el et al. (2016), evaluated the influence of various household characteristics on per capita consumption patterns currently prevailing in urban areas of Duhok city, Iraq. This paper presents the result of a survey of 230 households in Sirte city, Libya which contains information about demographic, socio-economic and household water consumption characteristics of the participants.

\section{MATERIALS AND METHODS}

\subsection{Study Area}

The city of Sirte, is located in the north of Libya between $31^{\circ} 12^{\prime} 32.11^{\prime \prime}$ North and $16^{\circ} 35^{\prime}$ 19.18' East (Figure 1). It has a population of around 70,000 inhabitants (MHU). Its climate is classified as arid affected by the Mediterranean Sea in the north and the desert in the south. 


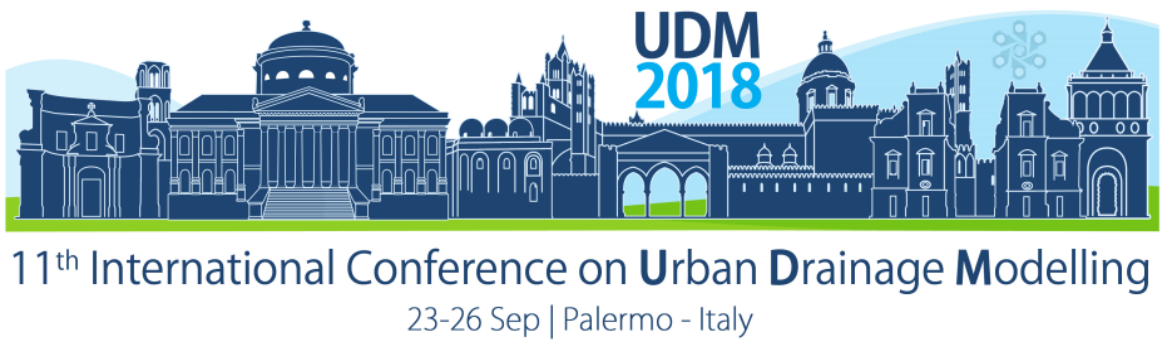

The rainy season in Sirte starts in September and lasts till March. The highest amount of rainfall is normally in January, while during July there are no rains. Water source for the city is from Man-Made River Project (MMRP).Water is supplied to households in Sirte city every day for 24 hours. However, some areas outside the city are sometimes supplied 3 to 4 times a week. Therefore, people outside the city store water in underground and overhead tanks and use it for different activities. Because of uncertainties due to power cuts even in the city, houses have storage facilities.
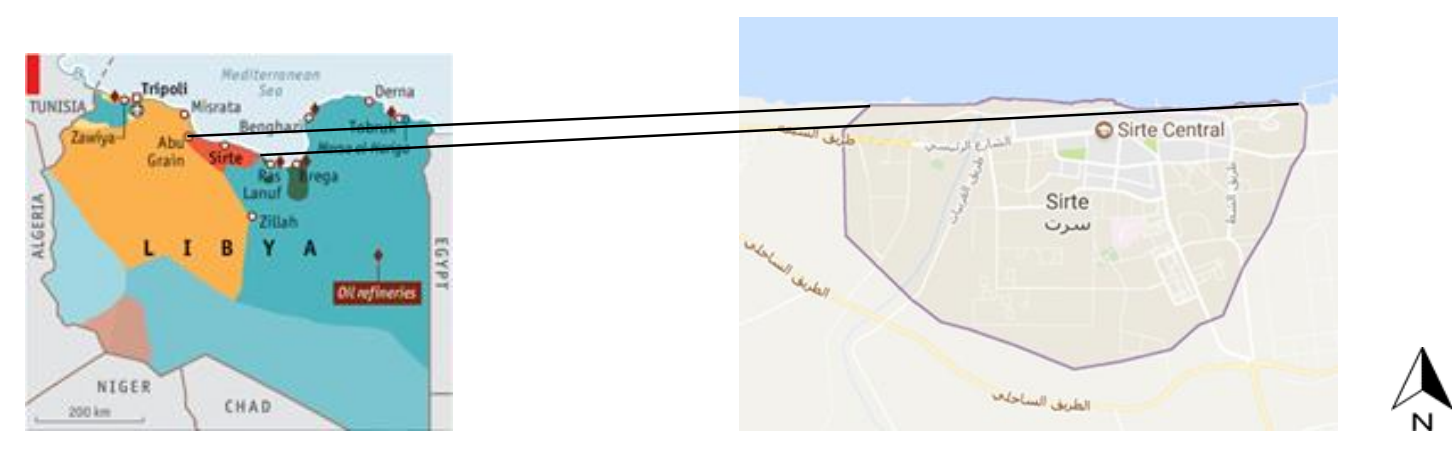

Figure 1. Location of Sirte city, Libya (Latitude.to 2017)

\subsection{Data collection}

In this study, data on household characteristics were collected using a comprehensive questionnaire survey. The questionnaires, each with about 67 multiple choice questions, were prepared in both English and Arabic language. Questions were on household and water enduse characteristics. The household characteristics questions included information on: number of people in the household (children, elders, adult males and females) and thier ages, household type, number of rooms, number of kitchens and toilets, number of floors, total builtup area, garden area and total montly income. On water end-use side, questions were on the frequencey, flow rate and duration of use of bath, shower, hand wash basin, toilet flushing, dishwashing, clothes swashing (manually or using machine), rooms, kitchens and toilets floor washing, garden watering, vehicle washing and swimming pool. For the winter season December 2017, the quesitionnaires were distributed to student at Sirte University in Libya as household representatives. Over 400 questionnaires were distributed and 230 replies were received. The data for the 230 questionnaires was transfered and analysed using IBM SPSS Statistics Version 24 package. The analysis included estimation of statistical parameters (i.e., avarage, minimum, maximum and distribuation shape identification through kurtosis and skewness) for the characteristics of the 230 households.

\section{RESULTS AND DISCUSSION}

\subsection{Household characteristics}

The analysis of household characteristics in the study area was based on 230 respondents as shown in Table 1. The analysis shows that the average number of people in a household is 6.84. In addition, the average number of children, adult males and females is 1.81, 2.11 and 2.48 respectively. The average number of elders above 65 years is 0.40 . The percentage of houses is $77.83 \%$ and $22.17 \%$ is apartments. Moreover, the total built up area for a house or apartment ranged between 100 and $650 \mathrm{~m}^{2}$ with about $35.23 \mathrm{~m}^{2}$ garden area, the minimum 


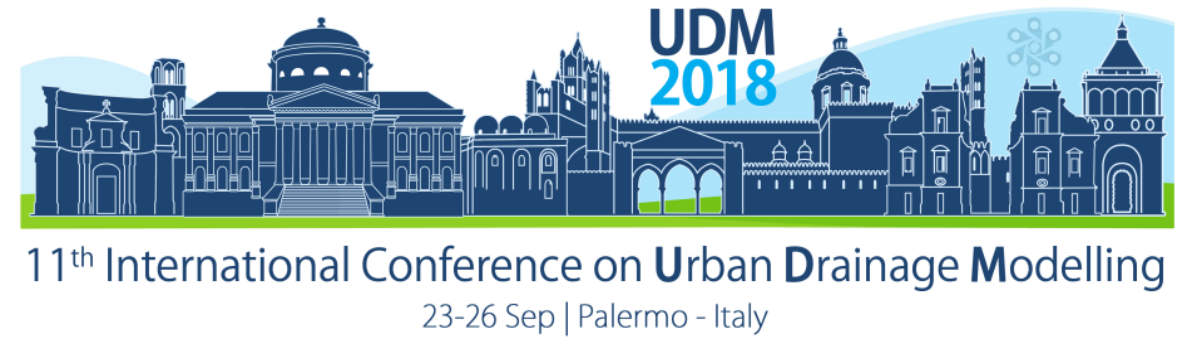

and maximum number of floors are 1 and 3 respectively. The average number of kitchens, toilets and rooms in a household are 1.52, 2.59 and 6.24 respectively. The average monthly household income is $368.92 \mathrm{LD}(£ 1.888=1 \mathrm{LYD})$.

Table 1. Summary of household characteristics in Sirte, Libya

\begin{tabular}{|c|c|c|c|c|c|c|c|c|}
\hline $\begin{array}{l}\text { Household } \\
\text { characteristics }\end{array}$ & Min. & Max. & Mean & Median & $\begin{array}{c}\text { Std. } \\
\text { Deviation }\end{array}$ & Skewnsess & Kutosis & $\begin{array}{c}\text { Confidence } \\
\text { interval } \\
(95 \%)\end{array}$ \\
\hline $\begin{array}{l}\text { No. of People in } \\
\text { household }\end{array}$ & 1.00 & 19.00 & 6.84 & 6.50 & 2.84 & 0.929 & 1.55 & 0.05 \\
\hline $\begin{array}{l}\text { No. of children } \\
(<15 \text { years })\end{array}$ & 0.00 & 6.00 & 1.81 & 2.00 & 1.77 & 0.460 & -1.09 & 0.13 \\
\hline $\begin{array}{l}\text { No. of adult males } \\
\text { (15-65 years) }\end{array}$ & 0.00 & 7.00 & 2.11 & 2.00 & 1.49 & 0.837 & 0.08 & 0.09 \\
\hline $\begin{array}{l}\text { No. of adult females } \\
\text { (15-65 year) }\end{array}$ & 0.00 & 9 & 2.48 & 2.00 & 1.66 & 1.04 & 1.07 & 0.09 \\
\hline $\begin{array}{l}\text { Number of adult } \\
(>65)\end{array}$ & 0.00 & 2.00 & 0.40 & 0.00 & 0.645 & 1.35 & 0.590 & 0.21 \\
\hline $\begin{array}{l}\text { Total built-up area } \\
\mathrm{m}^{2} \text { of all floors }\end{array}$ & 100 & 650 & 231.45 & 190 & 91.22 & 1.33 & 1.88 & 0.05 \\
\hline $\begin{array}{l}\text { Number of kitchens } \\
\text { in the household }\end{array}$ & 1.00 & 5.00 & 1.52 & 1.00 & 0.73 & 1.43 & 2.24 & 0.06 \\
\hline $\begin{array}{l}\text { Number of toilets } \\
\text { in the household }\end{array}$ & 1.00 & 6.00 & 2.59 & 2.00 & 1.05 & 1.03 & 0.44 & 0.05 \\
\hline $\begin{array}{l}\text { Number of rooms } \\
\text { in the household }\end{array}$ & 2.00 & 11.0 & 6.24 & 5.00 & 2.21 & 0.92 & -0.16 & 0.05 \\
\hline $\begin{array}{l}\text { Number of floors } \\
\text { In the household }\end{array}$ & 1.00 & 3.00 & 1.26 & 1.00 & 0.485 & 1.69 & 1.98 & 0.05 \\
\hline $\begin{array}{l}\text { Garden area in } \mathrm{m}^{2} \\
\text { in the household }\end{array}$ & 0.00 & 550 & 35.23 & 3.75 & 69.37 & 4.21 & 22.85 & 0.26 \\
\hline $\begin{array}{l}\text { Monthly family } \\
\text { income/household } \\
\text { (LYD, Libyan Dinar } \\
\text { per month) }\end{array}$ & 50.0 & 2500 & 368.92 & 300.0 & 280.12 & 3.03 & 15.91 & 0.10 \\
\hline Household type & \multicolumn{4}{|c|}{ Houses $77.83 \%$} & \multicolumn{4}{|c|}{ Apartments $22.17 \%$} \\
\hline
\end{tabular}




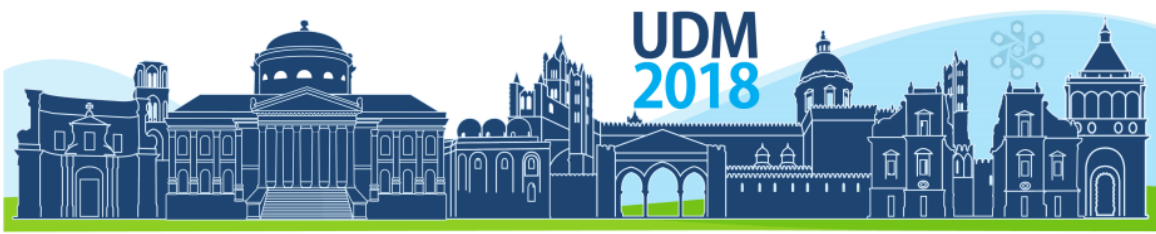

$11^{\text {th }}$ International Conference on Urban Drainage Modelling

23-26 Sep | Palermo - Italy

\subsection{Average per Capita Water end-use}

The average water consumption per capita was divided into end-uses which included bath, showering, hand wash basin, toilet flushing, dishwashing, laundry, house washing, garden watering, cooking, vehicle washing and swimming pool. The daily per capita water use for all activities are the function of the frequency, the duration and the flow rate. The average water consumption volumes and percentages for these end uses are shown in Figures 2 and 3 respectively. These values were obtained through questionnaire survey for households in the study area. The sum of the all the end-uses water consumption gives the average water consumption per capita in Sirte Libya as $354 \mathrm{l} / \mathrm{p} / \mathrm{d}$.

There are differences in average water consumptions with respect to type of house and gender. For instance, the average water consumption for apartments and houses is $329 \mathrm{l} / \mathrm{p} / \mathrm{d}$ and $362 \mathrm{l} / \mathrm{p} / \mathrm{d}$ receptively. While on average, females and males consume $369 \mathrm{l} / \mathrm{p} / \mathrm{d}$ and 337 $\mathrm{l} / \mathrm{p} / \mathrm{d}$ receptively. The result shows that females consumed more water than male because they stay most of the time at home.

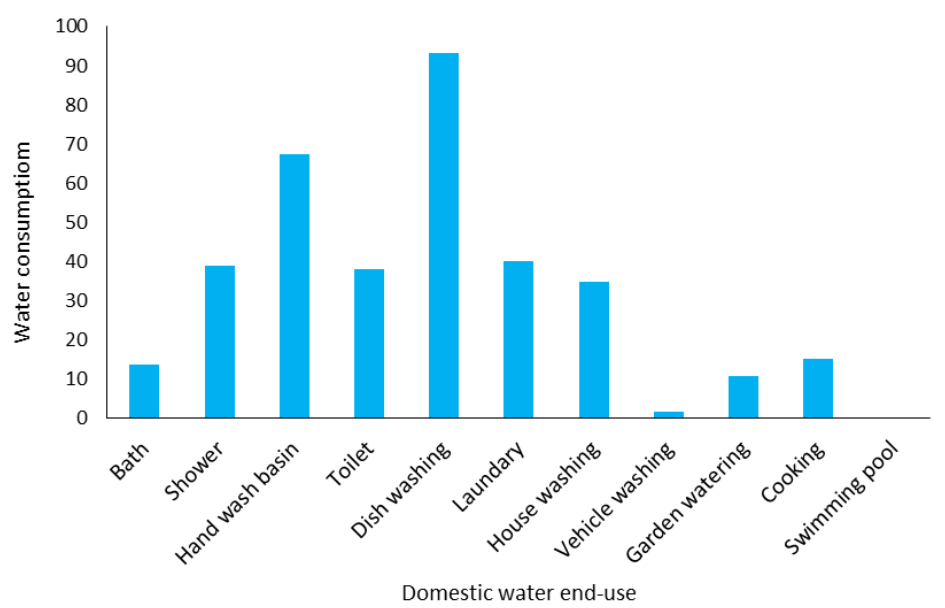

Figure2. Daily per capita average water consumption $(\mathrm{l} / \mathrm{p} / \mathrm{d})$

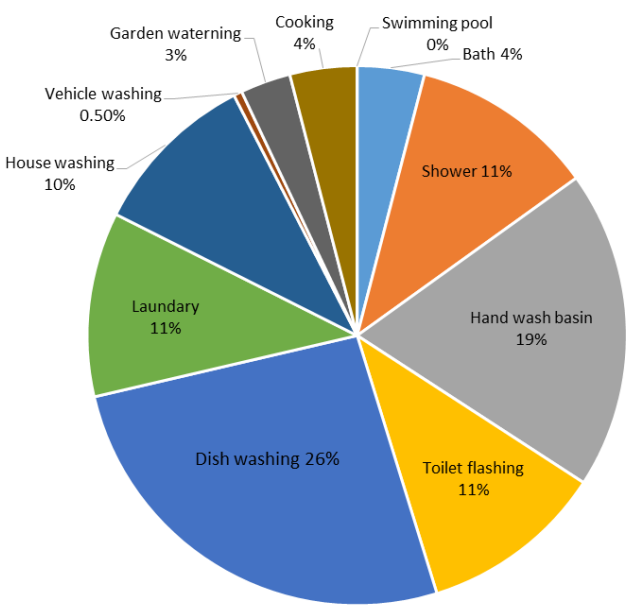

Figure 3. Percentage of enu-use water consumption 


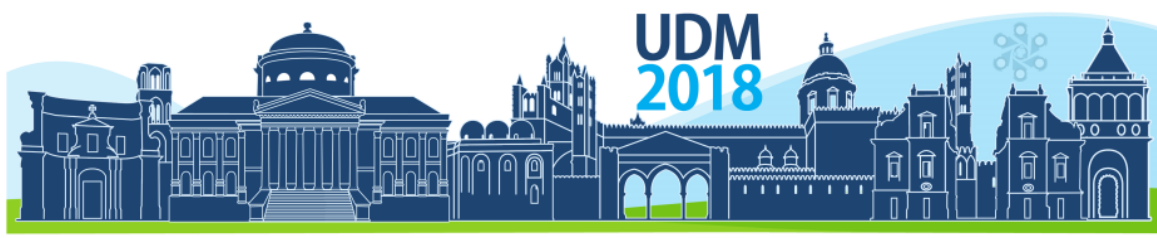

$11^{\text {th }}$ International Conference on Urban Drainage Modelling

23-26 Sep | Palermo - Italy

\subsection{Water user behaviour}

The water user behaviour was captured by recording the frequency and duration of use of different appliances. The results are summarised as below in Table 2.

Table 2. Summary of water user behaviour statistics

\begin{tabular}{|c|c|c|c|c|c|c|}
\hline \multirow{2}{*}{ Activity/appliance usage } & \multicolumn{3}{|c|}{ Frequency (person/day) } & \multicolumn{3}{|c|}{ Duration (minutes/person/day) } \\
\hline & Mean & Min-Max. & $\begin{array}{l}\text { Standard } \\
\text { Deviation }\end{array}$ & Mean & Min-Max. & $\begin{array}{l}\text { Standard } \\
\text { Deviation }\end{array}$ \\
\hline Bath & 0.08 & $0.00-0.57$ & 0.132 & - & - & - \\
\hline Shower & 0.64 & $0.14-2.00$ & 0.335 & 19.00 & $2.00-55.0$ & 11.67 \\
\hline Hand wash basin & 5.97 & $2.0-18.0$ & 2.12 & 5.25 & $3.00-10.0$ & 1.12 \\
\hline Toilet flushing & 5.00 & $2.0-10.0$ & 1.67 & - & - & - \\
\hline Cooking & 1.62 & $1.0-3.0$ & 0.546 & - & - & - \\
\hline Dish washing (manually) & 3.20 & $0.0-6.00$ & 1.41 & 8.80 & $0.0-27.50$ & 4.24 \\
\hline Dish washing (machine) & 0.35 & $0.0-3.0$ & 0.745 & - & - & - \\
\hline Laundry (manually) & 0.08 & $0.0-0.86$ & 0.162 & 2.69 & $0.0-50.0$ & 6.24 \\
\hline Laundry (machine) & 0.63 & $0.0-1.43$ & 0.290 & - & - & - \\
\hline Toilet washing & 1.66 & $1.0-4.0$ & 0.814 & 5.75 & $2.0-20.0$ & 2.65 \\
\hline Kitchen washing & 0.25 & $0.14-0.57$ & 0.122 & 6.37 & $2.0-18.0$ & 2.51 \\
\hline Rooms washing & 0.186 & $0.0-0.57$ & 0.11 & 13.0 & $0.0-37.5$ & 6.60 \\
\hline Vehicle washing & 0.05 & $0.0-0.29$ & 0.08 & 6.39 & $0.0-45.0$ & 11.21 \\
\hline Garden watering & 0.130 & $0.0-0.86$ & 0.172 & 11.96 & $0.0-87.5$ & 17.90 \\
\hline
\end{tabular}

Table 2 shows that the most frequently used appliance is hand wash basin which is used approximatly 6 times a day. People wash their hands during praying times and after toilets. However, vehicle washinig was the lowest frequency activity which is 0.05 per capita per day. This is because people perfer washing thier vehicle in garages. The second lowest activity is bathing which is 0.08 per capita per day. Although each appartment and house in Sirte city has a bath, people use it as shower in most cases with respect to duration of water consumption end-use, the shower has the highest duration which is 19 minutes. The duration for manual laundary was the lowest at around 3 minutes.

\subsection{Impact of Household Characteristics on the Total Average Water Consumption (I/hh/day)}

The analysis of impact of the household water consumption shows that there is a strong positive relationship between the number of people in the household and total water 


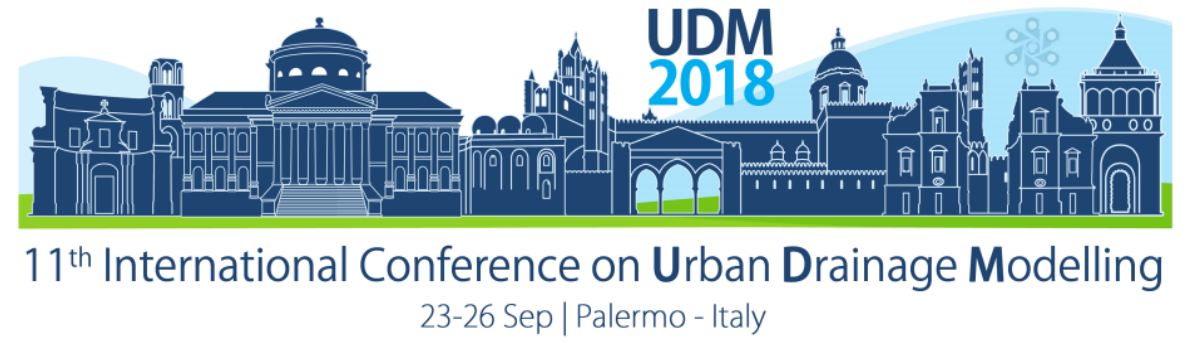

consumption. The Pearson correlation coefficient (PCC) is 0.77 . The correlation between builtup area and total water consumption $(P C C=0.42)$ is moderate. The data shows very weak correlation of consumption with the family income and garden area which is 0.21 and 0.1 respectively. This means the total household income does not seem to affect the water consumption because water is free. On the other hand, some people in Sirte do not water their gardens in winter.

The collected data is planned to be used to reduce wastewater generation profiles. These are planned to be used as an input to simulate the effects of water consumption on the drainage network for the city of Sirte

\section{CONCLUSIONS}

In this study, the household characteristics and average domestic water consumption of Sirte, Libya was analysed and determined using a questionnaire survey. IBN SPSS Statistics Version 24 package was used for data analysis. The analyses were split into household enduse types. From which, the average water consumption was found to be $354 \mathrm{l} / \mathrm{p} / \mathrm{d}$. The results showed that there is a strong and moderate impact on total household water consumption by family size and built-up area respectively. However, total family income and garden area have low influence on total household water consumption.

\section{ACKNOWLEDGEMENT}

The funding for this research has been provided by the Ministry of Higher Education and Scientific Research in Libya and is thankfully acknowledged.

\section{REFERENCES}

Arnell, N. W. (2004). Climate change and global water resources: SRES emissions and socio-economic scenarios. Global environmental change, 14(1), 31-52.

Beal, C. D., Stewart, R. A., \& Fielding, K. (2013). A novel mixed method smart metering approach to reconciling differences between perceived and actual residential end use water consumption. Journal of Cleaner Production, 60, 116-128.

Domene, E., \& Saurí, D. (2006). Urbanisation and water consumption: Influencing factors in the metropolitan region of Barcelona. Urban Studies, 43(9), 1605-1623.

Kenney, D. S., Goemans, C., Klein, R., Lowrey, J., \& Reidy, K. (2008). Residential water demand management: lessons from Aurora, Colorado. JAWRA Journal of the American Water Resources Association, 44(1), 192207.

Latitude.to 2017. Available from: http://latitude.to/map/ly/libya/cities/sirte (Accessed 03/11/2017)

Lee, D. J., Park, N. S., \& Jeong, W. (2012). End-use analysis of household water by metering: the case study in Korea. Water and Environment Journal, 26(4), 455-464.

Loh, M., \& Coghlan, P. (2003). Domestic water use study in Perth, Western Australia, 1998-2001. Perth: Water Corporation.

MHU. The Ministry of Housing and Utilities, Tripoli, Libya. Unpublished report.

Nauges, C., \& Van Den Berg, C. (2009). Perception of health risk and averting behavior: An analysis of household water consumption in Southwest Sri Lanka.

The world's Trusted currency Authority (2018), Available from:

https://www.xe.com/currencyconverter/convert/?Amount=1\&From=GBP\&To=LYD (Accessed 09/04/2018)

Wa'el A, H., Memon, F. A., \& Savic, D. A. (2016). Assessing and modelling the influence of household characteristics on per capita water consumption. Water Resources Management, 30(9), 2931-2955.

Willis, R. M., Stewart, R. A., Giurco, D. P., Talebpour, M. R., \& Mousavinejad, A. (2013). End use water consumption in households: impact of socio-demographic factors and efficient devices. Journal of Cleaner Production, 60, 107-115. 


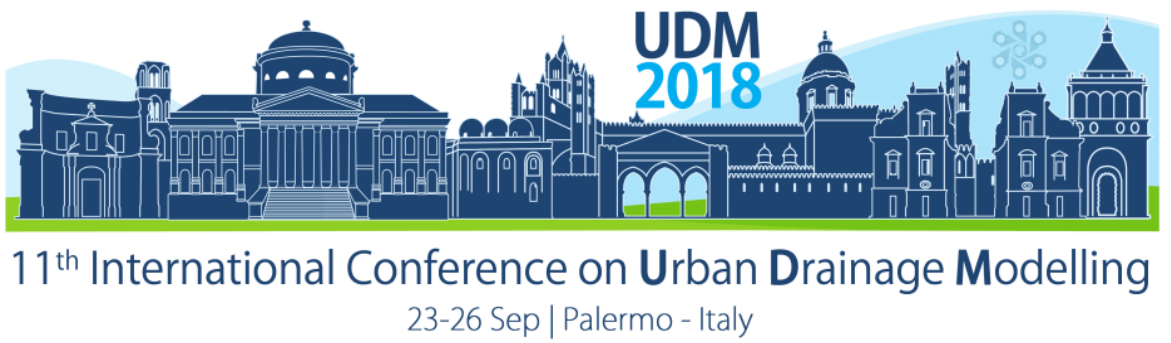

\title{
Applying Socioeconomic Optimisation on Blue-Green Climate Adaptation Projects in an Urban Catchment
}

\author{
Steffen Davidsen ${ }^{1}$, Thomas Kruse ${ }^{1}$, Trine Stausgaard Munk ${ }^{1}$ and Karsten Arnbjerg-Nielsen ${ }^{2}$ \\ ${ }^{1}$ Rambøll Water, Copenhagen S, Denmark \\ ${ }^{2}$ Technical University of Denmark, Department of Environmental Engineering, Kgs. Lyngby, Denmark
}

\begin{abstract}
Climate adaptation projects are often conducted without assessing the socioeconomic losses or benefits associated with the project. Methods for conducting socioeconomic assessments and optimisations have been proposed in various articles, but these methods often include more simulations than what is feasible for the common climate adaptation project. Identifying the optimum service or protection level for climate adaptation is important to avoid over or under investments, to understand the residual risks, and for informed decision-making and communication. This study develops a methodology for socioeconomic optimisation and applies it to the Kildeskovsrenden catchment in Gentofte, Denmark. The methodology requires many simulations to optimise the return period for climate adaptation. This study aims to reduce the number of simulations by defining the acceptable water level on terrain in collaboration with stakeholders. The return period combined with an acceptable water level on terrain constitutes the dimensioning criteria for the climate adaptation projects. Three return periods of 20,50 and 100 years in year 2100 make up the optimisation exercise of identifying the optimum service level. Following its application, a set of recommendations are developed to accompany the optimisation and strengthen the methodology, including the use of the risk density curve during initial assessment of the catchment. Although the optimisation is built on a reduced amount of simulations, the methodology still requires large resources for modelling and assessments of investment and damage costs.
\end{abstract}

Keywords: Socioeconomic; optimisation; climate adaptation

\section{INTRODUCTION}

Many urban areas are prone to increased risk of flooding in the future due to changes in precipitation patterns and city development. Protection of assets in the urban catchment with a high risk of flooding can be achieved through investments in infrastructure to handle water from high intensity precipitation events. Typically such projects are scoped to compare reduced cost of flooding versus investment cost in infrastructure or a political decision of complying with a prescribed protection level. A socioeconomic optimum describes the optimum between investment costs and reductions in costs of flood damages to society in the future and provides a method to asses investments in climate adaption and avoid over or under investments for society. However, expanding the scope to a full socioeconomic study may suggest higher or lower protection levels or suggest completely different types of measures.

A method for socioeconomic optimisation is proposed by Zhou et al. (2013) describing how the future benefits of climate adaptation can be compared against investment and maintenance costs. Though being a simple optimisation task of costs and benefits, the data needed for this method requires extensive planning and modelling to obtain costs of flooding at multiple return periods for multiple adaptation strategies. The method involves optimising both the maximum allowed water level on terrain and the return period for which this occurs. This requires 


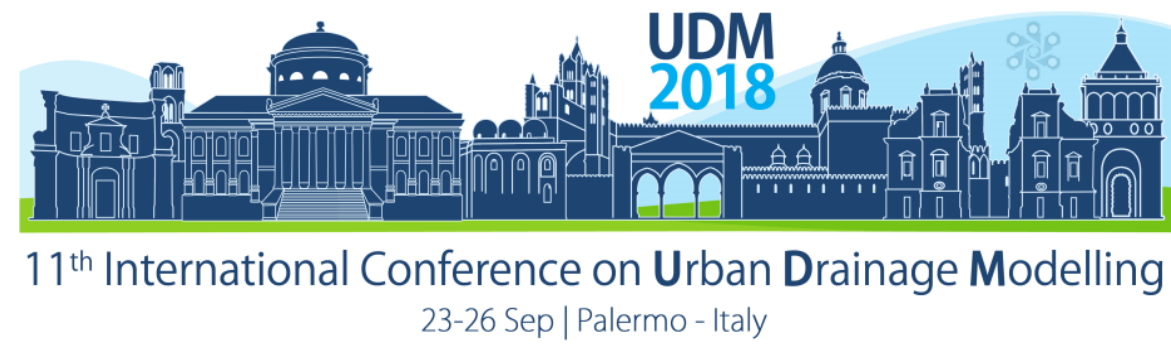

assessment of different flood mitigation strategies including numerous simulations often unfeasible in a climate adaptation project. The challenge of limiting the number of simulations is also evident when modelling both sea level rise and precipitation simultaneously as in Löwe et al. (2018) who suggest a solution where a limited number of hydraulic simulations are used for estimation of flood damages which is interpolated using a kriging metamodelling approach. The developed metamodel is then used to compute flood damages for additional scenarios at much lower computational costs.

This study proposes an alternative methodology to limit the number of calculations by defining the allowed water depth on terrain prior to the socioeconomic optimisation by involving key decision-makers, e.g. the municipality and utility companies. Thereby the socioeconomic optimisation is limited to a one-dimensional optimisation where damage and investment costs only vary with the return period or water level that is being adapted to. Furthermore, we suggest a modification to the methodology used in Zhou et al. (2013) for at more data driven selection of return periods for the socioeconomic analysis of climate adaption measures.

The approach is developed through application on the catchment of Kildeskovsrenden in Gentofte, Denmark. Three return periods of 20,50 and 100 years in year 2100, make up the optimisation exercise of identifying the optimum service level. The application is conducted in close cooperation with the local utility company and the municipality.

\section{MATERIALS AND METHODS}

The following section describes the required input data and applied method of the socioeconomic optimisation.

\subsection{Input to the socioeconomic optimisation}

The approach of socioeconomic optimisation proposed by Zhou et al. (2013) requires both the cost and benefits of the climate adaptation project. Benefits are expressed through reductions in costs of flooding (risk) and co-benefits from e.g. new recreative areas or improved air quality. Costs are estimated through investment and maintenance cost in each scenario.

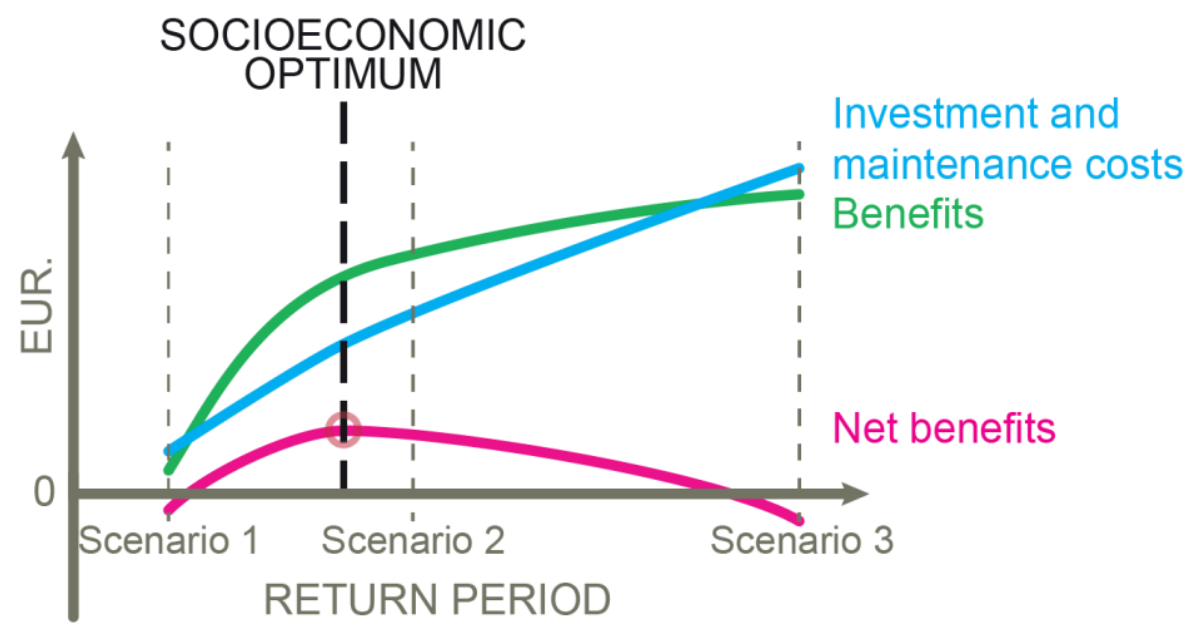

Figure 1. Concept of the optimisation between cost and benefits of the climate adaptation project. Minimum three scenarios are needed for the optimisation. 


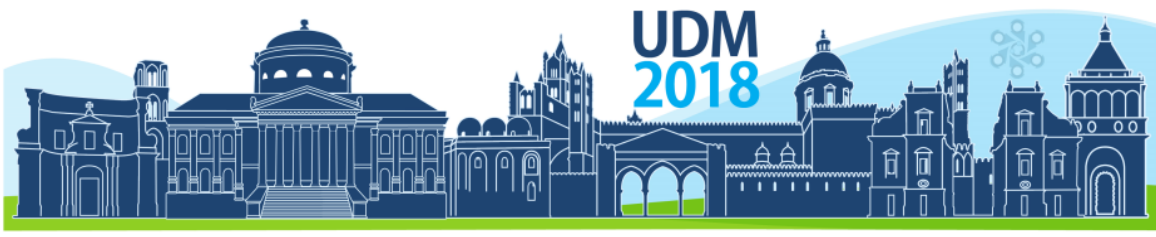

$11^{\text {th }}$ International Conference on Urban Drainage Modelling

23-26 Sep | Palermo - Italy

The costs of flood damages are expressed as the Expected Annual Damages of flooding as described in Olsen et al. (2015). Comparing the costs in a reference scenario to the reduced cost in a climate adapted scenario provides the benefits in terms of net reduction in risk when adapting the catchment to a certain return period. The investment and maintenance costs are estimated through the proposed adaptation strategies. All future cost and benefits are evaluated in a direct costs analysis with costs discounted to their Present Value (PV). Substracting costs from benefits provides the Net Present Value (NPV) which, if positive, is the socioeconomic benefit of the climate adaptation. The return period with the highest positive NPV is the socioeconomic optimum for climate adaptation.

\subsection{The Kildeskovsrenden catchment}

The case study is conducted on the Kildeskovsrenden catchment in Gentofte, Denmark. The catchment is flat and drains towards the sea at the eastern border of the catchment. The area is mainly covered by family houses and two large parks. An 1D-2D urban flood model of the current hydraulic network and surface formed the basis for making the three scenarios. The model covers 590ha including 169ha impervious areas, containing 2600 links and 2450 nodes, presented in Figure 2.

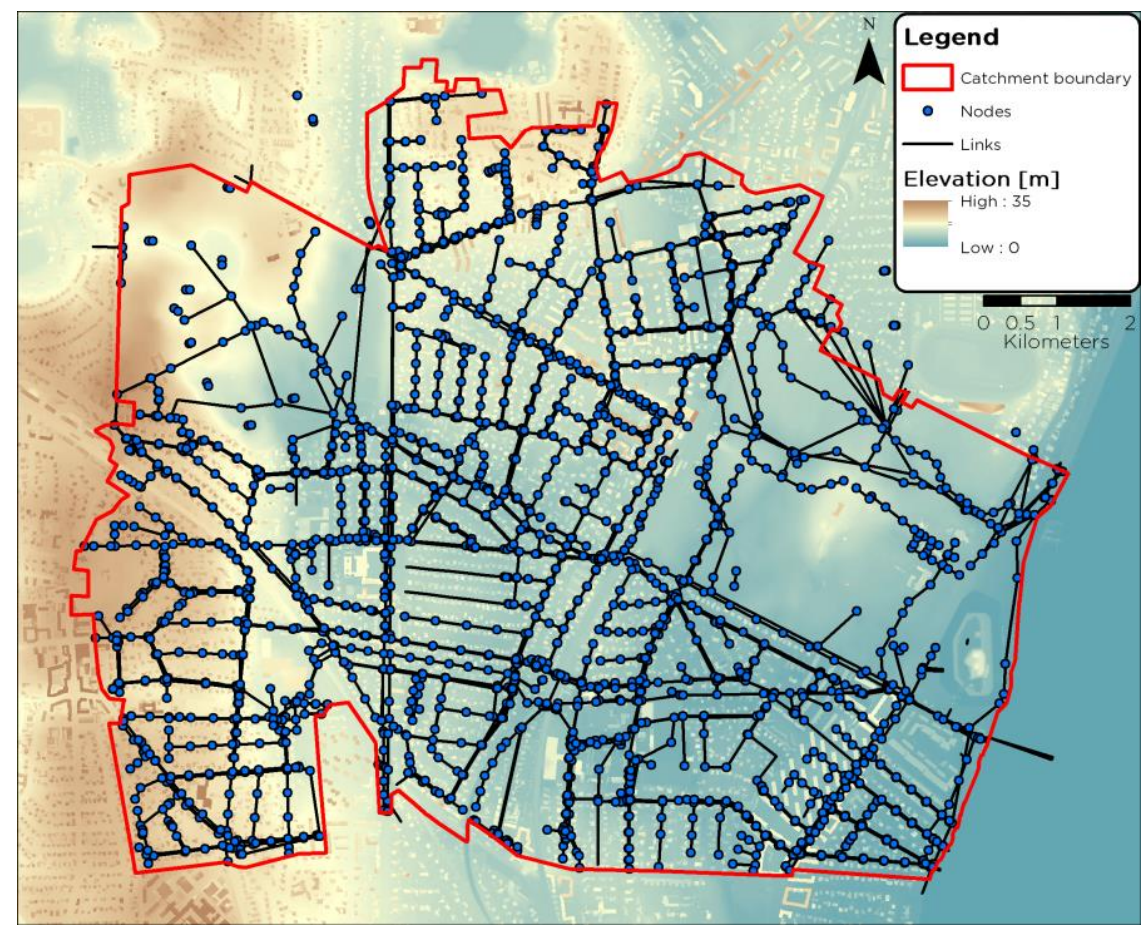

Figure 2. Overview of the 1D-2D coupled model of the Kildeskovsrenden catchment in Gentofte, Denmark.

\subsection{Developing scenarios}

The number of simulations required in the optimisation is reduced using input from the key stakeholders which for the Kildeskovsrenden catchment is the municipality and utility company. Through informative meetings and workshops with the stakeholders, the consequences of different water levels on terrain are discussed and a maximum allowed water level on terrain of $10 \mathrm{~cm}$ were identified. This roughly corresponds to the curb height of most roads in the catchment and is thus not expected to cause major damages. With a constant maximum water level on terrain, the only variable in the optimisation is the return period. 


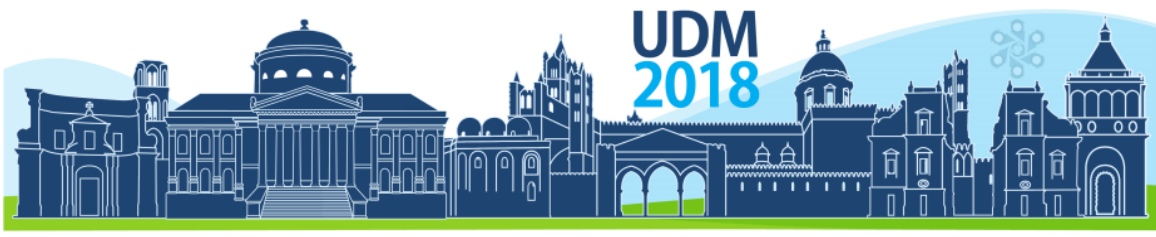

$11^{\text {th }}$ International Conference on Urban Drainage Modelling

23-26 Sep | Palermo - Italy

The next step, is to select return periods (potential service levels) for at least three scenarios with a span that must cover the point of the optimum. The return periods of 20,50 and 100 years in year 2100 are selected, partly chosen by the stakeholders and partly by experience from other studies. Each scenario requires simulation at multiple other return periods to assess the costs of flooding.

Climate adaptation plans are developed to each of these three return periods through 1D-2D urban flood models. These models allowed stakeholders to identify potentials for storage capacity and drainage solutions in the catchment, while fulfilling the criterion of maximum 10 $\mathrm{cm}$ water on the surface. The climate adaptation plans are then expressed spatially and in monetary terms by estimating associated investment and maintenance costs over time.

\section{RESULTS AND DISCUSSION}

Performing a socioeconomic optimisation of both the maximum water level on terrain and the associated return period requires extensive planning, modelling and resources that quickly becomes unfeasible to carry out in reality. It is therefore a necessity to simplify the socioeconomic optimisation in order to draw conclusions within the economic frame of the projects. In this study, the stakeholders were involved to decide a maximum allowed water level on terrain thereby limited the socioeconomic optimisation to only include the return period. Thus we avoided a comprehensive two-dimensional optimisation of both water level and return period. The optimisation is thus not resulting in an overall socioeconomic optimum, but an optimum within the stakeholders' acceptance of water on terrain. The actual socioeconomic optimum of water level on terrain and return period could very well be higher or lower than what is accepted by the stakeholders, thus the results of the optimisation may be rejected. Knowing the stakeholders' acceptance for water levels and return periods can therefore not only narrow down the socioeconomic optimisation, but also ensure the implementation of the new maximum allowed levels for water on terrain.

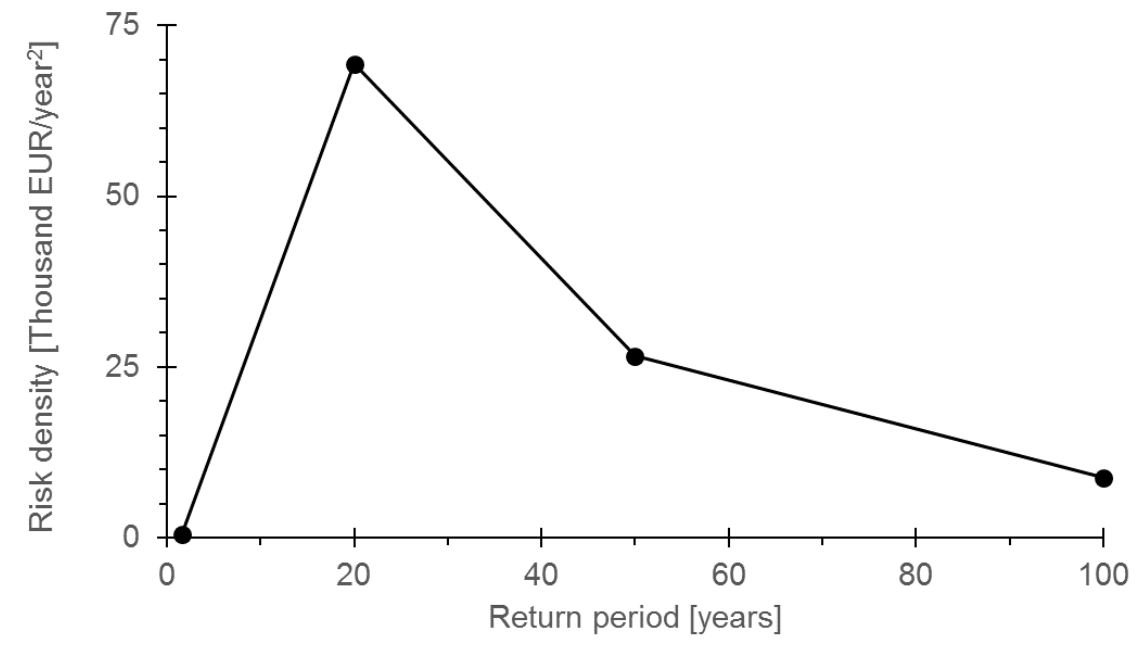

Figure 3. The risk density curve for the Kildeskovsrenden catchment. Return periods in the range from 15-50 years seem to contribute most significantly to the EAD.

The selection of return periods for the socioeconomic optimisation is usually based on no or very little data in the beginning of the analysis and is therefore often based on previous 


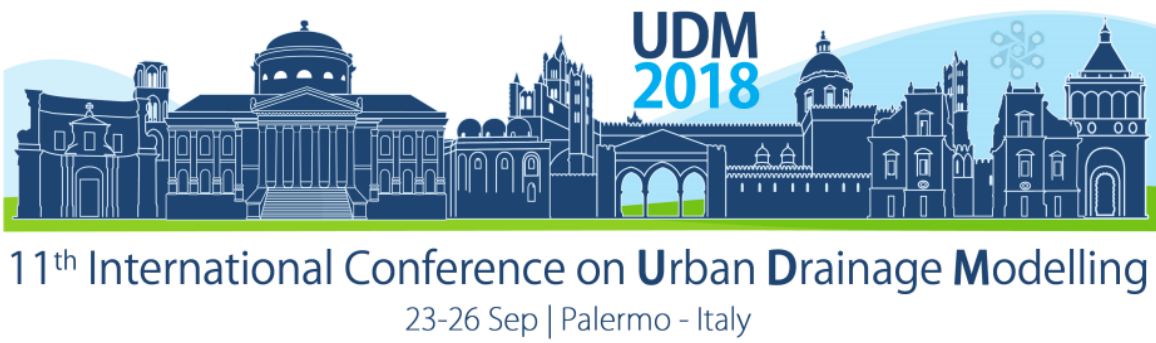

experience or political decisions. Without any preliminary knowledge of the damage curve there is a risk of selecting return periods that may not be appropriate for the analysis and lead to additional iterations to find a set of suitable return periods for the scenarios. For each new scenario the cost of flood damages, investments and maintenance must be assessed and is thus an expensive task to repeat for e.g. an utility company or municipality. It is therefore recommended, to examine the risk density curve introduced by Rosbjerg (2017) to make a more informed estimation of the return periods for the scenarios. The risk density curve for the Kildeskovsrenden catchment is presented in Figure 3 describing the distribution of how return periods contribute to the EAD of the catchment. The EAD is expressed at the integral over the risk density curve, thus the return periods from 15-50 years seem to contribute the most to the EAD. The different adaption strategies which are tested should therefore be within this range of return periods, since the socioeconomic optimum is expected to be within the same range where the benefit of the climate adaption is large, while adaption costs are reasonable.

\section{CONCLUSIONS}

The study applied a socioeconomic optimisation of the return period for water on terrain in the Kildeskovsrenden catchment. The socioeconomic optimisation method from Zhou et al. (2013) requires extensive development and modelling of different scenarios unfeasible in a flood mitigation project but input from stakeholders on e.g. maximum allowed water level on terrain can significantly reduce the number of required simulations along with increasing the likelihood that the proposed solutions will be implemented. The application of the method illustrates the potential for more informed decisions-making in the process of climate adaption projects, especially with relation to the selection of return periods for the socioeconomic optimisation. By inspecting the risk density curve prior to selection of return periods for the scenarios, several model simulation iterations can potentially be avoided. The risk density curve provides a better understanding of the behaviour of the damage curve and can help communicate, at which level adaptation will be especially effective to stakeholders prior to initiating the optimisation process.

\section{References}

Löwe, R., Urich, C., Kulahci, M., Radhakrishnan, M., Deletic, A. and Arnbjerg-Nielsen, K. (2018) Simulating flood risk under non-stationary climate and urban development conditions - Experimental setup for multiple hazards and a variety of scenarios. Environmental Modelling and Software 102, 155-171. https://doi.org/10.1016/j.envsoft.2018.01.008

Olsen, A.S., Zhou, Q., Linde, J.J. and Arnbjerg-Nielsen, K. (2015) Comparing methods of calculating expected annual damage in urban pluvial flood risk assessments. Water 7, 255-270. https://doi.org/10.3390/w7010255

Rosbjerg, D. (2017) Optimal adaptation to extreme rainfalls in current and future climate. Water Resources Research 53, 535-543. https://doi.org/10.1002/2016WR019718

Zhou, Q., Panduro, T.E., Thorsen, B.J. and Arnbjerg-Nielsen, K. (2013) Adaption to extreme rainfall with open urban drainage system: An integrated hydrological cost-benefit analysis. Environmental Management 51, 586-601. https://doi.org/10.1007/s00267-012-0010-8 


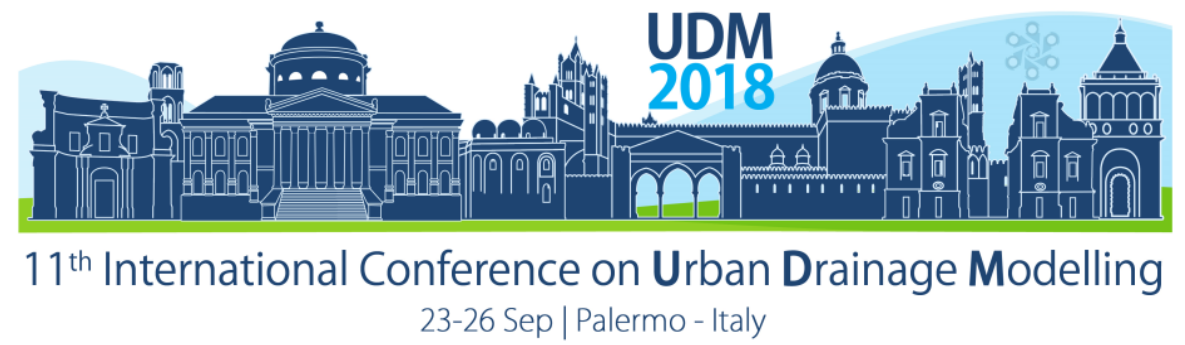

\title{
Virtual Reality in Water Sensitive Urban Design - new data and insight or just playful participation?
}

\author{
Peter M. Bach ${ }^{1,2, *}$, Hannah J. Bragge ${ }^{1}$, Meead Saberi ${ }^{3}$ \\ ${ }^{1}$ Monash Infrastructure Research Institute, Department of Civil Engineering, Monash University VIC Australia \\ ${ }^{2}$ Swiss Federal Institute of Aquatic Science \& Technology (Eawag), Switzerland \& ETH Zurich \\ ${ }^{3}$ Research Centre for Integrated Transport Innovation (rCITI), University of New South Wales, NSW, Australia \\ (corresponding author email: peterbach@gmail.com)
}

\begin{abstract}
Much research considers sustainability benefits of Water Sensitive Urban Design (WSUD), but does not include understanding of the scope of such design to enhance urban aesthetics. We used Virtual Reality (VR) simulations to identify factors affecting aesthetic preference in WSUD landscapes, exploring the use of realism and sitespecific results in landscape preference studies. Three VR simulations were developed using a $360^{\circ}$ camera and game development engine. Thirty $(\mathrm{N}=30)$ university students participated in the simulations. A survey elicited stated preference while revealed preference was obtained from tracking of users' location and field of view within the simulation. Discrete Choice Modelling was used to develop a general utility function for landscape perception. Orderliness and attractiveness were the most influential variables on preference to a specific environment. Openness and complexity showed strong correlations while no correlation was identified for perceptions of health of an environment. Surprisingly, participants preferred artificially constructed 'green' landscapes that evoked a sense of nature over natural remnant wetlands. Overall, the study demonstrated the potential of using VR for stakeholder/community involvement and a new data collection platform on user perception and engagement with green infrastructure.
\end{abstract}

Keywords: preference elicitation; community perception; urban design; discrete choice modelling; simulation

\section{INTRODUCTION}

Water Sensitive Urban Design (WSUD) has been prevalent in Melbourne's urban landscape for several decades (e.g. Brown and Clarke, 2007). Despite extensive uptake in urban drainage management, there is limited assessment of its value from economic and aesthetic perspectives. Understanding people's preferences towards certain types of green infrastructure is essential if the economic (Zhang and Fogarty, 2014), health and aesthetic benefits (Dobbie and Green, 2013) of WSUD are to be understood and models to test and evaluate their design and implementation are to be developed. Landscape preference studies, which can elicit useful social preference data for cost-benefit or other types of numerical models, have typically involved participants viewing visual stimuli in the form of photographs as on-site experiments are costly and time-consuming (Jorgensen, 2011). Concerns have, however, been raised over the realism of participants' experience. Data volume generated relative to the time-input into the experiment is furthermore questionable.

Advancements in virtual reality (VR) technology have led to new ways of supplementing environmental behavioural research (Smith, 2015) and supporting urban planning activities (Zhang et al., 2013). We build upon these works here by investigating whether VR technology can be used to better engage stakeholders and elicit new insights about the perception of WSUD within the urban environment for better planning, design and management. 


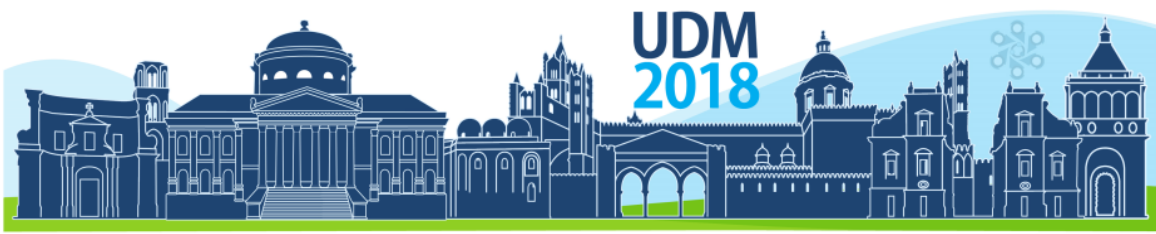

$11^{\text {th }}$ International Conference on Urban Drainage Modelling

23-26 Sep | Palermo - Italy

\section{MATERIALS AND METHODS}

\subsection{Developing VR Simulations}

We combined the benefits of a dynamic immersive environment with photographic realism. Three types of VR simulations of three distinct neighbourhoods in Melbourne, Australia, were developed. The chosen study sites: Docklands, Cranbourne Gardens and Lynbrook Estate (Figure 1) were selected based on their history with WSUD and significant amount of implemented 'green-blue' infrastructure. Transects comprising a series of $360^{\circ}$ images and videos were captured using a Nikon KeyMission 360 camera in different locations across the sites and then connected virtually to create an interactive simulation developed using the Unity game engine (unity3d.com). In the simulations, a user or 'player' can explore the environment by clicking on arrows within the user display to 'walk' along the network of connected images (see Figure 1).
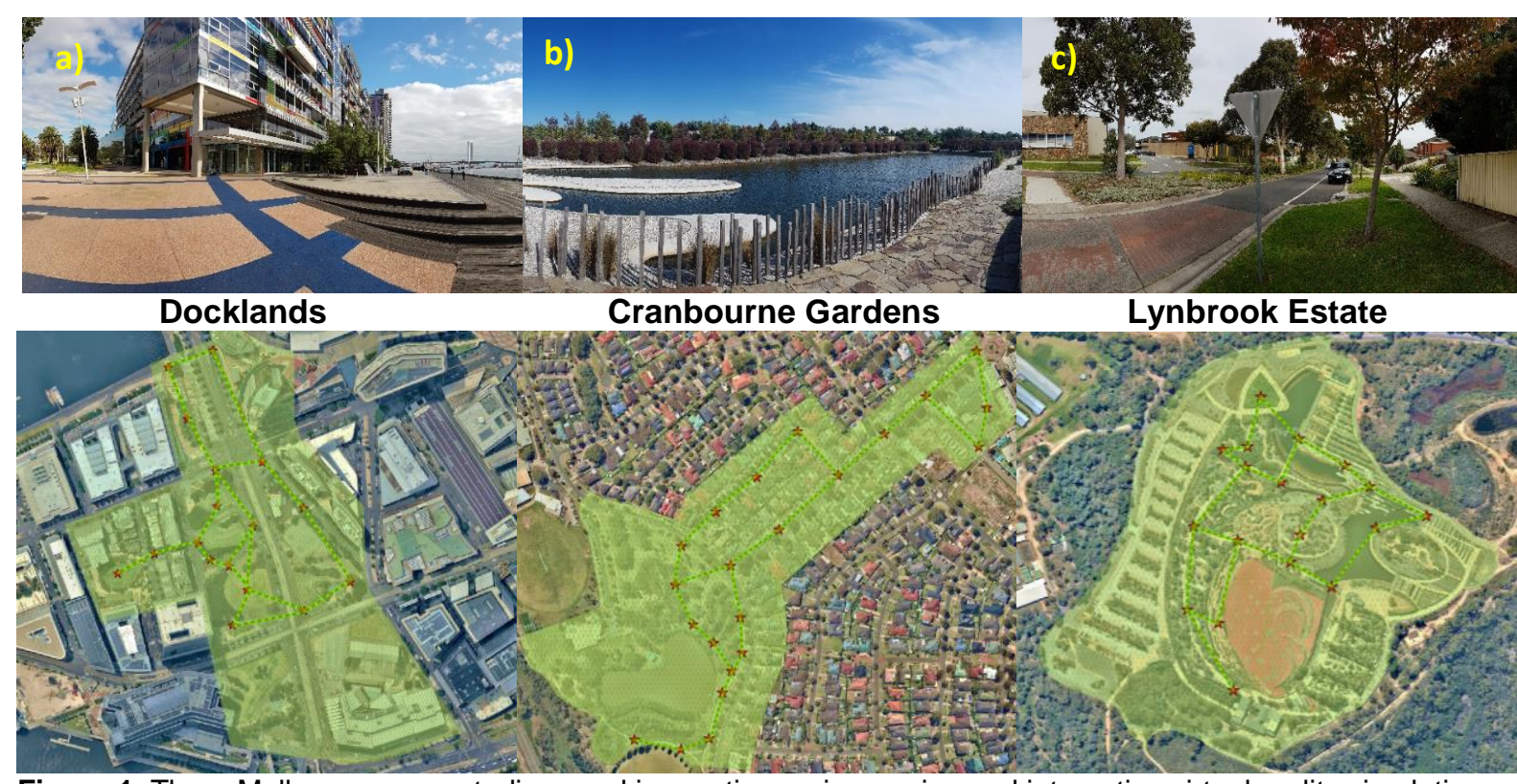

Figure 1. Three Melbourne case studies used in creating an immersive and interactive virtual reality simulation, (a) Docklands near Melbourne's city centre, (b) Royal Botanic Gardens Cranbourne and (c) Lynbrook estate

The three simulation types included: visualisation (using still $360^{\circ}$ images), virtualisation (looped $360^{\circ}$ videos), augmentation (still $360^{\circ}$ images with information overlay). During runtime, the program tracks players' location and logs (at $\Delta t=0.5 \mathrm{~s}$ ) where, within the spherical visual space, their field of view (FOV) was positioned. The simulations were run on a desktop computer screen with keyboard controls to reduce participant 'cybersickness' (Rebenitsch and Owen, 2016) that could occur with low-resolution images on wearable displays such as an Occulus Rift or Samsung Gear VR headset.

\subsection{Experimental Study \& Data Analysis}

Thirty $(\mathrm{N}=30)$ participants comprising university students (ages 18 to 28 years, gender split 50:50) were engaged in the simulation study. Each participant experienced all three simulations (in different orders) for up to 10 minutes each. The experimental procedure comprised: (1) four minutes of free exploration within the virtual environment, (2) rating aesthetic aspects of the environment on a 7-point Likert scale based on the framework by Dobbie and Green (2013), (3) repeating the process for another 4 minutes (with the option to 


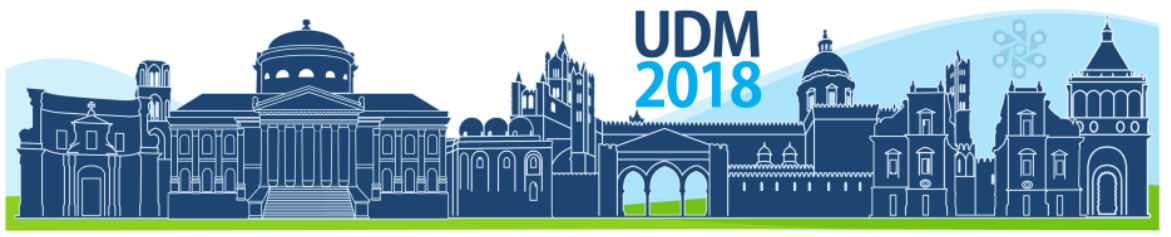

$11^{\text {th }}$ International Conference on Urban Drainage Modelling

23-26 Sep | Palermo - Italy

continue for 2 minutes longer) and (4) a final review of the experience. Data recorded from participant interviews encompassed 'stated' preference data, while information gathered through the software would encompass 'revealed' preference data. We conducted both quantitative and qualitative analysis of the data set.

We used discrete choice modelling to determine the landscape and participant-specific variables, which affect preference. A series of Multinomial-Logit utility functions were derived to investigate preference correlation to different variables including stated preference in relation to orderliness, openness, health, attractiveness, naturalness and complexity of the landscape. A Chi-squared distribution of the difference in log-likelihood between each model and the benchmark model of Lynbrook Estate was used to determine the significance of each variable. We report on variables with a confidence greater than $90 \%$.

\section{RESULTS AND DISCUSSION}

\subsection{Evaluation of Stated and Revealed Preferences}

Most participants preferred Cranbourne Gardens (67\%) over Docklands (26.7\%) and Lynbrook (6.7\%). Stated preference results revealed clear patterns that aligned well with the findings of Dobbie and Green (2013), i.e. that aesthetic aspects including bright light, green plans and cool water was valued. Additionally, 'interesting', 'varied' and 'likely to visit' were used in describing preferred landscapes. Revealed preferences, however, show notable contrasts.

Location tracking of participants showed an uneven exploration patterns among participants, despite an alignment in stated preferences. View tracking results from the experiment (two examples shown in Figure 2) revealed two forms of behaviour observed throughout the participants: path-finding and inquisition. Path-finding was represented by a clustering of points along key pathways in the map that indicate the direction to the next connected location in the simulation. Inquisitive behaviour was visible in locations where a notable WSUD asset (e.g. a constructed wetland or bioretention system) was present. The 'willingness to look around' did not correlate with landscape preference. For example, participants who preferred Cranbourne or Docklands, exhibited the most inquisitive behaviour in Lynbrook.

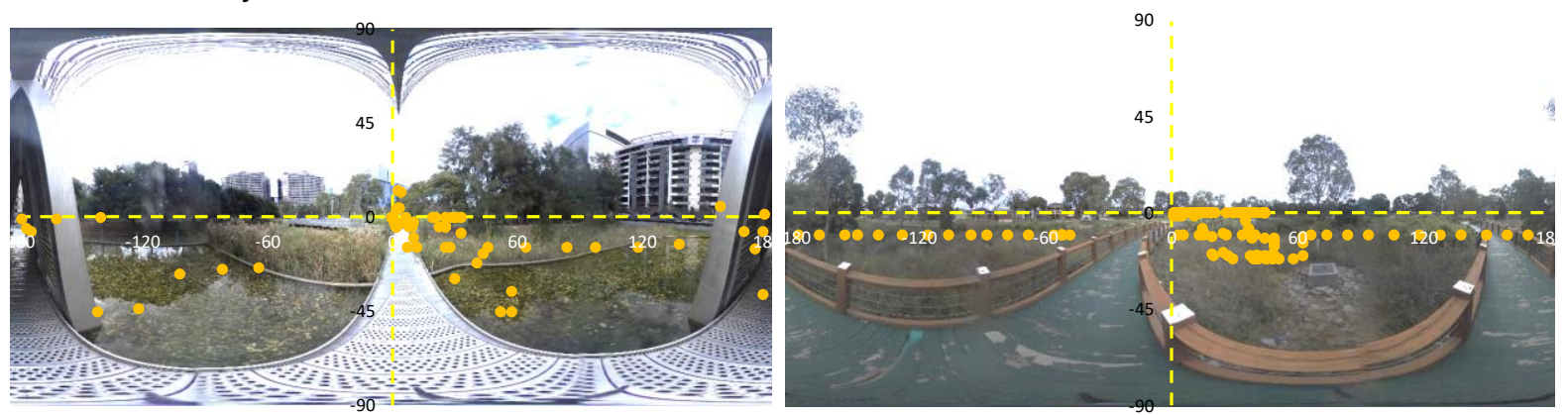

Figure 2. View tracking results showing a balanced focus between path-finding and inquiry of WSUD features

The discrete choice model aligns with participants' comments in the stated preference survey, but with some inconsistencies. The strongest explanatory power belonged to a model considering orderliness and attractiveness. Openness and complexity aligned with stated preferences and those in the literature. Interestingly, however, naturalness and health were 


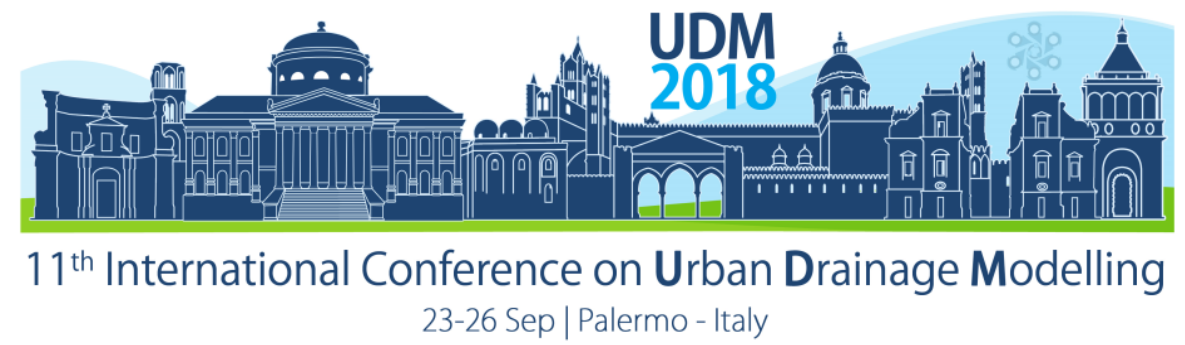

negatively correlated, suggesting that more anthropogenic environments were preferred over natural remnant vegetation and wetlands. Qualitative inquiry indicates, however, that meanings of naturalness and health may have been ambiguous in the study, explaining the discrepancy.

\subsection{Evaluating the use of VR}

The use of video (i.e. movement) in the virtualisation simulation was found to enhance realism for $50 \%$ of participants; the remaining $50 \%$ preferring higher resolution, sharper quality of still images in the visualisation simulation (i.e. the camera can capture higher resolution images than videos). Whilst the augmentation simulation provided useful additional information, its preference might have been predominantly due to the higher resolution and sharpness of using still images. Overall, all participants reported high levels of realism of the three VR simulations, but preference results from the discrete choice model were ultimately inconclusive, highlighting further work to improve data quality and usability in numerical models and other applications.

\section{CONCLUSIONS}

We investigate the potential of VR technology to enhance landscape preference studies about WSUD infrastructure. The simulations and experiments can be adapted and recreated with a modest amount of effort compared to the richness and diversity of data on stated and revealed preferences that can be gained. Outputs are consistent with existing findings on landscape studies, but with improved realism and immersion.

The study has provided insight into the potential of VR technology in enhancing landscape preference studies for WSUD and provides planners with a useful data acquisition and engagement platform. There is potential to use this data in a variety of models for WSUD design and simulation (e.g. agent-based models or WSUD uptake, design evaluation tools and $3 \mathrm{D}$ visualisation). Future work will refine the virtual simulation through creating a more seamless experience, achievable through greater image acquisition, more intuitive user controls and porting the application to wearable VR technology.

\section{ACKNOWLEDGMENTS}

This project is funded by the Australian Research Council (ARC) Discovery Early Career Researcher Award (DECRA) Project DE170100042, titled "Virtual Reality for Planning of Green Urban Water Infrastructure"

\section{REFERENCES}

Brown, R. and Clarke, J. (2007) Transition to Water Sensitive Urban Design - The Story of Melbourne, Australia, Melbourne, Australia: Facility for Advancing Water Biofiltration.

Dobbie, M. and Green, R. (2013) 'Public perceptions of freshwater wetlands in Victoria, Australia', Landscape and Urban Planning, 110, pp. 143-154.

Jorgensen, A. (2011) 'Beyond the view: Future directions in landscape aesthetics research', Landscape and Urban Planning, 100(4), pp. 353-355.

Rebenitsch, L. and Owen, C. (2016) 'Review on cybersickness in applications and visual displays', Virtual Reality, 20(2), pp. 101-125.

Smith, J. W. (2015) 'Immersive virtual environment technology to supplement environmental perception, preference and behavior research: A review with applications', International journal of environmental research and public health, 12(9), pp. 11486-11505.

Zhang, F. and Fogarty, J. (2014) Nonmarket valuation of water sensitive cities: current knowledge and issues, Working Paper 1513 School of Agricultural and Resource Economics, University of Western Australia.

Zhang, Y., Zhang, X. and Lin, L. (2013) 'Effectiveness Assessment on Urban Planning Analyzed in Virtual Reality Environments', JSW, 8(1), pp. 78-84. 


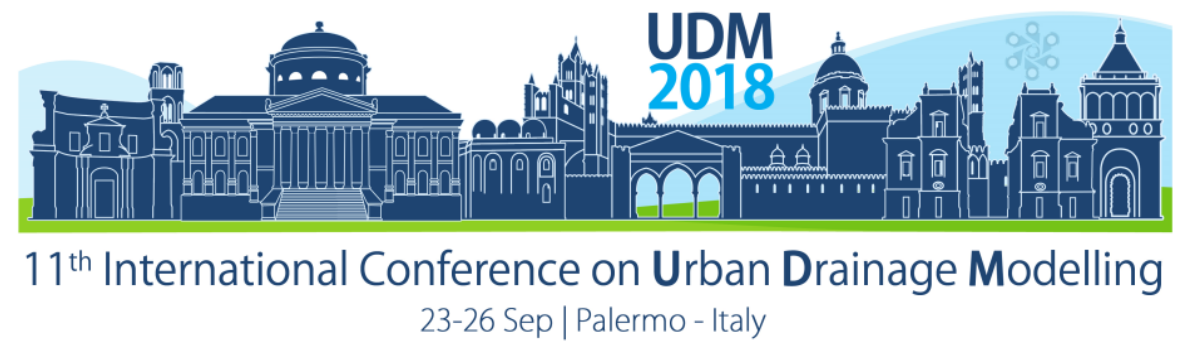

\title{
Conceptual Modeling of Micropollutant Fate in Sewer Systems - A GIS-Based Approach to Define Model Structure
}

\author{
Riccardo Delli Compagni ${ }^{1}$, Fabio Polesel ${ }^{2}$, Kerstin J.F. von Borries ${ }^{2}$, Zhen Zhang ${ }^{2}$, Andrea \\ Turolla ${ }^{1}$, Manuela Antonelli', Luca Vezzaro ${ }^{2}$ \\ ${ }^{1}$ Department of Civil and Environmetal Engineering (DICA), Politecnico di Milano, Milan, Italy \\ ${ }^{2}$ Deparment of Environmental Enginerring (DTU Environment), Technical University of Denmark, Kongens \\ Lyngby, Denmark
}

\begin{abstract}
A new approach to automate the challenging task of defining the complexity level for conceptual modelling of micropollutant (MP) fate in sewer system is here presented. The approach combines GIS information and advanced statistical techniques (e.g., cluster analysis) and provides for a realistic description of in-sewer hydraulic residence time (HRT), which is fundamental for simulating MP removal processes occurring during in-sewer transport. The conceptual model was first tested in a full-scale catchment, where HRT distribution was determined based on spatial distribution of discharge sources and following calibration against high-frequency flow rate data. The model was then used to predict the dynamics of an ideal MP (biodegradation half-life $=2.5$ h) at the outlet of the sewer system, revealing higher removal during in-sewer transport when considering an average HRT compared to a discrete HRT distribution. These results demonstrate that an intermediate complexity level, between highly detailed hydrodynamic models and simplified models, could be adopted for MP fate predictions while keeping computational demands reasonable. This latter aspect can be also of particular interest when an integrated modelling perspective (e.g., sewer and WWTP) is considered.
\end{abstract}

Keywords: GIS; cluster analysis; sewer system modelling.

\section{INTRODUCTION}

The development of models that properly describe transport and biochemical processes within a sewer is a challenging task due to the complex nature of the sewer itself and the lack of available information such as sewer network geometry. When dealing with the fate of reactive organic micropollutants (MP), further challenges arise due to the uncertainties linked to measurements and the poor mechanistic knowledge of the processes involved. Where available, detailed hydrodynamic models have been used to simulate pollutants fate (Shahvi et al., 2016) or to extract information that is relevant for MP fate estimation, such as hydraulic residence time (HRT) and MP discharge profiles (McCall at al., 2017). However, when such information is not available and computational demands are limited, conceptual modes can provide a valid alternative to simulate the transport and transformation of MPs. In large catchments, conceptual approaches have been proposed to simulate water quality at the inlet of wastewater treatment plants (WWTP) and their main focus has been on traditional water quality indicators (e.g., Flores-Alsina et al., 2014). The model library described in Vezzaro et al. (2014) provided a conceptual approach to simulate the fate of various MPs across the whole integrated urban wastewater system. When focusing on MP fate description, relevant parameters (especially the in-sewer hydraulic residence time, HRT) 


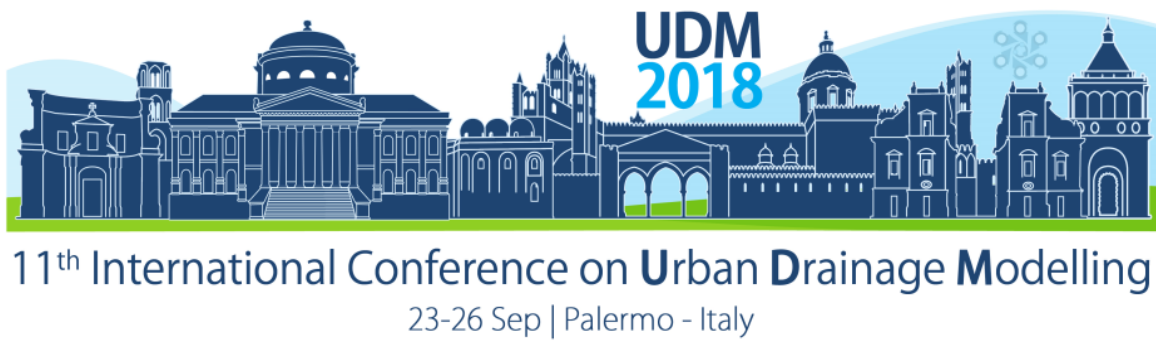

need to be considered in the model construction. HRT is in fact linked to the main MP fate processes (biodegradation, sorption) (Ramin et al., 2016), and its correct description is a key point for predicting MP occurrence in sewer outlets. However, hydrodynamic models of sewer catchments are rarely available, especially for large urban areas, and alternative data on water supply (e.g., water consumption, consumer locations) and sewer networks (pipeline) stored in Geographical Information Systems (GIS) may represent a valid option. In this study, we aimed at testing a new approach, which relies on available GIS information and advanced statistical techniques (cluster analysis), for defining the level of optimum complexity for conceptual sewer models where MP fate prediction is the primary objective.

\section{MATERIALS AND METHODS}

\subsection{Case Study}

The conceptual model approach was developed for a large sewer catchment with negligible industrial contribution. No detailed hydrodynamic model of the catchment is currently available. Water network data were provided by the local water utility, including shape files of the sewer pipeline network, the catchment area, the geographical location of points for potable water consumption along the drinking water distribution system (around 28.000), and the water consumption for each point over a reference period (1 year). WWTP inlet flow data (at 5-minute resolution) were available for the study period (January 2016-December 2016).

\subsection{Overview of the approach}

The developed approach comprised three steps, which are detailed below with respect to the procedures and the algorithms used.

\section{Step 1: Sewer Network Analysis and Daily Wastewater Profile Generation.}

The distance $d(m)$ between each wastewater generation point (equal to drinking water consumption point) and the WWTP inlet was calculated through the "networkx" python module using the Dijkstras algorithm. This provided a probability density distribution ( $p d d)$, where the mean represents the average household distance from the WWTP. The diurnal wastewater profile generation was estimated based on the pattern for diurnal drinking water $(d d w)$ consumption reported by Candelieri and Archetti (2014). Finally, the wastewater profile was obtained by scaling the $d d w$ profile by the annual water consumption. Water losses (e.g. water gardening) were also taken into account and assumed equal to $2 \%$ of the annual consumption (Butler et al., 2004).

\section{Step 2: Gaussian Mixture Model for Cluster Analysis.}

The pdd of the network distance was divided by an average flow velocity $v\left(0.8 \mathrm{~m}^{3} / \mathrm{s}\right.$, value after calibration against high-resolution influent flow rate measurements), to obtain a pdd for in-sewer HRT. Also, an automatic model calibration was performed to estimate groundwater infiltration. The HRT pdd was then used as input to the iterative Expectation-Maximation (EM) algorithm to optimise the Gaussian mixture model likelihood. The EM algorithm was used to determine the mean and variance of a number $n$ of Gaussian sub-distributions (also known as components), the combination of which fits the HRT pdd. The components denote the different sub-catchments, in which the main catchment was subdivided. 


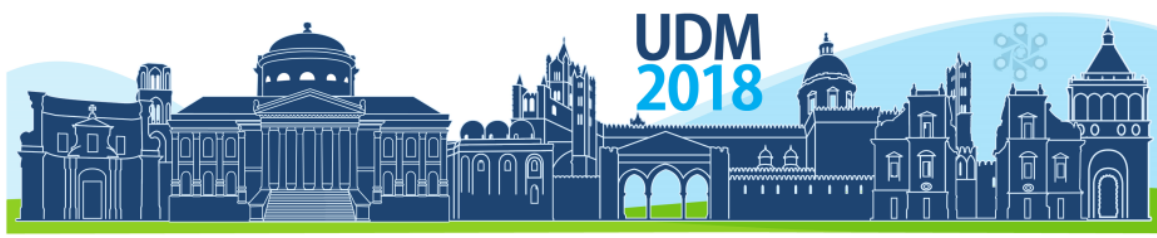

$11^{\text {th }}$ International Conference on Urban Drainage Modelling

23-26 Sep | Palermo - Italy

Step 3: Construction of the conceptual model.

The model was built by using the elements in the IUWS-MP library (Vezzaro et al., 2014), where the sewer network was simulated as a series of non-linear reservoirs (Saagi et al., 2016) in WEST® 2014 (DHI, Hørsholm, Denmark). For each sub-catchment the number of non-linear tanks was optimised to match the estimated HRT mean of step 2.

\section{RESULTS AND DISCUSSION}

\subsection{Sewer Network Analysis and cluster analysis}

The results of the cluster analysis and the conceptual model are shown in Figure 1a and b, respectively. The algorithm selected six components, indicating that six mean HRT values were sufficient for a proper representation of the HRT distribution in the catchment. Accordingly, six separate sub-catchments were identified and used for the definition of the conceptual model (Figure 1b).

a)

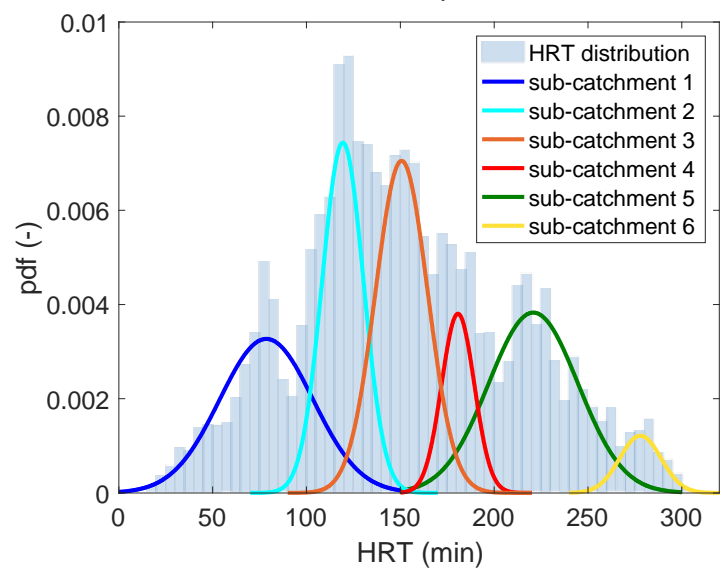

b)

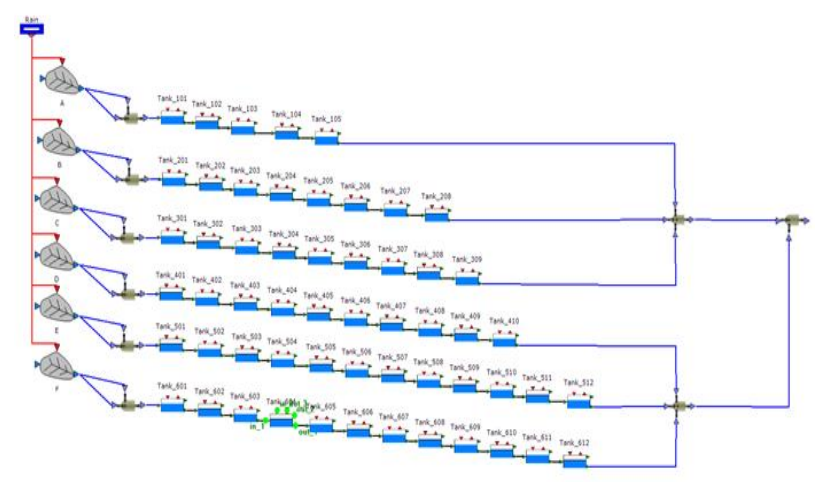

Figure 1. a) Result of the cluster analysis with identification of the sub-catchments and their corresponding HRT values (mean of each Gaussian distribution); b) conceptual model in WEST environment.

\subsection{Model results}

The conceptual model allowed to properly simulate flow dynamics (Figure 2a), being within the $10^{\text {th }}$ and $90^{\text {th }}$ percentile of measured data (180 days). Figure $2 \mathrm{~b}$ presents the concentration profiles at the sewer outlet of an ideal non-sorptive MP with biodegradation half-life $=2.5 \mathrm{~h}$ when a six-catchment model (red curve) and a single-catchment model (green area) is considered. For the single-catchment model, an average HRT value of approximately 2.5 hours (the mean of the HRT distribution) was assumed. The simulated MP profile differed for the two cases, with approximately $10 \%$ lower removal efficiency from excretion point to WWTP inlet for the six-catchment model. This observation highlights the influence of HRT description on the estimation of MP removal via biodegradation within the sewer system. 


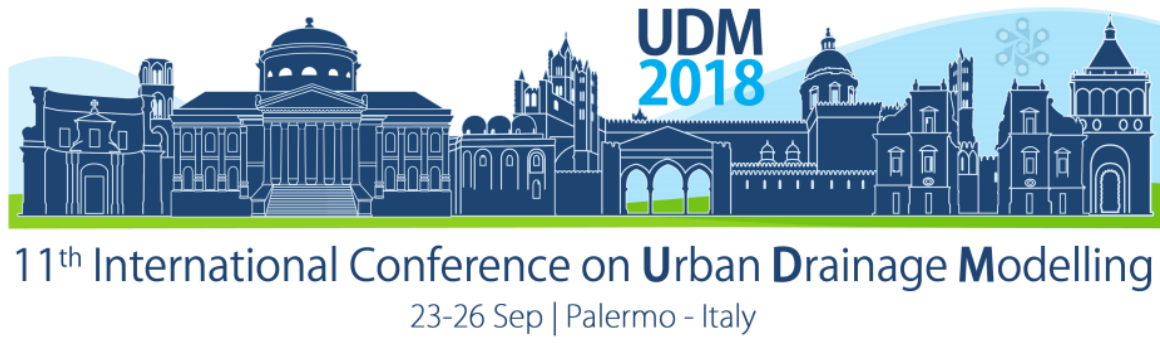

a)

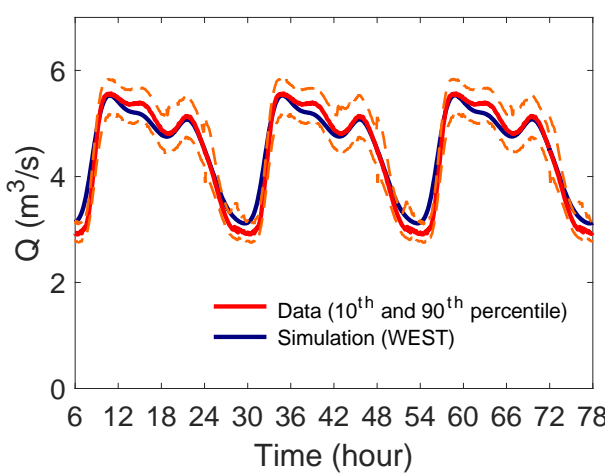

b)

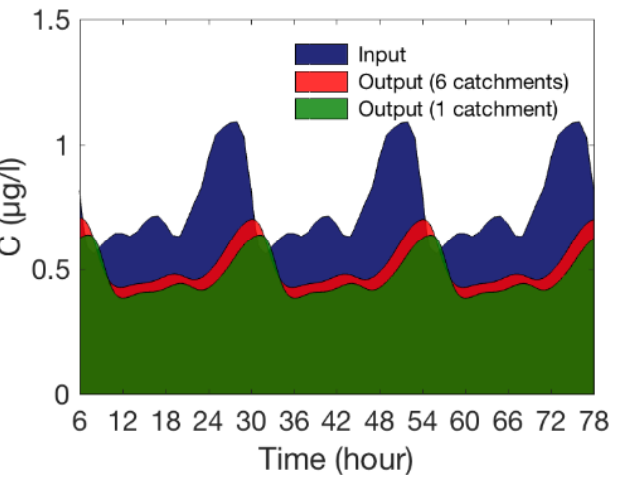

Figure 2. a) Comparison between measured data (red lines, median of 180 days) and the model (blue line) when six sub-catchments are considered; b) Comparison of profiles for an ideal non-sorptive and biodegradable MP when two different conceptual sewer models are considered (6 subcatchments in red, 1 subcatchment in green).

\section{CONCLUSIONS}

Through the combination of GIS-based information and statistical analysis, we were able to identify the optimal structure of a conceptual model aiming at simulating in-sewer HRT in a large urban catchment, while keeping model complexity as simple as possible. This approach allowed for successful simulation of flow dynamics and implications for MP fate predictions were evaluated. Preliminary simulation results revealed that multi-catchment models should be preferred, especially for degradable MPs, to avoid overestimation of their removal during in-sewer transport. Further investigation is currently ongoing to assess the effect of complexity level on in-sewer removal of MPs of different characteristics (e.g., higher or lower degradability).

\section{References}

Butler, D. and Davies J.W. (2004) Urban Drainage (Second ed.). Taylor \& Francis e-library.

Candelieri, A. and Archetti, F. (2014) Identify typical urban water demand pattern for a reliable short-term forecasting - The icewater project approach. Procedia Engineering, 89, 1004-1012.

Flores-Alsina, X., Saagi, R., Lindblom, E., Thirsing, C., Thornberg, D., Gernaey, K. V., and Jeppsson, U. (2014) Calibration and validation of a phenomenological influent pollutant disturbance scenario generator using fullscale data. Water Research, 51(0), 172-185.

Hvitved-Jacobsen, T., Vollertsen, J. and Haaning Nielsen., A. (2013) Sewer Processes, Microbial and Chemical Process Engineering of Sewer Networks, CRC Press, Taylor and Francis Group, New York, NY.

McCall, A. K., Palmitessa, R., Blumensaat, F., Morgenroth, E., Ort, C. (2017) Modeling in-sewer transformations at catchment scale - implications on drug consumption estimates in wastewater-based epidemiology, Water Research, 122, 655-668.

Saagi, R., Flores-Alsina, X., Fu, G., Butler, D., Gernaey, K. V, and Jeppsson, U. (2016) Catchment \& sewer network simulation model to benchmark control strategies within urban wastewater systems. Environmental Modelling and Software, 78, 16-30.

Ramin, P., Libonati Block A., Polesel F., Causanilles A., Emke, E., de Voogt, P., Plosz, B. (2016) Transformation and Sorption of Illicit Drug Biomarkers in Sewer Systems: Understanding the Role of Suspended Solids in Raw Wastewater. Environ. Sci. Technol. 50 (24), 13397-13408.

Shahvi, S., Orsi, E., Canziani, R., Larcan, E., Becciu, G. (2016) Study on industrial macropollutants discharges in Milan sewer system, Management of Environmental Quality: An International Journal, 27 (2), 194-209.

Vezzaro, L., Benedetti, L., Gevaert, V., De Keyser, W., Verdonck, F., De Baets, B., Nopens, I., Cloutier, F., Vanrolleghem, P.A., Mikkelsen, P.S., (2014). A model library for dynamic transport and fate of micropollutants in integssrated urban waste-water and stormwater systems. Environ. Model. Softw. 53, 9811 


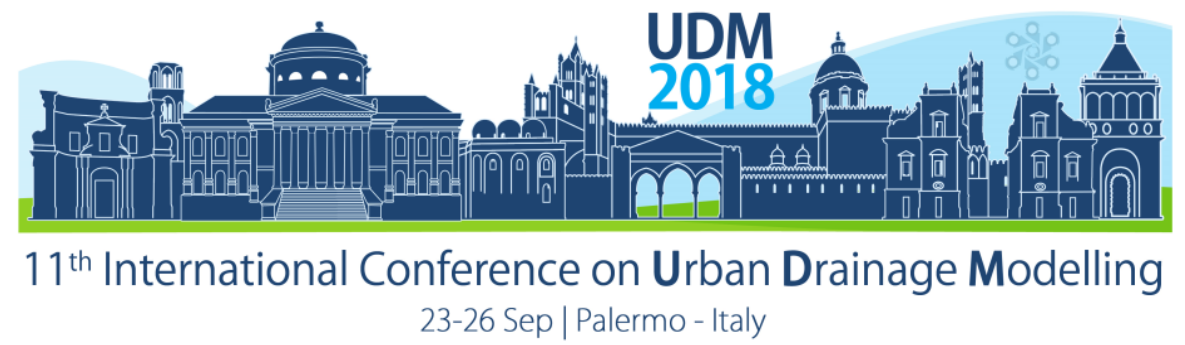

\title{
Valuable outcomes in urban hydrology deriving from CFD modelling approach
}

\author{
Lipeme Kouyi Gislain \\ Univ Lyon, INSA Lyon, DEEP, F-69621 Villeurbanne cedex, France
}

\begin{abstract}
In response to the global change, it is vital to think in-depth about the adaptability of urban waters and stormwater treatment and management structures. Approaches based on all spatial-temporal scales (controlled conditions in pilot tests, flows in field structures, transfer dynamic at watershed level, occasional or long-term experiments) should be enhanced in order to more effectively measure, understand and model urban stormwater transfer and transformation mechanisms in stormwater and sewer systems. Approaches have to combine measurements and modelling aspects. Using expertise in fluid mechanics by means of CFD modelling is crucial to tackle some urban hydrology issues in line with the design and behaviour of complicated facilities and structures (e.g. CSOs - combined sewer overflows, detention/retention and settling basins). CFD simulation outcomes show how this approach supports the instrumentation of complex CSO, reproduces sediment distribution in detention/retention basins, and help to design an original monitoring channel. Future work should focus on the simplification of meshing procedure and on further in-situ validation of CFD solutions.
\end{abstract}

Keywords: Advanced simulation, DSM-flux, Flow measurement, Settling processes

\section{INTRODUCTION}

It is clear that the transport and physical transformation (particulate separation by settling or due to turbulent shear stress) of urban water and stormwater are more complex in specific structures such as CSOs, stormwater detention basins, open channel junctions. Studying how these structures operate raises several scientific challenges such as how to take key measurements (flow rates, concentration in pollutants/contaminants etc.), evaluate the uncertainties relating to these measurements, and model their hydrodynamic behaviour (notably the issue of controlling boundary conditions) with a view to improving the monitoring, design and sizing. For this reason, CFD approach is useful to simulate flows in these structures and had notably been resulting in: i) the development of an instrumentation methodology for complicated CSO management (Lipeme Kouyi et al., 2005); ii) the optimization, using velocity field analysis, of the sensor placement downstream of a confluence (Mignot et al., 2012); iii) the identification of new flow structures downstream of dividing open channel flows (Momplot et al., 2017); iv) the transport of particulate contaminant in settling tank at laboratory scale (Adamsson et al., 2003). In terms of operational developments, CFD outcomes lead to: i) metrological procedures and practices; ii) monitoring of the quality of urban effluent; iii) the design of structures for managing, monitoring and treating urban water and stormwater. This paper aims at demonstrating the high interest of CFD approach in urban hydrology to tackle challenging issues related to flow measurements in complicated sites and sediment distribution in specific structures. This advanced numerical approach allows reducing costs regarding laboratory experiments and support practitioners for flow measurements that is crucial for urban waters and stormwater management. 


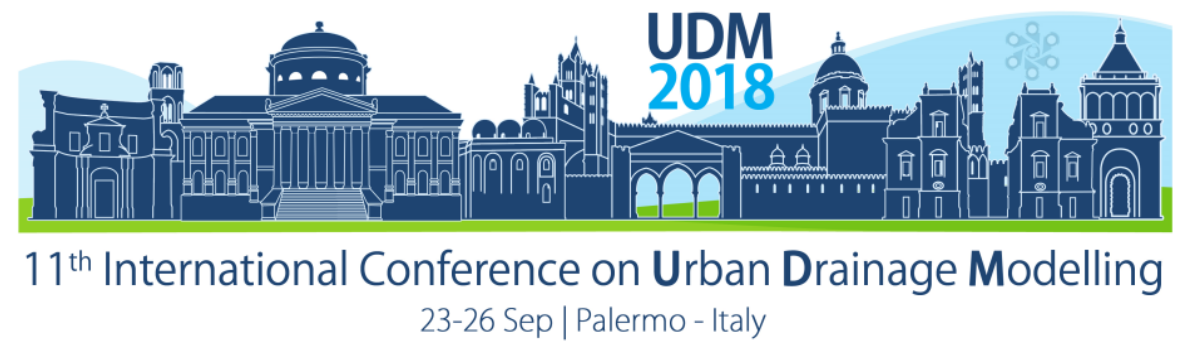

\section{MATERIALS AND METHODS}

\subsection{Presentation of overall CFD approach}

The numerical modelling of flows and solid transport is carried out by means of various CFD software packages using a multi-phase, steady or unsteady state formulation which solves the three-dimensional fundamental flow equations. An appropriate turbulence model is thus of great importance in order to obtain accurate numerical results. The key equations for fluid motion in the whole domain are: (1) the continuity equation for the incompressible fluid in Eulerian approach:

$\frac{\partial \overline{u_{i}}}{\partial x_{i}}=0$

and (2) the three Reynolds' time-Averaged Navier-Stokes (RANS) equations for an incompressible turbulent fluid flow for e.g. steady flow condition:

$\overline{u_{j}} \frac{\partial \overline{u_{i}}}{\partial x_{j}}=-g \frac{\partial z}{\partial x_{i}}-\frac{1}{\rho} \frac{\partial P}{\partial x_{i}}+\frac{\partial}{\partial x_{j}}\left(v \frac{\partial \overline{u_{i}}}{\partial x_{j}}-\overline{u_{i}^{\prime} u_{j}^{\prime}}\right)$

with $i$ and $j=1,2$ and 3, where $x_{i}$ represents the three coordinate axes, $\bar{u}_{i}$ the time-averaged velocity along axis $i, z$ the vertical elevation, $P$ the pressure, $\rho=1000 \mathrm{~kg} / \mathrm{m}^{3}$ the fluid density, $v=10^{-6} \mathrm{~m}^{2} / \mathrm{s}$ the fluid viscosity and the Reynolds stresses with the "prime sign" referring to time fluctuations. Solving Eqs. 1 and 2 requires a turbulence model to set the Reynolds stresses.

\subsection{Evaluation of CSOs discharge}

The measurement of the flow through complex combined sewer overflow structures in the frame of automated monitoring remains difficult. A methodology based on the use of a validated CFD modelling can be performed in order to improve the instrumentation of these structures. Several investigations have been done to validate CFD models (using Ansys Fluent package) against experimental data, as shown on figure 1. The analysis of the CFD results provides: i) a better understanding of the hydrodynamic behaviour, including the potential backflow effect - and ii) an ability to optimise the location of the water depth sensor. The measured water depth is used to assess the overflow rate by means of a numerical relationship.

In addition, CFD platform was used to design a new monitoring device in order to get reliable flow measurement data. The Device for Stormwater and combined sewer flows Monitoring and the control of pollutant fluxes (DSM-flux), represents a new pre-calibrated and pre-designed device to monitor and control the quantity and the quality of CSOs, as well as to trap sediments conveyed in these overflows. 


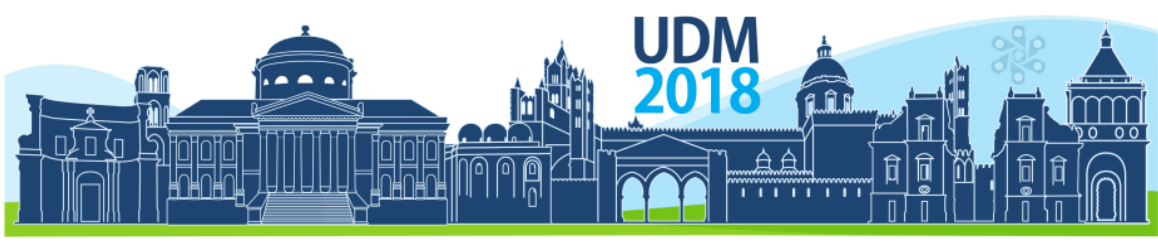

$11^{\text {th }}$ International Conference on Urban Drainage Modelling 23-26 Sep | Palermo - Italy

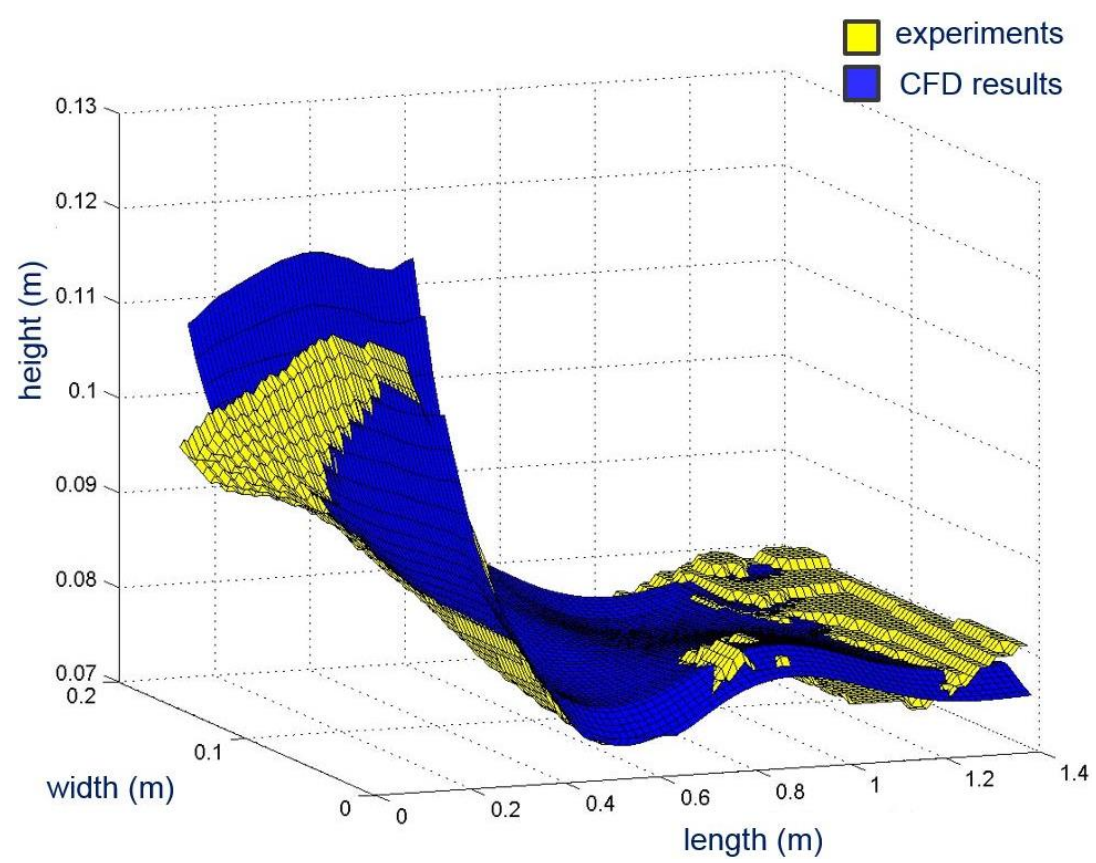

Figure 1. Comparison between 3D measured and simulated free surface along a CSOs.

\subsection{Particulate transport in a field detention/retention settling basin}

Stormwater detention basins are of great importance for the sustainable management of urban stormwater. Stormwater detention basins have two main functions: i) preventing flooding by mitigating peak flow and ii) trapping particulate pollutants by means of settling processes in order to preserve the quality of receiving waters. The processes of sedimentation and resuspension in these facilities are not well-understood and well-modelled. In order to gain a better understanding of these processes in real facilities, CFD modelling of hydrodynamic and sediment transport was carried out. Sediment transport is simulated using Discret Phase Model-DPM approach (e.g. Adamsson et al., 2003). An original bed boundary condition has been tested and is based on the comparison between the bed turbulent kinetic energy and the energy conveyed by particles thanks to its settling velocities.

\section{RESULTS AND DISCUSSION}

Several research groups have applied Computational Fluid Dynamics (CFD)-based methodologies to successfully obtain HQRs for complex CSO structures and have defined the optimal position of the corresponding water level sensors (Fach et al., 2009; Lipeme Kouyi et al., 2011). Isel et al. (2014) and Lipeme Kouyi et al. (2011) estimated relative uncertainty or mean error values around 10\% for higher discharges and 30\% for smaller overflows obtained by means of these CFD-based methods. Concerning overflow volumes for a CSO event, associated uncertainties are usually lower, even if Isel et al. (2014) obtained values that roughly exceed $14 \%$ for CFD-based methods.

It seems that stage-discharge relation (HQR) methods broadly present lower uncertainties. If applied at the CSO structure location, 3D modeling presents very satisfactory results but the obtained HQRs are site-dependent as CSO structures geometries are not standardized. Besides, the monitoring of CSO quality should be more representative if done directly at the overflow conduit and not upstream from the CSO structure or in its chamber where, for complex geometries, recirculation flows and concentration gradients may occur. Hence, a pre-calibrated 


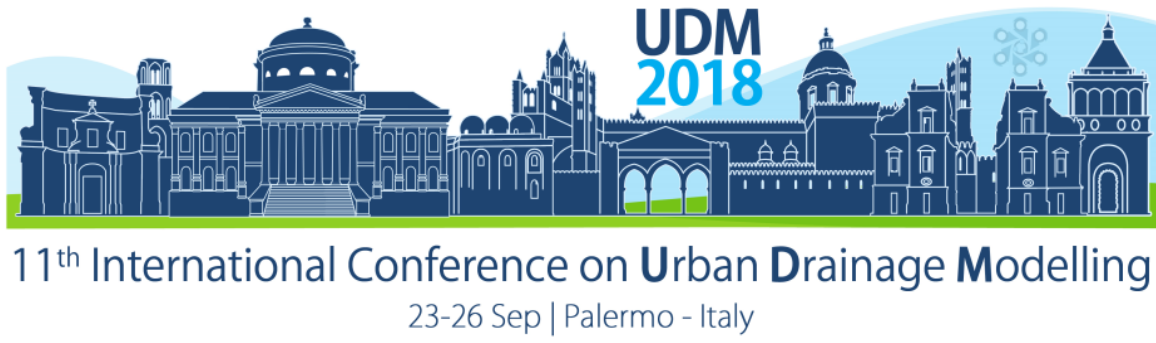

and pre-designed channels can be an appropriate solution to tackle all these issues. Thanks to CFD modelling, an original channel has been designed (figure 2). This channel demonstrates it robustness regarding flow measurements, whatever the hydraulic upstream conditions are (Mate Marin et al., 2018). Additional results on sediment distribution in retention/detention basins will be shown in the final full paper.

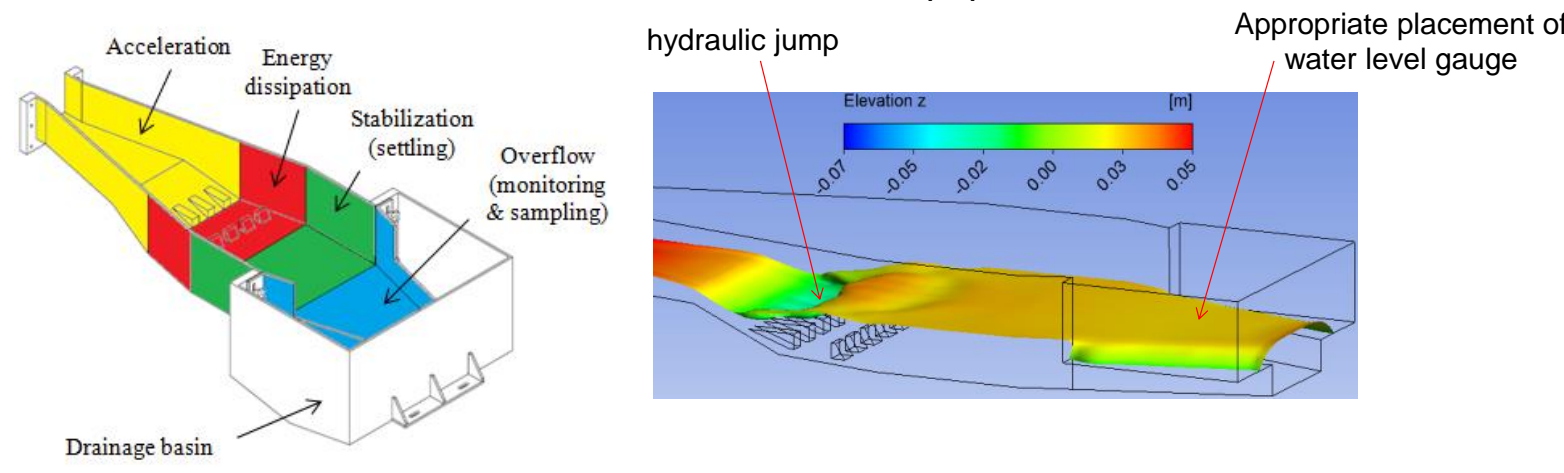

Figure 2. Schematic of the DSM-flux small-scaled physical model experimental set-up and related CFD simulated varying water level.

\section{CONCLUSIONS}

The research work presented herein highlights examples to demonstrate how combining experiments and CFD modelling, at various spatio-temporal scales, supports: i) the integrated instrumentation of CSO, ii) effective representation of the transport, settling and resuspension of the particulate pollutants in stormwater detention/retention basins, iii) the designing of an original channel for flow and pollutant monitoring. All these outcomes are crucial to strengthen urban waters and stormwater management under challenging several climatic and urban land uses constraints.

\section{References}

Adamsson, Å., Stovin, V., and Bergdahl, L. (2003). Bed shear stress boundary condition for storage tank sedimentation. Journal of Environmental Engineering, 129(7), 651-658.

Fach, S., Sitzenfrei, R., Rauch, W., 2009. Determining the spill flow discharge of combined sewer overflows using rating curves based on computational fluid dynamics instead of the standard weir equation. Wat. Sci. Tech. 60, 3035-3043. doi:10.2166/wst.2009.752

Isel, S., Dufresne, M., Fischer, M., Vazquez, J. (2014). Assessment of the overflow discharge in complex CSO chambers with water level measurements - On-site validation of a CFD-based methodology. Flow Meas. Instrum. 35, 39-43. doi:https://doi.org/10.1016/j.flowmeasinst.2013.11.003

Lipeme Kouyi, G., Bret, P., Didier, J.-M., Chocat, B., Billat, C., 2011. The use of CFD modelling to optimise measurement of overflow rates in a downstream-controlled dual-overflow structure. Wat. Sci. Tech. 64, 521527. doi:10.2166/wst.2011.162

Lipeme Kouyi, G., Vazquez, J., Gallin, Y., Rollet, D., Sadowski, A.G., 2005. Use of 3D modelling and several ultrasound sensors to assess overflow rate. Wat. Sci. Tech. 51, 187-194.

Mignot E., Bonakdari H., Knothe P., Lipeme Kouyi G., Bessette A., Rivière N. and Bertrand Krajewski J.-L. (2012). Experiments and 3D simulations of flow structures in junctions and their influence on location of flowmeters. Wat. Sci. Tech. 66(6), 1325-1332.

Mate Marín, A., Rivière, N., and Lipeme Kouyi, G. (2018). DSM-flux: A new technology for reliable Combined Sewer Overflow discharge monitoring with low uncertainties. Journal of environmental management, 215, 273-282.

Momplot A., Lipeme Kouyi G., Mignot E., Rivière N., Bertrand-Krajewski J.-L. (2017). Typology of the flow structures in dividing open channel flows. J. of Hydraulic Research, 55(1), 63-71, doi: 10.1080/00221686.2016.1212409. 


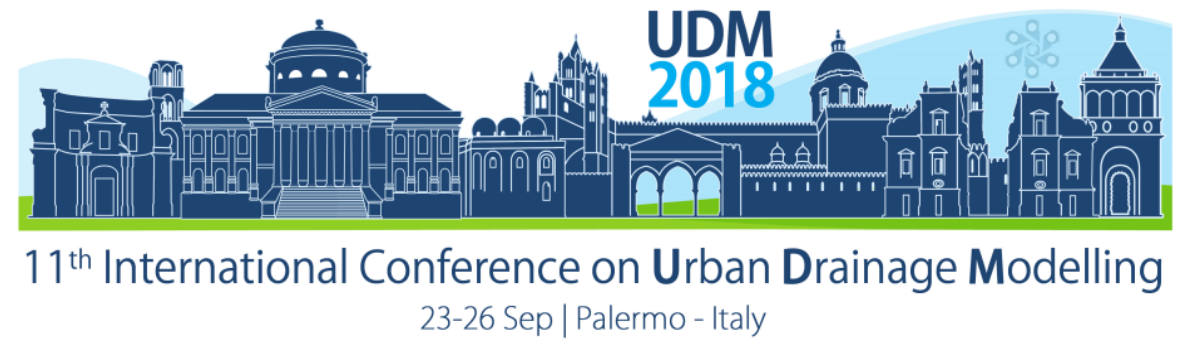

\title{
Modelling overland flow from local inflows in "almost no-time" using Self-Organizing Maps
}

\author{
João P. Leitão ${ }^{1, *}$, Mohamed Zaghloul ${ }^{2,3}$ and Vahid Moosavi ${ }^{2}$ \\ ${ }^{1}$ Eawag: Swiss Federal Institute of Aquatic Science and Technology, Department Urban Water Management, \\ Dübendorf, Switzerland \\ 2 ETHZ: Swiss Federal Institute of Technology Zurich, Department of Architecture, Zurich, Switzerland \\ ${ }^{3}$ Alexandria University, Faculty of fine arts, Department of Architecture, Alexandria, Egypt
}

(joaopaulo.leitao@eawag.ch, zaghloul@arch.ethz.ch,moosavi@arch.ethz.ch)

\begin{abstract}
Physically-based overland flow models are computationally demanding, hindering their use for real-time applications. Therefore, the development of fast (and reasonably accurate) overland flow models is needed if they are to be used to support flood mitigation decision making. In this study, we investigate the potential of Self-Organizing Maps to rapidly generate water depth and flood extent results. To conduct the study, we developed a floodsimulation specific SOM, using cellular automata flood model results and a synthetic DEM and inflow hydrograph. The preliminary results showed that water depth and flood extent results produced by the SOM are reasonably accurate and obtained in a very short period of time. Based on this, it seems that SOMs have the potential to provide critical flood information to support real-time flood mitigation decisions. The findings presented would however require further investigations to obtain general conclusions; these further investigations may include the consideration of real terrain representations, real water supply networks and realistic inflows from pipe bursts.
\end{abstract}

Keywords: Self-Organizing Maps; Flood modelling; Pipe burst; Point source runoff

\section{INTRODUCTION}

Physically-based overland flow models can be used, among other objectives, to support flood risk assessment and management. In urban areas, due to the large number of urban features, such as buildings, roads and also other smaller urban elements, spatial resolution of the terrain representation needs to be high to allow for accurate representation of overland flow characteristics (Leitão et al., 2009). The need for terrain high spatial resolution in urban areas makes these models computationally demanding due to the large number of terrain grid elements, hindering their use for real-time applications, such as urban flood forecasting and real-time urban flood mitigation decision making. To address the issue of long simulation times of physically-based flood models, simplified models such as cellular automata type (e.g. Guidolin et al., 2016) and data-driven models (e.g. Carbajal et al., 2017) have been proposed in recent years.

In this study we explore the potential of Self-Organizing Maps (SOMs) for modelling overland flow originated from point source inflows in real-time. The point source inflows can be originated from, for example, water supply pipe bursts. Pipe bursts are difficult to predict, and due to the considerable impact they can have on urban activities and urban elements, fast

Corresponding author 


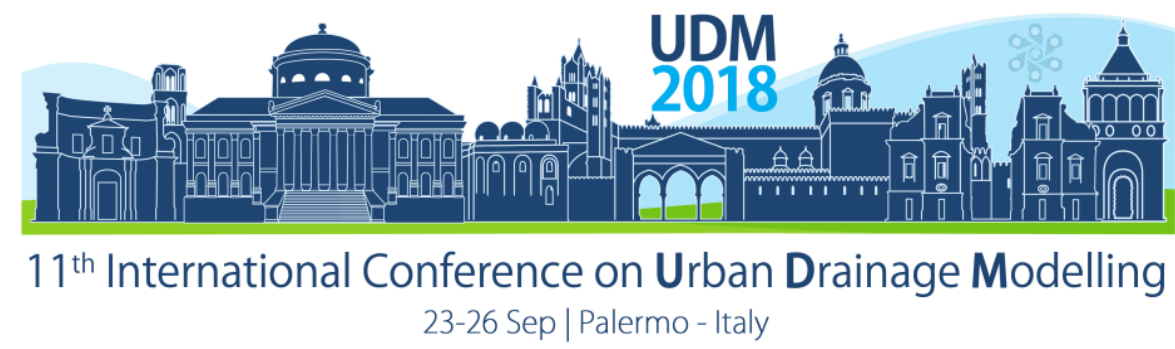

flood modelling tools are required to support real-time decisions on how to deploy temporary flood mitigation resources, such as sandbag flood protection walls. In order to evaluate the potential of SOMs for real-time flood modelling in urban areas, we perform an evaluation using a synthetic terrain surface presented by Néelz and Pender (2013) and a fast flood model based on cellular automata (Guidolin et al., 2016). We compare the accuracy of the SOM results evaluating water depth and flood extent at the end of simulation.

\section{SELF-ORGANIZING MAPS AND FLOOD MODELLING}

Self-Organizing Map is a data driven modelling method introduced by Kohonen (1982). From a mathematical point of view, SOM acts as a nonlinear data transformation in which data from high-dimensional space is transformed to low-dimensional space (usually a space of two or three dimensions), while the topology of the original high dimensional space is preserved. In addition to dimensionality reduction and visualization applications, SOM can also be used to predict parameter values or dimensions using data of each other parameter through nonlinear approximation functions (Barreto and Souza, 2006). Designing a proper feature set to represent the data of interest is an important challenging when developing SOMs.

In the literature, applications of SOMs to different fields can be found: wind field modelling (Zaghloul, 2017), air pollution monitoring (Moosavi et al., 2015) and river flood forecasting (Chang et al., 2007). In this work, we implemented a SOM to emulate overland flow in a fast manner when considering detailed terrain representation. The training data to train the SOM is generated from a fast cellular automata flood model proposed by Guidolin et al. (2016); the important SOM features are the position of water source and the 3D geometry around each point in the study area. Given these features plus the final water depths in each location, we train a SOM that learns the relationships between the local geometries, position of water source and the final water depth, and is able to generalize these relationships for new positions of water source without extra hydraulic simulations. An interesting aspect of our SOM features is that since we are focused on water depth at each point, by having only few sample simulations with different positions of water sources, we can generate a relatively large amount of data. However, since in our training data sets most of final water depths are $0 \mathrm{~m}$, we decided to train two different SOMs, one for locations with $0 \mathrm{~m}$ water depth and one for locations with positive values (water depth values below $0.03 \mathrm{~m}$ were converted to $0 \mathrm{~m}$ ). After training the SOMs, we combined the weight vectors of the two SOMs with K-Nearest Neighbourhood algorithm to predict the water depths of each point for new inflow locations. The SOM was implemented in Wolfram Mathematica (https://www.wolfram.com/mathematica) and in Grasshopper 3D environment (http://www.grasshopper3d.com).

\section{PREDICTION OF OVERLAND FLOW}

We used the Test 2 presented by Néelz and Pender (2013) as the test bed to explore the potential of SOMs to rapidly simulate flood conditions taking into account detailed terrain representations. This test was originally designed to evaluate the capability of flood models to simulate flood extent and water flood depth. In this particular study, we take advantage of the test detailed terrain representation and consider multiple inflow locations to mimic water supply pipe bursts. Twenty nine $(\mathrm{N}=29)$ different inflow locations were generated randomly to represent water supply network pipe mid-points (Figure 1). Twenty two out of the total locations were used to train the SOM (red points in Figure 1), and the remaining locations (seven 


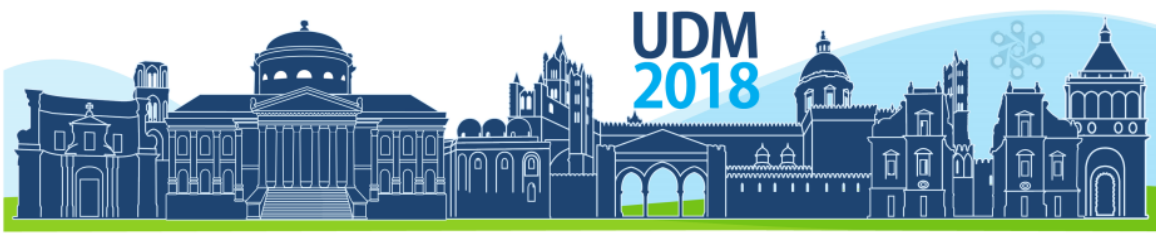

$11^{\text {th }}$ International Conference on Urban Drainage Modelling

23-26 Sep | Palermo - Italy

locations) were used for validation (yellow points in Figure 1). The hydrograph of Test 2 (Néelz and Pender, 2013) was used as the inflow at the inflow locations.

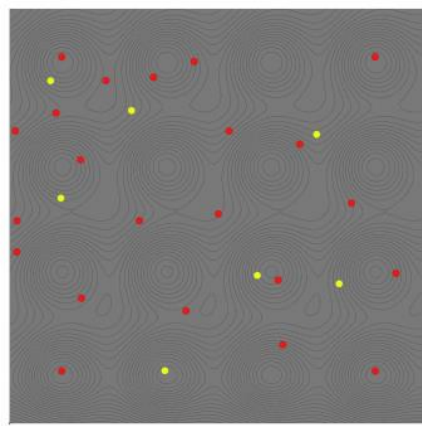

Figure 1. Inflow locations representing possible locations of pipe bursts (Red points represent the training inflow locations; Yellow points represent the validation inflow locations; Black lines represent surface contours)

\section{RESULTS}

The flood depth results obtained using the flood model and the SOM for validation locations did not differ significantly. Figure 2 presents graphically the differences between the SOM and flood model results for one of the seven validation configurations. The maximum water depth difference was $0.072 \mathrm{~m}$.
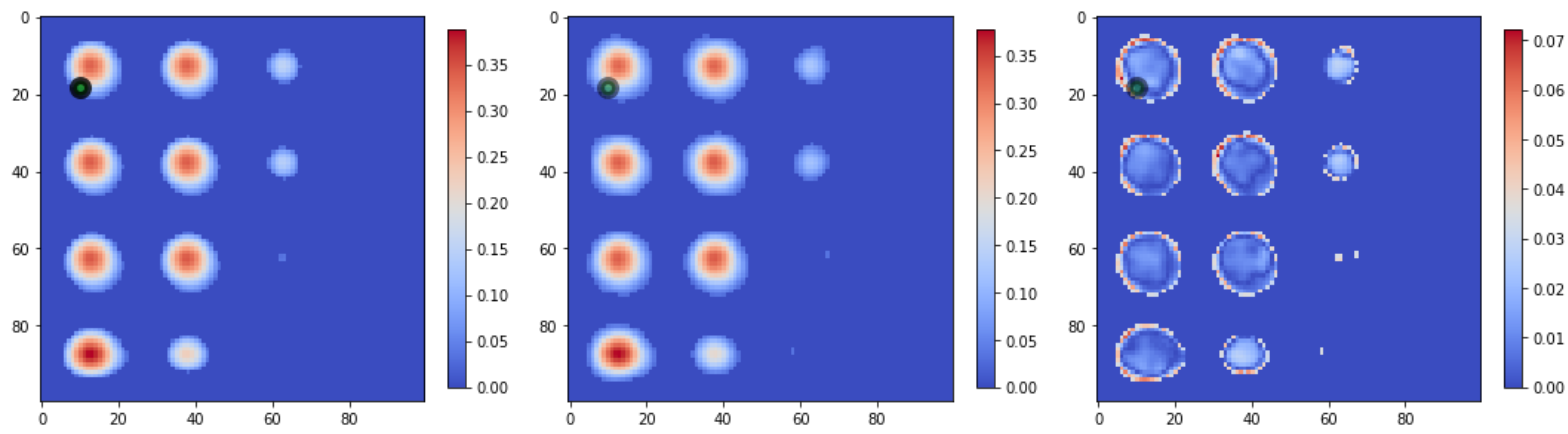

Figure 2. Flood depth results and absolute differences between SOM and flood depth model at the end of simulation. Left: flood model; Middle: SOM; Right: absolute differences between SOM and flood model results. The green-black point in the three panels represent the inflow location

For the specific case presented in this study, training the SOM using the 22 training events lasted approximately one hour on a conventional desktop computer (Intel Core i7 CPU, 8 GB RAM), without considering parallel threading. Computation time of flood model and SOM is presented in Table 1 alongside with water depth statistics for the cellular automata flood model and SOM results and their differences. As can be seen in Table 1, computation time was reduced around five times (80\%), while the mean water depth differences between the SOM and the flood model results were relatively small: $0.003 \mathrm{~m}$ for the mean absolute error which corresponds to a mean relative absolute error of approximately $10 \%$. It is worth noting that computation time reduction shall improve when the number of terrain grid elements and flood volume being simulated increase. Also, if a larger number of training data sets is used, the water depth and flood extent differences will tend to decrease. 


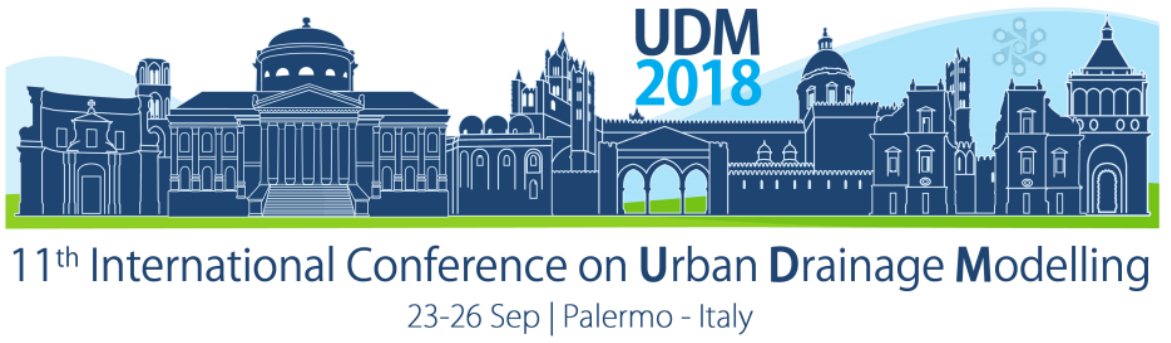

Table 1. Summary and comparison of flood model and SOM computation time and water depth results. Values in brackets represent relative differences

\begin{tabular}{lccccc} 
& \multirow{2}{*}{ Computation time } & \multicolumn{4}{c}{ Water depth } \\
\cline { 3 - 6 } & & Minimum & Maximum & Mean & St. Dev. \\
\hline Flood model & (approx.) $11 \mathrm{~s}$ & $0 \mathrm{~m}$ & $0.389 \mathrm{~m}$ & $0.024 \mathrm{~m}$ & $0.067 \mathrm{~m}$ \\
SOM & (less than) $2 \mathrm{~s}$ & $0 \mathrm{~m}$ & $0.378 \mathrm{~m}$ & $0.025 \mathrm{~m}$ & $0.064 \mathrm{~m}$ \\
Model results & $-9 \mathrm{~s}$ & $0.000 \mathrm{~m}$ & $0.072 \mathrm{~m}$ & $0.003 \mathrm{~m}$ & $0.009 \mathrm{~m}$ \\
differences & $(-80.0 \%)$ & $(0.0 \%)$ & $(159.0 \%)$ & $(10.7 \%)$ & $(16.6 \%)$ \\
\hline
\end{tabular}

\section{CONCLUSIONS}

We have investigated the potential of SOMs to simulate overland flow and flooding caused by point source inflows, such as water supply pipe bursts, using a detailed terrain representation case study. To our knowledge this is the first time that SOMs are used to simulate twodimensional urban flooding, specifically when caused by point source inflows. In a direct comparison, the results obtained with the SOM were obtained in a small time fraction and were similar to those produced by the fast cellular automata flood model, despite the relatively small number of SOM training events. This suggests that SOMs have the potential to be used for (i) real-time flood forecasting and also for (ii) supporting emergency flood mitigation decision making. Due to their fast computation times, these models can also be used for simulating hazardous substances spills and inform emergency services about the most effective mitigation actions. The findings presented here require further investigations to obtain general conclusions; these further investigations may include the consideration of real (larger and more complex) terrain representations, real water supply networks (topology) and realistic (e.g. time varied) inflows from pipe bursts.

\section{References}

Barreto, G.A., Souza, L.G.M. (2006). Adaptive filtering with the self-organizing map: A performance comparison, Neural Networks, 19(6), 785-798. Doi: 10.1016/j.neunet.2006.05.005

Carbajal, J. P., Leitão, J. P., Albert, C., Rieckermann, J. (2017). Appraisal of data-driven and mechanistic emulators of nonlinear simulators: The case of hydrodynamic urban drainage models. Environmental Modelling \& Software, 92, 17-27. Doi: 10.1016/j.envsoft.2017.02.006

Chang, F-J., Chang, L-C., Wang, Y. S. (2007). Enforced self-organizing map neural networks for river flood forecasting. Hydrological Processes, 21(6), 741-749. Doi: 10.1002/hyp.6262

Guidolin, M., Chen, A., Ghimire, B., Keedwell, E.C., Djordjević, S., Savić, D. (2016). A weighted cellular automata 2D inundation model for rapid flood analysis. Environmental Modelling \& Software, 84, 378-394. Doi: 10.1016/j.envsoft.2016.07.008

Kohonen, T. (1982). Self-organized formation of topologically correct feature maps. Biological cybernetics, 43(1), 59-69

Leitão, J.P., Boonya-Aroonnet, S., Prodanović, D., Maksimović, Č. (2009). The influence of digital elevation model resolution on overland flow networks for modelling urban pluvial flooding. Water Science and Technology, 60(12), 3137-3149. Doi: 10.2166/wst.2009.754

Moosavi, V., Aschwanden, G., Velasco, E. (2015). Finding candidate locations for aerosol pollution monitoring at street level using a data-driven methodology. Atmospheric Measurement Techniques, 8(9), 3563-3575. Doi: 10.5194/amt-8-3563-2015

Néelz, S., Pender, G. (2013). Benchmarking the latest generation of 2D hydraulic modelling packages. Environment Agency, Bristol, UK

Zaghloul, M. (2017). Machine-Learning aided Architectural Design - Synthesize Fast CFD by Machine-Learning. $\mathrm{PhD}$ thesis, ETH Zürich, Zurich, Switzerland 


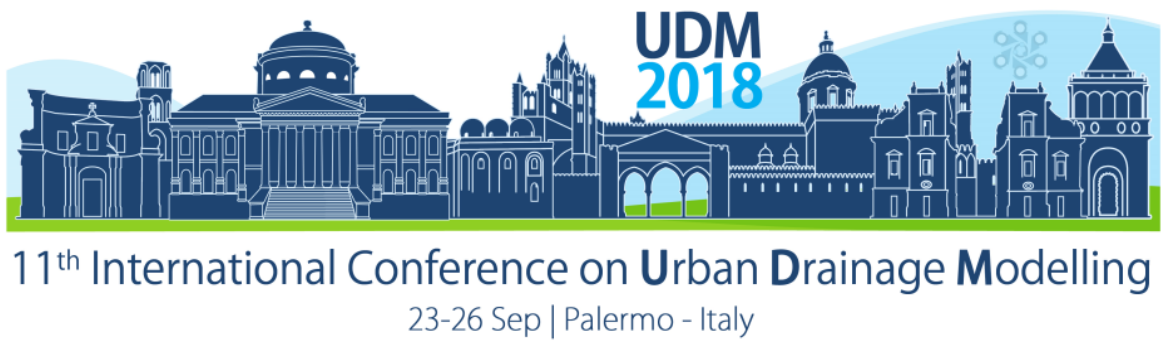

\title{
Parameter Sensitivity of a Microscale Hydrodynamic Model
}

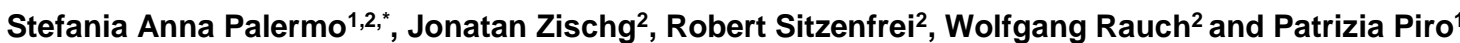 \\ ${ }^{1}$ University of Calabria, Department of Civil Engineering, Rende (CS), Italy \\ ${ }^{2}$ University of Innsbruck, Department of Infrastructure Engineering, Innsbruck, Austria \\ ${ }^{*}$ Corresponding author's e-mail: stefania.palermo@unical.it
}

\begin{abstract}
Here we present the results of a global sensitivity analysis (GSA) applied for a microscale hydrodynamic model, which combines pipe infrastructure and small scale source treatments in terms of raingardens (RGs). The aim is to identify the most influential model parameters to support the decision for future measurement installation sites and smart water control. For the model creation and simulation, the Storm Water Management Model (SWMM) is used. For the GSA method the Elementary Effect Test (EET) is applied, were uncertainties to 18 model input parameters, comprising 10 subcatchment and 8 Low Impact Development (LID) parameters, are assigned and analysed by 1,900 simulations. The model's responses are evaluated at four main RGs and for two model outputs: Inflow and Surface runoff at the RGs. First results show that the most sensitive factors are the Depression Storage Impervious and the Soil Hydraulic Conductivity for the Inflow and Surface Runoff at RGs, respectively.
\end{abstract}

Keywords: Elementary Effect Test; LID; Sensitivity; SWMM; Uncertainty.

\section{INTRODUCTION}

The emerging challenges due to ongoing urbanization and climate change require a transition from traditional drainage infrastructure towards a sustainable, smart and resilient urban water management.

One promising strategy is the implementation of decentralized stormwater controls, also known as e.g. Green Infrastructure (GI) or Low Impact Development (LID), which provide several benefits at multiple scales (Zischg et al. 2018, Maiolo et al. 2017). Different studies have analyzed those beneficial effects and many numerical and physical models were developed to prove Gl feasibility and performance (Garofalo et al. 2016). By implementing multiple small scale units in urban areas, a complex system of temporal storage facilities for managing stormwater runoff is created.

For the system optimization with regard of flood mitigation, pollutant reduction, sustainable irrigation, or recreational aspects, smart water control is needed. This can be achieved by equipping the existing drainage systems with low-cost sensors and controllers, in order to have a highly adaptive new green and grey stormwater system.

This work provides a first step towards the sustainable operation of the newly set up "Smart Campus" at the University of Innsbruck, where recently LID systems and multiple sensors have been implemented. The first objective of this study is to present the development of a detailed micro-scale hydrodynamic model. Secondly, the most influencing model parameters are identified through a sensitivity analysis, including the uncertainties of subcatchment and LID parameters.

\section{MATERIALS AND METHODS}

\subsection{Case study description}

The case study area is the University Campus Innsbruck, in Tyrol, Austria $\left(47^{\circ} 15^{\prime} 50.87^{\prime \prime} \mathrm{N}\right.$ $1^{\circ} 20^{\prime} 40.17^{\prime \prime E}$ ), where 12 Rain Gardens (RGs), 1 Green Roof (GR) and 3 Gravel Roofs were 


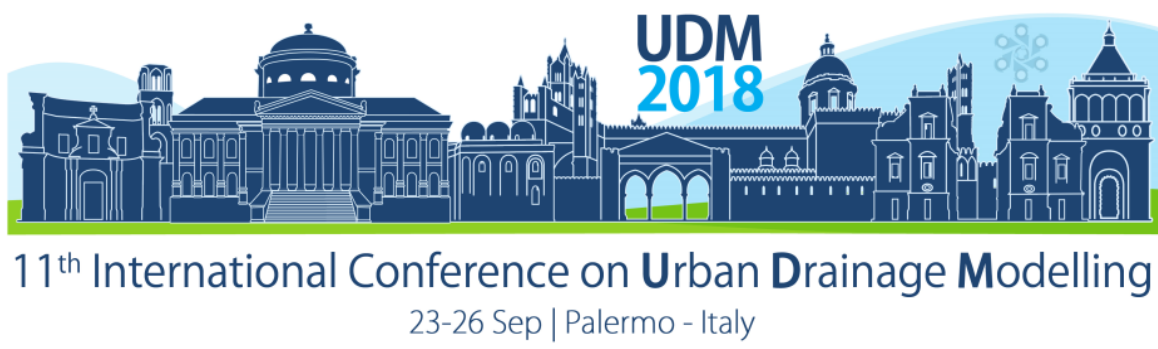

implemented to enable a more sustainable water management strategy and to make the Campus more attractive and resilient to flooding risk.

To connect impervious surface areas (e.g. pavements, streets) to those LIDs a new drainage system, consisting of a network of open channels (OCs) with a parabolic crosssection and PVC conduits (DN200) was built. This system supports the existing underground drainage network, composed of around $420 \mathrm{~m}$ of conduits (DN200 $\div$ DN600), which collect the rainwater only from the roofs. Thus, the total drainage system can be divided into two independent systems: one related to the RGs; and the second one concerning the old drainage network.

Four RGs with an area of $65 \mathrm{~m}^{2}$ each are located at the centre of the main square and receive the rainwater collected only by the OCs system. The others RGs (ranging from $16 \mathrm{~m}^{2}$ to $43 \mathrm{~m}^{2}$ ) intercept the stormwater runoff from different areas. Even if the RGs differ from each other regarding the area and the storage depth, they have identical stratigraphy, and consist of the following horizontal layers (from top to bottom): (1) a surface vegetated layer vegetated with a berm height of $26 \mathrm{~cm}$; (2) a soil layer with a thickness of $30 \mathrm{~cm}$, (3) a storage layer with varying depths and (4) an underdrain.

\subsection{Model development}

A detailed hydrodynamic model was developed considering the entire Campus drainage system. The dynamic rainfall-runoff simulation model PCSWMM (CHI PCSWMM), based on the EPA-SWMM version 5.1.012 (Rossman, 2015), was used. The model was built considering topographical data, land use classification, new and existing stormwater system, RG details, taken from construction plans and site measurements.

To obtain a detailed microscale model, the study area of 3.02 ha was divided into 252 subcatchments, which were precisely defined depending on changes of the surface slope and the land use. The drainage systems consists of 139 Junctions, 139 Conduits and 13 LID Controls (12 RG and $1 \mathrm{GR}$ ). The subcatchment width that describes the overland flow characteristic is generally an important and sensitive model parameter, especially for large subcatchments. For our microscale model, knowing all geometrical features of the system, it was calculated as the fraction between the subcatchment area and the flow length. The Soil Conservation Service (SCS) Curve Number (CN) method was considered for the infiltration method and the flow routing computations were based on the Dynamic Wave Equations.

\subsection{Sensitivity Analysis}

Taking into account that the implementation of the LID structures strongly influences the hydraulic performance of the drainage system and that most model input parameters are uncertain, a Global Sensitivity Analysis (GSA) was carried out. More specific, the Morris screening method (Morris, 1991), also known as Elementary Effect Test (EET), was used (Saltelli et al., 2008).

Two sensitivity measures, the standard deviation of the EET $(\sigma)$ and the mean of EET $(\mu)$ are calculated. The sampling strategy defines $r$ trajectories in the input space (here assumed equal to 100). This strategy selects the starting point randomly over a uniform grid of the parameter space and the subsequent points by moving one factor at a time (OAT) by a fixed amount $\Delta$, so that each trajectory allows for evaluating one Elementary Effect $(E E)$ per factor (Pianosi et al., 2016).

To consider the spatial variability of the model results ("prediction function"), the outcome of the four main circular RGs was evaluated at different horizontal layers for the presented case study (see section 2.1). 


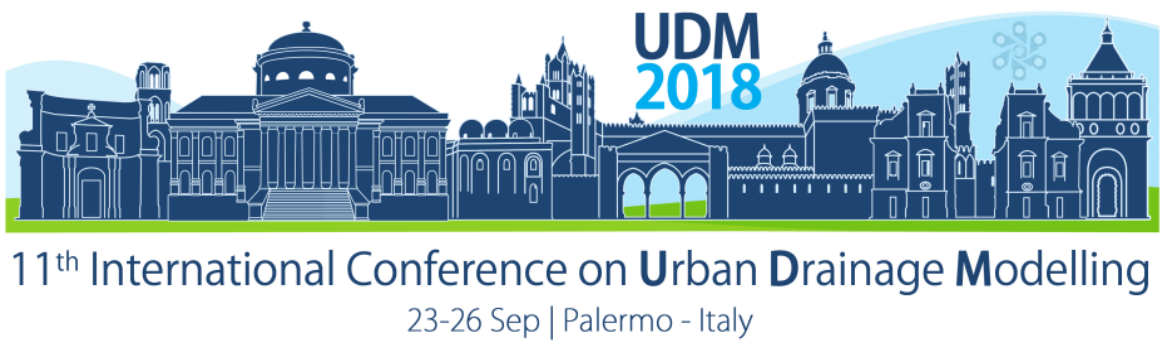

Starting from the assumption the site-specific subcatchment parameters, slope, width and area are measured physical features; the following 18 input parameters were selected for the GSA (see Table 1). For each parameter, the range of variability was chosen based on of their physical attributes and by considering reported values in the SWMM Manual (Rossman, 2015).

Table 1. Input parameters for GSA, meaning and corresponding range of variability taken from User SWMM Manual

\begin{tabular}{|c|c|c|c|c|}
\hline & $\mathbf{N}$ & Name of parameter & Meaning & Value range \\
\hline \multirow{10}{*}{ 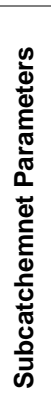 } & 1 & Imperv (\%) & Percent of impervious area & $90-100$ \\
\hline & 2 & Perv (\%) & Percent of pervious area & $0-10$ \\
\hline & 3 & $\begin{array}{l}\text { Depression storage -Imperv } \\
(\mathrm{mm})\end{array}$ & Depth of depression storage on impervious area & $1.27-2.54$ \\
\hline & 4 & Depression storage -Perv $(\mathrm{mm})$ & Depth of depression storage on pervious area & $2.54-5.08$ \\
\hline & 5 & N-Imperv & Manning's roughness coefficient for impervious area & $0.012-0.014$ \\
\hline & 6 & N-Perv & Manning's roughness coefficient for pervious area & $0.13-0.24$ \\
\hline & 7 & CN-Imperv & SCS runoff curve number for impervious area & $90-98$ \\
\hline & 8 & CN-Perv & SCS runoff curve number for pervious area & $30-61$ \\
\hline & 9 & Drying Time (days) & Time for a fully saturated soil to be completely dry & $2-14$ \\
\hline & 10 & OpenChannel Roughness & Manning's roughness coefficient for Open Channel & $0.022-0.026$ \\
\hline \multirow{8}{*}{ 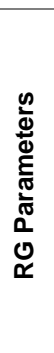 } & 11 & Vegetative Volume (fraction) & Fraction of volume within the surface storage depth filled with vegetation & $0.1-0.2$ \\
\hline & 12 & Porosity (volume fraction) & The volume of pore space relative to total volume of soil & $0.42-0.437$ \\
\hline & 13 & Field Capacity (volume fraction) & $\begin{array}{l}\text { Volume of pore water relative to total volume after the soil has been allowed to drain } \\
\text { fully }\end{array}$ & $0.062-0.105$ \\
\hline & 14 & Wilting Point (volume fraction) & $\begin{array}{l}\text { Volume of pore water relative to total volume for a well dried soil where only bound } \\
\text { water remain }\end{array}$ & $0.024-0.047$ \\
\hline & 15 & Conductivity $(\mathrm{mm} / \mathrm{hr})$ & Hydraulic conductivity for the fully saturated soil & $30-180$ \\
\hline & 16 & Conductivity Slope & Slope of the curve of log(conductivity) versus soil moisture content (dimensionless) & $30-60$ \\
\hline & 17 & Seepage rate $(\mathrm{mm} / \mathrm{hr})$ & The rate at which water seeps into the native soil below the layer & $30-180$ \\
\hline & 18 & Drain coefficient $(\mathrm{mm} / \mathrm{hr})$ & The drain coefficient $C$ which determines the rate of flow through a drain & $3-6$ \\
\hline
\end{tabular}

As previously mentioned, the four main circular RGs were considered for the sensitivity analysis of this study. The effect of the variability of each parameters was analysed by considering two different model outputs for the four RGs. The first one is the LID Total Inflow, which considers the total runoff intercepted in each $R G$ and takes into account the influence of the subcatchment parameters; the other one is the LID Surface Runoff to evaluate the hydrological performance of the RGs. To summarize the four main RGs with similar physical characteristics, but different intercepted surfaces, the mean values of these outputs are built. For the hydrodynamic simulation, design storm event with a return period of one year $(1.13$ $\mathrm{mm} / \mathrm{min}$ ) was used.

For carrying out the GSA 1,900 model runs are performed through a Matlab Script which uses SWMM and integrates the SAFE-toolbox (Pianosi et al., 2015).

\section{RESULTS AND DISCUSSION}

First results of the EET Sensitivity Analysis are reported in Figure 1, where the Mean of EEs versus their standard deviation (left side) and the Convergence plots (right side) are shown. In the graphs on the left side - where each input factor corresponds with one point - the point located at the more right side along the horizontal axis is the more influential one, while the higher up referring to the vertical axis is that one presents the larger degree of interactions with other factors. In the graphs on the right side, the sensitivity indexes are estimated using an increasing sample size by considering one line per factor, while the dashed lines represent confidence bounds (Pianosi et al., 2016). 


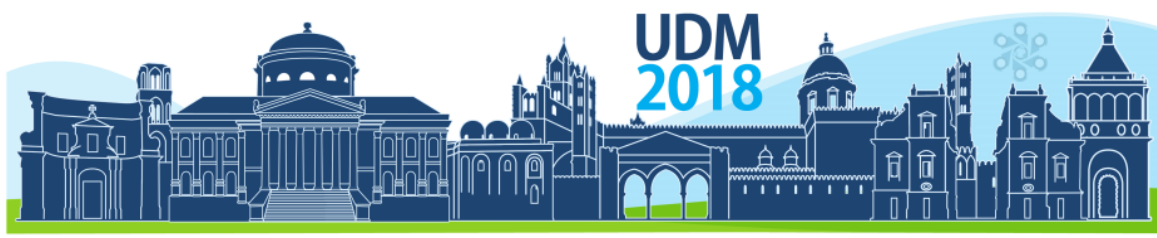

$11^{\text {th }}$ International Conference on Urban Drainage Modelling 23-26 Sep | Palermo - Italy

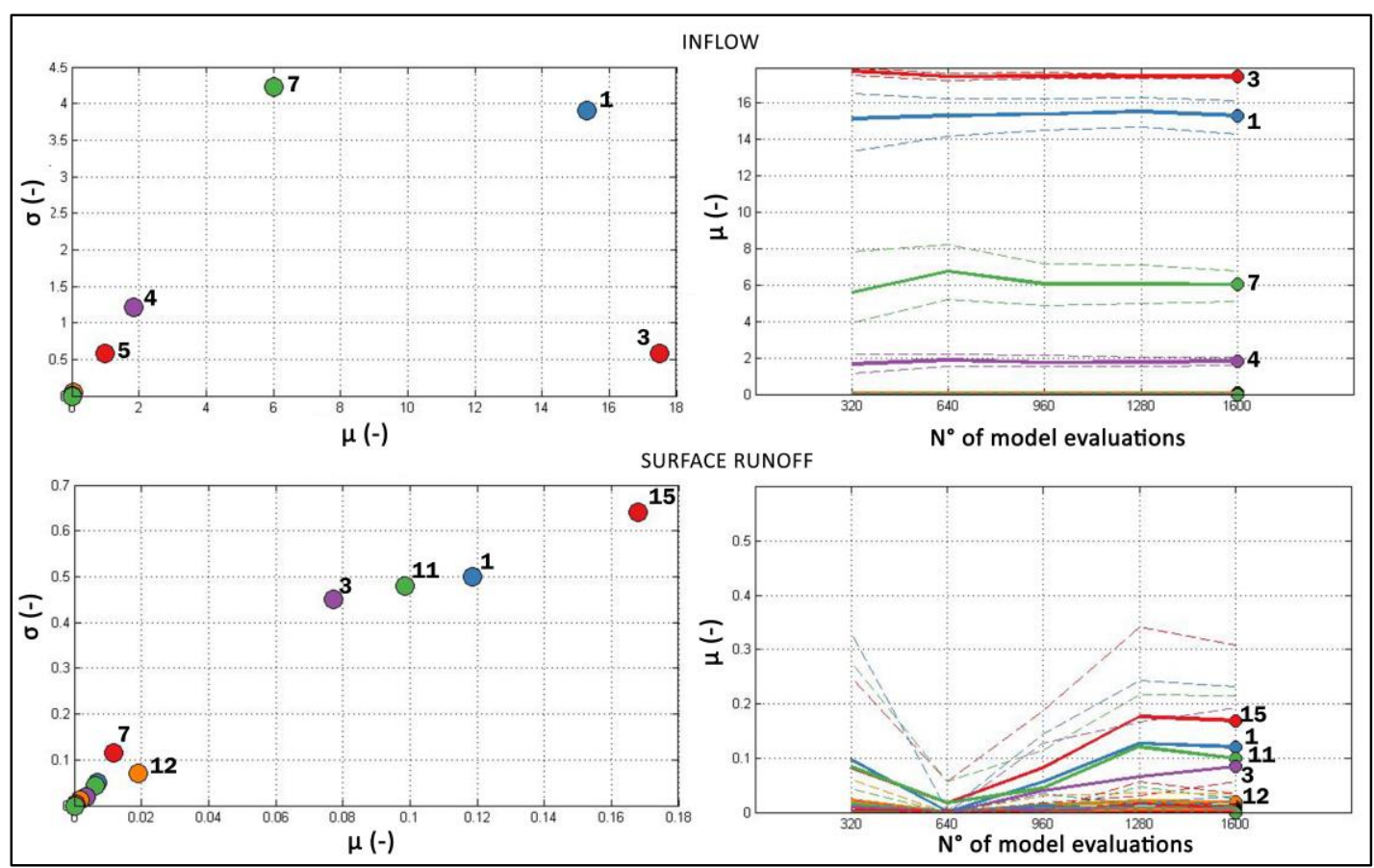

Figure 1. Results of GSA for the 2 model outputs in terms of: mean of EEs vs their standard deviation (left side) and the Convergence plots (right side). The number of each parameter are the same reported in Table 1.

Being the $\mu$ of EEs a measure on the global sensitivity, the findings show that the most influential factor for the LID Total Inflow output is the Depression Storage Impervious (3), the second one is the \% Impervious Area (1). Even if, the higher $\sigma$ is reached by the $C N$-Impervious (7), the factor 1 presents also a high $\sigma$, and this means that these two factors ( 7 and 1 ) have a huge degree of interaction with the other factors.

By considering the results obtained for the LID Surface Runoff outcome, it can be seen that the Soil Hydraulic Conductivity (15) is the most sensitive parameter and it presents also the greater degree of interaction with the other factors. The \% Impervious Area (1), the Vegetative Volume (11), and the Depression Storage Impervious (3) follow this result. The plots on the right side - where each $\mu$ index is estimated using an increasing sample size (one line per factor) - confirm previous findings in terms of most influential factors, also providing other details about the number of model evaluations needed to reach the convergence.

\section{CONCLUSIONS}

In this study, the development of a microscale model for enhancing the implementation of tools, devices and methods related to the smart campus project, i.e smart water management case study at the University Innsbruck was presented.

Moreover, a global sensitivity analysis (GSA) of the model was carried out in order to identify the most influential parameters. The model's performances were analysed at four RGs and for two model outputs (Inflow and Surface Runoff at the RG).

First results showed that an important role is taken by the Depression Storage Impervious parameter related to the Inflow outcome and that the Soil Hydraulic Conductivity is the more sensitive factor for the RG hydraulic performance. 


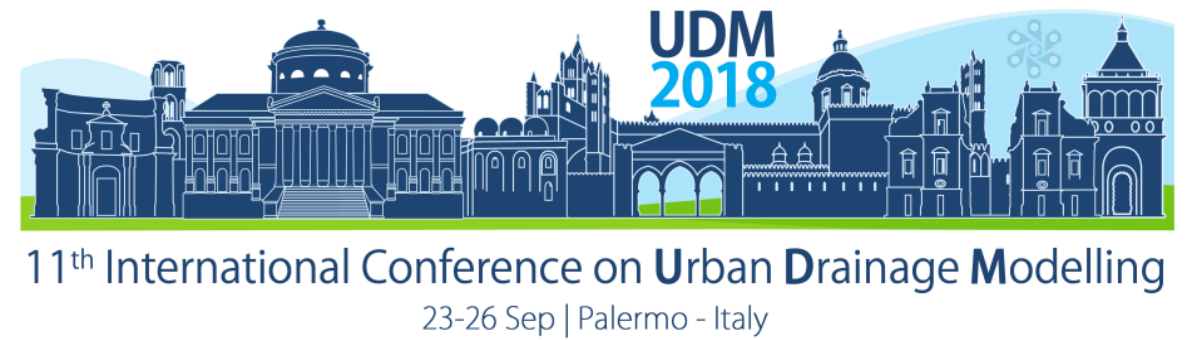

\section{Acknowledgments}

The authors would like to thank the $\mathrm{CHI}$ for the disposal of PCSWMM in the University Grant Program.

This research was funded by the Climate and Energy Fund within the Smart Cities program (project number 858782)

\section{References}

CHI PCSWMM. Available online: https://www.pcswmm.com/ (accessed on 20 March 2018).

Garofalo, G., Palermo, S., Principato, F., Theodosiou, T., \& Piro, P. (2016). The influence of hydrologic parameters on the hydraulic efficiency of an extensive green roof in mediterranean area. Water, 8(2), 44.

Maiolo, M., Carini, M., Capano, G., \& Piro, P. (2017). Synthetic sustainability index (SSI) based on life cycle assessment approach of low impact development in the Mediterranean area. Cogent Enqineering, 4(1), 1410272. Morris, M. D. (1991). Factorial sampling plans for preliminary computational experiments. Technometrics, 33(2), 161-174.

Morris, M. D. (1991). Factorial sampling plans for preliminary computational experiments. Technometrics, 33(2), 161-174.

Pianosi, F., Sarrazin, F., \& Wagener, T. (2015). A Matlab toolbox for global sensitivity analysis. Environmental Modelling \& Software, 70, 80-85.

Pianosi, F., Beven, K., Freer, J., Hall, J. W., Rougier, J., Stephenson, D. B., \& Wagener, T. (2016). Sensitivity analysis of environmental models: A systematic review with practical workflow. Environmental Modelling \& Software, 79, 214-232.

Rossman L.A., 2015. Storm Water Management Model - User's Manual, Version 5.1. Cincinnati: National Risk Management Research Laboratory, Office of Research and Development, US Environmental Protection Agency.

Saltelli, A., Ratto, M., Andres, T., Campolongo, F., Cariboni, J., Gatelli, D., Saisana, M., Tarantola, S., 2008. Global Sensitivity Analysis. The Primer. Wiley.

Zischg, J., Zeisl, P., Winkler, D., Rauch, W., \& Sitzenfrei, R. (2018). On the sensitivity of geospatial Low Impact Development locations to the centralized sewer network. Water Science and Technology, wst2018060. 


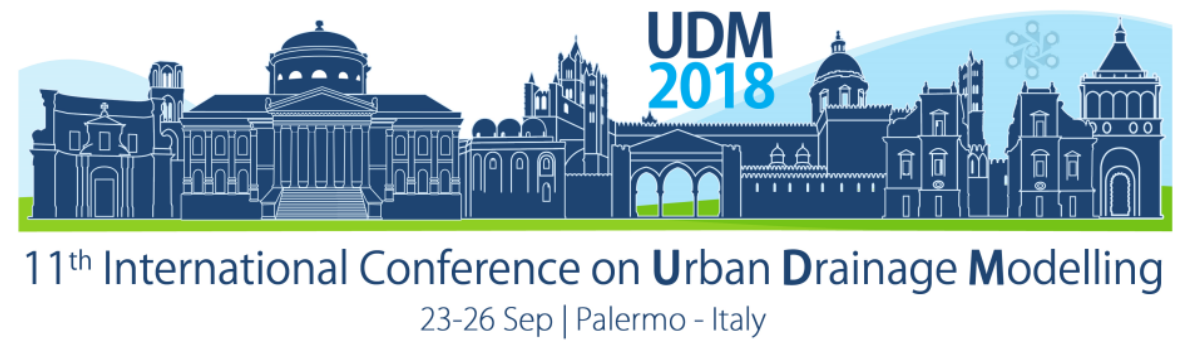

\title{
Modelling of Food Waste Disposer particle transport through a sewer network
}

\author{
Abigail Legge ${ }^{1}$, Andy Nichols ${ }^{1}$, Henriette Jensen ${ }^{2}$, Richard Ashley ${ }^{1,3}$ and Simon Tait ${ }^{1}$ \\ ${ }^{1}$ University of Sheffield, Department of Civil \& Structural Engineering, Sheffield, UK \\ 2 University of Sheffield, Department of Chemical \& Biological Engineering, Sheffield, UK \\ ${ }^{3}$ Ecofutures UK, Honley, UK
}

\begin{abstract}
Managing domestic food waste is challenging due to potential environmental and financial impacts. One solution is to divert this waste from landfill by using domestic food waste disposers to grind this energy rich material so it can be transported via traditional sewer networks. This resource can subsequently be made available for anaerobic digesters already in use at many larger wastewater treatment works. Water utilities however wish to understand the risks associated with this increased loading of food waste particles within their sewer systems. This work outlines the development of a novel modelling approach that has been empirically calibrated to predict transport and settling of food waste in sewers and to contribute to understanding if there are any risks associated with increased sewer settlement. The work has focused on dry weather flows as this poses the highest risk in terms of settlement and with specific attention on evening mealtimes $(6-8 \mathrm{pm})$ when food is most likely to be added to the sewer. The improved understanding and modelling capability is important for policy makers to help make informed decisions on whether food waste disposers are a viable, and potentially beneficial solution, for food-waste management.
\end{abstract}

Keywords: particle transport; food waste; sewer modelling

\section{INTRODUCTION}

Food Waste Disposers (FWD) are domestic under-sink units that grind up waste food which is then disposed of via the sewer network. This additional food waste has the potential to increase biogas production via anaerobic digestion at wastewater treatment plants whilst reducing the disposal of food waste to landfill sites. However, it is important to ensure that the introduction of additional food waste will not have a detrimental impact upon the performance of sewer networks, such as increasing the risk of sewer blockage or sedimentation.

There are several field studies available with qualitative observations (e.g. Mattson, J., et al, 2014), including a long term study at Surahammar (Evans, T., et al, 2010) supporting the usage of FWDs, however, qualitative information is an insufficient basis for development of a modelling tool to that can be applied generally to determine risks of sewer blockages.

This abstract describes an experimental and modelling approach to deliver quantitative evidence in the form of particle size distribution and settling velocity data. This will enable water utilities that manage sewer networks and WwTPs to assess whether there are any risks associated with the input of higher food waste loads into their systems. Current concerns from water utilities is that food waste poses an unwanted additional load on the WwTP and that it will contribute to in-sewer blockages.

\section{MATERIALS AND METHODS}

Food waste is diverse but can be categorised into a number of common groups containing individual foods; fruit, vegetables, meat, dairy and grains. A number of foods have been 


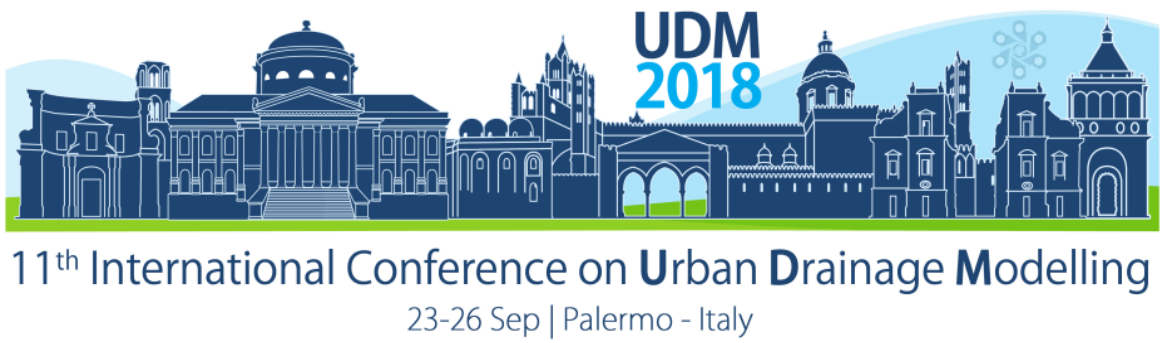

carefully characterised to determine the size distribution of particles produced by FWD and their respective settling velocities.

The project is investigating a small sewer network and linked WwTP in the South-West of England at Upper Rissington. The network and WwTP serves approximately 500 houses. The village is comprised of two distinct areas; one is the original village, with an older combined sewer network (serving around 260 properties), and the other is Victory Fields, a new downstream development with a new separate sewer network (serving 242 properties). FWDs have been installed in 150 of the new properties. The old combined network only feeds into the new network in 2 places and a third feed from the older combined network joins the new network after all the houses, but shortly before it feeds into the WwTP.

The foul sewer network serving Victory Fields is modelled in this study using a hydrodynamic sewer network model. The model has been calibrated for dry weather flows measured in the network and the results of these simulations combined with experimental data on particle characteristics are used to directly identify locations "at risk" of food-particle settling during the diurnal dry weather flow pattern.

The food particle data used has been collected using the technique outlined in the authors' ICUD 2017 abstract (Legge, A., et al. 2017). This involves wet sieving the food through phi scaled sieves and then obtaining maximum settling velocities for the particles found in each sieve. The foods processed using the model are carrot, potato, rice and eggshells.

\section{Modelling of Food Particle Transport using Infoworks ${ }^{\circledR}$}

A hydraulic network model of the Victory Fields network has been generated using InfoWorks ${ }^{\circledR}$. This can be viewed as one main line to the WwTP, with 6 tributary branches. 3 of the branches are input flows from the older combined parts of the network, the other 3 branches drain distinct sewer network zones in Victory Fields. The pipe sizes range from 100 $\mathrm{mm}$ to $225 \mathrm{~mm}$ with pipe gradients from $4.30 \mathrm{~mm} / \mathrm{m}$ to $153.06 \mathrm{~mm} / \mathrm{m}$ and averaging at 23.33 $\mathrm{mm} / \mathrm{m}$.

A flow measurement campaign has obtained flow data for the network which was used to calibrate the model. The flow meters were arranged so that all 6 branches had either a directly measured or calculable flow and there was also a flow meter positioned to take the whole network flow, just before the WwTP. The highest risk for settlement of particles is dry weather flow (DWF) as the system has wet weather inputs, so this is the flow that was used to calibrate the model.

To determine whether the particles are moving in suspension or bedload or if they're likely to be static at a given time the following subdivision was used, where $w=$ fall velocity of sediment and $u^{*}=$ shear velocity (Breusers, H. \& Raudkivi, A., 1991):

$$
\begin{array}{cc}
\infty>w / u^{*}>6 & \text { settlement } \\
6>w / u^{*}>2 & \text { bed load } \\
2>w / u^{*}>0.7 & \text { saltation } \\
0.7>w / u^{*}>0 & \text { suspension }
\end{array}
$$

As the most significant time of day would be when there is the highest risk of food being added to the network; $6 \mathrm{pm}, 7 \mathrm{pm}$ and $8 \mathrm{pm}$ were chosen as it was assumed UK evening meals usually take place between $6 \mathrm{pm}$ and $8 \mathrm{pm}$. The lowest flow for each pipe at any time over the $24 \mathrm{~h}$ period was also chosen as this is the flow that has the highest risk of settling. Each pipe in the network had it's flows isolated for these times. 


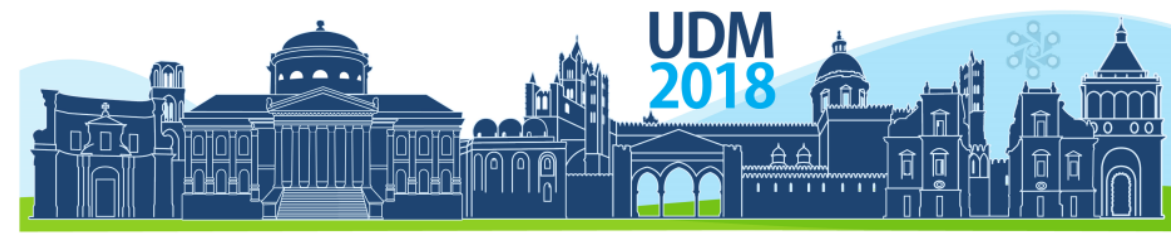

$11^{\text {th }}$ International Conference on Urban Drainage Modelling

23-26 Sep | Palermo - Italy

The foods evaluated using the model are carrot, potato and rice. These were chosen as representatives from the vegetable food-group and the grain food-group and are common foods typically found in published food waste mixes (Kim et al., 2015). Egg shells were also looked at using the model due to eggshell particles being referenced as visible in the network by Mattson, J., et al in their 2014 paper.

\section{RESULTS AND DISCUSSION}

\section{Transport of Food through the model}

In the model no locations were identified where the food samples would settle, even in the model's lowest flows $(0.02 \mathrm{~m}$ depth) for each pipe. The model was calibrated using measured flow rate from the field, but with a minimum of $0.02 \mathrm{~m}$ depth. The model results suggested that in this case the particles would remain either in suspension, saltation or bed load (no settling).

During the hours where food is most likely to be added to the sewer network, the flows are much higher than during times of lowest flow as this is when people are most likely to be at home and using water. During the hours of lowest flow, it is less likely that much, if any, food would be added to the network as these hours are predominantly either when most people are asleep or out at work, so would not be using a FWD. Therefore the likelihood investigated here is a worst case scenario.

Suspension

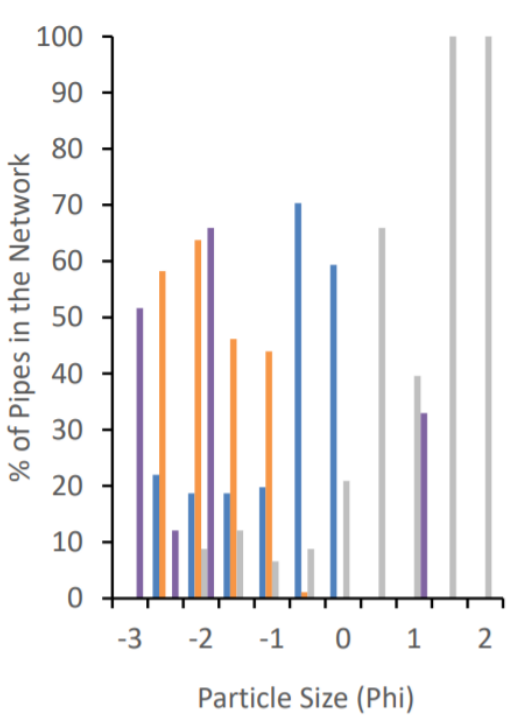

- Potato $\square$ Carrot $\square$ Rice $\square$ Eggs
Saltation

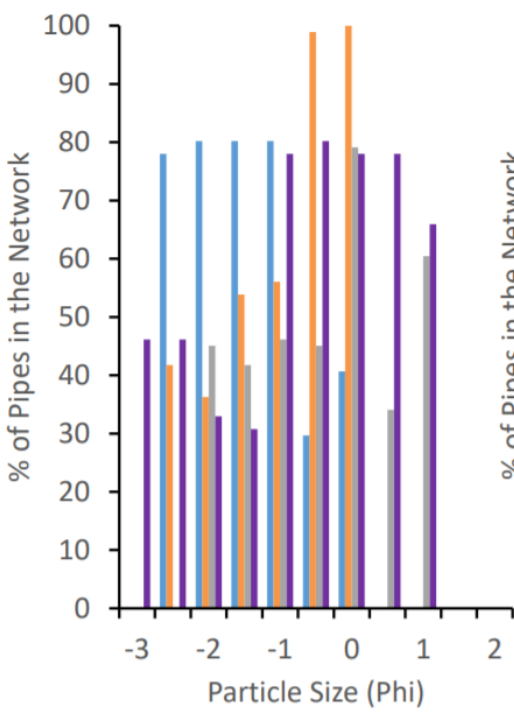

- Potato $n$ Carrot $n$ Rice Eggs
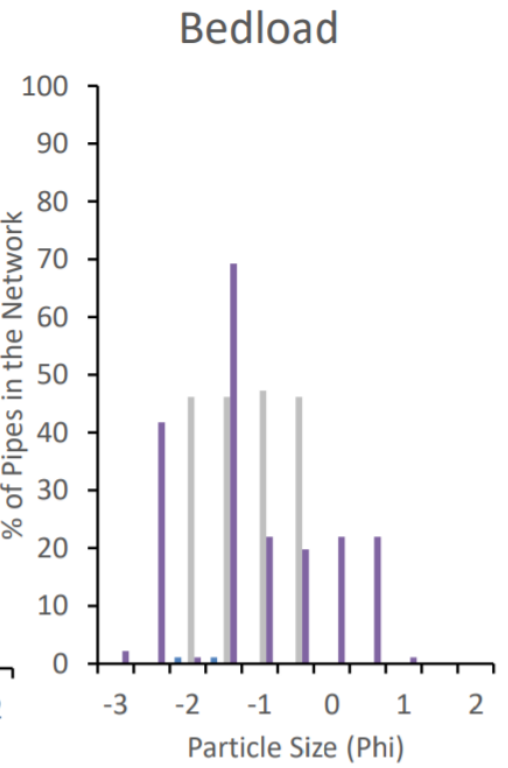

- Potato a Carrot nice Eggs

Fig 1. Representation of whether particles will be in bedload, saltation or in suspension for every pipe in the network during the lowest flow depth of $0.02 \mathrm{~m}$. As there was no settling in the model at this depth, no graph for settlement has been made. 


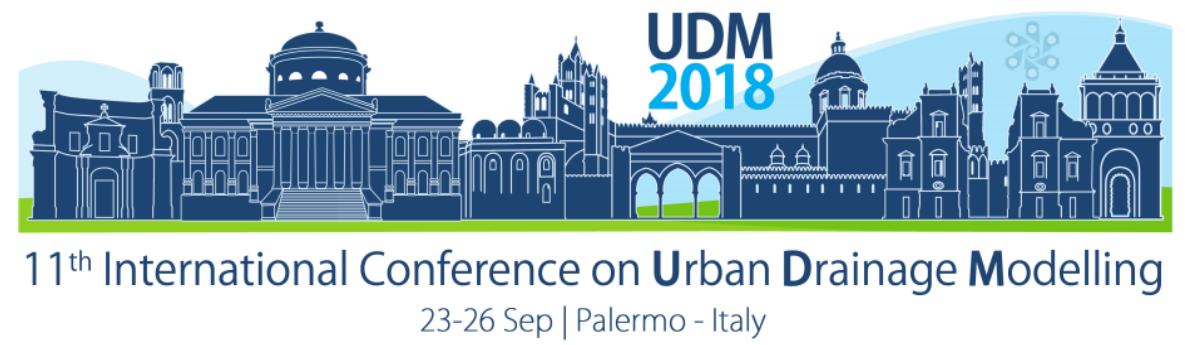

The results for the lowest depth (Fig. 2) suggest that the smaller, less dense particles move in suspension but that the larger denser particles are in saltation or bed load. It can be quite clearly seen that the eggshells, with their higher settling velocity, have a much greater proportion of particles in the bed load and few in suspension. This segregates particles from point of entry and suggests that residence time in sewers may vary dependent on the characteristics of the particles.

This model has assumed food particles to behave in a non-cohesive, uniform manner. Future research into the physical interactions of food particles would provide data for more accurate modelling of their behaviour in sewers. Also, the results presented are based on a limited number of food types. In reality, the types of food being used in food waste disposers are much more varied and once more foods have been tested there will be a greater number of particle sizes and settling velocities to model.

\section{CONCLUSIONS}

The model did not show any settling of the food particles in the sewer network. This suggests that particles generated using food waste disposers in the houses would not settle in this network. However, these results are based on a limited range of food types and other food types will need to be assessed. The model parameters have the lowest flow depth set at $0.02 \mathrm{~m}$, so it will be necessary to change these in order to examine particle behaviour at lower shear velocities It is possible that the eggshells, which have been seen deposited in sewers by Mattson, may settle out of the bed load if there is a lower flow in the sewer.

\section{References}

Breusers, H. \& Raudkivi, A., 1991. Scouring: hydraulic structures design manual, A.A.Balkema. Rotterdam

Evans T., Andersson P., Wievegg A. \& Carlson E., 2010. Surahammar: a case study of the impacts of installing food waste disposers in 50\% of households, Water and Environment Journal. 24. 309-331

Kim, M., Chowdhury, M., Nakhla, G. \& Keleman, M, 2015. Characterisation of typical household food wastes from disposers: fractionation of constituents and implications for resource recovery at wastewater treatment, Bioresource Technology. 183, 61-69

Legge, A., Jensen, H., Ashley, R., Tait, S. \& Nichols, A. 2017. Characterisation of particles from food waste disposers and their expected behaviour in sewers. Proceedings of 14th IWA/IAHR International Conference on Urban Drainage (ICUD), Prague, Czech Republic, 10-15 September 2017.

Mattsson, J., Hedström, A. \& Viklander, M., 2014. Long-term impacts on sewers following food waste disposer installation in housing areas, Environmental Technology. 35, 2643-2651 


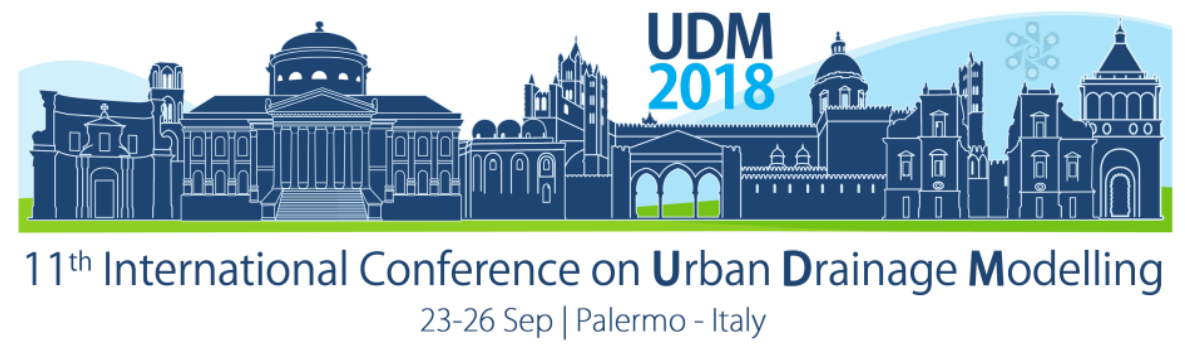

\title{
A Data-driven Method to Modeling Flows Across Combined Sewer Systems
}

\author{
Yao Hu${ }^{1}$ and Branko Kerkez ${ }^{1}$ \\ ${ }^{1}$ University of Michigan, Department of Civil and Environmental Engineering, Ann Arbor, United States
}

\begin{abstract}
We present a data-driven tool for calibrating and validating a model of flows across combined sewer systems that fuses sensor measurements with outputs of a large numerical model. Rather than relying on traditional recalibration of the numerical model, that requires adjusting the model's structure and parameters, our approach learns the causal relationship between model outputs, sensor measurements and observations of target variables. This allows new measurements to be ingested rapidly and flow predictions to be made without requiring the full recalibration of the model. We describe a data-driven tool built from Directed Information (DI) and Boosted Regression Trees (BRT) algorithms, and apply it to a major Midwestern city case study to demonstrate its strong performance for predicting flows. We discuss the generalizability of this DI-BRT method, which is well suited for models whose representations of the target systems are approximate, but whose parameters are too computationally expensive to calibrate using conventional approaches.
\end{abstract}

Keywords: Causality; Directed Information; Boosted Regression Trees

\section{INTRODUCTION}

A number of popular urban drainage models are in use to predict water flow across cities, including the Stormwater Management Model (SWMM), MIKE URBAN and HEC-HMS, to name a few. Often, these models need to be calibrated to be effective in prediction of flows. The conventional approach to calibrate numerical models seeks to adjust model structure and its parameters so that the model output can agree with the observations (Sun et al, 2015). Extra information is often required by the modelers to update their knowledge of the system and adjust model structure accordingly. Once the model structure is updated to the best knowledge of the modelers, calibration of the model parameters is needed to further bring down the differences between model output and observations. However, standard parameter calibration methods are subject to the curse of dimensionality where computational cost can increase exponentially as the number of calibrating parameters increases for a complex model.

To avoid the complexity arising from the model calibration, while also taking the advantage of the expertise and knowledge embedded in an existing numerical model, a datadriven approach can be used to synthesize the features that best explain the observations. This can include new sensor observations (rain, flows, etc), but also the outputs of an existing numerical model, which may not be fully calibrated. In these cases, the selection of input features becomes essential when a data-driven predictive algorithm is constructed. For example, the output of a numerical model can be selected as an input feature only when the model is a proper representation of the real-world system. Otherwise, the inclusion of model output can lead to overfitting in a data-driven scheme.

In this paper, we develop a data-driven method using Directed Information (DI) to select features that best explain flows for any given location across the combined sewer system, and then develop a regression model based on Boosted Regression Trees between observations of target variables and the features. The output of an existing numerical model is treated as one of the features and evaluated by the method. In the following section, we will describe the method and a case study is used to illustrate its application. 


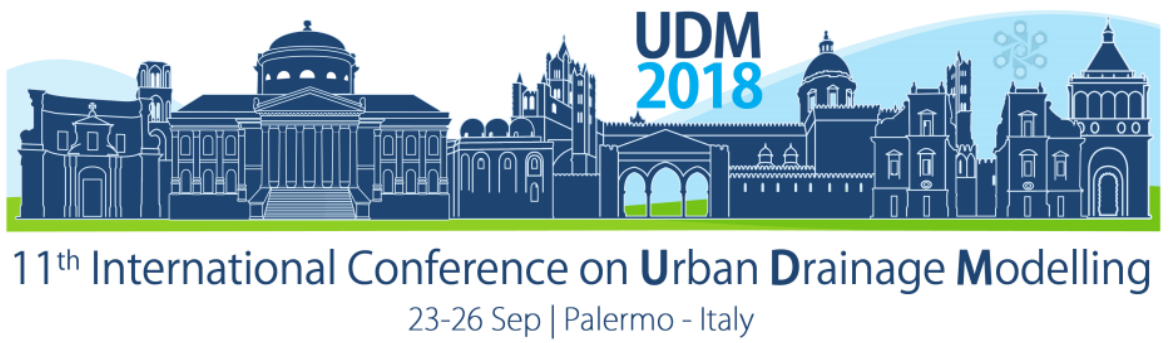

\section{MATERIALS AND METHODS}

\subsection{Directed Information}

Given a set of random processes $\mathbf{P}=\{\mathbf{X}, \mathbf{Y}, \ldots, \mathbf{Z}\}$, we want to predict the future of process $\mathbf{Y}$ using the rest processes in $\mathbf{P}$. If the future of $\mathbf{Y}$ can be better predicted by using the past of process $\mathbf{X}$ and other processes in $\mathbf{P}$ than that without using $\mathbf{X}$ in the prediction, we can then say $\mathbf{X}$ statistically causes $\mathbf{Y}$. This kind of statistical causation is defined as Granger Causality (Granger, 1969). In other words, $\mathbf{X}$ causes $\mathbf{Y}$ in the sense of Granger Causality if the past of $\mathbf{X}$ can help predict the future of $\mathbf{Y}$.

The information theoretic quantity known as Directed Information (DI) measures the statistical causation between random processes in the sense of Granger Causality, i.e., given a set of random processes $\mathbf{X}, \mathbf{Y}$ and $\mathbf{Z}$, the direction information (DI) from $\mathbf{X}$ to $\mathbf{Y}$ given $\mathbf{Z}$ is defined as the time-average expected log-likelihood ratio between two conditional probability distributions (known as Kullback-Leibler divergence) of $Y^{t}$, one conditioning on the past of $\mathbf{X}$, $\mathrm{X}^{1:-1}$ and the other not. The DI measurement is defined by Equation 1 (Kramer, 1998):

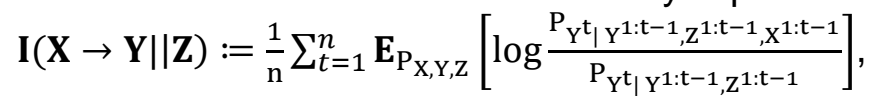

where $X_{1}{ }_{1} t_{2}$ denotes the process $\mathbf{X}$ from time step $t_{1}$ to $t_{2}$ inclusive. If the past of $\mathbf{X}$ can help predict the future of $\mathbf{Y}$, then the conditional probability with $X^{1: t-1}, P_{Y^{t}} \mid Y^{1: t-1}, z^{1: t-1}, x^{1: t-1}$ is larger than the conditional probability without $X^{1: t-1}, P_{Y^{t}} \mid Y^{1: t-1}, z^{1: t-1}$, and the expected log-likelihood of their ratio will be positive. Otherwise, if the past of $\mathbf{X}$ cannot help predict the future of $\mathbf{Y}$, then the two conditional probabilities are equal, in which case the expected log-likelihood of their ratio is zero. In other words, the future value of $\mathbf{Y}$ is conditionally independent from the past value of $\mathbf{X}, \mathbf{X}^{1: t-1}$ given the past value of $\mathbf{Y}$ and $\mathbf{Z}, Y^{1: t-1}$ and $Z^{1: t-1}$. Note that $\mathrm{DI}$ is measured in real values. For random processes $\mathbf{X}$ and $\mathbf{Y}$, the larger the $\mathrm{DI}$ value, the more causal influence $\mathbf{X}$ has on $\mathbf{Y}$.

\subsection{Boosted Regression Trees}

In computational urban models, the relationship between flow measurements and the selected features (e.g., model output or rainfall) can be complex and nonlinear. Supervised machine learning (ML) approaches which assume no prior knowledge of the relationship can be used to learn the complex relationship (Breiman 2001). Boosted Regression Trees (BRT) are one of the supervised ML algorithms that learns multiple regression trees from features and weighs them to describe the relationship between the observations and the features. BRTs apply boosting methods that create ensemble of regression models to improve the accuracy of model fitting. According to Caruana and Niculescu-Mizil (2006), BRT demonstrates the overall best predictive performance among supervised learning algorithms.

\subsection{Case Study}

A physically-based hydrological and hydraulic model was made available to the authors. The model was built using EPA Storm Water Management Model (SWMM) and was developed originally to represent combined sewer flows across Detroit sewer collection system (TenBroek et al., 1999). The total modeled area is $1963.2 \mathrm{~km}^{2}$, including $580.2 \mathrm{~km}^{2}$ covered by the combined sewer system and $1383.0 \mathrm{~km}^{2}$ by the separated sewer system (Figure 1). The 1998 version of the SWMM model was initially calibrated with limited flow data (Stonehouse et al., 2001). The latest 2012 version of the model has shown that it can represent large-scale flows well, but overestimates flows in may locations, especially upstream. In this case, the objective 


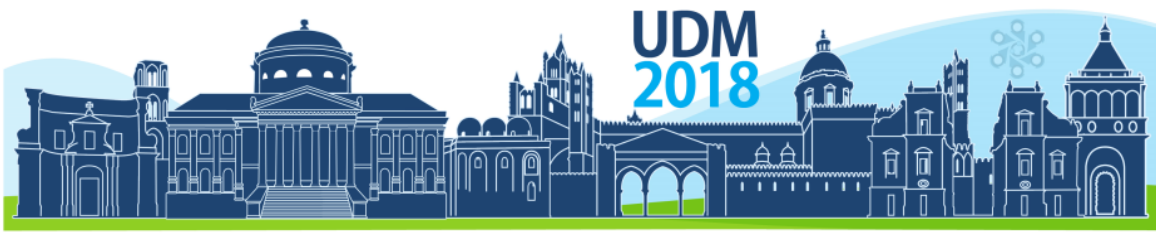

$11^{\text {th }}$ International Conference on Urban Drainage Modelling

23-26 Sep | Palermo - Italy

was to use the combination of Directed Information and Boosted Regression Trees (DI-BRT) method to reproduce the observations of flow (Figure 1).

To reproduce CSO discharges, the SWMM model was run for the 38 rain events between May and October from 2013 to 2015 to obtain modeled CSO discharge for the outfall of interest. Then, DI was used to find which features have statistical causal relationship with the observations of CSO discharge, including SWMM modeled discharges and measurements from 29 rain gages. Once influential features were selected by the DI test, they were fed to the Boosted Regression Trees (BRT) algorithm. For the BRT analysis, $60 \%$ of the data of the influential features were used to train the regression model and $40 \%$ were used for validation.

\section{RESULTS AND DISCUSSION}

The SWMM model significantly overestimated CSO discharge (Outfall \#14 in Figure 1). The overestimates (Pbias $=829.2 \%$, NSE $=-24.1$ and $R^{2}=0.39$ ) could likely be related to the oversimplification of the real-time operation rules that regulate CSO discharge or many other factors. For the Outfall \#14, 10 of the 30 variables were considered to have causal influence on the observations of CSO discharge. The model output was the most influential variable, confirming the model captures a major portion of the discharge variability. However, the large discrepancy between the model output and the observations led to identifying nine rain gages as also influential (G3, G8, G10, G13, G21, G24, G26, G30 and G34).

Daily CSO discharge modeled by the Boosted Regression Trees for Outfall \#14 had much better agreement with the measured daily CSO discharge (NSE $=0.60$ and $\mathrm{R}^{2}=0.62$ for validation). In this case, the overestimation of total CSO discharge during the validation period was reduced by a factor of 8 , to $6.6 \%$ of the measured CSO discharge. Even though the SWMM model tended to significantly overestimate measured CSO discharges, the Directed Information method still selected it as an influential feature. This suggests that the model structure is still capable of simulating the dynamics and variability of the discharges.

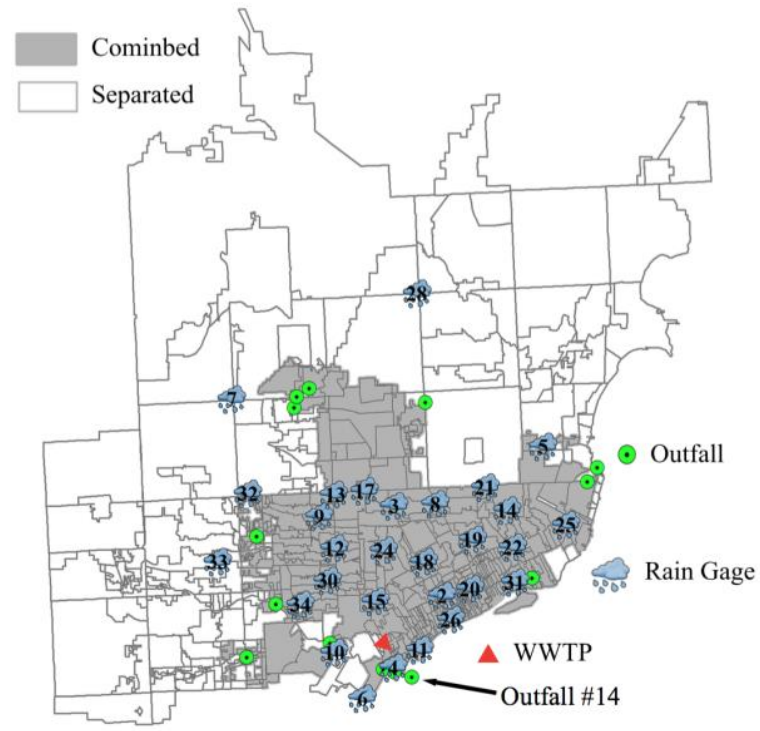

Figure 1 Detroit sewer collection system service area (combined (shaded) and separated); locations of 29 rain gages, the Great Lakes Water Authority Plant (GLWAP) and 14 major CSO outfalls.

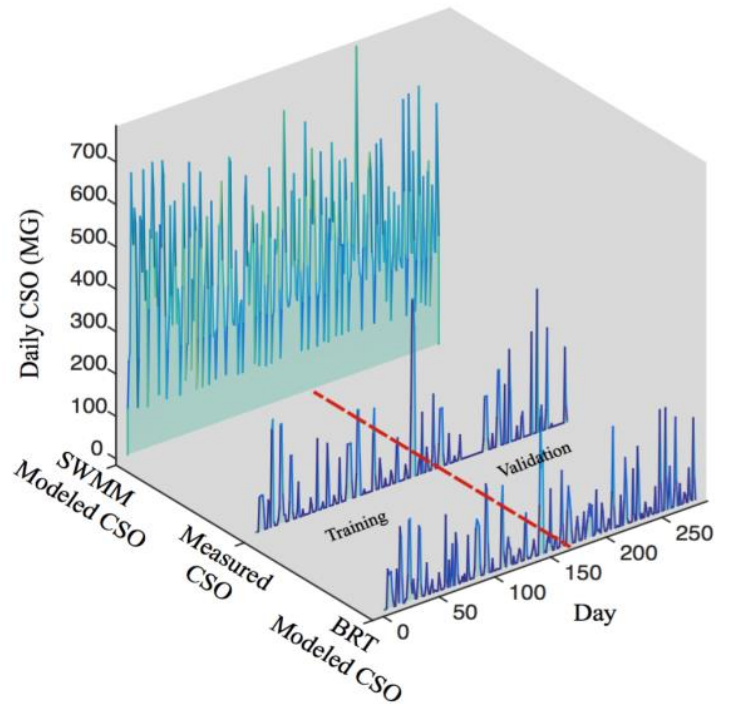

Figure 2 Comparison of CSO discharge (million gallons per day; MG) from the Outfall \#14 for all 38 CSO events between May and October from 2013 to 2015. The dashed line separates the data for calibration and validation. 


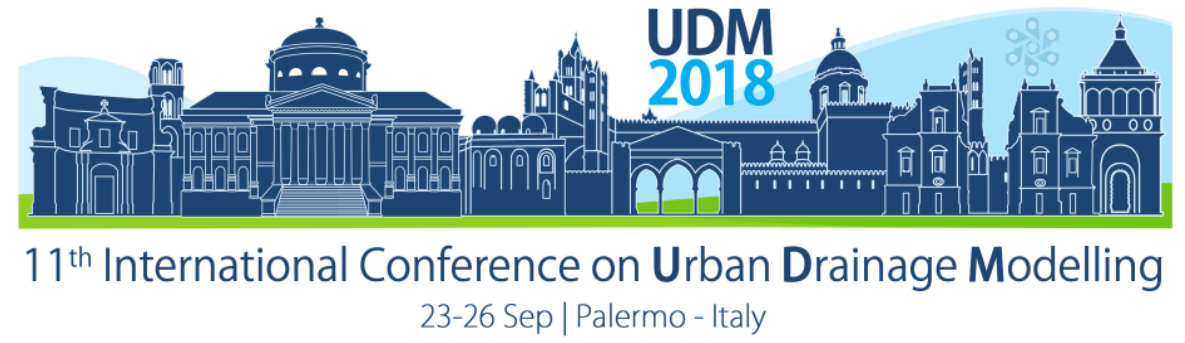

For some CSO outfalls, the SWMM output was not considered influential by the Directed Information (DI) test. For these outfalls, this could have been driven by the improper model representation of the system at these outfalls. For example, the operation rules of the CSO retention basins are not well represented by the SWMM model. When this occurs, it could require substantial adjustments of model structure and parameters. This is particularly critical if the numerical model will be used for scenario analysis and prediction.

\section{CONCLUSIONS}

In this paper, we introduced the DI-BRT method to reduce the discrepancy between model output and observations of the target variable without recalibrating the numerical model. The novelty of the method lies on two parts, the DI test and the BRT analysis. The DI test provides a new means to evaluate the model representation of the system at the locations of interest based on statistical causality. It is quite powerful, as it can be used to check if any adjustment of model structure is necessary. In addition, the test can select the useful features which can help improve model fitting, especially when Boosted Regression Trees are used for forecasting.

\section{References}

Breiman, L. (2001). Random forests. Machine learning, 45(1), 5-32.

Caruana, R., \& Niculescu-Mizil, A. (2006, June). An empirical comparison of supervised learning algorithms. In Proceedings of the 23rd international conference on Machine learning (pp. 161-168). ACM.

Granger, C. W., \& Ramanathan, R. (1984). Improved methods of combining forecasts. Journal of Forecasting, 3(2), 197-204.

Kramer, G. (1998). Directed information for channels with feedback (Doctoral dissertation, Eidgenossiche Technische Hochschule Zurich).

Stonehouse, M. C., TenBroek, M. J., Fujita, G. E., \& Dekker, T. J. (2001). An Installed Accuracy Assessment Using Dye Dilution Testing for Seven Common Flow Metering Technologies. Models and Applications to Urban Water Systems, Monograph, 9, 275.

Sun, N. Z., \& Sun, A. (2015). Model calibration and parameter estimation: for environmental and water resource systems. Springer.

Tenbroek, B. M., Bunyan, R. J. T., Whiting, G., Redman-White, W., Uren, M. J., Brunson, K. M., ... \& Edwards, C. F. (1999). Measurement of buried oxide thermal conductivity for accurate electrothermal simulation of SOI device. IEEE Transactions on Electron Devices, 46(1), 251-253. 


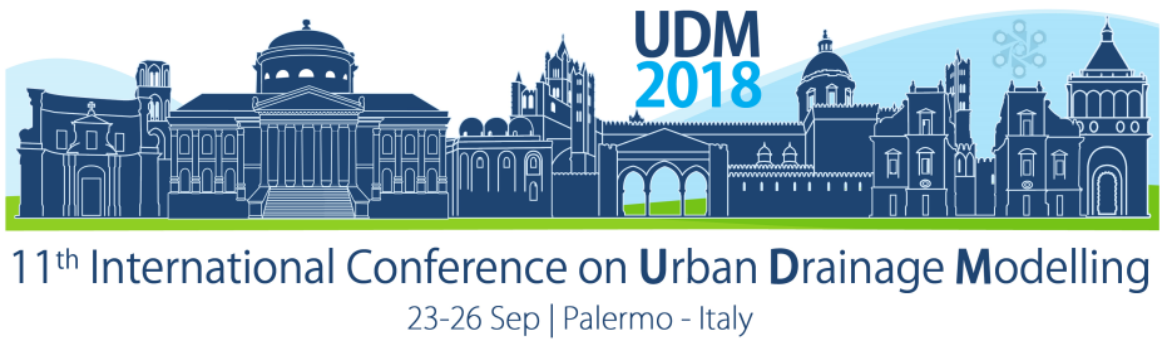

\title{
Leveraging Open Source Software and Parallel Computing for Model Predictive Control Simulation of Urban Drainage Systems using EPA-SWMM5 and Python
}

\author{
Jeffrey M. Sadler ${ }^{1}$, Jonathan L. Goodall, ${ }^{1,2}$, Madhur Behl ${ }^{2,3}$, and Mohamed M. Morsy ${ }^{1,4}$ \\ ${ }^{1}$ University of Virginia, Civil and Environmental Engineering, Charlottesville, Virginia, USA \\ ${ }^{2}$ University of Virginia, Computer Science, Charlottesville, Virginia, USA \\ ${ }^{3}$ University of Virginia, Systems and Information Engineering, Charlottesville, Virginia, USA \\ ${ }^{4}$ Cairo University, Irrigation and Hydraulics Department, Giza, Egypt
}

\begin{abstract}
The active control of stormwater systems is a potential solution to increased street flooding in low-lying, low-relief coastal cities due to climate change and accompanying sea level rise. Model predictive control (MPC) has been shown to be a successful control strategy generally and as well as for managing urban drainage specifically. This research describes and demonstrates the implementation of MPC for urban drainage systems using open source software (Python and The United States Environmental Protection Agency (EPA) Storm Water Management Model (SWMM5). The system was demonstrated using a simplified use case in which an actively-controlled outlet of a detention pond is simulated. The control of the pond's outlet influences the flood risk of a downstream node. For each step in the SWMM5 model, a series of policies for controlling the outlet are evaluated. The best policy is then selected using an evolutionary algorithm. The policies are evaluated against an objective function that penalizes primarily flooding and secondarily deviation of the detention pond level from a target level. Freely available Python libraries provide the key functionality for the MPC workflow: step-by-step running of the SWMM5 simulation, evolutionary algorithm implementation, and leveraging parallel computing. For perspective, the MPC results were compared to results from a rule-based approach and a scenario with no active control. The MPC approach produced a control policy that largely eliminated flooding (unlike the scenario with no active control) and maintained the detention pond's water level closer to a target level (unlike the rule-based approach).
\end{abstract}

Keywords: Active stormwater control; Model predictive control; Flood prevention; Low-relief coastal cities

\section{INTRODUCTION}

Stress on stormwater systems will likely increase as warmer global temperatures are predicted to cause more intense storm events on average (Berggren et al., 2012). At the same time, the effectiveness of coastal cities' stormwater systems will likely decrease due to sea level rise which reduces the already limited elevation head needed to drain stormwater from streets to receiving bodies. Since significant changes to existing stormwater infrastructure in coastal cities is often cost prohibitive, other options are needed to increase its effectiveness. An option for increasing the effectiveness of stormwater infrastructure is to actively manage the existing stormwater infrastructure, making it a "smart" system (Kerkez et al., 2016). This approach does not increase the actual capacity of stormwater infrastructure, but rather more efficiently uses the existing infrastructure, increasing its effective capacity. An example of active management of stormwater infrastructure would be the use of an automated valve at the outlet of a detention basin which can be opened or closed based on conditions and forecasts. 


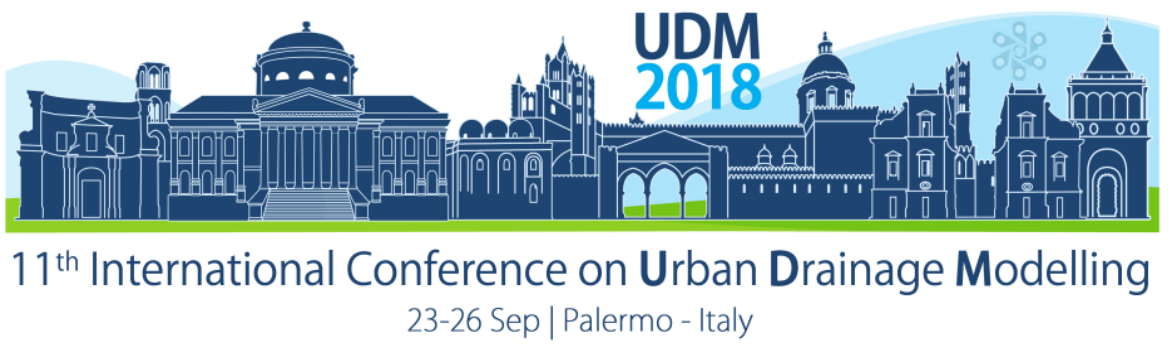

The effective control the actuators in a stormwater system can have a large impact on the system's ability to achieve its objective (e.g., minimize flooding). One approach to determining the optimum control policy for a system (i.e., which actuators should change, when to change them, and to what setting) is model predictive control (MPC). MPC has been used effectively in urban drainage scenarios by Gelormino and Ricker (1994). The non-linear behaviour of the urban drainage system, especially in coastal environments where backwater effects have to be considered, makes optimization difficult. These authors therefore converted the system into a linear approximation greatly simplifying the selection of the optimum control policy.

Another implementation of MPC was done by Heusch and Ostrowski (2011). Their approach used the United States Environmental Protection Agency's (EPA) Storm water Management Model version 5 (SWMM5) a public domain and widely used distributed dynamic rainfall-runoff model. Heusch and Ostrowski used SWMM5 to simulate the nonlinear dynamics of their urban drainage system as an "opaque" model meaning that the control policies were evaluated by the model without considering the mathematical form of the governing equations. This approach precludes the possibility of guaranteed optimality (a "practical optimum" can be found using a metaheuristic such as an evolutionary algorithm), but maintains the non-linear dynamics of the system.

Although Heusch and Ostrowski (2011) developed software that implements MPC with SWMM5, there were some drawbacks to their approach including sustainability and availability of the software which was closed-source and is no longer available. The main objective of this study was to create an open-source implementation of MPC for SWMM5. An additional objective was to leverage parallel computing since a computationally-expensive metaheuristic is needed. To accomplish these objectives, the open-source Python programming language was used in conjunction with SWMM5. To evaluate the MPC implementation, it was applied to a simplified use case. The MPC results were compared to the results from two other scenarios applied to the same use case: a rules-based approach and a scenario with no active control. The remainder of this abstract describes the methods used to implement the open-source MPC and the results of the evaluation. Finally a brief conclusion is given.

\section{Methods}

\subsection{MPC overview}

MPC consists of the following components: 1 ) information from the system, 2) a process model which accepts input from the system and is used to simulate the effect of a given control policy, and 3) an optimization routine to determine the optimum control policy. In MPC the optimization routine is performed at each control time step. For this routine: 1) system states are read from the system, 2) a series of control policies is evaluated, 3) the best control policy is selected, and 4) the best control policy is implemented. Although the best control policy is obtained for the

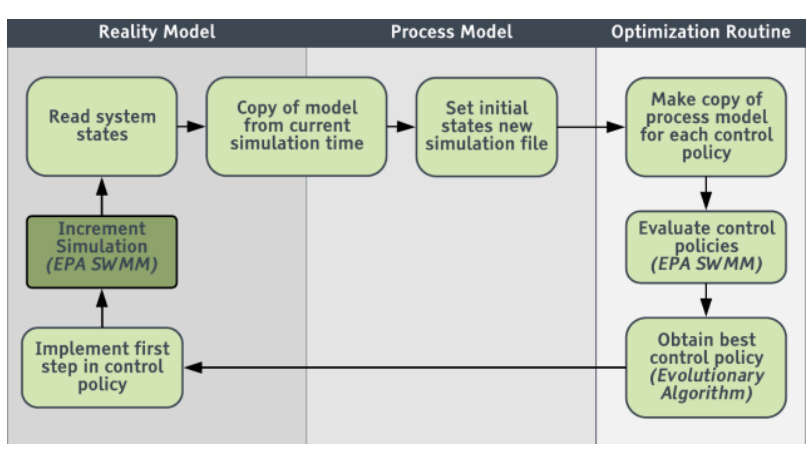

Figure 1. MPC workflow entire control horizon, only the first step in the control policy is used since the procedure occurs at every control time step. 


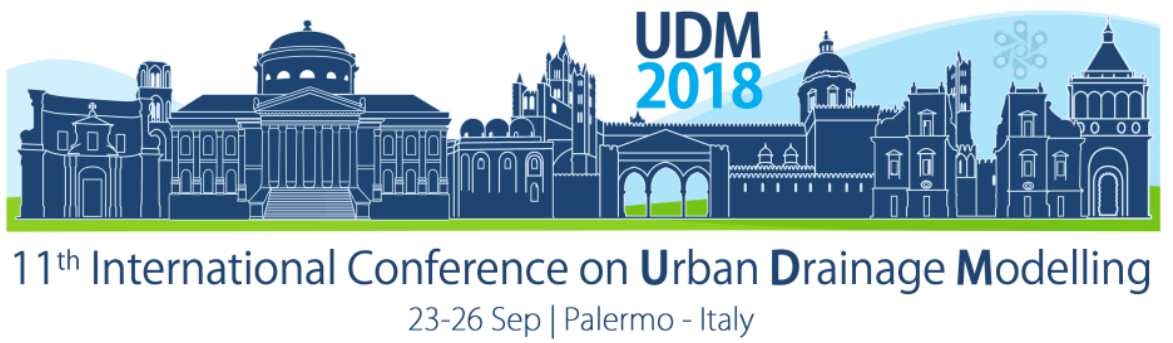

\subsection{MPC Implementation for SWMM5 using Python}

The design of our MPC implementation for SWMM5 using the Python programming language used three main Python libraries: pyswmm (https://github.com/OpenWaterAnalytics/ pyswmm), Distributed Evolutionary Algorithms for Python (DEAP) (https://github.com/DEAP/ deap), and Scalable COncurrent Operations in Python (SCOOP) (https://github.com/soravux/ scoop). The pyswmm library provides a Python interface to the SWMM5 model which is written in the $\mathrm{C}$ programming language. Through pyswmm, a SWMM5 model can be run step-by-step. This is a critical functionality for MPC since the best control policy needs to be found at each control time step. The DEAP library is used to select the best control policy using an evolutionary algorithm. The SCOOP library provides functionality for parallelizing the evolutionary algorithm execution.

The Python MPC workflow is shown in Figure 1. For each control time step, the system states are read from "reality". In our case we are simulating "reality" with a SWMM5 model, termed "reality model" in the figure. The system states that are read from the "reality model" are the heads at each node in the system and the flows at each link. Next these states are written to another SWMM5 model the "process model" in the figure. The DEAP library uses an evolutionary algorithm to select the practically optimum policy. To do this, many simulation runs of the process model are executed (one for each control policy) which is computationally expensive. Since the model runs are independent, this process can be parallelized using the

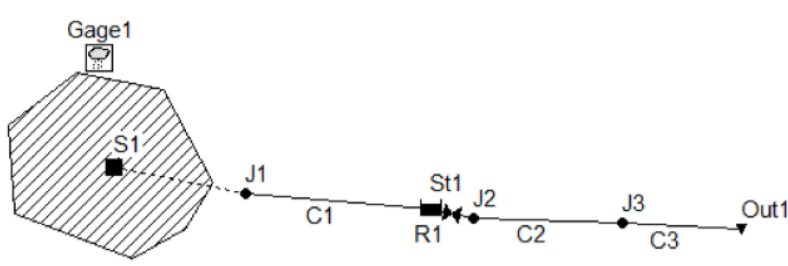

Figure 2. Schematic of simplified use case model functionality provided by the SCOOP library. The best policy selected by the evolutionary algorithm is returned to the "reality model" and implemented. The next time step is then executed and the process repeats.

\subsection{MPC Evaluation}

A simplified use case motivated by an actual flood-prone area in Norfolk, Virginia USA was used to evaluate our MPC implementation. A simple schematic of this is shown in Figure 2. In the use case a detention pond (St1) is upstream from a node (J3) at which we would like to minimize flooding. The active control of the outlet of the pond is simulated using an "orifice" structure in SWMM5 which can have a setting between 0 (completely closed) and 1 (completely open). Therefore the control policies for the use case were an array of settings between 0 and 1 , one setting for each control time step in the control horizon. To reduce the number of possible control settings to be evaluated by the computationally expensive evolutionary algorithm, the

Table 1. Rainfall data for evaluation use case

\begin{tabular}{|c|c|}
\hline Time & $\begin{array}{c}\text { Rainfall } \\
\text { depth [mm] }\end{array}$ \\
\hline 04:00 & 6.35 \\
\hline 05:00 & 12.7 \\
\hline 06:00 & 10.16 \\
\hline 07:00 & 6.35 \\
\hline 08:00 & 3.175 \\
\hline
\end{tabular}
settings were constrained to be even tenths (e.g., 0.1,0.2). The simulated rainfall event was an arbitrary synthetic event shown in Table 1. A control horizon of 6 hours was used with a control time step of 15 minutes. For the evolutionary algorithm, 8 generations were evaluated and the initial generation population was 80 individual policies.

In the use case, the control policies were evaluated using SWMM5 based on the following objective function

$$
\text { Cost }=\alpha F_{s t}+\beta F_{d s}+\phi D_{s t}
$$




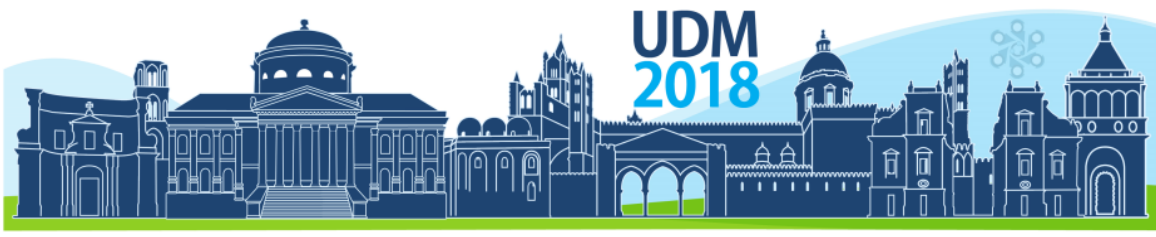

$11^{\text {th }}$ International Conference on Urban Drainage Modelling

23-26 Sep | Palermo - Italy

Where $F_{s t}$ is the total volume of flooding from the storage node in millions of gallons (1 gallon $=3.785$ liter), $F_{d s}$ is the total volume from the downstream node $\mathrm{J} 3$ in millions of gallons, and $D_{s t}$ is the average deviation from a target level for the detention pond in feet ( 1 foot in this case) ( 1 foot $=0.3048$ meter). The $\alpha, \beta$ and $\phi$ values are weight coefficients. In our case these values were 100,100 , and 0.05 , respectively. These values were chosen to give more weight to flooding than to deviation from the target level at the storage unit.

\section{Results}

The MPC implementation was successful at running as described above including the use of multiple processing cores through the SCOOP library. The control policy resulting from the MPC in the evaluation use case significantly reduced flooding at the downstream node compared to the passive control ( 0.01 million gallons of flooding compared to 0.05 million gallons, respectively). Additionally, the MPC policy was able maintain the depth at the storage node closer to the target value, something the rules-based approach was not able to do (see Figure 3).

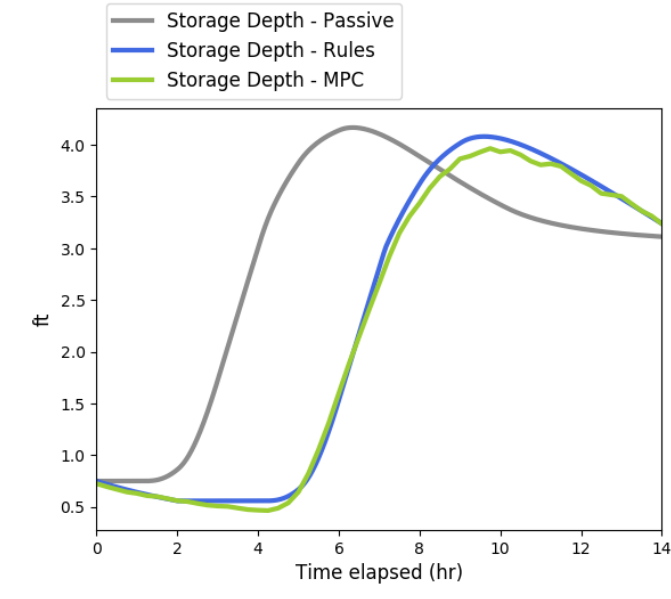

Figure 3. Depth of water in detention pond for three control scenarios

\section{Conclusions}

The objective of this research was to develop, implement, and evaluate an open-source solution for model predictive control (MPC) for the United States Environmental Protection Agency's (EPA) Stormwater Management Model (SWMM). The implementation was accomplished using the Python programming language and key Python libraries for step-bystep running of the model, use of evolutionary algorithms, and parallel computing. The system worked as designed and the resulting control policy significantly reduced flooding compared to a situation with no control in a simple, simulation use case. The MPC implementation described here can be used to perform MPC for any control in a SWMM5 model and could be useful for understanding the potential utility of smarter stormwater systems. The code is accessible at https://github.com/uva-hydroinformatics/swmm_mpc. Future improvements may include adjusting weights in the objective function and taking advantage of SWMM5's hotstart file capabilities to ensure consistency between the reality model and the process model.

\section{References}

Berggren, K., Olofsson, M., Viklander, M., Svensson, G., Gustafsson, A.-M., 2012. Hydraulic Impacts on Urban Drainage Systems due to Changes in Rainfall Caused by Climatic Change. J. Hydrol. Eng. 17, 92-98. https://doi.org/10.1061/(ASCE)HE.1943-5584.0000406

Gelormino, M.S., Ricker, N.L., 1994. Model-predictive control of a combined sewer system. Int. J. Control 59, 793816. https://doi.org/10.1080/00207179408923105

Heusch, S., Ostrowski, M., 2011. Model Predictive Control with SWMM. J. Water Manag. Model. https://doi.org/10.14796/JWMM.R241-14

Kerkez, B., Gruden, C., Lewis, M., Montestruque, L., Quigley, M., Wong, B., Bedig, A., Kertesz, R., Braun, T., Cadwalader, O., Poresky, A., Pak, C., 2016. Smarter Stormwater Systems. Environ. Sci. Technol. 50, 72677273. https://doi.org/10.1021/acs.est.5b05870 


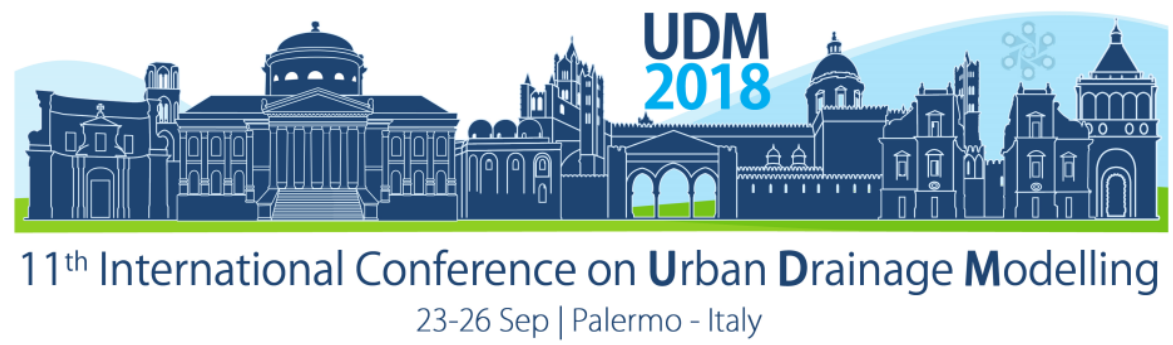

\title{
Remobilization of Sediments in Gully Pots During High Intensity Precipitation Events
}

\author{
Tone Merete Muthanna ${ }^{1}$ and Maria Viklander ${ }^{3}$ \\ ${ }^{1}$ Norwegian University of Science and Technology, Department of Civil and Environmental Engineering, \\ Trondheim, Norway \\ 2 Luleå University of Technology, Department of Civil, Environmental and Natural Resources Engineering,
} Luleå, Sweden

\begin{abstract}
The urban drainage system experiences increasing challenges due to limited capacity, increased precipitation amount, and intensity cause a higher risk of urban flooding and frequent combined sewer overflows (CSOs). This is a common problem in Norwegian cities, and around the world. The gully pots in the urban drainage system should trap sediments that is transported with stormwater and function as a pollutant trap for low flow events. However, this is dependent on regular maintenance for proper function. If poorly maintained the gully pots in the drainage systems can become a source of resuspension of accumulated sediments during high intensity rain events that. This can be a significant source of polluted sediment transported to receiving waters. This study investigates the pathways and occurrence of remobilization of sediments through the use of a SWMM model and a case study area in Damsgaard, Bergen. Steep slopes characterize the research catchment, with elevation ranges from sea level to $468 \mathrm{~m}$ above mean sea level. Built-up areas (i.e. buildings and roads) cover about $48.3 \%$ of the area while about 44.5 $\%$ of the catchment is forested. The case study illustrates how poorly maintained gully pots can be a net source of pollutants to receiving waters, in this case the Puddefjord fjord, where the City of Bergen wishes to establish swimmable water quality in the inner harbor areas.
\end{abstract}

Keywords: climate change; extreme events; sediment transport; gully pots; urban sewer systems

\section{INTRODUCTION}

Sustainable Drainage Structures (SuDS), and have become an integral part of the urban water systems. The SuDS have a wide range of functions from dampening runoff events, restoring urban water balance, improve water quality, ecological services, and blue -green elements in urban areas Sitzenfrei et al. (2013) among others. Operation and maintenance is essential for long term performance, but often a neglected aspect. Lack of, or inadequate frequency of maintenance ill lead to accumulation of sediments in gully pots, tanks and stormwater ponds. This sediments that can potentially be available for mobilization given a large storm event. Marsalek and Marsalek (1997) and Karlsson et al. (2010) showed that sediments from stormwater ponds and sedimentation tanks have elevated metal concentration in the sediment phase, increasing with decreasing particle size fraction. The sediments were found to be too polluted for reuse in the urban environment. Recent reports 


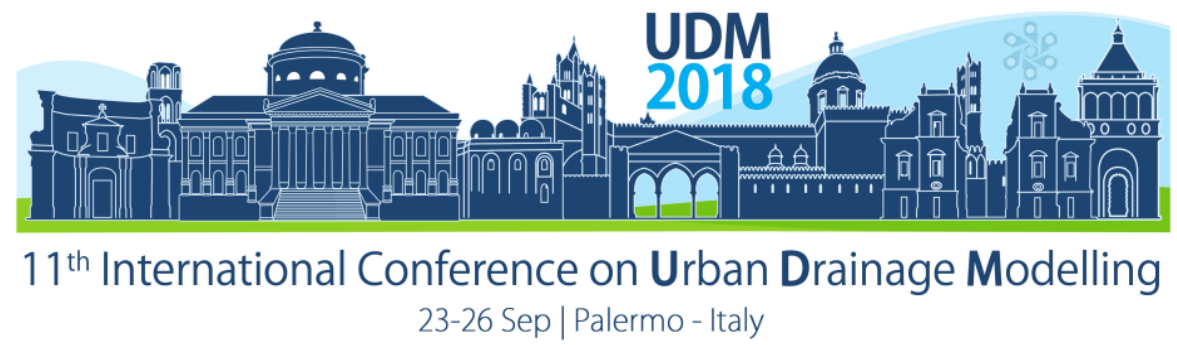

on climate change, such as the Fifth Assessment Report (IPCC 2013) and KLIMA 2100 (Hanssen-Bauer et al., 2015), indicate an increased risk for more heavy and frequent precipitation extremes. This will increase the risk of mobilizing sediments trapped in SuDS during heavy precipitation events.

Over the past decade large efforts have made in remediation of inner harbor areas of several Norwegian cities, eg. Oslo, Bergen and Trondheim. A study from Oslo tracing then stormwater pollution sources and the effect on the recipient showed a very clear linear pollution effect from the land to the sea and into the harbour (A. Oen, unpublished). Centuries of heavy polluting industry, shipyards and urban activities had left the harbor areas heavily polluted with organic pollutants, such as PCB, TBT and PAHs, and heavy metals like cadmium $(\mathrm{Cd})$, mercury $(\mathrm{Hg})$ and lead $(\mathrm{Pb})$. The main objectives have been to reestablish a health ecosystem, and swimmable and fishable water quality by dredging and covering the sea bottom. Mobilization of sediment through SuDs and urban stormwater systems pose a threat of re-polluting the cleaned inner harbors. In this paper the case of Puddefjord in Bergen is used a case study to present a methodology to assess the mobilization potential for different future climate scenarios under various maintenance scenarios.

\section{MATERIALS AND METHODS}

The methodology involves four steps combining modelling, risk assessment, and downscaling of future hydro-climatic extremes together with maintenance scenarios. The case study area was the Damsgaard Watershed, that drains into the Puddefjord inner harbour area in the city of Bergen, see Figure 1, below. The open source SWMM model was used to model water flow and sediment transport in the SuDS and the connected stormwater systems. Relevant future hydro-climatic extremes for use on a local SuDS scale cannot be directly extracted from the current climate projections available through e.g. the HanssenBauer et al. (2015) and IPCC (2013) reports because the spatial and temporal resolution of these projections is too coarse due to the scale and topography. In order to deal with this, downscaling techniques for translating the large-scale climate to the local scale has been developed (Maraun et al. 2010). In this methodology two statistical downscaling techniques; ESD (Benestad et al. 2008) and SDSM (Wilby et al. 2002) are used to bridge the gap between the global climate models and local projections, in combination with temporal disaggregation (e.g. the GEV-distribution). 


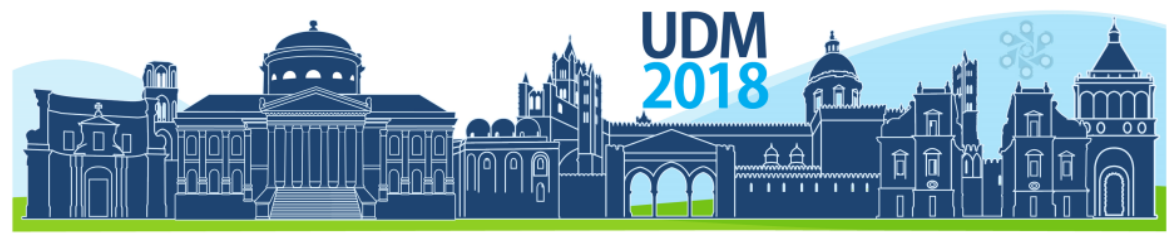

$11^{\text {th }}$ International Conference on Urban Drainage Modelling

23-26 Sep | Palermo - Italy

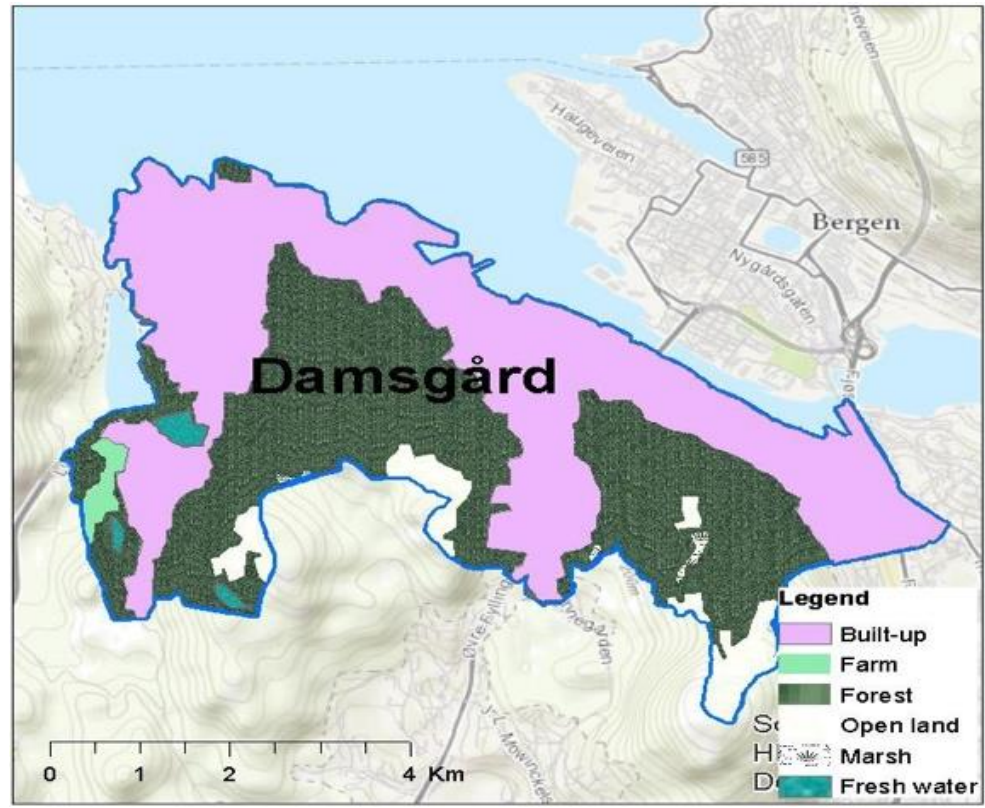

Figure 1. Landuse map of the Damsgård watershed.

\section{RESULTS AND DISCUSSION}

The SWMM model of Damsgaard was run for an array of future hydro climatic extreme events in order to identify the intensities and volumes that would result in remobilization of sediment build-up in gully pots, sedimentation tanks and ponds. This will further be used to identify the events that requires pre-cleaning of sediments trapped in SuDS in order to avoid remobilization and recontamination of the inner harbor area. This methodology provides a link to integrated asset management (IAM) of SuDS with sediment traps, that requires maintenance, with risk of (re)contamination of recipients. In a world with limited resources both with respect to monetary investments and human recourses, optimizing the steps taken becomes very crucial. The performance of SuDS during hydro-climatic extremes is important to document, and furthermore identify the most vulnerable/prone to sediment remobilization SuDs. During extreme events water quality is often considered secondary concern to water quantity and flood risks, however this paper demonstrates that there are still serious risks of receiving water contamination due in cases of poorly maintained SuDS.

Please take care that all terminology and notation used will be widely understood. Abbreviations and acronyms should be spelled out in full at their first occurrence in the text. SI units are strongly recommended. If non-SI units must be used, SI equivalents (or conversion factors) must also be given. Write equations in dimensionless form or in metric units. 


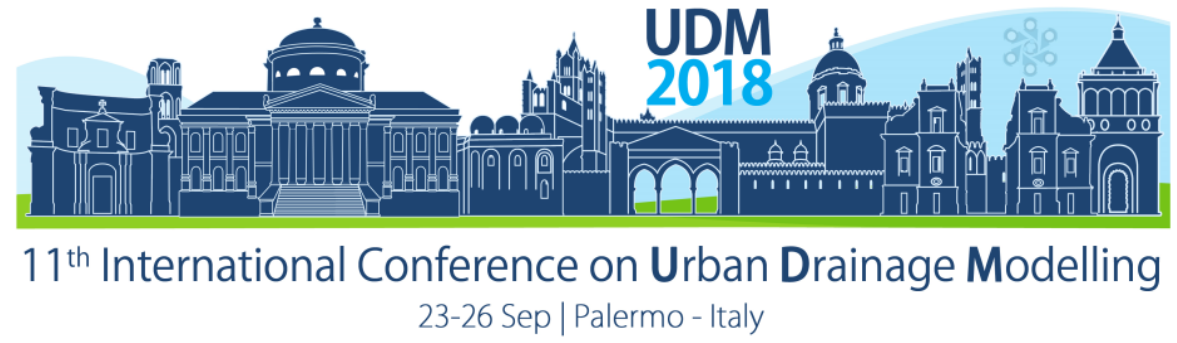

\section{CONCLUSIONS}

This paper presents the case of Puddefjord in Bergen, as a case for analyzing the risk of mobilization potential for sediments trapped in gully pots for different future climate scenarios under various maintenance scenarios. The results illustrate the need for an active and involved maintenance plan. Especially for the inner harbor areas where dredging and covering /capping has been taking place in order to clean up the inner harbor.

\section{References}

Benestad, R.E., Hanssen-Bauer, I. \& Chen, D., (2008). Empirical-statistical downscaling, World Scientific.

Dussaillant, A. R., A. Cuevas, and K. W. Potter: (2005), "Raingardens for stormwater infiltration and focused groundwater recharge simulations for different world climates". Water Supply 5(3-4), 173-179.

Hanssen-Bauer E.J., Haddeland, I., Hisdal, H., Mayer, S., I.F., (2015). Klima i Norge 2100., (2).

IPCC, (2013). Climate Change 2013: The Physical Science Basis. Contribution of Working Group I to the Fifth Assessment Report of the Intergovernmental Panel on Climate Change, Cambridge, United Kingdom and New York, NY, USA: Cambridge University Press. Available at: www.climatechange2013.org.

Karlsson, K., Viklander, M., Scholes, L., Revitt, M., (2010). "Heavy metal concentrations and toxicity in water and sediment from stormwater ponds and sedimnetation tanks". Journal of Hazardous Materials. 178(1-3), pp. 612-618.

Maraun, D., Wetterhall,F., Ireson, A.M., Chandler, R.E, Kendon, E.J, Widmann, M., Brienen, S., Rust, H.W, Sauter, T., Themessl, M., Venema, V.K.C, Chin, K.P., Goodess, C.M., Jones, R.G., Onof, C., Vrac, M., ThieleEich, I. (2010). " Precipitation downscaling under climate change: Recent developements to bridge the gap between dynamical models and the end user". Reviews of Geophysics, 48(2009RG000314), pp.1-38.

Marsalek, J., Marsalek, P.M., (1997). "Characteristics of sediments from a stormwater management pond". Water Science and Technology, 36(8-9), pp. 117-122.

Wilby, R. L., Dawson, C. W. \& Barrow, E. M. (2002). "SDSM - a decision support tool for the assessment of regional climate change impacts". Environmental Modelling \&amp; Software, 17(2), pp 147-159.

Sitzenfrei, R., Moderl, M., Rauch, W. (2013). "Assessing the impact of transitions from centralised to decentralised water solutions on existing infrastructures - Integrated city-scale analysis with VIBe". Water Research, 47(20), pp. 7251-7263. 


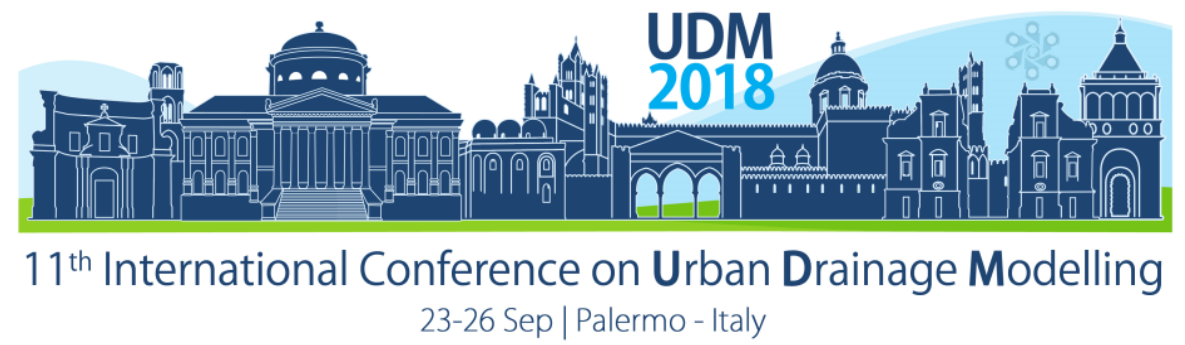

\title{
Distributed Sewer System RTC in Öhringen - On the Way to the Internet of Things
}

\author{
Manfred Schütze ${ }^{1}$, Nico Suchold ${ }^{1}$ and Horst Geiger ${ }^{2}$ \\ ${ }^{1}$ ifak e. V., Dept of Water and Energy, Magdeburg, Germany \\ 2 Öhringen Municipality, Öhringen, Germany
}

\begin{abstract}
The assessment of real time control (RTC) potential and the development of RTC systems is supported by a number of guidelines and evaluation tools. For the city of Öhringen in the South of Germany such a simulation-based evaluation has been carried out in preparation of implementation of an RTC system. RTC represents a good example of the application of concepts of "Internet of Things" (IoT), in particular if decentralised controllers are applied. On the way to the loT world, open platforms that enable web-based simulation without having to install a simulation engine on a local computer can support and simplify the planning and implementation process of RTC systems. This might be of particular benefit for smaller municipalities and consultancies who do not have the necessary simulators available, but need them only on a case-to-case basis. The paper illustrates these concepts for the Öhringen example.
\end{abstract}

Keywords: Internet of Things; Real time control; Web-based simulation

\section{INTRODUCTION}

Real time control of urban drainage systems, i.e. acting on the actuators (e.g. pumps, gates) of the drainage system based on information of monitored process variables (Schütze et al., 2004), is gaining increasing interest not only in scientific research, but also in numerous practical applications (García et al., 2015, Pabst, 2017, Saagi et al., 2017). Guidelines and planning aids to support the evaluation whether a given drainage system can benefit from control as well as guidelines to assist in RTC implementations are available for some time (DWA, 2005; Campisano and Sanfilippo, 2011). Schütze et al. (accepted) illustrate the application of the DWA M180 guideline on a fully worked example.

For the sewer system of the city of Öhringen in the South of Germany, home to 24000 inhabitants, such an evaluation of the RTC potential has been carried out. It emerges that the sewer system (which is mainly a combined sewer system) has some RTC potential, which stems also from the fact that the main direction of rainfall in the catchment is moving in a direction opposite to the main flows in the city's sewer system. Hence, further investigation of RTC for this system is merited/carried out.

One of the current trends in Information Technology now widely discussed in industry is "Internet of Things". Also in the area of urban drainage engineering, this term is used (Madsen, 2017). Such concepts of Information Technology and their application to wastewater systems are also within the focus of the recently founded working group KA13.5 ("Concepts of Internet of Things for Wastewater Technology") of the German Water Association (DWA) (Pachaly and Jumar, 2017). With the main principle of "Internet of Things" of exchanging and utilizing digital information between distributed elements, real time control 


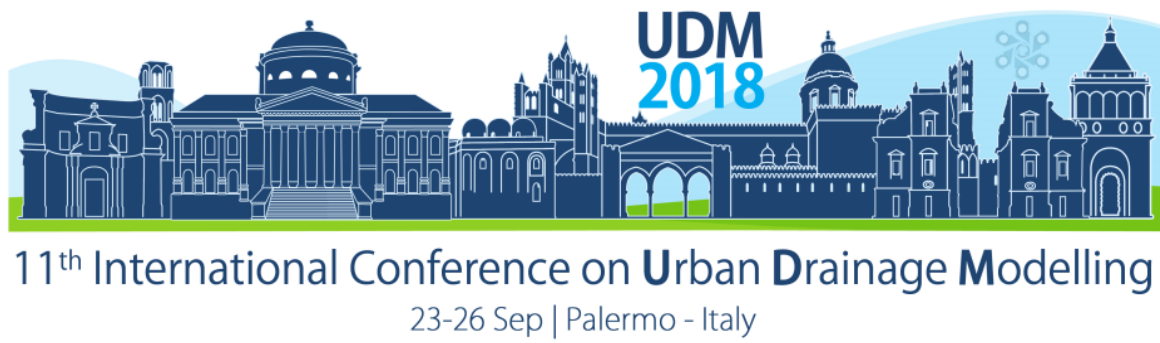

actually is a very good example of this concept. This holds true in particular if not only distributed sensors and actors are used for RTC but if the control algorithm itself is implemented in a distributed way by decentral controllers communicating with each other (as, for example, in Alex et al., 2008; Pabst, 2017). However, the concepts of the "Internet of Things" are not only important in the implementation phase of RTC systems, but also in the planning process. By using web- or cloud-based simulation concepts, the path into the loT world can be made easier and faster. This means that users - especially those who do not deal with daily simulation studies and the commissioning of RTC systems - can access RTC potential evaluators and simulation software via the Internet and are also supported by this environment when commissioning the distributed controller.

\section{CASE-STUDY: THE CITY OF ÖHRINGEN/GERMANY}

The city of Öhringen in the Hohenlohe district of Southern Germany has about 24000 inhabitants. Its sewer network, in large parts being a combined system, conveying combined sewage to the WWTP with a capacity of around $420 \mathrm{l} / \mathrm{s}$, is typical for German conditions. The sewer network has 25 storage tanks with a total volume of around $10000 \mathrm{~m}^{3}$. As an initial screening according to the evaluation table of DWA indicated control potential of the system. A model has been set up, using the hydrologic modules of the Simba\# simulator (ifak, 2018), in order to further analyse the control potential. Application of the Central Basin Approach, as described by DWA (2005), indicated that the sewer network system could benefit from control involving only 3 of its 25 tanks (Schütze et al., 2018). Figure 1 shows an outline of the sewer network as implemented in the Simba\# simulator. As the system has been represented by nested subsystems for clarity, the rectangles indicate subsystems, containing subcatchments, storage devices, transport pipes and overflow structures. The width of lines is proportional to dry weather flows (Sankey representation).

As a RTC algorithm, the generalised distributed control algorithm of Alex et al. (2008), associating a local controller to each controllable device with global controllers on a superior level coordinating the local controllers, is used for the simulation study. As advocated by van Daal et al. (2017), evaluation of RTC is done for a continuous long-term time series rather than for individual events. A rather simple control system, utilising only flow and water level information at the controlled tanks, manages to reduce the total overflow volume over 30 years from $8509757 \mathrm{~m}^{3}$ to $7880335 \mathrm{~m}^{3}$, i.e. by about $7 \%$. Table 1 shows, using a continuous time series of 1 year, that RTC not only reduces overflow volumes, but also ensures that existing storage volume is used in a more equalised way, thus adding to the sewer system's robustness with regard to unforeseen rainfall events. Hence, further analysis and implementation of RTC is merited. 
Proceedings of the 11th Int. Conference on Urban Drainage Modelling, 23-26 Sep. 2018, Palermo (ITALY). Ed. prof. Giorgio Mannina

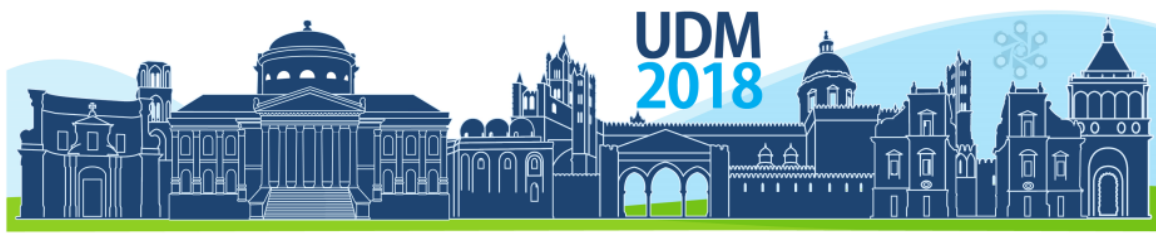

$11^{\text {th }}$ International Conference on Urban Drainage Modelling

23-26 Sep | Palermo - Italy

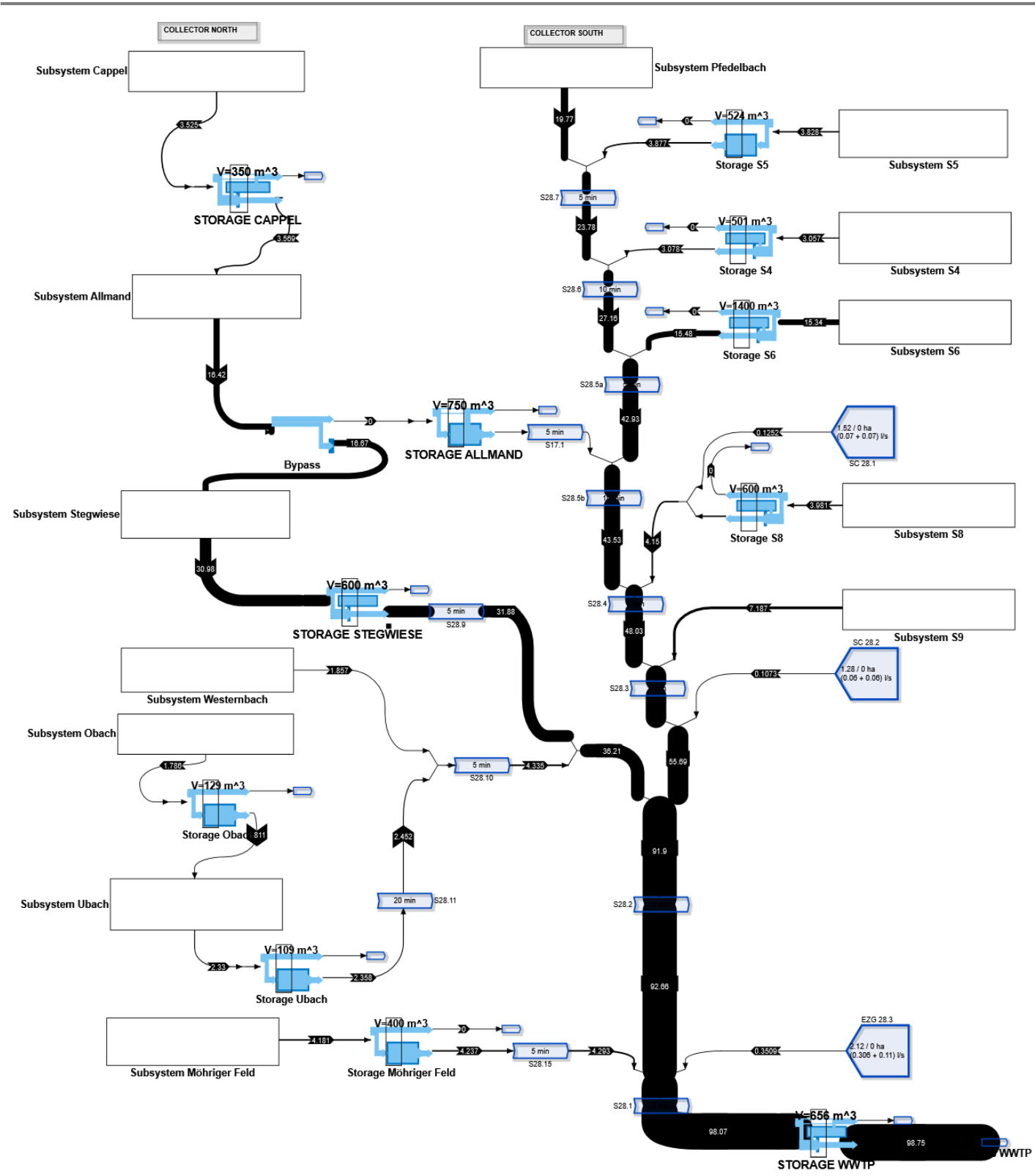

Figure 1. Öhringen sewer system, modelled in Simba\# (Numbers indicate dry weather flows in I/s)

Table 1. Overflow volumes and average filling degrees for selected storage structures Storage structure

Global control

\begin{tabular}{lcccc}
\cline { 2 - 5 } & $\begin{array}{c}\text { Overflow } \\
\text { volume }\left[\mathrm{m}^{3}\right]\end{array}$ & $\begin{array}{c}\text { Average filling } \\
\text { degree }\end{array}$ & $\begin{array}{c}\text { Overflow volume } \\
{\left[\mathrm{m}^{3}\right]}\end{array}$ & $\begin{array}{c}\text { Average filling } \\
\text { degree }\end{array}$ \\
\hline Storage tank "Cappel“ & 83570 & $9.2 \%$ & 75580 & $6.8 \%$ \\
Storage tank "Allmand" & 59820 & $2.1 \%$ & 63080 & $3.8 \%$ \\
Storage tank "Stegwiese" & 134600 & $7.7 \%$ & 137900 & $8.2 \%$ \\
Storage tank "WWTP" & 47850 & $3.9 \%$ & 44570 & $3.5 \%$ \\
Storage pipe "Obach" & 8310 & $9.1 \%$ & 6701 & $4.3 \%$ \\
Storage pipe „Ubach" & 19120 & $13.0 \%$ & 13320 & $4.0 \%$ \\
\hline
\end{tabular}




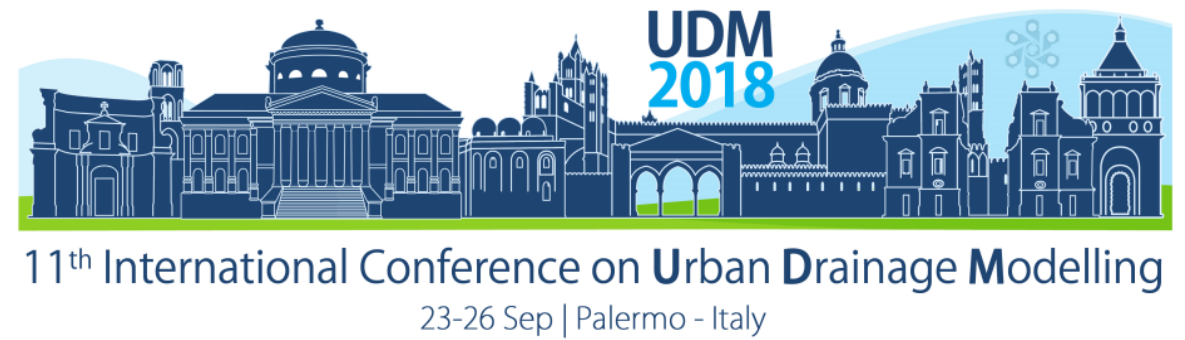

\section{CLOUD SUPPORTED PLANNING AND IOT CONCEPTS IN IMPLEMENTATION OF RTC}

Finally, the paper discusses how planning and implementation of RTC can be further supported by further digitalisation. Relevant aspects include accessing spatially distributed rainfall data (e.g., NiraWeb) through standardised interfaces (e.g. OPC-UA), cloud-based simulation concepts and a taylor-made chain of simulation and evaluation tools, which fits to the particular needs of the respective case study. This may be of particular interest to smaller cities and engineering consultancies who do not have the necessary simulators available, but need them only on a case-to-case basis. The paper shows how an open platform for data and services can be used to support web-based simulation concepts for the evaluation of RTC potential and simulation-based design, which also include the use of real-time weather data and predictive simulation of the system, and how the implementation of RTC in the context of the "Internet of Things", using an integration with OPC-UA as an example, can thus be simplified.

\section{ACKNOWLEDGEMENTS}

Acknowledgements are made to the German Federal Ministry of Economics and Energy (BMWi) for providing funding for the project „KOMMUNAL 4.0 - Customized Services für die Wasserwirtschaft" within its "Smart Service Welten" programme.

\section{References}

Alex, J., Schütze, M., Ogurek, M., Jumar, U. (2008): Systematic Design of Distributed Controllers for Sewer Networks; IFAC World Congress, Seoul

Campisano A., Sanfilippo U. (2011). Controllo in tempo reale dei sistemi di fognatura. Centro Studi Idraulica Urbana. Milano.

DWA (2005). Framework for Planning of Real Time Control of Sewer Networks. Advisory Leaflet DWA-180E 180E, German Association for Water, Wastewater and Waste, DWA, December 2005.

García, L., Barreiro-Gomez, J., Escobar, E., Téllez, D., Quijano, N., Ocampo-Martinez, C. (2015): Modeling and real-time control of urban drainage systems: A review. Adv. Water Resour., 85, 120 - 132.

ifak (2018): Simulationssystem Simba\#; Version 2.1.26, https://simba.ifak.eu/de/content/simba-sharp-water

Madsen, H. (2017): Digital Transformation of Water Systems; Keynote lecture: $14^{\text {th }}$ International Conference on Urban Drainage, Prague, September 2017

Pabst, M. (2017): Vorkonfektionierte Abflusssteuerung für Kanalnetzs; Veröffentlchungen des Institutes für Siedlungswasserwirtschaft und Abfalltechnik der Leibniz-Universität Hannover. Vol. 163,

Pachaly, U.; Jumar, U. (2017). Konzepte von Industrie 4.0 für die Abwasserwirtschaft. Korrespondenz Abwasser, 64, 6, 2017, $484-495$

Saagi, R., Flores-Alsina, X., Kroll, S., Gernaey, K.V., Jeppsson, U. (2017): A model library for simulation and benchmarking of integrated urban wastewater systems. Environmental Modelling and Software, 93, $282-$ 295

Schütze M., Campisano A., Colas H., Schilling W., Vanrolleghem P. (2004). Real time control of urban wastewater systems - where do we stand today? Journal of Hydrology, 299, 335-348

Schütze, M., Suchold, N., Geiger, H. (2018): Vernetzte Kanalnetzsteuerung Öhringen - Ein Pilotprojekt von Kommunal 4.0; 3. Expertenforum Regenüberlaufbecken; DWA-Landesverband Baden-Württemberg, Stuttgart, 27.02.2018

Schütze, M., Lange, M., Pabst, M., Haas, U. (accepted): Astlingen - a Benchmark for Real-Control Control (RTC); accepted for Wat. Sci. Tech.

Van Daal, P., Gruber, G., Langeveld, J., Muschalla, D., Clemens, F. (2017): Performance evaluation of real time control in urban wastewater systems in practice: Review and perspective. Env. Mod. Software, 95, 90 - 101 


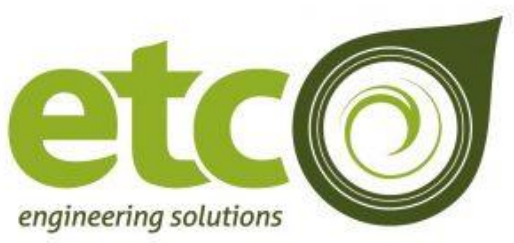

Hydromantis

D) Environmental Software Solutions, Inc.

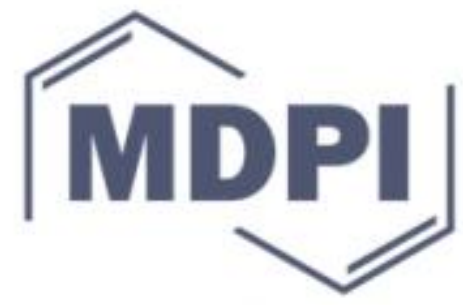

Academic Open Access Publishing since 1996

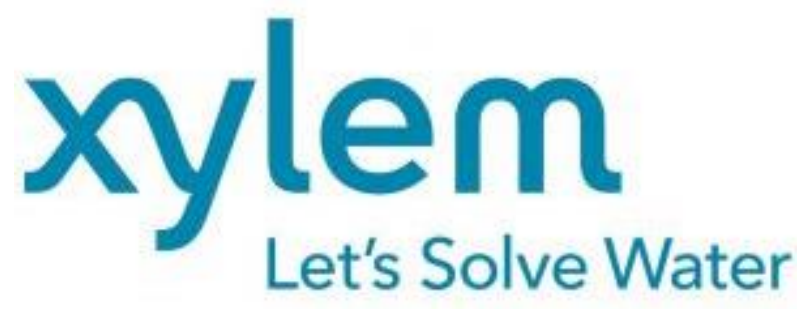

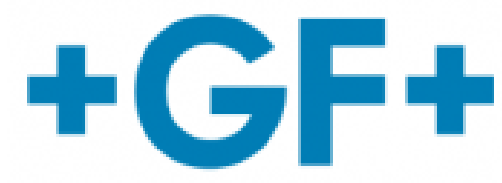

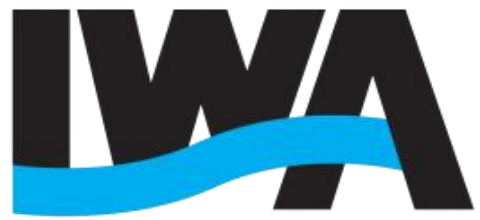

PUBLISHING

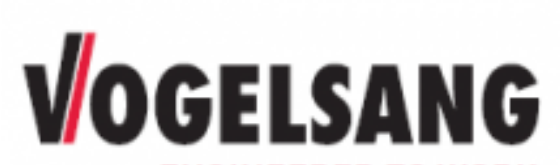

ENGINEERED TO WORK
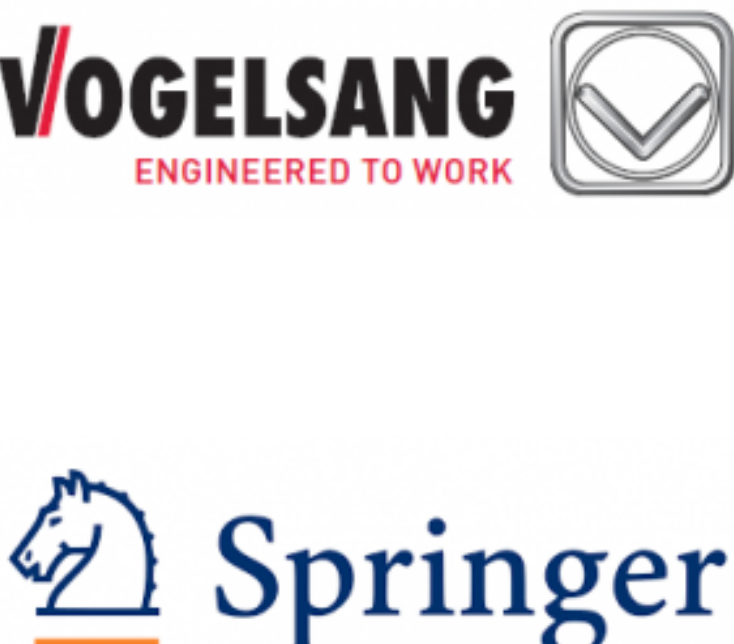

Springer

Conference is being held under the auspices of

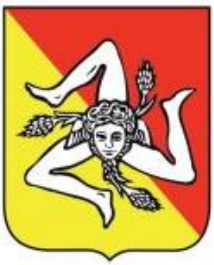

REGIONE SICILIANA

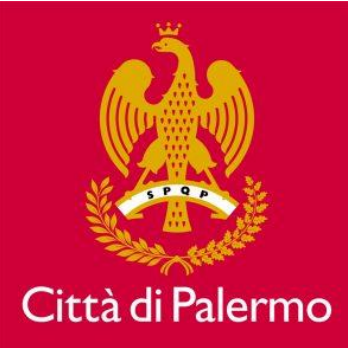

Città di Palermo 

Supported by

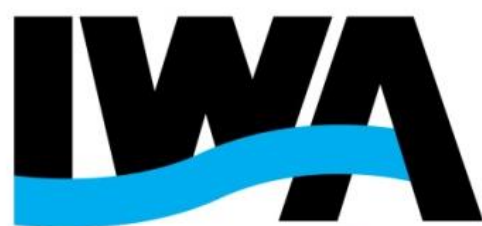

the international water association

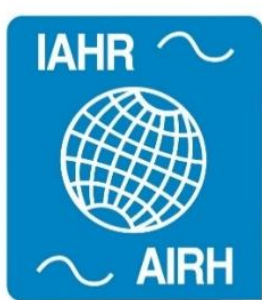

International Association for Hydro-Environment

Engineering and Research

Supported by

Spain Water and IWHR, China
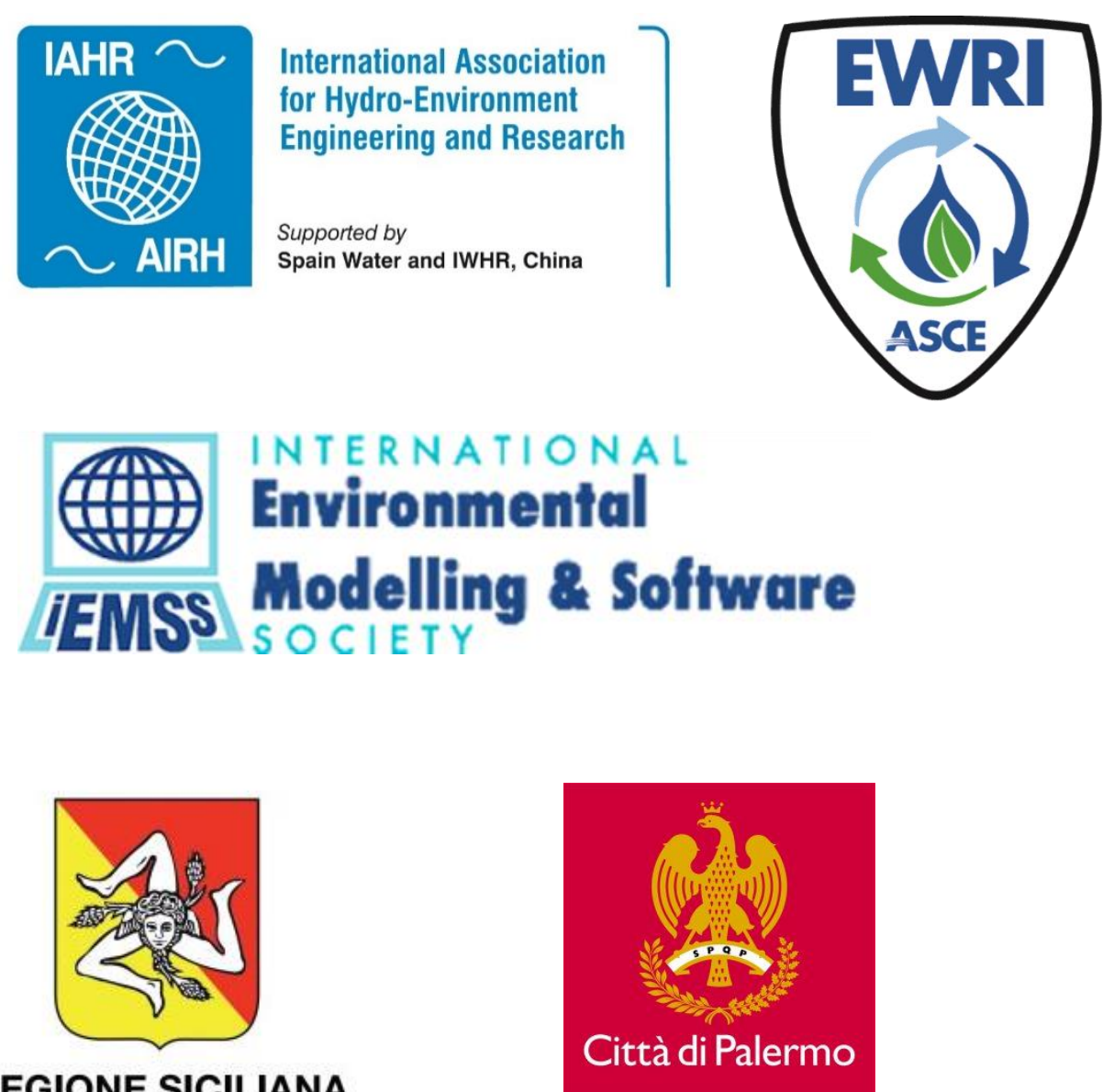